PNNL-18098

WTP-RPT-182, Rev. 0

Prepared for the U.S. Department of Energy

under Contract DE-AC05-76RL01830

\title{
Pulse Jet Mixing Tests With Noncohesive Solids
}

\author{
PA Meyer \\ JA Bamberger \\ CW Enderlin \\ JA Fort \\ BE Wells \\ SK Sundaram \\ PA Scott \\ MJ Minette \\ GL Smith \\ CA Burns \\ MS Greenwood \\ GP Morgen \\ EBK Baer \\ M White \\ SF Snyder \\ GF Piepel \\ BG Amidan \\ A Heredia-Langner
}

May 2009 


\title{
DISCLAIMER
}

This report was prepared as an account of work sponsored by an agency of the United States Government. Neither the United States Government nor any agency thereof, nor Battelle Memorial Institute, nor any of their employees, makes any warranty, express or implied, or assumes any legal liability or responsibility for the accuracy, completeness, or usefulness of any information, apparatus, product, or process disclosed, or represents that its use would not infringe privately owned rights. Reference herein to any specific commercial product, process, or service by trade name, trademark, manufacturer, or otherwise does not necessarily constitute or imply its endorsement, recommendation, or favoring by the United States Government or any agency thereof, or Battelle Memorial Institute. The views and opinions of authors expressed herein do not necessarily state or reflect those of the United States Government or any agency thereof.

\author{
PACIFIC NORTHWEST NATIONAL LABORATORY \\ operated by \\ BATTELLE \\ for the \\ UNITED STATES DEPARTMENT OF ENERGY \\ under Contract DE-AC05-76RL01830
}

Printed in the United States of America
Available to DOE and DOE contractors from the
Office of Scientific and Technical Information,
P.O. Box 62, Oak Ridge, TN 37831-0062;
ph: (865) 576-8401
fax: (865) 5765728
email: reports@adonis.osti.gov

\author{
Available to the public from the National Technical Information Service, \\ U.S. Department of Commerce, 5285 Port Royal Rd., Springfield, VA 22161 \\ ph: (800) 553-6847 \\ fax: (703) 605-6900 \\ email: orders@nits.fedworld.gov \\ online ordering: http://www.ntis.gov/ordering.htm
}


PNNL-18098

WTP-RPT-182, Rev. 0

\section{Pulse Jet Mixing Tests With Noncohesive Solids}

$\begin{array}{ll}\text { PA Meyer } & \text { JA Bamberger } \\ \text { JA Fort } & \text { BE Wells } \\ \text { PA Scott } & \text { MJ Minette } \\ \text { CA Burns } & \text { MS Greenwood } \\ \text { EBK Baer } & \text { SF Snyder } \\ \text { GF Piepel } & \text { BG Amidan }\end{array}$

PA Meyer

JA Fort

CA Burns

GF Piepel

\author{
JAmberger \\ MJ Minette \\ MS Greenwood \\ BG Amidan
}

\author{
CW Enderlin \\ SK Sundaram \\ GL Smith \\ GP Morgen \\ M White \\ A Heredia-Langner
}

\section{Additional Authors:}

$\begin{array}{llll}\text { SA Bailey } & \text { JC Bower } & \text { KM Denslow } & \text { DE Eakin } \\ \text { MR Elmore } & \text { PA Gauglitz } & \text { AD Guzman } & \text { BK Hatchell } \\ \text { DF Hopkins } & \text { DE Hurley } & \text { MD Johnson } & \text { LJ Kirihara } \\ \text { BD Lawler } & \text { JS Loveland } & \text { O D Mullen } & \text { MS Pekour } \\ \text { TJ Peters } & \text { PJ Robinson } & \text { MS Russcher } & \text { S Sande } \\ \text { CB Santoso } & \text { SV Shoemaker } & \text { SM Silva } & \text { DE Smith } \\ \text { Y Su } & \text { JJ Toth } & \text { JD Wiberg } & \text { X Yu }\end{array}$

N Zuljevic

May 2009

Key WTP R\&T References

Test Specification 24590-PTF-TSP-RT-06-007

Test Plan TP-RPP-WTP-480

Test Exceptions 24590-WTP-TEF-RT-07-00013

CCN 178425

CNN 190723

R\&T Focus Area Pretreatment

Prepared for

the U.S. Department of Energy

under Contract DE-AC05-76RL01830

Pacific Northwest National Laboratory

Richland, Washington 99352 


\section{Completeness of Testing}

This report describes the results of work and testing specified by Test Specification 24590-PTF-TSP-RT-06-007 and Test Plan TP-RPP-WTP-480. The work and any associated testing followed the quality assurance requirements outlined in the Test Specification 24590-PTF-TSP-RT-06-007 and Test Plan TP-RPP-WTP-480. The descriptions provided in this test report are an accurate account of both the conduct of the work and the data collected. Test plan results are reported. Also reported are any unusual or anomalous occurrences that are different from expected results. The test results and this report have been reviewed and verified.

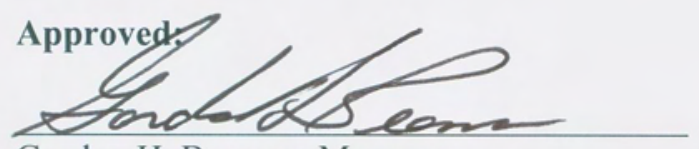

Gordon H. Beeman, Manager

RPP-WTP Support Program

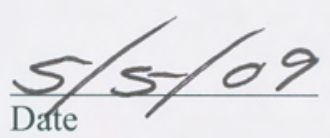




\begin{abstract}
This report summarizes results from pulse jet mixing (PJM) tests with noncohesive solids in Newtonian liquid. The tests were conducted during FY 2007 and 2008 to support the design of mixing systems for the Hanford Waste Treatment and Immobilization Plant (WTP). Tests were conducted at three geometric scales using noncohesive simulants, and the test data were used to develop models predicting two measures of mixing performance for full-scale WTP vessels. The models predict the cloud height (the height to which solids will be lifted by the PJM action) and the critical suspension velocity (the minimum velocity needed to ensure all solids are suspended off the floor, though not fully mixed). From the cloud height, the concentration of solids at the pump inlet can be estimated. The predicted critical suspension velocity for lifting all solids is not precisely the same as the mixing requirement for "disturbing” a sufficient volume of solids, but the values will be similar and closely related. These predictive models were successfully benchmarked against larger scale tests and compared well with results from computational fluid dynamics simulations.
\end{abstract}

The application of the models to assess mixing in WTP vessels is illustrated in examples for 13 distinct designs and selected operational conditions. The values selected for these examples are not final; thus the estimates of performance should not be interpreted as final conclusions of design adequacy or inadequacy. However, this work does reveal that several vessels may require adjustments to design, operating features, or waste feed properties to ensure confidence in operation. The models described in this report will prove to be valuable engineering tools to evaluate options as designs are finalized for the WTP. 



\section{Executive Summary}

This report summarizes results from pulse jet mixing (PJM) tests with noncohesive solids in Newtonian liquid conducted during FY 2007 and 2008 to support the design of mixing systems for the Hanford Waste Treatment and Immobilization Plant (WTP). This report does not address mixing behaviors of cohesive solids. Tests were conducted at three geometric scales using noncohesive simulants. The test data were used to develop mixing models that would predict two measures of mixing performance for full-scale WTP vessels: the cloud height (the height to which solids will be lifted by the PJM action) and the critical suspension velocity (the minimum velocity needed to ensure that all solids are suspended off the floor, though not fully mixed). From the cloud height, the concentration of solids at the pump inlet was estimated. For noncohesive solids, the velocity needed to lift the solids is slightly more demanding than the current mixing requirement of "disturbing" a sufficient volume of solids, but the values will be similar and closely related. Because satisfying the former also satisfies the latter, we report the minimum velocity predicted to lift solids.

We applied the models to 13 WTP mixing vessel designs using two defined waste conditions to illustrate how the models predict mixing performance. The examples predict two performance parameters: the pump inlet concentration and the critical suspension velocity for each vessel. One of the wastes was defined by design limits (Olsen 2008a), and one was derived from Hanford waste characterization reports (Wells et al. 2007). These examples show that, for the assumed conditions, several vessels would not satisfy the two requirements addressed in this work. This result suggests that, to satisfy the requirements, WTP should consider changes to design, operating conditions, or inlet waste properties, and the mixing models provide a means to evaluate the benefit that could be expected from any of these changes. Conversely, the models can be used to estimate the waste properties that can be accommodated by the current designs.

The mixing models were successfully benchmarked against a limited set of larger-scale test results from prior tests that used prototypic PJM geometries and prototypic operations. These benchmarking results provide confidence that the models can predict prototypic performance at larger scale, but also revealed a need for additional data to guide the choice of model input values selected by the user. Specifically, because the value of the characteristic settling velocity has a strong effect on the predicted performance, more work is needed to select the appropriate value.

We also compared the model predictions to the results generated by computational fluid dynamic (CFD) codes. For Tank HLP-22, both of our models predict concentration profiles that are consistent with the profile from the CFD model. For the conditions selected, the models and CFD both predict that the PJMs will not satisfy the performance requirements. The PJMs would not be sufficient to lift all solids from the floor of HLP-22, and the solids would not be well distributed, resulting in concentrations near the pump inlet that would exceed the $20 \mathrm{wt} \%$ maximum.

An example of predicted performance was also developed for an alternative design for the HLP-22 vessel, which included increasing the pulse jet velocity from $8 \mathrm{~m} / \mathrm{s}$ to $12 \mathrm{~m} / \mathrm{s}$, and increasing the jet nozzle diameter from 4 to 6 inches. This alternative configuration was predicted to improve performance, but, for the conditions evaluated, the models indicate it would not satisfy the suction inlet concentration or waste mobilization criteria. These results reflect a direct comparison of the predicted performance to the requirements, with no allowance for uncertainty in the model, performance of the mixing system, or waste properties. Appropriate margin should be added as required for the specific application. This example 
demonstrates how the models can be used to predict mixing performance trends and improvements based on potential design and/or operational changes.

There were several analysis and application improvement opportunities that became apparent during the production period of this report. The practicalities of schedule constraints and extensive QA implementation requirements necessary to support the NQA-1 needs of this document did not permit the inclusion of these improvements into this report. These improvements are discussed in the conclusions section.

The effort to develop a generalized basis for predicting PJM mixing performance involved substantial review of more conventional mixing systems, both mechanically agitated and steady jet systems. Much of the work presented in this report shows that the physics involved in a PJM mixed system are consistent with other mixing systems. However, the feature that separates a PJM system from others is that the energy input is not steady (pulsed). That difference has profound implications on the ability of the system to suspend all solids and to distribute solids vertically.

\section{Background}

The WTP is being designed and built to pretreat and vitrify the waste from Hanford's 177 underground waste storage tanks. Several process vessels will hold waste at various stages in the WTP. Many of these vessels will have mixing systems with requirements to maintain the waste in a safe condition and within the specified operating limits of the equipment.

In October 2005, a team of experts from industry, national laboratories, and universities (referred to as the External Flowsheet Review Team, or EFRT) was assembled by Bechtel National, Inc. (BNI) to conduct a thorough and in-depth review of the process flowsheet for the design of the WTP. Among the findings, the EFRT identified potential inadequate mixing of the vessels using PJMs as a technical issue; this issue is referred to as M3-Inadequate Design of Mixing Systems-Pulse Jet Mixers (referred to subsequently as M3).

In response to M3, BNI issued Test Specification 24590-PTF-TSP-RT-06-007 (Smith 2007) defining a test program to resolve the PJM mixing issue. The objective of this test program has been to close issues related to mixing system designs that could result in insufficient mixing and/or extended mixing times. These issues included a design basis that discounted the effects of large particles and of rapidly settling Newtonian slurries.

The test specification calls for geometrically scaled tests to be performed with simulants for developing models to be used for confirming the PJM design basis applied to WTP vessels. As part of project No. 53023, PNNL generated Test Plan TP-RPP-WTP-480 (Elmore et al. 2007) for conducting scaled tests.

The initial phase of testing conducted in July 2007 focused on HLP-22, the tank design identified by the EFRT as the most likely to fail to meet mixing requirements. Testing focused on the HLP-22 base line design performance and the relative performance of design alternatives. Specific tests were conducted that evaluated mixing performance related to the nozzle diameter and discharge velocity. Testing was conducted in the mid-scale [nominal 0.86-m- (34-in.-) diameter] tank to provide a relative comparison of designs with respect to the critical suspension velocity and cloud height. In the fall of 2007, additional 
parametric testing was conducted in the mid-scale vessel to evaluate the effect of several additional parameters on mixing performance. The initial testing identified that the HLP-22 PJM systems will have significant challenges when mixing fast-settling solids.

Following the initial test campaigns conducted in July 2007 and fall 2007, BNI generated test Exception 24590-WTP-TEF-RT-07-00013 (Hazen 2007). Testing to TP-RPP-WTP-480 Rev 0, ICN 1 (Elmore 2008) was conducted from March through July of 2008 in three test systems with nominal vessel diameters of $0.38,0.86$, and $1.78 \mathrm{~m}(15,34$, and $70 \mathrm{in}$.), respectively. The test campaign focused on parametric testing using 12-tube arrays, representing the HLP-22 configuration, and supplemented these with limited tests of 4- and 8-tube configurations. The 2008 test campaign used five simulants with size distributions significantly tighter than those employed during 2007 testing.

BNI issued two additional modifications for testing, one via SCN 71 (Hazen 2008a) that canceled cohesive and confirmatory testing, and the second via letter CCN 190723 (Hatzen 2008b) hat assigned the responsibility of applying the test results to determine if mixing systems meet WTP requirements to WTP M\&PE staff.

\section{Test Objectives}

The objectives of the M3 test program are presented in Table S.1 along with an explanation of how each objective was met. The objectives are quoted verbatim from Test Plan TP-RPP-WTP-480 (Elmore et al. 2007) and from Test Plan TP-RPP-WTP-480 R0.2 (Elmore et al. 2009). Because of their wording, Objectives 1 and 5 require additional explanation. Previous work indicated that the mixing performance of some WTP vessels may be inadequate at design conditions. The intent of Objectives 1 and 5 was to perform sufficient testing to assess mixing performance and provide strong evidence of inadequacy (if that was the conclusion). It was not the intent of these objectives to assume inadequate mixing and require strong experimental evidence to demonstrate adequate mixing.

Table S.1. M3 Test Program Objectives and Corresponding Discussion of Resolution

\begin{tabular}{|c|c|c|}
\hline Test Objectives & $\begin{array}{c}\text { Objective } \\
\text { Met }(\mathrm{Y} / \mathrm{N})\end{array}$ & Discussion \\
\hline $\begin{array}{l}\text { 1. Determine through experimental } \\
\text { results whether there is a high } \\
\text { probability that, for Tank HLP-22, } \\
0.10 \mathrm{~m} \text { ( } 4 \text { in.) nozzles operating at } \\
8 \mathrm{~m} / \mathrm{s} \text { discharge velocity (current } \\
\text { baseline design) will not be adequate } \\
\text { to resuspend settled solids. }\end{array}$ & Yes & $\begin{array}{l}\text { Application of the developed models (Section } 9 \text { ) indicated that } \\
0.10 \text {-m (4-in.) nozzles operating at } 8 \mathrm{~m} / \mathrm{s} \text { for a pulse volume } \\
\text { fraction of } 0.05 \text { would be insufficient to achieve full solids } \\
\text { suspension. Also, solids concentration at tank bottom exceeded } \\
20 \mathrm{wt} \% \text { for a bulk tank concentration of } 15.6 \mathrm{wt} \% \text {. }\end{array}$ \\
\hline
\end{tabular}


Table S.1. (contd)

\begin{tabular}{|c|c|c|}
\hline Test Objectives & $\begin{array}{l}\text { Objective } \\
\text { Met }(\mathrm{Y} / \mathrm{N})\end{array}$ & Discussion \\
\hline \multirow{3}{*}{$\begin{array}{l}\text { 2. Provide experimental results from } \\
\text { a scaled HLP-22 mixing system for } \\
\text { constant volume discharges that } \\
\text { provide the relative difference in } \\
\text { performance with respect to off- } \\
\text { bottom suspension for the following } \\
\text { conditions: } \\
\text { - Full-scale conditions of } 0.10 \mathrm{~m} \\
\text { (4-in.) diameter nozzles } \\
\text { operating at } 8 \mathrm{~m} / \mathrm{s} \text {. } \\
\text { - Full-scale conditions of } 0.10 \\
\text { (4-in.) diameter nozzles } \\
\text { operating at } 12 \mathrm{~m} / \mathrm{s} \text {. } \\
\text { - Full-scale conditions of } 0.15 \mathrm{~m} \\
\text { (6-in.) diameter nozzles } \\
\text { operating at } 8 \mathrm{~m} / \mathrm{s} \text {. } \\
\text { Full-scale conditions of } 0.15 \mathrm{~m} \\
\text { (6-in.) diameter nozzles } \\
\text { operating at } 12 \mathrm{~m} / \mathrm{s} \text {. }\end{array}$} & \multirow[t]{3}{*}{ 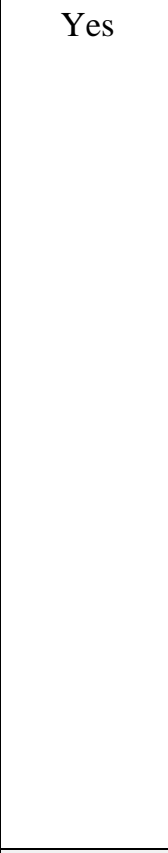 } & $\begin{array}{l}\text { Application of the developed models (Section 9) indicated that a } \\
0.15-\mathrm{m} \text { (6-in.) nozzle operating with a pulse volume fraction of } \\
0.05 \text { and } 22 \% \text { duty cycle improved performance (relative to } \mathrm{U}_{\mathrm{CS}} \text { ) } \\
\text { over a } 0.10-\mathrm{m} \text { (4-in.) nozzle with pulse volume fraction of } 0.05 \\
\text { and } 33 \% \text { duty cycle. For the conditions evaluated, the models } \\
\text { predicted that } 0.15 \mathrm{~m} \text { (6-in.) nozzles operating at } 12 \mathrm{~m} / \mathrm{s} \text { would not } \\
\text { achieve full solids suspension. } \\
\text { Following are magnitude-of-improvement comparisons from } \\
\text { Table 9.55: }\end{array}$ \\
\hline & & \begin{tabular}{cccc}
\multicolumn{2}{c}{ Vessel Velocity Nozzle } & \multicolumn{2}{c}{$\mathrm{U}_{95}$ Max Fill } \\
$\mathrm{m} / \mathrm{s}$ & in. & $\mathrm{U} / \mathrm{U}_{\mathrm{CS}}$ & $0.2 / \mathrm{W}_{0}{ }^{*}$
\end{tabular} \\
\hline & & $\begin{array}{lrccc}\text { HLP-22 } & 8 & 4 & 0.48 & 0.03^{(\mathrm{a})} \\
\text { HLP-22 } & 12 & 4 & 0.73 & 0.11^{(\mathrm{a})} \\
\text { HLP-22 } & 8 & 6 & 0.64 & 0.07^{(\mathrm{a})} \\
\text { HLP-22 } & 12 & 6 & 0.96 & 0.30 \\
\text { (a) indicates waste is considered fully settled on the } \\
\text { bottom for these conditions; the calculated ratio is } \\
\text { shown to indicate the relative performance only and } \\
\text { should not be construed to imply values of } \mathrm{W}_{0} * \text { that } \\
\text { are non-physically high. }\end{array}$ \\
\hline $\begin{array}{l}\text { 3. Obtain measurements of } \mathrm{U}_{\mathrm{CS}} \text { over } \\
\text { a range of test conditions in scaled } \\
\text { vessels to evaluate the dependence of } \\
\text { vessel performance on parameters } \\
\text { associated with waste properties, } \\
\text { equipment design, and process } \\
\text { operations. }\end{array}$ & Yes & $\begin{array}{l}\text { Testing was conducted at } 3 \text { test scales (Section } 4 \text { ). } \mathrm{U}_{\mathrm{CS}} \text { was } \\
\text { evaluated over a range of test conditions that exercised: } \\
\text { - } \quad \text { Geometric parameters: nozzle diameter, vessel diameter, } \\
\text { number of operating nozzles } \\
\text { - Operating parameters: drive time, cycle time, pulse discharge } \\
\text { volume, duty cycle } \\
\text { - Physical parameters: particle size, solids density, solids } \\
\text { concentration (see Section } 5 \text { for the range of each parameter } \\
\text { tested). }\end{array}$ \\
\hline $\begin{array}{l}\text { 4. Obtain test results at multiple } \\
\text { geometric scales to allow scaled test } \\
\text { result to be used to predict vessel } \\
\text { performance at full-scale. }\end{array}$ & Yes & $\begin{array}{l}\text { Testing was conducted in three test vessels with nominal tank } \\
\text { diameters of } 0.38,0.86 \text {, and } 1.78 \mathrm{~m}(15,34 \text {, and } 70 \mathrm{in} .)\end{array}$ \\
\hline $\begin{array}{l}\text { 5. Develop tools/models that will } \\
\text { allow WTP M\&PE staff to } \\
\text { rate/evaluate/bin WTP tanks designs } \\
\text { at a coarse level and to determine } \\
\text { with high confidence WTP vessels } \\
\text { that will not meet minimum required } \\
\text { performance levels. }\end{array}$ & Yes & $\begin{array}{l}\text { Models were developed for } \mathrm{U}_{\mathrm{CS}}, \mathrm{H}_{\mathrm{C}} \text {, and solids concentration at } \\
\text { the tank bottom to predict full-scale performance. Example } \\
\text { applications of the models were provided for several vessels and } \\
\text { waste conditions. }\end{array}$ \\
\hline $\begin{array}{l}\text { 6. Obtain test results, observations, } \\
\text { and experience that facilitate } \\
\text { development of a focused/ reduced } \\
\text { test matrix for M3 scaled tests. }\end{array}$ & Yes & $\begin{array}{l}\text { Planning for future tests will be limited to the parameters with the } \\
\text { strongest impact on vessel performance. The recommendations } \\
\text { for extending applicability of the models are covered in } \\
\text { Section } 10.3 \text { and include considerations for prototypic drive } \\
\text { systems, adjusting operating fill levels, varying viscosities, and } \\
\text { broad distribution simulant runs for both particle size and particle } \\
\text { density. }\end{array}$ \\
\hline
\end{tabular}




\section{Test Exceptions}

One test exception (Hazen 2007) was generated during the course of the M3 test program. Interim change notice ICN-TP-RPP-WTP-480_R0.1 was generated in response to the test exception. Table S.2 lists the test exception and the corresponding scope of work. In addition to the formal test exception, letters of direction were issued by BNI that modified testing objectives, one via SCN-71 (Hazen 2008a) that cancelled cohesive and confirmatory testing, and the second via letter CCN 190723 (Hazen 2008b) that assigned the responsibility of applying the test results to determine if mixing systems meet WTP requirements to WTP Mechanical and Process Engineering (M\&PE) staff. Consequently vessel evaluations in this document are to be considered as examples only.

\section{Results and Performance Against Success Criteria}

The success criteria were based on obtaining answers to several questions. The success criteria are listed in Table S.3 along with discussion of how the tests did (or did not) meet the success criteria. The success criteria are quoted verbatim from Test Plan TP-RPP-WTP-480 (Elmore et al. 2007) and from Test Plan TP-RPP-WTP-480 R0.2 (Elmore et al. 2009) . Because of their wording, Success Criteria 1 and 6 require additional explanation. Previous work had indicated that the mixing performance of some WTP vessels may be inadequate at design conditions. The intent of Success Criteria 1 and 6 was to perform sufficient testing to assess mixing performance and provide strong evidence of inadequacy (if that was the conclusion). It was not the intent of these success criteria to assume inadequate mixing, and require strong experimental evidence to demonstrate adequate mixing.

Table S.2. Test Exceptions Generated During the Test Program

\begin{tabular}{|c|c|}
\hline List Test Exceptions & Describe Test Exceptions \\
\hline $\begin{array}{l}\text { 24590-WTP-TEF- } \\
\text { RT-07-00013 } \\
\text { (Hazen 2007) }\end{array}$ & $\begin{array}{l}\text { The test exception specified that the M3 parametric tests were to be conducted in available test } \\
\text { platforms using the nonprototypic drive system to expedite the rating of all the plant vessels. The } \\
\text { change in direction was due to the delay in receiving the new test platforms and challenges to } \\
\text { develop a prototypic drive system for the smaller tanks in the expedited time frame. Expediting } \\
\text { the test program was expected to shorten it once the three all-acrylic test vessels arrived. } \\
\text { The test campaign outlined by the test exception consisted of: } \\
\text { 1. Screening testing that } \\
\text { - Provides mixing performance (ranking) for all plant vessels } \\
\text { - Includes parametric tests over reduced ranges and values } \\
\text { 2. Covers testing of cohesive and noncohesive simulants. } \\
\text { - Alended simulant studies that } \\
\text { - Examine the effects of wastes with constituents of multiple sizes and densities } \\
\text { - Examine the effects of particle size and density distribution width. } \\
\text { - } \text { - Provides technical basis of supporting enabling assumptions in response to reviewer } \\
\text { - comments } \\
\text { - Improves logistical and a greatly focused/reduced test matrix for future M3 scaled } \\
\text { - Geometric scale-up testing that } \\
\text { - Demonstrates whether exact geometric scaled testing of PJM mixing vessels is } \\
\text { The objective of the parametric tests was to identify the variables that strongly affect performance } \\
\text { and provide enough scaled information to support broad predictions of vessel performance. }\end{array}$ \\
\hline
\end{tabular}


Table S.3. Success Criteria for M3 Test Program

\begin{tabular}{|c|c|c|}
\hline List Success Criteria & \multicolumn{2}{|c|}{ Explain How Tests Did or Did Not Meet Success Criteria } \\
\hline \multirow{6}{*}{$\begin{array}{l}\text { 1. Do experimental results provide a } \\
\text { strong indication that the current } \\
\text { baseline design ( } 0.10 \mathrm{~m} \text { [4-in.] nozzles } \\
\text { at } 8 \mathrm{~m} / \mathrm{s} \text { discharge velocity) will not be } \\
\text { adequate for resuspending settled solids } \\
\text { in HLP-22 based on assessment using } \\
\text { just-suspended velocity as the critical } \\
\text { parameter? }\end{array}$} & \multicolumn{2}{|c|}{$\begin{array}{l}\text { Yes. Projected tank performances using current design and evaluating } \\
\text { pulse jet velocities and nozzle sizes show: }\end{array}$} \\
\hline & \multirow{2}{*}{$\begin{array}{c}\text { Vessel Velocity Nozzle } \\
\mathrm{m} / \mathrm{s}\end{array}$} & $\mathrm{U}_{95}$ Max Fill \\
\hline & & $0.2 / \mathrm{W}_{0} *$ \\
\hline & $\begin{array}{lll}\text { HLP-22 } & 8 & 4 \\
\end{array}$ & $0.48 \quad 0.03^{(\mathrm{a})}$ \\
\hline & \multicolumn{2}{|c|}{$\begin{array}{l}\text { (a) indicates waste is considered fully settled on the bottom } \\
\text { for these conditions; the calculated ratio is shown to indicate } \\
\text { the relative performance only and should not be construed to } \\
\text { imply values of } \mathrm{W}_{0} * \text { that are non-physically high. }\end{array}$} \\
\hline & \multicolumn{2}{|c|}{$\begin{array}{l}\text { These results indicate that the criterion for critical suspension velocity } \\
\left(U_{\mathrm{CS}}\right) \text { and pump inlet concentration will not be met for the } U_{95} \text { settling } \\
\text { velocity particle at } 8 \mathrm{~m} / \mathrm{s} \text { with a } 4 \text {-in. nozzle. }\end{array}$} \\
\hline \multirow[t]{5}{*}{$\begin{array}{l}\text { 2. Do experimental results indicate } \\
\text { that, for a constant pulse volume, } \\
\text { increasing discharge velocity to } 12 \mathrm{~m} / \mathrm{s} \\
\text { will improve mixing performance in } \\
\text { HLP-22? }\end{array}$} & \multicolumn{2}{|c|}{$\begin{array}{l}\text { Yes. Based on the application of the models (as discussed in Section 9), } \\
\text { performance does improve as nozzle velocity is increased to } 12 \mathrm{~m} / \mathrm{s} \text {. This } \\
\text { alternative configuration was an improvement, but for the conditions } \\
\text { evaluated, the model predicted the results would not satisfy the suction } \\
\text { inlet or waste mobilization criteria. }\end{array}$} \\
\hline & \multirow{2}{*}{$\begin{array}{c}\text { Vessel Velocity Nozzle } \\
\mathrm{m} / \mathrm{s}\end{array}$} & $\mathrm{U}_{95}$ Max Fill \\
\hline & & $0.2 / \mathrm{W}_{0} *$ \\
\hline & $\begin{array}{lll}\text { HLP-22 } & 12 & 4 \\
\end{array}$ & $0.73 \quad 0.11^{\text {(a) }}$ \\
\hline & \multicolumn{2}{|c|}{$\begin{array}{l}\text { a) indicates waste is considered fully settled on the bottom } \\
\text { for these conditions; the calculated ratio is shown to indicate } \\
\text { the relative performance only and should not be construed to } \\
\text { imply values of } \mathrm{W}_{0} * \text { that are non-physically high. }\end{array}$} \\
\hline \multirow{5}{*}{$\begin{array}{l}\text { 3. Do experimental results indicate } \\
\text { that, for a constant pulse volume, } \\
\text { increasing the nozzle diameter and } \\
\text { discharge velocity to } 0.15 \mathrm{~m} \text { ( } 6 \text { in.) and } \\
12 \mathrm{~m} / \mathrm{s} \text {, respectively, will improve the } \\
\text { mixing performance in HLP-22? An } \\
\text { evaluation will also be made for nozzle } \\
\text { diameter and discharge velocity of } \\
0.15 \mathrm{~m}(6 \text { in.) and } 8 \mathrm{~m} / \mathrm{s} \text {, respectively. }\end{array}$} & \multicolumn{2}{|c|}{$\begin{array}{l}\text { Yes. Based on the application of the models (discussed in Section 9), } \\
\text { performance does improve as nozzle size is increased to } 6 \text { inches. This } \\
\text { alternative configuration was an improvement, but, for the conditions } \\
\text { evaluated, the model predicted the results would not satisfy the suction } \\
\text { inlet or waste mobilization criteria. }\end{array}$} \\
\hline & Vessel Velocity Nozzle & $\begin{array}{r}\mathrm{U}_{95} \text { Max Fill } \\
0.2 / \mathrm{W}_{0} *\end{array}$ \\
\hline & $\begin{array}{lll}\text { HLP-22 } & 8 & 6\end{array}$ & $0.07^{(\mathrm{a})}$ \\
\hline & HLP-22 $12 \quad 6$ & $0.96 \quad 0.30$ \\
\hline & \multicolumn{2}{|c|}{$\begin{array}{l}\text { (a) indicates waste is considered fully settled on the bottom } \\
\text { for these conditions; the calculated ratio is shown to indicate } \\
\text { the relative performance only and should not be construed to } \\
\text { imply values of } \mathrm{W}_{0}{ }^{*} \text { that are non-physically high. }\end{array}$} \\
\hline $\begin{array}{l}\text { 4. Does the test apparatus and } \\
\text { methodology being used provide } \\
\text { results that are comparable to those } \\
\text { predicted by the client's jet mixing } \\
\text { correlation? }\end{array}$ & \multicolumn{2}{|c|}{$\begin{array}{l}\text { No longer applicable - Per direction of the WTP M3 Program Manager, } \\
\text { the comparison of the testing models with the original jet mixing } \\
\text { correlations is now WTP work scope. }\end{array}$} \\
\hline
\end{tabular}


Table S.3. (contd)

\begin{tabular}{l|l}
\hline \multicolumn{1}{c|}{ List Success Criteria } & \multicolumn{1}{c}{ Explain How Tests Did or Did Not Meet Success Criteria } \\
\hline $\begin{array}{l}\text { 5. Do test results adequately support } \\
\text { the project need for WTP M\&PE staff } \\
\text { to rate/evaluate/bin WTP tanks designs } \\
\text { at a coarse level? }\end{array}$ & $\begin{array}{l}\text { Yes. Predictive models for vessel performance were developed. Refer to } \\
\text { Section 9 for examples of how the models can be applied to predict } \\
\text { vessel performance with respect to criteria on UCs concentration at the } \\
\text { tank bottom (suction line inlet). }\end{array}$ \\
\hline $\begin{array}{l}\text { 6. Are test result models and examples } \\
\text { provided so WTP M\&TE staff can } \\
\text { provide recommendations on what } \\
\text { operating conditions/configurations }\end{array}$ & $\begin{array}{l}\text { Yes. Models are provided in Section 7 and the examples for vessels } \\
\text { HLP-22, FRP-02 A/B/C/D, PWD-15/16, PWD-33, PWD-43, PWD-44, } \\
\text { TCP-01, FEP-17 A/B, TLP-09 A/B, RLD-07, RLD-08, HOP-903/904, } \\
\text { and UFP-01 A/B are provided in Section 9. }\end{array}$ \\
$\begin{array}{l}\text { compliance? } \\
\begin{array}{l}\text { 7. In addition, do the tests illustrate } \\
\text { how PJM mixing performance is } \\
\text { affected by a change in any one of } \\
\text { several important variables in waste } \\
\text { properties or equipment design and } \\
\text { operation? }\end{array}\end{array}$ & $\begin{array}{l}\text { Yes. Refer to Section 7. } \\
\text { 8. Does this testing and data evaluation } \\
\text { allow for a focused/reduced test matrix } \\
\text { for M3 scaled tests? }\end{array}$ \\
$\begin{array}{l}\text { Yes. Success of benchmarking against previous results obtained for } \\
\text { larger-scale systems indicates strong predictive power and identifies the } \\
\text { parameters that have the greatest impact on performance. Future test } \\
\text { matrices will not include investigations of low-value parameters. }\end{array}$ \\
\hline
\end{tabular}

\section{Quality Requirements}

Pacific Northwest National Laboratory (PNNL) is operated by Battelle for the U.S. Department of Energy. Battelle's Pacific Northwest Division (PNWD) has a Quality Assurance Program that is based on requirements defined in the U.S. Department of Energy (DOE) Order 414.1C, "Quality Assurance," and 10 CFR 830, "Energy/Nuclear Safety Management,” Subpart A, “Quality Assurance Requirements.” PNWD has chosen to implement the requirements of DOE Order 414.1C and 10 CFR 830 Subpart A by integrating them into the Laboratory's management systems and daily operating processes.

PNNL implements the River Protection Project (RPP)-WTP quality requirements by performing work in accordance with the River Protection Project - Waste Treatment Plant Support Program (RPP-WTP) Quality Assurance Plan (RPP-WTP-QA-001, QAP). Work is performed to the quality requirements of NQA-1-1989 Part I, “Basic and Supplementary Requirements,” NQA-2a-1990 Part 2.7, and DOE/RW0333P Rev. 13, Quality Assurance Requirements and Descriptions (QARD). These quality requirements are implemented through the River Protection Project - Waste Treatment Plant Support Program (RPPWTP) Quality Assurance Manual (RPP-WTP-QA-003, QAM).

\section{Test Conditions}

The R\&T (research and technology) test conditions referred to in Table S.4 are summarized in Table 6.3 of Section 6. 
Table S.4. R\&T Test Conditions

\begin{tabular}{cc}
\hline List R\&T Test Conditions & Were Test Conditions Followed? \\
\hline 1. See Section 6, Table 6.3 & Yes \\
\hline
\end{tabular}

\section{Simulant Use}

The July and Fall 2007 test campaigns used Potter glass beads with a broad size distribution. The 2008 test campaign used five types of glass beads with significantly narrower size distributions than those used for the 2007 testing. The simulants are listed in Table S.5. The supernatant liquid for all testing was process water from the Applied Process Engineering Laboratory. The water was treated with Mt. Hood$480^{1}$ biocide and periodically cleaned using a standard pool filter with diatomaceous earth.

Table S.5. M3 Simulants Used for 2007 and 2008 Test Campaigns ${ }^{(a)}$

\begin{tabular}{cccc}
\hline Simulant Designation & $\begin{array}{c}\text { Particle Size, } \mathrm{d}_{50} \\
(\mu \mathrm{m})\end{array}$ & $\begin{array}{c}\text { Density } \\
\left(\mathrm{g} / \mathrm{cm}^{3}\right)\end{array}$ & Test Campaign \\
\hline p1d8 & 90 & 2.45 & 2007 \\
p1d7 & 178 & 2.45 & 2007 \\
p2d6 & 766 & 2.46 & 2007 \\
s1d5 & 44 & 2.50 & 2008 \\
s1d2 & 69 & 2.48 & 2008 \\
s1d1 & 167 & 2.46 & 2008 \\
s2d2 & 76 & 4.18 & 2008 \\
s2d1 & 164 & 4.17 & \\
\hline
\end{tabular}

(a) Particle size distributions for the simulants are shown in Table 3.6.

\section{Discrepancies and Follow-on Tests}

This section summarizes the discrepancies between the test systems and a fully scaled WTP vessel. These discrepancies are compromises that were made in the design of the test platforms in an attempt to meet the demands of the project schedule.

The successful benchmarking of models for mixing response variables against previous test results for large-scale systems using prototypic PJMs, prototypic operations, and complex simulants provide confidence that the compromises made in the geometric scaling and test system operation do not significantly affect the performance of the models. The main characteristics of the test system that differed from a perfectly scaled WTP vessel were the following:

- The test system used pulse tubes instead of PJMs. A pulse tube has a smaller diameter and volume than a PJM. This results in the open cross-sectional area of the test vessel being greater than that of a scaled WTP vessel.

- The pulse tubes used straight-bore nozzles that were 10 diameters long while PJMs have conicalshaped nozzles. The straight bore tubes provide a more idealized flow and minimize swirl effects, which can cause asymmetrical flow patterns.

\footnotetext{
${ }^{1}$ Mt. Hood Chemical Corporation material safety data sheet, product name: Mt. Hood 480, Portland, Oregon.
} 
- The pulse tubes were operated with intermittent flow compared with reciprocating flow in PJMs. The pulse tubes use suction lines located in the upper region of the tank. Therefore, the pulse tube cycle includes a quiescent period during the vent and refill portions of a PJM cycle.

- Testing was conducted using a 12-nozzle array constructed to represent that of the WTP HLP-22 vessel. The radial location of the nozzles in the scaled tanks was adjusted because of differing tank bottom contours to achieve an angle of incidence between the nozzle centerlines and the tank bottom similar to those in the full-scale HLP-22 vessel. After all the tests had been completed, a careful examination of the mid-sized test tank revealed that the bottom head contour was somewhat different than manufacturer's drawings. An evaluation of the data suggests that the models would likely fit the data somewhat more tightly if this discrepancy was fully accounted for. However, this work has not been pursued.

The relationships generated from the test data are expected to take the same form as those that would have been developed for data obtain using a prototypic drive system. A shift or offset in the relationship may exist between models developed from data using the two different drive systems. However, the shift is not expected to have a strong influence on the performance assessments presented in this report. The existence of the shift may affect predictions for full-scale vessel performance. To improve tank performance predictions, it is recommended that additional parametric testing with prototypic drive systems be conducted to establish an adjustment factor for full-cycle (reciprocating flow) operations. Additional testing is recommended to evaluate the effects of small cohesive particles with respect to correlation predictions.

\section{References}

Elmore MR, CW Enderlin, and PA Meyer. July 2007. M3 Testing Approach in Support of Tank HLP-22 Issues. TP-RPP-WTP-480, Pacific Northwest National Laboratory, Richland, Washington.

Elmore MR, CW Enderlin. January 2008. M3 Testing Approach in Support of Tank HLP-22 Issues. ICN-TP-RPP-WTP-480-R0.1, Pacific Northwest National Laboratory, Richland, Washington.

Elmore MR, CW Enderlin, and PA Meyer. January 2009. M3 Testing Approach in Support of Tank HLP-22 Issues ICN 0.2. TP-RPP-WTP-480 R0.2, Pacific Northwest National Laboratory, Richland, Washington.

Hazen H. October 2007. Contract No. DE-AC27-01RV14136, Hanford Tank Waste Treatment and Immobilization Plant, Memorandum of Agreement (MOA), 24590-QL-HC9-WA49-00001, PNNL R\&T Support,Subcontract Change Notice (SCN) No. 44 Additional Work Required by Test Exception Report 24590-WTP-TEF-RT-07-00013. Bechtel National Inc., Richland, Washington.

Hazen H. 2008a. Letter CCN 178425. Contract No. DE-AC27-01RV14136 - Hanford Tank Waste Treatment and Immobilization Plant, Memorandum of Agreement (MOA) 24590-QL-HC9-WA49-00001, PNNL R\&T Support, Subcontract Change Notice (SCN) No. 71 for Work Authorization (WA) 08 Work Cancellations. Bechtel National, Inc. , Richland, Washington.

Hazen H. 2008b. Contract No. DE-AC27-01RV14136, Hanford Tank Waste Treatment and Immobilization Plant, Memorandum of Agreement (MOA), 24590-QL-HC9-WA49-00001, PNNL R\&T 
Support, Direction for M3 WA2007-08 PJM Testing, Test Specification 24590-PTF-TSP-RT-06-006 Rev. 0. CCN 190723, Bechtel National Inc., Richland, Washington.

Smith GL. January 2007. Scaled Testing to Determine the Adequacy of the WTP Pulse Jet Mixer Designs. 24590-PTF-TSP-RT-06-007, Bechtel National Inc., Richland Washington.

Wells BE, MA Knight, EC Buck, SK Cooley, RC Daniel, LA Mahoney, PA Meyer, AP Poloski, JM Tingey, WS Callaway III, GA Cooke, ME Johnson, MG Thien, DJ Washenfelder, JJ Davis, MN Hall, GL Smith, SL Thomson, and Y Onishi. 2007. Estimate of Hanford Waste Insoluble Solid Particle Size and Density Distribution. PNWD-3824 (WTP-RPT-153 Rev. 0), Battelle - Pacific Northwest Division, Richland, Washington. 


\section{Acknowledgments}

The authors would like to thank Sheila Q. Bennett for valuable editorial support, Michael J. Parker and Mandi J. Oukrop for document production support, and William L. Kuhn and O. Dennis Mullen for their careful and thorough technical reviews and discussions. We appreciate and highly value their abilities to work flexibly and to put in the extra effort to support our M3 Mixing team to produce a wellthought-out and critically reviewed report summarizing all aspects of the project.

In addition to the authors, this work was supported by many dedicated staff involved in setting up experimental equipment and instrumentation, testing, data acquisition, data processing, and analysis. Crafts support was timely and helped us meet a demanding schedule. Engineering and administrative support occurred in a timely and effective manner when needed. These people are especially recognized for putting in extra effort to support the M3 Mixing Project.

$\begin{array}{llll}\text { Facility Operations and Engineering Support } & & \\ \text { CM Flaucher } & \text { JR Sapp } & \text { RL Meicenheimer } & \text { RC Brown } \\ \text { R Ewing } & \text { MR Townsend } & \text { GG Brodaczynski } & \text { TM Loftus } \\ \text { SP Panther } & \text { H Schulz } & \text { FB Knode } & \text { RM Jones } \\ \text { AM Sutherland } & \text { HR Shintaffer } & \text { DL Cravens } & \text { ER Langevin } \\ \text { RW Lucas } & \text { JL Allen } & \text { RL Gaston } & \text { CF Weems } \\ \text { JA Clark } & \text { RM Bechtol } & \text { JE Sandberg } & \text { DP Hebert } \\ \text { RN Blundon } & \text { MK Krouse } & \text { RL Mays } & \text { SB Saslow } \\ \text { ST Steer } & \text { DR Brawn } & \text { JJ Wodtli } & \text { D Bell } \\ \text { MH Hartzell } & \text { J Guajardo } & & \\ & & & \\ \text { Engineering and Administrative Support } & & \\ \text { WB Taylor } & \text { BE Watson } & \text { JA Willett } & \text { AP Poloski } \\ \text { JM Tingey } & \text { BF Saffell } & \text { JH Sachs } \\ \text { MR Zumhoff } & \text { SC Pratt } & \text { RD Daudt } & \text { WC Buchmiller } \\ \text { JK Young } & \text { EK Mercer } & \text { RL Johnson } & \text { DR Sisk } \\ \text { WF Mar } & \text { LK Angel } & \text { EC Golovich } & \text { JM Cuta } \\ \text { JA Bailey } & \text { RB Branton } & \text { CC Duncan } & \text { BK Bragg } \\ \text { RA Pappas } & \text { M Luna } & \text { JA Serkowski } & \text { DS Curtis } \\ \text { JB Lang } & \text { MM Watts } & \text { DS Sklarew } & \text { MS Fountain } \\ \text { JM Alzheimer } & \text { JM Billing } & \text { WR Park } & \text { JC Tucker } \\ \text { CM Flynn } & \text { SK Franks } & \text { RD Stahl } & \text { ST Yokuda } \\ \text { S Pilli } & \text { M Morra } & \text { J Larsen } & \text { SL Crowell } \\ \text { JT Munley } & \text { AI Thronas } & \text { DB Barnett } & \text { RC Daniel } \\ \text { KD Nelson } & \text { F Nigl } & \text { TM Koehler } & \text { AJ Heieren } \\ \text { JB Sorensen } & \text { DJ Corbett } & \text { KJ Lessor } & \text { NK Karri } \\ \text { JC Follansbee } & \text { JD Adgerson } & \text { MD Wojcik } & \text { AM Casella } \\ & & & \end{array}$





\section{Acronyms and Abbreviations}

\begin{tabular}{|c|c|}
\hline AEA & Atomic Energy Authority (UK) \\
\hline APEL & Applied Process Engineering Laboratory \\
\hline ASME & American Society of Mechanical Engineers \\
\hline BDC & bottom dead center \\
\hline BNFL & British Nuclear Fuels, Ltd. \\
\hline BNI & Bechtel National, Incorporated \\
\hline CDS & composite data spreadsheet \\
\hline CFD & computational fluid dynamics \\
\hline $\mathrm{CI}$ & confidence interval \\
\hline CONC & concentration \\
\hline DAS & data acquisition system \\
\hline DBE & design basis event \\
\hline DDE & dynamic data exchange \\
\hline DOE & Department of Energy \\
\hline EDS & energy-dispersive $\mathrm{x}$-ray spectroscopy \\
\hline EFRT & External Flowsheet Review Team \\
\hline$F \& D$ & flange and dish \\
\hline FFT & fast Fourier transform \\
\hline FIO & for information only \\
\hline FY & fiscal year \\
\hline GM & generalized model \\
\hline HS & head shape \\
\hline ID & inner diameter; case ID for test conditions (see Table 6.4 for Case ID coding) \\
\hline JPP & jet pump pair \\
\hline LS & lag storage \\
\hline LRB & laboratory record book \\
\hline M3 & EFRT technical issue M3-Inadequate Design of Mixing Systems-Pulse Jet Mixers \\
\hline $\mathrm{MHz}$ & megahertz \\
\hline MOA & memorandum of agreement \\
\hline MOV & maximum operating volume \\
\hline MR & multiple regression \\
\hline MSS & master spread sheet \\
\hline M\&PE & Mechanical and Process Engineering \\
\hline NCAW & neutralized current acid waste \\
\hline NPT & National Pipe Thread \\
\hline NQA & nuclear quality assurance \\
\hline
\end{tabular}




$\begin{array}{ll}\text { OD } & \text { outer diameter } \\ \text { OLS } & \text { ordinary least squares regression } \\ \text { PJM } & \text { pulse jet mixer (mixing) } \\ \text { PM } & \text { physical model } \\ \text { PNNL } & \text { Pacific Northwest National Laboratory } \\ \text { PNWD } & \text { Pacific Northwest Division } \\ \text { \%RSD } & \text { percent relative standard deviation } \\ \text { PSD } & \text { particle-size distribution } \\ \text { PSDD } & \text { particle-size and density distributions } \\ \text { PVC } & \text { polyvinyl chloride } \\ \text { PvM } & \text { predicted versus modeled } \\ \text { QA } & \text { quality assurance } \\ \text { QAM } & \text { Quality Assurance Manual } \\ \text { QAP } & \text { Quality Assurance Plan } \\ \text { QARD } & \text { Quality Assurance Requirements and Descriptions } \\ \text { R\&T } & \text { Research and Technology } \\ \text { RMC } & \text { root mean cubed } \\ \text { RMS } & \text { root mean squared } \\ \text { RPP } & \text { River Protection Project } \\ \text { RSD } & \text { relative standard deviation } \\ \text { SEM } & \text { scanning electron microscopy } \\ \text { TCT } & \text { test condition transmittal } \\ \text { UCC } & \text { ultrasonic command and control } \\ \text { UDS } & \text { undissolved solids } \\ \text { UDV } & \text { ultrasonic Doppler velocimetry } \\ \text { UFP } & \text { ultrafiltration process feed } \\ \text { UT } & \text { ultrasonic testing } \\ \text { UT-CDS } & \text { ultrasonic testing composite data spreadsheet } \\ \text { VFD } & \\ \text { WTP } & \text { warequency drive } \\ \text { WV } & \text { ireatment and Immobilization Plant } \\ \text { PAray jet configuration }\end{array}$




\section{Symbols}

\begin{tabular}{|c|c|}
\hline A1, A2, A3 & coefficient determined by experimental data \\
\hline B1, B2, B3 & exponent determined by experimental data \\
\hline $\mathrm{C}$ & concentration \\
\hline $\mathrm{C}_{0}$ & average solids concentration at the vessel bottom (at elevation 0 ) \\
\hline $\mathrm{C}_{0}^{\prime}$ & average solids concentration at the vessel bottom with finite fill level \\
\hline CS & critical suspension \\
\hline c & constant \\
\hline $\mathrm{C}(\mathrm{Z})$ & solids vertical distribution, concentration as a function of elevation \\
\hline $\mathrm{D}$ & diameter of tank \\
\hline $\mathrm{D}^{*}$ & nondimensional critical suspension defined by Eqs. (7.31 and 7.33) \\
\hline $\mathrm{D}_{\mathrm{I}}$ & diameter of impeller \\
\hline $\mathrm{D}_{\mathrm{PT}}$ & diameter of pulse tube \\
\hline DC & duty cycle $=t_{D} / t_{C}$ \\
\hline d & diameter of jet nozzle \\
\hline$d_{S}$ & diameter of solids particle \\
\hline $\mathrm{d}_{05}$ & diameter of fifth percentile particle \\
\hline$d_{50}$ & median particle diameter \\
\hline$d_{95}$ & diameter of $95^{\text {th }}$ percentile particle \\
\hline $\mathrm{E}$ & elliptical tank bottom \\
\hline $\mathrm{E}_{\mathrm{S}}$ & potential energy required to lift solids \\
\hline $\mathrm{E}_{\mathrm{V}}$ & jet energy imparted to tank during a pulse \\
\hline $\mathrm{F}$ & flanged and dished tank bottom \\
\hline $\mathrm{F}_{\mathrm{C}}$ & Froude number based on cloud height \\
\hline $\mathrm{F}_{\mathrm{CS}}$ & Froude number at critical suspension \\
\hline $\mathrm{F}_{\mathrm{CST}}$ & Froude number at critical suspension based on terminal settling velocity \\
\hline $\mathrm{F}_{\mathrm{CS} \text { TH }}$ & Froude number at critical suspension based on hindered settling velocity \\
\hline $\mathrm{F}_{\mathrm{D}}$ & Froude number based on tank diameter (D) \\
\hline $\mathrm{F}_{\mathrm{DT}}$ & Froude based on tank diameter (D) and settling velocity $\left(\mathrm{U}_{\mathrm{T}}\right)$ \\
\hline $\mathrm{F}_{\mathrm{HCT}}$ & Froude number based on cloud height $\left(\mathrm{H}_{\mathrm{C}}\right)$ and settling velocity $\left(\mathrm{U}_{\mathrm{T}}\right)$ \\
\hline $\mathrm{Fr}$ & Froude number $=\mathrm{U}^{2} /[\operatorname{gd}(\mathrm{s}-1)]$ \\
\hline $\mathrm{Fr}_{\mathrm{JS}}$ & Froude number at the just-suspended velocity \\
\hline $\mathrm{Fr}_{\mathrm{p}}$ & particle Froude number \\
\hline $\mathrm{F}_{\mathrm{S}}$ & densimetric Froude number \\
\hline $\mathrm{f}$ & function \\
\hline fct & functional relationship \\
\hline $\mathrm{Ga}$ & Galileo number \\
\hline
\end{tabular}




\begin{tabular}{|c|c|}
\hline $\mathrm{Ga}_{\mathrm{p}}$ & particle Galileo number \\
\hline Gr & gravity number - $(\mathrm{s}-1) \mathrm{g} \mathrm{d}^{2} /\left(v \mathrm{U}_{\mathrm{T}}\right)$ \\
\hline g & gravitational constant \\
\hline$g\left(y_{i}\right)$ & mathematical transformation \\
\hline $\mathrm{H}$ & fluid height, normal fill level \\
\hline $\mathrm{H}_{\text {bed }}$ & solids bed height measured by ultrasonic Doppler velocimetry \\
\hline $\mathrm{H}_{\mathrm{C}}$ & average peak cloud height \\
\hline $\mathrm{H}_{\mathrm{C}} *$ & nondimensional cloud height defined by Eqs. (7.32) and (7.40) \\
\hline $\mathrm{H}_{\text {CSpulsed }}$ & average peak cloud height at critical suspension for pulsed flow \\
\hline $\mathrm{H}_{\text {CSsteady }}$ & average peak cloud height at critical suspension for steady flow \\
\hline $\mathrm{H}_{\mathrm{CS}}$ & average peak cloud height at critical suspension \\
\hline $\mathrm{H}_{\text {dish }}$ & dish height \\
\hline $\mathrm{H}_{\mathrm{F}}$ & vessel fill height \\
\hline Jet & type of jet either pulsed or steady \\
\hline $\mathrm{K}_{\mathrm{Hc}}$ & geometric constant for cloud height \\
\hline $\mathrm{K}_{\mathrm{UCS}}$ & geometric constant for critical suspension velocity \\
\hline $\mathrm{k}$ & coefficient, constant for concentration profile \\
\hline $\mathrm{k}^{\prime}$ & jet configuration specific constant; coefficient \\
\hline $\mathrm{k}_{\mathrm{C}}$ & geometric constant for for $\mathrm{H}_{\mathrm{C}}$ for dish shape \\
\hline $\mathrm{k}_{\mathrm{D}}$ & nozzle discharge coefficient \\
\hline $\mathrm{k}_{\mathrm{U}}$ & geometric constant for $\mathrm{U}_{\mathrm{CS}}$ for dish shape \\
\hline $\mathrm{k}_{\mathrm{I}}$ & impeller specific constant \\
\hline $\mathrm{k}_{\mathrm{J}}$ & jet mixer specific constant \\
\hline $\mathrm{k}_{\mathrm{P}}$ & pulse-jet mixer specific constant \\
\hline $\mathrm{m}_{\mathrm{S}}$ & relative mass of solids (difference between solid mass and liquid it displaces) \\
\hline $\mathrm{N}$ & number of installed jets or pulse tubes \\
\hline $\mathrm{N}_{\mathrm{I}}$ & number of jets operating in the inner ring \\
\hline $\mathrm{N}_{\mathrm{J}}$ & number of operating jets/pulse tubes \\
\hline $\mathrm{N}_{\mathrm{JS}}$ & shaft speed for just-suspended condition (Zwietering-mechanical mixers) \\
\hline $\mathrm{N}_{\mathrm{O}}$ & number of jets operating in outer ring \\
\hline $\mathrm{N}_{\mathrm{S}}$ & $\begin{array}{l}\text { settling number (ratio of useful jet energy imparted to the tank during a pulse to energy } \\
\text { required to keep solids suspended during a pulse) }\end{array}$ \\
\hline$n$ & $\begin{array}{l}\text { velocity exponent; } 1,2,3 \text { corresponds to mass (peak average), momentum, and energy- } \\
\text { based average velocities }\end{array}$ \\
\hline $\mathrm{P}_{\mathrm{J}}$ & hydraulic power input at nozzles \\
\hline $\mathrm{P}_{\mathrm{V}}$ & effective jet hydraulic power \\
\hline PM & particle motion \\
\hline PPV & power per unit volume \\
\hline
\end{tabular}




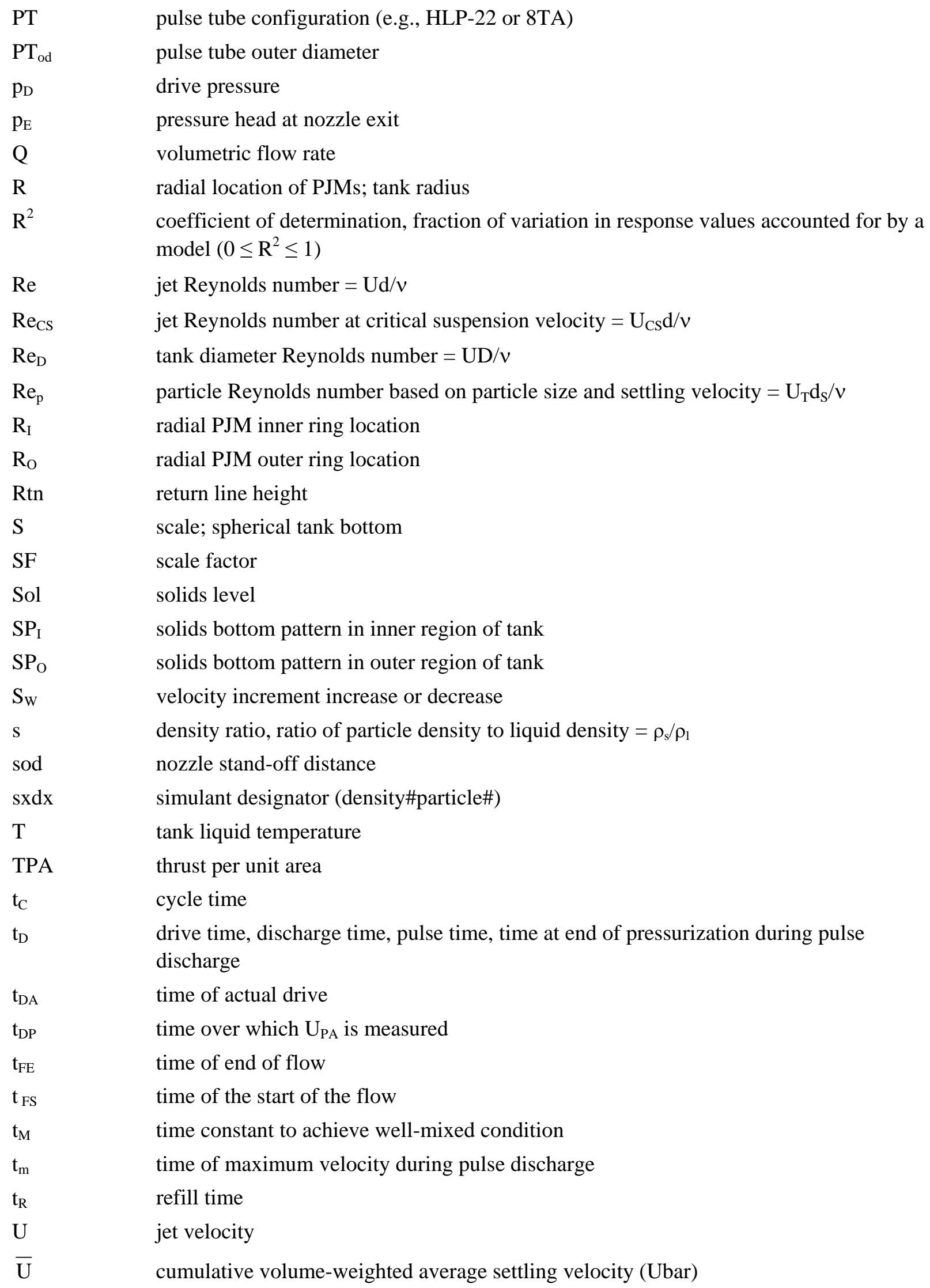




\begin{tabular}{|c|c|}
\hline $\bar{U}_{n}$ & cumulative volume-weighted average settling velocity for $\mathrm{n} \%$ of fastest-settling particles \\
\hline $\mathrm{U}_{\mathrm{C}}$ & $\begin{array}{l}\text { velocity required for complete suspension when the cloud height reaches the height } \\
\text { of the fluid } \mathrm{H}_{\mathrm{C}}=\mathrm{H}\end{array}$ \\
\hline $\mathrm{U}_{\mathrm{CS}}$ & critical suspension velocity, all solids suspended at the end of the pulse \\
\hline $\mathrm{U}_{\mathrm{CS} \_\mathrm{D}}$ & $\mathrm{U}_{\mathrm{CS}}$ condition based on decreasing velocity \\
\hline $\mathrm{U}_{\mathrm{CSM}}$ & $\mathrm{U}_{\mathrm{CS}}$ condition method of selection \\
\hline $\mathrm{U}_{\text {CSpulsed }}$ & critical suspension velocity for pulsed flow \\
\hline $\mathrm{U}_{\text {CSsteady }}$ & critical suspension velocity for steady flow \\
\hline $\mathrm{U}_{\mathrm{CSR}}$ & selected $\mathrm{U}_{\mathrm{CS}}$ condition for test \\
\hline $\mathrm{U}_{\mathrm{CS}} \mathrm{cen}$ & $\mathrm{U}_{\mathrm{CS}}$ condition determined visually at the tank center \\
\hline $\mathrm{U}_{\mathrm{CS}} \mathrm{udv}$ & $\mathrm{U}_{\mathrm{CS}}$ condition determine using ultrasonic Doppler velocimetry at the tank center \\
\hline $\mathrm{U}_{\mathrm{CS}} \mathrm{vis}$ & $\mathrm{U}_{\mathrm{CS}}$ condition determined visually \\
\hline $\mathrm{U}_{\mathrm{CS} 15}$ & critical suspension velocity in the small-scale vessel \\
\hline $\mathrm{U}_{\text {end }}$ & velocity at the end of pressurization during discharge \\
\hline $\mathrm{U}_{\mathrm{JS}}$ & jet velocity for off-bottom suspension (jet mixers) \\
\hline $\mathrm{U}_{\max }$ & maximum jet discharge velocity during pulse \\
\hline $\mathrm{U}_{\mathrm{PA}}$ & peak average velocity \\
\hline $\mathrm{U}_{\text {pulsed }}$ & pulse jet velocity \\
\hline $\mathrm{U}_{\mathrm{S}}$ & steady jet velocity \\
\hline $\mathrm{U}_{\text {steady }}$ & steady jet velocity \\
\hline $\mathrm{U}(\mathrm{t})^{\mathrm{n}}$ & instantaneous velocity \\
\hline $\mathrm{U}_{\mathrm{T}}$ & unhindered terminal settling velocity \\
\hline $\mathrm{U}_{\mathrm{TH}}$ & hindered terminal settling velocity \\
\hline $\mathrm{U}_{\mathrm{TH}}{ }^{\prime}$ & modified hindered settling velocity \\
\hline $\mathrm{U}_{\mathrm{pa}}$ & peak average velocity, which was either observed visually or computed \\
\hline $\mathrm{U}_{\mathrm{v}}$ & effective average vertical velocity \\
\hline $\mathrm{U}_{\mathrm{x}}$ & settling velocity of $x^{\text {th }}$ percentile of PSDD \\
\hline $\mathrm{U}_{0}$ & average velocity \\
\hline $\mathrm{U} 1$ & mass-based average pulse velocity \\
\hline $\mathrm{U} 2$ & momentum-based average root mean square (RMS) pulse velocity \\
\hline U3 & energy-based average root mean cubed pulse velocity \\
\hline $\mathrm{U}_{90}$ & settling velocity of $90^{\text {th }}$ percentile of PSDD \\
\hline $\mathrm{U}_{95}$ & settling velocity of $95^{\text {th }}$ percentile of PSDD \\
\hline$\overline{\mathrm{U}}_{90}, \mathrm{Ubar}_{90}$ & $\begin{array}{l}\text { volume weighted average settling velocity of } 90^{\text {th }} \text { percentile and above settling velocity } \\
\text { of PSDD (fastest settling } 10 \% \text { fraction) }\end{array}$ \\
\hline $\mathrm{U}(\mathrm{t})$ & instantaneous velocity at time $t$ \\
\hline $\mathrm{V}$ & nominal volume of tank \\
\hline$V_{\text {dish }}$ & dish volume \\
\hline
\end{tabular}




$\begin{array}{ll}\mathrm{V}_{\mathrm{P}} & \text { volume of pulse (per PJM) } \\ \mathrm{V}_{\mathrm{PT}} & \text { volume of pulse tube } \\ \mathrm{V} \% & \text { volume percent } \\ \mathrm{V}_{\mathrm{REF}} & \begin{array}{l}\text { reference volume based on the volume of a right circular cylinder of diameter D where } \\ \text { height equals diameter, } \mathrm{V}_{\mathrm{REF}}=\left(\pi \mathrm{D}^{3}\right) / 4\end{array} \\ \mathrm{~V}_{\mathrm{S}} & \text { volume of solid particulate } \\ \mathrm{V}_{\mathrm{T}} & \text { vessel volume } \\ \mathrm{vf} & \text { void fraction } \\ \mathrm{W}_{\mathrm{MP}} & \text { wt\% solids at maximum packing fraction } \\ \mathrm{W}_{0} & \text { wt\% solids at bottom } \\ \mathrm{W}_{0}{ }^{*} & \text { wt\% solids at bottom adjusted by a factor of } 1.5\left(\mathrm{~W}_{0}{ }^{*}=1.5 \mathrm{~W} \text { ) }\right. \\ \mathrm{w}_{\mathrm{Smax}} \% & \text { insoluble solids concentration (in wt\%) for the WTP vessels } \\ \mathrm{X} & \text { weight of solid per weight of liquid times } 100 \text { (percent); threshold velocity for } \\ & \text { distinguishing assumed zero flow from measured flow (comparator set point) } \\ \mathrm{x}_{\mathrm{ni}} & \text { predictor variables }\left(\mathrm{x}_{1}, \mathrm{x}_{2}, \ldots, \mathrm{x}_{\mathrm{n}}\right) \\ \mathrm{y} & \text { response variable } \\ \mathrm{Z} & \text { vertical elevation } \\ \mathrm{z} & \text { characteristic distance that jet travels }\end{array}$

\section{Greek Symbols}

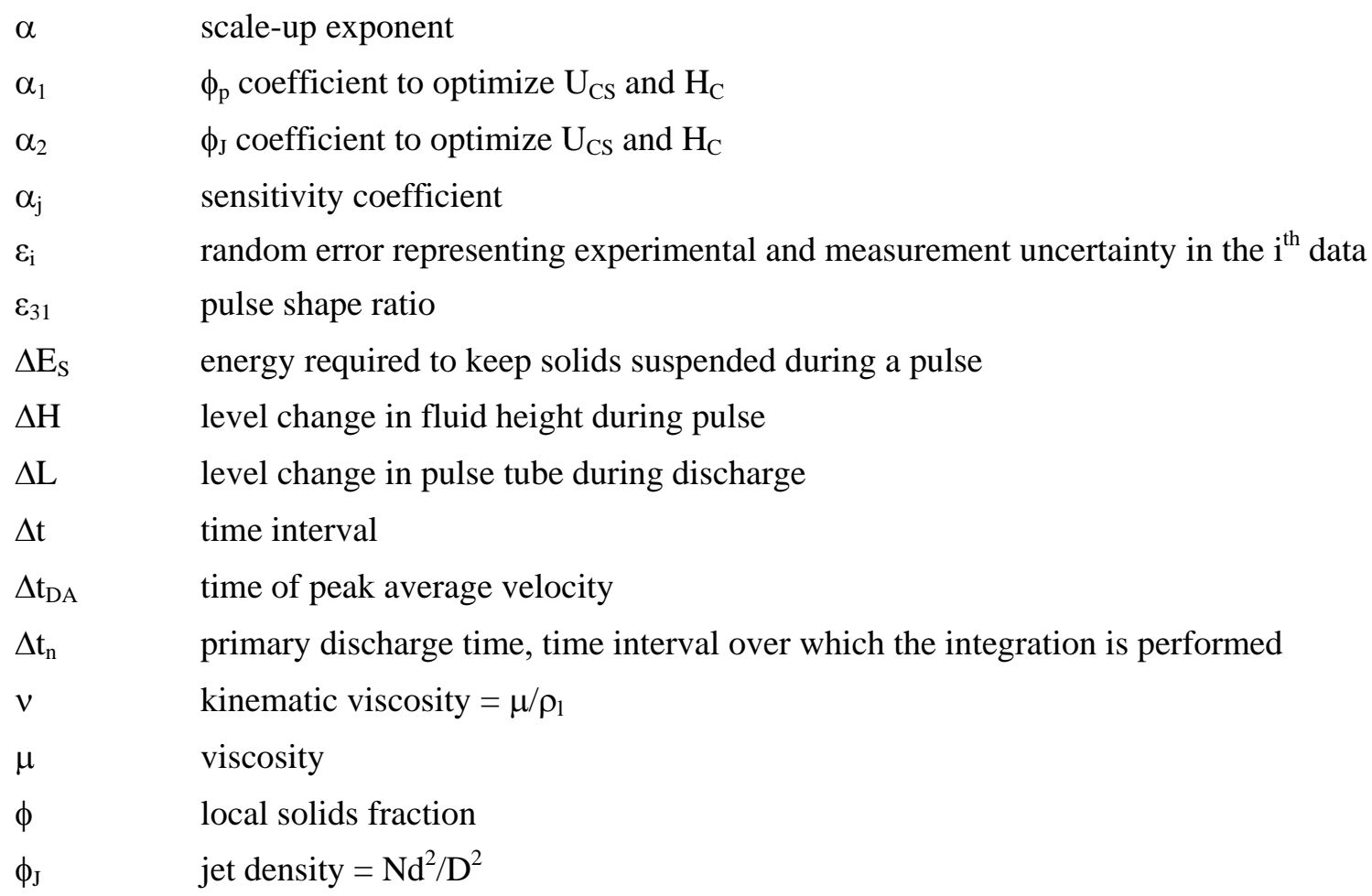




\begin{tabular}{|c|c|}
\hline$\phi_{\max }$ & packing fraction \\
\hline$\phi_{\mathrm{p}}$ & pulse volume fraction $=\mathrm{N} \mathrm{V}_{\mathrm{P}} / \mathrm{V}_{\mathrm{REF}}$ \\
\hline$\phi_{\mathrm{PT}}$ & ratio of pulse tube to vessel cross-sectional area $=\mathrm{N} \mathrm{D}_{\mathrm{PT}}^{2} / \mathrm{D}^{2}$ \\
\hline$\phi_{\mathrm{S}}$ & ratio of volume of solids particulate to reference volume $=V_{S} / V_{R E F}=V_{S} /\left(\pi D^{3} / 4\right)$ \\
\hline$\phi_{\text {Smax }}$ & solids volume fraction corresponding to maximum packing fraction \\
\hline$\rho$ & slurry density \\
\hline$\rho_{l}$ & liquid density \\
\hline$\rho_{\mathrm{s}}$ & solids density \\
\hline$\theta$ & impingement angle \\
\hline$\theta_{\mathrm{I}}$ & inner impingement angle \\
\hline$\theta_{\mathrm{O}}$ & outer impingement angle \\
\hline
\end{tabular}




\section{Contents}

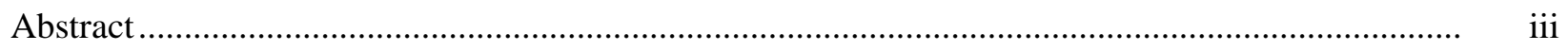

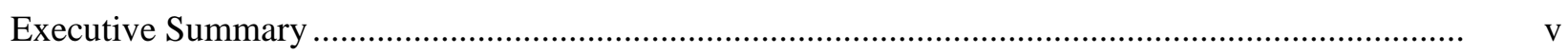

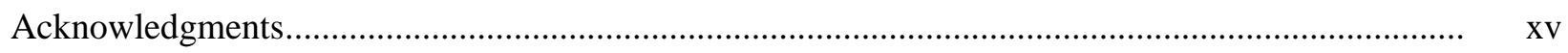

Acronyms and Abbreviations ................................................................................................. xvii

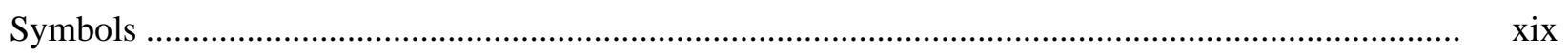

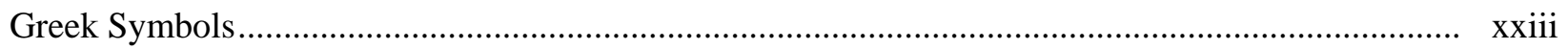

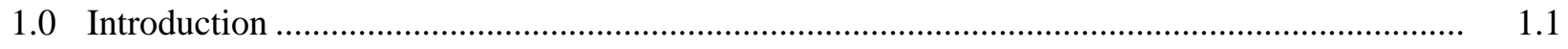

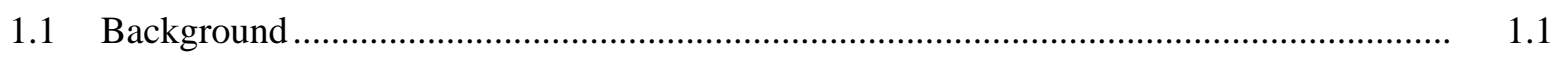

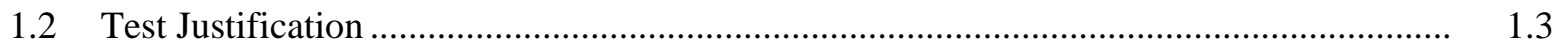

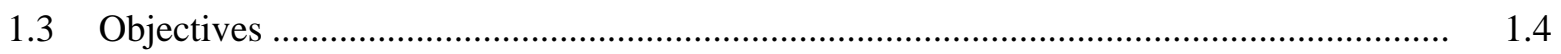

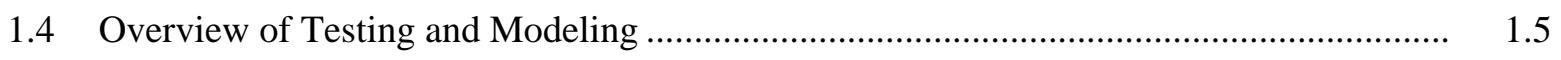

1.4.1 Model Development Approaches .................................................................... 1.5

1.4.2 Phased Approach to Testing............................................................................ 1.6

1.4.3 Scaled Testing Approach................................................................................. 1.6

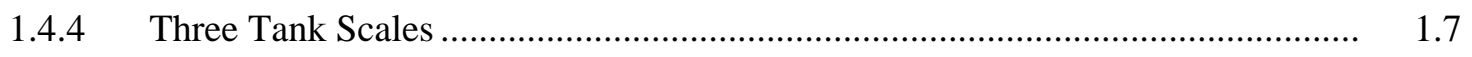

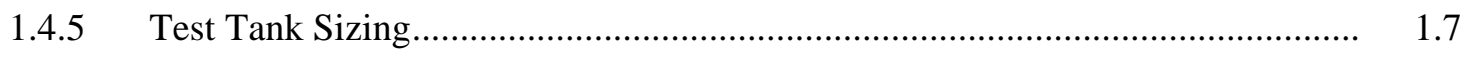

1.4.6 Mixing System Configuration ....................................................................... 1.8

1.4.7 Initial Testing to Define System Parameters that Meet Test Objectives .............. 1.8

1.4.8 Scaled Testing and Model Development.......................................................... 1.9

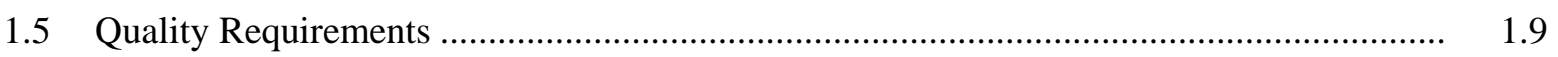

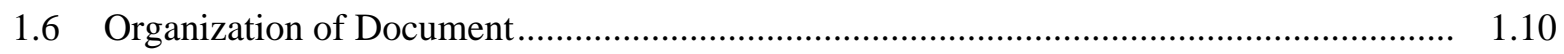

2.0 Technical Approach for Assessing WTP Mixing Systems.................................................... 2.1

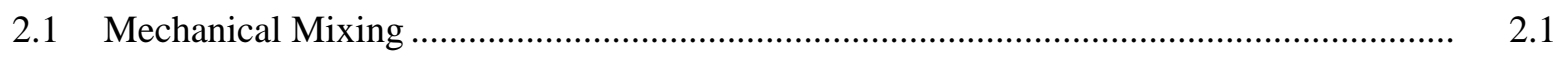

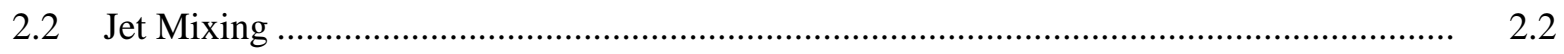

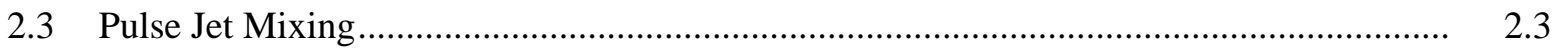

2.3.1 Pulse Jet Mixer Operation ............................................................................. 2.3

2.3.2 Expected Solids Behavior During PJM Operation ............................................. 2.6

2.3.3 Mixing Requirements .............................................................................. 2.7

2.3.4 Synopsis of Prior PJM Mixing Studies ....................................................... 2.7

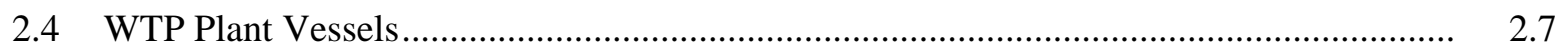

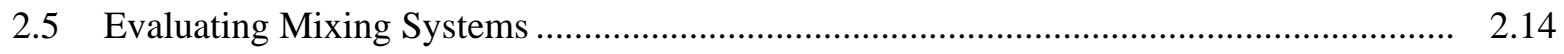

2.5.1 Mixing System Parameters........................................................................... 2.15

2.5.2 Just-Suspended Jet Velocity ........................................................................... 2.18

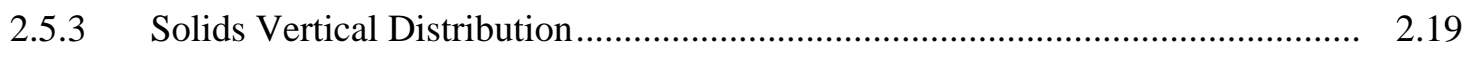

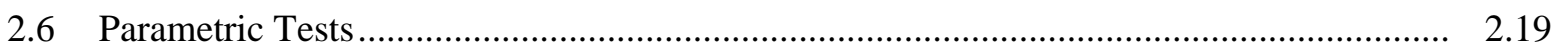

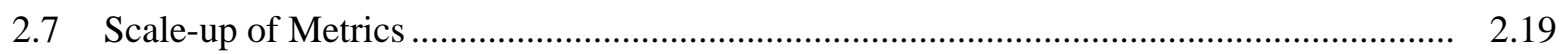




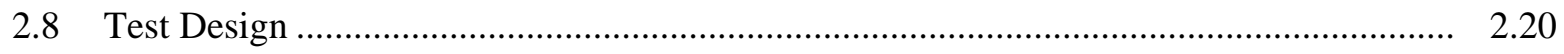

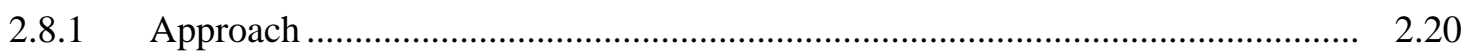

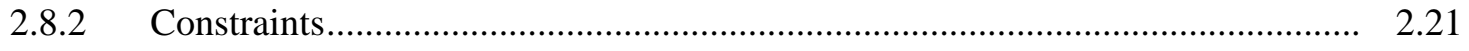

2.8.3 Plant Variable Ranges ............................................................................. 2.21

3.0 Hanford Waste Properties and Simulant Selection ............................................................

3.1 Hanford Waste Properties …........................................................................................

3.2 Selection of Slurry Property Ranges ….................................................................... 3.6

3.3 Characterization Techniques ............................................................................. 3.8

3.3.1 Density Measurement Technique.................................................................. 3.8

3.3.2 Packing Fraction Measurement Technique ...................................................... 3.8

3.3.3 Particle Size Measurement Technique ........................................................... 3.8

3.3.4 Simulant Selection and Characterization.......................................................... 3.8

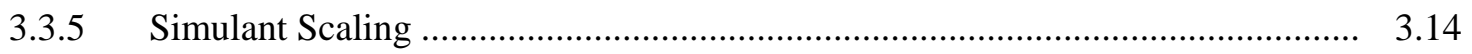

3.4 Simulant Preparation ......................................................................................... 3.14

3.4.1 Water Addition and Removal ................................................................... 3.15

3.4.2 Solids Addition and Removal..................................................................... 3.15

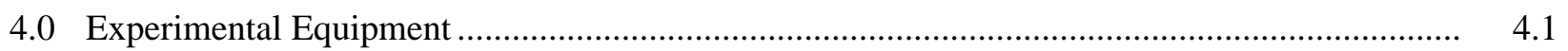

4.1 Modeling Tank HLP-22 Configuration......................................................................

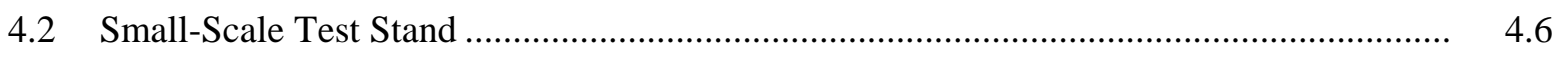

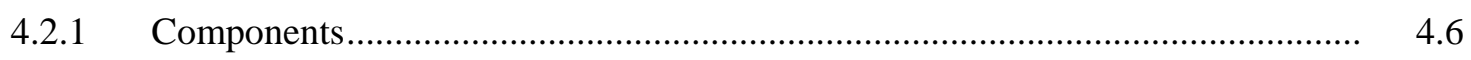

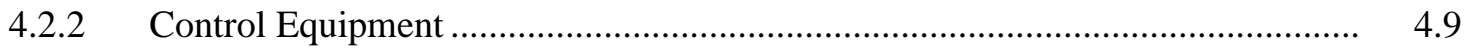

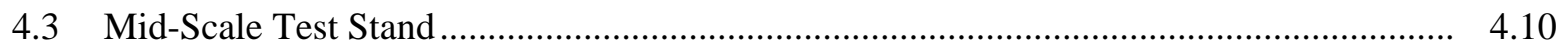

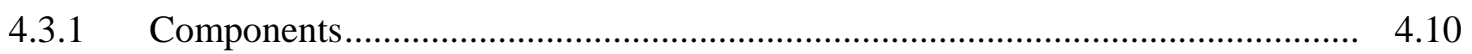

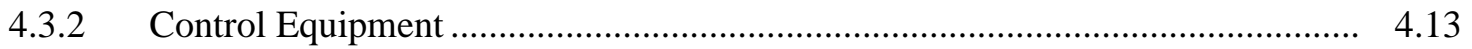

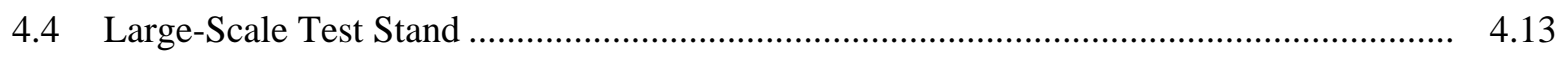

4.4.1 Components......................................................................................... 4.14

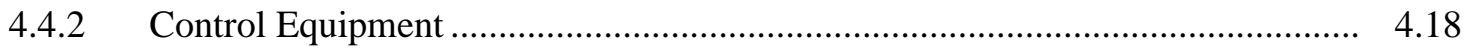

4.5 Pulse Flow Operating Parameters ............................................................................ 4.18

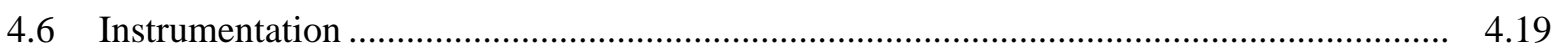

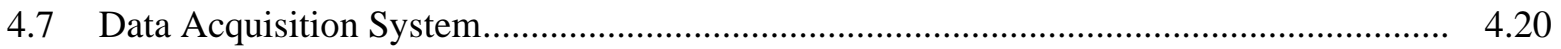

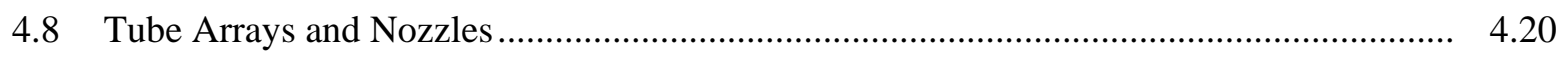

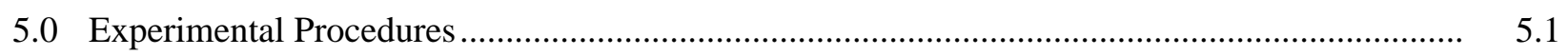

5.1 Testing Overview ................................................................................................ 5.1

5.2 Observation Procedures ......................................................................................... 5.3

5.2.1 Observation Procedures Used in 2007 ............................................................. 5.3

5.2.2 Observation Procedures Used in 2008 ........................................................... 5.6

5.3 Data Acquisition System Calculations.................................................................... 5.11

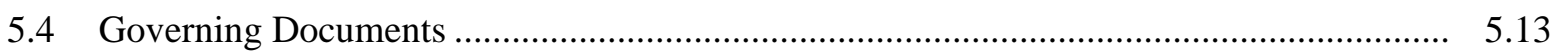

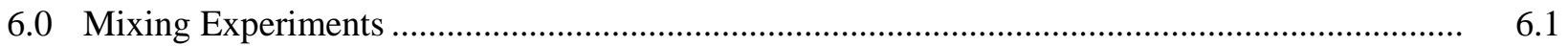




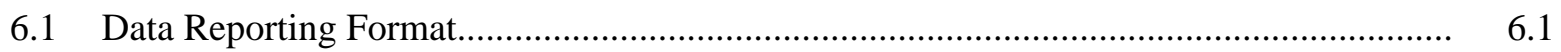

6.2 July 2007 Tests in Mid-Scale Tank with Spherical Head ................................................ 6.6

6.3 Fall 2007 Tests in Mid-Scale Tank with Spherical Head................................................. 6.13

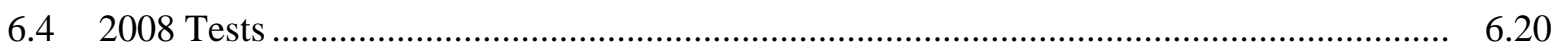

6.4.1 Small-Scale Tank Tests with Elliptical Head ................................................. 6.21

6.4.2 Mid-Scale Tests with Spherical Head ......................................................... 6.27

6.4.3 Large-Scale Tank Tests with Elliptical Head .................................................. 6.30

6.4.4 Large-Scale Tank Tests with Flanged and Dished Head................................... 6.35

6.4.5 Comparisons Among Tanks ............................................................................. 6.38

6.4.6 Repeat and Replicate Tests.................................................................. 6.40

6.5 Concentration Profiles............................................................................................... 6.43

6.5.1 Concentration Profile Measurements .................................................................. 6.43

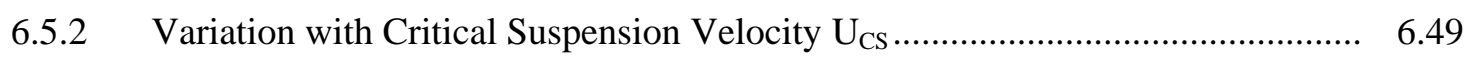

6.5.3 Variation with Radial Location ..................................................................... 6.49

6.5.4 Variation with Tank.................................................................................. 6.52

6.5.5 Variation with Nozzle Diameter and Number of Pulse Tubes ........................... 6.52

6.5.6 Variation with Concentration .......................................................................... 6.56

6.5.7 Variation with Duty Cycle ....................................................................... 6.56

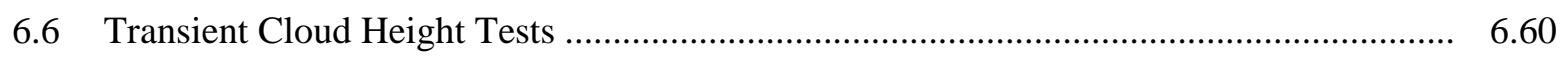

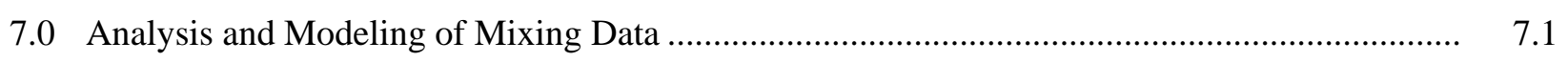

7.1 Analysis and Modeling Approach............................................................................. 7.1

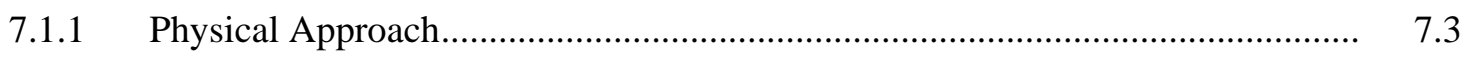

7.1.2 Statistical Multiple Regression Approach ........................................................ 7.3

7.2 Mixing Behavior ................................................................................................... 7.4

7.2.1 Parametric Sensitivity and Functional Form ................................................ 7.5

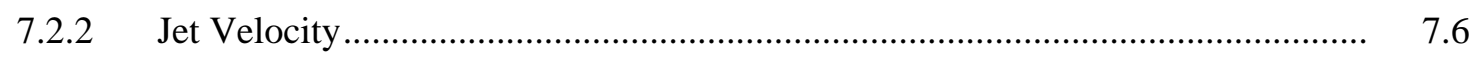

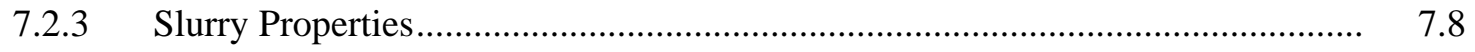

7.2.4 Operational Parameters …........................................................................... 7.13

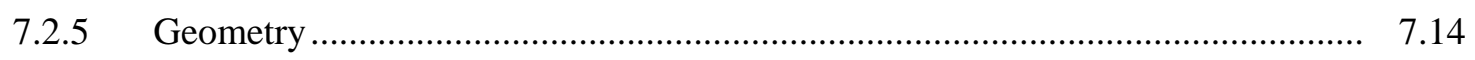

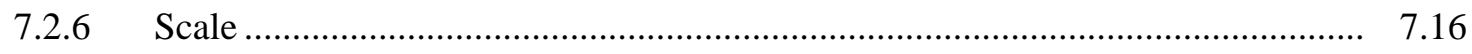

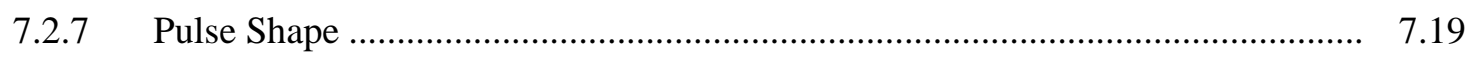

7.2.8 Aspects of Mixing Behavior Included in Model Development........................... 7.20

7.3 Physical Model Results ............................................................................................. $\quad 7.20$

7.3.1 Nondimensional Variables .......................................................................... 7.21

7.3.2 Physical Models for Critical Suspension Velocity and Cloud Height Based on Nondimensional Variables ........................................................................... $\quad 7.23$

7.3.3 Solids Vertical Distribution......................................................................... $\quad 7.29$

7.3.4 Summary of Physical Models........................................................................ $\quad 7.30$ 
7.4 Dimensional and Dimensionally Consistent Models for $\mathrm{U}_{\mathrm{CS}}$ and $\mathrm{H}_{\mathrm{C}}$ Developed Using the Statistical MR Approach

7.4.1 Development of $\mathrm{U}_{\mathrm{CS}}$ and $\mathrm{H}_{\mathrm{C}}$ Dimensional Models without Interaction Terms.... 7.32

7.4.2 $\mathrm{U}_{\mathrm{CS}}$ and $\mathrm{H}_{\mathrm{C}}$ Dimensionally Consistent (Generalized) Models ............................ 7.35

7.4.3 $\mathrm{U}_{\mathrm{CS}}$ and $\mathrm{H}_{\mathrm{C}}$ Dimensional Models with Interaction Terms................................ 7.37

7.5 Comparing Physical, Dimensional, and Generalized Models for $\mathrm{U}_{\mathrm{CS}}$ and $\mathrm{H}_{\mathrm{C}} \ldots \ldots \ldots \ldots \ldots \ldots . . . . . . . .38$

$7.6 \quad$ Possible Model Improvements.................................................................................... 7.39

7.6.1 Possible Improvements to Physical Models ....................................................... 7.39

7.6.2 Possible Improvements to Generalized Models ............................................... 7.40

7.7 Conclusions Regarding Possible Model Improvements .................................................... 7.41

8.0 Applicability and Benchmarking of Mixing Models ..........................................................

8.1 Accounting for Prototypic Conditions ...................................................................... 8.1

8.1.1 Geometry and Operation ........................................................................ 8.1

8.1.2 Accounting for Prototypic Fill Level ............................................................. 8.3

8.1.3 Accounting for Distributions of Particle Size and Density ............................... 8.4

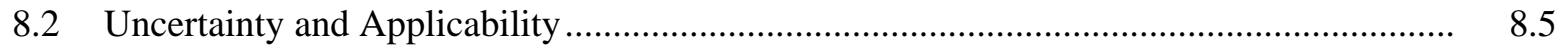

8.2.1 Measurement Uncertainty ......................................................................... 8.5

8.2.2 Experimental Uncertainty ........................................................................ 8.8

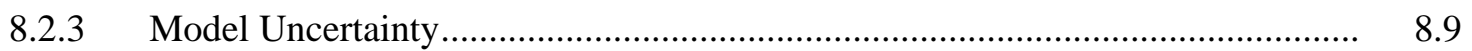

8.2.4 Uncertainty Associated with Applying Models to WTP Vessel Mixing.............. 8.10

8.2.5 Margin for Vessel Performance Evaluations.................................................... 8.11

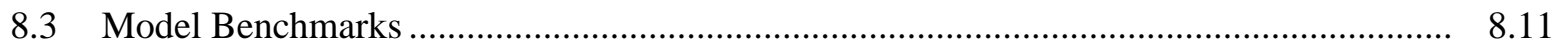

8.3.1 Mixing Tests with AZ-101/102 Filtration Waste Simulant................................. 8.13

8.3.2 Mixing Tests with Glass Bead Simulants........................................................ 8.20

8.3.3 Comparison with CFD Simulation ........................................................... 8.24

8.3.4 Benchmarking Summary ........................................................................... 8.25

9.0 WTP Mixing Systems Performance Examples............................................................... 9.1

9.1 Approach for Predicting Vessel Performance ............................................................... 9.1

9.1.1 Overview of Requirements...................................................................... 9.2

9.1.2 Assumptions and Limitations ........................................................................ 9.2

9.1.3 Uncertainties Related to the Application of the Mixing Models ......................... 9.3

9.1.4 Proposed Evaluation Methodology ................................................................ 9.4

9.2 Input Parameters for Plant Vessels ............................................................................. 9.7

9.2.1 Vessel Geometry and Operational Data .......................................................... 9.7

9.2.2 Waste Property Conditions......................................................................... 9.8

9.2.3 Dimensionless Variable Evaluation ................................................................ 9.9

9.2.4 Hanford Tank AZ-101 PSDD and Settling Velocity ......................................... 9.13

9.3 Vessel Evaluation Examples Using the Physical Models and the Design Point Limits ..... 9.17

9.3.1 FRP-02 A/B/C/D (Design Point) Physical Model............................................ 9.18 
9.3.2 HLP-22 8 m/s, 4-in. Nozzles (Design Point) Physical Model............................. 9.19

9.3.3 HLP-22 12 m/s, 4-in. Nozzles (Design Point) Physical Model........................... 9.. 9.20

9.3.4 HLP-22 8 m/s, 6-in. Nozzles (Design Point) Physical Model............................. 9.21

9.3.5 HLP-22 12 m/s, 6-inch Nozzles (Design Point) Physical Model ........................ 9.22

9.3.6 TCP-01 (Design Point) Physical Model .............................................................. 9.23

9.3.7 TLP-09 A/B (Design Point) Physical Model.................................................... 9.24

9.3.8 PWD-33 (Design Point) Physical Model ........................................................... 9.25

9.3.9 PWD-43 (Design Point) Physical Model ........................................................... 9.26

9.3.10 PWD-44 (Design Point) Physical Model .......................................................... 9.27

9.3.11 FEP-17 A/B (Design Point) Physical Model....................................................... 9.28

9.3.12 PWD-15/16 (Design Point) Physical Model ....................................................... 9.29

9.3.13 UFP-01 A/B (Design Point) Physical Model ..................................................... 9.30

9.3.14 RLD-07 (design point) Physical Model .......................................................... 9.31

9.3.15 RLD-08 (Design Point) Physical Model ......................................................... 9.32

9.3.16 HOP-903/904 (Design Point) Simple Calculation ............................................ 9.33

9.4 Vessel Evaluation Examples with the Physical Models and the Hanford Waste

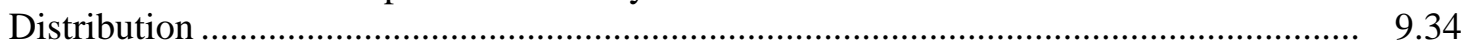

9.4.1 FRP-02 A/B/C/D (Hanford PSDD, $\rho_{\mathrm{l}}=1.1 \mathrm{~g} / \mathrm{cm}^{3}, \mu=1.5 \mathrm{cP}$ fluid) Physical Model ......................................................................................... 9.35

9.4.2 HLP-22 8 m/s, 4-in. (Hanford PSDD, $\rho_{\mathrm{l}}=1.1 \mathrm{~g} / \mathrm{cm}^{3}, \mu=1.5 \mathrm{cP}$ fluid) Physical

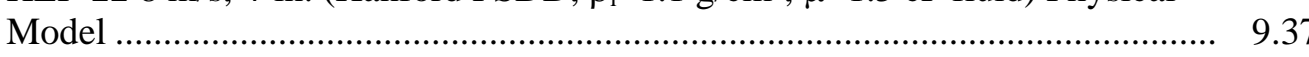

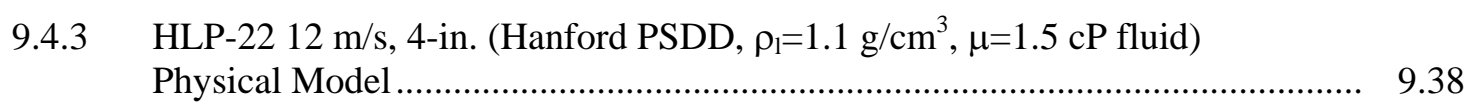

9.4.4 HLP-22 8 m/s, 6-in. (Hanford PSDD, $\rho_{\mathrm{l}}=1.1 \mathrm{~g} / \mathrm{cm}^{3}, \mu=1.5 \mathrm{cP}$ fluid) Physical Model ............................................................................................. 9.40

9.4.5 HLP-22 $12 \mathrm{~m} / \mathrm{s}$, 6-in. (Hanford PSDD, $\rho_{\mathrm{l}}=1.1 \mathrm{~g} / \mathrm{cm}^{3}, \mu=1.5 \mathrm{cP}$ fluid)

9.4.6 TCP-01 (Hanford PSDD, $\rho_{\mathrm{l}}=1.1 \mathrm{~g} / \mathrm{cm}^{3}, \mu=1.5 \mathrm{cP}$ fluid) Physical Model........... 9.42

9.4.7 TLP-09 A/B (Hanford PSDD, $\rho_{\mathrm{l}}=1.1 \mathrm{~g} / \mathrm{cm}^{3}, \mu=1.5 \mathrm{cP}$ fluid) Physical Model .... 9.43

9.4.8 PWD-33 (Hanford PSDD, $\rho_{\mathrm{l}}=1.1 \mathrm{~g} / \mathrm{cm}^{3}, \mu=1.5 \mathrm{cP}$ fluid) Physical Model ......... 9.44

9.4.9 PWD-43 (Hanford PSDD, $\rho_{\mathrm{l}}=1.1 \mathrm{~g} / \mathrm{cm}^{3}, \mu=1.5 \mathrm{cP}$ fluid) Physical Model ......... 9.46

9.4.10 PWD-44 (Hanford PSDD, $\rho_{\mathrm{l}}=1.1 \mathrm{~g} / \mathrm{cm}^{3}, \mu=1.5 \mathrm{cP}$ fluid) Physical Model ......... 9.47

9.4.11 FEP-17 A/B (Hanford PSDD, $\rho_{\mathrm{l}}=1.1 \mathrm{~g} / \mathrm{cm}^{3}, \mu=1.5 \mathrm{cP}$ fluid) Physical Model.... 9.48

9.4.12 PWD-15/16 (Hanford PSDD, $\rho_{\mathrm{l}}=1.1 \mathrm{~g} / \mathrm{cm}^{3}, \mu=1.5 \mathrm{cP}$ fluid) Physical Model .... 9.49

9.4.13 UFP-01 A/B (Hanford PSDD, $\rho_{\mathrm{l}}=1.1 \mathrm{~g} / \mathrm{cm}^{3}, \mu=1.5 \mathrm{cP}$ fluid) Physical Model .... 9.50

9.4.14 RLD-07 (Hanford PSDD, $\rho_{\mathrm{l}}=1.1 \mathrm{~g} / \mathrm{cm}^{3}, \mu=1.5 \mathrm{cP}$ fluid) Physical Model .......... 9.51

9.4.15 RLD-08 (Hanford PSDD, $\rho_{\mathrm{l}}=1.1 \mathrm{~g} / \mathrm{cm}^{3}, \mu=1.5 \mathrm{cP}$ fluid) Physical Model .......... 9.52

9.4.16 HOP-903/904 (Hanford PSDD, $\rho_{\mathrm{l}}=1.1 \mathrm{~g} / \mathrm{cm}^{3}, \mu=1.5 \mathrm{cP}$ fluid) Physical Model.. 9.53

9.5 Vessel Evaluation Examples Using the Generalized Models and the Hanford Waste Distribution 
9.5.1 FRP-02 A/B/C/D (Hanford PSDD, $\rho_{\mathrm{l}}=1.1 \mathrm{~g} / \mathrm{cm}^{3}, \mu=1.5 \mathrm{cP}$ fluid)

Generalized Model

9.5.2 HLP-22 $8 \mathrm{~m} / \mathrm{s}$, 4-in. (Hanford PSDD, $\rho_{\mathrm{l}}=1.1 \mathrm{~g} / \mathrm{cm}^{3}, \mu=1.5 \mathrm{cP}$ fluid) Generalized Model

9.5.3 HLP-22 $12 \mathrm{~m} / \mathrm{s}$, 4-in. (Hanford PSDD, $\rho_{\mathrm{l}}=1.1 \mathrm{~g} / \mathrm{cm}^{3}, \mu=1.5 \mathrm{cP}$ fluid) Generalized Model

9.5.4 HLP-22 $8 \mathrm{~m} / \mathrm{s}$, 6-in. (Hanford PSDD, $\rho_{\mathrm{l}}=1.1 \mathrm{~g} / \mathrm{cm}^{3}, \mu=1.5 \mathrm{cP}$ fluid) Generalized Model

9.5.5 HLP-22 $12 \mathrm{~m} / \mathrm{s}$, 6-in. (Hanford PSDD, $\rho_{\mathrm{l}}=1.1 \mathrm{~g} / \mathrm{cm}^{3}, \mu=1.5 \mathrm{cP}$ fluid) Generalized Model

9.5.6 TCP-01 (Hanford PSDD, $\rho_{\mathrm{l}}=1.1 \mathrm{~g} / \mathrm{cm}^{3}, \mu=1.5 \mathrm{cP}$ fluid) Generalized Model .. 9.60

9.5.7 TLP-09 A/B (Hanford PSDD, $\rho_{\mathrm{l}}=1.1 \mathrm{~g} / \mathrm{cm}^{3}, \mu=1.5 \mathrm{cP}$ fluid) Generalized Model

9.5.8 PWD-33 (Hanford PSDD, $\rho_{\mathrm{l}}=1.1 \mathrm{~g} / \mathrm{cm}^{3}, \mu=1.5 \mathrm{cP}$ fluid) Generalized Model

9.5.9 PWD-43 (Hanford PSDD, $\rho_{\mathrm{l}}=1.1 \mathrm{~g} / \mathrm{cm}^{3}, \mu=1.5 \mathrm{cP}$ fluid) Generalized Model

9.5.10 PWD-44 (Hanford PSDD, $\rho_{\mathrm{l}}=1.1 \mathrm{~g} / \mathrm{cm}^{3}, \mu=1.5 \mathrm{cP}$ fluid) Generalized Model

9.5.11 FEP-17 A/B (Hanford PSDD, $\rho_{\mathrm{l}}=1.1 \mathrm{~g} / \mathrm{cm}^{3}, \mu=1.5 \mathrm{cP}$ fluid) Generalized Model

9.5.12 PWD-15/16 (Hanford PSDD, $\rho_{\mathrm{l}}=1.1 \mathrm{~g} / \mathrm{cm}^{3}, \mu=1.5 \mathrm{cP}$ fluid) Generalized Model

9.5.13 UFP-01 A/B (Hanford PSDD, $\rho_{\mathrm{l}}=1.1 \mathrm{~g} / \mathrm{cm}^{3}, \mu=1.5 \mathrm{cP}$ fluid) Generalized Model

9.5.14 RLD-07 (Hanford PSDD, $\rho_{\mathrm{l}}=1.1 \mathrm{~g} / \mathrm{cm}^{3}, \mu=1.5 \mathrm{cP}$ fluid) Generalized Model

9.5.15 RLD-08 (Hanford PSDD, $\rho_{\mathrm{l}}=1.1 \mathrm{~g} / \mathrm{cm}^{3}, \mu=1.5 \mathrm{cP}$ fluid) Generalized Model

9.5.16 HOP-903/904 (Hanford PSDD, $\rho_{\mathrm{l}}=1.1 \mathrm{~g} / \mathrm{cm}^{3}, \mu=1.5 \mathrm{cP}$ fluid) Generalized Model

9.6 Summary of Vessel Performance Ratios................................................................... 9.71

10.0 Conclusions

10.1

10.1 Model Development

10.1

10.1.1 Recommendations for Using the Models

10.2

10.1.2 Estimates of Confidence.

10.2

10.2 WTP Vessel Performance Prediction Examples

10.3

10.3 Recommendations for Extending Applicability of the Models

10.4

10.4 Major Findings.

10.6

11.0 References 


\section{Figures}

2.1 Illustration of a Typical PJM System in a WTP Vessel .......................................................... 2.4

2.2 Illustration of Nozzle Velocity Transient During PJM Discharge ............................................ 2.5

2.3 Illustration of a Typical PJM System in a WTP Vessel ......................................................... 2.6

2.4 Some Common Mixing Metrics Applied to the 18 Distinct WTP Vessel Configurations ......... 2.14

2.5 Just-Suspended Speed as a Function of Fill Level for Mechanical Agitators ........................... 2.17

2.6 Effects of Fill Level on Cloud Height for Solids Suspension with Mechanical Agitators.......... 2.18

3.1 Cumulative Undissolved Solid Volume Percent as Function of Settling Velocity for Case 3 PSDD

3.2 Cumulative Undissolved Solid Volume Percent as Function of Cumulative Volume Weighted Average Settling Velocity for Case 3 PSDD.

3.3 Cumulative Volume Percent as a Function of Settling Velocity for Hanford PSDD Case 3 and Simulants

3.4 Cumulative Volume Percent as a Function of Cumulative Volume-Weighted Average for Hanford PSDD Case 3 and Simulants

3.5 XLSciTech as-Received Beads; (a) s1d2, (b) s2d2, (c) s1d1, and (d) s2d1.

3.6 As-Received Beads; (a) s1d5; (b) \#3 p2d6, (c) \#8 p1d7, and (d) \#12 p1d8

3.7 PSD around the Mean Particle Size of XLSciTech Microspheres and Potters Beads

3.8 SEM Pictures of Reused s1d2 Beads Removed during Testing.....

3.9 SEM Images of XLSciTech Microspheres at the Completion of Testing.

4.1 Schematic of Conceptual Arrangement of Test Tank and Drive System for HLP-22 Testing ...

4.2 Comparison of Profiles for F\&D and 2:1 Semi-Elliptical Tank Heads.

4.3 Illustration of Jet Impingement Angle, $\theta$, Which Is the Angle between the Vertically Downward Jet and the Bottom of the Tank at the Point of Impingement.

4.4 Illustration of the Change in Impingement Angles for Different Head Profiles .

4.5 Diagram of Small-Scale Test System Showing the HLP-22 12-Tube Array.

4.6 (a) Small-Scale Elliptical-Head Test Tank with Pulse Tubes Installed; (b) Pulse Tubes Mounted in the Tank

4.7 (a) Pump Skid with Pumps and Coriolis Flow Meter; (b) Pump Control Panel ....

4.8 The Pneumatic Butterfly Control Valve Mounted Between Pump Skid and Tank Skid .......

4.9 Diagram of Mid-Scale Test System (not to scale)

4.10 (a) Mid-Scale Test Tank with Pulse Tubes Installed; (b) View from Above with Upper Pulse Tube Support Rack and Static Pressure Tubes Visible

4.11 (a) Pump Skid with Pumps, Bladder Tanks, Suction and Discharge Manifolds; (b) Control Valve Assembly with Blue Pulse Control Valve, Air Control Valve (left of pulse control valve), Control Valve Pressure Reservoir, and Micro Motion Coriolis Flow Meter (behind reservoir)

4.12 Diagram of Large-Scale Test System with the 8-Tube Array (not to scale) ............................ 4.14

4.13 (a) Pulse Tube Assembly before Installation in Tank; (b) Close-up of Pulse Nozzles .............. 4.15

4.14 (a) Large-Scale Vessel Flanged and Dished Head; (b) 0.46-m (18-in.) Acrylic Viewing Port... 4.16 
4.15 (a) Pump Assembly and Coriolis Meters with Test Tank in Background and (b) Upper End of Pump System as it Enters the Manifold (the blue hoses are not yet attached to the pulse tubes); (c) Pump Assembly with Scaffolding, and (d) The Large-Scale Test Stand with the 8-Tube Array and Elliptical Head

4.16 Plan View of 12-Tube HLP-22 F\&D Orientation Between Inner and Outer Rings in the Large-Scale Tank

4.17 Plan View of 12-Tube HLP-22 Elliptical Array Orientation Between Inner and Outer Rings in the Large-Scale Tank

4.18 In-Tank Structural Support for the Tube Array in the Large-Scale Tank (as viewed from underneath the tank through the viewing window)....

4.19 Plan View of 8-Tube Array Orientation Between Inner and Outer Rings in Small-Scale Tank

4.20 (a) HLP-22 12-Tube Tank Array (not to scale); (b) 8-Tube Array in Large-Scale EllipticalHead Tank (not to scale).

5.1 Illustration of Relative Positions of Pulse Tubes and Nozzles in the Mid-Scale Test Tank in HLP-22 (12-tube) Configuration.

5.2 Photograph of Particulate Cloud near End of Pulse in Mid-Scale Tank Showing a Centrally Peaked Cloud and Measuring Tapes Used for Cloud Height Measurement (for information only)

5.3 Illustration of Nozzle Velocity as a Function of Time for Several Discharge Cycles

6.1 View from the Bottom of the Tank Showing (a) Pulse Tubes with No Simulant and (b) Mixing at Some Suspension and BP3 Mixing State.

6.2 Sequence of Photos Showing Growth of Mobilized Area (first 7 photos) and Solids Settling (last 5 photos) During Test 34E_6p1d8Yd_8 Conducted in the Mid-Scale Tank with 6-in. Full-Scale Nozzle, for Simulant p1d8 $\left(\rho_{\mathrm{s}}=2.45 \mathrm{~g} / \mathrm{cm}^{3}, \mathrm{~d}_{50}=90 \mu \mathrm{m}\right)$, Solids Fraction $\left(\phi_{\mathrm{S}}=0.005[\mathrm{Y}]\right)$ for Constant Duty Cycle (DC $\left.=0.18[\mathrm{~d}]\right)$ at Pulse Volume Fraction $\left(\phi_{\mathrm{p}}=0.048[\mathrm{~L} 8]\right)$.

6.3 Cloud Height as a Function of Velocity for Two Concentrations in the Mid-Scale Tank with Spherical Head for a Range of Pulse Volume Fractions: (a) Solids Fraction $\phi_{\mathrm{s}}=0.005$ [Y], (b) Solids Fraction $\phi_{\mathrm{S}}=0.016[\mathrm{X}]$

6.4 Cloud Height as a Function of Velocity for Two Duty Cycles in the Mid-Scale Tank with Spherical Head for a Range of Pulse Volume Fractions: (a) DC $=0.33$ [c], (b) DC $=0.18$ [d]

6.5 Cloud Height as Function of Velocity for Simulants p1d7 $\left(\rho_{\mathrm{s}}=2.45 \mathrm{~g} / \mathrm{cm}^{3}, \mathrm{~d}_{50}=178 \mu \mathrm{m}\right)$, p1d8 $\left(\rho_{\mathrm{s}}=2.45 \mathrm{~g} / \mathrm{cm}^{3}, \mathrm{~d}_{50}=90 \mu \mathrm{m}\right)$, and p2d6 $\left(\rho_{\mathrm{s}}=2.46 \mathrm{~g} / \mathrm{cm}^{3}, \mathrm{~d}_{50}=766 \mu \mathrm{m}\right)$ for Two Concentrations in the Mid-Scale Tank with Spherical Head: (a) Linear, (b) Log

6.6 Cloud Height as Function of Velocity for Two Duty Cycles for PJM Combinations: (a) DC $=0.18[\mathrm{~d}]$, (b) DC $=0.33[\mathrm{c}]$

6.7 Cloud Height as Function of Velocity for Two Duty Cycles for PJM Combinations: (a) DC $=0.18[\mathrm{~d}]$, (b) DC $=0.33[\mathrm{c}]$

6.8 Cloud Height as Function of Velocity for Two Fill Heights: H/D=0.7, Rtn/D=0.6, with a 6 in. Full-Scale Nozzle at Solids Fraction $\left(\phi_{\mathrm{S}}=0.005[\mathrm{Y}]\right)$, for Constant Duty Cycle (DC = 0.18 [d] $)$ at Pulse Volume Fraction $\left(\phi_{\mathrm{p}}=0.05\right)$ and Nozzle Combinations $\left(\mathrm{N}_{\mathrm{O}} / \mathrm{N}_{\mathrm{I}}=8 / 4\right.$ [_1] pink, 4/4 [_0] orange, 0/4 [_9] green) for Simulant p1d7 $\left(\rho_{\mathrm{s}}=2.45 \mathrm{~g} / \mathrm{cm}^{3}, \mathrm{~d}_{50}=178 \mu \mathrm{m}\right) \ldots \ldots .$. 
6.9 Cloud Height as Function of Velocity Comparing Results in July and Fall 2007 for Continuous Flow with d 0.4 in. Full-Scale, Solids Fraction $\left(\phi_{\mathrm{S}}=0.005\right.$ [Y]) for Constant DC (1-continuous flow) for Simulant p1d7 $\left(\rho_{\mathrm{s}}=2.45 \mathrm{~g} / \mathrm{cm}^{3}, \mathrm{~d}_{50}=178 \mu \mathrm{m}\right)$ and Data Sets Fall 2007 green, July 2007 orange and pink.

6.10 Cloud Height as Function of Velocity for Seven Concentrations, (a) all Concentrations, (b) 5 Concentrations

6.11 Cloud Height as Function of Velocity for Two Solids Fractions: (a) ( $\phi_{\mathrm{S}}=0.00155$ [Z]), (b) $\left(\phi_{\mathrm{S}}=0.005[\mathrm{Y}]\right)$

6.12 Cloud Height as Function of Velocity for Four Full-Scale Nozzle Diameters in Two Tank Configurations.

6.13 Cloud Height as Function of Velocity for Different Simulants

6.14 Cloud Height as a Function of Velocity for Three Simulants near $170 \mu \mathrm{m}$ Median Diameter...

6.15 Cloud Height as a Function of Velocity for Three Duty Cycles: (a) Duty Cycle $=0.18$ [d], (b) Duty Cycle $=0.33$ [c]. (c) Duty Cycle $=0.66$ [e].

6.16 Cloud Height as Function of Velocity for Three Duty Cycles (DC = 0.18 [d] gold [o], 0.33 [c] yellow [o], 0.66 [e] lime green [o])

6.17 Cloud Height as a Function of Velocity for Two Tank Configurations, HLP-22 (70E 4-in. full-scale nozzle 12 pulse tube array gold [o]) and 8TA (70E8 6-in. full-scale nozzle eight pulse tube array).

6.18 Cloud Height as Function of Velocity for Three Simulants: s1d2 $\left(\rho_{\mathrm{s}}=2.48 \mathrm{~g} / \mathrm{cm}^{3}, \mathrm{~d}_{50}=69\right.$ $\mu \mathrm{m})$ gold [o], s1d1 $\left(\rho_{\mathrm{s}}=2.46 \mathrm{~g} / \mathrm{cm}^{3}, \mathrm{~d}_{50}=166 \mu \mathrm{m}\right)$ aqua triangle, and s2d2 $\left(\rho_{\mathrm{s}}=4.18\right.$ $\left.\mathrm{g} / \mathrm{cm}^{3}, \mathrm{~d}_{50}=76 \mu \mathrm{m}\right)$ red diamond

6.19 Cloud Height as a Function of Velocity for Four Duty Cycles (DC = 0.18 [d] yellow [o], 0.25 [f] gold triangle [o], 0.33 [c] orange [o], 0.66 [e] red square).

6.20 Comparison of Tank Heads at Large Scale: 70E with Elliptical and 70F with F\&D Head ........

6.21 Comparison of Small, Mid-, Large Scale: (a) s2d2 ( $\left.\rho_{\mathrm{s}}=4.18 \mathrm{~g} / \mathrm{cm}^{3}, \mathrm{~d}_{50}=76 \mu \mathrm{m}\right)$ Shown at $15 \mathrm{E}$ and $70 \mathrm{E}$ with Elliptical, and 70F with Flanged and Dished Head; (b) s1d2 ( $\rho_{\mathrm{s}}=2.48$ $\left.\mathrm{g} / \mathrm{cm}^{3}, \mathrm{~d}_{50}=69 \mu \mathrm{m}\right)$ and $\mathrm{p} 1 \mathrm{~d} 8\left(\rho_{\mathrm{s}}=2.45 \mathrm{~g} / \mathrm{cm}^{3}, \mathrm{~d}_{50}=90 \mu \mathrm{m}\right)$ in all vessels

6.22 Comparison of Six Simulants in Four Tanks: (a) Linear Scale (b) Log Scale

6.23 Examples of Solids concentration by Volume as a Function of Cycle Fraction at an Elevation of $\mathrm{H} / \mathrm{D}=0.2$ and Radially Located at the Tank Center

6.24 Solids Concentration by Volume Profile Plots showing Minimum, Average, Maximum, and Standard Deviation of Concentration Measured for All Data Points

6.25 Comparison of Dimensional Profiles Below, at, or Above $U_{\mathrm{CS}}$

6.26 Comparison of Average Radial Concentration Profiles for Each Test at $\mathrm{R}=0$ (diamond symbol), 0.5 (triangle symbol), and 0.9 (square symbol) for Large-Scale F\&D and Elliptical Bottom Tanks at and Below $\mathrm{U}_{\mathrm{CS}}$ for Pulse Volume Fraction 0.05.

6.27 Comparison of Nondimensional Average Radial Concentration Profiles Across Tests at $\mathrm{R}=0$, 0.5, 0.9 for the Large-scale Flanged and Dished and Elliptical Bottomed Tanks at and below $\mathrm{U}_{\mathrm{CS}}$ (purple circle $<\mathrm{U}_{\mathrm{CS}}$ ) for Pulse Volume Fraction of 0.05 .

6.28 Concentration Profiles at $\mathrm{U}_{\mathrm{CS}}$ in the 15E, 34S, 70E, and 70F Tanks Segregated by Tank: (a-d) Dimensional Plots, (e-h) Nondimensional Plots 
6.29 Comparison of Tank Head Shape for Small-Scale Elliptical (15E, aqua diamonds) MidScale Spherical (shown as 34E, dark blue triangles) and Large-Scale F\&D (70E red squares) and Elliptical (70E green diamonds) Bottom Tanks at $\mathrm{U}_{\mathrm{CS}}$

6.30 Comparison of Dimensional and Nondimensional Plots of Pulse Tube Array (HLP-22 or 8TA), Number of Operating Pulse Tubes (4, 8, or 12) and Nozzle Diameter (4, 6, 8.5 [M] and 11.8 [L]in. Full Scale) for Small-Scale Elliptical (15E) and Large-Scale F\&D (70F) and Elliptical (70E) Bottom Tanks at $\mathrm{U}_{\mathrm{CS}}$

6.31 Concentration Profiles for the Five Simulants in the HLP-22 Tank Configuration.

6.32 Comparing Profiles for Simulants and Tanks at $\mathrm{U}_{\mathrm{CS}}$ for HLP-22 Tank Configuration as Solids Concentration $\phi_{\mathrm{S}}$ Increases from 0.00150 to 0.06 .

6.33 Concentration Profiles at Varying Duty Cycles.....

6.34 Cloud Height Transient Data Shown Dimensionally and Nondimensionally on Linear and Log Scales

7.1 Illustration of the Physical Meaning of the Sensitivity Coefficient; (a) Linear and Nonlinear Behavior, (b) Interaction between Variables.

7.2 Examples of $\mathrm{H}_{\mathrm{C}}$ Data as a Function of Jet Velocity; (a) Linear Scale, (b) Logarithmic Scale with $\mathrm{U}_{\mathrm{CS}}$ Conditions Denoted by Black Center.

7.3 Illustration of the Completely-Suspended Condition as an Energy Maxima with $\mathrm{U}_{\mathrm{CS}}$ Conditions Denoted by Black Center.

7.4 Behavior of $\mathrm{H}_{\mathrm{C}}$ Relative to Critical Suspension Condition for $\mathrm{U} \geq \mathrm{U}_{\mathrm{CS}}$ (all test conditions shown)...

7.5 Sensitivity Coefficients (effective power-law exponents) for Terminal Settling Velocity Given by Eq. (7.5a) with simulant designations shown on vertical (constant Ga) lines (FIO) ...

7.6 Illustrating the Benefit of Using Setting Velocity to Model $U_{C S}$ Data; (a) Dimensional, (b) Nondimensional.

7.7 Illustration of the Benefit of Using Setting Velocity to Model Cloud Height Data: (a) $\mathrm{F}_{\mathrm{CST}}$ Plotted as a Function of $\mathrm{Ga}(\mathrm{s}-1)^{1 / 2}$, (b) $\mathrm{F}_{\mathrm{CST}}$ Plotted as a Function of $\mathrm{U} / \mathrm{U}_{\mathrm{T}}$.

7.8 Effect of Solids Loading on $U_{C S}$ for Five Simulants in Small-Scale Tests: (a) $U_{C S} / U_{T}$ Plotted as a Function of $\phi_{\mathrm{S}}$, (b) $\mathrm{U}_{\mathrm{CS}} / \mathrm{U}_{\mathrm{TH}}$ Plotted as a Function of $\phi_{\mathrm{S}}$

7.9 Effect of Solids Loading on Cloud Height for Five Simulants in Small-Scale Tests:

(a) $1 / \mathrm{F}_{\mathrm{CST}}$ Plotted as a Function of $\mathrm{U}_{\mathrm{CS}} / \mathrm{U}_{\mathrm{T}}$, (b) $\phi_{\mathrm{S}} / \mathrm{F}_{\mathrm{CS} \text { TH }}\left(\mathrm{Phi} \mathrm{S}_{\mathrm{S}} / \mathrm{F}_{\mathrm{CS} \mathrm{TH}}\right)$ Plotted as a Function of $\mathrm{U}_{\mathrm{CS}} / \mathrm{U}_{\mathrm{TH}}$

7.10 Effect of Duty Cycle on Solids Suspension with Data from Small-Scale Vessel with Simulant s1d2 and $\phi_{\mathrm{S}}=0.015$; (a) $\mathrm{U}_{\mathrm{CS}}$, and (b) Cloud Height.

7.11 Effect of Pulse Volume Fraction ( $\phi_{\mathrm{p}}$ ) on Solids Suspension: (a) $U_{C S}$, (b) $H_{C}$ Data from 15-in. Vessel with Simulant s1d2 and $\phi_{\mathrm{S}}=0.015$.

7.12 Effect of Nozzle Diameter, Jet Diameter, and Number of Operating Pulse Tubes for Small-Scale Tank: (a) $\mathrm{U}_{\mathrm{CS}} / \mathrm{U}_{\mathrm{T}}$ as a Function of d, (b) $\mathrm{U}_{\mathrm{CS}} / \mathrm{U}_{\mathrm{T}}$ as a Function of $\phi_{\mathrm{J}}$.

7.13 Scale Dependence of $\mathrm{U}_{\mathrm{CS}}$ : $\mathrm{U}_{\mathrm{CS}} / \mathrm{U}_{\mathrm{CS} 15}$ versus Tank Diameter with Fit of Scale-up Data Showing Scale-Up Exponent of 0.276 .

7.14 Scale-up Exponent for Average Cloud Parameters $\left(\mathrm{U}^{\mathrm{n}} / \mathrm{H}_{\mathrm{C}}\right)_{\text {ave }}$ as a Function of Velocity Exponent, $\mathrm{n}$

7.15 Illustration of Nozzle Velocity Transient during PJM Discharge 
7.17 Fit of $\mathrm{U}_{\mathrm{CS}}$ Model to Experimental Data Using Nondimensional Variables $\mathrm{U}_{\mathrm{CS}} / \mathrm{U}_{\mathrm{TH}}$ and $\mathrm{D} / \mathrm{Ga}^{0.5}$

7.18 Fit of $\mathrm{H}_{\mathrm{C}}$ Model to Experimental Data Using Nondimensional Variables $\ln \left(\mathrm{H}_{\mathrm{C}}^{*}\right)$ and $\mathrm{U} / \mathrm{U}_{\mathrm{TH}}$.. $\quad 7.26$

7.19 Fit of $\mathrm{H}_{\mathrm{C}}$ Model to Experimental Data Using Nondimensional Variables $\mathrm{H}_{\mathrm{C}}^{*}$ and $\mathrm{U} / \mathrm{U}_{\mathrm{TH}} \ldots \ldots \ldots . \quad 7.26$

7.20 Log-Log Plot of Predicted Versus Measured $U_{\mathrm{CS}}(\mathrm{m} / \mathrm{s})$ Values for the Nondimensional Model in Eq. (7.41)

7.21 Log-Log Plot of Predicted Versus Measured $\mathrm{H}_{\mathrm{C}}(\mathrm{m})$ Values for the Nondimensional Model in Eq. (7.43)

7.22 Average Solids Vertical Distribution Data for All Tests; (a) Concentration as a Function of Elevation, (b) Normalized Profile for Estimating Concentration on Tank Bottom

7.23 Maximum Solids Vertical Distribution Data for all Tests; (a) Concentration as a Function of Elevation, (b) Normalized Profiles for Estimating Concentration on Tank Bottom......

7.24 Log-Log Plot of Predicted Versus Measured $U_{C S}(\mathrm{~m} / \mathrm{s})$ Values for the Nine-Term Dimensional Model in Eq. (7.52b) Fit to Full Data Set

7.25 Log-Log Plot of Predicted Versus Measured $\mathrm{H}_{\mathrm{C}}$ for 11-Term Dimensional Model in Eq. (7.53b) Fit to Full Data Set

7.26 Log-Log Plot of PvM U $U_{\mathrm{CS}}(\mathrm{m} / \mathrm{s})$ Values for the Nine-Term Generalized Model in Eq. (7.54b) with Eight Coefficients Fit to Full Data Set

7.27 Log-Log Plot of PvM H $\mathrm{H}_{\mathrm{C}}(\mathrm{m})$ Values for the 11-Term Generalized Model in Eq. (7.55b) with 10 Coefficients Fit to the Full Data Set.

8.1 Effective Settling Velocity Associated with Vertical Entrainment from Pump Suction Returns (FIO)

8.2 Illustration of How Finite Fill Level Affects Maximum Concentration

8.3 Illustration of How Stratification Results in Higher Effective Settling Velocities for Noncohesive Solids with a Broad Size Distribution: (a) Settling Velocity for a Well-Mixed Slurry, (b) Settling Velocity for a Stratified Slurry.

8.4 Prototypic PJM Tank in 336 Building (shown here with 8-PJM shrouded PJM cluster)

8.5 Concentration Profiles for Case 1: $17.6 \mathrm{wt} \%$ and Maximum Drive Using the (a) Physical Model and (b) Generalized Model, with $\mathrm{U}_{\mathrm{T}}=\mathrm{U}_{90}$ Optimized for the Physical Model

8.6 Concentration Profiles for Case 2: 17.6 wt\% and 50\% of Maximum Drive Using (a) Physical Model and (b) Generalized Model, with $\mathrm{U}_{\mathrm{T}}=\mathrm{U}_{90}$ Optimized for the Physical Model

8.7 Concentration Profiles for Case 3: $17.6 \mathrm{wt} \%, 10 \%$ of Maximum Drive Case Using (a) the Physical Model and (b) the Generalized Model, with $\mathrm{U}_{\mathrm{T}}=\mathrm{U}_{90}$ Optimized for the Physical Model

8.8 Concentration Profiles for Case 4: 28.3 wt\% and Maximum Drive Using (a) the Physical Model and (b) the Generalized Model, with $\mathrm{U}_{\mathrm{T}}=\mathrm{U}_{90}$ Optimized for the Physical Model

8.9 Concentration Profiles for Case 5: $28.3 \mathrm{wt} \%$ and 50\% of Maximum Drive Using (a) the Physical Model and (b) the Generalized Model, with $\mathrm{U}_{\mathrm{T}}=\mathrm{U}_{90}$ Optimized for the Physical Model

8.10 Concentration Profiles for Case 6: $28.3 \mathrm{wt} \%$ and 10\% of Maximum Drive Using (a) the Physical Model and (b) the Generalized Model, with $\mathrm{U}_{\mathrm{T}}=\mathrm{U}_{90}$ Optimized for the Physical Model 
8.11 Concentration Profiles for Case 7: $10 \mathrm{wt} \%$ and 75- $\mu \mathrm{m}$ Glass Beads Using (a) the Physical Model and (b) the Generalized Model, with $\mathrm{U}_{\mathrm{T}}=\mathrm{U}_{50}$ Optimized for the Physical Model

8.12 Concentration Profiles for Case 8: $20 \mathrm{wt} \%$ and 35- $\mu \mathrm{m}$ Glass Beads with 4 PJMs Operating Using (a) the Physical Model and (b) the Generalized Model, with $\mathrm{U}_{\mathrm{T}}=\mathrm{U}_{60}$ Optimized for the Physical Model.

8.13 Concentration Profiles for Case 9: $20 \mathrm{wt} \%$ and 35- $\mu \mathrm{m}$ Glass Beads with 2 PJMs Operating Using (a) the Physical Model and (b) the Generalized Model, with $\mathrm{U}_{\mathrm{T}}=\mathrm{U}_{60}$ Optimized for the Physical Model.

8.14 Velocity Profile (Drive Function) for HLP-22 (FIO).

8.15 Comparison of Model-Predicted Concentration Profiles with Predictions from CFD Simulation of HLP-22, 12 m/s, Normal Firing Case Using (a) the Physical Model and (b) the Generalized Model

9.1 Performance Ratio Example Using FEP-17 A/B

9.2 Test Data and Application Range for $\frac{\mathrm{U}}{\mathrm{U}_{\mathrm{TH}}}$

9.3 Test Data and Application Range for $\frac{\mathrm{D}^{*}}{\mathrm{Ga}^{0.5}}$

9.4 Test Data and Application Range for $\frac{\mathrm{d}}{\mathrm{D}}$.

9.5 Test Data and Application Range for $\frac{\mathrm{U}_{\mathrm{T}}}{\mathrm{U}}$

9.6 Test Data and Application Range for $\frac{(\mathrm{s}-1) \mathrm{gD}}{\mathrm{U}^{2}}$

9.7 Test Data and Application Range for $\frac{(\mathrm{s}-1) \mathrm{gD}}{\mathrm{U}_{\mathrm{T}}{ }^{2}}$

9.8 Cumulative Undissolved Solids Volume Fraction as a Function of Settling Velocity for AZ-101.....

9.9 Cumulative Undissolved Solids Volume Fraction as a Function of Cumulative Volume-Weighted Average Settling Velocity for AZ-101

9.10 Physical Model Predictions for FRP-02 A/B/C/D: (a) Concentration Profile at Maximum Fill, (b) Inlet Concentration and Suspension Ratio, (c) Maximum Solids Concentration Versus Loading Design Conditions, (d) $\mathrm{U}_{\mathrm{CS}}$ Versus Vessel Loading

9.11 Physical Model Predictions for HLP-22: (a) Concentration Profile at Max Fill, (b) Inlet Concentration and Suspension Ratio, (c) Maximum Solids Concentration Versus Loading Design Conditions, (d) $\mathrm{U}_{\mathrm{CS}}$ Versus Loading at $8 \mathrm{~m} / \mathrm{s}$, 4-in. Nozzles (design point).

9.12 Physical Model Predictions for HLP-22: (a) Concentration Profile at Max Fill, (b) Inlet Concentration and Suspension Ratio, (c) Maximum Solids Concentration Versus Loading Design Conditions, (d) $U_{\mathrm{CS}}$ Versus Loading at $12 \mathrm{~m} / \mathrm{s}$, 4-in. Nozzles (design point)

9.13 Physical Model Predictions for HLP-22: (a) Concentration Profile at Max Fill, (b) Inlet Concentration and Suspension Ratio, (c) Maximum Solids Concentration Versus Loading Design Conditions, (d) $\mathrm{U}_{\mathrm{CS}}$ Versus Loading at $8 \mathrm{~m} / \mathrm{s}$, 6-in. Nozzles (design point)..... 
9.14 Physical Model Predictions for HLP-22: (a) Concentration Profile at Max Fill, (b) Inlet Concentration and Suspension Ratio, (c) Maximum Solids Concentration Versus Loading Design Conditions, (d) $\mathrm{U}_{\mathrm{CS}}$ Versus Loading at $12 \mathrm{~m} / \mathrm{s}$, 6-in. Nozzles (design point).

9.15 Physical Model Predictions for TCP-01: (a) Concentration Profile at Max Fill, (b) Inlet Concentration and Suspension Ratio, (c) Maximum Solids Concentration Versus Loading Design Conditions, (d) $\mathrm{U}_{\mathrm{CS}}$ Versus Loading (design point).

9.16 Physical Model Predictions for TLP-09 A/B: (a) Concentration Profile at Max Fill, (b) Inlet Concentration and Suspension Ratio, (c) Maximum Solids Concentration Versus Loading Design Conditions, (d) $\mathrm{U}_{\mathrm{CS}}$ Versus Loading (design point) ...

9.17 Physical Model Predictions for PWD-33: (a) Concentration Profile at Max Fill, (b) Inlet Concentration and Suspension Ratio, (c) Maximum Solids Concentration Versus Loading Design Conditions, (d) $\mathrm{U}_{\mathrm{CS}}$ Versus Loading for PWD-33 (design point).

9.18 Physical Model Predictions for PWD-43: (a) Concentration Profile at Max Fill, (b) Inlet Concentration and Suspension Ratio, (c) Maximum Solids Concentration Versus Loading Design Conditions, (d) $\mathrm{U}_{\mathrm{CS}}$ Versus Loading (design point).

9.19 Physical Model Predictions for PWD-44: (a) Concentration Profile at Max Fill, (b) Inlet Concentration and Suspension Ratio, (c) Maximum Solids Concentration Versus Loading Design Conditions, (d) $\mathrm{U}_{\mathrm{CS}}$ Versus Loading (design point)....

9.20 Physical Model Predictions for FEP-17 A/B: (a) Concentration Profile at Max Fill, (b) Inlet Concentration and Suspension Ratio, (c) Maximum Solids Concentration Versus Loading Design Conditions, (d) $\mathrm{U}_{\mathrm{CS}}$ Versus Loading (design point)

9.21 Physical Model Predictions for PWD-15/16: (a) Concentration Profile at Max Fill, (b) Inlet Concentration and Suspension Ratio, (c) Maximum Solids Concentration Versus Loading Design Conditions, (d) $\mathrm{U}_{\mathrm{CS}}$ Versus Loading (design point).

9.22 Physical Model Predictions for UFP-01 A/B: (a) Concentration Profile at Max Fill, (b) Inlet Concentration and Suspension Ratio, (c) Maximum Solids Concentration Versus Loading Design Conditions, (d) $\mathrm{U}_{\mathrm{CS}}$ Versus Loading (design point) .....

9.23 Physical Model Predictions for RLD-07: (a) Concentration Profile at Max Fill, (b) Inlet Concentration and Suspension Ratio, (c) Maximum Solids Concentration Versus Loading Design Conditions, (d) $\mathrm{U}_{\mathrm{CS}}$ Versus Loading (design point).

9.24 Physical Model Predictions for RLD-08: (a) Concentration Profile at Max Fill, (b) Inlet Concentration and Suspension Ratio, (c) Maximum Solids Concentration Versus Loading Design Conditions, (d) $\mathrm{U}_{\mathrm{CS}}$ Versus Loading (design point)

9.25 Physical Model Predictions for HOP-903/904: (a) Concentration Profile at Max Fill, (b) Inlet Concentration and Suspension Ratio, (c) Maximum Solids Concentration Versus Loading Design Conditions, (d) $\mathrm{U}_{\mathrm{CS}}$ Versus Loading (design point) ....

9.26 Physical Model Predictions for FRP-02 A/B/C/D: (a) Concentration Profile at Max Fill, (b) Inlet Concentration and Suspension Ratio, (c) Maximum Solids Concentration Versus Loading Design Conditions, (d) $U_{C S}$ Versus Loading (Hanford PSDD, $\rho_{\mathrm{l}}=1.1 \mathrm{~g} / \mathrm{cm}^{3}, \mu=1.5$ cP fluid)

9.27 Physical Model Predictions for HLP-22: (a) Concentration Profile at Max Fill, (b) Inlet Concentration and Suspension Ratio, (c) Maximum Solids Concentration Versus Loading Design Conditions, (d ) $U_{\mathrm{CS}}$ Versus Loading at $8 \mathrm{~m} / \mathrm{s}$, 4-in. Nozzle (Hanford PSDD, $\rho_{\mathrm{l}}=1.1$ $\mathrm{g} / \mathrm{cm}^{3}, \mu=1.5 \mathrm{cP}$ fluid)

9.28 Physical Model Predictions for HLP-22: (a) Concentration Profile at Max Fill, (b) Inlet Concentration and Suspension Ratio, (c) Maximum Solids Concentration Versus Loading 
Design Conditions, (d) $U_{C S}$ Versus Loading at $12 \mathrm{~m} / \mathrm{s}$, 4-in. Nozzle (Hanford PSDD, $\rho_{l}=1.1$ $\mathrm{g} / \mathrm{cm}^{3}, \mu=1.5 \mathrm{cP}$ fluid).

9.29 Physical Model Predictions for HLP-22: (a) Concentration Profile at Max Fill, (b) Inlet Concentration and Suspension Ratio, (c) Maximum Solids Concentration Versus Loading Design Conditions, (d) $U_{\mathrm{CS}}$ Versus Loading at $8 \mathrm{~m} / \mathrm{s}$, 6-in. Nozzle, Hanford PSDD ....

9.30 Physical Model Predictions for HLP-22: (a) Concentration Profile at Max Fill, (b) Inlet Concentration and Suspension Ratio, (c) Maximum Solids Concentration Versus Loading Design Conditions, (d) $U_{C S}$ Versus Loading at $12 \mathrm{~m} / \mathrm{s}$ with a 6-in. Nozzle (Hanford PSDD, $\rho_{\mathrm{l}}=1.1 \mathrm{~g} / \mathrm{cm}^{3}, \mu=1.5 \mathrm{cP}$ fluid)

9.31 Physical Model Predictions for TCP-01: (a) Concentration Profile at Max Fill, (b) Inlet Concentration and Suspension Ratio, (c) Maximum Solids Concentration Versus Loading Design Conditions, (d) $U_{C S}$ Versus Loading (Hanford PSDD, $\rho_{\mathrm{l}}=1.1 \mathrm{~g} / \mathrm{cm}^{3}, \mu=1.5 \mathrm{cP}$ fluid) ...

9.32 Physical Model Predictions for TLP-09 A/B: (a) Concentration Profile at Max Fill, (b) Inlet Concentration and Suspension Ratio, (c) Maximum Solids Concentration Versus Loading Design Conditions, (d) $U_{C S}$ Versus Loading (Hanford PSDD, $\rho_{\mathrm{l}}=1.1 \mathrm{~g} / \mathrm{cm}^{3}, \mu=1.5$ cP fluid)

9.33 Physical Model Predictions for PWD-33: (a) Concentration Profile at Max Fill, (b) Inlet Concentration and Suspension Ratio, (c) Maximum Solids Concentration Versus Loading Design Conditions, (d) $U_{C S}$ Versus Loading (Hanford PSDD, $\rho_{\mathrm{l}}=1.1 \mathrm{~g} / \mathrm{cm}^{3}, \mu=1.5 \mathrm{cP}$ fluid) ...

9.34 Physical Model Predictions for PWD-43: (a) Concentration Profile at Max Fill, (b) Inlet Concentration and Suspension Ratio, (c) Maximum Solids Concentration Versus Loading Design Conditions, (d) $U_{C S}$ Versus Loading (Hanford PSDD, $\rho_{\mathrm{l}}=1.1 \mathrm{~g} / \mathrm{cm}^{3}, \mu=1.5 \mathrm{cP}$ fluid) ...

9.35 Physical Model Predictions for PWD-44: (a) Concentration Profile at Max Fill, (b) Inlet Concentration and Suspension Ratio, (c) Maximum Solids Concentration Versus Loading Design Conditions, (d) $U_{C S}$ Versus Loading (Hanford PSDD, $\rho_{\mathrm{l}}=1.1 \mathrm{~g} / \mathrm{cm}^{3}, \mu=1.5 \mathrm{cP}$ fluid) ...

9.36 Physical Model Predictions for FEP-17 A/B: (a) Concentration Profile at Max Fill, (b) Inlet Concentration and Suspension Ratio, (c) Maximum Solids Concentration Versus Loading Design Conditions, (d) $U_{\mathrm{CS}}$ Versus Loading (Hanford PSDD, $\rho_{\mathrm{l}}=1.1 \mathrm{~g} / \mathrm{cm}^{3}, \mu=1.5$ cP fluid)

9.37 Physical Model Predictions for PWD-15/16: (a) Concentration Profile at Max Fill, (b) Inlet Concentration and Suspension Ratio, (c) Maximum Solids Concentration Versus Loading Design Conditions, (d) $U_{\mathrm{CS}}$ Versus Loading (Hanford PSDD, $\rho_{\mathrm{l}}=1.1 \mathrm{~g} / \mathrm{cm}^{3}, \mu=1.5 \mathrm{cP}$ fluid) ...

9.38 Physical Model Predictions for UFP-01 A/B: (a) Concentration Profile at Max Fill, (b) Inlet Concentration and Suspension Ratio, (c) Maximum Solids Concentration Versus Loading Design Conditions, (d) $U_{C S}$ Versus Loading (Hanford PSDD, $\rho_{\mathrm{l}}=1.1 \mathrm{~g} / \mathrm{cm}^{3}, \mu=1.5$ cP fluid)

9.39 Physical Model Predictions for RLD-07: (a) Concentration Profile at Max Fill, (b) Inlet Concentration and Suspension Ratio, (c) Maximum Solids Concentration Versus Loading Design Conditions, (d) $\mathrm{U}_{\mathrm{CS}}$ Versus Loading (Hanford PSDD, $\rho_{\mathrm{l}}=1.1 \mathrm{~g} / \mathrm{cm}^{3}, \mu=1.5 \mathrm{cP}$ fluid) ...

9.40 Physical Model Predictions for RLD-08: (a) Concentration Profile at Max Fill, (b) Inlet Concentration and Suspension Ratio, (c) Maximum Solids Concentration Versus Loading Design Conditions, (d) $U_{\mathrm{CS}}$ Versus Loading (Hanford PSDD, $\rho_{\mathrm{l}}=1.1 \mathrm{~g} / \mathrm{cm}^{3}, \mu=1.5 \mathrm{cP}$ fluid) ... 9.52

9.41 Physical Model Predictions for HOP-903/904: (a) Concentration Profile at Max Fill, (b) Inlet Concentration and Suspension Ratio, (c) Maximum Solids Concentration Versus Loading for Design Condition, (d) $U_{C S}$ Versus Loading (Hanford PSDD, $\rho_{\mathrm{l}}=1.1 \mathrm{~g} / \mathrm{cm}^{3}$, $\mu=1.5 \mathrm{cP}$ fluid . 
9.42 Generalized Model Predictions for FRP-02 A/B/C/D: (a) Concentration Profile at Max Fill, (b) Inlet Concentration and Suspension Ratio, (c) Maximum Solids Concentration Versus Loading Design Conditions, (d) $U_{C S}$ Versus Loading (Hanford PSDD, $\rho_{1}=1.1 \mathrm{~g} / \mathrm{cm}^{3}$, $\mu=1.5 \mathrm{cP}$ fluid)

9.43 Generalized Model Predictions for HLP-22: (a) Concentration Profile at Max Fill, (b) Inlet Concentration and Suspension Ratio, (c) Maximum Solids Concentration Versus Loading Design Conditions, (d) $U_{\mathrm{CS}}$ Versus Loading (8 m/s, 4-in. nozzles, Hanford PSDD).

9.44 Generalized Model Predictions for HLP-22: (a) Concentration Profile at Max Fill, (b) Inlet Concentration and Suspension Ratio, (c) Maximum Solids Concentration Versus Loading Design Conditions, (d) $\mathrm{U}_{\mathrm{CS}}$ Versus Loading (12 m/s, 4-in. nozzles, Hanford PSDD).

9.45 Generalized Model Predictions for HLP-22: (a) Concentration Profile at Max Fill, (b) Inlet Concentration and Suspension Ratio, (c) Maximum Solids Concentration Versus Loading Design Conditions, (d) $U_{\mathrm{CS}}$ Versus Loading (Hanford PSDD, 8 m/s, 6-in. nozzles).

9.46 Generalized Model Predictions for HLP-22: (a) Concentration Profile at Max Fill, (b) Inlet Concentration and Suspension Ratio, (c) Maximum Solids Concentration Versus Loading Design Conditions, (d) $U_{\text {CS }}$ Versus Loading (Hanford PSDD, 12 m/s, 6-in. nozzles).

9.47 Generalized Model Predictions for TCP-01: (a) Concentration Profile at Max Fill, (b) Inlet Concentration and Suspension Ratio, (c) Maximum Solids Concentration Versus Loading Design Conditions, (d) $U_{C S}$ Versus Loading (Hanford PSDD, $\rho_{\mathrm{l}}=1.1 \mathrm{~g} / \mathrm{cm}^{3}, \mu=1.5 \mathrm{cP}$ fluid).

9.48 Generalized Model Predictions for TLP-09 A/B: (a) Concentration Profile at Max Fill, (b) Inlet Concentration and Suspension Ratio, (c) Maximum Solids Concentration Versus Loading Design Conditions, (d) $U_{C S}$ Versus Loading (Hanford PSDD, $\rho_{\mathrm{l}}=1.1 \mathrm{~g} / \mathrm{cm}^{3}$, $\mu=1.5 \mathrm{cP}$ fluid)

9.49 Generalized Model Predictions for PWD-33: (a) Concentration Profile at Max Fill, (b) Inlet Concentration and Suspension Ratio, (c) Maximum Solids Concentration Versus Loading Design Conditions; (d) $\mathrm{U}_{\mathrm{CS}}$ Versus Loading (Hanford PSDD, $\rho_{\mathrm{l}}=1.1 \mathrm{~g} / \mathrm{cm}^{3}$, $\mu=1.5 \mathrm{cP}$ fluid)

9.50 Generalized Model Predictions for PWD-43: (a) Concentration Profile at Max Fill, (b) Inlet Concentration and Suspension Ratio, (c) Maximum Solids Concentration Versus Loading Design Conditions, (d) $\mathrm{U}_{\mathrm{CS}}$ Versus Loading (Hanford PSDD, $\rho_{\mathrm{l}}=1.1 \mathrm{~g} / \mathrm{cm}^{3}, \mu=1$, $1.5 \mathrm{cP}$ fluid).

9.51 Generalized Model Predictions for PWD-44: (a) Concentration Profile at Max Fill, (b) Inlet Concentration and Suspension Ratio, (c) Maximum Solids Concentration Versus Loading Design Conditions, (d) $U_{C S}$ Versus Loading (Hanford PSDD, $\rho_{\mathrm{l}}=1.1 \mathrm{~g} / \mathrm{cm}^{3}$, $\mu=1.5 \mathrm{cP}$ fluid)

9.52 Generalized Model Predictions for FEP-17 A/B: (a) Concentration Profile at Max Fill, (b) Inlet Concentration and Suspension Ratio, (c) Maximum Solids Concentration Versus Loading Design Conditions, (d) $U_{C S}$ Versus Loading (Hanford PSDD, $\rho_{\mathrm{l}}=1.1 \mathrm{~g} / \mathrm{cm}^{3}$, $\mu=1.5 \mathrm{cP}$ fluid)

9.53 Generalized Model Predictions for PWD-15/16: (a) Concentration Profile at Max Fill, (b) Inlet Concentration and Suspension Ratio, (c) Maximum Solids Concentration Versus Loading Design Conditions, (d) $\mathrm{U}_{\mathrm{CS}}$ Versus Loading (Hanford PSDD, $\rho_{\mathrm{l}}=1.1 \mathrm{~g} / \mathrm{cm} 3$, $\mu=1.5 \mathrm{cP}$ fluid)

9.54 Generalized Model Predictions for UFP-01 A/B: (a) Concentration Profile at Max Fill, (b) Inlet Concentration and Suspension Ratio, (c) Maximum Solids Concentration Versus 
Loading Design Conditions, (d) $U_{C S}$ Versus Loading (Hanford PSDD, $\rho_{\mathrm{l}}=1.1 \mathrm{~g} / \mathrm{cm}^{3}$, $\mu=1.5 \mathrm{cP}$ fluid)

9.55 Generalized Model Predictions for RLD-07: (a) Concentration Profile at Max Fill, (b) Inlet Concentration and Suspension Ratio, (c) Maximum Solids Concentration Versus Loading Design Conditions, (d) $U_{\mathrm{CS}}$ Versus Loading (Hanford PSDD, $\rho_{\mathrm{l}}=1.1 \mathrm{~g} / \mathrm{cm}^{3}, \mu=1.5 \mathrm{cP}$ fluid).

9.56 Generalized Model Predictions for RLD-08: (a) Concentration Profile at Max Fill, (b) Inlet Concentration and Suspension Ratio, (c) Maximum Solids Concentration Versus Loading Design Conditions; (d) $U_{\mathrm{CS}}$ Versus Loading (Hanford PSDD, $\rho_{\mathrm{l}}=1.1 \mathrm{~g} / \mathrm{cm}^{3}, \mu=1.5 \mathrm{cP}$ fluid).

9.57 Generalized Model Predictions for HOP-903/904: (a) Concentration Profile at Max Fill, (b) Inlet Concentration and Suspension Ratio, (c) Maximum Solids Concentration Versus Loading Design Conditions, (d) $U_{C S}$ Versus Loading (Hanford PSDD, $\rho_{\mathrm{l}}=1.1 \mathrm{~g} / \mathrm{cm}^{3}$, $\mu=1.5$ cP fluid)

9.58 WTP Vessel Performance Ratio Summary Using $U_{95}$ and $\bar{U}_{90}$ Settling Velocities from the Hanford Tank Waste PSDD (Case 3) Using the Physical Models for $\mathrm{U}_{\mathrm{CS}}$ and $\mathrm{C}_{0}$ from Sections 7.3.2 to 7.3.4 with $\mathrm{C}_{0}$ modified to $\mathrm{W}_{0}{ }^{*}$, as Described in Section 9.1.4

9.59 WTP Vessel Performance Ratio Summary Using the Design-Limit Particle from Olsen (2008a) and the Physical Models for $\mathrm{U}_{\mathrm{CS}}$ and $\mathrm{C}_{0}$ from Section 7.3.2 to 7.3.4 modified to $\mathrm{W}_{0}{ }^{*}$ in Section 9.1.4

9.60 WTP Vessel Performance Ratio Summary Using $\mathrm{U}_{95}$ and $\overline{\mathrm{U}}_{90}$ Settling Velocities from the Hanford Waste PSDD (Case 3) Using the Generalized Models for $\mathrm{U}_{\mathrm{CS}}$ and $\mathrm{C}_{0}$ from Section 7.4.2 with $\mathrm{C}_{0}$ modified to $\mathrm{W}_{0}{ }^{*}$, as Described in Section 8.1.4

9.61 WTP Vessel Performance Ratio Summary Using the Design Limit Particle from Olsen (2008a) and Generalized Models for $\mathrm{U}_{\mathrm{CS}}$ and $\mathrm{C}_{0}$ from Section 7.4.2 with $\mathrm{C}_{0}$ modified to $\mathrm{W}_{0}{ }^{*}$, as Described in Section 9.1.4 


\section{Tables}

2.1 Description of Mixing States for Different Nozzle Velocities.............................................. 2.7

2.2 Geometric and Operational Data for Solids-Containing Vessels in the WTP-Dimensional Data.

2.3 Geometric and Operational Data for Solids-Containing Vessels in the WTPNondimensional Values...

2.4 Primary Mixing System Physical Parameters .................................................................... 2.15

2.5 Mixing System Nondimensional Variables.......................................................................... 2.16

2.6 Comparison of Scaled Test Approaches ......................................................................... 2.20

2.7 Preliminary Bracketing Noncohesive Property Ranges for the WTP ...................................... 2.22

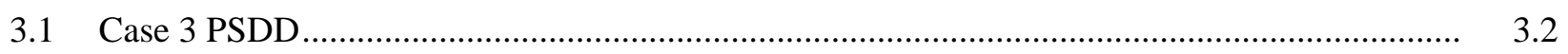

3.2 Solid Phase Compound Density, Volume Fraction, and Numerical Identification for Case 3 PSDD .....

3.3 Hanford Insoluble Solid Settling Velocity Percentiles for Case 3 PSDD ............................... 3.5

3.4 Hanford Insoluble Solid Settling Velocity Quantiles: $1.1 \mathrm{~g} / \mathrm{mL}$ and 1.5 cP Liquid Density

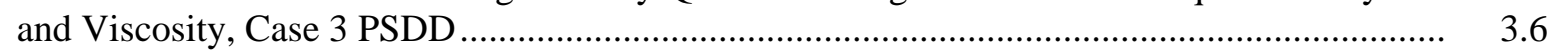

3.5 Bracketing Noncohesive Particle Test Ranges....................................................................

3.6 Simulant Characterization: As-Received, Post-Test, and Average Values .............................. 3.10

4.1 Comparison of Planned Pulse Tube Radius for Equivalent Angle of Impingement in Tank Heads Formed with F\&D and 2:1 Semi-Elliptical Heads ..................................................... 4.4

4.2 General PJM Configurations ......................................................................................

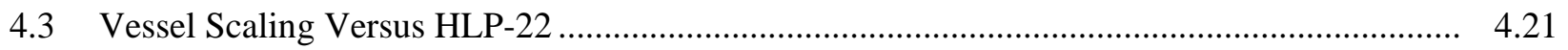

4.4 Tank and Pulse Tube Array Matrix................................................................................ 4.21

4.5 Measured HLP-22 12-Tube Array Positions......................................................................... 4.23

4.6 Measured 8-Tube Array Positions.................................................................................... 4.25

4.7 HLP-22 12-Tube Array Nozzle and Pulse Tube Sizes.......................................................... 4.25

4.8 8-Tube Array Nozzle and Pulse Tube Sizes........................................................................ 4.25

5.1 Mixing System Parameters .............................................................................................. 5.2

5.2 Particle Motion Descriptors ............................................................................................... 5.4

5.3 Solids Level Nomenclature ....................................................................................... 5.6

5.4 Pattern of Cleared Region Viewed from Beneath the Tank ................................................... 5.7

5.5 Procedures for $\mathrm{U}_{\mathrm{CS}}$ Observations …......................................................................... 5.9

5.6 Particle Motion Descriptors for Visual Observations ........................................................ 5.10

5.7 Documents Governing the 2007 and 2008 Tests............................................................. 5.13

6.1 Summary of Mixing Test General Conditions and Data ........................................................ 6.1

6.2 Test Parameter Description .......................................................................................... 6.2

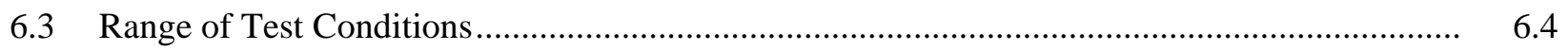

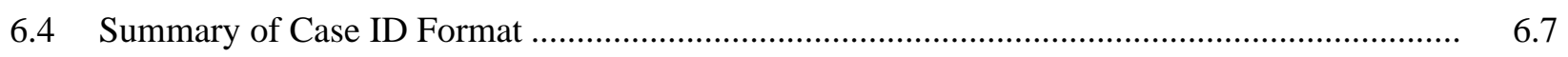

6.5 July 2007 Test Summary in Mid-Scale Tank with Spherical Head ........................................ 6.10 
6.6 Fall 2007 Test Summary in Mid-Scale Tank with Spherical Head......................................... 6.14

6.7 Summary of Fill Height and Return Line Height Test Conditions ........................................ 6.17

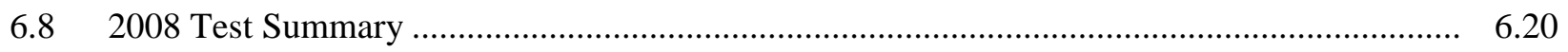

6.92008 Test Summary for Small-Scale Tank ................................................................ 6.22

6.102008 Test Summary for Mid-Scale Tank ......................................................................... 6.28

6.112008 Test Summary for Large-Scale Tank with Elliptical Head ........................................... 6.31

6.122008 Test Summary for Large-Scale Tank with Flanged and Dished Head ............................ 6.37

6.13 Near-Replicate and Near-Repeat Tests at Critical Suspension Conditions.............................. 6.41

6.14 Summary of Concentration Profile Cases ......................................................................... 6.45

7.1 As-Tested Dish Parameters and Geometric Coefficients for Various Dish Shapes................... 7.16

7.2 Direct Scale-up Data from Elliptical Tests: Ratios of Measured Variables at Large Versus Small Scales ............................................................................................................. $\quad 7.16$

7.3 Direct Scale-up Data from Elliptical Tests: Scale Exponents Based on Large- Versus

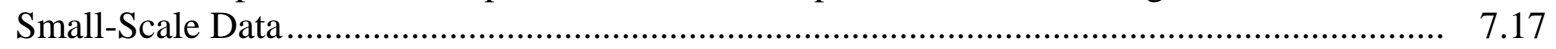

7.4 Basis for Comparing $\mathrm{U}_{\mathrm{CS}}$ and $\mathrm{H}_{\mathrm{C}}$ Models Fit to the Full Data Sets .....................................

8.1 Test Parameters and Associated Bounding Uncertainties.................................................... 8.6

8.2 Solids Inventory in AZ-101/102 Filtration Simulant .......................................................... 8.13

8.3 Solids PSDD for AZ-101/102 Filtration Simulant ............................................................. 8.14

8.4 Model Inputs for Prototypic PJM 336-Building Tests with AZ-101/102 Filtration Simulant .... 8.14

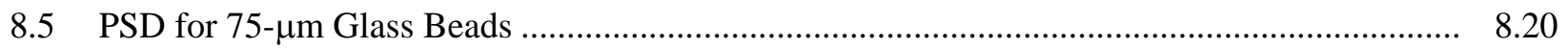

8.6 Model Inputs for 336-Building Tests with 75- $\mu \mathrm{m}$ Glass Beads............................................... 8.21

8.7 Model Inputs for 336-Building Tests with 35- $\mu \mathrm{m}$ Glass Beads............................................. 8.22

8.8 Model Inputs to Compare with CFD Simulation of HLP-22, 12 m/s Normal Firing Case......... 8.24

9.1 Sources of Physical Mixing System Parameters for Plant Vessels .......................................... 9.7

9.2 Vessel Geometry and Operations Data Used in WTP Vessel Assessments............................. 9.7

9.3 Vessel Solids Loading Data Used in Design Point Assessments ............................................ 9.8

9.4 Vessel Solids Loading Data Used in Hanford PSDD-Based Assessments ............................... 9.8

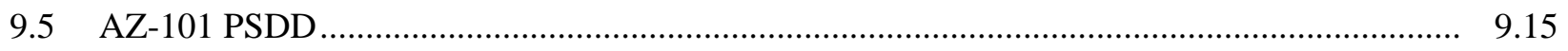

9.6 AZ-101 Insoluble Solids Settling Velocity Quantiles...................................................... 9.17

9.7 Physical Model Results for Design Point Conditions of FRP-02 …....................................... 9.18

9.8 Physical Model Results for Design Point Conditions for HLP-22 ......................................... 9.19

9.9 Physical Model Results for Design Point Conditions for HLP-22 .......................................... 9.20

9.10 Physical Model Results for Design Point Conditions for HLP-22 ........................................... 9.21

9.11 Physical Model Results for Design Point Conditions for HLP-22 .......................................... 9.22

9.12 Physical Model Results for Design Point Conditions for TCP-01 .......................................... 9.23

9.13 Physical Model Results for Design Point Conditions for TLP-09 .......................................... 9.24

9.14 Physical Model Results for Design Point Conditions for PWD-33 ......................................... 9.25

9.15 Physical Model Results for Design Point Conditions for PWD-43 ........................................ 9.26

9.16 Physical Model Results for Design Point Conditions for PWD-44 .......................................... 9.27 
9.17 Physical Model Results for Design Point Conditions for FEP-17 ......................................... 9.28

9.18 Physical Model Results for Design Point Conditions for PWD-15/16 ................................... 9.29

9.19 Physical Model Results for Design Point Conditions for UFP-01 .......................................... 9.30

9.20 Physical Model Results for Design Point Conditions for RLD-07 ......................................... 9.31

9.21 Physical Model Results for Design Point Conditions for RLD-08 .......................................... 9.32

9.22 Physical Model Results for Design Point Conditions for HOP-903/904 ….............................. 9.33

9.23 Physical Model Results for FRP-02 Using Hanford PSDD .................................................... 9.35

9.24 Physical Model Results for HLP-22 Using Hanford PSDD.................................................... 9.37

9.25 Physical Model Results for HLP-22 Using Hanford PSDD ................................................... 9.38

9.26 Physical Model Results for HLP-22 Using Hanford PSDD................................................... 9.40

9.27 Physical Model Results for HLP-22 Using Hanford PSDD................................................. 9.41

9.28 Physical Model Results TCP-01 Using Hanford PSDD …...................................................... 9.42

9.29 Physical Model Results for TLP-09 Using Hanford PSDD .................................................. 9.43

9.30 Physical Model Results for PWD-33 Using Hanford PSDD ................................................. 9.44

9.31 Physical Model Results for PWD-43 Using Hanford PSDD .................................................. 9.46

9.32 Physical Model Results for PWD-44 Using Hanford PSDD ................................................ 9.47

9.33 Physical Model Results for FEP-17 Using Hanford PSDD .................................................. 9.48

9.34 Physical Model Results for PWD-15/16 Using Hanford PSDD .............................................. 9.49

9.35 Physical Model Results for UFP-01 Using Hanford PSDD .................................................. 9.50

9.36 Physical Model Results for RLD-07 Using Hanford PSDD ................................................. 9.51

9.37 Physical Model Results for RLD-08 Using Hanford PSDD ................................................... 9.52

9.38 Physical Model Results for HOP-903/904 Using Hanford PSDD ........................................... 9.53

9.39 Generalized Model Results for FRP-02 Using Hanford PSDD ............................................. 9.55

9.40 Generalized Model Results for HLP-22 Using Hanford PSDD .............................................. 9.56

9.41 Generalized Model Results for HLP-22 Using Hanford PSDD ............................................. 9.57

9.42 Generalized Model Results for HLP-22 Using Hanford PSDD ............................................. 9.58

9.43 Model Results for Design Conditions for HLP-22 ............................................................... 9.59

9.44 Generalized Model Results for TCP-01 Using Hanford PSDD .............................................. 9.60

9.45 Generalized Model Results for TLP-09 Using Hanford PSDD .............................................. 9.61

9.46 Generalized Model Results for PWD-33 Using Hanford PSDD ….......................................... 9.62

9.47 Generalized Model Results for PWD-43 Using Hanford PSDD ............................................ 9.63

9.48 Generalized Model Results for PWD-44 Using Hanford PSDD ............................................ 9.64

9.49 Generalized Model Results for FEP-17 Using Hanford PSDD …........................................... 9.65

9.50 Generalized Model Results for PWD-15/16 Using Hanford PSDD ........................................ 9.66

9.51 Generalized Model Results for UFP-01 Using Hanford PSDD ............................................ 9.67

9.52 Generalized Model Results for RLD-07 Using Hanford PSDD ............................................. 9.68

9.53 Generalized Model Results for RLD-08 Using Hanford PSDD ............................................ 9.69

9.54 Generalized Model Results for HOP-903/904 Using Hanford PSDD .................................... 9.70

9.55 Impact of HLP-22 Design Variations Using the Physical Models........................................... 9.73 



\subsection{Introduction}

This report summarizes results from pulse jet mixing (PJM) tests for mixing noncohesive solids in Newtonian liquid. The tests were conducted during FY 2007 and 2008 to support the design of the mixing systems for the Hanford Waste Treatment and Immobilization Plant (WTP). Tests were conducted at three geometric scales using noncohesive simulants. The test data were used to develop new mixing models that can be used to predict the mixing performance of full-scale WTP vessels and to assess mixing system designs compared with performance requirements.

Section 1.1 describes the background associated with this project-the testing of PJM systems with noncohesive solids for evaluating the adequacy of WTP mixing. The justification supporting the tests performed is described in Section 1.2. Test objectives are listed in Section 1.3. An overview of the research is presented in Section 1.4; project Quality Assurance is described in Section 1.5; and the organization of the remainder of the document is listed in Section 1.6.

\subsection{Background}

The WTP at the Hanford Site is being designed and built to pretreat and vitrify a large portion of the waste stored in Hanford's 177 underground waste storage tanks. Several process vessels will hold the waste at various stages in the WTP. These vessels have the mixing ${ }^{1}$ system requirements to maintain conditions in which hydrogen gas accumulation stays below acceptable limits and the mixing within the vessels is sufficient to ensure that pump transfer and normal operations occur reliably (Olsen 2008a).

Some of the WTP process streams are slurries of solid particles suspended in Newtonian fluids that may behave as non-Newtonian slurries. The effects of large particles and rapidly settling slurries may affect mixing and the ability of the slurry to maintain particles in suspension.

The WTP Project uses PJM technology for tank mixing applications requiring solids suspension, solids mixing, fluid blending, and release of hydrogen gas. PJMs are driven by jet pump pairs (JPPs) that use compressed air as the motive force. The suction phase draws process liquid into the PJM from the vessel. The drive phase pressurizes the PJMs via a JPP. This pressurization discharges the PJM liquid at high velocity into the vessel, causing mixing to occur. The drive phase is followed by the vent phase, which allows for depressurization of the PJM by venting through the JPP into the pulse jet vent system. These three phases (suction, drive, and vent) make up the mixing cycle.

The PJMs can be operated in a continuous pulsing mode (e.g., all PJMs on during normal operation) or can be turned off for a time and restarted in the pulsing mode [e.g., for some post-design basis event (DBE) scenarios, vessels that use the 50/50 mixing rack design will only have half their PJMs operational], depending on process requirements. In vessels that contain particulates, solids will settle to the bottom between mixing periods. When the PJMs restart, the settled solids must be resuspended.

\footnotetext{
${ }^{1}$ Mixing is the mobilization and subsequent suspension of undissolved solids within a vessel. Mixing can have varying results: 1) a fully mixed vessel where the solids concentration is uniform throughout the vessel, 2) a partially mixed vessel where there is a solids concentration gradient that is higher at the bottom of the vessel, or 3) a poorly mixed vessel where the solids are disturbed but remain on or near the bottom of the vessel.
} 
Bechtel National, Inc. (BNI) has assessed the resuspension capabilities in the past using two available methods. One method used a BNI controlled proprietary correlation; the other used an approach recommended by Atomic Energy Authority of United Kingdom (AEA) called the "Bathija Off-Bottom Method" (Bathija 1982). BNI has determined that the proprietary resuspension correlation is the best method available at this time to evaluate potential risks with current PJM mixing system designs. ${ }^{1}$

In October 2005, an External Flowsheet Review Team (EFRT) made up of experts from industry, national laboratories, and universities was assembled by BNI to conduct a thorough, in-depth review of the process flowsheet for the design of the WTP. The following issues from the critical review of the process flowsheet (Smith 2007) are considered relevant to the mixing process:

- Issue M1: Piping that transports slurries will plug unless it is properly designed to minimize this risk. This design approach has not been followed consistently, which will lead to frequent shutdowns due to line plugging.

- Issue M2: Large, dense particles will accelerate erosive wear in mixing vessels. The effects of such particles on vessel life must be reevaluated.

- Issue M3: Issues were identified related to mixing system designs that will result in insufficient mixing and/or extended mixing times. These issues include a design basis that discounts the effects of large particles and of rapidly settling Newtonian slurries. There is also insufficient testing of the selected designs.

- Issue M4: The WTP has not demonstrated that its design is sufficiently flexible to reliably process all of the Hanford tank farm wastes at design throughputs.

- Issue M6: Many of the process operating limits have not been defined. Further testing is required to define process limits for WTP unit operations. Without this more complete understanding of each process, it will be difficult or impossible to define a practical operating range for each unit operation.

- Issue M12: Neither the caustic leaching nor the oxidative leaching process has been demonstrated at greater than bench scale. The small-scale experiments are capable of defining the leaching chemistry; however, they are limited in their ability to predict the effectiveness of these processes without a scale-up demonstration.

- Issue P9: The sampling system has not been demonstrated and may not prove adequate for handling slurries. This system is critical to the success of WTP operation. The completion of the planned testing is necessary to ensure sampling system adequacy. The capabilities of the current baseline sampling equipment need to be confirmed.

In response to Issue M3, Inadequate Design of Mixing Systems-Pulse Jet Mixers, BNI issued Test Specification 24590-PTF-TSP-RT-06-007 (Smith 2007), defining a test program to resolve the PJM issue. The objective of this test program has been to close issues related to mixing system designs that could result in insufficient mixing and/or extended mixing times. These issues included a design basis that discounted the effects of large particles and of rapidly settling Newtonian slurries.

\footnotetext{
${ }^{1}$ The proprietary method is essentially a correlation of data from small-scale, steady jet mixing tests. While it represents the best available data for assessing PJM off-bottom suspension capability in solids-containing vessels, the correlation does not specifically account for the effects of pulsation or nozzle geometry. In addition, the correlation database does not cover the range of particle sizes in Hanford waste.
} 
The test specification calls for performing geometrically scaled tests with simulants to generate data for developing models of vessel mixing performance. The models will be used to assess the PJM design basis for WTP vessels. As part of Project No. 53023, Pacific Northwest National Laboratory (PNNL) generated Test Plan TP-RPP-WTP-480 (Elmore et al. 2007) for conducting scaled tests.

Vessels with relatively lower solids concentrations have historically been termed "Newtonian vessels" to differentiate them from vessels containing slurries that exhibit bounding non-Newtonian rheology. ${ }^{1}$ However, this terminology may be misleading because there is a continuum of rheological behavior between these Newtonian and non-Newtonian vessels. In fact, some of the Newtonian vessels may exhibit non-Newtonian behavior under certain conditions. Some vessels with lower concentrations may have a small but finite yield stress under normal mixing conditions. Even a yield stress of a few Pascals may affect mixing performance, particularly with regard to gas retention and release behavior. Other Newtonian vessels with slurries exhibiting Newtonian behavior under normal mixing conditions may in fact become non-Newtonian in the absence of mixing (e.g., during a mixing system shutdown) as solids concentrations increase due to settling.

To avoid confusion between vessel nomenclature and slurry rheology, vessels previously termed Newtonian will hereafter be termed "solids-containing" if they contain solids and "liquid-containing" if they have no solids or trace solids. Those vessels previously termed non-Newtonian will be termed "high solids-containing."

Under normal mixing operations, the process areas of concern are solids off-bottom suspension, solids vertical distribution (i.e., concentration profiles), solids accumulation on the vessel bottom, and mixing times. For off-normal mixing operations, the process areas of concern are solids resuspension and overcoming increased rheological properties associated with solids settling. During post-DBE operations vessels may be operated intermittently, with mixing systems idle for 12 hours or longer. Hence, solids settling will occur to varying degrees.

The design-basis particle characteristics for mixing have been documented in Wells et al. (2007). These results were used to develop noncohesive simulants for testing PJM vessel mixing.

\subsection{Test Justification}

When the EFRT conducted a thorough and in-depth review of the process flowsheet for the design of the Hanford WTP, one of the issues identified was M3 (Smith 2007):

Issues were identified related to mixing system designs that will result in insufficient mixing and/or extended mixing times. These issues include a design basis that discounts the effects of large particles and of rapidly settling Newtonian slurries. There is also insufficient test data to support the selected designs.

Under normal mixing operations, process areas of concern include:

- Solids off-bottom suspension

\footnotetext{
${ }^{1}$ Vessels historically termed “non-Newtonian” include UFP-VSL-00002A/2B ultrafiltration feed process vessels, HLP-VSL-00027A/B HLW lag storage vessels, and the HLP-VSL-00028 high-level waste blend vessel.
} 
- Solids vertical distribution (concentration profile)

- Solids accumulation on the vessel bottom

- Mixing times.

For off-normal mixing operations, process areas of concern include:

- Solids resuspension

- Overcoming increased rheological properties associated with solids setting

- Ability to release hydrogen gas from settled solids following a DBE.

\subsection{Objectives}

The first two objectives for this work were provided by the client in Test Exception 24590-PTF-TSPRT-06-007 (Smith 2007) and were incorporated in Test Plan TP-RPP-WTP-480 (Elmore et al. 2007). Objectives three through six for this work were provided by the client in SCN 71 (Hazen 2008a) and letter CCN 190723 (Hazen 2008b) and were incorporated into Test Plan TP-RPP-WTP-480 R0.2 (Elmore et al. 2009). Both test plans were approved by the client:

1. Determine through experimental results whether there is a high probability that for vessel HLP-22, $0.10 \mathrm{~m}$ (4-in.) nozzles operating at $8 \mathrm{~m} / \mathrm{s}$ discharge velocity (current baseline design) will not be adequate for resuspending settled solids.

2. Provide experimental results from a scaled HLP-22 mixing system for constant volume discharges that provide the relative difference in performance with respect to off-bottom suspension for the following conditions:

- Full-scale conditions of 0.10-m- (4-in.-) diameter nozzles operating at $8 \mathrm{~m} / \mathrm{s}$

- Full-scale conditions of 0.10-m- (4-in.-) diameter nozzles operating at $12 \mathrm{~m} / \mathrm{s}$

- Full-scale conditions of 0.15-m- (6-in.-) diameter nozzles operating at $8 \mathrm{~m} / \mathrm{s}$

- Full-scale conditions of 0.15-m- (6-in.-) diameter nozzles operating at $12 \mathrm{~m} / \mathrm{s}$.

3. Obtain measurements of $\mathrm{U}_{\mathrm{CS}}{ }^{1}$ over a range of test conditions in scaled vessels to evaluate the dependence of vessel mixing performance on parameters associated with waste properties, equipment design, and process operations.

4. Obtain test results at multiple geometric scales to allow scaled test results to be used to predict vessel mixing performance at full scale.

5. Develop tools/models that will allow WTP Mechanical and Process Engineering (M\&PE) staff to rate/evaluate/bin WTP vessels designs at a coarse level and to determine with high confidence any WTP vessels that will not meet minimum required performance levels.

6. Obtain test results, observations, and experience that facilitate development of a focused/reduced test matrix for M3 scaled tests.

\footnotetext{
${ }^{1} \mathrm{U}_{\mathrm{CS}}$ is defined as the critical suspension velocity. At $\mathrm{U}_{\mathrm{CS}}$ the solids are completely suspended off the vessel bottom at the end of the jet pulse.
} 


\subsection{Overview of Testing and Modeling}

Scaled testing was selected as the most direct, accurate, and cost-effective approach to address and close the EFRT M3 issue. Parametric scaled testing of mixing systems was used to generate data from which mixing performance models were developed. These models were applied to assess all of the WTP solids-containing vessels. This scaled-testing approach was determined to be sufficient because it is commonly used in the mixing industry (Paul et al. 2004) and is technically appropriate.

\subsubsection{Model Development Approaches}

The development of mixing performance models naturally follows testing performed to generate data for model development. However, it is useful to discuss the model development approaches first so they can be referred to in subsequent sections.

Three approaches were used in this work to develop models for predicting mixing performance using data from scaled tests.

1. The physical approach involves fitting the data to functional forms derived from, or suggested by, a dimensionless analysis of the phenomena expected to affect mixing performance. The functional forms obtained through the physical approach provide similarity criteria for relating behavior observed during scaled tests to the behavior expected during corresponding full-scale operations, which enables predicting the performance of a full-scale system.

2. The empirical approach uses multiple regression (MR) methods to relate mixing performance variables to the test parameters. This approach provides for predicting the mixing performance as a function of system parameters. Because this approach includes the length scale (size) as a parameter, it also enables predicting the performance of a full-scale system.

3. The semi-empirical approach uses MR methods to relate mixing performance variables to nondimensional variables, which are functions of the test parameters. This approach is a combination of the first two approaches in that physical bases are still used in specifying the nondimensional variables but within a MR framework.

The empirical approach lacks a physical basis but provides a systematic evaluation of the dependence of the mixing performance on system parameters valid over the domain of the test data. The physical and semi-empirical approaches use physical reasoning to explain the effect of scale and other parameters on mixing performance. Hence, these two approaches increase the confidence in extrapolating results outside the domain of the test data. These two approaches also depend on the experience and subject knowledge of those proposing the functional forms for fitting the data. It is important to compare and reconcile the models resulting from the empirical and semi-empirical approaches with those from the physical approach. Used together, these three approaches provide technical reliability and credibility, improve the accuracy of extrapolation of model results to full scale, and reduce the extrapolation uncertainty.

Parametric mixing models derived from scaled test results using the three approaches have the following benefits:

- They provide for assessing the performance of WTP mixing systems and design-basis waste properties. 
- They are cost-effective because they greatly minimize the number of scaled vessel prototypes that would otherwise require testing.

- The models used to rate mixing system performance can be exercised to evaluate the effect of potential design changes, should they be required.

This parametric model-based scaled testing approach meets the WTP Project requirements for rating the design of the fluidic mixing systems in WTP vessels.

\subsubsection{Phased Approach to Testing}

Mixing studies to address EFRT Issue M3 will be conducted in phases to focus on differences in slurry physical properties. The distinction between vessels containing noncohesive and cohesive slurries has been based on anticipated solids concentrations of the waste in the vessels. Waste slurries containing a moderately low solids concentration can exhibit some non-Newtonian (cohesive) behavior, especially near the bottom of the vessel, during a planned or unplanned shutdown of mixing as solids settle. Conversely, some vessels contain slurries with a relatively high solids concentration that may still behave like Newtonian (noncohesive) slurries. Thus, both Newtonian and non-Newtonian slurries will be evaluated in the testing program and will account for variations in solids loading, solids properties, and rheology. The testing described in this report was conducted using noncohesive slurries. Tests to evaluate mixing performance with cohesive slurries are being considered for the future.

Given the different mixing system demands posed by noncohesive and cohesive slurry properties, as well as the need to determine flammable gas release capability for various conditions, the EFRT Issue M3 test program has been conducted based on simulant type. Tests described in this report address mixing system performance with noncohesive particulates, where solids suspension and settling are important. Some other solids mixing challenges that were not included in this phase of testing include evaluation of:

- Cohesive waste mixing, blending, and solids resuspension

- Gas retention and release behaviors in the solids-containing vessels.

The tests described in this report cover $d_{50}$ particle diameters ranging from 44 to $766 \mu \mathrm{m}$. The $44-\mu \mathrm{m} \mathrm{d}_{50^{-}}$ diameter solids did not reach the onset of cohesion or cohesive behavior. Therefore, the particle sizes and concentrations used in model development are in the Newtonian behavior regime.

\subsubsection{Scaled Testing Approach}

The approach for predicting the performance of full-scale systems based on tests in scaled systems is to maintain geometric similarity to the extent practicable (the mixing systems use cylindrical vessels with dished bottoms, conical downward pointing nozzles, etc.), test slurries with properties spanning the range of those in the full-scale system to the extent practicable, and controlling operation to span conditions expected in the full-scale system. Practical constraints prevented perfect compliance with these principles, but compliance was sufficient to meet the test objectives.

In general, mixing system performance for the solids-containing vessels in the WTP depends on the physical and rheological properties of their contents, the number and size of PJMs, vessel size (diameter), and the relative fill level. In addition, mixing performance depends on PJM operating conditions such as 
velocity $(\mathrm{U})$, drive time $\left(\mathrm{t}_{\mathrm{D}}\right)$, and duty cycle (DC), which is drive time divided by the cycle time $\left(\mathrm{t}_{\mathrm{C}}\right)$. The scaled testing approach included a series of tests in scaled vessels where these important parameters were varied and measured: relevant similarity criteria; critical suspension velocity $\left(\mathrm{U}_{\mathrm{CS}}\right)$; cloud height $\left(\mathrm{H}_{\mathrm{C}}\right)$, which is a visible interface above which the fluid is relatively quiescent; and solids vertical distribution $\mathrm{C}(\mathrm{Z})$. Mixing times and the distance along the tank bottom over which solids are mobilized by the PJM were not specifically determined.

The forms of physical models for the $\mathrm{U}_{\mathrm{CS}}$ and $\mathrm{H}_{\mathrm{C}}$ were based on similarity criteria and fitted to the test data. Models for the solids concentration at the bottom of a tank $\left(\mathrm{C}_{0}\right)$ and the solids vertical distribution $[\mathrm{C}(\mathrm{Z})]$ were developed from the $\mathrm{H}_{\mathrm{C}}$ model. The forms of empirical and semi-empirical models for $U_{C S}$ and $H_{C}$ were generalized forms of the physical models for $U_{C s}$ and $H_{C}$, which allow for possibly improving predictions as well as assessing the bases for the physical models. The physical models and semi-empirical models (subsequently referred to as generalized models) were used to evaluate the performance of the WTP project's mixing-system designs in the solids-containing vessels. These models may also be exercised to explore mixing performance sensitivity to waste properties.

\subsubsection{Three Tank Scales}

Three test scales were required to achieve the primary objective of rating the mixing systems in the largest solids-containing vessels in a timely and cost-effective manner. Mixing performance depends on vessel size (scale). It is necessary to vary vessel scale during testing to develop robust models. While some useful scale information can be achieved with only two tank sizes, using data from three tank sizes provides more-accurate models and enables assessing the predictive uncertainty of the models. This is especially important for applying the models to the largest of the WTP vessels. Not only are these vessels significantly larger than any practical test scale, they are also of the greatest concern regarding mixing.

There are additional benefits to testing at three scales as well. The test matrix was configured to perform more tests in the small-scale tank, thereby reducing the number of tests performed in the medium- and large-scale test tanks.

\subsubsection{Test Tank Sizing}

There was some latitude in the selection of the test tank sizes. Nominal sizes selected were small scale, $0.4 \mathrm{~m}$ (15 in.); mid scale, $0.9 \mathrm{~m}$ (34 in.); and large scale, $1.8 \mathrm{~m}$ (70 in) in diameter. ${ }^{1}$ The smallest tank [0.4 $\mathrm{m}$ (15 in.)] is large enough to ensure that the transitional flow regime is avoided. This was accomplished by making sure the jet Reynolds number (based on jet velocity and nozzle diameter) was at least 5,000. There is no physically based, upper size limit for the largest test tank; rather, cost and testing duration were the practical constraints. The largest tank is large enough to exercise a reasonable range of scales to develop the models. These nominal sizes were selected based on practical considerations associated with fabrication and availability of "standard” tank diameters.

The solids-containing vessels in the WTP are expected to have relative fill levels (fill height-todiameter ratios [H/D]) that range from 0.5 to 1.6. Given the parametric testing approach, it would be

\footnotetext{
${ }^{1}$ The scaled vessel size was approved by BNI via email transmittal, March 20, 2007, referencing Recommended Test Vessel Scales for the M-3 Mixing Test Program, from GL Smith to PA Scott, PA Meyer, and GH Beeman (PNNL). "Concurrence to Purchase Scaled Vessels for M3 PJM Mixing Systems Testing Program."
} 
desirable to test values of H/D that span this range, but this one parameter could not be varied due to equipment limitations. For the small- and mid-scale test systems, the test tanks were normally operated at an H/D of around 2.2 and 2.0, respectively, during testing. For the large-scale test system, the tank (which was supplied from an earlier testing program) was operated at an H/D of around 1.3. Specific fill levels for each test are included in Appendix B.

The test specification references the tank bottom (head) shape as 2:1 elliptical. The scaled-tank heads were specified to match the WTP vessel specifications, which include 2:1 elliptical and flange-and-dish (F\&D) head shapes. Tests were also conducted using a tank with a spherical head.

\subsubsection{Mixing System Configuration}

The test approach used PJM systems that are easily reconfigured to represent geometrically scaled versions of the solids-containing WTP vessels. By changing the configuration of the PJMs, any given test tank can be a geometric miniature of a given plant mixing system. Because the plant vessels vary widely in size, each test tank configuration represented a plant vessel reduced in size by the relative geometric scale factor, which depends not only on the size of the plant vessel but also on the size of the test tank (small, mid-sized, or large).

Reconfiguring the PJMs in the test tanks to replicate the prototypic mixing systems requires changing the number, size, and nozzle diameter of the pulse tubes, as well as the spatial arrangement of the pulse tube array. Hence, many pulse tubes of varying sizes would be required by this approach. Based on extensive previous testing experience (Bamberger et al. 2005), it is known that pulse tube reconfiguration is cumbersome and time-consuming. Adjusting operating parameters such as jet velocity, drive time, and duty cycle via the control system can also be time-consuming, especially when the fill level or simulant properties are changed. It is also challenging to accurately determine as-tested values for jet velocity and drive time, and typically significant post-processing and analysis are required. Given the need to test many different PJM configurations, as well as vary PJM operating parameters and simulant properties, using a simplified, flexible, and easily controllable intermittent jet mixing system alternative was required to complete testing in a reasonable time frame. This configuration was adequate to meet test objectives.

The external shape of pulse tubes (external form factor) has a minor effect on flow patterns within the tank. Geometric changes to the jet nozzles (such as modifying or eliminating the conical section) may have an effect on mixing. However, mixing effects due to nozzle geometry may well be handled by the application of simple geometric correction factors (similar to nozzle loss coefficients). PJM modeling was performed in a simplified geometry configuration using small-diameter pulse tubes (straight pipes). The effect of pulse tube shape on tank flow patterns was discussed but not evaluated during the parameter definition testing to determine whether inserts that model PJM shape were required. The number of tubes and their radial spacing was configured experimentally using an adjustable series of pulse tubes. The potential effects or differences in geometry are discussed in Section 8.1.

\subsubsection{Initial Testing to Define System Parameters that Meet Test Objectives}

The experimental program was conducted in stages. In July 2007, initial tests were conducted to vary parameters such as nozzle size and waste particle size in the mid-scale tank, which had been used in previous WTP experiments while the smaller and larger tanks were being fabricated. The July 2007 tests 
were designed to give an early indication of HLP-22 adequacy. More tests were conducted in the fall of 2007 (Fall 2007) to evaluate the experimental test stand equipment and answer operational questions specific to the use of this test stand. Factors evaluated included the effect of fill height in the test tank and the impacts of elevation of the return line that are unique to the testing system. The original objective of this test program was to obtain scalable metrics for assessing PJM vessel performance over a range of geometric scales using fixed simulant properties (i.e., scale-up, not similarity, of phenomena). The fill height through the majority of the test program was maximized with the intent of:

- Minimizing solids entrainment into the pulse system

- Maximizing the range of pulse tube velocities that could be assessed

- Minimizing the particle density and diameter that could be evaluated

- Maximize the cloud height elevation that could be measured.

The investigation of fill height during the Fall 2007 test effort was only to assess the effect fill height had on the results obtained in the current test setup. No attempt was made or was part of the test scope to evaluate the effect of the design operating levels for each of the WTP vessel types. The WTP fill heights were not investigated for the same reason.

\subsubsection{Scaled Testing and Model Development}

When the scaled tanks and additional real-time diagnostic instrumentation to measure key parameters were available, parametric testing began. The parametric test matrix for 2008 testing included refinements made based on the results of the 2007 testing. The refinements included the need for more simulant variation, collecting concentration data at multiple locations in the tank, inclusion of ultrasonic Doppler velocimetry (UDV) to speed up testing, and the need for testing at additional tank scales. In addition, simulant properties were refined to provide a tighter, more monodisperse particle size distribution (PSD). Testing was conducted in the three scaled tanks to complete the parametric variations. The scaled-tank test data sets were then used to develop mixing performance models using the three approaches described in Section 1.4.1.

\subsection{Quality Requirements}

Pacific Northwest National Laboratory (PNNL) is operated by Battelle for the U.S. Department of Energy. Its Pacific Northwest Division (PNWD) has a Quality Assurance Program that is based upon the requirements as defined in the U.S. Department of Energy (DOE) Order 414.1C, "Quality Assurance," and 10 CFR 830, "Energy/Nuclear Safety Management,” Subpart A, “Quality Assurance Requirements.” PNWD has chosen to implement the requirements of DOE Order 414.1C and 10 CFR 830 Subpart A by integrating them into the Laboratory's management systems and daily operating processes. The procedures needed to implement the requirements are documented through the Laboratory's Standards-Based Management System.

PNNL implements the WTP River Protection Project (RPP) quality requirements by performing work in accordance with the River Protection Project - Waste Treatment Plant Support Program (RPP-WTP) Quality Assurance Plan (RPP-WTP-QA-001, QAP). Work is performed to the quality requirements of NQA-1-1989 Part I, "Basic and Supplementary Requirements,” NQA-2a-1990 Part 2.7, and DOE/RW- 
0333P Rev. 13, Quality Assurance Requirements and Descriptions (QARD). These quality requirements are implemented through the RPP-WTP Quality Assurance Manual (RPP-WTP-QA-003, QAM). The analytical requirements are implemented through RPP-WTP's Statement of Work (RPP-WTP-QA-005) with the Radiochemical Processing Laboratory Analytical Service Operations.

Experiments that were not method-specific were performed in accordance with RPP-WTP's procedures QA-RPP-WTP-1101, “Scientific Investigations,” and QA RPP WTP-1201, “Calibration and Control of Measuring and Testing Equipment.” Properly calibrated measuring and test equipment was used to acquire sufficient data to produce quality results.

Additional equipment that may be used includes balances. Balances are calibrated annually by a certified contractor, QC Services, Portland, Oregon.

RPP-WTP addresses internal verification and validation activities by conducting an Independent Technical Review of the final data report in accordance with RPP-WTP's procedure QA-RPP-WTP-604. This review verifies that the reported results are traceable, that inferences and conclusions are soundly based, and the reported work satisfies the Test Plan objectives. This review procedure is part of PNNL's RPP-WTP Quality Assurance Manual.

\subsection{Organization of Document}

Section 2 describes mixing of solid-liquid systems for both steady and pulsed mixing. Hanford waste properties and simulant selection are described in Section 3. Experimental equipment, procedures, and data are described in Sections 4, 5, and 6, respectively. Section 7 discusses the analysis and modeling of mixing data. Methodology and examples of WTP vessels are presented in Sections 8 and 9. Conclusions and recommendations are provided in Section 10, and cited references are listed in Section 11.

Appendixes provide additional data and analyses. Ultrasonic instrumentation is described in Appendix A, and mixing data and concentration profile data are presented in Appendixes B and C, respectively. Statistical methods, data analysis, and modeling are described in Appendixes D, E, and F, respectively. 


\subsection{Technical Approach for Assessing WTP Mixing Systems}

Section 2 describes the technical approach used for assessing WTP mixing systems. This approach is the framework for the experiments and results presented in the remainder of the report. In Section 2.1 mechanical mixing is briefly discussed to provide a basis for the type of model used to describe agitatorbased mechanical mixing. The adaptation of this model for application to steady jet mixing is discussed in Section 2.2. Section 2.3 describes how the model can be expanded to incorporate pulse jet mixing. To provide background for rating WTP mixing systems, the WTP plant vessel configurations and operating conditions are described in Section 2.4. In Section 2.5 the approach for assessing the solids-handling capability of mixing systems is outlined. The type of parametric testing required to develop models for mixing performance in terms of mixing parameters is described in Section 2.6. Section 2.7 describes the scale-up strategy for mixing results. This is followed by a summary of factors and consideration involved in experimental test design in Section 2.9.

\subsection{Mechanical Mixing}

Agitation equipment is a significant component of solid-liquid mixing systems. The agitation approach and the vessel shape both contribute to mixing system performance. Three types of mixing approaches for slurries are briefly described, leading to the pulse jet mixing system whose performance is being evaluated in these studies. Models for mechanical mixing system performance lay the framework for extension to jet mixing and pulse jet mixing.

Mechanical mixing systems are based on bladed mixers of varying designs. Industrial correlations for mixing performance for bladed mixers have been used for over 50 years. One of these correlations (Zwietering 1958, Eq. 7) can be written in the form: ${ }^{1}$

$$
\mathrm{N}_{\mathrm{JS}}=\mathrm{k}_{\mathrm{I}}(\mathrm{g})^{0.45}(\mathrm{~s}-1)^{0.45}\left(\mathrm{~d}_{\mathrm{S}}\right)^{0.2}(\mathrm{X})^{0.13}\left(\mathrm{D}_{\mathrm{I}}\right)^{-0.85}(\mathrm{v})^{0.1}
$$

where

$\mathrm{N}_{\mathrm{JS}}=$ shaft speed for just-suspended condition (Zwietering mechanical mixers) (rev/s)

$\mathrm{k}_{\mathrm{I}}=$ impeller specific constant

$\mathrm{g}=$ gravitational constant $\left(\mathrm{m} / \mathrm{s}^{2}\right)$

$\mathrm{s}=$ ratio of particle density to liquid density (dimensionless)

$\mathrm{d}_{\mathrm{S}}=$ diameter of particle $(\mathrm{m})$

$\mathrm{X}=$ weight of solid per weight of liquid times 100 (percent)

$\mathrm{D}_{\mathrm{I}}=$ diameter of impeller $(\mathrm{m})$

$v=$ kinematic viscosity $\left(\mathrm{m}^{2} / \mathrm{s}\right)$.

This expression is dimensionally consistent, and as for all such expressions, can be put in an alternative form involving only dimensionless groups, such as:

\footnotetext{
${ }^{1}$ The Zwietering correlation has no vessel diameter, so there must be an assumption of vessel diameter relative to agitator blade diameter.
} 


$$
\mathrm{N}_{\mathrm{JS}} \sqrt{\frac{\mathrm{D}_{\mathrm{I}}}{(\mathrm{s}-1) \mathrm{g}}}=\mathrm{k}_{\mathrm{I}}\left(\frac{\mathrm{d}_{\mathrm{S}}}{\mathrm{D}_{\mathrm{I}}}\right)^{0.35}\left(\frac{\mathrm{g}(\mathrm{s}-1) \mathrm{d}_{\mathrm{s}}^{3}}{\mathrm{v}^{2}}\right)^{-0.05}
$$

where the left-hand-side is the square root of the Froude number. See Section 7.4.2 for examples of invoking dimensionless forms for statistically developed empirical models describing the results of M3 testing.

\subsection{Jet Mixing}

Jet mixing differs from agitator-based, liquid-solid mixing; the driving force is hydraulic rather than mechanical. A mechanical agitator works by shearing the fluid and propelling it around the mixing vessel. A jet mixer uses a pump to force the fluid through nozzles within the tank, creating high-velocity jets that entrain other fluid. The result is shear and circulation that mix the tank contents efficiently. For steady jet mixing. A power law expression similar to Eq. (2.1) can be written for the velocity required to just suspend particles from the floor of the vessel

$$
\mathrm{U}_{\mathrm{JS}}=\mathrm{k}_{\mathrm{J}}(\mathrm{g})^{0.5}(\mathrm{~s}-1)^{\alpha}\left(\mathrm{d}_{\mathrm{S}}\right)^{\beta}(\mathrm{X})^{\gamma}(\mathrm{D})^{\delta}(\mathrm{d})^{\varepsilon}(\mathrm{H} / \mathrm{D})^{\zeta}
$$

Equation (2.3) can be expressed in general functional form

$$
\mathrm{U}_{\mathrm{JS}}=\mathrm{f}\left(\mathrm{g},(\mathrm{s}-1), \mathrm{d}_{\mathrm{S}}, \mathrm{X}, \mathrm{D}, \mathrm{d}, \mathrm{H} / \mathrm{D}\right)
$$

where

$$
\begin{aligned}
& \mathrm{U}_{\mathrm{JS}}=\text { jet velocity for off-bottom suspension (jet mixers) } \\
& \mathrm{k}_{\mathrm{J}}=\text { jet mixer specific constant } \\
& \mathrm{g}=\text { gravitational constant }\left(\mathrm{m} / \mathrm{s}^{2}\right) \\
& \mathrm{s}=\text { ratio of particle density to liquid density (dimensionless) } \\
& \mathrm{d}_{\mathrm{S}}=\text { diameter of particle }(\mathrm{m}) \\
& \mathrm{X}=\text { weight of solid per weight of liquid times } 100 \text { (percent) } \\
& \mathrm{D}=\text { diameter of vessel } \\
& \mathrm{d}=\text { diameter of jet nozzle } \\
& \mathrm{H}=\text { fluid height } \\
& \mathrm{f}=\text { general function. }
\end{aligned}
$$

The exponents of the correlation in Eq. (2.3) are denoted by Greek letters. The exponent of the gravitational term is chosen to provide dimensional consistency with respect to time within the equation. The terms in Eq. (2.3) correspond to the similarly positioned terms in Eq. (2.1). However, no viscosity term is shown in Eq. (2.3) because viscosity was not varied during the development of Eq. (2.1).

PNNL has conducted many studies evaluating the performance of jet mixing applied to waste stored at Hanford both with respect to sludge mobilization (Powell et al. 1995a, 1995b, 1997; Shekarriz et al. 1997) and maintaining slurry uniformity (Liljegren and Bamberger 1992, Fort et al. 1993, Bamberger and Meyer 2001, Bamberger and Greenwood 2004, Bamberger et al. 2007, Fort et al. 2007). Jet mixing work 
was expanded to include understanding gas release events in Hanford double-shell tanks (Meyer and Wells 2000).

\subsection{Pulse Jet Mixing}

Pulse jet mixing differs significantly from steady jet mixing. This section describes the unique aspects of PJMs. In Section 2.3.1 PJM configuration and operation are described. In Section 2.3.2 the expected solids behavior during PJM operation is described. PJM mixing requirements are listed in Section 2.3.3, and previous pulse jet mixing studies are briefly described in Section 2.3.4.

\subsubsection{Pulse Jet Mixer Operation}

PJMs differ from mixers that sustain a steady jet to provide mixing in that jets are formed by alternating pressure and suction on fluid in pulse tubes coupled with jet nozzles, creating a pulsating flow. The nozzle end of the tube is immersed in the tank, while periodic pressure, vacuum, and venting are supplied to the opposite end. There are three operating modes for the pulse tube: 1) the drive mode, when pressure is applied to discharge the contents of the PJM tube at high velocity through the nozzle; 2) the refill mode, when vacuum is applied to refill the pulse tube; and 3) the vent mode, when the pressure is vented to atmosphere and the pulse tube and tank approach the same fill level. The PJM system uses these operating modes to produce a sequence of drive cycles that provide mixing in the vessel. In the right conditions, multiple pulse tubes, operating either in parallel or in sequence, can be used to effectively provide mixing in liquid/solid systems. The pulse tubes are oriented in rings one or two radii from the tank center. The PJMs are distributed uniformly around the vessel circumference.

A typical PJM system configuration in a vessel is shown schematically in Figure 2.1. The vessel shows diameter (D), volume (V), and fill level (H). There are $\mathrm{N}$ pulse jets in the vessel, each with pulse tube diameter $\left(\mathrm{D}_{\mathrm{PT}}\right)$ and volume $\left(\mathrm{V}_{\mathrm{PT}}\right)$. Each PJM has a conical nozzle with diameter $(\mathrm{d})$. The volume of fluid expelled during a pulse $\left(\mathrm{V}_{\mathrm{P}}\right)$ is about $80 \%$ of the pulse tube volume to avoid the potential for a pressurized air overblow (i.e., blowing pressurized air from the PJM tubes into the vessel must be avoided). Typically, the total pulse volume $\left(\mathrm{N} \times \mathrm{V}_{\mathrm{P}}\right)$ is approximately 5 to $10 \%$ of the operating volume of the vessel. During the drive phase the tube is pressurized, and a volume of slurry is discharged. The level change in the tube during discharge is $\Delta \mathrm{L}$ with a corresponding increase in waste level $(\Delta \mathrm{H})$, which is also about 5 to $10 \%$ of the operating level, H. Figure 2.1 illustrates a typical PJM system.

The discharge velocity during the drive phase is controlled by the drive pressure, the pressure head at the nozzle exit, and the nozzle loss coefficient. The average velocity $\left(\mathrm{U}_{0}\right)$ is given by

$$
\mathrm{U}_{0}=\frac{4 \mathrm{~V}_{\mathrm{p}}}{\pi \mathrm{d}^{2} \mathrm{t}_{\mathrm{D}}}
$$

where $t_{D}$ is drive time. The drive pressure $\left(p_{D}\right)$ required to produce the discharge velocity is approximated by

$$
\mathrm{p}_{\mathrm{D}}=\mathrm{p}_{\mathrm{E}}+\frac{\mathrm{k}_{\mathrm{D}}}{2} \rho \mathrm{U}_{0}^{2}
$$

where $\mathrm{p}_{\mathrm{E}}$ is pressure head at the nozzle exit, $\mathrm{k}_{\mathrm{D}}$ is nozzle discharge coefficient, and $\rho$ is slurry density. 


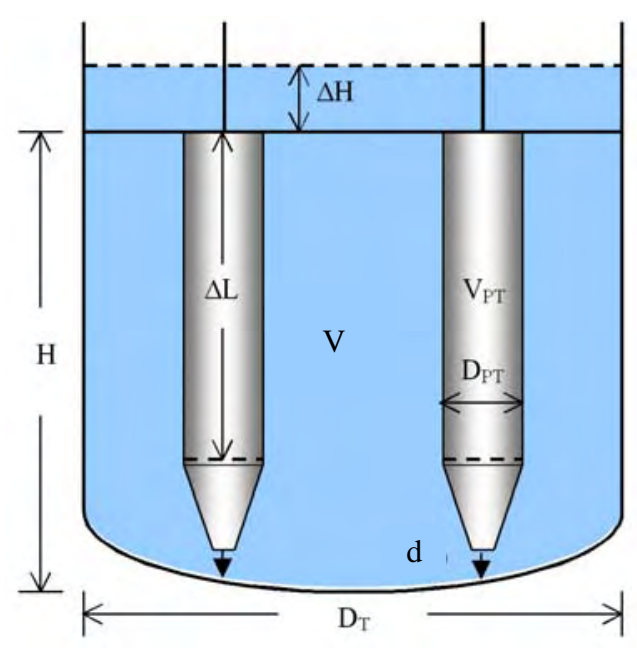

Figure 2.1. Illustration of a Typical PJM System in a WTP Vessel

Immediately after the drive phase, a vent is opened, and excess pressure is allowed to vent to atmosphere. During the suction phase, vacuum is applied to the pulse tube, which fills due to a combination of applied vacuum and difference in hydrostatic head between the fluid level and the level in the tube. The refill time $\left(t_{R}\right)$ is the sum of the vent and suction times. The total cycle time for PJM operation is given by

$$
\mathrm{t}_{\mathrm{C}}=\mathrm{t}_{\mathrm{D}}+\mathrm{t}_{\mathrm{R}}
$$

The average drive velocity is averaged both spatially and temporally. Spatially, the velocity varies over the cross section of the nozzle. Temporally, the velocity varies due to transients in the drive pressure and inertial effects. Figure 2.2 is an illustration of the temporal variation of velocity during one PJM cycle, referred to as a drive function. At the beginning of the drive phase, the fluid inside the PJM is stationary and must be accelerated. When the drive phase is over, some fluid continues to discharge due to the inertia of the moving column of fluid. The inertial effects depend on the physical size of the system. Pulse jet drive functions can vary considerably among mixing vessels in the WTP; mixing system scale, fill level, and slurry properties all have an effect. To compare PJM systems on a common basis, average velocities can be considered. These have the form:

$$
\mathrm{U}_{\mathrm{n}}=\left(\frac{1}{\Delta \mathrm{t}_{\mathrm{n}}} \int \mathrm{U}(\mathrm{t})^{\mathrm{n}} \mathrm{dt}\right)^{1 / \mathrm{n}} \mathrm{n}=1,2,3 \text {, and peak average with } \mathrm{n}=1, \Delta \mathrm{t}_{\mathrm{n}}=\text { primary discharge time }
$$

where $\mathrm{U}(\mathrm{t})$ is instantaneous velocity, $\Delta \mathrm{t}$ is the time interval over which the integration is performed, and $\mathrm{n}$ is a specified exponent. The cases $n=1,2,3$ correspond to mass, momentum, and energy-based average velocities. 


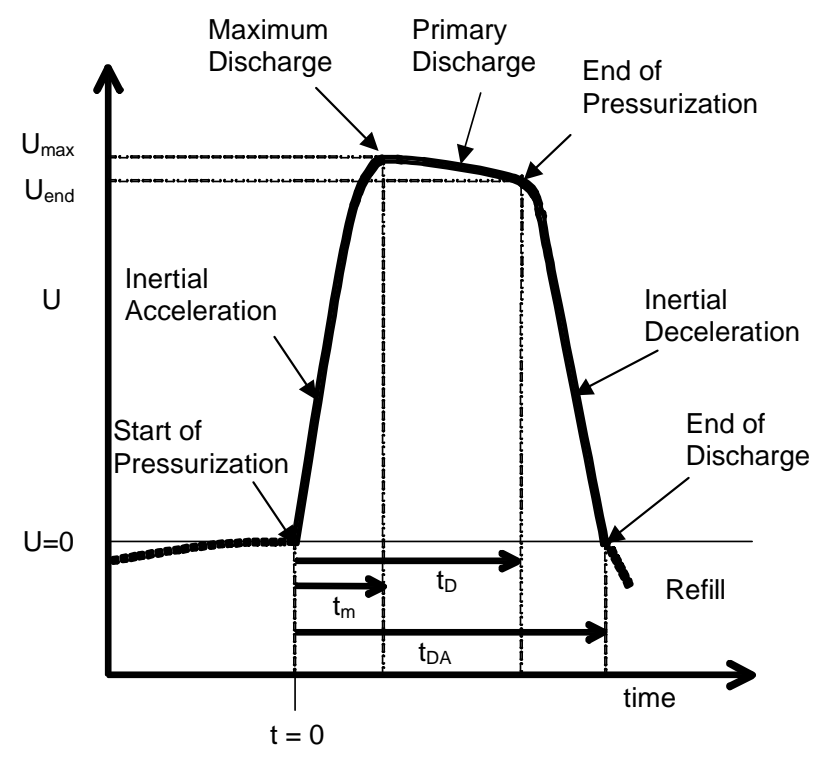

Figure 2.2. Illustration of Nozzle Velocity Transient During PJM Discharge

When the steady jet mixing correlation expressed by Eq. 2.3 is extended to pulse jet mixing, the correlation can be written in the expanded form:

$$
\mathrm{U}_{\mathrm{CS}}=\mathrm{k}_{\mathrm{P}}(\mathrm{g})^{0.5}(\mathrm{~s}-1)^{\alpha}\left(\mathrm{d}_{\mathrm{S}}\right)^{\beta}\left(\phi_{\mathrm{S}}\right)^{\gamma}(\mathrm{D})^{\delta}(\mathrm{d})^{\varepsilon}(\mathrm{DC})^{\zeta}(\mathrm{N})^{\eta}\left(\phi_{\mathrm{p}}\right)^{\theta}(\mathrm{H} / \mathrm{D})^{\mathrm{K}}
$$

As before, Eq. (2.9) can be expressed in general functional form as

$$
\mathrm{U}_{\mathrm{JS}}=\mathrm{f}\left(\mathrm{g},(\mathrm{s}-1), \mathrm{d}_{\mathrm{s}}, \phi_{\mathrm{S}}, \mathrm{D}, \mathrm{d}, \mathrm{DC}, \mathrm{N}, \phi_{\mathrm{p}}, \mathrm{DC}, \mathrm{H} / \mathrm{D}\right)
$$

where

$\mathrm{U}_{\mathrm{CS}}=$ critical suspension velocity, all solids suspended at the end of the pulse

$\mathrm{k}_{\mathrm{P}}=$ PJM specific constant

$\mathrm{g}=$ gravitational constant

$\mathrm{s}=$ ratio of particle density to liquid density $=\rho_{\mathrm{s}} / \rho_{\mathrm{l}}$

$\mathrm{d}_{\mathrm{S}}=$ diameter of particle $(\mathrm{m})$

$\phi_{\mathrm{S}}=$ solids volume fraction

$\mathrm{D}=$ diameter of vessel

$\mathrm{d}=$ diameter of jet nozzle

$\mathrm{DC}=$ duty cycle

$\mathrm{N}=$ number of tubes

$\phi_{\mathrm{p}}=$ pulse volume fraction

$\mathrm{H}=$ fluid height

$\mathrm{f}=$ general function.

Again, the terms in Eq. (2.9) correspond to the similarly positioned terms in Eq. (2.3) with solids volume fraction substituted for the weight-based term. The duty cycle is added to account for the pulsating flow. This pulse jet model (Eq. 2.9) does not include the ratio of radius of PJM nozzles to tank radius, although nozzle diameter and tank diameter are factored in separately. For the tests performed and 
discussed in this report, this parameter was matched either to that of HLP-22, with four inner and eight outer PJMs, or to an eight-tube array representing vessels with four inner and four outer PJMs.

\subsubsection{Expected Solids Behavior During PJM Operation}

During pulse jet mixing, fluid contained in pulse tubes submerged in the vessel is periodically expelled through the nozzles and into the vessel. This fluid mixes with fluid in the vessel, and solids entrained in the jet are mobilized. While the pulse tubes refill, solids suspended in the fluid may start to settle. This cyclic process is used to suspend, resuspend, and mix particulates contained in the vessel.

During the PJM cycle, process parameters affect the degree of mixing and solids motion that occurs. The jet velocity can be used to characterize the state of the solids within the vessel. There are four conditions of note:

1. The velocity at which the particles on the bottom of the tank are all in motion, complete solids suspension or critical suspension velocity $\left(\mathrm{U}_{\mathrm{CS}}\right)$.

2. The cloud height $\left(\mathrm{H}_{\mathrm{C}}\right)$ at each velocity, should one exist.

3. The jet velocity and pulse cycle for which the solids reach the liquid surface.

4. The PJM operating conditions under which the vertical concentration profile becomes uniform.

To illustrate the concepts of critical suspension velocity and cloud height that guided testing, Figure 2.3 shows the mixing conditions that may exist during gradual, sequential increases in pulse characteristics (duration and duty cycle) and jet velocity. Steady state is assumed to be achieved between each increase. The resulting mixing states are summarized in Table 2.1 and are related to these key characteristics.

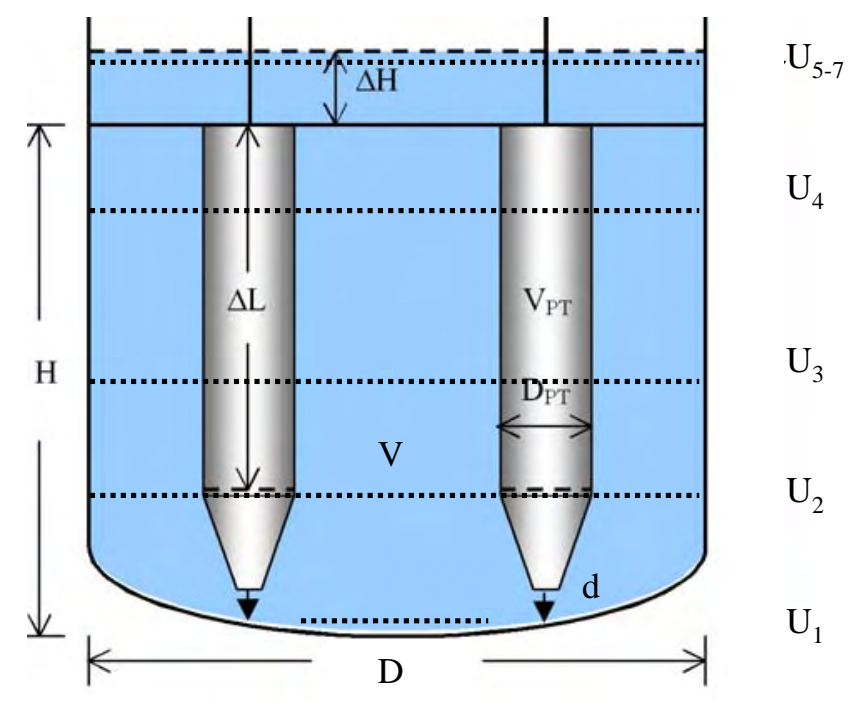

Figure 2.3. Illustration of a Typical PJM System in a WTP Vessel. Solids levels at $\mathrm{U}_{1}$ can be significantly higher than shown. 
Table 2.1. Description of Mixing States for Different Nozzle Velocities (U)

\begin{tabular}{|c|c|c|}
\hline Condition & Characteristic & Description \\
\hline $\mathrm{U}_{1}$ & $\mathrm{U}=0$ & At this initial condition, solids are settled in the vessel, and PJMs are not operating. \\
\hline $\mathrm{U}_{2}$ & $\mathrm{U}<\mathrm{U}_{\mathrm{CS}}$ & $\begin{array}{l}\text { PJMs are now pulsing, and jet velocity is less than required to completely suspend } \\
\text { particles at the end of the pulse. }\end{array}$ \\
\hline $\mathrm{U}_{3}$ & $\mathrm{U}=\mathrm{U}_{\mathrm{CS}}$ & $\begin{array}{l}\text { This is the velocity required to completely suspend the particles so that they are } \\
\text { moving about the tank floor at the end of the pulse. }\end{array}$ \\
\hline $\mathrm{U}_{4}$ & $\mathrm{U}>\mathrm{U}_{\mathrm{CS}} \mathrm{H}_{\mathrm{C}}<\mathrm{H}$ & $\begin{array}{l}\text { The velocity is above the critical suspension velocity. A particle interface, the cloud } \\
\text { height, may be visible below the maximum fluid fill height, } \mathrm{H} \text {. }\end{array}$ \\
\hline $\mathrm{U}_{5}$ & $\mathrm{H}_{\mathrm{C}}=\mathrm{H}, \mathrm{U}_{\mathrm{C}}$ & $\begin{array}{l}\text { The height of the cloud has reached the maximum fluid fill height } H \text {. The velocity at } \\
\text { this point is } U_{C} \text {, the velocity required for "complete suspension." }\end{array}$ \\
\hline $\mathrm{U}_{6}$ & $\mathrm{U}>\mathrm{U}_{\mathrm{C}}$ & $\begin{array}{l}\text { The velocity is greater than that required to sustain the cloud at the maximum fill } \\
\text { height, } \mathrm{H} \text {. }\end{array}$ \\
\hline $\mathrm{U}_{7}$ & $\mathrm{U}_{\max }$ & $\begin{array}{l}\text { The maximum velocity obtainable in the test fixture has been reached. The solids } \\
\text { concentration profile may be constant with elevation at this velocity, or perhaps } \\
\text { significant concentration gradients may still exist. }\end{array}$ \\
\hline
\end{tabular}

\subsubsection{Mixing Requirements}

Mixing requirements for the WTP are described in BNI document 24590-WTP-ES-PT-08-002 Rev. 0, Determination of Mixing Requirements for Pulse Jet-Mixed Vessels in the Waste Treatment Plant (Olsen 2008a). We do not provide analysis of WTP vessels using values from later revisions of that document in this report.

\subsubsection{Synopsis of Prior PJM Mixing Studies}

PNNL staff have conducted significant experimental and analytical studies investigating PJM performance for mixing non-Newtonian slurries (Bamberger et al. 2005, Meyer et al. 2006, Meyer and Etchells 2007, Bamberger et al. 2008) and conducted tests with neutralized current acid waste simulant (Bontha et al. 2000). The work with non-Newtonian slurries was expanded to determine the technical basis for scaling air sparging systems for mixing non-Newtonian slurries (Poloski et al. 2005, Guerrero and Restivo 2004). Experiments have been conducted to evaluate the performance of specific vessels, including the ultrafiltration feed process (UFP) and high-level waste lag storage (LS) vessels (Bates et al. 2003). These studies were expanded to define the technical bases for predicting mixing and flammable gas behavior in the ultrafiltration process feed (UFP) and lag storage (LS) vessels (Bontha et al. 2005). PJM controller and instrumentation performance were also evaluated (Bontha et al. 2007).

Prior to the scaled tests described in this report, PNNL conducted tests to demonstrate the ability to mix in a small-scale PJM test facility (Johnson et al. 2003), and scaling relationships were proposed by Bamberger and Meyer (2007).

\subsection{WTP Plant Vessels}

There are 32 different WTP solids-containing vessels with 18 unique geometries. All are planned to have PJM systems installed. Pertinent vessel design and operational conditions were supplied by the 
client and are shown in Tables $2.2^{1}$ and 2.3. ${ }^{2}$ Vessel volumes at normal operating fill levels vary from 22.7 to $1438 \mathrm{~m}^{3}$ (6 to $380 \mathrm{kgal}$ ). Vessel diameters range from about 3 to $14.6 \mathrm{~m}$ (10 to $48 \mathrm{ft}$ ), and operating levels vary from 2.4 to $9.8 \mathrm{~m} \mathrm{(8} \mathrm{to} 32 \mathrm{ft}$ ). About half the vessels have elliptical dish bottoms, and the rest have flanged and dish (F\&D) heads. The number of PJMs varies from 1 to 12 . All but the single-PJM designs involve single or double rings of pulse tubes. All of the baseline PJM designs have 0.10 -m (4-in.) nozzles elevated $0.15 \mathrm{~m}$ (6 in.) off the bottom. These nozzles are designed to operate at approximately $8 \mathrm{~m} / \mathrm{s}$ when the vessel is full. The volume of the pulse tubes varies significantly, with total pulse volume being about 5 to $10 \%$ of the vessel working volume. The drive times are related to the actual volume of the pulse tubes, and these also vary significantly, from 20 seconds to 4 minutes.

Various metrics can be applied to the WTP mixing systems to obtain an indication of relative mixing performance. Some are shown in Figure 2.4 along with the relative heights and diameters of the vessels. All parameters shown have been normalized by the largest value. For steady jet mixers, power per volume (PPV) is approximately $\mathrm{N} \mathrm{U}^{3} \mathrm{~d}^{2} /\left(\mathrm{D}^{2} \mathrm{H}\right)$, where $\mathrm{N}$ is number of PJMs. Thrust per area (TPA) is given by $N \rho \mathrm{U}^{2} \mathrm{~d}^{2} / \mathrm{D}^{2}$. The Froude number metric is given by $\mathrm{Nu}^{2} \mathrm{~d}^{2} /\left(\mathrm{gHD}^{2}\right)$. The range in these metrics illustrates some of the uncertainty on the adequacy of the mixing system designs and the wide range of conditions the M3 Test Program must consider. Design changes are being considered for some vessels due to relative ratings such as those shown in Figure 2.4. ${ }^{3}$ The primary changes being considered involve increasing jet velocity up to $12 \mathrm{~m} / \mathrm{s}$ and nozzle diameter up to $15 \mathrm{~cm}$ (6 in.).

\footnotetext{
${ }^{1}$ Data in the table are for information only (FIO). Email transmittal from GL Smith to PA Scott, PA Meyer et al., Feb. 23, 2007, 13:30:52. "PJM Mixing Systems Geometry: Documented in WTP Project Document CCN 146683," with attachment "WTP Project Memorandum CCN 146683_PJM Mixing Systems Geometry for M3 Testing_DRAFT_Feb20'07.pdf.”

${ }^{2}$ Nondimensional data in the table are for information only (FIO).

${ }^{3}$ Figure 2.4 is provided FIO.
} 
Table 2.2. Geometric and Operational Data for Solids-Containing Vessels in the WTP—Dimensional Data (FIO)

\begin{tabular}{|c|c|c|c|c|c|c|c|c|c|c|c|c|c|c|c|c|c|c|}
\hline ID & Vessel & $\begin{array}{c}50 / 50 \\
\text { Vessel } \\
(\mathrm{Y}, \mathrm{N})\end{array}$ & $\begin{array}{c}\text { Vessel } \\
\text { Sparged } \\
(\mathrm{Y}, \mathrm{N})\end{array}$ & $\begin{array}{c}\text { Max } \\
\text { Operating } \\
\text { Volume } \\
\text { (MOV) }\end{array}$ & $\begin{array}{c}\text { Working } \\
\text { Volume } \\
\text { (WV) }\end{array}$ & $\begin{array}{c}\text { Max } \\
\text { Operating } \\
\text { Volume }\end{array}$ & $\begin{array}{l}\text { Working } \\
\text { Volume }\end{array}$ & $\begin{array}{l}\text { Vessel } \\
\text { Dia. }\end{array}$ & $\begin{array}{c}\text { Vessel Bottom } \\
\text { Head Type }\end{array}$ & $\begin{array}{l}\text { Norm } \\
\text { Vessel } \\
\text { Waste } \\
\text { Depth }\end{array}$ & $\begin{array}{c}\text { Max } \\
\text { Vessel } \\
\text { Waste } \\
\text { Depth }\end{array}$ & $\begin{array}{c}\text { Min } \\
\text { Vessel } \\
\text { Waste } \\
\text { Depth }\end{array}$ & $\begin{array}{c}\text { Relative } \\
\text { Scale }\end{array}$ & $\begin{array}{l}\text { Nom } \\
\text { H/D }\end{array}$ & $\begin{array}{l}\text { Max } \\
\text { H/D }\end{array}$ & $\begin{array}{l}\text { Min } \\
\mathrm{H} / \mathrm{D}\end{array}$ & $\begin{array}{l}\text { PJM } \\
\text { Vol }\end{array}$ & $\begin{array}{l}\text { PJM } \\
\text { Vol }\end{array}$ \\
\hline- & - & - & - & gal & gal & $\mathrm{ft}^{3}$ & $\mathrm{ft}^{3}$ & $\mathrm{ft}$ & - & $\mathrm{ft}$ & $\mathrm{ft}$ & $\mathrm{ft}$ & - & - & - & - & gal & $\mathrm{ft}^{3}$ \\
\hline 1 & FEP-17A/B & $\mathrm{Y}$ & $\mathrm{N}$ & 71,292 & 56,223 & 9,530 & 7,516 & 22.0 & 2:1 elliptical & 21.60 & 26.20 & 2.00 & 2.1 & 0.98 & 1.19 & 0.09 & 885 & 118.3 \\
\hline 2 & FRP-02A/B/C/D & $\mathrm{N}$ & $\mathrm{N}$ & 406,800 & 379,891 & 54,381 & 50,784 & 47.0 & F\&D & 30.60 & 34.11 & 1.00 & 1.0 & 0.65 & 0.73 & 0.02 & 1,614 & 215.8 \\
\hline 3 & HLP-22 & $\mathrm{N}$ & $\mathrm{N}$ & 234,500 & 203,927 & 31,348 & 27,261 & 38.0 & F\&D & 26.56 & 30.27 & 7.63 & 1.2 & 0.70 & 0.80 & 0.20 & 1,693 & 226.3 \\
\hline 4 & HOP-903/904 & $\mathrm{N}$ & $\mathrm{N}$ & 8,199 & 5,808 & 1,096 & 776 & 12.0 & 2:1 elliptical & 7.87 & 10.30 & 2.26 & 3.9 & 0.66 & 0.86 & 0.19 & 115 & 15.4 \\
\hline 5 & PWD-15/16 & $\mathrm{N}$ & $\mathrm{N}$ & 105,850 & 87,657 & 14,150 & 11,718 & 22.0 & 2:1 elliptical & 32.68 & 39.08 & 4.17 & 2.1 & 1.49 & 1.78 & 0.19 & 540 & 72.2 \\
\hline 6 & PWD-33/43 & $\mathrm{Y}$ & $\mathrm{N}$ & 29,580 & 20,802 & 3,954 & 2,781 & 24.0 & F\&D & 7.71 & 10.89 & 2.34 & 2.0 & 0.32 & 0.45 & 0.10 & 265 & 35.4 \\
\hline 7 & PWD-44 & $\mathrm{Y}$ & $\mathrm{N}$ & 88,631 & 74,147 & 11,848 & 9,912 & 23.0 & 2:1 elliptical & 25.79 & 30.45 & 4.39 & 2.0 & 1.12 & 1.32 & 0.19 & 1,085 & 145.0 \\
\hline 8 & RDP-02A/B/C & $\mathrm{N}$ & $\mathrm{N}$ & 12,688 & 7,508 & 1,696 & 1,004 & 12.0 & 2:1 elliptical & 9.87 & 13.93 & 0.17 & 3.9 & 0.82 & 1.16 & 0.01 & 311 & 41.6 \\
\hline 9 & RLD-07 & $\mathrm{N}$ & $\mathrm{N}$ & 15,758 & 12,184 & 2,107 & 1,629 & 13.0 & F\&D & 13.14 & 15.59 & 2.18 & 3.6 & 1.01 & 1.20 & 0.17 & 207 & 27.7 \\
\hline 10 & RLD-08 & $\mathrm{N}$ & $\mathrm{N}$ & 10,628 & 8,681 & 1,421 & 1,160 & 13.0 & 2:1 elliptical & 9.87 & 11.79 & 2.19 & 3.6 & 0.76 & 0.91 & 0.17 & 214 & 28.6 \\
\hline 11 & TLP-09A/B & $\mathrm{N}$ & $\mathrm{N}$ & 114,060 & 87,138 & 15,248 & 11,649 & 26.0 & F\&D & 23.66 & 27.96 & 1.50 & 1.8 & 0.91 & 1.08 & 0.06 & 581 & 77.7 \\
\hline 12 & UFP-01A/B & $\mathrm{Y}$ & $\mathrm{N}$ & 64,626 & 54,536 & 8,639 & 7,290 & 20.0 & 2:1 elliptical & 24.87 & 29.05 & 2.00 & 2.4 & 1.24 & 1.45 & 0.10 & 693 & 92.6 \\
\hline 13 & UFP-62A/B/C & $\mathrm{N}$ & $\mathrm{N}$ & 30,072 & 25,503 & 4,020 & 3,409 & 15.0 & 2:1 elliptical & 20.54 & 24.00 & 2.21 & 3.1 & 1.37 & 1.60 & 0.15 & 251 & 33.6 \\
\hline 14 & CNP-03 & $\mathrm{N}$ & $\mathrm{N}$ & 18,750 & 15,350 & 2,507 & 2,052 & 14.0 & F\&D & 14.67 & 17.21 & 2.20 & 3.4 & 1.05 & 1.23 & 0.16 & 198 & 26.5 \\
\hline 15 & CNP-04 & $\mathrm{N}$ & $\mathrm{N}$ & 10,065 & 7,853 & 1,345 & 1,050 & 9.5 & F\&D & 19.61 & 15.44 & 2.13 & 4.9 & 2.06 & 1.63 & 0.22 & 129 & 17.2 \\
\hline 16 & CXP-04 & $\mathrm{N}$ & $\mathrm{N}$ & 9,393 & 7,840 & 1,256 & 1,048 & 10.5 & F\&D & 12.76 & 14.15 & 2.15 & 4.5 & 1.22 & 1.35 & 0.20 & 470 & 62.8 \\
\hline 17 & CXP-26A/B/C & $\mathrm{N}$ & $\mathrm{N}$ & 34,370 & 29,929 & 4,595 & 4,001 & 15.0 & 2:1 elliptical & 23.86 & 26.81 & 2.47 & 3.1 & 1.59 & 1.79 & 0.16 & 243 & 32.5 \\
\hline 18 & ТСР-01 & $\mathrm{N}$ & $\mathrm{N}$ & 129,963 & 103,200 & 17,374 & 13,796 & 26.5 & $\mathrm{~F} \& \mathrm{D}$ & 26.78 & 33.25 & 2.00 & 1.8 & 1.01 & 1.25 & 0.08 & 1,625 & 217.2 \\
\hline- & UFP-02A/B & $\mathrm{N}$ & $\mathrm{Y}$ & 36,561 & 26,778 & 4,887 & 3,580 & 14.0 & 2:1 elliptical & 24.85 & 30.68 & 2.00 & 3.4 & 1.78 & 2.19 & 0.14 & 606 & 81.0 \\
\hline- & HLP-27A/B & $\mathrm{N}$ & $\mathrm{Y}$ & 112,900 & 92,087 & 15,093 & 12,310 & 25.0 & F\&D & 26.73 & 32.40 & 3.20 & 1.9 & 1.07 & 1.30 & 0.13 & 1,405 & 187.8 \\
\hline - & HLP-28 & $\mathrm{N}$ & $\mathrm{Y}$ & 125,430 & 97,012 & 16,768 & 12,969 & 26.5 & F\&D & 25.27 & 32.65 & 2.00 & 1.8 & 0.95 & 1.23 & 0.08 & 1,555 & 207.9 \\
\hline - & CNP-01 & $\mathrm{N}$ & $\mathrm{N}$ & 108 & 108 & 15 & 15 & 4.0 & $F \& D$ & 1.60 & 1.60 & 0.00 & 11.8 & 0.40 & 0.40 & 0.00 & N/A & N/A \\
\hline - & CXP-01 & $\mathrm{N}$ & $\mathrm{N}$ & 92,850 & 85,038 & 12,412 & 11,368 & 23.0 & $F \& D$ & 28.69 & 31.39 & 1.50 & 2.0 & 1.25 & 1.36 & 0.07 & N/A & N/A \\
\hline- & CXP-05 & $\mathrm{N}$ & $\mathrm{N}$ & 883 & 486 & 118 & 65 & 5.0 & $\mathrm{~F} \& \mathrm{D}$ & 3.64 & 6.33 & 1.00 & 9.4 & 0.73 & 1.27 & 0.20 & N/A & N/A \\
\hline- & FEP-05 & $\mathrm{N}$ & $\mathrm{N}$ & 4,144 & 60 & 554 & 413 & 8.0 & $\mathrm{~F} \& \mathrm{D}$ & 6.68 & 9.46 & 1.50 & 5.9 & 0.84 & 1.18 & 0.19 & N/A & N/A \\
\hline- & PJV-02 & $\mathrm{N}$ & $\mathrm{N}$ & 7,408 & 6,141 & 990 & 821 & 10.0 & 2:1 elliptical & 11.29 & 13.50 & 1.42 & 4.7 & 1.13 & 1.35 & 0.14 & N/A & N/A \\
\hline- & PVP-01 & $\mathrm{N}$ & $\mathrm{N}$ & 1,650 & 1,547 & 221 & 207 & 6.0 & 2:1 elliptical & 7.81 & 8.31 & 1.50 & 7.8 & 1.30 & 1.39 & 0.25 & N/A & N/A \\
\hline - & TLP-02 & $\mathrm{N}$ & $\mathrm{N}$ & 1,916 & 45 & 256 & 157 & 6.0 & F\&D & 5.95 & 8.46 & 1.50 & 7.8 & 0.99 & 1.41 & 0.25 & N/A & N/A \\
\hline
\end{tabular}


Table 2.2. (contd)

\begin{tabular}{|c|c|c|c|c|c|c|c|c|c|c|c|c|c|c|c|c|c|c|c|c|c|}
\hline $\begin{array}{l}\text { PJM } \\
\text { Dia. }\end{array}$ & $\begin{array}{c}\text { PJM } \\
\text { Length }\end{array}$ & $\begin{array}{l}\text { Stroke } \\
\text { Length }\end{array}$ & $\begin{array}{l}\text { PJM } \\
\text { Type }\end{array}$ & $\begin{array}{l}\text { Total } \\
\text { PJMs }\end{array}$ & $\begin{array}{l}\text { PJM Vol } \\
\text { Fraction } \\
\text { of MOV } \\
@ 100 \% \\
\text { Stroke }\end{array}$ & $\begin{array}{c}\text { PJM Vol } \\
\text { Fraction } \\
\text { of WV @ } \\
80 \% \\
\text { Stroke }\end{array}$ & $\begin{array}{c}\text { Number } \\
\text { PJMs } \\
\text { Inner } \\
\text { Circle }\end{array}$ & $\begin{array}{l}\text { Radius } \\
\text { Inner } \\
\text { Circle }\end{array}$ & $\begin{array}{c}\text { Number } \\
\text { PJMs } \\
\text { Outer } \\
\text { Circle }\end{array}$ & $\begin{array}{c}\text { Radius } \\
\text { Outer } \\
\text { Circle }\end{array}$ & $\begin{array}{c}\text { Nozzle } \\
\text { Dia }\end{array}$ & $\begin{array}{l}\text { Normal } \\
\text { Nozzle } \\
\text { Velocity }\end{array}$ & $\begin{array}{l}\text { Norm } \\
\text { Drive } \\
\text { y Time }\end{array}$ & $\begin{array}{l}\text { Norm } \\
\text { PJM } \\
\text { Cycle } \\
\text { Time }\end{array}$ & $\begin{array}{l}\text { Norm } \\
\text { Duty } \\
\text { Cycle }\end{array}$ & $\begin{array}{c}\text { Peak } \\
\text { Nozzle } \\
\text { Velocity }\end{array}$ & $\begin{array}{l}\text { Min. } \\
\text { Drive } \\
\text { Time }\end{array}$ & $\begin{array}{l}\text { Min. } \\
\text { PJM } \\
\text { Cycle } \\
\text { Time }\end{array}$ & $\begin{array}{l}\text { Min } \\
\text { Duty } \\
\text { Cycle }\end{array}$ & ID & Vessel \\
\hline $\mathrm{ft}$ & $\mathrm{ft}$ & $\mathrm{ft}$ & - & - & - & - & - & in, & - & in. & in. & $\mathrm{m} / \mathrm{sec}$ & sec & $\mathrm{sec}$ & & $\mathrm{m} / \mathrm{sec}$ & sec & sec & - & - & - \\
\hline 3.00 & 18.4 & 14.7 & $E$ & 8 & 0.10 & 0.10 & 4.00 & 132.00 & 4.00 & 176.00 & 4.00 & 8 & 38 & 129 & 0.29 & 9.8 & 35 & 135 & 0.26 & 1 & FEP-17A/B \\
\hline 4.50 & 16.4 & 13.1 & $\mathrm{~J}$ & 12 & 0.05 & 0.04 & 4.00 & 158.00 & 8.00 & 394.00 & 4.00 & 8 & 80 & 217 & 0.37 & 12 & 40 & 266 & 0.15 & 2 & FRP-02A/B/C/D \\
\hline 4.50 & 16.9 & 13.5 & $\mathrm{~J}$ & 12 & 0.09 & 0.08 & 4.00 & 152.00 & 8.00 & 342.00 & 4.00 & 8 & 77 & 233 & 0.33 & 10.7 & 40 & 270 & 0.15 & 3 & HLP-22 \\
\hline 1.50 & 9.4 & 7.5 & A & 4 & 0.06 & 0.06 & 0.00 & 96.00 & 4.00 & - & 4.00 & 8 & 6 & 23 & 0.26 & 10.5 & 4 & 20 & 0.20 & 4 & HOP-903/904 \\
\hline 2.67 & 14.4 & 11.5 & $\mathrm{D}$ & 8 & 0.04 & 0.04 & 4.00 & 120.00 & 4.00 & 176.00 & 4.00 & 8 & 24 & 68 & 0.35 & 9 & 22 & 66 & 0.33 & 5 & PWD-15/16 \\
\hline 2.67 & 7.8 & 6.3 & $\mathrm{D}$ & 8 & 0.07 & 0.08 & 4.00 & 168.00 & 4.00 & 192.00 & 4.00 & 8 & 11 & 37 & 0.30 & 11 & 7 & 36 & 0.19 & 6 & PWD-33/43 \\
\hline 3.50 & 17.1 & 13.7 & $\mathrm{~F}$ & 8 & 0.10 & 0.09 & 4.00 & 138.00 & 4.00 & 184.00 & 4.00 & 8 & 52 & 158 & 0.33 & 10.5 & 38 & 150 & 0.25 & 7 & PWD-44 \\
\hline 2.67 & 8.9 & 7.1 & $\mathrm{D}$ & 4 & 0.10 & 0.13 & 0.00 & 96.00 & 4.00 & - & 4.00 & 8 & 13 & 45 & 0.29 & 10.8 & 10 & 49 & 0.20 & 8 & RDP-02A/B/C \\
\hline 2.00 & 9.8 & 7.9 & B & 4 & 0.05 & 0.05 & 0.00 & 104.00 & 4.00 & - & 4.00 & 8 & 9 & 33 & 0.27 & 10.6 & 7 & 33 & 0.21 & 9 & RLD-07 \\
\hline 2.00 & 10.2 & 8.1 & B & 4 & 0.08 & 0.08 & 0.00 & 104.00 & 4.00 & - & 4.00 & 8 & 9 & 31 & 0.29 & 11 & 7 & 35 & 0.20 & 10 & RLD-08 \\
\hline 3.50 & 10.1 & 8.1 & $\mathrm{~F}$ & 8 & 0.04 & 0.04 & 4.00 & 148.00 & 4.00 & 208.00 & 4.00 & 8 & 23 & 76 & 0.30 & 10 & 20 & 76 & 0.26 & 11 & TLP-09A/B \\
\hline 3.00 & 14.8 & 11.9 & $\mathrm{E}$ & 8 & 0.09 & 0.08 & 4.00 & 120.00 & 4.00 & 160.00 & 4.00 & 8 & 30 & 96 & 0.31 & 11.5 & 18 & 111 & 0.16 & 12 & UFP-01A/B \\
\hline 2.00 & 11.8 & 9.4 & B & 6 & 0.05 & 0.05 & 3.00 & 90.00 & 3.00 & 128.00 & 4.00 & 8 & 14 & 45 & 0.31 & 9 & 10 & 37 & 0.27 & 13 & UFP-62A/B/C \\
\hline 2.50 & 6.8 & 5.4 & $\mathrm{C}$ & 4 & 0.04 & 0.04 & 0.00 & 112.00 & 4.00 & - & 4.00 & 8 & 9 & 34 & 0.26 & 9.2 & 7 & 30 & 0.23 & 14 & CNP-03 \\
\hline 1.50 & 10.5 & 8.4 & A & 4 & 0.05 & 0.05 & 0.00 & 76.00 & 4.00 & - & 4.00 & 8 & 6 & 22 & 0.27 & 10 & 4 & 19 & 0.21 & 15 & CNP-04 \\
\hline 3.00 & 10.6 & 8.5 & $\mathrm{E}$ & 1 & 0.05 & 0.05 & 1.00 & 0.00 & 0.00 & - & 4.00 & 8 & 20 & 69 & 0.29 & 11 & 15 & 72 & 0.21 & 16 & CXP-04 \\
\hline 2.00 & 11.4 & 9.1 & B & 6 & 0.04 & 0.04 & 0.00 & 120.00 & 6.00 & - & 4.00 & 8 & 12 & 38 & 0.32 & 9 & 10 & 35 & 0.29 & 17 & CXP-26A/B/C \\
\hline 4.33 & 17.3 & 13.9 & $\mathrm{H}$ & 8 & 0.10 & 0.10 & 4.00 & 150.00 & 4.00 & 212.00 & 4.00 & 8 & 76 & 227 & 0.33 & 9 & 74 & 230 & 0.32 & 18 & TCP-01 \\
\hline 2.67 & 14.6 & 11.7 & $\mathrm{D}$ & 6 & 0.10 & 0.11 & 1.00 & - & 5.00 & 37.00 & 4.00 & 12 & 15 & 91 & 0.16 & 12 & 15 & 91 & 0.16 & - & UFP-02A/B \\
\hline 4.00 & 14.9 & 12.0 & G & 8 & 0.10 & 0.10 & 1.00 & - & 7.00 & 61.00 & 4.00 & 12 & 30 & 223 & 0.13 & 12 & 30 & 223 & 0.13 & - & HLP-27A/B \\
\hline 4.33 & 14.1 & 11.3 & $\mathrm{H}$ & 8 & 0.10 & 0.10 & 1.00 & - & 7.00 & 65.50 & 4.00 & 12 & 30 & 222 & 0.14 & $6+$ & 30 & 222 & 0.14 & - & HLP-28 \\
\hline N/A & N/A & N/A & N/A & 0 & N/A & N/A & N/A & N/A & N/A & N/A & N/A & N/A & N/A & N/A & N/A & N/A & N/A & N/A & N/A & - & CNP-01 \\
\hline N/A & N/A & N/A & N/A & 0 & N/A & N/A & N/A & N/A & N/A & N/A & N/A & N/A & N/A & N/A & N/A & N/A & N/A & N/A & N/A & - & CXP-01 \\
\hline N/A & N/A & N/A & N/A & 0 & N/A & N/A & N/A & N/A & N/A & N/A & N/A & N/A & N/A & N/A & N/A & N/A & N/A & N/A & N/A & - & CXP-05 \\
\hline N/A & N/A & N/A & N/A & 0 & N/A & N/A & N/A & N/A & N/A & N/A & N/A & N/A & N/A & N/A & N/A & N/A & N/A & N/A & N/A & - & FEP-05 \\
\hline N/A & N/A & N/A & N/A & 0 & N/A & N/A & N/A & N/A & N/A & N/A & N/A & N/A & N/A & N/A & N/A & N/A & N/A & N/A & N/A & - & PJV-02 \\
\hline N/A & N/A & N/A & N/A & 0 & N/A & N/A & N/A & N/A & N/A & N/A & N/A & N/A & N/A & N/A & N/A & N/A & N/A & N/A & N/A & - & PVP-01 \\
\hline N/A & N/A & N/A & N/A & 0 & N/A & N/A & N/A & N/A & N/A & N/A & N/A & N/A & N/A & N/A & N/A & N/A & N/A & N/A & N/A & - & TLP-02 \\
\hline
\end{tabular}


Table 2.3. Geometric and Operational Data for Solids-Containing Vessels in the WTP-Nondimensional Values (FIO)

\begin{tabular}{|c|c|c|c|c|c|c|c|c|c|c|c|c|}
\hline \multirow{2}{*}{ Vessel } & \multicolumn{2}{|l|}{$S$} & \multicolumn{2}{|c|}{$\mathrm{N}$} & \multicolumn{3}{|c|}{$\mathrm{d} / \mathrm{D}$} & \multicolumn{2}{|c|}{$\mathrm{H} / \mathrm{D}$} & \multirow{2}{*}{$\frac{8 / 4 \mathrm{in} . / 1 \mathrm{cP}}{\text { nom }}$} & \multirow{2}{*}{$\frac{8 / 4 \text { in. } / 25 \mathrm{cP}}{\min }$} & \multirow{2}{*}{$\frac{12 / 8 \mathrm{in} . / 1 \mathrm{cP}}{\max }$} \\
\hline & - & tot & in & out & 4in. & 6in. & 8in. & norm & $\max$ & & & \\
\hline FRP-02A/B/C/D & 1 & 12 & 4 & 8 & 7.10E-03 & $1.10 \mathrm{E}-02$ & $1.40 \mathrm{E}-02$ & $6.50 \mathrm{E}-01$ & 7.30E-01 & $8.10 \mathrm{E}+05$ & $3.30 \mathrm{E}+04$ & $3.40 \mathrm{E}+06$ \\
\hline HLP-22 & 1.2 & 12 & 4 & 8 & 8.80E-03 & $1.30 \mathrm{E}-02$ & $1.80 \mathrm{E}-02$ & 7.00E-01 & 8.00E-01 & $8.10 \mathrm{E}+05$ & $3.30 \mathrm{E}+04$ & $3.40 \mathrm{E}+06$ \\
\hline TCP-01 & 1.8 & 8 & 4 & 4 & $1.30 \mathrm{E}-02$ & $1.90 \mathrm{E}-02$ & $2.50 \mathrm{E}-02$ & $1.00 \mathrm{E}+00$ & $1.30 \mathrm{E}+00$ & $8.10 \mathrm{E}+05$ & $3.30 \mathrm{E}+04$ & $3.40 \mathrm{E}+06$ \\
\hline TLP-09A/B & 1.8 & 8 & 4 & 4 & $1.30 \mathrm{E}-02$ & $1.90 \mathrm{E}-02$ & $2.60 \mathrm{E}-02$ & $9.10 \mathrm{E}-01$ & $1.10 \mathrm{E}+00$ & $8.10 \mathrm{E}+05$ & $3.30 \mathrm{E}+04$ & $3.40 \mathrm{E}+06$ \\
\hline PWD-33/43 & 2 & 8 & 4 & 4 & $1.40 \mathrm{E}-02$ & $2.10 \mathrm{E}-02$ & $2.80 \mathrm{E}-02$ & 3.20E-01 & 4.50E-01 & $8.10 \mathrm{E}+05$ & $3.30 \mathrm{E}+04$ & $3.40 \mathrm{E}+06$ \\
\hline PWD-44 & 2 & 8 & 4 & 4 & $1.40 \mathrm{E}-02$ & $2.20 \mathrm{E}-02$ & $2.90 \mathrm{E}-02$ & $1.10 \mathrm{E}+00$ & $1.30 \mathrm{E}+00$ & $8.10 \mathrm{E}+05$ & $3.30 \mathrm{E}+04$ & $3.40 \mathrm{E}+06$ \\
\hline FEP-17A/B & 2.1 & 8 & 4 & 4 & $1.50 \mathrm{E}-02$ & $2.30 \mathrm{E}-02$ & $3.00 \mathrm{E}-02$ & $9.80 \mathrm{E}-01$ & $1.20 \mathrm{E}+00$ & $8.10 \mathrm{E}+05$ & $3.30 \mathrm{E}+04$ & $3.40 \mathrm{E}+06$ \\
\hline PWD-15/16 & 2.1 & 8 & 4 & 4 & $1.50 \mathrm{E}-02$ & $2.30 \mathrm{E}-02$ & $3.00 \mathrm{E}-02$ & $1.50 \mathrm{E}+00$ & $1.80 \mathrm{E}+00$ & $8.10 \mathrm{E}+05$ & $3.30 \mathrm{E}+04$ & $3.40 \mathrm{E}+06$ \\
\hline UFP-01A/B & 2.4 & 8 & 4 & 4 & $1.70 \mathrm{E}-02$ & $2.50 \mathrm{E}-02$ & $3.30 \mathrm{E}-02$ & $1.20 \mathrm{E}+00$ & $1.50 \mathrm{E}+00$ & $8.10 \mathrm{E}+05$ & $3.30 \mathrm{E}+04$ & $3.40 \mathrm{E}+06$ \\
\hline UFP-62A/B/C & 3.1 & 6 & 3 & 3 & 2.20E-02 & 3.30E-02 & 4.40E-02 & $1.40 \mathrm{E}+00$ & $1.60 \mathrm{E}+00$ & $8.10 \mathrm{E}+05$ & $3.30 \mathrm{E}+04$ & $3.40 \mathrm{E}+06$ \\
\hline CXP-26A/B/C & 3.1 & 6 & 6 & - & 2.20E-02 & 3.30E-02 & 4.40E-02 & $1.60 \mathrm{E}+00$ & $1.80 \mathrm{E}+00$ & $8.10 \mathrm{E}+05$ & $3.30 \mathrm{E}+04$ & $3.40 \mathrm{E}+06$ \\
\hline CNP-03 & 3.4 & 4 & 4 & - & $2.40 \mathrm{E}-02$ & 3.60E-02 & 4.80E-02 & $1.00 \mathrm{E}+00$ & $1.20 \mathrm{E}+00$ & $8.10 \mathrm{E}+05$ & $3.30 \mathrm{E}+04$ & $3.40 \mathrm{E}+06$ \\
\hline RLD-07 & 3.6 & 4 & 4 & - & 2.60E-02 & $3.80 \mathrm{E}-02$ & $5.10 \mathrm{E}-02$ & $1.00 \mathrm{E}+00$ & $1.20 \mathrm{E}+00$ & $8.10 \mathrm{E}+05$ & $3.30 \mathrm{E}+04$ & $3.40 \mathrm{E}+06$ \\
\hline RLD-08 & 3.6 & 4 & 4 & - & 2.60E-02 & $3.80 \mathrm{E}-02$ & $5.10 \mathrm{E}-02$ & 7.60E-01 & $9.10 \mathrm{E}-01$ & $8.10 \mathrm{E}+05$ & $3.30 \mathrm{E}+04$ & $3.40 \mathrm{E}+06$ \\
\hline HOP-903/904 & 3.9 & 4 & 4 & - & 2.80E-02 & $4.20 \mathrm{E}-02$ & $5.60 \mathrm{E}-02$ & $6.60 \mathrm{E}-01$ & 8.60E-01 & $8.10 \mathrm{E}+05$ & $3.30 \mathrm{E}+04$ & $3.40 \mathrm{E}+06$ \\
\hline RDP-02A/B/C & 3.9 & 4 & 4 & - & 2.80E-02 & 4.20E-02 & $5.60 \mathrm{E}-02$ & 8.20E-01 & $1.20 \mathrm{E}+00$ & $8.10 \mathrm{E}+05$ & $3.30 \mathrm{E}+04$ & $3.40 \mathrm{E}+06$ \\
\hline CXP-04 & 4.5 & 1 & 0 & - & $3.20 \mathrm{E}-02$ & $4.80 \mathrm{E}-02$ & 6.30E-02 & $1.20 \mathrm{E}+00$ & $1.30 \mathrm{E}+00$ & $8.10 \mathrm{E}+05$ & $3.30 \mathrm{E}+04$ & $3.40 \mathrm{E}+06$ \\
\hline CNP-04 & 4.9 & 4 & 4 & - & 3.50E-02 & $5.30 \mathrm{E}-02$ & $7.00 \mathrm{E}-02$ & $2.10 \mathrm{E}+00$ & $1.60 \mathrm{E}+00$ & $8.10 \mathrm{E}+05$ & $3.30 \mathrm{E}+04$ & $3.40 \mathrm{E}+06$ \\
\hline - & - & - & - & - & - & - & - & - & - & - & - & - \\
\hline $\min$ & 1 & 1 & - & - & 7.09E-03 & $1.06 \mathrm{E}-02$ & $1.42 \mathrm{E}-02$ & 3.21E-01 & 4.54E-01 & $8.13 \mathrm{E}+05$ & $3.25 E+04$ & $3.41 \mathrm{E}+06$ \\
\hline $\max$ & 4.95 & 12 & - & - & 3.51E-02 & $5.26 \mathrm{E}-02$ & 7.02E-02 & $2.06 \mathrm{E}+00$ & $1.79 \mathrm{E}+00$ & $8.13 \mathrm{E}+05$ & $3.25 E+04$ & $3.41 \mathrm{E}+06$ \\
\hline average & 2.81 & 6.5 & - & - & 1.99E-02 & 2.99E-02 & 3.98E-02 & $1.05 \mathrm{E}+00$ & $1.21 \mathrm{E}+00$ & $8.13 E+05$ & $3.25 E+04$ & $3.41 \mathrm{E}+06$ \\
\hline- & - & - & - & - & - & - & - & - & - & - & - & - \\
\hline Recommended Min & - & 1 & 4 & 4 & 0.007 & - & - & 0.3 & - & $3.25 \mathrm{E}+04$ & - & - \\
\hline Recommended Max & - & 12 & 4 & 8 & 0.04 & - & - & 2 & - & $3.40 \mathrm{E}+06$ & - & - \\
\hline
\end{tabular}


Table 2.3. (contd)

\begin{tabular}{|c|c|c|c|c|c|c|c|c|c|c|}
\hline \multirow[b]{4}{*}{ Vessel } & \multicolumn{10}{|c|}{ Primary Nondimensional Variables } \\
\hline & \multicolumn{2}{|c|}{ Density Ratio } & \multirow{2}{*}{$\begin{array}{c}\text { Froude No. } \\
\text { Fr } \\
\end{array}$} & \multicolumn{2}{|c|}{ Densimetric Froude No. } & \multirow{3}{*}{$\begin{array}{c}12 \mathrm{~m} / \mathrm{s} \\
\mathrm{F} \\
\text { norm } \\
\end{array}$} & \multirow{3}{*}{$\begin{array}{c}12 \mathrm{~m} / \mathrm{s} \\
\mathrm{Fs} \\
\mathrm{min} \\
\end{array}$} & \multirow{3}{*}{$\begin{array}{c}\frac{12 \mathrm{~m} / \mathrm{s}}{\mathrm{F}} \\
\max \\
\end{array}$} & \multirow{3}{*}{$\begin{array}{c}\text { \% Pulse } \\
\phi_{\mathrm{p}} \\
\text { norm } \\
\end{array}$} & \multirow{3}{*}{$\begin{array}{c}\text { Duty Cycle } \\
\text { DC } \\
\text { norm } \\
\end{array}$} \\
\hline & \multicolumn{2}{|c|}{$\mathrm{s}$} & & Fs & Fs & & & & & \\
\hline & $\min$ & $\max$ & norm & $\min$ & $\max$ & & & & & \\
\hline FRP-02A/B/C/D & 1.5 & 11 & 3.50E-01 & 3.50E-02 & 7.00E-01 & 7.90E-01 & $1.60 \mathrm{E}+00$ & 7.90E-02 & $9.10 \mathrm{E}-02$ & 3.50E-01 \\
\hline HLP-22 & 1.5 & 11 & 4.00E-01 & 4.00E-02 & 8.10E-01 & $9.10 \mathrm{E}-01$ & $1.80 \mathrm{E}+00$ & $9.10 \mathrm{E}-02$ & $2.50 \mathrm{E}-02$ & 3.40E-01 \\
\hline TCP-01 & 1.5 & 11 & 4.00E-01 & 4.00E-02 & 8.00E-01 & $9.00 \mathrm{E}-01$ & $1.80 \mathrm{E}+00$ & $9.00 \mathrm{E}-02$ & $5.00 \mathrm{E}-02$ & 3.30E-01 \\
\hline TLP-09A/B & 1.5 & 11 & 4.50E-01 & 4.50E-02 & $9.00 \mathrm{E}-01$ & $1.00 \mathrm{E}+00$ & $2.00 \mathrm{E}+00$ & 1.00E-01 & 3.60E-02 & 3.60E-01 \\
\hline PWD-33/43 & 1.5 & 11 & $1.40 \mathrm{E}+00$ & $1.40 \mathrm{E}-01$ & $2.80 \mathrm{E}+00$ & $3.10 \mathrm{E}+00$ & $6.20 \mathrm{E}+00$ & 3.10E-01 & 5.50E-02 & 3.30E-01 \\
\hline PWD-44 & 1.5 & 11 & 4.10E-01 & 4.10E-02 & 8.30E-01 & 9.30E-01 & $1.90 \mathrm{E}+00$ & 9.30E-02 & 2.10E-02 & 3.20E-01 \\
\hline FEP-17A/B & 1.5 & 11 & $5.00 \mathrm{E}-01$ & $5.00 \mathrm{E}-02$ & $9.90 \mathrm{E}-01$ & $1.10 \mathrm{E}+00$ & $2.20 \mathrm{E}+00$ & $1.10 \mathrm{E}-01$ & 9.70E-02 & 3.20E-01 \\
\hline PWD-15/16 & 1.5 & 11 & 3.30E-01 & 3.30E-02 & 6.50E-01 & 7.40E-01 & $1.50 \mathrm{E}+00$ & 7.40E-02 & $9.80 \mathrm{E}-02$ & 3.70E-01 \\
\hline UFP-01A/B & 1.5 & 11 & 4.30E-01 & 4.30E-02 & 8.60E-01 & $9.70 \mathrm{E}-01$ & $1.90 \mathrm{E}+00$ & $9.70 \mathrm{E}-02$ & 5.10E-02 & 3.40E-01 \\
\hline UFP-62A/B/C & 1.5 & 11 & 5.20E-01 & 5.20E-02 & $1.00 \mathrm{E}+00$ & $1.20 \mathrm{E}+00$ & $2.30 \mathrm{E}+00$ & $1.20 \mathrm{E}-01$ & 5.30E-02 & 2.60E-01 \\
\hline CXP-26A/B/C & 1.5 & 11 & $4.50 \mathrm{E}-01$ & $4.50 \mathrm{E}-02$ & $9.00 \mathrm{E}-01$ & $1.00 \mathrm{E}+00$ & $2.00 \mathrm{E}+00$ & $1.00 \mathrm{E}-01$ & 3.60E-02 & $3.00 \mathrm{E}-01$ \\
\hline CNP-03 & 1.5 & 11 & 7.30E-01 & 7.30E-02 & $1.50 \mathrm{E}+00$ & $1.60 \mathrm{E}+00$ & $3.30 \mathrm{E}+00$ & $1.60 \mathrm{E}-01$ & $9.40 \mathrm{E}-02$ & 2.70E-01 \\
\hline RLD-07 & 1.5 & 11 & 8.10E-01 & 8.10E-02 & $1.60 \mathrm{E}+00$ & $1.80 \mathrm{E}+00$ & $3.70 \mathrm{E}+00$ & $1.80 \mathrm{E}-01$ & 6.10E-02 & 2.90E-01 \\
\hline RLD-08 & 1.5 & 11 & $1.10 \mathrm{E}+00$ & $1.10 \mathrm{E}-01$ & $2.20 \mathrm{E}+00$ & $2.40 \mathrm{E}+00$ & $4.90 \mathrm{E}+00$ & $2.40 \mathrm{E}-01$ & 3.90E-02 & 3.20E-01 \\
\hline HOP-903/904 & 1.5 & 11 & $1.40 \mathrm{E}+00$ & $1.40 \mathrm{E}-01$ & $2.70 \mathrm{E}+00$ & $3.10 \mathrm{E}+00$ & $6.10 \mathrm{E}+00$ & 3.10E-01 & 8.20E-02 & 2.30E-01 \\
\hline RDP-02A/B/C & 1.5 & 11 & $1.10 \mathrm{E}+00$ & $1.10 \mathrm{E}-01$ & $2.20 \mathrm{E}+00$ & $2.40 \mathrm{E}+00$ & $4.90 \mathrm{E}+00$ & $2.40 \mathrm{E}-01$ & 5.50E-02 & 3.20E-01 \\
\hline CXP-04 & 1.5 & 11 & 8.40E-01 & 8.40E-02 & $1.70 \mathrm{E}+00$ & $1.90 \mathrm{E}+00$ & $3.80 \mathrm{E}+00$ & $1.90 \mathrm{E}-01$ & 5.90E-02 & 3.20E-01 \\
\hline CNP-04 & 1.5 & 11 & 5.50E-01 & 5.50E-02 & $1.10 \mathrm{E}+00$ & $1.20 \mathrm{E}+00$ & $2.50 \mathrm{E}+00$ & $1.20 \mathrm{E}-01$ & $9.50 \mathrm{E}-02$ & 2.70E-01 \\
\hline- & - & - & - & - & - & - & - & - & - & - \\
\hline $\min$ & 1.5 & 11 & 3.27E-01 & 3.27E-02 & $6.55 \mathrm{E}-01$ & 7.37E-01 & $1.47 \mathrm{E}+00$ & 7.37E-02 & 2.09E-02 & 2.34E-01 \\
\hline $\max$ & 1.5 & 11 & $1.39 \mathrm{E}+00$ & 1.39E-01 & $2.78 \mathrm{E}+00$ & $3.12 \mathrm{E}+00$ & $6.25 E+00$ & 3.12E-01 & 9.80E-02 & 3.71E-01 \\
\hline average & 1.5 & 11 & 6.71E-01 & 6.71E-02 & $1.34 \mathrm{E}+00$ & $1.51 \mathrm{E}+00$ & $3.02 \mathrm{E}+00$ & $1.51 \mathrm{E}-01$ & 6.11E-02 & 3.14E-01 \\
\hline- & - & - & - & - & - & - & - & - & - & - \\
\hline Recommended Min & 1.5 & - & - & $1.00 \mathrm{E}-01$ & - & - & - & - & 2.00E-02 & $2.00 \mathrm{E}-01$ \\
\hline Recommended Max & 11 & - & - & $6.00 \mathrm{E}+00$ & - & - & - & - & $1.50 \mathrm{E}-01$ & 4.00E-01 \\
\hline
\end{tabular}


Table 2.3. (contd)

\begin{tabular}{|c|c|c|c|c|c|c|c|}
\hline \multicolumn{7}{|c|}{ Primary Nondimensional Variables } & \multirow[b]{4}{*}{ Vessel } \\
\hline \multicolumn{4}{|c|}{ Particle Size Ratio } & \multicolumn{3}{|c|}{ Jet Density } & \\
\hline $\mathrm{d}_{\mathrm{S}} / \mathrm{d}$ & $\mathrm{d}_{\mathrm{S}} / \mathrm{d}$ & $\mathrm{d}_{\mathrm{S}} / \mathrm{d}$ & $\mathrm{d}_{\mathrm{S}} / \mathrm{d}$ & $\mathrm{N}^{1 / 2} \mathrm{~d} / \mathrm{D}$ & $\mathrm{N}^{1 / 2} \mathrm{~d} / \mathrm{D}$ & $\mathrm{N}^{1 / 2} \mathrm{~d} / \mathrm{D}$ & \\
\hline $\min (4 \mathrm{in})$. & $\max (4 i n)$. & $\min (8 \mathrm{in})$. & $\max (8 \mathrm{in})$. & 4in. & 6in. & 8in. & \\
\hline $9.80 \mathrm{E}-05$ & $9.80 \mathrm{E}-03$ & 4.90E-05 & 4.90E-03 & 0.025 & 0.037 & 0.049 & FRP-02A/B/C/D \\
\hline $9.80 \mathrm{E}-05$ & $9.80 \mathrm{E}-03$ & 4.90E-05 & 4.90E-03 & 0.030 & 0.046 & 0.061 & HLP-22 \\
\hline $9.80 \mathrm{E}-05$ & $9.80 \mathrm{E}-03$ & 4.90E-05 & 4.90E-03 & 0.036 & 0.053 & 0.071 & TCP-01 \\
\hline 9.80E-05 & $9.80 \mathrm{E}-03$ & 4.90E-05 & 4.90E-03 & 0.036 & 0.054 & 0.073 & TLP-09A/B \\
\hline $9.80 \mathrm{E}-05$ & $9.80 \mathrm{E}-03$ & 4.90E-05 & 4.90E-03 & 0.039 & 0.059 & 0.079 & PWD-33/43 \\
\hline $9.80 \mathrm{E}-05$ & $9.80 \mathrm{E}-03$ & $4.90 \mathrm{E}-05$ & 4.90E-03 & 0.041 & 0.061 & 0.082 & PWD-44 \\
\hline $9.80 \mathrm{E}-05$ & $9.80 \mathrm{E}-03$ & 4.90E-05 & 4.90E-03 & 0.043 & 0.064 & 0.086 & FEP-17A/B \\
\hline $9.80 \mathrm{E}-05$ & $9.80 \mathrm{E}-03$ & 4.90E-05 & 4.90E-03 & 0.043 & 0.064 & 0.086 & PWD-15/16 \\
\hline 9.80E-05 & $9.80 \mathrm{E}-03$ & $4.90 \mathrm{E}-05$ & $4.90 \mathrm{E}-03$ & 0.047 & 0.071 & 0.094 & UFP-01A/B \\
\hline $9.80 \mathrm{E}-05$ & $9.80 \mathrm{E}-03$ & 4.90E-05 & 4.90E-03 & 0.054 & 0.082 & 0.109 & UFP-62A/B/C \\
\hline $9.80 \mathrm{E}-05$ & $9.80 \mathrm{E}-03$ & 4.90E-05 & $4.90 \mathrm{E}-03$ & 0.054 & 0.082 & 0.109 & CXP-26A/B/C \\
\hline $9.80 \mathrm{E}-05$ & $9.80 \mathrm{E}-03$ & $4.90 \mathrm{E}-05$ & 4.90E-03 & 0.048 & 0.071 & 0.095 & CNP-03 \\
\hline $9.80 \mathrm{E}-05$ & $9.80 \mathrm{E}-03$ & $4.90 \mathrm{E}-05$ & $4.90 \mathrm{E}-03$ & 0.051 & 0.077 & 0.103 & RLD-07 \\
\hline 9.80E-05 & $9.80 \mathrm{E}-03$ & $4.90 \mathrm{E}-05$ & $4.90 \mathrm{E}-03$ & 0.051 & 0.077 & 0.103 & RLD-08 \\
\hline $9.80 \mathrm{E}-05$ & $9.80 \mathrm{E}-03$ & 4.90E-05 & 4.90E-03 & 0.056 & 0.083 & 0.111 & HOP-903/904 \\
\hline $9.80 \mathrm{E}-05$ & $9.80 \mathrm{E}-03$ & 4.90E-05 & 4.90E-03 & 0.056 & 0.083 & 0.111 & RDP-02A/B/C \\
\hline $9.80 \mathrm{E}-05$ & $9.80 \mathrm{E}-03$ & 4.90E-05 & 4.90E-03 & 0.032 & 0.048 & 0.063 & CXP-04 \\
\hline $9.80 \mathrm{E}-05$ & $9.80 \mathrm{E}-03$ & $4.90 \mathrm{E}-05$ & $4.90 \mathrm{E}-03$ & 0.070 & 0.105 & 0.140 & CNP-04 \\
\hline- & - & - & - & & & & - \\
\hline 9.84E-05 & $9.84 \mathrm{E}-03$ & 4.92E-05 & 4.92E-03 & 0.025 & 0.037 & 0.049 & $\min$ \\
\hline $9.84 \mathrm{E}-05$ & $9.84 \mathrm{E}-03$ & 4.92E-05 & 4.92E-03 & 0.070 & 0.105 & 0.140 & $\max$ \\
\hline $9.84 \mathrm{E}-05$ & $9.84 \mathrm{E}-03$ & 4.92E-05 & 4.92E-03 & 0.045 & 0.068 & 0.090 & average \\
\hline- & - & - & - & - & - & - & - \\
\hline $1.00 \mathrm{E}-02$ & - & - & - & - & - & - & Recommended Min \\
\hline $1.00 \mathrm{E}-04$ & - & - & - & - & - & - & Recommended Max \\
\hline
\end{tabular}




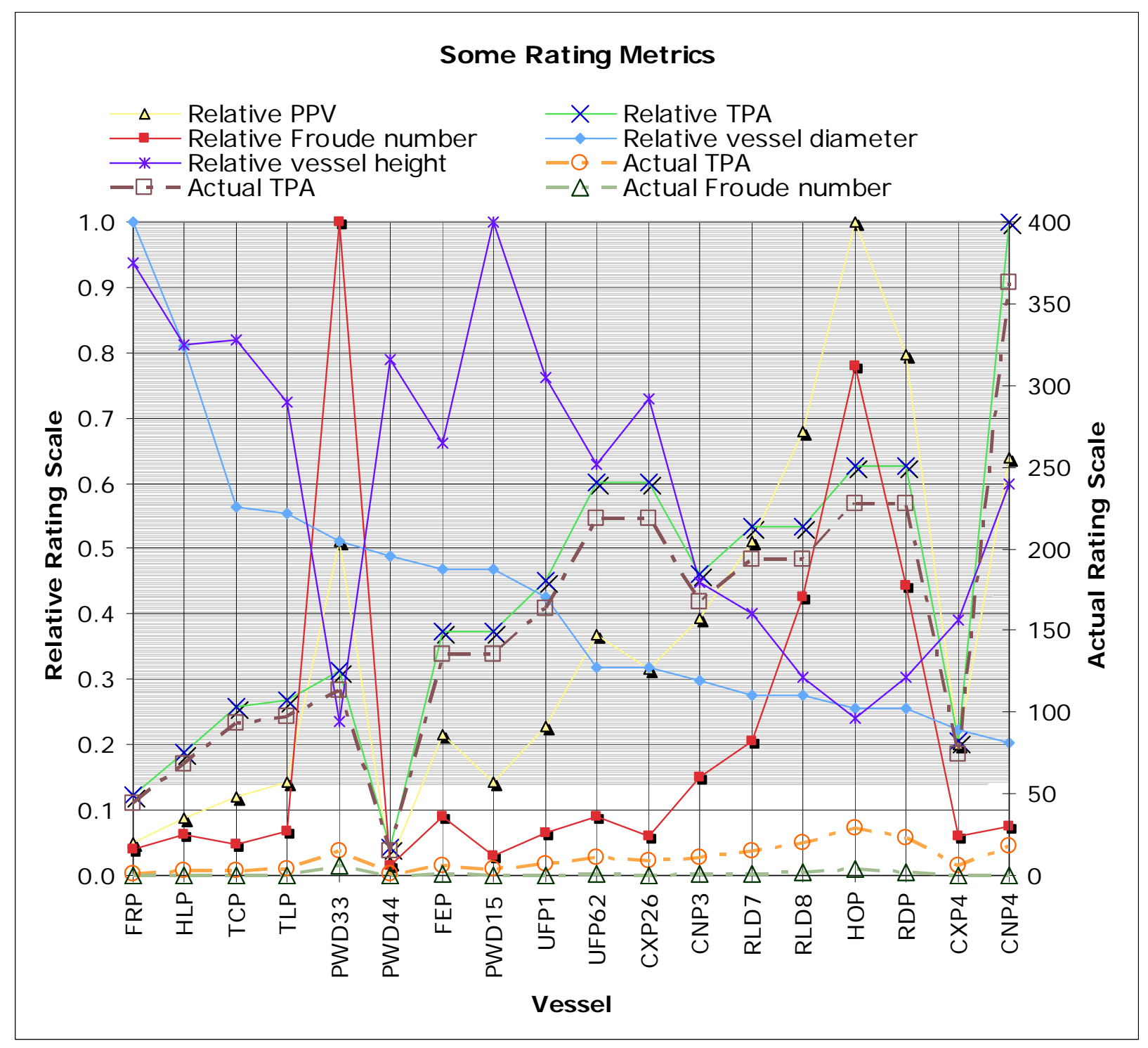

Figure 2.4. Some Common Mixing Metrics Applied to the 18 Distinct WTP Vessel Configurations (FIO)

\subsection{Evaluating Mixing Systems}

The general approach used to evaluate the solids-handling capability of the WTP mixing systems in solids-containing vessels is as follows:

- Develop simulants for noncohesive slurries with properties that bracket anticipated slurry properties in the WTP.

- Perform scaled tests with mixing systems that can be configured to span the geometric and operational parameter space of WTP mixing systems.

- Use well-established metrics to evaluate mixing performance over the testing parameter space.

- Use experimental data to develop models relating mixing performance to slurry properties, geometric parameters, and operational parameters. 
- Apply the models to the plant mixing systems and determine the limiting solids properties the mixing system can handle.

- Assess the acceptability of the limiting solids properties by considering the specific requirements for a given vessel and the percentage of Hanford waste that exceeds the limit.

If limiting conditions were deemed unacceptable, the models could then be exercised to evaluate design modifications.

\subsubsection{Mixing System Parameters}

The primary mixing system parameters shown in Table 2.4 are slurry properties, mixing system geometric parameters, and operational parameters. Mixing performance in general will depend on the values of these parameters, which can be formed into an equivalent set of dimensionless groups.

Table 2.4. Primary ${ }^{(a)}$ Mixing System Physical Parameters

\begin{tabular}{|c|c|c|}
\hline Slurry Properties/Variables & Symbol & Units \\
\hline Solids diameter & $\mathrm{d}_{\mathrm{S}}$ & $\mu \mathrm{m}$ \\
\hline Solids volume fraction & $\phi_{\mathrm{S}}$ & (b) \\
\hline Solids density & $\rho_{\mathrm{s}}$ & $\mathrm{g} / \mathrm{cm}^{3}$ \\
\hline Liquid density & $\rho_{l}$ & $\mathrm{~g} / \mathrm{cm}^{3}$ \\
\hline Liquid kinematic viscosity & $v=\mu / \rho_{1}$ & $\mathrm{~m}^{2} / \mathrm{s}$ \\
\hline \multicolumn{3}{|l|}{ Geometric Configuration } \\
\hline Vessel diameter & $\mathrm{D}$ & m (in.) \\
\hline Nozzle (jet) diameter & $\mathrm{d}$ & $\mathrm{m}$ (in.) \\
\hline Number PJMs ${ }^{(\mathrm{c})}$ & $\mathrm{N}$ & each \\
\hline Radial location of PJMs ${ }^{(\mathrm{c})}$ & $\mathrm{R}$ & $\mathrm{m}(\mathrm{ft})$ \\
\hline \multicolumn{3}{|l|}{ Operational Parameters } \\
\hline Fill level & $\mathrm{H}$ & m (in.) \\
\hline Pulse volume & $\mathrm{V}_{\mathrm{P}}$ & $\mathrm{m}^{3}$ \\
\hline Drive time & $t_{D}$ & $\mathrm{~s}$ \\
\hline Cycle time & $\mathrm{t}_{\mathrm{C}}$ & $\mathrm{s}$ \\
\hline Jet velocity & $\mathrm{U}$ & $\mathrm{m} / \mathrm{s}$ \\
\hline \multicolumn{3}{|c|}{$\begin{array}{l}\text { (a) Secondary variables such as settling velocity (derived from primary } \\
\text { measured variables such as particle size and particle density) are } \\
\text { discussed in Sections } 7,8 \text {, and } 9 \text {. } \\
\text { (b) Indicates the parameter is nondimensional. } \\
\text { (c) Includes single and double rings. }\end{array}$} \\
\hline
\end{tabular}

Dimensional analysis applied to the physical parameters in Table 2.4 results in 11 (13 parameters constrained by consistency in three units, mass, length, and time) nondimensional variables when considering single-ring PJM configurations. ${ }^{1}$ Double-ring PJM configurations introduce up to two more variables $\left(\mathrm{N}_{\mathrm{o}}\right.$ and $\left.\mathrm{R}_{\mathrm{o}} / \mathrm{D}\right)$. The primary nondimensional variables are shown in Table 2.5. These nondimensional variables are not unique; others can be selected that favor physical insight or specific

\footnotetext{
${ }^{1}$ This is true because all single-ring PJM configurations have the same relative radial positioning (R/D). Hence, $\mathrm{R} / \mathrm{D}$ is not a variable with respect to the plant mixing system designs.
} 
processes or provide better models of test data. However, they all can be expressed in terms of the physical parameters in Table 2.4.

Table 2.5. Mixing System Nondimensional Variables

\begin{tabular}{ll}
\hline Slurry Property & Nondimensional Variable \\
\hline Density ratio & $\mathrm{s}=\rho_{\mathrm{s}} / \rho_{\mathrm{l}}$ \\
$\begin{array}{l}\text { Solids volume fraction } \\
\text { Particle diameter ratio }\end{array}$ & $\begin{array}{l}\phi_{\mathrm{S}}=\mathrm{V}_{\mathrm{S}} / \mathrm{V}_{\mathrm{REF}} \text { where } \mathrm{V}_{\mathrm{REF}}=\left(\pi \mathrm{D}^{3}\right) / 4 \\
\mathrm{~d}_{\mathrm{S}} / \mathrm{D}\end{array}$ \\
\hline Geometric Properties & \\
\hline Nozzle diameter ratio & $\mathrm{d} / \mathrm{D}$ \\
Number of pulse tubes & $\mathrm{N}$ \\
Jet density & $\phi_{\mathrm{J}}=\mathrm{N}_{\mathrm{J}}(\mathrm{d} / \mathrm{D})^{2}$ \\
PJM location & $\mathrm{R} / \mathrm{D}$ \\
Ratio of pulse tube to vessel & $\phi_{\mathrm{PT}}=\mathrm{N}\left(\mathrm{D}_{\mathrm{PT}} / \mathrm{D}\right)^{2}$ \\
cross-sectional area & \\
\hline Operational Parameters & \\
\hline Fill level & $\mathrm{H} / \mathrm{D}$ \\
Pulse volume fraction & $\phi_{\mathrm{p}}=\mathrm{N} \mathrm{V}_{\mathrm{P}} / \mathrm{V}_{\mathrm{REF}}$ where $\mathrm{V}_{\mathrm{REF}}=\left(\pi \mathrm{D}^{3}\right) / 4$ \\
Duty cycle & $\mathrm{DC}=\mathrm{t}_{\mathrm{D}} / \mathrm{t}_{\mathrm{C}}$ \\
Jet Reynolds number & $\mathrm{Re}=\mathrm{U} \mathrm{d} / \mathrm{v}_{\text {Froude number }}$ \\
\hline
\end{tabular}

Some examples of other potentially useful nondimensional variables and their relationships with the physical parameters in Table 2.4 are given here:

Ratio of pulse time to fluid transit time in vessel:

$$
\mathrm{t}_{\mathrm{D}} \mathrm{U} / \mathrm{D}=\phi_{\mathrm{p}}(\mathrm{D} / \mathrm{d})^{2} / \mathrm{N}
$$

Particle Reynolds number

$$
\mathrm{Re}_{\mathrm{p}}=\mathrm{U}_{\mathrm{T}} \mathrm{d}_{\mathrm{S}} / v=\left(\mathrm{U}_{\mathrm{T}} / \mathrm{U}\right)\left(\mathrm{d}_{\mathrm{S}} / \mathrm{D}\right)(\mathrm{D} / \mathrm{d}) \mathrm{Re}
$$

Particle Froude number

$$
\mathrm{F}_{\mathrm{p}}=\mathrm{U}_{\mathrm{T}}^{2} / \mathrm{g} \mathrm{d}_{\mathrm{S}}
$$

Particle Galileo number

$$
\mathrm{Ga}_{\mathrm{p}}=(\mathrm{s}-1) \mathrm{gds}_{\mathrm{s}}{ }^{3} / v^{2}=\mathrm{Re}_{\mathrm{p}}{ }^{2} / \mathrm{Fr}_{\mathrm{p}}
$$

Settling velocity $\left(\mathrm{U}_{\mathrm{T}}\right)$ ratio

$$
U_{T} / U=f\left(\operatorname{Re}_{p}, F r_{p}\right)=g\left(U_{T} / U, d_{S} / D, d / D, R e, F r\right)
$$

Hindered settling velocity $\left(\mathrm{U}_{\mathrm{TH}}\right)$ ratio

$$
\mathrm{U}_{\mathrm{TH}} / \mathrm{U}=\mathrm{f}\left(\mathrm{U}_{\mathrm{T}} / \mathrm{U}, \phi_{\mathrm{S}}\right)
$$


In much of the mixing literature the solids content is defined in terms of a solids loading where the solids volume (or mass) is divided by the slurry volume (or mass). However, there is a significant advantage to describing the solids content relative to a reference volume that is independent of the fill level in the vessel. Just-suspended velocity and solids cloud height are found to depend on fill level when the solids loading is held constant. However, they tend to be independent of fill level when the total mass in the system is held constant. This phenomenon has been demonstrated for solids suspensions using mechanical agitators. ${ }^{1}$ Hicks and Myers measured just-suspended speed, $\mathrm{N}_{\mathrm{JS}}$, under two different conditions: keeping the solids loading constant while varying the liquid level and holding the solids mass constant while varying the liquid level. Some of their data are reproduced in Figure 2.5. When the solids loading was held constant, the data show that $\mathrm{N}_{\mathrm{JS}}$ increases with the fill level; however, when the solids mass was held constant, $\mathrm{N}_{\mathrm{JS}}$ was independent of fill level. These data make clear the benefit of basing $\phi_{\mathrm{S}}$ on a reference volume instead of the slurry volume. By doing so, just-suspended velocity should be independent of fill level $(\mathrm{H})$.

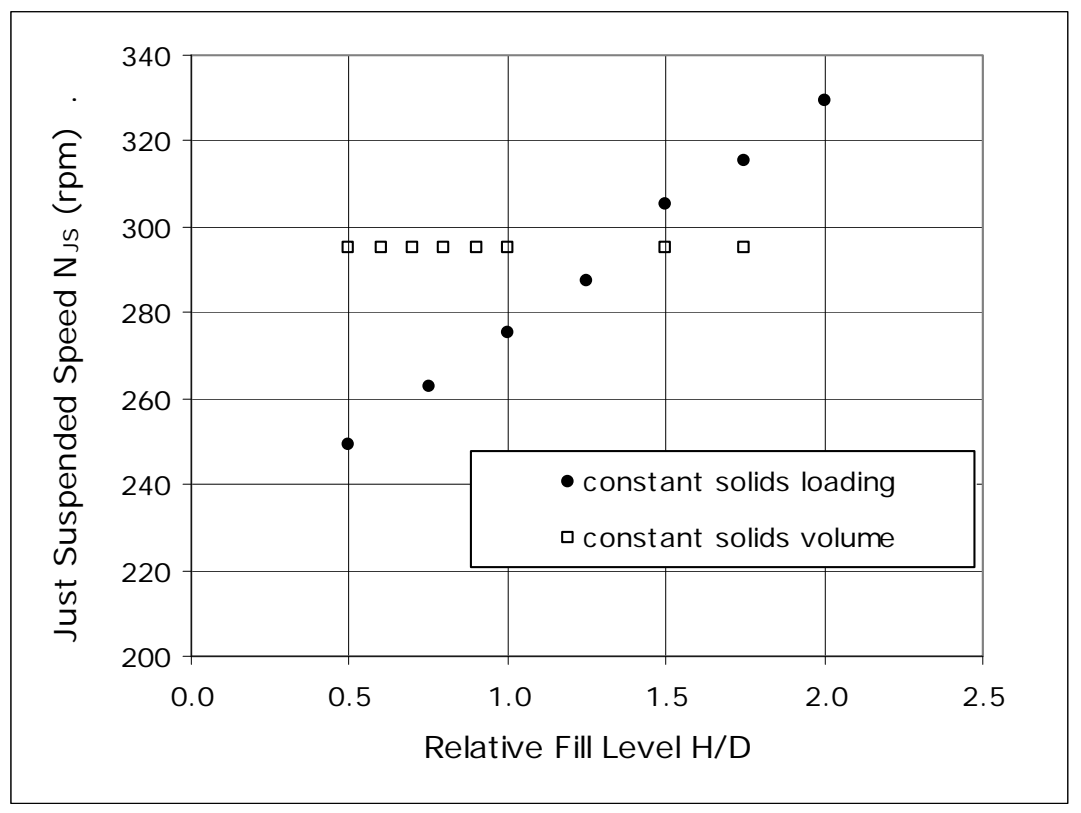

Figure 2.5. Just-Suspended Speed as a Function of Fill Level for Mechanical Agitators (data reproduced from Hicks and Myers) ${ }^{1}$

Hicks and Myers also looked at the effect of fill level on cloud height. They varied impeller speed and measured cloud height for two different fill levels. Some of those results are reproduced in Figure 2.6, where it is seen that fill level had negligible effect on cloud height.

In summary, when the solids fraction is based on reference volume, it is anticipated that test results for $\mathrm{U}_{\mathrm{CS}}$ and $\mathrm{H}_{\mathrm{C}}$ will be independent of fill level. It follows that solid vertical distribution will be independent of fill level as long as the cloud is less than the fill level. If the cloud reaches the liquid surface, the solids vertical distribution will depend on fill level.

\footnotetext{
${ }^{1}$ Hicks MT and KJ Myers. 1993. "Cloud Height, Fillet Volume, and the Effect of Multiple Impellers in Solids Suspension.” MIXING XIV, Santa Barbara, Calif. Engineering Foundation, New York, and North American Mixing Forum.
} 


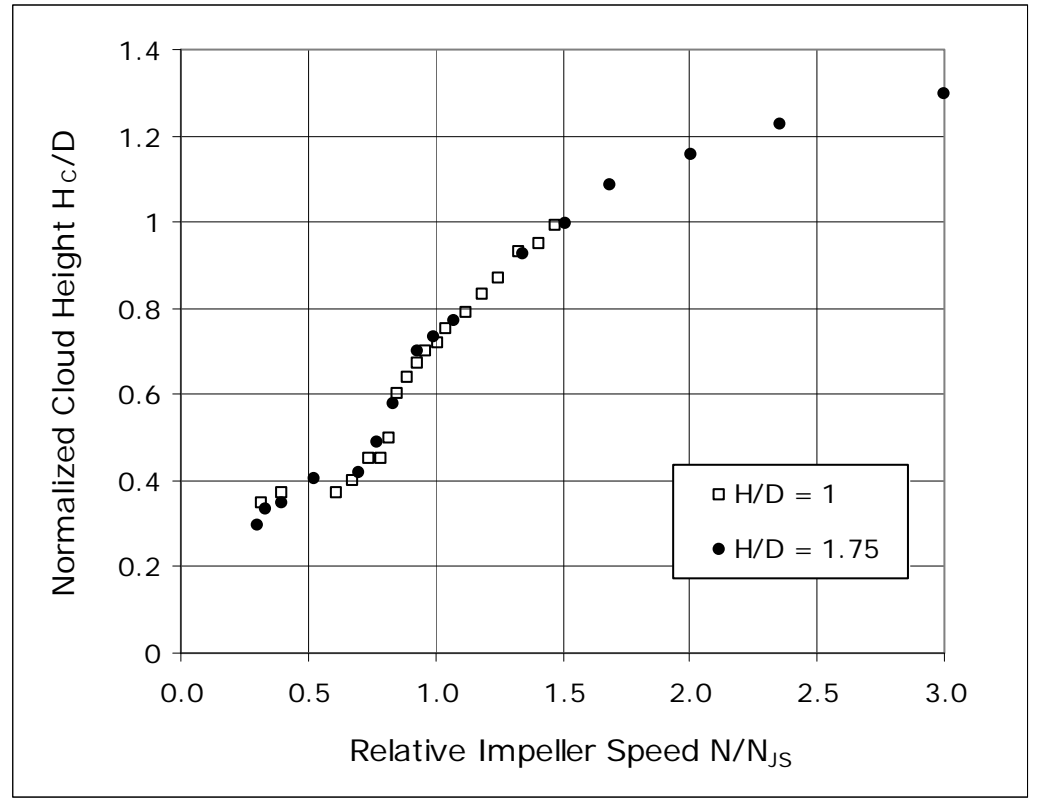

Figure 2.6. Effects of Fill Level on Cloud Height for Solids Suspension with Mechanical Agitators (data reproduced from Hicks and Myers) ${ }^{1}$

\subsubsection{Just-Suspended Jet Velocity}

The just-suspended jet velocity, $\mathrm{U}_{\mathrm{JS}}$, is defined for steady jet mixing as the discharge velocity required to completely suspend solids that are on the bottom of the vessel. For steady jet mixing, a commonly used criterion is that no solid particles are observed resting on the bottom for more than 1 to 2 seconds. For pulse jet mixing, a reasonable criterion would be that no solids remain on the bottom at the end of the pulse, or, alternatively, that all the solids that have settled during the refill period are completely resuspended during the subsequent pulse. For this study, the velocity to suspend all solids at the end of the pulse is defined as the critical suspension velocity $\left(\mathrm{U}_{\mathrm{CS}}\right)$.

In general it can be expected that $\mathrm{U}_{\mathrm{CS}}$ is a function of the important mixing parameters. This is expressed mathematically by

$$
\mathrm{U}_{\mathrm{CS}}=\mathrm{f}\left(\mathrm{d}_{\mathrm{S}}, \rho_{\mathrm{s}}, \rho_{\mathrm{l}}, \phi_{\mathrm{S}}, v, \mathrm{D}, \mathrm{d}, \mathrm{N}, \mathrm{V}_{\mathrm{P}}, \mathrm{R}, \mathrm{H}, \mathrm{t}_{\mathrm{D}}, \mathrm{t}_{\mathrm{C}}\right)
$$

The critical suspension velocity can also be expressed in terms of the (dimensionless) Froude number as

$$
\mathrm{F}_{\mathrm{CS}}=\mathrm{U}_{\mathrm{CS}}{ }^{2} / \mathrm{gd}(\mathrm{s}-1)=\mathrm{g}\left(\mathrm{s}, \phi_{\mathrm{S}}, \mathrm{d}_{\mathrm{S}} / \mathrm{D}, \mathrm{d} / \mathrm{D}, \mathrm{N}, \mathrm{R} / \mathrm{D}, \mathrm{H} / \mathrm{D}, \phi_{\mathrm{p}}, \mathrm{DC}, \mathrm{Re}_{\mathrm{CS}}\right)
$$

This Froude number can be interpreted as the ratio of jet kinetic energy to the potential energy required to suspend the mass of settled solids one particle diameter in elevation.

\footnotetext{
${ }^{1}$ Ibid.
} 


\subsubsection{Solids Vertical Distribution}

During mixing system operation, solids will become suspended off the bottom of the vessel. For continuous mixing, the solids fraction will achieve a stable distribution. With pulse jet mixing, changes in solids concentration may occur between pulses. By either assuming quasi-steady solids distributions or averaging over a drive cycle, the solids fraction vertical distribution can be expressed mathematically as

$$
\phi / \phi_{\mathrm{s}}(\mathrm{z} / \mathrm{D})=\mathrm{f}\left(\mathrm{s}, \phi_{\mathrm{s}}, \mathrm{d}_{\mathrm{s}} / \mathrm{D}, \mathrm{d} / \mathrm{D}, \mathrm{N}, \mathrm{R} / \mathrm{D}, \mathrm{H} / \mathrm{D}, \phi_{\mathrm{p}}, \mathrm{DC}, \mathrm{Re}, \mathrm{Fr}\right)
$$

where $\phi$ is the local solids fraction and $\mathrm{z} / \mathrm{D}$ is the normalized vertical elevation.

For some conditions a distinct interface, cloud height $\left(\mathrm{H}_{\mathrm{C}}\right)$, forms at a certain vertical elevation, with no solids suspended above. Cloud height can also be expressed in terms of the mixing parameters.

A useful measure of the degree of homogeneity is the relative standard deviation (RSD) of the solids fraction. The RSD can also be expressed as a function of the various nondimensional variables. This can be considered in future analyses.

\subsection{Parametric Tests}

Parametric testing is required to develop functional expressions (models) for the rating metrics in terms of the pertinent mixing parameters. In this regard the parameters, either physical or nondimensional, are essentially test variables. The functional expressions are essentially models of the parametric data. To achieve accuracy in rating the plant mixing systems, it is important to obtain accurate models of the scaled test data. To this end, the testing approach focused initially on identifying the most sensitive parameters. Sufficient data were collected to capture the dependencies between various parameters. Also, the parametric ranges tested were selected to span the range of plant conditions insofar as it is possible to achieve them (see Section 2.8.3 for a comparison of test conditions to WTP vessel conditions).

\subsection{Scale-up of Metrics}

Mixing results obtained from parametric scaled tests must be applied at plant scale. This section describes four potential approaches and discusses their relative strengths and limitations. With this understanding, a scale-up strategy is presented.

Table 2.6 lists four approaches for performing scaled tests and their limitations or consequences. All of the approaches involve geometric similarity. The magnitude of the limitations and relative differences between approaches are reduced as the test scale is increased. Approach 1 was used for a limited number of tests to satisfy the Test Specification as well as to aid in isolating the jet Reynolds number effects, which may be larger than expected due to periodic flow conditions. Approach 2 was used extensively for developing the models but is not relied upon for scale-up information per se. Approach 3 is a relatively new concept that replaces particle size with settling velocity as a variable. It has the potential to isolate the effects of scale to a single variable, though it is not clear what other limitations may exist. This approach would require determination of a characteristic or representative settling velocity for all simulants. Approach 4 is the standard commonly used in industrial mixing, in which scale-up laws are determined by testing with the same simulants at various scales. Many test conditions provide data that are applicable to some or all of the approaches, so using multiple approaches to scale up does not imply a big increase in test conditions. 
Table 2.6. Comparison of Scaled Test Approaches

\begin{tabular}{cllll}
\hline $\begin{array}{c}\text { Scaled } \\
\text { Test } \\
\text { Approach }\end{array}$ & \multicolumn{1}{c}{ Description } & \multicolumn{1}{c}{$\begin{array}{c}\text { Fundamental } \\
\text { Limitation/Requirement }\end{array}$} & \multicolumn{1}{c}{$\begin{array}{c}\text { Consequence at } \\
\text { Plant Scale }\end{array}$} & $\begin{array}{c}\text { Common } \\
\text { Name for } \\
\text { Approach }\end{array}$ \\
\hline 1 & $\begin{array}{l}\text { Match all full-scale } \\
\text { nondimensional variables at } \\
\text { small scale }\end{array}$ & $\begin{array}{l}\text { Forces s range higher and } \mathrm{d}_{\mathrm{S}} \\
\text { range significantly lower } \\
\text { (into cohesive regime) }\end{array}$ & $\begin{array}{l}\text { Plant conditions outside } \\
\text { range of mixing model, } \\
\text { especially for small } \mathrm{d}_{\mathrm{S}}\end{array}$ & $\begin{array}{l}\text { True } \\
\text { similarity }\end{array}$ \\
2 & $\begin{array}{l}\text { Test over complete range of } \\
\text { nondimensional variables }\end{array}$ & $\begin{array}{l}\text { Does not capture all } \\
\text { interactions and coupling } \\
\text { Plant conditions sometimes } \\
\text { outside range of mixing } \\
\text { model }\end{array}$ & $\begin{array}{l}\text { Parametric } \\
\text { approach }\end{array}$ \\
& $\begin{array}{l}\text { Match all nondimensional } \\
\text { variables except Re }\end{array}$ & Replace with $\mathrm{U}_{\mathrm{T}} / \mathrm{U}$ & Extrapolate in Re & $\begin{array}{l}\text { Relatively } \\
\text { new } \\
\text { approach } \\
\text { Industrial } \\
\text { approach }\end{array}$ \\
\hline
\end{tabular}

\subsection{Test Design}

This section summarizes factors and considerations involved in the experimental test design.

\subsubsection{Approach}

The following test design approach was used to ensure that robust models for rating metrics would be achieved by the test program.

- The conditions tested bracketed plant parameter ranges to the extent practical.

- Testing occurred at three scales to establish scale-up.

- Test variable ranges were extended so that test results are applicable to evaluating design improvements (such as large nozzles, more pulse tubes, etc.).

- Sufficient data were collected to develop models for rating metrics that, when applied to plant vessels, have reasonable uncertainty.

- Jet discharge characteristics were the same at all scales.

- The same instrumentation and measurement methods were used at all scales.

Shortly after the M3 testing program was planned, WTP needs changed to emphasize the importance of vessel HLP-22. In response, the original test design to evaluate each parameter at all three scales was modified to focus on the specific characteristics of HLP-22. This change reduced testing for parameters such as the number of PJM jets, nozzle diameters, particle densities, broad particle distributions, and similar parameters. A more limited set of these parameters was strategically tested to provide information for each parameter used in the models. 


\subsubsection{Constraints}

The following are constraints that were considered when designing and conducting tests. They fall into three categories: time, material hazards, and capacity of the test apparatus. For small-diameter simulants, the settling time may increase the time between conducting sequenced test runs, and solids may begin to exhibit cohesive behavior. Exotic simulants increase the cost for procurement; exotic fluids increase costs associated with handling, test apparatus cleaning, and disposal. The test apparatus operating space also constrains the tests conducted. The PJM valve response characteristics limit the pulse time. The capacity of the PJMs limits the pulse duration. Additional limitations include the following:

- Use of low-viscosity liquids was not pursued due to hazards associated with these fluids in the PNNL test fixtures.

- Maximum fluid jet velocity limits on larger vessels are in the range of $14 \mathrm{~m} / \mathrm{s}$.

- Specific constraints related to the vessel scale also exist. The scale of the vessel and ancillary piping limited the height of the fluid in the test vessel.

- PJM flow capacity is limited at the large test scale, so smaller WTP vessel conditions cannot be tested.

- When testing at small scale, Reynolds number requirements prevent matching Froude number at low velocities; this precludes testing of the largest plant vessels in the small test vessel.

- Drive function limitations associated with valve response time in the large vessel (large valves) may limit some pulse durations. However, the test conditions conducted for this report were not limited by the valve response times of the three test systems.

\subsubsection{Plant Variable Ranges}

Table 2.7 gives a summary of the ranges of nondimensional variables associated with WTP mixing systems. The test parameter ranges were designed to bracket these conditions. The extent to which these ranges were bracketed in the test data used for developing models is discussed in Section 9.2.3. 
Table 2.7. Preliminary Bracketing Noncohesive Property Ranges for the WTP $^{(a)}$

\begin{tabular}{|c|c|c|c|c|}
\hline Property & Symbol & Units & Minimum Value & Maximum Value \\
\hline \multicolumn{5}{|l|}{ Slurry Properties } \\
\hline Solids diameter ${ }^{(\mathrm{b})}$ & $\mathbf{d}_{\mathrm{S}}$ & $\mu \mathrm{m}$ & 10 & 1000 \\
\hline Solids volume fraction & $\phi_{\mathrm{s}}$ & fraction & 0.001 & 0.15 \\
\hline Density ratio & $\mathrm{s}=\rho_{\mathrm{s}} / \rho_{\mathrm{l}}$ & ratio & 1.5 & 11 \\
\hline Solids density ${ }^{(\mathrm{c})}$ & $\rho_{s}$ & $\mathrm{~g} / \mathrm{cm}^{3}$ & 2.2 & 11 \\
\hline Liquid density & $\rho_{l}$ & $\mathrm{~g} / \mathrm{cm}^{3}$ & 1 & 1.4 \\
\hline Slurry density & $\rho$ & $\mathrm{g} / \mathrm{cm}^{3}$ & 1 & 2.7 \\
\hline Viscosity & $\mu$ & $c P$ & 1 & 25 \\
\hline Kinematic viscosity & $v=\mu / \rho_{1}$ & $\mathrm{~m}^{2} / \mathrm{s}$ & 7.10E-07 & 2.50E-05 \\
\hline Settling velocity & $U_{T}$ & $\mathrm{~m} / \mathrm{s}$ & 1.10E-06 & $1.80 E-01$ \\
\hline Galileo number & $\mathrm{Ga}_{\mathrm{p}}=(\mathrm{s}-1) \mathrm{g} \mathrm{d}_{\mathrm{s}}{ }^{3} / \mathrm{v}^{2}$ & number & 7.80E-06 & $1.90 \mathrm{E}+05$ \\
\hline Particle Reynolds number & $\operatorname{Re}_{\mathrm{p}}=\mathrm{U}_{\mathrm{T}} \mathrm{d}_{\mathrm{S}} / v$ & number & 4.40E-07 & $7.30 \mathrm{E}+02$ \\
\hline Particle Froude number & $\mathrm{F}_{\mathrm{p}}=\mathrm{U}_{\mathrm{T}}^{2} /\left(\mathrm{g} \mathrm{d}_{\mathrm{S}}\right)$ & number & 2.40E-08 & $2.80 \mathrm{E}+00$ \\
\hline \multicolumn{5}{|l|}{ Geometric Configuration } \\
\hline Vessel diameter & D & $\mathrm{ft}$ & 9.5 & 47 \\
\hline Nozzle diameter ratio & d/D & number & 0.007 & 0.07 \\
\hline Number PJMs & $\mathbf{N}$ & number & 1 & 12 \\
\hline Number of PJMs in inner ring & $\mathbf{N}_{\mathbf{I}}$ & \multirow{2}{*}{$\begin{array}{l}\text { number } \\
\text { number }\end{array}$} & 0 & 4 \\
\hline Number of PJMs in outer ring & $\mathbf{N}_{\mathbf{O}}$ & & 0 & 8 \\
\hline \multicolumn{5}{|l|}{ Operational Parameters } \\
\hline Fill level ratio & H/D & number & 0.32 & 1.6 \\
\hline Drive time & $t_{D}$ & $\mathrm{~s}$ & 5.4 & 79 \\
\hline Duty cycle & DC & fraction & 0.23 & 0.37 \\
\hline Pulse volume fraction & $\phi_{\mathrm{p}}$ & fraction & 0.0039 & 0.13 \\
\hline Jet velocity & $\mathbf{U}$ & $\mathrm{m} / \mathrm{s}$ & 8 & 13 \\
\hline Reynolds number & $\mathrm{Re}=\mathrm{Ud} / \mathrm{v}$ & number & $3.30 \mathrm{E}+04$ & $3.40 \mathrm{E}+06$ \\
\hline Froude number & $\mathrm{F}=\mathrm{U}^{2} /(2 \mathrm{gd})$ & number & 0.3 & 2.3 \\
\hline Particle ratio & $\mathrm{d}_{\mathrm{S}} / \mathrm{d}$ & number & 4.90E-05 & $9.80 \mathrm{E}-03$ \\
\hline $\begin{array}{l}\text { (a) Data in Table } 2.7 \text { provided for ir } \\
\text { (b) Bold = Test variable. } \\
\text { (c) Italics = Secondary variable. }\end{array}$ & ormation only. & & & \\
\hline
\end{tabular}




\subsection{Hanford Waste Properties and Simulant Selection}

Properties that affect the mixing of noncohesive solids in liquid include the undissolved solids density, particle size, liquid density, and viscosity. A brief discussion of these parameters for Hanford waste is provided in Section 3.1. Simulant selection, characterization, and preparation are presented in Sections 3.2, 3.3, and 3.4, respectively.

\subsection{Hanford Waste Properties}

Wells et al. (2007) presents particle size and density distributions (PSDDs) based on the combination of particle size distributions (PSDs) of 19 Hanford sludge (i.e., non-saltcake waste) tanks and the insoluble solid-phase compounds from all 177 Hanford tanks. The Case 3 PSDD of Wells et al. (2007), which uses "minimal disturbance" PSDs and the crystal density of the solid phase, was selected as the basis for solid particle size and density.

The PSDD of Case 3 from Wells et al. (2007) is recommended by WTP Project Memorandum CCN 186332, from AW Etchells, Dupont Technology Consulting, to SA Saunders, BNI, on January 29, 2007, “Comments on the Input Particle Size Report,” as “...the most accurate and most conservative” approach. While the Case 4 PSDD more accurately represents the understanding of the system - that is, the larger particulate beyond the maximum observed primary particle size consists of agglomerates with interstitial liquid, which have a lower density than the primary particulate (crystal density) — the lack of data to model the fractal relation for individual solid-phase compounds, much less for their interactions, results in an estimate for the fractal dimension used for the Case 4 PSDD. Case 3 is selected over Case 1 because the PSD for Cases 1 and 2 was developed from "sonicated" data. Per WTP Project Memorandum CCN 186332, sonification “...is a very high energy and irreproducable process.” Further, sonication “...is much more energy intensive than pumping or mixing for many hours and is similar to grinding or milling.”

The Case 3 PSDD is provided by Wells et al. (2007) as a 3-dimensional matrix of volume-based probability of each solid-phase compound in a PSD "bin” and its density in that bin (Tables 3.1 and 3.2). The PSD bins represent the upper and lower size limit of the particles associated with a given bin. Thus, the volume fraction of insoluble solid particulate at a given size and density is specified for the Hanford waste volume. For example, in Tables 3.1 and 3.2, it can be seen that gibbsite, $\mathrm{Al}(\mathrm{OH})_{3}$, composes $51.5 \%$ of the Hanford insoluble solid particulate by volume, and that gibbsite particles greater than 7.7 and less than or equal to $10 \mu \mathrm{m}$ have a density of $2.42 \mathrm{~g} / \mathrm{mL}$ and compose $4 \%$ of the solids by volume.

To select representative solid simulants for mixing analysis based on the PSDD, the particle size and density are used in the settling velocity equations in Section 7. These are used in conjunction with the respective volume fraction to produce the cumulative volume-based probability of the settling velocity of Hanford insoluble solids in water (liquid density $1 \mathrm{~g} / \mathrm{mL}$, liquid viscosity, $1 \mathrm{cP}$ ). This cumulative probability distribution for settling velocity is shown in Figure 3.1 , where the median $\left(50^{\text {th }}\right.$ percentile) and $95^{\text {th }}$ percentile settling velocities by volume are approximately $4.6 \mathrm{E}-5$ and $3.8 \mathrm{E}-3 \mathrm{~m} / \mathrm{s}$, respectively. The volume-weighted average settling velocity $(\overline{\mathrm{U}})$ is determined by Eq. (3.1). 
Table 3.1. Case 3 PSDD (Wells et al. 2007)

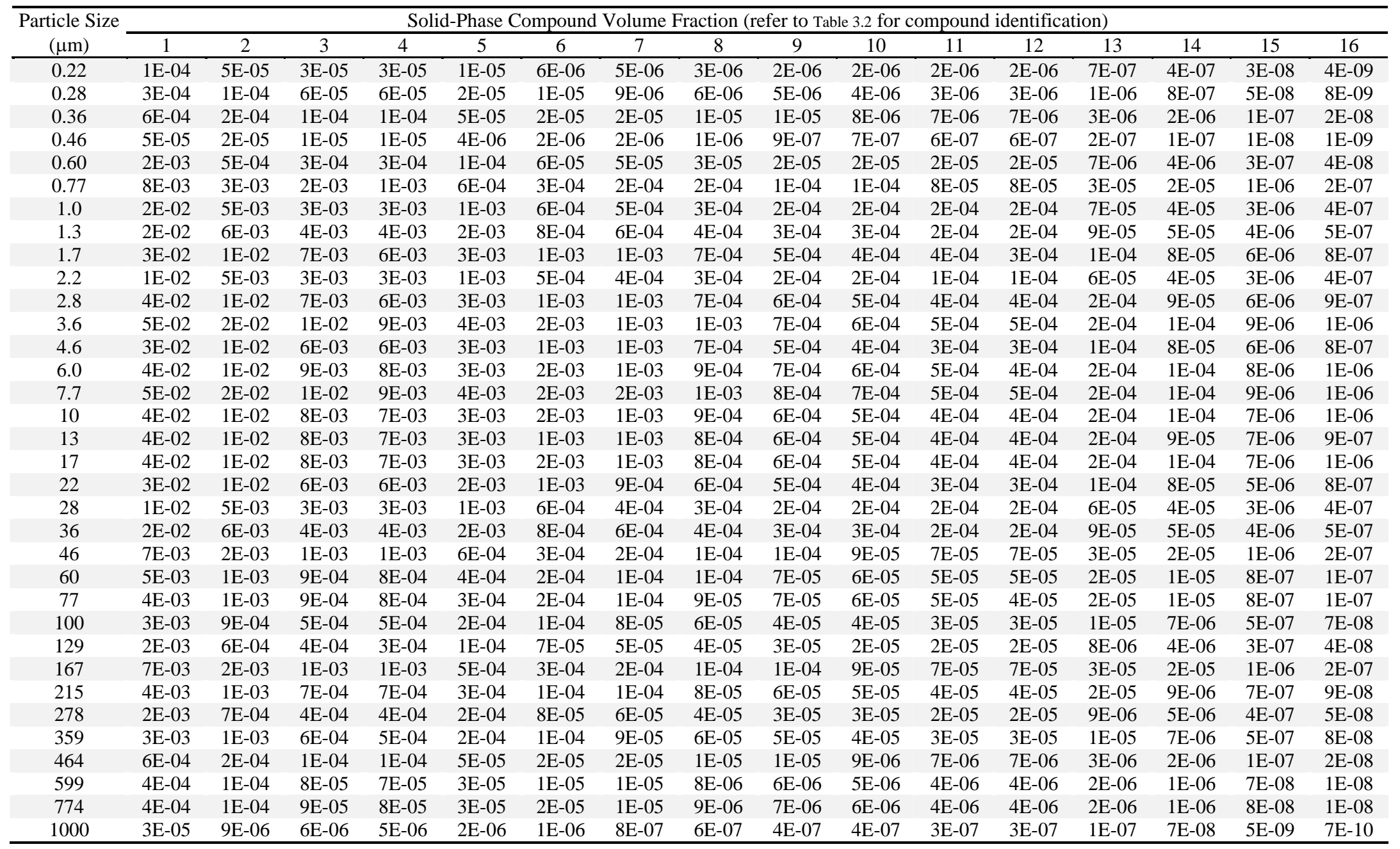


Table 3.2. Solid Phase Compound Density, Volume Fraction, and Numerical Identification for Case 3 PSDD (Wells et al. 2007)

\begin{tabular}{|c|c|c|c|}
\hline Solid-Phase Compound & Crystal Density $(\mathrm{g} / \mathrm{mL})$ & Volume Fraction & $\begin{array}{c}\text { Numerical } \\
\text { Identification }\end{array}$ \\
\hline $\mathrm{Al}(\mathrm{OH})_{3}$, Gibbsite & 2.42 & 0.515 & 1 \\
\hline$\left(\mathrm{NaAlSiO}_{4}\right)_{6} \cdot\left(\mathrm{NaNO}_{3}\right)_{1.6} \cdot 2 \mathrm{H}_{2} \mathrm{O}$ & 2.365 & 0.166 & 2 \\
\hline AlOOH, Boehmite & 3.01 & 0.106 & 3 \\
\hline $\mathrm{NaAlCO}_{3}(\mathrm{OH})_{2}$ & 2.42 & 0.095 & 4 \\
\hline $\mathrm{Fe}_{2} \mathrm{O}_{3}$ & 5.24 & 0.041 & 5 \\
\hline $\mathrm{Ca}_{5} \mathrm{OH}\left(\mathrm{PO}_{4}\right)_{3}$ & 3.14 & 0.020 & 6 \\
\hline $\mathrm{Na}_{2} \mathrm{U}_{2} \mathrm{O}_{7}$ & 5.617 & 0.016 & 7 \\
\hline $\mathrm{ZrO}_{2}$ & 5.68 & 0.011 & 8 \\
\hline $\mathrm{Bi}_{2} \mathrm{O}_{3}$ & 8.9 & 0.0081 & 9 \\
\hline $\mathrm{SiO}_{2}$ & 2.6 & 0.0069 & 10 \\
\hline $\mathrm{Ni}(\mathrm{OH})_{2}$ & 4.1 & 0.0055 & 11 \\
\hline $\mathrm{MnO}_{2}$ & 5.026 & 0.0054 & 12 \\
\hline $\mathrm{CaF}_{2}$ & 3.18 & 0.0023 & 13 \\
\hline $\mathrm{LaPO}_{4} \cdot 2 \mathrm{H}_{2} \mathrm{O}$ & 6.51 & 0.0013 & 14 \\
\hline $\mathrm{Ag}_{2} \mathrm{CO}_{3}$ & 6.077 & 0.000094 & 15 \\
\hline $\mathrm{PuO}_{2}$ & 11.43 & 0.000013 & 16 \\
\hline
\end{tabular}

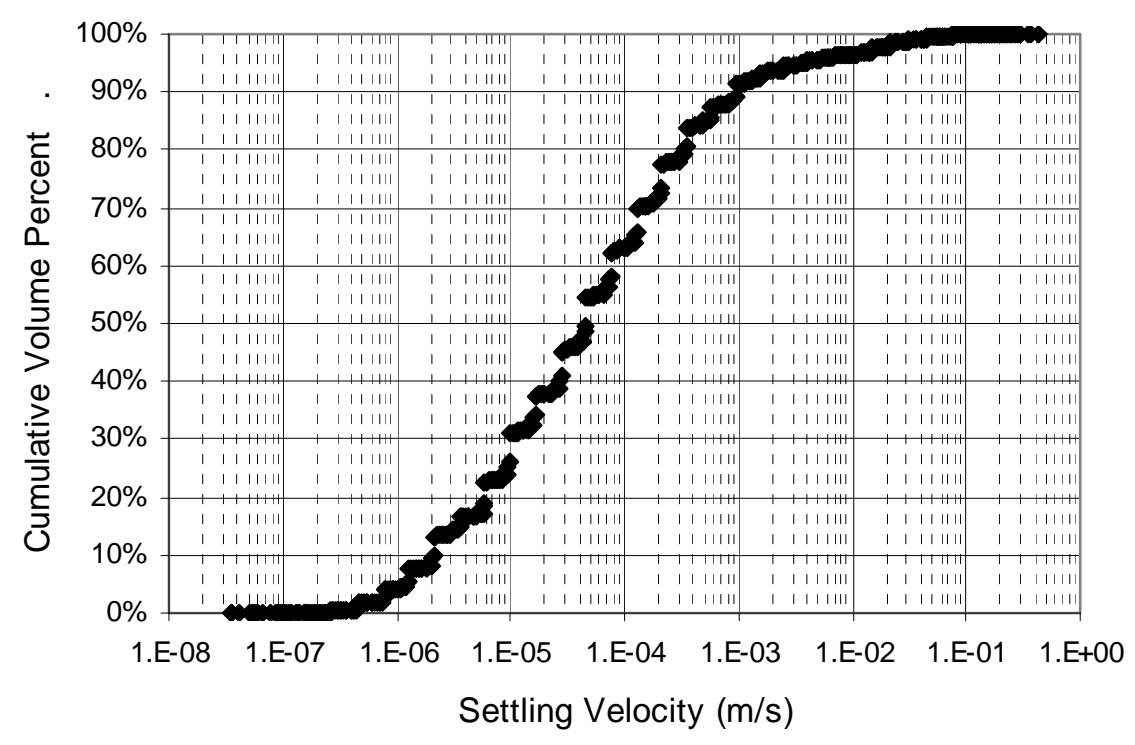

Figure 3.1. Cumulative Undissolved Solid Volume Percent as Function of Settling Velocity for Case 3 PSDD (Wells et al. 2007)

$$
\overline{\mathrm{U}}=\frac{\sum_{\mathrm{i}=1}^{\mathrm{n}} \mathrm{x}_{\mathrm{i}} \mathrm{U}_{\mathrm{i}}}{\sum_{\mathrm{i}=1}^{\mathrm{n}} \mathrm{x}_{\mathrm{i}}}
$$


where $x_{i}$ is the volume fraction of the $i^{\text {th }}$ solid relative to the total solid volume, $U_{i}$ is the settling velocity of the $\mathrm{i}^{\text {th }}$ solid, and $\mathrm{n}$ is the number of entries in the PSDD (particle size bins multiplied by the number of solid phase compounds). ${ }^{1}$

The volume-weighted average settling velocity is independent of the summation order (i.e., $\bar{U}$ may be computed by summation from either the minimum or maximum settling velocity). However, the volume-weighted average settling velocity of a specific volume fraction of the solid particles is dependent on the specific volume fraction. That is, one may consider the cumulative volume-weighted average settling velocity of, for example, $10 \%$ by volume of either the slowest- or fastest-settling solid particles. For the latter consideration, the volume-weighted average settling velocity is determined via Eq. (3.1) with $n$ set such that the fastest settling $10 \%$ of the solid particles by volume are included in the summation.

The cumulative volume-weighted average settling velocity summed from the fastest-settling solid particulate is shown in Figure 3.2. The plot is interpreted as the volume-weighted average settling velocity of the indicated fraction of the solid particles. For example, to determine the cumulative volumeweighted average settling velocity for the fastest-settling $10 \%$ by volume of the solid particles, read the value corresponding to the curve at the $10 \%$ value for cumulative volume fraction. Necessarily, the summation over $100 \%$ of the solid particulate results in $\overline{\mathrm{U}}$. The cumulative volume fraction of Figure 3.2 illustrates that the cumulative volume-weighted average settling velocity for the fastest-settling $10 \%$ by volume of the solid particles is the $90^{\text {th }}$ percentile of the cumulative volume-weighted average settling velocity summed from the fastest-settling solid particulate. Thus, the cumulative volume-weighted average settling velocity of the fastest-settling $10 \%$ of the solid particulate by volume is denoted by $\overline{\mathrm{U}}_{90}$.

From Figure 3.2, $\overline{\mathrm{U}}_{90}$ is approximately $1.4 \mathrm{E}-2 \mathrm{~m} / \mathrm{s}$. Case 3 PSDD settling velocity percentiles from Figures 3.1 and 3.2 are listed in Table 3.3. Altering the base liquid from water to a fluid with $1.1 \mathrm{~g} / \mathrm{mL}$ density and $1.5 \mathrm{cP}$ viscosity reduces the Case 3 PSDD settling velocity for all percentiles (Table 3.4).

The cumulative volume-weighted average settling velocity is an important physical quantity. A homogenous polydispersed system of solids in a liquid will settle with volume flux ( $\bar{U} C$ ), where $C$ is the solids volume concentration. For the Hanford Case 3 PSDD, $\bar{U}>U_{90}$ (Table 3.4). Also if vertical segregation is present in a mixing vessel, the fastest settling particulate will be at lower vessel elevations. Thus, the characteristic settling velocity in that region of the vessel will exceed $\bar{U}$.

\footnotetext{
${ }^{1}$ The binning of the PSDD affects a volume-weighted average computed using Eq. (3.1). For example, if particle size is considered instead of settling velocity, and one bin represents the entire distribution, the volume-weighted average is the maximum particle size. If the PSDD is binned so each particle size has a specific bin, the volumeweighted average is at its minimum. Thus, to provide a representative volume-weighted average, a minimum number of bins are required. Caution must be taken in applying Eq. (3.1) to ensure that binning is appropriate.
} 


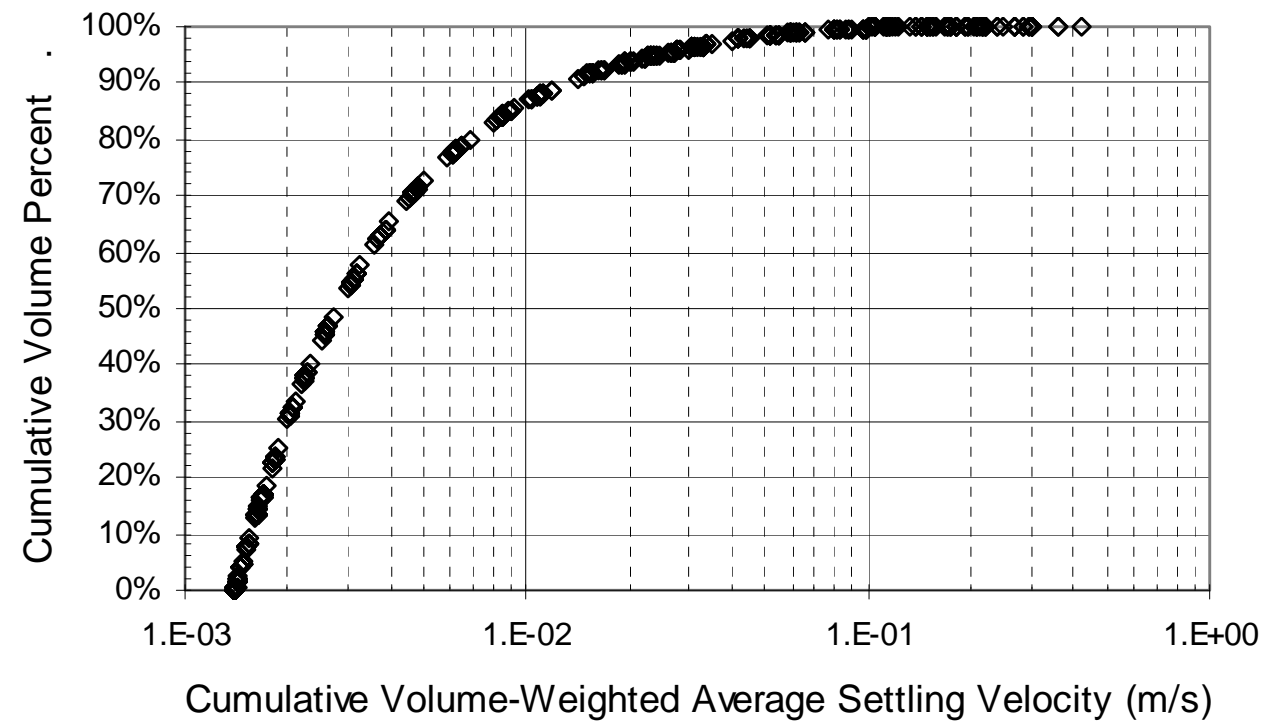

Figure 3.2. Cumulative Undissolved Solid Volume Percent as Function of Cumulative Volume Weighted Average Settling Velocity for Case 3 PSDD (Wells et al. 2007)

Table 3.3. Hanford Insoluble Solid Settling Velocity Percentiles for Case 3 PSDD (Wells et al. 2007)

\begin{tabular}{ccc}
\hline Percentiles (\%) & $\begin{array}{c}\text { Settling Velocity } \\
(\mathrm{m} / \mathrm{s})\end{array}$ & $\begin{array}{c}\text { Volume-Weighted } \\
\text { Average Settling } \\
\text { Velocity }(\mathrm{m} / \mathrm{s})^{(\mathrm{a})}\end{array}$ \\
\hline 5 & $1.2 \mathrm{E}-06$ & $1.5 \mathrm{E}-03$ \\
10 & $2.2 \mathrm{E}-06$ & $1.6 \mathrm{E}-03$ \\
25 & $9.5 \mathrm{E}-06$ & $1.9 \mathrm{E}-03$ \\
50 & $4.6 \mathrm{E}-05$ & $3.0 \mathrm{E}-03$ \\
55 & $6.4 \mathrm{E}-05$ & $3.2 \mathrm{E}-03$ \\
60 & $7.7 \mathrm{E}-05$ & $3.6 \mathrm{E}-03$ \\
65 & $1.2 \mathrm{E}-04$ & $4.0 \mathrm{E}-03$ \\
70 & $1.3 \mathrm{E}-04$ & $4.6 \mathrm{E}-03$ \\
75 & $2.1 \mathrm{E}-04$ & $5.8 \mathrm{E}-03$ \\
80 & $3.4 \mathrm{E}-04$ & $6.8 \mathrm{E}-03$ \\
85 & $5.0 \mathrm{E}-04$ & $8.9 \mathrm{E}-03$ \\
90 & $9.5 \mathrm{E}-04$ & $1.4 \mathrm{E}-02$ \\
95 & $3.8 \mathrm{E}-03$ & $2.4 \mathrm{E}-02$ \\
99 & $4.1 \mathrm{E}-02$ & $6.3 \mathrm{E}-02$ \\
\hline Volume Weighted Average & $1.4 \mathrm{E}-03$ & $1.4 \mathrm{E}-03$ \\
Minimum & $3.5 \mathrm{E}-08$ & $1.4 \mathrm{E}-03$ \\
Maximum & $4.2 \mathrm{E}-01$ & $4.2 \mathrm{E}-01$ \\
\hline (a) Summed from fastest-settling & solid particulate. & \\
\hline
\end{tabular}


Table 3.4. Hanford Insoluble Solid Settling Velocity Quantiles: $1.1 \mathrm{~g} / \mathrm{mL}$ and $1.5 \mathrm{cP}$ Liquid Density and Viscosity, Case 3 PSDD (Wells et al. 2007)

\begin{tabular}{|c|c|c|}
\hline Percentiles (\%) & $\begin{array}{c}\text { Settling Velocity } \\
(\mathrm{m} / \mathrm{s})\end{array}$ & $\begin{array}{c}\text { Volume-Weighted } \\
\text { Average Settling } \\
\text { Velocity }(\mathrm{m} / \mathrm{s})^{(\mathrm{a})} \\
\end{array}$ \\
\hline 5 & $7.6 \mathrm{E}-07$ & $1.1 \mathrm{E}-03$ \\
\hline 10 & $1.3 \mathrm{E}-06$ & $1.2 \mathrm{E}-03$ \\
\hline 25 & 5.8E-06 & $1.4 \mathrm{E}-03$ \\
\hline 50 & 2.9E-05 & $2.2 \mathrm{E}-03$ \\
\hline 55 & 3.9E-05 & 2.3E-03 \\
\hline 60 & 4.8E-05 & 2.6E-03 \\
\hline 65 & 7.5E-05 & $2.9 \mathrm{E}-03$ \\
\hline 70 & 8.5E-05 & $3.4 \mathrm{E}-03$ \\
\hline 75 & $1.3 \mathrm{E}-04$ & 4.3E-03 \\
\hline 80 & 2.1E-04 & $5.0 \mathrm{E}-03$ \\
\hline 85 & $3.2 \mathrm{E}-04$ & $6.5 \mathrm{E}-03$ \\
\hline 90 & $6.0 \mathrm{E}-04$ & $1.0 \mathrm{E}-02$ \\
\hline 95 & $2.5 \mathrm{E}-03$ & $1.8 \mathrm{E}-02$ \\
\hline 99 & $3.1 \mathrm{E}-02$ & $4.9 \mathrm{E}-02$ \\
\hline Volume-Weighted Average & $1.0 \mathrm{E}-03$ & $1.0 \mathrm{E}-03$ \\
\hline Minimum & $2.1 \mathrm{E}-08$ & $1.0 \mathrm{E}-03$ \\
\hline Maximum & $3.8 \mathrm{E}-01$ & $3.8 \mathrm{E}-01$ \\
\hline
\end{tabular}

\subsection{Selection of Slurry Property Ranges}

Solid particle simulants were selected to permit evaluation of mixing performance over a range of operating conditions. Physical properties of density and size distribution were considered. Initial particles selected were commercially available glass beads with a relatively broad size distribution. Tests in 2007 were conducted with these solids. To gain additional insight into the effect that the size distribution of the 2007 simulant on mixing parameters, particles with a much narrower size distribution were selected for the 2008 tests. The testing system limited the use of very small and low density particles because these particles would be removed from the testing tank by the pump inlet at the top of the tank. See Section 4 for system description. Section 8.1.3 discusses why the larger/ heavier particles with faster settling velocities are the controlling waste characteristics when stratification is present.

The property ranges for these simulants are summarized in Table 3.5, where values bound the ranges used during testing with noncohesive simulants.

Table 3.5. Bracketing Noncohesive Particle Test Ranges

\begin{tabular}{lcccc}
\hline \multicolumn{1}{c}{ Property } & Symbol & Units & $\begin{array}{c}\text { Test Range } \\
\text { Minimum Value }\end{array}$ & $\begin{array}{c}\text { Test Range } \\
\text { Maximum Value }\end{array}$ \\
\hline Solids size $\left(\mathrm{d}_{50}\right)$ & $\mathrm{d}_{\mathrm{S}}$ & $\mu \mathrm{m}$ & 44 & 766 \\
Solids density & $\rho_{\mathrm{s}}$ & $\mathrm{g} / \mathrm{cm}^{3}$ & 2.45 & 4.18 \\
Volume weighted average settling & $\mathrm{U}_{\mathrm{T}}$ & $\mathrm{m} / \mathrm{s}$ & 0.0017 & 0.11 \\
velocity (see Section 7 and Eq. 3.1) & & & & \\
\hline
\end{tabular}


Testing identified settling velocity as a parameter with a significant effect on mixing performance. The settling velocity range of the particles used is compared with that of PSDD Case 3 . Settling velocities for the PSDD Case 3 and simulants used in this program are plotted in Figure 3.3 and the volumeweighted average settling velocities summed from the fastest-settling particulate for both in Figure 3.4. The volume-weighted average settling velocity of the particles used in testing spans the range expected in PSDD Case 3.

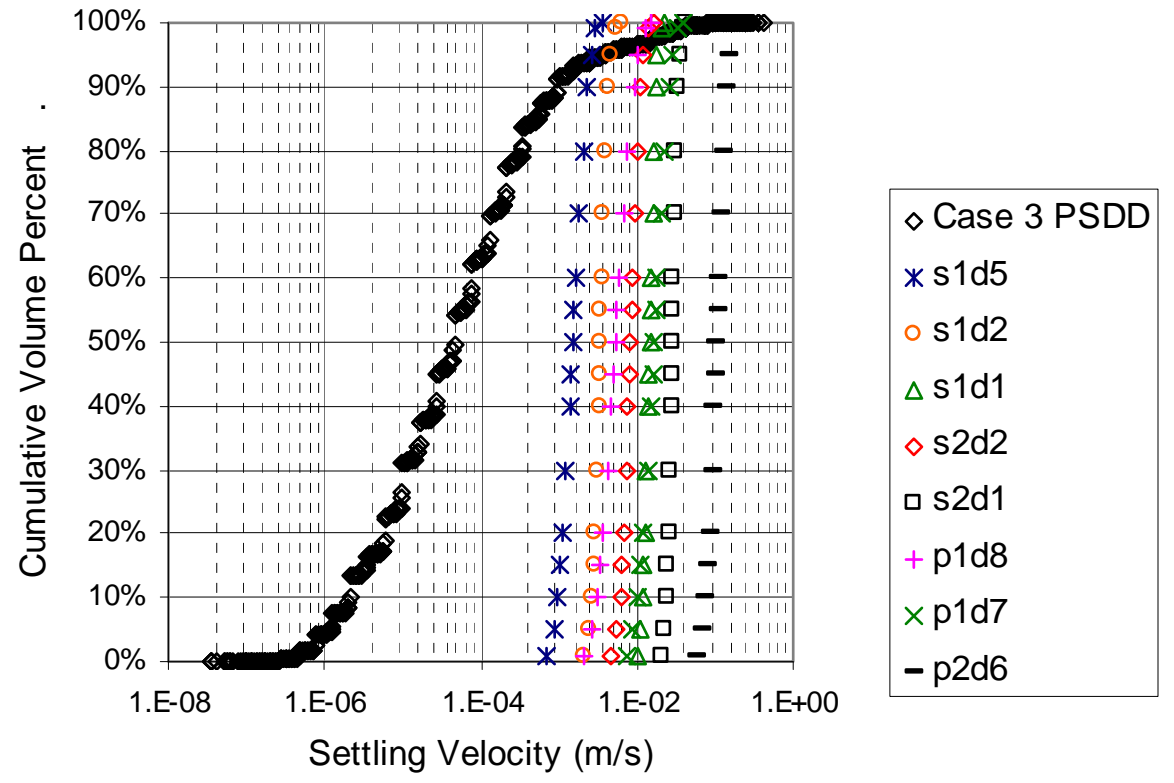

Figure 3.3. Cumulative Volume Percent as a Function of Settling Velocity for Hanford PSDD Case 3 and Simulants (see Table 3.6 for Simulant Identification)

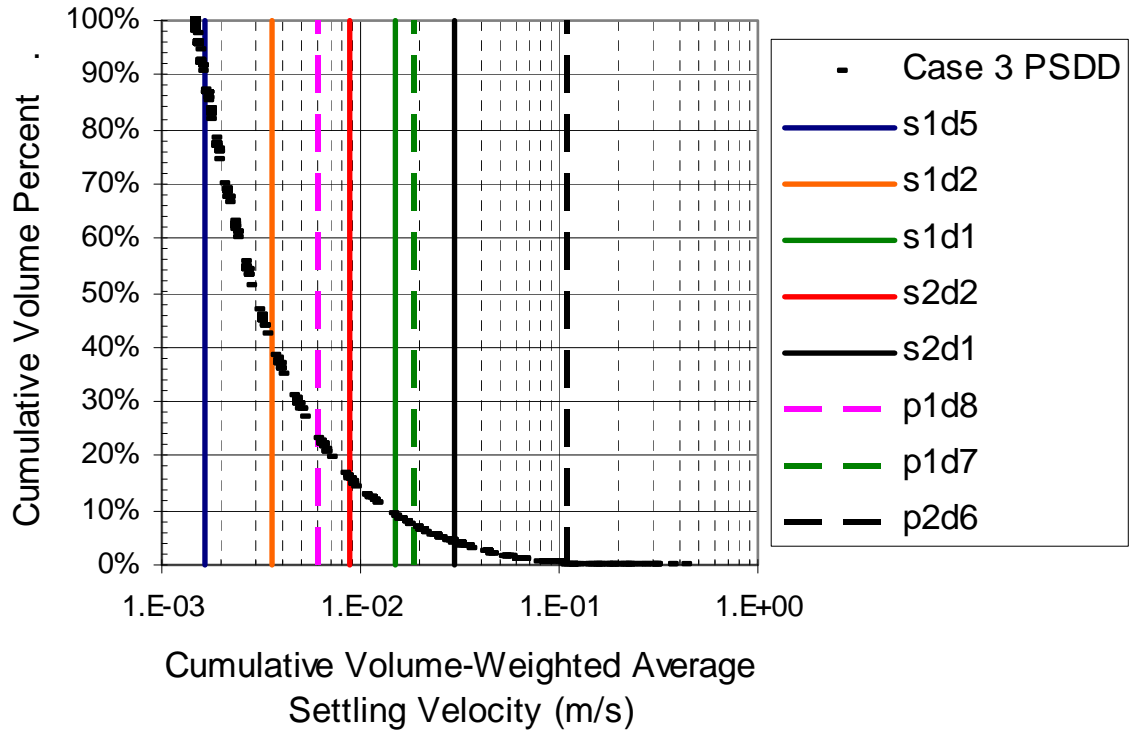

Figure 3.4. Cumulative Volume Percent as a Function of Cumulative Volume-Weighted Average for Hanford PSDD Case 3 and Simulants (see Table 3.6 for Simulant Identification) 


\subsection{Characterization Techniques}

Standard procedures were used to characterize particle density, packing fraction, and particle size, as described in the following subsections. Uncertainties of the measured parameters are provided in Section 6.1.

\subsubsection{Density Measurement Technique}

Particle density was determined by water displacement using a calibrated pycnometer. The procedure involves adding a known mass of beads to a calibrated pycnometer and determining the volume of water displaced by the beads. From this, density is readily obtained.

\subsubsection{Packing Fraction Measurement Technique}

The packing fraction of the beads in water was determined by adding a known mass of beads to a measuring cylinder with a known volume of deionized water. The beads were allowed to settle for 72 hours, and the final volume was measured. The void fraction of the beads was calculated using the settling volume in deionized water from which the packing fraction was calculated. The packing fraction is defined as one minus the void fraction, $\phi_{\max }$.

\subsubsection{Particle Size Measurement Technique}

PSDs were obtained using a Malvern ${ }^{1}$ Mastersizer 2000 with a Hydro G dispersion unit, which uses laser diffraction to obtain the PSD. Six measurements were used to obtain the average PSDs used throughout this report. Optimum measuring conditions were investigated whereby the pump and stirrer speed as well as sonication level were manipulated to ensure that the beads were well dispersed and an accurate, reproducible PSD was obtained. Subsampling is very important when measuring PSD; special care was taken when handling the dry glass beads to obtain a representative sample for analysis in accordance with TPR-RPP-WTP-626 Rev. 0. See Section 5 for specific test instruction references.

\subsubsection{Simulant Selection and Characterization}

The simulant parameters used to characterize the solids used during the mixing tests were particle size $\left(d_{s}\right)$ and particle density $\left(\rho_{s}\right)$. Two materials were chosen based on density: soda-lime glass with a density of approximately $2.5 \mathrm{~g} / \mathrm{cm}^{3}$ (denoted as “s1") and a high-density glass with a density of $4.2 \mathrm{~g} / \mathrm{cm}^{3}$ (denoted as “s2”). Tests were conducted using two types of PSDs: a broad size distribution for tests conducted in 2007 and a narrow size distribution for tests conducted in 2008.

Three sizes of Potters ${ }^{2}$ BALLOTINI ${ }^{\mathrm{TM}}$ impact beads, ${ }^{3}$ (designation 3, 8, and 12 in Table 3.6), were used during the 2007 tests. Three sizes of particles were manufactured by XL Science and Technology ${ }^{4}$

\footnotetext{
${ }^{1}$ Malvern Instruments Ltd., Worcestershire, UK, www.malvern.com.

${ }^{2}$ Potters Industries Inc, www.pottersbeads.com.

${ }^{3}$ http://www.pottersbeads.com/Literature/HiIndex--BallotiniBeads.pdf.

${ }^{4}$ XL Science and Technology, Richland, Wash.
} 
specifically for the tests conducted in 2008. These particles were made using the same manufacturing platform to obtain particles of different density and size with similar physical attributes such as PSD, particle shape, and surface properties. Given that commercially available beads have a specific industrial use in which particle size range is considered along with density, but the distribution of size is usually not a concern, the custom manufacturing of the beads enabled us to specify the consistency of the PSD. The shape (spherical nature) and surface properties of the particles were also considered when selecting the particles, along with the purity of the beads. To eliminate the mixing effects of irregularly shaped angular particles that can be present in low-grade beads, spherical particles free of surface irregularities and raw materials were chosen. The ability to reuse the beads was also a consideration when selecting the simulant composition.

\subsubsection{As-Received}

The as-received density and PSD were measured for all simulants before use, and samples were archived for future reference. Scanning electron microscopy (SEM) was also used to visually inspect the surface of the beads and identify any surface changes resulting from the drying and reuse of the beads during the course of testing. The as-received PSDs are given in Table 3.6 along with the density for both the XLSciTech and the Potters beads. In Table 3.6 and subsequently throughout the report, the solid particle simulants are designated by sxdx (where sx and $\mathrm{dx}$ are defined in Table 3.6). The nominal particle size as per the specifications provided by Potters Industries is also given in parentheses for all three Potters beads used previously.

Pictures obtained from SEM are shown in Figures 3.5 and 3.6 for both XLSciTech and Potters beads. The SEM images of the XLSciTech beads in Figure 3.5(a) through 3.5(d) show that the beads are free of dust and raw materials used during production. The shape and surface properties of these particles are well illustrated in Figure 3.5. The smaller soda-lime beads used in simulant s1d5 are shown in Figure 3.6(a). The presence of raw materials used to manufacture the beads (irregular, angular particles) is noted. These beads are of lower grade than the other beads used in this study that were manufactured by XLSciTech; they were manufactured with a broader PSD that was reduced by sieving through a $45 \mu \mathrm{m}$ sieve. Unlike the beads in Figure 3.5(a) through (d), the s1d5 simulant has some surface irregularities, holes, and small particulate matter adhered to the surface of the beads. Figure 3.6(b) through (d) shows SEM images of the Potters beads used in the 2007 tests. These beads are inexpensive beads manufactured for the metal finishing industry. From SEM images of the Potters beads, we can see that the larger beads, shown in Figure 3.6(b), are free of raw material, particulate matter, and dust. The honeycomb surface that can be seen on one of the beads results from the formation of surface bubbles during bead manufacturing. The white coating visible on one of the beads is also a contamination resulting from raw materials used. The smaller Potters beads, shown in Figure 3.6(c) and (d), appear to have small dust particles on the surface and raw material particles are present in increasing amounts with decrease in bead size. Smaller microspheres are more difficult to manufacture; the presence of irregular particles and conjoined beads is typical of low-grade beads in this size range.

The volume percent passing has been plotted as a function of the particles size for a given volume percent $\mathrm{d}(\mathrm{V} \%)$ normalized by the mean particle size $\left(\mathrm{d}_{50}\right)$ in Figure 3.7 for both XLSciTech and Potters beads. From this plot we are able to determine the PSD of the beads around the mean value. The four simulants, s1d1, s1d2, s2d1, and the s2d2, have tighter distributions around the particle mean size than the Potters beads and the s1d5 simulant. 
Table 3.6. Simulant Characterization: As-Received, Post-Test, and Average Values

\begin{tabular}{|c|c|c|c|c|c|c|c|c|c|c|c|c|c|c|c|c|}
\hline Simulant & $\begin{array}{l}\text { Density } \\
\mathrm{g} / \mathrm{cm}^{3}\end{array}$ & Packing Fraction & Condition & $\begin{array}{c}\mathrm{d}(0.01) \\
\mu \mathrm{m}\end{array}$ & $\begin{array}{c}\mathrm{d}(0.05) \\
\mu \mathrm{m}\end{array}$ & $\begin{array}{c}\mathrm{d}(0.10) \\
\mu \mathrm{m}\end{array}$ & $\begin{array}{c}\mathrm{d}(0.20) \\
\mu \mathrm{m}\end{array}$ & $\begin{array}{c}\mathrm{d}(0.30) \\
\mu \mathrm{m}\end{array}$ & $\begin{array}{c}\mathrm{d}(0.40) \\
\mu \mathrm{m}\end{array}$ & $\begin{array}{c}\mathrm{d}(0.50) \\
\mu \mathrm{m}\end{array}$ & $\begin{array}{c}\mathrm{d}(0.60) \\
\mu \mathrm{m}\end{array}$ & $\begin{array}{c}\mathrm{d}(0.70) \\
\mu \mathrm{m}\end{array}$ & $\begin{array}{c}\mathrm{d}(0.80) \\
\mu \mathrm{m}\end{array}$ & $\begin{array}{c}\mathrm{d}(0.90) \\
\mu \mathrm{m}\end{array}$ & $\begin{array}{c}\mathrm{d}(0.95) \\
\mu \mathrm{m}\end{array}$ & $\begin{array}{c}\mathrm{d}(0.99) \\
\mu \mathrm{m}\end{array}$ \\
\hline s1d1 & 2.46 & 0.59 & as received & 134.8 & 142.8 & 147.7 & 153.8 & 158.3 & 162.4 & 166.4 & 170.6 & 175.2 & 180.7 & 188.7 & 195.1 & 205.7 \\
\hline XLSciTech & & & post test & 132.6 & 140.0 & 145.6 & 153.6 & 158.6 & 162.8 & 166.8 & 171.0 & 175.6 & 181.1 & 189.0 & 195.5 & 208.2 \\
\hline XLSL150180 & & & average & 133.7 & 141.4 & 146.6 & 153.7 & 158.4 & 162.6 & 166.6 & 170.8 & 175.4 & 180.9 & 188.8 & 195.3 & 207.0 \\
\hline s1d2 & 2.48 & 0.63 & as received & 53.9 & 56.9 & 59.8 & 63.5 & 65.7 & 67.5 & 69.3 & 71.2 & 73.2 & 75.7 & 79.2 & 82.1 & 89.7 \\
\hline XLSciTech & & & post test & 53.6 & 56.6 & 59.4 & 63.3 & 65.5 & 67.4 & 69.2 & 71.1 & 73.2 & 75.7 & 79.2 & 82.3 & 90.3 \\
\hline XLSL063075 & & & average & 53.7 & 56.7 & 59.6 & 63.4 & 65.6 & 67.5 & 69.3 & 71.1 & 73.2 & 75.7 & 79.2 & 82.2 & 90.0 \\
\hline s1d5 & 2.50 & 0.60 & as received & 30.2 & 32.8 & 35.0 & 37.6 & 39.8 & 41.8 & 43.9 & 46.0 & 48.2 & 51.0 & 55.5 & 58.5 & 62.6 \\
\hline XLSciTech & & & post test & 30.2 & 32.9 & 35.2 & 37.8 & 40.1 & 42.2 & 44.4 & 46.7 & 49.2 & 52.2 & 56.3 & 59.5 & 64.6 \\
\hline $\begin{array}{l}\text { XLSL038063 } \\
\text { (sieved <45 } \mu \mathrm{m})\end{array}$ & & & average & 30.2 & 32.8 & 35.1 & 37.7 & 39.9 & 42.0 & 44.1 & 46.3 & 48.7 & 51.6 & 55.9 & 59.0 & 63.6 \\
\hline s2d1 & 4.17 & 0.60 & as received & 132.3 & 139.9 & 144.8 & 151.2 & 156.0 & 160.1 & 164.2 & 168.3 & 172.8 & 178.2 & 185.9 & 192.4 & 203.5 \\
\hline XLSciTech & & & post test & 134.9 & 142.4 & 147.0 & 152.9 & 157.1 & 160.9 & 164.5 & 168.3 & 172.3 & 177.1 & 184.2 & 190.1 & 200.6 \\
\hline XLHD150180 & & & average & 133.6 & 141.1 & 145.9 & 152.0 & 156.5 & 160.5 & 164.4 & 168.3 & 172.5 & 177.6 & 185.1 & 191.3 & 202.0 \\
\hline $\mathrm{s} 2 \mathrm{~d} 2$ & 4.18 & 0.63 & as received & 55.7 & 60.9 & 64.1 & 67.6 & 70.4 & 73.0 & 75.6 & 78.2 & 81.1 & 84.6 & 89.3 & 93.1 & 102.1 \\
\hline XLSciTech & & & post test & 56.0 & 61.6 & 64.6 & 68.1 & 70.9 & 73.6 & 76.2 & 78.8 & 81.8 & 85.2 & 89.9 & 93.7 & 103.4 \\
\hline XLHD067080 & & & average & 55.8 & 61.3 & 64.3 & 67.8 & 70.7 & 73.3 & 75.9 & 78.5 & 81.4 & 84.9 & 89.6 & 93.4 & 102.8 \\
\hline $\begin{array}{l}\text { p1d8 } \\
\text { Potters } \\
\text { Ballotine - } 12\end{array}$ & 2.45 & 0.57 & $\begin{array}{l}\text { as received } \\
\text { post test } \\
\text { average }\end{array}$ & 52.8 & 60.5 & 65.7 & 72.8 & 78.6 & 84.0 & 89.5 & 95.2 & 101.6 & 109.6 & 122.4 & 132.0 & 151.2 \\
\hline $\begin{array}{l}\text { p1d7 } \\
\text { Potters } \\
\text { Ballotine - } 8\end{array}$ & 2.45 & 0.57 & \begin{tabular}{|l} 
as received \\
post test \\
average
\end{tabular} & 106.3 & 121.3 & 131.4 & 145.4 & 156.8 & 167.4 & 178.0 & 189.2 & 201.9 & 217.7 & 240.7 & 260.6 & 296.0 \\
\hline $\begin{array}{l}\text { p2d6 } \\
\text { Potters } \\
\text { Ballotine - } 3\end{array}$ & 2.46 & 0.59 & \begin{tabular}{|l} 
as received \\
post test \\
average
\end{tabular} & 455.9 & 518.4 & 559.0 & 624.5 & 673.1 & 718.9 & 766.2 & 817.8 & 877.1 & 952.1 & 1067.8 & 1172.9 & 1376.9 \\
\hline
\end{tabular}




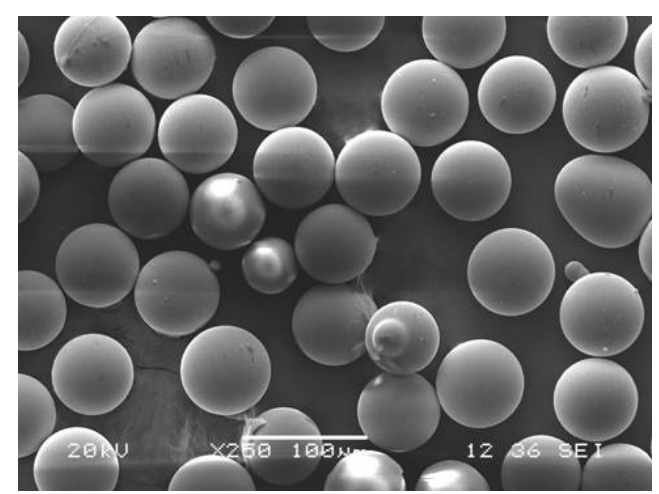

(a) s1d2 Soda-Lime Glass XLSciTech

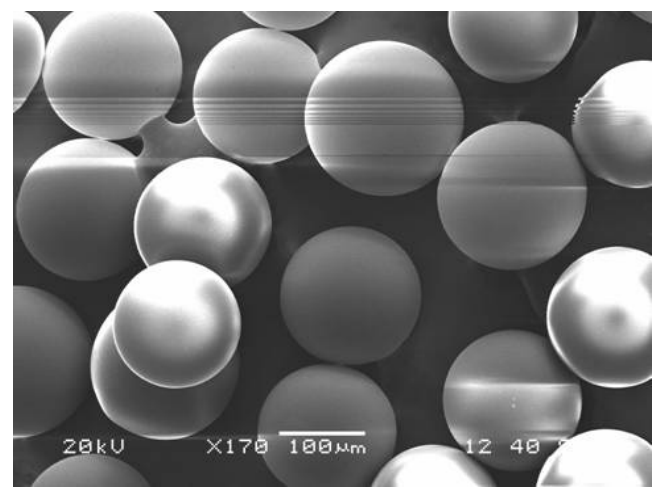

(c) s1d1 Soda-Lime Glass XLSciTech

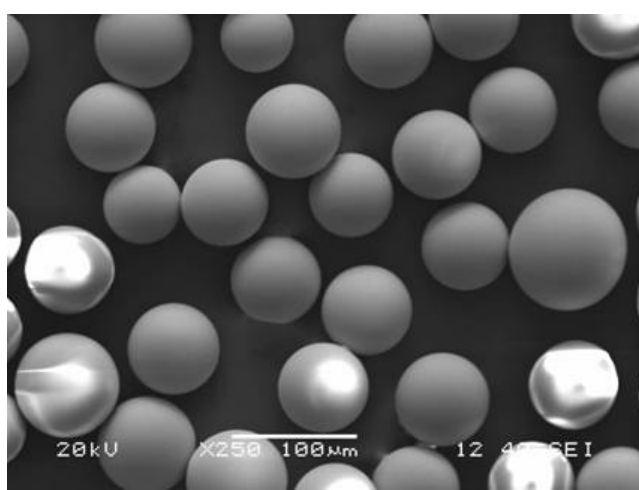

(b) s2d2 High-Density Glass XLSciTech

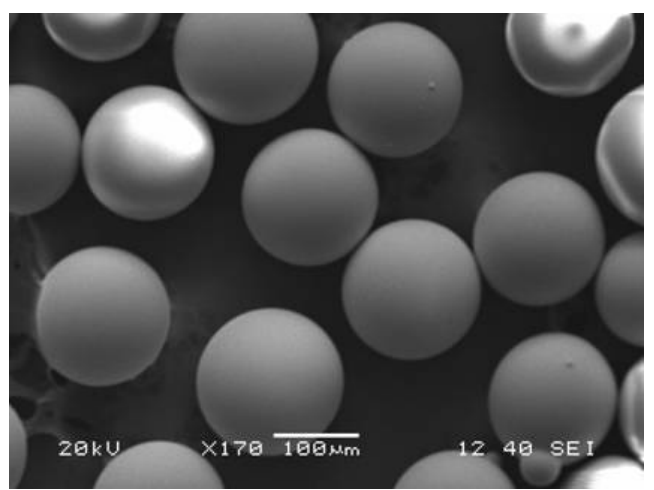

(d) s2d1 High-Density Glass XLSciTech

Figure 3.5. XLSciTech as-Received Beads; (a) s1d2, (b) s2d2, (c) s1d1, and (d) s2d1

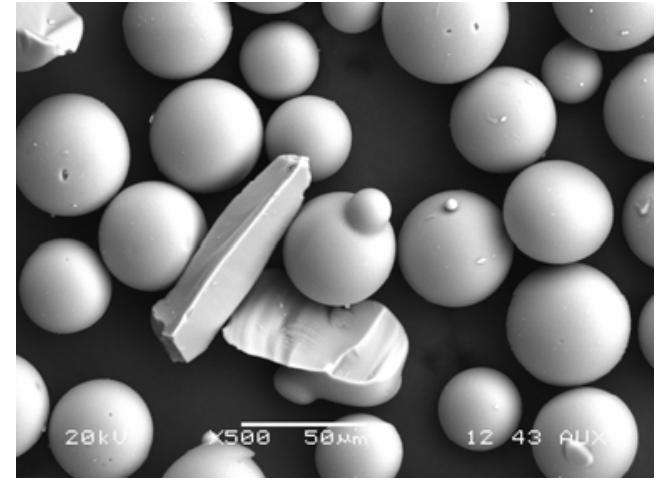

(a) s1d5 Soda-Lime Glass XLSciTech

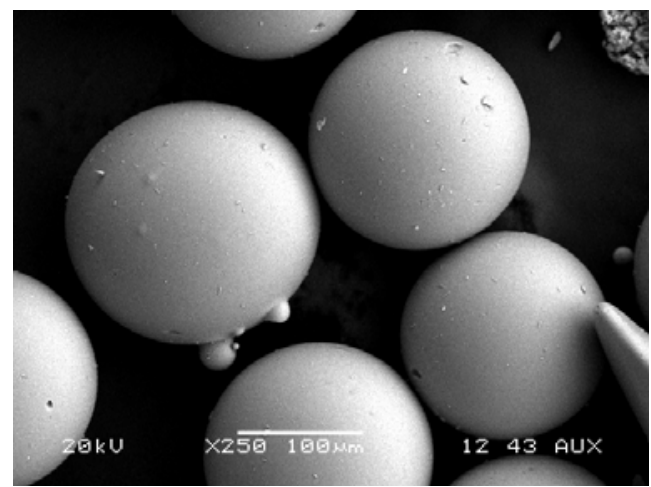

(c) p1d7 Potters \# 8 Soda-Lime Glass 150-212 $\mu \mathrm{m}$

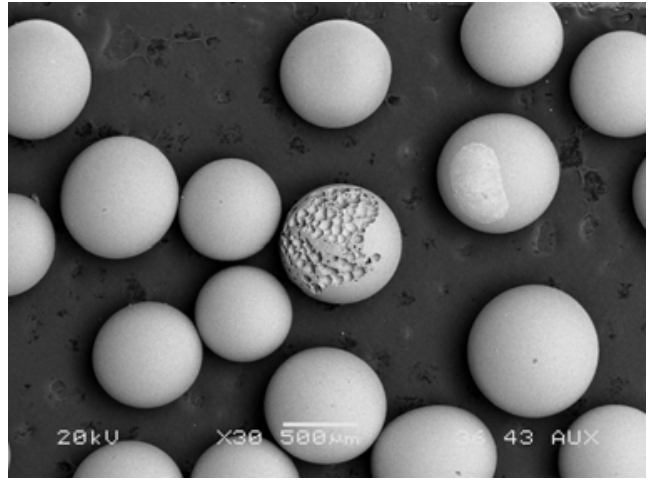

(b) p2d6 Potters \#3 Soda-Lime Glass 600-850 $\mu \mathrm{m}$

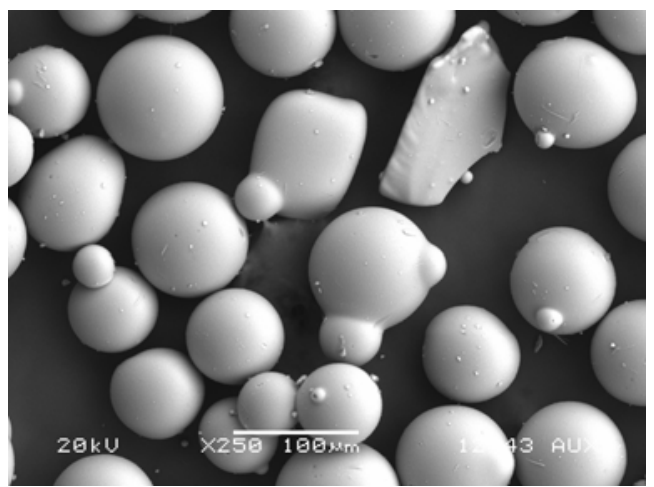

(d) p1d8 Potters \#12 Soda-Lime Glass 63-106 $\mu \mathrm{m}$

Figure 3.6. As-Received Beads; (a) s1d5; (b) \#3 p2d6, (c) \#8 p1d7, and (d) \#12 p1d8 


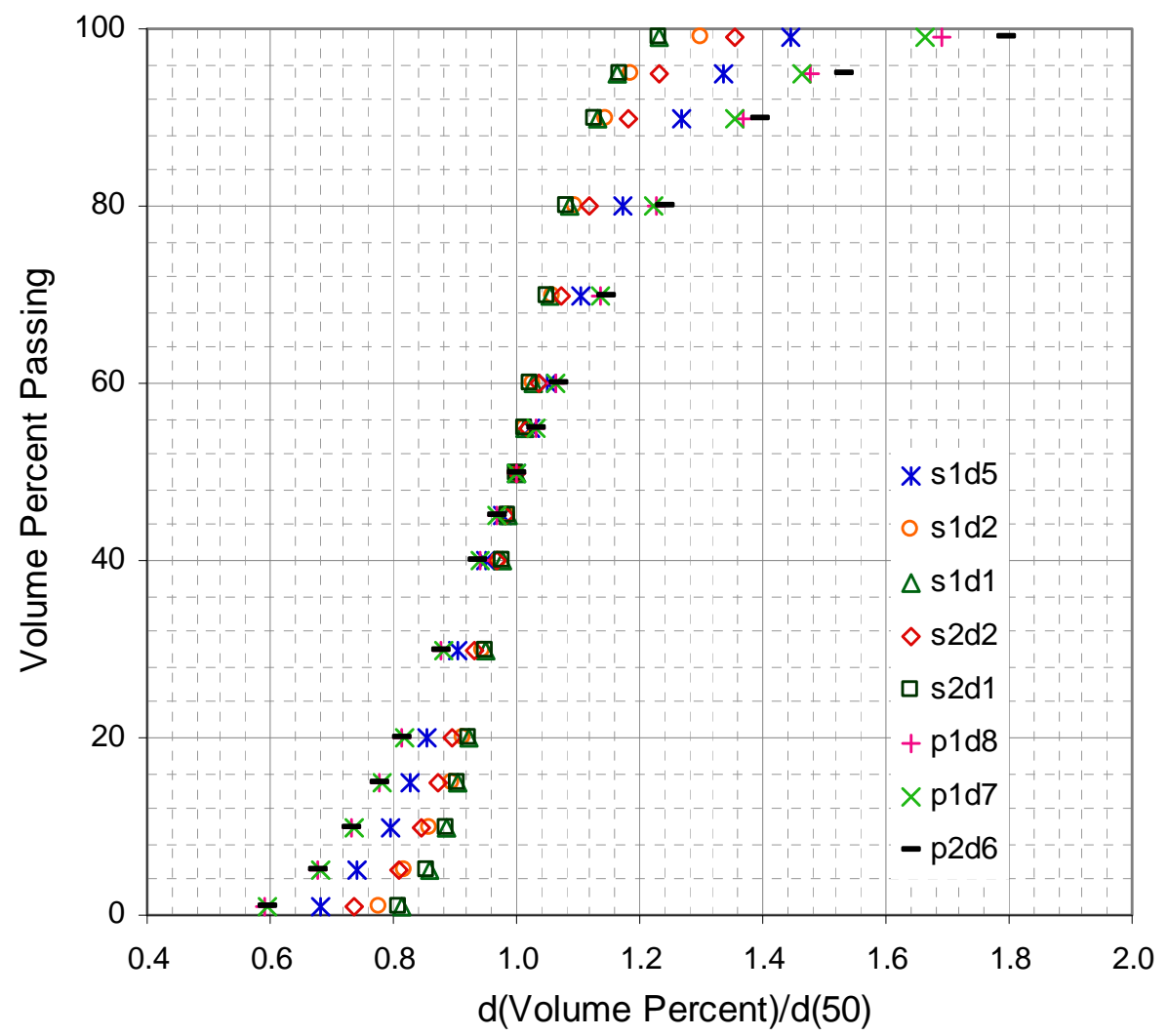

Figure 3.7. PSD around the Mean Particle Size of XLSciTech Microspheres and Potters Beads

\subsubsection{Post Test}

Once simulants were removed from the tanks after testing, they were oven dried, and PSD measurements were performed before reusing the beads as a simple, quick technique to determine whether the beads were changing due to the test conditions or from the drying process. The acceptance criterion implemented for the PSD measurements of the used beads was based on the method used to verify the instrument performance check. If the $d_{5}, d_{50}$, and $d_{95}$ values all fell within $\pm 10 \%$ of the as-received simulant values (Table 3.6), they were accepted for further use. The acceptance criterion for a check standard on the MS2000 using the Hydro G dispersion unit is \pm 5 (lower end) to 3\% (upper end). The moisture content of the simulant was also measured to verify that the beads were dry and ready to be reused. The s1d2 beads were used and dried multiple times in all three test tanks. It was observed during testing in the large-scale [1.78 $\mathrm{m}$ (70 in.)] tank, that if the s1d2 simulant was left overnight to settle at higher concentrations ( $>1.43 \%$ ) it was difficult to restart the PJMs the next day, and tubes were often plugged with beads. This phenomenon was not observed while testing in the mid-scale [0.864 m (34 in.)] tank. A SEM image of the s1d2 beads was taken during this test to ensure that the observations were not due to simulant fouling; at this point the simulant had been used and dried once. The SEM images obtained on the dried beads are given in Figure 3.8 (a) through (d). Note the difference in observation scale to Figures 3.5 and 3.6. The SEM images revealed that there were some bead clumps present and that crystals had formed on some of the beads. Clumped beads were readily dispersed on wetting, which was confirmed by observing the wet beads under an optical microscope. The difficulty in restarting the PJMs was not due to the presence of bead clumps found on dried, reused particles because minimal energy was required to disperse the clumped beads. 


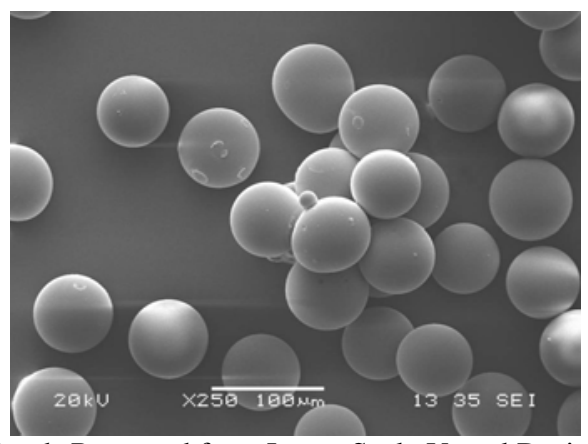

(a) s1d2 Beads Removed from Large-Scale Vessel During Testing

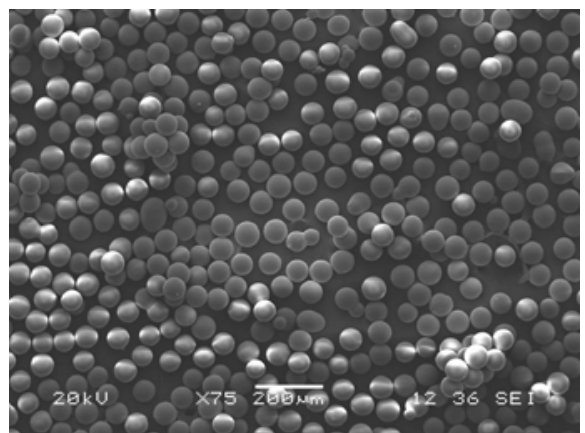

(c) s1d2 Beads Removed from Large-Scale Vessel During Testing

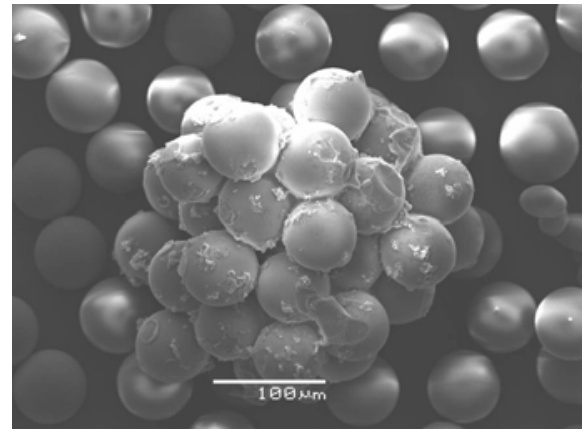

(b) s1d2 Beads After Testing in the Mid-Scale Vessel

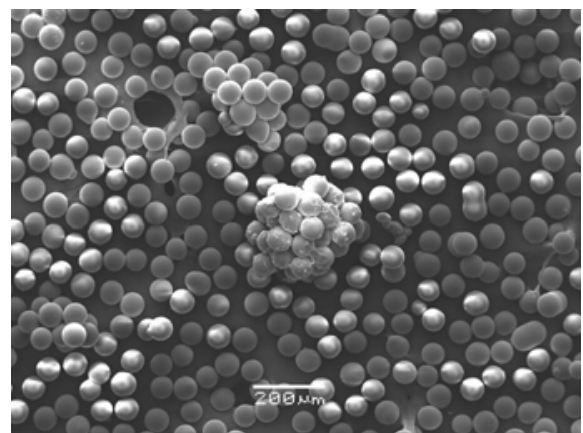

(d) s1d2 Beads Removed After Testing in the Mid-Scale Vessel

Figure 3.8. SEM Pictures of Reused s1d2 Beads Removed during Testing

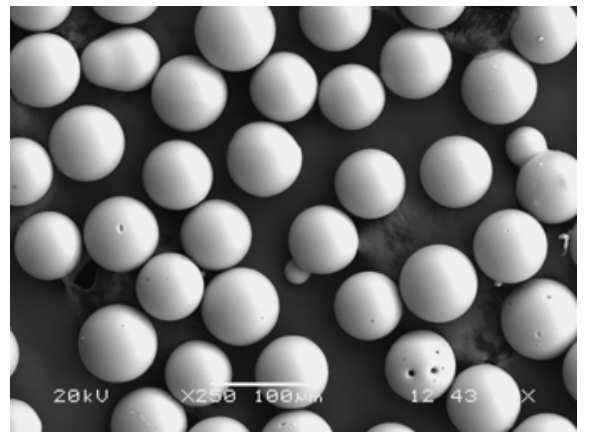

(a) s1d2 Soda-Lime Glass, XLSciTech

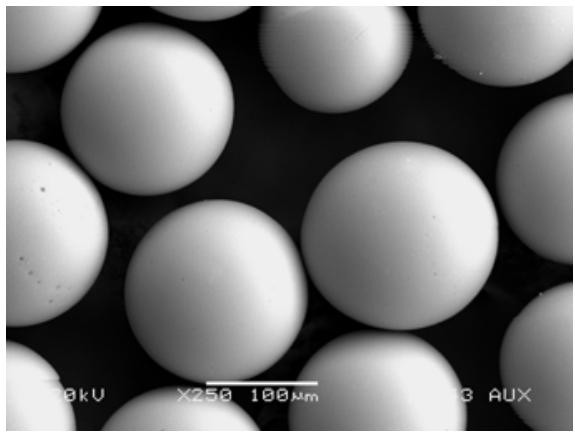

(c) s1d1 Soda-Lime Glass, XLSciTech

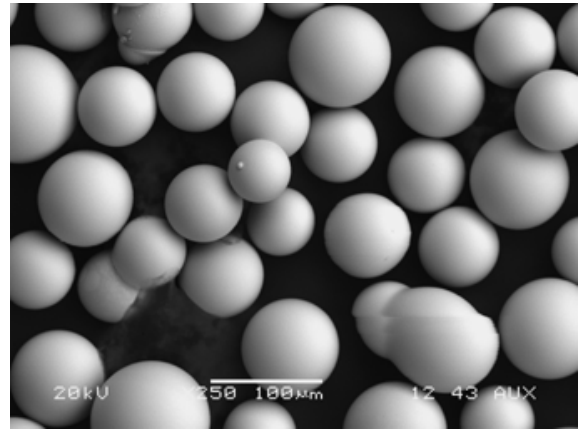

(b) s2d2 High-Density Glass, XLSciTech

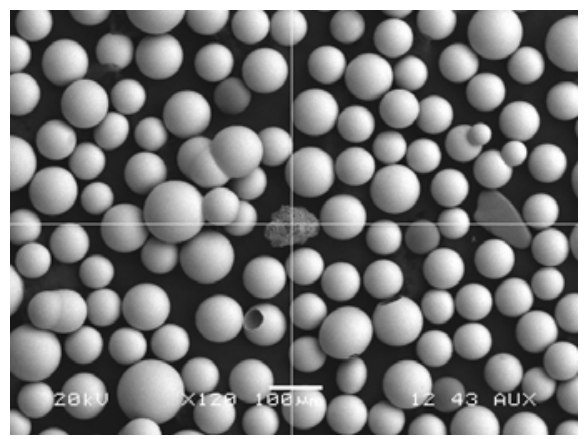

(d) s2d2 High-Density Glass, XLSciTech

Figure 3.9. SEM Images of XLSciTech Microspheres at the Completion of Testing 
It is not clear whether the bead clumping was due to slight dissolution of the soda-lime glass and surface precipitation during drying or to the cleaning product used on the inside of the large-scale tank wall (before initial use) being removed by the beads during testing, forming a thin coating on some of the beads. The difficulty restarting the PJMs at high bead concentrations was not observed while testing in the mid-scale tank because of the dual-shift operation and short test times, as well as the fact that higher concentrations of beads were not left overnight as they were routinely for the large-scale system. Nor was this observed in the small-scale [nominal $0.38 \mathrm{~m}$ (15 in.)] tank due to changes in the startup process that were necessary to clear air out of the nozzles prior to testing; this process ran continuous flows through each nozzle individually to clear entrained air before testing. It was noted, however, that metal particles from the pumps used during testing, especially from the large-scale tank, were present and visible in the simulant when removed from the tank. These particles tended to concentrate at the surface of the beads in the drying pans and were removed where possible. The metal particles were clearly visible to the observers, who were able to distinguish the simulant from metal during testing. The quantity of metal in the simulant was minute compared to the amount of simulant in the tanks. SEM images were taken at the end of testing and are given in Figure 3.9. A foreign particle is observed in Figure 3.9(d). Energy dispersive spectroscopy of the material revealed aluminum as the major component with a small amount of iron. No calcium or sodium was detected. The post-testing SEM images reveal that the simulants remained intact after multiple drying cycles and tests. In Figure 3.9(a), the s1d2 simulant used the most during testing no longer has any clumps, as observed initially during testing in the large-scale tank. The only minor observation is that some of the particles appear to have small holes in the surface, most likely due to a small particle originally adhered to the surface wearing off during testing.

The post-test PSD data are given in Table 3.6. These values are the average of all the PSD analyses of the simulants as received and during testing, between tests after each drying cycle. If we consider the values for $d_{05}, d_{50}$, and $d_{95}$ for all of the simulants, the difference between the as-received values obtained before testing and after testing all fall well within the limitations of reproducibility of the instrument, with the greatest difference less than $2 \%$.

\subsubsection{Recommended Values for Analysis}

The recommended particle size values for use in analyzing the mixing test data are given in Table 3.6. No change in PSD was observed between the as-received and post-test simulants.

\subsubsection{Simulant Scaling}

Nondimensional plots of all simulants for comparison of PSDs are shown in Figure 3.7.

\subsection{Simulant Preparation}

Tests were conducted with water and commercially available particulate (spherical glass beads). The solids were used in their as-received state. No additional segregation or manipulation of particle size of the received materials was conducted. No drying or sieving of the materials was generally required for as-received materials. ${ }^{1}$ Drying was used for reclaimed materials in the 2008 tests $\left(24 \mathrm{hr}\right.$ at $100^{\circ} \mathrm{C}$ was typical). Drying was verified by taking a representative subsample following the drying period and

\footnotetext{
${ }^{1}$ One simulant, s1d5, was sieved to obtain the desired PSD (see Section 3.3.4.1).
} 
verifying the moisture content. Drying was considered complete when a subsample moisture content reading of $1 \%$ or less had been obtained.

The inventory of simulant added to the test tank was recorded in the laboratory record book (LRB). During the test program, additions of solid simulant were made to the tank following previously executed test runs to increase the solids volume fraction. Water was added as needed to maintain the required fill level. The water used was from the Applied Process Engineering Laboratory (APEL) facility process or potable water lines and hence was chlorinated. Small amounts of biocide were added to the tanks during testing to prevent algae and bacteria. The addition of biocide was not considered quality effecting and was added to the tank systems as per the label directions provided by the manufacturer (Mt Hood Biocide).

\subsubsection{Water Addition and Removal}

The supernatant is the liquid phase of the simulant in the tank; only water was used as the supernatant for testing described in this report. The liquid inventory was monitored by taking measurements of the water fill level of the tank. Water was added to the tank as needed to bring the total fluid level up to the specified level. The water used was from the APEL facility process or potable water lines.

\subsubsection{Solids Addition and Removal}

The following describes addition of solids to the test vessel. Any calculation of the solids volume fraction within the test tank assumes there is no holdup of solids within the drive system plumbing.

- The mass of solids prior to the addition was determined based on previous LRB entries and entered into the LRB, including the cross reference to the prior entry.

- The total mass of solids was determined after adding solids and the results entered in the LRB.

When it was necessary to remove solids before a test system change, such as changing to a different simulant, the majority of the water was decanted and the wet solids dispositioned, either dried and reclaimed or discarded as appropriate. Samples were obtained periodically for archive and post-test measurements. 



\subsection{Experimental Equipment}

The configuration of the equipment used during the scaled mixing tests is described in this section. Section 4.1 gives an overview of the multiscale test systems. This section also describes the approach used to compensate for impingement angle when the HLP-22 vessel has a different bottom shape than the test tank.

Design details for the small-scale test stand are described in Section 4.2, the mid-scale test stand in Section 4.3, and the large-scale test stand in Section 4.4. Key elements of the test stands are the vessel size, differences in the drive systems versus the PJMs, and the bottom shapes available with each test stand. The method to generate pulsating flow is described in Section 4.5. Instrumentation and data acquisition are described in Sections 4.6 and 4.7, respectively.

The configuration of the pulse jet arrays and nozzles tested is described in Section 4.8. Key elements in this discussion include the different nozzle array configurations and tube numbers used, different nozzle sizes used, and an illustration of the impingement angles of the jets for the different shaped heads (bottoms).

\subsection{Modeling Tank HLP-22 Configuration}

Figure 4.1 is a schematic of the conceptual arrangement of the test systems. Tests were conducted in three test systems (small-, mid-, and large-scale) using acrylic tanks with diameters of $0.367,0.86$, and $1.78 \mathrm{~m}$ (14-7/16, 34, and 70 in.), respectively. Four different test tank head ${ }^{1}$ (bottom) profiles were prepared: flat, 100-to-6 F\&D, semi-elliptical, and spherical.

The small-scale system includes three tanks that can be used one at a time. Each of the three smallscale tanks has a different bottom profile: one has a flat head, one has a 2:1 elliptical head, and one has a 100-to-6 F\&D head. Only the 2:1 elliptical-headed small-scale tank was used during the tests described in this report.

The bottom of the mid-scale test vessel was understood to be a 2:1 elliptical head; however, post-test measurements and analysis of the tank more accurately characterized the head as a spherical segment (called spherical in this report) with a radius of curvature of approximately $0.51 \mathrm{~m}$ (20 in.) (FIO) ${ }^{2}$ and a $0.229 \mathrm{~m}$ (9 in.) depth. Therefore, the mid-scale tank is not completely geometrically similar to the smalland large-scale tanks.

The large-scale tank system has two heads (elliptical and F\&D) that can be exchanged using a flanged connection. Both heads are made of steel and modified with acrylic ports for viewing. A visual comparison of the 100-to-6 F\&D head and a 2:1 semi-elliptical head is provided in Figure 4.2.

\footnotetext{
${ }^{1}$ The tank "head" is the bottom surface of the tank. For the small- and mid-scale tanks, the head is integral to the tank. For the large-scale tank, the head is interchangeable by placing the 70-in. acrylic tube on the either the F\&D or elliptical heads.

${ }^{2}$ FIO data are included for information only and do not necessarily meet NQA1 standards.
} 


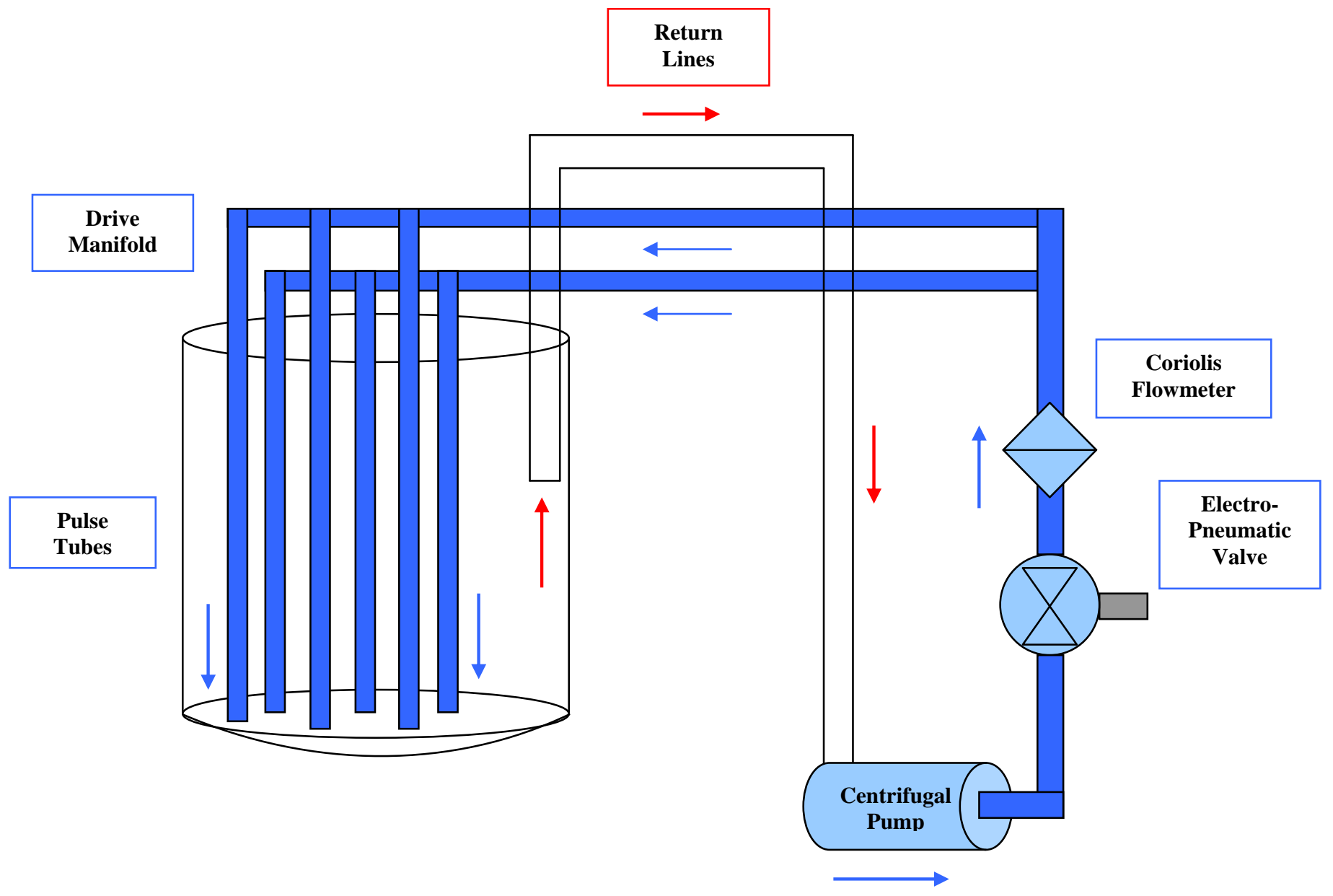

Figure 4.1. Schematic of Conceptual Arrangement of Test Tank and Drive System for HLP-22 Testing
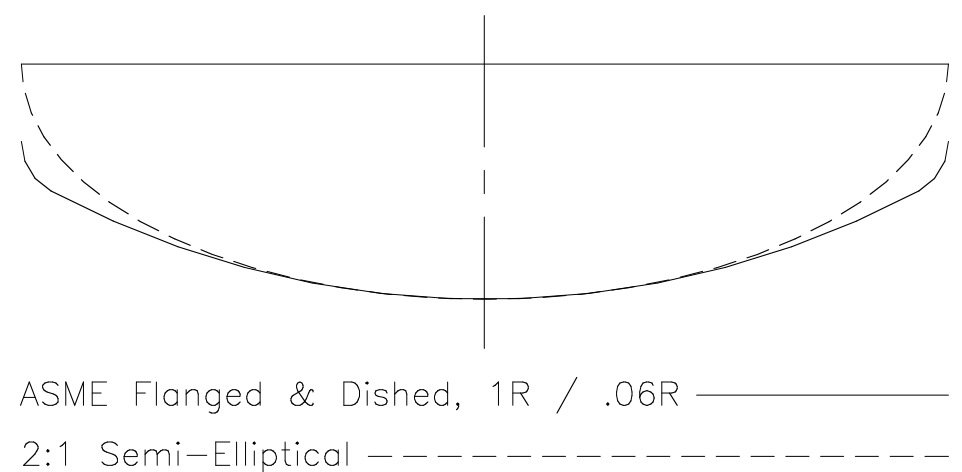

Figure 4.2. Comparison of Profiles for F\&D and 2:1 Semi-Elliptical Tank Heads

The HLP-22 vessel has an F\&D head (BNI 2007). The heads of scaled tanks used in the experiments are not all geometrically the same as the HLP-22 vessel, and the difference affects the flow geometry where PJM jets contact the head. This can be compensated for by slightly changing the radial locations of PJMs in the scaled systems to create geometrically similar jet impingement angles. 
The differences in tank head profiles result in different impingement angles between the vertical jet and the tank head. For the outer ring of PJMs, the differences in tank head profiles result in significantly different impingement angles at the same radius from the center. Figure 4.3 illustrates the impingement angle of the jets. To duplicate the impingement angle of an F\&D configuration (e.g., the HLP-22 vessel), the radial location of the outer PJM ring was changed to an elliptical configuration. Figure 4.4 illustrates the tank head elevation as a function of the nondimensional tank radius for F\&D, 2:1 semi-elliptical, and spherical tank heads to show the differences in impingement angles at the same radial position. The actual adjustments for the radial position and the resulting impingement angles are shown in Table 4.1 for the tube arrays used in testing, including as-tested impingement angles (FIO).

The PJMs are made of standard pipe with changeable nozzles at the ends. Because the F\&D head has shallower impingement angles than the semi-elliptical head, particularly at the outer tank radii, the distribution of flow toward the tank center and wall is altered. To achieve similar angles, the radial positions of the pulse tubes were adjusted based on the values provided in Table 4.1.

In the test planning, all three test systems were to operate with at least a 2:1 semi-elliptical head. The mid-scale system used a tank that had been supplied by other projects and was represented as a 2:1 semielliptical head. The other systems purchased at least one head as semi-elliptical and one head as F\&D. Testing was completed in the mid-scale system first due to its availability. The mid-scale tank failed several months after its use in testing, which allowed for a post-test measurement of the tank head.

The post-test measurements of the mid-scale tank head more accurately characterized the tank as having a spherical segment head with a 0.511-m (20.1-in.) radius and a 22.9-cm (9-in.) depth. This results in different jet impingement angles in the mid-scale tank than planned. The resulting difference between the planned and as-tested jet impingement angles for the mid-scale are shown in Table 4.2.

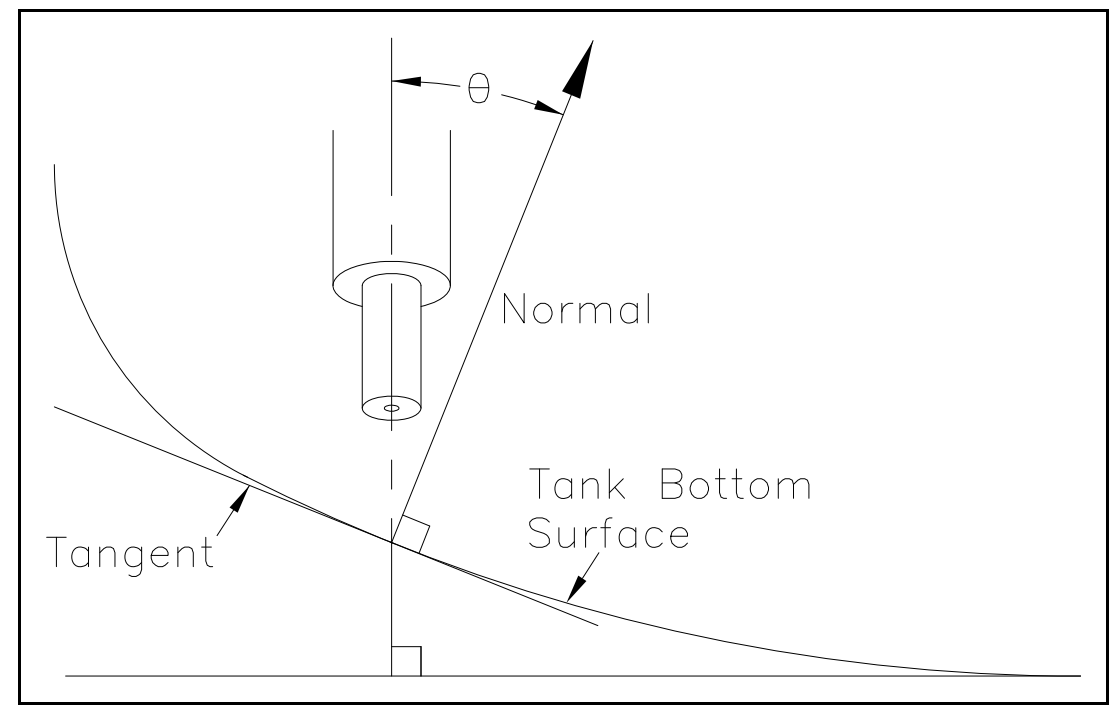

Figure 4.3. Illustration of Jet Impingement Angle, $\theta$, Which Is the Angle between the Vertically Downward Jet and the Bottom of the Tank at the Point of Impingement. (This definition agrees with the definition of the angle of incidence used in optics.) 


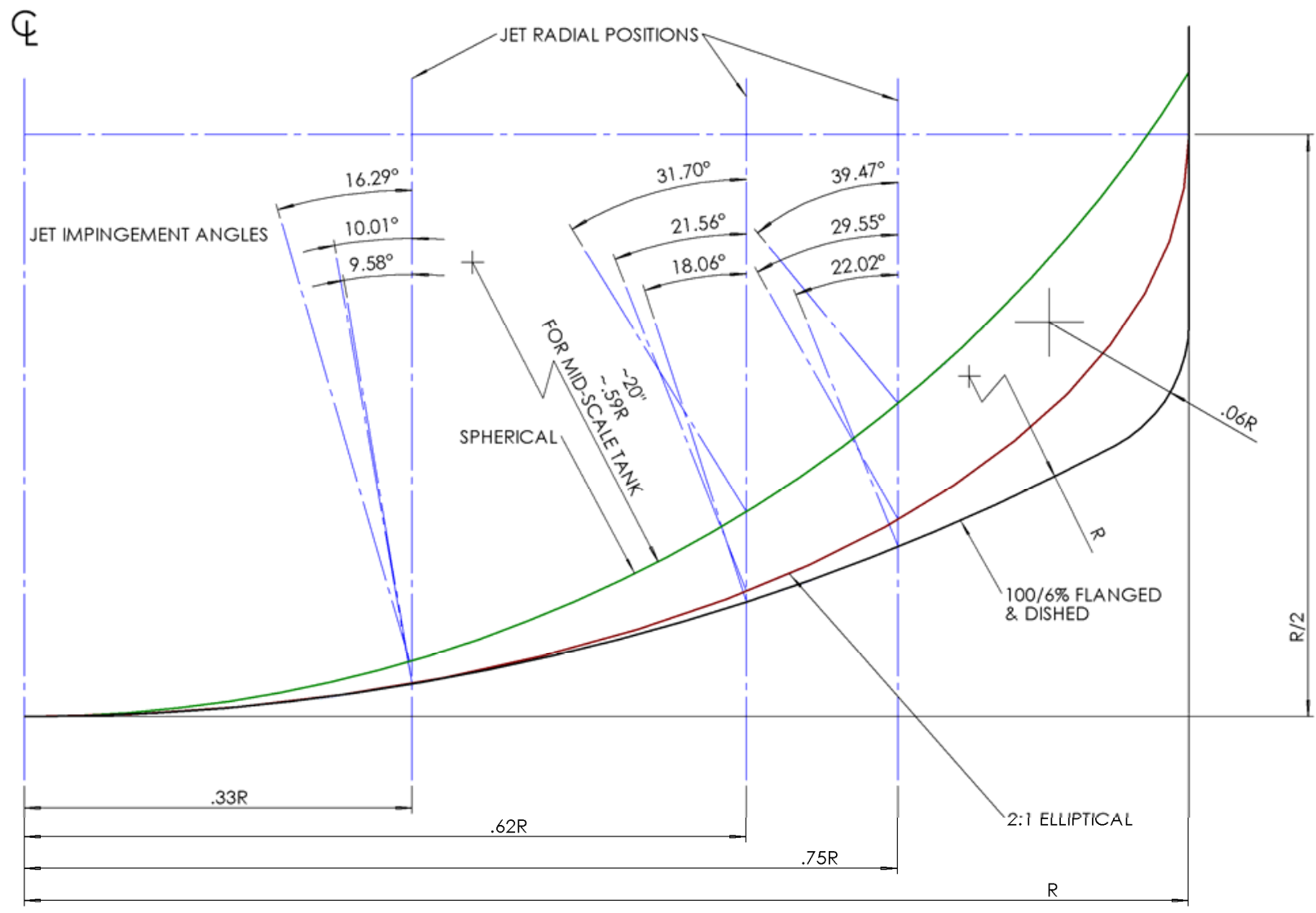

HEAD PROFILE COMPARISON, NORMALIZED TO TANK RADIUS

Figure 4.4. Illustration of the Change in Impingement Angles for Different Head Profiles. ${ }^{1}$ This illustration shows the shape using nondimensional tank radius for F\&D, spherical, and 2:1 semi-elliptical heads (FIO).

Table 4.1. Comparison of Planned Pulse Tube Radius for Equivalent Angle of Impingement in Tank Heads Formed with F\&D and 2:1 Semi-Elliptical Heads

\begin{tabular}{lcc}
\hline \multicolumn{1}{c}{ Parameter } & Inner Ring of PJMs & Outer Ring of PJMs \\
\hline $\begin{array}{l}\text { Radial position of PJM centerlines in Tank HLP-22 } \\
\text { design with F\&D head for tank head }\end{array}$ & $0.33 \mathrm{R}^{(\mathrm{a})}$ & $0.75 \mathrm{R}$ \\
$\begin{array}{l}\text { Angle of impingement } \\
\text { specified tank radius }\end{array}$ & 9.6 degree & 22.1 degree \\
$\begin{array}{l}\text { Radial position of PJM centerline in a semi-elliptical } \\
\text { tank head that matches the angle of impingement in the } \\
\text { F\&D tank head }\end{array}$ & $0.33 \mathrm{R}$ & $0.62 \mathrm{R}$ \\
\hline
\end{tabular}

(a) $\mathrm{R}=$ tank radius

(b) Figure 4.20 illustrates the angle of impingement.

\footnotetext{
${ }^{1}$ Actual impingement angles from the test are in Table 4.1. The illustration in Figure 4.4 is for information only.
} 
Table 4.2. General PJM Configurations

\begin{tabular}{|c|c|c|c|c|c|c|c|c|}
\hline \multirow{2}{*}{$\begin{array}{c}\text { Vessel } \\
\text { Configuration }\end{array}$} & \multicolumn{2}{|c|}{$\begin{array}{c}\text { Ratio of Inner Ring } \\
\text { Radius to Tank Radius } \\
\mathrm{R}_{\mathrm{I}} / \mathrm{R} \\
\end{array}$} & \multicolumn{2}{|c|}{$\begin{array}{c}\text { Ratio of Outer Ring } \\
\text { Radius to Tank } \\
\text { Radius } \mathrm{R}_{\mathrm{O}} / \mathrm{R} \\
\end{array}$} & \multicolumn{2}{|c|}{$\begin{array}{c}\text { Inner PJM } \\
\text { Impingement Angle } \theta_{\mathrm{I}} \\
\text { (deg) }\end{array}$} & \multicolumn{2}{|c|}{$\begin{array}{c}\text { Outer PJM } \\
\text { Impingement Angle } \\
\theta_{\mathrm{O}}(\mathrm{deg}) \\
\end{array}$} \\
\hline & Planned & As-Tested & Planned & As-Tested & Planned & $\begin{array}{l}\text { As-Tested } \\
\text { (FIO) }\end{array}$ & Planned & $\begin{array}{l}\text { As-Tested } \\
\text { (FIO) }\end{array}$ \\
\hline 15E 12-tube & 0.33 & 0.34 & 0.62 & 0.62 & 9.6 & $10.1^{(\mathrm{a})}$ & 22.1 & 21.8 \\
\hline $34 \mathrm{E} 12-$ tube $^{(\mathrm{b})}$ & 0.33 & 0.33 & 0.62 & 0.62 & 9.6 & 16.1 & 22.1 & 30.8 \\
\hline 70E 12-tube & 0.33 & 0.33 & 0.62 & 0.62 & 9.6 & 10.5 & 22.1 & 20.3 \\
\hline 70F 12-tube & 0.33 & 0.34 & 0.75 & 0.76 & 9.6 & 9.7 & 22.1 & 22.4 \\
\hline 15E 8-tube & $\mathrm{n} / \mathrm{a}$ & 0.50 & $\mathrm{n} / \mathrm{a}$ & 0.67 & $\mathrm{n} / \mathrm{a}$ & 16.0 & $\mathrm{n} / \mathrm{a}$ & 24.4 \\
\hline 70E 8-tube & $\mathrm{n} / \mathrm{a}$ & 0.50 & $\mathrm{n} / \mathrm{a}$ & 0.67 & $\mathrm{n} / \mathrm{a}$ & 16.1 & $\mathrm{n} / \mathrm{a}$ & 21.9 \\
\hline
\end{tabular}

(a) Data in italics are for information only.

(b) Planned values indicated for the mid-scale tank are those for the semi-elliptical tank head. No spherical segment values are indicated in the test plan.

For straight-bore nozzles, the bore has a minimum length of 10 diameters for each nozzle size tested. The proximity (1.5 nozzle diameters) ${ }^{1}$ of the nozzle discharge to the tank floor results in the core of the jet impacting the tank floor with minimal to no decrease in the centerline velocity of the jets. While not part of this testing program, computational fluid dynamics (CFD) modeling was performed by BNI to compare the applied shear stress on the tank floor produced from a conical nozzle with a 60-degree taper and a straight-bore nozzle. The straight-bore nozzle results agreed with literature values for floor shear stress (Beltaos and Rajaratnam 1977). The CFD results for a nozzle elevation of 1.5 nozzle diameters indicate that the conical nozzle results in a higher shear stress at the tank floor within approximately 10 nozzle diameters from the point of impact. The difference is greatly reduced between 10 and 20 diameters and appears negligible after 20 diameters.

For mobilization of solids on the tank floor (using CFD results), the straight-bore nozzles provide conservative results at lower discharge velocities in which the radial clearing of solids from the tank floor is less than that required for the critical suspension velocity to be achieved. As the discharge velocity is increased and solids mobilization is achieved at higher radial distances, the differences in solids mobilization obtained for conical and straight-bore nozzles are predicted by CFD analysis to become negligible.

To simplify and expedite the testing, the test apparatus was designed with a closed-loop, pumped-jet system with the pump return line near the liquid surface. Pulsation of the discharge flow was achieved by valve operation.

The test system for all three scales used centrifugal pumps to circulate water through the pulse tubes to simulate the pulse phase of the PJM system (the vacuum or suction refill phase is not simulated). The full-scale plant vessels contain PJMs that are much larger in diameter than the pulse tubes used in the test stands. A PJM is operated by applying an oscillating gas pressure to the headspace. During the highpressure part of the cycle, fluid is discharged from the PJM. When the headspace pressure is reduced (by venting and/or vacuum), the PJM refills with fluid from the tank. A PJM can hold the entire volume of

\footnotetext{
${ }^{1}$ In the small-scale vessel, 0.0049-m (0.193-in.) nozzles were tested at a standoff distance of 1.04 nozzle diameters.
} 
fluid that is discharged during the high-pressure portion of the cycle. The differences between the prototypic PJM system and the pulse tubes used in testing that are thought to be consequential include:

- The PJM system will pull both liquids and solids from the bottom of the vessel during the vacuum or suction refill phase. In the pulse tube system used in testing, the jets expel nearly pure water. This may increase the solids concentration that settles to the bottom of the tank. It may also result in a jet of lower bulk density and less premixing of the pulse volume and may lead to plugging of the PJM nozzles during discharge or between pulses, which is less likely in the PJM system. These conditions identify a benefit of conducting additional testing with a prototypic, full-cycle drive system.

- The diameters of the PJMs are much larger than the pulse tubes used in testing. The smaller diameters of the pulse tubes may result in less lifting of solids from the bottom to the upper regions of the tank as well as less alteration of radial and tangential circulation within a test tank (compared to a prototypic tank). This condition may identify a benefit of conducting additional testing with a prototypic PJM geometry.

- Flow within the pulse tubes is one-directional rather than reciprocating as in a PJM. During a pulse, liquid is suctioned from the top of the test vessel through the pump(s) outside the tank and returned to the tank through the pulse tubes. This imparts a circulatory flow through the ex-tank piping and a net upward flow through the constant tank fluid volume during the pulses.

In the test system that simulates PJM action, the pulse tubes are connected by a common manifold and activated using a centrifugal pump to generate the motive power. Pressure sensor ports on each pulse tube (after the manifold) allowed the flow to all the nozzles to be balanced or made uniform before testing starts. Cycling of the pump operation and the synchronized opening and closing of the control valve generate the periodic flow through the pulse tubes.

\subsection{Small-Scale Test Stand}

The small-scale test stand was located in the APEL high bay. The components of the small-scale test stand are described in Section 4.2.1, and the control equipment is described in Section 4.2.2.

\subsubsection{Components}

The small-scale test apparatus consists of several components, including three interchangeable transparent acrylic 0.367-m- (147/16-in.-) diameter tanks, a pump skid, plumbing connecting the tank to the pump skid, a liquid drive system, instrumentation, and a data acquisition system (DAS). The three tanks have different head geometries, flat, elliptical, or F\&D, but only the 2:1 elliptical-headed tank was selected for use during the tests described in this report because all three (small-, mid-, and large-scale) had elliptical heads. Thus the results from any of the three could be used to establish tank diameter scaling factors. (It was later determined that the elliptical shape of the mid-scale test stand was different than the elliptical shapes of the other two stands.) The test tanks, plumbing configuration, and pump skid discussed in this section are shown in Figure 4.5. The three test tanks in the small-scale apparatus are approximately $0.99-\mathrm{m}$ (387/8-in.) deep and open at the top. 


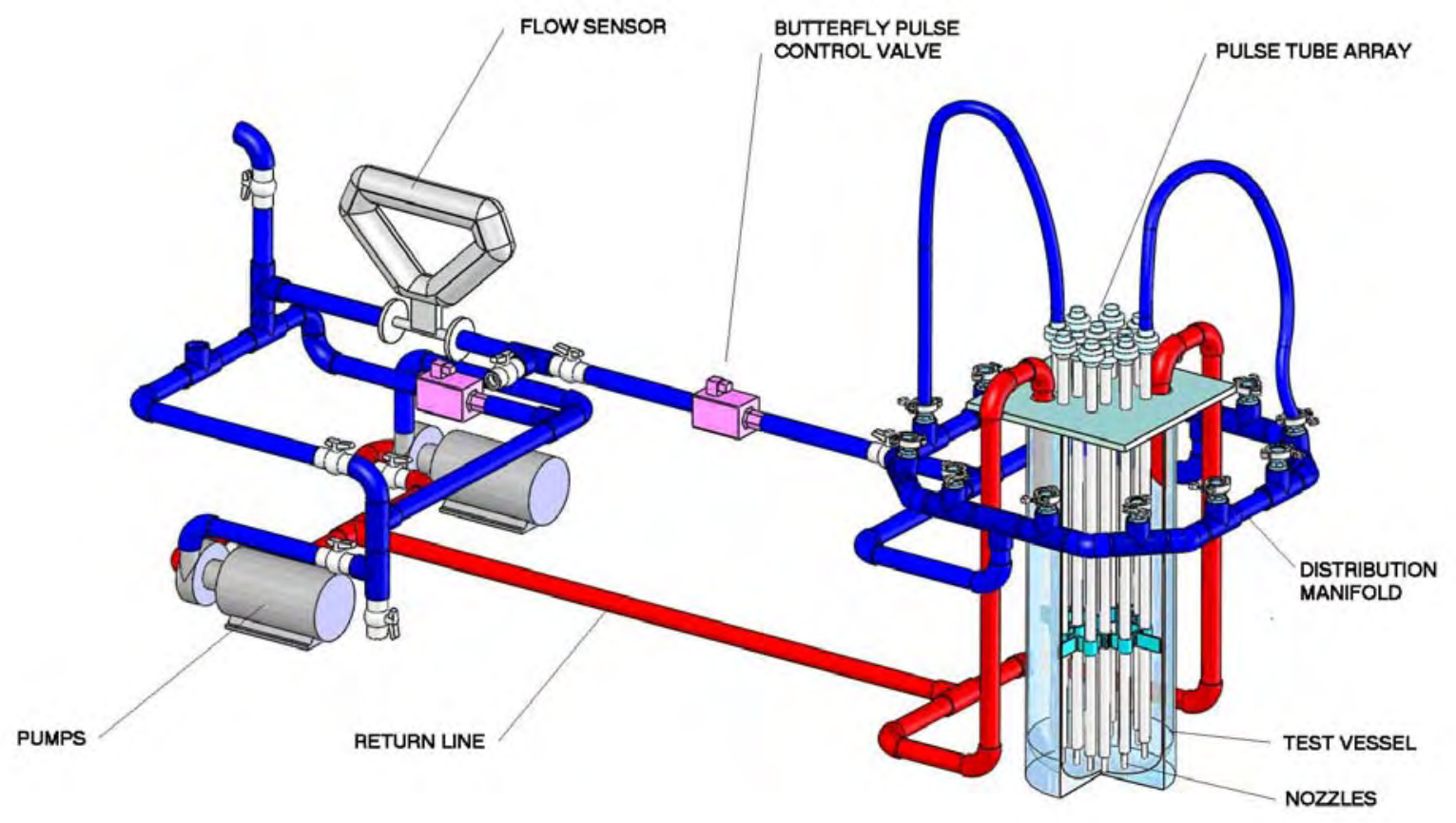

Figure 4.5. Diagram of Small-Scale Test System Showing the HLP-22 12-Tube Array (not to scale)

The elliptical-headed tank was mounted on the raised mobile test stand about $2 \mathrm{ft}$ off the floor to allow visual observation from beneath the tank head. An array of pulse tube assemblies (12 tubes for the HLP-022 configuration) was positioned in the tank with radial locations of $0.33 \mathrm{R}$ and $0.62 \mathrm{R}$ (see Table 4.2) to match impingement angles. The tank and pulse tube array were connected to the pumps and instrumentation via PVC piping.

Each pulse tube assembly consists of a nozzle at the bottom, a pulse tube body, and fittings at the top to attach the assembly to the flexible supply hoses and to mount liquid pressure sensors in the tube. The pulse tube bodies are made of Schedule 40 PVC pipe with a precision-machined nozzle glued or threaded at the bottom. The larger nozzles used pulse tubes with female-threaded ends, and the male-threaded discharge nozzles were threaded onto the ends of the pulse tube bodies. Smaller nozzles were glued to the pulse tube bodies. The nozzles have straight bores that are at least 10 nozzle diameters in length. The pulse tube assemblies are supported in the tank by precision-machined PVC and/or metal-channel frames and clamped with split-collar clamps to fix their elevations. Nozzle elevation is adjustable and was set for each pulse tube assembly using a machined spacer temporarily inserted into the end of the nozzle.

Each pulse tube assembly had a fitting at the top through which water flowed into the tube. On the side of the tube was a $1 / 4$-in. fitting attached to a static pressure probe in the pulse tube. Pulse tube assemblies were connected to a common supply manifold via approximately 1.2-m- (4-ft-) long by 1-in.diameter flexible hoses. ${ }^{1}$ Figure 4.6 depicts the small-scale test tank assembly.

\footnotetext{
${ }^{1}$ Pipe, tubing and fitting sizes in Sections 4.2, 4.3, and 4.4 are nominal/commercial standard sizes, not measured values.
} 


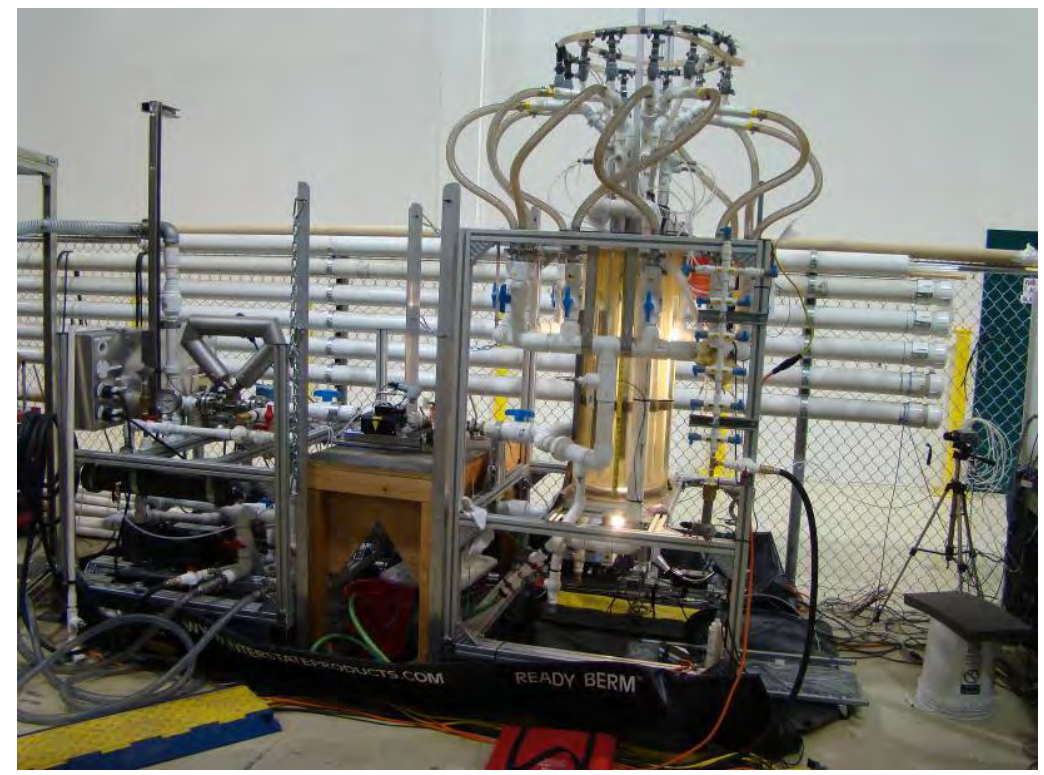

(a)

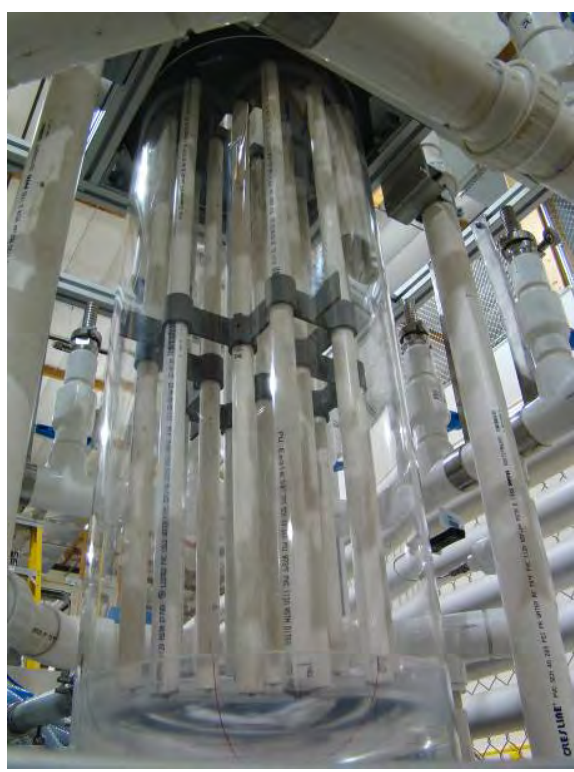

(b)

Figure 4.6. $\quad$ (a) Small-Scale Elliptical-Head Test Tank with Pulse Tubes Installed; (b) Pulse Tubes Mounted in the Tank

The test tank also contained two nominal 2-in.-diameter PVC drop-tube suction lines. The elevation of the suction lines was fixed. The inlet of the suction pipes was made of 2-in. Schedule 40 PVC pipe with the inlet sliced at an angle to reduce intake velocity and thus reduce the lifting force on the solids during testing. The suction pipes were connected to a common manifold that returns liquid to the pumps through PVC pipe and a flex hose between the skids (total line length is about $2.7 \mathrm{~m} \mathrm{[9} \mathrm{ft}]$ ). The configuration connected both suction lines for use during pump operations.

The manifolds for both the discharge and suction lines were on the tank skid. The system was set up for closed-loop operation. The pump skid included two centrifugal pumps, one $0.373 \mathrm{~kW}(1 / 2 \mathrm{hp})$ and one $0.755 \mathrm{~kW}$ (1 hp), that supplied the motive power for circulating liquid through the tank. The pumps were plumbed in parallel and wired to separate variable-frequency drives (VFDs). Additional detail on pump controls is presented in Section 4.2.1. Figure 4.7 presents photographs of the pump skid and Coriolis mass flow meter as well as the pump control panel. The pneumatic valve is pictured in Figure 4.8.

To simulate PJM action in the test system, the pulse tubes were connected by a common manifold and activated using a centrifugal pump to generate the motive power. Pressure ports on each pulse tube (after the manifold) allowed the flow to all nozzles to be balanced or made uniform before testing began.

Cycling of the pump operation and the synchronized opening and closing of the control valve generate the periodic flow through the pulse tubes. Flow within the pulse tubes was one-directional rather than reciprocating like a PJM. During a pulse, liquid was suctioned from the top of the test vessel through the pump(s) outside the tank and returned to the tank through the pulse tubes. 


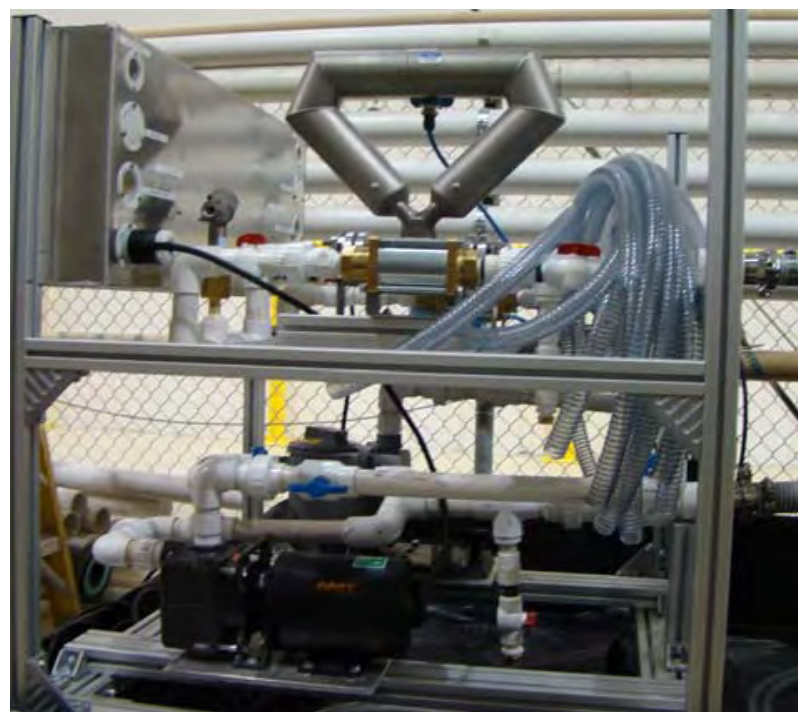

(a)

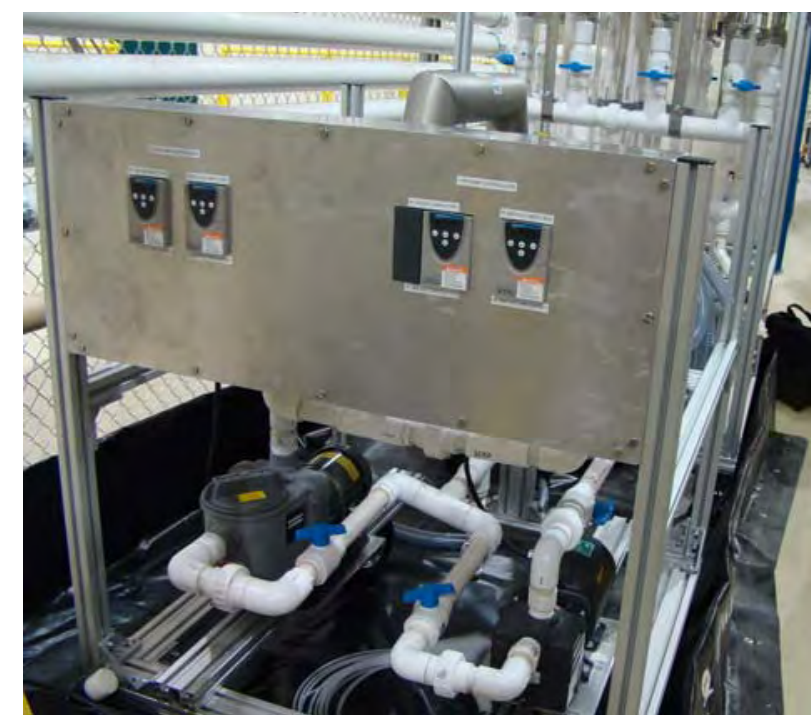

(b)

Figure 4.7. (a) Pump Skid with Pumps and Coriolis Flow Meter; (b) Pump Control Panel

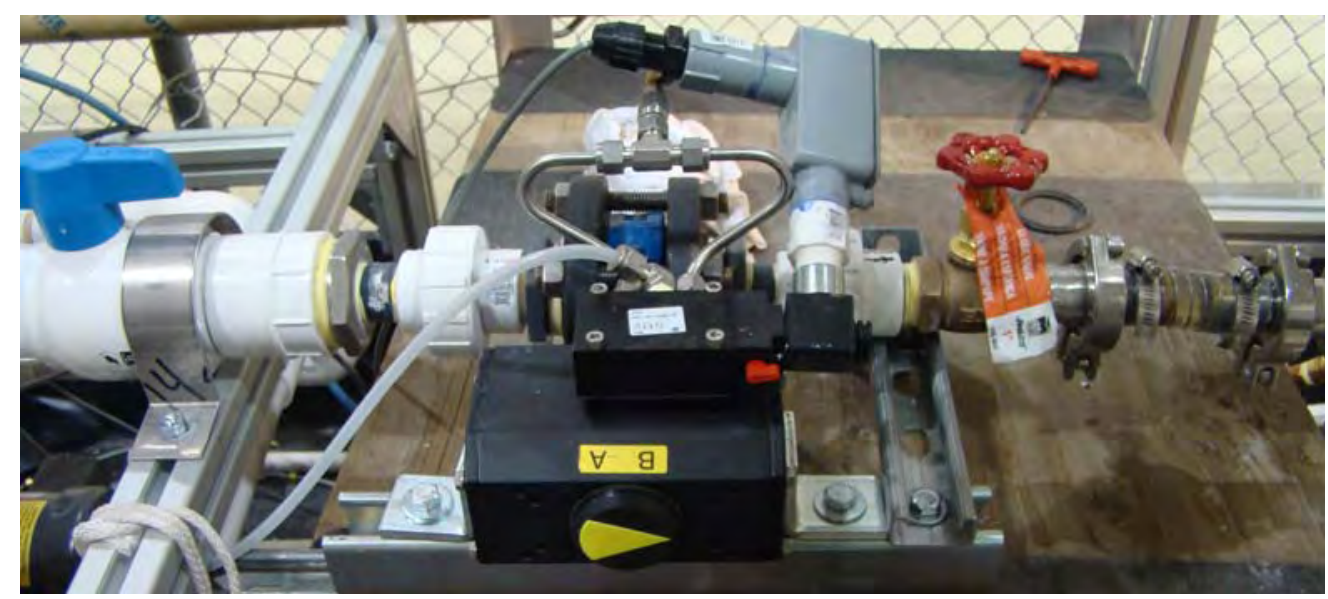

Figure 4.8. The Pneumatic Butterfly Control Valve Mounted Between Pump Skid and Tank Skid. The red throttle valve is also visible to the right of the butterfly valve.

\subsubsection{Control Equipment}

The following list presents an overview of the test equipment and controls for the small-scale test stand:

- The two centrifugal pumps were plumbed in parallel and driven by separate VFDs wired to dual setpoint boxes with two potentiometers for controlling pump speed. The dual set-point boxes allowed pump frequency to be cycled between two operating frequencies. (The dual set-point feature was not used during testing in the small-scale tank.) The frequency output of the VFDs was controlled by potentiometers that were adjusted manually. The timing for alternating between the dual frequency set points was controlled by the DAS or ultrasonic command and control (UCC) computer based on values for the cycle time and duty cycle that are manually entered.

- A nominal 1/2-in. ID pulse control valve was operated by a pneumatic actuator, which was controlled by an electric solenoid air control valve. An air reservoir was installed near the air control valve to 
minimize the response time of the pulse control valve. A throttle valve on the exhaust from the pneumatic actuator allowed for improved control of the wave shape. The pulse control valve was operated to pulse the discharge flow. An air regulator allowed the air pressure to the air control valve to be manually adjusted. The timing of a supply voltage provided by the DAS or UCC computer controlled the actuation of the pulse control valve. The potentiometers also controlled the pump frequency when the pulse control valve was not powered.

- Manual inputs for pulse cycle time and duty cycle are entered into either the DAS or the UCC system. These parameters controlled the timing of the supply voltage to the pump dual set-point boxes and the air control valve.

\subsection{Mid-Scale Test Stand}

The mid-scale test apparatus was located in the APEL high bay. The components of the mid-scale test stand are described in Section 4.3.1. The control equipment is described in Section 4.3.2.

\subsubsection{Components}

The mid-scale test apparatus consists of several components. The apparatus consisted of a transparent acrylic test tank, nominally $0.86 \mathrm{~m}$ (34 in.) in diameter, with a spherical segment head and integrated stand, a pump skid, plumbing connecting the test tank to the pump skid, a liquid drive system, instrumentation, and a DAS. The test tank, plumbing configuration, and pump skid are shown in the schematic in Figure 4.9.

The test tank was approximately 2.1-m (84-in.) deep with an open top. It was raised approximately $0.36 \mathrm{~m}$ (14 in.) above the floor to allow visual observations of the tank head. Moveable mirrors were installed under the tank to assist with visual observations of the tank head.

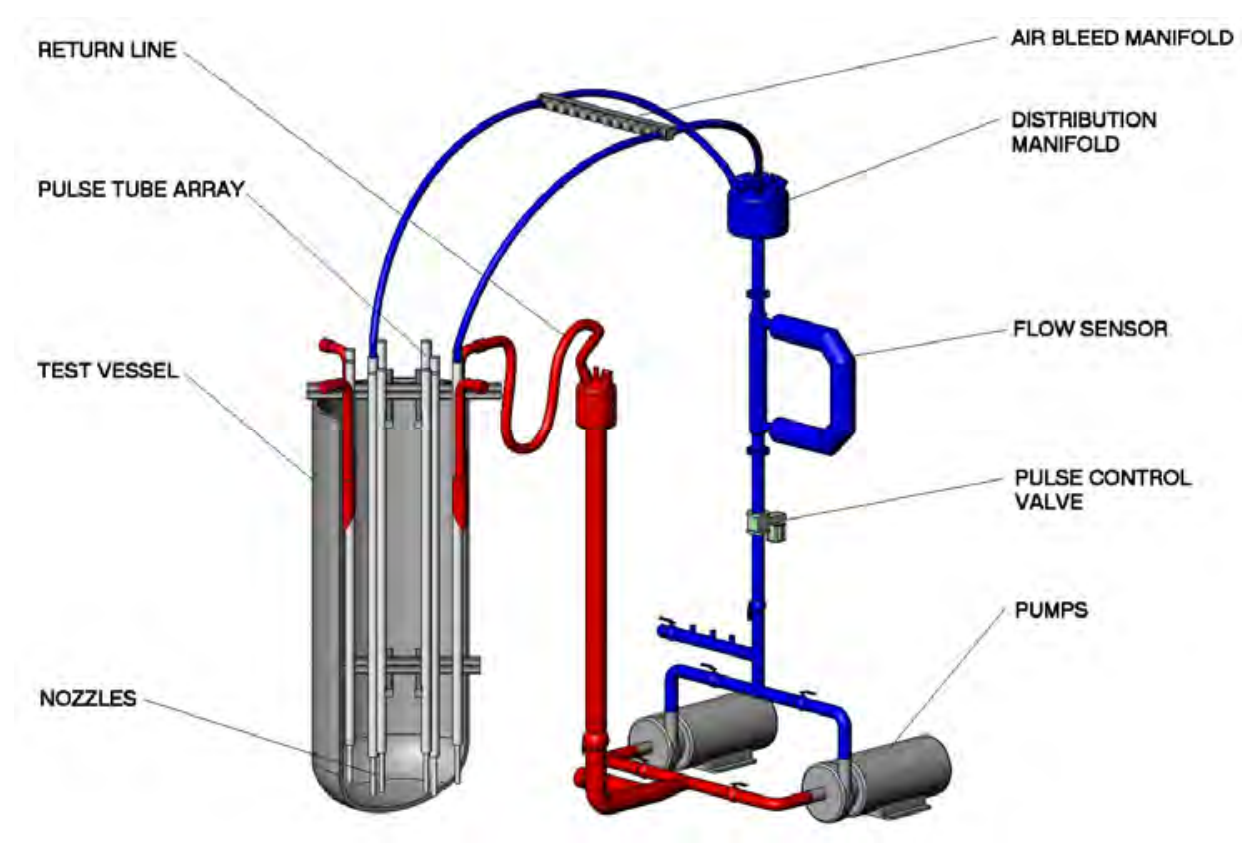

Figure 4.9. Diagram of Mid-Scale Test System (not to scale) 
The tank was supported by the floor on an integral clear plastic skirt within a steel frame under the pulse jet array (see Figure 4.9). An array of pulse tube assemblies (12 for the HLP-22 configuration) was suspended in the tank and centered with small standoffs. During the testing described in this report, a 2:1 elliptical head was assumed, so the inner tubes were located radially at $0.33 \mathrm{R}$, while the radius of the outer tubes was adjusted inward to $0.62 \mathrm{R}$ to compensate for the different impingement angle. After testing was completed, careful measurements revealed that the tank bottom was spherical, not 2:1 semi-elliptical. Hence, the radial positioning of the outer tubes did not compensate to match the HLP-22 F\&D bottom (see Table 4.2). The tank and pulse tube array were connected to the pumps and instrumentation via PVC piping.

The outer pulse tube radius was modified for the impingement angle when an elliptical head was used with the HLP-22 12-tube array. The pulse tubes were connected by a common manifold and were activated using one or both of the centrifugal pump(s) to push the liquid through the tubes. Pressure ports on each pulse tube (after the manifold) allowed the flow to all nozzles to be balanced or made uniform before testing started. Cycling of the pump operation and the synchronized opening and closing of the control valve generated the periodic flow through the pulse tubes, which was one-directional rather than reciprocating. During a pulse, liquid was suctioned from the top of the test vessel through the pump(s) outside the tank, and returned to the tank through the pulse tubes. Each pulse tube assembly consisted of a nozzle at the bottom, pulse tube body, and fittings at the top to attach the assembly to flexible supply hoses, to control liquid flow, and to measure liquid pressure in the tube. Pulse tube bodies were $3 / 4$ in. Schedule 40 PVC pipe with a bushing to nominal $3 / 4$ in. NPT (national pipe thread) female threads at the bottom. Various sizes of discharge nozzles were threaded to the bushings. The nozzles had straight bores at least 10 nozzle diameters long. The pulse tube assemblies were supported by an adjustable framework of metal channel, all-thread, and U-bolts. Nozzle elevation was adjustable and was set for each assembly using a machined spacer temporarily inserted into the end of the nozzle.

Each pulse tube assembly included a T-fitting at the top with the flow entering through the branch and discharging through the lower portion of the run. The top of the T-run was bushed to nominal $1 / 4$-in. NPT containing a compression fitting with a nominal $1 / 4$-in. tube configured to sense static pressure in the pulse tube. The tube assemblies were connected to a common manifold via flex hoses that were approximately

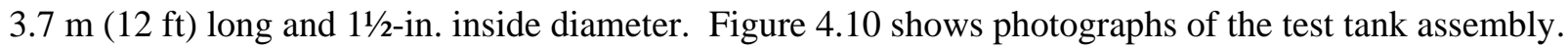
Figure 4.10(b) was taken from above the tank and shows the upper pulse tube support rack, the red valve handles for operating the tube or balancing the tube flow across the array, and static pressure tubes.

The test tank also had four nominal 2-in.-diameter PVC drop-tube suction lines at its perimeter. The elevation of the suction lines was adjustable. The inlet of the suction pipes was 3-in. Schedule 40 PVC pipe cut at an angle to reduce inlet velocity, which reduced lifting force on the solids lifted during testing. The suction pipes were connected to a common manifold via flex hoses that were approximately 3.7-m (12-ft) long by $2 \mathrm{in}$. in diameter. An isolation valve was connected to each suction line to assist with air purging. The configuration allowed one to four suction lines to be used during pump operations.

The manifolds for the discharge and suction lines were on the pump skid shown in Figure 4.11(a). The system was configured for closed-loop operation. The pump skid contained two $3.7 \mathrm{~kW}$ (5-hp) centrifugal pumps that supplied the motive power for circulating liquid through the tank. The pumps were plumbed in parallel and wired to separate VFDs. The pump skid also had three $0.125-\mathrm{m}^{3}$ (33-gal) accumulator/bladder tanks plumbed to the discharge line of the pumps. These tanks could be valved onor off-line to increase/decrease the hydraulic capacitance of the system. The air pressure in the bladder tanks could be adjusted to change the capacitance of the system. This feature was not used during testing. 


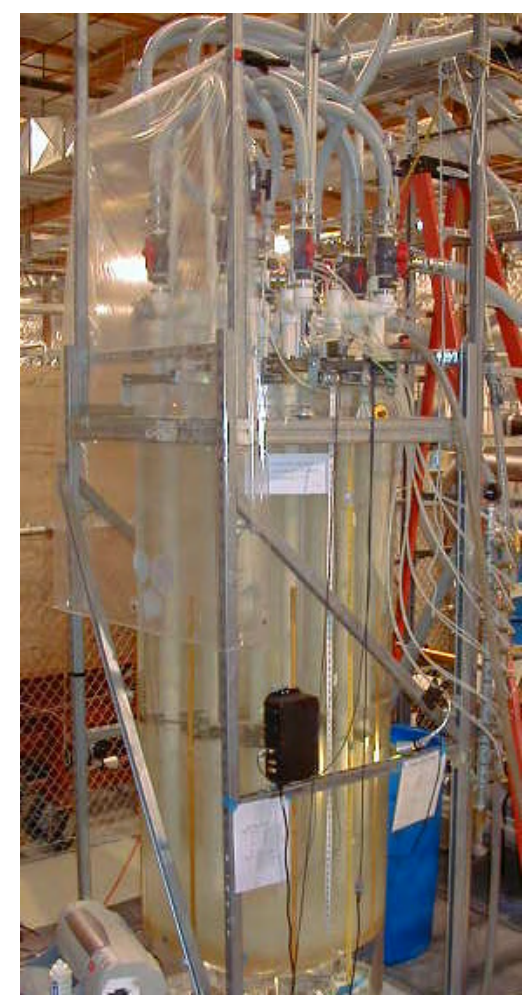

(a)

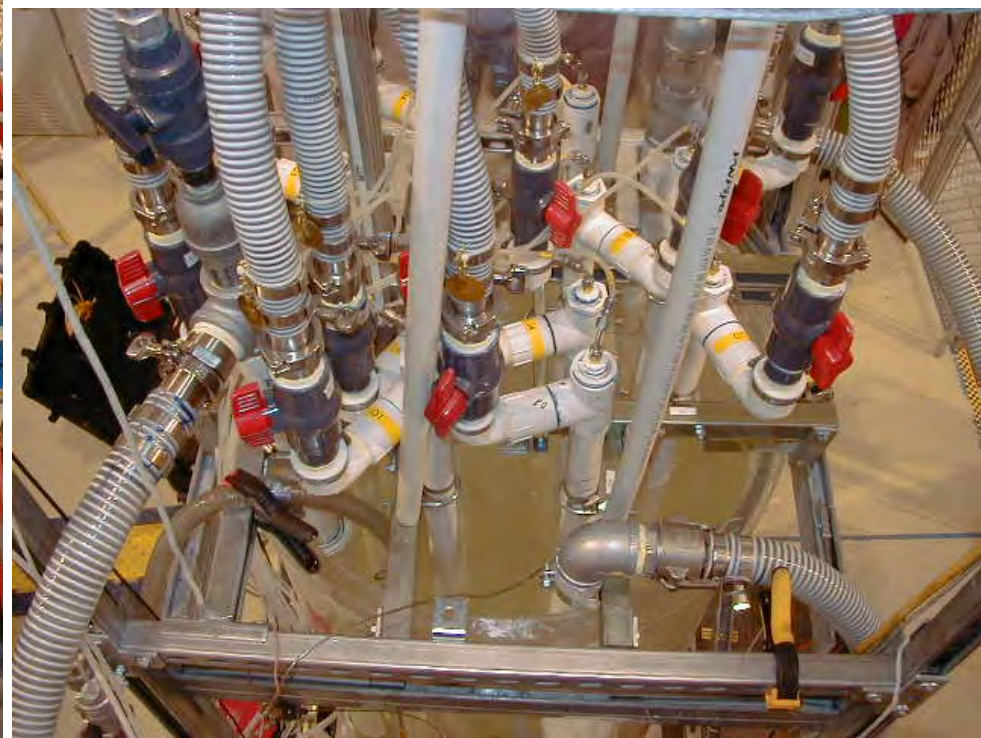

(b)

Figure 4.10. (a) Mid-Scale Test Tank with Pulse Tubes Installed; (b) View from Above with Upper Pulse Tube Support Rack and Static Pressure Tubes Visible

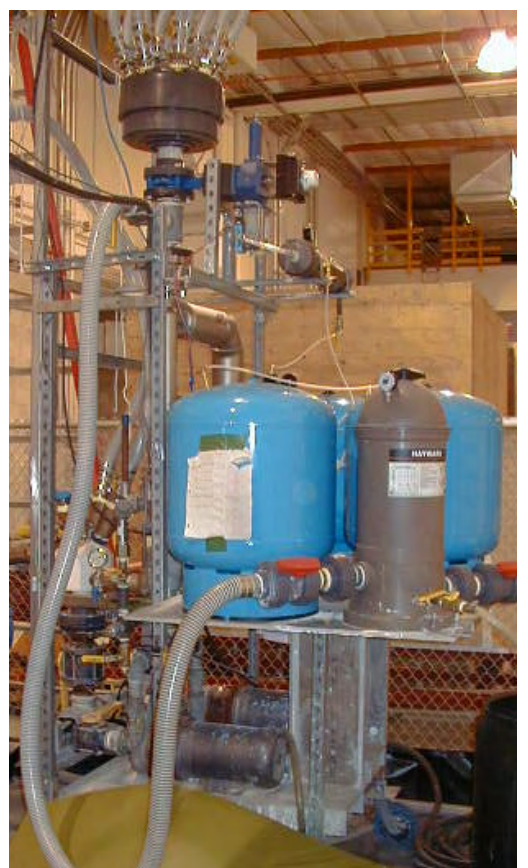

(a)

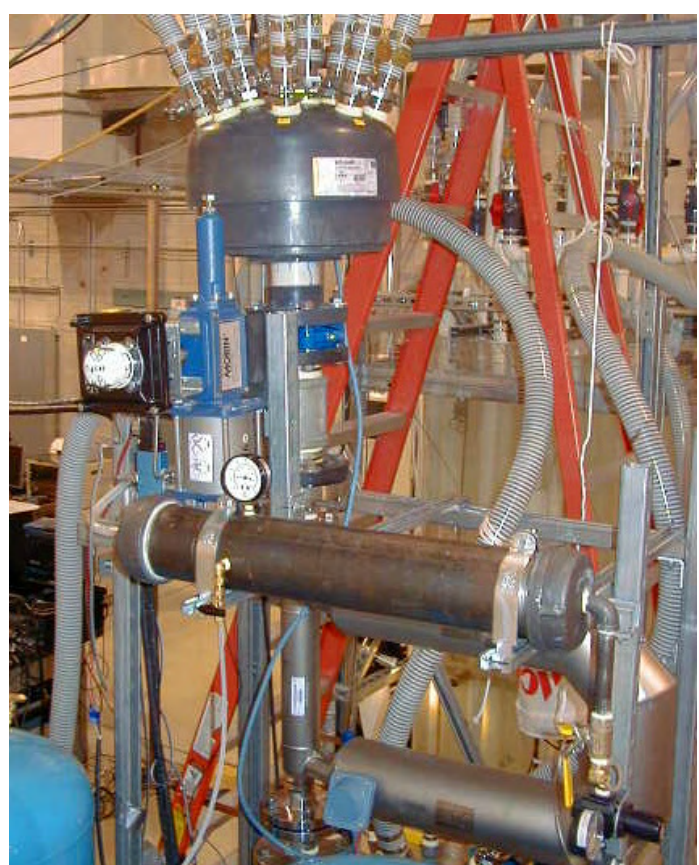

(b)

Figure 4.11. (a) Pump Skid with Pumps, Bladder Tanks, Suction and Discharge Manifolds; (b) Control Valve Assembly with Blue Pulse Control Valve, Air Control Valve (left of pulse control valve), Control Valve Pressure Reservoir, and Micro Motion Coriolis Flow Meter (behind reservoir) 
A pulse control valve (butterfly, or in 2007 tests, a pinch valve) was installed in the pump discharge line to help generate the pulsed flow through the nozzles. The pulse control valve was pneumatically operated via an air-control valve. An air reservoir was close-coupled to the air control valve to minimize the response time. The valve assembly and Coriolis mass flow meter are shown in Figure 4.11(b).

\subsubsection{Control Equipment}

This section provides an overview of the test equipment and controls for the mid-scale test stand. The control equipment consisted of:

- Two 3.7 kW (5-hp) centrifugal pumps plumbed in parallel and driven by separate VFDs wired to dual set-point boxes with two potentiometers for controlling pump speed. The dual set-point boxes allowed pump frequency to be cycled between two operating frequencies. The frequency output of the VFDs was controlled by manually adjusted potentiometers. The timing for the set points was controlled by the DAS or UCC based on values entered manually into the DAS or UCC.

- Compressed air piped to the air chambers of the bladder tanks and the air control valve. The compressed air supply line included a regulator for adjusting the feed pressure.

- The liquid side of the three bladder tanks piped in common to a nominal 2-in. cross that connected to the discharge line of the pumps. An isolation ball valve allowed the bladder tanks to be isolated from the drive system flow. (Testing from 7/2007 through 12/2007 indicated that these bladder tanks were not needed to meet project objectives. The bladder tanks were also not needed in the 2008 testing.) The gas sides of the bladder tanks were connected using $1 / 4$-in. tubing. An air regulator allowed the bladder tank gas pressure to be adjusted.

- A nominal 3-in. pulse control valve operated pneumatically by pressurizing the air control valve via the air reservoir and venting the air control valve to room atmosphere. The pulse control valve was operated by a pneumatic actuator, which was controlled by an electric solenoid valve. An air reservoir near the air control valve minimized the response time of the pulse control valve. A throttle valve on the exhaust from the pneumatic actuator allowed for improved control of the wave shape. The pulse control valve enabled pulsing of the discharge flow with adequate control of the fluid velocity wave form. An air regulator allowed air pressure to the air control valve to be adjusted manually to improve valve opening response times if needed. The timing of supply voltage provided by the DAS controlled actuation of the pulse control valve. The potentiometers could also control pump frequency when the pulse control valve was not powered. The pulse wave was controlled primarily by opening the pulse control valve for a controlled period of time (the pump would run at a preset speed, dead-heading when the pulse control valve was closed).

- Pulse cycle time and duty cycle are manually entered into the DAS or UCC system. These parameters controlled the timing of the supply voltage to the dual set-point boxes and air control valve.

- Initial tests in July 2007 only used the DAS, but UCC control had been implemented by the fall testing.

\subsection{Large-Scale Test Stand}

The large-scale test apparatus was located in the APEL high bay. The large-scale test stand components are described in Section 4.4.1. The control equipment is described in Section 4.4.2. 


\subsubsection{Components}

The large-scale test apparatus consists of several components. The large-scale test apparatus in the APEL high bay consisted of an acrylic 1.78-m- (70-in.-) diameter test tank, pump skid, plumbing connecting the test tank to the pump skid, a liquid drive system, instrumentation, and DAS. The tank had two interchangeable heads, an ASME 90-17 semi-elliptical and a 100-6 F\&D. The tank, plumbing configuration, and skid are shown in Figure 4.12.

The open-topped test tank was 2.36-m (923/4-in.) deep with the F\&D head and 2.52-m (991/8-in.) deep with the semi-elliptical head. The tank was raised above the floor to allow visual observation of the interior through a 0.46-m- (18-in.-) diameter acrylic viewing port in the middle of the head. The tank contained an array of pulse tube assemblies (12 for the HLP-22 configuration, 8- and 4-tube arrays to approximate those tank configurations (See Section 4.8) with radial and azimuthal locations geometrically scaled to the corresponding WTP vessel. The test system circulated water through the pulse tubes to simulate the pulse phase of the PJM system (the vacuum portion is not simulated). Pressure ports on each pulse tube (after the manifold) allowed flow to the nozzles to be balanced or made uniform before testing began. As discussed in Section 4.2, full-scale plant vessels contain PJMs instead of pulse tubes.

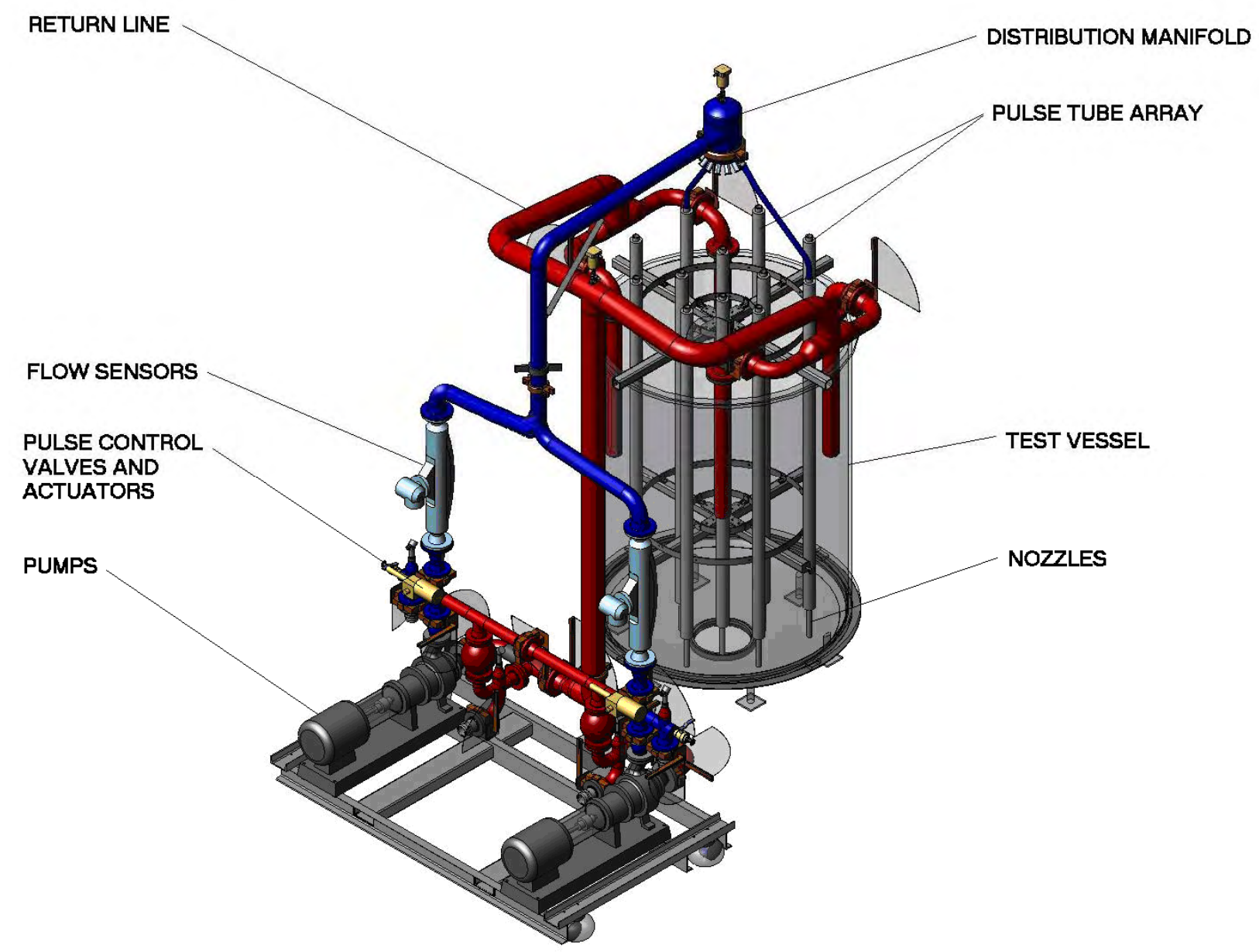

Figure 4.12. Diagram of Large-Scale Test System with the 8-Tube Array (not to scale) 
The pulse tubes were connected to a distribution manifold and activated by a pair of 18.6-kW (25-hp) centrifugal pumps to generate the motive power, using an electrically synchronized control valve at each pump outlet to generate the periodic flow through the pulse tubes. Flow within the pulse tubes was onedirectional rather than the reciprocating flow within a PJM. During a pulse, liquid was suctioned from the top of the test vessel through the pump(s) outside the tank and returned to the tank through the pulse tube.

Each pulse tube assembly consisted of a nozzle at the bottom, a pulse tube body, and fittings at the top to attach the assembly to the flexible supply hoses, control liquid flow, and measure static pressure in the tube. The pulse tube bodies were made of nominal 3-inch Schedule 40 PVC pipe with a bushing to nominal $3 / 4$ in. NPT female threads at the bottom. Various sizes of discharge nozzles are threaded into the bushings. The nozzles had straight bores at least 10 nozzle diameters long. The assemblies were supported by a retainer assembly of metal rings, unistrut channel, square tube stock, Delrin spacers, and U-bolts. Nozzle elevation was adjusted by changing the pulse tube clamping position on the retainer assembly and was set for each nozzle diameter using a machined aluminum spacer temporarily inserted into the end of the nozzle. The pulse tube assembly and nozzles are shown in Figure 4.13.

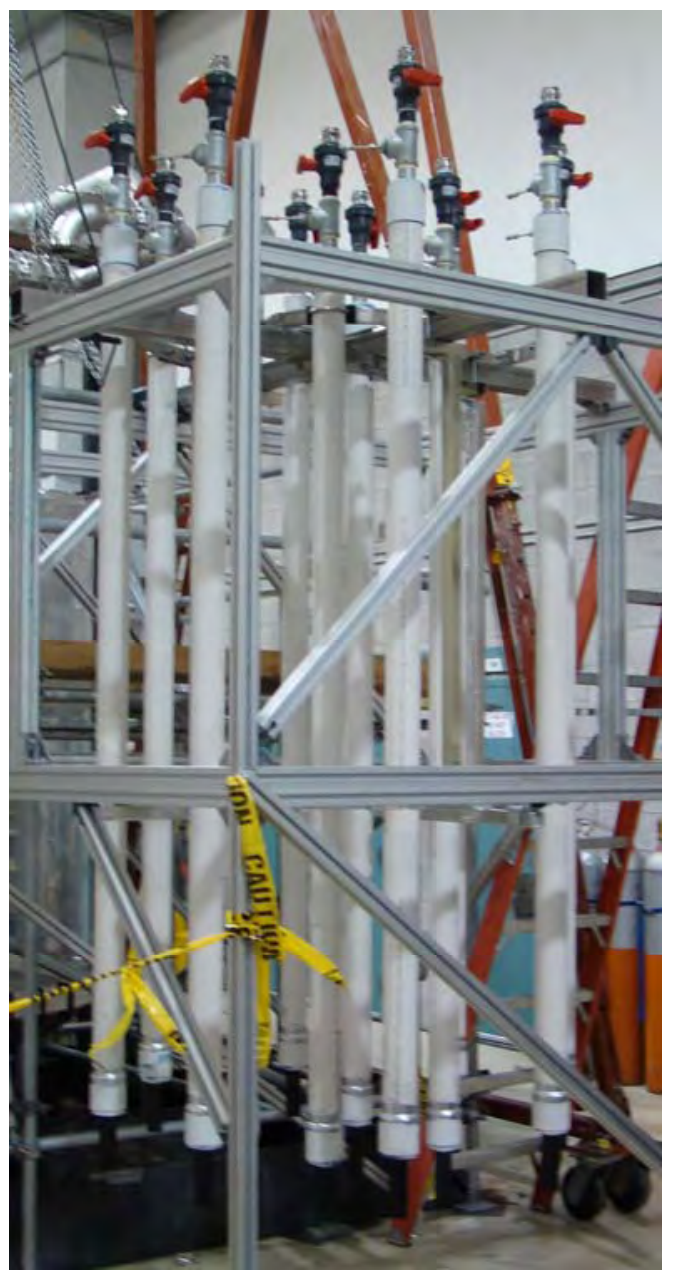

(a)

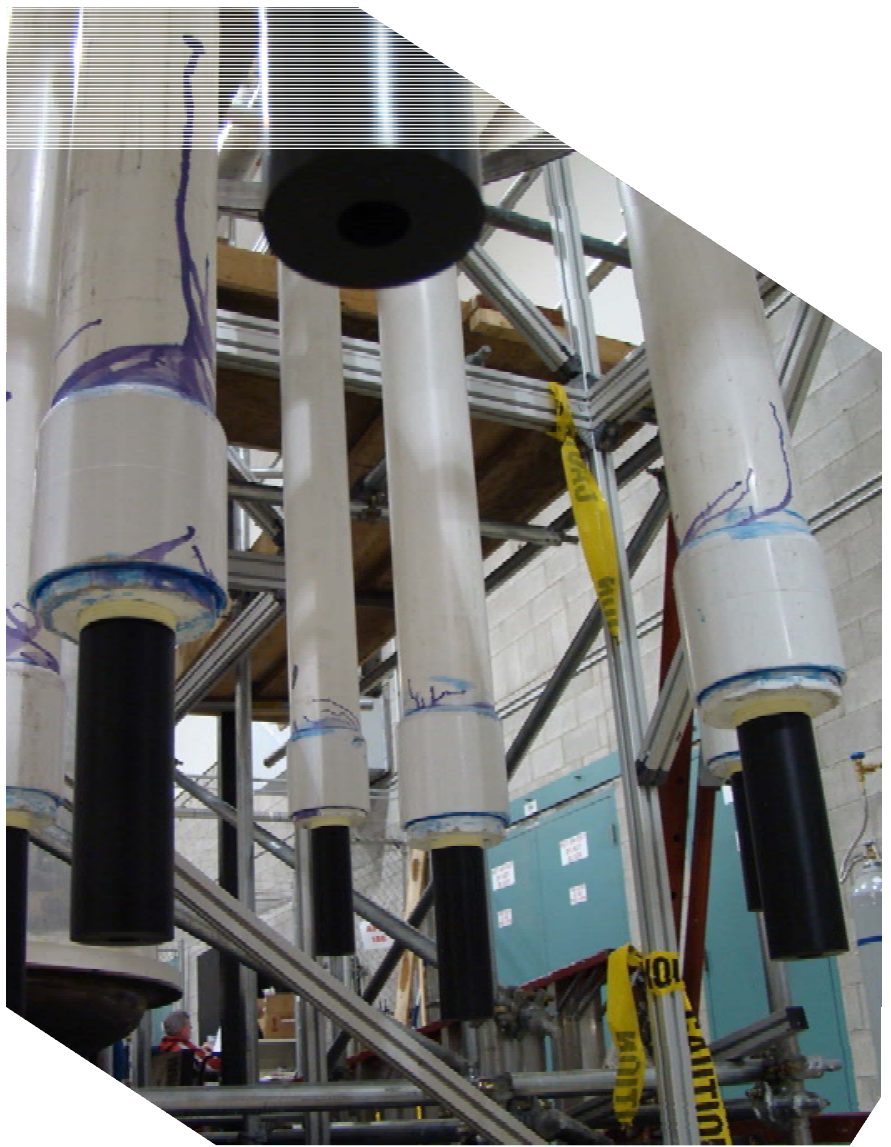

(b)

Figure 4.13. (a) Pulse Tube Assembly before Installation in Tank; (b) Close-up of Pulse Nozzles 
Each pulse tube assembly contained a ball valve at the top through which the water flowed into the tube. The valves enabled any number of the tubes to be shut down and provided a way to balance the flow between the active tubes. Below the valve was a T-fitting that mounted a static pressure tube aligned in the center bore of the pulse tube connected to a tree-type pressure-sensor manifold to sense the static pressure in individual pulse tubes to indicate relative flow rates. Pulse tube assemblies were connected to the distribution manifold via approximately 2.1-m- (7-ft-) long by 1/2-in.-diameter flex hoses mounted to the ball valves. Figure 4.14 presents photos of the F\&D tank assembly.

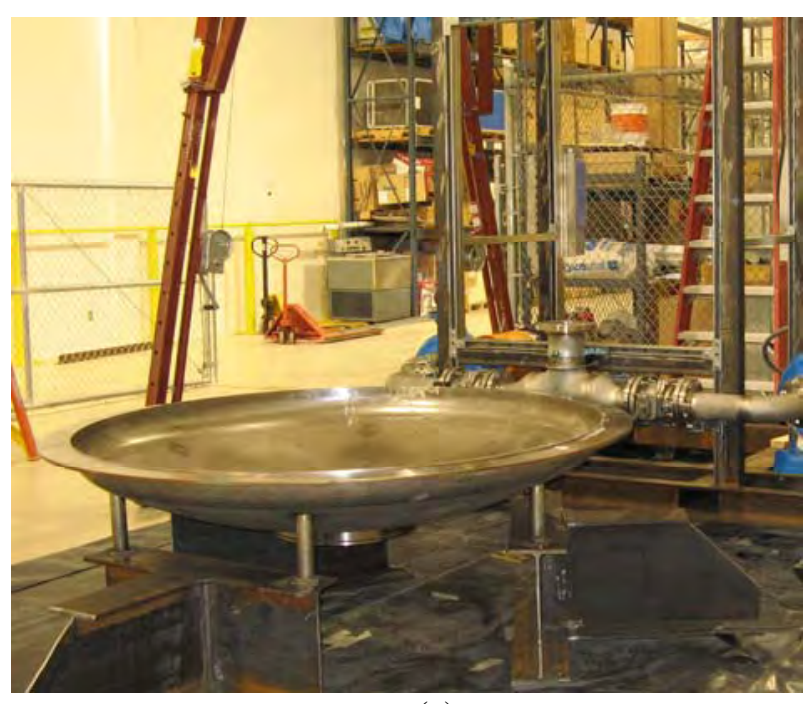

(a)

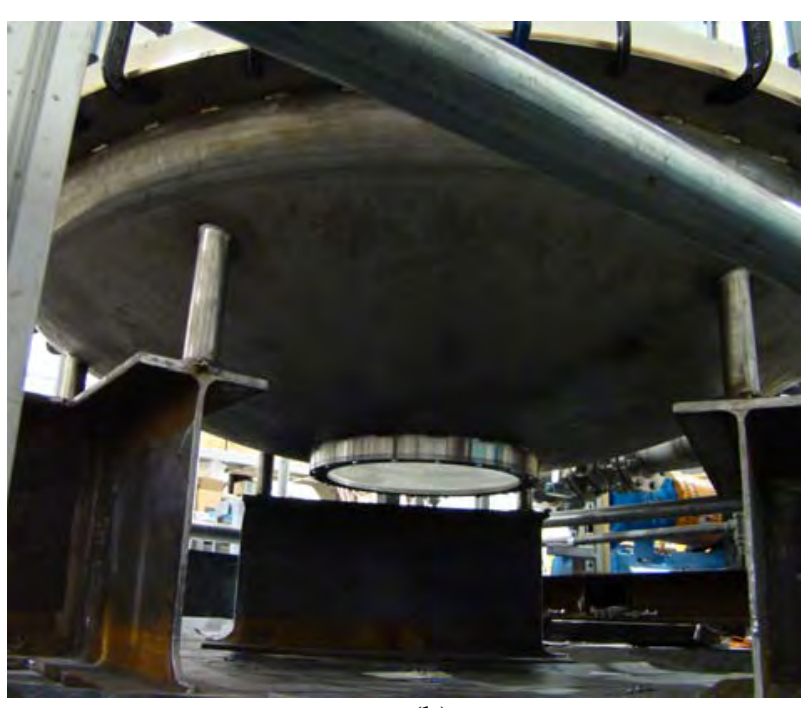

(b)

Figure 4.14. (a) Large-Scale Vessel Flanged and Dished Head; (b) 0.46-m (18-in.) Acrylic Viewing Port

The test tank also had four nominal 4-in.-diameter PVC drop-tube suction intakes at its perimeter. The suction intake pipes were nominal 4-in. PVC pipe with the submerged end cut off at an angle to reduce the fluid velocity around the inlet orifice. The placement of the suction intakes was intended to minimize the lifting of solids to the top of the tank. The suction intakes were connected to a return manifold via stainless steel pipes; full-flow ball valves on each suction intake allowed from one to four intakes to be used during pump operations.

Manifolds for both discharge and suction lines were supported over the tank by the pump skid. The system had a closed-loop configuration. The pump assembly is shown in Figure 4.15. 


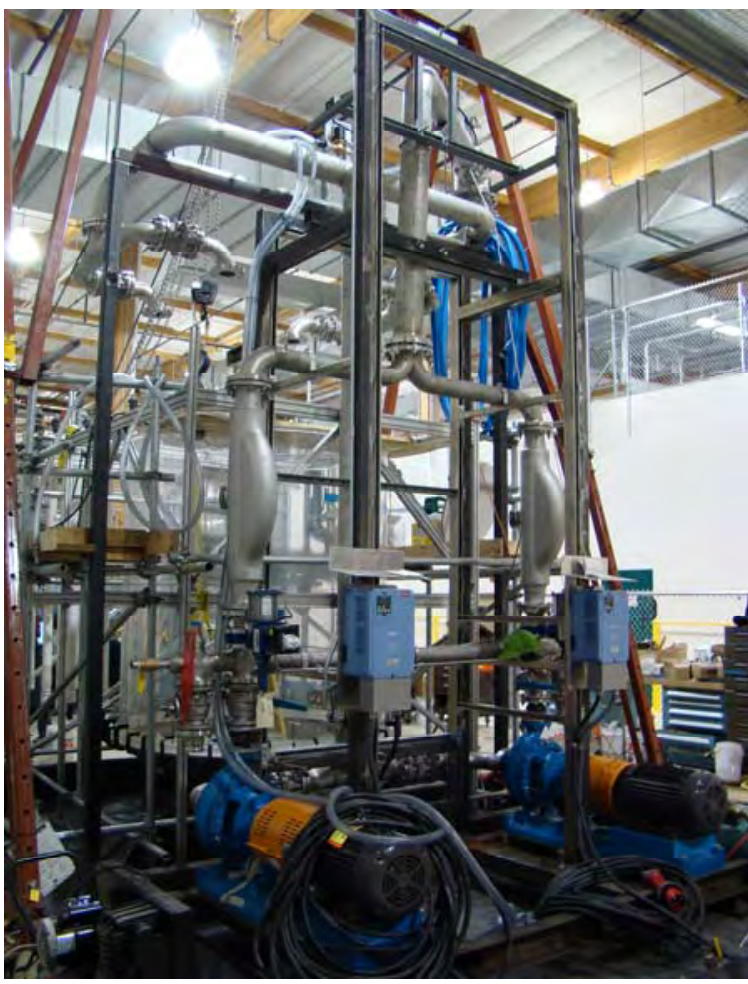

(a)

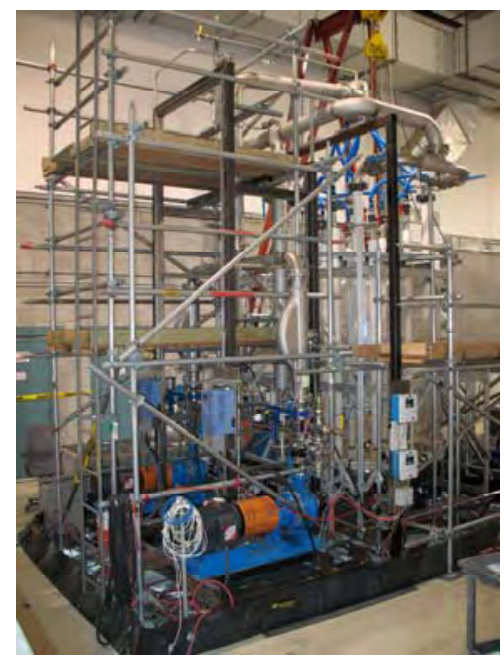

(c)

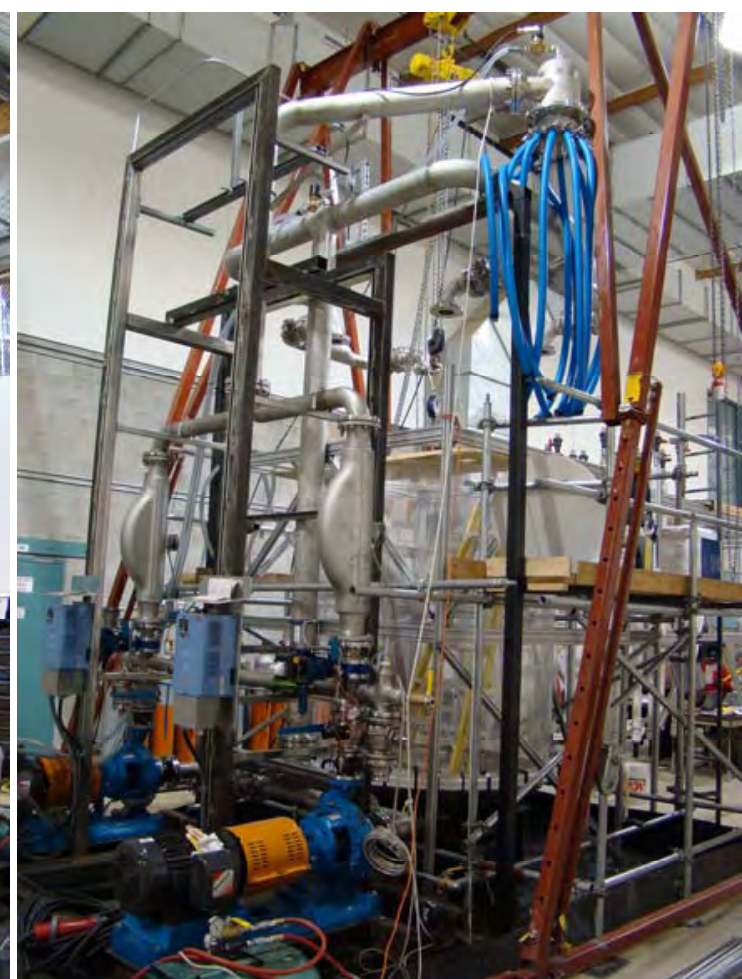

(b)

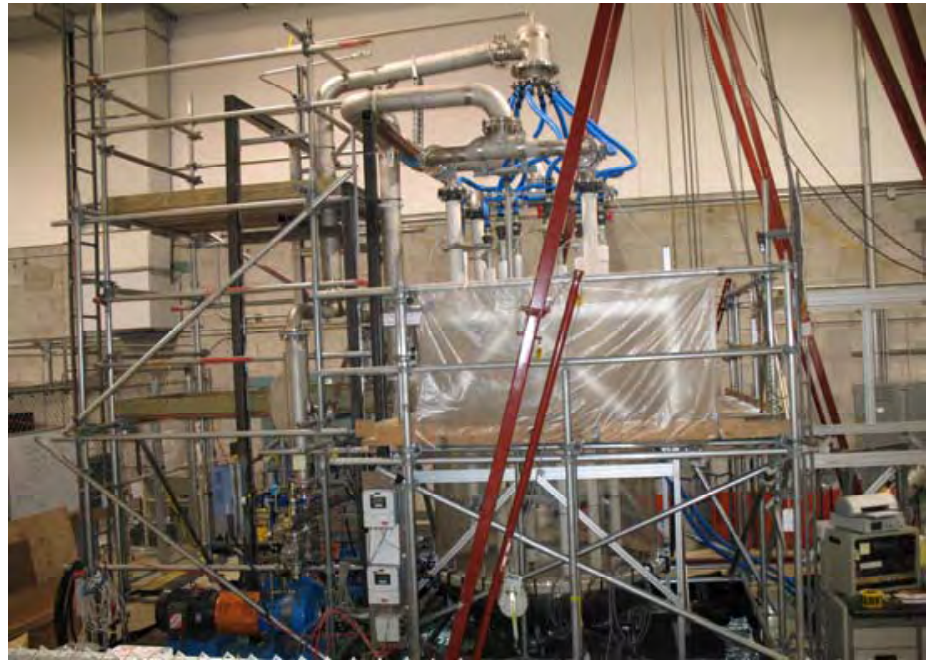

(d)

Figure 4.15. (a) Pump Assembly and Coriolis Meters with Test Tank in Background and (b) Upper End of Pump System as it Enters the Manifold (the blue hoses are not yet attached to the pulse tubes); (c) Pump Assembly with Scaffolding, and (d) The Large-Scale Test Stand with the 8-Tube Array and Elliptical Head 


\subsubsection{Control Equipment}

This section provides an overview of the test equipment and controls for the large-scale test stand. The control equipment consists of:

- Two 18.6-kW (25-hp) centrifugal pumps plumbed in parallel. The pumps were powered through a remotely controlled VFD that allowed two manually set pump-speed set points to be activated by the DAS or UCC with timing for set-point changes based on cycle time and duty cycle. [Note: the dual set-point feature was not used during large-scale (1.78-m, 70-in.) tank testing.] The VFDs also controlled the pump speed when the pulse control valves were not powered. The pump speed/jet discharge velocity relationship was determined for each test setup so the pump speed could be set quickly and accurately to produce any required velocity during the tests.

- Two nominal 3-in. pulse control valves were actuated pneumatically in response to a control signal from the DAS. The pulse control valves made it possible to pulse the discharge flow with a velocity and wave form that met testing requirements. An air regulator allowed the air pressure to the valveactuator to be manually adjusted, thereby adjusting the rate of opening and the jet pulse velocity rise. A throttle valve on the actuator exhaust allowed for closing rate control. The valve actuator control signal provided by the DAS could also signal the VFDs to alternate the pump speed between the high and low set points if desired.

- The jet pulse period and duration were set with manual inputs for pulse cycle time and duty cycle entered into the DAS or UCC. These parameters controlled the timing of the supply voltage to the pump dual set-point boxes and air control valve.

\subsection{Pulse Flow Operating Parameters}

The drive system was designed to provide a continuous steady flow or a pulsed, periodic flow. The following methods were available to generate a pulsed flow:

- Set the cycle time and duty cycle on the DAS or UCC computer. (While earlier testing used the DAS to control the pulse, later testing used the UCC because of its improved control of the pulse echo, Doppler, and attenuation system data collection.) Open the pulse control (butterfly) valve. Set the high-point pump frequency to obtain the desired volumetric flow or nozzle discharge velocity. Set the low-point pump frequency to zero. Allow the flow rate through the system to be controlled by the cycling of the pump frequency.

- Set the low- and high-point pump frequencies to the same value. Set the cycle time and duty cycle on the DAS or the UCC computer. Set the air pressure on the pulse control valve pneumatic supply line as needed up to the pressure recommended by the valve manufacturer. The pump will run at a constant speed while the pulse control valve cycles the flow in the pump discharge line. (Testing note: While all the methods for generating the pulse were allowed during testing, this pump running at constant speed was the method used to generate the pulse for all testing conducted for this report.)

- Use a combination of the pulse control valve operation and cycling of the pump speed set points to generate the pulsed flow.

The physical limitations of the drive system components caused the velocity pulse to deviate from a square wave, especially at high velocities. The various controls described were used to tune the system 
and provide some adjustment to the velocity pulse. The operating and control conditions required to achieve the desired pulsed flow were developed during the shakedown testing for each system.

\subsection{Instrumentation}

During the tests, several variables were monitored in the time domain and recorded to an electronic DAS file, including:

- Total volumetric flow rate to the nozzle array

- Specific gravity of the liquid downstream of the pump/s discharge

- Tank liquid temperature

- Pulse tube pressure, one tube monitored at a time (refer to description below).

Additionally, multiple ultrasonic devices were employed during the 2008 testing to monitor 1) the thickness of the settled solids layer on the bottom of the tank using UDV (described in Appendix A) and pulse echo techniques with external transducers attached to the bottom of the tank, and 2) the concentration of suspended solids at various depths in the tank during mixing using frequency attenuation (described in Appendix A) with horizontally oriented send-and-receive transducers. Signals from the ultrasonic instruments were recorded to the consolidated data sheet (CDS) file according to the Test Instruction. These signals were collected at discrete times and within the same time period that visual observations were recorded. No reportable ultrasonic data were collected during the 2007 tests in the mid-scale vessel, though some evaluation of the ultrasonic techniques was done in the Fall 2007 testing.

Several variables were monitored based on manual measurements or visual observations that were recorded to data sheets according to the Test Instruction. These variables were liquid level in the test tank, cloud height in the tank, and (as requested by the test engineer) observations of solids patterns and particle motion on the tank bottom. A Micro Motion Coriolis ${ }^{1}$ flow meter provided the volumetric flow rate and the specific gravity of the liquid downstream of the pumps and upstream of the discharge manifold in the small- and mid-scale vessels. An Endress+Hauser Coriolis ${ }^{2}$ meter provided the same measurements in the large-scale vessel. Air was removed from the high points in the system and instruments were oriented vertically (in the mid- and large systems) to avoid captured air from affecting the Coriolis meter signal. Type $\mathrm{J}$ thermocouples were installed to measure liquid temperatures.

The static pressure in the pulse tubes was measured using a common pressure transducer to balance the liquid flow through the discharge nozzles. Given identical geometries, identical flow rates produced similar pressure drops. The static pressure tubes installed in the top of each pulse tube are plumbed to a tree-type manifold with isolation valves to allow the static pressure in each tube to be measured.

Commercially available measuring equipment (tape measures, rulers, etc.) was used to obtain liquid levels, cloud heights, solid depths, and dimensions of observable patterns. The same type of equipment was used to obtain dimensions of the test configuration and place reference marks for test observations.

\footnotetext{
${ }^{1}$ Emerson Process Management, Micro Motion Americas Worldwide Headquarters, Boulder, Colo.

${ }^{2}$ Endress+Hauser Inc., Greenwood, Ind.
} 


\subsection{Data Acquisition System}

Data were collected from flow system instruments (flow, temperature, and pressure data) with DASYLab $^{1}$ software on a desktop PC running Windows XP called the DAS computer. The data acquisition board was an analog input/digital input/output (I/O) board. The recommended frequency and time averaging for data logging and recording by the DAS was specified in the Test Instruction or test condition transmittal. For ultrasonic measurements, data were collected by the UCC computer, a PC running Windows XP. Requirements for ultrasonic data collection were specified by the test condition transmittal. Starting with the 2008 tests, additional test data files called the CDS and the ultrasonic (UT) CDS were used.

A CDS was created for each DAS log file. The CDS contains values for parameters associated with the geometry and simulant that were listed in the master spreadsheet for post-test analysis. These values were obtained from the geometry and simulant configuration sheets. In addition, a single line of data associated with a single pulse cycle was written to the CDS by DASYLab worksheet via dynamic data exchange each time the program was manually triggered. The CDS file was printed and included in the data packages. Electronic copies of the DASYLab output file and the CDS were copied to the designated M3 server on the isolated M3 network after each test. Data from the electronic CDS were transferred to the master spreadsheet following the completion of a test.

A UT-CDS was also generated for each test in which data was obtained from the ultrasonic instrumentation. The UT-CDS data were also written to it for a single pulse cycle when manually triggered. The UT-CDS file was printed and included in the data packages. An electronic copy was placed on the designated M3 server on the isolated M3 network after each test. Data from the electronic UT-CDS was transferred to the master spreadsheet following the completion of a test.

\subsection{Tube Arrays and Nozzles}

The HLP-22 tube array configuration was used for all testing in the mid-scale vessel in 2007. Using this tube array, tests were conducted with 12 (8 outer and 4 inner), 8 (8 outer and no inner or 4 outer and 4 inner), 4 (4 outer and no inner or no outer and 4 inner) tubes.

During 2008 testing in all tanks was conducted with scaled tube arrays that included:

- A 12-tube array modeled from the F\&D head HLP-22 vessel (HLP-22 12-tube F\&D array)

- 12-tube arrays based on the HLP-22 vessel with the radius adjustment on the outer ring to standardize the impingement angle of the jets in tests using elliptical or spherical- head tanks (HLP-22 12-tube elliptical array)

- 8-tube arrays based on approximate radial positions for the grouping of 8-tube vessels, ${ }^{2}$ including FEP-17A/B, PWD-15/16, PWD-33/43, PWD-44, TCP-01, TLP-09A/B and UFP-01A/B. This array was also used for the 4-tube tests by leaving the outer radial rings open and closing the tubes/nozzles on the inner ring or vice versa.

\footnotetext{
${ }^{1}$ Measurement Computing Corporation, Norton, Mass.

${ }^{2}$ GL Smith (BNI), February 28, 2007. "Gary Smith's Action Items from: M3 PJM Mixing Program Status Meeting Held Tuesday Morning, February 27, 2007.” Email to PA Scott (PNNL) and PA Meyer (PNNL) including Excel file, "WTP Project Memorandum CCN 146683_Revised M3 PJM Mixing Systems Basic Data Final1.xls.”
} 
Tube arrays were scaled by the inner diameter of the test tank being used. Scaling of HLP-22 is shown in Table 4.3. The tube arrays used during tests across the tanks scales are shown in the matrix in Table 4.4. The HLP-22 12-tube F\&D and elliptical arrays were based on the 8 outer tube/4 inner tube orientations shown in Figure 4.16.

HLP-22 is an F\&D vessel that is $11.6 \mathrm{~m}$ ( $38 \mathrm{ft}$ ) in diameter [radius of $5.79 \mathrm{~m}$ (19 ft or $228 \mathrm{in}$.)] with an inner ring of four nozzles at a radius of $1.93 \mathrm{~m}$ (76 in.) $(0.33 \mathrm{R})$ and an outer ring of eight nozzles at a radius of $4.34 \mathrm{~m}$ (171 in.) (0.75 R) (BNI 2007). The spacing of the inner and outer rings for the largescale F\&D tank was scaled to $0.33 \mathrm{R}$ and $0.75 \mathrm{R}$, respectively.

Table 4.3. Vessel Scaling Versus HLP-22

\begin{tabular}{|c|c|c|c|}
\hline Vessel & Diameter (Inner) & $\begin{array}{l}\text { Relative } \\
\text { Scale }\end{array}$ & $\begin{array}{l}\text { Scale } \\
\text { Factor }\end{array}$ \\
\hline HLP-22 $2^{(a)}$ & 38 ft (11.58 m) & 1 & 1 \\
\hline $\begin{array}{l}\text { Small Scale } \\
\text { (APEL15) }\end{array}$ & 14 7/16 in. $(0.367 \mathrm{~m})$ & 0.0317 & 31.58 \\
\hline $\begin{array}{l}\text { Mid Scale } \\
\text { (APEL34) }\end{array}$ & 33. $7 / 8$ in. $(0.860 \mathrm{~m})$ near top of dish & 0.0743 & 13.46 \\
\hline $\begin{array}{l}\text { Large Scale } \\
\text { (APEL70) Elliptical Head }\end{array}$ & 70 in. $(1.78 \mathrm{~m})$ at top of $\operatorname{tank}^{(\mathrm{b})}$ & 0.1535 & 6.514 \\
\hline $\begin{array}{l}\text { Large Scale } \\
\text { (APEL70) F\&D Head }\end{array}$ & 69.16 in. $(1.76 \mathrm{~m})$ at top of dish ${ }^{(\mathrm{b})}$ & 0.1517 & 6.593 \\
\hline
\end{tabular}

(a) The data for HLP-22 were supplied by WTP in contractor CCN 146683; transmitted via email from GL Smith on $2 / 23 / 2007$.

(b) Used for calculation of PJM radial locations and impingement angles.

Table 4.4. Tank and Pulse Tube Array Matrix

\begin{tabular}{lcccc}
\hline & $\begin{array}{c}\text { HLP-22 12-Tube } \\
\text { Flange and Dish } \\
\text { Array }\end{array}$ & $\begin{array}{c}\text { HLP-22 12-Tube } \\
\text { Elliptical Array }\end{array}$ & $\begin{array}{c}\text { 8-Tube Array using } \\
\text { 8nly the 4 Inner or } \\
\text { Outer Tubes }\end{array}$ \\
\hline Small-Scale Elliptical & - & $\mathrm{X}$ & $\mathrm{X}$ & $\mathrm{X}$ \\
Mid-Scale Spherical $^{(\mathrm{a})}$ & - & $\mathrm{X}$ & - & - \\
Large-Scale F\&D & $\mathrm{X}$ & - & - & - \\
Large-Scale Elliptical & - & $\mathrm{X}$ & $\mathrm{X}$ & $\mathrm{X}$ \\
\hline
\end{tabular}

(a) While the mid-scale tank is described as an elliptical headed tank throughout all the testing documents, post-test measurement and analysis of the tank more accurately characterized the tank as having a spherical segment head with a $0.511 \mathrm{~m}$ (20.1 in.) radius and a $22.9 \mathrm{~cm}$ (9 in.) depth. 


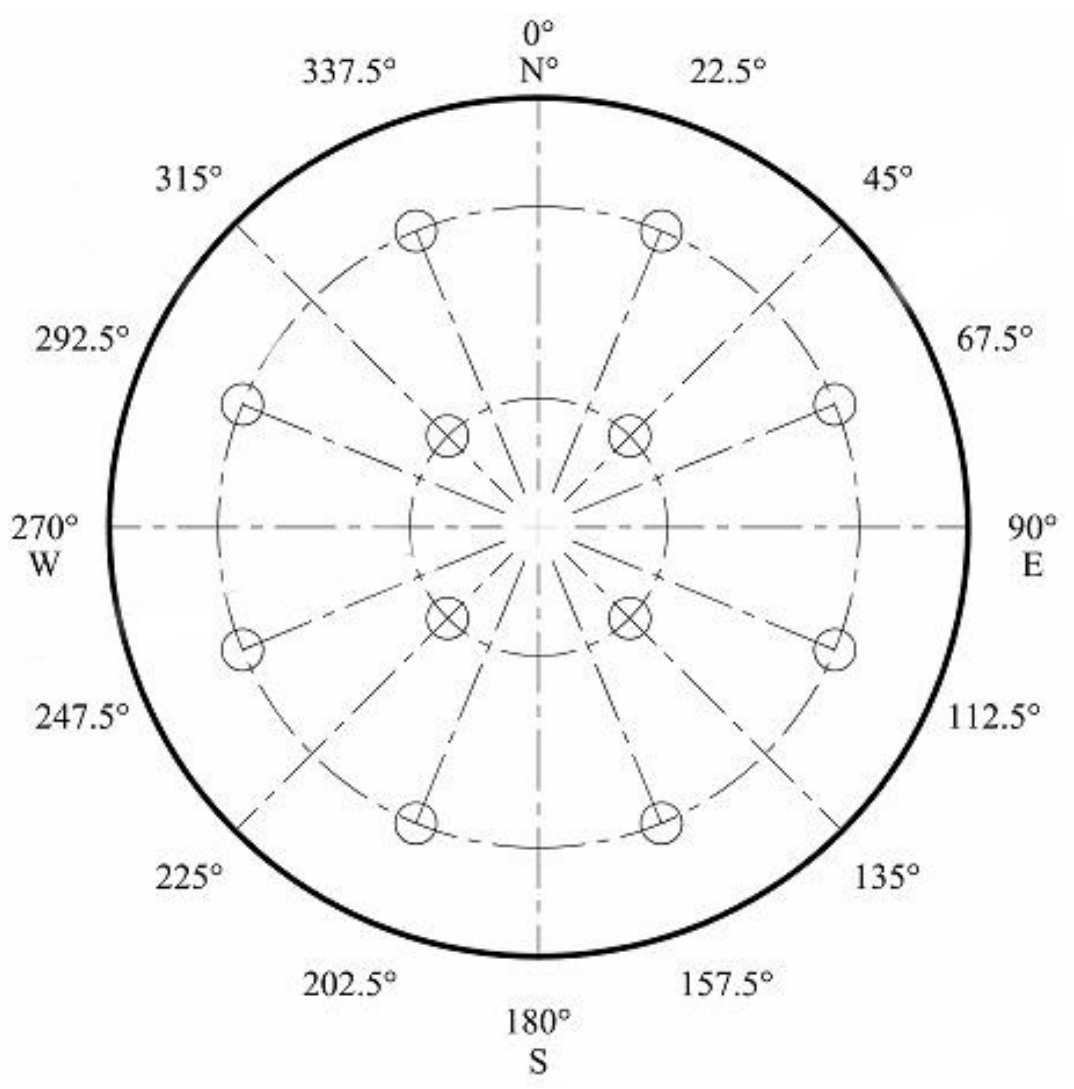

Figure 4.16. Plan View of 12 -Tube HLP-22 F\&D Orientation Between Inner and Outer Rings in the Large-Scale Tank. The as-tested inner-ring radius was $0.297 \mathrm{~m}$ (11.7 in.) and the as-tested outer-ring radius was $0.671 \mathrm{~m}$ (26.4 in.).

In the test tanks with elliptical heads, the HLP-22 12-tube elliptical arrays had the outer ring radial positioning reduced to $0.62 \mathrm{R}$. This adjusted for the difference in the nozzle impingement angle caused by the difference between F\&D head and the elliptical head (see Figure 4.17). The planned pulse tube locations based on equivalent impingement angles are shown in Table 4.1. The measured positions of the 12-tube arrays in the tanks are presented in Table 4.5.

Structural supports for the tube arrays inside the test tanks were constructed to limit interference with the particle cloud in the center of the tank. An example of the large-scale tank structural component is shown in Figure 4.18. The 8-tube array was configured to model approximate radial positions for the 8-tube tanks in the WTP, including FEP-17A/B, PWD-15/16, PWD-33/43, PWD-44, TCP-01, TLP-09A/B and UFP-01A/B. This array was also used for the 4-tube tests by leaving the outer radial rings open and closing the tubes/nozzles on the inner ring. The inner ring of 4 tubes was tested at a radius of $0.5 \mathrm{R}$ and the outer ring of 4 at $0.67 \mathrm{R}$. Figure 4.19 shows the orientation of the tubes during testing. 


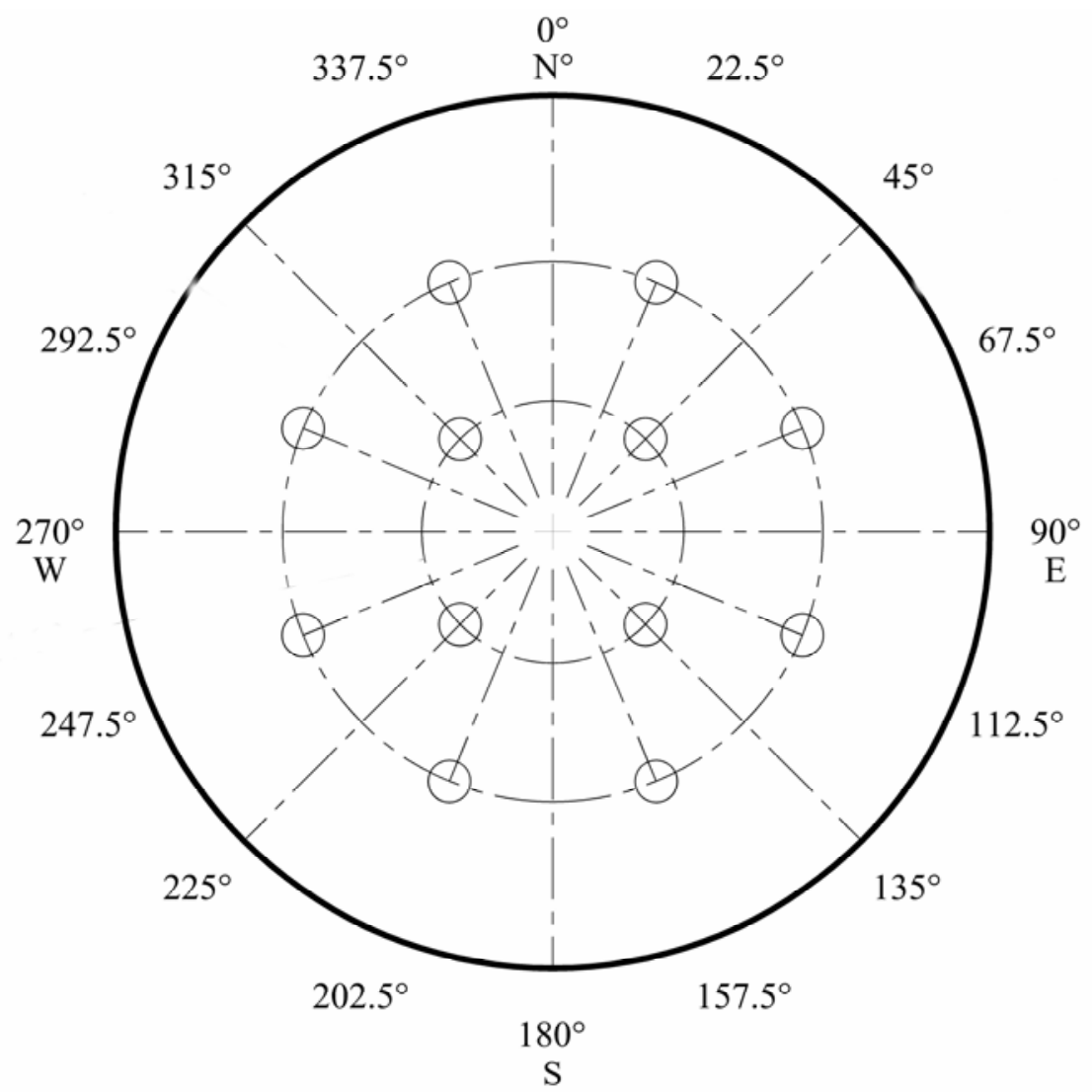

Figure 4.17. Plan View of 12-Tube HLP-22 Elliptical Array Orientation Between Inner and Outer Rings in the Large-Scale Tank. The as-tested outer ring radius was $0.555 \mathrm{~m}$ (21.85 in.); the inner ring radius was $0.292 \mathrm{~m}$ (11.5 in.).

Table 4.5. Measured HLP-22 12-Tube Array Positions

\begin{tabular}{|c|c|c|c|c|c|c|c|c|c|c|}
\hline & \multicolumn{2}{|c|}{ Tank Diameter } & \multicolumn{2}{|c|}{ Tank Radius } & \multicolumn{2}{|c|}{$\begin{array}{c}\text { Inner Tube } \\
\text { Radial position } \mathrm{R}_{\mathrm{i}}\end{array}$} & \multirow[t]{2}{*}{$\begin{array}{c}\text { Average } \\
\text { Inner } \\
\text { Tube } \\
\text { Radial } \\
\mathrm{R}_{\mathrm{i}} / \mathrm{R} \\
\end{array}$} & \multicolumn{2}{|c|}{$\begin{array}{c}\text { Outer Tube } \\
\mathrm{R}_{0}\end{array}$} & \multirow[t]{2}{*}{$\begin{array}{c}\text { Average } \\
\text { Outer } \\
\text { Tube } \\
\text { Radial } \\
\mathrm{R}_{0} / \mathrm{R}\end{array}$} \\
\hline & in. & $\mathrm{m}$ & in. & $\mathrm{m}$ & in. & $\mathrm{m}$ & & in. & $\mathrm{m}$ & \\
\hline $\begin{array}{l}\text { Small-Scale } \\
\text { Elliptical }\end{array}$ & 14.44 & 0.367 & 7.22 & 0.183 & 2.44 & 0.0620 & 0.34 & 4.5 & 0.114 & 0.62 \\
\hline $\begin{array}{l}\text { Mid-Scale } \\
\text { Spherical }^{(a)}\end{array}$ & 33.9 & 0.860 & 16.9 & 0.430 & 5.67 & 0.144 & 0.33 & 10.46 & 0.266 & 0.62 \\
\hline Large-Scale F\&D & 70.0 & 1.78 & 35.0 & 0.889 & 11.48 & 0.292 & 0.33 & 21.85 & 0.555 & 0.62 \\
\hline \multirow{2}{*}{$\begin{array}{l}\text { Large-Scale } \\
\text { Elliptical }\end{array}$} & $70.0^{(a)}$ & 1.78 & 34.6 & 0.878 & 11.68 & 0.297 & 0.34 & 26.40 & 0.671 & 0.76 \\
\hline & $69.16^{(\mathrm{b}}$ & 1.76 & & & & & & & & \\
\hline
\end{tabular}




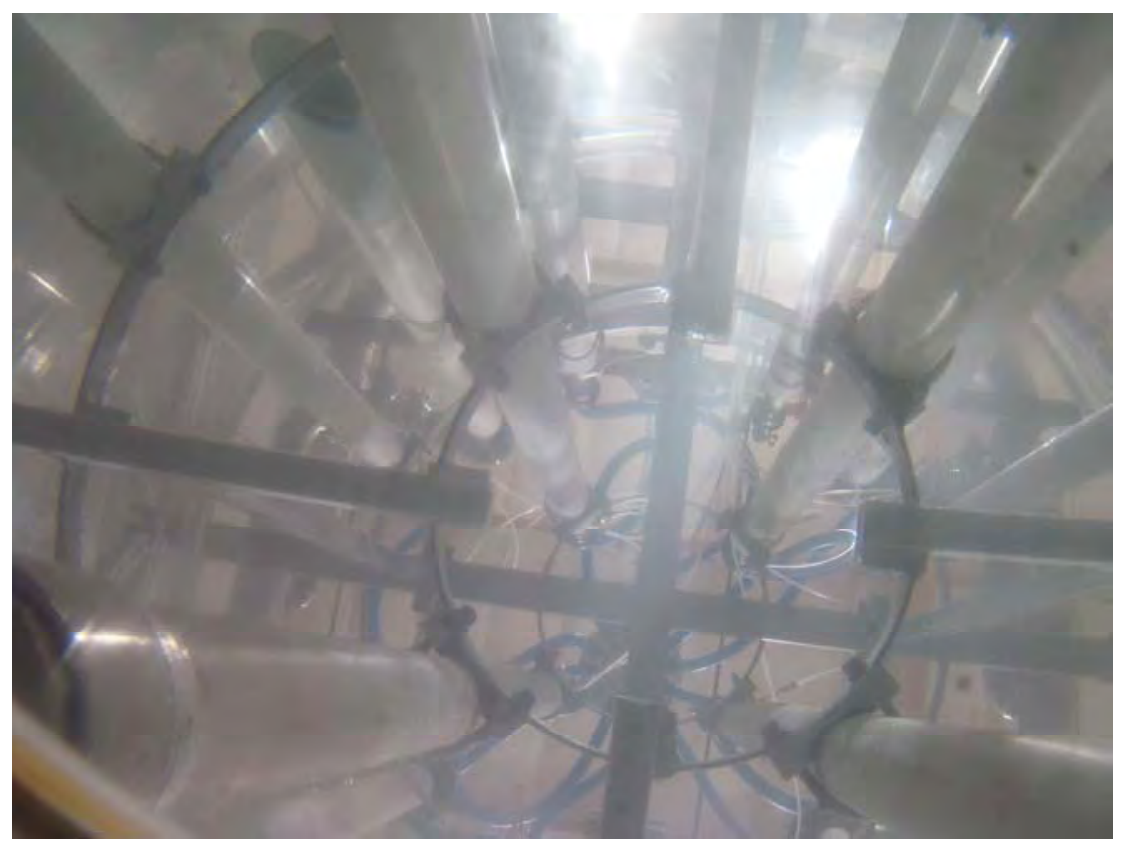

Figure 4.18. In-Tank Structural Support for the Tube Array in the Large-Scale Tank (as viewed from underneath the tank through the viewing window)

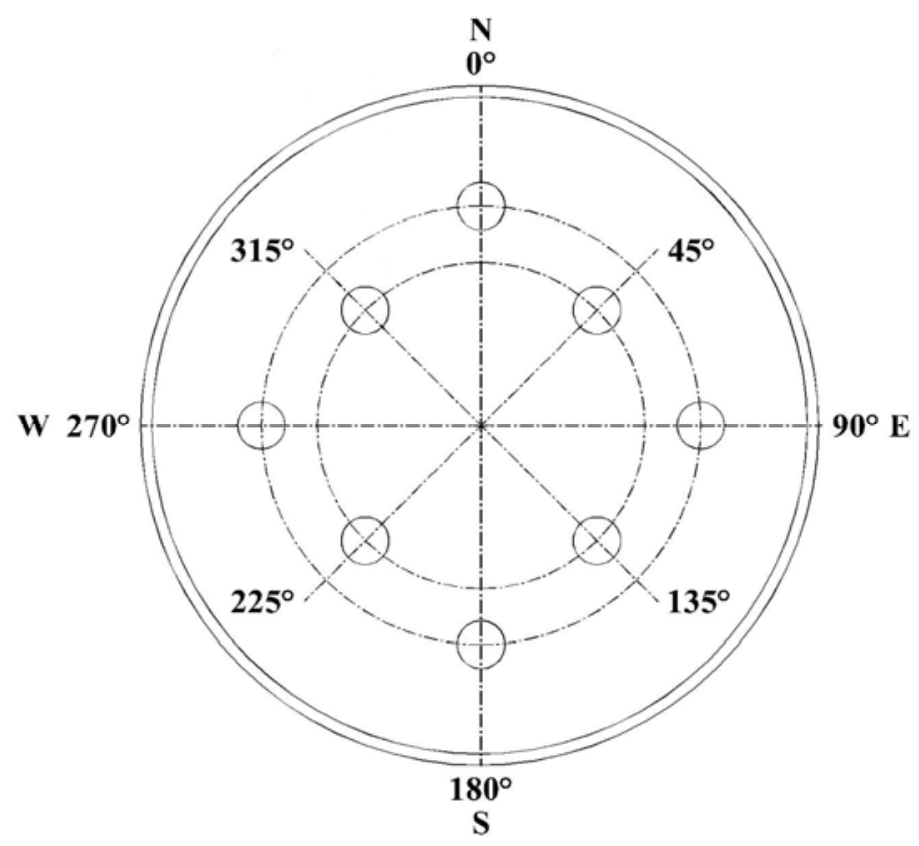

Figure 4.19. Plan View of 8-Tube Array Orientation Between Inner and Outer Rings in Small-Scale Tank

The positions of the 8-tube arrays in the tanks are listed in Table 4.6. Initial testing used two nozzle sets for each test stand. Nozzle diameters for the 12-tube arrays are shown in Table 4.7 and those for the 8-tube arrays in Table 4.8. The jet stand-off target for the nozzles was 1.5 jet nozzle diameters from the bottom of the tank. Additional nozzles were used in the 8-tube array tests to represent small, medium and large nozzle sizes in the 8-PJM tanks. Isometric views of the 8-tube array are shown in Figure 4.20. 
Table 4.6. Measured 8-Tube Array Positions

\begin{tabular}{|c|c|c|c|c|c|c|c|c|c|c|}
\hline & \multicolumn{2}{|c|}{ Tank Diameter } & \multicolumn{2}{|c|}{ Tank Radius } & \multicolumn{2}{|c|}{$\begin{array}{c}\text { Inner Tube } \\
\text { Bottom }\end{array}$} & \multirow{2}{*}{$\begin{array}{c}\text { Inner Tube } \\
\text { Radial } \\
\text { as-Tested }\end{array}$} & \multicolumn{2}{|c|}{$\begin{array}{c}\text { Outer Tube } \\
\text { Bottom }\end{array}$} & \multirow{2}{*}{$\begin{array}{c}\text { Outer Tube } \\
\text { Radial } \\
\text { as-Tested }\end{array}$} \\
\hline & in. & $\mathrm{m}$ & in. & $\mathrm{m}$ & in. & $\mathrm{m}$ & & in. & $\mathrm{m}$ & \\
\hline $\begin{array}{l}\text { Small-Scale } \\
\text { 8-Tube Small } \\
\text { Nozzle }\end{array}$ & $14-7 / 16$ & 0.367 & 7.22 & 0.183 & 3.61 & 0.0917 & 0.50 & 4.85 & 0.123 & 0.67 \\
\hline $\begin{array}{l}\text { Small-Scale } \\
\text { 8-Tube Medium } \\
\text { Nozzle }\end{array}$ & $14-7 / 16$ & 0.367 & 7.22 & 0.183 & 3.61 & 0.0917 & 0.50 & 4.85 & 0.123 & 0.67 \\
\hline $\begin{array}{l}\text { Small-Scale } \\
\text { 8-Tube Large } \\
\text { Nozzle }\end{array}$ & $14-7 / 16$ & 0.367 & 7.22 & 0.183 & 3.61 & 0.0917 & 0.50 & 4.85 & 0.123 & 0.67 \\
\hline $\begin{array}{l}\text { Large-Scale } \\
\text { 8-Tube }\end{array}$ & 70 & 1.78 & 35 & 0.89 & 17.5 & 0.44 & 0.50 & 23.5 & 0.60 & 0.67 \\
\hline
\end{tabular}

Table 4.7. HLP-22 12-Tube Array Nozzle and Pulse Tube Sizes

\begin{tabular}{|c|c|c|c|c|c|c|c|c|c|}
\hline \multirow[b]{2}{*}{ Vessel } & \multicolumn{2}{|c|}{$\begin{array}{l}\text { HLP-22 } 0.102 \text { m (4-in.) } \\
\text { Nominal Nozzle Equivalent }\end{array}$} & \multicolumn{2}{|c|}{$\begin{array}{c}\text { HLP-22 } 0.152 \mathrm{~m} \\
\text { (6-in.) Nominal } \\
\text { Nozzle } \\
\text { Equivalent }\end{array}$} & \multirow{2}{*}{$\begin{array}{c}\text { Pulse Tube } \\
\text { (Nominal size for }^{\text {Sched } 40 \text { PVC) }}{ }^{\text {(a) }} \\
\text { in. }\end{array}$} & \multicolumn{2}{|c|}{ Pulse Tube ID } & \multicolumn{2}{|c|}{$\begin{array}{c}\text { Pulse Tube } \\
\text { OD }\end{array}$} \\
\hline & in. & $\mathrm{cm}$ & in. & $\mathrm{cm}$ & & in. & $\mathrm{cm}$ & in. & $\mathrm{cm}$ \\
\hline Small-Scale & 0.126 & 0.320 & 0.191 & 0.485 & $3 / 4$ & 0.824 & (b) & 1.05 & (b) \\
\hline Mid-Scale & 0.297 & 0.75 & 0.446 & 1.13 & 1.5 & 1.61 & (b) & 1.9 & (b) \\
\hline Large-Scale & 0.613 & 1.56 & 0.920 & 2.34 & 3 & 3.068 & (b) & 3.5 & (b) \\
\hline $\begin{array}{l}\text { (a) All sche } \\
\text { PVC pla } \\
\text { (b) The AST }\end{array}$ & $\begin{array}{l}\text { e } 40 \text { PVC } \\
\text { pipe, Sc } \\
\text { standard }\end{array}$ & $\begin{array}{l}\text { rmation } \\
0,80 \text { anc } \\
\text { show me }\end{array}$ & $\begin{array}{l}\text { rom th } \\
0 \text { Ame } \\
\text { value }\end{array}$ & $\begin{array}{l}\text { STM I } \\
\text { an Nati }\end{array}$ & $\begin{array}{l}\text { ernational Design } \\
\text { nal Standard. }\end{array}$ & on: D & & & \\
\hline
\end{tabular}

Table 4.8. 8-Tube Array Nozzle and Pulse Tube Sizes

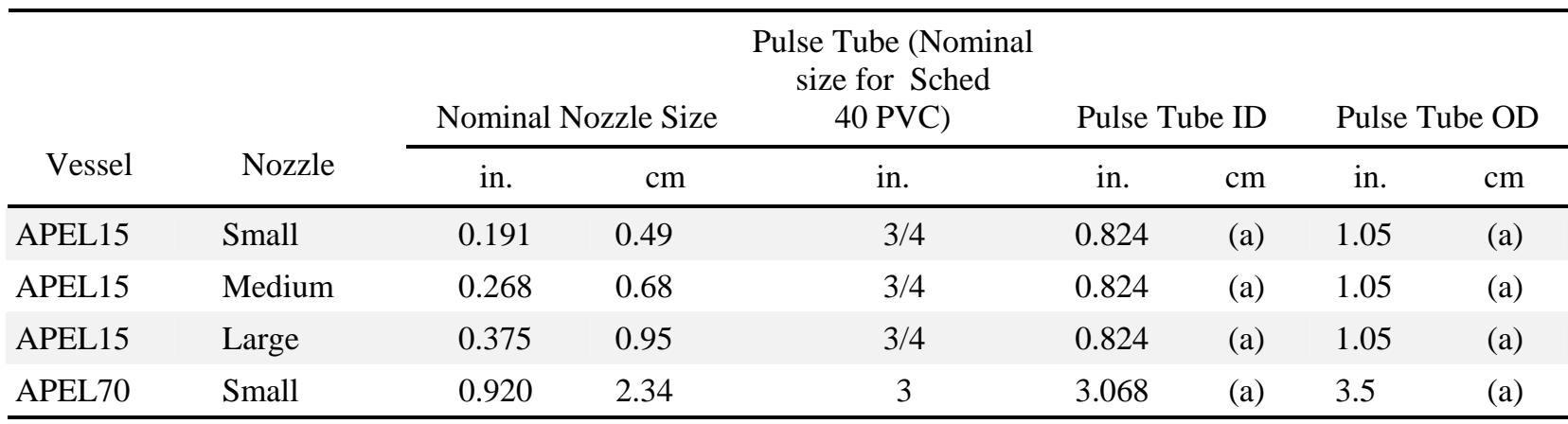

(a) The ASTM standard does not show metric values. 

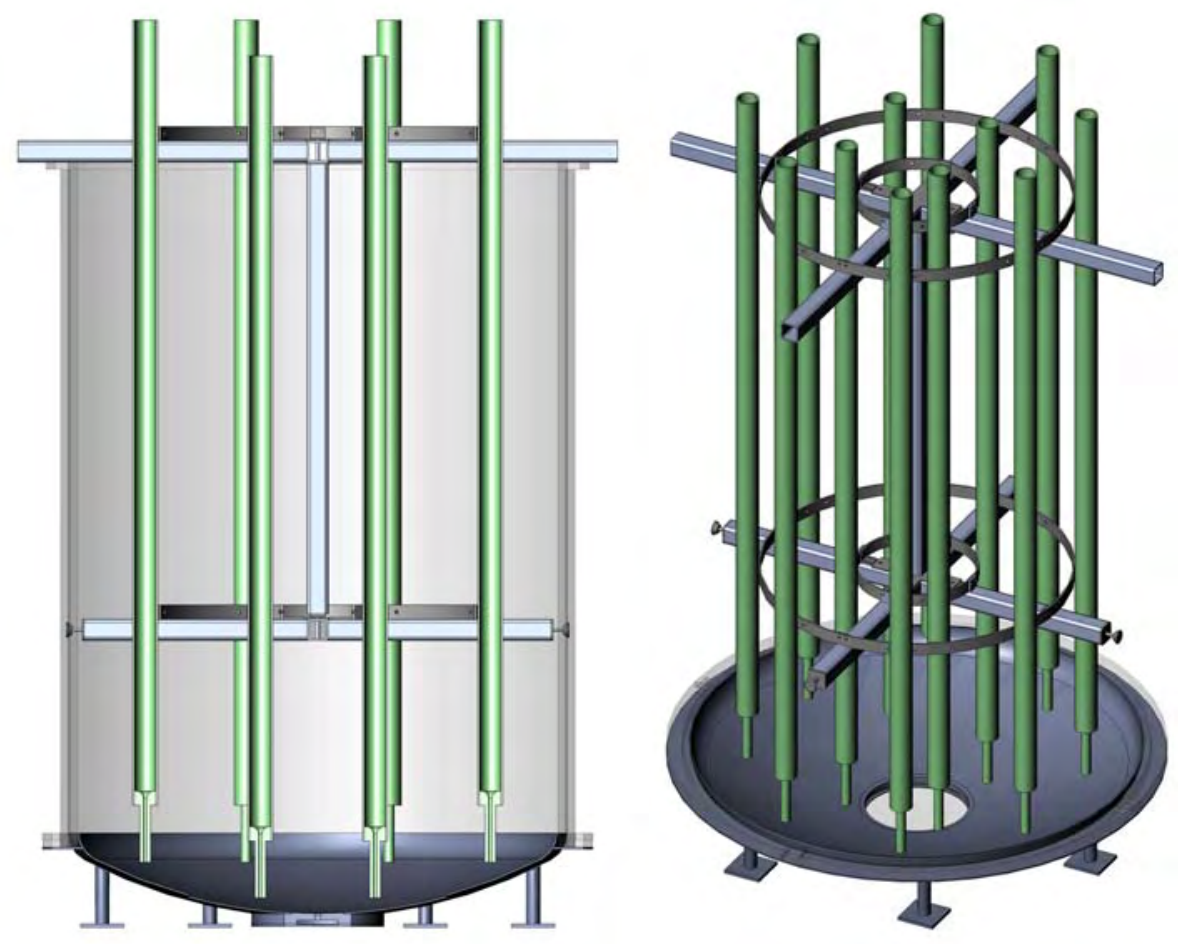

(a)
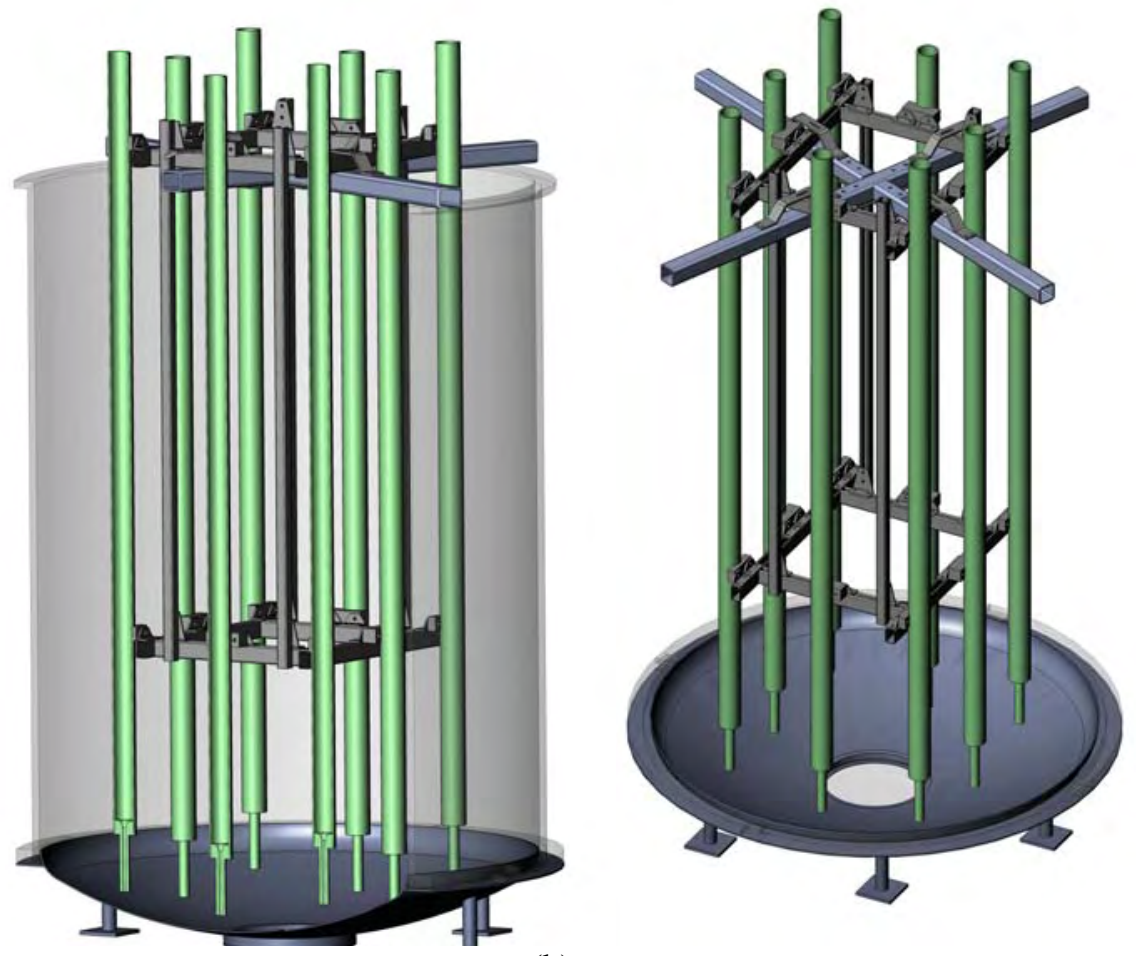

(b)

Figure 4.20. (a) HLP-22 12-Tube Tank Array (not to scale); (b) 8-Tube Array in Large-Scale EllipticalHead Tank (not to scale) 


\subsection{Experimental Procedures}

The experimental procedures used during the scaled mixing experiments are described in this section. The experiments were conducted in three test campaigns: July 2007, Fall 2007, and 2008. During each test campaign, improvements in testing protocol and instrumentation were implemented. However, the overall goal of the testing remained the same: to determine the $\mathrm{U}_{\mathrm{CS}}$ for each test and to determine the cloud height at a range of velocities surrounding $\mathrm{U}_{\mathrm{CS}}$. Section 5.1 gives an overview of the tests performed in each campaign. In Section 5.2, key observation procedures related to performance criteria are described. Only the elements of the procedures relating to the performance criteria are covered. Calculations performed in the DAS are described in Section 5.3. The test procedures and other documents used during the experiments are listed in Section 5.4. The full details of the experimental procedures used are contained in the test documents listed in Table 5.7.

\subsection{Testing Overview}

The main test objective was to observe the influence of vertically downward jets on noncohesive solids in a series of scaled tanks with several bottom shapes. As described in Section 4, the test tanks and bottom shapes included small-and large-scale tanks with elliptical bottoms, a mid-scale tank with a spherical bottom, and a large-scale tank with an F\&D bottom. Program test objectives are discussed in Section 1.3. The test campaigns were conducted to address the objectives (using numbering shown in Table S.1 from Executive Summary) as follows:

- July 2007 tests using only the mid-scale system were used mainly to address the first two program objectives regarding the nozzle size and operating velocities to be used in HLP-22.

- Fall 2007 tests began to examine the effect of several geometric parameters (still using only the midscale system); this addressed part of the third objective. The effects of variations in the number of operating nozzles, tank fill level, and height of the return suction line were investigated in preparation for further parametric tests performed in 2008.

- 2008 tests continued to evaluate the effect of various parameters (waste properties, equipment design, and process operations), and included scale effects by testing in all three scaled test systems (covering Objectives 3 and 4).

- Results from all three test campaigns were used to develop the models and identify the key parameters for vessel mixing performance (Objectives 5 and 6).

During testing, the downward-directed jets were operated in either a steady flow condition or a pulsed (periodic) flow condition. The mobilization of the solids resulting from the jets was evaluated based on:

- The motion/agitation of the particulate on the tank floor

- The elevation the solids reach within the tank; the height the solids material reaches in the tank is referred to as the cloud height $\left(\mathrm{H}_{\mathrm{C}}\right)$.

- Other observations deemed significant to characterize the system performance relative to mobilization and/or suspension of solids, such as patterns and dimensions of the cleared regions of the tank floor where particulate had been swept away. In the 2008 tests, measurements of the solids concentration profile were collected using ultrasonic attenuation methods (described in Appendix A). 
During testing in 2008, the client expressed significant interest in being able to predict waste concentrations at the suction pump inlet near the bottom of the HLP-22 vessel. Although not in the original test objectives, data collected during testing has been analyzed to provide understanding of solid concentrations near the tank bottom (see Sections 6 and 7 and Appendix C).

Testing was performed using water as the working fluid, and the temperature was recorded to determine the reference viscosity and density for post-test analysis. The test parameters of interest are listed in Table 5.1. Important operating parameters for a PJM vessel are jet velocity, duty cycle, drive time, cycle time, pulse volume fraction, solids volume fraction, and normalized fill level. The parameters that are important in tank design and the effect of tank design on material movement are tank diameter, nominal volume of tank, number of pulse tubes, radial PJM ring positions, nozzle diameter, and head shape. Parameters that reflect differences between test systems and a full-scale PJM vessel include return line height, impingement angle, scaling factors, and nozzle ratio.

Table 5.1. Mixing System Parameters

\begin{tabular}{|c|c|}
\hline Parameter & Symbol \\
\hline \multicolumn{2}{|c|}{ Dimensional } \\
\hline Tank diameter & $\mathrm{D}$ \\
\hline Normal fill level of tank & $\mathrm{H}$ \\
\hline Reference volume of tank where $\mathrm{V}_{\mathrm{REF}}=\pi \mathrm{D}^{3} / 4$ & $\mathrm{~V}_{\mathrm{REF}}$ \\
\hline Number of pulse tubes & $\mathrm{N}$ \\
\hline Number of operating jets & $\mathrm{N}_{\mathrm{J}}$ \\
\hline Number operating jets-(inner/outer) & $\mathrm{N}_{\mathrm{I}} / \mathrm{N}_{\mathrm{O}}$ \\
\hline Radial PJM ring position (inner/outer) & $\mathrm{R}_{\mathrm{I}} / \mathrm{R}_{\mathrm{O}}$ \\
\hline Impingement angle (inner/outer) & $\theta_{\mathrm{I}} / \theta_{\mathrm{O}}$ \\
\hline Nozzle diameter & d \\
\hline Jet velocity & $\mathrm{U}$ \\
\hline Drive time & $t_{D}$ \\
\hline Cycle time & $\mathrm{t}_{\mathrm{C}}$ \\
\hline Return line height & Rtn \\
\hline Head shape & HS \\
\hline \multicolumn{2}{|c|}{ Nondimensional } \\
\hline Scale factor & $\mathrm{S}$ \\
\hline Nozzle ratio & $\mathrm{d} / \mathrm{D}$ \\
\hline Normalized fill level & $\mathrm{H} / \mathrm{D}$ \\
\hline Solids volume fraction where $\phi_{\mathrm{S}}=\mathrm{V}_{\mathrm{S}} / \mathrm{V}_{\mathrm{REF}}$ & $\phi_{\mathrm{S}}$ \\
\hline Pulse volume fraction where $\phi_{\mathrm{p}}=\mathrm{NV} \mathrm{V}_{\mathrm{P}} / \mathrm{V}_{\mathrm{REF}}$ & $\phi_{\mathrm{p}}$ \\
\hline Duty cycle & DC \\
\hline Jet density where $\phi_{\mathrm{J}}=\mathrm{Nd}^{2} / \mathrm{D}^{2}$ & $\phi_{\mathrm{J}}$ \\
\hline
\end{tabular}

For an individual test, jet velocity was varied while solids volume fraction and normalized fill level were held constant. For a pulsed flow test, pulse volume fraction and duty cycle were also held constant, while drive time and cycle time were adjusted to achieve the desired duty cycle. All other system parameters from Table 5.1 were also held constant. Most tests were performed by starting from an initial 
condition at which settled solids were present on the tank floor (i.e., a starting velocity below $\mathrm{U}_{\mathrm{CS}}$ ) and incrementally increasing the velocity over the test. This type of test was called an upward velocity sweep. Critical suspension velocity determined from an upward sweep velocity is called $U_{\mathrm{CS}}$. Downward velocity sweep tests were also performed by starting from a velocity above $\mathrm{U}_{\mathrm{Cs}}$ and incrementally decreasing the velocity over the test. When critical suspension velocity is determined from a downward sweep test, it is called $\mathrm{U}_{\mathrm{CS} \_\mathrm{D}}$. Observations were recorded at each velocity as described in Section 5.2.

\subsection{Observation Procedures}

Observation procedures were developed and applied during the July and Fall 2007 test campaigns and were refined for 2008 as additional ultrasonic instrumentation became available to measure the thickness of the settled solids layer and the concentration profiles inside the suspended cloud. Both of the ultrasonic techniques are described in Appendix A. Solids layer thickness was recorded at the end of the pulse, while concentration profiles were obtained as a function of time throughout each pulse.

To assist with observations, each pulse tube in the mid-scale tank was given a unique identification, as shown in Figure 5.1. North was considered zero degrees, with the angle increasing clockwise when viewed from above. The tubes were labeled with a letter indicating relative radial position of the pulse tube, I for inner ring, $\mathrm{O}$ for outer ring, and a number for designating each tube at a particular tank radius.

For the example of the HLP-22 (12-tube) configuration shown in Figure 5.1, consider the inner ring of four nozzles starting at $45^{\circ}$. The tubes and nozzles are labeled I1 through I4, corresponding to angles of $45^{\circ}, 135^{\circ}, 225^{\circ}$, and $315^{\circ}$, respectively. Likewise, the labeling for the outer ring of tubes/nozzles starts at $22.5^{\circ}$ and increases sequentially in $45^{\circ}$ increments starting with $\mathrm{O} 1$ through $\mathrm{O} 8$.

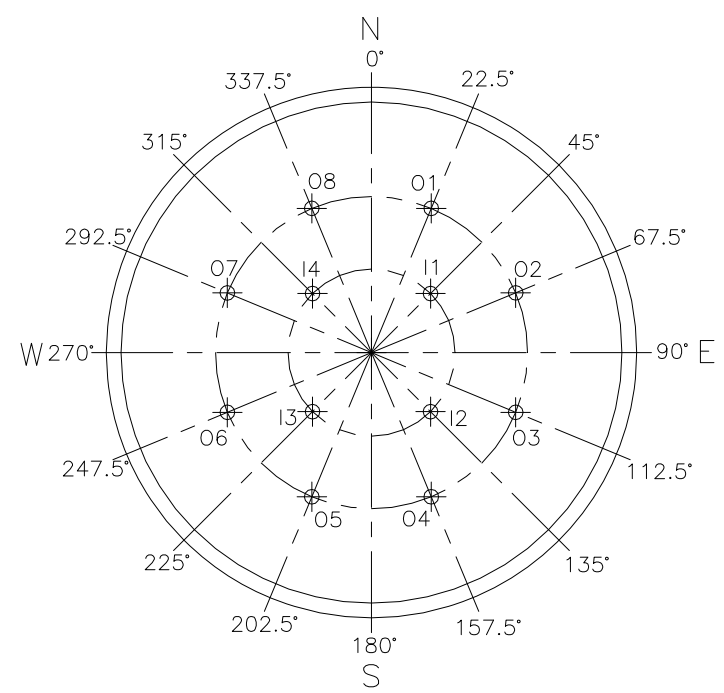

Figure 5.1. Illustration of Relative Positions of Pulse Tubes and Nozzles in the Mid-Scale Test Tank in HLP-22 (12-tube) Configuration

\subsubsection{Observation Procedures Used in 2007}

All observations were recorded when the motion in the tank appeared to have reached a steady-state condition (or a periodic condition that was considered a steady-state condition). The steady-state 
condition was said to exist when no visually observed changes in the solids behavior and no significant changes in the operating conditions were occurring. The test engineer determined the duration of operation required to achieve a steady condition. Prior to the collection of cloud height data, the test system was pulsed or operated until the clouds were stable. After the clouds were stable, the test engineer opened an "observation window" (i.e., a limited time period during which data were recorded) for the collection of cloud height, $\mathrm{U}_{\mathrm{CS}}$, and other data. During the observation window, data were collected for a period of at least five pulses with no observable changes over the five pulses. If the cloud conditions changed over the observation window, the window was closed, the cloud was stabilized, and a new observation window was then opened. The suggested minimum durations to demonstrate steady-state conditions were three minutes for steady jet operation and five cycles for pulsing jets, with no observable change in solids behavior over the duration. This was based on experience from the initial tests conducted using a 5-minute period for steady jets and 25 cycles for pulsing jets.

Four categories of phenomena were selected for observation: particle motion, cloud height, solids level, and the pattern of cleared region on the tank floor. These categories are explained in subsections 5.2.1.1 through 5.2.1.4. The categories were given scales, as discussed below. All but cloud height were observed through the transparent tank head by observers viewing directly or using mirrors placed on the floor under the tank-whichever method provided the best view in the circumstances.

\subsubsection{Particle Motion}

Particle motion was observed through the clear tank head and characterized using the two-letter abbreviations listed in Table 5.2.

Table 5.2. Particle Motion Descriptors ${ }^{(a)}$

\begin{tabular}{cll}
\hline $\begin{array}{c}\text { Abbreviation/ } \\
\text { Nomenclature }\end{array}$ & \multicolumn{1}{c}{ Meaning } & \multicolumn{1}{c}{ Description } \\
\hline NM & No motion & No or very little movement of solids. \\
SM & Some mobilization & $\begin{array}{l}\text { Some solids are moving but minimal or no observed } \\
\text { suspension. Some regions appear to have no moving } \\
\text { particles. } \\
\text { Some particles appear to be becoming suspended. Some } \\
\text { regions appear to have no moving particles remaining on the } \\
\text { tank floor. }\end{array}$ \\
AM & All moving, mostly suspended & $\begin{array}{l}\text { Essentially all solids are mobilized. No areas of non- } \\
\text { moving solids. }\end{array}$ \\
CS & Critical suspension & $\begin{array}{l}\text { Initial state of complete solids suspension (all moving off of } \\
\text { bottom). For pulsing jets, this is defined as all particles } \\
\text { moving at the end of a pulse cycle. }\end{array}$ \\
BC & Beyond critical suspension velocity & \begin{tabular}{l} 
Discharge velocity is greater than $\mathrm{U}_{\mathrm{CS} .}$. \\
\hline
\end{tabular}
\end{tabular}

(a) The critical observation for these tests was to determine $U_{\mathrm{CS}}$, the velocity at which the transition to/from the state of complete solids suspension occurred for incremental increases/decreases in nozzle discharge velocity. 


\subsubsection{Particle Cloud Height}

The particle cloud height was based on the upper height of the opaque cloud created by the suspension of solids, which may or may not be a well-defined boundary. The height was based on the cloud (see example in Figure 5.2), not the height of a few outlier particles. Measurements were taken with respect to a fixed reference point ${ }^{1}$ and recorded to the nearest 0.5 in., including the range (fluctuation) of any oscillation. For example, if cloud heights oscillated between 20 and 24 in., 20 to 24 in. was recorded.

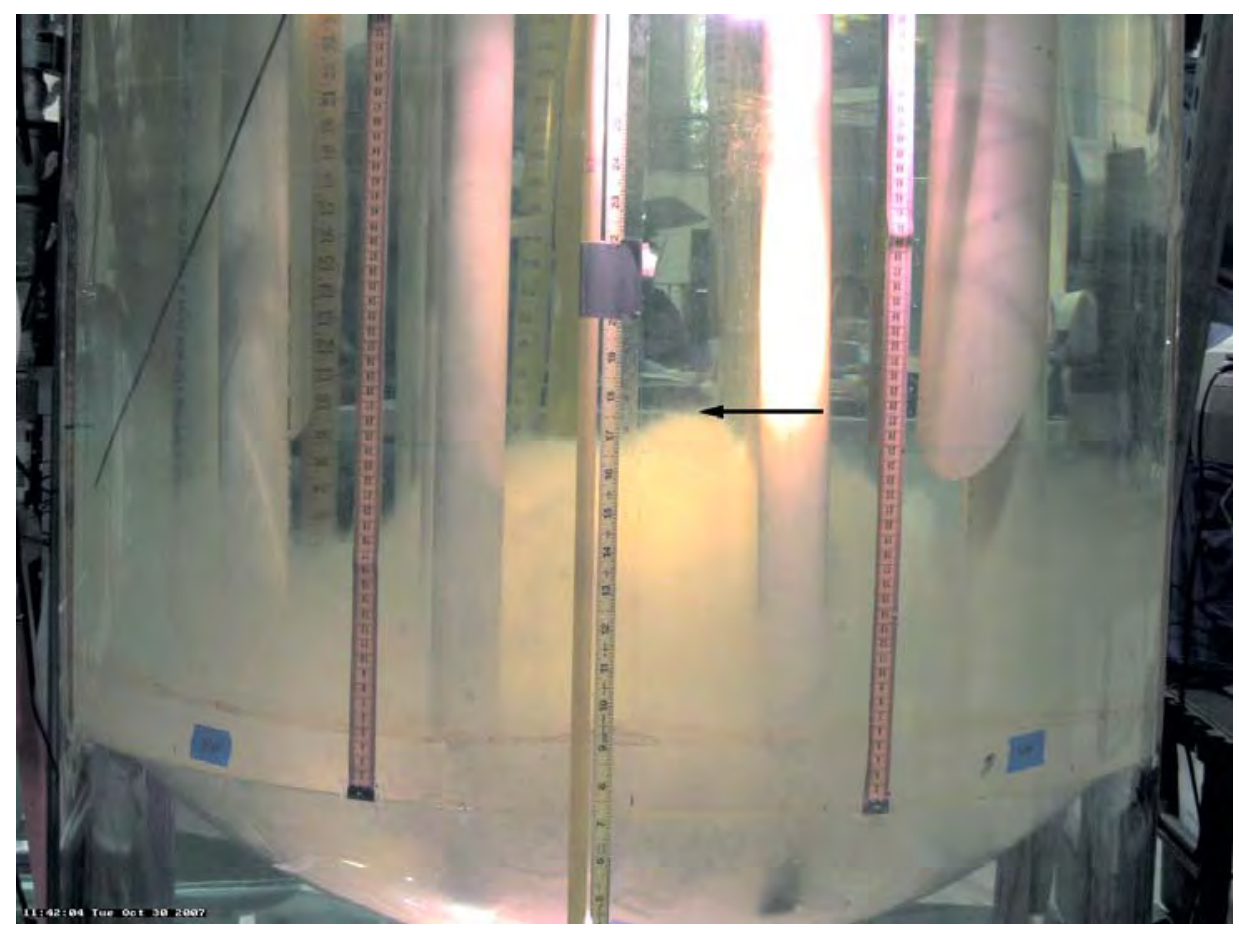

Figure 5.2. Photograph of Particulate Cloud near End of Pulse in Mid-Scale Tank Showing a Centrally Peaked Cloud and Measuring Tapes Used for Cloud Height Measurement (for information only). Arrow indicates the peak portion of the cloud that is measured to get cloud height.

\subsubsection{Solids Level}

The solids level was defined as the upper edge of settled solids in the bottom of the tank. The solids level could fall entirely within the dished bottom of the tank or, at high solids volume fraction, reach the vertical side of the tank. The top surface of settled solids in the dished bottom was optically distorted due to the curvature of the dish, which made a true level measurement more uncertain. Thus, solids level below the cylinder/elliptical bottom junction was described relative to the pulse tube nozzle rings (e.g., solids level was just below the outer nozzle ring). If the solids level was above the cylinder/dish junction, the level was measured in a manner similar to cloud height. Solids level observations were described using the nomenclature shown in Table 5.3.

\footnotetext{
${ }^{1}$ During initial testing in 2007, cloud height was measured from the top surface of the tank rim (and converted to height from bottom center for data analysis), but by October 2007 cloud height was being measured with respect to the bottom center of the tank.
} 
Table 5.3. Solids Level Nomenclature

\begin{tabular}{ll}
\hline Abbreviation/Nomenclature & \multicolumn{1}{c}{ Associated Observations } \\
\hline Record actual measurement & $\begin{array}{l}\text { Solids level was above the lower seam of the cylindrical portion of the tank. } \\
\text { SON }\end{array}$ \\
Solids level was above the nozzle discharge of the outer ring of nozzles but below \\
the lower seam of the cylindrical portion of the tank. \\
Solids level was above the nozzle discharge of the inner ring of nozzles but below \\
the nozzle discharge of the outer ring of nozzles. \\
SCO & $\begin{array}{l}\text { Settled solids observed in the center region of the tank but below the nozzle } \\
\text { discharge of the inner ring of nozzles. }\end{array}$ \\
SOO & $\begin{array}{l}\text { Solids observed only between outer nozzle ring and the end of tank. } \\
\text { NSS }\end{array}$ \\
\hline
\end{tabular}

\subsubsection{Pattern of Cleared Region}

The pattern of cleared region/settled solids column was described using the three-character nomenclature (two letters followed by a numeral) shown in Table 5.4. The settled solids may or may not have been moving.

\subsubsection{Observation Procedures Used in 2008}

All observations were recorded when the measured flow and the particle motion in the tank appeared to have reached steady state, and no observable change in solids behavior (e.g., transient behavior in cloud height) was detected over the observation period.

- Steady state for pulsed flow (a true periodic condition) was considered to exist when, for a period of 5 pulses, the charted instantaneous velocity, $u(t)$, yielded a visually observed peak average velocity, $\mathrm{U}_{\mathrm{PA}}$, which appeared to remain constant to within $\pm 5 \%$ (see Figure 5.3). $\mathrm{U}_{\mathrm{PA}}$ was obtained by visually monitoring a DAS velocity chart screen that was scaled to display the range of target $\mathrm{U}_{\mathrm{PA}}$ to $\pm 5 \%$.

- Steady state for steady flow conditions was said to exist when the steady jet velocity, $\mathrm{U}_{\mathrm{S}}$, was constant to within $\pm 5 \%$ over 2 minutes. $U_{\mathrm{S}}$ was a running time-average of the instantaneous velocity, $\mathrm{u}(\mathrm{t})$, taken over a time interval sufficient to smooth out noise in the velocity signal. $\mathrm{U}_{\mathrm{S}}$ was calculated by the DAS.

The time required to reach steady state may depend on the settling velocity of the simulant. Thus, observers needed to be cognizant of slow transients occurring in the mobilization of the solids. 
Table 5.4. Pattern of Cleared Region Viewed from Beneath the Tank

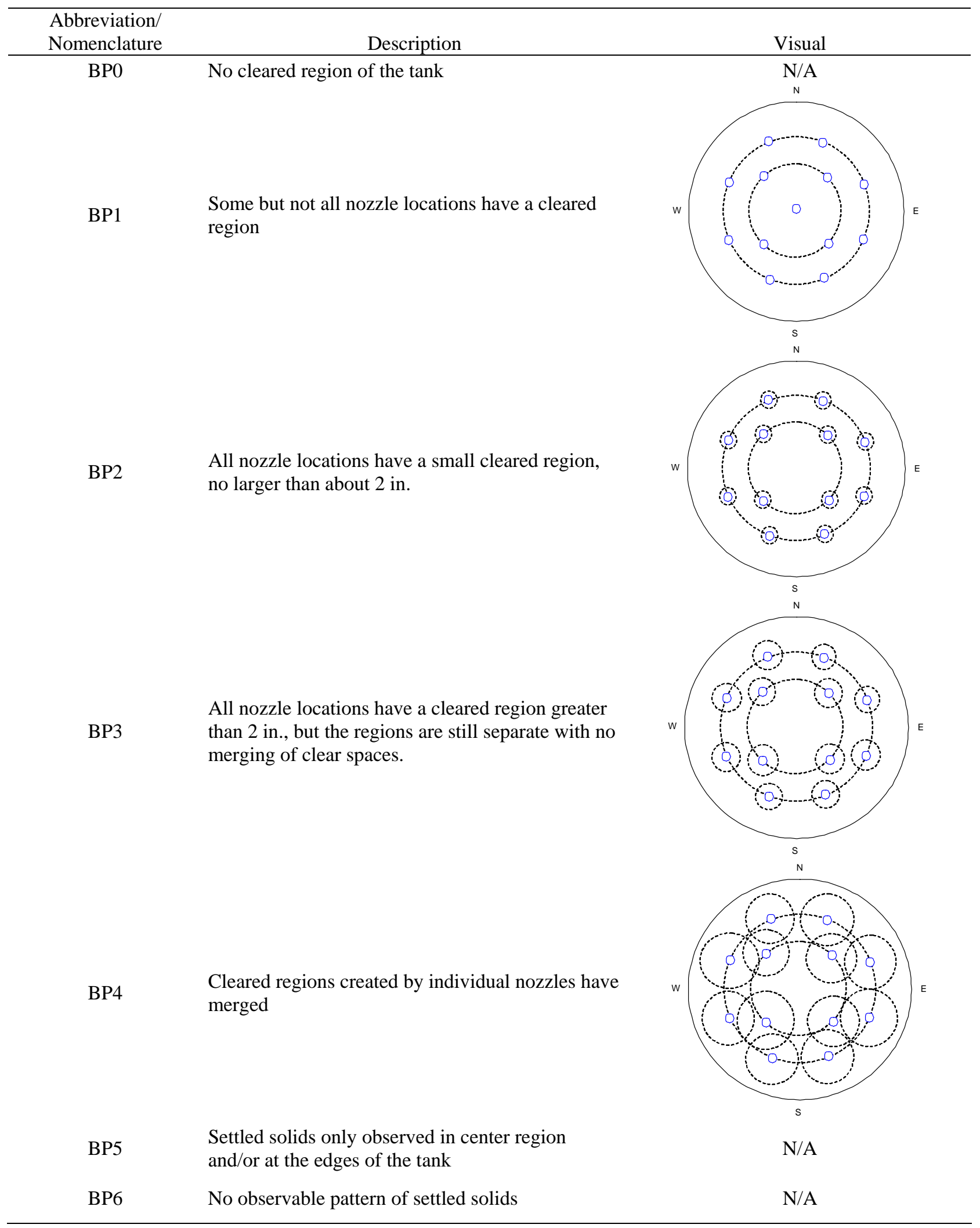




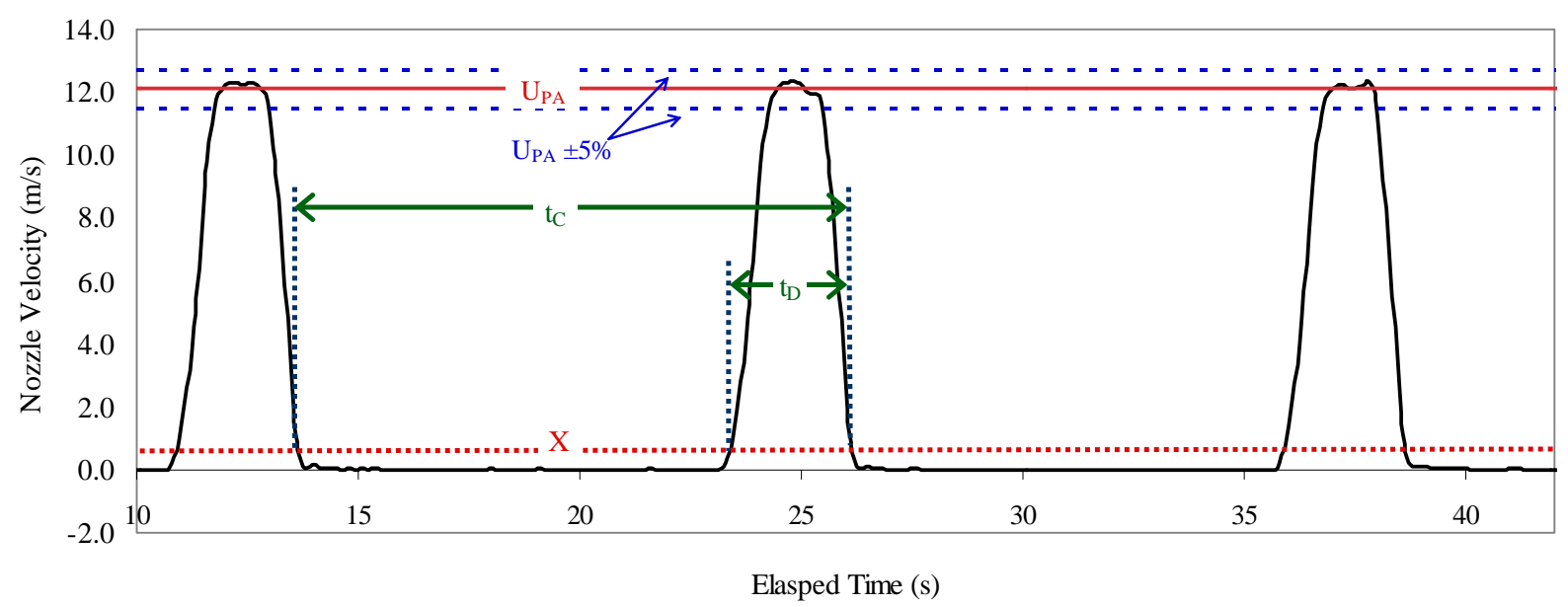

Figure 5.3. $\quad$ Illustration of Nozzle Velocity as a Function of Time for Several Discharge Cycles. $\mathrm{X}$, the set point used by the DAS, is a threshold velocity for distinguishing assumed zero flow from the pulse flow. A pulse or discharge is the portion of the cycle for which the velocity (calculated from the mass flow rate signal) is greater than $X . t_{D}$ is the discharge or pulse time. For this example assume target $\mathrm{U}_{\mathrm{PA}}=12.1 \mathrm{~m} / \mathrm{s}$ over the observation period.

Two phenomena were selected for visual observations of solids behavior: particle motion and particle cloud height, which are explained in subsections 5.2.2.1 and 5.2.2.2. These two phenomena most directly related and correlated to measurements taken at different scales; the observation of settled solids level and clearing pattern were omitted from the 2008 procedures. Observations of particle motion and cloud heights were taken at each test condition unless specified otherwise by the test condition transmittal (TCT). When specified in the TCT, attenuation data for concentration profiles were also taken. The procedures used for the attenuation data are covered in Section A.2 (Appendix A) and Section 6.5. Attenuation data were collected at specified velocity conditions only, generally at or just beyond $\mathrm{U}_{\mathrm{CS}}$.

\subsubsection{Particle Motion}

Two methods were used to monitor solids suspension: visual observation and detection of solids layer thickness at the end of the pulse using UDV. Particle motion was observed visually from beneath the transparent tank bottom or through the window in the bottom of the large-scale tank. Table 5.5 lists observation procedures; differences in procedures between tanks are shown in italics. Table 5.6 lists a scale of observations relative to the condition of visually determined $U_{\mathrm{CS}}$. The numeric scale used to describe particle motion in the 2008 tests was slightly simplified from the abbreviations used in 2007 in that all conditions below $U_{C S}$ were grouped together. The critical observation for these tests was to determine $U_{C S}$, the velocity at which the transition to/from the state of complete solids suspension occurred for incremental increases/decreases in nozzle discharge velocity. The test engineer decided whether sufficient resolution had been obtained for the increment between conditions. 
Table 5.5. Procedures for $\mathrm{U}_{\mathrm{CS}}$ Observations

\begin{tabular}{|c|c|}
\hline Small-Scale Test Observations & Mid- and Large-Scale Test Observations \\
\hline $\begin{array}{l}\text { Detection of } U_{\mathrm{CS}}[\mathrm{by} \text { UDV] was based on the layer of } \\
\text { settled solids monitored by the UDV transducer at tank } \\
\text { center. } \mathrm{U}_{\mathrm{CS}} \text { was considered to exist between discharge } \\
\text { velocities where the transducer sensed a solids layer } \\
\text { from } 0 \text { to } 4 \mathrm{~mm} \text { over at least } 5 \text { pulses. When deter- } \\
\text { mining } \mathrm{U}_{\mathrm{CS}} \text {, the minimum resolution of nozzle discharge } \\
\text { velocity is } \pm 0.2 \mathrm{~m} / \mathrm{s} \text {. To evaluate UDV results, the } \\
\text { velocities to be determined are those that over } 5 \text { pulses: }\end{array}$ & $\begin{array}{l}\text { Detection of } \mathrm{U}_{\mathrm{CS}} \text { [by UDV] was based on the layer of } \\
\text { settled solids monitored by a UDV transducer at tank } \\
\text { center. } \mathrm{U}_{\mathrm{CS}} \text { senses a solids layer from } 0 \text { to } 4 \mathrm{~mm} \text { during } \\
\text { the observation. When determining } \mathrm{U}_{\mathrm{CS}} \text {, target } \\
\text { resolution with respect to nozzle discharge velocity is } \pm \\
0.2 \mathrm{~m} / \mathrm{s} \text {. To evaluate UDV results, velocities to be } \\
\text { determined are those that: }\end{array}$ \\
\hline $\begin{array}{l}\text { 1) Yield a thin solids layer ideally between } 4 \text { and } \\
10 \mathrm{~mm}\left(<\mathrm{U}_{\mathrm{CS}} \text { corresponds to } \# 1 \text { from Table } 5.6\right) \text {. }\end{array}$ & $\begin{array}{l}\text { 1) Yield a solids layer between } 4 \text { and } 10 \mathrm{~mm}\left(<\mathrm{U}_{\mathrm{CS}} \text {, }\right. \\
\text { corresponds to \#1 from Table 5.6). }\end{array}$ \\
\hline $\begin{array}{l}\text { 2) Yield a solids layer ranging from } 0 \text { to }<4 \mathrm{~mm} \text { with at } \\
\text { least one of the } 5 \text { values }>0 \text { (this is considered the } \\
\text { UDV } \mathrm{U}_{\mathrm{CS}} \text { value; may correspond to } \# 2 \text { from } \\
\text { Table 5.6). These solids depths may be obtained } \\
\text { over a range of velocities. If values from } 0 \text { to } \\
<4 \mathrm{~mm} \text { are obtained, the } \mathrm{U}_{\mathrm{CS}} \text { is the highest velocity } \\
\text { that yields values of } 0 \text { to less than } 4 \mathrm{~mm} \text { with at least } \\
\text { one value in } 5 \text { greater than } 0 \text {. } \\
\text { - If no measurements meet the } 5 \text {-pulse criterion, } \\
\mathrm{U}_{\mathrm{CS}} \text { is the lowest velocity yielding all } 0 \text { values } \\
\text { that is within } 0.2 \mathrm{~m} / \mathrm{s} \text { of the lowest velocity to } \\
\text { yield a solids depth of } 4 \mathrm{~mm} \text { or more. }\end{array}$ & $\begin{array}{l}\text { 2) Yield a solids layer ranging from } 0 \text { to less than } 4 \mathrm{~mm} \\
\text { with at least one of the observed values greater than } \\
0 \text { (this is considered the UDV } \mathrm{U}_{\mathrm{CS}} \text { value; may corre- } \\
\text { spond to \#2 from Table 5.6) These depths may be } \\
\text { obtained over a range of velocities. If values from } 0 \\
\text { to less than } 4 \text { mm are obtained at multiple velocities, } \\
\text { the } U_{\mathrm{CS}} \text { is the highest velocity that meets this } \\
\text { criterion. } \\
\text { - If no measurements meet this criterion, } \mathrm{U}_{\mathrm{CS}} \text { is } \\
\text { the lowest velocity yielding all } 0 \text { values. }\end{array}$ \\
\hline $\begin{array}{l}\text { 3) Yield only } 0 \text { values for solids layer for a velocity no } \\
\text { more than } 0.2 \mathrm{~m} / \mathrm{s} \text { greater than that, which yielded a } \\
\text { solids layer ranging from } 0 \text { to less than } 4 \mathrm{~mm}\left(>\mathrm{U}_{\mathrm{CS}}\right. \\
\text { verifies that UDV } \mathrm{U}_{\mathrm{CS}} \text { was obtained at previous step; } \\
\text { may correspond to } \# 3 \text { from Table } 5.6) \text {. }\end{array}$ & $\begin{array}{l}\text { 3) Yield only } 0 \text { values for solids layer; ideally for } \\
\text { velocity no more than } 0.2 \mathrm{~m} / \mathrm{s} \text { greater than what } \\
\text { yielded a solids layer from } 0 \text { to less than } 4 \mathrm{~mm} \\
\left(>\mathrm{U}_{\mathrm{CS}} \text { verifies that UDV } \mathrm{U}_{\mathrm{CS}} \text { obtained in } \# 2 \text { may }\right. \\
\text { correspond to \#3 from Table } 5.6 \text { ). }\end{array}$ \\
\hline \multicolumn{2}{|c|}{$\begin{array}{l}\text { At the discretion of the test engineer or the TCT, additional velocities can be evaluated that yield solids layers } \\
\text { between } 5 \text { and } 20 \mathrm{~mm} \text { to help predict } U_{C S} \text { by curve fitting the data. }\end{array}$} \\
\hline \multicolumn{2}{|c|}{$\begin{array}{l}\text { It is expected that the visually observed detection of } U_{\mathrm{CS}} \text { may differ from that detected by the UDV transducer. It is } \\
\text { also expected that as particle size is reduced, greater ambiguity or disparity may exist in visually detecting } U_{\mathrm{CS} \text {. }} \\
\text { Neither condition creates problems because the goal is to define metrics that can predict full-scale vessel perform- } \\
\text { ance. If the detection of } U_{\mathrm{CS}} \text { or the metric of choice (visual or UDV-detected } U_{\mathrm{CS}} \text { ) is consistent at the different } \\
\text { geometric scales, the developed models will trend with scale. Test results over a range of particle diameters allow } \\
\text { comparison of visually observed } U_{\mathrm{CS}} \text { and UDV detected } U_{\mathrm{CS} \text {. }}\end{array}$} \\
\hline $\begin{array}{l}\text { UDV determination of } U_{\mathrm{CS}} \text { takes precedent over visual } \\
\text { measurements; thus the TCT may request only UDV } \\
\text { detection be used. Otherwise, both methods are used. } \\
\text { Note (Particle Motion): For any } U_{C S} \text { determination } \\
\text { (visual or UDV), velocity for reported } U_{C S} \text { values must } \\
\text { be bracketed by observations at velocities no more than } \\
0.2 \mathrm{~m} / \mathrm{s} \text { higher/lower (smaller increment acceptable). }\end{array}$ & $\begin{array}{l}\text { UDV determination of } \mathrm{U}_{\mathrm{CS}} \text { takes precedent over visual } \\
\text { measurements; thus the TCT may request only UDV } \\
\text { detection be used. Otherwise, both methods are used. }\end{array}$ \\
\hline
\end{tabular}


Table 5.6. Particle Motion Descriptors for Visual Observations

\begin{tabular}{|c|c|c|}
\hline Number & Meaning & Description \\
\hline 1 & Below critical suspension velocity $<\mathrm{U}_{\mathrm{CS}}$ & $\begin{array}{l}\text { Solids may be moving or partly suspended; regions of } \\
\text { settled particles are apparent (settled particles may be } \\
\text { moving). }\end{array}$ \\
\hline 2 & Critical suspension, $\mathrm{U}_{\mathrm{CS}}$ at tank center. & $\begin{array}{l}\text { Initial state of complete solids suspension (all moving off } \\
\text { bottom) occurs at the center of the tank at the end of the } \\
\text { fluid pulse while unsuspended particles exist elsewhere on } \\
\text { tank bottom. This behavior is not observed for all } \\
\text { combinations of simulants and geometries/tube arrays. }\end{array}$ \\
\hline 3 & Overall critical suspension ${ }^{(a)}$ & $\begin{array}{l}\text { Initial state of complete solids suspension (all moving off } \\
\text { bottom) occurs over entire tank. For pulsing jets, this is } \\
\text { defined as all particles moving at the end of a pulse. For } \\
\text { steady jets, any settling particles appear to lift off the } \\
\text { bottom within } 2 \text { sec of touching down. By definition this } \\
\text { behavior only exists at a single velocity for a given set of } \\
\text { operating, geometry, and physical conditions (not at } \\
\text { multiple velocities for the same test conditions). }\end{array}$ \\
\hline 4 & Beyond critical suspension velocity $>U_{C S}$ & $\begin{array}{l}\text { Discharge velocity is greater than } U_{C S} \text { For pulsing jets, } \\
\text { particles are fully suspended before the end of the pulse. }\end{array}$ \\
\hline
\end{tabular}

(a) In the large-scale systems, overall $U_{\mathrm{CS}}$ (condition 3) is not visually observable due to the steel heads (viewing ports only allow observation of the particulate at the bottom center). Only test conditions that yielded final solids suspension in the tank center in the 34- and 15-in. vessels were tested in the 70-in. system.

The center of the tank was selected as a readily scalable location to monitor the solids mobilization. Therefore, regardless of the test condition or potential pulse tube configuration, the solids mobilization at the tank center was monitored whether or not it was the final location on the tank bottom at which solids became mobilized. For this test program, the desire was to identify/determine metrics that could be used to evaluate trends over geometric scales. Without knowing what were the best metrics before testing, the decision was to monitor both the occurrence of a condition at a specific location as well as a defined condition regardless of location.

For the WTP test vessel configurations tested (e.g., HLP-22 and RDL-8), the center of the vessel was always the last location that the solids became mobilized. However, for other configurations evaluated to investigate the effects of pulse tube location, such as a four-tube configuration that consisted of only the inner ring of HLP-22 pulse tubes, the center region was not the last to mobilize. To accommodate the potential of having to monitor $\mathrm{U}_{\mathrm{CS}}$ other than at tank center, observation conditions 2 and 3 were defined (see Table 5.6).

Condition 2 was noted by the test observers for a discharge velocity if the $\mathrm{U}_{\mathrm{CS}}$ condition at the tank center was satisfied but solids elsewhere on the tank bottom were not fully suspended at the end of a pulse. This condition was never observed for the WTP configurations tested. This condition also could not be monitored in the 70-in. vessel due to the limited viewing port on the tank bottom. Therefore, testing in the 70-in. system was performed only for those configurations and conditions that yielded the location of final solids mobilization at the tank center. These conditions were later tested in the 15-in. system to confirm that final solids mobilization occurred at the tank center. It was assumed, based on 
these results, that final mobilization occurred at the tank center for the conditions tested in the 70-in. vessel.

For those cases where the final mobilization of solids on the tank bottom coincided with the tank center, condition 3 (Table 5.6) was noted by the test observers for the corresponding discharge velocity and the location of final suspension was given as the tank center. This is the condition occurring for all of the WTP configurations that were tested.

\subsubsection{Particle Cloud Height}

The particle cloud height was based on the upper height of the opaque cloud created by the suspension of solids at the center of the tank, which may or may not have been a well-defined boundary. The height was based on the cloud, not on the height of a few outlier particles. Note that cloud heights were measured the same way in the 2008 tests as they had been in the 2007 tests. The cloud heights tended to vary within a range of values during an observation period. Thus, in 2008 the procedure was modified to specify recording the range of cloud heights as upper and lower bounds.

- For steady flow the cloud heights were reported as the upper and lower bounds observed over a 1-minute interval. If the cloud height appeared constant the same value was recorded for both observations.

- For pulsed flow, the cloud heights were reported as the upper and lower bounds of the peak height of the opaque cloud (only one value per pulse) observed over at least three pulses (i.e., of the observed cloud heights only the minimum and maximum values are reported as the bounds). If the cloud height appeared constant the same value was recorded for both observations.

The average cloud height was determined by averaging the recorded upper and lower bound values. Cloud height was generally measured from the bottom center of the tank and data was always evaluated with respect to the bottom dead center of the tank. Measurements were recorded to the nearest $0.5 \mathrm{in}$. Measuring tapes were attached to the tank to facilitate these measurements.

\subsection{Data Acquisition System Calculations}

The DAS receives mass flow rate and fluid density signals from the Coriolis meter and converts those signals to instantaneous nozzle velocity, $\mathrm{u}(\mathrm{t})$, and volumetric flow rate, $\mathrm{Q}$ (as a function of time). From these the DAS can also calculate other parameters of interest. For the Fall 2007 and 2008 tests, the DAS was used to calculate the following values for each pulse cycle:

the average pulse velocity

$$
\mathrm{U} 1=\frac{\int \mathrm{U}(\mathrm{t}) \mathrm{dt}}{\mathrm{t}_{\mathrm{D}}}
$$


the average root-mean-squared pulse velocity

$$
\mathrm{U} 2=\left(\frac{\int \mathrm{U}(\mathrm{t})^{2} \mathrm{dt}}{\mathrm{t}_{\mathrm{D}}}\right)^{\frac{1}{2}}
$$

the average root-mean-cubed pulse velocity

$$
\mathrm{U} 3=\left(\frac{\int \mathrm{U}(\mathrm{t})^{3} \mathrm{dt}}{\mathrm{t}_{\mathrm{D}}}\right)^{\frac{1}{3}}
$$

the pulse volume fraction

$$
\phi_{\mathrm{p}}=\frac{\int \mathrm{Q}(\mathrm{t}) \mathrm{dt}}{\mathrm{V}_{\mathrm{REF}}}
$$

and the duty cycle

$$
D C=\frac{t_{D}}{t_{C}}
$$

where $t_{D}$, the pulse or discharge time, is the time from start of flow $\left(t_{F S}\right)$ to end of flow $\left(t_{F E}\right): t_{D}=t_{F E}-t_{F S}$, and $t_{C}$ is the cycle time. $V_{\mathrm{REF}}=(\pi / 4) \mathrm{D}^{3}$ is the reference volume based on the volume of a right circular cylinder of height and diameter D. Using a reference volume to model mixing performance is discussed further in Section 7.2.3.

The numerical integrations were performed over the duration of the pulse, from $t_{\mathrm{FS}}$ to $\mathrm{t}_{\mathrm{FE}}$. The specified calculation time periods are depicted in Figure 5.3. Also depicted is the parameter X (comparator set point), used in the DAS to determine the time periods. Parameter $\mathrm{X}$ is the velocity set point above which the system is judged to have flow and below which non-zero flow is assumed to be system variation and/or noise that is below the threshold velocity of interest for mobilization. Thus, $\mathrm{X}$ determines the start and end of flow used to determine $t_{D}$ and $t_{C}$ in Eq. (5.1) through (5.5).

For steady jet tests, the steady jet velocity, $\mathrm{U}_{\mathrm{S}}$, was calculated as a running time average of the instantaneous velocity, $\mathrm{u}(\mathrm{t})$, over a time interval sufficient to smooth out noise in the velocity signal.

Early testing conducted in July 2007 used the DAS to calculate the pulse volume fraction, $\phi_{\mathrm{p}}$, as shown in Eq. (5.4). However, the DAS performed the integration over the duration of the cycle (including the no-flow period prior to pulse), and the integration cycle was triggered by the valve drive voltage rather than nozzle velocity, $\mathrm{U}(\mathrm{t})$. The average velocities, $\mathrm{U} 1, \mathrm{U} 2$, and $\mathrm{U} 3$, were calculated similarly in post-test analysis. Several system improvements were made to the DAS after the July 2007 tests that allowed the additional calculations. 


\subsection{Governing Documents}

The tests were conducted based on test plans, test procedures, and test instructions. The documents controlling each test are listed in Table 5.7. This table also includes test procedures applicable to the ultrasonic methods and particle size analysis described in Appendix A and Section 3, respectively.

Table 5.7. Documents Governing the 2007 and 2008 Tests

\begin{tabular}{|c|c|c|c|}
\hline Document Type & Number & Title & Tes \\
\hline Test Plan & TP-RPP-WTP-480, Rev. 0 & M3 Testing Approach in Support of Tank HLP-22 & 2007 \\
\hline Test Procedure & TPR-RPP-WTP-522, Rev. 0 & Mobilization Experiments in 34-in. Test Tank & 2007 \\
\hline Test Instruction & TI-RPP-WTP-523, Rev. 0 & 34-in. Test Tank Instructions for Obtaining $\mathrm{V}_{\mathrm{JS}}{ }^{(\mathrm{a})}$ & 2007 \\
\hline Test Instruction & TI-RPP-WTP-526, Rev. 0 & Test Instructions for Benchmarking $\mathrm{V}_{\mathrm{JS}}$ Observers & 2007 \\
\hline Test Plan & TP-RPP-WTP-480, Rev. 0.1 & M3 Testing Approach in Support of Tank HLP-22 & 2008 \\
\hline Test Plan & TP-RPP-WTP-480, Rev. 0.2 & M3 Testing Approach in Support of Tank HLP-22 & 2009 \\
\hline Test Procedure & TPR-RPP-WTP-595, Rev. 0 & Mobilization Experiments in 34-in. Test Tank & 2008 \\
\hline Test Procedure & TPR-RPP-WTP-596, Rev. 0.1 & Mobilization Experiments in 15-in. Test Tank & 2008 \\
\hline Test Procedure & TPR-RPP-WTP-597, Rev. 0.1 & Mobilization Experiments in 70-in. Test Tank & 2008 \\
\hline Test Instruction & TI-RPP-WTP-598, Rev. 0 & 34-in. Test Tank Instructions for Obtaining $\mathrm{U}_{\mathrm{CS}}$ & 2008 \\
\hline Test Instruction & TI-RPP-WTP-600, Rev. 0 & 70-in. Test Tank Instructions for Obtaining $\mathrm{U}_{\mathrm{CS}}$ & 2008 \\
\hline Test Instruction & TI-RPP-WTP-636, Rev. 0 & 15-in. Test Tank Instructions for Obtaining $U_{\mathrm{CS}}$ & 2008 \\
\hline Test Procedure & TPR-RPP-WTP-608, Rev. 0 & $\begin{array}{l}\text { Calibration Procedure for Determining Velocity of } \\
\text { Ultrasonic Energy in Simulants }\end{array}$ & 2008 \\
\hline Test Procedure & TPR-RPP-WTP-626, Rev. 0 & Particle Size Analysis Using Malvern MS2000 & 2008 \\
\hline Test Procedure & TPR-RPP-WTP-628, Rev. 0 & $\begin{array}{l}\text { Procedure for Correlation of Ultrasonic Attenuation } \\
\text { and Slurry Concentration }\end{array}$ & 2008 \\
\hline Test Procedure & TPR-RPP-WTP-628, Rev. 0.1 & $\begin{array}{l}\text { Procedure for Correlation of Ultrasonic Attenuation } \\
\text { and Slurry Concentration }\end{array}$ & 2008 \\
\hline
\end{tabular}





\subsection{Mixing Experiments}

The mixing experiments and data obtained during the July 2007, Fall 2007, and 2008 mixing test campaigns are described in this section. In Section 6.1 the data reporting format is presented. In Sections 6.2, 6.3, and 6.4, the details of the three mixing test campaigns are summarized and cloud height results for specific tests are presented as functions of the nozzle velocity. Solids concentration by volume profile data are summarized in Section 6.5, and data from transient tests in which the cloud height at a constant nozzle velocity as a function of operation time from fully settled conditions are summarized in Section 6.6.

\subsection{Data Reporting Format}

The data from the mixing tests are summarized in Table 6.1 together with the general test conditions of tank scale (small, mid, or large) and head shape (elliptical, flanged and dished, or spherical). The first column of Table 6.1 lists the table number in Appendix B where the data is tabulated. The data are categorized by test campaigns denoted as tests conducted in 2008, July 2007, or Fall 2007. The tests conducted in 2008 used simulant from a different manufacturer than those conducted in 2007. The test details column shows the types of measurements used to determine the critical suspension velocity and the cloud height. The test data in Appendix B are listed chronologically based on increasing row number. The first several digits of the Appendix B row number are specified in the last column of Table 6.1. The tests conducted in 2008 in the elliptical or spherical head all start with the number 9 followed by the nominal tank diameter in inches. The tests conducted in 2008 using the flanged and dished head start with the nominal tank diameter in inches (70).

Table 6.1. Summary of Mixing Test General Conditions and Data

\begin{tabular}{|c|c|c|c|c|c|c|}
\hline Table & $\begin{array}{c}\text { Test } \\
\text { Campaign }\end{array}$ & $\begin{array}{l}\text { Tank } \\
\text { Scale }\end{array}$ & Head & $\begin{array}{l}\text { Simulant } \\
\text { Manufacturer }\end{array}$ & Test Details & $\begin{array}{l}\text { Row Number } \\
\text { Format }\end{array}$ \\
\hline B.3 & 2008 & $\begin{array}{l}\text { Small } \\
(15)\end{array}$ & $\begin{array}{l}\text { Elliptical } \\
\text { (E) }\end{array}$ & XLSciTech & $\begin{array}{l}\text { Visual observation of cloud height } \mathrm{H}_{\mathrm{C}} \text {. } \\
\text { Ultrasonic measurement of } \mathrm{U}_{\mathrm{CS}} \text { and } \\
\text { concentration. }\end{array}$ & $915 X X X X$ \\
\hline B. 4 & 2008 & $\begin{array}{l}\text { Mid } \\
(34)\end{array}$ & $\begin{array}{l}\text { Spherical } \\
\text { (S) }\end{array}$ & XLSciTech & $\begin{array}{l}\text { Visual observation of cloud height } \mathrm{H}_{\mathrm{C}} \text {. } \\
\text { Ultrasonic measurement of } \mathrm{U}_{\mathrm{CS}} \text { and } \\
\text { concentration. }\end{array}$ & 934XXXX \\
\hline B.5 & 2008 & $\begin{array}{l}\text { Large } \\
(70)\end{array}$ & $\begin{array}{l}\text { Elliptical } \\
\text { (E) }\end{array}$ & XLSciTech & $\begin{array}{l}\text { Visual observation of cloud height } \mathrm{H}_{\mathrm{C}} \text {. } \\
\text { Ultrasonic measurement of } \mathrm{U}_{\mathrm{CS}} \text { and } \\
\text { concentration. }\end{array}$ & $970 X X X X$ \\
\hline B.6 & 2008 & $\begin{array}{l}\text { Large } \\
(70)\end{array}$ & $\begin{array}{l}\text { Flanged and } \\
\text { dished }(F)\end{array}$ & XLSciTech & $\begin{array}{l}\text { Visual observation of cloud height } \mathrm{H}_{\mathrm{C}} \text {. } \\
\text { Ultrasonic measurement of } \mathrm{U}_{\mathrm{CS}} \text { and } \\
\text { concentration. }\end{array}$ & $70 X X X X$ \\
\hline B.7 & July 2007 & $\begin{array}{l}\text { Mid } \\
(34)\end{array}$ & $\begin{array}{l}\text { Spherical } \\
\text { (S) }\end{array}$ & Potters & $\begin{array}{l}\text { Visual observation of cloud height } \mathrm{H}_{\mathrm{C}} \text {. } \\
\text { Visual observation of } U_{\mathrm{CS}} \text {. }\end{array}$ & 2007XXXX \\
\hline B. 8 & Fall 2007 & $\begin{array}{l}\text { Mid } \\
(34)\end{array}$ & $\begin{array}{l}\text { Spherical } \\
\text { (S) }\end{array}$ & Potters & $\begin{array}{l}\text { Visual observation of cloud height } \mathrm{H}_{\mathrm{C} \text {. }} \\
\text { Visual observation of } \mathrm{U}_{\mathrm{CS}} \text {. }\end{array}$ & 709XXXX \\
\hline
\end{tabular}


The test data parameters tabulated in Appendix B are described in Table 6.2, and the measurement uncertainties are provided. The data in the first three rows of Appendix B are presented in the first three columns of Table 6.2.

Table 6.2. Test Parameter Description

\begin{tabular}{|c|c|c|c|c|}
\hline $\begin{array}{l}\text { Appendix B Column } \\
\text { Heading } \\
\end{array}$ & Units & Symbol & $\begin{array}{l}\text { Bounding Uncertainty }^{(\mathrm{a})} \\
\text { All or } \\
\text { small-/mid-/large-scale } \\
\end{array}$ & Description \\
\hline \multicolumn{5}{|c|}{ Location in Appendix $B$} \\
\hline Row 1 & Row 2 & Row 3 & Not included & Not included \\
\hline Row Number & text & MSS & N/A & numeric ID for data row \\
\hline Test & text & M/DDX & N/A & $\begin{array}{l}\text { notation for month, day and sequence of the test on } \\
\text { that day }\end{array}$ \\
\hline Case ID & text & ID & N/A & abbreviated test descriptor (see Table 6.4) \\
\hline Tank Diameter (measured) & in. & $\mathrm{D}$ & $\pm 0.07 / \pm 0.5 / \pm 0.2$ & inner diameter of cylindrical section of tank \\
\hline Head Shape & text & HS & N/A & shape (contour) of head for tank bottom \\
\hline Dish Height (head depth) & in. & $\mathrm{H}_{\text {dish }}$ & $\pm 0.2 / \pm 0.5 / \pm 0.5$ & $\begin{array}{l}\text { height of dish bottom interior measured from dish } \\
\text { bottom center }\end{array}$ \\
\hline Dish Volume (ideal shape) & in. $^{3}$ & $\mathrm{~V}_{\text {dish }}$ & $4 \% / 7 \% / 4 \%$ & $\begin{array}{l}\text { calculated volume of head (dish) assuming ideal } \\
\text { contour }\end{array}$ \\
\hline Tank Fill Height & in. & $\mathrm{H}$ & $\pm 0.3 / \pm 0.3 / \pm 0.5$ & height of liquid above bottom center of tank \\
\hline $\begin{array}{l}\text { Return Line Height } \\
\text { (average) }\end{array}$ & in. & Rtn & $\pm 0.3 / \pm 0.3 / \pm 0.5$ & $\begin{array}{l}\text { height of mid-line of return line opening above } \\
\text { bottom center of tank (return line opening incline) }\end{array}$ \\
\hline $\begin{array}{l}\text { Nozzle Inner Diameter } \\
\text { (average) }\end{array}$ & in. & d & $\pm 5 \mathrm{E}-4$ & average inner diameter for set of nozzles \\
\hline $\begin{array}{l}\text { Nozzle Stand-off Distance } \\
\text { (average) }\end{array}$ & in. & sod & \pm 0.08 & $\begin{array}{l}\text { average distance from the nozzle discharge to the } \\
\text { tank floor at the nozzle center line }\end{array}$ \\
\hline Pulse Tube Configuration & text & PT & N/A & $\begin{array}{l}\text { number and placement of pulse tubes including radial } \\
\text { and azimuthal coordinates }\end{array}$ \\
\hline Installed Nozzles & number & $\mathrm{N}$ & 0 & number of installed pulse tubes \\
\hline Outer Nozzles Operated & number & $\mathrm{N}_{\mathrm{O}}$ & 0 & number of pulse tubes operated in the outer ring \\
\hline Inner Nozzles Operated & number & $\mathrm{N}_{\mathrm{I}}$ & 0 & number of pulse tubes operated in the inner ring \\
\hline Pulse Tube Outer Diameter & in. & $\mathrm{PT}_{\text {od }}$ & \pm 0.01 & outer diameter of pulse tube \\
\hline $\begin{array}{l}\text { Outer PJM Radius } \\
\text { (average) }\end{array}$ & in. & $\mathrm{R}_{\mathrm{O}}$ & $\pm 0.03 / \pm 0.1 / \pm 0.2$ & $\begin{array}{l}\text { calculated average distance from pulse-tube array } \\
\text { centerline to nozzle centerlines in outer ring of pulse } \\
\text { tubes }\end{array}$ \\
\hline Inner PJM Radius (average) & in. & $\mathrm{R}_{\mathrm{I}}$ & $\pm 0.03 / \pm 0.1 / \pm 0.2$ & $\begin{array}{l}\text { calculated average distance from pulse-tube array } \\
\text { centerline to nozzle centerlines in inner ring of pulse } \\
\text { tubes }\end{array}$ \\
\hline $\begin{array}{l}\text { Outer PJM Impingement } \\
\text { Angle }\end{array}$ & deg & $\theta_{\mathrm{O}}$ & $\pm 1^{0}$ & $\begin{array}{l}\text { impingement angle between nozzle centerline, for } \\
\text { pulse tubes in outer ring, and the tangent plane of the } \\
\text { ideal head contour taken at the point directly below } \\
\text { the nozzle centerline. }\end{array}$ \\
\hline $\begin{array}{l}\text { Inner PJM Impingement } \\
\text { Angle }\end{array}$ & deg & $\theta_{\mathrm{I}}$ & $\pm 1^{0}$ & $\begin{array}{l}\text { impingement angle between nozzle centerline, for } \\
\text { pulse tubes in inner ring, and the tangent plane of the } \\
\text { ideal head contour taken at the point directly below } \\
\text { the nozzle centerline. }\end{array}$ \\
\hline $\begin{array}{l}\text { Ratio Outer PJM (average) } \\
\text { to Tank Radius }\end{array}$ & nondim & $\mathrm{R}_{\mathrm{O}} / \mathrm{R}$ & \pm 0.01 & ratio of $\mathrm{R}_{\mathrm{O}}$ to tank radius \\
\hline $\begin{array}{l}\text { Ratio Inner PJM (average) } \\
\text { to Tank Radius }\end{array}$ & nondim & $\mathrm{R}_{\mathrm{I}} / \mathrm{R}$ & \pm 0.01 & ratio of $\mathrm{R}_{\mathrm{I}}$ to tank radius \\
\hline
\end{tabular}


Table 6.2. (contd)

\begin{tabular}{|c|c|c|c|c|}
\hline $\begin{array}{l}\text { Appendix B Column } \\
\text { Heading }\end{array}$ & Units & Symbol & $\begin{array}{l}\text { Bounding Uncertainty } \\
\text { All or } \\
\text { small-/mid-/large-scale }\end{array}$ & Description \\
\hline \multicolumn{5}{|c|}{ Location in Appendix B } \\
\hline Row 1 & Row 2 & Row 3 & Not included & Not included \\
\hline Simulant & text & sxdx & N/A & $\begin{array}{l}\text { symbol combines simulant density (sx or px) and } \\
\text { particle diameter (dx) }\end{array}$ \\
\hline Solids Density & $\mathrm{g} / \mathrm{cm}^{3}$ & $\rho_{\mathrm{s}}$ & \pm 0.02 & solids simulant density \\
\hline Particle Diameter d5 & $\mu \mathrm{m}$ & $d_{5}$ & $\pm 10 \%$ of measurement & 5th percentile of particle diameter \\
\hline Particle Diameter d50 & $\mu \mathrm{m}$ & $d_{50}$ & $\pm 10 \%$ of measurement & 50th percentile of particle diameter \\
\hline Particle Diameter d95 & $\mu \mathrm{m}$ & $\mathrm{d}_{95}$ & $\pm 10 \%$ of measurement & 95th percentile of particle diameter \\
\hline Void Fraction & fraction & $\mathrm{vf}$ & \pm 0.06 & volume fraction of fluid in settled bed of solids \\
\hline Tank Water Temperature & $\mathrm{C}$ & $\mathrm{T}$ & $\pm 2^{0}$ & $\begin{array}{l}\text { temperature of water measured near tank wall at mid- } \\
\text { fill height }\end{array}$ \\
\hline Water Density & $\mathrm{g} / \mathrm{cm}^{3}$ & $\rho_{\mathrm{l}}$ & \pm 0.006 & $\begin{array}{l}\text { density of water in tank obtained from correlating } \\
\text { measured tank temperature with water density from } \\
\text { published source. }\end{array}$ \\
\hline $\begin{array}{l}\text { Solids Fraction (relative to } \\
\text { reference volume)) }\end{array}$ & fraction & $\phi_{\mathrm{S}}$ & $\pm 0.0004 / \pm 0.0008 / \pm 0.0006$ & $\begin{array}{l}\text { calculated solids fraction relative to reference volume } \\
\text { of a right circular cylinder with diameter and height } \\
\text { equal to the nominal tank diameter (14.5 in., } 34 \text { in, } \\
\text { or } 70 \text { in.). }\end{array}$ \\
\hline Pulse Volume Fraction & fraction & $\phi_{\mathrm{p}}$ & $\pm 0.001 / \pm 0.003 / \pm 0.002$ & $\begin{array}{l}\text { ratio of the volume of the total discharge pulse (sum } \\
\text { of all nozzles) to the volume of a right circular } \\
\text { cylinder with diameter and height equal to the } \\
\text { measured tank diameter (14-7/16 in.) or nominal tank } \\
\text { diameter ( } 70 \text { in. and } 34 \text { in.) }\end{array}$ \\
\hline Duty Cycle & fraction & DC & $\pm 0.003 / \pm 0.002 / \pm 0.0004$ & $\begin{array}{l}\text { fraction of the fluid discharge pulse cycle with fluid } \\
\text { flowing out the nozzles at a flow rate greater than the } \\
\text { Setpoint X. }\end{array}$ \\
\hline Cycle Time & $\mathrm{s}$ & $\mathrm{t}_{\mathrm{C}}$ & \pm 0.01 & period of the fluid discharge pulse cycle \\
\hline Pulsed or Steady Jet & text & Jet & N/A & indication of pulsed or steady flow in the tank \\
\hline $\begin{array}{l}\text { Us Steady Jet (discharge } \\
\text { velocity averaged) }\end{array}$ & $\mathrm{m} / \mathrm{s}$ & $\mathrm{U}_{\mathrm{S}}$ & $\pm 0.06 / \pm 0.03 / \pm 0.01$ & $\begin{array}{l}\text { steady jet velocity calculated by the DAS from } \\
\text { volume flow rate measurements }\end{array}$ \\
\hline U1 Pulsing Jet & $\mathrm{m} / \mathrm{s}$ & U1 & $\pm 0.07 / \pm 0.03 / \pm 0.02$ & $\begin{array}{l}\text { average pulse velocity calculated by DAS from } \\
\text { volume flow rate measurements [see Eq. (5.1)] }\end{array}$ \\
\hline U2 URMS & $\mathrm{m} / \mathrm{s}$ & $\mathrm{U} 2$ & $\pm 0.07 / \pm 0.03 / \pm 0.02$ & $\begin{array}{l}\text { average RMS (root mean square) pulse velocity } \\
\text { calculated by DAS [see Eq. (5.2)] }\end{array}$ \\
\hline U3 URM3 & $\mathrm{m} / \mathrm{s}$ & U3 & $\pm 0.07 / \pm 0.03 / \pm 0.02$ & $\begin{array}{l}\text { average RMC (root mean cubed) pulse velocity } \\
\text { calculated by DAS [see Eq. (5.3)] }\end{array}$ \\
\hline Discharge Velocity & $\mathrm{m} / \mathrm{s}$ & $\mathrm{U}$ & $\pm 0.9 / \pm 0.5 / \pm 0.3$ & $\begin{array}{l}\text { velocity obtained by visually averaging charted real- } \\
\text { time signal on DAS screen (UPA) and manually } \\
\text { recording values for individual discharge pulses with } \\
\text { an acceptable variation on the target velocity of } \pm \\
5 \% \text {. Visual averaging done for steady portion of } \\
\text { discharge pulse following any initial overshoot. }\end{array}$ \\
\hline $\begin{array}{l}\text { Critical Suspension } \\
\text { Velocity }\end{array}$ & $\mathrm{m} / \mathrm{s}$ & $\mathrm{U}_{\mathrm{CS}}$ & $\pm 0.9^{(\mathrm{b})} / \pm 0.5^{(\mathrm{b}, \mathrm{c})} / \pm 0.4^{(\mathrm{b})}$ & critical suspension velocity for the test conditions \\
\hline Average Peak Cloud Height & in. & $\mathrm{H}_{\mathrm{C}}$ & \pm 0.005 & average peak cloud height measured from dish center \\
\hline $\mathrm{U}_{\mathrm{CS}}$ Condition & $\mathrm{m} / \mathrm{s}$ & $\mathrm{U}_{\mathrm{CSR}}$ & $\pm 0.9^{(\mathrm{b})} / \pm 0.5^{(\mathrm{b}, \mathrm{c})} / \pm 0.4^{(\mathrm{b})}$ & $\begin{array}{l}\text { cell used to select the critical suspension velocity, } \\
\text { upon data analyst review of test data }\end{array}$ \\
\hline $\mathrm{U}_{\mathrm{CS}}$ Method & text & $\mathrm{U}_{\mathrm{CSM}}$ & N/A & $\begin{array}{l}\mathrm{U}_{\mathrm{cs}} \text { condition based on method indicated: Udv } \\
\text { measurements, visual observations (tankwide), or } \\
\text { visual observations (tank center) }\end{array}$ \\
\hline
\end{tabular}


Table 6.2. (contd)

\begin{tabular}{|c|c|c|c|c|}
\hline $\begin{array}{l}\text { Appendix B Column } \\
\text { Heading }\end{array}$ & Units & Symbol & $\begin{array}{l}\text { Bounding Uncertainty } \\
\text { All or } \\
\text { small-/mid-/large-scale }\end{array}$ & Description \\
\hline \multicolumn{5}{|c|}{ Location in Appendix B } \\
\hline Row 1 & Row 2 & Row 3 & Not included & Not included \\
\hline $\mathrm{U}_{\mathrm{CS}}$ Flag & text & $\mathrm{U}_{\mathrm{CS}} \mathrm{vis}$ & N/A & $\begin{array}{l}\text { flag for } \mathrm{U}_{\mathrm{CS}} \text { determined visually at current test } \\
\text { condition }\end{array}$ \\
\hline $\mathrm{U}_{\mathrm{CS}}$ Center Flag & text & $\mathrm{U}_{\mathrm{CS}} \mathrm{Cen}$ & N/A & $\begin{array}{l}\text { flag for } \mathrm{U}_{\mathrm{CS}} \text { determined visually at center of tank at } \\
\text { current test condition }\end{array}$ \\
\hline $\mathrm{U}_{\mathrm{CS}}$ UDV Flag & text & $\mathrm{U}_{\mathrm{CS}} \mathrm{udv}$ & N/A & $\begin{array}{l}\text { flag for } U_{\mathrm{CS}} \text { determined using ultrasonic Doppler } \\
\text { velocimeter at center of tank at current test condition }\end{array}$ \\
\hline $\begin{array}{l}\mathrm{U}_{\mathrm{CS}} \text { Based on Decreasing } \\
\text { Velocity }\end{array}$ & $\mathrm{m} / \mathrm{s}$ & $\mathrm{U}_{\mathrm{CS} \_\mathrm{D}}$ & $\pm 0.9^{(\mathrm{b})} / \pm 0.5^{(\mathrm{b}, \mathrm{c})} / \pm 0.4^{(\mathrm{b})}$ & $\begin{array}{l}\text { flag for } \mathrm{U}_{\mathrm{CS}} \text { determined after a decrease in velocity at } \\
\text { current test condition }\end{array}$ \\
\hline Sweep Increase / Decrease & text & $\mathrm{S}_{\mathrm{W}}$ & N/A & $\begin{array}{l}\text { Increase (I) or decrease (D) from last change. A } \\
\text { "(null)" is indicated as no change (start of day } \\
\text { velocity) or if recent history is indeterminant }\end{array}$ \\
\hline UDV Height Bed & $\mathrm{mm}$ & $\mathrm{H}_{\text {bed }}$ & \pm 2 & $\begin{array}{l}\text { indicated depth of settled solids determined by } \\
\text { ultrasonic Doppler velocimetry }\end{array}$ \\
\hline Particle Motion & text & PM & N/A & $\begin{array}{l}\text { particle motion descriptor based (see Table } 5.2 \text { for } \\
2007 \text { tests and Table } 5.7 \text { for } 2008 \text { tests) }\end{array}$ \\
\hline Solids Level & text & Sol & N/A & $\begin{array}{l}\text { visually determined solids level descriptor (see } \\
\text { Table 5.3) }\end{array}$ \\
\hline Outer Bottom Pattern & text & $\mathrm{SP}_{\mathrm{O}}$ & N/A & $\begin{array}{l}\text { visually determined outer cleared region viewed from } \\
\text { beneath the tank (see Table } 5.4 \text { ) }\end{array}$ \\
\hline Inner Bottom Pattern & text & $\mathrm{SP}_{\mathrm{I}}$ & N/A & $\begin{array}{l}\text { visually determined inner cleared region viewed from } \\
\text { beneath the tank (see Table 5.4) }\end{array}$ \\
\hline TDP & text & N/A & N/A & $\begin{array}{l}\text { Test Data Package number where original test data } \\
\text { recorded }\end{array}$ \\
\hline \multicolumn{5}{|c|}{$\begin{array}{l}\text { (a) Uncertainties indicated are bounding values for the entire test program and range of configurations tested. For many test } \\
\text { conditions/configurations, the uncertainties are significantly lower. }\end{array}$} \\
\hline \multirow[t]{2}{*}{ DSC } & $\begin{array}{l}\text { st cases l } \\
0,70038 \\
9700313\end{array}$ & $\begin{array}{l}\text { ted in Ap } \\
\text { The liste }\end{array}$ & $\begin{array}{l}\text { 9700060, } 9700068,970009 \\
\text { cases were not fully bound }\end{array}$ & $\begin{array}{l}\text { ISS row numbers 700223, 700224, 700324, 700237, } \\
9700119,9700121,9700126,9700144,9740232 \text {, } \\
\text { by the } \pm 0.2 \mathrm{~m} / \mathrm{s} \text { surrounding (sequential) }\end{array}$ \\
\hline & & 2007. & & \\
\hline
\end{tabular}

The parameter ranges and test count of the test campaigns are listed in Table 6.3. Note that during the Fall 2007 test campaign, broad ranges are shown for tank fill height and return line height. As stated in Section 1.4.7, these parameters were only varied to determine the limits of the test fixture performance.

Table 6.3. Range of Test Conditions

\begin{tabular}{llcccccc}
\hline & & \multicolumn{5}{c}{ Test Campaign } \\
Appendix B Column & & \multicolumn{5}{c}{ (Campaign - Nominal Tank Diameter - Head Shape Indicator) } \\
\cline { 3 - 8 } Heading & Units & 2008 15E & 2008 34S & 2008 70E & 2008 70F & July 2007 34S & Fall 2007 34S \\
\hline Row Number & text & $9150001-$ & $9340001-$ & $9700001-$ & $700204-$ & $20070019-$ & $7090002-$ \\
& & 9150793 & 9340234 & 9700338 & 700446 & 20071401 & 7091423 \\
Test & text & 62 & 19 & 37 & 27 & 30 & 81 \\
Case ID & text & 52 & 19 & 27 & 23 & 24 & 45 \\
Tank Diameter & in. & $14-7 / 16$ & $33-7 / 8$ & 70 & 70 & $33-7 / 8$ & $33-7 / 8$ \\
Head Shape & text & E & S & E & FD & S & S \\
Dish Height & in. & 3.25 & 9 & 19 & 12.7 & 9 & 9 \\
\hline
\end{tabular}


Table 6.3. (contd)

\begin{tabular}{|c|c|c|c|c|c|c|c|}
\hline \multirow{2}{*}{$\begin{array}{l}\text { Appendix B Column } \\
\text { Heading }\end{array}$} & \multirow[b]{2}{*}{ Units } & \multicolumn{6}{|c|}{$\begin{array}{c}\text { Test Campaign } \\
\text { (Campaign - Nominal Tank Diameter - Head shape Indicator) }\end{array}$} \\
\hline & & $200815 \mathrm{E}$ & $200834 S$ & $200870 \mathrm{E}$ & $200870 \mathrm{~F}$ & July 2007 34S & Fall 2007 34S \\
\hline Dish Volume & in. $^{3}$ & 354.8 & 4437.4 & 49770.7 & 30569 & 4437.4 & 4437.4 \\
\hline Tank Fill Height & in. & $33.5-36$ & $69-72$ & $91-94$ & $87.5-90.5$ & $65.8-76.1$ & $23.7-67.8$ \\
\hline Return Line Height & in. & $29-30$ & 66 & 80 & $83-5 / 8$ & 62 & $21.7-65-3 / 4$ \\
\hline Nozzle Inner Diameter & in. & $0.126-0.375$ & 0.297 & $0.613,0.92$ & $0.613,0.92$ & $0.297,0.446$ & $0.297,0.446$ \\
\hline Nozzle Standoff Distance & in. & $0.19-0.56$ & 0.45 & $0.92,1.38$ & $0.92,1.38$ & $0.45,0.67$ & $0.45,0.67$ \\
\hline Pulse Tube Configuration & text & HLP-22, 8TA & HLP-22 & HLP-22, 8TA & HLP-22 & HLP-22 & HLP-22 \\
\hline Installed Nozzles & number & 8,12 & 12 & 8,12 & 12 & 12 & 12 \\
\hline Outer Nozzles Operated & number & 4,8 & 8 & 4,8 & 8 & 8 & 8 \\
\hline Inner Nozzles Operated & number & 0,4 & 4 & 0,4 & 4 & 4 & 0,4 \\
\hline $\begin{array}{l}\text { Nozzle Combinations } \\
\text { (outer/inner) }\end{array}$ & $\begin{array}{l}\text { number/ } \\
\text { number }\end{array}$ & $\begin{array}{c}8 / 4 \text { (HLP 22) } \\
4 / 4,4 / 0 \\
\text { (8TA) }\end{array}$ & $8 / 4$ & $\begin{array}{l}8 / 4 \text { (HLP 22) } \\
4 / 4,4 / 0 \text { (8TA) }\end{array}$ & $8 / 4$ & $8 / 4$ & $\begin{array}{l}4 / 0,8 / 0,4 / 4 \\
8 / 4,0 / 4\end{array}$ \\
\hline $\begin{array}{l}\text { Pulse Tube Outer } \\
\text { Diameter }\end{array}$ & in. & 1.05 & 1.9 & 3.5 & 3.5 & 1.9 & 1.9 \\
\hline Outer PJM Radius & in. & $4.5,4.85$ & 10.46 & 21.85, 23.5 & 26.4 & 10.46 & 10.46 \\
\hline Inner PJM Radius & in. & 2.44, 3.61 & 5.67 & $11.48,17.48$ & 11.68 & 5.67 & 5.67 \\
\hline $\begin{array}{l}\text { FIO Outer PJM } \\
\text { Impingement Angle }\end{array}$ & deg & $21.8,24.4$ & 30.8 & $20.3,21.9$ & 22.4 & 30.8 & 30.8 \\
\hline $\begin{array}{l}\text { FIO Inner PJM } \\
\text { Impingement Angle }\end{array}$ & deg & $10.1,16$ & 16.1 & $10.5,16.1$ & 9.7 & 16.1 & 16.1 \\
\hline $\begin{array}{l}\text { Ratio Outer PJM to Tank } \\
\text { Radius }\end{array}$ & nondim & $0.62,0.67$ & 0.62 & $0.62,0.67$ & 0.75 & 0.62 & 0.62 \\
\hline $\begin{array}{l}\text { Ratio Inner PJM to Tank } \\
\text { Radius }\end{array}$ & nondim & $0.34,0.5$ & 0.33 & $0.33,0.5$ & 0.33 & 0.33 & 0.33 \\
\hline Simulant & text & $\begin{array}{l}\text { s1d1, s1d2, } \\
\text { s1d5, s2d1, } \\
\text { s2d2 }\end{array}$ & $\begin{array}{l}\text { s1d1, s1d2, } \\
\text { s2d1, s2d2 }\end{array}$ & $\begin{array}{l}\text { s1d1, s1d2, } \\
\text { s2d2 }\end{array}$ & $\begin{array}{l}\text { s1d1, s1d2, } \\
\text { s2d2 }\end{array}$ & $\begin{array}{l}\text { p1d7, p1d8, } \\
\text { p2d6 }\end{array}$ & p1d7, p1d8 \\
\hline Solids Density & $\mathrm{g} / \mathrm{cm}^{3}$ & $2.46-4.18$ & $2.46-4.18$ & $2.46-4.18$ & $2.46-4.18$ & $2.45-2.46$ & 2.45 \\
\hline Particle Diameter d5 & $\mu \mathrm{m}$ & $32.8-142.8$ & $56.9-142.8$ & 56.9-142.8 & 56.9-142.8 & $60.5-518.4$ & $60.5,121.3$ \\
\hline Particle Diameter d50 & $\mu \mathrm{m}$ & 43.9-166.4 & 69.3-166.4 & $69.3-166.4$ & $69.3-166.4$ & $89.5-766.2$ & $89.5,178.0$ \\
\hline Particle Diameter d95 & $\mu \mathrm{m}$ & 58.5-195.1 & $82.1-195.1$ & $82.1-195.1$ & 82.1-195.1 & $132.0-1172.9$ & $132.0,260.6$ \\
\hline Void Fraction & fraction & $0.37-0.41$ & $0.37-0.41$ & $0.37-0.41$ & $0.37-0.41$ & $0.41-0.43$ & 0.43 \\
\hline Tank Water Temp. & $\mathrm{C}$ & $20.4-34.2$ & $12.6-23.8$ & $17.3-27.1$ & $20.4-25.1$ & $22.0-30$ & $20.5-24.0$ \\
\hline Water Density & $\mathrm{g} / \mathrm{cm}^{3}$ & $0.997-1$ & $0.997-1$ & 0.993-0.996 & $0.994-0.996$ & 0.997-0.999 & 0.995-0.999 \\
\hline Solids Fraction & fraction & $0.0005-0.06$ & $\begin{array}{c}0.00015- \\
0.015\end{array}$ & $\begin{array}{c}0.00155- \\
0.015\end{array}$ & $\begin{array}{c}0.00155- \\
0.0143\end{array}$ & $\begin{array}{c}0.00485- \\
0.01592\end{array}$ & 0.00487 \\
\hline Pulse Volume Fraction & fraction & 0.050 .15 & 0.050 .1 & $0.05-0.15$ & $0.05-0.15$ & $0.025-0.1$ & $0.04-0.06$ \\
\hline Duty Cycle ${ }^{(a)}$ & fraction & $0.17-1$ & $0.18-0.5$ & $0.17-1$ & $0.14-0.67$ & $0.18-1$ & $0.18-1$ \\
\hline Cycle Time (pulsed tests) & $\mathrm{s}$ & $4.2-90.6$ & $10-75$ & 22.6-285 & 18.4-252 & $1-82$ & 12-190 \\
\hline Pulsed or Steady Jet & text & $\mathrm{P}, \mathrm{S}$ & $\mathrm{P}$ & $\mathrm{P}, \mathrm{S}$ & $\mathrm{P}$ & $\mathrm{P}, \mathrm{S}$ & $\mathrm{P}, \mathrm{S}$ \\
\hline Us Steady Jet & $\mathrm{m} / \mathrm{s}$ & $2-3.2$ & N/A & 3.5 & N/A & $1.5-9.1$ & $2-13.1$ \\
\hline U1 Pulsing Jet & $\mathrm{m} / \mathrm{s}$ & $0.8-14$ & $2.2-12.8$ & $2.9-14.7$ & $4.2-11.6$ & $1.8-11.4$ & $2.3-15.9$ \\
\hline U2 URMS & $\mathrm{m} / \mathrm{s}$ & $0.8-14.7$ & $2.2-13.2$ & 2.9-15.1 & $4.2-11.9$ & $1.8-12.8$ & $2.4-16.4$ \\
\hline U3 URM3 & $\mathrm{m} / \mathrm{s}$ & $0.8-15$ & $2.2-13.4$ & $2.9-15.4$ & $4.3-12$ & $1.9-13.5$ & $2.4-16.8$ \\
\hline Discharge Velocity & $\mathrm{m} / \mathrm{s}$ & $0.8-15$ & $2.2-14$ & 3-16.1 & $3.8-12.5$ & $1.5-15.2$ & $2-15$ \\
\hline Critical Suspension & $\mathrm{m} / \mathrm{s}$ & $1.3-11.8$ & $2.75-10.4$ & $4.3-14$ & $4.4-11.4$ & $2-8.5$ & $2.6-14$ \\
\hline
\end{tabular}


Table 6.3. (contd)

\begin{tabular}{|c|c|c|c|c|c|c|c|}
\hline \multirow{2}{*}{$\begin{array}{l}\text { Appendix B Column } \\
\text { Heading }\end{array}$} & \multirow[b]{2}{*}{ Units } & \multicolumn{6}{|c|}{$\begin{array}{c}\text { Test Campaign } \\
\text { (Campaign - Nominal Tank Diameter - Head shape Indicator) }\end{array}$} \\
\hline & & $200815 E$ & $200834 S$ & $200870 \mathrm{E}$ & $200870 \mathrm{~F}$ & July 2007 34S & Fall 2007 34S \\
\hline \multicolumn{8}{|l|}{ Velocity } \\
\hline $\begin{array}{l}\text { Average Peak Cloud } \\
\text { Height }\end{array}$ & in. & $3.25-27$ & $9.25-53.5$ & 21.5-88 & $18.5-51.5$ & $8.6-42.1$ & $8.5-51$ \\
\hline $\mathrm{U}_{\mathrm{CS}}$ Condition & $\mathrm{m} / \mathrm{s}$ & $1.3-11.8$ & 2.75-10.4 & $4.3-14$ & $4.4-11.4$ & $3.3-8.5$ & $3-14$ \\
\hline $\begin{array}{l}\mathrm{U}_{\mathrm{CS}} \text { based on Decreasing } \\
\text { Velocity }\end{array}$ & $\mathrm{m} / \mathrm{s}$ & N/A & $5-10.1$ & N/A & 6.6 & 3.9 & N/A \\
\hline UDV Height Bed & $\mathrm{mm}$ & $0-30.7$ & $0-41.6$ & $0-36.8$ & $0-40.2$ & N/A & N/A \\
\hline
\end{tabular}

A Case ID was assigned to each test that provided a concise summary of specific test parameters. The Case IDs are defined in Table 6.4. This notation is used to identify test conditions throughout the report. The first two digits (DD) of the Case ID show the tank diameter in inches (15, 34, or 70). The next digit (B) shows the head shape (E for elliptical, $\mathrm{F}$ for flanged and dished, and $\mathrm{S}$ for spherical). In some cases the head shape is shown as E8, which denotes tests conducted configured as an 8 tube array instead of a 12-tube array. The next digit (L) shows the full-scale nozzle diameter in inches (4, 6, $\mathrm{M}$ for 8.5, and $\mathrm{L}$ for 11.8). The next 4-digit sequence (MMNN) is the simulant code with MM showing the density and NN showing the nominal particle size. The next digit $(\mathrm{O}$, an upper case letter) shows the solids volume fraction. The next digit ( $\mathrm{P}$, a lower case letter) shows the nominal duty cycle. The last digit (Q) shows the nominal pulse volume fraction. For pulsating flow, $\mathrm{Q}$ is shown as an underscore followed by a number (such as _1). For steady flow with a reduced number of pulse tubes in operation, Q is shown as a dash followed by the number of outer nozzles in operation followed by the number of inner nozzles in operation (such as -80, 8 outer nozzles operating and 0 inner nozzles operating). Additional details are provided in Table 6.4.

\subsection{July 2007 Tests in Mid-Scale Tank with Spherical Head}

The July 2007 mixing test campaign was the first group of tests conducted at PNNL in response to Issue M3, Inadequate Design of Mixing Systems-Pulse Jet Mixers to evaluate noncohesive solids suspension using PJMs. During the initial tests, significant time was spent visually observing the flow patterns of the solid particulate on the tank bottom during operation of the PJMs to determine when $\mathrm{U}_{\mathrm{CS}}$, the critical suspension velocity, occurred. The visual observations were made from below the tank. An example of the view from beneath the mid-scale tank is shown in Figure 6.1. In Figure 6.1 (a) no solids are in the vessel; in each of the white pulse tubes the black plastic jet nozzle is visible. The four inner pulse tubes are visible as a square pattern. Around the tank perimeter the eight outer pulse tubes are visible. The four larger-diameter tubes with angled ends are the return lines. In the center of the tank bottom, an access plug is visible. In Figure 6.1(b) solids are in the vessel and the pulse tubes are operating; circular patterns in the settled solid particulate from the jets are visible; the black nozzles of the four inner jets may be observed. Blue taped cross patterns, placed on the bottom of the tank to indicate the size of the mobilized area, are visible in two of the inner jet rings. The cleared patterns from the ring of outer nozzles are also visible around the perimeter of the vessel. 
Table 6.4. Summary of Case ID Format

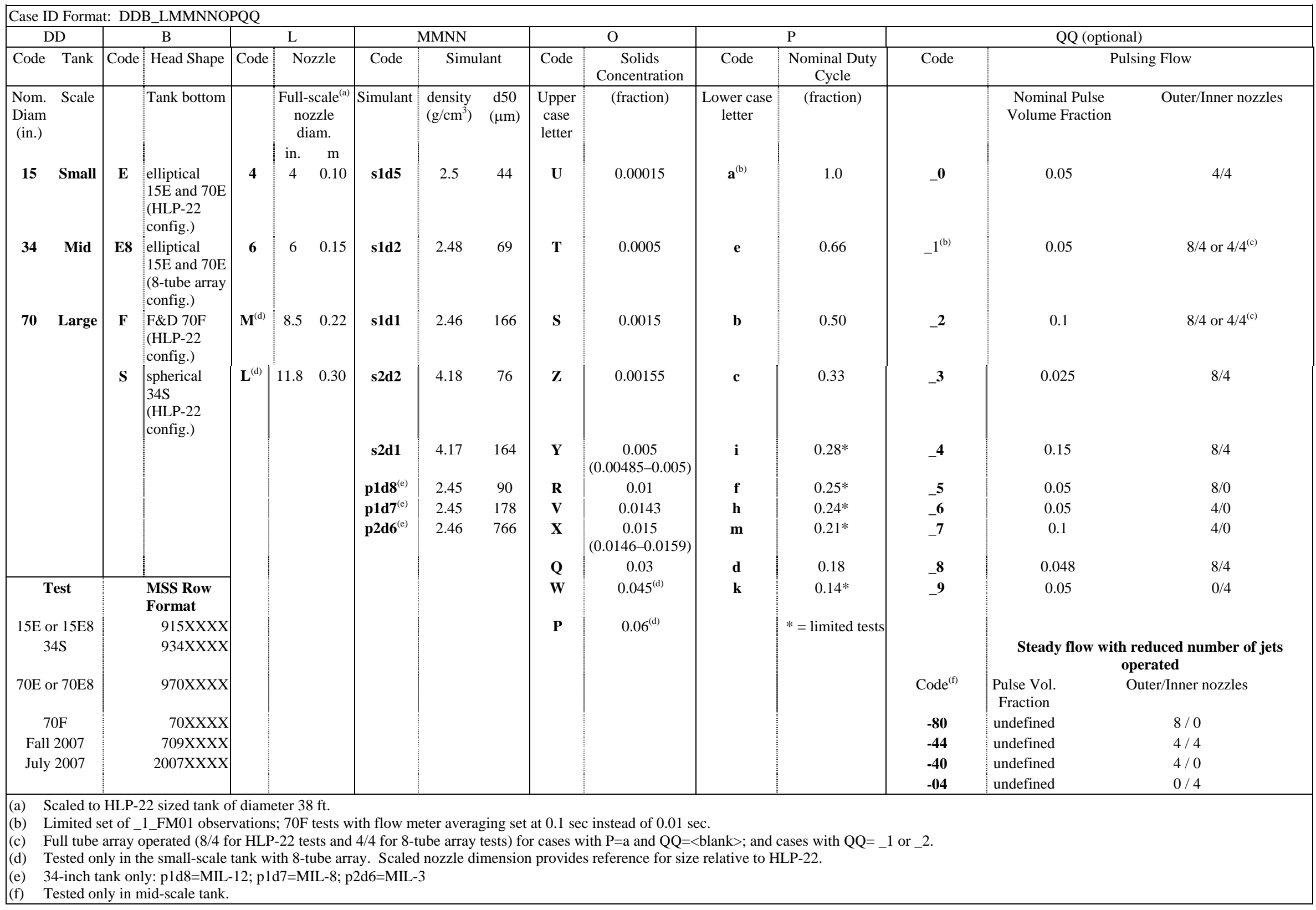




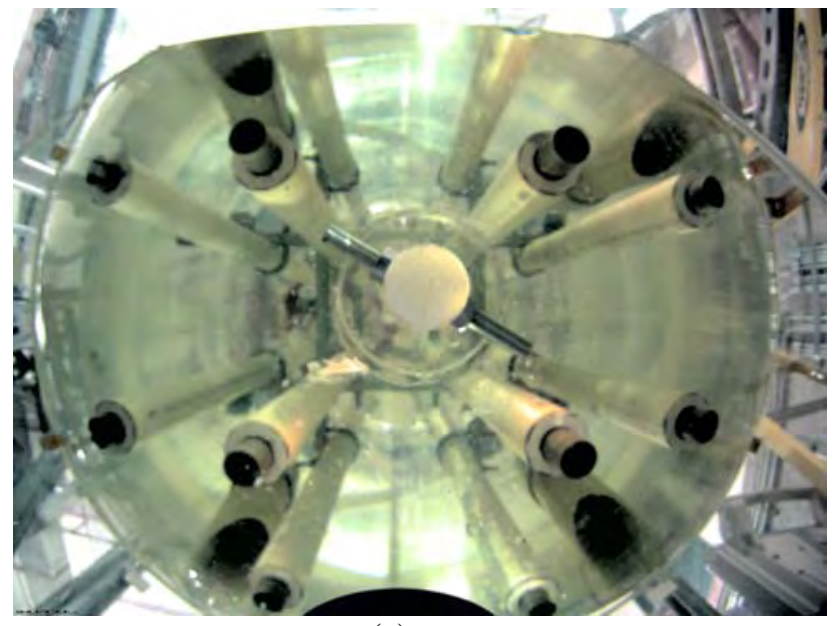

(a)

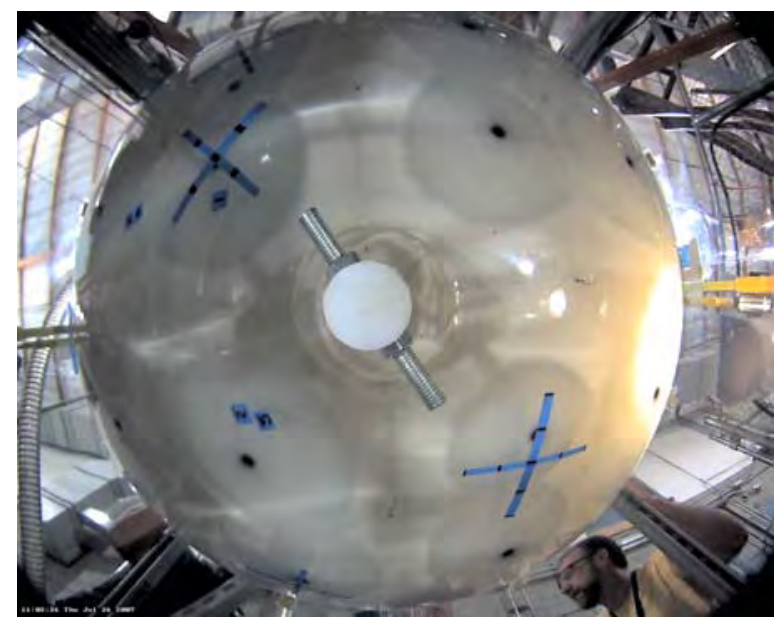

(b)

Figure 6.1. View from the Bottom of the Tank Showing (a) Pulse Tubes with No Simulant and (b) Mixing at Some Suspension and BP3 Mixing State

A 15-second sequence of the growth of the mobilized area in the settled solid particulate taken during the end of the drive portion of the pulse cycle is shown in Figure 6.2. During the drive portion of the pulse (the first seven photos during the sequence) fluid is exiting the nozzles and the black nozzle ends are visible. When the flow stops (between the $7^{\text {th }}$ and $8^{\text {th }}$ photos) the nozzles are not visible and the cleared area rapidly disappears (shown in the last three photos of the sequence) as the solids settle. In the last two photos of the sequence the solids appear to be fully settled.

All of the July 2007 tests were conducted in the mid-scale tank with a spherical head geometry using the HLP-22 pulse tube configuration with all tubes (8 outer and 4 inner [8/4]) operating and a liquid fill height of $\sim 2 \mathrm{H} / \mathrm{D}$ and a return line height of $1.8 \mathrm{H} / \mathrm{D}$. The nozzle stand-off distance was $1.5 \mathrm{~d}$.

The test conditions varied three simulants with solids density $\left(\rho_{\mathrm{s}}=2.45\right.$ and $\left.2.46 \mathrm{~g} / \mathrm{cm}^{3}\right)$ and particle diameters $\left(\mathrm{d}_{\mathrm{S}}=89,178\right.$, and $\left.766 \mu \mathrm{m}\right)$ identified as p1d7 $\left(\rho_{\mathrm{s}}=2.45 \mathrm{~g} / \mathrm{cm}^{3}, \mathrm{~d}_{50}=178 \mu \mathrm{m}\right), \mathrm{p} 1 \mathrm{~d} 8$ $\left(\rho_{\mathrm{s}}=2.45 \mathrm{~g} / \mathrm{cm}^{3}, d_{50}=90 \mu \mathrm{m}\right)$, and p2d6 $\left(\rho_{\mathrm{s}}=2.46 \mathrm{~g} / \mathrm{cm}^{3}, \mathrm{~d}_{50}=766 \mu \mathrm{m}\right)$; two nozzle diameters ( $d=0.297$ [4 in. full scale] and 0.446 in.[6 in. full scale]); two solids fractions ( $\phi_{\mathrm{S}}=0.005[\mathrm{Y}]$ and $0.016[\mathrm{X}])$; a series of duty cycles $(0.18$ [d], 0.33 [c], 0.50 [b], 1.00-continuous flow [a]); and several pulse volume fractions ( $\phi_{\mathrm{p}}=0.025$ [_3], 0.048 [_8], 0.1 [_2], and infinite-continuous flow). The test combinations are listed chronologically in Table 6.5. Data pairs of nozzle exit velocity (U) and cloud height $\left(\mathrm{H}_{\mathrm{C}}\right)$ were observed at a series of velocities starting below the $\mathrm{U}_{\mathrm{CS}}$, increasing above $\mathrm{U}_{\mathrm{CS}}$, and then ramping down. At times the velocity produced a cloud height that was below the straight section of the tank. The fact that the cloud height was in the tank head volume was noted, but the associated cloud height was not recorded. 


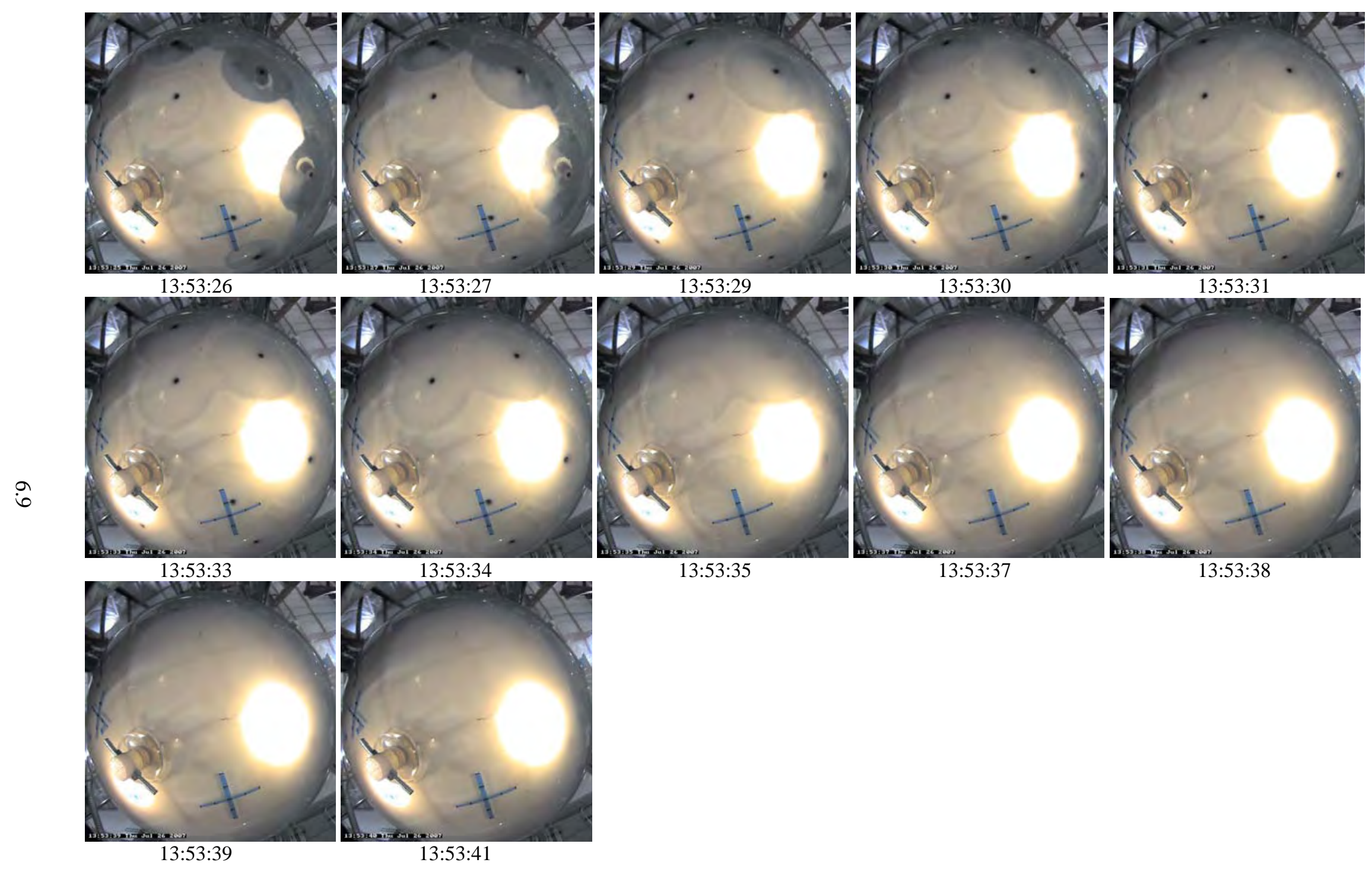

Figure 6.2. Sequence of Photos Showing Growth of Mobilized Area (first 7 photos) and Solids Settling (last 5 photos) During Test 34E_6p1d8Yd_8 Conducted in the Mid-Scale Tank with 6-in. Full-Scale Nozzle, for Simulant p1d8 $\left(\rho_{\mathrm{s}}=2.45 \mathrm{~g} / \mathrm{cm}^{3}, \mathrm{~d}_{50}=90 \mu \mathrm{m}\right)$, Solids Fraction $\left(\phi_{\mathrm{S}}=0.005[\mathrm{Y}]\right)$ for Constant Duty Cycle $\left(\mathrm{DC}=0.18\right.$ [d]) at Pulse Volume Fraction $\left(\phi_{\mathrm{p}}=0.048\right.$ [_8]). 
Table 6.5. July 2007 Test Summary in Mid-Scale Tank with Spherical Head

\begin{tabular}{|c|c|c|c|c|c|c|c|c|c|c|c|c|c|c|c|c|c|c|}
\hline Test & Case ID & $\begin{array}{l}\text { Tank } \\
\text { Fill } \\
\text { Height }\end{array}$ & $\begin{array}{c}\text { Return } \\
\text { Line } \\
\text { Height }\end{array}$ & $\begin{array}{c}\text { Nozzle } \\
\text { Inner } \\
\text { Diameter }\end{array}$ & $\begin{array}{l}\text { Nozzle } \\
\text { Standoff } \\
\text { Distance }\end{array}$ & $\begin{array}{c}\text { Pulse Tube } \\
\text { Configuration }\end{array}$ & $\begin{array}{c}\text { Installed } \\
\text { Nozzles }\end{array}$ & $\begin{array}{c}\text { Outer } \\
\text { Nozzles } \\
\text { Operated }\end{array}$ & $\begin{array}{c}\text { Inner } \\
\text { Nozzles } \\
\text { Operated }\end{array}$ & Simulant & $\begin{array}{c}\text { Solids } \\
\text { Density }\end{array}$ & $\begin{array}{l}\text { Particle } \\
\text { Diameter } \\
\text { d50 }\end{array}$ & $\begin{array}{l}\text { Solids } \\
\text { Fraction }\end{array}$ & $\begin{array}{l}\text { Pulse } \\
\text { Volume } \\
\text { Fraction }\end{array}$ & $\begin{array}{l}\text { Duty } \\
\text { Cycle }\end{array}$ & $\begin{array}{c}\text { Pulsed } \\
\text { or } \\
\text { Steady } \\
\text { Jet }\end{array}$ & $\begin{array}{c}\text { Fill } \\
\text { Height to } \\
\text { Diameter }\end{array}$ & $\begin{array}{l}\text { Return } \\
\text { Line } \\
\text { Height to } \\
\text { Diameter }\end{array}$ \\
\hline text & text & in. & in. & in. & in. & text & number & number & number & text & $\mathrm{g} / \mathrm{cm}^{3}$ & $\mathrm{~m}$ & fraction & fraction & fraction & text & ratio & ratio \\
\hline M/DDX & ID & $\mathrm{H}$ & Rtn & d & sod & PT & $\mathrm{N}$ & $\mathrm{N}_{\mathrm{O}}$ & $\mathrm{N}_{\mathrm{I}}$ & $\operatorname{sxdx}$ & $\rho_{\mathrm{s}}$ & $\mathrm{d}_{50}$ & $\phi_{\mathrm{S}}$ & $\phi_{\mathrm{p}}$ & DC & Jet & $\mathrm{H} / \mathrm{D}$ & Rtn/D \\
\hline 7/16 A1 & 34S_4p1d7Ya & 71.1 & 62 & 0.297 & 0.446 & HLP-22 & 12 & 8 & 4 & p1d7 & 2.45 & 0.000178 & 0.005 & undefined & 1.00 & $\mathrm{~S}$ & 2.1 & 1.8 \\
\hline 7/16 A2 & 34S_4p1d7Yc_8 & 71.1 & 62 & 0.297 & 0.446 & HLP-22 & 12 & 8 & 4 & p1d7 & 2.45 & 0.000178 & 0.005 & 0.050 & 0.33 & $\mathrm{P}$ & 2.1 & 1.8 \\
\hline 7/17 A1 & 34S_4p1d7Хa & 66.1 & 62 & 0.297 & 0.446 & HLP-22 & 12 & 8 & 4 & p1d7 & 2.45 & 0.000178 & 0.016 & undefined & 1.00 & $\mathrm{~S}$ & 2.0 & 1.8 \\
\hline 7/17 A2 & 34S_4p1d7Xc_8 & 66.1 & 62 & 0.297 & 0.446 & HLP-22 & 12 & 8 & 4 & p1d7 & 2.45 & 0.000178 & 0.016 & 0.048 & 0.33 & $\mathrm{P}$ & 2.0 & 1.8 \\
\hline 7/18 A1 & 34S_4p1d7Xc_8 & 76.1 & 62 & 0.297 & 0.446 & HLP-22 & 12 & 8 & 4 & p1d7 & 2.45 & 0.000178 & 0.016 & 0.048 & 0.33 & $\mathrm{P}$ & 2.2 & 1.8 \\
\hline 7/18 A2 & 34S_4p1d7Xc_2 & 76.1 & 62 & 0.297 & 0.446 & HLP-22 & 12 & 8 & 4 & p1d7 & 2.45 & 0.000178 & 0.016 & 0.100 & 0.33 & $\mathrm{P}$ & 2.2 & 1.8 \\
\hline 7/19 A1 & 34S_4p1d7Yc_8 & 67.6 & 62 & 0.297 & 0.446 & HLP-22 & 12 & 8 & 4 & p1d7 & 2.45 & 0.000178 & 0.005 & 0.048 & 0.33 & $\mathrm{P}$ & 2.0 & 1.8 \\
\hline 7/19 A2 & 34S_4p1d7Ya & 67.6 & 62 & 0.297 & 0.446 & HLP-22 & 12 & 8 & 4 & p1d7 & 2.45 & 0.000178 & 0.005 & undefined & 1.00 & $\mathrm{~S}$ & 2.0 & 1.8 \\
\hline 7/19 A3 & 34S_4p1d7Yc_2 & 67.6 & 62 & 0.297 & 0.446 & HLP-22 & 12 & 8 & 4 & p1d7 & 2.45 & 0.000178 & 0.005 & 0.100 & 0.33 & $\mathrm{P}$ & 2.0 & 1.8 \\
\hline 7/19 A4 & 34S_4p1d7Yd_8 & 67.6 & 62 & 0.297 & 0.446 & HLP-22 & 12 & 8 & 4 & p1d7 & 2.45 & 0.000178 & 0.005 & 0.048 & 0.18 & $\mathrm{P}$ & 2.0 & 1.8 \\
\hline $7 / 20 \mathrm{~A} 1$ & 34S_4p1d7Yyb_8 & 67.6 & 62 & 0.297 & 0.446 & HLP-22 & 12 & 8 & 4 & p1d7 & 2.45 & 0.000178 & 0.005 & 0.048 & 0.50 & $\mathrm{P}$ & 2.0 & 1.8 \\
\hline $7 / 20$ A2 & 34S_4p1d7Yc_3 & 67.6 & 62 & 0.297 & 0.446 & HLP-22 & 12 & 8 & 4 & p1d7 & 2.45 & 0.000178 & 0.005 & 0.025 & 0.33 & $\mathrm{P}$ & 2.0 & 1.8 \\
\hline 7/21 A1 & 34S_6p1d7Ya & 68.4 & 62 & 0.446 & 0.669 & HLP-22 & 12 & 8 & 4 & p1d7 & 2.45 & 0.000178 & 0.005 & undefined & 1.00 & $\mathrm{~S}$ & 2.0 & 1.8 \\
\hline 7/21 A2 & 34S_6p1d7Yyc_8 & 68.4 & 62 & 0.446 & 0.669 & HLP-22 & 12 & 8 & 4 & p1d7 & 2.45 & 0.000178 & 0.005 & 0.048 & 0.33 & $\mathrm{P}$ & 2.0 & 1.8 \\
\hline 7/23 A1 & 34S_6p1d7Yd_8 & 67.9 & 62 & 0.446 & 0.669 & HLP-22 & 12 & 8 & 4 & p1d7 & 2.45 & 0.000178 & 0.005 & 0.048 & 0.18 & $\mathrm{P}$ & 2.0 & 1.8 \\
\hline 7/23 A2 & 34S_6p1d7Yd_2 & 67.9 & 62 & 0.446 & 0.669 & HLP-22 & 12 & 8 & 4 & p1d7 & 2.45 & 0.000178 & 0.005 & 0.100 & 0.18 & $\mathrm{P}$ & 2.0 & 1.8 \\
\hline 7/23 A3 & 34S_6p1d7Yc_2 & 67.9 & 62 & 0.446 & 0.669 & HLP-22 & 12 & 8 & 4 & p1d7 & 2.45 & 0.000178 & 0.005 & 0.100 & 0.33 & $\mathrm{P}$ & 2.0 & 1.8 \\
\hline 7/23 A4 & 34S_6p1d7Yc_3 & 67.9 & 62 & 0.446 & 0.669 & HLP-22 & 12 & 8 & 4 & p1d7 & 2.45 & 0.000178 & 0.005 & 0.025 & 0.33 & $\mathrm{P}$ & 2.0 & 1.8 \\
\hline 7/23 A5 & 34S_6p1d7Yyb_8 & 67.9 & 62 & 0.446 & 0.669 & HLP-22 & 12 & 8 & 4 & p1d7 & 2.45 & 0.000178 & 0.005 & 0.048 & 0.50 & $\mathrm{P}$ & 2.0 & 1.8 \\
\hline 7/24 A1 & 34S_6p1d7Xa & 67.9 & 62 & 0.446 & 0.669 & HLP-22 & 12 & 8 & 4 & p1d7 & 2.45 & 0.000178 & 0.016 & undefined & 1.00 & $\mathrm{~S}$ & 2.0 & 1.8 \\
\hline 7/24 B1 & 34S_6p1d7Xd_8 & 67.9 & 62 & 0.446 & 0.669 & HLP-22 & 12 & 8 & 4 & p1d7 & 2.45 & 0.000178 & 0.016 & 0.048 & 0.18 & $\mathrm{P}$ & 2.0 & 1.8 \\
\hline 7/25 A1 & 34S_6p2d6Ya & 68.1 & 62 & 0.446 & 0.669 & HLP-22 & 12 & 8 & 4 & p2d6 & 2.46 & 0.000766 & 0.005 & undefined & 1.00 & $\mathrm{~S}$ & 2.0 & 1.8 \\
\hline 7/25 B1 & 34S_6p2d6Yd_8 & 68.1 & 62 & 0.446 & 0.669 & HLP-22 & 12 & 8 & 4 & $\mathrm{p} 2 \mathrm{~d} 6$ & 2.46 & 0.000766 & 0.005 & 0.048 & 0.18 & $\mathrm{P}$ & 2.0 & 1.8 \\
\hline 7/26 A1 & 34S_6p1d8Ya & 68.9 & 62 & 0.446 & 0.669 & HLP-22 & 12 & 8 & 4 & p1d8 & 2.45 & 0.000089 & 0.005 & undefined & 1.00 & $\mathrm{~S}$ & 2.0 & 1.8 \\
\hline 7/26 B1 & 34S_6p1d8Yd_8 & 68.9 & 62 & 0.446 & 0.669 & HLP-22 & 12 & 8 & 4 & p1d8 & 2.45 & 0.000089 & 0.005 & 0.048 & 0.18 & $\mathrm{P}$ & 2.0 & 1.8 \\
\hline 7/27 A1 & 34S_6p1d8Yd_8 & 68.9 & 62 & 0.446 & 0.669 & HLP-22 & 12 & 8 & 4 & p1d8 & 2.45 & 0.000089 & 0.005 & 0.048 & 0.18 & $\mathrm{P}$ & 2.0 & 1.8 \\
\hline 7/27 B1 & 34S_6p1d8Yc_8 & 68.9 & 62 & 0.446 & 0.669 & HLP-22 & 12 & 8 & 4 & p1d8 & 2.45 & 0.000089 & 0.005 & 0.048 & 0.33 & $\mathrm{P}$ & 2.0 & 1.8 \\
\hline 7/27 C1 & 34S_6p2d6Yd_8 & 68.1 & 62 & 0.446 & 0.669 & HLP-22 & 12 & 8 & 4 & p2d6 & 2.46 & 0.000766 & 0.005 & 0.048 & 0.18 & $\mathrm{P}$ & 2.0 & 1.8 \\
\hline 7/27 D1 & 34S_6p2d6Yc_8 & 68.1 & 62 & 0.446 & 0.669 & HLP-22 & 12 & 8 & 4 & p2d6 & 2.46 & 0.000766 & 0.005 & 0.048 & 0.33 & $\mathrm{P}$ & 2.0 & 1.8 \\
\hline 7/27 B2 & 34S_6p2d6Ya & 68.1 & 62 & 0.446 & 0.669 & HLP-22 & 12 & 8 & 4 & p2d6 & 2.46 & 0.000766 & 0.005 & undefined & 1.00 & $\mathrm{~S}$ & 2.0 & 1.8 \\
\hline
\end{tabular}


Selected July 2007 cloud height data are plotted as a function of velocity in Figures 6.3, 6.4, and 6.5. When identified, the $U_{C S}$ velocity is shown as the darkened symbol in the legend beneath the test; the method used to determine $U_{C S}$ is also shown. For example, in the legend for Figure 6.3 (a) each Case ID shows the $U_{C S}$ condition beneath it. The first Case ID (34S_4p1d7Yc_8) symbol is a green $X$, the corresponding $\mathrm{U}_{\mathrm{CS}}$ condition symbol is shown as a green $\mathrm{X}$ with a black background. The next three $\mathrm{U}_{\mathrm{CS}}$ condition symbols are shown as colored diamonds with black centers. The description to the right of the $U_{C S}$ condition shows the method used to determine $U_{C S}$, which is either "vis" or "vis dec." Vis means that the $\mathrm{U}_{\mathrm{CS}}$ condition was determined visually after an increase in velocity. Vis dec means that the $\mathrm{U}_{\mathrm{CS}}$ condition was determined visually after a decrease in velocity. In Figure 6.3, two concentrations are compared; in Figure 6.4, two duty cycles are compared; and in Figure 6.5, three simulants are compared.

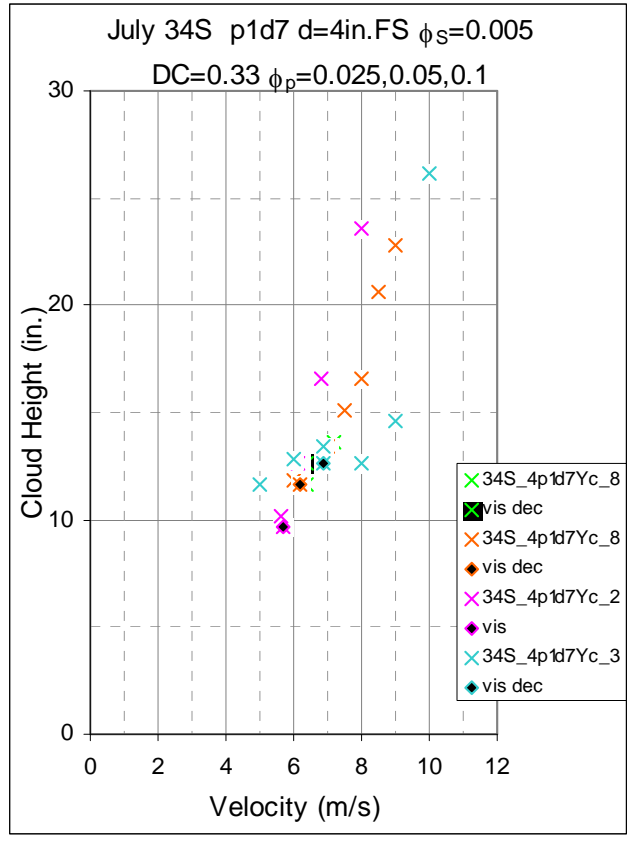

(a)

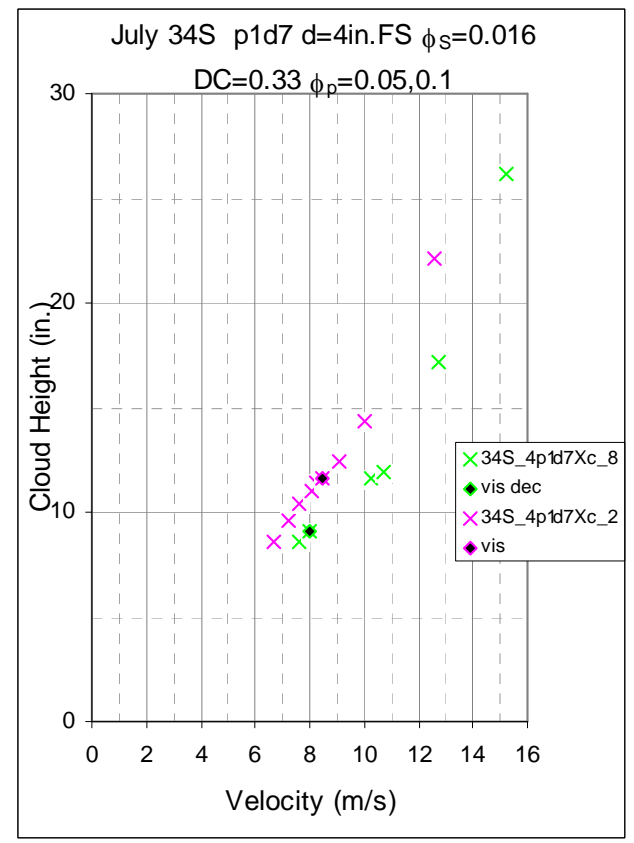

(b)

Figure 6.3. Cloud Height as a Function of Velocity for Two Concentrations in the Mid-Scale Tank with Spherical Head for a Range of Pulse Volume Fractions: (a) Solids Fraction $\phi_{\mathrm{S}}=0.005$ [Y], (b) Solids Fraction $\phi_{\mathrm{S}}=0.016[\mathrm{X}]$. Both use 4-in. full-scale nozzle for constant duty cycle $(\mathrm{DC}=0.33$ [c] $)$ and three pulse volume fractions $\left(\phi_{\mathrm{p}}=0.025[3], 0.048\right.$ [_8], 0.1 [_2]) for simulant p1d7 $\left(\rho_{\mathrm{s}}=2.45 \mathrm{~g} / \mathrm{cm}^{3}, d_{50}=178 \mu \mathrm{m}\right)$.

In Figure 6.4 (b) the data shown in pink have a higher solids fraction ( $\phi_{\mathrm{S}}=0.016$ [X, see Table 6.4]) than the other two sets of data with solids fraction $\left(\phi_{\mathrm{S}}=0.005[\mathrm{Y}]\right)$. Compared with the data shown in green with the same pulse volume fraction, the $\mathrm{U}_{\mathrm{CS}}$ condition occurs at an increased velocity. In Figure 6.5 the data shown in green have a higher solids fraction $\left(\phi_{\mathrm{S}}=0.016[\mathrm{X}]\right)$ and therefore higher $\mathrm{U}_{\mathrm{CS}}$ velocity than the other three sets of data with solids fraction $\left(\phi_{\mathrm{S}}=0.005[\mathrm{Y}]\right)$. 


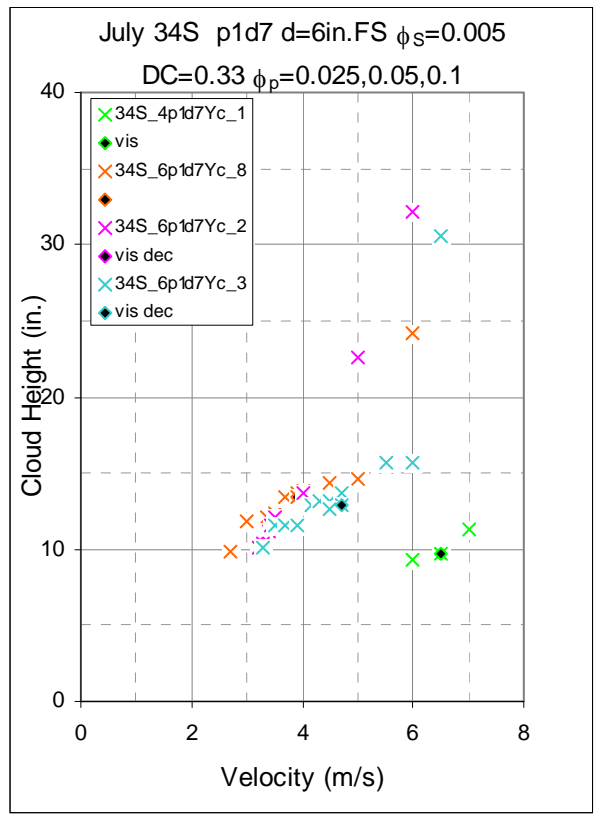

(a)

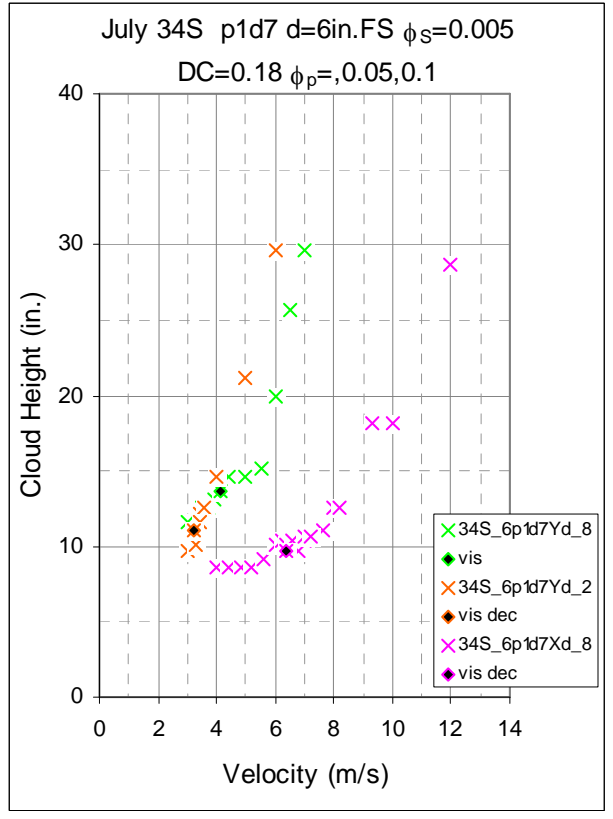

(b)

Figure 6.4. Cloud Height as a Function of Velocity for Two Duty Cycles in the Mid-Scale Tank with Spherical Head for a Range of Pulse Volume Fractions: (a) DC $=0.33$ [c], (b) DC $=0.18$ [d]. Both use 6 in. full-scale nozzles for constant solids fraction $\left(\phi_{\mathrm{S}}=0.005[\mathrm{Y}], 0.016[\mathrm{X}]\right)$ and two or four pulse volume fractions ( $\phi_{\mathrm{p}}=0.025$ [_3], 0.048 [_8], 0.05 [_1], 0.1 [_2]) for simulant p1d7 $\left(\rho_{\mathrm{s}}=2.45 \mathrm{~g} / \mathrm{cm}^{3}, \mathrm{~d}_{50}=178 \mu \mathrm{m}\right)$.

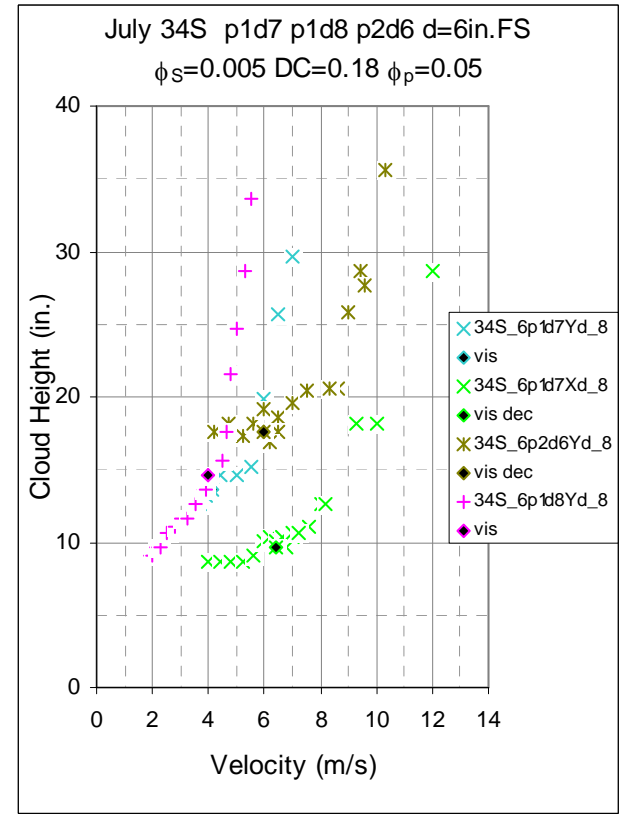

(a)

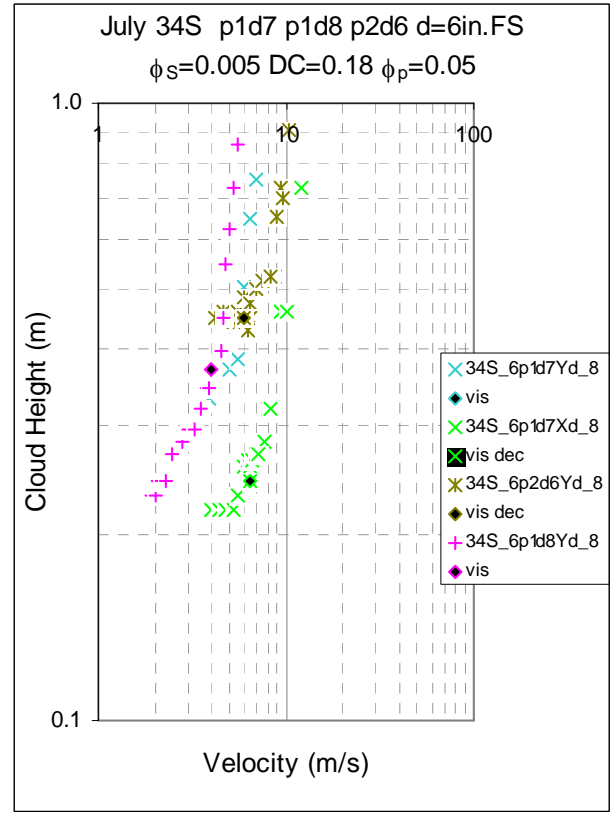

(b)

Figure 6.5. Cloud Height as Function of Velocity for Simulants p1d7 $\left(\rho_{\mathrm{s}}=2.45 \mathrm{~g} / \mathrm{cm}^{3}, \mathrm{~d}_{50}=178 \mu \mathrm{m}\right)$, p1d8 $\left(\rho_{\mathrm{s}}=2.45 \mathrm{~g} / \mathrm{cm}^{3}, \mathrm{~d}_{50}=90 \mu \mathrm{m}\right)$, and p2d6 $\left(\rho_{\mathrm{s}}=2.46 \mathrm{~g} / \mathrm{cm}^{3}, \mathrm{~d}_{50}=766 \mu \mathrm{m}\right)$ for Two Concentrations in the Mid-Scale Tank with Spherical Head: (a) Linear, (b) Log. 6-in. FullScale Nozzle at Solids Fraction $\left(\phi_{\mathrm{s}}=0.005\right.$ [Y], 0.016 [X])), Constant Duty Cycle $(\mathrm{DC}=0.18[\mathrm{~d}])$ and Pulse Volume Fraction $\left(\phi_{\mathrm{p}}=0.048\right.$ [ 8$\left.]\right)$ 


\subsection{Fall 2007 Tests in Mid-Scale Tank with Spherical Head}

The Fall 2007 tests were conducted to evaluate the experimental test stand equipment performance and address operational questions specific to the use of this test stand. Factors evaluated included the effect of liquid fill height in the test tank and the impacts of elevation of the return line. The investigation of fill height during the Fall 2007 test effort was only to assess the effect fill height had on the results obtained in the current test setup. No attempt was made or was part of the test scope to evaluate the impact of the design operating levels for each of the WTP vessel types.

The Fall 2007 test campaign followed the same procedures used during the July 2007 tests. The Fall 2007 tests were conducted with two simulants with differing particle size: $\mathrm{p} 1 \mathrm{~d} 7\left(\rho_{\mathrm{s}}=2.45 \mathrm{~g} / \mathrm{cm}^{3}, \mathrm{~d}_{50}=\right.$ $178 \mu \mathrm{m})$ and p1d8 $\left(\rho_{\mathrm{s}}=2.45 \mathrm{~g} / \mathrm{cm}^{3}, \mathrm{~d}_{50}=90 \mu \mathrm{m}\right)$, two nozzle diameters ( $\mathrm{d}=0.297$ [4 in. full scale] and 0.446 in. [6 in. full scale]), one solids fraction $\left(\phi_{\mathrm{S}}=0.004872\right.$ [Y]), and a series of duty cycles (DC = 0.018 [d], 0.33 [c] and 1.00-continuous flow [a]). Test conditions are listed chronologically in Table 6.6. The test parameters listed in Table 6.6 are the same as those presented for the July 2007 tests.

During the Fall 2007 test campaign, broad ranges are shown for tank fill height $(\mathrm{H})$ and return line elevation (Rtn). As stated in Section 1.4.7, these parameters were only varied to determine the limits of the test fixture performance. The nondimensional representations of these variable H/D and Rtn/D combinations are summarized in Table 6.7. The tests conducted at H/D of 2.0 and Rtn/D of 1.8 are within the standard range for these test parameters for tests conducted in the mid-scale tank. Tests conducted with $\mathrm{H} / \mathrm{D}$ and $\mathrm{Rtn} / \mathrm{D}$ values less than these were conducted to evaluate the test fixture performance.

Tests were conducted during the Fall 2007 test campaign, with combinations of the number of outer and inner pulse tubes in operation. The number of pulse tubes in operation can be determined from the last digit in the Case ID. These combinations included all tubes in operation with 8 outer and 4 inner (8/4) [shown as _ 1 in the Case ID], operating only the outer pulse tubes (8/0) [shown as _ 5 in the Case ID], operating 4 outer and 4 inner pulse tubes (4/4) [shown as _ 0 in the Case ID], operating four outer pulse tubes (4/0) [shown as _6 in the Case ID], and operating four inner pulse tubes (0/4) [shown as _9 in the Case ID]. Examples of the effects of operating with these pulse tube combinations are shown in Figures 6.6 through 6.8. When identified, the $\mathrm{U}_{\mathrm{CS}}$ velocity is shown as the darkened symbol in the legend beneath the test, and the method used to determine $\mathrm{U}_{\mathrm{CS}}$ is also shown. For example, in the legend for Figure 6.6 (a) each test Case ID shows the $U_{C S}$ condition beneath it. The first Case ID (34S_4p1d7Yd_1) symbol is a pink $\mathrm{X}$, the corresponding $\mathrm{U}_{\mathrm{CS}}$ condition symbol is shown as a pink outline around a black diamond. The next remaining $\mathrm{U}_{\mathrm{CS}}$ condition symbols are also shown as colored diamonds with black centers. The description to the right of the $\mathrm{U}_{\mathrm{CS}}$ condition shows the method used to determine $\mathrm{U}_{\mathrm{CS}}$, which is either "vis" or "vis dec." Vis means that the $\mathrm{U}_{\mathrm{CS}}$ condition was determined visually after an increase in velocity. Vis dec means that the $\mathrm{U}_{\mathrm{CS}}$ condition was determined visually after a decrease in velocity.

Figure 6.6 shows data for simulant p1d7 $\left(\rho_{\mathrm{s}}=2.45 \mathrm{~g} / \mathrm{cm}^{3}, \mathrm{~d}_{50}=178 \mu \mathrm{m}\right)$ with a 4 in. full-scale nozzle. Figure 6.7 shows data for simulant p1d8 $\left(\rho_{\mathrm{s}}=2.45 \mathrm{~g} / \mathrm{cm}^{3}, \mathrm{~d}_{50}=90 \mu \mathrm{m}\right)$ with a 4 in- full-scale nozzle. Figure 6.8 shows data for simulant p1d7 with a 6 in. full-scale nozzle. Duty cycles of 0.18 [d]are shown in Figure 6.6 (a), 6.7 (a) and 6.8. Duty cycles of 0.33 [c] are shown in Figure 6.6 (b) and 6.7 (b). 
Table 6.6. Fall 2007 Test Summary in Mid-Scale Tank with Spherical Head

\begin{tabular}{|c|c|c|c|c|c|c|c|c|c|c|c|c|c|c|c|c|c|c|}
\hline Test & Case ID & $\begin{array}{l}\text { Tank } \\
\text { Fill } \\
\text { Height }\end{array}$ & $\begin{array}{l}\text { Return } \\
\text { Line } \\
\text { Height }\end{array}$ & $\begin{array}{l}\text { Nozzle } \\
\text { Inner } \\
\text { Diameter }\end{array}$ & $\begin{array}{l}\text { Nozzle } \\
\text { Standoff } \\
\text { Distance }\end{array}$ & $\begin{array}{l}\text { Pulse Tube } \\
\text { Configuration }\end{array}$ & $\begin{array}{l}\text { Installed } \\
\text { Nozzles }\end{array}$ & $\begin{array}{c}\text { Outer } \\
\text { Nozzles } \\
\text { Operated }\end{array}$ & $\begin{array}{c}\text { Inner } \\
\text { Nozzles } \\
\text { Operated }\end{array}$ & & $\begin{array}{l}\text { Solids } \\
\text { Density }\end{array}$ & $\begin{array}{l}\text { Particle } \\
\text { Diameter } \\
\text { d50 }\end{array}$ & $\begin{array}{l}\text { Solids } \\
\text { Fraction }\end{array}$ & $\begin{array}{c}\text { Pulse } \\
\text { Volume } \\
\text { Fraction }\end{array}$ & $\begin{array}{l}\text { Duty } \\
\text { Cycle }\end{array}$ & $\begin{array}{l}\text { Pulsed } \\
\text { or } \\
\text { Steady } \\
\text { Jet }\end{array}$ & $\begin{array}{c}\text { Fill } \\
\text { Height to } \\
\text { Diameter }\end{array}$ & $\begin{array}{l}\text { Return Line } \\
\text { Height to } \\
\text { Diameter }\end{array}$ \\
\hline text & text & in. & in. & in. & in. & text & number & number & number & text & $\mathrm{g} / \mathrm{cm}^{3}$ & $\mathrm{~m}$ & fraction & fraction & fraction & text & ratio & ratio \\
\hline $\mathrm{M} / \mathrm{DDX}$ & ID & $\mathrm{H}$ & Rtn & $\mathrm{d}$ & sod & $\mathrm{PT}$ & $\mathrm{N}$ & $\mathrm{N}_{\mathrm{O}}$ & $\mathrm{N}_{\mathrm{I}}$ & sxdx & $\rho_{\mathrm{S}}$ & $\mathrm{d}_{50}$ & $\phi_{\mathrm{S}}$ & $\phi_{\mathrm{p}}$ & DC & Jet & $\mathrm{H} / \mathrm{D}$ & Rtn/D \\
\hline 10/17A1 & 34S_6p1d7Ya-80 & 67.8 & 61.8 & 0.446 & 0.669 & HLP-22 & 12 & 8 & 0 & p1d7 & 2.45 & 0.000178 & 0.004872 & undefined & 1 & $\mathrm{~S}$ & 2 & 1.8 \\
\hline 10/17A2 & 34S_6p1d7Yd_5 & 67.8 & 61.8 & 0.446 & 0.669 & HLP-22 & 12 & 8 & 0 & p1d7 & 2.45 & 0.000178 & 0.004872 & 0.05 & 0.18 & $\mathrm{P}$ & 2 & 1.8 \\
\hline 10/18A1 & 34S_6p1d7Ya-44 & 67.8 & 61.8 & 0.446 & 0.669 & HLP-22 & 12 & 4 & 4 & p1d7 & 2.45 & 0.000178 & 0.004872 & undefined & 1 & $\mathrm{~S}$ & 2 & 1.8 \\
\hline 10/18A2 & 34S_6p1d7Yd_0 & 67.8 & 61.8 & 0.446 & 0.669 & HLP-22 & 12 & 4 & 4 & p1d7 & 2.45 & 0.000178 & 0.004872 & 0.05 & 0.18 & $\mathrm{P}$ & 2 & 1.8 \\
\hline 10/18B1 & 34S_6p1d7Ya-40 & 67.8 & 61.8 & 0.446 & 0.669 & HLP-22 & 12 & 4 & 0 & p1d7 & 2.45 & 0.000178 & 0.004872 & undefined & 1 & S & 2 & 1.8 \\
\hline 10/18B2 & 34S_6p1d7Yd_6 & 67.8 & 61.8 & 0.446 & 0.669 & HLP-22 & 12 & 4 & 0 & p1d7 & 2.45 & 0.000178 & 0.004872 & 0.04 & 0.18 & $\mathrm{P}$ & 2 & 1.8 \\
\hline 10/19A1 & 34S_6p1d7Ya-04 & 67.8 & 61.8 & 0.446 & 0.669 & HLP-22 & 12 & 0 & 4 & p1d7 & 2.45 & 0.000178 & 0.004872 & undefined & 1 & S & 2 & 1.8 \\
\hline 10/19A2 & 34S_6p1d7Yd_9 & 67.8 & 61.8 & 0.446 & 0.669 & HLP-22 & 12 & 0 & 4 & p1d7 & 2.45 & 0.000178 & 0.004872 & 0.05 & 0.18 & $\mathrm{P}$ & 2 & 1.8 \\
\hline 10/26A1 & 34S_6p1d7Ya & 67.8 & 65.8 & 0.446 & 0.669 & HLP-22 & 12 & 8 & 4 & p1d7 & 2.45 & 0.000178 & 0.004872 & undefined & 1 & $\mathrm{~S}$ & 2 & 0.9 \\
\hline 10/26A2 & 34S_6p1d7Yd_1 & 67.8 & 65.8 & 0.446 & 0.669 & HLP-22 & 12 & 8 & 4 & p1d7 & 2.45 & 0.000178 & 0.004872 & 0.05 & 0.18 & $\mathrm{P}$ & 2 & 0.9 \\
\hline 10/26B1 & 34S_6p1d7Ya-44 & 67.8 & 65.8 & 0.446 & 0.669 & HLP-22 & 12 & 4 & 4 & p1d7 & 2.45 & 0.000178 & 0.004872 & undefined & 1 & S & 2 & 0.9 \\
\hline 10/26B2 & 34S_6p1d7Yd_0 & 67.8 & 65.8 & 0.446 & 0.669 & HLP-22 & 12 & 4 & 4 & p1d7 & 2.45 & 0.000178 & 0.004872 & 0.05 & 0.18 & $\mathrm{P}$ & 2 & 0.9 \\
\hline 10/29A1 & 34S_6p1d7Ya-04 & 67.8 & 65.8 & 0.446 & 0.669 & HLP-22 & 12 & 0 & 4 & p1d7 & 2.45 & 0.000178 & 0.004872 & undefined & 1 & S & 2 & 0.9 \\
\hline 10/29A2 & 34S_6p1d7Ym_9 & 67.8 & 65.8 & 0.446 & 0.669 & HLP-22 & 12 & 0 & 4 & p1d7 & 2.45 & 0.000178 & 0.004872 & 0.05 & 0.196 & $\mathrm{P}$ & 2 & 0.9 \\
\hline 10/29B1 & 34S_6p1d7Ya-40 & 67.8 & 65.8 & 0.446 & 0.669 & HLP-22 & 12 & 4 & 0 & p1d7 & 2.45 & 0.000178 & 0.004872 & undefined & 1 & S & 2 & 0.9 \\
\hline 10/29B2 & 34S_6p1d7Yd_6 & 67.8 & 65.8 & 0.446 & 0.669 & HLP-22 & 12 & 4 & 0 & p1d7 & 2.45 & 0.000178 & 0.004872 & 0.05 & 0.18 & $\mathrm{P}$ & 2 & 0.6 \\
\hline 10/30A1 & 34S_6p1d7Ya & 67.8 & 65.8 & 0.446 & 0.669 & HLP-22 & 12 & 8 & 4 & p1d7 & 2.45 & 0.000178 & 0.004872 & undefined & 1 & $\mathrm{~S}$ & 2 & 0.6 \\
\hline 10/30A2 & 34S_6p1d7Yd_1 & 67.8 & 65.8 & 0.446 & 0.669 & HLP-22 & 12 & 8 & 4 & p1d7 & 2.45 & 0.000178 & 0.004872 & 0.04 & 0.18 & $\mathrm{P}$ & 2 & 0.6 \\
\hline 10/30C1 & 34S_6p1d7Ya-04 & 67.8 & 65.8 & 0.446 & 0.669 & HLP-22 & 12 & 0 & 4 & p1d7 & 2.45 & 0.000178 & 0.004872 & undefined & 1 & S & 2 & 0.6 \\
\hline 10/30C2 & 34S_6p1d7Yd_9 & 67.8 & 65.8 & 0.446 & 0.669 & HLP-22 & 12 & 0 & 4 & p1d7 & 2.45 & 0.000178 & 0.004872 & 0.05 & 0.18 & $\mathrm{P}$ & 2 & 0.6 \\
\hline 10/31A1 & 34S_6p1d7Ya & 33.9 & 31.9 & 0.446 & 0.669 & HLP-22 & 12 & 8 & 4 & p1d7 & 2.45 & 0.000178 & 0.004872 & undefined & 1 & S & 1 & 0.9 \\
\hline 10/31A2 & 34S_6p1d7Yd_1 & 33.9 & 31.9 & 0.446 & 0.669 & HLP-22 & 12 & 8 & 4 & p1d7 & 2.45 & 0.000178 & 0.004872 & 0.05 & 0.18 & $\mathrm{P}$ & 1 & 0.9 \\
\hline 11/2A1 & 34S_6p1d7Ya-80 & 33.9 & 31.9 & 0.446 & 0.669 & HLP-22 & 12 & 8 & 0 & p1d7 & 2.45 & 0.000178 & 0.004872 & undefined & 1 & S & 1 & 0.9 \\
\hline 11/2A2 & 34S_6p1d7Yd_5 & 33.9 & 31.9 & 0.446 & 0.669 & HLP-22 & 12 & 8 & 0 & p1d7 & 2.45 & 0.000178 & 0.004872 & 0.05 & 0.18 & $\mathrm{P}$ & 1 & 0.9 \\
\hline 11/5A1 & 34S_6p1d7Ya-44 & 33.9 & 31.9 & 0.446 & 0.669 & HLP-22 & 12 & 4 & 4 & p1d7 & 2.45 & 0.000178 & 0.004872 & undefined & 1 & S & 1 & 0.9 \\
\hline 11/5A2 & 34S_6p1d7Yd_0 & 33.9 & 31.9 & 0.446 & 0.669 & HLP-22 & 12 & 4 & 4 & p1d7 & 2.45 & 0.000178 & 0.004872 & 0.05 & 0.18 & $\mathrm{P}$ & 1 & 0.9 \\
\hline 11/5B1 & 34S_6p1d7Ya-04 & 33.9 & 31.9 & 0.446 & 0.669 & HLP-22 & 12 & 0 & 4 & p1d7 & 2.45 & 0.000178 & 0.004872 & undefined & 1 & $\mathrm{~S}$ & 1 & 0.9 \\
\hline 11/5B2 & 34S_6p1d7Yd_9 & 33.9 & 31.9 & 0.446 & 0.669 & HLP-22 & 12 & 0 & 4 & p1d7 & 2.45 & 0.000178 & 0.004872 & 0.05 & 0.18 & $\mathrm{P}$ & 1 & 0.9 \\
\hline 11/6A1 & 34S_6p1d7Ya-40 & 33.9 & 31.9 & 0.446 & 0.669 & HLP-22 & 12 & 4 & 0 & p1d7 & 2.45 & 0.000178 & 0.004872 & undefined & 1 & S & 1 & 0.9 \\
\hline 11/6A2 & 34S_6p1d7Yd_6 & 33.9 & 31.9 & 0.446 & 0.669 & HLP-22 & 12 & 4 & 0 & p1d7 & 2.45 & 0.000178 & 0.004872 & 0.05 & 0.18 & $\mathrm{P}$ & 1 & 0.9 \\
\hline 11/7A1 & 34S_6p1d7Ya & 23.7 & 21.7 & 0.446 & 0.669 & HLP-22 & 12 & 8 & 4 & p1d7 & 2.45 & 0.000178 & 0.004872 & undefined & 1 & S & 0.7 & 0.6 \\
\hline 11/7A2 & 34S_6p1d7Yd_1 & 23.7 & 21.7 & 0.446 & 0.669 & HLP-22 & 12 & 8 & 4 & p1d7 & 2.45 & 0.000178 & 0.004872 & 0.05 & 0.18 & $\mathrm{P}$ & 0.7 & 0.6 \\
\hline
\end{tabular}


Table 6.6. (contd)

\begin{tabular}{|c|c|c|c|c|c|c|c|c|c|c|c|c|c|c|c|c|c|c|}
\hline Test & Case ID & $\begin{array}{l}\text { Tank } \\
\text { Fill } \\
\text { Height }\end{array}$ & $\begin{array}{l}\text { Return } \\
\text { Line } \\
\text { Height }\end{array}$ & $\begin{array}{l}\text { Nozzle } \\
\text { Inner } \\
\text { Diameter }\end{array}$ & $\begin{array}{l}\text { Nozzle } \\
\text { Standoff } \\
\text { Distance }\end{array}$ & $\begin{array}{l}\text { Pulse Tube } \\
\text { Configuration }\end{array}$ & $\begin{array}{l}\text { Installed } \\
\text { Nozzles }\end{array}$ & $\begin{array}{c}\text { Outer } \\
\text { Nozzles } \\
\text { Operated }\end{array}$ & $\begin{array}{c}\text { Inner } \\
\text { Nozzles } \\
\text { Operated }\end{array}$ & Simulant & $\begin{array}{l}\text { Solids } \\
\text { Density }\end{array}$ & $\begin{array}{l}\text { Particle } \\
\text { Diameter } \\
\text { d50 }\end{array}$ & $\begin{array}{l}\text { Solids } \\
\text { Fraction }\end{array}$ & $\begin{array}{l}\text { Pulse } \\
\text { Volume } \\
\text { Fraction }\end{array}$ & $\begin{array}{l}\text { Duty } \\
\text { Cycle }\end{array}$ & $\begin{array}{c}\text { Pulsed } \\
\text { or } \\
\text { Steady } \\
\text { Jet }\end{array}$ & $\begin{array}{c}\text { Fill } \\
\text { Height to } \\
\text { Diameter }\end{array}$ & $\begin{array}{l}\text { Return Line } \\
\text { Height to } \\
\text { Diameter }\end{array}$ \\
\hline text & text & in. & in. & in. & in. & text & number & number & number & text & $\mathrm{g} / \mathrm{cm}^{3}$ & $\mathrm{~m}$ & fraction & fraction & fraction & text & ratio & ratio \\
\hline $\mathrm{M} / \mathrm{DDX}$ & ID & $\mathrm{H}$ & Rtn & $\mathrm{d}$ & sod & $\mathrm{PT}$ & $\mathrm{N}$ & $\mathrm{N}_{\mathrm{O}}$ & $\mathrm{N}_{\mathrm{I}}$ & sxdx & $\rho_{\mathrm{S}}$ & $\mathrm{d}_{50}$ & $\phi_{\Sigma}$ & $\phi_{\mathrm{p}}$ & DC & Jet & $\mathrm{H} / \mathrm{D}$ & Rtn/D \\
\hline 11/7B1 & 34S_6p1d7Ya-44 & 23.7 & 21.7 & 0.446 & 0.669 & HLP-22 & 12 & 4 & 4 & p1d7 & 2.45 & 0.000178 & 0.004872 & undefined & 1 & $\mathrm{~S}$ & 0.7 & 0.6 \\
\hline 11/7B2 & 34S_6p1d7Yd_0 & 23.7 & 21.7 & 0.446 & 0.669 & HLP-22 & 12 & 4 & 4 & $\mathrm{p} 1 \mathrm{~d} 7$ & 2.45 & 0.000178 & 0.004872 & 0.05 & 0.18 & $\mathrm{P}$ & 0.7 & 0.6 \\
\hline 11/8A2 & 34S_6p1d7Yd_9 & 23.7 & 21.7 & 0.446 & 0.669 & HLP-22 & 12 & 0 & 4 & p1d7 & 2.45 & 0.000178 & 0.004872 & 0.05 & 0.18 & $\mathrm{P}$ & 0.7 & 0.6 \\
\hline 11/8C1 & 34S_6p1d7Ya & 33.9 & 31.9 & 0.446 & 0.669 & HLP-22 & 12 & 8 & 4 & p1d7 & 2.45 & 0.000178 & 0.004872 & undefined & 1 & S & 1 & 0.6 \\
\hline 11/8C2 & 34S_6p1d7Yd_1 & 33.9 & 31.9 & 0.446 & 0.669 & HLP-22 & 12 & 8 & 4 & p1d7 & 2.45 & 0.000178 & 0.004872 & 0.05 & 0.18 & $\mathrm{P}$ & 1 & 0.6 \\
\hline 11/8D2 & 34S_6p1d7Yd_0 & 33.9 & 31.9 & 0.446 & 0.669 & HLP-22 & 12 & 4 & 4 & p1d7 & 2.45 & 0.000178 & 0.004872 & 0.05 & 0.18 & $\mathrm{P}$ & 1 & 0.6 \\
\hline 11/9A1 & 34S_6p1d7Ya-04 & 33.9 & 31.9 & 0.446 & 0.669 & HLP-22 & 12 & 0 & 4 & p1d7 & 2.45 & 0.000178 & 0.004872 & undefined & 1 & S & 1 & 0.6 \\
\hline 11/9A2 & 34S_6p1d7Yd_9 & 33.9 & 31.9 & 0.446 & 0.669 & HLP-22 & 12 & 0 & 4 & $\mathrm{p} 1 \mathrm{~d} 7$ & 2.45 & 0.000178 & 0.004872 & 0.05 & 0.18 & $\mathrm{P}$ & 1 & 0.6 \\
\hline 11/14A1 & 34S_6p1d7Ya-44 & 67.8 & 65.8 & 0.446 & 0.669 & HLP-22 & 12 & 4 & 4 & p1d7 & 2.45 & 0.000178 & 0.004872 & undefined & 1 & S & 2 & 0.6 \\
\hline 11/14A2 & 34S_6p1d7Yd_0 & 67.8 & 65.8 & 0.446 & 0.669 & HLP-22 & 12 & 4 & 4 & p1d7 & 2.45 & 0.000178 & 0.004872 & 0.05 & 0.18 & $\mathrm{P}$ & 2 & 0.6 \\
\hline 11/14B1 & 34S_6p1d7Ya-44 & 67.8 & 61.8 & 0.446 & 0.669 & HLP-22 & 12 & 4 & 4 & p1d7 & 2.45 & 0.000178 & 0.004872 & undefined & 1 & S & 2 & 1.8 \\
\hline 11/14B2 & 34S_6p1d7Yd_0 & 67.8 & 61.8 & 0.446 & 0.669 & HLP-22 & 12 & 4 & 4 & p1d7 & 2.45 & 0.000178 & 0.004872 & 0.05 & 0.18 & $\mathrm{P}$ & 2 & 1.8 \\
\hline 11/14C1 & 34S_6p1d7Ya-04 & 67.8 & 61.8 & 0.446 & 0.669 & HLP-22 & 12 & 0 & 4 & p1d7 & 2.45 & 0.000178 & 0.004872 & undefined & 1 & S & 2 & 1.8 \\
\hline 11/14C2 & 34S_6p1d7Yd_9 & 67.8 & 61.8 & 0.446 & 0.669 & HLP-22 & 12 & 0 & 4 & p1d7 & 2.45 & 0.000178 & 0.004872 & 0.05 & 0.18 & $\mathrm{P}$ & 2 & 1.8 \\
\hline 11/14D1 & 34S_6p1d7Yc_1 & 67.8 & 61.8 & 0.446 & 0.669 & HLP-22 & 12 & 8 & 4 & p1d7 & 2.45 & 0.000178 & 0.004872 & 0.05 & 0.33 & $\mathrm{P}$ & 2 & 1.8 \\
\hline 11/15A1 & 34S_6p1d7Yc_0 & 67.8 & 61.8 & 0.446 & 0.669 & HLP-22 & 12 & 4 & 4 & p1d7 & 2.45 & 0.000178 & 0.004872 & 0.05 & 0.33 & $\mathrm{P}$ & 2 & 1.8 \\
\hline 11/15B1 & 34S_6p1d7Yc_9 & 67.8 & 61.8 & 0.446 & 0.669 & HLP-22 & 12 & 0 & 4 & p1d7 & 2.45 & 0.000178 & 0.004872 & 0.05 & 0.33 & $\mathrm{P}$ & 2 & 1.8 \\
\hline 11/15C1 & 34S_6p1d7Yc_6 & 67.8 & 61.8 & 0.446 & 0.669 & HLP-22 & 12 & 4 & 0 & p1d7 & 2.45 & 0.000178 & 0.004872 & 0.05 & 0.33 & $\mathrm{P}$ & 2 & 1.8 \\
\hline 11/19A1 & 34S_4p1d7Ya & 67.8 & 61.8 & 0.297 & 0.4455 & HLP-22 & 12 & 8 & 4 & p1d7 & 2.45 & 0.000178 & 0.004872 & undefined & 1 & S & 2 & 1.8 \\
\hline 11/19A2 & 34S_4p1d7Yd_1 & 67.8 & 61.8 & 0.297 & 0.4455 & HLP-22 & 12 & 8 & 4 & p1d7 & 2.45 & 0.000178 & 0.004872 & 0.05 & 0.18 & $\mathrm{P}$ & 2 & 1.8 \\
\hline 11/20A1 & 34S_4p1d7Ya-44 & 67.8 & 61.8 & 0.297 & 0.4455 & HLP-22 & 12 & 4 & 4 & p1d7 & 2.45 & 0.000178 & 0.004872 & undefined & 1 & S & 2 & 1.8 \\
\hline 11/20A2 & 34S_4p1d7Yd_0 & 67.8 & 61.8 & 0.297 & 0.4455 & HLP-22 & 12 & 4 & 4 & p1d7 & 2.45 & 0.000178 & 0.004872 & 0.05 & 0.18 & $\mathrm{P}$ & 2 & 1.8 \\
\hline 11/20B1 & 34S_4p1d7Ya-04 & 67.8 & 61.8 & 0.297 & 0.4455 & HLP-22 & 12 & 0 & 4 & p1d7 & 2.45 & 0.000178 & 0.004872 & undefined & 1 & S & 2 & 1.8 \\
\hline 11/20B2 & 34S_4p1d7Yd_9 & 67.8 & 61.8 & 0.297 & 0.4455 & HLP-22 & 12 & 0 & 4 & $\mathrm{p} 1 \mathrm{~d} 7$ & 2.45 & 0.000178 & 0.004872 & 0.05 & 0.18 & $\mathrm{P}$ & 2 & 1.8 \\
\hline 11/26A1 & 34S_4p1d7Ya-40 & 67.8 & 61.8 & 0.297 & 0.4455 & HLP-22 & 12 & 4 & 0 & p1d7 & 2.45 & 0.000178 & 0.004872 & undefined & 1 & S & 2 & 1.8 \\
\hline 11/26A2 & 34S_4p1d7Yd_6 & 67.8 & 61.8 & 0.297 & 0.4455 & HLP-22 & 12 & 4 & 0 & p1d7 & 2.45 & 0.000178 & 0.004872 & 0.05 & 0.18 & $\mathrm{P}$ & 2 & 1.8 \\
\hline 11/26B1 & 34S_4p1d7Yc_1 & 67.8 & 61.8 & 0.297 & 0.4455 & HLP-22 & 12 & 8 & 4 & p1d7 & 2.45 & 0.000178 & 0.004872 & 0.05 & 0.33 & $\mathrm{P}$ & 2 & 1.8 \\
\hline 11/26C1 & 34S_4p1d7Yc_0 & 67.8 & 61.8 & 0.297 & 0.4455 & HLP-22 & 12 & 4 & 4 & p1d7 & 2.45 & 0.000178 & 0.004872 & 0.05 & 0.33 & $\mathrm{P}$ & 2 & 1.8 \\
\hline 11/26D1 & 34S_4p1d7Yd_9 & 67.8 & 61.8 & 0.297 & 0.4455 & HLP-22 & 12 & 0 & 4 & p1d7 & 2.45 & 0.000178 & 0.004872 & 0.06 & 0.18 & $\mathrm{P}$ & 2 & 1.8 \\
\hline 11/26D2 & 34S_4p1d7Yc_9 & 67.8 & 61.8 & 0.297 & 0.4455 & HLP-22 & 12 & 0 & 4 & p1d7 & 2.45 & 0.000178 & 0.004872 & 0.05 & 0.33 & $\mathrm{P}$ & 2 & 1.8 \\
\hline 11/27A1 & 34S_4p1d7Yc_6 & 67.8 & 61.8 & 0.297 & 0.4455 & HLP-22 & 12 & 4 & 0 & p1d7 & 2.45 & 0.000178 & 0.004872 & 0.05 & 0.33 & $\mathrm{P}$ & 2 & 1.8 \\
\hline
\end{tabular}


Table 6.6. (contd)

\begin{tabular}{|c|c|c|c|c|c|c|c|c|c|c|c|c|c|c|c|c|c|c|}
\hline Test & Case ID & $\begin{array}{l}\text { Tank } \\
\text { Fill } \\
\text { Height }\end{array}$ & $\begin{array}{l}\text { Return } \\
\text { Line } \\
\text { Height }\end{array}$ & $\begin{array}{l}\text { Nozzle } \\
\text { Inner } \\
\text { Diameter }\end{array}$ & $\begin{array}{l}\text { Nozzle } \\
\text { Standoff } \\
\text { Distance }\end{array}$ & $\begin{array}{l}\text { Pulse Tube } \\
\text { Configuration }\end{array}$ & $\begin{array}{c}\text { Installed } \\
\text { Nozzles }\end{array}$ & $\begin{array}{c}\text { Outer } \\
\text { Nozzles } \\
\text { Operated }\end{array}$ & $\begin{array}{c}\text { Inner } \\
\text { Nozzles } \\
\text { Operated }\end{array}$ & Simulant & $\begin{array}{l}\text { Solids } \\
\text { Density }\end{array}$ & $\begin{array}{l}\text { Particle } \\
\text { Diameter } \\
\text { d50 }\end{array}$ & $\begin{array}{l}\text { Solids } \\
\text { Fraction }\end{array}$ & $\begin{array}{l}\text { Pulse } \\
\text { Volume } \\
\text { Fraction }\end{array}$ & $\begin{array}{l}\text { Duty } \\
\text { Cycle }\end{array}$ & $\begin{array}{l}\text { Pulsed } \\
\text { or } \\
\text { Steady } \\
\text { Jet }\end{array}$ & $\begin{array}{c}\text { Fill } \\
\text { Height to } \\
\text { Diameter }\end{array}$ & $\begin{array}{l}\text { Return Line } \\
\text { Height to } \\
\text { Diameter }\end{array}$ \\
\hline text & text & in. & in. & in. & in. & text & number & number & number & text & $\mathrm{g} / \mathrm{cm}^{3}$ & $\mathrm{~m}$ & fraction & fraction & fraction & text & ratio & ratio \\
\hline $\mathrm{M} / \mathrm{DDX}$ & ID & $\mathrm{H}$ & Rtn & $\mathrm{d}$ & sod & $\mathrm{PT}$ & $\mathrm{N}$ & $\mathrm{N}_{\mathrm{O}}$ & $\mathrm{N}_{\mathrm{I}}$ & sxdx & $\rho_{\mathrm{S}}$ & $\mathrm{d}_{50}$ & $\phi_{\Sigma}$ & $\phi_{\mathrm{p}}$ & DC & Jet & $\mathrm{H} / \mathrm{D}$ & Rtn/D \\
\hline 11/27B1 & 34S_4p1d7Ya-80 & 67.8 & 61.8 & 0.297 & 0.4455 & HLP-22 & 12 & 8 & 0 & p1d7 & 2.45 & 0.000178 & 0.004872 & undefined & 1 & $\mathrm{~S}$ & 2 & 1.8 \\
\hline 11/27B2 & 34S_4p1d7Yd_5 & 67.8 & 61.8 & 0.297 & 0.4455 & HLP-22 & 12 & 8 & 0 & p1d7 & 2.45 & 0.000178 & 0.004872 & 0.05 & 0.18 & $\mathrm{P}$ & 2 & 1.8 \\
\hline 11/27B3 & 34S_4p1d7Yc_5 & 67.8 & 61.8 & 0.297 & 0.4455 & HLP-22 & 12 & 8 & 0 & p1d7 & 2.45 & 0.000178 & 0.004872 & 0.05 & 0.33 & $\mathrm{P}$ & 2 & 1.8 \\
\hline 11/30A1 & 34S_4p1d8Ya & 67.8 & 61.8 & 0.297 & 0.4455 & HLP-22 & 12 & 8 & 4 & p1d8 & 2.45 & 8.95E-05 & 0.004872 & undefined & 1 & S & 2 & 1.8 \\
\hline 11/30A2 & 34S_4p1d8Yd_1 & 67.8 & 61.8 & 0.297 & 0.4455 & HLP-22 & 12 & 8 & 4 & p1d8 & 2.45 & 8.95E-05 & 0.004872 & 0.05 & 0.18 & $\mathrm{P}$ & 2 & 1.8 \\
\hline 11/30B1 & 34S_4p1d8Yc_1 & 67.8 & 61.8 & 0.297 & 0.4455 & HLP-22 & 12 & 8 & 4 & p1d8 & 2.45 & 8.95E-05 & 0.004872 & 0.05 & 0.33 & $\mathrm{P}$ & 2 & 1.8 \\
\hline 11/30C1 & 34S_4p1d8Ya-44 & 67.8 & 61.8 & 0.297 & 0.4455 & HLP-22 & 12 & 4 & 4 & p1d8 & 2.45 & 8.95E-05 & 0.004872 & undefined & 1 & S & 2 & 1.8 \\
\hline 11/30C2 & 34S_4p1d8Yd_0 & 67.8 & 61.8 & 0.297 & 0.4455 & HLP-22 & 12 & 4 & 4 & p1d8 & 2.45 & 8.95E-05 & 0.004872 & 0.05 & 0.18 & $\mathrm{P}$ & 2 & 1.8 \\
\hline 12/3A1 & 34S_4p1d8Yc_0 & 67.8 & 61.8 & 0.297 & 0.4455 & HLP-22 & 12 & 4 & 4 & p1d8 & 2.45 & 8.95E-05 & 0.004872 & 0.05 & 0.33 & $P$ & 2 & 1.8 \\
\hline 12/3B1 & 34S_4p1d8Ya-04 & 67.8 & 61.8 & 0.297 & 0.4455 & HLP-22 & 12 & 0 & 4 & p1d8 & 2.45 & 8.95E-05 & 0.004872 & undefined & 1 & S & 2 & 1.8 \\
\hline 12/3B2 & 34S_4p1d8Yd_9 & 67.8 & 61.8 & 0.297 & 0.4455 & HLP-22 & 12 & 0 & 4 & p1d8 & 2.45 & 8.95E-05 & 0.004872 & 0.05 & 0.18 & $\mathrm{P}$ & 2 & 1.8 \\
\hline 12/3C1 & 34S_4p1d8Yc_9 & 67.8 & 61.8 & 0.297 & 0.4455 & HLP-22 & 12 & 0 & 4 & p1d8 & 2.45 & 8.95E-05 & 0.004872 & 0.05 & 0.33 & $\mathrm{P}$ & 2 & 1.8 \\
\hline 12/4A1 & 34S_4p1d8Ya-40 & 67.8 & 61.8 & 0.297 & 0.4455 & HLP-22 & 12 & 4 & 0 & p1d8 & 2.45 & 8.95E-05 & 0.004872 & undefined & 1 & S & 2 & 1.8 \\
\hline $12 / 4 \mathrm{~A} 2$ & 34S_4p1d8Yd_6 & 67.8 & 61.8 & 0.297 & 0.4455 & HLP-22 & 12 & 4 & 0 & p1d8 & 2.45 & 8.95E-05 & 0.004872 & 0.05 & 0.18 & $\mathrm{P}$ & 2 & 1.8 \\
\hline 12/4B1 & 34S_4p1d8Yc_6 & 67.8 & 61.8 & 0.297 & 0.4455 & HLP-22 & 12 & 4 & 0 & p1d8 & 2.45 & 8.95E-05 & 0.004872 & 0.05 & 0.33 & $P$ & 2 & 1.8 \\
\hline $12 / 4 \mathrm{C} 1$ & 34S_4p1d8Ya-80 & 67.8 & 61.8 & 0.297 & 0.4455 & HLP-22 & 12 & 8 & 0 & p1d8 & 2.45 & 8.95E-05 & 0.004872 & undefined & 1 & S & 2 & 1.8 \\
\hline $12 / 4 \mathrm{C} 2$ & 34S_4p1d8Yd_5 & 67.8 & 61.8 & 0.297 & 0.4455 & HLP-22 & 12 & 8 & 0 & p1d8 & 2.45 & 8.95E-05 & 0.004872 & 0.05 & 0.18 & $P$ & 2 & 1.8 \\
\hline 12/4D1 & 34S_4p1d8Yc_5 & 67.8 & 61.8 & 0.297 & 0.4455 & HLP-22 & 12 & 8 & 0 & p1d8 & 2.45 & 8.95E-05 & 0.004872 & 0.05 & 0.33 & $P$ & 2 & 1.8 \\
\hline
\end{tabular}


Table 6.7. Summary of Fill Height and Return Line Height Test Conditions

\begin{tabular}{|c|c|c|c|c|c|c|c|}
\hline \multicolumn{2}{|c|}{ Test Campaign } & 2008 & 2008 & 2008 & 2008 & July 2007 & Fall 2007 \\
\hline \multicolumn{2}{|c|}{ Tank and Head } & $15 \mathrm{E}$ & $34 \mathrm{~S}$ & $70 \mathrm{E}$ & $70 \mathrm{~F}$ & $34 \mathrm{~S}$ & $34 \mathrm{~S}$ \\
\hline $\mathrm{H} / \mathrm{D}$ & Rtn/D & \multicolumn{6}{|c|}{ Number of Tests at Condition } \\
\hline 0.7 & 0.6 & - & - & - & - & - & 5 \\
\hline 1.0 & 0.6 & - & - & - & - & - & 5 \\
\hline 1.0 & 0.9 & - & - & - & - & - & 10 \\
\hline 1.3 & 1.1 & - & - & 37 & - & - & - \\
\hline 1.3 & 1.2 & - & - & - & 27 & - & - \\
\hline 2.0 & 0.6 & - & - & - & - & - & 6 \\
\hline 2.0 & 0.9 & - & - & - & - & - & 8 \\
\hline 2.0 & 1.8 & - & - & - & - & 30 & 47 \\
\hline 2.0 & 1.9 & - & 7 & - & - & - & - \\
\hline 2.1 & 1.9 & - & 12 & - & - & - & - \\
\hline 2.4 & 2.0 & 4 & - & - & - & - & - \\
\hline 2.3 & 2.1 & 1 & - & - & - & - & - \\
\hline 2.4 & 2.1 & 40 & - & - & - & - & - \\
\hline 2.5 & 2.1 & 17 & - & - & - & - & - \\
\hline
\end{tabular}

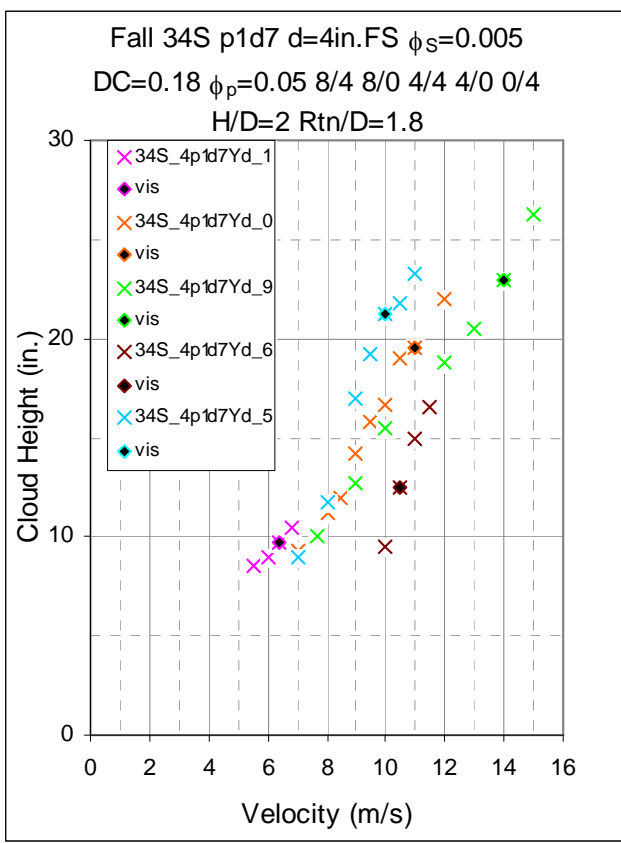

(a)

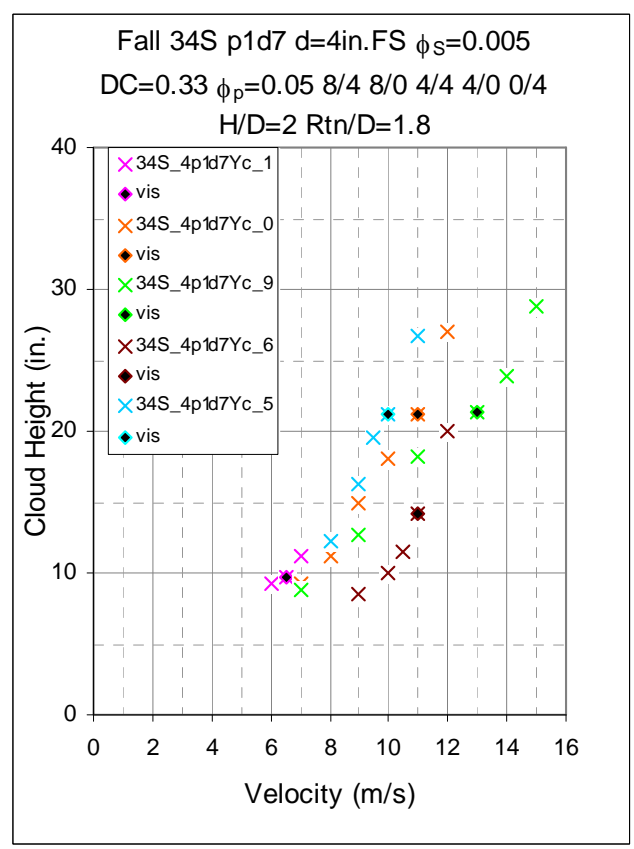

(b)

Figure 6.6. Cloud Height as Function of Velocity for Two Duty Cycles for PJM Combinations: (a) DC $=0.18$ [d], (b) DC $=0.33$ [c]. Both use 4 in. full-scale nozzle at solids fraction $\left(\phi_{\mathrm{S}}=0.005\right.$ [Y]), pulse volume fraction $\left(\phi_{\mathrm{P}}=0.05\right)$ and nozzle combinations $\mathrm{N}_{\mathrm{O}} / \mathrm{N}_{\mathrm{I}}=8 / 4$ [_1] pink, 8/0 [_5] aqua, 4/4 [_0] orange, 4/0 [_6] brown, 0/4 [_9] green) at fill level (H/D = 2) for simulant $\operatorname{p} 1 \mathrm{~d} 7\left(\rho_{\mathrm{s}}=2.45 \mathrm{~g} / \mathrm{cm}^{3}, \mathrm{~d}_{50}=178 \mu \mathrm{m}\right)$ 


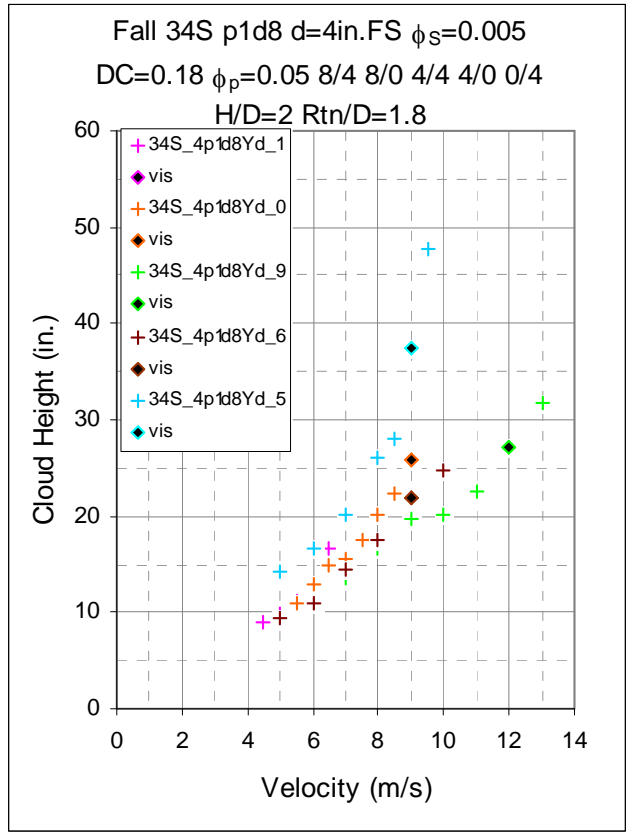

(a)

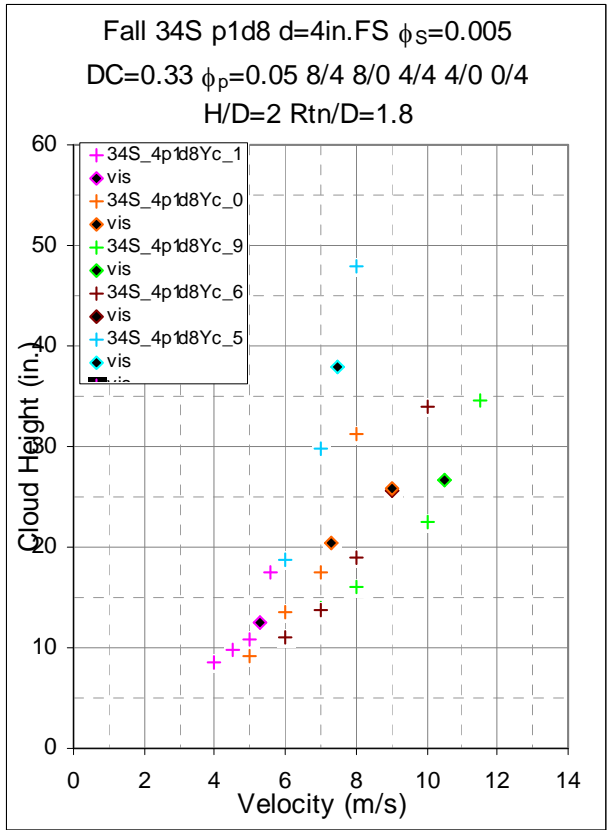

(b)

Figure 6.7. Cloud Height as Function of Velocity for Two Duty Cycles for PJM Combinations: (a) DC $=0.18$ [d], (b) DC $=0.33$ [c]. Both use 4 in. full-scale nozzle at solids fraction $\left(\phi_{\mathrm{S}}=0.005\right.$ [Y]), pulse volume fraction $\left(\phi_{\mathrm{P}}=0.05\right.$ and nozzle combinations $\left(\mathrm{N}_{\mathrm{O}} / \mathrm{N}_{\mathrm{I}}=8 / 4\right.$ [_1] pink, 8/0 [_5] aqua, 4/4 [_0] orange, 4/0 [_6] brown, 0/4 [_9] green) at fill level (H/D = 2) for simulant p1d8 $\left(\rho_{\mathrm{s}}=2.45 \mathrm{~g} / \mathrm{cm}^{3}, \mathrm{~d}_{50}=90 \mu \mathrm{m}\right)$.

In Figures 6.6 and 6.7, when the number of nozzles in operation is compared, the results follow this pattern: 12 nozzles [8/4] in operation produced the lowest critical suspension velocity. The critical suspension velocity increased when eight nozzles were operated; however, eight outer nozzles in operation [8/0] produced a lower critical suspension velocity than the [4/4] combination of four inner and four outer nozzles in operation. This is similar to what occurs when four nozzles are in operation. The critical suspension velocity increased when four nozzles were operated; however, four outer nozzles [4/0] in operation produced a lower critical suspension velocity than four inner nozzles in operation [0/4]. This trend in increase in critical suspension was observed for both duty cycles ( $\mathrm{DC}=0.18$ and 0.33 ).

In Figure 6.8 the test conditions are similar to those shown in Figure 6.7 (a) with two exceptions: 1) the full-scale nozzle size increased from 4 in. to 6 in. and 2) the tests were conducted at reduced fluid fill level with $\mathrm{H} / \mathrm{D}=0.7$ and $\mathrm{Rtn} / \mathrm{D}=0.6$. The data show the same trend with decrease in the number of PJMs, as shown in Figures 6.6 and 6.7. Due to the decrease in fill height, no cloud height data were obtained above the critical suspension velocity.

Several of the July 2007 tests were replicated during the Fall 2007 tests. Test conditions replicated in the July and Fall 2007 tests are plotted in Figure 6.9. These tests were conducted at continuous flow instead of pulsating flow with duty cycle of 1. The Fall 2007 data are shown in green, and the July 2007 data sets are shown in orange and pink. The data show that cloud height is essentially constant. 


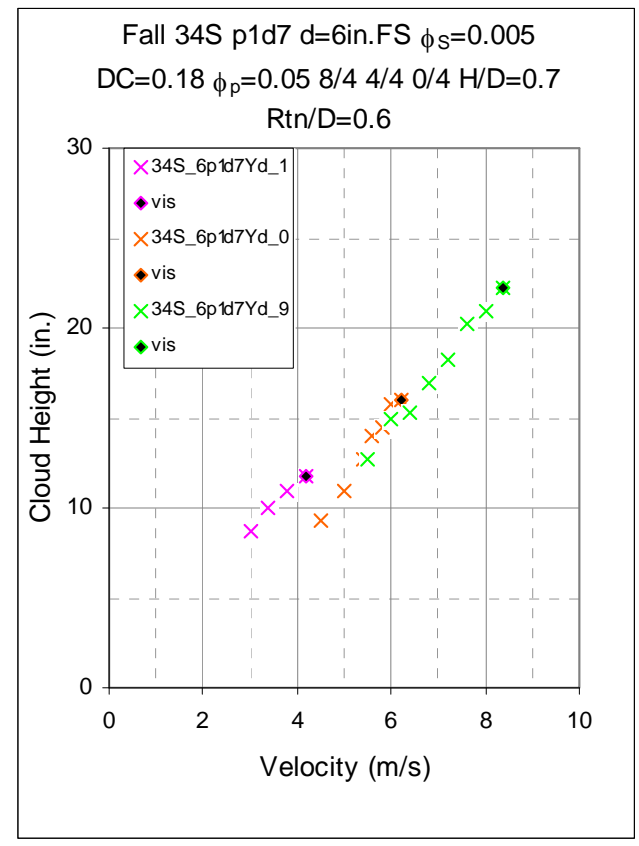

Figure 6.8. Cloud Height as Function of Velocity for Two Fill Heights: H/D=0.7, Rtn/ $D=0.6$, with a 6 in. Full-Scale Nozzle at Solids Fraction $\left(\phi_{\mathrm{S}}=0.005[\mathrm{Y}]\right)$, for Constant Duty Cycle (DC = 0.18 [d]) at Pulse Volume Fraction $\left(\phi_{\mathrm{p}}=0.05\right)$ and Nozzle Combinations $\left(\mathrm{N}_{\mathrm{O}} / \mathrm{N}_{\mathrm{I}}=8 / 4\right.$ [_1] pink, $4 / 4$ [_0] orange, 0/4 [_9] green) for Simulant p1d7 $\left(\rho_{\mathrm{s}}=2.45 \mathrm{~g} / \mathrm{cm}^{3}, \mathrm{~d}_{50}=178 \mu \mathrm{m}\right)$.

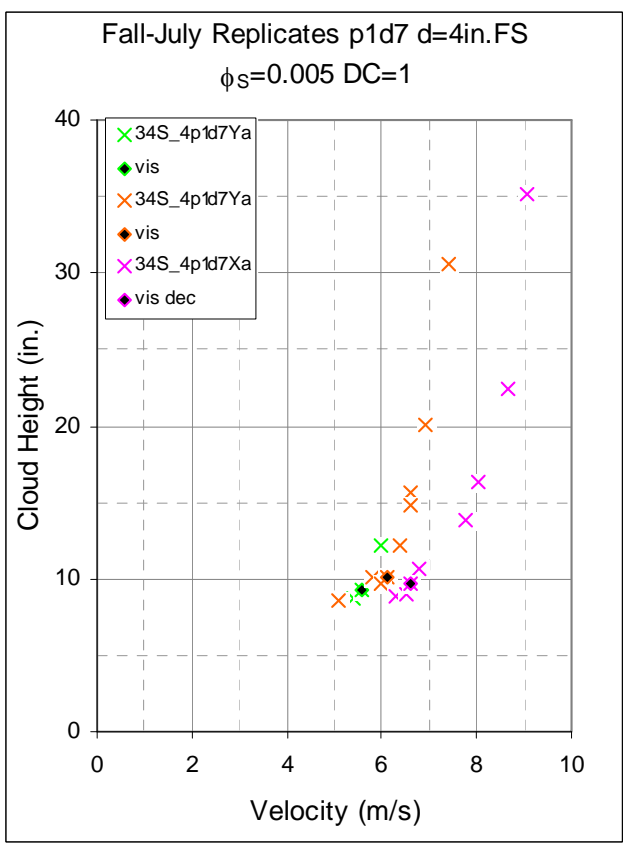

Figure 6.9. Cloud Height as Function of Velocity Comparing Results in July and Fall 2007 for Continuous Flow with d 0.4 in. Full-Scale, Solids Fraction $\left(\phi_{\mathrm{S}}=0.005\right.$ [Y]) for Constant DC (1-continuous flow) for Simulant p1d7 $\left(\rho_{\mathrm{s}}=2.45 \mathrm{~g} / \mathrm{cm}^{3}, \mathrm{~d}_{50}=178 \mu \mathrm{m}\right)$ and Data Sets Fall 2007 green, July 2007 orange and pink. 


\subsection{Tests}

The 2008 mixing test campaign was conducted using a new series of particles with narrower size distributions than the simulants of the prior test series (see Table 3.6). The tests were conducted with five simulants (three with lower density, two with higher density), as described in Section 3. Concentration varied extensively compared with the prior test series from 0.00015 to 0.06 solids fraction. Test condition ranges are listed in Table 6.3. The tests were conducted in three scaled tanks, small, mid and large. The large-scale tank tests were conducted with two head shapes, elliptical [E] and flanged and dished [F]; the small-scale tank tests were conduced with elliptical head [E]; and the mid-scale tank tests were conducted with a spherical head [S]. A brief summary of test conditions grouped by tank is provided in Table 6.8. Test conditions for the tests in these four tanks are summarized in Tables 6.9 (small-scale), 6.10 (midscale), 6.11 (large-scale elliptical head), and 6.12 (large-scale flanged and dished head). The majority of the variations in test conditions were conducted in the small-scale tank.

Table 6.8. 2008 Test Summary

\begin{tabular}{|c|c|c|c|c|}
\hline Test Tank & $\begin{array}{l}\text { Small-Scale with } \\
\text { Elliptical Head }\end{array}$ & $\begin{array}{l}\text { Mid-Scale with } \\
\text { Spherical Head }\end{array}$ & $\begin{array}{c}\text { Large-Scale with Elliptical } \\
\text { Head }\end{array}$ & $\begin{array}{c}\text { Large-Scale with } \\
\text { Flanged and Dished Head }\end{array}$ \\
\hline \multirow{4}{*}{$\begin{array}{l}\text { Full-scale nozzle } \\
\text { diameter, d }\end{array}$} & 4 & 4 & 4 & 4 \\
\hline & 6 & - & 6 & 6 \\
\hline & $8.5[\mathrm{M}]$ & - & - & - \\
\hline & 11.8 [L] & - & - & - \\
\hline \multirow{5}{*}{ Simulants, sxdx } & s1d5 & - & - & - \\
\hline & s1d1 & s1d1 & s1d1 & s1d1 \\
\hline & s1d2 & s1d2 & s1d2 & s1d2 \\
\hline & $\mathrm{s} 2 \mathrm{~d} 1$ & s2d1 & - & - \\
\hline & $\mathrm{s} 2 \mathrm{~d} 2$ & $\mathrm{~s} 2 \mathrm{~d} 2$ & s2d2 & $\mathrm{s} 2 \mathrm{~d} 2$ \\
\hline \multirow{9}{*}{$\begin{array}{l}\text { Solids volume } \\
\text { fraction, } \phi_{\mathrm{S}}\end{array}$} & $0.0005[\mathrm{~T}]$ & $0.0005[\mathrm{~T}]$ & - & - \\
\hline & $0.00155[\mathrm{Z}]$ & $0.00155[\mathrm{Z}]$ & $0.00155[\mathrm{Z}]$ & $0.00155[\mathrm{Z}]$ \\
\hline & $0.005[\mathrm{Y}]$ & $0.005[\mathrm{Y}]$ & $0.005[\mathrm{Y}]$ & $0.005[\mathrm{Y}]$ \\
\hline & $0.01[\mathrm{R}]$ & - & $0.01[\mathrm{R}]$ & $0.01[\mathrm{R}]$ \\
\hline & $0.0143[\mathrm{~V}]$ & - & $0.0143[\mathrm{~V}]$ & $0.0143[\mathrm{~V}]$ \\
\hline & $0.015[\mathrm{X}]$ & $0.015[\mathrm{X}]$ & $0.015[\mathrm{X}]$ & - \\
\hline & $0.03[\mathrm{Q}]$ & - & - & - \\
\hline & $0.045[\mathrm{~W}]$ & - & - & - \\
\hline & $0.060[\mathrm{P}]$ & - & - & - \\
\hline \multirow{5}{*}{ Duty Cycle, DC } & 0.18 [d] & 0.18 [d] & $0.18[\mathrm{~d}]$ & $0.18[\mathrm{~d}]$ \\
\hline & $0.33[\mathrm{c}]$ & $0.33[\mathrm{c}]$ & $0.33[c]$ & $0.33[c]$ \\
\hline & - & $0.50[\mathrm{~b}]$ & - & - \\
\hline & $0.66[\mathrm{e}]$ & $0.66[\mathrm{e}]$ & $0.66[\mathrm{e}]$ & $0.66[\mathrm{e}]$ \\
\hline & $1.0-$ continuous flow $[\mathrm{a}]$ & - & 1.0 - continuous flow $[\mathrm{a}]$ & \\
\hline \multirow{3}{*}{$\begin{array}{l}\text { Pulse volume } \\
\text { fraction, } \phi_{\mathrm{p}}\end{array}$} & $0.05\left[\_1\right]$ & 0.05 [_1] & $0.05\left[\_1\right]$ & 0.05 [_1] \\
\hline & $0.1[2]$ & $0.1[2]$ & $0.1[2]$ & $0.1[2]$ \\
\hline & 0.15 [ 4$]$ & - & 0.15 [ 4$]$ & 0.15 [4] \\
\hline \multirow{3}{*}{$\begin{array}{l}\text { PJM Array } \\
\text { Configuration }\end{array}$} & HLP-22 [8/4] & HLP-22 [8/4] & HLP-22 [8/4] & HLP-22 [8/4] \\
\hline & 8TA [4/4] & - & 8TA [4/4] & - \\
\hline & 8TA $[4 / 0]$ & - & 8TA $[4 / 0]$ & - \\
\hline
\end{tabular}




\subsubsection{Small-Scale Tank Tests with Elliptical Head}

The test conditions that were varied during the 2008 tests in the small-scale tank included five simulants: $\operatorname{s} 1 \mathrm{~d} 5\left(\rho_{\mathrm{s}}=2.5 \mathrm{~g} / \mathrm{cm}^{3}, \mathrm{~d}_{50}=44 \mu \mathrm{m}\right), \mathrm{s} 1 \mathrm{~d} 2\left(\rho_{\mathrm{s}}=2.48 \mathrm{~g} / \mathrm{cm}^{3}, \mathrm{~d}_{50}=69 \mu \mathrm{m}\right), \mathrm{s} 1 \mathrm{~d} 1\left(\rho_{\mathrm{s}}=\right.$ $\left.2.46 \mathrm{~g} / \mathrm{cm}^{3}, d_{50}=166 \mu \mathrm{m}\right), \mathrm{s} 2 \mathrm{~d} 2\left(\rho_{\mathrm{s}}=4.18 \mathrm{~g} / \mathrm{cm}^{3}, \mathrm{~d}_{50}=76 \mu \mathrm{m}\right)$, and s2d1 $\left(\rho_{\mathrm{s}}=4.17 \mathrm{~g} / \mathrm{cm}^{3}, \mathrm{~d}_{50}=164 \mu \mathrm{m}\right)$; four full-scale nozzle diameters $(\mathrm{d}=4,6,8.5[\mathrm{M}]$ and $11.8[\mathrm{~L}] \mathrm{in}$. full scale); a series of solids fractions $\left(\phi_{\mathrm{S}}=0.0005\right.$ [T, see Table 6.4], 0.00155 [Z], 0.005 [Y], 0.01 [R], 0.0143 [V], 0.015 [X], 0.03 [Q], 0.045 [W], $0.060[\mathrm{P}])$; a series of duty cycles (DC = 0.18 [d], 0.33 [c], 0.66 [e], 1.0-continuous flow [a]); and several pulse volume fractions ( $\phi_{\mathrm{p}}=0.05$ [_1], 0.1 [_2], 0.15 [_4]). These tests were conducted with two pulse tube configurations described by number of outer pulse tubes/number of inner pulse tubes: HLP-22 (8 outer and 4 inner pulse tubes with all pulse tubes in operation) and 8TA (4 outer and 4 inner pulse tube in operating combinations of $4 / 4$ and $4 / 0$ ). The pulse tube combinations are described in Table 6.4 designator QQ, which is part of the Case ID for each test. The test combinations are listed in Table 6.9

Data for cloud height as a function of velocity from the small-scale tests are shown in Figures 6.10 through 6.12. The plot legend presents the Case ID followed by the $\mathrm{U}_{\mathrm{CS}}$ velocity if it was measured for that case. When identified, the $\mathrm{U}_{\mathrm{CS}}$ velocity is shown as the darkened symbol in the legend beneath the test and the method used to determine $U_{\mathrm{CS}}$ is also shown. For example, in the legend for Figure 6.10 (a) each test Case ID shows the $U_{\text {CS }}$ condition beneath it. The first Case ID (34S_4s1d2Zc_1) symbol is a red circle with black outline, the corresponding $\mathrm{U}_{\mathrm{CS}}$ condition symbol is shown as a black circle with a red outline. The remaining $U_{\mathrm{CS}}$ condition symbols are shown as colored symbols with black centers. The color matches the corresponding Case ID above it. The description to the right of the $\mathrm{U}_{\mathrm{CS}}$ condition shows the method used to determine $U_{C S}$ which is either "udv" or "vis dec." Udv means that the $U_{C S}$ condition was determined ultrasonically after an increase in velocity. Vis dec means that the $U_{\mathrm{CS}}$ condition was determined visually after a decrease in velocity.

In Figure 6.10 the effects of concentration are observed with all parameters held constant except for solids volume fraction. Figure 6.10 (a) shows all concentrations in the series; 6.10 (b) shows the lowest five concentrations in the series. The concentration is color coded to increase as the rainbow from red to green. In Figure 6.10 (b) as concentration increases from 0.00155 to 0.03 , the velocity increases with concentration as seen from red, orange, gold, and yellow data points. In Figure 6.10 (a) the higher concentration points are also shown with lime and green shown on top of the other cases, especially at velocities below critical suspension velocity. 
Table 6.9. 2008 Test Summary for Small-Scale Tank

\begin{tabular}{|c|c|c|c|c|c|c|c|c|c|c|c|c|c|c|c|c|c|c|}
\hline Test & Case ID & $\begin{array}{c}\text { Tank } \\
\text { Fill } \\
\text { Height }\end{array}$ & $\begin{array}{l}\text { Return } \\
\text { Line } \\
\text { Height }\end{array}$ & $\begin{array}{l}\text { Nozzle } \\
\text { Inner } \\
\text { Diameter }\end{array}$ & $\begin{array}{l}\text { Nozzle } \\
\text { Standoff } \\
\text { Distance }\end{array}$ & $\begin{array}{l}\text { Pulse Tube } \\
\text { Configuration }\end{array}$ & $\begin{array}{c}\text { Installed } \\
\text { Nozzles }\end{array}$ & $\begin{array}{c}\text { Outer } \\
\text { Nozzles } \\
\text { Operated }\end{array}$ & $\begin{array}{c}\text { Inner } \\
\text { Nozzles } \\
\text { Operated }\end{array}$ & Simulant & $\begin{array}{l}\text { Solids } \\
\text { Density }\end{array}$ & $\begin{array}{l}\text { Particle } \\
\text { Diameter } \\
\text { d50 }\end{array}$ & $\begin{array}{l}\text { Solids } \\
\text { Fraction }\end{array}$ & $\begin{array}{l}\text { Pulse } \\
\text { Volume } \\
\text { Fraction }\end{array}$ & $\begin{array}{l}\text { Duty } \\
\text { Cycle }\end{array}$ & $\begin{array}{l}\text { Pulsed } \\
\text { or } \\
\text { Steady } \\
\text { Jet }\end{array}$ & $\begin{array}{c}\text { Fill } \\
\text { Height to } \\
\text { Diameter }\end{array}$ & $\begin{array}{l}\text { Return } \\
\text { Line } \\
\text { Height to } \\
\text { Diameter }\end{array}$ \\
\hline $\begin{array}{c}\text { text } \\
\text { M/DDX }\end{array}$ & $\begin{array}{c}\text { text } \\
\text { ID }\end{array}$ & $\begin{array}{c}\text { in. } \\
\mathrm{H}\end{array}$ & $\begin{array}{l}\text { in. } \\
\text { Rtn }\end{array}$ & $\begin{array}{c}\text { in. } \\
\text { d }\end{array}$ & $\begin{array}{l}\text { in. } \\
\text { sod }\end{array}$ & $\begin{array}{l}\text { text } \\
\text { PT }\end{array}$ & $\begin{array}{c}\text { number } \\
\mathrm{N}\end{array}$ & $\begin{array}{c}\text { number } \\
\mathrm{N}_{\mathrm{O}}\end{array}$ & $\begin{array}{c}\text { number } \\
\mathrm{N}_{\mathrm{I}}\end{array}$ & $\begin{array}{c}\text { text } \\
\text { sxdx }\end{array}$ & $\begin{array}{c}\mathrm{g} / \mathrm{cm}^{3} \\
\rho_{\mathrm{S}}\end{array}$ & $\begin{array}{c}\mathrm{m} \\
\mathrm{d}_{50}\end{array}$ & $\begin{array}{c}\text { fraction } \\
\phi_{\mathrm{S}}\end{array}$ & $\begin{array}{c}\text { fraction } \\
\phi_{p}\end{array}$ & $\begin{array}{l}\text { fraction } \\
\text { DC }\end{array}$ & $\begin{array}{c}\text { text } \\
\text { Jet }\end{array}$ & $\begin{array}{l}\text { ratio } \\
\text { H/D }\end{array}$ & $\begin{array}{c}\text { ratio } \\
\text { Rtn/D }\end{array}$ \\
\hline $6 / 6 \mathrm{~A}$ & 15E_4s1d2Zc_1 & 35 & 29 & 0.126 & 0.189 & HLP-22 & 12 & 8 & 4 & s1d2 & 2.48 & 0.000069 & 0.00155 & 0.05 & 0.33 & $\mathrm{P}$ & 2.4 & 2.0 \\
\hline $6 / 6 B$ & 15E_4s1d2Zd_1 & 35 & 29 & 0.126 & 0.189 & HLP-22 & 12 & 8 & 4 & s1d2 & 2.48 & 0.000069 & 0.00155 & 0.05 & 0.18 & $\mathrm{P}$ & 2.4 & 2.0 \\
\hline 6/9A & 15E_4s1d2Yc_1 & 35 & 29 & 0.126 & 0.189 & HLP-22 & 12 & 8 & 4 & s1d2 & 2.48 & 0.000069 & 0.005 & 0.05 & 0.33 & $\mathrm{P}$ & 2.4 & 2.0 \\
\hline 6/9B & 15E_4s1d2Rc_1 & 35 & 29 & 0.126 & 0.189 & HLP-22 & 12 & 8 & 4 & s1d2 & 2.48 & 0.000069 & 0.01 & 0.05 & 0.33 & $\mathrm{P}$ & 2.4 & 2.0 \\
\hline $6 / 10 \mathrm{~A}$ & 15E_4s1d2Rc_1 & 35 & 30 & 0.126 & 0.189 & HLP-22 & 12 & 8 & 4 & s1d2 & 2.48 & 0.000069 & 0.01 & 0.05 & 0.33 & $P$ & 2.4 & 2.1 \\
\hline $6 / 10 \mathrm{~B}$ & 15E_4s1d2Xc_1 & 35 & 30 & 0.126 & 0.189 & HLP-22 & 12 & 8 & 4 & s1d2 & 2.48 & 0.000069 & 0.015 & 0.05 & 0.33 & $\mathrm{P}$ & 2.4 & 2.1 \\
\hline $6 / 11 \mathrm{~A}$ & 15E_4s1d2Xd_1 & 34.5 & 30 & 0.126 & 0.189 & HLP-22 & 12 & 8 & 4 & s1d2 & 2.48 & 0.000069 & 0.015 & 0.05 & 0.18 & $\mathrm{P}$ & 2.4 & 2.1 \\
\hline $6 / 11 B$ & 15E_4s1d2Xa & 34.5 & 30 & 0.126 & 0.189 & HLP-22 & 12 & 8 & 4 & s1d2 & 2.48 & 0.000069 & 0.015 & undefined & 1.00 & S & 2.4 & 2.1 \\
\hline 6/11C & 15E_4s1d2Xc_1 & 34.5 & 30 & 0.126 & 0.189 & HLP-22 & 12 & 8 & 4 & s1d2 & 2.48 & 0.000069 & 0.015 & 0.05 & 0.33 & $\mathrm{P}$ & 2.4 & 2.1 \\
\hline $6 / 12 \mathrm{~A}$ & 15E_4s1d2Xe_1 & 34.75 & 30 & 0.126 & 0.189 & HLP-22 & 12 & 8 & 4 & s1d2 & 2.48 & 0.000069 & 0.015 & 0.05 & 0.66 & $\mathrm{P}$ & 2.4 & 2.1 \\
\hline $6 / 12 B$ & 15E_4s1d2Xc_2 & 34.75 & 30 & 0.126 & 0.189 & HLP-22 & 12 & 8 & 4 & s1d2 & 2.48 & 0.000069 & 0.015 & 0.10 & 0.33 & $\mathrm{P}$ & 2.4 & 2.1 \\
\hline $6 / 12 \mathrm{C}$ & 15E_4s1d2Xd_2 & 34.75 & 30 & 0.126 & 0.189 & HLP-22 & 12 & 8 & 4 & s1d2 & 2.48 & 0.000069 & 0.015 & 0.10 & 0.18 & $\mathrm{P}$ & 2.4 & 2.1 \\
\hline $6 / 12 \mathrm{D}$ & 15E_4s1d2Xe_2 & 34.75 & 30 & 0.126 & 0.189 & HLP-22 & 12 & 8 & 4 & s1d2 & 2.48 & 0.000069 & 0.015 & 0.10 & 0.66 & $\mathrm{P}$ & 2.4 & 2.1 \\
\hline $6 / 12 E$ & 15E_4s1d2Xc_4 & 34.75 & 30 & 0.126 & 0.189 & HLP-22 & 12 & 8 & 4 & s1d2 & 2.48 & 0.000069 & 0.015 & 0.15 & 0.32 & $\mathrm{P}$ & 2.4 & 2.1 \\
\hline 6/13A & 15E_4s1d2Xd_4 & 35 & 30 & 0.126 & 0.189 & HLP-22 & 12 & 8 & 4 & s1d2 & 2.48 & 0.000069 & 0.015 & 0.15 & 0.18 & $P$ & 2.4 & 2.1 \\
\hline 6/13B & 15E_4s1d2Xe_4 & 35 & 30 & 0.126 & 0.189 & HLP-22 & 12 & 8 & 4 & s1d2 & 2.48 & 0.000069 & 0.015 & 0.15 & 0.66 & $\mathrm{P}$ & 2.4 & 2.1 \\
\hline 6/13C & 15E_4s1d2Xd_1 & 35 & 30 & 0.126 & 0.189 & HLP-22 & 12 & 8 & 4 & s1d2 & 2.48 & 0.000069 & 0.015 & 0.05 & 0.17 & $\mathrm{P}$ & 2.4 & 2.1 \\
\hline $6 / 16 \mathrm{~A}$ & 15E_4s1d2Qc_1 & 35 & 30 & 0.126 & 0.189 & HLP-22 & 12 & 8 & 4 & s1d2 & 2.48 & 0.000069 & 0.03 & 0.05 & 0.33 & $\mathrm{P}$ & 2.4 & 2.1 \\
\hline $6 / 16 \mathrm{~B}$ & 15E_4s1d2Wc_1 & 34.75 & 30 & 0.126 & 0.189 & HLP-22 & 12 & 8 & 4 & s1d2 & 2.48 & 0.000069 & 0.045 & 0.05 & 0.33 & $\mathrm{P}$ & 2.4 & 2.1 \\
\hline 6/17A & 15E_4s1d2Wd_1 & 34.5 & 30 & 0.126 & 0.189 & HLP-22 & 12 & 8 & 4 & s1d2 & 2.48 & 0.000069 & 0.045 & 0.05 & 0.18 & $\mathrm{P}$ & 2.4 & 2.1 \\
\hline 6/17B & 15E_4s1d2Wa & 34.5 & 30 & 0.126 & 0.189 & HLP-22 & 12 & 8 & 4 & s1d2 & 2.48 & 0.000069 & 0.045 & undefined & 1.00 & S & 2.4 & 2.1 \\
\hline 6/17C & 15E_4s1d2Wc_1 & 34.5 & 30 & 0.126 & 0.189 & HLP-22 & 12 & 8 & 4 & s1d2 & 2.48 & 0.000069 & 0.045 & 0.05 & 0.34 & $\mathrm{P}$ & 2.4 & 2.1 \\
\hline 6/18A & 15E_4s1d2Pc_1 & 34.5 & 30 & 0.126 & 0.189 & HLP-22 & 12 & 8 & 4 & s1d2 & 2.48 & 0.000069 & 0.06 & 0.05 & 0.33 & $\mathrm{P}$ & 2.4 & 2.1 \\
\hline $6 / 18 B$ & 15E_4s2d2Zc_1 & 35 & 30 & 0.126 & 0.189 & HLP-22 & 12 & 8 & 4 & $\mathrm{~s} 2 \mathrm{~d} 2$ & 4.18 & 0.000076 & 0.00155 & 0.05 & 0.33 & $\mathrm{P}$ & 2.4 & 2.1 \\
\hline
\end{tabular}


Table 6.9. (contd)

\begin{tabular}{|c|c|c|c|c|c|c|c|c|c|c|c|c|c|c|c|c|c|c|}
\hline Test & Case ID & $\begin{array}{c}\text { Tank } \\
\text { Fill } \\
\text { Height }\end{array}$ & $\begin{array}{l}\text { Return } \\
\text { Line } \\
\text { Height }\end{array}$ & $\begin{array}{l}\text { Nozzle } \\
\text { Inner } \\
\text { Diameter }\end{array}$ & $\begin{array}{l}\text { Nozzle } \\
\text { Standoff } \\
\text { Distance }\end{array}$ & $\begin{array}{c}\text { Pulse Tube } \\
\text { Configuration }\end{array}$ & $\begin{array}{c}\text { Installed } \\
\text { Nozzles }\end{array}$ & $\begin{array}{c}\text { Outer } \\
\text { Nozzles } \\
\text { Operated }\end{array}$ & $\begin{array}{c}\text { Inner } \\
\text { Nozzles } \\
\text { Operated }\end{array}$ & Simulant & $\begin{array}{l}\text { Solids } \\
\text { Density }\end{array}$ & $\begin{array}{l}\text { Particle } \\
\text { Diameter } \\
\text { d50 }\end{array}$ & $\begin{array}{c}\text { Solids } \\
\text { Fraction }\end{array}$ & $\begin{array}{c}\text { Pulse } \\
\text { Volume } \\
\text { Fraction }\end{array}$ & $\begin{array}{l}\text { Duty } \\
\text { Cycle }\end{array}$ & $\begin{array}{l}\text { Pulsed } \\
\text { or } \\
\text { Steady } \\
\text { Jet }\end{array}$ & $\begin{array}{c}\text { Fill } \\
\text { Height to } \\
\text { Diameter }\end{array}$ & $\begin{array}{c}\text { Return } \\
\text { Line } \\
\text { Height to } \\
\text { Diameter }\end{array}$ \\
\hline $\begin{array}{c}\text { text } \\
\text { M/DDX }\end{array}$ & $\begin{array}{c}\text { text } \\
\text { ID }\end{array}$ & $\begin{array}{c}\text { in. } \\
\mathrm{H}\end{array}$ & $\begin{array}{l}\text { in. } \\
\text { Rtn }\end{array}$ & $\begin{array}{c}\text { in. } \\
\text { d }\end{array}$ & $\begin{array}{l}\text { in. } \\
\text { sod }\end{array}$ & $\begin{array}{c}\text { text } \\
\text { PT }\end{array}$ & $\begin{array}{c}\text { number } \\
\mathrm{N}\end{array}$ & $\begin{array}{c}\text { number } \\
\mathrm{N}_{\mathrm{O}}\end{array}$ & $\begin{array}{c}\text { number } \\
\mathrm{N}_{\mathrm{I}}\end{array}$ & $\begin{array}{c}\text { text } \\
\text { sxdx }\end{array}$ & $\begin{array}{c}\mathrm{g} / \mathrm{cm}^{3} \\
\rho_{\mathrm{S}}\end{array}$ & $\begin{array}{c}\mathrm{m} \\
\mathrm{d}_{50}\end{array}$ & $\begin{array}{c}\text { fraction } \\
\phi_{\mathrm{S}}\end{array}$ & $\begin{array}{c}\text { fraction } \\
\phi_{\mathrm{p}}\end{array}$ & $\begin{array}{l}\text { fraction } \\
\text { DC }\end{array}$ & $\begin{array}{c}\text { text } \\
\text { Jet }\end{array}$ & $\begin{array}{l}\text { ratio } \\
\text { H/D }\end{array}$ & $\begin{array}{c}\text { ratio } \\
\text { Rtn/D }\end{array}$ \\
\hline $6 / 19 \mathrm{~A}$ & 15E_4s2d2Zc_1 & 35 & 30 & 0.126 & 0.189 & HLP-22 & 12 & 8 & 4 & s2d2 & 4.18 & 0.000076 & 0.00155 & 0.05 & 0.33 & $\mathrm{P}$ & 2.4 & 2.1 \\
\hline 6/19B & 15E_4s2d2Zd_1 & 35 & 30 & 0.126 & 0.189 & HLP-22 & 12 & 8 & 4 & s2d2 & 4.18 & 0.000076 & 0.00155 & 0.05 & 0.18 & $\mathrm{P}$ & 2.4 & 2.1 \\
\hline $6 / 19 \mathrm{C}$ & 15E_4s2d2Yc_1 & 35 & 30 & 0.126 & 0.189 & HLP-22 & 12 & 8 & 4 & $\mathrm{~s} 2 \mathrm{~d} 2$ & 4.18 & 0.000076 & 0.005 & 0.05 & 0.34 & $\mathrm{P}$ & 2.4 & 2.1 \\
\hline $6 / 20 \mathrm{~A}$ & 15E_4s2d2Yc_1 & 35 & 30 & 0.126 & 0.189 & HLP-22 & 12 & 8 & 4 & $\mathrm{~s} 2 \mathrm{~d} 2$ & 4.18 & 0.000076 & 0.005 & 0.05 & 0.33 & $\mathrm{P}$ & 2.4 & 2.1 \\
\hline $6 / 20 \mathrm{~B}$ & 15E_4s2d2Xc_1 & 35 & 30 & 0.126 & 0.189 & HLP-22 & 12 & 8 & 4 & s2d2 & 4.18 & 0.000076 & 0.015 & 0.05 & 0.33 & $\mathrm{P}$ & 2.4 & 2.1 \\
\hline $6 / 23 \mathrm{~A}$ & 15E_4s2d2Xd_1 & 33.5 & 30 & 0.126 & 0.189 & HLP-22 & 12 & 8 & 4 & $\mathrm{~s} 2 \mathrm{~d} 2$ & 4.18 & 0.000076 & 0.015 & 0.05 & 0.19 & $\mathrm{P}$ & 2.3 & 2.1 \\
\hline $6 / 24 \mathrm{~A}$ & 15E_4s2d2Xd_1 & 35.25 & 30 & 0.126 & 0.189 & HLP-22 & 12 & 8 & 4 & $\mathrm{~s} 2 \mathrm{~d} 2$ & 4.18 & 0.000076 & 0.015 & 0.05 & 0.18 & $\mathrm{P}$ & 2.4 & 2.1 \\
\hline $6 / 24 \mathrm{~B}$ & 15E_4s2d2Wc_1 & 35.75 & 30 & 0.126 & 0.189 & HLP-22 & 12 & 8 & 4 & $\mathrm{~s} 2 \mathrm{~d} 2$ & 4.18 & 0.000076 & 0.045 & 0.05 & 0.33 & $\mathrm{P}$ & 2.5 & 2.1 \\
\hline $6 / 25 \mathrm{~A}$ & 15E_4s2d2Wc & 34.5 & 30 & 0.126 & 0.189 & HLP-22 & 12 & 8 & 4 & $\mathrm{~s} 2 \mathrm{~d} 2$ & 4.18 & 0.000076 & 0.045 & 0.05 & 0.33 & $\mathrm{P}$ & 2.4 & 2.1 \\
\hline $6 / 25 B$ & 15E_4s2d2Pc_1 & 34.5 & 30 & 0.126 & 0.189 & HLP-22 & 12 & 8 & 4 & $\mathrm{~s} 2 \mathrm{~d} 2$ & 4.18 & 0.000076 & 0.06 & 0.05 & 0.33 & $\mathrm{P}$ & 2.4 & 2.1 \\
\hline $6 / 26 A$ & 15E_4s1d1Zc_1 & 34.75 & 30 & 0.126 & 0.189 & HLP-22 & 12 & 8 & 4 & s1d1 & 2.46 & 0.000166 & 0.00155 & 0.05 & 0.33 & $\mathrm{P}$ & 2.4 & 2.1 \\
\hline $6 / 26 B$ & 15E_4s1d1Zd_1 & 34.75 & 30 & 0.126 & 0.189 & HLP-22 & 12 & 8 & 4 & s1d1 & 2.46 & 0.000166 & 0.00155 & 0.05 & 0.18 & $\mathrm{P}$ & 2.4 & 2.1 \\
\hline $6 / 27 \mathrm{~A}$ & 15E_4s1d1Yc_1 & 34.75 & 30 & 0.126 & 0.189 & HLP-22 & 12 & 8 & 4 & s1d1 & 2.46 & 0.000166 & 0.005 & 0.05 & 0.33 & $\mathrm{P}$ & 2.4 & 2.1 \\
\hline $6 / 27 \mathrm{~B}$ & 15E_4s1d1Yd_1 & 34.75 & 30 & 0.126 & 0.189 & HLP-22 & 12 & 8 & 4 & s1d1 & 2.46 & 0.000166 & 0.005 & 0.05 & 0.19 & $\mathrm{P}$ & 2.4 & 2.1 \\
\hline $6 / 27 \mathrm{C}$ & 15E_4s1d1Xc_1 & 35.5 & 30 & 0.126 & 0.189 & HLP-22 & 12 & 8 & 4 & s1d1 & 2.46 & 0.000166 & 0.015 & 0.05 & 0.33 & $\mathrm{P}$ & 2.5 & 2.1 \\
\hline $6 / 30 \mathrm{~A}$ & 15E_4s1d1Xc_1 & 35 & 30 & 0.126 & 0.189 & HLP-22 & 12 & 8 & 4 & s1d1 & 2.46 & 0.000166 & 0.015 & 0.05 & 0.33 & $\mathrm{P}$ & 2.4 & 2.1 \\
\hline 6/30B & 15E_4s1d5Zc_1 & 35 & 30 & 0.126 & 0.189 & HLP-22 & 12 & 8 & 4 & s1d5 & 2.5 & 0.000044 & 0.00155 & 0.05 & 0.33 & $\mathrm{P}$ & 2.4 & 2.1 \\
\hline 7/1A & 15E_4s1d5Zc_1 & 35 & 30 & 0.126 & 0.189 & HLP-22 & 12 & 8 & 4 & s1d5 & 2.5 & 0.000044 & 0.00155 & 0.05 & 0.33 & $\mathrm{P}$ & 2.4 & 2.1 \\
\hline 7/1B & 15E_4s1d5Yc_1 & 35 & 30 & 0.126 & 0.189 & HLP-22 & 12 & 8 & 4 & s1d5 & 2.5 & 0.000044 & 0.005 & 0.05 & 0.33 & $\mathrm{P}$ & 2.4 & 2.1 \\
\hline $7 / 2 \mathrm{~A}$ & 15E_4s2d1Tc_1 & 36 & 30 & 0.126 & 0.189 & HLP-22 & 12 & 8 & 4 & s2d1 & 4.17 & 0.000164 & 0.0005 & 0.05 & 0.33 & $\mathrm{P}$ & 2.5 & 2.1 \\
\hline $7 / 2 B$ & 15E_4s2d1Zc_1 & 36 & 30 & 0.126 & 0.189 & HLP-22 & 12 & 8 & 4 & s2d1 & 4.17 & 0.000164 & 0.00155 & 0.05 & 0.33 & $\mathrm{P}$ & 2.5 & 2.1 \\
\hline 7/3A & 15E_4s2d1Yc_1 & 35.5 & 30 & 0.126 & 0.189 & HLP-22 & 12 & 8 & 4 & s2d1 & 4.17 & 0.000164 & 0.005 & 0.05 & 0.33 & $\mathrm{P}$ & 2.5 & 2.1 \\
\hline 7/3B & 15E_4s2d1Xc_1 & 35.5 & 30 & 0.126 & 0.189 & HLP-22 & 12 & 8 & 4 & $\mathrm{~s} 2 \mathrm{~d} 1$ & 4.17 & 0.000164 & 0.015 & 0.05 & 0.33 & $\mathrm{P}$ & 2.5 & 2.1 \\
\hline $7 / 8 \mathrm{~A}$ & 15E8_6s1d2Zc_1 & 35 & 30 & 0.191 & 0.20246 & 8TA & 8 & 4 & 4 & s1d2 & 2.48 & 0.000069 & 0.00155 & 0.05 & 0.33 & $\mathrm{P}$ & 2.4 & 2.1 \\
\hline $7 / 8 \mathrm{~B}$ & 15E8_6s1d2Zc_2 & 35 & 30 & 0.191 & 0.20246 & 8TA & 8 & 4 & 4 & s1d2 & 2.48 & 0.000069 & 0.00155 & 0.10 & 0.33 & $\mathrm{P}$ & 2.4 & 2.1 \\
\hline $7 / 8 \mathrm{C}$ & 15E8_6s1d2Vc_1 & 36 & 30 & 0.191 & 0.20246 & 8TA & 8 & 4 & 4 & s1d2 & 2.48 & 0.000069 & 0.0143 & 0.05 & 0.34 & $\mathrm{P}$ & 2.5 & 2.1 \\
\hline 7/9A & 15E8_6s1d2Vc_2 & 36 & 30 & 0.191 & 0.2865 & 8TA & 8 & 4 & 4 & s1d2 & 2.48 & 0.000069 & 0.0143 & 0.10 & 0.33 & $\mathrm{P}$ & 2.5 & 2.1 \\
\hline 7/9B & 15E8_6s1d2Xc_1 & 36 & 30 & 0.191 & 0.2865 & 8TA & 8 & 4 & 4 & s1d2 & 2.48 & 0.000069 & 0.015 & 0.05 & 0.33 & $\mathrm{P}$ & 2.5 & 2.1 \\
\hline
\end{tabular}


Table 6.9. (contd)

\begin{tabular}{|c|c|c|c|c|c|c|c|c|c|c|c|c|c|c|c|c|c|c|}
\hline Test & Case ID & $\begin{array}{c}\text { Tank } \\
\text { Fill } \\
\text { Height }\end{array}$ & $\begin{array}{c}\text { Return } \\
\text { Line } \\
\text { Height }\end{array}$ & $\begin{array}{l}\text { Nozzle } \\
\text { Inner } \\
\text { Diameter }\end{array}$ & $\begin{array}{l}\text { Nozzle } \\
\text { Standoff } \\
\text { Distance }\end{array}$ & $\begin{array}{c}\text { Pulse Tube } \\
\text { Configuration }\end{array}$ & $\begin{array}{c}\text { Installed } \\
\text { Nozzles }\end{array}$ & $\begin{array}{c}\text { Outer } \\
\text { Nozzles } \\
\text { Operated } \\
\end{array}$ & $\begin{array}{c}\text { Inner } \\
\text { Nozzles } \\
\text { Operated } \\
\end{array}$ & Simulant & $\begin{array}{l}\text { Solids } \\
\text { Density }\end{array}$ & $\begin{array}{c}\text { Particle } \\
\text { Diameter } \\
\text { d50 }\end{array}$ & $\begin{array}{c}\text { Solids } \\
\text { Fraction }\end{array}$ & $\begin{array}{c}\text { Pulse } \\
\text { Volume } \\
\text { Fraction }\end{array}$ & $\begin{array}{l}\text { Duty } \\
\text { Cycle }\end{array}$ & $\begin{array}{l}\text { Pulsed } \\
\text { or } \\
\text { Steady } \\
\text { Jet } \\
\end{array}$ & $\begin{array}{c}\text { Fill } \\
\text { Height to } \\
\text { Diameter }\end{array}$ & $\begin{array}{l}\text { Return } \\
\text { Line } \\
\text { Height to } \\
\text { Diameter }\end{array}$ \\
\hline $\begin{array}{c}\text { text } \\
\text { M/DDX }\end{array}$ & $\begin{array}{c}\text { text } \\
\text { ID }\end{array}$ & $\begin{array}{c}\text { in. } \\
\mathrm{H}\end{array}$ & $\begin{array}{l}\text { in. } \\
\text { Rtn }\end{array}$ & $\begin{array}{c}\text { in. } \\
\text { d }\end{array}$ & $\begin{array}{l}\text { in. } \\
\text { sod }\end{array}$ & $\begin{array}{c}\text { text } \\
\text { PT }\end{array}$ & $\begin{array}{c}\text { number } \\
\mathrm{N}\end{array}$ & $\begin{array}{c}\text { number } \\
\mathrm{N}_{\mathrm{O}}\end{array}$ & $\begin{array}{c}\text { number } \\
\mathrm{N}_{\mathrm{I}}\end{array}$ & $\begin{array}{c}\text { text } \\
\text { sxdx }\end{array}$ & $\begin{array}{c}\mathrm{g} / \mathrm{cm}^{3} \\
\rho_{\mathrm{S}}\end{array}$ & $\begin{array}{c}\mathrm{m} \\
\mathrm{d}_{50}\end{array}$ & $\begin{array}{c}\text { fraction } \\
\phi_{\mathrm{S}}\end{array}$ & $\begin{array}{c}\text { fraction } \\
\phi_{\mathrm{p}}\end{array}$ & $\begin{array}{c}\text { fraction } \\
\text { DC }\end{array}$ & $\begin{array}{c}\text { text } \\
\text { Jet }\end{array}$ & $\begin{array}{l}\text { ratio } \\
\text { H/D }\end{array}$ & $\begin{array}{c}\text { ratio } \\
\text { Rtn/D }\end{array}$ \\
\hline 7/9C & 15E8_6s1d2Xc_2 & 36 & 30 & 0.191 & 0.2865 & $8 \mathrm{TA}$ & 8 & 4 & 4 & s1d2 & 2.48 & 0.000069 & 0.015 & 0.10 & 0.33 & $\mathrm{P}$ & 2.5 & 2.1 \\
\hline $7 / 10 \mathrm{~A}$ & $\begin{array}{l}\text { 15E8_Ms1d2Zc_ } \\
1\end{array}$ & 35.5 & 30 & 0.268 & 0.402 & 8TA & 8 & 4 & 4 & s1d2 & 2.48 & 0.000069 & 0.00155 & 0.05 & 0.33 & $\mathrm{P}$ & 2.5 & 2.1 \\
\hline 7/10B & $\begin{array}{l}15 E 8 \text { Es } \\
2\end{array}$ & 35.5 & 30 & 0.268 & 0.402 & $8 \mathrm{TA}$ & 8 & 4 & 4 & s1d2 & 2.48 & 0.000069 & 0.00155 & 0.10 & 0.33 & $\mathrm{P}$ & 2.5 & 2.1 \\
\hline 7/11A & $\begin{array}{l}\text { 15E8_Ms1d2Vc_ } \\
1\end{array}$ & 35 & 30 & 0.268 & 0.402 & $8 \mathrm{TA}$ & 8 & 4 & 4 & s1d2 & 2.48 & 0.000069 & 0.0143 & 0.05 & 0.33 & $\mathrm{P}$ & 2.4 & 2.1 \\
\hline 7/11B & $\begin{array}{l}15 \mathrm{E} 8 \text {-Ms1d2Vc_ } \\
2\end{array}$ & 35 & 30 & 0.268 & 0.402 & $8 \mathrm{TA}$ & 8 & 4 & 4 & s1d2 & 2.48 & 0.000069 & 0.0143 & 0.10 & 0.33 & $\mathrm{P}$ & 2.4 & 2.1 \\
\hline $7 / 14 \mathrm{~A}$ & 15E8_Ls1d2Zc_1 & 36 & 30 & 0.375 & 0.5625 & $8 \mathrm{TA}$ & 8 & 4 & 4 & s1d2 & 2.48 & 0.000069 & 0.00155 & 0.05 & 0.33 & $\mathrm{P}$ & 2.5 & 2.1 \\
\hline 7/14B & 15E8_Ls1d2Vc_1 & 36 & 30 & 0.375 & 0.5625 & $8 \mathrm{TA}$ & 8 & 4 & 4 & s1d2 & 2.48 & 0.000069 & 0.0143 & 0.05 & 0.34 & $\mathrm{P}$ & 2.5 & 2.1 \\
\hline $7 / 15 \mathrm{~A}$ & 15E8_Ls1d2Vc_7 & 35.5 & 30 & 0.375 & 0.5625 & 8TA & 8 & 4 & 0 & s1d2 & 2.48 & 0.000069 & 0.0143 & 0.10 & 0.33 & $\mathrm{P}$ & 2.5 & 2.1 \\
\hline $7 / 15 B$ & 15E8_Ls1d2Vc_2 & 35.5 & 30 & 0.375 & 0.5625 & 8TA & 8 & 4 & 4 & s1d2 & 2.48 & 0.000069 & 0.0143 & 0.10 & 0.33 & $\mathrm{P}$ & 2.5 & 2.1 \\
\hline $7 / 15 \mathrm{C}$ & 15E8_Ls1d2Vc_6 & 35.5 & 30 & 0.375 & 0.5625 & 8TA & 8 & 4 & 0 & s1d2 & 2.48 & 0.000069 & 0.0143 & 0.05 & 0.33 & $\mathrm{P}$ & 2.5 & 2.1 \\
\hline
\end{tabular}




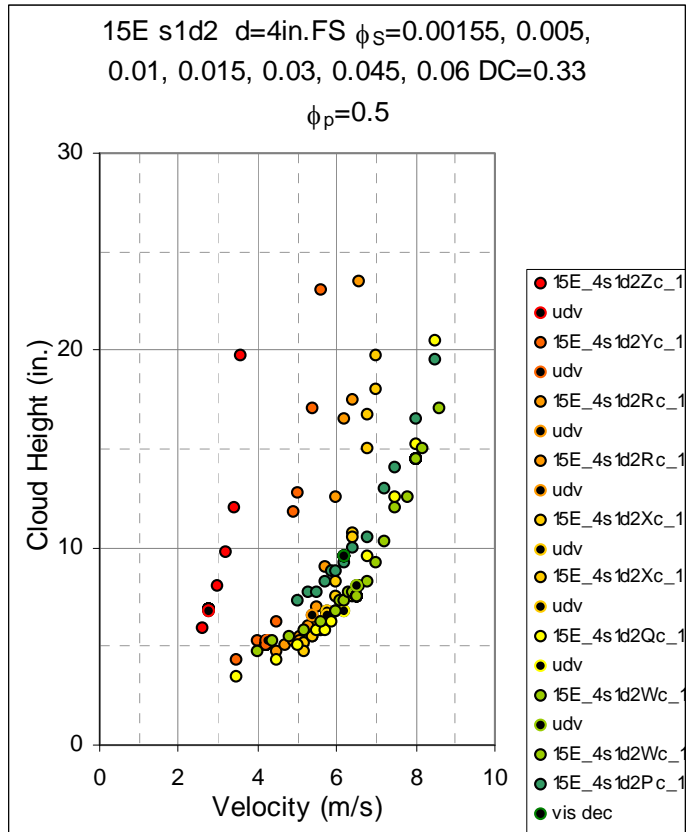

(a)

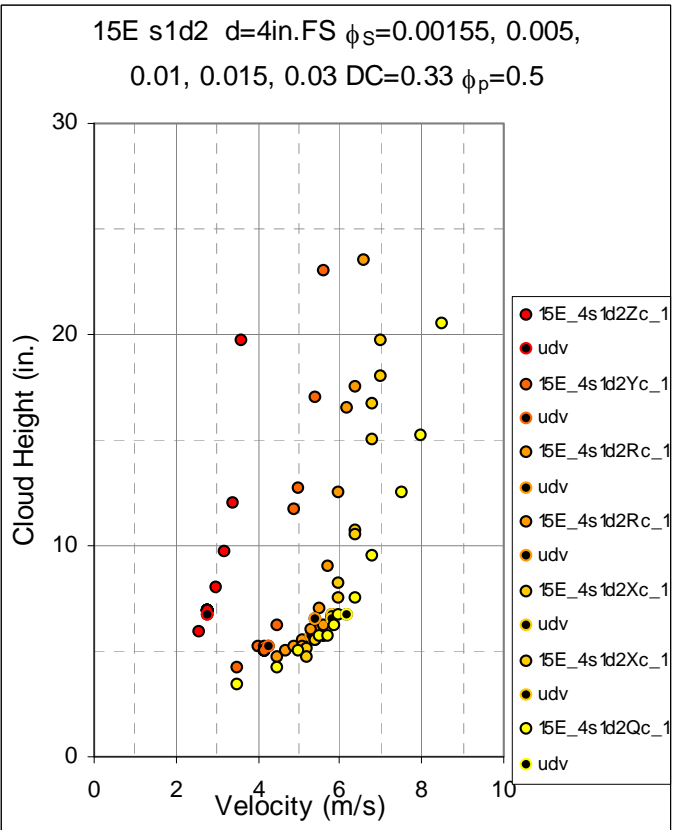

(b)

Figure 6.10. Cloud Height as Function of Velocity for Seven Concentrations, (a) all Concentrations, (b) 5 Concentrations. Test conditions are solids fractions $\left(\phi_{\mathrm{S}}=0.00155\right.$ [Z] red, 0.005 [Y] red-orange, $0.01[\mathrm{R}]$ light orange, $0.015[\mathrm{X}]$ gold, 0.03 [Q] yellow, 0.045 [W] lime, 0.06 [P] green), simulant s1d2 ( $\left.\rho_{\mathrm{s}}=2.48 \mathrm{~g} / \mathrm{cm}^{3}, \mathrm{~d}_{50}=69 \mu \mathrm{m}\right), 4 \mathrm{in}$. full-scale nozzle for duty cycle $(\mathrm{DC}=0.33)$ and pulse volume fraction $\left(\phi_{\mathrm{p}}=0.05\right)$.

In Figure 6.11 simulant is varied while other parameters are constant for two solids fractions. In Figure 6.11 (a) the solids fraction is 0.00155 [Z]; in Figure 6.11 (b) the solids fraction is 0.005 [Y]. In both (a) and (b) when the simulant density is held constant and the particle size increases the critical suspension velocity increases as the settling velocity of the simulants increases. When the simulant particle size is held constant and the simulant density increases the critical suspension velocity also increases as does the settling velocity. The simulant settling velocities are plotted in Figures 3.3 and 3.4. 


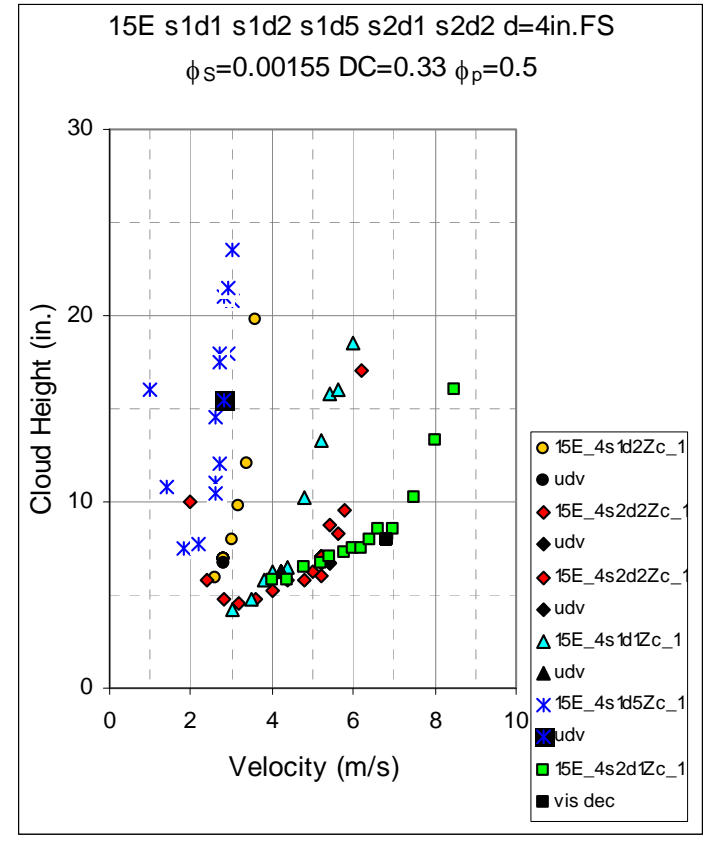

(a)

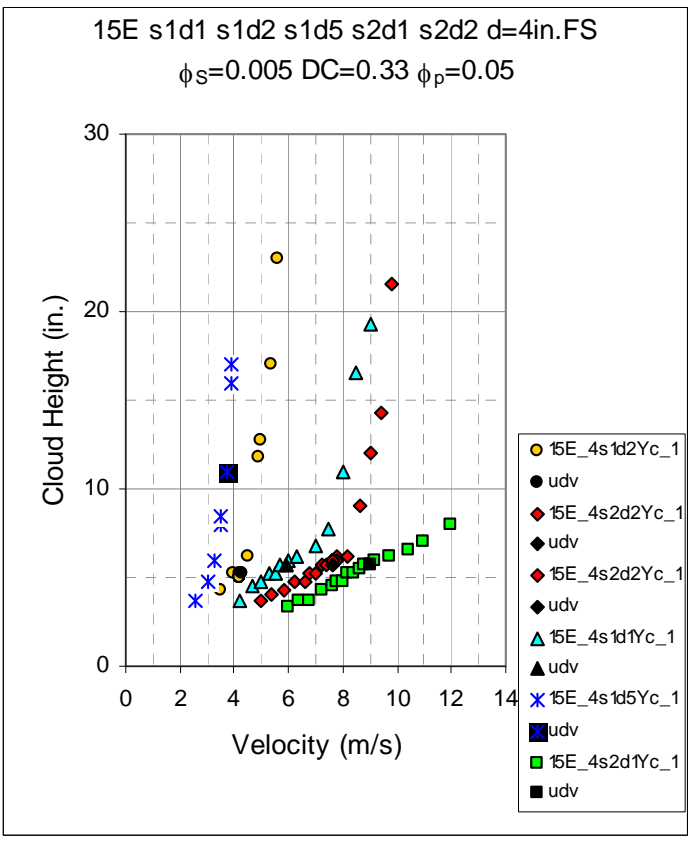

(b)

Figure 6.11. Cloud Height as Function of Velocity for Two Solids Fractions: (a) $\left(\phi_{\mathrm{S}}=0.00155\right.$ [Z]), (b) $\left(\phi_{\mathrm{S}}=0.005[\mathrm{Y}]\right)$. Both use five simulants: $\operatorname{s} 1 \mathrm{~d} 5\left(\rho_{\mathrm{s}}=2.5 \mathrm{~g} / \mathrm{cm}^{3}, \mathrm{~d}_{50}=44 \mu \mathrm{m}\right)$ blue asterisk, $\operatorname{s1d} 2\left(\rho_{\mathrm{s}}=2.48 \mathrm{~g} / \mathrm{cm}^{3}, \mathrm{~d}_{50}=69 \mu \mathrm{m}\right)$ gold circle, $\operatorname{s} 1 \mathrm{~d} 1\left(\rho_{\mathrm{s}}=2.46 \mathrm{~g} / \mathrm{cm}^{3}, \mathrm{~d}_{50}=166 \mu \mathrm{m}\right)$ aqua triangle, s2d2 $\left(\rho_{\mathrm{s}}=4.18 \mathrm{~g} / \mathrm{cm}^{3}, \mathrm{~d}_{50}=76 \mu \mathrm{m}\right)$ red diamond, and s2d1 $\left(\rho_{\mathrm{s}}=4.17 \mathrm{~g} / \mathrm{cm}^{3}, \mathrm{~d}_{50}=\right.$ $164 \mu \mathrm{m})$ green square , 4 in. full-scale nozzle, duty cycle ( $\mathrm{DC}=0.33$ [c]), and pulse volume fraction $\left(\phi_{\mathrm{p}}=0.05\right)$.

In Figure 6.12 the effect of varying nozzle diameter is shown for two tank pulse tube configurations, HLP-22 and 8TA (an eight tube array). The data suggest that the larger the nozzle diameter, the lower the critical suspension velocity. 


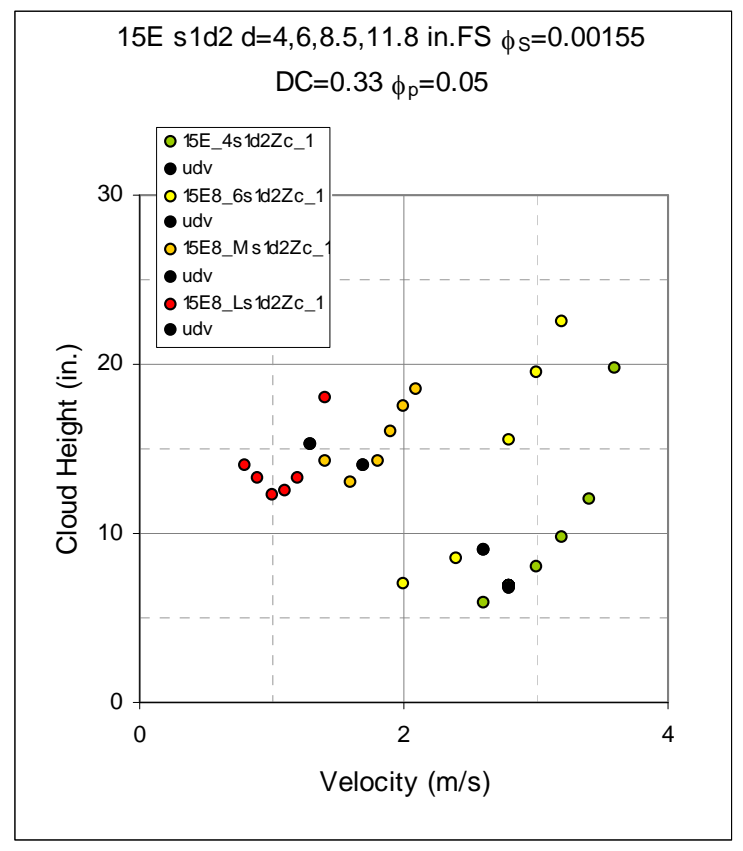

Figure 6.12. Cloud Height as Function of Velocity for Four Full-Scale Nozzle Diameters in Two Tank Configurations. Test conditions are simulant s1d2 $\left(\rho_{\mathrm{s}}=2.48 \mathrm{~g} / \mathrm{cm}^{3}, \mathrm{~d}_{50}=69 \mu \mathrm{m}\right)$ at solids fraction $\left(\phi_{\mathrm{S}}=0.00155[\mathrm{Z}]\right)$ for constant duty cycle $(\mathrm{DC}=0.33[\mathrm{c}])$ and pulse volume fraction $\left(\phi_{\mathrm{p}}=0.05\right)$ with full-scale nozzle diameters of 4 in. (green circles [o] HLP-22 ]8/4 pulse tubes]), 6 in. (yellow circles [o] 8TA [4/4 pulse tubes]), 8.5 in. ([M] gold circles [०] 8TA [4/4 pulse tubes]), 11.8 in. ([L] red circles [o] 8TA [4/4 pulse tubes]).

\subsubsection{Mid-Scale Tests with Spherical Head}

The test conditions that were varied during the 2008 tests in the mid-scale tank included four simulants: $\operatorname{s} 1 \mathrm{~d} 2\left(\rho_{\mathrm{s}}=2.48 \mathrm{~g} / \mathrm{cm}^{3}, \mathrm{~d}_{50}=69 \mu \mathrm{m}\right), \mathrm{s} 2 \mathrm{~d} 2\left(\rho_{\mathrm{s}}=4.18 \mathrm{~g} / \mathrm{cm}^{3}, \mathrm{~d}_{50}=76 \mu \mathrm{m}\right), \mathrm{s} 1 \mathrm{~d} 1\left(\rho_{\mathrm{s}}=\right.$ $\left.2.46 \mathrm{~g} / \mathrm{cm}^{3}, d_{50}=166 \mu \mathrm{m}\right)$, and s2d1 $\left(\rho_{\mathrm{s}}=4.17 \mathrm{~g} / \mathrm{cm}^{3}, \mathrm{~d}_{50}=164 \mu \mathrm{m}\right)$; one nozzle diameter $(\mathrm{d}=4 \mathrm{in}$. full scale); a series of solids fractions ( $\phi_{\mathrm{S}}=0.0005$ [T, see Table 6.4], 0.00155 [Z], 0.005 [Y], 0.0150 [X]); a series of duty cycles ( $\mathrm{DC}=0.18$ [d], $0.33[\mathrm{c}], 0.50[\mathrm{~b}], 0.66[\mathrm{e}])$; and two pulse volume fractions $\left(\phi_{\mathrm{p}}=\right.$ 0.05 [_1], 0.1 [_2]). These tests were conducted with pulse tube configuration of HLP-22, 8 outer pulse tubes and 4 inner pulse tubes [8/4] with all pulse tubes in operation. The test combinations are listed in Table 6.10 . 
Table 6.10. 2008 Test Summary for Mid-Scale Tank

\begin{tabular}{|c|c|c|c|c|c|c|c|c|c|c|c|c|c|c|c|c|c|c|}
\hline Test & Case ID & $\begin{array}{c}\text { Tank } \\
\text { Fill } \\
\text { Height }\end{array}$ & $\begin{array}{c}\text { Return } \\
\text { Line } \\
\text { Height }\end{array}$ & $\begin{array}{c}\text { Nozzle } \\
\text { Inner } \\
\text { Diameter }\end{array}$ & $\begin{array}{c}\text { Nozzle } \\
\text { Standoff } \\
\text { r Distance }\end{array}$ & $\begin{array}{l}\text { Pulse Tube } \\
\text { Configuration }\end{array}$ & $\begin{array}{l}\text { Installed } \\
\text { Nozzles }\end{array}$ & $\begin{array}{c}\text { Outer } \\
\text { Nozzles } \\
\text { Operated }\end{array}$ & $\begin{array}{c}\text { Inner } \\
\text { Nozzles } \\
\text { Operated }\end{array}$ & Simulant & $\begin{array}{c}\text { Solids } \\
\text { Density }\end{array}$ & $\begin{array}{l}\text { Particle } \\
\text { Diameter } \\
\text { d50 }\end{array}$ & $\begin{array}{l}\text { Solids } \\
\text { Fraction }\end{array}$ & $\begin{array}{l}\text { Pulse } \\
\text { Volume } \\
\text { Fraction }\end{array}$ & $\begin{array}{l}\text { Duty } \\
\text { Cycle }\end{array}$ & $\begin{array}{l}\text { Pulsed or } \\
\text { Steady Jet }\end{array}$ & $\begin{array}{c}\text { Fill } \\
\text { Height to } \\
\text { Diameter }\end{array}$ & $\begin{array}{l}\text { Return } \\
\text { Line } \\
\text { Height to } \\
\text { Diameter }\end{array}$ \\
\hline text & text & in. & in. & in. & in. & text & number & number & number & text & $\mathrm{g} / \mathrm{cm}^{3}$ & $\mathrm{~m}$ & fraction & fraction & fraction & text & ratio & ratio \\
\hline $\mathrm{M} / \mathrm{DDX}$ & ID & $\mathrm{H}$ & Rtn & $\mathrm{d}$ & sod & PT & $\mathrm{N}$ & $\mathrm{N}_{\mathrm{O}}$ & $\mathrm{N}_{\mathrm{I}}$ & sxdx & $\rho_{\mathrm{S}}$ & $\mathrm{d}_{50}$ & $\phi_{\mathrm{S}}$ & $\phi_{\mathrm{p}}$ & DC & Jet & $\mathrm{H} / \mathrm{D}$ & Rtn/D \\
\hline $3 / 5 \mathrm{~A}$ & 34S_4s1d1Zc_1 & 69 & 66 & 0.297 & 0.446 & HLP-22 & 12 & 8 & 4 & s1d1 & 2.46 & 0.000166 & 0.00155 & 0.05 & 0.34 & $\mathrm{P}$ & 2.0 & 1.9 \\
\hline 3/5B & 34S_4s1d1Zd_1 & 69 & 66 & 0.297 & 0.446 & HLP-22 & 12 & 8 & 4 & s1d1 & 2.46 & 0.000166 & 0.00155 & 0.05 & 0.18 & $\mathrm{P}$ & 2.0 & 1.9 \\
\hline $3 / 5 \mathrm{C}$ & 34S_4s1d1Zc_2 & 69 & 66 & 0.297 & 0.446 & HLP-22 & 12 & 8 & 4 & s1d1 & 2.46 & 0.000166 & 0.00155 & 0.10 & 0.33 & $\mathrm{P}$ & 2.0 & 1.9 \\
\hline $3 / 6 \mathrm{~A}$ & 34S_4s1d1Yc_1 & 69 & 66 & 0.297 & 0.446 & HLP-22 & 12 & 8 & 4 & s1d1 & 2.46 & 0.000166 & 0.005 & 0.05 & 0.34 & $\mathrm{P}$ & 2.0 & 1.9 \\
\hline $3 / 6 B$ & 34S_4s1d1Yd_1 & 69 & 66 & 0.297 & 0.446 & HLP-22 & 12 & 8 & 4 & s1d1 & 2.46 & 0.000166 & 0.005 & 0.05 & 0.19 & $\mathrm{P}$ & 2.0 & 1.9 \\
\hline $3 / 6 \mathrm{C}$ & 34S_4s1d1Xc_1 & 69 & 66 & 0.297 & 0.446 & HLP-22 & 12 & 8 & 4 & s1d1 & 2.46 & 0.000166 & 0.015 & 0.05 & 0.34 & $\mathrm{P}$ & 2.0 & 1.9 \\
\hline 3/7A & 34S_4s1d2Uc_1 & 69 & 66 & 0.297 & 0.446 & HLP-22 & 12 & 8 & 4 & $\mathrm{~s} 1 \mathrm{~d} 2$ & 2.48 & 0.000069 & 0.00015 & 0.05 & 0.33 & $\mathrm{P}$ & 2.0 & 1.9 \\
\hline 3/7B & 34S_4s1d2Tc_1 & 70 & 66 & 0.297 & 0.446 & HLP-22 & 12 & 8 & 4 & s1d2 & 2.48 & 0.000069 & 0.0005 & 0.05 & 0.33 & $\mathrm{P}$ & 2.1 & 1.9 \\
\hline $3 / 7 \mathrm{C}$ & 34S_4s1d2Sc_1 & 70 & 66 & 0.297 & 0.446 & HLP-22 & 12 & 8 & 4 & $\mathrm{~s} 1 \mathrm{~d} 2$ & 2.48 & 0.000069 & 0.0015 & 0.05 & 0.34 & $\mathrm{P}$ & 2.1 & 1.9 \\
\hline 3/9A & 34S_4s1d2Yc_1 & 70 & 66 & 0.297 & 0.446 & HLP-22 & 12 & 8 & 4 & s1d2 & 2.48 & 0.000069 & 0.005 & 0.05 & 0.34 & $\mathrm{P}$ & 2.1 & 1.9 \\
\hline 3/9B & 34S_4s1d2Yd_1 & 70 & 66 & 0.297 & 0.446 & HLP-22 & 12 & 8 & 4 & $\mathrm{~s} 1 \mathrm{~d} 2$ & 2.48 & 0.000069 & 0.005 & 0.05 & 0.19 & $\mathrm{P}$ & 2.1 & 1.9 \\
\hline 3/11A & 34S_4s2d2Tc_1 & 72 & 66 & 0.297 & 0.446 & HLP-22 & 12 & 8 & 4 & $\mathrm{~s} 2 \mathrm{~d} 2$ & 4.18 & 0.000076 & 0.0005 & 0.05 & 0.33 & $\mathrm{P}$ & 2.1 & 1.9 \\
\hline $3 / 11 B$ & 34S_4s2d2Zc_1 & 72 & 66 & 0.297 & 0.446 & HLP-22 & 12 & 8 & 4 & $\mathrm{~s} 2 \mathrm{~d} 2$ & 4.18 & 0.000076 & 0.00155 & 0.05 & 0.33 & $\mathrm{P}$ & 2.1 & 1.9 \\
\hline $3 / 11 \mathrm{C}$ & 34S_4s2d2Yd_1 & 72 & 66 & 0.297 & 0.446 & HLP-22 & 12 & 8 & 4 & $\mathrm{~s} 2 \mathrm{~d} 2$ & 4.18 & 0.000076 & 0.005 & 0.05 & 0.19 & $\mathrm{P}$ & 2.1 & 1.9 \\
\hline $3 / 12 \mathrm{~A}$ & 34S_4s2d2Yc_1 & 72 & 66 & 0.297 & 0.446 & HLP-22 & 12 & 8 & 4 & $\mathrm{~s} 2 \mathrm{~d} 2$ & 4.18 & 0.000076 & 0.005 & 0.05 & 0.34 & $\mathrm{P}$ & 2.1 & 1.9 \\
\hline $3 / 12 \mathrm{C}$ & 34S_4s2d2Xc_1 & 72 & 66 & 0.297 & 0.446 & HLP-22 & 12 & 8 & 4 & $\mathrm{~s} 2 \mathrm{~d} 2$ & 4.18 & 0.000076 & 0.015 & 0.05 & 0.35 & $\mathrm{P}$ & 2.1 & 1.9 \\
\hline $3 / 12 \mathrm{D}$ & 34S_4s2d2Xc_2 & 72 & 66 & 0.297 & 0.446 & HLP-22 & 12 & 8 & 4 & $\mathrm{~s} 2 \mathrm{~d} 2$ & 4.18 & 0.000076 & 0.015 & 0.10 & 0.33 & $\mathrm{P}$ & 2.1 & 1.9 \\
\hline $3 / 12 \mathrm{E}$ & 34S_4s2d2Xb_1 & 72 & 66 & 0.297 & 0.446 & HLP-22 & 12 & 8 & 4 & $\mathrm{~s} 2 \mathrm{~d} 2$ & 4.18 & 0.000076 & 0.015 & 0.05 & 0.50 & $\mathrm{P}$ & 2.1 & 1.9 \\
\hline $3 / 12 \mathrm{~F}$ & 34S_4s2d1Yc_1 & 70 & 66 & 0.297 & 0.446 & HLP-22 & 12 & 8 & 4 & $\mathrm{~s} 2 \mathrm{~d} 1$ & 4.17 & 0.000164 & 0.005 & 0.05 & 0.34 & $\mathrm{P}$ & 2.1 & 1.9 \\
\hline
\end{tabular}


Data from selected tests in the mid-scale vessel are shown in Figures 6.13 and 6.14. The plot legend presents the Case ID followed by the $U_{C S}$ velocity if it was measured for that case. When identified, the $\mathrm{U}_{\mathrm{CS}}$ velocity is shown as the darkened symbol in the legend beneath the test and the method used to determine $U_{\mathrm{CS}}$ is also shown. For example, in the legend for Figure 6.13 (a) each test Case ID shows the $\mathrm{U}_{\mathrm{CS}}$ condition beneath it. The first Case ID (34S_4s1d1Yc_1) symbol is an aqua triangle, the corresponding $\mathrm{U}_{\mathrm{CS}}$ condition symbol is shown as a black triangle. The next three $\mathrm{U}_{\mathrm{CS}}$ condition symbols are shown as either black symbols or colored symbols with black centers where the color matches that of the Case ID listed above it. The description to the right of the $\mathrm{U}_{\mathrm{CS}}$ condition shows the method used to determine $U_{C S}$ which is either "udv" or "vis dec." Udv means that the $U_{C S}$ condition was determined ultrasonically after an increase in velocity. Vis dec means that the $\mathrm{U}_{\mathrm{CS}}$ condition was determined visually after a decrease in velocity.

The four sxdx simulants are compared in Figure 6.13 (a) at the same solids fraction. In Figure 6.13 (b) two simulants are compared at three solids fractions. In both (a) and (b), when the simulant density is held constant and the particle size increases, the critical suspension velocity increases as the settling velocity of the simulants increases. When the simulant particle size is held constant and the simulant density increases, the critical suspension velocity also increases as does the settling velocity. The simulant settling velocities are plotted in Figures 3.3 and 3.4. In Figure 6.13 (b) the data are grouped based on solids fraction; the lowest solids fraction is shown by the circles, the mid solids fraction by the diamonds, and the largest solids fraction by squares. Within these groupings the critical suspension velocity increases with increasing settling velocity.

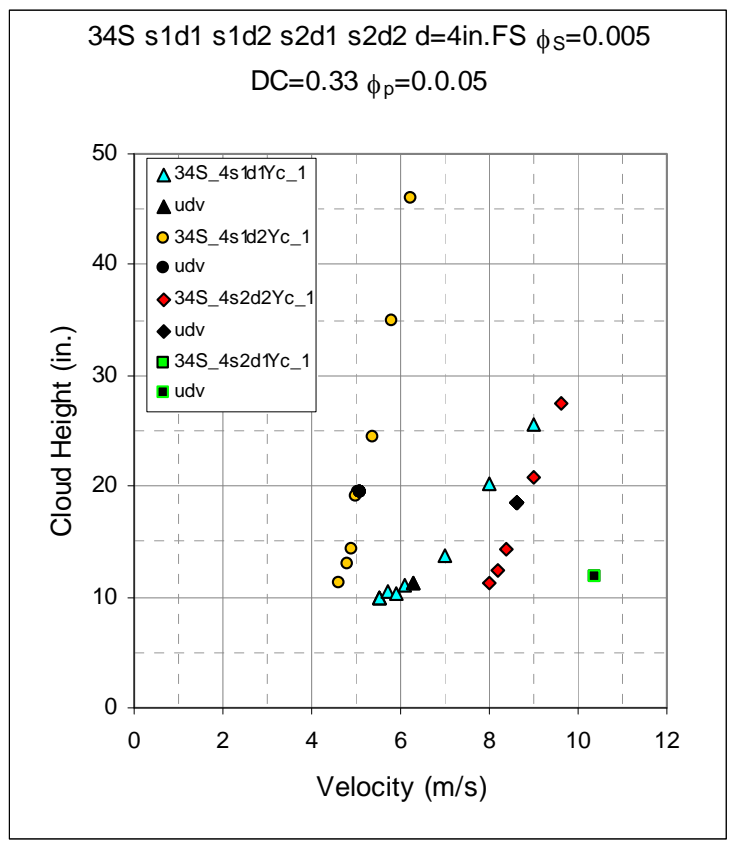

(a)

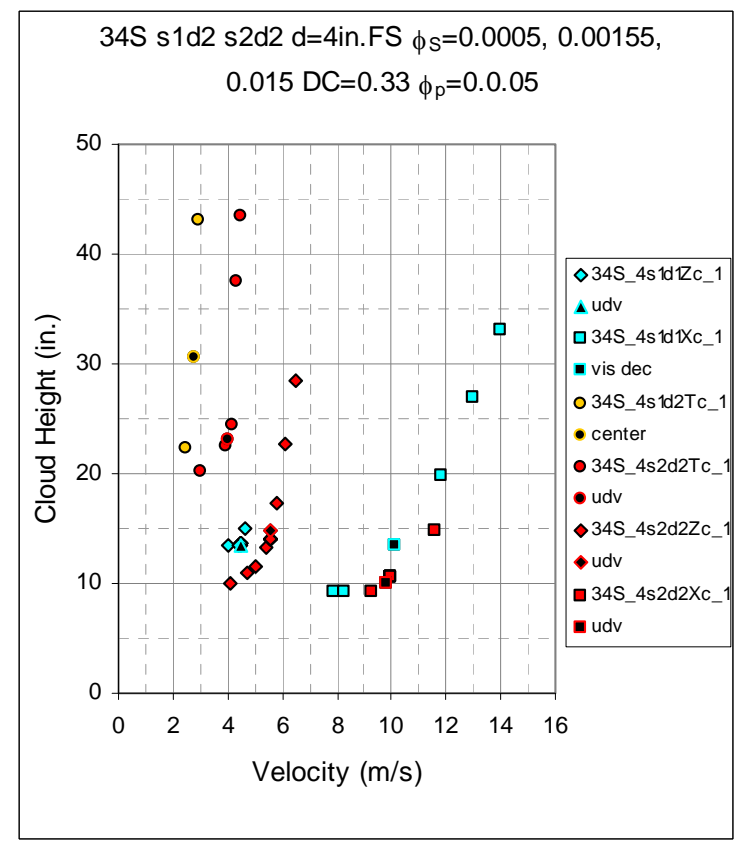

(b)

Figure 6.13. Cloud Height as Function of Velocity for Different Simulants. (a) Four simulants at solids fraction $\left(\phi_{\mathrm{S}}=0.005[\mathrm{Y}]\right)$, (b) two simulants at three solids fractions $\left(\phi_{\mathrm{S}}=0.0005[\mathrm{~T}]\right.$ circle, 0.00155 [Z] diamond, 0.015 [X] square) using a 4 in. full-scale nozzle with duty cycle (DC $=0.33[\mathrm{c}])$ and pulse volume fraction $\left(\phi_{\mathrm{p}}=0.05\right)$. Simulants are $\mathrm{s} 1 \mathrm{~d} 2\left(\rho_{\mathrm{s}}=2.48 \mathrm{~g} / \mathrm{cm}^{3}, \mathrm{~d}_{50}\right.$ $=69 \mu \mathrm{m})$ gold [o], s1d1 $\left(\rho_{\mathrm{s}}=2.46 \mathrm{~g} / \mathrm{cm}^{3}, \mathrm{~d}_{50}=166 \mu \mathrm{m}\right)$ aqua [o], s2d2 $\left(\rho_{\mathrm{s}}=4.18 \mathrm{~g} / \mathrm{cm}^{3}\right.$, $\left.\mathrm{d}_{50}=76 \mu \mathrm{m}\right)$ red [o], and s2d1 $\left(\rho_{\mathrm{s}}=4.17 \mathrm{~g} / \mathrm{cm}^{3}, \mathrm{~d}_{50}=164 \mu \mathrm{m}\right)$ green [o]. 
In Figure 6.14, the three simulants with median solids diameters near $170 \mu \mathrm{m}$ are compared. The simulant densities range from $\sim 2.5$ to $4.17 \mathrm{~g} / \mathrm{cm}^{3}$. Again the critical suspension velocity is shown to increase with density and with settling velocity.

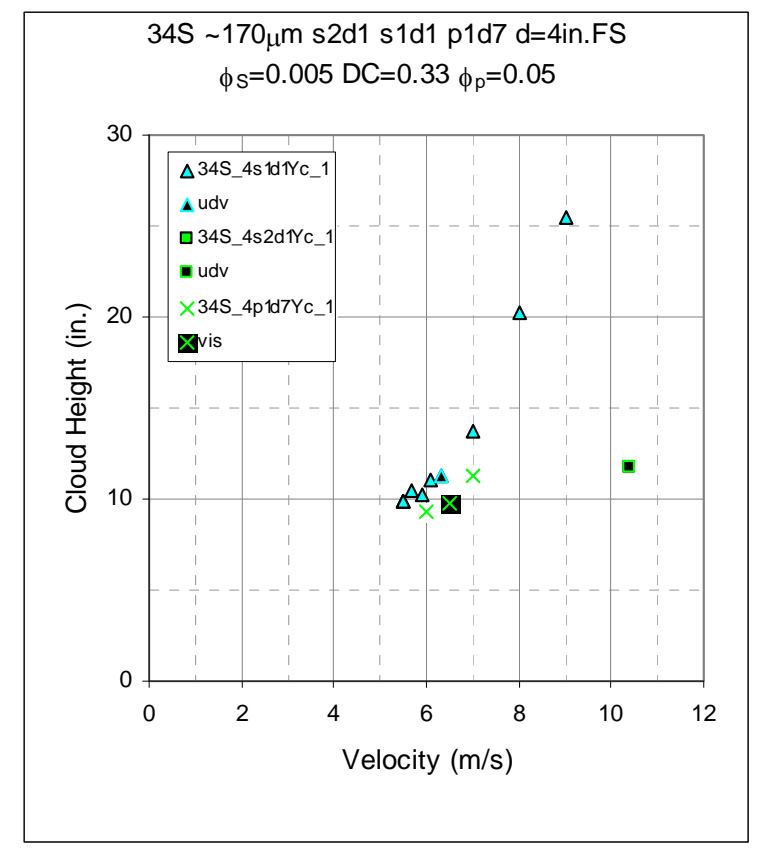

Figure 6.14. Cloud Height as a Function of Velocity for Three Simulants near $170 \mu \mathrm{m}$ Median Diameter. Test conditions are simulants: p1d7 $\left(\rho_{\mathrm{s}}=2.45 \mathrm{~g} / \mathrm{cm}^{3}, \mathrm{~d}_{50}=178 \mu \mathrm{m}\right)$ green $\mathrm{X}$ symbol, s1d1 $\left(\rho_{\mathrm{s}}=2.46 \mathrm{~g} / \mathrm{cm}^{3}, \mathrm{~d}_{50}=166 \mu \mathrm{m}\right)$ aqua triangle, $\mathrm{s} 2 \mathrm{~d} 1\left(\rho_{\mathrm{s}}=4.17 \mathrm{~g} / \mathrm{cm}^{3}, \mathrm{~d}_{50}=\right.$ $164 \mu \mathrm{m})$ green square with solids fraction $\left(\phi_{\mathrm{S}}=0.005\right.$ [Y]) using 4 in. full-scale nozzle with duty cycle $(\mathrm{DC}=0.33[\mathrm{c}])$ and pulse volume fraction $\left(\phi_{\mathrm{p}}=0.05\right)$.

\subsubsection{Large-Scale Tank Tests with Elliptical Head}

The test conditions that were varied during the 2008 tests in the large-scale tank with the elliptical head included three simulants: $\mathrm{s} 1 \mathrm{~d} 2\left(\rho_{\mathrm{s}}=2.48 \mathrm{~g} / \mathrm{cm}^{3}, \mathrm{~d}_{50}=69 \mu \mathrm{m}\right), \mathrm{s} 1 \mathrm{~d} 1\left(\rho_{\mathrm{s}}=2.46 \mathrm{~g} / \mathrm{cm}^{3}, \mathrm{~d}_{50}=166 \mu \mathrm{m}\right)$, and s2d2 $\left(\rho_{\mathrm{s}}=4.18 \mathrm{~g} / \mathrm{cm}^{3}, d_{50}=76 \mu \mathrm{m}\right)$; two nozzle diameters ( $d=4,6 \mathrm{in}$. full scale); a series of solids fractions $\left(\phi_{\mathrm{S}}=0.00155\right.$ [Z, see Table 6.4], 0.005 [Y], $0.01[\mathrm{R}], 0.0143[\mathrm{~V}]$, and $\left.0.015[\mathrm{X}]\right)$; a series of duty cycles $\left(\mathrm{DC}=0.18[\mathrm{~d}], 0.33[\mathrm{c}], 0.66[\mathrm{e}], 1.0\right.$-continuous[a]); and several pulse volume fractions $\left(\phi_{\mathrm{p}}\right.$ $=0.05$ [_1], 0.1 [_2], 0.15 [_4]). These tests were conducted with two pulse tube configurations, HLP-22 (8 outer and 4 inner pulse tubes with all in operation [8/4]) and 8TA (4 outer pulse tubes and 4 inner pulse tube in combinations of $4 / 4[4 / 4]$ and 4/0 [4/0]). The test combinations are listed in Table 6.11. 
Table 6.11. 2008 Test Summary for Large-Scale Tank with Elliptical Head

\begin{tabular}{|c|c|c|c|c|c|c|c|c|c|c|c|c|c|c|c|c|c|c|}
\hline Test & Case ID & $\begin{array}{c}\text { Tank Fill } \\
\text { Height }\end{array}$ & $\begin{array}{l}\text { Return } \\
\text { Line } \\
\text { Height }\end{array}$ & $\begin{array}{c}\text { Nozzle } \\
\text { Inner } \\
\text { Diameter }\end{array}$ & $\begin{array}{c}\text { Nozzle } \\
\text { Standoff } \\
\text { Distance } \\
\end{array}$ & $\begin{array}{c}\text { Pulse Tube } \\
\text { Configuratio } \\
\mathrm{n}\end{array}$ & $\begin{array}{c}\text { Installed } \\
\text { Nozzles } \\
\end{array}$ & $\begin{array}{c}\text { Outer } \\
\text { Nozzles } \\
\text { Operated } \\
\end{array}$ & $\begin{array}{c}\text { Inner } \\
\text { Nozzles } \\
\text { Operated } \\
\end{array}$ & Simulant & $\begin{array}{c}\text { Solids } \\
\text { Density } \\
\end{array}$ & $\begin{array}{c}\text { Particle } \\
\text { Diameter } \\
\text { d50 } \\
\end{array}$ & $\begin{array}{c}\text { Solids } \\
\text { Fraction } \\
\end{array}$ & $\begin{array}{c}\text { Pulse } \\
\text { Volume } \\
\text { Fraction } \\
\end{array}$ & $\begin{array}{l}\text { Duty } \\
\text { Cycle }\end{array}$ & $\begin{array}{c}\text { Pulsed or } \\
\text { Steady } \\
\text { Jet }\end{array}$ & $\begin{array}{c}\text { Fill } \\
\text { Height to } \\
\text { Diameter }\end{array}$ & $\begin{array}{c}\text { Return } \\
\text { Line } \\
\text { Height to } \\
\text { Diameter }\end{array}$ \\
\hline text & text & in. & in. & in. & in. & text & number & number & number & text & $\mathrm{g} / \mathrm{cm}^{3}$ & m & fraction & fraction & fraction & text & ratio & ratio \\
\hline M/DDX & ID & $\mathrm{H}$ & Rtn & $\mathrm{d}$ & sod & $\mathrm{PT}$ & $\mathrm{N}$ & $\mathrm{N}_{\mathrm{O}}$ & $\mathrm{N}_{\mathrm{I}}$ & sxdx & $\rho_{\mathrm{S}}$ & $\mathrm{d}_{50}$ & $\phi_{\mathrm{S}}$ & $\phi_{\mathrm{p}}$ & DC & Jet & $\mathrm{H} / \mathrm{D}$ & Rtn/D \\
\hline $5 / 8 \mathrm{~A}$ & 70E_4s1d2Zc_1 & 93 & 80 & 0.613 & 0.92 & HLP-22 & 12 & 8 & 4 & s1d2 & 2.48 & 0.000069 & 0.00155 & 0.05 & 0.33 & $\mathrm{P}$ & 1.3 & 1.1 \\
\hline $5 / 9 \mathrm{~A}$ & 70E_4s1d2Zc_1 & 93 & 80 & 0.613 & 0.92 & HLP-22 & 12 & 8 & 4 & s1d2 & 2.48 & 0.000069 & 0.00155 & 0.05 & 0.34 & $\mathrm{P}$ & 1.3 & 1.1 \\
\hline 5/9B & 70E_4s1d2Zd_1 & 93 & 80 & 0.613 & 0.92 & HLP-22 & 12 & 8 & 4 & s1d2 & 2.48 & 0.000069 & 0.00155 & 0.05 & 0.18 & $\mathrm{P}$ & 1.3 & 1.1 \\
\hline $5 / 12 \mathrm{~A}$ & 70E_4s1d2Yc_1 & 93 & 80 & 0.613 & 0.92 & HLP-22 & 12 & 8 & 4 & s1d2 & 2.48 & 0.000069 & 0.005 & 0.05 & 0.33 & $\mathrm{P}$ & 1.3 & 1.1 \\
\hline 5/12B & 70E_4s1d2Rc_1 & 93 & 80 & 0.613 & 0.92 & HLP-22 & 12 & 8 & 4 & s1d2 & 2.48 & 0.000069 & 0.01 & 0.05 & 0.33 & $\mathrm{P}$ & 1.3 & 1.1 \\
\hline $5 / 13 \mathrm{~A}$ & 70E_4s1d2Rc_1 & 92.5 & 80 & 0.613 & 0.92 & HLP-22 & 12 & 8 & 4 & s1d2 & 2.48 & 0.000069 & 0.01 & 0.05 & 0.34 & $\mathrm{P}$ & 1.3 & 1.1 \\
\hline 5/13B & 70E_4s1d2Rd_1 & 92.5 & 80 & 0.613 & 0.92 & HLP-22 & 12 & 8 & 4 & s1d2 & 2.48 & 0.000069 & 0.01 & 0.05 & 0.18 & $\mathrm{P}$ & 1.3 & 1.1 \\
\hline $5 / 13 \mathrm{C}$ & 70E_4s1d2Vc_1 & 92.5 & 80 & 0.613 & 0.92 & HLP-22 & 12 & 8 & 4 & s1d2 & 2.48 & 0.000069 & 0.0143 & 0.05 & 0.33 & $\mathrm{P}$ & 1.3 & 1.1 \\
\hline $5 / 14 \mathrm{~A}$ & 70E_4s1d2Vc_1 & 92.5 & 80 & 0.613 & 0.92 & HLP-22 & 12 & 8 & 4 & s1d2 & 2.48 & 0.000069 & 0.0143 & 0.05 & 0.33 & $\mathrm{P}$ & 1.3 & 1.1 \\
\hline $5 / 14 \mathrm{~B}$ & 70E_4s1d2Vd_1 & 92.5 & 80 & 0.613 & 0.92 & HLP-22 & 12 & 8 & 4 & s1d2 & 2.48 & 0.000069 & 0.0143 & 0.05 & 0.18 & $\mathrm{P}$ & 1.3 & 1.1 \\
\hline $5 / 15 \mathrm{~A}$ & 70E_4s1d2Vd_1 & 92.5 & 80 & 0.613 & 0.92 & HLP-22 & 12 & 8 & 4 & s1d2 & 2.48 & 0.000069 & 0.0143 & 0.05 & 0.19 & $\mathrm{P}$ & 1.3 & 1.1 \\
\hline 5/15B & 70E_4s1d2Ve_1 & 92.5 & 80 & 0.613 & 0.92 & HLP-22 & 12 & 8 & 4 & s1d2 & 2.48 & 0.000069 & 0.0143 & 0.05 & 0.66 & $\mathrm{P}$ & 1.3 & 1.1 \\
\hline $5 / 15 \mathrm{C}$ & 70E_4s1d2Vc_2 & 92.5 & 80 & 0.613 & 0.92 & HLP-22 & 12 & 8 & 4 & s1d2 & 2.48 & 0.000069 & 0.0143 & 0.10 & 0.33 & $\mathrm{P}$ & 1.3 & 1.1 \\
\hline $5 / 15 \mathrm{D}$ & 70E_4s1d2Vd_2 & 92.5 & 80 & 0.613 & 0.92 & HLP-22 & 12 & 8 & 4 & s1d2 & 2.48 & 0.000069 & 0.0143 & 0.10 & 0.17 & $\mathrm{P}$ & 1.3 & 1.1 \\
\hline $5 / 16 \mathrm{~A}$ & 70E_4s1d2Ve_2 & 92.5 & 80 & 0.613 & 0.92 & HLP-22 & 12 & 8 & 4 & s1d2 & 2.48 & 0.000069 & 0.0143 & 0.10 & 0.66 & $\mathrm{P}$ & 1.3 & 1.1 \\
\hline $5 / 16 B$ & 70E_4s1d2Vc_4 & 92.5 & 80 & 0.613 & 0.92 & HLP-22 & 12 & 8 & 4 & s1d2 & 2.48 & 0.000069 & 0.0143 & 0.15 & 0.33 & $\mathrm{P}$ & 1.3 & 1.1 \\
\hline $5 / 16 \mathrm{C}$ & 70E_4s1d2Vd_4 & 92.5 & 80 & 0.613 & 0.92 & HLP-22 & 12 & 8 & 4 & s1d2 & 2.48 & 0.000069 & 0.0143 & 0.15 & 0.18 & $\mathrm{P}$ & 1.3 & 1.1 \\
\hline $5 / 19 \mathrm{~A}$ & 70E_4s1d2Vd_4 & 91.5 & 80 & 0.613 & 0.92 & HLP-22 & 12 & 8 & 4 & s1d2 & 2.48 & 0.000069 & 0.0143 & 0.15 & 0.18 & $\mathrm{P}$ & 1.3 & 1.1 \\
\hline 5/19B & 70E_4s1d2Ve_4 & 91.5 & 80 & 0.613 & 0.92 & HLP-22 & 12 & 8 & 4 & s1d2 & 2.48 & 0.000069 & 0.0143 & 0.15 & 0.66 & $\mathrm{P}$ & 1.3 & 1.1 \\
\hline $5 / 19 \mathrm{C}$ & 70E_4s1d2Xc_1 & 91.5 & 80 & 0.613 & 0.92 & HLP-22 & 12 & 8 & 4 & s1d2 & 2.48 & 0.000069 & 0.015 & 0.05 & 0.33 & $\mathrm{P}$ & 1.3 & 1.1 \\
\hline $5 / 20 \mathrm{~A}$ & 70E_4s1d2Xc_1 & 91.5 & 80 & 0.613 & 0.92 & HLP-22 & 12 & 8 & 4 & s1d2 & 2.48 & 0.000069 & 0.015 & 0.05 & 0.33 & $\mathrm{P}$ & 1.3 & 1.1 \\
\hline $5 / 20 B$ & 70E_4s1d2Xd_1 & 91.5 & 80 & 0.613 & 0.92 & HLP-22 & 12 & 8 & 4 & s1d2 & 2.48 & 0.000069 & 0.015 & 0.05 & 0.19 & $\mathrm{P}$ & 1.3 & 1.1 \\
\hline $5 / 21 \mathrm{~A}$ & 70E_4s1d2Xd_1 & 91 & 80 & 0.613 & 0.92 & HLP-22 & 12 & 8 & 4 & s1d2 & 2.48 & 0.000069 & 0.015 & 0.05 & 0.19 & $\mathrm{P}$ & 1.3 & 1.1 \\
\hline $5 / 21 B$ & 70E_4s1d2Xa & 91 & 80 & 0.613 & 0.92 & HLP-22 & 12 & 8 & 4 & $\mathrm{~s} 1 \mathrm{~d} 2$ & 2.48 & 0.000069 & 0.015 & undefined & 1.00 & $\mathrm{~S}$ & 1.3 & 1.1 \\
\hline $5 / 22 \mathrm{~A}$ & 70E_4s2d2Zc_1 & 92.5 & 80 & 0.613 & 0.92 & HLP-22 & 12 & 8 & 4 & $\mathrm{~s} 2 \mathrm{~d} 2$ & 4.18 & 0.000076 & 0.00155 & 0.05 & 0.33 & $\mathrm{P}$ & 1.3 & 1.1 \\
\hline $5 / 27 \mathrm{~A}$ & 70E_4s2d2Zc_1 & 92 & 80 & 0.613 & 0.92 & HLP-22 & 12 & 8 & 4 & $\mathrm{~s} 2 \mathrm{~d} 2$ & 4.18 & 0.000076 & 0.00155 & 0.05 & 0.34 & $\mathrm{P}$ & 1.3 & 1.1 \\
\hline $5 / 27 \mathrm{~B}$ & 70E_4s2d2Yd_1 & 92 & 80 & 0.613 & 0.92 & HLP-22 & 12 & 8 & 4 & s2d2 & 4.18 & 0.000076 & 0.005 & 0.05 & 0.18 & $\mathrm{P}$ & 1.3 & 1.1 \\
\hline $5 / 27 \mathrm{C}$ & 70E_4s2d2Yc_1 & 92 & 80 & 0.613 & 0.92 & HLP-22 & 12 & 8 & 4 & $\mathrm{~s} 2 \mathrm{~d} 2$ & 4.18 & 0.000076 & 0.005 & 0.05 & 0.34 & $\mathrm{P}$ & 1.3 & 1.1 \\
\hline $5 / 28 \mathrm{~A}$ & 70E_4s2d2Yc_1 & 92 & 80 & 0.613 & 0.92 & HLP-22 & 12 & 8 & 4 & $\mathrm{~s} 2 \mathrm{~d} 2$ & 4.18 & 0.000076 & 0.005 & 0.05 & 0.33 & $\mathrm{P}$ & 1.3 & 1.1 \\
\hline $5 / 29 \mathrm{~A}$ & 70E_4s1d1Zd_1 & 92 & 80 & 0.613 & 0.92 & HLP-22 & 12 & 8 & 4 & s1d1 & 2.46 & 0.000166 & 0.00155 & 0.05 & 0.18 & $\mathrm{P}$ & 1.3 & 1.1 \\
\hline $5 / 29 B$ & 70E_4s1d1Zc_1 & 92 & 80 & 0.613 & 0.92 & HLP-22 & 12 & 8 & 4 & s1d1 & 2.46 & 0.000166 & 0.00155 & 0.05 & 0.33 & $\mathrm{P}$ & 1.3 & 1.1 \\
\hline $5 / 30 \mathrm{~A}$ & 70E_4s1d1Zc_1 & 92 & 80 & 0.613 & 0.92 & HLP-22 & 12 & 8 & 4 & s1d1 & 2.46 & 0.000166 & 0.00155 & 0.05 & 0.33 & $\mathrm{P}$ & 1.3 & 1.1 \\
\hline 7/17A & 70E8_6s1d2Zc_1 & 93 & 80 & 0.92 & 1.38 & 8TA & 8 & 4 & 4 & s1d2 & 2.48 & 0.000069 & 0.00155 & 0.05 & 0.33 & $\mathrm{P}$ & 1.3 & 1.1 \\
\hline
\end{tabular}


Table 6.11. (contd)

\begin{tabular}{|c|c|c|c|c|c|c|c|c|c|c|c|c|c|c|c|c|c|c|}
\hline Test & Case ID & $\begin{array}{c}\text { Tank Fill } \\
\text { Height }\end{array}$ & $\begin{array}{l}\text { Return } \\
\text { Line } \\
\text { Height }\end{array}$ & $\begin{array}{l}\text { Nozzle } \\
\text { Inner } \\
\text { Diameter }\end{array}$ & $\begin{array}{l}\text { Nozzle } \\
\text { Standoff } \\
\text { Distance }\end{array}$ & $\begin{array}{c}\text { Pulse Tube } \\
\text { Configuratio } \\
\text { n }\end{array}$ & $\begin{array}{c}\text { Installed } \\
\text { Nozzles }\end{array}$ & $\begin{array}{c}\text { Outer } \\
\text { Nozzles } \\
\text { Operated }\end{array}$ & $\begin{array}{c}\text { Inner } \\
\text { Nozzles } \\
\text { Operated }\end{array}$ & Simulant & $\begin{array}{l}\text { Solids } \\
\text { Density }\end{array}$ & $\begin{array}{l}\text { Particle } \\
\text { Diameter } \\
\text { d50 }\end{array}$ & $\begin{array}{l}\text { Solids } \\
\text { Fraction }\end{array}$ & $\begin{array}{l}\text { Pulse } \\
\text { Volume } \\
\text { Fraction }\end{array}$ & $\begin{array}{l}\text { Duty } \\
\text { Cycle }\end{array}$ & $\begin{array}{l}\text { Pulsed or } \\
\text { Steady } \\
\text { Jet }\end{array}$ & $\begin{array}{c}\text { Fill } \\
\text { Height to } \\
\text { Diameter }\end{array}$ & $\begin{array}{c}\text { Return } \\
\text { Line } \\
\text { Height to } \\
\text { Diameter }\end{array}$ \\
\hline text & text & in. & in. & in. & in. & text & number & number & number & text & $\mathrm{g} / \mathrm{cm}^{3}$ & $\mathrm{~m}$ & fraction & fraction & fraction & text & ratio & ratio \\
\hline M/DDX & ID & $\mathrm{H}$ & Rtn & $\mathrm{d}$ & sod & PT & $\mathrm{N}$ & $\mathrm{N}_{\mathrm{O}}$ & $\mathrm{N}_{\mathrm{I}}$ & sxdx & $\rho_{\mathrm{S}}$ & $d_{50}$ & $\phi_{\mathrm{S}}$ & $\phi_{\mathrm{p}}$ & DC & Jet & $\mathrm{H} / \mathrm{D}$ & Rtn/D \\
\hline 7/17B & 70E8_6s1d2Zc_2 & 93 & 80 & 0.92 & 1.38 & 8TA & 8 & 4 & 4 & s1d2 & 2.48 & 0.000069 & 0.00155 & 0.10 & 0.33 & $\mathrm{P}$ & 1.3 & 1.1 \\
\hline $7 / 18 \mathrm{~A}$ & 70E8_6s1d2Vc_1 & 94 & 80 & 0.92 & 1.38 & 8TA & 8 & 4 & 4 & s1d2 & 2.48 & 0.000069 & 0.0143 & 0.05 & 0.34 & $\mathrm{P}$ & 1.3 & 1.1 \\
\hline 7/18B & 70E8_6s1d2Vc_2 & 94 & 80 & 0.92 & 1.38 & 8TA & 8 & 4 & 4 & s1d2 & 2.48 & 0.000069 & 0.0143 & 0.10 & 0.33 & $\mathrm{P}$ & 1.3 & 1.1 \\
\hline $7 / 18 \mathrm{C}$ & 70E8_6s1d2Vc_7 & 94 & 80 & 0.92 & 1.38 & 8TA & 8 & 4 & 0 & s1d2 & 2.48 & 0.000069 & 0.0143 & 0.10 & 0.32 & $\mathrm{P}$ & 1.3 & 1.1 \\
\hline
\end{tabular}

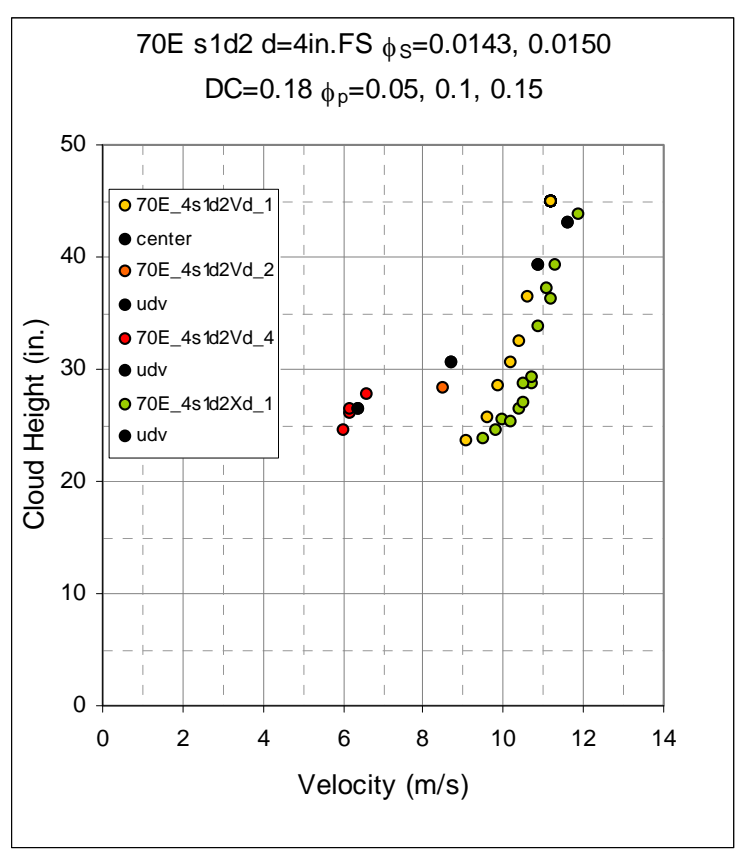

(a)

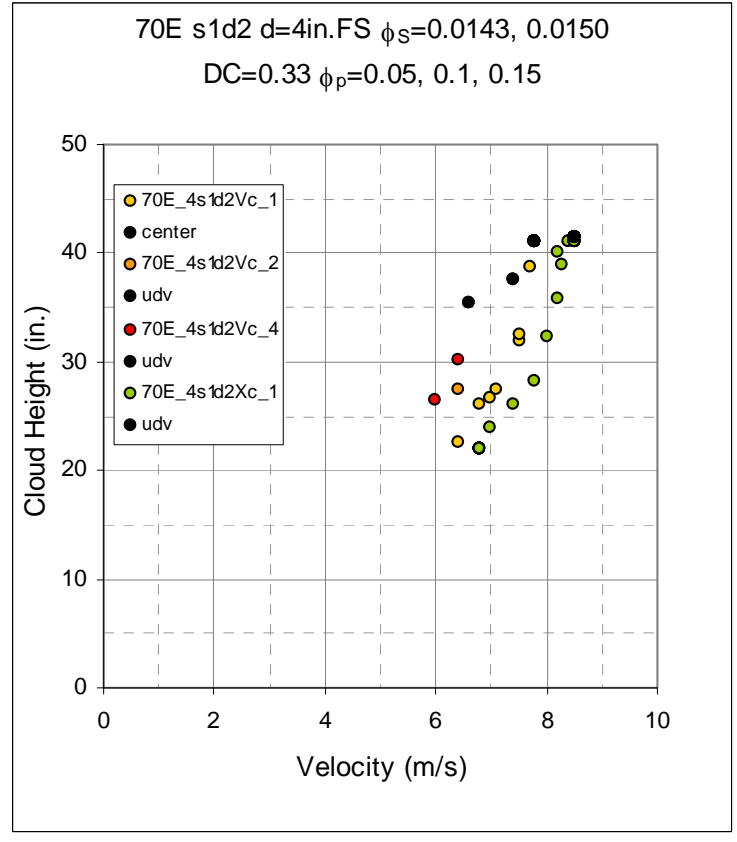

(b)

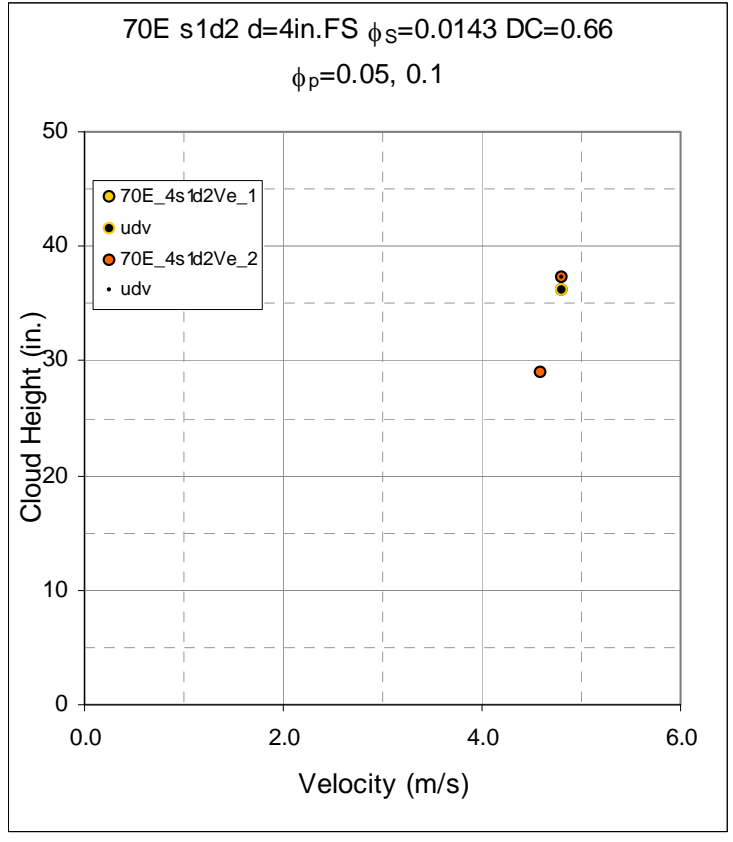

(c)

Figure 6.15. Cloud Height as a Function of Velocity for Three Duty Cycles: (a) Duty Cycle $=0.18$ [d], (b) Duty Cycle $=0.33$ [c]. (c) Duty Cycle $=0.66$ [e]. All use 4 in. full-scale nozzle with simulant s1d2 $\left(\rho_{\mathrm{s}}=2.48 \mathrm{~g} / \mathrm{cm}^{3}, \mathrm{~d}_{50}=69 \mu \mathrm{m}\right)$ at solids fraction $\left(\phi_{\mathrm{S}}=0.0143[\mathrm{~V}]\right)$ at pulse volume fractions $\left(\phi_{\mathrm{p}}=0.05\right.$ [_1] gold [o], 0.1 [_2] orange [o], 0.15 [_4] red [o]) and at solids fraction $\left(\phi_{\mathrm{S}}=0.015\right.$ [X]) at pulse volume fractions $\left(\phi_{\mathrm{p}}=0.05\right.$ [_1] lime green [o] 
Data from selected tests in the large-scale vessel with the elliptical head are shown in Figures 6.15 through 6.18. The plot legend presents the Case ID followed by the $\mathrm{U}_{\mathrm{CS}}$ velocity if it was measured for that case. When identified, the $U_{\mathrm{CS}}$ velocity is shown as the darkened symbol in the legend beneath the test and the method used to determine $\mathrm{U}_{\mathrm{CS}}$ is also shown. For example, in the legend for Figure 6.15 (a) each test Case ID shows the $U_{\text {CS }}$ condition beneath it. The first Case ID (70E_4s1d2Vd_1) symbol is a gold circle with a black border, the corresponding $\mathrm{U}_{\mathrm{CS}}$ condition symbol is shown as a black circle. The next three $U_{\text {CS }}$ condition symbols are shown as black symbols. In some cases the $U_{\text {CS }}$ symbols are shown as colored symbols with black centers where the color matches that of the Case ID listed above it. The description to the right of the $U_{\mathrm{CS}}$ condition shows the method used to determine $\mathrm{U}_{\mathrm{CS}}$ which is either "udv" or "center." Udv means that the $\mathrm{U}_{\mathrm{CS}}$ condition was determined ultrasonically after an increase in velocity. Center means that the $\mathrm{U}_{\mathrm{CS}}$ condition was determined visually through the viewing window in the center of the bottom of the test tank.

In Figure 6.15 (a), (b), and (c), three duty cycles are compared for up to three pulse volume fractions. The data are at two solids fractions, $\left(\phi_{\mathrm{S}}=0.0143[\mathrm{~V}]\right.$ and $0.015[\mathrm{X}]$. The critical suspension velocity decreases with increasing pulse volume fraction. The critical suspension velocity for the higher solids fraction case $\left(\phi_{\mathrm{S}}=0.015\right)$ is higher than that for the lower solids fraction case $\left(\phi_{\mathrm{S}}=0.0143\right)$.

In Figure 6.16 the three duty cycles 0.18 [d], 0.33 [c] and 0.66 [e] are compared while other conditions are held constant. This plot shows that the lower the duty cycle, the higher the critical suspension velocity.

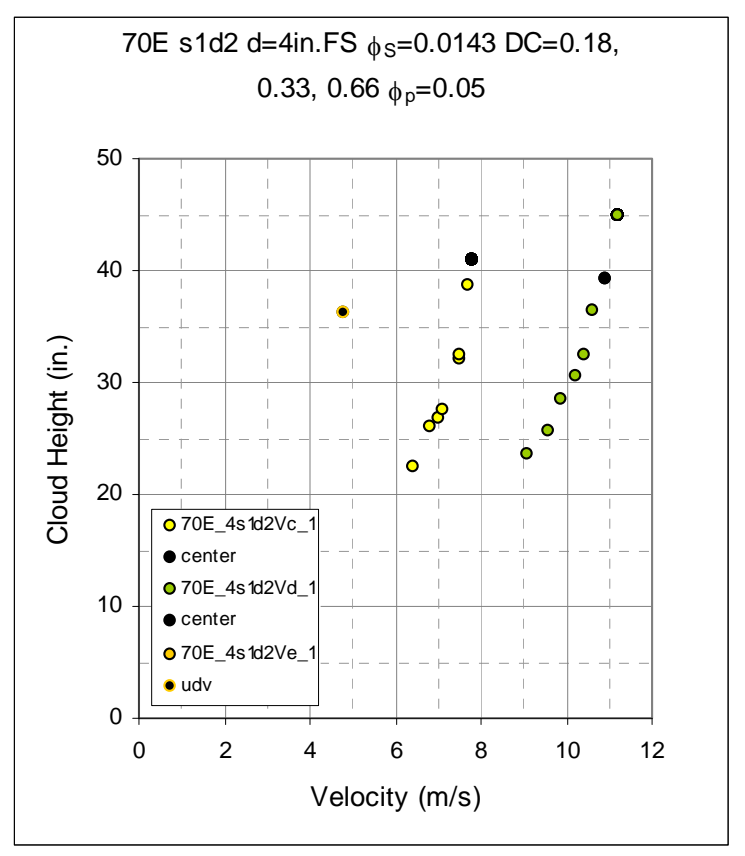

Figure 6.16. Cloud Height as Function of Velocity for Three Duty Cycles (DC $=0.18$ [d] gold [o], 0.33 [c] yellow [o], 0.66 [e] lime green [o]). Test conditions are simulant s1d2 ( $\rho_{\mathrm{s}}=2.48 \mathrm{~g} / \mathrm{cm}^{3}$, $\left.\mathrm{d}_{50}=69 \mu \mathrm{m}\right)$ at solids fraction $\left(\phi_{\mathrm{S}}=0.0143[\mathrm{~V}]\right)$ using $4 \mathrm{in}$. full-scale nozzle with pulse volume fraction $\left(\phi_{\mathrm{p}}=0.05\right)$. 
In Figure 6.17 differences between the HLP-22 (12-tube array with 8 outer and four inner nozzles with 4 in. diameter full-scale nozzle) and 8TA (8-tube array configuration 4 outer and 4 inner nozzles with 6 in. full-scale nozzles) can be observed. The 8-tube array configuration is shown in the Case ID by the E8 after the vessel diameter. The 8TA configuration has a lower critical suspension velocity than the HLP-22 configuration, and when comparing the two 8TA cases the lower pulse volume fraction has a higher critical suspension velocity.

In Figure 6.18 three simulants are compared with other conditions held constant. When simulant density is held constant, the smaller diameter particle (s1d2) has the lower critical suspension velocity than the larger diameter particle (s1d1). When the particle size is held constant, the lower density particle (s1d2) has the lower critical suspension velocity than the higher density particle (s2d2).

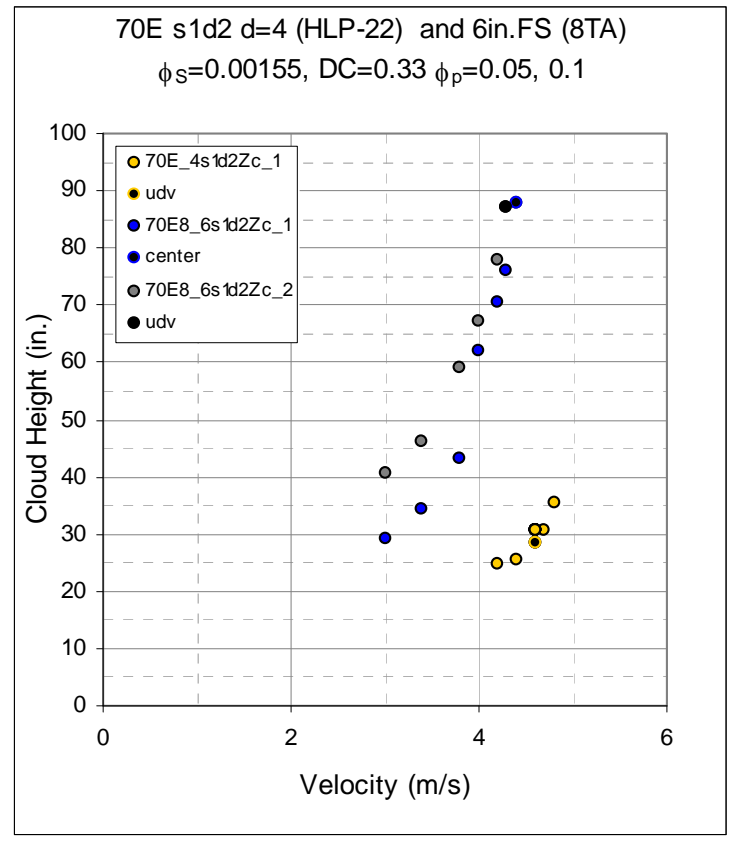

Figure 6.17. Cloud Height as a Function of Velocity for Two Tank Configurations, HLP-22 (70E 4-in. full-scale nozzle 12 pulse tube array gold [o]) and 8TA (70E8 6-in. full-scale nozzle eight pulse tube array). Test conditions are simulant s1d2 $\left(\rho_{\mathrm{s}}=2.48 \mathrm{~g} / \mathrm{cm}^{3}, \mathrm{~d}_{50}=69 \mu \mathrm{m}\right)$ at solids fraction $\left(\phi_{\mathrm{S}}=0.00155[\mathrm{Z}]\right)$ with duty cycle $(\mathrm{DC}=0.33[\mathrm{c}])$ and pulse volume fractions ( $\phi_{\mathrm{p}}=0.05$ [_1] blue [o], 0.1 [_2] gray [o]). 


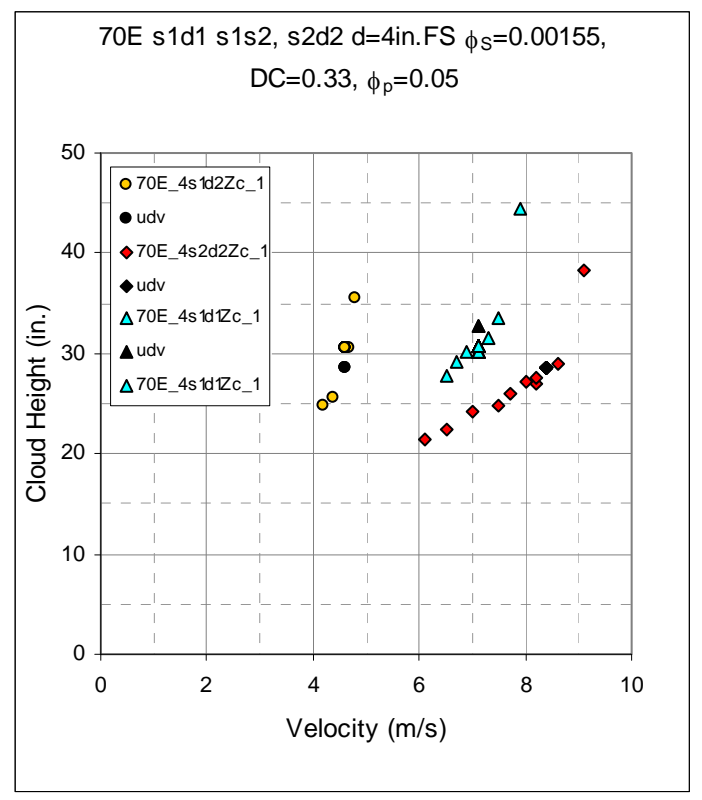

Figure 6.18. Cloud Height as Function of Velocity for Three Simulants: $s 1 d 2\left(\rho_{\mathrm{s}}=2.48 \mathrm{~g} / \mathrm{cm}^{3}, \mathrm{~d}_{50}=\right.$ $69 \mu \mathrm{m})$ gold [o], s1d1 $\left(\rho_{\mathrm{s}}=2.46 \mathrm{~g} / \mathrm{cm}^{3}, \mathrm{~d}_{50}=166 \mu \mathrm{m}\right)$ aqua triangle, and s2d2 $\left(\rho_{\mathrm{s}}=\right.$ $\left.4.18 \mathrm{~g} / \mathrm{cm}^{3}, \mathrm{~d}_{50}=76 \mu \mathrm{m}\right)$ red diamond. Test conditions are solids fraction $\left(\phi_{\mathrm{s}}=0.00155\right.$ [Z]) using 4 in. full-scale nozzle with duty cycle $(\mathrm{DC}=0.33$ [c]) and pulse volume fraction $\left(\phi_{\mathrm{p}}=0.05[1]\right)$.

\subsubsection{Large-Scale Tank Tests with Flanged and Dished Head}

The test conditions that were varied during the 2008 tests in the large-scale tank with the flanged and dished head included three simulants: $\operatorname{s} 1 \mathrm{~d} 2\left(\rho_{\mathrm{s}}=2.48 \mathrm{~g} / \mathrm{cm}^{3} \mathrm{~d}_{50}=69 \mu \mathrm{m}\right), \mathrm{s} 1 \mathrm{~d} 1\left(\rho_{\mathrm{s}}=2.46 \mathrm{~g} / \mathrm{cm}^{3}, \mathrm{~d}_{50}=\right.$ $166 \mu \mathrm{m})$, and s2d2 $\left(\rho_{\mathrm{s}}=4.18 \mathrm{~g} / \mathrm{cm}^{3}, \mathrm{~d}_{50}=76 \mu \mathrm{m}\right)$; two nozzle diameters ( $\mathrm{d}=4$ and 6 in. full scale); a series of solids fractions ( $\phi_{\mathrm{S}}=0.00155$ [Z, see Table 6.4], 0.005 [Y], $0.01[\mathrm{R}], 0.0143$ [V]); a series of duty cycles $(\mathrm{DC}=0.18$ [d], 0.33 [c], 0.66 [e] with a few limited tests at other values); and several pulse volume fractions ( $\phi_{\mathrm{p}}=0.05$ [_1], 0.1 [ 2 ], 0.15 [ 4 ]). These tests were conducted with one pulse tube configuration, HLP-22 (8 outer pulse tubes and 4 inner pulse tubes with all pulse tubes in operation). The test combinations are listed in Table 6.12 .

Data from selected tests in the large-scale tank with the flanged and dished head are shown in Figure 6.19. The plot legend presents the Case ID followed by the $U_{C S}$ velocity if it was measured for that case. When identified, the $U_{C S}$ velocity is shown as the darkened symbol in the legend beneath the test and the method used to determine $U_{\mathrm{CS}}$ is also shown. For example, in the legend for Figure 6.19 each Case ID shows the $U_{C S}$ condition beneath it. The first Case ID (70F_4s1d2Vc_1) symbol is an orange circle with a black border; the corresponding $\mathrm{U}_{\mathrm{CS}}$ condition symbol is shown as a black circle with an orange border. The next five $\mathrm{U}_{\mathrm{CS}}$ condition symbols are shown as black symbols with colored borders where the color matches that of the Case ID listed above it. The description to the right of the $\mathrm{U}_{\mathrm{CS}}$ condition shows the method used to determine $U_{\mathrm{CS}}$; udv means that the $U_{\mathrm{CS}}$ condition was determined ultrasonically after an increase in velocity. Four duty cycles (DC $=0.18$ [d], 0.25 [f], 0.33 [c], and 0.66 [e]) are compared while other conditions are constant. Repeat test identifications in Figure 6.19 are either repeat tests or additional data at that Case ID condition taken at a different time. The critical suspension velocity increases with decreasing duty cycle. 


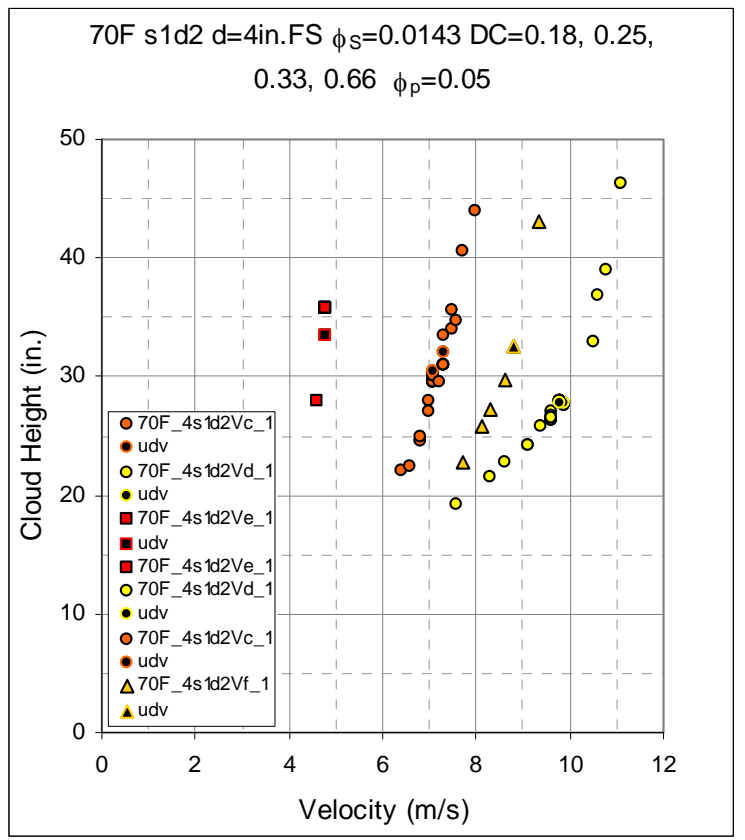

Figure 6.19. Cloud Height as a Function of Velocity for Four Duty Cycles (DC $=0.18$ [d] yellow [o], 0.25 [f] gold triangle [o], 0.33 [c] orange [o], 0.66 [e] red square). Test conditions are simulant s1d2 $\left(\rho_{\mathrm{s}}=2.48 \mathrm{~g} / \mathrm{cm}^{3}, \mathrm{~d}_{50}=69 \mu \mathrm{m}\right)$, at solids fraction $\left(\phi_{\mathrm{S}}=0.0143[\mathrm{~V}]\right)$ using with 4 in. full-scale nozzle and pulse volume fraction $\left(\phi_{p}=0.05\right)$. 
Table 6.12. 2008 Test Summary for Large-Scale Tank with Flanged and Dished Head

\begin{tabular}{|c|c|c|c|c|c|c|c|c|c|c|c|c|c|c|c|c|c|c|}
\hline Test & Case ID & $\begin{array}{c}\text { Tank } \\
\text { Fill } \\
\text { Height }\end{array}$ & $\begin{array}{l}\text { Return } \\
\text { Line } \\
\text { Height }\end{array}$ & $\begin{array}{c}\text { Nozzle } \\
\text { Inner } \\
\text { Diameter } \\
\end{array}$ & $\begin{array}{l}\text { Nozzle } \\
\text { Standoff } \\
\text { Distance } \\
\end{array}$ & $\begin{array}{c}\text { Pulse Tube } \\
\text { Configuration }\end{array}$ & $\begin{array}{l}\text { Installed } \\
\text { Nozzles } \\
\end{array}$ & $\begin{array}{c}\text { Outer } \\
\text { Nozzles } \\
\text { Operated } \\
\end{array}$ & $\begin{array}{c}\text { Inner } \\
\text { Nozzles } \\
\text { Operated } \\
\end{array}$ & Simulant & $\begin{array}{c}\text { Solids } \\
\text { Density } \\
\end{array}$ & $\begin{array}{c}\text { Particle } \\
\text { Diameter } \\
\text { d50 }\end{array}$ & $\begin{array}{l}\text { Solids } \\
\text { Fraction } \\
\end{array}$ & $\begin{array}{c}\text { Pulse } \\
\text { Volume } \\
\text { Fraction } \\
\end{array}$ & $\begin{array}{l}\text { Duty } \\
\text { Cycle }\end{array}$ & $\begin{array}{c}\text { Pulsed or } \\
\text { Steady } \\
\text { Jet }\end{array}$ & $\begin{array}{c}\text { Fill } \\
\text { Height to } \\
\text { Diameter } \\
\end{array}$ & $\begin{array}{c}\text { Return } \\
\text { Line } \\
\text { Height to } \\
\text { Diameter }\end{array}$ \\
\hline text & text & in. & in. & in. & in. & text & number & number & number & text & $\mathrm{g} / \mathrm{cm} 3$ & $\mathrm{~m}$ & fraction & fraction & fraction & text & ratio & ratio \\
\hline M/DDX & ID & $\mathrm{H}$ & Rtn & $\mathrm{d}$ & sod & PT & $\mathrm{N}$ & $\mathrm{N}_{\mathrm{O}}$ & $\mathrm{N}_{\mathrm{I}}$ & sxdx & $\rho_{\mathrm{s}}$ & $\mathrm{d}_{50}$ & $\phi_{\mathrm{s}}$ & $\phi_{\mathrm{p}}$ & DC & Jet & $\mathrm{H} / \mathrm{D}$ & Rtn/D \\
\hline $4 / 7 \mathrm{~A}$ & $\begin{array}{l}\text { 70F_6s2d2Yc_1_F } \\
\text { M01 }\end{array}$ & 88 & 83.6 & 0.92 & 1.38 & HLP-22 & 12 & 8 & 4 & $\mathrm{~s} 2 \mathrm{~d} 2$ & 4.18 & 0.000076 & 0.005 & 0.05 & 0.33 & $P$ & 1.3 & 1.2 \\
\hline $4 / 8 \mathrm{~A}$ & 70F_6s2d2Yh_1 & 89 & 83.6 & 0.92 & 1.38 & HLP-22 & 12 & 8 & 4 & $\mathrm{~s} 2 \mathrm{~d} 2$ & 4.18 & 0.000076 & 0.005 & 0.05 & 0.24 & $\mathrm{P}$ & 1.3 & 1.2 \\
\hline $4 / 10 \mathrm{~A}$ & 70F_4s2d2Yi_1 & 90.5 & 83.6 & 0.613 & 0.92 & HLP-22 & 12 & 8 & 4 & $\mathrm{~s} 2 \mathrm{~d} 2$ & 4.18 & 0.000076 & 0.005 & 0.05 & 0.28 & $\mathrm{P}$ & 1.3 & 1.2 \\
\hline $4 / 10 \mathrm{~B}$ & 70F_4s2d2Yk_1 & 90.5 & 83.6 & 0.613 & 0.92 & HLP-22 & 12 & 8 & 4 & s2d2 & 4.18 & 0.000076 & 0.005 & 0.05 & 0.14 & $\mathrm{P}$ & 1.3 & 1.2 \\
\hline $4 / 10 \mathrm{C}$ & 70F_4s2d2Yc_1 & 90.5 & 83.6 & 0.613 & 0.92 & HLP-22 & 12 & 8 & 4 & s2d2 & 4.18 & 0.000076 & 0.005 & 0.05 & 0.34 & $\mathrm{P}$ & 1.3 & 1.2 \\
\hline $4 / 14 \mathrm{~A}$ & 70F_4s1d1Zc_1 & 89 & 83.6 & 0.613 & 0.92 & HLP-22 & 12 & 8 & 4 & s1d1 & 2.46 & 0.000166 & 0.00155 & 0.05 & 0.32 & $\mathrm{P}$ & 1.3 & 1.2 \\
\hline $4 / 15 \mathrm{~A}$ & 70F_4s1d1Zc_2 & 88 & 83.6 & 0.613 & 0.92 & HLP-22 & 12 & 8 & 4 & s1d1 & 2.46 & 0.000166 & 0.00155 & 0.10 & 0.33 & $\mathrm{P}$ & 1.3 & 1.2 \\
\hline 4/15B & 70F_4s1d1Zc_44 & 88.5 & 83.6 & 0.613 & 0.92 & HLP-22 & 12 & 8 & 4 & s1d1 & 2.46 & 0.000166 & 0.00155 & 0.15 & 0.33 & $\mathrm{P}$ & 1.3 & 1.2 \\
\hline $4 / 15 \mathrm{C}$ & 70F_4s1d1Zc_2 & 88.5 & 83.6 & 0.613 & 0.92 & HLP-22 & 12 & 8 & 4 & s1d1 & 2.46 & 0.000166 & 0.00155 & 0.10 & 0.33 & $\mathrm{P}$ & 1.3 & 1.2 \\
\hline $4 / 16 \mathrm{~A}$ & 70F_4s1d2Zc_1 & 88.5 & 83.6 & 0.613 & 0.92 & HLP-22 & 12 & 8 & 4 & s1d2 & 2.48 & 0.000069 & 0.00155 & 0.05 & 0.33 & $\mathrm{P}$ & 1.3 & 1.2 \\
\hline $4 / 17 \mathrm{~A}$ & 70F_4s1d2Zc_1 & 87.5 & 83.6 & 0.613 & 0.92 & HLP-22 & 12 & 8 & 4 & s1d2 & 2.48 & 0.000069 & 0.00155 & 0.05 & 0.34 & $\mathrm{P}$ & 1.3 & 1.2 \\
\hline $4 / 18 \mathrm{~A}$ & 70F_4s1d2Yc_1 & 87.5 & 83.6 & 0.613 & 0.92 & HLP-22 & 12 & 8 & 4 & s1d2 & 2.48 & 0.000069 & 0.005 & 0.05 & 0.33 & $\mathrm{P}$ & 1.3 & 1.2 \\
\hline 4/18B & 70F_4s1d2Rc_1 & 87.5 & 83.6 & 0.613 & 0.92 & HLP-22 & 12 & 8 & 4 & s1d2 & 2.48 & 0.000069 & 0.01 & 0.05 & 0.34 & $\mathrm{P}$ & 1.3 & 1.2 \\
\hline $4 / 21 \mathrm{~A}$ & 70F_4s1d2Vc_1 & 87.5 & 83.6 & 0.613 & 0.92 & HLP-22 & 12 & 8 & 4 & s1d2 & 2.48 & 0.000069 & 0.0143 & 0.05 & 0.33 & $\mathrm{P}$ & 1.3 & 1.2 \\
\hline $4 / 22 \mathrm{~A}$ & 70F_4s1d2Vd_1 & 88 & 83.6 & 0.613 & 0.92 & HLP-22 & 12 & 8 & 4 & s1d2 & 2.48 & 0.000069 & 0.0143 & 0.05 & 0.18 & $P$ & 1.3 & 1.2 \\
\hline $4 / 22 B$ & 70F_4s1d2Vc_2 & 87.5 & 83.6 & 0.613 & 0.92 & HLP-22 & 12 & 8 & 4 & s1d2 & 2.48 & 0.000069 & 0.0143 & 0.10 & 0.33 & $\mathrm{P}$ & 1.3 & 1.2 \\
\hline $4 / 23 \mathrm{~A}$ & 70F_4s1d2Ve_1 & 87.5 & 83.6 & 0.613 & 0.92 & HLP-22 & 12 & 8 & 4 & s1d2 & 2.48 & 0.000069 & 0.0143 & 0.05 & 0.67 & $\mathrm{P}$ & 1.3 & 1.2 \\
\hline $4 / 23 B$ & 70F_4s1d2Ve_2 & 87.5 & 83.6 & 0.613 & 0.92 & HLP-22 & 12 & 8 & 4 & s1d2 & 2.48 & 0.000069 & 0.0143 & 0.10 & 0.66 & $\mathrm{P}$ & 1.3 & 1.2 \\
\hline $4 / 23 \mathrm{C}$ & 70F_4s1d2Ve_4 & 88 & 83.6 & 0.613 & 0.92 & HLP-22 & 12 & 8 & 4 & s1d2 & 2.48 & 0.000069 & 0.0143 & 0.15 & 0.66 & $\mathrm{P}$ & 1.3 & 1.2 \\
\hline $4 / 24 \mathrm{~A}$ & 70F_4s1d2Vc_4 & 88 & 83.6 & 0.613 & 0.92 & HLP-22 & 12 & 8 & 4 & s1d2 & 2.48 & 0.000069 & 0.0143 & 0.15 & 0.33 & $\mathrm{P}$ & 1.3 & 1.2 \\
\hline $4 / 24 B$ & 70F_4s1d2Vd_2 & 88 & 83.6 & 0.613 & 0.92 & HLP-22 & 12 & 8 & 4 & s1d2 & 2.48 & 0.000069 & 0.0143 & 0.10 & 0.19 & $P$ & 1.3 & 1.2 \\
\hline $4 / 25 \mathrm{~A}$ & 70F_4s1d2Vd_4 & 87.5 & 83.6 & 0.613 & 0.92 & HLP-22 & 12 & 8 & 4 & s1d2 & 2.48 & 0.000069 & 0.0143 & 0.15 & 0.18 & $\mathrm{P}$ & 1.3 & 1.2 \\
\hline $4 / 25 B$ & 70F_4s1d2Ve_1 & 87.5 & 83.6 & 0.613 & 0.92 & HLP-22 & 12 & 8 & 4 & s1d2 & 2.48 & 0.000069 & 0.0143 & 0.05 & 0.67 & $\mathrm{P}$ & 1.3 & 1.2 \\
\hline $4 / 25 \mathrm{C}$ & 70F_4s1d2Vc_2 & 87.5 & 83.6 & 0.613 & 0.92 & HLP-22 & 12 & 8 & 4 & s1d2 & 2.48 & 0.000069 & 0.0143 & 0.10 & 0.33 & $\mathrm{P}$ & 1.3 & 1.2 \\
\hline $4 / 28 \mathrm{~A}$ & 70F_4s1d2Vd_1 & 89.5 & 83.6 & 0.613 & 0.92 & HLP-22 & 12 & 8 & 4 & s1d2 & 2.48 & 0.000069 & 0.0143 & 0.05 & 0.18 & $\mathrm{P}$ & 1.3 & 1.2 \\
\hline $4 / 29 \mathrm{~A}$ & 70F_4s1d2Vc_1 & 89 & 83.6 & 0.613 & 0.92 & HLP-22 & 12 & 8 & 4 & s1d2 & 2.48 & 0.000069 & 0.0143 & 0.05 & 0.33 & $\mathrm{P}$ & 1.3 & 1.2 \\
\hline 4/29B & 70F_4s1d2Vf_1 & 89 & 83.6 & 0.613 & 0.92 & HLP-22 & 12 & 8 & 4 & s1d2 & 2.48 & 0.000069 & 0.0143 & 0.05 & 0.25 & $\mathrm{P}$ & 1.3 & 1.2 \\
\hline
\end{tabular}




\subsubsection{Comparisons Among Tanks}

Several tests were directly comparable among the four tanks. Plots of these data are shown in Figures 6.20 through 6.22. The plot legend presents the Case ID followed by the $U_{\text {CS }}$ velocity if it was measured for that case. When identified, the $U_{C S}$ velocity is shown as the darkened symbol in the legend beneath the test and the method used to determine $\mathrm{U}_{\mathrm{CS}}$ is also shown. For example, in the legend for Figure 6.20 each test Case ID shows the $\mathrm{U}_{\mathrm{CS}}$ condition beneath it. The first Case ID (70F_4s1d2Yc_1) symbol is a green circle with black outline, the corresponding $U_{\mathrm{CS}}$ condition symbol is shown as a black circle with a green outline. Other $\mathrm{U}_{\mathrm{CS}}$ condition symbols are shown as colored symbols with black centers. The color matches the corresponding Case ID above it. The description to the right of the $\mathrm{U}_{\mathrm{CS}}$ condition shows the method used to determine $U_{\mathrm{CS}}$ which is either "udv" or "vis." Udv means that the $\mathrm{U}_{\mathrm{CS}}$ condition was determined ultrasonically after an increase in velocity. Vis means that the $\mathrm{U}_{\mathrm{CS}}$ condition was determined visually after an increase in velocity.

In Figure 6.20, data obtained in the large-scale tanks with the elliptical and flanged and dished heads are compared. The data are similar and overlap at velocities greater than the critical suspension velocity.

In Figure 6.21, data from simulant s1d2 $\left(\rho_{\mathrm{s}}=2.48 \mathrm{~g} / \mathrm{cm}^{3}, \mathrm{~d}_{50}=69 \mu \mathrm{m}\right)$ and $\mathrm{s} 2 \mathrm{~d} 2\left(\rho_{\mathrm{s}}=4.18 \mathrm{~g} / \mathrm{cm}^{3}, \mathrm{~d}_{50}\right.$ $=76 \mu \mathrm{m}$ ) are shown, with tank diameter and head shape the only condition varied. Figure 6.21 (a) shows data for simulant s2d2. The elliptical head at the small- and large-scale produce data that seem to fall along the same line at velocities above $8 \mathrm{~m} / \mathrm{s}$, with the mid-scale spherical head slightly offset but parallel to the elliptical head data. Figure 6.21 (b) shows data for simulant s1d2 and p1d8, which have similar densities and mean diameters.

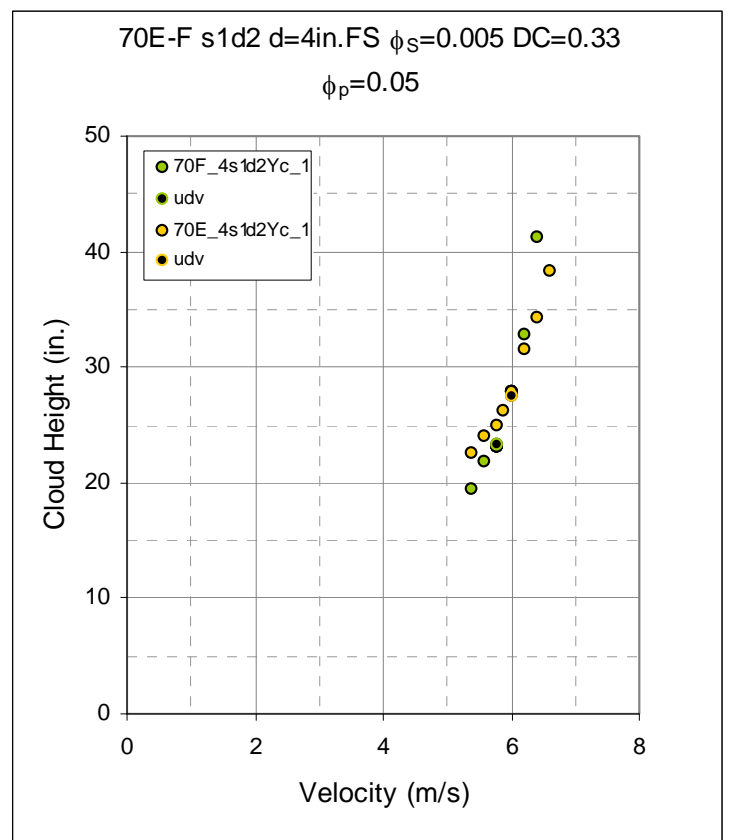

Figure 6.20. Comparison of Tank Heads at Large Scale: 70E with Elliptical and 70F with F\&D Head. Test conditions are simulant $\mathrm{s} 1 \mathrm{~d} 2\left(\rho_{\mathrm{s}}=2.48 \mathrm{~g} / \mathrm{cm}^{3}, \mathrm{~d}_{50}=69 \mu \mathrm{m}\right)$ at solids fraction $\left(\phi_{\mathrm{s}}=\right.$ $0.005[\mathrm{Y}])$ using 4 in. full-scale nozzle with duty cycle $(\mathrm{DC}=0.33[\mathrm{c}])$ and pulse volume fraction $\left(\phi_{\mathrm{p}}=0.05\right)$. 


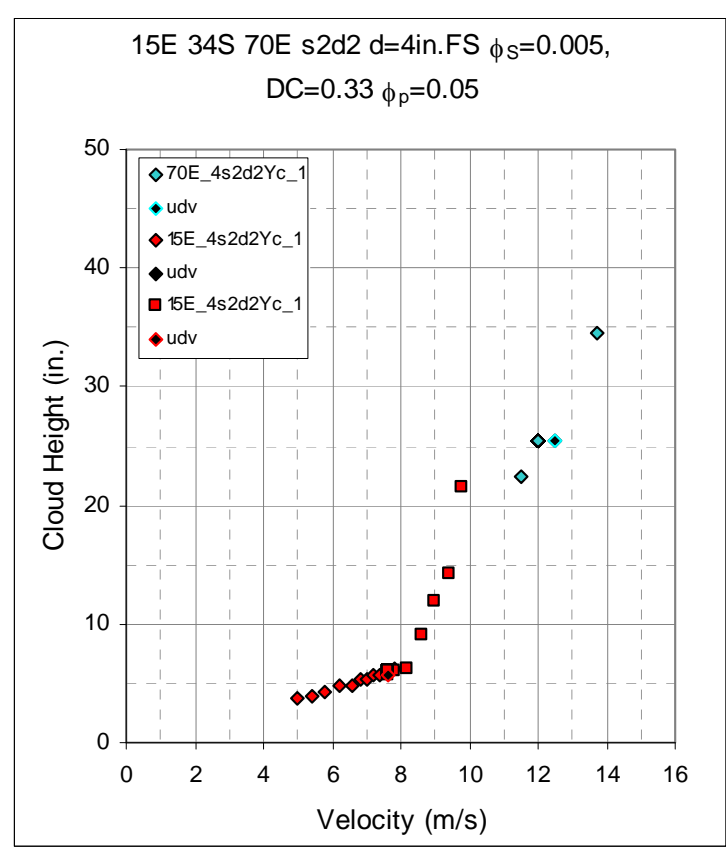

(a)

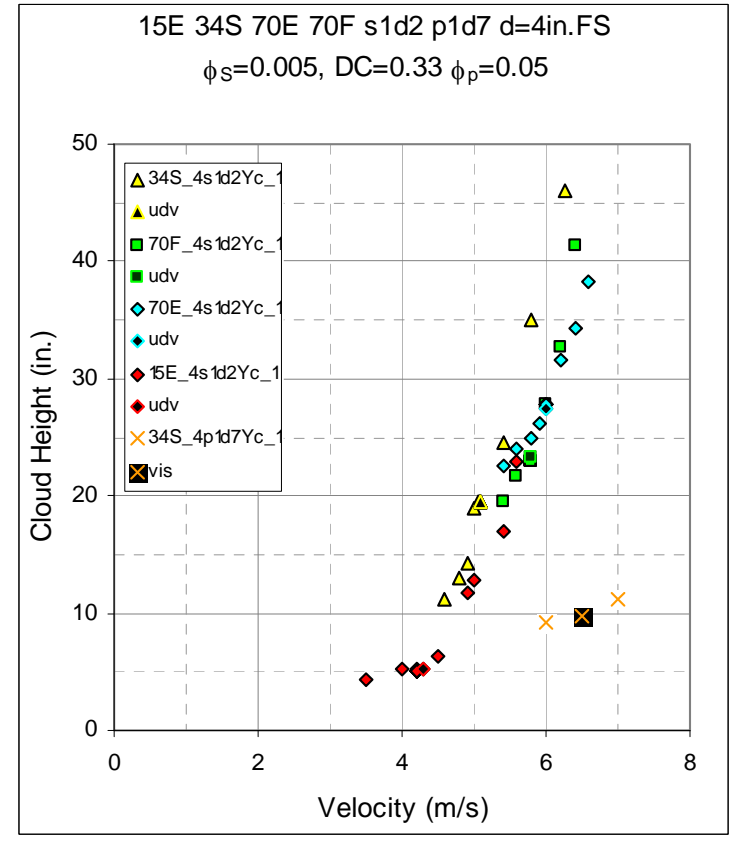

(b)

Figure 6.21. Comparison of Small, Mid-, Large Scale: (a) $\mathrm{s} 2 \mathrm{~d} 2\left(\rho_{\mathrm{s}}=4.18 \mathrm{~g} / \mathrm{cm}^{3}, \mathrm{~d}_{50}=76 \mu \mathrm{m}\right)$ Shown at $15 \mathrm{E}$ and $70 \mathrm{E}$ with Elliptical, and 70F with Flanged and Dished Head; (b) s1d2 $\left(\rho_{\mathrm{s}}=2.48 \mathrm{~g} / \mathrm{cm}^{3}, \mathrm{~d}_{50}=69 \mu \mathrm{m}\right)$ and p1d8 $\left(\rho_{\mathrm{s}}=2.45 \mathrm{~g} / \mathrm{cm}^{3}, \mathrm{~d}_{50}=90 \mu \mathrm{m}\right)$ in all vessels. Both are at solids fraction $\left(\phi_{\mathrm{S}}=0.005[\mathrm{Y}]\right)$ using 4 in. full-scale nozzle with duty cycle (DC = $0.33[\mathrm{c}])$ and pulse volume fraction $\left(\phi_{\mathrm{p}}=0.05\right)$.

In Figure 6.22, selected data from five simulants are compared, with simulant and tank the only conditions varied. In both the plots the simulant listing in the heading is in terms of increasing settling velocity, as shown in Figures 3.3 and 3.4. A linear plot shown in Figure 6.22 (a), and a log plot is provided in Figure 6.22 (b). Simulant s1d5 is shown by the blue asterisks, followed by s1d2 with gold filled symbols. Next is the p1d8 shown by magenta cross symbols; s2d2 is shown by red-filled diamond symbols; s1d1 is shown by aqua triangle symbols; $\mathrm{p} 1 \mathrm{~d} 7$ is shown by green $\mathrm{x}$ symbols; $\mathrm{s} 2 \mathrm{~d} 1$ is shown by green-filled square symbols. For the tests conducted in 2008, the mid-scale test symbols are outlined in red; the small-scale test symbols are outlined in black; the large-scale test with elliptical head symbols are outlined in blue; and the large-scale test with flanged and dished head symbols are outlined in green. Tests with the 2007 simulants and s1d5 symbols are not outlined.

In both 6.22 (a) and (b), when the simulant density is held constant and the particle size increases, the critical suspension velocity increases as the settling velocity of the simulants increases. When the simulant particle size is held constant and the simulant density increases, the critical suspension velocity also increases as does the settling velocity. The simulant settling velocities are plotted in Figures 3.3 and 3.4. 


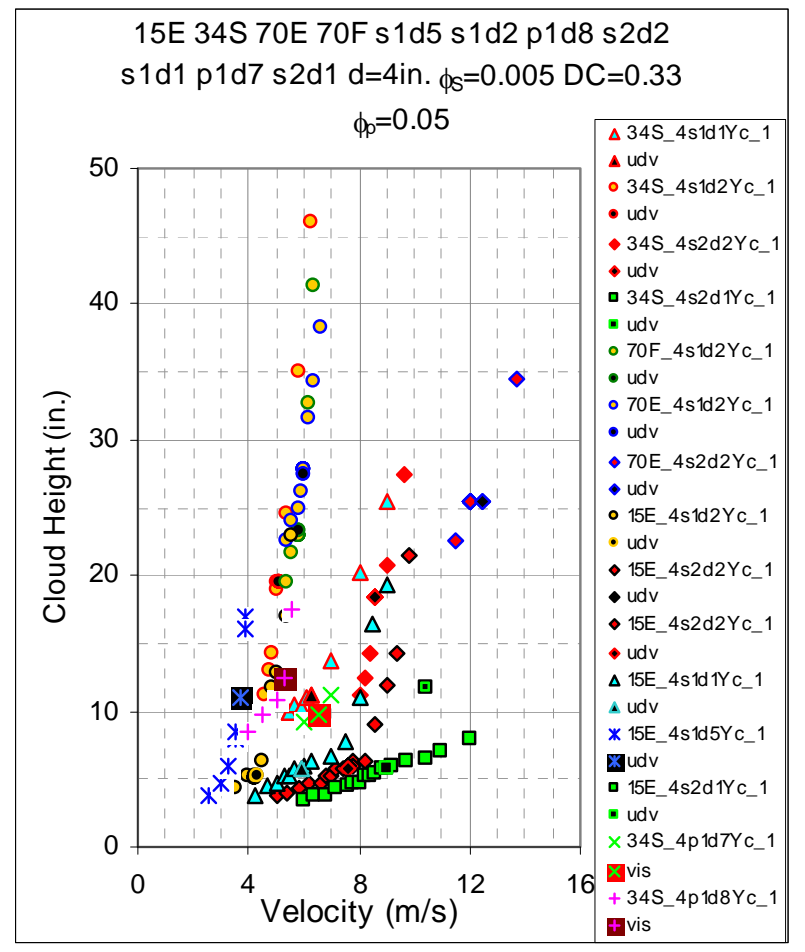

(a)

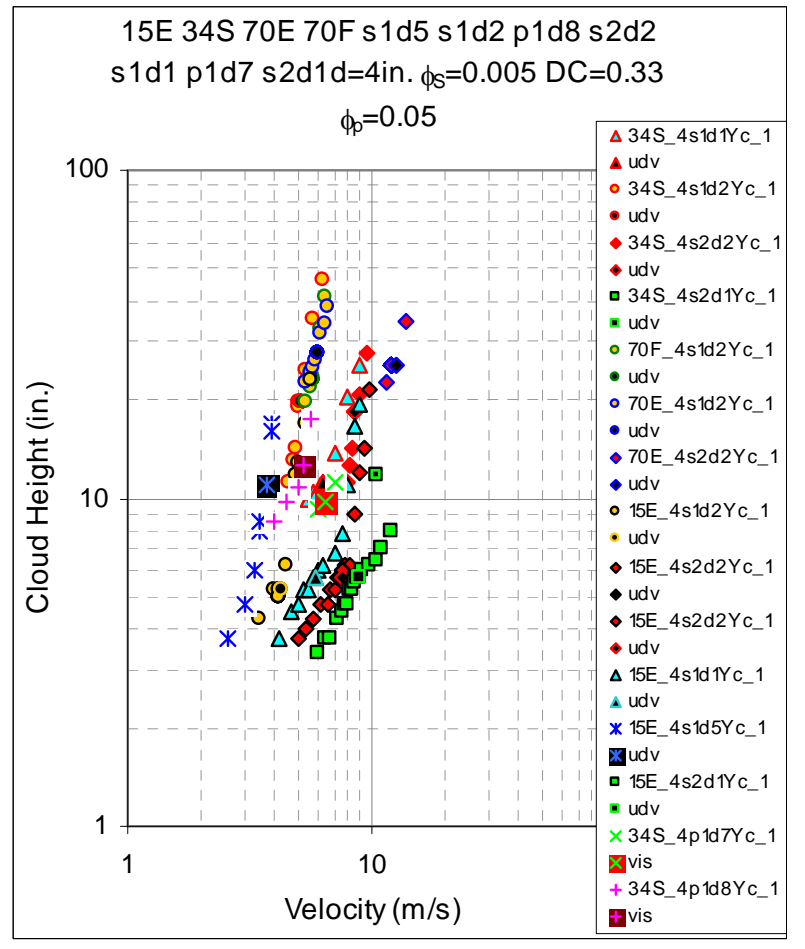

(b)

Figure 6.22. Comparison of Six Simulants in Four Tanks: (a) Linear Scale (b) Log Scale. All simulants at solids fraction $\left(\phi_{\mathrm{S}}=0.005[\mathrm{Y}]\right)$ using 4 in. full-scale nozzle with duty cycle (DC $=0.33$ [c]) and pulse volume fraction $\left(\phi_{\mathrm{p}}=0.05\right)$.

\subsubsection{Repeat and Replicate Tests}

During test campaigns tests with the same Case ID were often performed over multiple days. At times tests were conducted at similar or near similar conditions. These tests were called repeat tests, which were defined as tests performed at the same conditions one after another (or close in time), without a change of simulant. In addition, some tests were conducted during more than one test campaign or after a significant change such as a change of simulant. These tests were called replicate tests, which were defined as tests performed at the same set of conditions but at different times, with tests at other sets of conditions intervening. Only limited replicate tests involving the July 2007 and Fall 2007 test campaigns were performed. In addition to replicate tests, some repeat testing was performed within the July 2007, Fall 2007 and 2008 test campaigns. Table 6.13 lists the test conditions investigated with near-replicate and near-repeat testing. The terms near-replicate and near-repeat are used because the test conditions are close but not exactly the same for some test variables. The replicate and repeat data are discussed in Appendix E, Section E.3. 
Table 6.13. Near-Replicate and Near-Repeat Tests at Critical Suspension Conditions

\begin{tabular}{|c|c|c|c|c|c|c|c|c|c|c|c|c|c|c|c|c|c|}
\hline $\begin{array}{l}\text { Row } \\
\text { Number } \\
\end{array}$ & Case ID & Test & $\begin{array}{c}\text { Tank } \\
\text { Diameter }\end{array}$ & $\begin{array}{c}\text { Solids } \\
\text { Density }\end{array}$ & $\begin{array}{c}\text { Solids } \\
\text { Fraction }\end{array}$ & $\begin{array}{c}\text { Particle } \\
\text { Size }\end{array}$ & $\begin{array}{l}\text { Duty } \\
\text { Cycle }\end{array}$ & $\begin{array}{c}\text { Pulse } \\
\text { Volume } \\
\text { Fraction } \\
\end{array}$ & $\begin{array}{c}\text { Installed } \\
\text { Tubes } \\
\end{array}$ & $\begin{array}{c}\text { Operating } \\
\text { Tubes }\end{array}$ & $\begin{array}{l}\text { Outer } \\
\text { Tubes }\end{array}$ & $\begin{array}{l}\text { Inner } \\
\text { Tubes }\end{array}$ & $\begin{array}{c}\text { Nozzle } \\
\text { Inner } \\
\text { Diameter }\end{array}$ & $\begin{array}{l}\text { Head } \\
\text { Shape }\end{array}$ & $\begin{array}{c}\text { Discharge } \\
\text { Velocity }\end{array}$ & & \\
\hline text & text & text & in & $\mathrm{g} / \mathrm{cm}^{3}$ & fraction & $\mathrm{m}$ & fraction & fraction & Number & & Number & Number & in & text & $\mathrm{m} / \mathrm{s}$ & $\begin{array}{l}\text { Near- } \\
\text { Repeat }\end{array}$ & $\begin{array}{c}\text { Near- } \\
\text { Replicate }\end{array}$ \\
\hline MSS & ID & $\mathrm{M} / \mathrm{DDX}$ & D & $\mathrm{S}$ & $\phi_{\mathrm{s}}$ & $\mathrm{d}_{50}\left(\mathrm{~d}_{\mathrm{S}}\right)$ & $\mathrm{DC}$ & $\phi_{\mathrm{p}}$ & $\mathrm{N}$ & $\mathrm{N}_{\mathrm{J}}$ & $\mathrm{N}_{\mathrm{O}}$ & $\mathrm{N}_{\mathrm{I}}$ & $\mathrm{d}$ & $\mathrm{HS}$ & $\mathrm{U}$ & Set & Set \\
\hline 9150506 & 15E_4s1d1Xc_1 & $6 / 27 C$ & 14.4375 & 2.46 & 0.015 & 0.00017 & 0.334 & 0.050 & 12 & 12 & 8 & 4 & 0.126 & E & 8.2 & 1 & $-^{\text {(a) }}$ \\
\hline 9150516 & 15E_4s1d1Xc_1 & $6 / 30 \mathrm{~A}$ & 14.4375 & 2.46 & 0.015 & 0.00017 & 0.335 & 0.050 & 12 & 12 & 8 & 4 & 0.126 & E & 8.6 & 1 & - \\
\hline 9150048 & 15E_4s1d2Rc_1 & 6/9B & 14.4375 & 2.48 & 0.01 & $6.9 \mathrm{E}-05$ & 0.338 & 0.050 & 12 & 12 & 8 & 4 & 0.126 & E & 5.3 & 2 & - \\
\hline 9150053 & 15E_4s1d2Rc_1 & $6 / 10 \mathrm{~A}$ & 14.4375 & 2.48 & 0.01 & $6.9 \mathrm{E}-05$ & 0.331 & 0.050 & 12 & 12 & 8 & 4 & 0.126 & E & 5.4 & 2 & - \\
\hline 9150063 & 15E_4s1d2Xc_1 & $6 / 10 \mathrm{~B}$ & 14.4375 & 2.48 & 0.015 & $6.9 \mathrm{E}-05$ & 0.331 & 0.050 & 12 & 12 & 8 & 4 & 0.126 & E & 5.8 & 3 & - \\
\hline 9150108 & 15E_4s1d2Xc_1 & $6 / 11 C$ & 14.4375 & 2.48 & 0.015 & $6.9 \mathrm{E}-05$ & 0.333 & 0.050 & 12 & 12 & 8 & 4 & 0.126 & E & 5.8 & 3 & - \\
\hline 9150083 & 15E_4s1d2Xd_1 & $6 / 11 \mathrm{~A}$ & 14.4375 & 2.48 & 0.015 & $6.9 \mathrm{E}-05$ & 0.184 & 0.050 & 12 & 12 & 8 & 4 & 0.126 & $\mathrm{E}$ & 7.2 & 4 & - \\
\hline 9150174 & 15E_4s1d2Xd_1 & $6 / 13 \mathrm{C}$ & 14.4375 & 2.48 & 0.015 & $6.9 \mathrm{E}-05$ & 0.186 & 0.050 & 12 & 12 & 8 & 4 & 0.126 & E & 7.4 & 4 & - \\
\hline 9150412 & 15E_4s2d2Wc_1 & $6 / 24 B$ & 14.4375 & 4.18 & 0.045 & 7.6E-05 & 0.333 & 0.050 & 12 & 12 & 8 & 4 & 0.126 & E & 11.5 & 5 & - \\
\hline 9150419 & 15E_4s2d2Wc_1 & $6 / 25 \mathrm{~A}$ & 14.4375 & 4.18 & 0.045 & 7.6E-05 & 0.332 & 0.050 & 12 & 12 & 8 & 4 & 0.126 & E & 11.5 & 5 & - \\
\hline 9150345 & 15E_4s2d2Yc_1 & 6/19C & 14.4375 & 4.18 & 0.005 & 7.6E-05 & 0.335 & 0.050 & 12 & 12 & 8 & 4 & 0.126 & E & 7.6 & 6 & - \\
\hline 9150347 & 15E_4s2d2Yc_1 & $6 / 20 \mathrm{~A}$ & 14.4375 & 4.18 & 0.005 & 7.6E-05 & 0.334 & 0.050 & 12 & 12 & 8 & 4 & 0.126 & $\mathrm{E}$ & 7.6 & 6 & - \\
\hline 9150307 & 15E_4s2d2Zc_1 & 6/18B & 14.4375 & 4.18 & 0.00155 & 7.6E-05 & 0.337 & 0.050 & 12 & 12 & 8 & 4 & 0.126 & E & 5.4 & 7 & - \\
\hline 9150312 & 15E_4s2d2Zc_1 & 6/19A & 14.4375 & 4.18 & 0.00155 & 7.6E-05 & 0.334 & 0.050 & 12 & 12 & 8 & 4 & 0.126 & E & 5.2 & 7 & - \\
\hline 7091025 & 34S_4p1d7Yc_1 & 11/26B1 & 33.875 & 2.45 & 0.00487 & 0.00018 & 0.330 & 0.05105 & 12 & 12 & 8 & 4 & 0.297 & S & 6.5 & - & 1 \\
\hline 20070105 & 34S_4p1d7Yc_8 & 7/16 A2 & 33.875 & 2.45 & 0.00487 & 0.00018 & 0.330 & 0.05 & 12 & 12 & 8 & 4 & 0.297 & S & 6.4 & - & 1 \\
\hline 20070387 & 34S_4p1d7Yc_8 & 7/19 A1 & 33.875 & 2.45 & 0.00487 & 0.00018 & 0.330 & 0.048 & 12 & 12 & 8 & 4 & 0.297 & S & 6.2 & - & 1 \\
\hline 7090875 & 34S_4p1d7Yd_1 & 11/19A2 & 33.875 & 2.45 & 0.00487 & 0.00018 & 0.180 & 0.05325 & 12 & 12 & 8 & 4 & 0.297 & S & 6.4 & - & 2 \\
\hline 20070441 & 34S_4p1d7Yd_8 & 7/19 A4 & 33.875 & 2.45 & 0.00487 & 0.00018 & 0.180 & 0.048 & 12 & 12 & 8 & 4 & 0.297 & S & 6.4 & - & 2 \\
\hline 7090779 & 34S_6p1d7Yc_1 & 11/14D1 & 33.875 & 2.45 & 0.00487 & 0.00018 & 0.330 & 0.05109 & 12 & 12 & 8 & 4 & 0.446 & S & 4.5 & - & 3 \\
\hline 20070627 & 34S_6p1d7Yc_8 & 7/21 A2 & 33.875 & 2.45 & 0.00487 & 0.00018 & 0.330 & 0.048 & 12 & 12 & 8 & 4 & 0.446 & S & 4.0 & - & 3 \\
\hline 7090095 & 34S_6p1d7Yd_0 & 10/18A2 & 33.875 & 2.45 & 0.00487 & 0.00018 & 0.180 & 0.052 & 12 & 8 & 4 & 4 & 0.446 & S & 6.1 & 8 & - \\
\hline 7090244 & 34S_6p1d7Yd_0 & 10/26B2 & 33.875 & 2.45 & 0.00487 & 0.00018 & 0.180 & 0.050 & 12 & 8 & 4 & 4 & 0.446 & S & 6.1 & 8 & - \\
\hline 7090758 & 34S_6p1d7Yd_0 & $11 / 14 \mathrm{~A} 2$ & 33.875 & 2.45 & 0.00487 & 0.00018 & 0.180 & 0.050 & 12 & 8 & 4 & 4 & 0.446 & S & 7.0 & 8 & - \\
\hline 7090136 & 34S_6p1d7Yd_6 & 10/18B2 & 33.875 & 2.45 & 0.00487 & 0.00018 & 0.180 & 0.051 & 12 & 4 & 4 & 0 & 0.446 & S & 6.4 & 9 & - \\
\hline 7090298 & 34S_6p1d7Yd_6 & 10/29B2 & 33.875 & 2.45 & 0.00487 & 0.00018 & 0.180 & 0.050 & 12 & 4 & 4 & 0 & 0.446 & S & 6.2 & 9 & - \\
\hline
\end{tabular}


Table 6.13. (contd)

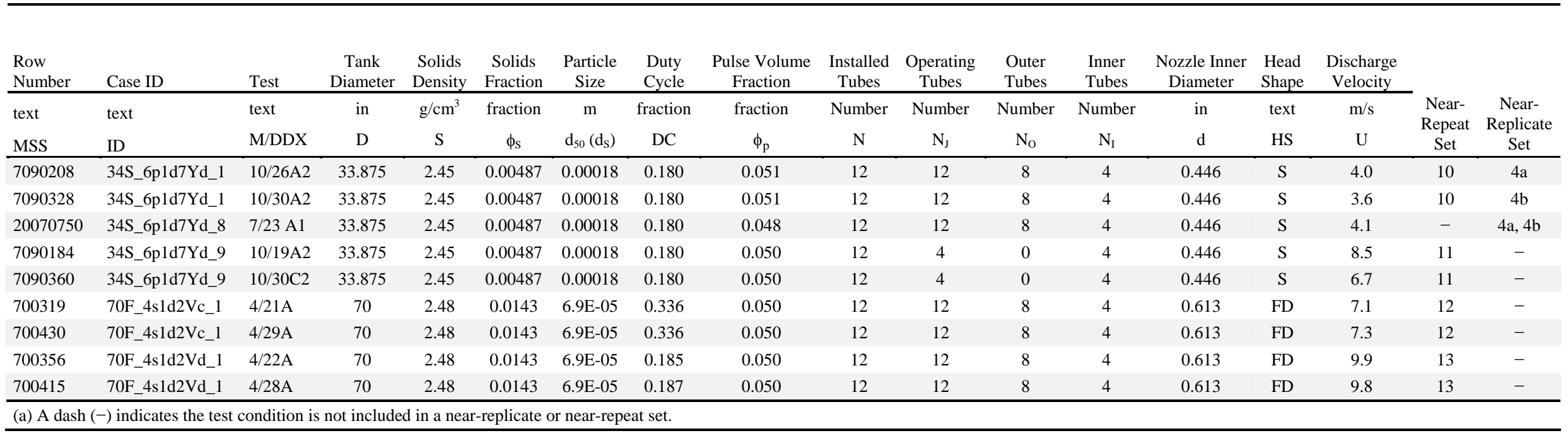

$\stackrel{\infty}{N}$ 


\subsection{Concentration Profiles}

During selected tests and at specific test conditions, the ultrasonic concentration probe described in Appendix A was used to measure the concentration of solids by volume in the cloud during a pulse cycle. The procedure for this measurement, the range of tests conducted, and a summary of the transient and averaged data are presented in Section 6.5.1. In Sections 6.5.2 through 6.5.7, the concentration profiles are compared to provide insight regarding variations of concentration profiles with critical suspension velocity, radial location, tank, nozzle diameter, concentration and duty cycle.

\subsubsection{Concentration Profile Measurements}

The concentration probe was suspended in the tank at a specified elevation and radial location. The most frequent radial location was in the tank center. Data from a series of five cycles at steady state conditions (see Section 6.5.1, Figure 6.23) were averaged to determine the average solids concentration by volume during a cycle at the probe location. The data in the five cycles were averaged at specified time steps in the cycle to provide transient data of solids concentration by volume during a cycle. Examples of these individual cycle data for all the test tanks are shown in Figure 6.23. The same test conditions and nondimensional probe location are shown for the four tanks: the small- and large-scale tanks with elliptical heads, the mid-scale tank with spherical head, and the large-scale tank with flanged and dished head.

For each tank the sequence of five cycles of transient solids concentration by volume measurements at that location are very similar in shape. Just after the start of the cycle an increase in concentration is visible when the pulse from the PJM mobilizes solids to the elevation of the probe. After the pulse stops the concentration decays. Near the end of the cycle some small fluctuations are observed due to solids settling back to the floor and rebounding in a "sloshing” manner. This sequence, an increase in concentration after pulse start followed by a decrease in concentration after pulse end, is observed when comparing the data for the three tanks.

The tests with concentration profile data are listed in Table 6.14. The table shows the test parameters and radial position of the probe. The first column lists the figure number where the data is found in Appendix C. The second column lists the test Case ID. This is followed by the operating parameters for that test. The measurements were taken at elevations within the cloud. For some tests in the large-scale tank, profiles were obtained at three radial locations: tank center [0R], halfway between the center and the wall [0.5R], and near the wall [0.9R], where $\mathrm{R}$ is the tank radius. Table 6.14 lists the "highest concentration test measurement location." This is the nondimensional elevation within the cloud where a measurement was taken. Above this location the cloud was not visually observable. These measurements are provided at the three radial measurement locations. This information is followed by the velocity, the critical suspension velocity, and the cloud height. The last column lists the test that shows the date of the measurement followed by the sequence during the day. If the data in the velocity column are shown in italics, the profile was taken at a velocity below $\mathrm{U}_{\mathrm{CS}}$; if the data in the velocity column are shown in bold, the profile was taken at a velocity above $\mathrm{U}_{\mathrm{CS}}$. All other entries were taken at the $\mathrm{U}_{\mathrm{CS}}$ condition.

The minimum, average, and maximum solids concentration by volume for each profile location and the standard deviation at that location were calculated based on five-cycle averages. This information is shown in Figure 6.24. For comparison the data are plotted dimensionally and nondimensionally. The 
dimensional plots show elevation (Z), on the y axis to provide a physical relationship with the elevation in the test tank. Concentration $(\mathrm{C}(\mathrm{Z}))$ is plotted on the $\mathrm{x}$ axis. Two data sets are shown in the dimensional plot: the entire concentration profile data set and the cases limited to the critical suspension condition. Linear fits are provided for each data set. The dimensional plots show that most concentration profile measurements occurred at the $\mathrm{U}_{\mathrm{CS}}$ condition. The nondimensional plots show elevation ( $\mathrm{Z}$ ) normalized with respect to cloud height $\left(\mathrm{H}_{\mathrm{C}}\right)$ on the y axis and concentration, $\mathrm{C}(\mathrm{Z})$ divided by solids loading $\left(\phi_{\mathrm{S}}\right)$ normalized with respect to the ratio of cloud height to tank diameter $\left(\mathrm{H}_{\mathrm{C}} / \mathrm{D}\right)$. The dimensional plots provide comparison between tanks; the nondimensional plots provide comparison between the clouds within the tanks. 
Table 6.14. Summary of Concentration Profile Cases

\begin{tabular}{|c|c|c|c|c|c|c|c|c|c|c|c|c|c|c|c|c|c|c|}
\hline \multirow{2}{*}{$\begin{array}{l}\text { Figure } \\
\text { Number }\end{array}$} & \multirow[b]{2}{*}{ Case ID } & \multirow{2}{*}{$\begin{array}{c}\text { Tank } \\
\text { Diameter }\end{array}$} & \multirow{2}{*}{$\begin{array}{l}\text { Head } \\
\text { Shape }\end{array}$} & \multirow{2}{*}{$\begin{array}{c}\text { Nozzle } \\
\text { Diameter }\end{array}$} & \multicolumn{2}{|c|}{$\begin{array}{c}\text { Number of } \\
\text { Nozzles } \\
\text { Operated }\end{array}$} & \multirow{2}{*}{ Density } & \multirow{2}{*}{$\begin{array}{c}\begin{array}{c}\text { Particle } \\
\text { Diameter }\end{array} \\
\text { d50 }\end{array}$} & \multirow{2}{*}{ Concentration } & \multirow{2}{*}{$\begin{array}{l}\text { Duty } \\
\text { Cycle }\end{array}$} & \multirow{2}{*}{$\begin{array}{l}\text { Pulse } \\
\text { Volume }\end{array}$} & \multicolumn{3}{|c|}{$\begin{array}{l}\text { Highest Concentration Test } \\
\text { Measurement Location }\end{array}$} & \multirow{2}{*}{ Velocity } & \multirow{2}{*}{$\begin{array}{c}\text { Velocity } \\
\text { at } U_{C S}\end{array}$} & \multirow{2}{*}{$\begin{array}{l}\text { Cloud } \\
\text { Height }\end{array}$} & \multirow[b]{2}{*}{ Test } \\
\hline & & & & & Outer & Inner & & & & & & at $0 \mathrm{R}$ & at $0.5 \mathrm{R}$ & at $0.9 \mathrm{R}$ & & & & \\
\hline text & text & in. & text & in. & integer & integer & $\mathrm{g} / \mathrm{cm}^{3}$ & $\mu \mathrm{m}$ & $\begin{array}{l}\text { volume } \\
\text { fraction }\end{array}$ & fraction & fraction & $\mathrm{Z} / \mathrm{D}$ & $\mathrm{Z} / \mathrm{D}$ & $\mathrm{Z} / \mathrm{D}$ & $\mathrm{m} / \mathrm{s}$ & $\mathrm{m} / \mathrm{s}$ & In. & text \\
\hline C.1 & 15E_4s1d2Zc_1 & $147 / 16$ & $\mathrm{E}$ & 0.126 & 8 & 4 & 2.48 & 69.3 & 0.00155 & 0.33 & 0.05 & 0.5 & $\mathrm{n} / \mathrm{a}$ & $\mathrm{n} / \mathrm{a}$ & 2.8 & 2.8 & 6.88 & $6 / 6 \mathrm{~A}$ \\
\hline C. 2 & 15E_4s1d2Yc_1 & $147 / 16$ & $\mathrm{E}$ & 0.126 & 8 & 4 & 2.48 & 69.3 & 0.005 & 0.33 & 0.05 & 0.4 & $\mathrm{n} / \mathrm{a}$ & $\mathrm{n} / \mathrm{a}$ & $4.2^{(\mathrm{a})}$ & 4.3 & 5 & $6 / 9 \mathrm{~A}$ \\
\hline C. 3 & 15E_4s1d2Xd_1 & $147 / 16$ & $\mathrm{E}$ & 0.126 & 8 & 4 & 2.48 & 69.3 & 0.015 & 0.18 & 0.05 & 0.4 & $\mathrm{n} / \mathrm{a}$ & $\mathrm{n} / \mathrm{a}$ & 7.2 & 7.2 & 5.75 & $6 / 11 \mathrm{~A}$ \\
\hline C. 4 & 15E_4s1d2Xc_1 & $147 / 16$ & E & 0.126 & 8 & 4 & 2.48 & 69.3 & 0.015 & 0.33 & 0.05 & 0.45 & $\mathrm{n} / \mathrm{a}$ & $\mathrm{n} / \mathrm{a}$ & 5.8 & 5.8 & 6.62 & $6 / 10 \mathrm{~B}$ \\
\hline C.5 & 15E_4s1d2Xe_1 & $147 / 16$ & E & 0.126 & 8 & 4 & 2.48 & 69.3 & 0.015 & 0.67 & 0.05 & 0.55 & $\mathrm{n} / \mathrm{a}$ & $\mathrm{n} / \mathrm{a}$ & 3.9 & 3.9 & 7.25 & $6 / 12 \mathrm{~A}$ \\
\hline C.6 & 15E_4s1d2Wd_1 & $147 / 16$ & E & 0.126 & 8 & 4 & 2.48 & 69.3 & 0.045 & 0.19 & 0.05 & 0.45 & $\mathrm{n} / \mathrm{a}$ & $\mathrm{n} / \mathrm{a}$ & 7.2 & 7.2 & 5.75 & $6 / 17 \mathrm{~A}$ \\
\hline C.7 & 15E_4s1d2Wc_1 & $147 / 16$ & E & 0.126 & 8 & 4 & 2.48 & 69.3 & 0.045 & 0.33 & 0.05 & 0.55 & $\mathrm{n} / \mathrm{a}$ & $\mathrm{n} / \mathrm{a}$ & 6.5 & 6.5 & 7.5 & $6 / 16 B$ \\
\hline C. 8 & 15E_4s1d2Wa & $147 / 16$ & E & 0.126 & 8 & 4 & 2.48 & 69.3 & 0.045 & 1.00 & undefined & 1 & $\mathrm{n} / \mathrm{a}$ & $\mathrm{n} / \mathrm{a}$ & 3 & 3 & 14.5 & $6 / 17 \mathrm{~B}$ \\
\hline C.9 & 15E_4s1d2Wc_1 & $147 / 16$ & E & 0.126 & 8 & 4 & 2.48 & 69.3 & 0.045 & 0.34 & 0.05 & 1 & $\mathrm{n} / \mathrm{a}$ & $\mathrm{n} / \mathrm{a}$ & $\mathbf{8}^{(\mathrm{a})}$ & 6.5 & 14.5 & $6 / 17 \mathrm{C}$ \\
\hline C.10 & 15E_4s1d2Pc_1 & $147 / 16$ & E & 0.126 & 8 & 4 & 2.48 & 69.3 & 0.06 & 0.34 & 0.05 & 0.7 & $\mathrm{n} / \mathrm{a}$ & $\mathrm{n} / \mathrm{a}$ & 6.2 & 6.2 & 9.5 & $6 / 18 \mathrm{~A}$ \\
\hline C.11 & 15E_4s2d2Zc_1 & $147 / 16$ & E & 0.126 & 8 & 4 & 4.18 & 75.6 & 0.00155 & 0.34 & 0.05 & 0.45 & $\mathrm{n} / \mathrm{a}$ & $\mathrm{n} / \mathrm{a}$ & 5.2 & 5.2 & 7 & 6/19A \\
\hline C.12 & 15E_4s2d2Xc_1 & $147 / 16$ & E & 0.126 & 8 & 4 & 4.18 & 75.6 & 0.015 & 0.33 & 0.05 & 0.4 & $\mathrm{n} / \mathrm{a}$ & $\mathrm{n} / \mathrm{a}$ & 11.8 & 11.8 & 6 & $6 / 20 \mathrm{~B}$ \\
\hline C.13 & 15E_4s2d2Yc_1 & $147 / 16$ & E & 0.126 & 8 & 4 & 4.18 & 75.6 & 0.005 & 0.33 & 0.05 & 0.4 & $\mathrm{n} / \mathrm{a}$ & $\mathrm{n} / \mathrm{a}$ & 7.6 & 7.6 & 6 & $6 / 20 \mathrm{~A}$ \\
\hline C.14 & 15E_4s1d1Zc_1 & $147 / 16$ & E & 0.126 & 8 & 4 & 2.46 & 166.4 & 0.00155 & 0.33 & 0.05 & 0.45 & $\mathrm{n} / \mathrm{a}$ & $\mathrm{n} / \mathrm{a}$ & 4.2 & 4.2 & 6.25 & $6 / 26 \mathrm{~A}$ \\
\hline C.15 & 15E_4s1d1Xc_1 & $147 / 16$ & E & 0.126 & 8 & 4 & 2.46 & 166.4 & 0.015 & 0.34 & 0.05 & 0.35 & $\mathrm{n} / \mathrm{a}$ & $\mathrm{n} / \mathrm{a}$ & 8.6 & 8.6 & 5.5 & $6 / 30 \mathrm{~A}$ \\
\hline C.16 & 15E_4s1d5Yc_1 & $147 / 16$ & E & 0.126 & 8 & 4 & 2.5 & 43.9 & 0.005 & 0.33 & 0.05 & 0.6 & $\mathrm{n} / \mathrm{a}$ & $\mathrm{n} / \mathrm{a}$ & 3.5 & 3.7 & 8.5 & $7 / 1 \mathrm{~B}$ \\
\hline C.17 & 15E_4s2d1Zc_1 & $147 / 16$ & E & 0.126 & 8 & 4 & 4.17 & 164.2 & 0.00155 & 0.33 & 0.05 & 0.6 & $\mathrm{n} / \mathrm{a}$ & $\mathrm{n} / \mathrm{a}$ & 6.8 & 6.8 & 8 & $7 / 2 \mathrm{~B}$ \\
\hline C.18 & 15E_6s1d2Vc_1 & $147 / 16$ & E & 0.191 & 4 & 4 & 2.48 & 69.3 & 0.0143 & 0.33 & 0.05 & 0.7 & $\mathrm{n} / \mathrm{a}$ & $\mathrm{n} / \mathrm{a}$ & 4.8 & 4.8 & 9.5 & $7 / 8 \mathrm{C}$ \\
\hline C.19 & 15E_6s1d2Xc_1 & $147 / 16$ & E & 0.191 & 4 & 4 & 2.48 & 69.3 & 0.015 & 0.33 & 0.05 & 0.6 & $\mathrm{n} / \mathrm{a}$ & $\mathrm{n} / \mathrm{a}$ & 4.6 & 4.6 & 8.5 & $7 / 9 B$ \\
\hline C. 20 & 15E_6s1d2Xc_2 & $147 / 16$ & E & 0.191 & 4 & 4 & 2.48 & 69.3 & 0.015 & 0.33 & 0.10 & 0.7 & $\mathrm{n} / \mathrm{a}$ & $\mathrm{n} / \mathrm{a}$ & 4.4 & 4.4 & 8.5 & $7 / 9 \mathrm{C}$ \\
\hline C. 21 & 15E_Ms1d2Vc_1 & $147 / 16$ & E & 0.268 & 4 & 4 & 2.48 & 69.3 & 0.0143 & 0.33 & 0.05 & 0.8 & $\mathrm{n} / \mathrm{a}$ & $\mathrm{n} / \mathrm{a}$ & 2.9 & 2.9 & 8.5 & $7 / 11 \mathrm{~A}$ \\
\hline C. 22 & 15E_Ls1d2Vc_1 & $147 / 16$ & E & 0.375 & 4 & 4 & 2.48 & 69.3 & 0.0143 & 0.34 & 0.05 & 0.7 & $\mathrm{n} / \mathrm{a}$ & $\mathrm{n} / \mathrm{a}$ & 1.9 & 1.9 & 9.5 & $7 / 14 \mathrm{~B}$ \\
\hline C. 23 & 15E_Ls1d2Vc_2 & $147 / 16$ & E & 0.375 & 4 & 4 & 2.48 & 69.3 & 0.0143 & 0.33 & 0.10 & 0.9 & $\mathrm{n} / \mathrm{a}$ & $\mathrm{n} / \mathrm{a}$ & 1.9 & 1.9 & 11.5 & $7 / 15 \mathrm{~B}$ \\
\hline C. 24 & 15E_Ls1d2Vc_7 & $147 / 16$ & E & 0.375 & 4 & 0 & 2.48 & 69.3 & 0.0143 & 0.34 & 0.10 & 0.9 & $\mathrm{n} / \mathrm{a}$ & $\mathrm{n} / \mathrm{a}$ & 2.5 & 2.5 & 11.5 & $7 / 15 \mathrm{~A}$ \\
\hline C. 25 & 34E_4s1d1Zc_1 & $337 / 8$ & S & 0.297 & 8 & 4 & 2.46 & 166.4 & 0.00155 & 0.34 & 0.05 & 0.4 & $\mathrm{n} / \mathrm{a}$ & $\mathrm{n} / \mathrm{a}$ & 4.5 & 4.5 & 13.75 & $3 / 5 \mathrm{~A}$ \\
\hline C. 26 & 34E_4s1d2Sc_1 & $337 / 8$ & S & 0.297 & 8 & 4 & 2.48 & 69.3 & 0.0015 & 0.34 & 0.05 & 0.6 & $\mathrm{n} / \mathrm{a}$ & $\mathrm{n} / \mathrm{a}$ & 3.7 & 3.7 & 19.75 & $3 / 7 \mathrm{C}$ \\
\hline C. 27 & 34E_4s1d2Yc_1 & $337 / 8$ & S & 0.297 & 8 & 4 & 2.48 & 69.3 & 0.005 & 0.34 & 0.05 & 0.7 & $\mathrm{n} / \mathrm{a}$ & $\mathrm{n} / \mathrm{a}$ & 5.1 & 5.1 & 19.5 & $3 / 9 \mathrm{~A}$ \\
\hline C. 28 & 34E_4s1d2Yd_1 & $337 / 8$ & S & 0.297 & 8 & 4 & 2.48 & 69.3 & 0.005 & 0.19 & 0.05 & 0.6 & $\mathrm{n} / \mathrm{a}$ & $\mathrm{n} / \mathrm{a}$ & 6.2 & 6 & 21 & $3 / 9 B$ \\
\hline C. 29 & 34E_4s2d2Zc_1 & $337 / 8$ & S & 0.297 & 8 & 4 & 4.18 & 75.6 & 0.00155 & 0.33 & 0.05 & 0.45 & $\mathrm{n} / \mathrm{a}$ & $\mathrm{n} / \mathrm{a}$ & 5.6 & 5.6 & 14 & $3 / 11 B$ \\
\hline C. 30 & 34E_4s2d2Xc_1 & $337 / 8$ & S & 0.297 & 8 & 4 & 4.18 & 75.6 & 0.015 & 0.34 & 0.05 & 0.35 & $\mathrm{n} / \mathrm{a}$ & $\mathrm{n} / \mathrm{a}$ & 10 & 9.8 & 10.5 & $3 / 12 \mathrm{C}$ \\
\hline C.31 & 34E_4s2d2Yc_1 & $337 / 8$ & S & 0.297 & 8 & 4 & 4.18 & 75.6 & 0.005 & 0.34 & 0.05 & 0.6 & $\mathrm{n} / \mathrm{a}$ & $\mathrm{n} / \mathrm{a}$ & 8.6 & 8.6 & 18.5 & $3 / 12 \mathrm{~A}$ \\
\hline
\end{tabular}


Table 6.14. (contd)

\begin{tabular}{|c|c|c|c|c|c|c|c|c|c|c|c|c|c|c|c|c|c|c|}
\hline \multirow{2}{*}{$\begin{array}{l}\text { Figure } \\
\text { Number }\end{array}$} & \multirow[b]{2}{*}{ Case ID } & \multirow{2}{*}{$\begin{array}{c}\text { Tank } \\
\text { Diameter }\end{array}$} & \multirow{2}{*}{$\begin{array}{l}\text { Head } \\
\text { Shape }\end{array}$} & \multirow{2}{*}{$\begin{array}{l}\text { Nozzle } \\
\text { Diameter }\end{array}$} & \multicolumn{2}{|c|}{$\begin{array}{c}\text { Number of } \\
\text { Nozzles } \\
\text { Operated } \\
\end{array}$} & \multirow[b]{2}{*}{ Density } & \multirow{2}{*}{$\begin{array}{c}\begin{array}{c}\text { Particle } \\
\text { Diameter }\end{array} \\
\mathrm{d} 50\end{array}$} & \multirow{2}{*}{ Concentration } & \multirow{2}{*}{$\begin{array}{l}\text { Duty } \\
\text { Cycle } \\
\end{array}$} & \multirow{2}{*}{$\begin{array}{l}\text { Pulse } \\
\text { Volume }\end{array}$} & \multicolumn{3}{|c|}{$\begin{array}{l}\text { Highest Concentration } \\
\text { Measurement Location }\end{array}$} & \multirow[b]{2}{*}{ Velocity } & \multirow{2}{*}{$\begin{array}{c}\text { Velocity } \\
\text { at } U_{\mathrm{CS}}\end{array}$} & \multirow{2}{*}{$\begin{array}{l}\text { Cloud } \\
\text { Height }\end{array}$} & \multirow[b]{2}{*}{ Test } \\
\hline & & & & & Outer & Inner & & & & & & at $0 \mathrm{R}$ & at $0.5 \mathrm{R}$ & at $0.9 \mathrm{R}$ & & & & \\
\hline text & text & in. & text & in. & integer & integer & $\mathrm{g} / \mathrm{cm}^{3}$ & $\mu \mathrm{m}$ & $\begin{array}{l}\text { volume } \\
\text { fraction }\end{array}$ & fraction & fraction & $\mathrm{Z} / \mathrm{D}$ & $\mathrm{Z} / \mathrm{D}$ & $\mathrm{Z} / \mathrm{D}$ & $\mathrm{m} / \mathrm{s}$ & $\mathrm{m} / \mathrm{s}$ & $\mathrm{m}$ & text \\
\hline C.32 & 70F_4s1d1Zc_1 & 70 & FD & 0.613 & 8 & 4 & 2.46 & 166.4 & 0.00155 & 0.33 & 0.05 & 0.4 & $\mathrm{n} / \mathrm{a}$ & $\mathrm{n} / \mathrm{a}$ & 6.7 & 6.7 & 25.5 & $4 / 14 \mathrm{~A}$ \\
\hline C.33 & 70F_4s1d1Zc_2 & 70 & FD & 0.613 & 8 & 4 & 2.46 & 166.4 & 0.00155 & 0.33 & 0.10 & 0.5 & $\mathrm{n} / \mathrm{a}$ & $\mathrm{n} / \mathrm{a}$ & 5.8 & 5.8 & 26 & $4 / 15 \mathrm{C}$ \\
\hline C. 34 & 70F_4s1d2Zc_1 & 70 & FD & 0.613 & 8 & 4 & 2.48 & 69.3 & 0.00155 & 0.34 & 0.05 & 0.45 & $\mathrm{n} / \mathrm{a}$ & $\mathrm{n} / \mathrm{a}$ & 4.4 & 4.4 & 28.25 & $4 / 17 \mathrm{~A}$ \\
\hline C. 35 & 70F_4s1d2Rc_1 & 70 & FD & 0.613 & 8 & 4 & 2.48 & 69.3 & 0.01 & 0.34 & 0.05 & 0.4 & $\mathrm{n} / \mathrm{a}$ & $\mathrm{n} / \mathrm{a}$ & 6.6 & 6.6 & 23 & $4 / 18 \mathrm{~B}$ \\
\hline С.36 & 70F_4s1d2Yc_1 & 70 & FD & 0.613 & 8 & 4 & 2.48 & 69.3 & 0.005 & 0.33 & 0.05 & 0.35 & $\mathrm{n} / \mathrm{a}$ & $\mathrm{n} / \mathrm{a}$ & 5.8 & 5.8 & 23 & $4 / 18 \mathrm{~A}$ \\
\hline С. 37 & 70F_4s1d2Vc_1 & 70 & FD & 0.613 & 8 & 4 & 2.48 & 69.3 & 0.0143 & 0.34 & 0.05 & 0.45 & $\mathrm{n} / \mathrm{a}$ & $\mathrm{n} / \mathrm{a}$ & 7.1 & 7.1 & 30 & $4 / 21 \mathrm{~A}$ \\
\hline С.38 & 70F_4s1d2Vc_1 & 70 & FD & 0.613 & 8 & 4 & 2.48 & 69.3 & 0.0143 & 0.34 & 0.05 & $\mathrm{n} / \mathrm{a}$ & 0.4 & $\mathrm{n} / \mathrm{a}$ & 7.1 & 7.1 & 30 & $4 / 21 \mathrm{~A}$ \\
\hline C.39 & 70F_4s1d2Vc_1 & 70 & FD & 0.613 & 8 & 4 & 2.48 & 69.3 & 0.0143 & 0.34 & 0.05 & $\mathrm{n} / \mathrm{a}$ & $\mathrm{n} / \mathrm{a}$ & 0.4 & 7.1 & 7.1 & 30 & $4 / 21 \mathrm{~A}$ \\
\hline C. 40 & 70F_4s1d2Vd_1 & 70 & FD & 0.613 & 8 & 4 & 2.48 & 69.3 & 0.0143 & 0.19 & 0.05 & 0.4 & $\mathrm{n} / \mathrm{a}$ & $\mathrm{n} / \mathrm{a}$ & 9.6 & 9.8 & 26.25 & $4 / 28 \mathrm{~A}$ \\
\hline C. 41 & 70F_4s1d2Vd_1 & 70 & FD & 0.613 & 8 & 4 & 2.48 & 69.3 & 0.0143 & 0.19 & 0.05 & 0.4 & $\mathrm{n} / \mathrm{a}$ & $\mathrm{n} / \mathrm{a}$ & 9.8 & 9.8 & 28 & $4 / 28 \mathrm{~A}$ \\
\hline C. 42 & 70F_4s1d2Vd_1 & 70 & FD & 0.613 & 8 & 4 & 2.48 & 69.3 & 0.0143 & 0.19 & 0.05 & 0.45 & $\mathrm{n} / \mathrm{a}$ & $\mathrm{n} / \mathrm{a}$ & 9.9 & 9.9 & 27.5 & $4 / 22 \mathrm{~A}$ \\
\hline C. 43 & 70F_4s1d2Vc_1 & 70 & FD & 0.613 & 8 & 4 & 2.48 & 69.3 & 0.0143 & 0.34 & 0.05 & 0.45 & $\mathrm{n} / \mathrm{a}$ & $\mathrm{n} / \mathrm{a}$ & 7.3 & 7.3 & 31 & $4 / 29 \mathrm{~A}$ \\
\hline C. 44 & 70F_4s1d2Ve_1 & 70 & FD & 0.613 & 8 & 4 & 2.48 & 69.3 & 0.0143 & 0.67 & 0.05 & 0.6 & $\mathrm{n} / \mathrm{a}$ & $\mathrm{n} / \mathrm{a}$ & 4.8 & 4.8 & 35.75 & $4 / 25 B$ \\
\hline C. 45 & 70F_4s1d2Vc_2 & 70 & FD & 0.613 & 8 & 4 & 2.48 & 69.3 & 0.0143 & 0.33 & 0.10 & 0.45 & $\mathrm{n} / \mathrm{a}$ & $\mathrm{n} / \mathrm{a}$ & 6.6 & 6.6 & 28.5 & $4 / 25 \mathrm{C}$ \\
\hline C. 46 & 70E_4s1d2Zc_1 & 70 & $\mathrm{E}$ & 0.613 & 8 & 4 & 2.48 & 69.3 & 0.00155 & 0.34 & 0.05 & 0.45 & $\mathrm{n} / \mathrm{a}$ & $\mathrm{n} / \mathrm{a}$ & 4.6 & 4.6 & 30.5 & $5 / 9 \mathrm{~A}$ \\
\hline C. 47 & 70E_4s1d2Yc_1 & 70 & E & 0.613 & 8 & 4 & 2.48 & 69.3 & 0.005 & 0.34 & 0.05 & 0.45 & $\mathrm{n} / \mathrm{a}$ & $\mathrm{n} / \mathrm{a}$ & 6 & 6 & 27.75 & $5 / 12 \mathrm{~A}$ \\
\hline C. 48 & 70E_4s1d2Vd_1 & 70 & E & 0.613 & 8 & 4 & 2.48 & 69.3 & 0.0143 & 0.19 & 0.05 & 0.6 & $\mathrm{n} / \mathrm{a}$ & $\mathrm{n} / \mathrm{a}$ & 11.2 & 10.9 & 45 & $5 / 15 \mathrm{~A}$ \\
\hline C. 49 & 70E_4s1d2Vd_1 & 70 & E & 0.613 & 8 & 4 & 2.48 & 69.3 & 0.0143 & 0.19 & 0.05 & $\mathrm{n} / \mathrm{a}$ & 0.6 & $\mathrm{n} / \mathrm{a}$ & 11.2 & 10.9 & 45 & $5 / 15 \mathrm{~A}$ \\
\hline C. 50 & 70E_4s1d2Vd_1 & 70 & E & 0.613 & 8 & 4 & 2.48 & 69.3 & 0.0143 & 0.19 & 0.05 & $\mathrm{n} / \mathrm{a}$ & $\mathrm{n} / \mathrm{a}$ & 0.6 & 11.2 & 10.9 & 45 & $5 / 15 \mathrm{~A}$ \\
\hline C. 51 & 70E_4s1d2Vc_1 & 70 & E & 0.613 & 8 & 4 & 2.48 & 69.3 & 0.0143 & 0.33 & 0.05 & 0.6 & $\mathrm{n} / \mathrm{a}$ & $\mathrm{n} / \mathrm{a}$ & 7.8 & 7.8 & 41 & $5 / 14 \mathrm{~A}$ \\
\hline C. 52 & 70E_4s1d2Vc_1 & 70 & E & 0.613 & 8 & 4 & 2.48 & 69.3 & 0.0143 & 0.33 & 0.05 & $\mathrm{n} / \mathrm{a}$ & 0.6 & $\mathrm{n} / \mathrm{a}$ & 7.8 & 7.8 & 41 & $5 / 14 \mathrm{~A}$ \\
\hline C.53 & 70E_4s1d2Vc_1 & 70 & E & 0.613 & 8 & 4 & 2.48 & 69.3 & 0.0143 & 0.33 & 0.05 & $\mathrm{n} / \mathrm{a}$ & $\mathrm{n} / \mathrm{a}$ & 0.6 & 7.8 & 7.8 & 41 & $5 / 14 \mathrm{~A}$ \\
\hline C. 54 & 70E_4s1d2Xc_1 & 70 & E & 0.613 & 8 & 4 & 2.48 & 69.3 & 0.015 & 0.33 & 0.05 & 0.35 & $\mathrm{n} / \mathrm{a}$ & $\mathrm{n} / \mathrm{a}$ & 6.8 & 8.5 & 22 & $5 / 20 \mathrm{~A}$ \\
\hline C. 55 & 70E_4s1d2Xc_1 & 70 & E & 0.613 & 8 & 4 & 2.48 & 69.3 & 0.015 & 0.34 & 0.05 & 0.7 & $\mathrm{n} / \mathrm{a}$ & $\mathrm{n} / \mathrm{a}$ & 8.5 & 8.5 & 41 & $5 / 20 \mathrm{~A}$ \\
\hline C. 56 & 70E_4s1d2Xc_1 & 70 & E & 0.613 & 8 & 4 & 2.48 & 69.3 & 0.015 & 0.34 & 0.05 & $\mathrm{n} / \mathrm{a}$ & 0.6 & $\mathrm{n} / \mathrm{a}$ & 8.5 & 8.5 & 41 & $5 / 20 \mathrm{~A}$ \\
\hline C. 57 & 70E_4s1d2Xc_1 & 70 & E & 0.613 & 8 & 4 & 2.48 & 69.3 & 0.015 & 0.34 & 0.05 & $\mathrm{n} / \mathrm{a}$ & $\mathrm{n} / \mathrm{a}$ & 0.7 & 8.5 & 8.5 & 41 & $5 / 20 \mathrm{~A}$ \\
\hline C. 58 & 70E_4s2d2Zc_1 & 70 & E & 0.613 & 8 & 4 & 4.18 & 75.6 & 0.00155 & 0.34 & 0.05 & 0.45 & $\mathrm{n} / \mathrm{a}$ & $\mathrm{n} / \mathrm{a}$ & 8.4 & 8.4 & 28.5 & $5 / 27 \mathrm{~A}$ \\
\hline C.59 & 70E_4s2d2Yc_1 & 70 & E & 0.613 & 8 & 4 & 4.18 & 75.6 & 0.005 & 0.33 & 0.05 & 0.4 & $\mathrm{n} / \mathrm{a}$ & $\mathrm{n} / \mathrm{a}$ & 12 & 12.5 & 25.5 & $5 / 28 \mathrm{~A}$ \\
\hline C. 60 & 70E_4s2d2Yc_1 & 70 & E & 0.613 & 8 & 4 & 4.18 & 75.6 & 0.005 & 0.33 & 0.05 & $\mathrm{n} / \mathrm{a}$ & 0.35 & $\mathrm{n} / \mathrm{a}$ & 12 & 12.5 & 25.5 & $5 / 28 \mathrm{~A}$ \\
\hline C.61 & 70E_4s2d2Yc_1 & 70 & E & 0.613 & 8 & 4 & 4.18 & 75.6 & 0.005 & 0.33 & 0.05 & $\mathrm{n} / \mathrm{a}$ & $\mathrm{n} / \mathrm{a}$ & 0.35 & 12 & 12.5 & 25.5 & $5 / 28 \mathrm{~A}$ \\
\hline C.62 & 70E_4s1d1Zc_1 & 70 & E & 0.613 & 8 & 4 & 2.46 & 166.4 & 0.00155 & 0.33 & 0.05 & 0.4 & $\mathrm{n} / \mathrm{a}$ & $\mathrm{n} / \mathrm{a}$ & 7.1 & 7.1 & 30.75 & $5 / 30 \mathrm{~A}$ \\
\hline C.63 & 70E_4s1d1Zc_1 & 70 & E & 0.613 & 8 & 4 & 2.46 & 166.4 & 0.00155 & 0.33 & 0.05 & $\mathrm{n} / \mathrm{a}$ & 0.4 & $\mathrm{n} / \mathrm{a}$ & 7.1 & 7.1 & 30.75 & $5 / 30 \mathrm{~A}$ \\
\hline C.64 & 70E_4s1d1Zc_1 & 70 & E & 0.613 & 8 & 4 & 2.46 & 166.4 & 0.00155 & 0.33 & 0.05 & $\mathrm{n} / \mathrm{a}$ & $\mathrm{n} / \mathrm{a}$ & 0.4 & 7.1 & 7.1 & 30.75 & $5 / 30 \mathrm{~A}$ \\
\hline C. 65 & 70E_6s1d2Vc_1 & 70 & E & 0.92 & 4 & 4 & 2.48 & 69.3 & 0.0143 & 0.34 & 0.05 & 0.85 & $\mathrm{n} / \mathrm{a}$ & $\mathrm{n} / \mathrm{a}$ & 6.8 & 6.8 & 70 & 7/18A \\
\hline C.66 & 70E_6s1d2Vc_2 & 70 & E & 0.92 & 4 & 4 & 2.48 & 69.3 & 0.0143 & 0.33 & 0.10 & 0.8 & $\mathrm{n} / \mathrm{a}$ & $\mathrm{n} / \mathrm{a}$ & 6.4 & 6.4 & 63 & $7 / 18 \mathrm{~B}$ \\
\hline
\end{tabular}



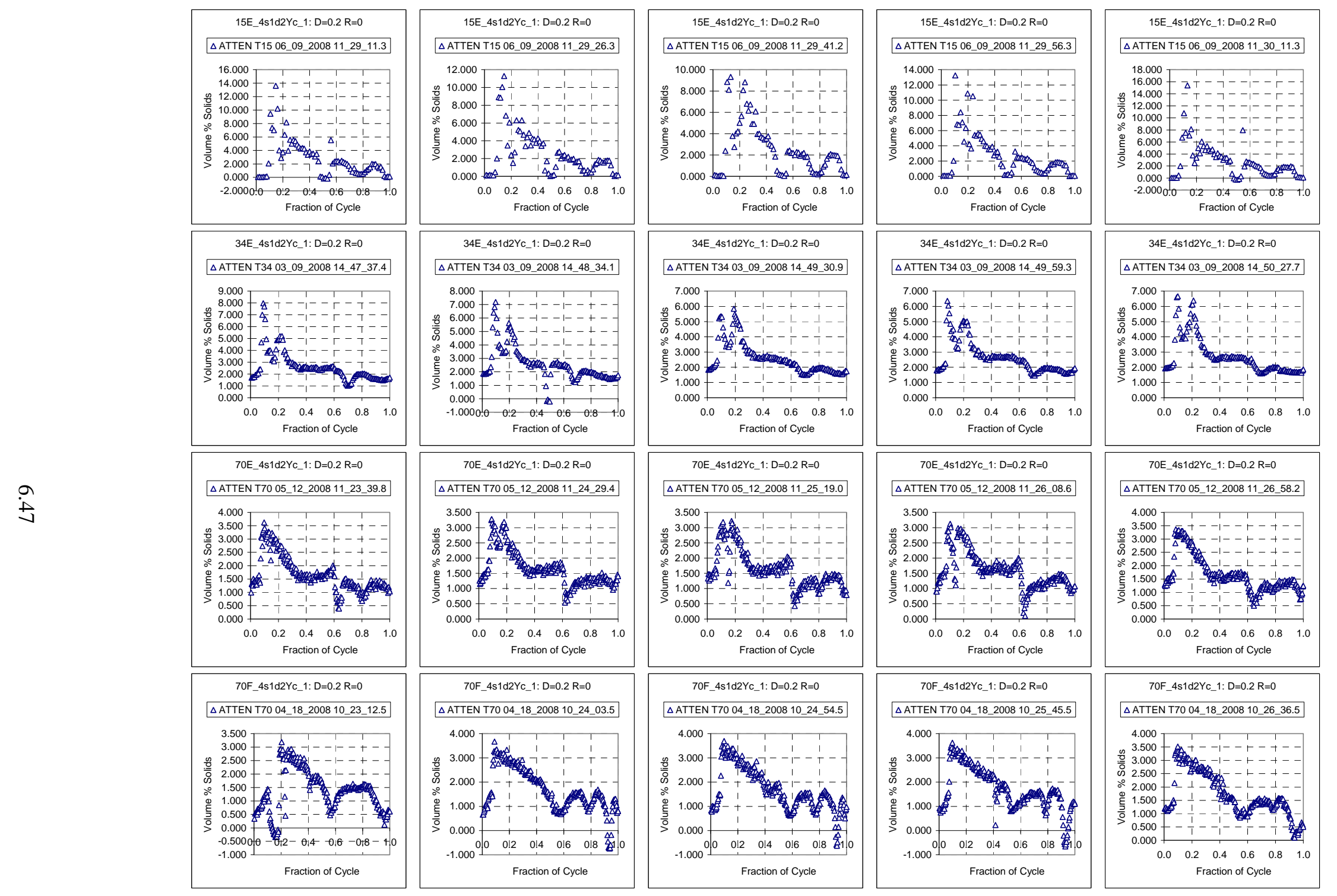

34E_451d2Yc_1: D=0.2 R=0
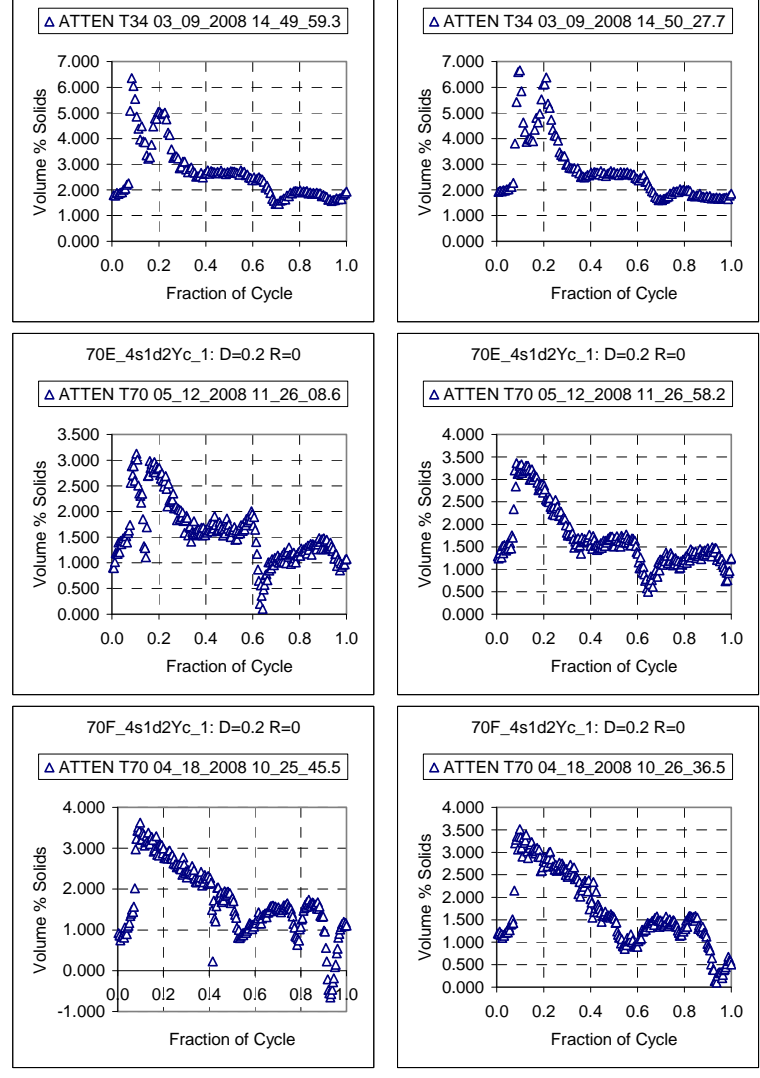

Figure 6.23. Examples of Solids concentration by Volume as a Function of Cycle Fraction at an Elevation of $H / D=0.2$ and Radially Located at the Tank Center. Test conditions are simulant s1d2 $\left(\rho_{\mathrm{s}}=2.48 \mathrm{~g} / \mathrm{cm}^{3}\right.$ and $\left.\mathrm{d}_{50}=69.2 \mu \mathrm{m}\right)$ at solids fraction of $\left(\phi_{\mathrm{s}}=0.005\right)$, duty cycle ( $\mathrm{DC}=0.33)$, and pulse volume fraction $\left(\phi_{\mathrm{p}}=0.05\right)$ for small- and large-scale tanks with elliptical heads, mid-scale tank with spherical head and large-scale tank with flanged and dished head. 

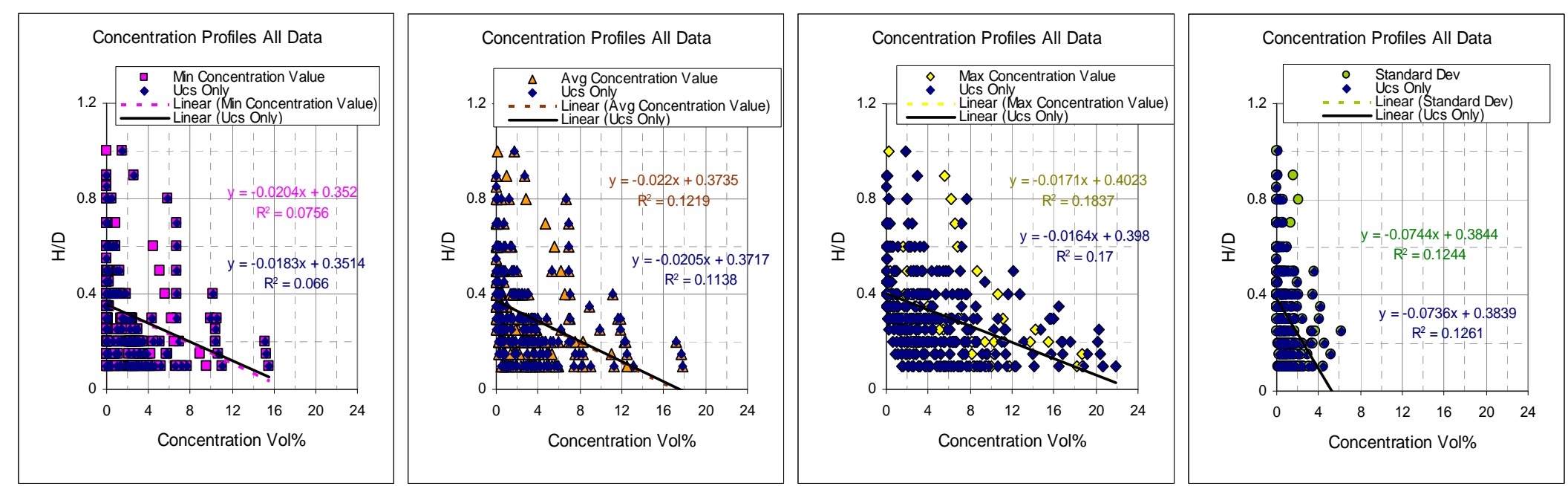

Dimensional Plots Showing All Data and Correlation in Color and UCS Data and Correlation in Blue
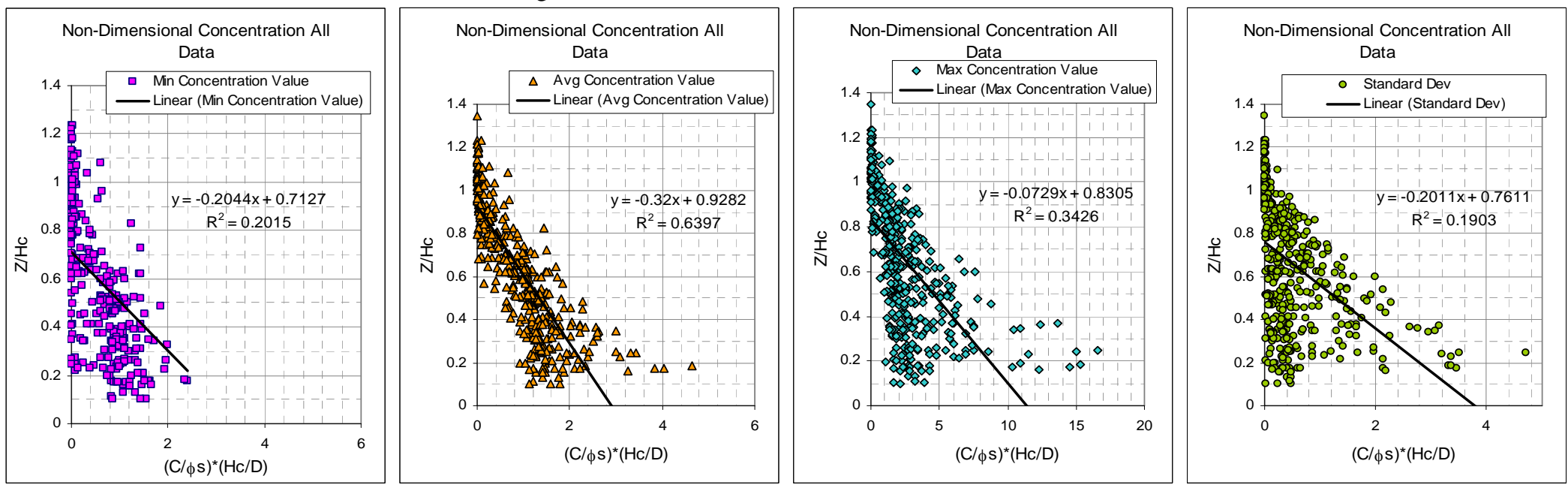

Nondimensional Plots Showing All Data and Correlations

Figure 6.24. Solids Concentration by Volume Profile Plots showing Minimum, Average, Maximum, and Standard Deviation of Concentration Measured for All Data Points 


\subsubsection{Variation with Critical Suspension Velocity $U_{c s}$}

The data in Table 6.14 show that solids concentration by volume profiles were taken at three $\mathrm{U}_{\mathrm{CS}}$ conditions: $<\mathrm{U}_{\mathrm{CS}}$, at $\mathrm{U}_{\mathrm{CS}}$, and $>\mathrm{U}_{\mathrm{CS}}$. The data obtained at these three $\mathrm{U}_{\mathrm{CS}}$ cases are plotted together and presented in Figure 6.25. These figures show the minimum, average, and maximum solids concentration at each elevation based on an average of five cycles. Four concentration profiles were obtained at velocities above the critical suspension velocity. These data were obtained at four solids fractions with two simulants and in three tanks. When viewing the concentration profiles it is useful to keep in mind that a fully mixed concentration profile would be represented by a constant concentration over the range of elevations within the cloud.

The data in the small-scale vessel (15E_4s1d2Wc_1) show that solids were suspended to a height equal to the tank diameter. These data provide a more vertical profile up to an elevation of $0.6 \mathrm{Z} / \mathrm{D}$, showing that this portion of the vessel is mixed more than that above this elevation. The next series of plots at $U_{\mathrm{CS}}$ shows that many profiles were obtained at this condition. One of the plots in the All Profiles at $U_{\mathrm{CS}}$ Avg (15E_4s1d2Wa) shows an almost vertical, fully mixed profile. This test was a continuous flow test, without jet pulsation. Five concentration profiles were obtained at concentrations below the critical suspension velocity. These data show significantly lower cloud heights than the other two conditions.

\subsubsection{Variation with Radial Location}

During six tests, solids concentration by volume profiles were obtained at three radial locations: $0 \mathrm{R}$, the tank center (shown by diamond symbol on plots), $0.5 \mathrm{R}$, halfway between the tank center and the tank wall (shown by triangle symbol on plots), and 0.9R, near the tank wall (shown by square symbol on plots). These data are plotted in Figure 6.26. Having data at three radial locations shows the interaction between the jets and solids throughout the tank and shows the uniformity or lack of radial uniformity in the concentration profiles at these locations. For the vessel to be fully mixed, the concentration profiles at these radial locations would be equal. Three simulants were tested: $\mathrm{s} 1 \mathrm{~d} 2\left(\rho_{\mathrm{s}}=2.48 \mathrm{~g} / \mathrm{cm}^{3}, \mathrm{~d}_{50}=\right.$ $69.2 \mu \mathrm{m})$, shown in (a-d); s1d1 $\left(\rho_{\mathrm{s}}=2.46 \mathrm{~g} / \mathrm{cm}^{3}, \mathrm{~d}_{50}=166 \mu \mathrm{m}\right)$, shown in $(\mathrm{e})$; and s2d2 $\left(\rho_{\mathrm{s}}=4.18 \mathrm{~g} / \mathrm{cm}^{3}\right.$, $\left.\mathrm{d}_{50}=76 \mu \mathrm{m}\right)$, shown in (f).

Figures 6.26 (a) and (b) compare the difference between the flanged and dished (a) and elliptical (b) heads. Figures (b) and (c) compare the effect of duty cycle, 0.33 in (b) and 0.18 in (c). The profiles are very similar, but (b) was taken at $\mathrm{U}_{\mathrm{CS}}$ and (c) was taken above $\mathrm{U}_{\mathrm{CS}}$. Increasing concentrations are compared in (b) and (d). As expected, $\mathrm{U}_{\mathrm{CS}}$ is higher at higher concentration; however, the concentration profiles are very similar. Figures (a-d) with s1d2 $\left(\rho_{\mathrm{s}}=2.48 \mathrm{~g} / \mathrm{cm}^{3}, \mathrm{~d}_{50}=69 \mu \mathrm{m}\right)$ all show that for a specific elevation the concentration at the three radial locations is similar with the concentration slightly higher at $\mathrm{R}=0$ the tank center line. This trend changes when simulants $\mathrm{s} 1 \mathrm{~d} 1\left(\rho_{\mathrm{s}}=2.46 \mathrm{~g} / \mathrm{cm}^{3}, \mathrm{~d}_{50}=\right.$ $166 \mu \mathrm{m})$, shown in (e), and s2d2 ( $\left.\rho_{\mathrm{s}}=4.18 \mathrm{~g} / \mathrm{cm}^{3}, \mathrm{~d}_{50}=76 \mu \mathrm{m}\right)$, shown in (f), profiles are examined. Profiles (e) with larger particle diameter and (f) denser simulant show a marked increase in the concentration at $\mathrm{R}=0$, the vertical tank centerline, at elevations up to $0.2 \mathrm{Z} / \mathrm{D}$; profile (f) was measured slightly below $\mathrm{U}_{\mathrm{CS}}$. 

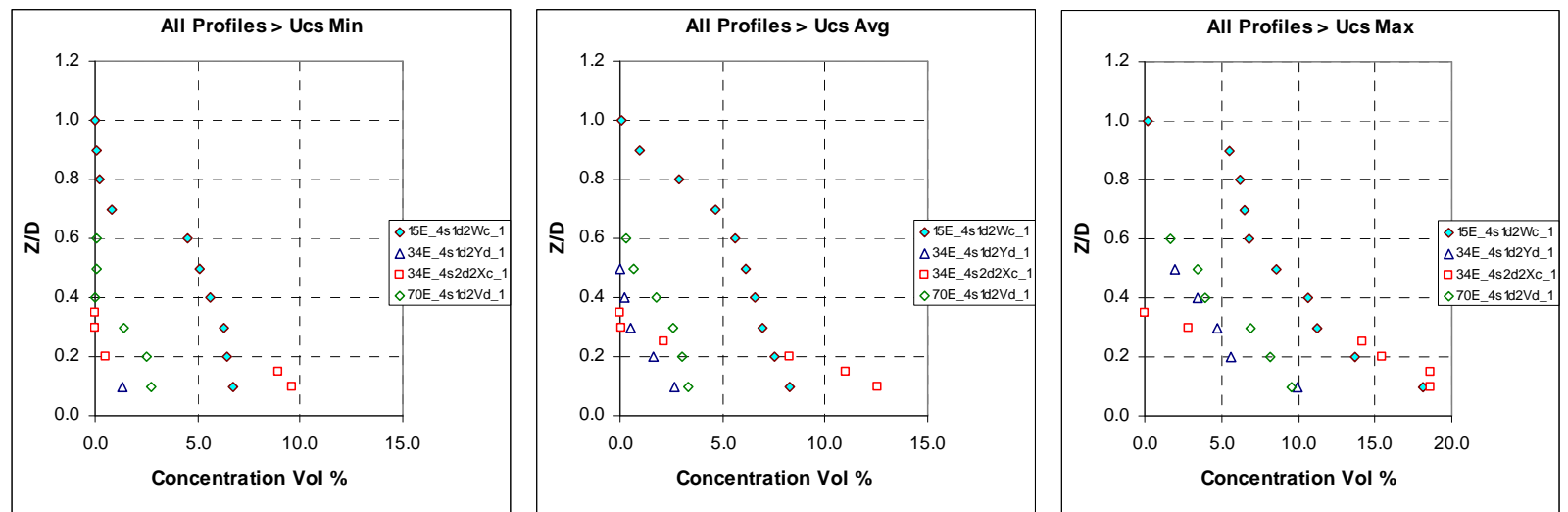

Velocities $>\mathrm{U}_{\mathrm{CS}}$
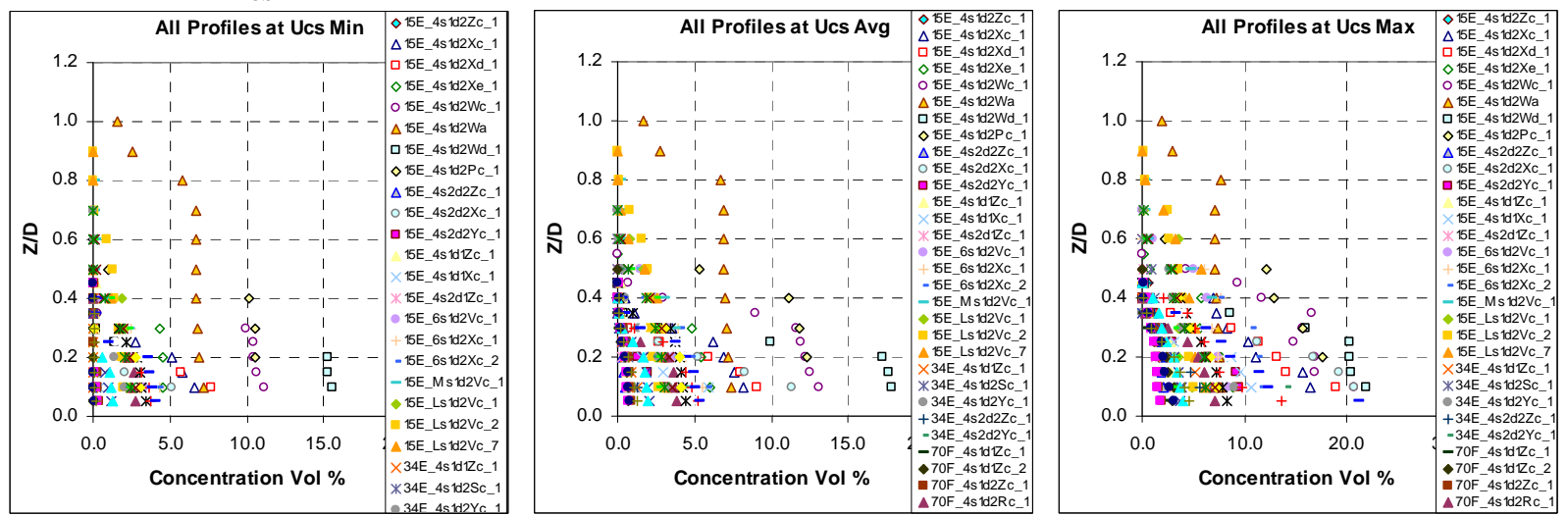

Velocity at $\mathrm{U}_{\mathrm{CS}}$
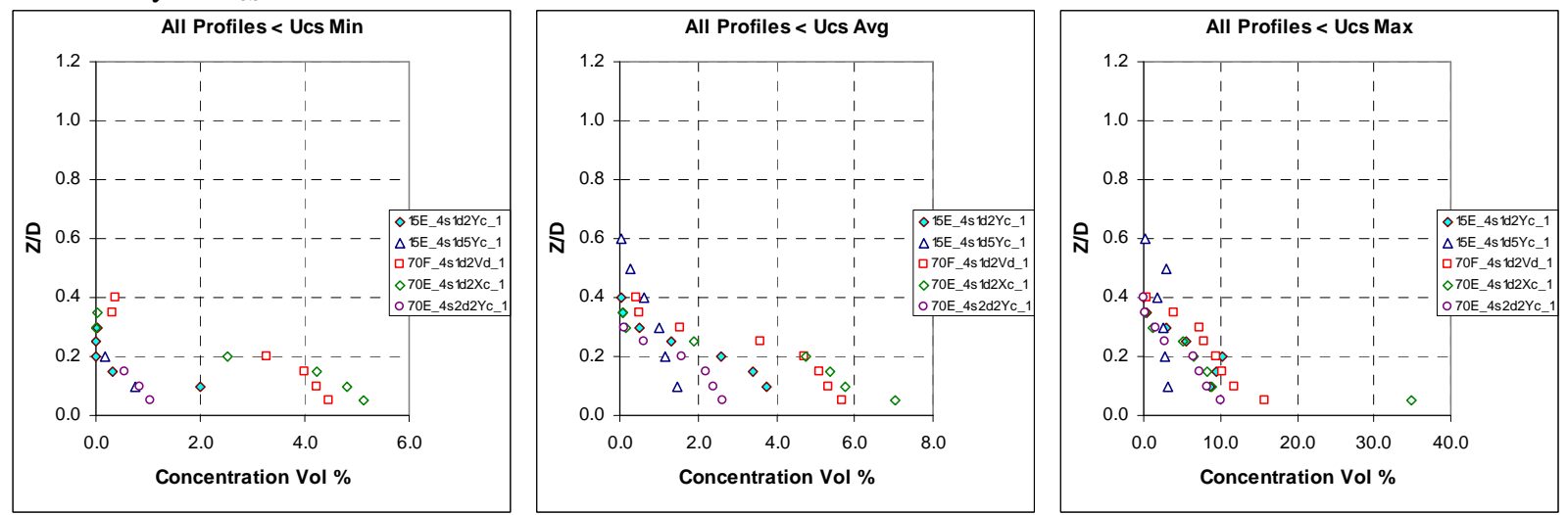

Velocity $<\mathrm{U}_{\mathrm{CS}}$

Figure 6.25. Comparison of Dimensional Profiles Below, at, or Above $U_{C S}$ 


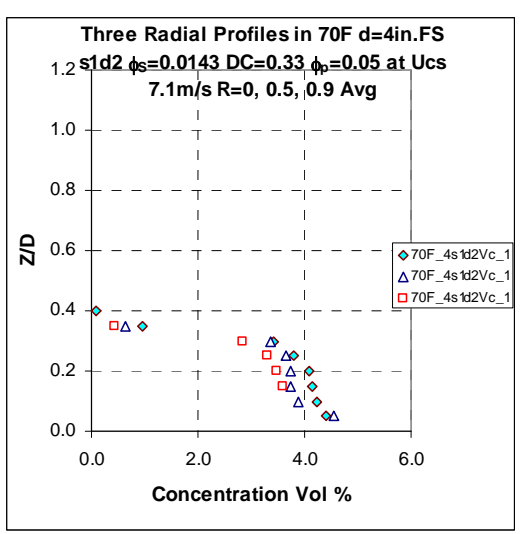

(a)

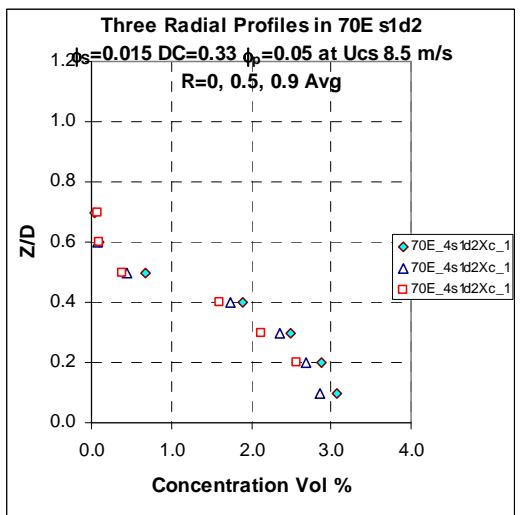

(d)

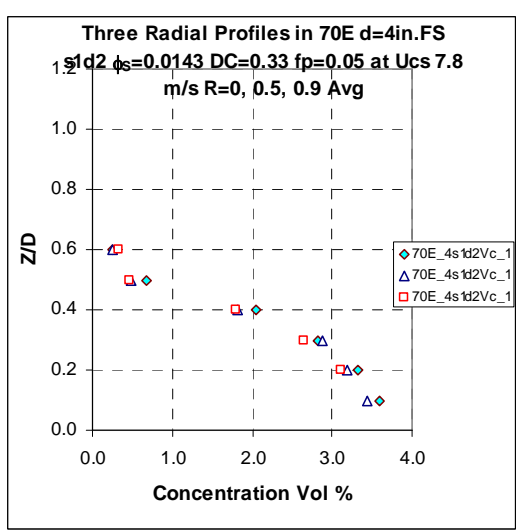

(b)

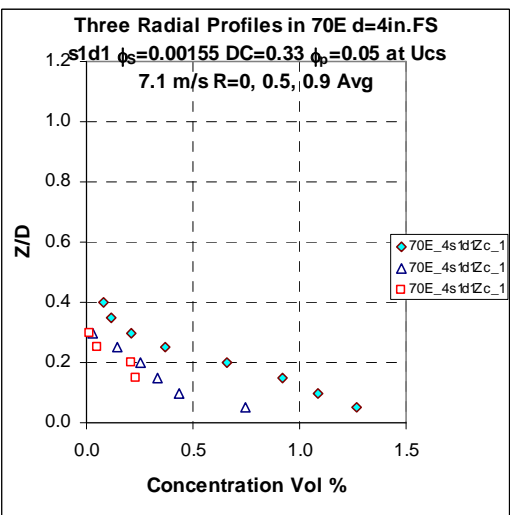

(e)

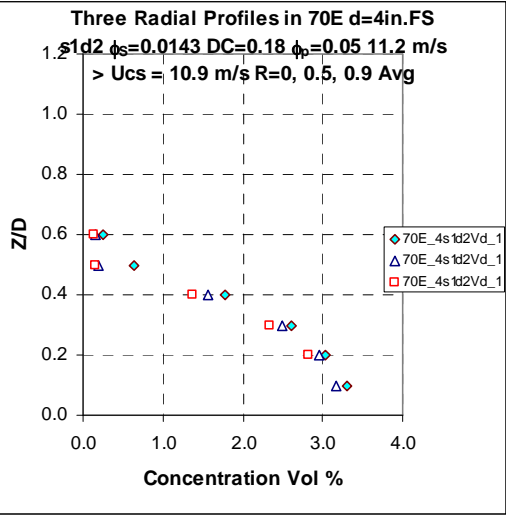

(c)

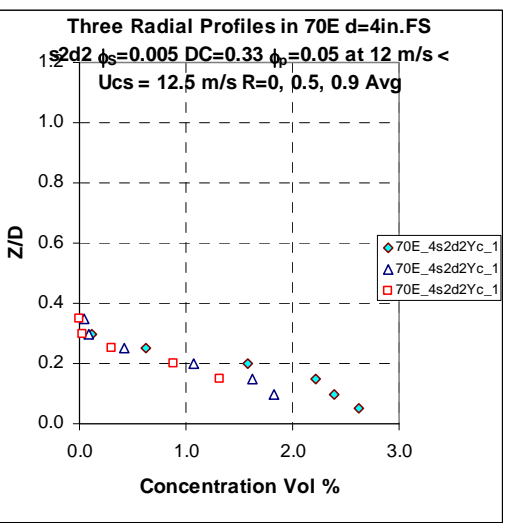

(f)

Figure 6.26. Comparison of Average Radial Concentration Profiles for Each Test at $\mathrm{R}=0$ (diamond symbol), 0.5 (triangle symbol), and 0.9 (square symbol) for Large-Scale F\&D and Elliptical Bottom Tanks at and Below $\mathrm{U}_{\mathrm{CS}}$ for Pulse Volume Fraction 0.05

In Figure 6.27, the nondimensional average profiles are compared between tests at each radial position. At $\mathrm{R}=0$ all of the profiles appear relatively similar except for the $\mathrm{s} 1 \mathrm{~d} 1\left(\rho_{\mathrm{s}}=2.46 \mathrm{~g} / \mathrm{cm}^{3}, \mathrm{~d}_{50}=\right.$ $166 \mu \mathrm{m}$ ) simulant (yellow triangle symbol), where higher concentrations are observed up to height $\mathrm{Z} / \mathrm{H}_{\mathrm{C}}$ $=0.4$. However, this is balanced by lower concentrations at $\mathrm{R}=0.5$ and $\mathrm{R}=0.9$. 

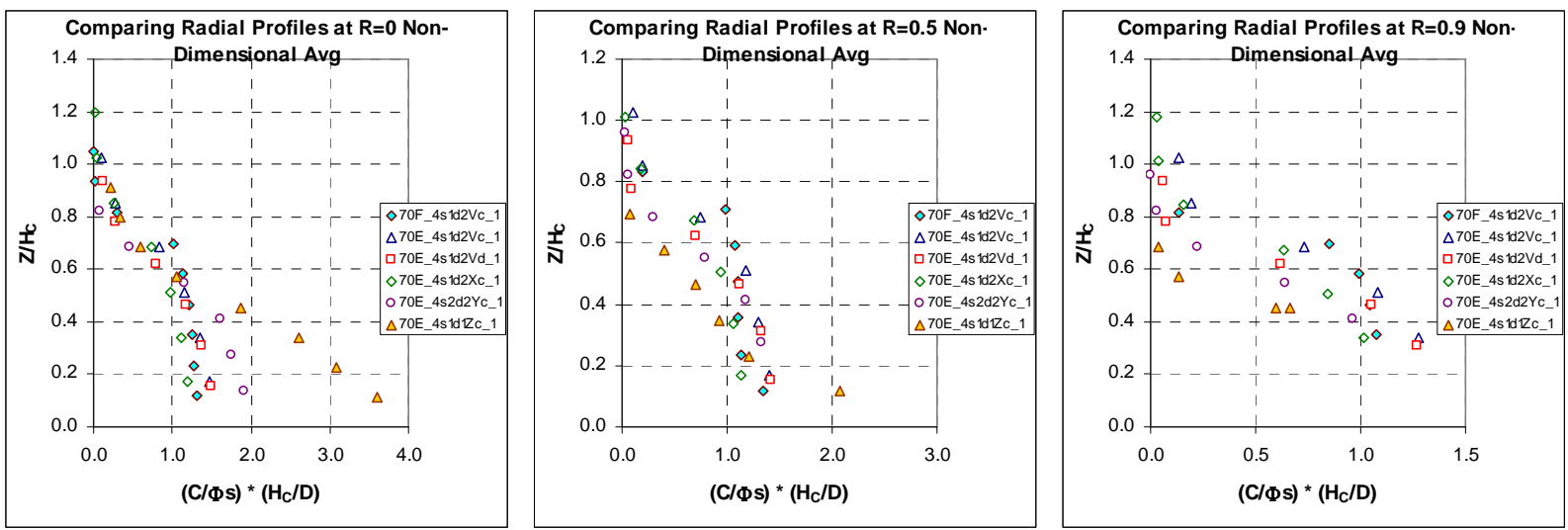

Figure 6.27. Comparison of Nondimensional Average Radial Concentration Profiles Across Tests at $\mathrm{R}=0$, 0.5, 0.9 for the Large-scale Flanged and Dished and Elliptical Bottomed Tanks at and below $\mathrm{U}_{\mathrm{CS}}$ (purple circle $<\mathrm{U}_{\mathrm{CS}}$ ) for Pulse Volume Fraction of 0.05 .

\subsubsection{Variation with Tank}

All solids concentration by volume profiles taken in the four tank configurations at $\mathrm{U}_{\mathrm{CS}}$ are plotted in Figure 6.28. Dimensional plots for small-, mid-, large-elliptical, and large flanged-and-dished are shown in (a-d), and corresponding nondimensional plots (e-h) are shown beneath. For an individual tank, at elevations above $0.4 \mathrm{Z} / \mathrm{H}_{\mathrm{C}}$ the data on the nondimensional plots tend to collapse onto one line. This can be observed in plots (f) and (g), where fewer tests were plotted.

Head shape is compared in Figure 6.29 (a-d) in four tanks for simulant s1d1 $\left(\rho_{\mathrm{s}}=2.46 \mathrm{~g} / \mathrm{cm}^{3}, \mathrm{~d}_{50}=\right.$ $166 \mu \mathrm{m})$ and in Figure $6.29(\mathrm{e}-\mathrm{h})$ in three tanks for simulant s2d2 $\left(\rho_{\mathrm{s}}=4.18 \mathrm{~g} / \mathrm{cm}^{3}, \mathrm{~d}_{50}=76 \mu \mathrm{m}\right)$. For the average concentration profile both the dimensional and nondimensional figures are provided. For both simulants the maximum elevation with a measured solids concentration was $\sim 0.4 \mathrm{Z} / \mathrm{D}$ for all tests. Only one flanged-and-dished test that matched the other conditions was available for the s1d1 $\left(\rho_{\mathrm{s}}=2.46 \mathrm{~g} / \mathrm{cm}^{3}\right.$, $\mathrm{d}_{50}=166 \mu \mathrm{m}$ ) simulant. This profile shows a slightly lower concentration at each elevation than the other head shapes.

\subsubsection{Variation with Nozzle Diameter and Number of Pulse Tubes}

Concentration profiles were measured using four nozzle diameters that scaled to $(4,6,8.5$, and 11.8 in. in the full-scale HLP-22 vessel. These tests also included evaluation of two pulse-tube configurations: HLP-22 (12 pulse tube array) and 8TA, which is an abbreviation for an eight pulse tube array. All of the concentration profiles obtained using the HLP-22 configuration were conducted with all pulse tubes ( 8 outer and 4 inner) operating. The concentration profiles obtained using the $6,8.5$, and 11.8 in. HLP-22 full-scale nozzle diameters using the 8TA configuration were conducted with all pulse tubes (4 outer and 4 inner) operating. In addition one profile was obtained with the 11.8 in. HLP-22 fullscale nozzle, with 4 outer and no inner pulse tubes operating. These data are shown in Figure 6.30. 


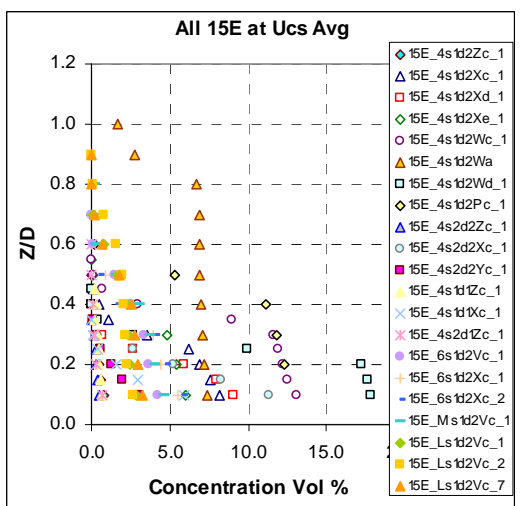

(a)

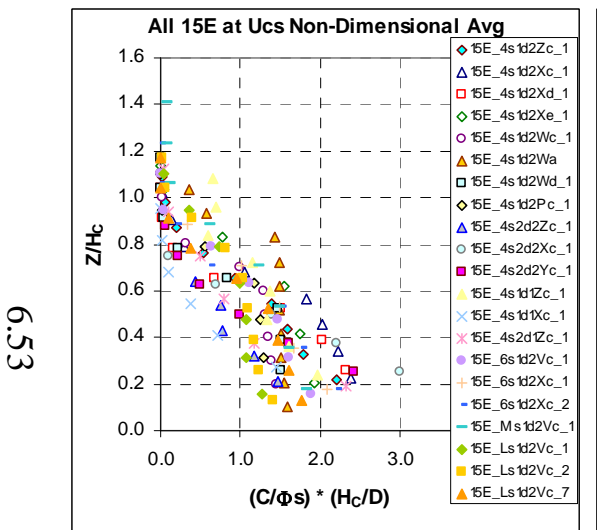

(e)

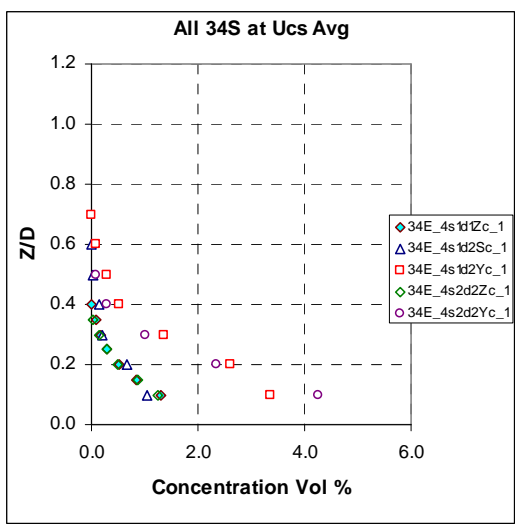

(b)

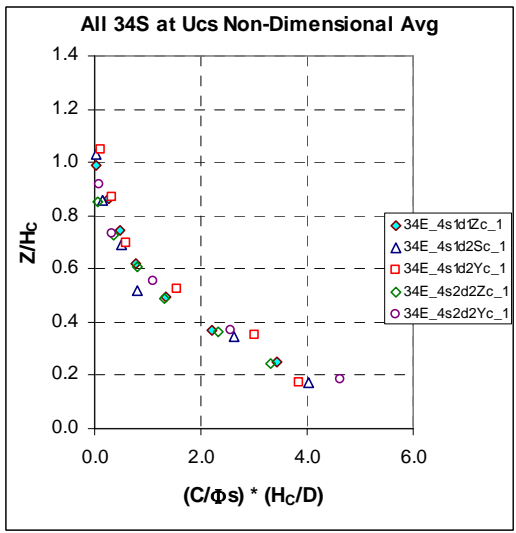

(f)

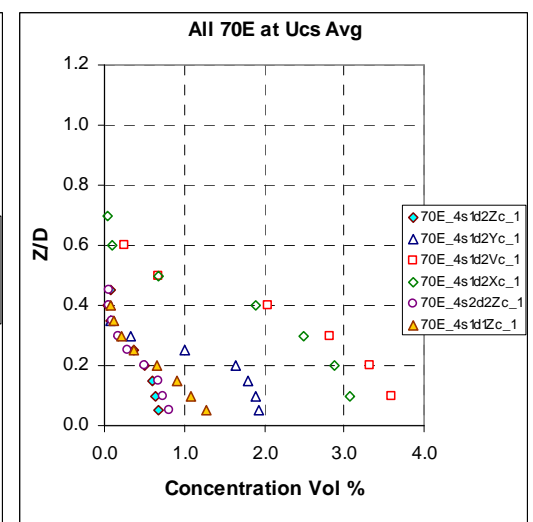

(c)

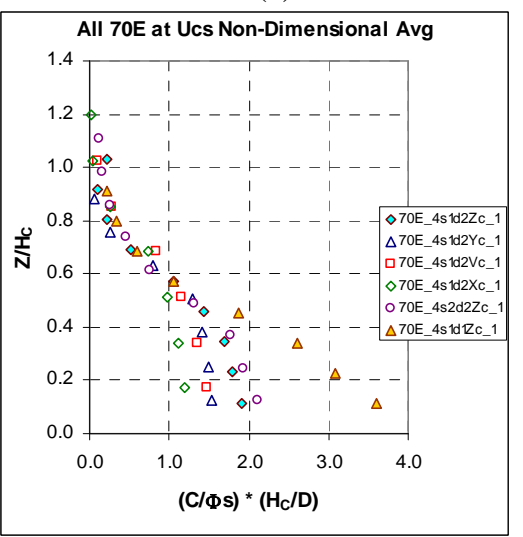

(g)

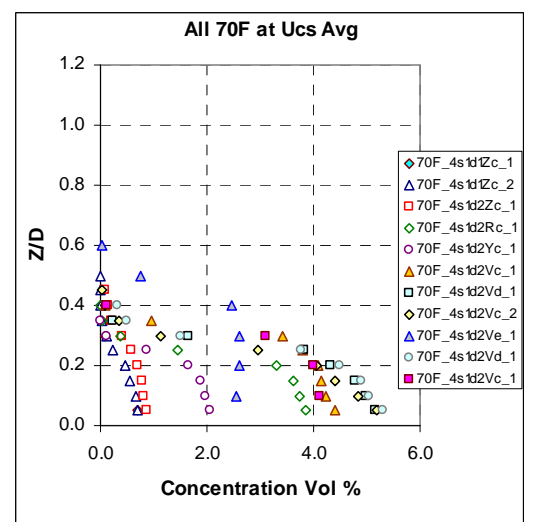

(d)

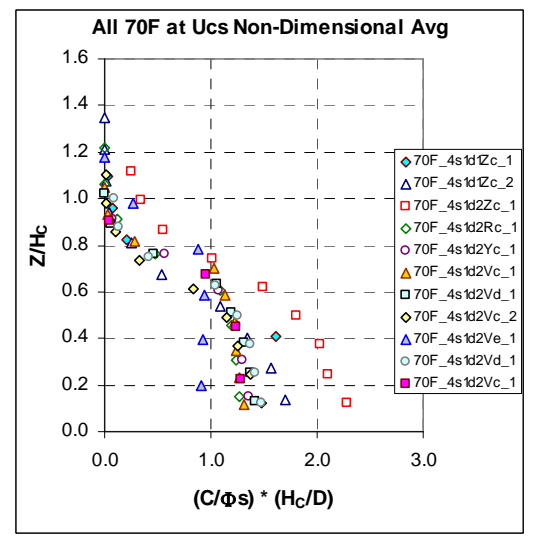

(h)

Figure 6.28. Concentration Profiles at $\mathrm{U}_{\mathrm{CS}}$ in the 15E, 34S, 70E, and 70F Tanks Segregated by Tank: (a-d) Dimensional Plots, (e-h) Nondimensional Plots 


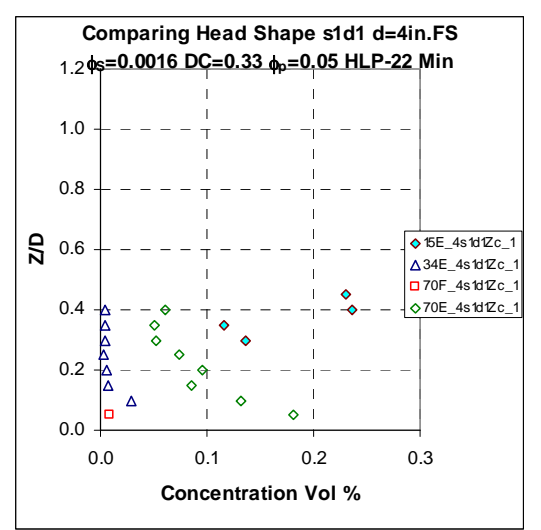

(a) Min

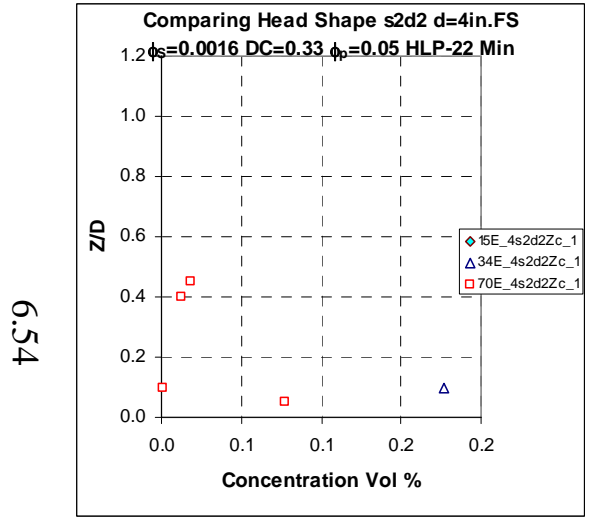

(e) Min

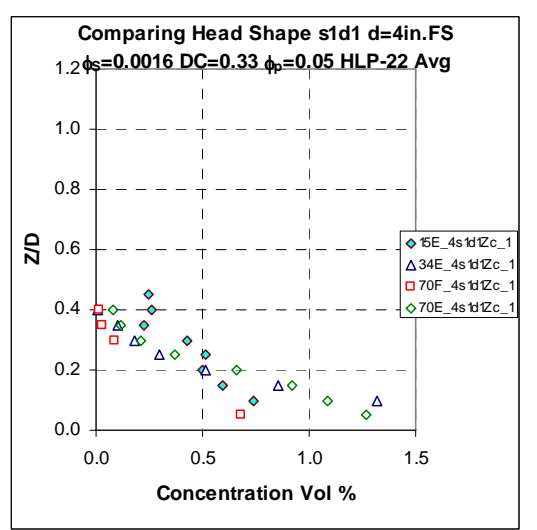

(b) Avg

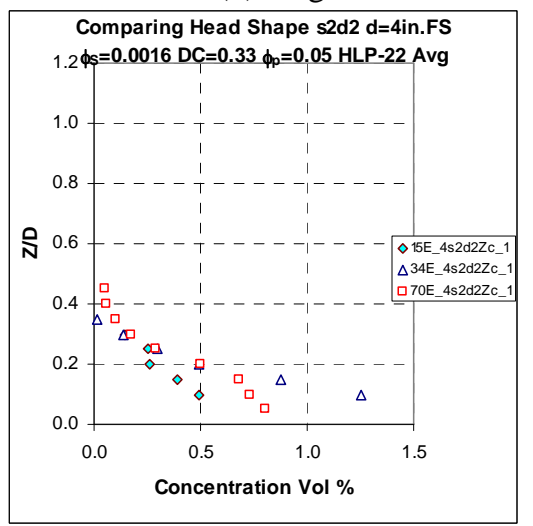

(f) Avg

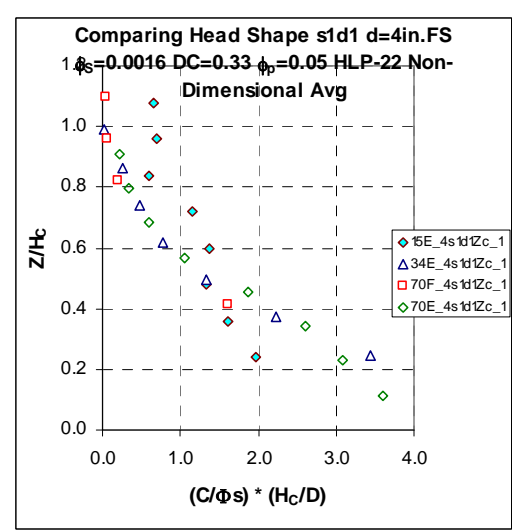

(c) Nondimensional

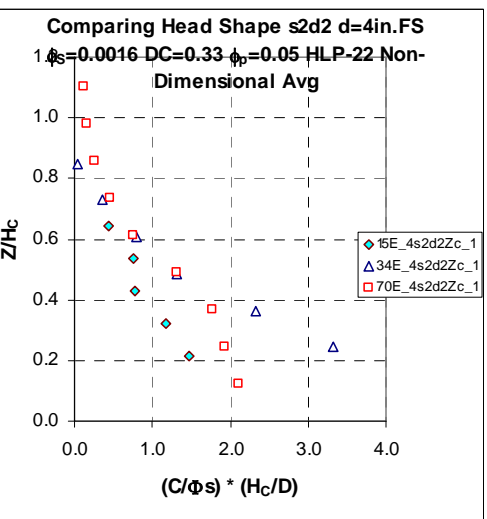

(g) Nondimensional

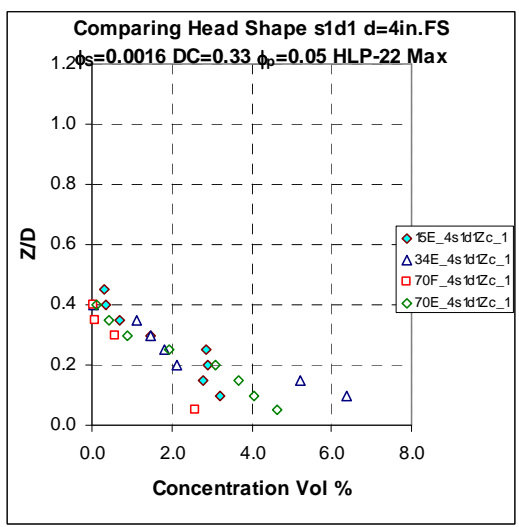

(d) Max

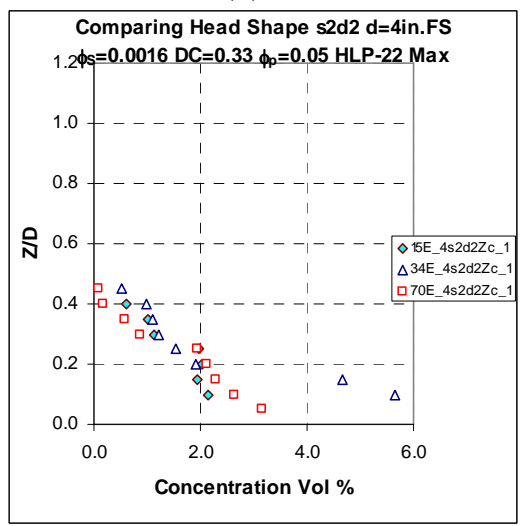

(h) Max

Figure 6.29. Comparison of Tank Head Shape for Small-Scale Elliptical (15E, aqua diamonds) Mid-Scale Spherical (shown as 34E, dark blue

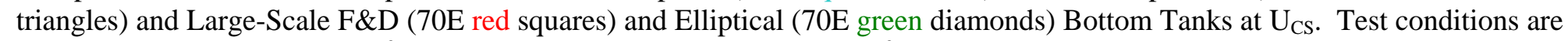
simulants s1d1 $\left(\rho_{\mathrm{s}}=2.46 \mathrm{~g} / \mathrm{cm}^{3}, \mathrm{~d}_{50}=166 \mu \mathrm{m}\right)$ and s2d2 $\left(\rho_{\mathrm{s}}=4.18 \mathrm{~g} / \mathrm{cm}^{3}, \mathrm{~d}_{50}=76 \mu \mathrm{m}\right)$, solids fraction $\left(\phi_{\mathrm{S}}=0.016\right)$, duty cycle $(\mathrm{DC}=$ $0.33)$, and pulse volume fraction $\left(\phi_{\mathrm{p}}=0.05\right)$. 


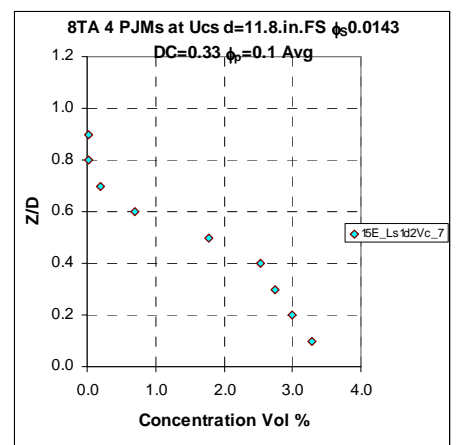

(a) 8TA 4 PJMs $\phi_{p} 0.1$

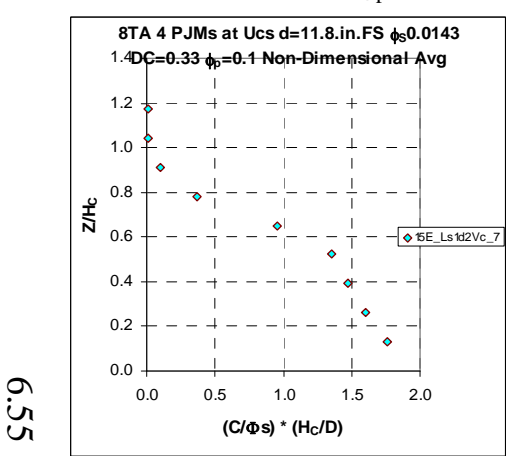

(f) 8TA 4 PJMs $\phi_{p} 0.1$

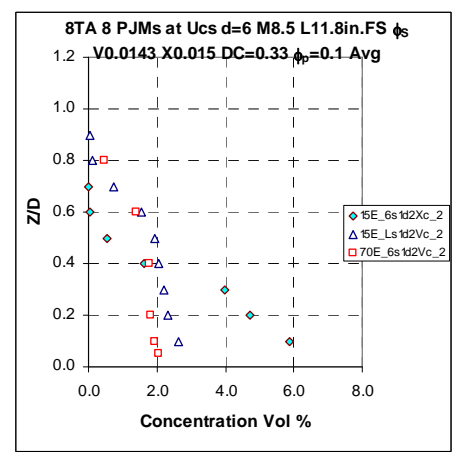

(b) 8TA 8 PJMs $\phi_{\mathrm{p}} 0.1$

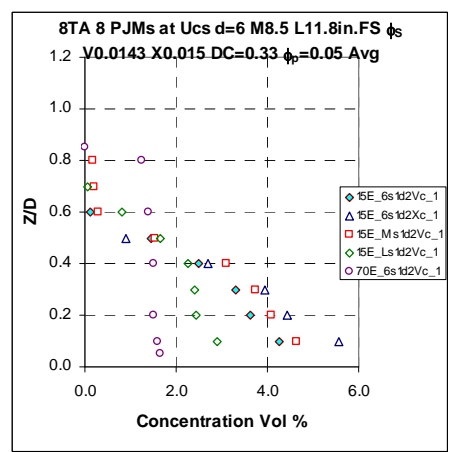

(c) 8TA 8 PJMs $\phi_{p} 0.05$

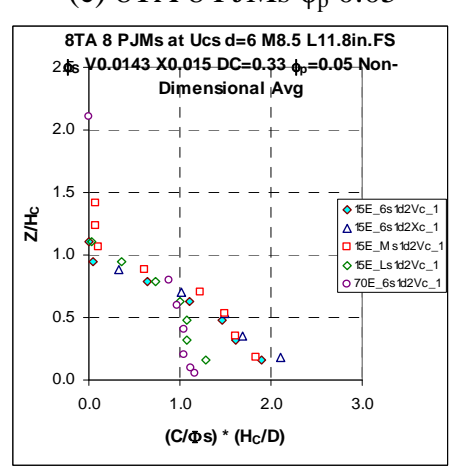

(h) 8TA 8 PJMs $\phi_{\mathrm{p}} 0.05$

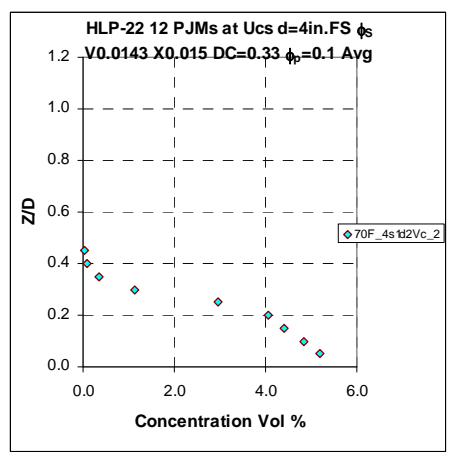

(d) HLP-22 12 PJMs $\phi_{\mathrm{p}} 0.1$

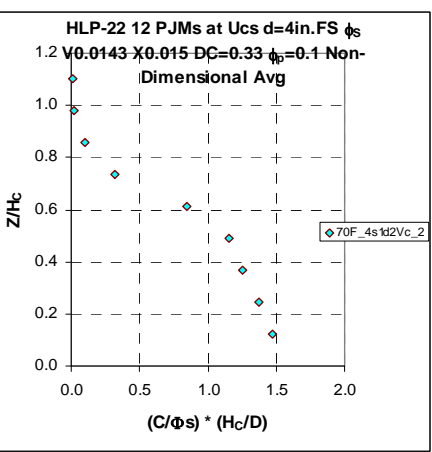

(i) HLP-22 12 PJMs $\phi_{\mathrm{p}} 0.1$

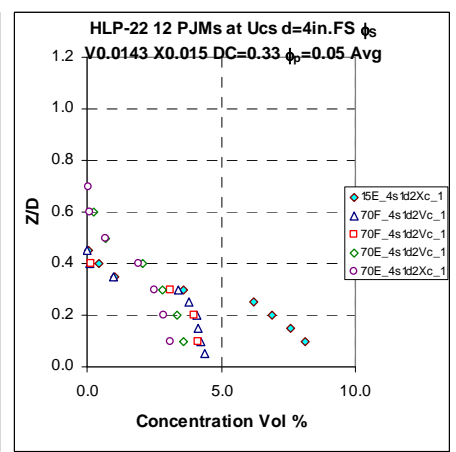

(e) HLP-22 12 PJMs $\phi_{\mathrm{p}} 0.05$

\section{HLP-22 12 PJMs at Ucs $d=4$ in.FS $\phi s$
$1.4 v 0.0143 \times 0.015$ DC $=0.33$ d $=0.05$ Non-}

$1.440 .0143 \times 0.015$ DC=0.33 $\phi_{p}=0.05$
Dimensional Avg
1.2

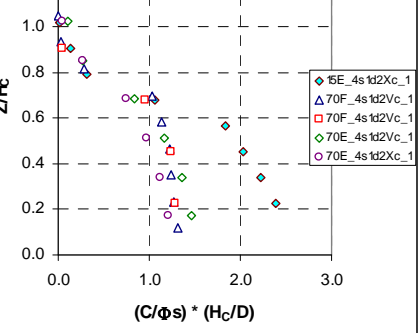

(j) HLP-22 12 PJMs $\phi_{\mathrm{p}} 0.05$

Figure 6.30. Comparison of Dimensional and Nondimensional Plots of Pulse Tube Array (HLP-22 or 8TA), Number of Operating Pulse Tubes (4, 8, or 12) and Nozzle Diameter (4, 6, 8.5 [M] and 11.8 [L]in. Full Scale) for Small-Scale Elliptical (15E) and Large-Scale F\&D (70F) and Elliptical (70E) Bottom Tanks at $\mathrm{U}_{\mathrm{CS}}$. Test conditions are simulant s1d2 $\left(\rho_{\mathrm{s}}=2.48 \mathrm{~g} / \mathrm{cm}^{3}, \mathrm{~d}_{50}=69 \mu \mathrm{m}\right)$, solids fraction $\left(\phi_{\mathrm{S}}=\right.$ $0.0143[\mathrm{~V}], 0.015[\mathrm{X}])$, duty cycle $(\mathrm{DC}=0.33$ [c] $)$, pulse volume fraction $\left(\phi_{\mathrm{p}}=0.1\right.$ [ 2 ], 0.05 [_1]). 


\subsubsection{Variation with Concentration}

Solids concentration by volume profiles taken with five simulants over a range of bulk solids concentrations are plotted in Figure 6.31. All profiles were taken at $\mathrm{U}_{\mathrm{CS}}$ except with stimulant s1d5 $\left(\rho_{\mathrm{s}}=2.5 \mathrm{~g} / \mathrm{cm}^{3}, \mathrm{~d}_{50}=44 \mu \mathrm{m}\right)$ where the velocity was $5 \%$ lower than $\mathrm{U}_{\mathrm{CS}}$. The two highest concentrations are shown in Figure 6.31 (b) red squares (0.06 solids fraction) and green diamonds (0.045 solids fraction) and the average profile shows a relatively high concentration from 0.1 to $0.4 \mathrm{Z} / \mathrm{D}$.

Concentration profiles taken with several simulants in different tanks are plotted in Figure 6.32. All profiles were taken at $\mathrm{U}_{\mathrm{CS}}$ with $4 \mathrm{in}$. full-scale nozzles at a duty cycle of 0.33 and pulse volume fraction of 0.05 . Solids fraction varies between plots.

\subsubsection{Variation with Duty Cycle}

Duty cycle is the fraction of time during the cycle that the fluid is discharging from the pulse tube. Tests were conducted over a range of duty cycles, including $0.18,0.33,0,0.66$, and 1.0 (a steady jet). Solids concentration by volume profiles obtained for these conditions are shown in Figure 6.33 (a-d). In (e) and (f), duty cycle is varied while other properties except tank diameter are held constant. The concentration profile for the steady jet (blue triangles) shown in (f) is constant to an elevation of $0.8 \mathrm{Z} / \mathrm{D}$ and reduced above that point. In (f) the duty cycle of 0.33 shows that the concentration in the tank is relatively constant to an elevation of $0.3 \mathrm{Z} / \mathrm{D}$, and the duty cycle of 0.18 shows that the concentration is relatively constant to an elevation of $0.2 \mathrm{Z} / \mathrm{D}$. 


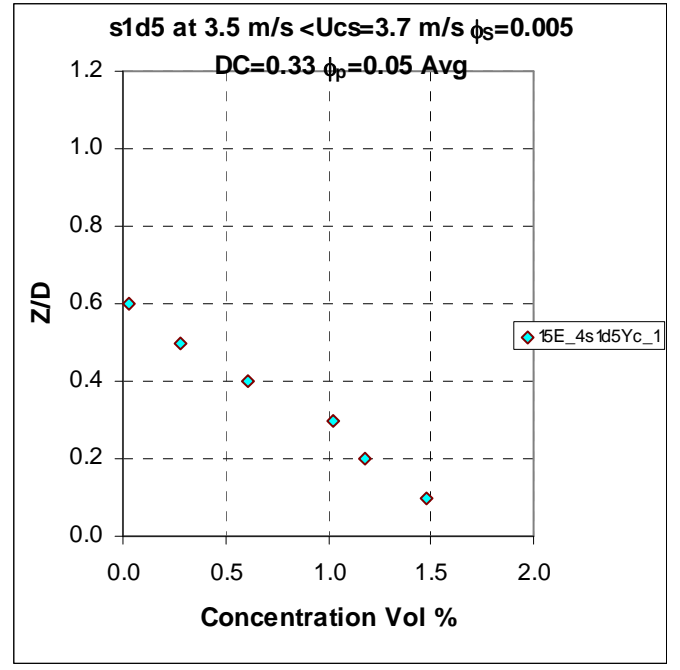

(a) $\mathrm{s} 1 \mathrm{~d} 5\left(\rho_{\mathrm{s}} 2.5 \mathrm{~g} / \mathrm{cm}^{3}, \mathrm{~d}_{50} 44 \mu \mathrm{m}\right)$

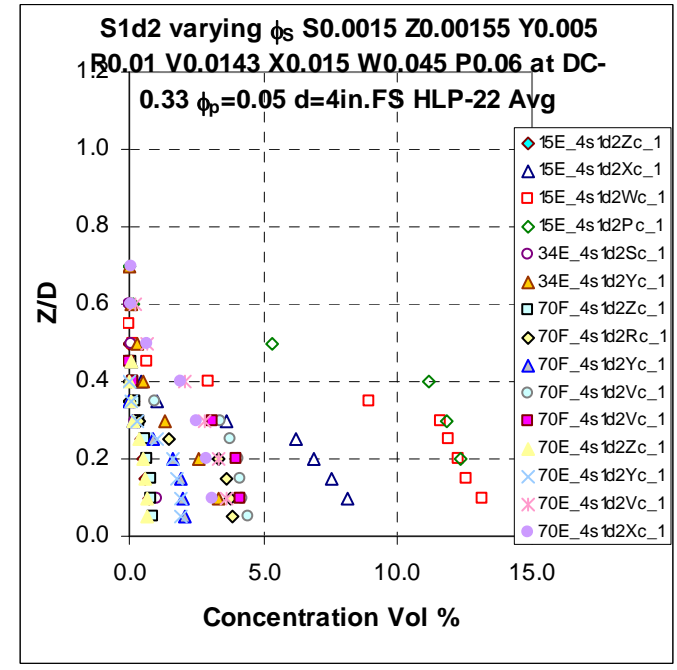

(b) $\mathrm{s} 1 \mathrm{~d} 2\left(\rho_{\mathrm{s}} 2.48 \mathrm{~g} / \mathrm{cm}^{3}, \mathrm{~d}_{50} 69 \mu \mathrm{m}\right)$

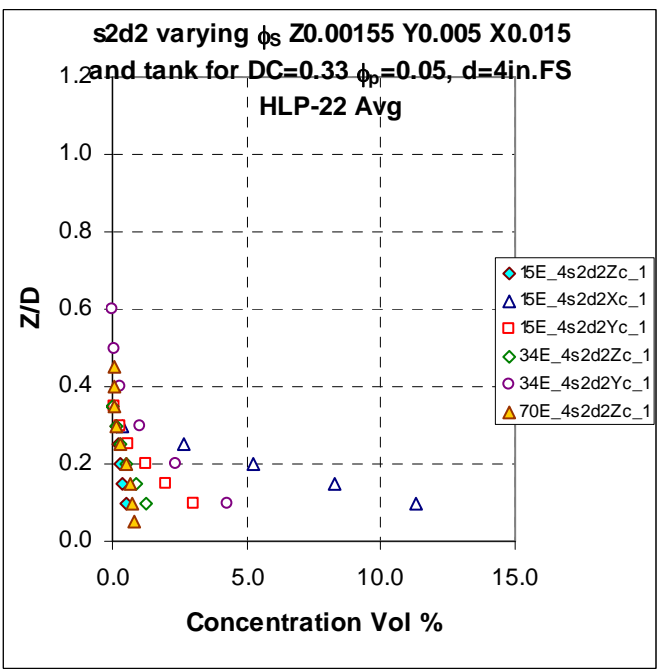

(d) $\mathrm{s} 2 \mathrm{~d} 2\left(\rho_{\mathrm{s}} 4.18 \mathrm{~g} / \mathrm{cm}^{3}, \mathrm{~d}_{50} 76 \mu \mathrm{m}\right)$

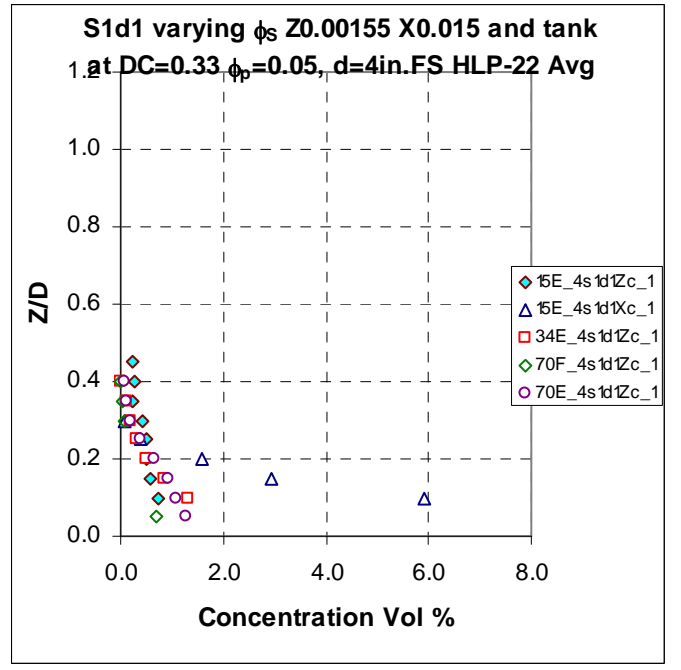

(c) $\operatorname{s} 1 \mathrm{~d} 1\left(\rho_{\mathrm{s}} 2.46 \mathrm{~g} / \mathrm{cm}^{3}, \mathrm{~d}_{50} 166 \mu \mathrm{m}\right)$

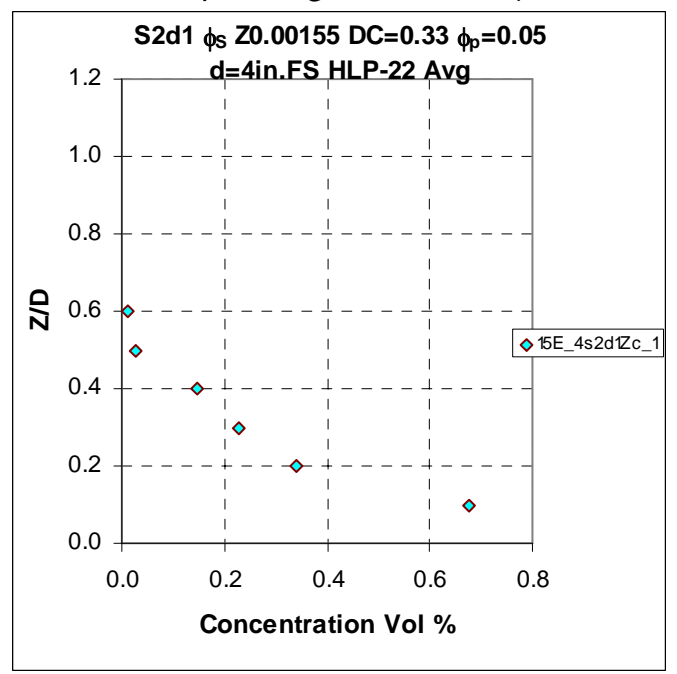

(e) $\mathrm{s} 2 \mathrm{~d} 1\left(\rho_{\mathrm{s}} 4.17 \mathrm{~g} / \mathrm{cm}^{3}, \mathrm{~d}_{50} 164 \mu \mathrm{m}\right)$

Figure 6.31. Concentration Profiles for the Five Simulants in the HLP-22 Tank Configuration. Test conditions are solids volume fraction $\left(\phi_{\mathrm{S}}=0.0015\right.$ [S], 0.00155 [Z], 0.005 [Y], 0.01 [R], 0.0143 [V], 0.015 [X], 0.045 [W], 0.06 [P]), nozzle diameter $\mathrm{d}=4 \mathrm{in}$. full-scale, duty cycle $(\mathrm{DC}=0.33[\mathrm{c}])$, pulse volume fraction $\left(\phi_{\mathrm{p}}=0.05\right.$ [_1]). 


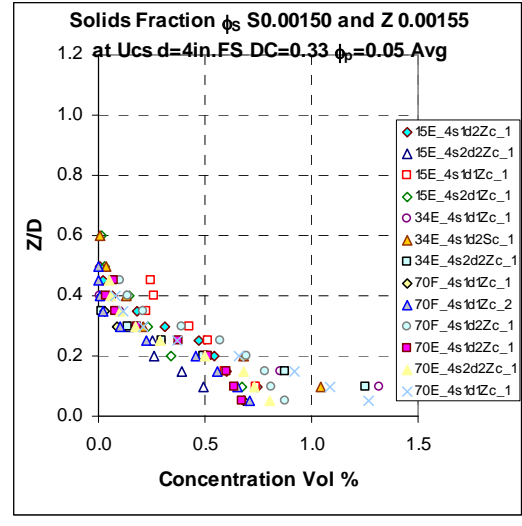

(a) $\phi_{\mathrm{S}} \mathrm{S} 0.00150, \mathrm{Z} 0.00155$

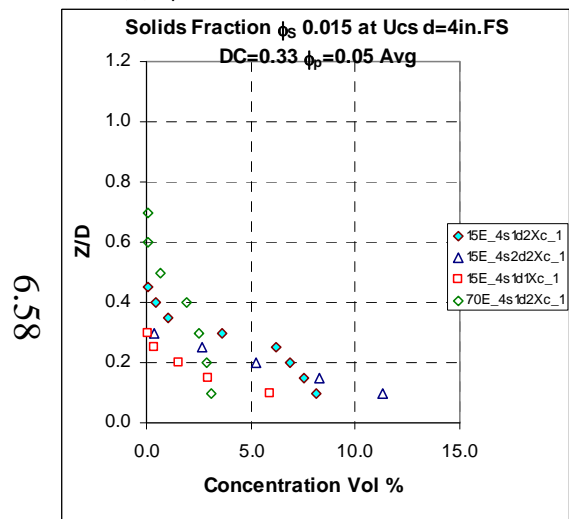

(e) $\phi_{\mathrm{S}} \mathrm{X} 0.015$

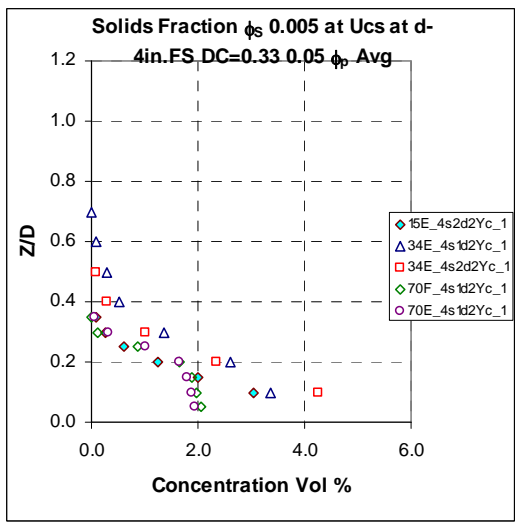

(b) $\phi_{\mathrm{S}} \mathrm{Y} 0.005$

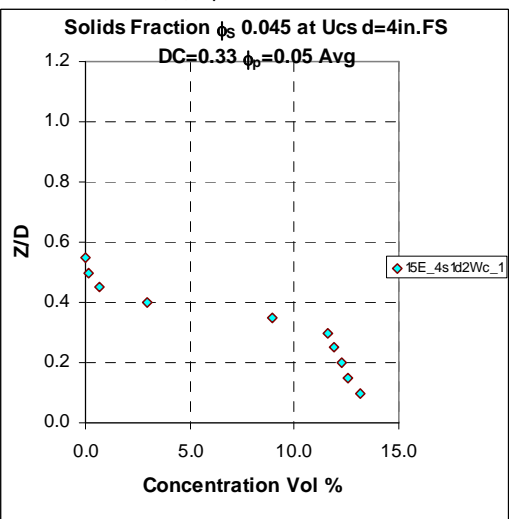

(f) $\phi_{\mathrm{S}} \mathrm{W} 0.045$

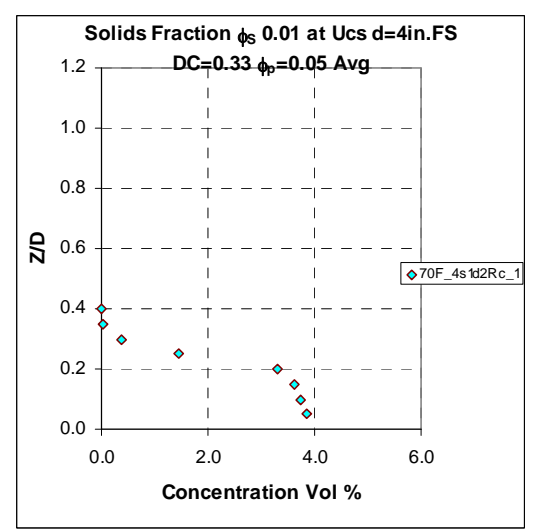

(c) $\phi_{\mathrm{S}} \mathrm{R} 0.01$

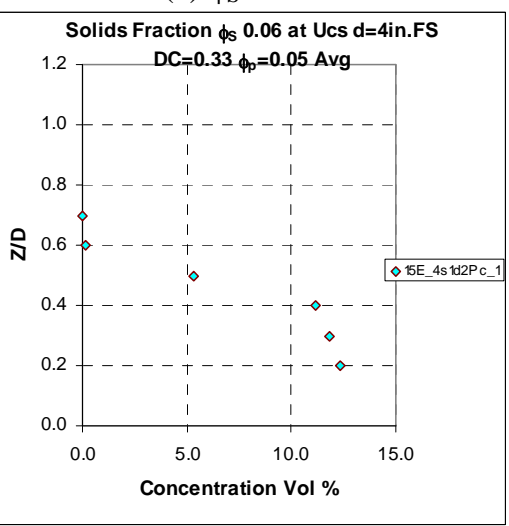

(g) $\phi_{\mathrm{S}} \mathrm{P} 0.06$

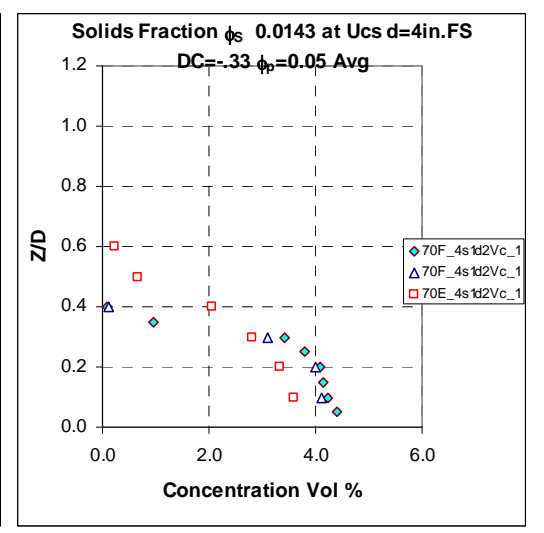

(d) $\phi_{\mathrm{S}} \mathrm{V} 0.0143$

Figure 6.32. Comparing Profiles for Simulants and Tanks at $U_{\mathrm{CS}}$ for HLP-22 Tank Configuration as Solids Concentration $\phi_{\mathrm{S}}$ Increases from 0.00150 to 0.06 . Test conditions are nozzle diameter $\mathrm{d}=4$ in. full-scale, solids volume fraction $\left(\phi_{\mathrm{S}}=0.00155\right.$ [Z], 0.005 [Y], 0.01 [R], $0.0143[\mathrm{~V}], 0.015$ [X], $0.045[\mathrm{~W}], 0.06$ [P])duty cycle (DC $=0.33$ [c]), pulse volume fraction $\left(\phi_{\mathrm{p}}=0.05\left[\_1\right]\right)$. 


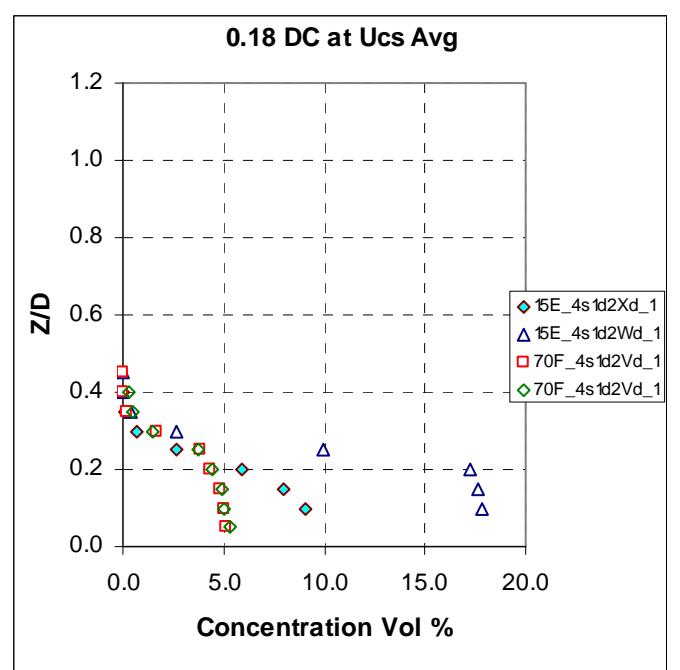

(a) DC $=0.18$ [d]

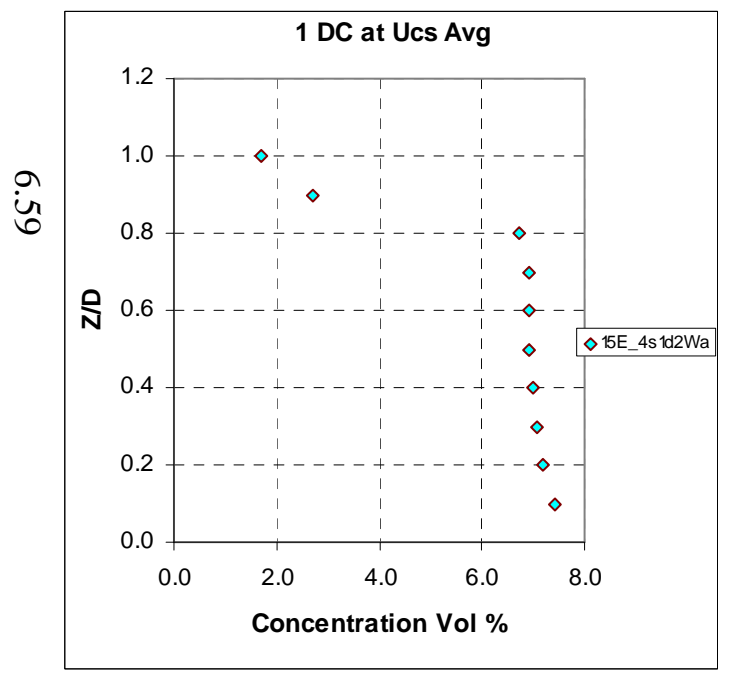

(d) DC $=1.0[\mathrm{a}]$

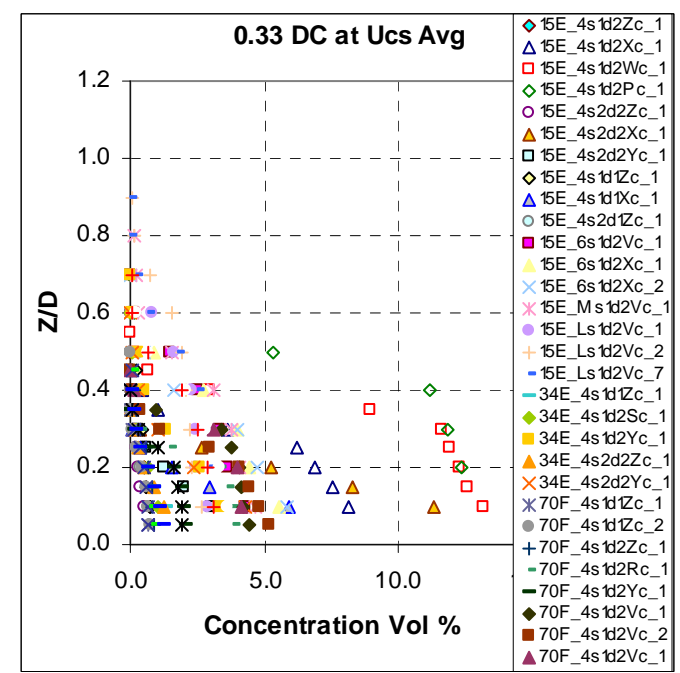

(b) $\mathrm{DC}=0.33[\mathrm{c}]$

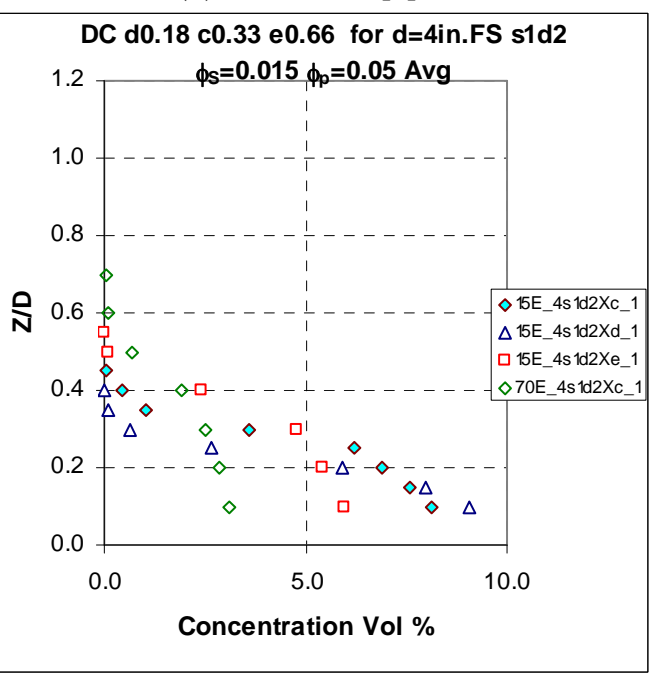

(e) $\mathrm{DC}=0.18$ [d], 0.33 [c], 0.66 [e]

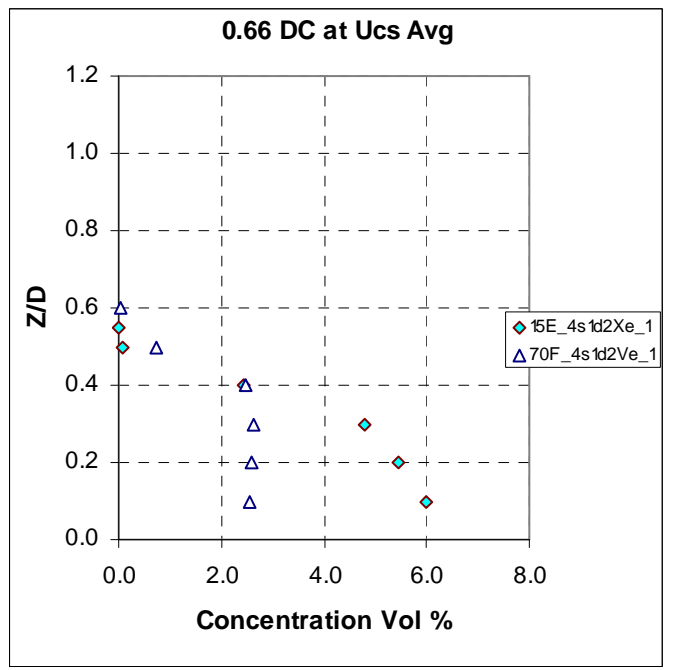

(c) DC 0.66 [e]

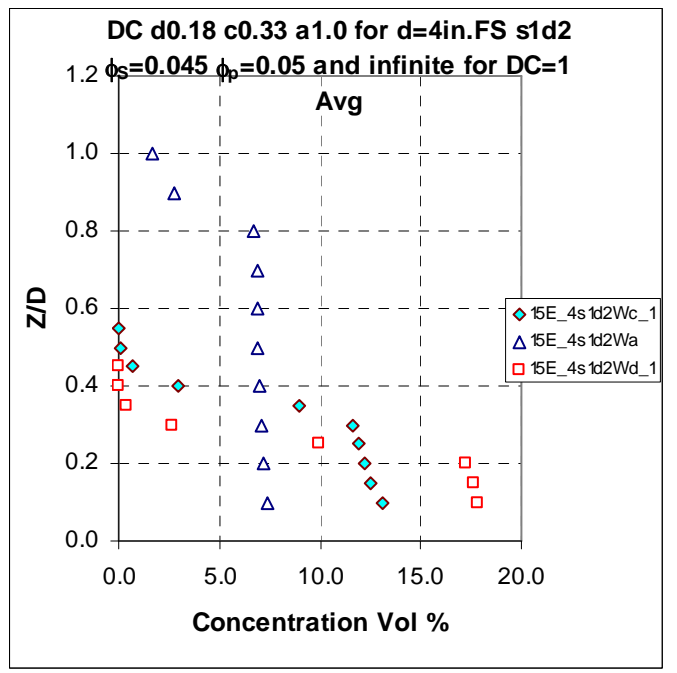

(f) $\mathrm{DC}=0.18$ [d], 0.33 [c], 1.0 [a]

Figure 6.33. Concentration Profiles at Varying Duty Cycles 


\subsection{Transient Cloud Height Tests}

Several transient tests cloud height were conducted. The solids in the tank were allowed to fully settle. For transient tests the target velocity and operating conditions were set at the start of the test to those of a previously obtained $U_{\mathrm{CS}}$ condition and held constant for the duration of the test. Cloud height measurements were taken every pulse as the test proceeded. The test continued until no growth trend was observed in the peak cloud height for approximately 10 cycles or more. These transient tests were conducted in four tanks using combinations of two simulants and three concentrations. The transient test cloud height data are plotted dimensionally and nondimensionally in Figure 6.34 and show that steady state was attained at approximately 10 pulse cycles, apparent in the flattening of trends in the semi-log plot of $\mathrm{H}_{\mathrm{C}} / \mathrm{H}_{\mathrm{CS}}$. Comparison of the transient test cloud heights to that reported for equivalent $\mathrm{U}_{\mathrm{CS}}$ conditions demonstrates that the testing methodology, incremental nozzle velocity increase, and reported cloud height measurements at each velocity (see Section 5), produced cloud height results that were independent of cycle count at the nozzle exit velocity condition. Data shown with FM1 at the end of the Case ID are shown for information only. 

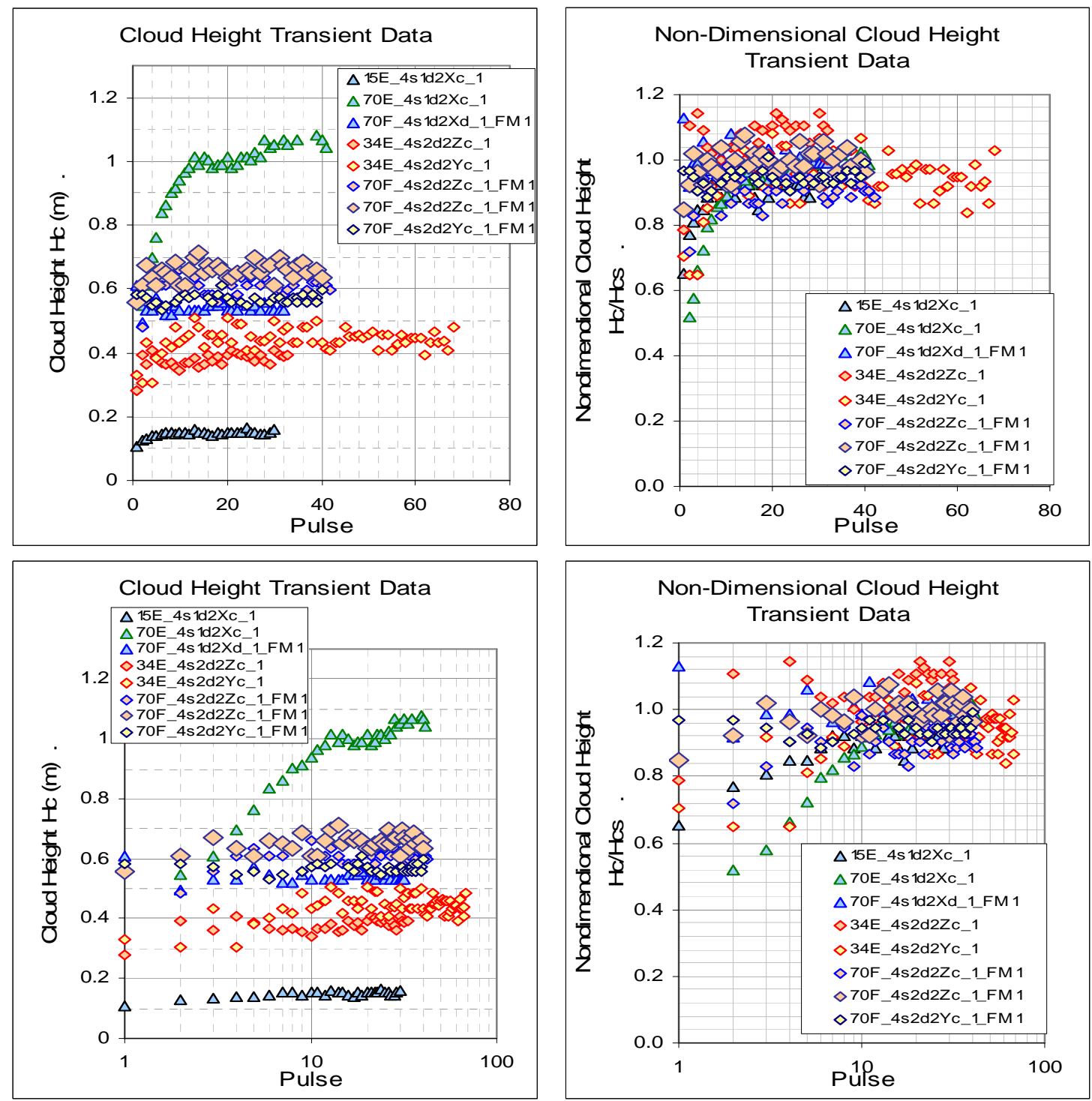

Figure 6.34. Cloud Height Transient Data Shown Dimensionally and Nondimensionally on Linear and Log Scales. Test conditions are simulant s1d2 $\left(\rho_{\mathrm{s}}=2.48 \mathrm{~g} / \mathrm{cm}^{3}, \mathrm{~d}_{50}=69 \mu \mathrm{m}\right)$ and s2d2 $\left(\rho_{\mathrm{s}}=4.18 \mathrm{~g} / \mathrm{cm}^{3}, \mathrm{~d}_{50}=76 \mu \mathrm{m}\right)$, solids fraction $\left(\phi_{\mathrm{s}}=0.015[\mathrm{X}], 0.00155[\mathrm{Z}], 0.005[\mathrm{Y}]\right)$ duty cycle $(\mathrm{DC}=0.18[\mathrm{~d}], 0.33[\mathrm{c}])$ pulse volume fraction $\left(\phi_{\mathrm{p}}=0.05\right)$. 



\subsection{Analysis and Modeling of Mixing Data}

This section presents an analysis of the mixing data, including critical suspension velocity $\left(\mathrm{U}_{\mathrm{CS}}\right)$, average peak cloud height $\left(\mathrm{H}_{\mathrm{C}}\right)$, and vertical solids distribution $(\mathrm{C}(\mathrm{Z}))$. Predictive models were developed for $\mathrm{U}_{\mathrm{CS}}, \mathrm{H}_{\mathrm{C}}$, and average solids concentration at the vessel bottom $\left(\mathrm{C}_{0}\right)$. In Section 8, the models are benchmarked by applying them to previous testing results in prototypic pulse jet mixer (PJM) systems as well as computational fluid dynamics (CFD) simulations. In Section 9, the models are used to evaluate the mixing performance of the WTP vessels with Hanford waste conditions. The models presented in this section are believed to be sufficient for evaluating (rating) the WTP vessels. However, given the design of the data set and the complexity of the mixing phenomena, improved models may be obtainable with additional analysis.

In Section 7.1 the approaches taken to develop models for the experimental data are described. In Section 7.2 the observed physical behavior and the various forms of test parameter functionality are discussed. In Section 7.3, the data for off-bottom suspension and vertical solids distribution are analyzed. In addition, models are presented for $\mathrm{U}_{\mathrm{CS}}, \mathrm{H}_{\mathrm{C}}, \mathrm{C}(\mathrm{Z})$, and $\mathrm{C}_{0}$ developed using a physical approach. The results of a statistical approach to develop $\mathrm{U}_{\mathrm{CS}}$ and $\mathrm{H}_{\mathrm{C}}$ models are summarized in Section 7.4, with more detailed discussion in Appendix F. The differences in model performance obtained using the two approaches are summarized in Section 7.5. Possible model improvements are discussed in Section 7.6.

\subsection{Analysis and Modeling Approach}

Experimental data sets can be analyzed in more than one way. We used graphical methods as well as modeling methods to analyze the M3 mixing experimental data. The goal of modeling is to develop mathematical equations for predicting mixing response variables as functions of relevant variables. Two approaches were used to analyze the mixing data and develop models:

- a physical approach based on hydrodynamic behavior

- a statistical approach involving multiple regression (MR) analysis of the data.

In very general terms, the hydrodynamic behavior observed in a scaled system is related to the behavior that would be observed in the full-scale system because the behavior in both systems is controlled by the same physical laws. So, for both systems we have the same general relationship:

[behavior controlling the performance] $=\mathrm{f}$ [the system and conditions imposed on it]

where "f" is some comprehensive function; "behavior" means the transient spatial distribution of velocity, solids, and settling rate; and "the system and conditions imposed on it" means location and history of momentum added by the PJMs, the physical boundary, and material properties.

The system conditions cannot be represented by a single parameter. Rather, several parameters are required. The geometry, choice of materials, and operational scheme of the experiment can be represented by parameters such as the ratio of total volume of solids to total volume of liquid and the velocity at an entrance nozzle averaged over the peak pulse period. The mixing performance can be represented by measurements of response variables such as $\mathrm{U}_{\mathrm{CS}}, \mathrm{H}_{\mathrm{C}}, \mathrm{C}(\mathrm{Z})$, and $\mathrm{C}_{0}$. These performance variables are then measured for test combinations of parameters defining the system (e.g., scale, solids loading) and the conditions imposed on it (e.g., jet velocity). 
It is known a priori that the functional relationship (f) depends on the physical laws controlling the behavior, namely, the conservation of momentum for hydrodynamic systems. Unfortunately, the resulting behavior is too complex to be predicted directly from this. But, from the dimensionless forms of physical laws, dimensionless groups that represent "behavior" and "conditions imposed” can be identified. These dimensionless groups in turn identify how the data can be reduced to their simplest and most instructive form before seeking the form of $\mathrm{f}$. A classic example is the stream-wise pressure drop due to flow of fluid in a pipe, where the physical laws dictate that the pressure drop (in the form of a dimensionless group, the friction factor) depends on only the Reynolds number (a dimensionless group). Although $\mathrm{f}$ cannot be derived theoretically, plotting the data reduced to these dimensionless groups essentially “draws” f.

For the goal of developing mixing models applicable to WTP use, there is a substantial benefit to following this philosophy. If dimensionless groups related by the physical laws can be identified, the effect of length scale can be subsumed into one or more groups. Then, models developed from experimental data over the ranges of the controlling dimensionless groups expected in the full-scale system can be interpreted as interpolating the data over the ranges of dimensionless groups rather than extrapolating over scale. Predictive models are generally more accurate and thus subject to less uncertainty when interpolating than when extrapolating.

Obviously, and unfortunately, the system of interest is too complicated to surrender to direct analysis based on physical laws. The attempt can be made, however, to correlate the data or parts of it based on dimensionless groups suggested by the physical laws using trial functional forms that can be derived or rationalized from the physical laws.

The above physical approach cannot be relied upon solely. It must be complemented with a general approach wherein the data are analyzed without presuming physically based relationships. This general approach involves fitting functional relationships to the data using MR tools. This approach is discussed in Appendix D. In Appendix E the nature of the data obtained and their internal structure are discussed. The resulting MR models are presented and discussed in Appendix F. The MR models were developed using a power-law relationship between the response variable and predictor variables. The basis for using power-law relationships is discussed in Appendix F.

The physically based functions developed in Sections 7.2 and 7.3 result in power-law model forms, with some variations. This form often is found when making physical laws dimensionless and is consistent (as described in Section 2) with scaling approaches traditionally used for other types of mixing systems. Model forms obtained using the general approach without considering dimensional analysis or the controlling physical laws can be put into dimensionless forms. This serves both to confirm dimensional consistency and to facilitate comparisons with the inherently dimensionless model forms obtained based on physical reasoning.

The physical and statistical MR approaches are described in Sections 7.1.1 and 7.1.2, respectively. The results of the physical approach are presented in Sections 7.2and 7.3.1 to 7.3.4. The results of the statistical approach are summarized in Section 7.4, with more detailed discussion in Appendix F. The differences in model performance obtained using the two approaches (stemming in part from their underlying assumptions, limitations, and developmental histories) are summarized in Section 7.5. 


\subsubsection{Physical Approach}

Using the physical approach we consider the data from the perspective of the physical processes underlying the observed behavior. This approach is based on the understanding that hydrodynamic behavior is governed by underlying physical laws - conservation of mass, momentum, and energyapplied to the liquid and solid phases and subject to the appropriate geometric and temporal boundary conditions of the mixing apparatus. Using this approach, the fundamental variables governing mixing behavior are non-dimensional (for example, ratios of generalized forces, velocities, or diffusivities), based on presumed underlying physical laws. Actual mixing behavior is complex, with solids concentration varying spatially and temporally. An enormous amount of high-quality data would be required to fully describe this behavior. However, the observable behavior (i.e., averaged over space and time) are governed by the same underlying physical laws. Examples of observable behavior are $\mathrm{U}_{\mathrm{CS}}$ and $\mathrm{H}_{\mathrm{C}}$. The goal of the physical approach is thus to identify the relationships based on physical laws that describe the behavior of $\mathrm{U}_{\mathrm{CS}}$ and $\mathrm{H}_{\mathrm{C}}$. The physical approach to analyzing and modeling the data involves the following steps:

- Identify the underlying physical laws that likely govern mixing performance and the fundamental dimensionless groups associated with them. The goal is to identify the most dominant dimensionless groups. The choice of dimensionless groups is not unique; experience, physical insight, or trial and error can all be used in choosing them.

- Find relationships among dimensionless groups. Plotting one group as a function of another while holding others constant reveals relationships among the groups. The power of this approach is that it reveals the form of the fundamental relationship regardless of its complexity.

- Find physically reasonable functions that describe the relationships. Many alternative functional forms can be fit to data. The goal is to find the simplest, physically reasonable functions that represent the observed behavior. The limiting forms of the functions when variables are extrapolated to small or large values should give physically sensible results. When a specific relationship between measured parameters and characteristics known to influence the behavior of the system is understood, substituting the calculated characteristic for the measurements used to calculate it removes the complexity of the known relationship from the overall relationship (e.g., f) being determined. This simplifies correlating performance variables in terms of remaining properties. The principal example of this is limiting behavior in the particle settling velocity relative to the fluid in which it is embedded. This is illustrated in Section 7.2.3, where slurry properties are discussed. In that section, knowledge of the relationship between the particle settling velocity and slurry properties is used to introduce settling velocity as a composite representative property.

The relationships developed from this type of approach are then incorporated into a model that can be applied to WTP conditions for evaluating mixing performance. Statistical methods to evaluate uncertainty and goodness of fit to the data can in principle be applied (although more complicated methods than those associated with the statistical MR approach discussed in Appendix D may be required). The value of the physical approach is that the resulting models have a physical basis in addition to a numerical basis, thereby increasing confidence in their applicability.

\subsubsection{Statistical Multiple Regression Approach}

As noted in Section 7.1, physical models must be complemented with more general models developed without assuming specific physical relationships. This provides an independent check on the assumptions 
on which the physical models are based. The greater the agreement between the resulting models, the greater the confidence in both.

The statistical MR approach applies statistical methods for MR to the experimental data to develop, evaluate, and validate empirical or semi-empirical models and to take advantage of systematic methods for quantifying their uncertainties. An MR model expresses the relationship in the experimental data between a response variable $(\mathrm{y})$ and multiple predictor variables $\left(\mathrm{x}_{1}, \mathrm{x}_{2}, \ldots, \mathrm{x}_{\mathrm{n}}\right)$ :

$$
g\left(y_{i}\right)=f\left(x_{1 i}, x_{2 i}, \ldots, x_{n i}\right)+\varepsilon_{i}
$$

In this general expression, $\mathrm{g}\left(\mathrm{y}_{\mathrm{i}}\right)$ is an appropriate mathematical transformation of the response variable $\mathrm{y}$ for the $i^{\text {th }}$ data point; $f\left(x_{1 i}, x_{2 i}, \ldots, x_{n i}\right)$ denotes a function of the predictor variable values $x_{1 i}, x_{2 i}, \ldots, x_{n i}$ for the $\mathrm{i}^{\text {th }}$ data point; and $\varepsilon_{\mathrm{i}}$ is a random error representing experimental and measurement uncertainty in the $\mathrm{i}^{\text {th }}$ data point. To satisfy the requirements for ordinary least squares (OLS) regression, the random errors $\varepsilon_{\mathrm{i}}$ must be statistically independent and come from the same probability distribution (and thus have the same standard deviation). The functional relationship $\mathrm{f}\left(\mathrm{x}_{1 \mathrm{i}}, \mathrm{x}_{2 \mathrm{i}}, \ldots, \mathrm{x}_{\mathrm{ni}}\right)$ may be completely empirical or also include subject matter knowledge and experience (semi-empirical). The mixing response variables (y) modeled using the MR approach were $\mathrm{U}_{\mathrm{CS}}$ and $\mathrm{H}_{\mathrm{C}}$. The approach discussed in Section 7.3.3 to obtain a model for $\mathrm{C}_{0}$ from the model for $\mathrm{H}_{\mathrm{C}}$ may also be applied to statistically developed MR models. The predictor variables $\mathrm{x}_{\mathrm{i}}$ in Eq. (7.1) are generally test variables or functions of test variables (e.g., dimensionless groups).

The statistical MR approach can also be applied to dimensionless groups formed systematically as products or ratios of subsets of dimensional variables. This ensures dimensional consistency of the resulting model, as discussed later in Section 7.4. In what is subsequently referred to as the generalized approach, the dimensionless groups are formed as functions of the dimensional variables. This can always be done based on the dimensions alone, without presuming specific physical relationships as a basis for the grouping. However, as for any dimensional analysis of hydrodynamic systems, the resulting groups can be given physical interpretations after the model is constructed. Thus, this approach also facilitates comparing the results of the physical and generalized approaches.

The statistical MR methods and formulas that were applied are discussed in Appendix D. Appendix E contains assessments of the experimental data that are useful in guiding the development of MR models and assessing their reasonableness. Section 7.4 summarizes the $U_{C S}$ and $H_{C}$ models developed using the statistical MR approach, where the model forms used are generalizations of those developed subsequently using the physical approach discussed in Section 7.1.1. The statistical MR models summarized in Section 7.4 are discussed in more detail in Appendix F.

\subsection{Mixing Behavior}

This section presents an overview of the observed physical behavior for critical suspension velocity $\left(\mathrm{U}_{\mathrm{CS}}\right)$ and average peak cloud height $\left(\mathrm{H}_{\mathrm{C}}\right)$. The functional dependence of $\mathrm{U}_{\mathrm{CS}}$ and $\mathrm{H}_{\mathrm{C}}$ on the test parameters is discussed, and the basis for various functional forms for modeling important trends and behaviors is developed. The data presented in this section represent a small sample of the complete data set selected to illustrate the important relationships. 


\subsubsection{Parametric Sensitivity and Functional Form}

In general, we expect the mixing metrics $\left(\mathrm{U}_{\mathrm{CS}}, \mathrm{H}_{\mathrm{C}}\right)$ to be functions of the various geometric, operational, and physical parameters. Expressed mathematically, $\mathrm{y}=\mathrm{f}\left(\mathrm{x}_{1}, \mathrm{x}_{2}, \ldots, \mathrm{x}_{\mathrm{n}}\right)$, where $\mathrm{y}$ is any variable, dimensional or nondimensional, and $\mathrm{x}_{\mathrm{i}}(\mathrm{i}=1$ to $\mathrm{n})$ is all the other parameters on which y may depend. The sensitivity coefficient, $\alpha_{\mathrm{j}}$, is a useful way to quantify the dependence of one variable on another. It is defined as

$$
\alpha_{j}=\frac{x_{i}}{f\left(x_{1}, x_{2}, \ldots, x_{n}\right)} \frac{\partial f\left(x_{1}, x_{2}, \ldots, x_{n}\right)}{\partial x_{j}}=\frac{\partial \ln (y)}{\partial \ln \left(x_{j}\right)}
$$

The derivative in Eq. (7.2) is the partial derivative, meaning all other variables $\left(\mathrm{x}_{\mathrm{i} \neq \mathrm{j}}\right)$ are held constant when the derivative is carried out.

If $\ln (\mathrm{y})$ is plotted versus $\ln \left(\mathrm{x}_{\mathrm{j}}\right), \alpha_{\mathrm{j}}$ is the local slope, as illustrated in Figure 7.1. If $\alpha_{\mathrm{j}}$ is constant, the functional form is a power law:

$$
y=k\left(x_{i \neq j}\right) x_{j}^{\alpha}
$$

Here the coefficient, $\mathrm{k}$, is a constant with respect to $\mathrm{x}_{\mathrm{j}}$, but it can depend on the other variables. This is illustrated by the two parallel lines in Figure 7.1.

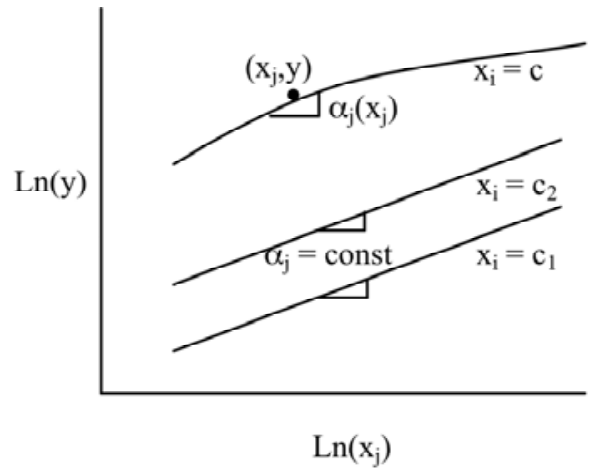

(a)

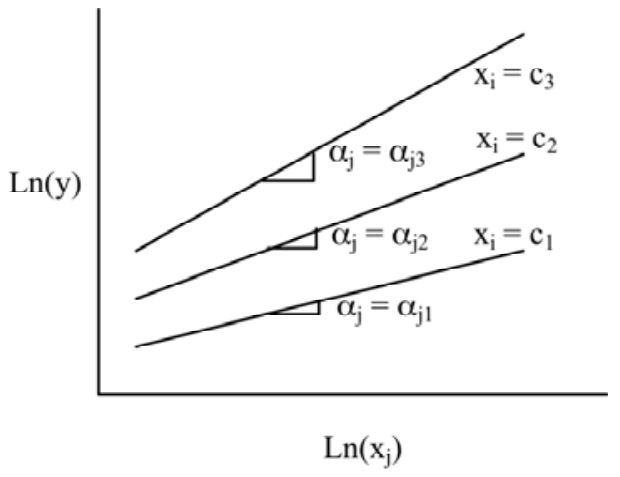

(b)

Figure 7.1. Illustration of the Physical Meaning of the Sensitivity Coefficient; (a) Linear and Nonlinear Behavior, (b) Interaction between Variables

When $\alpha_{\mathrm{j}}$ is not a constant, the data plotted on a $\ln (\mathrm{y})$ versus $\ln \left(\mathrm{x}_{\mathrm{j}}\right)$ may be curved or have different slopes depending on other variables. When the relationship is curved it is referred to as nonlinear behavior; it is understood that this means nonlinear with respect to a logarithmic scale. When $\alpha_{j}=f\left(x_{i}\right)$, there is an apparent coupling or interaction between two or more variables. This can result either from some actual physical interaction beyond that represented by the power-law form or potentially from a different functional relationship. The power law implies that the effects of all parameters are multiplicative. But, if two parameters affect the performance in some additive fashion, where the effect of one does not depend on the other, the true functional form would involve a sum, rather than a product, of terms. In this case, forcing the data into the power-law form would result in sensitivity coefficients that are not constant. The case of interactions (apparent or actual) is illustrated in Figure 7.1(b). 


\subsubsection{Jet Velocity}

The majority of the testing performed involved varying the jet velocity, starting below $\mathrm{U}_{\mathrm{CS}}$ and increasing it until equipment limitations (such as either solids entrainment into the pump returns or flow rate limits) were approached. Figure 7.2 shows several examples of $\mathrm{H}_{\mathrm{C}}$ plotted versus the corresponding velocity, U. Also shown in the plots by the symbols with black centers are the critical suspension conditions, $\mathrm{U}_{\mathrm{CS}}$ and $\mathrm{H}_{\mathrm{CS}}$. For most test conditions $\mathrm{H}_{\mathrm{C}}$ was an increasing function of velocity. However, under certain circumstances $\mathrm{H}_{\mathrm{C}}$ initially decreased, went through a minimum, and then increased at higher velocities. This behavior was visible in the small-scale tank. This phenomenon may have occurred in the larger tanks as well, but, if so, it was not detectable because the clouds were below the dish bottom knuckle and thus not visible. This appears to be because only a small fraction of the solids were suspended at lower velocities, which allowed the solids plume to rise higher. As the velocity was increased, more of the settled solids were suspended, resulting in a higher solid loading in the plume and thus a lower cloud height. When most or all of the solids were suspended, increasing the velocity increased cloud height.

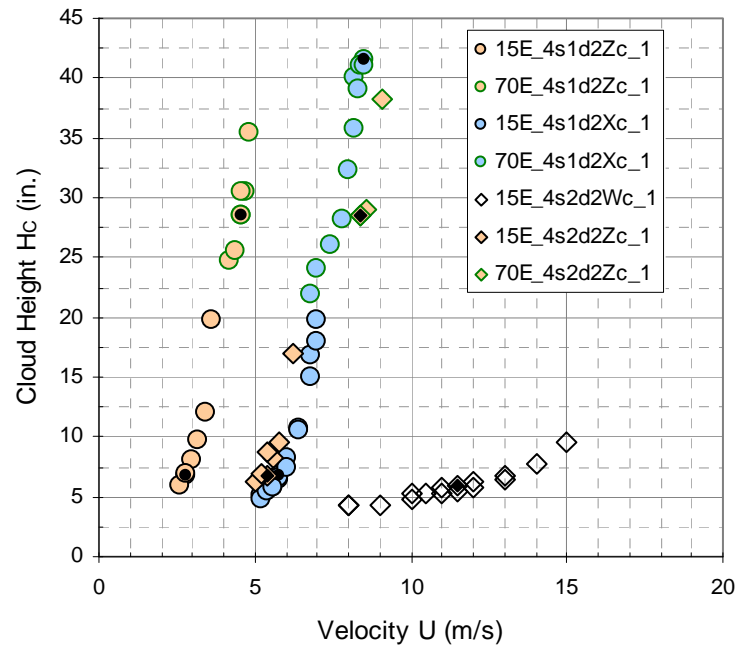

(a)

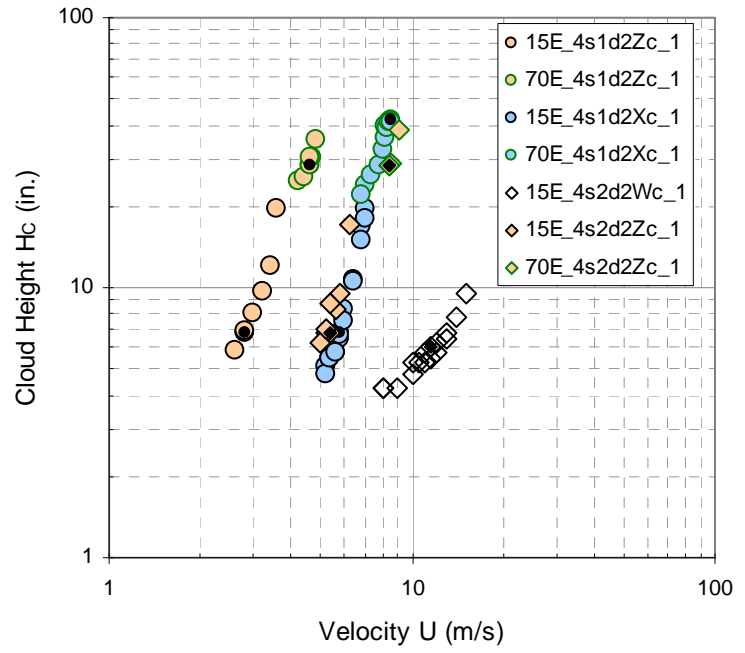

(b)

Figure 7.2. Examples of $\mathrm{H}_{\mathrm{C}}$ Data as a Function of Jet Velocity; (a) Linear Scale, (b) Logarithmic Scale with $\mathrm{U}_{\mathrm{CS}}$ Conditions Denoted by Black Center

The velocity exponent tends to increase with $\mathrm{H}_{\mathrm{C}}$, which can be seen from the $\ln \left(\mathrm{H}_{\mathrm{C}}\right)$ versus $\ln (\mathrm{U})$ plot in Figure 7.2. The exponent generally is about 2 for velocities just above $U_{C S}$ and approaches 3 or 4 as $U$ is increased. Cloud height is generally expected to be nonlinear in jet velocity, and the power-law form may be insufficient to accurately describe the function. However, it may provide an adequate approximation for $\mathrm{U} \geq \mathrm{U}_{\mathrm{CS}}$.

An interesting feature of the $\mathrm{H}_{\mathrm{C}}$ behavior is shown in Figure 7.3. Here the Froude number based on cloud height $\left(\mathrm{F}_{\mathrm{C}}\right)$ is plotted versus jet velocity:

$$
F_{C}=\frac{U^{2}}{(s-1) g H_{C}}
$$




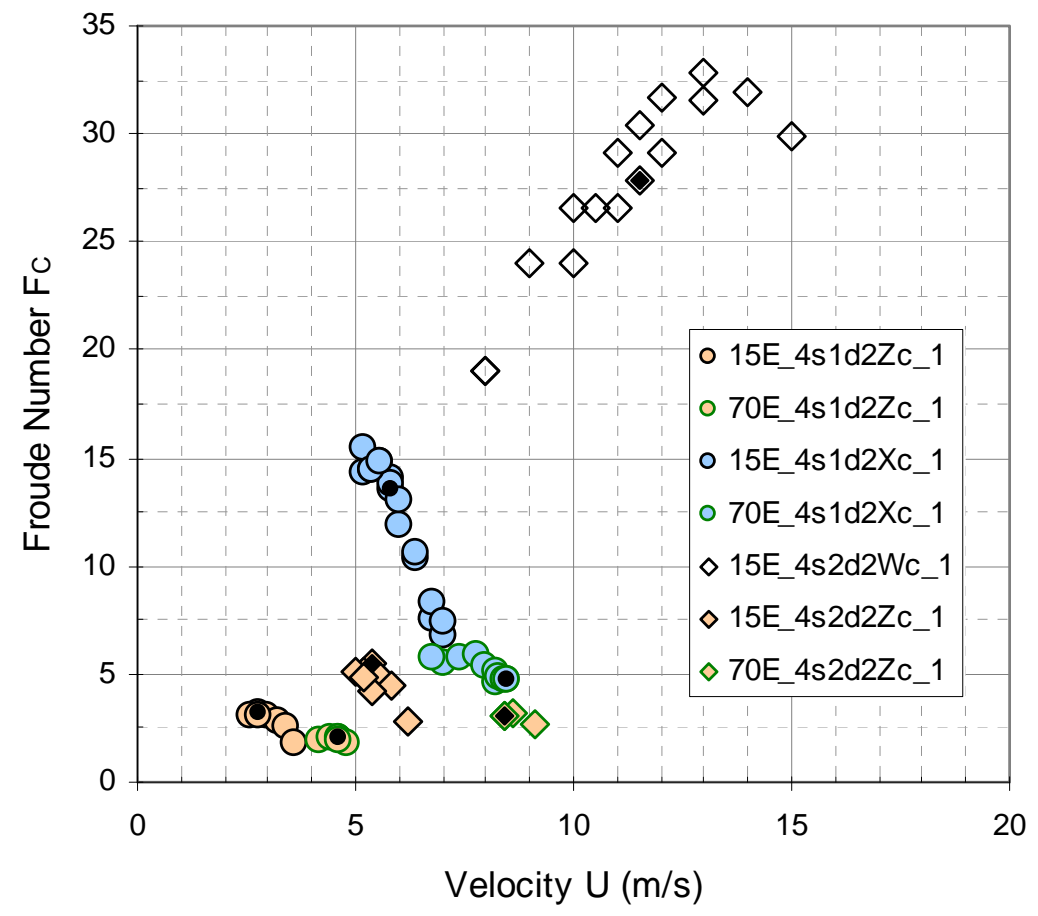

Figure 7.3. Illustration of the Completely-Suspended Condition as an Energy Maxima with $\mathrm{U}_{\mathrm{CS}}$ Conditions Denoted by Black Center

A maximum in $\mathrm{F}_{\mathrm{C}}$ occurs near the $\mathrm{U}_{\mathrm{CS}}$ condition, giving some insight into the processes of off-bottom suspension and vertical distribution. $\mathrm{F}_{\mathrm{C}}$ can be interpreted as the ratio of jet kinetic energy to solids potential energy. Below $U_{C S}$ much of the jet energy apparently goes into the erosion process of mobilizing solids off the tank bottom. Once all of the solids are suspended, $F_{C}$ decreases with increasing velocity, implying the additional energy goes into lifting the solids cloud.

Given the apparent transition in physical behavior that occurs at the critical suspension (CS) condition, one might suspect that cloud height behavior relative to $\mathrm{CS}$ condition $\left(\mathrm{H}_{\mathrm{C}} / \mathrm{H}_{\mathrm{CS}}\right)$ is independent of other parameters. That is, it seems reasonable that the CS condition may be independent of other parameters and may contain most or all of the important functionality. Figure 7.4 shows $\mathrm{H}_{\mathrm{C}} / \mathrm{H}_{\mathrm{Cs}}$ plotted versus $\mathrm{U} / \mathrm{U}_{\mathrm{CS}}$ for the data set where $\mathrm{U} / \mathrm{U}_{\mathrm{CS}} \geq 1$. There is some correlation between the two variables, though there is clearly significant scatter. However, the result shows that, on average, $\mathrm{H}_{\mathrm{C}} / \mathrm{H}_{\mathrm{CS}} \sim\left(\mathrm{U} / \mathrm{U}_{\mathrm{CS}}\right)^{2}$, meaning that over the entire range of test conditions $\mathrm{F}_{\mathrm{C}}$ is on average approximately equal to $\mathrm{F}_{\mathrm{CS}}$, the Froude number at critical suspension. The deviation from this average condition is evidently dependent on the other test parameters. 


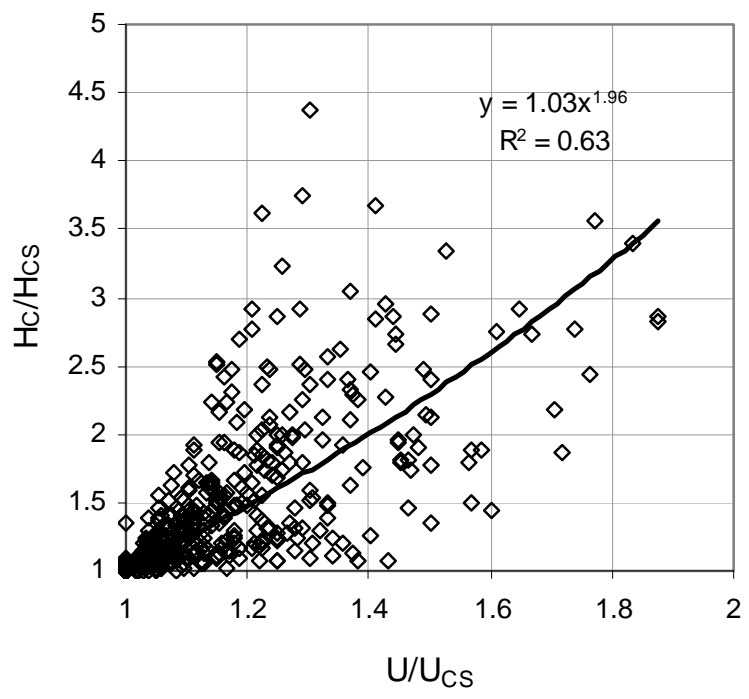

Figure 7.4. Behavior of $\mathrm{H}_{\mathrm{C}}$ Relative to Critical Suspension Condition for $U \geq \mathrm{U}_{\mathrm{CS}}$ (all test conditions shown)

\subsubsection{Slurry Properties}

It is common practice to attempt correlations for off-bottom suspension and vertical solids distribution using density ratio $(\mathrm{s})$, solids diameter $\left(\mathrm{d}_{\mathrm{s}}\right)$, and kinematic viscosity $(\mathrm{v})$. An alternative approach is to introduce the unhindered terminal settling velocity $\left(\mathrm{U}_{\mathrm{T}}\right)$. For monodisperse spherical particles, a useful relation for calculating $U_{\mathrm{T}}$ is given by Camenen (2007) in terms of the Galileo number (Ga):

$$
\mathrm{U}_{\mathrm{T}}=\frac{v}{\mathrm{~d}_{\mathrm{S}}}(\sqrt{15+\sqrt{\mathrm{Ga} / 0.3}}-\sqrt{15})^{2}
$$

which may be written as

$$
\operatorname{Re}_{\mathrm{p}}^{1 / 2}=\sqrt{\frac{\mathrm{d}_{\mathrm{S}} \mathrm{U}_{\mathrm{T}}}{v}}=\sqrt{15+\sqrt{\mathrm{Ga} / 0.3}}-\sqrt{15}
$$

where

$$
\mathrm{Ga}=\frac{(\mathrm{s}-1) g \mathrm{~d}_{\mathrm{s}}^{3}}{v^{2}}
$$

The square of the left side of Eq. (7.5b) is the (dimensionless) Reynolds number based on the particle size and settling velocity $\left(\mathrm{Re}_{\mathrm{p}}\right)$, which a priori from hydrodynamic principles is a function of only the (dimensionless) Galileo number, as specified in this equation. This is an example of using knowledge of the underlying physical laws to obtain a behavior $=\mathrm{f}$ (conditions) relationship, as addressed in Section 7.1. Using values of $U_{T}$ calculated with Eq. (7.5a) as a modeling parameter (instead of the value of $d_{S}$ it represents through the Galileo number) avoids adding the complexity of this relationship to the complexity of either a physical model or a generalized model. This is apparent in Figure 7.5 and explained below the figure, which is shown for information only. 


\section{$\mathbf{U}_{\mathrm{T}}$ Physical Property Sensitivity \\ Corresponding to $s=2.5$ in water at standard temperature and pressure}

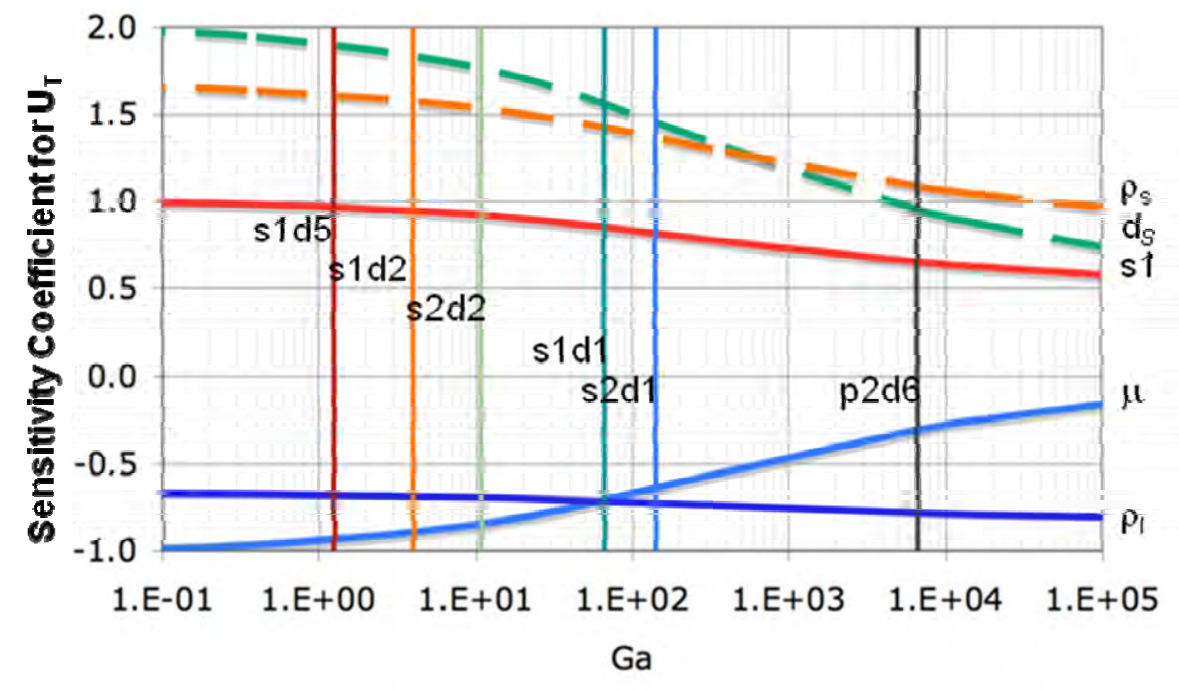

Figure 7.5. Sensitivity Coefficients (effective power-law exponents) for Terminal Settling Velocity Given by Eq. (7.5a) with simulant designations shown on vertical (constant Ga) lines (FIO)

There are several reasons to expect that this approach may be superior to simple power-law expressions. First, even though $U_{\mathrm{T}}$ may not be representative of the overall process occurring in the tank, functionally it is a characteristic scale for many complex processes occurring in the slurry. Local settling rates within the tank vary spatially and temporally. Solid particle interactions, especially at higher local concentrations, affect the settling rate. Turbulent transport processes also compete with gravitational settling. Solids off-bottom suspension is a complex balance between erosion and deposition behavior. In these complex processes, the unhindered settling velocity is pertinent at the scale of individual particles, no matter how complex the flow field around them. For example, hindered settling rates tend to be proportional to $\mathrm{U}_{\mathrm{T}}$, and local unsteady force and energy interactions between the liquid and solid phases depend on various scales involving $\mathrm{U}_{\mathrm{T}}$.

Second, when expressed as a function of $\mathrm{s}, \mathrm{d}_{\mathrm{S}}$, and $\mathrm{v}, \mathrm{U}_{\mathrm{T}}$ is a more complex function than can be expressed by typical power-law terms. In general, one can express

$$
\mathrm{U}_{\mathrm{T}} \propto(\mathrm{s}-1)^{\mathrm{a}_{1}} \mathrm{~d}_{\mathrm{S}}^{\mathrm{a}_{2}} \mathrm{v}^{\mathrm{a}_{3}}
$$

only for a limited range of conditions. For example, Eq. (7.5a) has the form

$$
\mathrm{U}_{\mathrm{T}}=\frac{\mathrm{v}}{\mathrm{d}_{\mathrm{S}}} \mathrm{f}(\mathrm{Ga})
$$

For small and large Ga, the limiting results are, respectively,

$$
\mathrm{Ga}<<1 \quad \operatorname{Re}_{\mathrm{P}} \approx \mathrm{Ga} \quad \mathrm{U}_{\mathrm{T}} \approx \mathrm{vd}_{\mathrm{S}}^{-1} \mathrm{Ga}=(\mathrm{s}-1) \mathrm{g} v^{-1} \mathrm{~d}_{\mathrm{S}}^{2}
$$

and 


$$
\mathrm{Ga}>>1 \quad \mathrm{Re}_{\mathrm{P}} \approx \mathrm{Ga}^{0.5} \quad \mathrm{U}_{\mathrm{T}} \approx \mathrm{vd}_{\mathrm{S}}^{-1} \mathrm{Ga}^{0.5}=(\mathrm{s}-1)^{0.5} \mathrm{~g}^{0.5} \mathrm{~d}_{\mathrm{S}}^{0.5}
$$

For all other values of $\mathrm{Ga}$, the exponents on $\mathrm{s}, \mathrm{d}_{\mathrm{s}}$, and $v$ are functions of $\mathrm{Ga}$, as shown in Figure 7.5. The values of Ga for several simulants used in the M3 testing are shown as vertical bars in Figure 7.5.

The third benefit of introducing $\mathrm{U}_{\mathrm{T}}$ as a parameter in mixing models is that it relates mixing solids with a broad particle size distribution. An average settling velocity has greater physical meaning than an average particle size. The average settling velocity is the volume-weighted sum of the individual particle settling velocities and is the rate at which the distribution settles insofar as it is well-mixed. The average particle size, on the other hand, is purely a geometric average, with little meaning in terms of the physical process.

Figure 7.6 illustrates the benefit of using $\mathrm{U}_{\mathrm{T}}$ to correlate off-bottom suspension data from tests with five different simulants in the small-scale tank configured with HLP-22 geometry and operational conditions. When the $U_{C S}$ data are plotted dimensionally versus $d_{S}$ in Figure 7.6(a), there is not a simple relationship. The exponent on $\mathrm{d}_{\mathrm{S}}$ depends on the density ratio and has a value of 0.35 for $\mathrm{s}=2.5$ and 0.22 for $\mathrm{s}=4$.2. However, when $\mathrm{U}_{\mathrm{CS}}$ is normalized by $\mathrm{U}_{\mathrm{T}}$ and plotted versus $\mathrm{Ga}$ in Figure 7.6(b), a good model is observed with $\mathrm{U}_{\mathrm{CS}} / \mathrm{U}_{\mathrm{T}} \sim \mathrm{Ga}^{-0.43}$.

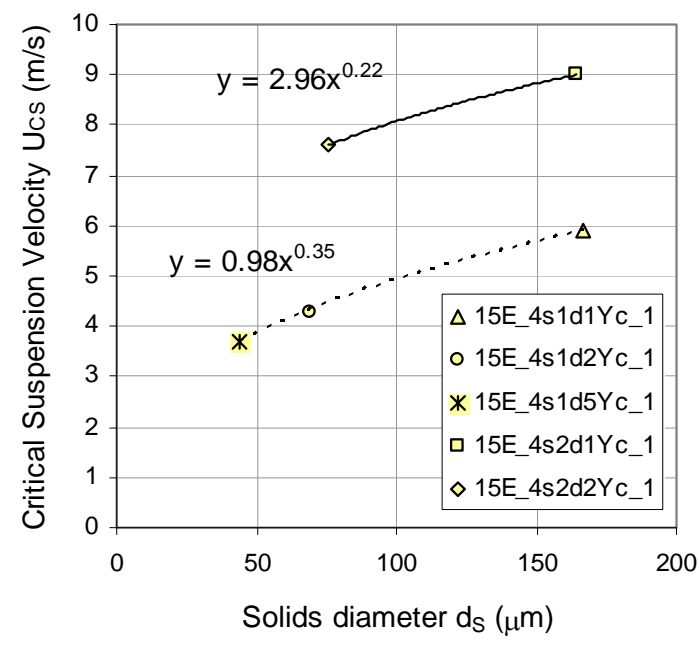

(a)

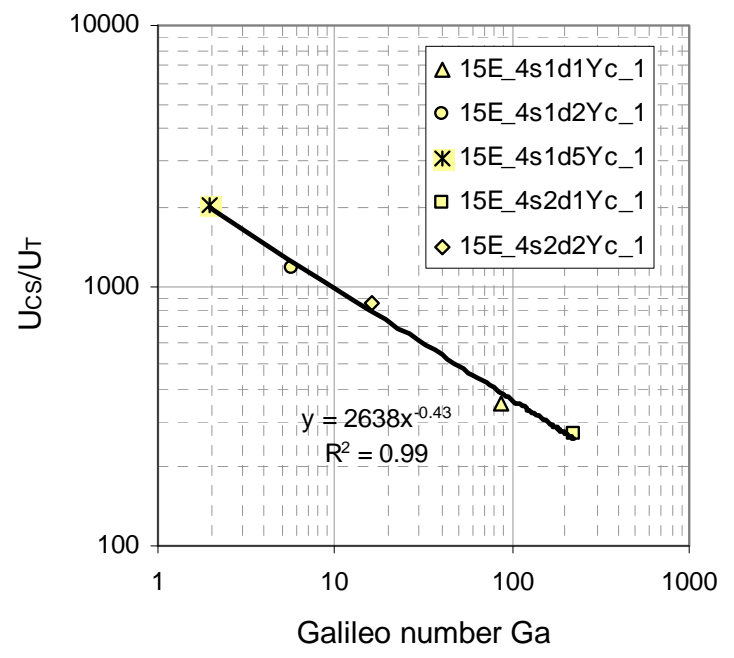

(b)

Figure 7.6. Illustrating the Benefit of Using Setting Velocity to Model $U_{\text {CS }}$ Data; (a) Dimensional, (b) Nondimensional

Figure 7.7 illustrates the use of $U_{T}$ in modeling cloud height data. Figure 7.7 (a) shows that when the critical suspension Froude number based on $\mathrm{H}_{\mathrm{CS}}$ and $\mathrm{U}_{\mathrm{T}}\left(\mathrm{F}_{\mathrm{CST}}\right)$ is used, it correlates well with a function of $\mathrm{Ga}$ and (s-1). In Figure 7.7 (b), the Froude number (in Eq. 7.4) based on $\mathrm{H}_{\mathrm{C}}$ and $\mathrm{U}_{\mathrm{T}}$ is plotted versus $\mathrm{U} / \mathrm{U}_{\mathrm{T}}$. Also shown is the nondimensional cloud height data for $\mathrm{U} / \mathrm{U}_{\mathrm{CS}} \geq 1$. 


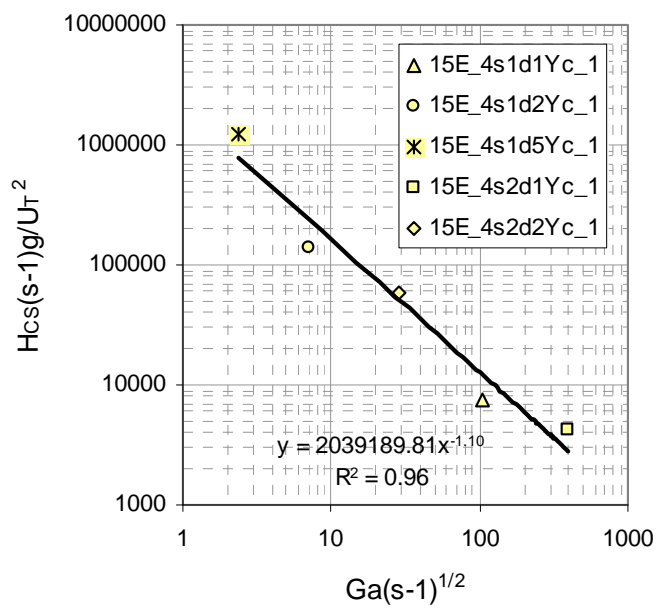

(a)

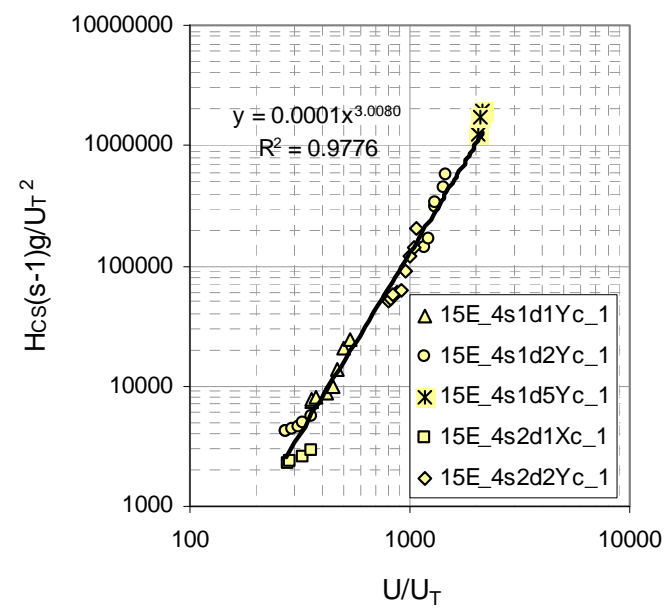

(b)

Figure 7.7. Illustration of the Benefit of Using Setting Velocity to Model Cloud Height Data: (a) $F_{\text {CST }}$ Plotted as a Function of $\mathrm{Ga}(\mathrm{s}-1)^{1 / 2}$, (b) $\mathrm{F}_{\mathrm{CST}}$ Plotted as a Function of $\mathrm{U} / \mathrm{U}_{\mathrm{T}}$

The effect of solids volume fraction $\left(\phi_{\mathrm{S}}\right)$ on $\mathrm{U}_{\mathrm{CS}}$ is illustrated in Figure $7.8(\mathrm{a})$, where data for all simulants in the small-scale tank are shown. At low concentration, the exponent on $\phi_{\mathrm{S}}$ is about 0.3. As solids loading is increased the exponent is reduced, becoming equal to zero when $\phi_{\mathrm{S}}$ is about $0.03-0.04$. Further increases in solids loading result in decreased $\mathrm{U}_{\mathrm{CS}}$. This behavior is consistent with the phenomenon of hindered settling. At higher solids loading the clouds are low, and the local concentration near the bottom of the tank becomes very high. The concentration where the maximum occurs is clearly a function of the particle properties; hence, the nonlinear interaction is complicated.

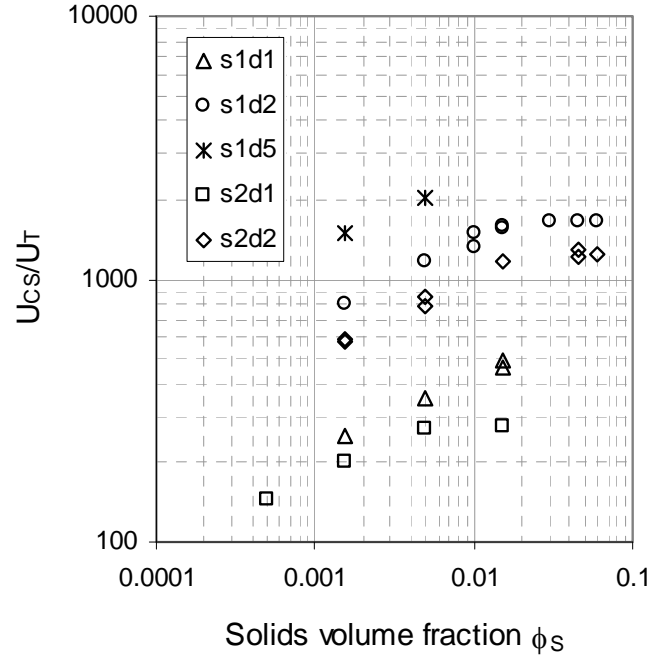

(a)

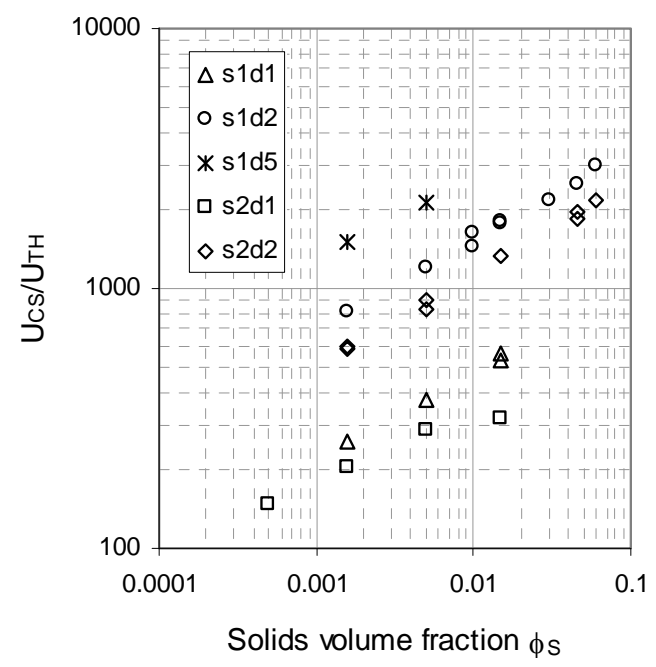

(b)

Figure 7.8. Effect of Solids Loading on $U_{C S}$ for Five Simulants in Small-Scale Tests: (a) $U_{C S} / U_{T}$ Plotted as a Function of $\phi_{\mathrm{S}}$, (b) $\mathrm{U}_{\mathrm{CS}} / \mathrm{U}_{\mathrm{TH}}$ Plotted as a Function of $\phi_{\mathrm{S}}$ 
As a first-order means of accounting for the observed behavior, we introduce a modified settling velocity $\left(\mathrm{U}_{\mathrm{TH}}\right)$ that is analogous in form to models for hindered settling:

$$
\mathrm{U}_{\mathrm{TH}}=\mathrm{U}_{\mathrm{T}}\left(1-\phi_{\mathrm{S}} / \phi_{\mathrm{S} \max }\right)^{\mathrm{p}}
$$

Subsequently, $\mathrm{U}_{\mathrm{TH}}$ is referred to as the terminal hindered settling velocity. Thus, for a specific test condition, since $\phi_{\mathrm{S}}$ is constant, the hindered settling velocity of Eq. (7.11) is constant for that test.

In Eq. (7.11), the term $\phi_{\text {Smax }}$ is the solids fraction corresponding to maximum packing, and $\mathrm{p}$ is an empirical constant. For our simulants, $\phi_{\text {Smax }}$ ranged from about 0.57 to 0.63 with an average of about 0.60 (Table 3.6). Figure $7.8 \mathrm{~b}$ shows the same data with $\mathrm{U}_{\mathrm{CS}} / \mathrm{U}_{\mathrm{TH}}$ plotted versus $\phi_{\mathrm{S}}$, where $\phi_{\mathrm{Smax}}=0.5$ was used (as noted above with regards to Eq. (7.11), $\phi_{\mathrm{S}}$ is the solid volume fraction for the reference volume $\left(\mathrm{V}_{\mathrm{REF}}\right)$, thus $\phi_{\text {Smax }}=0.5$ has essentially no effect on the results). With the addition of the term for hindered terminal settling velocity, the slopes for the different particles are now approximately constant.

The effect of solids loading on cloud height is demonstrated in Figure 7.9. Here inverse Froude number based on $\mathrm{H}_{\mathrm{CS}}$ and $\mathrm{U}_{\mathrm{T}}$ is shown versus $\mathrm{U}_{\mathrm{CS}} / \mathrm{U}_{\mathrm{T}}$ in Figure 7.9 (a). Figure 7.9 (b) accounts for the hindered settling effect by using $U_{\mathrm{TH}}$ in both the Froude number and the velocity ratio. Also, the inverse Froude number is multiplied by $\phi_{\mathrm{s}}$, which accounts for the difference in solids loadings.

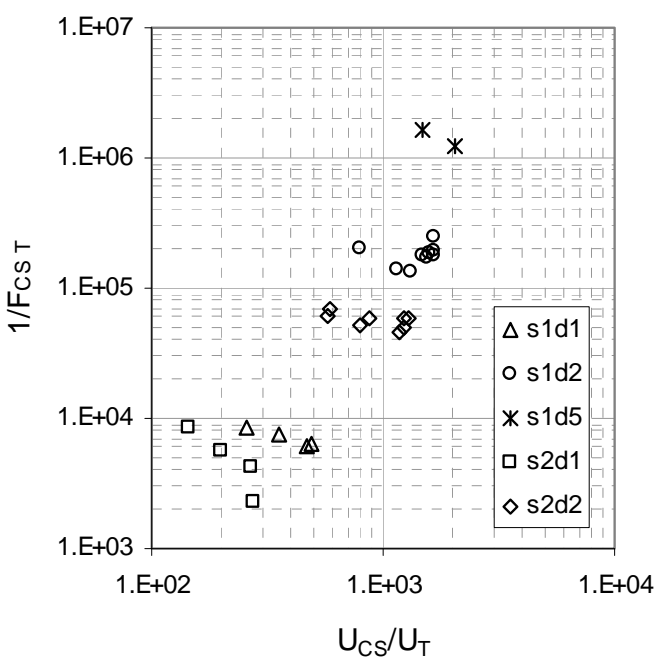

(a)

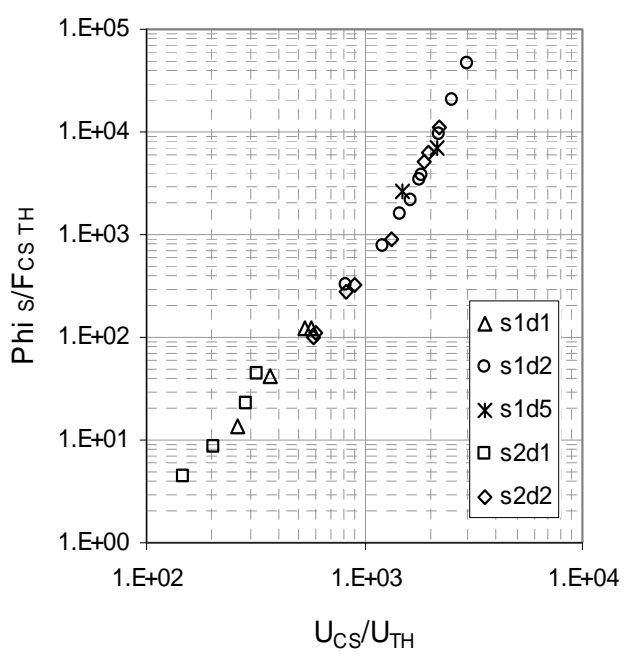

(b)

Figure 7.9. Effect of Solids Loading on Cloud Height for Five Simulants in Small-Scale Tests:

(a) $1 / F_{C S T}$ Plotted as a Function of $U_{\mathrm{CS}} / \mathrm{U}_{\mathrm{T}}$, (b) $\phi_{\mathrm{S}} / \mathrm{F}_{\mathrm{CS} \text { TH }}\left(\mathrm{Phi}_{\mathrm{S}} / \mathrm{F}_{\mathrm{CS} \mathrm{TH}}\right)$ Plotted as a Function of $\mathrm{U}_{\mathrm{CS}} / \mathrm{U}_{\mathrm{TH}}$

Viscosity was not one of the variables in the test data. While a recommendation of this report is to include viscosity effects in limited follow-on experiments, the effect of viscosity is included implicitly in the particle settling velocity. Testing will help assess whether the influence of viscosity extends beyond particle settling. 


\subsubsection{Operational Parameters}

The primary operational parameters are duty cycle (DC) and pulse volume fraction $\left(\phi_{\mathrm{p}}\right)$. These two terms describe the unsteady jet mixing effects. In the WTP vessel mixing designs, duty cycle ranges from about 0.18 to 0.35 . Tests at higher duty cycle were included to obtain some insight into the potential benefit of sequential operation and to compare the data with steady jet mixing results. In the WTP vessel mixing design, $\phi_{\mathrm{p}}$ ranges from about 0.04 to 0.1 . Testing was performed for $\phi_{\mathrm{p}}$ up to 0.15 to gain some understanding of the performance of large pulse tubes. Values for these parameters are found in Appendix B, in columns 4 and 5 of the data tables for each test. Figure 7.10 shows the effects of duty cycle on $\mathrm{U}_{\mathrm{CS}}$ and $\mathrm{H}_{\mathrm{CS}}$. Data are from the small-scale tank with $\phi_{\mathrm{S}}=0.015$ for values of pulse volume fraction. The sensitivity of duty cycle on $U_{C S}$ depends on pulse volume fraction. For small values of $\phi_{\mathrm{p}}$, $\mathrm{U}_{\mathrm{CS}} \sim \mathrm{DC}^{-1 / 2}$. For larger values of $\phi_{\mathrm{p}}$ and smaller values of duty cycle, $\mathrm{U}_{\mathrm{CS}}$ is relatively insensitive to duty cycle. Figure 7.10b shows $\mathrm{H}_{\mathrm{CS}}$ is a strong function of DC. In Figure 7.11 the same data are plotted versus $\phi_{\mathrm{p}}$ for families of constant DC.

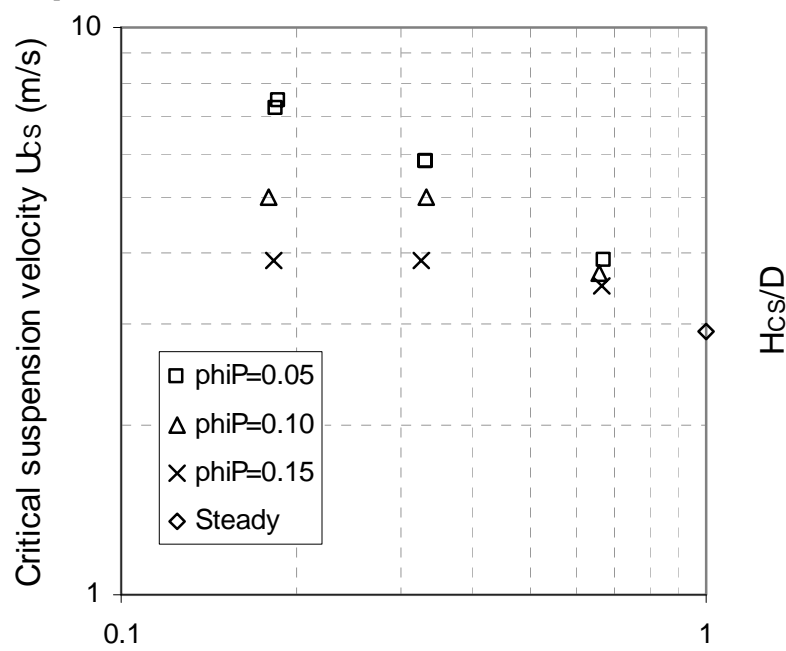

Duty cycle DC

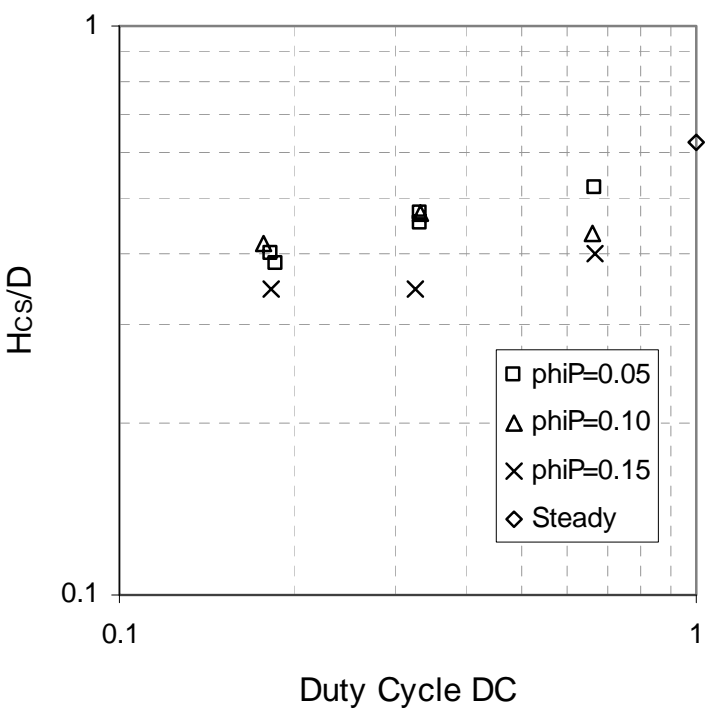

(b)

Figure 7.10. Effect of Duty Cycle on Solids Suspension with Data from Small-Scale Vessel with Simulant s1d2 and $\phi_{\mathrm{S}}=0.015$; (a) $\mathrm{U}_{\mathrm{CS}}$, and (b) Cloud Height

From the $\mathrm{U}_{\mathrm{CS}}$ and $\mathrm{H}_{\mathrm{CS}}$ data shown in Figure 7.10, one can obtain a sense for the difference between pulse jet mixing $(\mathrm{DC}<1)$ and steady jet mixing $(\mathrm{DC}=1)$. For $\phi_{\mathrm{p}}=0.05$ and $\mathrm{DC}=0.18, \mathrm{U}_{\mathrm{CSpulsed}} / \mathrm{U}_{\mathrm{CSsteady}}$ is approximately 2.5 and $\mathrm{H}_{\mathrm{CSpulsed}} / \mathrm{H}_{\mathrm{CSsteady}}$ is approximately 0.6. Using the approximate relationship from Section 7.2.2, $\mathrm{H}_{\mathrm{C}} / \mathrm{H}_{\mathrm{CS}} \sim\left(\mathrm{U} / \mathrm{U}_{\mathrm{CS}}\right)^{2}$, for the same cloud height (equivalent vertical distribution) we find $\mathrm{U}_{\text {pulsed }} / \mathrm{U}_{\text {steady }}=0.6^{-1 / 2} * 2.5=3.2$. Hence, the pulse jet velocity must be about 3 times larger than the steady jet velocity for equivalent cloud height. Because the hydraulic mixing power is proportional to $\mathrm{U}^{3}$ (see Section 7.3.1), it follows that the pulse jet requires 27 times more power for the same cloud height. This is instantaneous jet power; for average power the duty cycle must be factored in. Hence, for this example, $\mathrm{DC}=0.18$ and average pulse jet power is $0.18 * 27=4.9$. Even after factoring in duty cycle, about five times more total energy is required for pulse jets. The difference between pulse jet and steady jet mixing is greatly reduced as DC is increased. For example, if $\mathrm{DC}=0.5$, as used in the previous example, the instantaneous power required for equivalent mixing is about $5 \mathrm{X}$, and the average power is about $2.5 \mathrm{X}$. 


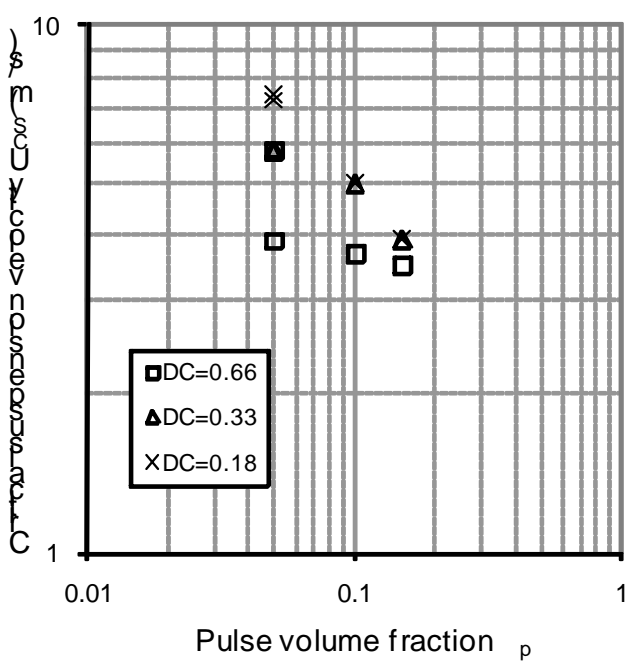

(a)

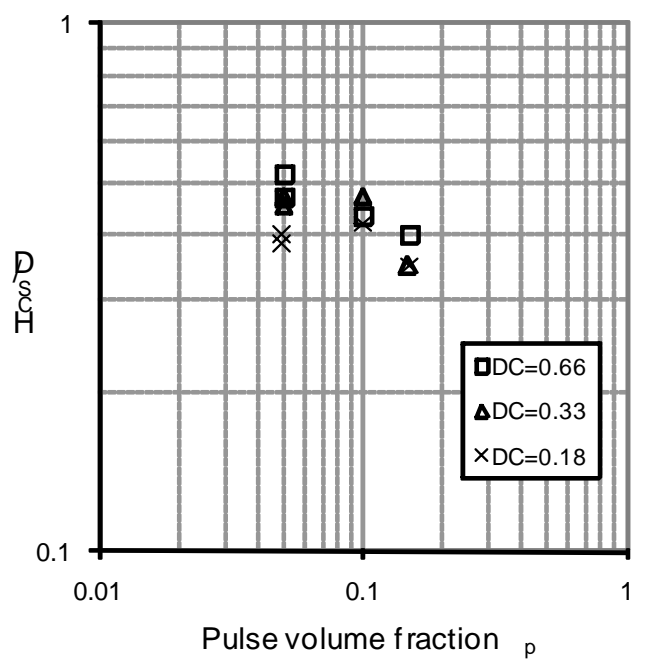

(b)

Figure 7.11. Effect of Pulse Volume Fraction $\left(\phi_{\mathrm{p}}\right)$ on Solids Suspension: (a) $U_{C S}$, (b) $H_{C}$ Data from 15-in. Vessel with Simulant s1d2 and $\phi_{\mathrm{S}}=0.015$

\subsubsection{Geometry}

The primary geometric variables include number of jets (N), jet diameter (d), and tank diameter (D). Also important is the dished bottom, the radial arrangement of PJMs, and the impingement angle of the jets on the bottom. Other geometric variables include PJM outer diameter and nozzle shape and standoff.

Figure 7.12 demonstrates the value of the jet density $\left(\phi_{\mathrm{J}}\right)$ where

$$
\phi_{\mathrm{J}}=\mathrm{N}(\mathrm{d} / \mathrm{D})^{2}
$$

for multiple jet systems. Figure 7.12 (a) shows $U_{C S} / U_{T}$ versus nozzle diameter for $N=4$, 8, and 12; Figure 7.12 (b) shows the same data plotted versus $\phi_{\mathrm{J}}$. The result indicates

$$
\mathrm{U}_{\mathrm{CS}} \sim \mathrm{N}^{1 / 2} \mathrm{~d}
$$

which is the nozzle diameter for the total jet discharge area.

Several different dish bottom geometries were tested, with relevant parameters shown in Table 7.1 (FIO). The effect of geometry can be explored by introducing leading geometric constants $\left(\mathrm{k}_{\mathrm{U}}\right.$ and $\left.\mathrm{k}_{\mathrm{C}}\right)$ for $\mathrm{U}_{\mathrm{CS}}$ and $\mathrm{H}_{\mathrm{C}}$, respectively ${ }^{1}$. Best-fit values for these were determined for the $70 \mathrm{~F}$ and $34 \mathrm{~S}$ tanks; the constants for $15 \mathrm{E}$ and $70 \mathrm{E}$ are defined to be 1 . When less than 12 operating jets were tested in any of the geometries, the dish constant was not adjusted even if the radial position was adjusted. Any geometric effects associated with different impingement angles were not accounted for in the constants shown in Table 7.1. The constants for the F\&D head in the large-scale tank were found to be 0.94 and 1.04 for $\mathrm{U}_{\mathrm{CS}}$ and $\mathrm{H}_{\mathrm{C}}$, respectively.

\footnotetext{
${ }^{1}$ The geometric constants are multipliers on the right side of a correlation for $U_{C S}$ and $H_{C}$. For example $U_{C S}=k_{U} x$ $\mathrm{f}$ (test variables), where $\mathrm{k}_{\mathrm{U}}$ is only a function of dish shape.
} 

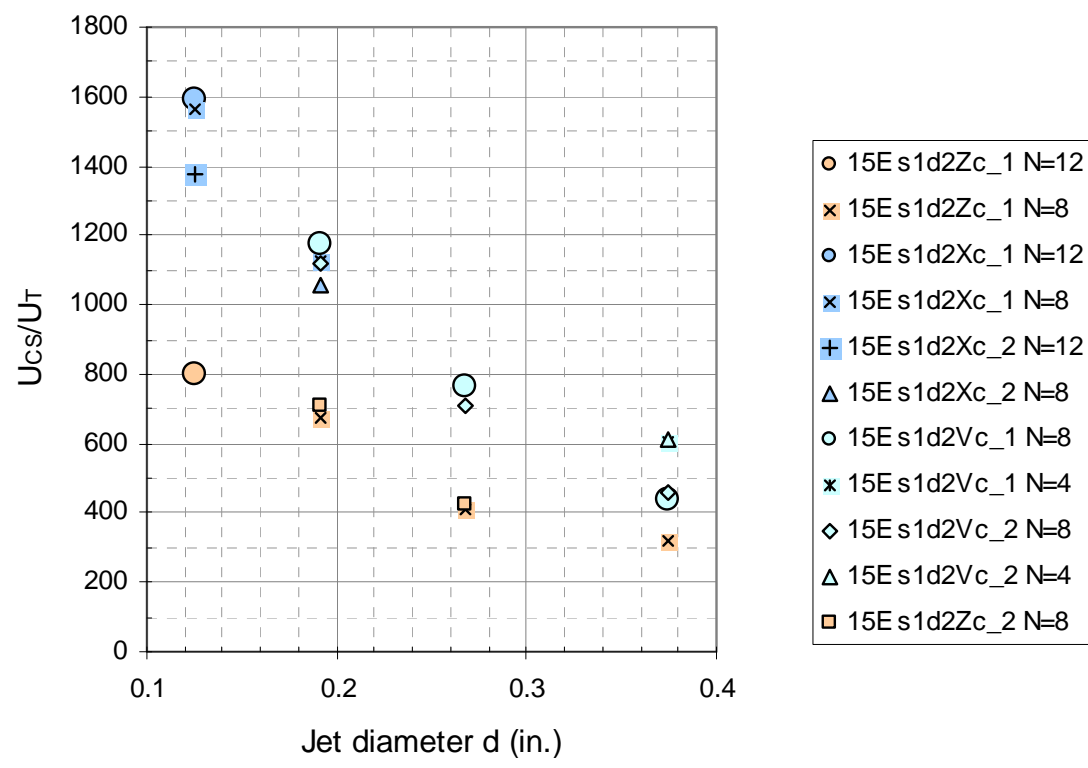

(a)

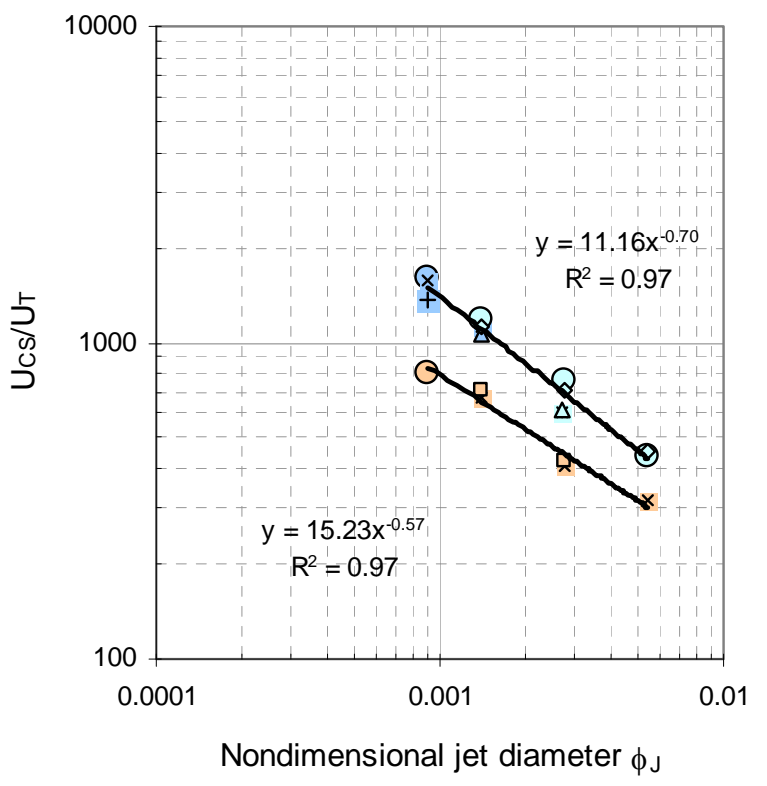

0 15E s1d2Zc_1 N=12
$\times 15 E$ s1d2Zc_1 N=8
$015 E$ s1d2Xc_1 N=12
$\times 15 E$ s1d2Xc_1 N=8
$+15 E$ s1d2Xc_2 N=12
$\Delta$ 15E s1d2Xc_2 N=8
$015 E$ s1d2Vc_1 N=8
$* 15 E$ s1d2Vc_1 N=4
$\diamond 15 E$ s1d2Vc_2 N=8
$\Delta 15 E$ s1d2Vc_2 N=4
$\square 15 E$ s1d2Zc_2 N=8

(b)

Figure 7.12. Effect of Nozzle Diameter, Jet Diameter, and Number of Operating Pulse Tubes for Small-Scale Tank: (a) $\mathrm{U}_{\mathrm{CS}} / \mathrm{U}_{\mathrm{T}}$ as a Function of d, (b) $\mathrm{U}_{\mathrm{CS}} / \mathrm{U}_{\mathrm{T}}$ as a Function of $\phi_{\mathrm{J}}$

In principle, we could model the geometric constants in terms of ring radius and impingement angle. Because of the limited number of combinations tested, this was considered to add little value over a simple dish constant. The values obtained for the dish constants are reasonable when considering the likely geometric effect on the bulk flow in the tank. 
Table 7.1. As-Tested Dish Parameters and Geometric Coefficients for Various Dish Shapes (FIO)

\begin{tabular}{|c|c|c|c|c|c|c|c|}
\hline $\begin{array}{l}\text { Tank and } \\
\text { PJM } \\
\text { Configuration }\end{array}$ & $\begin{array}{l}\text { Dish } \\
\text { Type }\end{array}$ & $\begin{array}{c}\text { Inner Ring } \\
\text { Radius/Tank } \\
\text { Radius }\end{array}$ & $\begin{array}{c}\text { Outer Ring } \\
\text { Radius/Tank } \\
\text { Radius }\end{array}$ & $\begin{array}{c}\text { Inner Ring } \\
\text { Impingement } \\
\text { Angle }\end{array}$ & $\begin{array}{c}\text { Outer Ring } \\
\text { Impingement } \\
\text { Angle }\end{array}$ & $\begin{array}{c}\text { Geometric } \\
\text { Constant } \\
\text { for } U_{\mathrm{CS}}\end{array}$ & $\begin{array}{c}\text { Geometric } \\
\text { Constant } \\
\text { for } \mathrm{H}_{\mathrm{C}}\end{array}$ \\
\hline Tank & & $\mathrm{R}_{\mathrm{I}} / \mathrm{R}$ & $\mathrm{R}_{\mathrm{O}} / \mathrm{R}$ & $\theta_{\mathrm{I}}$ & $\theta_{\mathrm{O}}$ & $\mathrm{k}_{\mathrm{U}}$ & $\mathrm{k}_{\mathrm{C}}$ \\
\hline 15E 4/8-tube & $\begin{array}{l}2: 1 \\
\text { Elliptical }\end{array}$ & 0.50 & 0.67 & $16.0^{\circ}$ & $24.4^{\circ}$ & NA & NA \\
\hline 15E 12-tube & $\begin{array}{l}2: 1 \\
\text { Elliptical }\end{array}$ & 0.34 & 0.62 & $10.1^{\circ}$ & $21.8^{\circ}$ & 1 & 1 \\
\hline 70E 4/8-tube & $\begin{array}{l}2: 1 \\
\text { Elliptical }\end{array}$ & 0.50 & 0.67 & $16.1^{\circ}$ & $21.9^{\circ}$ & NA & NA \\
\hline 70E 12-tube & $\begin{array}{l}2: 1 \\
\text { Elliptical }\end{array}$ & 0.33 & 0.62 & $10.5^{\circ}$ & $20.3^{\circ}$ & 1 & 1 \\
\hline 70F 12-tube & $\mathrm{F} \& \mathrm{D}$ & 0.34 & 0.76 & $9.7^{\circ}$ & $22.4^{\circ}$ & 0.94 & 1.04 \\
\hline 34S 12-tube & Spherical & 0.33 & 0.62 & $16.1^{\circ}$ & $30.8^{\circ}$ & 0.85 & 1.35 \\
\hline
\end{tabular}

\subsubsection{Scale}

Direct scale-up data were obtained for the 14 different test conditions evaluated in the 15E and 70E tanks; these conditions are shown in Table 7.2. The exponent on tank scale (referred to as the scale-up exponent, $\alpha$ ) is given by

$$
\alpha=\frac{\ln \left(\mathrm{y}_{70} / \mathrm{y}_{15}\right)}{\ln \left(\mathrm{SF}_{70-15}\right)}
$$

where $\mathrm{y}_{70}$ and $\mathrm{y}_{15}$ are measured variables $\left(\mathrm{U}_{\mathrm{CS}}\right.$ or $\left.\mathrm{H}_{\mathrm{CS}}\right)$ in the large- and small-scale tanks, respectively, and the scale factor (SF) is $\mathrm{SF}_{70-15}=\mathrm{D}_{70} / \mathrm{D}_{15}=70 / 14.44=4.85$.

Table 7.2. Direct Scale-up Data from Elliptical Tests: Ratios of Measured Variables at Large Versus Small Scales

\begin{tabular}{|c|c|c|c|c|c|c|c|c|c|c|c|}
\hline \multicolumn{5}{|c|}{ Condition } & \multicolumn{4}{|c|}{ Critical Suspension Conditions } & \multicolumn{3}{|c|}{ Average Cloud Data for $U \geq U_{\mathrm{CS}}$} \\
\hline d & Simulant & $\phi_{\mathrm{S}}$ & DC & $\phi_{\mathrm{p}}$ & $\mathrm{U}_{\mathrm{CS}}$ & $\mathrm{H}_{\mathrm{CS}}$ & $\mathrm{U}_{\mathrm{CS}}^{2} / \mathrm{H}_{\mathrm{CS}}$ & $\mathrm{U}_{\mathrm{CS}}^{3} / \mathrm{H}_{\mathrm{CS}}$ & $\left(\mathrm{U}^{2} / \mathrm{H}_{\mathrm{C}}\right) \mathrm{avg}$ & $\left(\mathrm{U}^{3} / \mathrm{H}_{\mathrm{C}}\right) \mathrm{avg}$ & $\left(\mathrm{U}^{4} / \mathrm{H}_{\mathrm{C}}\right) \mathrm{avg}$ \\
\hline 4 & s1d1 & 0.00155 & 0.18 & 0.05 & 1.58 & 4.52 & 0.55 & 0.87 & 0.65 & 1.14 & 1.94 \\
\hline 4 & s1d1 & 0.00155 & 0.33 & 0.05 & 1.69 & 5.24 & 0.55 & 0.92 & 0.72 & 1.17 & 1.89 \\
\hline 4 & s1d2 & 0.00155 & 0.18 & 0.05 & 1.59 & 3.85 & 0.65 & 1.04 & 0.75 & 1.15 & 1.75 \\
\hline 4 & s1d2 & 0.015 & 0.18 & 0.05 & 1.61 & 7.48 & 0.35 & 0.56 & 0.38 & 0.55 & 0.80 \\
\hline 4 & s1d2 & 0.00155 & 0.34 & 0.05 & 1.64 & 4.22 & 0.64 & 1.05 & 0.70 & 1.05 & 1.57 \\
\hline 4 & s1d2 & 0.005 & 0.34 & 0.05 & 1.40 & 5.24 & 0.37 & 0.52 & 0.54 & 0.73 & 0.99 \\
\hline 4 & s1d2 & 0.01 & 0.34 & 0.05 & 1.36 & 6.22 & 0.30 & 0.40 & 0.43 & 0.57 & 0.75 \\
\hline 4 & s1d2 & 0.015 & 0.34 & 0.05 & 1.47 & 6.38 & 0.34 & 0.49 & 0.45 & 0.57 & 0.73 \\
\hline 4 & $\mathrm{~s} 2 \mathrm{~d} 2$ & 0.00155 & 0.34 & 0.05 & 1.62 & 4.22 & 0.62 & 1.00 & 0.66 & 1.08 & 1.75 \\
\hline 4 & $\mathrm{~s} 2 \mathrm{~d} 2$ & 0.005 & 0.34 & 0.05 & 1.64 & 4.43 & 0.61 & 1.00 & 0.57 & 0.89 & 1.38 \\
\hline 6 & s1d2 & 0.0143 & 0.33 & 0.05 & 1.42 & 7.33 & 0.27 & 0.39 & 0.30 & 0.42 & 0.57 \\
\hline 6 & s1d2 & 0.00155 & 0.33 & 0.05 & 1.69 & 9.78 & 0.29 & 0.50 & 0.40 & 0.63 & 0.96 \\
\hline 6 & s1d2 & 0.0143 & 0.33 & 0.05 & 1.45 & 6.45 & 0.33 & 0.48 & 0.50 & 0.73 & 1.07 \\
\hline 6 & s1d2 & 0.00155 & 0.33 & 0.05 & 1.54 & 5.35 & 0.44 & 0.68 & 0.35 & 0.47 & 0.64 \\
\hline \multicolumn{5}{|c|}{ Average } & 1.55 & 5.77 & 0.45 & 0.71 & 0.53 & 0.80 & 1.20 \\
\hline \multicolumn{5}{|c|}{ Standard Deviation } & 0.11 & 1.64 & 0.15 & 0.26 & 0.15 & 0.27 & 0.50 \\
\hline
\end{tabular}


Table 7.2 shows values of the ratios $\mathrm{y}_{70} / \mathrm{y}_{15}$ for $\mathrm{y}=\mathrm{U}_{\mathrm{CS}}$ and $\mathrm{H}_{\mathrm{CS}}$, as well as other variables. The quantity $\mathrm{U}_{\mathrm{CS}}^{2} / \mathrm{H}_{\mathrm{CS}}$ is the simplified Froude number, and $\mathrm{U}_{\mathrm{CS}}^{3} / \mathrm{H}_{\mathrm{CS}}$ is a power-type number. The other terms required for dimensional consistency [density ratio (s), gravitational constant (g), etc.] are neglected because they will cancel out in the ratios. The average ratios in Table 7.2 for $\mathrm{H}_{\mathrm{C}}$ data with $\mathrm{U} \geq \mathrm{U}_{\mathrm{CS}}$ were obtained by averaging the indicated variables for each test. This was necessary because, in general, values of $\mathrm{H}_{\mathrm{C}}$ and $\mathrm{U}$ were not the same for tests at both scales. The scale-up exponents derived from the ratios are shown in Table 7.3.

Table 7.3. Direct Scale-up Data from Elliptical Tests: Scale Exponents Based on Large- Versus Small-Scale Data

\begin{tabular}{|c|c|c|c|c|c|c|c|c|c|c|c|}
\hline \multicolumn{5}{|c|}{ Condition } & \multicolumn{4}{|c|}{ Critical Suspension Conditions } & \multicolumn{3}{|c|}{ Average Cloud Data for $U \geq U_{C S}$} \\
\hline $\mathrm{d}$ & Simulant & $\phi_{\mathrm{S}}$ & DC & $\phi_{\mathrm{p}}$ & $\mathrm{U}_{\mathrm{CS}}$ & $\mathrm{H}_{\mathrm{CS}}$ & $\mathrm{U}_{\mathrm{CS}}^{2} / \mathrm{H}_{\mathrm{CS}}$ & $\mathrm{U}^{3}{ }_{\mathrm{CS}} / \mathrm{H}_{\mathrm{CS}}$ & $\left(\mathrm{U}^{2} / \mathrm{H}_{\mathrm{C}}\right) \mathrm{avg}$ & $\left(\mathrm{U}^{3} / \mathrm{H}_{\mathrm{C}}\right) \mathrm{avg}$ & $\left(\mathrm{U}^{4} / \mathrm{H}_{\mathrm{C}}\right) \mathrm{avg}$ \\
\hline 4 & s1d1 & 0.00155 & 0.18 & 0.05 & 0.29 & 0.96 & -0.38 & -0.09 & -0.27 & 0.08 & 0.42 \\
\hline 4 & s1d1 & 0.00155 & 0.33 & 0.05 & 0.33 & 1.05 & -0.38 & -0.05 & -0.21 & 0.10 & 0.40 \\
\hline 4 & s1d2 & 0.00155 & 0.18 & 0.05 & 0.29 & 0.85 & -0.27 & 0.02 & -0.18 & 0.09 & 0.35 \\
\hline 4 & s1d2 & 0.015 & 0.18 & 0.05 & 0.30 & 1.27 & -0.67 & -0.37 & -0.61 & -0.37 & -0.14 \\
\hline 4 & s1d2 & 0.00155 & 0.34 & 0.05 & 0.31 & 0.91 & -0.28 & 0.03 & -0.23 & 0.03 & 0.29 \\
\hline 4 & s1d2 & 0.005 & 0.34 & 0.05 & 0.21 & 1.05 & -0.63 & -0.42 & -0.39 & -0.20 & -0.01 \\
\hline 4 & s1d2 & 0.01 & 0.34 & 0.05 & 0.19 & 1.16 & -0.77 & -0.58 & -0.53 & -0.36 & -0.18 \\
\hline 4 & s1d2 & 0.015 & 0.34 & 0.05 & 0.24 & 1.17 & -0.69 & -0.45 & -0.51 & -0.35 & -0.20 \\
\hline 4 & $\mathrm{~s} 2 \mathrm{~d} 2$ & 0.00155 & 0.34 & 0.05 & 0.30 & 0.91 & -0.30 & 0.00 & -0.26 & 0.05 & 0.36 \\
\hline 4 & $\mathrm{~s} 2 \mathrm{~d} 2$ & 0.005 & 0.34 & 0.05 & 0.32 & 0.94 & -0.31 & 0.00 & -0.36 & -0.08 & 0.21 \\
\hline 6 & s1d2 & 0.0143 & 0.33 & 0.05 & 0.22 & 1.26 & -0.82 & -0.60 & -0.77 & -0.56 & -0.35 \\
\hline 6 & s1d2 & 0.00155 & 0.33 & 0.05 & 0.33 & 1.44 & -0.78 & -0.44 & -0.57 & -0.30 & -0.02 \\
\hline 6 & s1d2 & 0.0143 & 0.33 & 0.05 & 0.24 & 1.18 & -0.71 & -0.47 & -0.44 & -0.20 & 0.04 \\
\hline 6 & s1d2 & 0.00155 & 0.33 & 0.05 & 0.27 & 1.06 & -0.52 & -0.25 & -0.67 & -0.47 & -0.28 \\
\hline \multicolumn{5}{|c|}{ Average } & 0.28 & 1.09 & -0.54 & -0.26 & -0.43 & -0.18 & 0.06 \\
\hline \multicolumn{5}{|c|}{ Standard Deviation } & 0.05 & 0.17 & 0.21 & 0.24 & 0.19 & 0.23 & 0.27 \\
\hline
\end{tabular}

Some examples of the scale-up data for $\mathrm{U}_{\mathrm{CS}}$ are shown in Figure 7.13. The upper plot shows the $\mathrm{U}_{\mathrm{CS}} / \mathrm{U}_{\mathrm{CS} 15}$, and the lower plot shows a best fit of scale-up data. The average scale-up exponent for $\mathrm{U}_{\mathrm{CS}}$ based on the data is $0.28 \pm 0.05$. The scale-up data for $\mathrm{H}_{\mathrm{C}}$ equal to and above $\mathrm{U}_{\mathrm{CS}}$ indicates non-powerlaw behavior since the scale-up exponents for the averaged variables $\mathrm{U}^{\mathrm{n}} / \mathrm{H}_{\mathrm{C}}$ show a dependence on the velocity exponent $\mathrm{n}$. Figure 7.14 shows the scale-up exponent versus $\mathrm{n}$ for the average cloud data. For tests at a given scale it turns out that $\mathrm{H}_{\mathrm{C}} \sim \mathrm{U}^{3}$ is a reasonable approximation of cloud behavior (see Figure 7.7). Based on this we would expect an average cloud height scale-up exponent of about 0.2.

Studies of the complete data set yield cloud scale-up exponent values ranging from 0.1 to 0.4 , depending on the details of the fitting approach and which data are included. Gravitational work-energy arguments alone suggest $\mathrm{H}_{\mathrm{C}}$ is independent of scale. However, if $\phi_{\mathrm{s}}$ is held constant as scale is increased (in which case the volume of solids increases with the cube of the scale), the average solids concentration in clouds of constant height will increase proportional to scale (because the volume of the cloud would increase only as the square of the scale). Hence, the settling velocity would be reduced because of the hindering effect, and the cloud height could not be constant, but would have to increase slightly. If the same energy arguments are applied to the change in cloud position due to a single pulse, scale comes into play from the presence of concentration gradients. Scale also can contribute through the jet Reynolds number. While all testing occurred at conditions above the turbulent transition for free jets, there still can be a weak Reynolds number effect. For example, the floor shear stress in a turbulent boundary layer is proportional to $\mathrm{Re}^{-1 / 5}$ (Schlichting 1979). It is not known exactly how the shear stress Re dependence 
directly translates to the impinging jet and associated slurry flow, but it is reasonable that it would be would be on the order of 0.1 . Thus, a scale-up on the order of $0.2-0.4$ due to the combined effects mentioned here is reasonable.

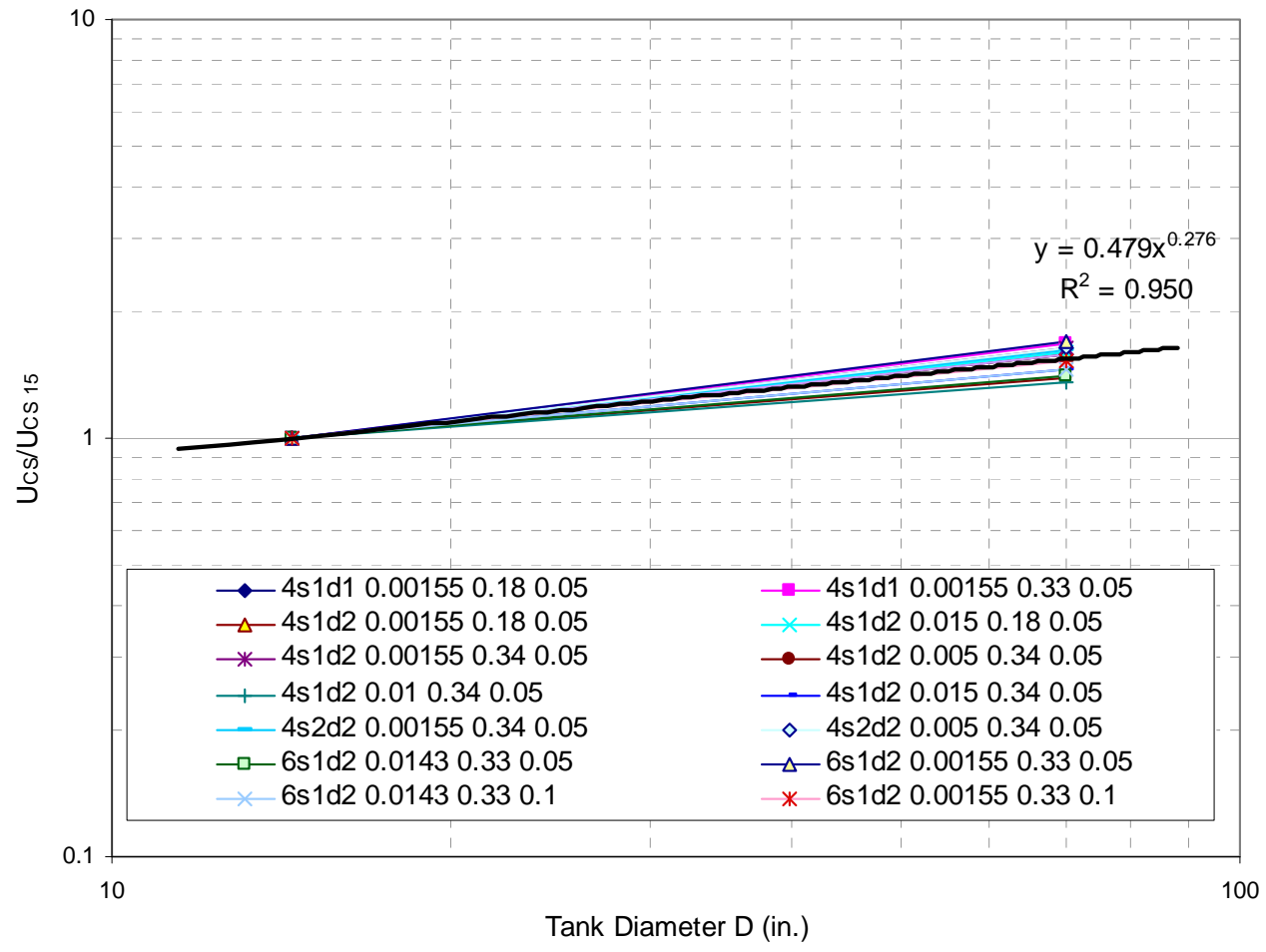

Figure 7.13. Scale Dependence of $\mathrm{U}_{\mathrm{Cs}}$ : $\mathrm{U}_{\mathrm{CS}} / \mathrm{U}_{\mathrm{CS} 15}$ versus Tank Diameter with Fit of Scale-up Data Showing Scale-Up Exponent of 0.276.

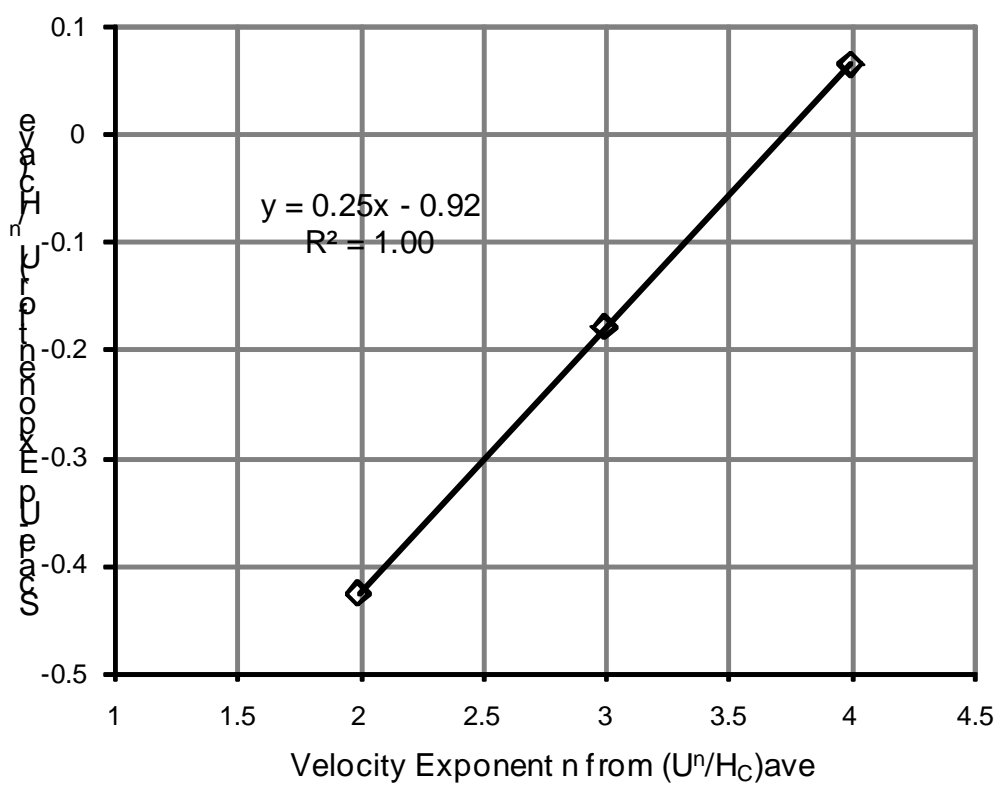

Figure 7.14. Scale-up Exponent for Average Cloud Parameters $\left(\mathrm{U}^{\mathrm{n}} / \mathrm{H}_{\mathrm{C}}\right)_{\text {ave }}$ as a Function of Velocity Exponent, $n$ 


\subsubsection{Pulse Shape}

This section addresses the effects of pulse shape on $\mathrm{U}_{\mathrm{CS}}$ and $\mathrm{H}_{\mathrm{C}}$. Pulse shape varied during testing as a function of average jet velocity and test scale. A generic drive function is shown in Figure 7.15. To account for these variations, four different velocity integrals were computed from the test data. These all have the form:

$$
\mathrm{U}_{\mathrm{n}}=\left(\frac{1}{\Delta \mathrm{t}_{\mathrm{n}}} \int \mathrm{U}(\mathrm{t})^{\mathrm{n}} \mathrm{dt}\right)^{1 / \mathrm{n}} \quad \mathrm{n}=1,2,3 \text {, and peak average with } \mathrm{n}=1, \Delta \mathrm{t}_{\mathrm{n}}=\text { primary discharge time }
$$

where $\mathrm{U}(\mathrm{t})$ is instantaneous velocity, and $\Delta \mathrm{t}_{\mathrm{n}}$ is the time interval over which the integration is performed. The velocities $U_{1}, U_{2}$, and $U_{3}$ correspond to mass, momentum, and energy-based average velocities, respectively, where $\Delta \mathrm{t} \approx \mathrm{t}_{\mathrm{DA}}$. The velocity, $\mathrm{U}_{\mathrm{pa}}$, corresponds to the peak average velocity, which was observed visually or computed. The time interval for $\mathrm{U}_{\mathrm{pa}}$ is $\Delta \mathrm{t}_{\mathrm{m}}-\mathrm{t}_{\mathrm{D}}$, times associated within $\mathrm{U}_{\max }$ and $\mathrm{U}_{\text {end. }}$.

In analyzing the test data, the peak average velocity was used with the pulse shape ratio $\varepsilon_{31}$ :

$$
\varepsilon_{31}=\mathrm{U}_{3} / \mathrm{U}_{1}-1
$$

The pulse shape ratio is equal to 0 for a square wave and may be as high as $0.4-0.5$ for prototypic PJMs at plant scale. During testing, $\varepsilon_{31}$ varied from $\sim 0.01-0.3$, as shown in Figure 7.16. Analysis of the data indicates that $\mathrm{U}_{\mathrm{CS}} \sim\left(1+\varepsilon_{31}\right)^{0.4}$ and $\mathrm{H}_{\mathrm{C}} \sim\left(1+\varepsilon_{31}\right)^{-0.35}$ (FIO).

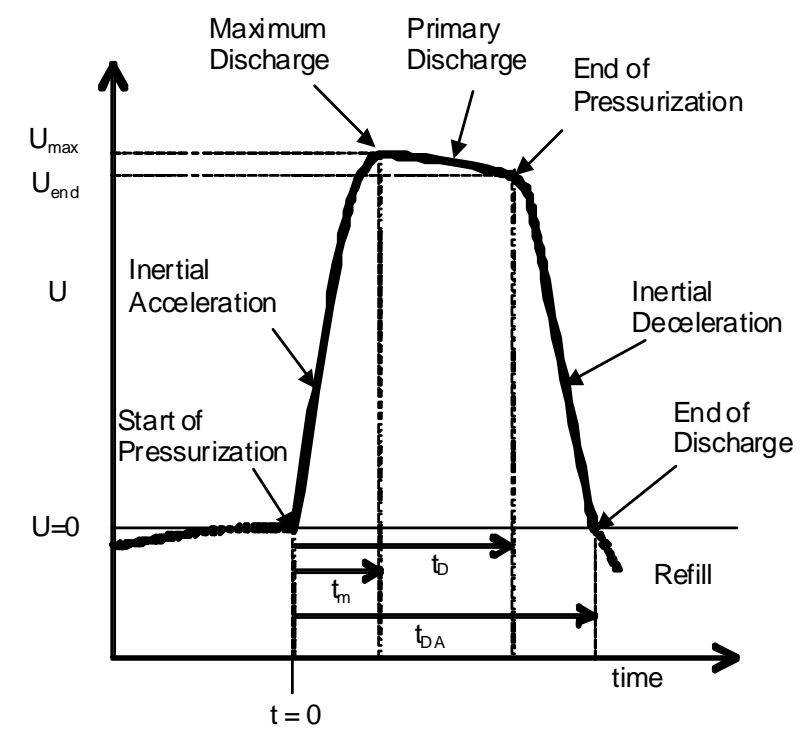

Figure 7.15. Illustration of Nozzle Velocity Transient during PJM Discharge 


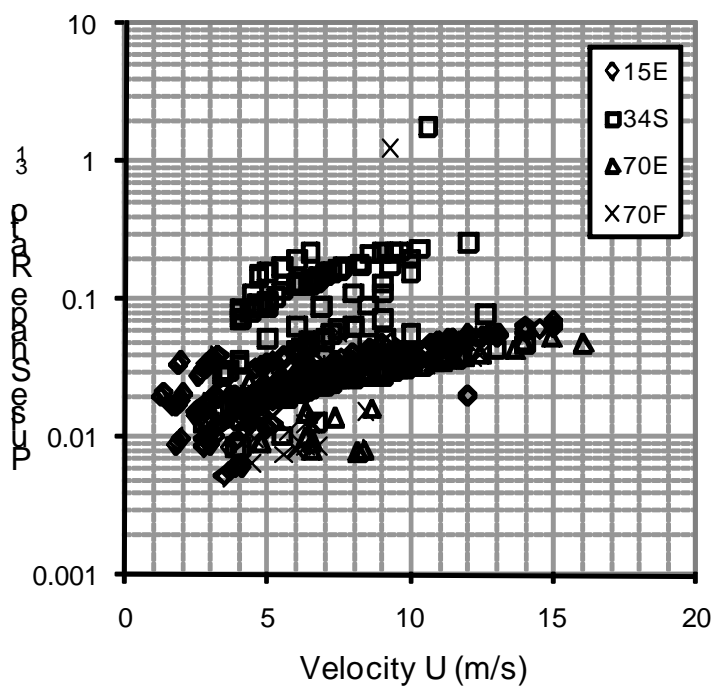

Figure 7.16. Pulse Shape Ratio versus Peak Average Velocity for Tests at Three Scales

\subsubsection{Aspects of Mixing Behavior Included in Model Development}

Not all of the mixing behavior aspects addressed in the previous subsections were included in limited model development efforts discussed subsequently in Sections 7.3 and 7.4. Specifically, experimental data were used that met the criteria

- $\mathrm{DC}<0.7$ (no steady jet data were included)

- $\mathrm{U} / \mathrm{U}_{\mathrm{CS}} \geq 1$ or the $\mathrm{H}_{\mathrm{C}}$ model $^{1}$

- Ratio of the return line height to the tank diameter $\geq 1$.

Additionally, the following variables were not included in the models:

- Dish geometric constants $\mathrm{k}_{\mathrm{U}}$ and $\mathrm{k}_{\mathrm{C}}$. The effects of dish geometry were not included in the models.

- Pulse shape parameter $\varepsilon_{31}$.

\subsection{Physical Model Results}

The nondimensional variables and models developed using the physical approach are described in Sections 7.3.1 to 7.3.4. Section 7.3.1 presents the nondimensional variables used to develop mixing models for $\mathrm{U}_{\mathrm{CS}}, \mathrm{H}_{\mathrm{C}}, \mathrm{C}(\mathrm{Z})$, and $\mathrm{C}_{0}$. Section 7.3.2 discusses the models developed for $\mathrm{U}_{\mathrm{CS}}$ and $\mathrm{H}_{\mathrm{C}}$ using the physical approach described in Section 7.1.1. Section 7.3.3 presents the models for solids vertical distribution $[\mathrm{C}(\mathrm{Z})]$ and $\mathrm{C}_{0}$ developed using the physical approach. Section 7.3.4 summarizes the physical model equations and coefficients for $\mathrm{U}_{\mathrm{CS}}, \mathrm{H}_{\mathrm{C}}, \mathrm{C}(\mathrm{Z})$, and $\mathrm{C}_{0}$.

\footnotetext{
${ }^{1}$ It is reasonable to exclude data below $\mathrm{U}_{\mathrm{CS}}$ for modeling $\mathrm{H}_{\mathrm{C}}$ because below $\mathrm{U}_{\mathrm{CS}}$ the quantity of the solids that are fully suspended is unknown.
} 


\subsubsection{Nondimensional Variables}

The analyses presented in Section 7.2 indicate that using nondimensional variables to describe the data works reasonably well. Hence, we envision a model for $U_{C S}$ of the form

$$
\mathrm{U}_{\mathrm{CS}} / \mathrm{U}_{\mathrm{T}}=\mathrm{k}_{\mathrm{U}} \mathrm{f}\left(\mathrm{F}_{\mathrm{DT}}, \mathrm{s}, \mathrm{Ga}, \phi_{\mathrm{S}}, \phi_{\mathrm{J}}, \phi_{\mathrm{p}}, \mathrm{DC}, \varepsilon_{31}, \mathrm{Re}\right)
$$

where the Froude number $\left(\mathrm{F}_{\mathrm{DT}}\right)$ is based on $\mathrm{U}_{\mathrm{T}}$ and tank diameter:

$$
\mathrm{F}_{\mathrm{DT}}=\frac{\mathrm{U}_{\mathrm{T}}^{2}}{(\mathrm{~s}-1) \mathrm{gD}}
$$

The leading constant, $\mathrm{k}_{\mathrm{U}}$, in Eq. (7.17) accounts for the different dish geometries. Similarly, we envision a model for $\mathrm{H}_{\mathrm{C}}$ of the form

$$
\mathrm{F}_{\mathrm{H}_{\mathrm{C}} \mathrm{T}}=\mathrm{k}_{\mathrm{C}} \mathrm{f}\left(\mathrm{U} / \mathrm{U}_{\mathrm{T}}, \mathrm{s}, \mathrm{Ga}, \phi_{\mathrm{S}}, \phi_{\mathrm{J}}, \phi_{\mathrm{p}}, \mathrm{DC}, \varepsilon_{31}, \mathrm{Re}\right)
$$

where the Froude number $\left(\mathrm{F}_{\mathrm{H}_{\mathrm{C}} \mathrm{T}}\right.$ ) based on $\mathrm{H}_{\mathrm{C}}$ and $\mathrm{U}_{\mathrm{T}}$ is

$$
\mathrm{F}_{\mathrm{H}_{\mathrm{C}} \mathrm{T}}=\frac{\mathrm{U}_{\mathrm{T}}^{2}}{(\mathrm{~s}-1) \mathrm{gH}_{\mathrm{C}}}
$$

Again, the leading constant, $\mathrm{k}_{\mathrm{C}}$, in Eq. (7.19) accounts for dish geometry.

Additional physical insight and simplification can be obtained by considering a nondimensional settling number $\left(\mathrm{N}_{\mathrm{S}}\right)$. Bamberger et al. (1990) and Liljegren and Bamberger (1992) introduced this parameter for correlating solids vertical distribution when mixing with submerged rotating jets. They interpreted the settling number as the ratio of "jet hydraulic power to the viscous dissipation rate due to settling." As it turns out, the dissipation rate is equivalent to the rate at which potential energy increased lifting the solids cloud during a pulse.

The flow field resulting from a pulse jet behaves essentially like a steady jet if the drive time is large compared with the flow establishment time. The ratio of these two time scales is $\phi_{\mathrm{p}} / \phi_{\mathrm{J}}$, which, in general, was much greater than 1 for the test conditions as well as plant conditions. The value of $\phi_{\mathrm{p}} / \phi_{\mathrm{J}}$ for the plant vessels varies from $\sim 12$ (HOP-903/904) to $\sim 75$ (TCP-01). The range of $\phi_{\mathrm{p}} / \phi_{\mathrm{J}}$ covered during testing was approximately 9 to 170 .

The hydraulic power input at the nozzles $\left(\mathrm{P}_{\mathrm{J}}\right)$ is

$$
\mathrm{P}_{\mathrm{J}}=\frac{1}{2} \rho \mathrm{U}_{2}^{2} \mathrm{U}_{1} \frac{\pi \mathrm{Nd}^{2}}{4}
$$

Jet power is dissipated as the jets spread out and entrain fluid. Rajaratnam (1976) shows that the jet energy at a distance $\mathrm{z}$ from the nozzle is reduced by $\sim \mathrm{d} / \mathrm{z}$. Because the jet velocity is reduced in the same manner, the jet power is reduced by $\sim(\mathrm{d} / \mathrm{z})^{2}$. If we take the characteristic distance the jet travels ${ }^{1}$ as

\footnotetext{
${ }^{1}$ The characteristic length scale over which the jet travels depends only on geometry for a Newtonian impinging jet. The choice of length scale is somewhat arbitrary. One length scale is the vessel diameter, another is the cube root of vessel volume, and a third could be cloud height. The expression used is a reasonable choice for characteristic length scale because it accounts for the reduced work a single jet must do when multiple jets are present. It is similar to the concept of the geometric zone of influence of a single jet.
} 


$$
\mathrm{Z} \sim \mathrm{D} / \sqrt{\mathrm{N}}
$$

then the effective jet hydraulic power $\left(\mathrm{P}_{\mathrm{V}}\right)$ is

$$
\mathrm{P}_{\mathrm{V}}=\mathrm{CP}_{\mathrm{J}} \phi_{\mathrm{J}}
$$

where $\mathrm{c}$ is a constant. Substituting for $\mathrm{P}_{\mathrm{J}}$ we obtain

$$
\mathrm{P}_{\mathrm{V}}=\mathrm{c} \frac{\pi}{4} \rho \mathrm{U}_{2}^{2} \mathrm{U}_{1} \phi_{\mathrm{J}}^{2} \mathrm{D}^{2}
$$

The useful jet energy $\left(E_{V}\right)$ imparted to the tank during a pulse is

$$
\mathrm{E}_{\mathrm{V}}=\mathrm{P}_{\mathrm{V}} \mathrm{t}_{\mathrm{D}}
$$

During each cycle, the solids settle proportional to the settling distance, $\mathrm{t}_{\mathrm{C}} \mathrm{U}_{\mathrm{T}}$, where $\mathrm{t}_{\mathrm{C}}$ is the cycle time. The relative mass of solids $\left(\mathrm{m}_{\mathrm{S}}\right.$ ) (difference between solid mass and the mass of the liquid it displaces) is

$$
\mathrm{m}_{\mathrm{s}}=\left(\rho_{\mathrm{s}}-\rho_{1}\right) \phi_{\mathrm{s}} \frac{\pi}{4} \mathrm{D}^{3}
$$

Hence the energy required to keep the solids suspended during a pulse $\left(\Delta \mathrm{E}_{\mathrm{S}}\right)$ is

$$
\Delta \mathrm{E}_{\mathrm{S}}=\mathrm{m}_{\mathrm{S}} \mathrm{g}\left(\mathrm{t}_{\mathrm{C}} \mathrm{U}_{\mathrm{T}}\right)=\left(\frac{\pi}{4} \mathrm{D}^{3} \phi_{\mathrm{S}}(\mathrm{s}-1) \rho_{\mathrm{l}}\right) \mathrm{g}\left(\mathrm{t}_{\mathrm{C}} \mathrm{U}_{\mathrm{T}}\right)
$$

The settling number $\mathrm{N}_{\mathrm{S}}$ is given by the ratio

$$
\mathrm{N}_{\mathrm{S}}=\mathrm{E}_{\mathrm{V}} / \Delta \mathrm{E}_{\mathrm{S}}=\frac{\mathrm{U}}{\mathrm{U}_{\mathrm{T}}} \frac{\mathrm{U}^{2} \phi_{\mathrm{J}}^{2} \mathrm{DC}}{(\mathrm{s}-1) \mathrm{g} \phi_{\mathrm{S}} \mathrm{D}} \mathrm{f}\left(\varepsilon_{31}\right)
$$

We made the assumption that

$$
\mathrm{U}_{1} \mathrm{U}_{2}^{2}=\mathrm{U}^{3} \mathrm{f}\left(\varepsilon_{31}\right)
$$

which allows using the average peak velocity in developing and applying any mixing model. The function $\mathrm{f}\left(\varepsilon_{31}\right)$ is easily approximated by a power-law term.

$\mathrm{N}_{\mathrm{S}}$ given by Eq. (7.28) has all the main variables with the exception of $\mathrm{H}_{\mathrm{C}}$ and $\phi_{\mathrm{p}}$. The following relations are also useful:

Settling number

$$
\mathrm{N}_{\mathrm{S}}=\left(\frac{\mathrm{U}}{\mathrm{U}_{\mathrm{T}}}\right)^{3} \mathrm{~F}_{\mathrm{DT}} \frac{\phi_{\mathrm{J}}^{2} \mathrm{DC}}{\phi_{\mathrm{S}}} \mathrm{f}\left(\varepsilon_{31}\right)
$$

Nondimensional critical suspension $\mathrm{D}^{*}=\frac{1}{\mathrm{~F}_{\mathrm{DT}}} \frac{\phi_{\mathrm{S}}}{\phi_{\mathrm{J}}^{2} \mathrm{DC}} \mathrm{f}\left(\varepsilon_{31}\right)=\frac{1}{\mathrm{~N}_{\mathrm{S}}}\left(\frac{\mathrm{U}}{\mathrm{U}_{\mathrm{T}}}\right)^{3}$ 
Nondimensional cloud height $\mathrm{H}_{\mathrm{C}}^{*}=\frac{1}{\mathrm{~F}_{\mathrm{H}_{\mathrm{C}} \mathrm{T}}} \frac{\phi_{\mathrm{S}}}{\phi_{\mathrm{J}}^{2} \mathrm{DC}} \mathrm{f}\left(\varepsilon_{31}\right)=\frac{\mathrm{H}_{\mathrm{C}} / \mathrm{D}}{\mathrm{N}_{\mathrm{S}}}\left(\frac{\mathrm{U}}{\mathrm{U}_{\mathrm{T}}}\right)^{3}$

These nondimensional variables are used to construct models for mixing response variables in Section 7.3.2.

\subsubsection{Physical Models for Critical Suspension Velocity and Cloud Height Based on Nondimensional Variables}

This section presents models for $\mathrm{U}_{\mathrm{CS}}$ and $\mathrm{H}_{\mathrm{C}}$ developed using the physical approach described in Section 7.1.1. Hence, these models are subsequently referred to as the physical models. The physical models were developed using nondimensional variables presented in Section 7.3.1.

The nondimensional critical suspension variable $D^{*}$ in Eq. (7.31) may be rewritten by 1) using the hindered terminal settling velocity $\left(\mathrm{U}_{\mathrm{TH}}\right)$ in place of the terminal settling velocity $\left(\mathrm{U}_{\mathrm{T}}\right)$, 2) including the pulse volume fraction $\left(\phi_{\mathrm{p}}\right)$ in the relationship, and 3) allowing the exponent of $\phi_{\mathrm{J}}$ to be determined by the experimental data. These changes give

$$
\mathrm{D}^{*}=\frac{\mathrm{D}(\mathrm{s}-1) \mathrm{g} \phi_{\mathrm{S}}}{\mathrm{DC} \mathrm{U}_{\mathrm{TH}}^{2} \phi_{\mathrm{p}}^{\alpha_{1}} \phi_{\mathrm{J}}^{\alpha_{2}}}
$$

where $\alpha_{1}$ and $\alpha_{2}$ are coefficients to capture the effects of $\phi_{\mathrm{p}}$ and $\phi_{\mathrm{J}}$ (which were varied in testing). The $\alpha_{1}$ and $\alpha_{2}$ coefficients were determined (by methods for fitting models to data) to optimize the $\mathrm{U}_{\mathrm{Cs}}$ and $\mathrm{H}_{\mathrm{C}}$ model fits to the data set. $\mathrm{U}_{\mathrm{TH}}$ is the modified hindered-settling velocity introduced in Section 7.2.3 and rewritten as

$$
\mathrm{U}_{\mathrm{TH}}=\mathrm{U}_{\mathrm{T}}\left(1-\phi_{\mathrm{S}} / 0.5\right)^{4.5}
$$

The value of the exponent p in Eq. (7.11) equal to 4.5 was found to give a reasonable fit.

The nondimensional model form for $\mathrm{U}_{\mathrm{CS}}$ is expressed in terms of the nondimensional critical suspension variable $\mathrm{D}^{*}$ as

$$
\frac{\mathrm{U}_{\mathrm{CS}}}{\mathrm{U}_{\mathrm{TH}}}=\mathrm{A}\left(\mathrm{D} * \mathrm{Ga}^{-0.5}\right)^{\mathrm{B}}
$$

where A and B are coefficients to be estimated from the experimental data.

As discussed in Section 7.3.1 regarding the settling number $\left(\mathrm{N}_{\mathrm{S}}\right)$, the ratio $\mathrm{U}_{\mathrm{CS}} / \mathrm{U}_{\mathrm{T}}$ is related to the ratio of viscous power dissipated by suspending the particles to the power of the PJMs. Because the mass of suspended particles is constant, the power required to suspend them depends on their dissipation power per mass. For small particles, viscous stresses dominate inertial stresses attending their settling such that the settling velocity occurs when viscous and gravitational stresses balance; that is, when the gravity number (Gr) is unity where

$$
\mathrm{Gr}=\frac{(\mathrm{s}-1) \mathrm{gd}^{2}}{v \mathrm{U}_{\mathrm{T}}}
$$


Also, the gravity number, Reynolds, Froude, and Galileo numbers are related by

$$
\mathrm{Ga}=\frac{\mathrm{Re}^{2}}{\mathrm{Fr}}=\mathrm{ReGr}
$$

Hence, for small particles, Gr $~ 1$ and Ga is small, and Ga Re, consistent with Eq. (7.9). For large particles, inertial stresses dominate viscous stresses, such that the settling velocity occurs when inertial and gravitational stresses balance; that is, when the Froude number ( $\mathrm{Fr}$ ) is unity. Hence, for large particles, $\mathrm{Re} \sim 1$ and $\mathrm{Ga}$ is large, and $\mathrm{Ga} \sim \mathrm{Re}^{2}$, consistent with Eq. (7.10). The rate of dissipation of power of settling particles per mass of particles is simply $(\mathrm{s}-1) \mathrm{gU}_{\mathrm{T}}$. Then the ratio of the power per mass dissipated by small particles to the power per mass dissipated by large particles is

$$
\frac{\left(\mathrm{U}_{\mathrm{T}}\right)_{\mathrm{Gr}=1}}{\left(\mathrm{U}_{\mathrm{T}}\right)_{\mathrm{Fr}=1}}=\frac{\frac{(\mathrm{s}-1) \mathrm{gd}^{2}}{v}}{\sqrt{(\mathrm{s}-1) \mathrm{gd}}}=\sqrt{\frac{(\mathrm{s}-1) \mathrm{gd}^{3}}{v^{2}}}=\sqrt{\mathrm{Ga}}
$$

Hence, the appearance of $\sqrt{\mathrm{Ga}}$ in Eq. (7.35) helps describe the power required to suspend the particles. This is physically reasonable because Eq. (7.35) is related (see Eq. 7.30) to the fraction of PJM power required to suspend the particles. This relationship also helps explain Figure 7.6.

The nondimensional model form for $\mathrm{H}_{\mathrm{C}}$ is expressed as

$$
\ln \left(\mathrm{H}_{\mathrm{C}}^{*}\right)=\mathrm{C}\left(\frac{\mathrm{U}}{\mathrm{U}_{\mathrm{TH}}}\right)^{\mathrm{G}}
$$

where $\mathrm{C}$ and $\mathrm{G}$ are coefficients to be estimated from the experimental data and

$$
\mathrm{H}_{\mathrm{C}}^{*}=\frac{\mathrm{H}_{\mathrm{C}}}{\mathrm{D}} \mathrm{D}^{*}=\frac{\mathrm{H}_{\mathrm{C}}(\mathrm{s}-1) \mathrm{g} \phi_{\mathrm{S}}}{\mathrm{DC} \mathrm{U}_{\mathrm{TH}}^{2} \phi_{\mathrm{p}}^{\alpha_{1}} \phi_{\mathrm{J}}^{\alpha_{2}}}
$$

All other variables in both models are as previously defined.

The nondimensional model forms for $\mathrm{U}_{\mathrm{CS}}$ and $\mathrm{H}_{\mathrm{C}}$, given in Eq. (7.38) and (7.39), respectively, were linearized as

$$
\ln \left(\frac{\mathrm{U}_{\mathrm{CS}}}{\mathrm{U}_{\mathrm{TH}}}\right)=\ln (\mathrm{A})+\mathrm{B} \ln \left(\mathrm{D} * \mathrm{Ga}^{-0.5}\right)
$$

and

$$
\ln \left[\ln \left(\mathrm{H}_{\mathrm{C}}^{*}\right)\right]=\ln (\mathrm{C})+\mathrm{G} \ln \left(\frac{\mathrm{U}}{\mathrm{U}_{\mathrm{TH}}}\right)
$$

Eq. (7.41) and (7.42) were fit to the experimental data set using the ordinary least squares (OLS) regression capability of Excel ${ }^{\circledR}$. The summation of the $\mathrm{R}^{2}$ values from the OLS regression for Eq. (7.41) and 
(7.42) was maximized using the Excel ${ }^{\circledR}$ Solver by adjusting the coefficients $\alpha_{1}$ and $\alpha_{2}$ of $D^{*}$ in Eq. (7.33). This resulted in $\alpha_{1}=0.698$ and $\alpha_{2}=1.714$.

With $\alpha_{1}=0.698$ and $\alpha_{2}=1.714$, the OLS regression provided $\mathrm{A}=2.220, \mathrm{~B}=0.284, \mathrm{C}=8.847$, and $\mathrm{D}=0.131$. The resulting nondimensional models for $\mathrm{U}_{\mathrm{CS}}$ and $\mathrm{H}_{\mathrm{C}}$ are thus

$$
\frac{\mathrm{U}_{\mathrm{CS}}}{\mathrm{U}_{\mathrm{TH}}}=2.220\left(\mathrm{D} * \mathrm{Ga}^{-0.5}\right)^{0.284}
$$

and

$$
\ln \left(\mathrm{H}_{\mathrm{C}}^{*}\right)=8.847\left(\frac{\mathrm{U}}{\mathrm{U}_{\mathrm{TH}}}\right)^{0.131}
$$

Figures 7.17 and 7.18 show the fits of the nondimensional $\mathrm{U}_{\mathrm{CS}}$ and $\mathrm{H}_{\mathrm{C}}$ models, respectively, to the experimental data using the nondimensional variables appearing on the left (y-axis) and right (x-axis) sides of each model.

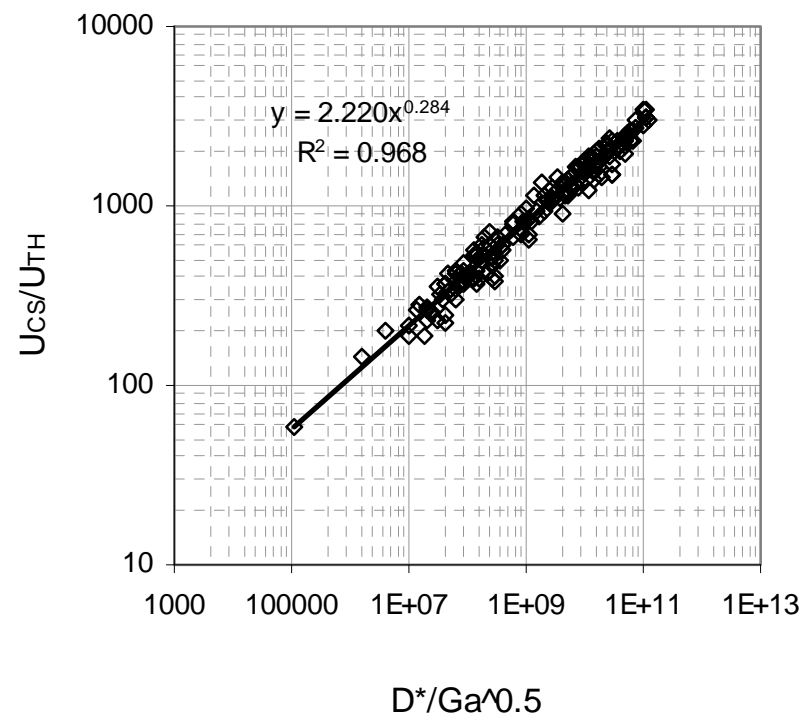

Figure 7.17. Fit of $U_{\mathrm{CS}}$ Model to Experimental Data Using Nondimensional Variables $\mathrm{U}_{\mathrm{CS}} / \mathrm{U}_{\mathrm{TH}}$ and $\mathrm{D} * / \mathrm{Ga}^{0.5}$ 


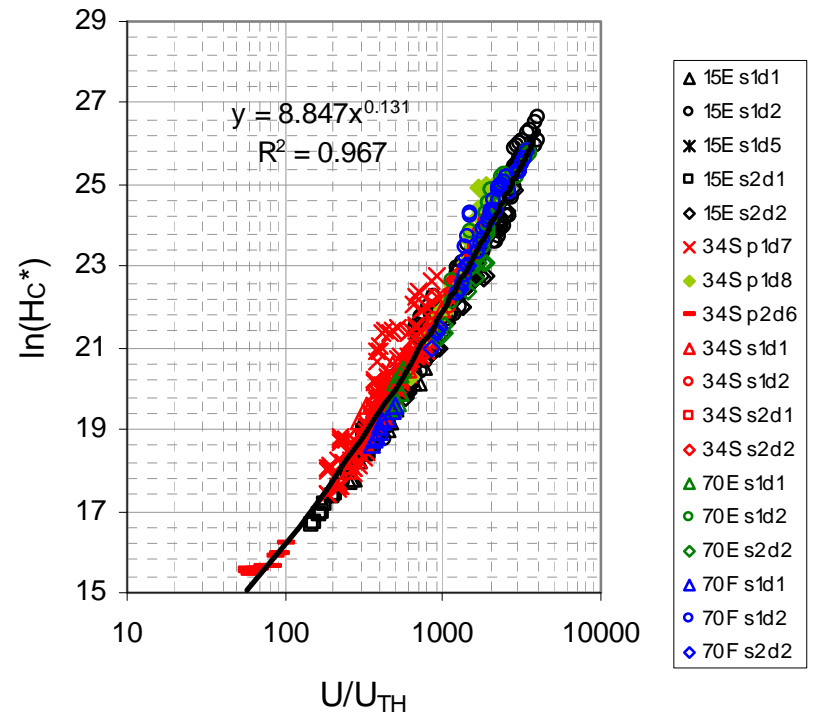

Figure 7.18. Fit of $H_{C}$ Model to Experimental Data Using Nondimensional Variables $\ln \left(H_{C}^{*}\right)$ and $U / U_{T H}$

Figure 7.19 shows the fit of the following nondimensional model form for $\mathrm{H}_{\mathrm{C}}$ :

$$
\mathrm{H}_{\mathrm{C}}^{*}=\mathrm{E}\left(\frac{\mathrm{U}}{\mathrm{U}_{\mathrm{TH}}}\right)^{\mathrm{F}}
$$

to the cloud height data, where $\mathrm{E}$ and $\mathrm{F}$ are coefficients estimated from the data. This nondimensional model for $\mathrm{H}_{\mathrm{C}}$ is similar to Eq. (7.39) but without the natural logarithm of $\mathrm{H}_{\mathrm{C}}^{*}$ on the left side. Fitting Eq. (7.45) to the same data discussed earlier yields $E=17.780$ and $F=2.775$. An $F$ exponent of 3 would correspond to $\mathrm{N}_{\mathrm{S}}=$ constant. Hence the behavior is very close to constant $\mathrm{N}_{\mathrm{S}}$.

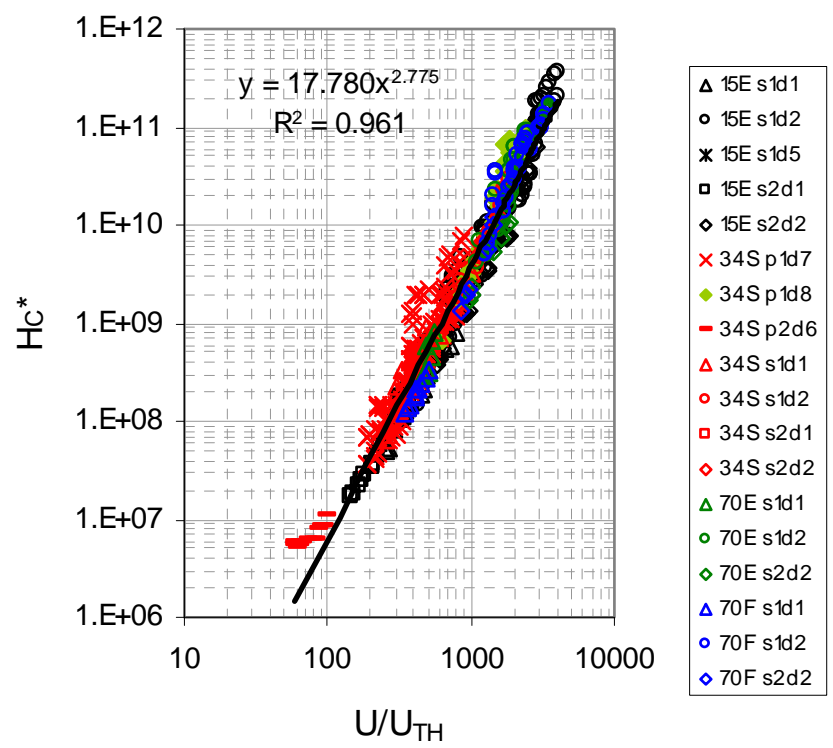

Figure 7.19. Fit of $H_{C}$ Model to Experimental Data Using Nondimensional Variables $H_{C}^{*}$ and $U / U_{T H}$ 
The nondimensional variables used in the $\mathrm{U}_{\mathrm{CS}}$ model of Eq. (7.43) and the $\mathrm{H}_{\mathrm{C}}$ model of Eq. (7.44) include some of the same variables on each side of the model. This can cause spurious correlation (see Section D.1.3 of Appendix D), which results in higher $\mathrm{R}^{2}$ values and tighter fits than exist for the dimensional response variables $\left(\mathrm{U}_{\mathrm{CS}}\right.$ and $\left.\mathrm{H}_{\mathrm{C}}\right)$. The goodness of fits of the $\mathrm{U}_{\mathrm{CS}}$ and $\mathrm{H}_{\mathrm{C}}$ models to the data using predicted versus measured plots (see Section D.3.2 of Appendix D) are shown in Figures F.8 and F.15 of Appendix F. For convenience, these plots are reproduced here as Figures $7.20\left(\mathrm{U}_{\mathrm{CS}}\right)$ and 7.21 $\left(\mathrm{H}_{\mathrm{C}}\right)$, respectively. The $\mathrm{R}^{2}$ values in Figures 7.17 and 7.18 are calculated using predicted and actual values of $\ln \left(\mathrm{U}_{\mathrm{CS}} / \mathrm{U}_{\mathrm{TH}}\right)$ and $\ln \left[\ln \left(\mathrm{H}_{\mathrm{C}}^{*}\right)\right]$, respectively. On the other hand, the $\mathrm{R}^{2}$ values in Figures 7.20 and 7.21 are calculated using predicted and measured values of $\ln \left(\mathrm{U}_{\mathrm{CS}}\right)$ and $\ln \left(\mathrm{H}_{\mathrm{C}}\right)$, respectively. Hence, the $\mathrm{R}^{2}$ values in Figures 7.17 and 7.18 are calculated in different units than those in Figures 7.20 and 7.21 and thus are not directly comparable; still, they may be compared as indicators of the degree of spurious correlation.

The effect of spurious correlation in the physical models for $\mathrm{U}_{\mathrm{CS}}$ and $\mathrm{H}_{\mathrm{C}}$ can be assessed by comparing Figure 7.17 with Figure $7.20\left(\mathrm{U}_{\mathrm{CS}}\right)$ and Figure 7.18 with Figure $7.21\left(\mathrm{H}_{\mathrm{C}}\right)$. Figures 7.20 and 7.21 look directly at how well $\mathrm{U}_{\mathrm{CS}}$ and $\mathrm{H}_{\mathrm{C}}$ are predicted for the physical models and thus are not affected by spurious correlation like Figures 7.17 and 7.18 are. For the $\mathrm{U}_{\mathrm{CS}}$ physical model, the broader scatter and smaller $\mathrm{R}^{2}=0.896$ in Figure 7.20 compared with the tighter scatter and larger $\mathrm{R}^{2}=0.966$ in Figure 7.17 indicates the physical model is subject to relatively low spurious correlation, but even the smaller $\mathrm{R}^{2}$ value is reasonably large. However, the much broader scatter and smaller $R^{2}=0.493$ in Figure 7.21 compared with the substantially tighter scatter and larger $\mathrm{R}^{2}=0.967$ in Figure 7.18 indicates the physical model for $\mathrm{H}_{\mathrm{C}}$ is subject to substantial spurious correlation. Also, Figure 7.21 shows that the physical model for $\mathrm{H}_{\mathrm{C}}$ tends to significantly underpredict $\mathrm{H}_{\mathrm{C}}$ for much of the data from the Fall 2007 testing, particularly those tests with 4 PJMs in operation. Improved results can be obtained by including the dish geometry constant as well as additional functionality for tube number $(\mathrm{N})$ in the model; however, this was not done given higher priorities and time constraints. 


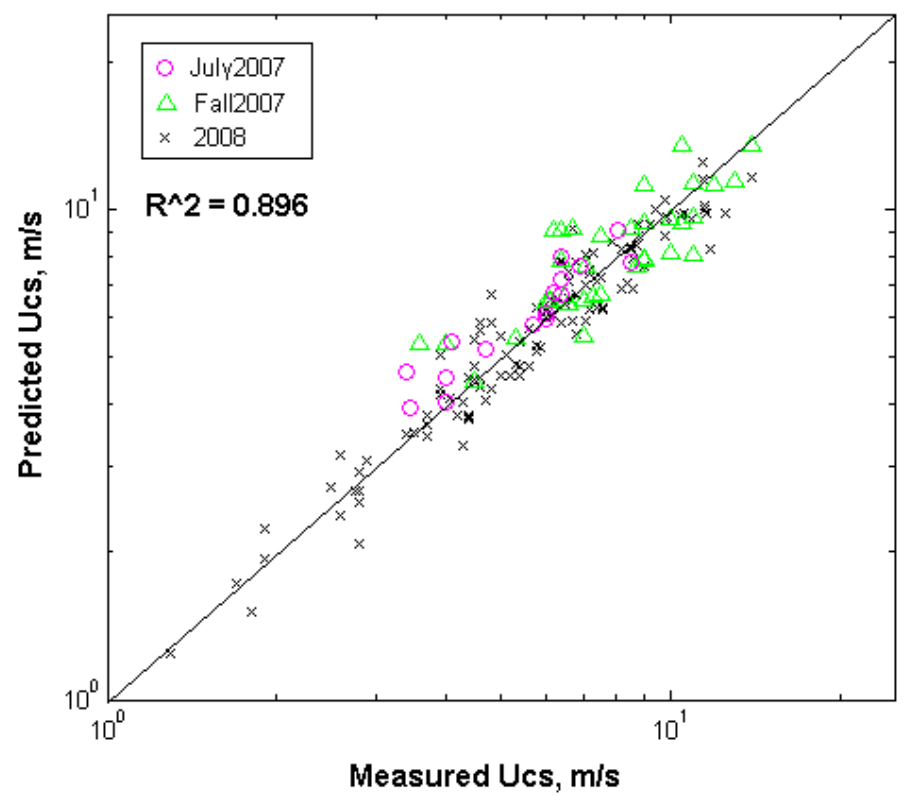

Figure 7.20. Log-Log Plot of Predicted Versus Measured $U_{\mathrm{CS}}(\mathrm{m} / \mathrm{s})$ Values for the Nondimensional Model in Eq. (7.41). The 45-degree line represents perfect prediction where predicted $\mathrm{U}_{\mathrm{CS}}$ values equal measured $\mathrm{U}_{\mathrm{CS}}$ values.

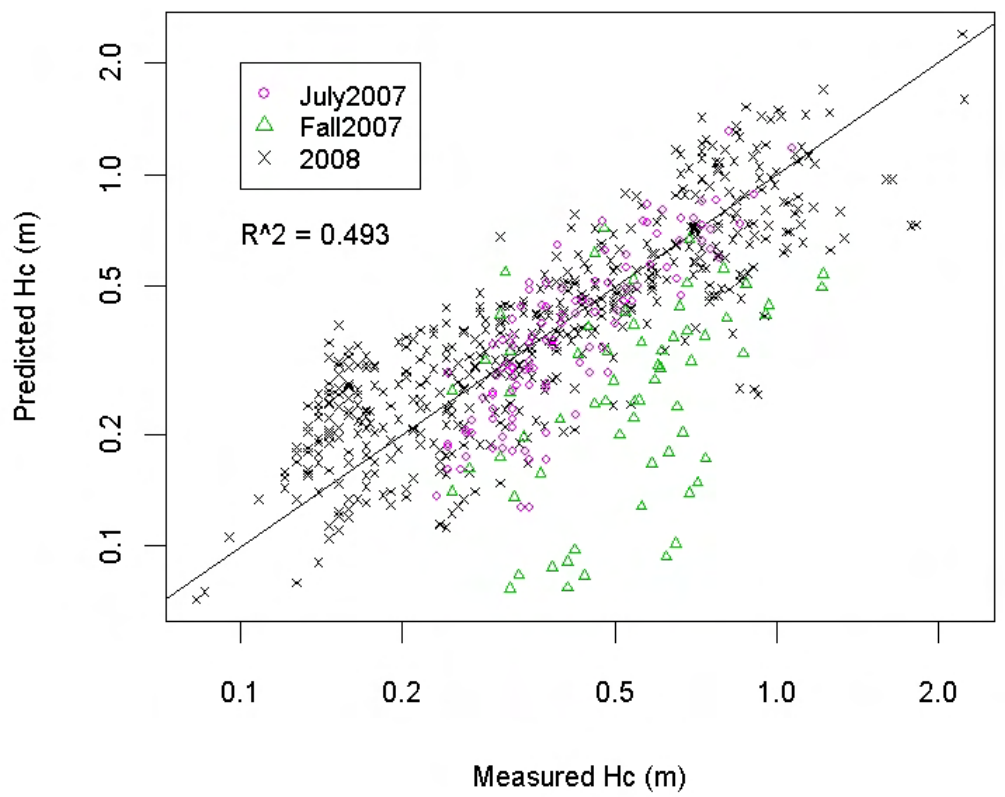

Figure 7.21. Log-Log Plot of Predicted Versus Measured $H_{C}(m)$ Values for the Nondimensional Model in Eq. (7.43). The 45-degree line represents perfect prediction where predicted $\mathrm{H}_{\mathrm{C}}$ values equal measured $\mathrm{H}_{\mathrm{C}}$ values.

The statistical MR approach to modeling (described in Section 7.1.2) was also investigated as a way to develop models not affected by spurious correlations. The results from that approach are summarized in Section 7.4 and discussed in more detail in Appendix F. 


\subsubsection{Solids Vertical Distribution}

Solids vertical concentration data (determined as described in Section 6.5) are shown in Figure 7.22. Profiles were taken at tank center. The data are from approximately 64 tests in all three scales, where for each test the solids vertical concentration data were averaged over five pulses. Also shown is the normalized average concentration at the tank bottom, $\left(\mathrm{C}_{0} / \phi_{\mathrm{S}}\right)\left(\mathrm{H}_{\mathrm{C}} / \mathrm{D}\right)$, which is plotted as a function of $\mathrm{Z} / \mathrm{H}_{\mathrm{C}} \cdot \mathrm{C}_{0}$ is the average concentration on the tank bottom, and $\mathrm{Z}$ is the elevation within the cloud.

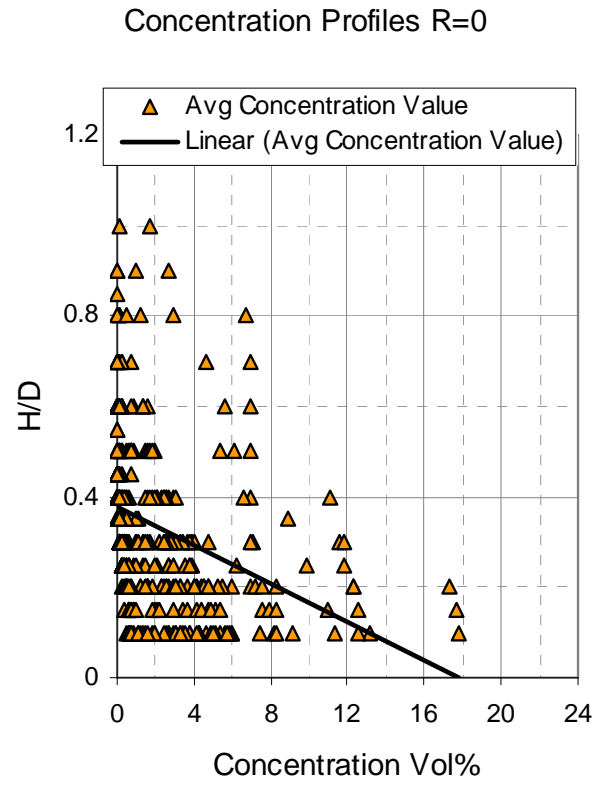

(a)

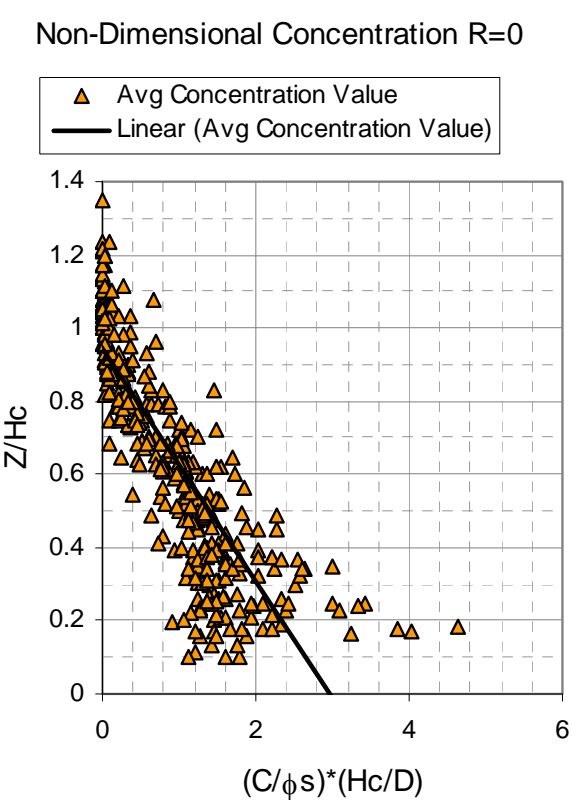

(b)

Figure 7.22. Average Solids Vertical Distribution Data for All Tests; (a) Concentration as a Function of Elevation, (b) Normalized Profile for Estimating Concentration on Tank Bottom

If the area under a concentration profile is less than that of a linear curve, solids are either near or on the tank bottom or higher concentrations exist at other radial locations. Conversely, if the area is larger, the concentration is lower at larger radius. Actual radial variations in the concentration and departures from linear profiles over height are described and discussed in Section 6. Because such departures are complex and have not been estimated by separate models, here we assume a linear profile with height and a uniform radial profile throughout a cloud. Then the average concentration on the tank bottom is

$$
\mathrm{C}_{0}=\mathrm{k} \phi_{\mathrm{S}}\left(\mathrm{H}_{\mathrm{C}} / \mathrm{D}\right)^{-1}
$$

where $\mathrm{C}_{0}$ is in volume percent. For a fully homogenously mixed system with $\mathrm{C}_{0} / \phi_{\mathrm{S}}=\mathrm{H}_{\mathrm{C}} / \mathrm{D}=1, \mathrm{k}=2$ satisfies mass conservation for a linear profile from $C_{0} / \phi_{S}=0$ at $H_{C} / D=1$ to $C_{0} / \phi_{S}=2$ at $H_{C} / D=0$. The linear curve fit of the data, shown in Figure 7.22 (b), gives $k=3$ (linear curve fit intersects the abscissa, $\mathrm{Z} / \mathrm{H}_{\mathrm{C}}=0$, at approximately 3 ). The average maximum concentration data, as shown in Figure 7.23, indicate that the maximum concentration is significantly larger than the average concentration. This suggests the concentration on the bottom may be quite a bit higher than indicated by $\mathrm{k}=3$. Therefore, in applying Eq. (7.46), the concentration at the tank floor is estimated with $\mathrm{k}=2$. 
Because we used a linear concentration profile with zero concentration at the elevation of $\mathrm{H}_{\mathrm{C}}$ to determine $\mathrm{C}_{0}$, we estimate the concentration at any elevation $\mathrm{Z}$ within the cloud to be

$$
\begin{aligned}
\mathrm{C}(\mathrm{Z}) & =\mathrm{C}_{0}\left(1-\mathrm{Z} / \mathrm{H}_{\mathrm{C}}\right) \\
& =\mathrm{k} \phi_{\mathrm{S}}\left(\mathrm{H}_{\mathrm{C}} / \mathrm{D}\right)^{-1}\left[1-\mathrm{Z} / \mathrm{H}_{\mathrm{C}}\right]
\end{aligned}
$$

where $\mathrm{k}=2$ was chosen as described above.

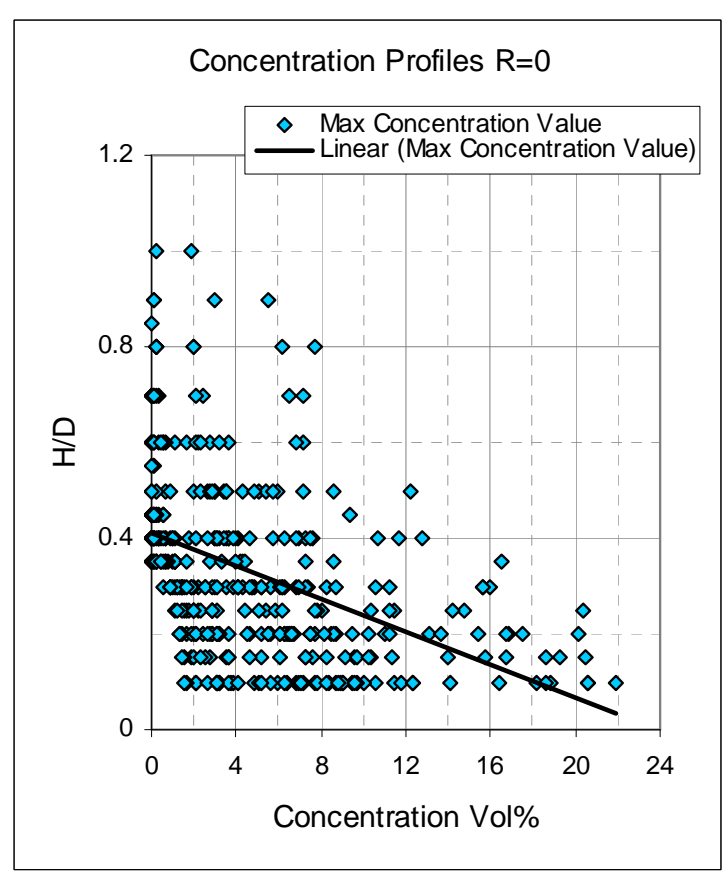

(a)

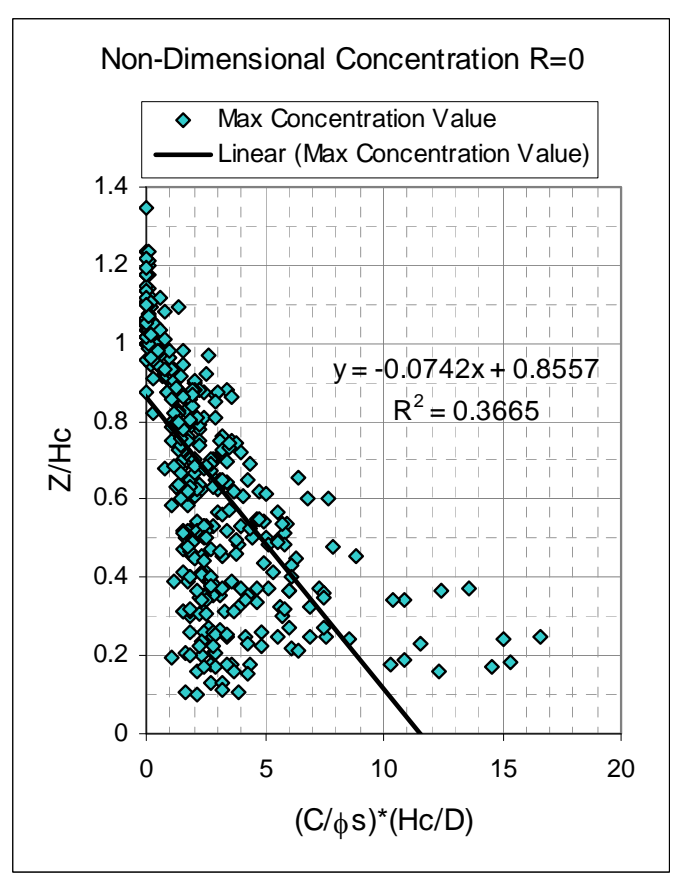

(b)

Figure 7.23. Maximum Solids Vertical Distribution Data for all Tests; (a) Concentration as a Function of Elevation, (b) Normalized Profiles for Estimating Concentration on Tank Bottom

\subsubsection{Summary of Physical Models}

This section summarizes the physical models for $\mathrm{U}_{\mathrm{CS}}, \mathrm{H}_{\mathrm{C}}, \mathrm{C}_{0}$, and $\mathrm{C}(\mathrm{Z})$ from Sections 7.3.2 and 7.3.3. For $\mathrm{U}_{\mathrm{CS}}$, expanding Eq. (7.43) and using Eq. (7.33) yields

$$
\mathrm{U}_{\mathrm{CS}}=2.220 \mathrm{U}_{\mathrm{TH}}\left(\frac{\mathrm{D}(\mathrm{s}-1) \mathrm{g}}{\mathrm{U}_{\mathrm{TH}}^{2}}\right)^{0.284} \phi_{\mathrm{J}}{ }^{-0.487} \mathrm{DC}^{-0.284} \phi_{\mathrm{S}}{ }^{0.284} \phi_{\mathrm{p}}{ }^{-0.198} \mathrm{Ga}^{-0.142}
$$

Similarly for $\mathrm{H}_{\mathrm{C}}$, expanding Eq. (7.44) and using Eq. (7.40) yields

$$
\mathrm{H}_{\mathrm{C}}=\frac{\mathrm{DC} \cdot \mathrm{U}_{\mathrm{TH}}^{2} \phi_{\mathrm{p}}{ }^{0.698} \phi_{\mathrm{J}}^{1.714}}{(\mathrm{~s}-1) \mathrm{g} \phi_{\mathrm{S}}} \cdot \exp \left[8.847\left(\frac{\mathrm{U}}{\mathrm{U}_{\mathrm{TH}}}\right)^{0.131}\right]
$$

The model for solids concentration on the vessel floor is obtained by substituting Eq. (7.49) into Eq. (7.46) with $\mathrm{k}=2$, which yields 


$$
\mathrm{C}_{0}=\frac{2 \mathrm{D}(\mathrm{s}-1) \mathrm{g} \phi_{\mathrm{S}}{ }^{2}}{\mathrm{DC} \cdot \mathrm{U}_{\mathrm{TH}}{ }^{2} \phi_{\mathrm{p}}{ }^{0.698} \phi_{\mathrm{J}}{ }^{1.714}} \cdot \frac{1}{\exp \left[8.847\left(\frac{\mathrm{U}}{\mathrm{U}_{\mathrm{TH}}}\right)^{0.131}\right]}
$$

Finally, the model for the solids concentration at height $\mathrm{Z}(\mathrm{m})$ assuming a linear profile is obtained by substituting Eq. (7.49) into Eq. (7.47) with $\mathrm{k}=2$, which gives

$$
\begin{aligned}
\mathrm{C}(\mathrm{Z}) & =2 \phi_{\mathrm{S}}\left\{\frac{\mathrm{DC} \cdot \mathrm{U}_{\mathrm{TH}}{ }^{2} \phi_{\mathrm{p}}{ }^{0.698} \phi_{\mathrm{J}}{ }^{1.714}}{\mathrm{D}(\mathrm{s}-1) \mathrm{g} \phi_{\mathrm{S}}} \cdot \exp \left[8.847\left(\frac{\mathrm{U}}{\mathrm{U}_{\mathrm{TH}}}\right)^{0.131}\right]\right\}^{-1} \\
& \bullet\left[1-\frac{\mathrm{Z}}{\frac{\mathrm{DC} \cdot \mathrm{U}_{\mathrm{TH}}^{2} \phi_{\mathrm{p}}^{0.698} \phi_{\mathrm{J}}^{1.714}}{(\mathrm{~s}-1) \mathrm{g} \phi_{\mathrm{S}}} \cdot \exp \left[8.847\left(\frac{\mathrm{U}}{\mathrm{U}_{\mathrm{TH}}}\right)^{0.131}\right]}\right]
\end{aligned}
$$

The models for $\mathrm{U}_{\mathrm{CS}}$ and $\mathrm{H}_{\mathrm{C}}$ were obtained using plots of nondimensional variables, as described in Section 7.3.2. Better fitting models for $\mathrm{U}_{\mathrm{CS}}$ and $\mathrm{H}_{\mathrm{C}}$ [hence $\mathrm{C}_{0}$ and $\mathrm{C}(\mathrm{Z})$ ] are readily attainable by allowing the exponents on the terms involving $(\mathrm{s}-1), \mathrm{DC}, \phi_{\mathrm{S}}$, and $\mathrm{Ga}$ to be estimated from the experimental data. (The statistical MR models summarized in Section 7.4 and discussed in more detail in Appendix F are generally based on such generalizations of the physical models.) Additionally, a scale-up term for $\mathrm{H}_{\mathrm{C}}$ can be added. It was these types of generalizations of the physical model that were investigated in Appendix F using the MR modeling approach.

The effects of dish geometry could also be included to improve the models, although the M3 testing data provide a limited basis for doing so (as discussed at the end of Section F.2.2 in Appendix F). Improvements to models could also be made by breaking the data set into subgroups. For example, the majority of M3 testing was performed with 12-tube arrays, and only a limited number of tests used 4- and 8-tube arrays. Further, functionality plots (Figures E.7 and E.23 in Appendix E) show that the dependence of $\mathrm{U}_{\mathrm{CS}}$ and $\mathrm{H}_{\mathrm{CS}}$ (and presumably also $\mathrm{H}_{\mathrm{C}}$ ) on the number of operating pulse tubes is not exactly a power-law relationship. Hence, a 12-tube-only data group could be used to develop models tailored for application to vessels HLP-22 and FRP-02 only. Such models would be expected to be better predictors for these 12-tube vessels because they were developed using these data only. Models for a subset of the data that eliminated subranges of some variables are discussed in Appendix F. However, that work did not consider the 12-tube-only subset.

Potential improvements to the models are discussed in more detail in Section 7.6.

\subsection{Dimensional and Dimensionally Consistent Models for $U_{c s}$ and $\mathrm{H}_{\mathrm{C}}$ Developed Using the Statistical MR Approach}

To provide direction for developing models for $\mathrm{U}_{\mathrm{CS}}$ and $\mathrm{H}_{\mathrm{C}}$ using the $\mathrm{MR}$ approach, functional dependencies of mixing response variables on test variables were investigated graphically, as described in 
Sections F.2.1 ( $\left.\mathrm{U}_{\mathrm{CS}}\right)$ and F.3.1 $\left(\mathrm{H}_{\mathrm{C}}\right)$ of Appendix F. The investigations concluded that functional dependencies for several test variables are well approximated by a power-law relationship. For a few test variables, a power-law relationship did not provide the best approximation but was adequate as a firstorder approximation. Even in those cases the power-law relationship was adequate over most of the ranges of variables studied in M3 testing. There was not sufficient time or budget to develop the complicated models that would result from different forms of dependence of mixing response variables on test variables. Hence, model forms based on the power-law form were pursued.

As discussed in Section 7.1.2, statistical MR methods were used to develop and fit $\mathrm{U}_{\mathrm{Cs}}$ and $\mathrm{H}_{\mathrm{C}}$ models to the experimental data. The statistical MR methods used are discussed in Appendix D. The results of graphically assessing the experimental data prior to developing MR models are presented in Appendix E. Appendix F contains a discussion of the approaches and results of fitting three kinds of models to the experimental data using MR:

- dimensional models without interaction terms

- dimensionally consistent models without interaction terms, subsequently referred to as generalized models

- dimensional models with two variable interaction terms.

The term interaction is used in the following way: Two variables interact if the effect on the response variable (e.g., $\mathrm{U}_{\mathrm{CS}}$ or $\mathrm{H}_{\mathrm{C}}$ ) of one variable depends on the value of the second variable. Each of the three types of models listed in the bullets is further discussed for $\mathrm{U}_{\mathrm{CS}}$ and $\mathrm{H}_{\mathrm{C}}$ in the following subsections.

All three kinds of models (for each of $\mathrm{U}_{\mathrm{CS}}$ and $\mathrm{H}_{\mathrm{C}}$ ) were fit by MR to two data sets, referred to as the full data set and the trimmed data set. These two data sets are discussed in Appendix F, Section F.1.1. The full data set included all relevant data points (173 test conditions) for $\mathrm{U}_{\mathrm{CS}}$ and $\mathrm{H}_{\mathrm{C}}$ as discussed in Section 7.3.2. Only data with $\mathrm{U} \geq \mathrm{U}_{\mathrm{CS}}$ were used to model $\mathrm{H}_{\mathrm{C}}$. The trimmed data set excludes data with DC $>0.41$ (which eliminates 11 of 173 test conditions), $\phi_{\mathrm{S}}>0.016$ (which eliminates 7 of 173 test conditions), and $d_{S}\left(d_{50}\right)>1.8 \mathrm{E}-04$ (which eliminates 1 of 173 test conditions). The functional dependence of $U_{C s}$ and/or $H_{C}$ on these three predictor variables was observed to change within the excluded ranges. It was expected that more accurate models with less uncertainty could be obtained over the trimmed data set; however, models over the full data set (the one used to develop the physical models in Sections 7.3.2 to 7.3.4) are of primary interest. Thus, only the models fit to the full data set are discussed in the remainder of Section 7.4. Models fit to the trimmed data set are discussed in Appendix F.

The $\mathrm{U}_{\mathrm{CS}}$ and $\mathrm{H}_{\mathrm{C}}$ models developed using the full data set with the statistical MR approach are described in Sections 7.4.1 to 7.4.3. Although it was not done for this report, any of the statistical MR models for $\mathrm{H}_{\mathrm{C}}$ could be used with the approach discussed in Section 7.3.3 for modeling $\mathrm{C}(\mathrm{Z})$ and $\mathrm{C}_{0}$.

\subsubsection{Development of $U_{c s}$ and $H_{C}$ Dimensional Models without Interaction Terms}

The dimensional models for $\mathrm{U}_{\mathrm{CS}}$ and $\mathrm{H}_{\mathrm{C}}$ were developed as follows. The nondimensional variables on both sides of the $U_{C s}$ and $H_{C}$ nondimensional models of Section 7.3.2 to 7.3.4 were expressed in terms of their separate component test variables. These model forms were next rewritten with only the response variable $\left(\mathrm{U}_{\mathrm{CS}}\right.$ or $\left.\mathrm{H}_{\mathrm{C}}\right)$ on the left side of the model and the predictor variables on the right. Then the terms for each test variable were collected, and each collected term was assigned a coefficient to be estimated from the data using MR. By assigning a separate coefficient for each predictor variable, we obtained a 
generalized form of the physical model on which it was based. The results from fitting the resulting model forms to the experimental data are summarized here with references to Appendix F, where more detail can be found.

\subsubsection{1 $\mathrm{U}_{\mathrm{cs}}$ Dimensional Models without Interaction Terms}

The dimensional model forms without interaction terms for $U_{C S}$ are listed as Eq. (F.8a) and (F.8b) in Appendix F. Sections F.2.2 and F.2.4.1 discuss how these $U_{C S}$ model forms were developed. In addition, Section F.3.1 contains an explanation of why MR software was used to fit Eq. (F.8b) instead of Eq. (F.8a) to experimental data. The results of fitting Eq. (F.8b) to the full data set are given in Table F.1 and discussed in Section F.2.4.2. The predicted-versus-measured (PvM) plot (Section D.3.2 of Appendix D) showing the goodness of fit of the $\mathrm{U}_{\mathrm{CS}}$ dimensional model form without interactions to the full data set is presented as Figure F.2.

The resulting $\mathrm{U}_{\mathrm{CS}}$ dimensional models without interaction terms for the full data set, in Eq. (F.11a) and (F.11b) in Appendix F, are

$$
\begin{aligned}
\mathrm{U}_{\mathrm{CS}} & =0.309(\mathrm{D})^{1.321}(\mathrm{~s}-1)^{0.471}\left(\phi_{\mathrm{S}}\right)^{0.222}\left(\mathrm{U}_{\mathrm{T}}\right)^{0.148}(\mathrm{DC})^{-0.247}\left(\phi_{\mathrm{p}}\right)^{-0.211} \\
& \times\left(\mathrm{N}_{\mathrm{J}}\right)^{-0.525}(\mathrm{~d})^{-1.072}
\end{aligned}
$$

and

$$
\begin{aligned}
\ln \left(\mathrm{U}_{\mathrm{CS}}\right) & =-1.173+1.321 \ln (\mathrm{D})+0.471 \ln (\mathrm{s}-1)+0.222 \ln \left(\phi_{\mathrm{S}}\right)+0.148 \ln \left(\mathrm{U}_{\mathrm{T}}\right) \\
& -0.247 \ln (\mathrm{DC})-0.211 \ln \left(\phi_{\mathrm{p}}\right)-0.525 \ln \left(\mathrm{N}_{\mathrm{J}}\right)-1.072 \ln (\mathrm{d})
\end{aligned}
$$

The $\mathrm{U}_{\mathrm{CS}}$ dimensional model was fit to the full data set in the form of Eq. (7.52b) and also used to calculate model prediction uncertainties. It is also useful to view the $U_{\mathrm{CS}}$ model in the Eq. (7.52a) form. The PvM plot for these models from Figure F.2 is reproduced in Figure 7.24. The $R^{2}=0.913$ value indicates that the model accounts for $91.3 \%$ of the variation in the $\ln \left(U_{\mathrm{CS}}\right)$ values for the full data set.

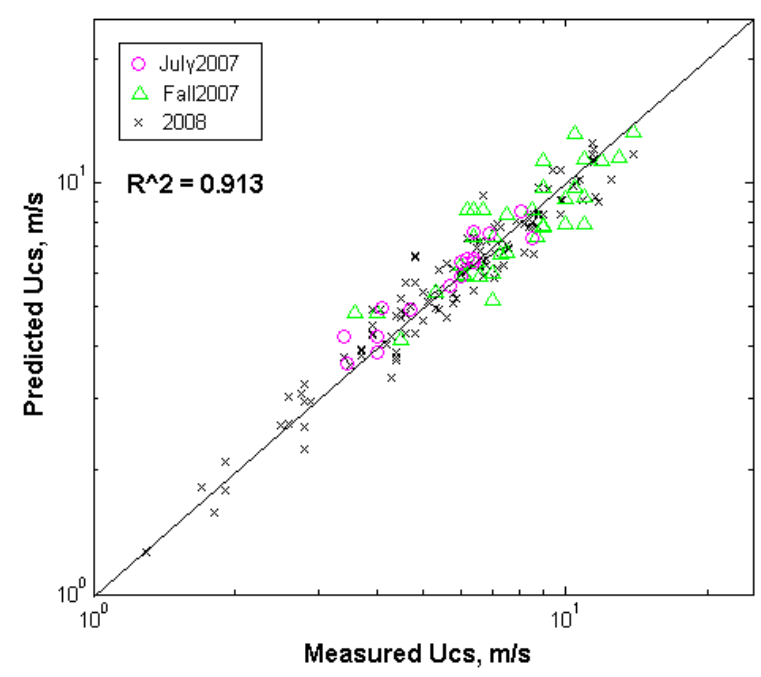

Figure 7.24. Log-Log Plot of Predicted Versus Measured $U_{C S}(m / s)$ Values for the Nine-Term Dimensional Model in Eq. (7.52b) Fit to Full Data Set. The 45-degree line represents perfect prediction where predicted equal measured $\mathrm{U}_{\mathrm{CS}}$ values. The $\mathrm{R}^{2}$ value was calculated using predicted and measured values of $\ln \left(\mathrm{U}_{\mathrm{CS}}\right)$. 
The exponents in Eq. (7.52a) for the $\mathrm{U}_{\mathrm{CS}}$ dimensional model agree qualitatively with those in Eq. (7.30) for the $U_{C S}$ physical model if the settling number is assumed to be constant.

\subsubsection{2 $\quad \mathrm{H}_{\mathrm{C}}$ Dimensional Models without Interaction Terms}

The dimensional model forms without interaction terms for $\mathrm{H}_{\mathrm{C}}$ are listed as Eq. (F.21a) and (F.21b) in Appendix F. Sections F.3.2 and F.3.4.1 discuss how these $\mathrm{H}_{\mathrm{C}}$ model forms were developed. The results of fitting Eq. (F.22b) to the full data set are given in Table F.8 and discussed in Section F.3.4.2 of Appendix F. The PvM plots showing the goodness of fit of the $\mathrm{H}_{\mathrm{C}}$ dimensional model form without interactions to the full data set is given in Figure F.9.

The resulting $\mathrm{H}_{\mathrm{C}}$ dimensional models without interaction terms for the full data set, listed in Eq. (F.24a) and (F.24b) in Appendix F, are

$$
\begin{aligned}
\mathrm{H}_{\mathrm{C}} & =1.079(\mathrm{D})^{-1.191}(\mathrm{~s}-1)^{-0.836}\left(\phi_{\mathrm{S}}\right)^{-0.623}\left(1-\phi_{\mathrm{S}}\right)^{-17.502}\left(\mathrm{U}_{\mathrm{T}}\right)^{-0.412}(\mathrm{DC})^{0.371} \\
& \times\left(\phi_{\mathrm{p}}\right)^{0.218}\left(\mathrm{~N}_{\mathrm{J}}\right)^{0.330}(\mathrm{~d})^{1.722}(\mathrm{U})^{1.378}
\end{aligned}
$$

and

$$
\begin{aligned}
\ln \left(\mathrm{H}_{\mathrm{C}}\right) & =0.076-1.191 \ln (\mathrm{D})-0.836 \ln (\mathrm{s}-1)-0.623 \ln \left(\phi_{\mathrm{S}}\right)-17.502 \ln \left(1-\phi_{\mathrm{S}}\right) \\
& -0.412 \ln \left(\mathrm{U}_{\mathrm{T}}\right)+0.371 \ln (\mathrm{DC})+0.218 \ln \left(\phi_{\mathrm{p}}\right)+0.330 \ln \left(\mathrm{N}_{\mathrm{J}}\right)+1.722 \ln (\mathrm{d}) \\
& +1.378 \ln (\mathrm{U}) .
\end{aligned}
$$

The $\mathrm{H}_{\mathrm{C}}$ dimensional model was fit to the full data set in the form of Eq. (7.53b) and also used to calculate model prediction uncertainties. It is also useful to view the $\mathrm{H}_{\mathrm{C}}$ dimensional model in the Eq. (7.53a) form. The PvM plot for these models from Figure F.9 is reproduced in Figure 7.25. The $\mathrm{R}^{2}=$ 0.830 value indicates the model accounts for $83 \%$ of the variation in the $\ln \left(\mathrm{H}_{\mathrm{C}}\right)$ values for the full data set.

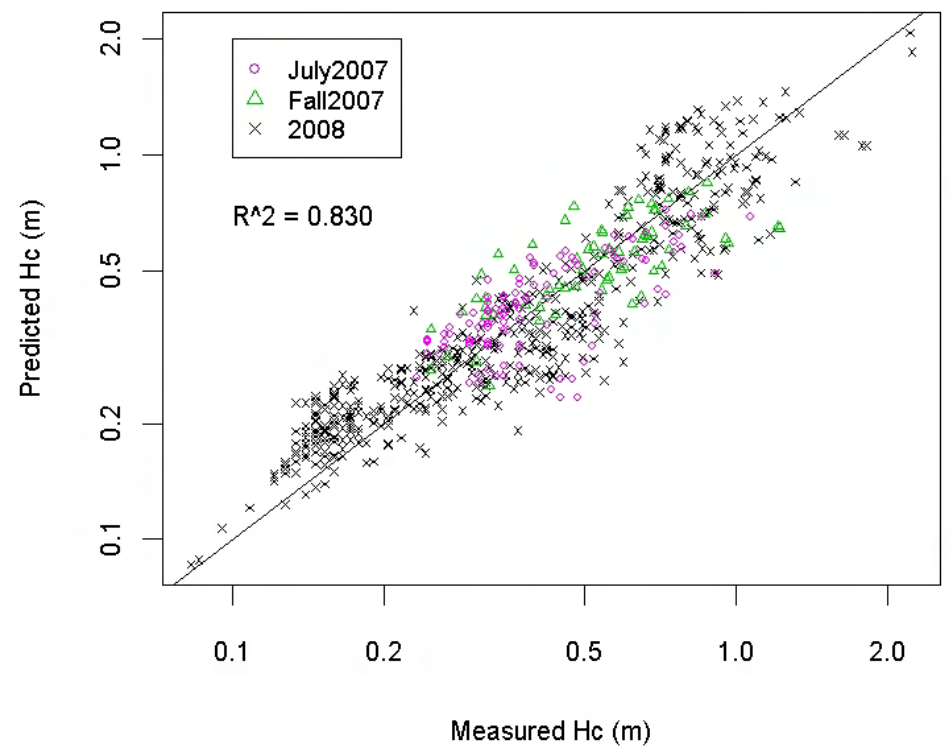

Figure 7.25. Log-Log Plot of Predicted Versus Measured $\mathrm{H}_{\mathrm{C}}$ for 11 -Term Dimensional Model in Eq. (7.53b) Fit to Full Data Set. The 45-degree line represents perfect prediction where predicted equal measured $\mathrm{H}_{\mathrm{C}} ; \mathrm{R}^{2}$ was calculated using predicted and measured $\ln \left(\mathrm{H}_{\mathrm{C}}\right)$. 
The large negative coefficient of -17.502 on the $\left(1-\phi_{\mathrm{S}}\right)$ term in Eq. (7.53a) and (7.53b) requires some explanation because it stands out from other coefficients. As seen in Table F.8 of Appendix F, this term in the $\mathrm{H}_{\mathrm{C}}$ models is highly statistically significant. Having both $\phi_{\mathrm{S}}$ and $\left(1-\phi_{\mathrm{S}}\right)$ terms in Eq. (7.53a) and (7.53b) serves to model the curvature effect of $\phi_{S}$ on $H_{C}$. This curvature can be seen in the functionality plot of $\phi_{\mathrm{S}}$ for $\mathrm{H}_{\mathrm{CS}}$ in Figure E.28 of Appendix E. A model like Eq. (7.53b), but fit without the $\left(1-\phi_{S}\right)$ term, show biased predictions of $\mathrm{H}_{\mathrm{C}}$ for $\phi_{\mathrm{S}}>0.015$. Finally, when the coefficient 17.502 is combined with $\left(1-\phi_{\mathrm{S}}\right)$ values in the M3 test data set (ranging from 0.94 to 0.9995$)$, the range of contributions of this term to model predictions is smaller than for several other model terms. Hence, the $\left(1-\phi_{\mathrm{S}}\right)^{-17.502}$ and $-17.502 \ln \left(1-\phi_{\mathrm{S}}\right)$ terms in Eq. (7.53a) and (7.53b) are appropriate for the range of $\phi_{\mathrm{S}}$ studied in M3 testing. However, caution is advised if these $\mathrm{H}_{\mathrm{C}}$ models need to be extrapolated to $\phi_{\mathrm{S}}$ values outside the range of M3 testing.

\subsection{2 $\quad U_{c s}$ and $H_{C}$ Dimensionally Consistent (Generalized) Models}

The dimensional model forms for $\mathrm{U}_{\mathrm{CS}}$ and $\mathrm{H}_{\mathrm{C}}$ in Eq. (F.46a) and (F.47a), respectively, may be dimensionally consistent only through attaching the correct units to the constant term. Dimensionally consistent models with a dimensionless constant term may be preferred. Hence, dimensionally consistent versions of the dimensional models for $\mathrm{U}_{\mathrm{CS}}$ and $\mathrm{H}_{\mathrm{C}}$ were developed. The intent was to achieve dimensional consistency while maintaining, to the extent possible, the generalizations of the $\mathrm{U}_{\mathrm{Cs}}$ and $\mathrm{H}_{\mathrm{C}}$ dimensional models compared to the nondimensional models in Sections 7.3.2 to 7.3.4. This was accomplished by grouping the dimensional predictor variables to form dimensionless predictor variables so that the model constant is dimensionless. For ease of subsequent discussion, the dimensionally consistent models without interaction terms are henceforth referred to as the generalized models.

\subsubsection{1 $U_{c s}$ Generalized Models}

The generalized model forms for $\mathrm{U}_{\mathrm{CS}}$ are listed as Eq. (F.9a) and (F.9b) in Section F.2.4.1 of Appendix F. That section discusses how these $U_{C S}$ model forms were developed. The results of fitting Eq. (F.9b) to the full data set are given in Table F.3 and discussed in Section F.2.4.3. The predicted versus modeled (PvM) plot showing the goodness of fit of the $U_{\mathrm{CS}}$ generalized model form to the full data set is given in Figure F.4.

The resulting $\mathrm{U}_{\mathrm{CS}}$ generalized models for the full data set, listed in Eq. (F.13a) and (F.13b) of Appendix F, are

$$
\mathrm{U}_{\mathrm{CS}}=0.273 \mathrm{U}_{\mathrm{T}}\left(\frac{\mathrm{D}(\mathrm{s}-1) \mathrm{g}}{\mathrm{U}_{\mathrm{T}}^{2}}\right)^{0.397}\left(\frac{\mathrm{d}}{\mathrm{D}}\right)^{-0.991}(\mathrm{~s}-1)^{0.086} \mathrm{DC}^{-0.205} \phi_{\mathrm{S}}^{0.243} \phi_{\mathrm{p}}^{-0.221} \mathrm{~N}_{\mathrm{J}}^{-0.511}
$$

and

$$
\begin{aligned}
\ln \left(\mathrm{U}_{\mathrm{CS}}\right)= & -1.297+\ln \left(\mathrm{U}_{\mathrm{T}}\right)+0.397 \ln \left(\frac{\mathrm{D}(\mathrm{s}-1) \mathrm{g}}{\mathrm{U}_{\mathrm{T}}^{2}}\right)-0.991 \ln \left(\frac{\mathrm{d}}{\mathrm{D}}\right)+0.086 \ln (\mathrm{s}-1) \\
& -0.205 \ln (\mathrm{DC})+0.243 \ln \left(\phi_{\mathrm{S}}\right)-0.221 \ln \left(\phi_{\mathrm{p}}\right)-0.511 \ln \left(\mathrm{N}_{\mathrm{J}}\right)
\end{aligned}
$$


The $\mathrm{U}_{\mathrm{CS}}$ generalized model was fit to the full data set in the form of Eq. (7.54b). However, it is also useful to view the $\mathrm{U}_{\mathrm{CS}}$ model in the Eq. (7.54a) form. The PvM plot for these models from Figure F.4 is reproduced in Figure 7.26 for convenience. The $\mathrm{R}^{2}=0.867$ value indicates that the generalized model accounts for $86.7 \%$ of the variation in the $\ln \left(\mathrm{U}_{\mathrm{CS}}\right)$ values for the full data set. This is somewhat less than the $91.3 \%$ accounted for by the $\mathrm{U}_{\mathrm{CS}}$ dimensional model without interaction terms. As discussed in Section F.2.4, this suggests that the generalized model form may not represent the dependence of $U_{C S}$ on $\mathrm{U}_{\mathrm{T}}$ as well as the dimensional model without interaction terms. However, the advantage of Eq. (7.54a) and (7.54b) being based on physically interpretable, nondimensional variables may be considered an advantage for extrapolative application of the model.

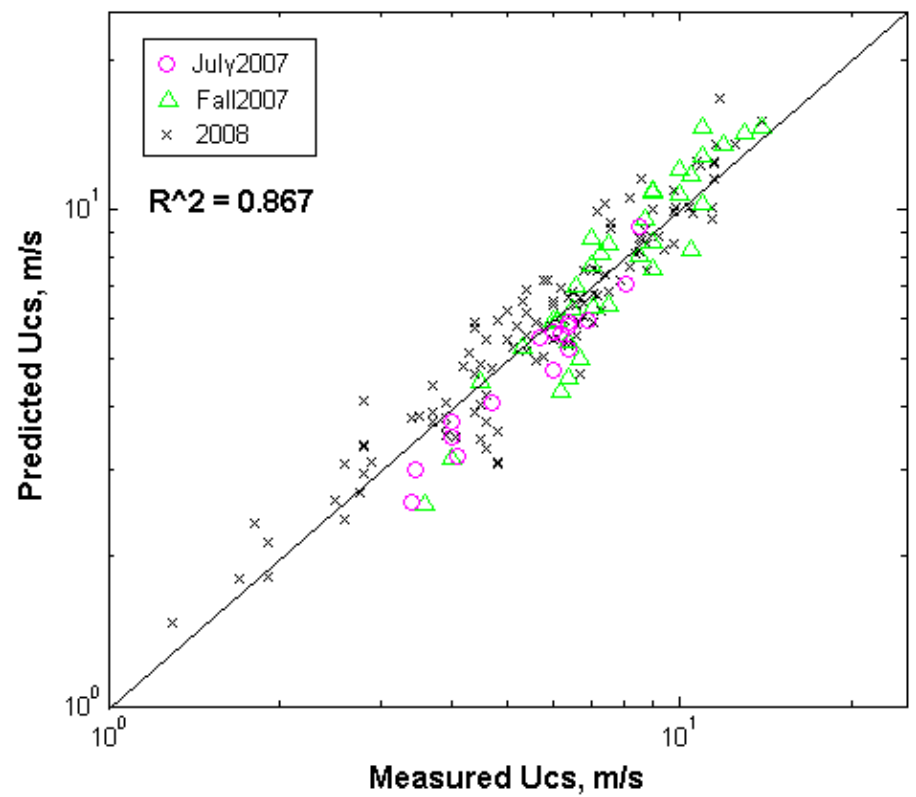

Figure 7.26. Log-Log Plot of PvM $\mathrm{U}_{\mathrm{CS}}(\mathrm{m} / \mathrm{s})$ Values for the Nine-Term Generalized Model in Eq. (7.54b) with Eight Coefficients Fit to Full Data Set. The 45-degree line represents perfect prediction where predicted and measured $\mathrm{U}_{\mathrm{CS}}$ values are equal. The $\mathrm{R}^{2}$ value was calculated using predicted and measured values of $\ln \left(\mathrm{U}_{\mathrm{CS}}\right)$.

\subsubsection{2 $\quad H_{C}$ Generalized Models}

The generalized model forms for $\mathrm{H}_{\mathrm{C}}$ are listed as Eq. (F.22a) and (F.22b) in Appendix F. Section F.3.4.1 discusses how these $\mathrm{H}_{\mathrm{C}}$ model forms were developed. The results of fitting Eq. (F.22b) to the full data set are given in Table F.10 and discussed in Section F.3.4.3 of Appendix F. The PvM plot showing the goodness of fit of the $\mathrm{H}_{\mathrm{C}}$ generalized model form to the full data set is given in Figure F.11.

The resulting $\mathrm{H}_{\mathrm{C}}$ generalized models for the full data set, listed in Eq. (F.26a) and (F.26b) in Appendix F, are

$$
\begin{aligned}
\mathrm{H}_{\mathrm{C}} & =3.040 \mathrm{D}\left(\frac{\mathrm{U}^{2}}{\mathrm{D}(\mathrm{s}-1) \mathrm{g}}\right)^{0.473}\left(\frac{\mathrm{d}}{\mathrm{D}}\right)^{1.693}(\mathrm{~s}-1)^{-0.356}\left(\frac{\mathrm{U}_{\mathrm{T}}}{\mathrm{U}}\right)^{-0.410} \mathrm{DC}^{0.364} \\
& \times \phi_{\mathrm{S}}^{-0.616}\left(1-\phi_{\mathrm{s}}\right)^{-17.206} \phi_{\mathrm{p}}^{0.213} \mathrm{~N}_{\mathrm{J}}^{0.320}
\end{aligned}
$$


and

$$
\begin{aligned}
& \ln \left(\mathrm{H}_{\mathrm{C}}\right)=1.112+\ln (\mathrm{D})+0.473 \ln \left(\frac{\mathrm{U}^{2}}{\mathrm{D}(\mathrm{s}-1) \mathrm{g}}\right)+1.693 \ln \left(\frac{\mathrm{d}}{\mathrm{D}}\right)-0.356 \ln (\mathrm{s}-1)-0.410 \ln \left(\frac{\mathrm{U}_{\mathrm{T}}}{\mathrm{U}}\right) \\
& +0.364 \ln (\mathrm{DC})-0.616 \ln \left(\phi_{\mathrm{S}}\right)-17.206 \ln \left(1-\phi_{\mathrm{S}}\right)+0.213 \ln \left(\phi_{\mathrm{p}}\right)+0.320 \ln \left(\mathrm{N}_{\mathrm{J}}\right)
\end{aligned}
$$

The $\mathrm{H}_{\mathrm{C}}$ generalized model was fit to the full data set in Eq. (7.55b). However, it is also useful to view the $\mathrm{H}_{\mathrm{C}}$ dimensionally consistent model in the Eq. (7.55a) form. The PvM plot for these models from Figure F.11 is reproduced in Figure 7.27. The $\mathrm{R}^{2}=0.830$ value indicates the $\mathrm{H}_{\mathrm{C}}$ generalized model accounts for $83 \%$ of the variation in the $\ln \left(\mathrm{H}_{\mathrm{C}}\right)$ values for the full data set. This matches the $\mathrm{H}_{\mathrm{C}}$ dimensional model without interactions, which is nearly dimensionally consistent, as discussed in Section F.3.4.3.

The large negative coefficient of -17.206 on the $\left(1-\phi_{S}\right)$ term in Eq. (7.55a) and (7.55b) requires some explanation because it stands out from other coefficients. As seen in Table F.10 of Appendix F, this term in the $\mathrm{H}_{\mathrm{C}}$ models is highly statistically significant. Other justification for this term is similar to that discussed at the end of Section 7.4.1.2.

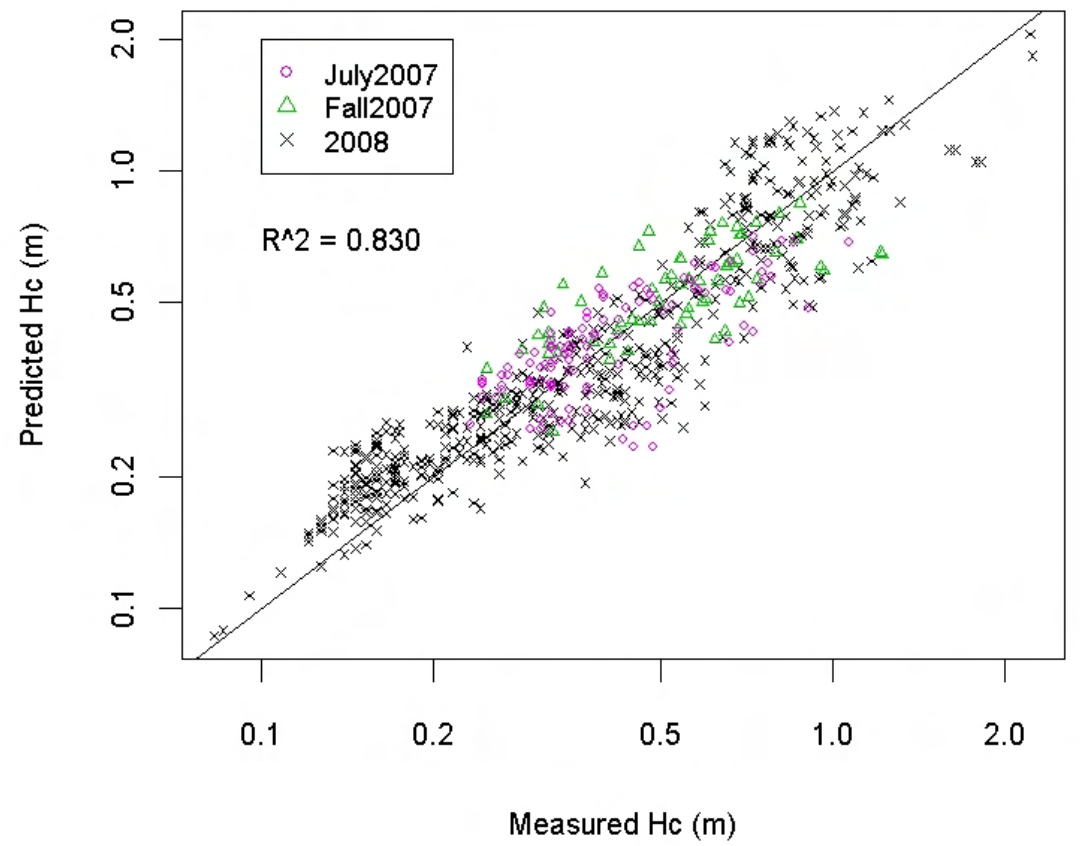

Figure 7.27. Log-Log Plot of PvM $\mathrm{H}_{\mathrm{C}}(\mathrm{m})$ Values for the 11-Term Generalized Model in Eq. (7.55b) with 10 Coefficients Fit to the Full Data Set. The 45-degree line represents perfect prediction where predicted equal measured $\mathrm{H}_{\mathrm{C}}$ values. The $\mathrm{R}^{2}$ value was calculated using predicted and measured values of $\ln \left(\mathrm{H}_{\mathrm{C}}\right)$.

\subsection{3 $U_{c s}$ and $H_{C}$ Dimensional Models with Interaction Terms}

The method used to add interactions to the $\mathrm{U}_{\mathrm{CS}}$ and $\mathrm{H}_{\mathrm{C}}$ dimensional model forms and the results of fitting these model forms to the full and trimmed data sets are discussed in Sections F.2.5 and F.3.5 of Appendix F. Adding interaction terms moderately improved the interpolative prediction performance of the dimensional models without interaction terms. However, extrapolative use of models with interaction 
terms can yield significantly inaccurate predictions. Hence, it is recommended the dimensional models with interaction terms be limited to interpolative use within the region of conditions covered during experimental testing (see Section F.5 of Appendix F).

\subsection{Comparing Physical, Dimensional, and Generalized Models for $\mathrm{U}_{\mathrm{CS}}$ and $\mathrm{H}_{\mathrm{C}}$}

The abilities of the $\mathrm{U}_{\mathrm{CS}}$ and $\mathrm{H}_{\mathrm{C}}$ models (physical, dimensional without interactions, generalized, and dimensional with interactions) to predict the $\mathrm{U}_{\mathrm{CS}}$ and $\mathrm{H}_{\mathrm{C}}$ full data sets are now assessed by comparing the model $\mathrm{R}^{2}$ values and PvM plots. Recall that the full data sets for $\mathrm{U}_{\mathrm{CS}}$ and $\mathrm{H}_{\mathrm{C}}$ were used to develop and fit the models; thus, using the same data to assess their performance consists of model evaluation rather than model validation. Leave-one-out cross-validation of the dimensional models without and with interactions using the full data set was performed via the $\mathrm{R}_{\mathrm{P}}^{2}$ statistic [see Appendix F, Sections F.2.4.2 and F.2.5 $\left(\mathrm{U}_{\mathrm{CS}}\right)$ and Sections F.3.4.2 and F.3.5 $\left(\mathrm{H}_{\mathrm{C}}\right)$ ]. Validation (benchmarking) of the physical and generalized models is discussed in Section 8.

Table 7.4 lists the $\mathrm{R}^{2}$ values and locations of the PvM plots for each of the $\mathrm{U}_{\mathrm{CS}}$ and $\mathrm{H}_{\mathrm{C}}$ models fit to the full data sets for $\mathrm{U}_{\mathrm{CS}}$ and $\mathrm{H}_{\mathrm{C}}$ (described in Section 7.3.2 and Section F.1.1 of Appendix F). Table 7.4 shows that the $\mathrm{U}_{\mathrm{CS}}$ and $\mathrm{H}_{\mathrm{C}}$ dimensional models with interactions have the highest $\mathrm{R}^{2}$ values. However, as noted in Section 7.4.3, and discussed more in Sections F.2.5 and F.3.5 of Appendix F, models with interaction terms should only be used for extrapolative predictions after substantial extrapolative validation. Because such validation work has not been performed, the dimensional models with interaction terms should only be used for interpolative predictions inside the test-variable region experimentally investigated during M3 testing.

Table 7.4. Basis for Comparing $\mathrm{U}_{\mathrm{CS}}$ and $\mathrm{H}_{\mathrm{C}}$ Models Fit to the Full Data Sets

\begin{tabular}{|c|c|c|c|c|}
\hline \multirow[b]{2}{*}{ Model Type } & \multicolumn{2}{|c|}{$\mathrm{U}_{\mathrm{CS}}$ Model } & \multicolumn{2}{|c|}{$\mathrm{H}_{\mathrm{C}}$ Model } \\
\hline & $\mathrm{R}^{2}$ & PvM Plot(a) & $\mathrm{R}^{2}$ & PvM Plot \\
\hline \multirow{2}{*}{ Physical } & \multirow{2}{*}{0.896} & Figure 7.20 & \multirow{2}{*}{0.493} & Figure 7.21 \\
\hline & & Figure F.8 & & Figure F.15 \\
\hline \multirow{2}{*}{ Dimensional without interactions } & \multirow{2}{*}{0.913} & Figure 7.24 & \multirow{2}{*}{0.830} & Figure 7.25 \\
\hline & & Figure F.2 & & Figure F.9 \\
\hline \multirow{2}{*}{$\begin{array}{l}\text { Generalized } \\
\text { (dimensionally consistent } \\
\text { without interactions) }\end{array}$} & \multirow[b]{2}{*}{0.867} & & \multirow[b]{2}{*}{0.830} & Fioure 727 \\
\hline & & Figure F.4 & & Figure F.11 \\
\hline Dimensional with interactions & 0.939 & Figure F.6 & 0.861 & Figure F.13 \\
\hline
\end{tabular}

For $\mathrm{U}_{\mathrm{CS}}$, the dimensional model without interactions fits the full data set the best, followed by the physical model, and finally the generalized model. A choice among these models should depend on their performance in benchmarking (validation) work, as well as subject matter knowledge and expectations regarding how appropriate each model is for extrapolative prediction.

For $\mathrm{H}_{\mathrm{C}}$, the dimensional model without interaction terms and the generalized model are essentially equivalent, because the former is nearly dimensionally consistent without restricting the model to be so. 
Hence, either one of these models could be used. The physical model for $\mathrm{H}_{\mathrm{C}}$ does not predict the full data set as well as the other two models.

The benchmarking performance of the physical and generalized models for each of $U_{C s}$ and $H_{C}$ are compared in Section 8. These models were selected for additional investigation because they both use nondimensional variables as predictor variables and thus each have a physical basis for interpretation.

\subsection{Possible Model Improvements}

Possible improvements to the physical and generalized models are discussed in Sections 7.6.1 and 7.6.2, respectively. Section 7.6.3 makes some concluding remarks regarding possible model improvements.

\subsubsection{Possible Improvements to Physical Models}

The physical models for $\mathrm{U}_{\mathrm{CS}}$ and $\mathrm{H}_{\mathrm{C}}$ were obtained by plotting basic nondimensional variables with fewer coefficients estimated from the data (using model fitting methods) than the MR models. Various additional physical models were explored. These are briefly described and discussed here.

Better parameter fits: By allowing the exponents on (s-1), DC, $\phi_{\mathrm{S}}$, and Ga to vary, better-fitting models were achieved. The models were improved further by introducing additional terms such as (1-DC) and $\left(1-\phi_{\mathrm{p}}\right)$.

Including dish geometry: When different dish geometries are accounted for by an adjustable leading constant, improvement in the model fits is achieved. This is particularly true for data points from testing in the mid-scale (34-in.) tank.

Limited data sets and parameter ranges: Improvements could also be made by breaking the data set into subgroups and fitting separate models for each. For example, a 12-tube-only data group (which makes up the vast majority of M3 testing data) and models could be developed for application to the HLP-22 and FRP-02 vessels. Further improvements could be achieved by limiting some of the variable ranges such as $\mathrm{DC}<0.4$ and $\phi_{\mathrm{S}} \leq 0.015$.

Including scale term for cloud height: Several different approaches to introducing the effect of scale into the cloud height model were explored. These include Reynolds number based jet diameter, Re, Reynolds number based on tank diameter $\left(\mathrm{Re}_{\mathrm{D}}\right)$, nondimensional critical suspension parameter $\mathrm{D}^{*}$, and Froude number based on tank diameter $\left(\mathrm{F}_{\mathrm{D}}\right)$. The best model fit to the data is achieved when both $\mathrm{D}^{*}$ and Re are used. This is reasonable because Re is not so much a scale-up term as a way of capturing the effect of the jet turbulence level. We expect some jet Reynolds number effect to be present in the data taken from the small-scale (15-in.) tank. Hence it is reasonable that the model fit would be improved by inclusion of the term. However, we also expect there to be little or no Re effect for large-scale vessels. So while inclusion of Re provides a better data fit, it probably does not provide more accurate predictions at large scale.

Accounting for vertical solids entrainment: The slight curvature seen in the cloud height data in Figures 7.19 and 7.20 is likely due to the vertical entrainment effect of the closed loop pump returns. 
When the settling velocity is small, $\mathrm{U} / \mathrm{U}_{\mathrm{TH}}$ becomes large and the potential for entrainment is high. This is consistent with the slight upward curvature observed when $\mathrm{H}_{\mathrm{C}} *$ is plotted versus $U / \mathrm{U}_{\mathrm{TH}}$.

Prototypic PJMs induce a periodic bulk vertical motion, which on average has zero velocity, so the average level remains stationary. The test apparatus used a closed-loop pump system where the drive phase was achieved by opening a valve, and refill was modeled by simply closing the valve. The absence of the refill contribution results in a net upward vertical displacement of the bulk fluid during each drive cycle. The effective average vertical velocity induced $\left(U_{V}\right)$ is

$$
\mathrm{U}_{\mathrm{V}}=\phi_{\mathrm{J}} \mathrm{DC} \mathrm{U}
$$

which will affect the test results if it is comparable to the settling velocity. To account for this effect, we introduce the modified setting velocity, $\mathrm{U}_{\mathrm{TH}}^{\prime}$ :

$$
\mathrm{U}_{\mathrm{TH}}^{\prime}=\mathrm{U}_{\mathrm{TH}}-\mathrm{U}_{\mathrm{v}}
$$

given by

$$
\frac{\mathrm{U}}{\mathrm{U}_{\mathrm{TH}}^{\prime}}=\frac{\mathrm{U}}{\mathrm{U}_{\mathrm{TH}}\left(1-\phi_{\mathrm{J}} \mathrm{DC} \frac{\mathrm{U}}{\mathrm{U}_{\mathrm{TH}}}\right)}
$$

Very good data fits were achieved for both $\mathrm{H}_{\mathrm{C}}$ and $\mathrm{U}_{\mathrm{CS}}$ when the effective settling velocity was used instead of $\mathrm{U}_{\mathrm{TH}}$, and the effect of scale was included through $\mathrm{D}^{*}$ and Re. The model fits to the data had an $\mathrm{R}^{2}$ of 0.97 for $\mathrm{U}_{\mathrm{CS}}$ and 0.93 for $\mathrm{H}_{\mathrm{C}}$. While this approach gives very good fits to the test data, it produces some unrealistic results when applied at plant scale, where the effective settling velocity is replaced with the regular settling velocity. This suggests that not all of the curvature in the cloud height data is due to the vertical entrainment effect. It is therefore not possible to know the exact magnitude of the vertical entrainment without performing tests with prototypic drive systems.

\subsubsection{Possible Improvements to Generalized Models}

As discussed in Sections F.2.1 and F.3.1 of Appendix F, a power-law relationship was deemed best or adequate (for a first-order approximation) for statistically modeling the dependence of $\mathrm{U}_{\mathrm{CS}}$ and $\mathrm{H}_{\mathrm{C}}$ on the primary M3 test variables. However, that discussion also indicated that improvements to statistical MR models (as well as physical models) are possible by considering relationship forms other than the powerlaw for different test variables.

Based on the functionality plots for $\mathrm{U}_{\mathrm{CS}}$ in Figures E.6 to E.16, test variables for which non-powerlaw relationships may be beneficial are $\mathrm{N}_{J}$ (the number of operating jets), DC $>0.33$ for some conditions, and $\phi_{\mathrm{S}}>0.015$. Based on the functionality plots in Figures E.17 to E.32 for $\mathrm{H}_{\mathrm{CS}}$, test variables for which non-power-law relationships may be beneficial are $\mathrm{N}_{\mathrm{J}}$ (the number of operating jets), $\phi_{\mathrm{S}}>0.015$, and the smallest and largest values of $d_{S}$ and $U_{T}$ (for which very few tests were performed).

Other improvements discussed in Section 7.6.1, such including a dish geometry term, fitting models to subgroups of the data, and accounting for vertical solids entrainment, are also possibilities for improving statistical MR models. 
Finally, a response surface methodology approach to developing polynomial-type models was investigated for $\mathrm{U}_{\mathrm{CS}}$ and $\mathrm{H}_{\mathrm{C}}$, but it did not lead to improved models. See Sections F.2.1 and F.3.1 of Appendix $\mathrm{F}$ for additional discussion of this topic.

\subsection{Conclusions Regarding Possible Model Improvements}

All of the improvements discussed in Sections 7.6.1 and 7.6.2 would result in better-fitting models. The physical approach used to develop the models discussed in Section 7.3 was based on the philosophy that the simplest explanation consistent with data supersedes any more complicated explanation. Given the overall uncertainty and the primary desire of the WTP project to rate and evaluate all of the plant vessels, it is not clear whether the predictive capability of a better-fitting model would be an improvement when it comes to rating the WTP vessels. As the complexity of a model form is increased to improve the fit when interpolating, there may be less confidence the form remains valid when extrapolating. However, some model improvements could improve model extrapolation as well as interpolation performance. For example, this appears to be the case for the $\mathrm{H}_{\mathrm{C}}$ model developed by the generalized approach, which significantly improves on the $\mathrm{H}_{\mathrm{C}}$ model developed by the physical approach (compare Figures 7.21 and 7.27). Ultimately, it was decided to investigate both the physical and generalized models for $\mathrm{U}_{\mathrm{CS}}$ and $\mathrm{H}_{\mathrm{C}}$ in Sections 8 and 9 .

It is envisioned that there are ways to improve the models (as discussed in Section 7.6) that would be beneficial for interpolative as well as extrapolative prediction performance. However, per direction from the WTP project, no model improvement efforts were to be conducted as part of revising the report to address formal comments. Such model-improvement efforts are left to future work if it is determined improved models are needed for WTP applications. 



\subsection{Applicability and Benchmarking of Mixing Models}

This section addresses the applicability of the mixing models presented in Section 7 to the WTP mixing systems. Section 8.1 addresses how the work accounted for prototypic geometries, operation, and slurry properties. Section 8.2 discusses the sources of uncertainty, bias, and margin. Finally, Section 8.3 provides the results of some benchmarking exercises where the mixing models were applied and the results compared to data from previous testing in prototypic PJM systems and as well as calculations from some CFD simulations.

\subsection{Accounting for Prototypic Conditions}

The testing equipment used to produce the data for this report had some features that were not prototypic of PJM mixing designs, and some of the differences would be expected to affect the data. This section discusses how the departures from prototypic designs would be manifested in the data and what accommodations or adjustments were made.

\subsubsection{Geometry and Operation}

The geometry and operational aspects of the M3 test program that were different from prototypic PJM operation are discusssed in the following:

- Jet slurry density: The jet slurry density during discharge will be higher with prototypic PJMs than with the pulse tubes tested, which discharged liquid only. Actual densities will be 5 to $10 \%$ higher with slurry being discharged from the PJM, as long as the designs are able to suspend solids. ${ }^{1}$ To estimate the effect of higher jet density, we can examine the effect of increased liquid density on $U_{\mathrm{CS}}$ and $\mathrm{H}_{\mathrm{C}}$. For typical conditions, a $5 \%$ increase in density increases $\mathrm{U}_{\mathrm{CS}}$ by about $1 \%$ and decreases $\mathrm{H}_{\mathrm{C}}$ by about 3\%; hence, the effect of applying the models to prototypic systems which discharge slurries should be minor.

- Suction effects: The flow field resulting from suction during the PJM refill has little effect on the mixing within the vessel. The induced velocity during suction at some distance (z) from the nozzle (with diameter, $d$ ) decreases away from the nozzle in proportion to $(\mathrm{d} / \mathrm{z})^{2}$, whereas during discharge the velocity decreases by $(\mathrm{d} / \mathrm{z})$. When the relationship between drive and refill flow rates are considered, the ratio of the suction velocity to the jet velocity is approximately $[D C /(1-D C)](d / z)^{2}$, where DC is the duty cycle. For a 10.2-cm (4-in.) nozzle and a $33 \%$ DC, the ratio is 0.02 at $50.8 \mathrm{~cm}$ (20 in.) from the nozzle. The suction-induced flow field becomes larger closer to the nozzle. However, the area closest to the nozzle is also the area most impacted by the jet flow. Thus, the effect should be negligible of disregarding the suction-induced flow field in applying the models to prototypic systems which have refill suction.

- Nozzle geometry: Prototypic PJMs have conical nozzles, unlike the straight nozzles used for testing. The effect of nozzle geometry was explored by BNI using the FLUENT ${ }^{2}$ CFD model. Floor shear

\footnotetext{
${ }^{1}$ Actual jet density may be much higher for designs that are unable to suspend solids well. Hence high densities would be associated with inadequate designs and the effect of higher jet densities would only exacerbate problems in those vessels. For vessels that mix well, the impact of this approximation would be relatively small.

2 http://www.fluent.com/
} 
stress profiles were computed for both nozzle types. While there was some difference near the nozzle, far from the nozzle the differences where negligible. This finding is consistent with the wellaccepted observation that the detail of nozzle cross-section geometry is lost far from the orifice, with the hydraulic diameter being the controlling parameter. The effect of applying the models to prototypic systems that have conical nozzles should thus be negligible.

- Pulse Tube Outer Diameter: Prototypic pulse tubes have much larger diameters than the straight pipes used during testing. There are two potential effects of this simplification to consider, flow-field effects and volumetric displacement effects. The effect of pulse tube diameter on the overall flowfield in the vessel should be negligible. For off-bottom suspension, the primary flow is at the vessel bottom, beneath the nozzles, and is therefore unaffected by pulse tube diameter. For solids vertical distribution, the upwelling flow is important. The primary vertical flow occurs at the center of the vessel, with lesser upwells occurring between adjacent pulse tubes, particularly for the 12-tube designs. A useful parameter to consider is

$$
\phi_{\mathrm{PT}}=\mathrm{N}\left(\mathrm{D}_{\mathrm{PT}} / \mathrm{D}\right)^{2} \text {, }
$$

the ratio of total pulse tube cross-sectional area to the vessel cross-sectional area. For the plant vessels, this ratio varies from 0.063 for HOP-903/904 to 0.214 for TCP-01. For HLP-22 the value is 0.168. If the upwelling flow was uniform and confined by the vessel diameter, the effect of an area reduction equivalent to this ratio would result in velocities increased by $\left(1-\phi_{\mathrm{PT}}\right)^{-1}$, corresponding to a velocity increase of about $20 \%$ for HLP-22. However, the upwell flows are not uniform over the vessel diameter. The width of the upwell flows scale with nozzle diameter and are therefore much smaller than the vessel diameter. Hence, it is expected that actual increased upwell velocity associated with prototypic pulse tube outer diameters is much smaller than $\left(1-\phi_{\mathrm{PT}}\right)^{-1}$.

The potential magnitude of the displacement effect associated with pulse tube diameter can be estimated by the derivation leading to the definition of $\mathrm{H}_{\mathrm{C}}{ }^{*}$ given by Eq. (7.32). When considering the displaced volume associated with pulse tube diameter, the slurry mass in Eq. (7.26) is multiplied by (1- $\left.\phi_{\mathrm{PT}}\right)$. This results in the nondimensional cloud height parameter $\mathrm{H}_{\mathrm{C}}{ }^{*}$ given by Eq. (7.32) being multiplied by (1- $\left.\phi_{\mathrm{PT}}\right)$ and suggests actual clouds could be increased by a factor of $\left(1-\phi_{\mathrm{PT}}\right)^{-1}$ due to the displacement effect of pulse tube outer diameter.

- Solids vertical entrainment: The vertical entrainment effect associated with the closed loop operation of the test apparatus was discussed in Section 7.6 and pictured in Figure 8.1. The effect suggests that predicted cloud height for plant vessels will be lower than that predicted by the correlations, which were based on data from tests with entrainment. The modified settling velocity introduced in Section 7.6 can be used to estimate the magnitude of the potential effect in terms of an effective settling velocity. The term $\left(1-\phi_{\mathrm{J}} \mathrm{DCU} / \mathrm{U}_{\mathrm{TH}}\right)$ in Eq. (7.48) can be interpreted as the correction factor required to apply to the prototypic settling velocity to account for the entrainment effect. For example, for conditions corresponding to HLP-22 and taking $\mathrm{U}_{\mathrm{TH}}$ to be $1 \mathrm{~cm} / \mathrm{s}$, the correction factor is $\sim 0.63$, implying that the predicted result would be relevant for a slurry with settling velocity of $0.63 \mathrm{~cm} / \mathrm{s}$. Conversely, a settling velocity of $1.57 \mathrm{~cm} / \mathrm{s}$ would be used in the correlation to predict the cloud height for a slurry with an actual settling velocity of $1 \mathrm{~cm} / \mathrm{s}$.

In summary, the effects of vertical entrainment associated with the nonprototypic drive system can be accounted for by modifying the settling velocity in the rating equations according to Eq. (7.48). 


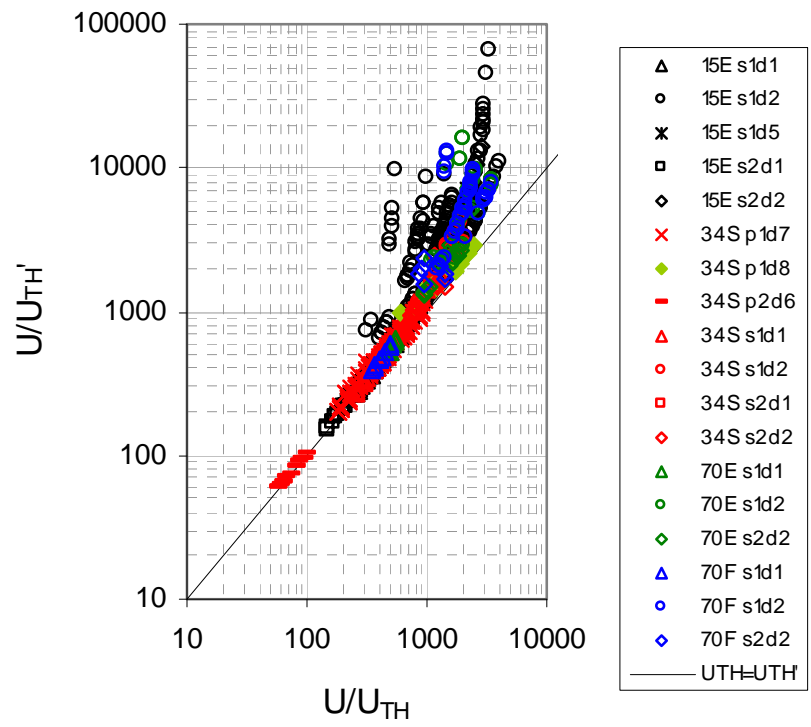

Figure 8.1. Effective Settling Velocity Associated with Vertical Entrainment from Pump Suction Returns (FIO)

\subsubsection{Accounting for Prototypic Fill Level}

The results of Hicks, which were discussed in Section 2, demonstrated that $\mathrm{U}_{\mathrm{CS}}$ is insensitive to fill level when the solids loading is based on a reference volume and not the slurry volume. Similarly, cloud height is also insensitive to fill level as long as the cloud is below the fill level. It follows therefore that solids vertical distribution is also independent of fill level as long as the cloud is below the fill level. However, once the cloud reaches the fill level, the solids vertical distribution will depend on the fill level.

The cloud height models (physical and generalized) developed from the test data can be accurately used to predict cloud height. If the model produces a cloud height that exceeds the fill level, this application is obviously not physical. In this case the predicted cloud height is simply the fill level. However, the concentration profile will not be accurately predicted by the model and an adjustment is required.

We handle the effect of fill level on solids concentration in the following way:

- When using a physical or generalized model to determine $\mathrm{H}_{\mathrm{C}}$, if $\mathrm{H}_{\mathrm{C}} \leq \mathrm{H}_{\mathrm{F}}$ the result is valid, and the concentration at the floor, $\mathrm{C}_{0}$, is estimated by the linear concentration profile model, $\mathrm{C}(\mathrm{Z})$ (Eq. 7.47), as developed in Section 7.3.3:

$$
\frac{\mathrm{C}_{0}}{\phi_{\mathrm{S}}}=\frac{\mathrm{k}}{\mathrm{H}_{\mathrm{C}} / \mathrm{D}}
$$

- For predicted $\mathrm{H}_{\mathrm{C}}>\mathrm{H}_{\mathrm{F}}$, we set $\mathrm{H}_{\mathrm{C}}=\mathrm{H}_{\mathrm{F}}$, the fill height, as shown in Figure 8.2. Then a corrected $\mathrm{C}_{0}$ is determined from this value of $\mathrm{H}_{\mathrm{C}}$ by matching both the total mass and the concentration gradient. 


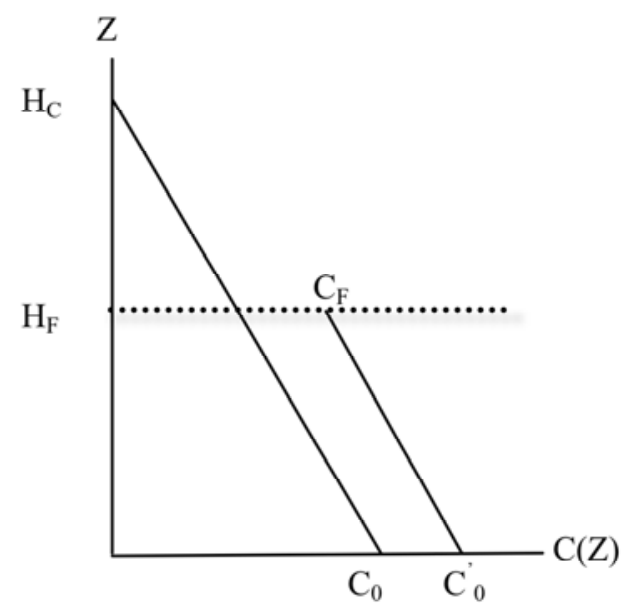

Figure 8.2. Illustration of How Finite Fill Level Affects Maximum Concentration

- Using $\mathrm{k}=2$ for a linear distribution that conserves mass (Section 7.3.3), the equation for the corrected average solids concentration at the floor $\left(C_{0}^{\prime}\right)$ is given by

$$
\frac{\mathrm{C}_{0}^{\prime}}{\phi_{\mathrm{S}}}=\frac{1}{\mathrm{H}_{\mathrm{F}} / \mathrm{D}}+\frac{1}{4}\left(\frac{\mathrm{C}_{0}}{\phi_{\mathrm{S}}}\right)^{2} \frac{\mathrm{H}_{\mathrm{F}}}{\mathrm{D}}
$$

- The associated equation for average concentration at the fill height $\left(\mathrm{C}_{\mathrm{F}}\right)$ is given by

$$
\frac{\mathrm{C}_{\mathrm{F}}}{\phi_{\mathrm{S}}}=\frac{1}{\mathrm{H}_{\mathrm{F}} / \mathrm{D}}-\frac{1}{4}\left(\frac{\mathrm{C}_{0}}{\phi_{\mathrm{S}}}\right)^{2} \frac{\mathrm{H}_{\mathrm{F}}}{\mathrm{D}}
$$

In both Eq. (8.3) and Eq. (8.4), $\mathrm{C}_{0}$ is the concentration at the floor given by Eq. (8.2) using the initial prediction of cloud height.

\subsubsection{Accounting for Distributions of Particle Size and Density}

One of the advantages of using the settling velocity in the mixing models is that it has a consistent physical meaning regardless of the size distribution of the solids. For a slurry that is well mixed such that no stratification in particle size or density exists, the volume-weighted average settling velocity ( $\bar{U}$ ) is a good representation of the actual settling. (See Section 3 for a discussion of volume-weighted averages and terminology). This well-mixed condition is illustrated in Figure 8.3 (a). Also shown in Figure 8.3 (b) is the same slurry with some degree of stratification. The average settling velocity near the bottom of the vessel will be much higher than that near the top if significant stratification is present. Because of this, we expect that the characteristic settling velocity that best represents mixing performance is one that describes the faster settling part of the size distribution $\left(U_{T}>\bar{U}\right.$, e.g., $U_{90}, U_{95}$, etc.). Therefore, for slurries with particle size distributions, the appropriate settling velocity for evaluating the sufficiency of a PJM operating with certain system parameters must be significantly larger than the nominal volumefraction-averaged settling velocity, which itself is significantly larger than the median settling velocity. (For example, see Table 9.6, comparing the 50th percentile velocity to the volume-weighted average). This is reasonable given the physical process involved and is consistent with some industrial experience. 


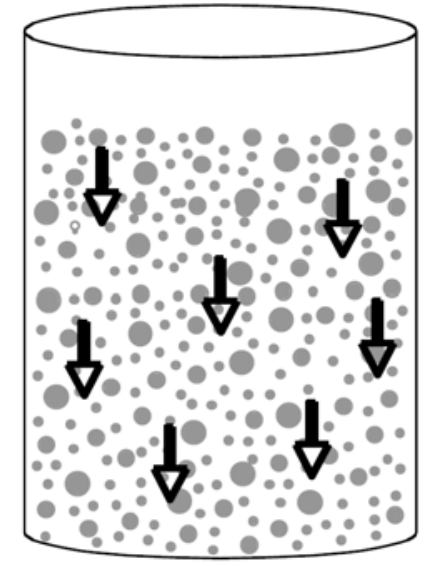

(a)

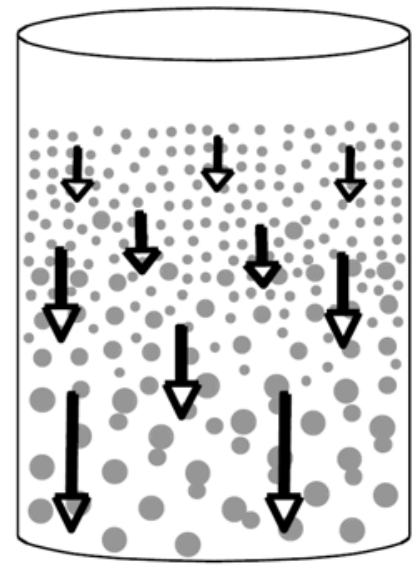

(b)

Figure 8.3. Illustration of How Stratification Results in Higher Effective Settling Velocities for Noncohesive Solids with a Broad Size Distribution: (a) Settling Velocity for a Well-Mixed Slurry, (b) Settling Velocity for a Stratified Slurry

\subsection{Uncertainty and Applicability}

Sections 8.2.1 to 8.2.4 discuss several types of uncertainty associated with the experimental data, models developed from the data, and applying the models to predict mixing performance of WTP vessels.

\subsubsection{Measurement Uncertainty}

Measurement uncertainties were associated with four categories of parameters: geometric, operational, physical (simulant parameters), and performance ( $\mathrm{U}_{\mathrm{CS}}, \mathrm{H}_{\mathrm{C}}, \mathrm{C}_{0}$, and $\mathrm{C}(\mathrm{Z})$ ). Each category is discussed below.

\subsubsection{Geometric Parameters}

Geometric parameters are those associated with the geometric configuration of the test setup. Most were measured before and after a test as part of the configuration management of the test setup. The geometric parameters include tank diameter, nozzle diameter, nozzle standoff distance, nozzle radial position, nozzle azimuthal location, profile of tank bottom contour, suction line elevation, suction line position, and liquid elevation. For some parameters such as nozzle diameter, measurements were made and recorded for each individual component. The average values of these measurements were used for developing the models and post-test analysis. The uncertainties for the geometric parameters are listed in Table 8.1. 
Table 8.1. Test Parameters and Associated Bounding Uncertainties

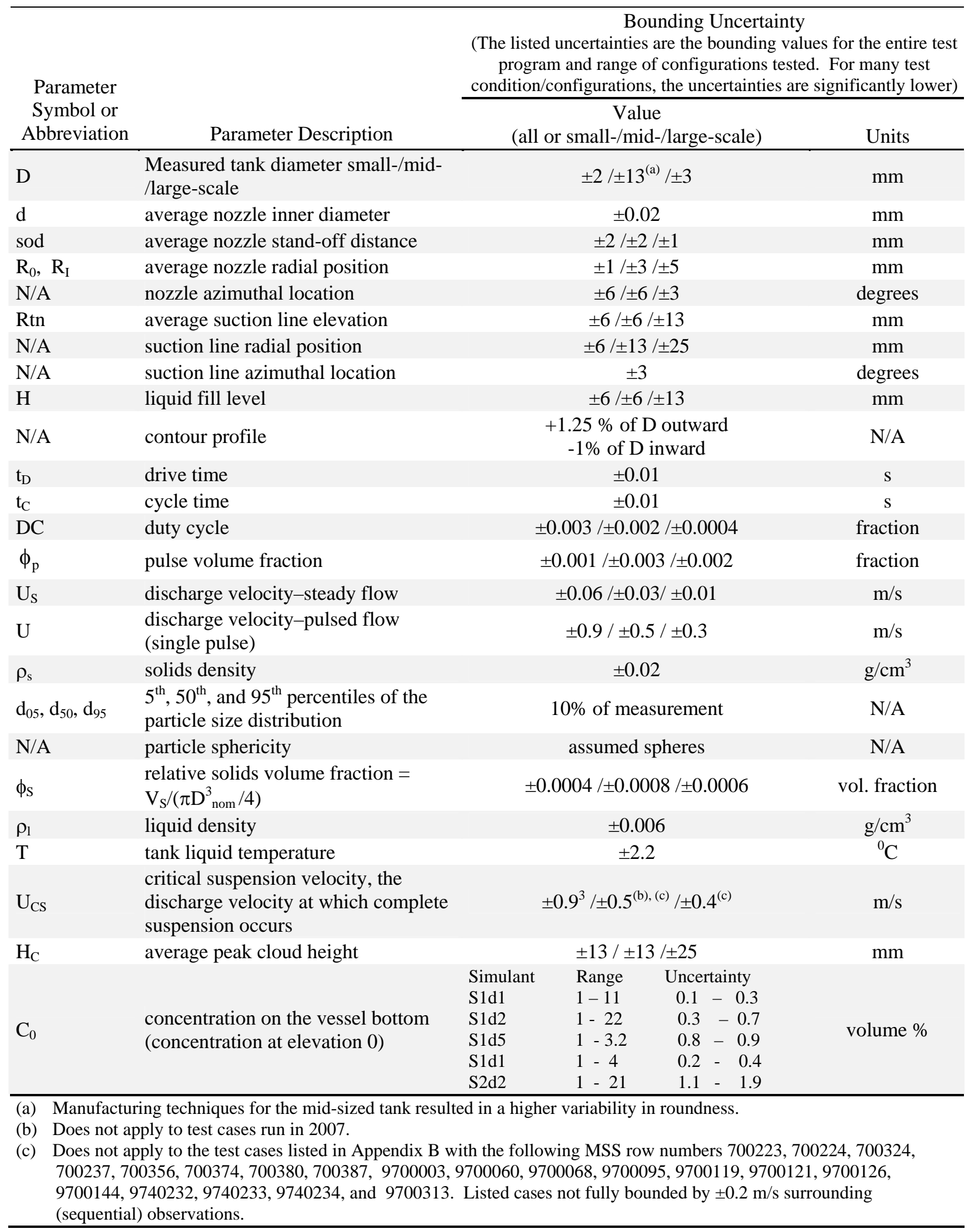


The contour of the tank bottom is an important geometrical parameter, and no single measurement is sufficient to characterize it. Instead, specifications for head shapes such as elliptical, F\&D, and spherical are used to characterize the tank bottom contour. The heads were profiled along diametric lines to assess how well the tank bottom complied with the specified head shapes. The manufacturing process influenced the uniformity/variability of the head shape (e.g., the small-scale tank heads were small enough that acrylic stock was machined to the prescribed contours). The mid-scale tank was an existing tank with a molded acrylic bottom. As described in Section 4.1 and Table 4.2, tests were planned assuming the midscale vessel had a 2:1 semi-elliptical head, but it was discovered and verified afterward to be spherical. For the mid-scale tank the uncertainties in Table 8.1 apply to the as-tested, not planned, measurements. The large-scale tank used standard commercial steel heads that were cut, welded, and ground to insert acrylic windows and add flanges to mate to the acrylic cylinder section. Based on the prescribed fabrication tolerances and profile measurement, the bottom contours for each test tank matched the specified shapes (e.g., $100-6 \mathrm{~F} \& \mathrm{D}$ ) to within $\pm 1 \%{ }^{1}$ of the test tank diameter.

\subsubsection{Operational Parameters}

Operational parameters were used to control and define the pulse cycle. Measurements or calculations based on direct measurements were used to evaluate all of the operational parameters as opposed to relying on calibrated control inputs. The operational parameters included drive time, cycle time, duty cycle, pulse volume fraction (i.e., discharge volume), and discharge velocity (both for steady-state and pulsed-flow conditions). The time parameters associated with the pulse cycle were determined by analyzing, in real time, the fluid flow pulse from the Coriolis flow meter. The fluid-flow pulse is geometrically squared in real time using a DAS comparator module to facilitate pulse signal analysis. These realtime calculations were compared with the timing obtained from the pulse tube pressure measurements to check for anomalies. Because of the intermittent drive system that was used, the pulse volume fraction and discharge velocity were obtained from volumetric flow measurements using Coriolis mass flow meters that measured the total flow rate for all of the nozzles. The discharge velocity was calculated using the nozzle diameter and the number of tubes being operated. To verify balanced flow through the nozzles, the pressure drop across the nozzles was periodically measured using a single pressure transmitter. The pressure check was performed for conditions exceeding complete suspension (the condition of unsuspended solids can cause an imbalance in flow through the tubes due to varying flow restrictions for each nozzle). The acceptable variation in the measured pressure drop for all of the nozzles was $0.2 \mathrm{psi}$ $(1.4 \mathrm{kPa})$. The uncertainties for the operational parameters are listed in Table 8.1.

\subsubsection{Physical Parameters}

The physical parameters consist mainly of the simulant properties and include the solids density, particle size distribution, particle sphericity, relative solids loading, liquid density, and liquid temperature. All of these simulant properties were well characterized within a relatively small degree of uncertainty that is not expected to contribute significantly to the overall uncertainty of the correlated models. The uncertainties for the listed physical parameters are listed in Table 8.1.

\footnotetext{
${ }^{1}$ For information only.
} 


\subsubsection{Performance Parameters}

The parameters measured to evaluate the mixing performance of a tank for a given configuration included the discharge velocity required for complete suspension $\left(\mathrm{U}_{\mathrm{CS}}\right)$, the average peak elevation of the opaque solids cloud $\left(\mathrm{H}_{\mathrm{C}}\right)$, and the solids concentration as a function of elevation, $\mathrm{C}(\mathrm{Z})$.

Measured values of $\mathrm{U}_{\mathrm{CS}}$ obtained in the tanks were typically distinguishable within approximately $0.2 \mathrm{~m} / \mathrm{s}$ and repeatable to within approximately $0.3 \mathrm{~m} / \mathrm{s}$. In the mid-scale tank some instances of replicate conditions yielded differences of $0.5 \mathrm{~m} / \mathrm{s}$ for $\mathrm{U}_{\mathrm{CS}}$.

The visual measurements of $\mathrm{H}_{\mathrm{C}}$ were obtained by capturing the peak elevation of the opaque cloud. The variability of cloud height was high due to the transient and turbulent nature of the rising plumes. The interface between the plume of suspended solids and the clear supernatant liquid was very dynamic with the clear interface in solids concentration creating a nonuniform (wavy) interface. These variations in cloud height depend on tank scale as well as operational and simulant properties. Therefore, the cloud heights were measured and recorded over a prescribed number of pulses for a given test condition, and the average value of the recorded cloud heights was used as the representative cloud height. Because the measurement of clouds involved sampling a fluctuating quantity, the overall fit of $\mathrm{H}_{\mathrm{C}}$ models to data is likely accurate. This is not unlike the ability to measure sea level fairly accurately even when the waveheight fluctuations far exceed the desired resolution of the measurement. As such, the average values are considered more representative and meaningful than any single measurement.

\subsubsection{Experimental Uncertainty}

Replicate and repeated tests are needed to identify systematic errors introduced inadvertently during testing and to quantify random errors (uncertainty) in testing. Highly prescriptive testing and measuring procedures, and the mechanical aspect of the measurements, were used to reduce the likelihood of any significant random or systematic error. However, random uncertainties cannot be completely avoided in experimental work. A limited number of near-replicate tests were performed, and a relatively small number of tests were conducted with near-repeat conditions. ${ }^{1}$ Section E.3 of Appendix E presents the results of using the results from limited near-replicate tests and near-repeat conditions to quantify experimental and measurement uncertainties in $\mathrm{U}_{\mathrm{CS}}$ and $\mathrm{H}_{\mathrm{C}}$. Based on the limited near-replicate test results, estimates of experimental uncertainties are $\% \mathrm{RSD}^{2}=5.3$ for $\mathrm{U}_{\mathrm{CS}}$ and $\% \mathrm{RSD}=13.3$ for $\mathrm{H}_{\mathrm{CS}}$ and $\mathrm{H}_{\mathrm{C}}$. These results indicate that the relative experimental uncertainties in determining $\mathrm{H}_{\mathrm{CS}}$ and $\mathrm{H}_{\mathrm{C}}$ are notably larger than in determining $\mathrm{U}_{\mathrm{CS}}$.

Some features of the experimental setup were not prototypic of the WTP designs and could contribute to systematic or random uncertainties, as discussed below.

\footnotetext{
${ }^{1}$ Replicate tests are tests using the same set of test conditions at different times with tests at other conditions in between. Repeat tests involve performing tests with the same set of test conditions at successive times, with no change of simulant intervening. Repeat tests are shown by a different test date. In some cases, during a test with a given Case ID, researchers returned to a test condition. This was called a repeat condition, not a repeat test. Variability in test results is typically much greater for replicate tests than repeat tests or repeat conditions. In situations where test conditions are close but not exactly the same, the terminology of near-replicate and near-repeat tests or conditions is used.

${ }^{2} \%$ RSD $=$ percent relative standard deviation.
} 
- Solids vertical entrainment due to pump return: The design of the testing systems included pump suction inlets at the top of the testing tanks that were necessary for system operation. This upward draw of liquids in the tank creates an upward flow that results in higher clouds. The effect of this is negligible on $\mathrm{U}_{\mathrm{CS}}$. For $\mathrm{H}_{\mathrm{C}}$, the effect is that the model will over predict cloud heights in proportion to the modified settling velocity discussed in Section 8.1.

- Tank liquid levels: The fill level for liquids in the testing tanks, relative to tank diameter, ranged from 1.1 to 2.0, whereas the relative fill height for HLP-22 is 0.7. Little bias is introduced on cloud height for cases where the clouds are predicted to be very low or where very good mixing in the tank is projected. The effect of relative fill levels for cloud heights in the marginal regime is less certain.

\subsubsection{Model Uncertainty}

This section discusses various contributions to model uncertainty, that is, uncertainty in predictions made with models for the mixing response variables. Model uncertainty could be systematic (causing predictions to be biased) or random (predictions generally accurate, but imprecise).

- Model form: The mathematical forms of models must provide for adequately approximating the true, unknown relationships between the mixing responses and the test variables. Within the region of test variable combinations, the adequacy of a model form (with respect to systematic and random uncertainties) can be assessed by goodness-of-fit statistics and graphical methods. For extrapolative use of the models, model forms must be defensible based on physical considerations and previous modeling work. Of particular interest is uncertainty with respect to the scale effect. The model forms in this report are based on a power-law dependency for the scale effect, which are expected to provide for unbiased extrapolation of scale effects.

- Model fit: There is uncertainty in the models associated with imperfect mathematical fits to the data. The models presented in Sections 7.3.2 to 7.3.4 emphasized establishing reasonable physical models over seeking better numerical fits, because the former is essential when extrapolating to capture the relevant physics of the system. Generalizations and expansions of physical-based models for $\mathrm{U}_{\mathrm{CS}}$ and $\mathrm{H}_{\mathrm{C}}$ were investigated using the MR approach are discussed in Appendix F. The MR models for $U_{C S}$ and $\mathrm{H}_{\mathrm{C}}$ are summarized in Section 7.4.

- Ranges of variables: Limited ranges of some of variables were tested. We explored a broad range of particle sizes, including those comparable to the largest expected in the Hanford waste. We expect extrapolation to smaller particles should be acceptable insofar as cohesive effects are avoided. No tests were conducted with multiple sizes of particles. Density was tested over a fairly narrow range ( 2.5 to $4.3 \mathrm{~g} / \mathrm{cm}^{3}$ ), and no tests were conducted with multiple-density particles. Hanford waste encompasses a range of viscosity and of non-Newtonian rheology, neither of which was evaluated in this program. Finally, most of the testing was conducted with a 12-tube configuration, representing the HLP-22 design. Relatively few data were generated on 4- and 8-tube configurations.

- Interactive effects of variables: A statistically designed test matrix ${ }^{1}$ was not used to specify the test combinations in the M3 mixing study; thus there were gaps in the coverage of test variable combina-

\footnotetext{
${ }^{1}$ A statistically developed test matrix was generated as a part of the test plan (WTP-RPP-TP-491 "Test Plan for Scaled Testing to Determine Adequacy of the WTP Pulse Jet Mixer Designs - Phase 1,” May 2007) developed during the initial stages of the M3 Mixing program. This statistically developed test approach was tabled in favor of the testing presented in this report. The change was made to address changing client considerations. The information learned while developing the prior test plan was used to guide simulant and other variable range selections for these tests.
} 
tions over the region of interest. Thus, the experimental data may provide limited or no basis for understanding and quantifying interactive effects of some test variables, and test variable interactions identified as significant in the MR modeling (Appendix F) will only include interactions with sufficient data to assess them. Also, the M3 mixing testing focused on certain combinations of some test variables (design values), so that the coverage of the test variable space was focused in some subregions and less focused in others. This means that the uncertainties of model predictions of the mixing responses will tend to be higher where there are limited or no data and smaller where there are more data. Within the region of test variable combinations investigated, the effects of uneven distribution of test combinations are accounted for by statistical methods for quantifying uncertainties of model predictions. However, care should be taken when applying the models to explore operational scenarios outside the test region of variables or for combinations within the region but not tested. One such case is large duty cycle, high $\phi_{\mathrm{S}}$, small $\mathrm{d}_{\mathrm{s}}$, and large density ratio (s).

- Cloud height scaling factor: Examinations of cloud height test results from the small- and large-scale elliptical tank tests indicate that a tank scaling factor for the cloud height model may be appropriate. A tank-size scaling factor was not included in the physical model for $\mathrm{H}_{\mathrm{C}}$ but was included in the generalized model for $\mathrm{H}_{\mathrm{C}}$. A sensitivity check for $\mathrm{H}_{\mathrm{C}}$ scaling factors shows that for HLP-22 the inclusion of scale-up factor exponents of $0.1,0.2$, and 0.3 would result in an $\mathrm{H}_{\mathrm{C}}$ increase $\left(\mathrm{C}_{0}\right.$ decrease) of factors of 1.2, 1.45, and 1.75, respectively. A sensitivity check for $\mathrm{H}_{\mathrm{C}}$ scaling factors (using the physical model) shows that, for a 20-ft- (6.1-m-) diameter tank, the inclusion of scale-up factors exponent of $0.1,0.2$, and 0.3 would result in an $\mathrm{H}_{\mathrm{C}}$ increase $\left(\mathrm{C}_{0}\right.$ decrease $)$ of factor of 1.13 , 1.27 , and 1.43 , respectively. The impact would continue to be reduced for tank diameters less than $20 \mathrm{ft}(6.1 \mathrm{~m}){ }^{1}$

\subsubsection{Uncertainty Associated with Applying Models to WTP Vessel Mixing}

Using the models to evaluate designs or operational options will require additional judgment on the part of the user. The models assume perfect knowledge of the waste properties, including the assumption that the wastes are uniform and will behave consistently within the mixing system. The experimental data do not include investigations on the effects of broad size or density distributions, and, at this time, allowance should be made for potential interactive effects of variables that were not experimentally investigated.

- Nonprototypic factors: As previously discussed, there were several nonprototypic aspects to the testing, including imperfect geometric similitude as well as operational differences such as refill operation and level change. We believe that most of these differences are secondary effects and do not contribute to performance differences significant enough to change a performance category (discussed in Section 9). This assertion is mainly based on the requirement for sufficient energy to perform mixing functions. If there is insufficient energy to achieve good solids suspension by a significant margin, geometric differences cannot reasonably make up for that deficit. Alternatively, we recognize that nonprototypic geometry at one scale could make a significant difference in the fullscale prediction. This position is supported by relative accuracy of the models in predicting results of larger-scale tests done by others (Bontha et al. 2000; 2003a, b) (see Section 8.3).

\footnotetext{
${ }^{1}$ This cloud height scaling factor discussion is FIO.
} 
- Hanford waste: There are many dimensions of uncertainty and variability associated with Hanford waste. Further, the PSDD has implicit and explicit uncertainties that are very difficult to quantify given the inherent limitations of accurately characterizing radioactive waste. Even if we assume the PSDD is highly accurate, it represents average properties for the entire inventory, and on a batch basis there could be significant variability. For example, this could mean the $\mathrm{U}_{95}$ for a given batch is significantly higher than the Hanford bulk average value. The uncertainty associated with waste properties will become important when applying the models (such as in the vessel example evaluations in Section 9). However, it does not introduce uncertainty into the model itself.

- Operational alternatives: The models provide insight to parameters that could be manipulated to achieve improvements in mixing performance, such as reducing the solids concentration or lowering the fill height of the vessel. These relationships are inferred from the model form, but more work would be needed to demonstrate how well the model can predict these options.

\subsubsection{Margin for Vessel Performance Evaluations}

Although margins should certainly be applied to compensate for the uncertainties in applying the models, we have not addressed the appropriate value to use for design confidence or to address operational risk. The example performance evaluations of WTP vessels in Section 9 include no margin.

\subsection{Model Benchmarks}

Results of comparing model predictions against experimental results are shown in this section for several experiments conducted in the 336 Building large-scale test facility at PNNL. This section also discusses the comparison between model predictions and predictions made for a full-scale vessel (HLP-22) using a CFD model. These benchmarks investigate whether the models give reasonable results for prototypic conditions prior to using them in application examples for the full-scale WTP vessels. Further, the comparison of predicted results with independent experiments and CFD calculations provides support for selecting a characteristic settling rate for a known particle size distribution such that one defined particle can be used to represent the behavior of the material in a mixing system.

The benchmark experiments performed in the 336 Building used actual PJMs and JPPs and were therefore prototypic of full-scale WTP vessels. The 12.75-ft-(3.9-m-) diameter tank and 4-PJM arrangement (pictured with 8-PJM array in Figure 8.4) is actually very close to a full-scale model of the WTP vessel RLD-8. Two of the experiments conducted in this prototypic system used glass beads in water, similar to what was used for M3 model development. However, another experiment conducted in this prototypic system used a complex physical simulant with a wide range of particle sizes and densities. This test was a closer approximation to what will be seen with Hanford waste in the WTP vessels. The 336-Building experiments are an intermediate step between the highly idealized experiments upon which the models in this report are based and the full complexity of the conditions in the actual WTP vessels. 


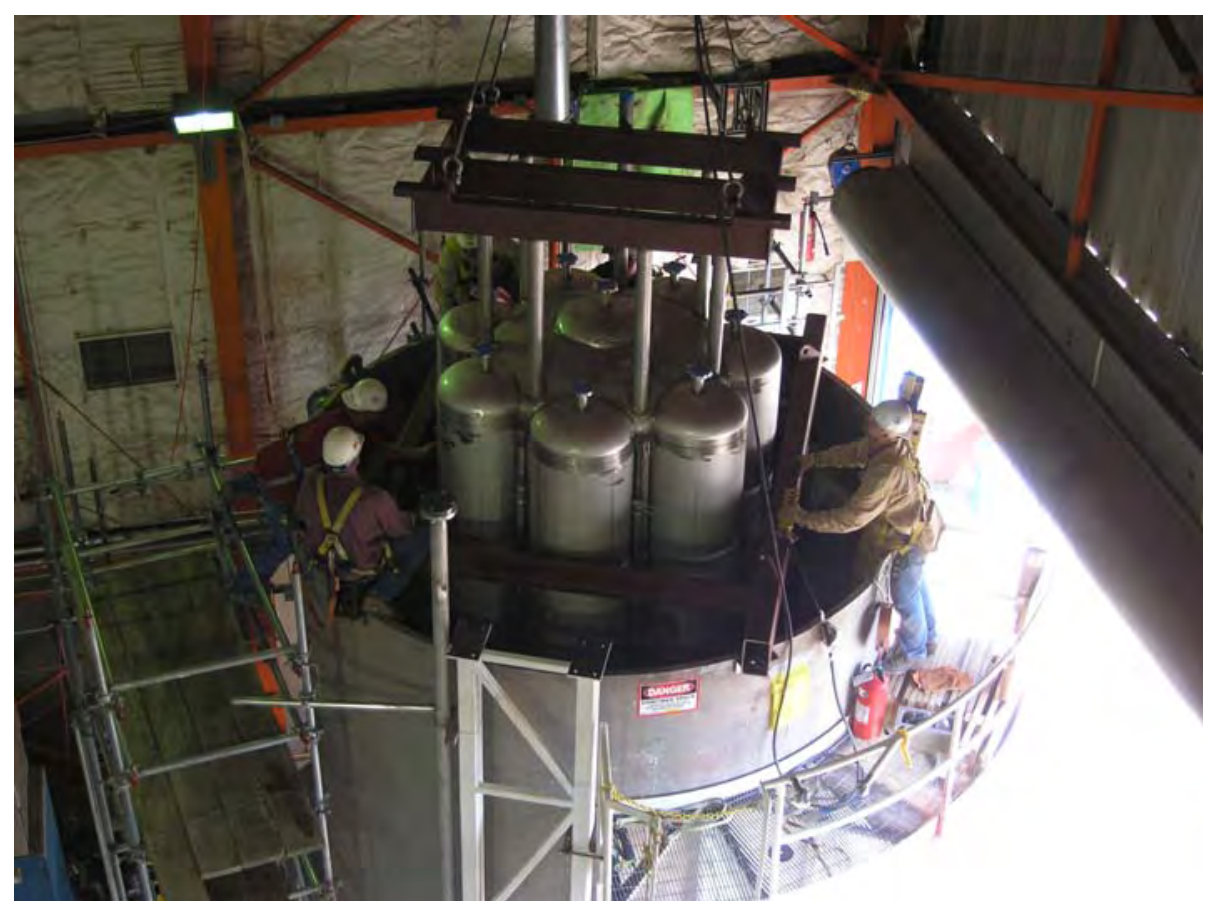

Figure 8.4. Prototypic PJM Tank in 336 Building (shown here with 8-PJM shrouded PJM cluster)

In all of the experiments used as benchmarks, the objectives did not require assessing $\mathrm{U}_{\mathrm{CS}}$. Indeed, that determination would be very difficult in a steel tank with a 2-in.-thick wall. Hence, only the cloud height and vertical solids concentration profiles can be compared. In fact, the cloud height was not explicitly measured but inferred from the concentration profile that was constructed from point concentration measurements. The concentration measurements consisted of slurry density measurements from flow loops with inlets at various depths and lateral positions. Thus, the techniques used to measure cloud height and concentration profile were different for the benchmark and current tests. In each benchmark case, we applied both the physical and generalized models for $\mathrm{U}_{\mathrm{CS}}$ and $\mathrm{H}_{\mathrm{C}}$, as well as the linear concentration profile model based on the models for $\mathrm{H}_{\mathrm{C}}$. The physical models for $\mathrm{U}_{\mathrm{Cs}}$ and $\mathrm{H}_{\mathrm{C}}$ are presented in Sections 7.3.3 and 7.3.5, while the generalized models are presented in Section 7.4. The linear concentration profile model is presented in Sections 7.3.4 and 8.1.2. ${ }^{1}$ Lacking measurements for comparison, the model-predicted $U_{\mathrm{CS}}$ is reported for each benchmark case for information. One qualitative comparison that can be made for $\mathrm{U}_{\mathrm{CS}}$ is the solids inventory represented in the concentration profile versus what may still be on the floor.

The approach used in each benchmark was to use model inputs that were consistent with the experimental conditions. The one exception was particle-settling velocity, which was varied within the range of the PSDD to determine what value produced a best match between the cloud height and concentration profile predicted by the models and the concentration profile established in the experiment. This optimization was done with the physical cloud height model and the results are shown here. The generalized model was run with settling velocities identical to those developed based on the physical cloud height model. Comments are included with each benchmark about differences observed when

\footnotetext{
${ }^{1}$ Because both cloud height models (physical and generalized) were always applied in concert with the concentration profile model from Section 7.3.4, subsequent reference to physical or generalized cloud height models also includes the concentration profile model.
} 
optimizing particle settling velocity for the generalized model. $\mathrm{U}_{\mathrm{CS}}$ models were always run with the particle settling velocity that was selected for use with the respective cloud height model.

\subsubsection{Mixing Tests with AZ-101/102 Filtration Waste Simulant}

The AZ-101/102 Filtration Waste Simulant tests are described in Bontha et al. (2000) and continue to be referenced frequently as PJM mixing tests with a broad size and density distribution of settling solids. The simulant recipe was initially developed to physically represent the AZ-101/102 solids for cross-flow ultrafiltration equipment tests. To simulate the washed solids, the aqueous liquid phase was water with $0.01 \mathrm{M} \mathrm{NaOH}$. The recipe is described in full in Golcar et al. (2000), and the solids inventory is shown in Table 8.2. The solid particulate PSDD is listed in Table 8.3.

In an application of the $\mathrm{H}_{\mathrm{C}}$ and $\mathrm{C}(\mathrm{Z})$ models, a key parameter choice is particle settling velocity. A range of particle-settling velocities were investigated to determine the best match between the experimentally measured concentration profile and that predicted by the physical model for $\mathrm{C}(\mathrm{Z})$. The optimal particle-settling velocity was determined in this fashion for each of the six separate benchmark cases considered (three different duty cycles at two different solids loadings). As an example at the lower end of the settling velocity range, using $\mathrm{U}_{50}$ does not provide realistic results. The physical models for $\mathrm{H}_{\mathrm{C}}$ and $\mathrm{C}(\mathrm{Z})$ predict in all cases that the slurry would be uniformly mixed to the fill height, which is clearly not borne out in the measured data. As an example at the upper end of the settling-velocity range, $\mathrm{U}_{95}$ gave results that were not as representative as $U_{90}$ (which was selected for use with the physical model). Later work to optimize particle settling velocity for the $\mathrm{H}_{\mathrm{C}}$ and $\mathrm{C}(\mathrm{Z})$ generalized models showed that they gave equally representative results using the $\mathrm{U}_{90}$ and $\mathrm{U}_{95}$ settling velocities.

Table 8.2. Solids Inventory in AZ-101/102 Filtration Simulant (reproduced from Golcar et al. 2000)

\begin{tabular}{|c|c|c|c|c|c|}
\hline $\begin{array}{l}\text { Compounds } \\
\text { Bearing }\end{array}$ & $\begin{array}{l}\text { Total } \\
\mathrm{wt} \%\end{array}$ & Mineral Phase & Powder Grade & Mean Volume PSDD & $\begin{array}{c}\text { Component } \\
\text { wt } \%\end{array}$ \\
\hline \multirow[t]{3}{*}{ Iron } & 58 & Hematite & Iron oxide No: 07-5001 & $22 \mu \mathrm{m}$ & 17.4 \\
\hline & & & Red iron oxide No: 07-3752 & $2-3 \mu \mathrm{m}$ & 29.0 \\
\hline & & & $\begin{array}{l}\text { Synthetic red iron oxide No: 07- } \\
2568\end{array}$ & $0.6 \mu \mathrm{m}$ & 11.6 \\
\hline \multirow[t]{4}{*}{ Aluminum } & 24 & Boehmite $^{(a)}$ & HiQ-10 alumina & $50 \mu \mathrm{m}^{(\mathrm{b})}$ & 7.2 \\
\hline & & Gibbsite $^{1}$ & C-231 ground white hydrate & $14 \mu \mathrm{m}$ (broad) & 8.4 \\
\hline & & & SpaceRite S-23 alumina & $7.5 \mu \mathrm{m}$ (broad) & 5.04 \\
\hline & & & SpaceRite S-11 alumina & $0.25 \mu \mathrm{m}$ (narrow) & 3.36 \\
\hline Zirconium & 13 & $\begin{array}{l}\text { Zirconium } \\
\text { hydroxide }\end{array}$ & $\begin{array}{l}\text { Zirconium hydroxide; product code: } \\
\text { FZO922/01 }\end{array}$ & $15 \mu \mathrm{m}$ & 13.0 \\
\hline Silicon & 5 & Nepheline & Spectrum A 400 nepheline syenite & $10 \mu \mathrm{m}$ & 5.0 \\
\hline
\end{tabular}

(a) Gibbsite/Boehmite ratio $=2.33$.

(b) This value is corrected from Table S.1 in Golcar et al. (2000). The corrected value is $d_{50}$, from the manufacturer's MSDS, which is also included in the Golcar report. 
Table 8.3. Solids PSDD for AZ-101/102 Filtration Simulant

\begin{tabular}{ccc}
\hline $\begin{array}{c}\text { Particle Size } \\
(\mu \mathrm{m})\end{array}$ & $\begin{array}{c}\text { Volume } \\
\text { Fraction }\end{array}$ & $\begin{array}{c}\text { Undissolved Solids Density } \\
\left(\mathrm{g} / \mathrm{cm}^{3}\right)\end{array}$ \\
\hline 0.25 & 0.05 & 2.42 \\
0.6 & 0.10 & 5 \\
2.5 & 0.21 & 5 \\
7.5 & 0.07 & 2.42 \\
10 & 0.07 & 2.66 \\
14 & 0.12 & 2.42 \\
15 & 0.15 & 3.25 \\
22 & 0.12 & 5 \\
50 & 0.10 & 3.01 \\
\hline
\end{tabular}

This section compares measured $\mathrm{H}_{\mathrm{C}}$ and $\mathrm{C}(\mathrm{Z})$ results versus model-predicted results using both the physical and generalized models, with the settling velocity optimized for the physical model. This settling velocity $\left(\mathrm{U}_{90}\right)$ is shown in Table 8.4 along with other input parameters used in the models. Work to optimize the settling velocity for the generalized models was performed in some cases, and the results are mentioned in those cases. Plotted concentration profile results for the six separate cases are shown consecutively in Figures 8.5 to 8.16.

Table 8.4. Model Inputs for Prototypic PJM 336-Building Tests with AZ-101/102 Filtration Simulant $\left(\mathrm{U}_{\mathrm{T}}=\mathrm{U}_{90}\right)$

\begin{tabular}{cccccccccc}
\hline Case \# & \% Max Drive & wt\% Solids & $\phi_{\mathrm{S}}$ & $\mathrm{DC}^{(\mathrm{a})}$ & $\phi_{\mathrm{p}}$ & $\phi_{\mathrm{J}}$ & $\mathrm{H} / \mathrm{D}$ & $\mathrm{U}(\mathrm{m} / \mathrm{s})$ & $\mathrm{U}_{\mathrm{T}}(\mathrm{mm} / \mathrm{s})$ \\
\hline 1 & $100 \%$ & 17.6 & 0.044 & 0.22 & 0.077 & 0.0027 & 0.82 & 8 & 0.99 \\
2 & $50 \%$ & 17.6 & 0.044 & 0.11 & 0.077 & 0.0027 & 0.82 & 8 & 0.99 \\
3 & $10 \%$ & 17.6 & 0.044 & 0.022 & 0.077 & 0.0027 & 0.82 & 8 & 0.99 \\
4 & $100 \%$ & 28.3 & 0.082 & 0.22 & 0.077 & 0.0027 & 0.86 & 8 & 0.99 \\
5 & $50 \%$ & 28.3 & 0.082 & 0.11 & 0.077 & 0.0027 & 0.86 & 8 & 0.99 \\
6 & $10 \%$ & 28.3 & 0.082 & 0.022 & 0.077 & 0.0027 & 0.86 & 8 & 0.99 \\
\hline
\end{tabular}

(a) The physical and generalized models for $\mathrm{H}_{\mathrm{C}}$ and $\mathrm{C}(\mathrm{Z})$ used data over the approximate range $0.14 \leq$ DC $\leq 0.67$. Hence, 4 of the 6 cases require extrapolating the $H_{C}$ and $C(Z)$ models with respect to DC.

\subsubsection{Case 1}

The maximum drive case at the lower solids loading (17.6 wt\%) is shown for the physical and generalized models in Figure 8.5. The solids loading for a uniform state is shown as the red line, and the experimental measurements can be compared with this to check mass balance. The data in this case show a significant degree of stratification in the upper $~ 25 \%$ of the tank; however, concentrations over the rest of the tank are not increased over the fully mixed value (17.6 wt\%). The difference may be explained by an increase in wt\% at the bottom, higher concentrations in other parts of the tank, or measurement uncertainty. The physical and generalized models predicted $U_{C S}=7.2$ and $9.3 \mathrm{~m} / \mathrm{s}$, respectively, which are both near the experimental drive velocity of $8 \mathrm{~m} / \mathrm{s}$. These values suggest that the solids should be suspended or nearly suspended, and this is consistent with observations during the experiment for all cases tested where a settled solids layer could not be detected on the floor. ${ }^{1}$

\footnotetext{
${ }^{1}$ Jagan Bontha, personal communication to James Fort (PNNL).
} 


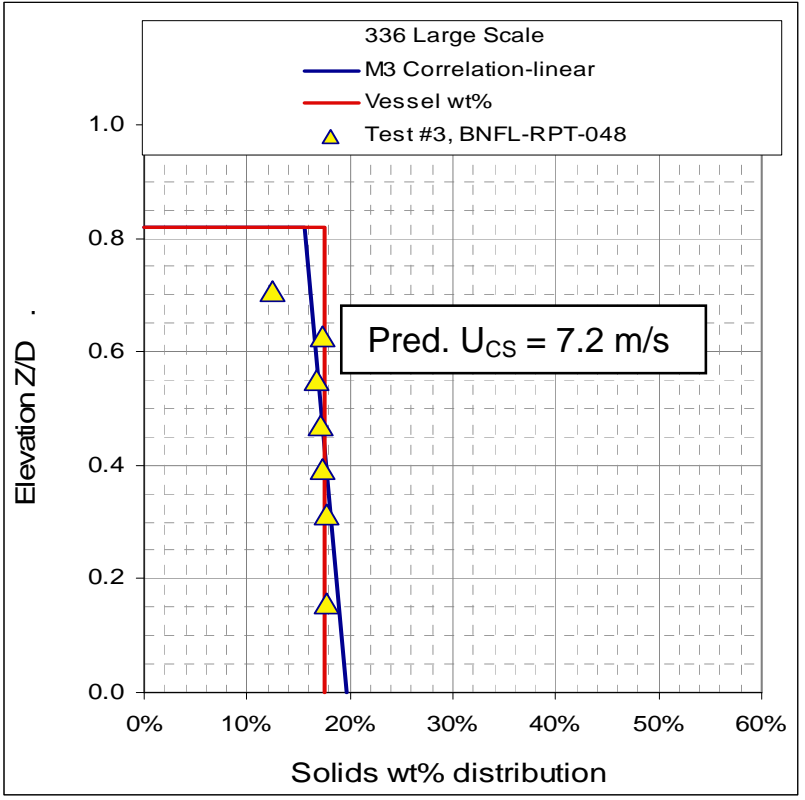

(a)

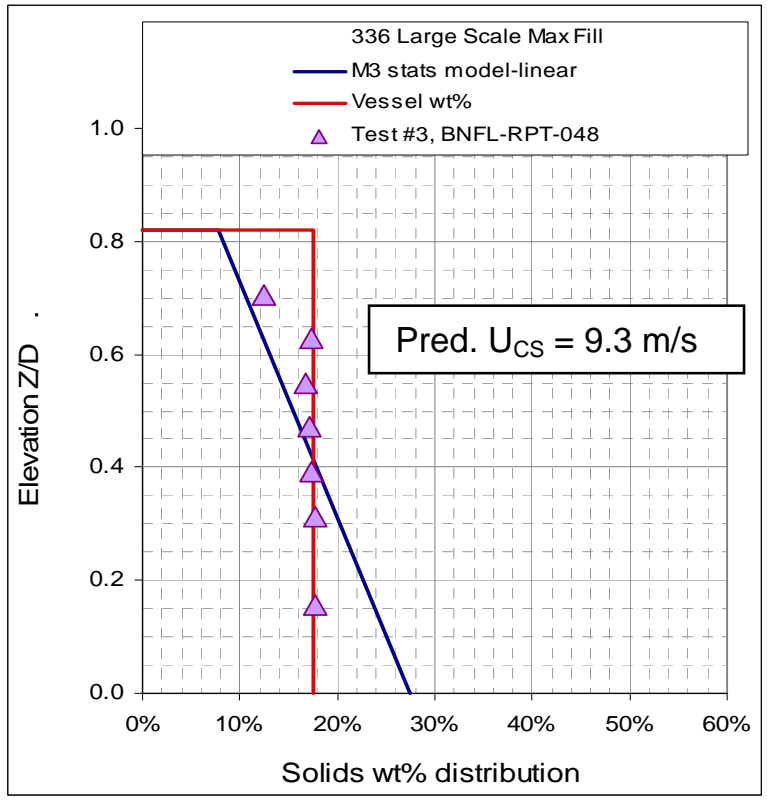

(b)

Figure 8.5. Concentration Profiles for Case 1: $17.6 \mathrm{wt} \%$ and Maximum Drive Using the (a) Physical Model and (b) Generalized Model, with $\mathrm{U}_{\mathrm{T}}=\mathrm{U}_{90}$ Optimized for the Physical Model

The cloud height model is used to predict a solids concentration distribution using a linear fit (blue line), as given by Eq. (7.47) in Section 7.3.3. The predicted variation from both physical and generalized cloud height models matches the data at mid-height but does not capture the curvature at the top. However, this is reasonable agreement for the linear solids distribution model being used. In this case, a key part of that distribution model is to redistribute the solids while matching the initial predicted gradient for cloud heights that are predicted above the fill height $\left(\mathrm{H}_{\mathrm{F}}\right)$ (see Eq. 8.4 and 8.5). Using the generalized model for $\mathrm{H}_{\mathrm{C}}$ in Eqs. (8.3), (8.4) and (8.5) predicts a smaller initial cloud height and a not-as-steep gradient in the concentration profile, shown in Figure 8.5 (b), compared with the results for the physical model, shown in Figure 8.5 (a).

\subsubsection{Case 2}

Results for the 50\% max drive case at the lower solids concentration (17.6 wt\%) are shown in Figure 8.6. The physical and generalized models predicted $\mathrm{U}_{\mathrm{CS}}=8.8$ and $10.7 \mathrm{~m} / \mathrm{s}$, respectively, which are both higher than the experimental drive velocity of $8 \mathrm{~m} / \mathrm{s}$. The amount of suspended solids suggested by the measured concentration profile depends on the interpretation of the curve above and below the measurement points; it could be equal to or somewhat less than Case 1. The stratification is more pronounced than in Case 1 with wt\% values exceeding the uniformly mixed value below $40 \%$ of the fill height $(\mathrm{H} / \mathrm{D}=0.4)$. In Figure 8.6, the straight-line distributions from both models show a reasonable slope change from Case 1, shown in Figure 8.5. The physical model, shown in Figure 8.6 (a), more closely approximates the data near the tank bottom and the generalized model, shown in Figure 8.6 (b), agrees better at the top. 


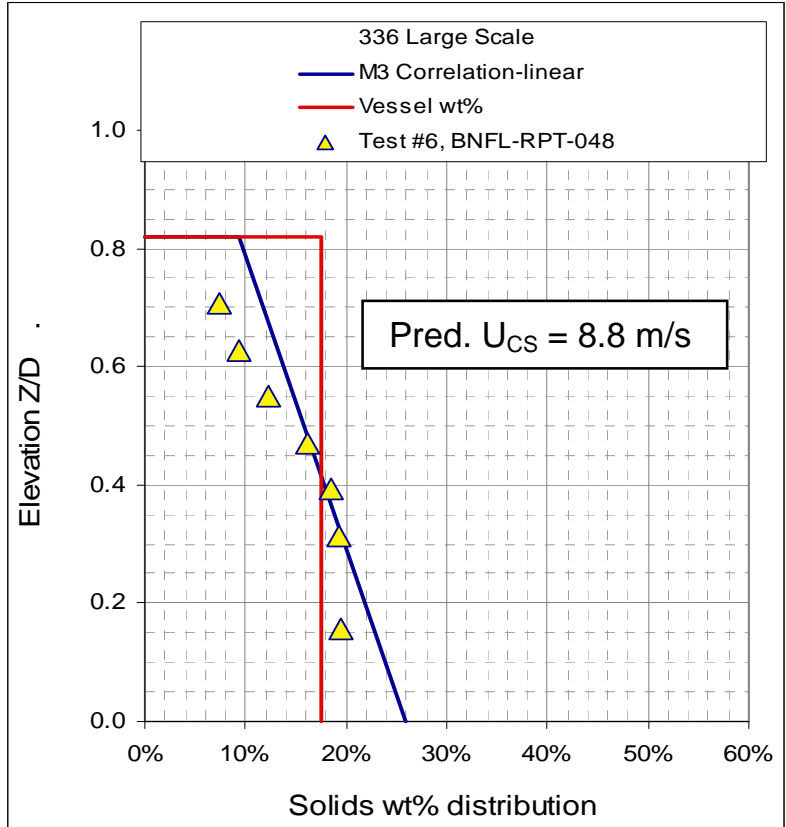

(a)

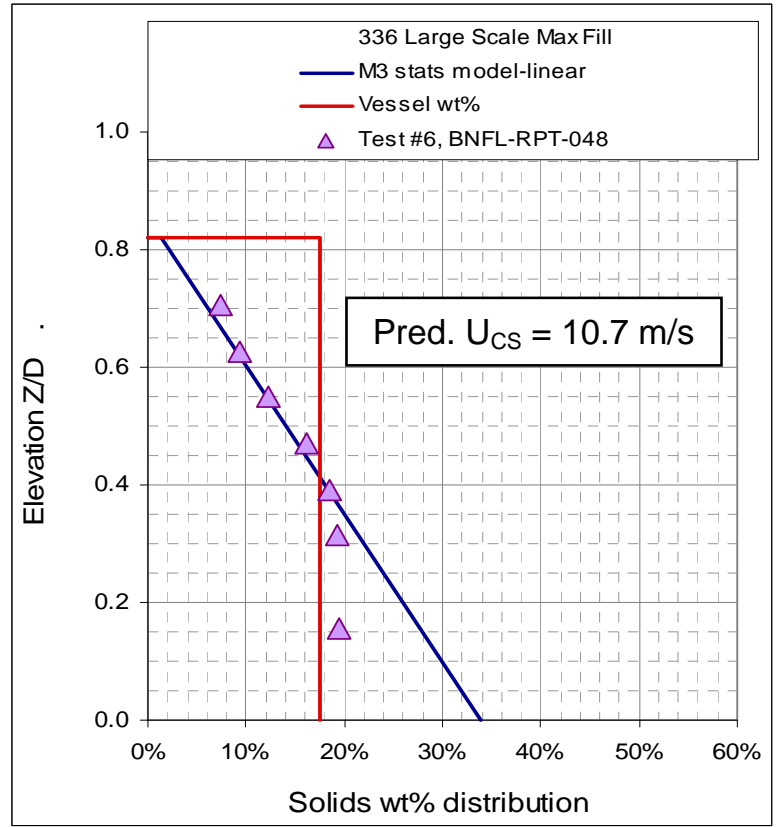

(b)

Figure 8.6. Concentration Profiles for Case 2: 17.6 wt $\%$ and 50\% of Maximum Drive Using (a) Physical Model and (b) Generalized Model, with $\mathrm{U}_{\mathrm{T}}=\mathrm{U}_{90}$ Optimized for the Physical Model

\subsubsection{Case 3}

Results for the $10 \%$ max drive case at the lower solids concentration (17.6 wt\%) are shown in Figure 8.7. The physical and generalized models predicted $U_{C S}=13.8$ and $14.9 \mathrm{~m} / \mathrm{s}$, respectively, which are both well above the experimental drive velocity of $8 \mathrm{~m} / \mathrm{s}$. Again, the amount of suspended solids indicated by the concentration measurements depends on the interpretation of the curve beyond these points. But one could argue that the same amount of solids is suspended as in Case 2. The stratification is much more pronounced for this case with the cloud height below the fill level and measured wt\% significantly exceeding the uniformly mixed value below $35 \%$ of the fill height $(\mathrm{H} / \mathrm{D}=0.35)$. The physical model significantly underpredicts cloud height for this case, and consequently the resulting concentration distributions are not close to the slope in the experimental data. The generalized model also underpredicts the cloud height, but the average slope is a closer approximation to the data. 


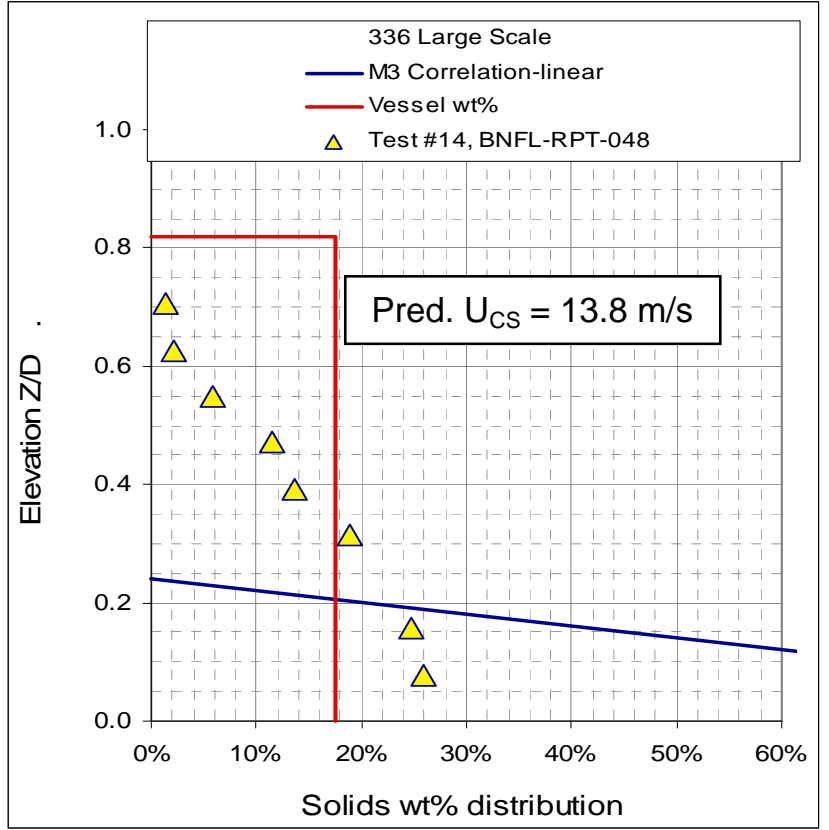

(a)

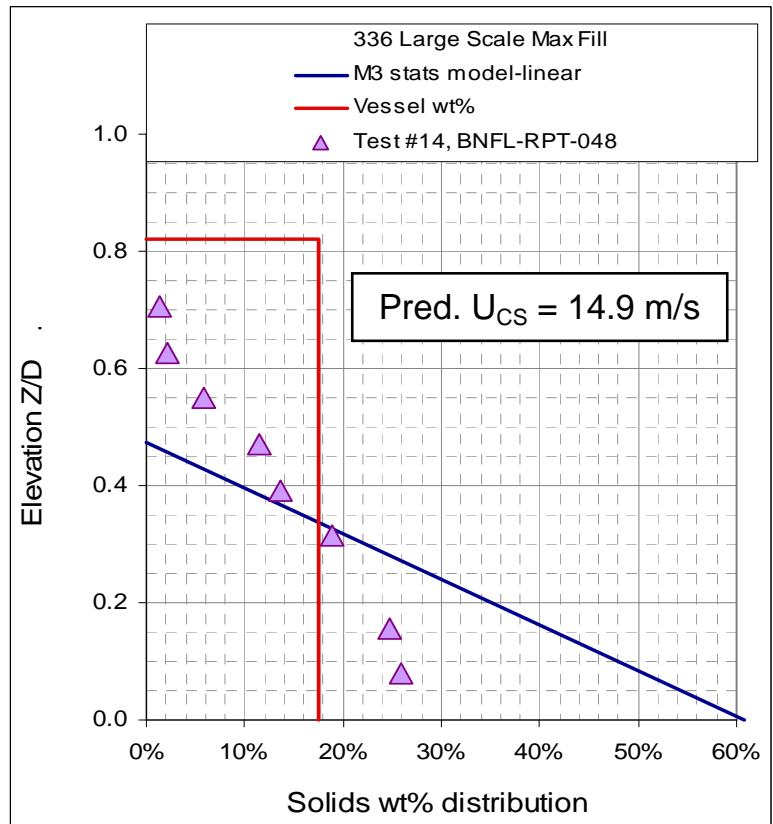

(b)

Figure 8.7 Concentration Profiles for Case 3: $17.6 \mathrm{wt} \%$, 10\% of Maximum Drive Case Using (a) the Physical Model and (b) the Generalized Model, with $\mathrm{U}_{\mathrm{T}}=\mathrm{U}_{90}$ Optimized for the Physical Model

\subsubsection{Case 4}

Results for the $100 \%$ max drive case at the higher solids concentration (28.3 wt \%) are shown in Figure 8.8. The physical and generalized models predicted $U_{\mathrm{CS}}=7.2$ and $10.8 \mathrm{~m} / \mathrm{s}$, respectively, compared with the experimental drive velocity of $8 \mathrm{~m} / \mathrm{s}$. The appearance of the measured concentration data is of a uniformly mixed system at approximately $27 \mathrm{wt} \%$. The behavior at the top and bottom of the tank cannot be determined from these measurements. However, their magnitude and uniformity suggest a well-mixed state with solids suspended off the floor. This is consistent with the physical model prediction of $U_{C S}$, but is not consistent with the higher value predicted by the generalized model. The predicted concentration profile using the physical model is consistent with the measurements, while the concentration profile predicted using the generalized model is not as good in this case.

\subsubsection{Case 5}

Results for the $50 \%$ max drive case at the higher solids concentration (28.3 wt\%) are shown in Figure 8.9. The physical and generalized models predicted $\mathrm{U}_{\mathrm{CS}}=8.8$ and $12.4 \mathrm{~m} / \mathrm{s}$, respectively, compared with the experimental drive velocity of $8 \mathrm{~m} / \mathrm{s}$. The shape of the concentration profile shown by the measured data is very similar to Case 1 , the $100 \%$ drive case at the lower solids loading. Again, depending on the actual shape of this profile above the uppermost measurement point, there could be a high solids concentration near the floor. For this case, arguing which of the $\mathrm{U}_{\mathrm{CS}}$ predictions is more reasonable requires more information than can be provided by these measurements. The qualitative comparisons of the measurements and the predicted concentration profiles using the physical model, shown in Figure 8.9 (a), and the generalized model, shown in Figure 8.9 (b), are similar. Both predictions are plausible representations of the measured data. 


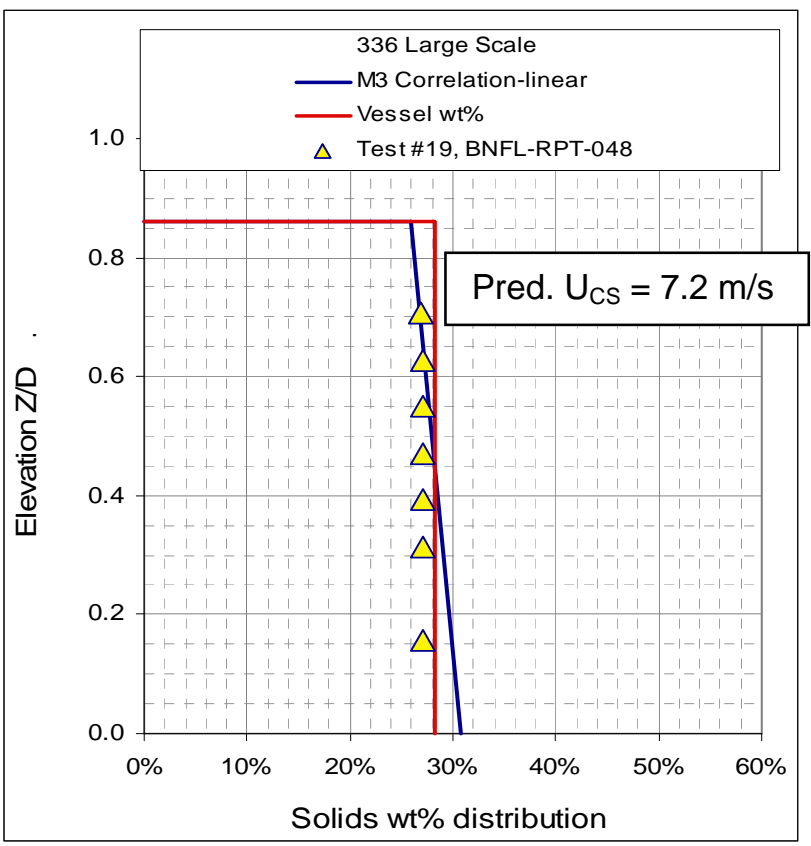

(a)

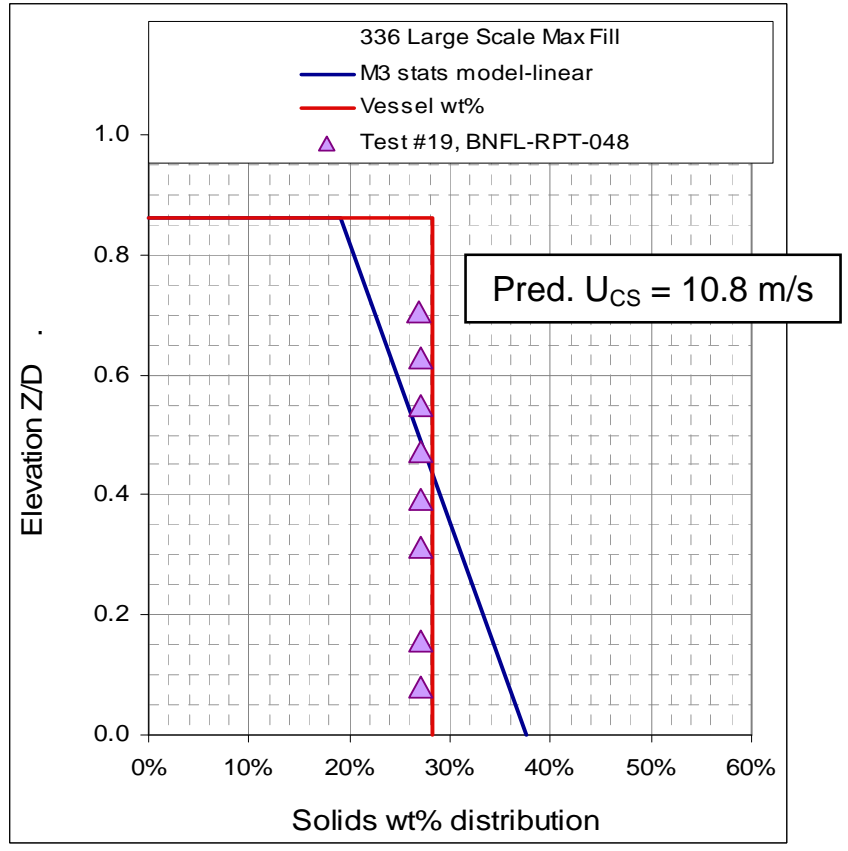

(b)

Figure 8.8. Concentration Profiles for Case 4: $28.3 \mathrm{wt} \%$ and Maximum Drive Using (a) the Physical Model and (b) the Generalized Model, with $\mathrm{U}_{\mathrm{T}}=\mathrm{U}_{90}$ Optimized for the Physical Model

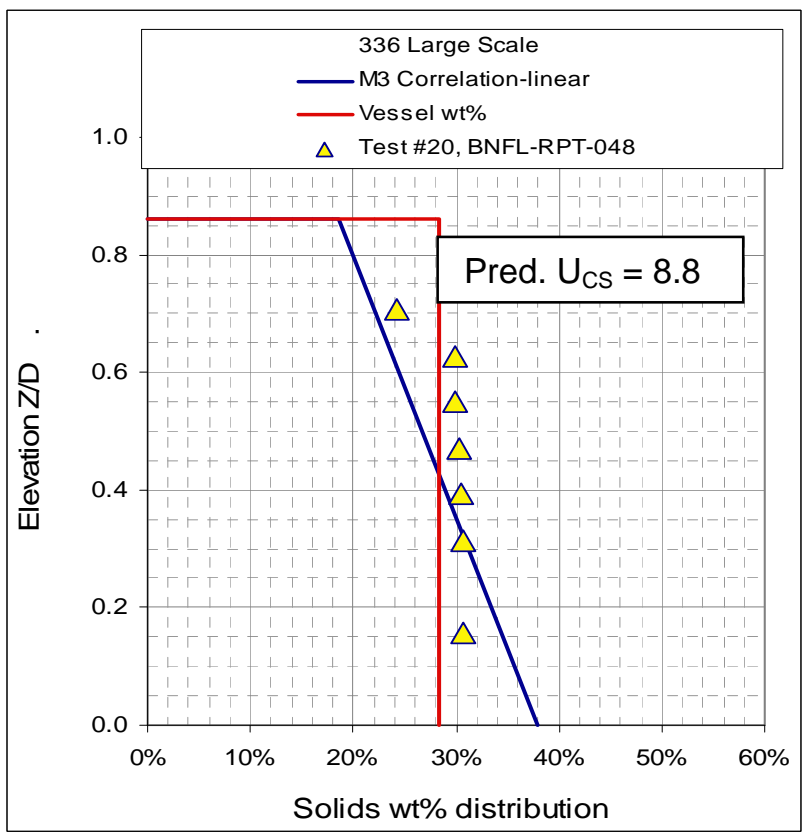

(a)

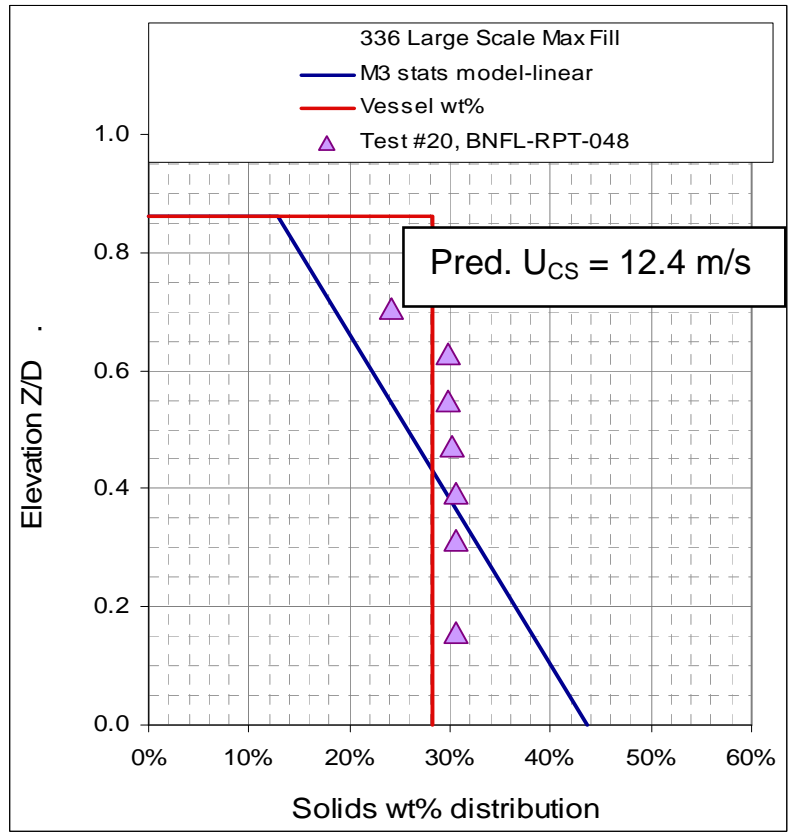

(b)

Figure 8.9. Concentration Profiles for Case 5: 28.3 wt $\%$ and 50\% of Maximum Drive Using (a) the Physical Model and (b) the Generalized Model, with $\mathrm{U}_{\mathrm{T}}=\mathrm{U}_{90}$ Optimized for the Physical Model 


\subsubsection{Case 6}

Results for the $10 \%$ max drive case at the higher solids concentration (28.3 wt $\%$ ) are shown in Figure 8.10. The physical and generalized models predicted $U_{C S}=13.9$ and $17.3 \mathrm{~m} / \mathrm{s}$, respectively, which are both significantly greater than the experimental drive velocity of $8 \mathrm{~m} / \mathrm{s}$. This is consistent with the solids inventory indicated by the measured concentration profile being significantly less than the total solids loading.

The qualitative comparisons of the concentration profiles using the physical and generalized models are similar to what was observed in Figures 8.9 and 8.10 for Case 3. The generalized model prediction is best in both Case 3 and Case 6, but the assumed linear concentration profile is not very satisfying for either model. The vessel slurry is stratified with the bulk of the solids below $\mathrm{Z} / \mathrm{D}=0.5$. The measured concentrations indicate a large amount of solids are below the lowest measurement point.

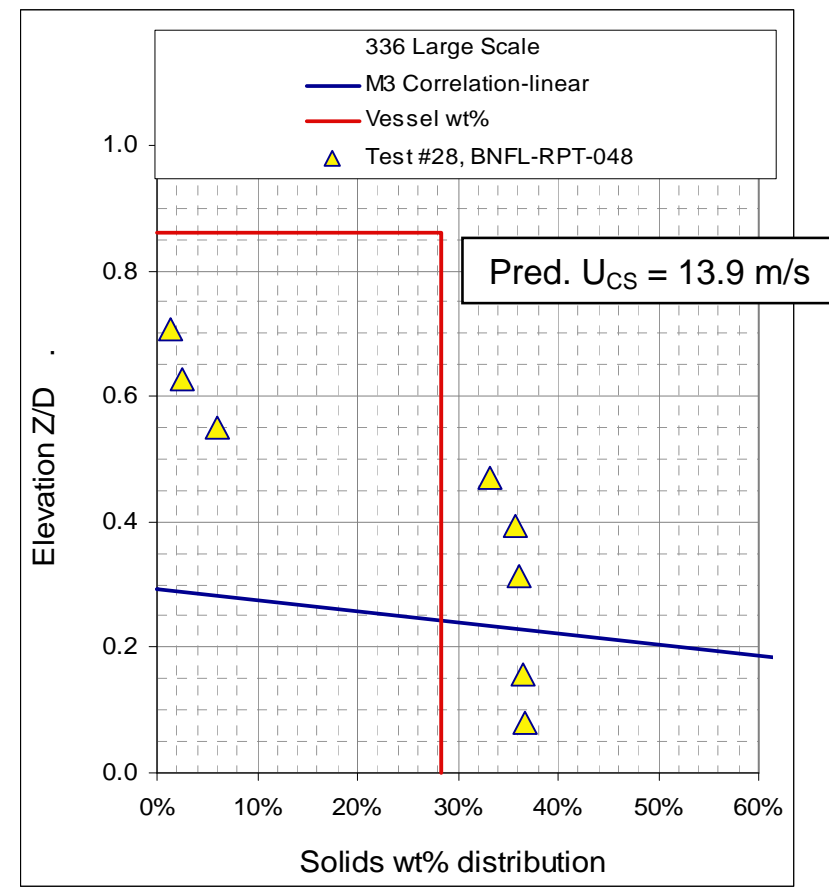

(a)

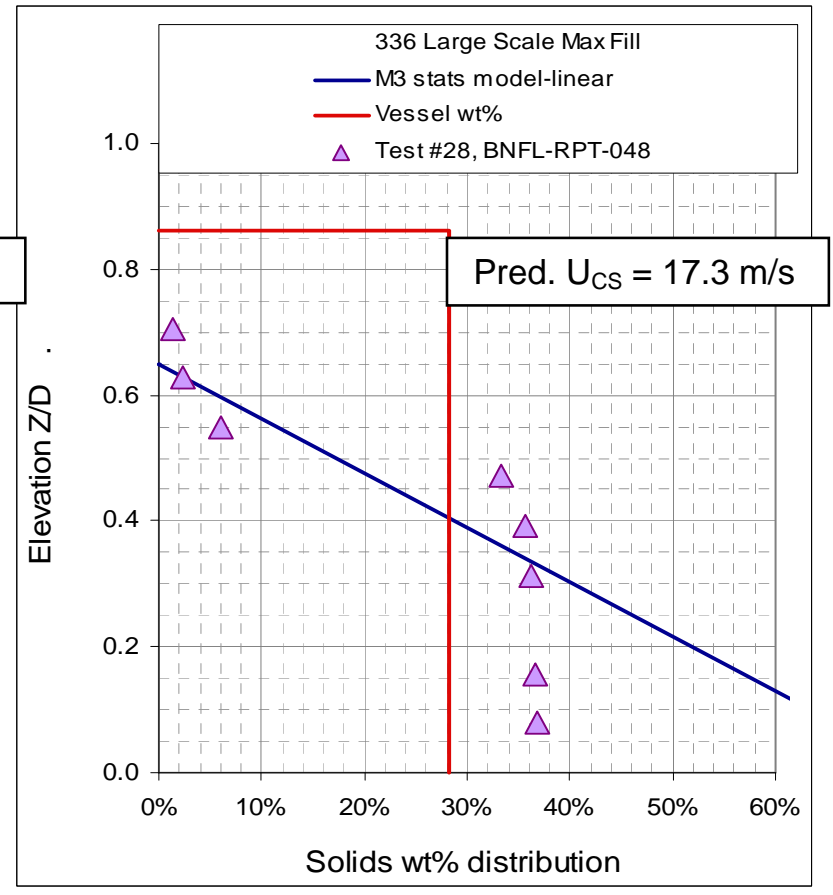

(b)

Figure 8.10. Concentration Profiles for Case 6: $28.3 \mathrm{wt} \%$ and $10 \%$ of Maximum Drive Using (a) the Physical Model and (b) the Generalized Model, with $\mathrm{U}_{\mathrm{T}}=\mathrm{U}_{90}$ Optimized for the Physical Model

\subsubsection{Discussion of Results}

Note from Table 8.4 that $\mathrm{DC}=0.022$ in Cases 3 and 6, which is well outside the DC $>0.18$ range tested and used to develop the models. This may be the reason the physical and generalized models for $\mathrm{C}(\mathrm{Z})$ performed the worst for Cases 3 and 6. For Cases 2 and 5, DC $=0.11$, which is also outside this range. Although the physical and generalized models performed better for these cases, there still was a noticeable difference in model-predicted versus measured concentration profile. Finally, Cases 1 and 4 had DC $=0.22$, which was inside the range tested. The physical and generalized models performed the 
best for these cases. This suggests that the physical and generalized models for $\mathrm{H}_{\mathrm{C}}, \mathrm{C}_{0}$, and $\mathrm{C}(\mathrm{Z})$ should not be extrapolated to duty cycle values much lower than the lowest value tested $(0.14)$.

\subsubsection{Mixing Tests with Glass Bead Simulants}

Two additional sets of experiments were performed in the 4-PJM, 12.75-ft (3.9-m) tank in the 336 Building during the 2001 to 2003 time period. Both of these sets of experiments were for CFD code validation. Comparisons of model-predicted and measured concentration profiles from those two sets of experiments are provided in subsections 8.3.2.1 and 8.3.2.2.

\subsubsection{Tests with 75- $\mu \mathrm{m}$ Glass Beads}

The first test used $75-\mu \mathrm{m}$ glass beads as the solids. This experiment and results are described in Bontha et al. (2003a). These tests used a single loading of $10 \mathrm{wt} \%$ solids in water. This particle had a relatively high settling rate and was selected for this test to give incomplete suspension under normal PJM operations.

The distribution of particle sizes was typical of industrial-grade glass beads. The PSD from Bontha et al. (2003a, Appendix E) is reproduced in Table 8.5. Of the particle settling velocities that were tested with the physical model, the best agreement with the measured concentration profile was given with $U_{50}$. This is a settling rate of $4.05 \mathrm{~mm} / \mathrm{s}$. Model input parameters for this benchmark are shown in Table 8.6.

Table 8.5. PSD for 75- $\mu \mathrm{m}$ Glass Beads (from Bontha et al. 2003a, p. E.2)

\begin{tabular}{c|c}
\hline \multicolumn{2}{c}{$\begin{array}{c}\text { Particle Size Distribution of Potter } \\
\text { Chemical C.2530 Glass Beads }\end{array}$} \\
\hline Particle Size $(\mu \mathrm{m})$ & vol\% \\
\hline 37.00 & 0.00 \\
40.35 & 0.15 \\
44.00 & 0.35 \\
47.98 & 0.71 \\
52.33 & 1.86 \\
57.06 & 4.18 \\
62.23 & 7.88 \\
67.86 & 13.68 \\
74.00 & 16.88 \\
80.70 & 17.54 \\
88.00 & 15.20 \\
95.96 & 9.87 \\
104.65 & 5.99 \\
114.12 & 3.11 \\
124.45 & 1.48 \\
135.71 & 0.78 \\
148.00 & 0.34 \\
161.39 & 0.00 \\
\hline
\end{tabular}


Table 8.6. Model Inputs for 336-Building Tests with 75- $\mu \mathrm{m}$ Glass Beads $\left(\mathrm{U}_{\mathrm{T}}=\mathrm{U}_{50}\right)$

\begin{tabular}{cccccccccc}
\hline Case \# & Case & wt\% Solids & $\phi_{\mathrm{S}}$ & $\mathrm{DC}$ & $\phi_{\mathrm{p}}$ & $\phi_{\mathrm{J}}$ & $\mathrm{H} / \mathrm{D}$ & $\mathrm{U}(\mathrm{m} / \mathrm{s})$ & $\mathrm{U}_{\mathrm{T}}(\mathrm{mm} / \mathrm{s})$ \\
\hline 7 & 4 PJMs & 10 & 0.042 & 0.14 & 0.056 & 0.0027 & 0.99 & 6.8 & 4.05 \\
\hline
\end{tabular}

Model results for this case are compared with the experimental data in Figure 8.11. The $\mathrm{U}_{\mathrm{CS}}$ predictions are $9.3 \mathrm{~m} / \mathrm{s}$ for the physical model and $10.7 \mathrm{~m} / \mathrm{s}$ for the generalized model. These values are both well above the $6.8 \mathrm{~m} / \mathrm{s}$ experimental drive velocity. The integrated area under the measured concentrations is comparable to the average solids loading. Again, we have no data to compare with this prediction, but if correct it would suggest that some part of the solids inventory may not have been mobilized.

As for the model predictions for the cloud height and concentration profile, the physical model underpredicts the cloud height and consequently the concentration profile is too shallow. The generalized model overpredicts the cloud height, which results in a concentration profile that is steeper than that associated with the experimental concentration measurements. Later tests that optimized the settling velocity for the generalized model showed best agreement with this case using the $\mathrm{U}_{95}$ particle-settling velocity. Hence, the predicted concentration profile for the generalized model using $U_{T}=U_{95}$ would agree more closely with the measured profile, shown in Figure 8.11 (b).

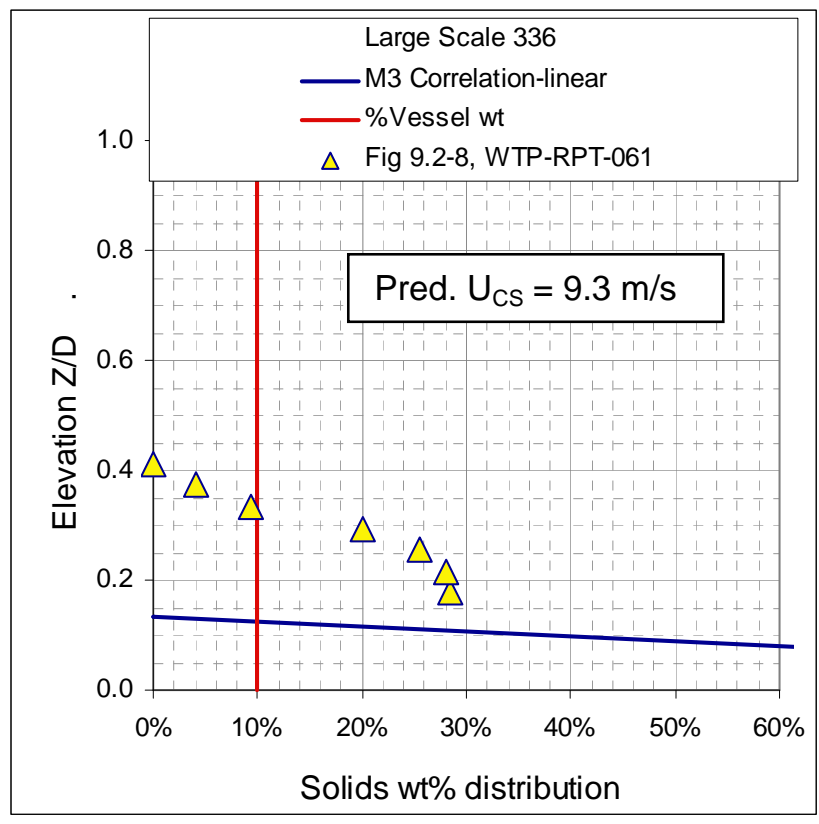

(a)

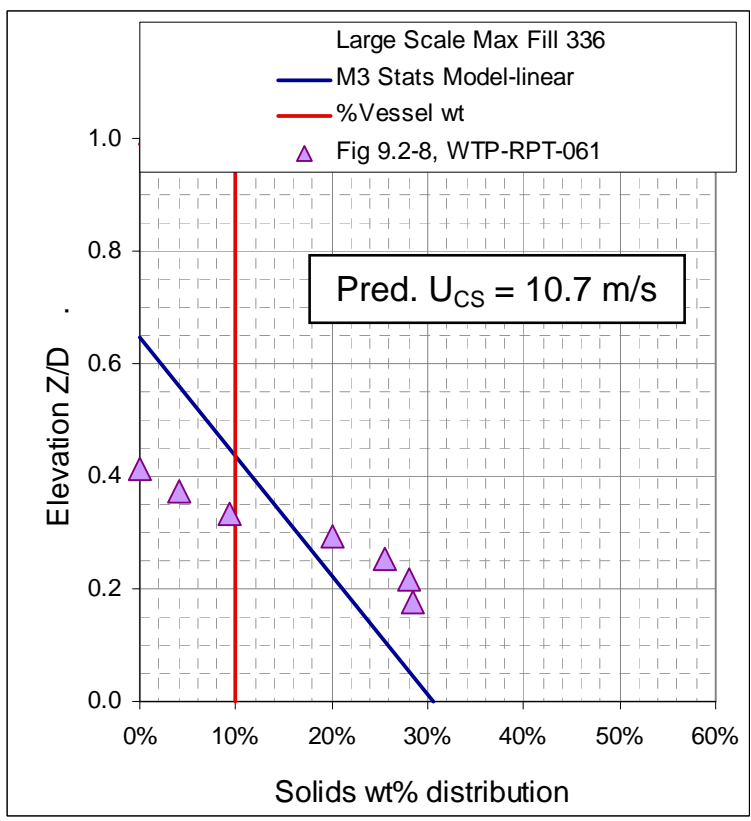

(b)

Figure 8.11. Concentration Profiles for Case 7: $10 \mathrm{wt} \%$ and 75- $\mu \mathrm{m}$ Glass Beads Using (a) the Physical Model and (b) the Generalized Model, with $\mathrm{U}_{\mathrm{T}}=\mathrm{U}_{50}$ Optimized for the Physical Model

\subsubsection{Mixing Tests with $35-\mu \mathrm{m}$ Glass Beads}

The second set of experiments used $35-\mu \mathrm{m}$ glass beads as the solids, and water was again used as the liquid phase. This test is described in Bontha et al. (2003b). The relative distribution of the 35- $\mu \mathrm{m}$ 
particle size was broader than that of the $75-\mu \mathrm{m}$ particle described in subsection 8.3.2.1. Like the benchmark with the larger glass beads, the best agreement between the physical model and measured concentration profile was found near the middle of the particle size range, at $d_{60}(37 \mu \mathrm{m})$. Because the particle density is constant, this is $U_{60}$, which in water corresponds to a settling rate of $1.06 \mathrm{~mm} / \mathrm{s}$.

Two test cases from this experiment were selected for comparison with the physical and generalized models. Both are for the $20 \mathrm{wt} \%$ solids: one with 4 PJMs operating and the other at a reduced power level reflected by running just 2 PJMs. The input parameters for the model applied to these two benchmarks are shown in Table 8.7.

Table 8.7. Model Inputs for 336-Building Tests with $35-\mu \mathrm{m}$ Glass Beads $\left(\mathrm{U}_{\mathrm{T}}=\mathrm{U}_{60}\right)$

\begin{tabular}{cccccccccc}
\hline Case \# & Case & \multirow{2}{*}{ wt\% Solids } & $\phi_{\mathrm{S}}$ & $\mathrm{DC}$ & $\phi_{\mathrm{p}}$ & $\phi_{\mathrm{J}}$ & $\mathrm{H} / \mathrm{D}$ & $\mathrm{U}(\mathrm{m} / \mathrm{s})$ & $\mathrm{U}_{\mathrm{T}}(\mathrm{mm} / \mathrm{s})$ \\
\hline 8 & 4 PJMs & 20 & 0.085 & 0.22 & 0.070 & 0.0027 & 0.93 & 8.3 & 1.06 \\
9 & 2 PJMs & 20 & 0.085 & 0.22 & 0.036 & 0.0014 & 0.93 & 8.0 & 1.06 \\
\hline
\end{tabular}

Model results for Case 8 (4 PJMs) are compared with the experimental data, shown in Figure 8.12, and Case 9 (2 PJMs) is shown in Figure 8.13. In the 4-PJM test (Case 8), Figure 8.12 shows that the integrated profile associated with the concentration measurements agrees with the total solids inventory, and this is consistent with predicted $U_{C S}$ values $(6.0 \mathrm{~m} / \mathrm{s}$ for the physical model and $8.4 \mathrm{~m} / \mathrm{s}$ for the generalized model) being less than or equal to the experimental drive velocity $(8.3 \mathrm{~m} / \mathrm{s})$. The predicted concentration profiles for the 4-PJM case are reasonable approximations of the data for both the physical and generalized models.

For the 2-PJM test (Case 9), the measured concentration data, shown in Figure 8.13, show significant stratification. The measured profile is nearly symmetric vertically about the fully mixed concentration line at $20 \mathrm{wt} \%$, and roughly accounts for the total solids inventory. Concentration measurements were not available near the bottom for this test, so it is difficult to rule out a higher concentration zone near the floor. The presence of incompletely suspended solids would be consistent with the predicted $\mathrm{U}_{\mathrm{CS}}$ values of 9.6 and $13.9 \mathrm{~m} / \mathrm{s}$ using the physical and generalized models, which are well in excess of the $8 \mathrm{~m} / \mathrm{s}$ experimental drive velocity. For the predicted concentration profiles, the physical model somewhat overpredicts the cloud in the 2-PJM case, but the trend is approximately correct. The generalized model significantly overpredicts the cloud height with this settling velocity $\left(\mathrm{U}_{\mathrm{T}}=\mathrm{U}_{60}\right)$. Later investigations with particle settling velocity optimized for the generalized model showed best agreement with the measured concentration profile using the $\mathrm{U}_{95}$ particle settling velocity. Hence, the predicted concentration profile for the generalized model using $\mathrm{U}_{\mathrm{T}}=\mathrm{U}_{95}$ would agree more closely with the measured profile shown in Figure 8.13 (b). 


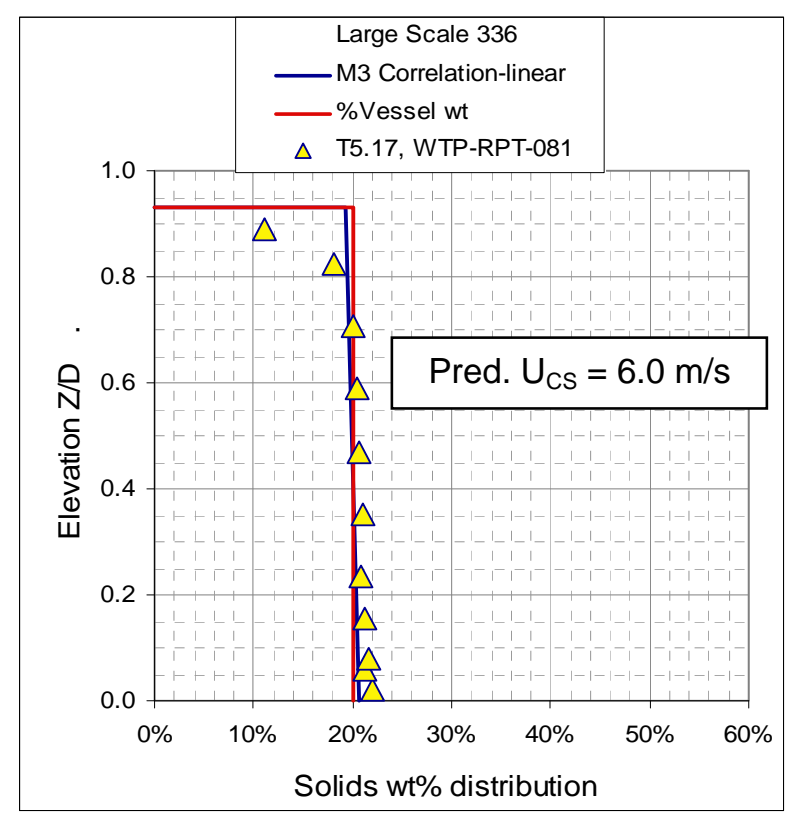

(a)

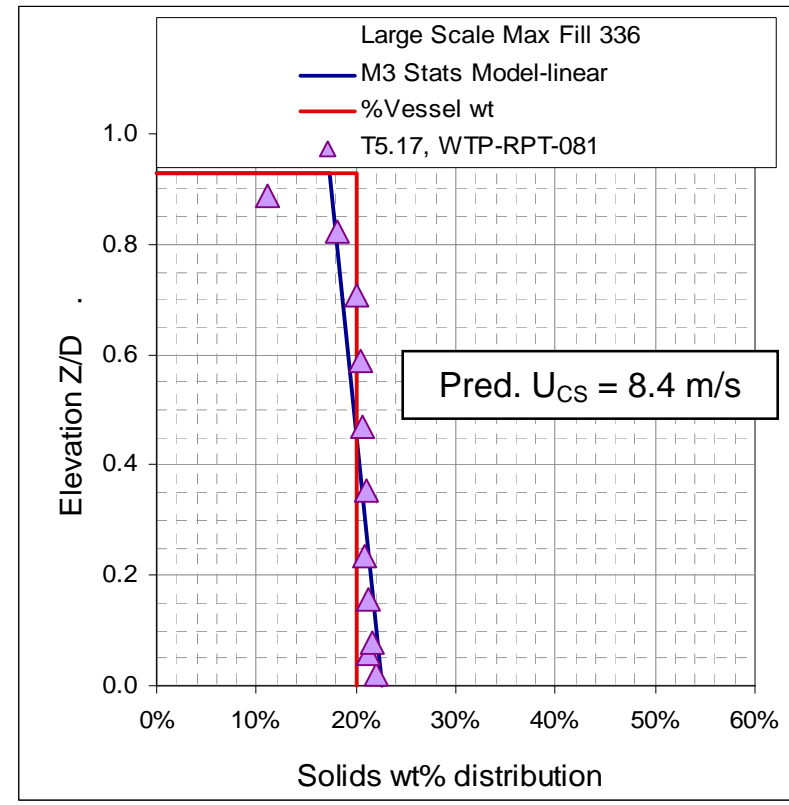

(b)

Figure 8.12. Concentration Profiles for Case 8: $20 \mathrm{wt} \%$ and $35-\mu \mathrm{m}$ Glass Beads with 4 PJMs Operating Using (a) the Physical Model and (b) the Generalized Model, with $\mathrm{U}_{\mathrm{T}}=\mathrm{U}_{60}$ Optimized for the Physical Model

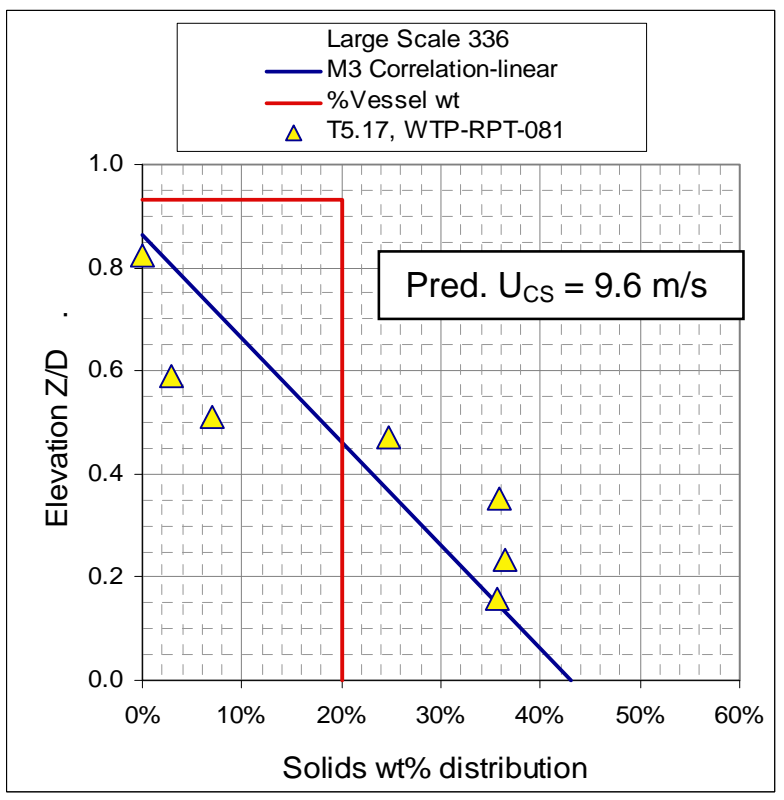

(a)

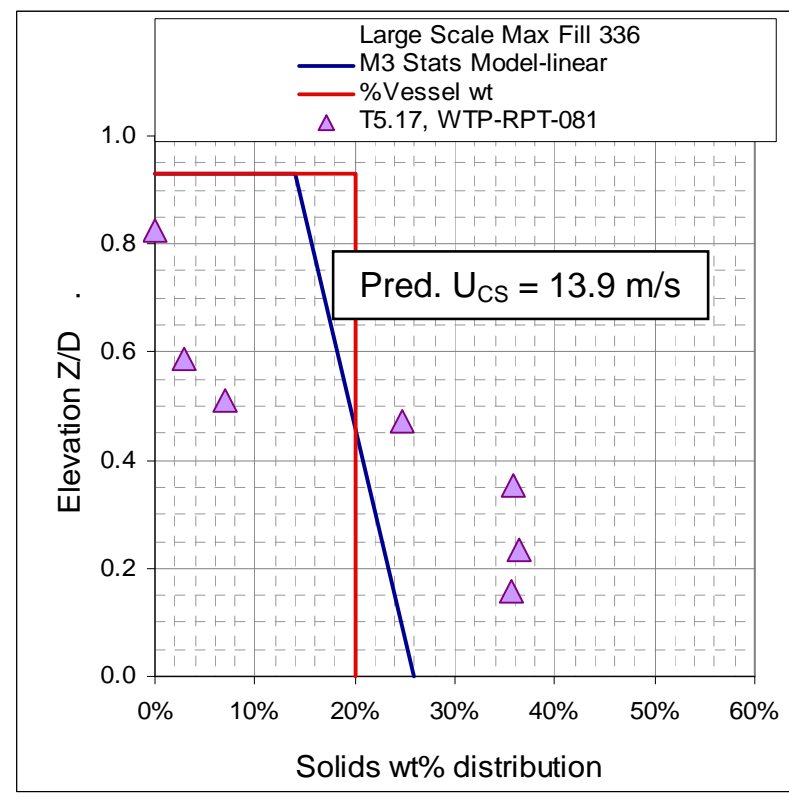

(b)

Figure 8.13. Concentration Profiles for Case 9: $20 \mathrm{wt} \%$ and 35- $\mu \mathrm{m}$ Glass Beads with 2 PJMs Operating Using (a) the Physical Model and (b) the Generalized Model, with $\mathrm{U}_{\mathrm{T}}=\mathrm{U}_{60}$ Optimized for the Physical Model 


\subsubsection{Comparison with CFD Simulation}

CFD simulations have been used routinely by BNI to predict vessel mixing behavior for the WTP vessels. These simulations have been repeated as CFD models improve and as best-estimate conditions for the vessels change. As a supplement to the benchmarking experiments, predictions made with the physical and generalized models were compared with recent CFD model predictions for vessel HLP-22. Satisfactory agreement in this case demonstrates consistency between the experiment-based models and the CFD model.

The model input parameters for conditions of the CFD simulation are shown in Table 8.8. These inputs were taken from the list of CFD model inputs, with the exception of the drive velocity and duty cycle, which were obtained from the PJM velocity profile, shown in Figure 8.14, and particle settling velocity, which was calculated with Eq. (7.5) using the 60-micron particle diameter used in the simulation and particle density and fluid properties in Table 8.8.

Table 8.8. Model Inputs to Compare with CFD Simulation of HLP-22, $12 \mathrm{~m} / \mathrm{s}$ Normal Firing Case ${ }^{(a)}$

\begin{tabular}{ccccccccccc}
\hline $\begin{array}{c}\rho_{\mathrm{l}} \\
\left(\mathrm{kg} / \mathrm{m}^{3}\right)\end{array}$ & $\begin{array}{c}\mu_{\mathrm{l}} \\
(\mathrm{cP})\end{array}$ & $\begin{array}{c}\mathrm{wt} \% \\
\text { Solids }\end{array}$ & $\begin{array}{c}\rho_{\mathrm{s}} \\
\left(\mathrm{kg} / \mathrm{m}^{3}\right)\end{array}$ & $\phi_{\mathrm{S}}$ & $\mathrm{DC}$ & $\phi_{\mathrm{p}}$ & $\phi_{\mathrm{J}}$ & $\mathrm{H} / \mathrm{D}$ & $\begin{array}{c}\mathrm{U} \\
(\mathrm{m} / \mathrm{s})\end{array}$ & $\begin{array}{c}\mathrm{U}_{\mathrm{T}} \\
(\mathrm{mm} / \mathrm{s})\end{array}$ \\
\hline 1.13 & 2.2 & 8.1 & 2.9 & 0.026 & 0.33 & 0.05 & 0.00092 & 0.8 & 12 & 1.49 \\
\hline
\end{tabular}

(a) B. Rosendall, “Update on HLP22.” HLP22_Results_082708_BMR.ppt.

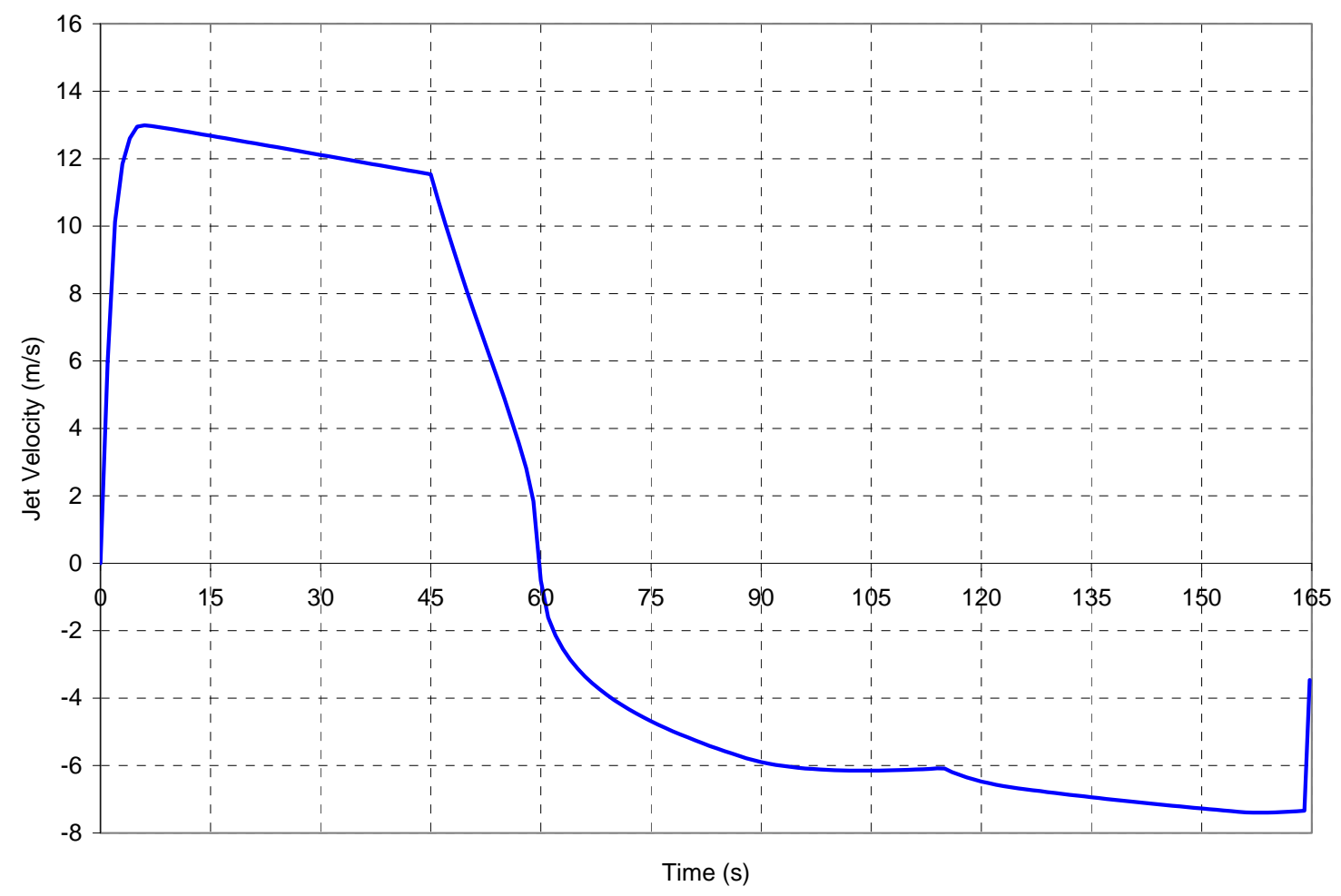

Figure 8.14. Velocity Profile (Drive Function) for HLP-22 (FIO) 
Initial model applications for $\mathrm{C}(\mathrm{Z})$ and $\mathrm{U}_{\mathrm{CS}}$ were made with the average velocity during the 60 -sec PJM discharge, approximately $11 \mathrm{~m} / \mathrm{s}$. The associated duty cycle was 0.36 (60/165). The final model applications shown here were made with the $12 \mathrm{~m} / \mathrm{s}$ average velocity over the 45-second drive portion of the cycle, and the associated duty cycle was 0.33 (45/165). Both give approximately the same cloud height, which suggests that the increased velocity compensates for the reduction in duty cycle.

Cloud height and concentration profile model results for this case are compared with CFD results for the physical model, shown in Figure 8.15 (a), and the generalized model, shown in Figure 8.15 (b). The solids concentration from the CFD model is the average over the final cycle in the simulation at the centerline of the vessel. The simulation was not yet at steady state but seems close. The physical model overpredicts the concentration profile, but the generalized model concentration profile agrees well with that of the CFD model. Note that no optimization can be done for either model in terms of particle settling velocity because this is a monodisperse system, and therefore has a prescribed settling velocity. Both show a highly stratified system. The integrated mass fraction for the CFD model is 0.064 (6.4 wt\%), so much of the solids are still on the tank bottom. This is consistent with the drive velocity $(12 \mathrm{~m} / \mathrm{s})$ being significantly below predicted values of $U_{\mathrm{CS}}(14.1 \mathrm{~m} / \mathrm{s}$ for physical model and $17.9 \mathrm{~m} / \mathrm{s}$ for the generalized model).

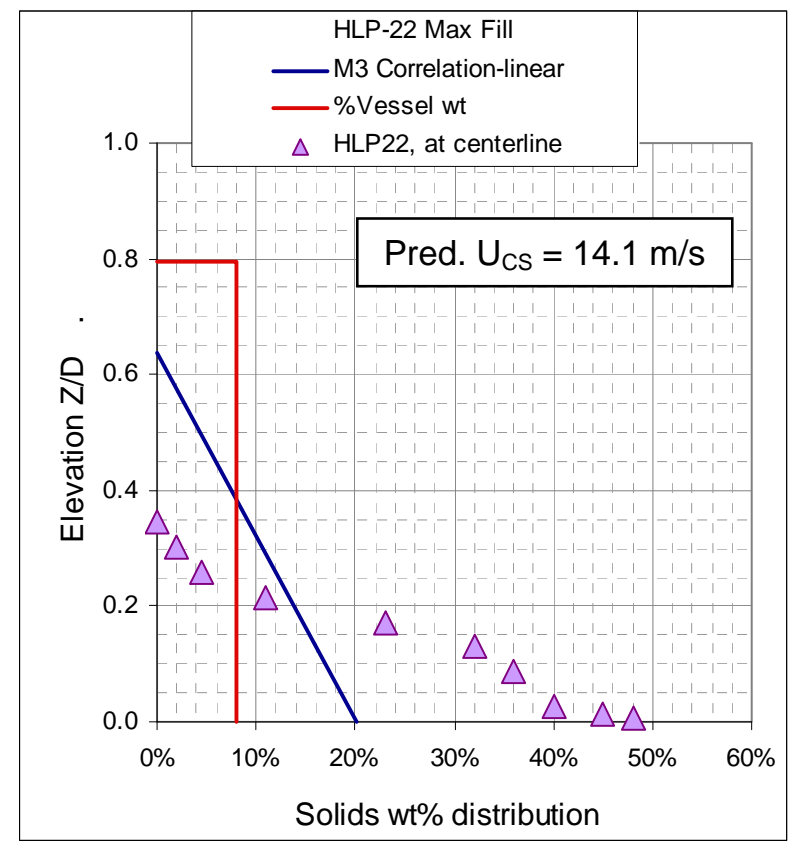

(a)

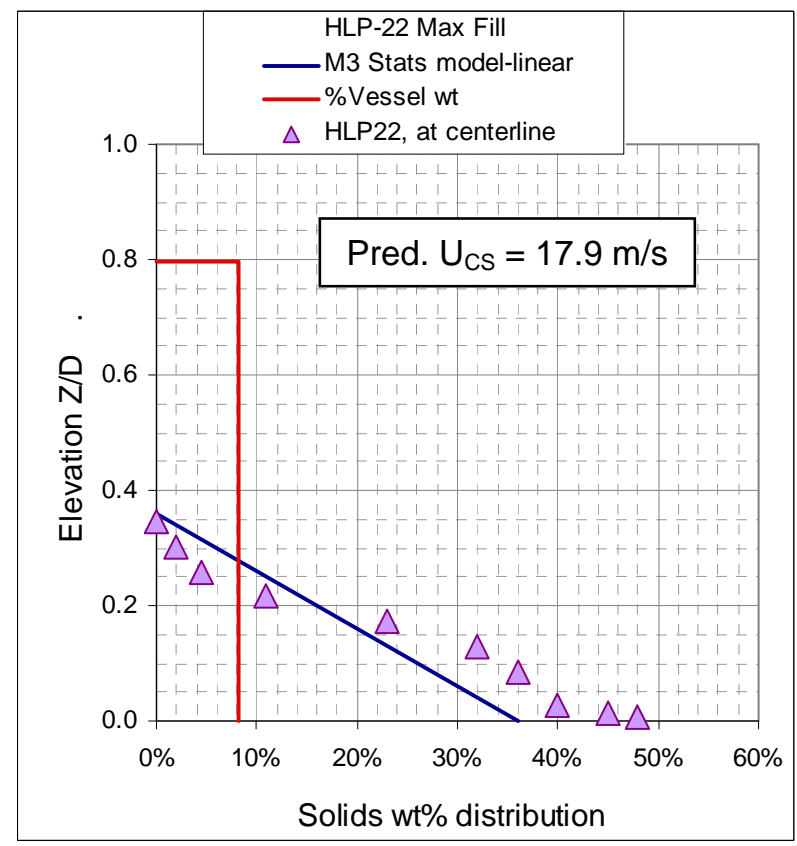

(b)

Figure 8.15. Comparison of Model-Predicted Concentration Profiles with Predictions from CFD Simulation of HLP-22, 12 m/s, Normal Firing Case Using (a) the Physical Model and (b) the Generalized Model

\subsubsection{Benchmarking Summary}

Predictions using the $\mathrm{U}_{\mathrm{CS}}, \mathrm{H}_{\mathrm{C}}$, and $\mathrm{C}(\mathrm{Z})$ models presented in Sections 7.3 and 7.4, with $\mathrm{C}(\mathrm{Z})$ corrections for fill level presented in Section 8.1.2, were compared with experimental results for the available set of larger-scale experiments that mixed particle suspensions with PJMs. These benchmarks spanned a 
wide range of noncohesive simulants and degrees of mixing. The objectives of these experiments did not require the identification of $U_{C S}$, so that parameter was not available for evaluation.

Benchmark comparisons in cloud height/concentration profiles and critical suspension velocities showed the following:

- Settling velocities representing various fractions of the simulant PSDD were evaluated to find one providing the best agreement with the experimentally measured concentration profiles.

- For the physical model, a characteristic particle settling velocity on the high end of PSDD ( $\left.\mathrm{U}_{90}\right)$ gave the best match in the benchmarks of neutralized current acid waste (NCAW) filtration simulants. This same model required a settling velocity in the middle of the particle size range $\left(\mathrm{U}_{50}\right.$ or $\left.\mathrm{U}_{60}\right)$ to match the measured concentration profiles in the benchmarks against the glass bead simulants.

- For the generalized model, a characteristic particle settling velocity of either $U_{90}$ or $U_{95}$ gave equally good results for the NCAW filtration simulants, but in contrast to the physical model, the generalized model also gave best fit with the glass simulants with $\mathrm{U}_{95}$.

- For settling velocities indicated above, cloud heights were in reasonably good agreement with benchmark measurements as long as duty cycle was in the range of the test data upon which the models were based. The associated concentration profiles were qualitatively correct, at least to the extent that a linear model could reproduce often complicated concentration profiles. In the cases for the NCAW filtration simulant, where the duty cycle was well below that used in the current experiments, cloud heights and associated concentration profiles were not consistent with the benchmark measurements. This indicates that models should not be used to extrapolate outside of the test duty cycle range and in general suggests that model predictions based on extrapolation of other test variables may not be correct.

- Geometric and operational simplifications made in the experiments apparently did not adversely affect the development of models that can be applied to prototypic equipment.

- Although measured values of critical suspension velocity were not obtained in the benchmark experiments, physical and generalized model predictions of critical suspension velocity were usually consistent with solids suspension in measured concentration profiles. The values of $U_{\mathrm{CS}}$ predicted by the generalized model were always larger than those predicted by the physical model.

In summary, the benchmark results allow us to move ahead to vessel assessment examples in Section 9 with confidence that, if used with an appropriate settling velocity and with system operating parameters that are within the range of the test data, model predictions will be consistent with observed physical responses. This is in light of the intended use of the models to identify WTP vessel mixing designs that are adequate or inadequate, and not as precise predictors of system performance. Based in particular on the results for the NCAW filtration simulant, these benchmarks support use of a $\mathrm{U}_{95}$ particle setting velocity when representing the Hanford waste in the WTP vessel assessments. 


\subsection{WTP Mixing Systems Performance Examples}

This section presents examples of the application of the developed models to assess two of the established WTP vessel mixing performance metrics: off-bottom suspension and concentration near the pump suction inlet. Model predictions of the concentration near the vessel bottom $\left(\mathrm{C}_{0}\right)$ may be compared to the vessel performance requirement for concentration at the suction pump inlet. Model predictions of critical suspension velocity $\left(\mathrm{U}_{\mathrm{CS}}\right)^{1}$ are a close indicator of the current requirement to disturb all settled solids in the vessel. Assessing other performance requirements related to mixing (such as gas retention and release, or blending times) are not within the scope of the work.

Evaluation of WTP vessel performance was made using two sets of assumed waste conditions. One set of conditions was defined for each vessel by the WTP mixing requirements document (Olsen 2008a ), and these are referred to as the "design point" conditions in this section. The second set was extracted from the Hanford PSDD and is provided for comparison. In both cases the results from the models show how predicted performance for the assumed conditions would relate to the requirements. This is a useful illustration of applying the models, but it is not sufficient for design decisions and not intended to be used without considering other uncertainties and risks. Design margin must be applied to account for uncertainties in the waste properties that will be received and any discrepancy between actual PJM performance and the design value, in addition to the uncertainties inherent in the models. Determining whether mixing systems for solids-containing WTP vessels meet WTP project mixing flowsheet requirements had originally been in the scope of the work documented in this report, but that responsibility was reassigned to the WTP M\&PE group (Hazen 2008b).

Section 9.1 provides an overview of the approach used to predict vessel performance for the examples. Section 9.2 describes the input parameters for the evaluation. Section 9.3 gives the specific vessel performance examples at the design point conditions supplied by WTP using the physical models for $\mathrm{U}_{\mathrm{CS}}, \mathrm{H}_{\mathrm{C}}$, and $\mathrm{C}_{0}$ from Sections 7.3.2 to 7.3.4. Section 9.4 presents predictions of vessel performance using the same models with the waste conditions extracted from the Hanford PSDD. Section 9.5 presents predictions of vessel performance for the same waste conditions as Section 9.4 but uses the generalized models discussed in Section 7.4. Section 9.6 summarizes the results.

\subsection{Approach for Predicting Vessel Performance}

Evaluating the mixing system design for a particular WTP vessel involves comparing the predicted performance with the required performance. For the WTP vessels, the mixing requirements (Olsen 2008a) and the vessel and PJM mixing system design parameters (BNI 2007 ${ }^{2}$ ) were provided by the client. The predicted performance can be calculated using the models with these inputs and assumed waste properties. The evaluation then becomes a direct comparison of predictions with requirements, with no allowance for uncertainty or design margin. This is not to imply that uncertainties and design margins aren't important, just that they were not included in the examples considered. For the different waste or design limit conditions, the physical and generalized models were used to predict 1) the velocity

\footnotetext{
${ }^{1} \mathrm{U}_{\mathrm{CS}}$ is the velocity at which all solids are suspended at the end of the drive cycle of the PJM pulse. $\mathrm{U}_{\mathrm{CS}}$ velocity is not the velocity required to fully mix the solids in the tank. During testing, simulant clouds would often remain near the bottom of the tank when the $\mathrm{U}_{\mathrm{CS}}$ velocity had been achieved.

${ }^{2}$ Email communication from GL Smith to PA Scott February 23, 2007 regarding CCN 51865.
} 
needed for off-bottom suspension $\left(\mathrm{U}_{\mathrm{CS}}\right)$ and 2) the average solids concentration at the floor of the vessel $\left(\mathrm{C}_{0}\right)$. The requirements and the use of these variables to evaluate these requirements are discussed in Section 9.1.1.

\subsubsection{Overview of Requirements}

The WTP has established nine performance criteria that apply to the various mixing systems. Not all of these criteria apply to all WTP vessels. For the solids-containing WTP PJM vessels, the developed models allow for evaluating the following two criteria:

- Maintain the solids concentration at the pump suction lower than $20 \mathrm{wt} \%$ to prevent line plugging

- Ensure that the solids (above a minimal fraction) are disturbed to release flammable gas.

The first criterion is related to the solids concentrations at the pump inlet of the vessel. The models presented in this report predict the solids concentration near the floor of the vessel rather than precisely at the pump suction inlet. The difference in elevation is negligible, and the predicted value is expected to be within the uncertainty of the prediction. The second criterion for disturbing the solids is not quite the same as the $\mathrm{U}_{\mathrm{CS}}$ predicted by the models. A predicted $\mathrm{U}_{\mathrm{CS}}$ value represents the condition under which all of the solids have just barely been suspended at the end of the pulse, and thus represents a minimal condition or satisfying the solids disturbance requirement.

\subsubsection{Assumptions and Limitations}

Testing requires controllable conditions, measurable results, and some compromises. In this program, testing was conducted using noncohesive simulants of tightly controlled single-size distribution, singledensity spherical particulate in a water medium (distribution and density ranges of each simulant are discussed in Section 3). These physical properties are not identical to actual wastes, of course, but the settling velocities that were investigated covered the range of interest for Hanford waste (see Figure 3.4). In addition, the test equipment used was not prototypic in geometry (size of tank and relative size of tank internals) or performance (full cycle PJMs), and some compromises and assumptions were required. As such, there are some caveats to the conclusions. Important assumptions and limitations follow:

- The Hanford PSDD (Wells et al. 2007) Case 3 is assumed to represent reasonable and actual waste conditions entering the WTP. The waste characterizations in Hanford PSDD examine the full suite of Hanford tank wastes. The individual treatment batches of waste that will be delivered to the WTP will be subsets of the total Hanford waste. The characteristics of an individual batch will vary from those characterized in the Hanford PSDD.

- The mixing performance models were developed for noncohesive solids. As such they do not apply to wastes exhibiting cohesive properties. Cohesive wastes have an additional interparticle bonding force that must be overcome to mobilize them in a vessel; the force can change mixing behavior in the vessel.

- Testing for this report was conducted using simulants with very narrow PSDD. The results from the tight distribution testing were used to create models that were compared with benchmark tests that had broader distributions and/or multiple particle sizes and densities (Section 8). The models were applied assuming that a single settling velocity can be used to represent a broader particle size and density distribution. Although broad particle ranges were not tested, it is assumed that these effects 
are adequately accounted for in the models using settling velocity terms. Results for the NCAW filtration simulant benchmark support use of a $U_{95}$ particle settling velocity in the vessel ratings.

- The test systems did not use a prototypic (reciprocating) pulsing action but a drive (recirculating) action. This resulted in a net upward velocity in the vessel that would not be present in a prototypic system and would tend to increase the height of a cloud. In that sense, the system used for testing was nonconservative. On the other hand, the recirculating pulse did not withdraw solids into a PJM, and that results in a pulse consisting only of water rather than the more dense slurry that would result from a prototypic system. This difference would likely result in a higher velocity being needed for off-bottom suspension than would be needed in a prototypic system.

- The PJMs in the test system were straight pipes of a much smaller diameter than geometrically scaled PJMs and did not have the same nozzle shape. These differences were assumed to be of second order in terms of variables that would affect performance.

- The preponderant test data were collected for a PJM configuration that was scaled down from HLP22, which has 12 PJMs. This tends to favor predictions of similar configurations. The limited 8- and 4-tube tests indicate that the mixing models can be applied to those configurations as well, but the results may have more uncertainty or some bias.

The comparisons of model predictions with mixing results for benchmark experiments (in larger-scale vessels with actual PJM and representative PSDDs) discussed in Section 8 indicate the ability of models to predict mixing performance in actual WTP vessels. Although good comparisons could not be achieved for all benchmark cases, the results allow us to proceed to assessing vessel mixing performance with confidence that model predictions are reasonably consistent with observed physical responses. This is sufficient in light of the intended use of the models to identify adequacy or inadequacy of mixing system designs, but not for close prediction of performance to assess design margins.

\subsubsection{Uncertainties Related to the Application of the Mixing Models}

Several types of uncertainty related to testing and development of the mixing models were discussed in Section 8.2.4. When applying the models to specific cases, additional assumptions are required related to the waste properties and the actual performance of the design. If the models were considered perfect predictors, performance uncertainty would be related to the selection of the appropriate settling velocity and any deviation of the pulse jets from design values. Of these two, the waste properties likely introduce the greater uncertainty. This is due to the variations in waste properties for individual treatment batches from the total Hanford wastes described in the PSDD (Wells et al. 2007).

The models can be used to predict the mixing performance at defined conditions and then exercised to determine the sensitivity of a WTP vessel mixing design to changes in conditions. Such sensitivity analyses have not been conducted, but would provide insight to alternatives or modifications that could improve mixing performance. The sensitivity can be used to determine how design and operating margins should be selected and where they should be applied. For example, a change in design will affect the margin for all waste streams but may not be needed for most of them. Alternatively, a change in feed characteristics, such as volume percent solids, may be implemented only on problematic wastes streams to achieve sufficient margin. 


\subsubsection{Proposed Evaluation Methodology}

In the following examples, the WTP vessels were grouped into similar design and operational types, and performance metrics were evaluated for the vessel types. Additional assessments for HLP-22 were conducted to provide key information for design modification options. The assessment of the vessel types is based on two performance metrics:

- Solids concentration metric: This metric is the predicted concentration at the floor relative to $20 \mathrm{wt} \%$. The value of $20 \mathrm{wt} \%$ is the client-supplied upper concentration limit at the pump inlet (normally at the bottom of the vessel, within $1 \mathrm{ft}$ of the floor). The model given by Eq. (7.50) gives the floor concentration in terms of volume fraction $\mathrm{C}_{0}$. In evaluating plant vessels it is useful to express the solids concentration as the weight fraction (or as shown in the tables for the examples as a wt\% where $\mathrm{W}_{0}$ is multiplied by 100 ), $\mathrm{W}_{0}$, which is related to the volume fraction by

$$
\mathrm{W}_{0}=\frac{\mathrm{sC}_{0}}{(\mathrm{~s}-1) \mathrm{C}_{0}+1}
$$

To compensate for observed underprediction of the concentration at the floor (as discussed in Section 7.3.3), the model-predicted $\mathrm{W}_{0}$ is multiplied by 1.5. Therefore the metric is

$$
\text { Concentration Metric }=\frac{0.20}{\mathrm{~W}_{0}^{*}}
$$

where, $\mathrm{W}_{0}{ }^{*}=1.5 \mathrm{~W}_{0}$. Hence when $0.20 / \mathrm{W}_{0}{ }^{*}>1$ the concentration on the floor is predicted to be less than $20 \mathrm{wt} \%$. This criterion, however, does not necessarily imply a well-mixed vessel with good vertical solids distribution. For that to be achieved, the value of $\mathrm{C}_{0}$ needs to approach the average solids loading in the vessel.

- Solids suspension metric: This metric compares the vessel's design velocity with the modelpredicted $\mathrm{U}_{\mathrm{CS}}$. While achieving $\mathrm{U}_{\mathrm{CS}}$ in general may not provide sufficient mixing in a vessel, it is generally considered to be a minimum requirement for a robust mixing system. The suspension metric is given by

$$
\text { Suspension Metric }=\frac{U_{\text {design }}}{U_{C S}}
$$

where $\mathrm{U}_{\text {design }} / \mathrm{U}_{\mathrm{CS}}>1$ implies the design is sufficient to just suspend the all solids off the floor by the end of the PJM drive pulse.

The example assessments were conducted using three sets of waste properties. The waste properties used in the evaluation included:

- $\mathrm{U}_{95}$ : This is the $95^{\text {th }}$ percentile of the particle settling velocity distribution, based on the Hanford tank waste PSDD Case 3. Use of the 95th percentile is supported by the results of the model benchmarking (Section 8).

- $\overline{\mathrm{U}}_{90}$ : This is the volume-weighted average settling velocity for the fastest settling $10 \%$ of the Hanford tank waste. 
- Design limit particle: For assessing the vessel types, WTP provided Determination of Mixing Requirements for Pulse-Jet-Mixed Vessels in the Waste Treatment Plant (24590-WTP-ES-PET08-002, Rev. 0) (Olsen 2008a). This requirements document identified the upper limit for waste concentrations and particle characteristics for each vessel. While upper limits were specified, the PSDDs were not identified. The vessels were also assessed using the design-limit particle.

The $\mathrm{U}_{95}$ and $\overline{\mathrm{U}}_{90}$ settling velocities and the design limit particle are used to establish an evaluation range for assessing the vessel types.

The examples provided can be used by the WTP M\&PE group for assessing the mixing designs of WTP vessels. The examples show a combined assessment of the two criteria (concentration at the pump inlet using $\mathrm{W}_{0}{ }^{*}$ and off-bottom solids suspension using $\mathrm{U}_{\mathrm{CS}}$ ) that can be used to evaluate a vessel type. The performance ratios for $\mathrm{U}_{\mathrm{CS}}\left(\mathrm{U}_{\text {design }} / \mathrm{U}_{\mathrm{CS}}=\right.$ design velocity/ $\mathrm{U}_{\mathrm{CS}}$ predicted $)$ and for suction inlet concentration $\left(0.20 / \mathrm{W}_{0}{ }^{*}=20 \% / \mathrm{W}_{0}{ }^{*}\right)$ can be compared to 1.0 to assess whether the criteria are met. The WTP M\&PE group could use these ratios to assess whether mixing designs for WTP vessels meet plant needs. However, the ratios would need to be adjusted upward by proper engineering margins. These engineering design margins must take into consideration waste feed variations, operating variations, uncertainties in the models, design sensitivities, and other engineering concerns.

Figure 9.1 (b) shows an example of vessel type FEP-17 A/B using the $\mathrm{U}_{95}$ and $\overline{\mathrm{U}}_{90}$ settling velocity from the Hanford waste tanks (Hanford PSDD Case 3). In this example, the $\mathrm{U}_{\text {design }} / \mathrm{U}_{C S}$ value is less than 1 for wastes with $U_{95}$ and $\bar{U}_{90}$ settling velocities. Hence, the suspension of solids is predicted to be less than the requirement for both settling velocities. The second criterion for the pump inlet concentration assessment uses the $0.20 / \mathrm{W}_{0}{ }^{*}$ ratio. For wastes with $\mathrm{U}_{95}$ (U95) and $\overline{\mathrm{U}}_{90}$ (Ubar90) settling velocities, the vessel type would not satisfy the requirement. If the WTP M\&PE group used the assessment basis above for this example, vessel-type FEP-17 A/B would not meet plant needs using the combined (suspension of solids and waste concentration at the pump inlet) performance ratios.

The vessel performance examples include other important figures to support the WTP M\&PE assessments of the vessel types for the conditions evaluated. These figures (which may contain curves for one or more waste conditions) include:

- A plot of $\mathrm{U}_{\mathrm{CS}}$ velocities, shown in Figure 9.1 (d), necessary to maintain a concentration of $20 \mathrm{wt} \%$ at the suction inlet $\left(\sim \mathrm{W}_{0}{ }^{*}\right)$ for different bulk solids concentrations in the vessel listed as average (wt\%) solids concentration in the vessel. This can be used as a quick performance sensitivity check for a vessel; the procedure matches current or alternative design velocities to operationally acceptable vessel solids loadings. Engineering design margins would need to be added to these figures by WTP M\&PE.

- Vessel concentration distributions at the design velocity plotted for each example (or set of conditions) shown in Figure 9.1 (a). For a given vessel solids loading, the elevation of the waste cloud divided by the diameter of the vessel (Z/D) is compared to the $\mathrm{wt} \%$ solids (solids wt\% distribution). An idealized curve for a fully mixed (homogenous) vessel (at the given solids loading or bulk solids wt\% in the vessel) is also provided. The closer the design performance curve is to the idealized curve, the better mixed the vessel is at the design velocity. Conversely, a lower solids 
distribution curve indicates the waste cloud will remain near the bottom of the vessel, thereby increasing concentrations at the suction inlet.

- A graph of the maximum solids concentration on the tank bottom $\left(\mathrm{W}_{0}{ }^{*}\right)$ compared with average (bulk wt\%) solids concentration in the vessel, shown in Figure 9.1 (c). This plot is based at the vessel's design velocity and can be used as a quick performance sensitivity check for the tank to match current or alternative vessel solids loading options to meet pump inlet concentration requirements.

These plots are based on the maximum operating fill height from Olsen (2008a). Engineering design margins would need to be added to these figures by WTP M\&PE.

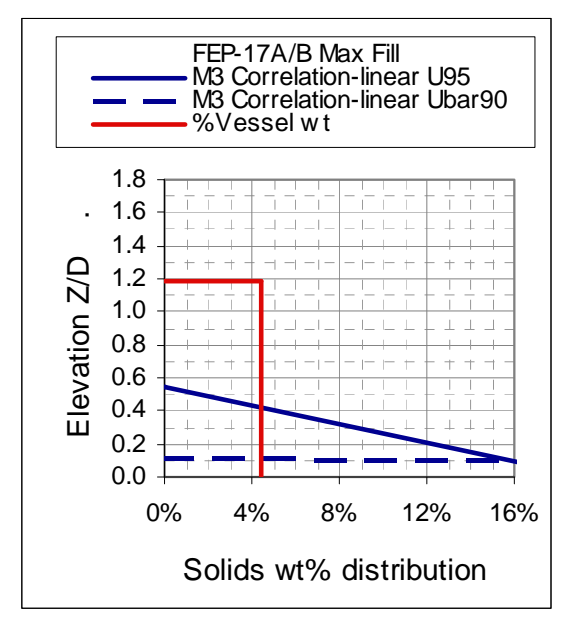

(a)

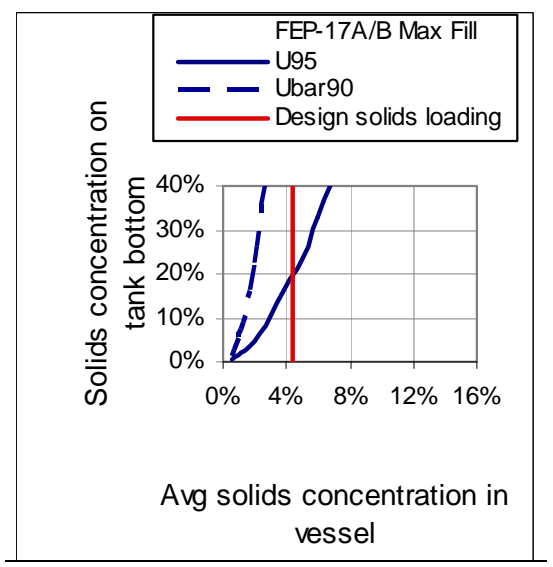

(c)

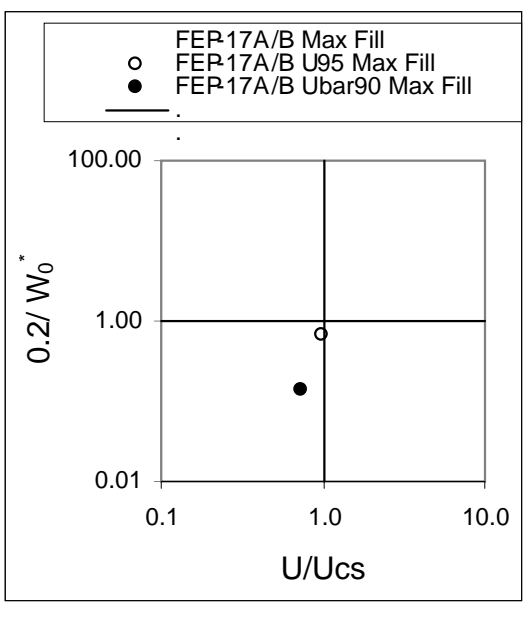

(b)

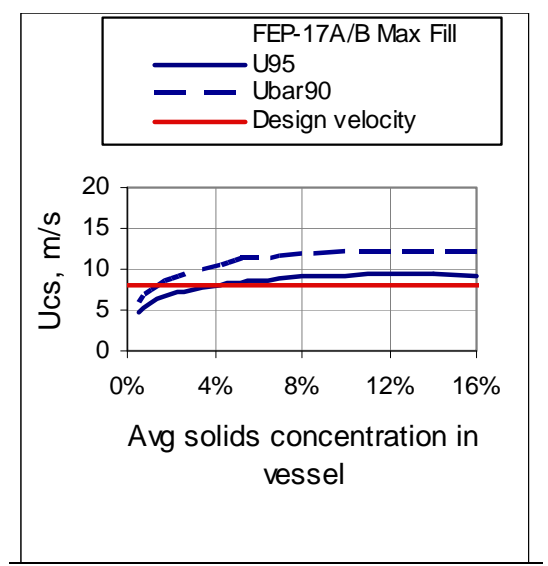

(d)

Figure 9.1. Performance Ratio Example Using FEP-17 A/B. Engineering margins would need to be added to the design ratio acceptance range by WTP M\&PE. (a) Concentration distribution at design velocity, (b) FEP-17 A/B using the $\mathrm{U}_{95}$ and $\overline{\mathrm{U}}_{90}$ settling velocities, (c) maximum solids concentration on the tank bottom $\left(\mathrm{W}_{0}{ }^{*}\right)$ compared with average (bulk wt\%) solids concentration in the vessel, (d) $\mathrm{U}_{\mathrm{CS}}$ velocities to maintain $20 \mathrm{wt} \%$ at the suction inlet. 


\subsection{Input Parameters for Plant Vessels}

Input parameters for the example vessel assessments came from two sources, as shown in Table 9.1. Vessel geometry and operations data tables were taken from CCN151865 (BNI 2007), and solids loading data were found in mixing requirements (Olsen 2008a, Table 6).

Table 9.1. Sources of Physical Mixing System Parameters for Plant Vessels

\begin{tabular}{ll}
\hline \multicolumn{1}{c}{ Information Type } & WTP Source of Information \\
\hline $\begin{array}{l}\text { Vessel sizes, PJM number, nozzle size, duty cycle, pulse volume fractions, } \\
\text { maximum liquid operating levels }\end{array}$ & CCN 151865 (CNN 2007) \\
$\begin{array}{l}\text { Operational information such as limits for bulk solids loading, particle size, average } \\
\text { particle density, liquid density, and liquid rheology }\end{array}$ & Olsen (2008a) \\
\hline
\end{tabular}

\subsubsection{Vessel Geometry and Operational Data}

The vessel geometry and operations data were converted to model-specific parameters as required. The reference volume $\left(\mathrm{V}_{\mathrm{REF}}\right)$ for each WTP vessel was calculated using the vessel diameter. Other parameters $\left(\phi_{\mathrm{p}}\right.$ and $\left.\phi_{\mathrm{J}}\right)$ were computed from vessel geometry for an 80\% PJM stroke. The vessel geometry and operations data that were used as model inputs are shown in Table 9.2. Fill levels (expressed as H/D) are for maximum fill conditions. Duty cycles for the 4-in. cases were used as listed, with the assumption that the new jet pump pairs (JPPs) would operate at the recently proposed $12 \mathrm{~m} / \mathrm{s}$. For the 6-in. cases, suction time was assumed to remain the same as the 4-in. cases, and the drive time was assumed to scale with increased flow area. This reduced the duty cycle for the 6 -in. cases from 0.33 to 0.22 .

Table 9.2. Vessel Geometry and Operations Data Used in WTP Vessel Assessments

\begin{tabular}{|c|c|c|c|c|c|c|c|c|c|c|}
\hline Vessel & $\mathrm{w}_{\text {Smax }} \%^{(\mathrm{a})}$ & $\begin{array}{c}V_{\text {REF }} \\
\left(\mathrm{ft}^{3}\right)^{(\mathrm{b})}\end{array}$ & $\mathrm{N}$ & $\begin{array}{c}\mathrm{D} \\
(\mathrm{ft})^{(\mathrm{b})}\end{array}$ & $\begin{array}{c}\mathrm{d} \\
\left(\text { (in. }^{(\mathrm{b})}\right.\end{array}$ & $\phi_{\mathrm{p}}$ & $\phi_{\mathrm{J}}$ & $\mathrm{H} / \mathrm{D}$ & $\begin{array}{c}\mathrm{U} \\
(\mathrm{m} / \mathrm{s})\end{array}$ & DC \\
\hline FRP-02A/B/C/D & 0.049 & 81542 & 12 & 47.0 & 4.0 & 0.025 & 0.00060 & 0.73 & 8 & 0.37 \\
\hline HLP-22 (4in,8m/s) & 0.154 & 43096 & 12 & 38.0 & 4.0 & 0.050 & 0.00092 & 0.80 & 8 & 0.33 \\
\hline HLP-22 (4in,12m/s) & 0.154 & 43096 & 12 & 38.0 & 4.0 & 0.050 & 0.00092 & 0.80 & 12 & 0.33 \\
\hline HLP-22 (6in,8m/s) & 0.154 & 43096 & 12 & 38.0 & 6.0 & 0.050 & 0.00208 & 0.80 & 8 & 0.22 \\
\hline HLP-22 (6in,12m/s) & 0.154 & 43096 & 12 & 38.0 & 6.0 & 0.050 & 0.00208 & 0.80 & 12 & 0.22 \\
\hline TCP-01 & 0.027 & 14616 & 8 & 26.5 & 4.0 & 0.095 & 0.00127 & 1.25 & 8 & 0.33 \\
\hline TLP-09A/B & 0.003 & 13804 & 8 & 26.0 & 4.0 & 0.036 & 0.00131 & 1.08 & 8 & 0.30 \\
\hline PWD-33 & 0.081 & 10857 & 8 & 24.0 & 4.0 & 0.021 & 0.00154 & 0.45 & 8 & 0.30 \\
\hline PWD-43 & 0.002 & 10857 & 8 & 24.0 & 4.0 & 0.021 & 0.00154 & 0.45 & 8 & 0.30 \\
\hline PWD-44 & 0.081 & 9556 & 8 & 23.0 & 4.0 & 0.097 & 0.00168 & 1.32 & 8 & 0.33 \\
\hline FEP-17A/B & 0.044 & 8363 & 8 & 22.0 & 4.0 & 0.091 & 0.00184 & 1.19 & 8 & 0.29 \\
\hline PWD-15/16 & 0.03 & 8363 & 8 & 22.0 & 4.0 & 0.055 & 0.00184 & 1.78 & 8 & 0.35 \\
\hline UFP-01A/B & 0.038 & 6283 & 8 & 20.0 & 4.0 & 0.094 & 0.00222 & 1.45 & 8 & 0.31 \\
\hline RLD-07 & 0.022 & 1726 & 4 & 13.0 & 4.0 & 0.051 & 0.00263 & 1.20 & 8 & 0.27 \\
\hline RLD-08 & 0.022 & 1726 & 4 & 13.0 & 4.0 & 0.053 & 0.00263 & 0.91 & 8 & 0.29 \\
\hline HOP-903/904 & 0.01 & 1357 & 4 & 12.0 & 4.0 & 0.036 & 0.00309 & 0.86 & 8 & 0.26 \\
\hline
\end{tabular}

(a) $\mathrm{w}_{\mathrm{Smax}} \%$ is the designed insoluble solids concentration (in wt\%) for the WTP vessels.

(b) Units need to be converted from English to metric before being used in the physical and generalized models. 


\subsubsection{Waste Property Conditions}

Waste conditions that were used in the vessel assessments are summarized in Tables 9.3 and 9.4. Table 9.3 shows inputs used in the design point cases; Table 9.4 shows corresponding inputs used in the Hanford PSDD-based cases.

Table 9.3. Vessel Solids Loading Data Used in Design Point Assessments

\begin{tabular}{lcccccc}
\hline \multicolumn{1}{c}{ Vessel } & $\begin{array}{c}\text { Solids } \\
\text { Loading } \\
(\mathrm{wt} \%)\end{array}$ & $\begin{array}{c}\text { Particle } \\
\text { Size } \\
(\mu \mathrm{m})\end{array}$ & $\begin{array}{c}\text { Particle } \\
\text { Density } \\
\left(\mathrm{g} / \mathrm{cm}^{3}\right)\end{array}$ & $\begin{array}{c}\text { Liquid } \\
\text { Density } \\
\left(\mathrm{g} / \mathrm{cm}^{3}\right)\end{array}$ & $\begin{array}{c}\text { Liquid } \\
\text { Viscosity } \\
(\mathrm{cP})\end{array}$ & $\begin{array}{c}\text { Unhindered Terminal } \\
\text { Settling Velocity }\left(\mathrm{U}_{\mathrm{T}}\right) \\
(\mathrm{m} / \mathrm{s})\end{array}$ \\
\hline FRP-02A/B/C/D & 4.9 & 50 & 2.18 & 1.1 & 1.5 & $9.36 \mathrm{E}-4$ \\
HLP-22 & 15.4 & 210 & 2.18 & 1.1 & 1.5 & $1.25 \mathrm{E}-2$ \\
TCP-01 & 2.7 & 164 & 3.60 & 1.2 & 2.0 & $1.33 \mathrm{E}-2$ \\
TLP-09A/B & 0.3 & 164 & 3.60 & 1.1 & 1.5 & $1.74 \mathrm{E}-2$ \\
PWD-33 & 8.1 & 210 & 2.18 & 1.0 & 1.0 & $1.81 \mathrm{E}-2$ \\
PWD-43 & 0.2 & 210 & 2.18 & 1.0 & 1.0 & $1.81 \mathrm{E}-2$ \\
PWD-44 & 8.1 & 210 & 2.18 & 1.0 & 1.0 & $1.81 \mathrm{E}-2$ \\
FEP-17A/B & 4.4 & 50 & 2.18 & 1.1 & 1.5 & $9.36 \mathrm{E}-4$ \\
PWD-15/16 & 3.0 & 210 & 2.18 & 1.0 & 1.0 & $1.81 \mathrm{E}-2$ \\
UFP-01A/B & 3.8 & 210 & 2.18 & 1.1 & 1.5 & $1.25 \mathrm{E}-2$ \\
RLD-07 & 2.2 & 210 & 2.18 & 1.0 & 1.0 & $1.81 \mathrm{E}-2$ \\
RLD-08 & 2.2 & 210 & 2.18 & 1.0 & 1.0 & $1.81 \mathrm{E}-2$ \\
HOP-903/904 & 1.0 & 210 & 2.18 & 1.0 & 1.0 & $1.81 \mathrm{E}-2$ \\
\hline
\end{tabular}

Table 9.4. Vessel Solids Loading Data Used in Hanford PSDD-Based Assessments

\begin{tabular}{lcccccc}
\hline \multicolumn{1}{c}{ Vessel } & $\begin{array}{c}\text { Solids } \\
\text { Loading } \\
(\mathrm{wt} \%)\end{array}$ & $\begin{array}{c}\text { Particle } \\
\text { Density } \\
\left(\mathrm{g} / \mathrm{cm}^{3}\right)\end{array}$ & $\begin{array}{c}\text { Liquid } \\
\text { Density } \\
\left(\mathrm{g} / \mathrm{cm}^{3}\right)\end{array}$ & $\begin{array}{c}\text { Liquid } \\
\text { Viscosity } \\
(\mathrm{cP})\end{array}$ & $\begin{array}{c}\text { Particle Settling } \\
\text { Velocity } \\
\mathrm{U}_{95}(\mathrm{~m} / \mathrm{s})\end{array}$ & $\begin{array}{c}\text { Particle Settling } \\
\text { Velocity } \\
\overline{\mathrm{U}}_{90}(\mathrm{~m} / \mathrm{s})\end{array}$ \\
\hline FRP-02A/B/C/D & 4.9 & 2.78 & 1.1 & 1.5 & $2.50 \mathrm{E}-3$ & $1.04 \mathrm{E}-2$ \\
HLP-22 & 15.4 & 2.78 & 1.1 & 1.5 & $2.50 \mathrm{E}-3$ & $1.04 \mathrm{E}-2$ \\
TCP-01 & 2.7 & 2.78 & 1.1 & 1.5 & $2.50 \mathrm{E}-3$ & $1.04 \mathrm{E}-2$ \\
TLP-09A/B & 0.3 & 2.78 & 1.1 & 1.5 & $2.50 \mathrm{E}-3$ & $1.04 \mathrm{E}-2$ \\
PWD-33 & 8.1 & 2.78 & 1.1 & 1.5 & $2.50 \mathrm{E}-3$ & $1.04 \mathrm{E}-2$ \\
PWD-43 & 0.2 & 2.78 & 1.1 & 1.5 & $2.50 \mathrm{E}-3$ & $1.04 \mathrm{E}-2$ \\
PWD-44 & 8.1 & 2.78 & 1.1 & 1.5 & $2.50 \mathrm{E}-3$ & $1.04 \mathrm{E}-2$ \\
FEP-17A/B & 4.4 & 2.78 & 1.1 & 1.5 & $2.50 \mathrm{E}-3$ & $1.04 \mathrm{E}-2$ \\
PWD-15/16 & 3.0 & 2.78 & 1.1 & 1.5 & $2.50 \mathrm{E}-3$ & $1.04 \mathrm{E}-2$ \\
UFP-01A/B & 3.8 & 2.78 & 1.1 & 1.5 & $2.50 \mathrm{E}-3$ & $1.04 \mathrm{E}-2$ \\
RLD-07 & 2.2 & 2.78 & 1.1 & 1.5 & $2.50 \mathrm{E}-3$ & $1.04 \mathrm{E}-2$ \\
RLD-08 & 2.2 & 2.78 & 1.1 & 1.5 & $2.50 \mathrm{E}-3$ & $1.04 \mathrm{E}-2$ \\
HOP-903/904 & 1.0 & 2.78 & 1.1 & 1.5 & $2.50 \mathrm{E}-3$ & $1.04 \mathrm{E}-2$ \\
\hline
\end{tabular}

The solids loading data is the maximum concentration from the mixing requirements (Olsen 2008a). Solids and liquid properties depended on whether the design cases (Table 9.3) or Hanford PSDD (Table 9.4) were being evaluated. Olsen (2008a) included liquid density but did not specify liquid viscosity. For the design point examples in Section 9.3, where density was specified as $1 \mathrm{~g} / \mathrm{cm}^{3}$, the 
viscosity of water was used ( $1 \mathrm{cP}$ ). If the density was specified as $1.1 \mathrm{~g} / \mathrm{cm}^{3}$, a viscosity of $1.5 \mathrm{cP}$ was used. For the single vessel with a liquid density of $1.2 \mathrm{~g} / \mathrm{cm}^{3}$ specified, a viscosity of $2 \mathrm{cP}$ was used. The fluid viscosities were based on measurements of Hanford waste with the specified densities (Wells et al. 2007). The settling velocities in Table 9.3 were calculated from the liquid and particulate properties shown for each vessel (as per Section 7).

A uniform liquid density of $1.1 \mathrm{~g} / \mathrm{cm}^{3}$ was used in the Hanford PSDD cases with a fluid viscosity of $1.5 \mathrm{cP}$. The settling velocities in Table 9.4 were calculated from the Hanford PSDD as presented in Table 3.4 and were assigned the same for all vessels evaluated.

\subsubsection{Dimensionless Variable Evaluation}

The $\mathrm{U}_{\mathrm{CS}}$ and $\mathrm{H}_{\mathrm{C}}$ physical models presented in Sections 7.3.2 and 7.3.4, and the generalized models presented in Section 7.4, are functions of dimensionless variables. The values of these dimensionless variables were evaluated for the WTP vessel mixing systems, relative to the ranges of the variables for the test data and benchmark cases in Section 8. The dimensionless variables from the physical models for $\mathrm{U}_{\mathrm{CS}}$ and $\mathrm{H}_{\mathrm{C}}$ include:

Ratio of jet velocity to hindered terminal settling velocity

$$
\frac{\mathrm{U}}{\mathrm{U}_{\mathrm{TH}}}
$$

Ratio of $\mathrm{D}^{*}$ to square root of the Galileo number

$$
\frac{\mathrm{D}^{*}}{\mathrm{Ga}^{0.5}}
$$

The dimensionless variables from the generalized models for $\mathrm{U}_{\mathrm{CS}}$ and $\mathrm{H}_{\mathrm{C}}$ include:

Ratio of jet diameter to tank diameter

$$
\frac{\mathrm{d}}{\mathrm{D}}
$$

Ratio of unhindered terminal settling velocity to jet velocity

$$
\frac{\mathrm{U}_{\mathrm{T}}}{\mathrm{U}}
$$

Froude number based on jet velocity and tank diameter

$$
\frac{(\mathrm{s}-1) \mathrm{gD}}{\mathrm{U}^{2}}
$$

Froude number based on unhindered terminal settling velocity and tank diameter

$$
\frac{(\mathrm{s}-1) \mathrm{gD}}{\mathrm{U}_{\mathrm{T}}{ }^{2}}
$$


The test data set is the same as that described in Section 7.3.2 (the complete data set is listed in Appendix B). The benchmark and WTP vessel parameters are taken from Section 8 and Tables 9.2 and 9.4. The dimensionless variables for the test data are presented in Figures 9.2 through 9.7 as cumulative probability distributions (M3 tests). Thus, for example, from Figure 9.2, 10\% of the test data had $\mathrm{U} / \mathrm{U}_{\mathrm{TH}}$ less than approximately 3E2 and 90\% greater than 3E2. In Figures 9.2 to 9.7, the WTP vessels are designated by name, and the benchmarks are denoted by "BM."

For dimensionless variables with a terminal or hindered settling velocity (Eq. 9.3, 9.4, 9.6, and 9.8), the vertical location of the WTP vessel and benchmark data points represent the quantiles (also known as percentiles) of the settling velocities used in application. For the WTP vessels, 0.95 denotes $\mathrm{U}_{95}$, and 0.9 denotes $\overline{\mathrm{U}}_{90}$. The 90th, 60th, and 50th percentiles are the settling velocities used for the respective benchmarks (see Section 8). For the dimensionless variables of Eq. (9.5) and (9.7), the vertical location of the WTP vessel and benchmark data points at 0.5 is arbitrary.

In general, the WTP vessel and benchmark data points are within or close to the test data range. However, some extrapolation does occur for four of the six nondimensional variables. Thus, application of the $\mathrm{U}_{\mathrm{CS}}$ and $\mathrm{H}_{\mathrm{C}}$ models is via interpolation or minor to moderate extrapolation.

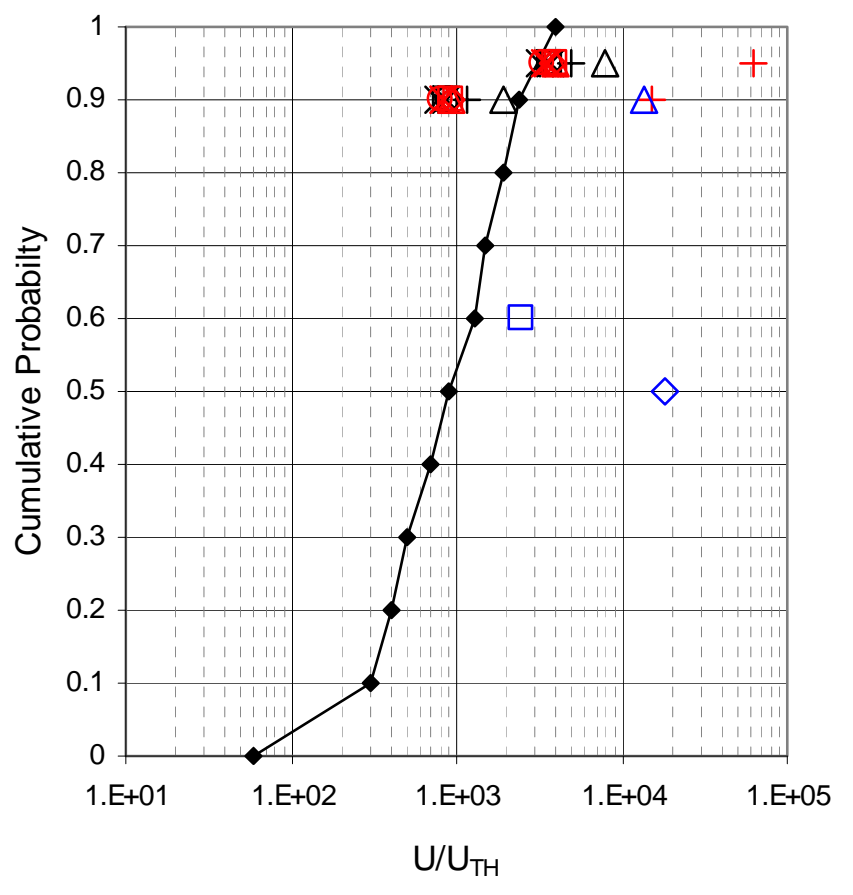

\begin{tabular}{|c|c|}
\hline \multicolumn{2}{|c|}{$\multimap \mathrm{M} 3$ Tests } \\
\hline$\square$ & FRP-02A/B/C/D \\
\hline$\Delta$ & HLP-22 \\
\hline$x$ & TCP-01 \\
\hline * & TLP-09A/B \\
\hline 0 & PWD-33/43 \\
\hline+ & PWD-44 \\
\hline$\diamond$ & FEP-17A/B \\
\hline$\square$ & PWD-15/16 \\
\hline$\Delta$ & UFP-01A/B \\
\hline $\mathrm{x}$ & RLD-07 \\
\hline * & RLD-08 \\
\hline O & HOP-903/904 \\
\hline+ & RDP-02A/B/C \\
\hline$\diamond$ & BM 35 glass \\
\hline$\square$ & BM 75 glass \\
\hline$\Delta$ & BM FS \\
\hline
\end{tabular}

Figure 9.2. Test Data and Application Range for $\frac{\mathrm{U}}{\mathrm{U}_{\mathrm{TH}}}$ 


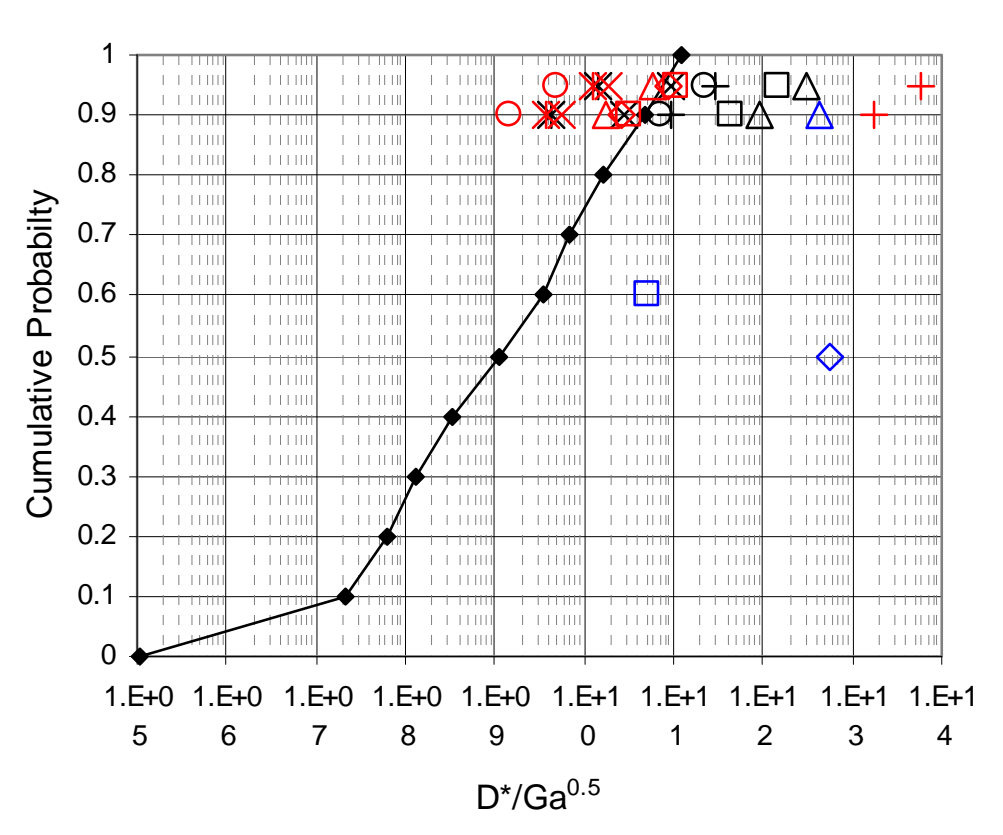

$\begin{array}{|ll|}\longrightarrow & \text { M3 Tests } \\ \Delta & \text { FRP-02A/B/C/D } \\ \times & \text { HLP-22 } \\ * & \text { TLP-01 } \\ \circ & \text { PWD-33/43 } \\ + & \text { PWD-44 } \\ \diamond & \text { FEP-17A/B } \\ \square & \text { PWD-15/16 } \\ \Delta & \text { UFP-01A/B } \\ \times & \text { RLD-07 } \\ * & \text { RLD-08 } \\ \circ & \text { HOP-903/904 } \\ + & \text { RDP-02A/B/C } \\ \diamond & \text { BM 35 glass } \\ \square & \text { BM 75 glass } \\ \Delta & \text { BM FS, Test 3 }\end{array}$

Figure 9.3. Test Data and Application Range for $\frac{\mathrm{D}^{*}}{\mathrm{Ga}^{0.5}}$

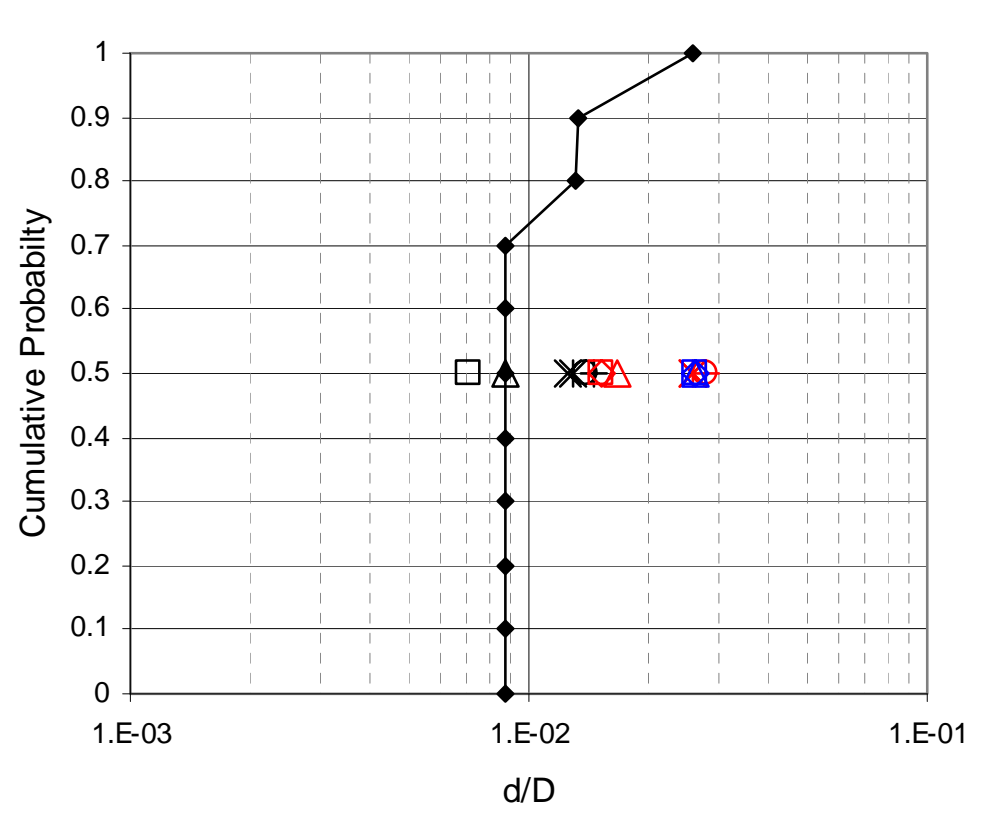

\begin{tabular}{|ll|}
\hline$\sim$ & M3 Tests \\
$\Delta$ & FRP-02A/B/C/D \\
$\times$ & HLP-22 \\
$*$ & TCP-01 \\
$\circ$ & TLP-09A/B \\
+ & PWD-33/43 \\
$\diamond$ & FEP-17A/B \\
$\square$ & PWD-15/16 \\
$\Delta$ & UFP-01A/B \\
$\times$ & RLD-07 \\
$*$ & RLD-08 \\
$\circ$ & HOP-903/904 \\
+ & RDP-02A/B/C \\
$\diamond$ & BM 35 glass \\
$\square$ & BM 75 glass \\
$\Delta$ & BM FS
\end{tabular}

Figure 9.4. Test Data and Application Range for $\frac{d}{D}$ 


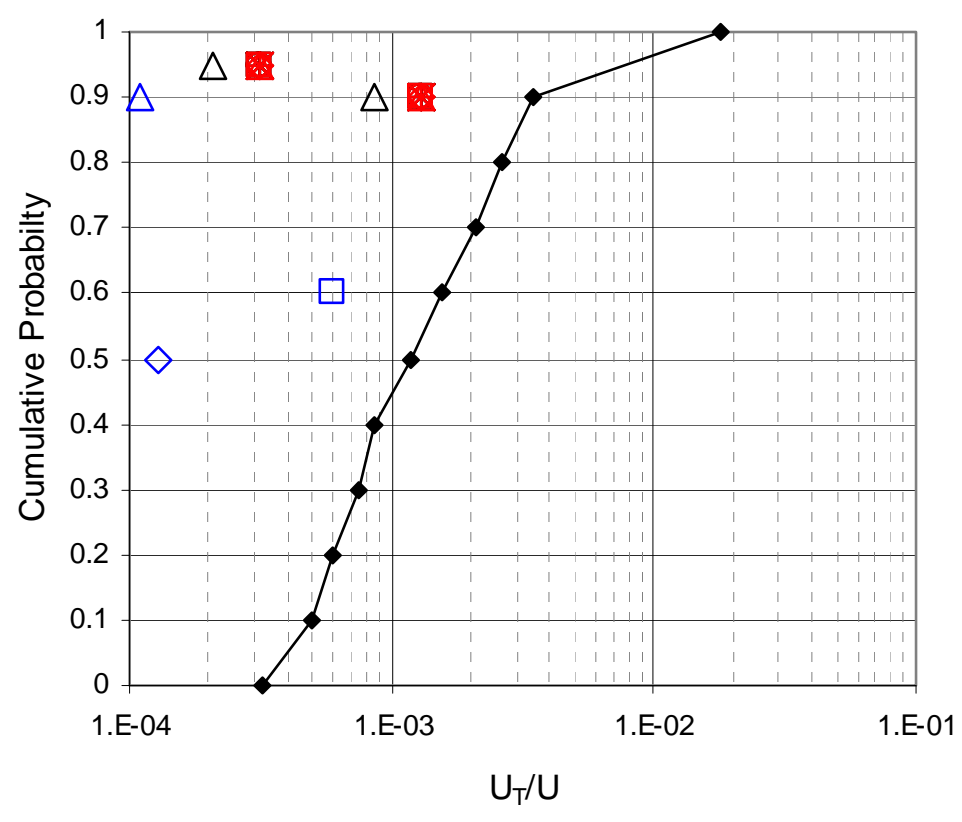

$\begin{array}{|ll|}\longrightarrow & \text { M3 Tests } \\ \Delta & \text { HLP-02A/B/C/D } \\ \times & \text { TCP-01 } \\ * & \text { TLP-09A/B } \\ \circ & \text { PWD-33/43 } \\ + & \text { PWD-44 } \\ \diamond & \text { FEP-17A/B } \\ \square & \text { PWD-15/16 } \\ \Delta & \text { UFP-01A/B } \\ \times & \text { RLD-07 } \\ * & \text { RLD-08 } \\ \circ & \text { HOP-903/904 } \\ + & \text { RDP-02A/B/C } \\ \diamond & \text { BM 35 glass } \\ \square & \text { BM 75 glass } \\ \Delta & \text { BM FS }\end{array}$

Figure 9.5. Test Data and Application Range for $\frac{\mathrm{U}_{\mathrm{T}}}{\mathrm{U}}$

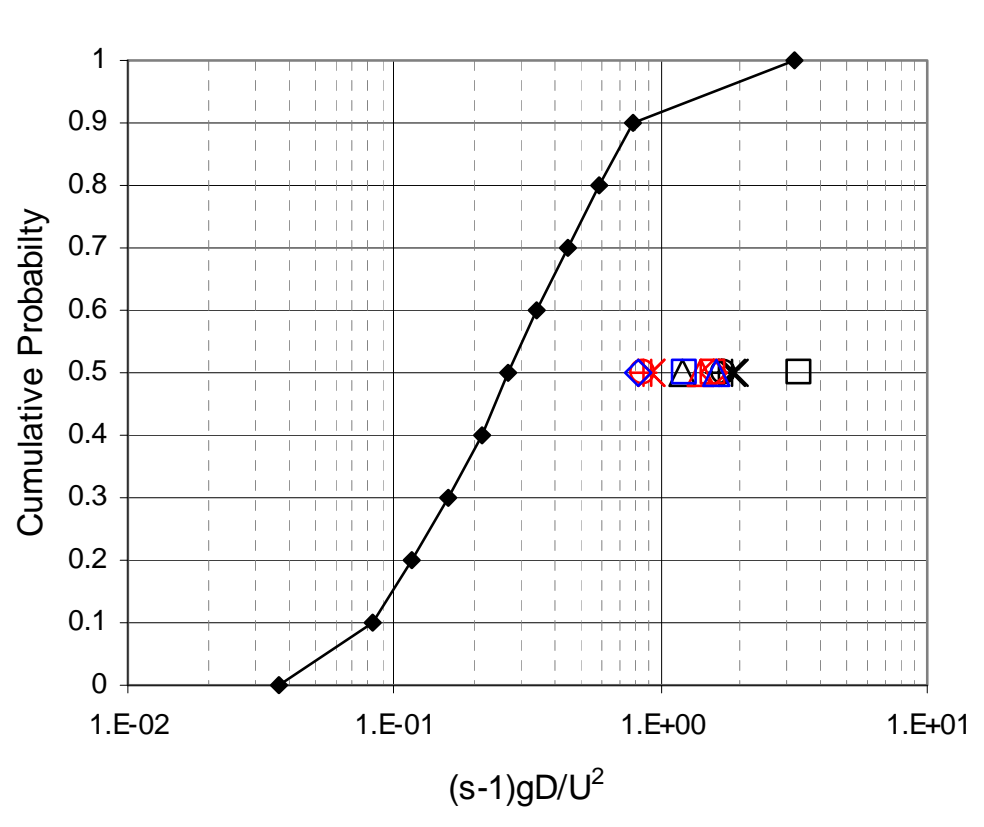

\begin{tabular}{|cl|}
\hline$\sim$ & M3 Tests \\
$\Delta$ & FRP-02A/B/C/D \\
$\times$ & TCP-22 \\
$*$ & TLP-09A/B \\
$\circ$ & PWD-33/43 \\
+ & PWD-44 \\
$\diamond$ & FEP-17A/B \\
$\square$ & PWD-15/16 \\
$\Delta$ & UFP-01A/B \\
$\times$ & RLD-07 \\
$*$ & RLD-08 \\
$\circ$ & HOP-903/904 \\
+ & RDP-02A/B/C \\
$\diamond$ & BM 35 glass \\
$\square$ & BM 75 glass \\
$\Delta$ & BM FS \\
\hline
\end{tabular}

Figure 9.6. Test Data and Application Range for $\frac{(\mathrm{s}-1) \mathrm{gD}}{\mathrm{U}^{2}}$ 


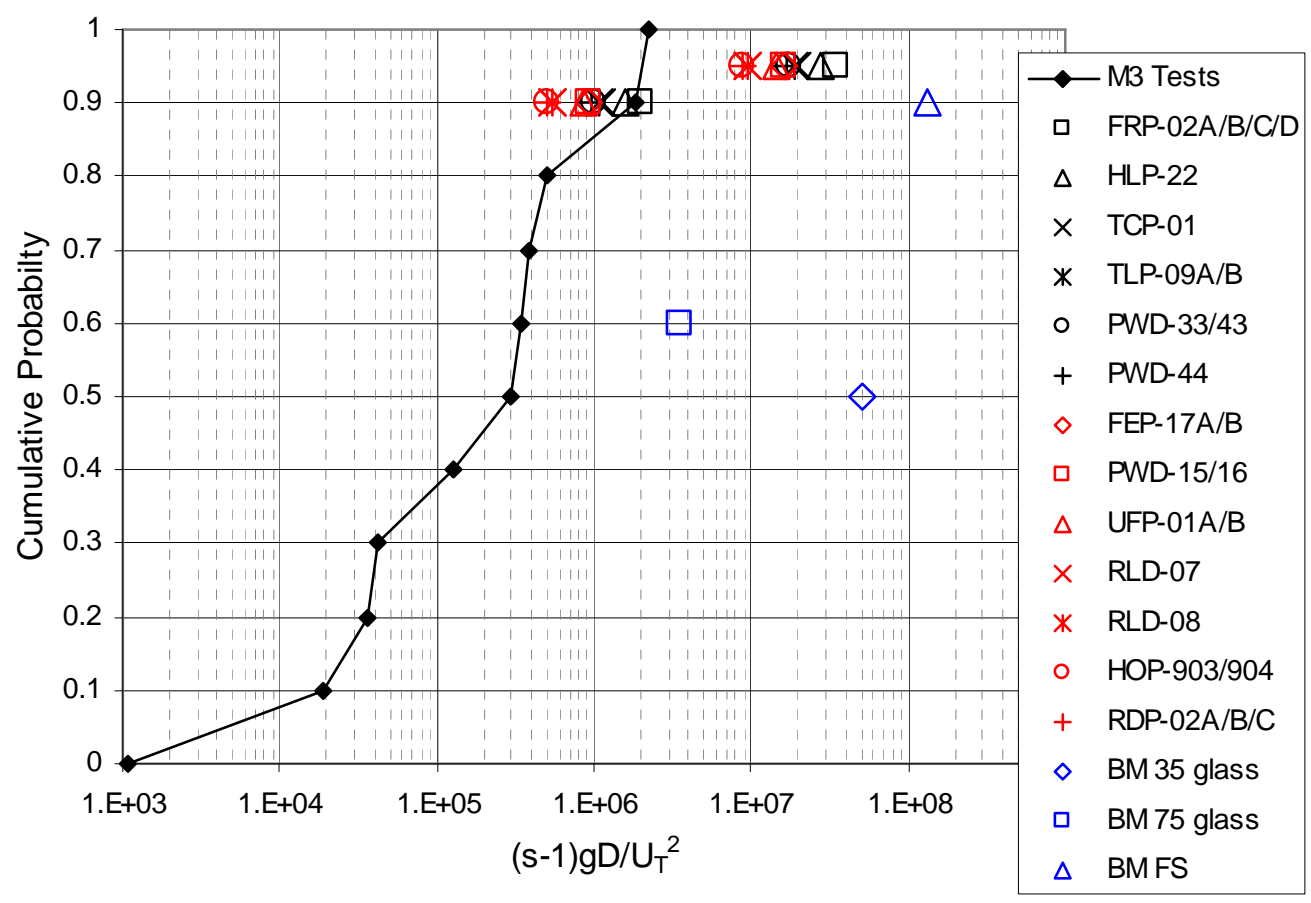

Figure 9.7. Test Data and Application Range for $\frac{(\mathrm{s}-1) \mathrm{gD}}{\mathrm{U}_{\mathrm{T}}{ }^{2}}$

\subsubsection{Hanford Tank AZ-101 PSDD and Settling Velocity}

The in situ settling velocity for AZ-101 is compared with a PSDD-based settling velocity to investigate the applicability of the settling velocity approach for systems with distributions of solid size and density.

Two 300-hp mixer pumps were used to mobilize the sediment layer in AZ-101 from April to May 2000 (Carlson et al. 2001). The capability of the mixer pumps to mobilize the sediment was tracked with the following:

- thermocouples located throughout the waste and in the tank floor

- a gamma monitoring system (detects radionuclides)

- a suspended-solids profiler (uses light reflectance to determine turbidity)

- an ultrasonic interface level analyzer.

Carlson et al. (2001) report that, for the oscillatory operation of both mixer pumps, the AZ-101 thermocouple data indicated that the majority of the sediment was mobilized. The gamma monitoring system, suspended-solids profiler, and ultrasonic interface level analyzer data indicated that 1) significant settling occurs as soon as mixer pump operations are concluded and 2) significant settling occurs in the first 8 to 12 hours. The unhindered settling rate was determined as $2.2 \mathrm{~m} / \mathrm{hr}(6 \mathrm{E}-4 \mathrm{~m} / \mathrm{s})$. In consideration of the "...high unhindered settling rate determined from the test data," Carlson et al. (2001) recommended “...that mixer pumps be operated to maintain solids in suspension during future deliveries of waste from 
this tank (AZ-101) to the WTP. This will maintain the solid phase in a more uniform concentration during batch deliveries that are expected to last approximately 20 hours each.”

An AZ-101 PSDD was created according to the Case 3 approach of Wells et al. (2007). The Case 3 PSDD is provided in Section 3.1. The AZ-101 minimal disturbance PSD was combined with the insoluble solid-phase compounds, volume fractions thereof, and crystal densities (Wells et al. 2007, Table A.4 and Section 3.2). The resulting PSDD is provided in Table 9.5. Like the PSDDs of Wells et al. (2007), the AZ-101 PSDD in Table 9.5 is a 3-dimensional matrix of volume-based probability of each solid-phase compound in a PSD bin and its density in that bin. The PSDD bins represent the upper and lower size limit of the particles in each bin. For example, in Table 9.5 it can be seen that gibbsite $\left[\mathrm{Al}(\mathrm{OH})_{3}\right]$ makes up $75 \%$ of the solid particulate by volume, and gibbsite particles $>7.74 \mu \mathrm{m}$ and less than or equal to $10 \mu \mathrm{m}$ have a density of $2.42 \mathrm{~g} / \mathrm{cm}^{3}$ and make up $3.6 \%$ of the solids by volume.

The particle size and density of the AZ-101 PSDD are used in the settling velocity equations in Section 7 in conjunction with the volume fraction to produce the cumulative volume-based probability of the settling velocity of the AZ-101 insoluble solids (Figure 9.2) as per Section 3.1. In Figure 9.2, the $50^{\text {th }}$ (median) and $95^{\text {th }}$ percentiles by volume of settling velocity are approximately $6.4 \mathrm{E}-6$ and $2.3 \mathrm{E}-4 \mathrm{~m} / \mathrm{s}$, respectively.

As in Section 3.1, a volume-weighted average of a specified fraction of the solids by volume may be determined, resulting in the cumulative average settling velocity of Figure 9.3. In the figure, the volumeweighted average settling velocity of the fastest $10 \%$ by volume is $4.8 \mathrm{E}-5 \mathrm{~m} / \mathrm{s}$.

The percentiles of settling velocity for the AZ-101 PSDD from Figures 9.8 and 9.9 are provided in Table 9.6. In the table it can be seen that the unhindered settling rate of Carlson et al. (2001), $6 \mathrm{E}-4 \mathrm{~m} / \mathrm{s}$, is greater than both the $99^{\text {th }}$ percentile by volume of the settling velocity and the volume-weighted average of the fastest $1 \%$.

Comparing the AZ-101 unhindered settling rate from Carlson et al. (2001), 6E-4 m/s, with the settling velocities of the Hanford PSDD (Table 3.3) indicates the AZ-101 settling rate is between the $85^{\text {th }}$ to $90^{\text {th }}$ percentiles of the settling velocity distribution from the Hanford PSDD. This suggests that 10 to $15 \%$ of the Hanford insoluble solids by volume may be expected to settle at a rate equal to or greater than that indicated by the in situ settling data for AZ-101. 
Table 9.5. AZ-101 PSDD

\begin{tabular}{|c|c|c|c|c|c|c|c|c|c|}
\hline \multirow{4}{*}{$\begin{array}{l}\text { Particle Size } \\
\qquad(\mu \mathrm{m})\end{array}$} & \multicolumn{9}{|c|}{ Solid Phase Compounds and Density $\left(\mathrm{g} / \mathrm{cm}^{3}\right)$} \\
\hline & $\mathrm{Al}(\mathrm{OH})_{3}$ & $\mathrm{Fe}_{2} \mathrm{O}_{3}$ & $\mathrm{ZrO}_{2}$ & $\mathrm{Ca}_{5} \mathrm{OH}\left(\mathrm{PO}_{4}\right)_{3}$ & $\mathrm{Ni}(\mathrm{OH})_{2}$ & $\mathrm{Na}_{2} \mathrm{U}_{2} \mathrm{O}_{7}$ & $\mathrm{MnO}_{2}$ & $\mathrm{LaPO}_{4} \cdot 2 \mathrm{H}_{2} \mathrm{O}$ & $\mathrm{PuO}_{2}$ \\
\hline & 2.42 & 5.24 & 5.68 & 3.14 & 4.1 & 5.617 & 5.026 & 6.51 & 11.43 \\
\hline & \multicolumn{9}{|c|}{ Solid Volume Fraction } \\
\hline 0.22 & $3.8 \mathrm{E}-04$ & 7.7E-05 & 2.4E-05 & $6.9 \mathrm{E}-06$ & 6.7E-06 & $4.9 \mathrm{E}-06$ & $1.1 \mathrm{E}-06$ & 3.7E-06 & $2.5 \mathrm{E}-08$ \\
\hline 0.28 & $9.1 \mathrm{E}-03$ & $1.9 \mathrm{E}-03$ & 5.7E-04 & $1.7 \mathrm{E}-04$ & $1.6 \mathrm{E}-04$ & $1.2 \mathrm{E}-04$ & 2.7E-05 & $9.0 \mathrm{E}-05$ & $6.0 \mathrm{E}-07$ \\
\hline 0.36 & $1.0 \mathrm{E}-02$ & $2.1 \mathrm{E}-03$ & $6.4 \mathrm{E}-04$ & $1.9 \mathrm{E}-04$ & $1.8 \mathrm{E}-04$ & $1.3 \mathrm{E}-04$ & $3.1 \mathrm{E}-05$ & $1.0 \mathrm{E}-04$ & $6.8 \mathrm{E}-07$ \\
\hline 0.46 & 1.3E-02 & 2.7E-03 & $8.4 \mathrm{E}-04$ & $2.5 \mathrm{E}-04$ & 2.4E-04 & 1.7E-04 & 4.0E-05 & 1.3E-04 & 8.8E-07 \\
\hline 0.60 & $1.8 \mathrm{E}-02$ & 3.6E-03 & $1.1 \mathrm{E}-03$ & $3.2 \mathrm{E}-04$ & 3.1E-04 & 2.3E-04 & 5.3E-05 & $1.7 \mathrm{E}-04$ & $1.2 \mathrm{E}-06$ \\
\hline 0.77 & 2.2E-02 & 4.5E-03 & $1.4 \mathrm{E}-03$ & $4.0 \mathrm{E}-04$ & $3.9 \mathrm{E}-04$ & $2.9 \mathrm{E}-04$ & $6.5 \mathrm{E}-05$ & 2.2E-04 & $1.4 \mathrm{E}-06$ \\
\hline 1.00 & $5.4 \mathrm{E}-02$ & $1.1 \mathrm{E}-02$ & $3.4 \mathrm{E}-03$ & $9.9 \mathrm{E}-04$ & $9.6 \mathrm{E}-04$ & $7.0 \mathrm{E}-04$ & $1.6 \mathrm{E}-04$ & 5.3E-04 & $3.6 \mathrm{E}-06$ \\
\hline 1.29 & $5.1 \mathrm{E}-02$ & $1.0 \mathrm{E}-02$ & $3.2 \mathrm{E}-03$ & 9.3E-04 & $9.0 \mathrm{E}-04$ & $6.6 \mathrm{E}-04$ & $1.5 \mathrm{E}-04$ & $5.0 \mathrm{E}-04$ & $3.4 \mathrm{E}-06$ \\
\hline 1.67 & 4.6E-02 & $9.4 \mathrm{E}-03$ & $2.9 \mathrm{E}-03$ & $8.5 \mathrm{E}-04$ & $8.2 \mathrm{E}-04$ & $6.0 \mathrm{E}-04$ & $1.4 \mathrm{E}-04$ & 4.6E-04 & $3.0 \mathrm{E}-06$ \\
\hline 2.15 & $6.1 \mathrm{E}-02$ & $1.2 \mathrm{E}-02$ & $3.8 \mathrm{E}-03$ & $1.1 \mathrm{E}-03$ & $1.1 \mathrm{E}-03$ & $7.9 \mathrm{E}-04$ & $1.8 \mathrm{E}-04$ & $6.0 \mathrm{E}-04$ & 4.0E-06 \\
\hline 2.78 & 5.6E-02 & $1.1 \mathrm{E}-02$ & $3.5 \mathrm{E}-03$ & $1.0 \mathrm{E}-03$ & $1.0 \mathrm{E}-03$ & 7.3E-04 & $1.7 \mathrm{E}-04$ & $5.6 \mathrm{E}-04$ & 3.7E-06 \\
\hline 3.59 & $6.0 \mathrm{E}-02$ & $1.2 \mathrm{E}-02$ & 3.8E-03 & $1.1 \mathrm{E}-03$ & $1.1 \mathrm{E}-03$ & 7.9E-04 & $1.8 \mathrm{E}-04$ & $6.0 \mathrm{E}-04$ & 4.0E-06 \\
\hline 4.64 & $6.8 \mathrm{E}-02$ & $1.4 \mathrm{E}-02$ & 4.3E-03 & $1.3 \mathrm{E}-03$ & $1.2 \mathrm{E}-03$ & $8.9 \mathrm{E}-04$ & 2.0E-04 & $6.8 \mathrm{E}-04$ & 4.5E-06 \\
\hline 5.99 & $6.2 \mathrm{E}-02$ & $1.3 \mathrm{E}-02$ & $3.9 \mathrm{E}-03$ & $1.1 \mathrm{E}-03$ & $1.1 \mathrm{E}-03$ & $8.1 \mathrm{E}-04$ & $1.8 \mathrm{E}-04$ & $6.1 \mathrm{E}-04$ & 4.1E-06 \\
\hline 7.74 & 6.3E-02 & $1.3 \mathrm{E}-02$ & $4.0 \mathrm{E}-03$ & $1.2 \mathrm{E}-03$ & $1.1 \mathrm{E}-03$ & 8.3E-04 & $1.9 \mathrm{E}-04$ & 6.3E-04 & 4.2E-06 \\
\hline 10.00 & 3.6E-02 & 7.3E-03 & 2.2E-03 & $6.6 \mathrm{E}-04$ & 6.3E-04 & 4.7E-04 & $1.1 \mathrm{E}-04$ & $3.5 \mathrm{E}-04$ & $2.4 \mathrm{E}-06$ \\
\hline 12.92 & 3.5E-02 & 7.2E-03 & 2.2E-03 & $6.5 \mathrm{E}-04$ & $6.2 \mathrm{E}-04$ & 4.6E-04 & $1.0 \mathrm{E}-04$ & 3.5E-04 & 2.3E-06 \\
\hline 16.68 & $3.2 \mathrm{E}-02$ & $6.6 \mathrm{E}-03$ & $2.0 \mathrm{E}-03$ & $6.0 \mathrm{E}-04$ & $5.8 \mathrm{E}-04$ & $4.2 \mathrm{E}-04$ & 9.7E-05 & $3.2 \mathrm{E}-04$ & $2.1 \mathrm{E}-06$ \\
\hline 21.54 & 2.8E-02 & $5.7 \mathrm{E}-03$ & $1.8 \mathrm{E}-03$ & $5.2 \mathrm{E}-04$ & $5.0 \mathrm{E}-04$ & 3.7E-04 & 8.4E-05 & $2.8 \mathrm{E}-04$ & $1.8 \mathrm{E}-06$ \\
\hline 27.83 & 2.3E-02 & 4.7E-03 & $1.5 \mathrm{E}-03$ & 4.3E-04 & 4.1E-04 & $3.0 \mathrm{E}-04$ & 6.9E-05 & 2.3E-04 & $1.5 \mathrm{E}-06$ \\
\hline 35.94 & 4.7E-03 & $9.5 \mathrm{E}-04$ & 2.9E-04 & 8.6E-05 & 8.3E-05 & 6.1E-05 & $1.4 \mathrm{E}-05$ & 4.6E-05 & $3.1 \mathrm{E}-07$ \\
\hline $\begin{array}{l}\text { Total Solid- } \\
\text { Phase Volume } \\
\text { Fraction }\end{array}$ & 0.75 & 0.15 & 0.047 & 0.014 & 0.013 & 0.010 & 0.002 & 0.007 & 0.00005 \\
\hline
\end{tabular}




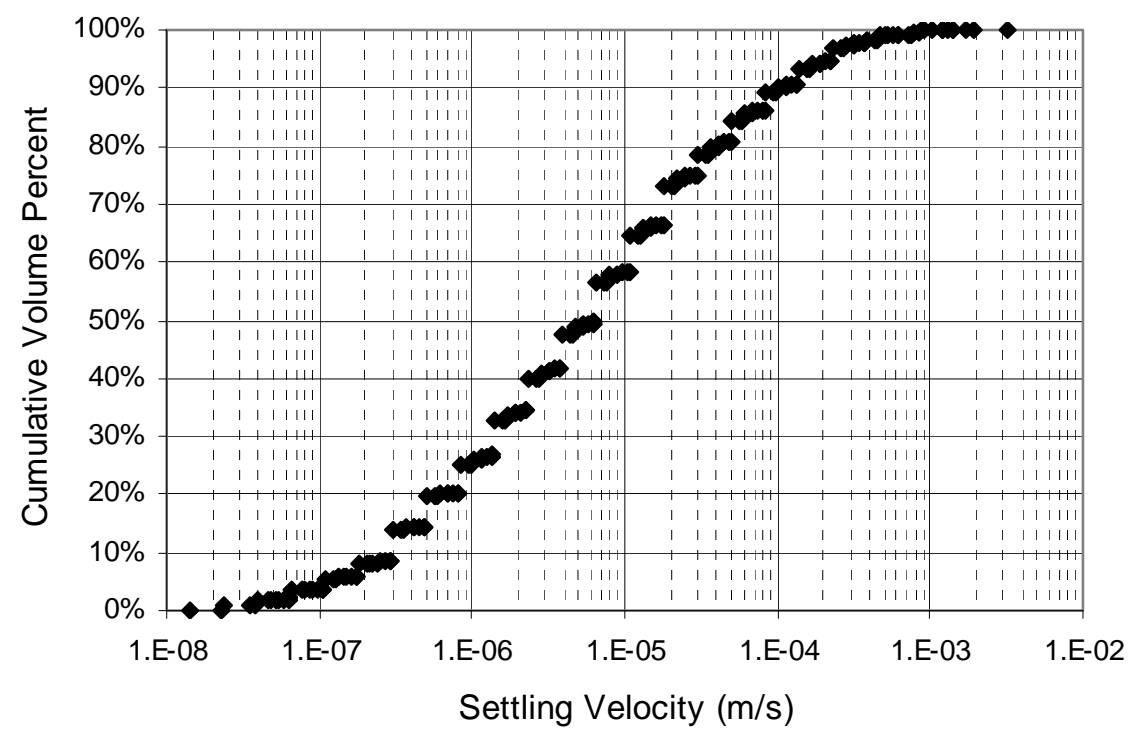

Figure 9.8. Cumulative Undissolved Solids Volume Fraction as a Function of Settling Velocity for AZ-101

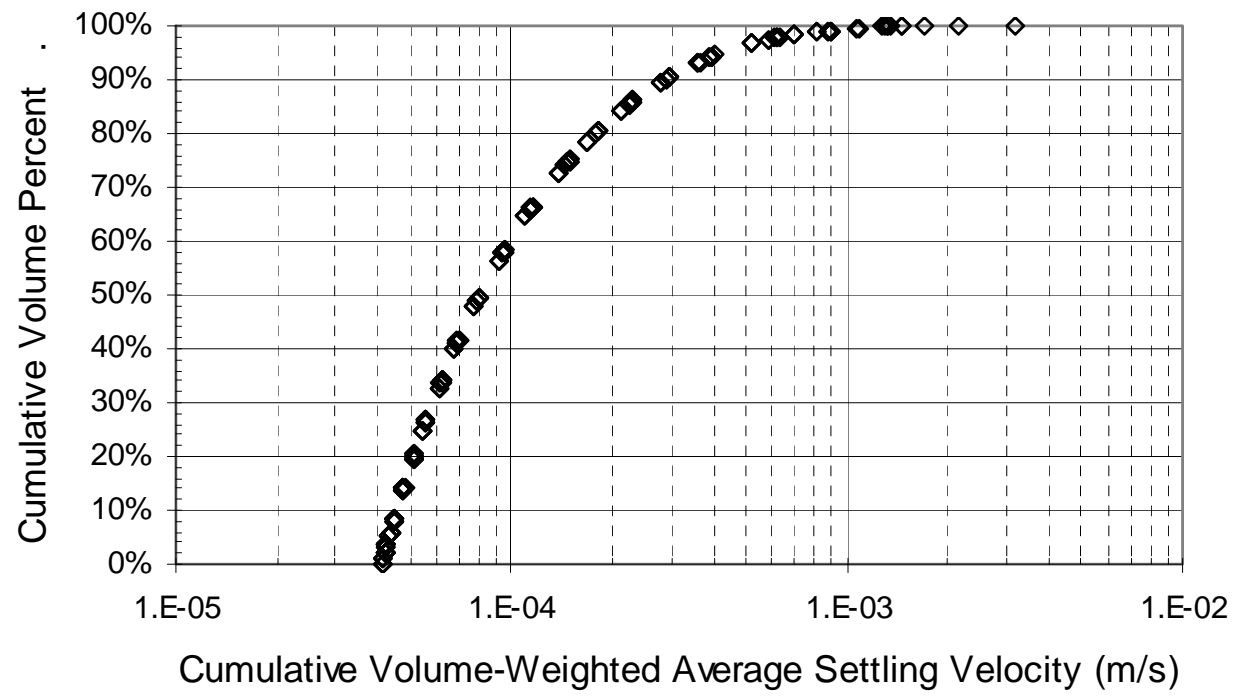

Figure 9.9. Cumulative Undissolved Solids Volume Fraction as a Function of Cumulative Volume-Weighted Average Settling Velocity for AZ-101 
Table 9.6. AZ-101 Insoluble Solids Settling Velocity Quantiles (see Section 3.1 for discussion of volume-weighted averaging and summations)

\begin{tabular}{ccc}
\hline Percentiles (\%) & $\begin{array}{c}\text { Settling Velocity } \\
(\mathrm{m} / \mathrm{s})\end{array}$ & $\begin{array}{c}\text { Volume-Weighted } \\
\text { Average Settling } \\
\text { Velocity }(\mathrm{m} / \mathrm{s})^{\mathrm{a})}\end{array}$ \\
\hline 5 & $1.1 \mathrm{E}-07$ & $4.3 \mathrm{E}-05$ \\
10 & $3.0 \mathrm{E}-07$ & $4.8 \mathrm{E}-05$ \\
25 & $9.8 \mathrm{E}-07$ & $5.5 \mathrm{E}-05$ \\
50 & $6.4 \mathrm{E}-06$ & $9.1 \mathrm{E}-05$ \\
55 & $6.4 \mathrm{E}-06$ & $9.1 \mathrm{E}-05$ \\
60 & $1.1 \mathrm{E}-05$ & $1.1 \mathrm{E}-04$ \\
65 & $1.3 \mathrm{E}-05$ & $1.1 \mathrm{E}-04$ \\
70 & $1.8 \mathrm{E}-05$ & $1.4 \mathrm{E}-04$ \\
75 & $2.9 \mathrm{E}-05$ & $1.5 \mathrm{E}-04$ \\
80 & $3.7 \mathrm{E}-05$ & $1.8 \mathrm{E}-04$ \\
85 & $5.9 \mathrm{E}-05$ & $2.2 \mathrm{E}-04$ \\
90 & $9.8 \mathrm{E}-05$ & $2.9 \mathrm{E}-04$ \\
95 & $2.3 \mathrm{E}-04$ & $5.2 \mathrm{E}-04$ \\
99 & $5.2 \mathrm{E}-04$ & $8.7 \mathrm{E}-04$ \\
\hline Volume Weighted Average & $4.1 \mathrm{E}-05$ & $4.1 \mathrm{E}-05$ \\
Minimum & $1.4 \mathrm{E}-08$ & $4.1 \mathrm{E}-05$ \\
Maximum & $3.2 \mathrm{E}-03$ & $3.2 \mathrm{E}-03$ \\
\hline (a) Summed from fastest-settling & \\
\hline
\end{tabular}

\subsection{Vessel Evaluation Examples Using the Physical Models and the Design Point Limits}

This section includes examples of assessing mixing performance of WTP vessels at the design point limits from Olsen (2008a). Since particle distributions are not specified in Olsen (2008a), the particles specified in the design limit section were used for these model inputs. Many of the vessel evaluations show two points labeled “design” and “design2.” Design denotes a solids density of $2.18 \mathrm{~g} / \mathrm{cm}^{3}$ established in Olsen (2008a, Table 6), and design 2 denotes a solids density of $2.78 \mathrm{~g} / \mathrm{cm}^{3}$ (which is believed to better represent the solids density). This information is presented in the tables and figures that make up Sections 9.3.1 through 9.3.16.

The evaluation in this section used the physical models for $\mathrm{U}_{\mathrm{CS}}, \mathrm{H}_{\mathrm{C}}$ and $\mathrm{C}_{0}$ from Section 7.3.4 with $\mathrm{C}_{0}$ modified to $\mathrm{W}_{0}{ }^{*}$ as described in Section 9.1.4. The vessel geometry and operating conditions used are listed in Table 9.2 with vessel loading shown in Table 9.3.

These examples are for the vessel conditions that were provided in Olsen (2008a). This document has recently been revised to Olsen (2008b); however, these examples are based on Olsen (2008a). The examples are provided for the specific set of conditions described above. The analysis of the vessels used in the examples has been reassigned to the WTP M\&PE group per Hazen (2008b).

Note that Tables 9.7 through 9.22 display only a few significant figures. The calculations are not based on this reduced number of digits. Therefore, small calculation differences are observed when using the displayed rounded numbers for calculations. 


\subsubsection{FRP-02 A/B/C/D (Design Point) Physical Model}

Table 9.7 presents the results of the physical model for design point conditions of FRP-02 A/B/C/D. Figure 9.10 shows the physical model predictions at maximum fill for FRP-02 A/B/C/D.

Table 9.7. Physical Model Results for Design Point Conditions of FRP-02

\begin{tabular}{lccccc}
\hline \multicolumn{2}{c}{ FRP-02A/B/C/D Design Max Fill } & \multicolumn{3}{c}{ FRP-02A/B/C/D Design2 Max Fill } \\
\hline $\mathrm{U}(\mathrm{m} / \mathrm{s})$ & $\mathrm{U}_{\mathrm{CS}}(\mathrm{m} / \mathrm{s})$ & $\mathrm{U} / \mathrm{U}_{\mathrm{CS}}$ & $\mathrm{U}(\mathrm{m} / \mathrm{s})$ & $\mathrm{U}_{\mathrm{CS}}(\mathrm{m} / \mathrm{s})$ & $\mathrm{U}_{\mathrm{CS}}$ \\
8 & 14.3 & 0.56 & 8 & 17.4 & 0.46 \\
$\mathrm{H} / \mathrm{D}$ & $\mathrm{H}_{\mathrm{C}} / \mathrm{D}$ & $\mathrm{H}_{\mathrm{C}} / \mathrm{H}$ & $\mathrm{H} / \mathrm{D}$ & $\mathrm{H}_{\mathrm{C}} / \mathrm{D}$ & $\mathrm{H}_{\mathrm{C}} / \mathrm{H}$ \\
0.73 & 0.17 & 0.24 & 0.73 & 0.06 & 0.08 \\
$\mathrm{~W}(\mathrm{wt} \%)$ & $\mathrm{W}_{0}{ }^{*}(\mathrm{wt} \%)$ & $0.2 / \mathrm{W}_{0}{ }^{*}$ & $\mathrm{~W}(\mathrm{wt} \%)$ & $\mathrm{W}_{0}{ }^{*}(\mathrm{wt} \%)$ & $0.2 / \mathrm{W}_{0}{ }^{*}$ \\
4.9 & 62.2 & 0.32 & 4.9 & $>\mathrm{W}_{\mathrm{MP}}{ }^{(\mathrm{a})}$ & 0.11 \\
\hline
\end{tabular}

(a) Calculated value exceeds maximum packing fraction $\left(\mathrm{C}_{\mathrm{MP}}\right)$.

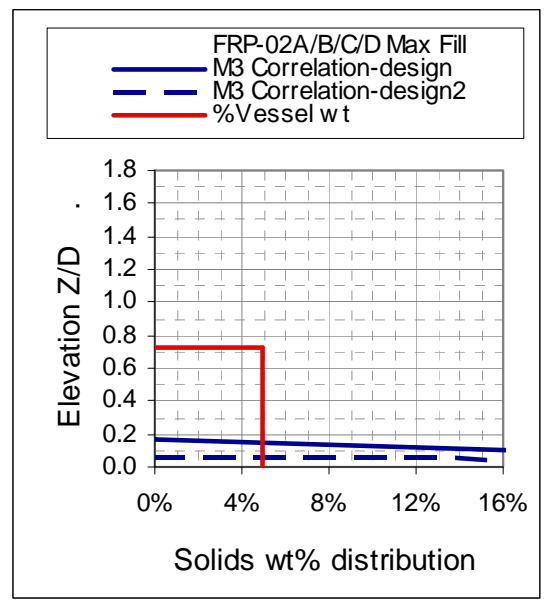

(a)

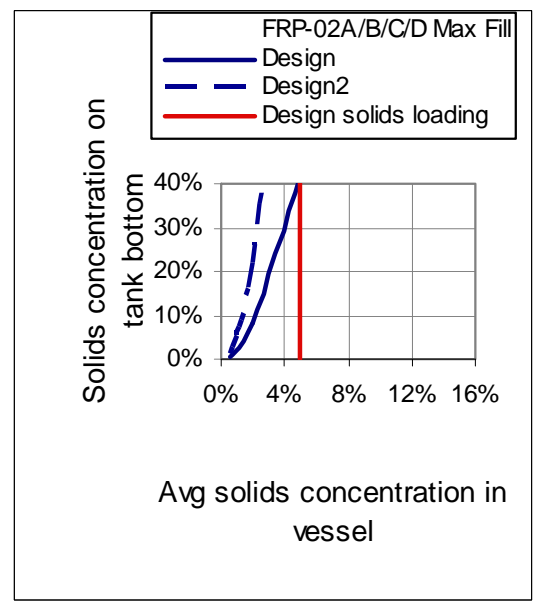

(c)

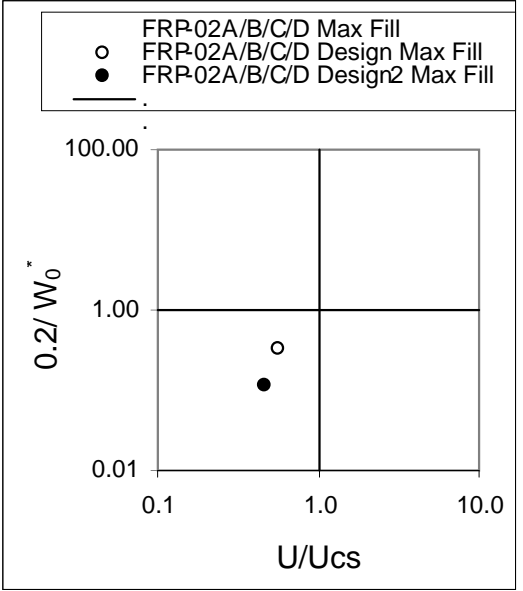

(b)

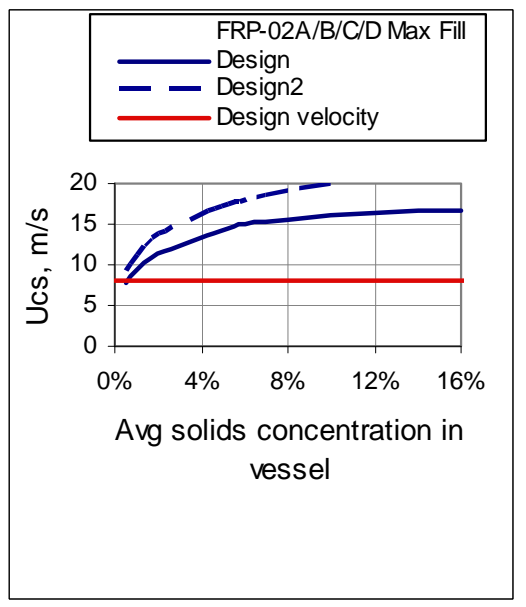

(d)

Figure 9.10. Physical Model Predictions for FRP-02 A/B/C/D: (a) Concentration Profile at Maximum Fill, (b) Inlet Concentration and Suspension Ratio, (c) Maximum Solids Concentration Versus Loading Design Conditions, (d) $\mathrm{U}_{\mathrm{CS}}$ Versus Vessel Loading 


\subsubsection{HLP-22 8 m/s, 4-in. Nozzles (Design Point) Physical Model}

Table 9.8 presents the physical model results for design point conditions for HLP-22, and Figure 9.11 depicts the physical model predictions for HLP-22 for 8 m/s with 4-in. nozzles.

Table 9.8. Physical Model Results for Design Point Conditions for HLP-22

\begin{tabular}{cccccc}
\hline \multicolumn{3}{c}{ HLP-22 Design Max Fill } & \multicolumn{3}{c}{ HLP-22 Design2 Max Fill } \\
\hline $\mathrm{U}(\mathrm{m} / \mathrm{s})$ & $\mathrm{U}_{\mathrm{CS}}(\mathrm{m} / \mathrm{s})$ & $\mathrm{U} / \mathrm{U}_{\mathrm{CS}}$ & $\mathrm{U}(\mathrm{m} / \mathrm{s})$ & $\mathrm{U}_{\mathrm{CS}}(\mathrm{m} / \mathrm{s})$ & $\mathrm{U} / \mathrm{U}_{\mathrm{CS}}$ \\
8 & 19.1 & 0.42 & 8 & 23.9 & 0.33 \\
$\mathrm{H} / \mathrm{D}$ & $\mathrm{H}_{\mathrm{C}} / \mathrm{D}$ & $\mathrm{H}_{\mathrm{C}} / \mathrm{H}$ & $\mathrm{H} / \mathrm{D}$ & $\mathrm{H}_{\mathrm{C}} / \mathrm{D}$ & $\mathrm{H}_{\mathrm{C}} / \mathrm{H}$ \\
0.80 & 0.01 & 0.01 & 0.80 & 0.01 & 0.01 \\
$\mathrm{~W}(\mathrm{wt} \%)$ & $\mathrm{W}_{0}{ }^{*}(\mathrm{wt} \%)$ & $0.2 / \mathrm{W}_{0}{ }^{*}$ & $\mathrm{~W}(\mathrm{wt} \%)$ & $\mathrm{W}_{0}{ }^{*}(\mathrm{wt} \%)$ & $0.2 / \mathrm{W}_{0}{ }^{*}$ \\
15.4 & $>\mathrm{W}_{\mathrm{MP}}{ }^{(\mathrm{a})}$ & 0.005 & 15.4 & $>\mathrm{W}_{\mathrm{MP}}{ }^{(\mathrm{a})}$ & 0.002 \\
\hline
\end{tabular}

(a) Calculated value exceeds maximum packing fraction.

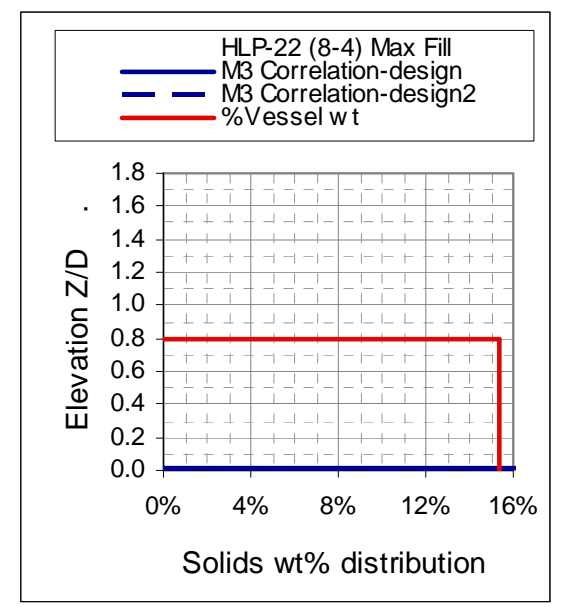

(a)

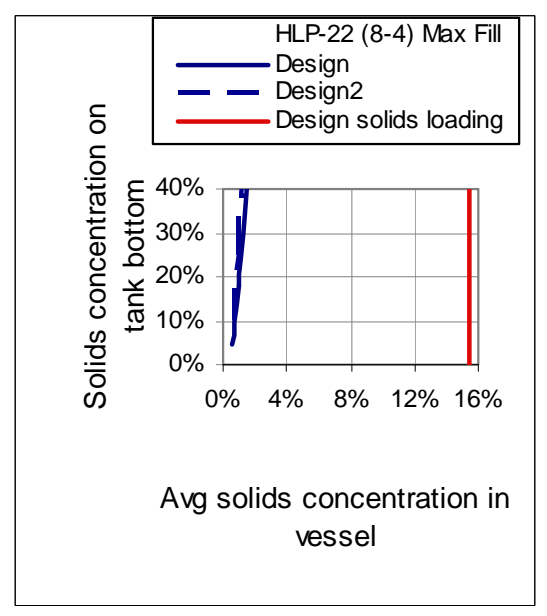

(c)

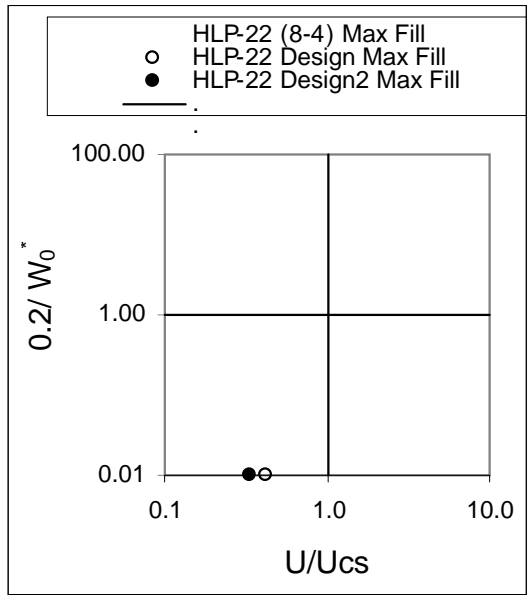

(b)

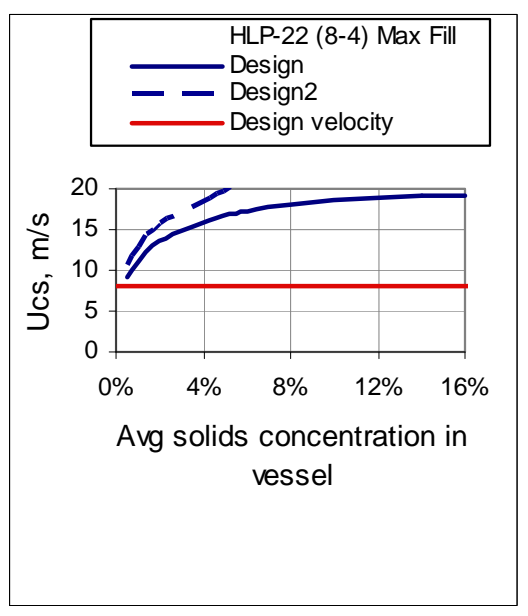

(d)

Figure 9.11. Physical Model Predictions for HLP-22: (a) Concentration Profile at Max Fill, (b) Inlet Concentration and Suspension Ratio, (c) Maximum Solids Concentration Versus Loading Design Conditions, (d) $\mathrm{U}_{\mathrm{CS}}$ Versus Loading at $8 \mathrm{~m} / \mathrm{s}$, 4-in. Nozzles (design point) 


\subsubsection{HLP-22 12 m/s, 4-in. Nozzles (Design Point) Physical Model}

Table 9.9 presents the physical model results for design point conditions for HLP-22, and Figure 9.12 depicts the physical model predictions for HLP-22 with 4-in. nozzles.

Table 9.9. Physical Model Results for Design Point Conditions for HLP-22

\begin{tabular}{cccccc}
\hline \multicolumn{2}{c}{ HLP-22 Design Max Fill } & \multicolumn{3}{c}{ HLP-22 Design2 Max Fill } \\
\hline $\mathrm{U}(\mathrm{m} / \mathrm{s})$ & $\mathrm{U}_{\mathrm{CS}}(\mathrm{m} / \mathrm{s})$ & $\mathrm{U} / \mathrm{U}_{\mathrm{CS}}$ & $\mathrm{U}(\mathrm{m} / \mathrm{s})$ & $\mathrm{U}_{\mathrm{CS}}(\mathrm{m} / \mathrm{s})$ & $\mathrm{U} / \mathrm{U}_{\mathrm{CS}}$ \\
12 & 19.1 & 0.63 & 12 & 23.9 & 0.50 \\
$\mathrm{H} / \mathrm{D}$ & $\mathrm{H}_{\mathrm{C}} / \mathrm{D}$ & $\mathrm{H}_{\mathrm{C}} / \mathrm{H}$ & $\mathrm{H} / \mathrm{D}$ & $\mathrm{H}_{\mathrm{C}} / \mathrm{D}$ & $\mathrm{H}_{\mathrm{C}} / \mathrm{H}$ \\
0.80 & 0.03 & 0.04 & 0.80 & 0.02 & 0.02 \\
$\mathrm{~W}(\mathrm{wt} \%)$ & $\mathrm{W}_{0}{ }^{*}(\mathrm{wt} \%)$ & $0.2 / \mathrm{W}_{0}{ }^{*}$ & $\mathrm{~W}(\mathrm{wt} \%)$ & $\mathrm{W}_{0}{ }^{*}(\mathrm{wt} \%)$ & $0.2 / \mathrm{W}_{0}{ }^{*}$ \\
15.4 & $>\mathrm{W}_{\mathrm{MP}}{ }^{(\mathrm{a})}$ & 0.02 & 15.4 & $>\mathrm{W}_{\mathrm{MP}}{ }^{(\mathrm{a})}$ & 0.01 \\
\hline
\end{tabular}

(a) Calculated value exceeds maximum packing fraction.
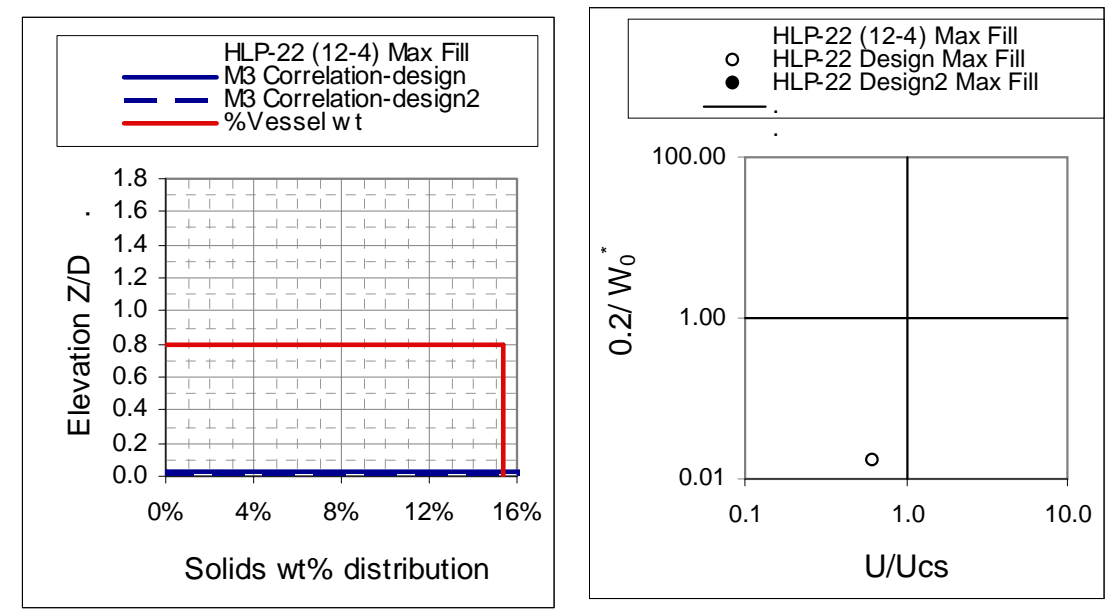

(a)

(b) Note Design 2 point is off the lower end of the chart

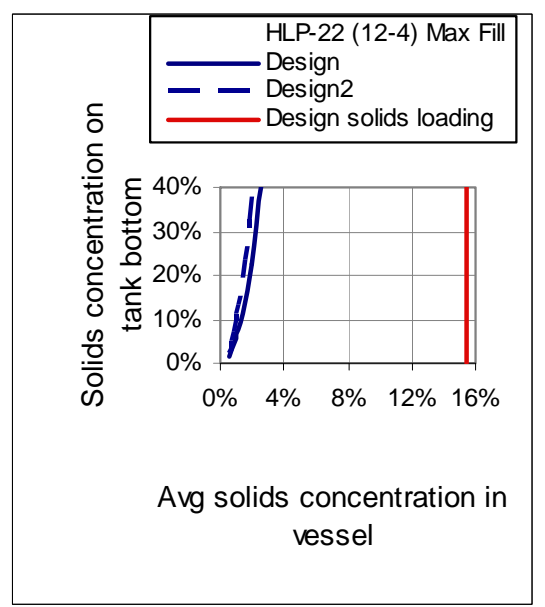

(c)

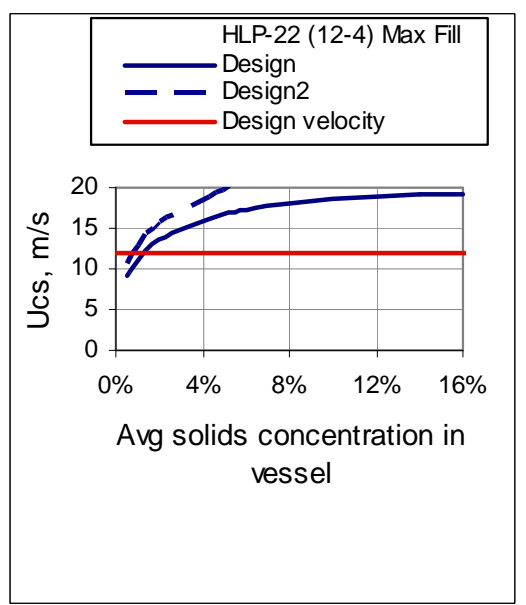

(d)

Figure 9.12. Physical Model Predictions for HLP-22: (a) Concentration Profile at Max Fill, (b) Inlet Concentration and Suspension Ratio, (c) Maximum Solids Concentration Versus Loading Design Conditions, (d) $U_{\mathrm{CS}}$ Versus Loading at $12 \mathrm{~m} / \mathrm{s}$, 4-in. Nozzles (design point) 


\subsubsection{HLP-22 8 m/s, 6-in. Nozzles (Design Point) Physical Model}

Table 9.10 lists the physical model results for design point conditions for HLP-22, and Figure 9.13 shows the physical model predictions at max fill for HLP-22 for $8 \mathrm{~m} / \mathrm{s}$ with 6-in. nozzles.

Table 9.10. Physical Model Results for Design Point Conditions for HLP-22

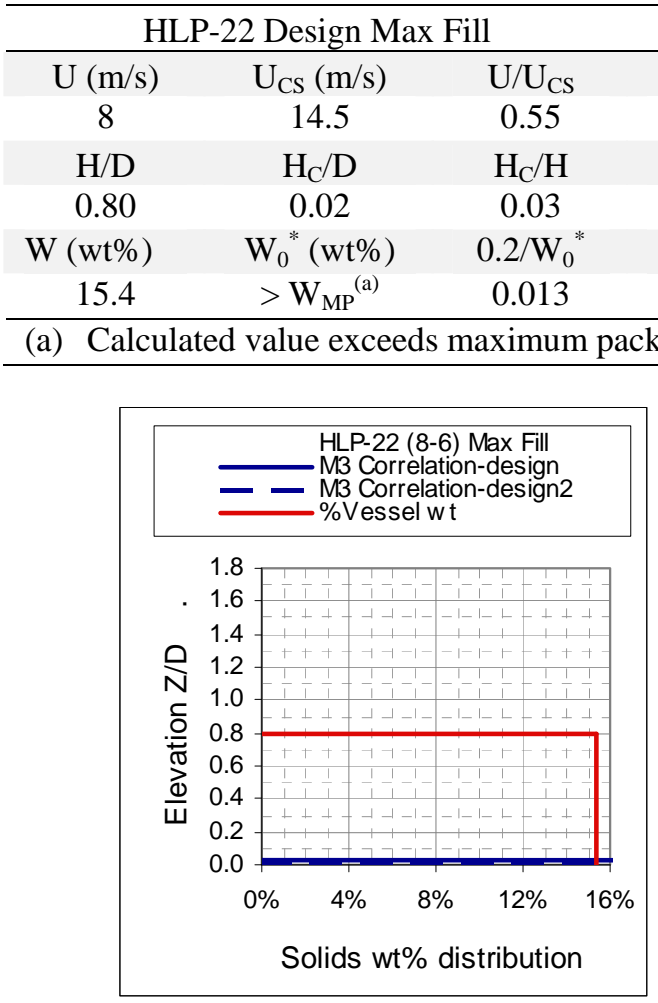

(a)

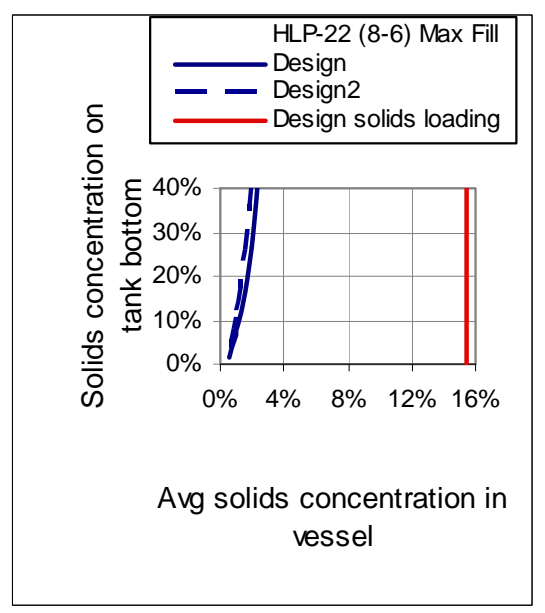

(c) HLP-22 Design2 Max Fill

$\begin{array}{ccc}\mathrm{U}(\mathrm{m} / \mathrm{s}) & \mathrm{U}_{\mathrm{CS}}(\mathrm{m} / \mathrm{s}) & \mathrm{U} / \mathrm{U}_{\mathrm{CS}} \\ 8 & 18.1 & 0.44 \\ \mathrm{H} / \mathrm{D} & \mathrm{H}_{\mathrm{C}} / \mathrm{D} & \mathrm{H}_{\mathrm{C}} / \mathrm{H} \\ 0.80 & 0.01 & 0.02 \\ \mathrm{~W}(\mathrm{wt} \%) & \mathrm{W}_{0}{ }^{*}(\mathrm{wt} \%) & 0.2 / \mathrm{W}_{0}{ }^{*} \\ 15.4 & >\mathrm{W}_{\mathrm{MP}}{ }^{\text {(a) }} & 0.007\end{array}$

\section{4}

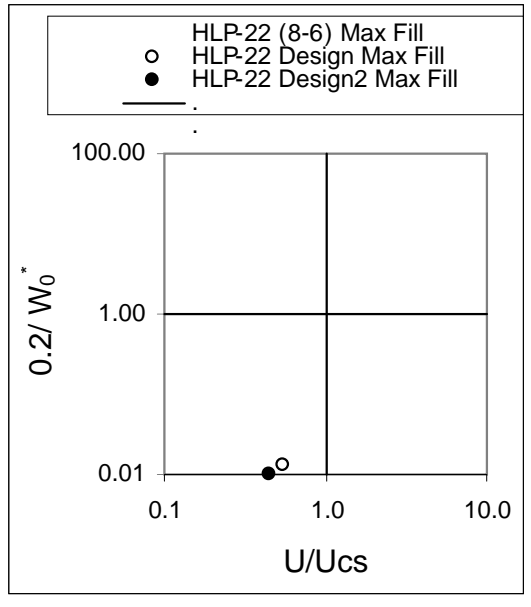

(b)

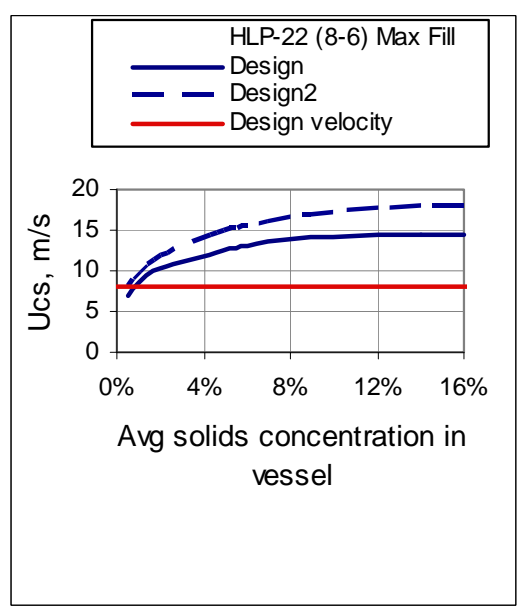

(d)

Figure 9.13. Physical Model Predictions for HLP-22: (a) Concentration Profile at Max Fill, (b) Inlet Concentration and Suspension Ratio, (c) Maximum Solids Concentration Versus Loading Design Conditions, (d) $U_{C S}$ Versus Loading at $8 \mathrm{~m} / \mathrm{s}, 6$-in. Nozzles (design point) 


\subsubsection{HLP-22 12 m/s, 6-inch Nozzles (Design Point) Physical Model}

Table 9.11 contains the results for the physical model for design point conditions for HLP-22, and Figure 9.14 presents physical model predictions for HLP-22 for 12 m/s with 6-in. nozzles.

Table 9.11. Physical Model Results for Design Point Conditions for HLP-22

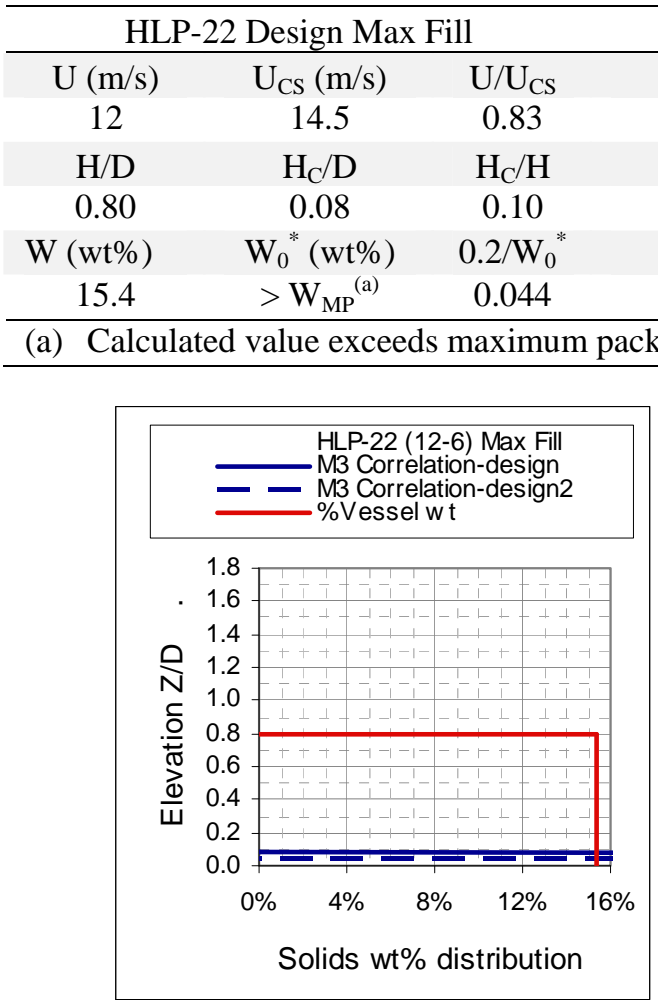

(a)

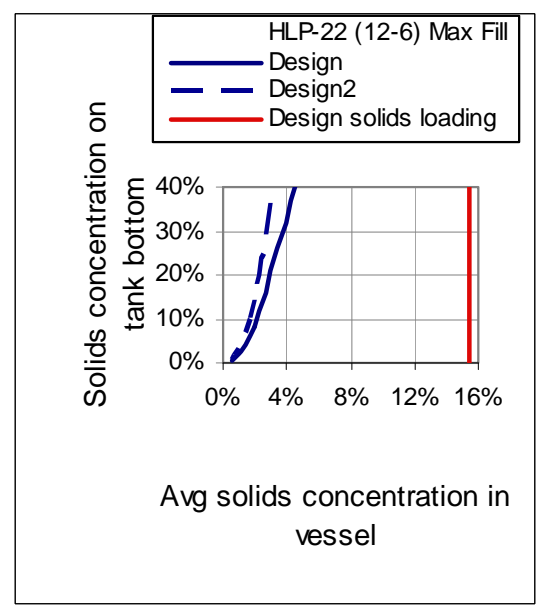

(c)

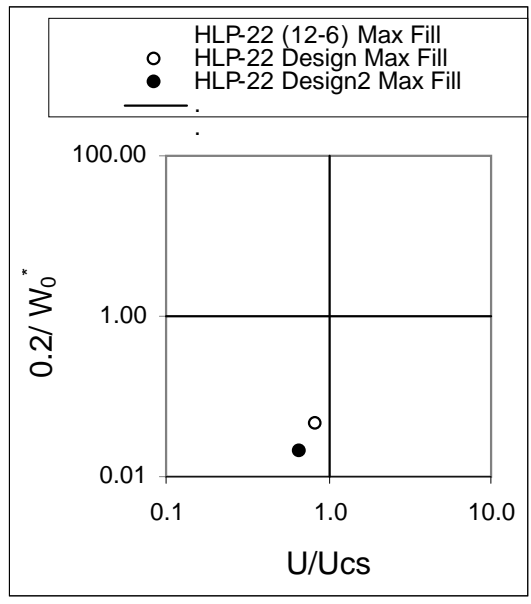

(b)

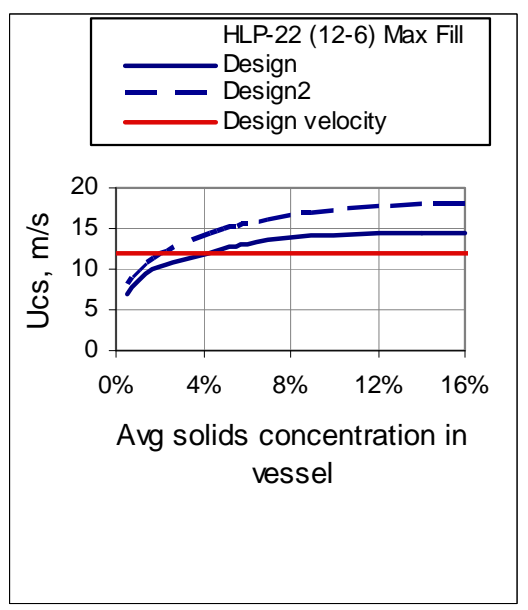

(d)

Figure 9.14. Physical Model Predictions for HLP-22: (a) Concentration Profile at Max Fill, (b) Inlet Concentration and Suspension Ratio, (c) Maximum Solids Concentration Versus Loading Design Conditions, (d) $\mathrm{U}_{\mathrm{CS}}$ Versus Loading at $12 \mathrm{~m} / \mathrm{s}$, 6-in. Nozzles (design point) 


\subsubsection{TCP-01 (Design Point) Physical Model}

Table 9.12 lists the physical model results for design point conditions for TCP-01, and Figure 9.15 depicts the physical model predictions for TCP-01.

Table 9.12. Physical Model Results for Design Point Conditions for TCP-01

\begin{tabular}{c|c|c}
\hline \multicolumn{3}{c}{ TCP-01 Design Max Fill } \\
\hline $\mathrm{U}(\mathrm{m} / \mathrm{s})$ & $\mathrm{U}_{\mathrm{CS}}(\mathrm{m} / \mathrm{s})$ & $\mathrm{U} / \mathrm{U}_{\mathrm{CS}}$ \\
8 & 13.4 & 0.60 \\
$\mathrm{H} / \mathrm{D}$ & $\mathrm{H}_{\mathrm{C}} / \mathrm{D}$ & $\mathrm{H}_{\mathrm{C}} / \mathrm{H}$ \\
1.25 & 0.06 & 0.05 \\
$\mathrm{~W}(\mathrm{wt} \%)$ & $\mathrm{W}_{0}{ }^{*}(\mathrm{wt} \%)$ & $0.2 / \mathrm{W}_{0}{ }^{*}$ \\
2.7 & $>\mathrm{W}_{\mathrm{MP}}{ }^{(\mathrm{a})}$ & 0.12 \\
\hline
\end{tabular}

(a) Calculated value exceeds maximum packing fraction.

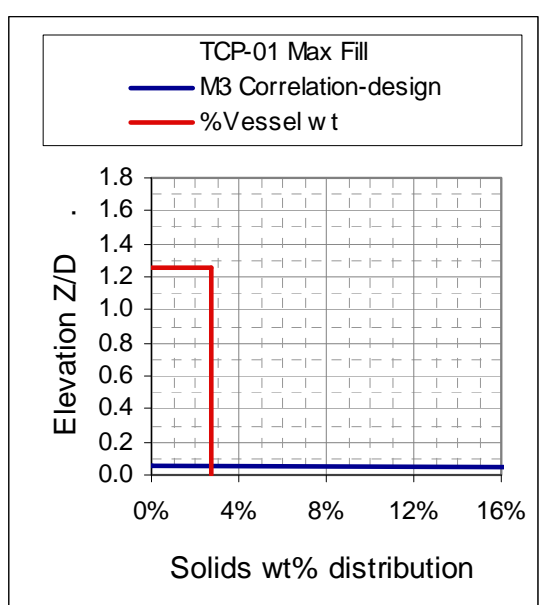

(a)

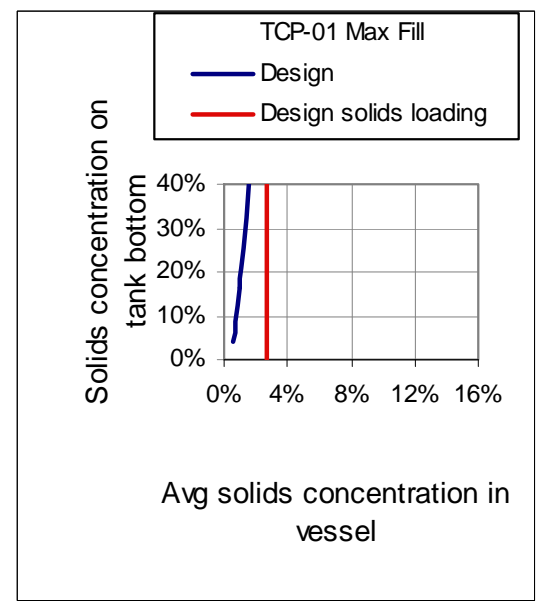

(c)

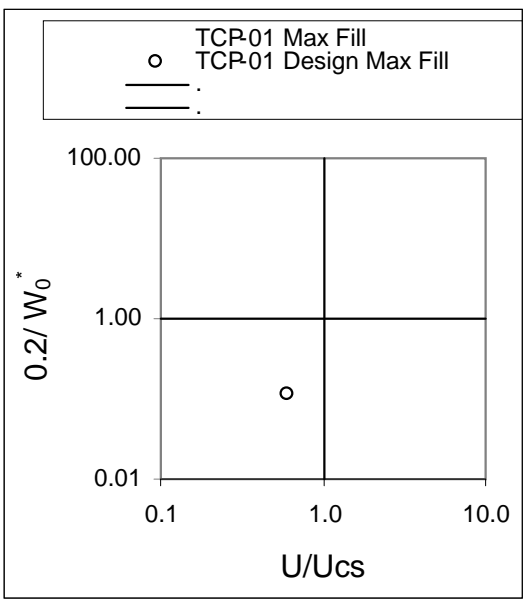

(b)

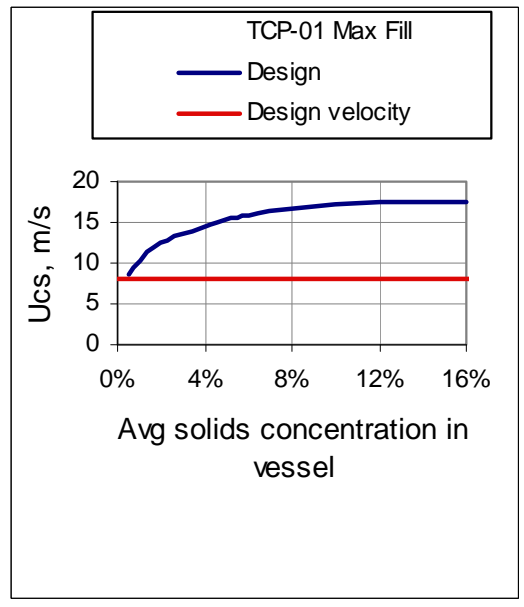

(d)

Figure 9.15. Physical Model Predictions for TCP-01: (a) Concentration Profile at Max Fill, (b) Inlet Concentration and Suspension Ratio, (c) Maximum Solids Concentration Versus Loading Design Conditions, (d) $\mathrm{U}_{\mathrm{CS}}$ Versus Loading (design point) 


\subsubsection{TLP-09 A/B (Design Point) Physical Model}

Table 9.13 lists the physical model results for design point conditions for TLP-09 A/B, and Figure 9.16 depicts the physical model predictions for TLP-09 A/B.

Table 9.13. Physical Model Results for Design Point Conditions for TLP-09

\begin{tabular}{c|c|c}
\hline \multicolumn{3}{c}{ TLP-09A/B Design Max Fill } \\
\hline$\underline{\mathrm{U}(\mathrm{m} / \mathrm{s})}$ & $\underline{\mathrm{U}}_{\mathrm{CS}}(\mathrm{m} / \mathrm{s})$ & $\frac{\underline{\mathrm{U}}_{\mathrm{U}}}{\mathrm{CS}}$ \\
\hline & 9.1 & 0.88 \\
$\mathrm{H} / \mathrm{D}$ & $\mathrm{H}_{\mathrm{C}} / \mathrm{D}$ & $\mathrm{H}_{\mathrm{C}} / \mathrm{H}$ \\
1.08 & 0.24 & 0.22 \\
$\mathrm{~W}(\mathrm{wt} \%)$ & $\mathrm{W}_{0}{ }^{*}(\mathrm{wt} \%)$ & $0.2 / \mathrm{W}_{0}{ }^{*}$ \\
0.3 & 4.1 & 4.92 \\
\hline
\end{tabular}

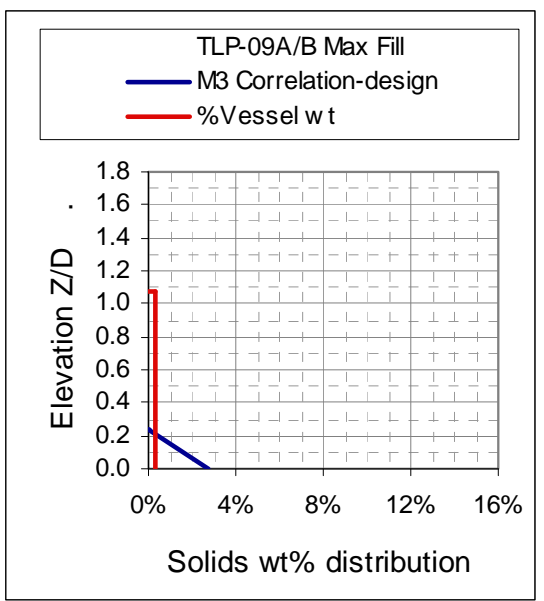

(a)

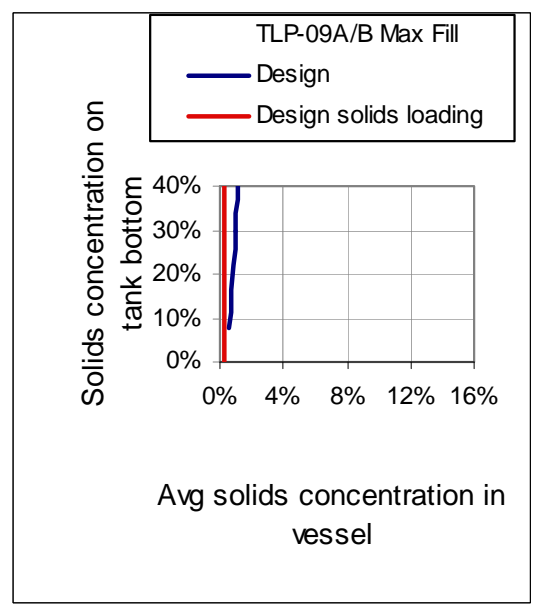

(c)

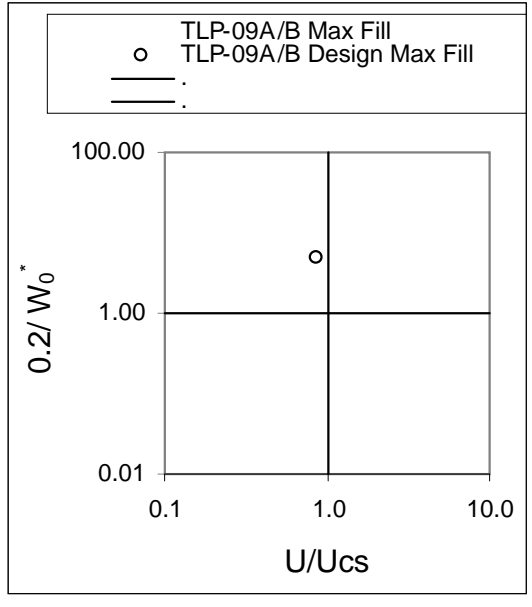

(b)

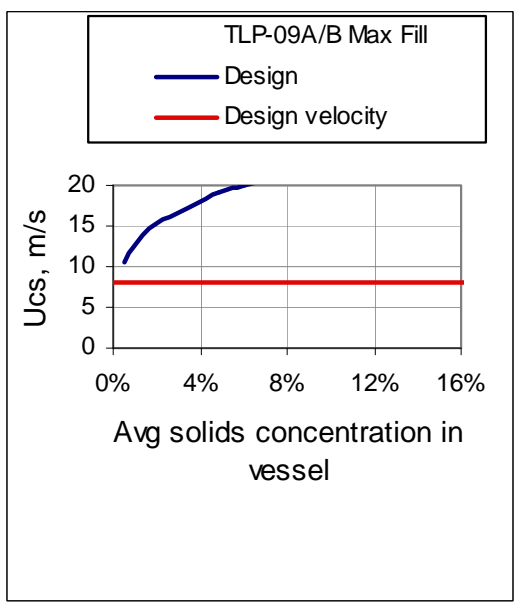

(d)

Figure 9.16. Physical Model Predictions for TLP-09 A/B: (a) Concentration Profile at Max Fill, (b) Inlet Concentration and Suspension Ratio, (c) Maximum Solids Concentration Versus Loading Design Conditions, (d) $\mathrm{U}_{\mathrm{CS}}$ Versus Loading (design point) 


\subsubsection{PWD-33 (Design Point) Physical Model}

Table 9.14 lists the physical model results for design point conditions for PWD-33, and Figure 9.17 depicts the physical model predictions for PWD-33.

Table 9.14. Physical Model Results for Design Point Conditions for PWD-33

\begin{tabular}{cccccc}
\hline \multicolumn{3}{c}{ PWD-33 Design Max Fill } & \multicolumn{3}{c}{ PWD-33 Design2 Max Fill } \\
\hline $\mathrm{U}(\mathrm{m} / \mathrm{s})$ & $\mathrm{U}_{\mathrm{CS}}(\mathrm{m} / \mathrm{s})$ & $\mathrm{U} / \mathrm{U}_{\mathrm{CS}}$ & $\mathrm{U}(\mathrm{m} / \mathrm{s})$ & $\mathrm{U}_{\mathrm{CS}}(\mathrm{m} / \mathrm{s})$ & $\mathrm{U} / \mathrm{U}_{\mathrm{CS}}$ \\
8 & 15.0 & 0.53 & 8 & 17.5 & 0.46 \\
$\mathrm{H} / \mathrm{D}$ & $\mathrm{H}_{\mathrm{C}} / \mathrm{D}$ & $\mathrm{H}_{\mathrm{C}} / \mathrm{H}$ & $\mathrm{H} / \mathrm{D}$ & $\mathrm{H}_{\mathrm{C}} / \mathrm{D}$ & $\mathrm{H}_{\mathrm{C}} / \mathrm{H}$ \\
0.45 & 0.03 & 0.06 & 0.45 & 0.02 & 0.04 \\
$\mathrm{~W}(\mathrm{wt} \%)$ & $\mathrm{W}_{0}{ }^{*}(\mathrm{wt} \%)$ & $0.2 / \mathrm{W}_{0}{ }^{*}$ & $\mathrm{~W}(\mathrm{wt} \%)$ & $\mathrm{W}_{0}{ }^{*}(\mathrm{wt} \%)$ & $0.2 / \mathrm{W}_{0}{ }^{*}$ \\
8.1 & $>\mathrm{W}_{\mathrm{MP}}{ }^{(\mathrm{a})}$ & 0.05 & 8.1 & $>\mathrm{W}_{\mathrm{MP}}{ }^{(\mathrm{a})}$ & 0.03 \\
\hline
\end{tabular}

(a) Calculated value exceeds maximum packing fraction.

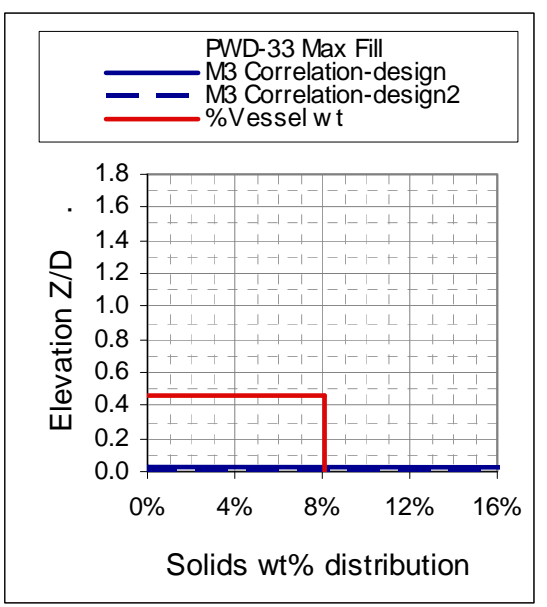

(a)

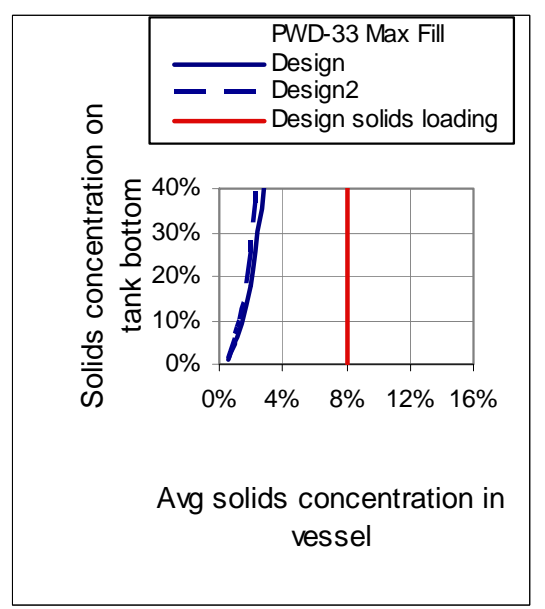

(c)

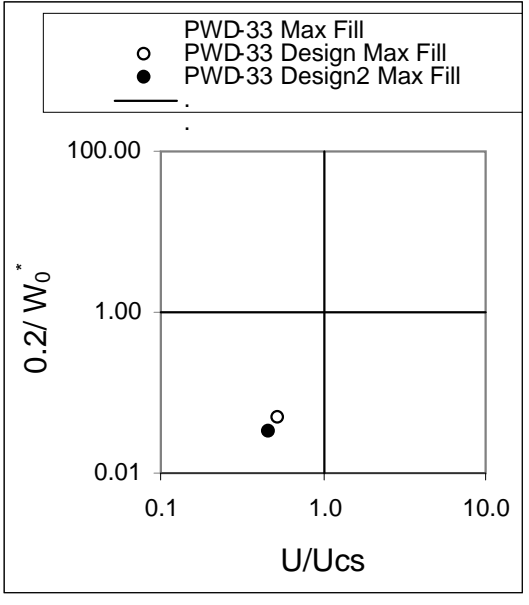

(b)

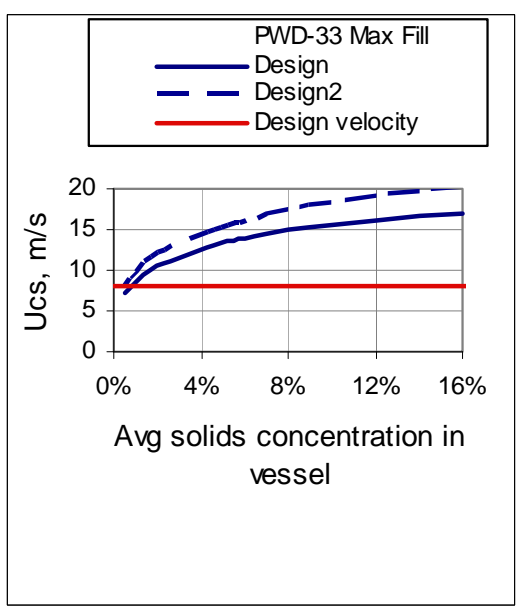

(d)

Figure 9.17. Physical Model Predictions for PWD-33: (a) Concentration Profile at Max Fill, (b) Inlet Concentration and Suspension Ratio, (c) Maximum Solids Concentration Versus Loading Design Conditions, (d) $U_{\mathrm{CS}}$ Versus Loading for PWD-33 (design point) 


\subsubsection{PWD-43 (Design Point) Physical Model}

Table 9.15 lists the physical model results for design point conditions for PWD-43, and Figure 9.18 depicts the physical model predictions for PWD-43.

Table 9.15. Physical Model Results for Design Point Conditions for PWD-43

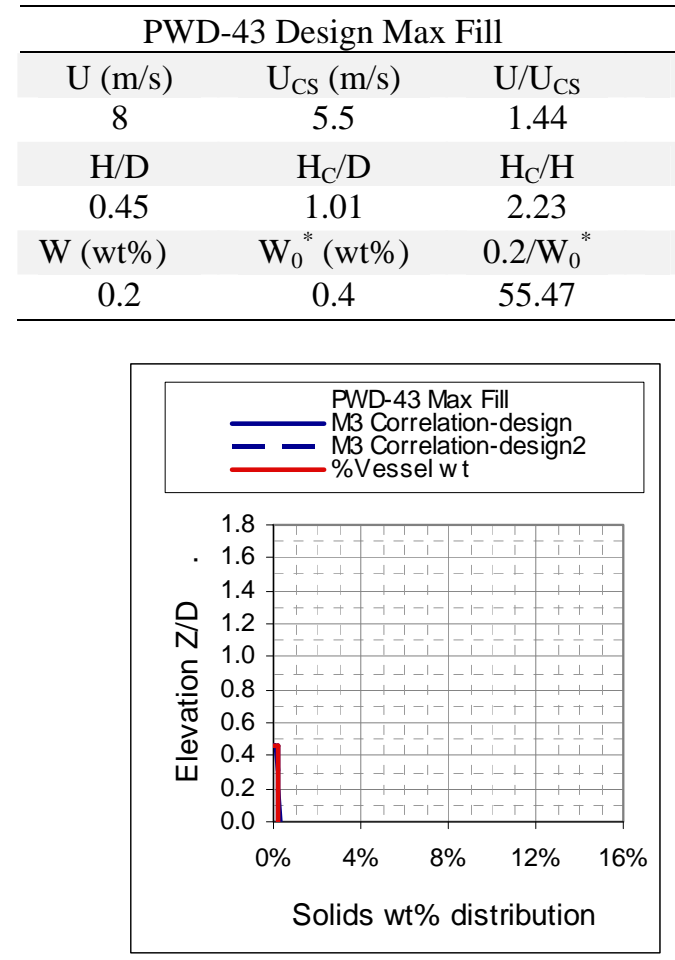

(a)

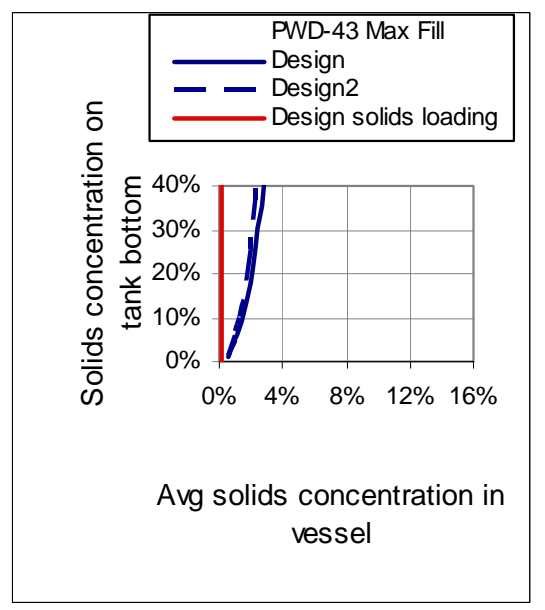

(c)

PWD-43 Design2 Max Fill

$\begin{array}{ccc}\mathrm{U}(\mathrm{m} / \mathrm{s}) & \mathrm{U}_{\mathrm{CS}}(\mathrm{m} / \mathrm{s}) & \mathrm{U} / \mathrm{U}_{\mathrm{CS}} \\ 8 & 6.3 & 1.26 \\ \mathrm{H} / \mathrm{D} & \mathrm{H}_{\mathrm{C}} / \mathrm{D} & \mathrm{H}_{\mathrm{C}} / \mathrm{H} \\ 0.45 & 0.71 & 1.57 \\ \mathrm{~W}(\mathrm{wt} \%) & \mathrm{W}_{0}{ }^{*}(\mathrm{wt} \%) & 0.2 / \mathrm{W}_{0}{ }^{*} \\ 0.2 & 0.4 & 47.45\end{array}$

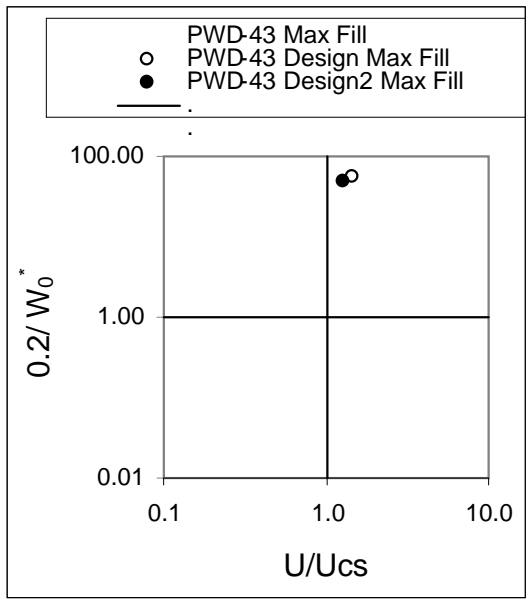

(b)

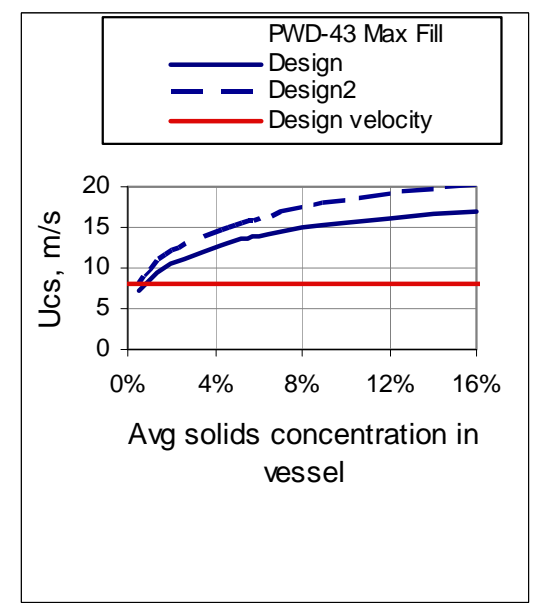

(d)

Figure 9.18. Physical Model Predictions for PWD-43: (a) Concentration Profile at Max Fill, (b) Inlet Concentration and Suspension Ratio, (c) Maximum Solids Concentration Versus Loading Design Conditions, (d) $\mathrm{U}_{\mathrm{CS}}$ Versus Loading (design point) 


\subsubsection{PWD-44 (Design Point) Physical Model}

Table 9.16 presents the physical model results for design point conditions for PWD-44, and Figure 9.19 shows the physical model predictions for PWD-44.

Table 9.16. Physical Model Results for Design Point Conditions for PWD-44

\begin{tabular}{cccccc}
\hline \multicolumn{3}{c}{ PWD-44 Design Max Fill } & \multicolumn{3}{c}{ PWD-44 Design2 Max Fill } \\
\hline $\mathrm{U}(\mathrm{m} / \mathrm{s})$ & $\mathrm{U}_{\mathrm{CS}}(\mathrm{m} / \mathrm{s})$ & $\mathrm{U} / \mathrm{U}_{\mathrm{CS}}$ & $\mathrm{U}(\mathrm{m} / \mathrm{s})$ & $\mathrm{U}_{\mathrm{CS}}(\mathrm{m} / \mathrm{s})$ & $\mathrm{U} / \mathrm{U}_{\mathrm{CS}}$ \\
8 & 12.0 & 0.67 & 8 & 14.4 & 0.56 \\
$\mathrm{H} / \mathrm{D}$ & $\mathrm{H}_{\mathrm{C}} / \mathrm{D}$ & $\mathrm{H}_{\mathrm{C}} / \mathrm{H}$ & $\mathrm{H} / \mathrm{D}$ & $\mathrm{H}_{\mathrm{C}} / \mathrm{D}$ & $\mathrm{H}_{\mathrm{C}} / \mathrm{H}$ \\
1.32 & 0.04 & 0.03 & 1.32 & 0.03 & 0.02 \\
$\mathrm{~W}(\mathrm{wt} \%)$ & $\mathrm{W}_{0}{ }^{*}(\mathrm{wt} \%)$ & $0.2 / \mathrm{W}_{0}{ }^{*}$ & $\mathrm{~W}(\mathrm{wt} \%)$ & $\mathrm{W}_{0}{ }^{*}(\mathrm{wt} \%)$ & $0.2 / \mathrm{W}_{0}{ }^{*}$ \\
8.1 & $>\mathrm{W}_{\mathrm{MP}}{ }^{(\mathrm{a})}$ & 0.03 & 8.1 & $>\mathrm{W}_{\mathrm{MP}}{ }^{(\mathrm{a})}$ & 0.02 \\
\hline
\end{tabular}

(a) Calculated value exceeds maximum packing fraction.

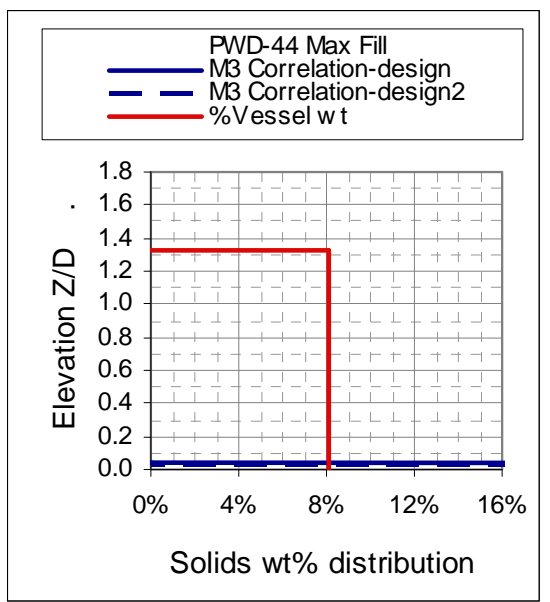

(a)

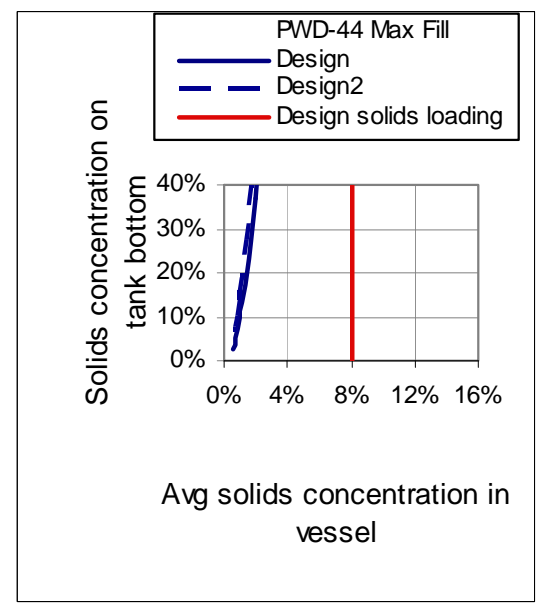

(c)

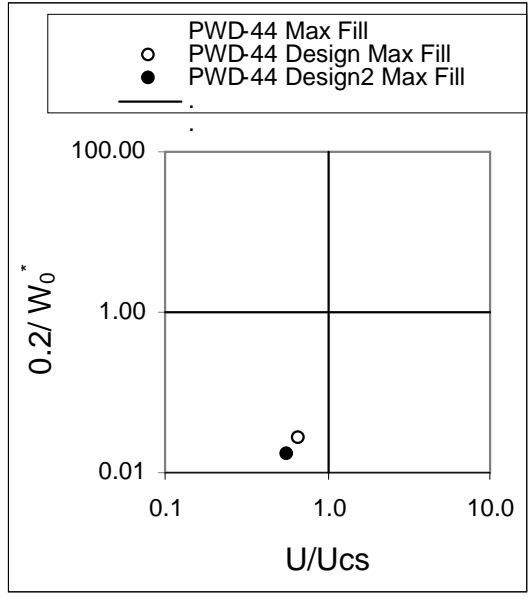

(b)

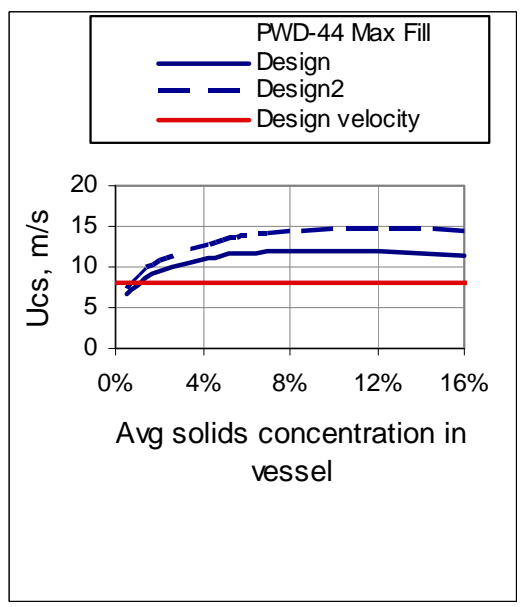

(d)

Figure 9.19. Physical Model Predictions for PWD-44: (a) Concentration Profile at Max Fill, (b) Inlet Concentration and Suspension Ratio, (c) Maximum Solids Concentration Versus Loading Design Conditions, (d) $U_{\mathrm{CS}}$ Versus Loading (design point) 


\subsubsection{FEP-17 A/B (Design Point) Physical Model}

Table 9.17 lists the physical model results for design point conditions for FEP-17 A/B, and Figure 9.20 depicts the physical model predictions for FEP-17 A/B.

Table 9.17. Physical Model Results for Design Point Conditions for FEP-17

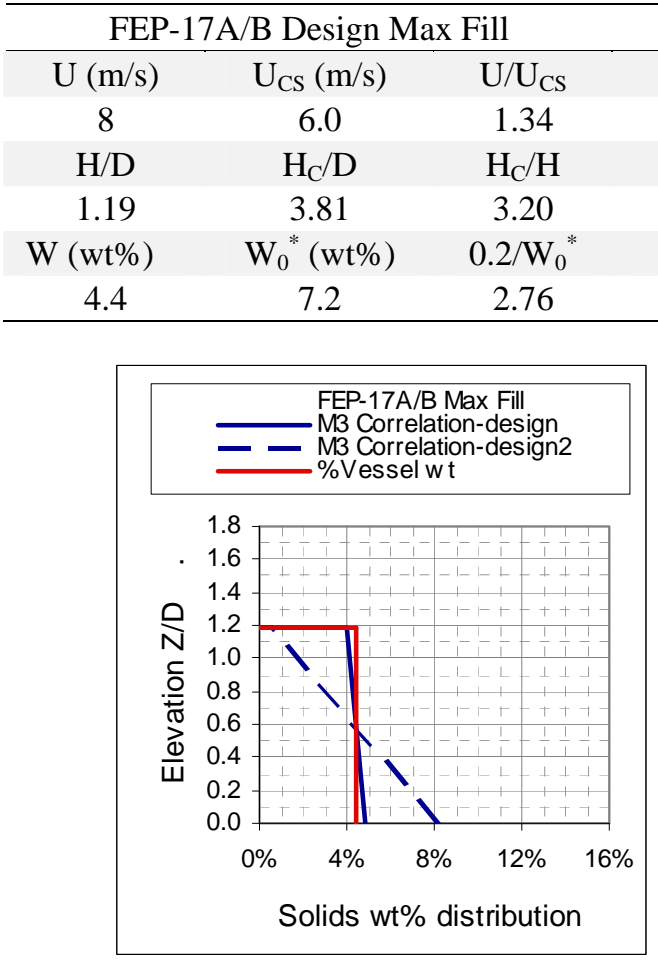

(a)

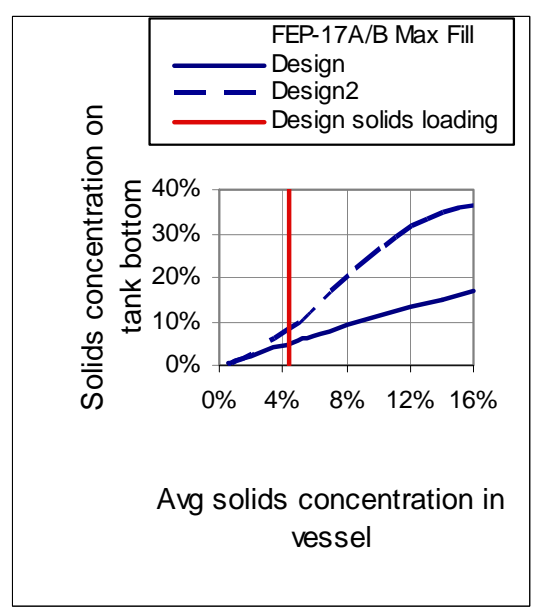

(c)

\begin{tabular}{ccc}
\multicolumn{3}{c}{ FEP-17A/B Design2 Max Fill } \\
$\mathrm{U}(\mathrm{m} / \mathrm{s})$ & $\mathrm{U}_{\mathrm{CS}}(\mathrm{m} / \mathrm{s})$ & $\mathrm{U} / \mathrm{U}_{\mathrm{CS}}$ \\
8 & 7.3 & 1.09 \\
$\mathrm{H} / \mathrm{D}$ & $\mathrm{H}_{\mathrm{C}} / \mathrm{D}$ & $\mathrm{H}_{\mathrm{C}} / \mathrm{H}$ \\
1.19 & 1.28 & 1.08 \\
$\mathrm{~W}(\mathrm{wt} \%)$ & $\mathrm{W}_{0}{ }^{*}(\mathrm{wt} \%)$ & $0.2 / \mathrm{W}_{0}{ }^{*}$ \\
4.4 & 12.3 & 1.63 \\
\hline
\end{tabular}

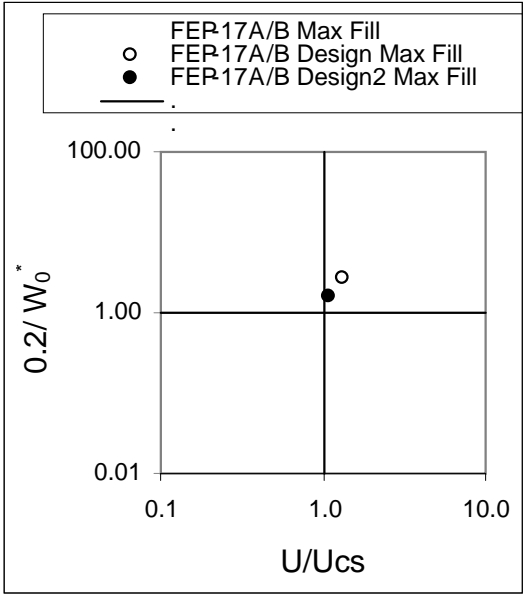

(b)

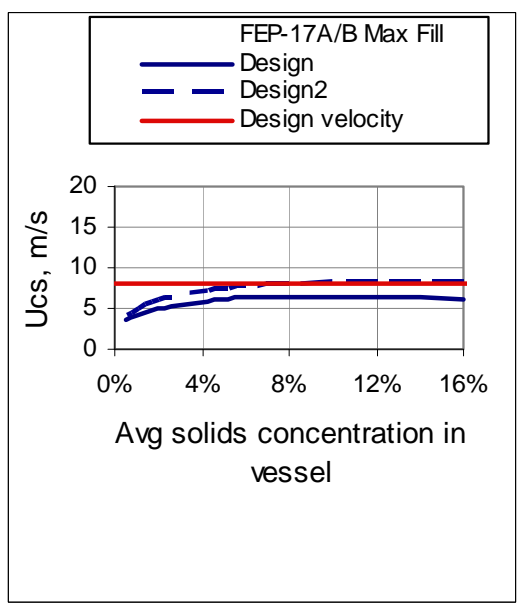

(d)

Figure 9.20. Physical Model Predictions for FEP-17 A/B: (a) Concentration Profile at Max Fill, (b) Inlet Concentration and Suspension Ratio, (c) Maximum Solids Concentration Versus Loading Design Conditions, (d) $\mathrm{U}_{\mathrm{CS}}$ Versus Loading (design point) 


\subsubsection{PWD-15/16 (Design Point) Physical Model}

Table 9.18 lists the physical model results for design point conditions for PWD-15/16, and Figure 9.21 depicts the physical model predictions for PWD-15/16.

Table 9.18. Physical Model Results for Design Point Conditions for PWD-15/16

\begin{tabular}{cccccc}
\hline \multicolumn{2}{c}{ PWD-15/16 Design Max Fill } & \multicolumn{3}{c}{ PWD-15/16 Design2 Max Fill } \\
\hline $\mathrm{U}(\mathrm{m} / \mathrm{s})$ & $\mathrm{U}_{\mathrm{CS}}(\mathrm{m} / \mathrm{s})$ & $\mathrm{U} / \mathrm{U}_{\mathrm{CS}}$ & $\mathrm{U}(\mathrm{m} / \mathrm{s})$ & $\mathrm{U}_{\mathrm{CS}}(\mathrm{m} / \mathrm{s})$ & $\mathrm{U} / \mathrm{U}_{\mathrm{CS}}$ \\
8 & 11.3 & 0.71 & 8 & 13.2 & 0.61 \\
$\mathrm{H} / \mathrm{D}$ & $\mathrm{H}_{\mathrm{C}} / \mathrm{D}$ & $\mathrm{H}_{\mathrm{C}} / \mathrm{H}$ & $\mathrm{H} / \mathrm{D}$ & $\mathrm{H}_{\mathrm{C}} / \mathrm{D}$ & $\mathrm{H}_{\mathrm{C}} / \mathrm{H}$ \\
1.78 & 0.07 & 0.04 & 1.78 & 0.05 & 0.03 \\
$\mathrm{~W}(\mathrm{wt} \%)$ & $\mathrm{W}_{0}{ }^{*}\left(\mathrm{wt}^{*}\right)$ & $0.2 / \mathrm{W}_{0}{ }^{*}$ & $\mathrm{~W}(\mathrm{wt} \%)$ & $\mathrm{W}_{0}{ }^{*}(\mathrm{wt} \%)$ & $0.2 / \mathrm{W}_{0}{ }^{*}$ \\
3 & $>\mathrm{W}_{\mathrm{MP}}{ }^{(\mathrm{a})}$ & 0.08 & 3 & $>\mathrm{W}_{\mathrm{MP}}{ }^{(\mathrm{a})}$ & 0.06 \\
\hline
\end{tabular}

(a) Calculated value exceeds maximum packing fraction.

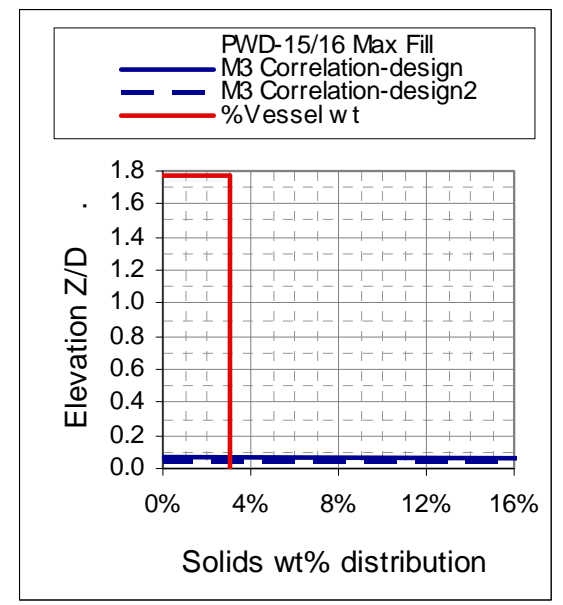

(a)

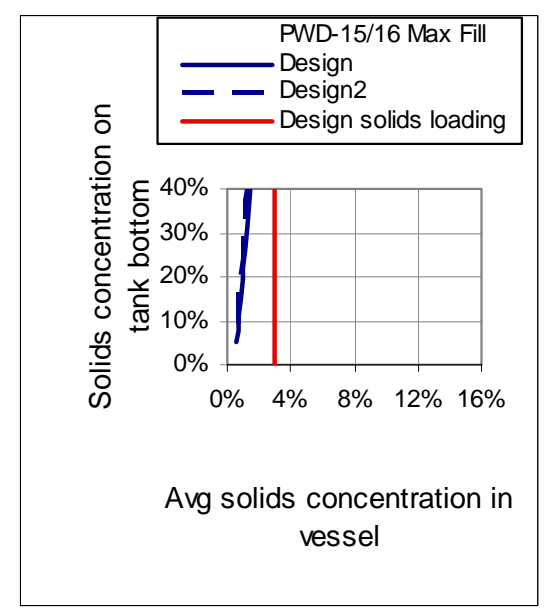

(c)

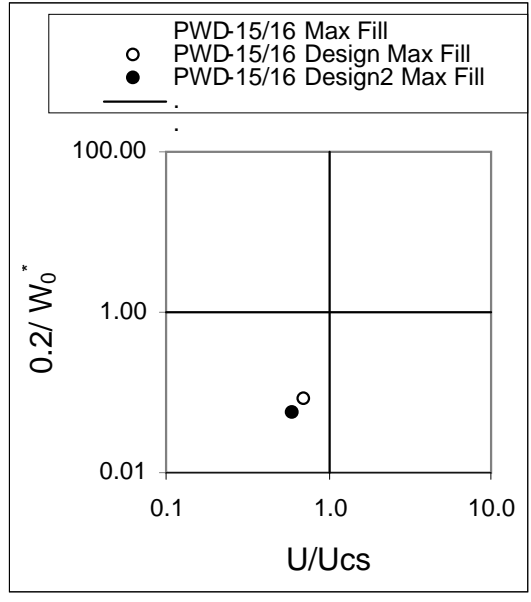

(b)

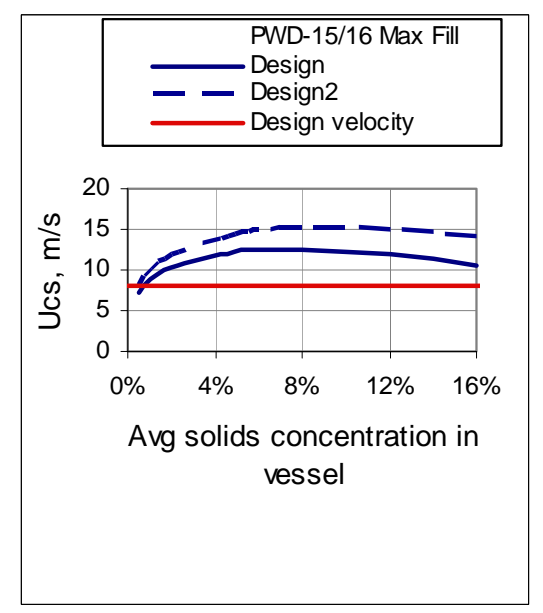

(d)

Figure 9.21. Physical Model Predictions for PWD-15/16: (a) Concentration Profile at Max Fill, (b) Inlet Concentration and Suspension Ratio, (c) Maximum Solids Concentration Versus Loading Design Conditions, (d) $\mathrm{U}_{\mathrm{CS}}$ Versus Loading (design point) 


\subsubsection{UFP-01 A/B (Design Point) Physical Model}

Table 9.19 lists the physical model results for design point conditions for UFP-01 A/B, and Figure 9.22 depicts the physical model predictions for UFP-01 A/B.

Table 9.19. Physical Model Results for Design Point Conditions for UFP-01

\begin{tabular}{cccccc}
\hline \multicolumn{2}{c}{$\mathrm{UFP}-01 \mathrm{~A} / \mathrm{B}$ Design Max Fill } & \multicolumn{3}{c}{$\mathrm{UFP}-01 \mathrm{~A} / \mathrm{B}$ Design2 Max Fill } \\
\hline $\mathrm{U}(\mathrm{m} / \mathrm{s})$ & $\mathrm{U}_{\mathrm{CS}}(\mathrm{m} / \mathrm{s})$ & $\mathrm{U} / \mathrm{U}_{\mathrm{CS}}$ & $\mathrm{U}(\mathrm{m} / \mathrm{s})$ & $\mathrm{U}_{\mathrm{CS}}(\mathrm{m} / \mathrm{s})$ & $\mathrm{U}_{\mathrm{CS}}$ \\
8 & 8.6 & 0.93 & 8 & 10.4 & 0.77 \\
$\mathrm{H} / \mathrm{D}$ & $\mathrm{H}_{\mathrm{C}} / \mathrm{D}$ & $\mathrm{H}_{\mathrm{C}} / \mathrm{H}$ & $\mathrm{H} / \mathrm{D}$ & $\mathrm{H}_{\mathrm{C}} / \mathrm{D}$ & $\mathrm{H}_{\mathrm{C}} / \mathrm{H}$ \\
1.45 & 0.19 & 0.13 & 1.45 & 0.11 & 0.08 \\
$\mathrm{~W}(\mathrm{wt} \%)$ & $\mathrm{W}_{0}{ }^{*}(\mathrm{wt} \%)$ & $0.2 / \mathrm{W}_{0}{ }^{*}$ & $\mathrm{~W}(\mathrm{wt} \%)$ & $\mathrm{W}_{0}{ }^{*}(\mathrm{wt} \%)$ & $0.2 / \mathrm{W}_{0}{ }^{*}$ \\
3.8 & $>\mathrm{W}_{\mathrm{MP}}{ }^{(\mathrm{a})}$ & 0.23 & 3.8 & $>\mathrm{W}_{\mathrm{MP}}{ }^{(\mathrm{a})}$ & 0.13 \\
\hline
\end{tabular}

(a) Calculated value exceeds maximum packing fraction.

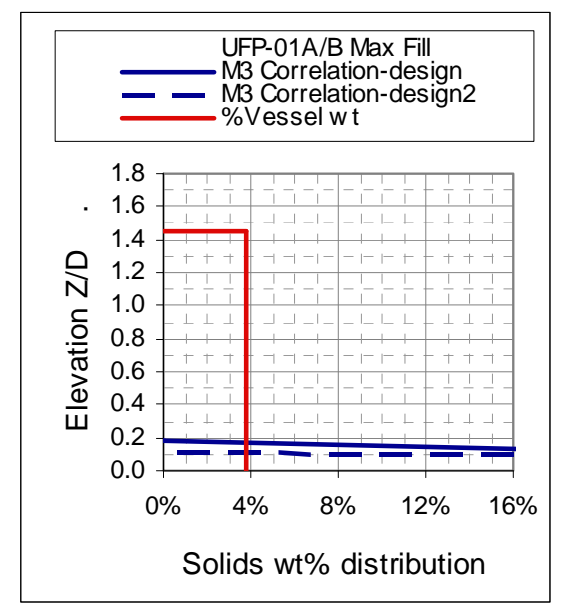

(a)

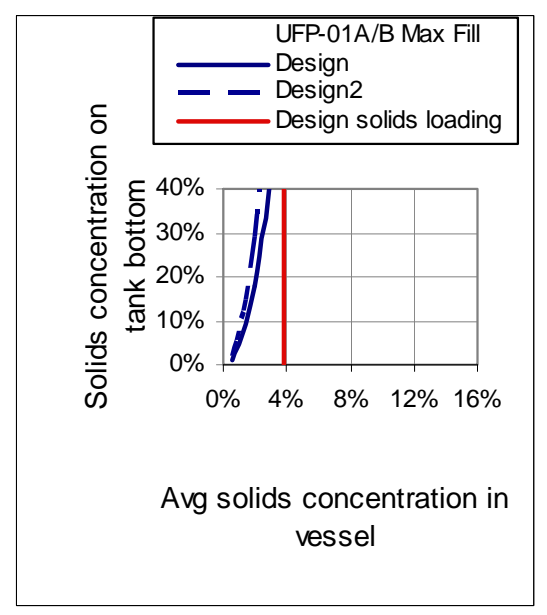

(c)

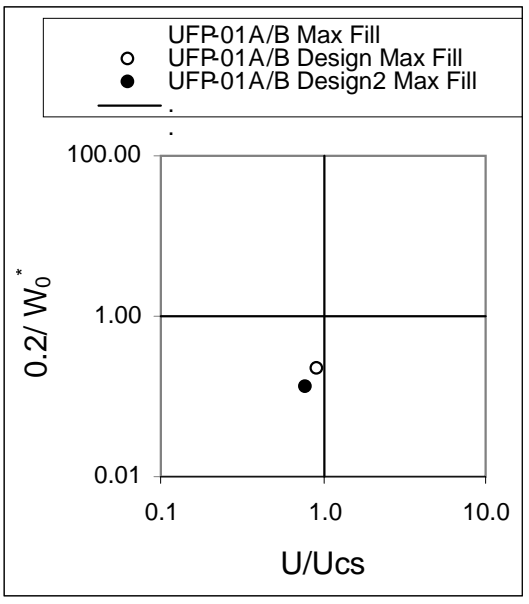

(b)

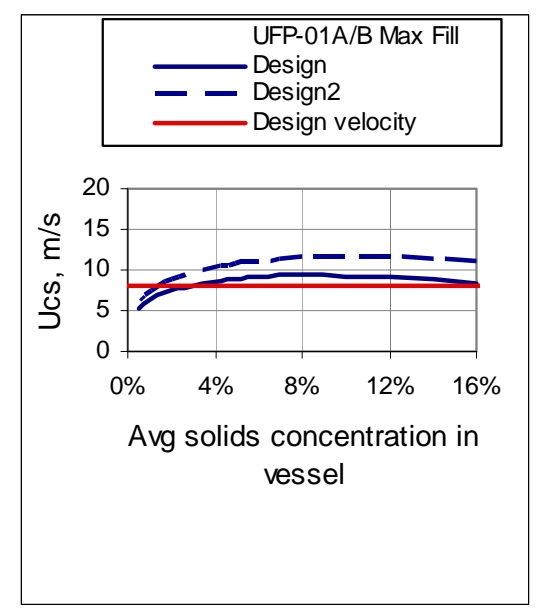

(d)

Figure 9.22. Physical Model Predictions for UFP-01 A/B: (a) Concentration Profile at Max Fill, (b) Inlet Concentration and Suspension Ratio, (c) Maximum Solids Concentration Versus Loading Design Conditions, (d) $\mathrm{U}_{\mathrm{CS}}$ Versus Loading (design point) 


\subsubsection{RLD-07 (design point) Physical Model}

Table 9.20 lists the physical model results for design point conditions for RLD-07, and Figure 9.23 presents the physical model predictions for RLD-07.

Table 9.20. Physical Model Results for Design Point Conditions for RLD-07

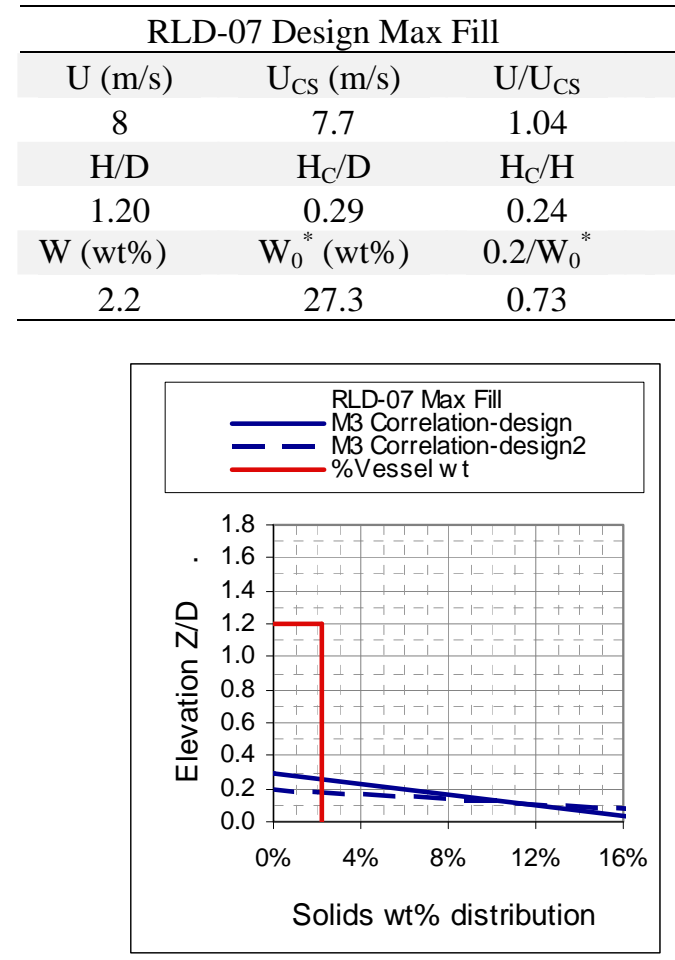

(a)

\begin{tabular}{ccc}
\multicolumn{3}{c}{ RLD-07 Design2 Max Fill } \\
\hline $\mathrm{U}(\mathrm{m} / \mathrm{s})$ & $\mathrm{U}_{\mathrm{CS}}(\mathrm{m} / \mathrm{s})$ & $\mathrm{U} / \mathrm{U}_{\mathrm{CS}}$ \\
8 & 8.9 & 0.90 \\
$\mathrm{H} / \mathrm{D}$ & $\mathrm{H}_{\mathrm{C}} / \mathrm{D}$ & $\mathrm{H}_{\mathrm{C}} / \mathrm{H}$ \\
1.20 & 0.20 & 0.17 \\
$\mathrm{w}(\mathrm{wt} \%)$ & $\mathrm{W}_{0}{ }^{*}(\mathrm{wt} \%)$ & $0.2 / \mathrm{W}_{0}{ }^{*}$ \\
2.2 & 39.7 & 0.50 \\
\hline
\end{tabular}

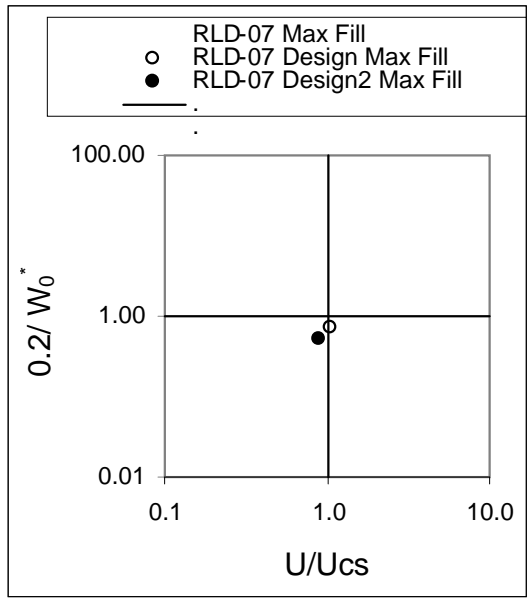

(b)

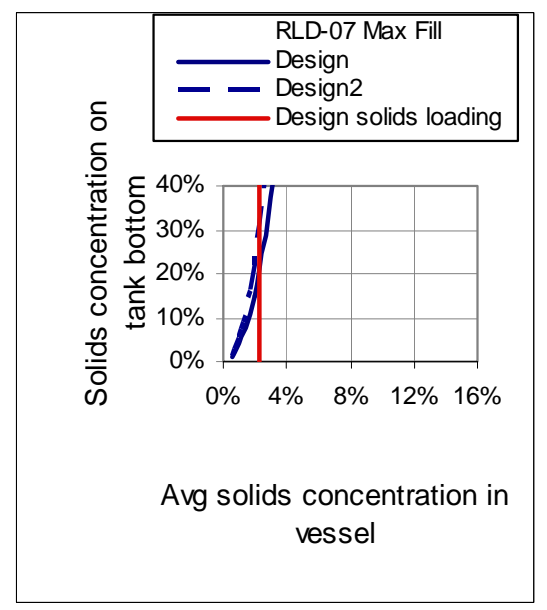

(c)

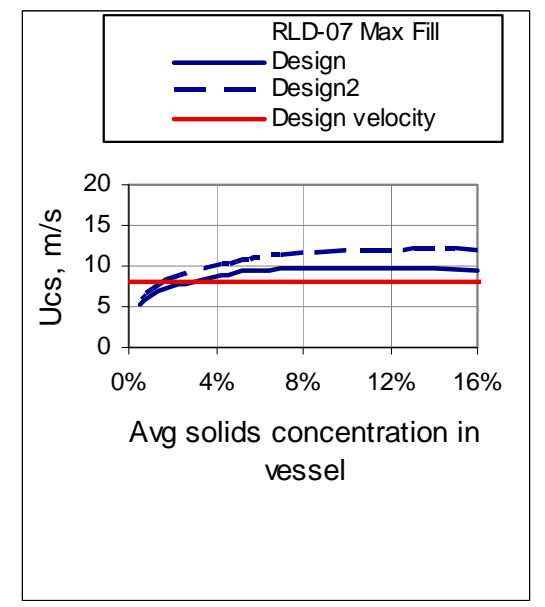

(d)

Figure 9.23. Physical Model Predictions for RLD-07: (a) Concentration Profile at Max Fill, (b) Inlet Concentration and Suspension Ratio, (c) Maximum Solids Concentration Versus Loading Design Conditions, (d) $\mathrm{U}_{\mathrm{CS}}$ Versus Loading (design point) 


\subsubsection{RLD-08 (Design Point) Physical Model}

Table 9.21 presents the physical model results for design point conditions for RLD-08, and Figure 9.24 depicts the physical model predictions for RLD-08.

Table 9.21. Physical Model Results for Design Point Conditions for RLD-08

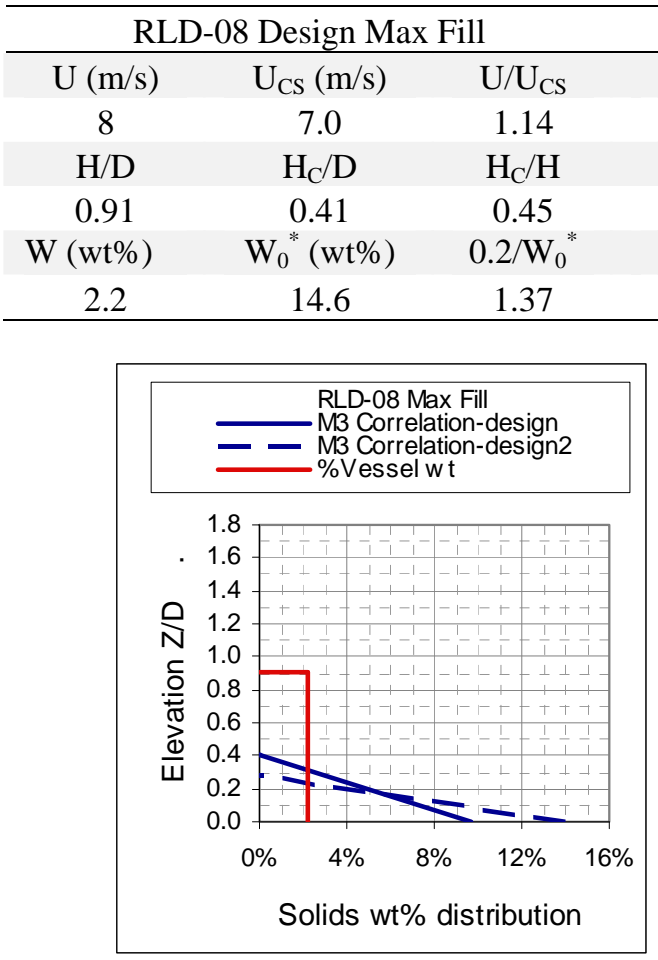

(a)

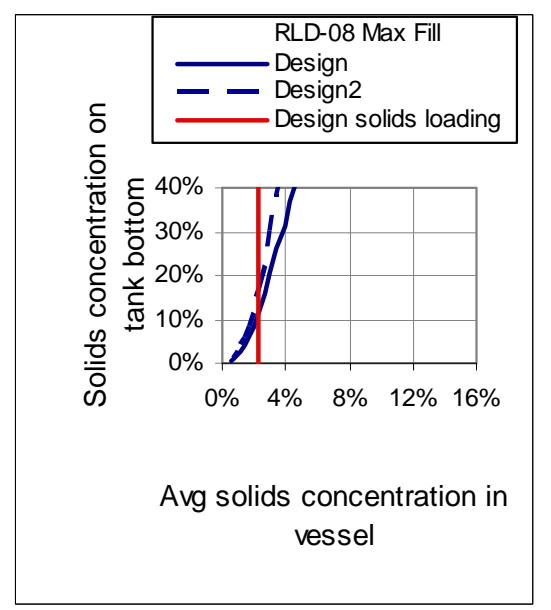

(c)

RLD-08 Design2 Max Fill

\begin{tabular}{ccc}
$\mathrm{U}(\mathrm{m} / \mathrm{s})$ & $\mathrm{U}_{\mathrm{CS}}(\mathrm{m} / \mathrm{s})$ & $\mathrm{U} / \mathrm{U}_{\mathrm{CS}}$ \\
8 & 8.1 & 0.99 \\
$\mathrm{H} / \mathrm{D}$ & $\mathrm{H}_{\mathrm{C}} / \mathrm{D}$ & $\mathrm{H}_{\mathrm{C}} / \mathrm{H}$ \\
0.91 & 0.28 & 0.31 \\
$\mathrm{~W}(\mathrm{wt} \%)$ & $\mathrm{W}_{0}{ }^{*}(\mathrm{wt} \%)$ & $0.2 / \mathrm{W}_{0}{ }^{*}$ \\
2.2 & 21.0 & 0.95 \\
\hline
\end{tabular}

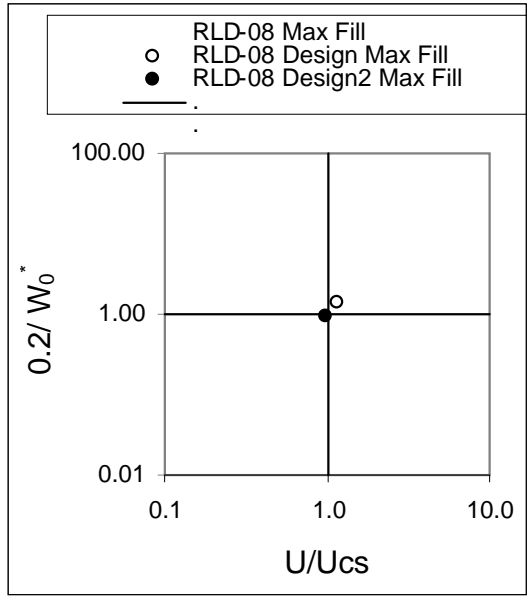

(b)

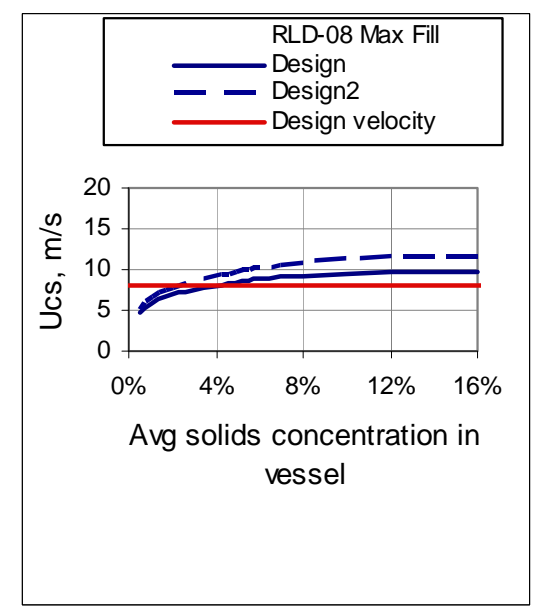

(d)

Figure 9.24. Physical Model Predictions for RLD-08: (a) Concentration Profile at Max Fill, (b) Inlet Concentration and Suspension Ratio, (c) Maximum Solids Concentration Versus Loading Design Conditions, (d) $\mathrm{U}_{\mathrm{CS}}$ Versus Loading (design point) 


\subsubsection{HOP-903/904 (Design Point) Simple Calculation}

Table 9.22 lists the physical model results for design point conditions for HOP-903/904, and Figure 9.25depicts the physical model predictions for HOP-903/904.

Table 9.22. Physical Model Results for Design Point Conditions for HOP-903/904

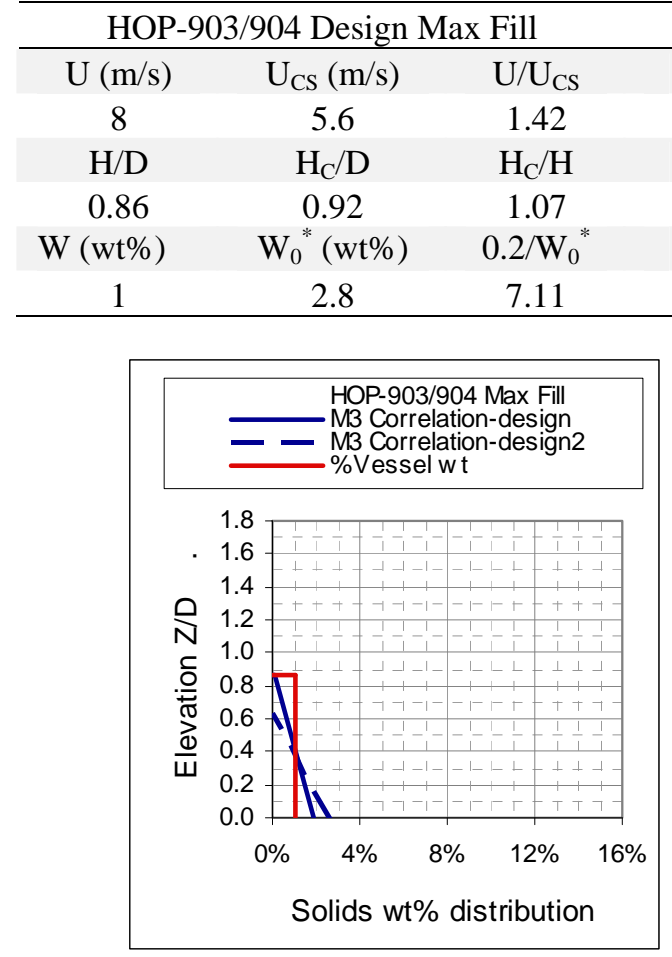

(a)

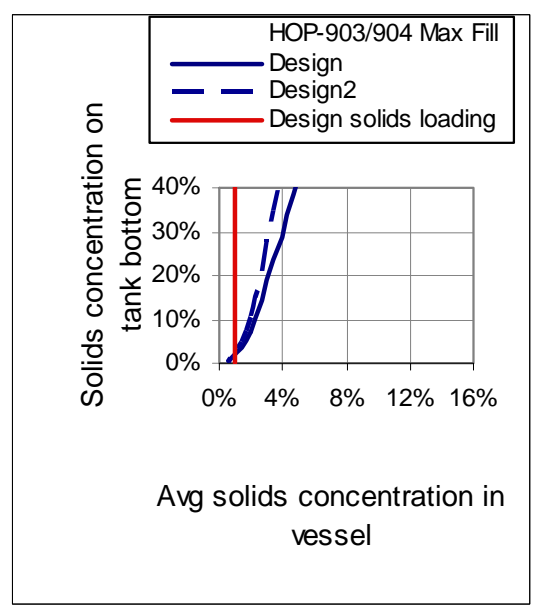

(c)

\begin{tabular}{ccc} 
HOP-903/904 Design2 Max Fill \\
\hline $\mathrm{U}(\mathrm{m} / \mathrm{s})$ & $\mathrm{U}_{\mathrm{CS}}(\mathrm{m} / \mathrm{s})$ & $\mathrm{U} / \mathrm{U}_{\mathrm{CS}}$ \\
8 & 6.5 & 1.23 \\
$\mathrm{H} / \mathrm{D}$ & $\mathrm{H}_{\mathrm{C}} / \mathrm{D}$ & $\mathrm{H}_{\mathrm{C}} / \mathrm{H}$ \\
0.86 & 0.64 & 0.75 \\
$\mathrm{~W}(\mathrm{wt} \%)$ & $\mathrm{W}_{0}{ }^{*}(\mathrm{wt} \%)$ & $0.2 / \mathrm{W}_{0}{ }^{*}$ \\
1 & 4.0 & 4.99 \\
\hline
\end{tabular}

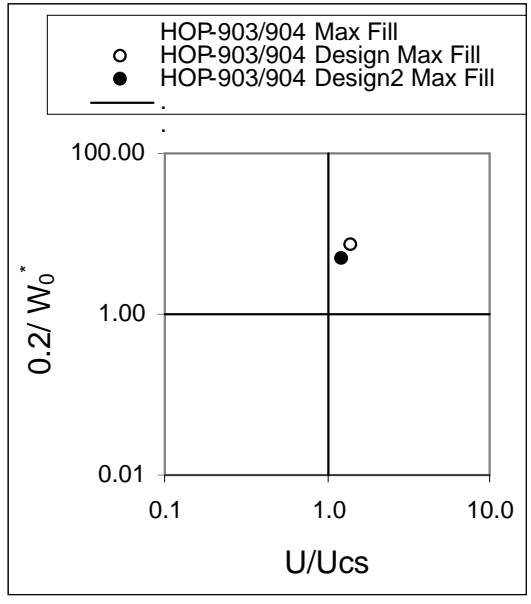

(b)

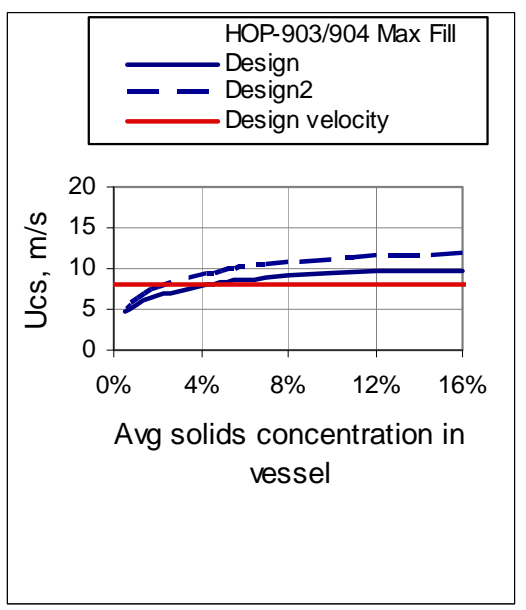

(d)

Figure 9.25. Physical Model Predictions for HOP-903/904: (a) Concentration Profile at Max Fill, (b) Inlet Concentration and Suspension Ratio, (c) Maximum Solids Concentration Versus Loading Design Conditions, (d) $\mathrm{U}_{\mathrm{CS}}$ Versus Loading (design point) 


\subsection{Vessel Evaluation Examples with the Physical Models and the Hanford Waste Distribution}

Mixing performance of WTP vessels was evaluated based on the Hanford waste distribution using the physical models for $\mathrm{U}_{\mathrm{CS}}, \mathrm{H}_{\mathrm{C}}$, and $\mathrm{C}_{0}$, as described in Sections 7.3.2 to 7.3.4 with $\mathrm{C}_{0}$ modified to $\mathrm{W}_{0}{ }^{*}$, as described in Section 9.1.4. The results of the evaluations are presented in Sections 9.4.1 through 9.4.16.

The Hanford waste settling properties used in the examples in this section include the following:

- $\mathrm{U}_{95}$ : This is the $95^{\text {th }}$ percentile of the particle-settling velocity distribution based on the Hanford tank waste PSDD (Case 3). The use of the 95th percentile is supported by the results of the model benchmarking and is similar to common industry practice of using the 95th percentile of particle size when designing slurry handling equipment.

- $\overline{\mathrm{U}}_{90}$ : This is the average settling velocity for the fastest settling $10 \%$ of the Hanford tank waste. The $\mathrm{U}_{95}$ and $\overline{\mathrm{U}}_{90}$ are used to establish the primary range for assessing the vessel types.

- A uniform liquid density of $1.15 \mathrm{~g} / \mathrm{cm}^{3}$; this was used in the Hanford PSDD cases with a fluid viscosity of $1.5 \mathrm{cP}$.

The vessel geometry and operating conditions are listed in Table 9.2 with vessel loading shown in Table 9.4.

These examples are for the vessel conditions that were provided in Olsen (2008a). This document has recently been revised to Rev.1 (Olsen 2008b) ; however, these examples are based on Rev. 0 (Olsen 2008a). The examples are provided for the specific set of conditions described above. The analysis of the vessels used in the examples has been reassigned to the WTP M\&PE group (Hazen 2008b).

Note that Tables 9.23 through 9.38 display only a few significant figures. The calculations are not based on this reduced number of digits. Therefore, small calculation differences are observed when using the displayed rounded numbers for calculations. 


\subsubsection{FRP-02 A/B/C/D (Hanford PSDD, $\rho_{\mathrm{l}}=1.1 \mathrm{~g} / \mathrm{cm}^{3}, \mu=1.5 \mathrm{cP}$ fluid) Physical Model}

Table 9.23 lists the physical model results for FRP-02 A/B/C/D using the Hanford PSDD, and Figure 9.26 shows the physical model predictions for FRP-02 A/B/C/D based on the Hanford waste distribution.

Table 9.23. Physical Model Results for FRP-02 Using Hanford PSDD

\begin{tabular}{cccccc}
\hline \multicolumn{2}{c}{ FRP-02A/B/C/D U $\mathrm{U}_{95}$ Max Fill } & \multicolumn{3}{c}{ FRP-02A/B/C/D $\overline{\mathrm{U}}_{90}$ Max Fill } \\
\hline $\mathrm{U}(\mathrm{m} / \mathrm{s})$ & $\mathrm{U}_{\mathrm{CS}}(\mathrm{m} / \mathrm{s})$ & $\mathrm{U} / \mathrm{U}_{\mathrm{CS}}$ & $\mathrm{U}(\mathrm{m} / \mathrm{s})$ & $\mathrm{U}_{\mathrm{CS}}(\mathrm{m} / \mathrm{s})$ & $\mathrm{U} / \mathrm{U}_{\mathrm{CS}}$ \\
8 & 19.4 & 0.41 & 8 & 25.6 & 0.31 \\
$\mathrm{H} / \mathrm{D}$ & $\mathrm{H}_{\mathrm{C}} / \mathrm{D}$ & $\mathrm{H}_{\mathrm{C}} / \mathrm{H}$ & $\mathrm{H} / \mathrm{D}$ & $\mathrm{H}_{\mathrm{C}} / \mathrm{D}$ & $\mathrm{H}_{\mathrm{C}} / \mathrm{H}$ \\
0.73 & 0.03 & 0.04 & 0.73 & 0.01 & 0.01 \\
$\mathrm{~W}(\mathrm{wt} \%)$ & $\mathrm{W}_{0}{ }^{*}(\mathrm{wt} \%)$ & $0.2 / \mathrm{W}_{0}{ }^{*}$ & $\mathrm{~W}(\mathrm{wt} \%)$ & $\mathrm{W}_{0}{ }^{*}(\mathrm{wt} \%)$ & $0.2 / \mathrm{W}_{0}{ }^{*}$ \\
4.9 & $>\mathrm{W}_{\mathrm{MP}}{ }^{(\mathrm{a})}$ & 0.05 & 4.9 & $>\mathrm{W}_{\mathrm{MP}}{ }^{(\mathrm{a})}$ & 0.01 \\
\hline
\end{tabular}

(a) Calculated value exceeds maximum packing fraction.

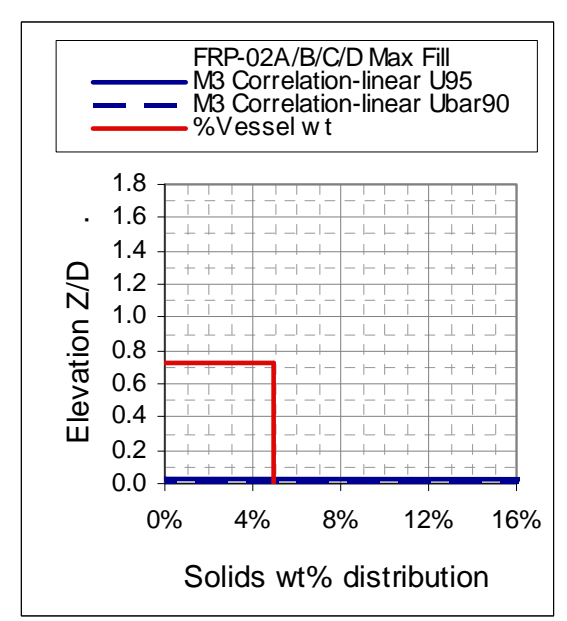

(a)

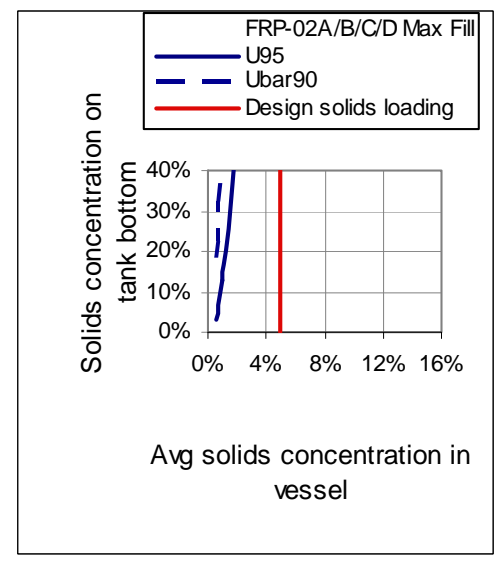

(c)

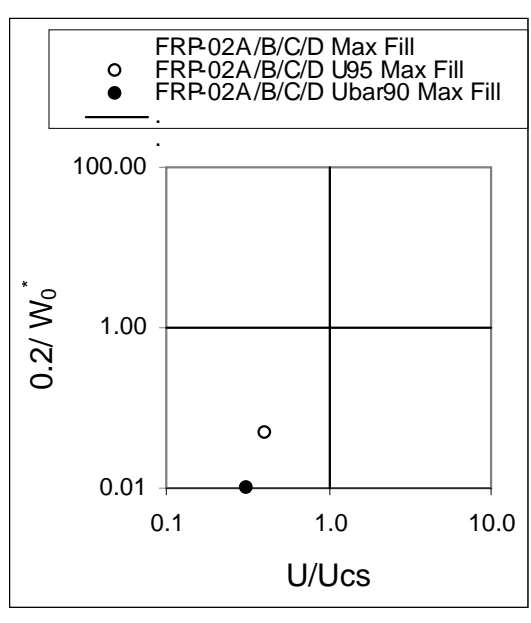

(b)

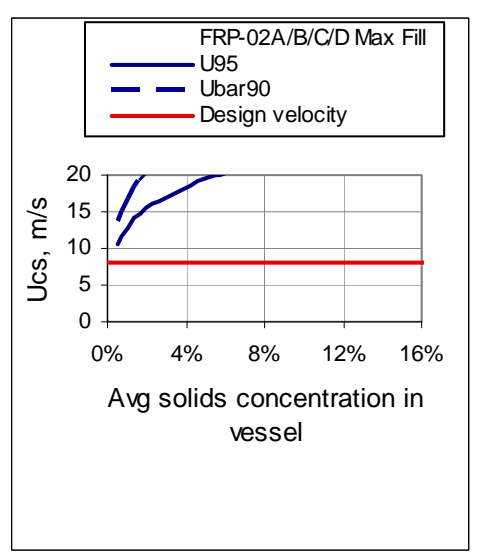

(d)

Figure 9.26. Physical Model Predictions for FRP-02 A/B/C/D: (a) Concentration Profile at Max Fill, (b) Inlet Concentration and Suspension Ratio, (c) Maximum Solids Concentration Versus Loading Design Conditions, (d) $\mathrm{U}_{\mathrm{CS}}$ Versus Loading (Hanford PSDD, $\rho_{\mathrm{l}}=1.1 \mathrm{~g} / \mathrm{cm}^{3}$, $\mu=1.5$ cP fluid) 
The characteristic settling rate selected for a vessel assessment affects the predictions of $\mathrm{U}_{\mathrm{CS}}$. To illustrate the sensitivity of this input value, another calculation for FRP-02 is provided assuming conditions that are likely bounding in a non-conservative direction (i.e., the actual performance would likely be worse than these predicted values). The bounding condition for calculating $\mathrm{U}_{\mathrm{CS}}$ uses a particle settling rate, $U_{T}$, which is the average of the entire distribution of the Hanford PSDD. This particle settling rate is $1.02 \mathrm{E}-3 \mathrm{~m} / \mathrm{s}$, and corresponds to a particle diameter $\mathrm{d}$ of 42 microns with a specific gravity of 2.78. Under these conditions, the $\mathrm{U}_{\mathrm{CS}}$ is predicted to be $16.1 \mathrm{~m} / \mathrm{s}$.

Similarly, the solids concentration at the bottom of the vessel is sensitive to the gradient of the solids concentration within the cloud. Observations and attenuation (concentration) measurements taken during testing identified much higher concentrations of solids near the bottom of the test vessels than at the peak of the recorded cloud. A non-conservatively bounding condition for calculating the concentration at the pump suction is based on an assumption that the suspension of solids would be perfectly (homogeneously) mixed up to the peak of the cloud. In this example, the cloud height is calculated using the $U_{95}$ particle settling velocity, and the cloud height that corresponds to a pump suction concentration of $20 \mathrm{wt} \%$ is $8.4 \mathrm{ft}$. Using the physical model, the jet velocity $\mathrm{U}$ required to lift solids to $8.4 \mathrm{ft}$ would need to be $13.8 \mathrm{~m} / \mathrm{s}$. 


\subsubsection{HLP-22 $8 \mathrm{~m} / \mathrm{s}$, 4-in. (Hanford PSDD, $\rho_{\mathrm{l}}=1.1 \mathrm{~g} / \mathrm{cm}^{3}, \mu=1.5 \mathrm{cP}$ fluid) Physical Model}

Table 9.24 lists physical model results for HLP-22, and Figure 9.27 shows the physical model predictions for HLP-22 at $8 \mathrm{~m} / \mathrm{s}$ with a 4-in. nozzle based on the Hanford waste distribution.

Table 9.24. Physical Model Results for HLP-22 Using Hanford PSDD

\begin{tabular}{|c|c|c|c|c|c|}
\hline \multicolumn{3}{|c|}{ HLP-22 U U Max Fill } & \multicolumn{3}{|c|}{ HLP-22 $\overline{\mathrm{U}}_{90}$ Max Fill } \\
\hline $\mathrm{U}(\mathrm{m} / \mathrm{s})$ & $\mathrm{U}_{\mathrm{CS}}(\mathrm{m} / \mathrm{s})$ & $\mathrm{U} / \mathrm{U}_{\mathrm{CS}}$ & $\mathrm{U}(\mathrm{m} / \mathrm{s})$ & $\mathrm{U}_{\mathrm{CS}}(\mathrm{m} / \mathrm{s})$ & $\mathrm{U} / \mathrm{U}_{\mathrm{CS}}$ \\
\hline 8 & 16.5 & 0.48 & 8 & 21.7 & 0.37 \\
\hline $\mathrm{H} / \mathrm{D}$ & $\mathrm{H}_{\mathrm{C}} / \mathrm{D}$ & $\mathrm{H}_{\mathrm{C}} / \mathrm{H}$ & H/D & $\mathrm{H}_{\mathrm{C}} / \mathrm{D}$ & $\mathrm{H}_{\mathrm{C}} / \mathrm{H}$ \\
\hline 0.80 & 0.05 & 0.06 & 0.80 & 0.01 & 0.01 \\
\hline W (wt\%) & $\mathrm{W}_{0}{ }^{*}(\mathrm{wt} \%)$ & $0.2 / \mathrm{W}_{0}{ }^{*}$ & W (wt\%) & $\mathrm{W}_{0}{ }^{*}(\mathrm{wt} \%)$ & $0.2 / \mathrm{W}_{0}^{*}$ \\
\hline 15.4 & $>\mathrm{W}_{\mathrm{MP}}^{(\mathrm{a})}$ & 0.03 & 15.4 & $>\mathrm{W}_{\mathrm{MP}}^{(\mathrm{a})}$ & 0.004 \\
\hline
\end{tabular}

(a) Calculated value exceeds maximum packing fraction.

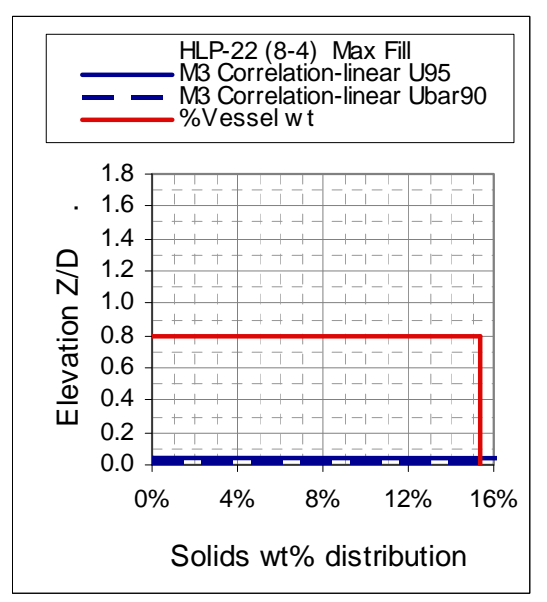

(a)

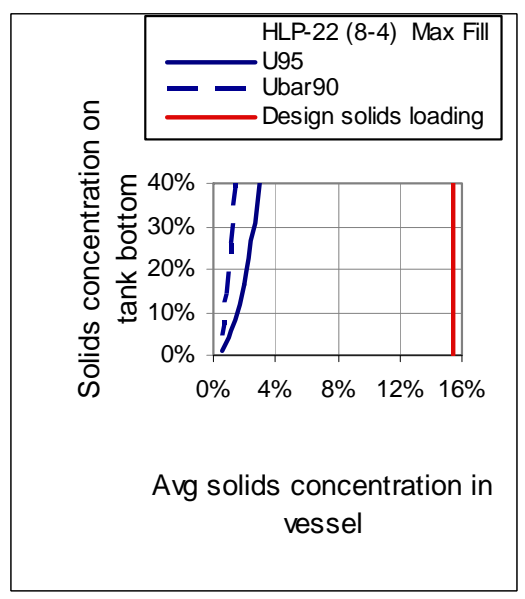

(c)

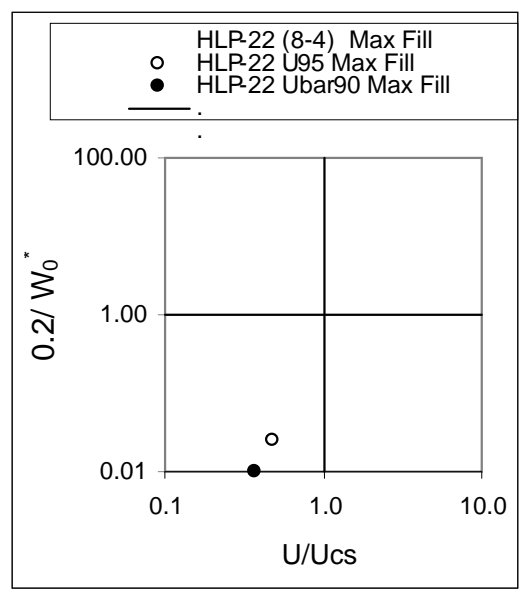

(b)

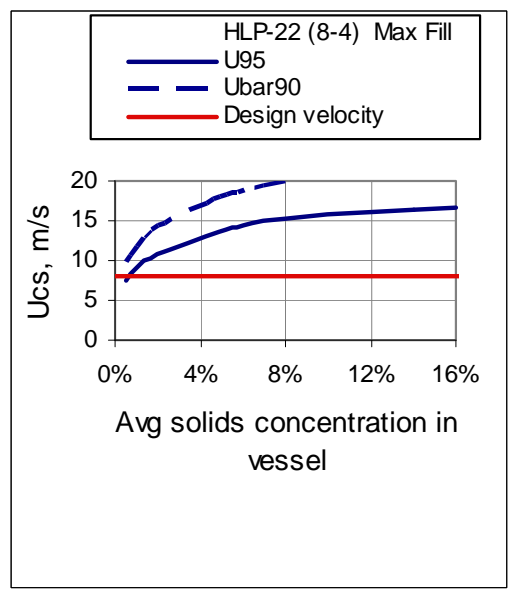

(d)

Figure 9.27. Physical Model Predictions for HLP-22: (a) Concentration Profile at Max Fill, (b) Inlet Concentration and Suspension Ratio, (c) Maximum Solids Concentration Versus Loading Design Conditions, (d ) $\mathrm{U}_{\mathrm{CS}}$ Versus Loading at $8 \mathrm{~m} / \mathrm{s}$, 4-in. Nozzle (Hanford PSDD, $\rho_{\mathrm{l}}=1.1 \mathrm{~g} / \mathrm{cm}^{3}, \mu=1.5 \mathrm{cP}$ fluid) 


\subsubsection{HLP-22 $12 \mathrm{~m} / \mathrm{s}$, 4-in. (Hanford PSDD, $\rho_{\mathrm{l}}=1.1 \mathrm{~g} / \mathrm{cm}^{3}, \mu=1.5 \mathrm{cP}$ fluid) Physical Model}

Table 9.25 presents the physical model results for HLP-22, and Figure 9.28 shows the physical model predictions for HLP-22 at $12 \mathrm{~m} / \mathrm{s}$ with a 4-in. nozzle using the Hanford PSDD.

Table 9.25. Physical Model Results for HLP-22 Using Hanford PSDD

\begin{tabular}{cccccc}
\hline \multicolumn{3}{c}{ HLP-22 $\mathrm{U}_{95}$ Max Fill } & \multicolumn{3}{c}{$\mathrm{HLP}-22 \overline{\mathrm{U}}_{90}$ Max Fill } \\
\hline $\mathrm{U}(\mathrm{m} / \mathrm{s})$ & $\mathrm{U}_{\mathrm{CS}}(\mathrm{m} / \mathrm{s})$ & $\mathrm{U} / \mathrm{U}_{\mathrm{CS}}$ & $\mathrm{U}(\mathrm{m} / \mathrm{s})$ & $\mathrm{U}_{\mathrm{CS}}(\mathrm{m} / \mathrm{s})$ & $\mathrm{U} / \mathrm{U}_{\mathrm{CS}}$ \\
12 & 16.5 & 0.73 & 12 & 21.7 & 0.55 \\
$\mathrm{H} / \mathrm{D}$ & $\mathrm{H}_{\mathrm{C}} / \mathrm{D}$ & $\mathrm{H}_{\mathrm{C}} / \mathrm{H}$ & $\mathrm{H} / \mathrm{D}$ & $\mathrm{H}_{\mathrm{C}} / \mathrm{D}$ & $\mathrm{H}_{\mathrm{C}} / \mathrm{H}$ \\
0.80 & 0.21 & 0.26 & 0.80 & 0.03 & 0.03 \\
$\mathrm{~W}(\mathrm{wt} \%)$ & $\mathrm{W}_{0}{ }^{*}(\mathrm{wt} \%)$ & $0.2 / \mathrm{W}_{0}{ }^{*}$ & $\mathrm{~W}(\mathrm{wt} \%)$ & $\mathrm{W}_{0}{ }^{*}(\mathrm{wt} \%)$ & $0.2 / \mathrm{W}_{0}{ }^{*}$ \\
15.4 & $>\mathrm{W}_{\mathrm{MP}}{ }^{(\mathrm{a})}$ & 0.11 & 15.4 & $>\mathrm{W}_{\mathrm{MP}}{ }^{(\mathrm{a})}$ & 0.01 \\
\hline
\end{tabular}

(a) Calculated value exceeds maximum packing fraction.

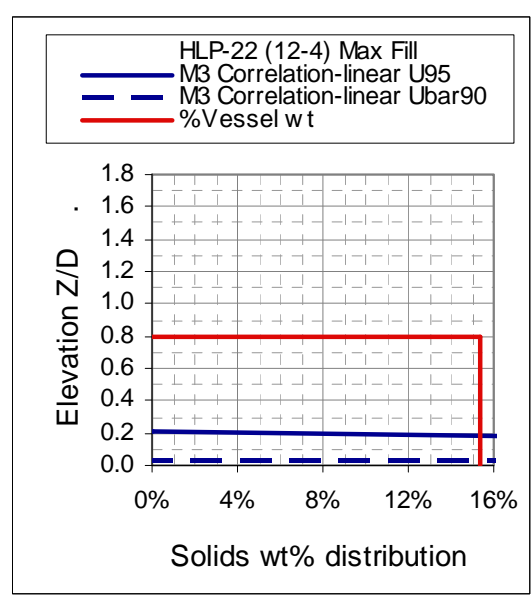

(a)

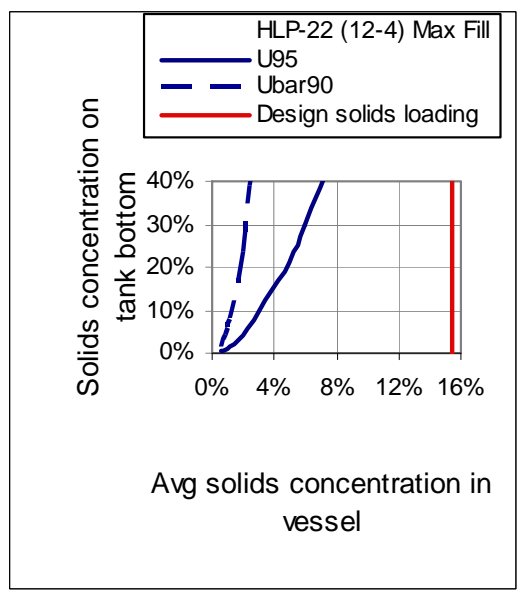

(c)

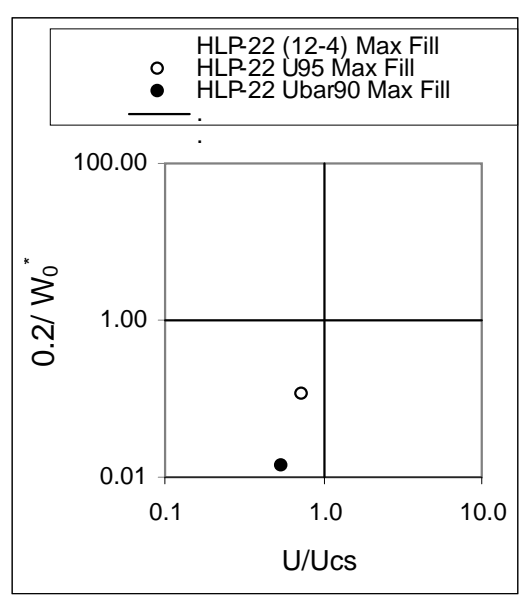

(b)

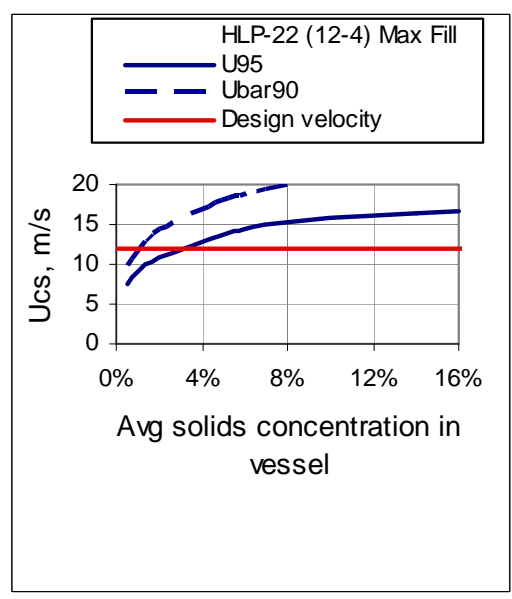

(d)

Figure 9.28. Physical Model Predictions for HLP-22: (a) Concentration Profile at Max Fill, (b) Inlet Concentration and Suspension Ratio, (c) Maximum Solids Concentration Versus Loading Design Conditions, (d) $\mathrm{U}_{\mathrm{CS}}$ Versus Loading at $12 \mathrm{~m} / \mathrm{s}$, 4-in. Nozzle (Hanford PSDD, $\rho_{\mathrm{l}}=1.1 \mathrm{~g} / \mathrm{cm}^{3}, \mu=1.5 \mathrm{cP}$ fluid) 
The characteristic settling rate selected for a vessel assessment affects the predictions of $\mathrm{U}_{\mathrm{Cs}}$. To illustrate the sensitivity of this input value, another calculation for HLP-22 (12 m/s, 4 inch nozzles) is provided assuming conditions that are likely bounding in a non-conservative direction (i.e., the actual performance would likely be worse than these predicted values). The bounding condition for calculating $\mathrm{U}_{\mathrm{CS}}$ uses a particle settling rate, $\mathrm{U}_{\mathrm{T}}$, which is the average of the entire distribution of the Hanford PSDD. This particle settling rate is $1.02 \mathrm{E}-3 \mathrm{~m} / \mathrm{s}$, and corresponds to a particle diameter $\mathrm{d}$ of 42 microns with a specific gravity of 2.78 . Under these conditions, the $U_{\mathrm{CS}}$ is predicted to be $13.7 \mathrm{~m} / \mathrm{s}$.

Similarly, the solids concentration at the bottom of the vessel is sensitive to the gradient of the solids concentration within the cloud. Observations and attenuation (concentration) measurements taken during testing identified much higher concentrations of solids near the bottom of the test vessels than at the peak of the recorded cloud. A non-conservatively bounding condition for calculating the concentration at the pump suction is based on an assumption that the suspension of solids would be perfectly (homogeneously) mixed up to the peak of the cloud. In this example, the cloud height is calculated using the $\mathrm{U}_{95}$ particle settling velocity, and the cloud height that corresponds to a pump suction concentration of $20 \mathrm{wt} \%$ is $23.3 \mathrm{ft}$. Using the physical model, the jet velocity $\mathrm{U}$ required to lift solids to $23.3 \mathrm{ft}$ would need to be $15.9 \mathrm{~m} / \mathrm{s}$. 


\subsubsection{HLP-22 $8 \mathrm{~m} / \mathrm{s}, 6$-in. (Hanford PSDD, $\rho_{\mathrm{l}}=1.1 \mathrm{~g} / \mathrm{cm}^{3}, \mu=1.5 \mathrm{cP}$ fluid) Physical Model}

Table 9.26 lists the physical model results for HLP-22, and Figure 9.29 presents the physical model predictions for HLP-22 at 8 m/s, a 6-in. nozzle, and using the Hanford PSDD.

Table 9.26. Physical Model Results for HLP-22 Using Hanford PSDD

\begin{tabular}{cccccc}
\hline \multicolumn{3}{c}{ HLP-22 $\mathrm{U}_{95}$ Max Fill } & \multicolumn{3}{c}{ HLP-22 $\overline{\mathrm{U}}_{90}$ Max Fill } \\
\hline $\mathrm{U}(\mathrm{m} / \mathrm{s})$ & $\mathrm{U}_{\mathrm{CS}}(\mathrm{m} / \mathrm{s})$ & $\mathrm{U} / \mathrm{U}_{\mathrm{CS}}$ & $\mathrm{U}(\mathrm{m} / \mathrm{s})$ & $\mathrm{U}_{\mathrm{CS}}(\mathrm{m} / \mathrm{s})$ & $\mathrm{U} / \mathrm{U}_{\mathrm{CS}}$ \\
8 & 12.5 & 0.64 & 8 & 16.4 & 0.49 \\
$\mathrm{H} / \mathrm{D}$ & $\mathrm{H}_{\mathrm{C}} / \mathrm{D}$ & $\mathrm{H}_{\mathrm{C}} / \mathrm{H}$ & $\mathrm{H} / \mathrm{D}$ & $\mathrm{H}_{\mathrm{C}} / \mathrm{D}$ & $\mathrm{H}_{\mathrm{C}} / \mathrm{H}$ \\
0.80 & 0.12 & 0.15 & 0.80 & 0.02 & 0.03 \\
$\mathrm{~W}(\mathrm{wt} \%)$ & $\mathrm{W}_{0}{ }^{*}(\mathrm{wt} \%)$ & $0.2 / \mathrm{W}_{0}{ }^{*}$ & $\mathrm{~W}(\mathrm{wt} \%)$ & $\mathrm{W}_{0}{ }^{*}(\mathrm{wt} \%)$ & $0.2 / \mathrm{W}_{0}{ }^{*}$ \\
15.4 & $>\mathrm{W}_{\mathrm{MP}}{ }^{(\mathrm{a})}$ & 0.07 & 15.4 & $>\mathrm{W}_{\mathrm{MP}}{ }^{(\mathrm{a})}$ & 0.011 \\
\hline
\end{tabular}

(a) Calculated value exceeds maximum packing fraction.

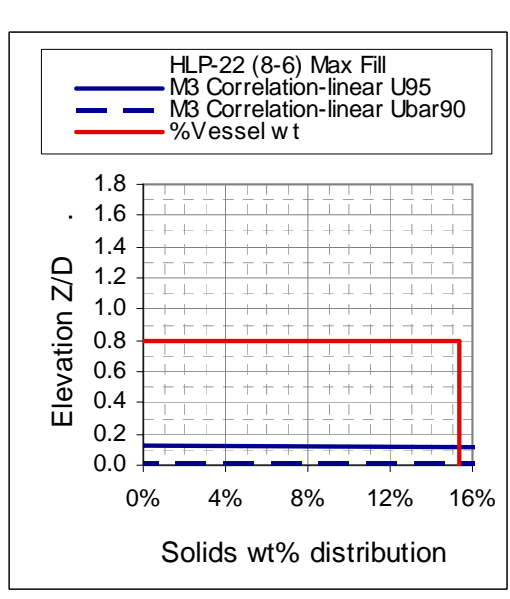

(a)

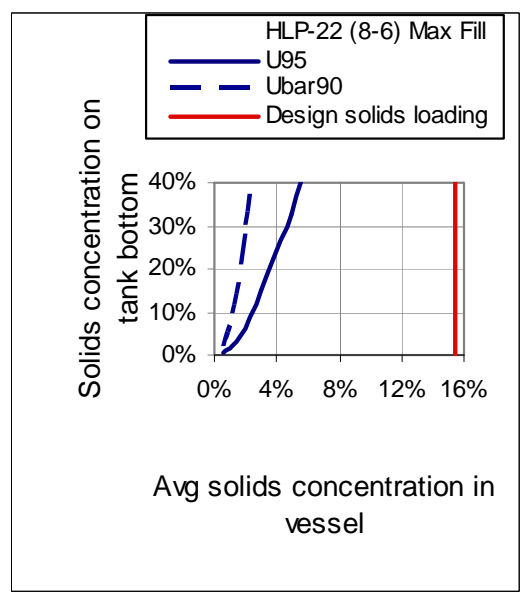

(c)

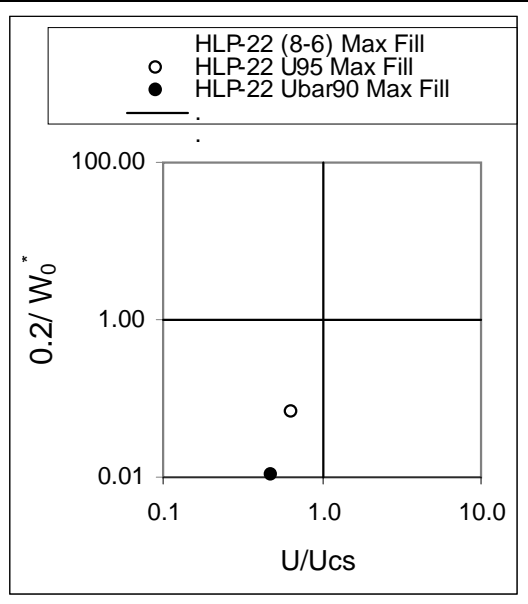

(b)

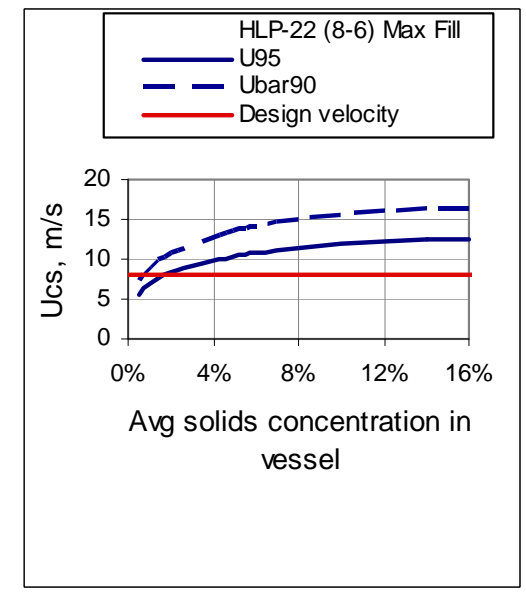

(d)

Figure 9.29. Physical Model Predictions for HLP-22: (a) Concentration Profile at Max Fill, (b) Inlet Concentration and Suspension Ratio, (c) Maximum Solids Concentration Versus Loading Design Conditions, (d) $U_{\mathrm{CS}}$ Versus Loading at $8 \mathrm{~m} / \mathrm{s}$, 6-in. Nozzle, Hanford PSDD 


\subsubsection{HLP-22 $12 \mathrm{~m} / \mathrm{s}, 6$-in. (Hanford PSDD, $\rho_{\mathrm{l}}=1.1 \mathrm{~g} / \mathrm{cm}^{3}, \mu=1.5 \mathrm{cP}$ fluid) Physical Model}

Table 9.27 lists the physical model results for HLP-22, and Figure 9.30 presents the physical model predictions for HLP-22 at $12 \mathrm{~m} / \mathrm{s}$ with a 6-in. nozzle using the Hanford PSDD.

Table 9.27. Physical Model Results for HLP-22 Using Hanford PSDD

\begin{tabular}{cccccc}
\hline \multicolumn{3}{c}{ HLP-22 $\mathrm{U}_{95}$ Max Fill } & \multicolumn{3}{c}{$\mathrm{HLP}-22 \overline{\mathrm{U}}_{90}$ Max Fill } \\
\hline $\mathrm{U}(\mathrm{m} / \mathrm{s})$ & $\mathrm{U}_{\mathrm{CS}}(\mathrm{m} / \mathrm{s})$ & $\mathrm{U} / \mathrm{U}_{\mathrm{CS}}$ & $\mathrm{U}(\mathrm{m} / \mathrm{s})$ & $\mathrm{U}_{\mathrm{CS}}(\mathrm{m} / \mathrm{s})$ & $\mathrm{U} / \mathrm{U}_{\mathrm{CS}}$ \\
12 & 12.5 & 0.96 & 12 & 16.4 & 0.73 \\
$\mathrm{H} / \mathrm{D}$ & $\mathrm{H}_{\mathrm{C}} / \mathrm{D}$ & $\mathrm{H}_{\mathrm{C}} / \mathrm{H}$ & $\mathrm{H} / \mathrm{D}$ & $\mathrm{H}_{\mathrm{C}} / \mathrm{D}$ & $\mathrm{H}_{\mathrm{C}} / \mathrm{H}$ \\
0.80 & 0.55 & 0.69 & 0.80 & 0.07 & 0.09 \\
$\mathrm{~W}(\mathrm{wt} \%)$ & $\mathrm{W}_{0}{ }^{*}(\mathrm{wt} \%)$ & $0.2 / \mathrm{W}_{0}{ }^{*}$ & $\mathrm{~W}(\mathrm{wt} \%)$ & $\mathrm{W}_{0}{ }^{*}(\mathrm{wt} \%)$ & $0.2 / \mathrm{W}_{0}{ }^{*}$ \\
15.4 & 67.2 & 0.30 & 15.4 & $>\mathrm{W}_{\mathrm{MP}}{ }^{(\mathrm{a})}$ & 0.038 \\
\hline
\end{tabular}

(a) Calculated value exceeds maximum packing fraction.

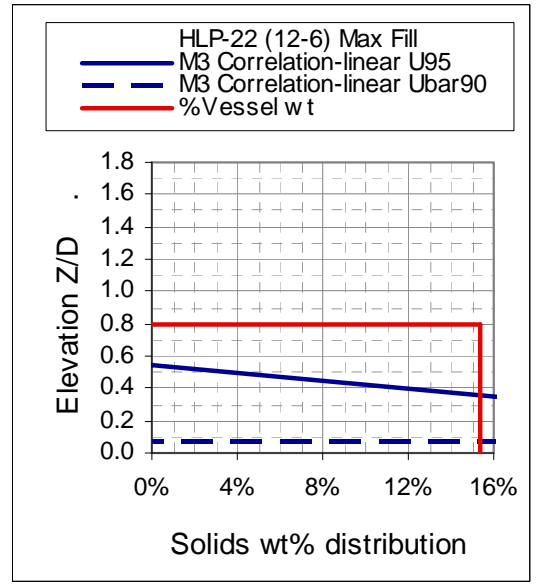

(a)

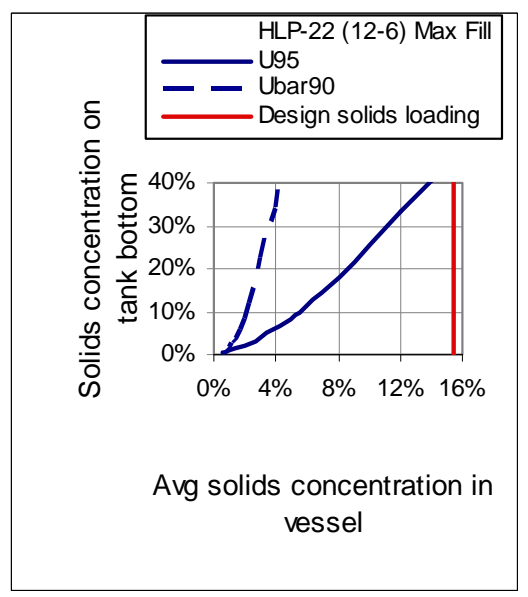

(c)

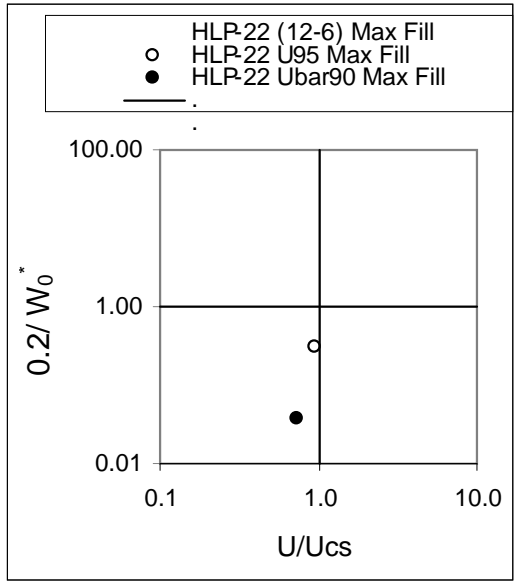

(b)

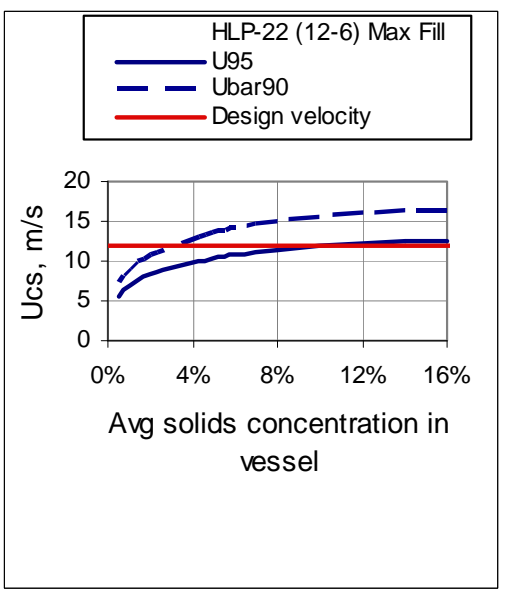

(d)

Figure 9.30. Physical Model Predictions for HLP-22: (a) Concentration Profile at Max Fill, (b) Inlet Concentration and Suspension Ratio, (c) Maximum Solids Concentration Versus Loading Design Conditions, (d) $\mathrm{U}_{\mathrm{CS}}$ Versus Loading at $12 \mathrm{~m} / \mathrm{s}$ with a 6-in. Nozzle (Hanford PSDD, $\rho_{\mathrm{l}}=1.1 \mathrm{~g} / \mathrm{cm}^{3}, \mu=1.5 \mathrm{cP}$ fluid) 


\subsubsection{TCP-01 (Hanford PSDD, $\rho_{\mathrm{l}}=1.1 \mathrm{~g} / \mathrm{cm}^{3}, \mu=1.5 \mathrm{cP}$ fluid) Physical Model}

Table 9.28 presents the physical model results for TCP-01 using the Hanford PSDD, and Figure 9.31 shows the physical model predictions for TCP-01 using the Hanford PSDD.

Table 9.28. Physical Model Results TCP-01 Using Hanford PSDD

\begin{tabular}{cccccc}
\hline \multicolumn{3}{c}{ TCP-01 $\mathrm{U}_{95}$ Max Fill } & \multicolumn{3}{c}{$\mathrm{TCP}-01 \overline{\mathrm{U}}_{90}$ Max Fill } \\
\hline $\mathrm{U}(\mathrm{m} / \mathrm{s})$ & $\mathrm{U}_{\mathrm{CS}}(\mathrm{m} / \mathrm{s})$ & $\mathrm{U} / \mathrm{U}_{\mathrm{CS}}$ & $\mathrm{U}(\mathrm{m} / \mathrm{s})$ & $\mathrm{U}_{\mathrm{CS}}(\mathrm{m} / \mathrm{s})$ & $\mathrm{U} / \mathrm{U}_{\mathrm{CS}}$ \\
8 & 9.0 & 0.89 & 8 & 11.8 & 0.68 \\
$\mathrm{H} / \mathrm{D}$ & $\mathrm{H}_{\mathrm{C}} / \mathrm{D}$ & $\mathrm{H}_{\mathrm{C}} / \mathrm{H}$ & $\mathrm{H} / \mathrm{D}$ & $\mathrm{H}_{\mathrm{C}} / \mathrm{D}$ & $\mathrm{H}_{\mathrm{C}} / \mathrm{H}$ \\
1.25 & 0.39 & 0.31 & 1.25 & 0.08 & 0.06 \\
$\mathrm{~W}(\mathrm{wt} \%)$ & $\mathrm{W}_{0}{ }^{*}(\mathrm{wt} \%)$ & $0.2 / \mathrm{W}_{0}{ }^{*}$ & $\mathrm{~W}(\mathrm{wt} \%)$ & $\mathrm{W}_{0}{ }^{*}(\mathrm{wt} \%)$ & $0.2 / \mathrm{W}_{0}{ }^{*}$ \\
2.7 & 25.8 & 0.77 & 2.7 & $>\mathrm{W}_{\mathrm{MP}}{ }^{(a)}$ & 0.16 \\
\hline
\end{tabular}

(a) Calculated value exceeds maximum packing fraction.

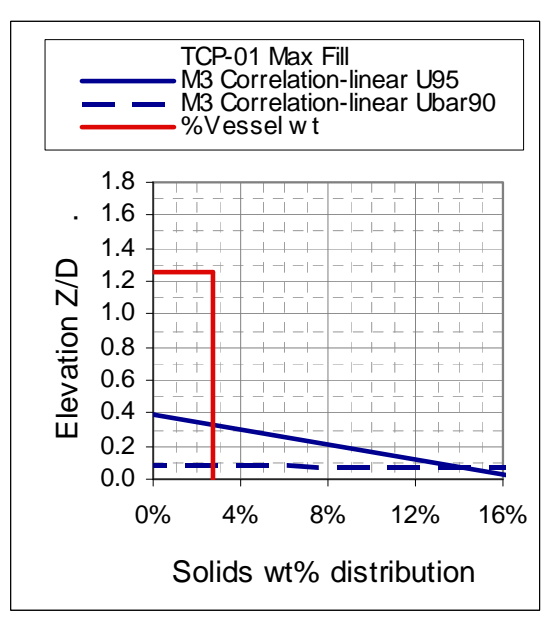

(a)

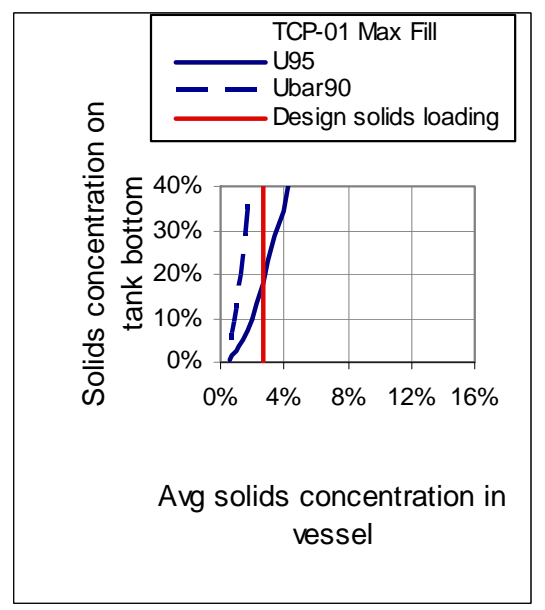

(c)

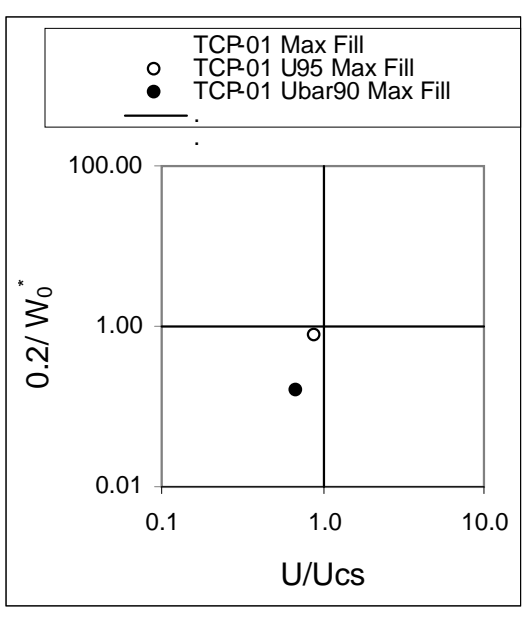

(b)

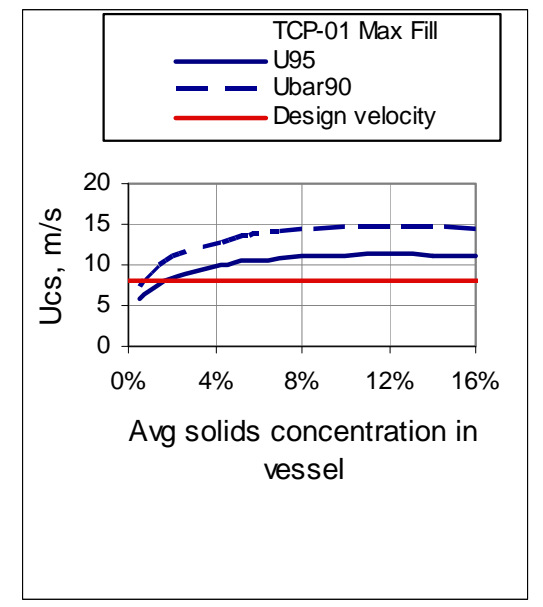

(d)

Figure 9.31. Physical Model Predictions for TCP-01: (a) Concentration Profile at Max Fill, (b) Inlet Concentration and Suspension Ratio, (c) Maximum Solids Concentration Versus Loading Design Conditions, (d) $\mathrm{U}_{\mathrm{CS}}$ Versus Loading (Hanford PSDD, $\rho_{\mathrm{l}}=1.1 \mathrm{~g} / \mathrm{cm}^{3}, \mu=1.5 \mathrm{cP}$ fluid) 


\subsubsection{TLP-09 A/B (Hanford PSDD, $\rho_{\mathrm{l}}=1.1 \mathrm{~g} / \mathrm{cm}^{3}, \mu=1.5 \mathrm{cP}$ fluid) Physical Model}

Table 9.29 lists the physical model results for TLP-09 A/B, and Figure 9.32 depicts the physical model predictions for TLP-09 A/B using the Hanford PSDD.

Table 9.29. Physical Model Results for TLP-09 Using Hanford PSDD

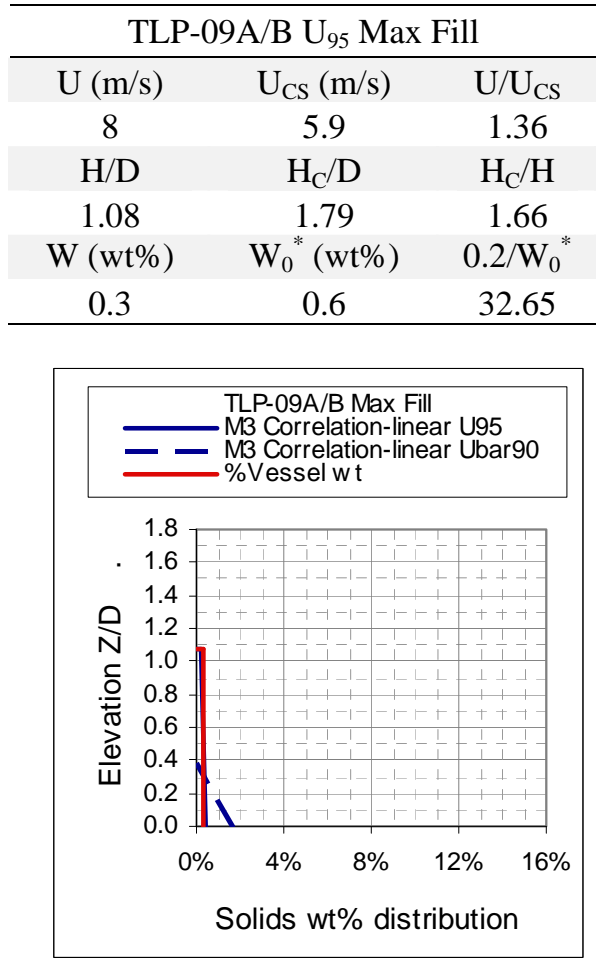

(a)

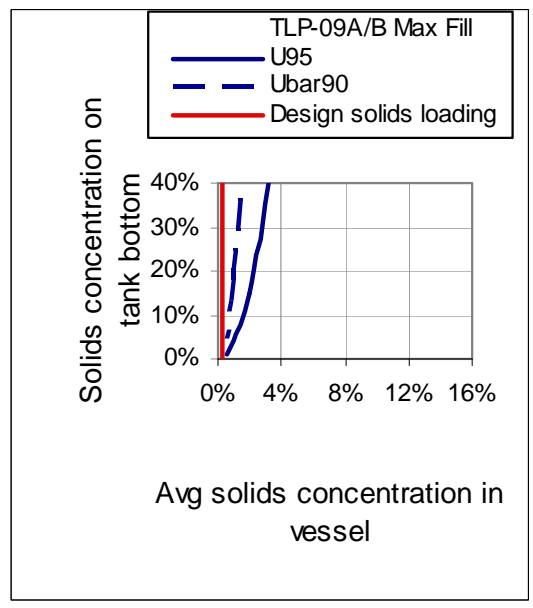

(c)

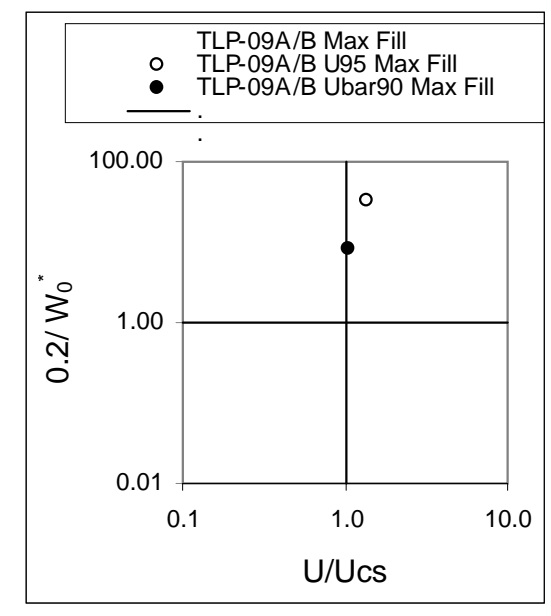

(b)

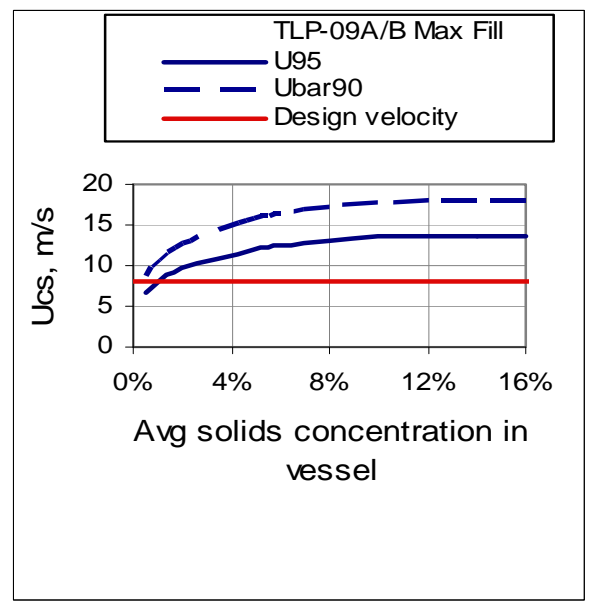

(d)

Figure 9.32. Physical Model Predictions for TLP-09 A/B: (a) Concentration Profile at Max Fill, (b) Inlet Concentration and Suspension Ratio, (c) Maximum Solids Concentration Versus Loading Design Conditions, (d) $\mathrm{U}_{\mathrm{CS}}$ Versus Loading (Hanford PSDD, $\rho_{\mathrm{l}}=1.1 \mathrm{~g} / \mathrm{cm}^{3}$, $\mu=1.5$ cP fluid) 


\subsubsection{PWD-33 (Hanford PSDD, $\rho_{\mathrm{l}}=1.1 \mathrm{~g} / \mathrm{cm}^{3}, \mu=1.5 \mathrm{cP}$ fluid) Physical Model}

Table 9.30 presents physical model results for PWD-33, and Figure 9.33 shows the physical model predictions for PWD-33 using the Hanford PSDD.

Table 9.30. Physical Model Results for PWD-33 Using Hanford PSDD

\begin{tabular}{cccccc}
\hline \multicolumn{3}{c}{ PWD-33 $\mathrm{U}_{95}$ Max Fill } & \multicolumn{3}{c}{ PWD-33 $\overline{\mathrm{U}}_{90}$ Max Fill } \\
\hline $\mathrm{U}(\mathrm{m} / \mathrm{s})$ & $\mathrm{U}_{\mathrm{CS}}(\mathrm{m} / \mathrm{s})$ & $\mathrm{U} / \mathrm{U}_{\mathrm{CS}}$ & $\mathrm{U}(\mathrm{m} / \mathrm{s})$ & $\mathrm{U}_{\mathrm{CS}}(\mathrm{m} / \mathrm{s})$ & $\mathrm{U} / \mathrm{U}_{\mathrm{CS}}$ \\
8 & 11.4 & 0.70 & 8 & 15.0 & 0.53 \\
$\mathrm{H} / \mathrm{D}$ & $\mathrm{H}_{\mathrm{C}} / \mathrm{D}$ & $\mathrm{H}_{\mathrm{C}} / \mathrm{H}$ & $\mathrm{H} / \mathrm{D}$ & $\mathrm{H}_{\mathrm{C}} / \mathrm{D}$ & $\mathrm{H}_{\mathrm{C}} / \mathrm{H}$ \\
0.45 & 0.17 & 0.38 & 0.45 & 0.04 & 0.08 \\
$\mathrm{~W}(\mathrm{wt} \%)$ & $\mathrm{W}_{0}{ }^{*}(\mathrm{wt} \%)$ & $0.2 / \mathrm{W}_{0}{ }^{*}$ & $\mathrm{~W}(\mathrm{wt} \%)$ & $\mathrm{W}_{0}{ }^{*}(\mathrm{wt} \%)$ & $0.2 / \mathrm{W}_{0}{ }^{*}$ \\
8.1 & 64.4 & 0.31 & 8.1 & $>\mathrm{W}_{\mathrm{MP}}{ }^{(\mathrm{a})}$ & 0.06 \\
\hline
\end{tabular}

(a) Calculated value exceeds maximum packing fraction.

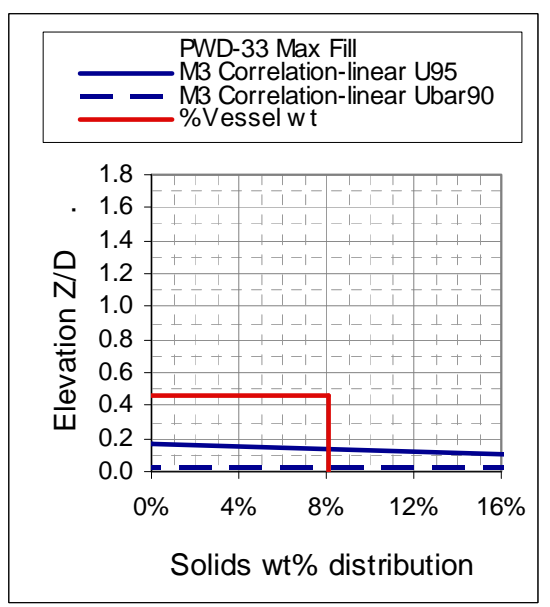

(a)

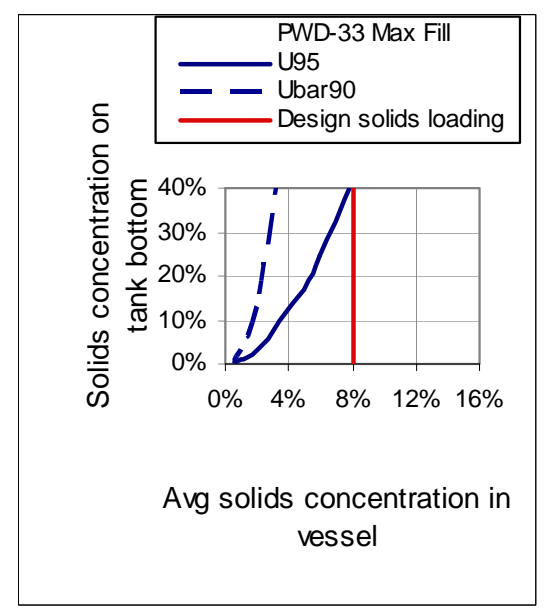

(c)

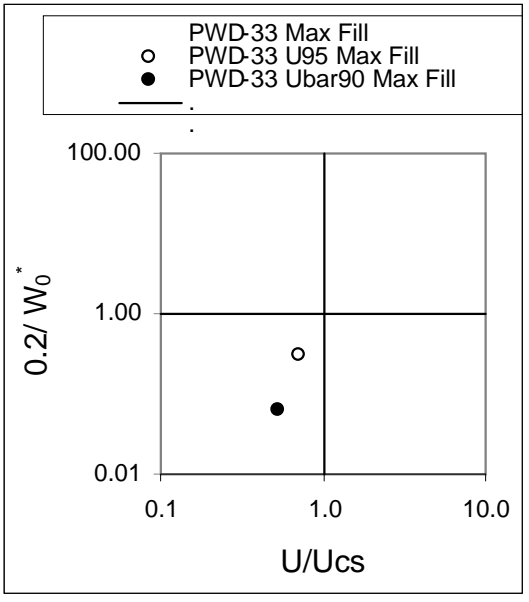

(b)

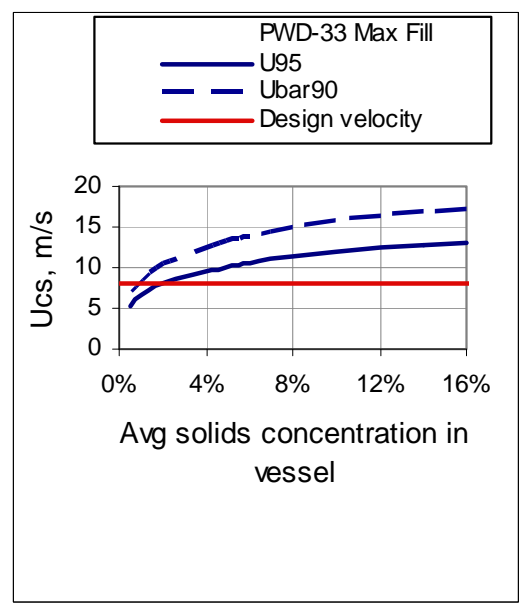

(d)

Figure 9.33. Physical Model Predictions for PWD-33: (a) Concentration Profile at Max Fill, (b) Inlet Concentration and Suspension Ratio, (c) Maximum Solids Concentration Versus Loading Design Conditions, (d) $U_{C S}$ Versus Loading (Hanford PSDD, $\rho_{\mathrm{l}}=1.1 \mathrm{~g} / \mathrm{cm}^{3}, \mu=1.5 \mathrm{cP}$ fluid) 
The characteristic settling rate selected for a vessel assessment affects the predictions of $\mathrm{U}_{\mathrm{CS}}$. To illustrate the sensitivity of this input value, another calculation for PWD-33 is provided assuming conditions that are likely bounding in a non-conservative direction (i.e., the actual performance would likely be worse than these predicted values). The bounding condition for calculating $\mathrm{U}_{\mathrm{CS}}$ uses a particle settling rate, $U_{T}$, which is the average of the entire distribution of the Hanford PSDD. This particle settling rate is $1.02 \mathrm{E}-3 \mathrm{~m} / \mathrm{s}$, and corresponds to a particle diameter $\mathrm{d}$ of 42 microns with a specific gravity of 2.78. Under these conditions, the $\mathrm{U}_{\mathrm{CS}}$ is predicted to be $9.4 \mathrm{~m} / \mathrm{s}$.

Similarly, the solids concentration at the bottom of the vessel is sensitive to the gradient of the solids concentration within the cloud. Observations and attenuation (concentration) measurements taken during testing identified much higher concentrations of solids near the bottom of the test vessels than at the peak of the recorded cloud. A non-conservatively bounding condition for calculating the concentration at the pump suction is based on an assumption that the suspension of solids would be perfectly (homogeneously) mixed up to the peak of the cloud. In this example, the cloud height is calculated using the $\mathrm{U}_{95}$ particle settling velocity, and the cloud height that corresponds to a pump suction concentration of $20 \mathrm{wt} \%$ is $4.4 \mathrm{ft}$. Using the physical model, the jet velocity $\mathrm{U}$ required to lift solids to $4.4 \mathrm{ft}$ would need to be $8.1 \mathrm{~m} / \mathrm{s}$. 


\subsubsection{PWD-43 (Hanford PSDD, $\rho_{\mathrm{l}}=1.1 \mathrm{~g} / \mathrm{cm}^{3}, \mu=1.5 \mathrm{cP}$ fluid) Physical Model}

Table 9.31 presents physical model results for PWD-43, and Figure 9.34 depicts the physical model predictions for PWD-43 using the Hanford PSDD.

Table 9.31. Physical Model Results for PWD-43 Using Hanford PSDD

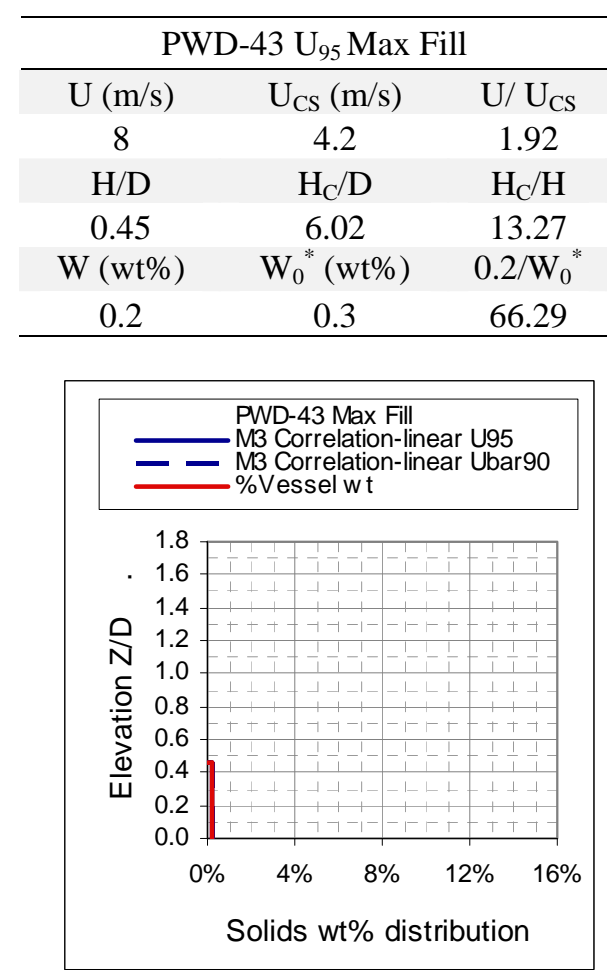

(a)

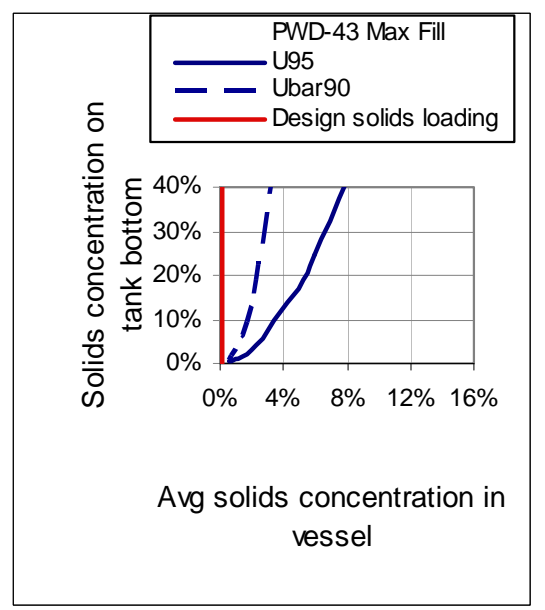

(c)

\begin{tabular}{ccc}
\multicolumn{3}{c}{ PWD-43 $\overline{\mathrm{U}}_{90}$ Max Fill } \\
$\mathrm{U}(\mathrm{m} / \mathrm{s})$ & $\mathrm{U}_{\mathrm{CS}}(\mathrm{m} / \mathrm{s})$ & $\mathrm{U} / \mathrm{U}_{\mathrm{CS}}$ \\
8 & 5.5 & 1.46 \\
$\mathrm{H} / \mathrm{D}$ & $\mathrm{H}_{\mathrm{C}} / \mathrm{D}$ & $\mathrm{H}_{\mathrm{C}} / \mathrm{H}$ \\
0.45 & 1.33 & 2.92 \\
$\mathrm{~W}(\mathrm{wt} \%)$ & $\mathrm{W}_{0}{ }^{*}(\mathrm{wt} \%)$ & $0.2 / \mathrm{W}_{0}{ }^{*}$ \\
0.2 & 0.3 & 59.67 \\
\hline
\end{tabular}

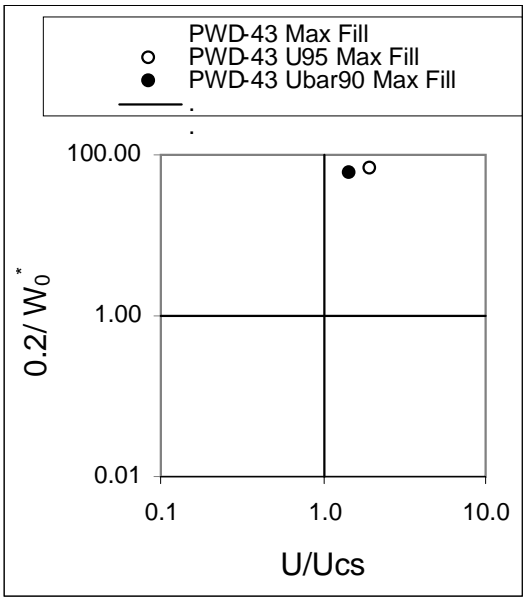

(b)

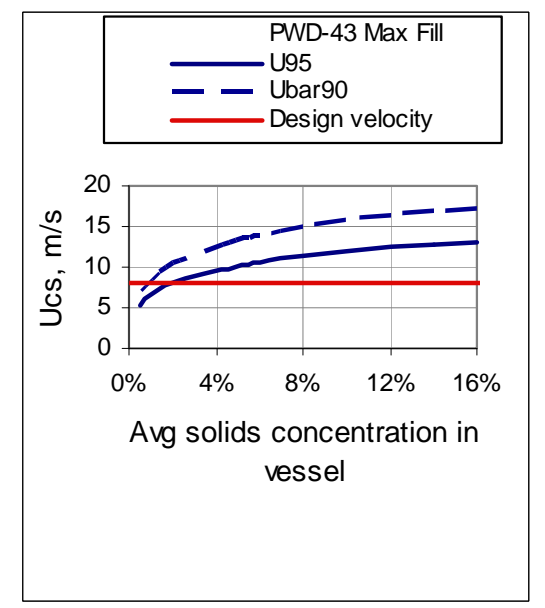

(d)

Figure 9.34. Physical Model Predictions for PWD-43: (a) Concentration Profile at Max Fill, (b) Inlet Concentration and Suspension Ratio, (c) Maximum Solids Concentration Versus Loading Design Conditions, (d) $U_{\text {CS }}$ Versus Loading (Hanford PSDD, $\rho_{1}=1.1 \mathrm{~g} / \mathrm{cm}^{3}, \mu=1.5 \mathrm{cP}$ fluid) 


\subsubsection{PWD-44 (Hanford PSDD, $\rho_{\mathrm{l}}=1.1 \mathrm{~g} / \mathrm{cm}^{3}, \mu=1.5 \mathrm{cP}$ fluid) Physical Model}

Table 9.32 presents physical model results for PWD-44 using the Hanford PSDD, and Figure 9.35 depicts the physical model predictions for PWD-44 using the Hanford PSDD.

Table 9.32. Physical Model Results for PWD-44 Using Hanford PSDD

\begin{tabular}{cccccc}
\hline \multicolumn{3}{c}{ PWD-44 $\mathrm{U}_{95}$ Max Fill } & \multicolumn{3}{c}{ PWD-44 $\overline{\mathrm{U}}_{90}$ Max Fill } \\
\hline $\mathrm{U}(\mathrm{m} / \mathrm{s})$ & $\mathrm{U}_{\mathrm{CS}}(\mathrm{m} / \mathrm{s})$ & $\mathrm{U} / \mathrm{U}_{\mathrm{CS}}$ & $\mathrm{U}(\mathrm{m} / \mathrm{s})$ & $\mathrm{U}_{\mathrm{CS}}(\mathrm{m} / \mathrm{s})$ & $\mathrm{U} / \mathrm{U}_{\mathrm{CS}}$ \\
8 & 9.3 & 0.86 & 8 & 12.2 & 0.66 \\
$\mathrm{H} / \mathrm{D}$ & $\mathrm{H}_{\mathrm{C}} / \mathrm{D}$ & $\mathrm{H}_{\mathrm{C}} / \mathrm{H}$ & $\mathrm{H} / \mathrm{D}$ & $\mathrm{H}_{\mathrm{C}} / \mathrm{D}$ & $\mathrm{H}_{\mathrm{C}} / \mathrm{H}$ \\
1.32 & 0.35 & 0.26 & 1.32 & 0.06 & 0.05 \\
$\mathrm{~W}(\mathrm{wt} \%)$ & $\mathrm{W}_{0}{ }^{*}(\mathrm{wt} \%)$ & $0.2 / \mathrm{W}_{0}{ }^{*}$ & $\mathrm{~W}(\mathrm{wt} \%)$ & $\mathrm{W}_{0}{ }^{*}(\mathrm{wt} \%)$ & $0.2 / \mathrm{W}_{0}{ }^{*}$ \\
8.1 & $>\mathrm{W}_{\mathrm{MP}}{ }^{(\mathrm{a})}$ & 0.22 & 8.1 & $>\mathrm{W}_{\mathrm{MP}}{ }^{(\mathrm{a})}$ & 0.04 \\
\hline
\end{tabular}

(a) Calculated value exceeds maximum packing fraction.

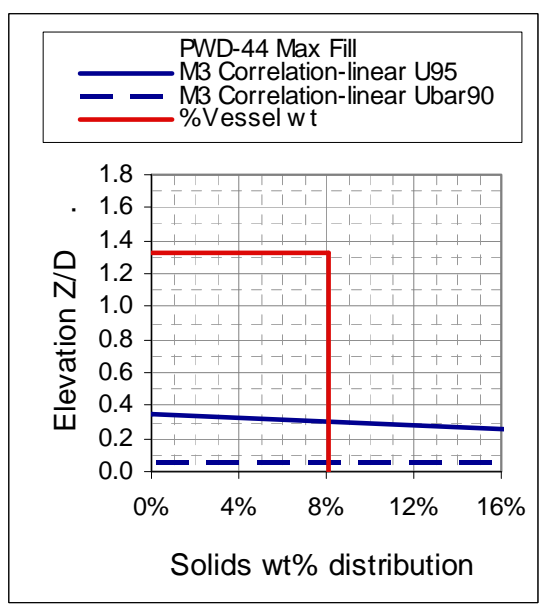

(a)

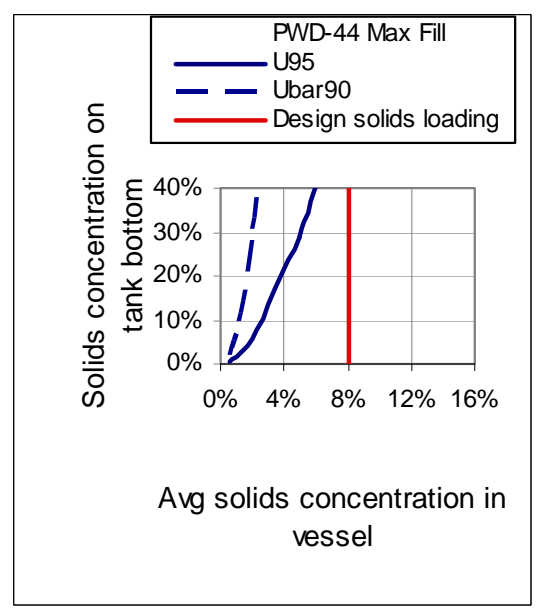

(c)

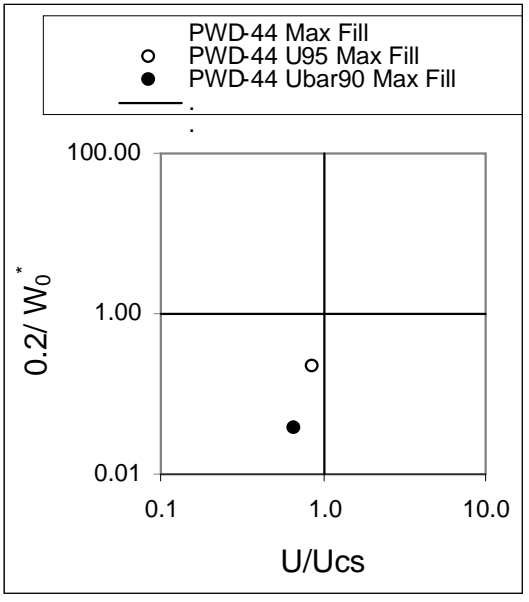

(b)

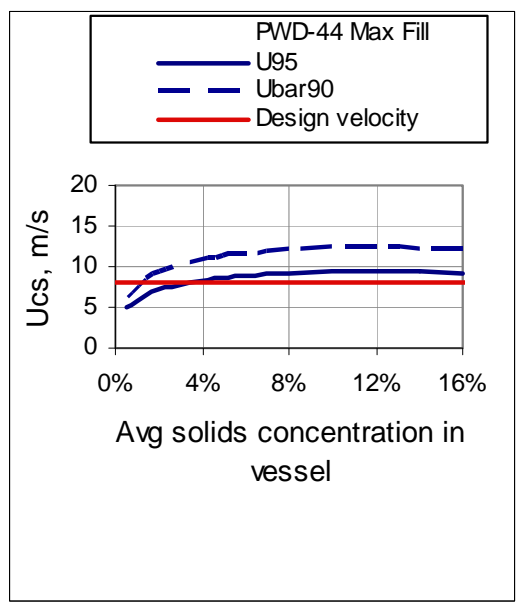

(d)

Figure 9.35. Physical Model Predictions for PWD-44: (a) Concentration Profile at Max Fill, (b) Inlet Concentration and Suspension Ratio, (c) Maximum Solids Concentration Versus Loading Design Conditions, (d) $U_{C S}$ Versus Loading (Hanford PSDD, $\rho_{\mathrm{l}}=1.1 \mathrm{~g} / \mathrm{cm}^{3}, \mu=1.5 \mathrm{cP}$ fluid) 


\subsubsection{FEP-17 A/B (Hanford PSDD, $\rho_{l}=1.1 \mathrm{~g} / \mathrm{cm}^{3}, \mu=1.5 \mathrm{cP}$ fluid) Physical Model}

Table 9.33 presents physical model results for FEP-17 A/B using the Hanford PSDD, and Figure 9.36 depicts the physical model predictions for FEP-17 A/B using the Hanford PSDD.

Table 9.33. Physical Model Results for FEP-17 Using Hanford PSDD

\begin{tabular}{cccccc}
\hline \multicolumn{3}{c}{ FEP-17A/B U U5 Max Fill } & \multicolumn{3}{c}{ FEP-17A/B $\overline{\mathrm{U}}_{90}$ Max Fill } \\
\hline $\mathrm{U}(\mathrm{m} / \mathrm{s})$ & $\mathrm{U}_{\mathrm{CS}}(\mathrm{m} / \mathrm{s})$ & $\mathrm{U} / \mathrm{U}_{\mathrm{CS}}$ & $\mathrm{U}(\mathrm{m} / \mathrm{s})$ & $\mathrm{U}_{\mathrm{CS}}(\mathrm{m} / \mathrm{s})$ & $\mathrm{U} / \mathrm{U}_{\mathrm{CS}}$ \\
8 & 8.2 & 0.98 & 8 & 10.8 & 0.74 \\
$\mathrm{H} / \mathrm{D}$ & $\mathrm{H}_{\mathrm{C}} / \mathrm{D}$ & $\mathrm{H}_{\mathrm{C}} / \mathrm{H}$ & $\mathrm{H} / \mathrm{D}$ & $\mathrm{H}_{\mathrm{C}} / \mathrm{D}$ & $\mathrm{H}_{\mathrm{C}} / \mathrm{H}$ \\
1.19 & 0.54 & 0.45 & 1.19 & 0.11 & 0.09 \\
$\mathrm{~W}(\mathrm{wt} \%)$ & $\mathrm{W}_{0}{ }^{*}(\mathrm{wt} \%)$ & $0.2 / \mathrm{W}_{0}{ }^{*}$ & $\mathrm{~W}(\mathrm{wt} \%)$ & $\mathrm{W}_{0}{ }^{*}(\mathrm{wt} \%)$ & $0.2 / \mathrm{W}_{0}{ }^{*}$ \\
4.4 & 29.1 & 0.69 & 4.4 & $>\mathrm{W}_{\mathrm{MP}}{ }^{(\mathrm{a})}$ & 0.14 \\
\hline
\end{tabular}

(a) Calculated value exceeds maximum packing fraction.

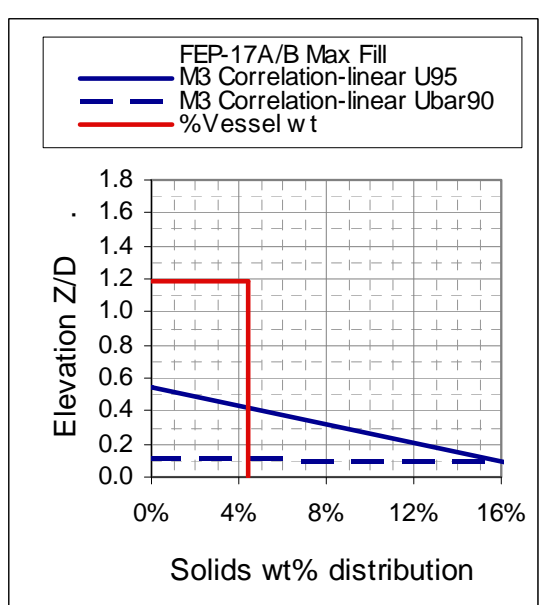

(a)

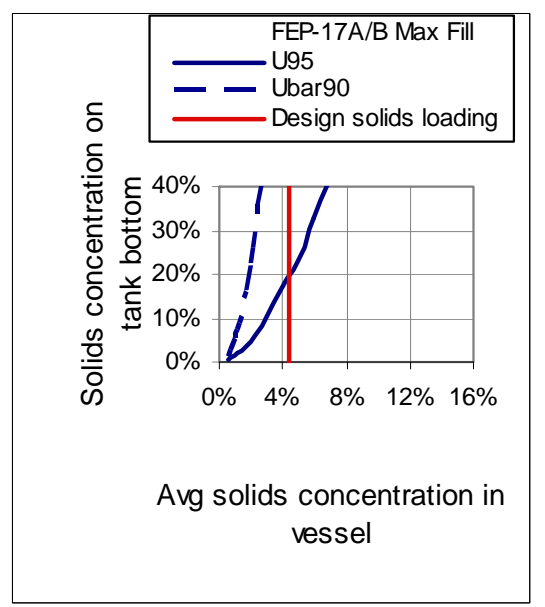

(c)

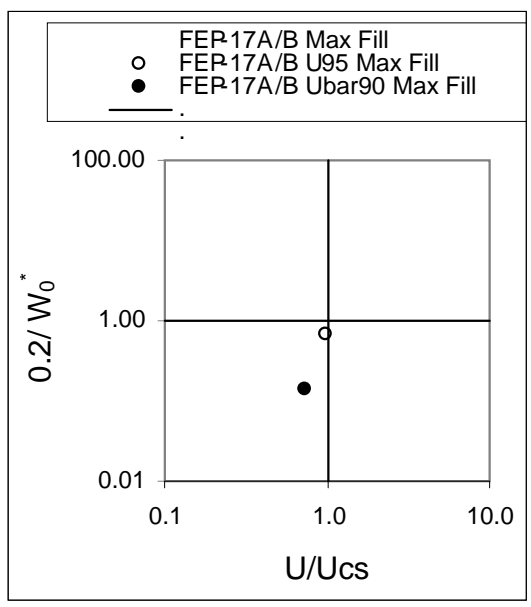

(b)

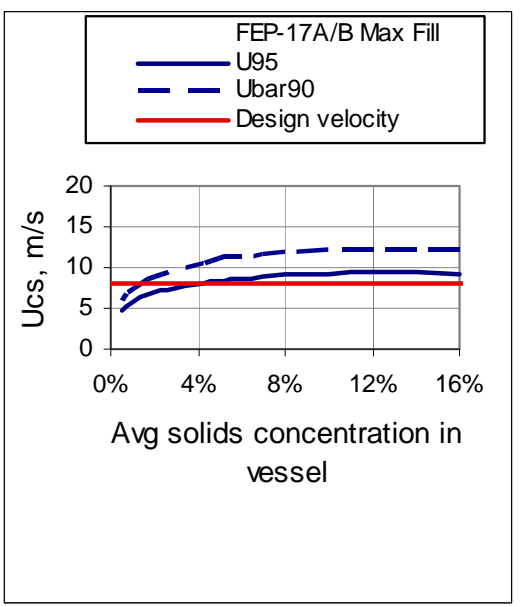

(d)

Figure 9.36. Physical Model Predictions for FEP-17 A/B: (a) Concentration Profile at Max Fill, (b) Inlet Concentration and Suspension Ratio, (c) Maximum Solids Concentration Versus Loading Design Conditions, (d) $\mathrm{U}_{\mathrm{CS}}$ Versus Loading (Hanford PSDD, $\rho_{\mathrm{l}}=1.1 \mathrm{~g} / \mathrm{cm}^{3}$, $\mu=1.5$ cP fluid) 


\subsubsection{PWD-15/16 (Hanford PSDD, $\rho_{1}=1.1 \mathrm{~g} / \mathrm{cm}^{3}, \mu=1.5 \mathrm{cP}$ fluid) Physical Model}

Table 9.34 lists physical model results for PWD-15/16 using the Hanford PSDD, and Figure 9.37 presents the physical model predictions for PWD-15/16 using the Hanford PSDD.

Table 9.34. Physical Model Results for PWD-15/16 Using Hanford PSDD

\begin{tabular}{cccccc}
\hline \multicolumn{3}{c}{ PWD-15/16 $\mathrm{U}_{95}$ Max Fill } & \multicolumn{3}{c}{$\mathrm{PWD}-15 / 16 \overline{\mathrm{U}}_{90}$ Max Fill } \\
\hline $\mathrm{U}(\mathrm{m} / \mathrm{s})$ & $\mathrm{U}_{\mathrm{CS}}(\mathrm{m} / \mathrm{s})$ & $\mathrm{U} / \mathrm{U}_{\mathrm{CS}}$ & $\mathrm{U}(\mathrm{m} / \mathrm{s})$ & $\mathrm{U}_{\mathrm{CS}}(\mathrm{m} / \mathrm{s})$ & $\mathrm{U} / \mathrm{U}_{\mathrm{CS}}$ \\
8 & 8.6 & 0.93 & 8 & 11.3 & 0.71 \\
$\mathrm{H} / \mathrm{D}$ & $\mathrm{H}_{\mathrm{C}} / \mathrm{D}$ & $\mathrm{H}_{\mathrm{C}} / \mathrm{H}$ & $\mathrm{H} / \mathrm{D}$ & $\mathrm{H}_{\mathrm{C}} \mathrm{D}$ & $\mathrm{H}_{\mathrm{C}} / \mathrm{H}$ \\
1.78 & 0.46 & 0.26 & 1.78 & 0.09 & 0.05 \\
$\mathrm{~W}(\mathrm{wt} \%)$ & $\mathrm{W}_{0}{ }^{*}(\mathrm{wt} \%)$ & $0.2 / \mathrm{W}_{0}{ }^{*}$ & $\mathrm{~W}(\mathrm{wt} \%)$ & $\mathrm{W}_{0}{ }^{*}(\mathrm{wt} \%)$ & $0.2 / \mathrm{W}_{0}{ }^{*}$ \\
3 & 35.1 & 0.57 & 3 & $>\mathrm{W}_{\mathrm{MP}}{ }^{(a)}$ & 0.11 \\
\hline
\end{tabular}

(a) Calculated value exceeds maximum packing fraction.

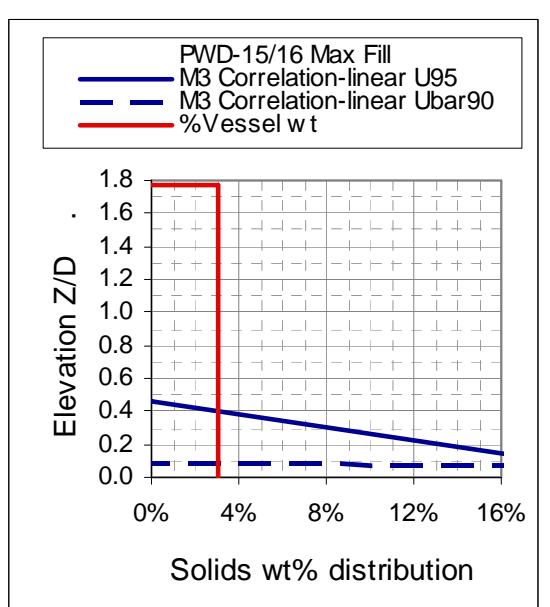

(a)

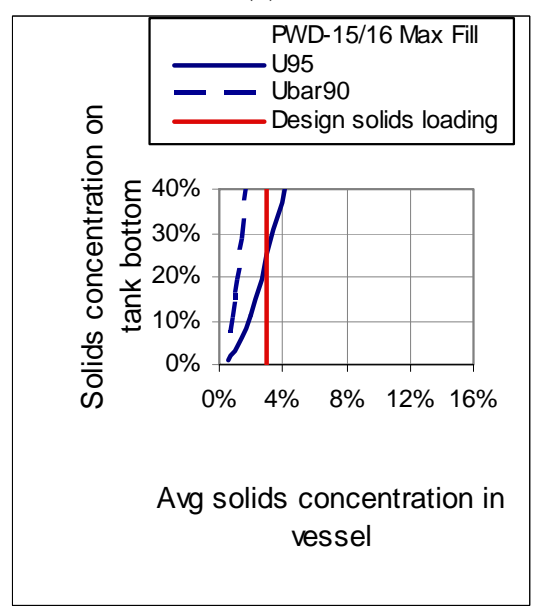

(c)

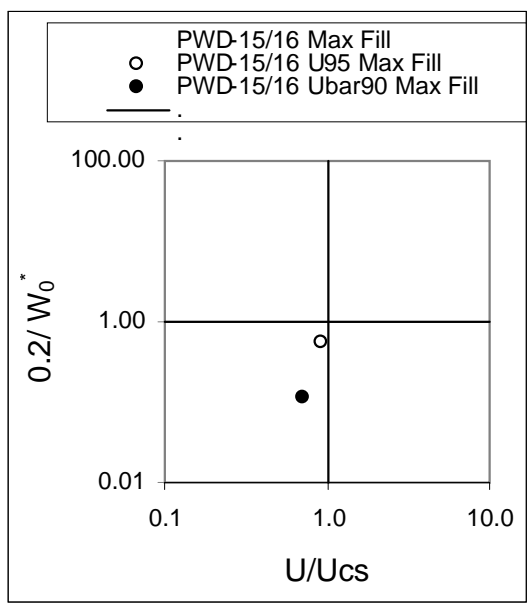

(b)

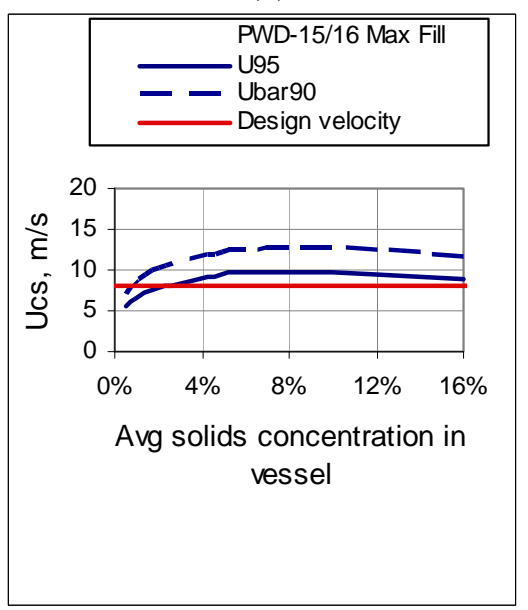

(d)

Figure 9.37. Physical Model Predictions for PWD-15/16: (a) Concentration Profile at Max Fill, (b) Inlet Concentration and Suspension Ratio, (c) Maximum Solids Concentration Versus Loading Design Conditions, (d) $U_{\text {CS }}$ Versus Loading (Hanford PSDD, $\rho_{\mathrm{l}}=1.1 \mathrm{~g} / \mathrm{cm}^{3}, \mu=1.5 \mathrm{cP}$ fluid) 


\subsubsection{UFP-01 A/B (Hanford PSDD, $\rho_{l}=1.1 \mathrm{~g} / \mathrm{cm}^{3}, \mu=1.5 \mathrm{cP}$ fluid) Physical Model}

Table 9.35 presents physical model results for UFP-01 A/B, and Figure 9.38 presents the physical model predictions for UFP-01 A/B using the Hanford PSDD.

Table 9.35. Physical Model Results for UFP-01 Using Hanford PSDD

\begin{tabular}{cccccc}
\hline \multicolumn{3}{c}{ UFP-01A/B U $\mathrm{U}_{95}$ Max Fill } & \multicolumn{3}{c}{$\mathrm{UFP}-01 \mathrm{~A} / \mathrm{B} \overline{\mathrm{U}}_{90}$ Max Fill } \\
\hline $\mathrm{U}(\mathrm{m} / \mathrm{s})$ & $\mathrm{U}_{\mathrm{CS}}(\mathrm{m} / \mathrm{s})$ & $\mathrm{U} / \mathrm{U}_{\mathrm{CS}}$ & $\mathrm{U}(\mathrm{m} / \mathrm{s})$ & $\mathrm{U}_{\mathrm{CS}}(\mathrm{m} / \mathrm{s})$ & $\mathrm{U} / \mathrm{U}_{\mathrm{CS}}$ \\
8 & 7.2 & 1.12 & 8 & 9.4 & 0.85 \\
$\mathrm{H} / \mathrm{D}$ & $\mathrm{H}_{\mathrm{C}} / \mathrm{D}$ & $\mathrm{H}_{\mathrm{C}} / \mathrm{H}$ & $\mathrm{H} / \mathrm{D}$ & $\mathrm{H}_{\mathrm{C}} / \mathrm{D}$ & $\mathrm{H}_{\mathrm{C}} / \mathrm{H}$ \\
1.45 & 0.87 & 0.60 & 1.45 & 0.17 & 0.12 \\
$\mathrm{~W}(\mathrm{wt} \%)$ & $\mathrm{W}_{0}{ }^{*}(\mathrm{wt} \%)$ & $0.2 / \mathrm{W}_{0}{ }^{*}$ & $\mathrm{~W}(\mathrm{wt} \%)$ & $\mathrm{W}_{0}{ }^{*}(\mathrm{wt} \%)$ & $0.2 / \mathrm{W}_{0}{ }^{*}$ \\
3.8 & 19.0 & 1.05 & 3.8 & $>\mathrm{W}_{\mathrm{MP}}{ }^{(\mathrm{a})}$ & 0.21 \\
\hline
\end{tabular}

(a) Calculated value exceeds maximum packing fraction.

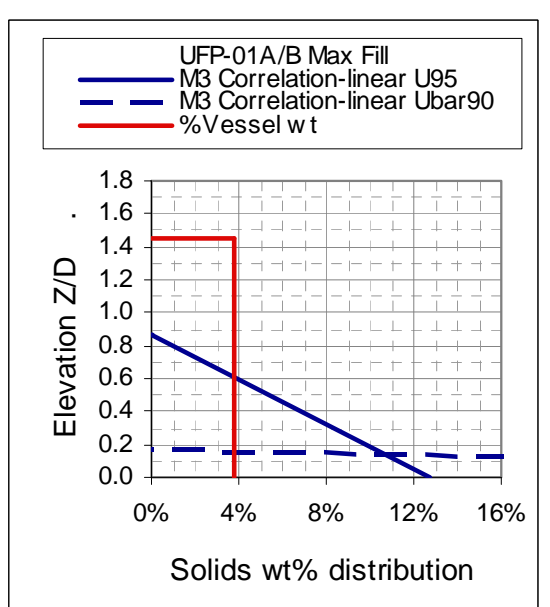

(a)

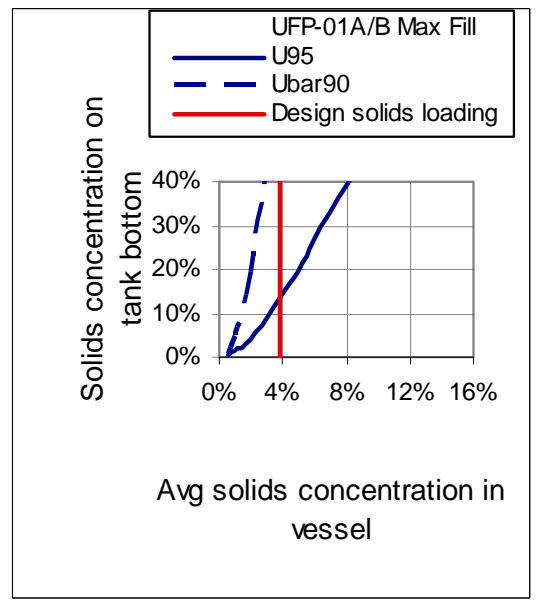

(c)

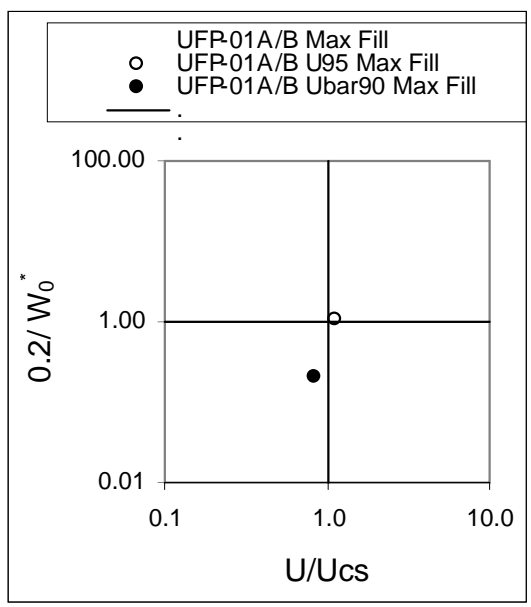

(b)

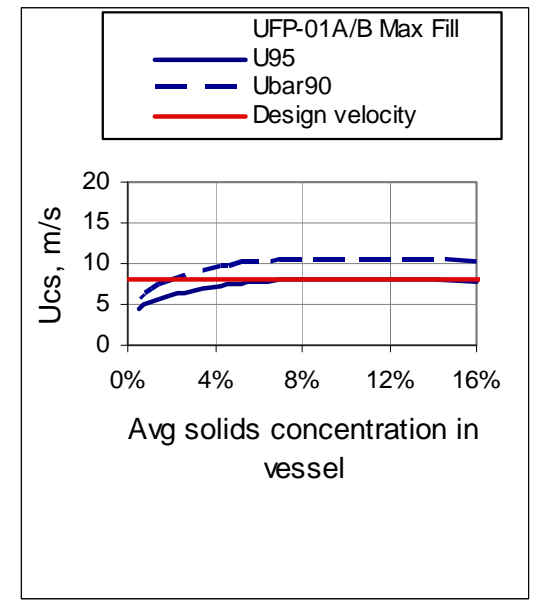

(d)

Figure 9.38. Physical Model Predictions for UFP-01 A/B: (a) Concentration Profile at Max Fill, (b) Inlet Concentration and Suspension Ratio, (c) Maximum Solids Concentration Versus Loading Design Conditions, (d) $\mathrm{U}_{\mathrm{CS}}$ Versus Loading (Hanford PSDD, $\rho_{\mathrm{l}}=1.1 \mathrm{~g} / \mathrm{cm}^{3}$, $\mu=1.5$ cP fluid) 


\subsubsection{RLD-07 (Hanford PSDD, $\rho_{\mathrm{l}}=1.1 \mathrm{~g} / \mathrm{cm}^{3}, \mu=1.5 \mathrm{cP}$ fluid) Physical Model}

Table 9.36 presents physical model results for RLD-07, and Figure 9.39 shows the physical model predictions for RLD-07 using the Hanford PSDD.

Table 9.36. Physical Model Results for RLD-07 Using Hanford PSDD

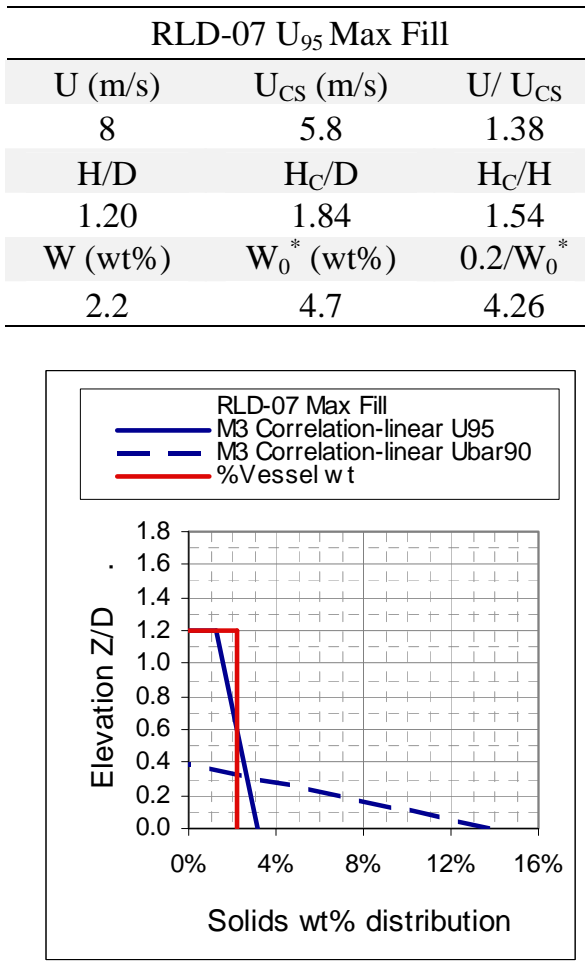

(a)

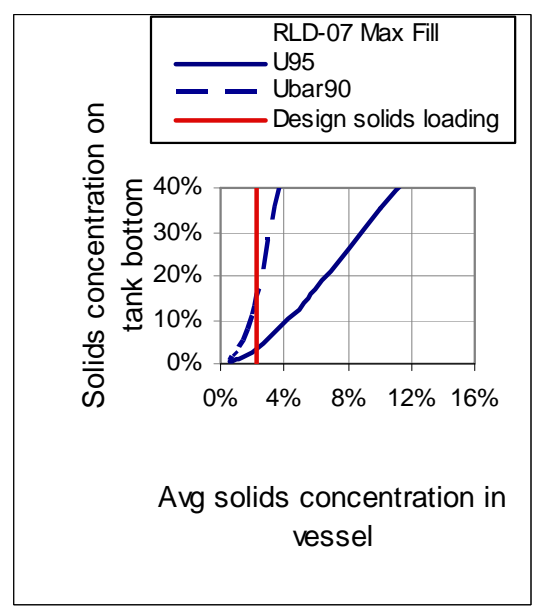

(c)

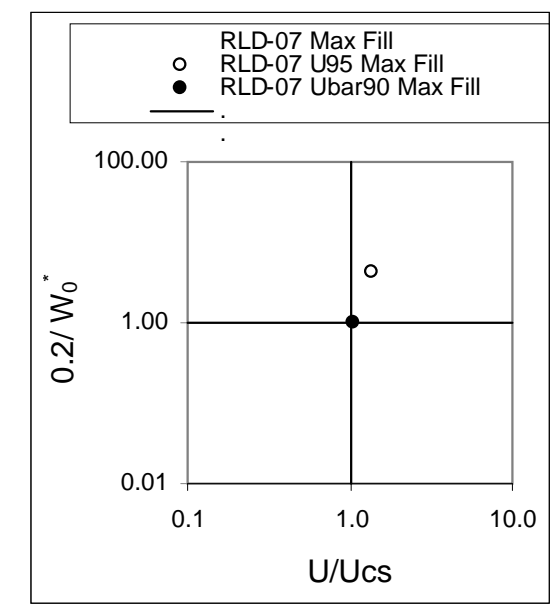

(b)

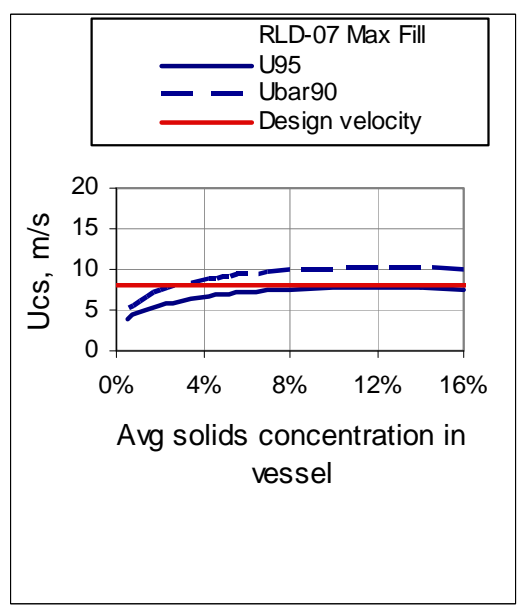

(d)

Figure 9.39 Physical Model Predictions for RLD-07: (a) Concentration Profile at Max Fill, (b) Inlet Concentration and Suspension Ratio, (c) Maximum Solids Concentration Versus Loading Design Conditions, (d) $U_{C S}$ Versus Loading (Hanford PSDD, $\rho_{\mathrm{l}}=1.1 \mathrm{~g} / \mathrm{cm}^{3}, \mu=1.5 \mathrm{cP}$ fluid) 


\subsubsection{RLD-08 (Hanford PSDD, $\rho_{\mathrm{l}}=1.1 \mathrm{~g} / \mathrm{cm}^{3}, \mu=1.5 \mathrm{cP}$ fluid) Physical Model}

Table 9.37 lists physical model results for RLD-08, and Figure 9.40 shows physical model predictions for RLD-08 using the Hanford PSDD.

Table 9.37. Physical Model Results for RLD-08 Using Hanford PSDD

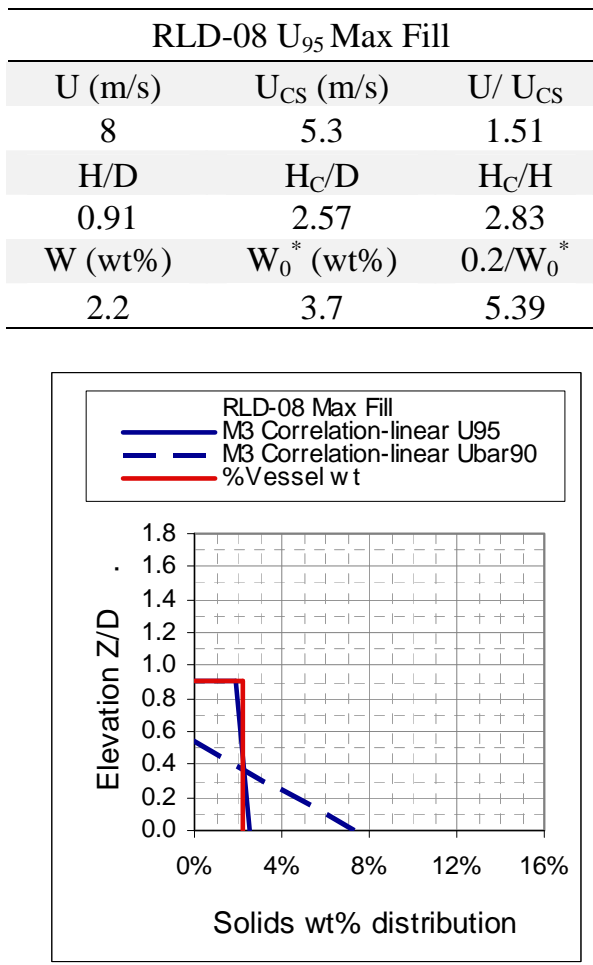

(a)

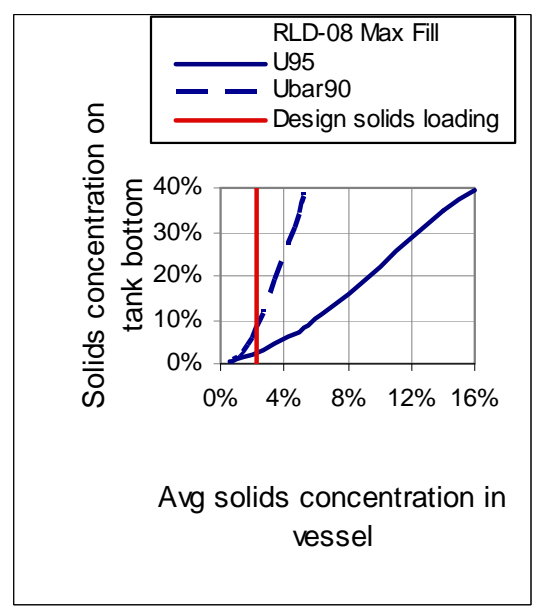

(c)

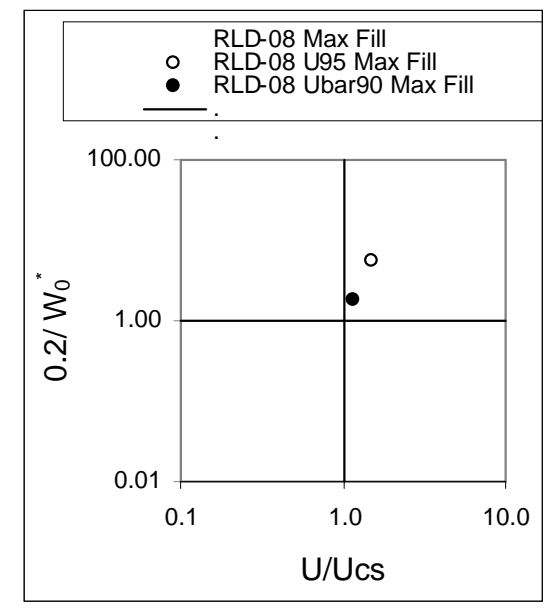

(b)

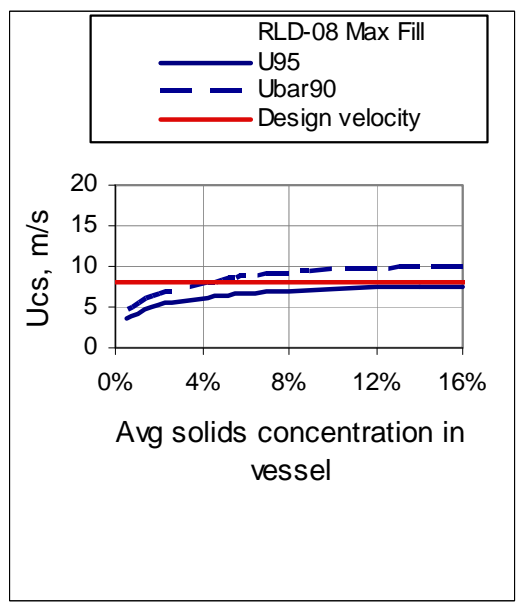

(d)

Figure 9.40. Physical Model Predictions for RLD-08: (a) Concentration Profile at Max Fill, (b) Inlet Concentration and Suspension Ratio, (c) Maximum Solids Concentration Versus Loading Design Conditions, (d) $U_{C S}$ Versus Loading (Hanford PSDD, $\rho_{\mathrm{l}}=1.1 \mathrm{~g} / \mathrm{cm}^{3}, \mu=1.5 \mathrm{cP}$ fluid) 


\subsubsection{HOP-903/904 (Hanford PSDD, $\rho_{\mathrm{l}}=1.1 \mathrm{~g} / \mathrm{cm}^{3}, \mu=1.5 \mathrm{cP}$ fluid) Physical Model}

Table 9.38 lists physical model results for HOP-903/904, and Figure 9.41 depicts physical model predictions for HOP-903/904 using the Hanford PSDD.

Table 9.38. Physical Model Results for HOP-903/904 Using Hanford PSDD

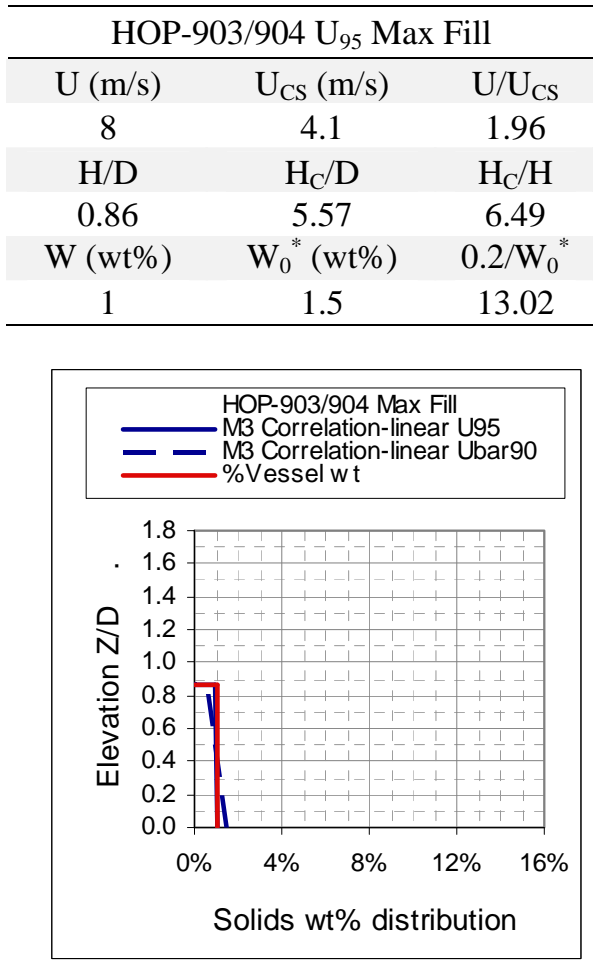

(a)

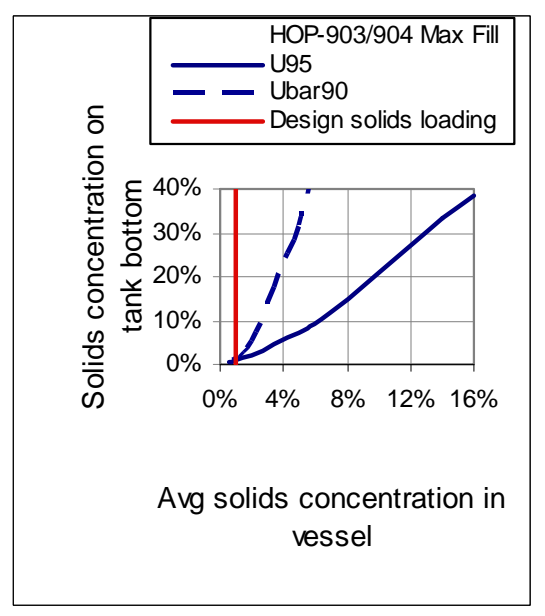

(c)

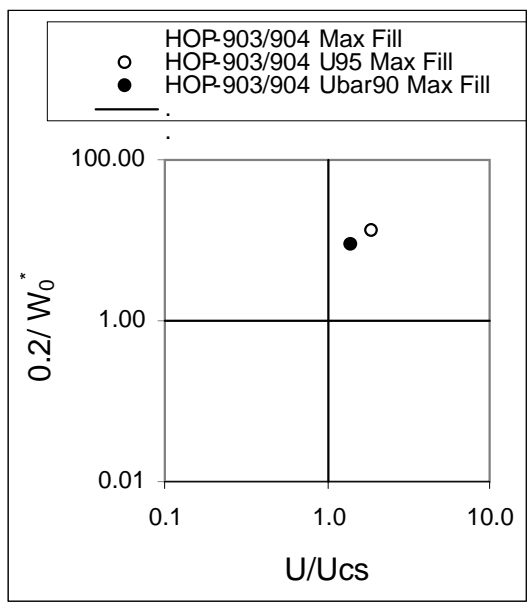

(b)

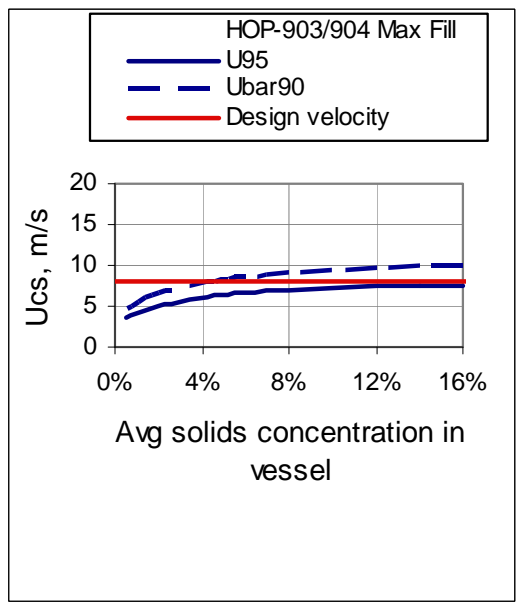

(d)

Figure 9.41. Physical Model Predictions for HOP-903/904: (a) Concentration Profile at Max Fill, (b) Inlet Concentration and Suspension Ratio, (c) Maximum Solids Concentration Versus Loading for Design Condition, (d) $U_{C S}$ Versus Loading (Hanford PSDD, $\rho_{1}=1.1 \mathrm{~g} / \mathrm{cm}^{3}$, $\mu=1.5$ cP fluid) 


\subsection{Vessel Evaluation Examples Using the Generalized Models and the Hanford Waste Distribution}

Mixing performance of WTP vessels was evaluated based on the Hanford waste distribution using the generalized models for $\mathrm{U}_{\mathrm{CS}}$ and $\mathrm{H}_{\mathrm{C}}$ statistically developed in Appendix $\mathrm{F}$ and summarized in Section 7.4. The $\mathrm{H}_{\mathrm{C}}$ generalized model was substituted in the $\mathrm{C}_{0}$ model discussed in Sections 7.3.3 and 7.3.4, with $\mathrm{C}_{0}$ Model modified to $\mathrm{W}_{0}{ }^{*}$, as described in Section 9.1.4. The results of the evaluations are presented in Sections 9.5.1 through 9.5.16.

The Hanford waste settling properties and particle characteristics used in the examples are the same as those used in Section 9.4. The vessel geometry and operating conditions are listed in Table 9.2, and vessel loading is shown in Table 9.4. These examples are for the vessel conditions that were provided in Olsen (2008a).

Note that Tables 9.39 through 9.54 display only a few significant figures. The calculations are not based on this reduced number of digits. Therefore, small calculation differences are observed when using the displayed rounded numbers for calculations. 


\subsubsection{FRP-02 A/B $/ C / D$ (Hanford PSDD, $\rho_{\mathrm{l}}=1.1 \mathrm{~g} / \mathrm{cm}^{3}, \mu=1.5 \mathrm{cP}$ fluid) Generalized Model}

Table 9.39 lists generalized model results for FRP-02 A/B/C/D using the Hanford PSDD. Figure 9.42 presents the generalized model predictions for FRP-02 A/B/C/D using the Hanford PSDD.

Table 9.39. Generalized Model Results for FRP-02 Using Hanford PSDD

\begin{tabular}{cccccc}
\hline \multicolumn{2}{c}{ FRP-02A/B/C/D U $\mathrm{U}_{95}$ Max Fill } & \multicolumn{3}{c}{ FRP-02A/B/C/D $\overline{\mathrm{U}}_{90}$ Max Fill } \\
\hline $\mathrm{U}(\mathrm{m} / \mathrm{s})$ & $\mathrm{U}_{\mathrm{CS}}(\mathrm{m} / \mathrm{s})$ & $\mathrm{U} / \mathrm{U}_{\mathrm{CS}}$ & $\mathrm{U}(\mathrm{m} / \mathrm{s})$ & $\mathrm{U}_{\mathrm{CS}}(\mathrm{m} / \mathrm{s})$ & $\mathrm{U} / \mathrm{U}_{\mathrm{CS}}$ \\
8 & 26.0 & 0.31 & 8 & 34.8 & 0.23 \\
$\mathrm{H} / \mathrm{D}$ & $\mathrm{H}_{\mathrm{C}} / \mathrm{D}$ & $\mathrm{H}_{\mathrm{C}} / \mathrm{H}$ & $\mathrm{H} / \mathrm{D}$ & $\mathrm{H}_{\mathrm{C}} / \mathrm{D}$ & $\mathrm{H}_{\mathrm{C}} / \mathrm{H}$ \\
0.73 & 0.11 & 0.16 & 0.73 & 0.06 & 0.09 \\
$\mathrm{~W}(\mathrm{wt} \%)$ & $\mathrm{W}_{0}{ }^{*}(\mathrm{wt} \%)$ & $0.2 / \mathrm{W}_{0}{ }^{*}$ & $\mathrm{~W}(\mathrm{wt} \%)$ & $\mathrm{W}_{0}{ }^{*}(\mathrm{wt} \%)$ & $0.2 / \mathrm{W}_{0}{ }^{*}$ \\
4.9 & $>\mathrm{W}_{\mathrm{MP}}{ }^{(\mathrm{a})}$ & 0.21 & 4.9 & $>\mathrm{W}_{\mathrm{MP}}{ }^{(\mathrm{a})}$ & 0.12 \\
\hline
\end{tabular}

(a) Calculated value exceeds maximum packing fraction.

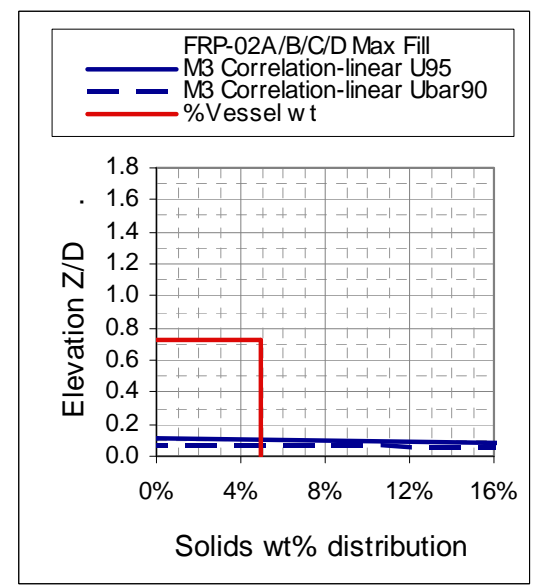

(a)

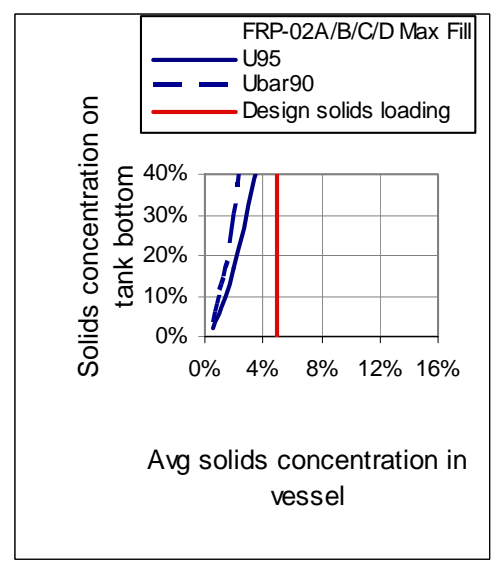

(c)

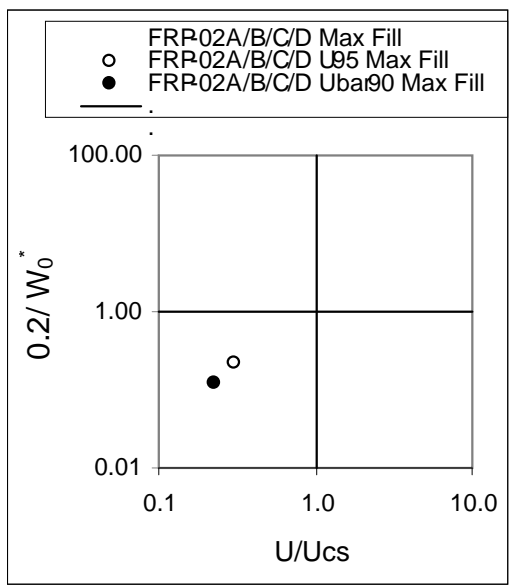

(b)

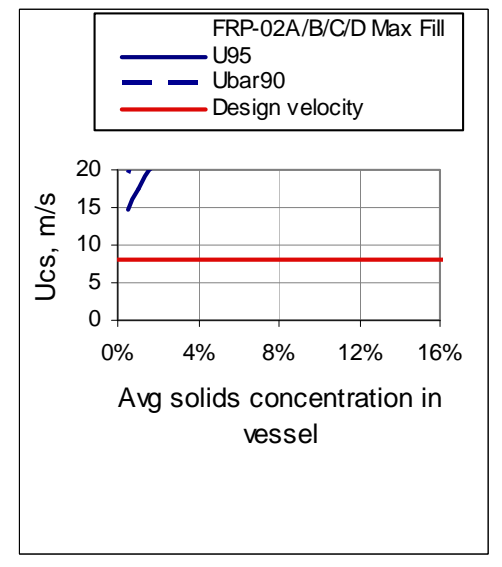

(d)

Figure 9.42. Generalized Model Predictions for FRP-02 A/B/C/D: (a) Concentration Profile at Max Fill, (b) Inlet Concentration and Suspension Ratio, (c) Maximum Solids Concentration Versus Loading Design Conditions, (d) $\mathrm{U}_{\mathrm{CS}}$ Versus Loading (Hanford PSDD, $\rho_{\mathrm{l}}=1.1 \mathrm{~g} / \mathrm{cm}^{3}$, $\mu=1.5$ cP fluid) 


\subsubsection{HLP-22 $8 \mathrm{~m} / \mathrm{s}$, 4-in. (Hanford PSDD, $\rho_{l}=1.1 \mathrm{~g} / \mathrm{cm}^{3}, \mu=1.5 \mathrm{cP}$ fluid) Generalized Model}

Table 9.40 presents the generalized model results for HLP-22 using Hanford PSDD. Figure 9.43 presents the generalized model predictions for HLP-22 using the Hanford PSDD.

Table 9.40. Generalized Model Results for HLP-22 Using Hanford PSDD

\begin{tabular}{|c|c|c|c|c|c|}
\hline \multicolumn{3}{|c|}{ HLP-22 U ${ }_{95}$ Max Fill } & \multicolumn{3}{|c|}{ HLP-22 $\overline{\mathrm{U}}_{90}$ Max Fill } \\
\hline $\mathrm{U}(\mathrm{m} / \mathrm{s})$ & $\mathrm{U}_{\mathrm{CS}}(\mathrm{m} / \mathrm{s})$ & $\mathrm{U} / \mathrm{U}_{\mathrm{CS}}$ & $\mathrm{U}(\mathrm{m} / \mathrm{s})$ & $\mathrm{U}_{\mathrm{CS}}(\mathrm{m} / \mathrm{s})$ & $\mathrm{U} / \mathrm{U}_{\mathrm{CS}}$ \\
\hline 8 & 23.3 & 0.34 & 8 & 31.3 & 0.26 \\
\hline H/D & $\mathrm{H}_{\mathrm{C}} / \mathrm{D}$ & $\mathrm{H}_{\mathrm{C}} / \mathrm{H}$ & H/D & $\mathrm{H}_{\mathrm{C}} / \mathrm{D}$ & $\mathrm{H}_{\mathrm{C}} / \mathrm{H}$ \\
\hline 0.80 & 0.18 & 0.23 & 0.80 & 0.10 & 0.13 \\
\hline $\mathrm{W}(\mathrm{wt} \%)$ & $\mathrm{W}_{0}{ }^{*}(\mathrm{wt} \%)$ & $0.2 / \mathrm{W}_{0}^{*}$ & $\mathrm{~W}(\mathrm{wt} \%)$ & $\mathrm{W}_{0}{ }^{*}(\mathrm{wt} \%)$ & $0.2 / \mathrm{W}_{0}{ }^{*}$ \\
\hline 15.4 & $>\mathrm{W}_{\mathrm{MP}}^{(\mathrm{a})}$ & 0.10 & 15.4 & $>\mathrm{W}_{\mathrm{MP}}^{(\mathrm{a})}$ & 0.05 \\
\hline
\end{tabular}

(a) Calculated value exceeds maximum packing fraction.

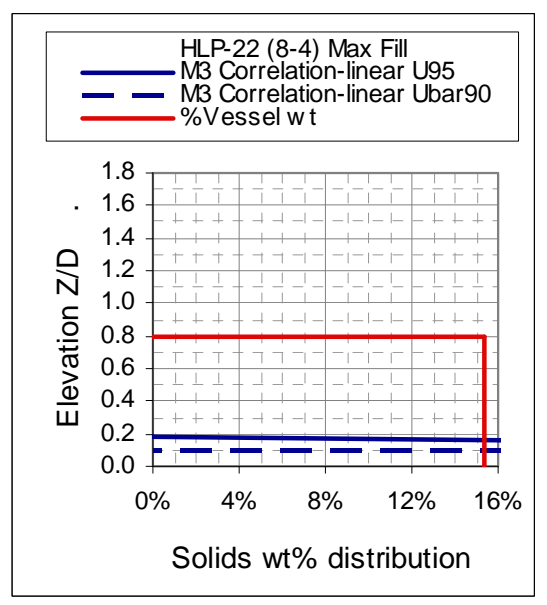

(a)

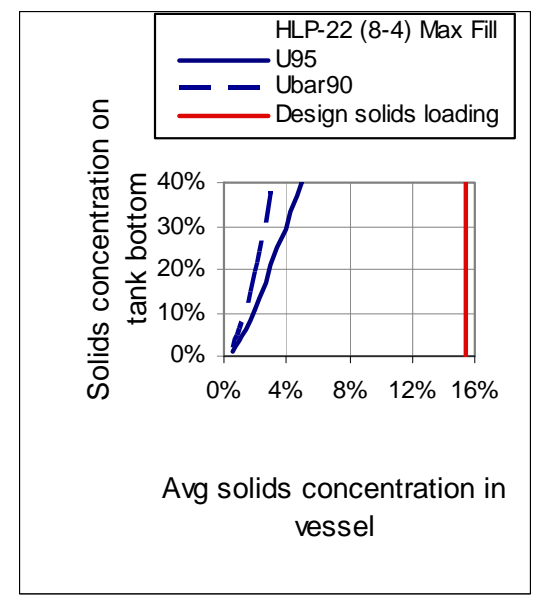

(c)

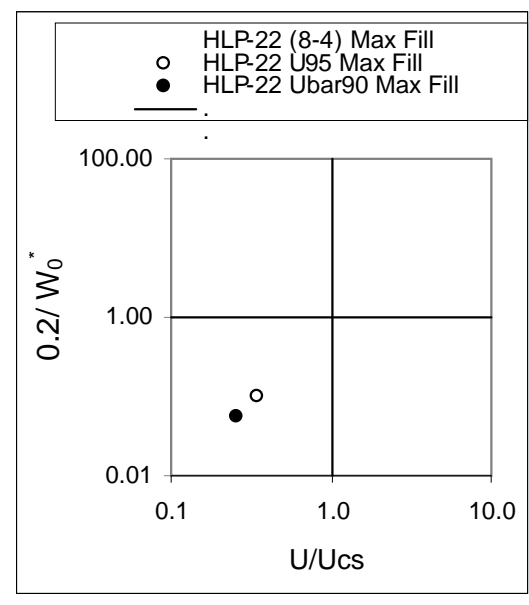

(b)

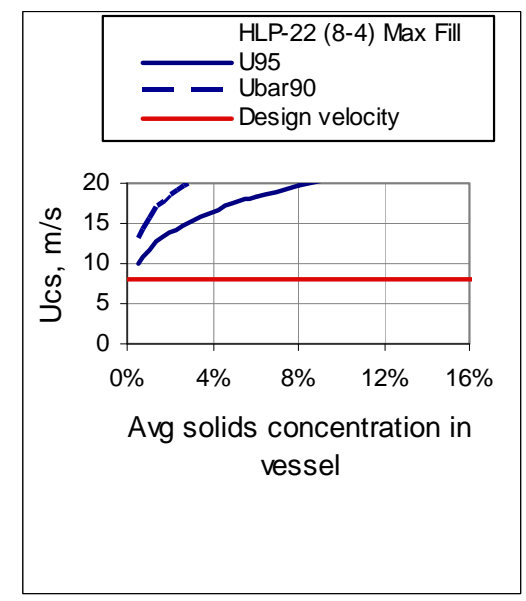

(d)

Figure 9.43. Generalized Model Predictions for HLP-22: (a) Concentration Profile at Max Fill, (b) Inlet Concentration and Suspension Ratio, (c) Maximum Solids Concentration Versus Loading Design Conditions, (d) $\mathrm{U}_{\mathrm{CS}}$ Versus Loading (8 m/s, 4-in. nozzles, Hanford PSDD) 


\subsubsection{HLP-22 $12 \mathrm{~m} / \mathrm{s}$, 4-in. (Hanford PSDD, $\rho_{\mathrm{I}}=1.1 \mathrm{~g} / \mathrm{cm}^{3}, \mu=1.5 \mathrm{cP}$ fluid) Generalized Model}

Table 9.41 lists generalized model results for HLP-22 using the Hanford PSDD. Figure 9.44 presents the generalized model predictions for HLP-22 using the Hanford PSDD.

Table 9.41. Generalized Model Results for HLP-22 Using Hanford PSDD

\begin{tabular}{cccccc}
\hline \multicolumn{3}{c}{ HLP-22 $\mathrm{U}_{95}$ Max Fill } & \multicolumn{3}{c}{ HLP-22 $\overline{\mathrm{U}}_{90}$ Max Fill } \\
\hline $\mathrm{U}(\mathrm{m} / \mathrm{s})$ & $\mathrm{U}_{\mathrm{CS}}(\mathrm{m} / \mathrm{s})$ & $\mathrm{U} / \mathrm{U}_{\mathrm{CS}}$ & $\mathrm{U}(\mathrm{m} / \mathrm{s})$ & $\mathrm{U}_{\mathrm{CS}}(\mathrm{m} / \mathrm{s})$ & $\mathrm{U} / \mathrm{U}_{\mathrm{CS}}$ \\
12 & 23.3 & 0.51 & 12 & 31.3 & 0.38 \\
$\mathrm{H} / \mathrm{D}$ & $\mathrm{H}_{\mathrm{C}} / \mathrm{D}$ & $\mathrm{H}_{\mathrm{C}} / \mathrm{H}$ & $\mathrm{H} / \mathrm{D}$ & $\mathrm{H}_{\mathrm{C}} / \mathrm{D}$ & $\mathrm{H}_{\mathrm{C}} / \mathrm{H}$ \\
0.80 & 0.31 & 0.39 & 0.80 & 0.18 & 0.22 \\
$\mathrm{~W}(\mathrm{wt} \%)$ & $\mathrm{W}_{0}{ }^{*}(\mathrm{wt} \%)$ & $0.2 / \mathrm{W}_{0}{ }^{*}$ & $\mathrm{~W}(\mathrm{wt} \%)$ & $\mathrm{W}_{0}{ }^{*}(\mathrm{wt} \%)$ & $0.2 / \mathrm{W}_{0}{ }^{*}$ \\
15.4 & $>\mathrm{W}_{\mathrm{MP}}{ }^{(\mathrm{a})}$ & 0.17 & 15.4 & $>\mathrm{W}_{\mathrm{MP}}{ }^{(\mathrm{a})}$ & 0.09 \\
\hline
\end{tabular}

(a) Calculated value exceeds maximum packing fraction.

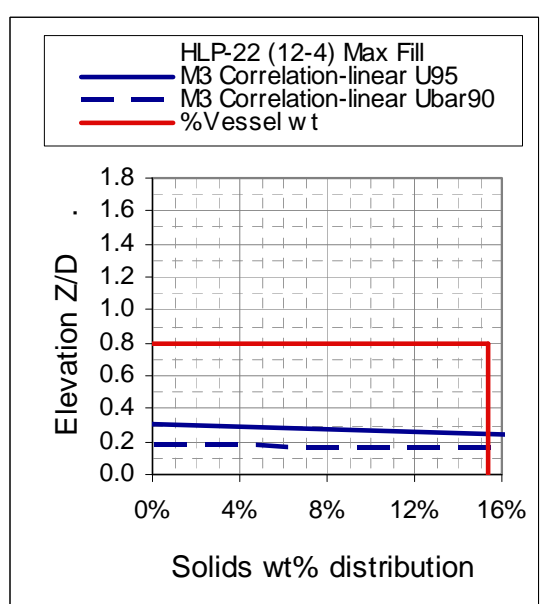

(a)

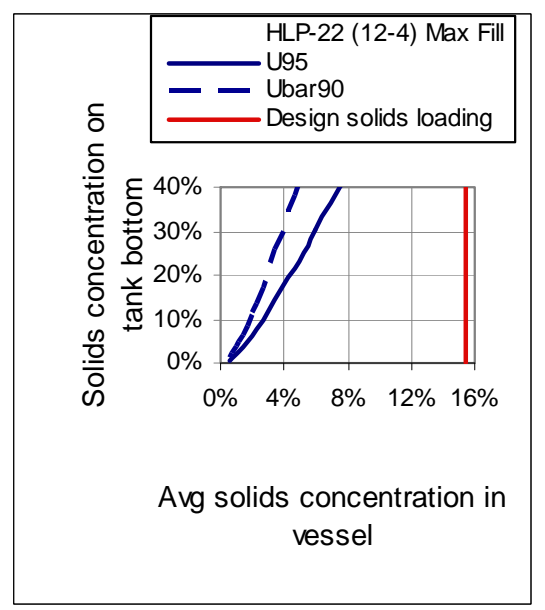

(c)

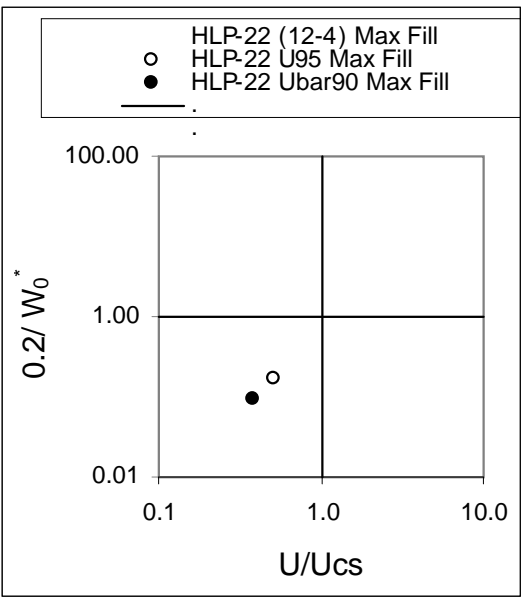

(b)

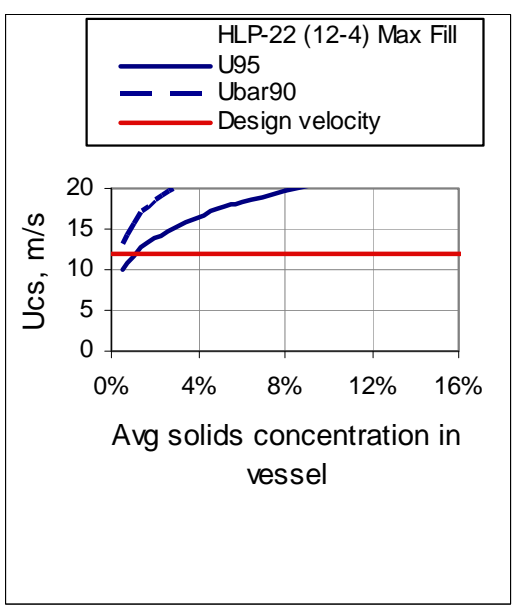

(d)

Figure 9.44. Generalized Model Predictions for HLP-22: (a) Concentration Profile at Max Fill, (b) Inlet Concentration and Suspension Ratio, (c) Maximum Solids Concentration Versus Loading Design Conditions, (d) $\mathrm{U}_{\mathrm{CS}}$ Versus Loading (12 m/s, 4-in. nozzles, Hanford PSDD) 


\subsubsection{HLP-22 $8 \mathrm{~m} / \mathrm{s}$, 6-in. (Hanford PSDD, $\rho_{l}=1.1 \mathrm{~g} / \mathrm{cm}^{3}, \mu=1.5 \mathrm{cP}$ fluid) Generalized Model}

Table 9.42 presents generalized model results for HLP-22 using the Hanford PSDD. Figure 9.45 shows the generalized model predictions for HLP-22 8 m/s, 6-in. (8 m/s, 6-in. nozzle).

Table 9.42. Generalized Model Results for HLP-22 Using Hanford PSDD

\begin{tabular}{cccccc}
\hline \multicolumn{3}{c}{ HLP-22 $\mathrm{U}_{95}$ Max Fill } & \multicolumn{3}{c}{ HLP-22 $\overline{\mathrm{U}}_{90}$ Max Fill } \\
\hline $\mathrm{U}(\mathrm{m} / \mathrm{s})$ & $\mathrm{U}_{\mathrm{CS}}(\mathrm{m} / \mathrm{s})$ & $\mathrm{U} / \mathrm{U}_{\mathrm{CS}}$ & $\mathrm{U}(\mathrm{m} / \mathrm{s})$ & $\mathrm{U}_{\mathrm{CS}}(\mathrm{m} / \mathrm{s})$ & $\mathrm{U} / \mathrm{U}_{\mathrm{CS}}$ \\
8 & 17.0 & 0.47 & 8 & 22.8 & 0.35 \\
$\mathrm{H} / \mathrm{D}$ & $\mathrm{H}_{\mathrm{C}} / \mathrm{D}$ & $\mathrm{H}_{\mathrm{C}} / \mathrm{H}$ & $\mathrm{H} / \mathrm{D}$ & $\mathrm{H}_{\mathrm{C}} / \mathrm{D}$ & $\mathrm{H}_{\mathrm{C}} / \mathrm{H}$ \\
0.80 & 0.31 & 0.39 & 0.80 & 0.17 & 0.22 \\
$\mathrm{~W}(\mathrm{wt} \%)$ & $\mathrm{W}_{0}{ }^{*}(\mathrm{wt} \%)$ & $0.2 / \mathrm{W}_{0}{ }^{*}$ & $\mathrm{~W}(\mathrm{wt} \%)$ & $\mathrm{W}_{0}{ }^{*}(\mathrm{wt} \%)$ & $0.2 / \mathrm{W}_{0}{ }^{*}$ \\
15.4 & $>\mathrm{W}_{\mathrm{MP}}{ }^{(\mathrm{a})}$ & 0.17 & 15.4 & $>\mathrm{W}_{\mathrm{MP}}{ }^{(\mathrm{a})}$ & 0.09 \\
\hline
\end{tabular}

(a) Calculated value exceeds maximum packing fraction.

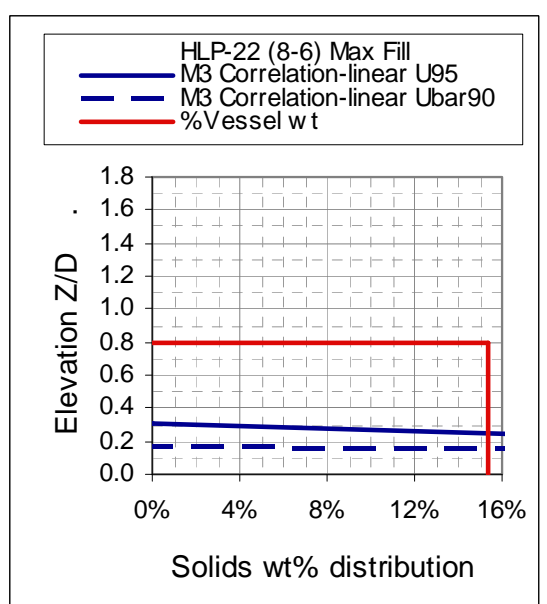

(a)

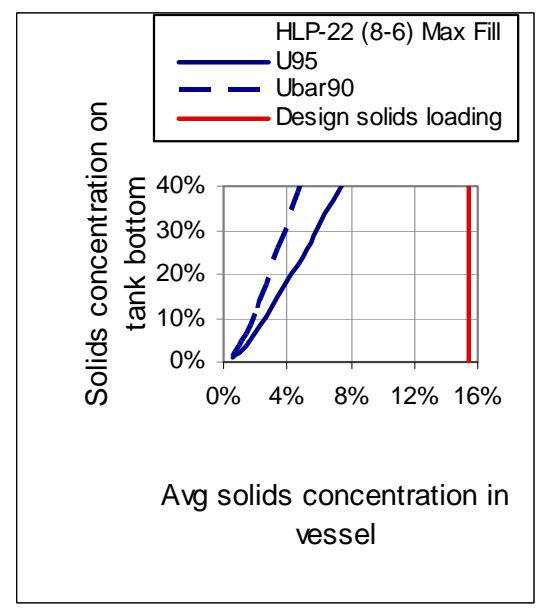

(c)

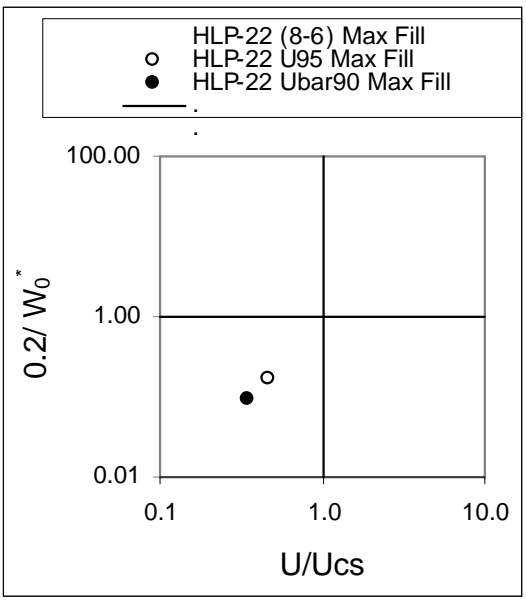

(b)

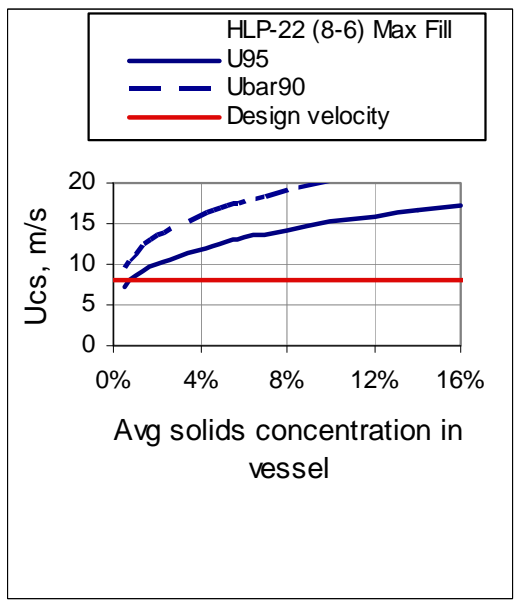

(d)

Figure 9.45. Generalized Model Predictions for HLP-22: (a) Concentration Profile at Max Fill, (b) Inlet Concentration and Suspension Ratio, (c) Maximum Solids Concentration Versus Loading Design Conditions, (d) $\mathrm{U}_{\mathrm{CS}}$ Versus Loading (Hanford PSDD, 8 m/s, 6-in. nozzles) 


\subsubsection{HLP-22 $12 \mathrm{~m} / \mathrm{s}$, 6-in. (Hanford PSDD, $\rho_{\mathrm{I}}=1.1 \mathrm{~g} / \mathrm{cm}^{3}, \mu=1.5 \mathrm{cP}$ fluid) Generalized Model}

Table 9.43 contains generalized model results for HLP-22 using the Hanford PSDD. Figure 9.46 presents the generalized model predictions for HLP-22 (Hanford PSDD, 12 m/s, 6-in. nozzle).

Table 9.43. Model Results for Design Conditions for HLP-22

\begin{tabular}{cccccc}
\hline \multicolumn{3}{c}{ HLP-22 $\mathrm{U}_{95}$ Max Fill } & \multicolumn{3}{c}{$\mathrm{HLP}-22 \overline{\mathrm{U}}_{90}$ Max Fill } \\
\hline $\mathrm{U}(\mathrm{m} / \mathrm{s})$ & $\mathrm{U}_{\mathrm{CS}}(\mathrm{m} / \mathrm{s})$ & $\mathrm{U} / \mathrm{U}_{\mathrm{CS}}$ & $\mathrm{U}(\mathrm{m} / \mathrm{s})$ & $\mathrm{U}_{\mathrm{CS}}(\mathrm{m} / \mathrm{s})$ & $\mathrm{U} / \mathrm{U}_{\mathrm{CS}}$ \\
12 & 17.0 & 0.71 & 12 & 22.8 & 0.53 \\
$\mathrm{H} / \mathrm{D}$ & $\mathrm{H}_{\mathrm{C}} / \mathrm{D}$ & $\mathrm{H}_{\mathrm{C}} / \mathrm{H}$ & $\mathrm{H} / \mathrm{D}$ & $\mathrm{H}_{\mathrm{C}} / \mathrm{D}$ & $\mathrm{H}_{\mathrm{C}} / \mathrm{H}$ \\
0.80 & 0.54 & 0.67 & 0.80 & 0.30 & 0.38 \\
$\mathrm{~W}(\mathrm{wt} \%)$ & $\mathrm{W}_{0}{ }^{*}(\mathrm{wt} \%)$ & $0.2 / \mathrm{W}_{0}{ }^{*}$ & $\mathrm{~W}(\mathrm{wt} \%)$ & $\mathrm{W}_{0}{ }^{*}(\mathrm{wt} \%)$ & $0.2 / \mathrm{W}_{0}{ }^{*}$ \\
15.4 & 68.6 & 0.29 & 15.4 & $>\mathrm{W}_{\mathrm{MP}}{ }^{(\mathrm{a})}$ & 0.16 \\
\hline
\end{tabular}

(a) Calculated value exceeds maximum packing fraction.

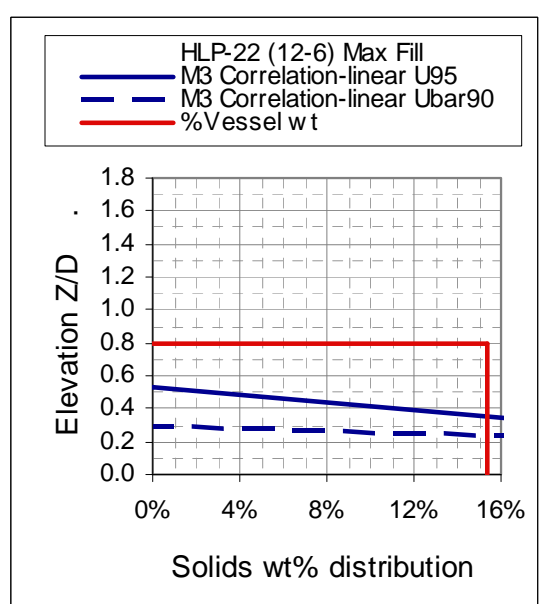

(a)

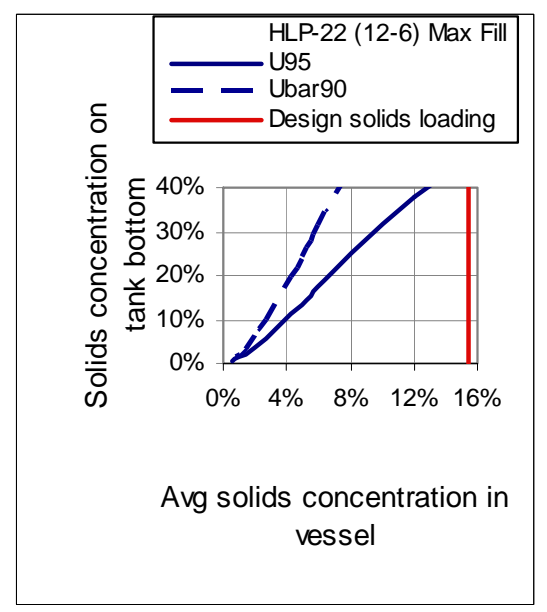

(c)

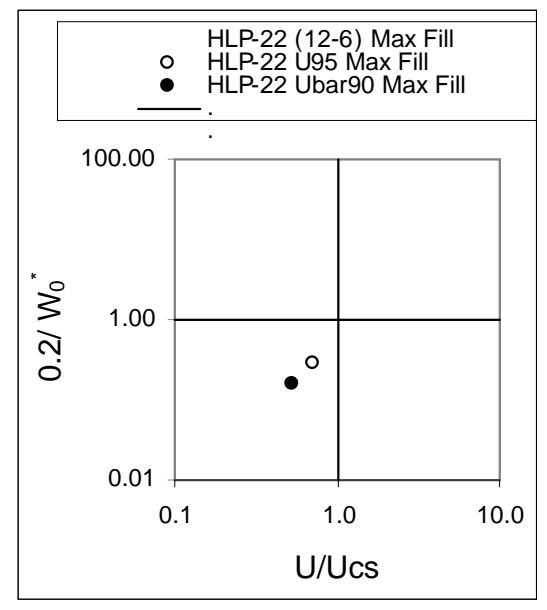

(b)

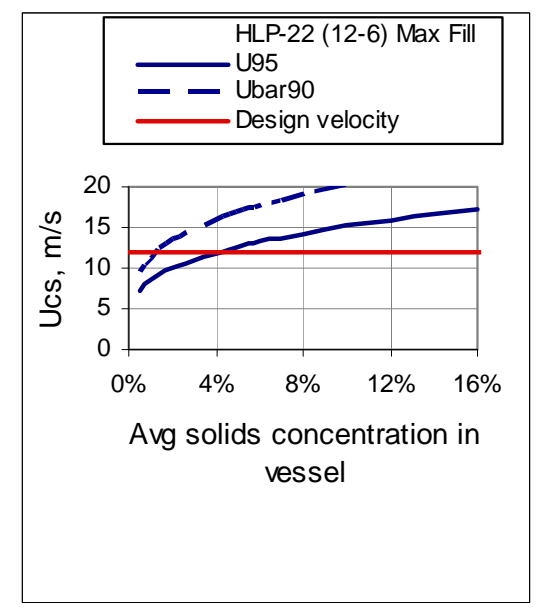

(d)

Figure 9.46. Generalized Model Predictions for HLP-22: (a) Concentration Profile at Max Fill, (b) Inlet Concentration and Suspension Ratio, (c) Maximum Solids Concentration Versus Loading Design Conditions, (d) $\mathrm{U}_{\mathrm{CS}}$ Versus Loading (Hanford PSDD, 12 m/s, 6-in. nozzles) 


\subsubsection{TCP-01 (Hanford PSDD, $\rho_{\mathrm{l}}=1.1 \mathrm{~g} / \mathrm{cm}^{3}, \mu=1.5 \mathrm{cP}$ fluid) Generalized Model}

Table 9.44 shows generalized model results for TCP-01 using the Hanford PSDD, and Figure 9.47 presents the generalized model predictions for TCP-01 (Hanford PSDD, $\rho_{\mathrm{l}}=1.1 \mathrm{~g} / \mathrm{cm}^{3}, \mu=1.5 \mathrm{cP}$ fluid).

Table 9.44. Generalized Model Results for TCP-01 Using Hanford PSDD

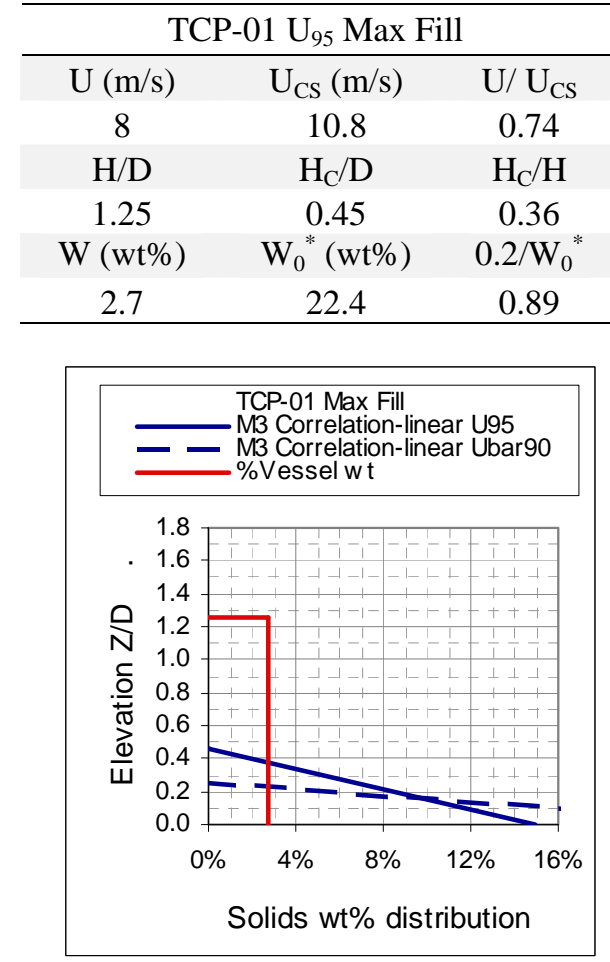

(a)

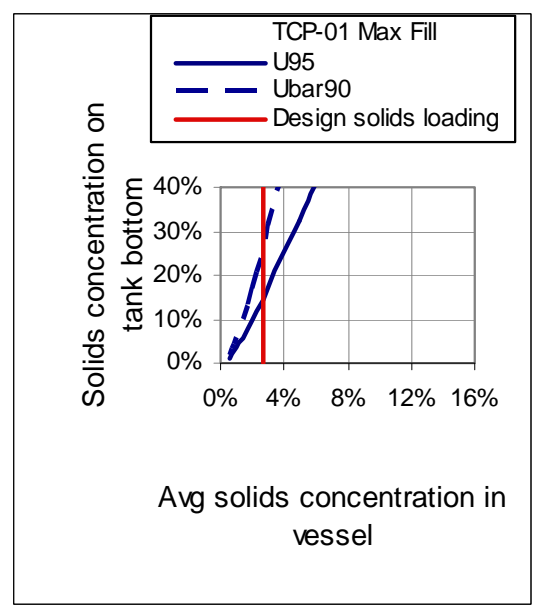

(c)

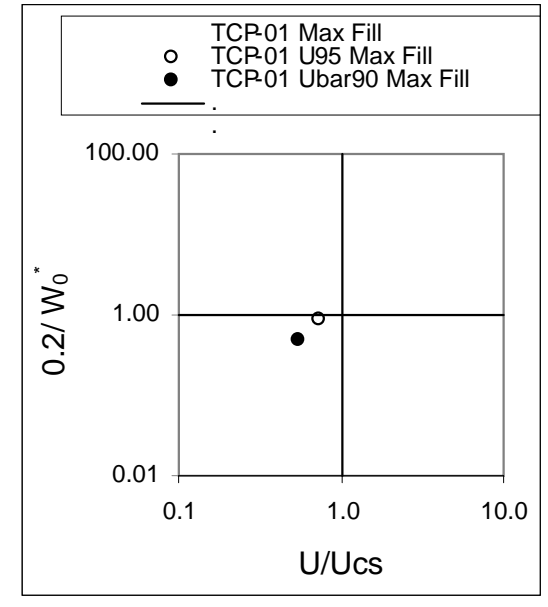

(b)

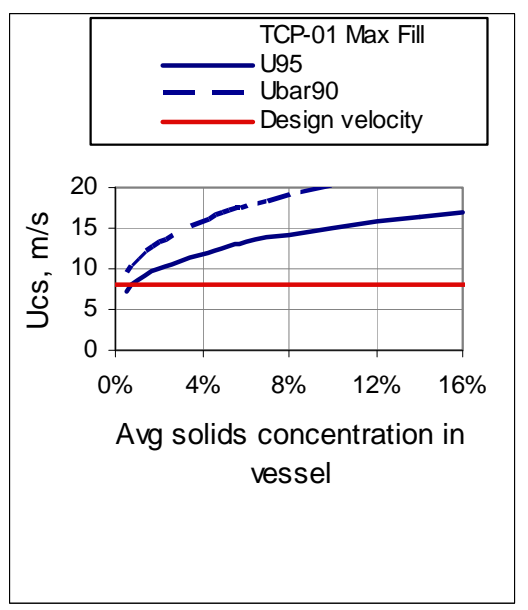

(d)

Figure 9.47. Generalized Model Predictions for TCP-01: (a) Concentration Profile at Max Fill, (b) Inlet Concentration and Suspension Ratio, (c) Maximum Solids Concentration Versus Loading Design Conditions, (d) $U_{C S}$ Versus Loading (Hanford PSDD, $\rho_{\mathrm{l}}=1.1 \mathrm{~g} / \mathrm{cm}^{3}, \mu=1.5 \mathrm{cP}$ fluid) 


\subsubsection{TLP-09 A/B (Hanford PSDD, $\rho_{\mathrm{I}}=1.1 \mathrm{~g} / \mathrm{cm}^{3}, \mu=1.5 \mathrm{cP}$ fluid) Generalized Model}

Table 9.45 lists generalized model results for TLP-09 A/B using the Hanford PSDD, and Figure 9.48 presents the generalized model predictions for TLP-09 A/B (Hanford PSDD, $\rho_{\mathrm{l}}=1.1 \mathrm{~g} / \mathrm{cm}^{3}, \mu=1.5 \mathrm{cP}$ fluid).

Table 9.45. Generalized Model Results for TLP-09 Using Hanford PSDD

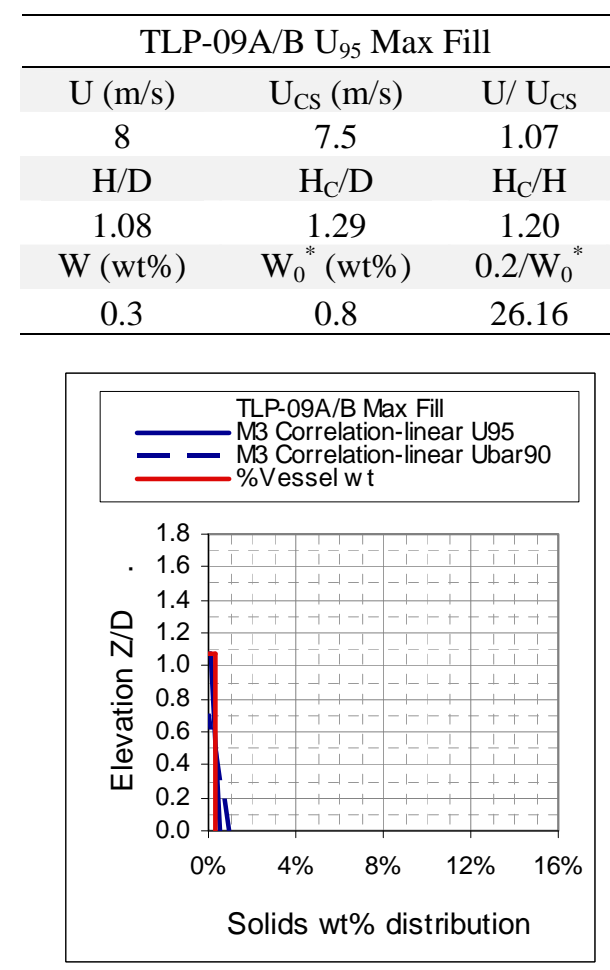

(a)

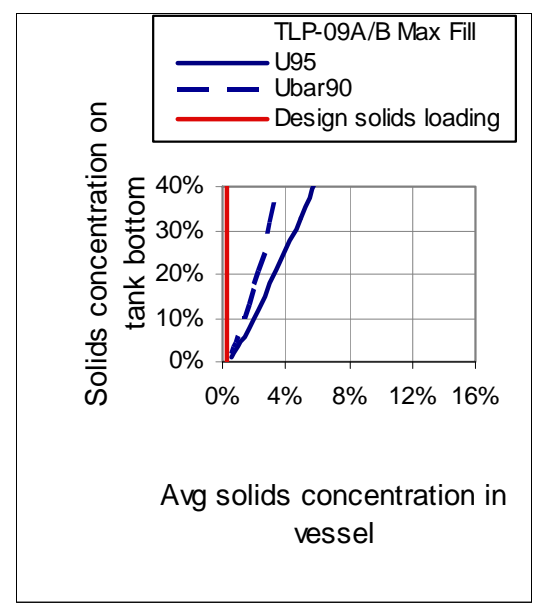

(c)

\begin{tabular}{ccc}
\multicolumn{3}{c}{ TLP-09A/B $\overline{\mathrm{U}}_{90}$ Max Fill } \\
\hline $\mathrm{m} / \mathrm{s})$ & $\mathrm{U}_{\mathrm{CS}}(\mathrm{m} / \mathrm{s})$ & $\mathrm{U} / \mathrm{U}_{\mathrm{CS}}$ \\
8 & 10.1 & 0.80 \\
$\mathrm{H} / \mathrm{D}$ & $\mathrm{H}_{\mathrm{C}} / \mathrm{D}$ & $\mathrm{H}_{\mathrm{C}} / \mathrm{H}$ \\
1.08 & 0.72 & 0.67 \\
$(\mathrm{wt} \%)$ & $\mathrm{W}_{0}{ }^{*}(\mathrm{wt} \%)$ & $0.2 / \mathrm{W}_{0}{ }^{*}$ \\
0.3 & 1.3 & 14.82 \\
\hline
\end{tabular}

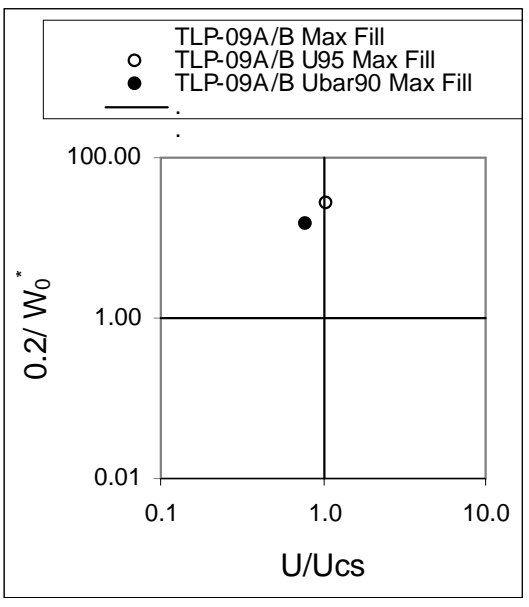

(b)

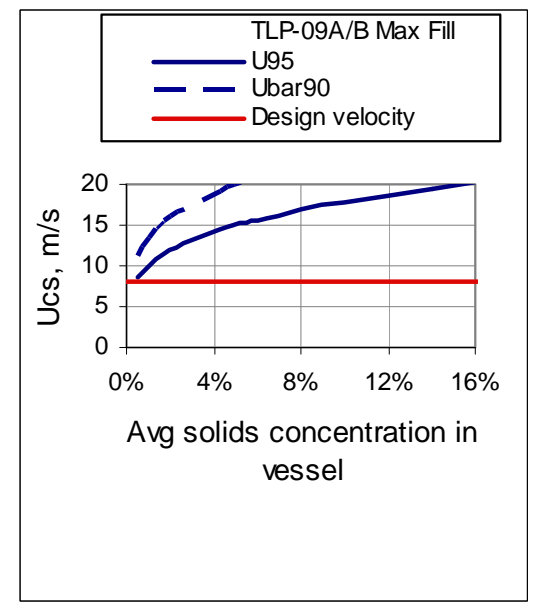

(d)

Figure 9.48. Generalized Model Predictions for TLP-09 A/B: (a) Concentration Profile at Max Fill, (b) Inlet Concentration and Suspension Ratio, (c) Maximum Solids Concentration Versus Loading Design Conditions, (d) $\mathrm{U}_{\mathrm{CS}}$ Versus Loading (Hanford PSDD, $\rho_{\mathrm{l}}=1.1 \mathrm{~g} / \mathrm{cm}^{3}$, $\mu=1.5$ cP fluid) 


\subsubsection{PWD-33 (Hanford PSDD, $\rho_{\mathrm{l}}=1.1 \mathrm{~g} / \mathrm{cm}^{3}, \mu=1.5 \mathrm{cP}$ fluid) Generalized Model}

Table 9.46 contains generalized model results for PWD-33 using the Hanford PSDD, and Figure 9.49 shows generalized model predictions for PWD-33 (Hanford PSDD, $\rho_{\mathrm{l}}=1.1 \mathrm{~g} / \mathrm{cm}^{3}, \mu=1.5 \mathrm{cP}$ fluid).

Table 9.46. Generalized Model Results for PWD-33 Using Hanford PSDD

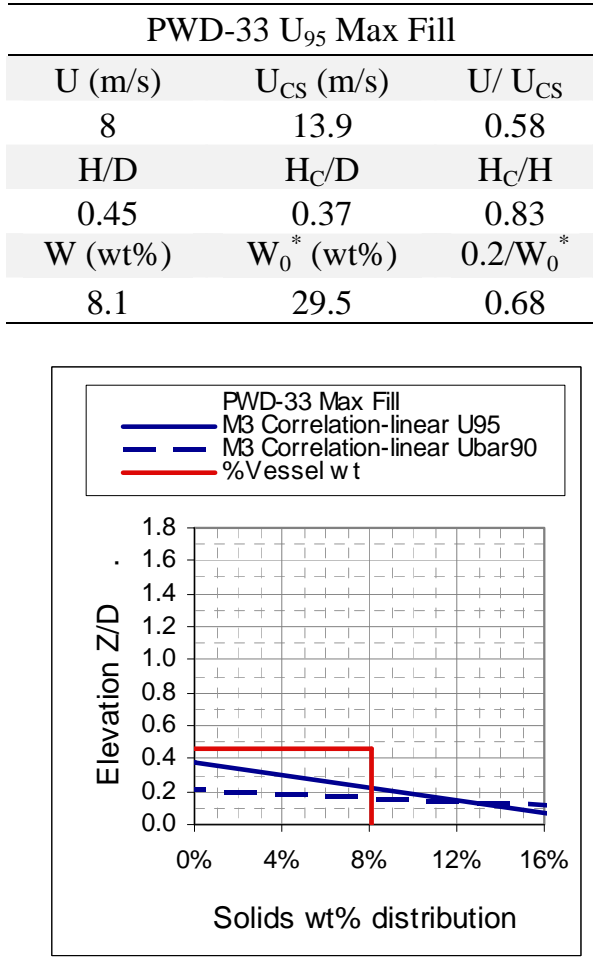

(a)

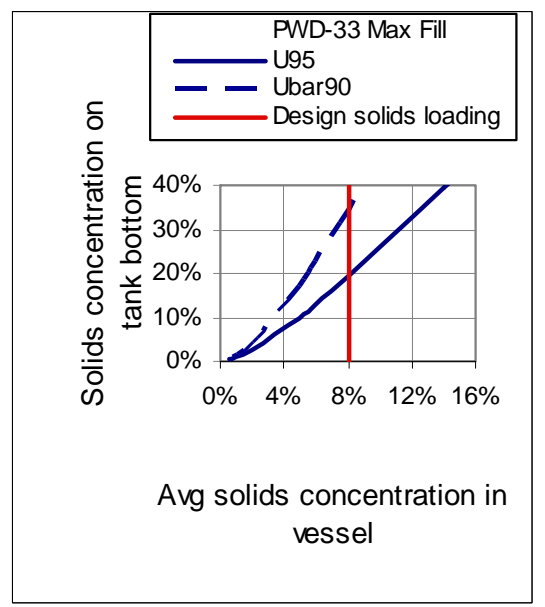

(c)

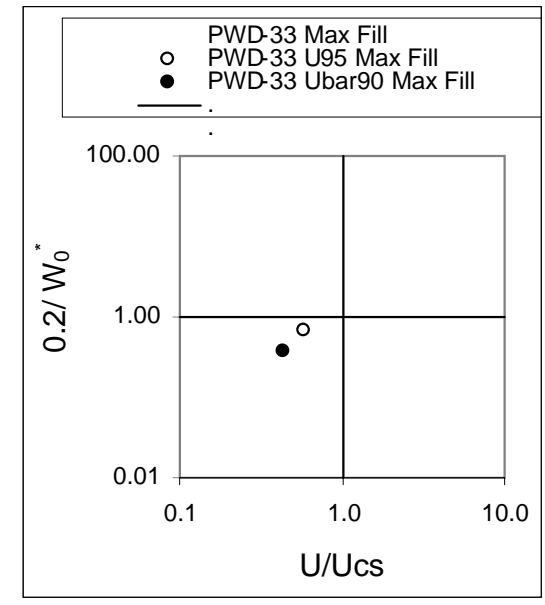

(b)

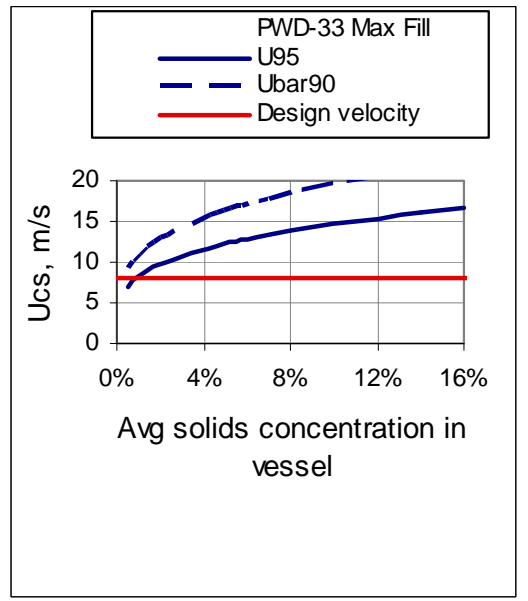

(d)

Figure 9.49. Generalized Model Predictions for PWD-33: (a) Concentration Profile at Max Fill, (b) Inlet Concentration and Suspension Ratio, (c) Maximum Solids Concentration Versus Loading Design Conditions; (d) $U_{C S}$ Versus Loading (Hanford PSDD, $\rho_{\mathrm{l}}=1.1 \mathrm{~g} / \mathrm{cm}^{3}$, $\mu=1.5$ cP fluid) 


\subsubsection{PWD-43 (Hanford PSDD, $\rho_{\mathrm{l}}=1.1 \mathrm{~g} / \mathrm{cm}^{3}, \mu=1.5 \mathrm{cP}$ fluid) Generalized Model}

Table 9.47 presents generalized model results for PWD-43 using the Hanford PSDD. Figure 9.50 shows generalized model predictions for PWD-43 (Hanford PSDD, $\rho_{\mathrm{l}}=1.1 \mathrm{~g} / \mathrm{cm}^{3}, \mu=1.5 \mathrm{cP}$ fluid).

Table 9.47. Generalized Model Results for PWD-43 Using Hanford PSDD

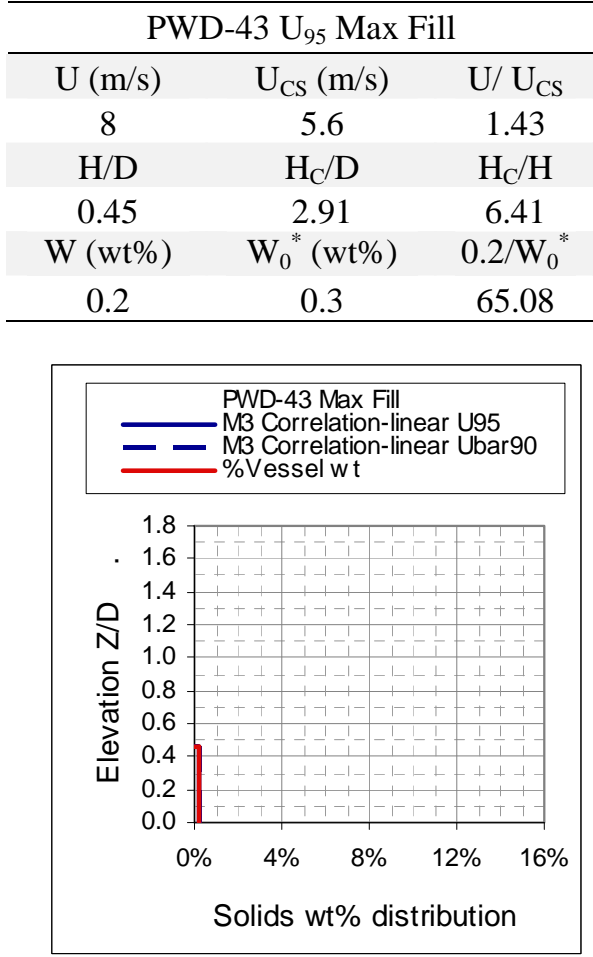

(a)

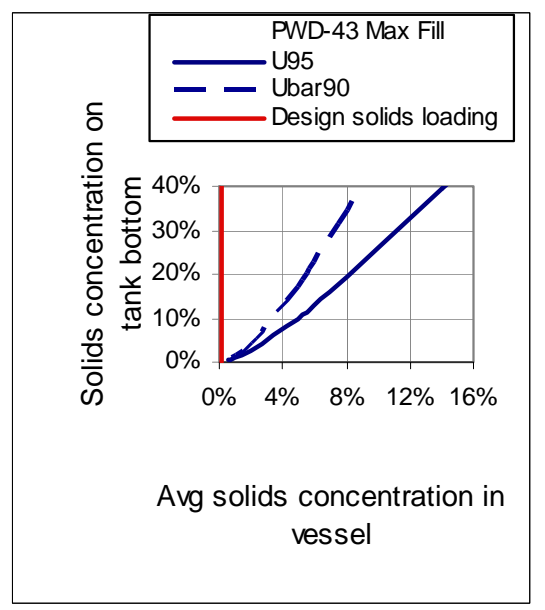

(c)

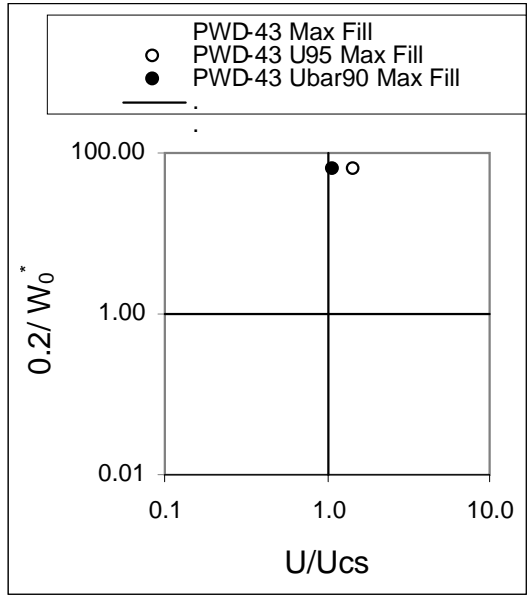

(b)

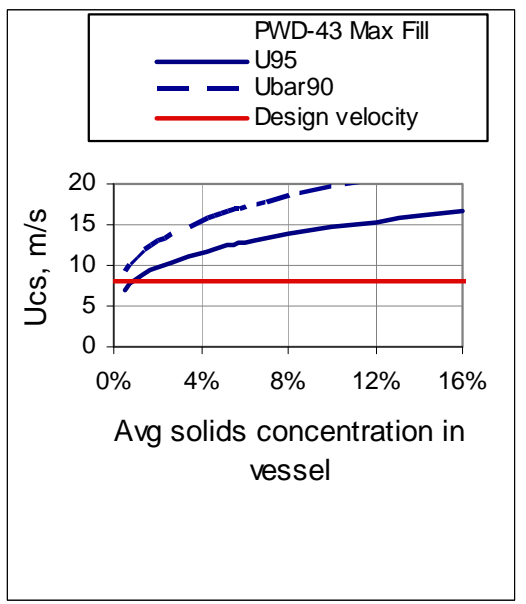

(d)

Figure 9.50. Generalized Model Predictions for PWD-43: (a) Concentration Profile at Max Fill, (b) Inlet Concentration and Suspension Ratio, (c) Maximum Solids Concentration Versus Loading Design Conditions, (d) $U_{C S}$ Versus Loading (Hanford PSDD, $\rho_{\mathrm{l}}=1.1 \mathrm{~g} / \mathrm{cm}^{3}, \mu=1,1.5 \mathrm{cP}$ fluid) 


\subsubsection{PWD-44 (Hanford PSDD, $\rho_{\mathrm{l}}=1.1 \mathrm{~g} / \mathrm{cm}^{3}, \mu=1.5 \mathrm{cP}$ fluid) Generalized Model}

Table 9.48 lists generalized model results for PWD-44 using the Hanford PSDD. Figure 9.51 shows generalized model predictions for PWD-44 (Hanford PSDD, $\rho_{\mathrm{l}}=1.1 \mathrm{~g} / \mathrm{cm}^{3}, \mu=1.5 \mathrm{cP}$ fluid).

Table 9.48. Generalized Model Results for PWD-44 Using Hanford PSDD

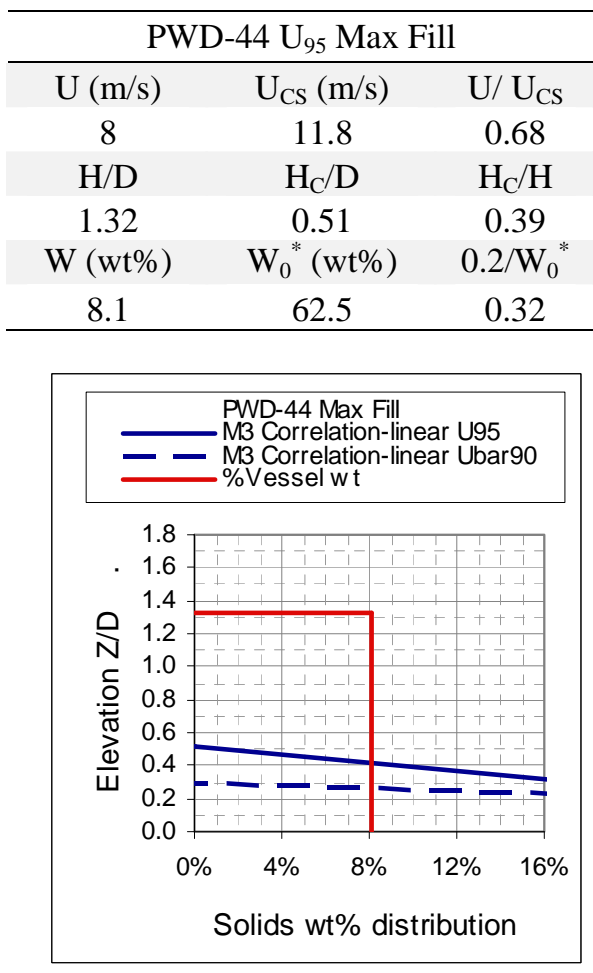

(a)

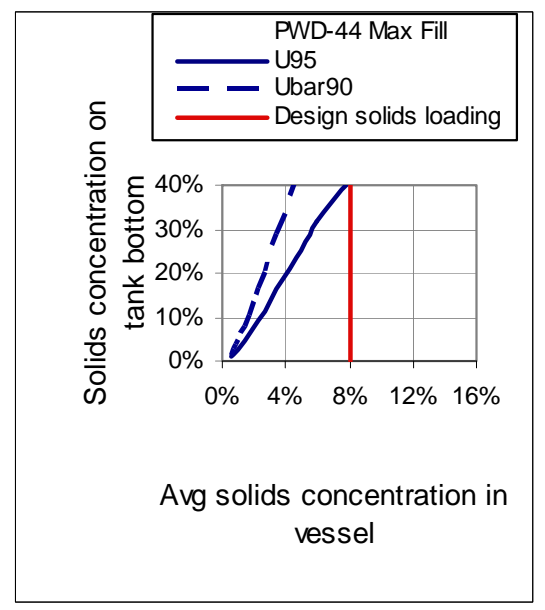

(c)

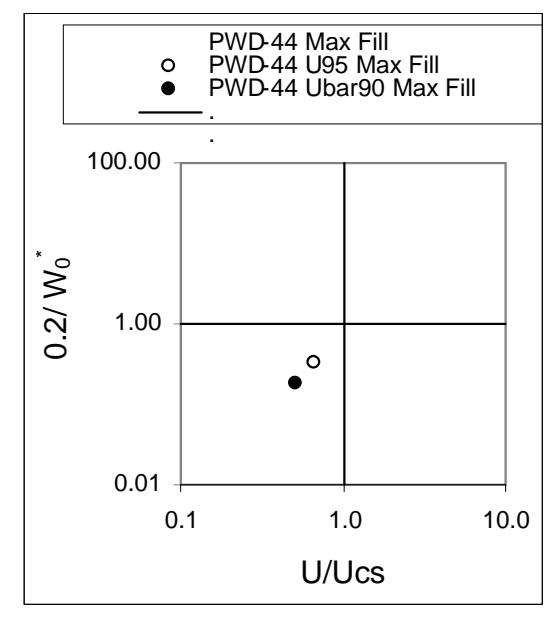

(b)

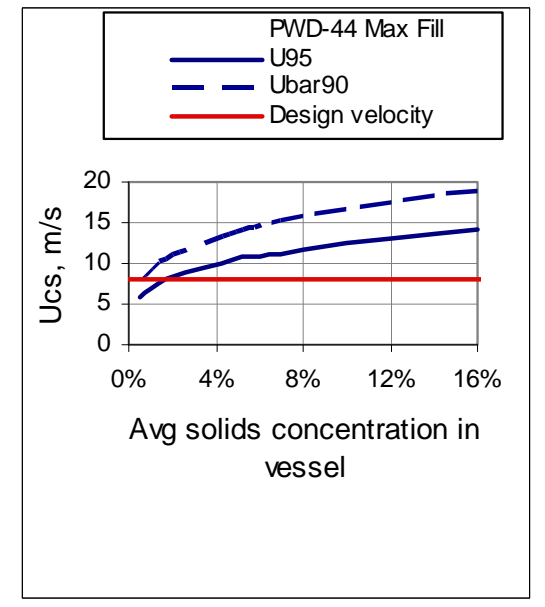

(d)

Figure 9.51. Generalized Model Predictions for PWD-44: (a) Concentration Profile at Max Fill, (b) Inlet Concentration and Suspension Ratio, (c) Maximum Solids Concentration Versus Loading Design Conditions, (d) $\mathrm{U}_{\mathrm{CS}}$ Versus Loading (Hanford PSDD, $\rho_{\mathrm{l}}=1.1 \mathrm{~g} / \mathrm{cm}^{3}$, $\mu=1.5$ cP fluid) 


\subsubsection{FEP-17 A/B (Hanford PSDD, $\rho_{\mathrm{I}}=1.1 \mathrm{~g} / \mathrm{cm}^{3}, \mu=1.5 \mathrm{cP}$ fluid) Generalized Model}

Table 9.49 presents generalized model results for FEP-17 A/B using the Hanford PSDD. Figure 9.52 depicts generalized model predictions for FEP-17 A/B (Hanford PSDD, $\rho_{\mathrm{l}}=1.1 \mathrm{~g} / \mathrm{cm}^{3}, \mu=1.5 \mathrm{cP}$ fluid).

Table 9.49. Generalized Model Results for FEP-17 Using Hanford PSDD

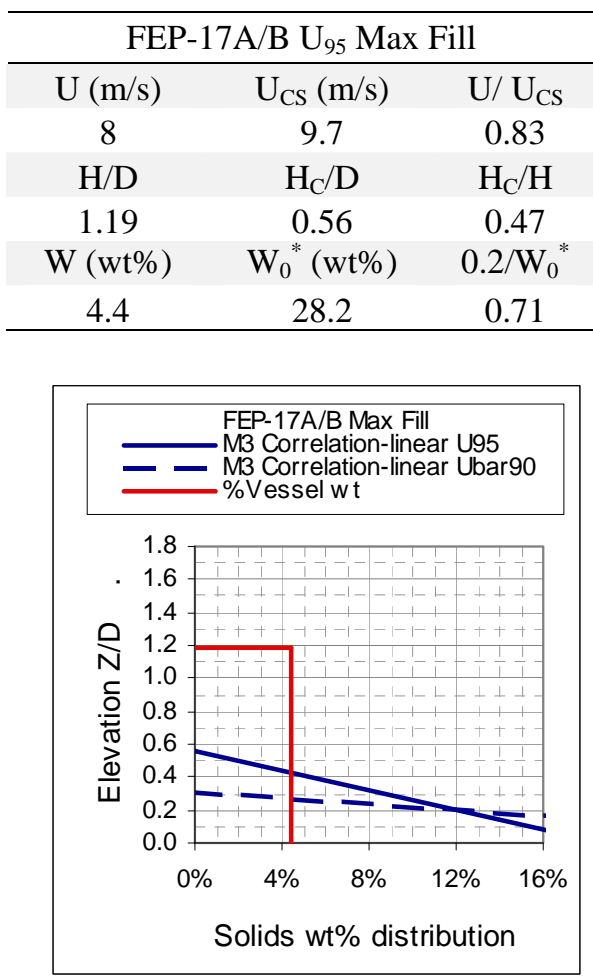

(a)

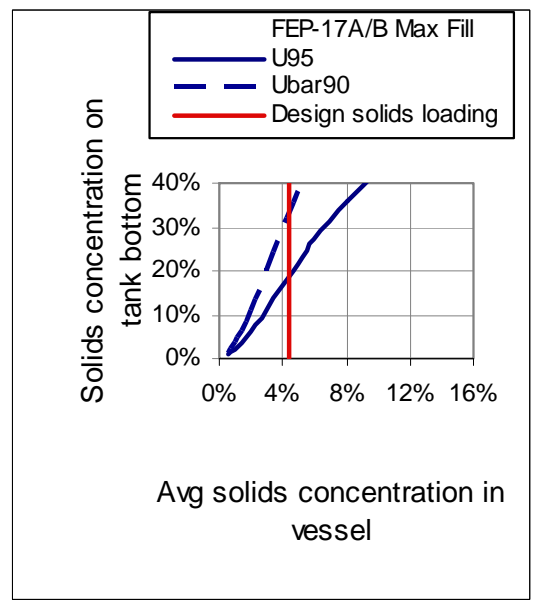

(c)
FEP-17A/B $\overline{\mathrm{U}}_{90}$ Max Fill

\begin{tabular}{ccc}
$\mathrm{U}(\mathrm{m} / \mathrm{s})$ & $\mathrm{U}_{\mathrm{CS}}(\mathrm{m} / \mathrm{s})$ & $\mathrm{U} / \mathrm{U}_{\mathrm{CS}}$ \\
8 & 13.0 & 0.62 \\
$\mathrm{H} / \mathrm{D}$ & $\mathrm{H}_{\mathrm{C}} / \mathrm{D}$ & $\mathrm{H}_{\mathrm{C}} / \mathrm{H}$ \\
1.19 & 0.31 & 0.26 \\
$\mathrm{~W}(\mathrm{wt} \%)$ & $\mathrm{W}_{0}{ }^{*}(\mathrm{wt} \%)$ & $0.2 / \mathrm{W}_{0}{ }^{*}$ \\
4.4 & 50.5 & 0.40 \\
\hline
\end{tabular}

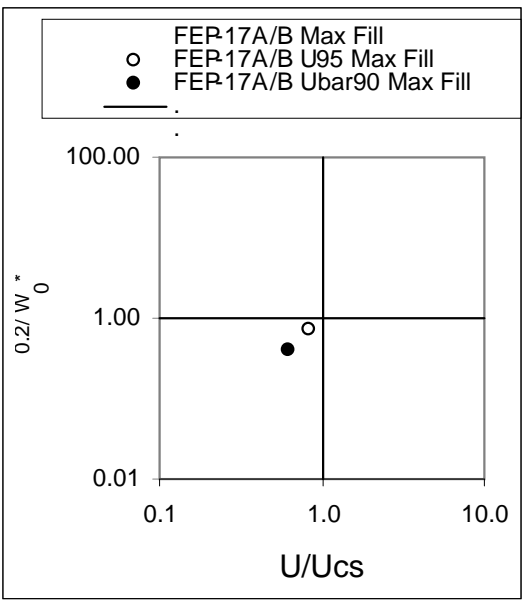

(b)

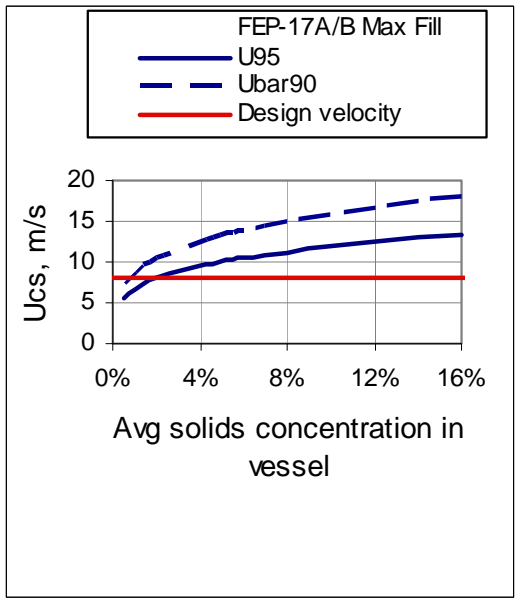

(d)

Figure 9.52. Generalized Model Predictions for FEP-17 A/B: (a) Concentration Profile at Max Fill, (b) Inlet Concentration and Suspension Ratio, (c) Maximum Solids Concentration Versus Loading Design Conditions, (d) $\mathrm{U}_{\mathrm{CS}}$ Versus Loading (Hanford PSDD, $\rho_{\mathrm{l}}=1.1 \mathrm{~g} / \mathrm{cm}^{3}$, $\mu=1.5$ cP fluid) 


\subsubsection{PWD-15/16 (Hanford PSDD, $\rho_{\mathrm{l}}=1.1 \mathrm{~g} / \mathrm{cm}^{3}, \mu=1.5 \mathrm{cP}$ fluid) Generalized Model}

Table 9.50 contains generalized model results for PWD-15/16 using the Hanford PSDD. Figure 9.53 presents generalized model predictions for PWD-15/16 (Hanford PSDD, $\rho_{l}=1.1 \mathrm{~g} / \mathrm{cm}^{3}, \mu=1.5 \mathrm{cP}$ fluid).

Table 9.50. Generalized Model Results for PWD-15/16 Using Hanford PSDD

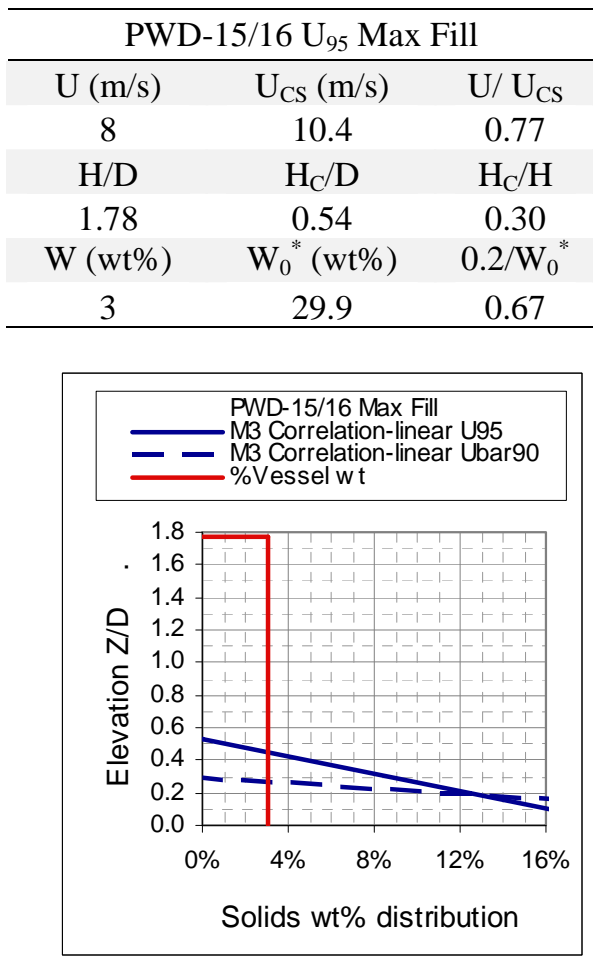

(a)

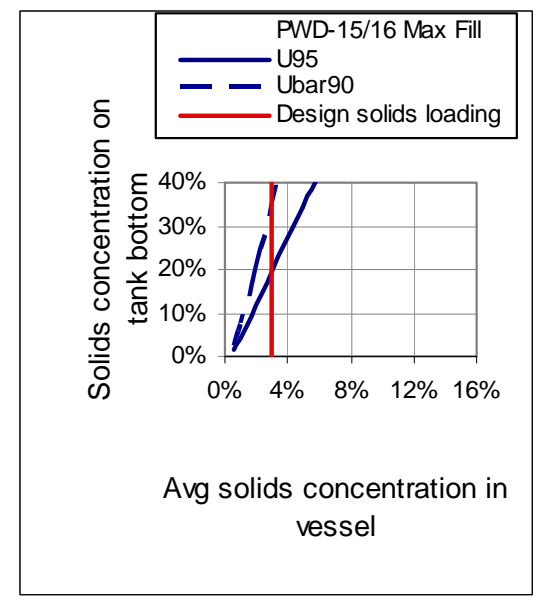

(c)

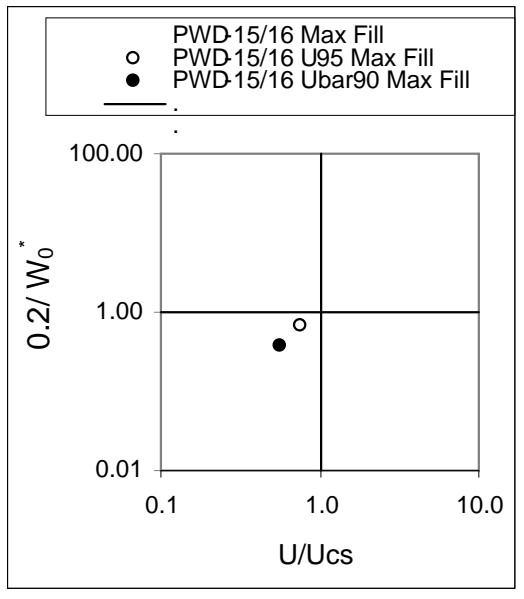

(b)

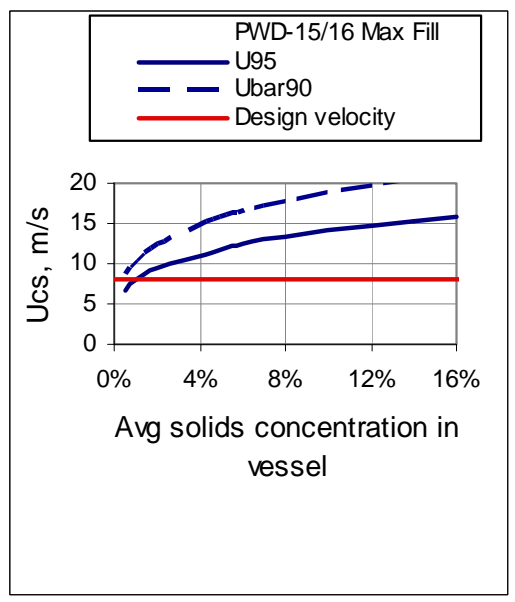

(d)

Figure 9.53. Generalized Model Predictions for PWD-15/16: (a) Concentration Profile at Max Fill, (b) Inlet Concentration and Suspension Ratio, (c) Maximum Solids Concentration Versus Loading Design Conditions, (d) $\mathrm{U}_{\mathrm{CS}}$ Versus Loading (Hanford PSDD, $\rho_{\mathrm{l}}=1.1 \mathrm{~g} / \mathrm{cm} 3$, $\mu=1.5$ cP fluid) 


\subsubsection{UFP-01 A/B (Hanford PSDD, $\rho_{\mathrm{l}}=1.1 \mathrm{~g} / \mathrm{cm}^{3}, \mu=1.5 \mathrm{cP}$ fluid) Generalized Model}

Table 9.51 presents generalized model results for UFP-01 A/B using the Hanford PSDD. Figure 9.54 shows generalized model predictions for UFP-01 A/B (Hanford PSDD, $\rho_{\mathrm{l}}=1.1 \mathrm{~g} / \mathrm{cm}^{3}, \mu=1.5 \mathrm{cP}$ fluid).

Table 9.51. Generalized Model Results for UFP-01 Using Hanford PSDD

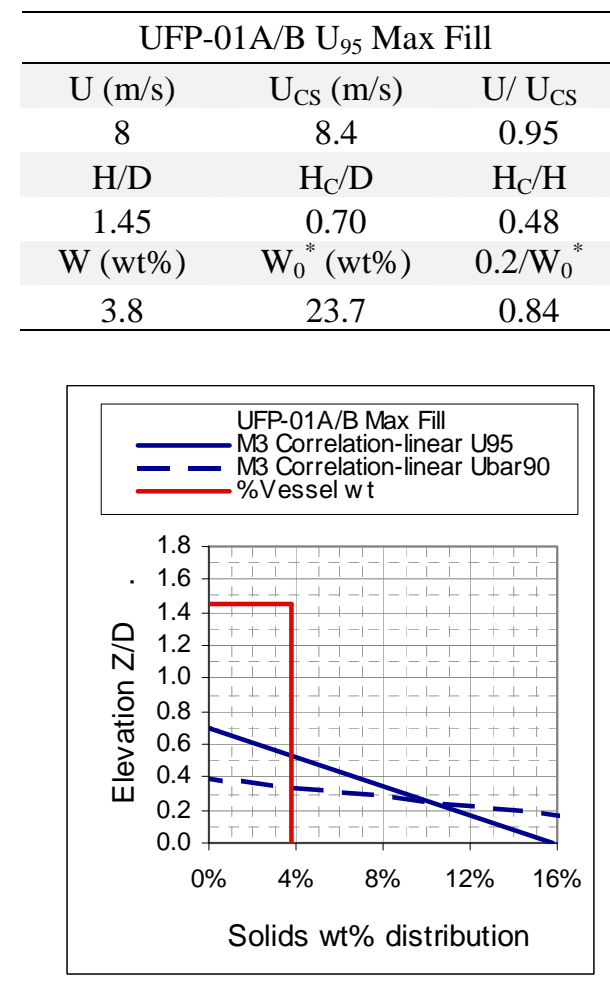

(a)

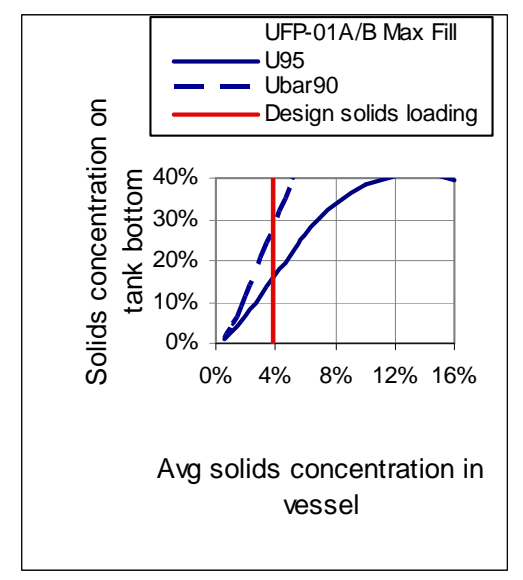

(c)

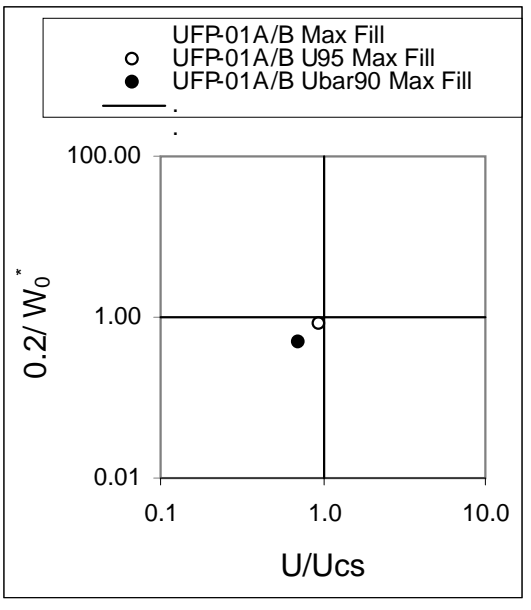

(b)

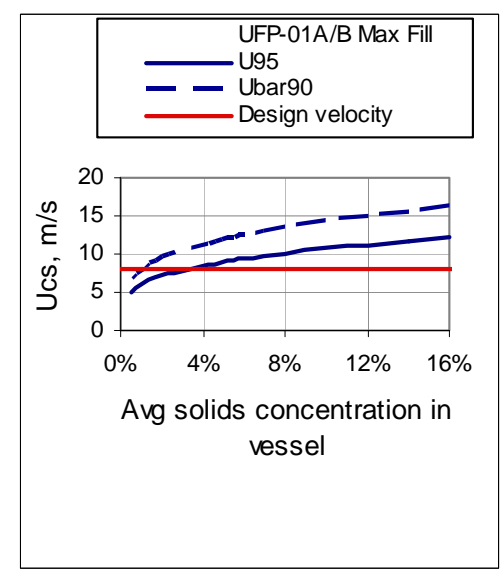

(d)

Figure 9.54. Generalized Model Predictions for UFP-01 A/B: (a) Concentration Profile at Max Fill, (b) Inlet Concentration and Suspension Ratio, (c) Maximum Solids Concentration Versus Loading Design Conditions, (d) $\mathrm{U}_{\mathrm{CS}}$ Versus Loading (Hanford PSDD, $\rho_{\mathrm{l}}=1.1 \mathrm{~g} / \mathrm{cm}^{3}$, $\mu=1.5$ cP fluid) 


\subsubsection{RLD-07 (Hanford PSDD, $\rho_{\mathrm{l}}=1.1 \mathrm{~g} / \mathrm{cm}^{3}, \mu=1.5 \mathrm{cP}$ fluid) Generalized Model}

Table 9.52 contains generalized model results for RLD-07 using the Hanford PSDD. Figure 9.55 presents generalized model predictions for RLD-07 (Hanford PSDD, $\rho_{\mathrm{l}}=1.1 \mathrm{~g} / \mathrm{cm}^{3}, \mu=1.5 \mathrm{cP}$ fluid).

Table 9.52. Generalized Model Results for RLD-07 Using Hanford PSDD

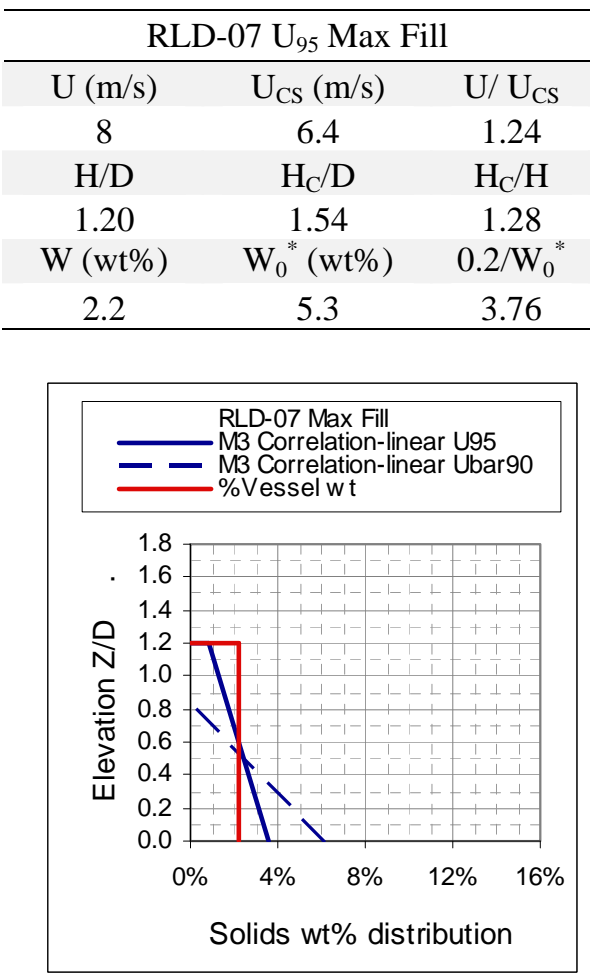

(a)

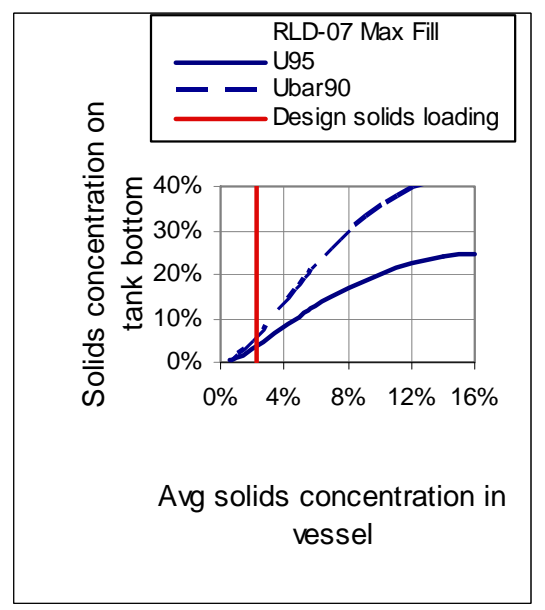

(c)

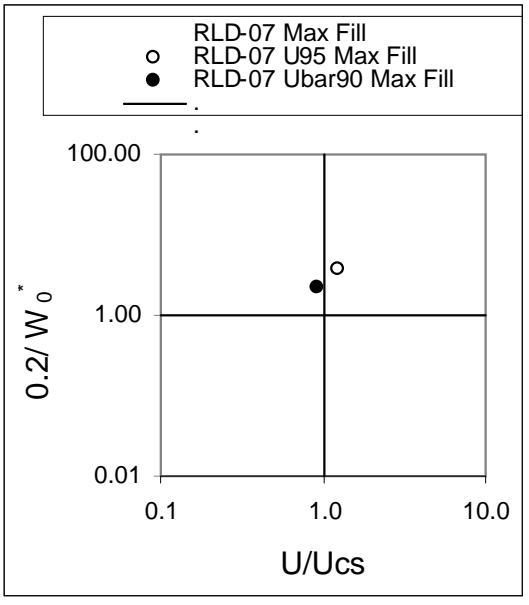

(b)

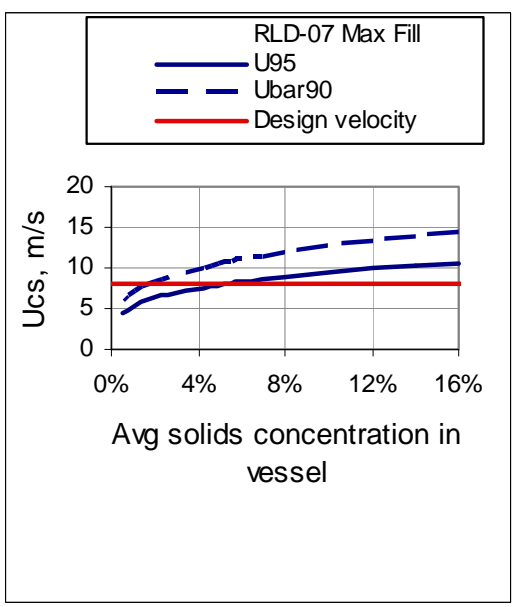

(d)

Figure 9.55. Generalized Model Predictions for RLD-07: (a) Concentration Profile at Max Fill, (b) Inlet Concentration and Suspension Ratio, (c) Maximum Solids Concentration Versus Loading Design Conditions, (d) $U_{C S}$ Versus Loading (Hanford PSDD, $\rho_{\mathrm{l}}=1.1 \mathrm{~g} / \mathrm{cm}^{3}$, $\mu=1.5$ cP fluid) 


\subsubsection{RLD-08 (Hanford PSDD, $\rho_{l}=1.1 \mathrm{~g} / \mathrm{cm}^{3}, \mu=1.5 \mathrm{cP}$ fluid) Generalized Model}

Table 9.53 lists generalized model results for RLD-08 using the Hanford PSDD. Figure 9.56 presents generalized model predictions for RLD-08 (Hanford PSDD, $\rho_{l}=1.1 \mathrm{~g} / \mathrm{cm}^{3}, \mu=1.5 \mathrm{cP}$ fluid).

Table 9.53. Generalized Model Results for RLD-08 Using Hanford PSDD

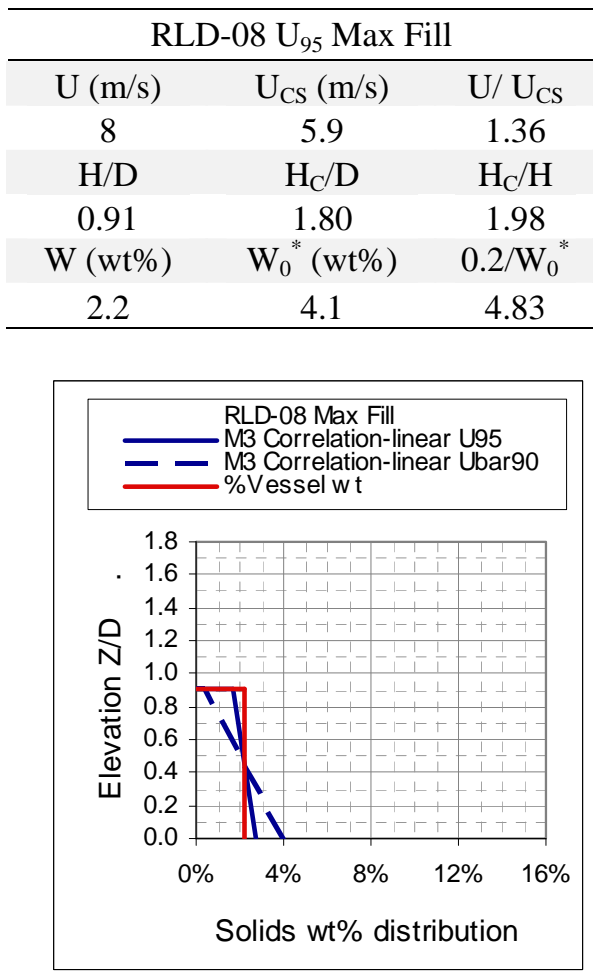

(a)

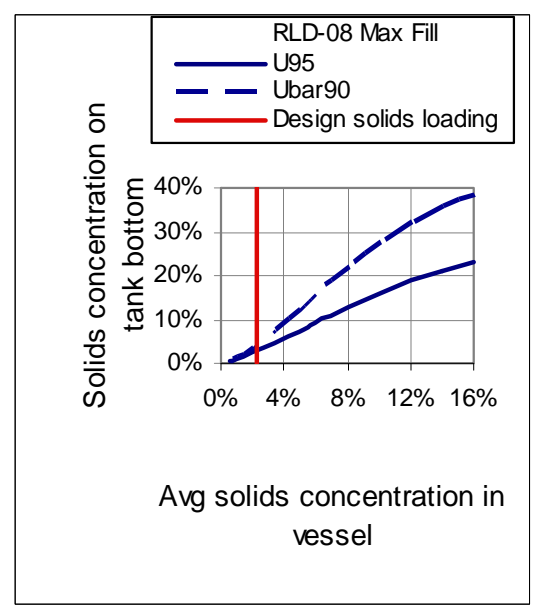

(c)

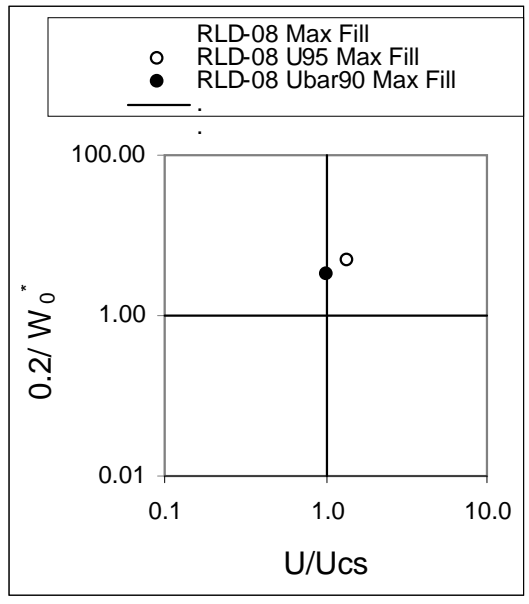

(b)

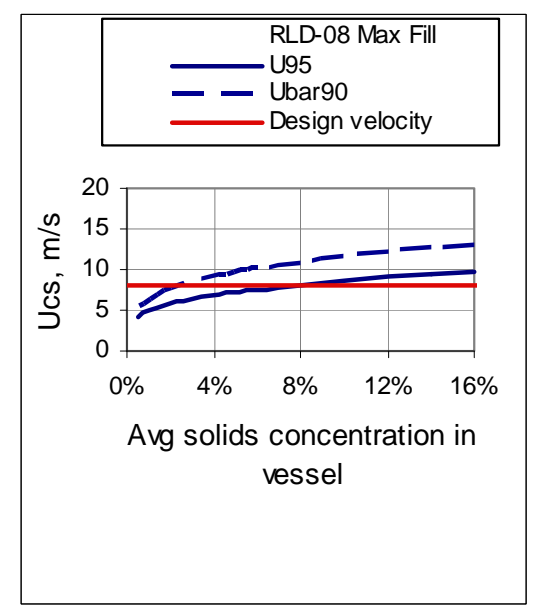

(d)

Figure 9.56. Generalized Model Predictions for RLD-08: (a) Concentration Profile at Max Fill, (b) Inlet Concentration and Suspension Ratio, (c) Maximum Solids Concentration Versus Loading Design Conditions; (d) $\mathrm{U}_{\mathrm{CS}}$ Versus Loading (Hanford PSDD, $\rho_{\mathrm{l}}=1.1 \mathrm{~g} / \mathrm{cm}^{3}$, $\mu=1.5$ cP fluid) 


\subsubsection{HOP-903/904 (Hanford PSDD, $\rho_{\mathrm{l}}=1.1 \mathrm{~g} / \mathrm{cm}^{3}, \mu=1.5 \mathrm{cP}$ fluid) Generalized Model}

Table 9.54 lists generalized model results for HOP-903/904 using the Hanford PSDD. Figure 9.57 shows generalized model predictions for HOP-903/904 (Hanford PSDD, $\rho_{\mathrm{l}}=1.1 \mathrm{~g} / \mathrm{cm}^{3}, \mu=1.5 \mathrm{cP}$ fluid).

Table 9.54. Generalized Model Results for HOP-903/904 Using Hanford PSDD

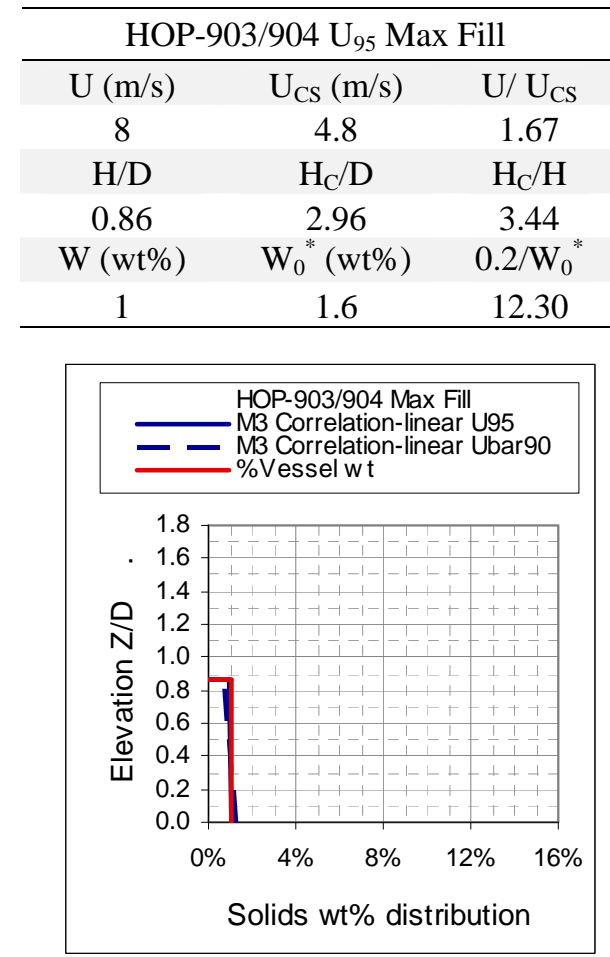

(a)

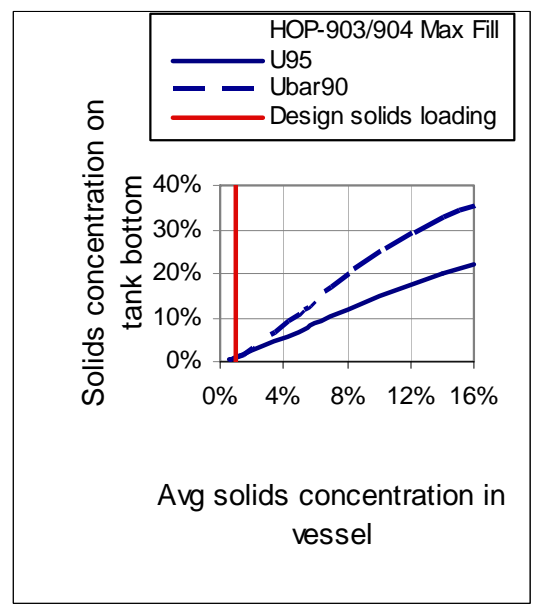

(c)

\begin{tabular}{ccc}
\multicolumn{3}{c}{ HOP-903/904 $\overline{\mathrm{U}}_{90}$ Max Fill } \\
$\mathrm{U}(\mathrm{m} / \mathrm{s})$ & $\mathrm{U}_{\mathrm{CS}}(\mathrm{m} / \mathrm{s})$ & $\mathrm{U} / \mathrm{U}_{\mathrm{CS}}$ \\
8 & 6.4 & 1.25 \\
$\mathrm{H} / \mathrm{D}$ & $\mathrm{H}_{\mathrm{C}} / \mathrm{D}$ & $\mathrm{H}_{\mathrm{C}} / \mathrm{H}$ \\
0.86 & 1.65 & 1.92 \\
$\mathrm{~W}(\mathrm{wt} \%)$ & $\mathrm{W}_{0}{ }^{*}(\mathrm{wt} \%)$ & $0.2 / \mathrm{W}_{0}{ }^{*}$ \\
1 & 1.9 & 10.49
\end{tabular}

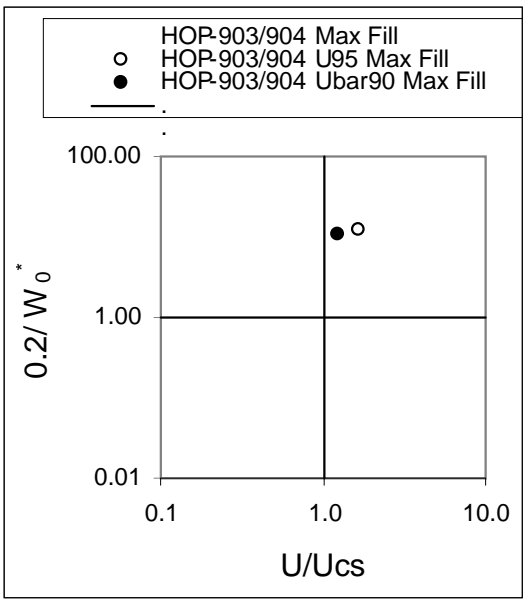

(b)

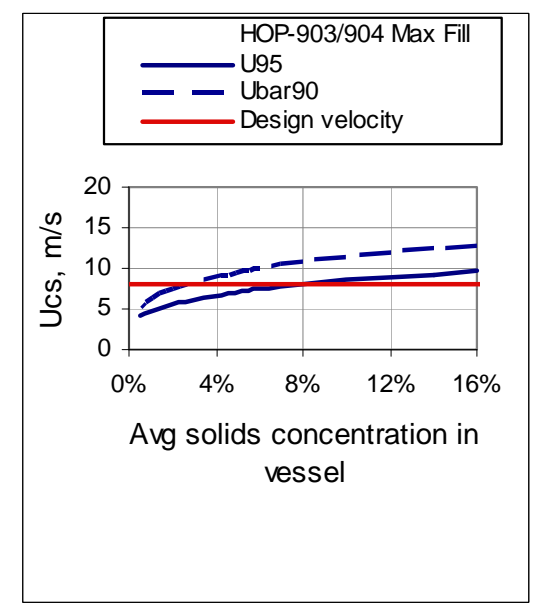

(d)

Figure 9.57. Generalized Model Predictions for HOP-903/904: (a) Concentration Profile at Max Fill, (b) Inlet Concentration and Suspension Ratio, (c) Maximum Solids Concentration Versus Loading Design Conditions, (d) $\mathrm{U}_{\mathrm{CS}}$ Versus Loading (Hanford PSDD, $\rho_{\mathrm{l}}=1.1 \mathrm{~g} / \mathrm{cm}^{3}, \mu=$ $1.5 \mathrm{cP}$ fluid) 


\subsection{Summary of Vessel Performance Ratios}

The vessel examples, including performance predictions, are provided using both physical and generalized models. These examples are for the vessel conditions provided in Olsen (2008a) and illustrate how the models can be used to predict vessel performance for the specific set of conditions described in Sections 9.1 through 9.5. The analysis of the vessels used in the examples has now been reassigned to the WTP M\&PE group (Hazen 2008b).

Figure 9.58 shows the summary of the predicted vessel performance ratios using the representative $\mathrm{U}_{95}$ and $\overline{\mathrm{U}}_{90}$ settling velocities from the Hanford tank waste PSDD (Case 3) with the physical models for $\mathrm{U}_{\mathrm{CS}}$ and $\mathrm{C}_{0}$ from Sections 7.3.2 to 7.3.4. Figure 9.59 presents a summary of the predicted vessel performance ratios using the design-limit particles specified in Olsen (2008a) with the physical models for $\mathrm{U}_{\mathrm{CS}}$ and $\mathrm{C}_{0}$ from Sections 7.3.2 to 7.3.4.

For Figures 9.58 through 9.61:

- Using the performance ratios for $\mathrm{U}_{\mathrm{CS}}\left(\mathrm{U}_{\text {design }} / \mathrm{U}_{\mathrm{CS}}\right)$ and suction inlet concentration $\left(0.20 / \mathrm{W}_{0}{ }^{*}\right)$, vessels can be assessed as satisfying these two requirements when both ratios are above 1.0. Design margin applied by the WTP M\&PE group will increase the required performance ratio.

- The lowest solids concentration metric values shown are below a condition that would result in a fully settled layer of waste in the bottom of the vessel. The concentration performance ratios have not been adjusted to the maximum packing factor limit (for these cases a fully settled bed is predicted) and are shown as calculated to indicate relative performance.

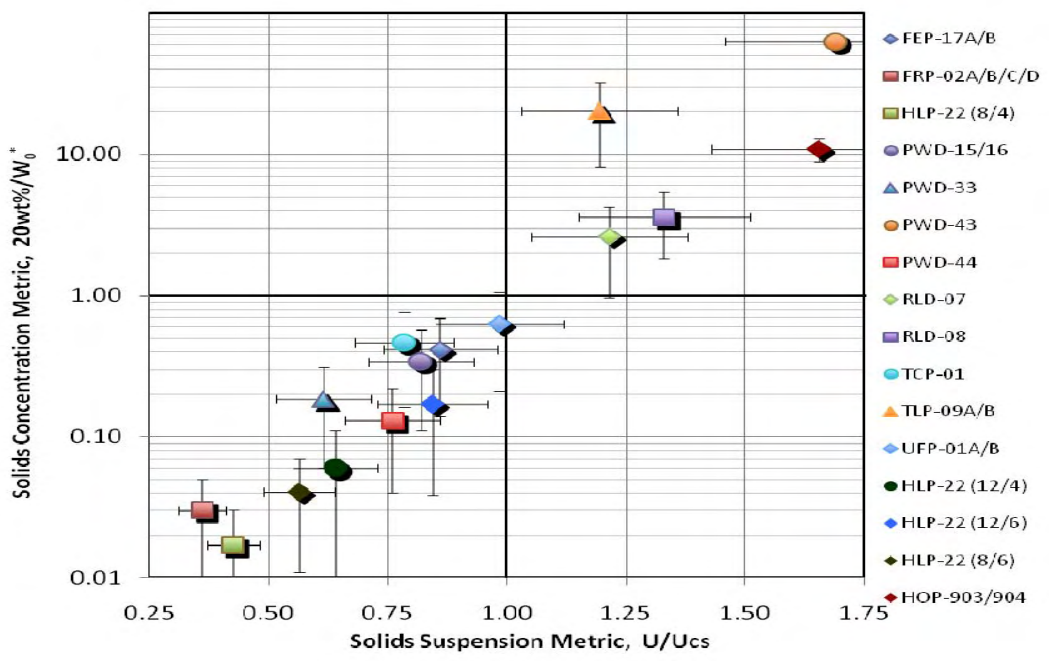

Figure 9.58. WTP Vessel Performance Ratio Summary Using $U_{95}$ and $\bar{U}_{90}$ Settling Velocities from the Hanford Tank Waste PSDD (Case 3) Using the Physical Models for $\mathrm{U}_{\mathrm{CS}}$ and $\mathrm{C}_{0}$ from Sections 7.3.2 to 7.3.4 with $\mathrm{C}_{0}$ modified to $\mathrm{W}_{0}{ }^{*}$, as Described in Section 9.1.4. The boundary bars shown are for the $\mathrm{U}_{95}$ and $\overline{\mathrm{U}}_{90}$ particle ranges evaluated. 


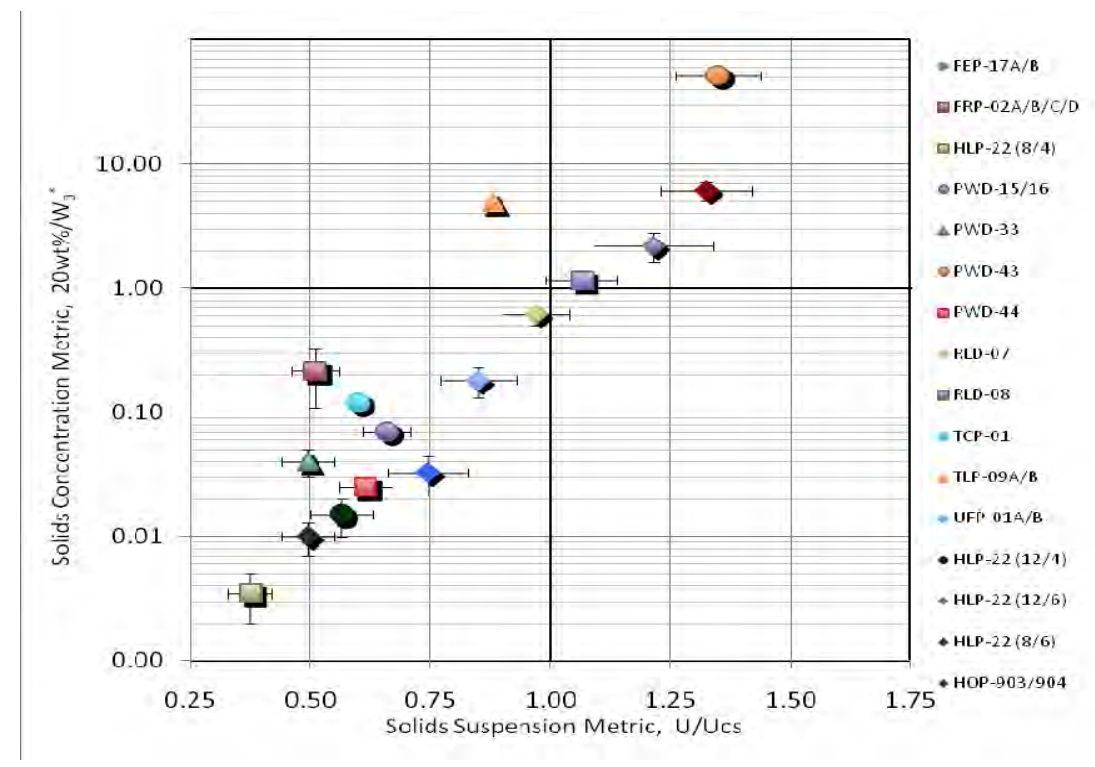

Figure 9.59. WTP Vessel Performance Ratio Summary Using the Design-Limit Particle from Olsen (2008a) and the Physical Models for $\mathrm{U}_{\mathrm{CS}}$ and $\mathrm{C}_{0}$ from Section 7.3.2 to 7.3.4 modified to $\mathrm{W}_{0}{ }^{*}$ in Section 9.1.4. The boundary bars shown are for the particle density range evaluated.

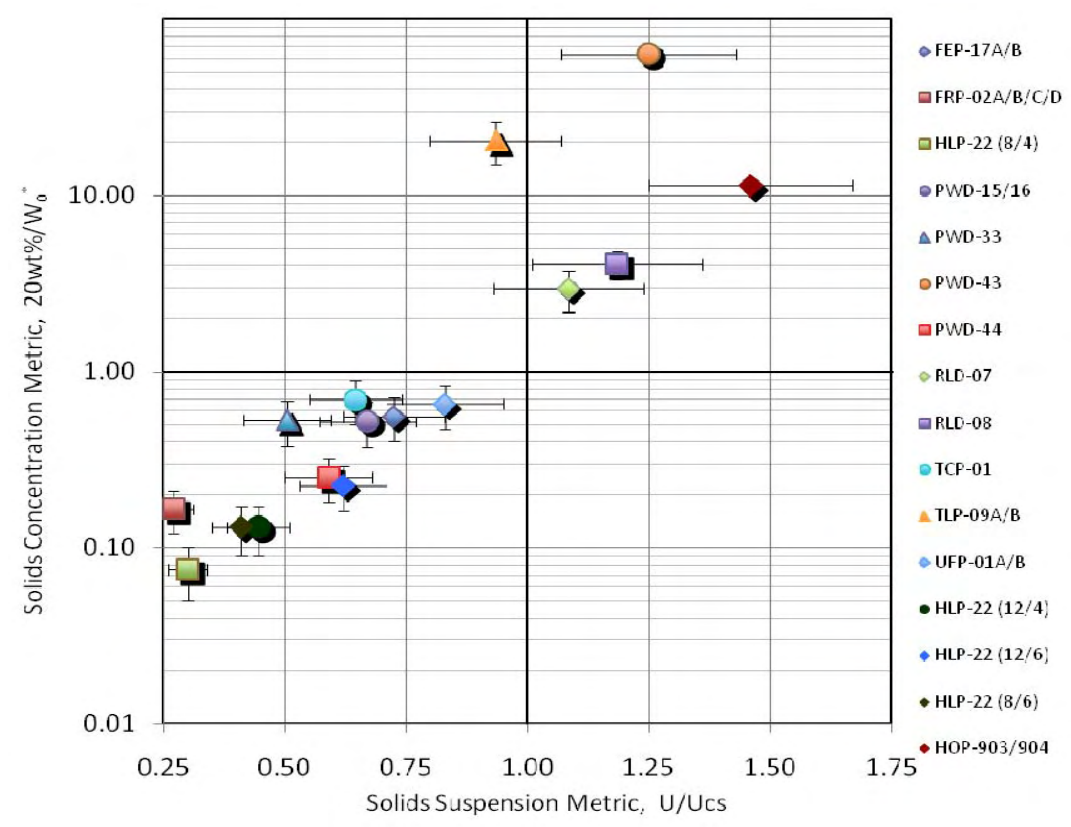

Figure 9.60. WTP Vessel Performance Ratio Summary Using $U_{95}$ and $\bar{U}_{90}$ Settling Velocities from the Hanford Waste PSDD (Case 3) Using the Generalized Models for $\mathrm{U}_{\mathrm{CS}}$ and $\mathrm{C}_{0}$ from Section 7.4.2 with $\mathrm{C}_{0}$ modified to $\mathrm{W}_{0}{ }^{*}$, as Described in Section 8.1.4. The boundary bars shown are for the $\mathrm{U}_{95}$ and $\overline{\mathrm{U}}_{90}$ particle ranges evaluated. 


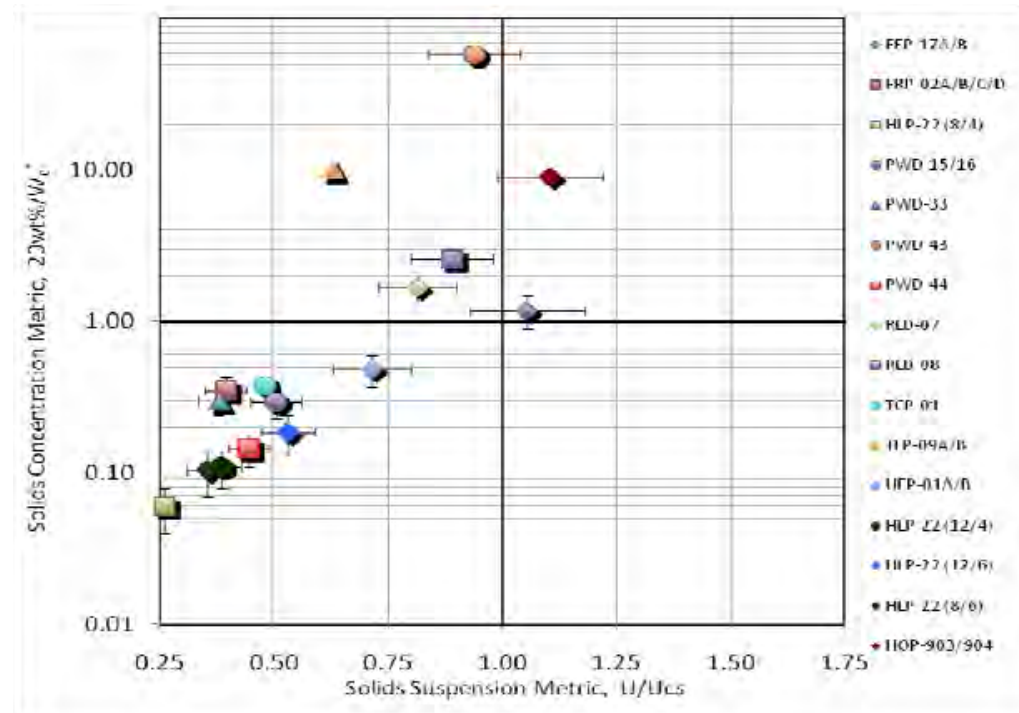

Figure 9.61. WTP Vessel Performance Ratio Summary Using the Design Limit Particle from Olsen (2008a) and Generalized Models for $\mathrm{U}_{\mathrm{CS}}$ and $\mathrm{C}_{0}$ from Section 7.4.2 with $\mathrm{C}_{0}$ modified to $\mathrm{W}_{0}{ }^{*}$, as Described in Section 9.1.4. The boundary bars shown are for the particle density range evaluated.

The HLP-22 vessel was also evaluated using $12 \mathrm{~m} / \mathrm{s}$ pulse jet velocity with 6-in. nozzles. This alternative configuration was an improvement over the $8 \mathrm{~m} / \mathrm{s}$ pulse jet velocity with 4 -in. nozzles (in Olsen 2008a), but for the conditions evaluated, the physical models for $\mathrm{U}_{\mathrm{CS}}$ and $\mathrm{W}_{0}{ }^{*}$ predicted the results would not satisfy the suction inlet or waste mobilization criteria. Other HLP-22 vessel configurations were also evaluated (from Criteria 2 and 3 in Table S.1). The performance predicted for all HLP-22 vessel configurations is summarized in Table 9.55. The HLP-22 design with 6-in. nozzle and DC reduced from 33 to $22 \%$ for 4 -in. nozzles provided improved performance for vessel mixing performance with respect to solids mobilization. That assessment is summarized in Table 9.55.

Performance ratios for the WTP vessels were also predicted using design limit particles and the settling characteristic from the Hanford waste tanks as described in the Hanford PSDD Case 3 (Wells et al. 2007). The results from using the physical models and the generalized models are relatively consistent, with slight variations when evaluated using the waste characteristics listed in Tables 9.3 and 9.4. The differences are that the generalized model normally predicts a higher $U_{C S}$ velocity requirement and a lower concentration on the vessel floor.

Table 9.55. Impact of HLP-22 Design Variations Using the Physical Models

\begin{tabular}{|c|c|c|c|c|c|c|c|c|}
\hline \multirow[b]{2}{*}{ Vessel } & \multirow{2}{*}{$\begin{array}{l}\text { Nozzle Velocity } \\
(\mathrm{m} / \mathrm{s})\end{array}$} & \multirow{2}{*}{$\begin{array}{l}\text { Nozzle Diameter } \\
\text { (in.) }\end{array}$} & \multicolumn{3}{|c|}{$\mathrm{U}_{95}$ Max Fill } & \multicolumn{3}{|c|}{$\overline{\mathrm{U}}_{90}$ Max Fill } \\
\hline & & & $\mathrm{U} / \mathrm{U}_{\mathrm{CS}}$ & $\mathrm{H}_{\mathrm{C}} / \mathrm{H}$ & $0.2 / \mathrm{W}_{0}$ & $\mathrm{U} / \mathrm{U}_{\mathrm{CS}}$ & $\mathrm{H}_{\mathrm{C}} / \mathrm{H}$ & $0.2 / \mathrm{W}_{0}{ }^{*}$ \\
\hline HLP-22 & 8 & 4 & 0.48 & $0.06^{(\mathrm{a})}$ & $0.03^{(\mathrm{a})}$ & 0.37 & $0.01^{(\mathrm{a})}$ & $0.004^{(\mathrm{a})}$ \\
\hline HLP-22 & 12 & 4 & 0.73 & 0.26 & $0.11^{\text {(a) }}$ & 0.55 & $0.03^{(a)}$ & $0.01^{\text {(a) }}$ \\
\hline HLP-22 & 8 & 6 & 0.64 & 0.15 & $0.07^{(a)}$ & 0.49 & $0.03^{(a)}$ & $0.01^{\text {(a) }}$ \\
\hline HLP-22 & 12 & 6 & 0.96 & 0.69 & 0.30 & 0.73 & $0.09^{(a)}$ & $0.04^{(\mathrm{a})}$ \\
\hline
\end{tabular}

(a) Indicates that the waste is considered fully settled on the bottom of the vessel for these conditions; the calculated ratio is shown to indicate relative performance only, and should not be construed to imply values of $\mathrm{W}_{0}{ }^{*}$ that are non-physically high. 



\subsection{Conclusions}

This section summarizes the significant conclusions and insights resulting from this work. The development of the predictive models is discussed in Section 10.1, followed in Section 10.2 by examples of the application of the models to predict performance of the WTP designs that satisfy two criteria. In Section 10.3 we present a brief list of opportunities to extend and improve the models. Section 10.4 contains a list of observations and accomplishments.

\subsection{Model Development}

Data from hundreds of scaled experiments were analyzed to develop models that can predict the performance of PJM systems for mixing noncohesive solids in Newtonian liquids. The models were developed using two independent approaches. The first, or physical approach, involved fitting the data to functional forms derived from (or suggested by) a dimensionless analysis of the phenomena expected to affect the performance variables. Models resulting from this approach are referred to as physical models. The second approach used multiple-regression methods to develop empirical models relating specified performance variables to the test parameters. The empirical models were re-expressed in terms of dimensionless variables that are physically interpretable. Models resulting from this approach are referred to as generalized models. The combination of these two approaches provides technical reliability and credibility, improves the accuracy of extrapolating model results to full scale, and reduces the extrapolation uncertainty.

For given waste characteristics and vessel design, the physical and generalized models provide predictions of the maximum height that solids will be lifted (the cloud height, $\mathrm{H}_{\mathrm{C}}$ ) and the minimum velocity required to suspend all of the solids (the critical-suspension velocity, $\mathrm{U}_{\mathrm{CS}}$ ). From the cloud height, a solids concentration can be estimated at any elevation in the vessel.

Confidence in these models has been established by benchmarking predictions for PJM mixing experiments that were conducted on a larger scale using a range of simulant properties. As a part of the benchmarking exercise, we determined that the most reliable and accurate indicator for the mixing behavior of a waste with a broad particle size and density distribution was to select a particle at the $95^{\text {th }}$ percentile of the particle settling velocity distribution. The benchmarking results (while limited to a single waste distribution) show strong qualitative agreement between the predictions and the measured values.

Confidence in applying the models to WTP vessels was gained by comparing the experimental ranges of dimensionless variables used to build the models to the values expected in full-scale WTP operations. These comparisons, illustrated in Section 9.2.3, show that for most applications the ranges of dimensionless variables covered by testing encompass the values of those variables for WTP vessels. That outcome greatly reduces the risks that can result from model extrapolation.

Another indicator of accuracy was provided by CFD. Model predictions were compared with CFD model predictions for Tank HLP-22. The models predicted cloud heights that were consistent with the solids concentration profiles from the CFD model. For the conditions selected, all predictions show a highly stratified system, which is expected when the design drive velocity (Olsen 2008a) is significantly below $\mathrm{U}_{\mathrm{CS}}$. 
The physical and generalized models produce slightly different predictions. Until more opportunities for benchmarking are available, we recommend both models be used as a means of checking for sensitivities.

\subsubsection{Recommendations for Using the Models}

The predictions from any model will be no better than the quality of the inputs, of course, and we emphasize the importance of using the appropriate waste properties. The benchmarking exercise revealed that selecting the $\mathrm{U}_{95}$ setting velocity may generate a slightly conservative prediction. The user must also apply appropriate margins to account for possible inaccuracies and uncertainties in the model predictions, as well as other uncertainties in PJM performance or waste properties. At the current level of development, we consider the models appropriate for determining 1) the conditions that would challenge a given design or, conversely, 2) the minimum PJM operating parameters needed to achieve the two performance criteria for a given vessel-waste combination. In either case, the predictions of conditions that "just meet" the requirements are also conditions that are not well mixed (per Olsen 2008a, the WTP vessels do not have a requirement to be well mixed). The uncertainties inherent in these mixing systems suggest that a design margin is needed to ensure thatvessel performance will always be sufficient in a specific system.

\subsubsection{Estimates of Confidence}

One benefit of using statistical methods to develop a model is that statistical intervals (e.g., a 95\% confidence interval) can be explicitly calculated for a model prediction at a defined set of parameters. Formulas for statistical intervals are presented in Appendix D for dimensional models. Formulas could be developed for the dimensionless-variable (generalized) models, but were not because of additional complications and time/budget constraints. Instead, as shown in Appendix F, the dimensional and generalized models are very close to the same form and provide nearly the same results. Hence, the uncertainties for the generalized models are expected to be similar to those obtained for the dimensional models because the forms and fits are similar.

This suggests that it is reasonable to apply the confidence intervals for dimensional models to the generalized models. The example shown in Appendix F for a 1.778-m (70-in.) tank yields a 95\% confidence interval (95\% CI) for $\mathrm{U}_{\mathrm{CS}}$ of approximately 1.8 to $2.1 \mathrm{~m} / \mathrm{s}$, or roughly $\pm 7 \%$ of the predicted value. For $\mathrm{H}_{\mathrm{C}}$, the $95 \% \mathrm{CI}$ is from 0.70 to $0.82 \mathrm{~m}$, which, for illustration, is about $\pm 8 \%$ of the predicted value. A similar calculation for a hypothetical 10 -m (32.7-ft) tank diameter yields values of about $\pm 11 \%$ for $\mathrm{U}_{\mathrm{CS}}$ and about $\pm 13 \%$ for $\mathrm{H}_{\mathrm{C}}$.

Note that the statistical methods for calculating uncertainties of model predictions assume that the mathematical form of the model well approximates the true underlying relationship. While the $\mathrm{U}_{\mathrm{CS}}$ models fit the experimental data better than the $\mathrm{H}_{\mathrm{C}}$ models, predictions for both mixing responses will likely have some inaccuracy. Appropriate margins are needed to account for the fact that no model will perfectly represent the true underlying relationship.

For a full-scale application the actual waste properties must be known, and the degree to which they are measured or inaccurately estimated will contribute to prediction error. It is possible to statistically combine uncertainties from the model itself and from model inputs. However, for this report we have assumed perfect knowledge of the physical and rheological properties. 


\subsection{WTP Vessel Performance Prediction Examples}

The WTP vessels were grouped into 13 distinct design and operational vessel types in Section 9, and performance predictions were developed for these vessels using the operating conditions discussed in Section 9. Additional performance predictions for HLP-22 were conducted to provide information for specific design modification options. The models provide performance metrics relative to requirements:

- Achieve complete suspension of solids (while this is not the specific WTP performance requirement for disturbing solids above a de minimis quantity, the two conditions are expected to be very close in value)

- Maintain suspended solids concentration at the pump suction at less than $20 \mathrm{wt} \%$.

The example performance predictions were conducted using both the physical models and the generalized models. Performance was calculated for each vessel using two different assumed conditions for the waste properties. One condition is defined as the Hanford PSDD Case \#3, and second set of waste properties was specified by WTP (Olsen 2008a). Performance predictions were developed assuming particle settling velocities described by the $95^{\text {th }}$ percentile $\left(\mathrm{U}_{95}\right)$ and the fastest settling $10 \%$ fraction ( $\overline{\mathrm{U}}_{90}$ )for the Hanford PSDD and used the limiting particle size and density to establish the settling rate for the WTP design conditions. This use of a characteristic single settling rate to represent a broad waste distribution was developed in the benchmarking in Section 8.

The example predications for the WTP vessel designs indicate a broad range of mixing performance. These calculated values provide a technically sound basis to identify those vessels that easily satisfy the requirements and those that fall quite short. Vessels predicted to fall close to the requirements should be evaluated further using additional methods. Final assessment of design adequacy will be made by the WTP M\&PE Group (Hazen 2008b).

We applied both the physical models and the generalized models to all 13 distinct design types, and the results were nearly identical. That is, both models identified the same vessels predicted to easily satisfy requirements and were similarly consistent in identifying the group of vessels predicted to be seriously deficient.

The HLP-22 vessel performance was also predicted using $12 \mathrm{~m} / \mathrm{s}$ pulse jet velocity with 6-in. nozzles. While this alternative configuration is predicted to improve performance, the models also show that the performance would not satisfy the suction inlet or waste mobilization criteria for the conditions evaluated (Sections 9.3, 9.4, and 9.5).

The sensitivity of predicted performance to the selection of input values was illustrated by developing two favorably bounding scenarios: one for the characteristic settling rate that affects the prediction of $\mathrm{U}_{\mathrm{CS}}$, and one for the solids concentration profile, which affects $\mathrm{W}_{0}$. Benchmarking comparisons suggest the use of a settling rate that is faster than the average (e.g. $U_{95}$ or $\bar{U}_{90}$ ), but the most appropriate value has not been well-established. The sensitivity of this input value is illustrated by assuming conditions that are likely bounding in a non-conservative direction (i.e., the actual performance would likely be worse than these predicted values). A bounding calculation (Section 9.4.1) for $\mathrm{U}_{\mathrm{CS}}$ based on a particle settling rate that is the average of the entire distribution of the Hanford PSD shows that the $\mathrm{U}_{\mathrm{CS}}$ for the FRP-02 
vessel is predicted to be $13.1 \mathrm{~m} / \mathrm{s}$, compared to a prediction based on the $\mathrm{U}_{95}$ particle settling rate of 19.4 $\mathrm{m} / \mathrm{s}$. Additional testing would help refine the best value to use.

Similarly, the prediction of solids concentration at the bottom of the vessel is sensitive to the assumed gradient of the solids concentration within the cloud. Observations and attenuation (concentration) measurements taken during testing indicated higher concentrations of solids near the bottom of the test vessels than at the peak of the recorded cloud, but the concentration profile was not well defined. A nonconservatively bounding condition for calculating the concentration at the pump suction was based on an assumption that the suspension of solids would be perfectly (homogeneously) mixed up to the peak of the cloud. Again using the FRP-02 example, the cloud height that corresponds to a uniform concentration of $20 \mathrm{wt} \%$ is 8.4 feet. Using the physical model and the $\mathrm{U}_{95}$ particle settling velocity to calculate cloud height, the jet velocity $U$ required to lift solids to $8.4 \mathrm{ftwould}$ need to be $13.8 \mathrm{~m} / \mathrm{s}$. Tests with distributions of solids coupled with measurements of solids concentrations near the vessel floor would help narrow the range of predicted concentrations at the pump suction. Actual performance is not expected to be this favorable.

\subsection{Recommendations for Extending Applicability of the Models}

The experimental program involved three scales of test vessels, state-of-the-art instrumentation and control equipment, and several high-quality simulants to conduct tests on a complex and transient fluid system. The goal was to develop general models that would capture the relevant geometric, operational, and waste properties to generate accurate predictions. The testing program was limited in scope to Newtonian fluids operating with noncohesive solids, and not all of the parameters that could affect performance were investigated.

Extending the capability of the models should consider the following opportunities:

- Testing with prototypic drive systems is needed to evaluate effects of small cohesive particles and to establish an adjustment factor for full-cycle (reciprocating flow) operations. In addition, testing at different fill levels could be evaluated to assess limits for solids loading.

- Performance for mixtures of solids (sizes and densities) has been predicted but has not been tested or confirmed. Some limited investigation should be conducted so that interactions among these physical properties can be evaluated.

- Most of the testing was conducted with the 12-tube configuration, and relatively few data were collected for 4- and 8-tube designs. Hence, the models favor the 12-PJM designs, but the degree to which adjustments are needed for other configurations is uncertain.

- Testing did not evaluate the effect of viscosity, although we have included its effect in the models. The influence of viscosity on both fluid flow and particle settling rate has been studied by others, and we do not expect that PJM mixing systems will behave differently than conventional mechanical systems relative to this parameter, so only limited testing should be needed.

- Benchmarking against larger scaled tests was considered successful, but more data from other relevant experiments would help build confidence in the models and assess sensitivity of results to input values. 
- Methods for quantifying and combining all uncertainties associated with mixing response models should be pursued. Statistical uncertainty intervals for quantifying model fitting uncertainty are presented in Appendix D, Section D.6 for the generalized model, and illustrated in Appendix F, Section F.4. However, such methods need to be extended for application to the other model forms. Further, statistical intervals should be developed that combine model-fitting uncertainty with the uncertainty from propagating uncertainties in the predictor variables of a model. Methods for quantifying possible inaccuracies or uncertainties associated with the form of the model should also be investigated.

Additionally, there were several analysis and application improvement opportunities that became apparent during the production period of this report. The practicalities of schedule constraints and extensive QA implementation requirements necessary to support the NQA-1 needs of this document did not permit the inclusion of these improvements into this report. The improvement opportunities are ${ }^{1}$ :

- Adding a tube number term to the physical model - The physical model was originally developed using a data set that excluded the Fall 2007 test data. The Fall 2007 data set included a substantial number of tests with 4 and 8 jets. When the additional data were included, the cloud height model was found to underpredict much of the 4- and 8-tube results. It was determined that the fit of cloud height $\left(\mathrm{H}_{\mathrm{C}}\right)$ model to the complete data set was significantly improved by simply introducing into the $\mathrm{H}_{\mathrm{C}}$ physical model the number of operating tubes as an unconstrained correlating parameter in the model. While this change to the $\mathrm{H}_{\mathrm{C}}$ physical model is small, the ramifications to the benchmarking and model application are likely to be significant, as described below.

- Benchmarking approach - The initial benchmarking of the models against previous test data from a large-scale prototypic testing was somewhat qualitative. Consequently, the selection of $U_{95}$ as the settling velocity that best characterizes mixing when the model is applied to slurries with a broad particle size distribution (PSD) lacked a rigorous basis. A better approach was to systematically determine the best-fit value of $U_{\mathrm{T}}$ for each benchmark case. This was briefly explored for two meaningful cases: a favorably conservative bound, and a best estimate. The favorably conservative bound involved the assuming the maximum concentration measured in each of the benchmark test cases was the value that was at the floor of the test tank. The best-estimate method involved estimating the concentration at the floor by applying mass conservation.

- Benchmarking results - The benchmarking approach described above can be systematically applied to the benchmark test cases using the improved physical model mentioned previously. The resulting best-fit values for settling velocity where approximately $\bar{U}_{40}$ for the favorably conservative bound and approximately $\overline{\mathrm{U}}_{60}$ for the best estimate. When these values are translated to the Hanford PSDD, they correspond to approximately $\mathrm{U}_{94}$ and $\mathrm{U}_{96}$, respectively. It turns out that the $\mathrm{U}_{95}$ value recommended in this report is bounded by these more systematically determined values, and a more rigorous treatment of the benchmarking data would provide a clear technical basis for this choice.

- Vessel evaluation methodology - There are two improvements to the vessel evaluations that will be significant. First, based on the benchmarking approach mentioned above, the settling velocity values of $\mathrm{U}_{95}$ and $\overline{\mathrm{U}}_{90}$ can be replaced with the systematically determined values (approximately $\overline{\mathrm{U}}_{40}$

\footnotetext{
${ }^{1}$ The information on the potential model improvements has not been reviewed through the QA process, the discussions above are "For Information Only."
} 
and $\bar{U}_{60}$, and approximately $\mathrm{U}_{94}$ and $\mathrm{U}_{96}$, respectively). The results in much tighter range of predicted performance in the plant vessels.

The second improvement relates to the concentration performance metric. The approach used to predict the concentration on the floor of a prototypic vessel involved several assumptions. First, it was assumed the solids vertical distributions are linear. While this is indeed correct to first order for the average of all data, it is clear that in many cases it was not the case. Also it was assumed that the value of concentration on the floor could be linearly extrapolated from the profiles. Finally, a method was used to translate concentration profiles from predicted high clouds that exceeded actual fill levels into concentration profiles within the finite fill level. In the absence of actual measurements of concentration near the floor of vessels, the above-mentioned assumptions result in unquantifiable uncertainty for the calculated concentration at the floor of the vessel. In light of this uncertainty, an alternative performance metric that is more closely and directly tied to the actual test data is the jet velocity required to achieve a solids cloud that reaches the fill level in the prototypic vessel. The magnitude of this velocity relative to the design velocity is an important indicator of a given design's ability to vertically distribute solids. Floor concentrations can still be inferred from this approach by assuming uniform or linear concentration profiles.

\subsection{Major Findings}

The effort to develop a generalized basis for predicting PJM mixing performance involved substantial review of more conventional mixing systems, both mechanically agitated and with steady jets. Much of the work presented in this report shows that the physics involved in a PJM mixed system are consistent with other systems. However, the feature that separates a PJM system from others is that the energy input is unsteady (pulsed). That difference has profound implications on the ability of the system to achieve specific functions, as summarized below.

Off-bottom suspension. The test results indicate that the off-bottom suspension characteristics of PJMs are similar to those of steady jet mixers and mechanical agitators. The dependence of $U_{C S}$ on solids loading, particle characteristics, nozzle diameter, and vessel scale are similar to the dependencies found for other mixing systems. The pulsation effects are readily accounted for by the inclusion of additional parameters such as the duty cycle and pulse volume fraction. However an important feature unique to pulsed jet mixing is that off-bottom suspension is intrinsically cyclical. At the $\mathrm{U}_{\mathrm{CS}}$ condition, the solids are completely off the bottom of the vessel only for a moment at the end of the pulse. Even when the pulse velocity is operated above the $\mathrm{U}_{\mathrm{CS}}$, solids will settle on the vessel floor during the time the PJM is refilling.

Solids vertical distribution. The test results indicate that the ability of PJMs to vertically distribute solids is significantly diminished compared with steady jets mixers and mechanical agitators. There is a significant penalty associated the refill period of the pulse cycle. Evidently, during the refill period the upward momentum of the primary flow created from the previous pulse is lost. Hence, the steady-state concentration distribution that would be attained for continuous mixing is not achieved for solid-liquid systems with pulsed jets. This effect is not simply due to particle settling during the refill period, as it is observed for small and large particles alike. Rather, it appears to be dominated by gravitational dynamics of the stratified bulk slurry. Another consequence of the pulsation is that significant temporal variation in 
concentration occurs during the discharge period, particularly near the bottom of the vessel. The ramifications of these transients to mixing and transfer requirements deserve a careful assessment.

Settling velocity. The inclusion of settling velocity as a correlating parameter was found to be beneficial for monodisperse simulants. It also provides a physically meaningful way to characterize mixing in slurries with a broad size and density distribution. It was argued that a settling velocity greater than the volume-weighted mean is the appropriate choice. While more data are required to fully establish this, the results of benchmarking clearly support the finding and suggest that the appropriate settling velocity is greatly influenced by the fastest-settling particles. 



\subsection{References}

Bamberger JA and MS Greenwood. 2004. “Using Ultrasonic Attenuation to Monitor Slurry Mixing in Real Time.” Ultrasonics 42(1-9):145-148.

Bamberger JA and PA Meyer. 2001. "Using Oscillating Jets to Maintain Solids in Suspension An Integrated Experimental and Computational Investigation.” PNNL-SA-34149, Pacific Northwest National Laboratory, Richland, Washington.

Bamberger JA and PA Meyer. 2007. “Characterizing Pulsating Mixing of Slurries.” Proceedings of FEDSM2007 5th Joint ASME/JSME Fluids Engineering Conference 2 (FEDSM2007-37666):201-205. American Society of Mechanical Engineers, New York.

Bamberger JA, PS Lowery, and LM Liljegren. 1990. Strategy Plan A Methodology to Predict the Uniformity of Double-Shell Tank Waste Slurries Based on Mixing Pump Operation. PNL-7665, Pacific Northwest Laboratory, Richland, Washington.

Bamberger JA, LM Liljegren, CW Enderlin, PA Meyer, MS Greenwood, PA Titzler, and G Terrones. 2007. Final Report One-Twelfth-Scale Mixing Experiments to Characterize Double-Shell Tank Slurry Uniformity. PNNL-16859, Pacific Northwest National Laboratory, Richland, Washington.

Bamberger JA, PA Meyer, JR Bontha, CW Enderlin, DA Wilson, AP Poloski, JA Fort, ST Yokuda, HD Smith, F Nigl, MA Friedrich, DE Kurath, GL Smith, JM Bates, and MA Gerber. 2005. Technical Basis for Testing Scaled Pulse Jet Mixing Systems for Non-Newtonian Slurries. PNWD-3551 (WTP-RPT-113) Rev. 0, Battelle - Pacific Northwest Division, Richland, Washington.

Bamberger JA, PA Meyer, JR Bontha, JA Fort, F Nigl, JM Bates, CW Enderlin, ST Yokuda, DE Kurath, AP Poloski, HD Smith, GL Smith, and MA Gerber. 2008. "Evaluating Pulse Jet Mixing with NonNewtonian Slurries.” Proceedings of IMECE2007 2007 ASME International Mechanical Engineering Congress and Exposition, 8(IMECE2007-42223):1909-1930. American Society of Mechanical Engineers, New York.

Bates JM, JW Brothers, JM Alzheimer, DE Wallace, and PA Meyer. 2003. Test Results for Pulse Jet Mixers in Prototypic Ultrafiltration Feed Process and High-Level Waste Lag Storage Vessels. PNWD3496, WTP-RPT-110 Rev. 0, Battelle - Pacific Northwest Division, Richland, Washington.

Bathija PR. 1982. Jet Mixing Design and Applications. Chemical Engineering. 13 Dec., 89(25):89-94.

Beltaos S and N Rajaratnam. 1977. “Impingement of Axisymmetric Developing Jets.” J. Hydraulic Research 15(4): 311-326.

BNI. 2007. WTP Project Memorandum CCN 151865. Contractor Change Notice for the Waste Treatment Plant Vessel PJM Data Table. Bechtel National Incorporated, Richland, Washington. 
Bontha JR, GR Golcar, and N Hannigan. 2000. Demonstration and Optimization of BNFL's Pulsed Jet Mixing and RFD Sampling Systems Performance Using NCAW Simulant. PNWD-3054 (BNFL-RPT048) Rev. 0, Battelle - Pacific Northwest Division, Richland, Washington.

Bontha JR, TE Michener, DS Trent, JM Bates, and MD Johnson. 2003a. Development and Assessment of the TEMPEST CFD Model of the Pulsed Jet Mixing Systems. PNWD-3261 (WTP-RPT-061) Rev. 0, Battelle - Pacific Northwest Division, Richland, Washington.

Bontha JR, JM Bates, CW Enderlin, and MG Dodson. 2003b. Large Tank Experimental Data for Validation of the FLUENT CFD Model of Pulsed Jet Mixers. PNWD-3303 (WTP-RPT-081) Rev. 0, Battelle - Pacific Northwest Division, Richland, Washington.

Bontha JR, CW Stewart, DE Kurath, PA Meyer, ST Arm, CE Guzman-Leong, MS Fountain, M Friedrich, SA Hartley, LK Jagoda, CD Johnson, KS Koschik, DL Lessor, F Nigl, RL Russell, GL Smith, W Yantasee, and ST Yokuda. 2005. Technical Basis for Predicting Mixing and Flammable Gas Behavior in the Ultrafiltration Feed Process and High-Level Waste Lag Storage Vessels with Non-Newtonian Slurries. PNWD-3676 (WTP-RPT-132) Rev. 0, Battelle - Pacific Northwest Division, Richland, Washington.

Bontha JR, DE Kurath, AP Poloski, WC Buchmiller, WH Combs, ED Johnson, HC Webber, and KL Herman. 2007. Pulse Jet Mixer Controller and Instrumentation Testing. PNWD-3828 (WTP-RPT146) Rev. 0, Battelle - Pacific Northwest Division, Richland, Washington.

Camenen B. 2007. "Simple and General Formula for the Settling Velocity of Particles.” Journal of Hydraulic Engineering - ASCE 133(2):229-233.

Carlson AB, PJ Certa, TM Hohl, JR Bellomy, TW Crawford, DC Hedengren, AM Templeton, HS Fisher, SJ Geelhood, DG Douglas, and WJ Ulbricht. 2001. Test Report, 241-AZ-101 Mixer Pump Test. RPP6548, Rev. 1, CH2MHill Hanford Group, Inc., Richland, Washington.

Elmore MR, CW Enderlin, and PA Meyer. July 2007. “M3 Testing Approach in Support of Tank HLP-22 Issues.” TP-RPP-WTP-480, Pacific Northwest National Laboratory, Richland, Washington.

Elmore MR, CW Enderlin, and PA Meyer. February 2008. "M3 Testing Approach in Support of Tank HLP-22 Issues.” TP-RPP-WTP-480 Rev. 0, ICN 1, Pacific Northwest National Laboratory, Richland, Washington.

Fort JA, JA Bamberger, JM Bates, CW Enderlin, and MR Elmore. 1993. 1/12-Scale Physical Modeling Experiments in Support of 241-SY-101 Hydrogen Mitigation. PNL-8476, Pacific Northwest Laboratory, Richland, Washington.

Fort JA, JA Bamberger, PA Meyer, and CW Stewart. 2007. Initial Investigation of Waste Feed Delivery Tank Mixing and Sampling Issues. PNNL-17043, Pacific Northwest National Laboratory, Richland, Washington.

Golcar GR, NG Colton, JG Darab, and HD Smith. 2000. Hanford Tank Waste Simulant Specification and Their Applicability for the Retrieval, Pretreatment, and Vitrification Processes. PNWD-2455, Battelle Pacific Northwest Division, Richland, Washington. 
Guerrero HA and M Restivo. 2004. Final Report UFP Restart and Sparger Testing. WSRC-TR-200400488, Rev. 0, SRNL-RPP-2004-00066 Rev. 0, Westinghouse Savannah River Company, Aiken, South Carolina.

Hazen H. 2008a. Contract No. DE-AC27-01RV14136, Hanford Tank Waste Treatment and Immobilization Plant, Memorandum of Agreement (MOA), 24590-QL-HC9-WA49-00001, PNNL R\&T Support, Direction for M3 WA2007-08 PJM Testing, Test Specification 24590-PTF-TSP-RT-06-006 Rev. 0. CCN 190723, Bechtel National Inc., Richland, Washington.

Hazen, H. 2008b. Letter CCN 178425. Contract No. DE-AC27-01RV14136 - Hanford Tank Waste Treatment and Immobilization Plant, Memorandum of Agreement (MOA) 24590-QL-HC9-WA49-00001, PNNL R\&T Support, Subcontract Change Notice (SCN) No. 71 for Work Authorization (WA) 08 Work Cancellations. Bechtel National, Inc. , Richland, Washington.

Johnson MD, JR Bontha, and JM Bates. 2003. Demonstration of Ability to Mix in a Small-Scale PulsedJet Mixer Test Facility. PNWD-3273 (WTP-RPT-077) Rev. 0, Battelle - Pacific Northwest Division, Richland, Washington.

Johnson MD, MA Gerber, JR Bontha, AP Poloski, RT Hallen, SK Sundaram, and DE Wallae. 2005. Hybrid Mixing System Test Results for Prototype Ultrafiltration Feed Process and High-Level Waste Lag Storage Vessels. PNWD-3586 (WTP-RPT-128) Rev. 0, Battelle - Pacific Northwest Division, Richland, Washington.

Kurath DE, PA Meyer, JR Bontha, AP Poloski, JA Fort, WH Combs, WC Buchmiller, ID Welch, and MD Bleich. 2007. Assessment of Pulse Tube Mixing for Vessels Containing Non-Newtonian Slurries. PNWD-3827 (WTP-RPT-155) Rev. 0, Pacific Northwest National Laboratory, Richland, Washington.

Kurath DE, PA Meyer, JR Bontha, AP Poloski, JA Fort, WH Combs, WC Buchmiller, ID Welch, and MD Bleich. 2007. Assessment of Pulse Tube Mixing for Vessels Containing Non-Newtonian Slurries. PNWD-3827 (WTP-RPT-155) Rev. 0, Battelle - Pacific Northwest Division, Richland, Washington.

Liljegren LM and JA Bamberger. 1992. “A Methodology to Predict the Uniformity of Double-Shell Waste Slurries Based on Mixer Pump Operation.” PNL-SA-20281, Pacific Northwest National Laboratory, Richland, Washington.

Meyer PA and AW Etchells. 2007. "Mixing with Intermittent Jets with Application in Handling Radioactive Waste Sludges.” Chemical Engineering Research and Design, 85(5):691-696.

Meyer PA and BE Wells. 2000. “Understanding Gas Release Events in Hanford Double Shell Tanks.” PNNL-SA-32640, Pacific Northwest National Laboratory, Richland, Washington.

Meyer PA, DE Kurath, and CW Stewart. 2005. Overview of the Non-Newtonian Pulse Jet Mixer Test Program. PNWD-3677 (WTP-RPT-127) Rev. 0, Pacific Northwest National Laboratory, Richland, Washington.

Meyer PA, DE Kurath, JA Bamberger, AW Etchells and SM Barnes. 2006. "Scaling Laws for ReducedScale Tests of Pulse Jet Mixing Systems in Non-Newtonian Slurries: Mixing Cavern Behavior." 2006 
Waste Management Symposium, Tucson, Arizona, WM Symposia, Inc. Available online at http://www.wmsym.org/abstracts/2006/index.html.

Olsen J. 2008a. Determination of Mixing Requirements for Pulse-Jet-Mixed Vessels in the Waste Treatment Plant. 24590-WTP-ES-PT-08-002, Rev. 0. Bechtel National Incorporated, Richland, Washington.

Olsen J. 2008b. Determination of Mixing Requirements for Pulse-Jet-Mixed Vessels in the Waste Treatment Plant. 24590-WTP-ES-PT-08-002, Rev. 1. Bechtel National Incorporated, Richland, Washington.

Paul EL, VA Atiemo-Obeng, and SM Kresta (Eds.). 2004. Handbook of Industrial Mixing. John Wiley \& Sons, Inc., Hoboken, New Jersey.

Poloski AP, ST Arm, JA Bamberger, DB Barnett, RS Brown, BJ Cook, CW Enderlin, MS Fountain, M Friedrich, BG Fritz, RP Mueller, F Nigl, Y Onishi, LA Schienbein, LA Snow, S Tzemos, M White, and JA Vucelick. 2005. Technical Basis for Scaling of Air Sparging Systems for Mixing in Non Newtonian Slurries. PNWD-3541, Battelle Pacific Northwest Division, Richland, Washington.

Poloski AP, ST Arm, OP Bredt, TB Calloway, Y Onishi, RA Peterson, GL Smith, and HD Smith. 2006a. Final Report: Technical Basis for HLW Vitrification Stream Physical and Rheological Property Bounding Conditions. PNWD-3675 (WTP-RPT-112) Rev. 0, Pacific Northwest National Laboratory, Richland, Washington.

Poloski AP, RC Daniel, DR Rector, PR Bredt, and BC Buck. 2006b. Characterization and Correlation of Particle-Level Interactions to the Macroscopic Rheology of Powders, Granular Slurries, and Colloidal Suspensions. PNNL-16133, Pacific Northwest National Laboratory, Richland, Washington.

Poloski AP, BE Wells, JM Tingey, LA Mahoney, MN Hall, SL Thomson, GL Smith, ME Johnson, JE Meacham, MA Knight, MG Thien, JJ Davis, and Y Onishi. 2007. Estimate of Hanford Waste Rheology and Settling Behavior. PNNL-16857 (WTP-RPT-154 Rev. 0), Pacific Northwest National Laboratory, Richland, Washington.

Powell MR, CM Gates, CR Hymas, MA Sprecher, and NJ Morter. 1995a. Fiscal Year 1994 1/25 ${ }^{\text {th }}$-Scale Sludge Mobilization Testing. PNL-10582, Pacific Northwest National Laboratory, Richland, Washington.

Powell MR, GR Golcar, CR Hymas, and RL McKay. 1995b. Fiscal Year 1993 1/25 ${ }^{\text {th }}$-Scale Sludge Mobilization Testing. PNL-10464, Pacific Northwest National Laboratory, Richland, Washington.

Powell MR, Y Onishi, and R Shekarriz. 1997. Research on Jet Mixing of Settled Sludges in Nuclear Waste Tanks at Hanford and Other DOE Sites: A Historical Perspective. PNNL-11686, Pacific Northwest National Laboratory, Richland, Washington.

Pratt GM and C Bogaerts. 2002. Mechanical Systems Design Guide: Vessel Sizing, 24590-WTP-GPCM-019, Rev. 1. Bechtel National Incorporated, Richland Washington.

Rajaratnam N. 1976. Turbulent Jets. Elsevier Science Publishers, New York. 
Saunders SA and PJ Keuhlen. 2008. Issue Response Plan for Implementation of External Flowsheet Review Team (EFRT) Recommendations - M3, Inadequate Mixing System Design, 24950-WTP-PLENG-06-0013, Rev. 3, Bechtel National Inc., Richland Washington.

Schlichting, H. 1979. Boundary-layer theory. McGraw-Hill, New York.

Shekarriz A, KJ Hammad, MR Powell. 1997. Evaluation of Scaling Correlations for Mobilization of Double-Shell Tank Waste. PNNL-11737, Pacific Northwest National Laboratory, Richland, Washington.

Smith GL. January 2007. Scaled Testing to Determine the Adequacy of the WTP Pulse Jet Mixer Designs. 24590-PTF-TSP-RT-06-007, Bechtel National Inc., Richland Washington.

Urie MW, GM Mong, PR Bredt, AP Poloski, JA Campbell, RD Scheele, OT Farmer, CZ Soderquist, SK Fiskum, RG Swoboda, LR Greenwood, MP Thomas, EW Hoppe, JJ Wagner, and LK Jagoda. 2002. Chemical Analysis and Physical Property Testing of 241-AZ-101 Tank Waste-Supernatant and Centrifuged Solids. PNWD-3215 (WTP-RPT-048) Rev. 0, Battelle - Pacific Northwest Division, Richland, Washington.

Wells BE, MA Knight, EC Buck, SK Cooley, RC Daniel, LA Mahoney, PA Meyer, AP Poloski, JM Tingey, WS Callaway III, GA Cooke, ME Johnson, MG Thien, DJ Washenfelder, JJ Davis, MN Hall, GL Smith, SL Thomson, and Y Onishi. 2007. Estimate of Hanford Waste Insoluble Solid Particle Size and Density Distribution. PNWD-3824 (WTP-RPT-153) Rev. 0, Battelle - Pacific Northwest Division, Richland, Washington.

Wilson KC, GR Addie, and A Sellgren. 2006. Slurry Transport Using Centrifugal Pumps, $3^{\text {rd }}$ Edition. Springer Science, New York.

Zwietering TN. 1958. "Suspending of Solid Particles in Liquid by Agitators." Chemical Engineering Science, 8:244-253. 



\section{Appendix A}

\section{Ultrasonic Instrumentation}

MS Greenwood

GP Morgen 



\section{Appendix A}

\section{Contents}

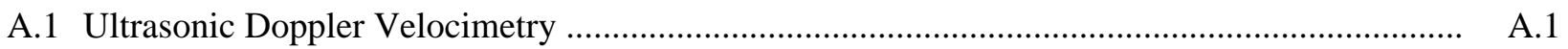

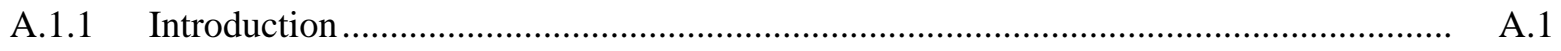

A.1.2 UDV - M3 Application ................................................................................... A.4

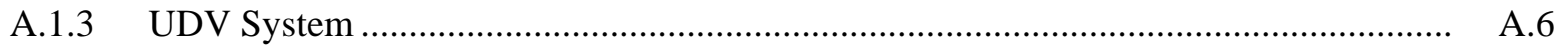

A.2 Ultrasonic Concentration Probe................................................................................. A.7

A.2.1 Data Acquisition Systems and Measurement of Attenuation..................................... A.9

A.2.2 Calculation of Attenuation ................................................................................ A.10

A.2.3 Relationship Between Concentration and Attenuation ............................................ A.12

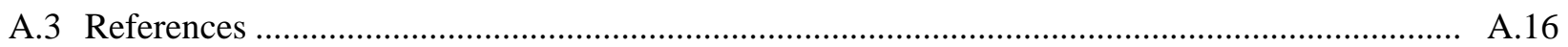

\section{Figures}

A.1 Schematic of Typical UDV Application ....................................................................... A.2

A.2 UDV Applied to the Measurement of a Settled Bed in a Mixing Tank .................................. A.4

A.3 Ultrasonic Transducers Mounted to the Small-Scale Tank Bottom........................................ A.5

A.4 UDV - M3 Block Diagram ..................................................................................... A.6

A.5 Photograph of the Concentration Sensor near the Bottom of the Small-Scale Tank .............. A.8

A.6 Concentration Sensor Configuration................................................................................. A.8

A.7 Schematic Diagram of the DAS .............................................................................. A.10

A.8 Voltage Versus Time Signal in Top Panel and the FFT of Each Signal in the Bottom

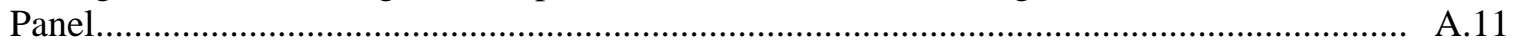

A.9 Example of Attenuation Versus Frequency for Slurry of s1d2 Particulate Using 3.5 MHz Transducers.

A.10 Mixer and Baffle Unit for Laboratory Measurements of Attenuation and Slurry Concentration

A.11 Concentration and Attenuation Measurements for Slurries s1d1, s1d2, and s1d5 for Determination of the Slope of the Straight Line Through the Data Points....

A.12 Concentration and Attenuation Measurements for Slurries s2d1 and s2d2 for Determination of the Slope of the Straight Line Through the Data Points.

\section{Tables}

A.1 Values of CONC for Five Simulants and Seven Frequencies. 



\section{Acronyms/Abbreviations}

A

Atten

CONC

DAS

FFT

PC

PNNL

UCC

UDV

C

D

$\mathrm{D}_{\max }$

$\mathrm{f}$

$f_{D}$

$\mathrm{k}$

$\mathrm{N}$

$\mathrm{R}$

$\mathrm{t}$

$\mathrm{v}$

$\mathrm{V}_{\max }$

$\mathrm{V}_{\mathrm{F}}$

$\mathrm{V}_{\text {particles }}$

$\mathrm{V}_{\text {liquid }}$

$\mathrm{X}$
Fast Fourier Transform amplitude

attenuation

concentration

data acquisition system

Fast Fourier Transform

personal computer

Pacific Northwest National Laboratory

ultrasonic command and control (computer)

ultrasonic Doppler velocimeter

\section{Symbols}

frequency bandwidth

speed of sound in the fluid

distance between transducer faces

maximum distance

ultrasonic frequency

Doppler frequency shift

angular wave number, $2 \pi / \lambda$

number of cycles

repetition rate time

time

particle velocity

maximum velocity

volume fraction

volume occupied by particles in sample

volume of liquid in the sample

distance 


\section{Greek Symbols}

$\begin{array}{ll}\Delta_{\mathrm{R}} & \text { range resolution } \\ \lambda & \text { wavelength } \\ \theta & \text { angle of transducer with respect to pipe centerline } \\ \rho_{\text {slurry }} & \text { density of the slurry } \\ \rho_{\text {part }} & \text { density of the particulate } \\ \rho_{\text {wtr }} & \text { density of the liquid } \\ \phi & \text { phase } \\ \omega & \text { angular frequency, } 2 \pi \mathrm{f}\end{array}$

A.iv 


\section{Appendix A}

\section{Ultrasonic Instrumentation}

Two ultrasonic instruments are used to characterize solids suspension during mixing. The ultrasonic Doppler velocimeter (UDV), which is described in Section A.1, was adapted to determine the thickness of the nonmoving settled layer of solids in the vessel by detecting vertical movement of the particles at the interface with the settled solids. The ultrasonic concentration probe, which is described in Section A.2, was applied to detect the suspended solids concentration at a desired location in the vessel.

The UDV and the ultrasonic concentration probe (classified as category-2 measurement equipment) evaluate the desired metrics based on relative measurements. The relative measurements are correlated with results obtained from a series of working standards. A series of working standards is created for each simulant used in the test platform, and the correlations developed are specific to each simulant.

For the UDV instrument, the working standards are gravity-settled beds of varying depth for which the time of flight of the ultrasonic signal is measured. A linear least squares fit is used to correlate the depth of the working standard as a function of the measured time of flight. The slope of this relationship provides the speed of sound through the settled bed. The determined speed of sound is used during the experiments to calculate the range (distance increments) at which the interface between nonmoving and moving particles is found, reported as the thickness of the settled bed.

For the attenuation probe, the ultrasonic attenuation, relative to the attenuation through the carrier liquid (supernatant liquid), over a known distance is measured for a series of working standards varying in volume concentration. Working standards are created for each simulant used. The ultrasonic attenuation is measured over a frequency spectrum, and from the data set the volume percent solids can be correlated as a function of the ultrasonic attenuation for a given frequency. By comparing the attenuation for a given simulant to the baseline attenuation for the carrier liquid, optimum frequencies can be selected (based on sensitivity of attenuation of signal at the specific frequency) for monitoring solids concentration during testing.

\section{A.1 Ultrasonic Doppler Velocimetry}

The UDV theory of operation is described in Section A.1.1. The method for measuring the slurry bed thickness is described in Section A.1.2. The components of the UDV system for detecting the interface between the settled and moving particles are listed in Section A.1.3.

\section{A.1.1 Theory of Operation}

An advanced UDV method that provides nondisruptive measurements of a flowing fluid or slurry has been developed by Pacific Northwest National Laboratory (PNNL). The method is based on integration of spatially resolved ultrasonic Doppler backscatter measurements and forward-scatter attenuation measurements. The method provides a flow velocity profile and shear stress values across the diameter of the process pipe for both Newtonian and non-Newtonian fluids. The device is designed for use on a large 
variety of products, including food products, consumer products, and polymer process streams. A complete description of UDV can be found in U.S. Patent No. 6,871,148 B2 (Morgen et al. 2002).

This Doppler-based system operates by generating a tone burst, a specific number of cycles of a sinusoidal waveform ( $\mathrm{N}$ sinewave cycles) at a specific repetition rate. Depending on the application and material properties of the test medium, the frequency of the sinusoidal waveform is typically $200 \mathrm{kHz}$ to $10 \mathrm{MHz}$. The tone burst signal is applied to an ultrasonic transducer that transmits ultrasound into the material being monitored. The repetition rate is the frequency (rate) at which the tone burst signal is applied to the transducer. After the tone burst (ultrasound) is transmitted into the test material, the same transducer is used to receive ultrasound echoes from scattering particles in the test material. The transducer converts the ultrasound echoes into an electronic signal that is amplified and analyzed.

The UDV system relies on measurement of the Doppler frequency shift of moving particles within the material flowing in the pipe, as shown in Figure A.1. Using a short ultrasonic pulse system, the crosssectional velocity profile can be obtained from the Doppler shift at each differential range point. The Doppler frequency shift $\left(f_{D}\right)$ is given by Eq. (A.1):

$$
\mathrm{f}_{\mathrm{D}}=\frac{2 \mathrm{v} \cos \theta}{\mathrm{c}} \mathrm{f}
$$

where $v$ is the particle velocity, $c$ is the speed of sound in the fluid, $f$ is the ultrasonic frequency, and $\theta$ is the angle of the transducer with respect to the pipe centerline. For example, the Doppler shift for a particle moving with velocity of $1 \mathrm{~m} / \mathrm{s}$ in water with speed of sound equal to $1500 \mathrm{~m} / \mathrm{s}$, a transducer angle of $45^{\circ}$, and an ultrasonic frequency of $5 \mathrm{MHz}$ is $4.714 \mathrm{kHz}$.

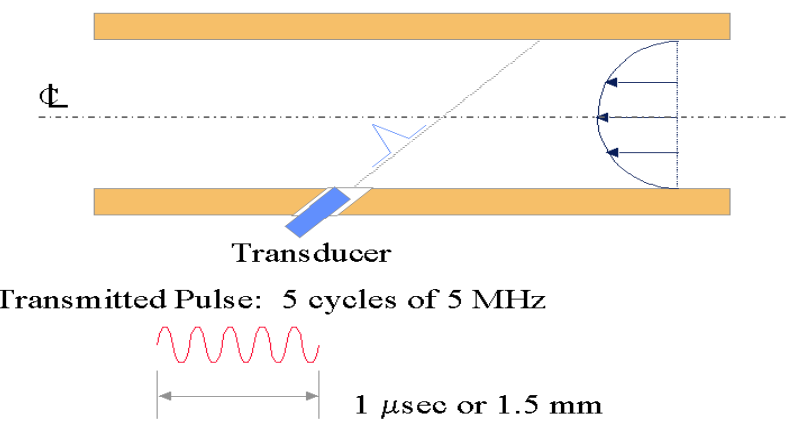

Figure A.1. Schematic of Typical UDV Application

To obtain good range resolution, it is essential to transmit a short ultrasonic pulse. The range resolution is approximately equal to one-half of the spatial width of the pulse. For $\mathrm{N}$ sine-wave cycles of wavelength $\lambda$, the range resolution $\Delta_{\mathrm{R}}$ is approximately

$$
\Delta_{\mathrm{R}}=\mathrm{N} \frac{\lambda}{2}
$$

For example, 5 cycles of $5 \mathrm{MHz}$ (0.3-mm wavelength for speed of sound of water) results in a range resolution of approximately $0.75 \mathrm{~mm}$. 
Obtaining good resolution creates a problem for the measurement of the Doppler frequency shift, which is typically in the $1-$ to $10-\mathrm{kHz}$ frequency range. A gated sinewave (tone burst) of frequency $\mathrm{f}$ and $\mathrm{N}$ cycles has a relatively wide frequency bandwidth, $\mathrm{B}$, of approximately

$$
\mathrm{B}=\frac{\mathrm{f}}{\mathrm{N}}
$$

For a tone burst signal of 5 cycles of $5 \mathrm{MHz}$, the bandwidth (B) is $1 \mathrm{MHz}$. The Doppler shift needs to be on the order of or larger than $\mathrm{B}$ to be distinguishably measurable from the frequency spectrum of the signal scattered from the particles. Doppler shifts this large would only be expected if the fluid velocity were on the same order as the speed of sound in the fluid. Velocities of interest in pipe flow problems are much lower than the speed of sound. A fixed operating frequency, $\mathrm{f}$, is used, so reducing the bandwidth by increasing $\mathrm{N}$ would allow for good Doppler velocity resolution, but it results in directly degrading the range resolution per Eq. (A.2). To resolve this conflict, data from multiple transmit and receive sequences occurring at the repetition rate are acquired over a long time interval (1 to $20 \mathrm{sec}$ ) to obtain a number of data points from each differential range section in the flowing material. The repetition rate may vary from $100 \mathrm{~Hz}$ to $20 \mathrm{kHz}$.

This measurement method has several limitations. One is an aliasing artifact introduced by the repetition rate that causes incorrect velocity measurements. This is a Nyquist limitation associated with the discrete sampling of Doppler frequency. The aliasing artifact occurs when the Doppler-induced frequency shift exceeds one-half the repetition rate. Using $\mathrm{R}$ to denote the repetition rate, in equation form this becomes

$$
\mathrm{f}_{\mathrm{D}} \leq \frac{\mathrm{R}}{2}
$$

Substituting Eq. (A.1) with the angle equal to 0 gives

$$
\mathrm{v} \leq \frac{\mathrm{cR}}{4 \mathrm{f}}
$$

or

$$
\mathrm{V}_{\max }=\frac{\mathrm{cR}}{4 \mathrm{f}}
$$

Increasing the repetition rate for a given speed of sound and transducer frequency increases the maximum particle velocity $\left(\mathrm{V}_{\max }\right)$ that can be measured.

Another limitation of this measurement method is the distance that can be measured, or the range of UDV. The repetition rate is limited by the round-trip time for the ultrasound to travel from the transducer to a particle and back. Using the form distance $=$ velocity $\times$ time, where distance is $2 \mathrm{D}_{\max }$ (round-trip distance), velocity is c (speed of sound), and time is $1 / \mathrm{R}$ (repetition rate) results in the equation

$$
\mathrm{D}_{\max }=\frac{\mathrm{C}}{2 \mathrm{R}}
$$


Combining Eq. (A.6) and (A.7) links the maximum velocity, $\mathrm{V}_{\max }$, and the maximum distance, $\mathrm{D}_{\max }$, parameters by the following equation:

$$
\mathrm{D}_{\max } \mathrm{V}_{\max }=\frac{\mathrm{c}^{2}}{8 \mathrm{f}}
$$

\section{A.1.2 Measuring Slurry Bed Thickness}

To support testing, the operation of the UDV system was adapted to identify the boundary between moving slurry with suspended particles and a settled bed of particles (see Figure A.2). This boundary, if present, indicates that the particles are not fully suspended. The depth of this boundary corresponds to the depth of the settled bed.

As depicted in Figure A.2, the UDV ultrasonic transducer is mounted on the bottom of the mixing tank at an angle of 0 degrees relative to the centerline of the pipe shown in Figure A.1. In actual practice, a mounting ring with a 7-degree angle was used to mount the transducer to the tank; this reduced the multipath return signals between the transducer and the inside tank wall. Figure A.3 is a picture of the UDV transducer mounted to the bottom of the small-scale (15-in.) tank.
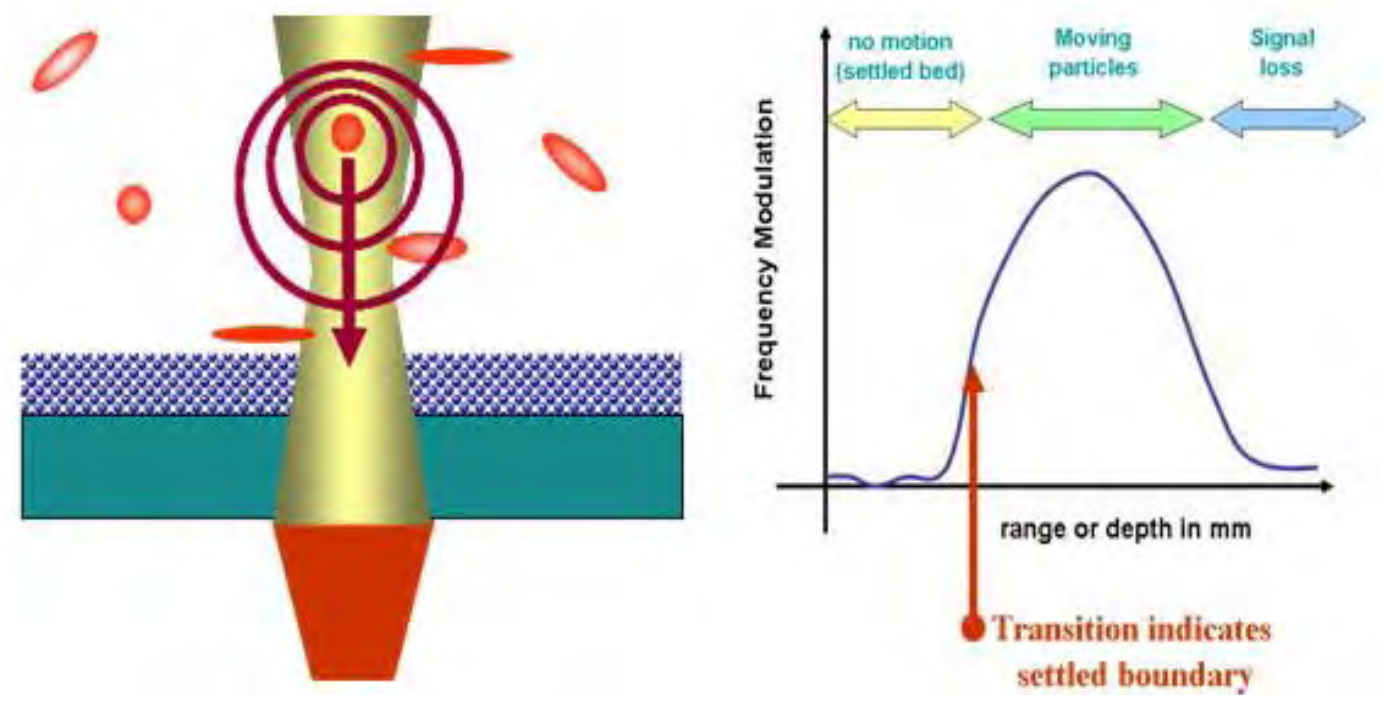

Figure A.2. UDV Applied to the Measurement of a Settled Bed in a Mixing Tank

The ultrasound transmit tone burst used for all testing was 4 cycles of $2.25 \mathrm{MHz}$, which results in a range resolution of approximately $1.33 \mathrm{~mm}$ (Eq. A.2) based on the speed of sound in water, $1500 \mathrm{~m} / \mathrm{s}$. The speed of sound in the simulants used in testing ranged from about 1400 to $1700 \mathrm{~m} / \mathrm{s}$, resulting in range resolutions of 1.24 to $1.51 \mathrm{~mm}$. To support this calculation and the ranging calculations used to generate the velocity profile plots, the speed of sound was measured for each simulant using Calibration Procedure for Determining Velocity of Ultrasonic Energy in Simulants (TPR-RPP-WTP-608). 


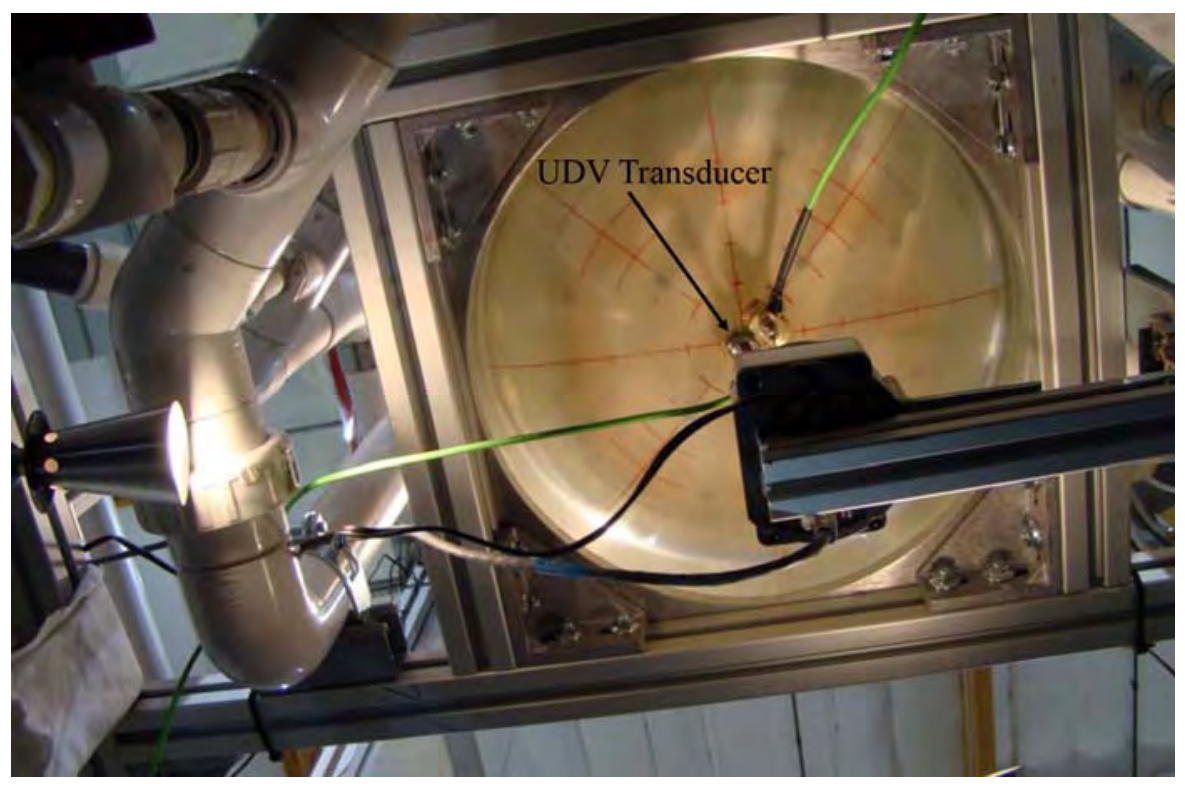

Figure A.3. Ultrasonic Transducers Mounted to the Small-Scale Tank Bottom

The repetition rate used for most of the testing was in the 5- to $5.5-\mathrm{kHz}$ range. Operating procedures allowed the repetition rate to be varied from 1 to $10 \mathrm{kHz}$. Small adjustments to the repetition rate were occasionally required to eliminate extraneous ultrasound signals from fixed objects in the tank, or even the surface of the water in the tank, that could occur during the actual sampling of the Doppler signal. For a nominal $5 \mathrm{kHz}$ repetition rate and the speed of sound range previously listed for the simulants tested, equation (A.7) indicates the maximum range varies from 14 to $17 \mathrm{~cm}$. The calculated maximum range distances are larger than the actual measurement range of $4 \mathrm{~cm}$ used during testing, and this was not a factor during UDV measurements. Using the same conditions and applying equation (A.6) indicates the maximum particle velocity varies from 77 to $94 \mathrm{~cm} / \mathrm{s}$ before aliasing would be a factor. Aliasing was not a factor during UDV measurements.

The UDV data acquisition is triggered by a pulse signal generated from the ultrasonic command and control (UCC) computer. The UDV trigger signal is set up to occur at the end of the valve open time, when the depth of the settled bed should be at a minimum. The standard UDV analysis was conducted to generate a velocity profile plot. These data are then analyzed to determine the range where there is a transition from stationary to moving particles. The range value is reported as the settled bed depth. A block diagram of the UDV system as used during testing is illustrated in Figure A.4.

The transmitted tone burst, 4 cycles of $2.25 \mathrm{MHz}$, is output through a diplexer to the transducer. The ultrasound travels into the tank and is scattered by particles. Some of the ultrasound returns to the transducer, which generates a receive signal that is routed by the Diplexer to an external 40-dB wideband amplifier. The output of the amplifier goes directly into the R\#1 input on UDV. For M3 operations, the UCC system sends a trigger signal to UDV that controls when data are acquired and analyzed to determine the bed layer depth. The UDV trigger was set to occur 0.4 to 0.0 seconds before the closure of the valve that controls flow into the tank. After calculating the bed layer depth, UDV transmits the depth data and a time stamp to the UCC via the network connection. All data files logged during data acquisition are downloaded to the M3 server. 


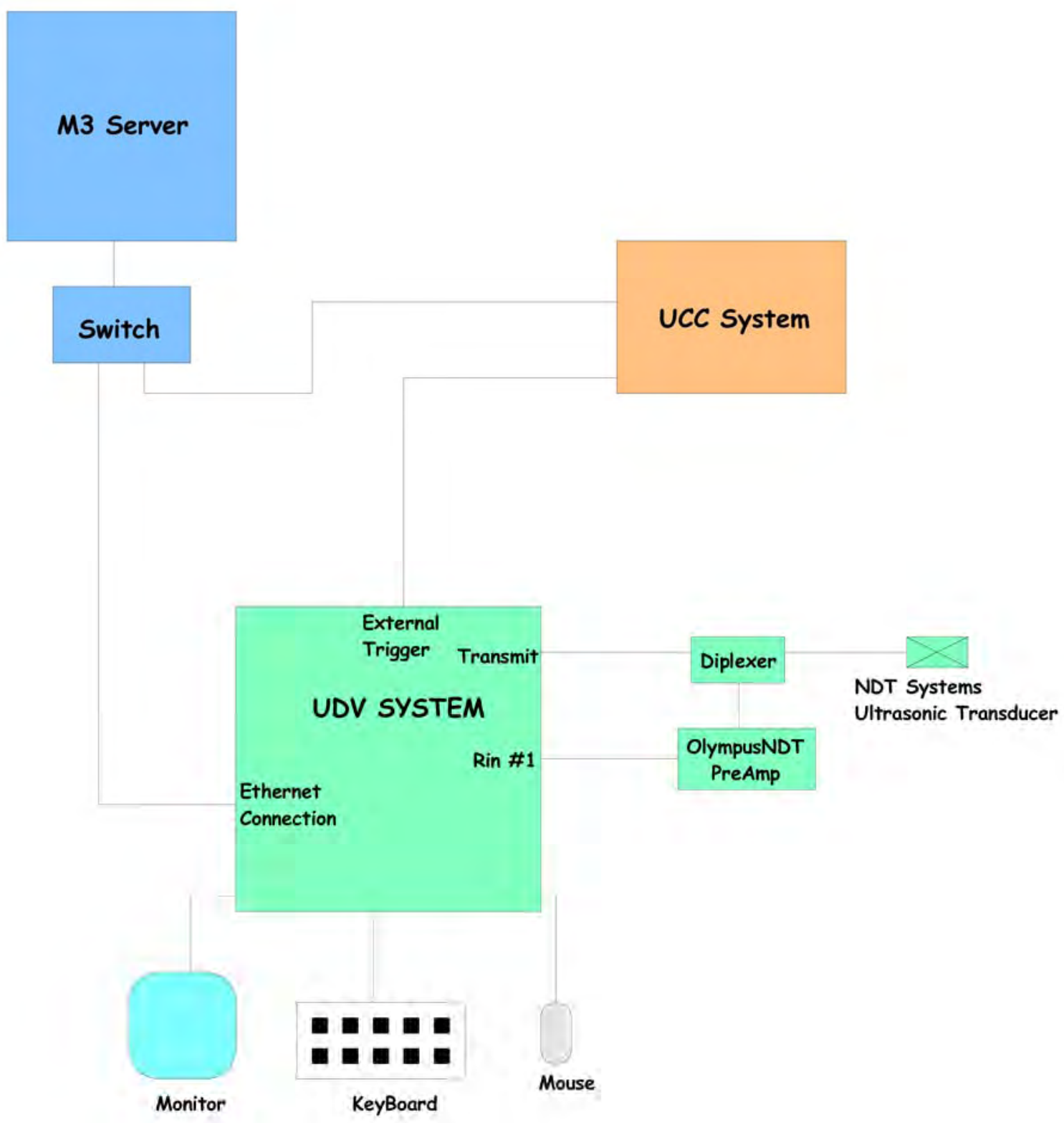

Figure A.4. UDV Component Diagram

\section{A.1.3 UDV System Components}

The UDV system hardware is based around the Arcom Olympus EBX single-board personal computer (PC). The UDV system has a monitor, keyboard, and mouse that are used to select operating parameters and display results. Following is a listing of the major components of the UDV system.

1. Arcom Olympus EBX Single-Board Computer

- $1 \mathrm{GHz}$ Pentium III

- $256 \mathrm{MB} / 512 \mathrm{MB}$ RAM

- $\quad$ Standard PC I/O (comm, parallel, IDE, video, keyboard and mouse, USB)

- 1 PCI expansion slot 
- PC104 expansion bus

2. CyberResearch PCIDAQ 2012

- 4-channel 12-bit simultaneous sampling

- 20 MSamples/second max rate on all channels

3. PNNL-Developed Analog Circuit Board

- PC 104 bus

- Signal conditioning - filter/gain/time variable gain

- Mixer/down converter - I/Q Doppler frequency signal

4. PNNL-Developed Digital Circuit Board

- PC104 bus

- Generates fundamental transducer operating frequency

- Generates transmit "tone burst"

- Generates repetition rate

- Synchronizes transmit - receive - data acquisition timing.

\section{A.2 Ultrasonic Concentration Probe}

The ultrasonic concentration probe operates by determining the attenuation of an ultrasonic pulse over a frequency spectrum when it passes through fluid or slurry from the transmit transducer to the receive transducer. The concentration is determined by comparing the attenuation for a given simulant to the baseline attenuation for the carrier liquid and by using a correlation developed for that simulant using a reference standard for the volume percent solids as a function of the ultrasonic attenuation for a given frequency.

Figure A.5 is a photograph of the ultrasonic concentration probe sensor in the small-scale tank for the mixing studies, and Figure A.6 illustrates the concentration sensor hardware. The two ultrasonic sensors are shown as black discs on the mounting hardware. A voltage pulse is sent to the transmit transducer, causing the piezoelectric crystal to vibrate and emit ultrasound. The ultrasound reaches the receive transducer, causing the piezoelectric crystal to vibrate, and this in turn produces a voltage signal. As the ultrasound travels through the slurry, its intensity is attenuated based on interaction with particles in the slurry, and the receive transducer measures a smaller voltage signal than it would for water. Thus, there is a direct correspondence between the attenuation of the signal and the concentration of the slurry. The attenuation is also dependent on the type and size of the particulate. In the mixing tests, the attenuation of the ultrasound was measured. Laboratory measurements are required to relate the measured attenuation to the concentration. This relationship has the following form for slurry concentration in units of volume percentage:

$$
\text { Volume Percentage }=\text { CONC } \times \text { Attenuation }
$$

Laboratory measurements were required to obtain the concentration constant (CONC) for each type of particulate and for each ultrasonic frequency used in the tests. (Though laboratory measurements are discussed in more detail in the next section.) During laboratory measurements, slurry is placed in a mixing vessel with a mechanical stirrer to keep it suspended. The two transducers mounted in the wall of the vessel are separated by $5 \mathrm{~cm}$, which is the same distance as used in the tests. 


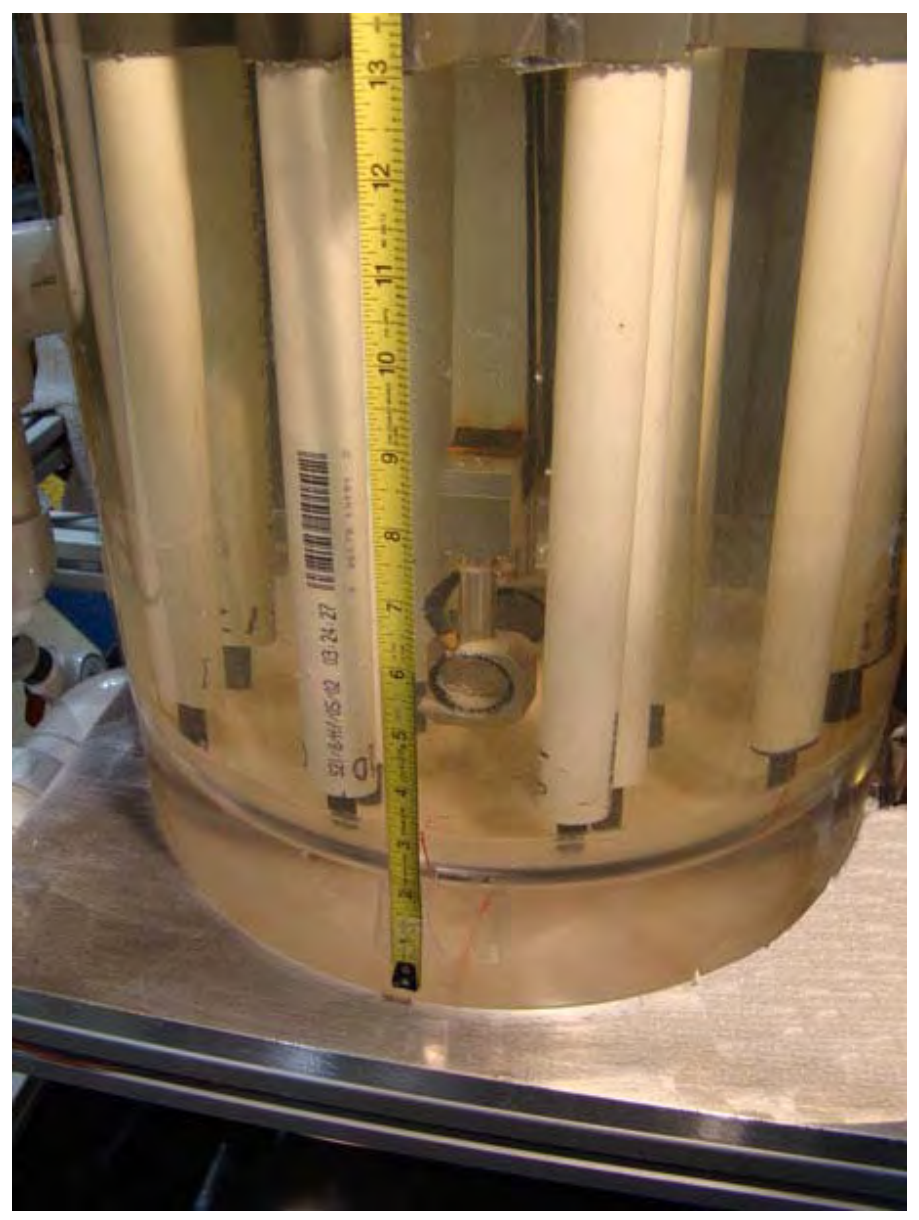

Figure A.5. Photograph of the Concentration Sensor near the Bottom of the Small-Scale Tank. The transducer faces are separated by $5.08 \mathrm{~cm}$ (2 in.).

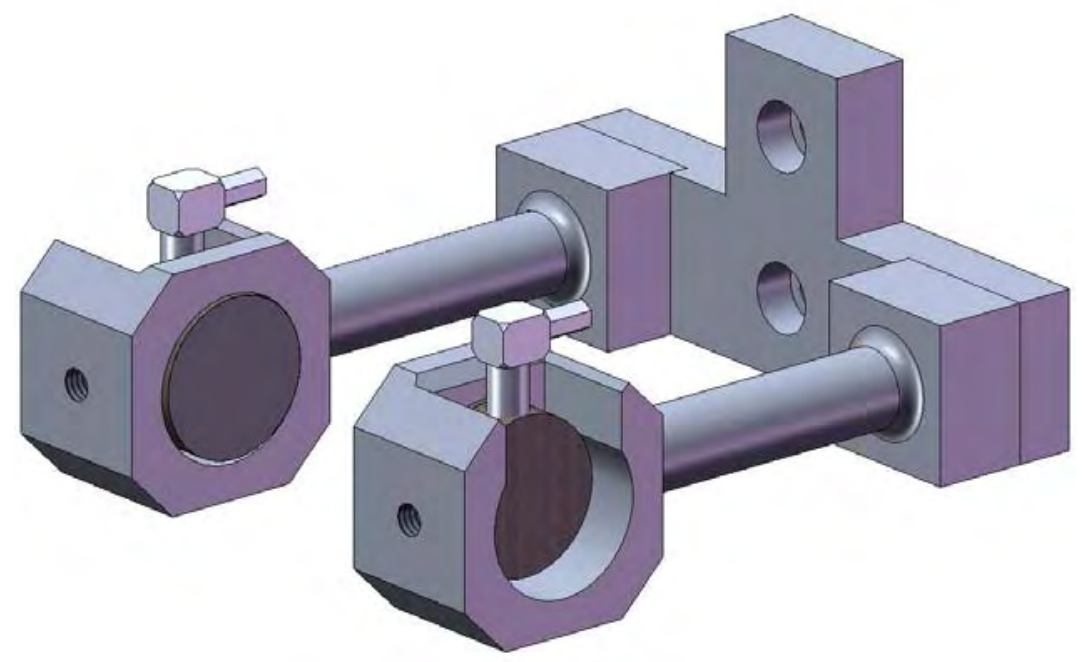

Figure A.6. Concentration Sensor Configuration 
The data acquisition system (DAS) is used to measure the attenuation. Using a pipette, a sample of the slurry between the transducer faces is extracted, and the density of the sample is determined using a pycnometer to measure mass and volume. The density is used to determine the volume percentage of the slurry. Plotting the volume percentage on the vertical axis of a graph and the attenuation (at a specified frequency) on horizontal axis yields a straight line, confirming the validity of linear Eq. (A.9). The slope of this line is equal to the concentration constant in Eq. (A.9). The values of the concentration constant can then be used to analyze the attenuation data and obtain the concentration in volume percentage for many different locations within the tank.

\section{A.2.1 Data Acquisition System and Measurement of Attenuation}

The DAS developed at PNNL has been used for many years for investigations of physical properties of liquids and slurries, such as density, viscosity, attenuation measurements, and velocity of sound (Greenwood and Bamberger 2002, 2004; Bamberger and Greenwood 2004; Greenwood 2004). A schematic diagram of the DAS, shown in Figure A.7, consists of a computer-controlled pulser-receiver, a computer with a digitizer card, and a multiplexer to switch the electronics from the current transducer pair to another pair. The maximum number of transducer pairs is six. The DAS for the M3 mixing experiments used only one transducer pair, while measurements with a second DAS, for determining the value of concentration in Eq. (A.9), used two transducer pairs. The pulser-receiver sends a short voltage pulse to the transmit transducer and amplifies the signal obtained by the receive transducer. The analog signal, produced at the output of the pulser-receiver, is sent to a digitizer in the computer. The 12-bit digitizer analyzes the voltage into $2^{12}$ (or 4096) bins for high accuracy. The data acquisition code, written in the MATLAB language, is completely automated and has the following functions: 1) sets the parameters for the digitizer, pulser-receiver, and the multiplexer; 2) performs the desired calculations using the digitized voltage-versus-time signal; and 3) stores information in a file.

This DAS was modified to determine the attenuation for this project. The pulser-receiver sends out a pulse at the pulser connection each time it receives a trigger signal. This trigger signal can be generated internally in the pulser-receiver at a specified pulse-repetition rate or can be externally triggered. Because the timing of events in the tank is very important, an external trigger signal from the UCC computer was sent to the trigger input on the pulser-receiver, as shown in Figure A.7, at 5 signals per second. With each trigger signal, the pulser-receiver sends a short voltage pulse to the transmit transducer. For a $3.5-\mathrm{MHz}$ transmit transducer, this signal consisted of a negative voltage of several hundred volts (depending upon the value in the setup code) for a time of about 143 nanoseconds. This caused the piezoelectric crystal to vibrate and produce a pulse similar to that shown in Figure A.8. The frequency content of the signal is determined using a fast Fourier transform (FFT), as shown in Figure A.8. The signal from the receive transducer was analyzed to determine the attenuation at 5 values per second. Each attenuation value was sent to the UCC computer. At this high rate, no signal averaging was used and the gain was not changed during the data acquisition. Thus, the slurry concentration between the transducer faces could be captured every 0.2 seconds. 


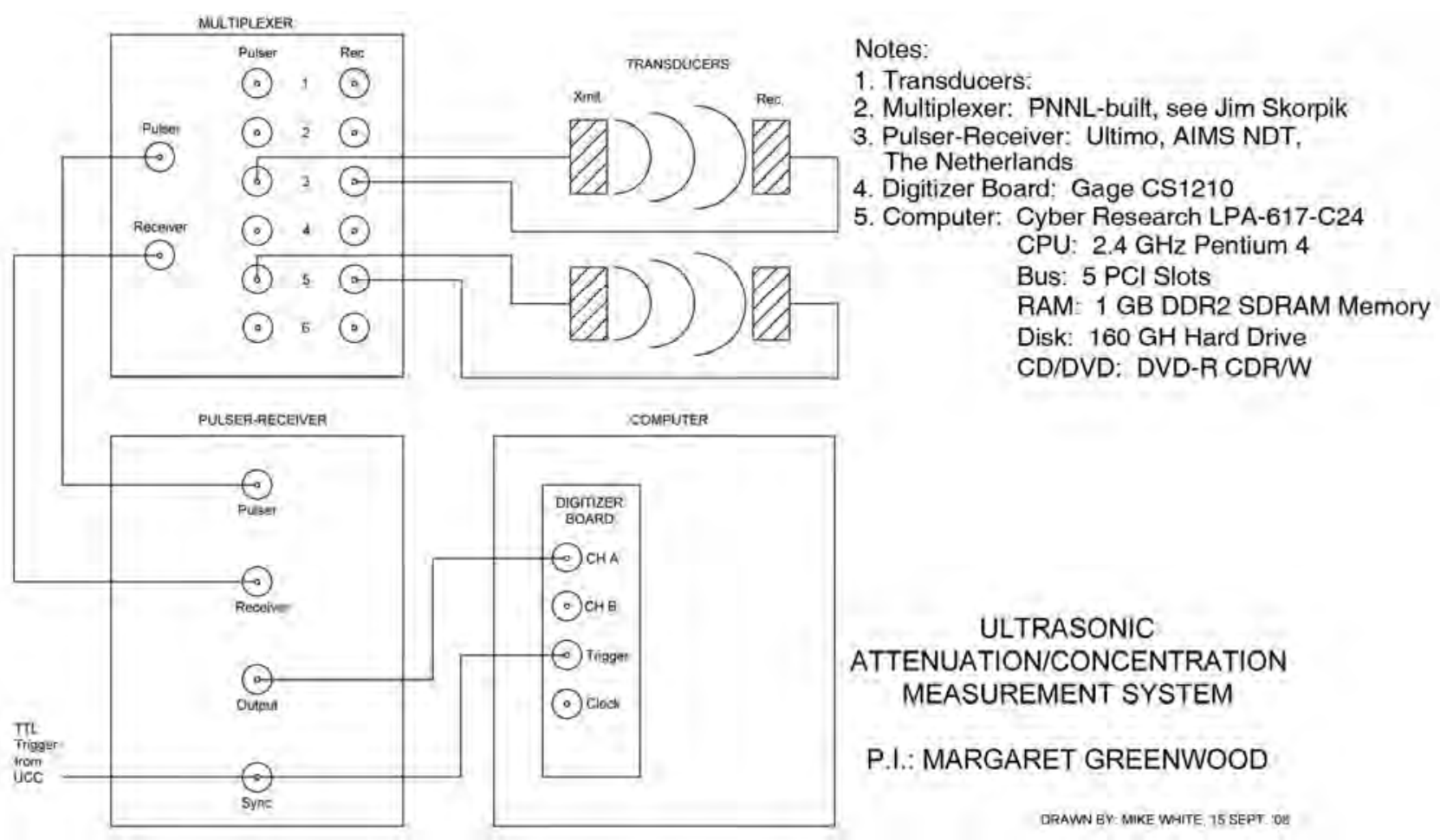

Figure A.7. Schematic Diagram of the DAS

\section{A.2.2 Calculation of Attenuation}

The top section of Figure A.8 shows the voltage signal as a function of time (hereafter called the time signal) for water, a slurry, and a highly concentrated slurry (very highly attenuative) and demonstrates the attenuation of the signal resulting from different concentrations of the slurry. Each time signal is analyzed by obtaining the FFT of the time signal, and the results are shown in the bottom panel. The results of the FFT show that the time signal contains many frequencies, which peak at $5 \mathrm{MHz}$ in this example. These effects are due to the bandwidth of the transducers.

Conceptually, the short time signal can be viewed as a superposition of many plane waves of different frequencies. That is, all of the plane waves added together yield the short time signal. A plane wave traveling in the $x$-direction has a form given by Asin $(k x-\omega t+\varphi)$, where $k=2 \pi$ and $\omega=2 \pi$. The FFT analysis provides the FFT amplitude, $\mathrm{A}$, and the phase, $\varphi$, for a large range of frequencies. Thus, the short time signal is viewed as composed of plane waves of many different frequencies and phases. Because the attenuation of a plane wave passing through a slurry depends on frequency, the information contained in the FFT can be used to calculate the attenuation for a range of frequencies. The attenuation relative to water is defined as

$$
\text { Attenuation }=(-20 / \mathrm{D}) \log 10 \text { (FFT amplitude for slurry/FFT amplitude for water) }
$$

The units of attenuation are decibels (dB) per the length unit used for the distance D between the transducer faces. 

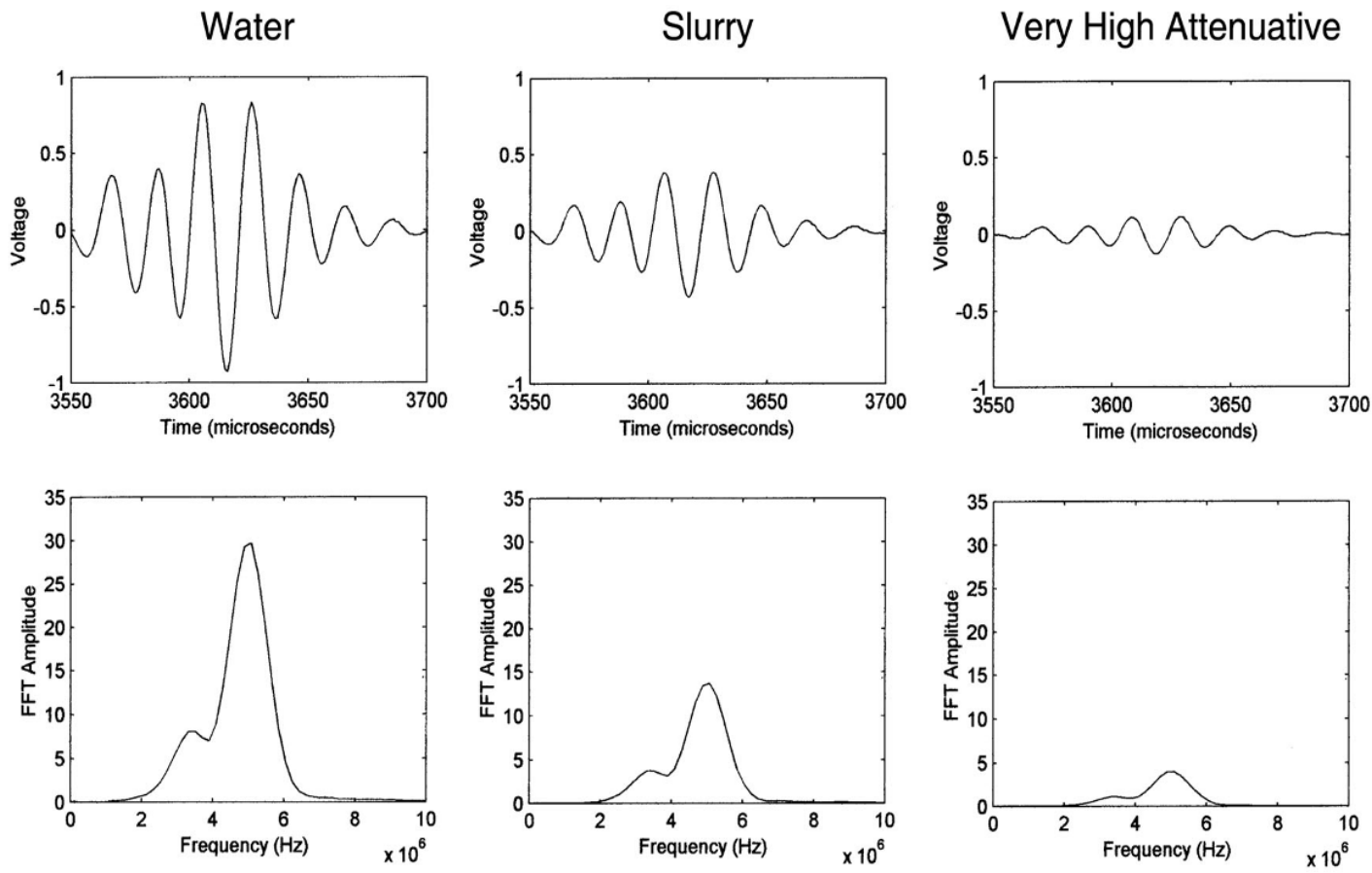

Figure A.8. Voltage Versus Time Signal in Top Panel and the FFT of Each Signal in the Bottom Panel

As an example, the attenuation of the slurry in the middle panel of Figure A.8 can be easily calculated for the peak, which occurs at $5 \mathrm{MHz}$. The peak for water has an FFT amplitude of 29.5 units, while that for the slurry has an amplitude of 13.5 units. If the distance between the two transducers faces is $5 \mathrm{~cm}$, the attenuation is equal to $1.36 \mathrm{~dB} / \mathrm{cm}$. In this plot, similar calculations can be carried out for frequencies ranging from about 2.5 to $6 \mathrm{MHz}$.

The data acquisition code for this application used the procedure described above for calculating the attenuation. The first step was to obtain the frequency spectrum for water, similar to the left bottom panel in Figure A.8, which resulted in values of the FFT amplitude as a function of frequency being stored in a file. This water calibration was carried out at least once every two hours during testing, with the sensor moved to the top of the tank and the pulse jet mixers not operating so the calibration was performed in clear water.

During data acquisition, a frequency spectrum similar to that shown in the lower middle panel of Figure A.8 was obtained every 0.2 seconds. The code calculated attenuation over a range of frequencies and an example is shown in Figure A.9. The attenuation at one frequency value was sent to the UCC, and the attenuation for five frequency values was saved to a file in the DAS computer. Because the attenuation of ultrasound increases with the frequency, the objective is to choose a frequency for the UCC that is not too attenuative but large enough that changes in attenuation and the resulting slurry concentration can be observed. 


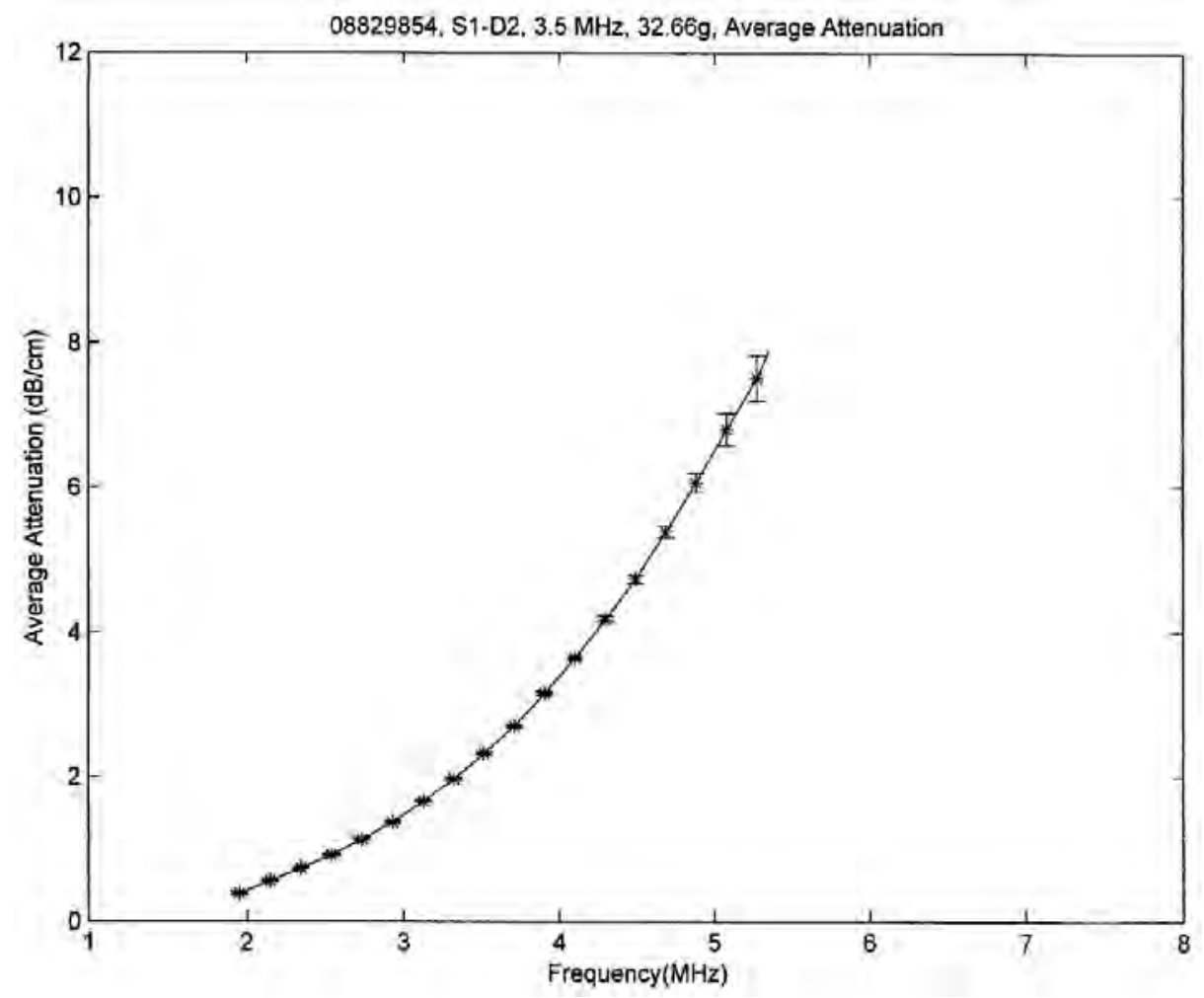

Figure A.9. Example of Attenuation Versus Frequency for Slurry of s1d2 Particulate Using $3.5 \mathrm{MHz}$ Transducers

\section{A.2.3 Relationship Between Concentration and Attenuation}

The experimental apparatus shown in Figure A.10 consists of a vessel that has a $5 \times 5$-cm cross section of with rounded corners and is 7.5-cm high. Four transducers are mounted in the wall, which permits the attenuation to be measured for two pairs of transducers with different center frequencies, using the multiplexer to switch the electronics to the desired pair. The simulant is kept in uniform suspension by a variable-speed vertical axis propeller mixer at the bottom of the test vessel. A baffle unit is placed in the vessel to reduce the vortex caused by the stirrer and to provide a more uniform suspension. A second DAS, identical to the first, was used to obtain data at a laboratory in the 2400 Stevens Building.

A slurry sample was extracted between the two transducer faces using a pipette or a syringe. The sample was placed in a pycnometer, and the density of the sample was determined. The slurry concentration was specified by the density $\rho_{\text {slurry }}$, the volume fraction $\left(\mathrm{V}_{\mathrm{F}}\right)$, or the volume percentage. The basic definition of the $\mathrm{V}_{\mathrm{F}}$ is the volume of the particles divided by total volume of the sample:

$$
\mathrm{V}_{\mathrm{F}}=\mathrm{V}_{\text {particles }} /\left(\mathrm{V}_{\text {particles }}+\mathrm{V}_{\text {liquid }}\right)
$$

where $\mathrm{V}_{\text {particles }}$ is the volume occupied by the particles in the sample, and $\mathrm{V}_{\text {liquid }}$ is the volume of the liquid in the sample, which is usually water. 

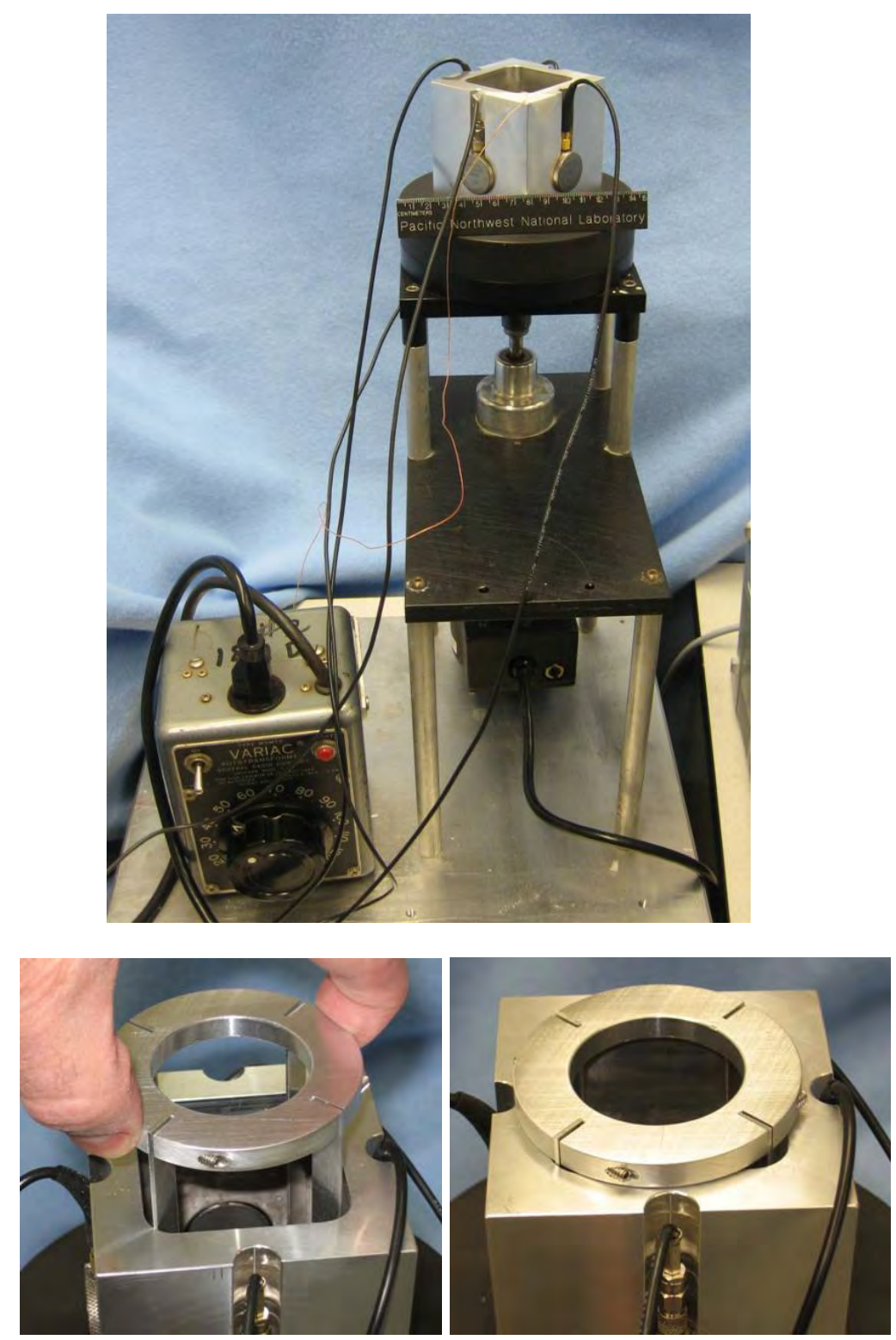

Figure A.10. Mixer and Baffle Unit for Laboratory Measurements of Attenuation and Slurry Concentration

The volume fraction is related to the density of the slurry, $\rho_{\text {slurry }}$, the density of the particulate, $\rho_{\text {part }}$, and the density of the liquid, $\rho_{\mathrm{wtr}}$ :

$$
\mathrm{V}_{\mathrm{F}}=\left(\rho_{\text {slurry }}-\rho_{\mathrm{wtr}}\right) /\left(\rho_{\text {part }}-\rho_{\mathrm{wtr}}\right)
$$

The volume percentage is related to the volume fraction in the usual manner:

$$
\text { Volume Percentage }=100\left(\mathrm{~V}_{\mathrm{F}}\right)
$$

The attenuation measurements were obtained using a DAS that is very similar to that used for the M3 mixing tests. The attenuation measurement tests were conducted in the 2400 Stevens Building. The code to measure the attenuation is similar to that used for M3 tests, except that the output has been modified to 
record the values of the attenuation for a larger number of frequencies, obtain an average attenuation over 1000 runs, and obtain the standard deviation. The slurry sample is extracted between the transducer faces while the slurry is being stirred. Usually three samples were extracted for each concentration of slurry.

Data were obtained for the five types of particulate used in the mixing tests: s1d5, s1d1, s1d2, s2d1, and s2d2. The simulant properties are described in Section 3 of the report. A data input file was generated that contains the attenuation and the corresponding density measurements for several concentrations of slurry. A MATLAB code named attentoconc.m read the input file. For each simulant sample taken during a run, the density was converted to a volume percentage, and the average volume percentage value and its standard deviation for each run were obtained. Also, for each simulant concentration tested, the average attenuation and its standard deviation were obtained for several runs of 1000 data points (measurements). The data for each simulant were plotted with the attenuation along the horizontal axis and the volume percentage along the vertical axis. Each data point contains an uncertainty in the attenuation and an uncertainty in the volume percentage. The code uses a weighted total least-squaresstraight-line fit to the data for each simulant using uncertainties in both the attenuation and the volume percentage and determines CONC, the slope of the straight line. Theory (Eq. A.9) predicts a straight line passing through the origin, and this is confirmed by the results of these experiments.

It is assumed that each particle in the slurry contributes to the attenuation in the same manner. Thus, if the volume percentage of the slurry is, for example, doubled, then the number of particles in the slurry is doubled. The attenuation is also expected to double in this example. Thus, the attenuation and volume percentage are related linearly, as shown in Eq. (A.9). In these experiments, the attenuation relative to water is measured, as shown by Eq. (A.10). This means that the attenuation of water is identically zero. That is, if the slurry is taken to be water, then the numerator and denominator in Eq. (A.10) are the same, and the attenuation is equal to zero. Thus, in Figures A.11 and A.12 (and similar figures), the data point for water is at the origin. The slope of the line is calculated by finding the best fit through the data points, with uncertainties in attenuation and uncertainties in volume percentage included in the calculation. In this calculation, the attenuation for water has an uncertainty of $0.02 \mathrm{~dB} / \mathrm{cm}$ and an uncertainty of $0.02 \%$ for volume percentage, so the intercept is a very small number.

The data for slurries for three particulates, s1d1, s1d2, and s1d5, are shown in Figure A.11 for an ultrasonic frequency of $3.125 \mathrm{MHz}$. Similar data are presented in Figure A.12 for slurries of s2d1 and s2d2. A straight line passing through the origin has the form given by Eq. (A.9), where the value of CONC is the slope of the straight line on a graph of volume percentage (vertical axis) versus the attenuation (horizontal axis).

In Figure A.11, data are shown for three simulants. Simulant s1d1 shows fairly large error bars for the three smallest volume percentages, but the data points are within two standard deviations of the straight line. The error bars for attenuation at these small volume percentages are large because the slurry is so granular for these large-diameter particles. Note that the error bars in attenuation decrease for the smaller diameter particles, such as simulants s1d5 and s1d2, because the slurry is more uniform. The two data points for the higher volume percentages have small uncertainties and are very close to the straight line for s1d1. 


\section{Concentration vs. Attenuation at 3.125 MHz for S1 Simulants}

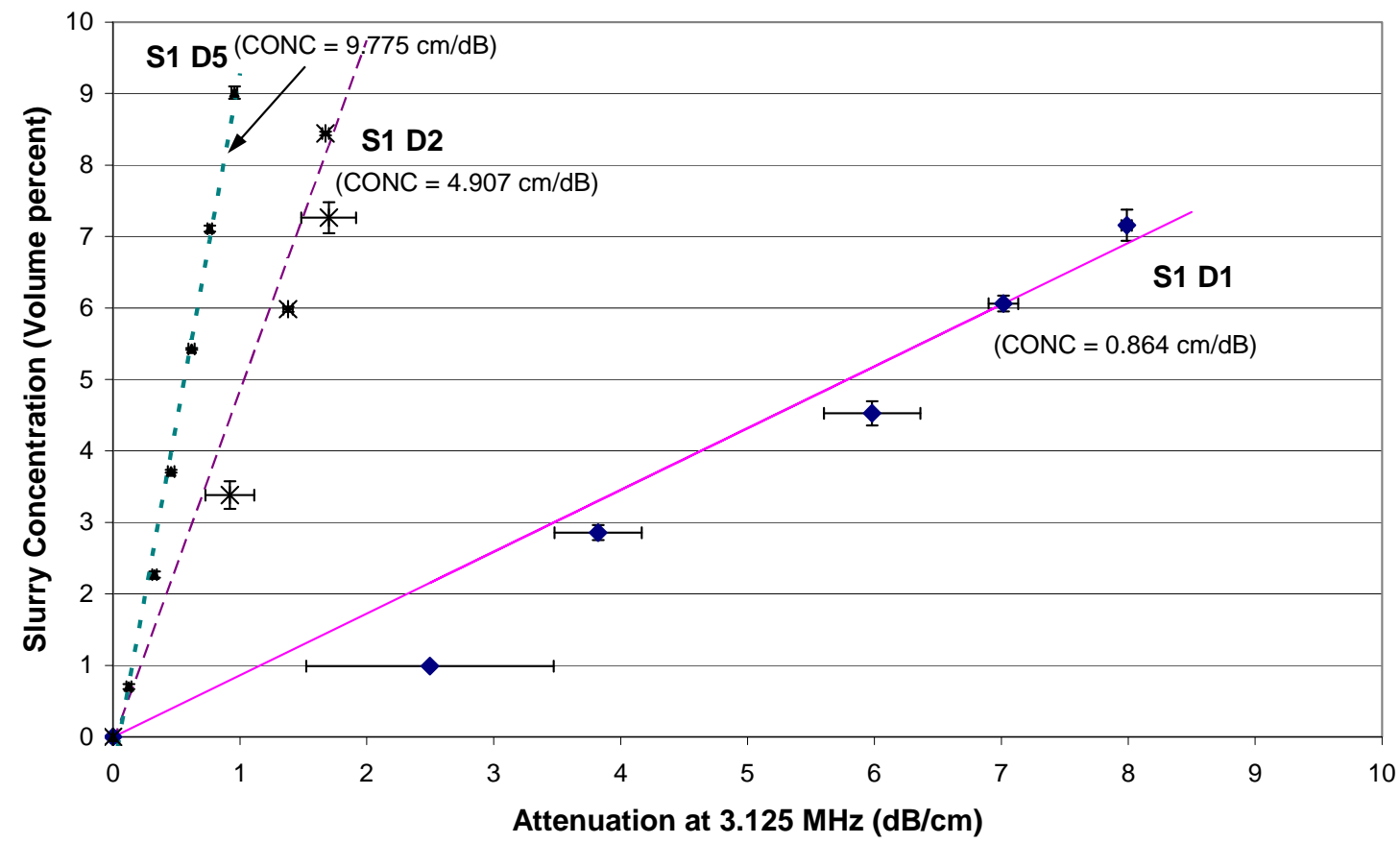

Figure A.11. Concentration and Attenuation Measurements for Slurries s1d1, s1d2, and s1d5 for Determination of the Slope of the Straight Line Through the Data Points

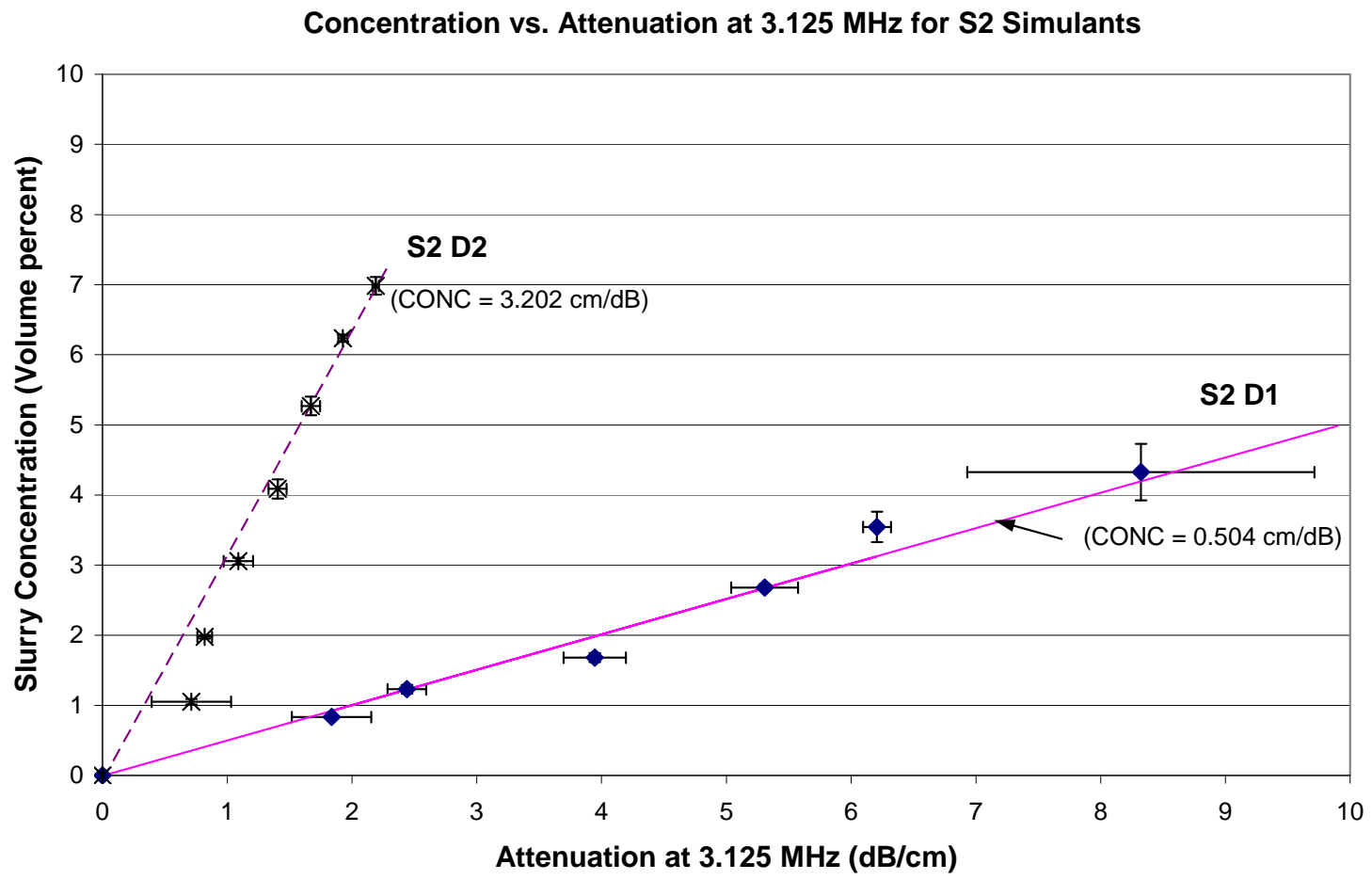

Figure A.12. Concentration and Attenuation Measurements for Slurries s2d1 and s2d2 for Determining the Slope of the Straight Line Through the Data Points 
In Figure A.12, the data point for s2d1 for the greatest concentration has large uncertainties. The calculation for the slope was repeated excluding this data point and yielded a slope of $0.506 \mathrm{~cm} / \mathrm{dB}$, a negligible change. This shows the validity of the original calculation because the slope is determined essentially by the five data points with smaller uncertainties and water.

The two graphs show the effects of particle diameter and density on attenuation value. Eq. (A.9) shows that attenuation is given by volume percentage divided by concentration constant (CONC). Figure A.11 for simulant s1 and Figure A.12 for s2 considers a constant slurry concentration of 4\%. In both figures, attenuation increases as CONC decreases. Therefore, for each simulant, the attenuation increases as particle size increases. However, density also has an effect when both simulants are considered. For simulant pairs s1d1/s2d1 and s1d2/s2d2, both members of the pair have similar particle diameters, either $\mathrm{d} 1$ or $\mathrm{d} 2$. For each pair, the attenuation is greater for the denser stimulant, s2. By arranging the values of CONC in Table A.1 for a single frequency from the largest value of CONC to the smallest, we find the following order for increasing attenuation at the same slurry concentration: s1d5 (lowest), s1d2, s2d2, s1d1, and s2d1 (highest).

For the five simulants and the frequencies used in the M3 tests, Table A.1 provides the values of the constant CONC. To analyze the data from the M3 tests, the attenuation at the specified frequency is multiplied by the appropriate value of CONC to yield the slurry concentration in volume percentage.

Table A.1. Values of CONC for Five Simulants and Seven Frequencies

\begin{tabular}{crrrrr}
\hline $\begin{array}{c}\text { UCC } \\
\begin{array}{c}\text { Frequency, } \\
\text { MHz }\end{array}\end{array}$ & $\begin{array}{c}\text { s1d2, } \\
\text { CONC, } \\
\text { cm/dB }\end{array}$ & $\begin{array}{c}\text { s1d1, } \\
\text { CONC, } \\
\text { cm/dB }\end{array}$ & $\begin{array}{r}\text { s1d5, } \\
\text { CONC, } \\
\text { cm/dB }\end{array}$ & $\begin{array}{r}\text { s2d1, } \\
\text { CONC, } \\
\text { cm/dB }\end{array}$ & $\begin{array}{r}\text { s2d2, } \\
\text { CONC, } \\
\text { cm/dB }\end{array}$ \\
\hline 3.906 & 2.602 & 0.530 & 5.765 & 0.323 & 1.645 \\
3.125 & 4.907 & 0.864 & 9.775 & 0.504 & 3.202 \\
2.930 & 5.888 & 1.017 & 11.236 & 0.588 & 3.890 \\
2.734 & 7.130 & 1.221 & 13.138 & 0.701 & 4.785 \\
2.539 & 8.768 & 1.503 & 15.470 & 0.858 & 5.943 \\
2.344 & 10.009 & 1.806 & 21.812 & 1.086 & 7.836 \\
1.953 & 14.187 & 3.175 & 26.917 & 1.928 & 12.648 \\
\hline
\end{tabular}

\section{A.3 References}

Bamberger JA and MS Greenwood. 2004. "Measuring fluid and slurry density and solids concentration non-invasively.” Ultrasonics 42:563-567.

Greenwood MS. 2004. "Self-Calibrating System and Technique for Ultrasonic Determination of Fluid Properties.” U.S. Patent 6,763,698.

Greenwood MS and JA Bamberger. 2002. "Measurement of Viscosity and Shear Wave Velocity of a Liquid or Slurry for On-line Process Control.” Ultrasonics 39:623-630.

Greenwood MS and JA Bamberger. 2004. "Self-calibrating sensor for measuring density through stainless steel pipeline wall.” Journal of Fluids Engineering-Transactions of the ASME 126:189-192.

Morgen GP, RA Pappas, DM Pfund, WC Weimer, DM Sheen, and BJ Burghard. 2002. "Ultrasonic system and technique for fluid characterization.” U.S. Patent 6,871,148. 
Appendix B

Mixing Data 



\section{Contents}

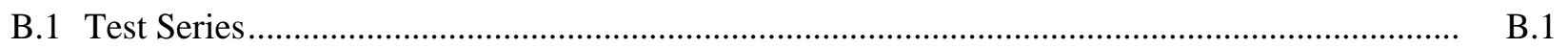

B.2 Key for Case IDs and MSS Row Numbers ....................................................................... B.3

B.3 Data from 2008 Tests in Small-Scale Vessel with Elliptical Head A.1 …................................ B.4

B.4 Data from 2008 Tests in Mid-Scale Vessel with Spherical Head A.1 ...................................... B.48

B.5 Data from 2008 Tests in Large-Scale Vessel with Elliptical Head A.1 ….................................. B.56

B.6 Data from 2008 in Large-Scale Vessel with Flanged and Dished Head A.1 ............................. B.78

B.7 Data from July 2007 Tests in Mid-Scale Vessel with Spherical Head A1 _................................ B.92

B.8 Data from Fall 2007 Tests in Mid-Scale Vessel with Spherical Head A.1 ................................. B.108 



\section{For Information Only}

\section{Appendix B}

\section{Mixing Data}

Mixing data from tests conducted in several scaled tanks are listed in Appendix B. The data from the mixing tests are summarized in Table B.1 together with the general test conditions of tank scale (small, mid, or large) and head shape (elliptical, flanged and dished, or spherical). The first column of Table B.1 lists the table number in Appendix B where the data is tabulated. The data is categorized by test campaigns denoted as tests conducted in 2008 or July or Fall 2007. The tests conducted in 2008 used simulant from a different manufacturer than those tests conducted in 2007. The test details column shows the types of measurements used to determine the critical suspension velocity and the cloud height. The test data in Appendix B is listed chronologically based on increasing row number. The first several digits of the Appendix B row number are specified in the last column of Table B.1. The tests conducted in 2008 in the elliptical or spherical head all start with the number 9 followed by the nominal tank diameter in inches. The tests conducted in 2008 using the flanged and dished head start with the nominal tank diameter in inches (70).

Table B.1. Summary of Mixing Test General Conditions and Data

\begin{tabular}{|c|c|c|c|c|c|c|}
\hline Table & $\begin{array}{c}\text { Test } \\
\text { Campaign }\end{array}$ & $\begin{array}{l}\text { Tank } \\
\text { Scale }\end{array}$ & Head & $\begin{array}{l}\text { Simulant } \\
\text { Manufacturer }\end{array}$ & Test Details & $\begin{array}{l}\text { Row Number } \\
\text { Format }\end{array}$ \\
\hline B.3 & 2008 & $\begin{array}{c}\text { Small } \\
(15)\end{array}$ & $\begin{array}{l}\text { Elliptical } \\
\text { (E) }\end{array}$ & XLSciTech & $\begin{array}{l}\text { Visual observation of cloud height } \mathrm{H}_{\mathrm{C} .} \text {. } \\
\text { Ultrasonic measurement of } \mathrm{U}_{\mathrm{CS}} \text { and } \\
\text { concentration. }\end{array}$ & $915 X X X X$ \\
\hline B. 4 & 2008 & $\begin{array}{l}\text { Mid } \\
(34)\end{array}$ & $\begin{array}{l}\text { Spherical } \\
\text { (S) }\end{array}$ & XLSciTech & $\begin{array}{l}\text { Visual observation of cloud height } \mathrm{H}_{\mathrm{C} .} \text {. } \\
\text { Ultrasonic measurement of } \mathrm{U}_{\mathrm{CS}} \text { and } \\
\text { concentration. }\end{array}$ & 934XXXX \\
\hline B.5 & 2008 & $\begin{array}{l}\text { Large } \\
(70)\end{array}$ & $\begin{array}{l}\text { Elliptical } \\
\text { (E) }\end{array}$ & XLSciTech & $\begin{array}{l}\text { Visual observation of cloud height } \mathrm{H}_{\mathrm{C}} \text {. } \\
\text { Ultrasonic measurement of } \mathrm{U}_{\mathrm{CS}} \text { and } \\
\text { concentration. }\end{array}$ & $970 \mathrm{XXXX}$ \\
\hline B.6 & 2008 & $\begin{array}{l}\text { Large } \\
(70)\end{array}$ & $\begin{array}{l}\text { Flanged and } \\
\text { dished }(\mathrm{F})\end{array}$ & XLSciTech & $\begin{array}{l}\text { Visual observation of cloud height } \mathrm{H}_{\mathrm{C} .} \text {. } \\
\text { Ultrasonic measurement of } \mathrm{U}_{\mathrm{CS}} \text { and } \\
\text { concentration. }\end{array}$ & $70 X X X X$ \\
\hline B.7 & July 2007 & $\begin{array}{l}\text { Mid } \\
(34)\end{array}$ & $\begin{array}{l}\text { Spherical } \\
\text { (S) }\end{array}$ & Potters & $\begin{array}{l}\text { Visual observation of cloud height } \mathrm{H}_{\mathrm{C}} \text {. } \\
\text { Visual observation of } \mathrm{U}_{\mathrm{CS}} \text {. }\end{array}$ & 2007XXXX \\
\hline B. 8 & Fall 2007 & $\begin{array}{l}\text { Mid } \\
(34)\end{array}$ & $\begin{array}{l}\text { Spherical } \\
\text { (S) }\end{array}$ & Potters & $\begin{array}{l}\text { Visual observation of cloud height } \mathrm{H}_{\mathrm{C} .} \\
\text { Visual observation of } \mathrm{U}_{\mathrm{CS}} \text {. }\end{array}$ & 709XXXX \\
\hline
\end{tabular}

A Case ID was assigned to each test that provided a concise summary of specific test parameters. The Case IDs are defined in Table B.2. This notation is used to identify test conditions throughout the report. The first two digits (DD) of the Case ID show the tank diameter in inches (15, 34, or 70). The next digit (B) shows the head shape (E for elliptical, $F$ for flanged and dished, and $S$ for spherical). In 


\section{For Information Only}

some cases the head shape is shown as E8. This denotes when tests were conducted with an 8 tube array instead of a 12 tube array. The next digit (L) shows the full-scale nozzle diameter in inches (4, 6, M for 8.5, and $\mathrm{L}$ for 11.8). The next 4 digit sequence (MMNN) is the simulant code with MM showing the density and NN showing the nominal particle size. The next digit (O, an upper case letter) shows the solids volume fraction. The next digit ( $\mathrm{P}$, a lower case letter) shows the nominal duty cycle. The last digit (Q) shows the nominal pulse volume fraction. For pulsating flow $\mathrm{Q}$ is shown as an underscore followed by a number (such as_1). For steady flow with a reduced number of pulse tubes in operation Q is shown as a dash followed by the number of outer nozzles in operation followed by the number of inner nozzles in operation (such as -80, 8 outer nozzles operating and 0 inner nozzles operating). Additional details are provided in Table B.2.

The test data are listed in Tables B.3 through B.8. The test data parameters tabulated in Appendix B Tables B.3 through B.8 are described in Table 6.2 and the measurement uncertainties are also provided. The data in the first three rows of Appendix B are presented in the first three columns of Table 6.2. The data in Tables B.3 through B.8 is presented on two sheets to be viewed side by side. The Row is the first column heading of the left part of the table (shown in the caption as A.X) and the last column heading of the right part of the table (shown in the caption as B.X).

The row number listed as the first column of Tables B.3 through B.8 may have either an M or MX listed to the right of the number. M signifies that the row of data was used for development of the critical suspension and cloud height models. X signifies that the row of data was included in the model, however, the test was conducted at a return line height that was lower than listed and the row should have been excluded from the model data set. Rows affected are 7090186-7090366 and 7090616-7090759. Only ten rows in this range were included in the model. Rows with Case IDs 10/26A1 through 10/29B2 have return line heightss of 31.875 in. Rows with Case IDs 10/31A1 through 10/30C2 and 11/8C1 through 11/14A2 have return line heights of 21.7125 in. 
Table B.2. Key for Case IDs and MSS Row Numbers

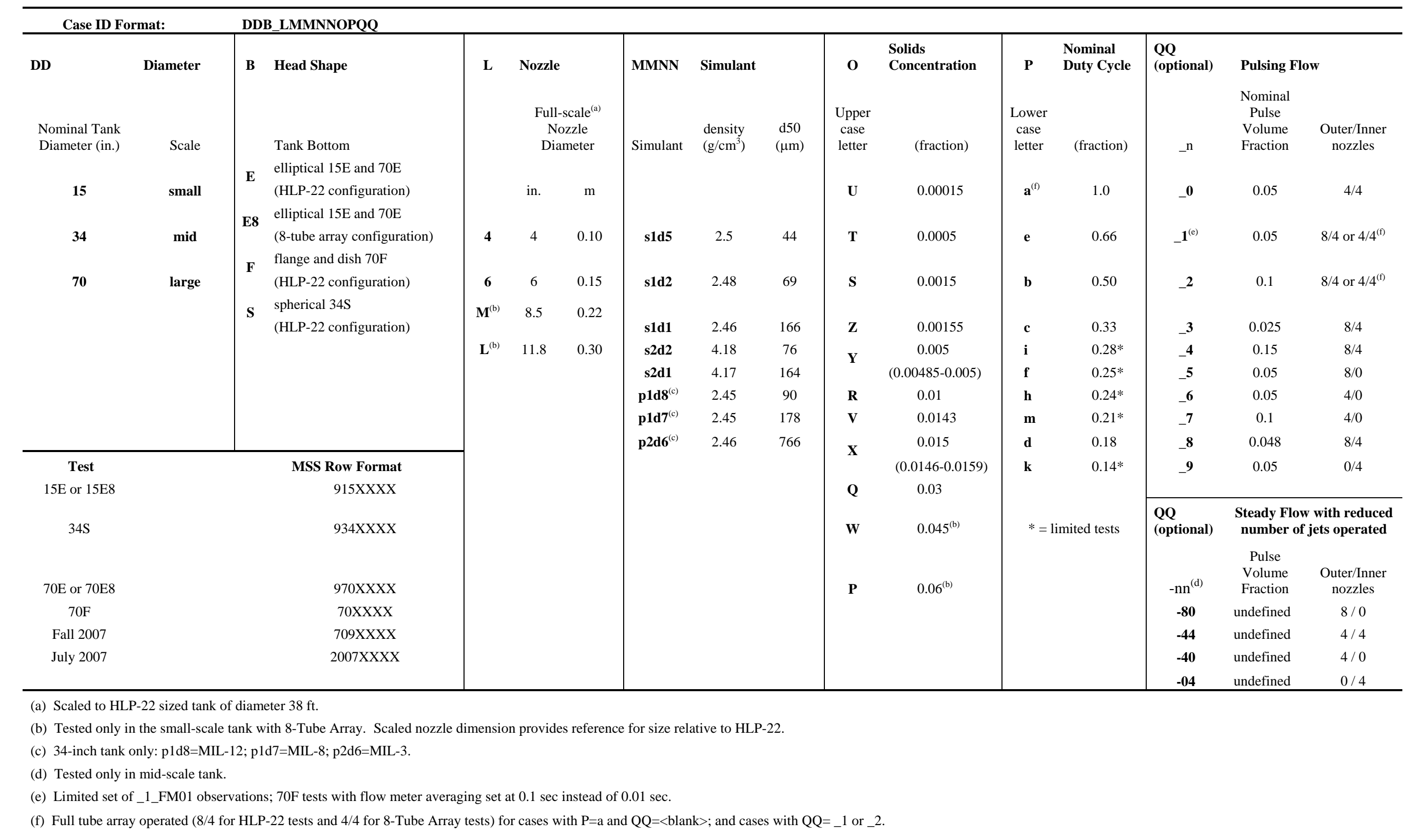


Table B.3. Data from 2008 Tests in Small-Scale Vessel with Elliptical Head A.1

\begin{tabular}{|c|c|c|c|c|c|c|c|c|c|c|c|c|c|c|c|c|c|c|c|c|c|c|c|c|c|c|c|}
\hline $\begin{array}{c}\text { Row } \\
\text { Number }\end{array}$ & Test & Case ID & $\begin{array}{l}\text { Tank } \\
\text { Diameter }\end{array}$ & $\begin{array}{l}\text { Head } \\
\text { Shape }\end{array}$ & $\begin{array}{c}\text { Dish } \\
\text { Height }\end{array}$ & $\begin{array}{c}\text { Dish } \\
\text { Volume }\end{array}$ & \begin{tabular}{|c|} 
Tank \\
Fill \\
Height \\
\end{tabular} & \begin{tabular}{|l|} 
Returm \\
Line \\
Height \\
\end{tabular} & $\begin{array}{c}\text { Nozzle } \\
\text { Inner } \\
\text { Diameter }\end{array}$ & $\begin{array}{l}\text { Nozzle } \\
\text { Stand-off } \\
\text { Distance } \\
\end{array}$ & $\begin{array}{l}\text { Pusse Tube } \\
\text { Configuration }\end{array}$ & $\begin{array}{l}\text { Installed } \\
\text { Nozzles } \\
\text { Nates }\end{array}$ & $\begin{array}{c}\text { Outer } \\
\text { Nozles } \\
\text { Opperated } \\
\end{array}$ & $\begin{array}{c}\text { Inner } \\
\text { Nozzles } \\
\text { Opperated } \\
\end{array}$ & \begin{tabular}{c|}
$\begin{array}{c}\text { Pulse Tube } \\
\text { Outer } \\
\text { Diameter }\end{array}$ \\
\end{tabular} & \begin{tabular}{|c|} 
Outer \\
PuM \\
Radius \\
\end{tabular} & \begin{tabular}{|l|} 
Inner \\
PuM \\
Radius \\
\end{tabular} & $\begin{array}{c}\text { "FOO' Outer PJM } \\
\text { Impingement } \\
\text { Angle }\end{array}$ & $\begin{array}{c}\text { "FOO' Inner PJM } \\
\text { Impingement } \\
\text { Angle }\end{array}$ & $\begin{array}{c}\text { Ratio Outer } \\
\text { PJMto Tank } \\
\text { Radius } \\
\end{array}$ & $\begin{array}{c}\text { Ratio Inner } \\
\text { PJMt To Tank } \\
\text { Radius } \\
\end{array}$ & Simulant & $\begin{array}{l}\text { Solidis } \\
\text { Density }\end{array}$ & $\begin{array}{c}\begin{array}{c}\text { Particle } \\
\text { Diameter } \\
\text { d5 }\end{array} \\
\end{array}$ & $\begin{array}{c}\text { Particle } \\
\text { Diameter } \\
\text { d50 }\end{array}$ & $\begin{array}{c}\begin{array}{c}\text { Particle } \\
\text { Diameter } \\
\text { d955 }\end{array} \\
\end{array}$ & $\begin{array}{l}\text { Void } \\
\text { Fraction }\end{array}$ \\
\hline text & text & text & in. & text & in. & in. ${ }^{3}$ & in. & in. & in. & in. & text & number & number & number & in. & in. & in. & deg & deg & nondim & nondim & text & $\mathrm{g} / \mathrm{cm}^{3}$ & $\mathrm{~m}$ & $\mathrm{~m}$ & $\mathrm{~m}$ & fraction \\
\hline MSS & MDDX & $\mathrm{ID}$ & $\mathrm{D}$ & HS & Hossh & $V_{\text {dash }}$ & $\mathrm{H}$ & Rtn & $d$ & sod & PT & $\mathrm{N}$ & $\mathrm{No}$ & $\mathrm{N}$ & $\mathrm{PT}_{\alpha \mathrm{d}}$ & $R_{0}$ & $R$ & $\theta_{\circ}$ & $\theta_{1}$ & $\mathrm{RodR}$ & $R / R$ & sxdx & $\rho_{\mathrm{s}}$ & $\mathrm{d}$ & $\mathrm{d} \mathrm{d}_{0}$ & des & $\mathrm{vf}$ \\
\hline 9150001 & $6 / 6 \mathrm{~A}$ & 15E_4s1d27c_1 & $147 / 16$ & $E$ & 3.25 & 354.8 & 35 & 29 & 0.126 & 0.189 & HLP-22 & 12 & 8 & 4 & 1.05 & 4.5 & 2.4 & 21.8 & 10.1 & 0.62 & 0.34 & s1d2 & 2.48 & 0.0000569 & 0.0000693 & 0.0000821 & 0.3750 \\
\hline $9150002 \mathrm{M}$ & 6/6A & 15E_4s1d27c_1 1 & $147 / 16$ & $E$ & 3.25 & 354.8 & 35 & 29 & 0.126 & 0.189 & HLP-22 & 12 & 8 & 4 & 1.05 & 4.5 & 24 & 21.8 & 10.1 & 0.62 & 0.34 & s1d2 & 2.48 & 0.0000569 & 0.0000693 & 0.0000821 & 0.3750 \\
\hline $9150003 \mathrm{M}$ & $6 / 6 \mathrm{~A}$ & 15E_4s1d27c__ 1 & 147116 & E & 3.25 & 354.8 & 35 & 29 & 0.126 & 0.189 & HLP-22 & 12 & 8 & 4 & 1.05 & 4.5 & 2.4 & 21.8 & 10.1 & 0.62 & 0.34 & s1d2 & 2.48 & 0.0000569 & 0.0000693 & 0.0000821 & 0.3750 \\
\hline $9150004 \mathrm{M}$ & $6 / 6 \mathrm{~A}$ & 15E_4sid27c_ 1 & $147 / 16$ & E & 3.25 & 354.8 & 35 & 29 & 0.126 & 0.189 & HLP-22 & 12 & 8 & 4 & 1.05 & 4.5 & 2.4 & 21.8 & 10.1 & 0.62 & 0.34 & s1d2 & 2.48 & 0.0000569 & 0.0000693 & 0.0000821 & 0.3750 \\
\hline $9150005 \mathrm{M}$ & 6/6A & 15E_4s1d27c_1 & $147 / 16$ & $E$ & 3.25 & 354.8 & 35 & 29 & 0.126 & 0.189 & HLP-22 & 12 & 8 & 4 & 1.05 & 4.5 & 2.4 & 21.8 & 10.1 & 0.62 & 0.34 & s1d2 & 2.48 & 0.0000569 & 0.0000693 & 0.0000821 & 0.3750 \\
\hline 9150006m & $6 / 6 \mathrm{~A}$ & $15 \mathrm{E} \_4 \mathrm{~s} 1 \mathrm{~d} 2 Z \mathrm{C} \_1$ & 147116 & E & 3.25 & 354.8 & 35 & 29 & 0.126 & 0.189 & HLP-22 & 12 & 8 & 4 & 1.05 & 4.5 & 2.4 & 21.8 & 10.1 & 0.62 & 0.34 & s1d2 & 2.48 & 0.0000569 & 0.0000693 & 0.0000821 & 0.3750 \\
\hline $9150007 \mathrm{M}$ & 6/6A & 15E_4s1d27c_1 & $147 / 16$ & $E$ & 3.25 & 354.8 & 35 & 29 & 0.126 & 0.189 & HLP-22 & 12 & 8 & 4 & 1.05 & 4.5 & 2.4 & 21.8 & 10.1 & 0.62 & 0.34 & s1d2 & 2.48 & 0.0000569 & 0.0000693 & 0.0000821 & 0.3750 \\
\hline 9150008 & $6 / 6 \mathrm{~A}$ & $15 E \_4 s 1 d 2 Z c \_1$ & 147116 & E & 3.25 & 354.8 & 35 & 29 & 0.126 & 0.189 & HLP-22 & 12 & 8 & 4 & 1.05 & 4.5 & 2.4 & 21.8 & 10.1 & 0.62 & 0.34 & s1d2 & 2.48 & 0.0000569 & 0.0000693 & 0.0000821 & 0.3750 \\
\hline 9150009 & 6/6A & 15E_4s1d2ZC_ _ & 147116 & E & 3.25 & 354.8 & 35 & 29 & 0.126 & 0.189 & HLP-22 & 12 & 8 & 4 & 1.05 & 4.5 & 2.4 & 21.8 & 10.1 & 0.62 & 0.34 & s1d2 & 2.48 & 0.0000569 & 0.0000693 & 0.0000821 & 0.3750 \\
\hline 9150010 & 6/6A & 15E_4sId2Z_c_1 & 147116 & E & 3.25 & 354.8 & 35 & 29 & 0.126 & 0.189 & HLP-22 & 12 & 8 & 4 & 1.05 & 4.5 & 2.4 & 21.8 & 10.1 & 0.62 & 0.34 & s1d2 & 2.48 & 0.0000569 & 0.0000693 & 0.0000821 & 0.3750 \\
\hline 9150011 & 6/6A & 15E_4s1d27c_1 & $147 / 16$ & $E$ & 3.25 & 354.8 & 35 & 29 & 0.126 & 0.189 & HLP-22 & 12 & 8 & 4 & 1.05 & 4.5 & 2.4 & 21.8 & 10.1 & 0.62 & 0.34 & s1d2 & 2.48 & 0.0000569 & 0.0000693 & 0.0000821 & 0.3750 \\
\hline 9150012 & 6/6A & 15E_4S1d2Z___ 1 & $147 / 16$ & $E$ & 3.25 & 354.8 & 35 & 29 & 0.126 & 0.189 & HLP-22 & 12 & 8 & 4 & 1.05 & 4.5 & 2.4 & 21.8 & 10.1 & 0.62 & 0.34 & s1d2 & 2.48 & 0.0000569 & 0.0000693 & 0.0000821 & 0.3750 \\
\hline 9150013 & $6 / 6 \mathrm{~A}$ & $15 E \_4 s 1 d 2 Z \mathrm{c} \_1$ & 147116 & E & 3.25 & 354.8 & 35 & 29 & 0.126 & 0.189 & HLP-22 & 12 & 8 & 4 & 1.05 & 4.5 & 2.4 & 21.8 & 10.1 & 0.62 & 0.34 & $51 d 2$ & 2.48 & 0.0000569 & 0.0000693 & 0.0000821 & 0.3750 \\
\hline 9150014 & $6 / 6 \mathrm{~A}$ & 15E_4sid227c 1 & $147 / 16$ & E & 3.25 & 354.8 & 35 & 29 & 0.126 & 0.189 & HLP -22 & 12 & 8 & 4 & 1.05 & 4.5 & 2.4 & 21.8 & 10.1 & 0.62 & 0.34 & s1d2 & 2.48 & 0.0000569 & 0.0000693 & 0.0000821 & 0.3750 \\
\hline 9150015 & $6 / 6 \mathrm{~A}$ & 15E_4s1d27c_1 & 147116 & $\mathrm{E}$ & 3.25 & 354.8 & 35 & 29 & 0.126 & 0.189 & HLP-22 & 12 & 8 & 4 & 1.05 & 4.5 & 2.4 & 21.8 & 10.1 & 0.62 & 0.34 & s1d2 & 2.48 & 0.0000569 & 0.0000693 & 0.0000821 & 0.3750 \\
\hline 9150016 & 6/6A & 15E_4sid227c_1 & $147 / 16$ & $E$ & 3.25 & 354.8 & 35 & 29 & 0.126 & 0.189 & HLP-22 & 12 & 8 & 4 & 1.05 & 4.5 & 2.4 & 21.8 & 10.1 & 0.62 & 0.34 & s1d2 & 2.48 & 0.0000569 & 0.0000693 & 0.0000821 & 0.3750 \\
\hline 9150017 & 6/6B & 15E_4s1d27d_1 & $147 / 16$ & $\mathrm{E}$ & 3.25 & 354.8 & 35 & 29 & 0.126 & 0.189 & HLP-22 & 12 & 8 & 4 & 1.05 & 4.5 & 2.4 & 21.8 & 10.1 & 0.62 & 0.34 & s1d2 & 2.48 & 0.0000569 & 0.0000693 & 0.0000821 & 0.3750 \\
\hline 9150018 & $6 / 6 \mathrm{~B}$ & 15E_4s1d2Zd_1 & 147116 & E & 3.25 & 354.8 & 35 & 29 & 0.126 & 0.189 & HLP-22 & 12 & 8 & 4 & 1.05 & 4.5 & 2.4 & 21.8 & 10.1 & 0.62 & 0.34 & s1d2 & 2.48 & 0.0000569 & 0.0000693 & 0.0000821 & 0.3750 \\
\hline $9150019 \mathrm{M}$ & $6 / 6 \mathrm{~B}$ & 15E_4sid27d_1 & 147116 & E & 3.25 & 354.8 & 35 & 29 & 0.126 & 0.189 & HLP. 22 & 12 & 8 & 4 & 1.05 & 4.5 & 2.4 & 21.8 & 10.1 & 0.62 & 0.34 & s1d2 & 2.48 & 0.0000569 & 0.0000693 & 0.0000821 & 0.3750 \\
\hline $9150020 \mathrm{M}$ & $6 / 6 \mathrm{~B}$ & 15E_4sId2Z2_1 & 147116 & $\mathrm{E}$ & 3.25 & 354.8 & 35 & 29 & 0.126 & 0.189 & HLP-22 & 12 & 8 & 4 & 1.05 & 4.5 & 2.4 & 21.8 & 10.1 & 0.62 & 0.34 & s1d2 & 2.48 & 0.0000569 & 0.0000693 & 0.0000821 & 0.3750 \\
\hline $9150021 \mathrm{M}$ & $616 \mathrm{~B}$ & 15E_4sid2Zd_1 & $147 / 16$ & $E$ & 3.25 & 354.8 & 35 & 29 & 0.126 & 0.189 & HLP-22 & 12 & 8 & 4 & 1.05 & 4.5 & 2.4 & 21.8 & 10.1 & 0.62 & 0.34 & s1d2 & 2.48 & 0.0000569 & 0.0000693 & 0.0000821 & 0.3750 \\
\hline $9150022 \mathrm{M}$ & $6 / 6 \mathrm{~B}$ & 15E_4sid27d_1 & 147116 & $E$ & 3.25 & 354.8 & 35 & 29 & 0.126 & 0.189 & HLP-22 & 12 & 8 & 4 & 1.05 & 4.5 & 2.4 & 21.8 & 10.1 & 0.62 & 0.34 & s1d2 & 2.48 & 0.0000569 & 0.0000693 & 0.00000211 & 0.3750 \\
\hline 9150023M & $6 / 6 \mathrm{~B}$ & 15E_4s1d2Zd_1 & 147116 & E & 3.25 & 354.8 & 35 & 29 & 0.126 & 0.189 & HLP-22 & 12 & 8 & 4 & 1.05 & 4.5 & 2.4 & 21.8 & 10.1 & 0.62 & 0.34 & s1d2 & 2.48 & 0.0000569 & 0.0000693 & 0.0000821 & 0.3750 \\
\hline $9150024 \mathrm{M}$ & $6 / 6 \mathrm{~B}$ & 15E_4s1d27d_1 & 147116 & E & 3.25 & 354.8 & 35 & 29 & 0.126 & 0.189 & HLP. 22 & 12 & 8 & 4 & 1.05 & 4.5 & 24 & 21.8 & 10.1 & 0.62 & 0.34 & s1d2 & 2.48 & 0.0000569 & 0.0000693 & 0.0000821 & 0.3750 \\
\hline $9150025 \mathrm{M}$ & $616 \mathrm{~B}$ & 15E_4sId2ZZ__1 & 147116 & $E$ & 3.25 & 354.8 & 35 & 29 & 0.226 & 0.189 & HLP-22 & 12 & 8 & 4 & 1.05 & 4.5 & 2.4 & 21.8 & 10.1 & 0.62 & 0.34 & s1d2 & 2.48 & 0.0000569 & 0.0000693 & 0.0000821 & 0.3750 \\
\hline $9150026 \mathrm{M}$ & $616 \mathrm{~B}$ & 15E_4sid27d_1 & $147 / 16$ & $E$ & 3.25 & 354.8 & 35 & 29 & 0.126 & 0.189 & HLP-22 & 12 & 8 & 4 & 1.05 & 4.5 & 2.4 & 21.8 & 10.1 & 0.62 & 0.34 & s1d2 & 2.48 & 0.0000569 & 0.0000693 & 0.0000821 & 0.3750 \\
\hline 9150027 & 6/9A & 15E_4SId2YY__1 & 147116 & $E$ & 3.25 & 354.8 & 35 & 29 & 0.126 & 0.189 & HLP-22 & 12 & 8 & 4 & 1.05 & 4.5 & 2.4 & 21.8 & 10.1 & 0.62 & 0.34 & s1d2 & 2.48 & 0.0000569 & 0.0000693 & 0.00000211 & 0.3750 \\
\hline 9150028 & $6 / 9 \mathrm{~A}$ & 15E_4sid2YC_1 & 147116 & E & 3.25 & 354.8 & 35 & 29 & 0.126 & 0.189 & HLP-22 & 12 & 8 & 4 & 1.05 & 4.5 & 2.4 & 21.8 & 10.1 & 0.62 & 0.34 & s1d2 & 2.48 & 0.0000569 & 0.0000693 & 0.0000821 & 0.3750 \\
\hline 9150029 & $6 / 9 A$ & 15E_4s1d2Yc_1 & 147116 & $E$ & 3.25 & 354.8 & 35 & 29 & 0.126 & 0.189 & HLP-22 & 12 & 8 & 4 & 1.05 & 4.5 & 24 & 21.8 & 10.1 & 0.62 & 0.34 & s1d2 & 2.48 & 0.0000569 & 0.0000693 & 0.0000821 & 0.3750 \\
\hline $9150030 \mathrm{M}$ & $6 / 9 A$ & $15 \mathrm{E} \_4 \mathrm{~s} 1 \mathrm{~d} 2 \mathrm{Yc} \_1$ & 147116 & E & 3.25 & 354.8 & 35 & 29 & 0.126 & 0.189 & HLP-22 & 12 & 8 & 4 & 1.05 & 4.5 & 2.4 & 21.8 & 10.1 & 0.62 & 0.34 & s1d2 & 2.48 & 0.0000569 & 0.0000693 & 0.0000821 & 0.3750 \\
\hline 9150031M & $6 / 9 A$ & 15E_4SId2YY_ 1 & $147 / 16$ & $E$ & 3.25 & 354.8 & 35 & 29 & 0.126 & 0.189 & HLP-22 & 12 & 8 & 4 & 1.05 & 4.5 & 2.4 & 21.8 & 10.1 & 0.62 & 0.34 & s1d2 & 2.48 & 0.0000569 & 0.0000693 & 0.0000821 & 0.3750 \\
\hline $9150032 \mathrm{M}$ & 6/9A & 15E_4SId2YY__1 & 147116 & $E$ & 3.25 & 354.8 & 35 & 29 & 0.126 & 0.189 & HLP-22 & 12 & 8 & 4 & 1.05 & 4.5 & 2.4 & 21.8 & 10.1 & 0.62 & 0.34 & s1d2 & 2.48 & 0.0000569 & 0.0000693 & 0.00000211 & 0.3750 \\
\hline $9150033 \mathrm{M}$ & $6 / 9 A$ & 15E_4sid2YC_1 & 147116 & E & 3.25 & 354.8 & 35 & 29 & 0.126 & 0.189 & HLP-22 & 12 & 8 & 4 & 1.05 & 4.5 & 2.4 & 21.8 & 10.1 & 0.62 & 0.34 & s1d2 & 2.48 & 0.0000569 & 0.0000693 & 0.0000821 & 0.3750 \\
\hline 9150034M & $6 / 9 A$ & $15 \mathrm{E} \_4 \mathrm{~s} 1 \mathrm{~d} 2 \mathrm{YC} \_1$ & 147116 & E & 3.25 & 354.8 & 35 & 29 & 0.126 & 0.189 & HLP-22 & 12 & 8 & 4 & 1.05 & 4.5 & 2.4 & 21.8 & 10.1 & 0.62 & 0.34 & s1d2 & 2.48 & 0.0000569 & 0.0000693 & 0.0000821 & 0.3750 \\
\hline 9150035M & $6 / 9 \mathrm{~A}$ & $15 \mathrm{E} \_4 \mathrm{~s} 1 \mathrm{~d} 2 \mathrm{YC} \_1$ & $147 / 16$ & E & 3.25 & 354.8 & 35 & 29 & 0.126 & 0.189 & HLP-22 & 12 & 8 & 4 & 1.05 & 4.5 & 24 & 21.8 & 10.1 & 0.62 & 0.34 & s1d2 & 2.48 & 0.0000569 & 0.0000693 & 0.0000821 & 0.3750 \\
\hline 9150035.1 & $6 / 9 A$ & $15 \mathrm{E} \_4 \mathrm{~s} 1 \mathrm{~d} 2 \mathrm{YC} \_1$ & 147116 & E & 3.25 & 354.8 & 35 & 29 & 0.126 & 0.189 & HLP-22 & 12 & 8 & 4 & 1.05 & 4.5 & 2.4 & 21.8 & 10.1 & 0.62 & 0.34 & s1d2 & 2.48 & 0.0000569 & 0.0000693 & 0.0000821 & 0.3750 \\
\hline 9150035.2 & 6/9A & 15E_4SId2YY__1 & $147 / 16$ & $E$ & 3.25 & 354.8 & 35 & 29 & 0.126 & 0.189 & HLP-22 & 12 & 8 & 4 & 1.05 & 4.5 & 2.4 & 21.8 & 10.1 & 0.62 & 0.34 & s1d2 & 2.48 & 0.0000569 & 0.0000693 & 0.00000211 & 0.3750 \\
\hline 9150035.3 & $6 / 9 \mathrm{~A}$ & 15E_4sid2YC_1 & 147116 & E & 3.25 & 354.8 & 35 & 29 & 0.126 & 0.189 & HLP-22 & 12 & 8 & 4 & 1.05 & 4.5 & 2.4 & 21.8 & 10.1 & 0.62 & 0.34 & s1d2 & 2.48 & 0.0000569 & 0.0000693 & 0.0000821 & 0.3750 \\
\hline 9150035.4 & $6 / 9 A$ & $15 \mathrm{E} \_4 \mathrm{~s} 1 \mathrm{~d} 2 \mathrm{YC} \_1$ & & E & 3.25 & 354.8 & 35 & 29 & 0.126 & 0.18 & & 12 & 8 & 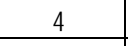 & 100 & 4.5 & 2.4 & & & & & s1d2 & 2.48 & 0.0000569 & & & \\
\hline $\begin{array}{ll}9150035.5 \\
\end{array}$ & $6 / 9 \mathrm{~A}$ & $15 \mathrm{E} \_4 \mathrm{~s} 1 \mathrm{~d} 2 \mathrm{YC} \_1$ & $147 / 16$ & E & 3.25 & 354.8 & 35 & 29 & 0.126 & 0.189 & HLP-22 & 12 & 8 & 4 & 1.05 & 4.5 & 2.4 & 21.8 & 10.1 & 0.62 & 0.34 & s1d2 & 2.48 & 0.0000569 & 0.0000693 & 0.0000821 & 0.3750 \\
\hline & & & & & & & & & 0.120 & 0.189 & HLP-22 & & & & 10 & 4.5 & 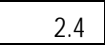 & & & 0.02 & 0.5 & 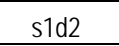 & 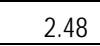 & & & & \\
\hline
\end{tabular}


Table B.3. Data from 2008 Tests in Small-Scale Vessel with Elliptical Head B.1

\begin{tabular}{|c|c|c|c|c|c|c|c|c|c|c|c|c|c|c|c|c|c|c|c|c|c|c|c|c|c|c|c|c|c|}
\hline $\begin{array}{l}\text { Tank Water } \\
\text { Temperature }\end{array}$ & $\begin{array}{c}\text { Water } \\
\text { Densiyy }\end{array}$ & \begin{tabular}{|c|} 
Solids \\
Fraction
\end{tabular} & $\begin{array}{c}\text { Pulse } \\
\text { Volume } \\
\text { Fraction }\end{array}$ & $\begin{array}{l}\text { Duty } \\
\text { Cycle }\end{array}$ & $\begin{array}{l}\text { Cycle } \\
\text { Time }\end{array}$ & $\begin{array}{c}\begin{array}{c}\text { Pulsed } \\
\text { or } \\
\text { Steady } \\
\text { Jet }\end{array} \\
\end{array}$ & $\begin{array}{c}\text { Us } \\
\text { Steaady } \\
\text { Jet }\end{array}$ & $\begin{array}{c}\text { U1 } \\
\text { Pulsing } \\
\text { Jet } \\
\text { Jet }\end{array}$ & $\begin{array}{c}\text { U2 } \\
\text { URMS }\end{array}$ & \begin{tabular}{|c} 
U3 \\
URMB \\
\end{tabular} & \begin{tabular}{|c|} 
Discharge \\
Velocity
\end{tabular} & $\begin{array}{c}\text { Citical } \\
\text { Suspension } \\
\text { velocity }\end{array}$ & $\begin{array}{c}\text { Average } \\
\text { Peak loud } \\
\text { Height }\end{array}$ & $\begin{array}{c}\text { UCS } \\
\text { Condition }\end{array}$ & $\begin{array}{c}\text { UCS } \\
\text { Nethod }\end{array}$ & $\begin{array}{l}\text { UCS } \\
\text { Fag }\end{array}$ & $\begin{array}{l}\text { ucs } \\
\text { Center } \\
\text { Hag }\end{array}$ & $\begin{array}{l}\text { UCS } \\
\text { unv } \\
\text { Hag }\end{array}$ & $\begin{array}{l}\text { UCS based } \\
\text { on } \\
\text { Decreasing } \\
\text { Velocity }\end{array}$ & $\begin{array}{l}\text { Sweep } \\
\text { Innerase I } \\
\text { Decrease }\end{array}$ & \begin{tabular}{|c|} 
UDV \\
Height \\
Bed
\end{tabular} & $\begin{array}{c}\text { Patricle } \\
\text { Motion }\end{array}$ & $\begin{array}{l}\text { Solids } \\
\text { Level } \\
\end{array}$ & \begin{tabular}{|c|} 
Outer \\
Botom \\
Pattem
\end{tabular} & $\mid$\begin{tabular}{|c|} 
Inner \\
Botom \\
Patem
\end{tabular} & Case ID & Test & TDP & $\begin{array}{c}\text { Row } \\
\text { Number }\end{array}$ \\
\hline c & $\mathrm{g} / \mathrm{cm}^{3}$ & fraction & fraction & fraction & $\mathrm{s}$ & text & $\mathrm{m} / \mathrm{s}$ & $\mathrm{m} / \mathrm{s}$ & $\mathrm{m} / \mathrm{s}$ & m/s & \begin{tabular}{|l|}
$\mathrm{m} / \mathrm{s}$ \\
\end{tabular} & $\begin{array}{ll}\mathrm{m} / \mathrm{s} \\
\end{array}$ & in. & $m / s$ & text & text & text & text & m/s & text & $\mathrm{mm}$ & text & text & text & \begin{tabular}{|l|} 
text \\
\end{tabular} & text & text & text & text \\
\hline $\mathrm{T}$ & $\rho$ & $\phi_{\mathrm{s}}$ & $\phi_{p_{a}}$ & $D C$ & $t_{c}$ & Jet & $U_{s}$ & $\mathrm{uI}_{1}$ & $\mathrm{U} 2$ & U3 & $u$ & Uss & $\mathrm{HC}_{\mathrm{C}}$ & Utse & Usu & Uosvis & Ussen & Ussudv & $U_{c s} \mathrm{D}$ & $s_{\mathrm{v}}$ & $\mathrm{H}_{\mathrm{hed}}$ & PM & sol & $\mathrm{SP}_{\mathrm{o}}$ & $\mathrm{SP}_{1}$ & ID & MDDX & $\mathrm{IDP}$ & MSS \\
\hline 20.8 & 1.000 & 0.00155 & 0.050 & 0.329 & 23.8 & $\mathrm{P}$ & NA & 2.56 & 2.57 & 2.58 & 2.60 & 2.80 & 5.88 & NA & NA & NA & NA & $\mathrm{NA}$ & NA & (null) & 4.1 & 1 & NA & NA & NA & 15E_4s1d2Zc_ _1 & $6 / 6 \mathrm{~A}$ & TDP-172 & 9150001 \\
\hline 21.0 & 1.000 & 0.00155 & 0.050 & 0.331 & 22.0 & $\mathrm{P}$ & NA & 2.74 & 2.76 & 2.77 & 2.80 & 2.80 & 6.75 & 2.80 & udv & NA & NA & ucsudv & NA & 1 & 23 & 1 & NA & NA & NA & 15E_4sId2Zc_ 1 & $6 / 6 \mathrm{~A}$ & TDP-172 & 9150002 \\
\hline 21.3 & 1.000 & 0.00155 & 0.050 & 0.333 & 20.6 & $\mathrm{P}$ & NA & 2.94 & 2.96 & 2.97 & 3.00 & 280 & 8.00 & NA & NA & NA & Ucscen & NA & NA & 1 & 0.0 & 2 & NA & NA & NA & 15E_4sid27c_1 & 6/6A & TDP-172 & 9150003 \\
\hline 21.5 & 1.000 & 0.00155 & 0.050 & 0.334 & 19.2 & $\mathrm{P}$ & NA & 3.12 & 3.15 & 3.16 & 3.20 & 2.80 & 9.75 & NA & NA & Ucsis & NA & NA & NA & $\mathrm{I}$ & 0.0 & 3 & NA & NA & NA & 15E_4s1d2Zc_ 1 & 6/6A & TDP-172 & 9150004 \\
\hline 21.7 & 1.000 & 0.00155 & 0.050 & 0.336 & 18.0 & $\mathrm{P}$ & NA & 3.32 & 3.35 & 3.36 & 3.40 & 2.80 & 12.00 & NA & NA & NA & NA & NA & NA & 1 & 0.0 & 4 & NA & NA & NA & 15E_4sId2Zc_ 1 & $6 / 6 \mathrm{~A}$ & TDP-172 & 9150005 \\
\hline 21.9 & 1.000 & 0.00155 & 0.050 & 0.337 & 17.0 & $\mathrm{P}$ & NA & 3.52 & 3.55 & 3.56 & 3.60 & 2.80 & 19.75 & NA & NA & NA & NA & $\mathrm{NA}$ & NA & 1 & 1.5 & 4 & NA & $\mathrm{NA}$ & NA & 15E_4s1d2Z___1 & 6/6A & TDP-172 & 9150006 \\
\hline 22.4 & 0.999 & 0.00155 & 0.050 & 0.332 & 22.0 & $\mathrm{P}$ & NA & 2.74 & 2.76 & 2.77 & 2.80 & 2.80 & 6.88 & NA & NA & NA & NA & NA & NA & D & 2.7 & 1 & NA & NA & NA & 15E_4s1d2Zc_ 1 & $6 / 6 \mathrm{~A}$ & TDP-172 & 9150007 \\
\hline 22.4 & 0.999 & 0.00155 & 0.050 & 0.332 & 22.0 & $\mathrm{P}$ & NA & 2.74 & 2.76 & 2.77 & 2.80 & 280 & 6.88 & NA & NA & NA & NA & NA & NA & NA & 3.4 & NA & NA & NA & NA & 15E_4sid27c_1 & $6 / 6 \mathrm{~A}$ & TDP-172 & 9150008 \\
\hline 22.4 & 0.999 & 0.00155 & 0.050 & 0.332 & 22.0 & $\mathrm{P}$ & NA & 2.74 & 2.76 & 2.77 & 2.80 & 2.80 & 6.88 & NA & NA & NA & NA & NA & NA & NA & 2.9 & NA & NA & NA & NA & 15E_4s1d2Zc_ 1 & $6 / 6 \mathrm{~A}$ & TDP-172 & 9150009 \\
\hline 22.4 & 0.999 & 0.00155 & 0.050 & 0.332 & 22.0 & $\mathrm{P}$ & NA & 2.74 & 2.76 & 2.77 & 2.80 & 2.80 & 6.88 & NA & NA & NA & NA & NA & NA & NA & 2.4 & NA & NA & NA & NA & 15E_4s1d2Zc_ 1 & $6 / 6 \mathrm{~A}$ & TDP-172 & 9150010 \\
\hline 22.4 & 0.999 & 0.00155 & 0.050 & 0.332 & 22.0 & $\mathrm{P}$ & NA & 2.74 & 2.76 & 2.77 & 2.80 & 2.80 & 6.88 & NA & NA & NA & NA & NA & NA & NA & 8.6 & NA & NA & NA & NA & 15E_4s1d2Zc_1 1 & $6 / 6 \mathrm{~A}$ & TDP-172 & 9150011 \\
\hline 22.4 & 0.999 & 0.00155 & 0.050 & 0.332 & 22.0 & $\mathrm{P}$ & NA & 2.74 & 2.76 & 2.77 & 2.80 & 2.80 & 6.88 & NA & NA & NA & NA & NA & NA & NA & 3.6 & NA & NA & NA & NA & 15E_4sId2Zc_ 1 & $6 / 6 \mathrm{~A}$ & TDP-172 & 9150012 \\
\hline 22.4 & 0.999 & 0.00155 & 0.050 & 0.332 & 22.0 & $\mathrm{P}$ & NA & 2.74 & 2.76 & 2.77 & 2.80 & 280 & 6.88 & NA & NA & NA & NA & NA & NA & NA & 0.7 & NA & NA & NA & NA & 15E_4sid27c_1 & $6 / 6 \mathrm{~A}$ & TDP-172 & 9150013 \\
\hline 22.4 & 0.999 & 0.00155 & 0.050 & 0.332 & 22.0 & $\mathrm{P}$ & NA & 2.74 & 2.76 & 2.77 & 2.80 & 2.80 & 6.88 & NA & NA & NA & NA & NA & NA & NA & 20.2 & NA & NA & NA & NA & 15E_4sId2Zc_ 1 & $6 / 6 \mathrm{~A}$ & TDP-172 & 9150014 \\
\hline 22.4 & 0.999 & 0.00155 & 0.050 & 0.332 & 22.0 & $\mathrm{P}$ & NA & 2.74 & 2.76 & 2.77 & 2.80 & 2.80 & 6.88 & NA & NA & NA & NA & NA & NA & NA & 4.2 & NA & NA & NA & NA & 15E_4sId2Zc_ 1 & $6 / 6 \mathrm{~A}$ & TDP-172 & 9150015 \\
\hline 22.4 & 0.999 & 0.00155 & 0.050 & 0.332 & 22.0 & $\mathrm{P}$ & NA & 2.74 & 2.76 & 2.77 & 2.80 & 2.80 & 6.88 & NA & NA & NA & NA & NA & NA & NA & 4.1 & NA & NA & NA & NA & 15E_4sId2Zc_ 1 & $6 / 6 \mathrm{~A}$ & TDP-172 & 9150016 \\
\hline 22.9 & 0.999 & 0.00155 & 0.050 & 0.179 & 40.6 & $\mathrm{P}$ & NA & 2.74 & 2.76 & 2.77 & 2.80 & 3.40 & 5.63 & NA & NA & NA & NA & NA & NA & (null) & 4.2 & 1 & NA & NA & NA & 15E_4sId2Zd_ 1 & $6 / 6 \mathrm{~B}$ & TDP-172 & 9150017 \\
\hline 23.1 & 0.999 & 0.00155 & 0.050 & 0.181 & 35.4 & $\mathrm{P}$ & NA & 3.11 & 3.14 & 3.15 & 3.20 & 3.40 & 6.50 & NA & NA & NA & NA & NA & NA & 1 & 3.8 & 1 & NA & NA & NA & 15E_4sid27d_1 & $616 \mathrm{~B}$ & TDP-172 & 9150018 \\
\hline 23.2 & 1.000 & 0.00155 & 0.050 & 0.182 & 33.2 & $\mathrm{P}$ & NA & 3.32 & 3.35 & 3.36 & 3.40 & 3.40 & 6.88 & 3.40 & udv & Ucsis & NA & ucsudv & NA & 1 & 0.0 & 3 & NA & NA & NA & 15E_4s1d27d_1 & $6 / 6 \mathrm{~B}$ & TDP-172 & 9150019 \\
\hline 23.6 & 1.000 & 0.00155 & 0.050 & 0.182 & 31.4 & $\mathrm{P}$ & NA & 3.49 & 3.53 & 3.54 & 3.60 & 3.40 & 8.50 & NA & NA & NA & NA & NA & NA & 1 & 0.0 & 4 & NA & NA & NA & 15E_4sid27d_1 & $6 / 6 B$ & TDP-172 & 9150020 \\
\hline 24.3 & 0.999 & 0.00155 & 0.050 & 0.183 & 29.6 & $\mathrm{P}$ & NA & 3.70 & 3.74 & 3.75 & 3.80 & 3.40 & 9.75 & NA & NA & NA & NA & NA & NA & 1 & 0.0 & 4 & NA & NA & NA & 15E_4sId2Zd__ I & $6 / 6 \mathrm{~B}$ & TDP-172 & 9150021 \\
\hline 24.5 & 0.999 & 0.00155 & 0.050 & 0.184 & 28.0 & $\mathrm{P}$ & NA & 3.88 & 3.92 & 3.94 & 4.00 & 3.40 & 13.00 & NA & NA & NA & NA & NA & NA & 1 & 0.0 & 4 & NA & NA & NA & 15E_4sId2Zd_ 1 & $6 / 6 \mathrm{~B}$ & TDP-172 & 9150022 \\
\hline 24.7 & 0.999 & 0.00155 & 0.050 & 0.185 & 26.6 & $\mathrm{P}$ & NA & 4.08 & 4.12 & 4.15 & 4.20 & 3.40 & 14.25 & NA & NA & NA & NA & NA & NA & 1 & 0.0 & 4 & NA & NA & NA & 15E_4sid27d_1 & $6 / 6 \mathrm{~B}$ & TDP-172 & 9150023 \\
\hline 24.9 & 0.999 & 0.00155 & 0.050 & 0.186 & 25.4 & $\mathrm{P}$ & NA & 4.25 & 4.30 & 4.33 & 4.40 & 3.40 & 17.00 & NA & NA & NA & NA & NA & NA & 1 & 0.0 & 4 & NA & NA & NA & 15E_4s1d27d_1 & $6 / 6 B$ & TDP-172 & 9150024 \\
\hline 25.0 & 0.999 & 0.00155 & 0.050 & 0.187 & 24.2 & $\mathrm{P}$ & NA & 4.46 & 4.52 & 4.54 & 4.60 & 3.40 & 18.00 & NA & NA & NA & NA & NA & NA & 1 & 0.0 & 4 & NA & NA & NA & 15E_4sid27d_1 & $6 / 6 B$ & TDP-172 & 9150025 \\
\hline 25.3 & 0.999 & 0.00155 & 0.050 & 0.188 & 23.2 & $\mathrm{P}$ & NA & 4.60 & 4.66 & 4.69 & 4.80 & 3.40 & 25.25 & NA & NA & NA & NA & NA & NA & 1 & 0.0 & 4 & NA & NA & NA & 15E_4sId2Zd__ _ & $6 / 6 B$ & TDP-172 & 9150026 \\
\hline 22.9 & 1.000 & 0.00500 & 0.050 & 0.333 & 17.6 & $\mathrm{P}$ & NA & 3.40 & 3.43 & 3.44 & 3.50 & 4.3 & 4.25 & NA & NA & A & NA & NA & NA & 1 & 9.5 & 1 & NA & NA & NA & 15E_4sId2YC_1 & $6 / 9 \mathrm{~A}$ & TDP-173 & 9150027 \\
\hline 23.1 & 0.999 & 0.00500 & 0.050 & 0.336 & 15.4 & $\mathrm{P}$ & NA & 3.88 & 3.92 & 3.94 & 4.00 & 4.30 & 5.25 & NA & NA & NA & NA & NA & NA & 1 & 3.7 & 1 & NA & NA & NA & 15E_4sid2YC_1 & $6 / 9 A$ & TDP-173 & 9150028 \\
\hline 23.5 & 0.999 & 0.00500 & 0.050 & 0.329 & 15.0 & $\mathrm{P}$ & NA & 4.06 & 4.10 & 4.12 & 4.20 & 4.30 & 5.25 & NA & NA & Ucsis & NA & NA & NA & 1 & 3.7 & 3 & NA & NA & NA & 15E_4s1d2YC_ 1 & 6/9A & TDP-173 & 9150029 \\
\hline 24.0 & 0.999 & 0.00500 & 0.050 & 0.329 & 14.6 & $\mathrm{P}$ & NA & 4.15 & 4.20 & 4.23 & 4.30 & 4.30 & 5.25 & 4.30 & udv & NA & NA & ucsuav & NA & 1 & 2.5 & 4 & NA & NA & NA & 15E_4s1d2YC_1 & $6 / 9 A$ & TDP-173 & 9150030 \\
\hline 24.4 & 0.999 & 0.00500 & 0.050 & 0.330 & 13.8 & $\mathrm{P}$ & NA & 4.36 & 4.41 & 4.44 & 4.50 & 4.30 & 6.25 & NA & NA & NA & NA & NA & NA & $\mathrm{I}$ & 0.0 & 4 & NA & NA & NA & 15E_4s1d2Yc_1 & $6 / 9 \mathrm{~A}$ & TDP-173 & 9150031 \\
\hline 24.7 & 0.999 & 0.00500 & 0.050 & 0.334 & 12.8 & $\mathrm{P}$ & NA & 4.68 & 4.76 & 4.79 & 4.90 & 4.30 & 11.75 & NA & NA & NA & NA & NA & NA & 1 & 0.0 & 4 & NA & NA & NA & 15E_4sId2YC_ 1 & 6/9A & TDP-173 & 9150032 \\
\hline 25.1 & 0.999 & 0.00500 & 0.050 & 0.333 & 12.6 & $\mathrm{P}$ & NA & 4.81 & 4.88 & 4.91 & 5.00 & 4.30 & 12.75 & NA & NA & NA & NA & NA & NA & 1 & 0.0 & 4 & NA & NA & NA & 15E_4sid2YC_1 & $6 / 9 A$ & TDP-173 & 9150033 \\
\hline 25.3 & 0.999 & 0.00500 & 0.050 & 0.338 & 11.6 & $\mathrm{P}$ & NA & 5.15 & 5.23 & 5.27 & 5.40 & 4.30 & 17.00 & NA & NA & NA & NA & NA & NA & 1 & 0.0 & 4 & NA & NA & NA & 15E_4sId2YC_ 1 & 6/9A & TDP-173 & 9150034 \\
\hline 25.7 & 0.999 & 0.00500 & 0.050 & 0.335 & 11.2 & $\mathrm{P}$ & NA & 5.34 & 5.43 & 5.47 & 5.60 & 4.30 & 23.00 & NA & NA & NA & NA & NA & NA & 1 & 0.0 & 4 & NA & NA & NA & 15E_4s1d2YC_1 & 6/9A & TDP-173 & 9150035 \\
\hline 26.9 & 0.999 & 0.00500 & 0.050 & 0.330 & 15.0 & $\mathrm{P}$ & NA & 4.07 & 4.11 & 4.13 & & & 5.00 & NA & NA & NA & NA & NA & NA & NA & n/a & NA & NA & NA & NA & 15E_4sid2YC_ 1 & $6 / 9 \mathrm{~A}$ & TDP-173 & 9150035.1 \\
\hline 26.9 & 0.999 & 0.00500 & 0.050 & 0.330 & 15.0 & $\mathrm{P}$ & $\mathrm{NA}$ & 4.07 & 4.11 & 4.13 & 4.20 & 4.30 & 5.00 & NA & $\mathrm{NA}$ & NA & NA & NA & NA & NA & $\mathrm{N} / \mathrm{a}$ & $\mathrm{NA}$ & NA & $\mathrm{NA}$ & NA & 15E_4s1d2Yc_1 & 6/9A & TDP-173 & 9150035.2 \\
\hline 26.9 & 0.999 & 0.00500 & 0.050 & 0.330 & 15.0 & $\mathrm{P}$ & NA & 4.07 & 4.11 & 4.13 & 4.20 & 4.30 & 5.00 & NA & NA & NA & NA & NA & NA & NA & $\mathrm{n} / \mathrm{a}$ & NA & NA & NA & NA & 15E_4s1d2YC_1 & $6 / 9 A$ & TDP-173 & 9150035.3 \\
\hline 26.9 & 0.999 & 0.00500 & 0.050 & 0.330 & 15.0 & $\mathrm{P}$ & NA & 4.07 & 4.11 & 4.13 & 4.20 & 4.30 & 5.00 & NA & NA & NA & NA & NA & NA & NA & na & NA & NA & NA & NA & 15E_-4sid2YC 1 & 6/9A & TDP-173 & 9150035.4 \\
\hline 26.9 & 0.999 & 0.00500 & 0.050 & 0.330 & 15.0 & $P$ & NA & $\begin{array}{ll}4.07 \\
\end{array}$ & 4.11 & 4.13 & 4.20 & 4.30 & 5.00 & NA & NA & $\mathrm{NA}$ & NA & $\mathrm{NA}$ & NA & NA & naa & NA & NA & NA & NA & 15E_4s1d2YC_1 & 6/9A & TDP-173 & 9150035.5 \\
\hline 26.9 & 0.999 & 0.00500 & 0.050 & 0.330 & 15.0 & $\mathrm{P}$ & NA & 4.07 & 4.11 & 4.13 & 4.20 & 4.30 & 5.00 & NA & NA & NA & NA & NA & NA & NA & na & NA & NA & NA & NA & 15E_4sid2YC_1 & 6/9A & TDP-173 & 915003 \\
\hline
\end{tabular}


Table B.3. Data from 2008 Tests in Small-Scale Vessel with Elliptical Head A.2

\begin{tabular}{|c|c|c|c|c|c|c|c|c|c|c|c|c|c|c|c|c|c|c|c|c|c|c|c|c|c|c|c|}
\hline $\begin{array}{l}\text { Row } \\
\text { Number }\end{array}$ & Test & Case ID & $\begin{array}{c}\text { Tank } \\
\text { Diameter }\end{array}$ & $\begin{array}{l}\text { Head } \\
\text { Shape }\end{array}$ & $\begin{array}{c}\text { Dish } \\
\text { Height }\end{array}$ & $\begin{array}{l}\text { Dish } \\
\text { Volume }\end{array}$ & \begin{tabular}{|c|} 
Tank \\
Fill \\
Height \\
Hegle
\end{tabular} & $\begin{array}{l}\text { Retum } \\
\text { Line } \\
\text { Height } \\
\end{array}$ & $\begin{array}{c}\text { Nozzle } \\
\text { Inner } \\
\text { Diameter }\end{array}$ & 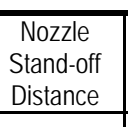 & $\begin{array}{l}\text { Pulse Tube } \\
\text { Configuration }\end{array}$ & $\begin{array}{l}\text { Installed } \\
\text { Nozzles }\end{array}$ & 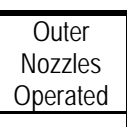 & $\begin{array}{c}\text { Inner } \\
\text { Nozzles } \\
\text { Opperated } \\
\end{array}$ & $\begin{array}{c}\begin{array}{c}\text { Pulse Tube } \\
\text { Outer } \\
\text { Diameter }\end{array} \\
\end{array}$ & \begin{tabular}{|l|} 
Outer \\
PJM \\
Radius \\
\end{tabular} & \begin{tabular}{|l|} 
Inner \\
PJM \\
Radius \\
\end{tabular} & $\begin{array}{c}\text { "FO" Outer PJM } \\
\text { Impingement } \\
\text { Angle }\end{array}$ & $\begin{array}{c}\text { "FFO" Inner PJM } \\
\text { Impingement } \\
\text { Angle }\end{array}$ & $\begin{array}{c}\text { Ratio Outer } \\
\text { PJM to Tank } \\
\text { Radius } \\
\end{array}$ & $\begin{array}{c}\text { Ratio Inner } \\
\text { PJMt to Tank } \\
\text { Radius } \\
\end{array}$ & Simulant & $\begin{array}{l}\text { Solids } \\
\text { Density }\end{array}$ & $\begin{array}{c}\begin{array}{c}\text { Particle } \\
\text { Diameter } \\
\text { d5 }\end{array} \\
\end{array}$ & $\begin{array}{c}\begin{array}{c}\text { Particle } \\
\text { Diameter } \\
\text { a50 }\end{array} \\
\end{array}$ & $\begin{array}{c}\begin{array}{c}\text { Particle } \\
\text { Diameter } \\
\text { cl95 }\end{array} \\
\end{array}$ & $\begin{array}{c}\text { Void } \\
\text { Fraction }\end{array}$ \\
\hline text & text & text & in. & text & in. & in. ${ }^{3}$ & in. & in. & in. & in. & text & number & number & number & in. & in. & in. & deg & deg & nondim & nondim & text & $\mathrm{g} / \mathrm{cm}^{3}$ & $\mathrm{~m}$ & $\mathrm{~m}$ & $\mathrm{~m}$ & fraction \\
\hline MSS & MDDX & $\mathrm{ID}$ & $\mathrm{D}$ & HS & Hosh & $V_{\text {dsh }}$ & $\mathrm{H}$ & $\operatorname{Rn}$ & $d$ & sod & PT & $\mathrm{N}$ & $\mathrm{Nb}_{\mathrm{b}}$ & $\mathrm{N}$ & $\mathrm{PT}_{\alpha \mathrm{d}}$ & $R_{0}$ & $R$ & $\theta_{0}$ & $\theta_{1}$ & $\mathrm{RdR}$ & $R / R$ & sxdx & $\rho_{\mathrm{s}}$ & $d_{b}$ & $\mathrm{~d}_{60}$ & $\frac{d 65}{d}$ & vf \\
\hline 9150035.7 & $699 A$ & 15E_4s1d2YC_1 & $147 / 16$ & $E$ & 3.25 & 354.8 & 35 & 29 & 0.226 & 0.189 & HLP-22 & 12 & 8 & 4 & 1.05 & 4.5 & 2.4 & 21.8 & 10.1 & 0.62 & 0.34 & $\mathrm{~s} 1 \mathrm{~d} 2$ & 2.48 & 0.0000569 & 0.0000693 & 0.0000821 & 0.3750 \\
\hline 9150036 & $6 / 9 \mathrm{~A}$ & 15E_4s1d2YC_1 & $147 / 16$ & $E$ & 3.25 & \begin{tabular}{ll|}
354.8 \\
\end{tabular} & 35 & 29 & 0.126 & 0.189 & HLP -22 & 12 & 8 & 4 & 1.05 & 4.5 & 2.4 & 21.8 & 10.1 & 0.62 & 0.34 & s1d2 & 2.48 & 0.0000569 & 0.0000693 & 0.0000821 & 0.3750 \\
\hline 9150037 & $6 / 9 A$ & 15E_4s1d2Yc_1 & 147116 & E & 3.25 & 354.8 & 35 & 29 & 0.126 & 0.189 & HLP-22 & 12 & 8 & 4 & 1.05 & 4.5 & 2.4 & 21.8 & 10.1 & 0.62 & 0.34 & s1d2 & 2.48 & 0.0000569 & 0.0000693 & 0.0000821 & 0.3750 \\
\hline 9150038 & $6 / 9 \mathrm{~A}$ & 15E_4s1d2YC_1 & 147116 & E & 3.25 & 354.8 & 35 & 29 & 0.126 & 0.189 & HLP-22 & 12 & 8 & 4 & 1.05 & 4.5 & 2.4 & 21.8 & 10.1 & 0.62 & 0.34 & s1d2 & 2.48 & 0.0000569 & 0.0000693 & 0.0000821 & 0.3750 \\
\hline 9150039 & 6/9A & 15E_4s1d2YC_1 & $147 / 16$ & E & 3.25 & 354.8 & 35 & 29 & 0.226 & 0.189 & HLP-22 & 12 & 8 & 4 & 1.05 & 4.5 & 2.4 & 21.8 & 10.1 & 0.62 & 0.34 & s1d2 & 2.48 & 0.0000569 & 0.0000693 & 0.0000821 & 0.3750 \\
\hline 9150040 & $6 / 9 \mathrm{~A}$ & 15E_4s1d2YC_1 & $147 / 16$ & $\mathrm{E}$ & 3.25 & 354.8 & 35 & 29 & 0.226 & 0.189 & HLP-22 & 12 & 8 & 4 & 1.05 & 4.5 & 2.4 & 21.8 & 10.1 & 0.62 & 0.34 & s1d2 & 2.48 & 0.0000569 & 0.0000693 & 0.0000821 & 0.3750 \\
\hline 9150041 & $6 / 9 \mathrm{~A}$ & 15E_4S1d2YC_1 & $147 / 16$ & $E$ & 3.25 & \begin{tabular}{ll|}
354.8 \\
\end{tabular} & 35 & 29 & 0.126 & 0.189 & HLP-22 & 12 & 8 & 4 & 1.05 & 4.5 & 2.4 & 21.8 & 10.1 & 0.62 & 0.34 & s1d2 & 2.48 & 0.0000569 & 0.0000693 & 0.0000821 & 0.3750 \\
\hline 9150042 & $6 / 9 \mathrm{~A}$ & $15 E \_4 s 1 d 2 Y c \_1$ & $147 / 16$ & E & 3.25 & 354.8 & 35 & 29 & 0.126 & 0.189 & HLP-22 & 12 & 8 & 4 & 1.05 & 4.5 & 2.4 & 21.8 & 10.1 & 0.62 & 0.34 & $\mathrm{~s} 1 \mathrm{~d} 2$ & 2.48 & 0.0000569 & 0.0000693 & 0.0000821 & 0.3750 \\
\hline 9150043 & $6 / 9 \mathrm{~A}$ & 15E_4s1d2YC_1 & 147116 & E & 3.25 & 354.8 & 35 & 29 & 0.126 & 0.189 & HLP-22 & 12 & 8 & 4 & 1.05 & 4.5 & 2.4 & 21.8 & 10.1 & 0.62 & 0.34 & $\mathrm{~s} 1 \mathrm{~d} 2$ & 2.48 & 0.0000569 & 0.0000693 & 0.0000821 & 0.3750 \\
\hline 9150044 & $6 / 9 \mathrm{~B}$ & 15E_4s1d2Rc_1 1 & $147 / 16$ & E & 3.25 & 354.8 & 35 & 29 & 0.126 & 0.189 & HLP-22 & 12 & 8 & 4 & 1.05 & 4.5 & 2.4 & 21.8 & 10.1 & 0.62 & 0.34 & s1d2 & 2.48 & 0.0000569 & 0.0000693 & 0.0000821 & 0.3750 \\
\hline 9150045 & $6 / 9 B$ & 15E_4sid2Rc_1 & $147 / 16$ & $\mathrm{E}$ & 3.25 & 354.8 & 35 & 29 & 0.126 & 0.189 & HLP-22 & 12 & 8 & 4 & 1.05 & 4.5 & 2.4 & 21.8 & 10.1 & 0.62 & 0.34 & s1d2 & 2.48 & 0.0000569 & 0.0000693 & 0.0000821 & 0.3750 \\
\hline 9150046 & $6 / 9 \mathrm{~B}$ & 15E_4s1d2Rc_1 & $147 / 16$ & $E$ & 3.25 & 354.8 & 35 & 29 & 0.126 & 0.189 & HLP-22 & 12 & 8 & 4 & 1.05 & 4.5 & 2.4 & 21.8 & 10.1 & 0.62 & 0.34 & $\mathrm{~s} 1 \mathrm{~d} 2$ & 2.48 & 0.0000569 & 0.0000693 & 0.0000821 & 0.3750 \\
\hline 9150047 & $6 / 98$ & 15E_4s1d2Rc_1 & $147 / 16$ & $\mathrm{E}$ & 3.25 & 354.8 & 35 & 29 & 0.126 & 0.189 & HLP-22 & 12 & 8 & 4 & 1.05 & 4.5 & 2.4 & 21.8 & 10.1 & 0.62 & 0.34 & $\mathrm{~s} 1 \mathrm{~d} 2$ & 2.48 & 0.0000569 & 0.0000693 & 0.0000821 & 0.3750 \\
\hline $9150048 \mathrm{M}$ & 699 & 15E_4s1d2Rc_1 & 147116 & E & 3.25 & 354.8 & 35 & 29 & 0.126 & 0.189 & HLP-22 & 12 & 8 & 4 & 1.05 & 4.5 & 2.4 & 21.8 & 10.1 & 0.62 & 0.34 & $\mathrm{sid2}$ & 2.48 & 0.0000569 & 0.0000693 & 0.0000821 & 0.3750 \\
\hline $9150049 \mathrm{M}$ & $6 / 98$ & 15E_4sId2Re 1 & $147 / 16$ & E & 3.25 & 354.8 & 35 & 29 & 0.126 & 0.189 & HLP-22 & 12 & 8 & 4 & 1.05 & 4.5 & 2.4 & 21.8 & 10.1 & 0.62 & 0.34 & s1d2 & 2.48 & 0.0000569 & 0.0000693 & 0.0000821 & 0.3750 \\
\hline $9150050 \mathrm{M}$ & $6 / 9 B$ & 15E_4s1d2Rc_1 & 147116 & $\mathrm{E}$ & 3.25 & 354.8 & 35 & 29 & 0.126 & 0.189 & HLP-22 & 12 & 8 & 4 & 1.05 & 4.5 & 2.4 & 21.8 & 10.1 & 0.62 & 0.34 & s1d2 & 2.48 & 0.0000569 & 0.0000693 & 0.0000821 & 0.3750 \\
\hline 9150051 & 6/10A & 15E_4sId2RC_1 & $147 / 16$ & $E$ & 3.25 & \begin{tabular}{ll|}
354.8 \\
\end{tabular} & 35 & 30 & 0.126 & 0.189 & HLP-22 & 12 & 8 & 4 & 1.05 & 4.5 & 2.4 & 21.8 & 10.1 & 0.62 & 0.34 & s1d2 & 2.48 & 0.0000569 & 0.0000693 & 0.0000821 & 0.3750 \\
\hline 9150052 & 6/10A & 15E_4s1d2Rc_1 & $147 / 16$ & E & 3.25 & 354.8 & 35 & 30 & 0.126 & 0.189 & HLP-22 & 12 & 8 & 4 & 1.05 & 4.5 & 2.4 & 21.8 & 10.1 & 0.62 & 0.34 & 5102 & 2.48 & 0.0000569 & 0.0000693 & 0.0000821 & 0.3750 \\
\hline $9150053 \mathrm{M}$ & 6/10A & 15E_4s1d2Rc_1 & 147116 & E & 3.25 & 354.8 & 35 & 30 & 0.126 & 0.189 & HLP-22 & 12 & 8 & 4 & 1.05 & 4.5 & 2.4 & 21.8 & 10.1 & 0.62 & 0.34 & 5102 & 2.48 & 0.0000569 & 0.0000693 & 0.0000821 & 0.3750 \\
\hline $9150054 \mathrm{M}$ & 6/10A & 15E_4s1d2Rc_1 1 & $147 / 16$ & E & 3.25 & 354.8 & 35 & 30 & 0.126 & 0.189 & HLP-22 & 12 & 8 & 4 & 1.05 & 4.5 & 2.4 & 21.8 & 10.1 & 0.62 & 0.34 & s1d2 & 2.48 & 0.0000569 & 0.0000693 & 0.0000821 & 0.3750 \\
\hline $9150055 \mathrm{M}$ & 6/10A & 15E_4s1d2Rc_1 & 147116 & $\mathrm{E}$ & 3.25 & 354.8 & 35 & 30 & 0.126 & 0.189 & HLP-22 & 12 & 8 & 4 & 1.05 & 4.5 & 2.4 & 21.8 & 10.1 & 0.62 & 0.34 & s1d2 & 2.48 & 0.0000569 & 0.0000693 & 0.0000821 & 0.3750 \\
\hline $9150056 \mathrm{M}$ & 6/10A & 15E_4s1d2Rc_1 & $147 / 16$ & $\mathrm{E}$ & 3.25 & 354.8 & 35 & 30 & 0.126 & 0.189 & HLP-22 & 12 & 8 & 4 & 1.05 & 4.5 & 2.4 & 21.8 & 10.1 & 0.62 & 0.34 & s1d2 & 2.48 & 0.0000569 & 0.0000693 & 0.0000821 & 0.3750 \\
\hline $9150057 \mathrm{M}$ & 6/10A & 15E_4s1d2Rc_1 & $147 / 16$ & $\mathrm{E}$ & 3.25 & 354.8 & 35 & 30 & 0.126 & 0.189 & HLP-22 & 12 & 8 & 4 & 1.05 & 4.5 & 2.4 & 21.8 & 10.1 & 0.62 & 0.34 & s1d2 & 2.48 & 0.0000569 & 0.0000693 & 0.0000021 & 0.3750 \\
\hline $9150058 \mathrm{M}$ & 6/10A & 15E_4s1d2Rc_1 & 147116 & E & 3.25 & 354.8 & 35 & 30 & 0.126 & 0.189 & HLP-22 & 12 & 8 & 4 & 1.05 & 4.5 & 2.4 & 21.8 & 10.1 & 0.62 & 0.34 & s1d2 & 2.48 & 0.0000569 & 0.0000693 & 0.0000821 & 0.3750 \\
\hline $9150059 \mathrm{M}$ & 6/10A & 15E_4s1d2Rc_1 1 & $147 / 16$ & E & 3.25 & 354.8 & 35 & 30 & 0.126 & 0.189 & HLP-22 & 12 & 8 & 4 & 1.05 & 4.5 & 2.4 & 21.8 & 10.1 & 0.62 & 0.34 & s1d2 & 2.48 & 0.0000569 & 0.0000693 & 0.0000821 & 0.3750 \\
\hline 9150060 & $6 / 10 B$ & 15E_4s1d2Xc_1 & 147116 & $\mathrm{E}$ & 3.25 & 354.8 & 35 & 30 & 0.126 & 0.189 & HLP-22 & 12 & 8 & 4 & 1.05 & 4.5 & 2.4 & 21.8 & 10.1 & 0.62 & 0.34 & s1d2 & 2.48 & 0.0000569 & 0.0000693 & 0.0000821 & 0.3750 \\
\hline 9150061 & $6 / 10 B$ & 15E_4s1d2XC_1 & $147 / 16$ & $E$ & 3.25 & \begin{tabular}{ll|}
354.8 \\
\end{tabular} & 35 & 30 & 0.126 & 0.189 & HLP-22 & 12 & 8 & 4 & 1.05 & 4.5 & 2.4 & 21.8 & 10.1 & 0.62 & 0.34 & s1d2 & 2.48 & 0.0000569 & 0.0000693 & 0.0000821 & 0.3750 \\
\hline 9150062 & $6 / 10 \mathrm{~B}$ & 15E_4s1d2Xc_1 & $147 / 16$ & $E$ & 3.25 & \begin{tabular}{ll|}
354.8 \\
\end{tabular} & 35 & 30 & 0.126 & $\begin{array}{ll}0.189 \\
\end{array}$ & HLP-22 & 12 & 8 & 4 & 1.05 & 4.5 & 2.4 & 21.8 & 10.1 & 0.62 & 0.34 & s1d2 & 2.48 & 0.0000569 & 0.0000693 & 0.0000021 & 0.3750 \\
\hline $9150063 \mathrm{M}$ & $6 / 10 \mathrm{~B}$ & 15E_4s1d2Xc_1 & 147116 & $E$ & 3.25 & \begin{tabular}{ll|}
354.8 \\
\end{tabular} & 35 & 30 & 0.126 & $\begin{array}{ll}0.189 \\
\end{array}$ & HLP-22 & 12 & 8 & 4 & 1.05 & 4.5 & 2.4 & 21.8 & 10.1 & 0.62 & 0.34 & s1d2 & 2.48 & 0.0000569 & 0.0000693 & 0.0000821 & 0.3750 \\
\hline $9150064 \mathrm{M}$ & 6/10B & 15E_4s1d2Xc_1 & $147 / 16$ & E & 3.25 & 354.8 & 35 & 30 & 0.126 & 0.189 & HLP-22 & 12 & 8 & 4 & 1.05 & 4.5 & 2.4 & 21.8 & 10.1 & 0.62 & 0.34 & s1d2 & 2.48 & 0.0000569 & 0.0000693 & 0.0000821 & 0.3750 \\
\hline $9150065 \mathrm{M}$ & $6 / 10 B$ & 15E_4s1d2Xc_1 & 147116 & $\mathrm{E}$ & 3.25 & 354.8 & 35 & 30 & 0.126 & 0.189 & HLP-22 & 12 & 8 & 4 & 1.05 & 4.5 & 2.4 & 21.8 & 10.1 & 0.62 & 0.34 & s1d2 & 2.48 & 0.0000569 & 0.0000693 & 0.0000821 & 0.3750 \\
\hline $9150066 \mathrm{M}$ & 6/10B & 15E_4s1d2Xc_1 & $147 / 16$ & $E$ & 3.25 & \begin{tabular}{ll|}
354.8 \\
\end{tabular} & 35 & 30 & 0.126 & 0.189 & HLP-22 & 12 & 8 & 4 & 1.05 & 4.5 & 2.4 & 21.8 & 10.1 & 0.62 & 0.34 & s1d2 & 2.48 & 0.0000569 & 0.0000693 & 0.0000821 & 0.3750 \\
\hline 9150067M & $6 / 10 B$ & 15E_4s1d2Xc_1 & 147116 & $E$ & 3.25 & \begin{tabular}{ll|}
354.8 \\
\end{tabular} & 35 & 30 & 0.126 & 0.189 & HLP-22 & 12 & 8 & 4 & 1.05 & 4.5 & 2.4 & 21.8 & 10.1 & 0.62 & 0.34 & s1d2 & 2.48 & 0.0000569 & 0.0000693 & 0.0000821 & 0.3750 \\
\hline 9150067.1 & 6/10B & 15E_4s1d2Xc_1 & 147116 & E & 3.25 & 354.8 & 35 & 30 & 0.126 & 0.189 & HLP-22 & 12 & 8 & 4 & 1.05 & 4.5 & 2.4 & 21.8 & 10.1 & 0.62 & 0.34 & s1d2 & 2.48 & 0.0000569 & 0.0000693 & 0.0000821 & 0.3750 \\
\hline 9150067.2 & $6 / 10 \mathrm{~B}$ & 15E_4sII2Xc_1 & $147 / 16$ & E & 3.25 & 354.8 & 35 & 30 & 0.226 & 0.189 & HLP-22 & 12 & 8 & 4 & 1.05 & 4.5 & 2.4 & 21.8 & 10.1 & 0.62 & 0.34 & s1d2 & 2.48 & 0.0000569 & 0.0000693 & 0.0000821 & 0.3750 \\
\hline 9150067.3 & $6 / 10 B$ & 15E_4s1d2Xc_1 & 147116 & $\mathrm{E}$ & 3.25 & 354.8 & 35 & 30 & 0.126 & 0.189 & HLP-22 & 12 & 8 & 4 & 1.05 & 4.5 & 2.4 & 21.8 & 10.1 & 0.62 & 0.34 & s1d2 & 2.48 & 0.0000569 & 0.0000693 & 0.0000821 & 0.3750 \\
\hline 9150067.4 & $6 / 10 B$ & 15E_4s1d2Xc_1 & $147 / 16$ & $\mathrm{E}$ & 3.25 & 354.8 & 35 & 30 & 0.126 & 0.189 & HLP-22 & 12 & 8 & 4 & 1.05 & 4.5 & 2.4 & 21.8 & 10.1 & 0.62 & 0.34 & s1d2 & 2.48 & 0.0000569 & 0.0000693 & 0.0000821 & 0.3750 \\
\hline 9150067.5 & 6/10B & 15E_4s1d2Xc_1 & $147 / 16$ & $E$ & 3.25 & 354.8 & 35 & 30 & 0.126 & 0.189 & HLP-22 & 12 & 8 & 4 & 1.05 & 4.5 & 2.4 & 21.8 & 10.1 & 0.62 & 0.34 & s1d2 & 2.48 & 0.0000569 & 0.0000693 & 0.0000821 & 0.3750 \\
\hline $9150068 \mathrm{M}$ & 6/10B & 15E_4s1d2Xc_1 & 147116 & $E$ & 3.25 & 354.8 & 35 & 30 & 0.126 & 0.189 & HLP-22 & 12 & 8 & 4 & 1.05 & 4.5 & 2.4 & 21.8 & 10.1 & 0.62 & 0.34 & s1d2 & 2.48 & 0.0000569 & 0.0000693 & 0.0000821 & 0.3750 \\
\hline 9150069 & $6 / 10 \mathrm{~B}$ & 15E_4sid2Xc_1 & $147 / 16$ & E & 3.25 & 354.8 & 35 & 30 & 0.226 & 0.189 & HLP-22 & 12 & 8 & 4 & 1.05 & 4.5 & 2.4 & 21.8 & 10.1 & 0.62 & 0.34 & s1d2 & 2.48 & 0.0000569 & 0.0000693 & 0.0000821 & 0.3750 \\
\hline 9150070 & 6/10B & $15 E_{2} 4 \mathrm{~s} 1 \mathrm{~d} 2 \times \mathrm{c}_{1} 1$ & $147 / 16$ & E & 3.25 & 354.8 & 35 & 30 & 0.126 & 0.189 & HLP-22 & 12 & 8 & 4 & 1.05 & 4.5 & 2.4 & 21.8 & 10.1 & 0.62 & 0.34 & s1d2 & 2.48 & 0.0000569 & 0.0000693 & 0.0000821 & 0.3750 \\
\hline
\end{tabular}


Table B.3. Data from 2008 Tests in Small-Scale Vessel with Elliptical Head B.2

\begin{tabular}{|c|c|c|c|c|c|c|c|c|c|c|c|c|c|c|c|c|c|c|c|c|c|c|c|c|c|c|c|c|c|}
\hline $\begin{array}{l}\text { Tank Water } \\
\text { Temperature }\end{array}$ & $\begin{array}{l}\text { Water } \\
\text { Density }\end{array}$ & $\begin{array}{c}\text { Solids } \\
\text { Fraction }\end{array}$ & $\begin{array}{c}\text { Pulse } \\
\text { Volume } \\
\text { Fracion }\end{array}$ & $\begin{array}{l}\text { Dury } \\
\text { Cyde }\end{array}$ & $\begin{array}{l}\text { Oyde } \\
\text { Time }\end{array}$ & $\begin{array}{c}\text { Pulsed } \\
\text { or } \\
\text { Steacdy } \\
\text { Jet } \\
\end{array}$ & $\begin{array}{c}\text { Us } \\
\text { Steacy } \\
\text { Jet }\end{array}$ & $\begin{array}{c}\text { U1 } \\
\text { Pulsing } \\
\text { Jet }\end{array}$ & $\begin{array}{c}\text { U2 } \\
\text { URMS }\end{array}$ & $\begin{array}{l}\text { U3 } \\
\text { URNB }\end{array}$ & 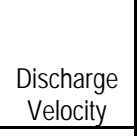 & $\begin{array}{c}\text { Citical } \\
\text { Suspension } \\
\text { Velocity }\end{array}$ & $\begin{array}{c}\text { Average } \\
\text { Peak Coud } \\
\text { Height } \\
\end{array}$ & $\begin{array}{c}\text { UCS } \\
\text { Condition }\end{array}$ & $\begin{array}{c}\text { UCS } \\
\text { Method }\end{array}$ & $\begin{array}{l}\text { UCS } \\
\text { Hag }\end{array}$ & $\begin{array}{c}\text { ucs } \\
\text { Center } \\
\text { Flag }\end{array}$ & $\begin{array}{c}\text { ucsuav } \\
\text { Fag }\end{array}$ & $\begin{array}{l}\text { UCS based } \\
\text { on } \\
\text { Decreasing } \\
\text { Velocity }\end{array}$ & $\begin{array}{l}\text { Sweep } \\
\text { Increase/ } \\
\text { Decrease }\end{array}$ & $\begin{array}{c}\text { UDV } \\
\text { Height } \\
\text { Bed }\end{array}$ & $\begin{array}{c}\text { Particle } \\
\text { Motion }\end{array}$ & $\begin{array}{l}\text { Solids } \\
\text { Level }\end{array}$ & $\begin{array}{l}\text { Outer } \\
\text { Bottom } \\
\text { Patem }\end{array}$ & \begin{tabular}{|l} 
Inner \\
Botom \\
Batter \\
\end{tabular} & Case ID & Test & TDP & $\begin{array}{l}\text { Row } \\
\text { Number }\end{array}$ \\
\hline $\mathrm{c}$ & $\mathrm{g} / \mathrm{cm}^{3}$ & fraction & fraction & fraction & $\mathrm{s}$ & text & $\mathrm{m} / \mathrm{s}$ & $\mathrm{m} / \mathrm{s}$ & m/s & m/s & m/s & $\mathrm{m} / \mathrm{s}$ & in. & $\mathrm{m} / \mathrm{s}$ & text & text & text & text & $\mathrm{m} / \mathrm{s}$ & text & $m \mathrm{~m}$ & text & text & text & text & text & text & text & text \\
\hline $\mathrm{T}$ & $\rho$ & $\phi_{\mathrm{s}}$ & $\phi_{p_{0}}$ & $\mathrm{DC}$ & $t_{c}$ & Jet & $U_{s}$ & $\mathrm{U}_{1}$ & $\mathrm{U} 2$ & U3 & $u$ & $u_{\text {us }}$ & $\mathrm{H}_{\mathrm{c}}$ & $U_{\text {Cor }}$ & $U_{\text {cosn }}$ & Ussis & Uscen & Ussuar & $U_{\text {CS } D} \mathrm{D}$ & $\mathrm{s}_{\mathrm{v}}$ & $\mathrm{H}_{\text {bod }}$ & $\mathrm{PM}$ & Sol & $\mathrm{SPO}_{\mathrm{O}}$ & $\mathrm{SP}_{1}$ & ID & MDDX & $\mathrm{TDP}$ & MSS \\
\hline 26.9 & 0.999 & 0.00500 & 0.050 & 0.330 & 15.0 & $\mathrm{P}$ & $\mathrm{NA}$ & 4.07 & 4.11 & 4.13 & 4.20 & 4.30 & 5.00 & NA & NA & NA & NA & NA & NA & NA & $\mathrm{Na}$ & NA & $\mathrm{NA}$ & NA & NA & 15E_4s1d2YC_ 1 & 6/9A & TDP-173 & 9150035.7 \\
\hline 26.9 & 0.999 & 0.00500 & 0.050 & 0.330 & 15.0 & $\mathrm{P}$ & NA & 4.07 & 4.11 & 4.13 & 4.20 & 4.30 & 5.00 & NA & NA & NA & NA & NA & NA & NA & 3.9 & NA & NA & NA & NA & 15E_4sid2Y__1 & 6/9A & TDP-173 & 9150037 \\
\hline 26.9 & 0.999 & 0.00500 & 0.050 & 0.330 & 15.0 & $\mathrm{P}$ & NA & 4.07 & 4.11 & 4.13 & 4.20 & 4.30 & 5.00 & NA & NA & NA & NA & NA & NA & NA & 3.8 & NA & NA & NA & NA & 15E_4s1d2YC_1 & $6 / 9 A$ & TDP-173 & 9150038 \\
\hline 26.9 & 0.999 & 0.00500 & 0.050 & 0.330 & 15.0 & $\mathrm{P}$ & NA & 4.07 & 4.11 & 4.13 & 4.20 & 4.30 & 5.00 & NA & NA & NA & NA & NA & NA & NA & 4.4 & NA & NA & NA & NA & 15E_4s1d2Yc_1 & $6 / 9 A$ & TDP-173 & 9150039 \\
\hline 26.9 & 0.999 & 0.00500 & 0.050 & 0.330 & 15.0 & $\mathrm{P}$ & NA & 4.07 & 4.11 & 4.13 & 4.20 & 4.30 & 5.00 & NA & NA & NA & NA & NA & NA & NA & 3.8 & NA & NA & NA & NA & 15E_4sid2Yc 1 & $6 / 9 A$ & TDP-173 & 9150040 \\
\hline 26.9 & 0.999 & 0.00500 & 0.050 & 0.330 & 15.0 & $\mathrm{P}$ & NA & 4.07 & 4.11 & 4.13 & 4.20 & 4.30 & 5.00 & NA & NA & NA & NA & NA & NA & NA & 7.0 & NA & NA & NA & NA & 15E_4sid2YC_1 & $6 / 9 \mathrm{~A}$ & TDP-173 & 9150041 \\
\hline 26.9 & 0.999 & 0.00500 & 0.050 & 0.330 & 15.0 & $\mathrm{P}$ & NA & 4.07 & 4.11 & 4.13 & 4.20 & 4.30 & 5.00 & NA & NA & NA & NA & NA & NA & NA & 4.1 & NA & NA & NA & NA & 15E_4s1d2Yc_1 & 6/9A & TDP-173 & 9150043 \\
\hline 27.2 & 0.998 & 0.01000 & 0.050 & 0.331 & 14.0 & $\mathrm{P}$ & NA & 4.34 & 4.40 & 4.42 & 4.50 & 5.30 & 4.75 & NA & NA & NA & NA & NA & NA & 1 & 8.4 & 1 & NA & NA & NA & 15E_4sId2Rc_1 & $6 / 98$ & TDP-174 & 9150044 \\
\hline 27.5 & 0.998 & 0.01000 & 0.050 & 0.332 & 13.4 & $\mathrm{P}$ & NA & 4.53 & 4.59 & 4.61 & 4.70 & 5.30 & 5.00 & NA & NA & NA & NA & NA & NA & 1 & 7.6 & 1 & NA & NA & NA & 15E_4sid2Rc_1 & $6 / 9 B$ & TDP-174 & 9150045 \\
\hline 27.6 & 0.998 & 0.01000 & 0.050 & 0.333 & 12.8 & $\mathrm{P}$ & NA & 4.71 & 4.77 & 4.80 & 4.90 & 5.30 & 5.25 & NA & NA & NA & NA & NA & NA & 1 & 6.8 & 1 & NA & $\mathrm{NA}$ & NA & 15E_4sid2Rc_1 & $6 / 98$ & TDP-174 & 9150046 \\
\hline 28.0 & 0.998 & 0.01000 & 0.050 & \begin{tabular}{l|l}
0.335 \\
\end{tabular} & 12.2 & $\mathrm{P}$ & NA & 4.88 & 4.95 & 4.98 & 5.10 & 5.30 & 5.50 & NA & NA & NA & NA & NA & NA & 1 & 4.8 & 1 & NA & NA & NA & 15E_4sid2R__1 & 6/9B & TDP-174 & 9150047 \\
\hline 28.3 & 0.998 & 0.01000 & 0.050 & 0.338 & 11.6 & $\mathrm{P}$ & NA & 5.07 & 5.15 & 5.18 & 5.30 & 5.30 & 5.75 & 5.30 & udv & NA & NA & Ucsudv & NA & 1 & 3.7 & 1 & NA & NA & NA & 15E_4sid2R__1 & $6 / 98$ & TDP-174 & 9150048 \\
\hline 28.6 & 0.998 & 0.01000 & 0.050 & 0.330 & 11.6 & $\mathrm{P}$ & NA & 5.24 & 5.33 & 5.37 & 5.50 & 5.30 & 6.00 & NA & NA & ucsis & NA & NA & NA & 1 & 0.6 & 3 & NA & NA & NA & 15E_SSId2RC_1 & $6 / 98$ & TDP-174 & 9150049 \\
\hline 29.4 & 0.998 & 0.01000 & 0.050 & 0.330 & 11.2 & $\mathrm{P}$ & NA & 5.39 & 5.47 & 5.51 & 5.60 & 5.30 & 6.25 & NA & NA & NA & NA & NA & NA & $\mathrm{I}$ & 0.0 & 4 & NA & NA & NA & 15E_4s1d2Rc_1 & $6 / 9 \mathrm{~B}$ & TDP-174 & 9150050 \\
\hline 22.7 & 0.999 & 0.01000 & 0.050 & 0.329 & 12.4 & $\mathrm{P}$ & NA & 4.89 & 4.96 & 4.99 & 5.10 & 5.40 & 5.25 & NA & NA & NA & NA & NA & NA & $\mathrm{D}$ & 3.7 & 1 & NA & NA & NA & 15E_4sid2R__1 & 6/10A & TDP-175 & 9150051 \\
\hline 22.9 & 0.999 & 0.01000 & 0.050 & 0.330 & 12.0 & $\mathrm{P}$ & NA & 5.07 & 5.15 & 5.18 & 5.30 & 5.40 & 6.00 & NA & NA & NA & NA & NA & NA & 1 & 3.7 & 1 & NA & NA & NA & 15E_4sid2R__1 & $6 / 10 \mathrm{~A}$ & TDP-175 & 9150052 \\
\hline 23.1 & 0.999 & 0.01000 & 0.050 & 0.331 & 11.8 & $\mathrm{P}$ & NA & 5.16 & 5.24 & 5.28 & 5.40 & 5.40 & 6.50 & 5.40 & udv & Ucsis & NA & Ucsudv & NA & $\mathrm{I}$ & 2.9 & 3 & NA & NA & NA & 15E_4sid2Rc_1 & 6/10A & TDP-175 & 9150053 \\
\hline 23.3 & 0.999 & 0.01000 & 0.050 & 0.331 & 11.6 & $\mathrm{P}$ & NA & 5.25 & 5.33 & 5.37 & 5.50 & 5.40 & 7.00 & NA & NA & NA & NA & NA & NA & 1 & 0.0 & 4 & NA & NA & NA & 15E_4sId2Rc_1 & 6/10A & TDP-175 & 9150054 \\
\hline 24.0 & 0.999 & 0.01000 & 0.050 & \begin{tabular}{l|l}
0.337 \\
\end{tabular} & 10.0 & $\mathrm{P}$ & NA & 5.90 & 6.00 & 6.05 & 6.20 & 5.40 & 16.50 & NA & NA & NA & NA & NA & NA & 1 & 0.0 & 4 & NA & NA & NA & 15E_4sid2R__1 & 6/10A & TDP-175 & 9150057 \\
\hline 24.2 & 0.999 & 0.01000 & 0.050 & 0.336 & 9.8 & $\mathrm{P}$ & NA & 6.08 & 6.19 & 6.24 & 6.40 & 5.40 & 17.50 & NA & NA & NA & NA & NA & NA & $\mathrm{I}$ & 0.0 & 4 & NA & NA & NA & 15E_4sid2Rc_1 & 6/10A & TDP-175 & 9150058 \\
\hline 24.5 & 0.999 & 0.01000 & 0.050 & 0.334 & 9.6 & $\mathrm{P}$ & NA & 6.25 & 6.37 & 6.43 & 6.60 & 5.40 & 23.50 & NA & NA & NA & NA & NA & NA & 1 & 0.0 & 4 & NA & NA & NA & 15E_4s1d2R__1 & 6/10A & TDP-175 & 9150059 \\
\hline 22.8 & 0.999 & 0.01500 & 0.050 & 0.328 & 12.2 & $\mathrm{P}$ & NA & 4.96 & 5.04 & 5.08 & 5.20 & 5.80 & 5.13 & NA & NA & NA & NA & NA & NA & (null) & 7.6 & 1 & NA & NA & NA & 15E_4sid2X__1 & $6 / 10 \mathrm{~B}$ & TDP-176 & 9150060 \\
\hline 22.9 & 1.000 & 0.01500 & 0.050 & 0.329 & 11.8 & $\mathrm{P}$ & NA & 5.14 & 5.23 & 5.27 & 5.40 & 5.80 & 5.50 & NA & NA & NA & NA & NA & NA & 1 & 4.2 & 1 & NA & NA & NA & 15E_4sid2X__1 & $6 / 10 B$ & TDP-176 & 9150061 \\
\hline 22.9 & 1.000 & 0.01500 & 0.050 & 0.330 & 11.4 & $\mathrm{P}$ & NA & 5.35 & 5.44 & 5.48 & 5.60 & 5.80 & 5.75 & NA & NA & NA & NA & NA & NA & 1 & 3.8 & 1 & NA & NA & NA & 15E_4sid2X__1 & $6 / 10 B$ & TDP-176 & 9150062 \\
\hline 23.0 & 1.000 & 0.01500 & 0.050 & 0.331 & 11.0 & $\mathrm{P}$ & NA & 5.52 & 5.61 & 5.66 & 5.80 & 5.80 & 6.75 & 5.80 & udv & Ucsis & NA & ucsudv & NA & $\mathrm{I}$ & 1.5 & 3 & NA & NA & NA & 15E_4s1d2Xc_1 & $6 / 10 \mathrm{~B}$ & TDP-176 & 9150063 \\
\hline 23.1 & 1.000 & 0.01500 & 0.050 & 0.332 & 10.6 & $\mathrm{P}$ & NA & 5.70 & 5.80 & 5.84 & 6.00 & 5.80 & 8.25 & NA & NA & NA & NA & NA & NA & 1 & 0.0 & 4 & NA & $\mathrm{NA}$ & NA & 15E_4sid2Xc_1 & 6/10B & TDP-176 & 9150064 \\
\hline 23.1 & 0.999 & 0.01500 & 0.050 & 0.335 & 9.8 & $\mathrm{P}$ & NA & 6.07 & 6.17 & 6.23 & 6.40 & 5.80 & 10.75 & NA & NA & NA & NA & NA & NA & $\mathrm{I}$ & 0.0 & 4 & NA & NA & NA & 15E_4s1d2X__ 1 & $6 / 10 \mathrm{~B}$ & TDP-176 & 9150065 \\
\hline 23.3 & 0.999 & 0.01500 & 0.050 & 0.338 & 9.2 & $\mathrm{P}$ & NA & 6.42 & 6.54 & 6.60 & 6.80 & 5.80 & 16.75 & NA & NA & NA & NA & NA & NA & 1 & 0.0 & 4 & NA & NA & NA & 15E_4sid2X__1 & $6 / 10 B$ & TDP-176 & 9150066 \\
\hline 23.4 & 0.999 & 0.01500 & 0.050 & 0.335 & 9.0 & $P$ & NA & 6.60 & 6.73 & 6.80 & 7.00 & 5.80 & 19.75 & NA & NA & NA & NA & NA & NA & 1 & 0.0 & 4 & NA & NA & NA & 15E_4sid2Xc_1 & $6 / 10 B$ & TDP-176 & 9150067 \\
\hline 23.7 & 0.999 & 0.01500 & 0.050 & 0.330 & 11.0 & $\mathrm{P}$ & NA & 5.53 & 5.62 & 5.67 & 5.80 & 5.80 & 6.63 & NA & NA & NA & NA & NA & NA & NA & $\mathrm{na}$ & NA & NA & NA & NA & 15E_4s1d2X__1 & 6/10B & TDP-176 & 9150067.1 \\
\hline 23.7 & 0.999 & 0.01500 & 0.050 & 0.330 & 11.0 & $\mathrm{P}$ & NA & 5.53 & 5.62 & 5.67 & 5.80 & 5.80 & 6.63 & NA & NA & NA & NA & NA & NA & NA & $\mathrm{n} / \mathrm{a}$ & NA & NA & NA & NA & 15E_4sid2Xc_1 & 6/10B & TDP-176 & 9150067.2 \\
\hline 23.7 & 0.999 & 0.01500 & 0.050 & 0.330 & 11.0 & $\mathrm{P}$ & NA & 5.53 & 5.62 & 5.67 & 5.80 & 5.80 & 6.63 & NA & NA & NA & NA & NA & NA & NA & $\mathrm{n} / \mathrm{a}$ & NA & NA & NA & NA & 15E_4sid2X__1 & $6 / 10 \mathrm{~B}$ & TDP-176 & 9150067.3 \\
\hline 23.7 & 0.999 & 0.01500 & 0.050 & 0.330 & 11.0 & $\mathrm{P}$ & NA & 5.53 & 5.62 & 5.67 & 5.80 & 5.80 & 6.63 & NA & NA & NA & NA & NA & NA & NA & $\mathrm{n} / \mathrm{a}$ & NA & NA & NA & NA & 15E_4sid2X__ _ & $6 / 10 B$ & TDP-176 & 9150067.4 \\
\hline 23.7 & 0.999 & 0.01500 & 0.050 & 0.330 & 11.0 & $\mathrm{P}$ & NA & 5.53 & 5.62 & 5.67 & 5.80 & 5.80 & 6.63 & NA & NA & NA & NA & NA & NA & NA & na & NA & NA & NA & NA & 15E_4sid2Xc_1 & $6 / 10 B$ & TDP-176 & 9150067.5 \\
\hline 23.7 & 0.999 & 0.01500 & 0.050 & 0.330 & 11.0 & $\mathrm{P}$ & NA & 5.53 & 5.62 & 5.67 & 5.80 & 5.80 & 6.63 & NA & NA & Ucsis & NA & NA & NA & 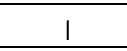 & 3.7 & 3 & NA & NA & NA & 15E_4s1d2X__1 & 6/10B & TDP-176 & 9150068 \\
\hline 23.7 & 0.999 & 0.01500 & 0.050 & 0.330 & 11.0 & $\mathrm{P}$ & NA & 5.53 & 5.62 & 5.67 & 5.80 & 5.80 & 6.63 & NA & NA & NA & NA & NA & NA & NA & 2.2 & NA & NA & NA & NA & 15E_4s1d2Xc_1 & 6/10B & TDP-176 & 9150069 \\
\hline 23.7 & 0.999 & 0.01500 & 0.050 & 0.330 & 11.0 & $\mathrm{P}$ & NA & 5.53 & 5.62 & 5.67 & 5.80 & 5.80 & 6.63 & NA & NA & NA & NA & NA & NA & NA & 2.9 & NA & NA & NA & NA & 15E_4sid2X__1 & 6/10B & TDP-176 & 9150070 \\
\hline
\end{tabular}


Table B.3. Data from 2008 Tests in Small-Scale Vessel with Elliptical Head A.3

\begin{tabular}{|c|c|c|c|c|c|c|c|c|c|c|c|c|c|c|c|c|c|c|c|c|c|c|c|c|c|c|c|}
\hline $\begin{array}{c}\text { Row } \\
\text { Number }\end{array}$ & Test & Case ID & $\begin{array}{c}\text { Tank } \\
\text { Diameter }\end{array}$ & $\begin{array}{l}\text { Head } \\
\text { Shape }\end{array}$ & $\begin{array}{c}\text { Dish } \\
\text { Height }\end{array}$ & $\begin{array}{l}\text { Dish } \\
\text { Volume }\end{array}$ & \begin{tabular}{|c|} 
Tank \\
Fill \\
Height \\
Hegle
\end{tabular} & $\begin{array}{l}\text { Return } \\
\text { Line } \\
\text { Height } \\
\end{array}$ & $\begin{array}{c}\text { Nozzle } \\
\text { Imner } \\
\text { Diameter }\end{array}$ & $\begin{array}{l}\text { Nozzle } \\
\text { Stanc-off } \\
\text { Distance }\end{array}$ & $\begin{array}{l}\text { Pulse Tube } \\
\text { Configuration }\end{array}$ & \begin{tabular}{|l} 
Installed \\
Nozzles
\end{tabular} & 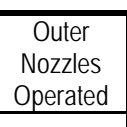 & $\begin{array}{c}\text { Inner } \\
\text { Nozzles } \\
\text { Opperated } \\
\end{array}$ & $\begin{array}{c}\begin{array}{c}\text { Pulse Tube } \\
\text { Outer } \\
\text { Diameter }\end{array} \\
\end{array}$ & \begin{tabular}{|l|} 
Outer \\
PJM \\
Radius \\
\end{tabular} & $\begin{array}{c}\text { Inner } \\
\text { PJM } \\
\text { Radius } \\
\text { Pains }\end{array}$ & $\begin{array}{c}\text { "FO" Outer PJM } \\
\text { Impingement } \\
\text { Angle }\end{array}$ & $\begin{array}{c}\text { "FO" Inner PJM } \\
\text { Impingement } \\
\text { Angle }\end{array}$ & $\begin{array}{c}\text { Ratio Outer } \\
\text { PJM to Tank } \\
\text { Radius } \\
\end{array}$ & $\begin{array}{c}\text { Ratio Inner } \\
\text { PJM to Tank } \\
\text { Radius } \\
\end{array}$ & Simulant & $\begin{array}{l}\text { Solids } \\
\text { Density }\end{array}$ & \begin{tabular}{|c|} 
Particle \\
Diameter \\
d 5 \\
\end{tabular} & $\begin{array}{c}\begin{array}{c}\text { Particle } \\
\text { Diameter } \\
\text { d50 }\end{array} \\
\end{array}$ & $\begin{array}{c}\begin{array}{c}\text { Particle } \\
\text { Diameter } \\
\text { d95 }\end{array} \\
\end{array}$ & $\begin{array}{c}\text { Void } \\
\text { Fraction }\end{array}$ \\
\hline text & text & text & in. & text & in. & in. ${ }^{3}$ & in. & in. & in. & in. & text & number & number & number & in. & in. & in. & deg & deg & nondim & nondim & text & $\mathrm{g} / \mathrm{cm}^{3}$ & $\mathrm{~m}$ & $\mathrm{~m}$ & $\mathrm{~m}$ & fraction \\
\hline MSS & MIDDX & ID & $\mathrm{D}$ & $\mathrm{HS}$ & Hosh & $V_{\text {dish }}$ & $\mathrm{H}$ & Rtn & $d$ & sod & PT & $\mathrm{N}$ & $\mathrm{No}$ & $\mathrm{N}$ & $P \mathrm{PT}_{\alpha d}$ & $R_{0}$ & $R$ & $\theta_{0}$ & $\theta_{1}$ & RolR & $R / R$ & sxdx & $\rho_{\mathrm{s}}$ & $d_{s}$ & $d_{60}$ & $d_{05}$ & $\mathrm{vf}$ \\
\hline 9150071 & $6 / 10 B$ & 15E_4s1d2X__1 & $147 / 16$ & $E$ & 3.25 & 354.8 & 35 & 30 & 0.126 & 0.189 & HLP-22 & 12 & 8 & 4 & 1.05 & 4.5 & 2.4 & 21.8 & 10.1 & 0.62 & 0.34 & s1d2 & 2.48 & 0.0000569 & 0.0000693 & 0.0000821 & 0.3750 \\
\hline 9150072 & $610 \mathrm{~B}$ & 15E_4sid2Xc_1 & $147 / 16$ & $E$ & 3.25 & \begin{tabular}{ll|}
354.8 \\
\end{tabular} & 35 & 30 & 0.126 & 0.189 & HLP-22 & 12 & 8 & 4 & 1.05 & 4.5 & 2.4 & 21.8 & 10.1 & 0.62 & 0.34 & $\mathrm{sid2} 2$ & 2.48 & \begin{tabular}{|l|l|}
0.0000569 \\
\end{tabular} & 0.0000693 & 0.0000821 & 0.3750 \\
\hline 9150073 & $6 / 10 \mathrm{~B}$ & $15 E_{-} 4 \mathrm{~s} 1 \mathrm{~d} 2 \mathrm{X} \mathrm{c}_{-} 1$ & $147 / 16$ & E & 3.25 & 354.8 & 35 & 30 & 0.126 & 0.189 & HLP-22 & 12 & 8 & 4 & 1.05 & 4.5 & 2.4 & 21.8 & 10.1 & 0.62 & 0.34 & $\mathrm{sid2}$ & 2.48 & \begin{tabular}{|l|l|}
0.0000569 \\
\end{tabular} & 0.0000693 & 0.0000821 & 0.3750 \\
\hline 9150074 & $6 / 10 \mathrm{~B}$ & 15E_4sid2X__1 & $147 / 16$ & $E$ & 3.25 & 354.8 & 35 & 30 & 0.126 & 0.189 & HLP-22 & 12 & 8 & 4 & 1.05 & 4.5 & 2.4 & 21.8 & 10.1 & 0.62 & 0.34 & s1d2 & 2.48 & \begin{tabular}{|l|l|}
0.00005699 \\
\end{tabular} & 0.0000693 & 0.0000821 & 0.3750 \\
\hline 9150075 & $6 / 10 \mathrm{~B}$ & 15E_4s1d2Xc_1 & $147 / 16$ & $\mathrm{E}$ & 3.25 & 354.8 & 35 & 30 & 0.126 & 0.189 & HLP-22 & 12 & 8 & 4 & 1.05 & 4.5 & 2.4 & 21.8 & 10.1 & 0.62 & 0.34 & $\mathrm{s1d2}$ & 2.48 & \begin{tabular}{|l|l|}
0.0000569 \\
\end{tabular} & 0.0000693 & 0.0000821 & 0.3750 \\
\hline 9150076 & $610 \mathrm{~B}$ & 15E_4s1d2X__1 & $147 / 16$ & $E$ & 3.25 & 354.8 & 35 & 30 & 0.126 & 0.189 & HLP-22 & 12 & 8 & 4 & 1.05 & 4.5 & 24 & 21.8 & 10.1 & 0.62 & 0.34 & s1d2 & 2.48 & \begin{tabular}{|l}
0.0000569 \\
\end{tabular} & 0.0000693 & 0.0000821 & 0.3750 \\
\hline 9150077 & $610 \mathrm{~B}$ & 15E_4S1d2Xc_ 1 & $147 / 16$ & $E$ & 3.25 & 354.8 & 35 & 30 & 0.126 & 0.189 & HLP-22 & 12 & 8 & 4 & 1.05 & 4.5 & 2.4 & 21.8 & 10.1 & 0.62 & 0.34 & $\mathrm{sid2}$ & 2.48 & \begin{tabular}{|l|l|}
0.0000569 \\
\end{tabular} & 0.0000693 & 0.0000821 & 0.3750 \\
\hline 9150078 & 6/11A & 15E_4sid2Xd_1 & $147 / 16$ & E & 3.25 & 354.8 & $341 / 2$ & 30 & 0.126 & 0.189 & HLP-22 & 12 & 8 & 4 & 1.05 & 4.5 & 2.4 & 21.8 & 10.1 & 0.62 & 0.34 & s1d2 & 2.48 & \begin{tabular}{|l|l|}
0.0000569 \\
\end{tabular} & 0.0000693 & 0.0000821 & 0.3750 \\
\hline 9150079 & 6/11A & 15E_4sid2Xd_1 & $147 / 16$ & $E$ & 3.25 & 354.8 & $341 / 2$ & 30 & 0.126 & 0.189 & HLP-22 & 12 & 8 & 4 & 1.05 & 4.5 & 2.4 & 21.8 & 10.1 & 0.62 & 0.34 & s1d2 & 2.48 & \begin{tabular}{|l|l|}
0.00005699 \\
\end{tabular} & 0.0000693 & 0.0000821 & 0.3750 \\
\hline 9150030 & 6/11A & 15E_4s1d2Xd 11 & $147 / 16$ & $\mathrm{E}$ & 3.25 & 354.8 & $34 / 2$ & 30 & 0.126 & 0.189 & HLP-22 & 12 & 8 & 4 & 1.05 & 4.5 & 24 & 21.8 & 10.1 & 0.62 & 0.34 & s1d2 & 2.48 & \begin{tabular}{|l|l|}
0.0000569 \\
\end{tabular} & 0.0000693 & 0.0000821 & 0.3750 \\
\hline 9150081 & 6/11A & 15E_4sid2Xd_1 & $147 / 16$ & $\mathrm{E}$ & 3.25 & 354.8 & $341 / 2$ & 30 & 0.126 & 0.189 & HLP-22 & 12 & 8 & 4 & 1.05 & 4.5 & 2.4 & 21.8 & 10.1 & 0.62 & 0.34 & sid2 & 2.48 & \begin{tabular}{|l|l|}
0.0000569 \\
\end{tabular} & 0.0000693 & 0.0000821 & 0.3750 \\
\hline 9150082 & $6 / 11 \mathrm{~A}$ & 15E_4s1d2Xd_1 & $147 / 16$ & $E$ & 3.25 & 354.8 & $341 / 2$ & 30 & 0.126 & 0.189 & HLP-22 & 12 & 8 & 4 & 1.05 & 4.5 & 24 & 21.8 & 10.1 & 0.62 & 0.34 & $\mathrm{sid2}$ & 2.48 & \begin{tabular}{|l|l|}
0.0000569 \\
\end{tabular} & 0.0000693 & 0.0000821 & 0.3750 \\
\hline 9150083M & 6/11A & 15E_4sid2Xd_1 & $147 / 16$ & $\mathrm{E}$ & 3.25 & 354.8 & $341 / 2$ & 30 & 0.126 & 0.189 & HLP-22 & 12 & 8 & 4 & 1.05 & 4.5 & 2.4 & 21.8 & 10.1 & 0.62 & 0.34 & $\mathrm{sid2}$ & 2.48 & \begin{tabular}{|l}
0.0000569 \\
\end{tabular} & 0.0000693 & 0.0000821 & 0.3750 \\
\hline $9150084 \mathrm{M}$ & 6/11A & 15E_4sid2Xd_1 & $147 / 16$ & $E$ & 3.25 & 354.8 & $341 / 2$ & 30 & 0.126 & 0.189 & HLP-22 & 12 & 8 & 4 & 1.05 & 4.5 & 2.4 & 21.8 & 10.1 & 0.62 & 0.34 & s1d2 & 2.48 & \begin{tabular}{|l|l|}
0.00005699 \\
\end{tabular} & 0.0000693 & 0.0000821 & 0.3750 \\
\hline $9150005 \mathrm{M}$ & $6 / 11 \mathrm{~A}$ & 15E_4s1d2Xd_ 11 & $147 / 16$ & $\mathrm{E}$ & 3.25 & 354.8 & $34 / 2$ & 30 & 0.126 & 0.189 & HLP-22 & 12 & 8 & 4 & 1.05 & 4.5 & 24 & 21.8 & 10.1 & 0.62 & 0.34 & s1d2 & 2.48 & \begin{tabular}{|l|l|}
0.0000569 \\
\end{tabular} & 0.0000693 & 0.0000821 & 0.3750 \\
\hline $9150086 \mathrm{M}$ & 6/11A & 15E_4sid2Xd_1 & $147 / 16$ & $\mathrm{E}$ & 3.25 & 354.8 & $341 / 2$ & 30 & 0.126 & 0.189 & HLP-22 & 12 & 8 & 4 & 1.05 & 4.5 & 2.4 & 21.8 & 10.1 & 0.62 & 0.34 & sid2 & 2.48 & \begin{tabular}{|l|l}
0.0000569 \\
\end{tabular} & 0.0000693 & 0.0000821 & 0.3750 \\
\hline 9150087M & $6 / 11 \mathrm{~A}$ & 15E_4sId2Xd_1 & $147 / 16$ & $E$ & 3.25 & 354.8 & $341 / 2$ & 30 & 0.126 & 0.189 & HLP-22 & 12 & 8 & 4 & 1.05 & 4.5 & 2.4 & 21.8 & 10.1 & 0.62 & 0.34 & s1d2 & 2.48 & \begin{tabular}{|l|l|}
0.0000569 \\
\end{tabular} & 0.0000693 & 0.0000821 & 0.3750 \\
\hline 9150087.1 & 6/11A & 15E_4sid2Xd_1 & $147 / 16$ & $\mathrm{E}$ & 3.25 & 354.8 & $341 / 2$ & 30 & 0.126 & 0.189 & HLP-22 & 12 & 8 & 4 & 1.05 & 4.5 & 2.4 & 21.8 & 10.1 & 0.62 & 0.34 & $\mathrm{~s} 1 \mathrm{~d} 2$ & 2.48 & \begin{tabular}{|l|l|}
0.0000569 \\
\end{tabular} & 0.0000693 & 0.0000821 & 0.3750 \\
\hline 9150087.2 & 6/11A & 15E_4sid2Xd_1 & $147 / 16$ & $E$ & 3.25 & 354.8 & $341 / 2$ & 30 & 0.126 & 0.189 & HLP-22 & 12 & 8 & 4 & 1.05 & 4.5 & 2.4 & 21.8 & 10.1 & 0.62 & 0.34 & s1d2 & 2.48 & \begin{tabular}{|l|l|}
0.00005699 \\
\end{tabular} & 0.0000693 & 0.0000821 & 0.3750 \\
\hline 9150087.3 & 6/11A & 15E_4sId2Xd 11 & $147 / 16$ & $\mathrm{E}$ & 3.25 & 354.8 & $341 / 2$ & 30 & 0.126 & 0.189 & HLP-22 & 12 & 8 & 4 & 1.05 & 4.5 & 24 & 21.8 & 10.1 & 0.62 & 0.34 & s1d2 & 2.48 & \begin{tabular}{|l|l|}
0.0000569 \\
\end{tabular} & 0.0000693 & 0.0000821 & 0.3750 \\
\hline 9150087.4 & 6/11A & 15E_4sid2Xd_1 & $147 / 16$ & $\mathrm{E}$ & 3.25 & 354.8 & $341 / 2$ & 30 & 0.126 & 0.189 & HLP-22 & 12 & 8 & 4 & 1.05 & 4.5 & 2.4 & 21.8 & 10.1 & 0.62 & 0.34 & sid2 & 2.48 & \begin{tabular}{|l|l}
0.0000569 \\
\end{tabular} & 0.0000693 & 0.0000821 & 0.3750 \\
\hline 9150087.5 & 6/11A & 15E_4s1d2Xd_1 & $147 / 16$ & $E$ & 3.25 & 354.8 & $341 / 2$ & 30 & 0.126 & 0.189 & HLP-22 & 12 & 8 & 4 & 1.05 & 4.5 & 2.4 & 21.8 & 10.1 & 0.62 & 0.34 & s1d2 & 2.48 & \begin{tabular}{|l|l}
0.0000569 \\
\end{tabular} & 0.0000693 & 0.0000821 & 0.3750 \\
\hline $9150088 \mathrm{M}$ & 6/11A & 15E_4sid2Xd_1 & $147 / 16$ & $\mathrm{E}$ & 3.25 & 354.8 & $341 / 2$ & 30 & 0.126 & 0.189 & HLP-22 & 12 & 8 & 4 & 1.05 & 4.5 & 2.4 & 21.8 & 10.1 & 0.62 & 0.34 & $\mathrm{sid2}$ & 2.48 & \begin{tabular}{|l}
0.0000569 \\
\end{tabular} & 0.0000693 & 0.0000821 & 0.3750 \\
\hline 9150089 & 6/11A & 15E_4sid2Xd_1 & $147 / 16$ & $E$ & 3.25 & 354.8 & $341 / 2$ & 30 & 0.126 & 0.189 & HLP-22 & 12 & 8 & 4 & 1.05 & 4.5 & 2.4 & 21.8 & 10.1 & 0.62 & 0.34 & s1d2 & 2.48 & \begin{tabular}{|l|l|}
0.00005699 \\
\end{tabular} & 0.0000693 & 0.0000821 & 0.3750 \\
\hline 9150090 & 6/11A & 15E_4sId2Xd_ 1 & $147 / 16$ & $\mathrm{E}$ & 3.25 & 354.8 & $341 / 2$ & 30 & 0.126 & 0.189 & HLP-22 & 12 & 8 & 4 & 1.05 & 4.5 & 2.4 & 21.8 & 10.1 & 0.62 & 0.34 & s1d2 & 2.48 & \begin{tabular}{|l|l|}
0.0000569 \\
\end{tabular} & 0.0000693 & 0.0000821 & 0.3750 \\
\hline 9150091 & 6/11A & 15E_4sid2Xd_1 & $147 / 16$ & $\mathrm{E}$ & 3.25 & 354.8 & $341 / 2$ & 30 & 0.126 & 0.189 & HLP-22 & 12 & 8 & 4 & 1.05 & 4.5 & 2.4 & 21.8 & 10.1 & 0.62 & 0.34 & s1d2 & 2.48 & \begin{tabular}{|l|l}
0.0000569 \\
\end{tabular} & 0.0000693 & 0.0000821 & 0.3750 \\
\hline 9150092 & $6 / 11 \mathrm{~A}$ & 15E_4sId2Xd_1 & $147 / 16$ & $E$ & 3.25 & 354.8 & $341 / 2$ & 30 & 0.126 & 0.189 & HLP-22 & 12 & 8 & 4 & 1.05 & 4.5 & 2.4 & 21.8 & 10.1 & 0.62 & 0.34 & s1d2 & 2.48 & \begin{tabular}{|l|l|}
0.0000569 \\
\end{tabular} & 0.0000693 & 0.0000821 & 0.3750 \\
\hline 9150093 & $6 / 11 \mathrm{~A}$ & 15E_4sid2Xd_1 & $147 / 16$ & $\mathrm{E}$ & 3.25 & 354.8 & $341 / 2$ & 30 & 0.126 & 0.189 & HLP-22 & 12 & 8 & 4 & 1.05 & 4.5 & 2.4 & 21.8 & 10.1 & 0.62 & 0.34 & $\mathrm{sid2}$ & 2.48 & \begin{tabular}{|l}
0.0000569 \\
\end{tabular} & 0.0000693 & 0.0000821 & 0.3750 \\
\hline 9150094 & 6/11A & 15E_4sid2Xd_1 & $147 / 16$ & $E$ & 3.25 & \begin{tabular}{ll|}
354.8 \\
\end{tabular} & $341 / 2$ & 30 & 0.126 & 0.189 & HLP-22 & 12 & 8 & 4 & 1.05 & 4.5 & 2.4 & 21.8 & 10.1 & 0.62 & 0.34 & $\mathrm{sid2}$ & 2.48 & \begin{tabular}{|l|l|}
0.0000569 \\
\end{tabular} & 0.0000693 & 0.0000821 & 0.3750 \\
\hline 9150095 & 6/11A & 15E_4sId2Xd 11 & $147 / 16$ & E & 3.25 & 354.8 & $341 / 2$ & 30 & 0.126 & 0.189 & HLP-22 & 12 & 8 & 4 & 1.05 & 4.5 & 2.4 & 21.8 & 10.1 & 0.62 & 0.34 & s1d2 & 2.48 & \begin{tabular}{|l|l|}
0.0000569 \\
\end{tabular} & 0.0000693 & 0.0000821 & 0.3750 \\
\hline 9150096 & 6/11A & 15E_4sid2Xd_1 & $147 / 16$ & $\mathrm{E}$ & 3.25 & 354.8 & $341 / 2$ & 30 & 0.126 & 0.189 & HLP-22 & 12 & 8 & 4 & 1.05 & 4.5 & 2.4 & 21.8 & 10.1 & 0.62 & 0.34 & s1d2 & 2.48 & \begin{tabular}{|l|l}
0.0000569 \\
\end{tabular} & 0.0000693 & 0.0000821 & 0.3750 \\
\hline 9150097 & $6 / 11 \mathrm{~B}$ & 15E_4sid2Xa & $147 / 16$ & $E$ & 3.25 & \begin{tabular}{ll|}
354.8 \\
\end{tabular} & $341 / 2$ & 30 & 0.126 & 0.189 & HLP-22 & 12 & 8 & 4 & 1.05 & 4.5 & 2.4 & 21.8 & 10.1 & 0.62 & 0.34 & s1d2 & 2.48 & \begin{tabular}{|l|l|}
0.0000569 \\
\end{tabular} & 0.0000693 & 0.0000821 & 0.3750 \\
\hline 9150098 & $6 / 11 B$ & 15E_4sid2Xa & $147 / 16$ & $E$ & 3.25 & 354.8 & $341 / 2$ & 30 & 0.126 & 0.189 & HLP-22 & 12 & 8 & 4 & 1.05 & 4.5 & 2.4 & 21.8 & 10.1 & 0.62 & 0.34 & $\mathrm{sid2} 2$ & 2.48 & 0.0000569 & 0.0000693 & 0.0000821 & 0.3750 \\
\hline 9150099 & $6 / 11 \mathrm{~B}$ & 15E_451d2Xa & $147 / 16$ & $E$ & 3.25 & 354.8 & $341 / 2$ & 30 & 0.126 & 0.189 & HLP-22 & 12 & 8 & 4 & 1.05 & 4.5 & 2.4 & 21.8 & 10.1 & 0.62 & 0.34 & $\mathrm{sid2}$ & 2.48 & \begin{tabular}{|l|l}
0.0000569 \\
\end{tabular} & 0.0000693 & 0.0000821 & 0.3750 \\
\hline 9150100 & 6/11B & 15E_4sidaxa & $147 / 16$ & E & 3.25 & 354.8 & $341 / 2$ & 30 & 0.126 & 0.189 & HLP-22 & 12 & 8 & 4 & 1.05 & 4.5 & 2.4 & 21.8 & 10.1 & 0.62 & 0.34 & s1d2 & 2.48 & $\begin{array}{l}0.0000569 \\
\end{array}$ & 0.0000693 & 0.0000821 & 0.3750 \\
\hline 9150101 & $6 / 11 B$ & 15E_4sid2Xa & $147 / 16$ & $\mathrm{E}$ & 3.25 & 354.8 & $341 / 2$ & 30 & 0.126 & 0.189 & HLP-22 & 12 & 8 & 4 & 1.05 & 4.5 & 2.4 & 21.8 & 10.1 & 0.62 & 0.34 & s1d2 & 2.48 & \begin{tabular}{|l|l}
0.0000569 \\
\end{tabular} & 0.0000693 & 0.0000821 & 0.3750 \\
\hline 9150102 & $6 / 11 B$ & 15E_4sid2Xa & $147 / 16$ & $E$ & 3.25 & 354.8 & $341 / 2$ & 30 & 0.126 & 0.189 & HLP-22 & 12 & 8 & 4 & 1.05 & 4.5 & 24 & 21.8 & 10.1 & 0.62 & 0.34 & s1d2 & 2.48 & \begin{tabular}{|l|l}
0.0000569 \\
\end{tabular} & 0.0000693 & 0.0000821 & 0.3750 \\
\hline 9150103 & $6 / 11 \mathrm{~B}$ & 15E_4s1d2Xa & $147 / 16$ & $E$ & 3.25 & 354.8 & $341 / 2$ & 30 & 0.126 & 0.189 & HLP-22 & 12 & 8 & 4 & 1.05 & 4.5 & 2.4 & 21.8 & 10.1 & 0.62 & 0.34 & $\mathrm{sid2}$ & 2.48 & \begin{tabular}{|l|l|}
0.0000569 \\
\end{tabular} & 0.0000693 & 0.0000821 & 0.3750 \\
\hline 9150104 & $6 / 11 \mathrm{~B}$ & 15E_4s1d2Xa & $147 / 16$ & $E$ & 3.25 & 354.8 & $341 / 2$ & 30 & 0.126 & 0.189 & HLP-22 & 12 & 8 & 4 & 1.05 & 4.5 & 2.4 & 21.8 & 10.1 & 0.62 & 0.34 & $\mathrm{sid2}$ & 2.48 & \begin{tabular}{|l|l|}
0.0000569 \\
\end{tabular} & 0.0000693 & 0.0000821 & 0.3750 \\
\hline 9150105 & $6 / 11 \mathrm{C}$ & 15E_4sId $2 \times 1$ & $147 / 16$ & E & 3.25 & 354.8 & $34 / 2$ & 30 & 0.126 & 0.189 & HLP-22 & 12 & 8 & 4 & 1.05 & 4.5 & 2.4 & 21.8 & 10.1 & 0.62 & 0.34 & s1d2 & 2.48 & \begin{tabular}{|l|l|}
0.0000569 \\
\end{tabular} & 0.0000693 & 0.0000821 & 0.3750 \\
\hline 9150106 & $6 / 11 \mathrm{c}$ & 15E_4s1d2X__1 & $147 / 16$ & E & 3.25 & 354.8 & $341 / 2$ & 30 & 0.126 & 0.189 & HLP-22 & 12 & 8 & 4 & 1.05 & 4.5 & 2.4 & 21.8 & 10.1 & 0.62 & 0.34 & s1d2 & 2.48 & $\begin{array}{l}0.0000569 \\
\end{array}$ & 0.0000693 & 0.0000821 & 0.3750 \\
\hline
\end{tabular}


Table B.3. Data from 2008 Tests in Small-Scale Vessel with Elliptical Head B.3

\begin{tabular}{|c|c|c|c|c|c|c|c|c|c|c|c|c|c|c|c|c|c|c|c|c|c|c|c|c|c|c|c|c|c|}
\hline $\begin{array}{l}\text { Tank Water } \\
\text { Temperature }\end{array}$ & $\begin{array}{l}\text { Water } \\
\text { Density }\end{array}$ & $\begin{array}{l}\text { Solids } \\
\text { Fraction }\end{array}$ & $\begin{array}{l}\text { Pulse } \\
\text { Volume } \\
\text { Fraction }\end{array}$ & $\begin{array}{l}\text { Duty } \\
\text { Cyde }\end{array}$ & $\begin{array}{l}\text { Oyde } \\
\text { Time }\end{array}$ & $\begin{array}{c}\text { Pulsed } \\
\text { or } \\
\text { Steacy } \\
\text { Jet } \\
\end{array}$ & $\begin{array}{c}\text { Us } \\
\text { Steacy } \\
\text { Jet }\end{array}$ & $\begin{array}{c}\text { Pul } \\
\text { Pulsing } \\
\text { Jet }\end{array}$ & \begin{tabular}{|l} 
UR \\
URNS \\
\end{tabular} & $\begin{array}{c}\text { US } \\
\text { URNB } \\
\end{array}$ & \begin{tabular}{|l} 
Discharge \\
Velocity
\end{tabular} & $\begin{array}{c}\text { Oitical } \\
\text { Suspension } \\
\text { Velocity }\end{array}$ & $\begin{array}{c}\text { Average } \\
\text { Peak louud } \\
\text { Height } \\
\end{array}$ & \begin{tabular}{|c} 
UCS \\
Condition
\end{tabular} & $\begin{array}{l}\text { UCS } \\
\text { Method }\end{array}$ & $\begin{array}{l}\text { UCS } \\
\text { Flag }\end{array}$ & $\begin{array}{c}\text { UCs } \\
\text { Center } \\
\text { Hag }\end{array}$ & $\begin{array}{c}\text { Ucs uad } \\
\text { Hag }\end{array}$ & $\begin{array}{c}\text { Ucs based } \\
\text { on } \\
\text { Decreasing } \\
\text { Velocity }\end{array}$ & $\begin{array}{c}\text { Sneep } \\
\text { Increase I } \\
\text { Decrease }\end{array}$ & $\begin{array}{c}\text { UDV } \\
\text { Height } \\
\text { Bed } \\
\text { Bed }\end{array}$ & $\begin{array}{l}\text { Particle } \\
\text { Notion }\end{array}$ & \begin{tabular}{|l} 
Solids \\
Level
\end{tabular} & \begin{tabular}{|l} 
Outer \\
Botomm \\
Paterm \\
\end{tabular} & $\begin{array}{l}\text { Inner } \\
\text { Botomom } \\
\text { Patter }\end{array}$ & Case ID & Test & TDP & $\begin{array}{l}\text { Row } \\
\text { Number }\end{array}$ \\
\hline C & $\mathrm{g} / \mathrm{cm}^{3}$ & fraction & fraction & fraction & $s$ & text & $\mathrm{m} / \mathrm{s}$ & $\mathrm{m} / \mathrm{s}$ & $\mathrm{m} / \mathrm{s}$ & $\mathrm{m} / \mathrm{s}$ & $\mathrm{m} / \mathrm{s}$ & $\mathrm{m} / \mathrm{s}$ & in. & $\mathrm{m} / \mathrm{s}$ & text & text & text & text & \begin{tabular}{|l|}
$\mathrm{m} / \mathrm{s}$ \\
\end{tabular} & text & $\mathrm{mm}$ & text & text & text & text & text & text & text & text \\
\hline$T$ & $\rho$ & $\phi_{\mathrm{s}}$ & $\phi_{p}$ & $\mathrm{DC}$ & $t_{c}$ & Jet & $u_{s}$ & $\mathrm{U}_{1}$ & $\mathrm{U} 2$ & U3 & $u$ & Uss & $\mathrm{H}_{\mathrm{c}}$ & Uosp & Unsm & Uosvis & Uscen & Usosuck & Us_D & $\mathrm{S}_{\mathrm{N}}$ & $\mathrm{H}_{\mathrm{bed}}$ & $\mathrm{PM}$ & Sol & $\mathrm{SP}_{\mathrm{o}}$ & $S P_{1}$ & ID & MDDX & $\mathrm{TDP}$ & MSS \\
\hline 23.7 & 0.999 & 0.01500 & 0.050 & 0.330 & 11.0 & $\mathrm{P}$ & NA & 5.53 & 5.62 & 5.67 & 5.80 & 5.80 & 6.63 & NA & NA & NA & NA & NA & NA & NA & 3.7 & NA & NA & NA & NA & 15E_4s1d2Xc_1 & $6 / 10 B$ & TDP-176 & 9150071 \\
\hline 23.7 & 0.999 & 0.01500 & 0.050 & 0.330 & 111.0 & $\mathrm{P}$ & NA & 5.53 & 5.62 & 5.67 & 5.80 & 5.80 & 6.63 & NA & NA & NA & NA & NA & NA & NA & 1.5 & NA & NA & NA & NA & 15E_4sidd2Xc1 1 & 6/10B & TDP-176 & 9150072 \\
\hline 23.7 & 0.999 & 0.01500 & 0.050 & 0.330 & 11.0 & $\mathrm{P}$ & NA & 5.53 & 5.62 & 5.67 & 5.80 & 5.80 & 6.63 & NA & NA & NA & NA & NA & NA & NA & 1.5 & NA & NA & NA & NA & 15E_4s1d2X___ & $6 / 10 B$ & TDP-176 & 9150073 \\
\hline 23.7 & 0.999 & 0.01500 & 0.050 & 0.330 & 11.0 & $\mathrm{P}$ & NA & 5.53 & 5.62 & 5.67 & 5.80 & 5.80 & 6.63 & NA & NA & NA & NA & NA & NA & NA & 3.7 & NA & NA & NA & NA & 15E_4s1d2Xc_1 & 61108 & TDP-176 & 9150074 \\
\hline 23.7 & 0.999 & 0.01500 & 0.050 & 0.330 & 11.0 & $\mathrm{P}$ & NA & 5.53 & 5.62 & 5.67 & 5.80 & 5.80 & 6.63 & NA & NA & NA & NA & NA & NA & NA & 2.9 & NA & NA & NA & NA & 15E_4s1d2Xc_1 & $6 / 10 B$ & TDP-176 & 9150075 \\
\hline 23.7 & 0.999 & 0.01500 & 0.050 & 0.330 & 11.0 & $\mathrm{P}$ & NA & 5.53 & 5.62 & 5.67 & 5.80 & 5.80 & 6.63 & NA & NA & NA & NA & NA & NA & NA & 4.0 & NA & NA & NA & NA & 15E_4s1d2Xc_1 & $6 / 10 \mathrm{~B}$ & TDP-176 & 9150076 \\
\hline 23.7 & 0.999 & 0.01500 & 0.050 & 0.330 & 11.0 & $\mathrm{P}$ & NA & 5.53 & 5.62 & 5.67 & 5.80 & 5.80 & 6.63 & NA & NA & NA & NA & NA & NA & NA & 2.2 & NA & NA & NA & NA & 15E_4s1d2Xc_1 & $6 / 10 B$ & TDP-176 & 9150077 \\
\hline 20.4 & 1000 & 0.01500 & 0.050 & 0.180 & 18.8 & $\mathrm{P}$ & NA & 5.88 & 5.99 & 6.04 & 6.20 & 7.20 & 4.75 & NA & NA & NA & NA & NA & NA & (null) & 7.6 & 1 & NA & NA & NA & 15E_4s1d2Xd_1 & $6 / 11 \mathrm{~A}$ & TDP-17T & 9150078 \\
\hline 20.5 & 1000 & 0.01500 & 0.050 & 0.181 & 18.2 & $\mathrm{P}$ & NA & 6.06 & 6.18 & 6.23 & 6.40 & 7.20 & 5.00 & NA & NA & NA & NA & NA & NA & 1 & 5.8 & 1 & NA & NA & NA & 15E_4s1d2Xd_1 & $6 / 11 \mathrm{~A}$ & TDP-177 & 9150079 \\
\hline 20.7 & 1000 & 0.01500 & 0.050 & 0.182 & 17.6 & $\mathrm{P}$ & NA & 6.24 & 6.36 & 6.42 & 6.60 & 7.20 & 5.25 & NA & NA & NA & NA & NA & NA & 1 & 4.3 & 1 & NA & NA & NA & 15E_4s1d2Xd_1 1 & $6 / 11 \mathrm{~A}$ & TDP-177 & 9150080 \\
\hline 20.9 & 1000 & 0.01500 & 0.050 & 0.182 & 17.0 & $\mathrm{P}$ & NA & 6.41 & 6.54 & 6.60 & 6.80 & 7.20 & 5.25 & NA & NA & NA & NA & NA & NA & 1 & 3.7 & 1 & NA & NA & NA & 15E_4s1d2Xd_1 & $6 / 11 \mathrm{~A}$ & TDP-177 & 9150081 \\
\hline 21.1 & 1000 & 0.01500 & 0.050 & 0.183 & 16.6 & $\mathrm{P}$ & NA & 6.60 & 6.73 & 6.80 & 7.00 & 7.20 & 5.75 & NA & NA & NA & NA & NA & NA & 1 & 3.7 & 1 & NA & NA & NA & 15E_4s1d2Xd_1 & $6 / 11 \mathrm{~A}$ & TDP-177 & 9150082 \\
\hline 21.3 & 1000 & 0.01500 & 0.050 & 0.184 & 16.0 & $\mathrm{P}$ & NA & 6.77 & 6.91 & 6.98 & 7.20 & 7.20 & 5.75 & 7.20 & udv & ucsis & NA & ucsuav & NA & 1 & 3.7 & 3 & NA & NA & NA & 15E_4s1d2Xd_1 & $6 / 11 \mathrm{~A}$ & TDP-177 & 9150083 \\
\hline 21.6 & 1000 & 0.01500 & 0.050 & 0.185 & 15.6 & $\mathrm{P}$ & NA & 6.94 & 7.09 & 7.16 & 7.40 & 7.20 & 6.25 & NA & NA & NA & NA & NA & NA & 1 & 0.0 & 4 & NA & NA & NA & 15E_4s1d2Xd_1 & $6 / 11 \mathrm{~A}$ & TDP-177 & 9150084 \\
\hline 21.9 & 1000 & 0.01500 & 0.050 & 0.182 & 14.6 & $\mathrm{P}$ & NA & 7.49 & 7.65 & 7.73 & 8.00 & 7.20 & 8.00 & NA & NA & NA & NA & NA & NA & 1 & 0.0 & 4 & NA & NA & NA & 15E_4s1d2Xd_1 & $6 / 11 \mathrm{~A}$ & TDP-17T & 9150085 \\
\hline 22.2 & 0.999 & 0.01500 & 0.050 & 0.184 & 13.6 & $\mathrm{P}$ & NA & 8.00 & 8.19 & 8.28 & 8.60 & 7.20 & 12.50 & NA & NA & NA & NA & NA & NA & 1 & 0.0 & 4 & NA & NA & NA & 15E_4s1d2Xd_1 & $6 / 11 \mathrm{~A}$ & TDP-177 & 9150086 \\
\hline 22.4 & 1000 & 0.01500 & 0.050 & 0.185 & 13.0 & $\mathrm{P}$ & NA & 8.36 & 8.57 & 8.68 & 9.00 & 7.20 & 16.50 & NA & NA & NA & NA & NA & NA & 1 & 0.0 & 4 & NA & NA & NA & 15E_4s1d2Xd_1 & $6 / 11 \mathrm{~A}$ & TDP-177 & 9150087 \\
\hline 23.2 & 1000 & 0.01500 & 0.050 & 0.184 & 16.0 & $\mathrm{P}$ & NA & 6.80 & 6.93 & 7.00 & 7.20 & 7.20 & 5.75 & NA & NA & NA & NA & NA & NA & NA & $\mathrm{na}$ & NA & NA & NA & NA & 15E_4s1d2Xd_1 & $6 / 11 \mathrm{~A}$ & TDP-177 & 9150087.1 \\
\hline 23.2 & 1000 & 0.01500 & 0.050 & 0.184 & 16.0 & $\mathrm{P}$ & NA & 6.80 & 6.93 & 7.00 & 7.20 & 7.20 & 5.75 & NA & NA & NA & NA & NA & NA & NA & na & NA & NA & NA & NA & 15E_4s1d2Xd_1 & $6 / 11 \mathrm{~A}$ & TDP-177 & 9150087.2 \\
\hline 23.2 & 1000 & 0.01500 & 0.050 & 0.184 & 16.0 & $\mathrm{P}$ & NA & 6.80 & 6.93 & 7.00 & 7.20 & 7.20 & 5.75 & NA & NA & NA & NA & NA & NA & NA & wa & NA & NA & NA & NA & 15E_4s1d2Xd_1 & $6 / 11 \mathrm{~A}$ & TDP-177 & 9150087.3 \\
\hline 23.2 & 1000 & 0.01500 & 0.050 & 0.184 & 16.0 & $\mathrm{P}$ & NA & 6.80 & 6.93 & 7.00 & 7.20 & 7.20 & 5.75 & NA & NA & NA & NA & NA & NA & NA & na & NA & NA & NA & NA & 15E_4s1d2Xd_1 & $6 / 11 \mathrm{~A}$ & TDP-177 & 9150087.4 \\
\hline 23.2 & 1000 & 0.01500 & 0.050 & 0.184 & 16.0 & $\mathrm{P}$ & NA & 6.80 & 6.93 & 7.00 & 7.20 & 7.20 & 5.75 & NA & NA & NA & NA & NA & NA & NA & wa & NA & NA & NA & NA & 15E_4s1d2Xd_1 & $6 / 11 \mathrm{~A}$ & TDP-177 & 9150087.5 \\
\hline 23.2 & 1000 & 0.01500 & 0.050 & 0.184 & 16.0 & $\mathrm{P}$ & NA & 6.80 & 6.93 & 7.00 & 7.20 & 7.20 & 5.75 & NA & vis dec & ucsis & NA & NA & 7.20 & D & 3.7 & 3 & NA & NA & NA & 15E_4s1d2Xd_1 & 6/11A & TDP-177 & 9150088 \\
\hline 23.2 & 1000 & 0.01500 & 0.050 & 0.184 & 16.0 & $\mathrm{P}$ & NA & 6.80 & 6.93 & 7.00 & 7.20 & 7.20 & 5.75 & NA & NA & NA & NA & NA & NA & NA & 3.7 & NA & NA & NA & NA & 15E_4s1d2Xd_1 & $6 / 11 \mathrm{~A}$ & TDP-177 & 9150089 \\
\hline 23.2 & 1000 & 0.01500 & 0.050 & 0.184 & 16.0 & $\mathrm{P}$ & NA & 6.80 & 6.93 & 7.00 & 7.20 & 7.20 & 5.75 & NA & NA & NA & NA & NA & NA & NA & 3.7 & NA & NA & NA & NA & 15E_4s1d2Xd_1 & 6/11A & TDP-17T & 9150090 \\
\hline 23.2 & 1.000 & 0.01500 & 0.050 & 0.184 & 16.0 & $\mathrm{P}$ & NA & 6.80 & 6.93 & 7.00 & 7.20 & 7.20 & 5.75 & NA & NA & NA & NA & NA & NA & NA & 3.7 & NA & NA & NA & NA & 15E_4s1d2Xd_1 & $6 / 11 \mathrm{~A}$ & TDP-177 & 9150091 \\
\hline 23.2 & 1000 & 0.01500 & 0.050 & 0.184 & 16.0 & $\mathrm{P}$ & NA & 6.80 & 6.93 & 7.00 & 7.20 & 7.20 & 5.75 & NA & NA & NA & NA & NA & NA & NA & 3.7 & NA & NA & NA & NA & 15E_4s1d2Xd_1 & $6 / 11 \mathrm{~A}$ & TDP-177 & 9150092 \\
\hline 23.2 & 1000 & 0.01500 & 0.050 & 0.184 & 16.0 & $\mathrm{P}$ & NA & 6.80 & 6.93 & 7.00 & 7.20 & 7.20 & 5.75 & NA & NA & NA & NA & NA & NA & NA & 3.7 & NA & NA & NA & NA & 15E_4sid2Xd_1 & $6 / 11 \mathrm{~A}$ & TDP-177 & 9150093 \\
\hline 23.2 & 1000 & 0.01500 & 0.050 & 0.184 & 16.0 & $\mathrm{P}$ & NA & 6.80 & 6.93 & 7.00 & 7.20 & 7.20 & 5.75 & NA & NA & NA & NA & NA & NA & NA & 3.7 & NA & NA & NA & NA & 15E_4s1d2Xd_1 & $6 / 11 \mathrm{~A}$ & TDP-177 & 9150094 \\
\hline 23.2 & 1.000 & 0.01500 & 0.050 & 0.184 & 16.0 & $\mathrm{P}$ & NA & 6.80 & 6.93 & 7.00 & 7.20 & 7.20 & 5.75 & NA & NA & NA & NA & NA & NA & NA & 3.8 & NA & NA & NA & NA & 15E_4sId2Xd_1 & $6 / 11 \mathrm{~A}$ & TDP-17T & 9150095 \\
\hline 23.2 & 1000 & 0.01500 & 0.050 & 0.184 & 16.0 & $\mathrm{P}$ & NA & 6.80 & 6.93 & 7.00 & 7.20 & 7.20 & 5.75 & NA & NA & NA & NA & NA & NA & NA & 0.7 & NA & NA & NA & NA & 15E_4s1d2Xd_1 & $6 / 11 \mathrm{~A}$ & TDP-17T & 9150096 \\
\hline 23.8 & 0.999 & 0.01500 & undefined & 1.000 & infinite & $\mathrm{s}$ & 2.51 & na & na & na & 2.50 & 2.90 & 4.38 & NA & NA & NA & NA & NA & NA & (null) & 9.4 & 1 & NA & NA & NA & 15E_4s1d2Xa & $6 / 11 \mathrm{~B}$ & TDP-177 & 9150097 \\
\hline 23.8 & 0.999 & 0.01500 & undefined & 1.000 & infinite & $\mathrm{s}$ & 2.70 & wa & wa & wa & 2.70 & 2.90 & 5.75 & NA & NA & NA & NA & NA & NA & 1 & 7.0 & 1 & NA & NA & NA & 15E_4sidi2xa & $6 / 11 \mathrm{~B}$ & TDP-177 & 9150098 \\
\hline 23.8 & 0.999 & 0.01500 & undefined & 1.000 & infinite & $\mathrm{s}$ & 2.71 & na & na & $\mathrm{na}$ & 2.70 & 2.90 & 5.75 & NA & NA & NA & NA & NA & NA & D & 6.0 & 1 & NA & NA & NA & 15E__sididxa & $6 / 11 \mathrm{~B}$ & TDP-177 & 9150099 \\
\hline 23.9 & 0.999 & 0.01500 & undefined & 1.000 & infinite & $\mathrm{s}$ & 2.80 & $\mathrm{na}$ & $\mathrm{na}$ & wa & 2.80 & 2.90 & 7.25 & NA & NA & NA & NA & NA & NA & 1 & 3.0 & 1 & NA & NA & NA & 15E_451d22Xa & 6/11B & TDP-177 & 9150100 \\
\hline 23.8 & 0.999 & 0.01500 & undefined & 1.000 & infinite & $s$ & 2.90 & wa & wa & na & 2.90 & 2.90 & 9.00 & 2.90 & udv & ucsis & NA & ucsudv & NA & 1 & 0.0 & 3 & NA & NA & NA & 15E_4s1d2Xa & $6 / 11 \mathrm{~B}$ & TDP-17T & 9150101 \\
\hline 23.9 & 0.999 & 0.01500 & undefined & 1.000 & infinite & $\mathrm{s}$ & 3.01 & na & na & na & 3.00 & 2.90 & 11.00 & NA & NA & NA & NA & NA & NA & 1 & 0.0 & 4 & NA & NA & NA & 15E_4s1d2Xa & $6 / 11 \mathrm{~B}$ & TDP-177 & 9150102 \\
\hline 23.9 & 0.999 & 0.01500 & undefined & 1.000 & infinite & $\mathrm{s}$ & 3.11 & wa & wa & wa & 3.10 & 2.90 & 13.50 & NA & NA & NA & NA & NA & NA & 1 & 0.0 & 4 & NA & NA & NA & 15E_4s1d2xa & $6 / 11 \mathrm{~B}$ & TDP-177 & 9150103 \\
\hline 23.9 & 0.999 & 0.01500 & undefined & 1.000 & infinite & $\mathrm{s}$ & 3.21 & $\mathrm{Na}$ & $\mathrm{ra}$ & $\mathrm{na}$ & 3.20 & 2.90 & 16.50 & NA & NA & NA & NA & NA & NA & 1 & 0.0 & 4 & NA & NA & NA & 15E_4s1d2Xa & $6 / 11 \mathrm{~B}$ & TDP-177 & 9150104 \\
\hline 24.0 & 0.999 & 0.01500 & \begin{tabular}{|l|}
0.050 \\
\end{tabular} & 0.329 & 122 & $\mathrm{P}$ & NA & 4.96 & 5.04 & \begin{tabular}{|l|l|}
5.08 \\
\end{tabular} & 5.20 & 5.80 & 4.75 & NA & NA & NA & NA & NA & NA & (null) & 6.1 & 1 & NA & NA & NA & 15E_4s1d2Xc_1 & $6 / 11 \mathrm{C}$ & TDP-177 & 9150105 \\
\hline 24.2 & 0.999 & 0.01500 & 0.050 & 0.330 & 11.8 & $\mathrm{P}$ & NA & 5.14 & 5.23 & 5.27 & 5.40 & 5.80 & 5.50 & NA & NA & NA & NA & NA & NA & & 5.0 & 1 & NA & NA & NA & 15E_4s1d2Xc_1 & 6/11c & TDP-17T & 9150106 \\
\hline
\end{tabular}


Table B.3. Data from 2008 Tests in Small-Scale Vessel with Elliptical Head A.4

\begin{tabular}{|c|c|c|c|c|c|c|c|c|c|c|c|c|c|c|c|c|c|c|c|c|c|c|c|c|c|c|c|}
\hline $\begin{array}{c}\text { Row } \\
\text { Number }\end{array}$ & Test & Case ID & $\begin{array}{c}\text { Tank } \\
\text { Diameter }\end{array}$ & $\begin{array}{l}\text { Head } \\
\text { Shape }\end{array}$ & $\begin{array}{c}\text { Dish } \\
\text { Height }\end{array}$ & $\begin{array}{l}\text { Dish } \\
\text { Volume }\end{array}$ & $\begin{array}{c}\text { Tank } \\
\text { Fill } \\
\text { Height } \\
\end{array}$ & $\begin{array}{l}\text { Return } \\
\text { Line } \\
\text { Height } \\
\end{array}$ & $\begin{array}{c}\text { Nozzle } \\
\text { Imner } \\
\text { Diameter }\end{array}$ & $\begin{array}{l}\text { Nozzle } \\
\text { Stanc-off } \\
\text { Distance }\end{array}$ & $\begin{array}{l}\text { Pulse Tube } \\
\text { Configuration }\end{array}$ & $\begin{array}{l}\text { Installed } \\
\text { Nozzles }\end{array}$ & 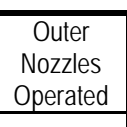 & $\begin{array}{c}\text { Inner } \\
\text { Nozzles } \\
\text { Opperated } \\
\end{array}$ & $\begin{array}{c}\text { Pulse Tube } \\
\text { Outer } \\
\text { Diameter } \\
\end{array}$ & \begin{tabular}{|l|} 
Outer \\
PJM \\
Radius \\
\end{tabular} & $\begin{array}{c}\text { Inner } \\
\text { PJM } \\
\text { Radius } \\
\text { Pains }\end{array}$ & $\begin{array}{c}\text { "FO" Outer PJM } \\
\text { Impingement } \\
\text { Angle }\end{array}$ & $\begin{array}{c}\text { "FO" Inner PJM } \\
\text { Impingement } \\
\text { Angle }\end{array}$ & $\begin{array}{c}\text { Ratio Outer } \\
\text { PJM to Tank } \\
\text { Radius } \\
\end{array}$ & $\begin{array}{c}\text { Ratio Inner } \\
\text { PJM to Tank } \\
\text { Radius } \\
\end{array}$ & Simulant & $\begin{array}{l}\text { Solids } \\
\text { Density }\end{array}$ & \begin{tabular}{|c|} 
Particle \\
Diameter \\
d 5 \\
\end{tabular} & $\begin{array}{c}\begin{array}{c}\text { Particle } \\
\text { Diameter } \\
\text { d50 }\end{array} \\
\end{array}$ & $\begin{array}{c}\begin{array}{c}\text { Particle } \\
\text { Diameter } \\
\text { d95 }\end{array} \\
\end{array}$ & $\begin{array}{c}\text { Void } \\
\text { Fraction }\end{array}$ \\
\hline text & text & text & in. & text & in. & in. ${ }^{3}$ & in. & in. & in. & in. & text & number & number & number & in. & in. & in. & deg & deg & nondim & nondim & text & $\mathrm{g} / \mathrm{cm}^{3}$ & $\mathrm{~m}$ & $\mathrm{~m}$ & $\mathrm{~m}$ & fraction \\
\hline MSS & MDDX & ID & $\mathrm{D}$ & $\mathrm{HS}$ & Hosh & $V_{\text {dath }}$ & $\mathrm{H}$ & Rtn & $d$ & sod & PT & $\mathrm{N}$ & $\mathrm{N}_{b}$ & $\mathrm{~N}$ & $P \mathrm{PT}_{\alpha d}$ & $R_{0}$ & $R$ & $\theta_{0}$ & $\theta_{1}$ & RolR & $R / R$ & sxdx & $\rho_{\mathrm{s}}$ & $d_{s}$ & $d_{60}$ & $d_{05}$ & $\mathrm{vf}$ \\
\hline 9150107 & $6 / 11 \mathrm{C}$ & 15E_4s1d2Xc_1 & $147 / 16$ & $E$ & 3.25 & 354.8 & $341 / 2$ & 30 & 0.126 & 0.189 & HLP-22 & 12 & 8 & 4 & 1.05 & 4.5 & 2.4 & 21.8 & 10.1 & 0.62 & 0.34 & s1d2 & 2.48 & 0.0000569 & 0.0000693 & 0.0000821 & 0.3750 \\
\hline $9150108 \mathrm{M}$ & 6/11c & 15E_4sid2Xc_1 & $147 / 16$ & $E$ & 3.25 & 354.8 & $341 / 2$ & 30 & 0.126 & 0.189 & HLP-22 & 12 & 8 & 4 & 1.05 & 4.5 & 2.4 & 21.8 & 10.1 & 0.62 & 0.34 & $\mathrm{sid2} 2$ & 2.48 & \begin{tabular}{|l|l|}
0.0000569 \\
\end{tabular} & 0.0000693 & 0.0000821 & 0.3750 \\
\hline 9150109M & 6/11c & $15 E_{-} 4 \mathrm{~s} 1 \mathrm{~d} 2 \mathrm{X} \mathrm{c}_{-} 1$ & $147 / 16$ & E & 3.25 & 354.8 & $341 / 2$ & 30 & 0.126 & 0.189 & HLP-22 & 12 & 8 & 4 & 1.05 & 4.5 & 2.4 & 21.8 & 10.1 & 0.62 & 0.34 & $\mathrm{sid2}$ & 2.48 & \begin{tabular}{|l|l|}
0.0000569 \\
\end{tabular} & 0.0000693 & 0.0000821 & 0.3750 \\
\hline $9150110 \mathrm{~m}$ & 6/11c & 15E_4sid2Xc_1 & $147 / 16$ & $E$ & 3.25 & 354.8 & $341 / 2$ & 30 & 0.126 & 0.189 & HLP-22 & 12 & 8 & 4 & 1.05 & 4.5 & 2.4 & 21.8 & 10.1 & 0.62 & 0.34 & s1d2 & 2.48 & \begin{tabular}{|l|l|}
0.00005699 \\
\end{tabular} & 0.0000693 & 0.0000821 & 0.3750 \\
\hline 9150111M & $6 / 111 \mathrm{c}$ & 15E_4s1d2Xc_1 & $147 / 16$ & $\mathrm{E}$ & 3.25 & 354.8 & $341 / 2$ & 30 & 0.126 & 0.189 & HLP-22 & 12 & 8 & 4 & 1.05 & 4.5 & 2.4 & 21.8 & 10.1 & 0.62 & 0.34 & $\mathrm{s1d2}$ & 2.48 & \begin{tabular}{|l|l|}
0.0000569 \\
\end{tabular} & 0.0000693 & 0.0000821 & 0.3750 \\
\hline $9150112 \mathrm{M}$ & 6/11c & 15E_4s1d2Xc_1 & $147 / 16$ & $\mathrm{E}$ & 3.25 & 354.8 & $341 / 2$ & 30 & 0.126 & 0.189 & HLP-22 & 12 & 8 & 4 & 1.05 & 4.5 & 24 & 21.8 & 10.1 & 0.62 & 0.34 & s1d2 & 2.48 & \begin{tabular}{|l}
0.0000569 \\
\end{tabular} & 0.0000693 & 0.0000821 & 0.3750 \\
\hline 9150113 & 6/11c & 15E_4SId2X 21 & $147 / 16$ & $E$ & 3.25 & 354.8 & $341 / 2$ & 30 & 0.126 & 0.189 & HLP-22 & 12 & 8 & 4 & 1.05 & 4.5 & 2.4 & 21.8 & 10.1 & 0.62 & 0.34 & $\mathrm{sid2}$ & 2.48 & \begin{tabular}{|l|l|}
0.0000569 \\
\end{tabular} & 0.0000693 & 0.0000821 & 0.3750 \\
\hline 9150114 & $6 / 11 \mathrm{C}$ & 15E_4s1d2Xc_1 & $147 / 16$ & E & 3.25 & 354.8 & $341 / 2$ & 30 & 0.126 & 0.189 & HLP-22 & 12 & 8 & 4 & 1.05 & 4.5 & 2.4 & 21.8 & 10.1 & 0.62 & 0.34 & s1d2 & 2.48 & \begin{tabular}{|l|l|}
0.0000569 \\
\end{tabular} & 0.0000693 & 0.0000821 & 0.3750 \\
\hline 9150115 & $6 / 11 \mathrm{C}$ & 15E_4sid2X__1 & $147 / 16$ & $E$ & 3.25 & 354.8 & $341 / 2$ & 30 & 0.126 & 0.189 & HLP-22 & 12 & 8 & 4 & 1.05 & 4.5 & 2.4 & 21.8 & 10.1 & 0.62 & 0.34 & s1d2 & 2.48 & \begin{tabular}{|l|l|}
0.00005699 \\
\end{tabular} & 0.0000693 & 0.0000821 & 0.3750 \\
\hline 9150116 & $6 / 11 \mathrm{c}$ & 15E_4s1d2Xc 1 & $147 / 16$ & $\mathrm{E}$ & 3.25 & 354.8 & $341 / 2$ & 30 & 0.126 & 0.189 & HLP-22 & 12 & 8 & 4 & 1.05 & 4.5 & 24 & 21.8 & 10.1 & 0.62 & 0.34 & s1d2 & 2.48 & \begin{tabular}{|l|l|}
0.0000569 \\
\end{tabular} & 0.0000693 & 0.0000821 & 0.3750 \\
\hline 9150117 & $6 / 11 \mathrm{c}$ & 15E_4s1d2Xc_1 & $147 / 16$ & $\mathrm{E}$ & 3.25 & 354.8 & $341 / 2$ & 30 & 0.126 & 0.189 & HLP-22 & 12 & 8 & 4 & 1.05 & 4.5 & 2.4 & 21.8 & 10.1 & 0.62 & 0.34 & sid2 & 2.48 & \begin{tabular}{|l|l|}
0.0000569 \\
\end{tabular} & 0.0000693 & 0.0000821 & 0.3750 \\
\hline 9150118 & $6 / 11 \mathrm{c}$ & 15E_4s1d2Xc_1 & $147 / 16$ & $E$ & 3.25 & 354.8 & $341 / 2$ & 30 & 0.126 & 0.189 & HLP-22 & 12 & 8 & 4 & 1.05 & 4.5 & 24 & 21.8 & 10.1 & 0.62 & 0.34 & $\mathrm{sid2}$ & 2.48 & \begin{tabular}{|l|l|}
0.0000569 \\
\end{tabular} & 0.0000693 & 0.0000821 & 0.3750 \\
\hline 9150119 & $6 / 11 \mathrm{C}$ & 15E_4sid2Xc_ 1 & $147 / 16$ & $\mathrm{E}$ & 3.25 & 354.8 & $341 / 2$ & 30 & 0.126 & 0.189 & HLP-22 & 12 & 8 & 4 & 1.05 & 4.5 & 2.4 & 21.8 & 10.1 & 0.62 & 0.34 & $\mathrm{sid2}$ & 2.48 & \begin{tabular}{|l}
0.0000569 \\
\end{tabular} & 0.0000693 & 0.0000821 & 0.3750 \\
\hline 9150120 & $6 / 11 \mathrm{C}$ & 15E_4sid2Xc_1 & $147 / 16$ & $E$ & 3.25 & 354.8 & $341 / 2$ & 30 & 0.126 & 0.189 & HLP-22 & 12 & 8 & 4 & 1.05 & 4.5 & 2.4 & 21.8 & 10.1 & 0.62 & 0.34 & s1d2 & 2.48 & \begin{tabular}{|l|l|}
0.00005699 \\
\end{tabular} & 0.0000693 & 0.0000821 & 0.3750 \\
\hline 9150121 & $6 / 11 \mathrm{c}$ & 15E_4sId2Xc 1 & $147 / 16$ & $\mathrm{E}$ & 3.25 & 354.8 & $341 / 2$ & 30 & 0.126 & 0.189 & HLP-22 & 12 & 8 & 4 & 1.05 & 4.5 & 24 & 21.8 & 10.1 & 0.62 & 0.34 & s1d2 & 2.48 & \begin{tabular}{|l|l|}
0.0000569 \\
\end{tabular} & 0.0000693 & 0.0000821 & 0.3750 \\
\hline 9150122 & $6 / 11 \mathrm{c}$ & 15E_4s1d2Xc_1 & $147 / 16$ & $\mathrm{E}$ & 3.25 & 354.8 & $341 / 2$ & 30 & 0.126 & 0.189 & HLP-22 & 12 & 8 & 4 & 1.05 & 4.5 & 2.4 & 21.8 & 10.1 & 0.62 & 0.34 & sid2 & 2.48 & \begin{tabular}{|l|l}
0.0000569 \\
\end{tabular} & 0.0000693 & 0.0000821 & 0.3750 \\
\hline 9150123 & $6 / 11 \mathrm{c}$ & 15E_4sId2Xc_1 & $147 / 16$ & $E$ & 3.25 & 354.8 & $341 / 2$ & 30 & 0.126 & 0.189 & HLP-22 & 12 & 8 & 4 & 1.05 & 4.5 & 2.4 & 21.8 & 10.1 & 0.62 & 0.34 & s1d2 & 2.48 & \begin{tabular}{|l|l|}
0.0000569 \\
\end{tabular} & 0.0000693 & 0.0000821 & 0.3750 \\
\hline 9150124 & $6 / 11 \mathrm{C}$ & 15E_4sid2Xc_1 1 & $147 / 16$ & $\mathrm{E}$ & 3.25 & 354.8 & $341 / 2$ & 30 & 0.126 & 0.189 & HLP-22 & 12 & 8 & 4 & 1.05 & 4.5 & 2.4 & 21.8 & 10.1 & 0.62 & 0.34 & $\mathrm{~s} 1 \mathrm{~d} 2$ & 2.48 & \begin{tabular}{|l|l|}
0.0000569 \\
\end{tabular} & 0.0000693 & 0.0000821 & 0.3750 \\
\hline 9150125 & $6 / 11 \mathrm{C}$ & 15E_4sid2X__1 & $147 / 16$ & $E$ & 3.25 & 354.8 & $341 / 2$ & 30 & 0.126 & 0.189 & HLP-22 & 12 & 8 & 4 & 1.05 & 4.5 & 2.4 & 21.8 & 10.1 & 0.62 & 0.34 & s1d2 & 2.48 & \begin{tabular}{|l|l|}
0.00005699 \\
\end{tabular} & 0.0000693 & 0.0000821 & 0.3750 \\
\hline 9150126 & $6 / 11 \mathrm{c}$ & 15E_4s1d2Xc 1 & $147 / 16$ & $\mathrm{E}$ & 3.25 & 354.8 & $341 / 2$ & 30 & 0.126 & 0.189 & HLP-22 & 12 & 8 & 4 & 1.05 & 4.5 & 24 & 21.8 & 10.1 & 0.62 & 0.34 & s1d2 & 2.48 & \begin{tabular}{|l|l|}
0.0000569 \\
\end{tabular} & 0.0000693 & 0.0000821 & 0.3750 \\
\hline 9150127 & $6 / 11 \mathrm{c}$ & 15E_4s1d2Xc_1 & $147 / 16$ & $\mathrm{E}$ & 3.25 & 354.8 & $341 / 2$ & 30 & 0.126 & 0.189 & HLP-22 & 12 & 8 & 4 & 1.05 & 4.5 & 2.4 & 21.8 & 10.1 & 0.62 & 0.34 & sid2 & 2.48 & \begin{tabular}{|l|l}
0.0000569 \\
\end{tabular} & 0.0000693 & 0.0000821 & 0.3750 \\
\hline 9150128 & $6 / 11 \mathrm{C}$ & 15E_4s1d2Xc_1 & $147 / 16$ & $E$ & 3.25 & 354.8 & $341 / 2$ & 30 & 0.126 & 0.189 & HLP-22 & 12 & 8 & 4 & 1.05 & 4.5 & 2.4 & 21.8 & 10.1 & 0.62 & 0.34 & s1d2 & 2.48 & \begin{tabular}{|l|l}
0.0000569 \\
\end{tabular} & 0.0000693 & 0.0000821 & 0.3750 \\
\hline 9150129 & 6/11C & 15E_4sid2Xc_ 1 & $147 / 16$ & $\mathrm{E}$ & 3.25 & 354.8 & $341 / 2$ & 30 & 0.126 & 0.189 & HLP-22 & 12 & 8 & 4 & 1.05 & 4.5 & 2.4 & 21.8 & 10.1 & 0.62 & 0.34 & $\mathrm{sid2}$ & 2.48 & \begin{tabular}{|l}
0.0000569 \\
\end{tabular} & 0.0000693 & 0.0000821 & 0.3750 \\
\hline 9150130 & 6/111C & 15E_4sid2X__1 & $147 / 16$ & $E$ & 3.25 & 354.8 & $341 / 2$ & 30 & 0.126 & 0.189 & HLP-22 & 12 & 8 & 4 & 1.05 & 4.5 & 2.4 & 21.8 & 10.1 & 0.62 & 0.34 & s1d2 & 2.48 & \begin{tabular}{|l|l|}
0.00005699 \\
\end{tabular} & 0.0000693 & 0.0000821 & 0.3750 \\
\hline 9150131 & $6 / 11 \mathrm{c}$ & 15E_4sId2Xc 1 & $147 / 16$ & $\mathrm{E}$ & 3.25 & 354.8 & $341 / 2$ & 30 & 0.126 & 0.189 & HLP-22 & 12 & 8 & 4 & 1.05 & 4.5 & 2.4 & 21.8 & 10.1 & 0.62 & 0.34 & s1d2 & 2.48 & \begin{tabular}{|l|l|}
0.0000569 \\
\end{tabular} & 0.0000693 & 0.0000821 & 0.3750 \\
\hline 9150132 & 6/12A & 15E_4sid2Xe_1 & $147 / 16$ & $\mathrm{E}$ & 3.25 & 354.8 & $343 / 4$ & 30 & 0.126 & 0.189 & HLP-22 & 12 & 8 & 4 & 1.05 & 4.5 & 2.4 & 21.8 & 10.1 & 0.62 & 0.34 & s1d2 & 2.48 & \begin{tabular}{|l|l}
0.0000569 \\
\end{tabular} & 0.0000693 & 0.0000821 & 0.3750 \\
\hline 9150133 & $6 / 12 \mathrm{~A}$ & 15E_4sId2Xe_1 & $147 / 16$ & $E$ & 3.25 & \begin{tabular}{ll|}
354.8 \\
\end{tabular} & $343 / 4$ & 30 & 0.126 & 0.189 & HLP-22 & 12 & 8 & 4 & 1.05 & 4.5 & 2.4 & 21.8 & 10.1 & 0.62 & 0.34 & s1d2 & 2.48 & \begin{tabular}{|l|l|}
0.0000569 \\
\end{tabular} & 0.0000693 & 0.0000821 & 0.3750 \\
\hline 9150134 & $6 / 12 \mathrm{~A}$ & 15E_4sid2Xe_1 & $147 / 16$ & $\mathrm{E}$ & 3.25 & 354.8 & $343 / 4$ & 30 & 0.126 & 0.189 & HLP-22 & 12 & 8 & 4 & 1.05 & 4.5 & 2.4 & 21.8 & 10.1 & 0.62 & 0.34 & $\mathrm{sid2}$ & 2.48 & \begin{tabular}{|l}
0.0000569 \\
\end{tabular} & 0.0000693 & 0.0000821 & 0.3750 \\
\hline $9150135 \mathrm{M}$ & 6/12A & 15E_4sid2Xe_1 & $147 / 16$ & $E$ & 3.25 & \begin{tabular}{ll|}
354.8 \\
\end{tabular} & $343 / 4$ & 30 & 0.126 & 0.189 & HLP-22 & 12 & 8 & 4 & 1.05 & 4.5 & 2.4 & 21.8 & 10.1 & 0.62 & 0.34 & $\mathrm{sid2}$ & 2.48 & \begin{tabular}{|l|l|}
0.0000569 \\
\end{tabular} & 0.0000693 & 0.0000821 & 0.3750 \\
\hline $9150136 \mathrm{M}$ & 6/12A & 15E_4sId2Xe 11 & $147 / 16$ & E & 3.25 & 354.8 & $343 / 4$ & 30 & 0.126 & 0.189 & HLP-22 & 12 & 8 & 4 & 1.05 & 4.5 & 2.4 & 21.8 & 10.1 & 0.62 & 0.34 & s1d2 & 2.48 & \begin{tabular}{|l|l|}
0.0000569 \\
\end{tabular} & 0.0000693 & 0.0000821 & 0.3750 \\
\hline 9150137M & 6/12A & 15E_4sid2Xe_1 & $147 / 16$ & $\mathrm{E}$ & 3.25 & 354.8 & $343 / 4$ & 30 & 0.126 & 0.189 & HLP-22 & 12 & 8 & 4 & 1.05 & 4.5 & 2.4 & 21.8 & 10.1 & 0.62 & 0.34 & s1d2 & 2.48 & \begin{tabular}{|l|l}
0.0000569 \\
\end{tabular} & 0.0000693 & 0.0000821 & 0.3750 \\
\hline 9150137.1 & 6/12A & 15E_4sId2Xe_1 & $147 / 16$ & $E$ & 3.25 & \begin{tabular}{ll|}
354.8 \\
\end{tabular} & $343 / 4$ & 30 & 0.126 & 0.189 & HLP-22 & 12 & 8 & 4 & 1.05 & 4.5 & 2.4 & 21.8 & 10.1 & 0.62 & 0.34 & s1d2 & 2.48 & \begin{tabular}{|l|l|}
0.0000569 \\
\end{tabular} & 0.0000693 & 0.0000821 & 0.3750 \\
\hline 9150137.2 & 6/12A & 15E_4sid2Xe_1 & $147 / 16$ & $E$ & 3.25 & 354.8 & $343 / 4$ & 30 & 0.126 & 0.189 & HLP-22 & 12 & 8 & 4 & 1.05 & 4.5 & 2.4 & 21.8 & 10.1 & 0.62 & 0.34 & $\mathrm{sid2} 2$ & 2.48 & 0.0000569 & 0.0000693 & 0.0000821 & 0.3750 \\
\hline 9150137.3 & 6/12A & 15E_4sid2Xe_1 & $147 / 16$ & $E$ & 3.25 & 354.8 & $343 / 4$ & 30 & 0.126 & 0.189 & HLP-22 & 12 & 8 & 4 & 1.05 & 4.5 & 2.4 & 21.8 & 10.1 & 0.62 & 0.34 & $\mathrm{sid2}$ & 2.48 & \begin{tabular}{|l|l}
0.0000569 \\
\end{tabular} & 0.0000693 & 0.0000821 & 0.3750 \\
\hline 9150137.4 & 6/12A & 15E_4sid2Xe 1 & $147 / 16$ & E & 3.25 & 354.8 & $343 / 4$ & 30 & 0.126 & 0.189 & HLP-22 & 12 & 8 & 4 & 1.05 & 4.5 & 2.4 & 21.8 & 10.1 & 0.62 & 0.34 & s1d2 & 2.48 & $\begin{array}{l}0.0000569 \\
\end{array}$ & 0.0000693 & 0.0000821 & 0.3750 \\
\hline 9150137.5 & 6/12A & 15E_4sid2Xe_ 1 & $147 / 16$ & $\mathrm{E}$ & 3.25 & 354.8 & $343 / 4$ & 30 & 0.126 & 0.189 & HLP-22 & 12 & 8 & 4 & 1.05 & 4.5 & 2.4 & 21.8 & 10.1 & 0.62 & 0.34 & s1d2 & 2.48 & \begin{tabular}{|l|l}
0.0000569 \\
\end{tabular} & 0.0000693 & 0.0000821 & 0.3750 \\
\hline 9150138M & 6/12A & 15E_4sid2Xe_1 & $147 / 16$ & $E$ & 3.25 & 354.8 & $343 / 4$ & 30 & 0.126 & 0.189 & HLP-22 & 12 & 8 & 4 & 1.05 & 4.5 & 24 & 21.8 & 10.1 & 0.62 & 0.34 & s1d2 & 2.48 & \begin{tabular}{|l|l}
0.0000569 \\
\end{tabular} & 0.0000693 & 0.0000821 & 0.3750 \\
\hline 9150139 & 6/12A & 15E_4sid2Xe_1 & $147 / 16$ & $\mathrm{E}$ & 3.25 & 354.8 & $343 / 4$ & 30 & 0.126 & 0.189 & HLP-22 & 12 & 8 & 4 & 1.05 & 4.5 & 2.4 & 21.8 & 10.1 & 0.62 & 0.34 & $\mathrm{sid2}$ & 2.48 & \begin{tabular}{|l|l|}
0.0000569 \\
\end{tabular} & 0.0000693 & 0.0000821 & 0.3750 \\
\hline 9150139.1 & $6 / 12 \mathrm{~A}$ & 15E_4sid2Xe_1 & $147 / 16$ & $E$ & 3.25 & 354.8 & $343 / 4$ & 30 & 0.126 & 0.189 & HLP-22 & 12 & 8 & 4 & 1.05 & 4.5 & 2.4 & 21.8 & 10.1 & 0.62 & 0.34 & $\mathrm{sid2}$ & 2.48 & \begin{tabular}{|l|l|}
0.0000569 \\
\end{tabular} & 0.0000693 & 0.0000821 & 0.3750 \\
\hline 9150140 & 6/12A & 15E_4sId2Xe_1 & $147 / 16$ & E & 3.25 & 354.8 & $343 / 4$ & 30 & 0.126 & 0.189 & HLP-22 & 12 & 8 & 4 & 1.05 & 4.5 & 2.4 & 21.8 & 10.1 & 0.62 & 0.34 & s1d2 & 2.48 & \begin{tabular}{|l|l|}
0.0000569 \\
\end{tabular} & 0.0000693 & 0.0000821 & 0.3750 \\
\hline 9150140.1 & $6 / 12 \mathrm{~A}$ & & $147 / 16$ & E & 3.25 & 354.8 & $343 / 4$ & 30 & 0.126 & 0.189 & HLP-22 & 12 & 8 & 4 & 1.05 & 4.5 & 2.4 & 21.8 & 10.1 & 0.62 & 0.34 & s1d2 & 2.48 & $\begin{array}{l}0.0000569 \\
\end{array}$ & 0.0000693 & 0.0000821 & 0.3750 \\
\hline
\end{tabular}


Table B.3. Data from 2008 Tests in Small-Scale Vessel with Elliptical Head B.4

\begin{tabular}{|c|c|c|c|c|c|c|c|c|c|c|c|c|c|c|c|c|c|c|c|c|c|c|c|c|c|c|c|c|c|}
\hline $\begin{array}{l}\text { Tank Water } \\
\text { Temperature }\end{array}$ & $\begin{array}{l}\text { Water } \\
\text { Density }\end{array}$ & $\begin{array}{c}\text { Solids } \\
\text { Fraction }\end{array}$ & $\begin{array}{c}\text { Pulse } \\
\text { Volume } \\
\text { Fracion }\end{array}$ & $\begin{array}{l}\text { Dury } \\
\text { Cyde }\end{array}$ & $\begin{array}{l}\text { Oyde } \\
\text { Time }\end{array}$ & $\begin{array}{c}\text { Pulsed } \\
\text { or } \\
\text { Steacdy } \\
\text { Jet } \\
\end{array}$ & $\begin{array}{c}\text { Us } \\
\text { Steacy } \\
\text { Jet }\end{array}$ & $\begin{array}{c}\text { U1 } \\
\text { Pulsing } \\
\text { Jet }\end{array}$ & $\begin{array}{c}\text { U2 } \\
\text { URMS }\end{array}$ & $\begin{array}{l}\text { UB } \\
\text { URNB } \\
\text { Un }\end{array}$ & 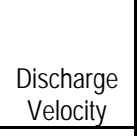 & $\begin{array}{c}\text { Citical } \\
\text { Suspension } \\
\text { Velocity }\end{array}$ & $\begin{array}{c}\text { Average } \\
\text { Peak Coud } \\
\text { Height } \\
\end{array}$ & $\begin{array}{c}\text { UCS } \\
\text { Condition }\end{array}$ & $\begin{array}{c}\text { UCS } \\
\text { Method }\end{array}$ & $\begin{array}{l}\text { UCS } \\
\text { Hag }\end{array}$ & $\begin{array}{c}\text { ucs } \\
\text { Center } \\
\text { Flag }\end{array}$ & $\begin{array}{c}\text { ucsuav } \\
\text { Fag }\end{array}$ & $\begin{array}{l}\text { UCS based } \\
\text { on } \\
\text { Decreasing } \\
\text { Velocity }\end{array}$ & $\begin{array}{l}\text { Sweep } \\
\text { Increase/ } \\
\text { Decrease }\end{array}$ & $\begin{array}{c}\text { UDV } \\
\text { Height } \\
\text { Bed }\end{array}$ & $\begin{array}{c}\text { Particle } \\
\text { Motion }\end{array}$ & $\begin{array}{l}\text { Solids } \\
\text { Level }\end{array}$ & $\begin{array}{l}\text { Outer } \\
\text { Bottom } \\
\text { Patem }\end{array}$ & \begin{tabular}{|l} 
Inner \\
Botom \\
Batter \\
\end{tabular} & Case ID & Test & TDP & $\begin{array}{l}\text { Row } \\
\text { Number }\end{array}$ \\
\hline $\mathrm{c}$ & $\mathrm{g} / \mathrm{cm}^{3}$ & fraction & fraction & fraction & $\mathrm{s}$ & text & $\mathrm{m} / \mathrm{s}$ & $\mathrm{m} / \mathrm{s}$ & m/s & m/s & m/s & $\mathrm{m} / \mathrm{s}$ & in. & $m / s$ & text & text & text & text & $\mathrm{m} / \mathrm{s}$ & text & $m \mathrm{~m}$ & text & text & text & text & text & text & text & text \\
\hline$T$ & $\rho$ & $\phi_{\mathrm{s}}$ & $\phi_{p_{0}}$ & $\mathrm{DC}$ & $t_{c}$ & Jet & $U_{s}$ & $\mathrm{U}_{1}$ & $\mathrm{U} 2$ & U3 & $u$ & $u_{\text {us }}$ & $\mathrm{H}_{\mathrm{c}}$ & $U_{\text {CSR }}$ & $U_{\text {cosn }}$ & Ussis & Uscen & Ussuar & $U_{\text {CS } D} \mathrm{D}$ & $\mathrm{s}_{\mathrm{v}}$ & Head & $\mathrm{PM}$ & Sol & $\mathrm{SPO}_{\mathrm{O}}$ & $\mathrm{SP}_{1}$ & ID & MDDX & $\mathrm{TDP}$ & MSS \\
\hline 24.3 & 0.999 & 0.01500 & 0.050 & $\begin{array}{ll}0.331 \\
\end{array}$ & 11.4 & $\mathrm{P}$ & $\mathrm{NA}$ & 5.33 & 5.41 & 5.46 & 5.60 & 5.80 & 5.75 & NA & NA & NA & NA & NA & NA & 1 & 3.8 & 1 & $\mathrm{NA}$ & NA & NA & 15E_4s1d2X__ 1 & $6 / 11 \mathrm{C}$ & TDP-177 & 9150107 \\
\hline 24.5 & 0.999 & 0.01500 & 0.050 & $\begin{array}{ll}0.334 \\
\end{array}$ & 10.6 & $\mathrm{P}$ & NA & 5.67 & 5.78 & 5.82 & 6.00 & 5.80 & 7.50 & NA & NA & NA & NA & NA & NA & 1 & 0.0 & 4 & NA & NA & NA & 15E_4sid2X__1 & $6 / 11 \mathrm{C}$ & TDP-177 & 9150109 \\
\hline 24.7 & 0.999 & 0.01500 & 0.050 & 0.332 & 10.0 & $\mathrm{P}$ & NA & 6.06 & 6.17 & 6.23 & 6.40 & 5.80 & 10.50 & NA & NA & NA & NA & NA & NA & $\mathrm{I}$ & 0.0 & 4 & NA & NA & NA & 15E_4s1d2Xc_1 & 6/11c & TDP-177 & 9150110 \\
\hline 24.9 & 0.999 & 0.01500 & 0.050 & 0.332 & 9.4 & $\mathrm{P}$ & NA & 6.44 & 6.56 & 6.62 & 6.80 & 5.80 & 15.00 & NA & NA & NA & NA & NA & NA & $\mathrm{I}$ & NA & 4 & NA & NA & NA & 15E_4s1d2Xc_1 & 6/11c & TDP-177 & 9150111 \\
\hline 25.1 & 0.999 & 0.01500 & 0.050 & 0.334 & 9.0 & $\mathrm{P}$ & NA & 6.60 & 6.73 & 6.80 & 7.00 & 5.80 & 18.00 & NA & NA & NA & NA & NA & NA & 1 & 0.0 & 4 & NA & NA & NA & 15E_4sid2Xc 1 & 6/11c & TDP-17T & 9150112 \\
\hline 25.4 & 0.999 & 0.01500 & 0.050 & 0.333 & 111.0 & $\mathrm{P}$ & NA & 5.50 & 5.59 & 5.64 & 5.80 & 5.80 & NA & NA & NA & NA & NA & NA & NA & 1 & 15.4 & $\mathrm{n} / \mathrm{a}$ & NA & NA & NA & 15E_4sid2X__1 & $6 / 11 \mathrm{C}$ & TDP-177 & 9150113 \\
\hline 25.4 & 0.999 & 0.01500 & 0.050 & 0.333 & 11.0 & $\mathrm{P}$ & NA & 5.50 & 5.59 & 5.64 & 5.80 & 5.80 & NA & NA & NA & NA & NA & NA & NA & NA & 3.7 & NA & NA & NA & NA & 15E_4s1d2Xc_1 & 6/11c & TDP-177 & 9150115 \\
\hline 25.4 & 0.999 & 0.01500 & 0.050 & 0.333 & 11.0 & $\mathrm{P}$ & NA & 5.50 & 5.59 & 5.64 & 5.80 & 5.80 & NA & NA & NA & NA & NA & NA & NA & NA & 3.7 & NA & NA & NA & NA & 15E_4sId2X__1 & 6/11c & TDP-177 & 9150116 \\
\hline 25.4 & 0.999 & 0.01500 & 0.050 & 0.333 & 11.0 & $\mathrm{P}$ & NA & 5.50 & 5.59 & 5.64 & 5.80 & 5.80 & NA & NA & NA & NA & NA & NA & NA & NA & 3.7 & NA & NA & NA & NA & 15E_4sid $2 \times c_{1} 1$ & $6 / 11 \mathrm{C}$ & TDP-177 & 9150117 \\
\hline 25.4 & 0.999 & 0.01500 & 0.050 & 0.333 & 111.0 & $\mathrm{P}$ & NA & 5.50 & 5.59 & 5.64 & 5.80 & 5.80 & NA & NA & NA & NA & NA & NA & NA & NA & 3.7 & NA & NA & $\mathrm{NA}$ & NA & 15E_4sid2X___ & $6 / 11 \mathrm{C}$ & TDP-177 & 9150118 \\
\hline 25.4 & 0.999 & 0.01500 & 0.050 & 0.333 & 11.0 & $\mathrm{P}$ & NA & 5.50 & 5.59 & 5.64 & 5.80 & 5.80 & NA & NA & NA & NA & NA & NA & NA & NA & 0.0 & NA & NA & NA & NA & 15E_4sid2X__1 & $6 / 11 \mathrm{C}$ & TDP-177 & 9150119 \\
\hline 25.4 & 0.999 & 0.01500 & 0.050 & 0.333 & 11.0 & $\mathrm{P}$ & NA & 5.50 & 5.59 & 5.64 & 5.80 & 5.80 & NA & NA & NA & NA & NA & NA & NA & NA & 0.0 & NA & NA & NA & NA & 15E_4sid2Xc_1 & 6/11c & TDP-177 & 9150120 \\
\hline 25.4 & 0.999 & 0.01500 & 0.050 & 0.333 & 11.0 & $P$ & NA & 5.50 & 5.59 & 5.64 & 5.80 & 5.80 & NA & NA & NA & NA & NA & NA & NA & NA & 3.7 & NA & NA & NA & NA & $15 E_{4} \operatorname{sid} 12 \times \mathrm{c}_{1} 1$ & 6/11c & TDP-17 & 9150121 \\
\hline 25.4 & 0.999 & 0.01500 & 0.050 & 0.333 & 11.0 & $\mathrm{P}$ & NA & 5.50 & 5.60 & 5.64 & 5.80 & 5.80 & NA & NA & NA & NA & NA & NA & NA & NA & 0.0 & $\mathrm{na}$ & NA & NA & NA & 15E_4s1d2Xc_1 & 6/11c & TDP-177 & 9150122 \\
\hline 25.4 & 0.999 & 0.01500 & 0.050 & 0.333 & 111.0 & $\mathrm{P}$ & NA & 5.50 & 5.60 & 5.64 & 5.80 & 5.80 & NA & NA & NA & NA & NA & NA & NA & NA & 3.7 & NA & NA & NA & NA & 15E_4sid2X__1 & $6 / 11 \mathrm{C}$ & TDP-177 & 9150123 \\
\hline 25.4 & 0.999 & 0.01500 & 0.050 & 0.333 & 11.0 & $\mathrm{P}$ & NA & 5.50 & 5.60 & 5.64 & 5.80 & 5.80 & NA & NA & NA & NA & NA & NA & NA & NA & 0.0 & NA & NA & NA & NA & 15E_4sid2X__1 & $6 / 11 \mathrm{C}$ & TDP-177 & 9150124 \\
\hline 25.4 & 0.999 & 0.01500 & 0.050 & 0.333 & 11.0 & $\mathrm{P}$ & NA & 5.50 & 5.60 & 5.64 & 5.80 & 5.80 & NA & NA & NA & NA & NA & NA & NA & NA & 3.7 & NA & NA & NA & NA & 15E_4sid2X__1 & 6/11c & TDP-177 & 9150125 \\
\hline 25.4 & 0.999 & 0.01500 & 0.050 & 0.333 & 11.0 & $\mathrm{P}$ & NA & 5.50 & 5.60 & 5.64 & 5.80 & 5.80 & NA & NA & NA & NA & NA & NA & NA & NA & 3.7 & NA & NA & NA & NA & 15E_4sId2X__1 & 6/11c & TDP-177 & 9150126 \\
\hline 25.4 & 1.000 & 0.01500 & 0.050 & 0.333 & 11.0 & $\mathrm{P}$ & NA & 5.50 & 5.59 & 5.64 & 5.80 & 5.80 & NA & NA & NA & NA & NA & NA & NA & NA & 3.7 & NA & NA & NA & NA & 15E_4sid2X__1 & $6 / 11 \mathrm{C}$ & TDP-177 & 9150129 \\
\hline 25.4 & 0.999 & 0.01500 & 0.050 & 0.333 & 11.0 & $\mathrm{P}$ & NA & 5.50 & 5.59 & 5.64 & 5.80 & 5.80 & NA & NA & NA & NA & NA & NA & NA & NA & 3.7 & $\mathrm{Na}$ & NA & NA & NA & 15E_4sid2X__ 1 & $6 / 11 \mathrm{C}$ & TDP-177 & 9150130 \\
\hline 25.5 & 0.999 & 0.01500 & 0.050 & 0.332 & 11.0 & $\mathrm{P}$ & NA & 5.51 & 5.60 & 5.64 & 5.80 & 5.80 & NA & NA & NA & NA & NA & NA & NA & NA & 0.0 & $\mathrm{na}$ & NA & NA & NA & 15E_4sid2X__ 1 & 6/11c & TDP-177 & 9150131 \\
\hline 21.1 & 1.000 & 0.01500 & 0.050 & 0.661 & 9.0 & $\mathrm{P}$ & NA & 3.38 & 3.42 & 3.44 & 3.50 & 3.90 & 5.13 & NA & NA & NA & NA & NA & NA & (null) & 6.1 & 1 & NA & NA & NA & 15E_4s1d2Xe_1 & 6/12A & TDP-178 & 9150132 \\
\hline 21.1 & 1.000 & 0.01500 & 0.050 & 0.664 & 8.4 & $\mathrm{P}$ & NA & 3.57 & 3.61 & 3.63 & 3.70 & 3.90 & 6.25 & NA & NA & NA & NA & NA & NA & 1 & 2.5 & 1 & NA & NA & NA & 15E_4sid2Xe_1 & 6/12A & TDP-178 & 9150133 \\
\hline 21.4 & 1.000 & 0.01500 & 0.050 & $\begin{array}{ll}.6655 \\
\end{array}$ & 8.4 & $\mathrm{P}$ & NA & 3.57 & 3.61 & 3.63 & 3.70 & 3.90 & 6.25 & NA & NA & NA & NA & NA & NA & $\mathrm{D}$ & 3.8 & 1 & NA & NA & NA & 15E_4sid2Xe_1 & 6/12A & TDP-178 & 9150134 \\
\hline 21.3 & 1.000 & 0.01500 & 0.050 & 0.668 & 8.0 & $\mathrm{P}$ & NA & 3.75 & 3.79 & 3.82 & 3.90 & 3.90 & 7.50 & 3.90 & udv & Ucsis & NA & ucsudv & NA & $\mathrm{I}$ & 0.0 & 3 & NA & NA & NA & 15E_4sid2Xe_1 & 6/12A & TDP-178 & 9150135 \\
\hline 21.6 & 1.000 & 0.01500 & 0.050 & 0.660 & 7.6 & $\mathrm{P}$ & NA & 3.95 & 4.00 & 4.03 & 4.10 & 3.90 & 9.50 & NA & NA & NA & NA & NA & NA & 1 & 0.0 & 4 & NA & $\mathrm{NA}$ & NA & 15E_4sid2Xe_1 & 6/12A & TDP-178 & 9150136 \\
\hline 21.6 & 1.000 & 0.01500 & 0.050 & 0.665 & 7.0 & $\mathrm{P}$ & NA & 4.30 & 4.36 & 4.39 & 4.50 & 3.90 & 14.50 & NA & NA & NA & NA & NA & NA & 1 & 0.0 & 4 & NA & NA & NA & 15E_4sid2Xe_1 & 6/12A & TDP-178 & 9150137 \\
\hline 22.0 & 1.000 & 0.01500 & 0.050 & 0.667 & 8.0 & $\mathrm{P}$ & NA & 3.75 & 3.80 & 3.82 & 3.90 & 3.90 & 7.25 & NA & NA & NA & NA & NA & NA & NA & $\mathrm{na}$ & NA & NA & NA & NA & 15E_4sid2Xe_1 & 6/12A & TDP-178 & 9150137.1 \\
\hline 22.0 & 1.000 & 0.01500 & 0.050 & $\begin{array}{ll}0.667 \\
\end{array}$ & 8.0 & $P$ & NA & 3.75 & 3.80 & 3.82 & 3.90 & 3.90 & 7.25 & NA & NA & NA & NA & NA & NA & NA & $\mathrm{n} / \mathrm{a}$ & NA & NA & NA & NA & 15E_4sid2Xe_1 & 6/12A & TDP-178 & 9150137.2 \\
\hline 22.0 & 1.000 & 0.01500 & 0.050 & \begin{tabular}{l|l}
.667 \\
\end{tabular} & 8.0 & $\mathrm{P}$ & NA & 3.75 & 3.80 & 3.82 & 3.90 & 3.90 & 7.25 & NA & NA & NA & NA & NA & NA & NA & $\mathrm{n} / \mathrm{a}$ & NA & $\mathrm{NA}$ & NA & NA & 15E_4sId2Xe_1 & 6/12A & TDP-178 & 9150137.3 \\
\hline 22.0 & 1.000 & 0.01500 & 0.050 & 0.667 & 8.0 & $\mathrm{P}$ & NA & 3.75 & 3.80 & 3.82 & 3.90 & 3.90 & 7.25 & NA & NA & NA & NA & NA & NA & NA & $\mathrm{n} / \mathrm{a}$ & NA & NA & NA & NA & 15E_4sid2Xe_1 & 6/12A & TDP-178 & 9150137.4 \\
\hline 22.0 & 1.000 & 0.01500 & 0.050 & 0.667 & 8.0 & $\mathrm{P}$ & NA & 3.75 & 3.80 & 3.82 & 3.90 & 3.90 & 7.25 & NA & NA & NA & NA & NA & NA & NA & $\mathrm{n} / \mathrm{a}$ & NA & NA & NA & NA & 15E_4sid2Xe_1 & 6/12A & TDP-178 & 9150137.5 \\
\hline 22.0 & 1.000 & 0.01500 & 0.050 & 0.667 & 8.0 & $\mathrm{P}$ & NA & 3.75 & 3.80 & 3.82 & 3.90 & 3.90 & 7.25 & NA & NA & UcSis & NA & NA & NA & 1 & 0.0 & 3 & NA & NA & NA & 15E_4sid2Xe_1 & 6/12A & TDP-178 & 9150138 \\
\hline 22.0 & 1.000 & 0.01500 & 0.050 & $\begin{array}{ll}0.667 \\
\end{array}$ & 8.0 & $\mathrm{P}$ & NA & 3.75 & 3.80 & 3.82 & 3.90 & 3.90 & 7.25 & NA & NA & NA & NA & NA & NA & NA & 0.0 & NA & NA & NA & NA & 15E_4sid2Xe_1 & 6/12A & TDP-178 & 9150139 \\
\hline 22.0 & 1.000 & 0.01500 & 0.050 & 0.667 & 8.0 & $\mathrm{P}$ & NA & 3.75 & 3.80 & 3.82 & 3.90 & 3.90 & 7.25 & NA & NA & NA & NA & NA & NA & NA & $\mathrm{n} / \mathrm{a}$ & NA & NA & NA & NA & 15E_4sId2Xe_1 & 6/12A & TDP-178 & 9150139.1 \\
\hline 22.0 & 1.000 & 0.01500 & 0.050 & 0.667 & 8.0 & $\mathrm{P}$ & NA & 3.75 & 3.80 & 3.82 & 3.90 & 3.90 & 7.25 & NA & NA & NA & NA & NA & NA & NA & 0.0 & NA & NA & NA & NA & 15E_4sId2Xe_1 & 6/12A & TDP-178 & 9150140 \\
\hline 22.0 & 1.000 & 0.01500 & 0.050 & 0.667 & 8.0 & $\mathrm{P}$ & NA & 3.75 & 3.80 & 3.82 & 3.90 & 3.90 & 7.25 & NA & NA & NA & NA & NA & NA & NA & $\mathrm{na}$ & NA & NA & NA & NA & 15E_4sid2Xe_1 & $6 / 12 \mathrm{~A}$ & TDP-178 & 9150140.1 \\
\hline
\end{tabular}


Table B.3. Data from 2008 Tests in Small-Scale Vessel with Elliptical Head A.5

\begin{tabular}{|c|c|c|c|c|c|c|c|c|c|c|c|c|c|c|c|c|c|c|c|c|c|c|c|c|c|c|c|}
\hline $\begin{array}{l}\text { Row } \\
\text { Number }\end{array}$ & Test & Case ID & $\begin{array}{l}\text { Tank } \\
\text { Diameter }\end{array}$ & $\begin{array}{l}\text { Head } \\
\text { Shape }\end{array}$ & \begin{tabular}{|c} 
Dish \\
Height
\end{tabular} & $\begin{array}{l}\text { Dish } \\
\text { Volume }\end{array}$ & $\begin{array}{c}\text { Tank Fill } \\
\text { Height }\end{array}$ & $\begin{array}{l}\text { Return } \\
\text { Line } \\
\text { Height }\end{array}$ & $\begin{array}{l}\text { Nozzle } \\
\text { liner } \\
\text { Dineter } \\
\text { Dianter }\end{array}$ & $\begin{array}{l}\text { Nozzle } \\
\text { Stand-off } \\
\text { Distance }\end{array}$ & $\begin{array}{l}\text { Pulse Tube } \\
\text { Configuration }\end{array}$ & $\begin{array}{l}\text { Installed } \\
\text { Nozzles }\end{array}$ & $\begin{array}{l}\text { Outer } \\
\text { Nozzles } \\
\text { Operated }\end{array}$ & $\begin{array}{c}\text { Inner } \\
\text { Noveles } \\
\text { Operated }\end{array}$ & $\begin{array}{c}\text { Pulse Tube } \\
\text { Outer } \\
\text { Diameter }\end{array}$ & $\begin{array}{c}\text { Outer } \\
\text { PMM } \\
\text { Radius }\end{array}$ & $\begin{array}{c}\text { Inner PJM } \\
\text { Radius }\end{array}$ & $\begin{array}{c}\text { "FIO" Outer PJM } \\
\text { Impingement } \\
\text { Angle }\end{array}$ & $\begin{array}{l}\text { "FO" Inner PJM } \\
\text { Impingement Angle }\end{array}$ & $\begin{array}{l}\begin{array}{l}\text { Ratio Outer PJM } \\
\text { to Tank Radius }\end{array} \\
\end{array}$ & \begin{tabular}{|l}
$\begin{array}{c}\text { Ratio Inner PJM } \\
\text { to Tank Radius }\end{array}$ \\
\end{tabular} & Simulant & $\begin{array}{l}\text { Solids } \\
\text { Density }\end{array}$ & $\begin{array}{c}\text { Particle } \\
\text { Diameter d5 }\end{array}$ & \begin{tabular}{c|} 
Particle \\
Diameter d50
\end{tabular} & \begin{tabular}{c|c} 
Patricle \\
Diameter d95
\end{tabular} & $\begin{array}{c}\text { Void } \\
\text { Fraction }\end{array}$ \\
\hline text & text & text & in. & text & in. & in. ${ }^{3}$ & in. & in. & in. & in. & text & number & number & number & in. & in. & in. & deg & deg & nondim & nondim & text & $g / \mathrm{cm}^{3}$ & m & m & m & fraction \\
\hline MSS & MDDX & ID & $\mathrm{D}$ & $\mathrm{HS}$ & Hosh & $V_{\text {dish }}$ & $\mathrm{H}$ & Rn & $d$ & sod & PT & $\mathrm{N}$ & $\mathrm{Nb}$ & $\mathrm{N}$ & $\mathrm{PT}_{\alpha \mathrm{d}}$ & $\mathrm{Ro}_{\mathrm{o}}$ & $R$ & $\theta_{0}$ & $\theta_{1}$ & $\mathrm{Rd} d \mathrm{R}$ & $R / R$ & sxdx & $\rho_{s}$ & $d_{b}$ & $\mathrm{~d}_{60}$ & $d_{65}$ & $\mathrm{vf}$ \\
\hline 9150141 & $6 / 12 \mathrm{~A}$ & 15E_4sid2Xe_1 & $147 / 16$ & $E$ & 3.25 & 354.8 & 34344 & 30 & 0.226 & 0.189 & HLP.22 & 12 & 8 & 4 & 1.05 & 4.5 & 2.4 & 21.8 & 10.1 & 0.62 & 0.34 & s1d2 & 2.48 & 0.0000569 & 0.0000693 & 0.0000821 & 0.3750 \\
\hline 9150141.1 & 6/12A & $15 E \_4 s 1 d 2 X e \_1$ & $147 / 16$ & $E$ & 3.25 & 354.8 & 34344 & 30 & 0.126 & 0.189 & HLP-22 & 12 & 8 & 4 & 1.05 & 4.5 & 24 & 21.8 & 10.1 & 0.62 & 0.34 & s1d2 & 2.48 & 0.0000569 & 0.0000693 & 0.0000821 & 0.3750 \\
\hline 9150142 & 6/12A & 15E_4s1d2Xe_1 & $147 / 16$ & $E$ & 3.25 & 354.8 & 34344 & 30 & 0.126 & 0.189 & HLP-22 & 12 & 8 & 4 & 1.05 & 4.5 & 2.4 & 21.8 & 10.1 & 0.62 & 0.34 & s1d2 & 2.48 & 0.0000569 & $\begin{array}{ll}0.0000693 \\
\end{array}$ & 0.0000821 & 0.3750 \\
\hline 9150142.1 & 6/12A & 15E_4s1d2Xe_1 & $147 / 16$ & E & 3.25 & 354.8 & 34344 & 30 & 0.126 & 0.189 & HLP-22 & 12 & 8 & 4 & 1.05 & 4.5 & 24 & 21.8 & 10.1 & 0.62 & 0.34 & s1d2 & 248 & 0.0000569 & 0.0000693 & 0.0000821 & 0.3750 \\
\hline 9150143 & $612 \mathrm{~A}$ & 15E_4s1d2Xe_1 & $147 / 16$ & $E$ & 3.25 & 354.8 & 34344 & 30 & 0.126 & 0.189 & HLP-22 & 12 & 8 & 4 & 1.05 & 4.5 & 24 & 21.8 & 10.1 & 0.62 & 0.34 & s1d2 & 248 & 0.0000569 & 0.0000693 & 0.0000821 & 0.3750 \\
\hline 9150144 & $6 / 12 \mathrm{~B}$ & $15 E \_4 s 1 d 2 \times c \_2$ & $147 / 16$ & $E$ & 3.25 & 354.8 & 34344 & 30 & 0.126 & 0.189 & HLP-22 & 12 & 8 & 4 & 1.05 & 4.5 & 24 & 21.8 & 10.1 & 0.62 & 0.34 & s1d2 & 248 & 0.0000569 & . 0.0000693 & 0.0000821 & 0.3750 \\
\hline 9150145 & 6/128 & $15 \mathrm{1}$ _4s1d2X__2 & $147 / 16$ & $E$ & 3.25 & 354.8 & 34344 & 30 & 0.126 & 0.189 & HLP-22 & 12 & 8 & 4 & 1.05 & 4.5 & 24 & 21.8 & 10.1 & 0.62 & 0.34 & s1d2 & 2.48 & 0.0000569 & 0.0000693 & 0.0000821 & 0.3750 \\
\hline 9150146 & $6 / 12 \mathrm{~B}$ & $15 E \_4 s 1 d 2 \times c \_2$ & $147 / 16$ & $E$ & 3.25 & 354.8 & 34344 & 30 & 0.126 & 0.189 & HLP-22 & 12 & 8 & 4 & 1.05 & 4.5 & 24 & 21.8 & 10.1 & 0.62 & 0.34 & s1d2 & 2.48 & 0.0000569 & $\begin{array}{ll}0.00006933 \\
\end{array}$ & 0.0000821 & 0.3750 \\
\hline 9150147 & $6 / 12 \mathrm{~B}$ & $15 \mathrm{1}$ _4s1d2Xc_2 & $147 / 16$ & $E$ & 3.25 & 354.8 & 34344 & 30 & 0.126 & 0.189 & HLP-22 & 12 & 8 & 4 & 1.05 & 4.5 & 24 & 21.8 & 10.1 & 0.62 & 0.34 & s1d2 & 248 & 0.0000569 & 0.0000693 & 0.0000821 & 0.3750 \\
\hline 9150148 & $6 / 12 \mathrm{~B}$ & $15 E_{4} 4 \mathrm{~s} 1 \mathrm{~d} 2 \times \mathrm{C}_{2} 2$ & $147 / 16$ & $E$ & 3.25 & 354.8 & 34344 & 30 & 0.126 & 0.189 & HLP-22 & 12 & 8 & 4 & 1.05 & 4.5 & 24 & 21.8 & 10. & 0.62 & 0.34 & s1d2 & 2.48 & 0.0000569 & 0.0000693 & 0.0000821 & 0.3750 \\
\hline $9150149 \mathrm{M}$ & $6 / 12 \mathrm{~B}$ & $15 E$-4S1d2Xc 2 & $147 / 16$ & E & 3.25 & 354.8 & 3434 & 30 & 0.126 & 0.189 & HLP-22 & 12 & 8 & 4 & 1.05 & 4.5 & 24 & 21.8 & 10.1 & 0.62 & 0.34 & s1d2 & 248 & 0.0000569 & 0.0000693 & 0.0000821 & 0.3750 \\
\hline 9150150M & $6 / 12 \mathrm{~B}$ & $15 E_{4} 4 \mathrm{~s} 1 \mathrm{~d} 2 \times \mathrm{c}_{\mathrm{c} 2}$ & $147 / 16$ & E & 3.25 & $354.8 \mathrm{\gamma}$ & 34344 & 30 & 0.126 & 0.189 & HLP-22 & 12 & 8 & 4 & 1.05 & 4.5 & 24 & 21.8 & 10.1 & 0.62 & 0.34 & s1d2 & 248 & 0.0000569 & $\begin{array}{l}0.0000693 \\
\end{array}$ & 0.0000821 & 0.3750 \\
\hline 9150151 & $6 / 12 \mathrm{C}$ & 15E_4s1d2Xd_2 & $147 / 16$ & $E$ & 3.25 & 354.8 & 34344 & 30 & 0.126 & 0.189 & HLP-22 & 12 & 8 & 4 & 1.05 & 4.5 & 24 & 21.8 & 10.1 & 0.62 & 0.34 & s1d2 & 2.48 & 0.0000569 & 0.0000693 & 0.0000821 & 0.3750 \\
\hline $9150152 \mathrm{M}$ & $6 / 12 \mathrm{C}$ & 15E_4s1d2Xd_2 & $147 / 16$ & $E$ & 3.25 & 354.8 & $343 / 4$ & 30 & 0.126 & 0.189 & HLP-22 & 12 & 8 & 4 & 105 & 4.5 & 24 & 218 & 10.1 & 0.62 & 0.34 & s1d2 & 248 & 0.0000569 & 0.0000693 & 0.0000821 & 0.3750 \\
\hline $9150153 \mathrm{M}$ & $6 / 12 c$ & $15 \mathrm{E}$-4s $1 \mathrm{~d} 2 \mathrm{2} \mathrm{d} \mathrm{d} 2$ & 147716 & $E$ & 3.25 & 354.8 & 34344 & 30 & 0.126 & 0.189 & HLP-22 & 12 & 8 & 4 & 1.05 & 4.5 & 24 & 21.8 & 10.1 & 0.62 & 0.34 & s1d2 & 2.48 & 0.0000569 & 0.0000693 & 0.0000821 & 0.3750 \\
\hline 9150154 & $6 / 12 \mathrm{D}$ & 15E_4s1d2Xe_2 & 147116 & $E$ & 3.25 & 354.8 & 34344 & 30 & 0.126 & 0.189 & HLP-22 & 12 & 8 & 4 & 1.05 & 4.5 & 24 & 21.8 & 10.1 & 0.62 & 0.34 & $\mathrm{~s} 1 \mathrm{~d} 2$ & 2.48 & 0.0000569 & 0.0000693 & 0.0000821 & 0.3750 \\
\hline $9150155 \mathrm{M}$ & $6 / 12 \mathrm{D}$ & $15 E_{4} 4 \mathrm{~s} 1 \mathrm{~d} 2 \mathrm{X} \mathrm{Z}_{2} 2$ & 147716 & $E$ & 3.25 & 354.8 & 34344 & 30 & 0.126 & 0.189 & HLP-22 & 12 & 8 & 4 & 1.05 & 4.5 & 24 & 21.8 & 10.1 & 0.62 & 0.34 & s1d2 & 2.48 & 0.0000569 & 0.0000693 & 0.0000821 & 0.3750 \\
\hline $915015 \mathrm{~cm}$ & 6/12D & 15E_4s1d2Xe_2 & $147 / 16$ & $E$ & 3.25 & 354.8 & 34344 & 30 & 0.126 & 0.189 & HLP-22 & 12 & 8 & 4 & 1.05 & 4.5 & 24 & 21.8 & 10. & 0.62 & 0.34 & s1d2 & 2.48 & 0.0000569 & 0.0000693 & 0.0000821 & 0.3750 \\
\hline 9150157 & 6/12E & $15 \mathrm{E}_{4} 4 \mathrm{~s} 1 \mathrm{~d} 2 \mathrm{C}_{\mathrm{C}} 4$ & $147 / 16$ & $E$ & 3.25 & 354.8 & $343 / 4$ & 30 & 0.126 & 0.189 & HLP-22 & 12 & 8 & 4 & 1.05 & 4.5 & 24 & 21.8 & 10.1 & 0.62 & 0.34 & $\mathrm{~s} 1 \mathrm{~d} 2$ & 248 & 0.0000569 & 0.0000693 & 0.0000821 & 0.3750 \\
\hline $9150158 \mathrm{M}$ & 6/12E & $15 \mathrm{15}$ _4s1d2Xc_4 & $147 / 16$ & $E$ & 3.25 & 354.8 & $343 / 4$ & 30 & 0.126 & 0.189 & HLP-22 & 12 & 8 & 4 & 1.05 & 4.5 & 24 & 21.8 & 10.1 & 0.62 & 0.34 & s1d2 & 2.48 & 0.0000569 & 0.0000693 & 0.0000821 & 0.3750 \\
\hline $9150159 \mathrm{M}$ & 6/12E & $15 \mathrm{E}_{4} 4 \mathrm{~s} 1 \mathrm{~d} 2 \mathrm{C}_{\mathrm{C}} 4$ & $147 / 16$ & $E$ & 3.25 & 354.8 & $343 / 4$ & 30 & 0.126 & 0.189 & HLP-22 & 12 & 8 & 4 & 1.05 & 4.5 & 2.4 & 21.8 & 10.1 & 0.62 & 0.34 & s1d2 & 248 & 0.0000569 & 0.0000693 & 0.0000821 & 0.3750 \\
\hline 9150160 & 6/13A & 15E_4s1d2Xd_4 & $147 / 16$ & $E$ & 3.25 & 354.8 & 35 & 30 & 0.126 & 0.189 & HLP-22 & 12 & 8 & 4 & 1.05 & 4.5 & 24 & 21.8 & 10.1 & 0.62 & 0.34 & s1d2 & 2.48 & 0.0000569 & 0.0000693 & 0.0000821 & 0.3750 \\
\hline $9150161 \mathrm{M}$ & 613A & 15E_4s1d2Xd_4 4 & $147 / 16$ & $\mathrm{E}$ & 3.25 & 354.8 & 35 & 30 & 0.126 & 0.189 & HLP.22 & 12 & 8 & 4 & 1.05 & 4.5 & 24 & 21.8 & 10. & 0.62 & 0.34 & s1d2 & 2.48 & 0.0000569 & 0.0000693 & 0.0000821 & 0.3750 \\
\hline $9150162 \mathrm{M}$ & 6/13A & 15E_4s1d2Xd_4 & 147716 & $E$ & 3.25 & 354.8 & 35 & 30 & 0.126 & 0.189 & HLP-22 & 12 & 8 & 4 & 1.05 & 4.5 & 24 & 21.8 & 10.1 & 0.62 & 0.34 & s1d2 & 2.48 & 0.0000569 & 0.0000693 & 0.0000821 & 0.3750 \\
\hline 9150163 & 6/13B & 15E_4s1d2Xe_4 & $147 / 16$ & $E$ & 3.25 & 354.8 & 35 & 30 & 0.126 & 0.189 & HLP-22 & 12 & 8 & 4 & 1.05 & 4.5 & 24 & 21.8 & 10.1 & 0.62 & 0.34 & s1d2 & 248 & 0.0000569 & 0.0000693 & 0.0000821 & 0.3750 \\
\hline 9150164 & 6/138 & 15E_4s1d2Xe_4 4 & $147 / 16$ & $E$ & 3.25 & 354.8 & 35 & 30 & 0.126 & 0.189 & HLP-22 & 12 & 8 & 4 & 1.05 & 4.5 & 24 & 21.8 & 10.1 & 0.62 & 0.34 & s1d2 & 248 & 0.0000569 & 0.0000693 & 0.0000821 & 0.3750 \\
\hline $9150165 \mathrm{M}$ & 6/13B & $15 E \_4 s 1 d 2 \times e \_4$ & $147 / 16$ & $E$ & 3.25 & 354.8 & 35 & 30 & 0.126 & 0.189 & HLP-22 & 12 & 8 & 4 & 1.0 & 4.5 & 24 & 21.8 & 10.1 & 0.62 & 0.34 & s1d2 & 2.48 & 0.0000569 & 0.0000693 & 0.0000821 & 0.3750 \\
\hline $9150166 \mathrm{M}$ & 6/13B & 15E_4s1d2Xe_4 4 & $147 / 16$ & $E$ & 3.25 & 354.8 & 35 & 30 & 0.126 & 0.189 & HLP-22 & 12 & 8 & 4 & 1.05 & 4.5 & 24 & 21.8 & 10.1 & 0.62 & 0.34 & s1d2 & 2.48 & 0.0000569 & 0.0000693 & 0.0000821 & 0.3750 \\
\hline 9150167 & $6 / 13 c$ & 15E_4s1d2Xd_1 & 147116 & $\mathrm{E}$ & 3.25 & 354.8 & 35 & 30 & 0.126 & 0.189 & HLP-22 & 12 & 8 & 4 & 1.05 & 4.5 & 24 & 21.8 & 10.1 & 0.62 & 0.34 & $\mathrm{sid2}$ & 2.48 & 0.0000569 & 0.0000693 & 0.0000821 & 0.3750 \\
\hline 9150168 & 6/13c & 15E_4s1d2Xd_1 & $147 / 16$ & $E$ & 3.25 & 354.8 & 35 & 30 & 0.126 & 0.189 & HLP-22 & 12 & 8 & 4 & 1.05 & 4.5 & 24 & 21.8 & 10.1 & 0.62 & 0.34 & s1d2 & 2.48 & 0.0000569 & 0.0000693 & 0.0000821 & 0.3750 \\
\hline 9150169 & $6 / 13 \mathrm{C}$ & 15E_4s1d2Xd 1 & $147 / 16$ & $E$ & 3.25 & 354.8 & 35 & 30 & 0.126 & 0.189 & HLP-22 & 12 & 8 & 4 & 1.05 & 4.5 & 24 & 21.8 & 10.1 & 0.62 & 0.34 & s1d2 & 2.48 & 0.0000569 & 0.0000693 & 0.0000821 & 0.3750 \\
\hline 9150170 & $6 / 13 c$ & 15E_4s1d2Xd_1 1 & $147 / 16$ & $E$ & 3.25 & 354.8 & 35 & 30 & 0.126 & 0.189 & HLP-22 & 12 & 8 & 4 & 1.05 & 4.5 & 24 & 21.8 & 10.1 & 0.62 & 0.34 & $\mathrm{~s} 1 \mathrm{~d} 2$ & 2.48 & 0.0000569 & 0.0000693 & 0.0000821 & 0.3750 \\
\hline 9150171 & $6 / 13 \mathrm{C}$ & 15E_4s1d2Xd_1 & 147116 & $E$ & 3.25 & 354.8 & 35 & 30 & 0.126 & 0.189 & HLP 22 & 12 & 8 & 4 & 1.05 & 4.5 & 24 & 21.8 & 10.1 & 0.62 & 0.34 & $\mathrm{sid2}$ & 2.48 & 0.0000569 & 0.0000693 & 0.0000821 & 0.3750 \\
\hline 9150172 & $6 / 13 \mathrm{C}$ & 15E_4s1d2Xd_1 & $147 / 16$ & $E$ & 3.25 & 354.8 & 35 & 30 & 0.126 & 0.189 & HLP-22 & 12 & 8 & 4 & 1.05 & 4.5 & 24 & 21.8 & 10.1 & 0.62 & 0.34 & $\mathrm{~s} 1 \mathrm{~d} 2$ & 2.48 & 0.0000569 & 0.0000693 & 0.0000821 & 0.3750 \\
\hline 9150173 & 6/13C & 15E_4s1d2Xd_1 & $147 / 16$ & $E$ & 3.25 & 354.8 & 35 & 30 & 0.126 & 0.189 & HLP-22 & 12 & 8 & 4 & 1.05 & 4.5 & 24 & 21.8 & 10.1 & 0.62 & 0.34 & $\mathrm{~s} 1 \mathrm{~d} 2$ & 2.48 & 0.0000569 & 0.0000693 & 0.0000821 & 0.3750 \\
\hline $9150174 \mathrm{M}$ & $6 / 13 \mathrm{C}$ & 15E_4s1d2Xd_1 & 147716 & $E$ & 3.25 & 354.8 & 35 & 30 & 0.126 & 0.189 & HLP-22 & 12 & 8 & 4 & 1.05 & 4.5 & 24 & 21.8 & 10.1 & 0.62 & 0.34 & $\mathrm{~s} 1 \mathrm{~d} 2$ & 2.48 & 0.0000569 & 0.0000693 & 0.0000821 & 0.3750 \\
\hline $9150175 \mathrm{M}$ & $6 / 13 \mathrm{C}$ & 15E_4s1d2Xd 11 & $147 / 16$ & $E$ & 3.25 & 354.8 & 35 & 30 & 0.126 & 0.189 & HLP 22 & 12 & 8 & 4 & 1.05 & 4.5 & 24 & 21.8 & 10.1 & 0.62 & 0.34 & $\mathrm{sid} 2$ & 2.48 & 0.0000569 & 0.0000693 & 0.0000821 & 0.3750 \\
\hline $9150176 \mathrm{M}$ & $6 / 13 \mathrm{C}$ & 15E_4s1d2Xd_1 & $147 / 16$ & $\mathrm{E}$ & 3.25 & 354.8 & 35 & 30 & 0.126 & 0.189 & HLP-22 & 12 & 8 & 4 & 1.05 & 4.5 & 24 & 21.8 & 10.1 & 0.62 & 0.34 & $\mathrm{sid2}$ & 2.48 & 0.0000569 & 0.0000693 & 0.0000821 & 0.3750 \\
\hline $915017 \mathrm{mM}$ & $6 / 13 \mathrm{C}$ & 15E_4s1d2Xd_1 & $147 / 16$ & $E$ & 3.25 & 354.8 & 35 & 30 & 0.126 & 0.189 & & 12 & 8 & 4 & & 4.5 & 2.4 & $211>>0$ & & & & & & & & & \\
\hline $9150178 \mathrm{M}$ & 6/13c & 15E_4sid2Xd_1 1 & $147 / 16$ & $E$ & 3.25 & 354.8 & 35 & 30 & 0.126 & 0.189 & HLP-22 & 12 & 8 & 4 & 1.05 & 4.5 & 24 & 21.8 & 10.1 & 0.62 & 0.34 & s1d2 & 2.48 & $\begin{array}{l}0.0000569 \\
\end{array}$ & \begin{tabular}{|c|}
0.0000693 \\
\end{tabular} & 0.0000821 & 0.3750 \\
\hline $9150179 \mathrm{M}$ & 6/13c & 15E 4sid2Xd 1 & $147 / 16$ & $E$ & 3.25 & 354.8 & 35 & 30 & 0.126 & 0.189 & HLP-22 & 12 & 8 & 4 & 1.05 & 4.5 & 24 & 21.8 & 10.1 & 0.62 & 0.34 & $\mathrm{sid2}$ & 2.48 & 0.0000569 & 0.0000693 & 0.0000821 & 0.3750 \\
\hline
\end{tabular}


Table B.3. Data from 2008 Tests in Small-Scale Vessel with Elliptical Head B.5

\begin{tabular}{|c|c|c|c|c|c|c|c|c|c|c|c|c|c|c|c|c|c|c|c|c|c|c|c|c|c|c|c|c|c|}
\hline $\begin{array}{l}\text { Tank Water } \\
\text { Temperature }\end{array}$ & $\begin{array}{l}\text { Water } \\
\text { Density }\end{array}$ & $\begin{array}{l}\text { Solids } \\
\text { Fraction }\end{array}$ & $\begin{array}{c}\text { Pulse } \\
\text { Volume } \\
\text { Fraction }\end{array}$ & $\begin{array}{l}\text { Duty } \\
\text { Cycle }\end{array}$ & $\begin{array}{c}\text { Cycle } \\
\text { Time }\end{array}$ & $\begin{array}{c}\text { Pulsed } \\
\text { or } \\
\text { Steady } \\
\text { Jet } \\
\end{array}$ & $\begin{array}{l}\text { Us } \\
\text { Steady } \\
\text { Jet }\end{array}$ & $\begin{array}{l}\text { O1 } \\
\text { Pulsing } \\
\text { Jet }\end{array}$ & \begin{tabular}{|c|} 
UR \\
URNS \\
\end{tabular} & $\begin{array}{c}\text { U3 } \\
\text { URNB } \\
\end{array}$ & \begin{tabular}{|c|} 
Discharge \\
Velocity \\
\end{tabular} & $\begin{array}{c}\text { Citical } \\
\text { Suspension } \\
\text { Velocity }\end{array}$ & $\begin{array}{c}\text { Average } \\
\text { Peak Coud } \\
\text { Height } \\
\end{array}$ & \begin{tabular}{|c} 
UCS \\
Condition \\
\end{tabular} & $\begin{array}{c}\text { UCS } \\
\text { Method }\end{array}$ & $\begin{array}{l}\text { UCS } \\
\text { Hag }\end{array}$ & $\begin{array}{c}\text { ucs } \\
\text { Center } \\
\text { Flag }\end{array}$ & $\begin{array}{c}\text { ucs udv } \\
\text { Fag } \\
\end{array}$ & \begin{tabular}{|c|} 
UCS based \\
on \\
Decreasing \\
Velocity \\
\end{tabular} & $\begin{array}{l}\text { Sweep } \\
\text { Increase/ } \\
\text { Decrease }\end{array}$ & \begin{tabular}{|c|} 
UDV \\
Height \\
Bed \\
\end{tabular} & $\begin{array}{c}\text { Patride } \\
\text { Motion }\end{array}$ & $\begin{array}{l}\text { Solids } \\
\text { Level }\end{array}$ & \begin{tabular}{|l} 
Outer \\
Bototom \\
Pattem \\
\end{tabular} & \begin{tabular}{|l|} 
Inner \\
Bototom \\
Pattem \\
\end{tabular} & Case ID & Test & TDP & $\begin{array}{l}\text { Row } \\
\text { Number }\end{array}$ \\
\hline $\mathrm{C}$ & $\mathrm{g} / \mathrm{cm}^{3}$ & fraction & fraction & fraction & $\mathrm{s}$ & text & $\mathrm{m} / \mathrm{s}$ & $\mathrm{m} / \mathrm{s}$ & m/s & $\mathrm{m} / \mathrm{s}$ & $\mathrm{m} / \mathrm{s}$ & $\mathrm{m} / \mathrm{s}$ & in. & m/s & text & text & text & \begin{tabular}{|l|} 
text \\
\end{tabular} & m/s & text & $\mathrm{mm}$ & text & text & text & text & text & text & text & text \\
\hline $\mathrm{T}$ & $\rho$ & $\phi_{\mathrm{s}}$ & $\phi_{p}$ & $D C$ & $t_{c}$ & Jet & $u_{s}$ & $\mathrm{U}_{1}$ & $\mathrm{U} 2$ & U3 & $u$ & Uss & $\mathrm{H}_{c}$ & USSR & Uasn & Unsis & Uscen & Usuldv & Uos_D & $\mathrm{S}_{\mathrm{w}}$ & $\mathrm{H}_{\text {bed }}$ & $\mathrm{PM}$ & sol & $\mathrm{SPo}$ & $\mathrm{SP}_{1}$ & $\mathrm{ID}$ & MDDX & IDP & MSS \\
\hline 22.0 & 1.000 & 0.01500 & 0.050 & 0.667 & 8.0 & $\mathrm{P}$ & NA & 3.75 & 3.80 & 3.82 & 3.90 & 3.90 & 7.25 & NA & NA & NA & NA & NA & NA & NA & 0.0 & NA & NA & NA & NA & 15E_4sid2Xe_1 & 6/12A & TDP-178 & 9150141 \\
\hline 22.0 & 1.000 & 0.01500 & 0.050 & 0.667 & 8.0 & $\mathrm{P}$ & NA & 3.75 & 3.80 & 3.82 & 3.90 & 3.90 & 7.25 & NA & NA & NA & NA & NA & NA & NA & na & NA & NA & NA & NA & 15E_4sidd2Xe 1 & $6 / 12 \mathrm{~A}$ & TDP-178 & 9150141.1 \\
\hline 22.0 & 1.000 & 0.01500 & 0.050 & 0.667 & 8.0 & $\mathrm{P}$ & NA & 3.75 & 3.80 & 3.82 & 3.90 & 3.90 & 7.25 & NA & NA & NA & NA & NA & NA & NA & 17.6 & NA & NA & NA & NA & 15E_4sid2Xe_1 & $6 / 12 A$ & TDP-178 & 9150142 \\
\hline 22.0 & 1.000 & 0.01500 & 0.050 & 0.667 & 8.0 & $\mathrm{P}$ & NA & 3.75 & 3.80 & 3.82 & 3.90 & 3.90 & 7.25 & NA & NA & NA & NA & NA & NA & NA & $n / a$ & NA & NA & NA & NA & 15E_4sid2Xe_1 & 6/12A & TDP-178 & 9150142.1 \\
\hline 22.0 & 1.000 & 0.01500 & 0.050 & 0.667 & 8.0 & $\mathrm{P}$ & NA & 3.75 & 3.80 & 3.82 & 3.90 & 3.90 & 7.25 & NA & NA & NA & NA & NA & NA & NA & 3.7 & NA & NA & NA & NA & 15E_4sid2Xe_1 & $6 / 12 \mathrm{~A}$ & TDP-178 & 9150143 \\
\hline 22.6 & 1.000 & 0.01500 & 0.100 & 0.329 & 32.2 & $\mathrm{P}$ & NA & 3.80 & 3.82 & 3.83 & 3.90 & 5.00 & NA & NA & NA & NA & NA & NA & NA & 1 & 11.0 & 1 & NA & NA & NA & 15E_4s1d2Xc_ 2 & $6 / 128$ & TDP-178 & 9150144 \\
\hline 22.8 & 0.999 & 0.01500 & 0.101 & 0.330 & 29.6 & $\mathrm{P}$ & NA & 4.12 & 4.14 & 4.16 & 4.20 & 5.00 & NA & NA & NA & NA & NA & NA & NA & 1 & 4.3 & 1 & NA & NA & NA & 15E_4sid2Xc_2 & $6 / 12 B$ & TDP-178 & 9150145 \\
\hline 23.0 & 0.999 & 0.01500 & 0.100 & 0.332 & 27.0 & $\mathrm{P}$ & NA & 4.49 & 4.52 & 4.54 & 4.60 & 5.00 & NA & NA & NA & NA & NA & NA & NA & 1 & 4.0 & 1 & NA & NA & NA & 15E_4sid2Xc_2 & $6 / 128$ & TDP-178 & 9150147 \\
\hline 23.1 & 1.000 & 0.01500 & 0.101 & 0.332 & 25.8 & $\mathrm{P}$ & NA & 4.70 & 4.73 & 4.75 & 4.80 & 5.00 & 6.00 & NA & NA & ucsis & NA & NA & NA & 1 & 2.8 & 3 & NA & NA & NA & 15E_4sid $2 X \mathrm{C} \_2$ & 6/12B & TDP-178 & 9150148 \\
\hline 23.3 & 1.000 & 0.01500 & 0.101 & 0.333 & 24.8 & $\mathrm{P}$ & NA & 4.88 & 4.92 & 4.94 & 5.00 & 5.00 & 6.75 & \begin{tabular}{|l|} 
\\
\end{tabular} & NA & NA & NA & ucsudv & NA & 1 & 0.0 & 4 & NA & NA & NA & 15E_4s1d2Xc_ 2 & $6 / 128$ & TDP-178 & 9150149 \\
\hline 23.4 & 1.000 & 0.01500 & 0.101 & 0.334 & 23.8 & $\mathrm{P}$ & NA & 5.07 & 5.11 & 5.13 & 5.20 & 5.00 & 7.25 & NA & NA & NA & NA & NA & NA & 1 & 0.0 & 4 & NA & NA & NA & 15E_4s1d $2 X \mathrm{C} \_2$ & 6/12B & TDP-178 & 9150150 \\
\hline 24.3 & 0.999 & 0.01500 & 0.100 & 0.178 & 48.0 & $\mathrm{P}$ & NA & 4.68 & 4.71 & 4.73 & 4.80 & 5.00 & 5.75 & NA & NA & NA & NA & NA & NA & D & 3.7 & 1 & NA & NA & NA & 15E_4sid2Xd_2 & $6 / 12 \mathrm{C}$ & TDP-178 & 9150151 \\
\hline 24.5 & 0.999 & 0.01500 & 0.100 & 0.179 & 46.0 & $\mathrm{P}$ & NA & 4.88 & 4.92 & 4.94 & 5.00 & 5.00 & 6.00 & 5.00 & NA & ucsis & NA & ucsudv & NA & 1 & 0.7 & 3 & NA & NA & NA & 15E_4sid2Xd_2 & $6 / 12 \mathrm{C}$ & TDP-178 & 9150152 \\
\hline 24.6 & 0.999 & 0.01500 & 0.100 & 0.179 & 44.2 & $\mathrm{P}$ & NA & 5.07 & 5.11 & 5.13 & 5.20 & 5.00 & 6.25 & NA & NA & NA & NA & NA & NA & $\mathrm{I}$ & 0.0 & 4 & NA & NA & NA & 15E_4sid2Xd_2 & $6 / 12 \mathrm{C}$ & TDP-178 & 9150153 \\
\hline 24.9 & 0.999 & 0.01500 & 0.100 & 0.657 & 18.0 & $\mathrm{P}$ & NA & 3.40 & 3.41 & 3.42 & 3.50 & 3.70 & 5.00 & NA & NA & NA & NA & NA & NA & $\mathrm{I}$ & 3.8 & 1 & NA & $\mathrm{NA}$ & NA & 15E_4sid2Xe_2 & $6 / 12 \mathrm{D}$ & TDP-178 & 9150154 \\
\hline 25.1 & 0.999 & 0.01500 & 0.100 & 0.659 & 16.8 & $\mathrm{P}$ & NA & 3.63 & 3.65 & 3.66 & 3.70 & 3.70 & 6.25 & \begin{tabular}{|l|}
3.70 \\
\end{tabular} & udv & Ucsis & NA & ucsudv & NA & 1 & 0.6 & 3 & NA & NA & NA & 15E_4sid $2 X e \_2$ & 6/12D & TDP-178 & 9150155 \\
\hline 25.3 & 0.999 & 0.01500 & 0.100 & 0.660 & 15.8 & $\mathrm{P}$ & NA & 3.82 & 3.85 & 3.86 & 3.90 & 3.70 & 7.25 & NA & NA & NA & NA & NA & NA & 1 & 0.0 & 4 & NA & NA & NA & 15E_4sid2Xe_2 & 6/12D & TDP-178 & 9150156 \\
\hline 25.5 & 0.999 & 0.01500 & 0.149 & 0.324 & 50.6 & $\mathrm{P}$ & NA & 3.64 & 3.65 & 3.66 & 3.70 & 3.90 & 4.75 & NA & NA & NA & NA & NA & NA & $\mathrm{D}$ & 4.1 & 1 & NA & NA & NA & 15E_4sid2X___4 & 6/12E & TDP-178 & 9150157 \\
\hline 25.7 & 0.999 & 0.01500 & 0.150 & 0.325 & 48.0 & $\mathrm{P}$ & NA & 3.85 & 3.87 & 3.87 & 3.90 & 3.90 & 5.00 & 3.90 & udv & ucsis & NA & ucsudv & NA & 1 & 2.9 & 3 & NA & NA & NA & 15E_4sid2X__4 & $6112 \mathrm{E}$ & TDP-178 & 9150158 \\
\hline 23.2 & 0.999 & 0.01500 & 0.151 & 0.182 & 90.6 & $\mathrm{P}$ & NA & 3.66 & 3.67 & 3.68 & 3.70 & 3.90 & 4.75 & NA & NA & NA & NA & NA & NA & (null) & 3.7 & 1 & NA & NA & NA & 15E_4sid2Xd_4 & $6 / 13 \mathrm{~A}$ & TDP-179 & 9150160 \\
\hline 23.5 & 0.999 & 0.01500 & 0.151 & 0.182 & 86.0 & $\mathrm{P}$ & NA & 3.85 & 3.86 & 3.87 & 3.90 & 3.90 & 5.00 & \begin{tabular}{|l|}
3.90 \\
\end{tabular} & udv & ucsis & NA & ucsudv & NA & 1 & 2.2 & 3 & NA & NA & NA & 15E_4sid2Xd_4 & 6/13A & TDP-179 & 9150161 \\
\hline 23.7 & 0.999 & 0.01500 & 0.151 & 0.183 & 81.8 & $\mathrm{P}$ & NA & 4.04 & 4.06 & 4.07 & 4.10 & 3.90 & 5.50 & NA & NA & NA & NA & NA & NA & 1 & 0.0 & 4 & NA & NA & NA & 15E_4sid2Xd_4 & 6/13A & TDP-179 & 9150162 \\
\hline 24.4 & 0.999 & 0.01500 & 0.151 & 0.663 & 28.8 & $\mathrm{P}$ & NA & 3.16 & 3.17 & 3.17 & 3.20 & 3.50 & 4.25 & NA & NA & NA & NA & NA & NA & 1 & 5.3 & 1 & NA & NA & NA & 15E_4sid2Xe_4 & $6 / 138$ & TDP-179 & 9150163 \\
\hline 24.6 & 0.999 & 0.01500 & 0.151 & 0.664 & 27.2 & $\mathrm{P}$ & NA & 3.35 & 3.37 & 3.37 & 3.40 & 3.50 & 5.25 & NA & NA & NA & NA & NA & NA & 1 & 2.9 & 1 & NA & NA & NA & 15E_4sid2Xe 4 & $6 / 13 B$ & TDP-179 & 9150164 \\
\hline 24.9 & 0.999 & 0.01500 & 0.151 & 0.664 & 26.4 & $\mathrm{P}$ & NA & 3.45 & 3.46 & 3.47 & 3.50 & 3.50 & 5.75 & \begin{tabular}{|l|}
3.50 \\
\end{tabular} & udv & Ucsis & NA & ucsudv & NA & 1 & 2.2 & 3 & NA & NA & NA & 15E_4sid2Xe_4 & $6 / 13 B$ & TDP-179 & 9150165 \\
\hline 25.1 & 0.999 & 0.01500 & 0.151 & 0.665 & 24.8 & $\mathrm{P}$ & NA & 3.66 & 3.67 & 3.68 & 3.70 & 3.50 & 6.50 & NA & NA & NA & NA & NA & NA & 1 & 0.0 & 4 & NA & NA & NA & 15E_4sid2Xe_4 & 6/13B & TDP-179 & 9150166 \\
\hline 25.6 & 0.999 & 0.01500 & 0.050 & 0.175 & 26.0 & $\mathrm{P}$ & NA & 4.38 & 4.44 & 4.47 & 4.60 & 7.40 & 3.38 & NA & NA & NA & NA & NA & NA & (null) & 15.2 & 1 & NA & NA & NA & 15E_4sid2Xd_1 & $6 / 13 c$ & TDP-179 & 9150167 \\
\hline 26.0 & 0.999 & 0.01500 & 0.050 & 0.181 & 19.0 & $\mathrm{P}$ & NA & 5.84 & 5.96 & 6.01 & 6.20 & 7.40 & 4.75 & NA & NA & NA & NA & NA & NA & 1 & 5.8 & 1 & NA & NA & NA & 15E_4sid2Xd_1 & $6 / 13 \mathrm{C}$ & TDP-179 & 9150168 \\
\hline 26.2 & 0.999 & 0.01500 & 0.050 & 0.182 & 18.4 & $\mathrm{P}$ & NA & 6.00 & 6.13 & 6.19 & 6.40 & 7.40 & 4.75 & NA & NA & NA & NA & NA & NA & $\mathrm{I}$ & 5.1 & 1 & NA & NA & NA & 15E_4sid2Xd_1 & $6013 \mathrm{C}$ & \begin{tabular}{|l|l|} 
TDP-179 \\
\end{tabular} & 9150169 \\
\hline 26.4 & 0.999 & 0.01500 & 0.050 & 0.183 & 17.6 & $\mathrm{P}$ & NA & 6.20 & 6.33 & 6.40 & 6.60 & 7.40 & 5.00 & NA & NA & NA & NA & NA & NA & 1 & 3.7 & 1 & NA & NA & NA & 15E_4sid2Xd_1 & $6 / 13 \mathrm{C}$ & TDP-179 & 9150170 \\
\hline 26.6 & 0.999 & 0.01500 & 0.050 & 0.184 & 17.0 & $\mathrm{P}$ & NA & 6.38 & 6.53 & 6.59 & 6.80 & 7.40 & 5.25 & NA & NA & NA & NA & NA & NA & 1 & 4.0 & 1 & NA & NA & NA & 15E_4sid2Xd_1 & $6 / 13 c$ & TDP-179 & 9150171 \\
\hline 26.9 & 0.999 & 0.01500 & 0.050 & 0.185 & 16.6 & $\mathrm{P}$ & NA & 6.57 & 6.72 & 6.79 & 7.00 & 7.40 & 5.50 & NA & NA & Ucsis & NA & NA & NA & 1 & 3.7 & 3 & NA & NA & NA & 15E_4sId2X__1 1 & $6 / 13 \mathrm{C}$ & TDP-179 & 9150172 \\
\hline 27.0 & 0.999 & 0.01500 & 0.050 & 0.186 & 16.0 & $\mathrm{P}$ & NA & 6.73 & 6.89 & 6.97 & 7.20 & 7.40 & 5.50 & NA & NA & NA & NA & NA & NA & 1 & 3.7 & 4 & NA & NA & NA & 15E_4sid2Xd_1 & $6 / 13 \mathrm{C}$ & TDP-179 & 9150173 \\
\hline 27.8 & 0.998 & 0.01500 & 0.050 & 0.186 & 15.6 & $\mathrm{P}$ & NA & 6.92 & 7.09 & 7.17 & 7.40 & 7.40 & 5.50 & 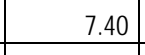 & udv & NA & NA & ucsudv & NA & $\mathrm{I}$ & 0.7 & 4 & NA & NA & NA & 15E_4sid2Xd_1 & $6 / 13 \mathrm{C}$ & TDP-179 & 9150174 \\
\hline 28.1 & 0.998 & 0.01500 & 0.050 & 0.187 & 15.2 & $\mathrm{P}$ & NA & 7.09 & 7.27 & 7.35 & 7.60 & 7.40 & 5.75 & NA & NA & NA & NA & NA & NA & 1 & 0.0 & 4 & NA & NA & NA & 15E_4sid2Xd_1 & $6 / 13 \mathrm{C}$ & TDP-179 & 9150175 \\
\hline 28.4 & 0.998 & 0.01500 & 0.050 & 0.185 & 14.6 & $\mathrm{P}$ & NA & 7.42 & 7.62 & 7.71 & 8.00 & 7.40 & 6.25 & NA & NA & NA & NA & NA & NA & 1 & 0.0 & 4 & NA & NA & NA & 15E_4sid2Xd_1 & $6 / 13 \mathrm{C}$ & TDP-179 & 9150176 \\
\hline 28.8 & 0.998 & 0.01500 & 0.050 & 0.188 & 13.4 & $\mathrm{P}$ & NA & 7.95 & 8.18 & 8.30 & 8.60 & 7.40 & 8.50 & NA & NA & NA & NA & NA & NA & 1 & 0.0 & 4 & NA & NA & NA & 15E_4sIdDXd_1 & $6 / 13 \mathrm{C}$ & TDP-179 & 915017 \\
\hline 29.0 & 0.998 & 0.01500 & 0.050 & 0.188 & 12.8 & $\mathrm{P}$ & NA & 8.26 & 8.53 & 8.66 & 9.00 & 7.40 & 11.00 & NA & NA & NA & NA & NA & NA & 1 & 0.0 & 4 & $\mathrm{NA}$ & NA & NA & 15E_4sid2Xd_1 1 & $6 / 13 c$ & TDP-179 & 9150178 \\
\hline 29.5 & 0.998 & 0.01500 & 0.050 & 0.184 & 12.8 & $\mathrm{P}$ & NA & 8.50 & 8.78 & 8.91 & 9.30 & 7.40 & 11.00 & NA & NA & NA & NA & NA & NA & 5 & 0.0 & 4 & NA & NA & NA & 15E_4s1d2Xd_1 & $6 / 13 \mathrm{C}$ & TDP-179 & 9150179 \\
\hline
\end{tabular}


Table B.3. Data from 2008 Tests in Small-Scale Vessel with Elliptical Head A.6

\begin{tabular}{|c|c|c|c|c|c|c|c|c|c|c|c|c|c|c|c|c|c|c|c|c|c|c|c|c|c|c|c|}
\hline $\begin{array}{l}\text { Row } \\
\text { Number }\end{array}$ & Test & Case ID & $\begin{array}{l}\text { Tank } \\
\text { Diameter }\end{array}$ & $\begin{array}{l}\text { Head } \\
\text { Shape }\end{array}$ & \begin{tabular}{|c} 
Dish \\
Height
\end{tabular} & $\begin{array}{l}\text { Dish } \\
\text { Volume }\end{array}$ & $\begin{array}{c}\text { Tank Fill } \\
\text { Height }\end{array}$ & $\begin{array}{l}\text { Return } \\
\text { Line } \\
\text { Height }\end{array}$ & $\begin{array}{l}\text { Nozzle } \\
\text { liner } \\
\text { Dineter } \\
\text { Dianter }\end{array}$ & $\begin{array}{l}\text { Nozzle } \\
\text { Stand-off } \\
\text { Distance }\end{array}$ & $\begin{array}{l}\text { Pulse Tube } \\
\text { Configuration }\end{array}$ & $\begin{array}{l}\text { Installed } \\
\text { Nozzles }\end{array}$ & $\begin{array}{l}\text { Outer } \\
\text { Nozzles } \\
\text { Operated }\end{array}$ & $\begin{array}{c}\text { Inner } \\
\text { Noveles } \\
\text { Operated }\end{array}$ & $\begin{array}{c}\text { Pulse Tube } \\
\text { Outer } \\
\text { Diameter }\end{array}$ & $\begin{array}{c}\text { Outer } \\
\text { PMM } \\
\text { Radius }\end{array}$ & $\begin{array}{c}\text { Inner PJM } \\
\text { Radius }\end{array}$ & $\begin{array}{c}\text { "FIO" Outer PJM } \\
\text { Impingement } \\
\text { Angle }\end{array}$ & $\begin{array}{l}\text { "FO' Inner PJM } \\
\text { Impingement Angle }\end{array}$ & $\begin{array}{l}\text { Ratio Outer PJn } \\
\text { to Tank Radius }\end{array}$ & \begin{tabular}{|l}
$\begin{array}{c}\text { Ratio Inner PJM } \\
\text { to Tank Radius }\end{array}$ \\
\end{tabular} & Simulant & $\begin{array}{l}\text { Solids } \\
\text { Density }\end{array}$ & $\begin{array}{c}\text { Particle } \\
\text { Diameter d5 }\end{array}$ & \begin{tabular}{c|} 
Particle \\
Diameter d50
\end{tabular} & \begin{tabular}{c|c} 
Patricle \\
Diameter d95
\end{tabular} & $\begin{array}{c}\text { Void } \\
\text { Fracion } \\
\end{array}$ \\
\hline text & text & text & in. & text & in. & in. ${ }^{3}$ & in. & in. & in. & in. & text & number & number & number & in. & in. & in. & deg & deg & nondim & nondim & text & $g / \mathrm{cm}^{3}$ & m & m & m & fraction \\
\hline MSS & MDDX & ID & $\mathrm{D}$ & $\mathrm{HS}$ & Hosh & $V_{\text {dish }}$ & $\mathrm{H}$ & Rn & $d$ & sod & PT & $\mathrm{N}$ & $\mathrm{Nb}$ & $\mathrm{N}$ & $\mathrm{PT}_{\alpha \mathrm{d}}$ & $\mathrm{Ro}_{\mathrm{o}}$ & $R$ & $\theta_{0}$ & $\theta_{1}$ & $\mathrm{Rd} d \mathrm{R}$ & $R / R$ & sxdx & $\rho_{s}$ & $d_{b}$ & $\mathrm{~d}_{60}$ & $d_{65}$ & $\mathrm{vf}$ \\
\hline 9150180 & $6 / 16 \mathrm{~A}$ & 15E_4s1d2QC_1 & $147 / 16$ & $E$ & 3.25 & 354.8 & 35 & 30 & 0.226 & 0.189 & HLP.22 & 12 & 8 & 4 & 1.05 & 4.5 & 2.4 & 21.8 & 10.1 & 0.62 & 0.34 & s1d2 & 2.48 & 0.0000569 & 0.0000693 & 0.0000821 & 0.3750 \\
\hline 9150181 & $6116 \mathrm{~A}$ & 15E_4s1d2QC_1 & $147 / 16$ & $E$ & 3.25 & 354.8 & 35 & 30 & 0.126 & 0.189 & HLP. 22 & 12 & 8 & 4 & 1.05 & 4.5 & 24 & 21.8 & 10.1 & 0.62 & 0.34 & s1d2 & 2.48 & 0.0000569 & $\begin{array}{ll}0.0000693 \\
\end{array}$ & 0.0000821 & 0.3750 \\
\hline 9150182 & $6 / 16 \mathrm{~A}$ & 15E_4s1d2QC_1 & $147 / 16$ & $E$ & 3.25 & 354.8 & 35 & 30 & 0.126 & 0.189 & HLP-22 & 12 & 8 & 4 & 1.05 & 4.5 & 2.4 & 21.8 & 10.1 & 0.62 & 0.34 & s1d2 & 2.48 & 0.0000569 & $\begin{array}{ll}0.0000693 \\
\end{array}$ & 0.0000821 & 0.3750 \\
\hline 9150183 & 6/16A & 15E_4s1d2Qc_1 1 & $147 / 16$ & E & 3.25 & 354.8 & 35 & 30 & 0.126 & 0.189 & HLP-22 & 12 & 8 & 4 & 1.05 & 4.5 & 24 & 21.8 & 10.1 & 0.62 & 0.34 & s1d2 & 248 & 0.0000569 & 0.0000693 & 0.0000821 & 0.3750 \\
\hline 9150184 & 616A & 15E_4s1d2Qc_1 & $147 / 16$ & $E$ & 3.25 & 354.8 & 35 & 30 & 0.126 & 0.189 & HLP-22 & 12 & 8 & 4 & 1.05 & 4.5 & 2.4 & 21.8 & 10.1 & 0.62 & 0.34 & s1d2 & 248 & 0.0000569 & 0.0000693 & 0.0000821 & 0.3750 \\
\hline 9150185 & 6/16A & 15E_4s1d2Qc_1 & $147 / 16$ & $E$ & 3.25 & 354.8 & 35 & 30 & 0.126 & 0.189 & HLP-22 & 12 & 8 & 4 & 1.05 & 4.5 & 2.4 & 21.8 & 10.1 & 0.62 & 0.34 & s1d2 & 248 & 0.0000569 & 0.0000693 & 0.0000821 & 0.3750 \\
\hline 9150186 & 6/16A & 15E_4s1d2Qc_1 & $147 / 16$ & $E$ & 3.25 & 354.8 & 35 & 30 & 0.126 & 0.189 & HLP-22 & 12 & 8 & 4 & 1.05 & 4.5 & 24 & 21.8 & 10.1 & 0.62 & 0.34 & s1d2 & 2.48 & 0.0000569 & 0.0000693 & 0.0000821 & 0.3750 \\
\hline $9150187 \mathrm{M}$ & 6/16A & 15E_4s1d2QC_1 & 147116 & $E$ & 3.25 & 354.8 & 35 & 30 & 0.126 & 0.189 & HLP-22 & 12 & 8 & 4 & 1.05 & 4.5 & 24 & 21.8 & 10.1 & 0.62 & 0.34 & s1d2 & 2.48 & 0.0000569 & 0.0000693 & 0.0000821 & 0.3750 \\
\hline $9150188 \mathrm{M}$ & 6/16A & 15E_4s1d2Qc_1 & 147716 & $E$ & 3.25 & 354.8 & 35 & 30 & 0.126 & 0.189 & HLP-22 & 12 & 8 & 4 & 1.05 & 4.5 & 24 & 21.8 & 10.1 & 0.62 & 0.34 & s1d2 & 248 & 0.0000569 & 0.0000693 & 0.0000821 & 0.3750 \\
\hline $9150189 \mathrm{M}$ & 6/16A & 15E_4s1d2Qc_1 & $147 / 16$ & $E$ & 3.25 & 354.8 & 35 & 30 & 0.126 & 0.189 & HLP-22 & 12 & 8 & 4 & 1.05 & 4.5 & 24 & 21.8 & 10. & 0.62 & 0.34 & s1d2 & 2.48 & 0.0000569 & 0.0000693 & 0.0000821 & 0.3750 \\
\hline $9150191 \mathrm{M}$ & 6/16A & 15E_4s1d2Qc_1 & 147716 & $E$ & 3.25 & 354.8 & 35 & 30 & 0.126 & 0.189 & HLP-22 & 12 & 8 & 4 & 1.05 & 4.5 & 24 & 21.8 & 10.1 & 0.62 & 0.34 & s1d2 & 2.48 & 0.0000569 & 0.0000693 & 0.0000821 & 0.3750 \\
\hline 9150192M & $6 / 16 \mathrm{~A}$ & 15E-4sid2QR_ 1 & $147 / 16$ & E & 3.25 & 354.8 & 35 & 30 & 0.126 & 0.189 & HLP-22 & 12 & 8 & 4 & 1.05 & 4.5 & 24 & 21.8 & 10.1 & 0.62 & 0.34 & s1d2 & 248 & 0.0000569 & $\begin{array}{l}0.0000693 \\
\end{array}$ & 0.0000821 & 0.3750 \\
\hline $9150193 \mathrm{M}$ & 6/16A & 15E_4s1d2Q__1 & $147 / 16$ & $E$ & 3.25 & 354.8 & 35 & 30 & 0.126 & 0.189 & HLP-22 & 12 & 8 & 4 & 1.05 & 4.5 & 24 & 21.8 & 10.1 & 0.62 & 0.34 & s1d2 & 2.48 & 0.0000569 & 0.0000693 & 0.0000821 & 0.3750 \\
\hline 9150194 & 6/16B & 15E_4s1d2WC_1 & $147 / 16$ & $E$ & 3.25 & 354.8 & $343 / 4$ & 30 & 0.126 & 0.189 & HLP-22 & 12 & 8 & 4 & 105 & 4.5 & 24 & 218 & 10.1 & 0.62 & 0.34 & s1d2 & 248 & 0.0000569 & 0.0000693 & 0.0000821 & 0.3750 \\
\hline 9150195 & 6/16B & 15E_4s1d2WC_1 & $147 / 16$ & $E$ & 3.25 & 354.8 & 34344 & 30 & 0.126 & 0.189 & HLP-22 & 12 & 8 & 4 & 1.05 & 4.5 & 24 & 21.8 & 10.1 & 0.62 & 0.34 & s1d2 & 248 & 0.0000569 & 0.0000693 & 0.0000821 & 0.3750 \\
\hline 9150196 & $6 / 16 \mathrm{~B}$ & 15E_4S1d2WE_ 11 & 147116 & $E$ & 3.25 & 354.8 & 34344 & 30 & 0.126 & 0.189 & HLP-22 & 12 & 8 & 4 & 1.05 & 4.5 & 24 & 21.8 & 10.1 & 0.62 & 0.34 & $\mathrm{~s} 1 \mathrm{~d} 2$ & 2.48 & 0.0000569 & 0.0000693 & 0.0000821 & 0.3750 \\
\hline 9150197 & 6/16B & 15E_4s1d2WC_1 & 147716 & $E$ & 3.25 & 354.8 & 34344 & 30 & 0.126 & 0.189 & HLP-22 & 12 & 8 & 4 & 1.05 & 4.5 & 24 & 21.8 & 10.1 & 0.62 & 0.34 & s1d2 & 2.48 & 0.0000569 & 0.0000693 & 0.0000821 & 0.3750 \\
\hline 9150198 & 6/168 & 15E_4s1d2Wc_1 & $147 / 16$ & $E$ & 3.25 & 354.8 & 34344 & 30 & 0.126 & 0.189 & HLP-22 & 12 & 8 & 4 & 1.05 & 4.5 & 24 & 21.8 & 10. & 0.62 & 0.34 & s1d2 & 2.48 & 0.0000569 & 0.0000693 & 0.0000821 & 0.3750 \\
\hline 9150199 & 6/16B & 15E_4s1d2WC_1 & $147 / 16$ & $E$ & 3.25 & 354.8 & 34344 & 30 & 0.126 & 0.189 & HLP-22 & 12 & 8 & 4 & 1.05 & 4.5 & 24 & 21.8 & 10.1 & 0.62 & 0.34 & $\mathrm{~s} 1 \mathrm{~d} 2$ & 2.48 & 0.0000569 & 0.0000693 & 0.0000821 & 0.3750 \\
\hline 9150200 & 6/16B & 15E_4s1d2WC_1 & $147 / 16$ & $E$ & 3.25 & 354.8 & $343 / 4$ & 30 & 0.126 & 0.189 & HLP-22 & 12 & 8 & 4 & 1.05 & 4.5 & 24 & 21.8 & 10.1 & 0.62 & 0.34 & s1d2 & 2.48 & 0.0000569 & 0.0000693 & 0.0000821 & 0.3750 \\
\hline 9150201 & $6 / 16 \mathrm{~B}$ & 15E_4s1d2WC_ 1 & $147 / 16$ & $E$ & 3.25 & 354.8 & $343 / 4$ & 30 & 0.126 & 0.189 & HLP-22 & 12 & 8 & 4 & 1.05 & 4.5 & 2.4 & 21.8 & 10.1 & 0.62 & 0.34 & s1d2 & 248 & 0.0000569 & 0.0000693 & 0.0000821 & 0.3750 \\
\hline 9150202 & 6/16B & 15E_4s1d2WC_1 & $147 / 16$ & $E$ & 3.25 & 354.8 & $343 / 4$ & 30 & 0.126 & 0.189 & HLP-22 & 12 & 8 & 4 & 1.05 & 4.5 & 24 & 21.8 & 10.1 & 0.62 & 0.34 & s1d2 & 2.48 & 0.0000569 & $\begin{array}{ll}0.0000693 \\
\end{array}$ & 0.0000821 & 0.3750 \\
\hline 9150203 & 61168 & 15E_4s1d2WE_1 & $147 / 16$ & $E$ & 3.25 & 354.8 & $343 / 4$ & 30 & 0.126 & 0.189 & HLP.22 & 12 & 8 & 4 & 1.05 & 4.5 & 24 & 21.8 & 10. & 0.62 & 0.34 & s1d2 & 2.48 & 0.0000569 & $\begin{array}{ll}0.0000693 \\
\end{array}$ & 0.0000821 & 0.3750 \\
\hline $9150204 \mathrm{M}$ & 6/16B & 15E_4s1d2WC_1 & $147 / 16$ & $E$ & 3.25 & 354.8 & $343 / 4$ & 30 & 0.126 & 0.189 & HLP-22 & 12 & 8 & 4 & 1.05 & 4.5 & 24 & 21.8 & 10.1 & 0.62 & 0.34 & s1d2 & 2.48 & 0.0000569 & 0.0000693 & 0.0000821 & 0.3750 \\
\hline $9150205 \mathrm{M}$ & $6 / 16 \mathrm{~B}$ & 15E_4SIdI2WC_1 & $147 / 16$ & $E$ & 3.25 & 354.8 & $343 / 4$ & 30 & 0.126 & 0.189 & HLP-22 & 12 & 8 & 4 & 1.05 & 4.5 & 24 & 21.8 & 10.1 & 0.62 & 0.34 & s1d2 & 248 & 0.0000569 & 0.0000693 & 0.0000821 & 0.3750 \\
\hline $9150206 \mathrm{M}$ & 6/168 & 15E_4s1d2WC_1 & $147 / 16$ & $E$ & 3.25 & 354.8 & $343 / 4$ & 30 & 0.126 & 0.189 & HLP-22 & 12 & 8 & 4 & 1.05 & 4.5 & 24 & 21.8 & 10.1 & 0.62 & 0.34 & s1d2 & 248 & 0.0000569 & 0.0000693 & 0.0000821 & 0.3750 \\
\hline $9150207 \mathrm{M}$ & $6 / 16 \mathrm{~B}$ & 15E_4s1d2Wc_1 & $147 / 16$ & $E$ & 3.25 & 354.8 & $343 / 4$ & 30 & 0.126 & 0.189 & HLP-22 & 12 & 8 & 4 & 1.0 & 4.5 & 24 & 21.8 & 10.1 & 0.62 & 0.34 & s1d2 & 2.48 & 0.0000569 & 0.0000693 & 0.0000821 & 0.3750 \\
\hline $9150208 \mathrm{M}$ & 6/168 & 15E_4s1d2WC_1 & $147 / 16$ & $E$ & 3.25 & 354.8 & $343 / 4$ & 30 & 0.126 & 0.189 & HLP-22 & 12 & 8 & 4 & 1.05 & 4.5 & 24 & 21.8 & 10.1 & 0.62 & 0.34 & s1d2 & 2.48 & 0.0000569 & 0.0000693 & 0.0000821 & 0.3750 \\
\hline $9150209 \mathrm{M}$ & $6 / 16 \mathrm{~B}$ & 15E_4S1d 2 WE_ 11 & 147116 & $\mathrm{E}$ & 3.25 & 354.8 & $343 / 4$ & 30 & 0.126 & 0.189 & HLP-22 & 12 & 8 & 4 & 1.05 & 4.5 & 24 & 21.8 & 10.1 & 0.62 & 0.34 & s1d2 & 2.48 & 0.0000569 & 0.0000693 & 0.0000821 & 0.3750 \\
\hline $9150210 \mathrm{M}$ & $6 / 16 \mathrm{~B}$ & 15E_4s1d2Wc_1 & $147 / 16$ & $E$ & 3.25 & 354.8 & $343 / 4$ & 30 & 0.126 & 0.189 & HLP-22 & 12 & 8 & 4 & 1.05 & 4.5 & 24 & 21.8 & 10.1 & 0.62 & 0.34 & s1d2 & 2.48 & 0.0000569 & 0.0000693 & 0.0000821 & 0.3750 \\
\hline $9150211 \mathrm{M}$ & $6 / 16 \mathrm{~B}$ & 15E_4S1d2WE_1 & $147 / 16$ & $E$ & 3.25 & 354.8 & $343 / 4$ & 30 & 0.126 & 0.189 & HLP-22 & 12 & 8 & 4 & 1.05 & 4.5 & 24 & 21.8 & 10.1 & 0.62 & 0.34 & s1d2 & 2.48 & 0.0000569 & 0.0000693 & 0.0000821 & 0.3750 \\
\hline $9150212 \mathrm{M}$ & $6 / 16 \mathrm{~B}$ & 15E_4s1d2WC_1 & $147 / 16$ & $E$ & 3.25 & 354.8 & $343 / 4$ & 30 & 0.126 & 0.189 & HLP-22 & 12 & 8 & 4 & 1.05 & 4.5 & 24 & 21.8 & 10.1 & 0.62 & 0.34 & $\mathrm{~s} 1 \mathrm{~d} 2$ & 2.48 & 0.0000569 & 0.0000693 & 0.0000821 & 0.3750 \\
\hline 9150212.1 & 6116B & 15E_4S1d2W__ 1 & 147116 & $E$ & 3.25 & 354.8 & $343 / 4$ & 30 & 0.126 & 0.189 & HLP 22 & 12 & 8 & 4 & 1.05 & 4.5 & 24 & 21.8 & 10.1 & 0.62 & 0.34 & $\mathrm{sid2}$ & 2.48 & 0.0000569 & 0.0000693 & 0.0000821 & 0.3750 \\
\hline 9150212.2 & 6/16B & 15E_4s1d2Wc_1 & $147 / 16$ & $E$ & 3.25 & 354.8 & $343 / 4$ & 30 & 0.126 & 0.189 & HLP-22 & 12 & 8 & 4 & 1.05 & 4.5 & 24 & 21.8 & 10.1 & 0.62 & 0.34 & & 2.48 & 0.0000569 & 0.0000693 & 0.0000821 & 0.3750 \\
\hline 91502123 & $6 / 16 \mathrm{~B}$ & 15E_4s1d2Wc_1 & $147 / 16$ & $E$ & 3.25 & 354.8 & $343 / 4$ & 30 & 0.126 & 0.189 & HLP-22 & 12 & 8 & 4 & 1.05 & 4.5 & 24 & 21.8 & 10.1 & 0.62 & 0.34 & $\mathrm{~s} 1 \mathrm{~d} 2$ & 2.48 & 0.0000569 & 0.0000693 & 0.0000821 & 0.3750 \\
\hline 91502124 & $6 / 16 \mathrm{~B}$ & 15E_4s1d2WC_ 1 & $147 / 16$ & $E$ & 3.25 & 354.8 & $343 / 4$ & 30 & 0.126 & 0.189 & HLP-22 & 12 & 8 & 4 & 1.05 & 4.5 & 24 & 21.8 & 10.1 & 0.62 & 0.34 & $\mathrm{~s} 1 \mathrm{~d} 2$ & 2.48 & 0.0000569 & 0.0000693 & 0.0000821 & 0.3750 \\
\hline $9150213 \mathrm{M}$ & 6/16B & 15E_4S1d2WC 11 & $147 / 16$ & $E$ & 3.25 & 354.8 & $343 / 4$ & 30 & 0.126 & 0.189 & HLP 22 & 12 & 8 & 4 & 1.05 & 4.5 & 24 & 21.8 & 10.1 & 0.62 & 0.34 & $\mathrm{sid} 2$ & 2.48 & 0.0000569 & 0.0000693 & 0.0000821 & 0.3750 \\
\hline 9150214 & 6/16B & 15E_4S1d2WC_ _1 & 147116 & $\mathrm{E}$ & 3.25 & 354.8 & $343 / 4$ & 30 & 0.126 & 0.189 & HLP-22 & 12 & 8 & 4 & 1.05 & 4.5 & 24 & 21.8 & 10.1 & 0.62 & 0.34 & $\mathrm{sid2}$ & 2.48 & 0.0000569 & 0.0000693 & 0.0000821 & 0.3750 \\
\hline 9150215 & 6/168 & 15E_4sidzWC_1 & $147 / 16$ & $E$ & 3.25 & 354.8 & $343 / 4$ & 30 & 0.126 & 0.189 & & 12 & 8 & 4 & & 4.5 & 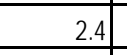 & 2 & & & & & & & $\begin{array}{ll}0.0000693 \\
\end{array}$ & & \\
\hline 9150216 & 616B & 15E_4S1d2WL_1 & $147 / 16$ & $E$ & 3.25 & 354.8 & $343 / 4$ & 30 & 0.126 & 0.189 & HLP -22 & 12 & 8 & 4 & 1.05 & 4.5 & 24 & 21.8 & 10.1 & 0.62 & 0.34 & s1d2 & 2.48 & $\begin{array}{l}0.0000569 \\
\end{array}$ & \begin{tabular}{|c|}
0.0000693 \\
\end{tabular} & 0.0000821 & 0.3750 \\
\hline 9150217 & 6/16B & 15E 4s1d2Wc 1 & $147 / 16$ & $E$ & 3.25 & 354.8 & $343 / 4$ & 30 & 0.126 & 0.189 & HLP-22 & 12 & 8 & 4 & 1.05 & 4.5 & 24 & 21.8 & 10.1 & 0.62 & 0.34 & s1d2 & 2.48 & 0.0000569 & 0.0000693 & 0.0000821 & 0.3750 \\
\hline
\end{tabular}


Table B.3. Data from 2008 Tests in Small-Scale Vessel with Elliptical Head B.6

\begin{tabular}{|c|c|c|c|c|c|c|c|c|c|c|c|c|c|c|c|c|c|c|c|c|c|c|c|c|c|c|c|c|c|}
\hline $\begin{array}{l}\text { Tank Water } \\
\text { Temperature }\end{array}$ & \begin{tabular}{|c|} 
Water \\
Density
\end{tabular} & $\begin{array}{l}\text { Solids } \\
\text { Fraction }\end{array}$ & \begin{tabular}{|c|} 
Pulse \\
Volume \\
Fraction \\
\end{tabular} & \begin{tabular}{|l} 
Duty \\
Cycle
\end{tabular} & $\begin{array}{l}\text { Oydle } \\
\text { Time }\end{array}$ & \begin{tabular}{|l|} 
Pulsed or \\
Steacy Jet
\end{tabular} & $\begin{array}{l}\text { Us } \\
\text { Steady } \\
\text { Jet }\end{array}$ & $\mid$\begin{tabular}{|c|} 
U1 \\
Pulsin \\
g Jet
\end{tabular} & \begin{tabular}{|c} 
U2 \\
URMS
\end{tabular} & \begin{tabular}{|c|} 
U3 \\
URMB
\end{tabular} & $\begin{array}{c}\text { Discharge } \\
\text { Velocity }\end{array}$ & $\begin{array}{c}\text { Critical } \\
\text { Suspension } \\
\text { Velocity }\end{array}$ & \begin{tabular}{|c} 
Average Peak \\
Cound Height
\end{tabular} & \begin{tabular}{|c|} 
UCS \\
Condition
\end{tabular} \mid & $\begin{array}{l}\text { UCS } \\
\text { Method }\end{array}$ & UCS Aag & $\begin{array}{l}\text { UCS Center } \\
\text { Flag }\end{array}$ & $\begin{array}{c}\text { UCS udv } \\
\text { Fag }\end{array}$ & $\begin{array}{l}\text { UCS based on } \\
\text { Decreasing } \\
\text { Velocity }\end{array}$ & $\begin{array}{l}\text { Sweep } \\
\text { Increase/ } \\
\text { Decrease }\end{array}$ & \begin{tabular}{|c|} 
UDV \\
Height \\
Bed
\end{tabular} & $\begin{array}{l}\text { Particle } \\
\text { Motion }\end{array}$ & \begin{tabular}{|l|} 
Solids \\
Level
\end{tabular} & \begin{tabular}{|l} 
Outer \\
Bototom \\
Pattem
\end{tabular} & $\mid$\begin{tabular}{c|} 
Inner \\
Bottom \\
Pattem
\end{tabular} & Case ID & Test & TDP & $\begin{array}{l}\text { Row } \\
\text { Number }\end{array}$ \\
\hline c & $g / \mathrm{cm}^{3}$ & fraction & fraction & fraction & $\mathrm{s}$ & text & $\mathrm{m} / \mathrm{s}$ & $\mathrm{m} / \mathrm{s}$ & $\mathrm{m} / \mathrm{s}$ & m/s & \begin{tabular}{|l|}
$\mathrm{m} / \mathrm{s}$ \\
\end{tabular} & \begin{tabular}{|l|}
$\mathrm{m} / \mathrm{s}$ \\
\end{tabular} & in. & m/s & text & text & text & \begin{tabular}{|l|} 
text \\
\end{tabular} & $\mathrm{ms}$ & text & $\mathrm{mm}$ & text & \begin{tabular}{|l|} 
text \\
\end{tabular} & text & text & text & text & text & text \\
\hline $\mathrm{T}$ & $\rho$ & $\phi_{\mathrm{s}}$ & $\phi_{p}$ & $D C$ & tc & Jet & $u_{s}$ & $\mathrm{U}_{1}$ & $\mathrm{U} 2$ & U3 & $u$ & Uss & $H_{\mathrm{C}}$ & U Cos & Uasn & \begin{tabular}{|l|} 
Ussis \\
\end{tabular} & Uscen & Usoudv & $u_{s \leq} \mathrm{D}$ & $\mathrm{s}_{\mathrm{v}}$ & $H_{\text {bed }}$ & $\mathrm{PM}$ & Sol & SPo & $\mathrm{SP}_{\mathrm{I}}$ & ID & MDDX & $\operatorname{TDP}$ & MSS \\
\hline 23.4 & 0.999 & 0.03000 & 0.050 & 0.335 & $18 . c$ & $\mathrm{P}$ & NA & 3.35 & 3.38 & $\begin{array}{r}3.40 \\
\end{array}$ & 3.50 & 6.20 & 3.38 & NA & NA & NA & NA & NA & NA & (null) & 22.0 & 1 & NA & NA & NA & 15E_4s1d2QC_1 & 6116A & TDP-180 & 9150180 \\
\hline 23.4 & 0.999 & 0.03000 & 0.050 & 0.332 & $14 . c$ & $\mathrm{P}$ & NA & 4.31 & 4.37 & 4.40 & 4.50 & 6.20 & 4.25 & NA & NA & NA & NA & NA & NA & 1 & 10.7 & 1 & NA & NA & NA & 15E_4sid2QQ__1 & 6/16A & TDP-180 & 9150181 \\
\hline 23.4 & 1.000 & 0.03000 & 0.050 & 0.336 & 12.6 & $\mathrm{P}$ & NA & 4.75 & 4.82 & 4.86 & 5.00 & 6.20 & 5.00 & NA & NA & NA & NA & NA & NA & 1 & 10.9 & 1 & NA & NA & NA & 15E_4SIdR2Q__1 & 6/16A & TDP-180 & 9150182 \\
\hline 23.5 & 0.999 & 0.03000 & 0.050 & 0.339 & 11.4 & $\mathrm{P}$ & NA & 5.21 & 5.30 & 5.34 & 5.50 & 6.20 & 5.75 & NA & NA & NA & NA & NA & NA & 1 & 4.5 & 1 & NA & NA & NA & 15E_4s1d2Qd_ 1 & 6/16A & TDP-180 & 9150183 \\
\hline 23.7 & 0.999 & 0.03000 & 0.050 & 0.336 & $11 . c$ & $\mathrm{P}$ & NA & 5.39 & 5.49 & 5.53 & 5.70 & 6.20 & 5.75 & NA & NA & NA & NA & NA & NA & 1 & 4.2 & 1 & NA & NA & NA & 15E_4s1d2Qc_1 & 6/16A & TDP-180 & 9150184 \\
\hline 23.8 & 1.000 & 0.03000 & 0.050 & 0.336 & 10.6 & $\mathrm{P}$ & NA & 5.58 & 5.68 & 5.73 & 5.90 & 6.20 & 6.25 & NA & NA & NA & NA & $\mathrm{NA}$ & NA & 1 & 3.8 & 1 & NA & NA & NA & 15E_4s1d2Qc_1 & 6/16A & TDP-180 & 9150185 \\
\hline 23.9 & 0.999 & 0.03000 & 0.050 & \begin{tabular}{l|l}
0.337 \\
\end{tabular} & 10.4 & $\mathrm{P}$ & NA & 5.69 & 5.80 & 5.85 & 6.00 & 6.20 & 6.75 & NA & NA & UCSvis & NA & NA & NA & 1 & 3.7. & 3 & NA & NA & NA & 15E_4s1d2QC_1 & 6/16A & TDP-180 & 9150186 \\
\hline 24.1 & 0.999 & 0.03000 & 0.050 & 0.328 & 10.4 & $\mathrm{P}$ & NA & 5.85 & 5.96 & 6.02 & 6.20 & 6.20 & 6.75 & \begin{tabular}{|l|}
6.20 \\
\end{tabular} & uad & NA & NA & ucsudv & NA & 1 & 3.7 & 4 & NA & NA & NA & 15E_4s1d2QC_1 & 6/16A & TDP-180 & 9150187 \\
\hline 24.2 & 0.999 & 0.03000 & 0.050 & 0.329 & $10 . c$ & $\mathrm{P}$ & NA & 6.05 & 6.17 & 6.23 & 6.40 & 6.20 & 7.50 & NA & NA & NA & NA & NA & NA & & 0.0 & 4 & NA & NA & NA & 15E_4s1d2QC_1 & 6/16A & TDP-180 & 9150188 \\
\hline 24.3 & 0.999 & 0.03000 & 0.050 & 0.332 & 9.4 & $\mathrm{P}$ & NA & 6.43 & 6.55 & 6.62 & 6.80 & 6.20 & 9.50 & NA & NA & NA & NA & NA & NA & 1 & 0.0 & 4 & NA & NA & NA & 15E_4sid2QC_1 & 6116A & TDP-180 & 9150189 \\
\hline 24.7 & 0.999 & 0.03000 & 0.050 & 0.337 & 8.4 & $\mathrm{P}$ & NA & 7.03 & 7.19 & 7.27 & 7.50 & 6.20 & 12.50 & NA & NA & NA & NA & NA & NA & 1 & 0.0 & 4 & NA & NA & NA & 15E_4s1d2QC_1 & 6116A & TDP-180 & 9150191 \\
\hline 24.9 & 0.999 & 0.03000 & 0.050 & 0.328 & 8.1 & $\mathrm{P}$ & NA & 7.49 & 7.66 & 7.74 & 8.00 & 6.20 & 15.25 & NA & NA & NA & NA & NA & NA & 1 & 0.0 & 4 & NA & NA & $\mathrm{NA}$ & 15E_4s1d2Qc_1 & 6/16A & TDP-180 & 9150192 \\
\hline 25.1 & 0.999 & 0.03000 & 0.050 & 0.332 & 7.6 & $\mathrm{P}$ & NA & 7.92 & 8.11 & 8.20 & 8.50 & 6.20 & 20.50 & NA & NA & NA & NA & NA & NA & 1 & 0.0 & 4 & NA & NA & NA & 15E_4s1d2QC_1 & 6/16A & TDP-180 & 9150193 \\
\hline 25.7 & 0.999 & 0.04500 & 0.050 & 0.331 & 15.5 & $\mathrm{P}$ & $\mathrm{NA}$ & 3.81 & 3.87 & 3.89 & 4.00 & 6.50 & 4.75 & NA & NA & NA & NA & $\mathrm{NA}$ & NA & (null) & 17.1 & 1 & NA & $\mathrm{NA}$ & NA & 15E_4sIdZWC_1 & 6/16B & TDP-181 & 9150194 \\
\hline 25.8 & 0.999 & 0.04500 & 0.050 & 0.333 & 14.4 & $P$ & $\mathrm{NA}$ & 4.20 & 4.26 & 4.29 & 4.40 & 6.50 & 5.25 & NA & NA & $\mathrm{NA}$ & NA & NA & NA & 1 & 16.1 & 1 & NA & $\mathrm{NA}$ & NA & 15E_4s1d2WE_ 1 & 6/16B & TDP-181 & 9150195 \\
\hline 25.8 & 0.999 & 0.04500 & 0.050 & 0.332 & 13.2 & $\mathrm{P}$ & NA & 4.57 & 4.64 & 4.68 & 4.80 & 6.50 & 5.50 & NA & NA & NA & NA & NA & NA & 1 & 12.6 & 1 & NA & NA & NA & 15E_4s1d2WC_1 & 6/16B & TDP-181 & 9150196 \\
\hline 25.9 & 0.999 & 0.04500 & 0.050 & 0.334 & 12.2 & $\mathrm{P}$ & NA & 4.93 & 5.00 & 5.04 & 5.20 & 6.50 & 5.75 & NA & NA & NA & NA & NA & NA & & 8.6 & 1 & NA & NA & NA & 15E_4s1d2WC_1 & 6/16B & IDP-181 & 9150197 \\
\hline 26.1 & 0.999 & 0.04500 & 0.050 & 0.332 & 11.4 & $\mathrm{P}$ & NA & 5.30 & 5.38 & 5.43 & 5.60 & 6.50 & 6.25 & NA & NA & NA & NA & NA & NA & 1 & 5.8 & 1 & NA & NA & NA & 15E_4s1d2WC_1 & 6/16B & IDP-181 & 9150198 \\
\hline 26.2 & 0.999 & 0.04500 & 0.050 & 0.335 & 10.6 & $\mathrm{P}$ & NA & 5.67 & 5.77 & 5.82 & 6.00 & 6.50 & 6.75 & NA & NA & NA & NA & NA & NA & 1 & 3.7 & 1 & NA & NA & NA & 15E_4s1d2WC 1 & $6 / 16 \mathrm{~B}$ & TDP-181 & 9150199 \\
\hline 26.2 & 0.999 & 0.04500 & 0.050 & 0.336 & 10.4 & $\mathrm{P}$ & NA & 5.76 & 5.87 & 5.92 & 6.10 & 6.50 & 7.25 & NA & NA & NA & NA & NA & NA & 1 & 3.7. & 1 & NA & $\mathrm{NA}$ & NA & 15E_4s1d2WE_1 1 & 6116B & TDP-181 & 9150200 \\
\hline 26.6 & 0.999 & 0.04500 & 0.050 & 0.332 & 10.4 & $\mathrm{P}$ & NA & 5.83 & 5.95 & 6.00 & 6.20 & 6.50 & 7.25 & NA & NA & NA & NA & NA & NA & 1 & 29 & 1 & NA & NA & NA & 15E_4s1d2WC_1 & 6/16B & TDP-181 & 9150201 \\
\hline 26.7 & 0.999 & 0.04500 & 0.050 & 0.333 & $10 . c$ & $\mathrm{P}$ & NA & 5.96 & 6.07 & 6.12 & 6.30 & 6.50 & 7.75 & NA & NA & UCShis & NA & NA & $\mathrm{N}$ & & 0.7. & 3 & NA & NA & NA & 15E_4s1d2WE_1 & $6 / 16 \mathrm{~B}$ & TDP-181 & 9150202 \\
\hline 26.9 & 0.999 & 0.04500 & 0.050 & 0.330 & $10 . c$ & $\mathrm{P}$ & NA & 6.04 & 6.15 & 6.21 & 6.40 & 6.50 & 7.75 & NA & NA & NA & NA & NA & NA & 1 & 0.6 & 4 & NA & NA & NA & 15E_4s1d2WC_1 & 6/16B & TDP-181 & 9150203 \\
\hline 27.1 & 0.999 & 0.04500 & 0.050 & 0.332 & 9.8 & $\mathrm{P}$ & NA & 6.13 & 6.25 & 6.31 & 6.50 & 6.50 & 8.00 & \begin{tabular}{|l|}
6.50 \\
\end{tabular} & uar & NA & NA & ucsudv & NA & 1 & 1.2 & 4 & NA & NA & NA & 15E_4S1d2WE_1 & 6116B & TDP-181 & 9150204 \\
\hline 27.3 & 0.998 & 0.04500 & 0.050 & 0.329 & 9.8 & $\mathrm{P}$ & NA & 6.22 & 6.34 & 6.40 & 6.60 & 6.50 & 8.00 & NA & NA & NA & NA & NA & NA & 1 & 0.0 & 4 & NA & NA & NA & 15E_4s1d2WC_1 & 6/16B & TDP-181 & 9150205 \\
\hline 27.5 & 0.999 & 0.04500 & 0.050 & 0.331 & 9.4 & $\mathrm{P}$ & NA & 6.40 & 6.53 & 6.59 & 6.80 & 6.50 & 8.25 & NA & NA & NA & NA & NA & $\mathrm{N}$ & 1 & 0.0 & 4 & NA & NA & NA & 15E_4s1d2WC_1 & 6/16B & TDP-181 & 9150206 \\
\hline 27.7 & 0.999 & 0.04500 & 0.050 & 0.335 & 9.6 & $\mathrm{P}$ & NA & 6.59 & 6.72 & 6.78 & 7.00 & 6.50 & 9.25 & NA & NA & NA & NA & NA & NA & & 0.0 & 4 & NA & NA & NA & 15E_4sIdZWC_1 & 6/16B & TDP-181 & 9150207 \\
\hline 27.8 & 0.999 & 0.04500 & 0.050 & 0.336 & 8.8 & $\mathrm{P}$ & NA & 6.77 & 6.91 & 6.98 & 7.20 & 6.50 & 10.25 & NA & NA & NA & NA & NA & NA & 1 & 0.0 & 4 & NA & $\mathrm{NA}$ & NA & 15E_4s1d2WC_1 & 6/16B & TDP-181 & 9150208 \\
\hline 28.2 & 0.998 & 0.04500 & 0.050 & \begin{tabular}{l|l}
0.337 \\
\end{tabular} & 8.4 & $\mathrm{P}$ & NA & 7.07 & 7.22 & 7.29 & 7.50 & 6.50 & 12.00 & NA & NA & NA & NA & NA & NA & 1 & 0.0 & 4 & NA & NA & NA & 15E_4s1d2WC_1 & 6/16B & TDP-181 & 9150209 \\
\hline 28.3 & 0.998 & 0.04500 & 0.050 & 0.334 & 8.2 & $\mathrm{P}$ & NA & 7.34 & 7.49 & 7.57 & 7.80 & 6.50 & 12.50 & NA & NA & $N A$ & $\mathrm{NA}$ & NA & $N$ & & 0.0 & 4 & NA & NA & NA & 15E_4s1d2WE_1 & $6 / 16 \mathrm{~B}$ & TDP-181 & 9150210 \\
\hline 28.6 & 0.998 & 0.04500 & 0.050 & 0.335 & 7.8 & $P$ & NA & 7.69 & 7.86 & 7.95 & 8. & 6.50 & 15.00 & NA & NA & NA & NA & NA & NA & 1 & 0.0 & 4 & NA & NA & NA & 15E_4sIdZWC_1 & $616 \mathrm{~B}$ & TDP-181 & 9150211 \\
\hline 28.8 & 0.998 & 0.04500 & 0.050 & 0.338 & 7.4 & $\mathrm{P}$ & NA & 8.04 & 8.23 & 8.32 & 8.60 & 6.50 & 17.00 & NA & NA & NA & NA & NA & NA & 1 & 0.0 & 4 & NA & NA & NA & 15E_4s1d2WL_1 & $6116 \mathrm{~B}$ & TDP-181 & 9150212 \\
\hline 29.2 & 0.998 & 0.04500 & 0.050 & 0.332 & 9.8 & $P$ & NA & 6.14 & 6.26 & 6.32 & 6.50 & 6.50 & 7.50 & NA & NA & NA & NA & NA & NA & $\mathrm{NA}$ & nna & NA & NA & NA & NA & 15E_4s1d2WC_1 & 6116B & TDP-181 & 9150212.1 \\
\hline 29.2 & 0.998 & 0.04500 & 0.050 & 0.332 & 9.8 & $P$ & NA & 6.14 & 6.26 & 6.32 & 6.50 & 6.50 & 7.50 & NA & NA & $N A$ & $\mathrm{NA}$ & NA & NA & $\mathrm{NA}$ & n/a & NA & $\mathrm{NA}$ & $N A$ & $N A$ & 15E_4s1d2WE__1 & $6116 \mathrm{~B}$ & TDP-181 & 9150212.2 \\
\hline 29.2 & 0.998 & 0.04500 & 0.050 & 0.332 & 9.8 & $\mathrm{P}$ & NA & 6.14 & 6.26 & 6.32 & 6.50 & 6.50 & 7.50 & NA & NA & NA & NA & NA & NA & NA & r/a & NA & NA & NA & NA & 15E_4SIdZWC_1 & $6 / 16 \mathrm{~B}$ & TDP-181 & 9150212.3 \\
\hline 29.2 & 0.998 & 0.04500 & 0.050 & 0.332 & 9.8 & $\mathrm{P}$ & NA & 6.14 & 6.26 & 6.32 & 6.50 & 6.50 & 7.50 & NA & NA & NA & NA & NA & NA & NA & naa & NA & NA & $\mathrm{NA}$ & NA & 15E_4s1d2WE_ 1 & 6/16B & TDP-181 & 9150212.4 \\
\hline 29.2 & 0.998 & 0.04500 & 0.050 & 0.332 & 9.8 & $\mathrm{P}$ & NA & 6.14 & 6.26 & 6.32 & 6.50 & 6.50 & 7.50 & NA & NA & NA & NA & NA & NA & 1 & \begin{tabular}{r|}
2.5 \\
\end{tabular} & 4 & NA & NA & $\mathrm{NA}$ & 15E_4S1d2WC_1 & 6116B & TDP-181 & 9150213 \\
\hline 29.2 & $\begin{array}{ll}0.998 \\
\end{array}$ & 0.04500 & 0.050 & 0.332 & 9.8 & $\mathrm{P}$ & NA & 6.14 & 6.26 & 6.32 & 6.50 & 6.50 & 7.50 & NA & NA & NA & NA & NA & NA & NA & 19. & NA & NA & NA & NA & 15E_4s1d2WC_1 & $6 / 16 \mathrm{~B}$ & TDP-181 & 9150214 \\
\hline 29.2 & 0.998 & 0.04500 & 0.050 & 0.332 & 9.8 & $\mathrm{P}$ & NA & 6.14 & 6.26 & 6.32 & 6.50 & 6.50 & 7.50 & NA & NA & NA & NA & NA & NA & NA & 2.5 & NA & $\mathrm{NA}$ & NA & NA & 15E_4s1d2WE_1 & $6 / 16 \mathrm{~B}$ & TDP-181 & 9150215 \\
\hline 29.2 & 0.998 & 0.04500 & 0.050 & 0.332 & 9.8 & $\mathrm{P}$ & NA & 6.14 & 6.26 & 6.32 & 6.50 & 6.50 & & NA & NA & NA & NA & NA & NA & NA & 12. & NA & NA & NA & NA & 15E_4s1d2WC_1 & $6 / 16 \mathrm{~B}$ & TDP-181 & 9150216 \\
\hline 29.2 & 0.998 & 0.04500 & \begin{tabular}{|l|}
0.050 \\
\end{tabular} & 0.332 & 9.8 & $P$ & NA & 6.14 & \begin{tabular}{|l|} 
\\
\end{tabular} & 6.32 & 6.50 & 6.50 & 7.50 & NA & NA & NA & NA & NA & NA & NA & 0.6 & NA & NA & NA & NA & 15E_4S1d2WC_1 & 6/16B & TDP-181 & 9150217 \\
\hline
\end{tabular}


Table B.3. Data from 2008 Tests in Small-Scale Vessel with Elliptical Head A.7

\begin{tabular}{|c|c|c|c|c|c|c|c|c|c|c|c|c|c|c|c|c|c|c|c|c|c|c|c|c|c|c|c|}
\hline $\begin{array}{l}\text { Row } \\
\text { Number }\end{array}$ & Test & Case ID & $\begin{array}{l}\text { Tank } \\
\text { Diameter }\end{array}$ & $\begin{array}{l}\text { Head } \\
\text { Shape }\end{array}$ & \begin{tabular}{|c} 
Dish \\
Height
\end{tabular} & $\begin{array}{l}\text { Dish } \\
\text { Volume }\end{array}$ & $\begin{array}{l}\text { Tank FIII } \\
\text { Height }\end{array}$ & $\begin{array}{c}\text { Retur } \\
\text { Line } \\
\text { Height }\end{array}$ & \begin{tabular}{|c|} 
Nozzle \\
Inner \\
Diameter \\
\end{tabular} & $\begin{array}{l}\text { Nozzle } \\
\text { Stand-off } \\
\text { Distance }\end{array}$ & $\begin{array}{l}\text { Pulse Tube } \\
\text { Configuration }\end{array}$ & $\begin{array}{l}\text { Installed } \\
\text { Nozzles }\end{array}$ & $\begin{array}{l}\text { Outer } \\
\text { Nozzles } \\
\text { Operated }\end{array}$ & $\begin{array}{c}\text { Inner } \\
\text { Noveles } \\
\text { Operated }\end{array}$ & $\begin{array}{c}\text { Pulse Tube } \\
\text { Outer } \\
\text { Diameter }\end{array}$ & $\begin{array}{c}\text { Outer } \\
\text { PMM } \\
\text { Radius }\end{array}$ & $\begin{array}{c}\text { Inner PJM } \\
\text { Radius }\end{array}$ & $\begin{array}{c}\text { "FIO" Outer PJM } \\
\text { Impingement } \\
\text { Angle }\end{array}$ & $\begin{array}{l}\text { "FO' Inner PJM } \\
\text { Impingement Angle }\end{array}$ & $\begin{array}{l}\begin{array}{l}\text { Ratio Outer PJM } \\
\text { to Tank Radius }\end{array} \\
\end{array}$ & \begin{tabular}{|l}
$\begin{array}{c}\text { Ratio Inner PJM } \\
\text { to Tank Radius }\end{array}$ \\
\end{tabular} & Simulant & $\begin{array}{l}\text { Solids } \\
\text { Density }\end{array}$ & $\begin{array}{c}\text { Particle } \\
\text { Diameter d5 }\end{array}$ & \begin{tabular}{c|} 
Particle \\
Diameter d50
\end{tabular} & \begin{tabular}{c|c} 
Patricle \\
Diameter d95
\end{tabular} & $\begin{array}{c}\text { Void } \\
\text { Fracion } \\
\end{array}$ \\
\hline text & text & text & in. & text & in. & in. ${ }^{3}$ & in. & in. & in. & in. & text & number & number & number & in. & in. & in. & deg & deg & nondim & nondim & text & $\mathrm{g} / \mathrm{cm}^{3}$ & $\mathrm{~m}$ & \begin{tabular}{l|}
$\mathrm{m}$ \\
\end{tabular} & $m$ & fraction \\
\hline MSS & MDDX & ID & $\mathrm{D}$ & $\mathrm{HS}$ & Hosh & $V_{\text {dash }}$ & $\mathrm{H}$ & Rn & $d$ & sod & PT & $\mathrm{N}$ & $\mathrm{Nb}$ & $\mathrm{N}$ & $\mathrm{PT}_{\alpha \mathrm{d}}$ & $\mathrm{Ro}_{\mathrm{o}}$ & $R$ & $\theta_{0}$ & $\theta_{1}$ & $\mathrm{Rd} d \mathrm{R}$ & $R / R$ & sxdx & $\rho_{s}$ & $d_{b}$ & $\mathrm{~d}_{60}$ & $d_{65}$ & $\mathrm{vf}$ \\
\hline 9150218 & $6 / 16 \mathrm{~B}$ & 15E_4s1d2Wc_1 & $147 / 16$ & $E$ & 3.25 & 354.8 & $343 / 4$ & 30 & 0.126 & 0.189 & HLP.22 & 12 & 8 & 4 & 1.05 & 4.5 & 2.4 & 21.8 & 10.1 & 0.62 & 0.34 & s1d2 & 2.48 & 0.0000569 & 0.0000693 & 0.0000821 & 0.3750 \\
\hline 9150219 & $6 / 16 \mathrm{~B}$ & 15E_4s1d2WW__1 & $147 / 16$ & $E$ & 3.25 & 354.8 & $343 / 4$ & 30 & 0.126 & 0.189 & HLP. 22 & 12 & 8 & 4 & 1.05 & 4.5 & 2.4 & 21.8 & 10.1 & 0.62 & 0.34 & s1d2 & 2.48 & 0.0000569 & $\begin{array}{ll}0.0000693 \\
\end{array}$ & 0.0000821 & 0.3750 \\
\hline 9150220 & 6/168 & 15E_4s1d2WC_1 & $147 / 16$ & $E$ & 3.25 & 354.8 & $343 / 4$ & 30 & 0.126 & 0.189 & HLP-22 & 12 & 8 & 4 & 1.05 & 4.5 & 2.4 & 21.8 & 10.1 & 0.62 & 0.34 & s1d2 & 2.48 & 0.0000569 & $\begin{array}{ll}0.0000693 \\
\end{array}$ & 0.0000821 & 0.3750 \\
\hline 9150221 & 6/16B & 15E_4sIdI2WC_ 1 & $147 / 16$ & $E$ & 3.25 & 354.8 & $343 / 4$ & 30 & 0.126 & 0.189 & HLP 22 & 12 & 8 & 4 & 1.05 & 4.5 & 2.4 & 21.8 & 10.1 & 0.62 & 0.34 & $\mathrm{~s} 1 \mathrm{~d} 2$ & 248 & 0.0000569 & 0.0000693 & 0.0000821 & 0.3750 \\
\hline 9150222 & 6/168 & 15E_4s1d2WC_1 & $147 / 16$ & $E$ & 3.25 & 354.8 & $343 / 4$ & 30 & 0.126 & 0.189 & HLP-22 & 12 & 8 & 4 & 1.05 & 4.5 & 2.4 & 21.8 & 10.1 & 0.62 & 0.34 & s1d2 & 248 & 0.0000569 & 0.0000693 & 0.0000821 & 0.3750 \\
\hline 9150223 & 6/16B & 15E_4s1d2WC_1 & $147 / 16$ & $\mathrm{E}$ & 3.25 & 354.8 & $343 / 4$ & 30 & 0.126 & 0.189 & HLP-22 & 12 & 8 & 4 & 1.05 & 4.5 & 2.4 & 21.8 & 10.1 & 0.62 & 0.34 & s1d2 & 248 & 0.0000569 & 0.0000693 & 0.0000821 & 0.3750 \\
\hline 9150224 & 61717A & 15E_4s1d2WW_1 & $147 / 16$ & $E$ & 3.25 & 354.8 & $341 / 2$ & 30 & 0.126 & 0.189 & HLP-22 & 12 & 8 & 4 & 1.05 & 4.5 & 2.4 & 21.8 & 10.1 & 0.62 & 0.34 & s1d2 & 2.48 & 0.0000569 & 0.0000693 & 0.0000821 & 0.3750 \\
\hline 9150225 & 6/177A & 15E_4S1d2WW_ 1 & $147 / 16$ & $E$ & 3.25 & 354.8 & $341 / 2$ & 30 & 0.126 & 0.189 & HLP-22 & 12 & 8 & 4 & 1.05 & 4.5 & 2.4 & 21.8 & 10.1 & 0.62 & 0.34 & s1d2 & 2.48 & 0.0000569 & 0.0000693 & 0.0000821 & 0.3750 \\
\hline 9150226 & $6 / 17 \mathrm{~A}$ & 15E_4s1d2Wd_1 & 147716 & $E$ & 3.25 & 354.8 & $341 / 2$ & 30 & 0.126 & 0.189 & HLP-22 & 12 & 8 & 4 & 1.05 & 4.5 & 2.4 & 21.8 & 10.1 & 0.62 & 0.34 & s1d2 & 248 & 0.0000569 & 0.0000693 & 0.0000821 & 0.3750 \\
\hline 9150227 & 6/177A & 15E_4s1d2Wd_1 & $147 / 16$ & $E$ & 3.25 & 354.8 & $341 / 2$ & 30 & 0.126 & 0.189 & HLP-22 & 12 & 8 & 4 & 1.05 & 4.5 & 24 & 21.8 & 10. & 0.62 & 0.34 & s1d2 & 2.48 & 0.0000569 & 0.0000693 & 0.0000821 & 0.3750 \\
\hline 9150228 & 6177 & 15E_4S1d2Wd 11 & 147116 & E & 3.25 & 354.8 & $341 / 2$ & 30 & 0.126 & 0.189 & HLP-22 & 12 & 8 & 4 & 1.05 & 4.5 & 2.4 & 21.8 & 10.1 & 0.62 & 0.34 & s1d2 & 248 & 0.0000569 & 0.0000693 & 0.0000821 & 0.3750 \\
\hline 9150229 & 6/17A & 15E -4S1d2WWA 1 & $147 / 16$ & E & 3.25 & $354.8 \mathrm{\gamma}$ & $341 / 2$ & 30 & 0.126 & 0.189 & HLP-22 & 12 & 8 & 4 & 1.05 & 4.5 & 2.4 & 21.8 & 10.1 & 0.62 & 0.34 & s1d2 & 248 & 0.0000569 & $\begin{array}{l}0.0000693 \\
\end{array}$ & 0.0000821 & 0.3750 \\
\hline 9150230 & $6 / 17 \mathrm{~A}$ & 15E_4s1d2Wd_1 & $147 / 16$ & $E$ & 3.25 & 354.8 & $341 / 2$ & 30 & 0.126 & 0.189 & HLP-22 & 12 & 8 & 4 & 1.05 & 4.5 & 2.4 & 21.8 & 10.1 & 0.62 & 0.34 & s1d2 & 2.48 & 0.0000569 & 0.0000693 & 0.0000821 & 0.3750 \\
\hline 9150231 & 6117A & 15E_4s1d2Wd_1 & $147 / 16$ & $E$ & 3.25 & 354.8 & $341 / 2$ & 30 & 0.126 & 0.189 & HLP-22 & 12 & 8 & 4 & 105 & 4.5 & 24 & 218 & 10.1 & 0.62 & 0.34 & s1d2 & 248 & 0.0000569 & \begin{tabular}{|c|}
0.0000693 \\
\end{tabular} & 0.0000821 & 0.3750 \\
\hline 9150232 & 6/17A & 15E_4s1d2Wd_1 & 147716 & $E$ & 3.25 & 354.8 & $341 / 2$ & 30 & 0.126 & 0.189 & HLP-22 & 12 & 8 & 4 & 1.05 & 4.5 & 2.4 & 21.8 & 10.1 & 0.62 & 0.34 & $\mathrm{~s} 1 \mathrm{~d} 2$ & 248 & 0.0000569 & 0.0000693 & 0.0000821 & 0.3750 \\
\hline $9150233 \mathrm{M}$ & 6/177A & 15E_4s1d2WW_1 1 & 147116 & $E$ & 3.25 & 354.8 & $341 / 2$ & 30 & 0.126 & 0.189 & HLP-22 & 12 & 8 & 4 & 1.05 & 4.5 & 2.4 & 21.8 & 10.1 & 0.62 & 0.34 & $\mathrm{~s} 1 \mathrm{~d} 2$ & 2.48 & 0.0000569 & 0.0000693 & 0.0000821 & 0.3750 \\
\hline $9150234 \mathrm{M}$ & 6/17A & 15E_4s1d2Wd_1 & 147716 & $E$ & 3.25 & 354.8 & $341 / 2$ & 30 & 0.126 & 0.189 & HLP-22 & 12 & 8 & 4 & 1.05 & 4.5 & 2.4 & 21.8 & 10.1 & 0.62 & 0.34 & s1d2 & 2.48 & 0.0000569 & 0.0000693 & 0.0000821 & 0.3750 \\
\hline $9150235 \mathrm{M}$ & 6177A & 15E_4s1d2Wd_1 & $147 / 16$ & $E$ & 3.25 & 354.8 & $341 / 2$ & 30 & 0.126 & 0.189 & HLP-22 & 12 & 8 & 4 & 1.05 & 4.5 & 2.4 & 21.8 & 10. & 0.62 & 0.34 & s1d2 & 2.48 & 0.0000569 & $\begin{array}{ll}0.0000693 \\
\end{array}$ & 0.0000821 & 0.3750 \\
\hline $9150236 \mathrm{M}$ & $6 / 17 \mathrm{~A}$ & 15E_4s1d2Wd_1 & $147 / 16$ & $E$ & 3.25 & 354.8 & $341 / 2$ & 30 & 0.126 & 0.189 & HLP-22 & 12 & 8 & 4 & 1.05 & 4.5 & 2.4 & 21.8 & 10.1 & 0.62 & 0.34 & $\mathrm{~s} 1 \mathrm{~d} 2$ & 2.48 & 0.0000569 & 0.0000693 & 0.0000821 & 0.3750 \\
\hline $9150237 \mathrm{M}$ & 6/177A & 15E_4S1d 2Wd 1 1 & $147 / 16$ & E & 3.25 & 354.8 & $341 / 2$ & 30 & 0.126 & 0.189 & HLP-22 & 12 & 8 & 4 & 1.05 & 4.5 & 24 & 21.8 & 10.1 & 0.62 & 0.34 & s1d2 & 2.48 & 0.0000569 & 0.0000693 & 0.0000821 & 0.3750 \\
\hline $9150238 \mathrm{M}$ & 6/17A & 15E_4s1d2Wd_1 & $147 / 16$ & $E$ & 3.25 & 354.8 & $341 / 2$ & 30 & 0.126 & 0.189 & HLP-22 & 12 & 8 & 4 & 1.05 & 4.5 & 2.4 & 21.8 & 10.1 & 0.62 & 0.34 & s1d2 & 248 & 0.0000569 & 0.0000693 & 0.0000821 & 0.3750 \\
\hline $9150239 \mathrm{M}$ & 61717A & 15E_4s1d2Wd_1 & $147 / 16$ & $E$ & 3.25 & 354.8 & $341 / 2$ & 30 & 0.126 & 0.189 & HLP-22 & 12 & 8 & 4 & 1.05 & 4.5 & 2.4 & 21.8 & 10.1 & 0.62 & 0.34 & s1d2 & 2.48 & 0.0000569 & 0.0000693 & 0.0000821 & 0.3750 \\
\hline $9150240 \mathrm{M}$ & $6 / 17 \mathrm{~A}$ & 15E_4s1d2Wd_1 & $147 / 16$ & $\mathrm{E}$ & 3.25 & 354.8 & $341 / 2$ & 30 & 0.126 & 0.189 & HLP.22 & 12 & 8 & 4 & 1.05 & 4.5 & 2.4 & 21.8 & 10. & 0.62 & 0.34 & s1d2 & 2.48 & 0.0000569 & 0.0000693 & 0.0000821 & 0.3750 \\
\hline 9150240.1 & 6177A & 15E_4sIdzWW_ 1 & $147 / 16$ & $E$ & 3.25 & 354.8 & $341 / 2$ & 30 & 0.126 & 0.189 & HLP.22 & 12 & 8 & 4 & 1.05 & 4.5 & 2.4 & 21.8 & 10.1 & 0.62 & 0.34 & s1d2 & 2.48 & 0.0000569 & 0.0000693 & 0.0000821 & 0.3750 \\
\hline 9150240.2 & 6117A & 15E_4S1d2WW_ 1 & $147 / 16$ & $E$ & 3.25 & 354.8 & $341 / 2$ & 30 & 0.126 & 0.189 & HLP-22 & 12 & 8 & 4 & 1.05 & 4.5 & 2.4 & 21.8 & 10.1 & 0.62 & 0.34 & s1d2 & 248 & 0.0000569 & 0.0000693 & 0.0000821 & 0.3750 \\
\hline 9150240.3 & 61717A & 15E_4s1d2Wd_1 & $147 / 16$ & $E$ & 3.25 & 354.8 & $341 / 2$ & 30 & 0.126 & 0.189 & HLP-22 & 12 & 8 & 4 & 1.05 & 4.5 & 2.4 & 21.8 & 10.1 & 0.62 & 0.34 & s1d2 & 248 & 0.0000569 & 0.0000693 & 0.0000821 & 0.3750 \\
\hline 9150240.4 & 6177A & 15E_4s1d2Wd_1 & $147 / 16$ & $E$ & 3.25 & 354.8 & $341 / 2$ & 30 & 0.126 & 0.189 & HLP-22 & 12 & 8 & 4 & 1.0 & 4.5 & 24 & 21.8 & 10.1 & 0.62 & 0.34 & s1d2 & 2.48 & 0.0000569 & \begin{tabular}{|c|}
0.0000693 \\
\end{tabular} & 0.0000821 & 0.3750 \\
\hline 9150240.5 & $6 / 17 \mathrm{~A}$ & 15E_4s1d2Wd_1 & $147 / 16$ & $E$ & 3.25 & 354.8 & $341 / 2$ & 30 & 0.126 & 0.189 & HLP-22 & 12 & 8 & 4 & 1.05 & 4.5 & 2.4 & 21.8 & 10.1 & 0.62 & 0.34 & s1d2 & 2.48 & 0.0000569 & 0.0000693 & 0.0000821 & 0.3750 \\
\hline 9150240.6 & 6/177A & 15E_4S1dI2Wd_ I & 147116 & $E$ & 3.25 & 354.8 & $341 / 2$ & 30 & 0.126 & 0.189 & HLP-22 & 12 & 8 & 4 & 1.05 & 4.5 & 2.4 & 21.8 & 10.1 & 0.62 & 0.34 & s1d2 & 2.48 & 0.0000569 & 0.0000693 & 0.0000821 & 0.3750 \\
\hline 9150240.7 & $6 / 17 \mathrm{~A}$ & 15E_4s1d2Wd_1 & $147 / 16$ & $E$ & 3.25 & 354.8 & $341 / 2$ & 30 & 0.126 & 0.189 & HLP-22 & 12 & 8 & 4 & 1.05 & 4.5 & 2.4 & 21.8 & 10.1 & 0.62 & 0.34 & s1d2 & 2.48 & 0.0000569 & 0.0000693 & 0.0000821 & 0.3750 \\
\hline $9150241 \mathrm{M}$ & 6177A & 15E_4s1d2Wd_1 & $147 / 16$ & $E$ & 3.25 & 354.8 & $341 / 2$ & 30 & 0.126 & 0.189 & HLP-22 & 12 & 8 & 4 & 1.05 & 4.5 & 2.4 & 21.8 & 10.1 & 0.62 & 0.34 & s1d2 & 2.48 & 0.0000569 & 0.0000693 & 0.0000821 & 0.3750 \\
\hline 9150242 & 6117A & 15E_4s1d2Wd_1 & $147 / 16$ & $E$ & 3.25 & 354.8 & $341 / 2$ & 30 & 0.126 & 0.189 & HLP-22 & 12 & 8 & 4 & 1.05 & 4.5 & 2.4 & 21.8 & 10.1 & 0.62 & 0.34 & $\mathrm{~s} 1 \mathrm{~d} 2$ & 2.48 & 0.0000569 & 0.0000693 & 0.0000821 & 0.3750 \\
\hline 9150243 & 6177A & 15E_4S1d2Wd_ 1 1 & 147116 & $\mathrm{E}$ & 3.25 & 354.8 & $341 / 2$ & 30 & 0.126 & 0.189 & HLP 22 & 12 & 8 & 4 & 1.05 & 4.5 & 2.4 & 21.8 & 10.1 & 0.62 & 0.34 & $\mathrm{sid2}$ & 2.48 & 0.0000569 & 0.0000693 & 0.0000821 & 0.3750 \\
\hline 9150244 & 6117A & 15E_4s1d2Wd_1 & $147 / 16$ & $E$ & 3.25 & 354.8 & $341 / 2$ & 30 & 0.126 & 0.189 & HLP-22 & 12 & 8 & 4 & 1.05 & 4.5 & 2.4 & 21.8 & 10.1 & 0.62 & 0.34 & $\mathrm{~s} 1 \mathrm{~d} 2$ & 2.48 & 0.0000569 & 0.0000693 & 0.0000821 & 0.3750 \\
\hline 9150245 & 6/17A & 15E_4s1d2Wd_1 & $147 / 16$ & $E$ & 3.25 & 354.8 & $341 / 2$ & 30 & 0.126 & 0.189 & HLP-22 & 12 & 8 & 4 & 1.05 & 4.5 & 2.4 & 21.8 & 10.1 & 0.62 & 0.34 & $\mathrm{~s} 1 \mathrm{~d} 2$ & 2.48 & 0.0000569 & $\begin{array}{ll}0.0000693 \\
\end{array}$ & 0.0000821 & 0.3750 \\
\hline 9150246 & 6/17A & 15E_4s1d2Wd_1 & $147 / 16$ & $E$ & 3.25 & 354.8 & $341 / 2$ & 30 & 0.126 & 0.189 & HLP-22 & 12 & 8 & 4 & 1.05 & 4.5 & 2.4 & 21.8 & 10.1 & 0.62 & 0.34 & $\mathrm{~s} 1 \mathrm{~d} 2$ & 2.48 & 0.0000569 & 0.0000693 & 0.0000821 & 0.3750 \\
\hline 9150247 & 6177A & 15E_4S1d2Wd 1 & $147 / 16$ & $E$ & 3.25 & 354.8 & $341 / 2$ & 30 & 0.126 & 0.189 & HLP 22 & 12 & 8 & 4 & 1.05 & 4.5 & 24 & 21.8 & 10.1 & 0.62 & 0.34 & $\mathrm{sid} 2$ & 2.48 & 0.0000569 & 0.0000693 & 0.0000821 & 0.3750 \\
\hline 9150248 & 6/17A & 15E_4s1d2WW_1 1 & $147 / 16$ & $\mathrm{E}$ & 3.25 & 354.8 & $341 / 2$ & 30 & 0.126 & 0.189 & HLP-22 & 12 & 8 & 4 & 1.05 & 4.5 & 2.4 & 21.8 & 10.1 & 0.62 & 0.34 & $\mathrm{sid2}$ & 2.48 & 0.0000569 & 0.0000693 & 0.0000821 & 0.3750 \\
\hline 9150249 & 61178 & & \begin{tabular}{ll|}
$147 / 16$ \\
\end{tabular} & $E$ & 3.25 & 354.8 & 341 & 30 & 0.126 & 0.189 & & 12 & 8 & 4 & & 4.5 & 2.4 & & & & 0.34 & & & & & & \\
\hline 9150250 & 61778 & 15E_4sidawa & $147 / 16$ & $E$ & 3.25 & 354.8 & $341 / 2$ & 30 & 0.126 & 0.189 & HLP-22 & 12 & 8 & 4 & 1.05 & 4.5 & 2.4 & 21.8 & 10.1 & 0.62 & 0.34 & s1d2 & 2.48 & 0.0000569 & 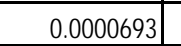 & 0.0000821 & 0.3750 \\
\hline 9150251 & 61178 & 15E_4sidzW & $147 / 16$ & $E$ & 3.25 & 354.8 & $341 / 2$ & 30 & \begin{tabular}{|l|}
0.126 \\
\end{tabular} & 0.189 & HLP-22 & 12 & 8 & 4 & 1.05 & 4.5 & 2.4 & 21.8 & 10.1 & 0.62 & 0.34 & s1d2 & 2.48 & 0.0000569 & 0.0000693 & 0.0000821 & 0.3750 \\
\hline
\end{tabular}


Table B.3. Data from 2008 Tests in Small-Scale Vessel with Elliptical Head B.7

\begin{tabular}{|c|c|c|c|c|c|c|c|c|c|c|c|c|c|c|c|c|c|c|c|c|c|c|c|c|c|c|c|c|c|}
\hline $\begin{array}{l}\text { Tank Water } \\
\text { Temperature }\end{array}$ & \begin{tabular}{|c|} 
Water \\
Density
\end{tabular} & $\begin{array}{c}\text { Solids } \\
\text { Fraction }\end{array}$ & \begin{tabular}{|c|} 
Pulse \\
Volume \\
Fraction \\
\end{tabular} & \begin{tabular}{|l} 
Duty \\
Cycle
\end{tabular} & $\begin{array}{l}\text { Oycle } \\
\text { Time }\end{array}$ & \begin{tabular}{|l} 
Pulsed or \\
Steacy Jet \\
\end{tabular} & \begin{tabular}{|c|} 
Us \\
Steacy \\
Jet \\
\end{tabular} & \begin{tabular}{|c|} 
U1 \\
Pulsin \\
g Jet \\
\end{tabular} & $\begin{array}{c}\text { U2 } \\
\text { URMS }\end{array}$ & \begin{tabular}{|c|} 
U3 \\
URNB \\
\end{tabular} & $\begin{array}{c}\text { Discharge } \\
\text { Velocity }\end{array}$ & 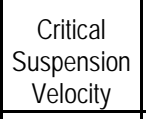 & \begin{tabular}{|c} 
Average Peak \\
doud height
\end{tabular} & \begin{tabular}{|c|} 
uCs \\
Condition
\end{tabular} & $\begin{array}{l}\text { UCS } \\
\text { Method }\end{array}$ & UCS $\mathrm{Hag}$ & $\begin{array}{c}\text { UCS Center } \\
\text { Hag }\end{array}$ & $\begin{array}{l}\text { UCSuadv } \\
\text { Flag }\end{array}$ & \begin{tabular}{|c} 
UCS based on \\
Decreasing \\
Velocity
\end{tabular} & $\begin{array}{l}\text { Swreep } \\
\text { Increase / } \\
\text { Decrease }\end{array}$ & \begin{tabular}{|c|} 
UDV \\
Height \\
Bed \\
\end{tabular} & $\begin{array}{l}\text { Particle } \\
\text { Motion }\end{array}$ & \begin{tabular}{|l|} 
Solids \\
Level \\
\end{tabular} & \begin{tabular}{|c|} 
Outer \\
Bototom \\
Patem
\end{tabular} & \begin{tabular}{|l|} 
Inner \\
Botomom \\
Patem
\end{tabular} & Case ID & Test & IDP & $\begin{array}{l}\text { Row } \\
\text { Number }\end{array}$ \\
\hline c & $g / \mathrm{cm}^{3}$ & fraction & fraction & fraction & $\mathrm{s}$ & text & \begin{tabular}{|l|}
$\mathrm{m} / \mathrm{s}$ \\
\end{tabular} & $\mathrm{m} / \mathrm{s}$ & $\mathrm{m} / \mathrm{s}$ & m/s & $\mathrm{m} / \mathrm{s}$ & \begin{tabular}{|l|}
$\mathrm{m} / \mathrm{s}$ \\
\end{tabular} & in. & $\mathrm{m} / \mathrm{s}$ & text & text & text & text & m/s & text & $\mathrm{mm}$ & text & \begin{tabular}{|l|} 
text \\
\end{tabular} & \begin{tabular}{|l|} 
text \\
\end{tabular} & \begin{tabular}{|l|} 
text \\
\end{tabular} & text & text & text & text \\
\hline $\mathrm{T}$ & $\rho$ & $\phi_{\mathrm{s}}$ & $\phi_{p}$ & $D C$ & tc & Jet & $u_{s}$ & $\mathrm{U}_{1}$ & $\mathrm{U} 2$ & U3 & $u$ & Uss & $H_{\mathrm{C}}$ & U Cos & Uasn & \begin{tabular}{|l|} 
Ussis \\
\end{tabular} & Usseen & Usoudv & $u_{s \leq} \mathrm{D}$ & $\mathrm{s}_{\mathrm{v}}$ & $H_{\text {hed }}$ & $\mathrm{PM}$ & Sol & SPo & $\mathrm{SP}_{\mathrm{I}}$ & ID & MDDX & $\operatorname{TDP}$ & MSS \\
\hline 29.2 & 0.998 & 0.04500 & 0.050 & 0.332 & 9.8 & $\mathrm{P}$ & NA & 6.14 & 6.26 & $\begin{array}{r}6.32 \\
\end{array}$ & 6.50 & 6.50 & 7.50 & NA & NA & NA & NA & NA & NA & NA & 1.2 & NA & NA & NA & NA & 15E_4sId2WW_ 1 & 6/16B & TDP-181 & 9150218 \\
\hline 29.2 & 0.998 & 0.04500 & 0.050 & 0.332 & 9.8 & $\mathrm{P}$ & NA & 6.14 & 6.26 & 6.32 & 6.50 & 6.50 & 7.50 & NA & NA & NA & NA & NA & NA & $\mathrm{NA}$ & 0.0 & NA & NA & NA & NA & 15E_4s1d2WC_1 & 6/16B & TDP-181 & 9150219 \\
\hline 29.2 & 0.998 & 0.04500 & 0.050 & 0.332 & 9.8 & $\mathrm{P}$ & NA & 6.14 & 6.26 & 6.32 & 6.50 & 6.50 & 7.50 & NA & NA & NA & NA & NA & NA & NA & 3.1 & NA & NA & NA & NA & 15E_4S1d2WE_1 & 6/16B & TDP-181 & 9150220 \\
\hline 29.2 & 0.998 & 0.04500 & 0.050 & 0.332 & 9.8 & $\mathrm{P}$ & NA & 6.14 & 6.26 & 6.32 & 6.50 & 6.50 & 7.50 & NA & NA & NA & NA & NA & NA & NA & 0.0 & NA & NA & NA & NA & 15E_4s1d2Wc_1 & 6/16B & TDP-181 & 9150221 \\
\hline 29.2 & 0.998 & 0.04500 & 0.050 & 0.332 & 9.8 & $\mathrm{P}$ & NA & 6.14 & 6.26 & 6.32 & 6.50 & 6.50 & 7.50 & NA & NA & NA & NA & NA & NA & NA & 3.1 & NA & NA & NA & NA & 15E_4s1d2WC_1 & 6/16B & TDP-181 & 9150222 \\
\hline 29.2 & 0.998 & 0.04500 & 0.050 & 0.332 & 9.8 & $\mathrm{P}$ & NA & 6.14 & 6.26 & 6.32 & 6.50 & 6.50 & 7.50 & NA & NA & NA & NA & $\mathrm{NA}$ & NA & NA & 25 & NA & $\mathrm{NA}$ & NA & NA & 15E_4S1d2WC_1 & 6/16B & TDP-181 & 9150223 \\
\hline 24.5 & 0.999 & 0.04500 & 0.050 & 0.183 & 29.0 & $\mathrm{P}$ & NA & 3.79 & 3.84 & 3.87 & 4.00 & 7.20 & 3.50 & NA & NA & NA & NA & NA & NA & (null) & 22.0 & 1 & NA & NA & NA & 15E_4s1d2Wd_1 & 6/17A & TDP-182 & 9150224 \\
\hline 24.5 & 0.999 & 0.04500 & 0.050 & 0.184 & 26.2 & $\mathrm{P}$ & NA & 4.17 & 4.23 & 4.26 & 4.40 & 7.20 & 3.75 & NA & NA & NA & NA & NA & NA & 1 & 18.8 & 1 & NA & NA & NA & 15E_4s1d2Wd_1 & 6117A & TDP-182 & 9150225 \\
\hline 24.7 & 0.999 & 0.04500 & 0.050 & 0.184 & 24.0 & $\mathrm{P}$ & NA & 4.54 & 4.61 & 4.64 & 4.80 & 7.20 & 4.25 & NA & NA & NA & NA & NA & NA & & 16.4 & 1 & NA & NA & NA & 15E_4s1d2Wd_1 & 6/17A & TDP-182 & 9150226 \\
\hline 24.7 & 0.999 & 0.04500 & 0.050 & 0.185 & 22.0 & $\mathrm{P}$ & NA & 4.91 & 4.99 & 5.03 & 5.20 & 7.20 & 4.50 & NA & NA & NA & NA & NA & NA & 1 & 13.5 & 1 & NA & NA & NA & 15E_4s1d2Wd__1 & 6117А & TDP-182 & 9150227 \\
\hline 24.8 & 0.999 & 0.04500 & 0.050 & 0.186 & 19.0 & $\mathrm{P}$ & NA & 5.65 & 5.75 & 5.80 & 6.00 & 7.20 & 5.25 & NA & NA & NA & NA & NA & NA & 1 & 6.5 & 1 & NA & NA & NA & 15E_4s1d2Wd_1 & 6117A & TDP-182 & 9150228 \\
\hline 25.0 & 0.999 & 0.04500 & 0.050 & 0.187 & 17.8 & $\mathrm{P}$ & NA & 6.03 & 6.14 & 6.20 & 6.40 & 7.20 & 5.50 & NA & NA & NA & NA & NA & NA & 1 & 3.9 & 1 & NA & NA & $\mathrm{NA}$ & 15E_4s1d2Wd_1 1 & 6117A & TDP-182 & 9150229 \\
\hline 25.1 & 0.999 & 0.04500 & 0.050 & 0.188 & 17.2 & $\mathrm{P}$ & NA & 6.21 & 6.33 & 6.39 & 6.60 & 7.20 & 5.75 & NA & NA & NA & NA & NA & NA & 1 & 3.8 & 1 & NA & NA & NA & 15E_4s1d2Wd_1 & 6117A & TDP-182 & 9150230 \\
\hline 25.2 & 0.999 & 0.04500 & 0.050 & 0.189 & 16.6 & $\mathrm{P}$ & $\mathrm{NA}$ & 6.41 & 6.53 & 6.60 & 6.80 & 7.20 & 5.75 & NA & NA & NA & NA & $\mathrm{NA}$ & NA & & 3.8 & 1 & NA & $\mathrm{NA}$ & NA & 15E_4sIdZWd_1 & $6 / 17 \mathrm{~A}$ & TDP-182 & 9150231 \\
\hline 25.4 & 0.999 & 0.04500 & 0.050 & 0.187 & 16.2 & $P$ & $\mathrm{NA}$ & 6.58 & 6.71 & 6.78 & 7.00 & 7.20 & 6.00 & NA & NA & $\mathrm{NA}$ & NA & NA & NA & 1 & 3.8 & 1 & NA & $\mathrm{NA}$ & NA & 15E_4s1d2Wd_1 & 6/17A & TDP-182 & 9150232 \\
\hline 25.6 & 0.999 & 0.04500 & 0.050 & 0.188 & 15.8 & $\mathrm{P}$ & NA & 6.78 & 6.91 & 6.98 & 7.20 & 7.20 & 6.00 & \begin{tabular}{|l|}
7.20 \\
\end{tabular} & uav & NA & NA & ucsudv & NA & 1 & 2.5 & 1 & NA & NA & NA & 15E_4s1d2Wd_1 & 6/17A & IDP-182 & 9150233 \\
\hline 25.8 & 0.999 & 0.04500 & 0.050 & 0.187 & 15.4 & $\mathrm{P}$ & NA & 6.95 & 7.10 & 7.17 & 7.40 & 7.20 & 6.25 & NA & NA & \begin{tabular}{|l|} 
UCShis \\
\end{tabular} & NA & NA & NA & & 0.0 & 3 & NA & NA & NA & 15E_4s1d2Wd_1 & 6117A & TDP-182 & 9150234 \\
\hline 25.9 & 0.999 & 0.04500 & 0.050 & 0.187 & 15.0 & $\mathrm{P}$ & NA & 7.13 & 7.28 & 7.36 & 7.60 & 7.20 & 6.75 & NA & NA & NA & NA & NA & NA & 1 & 0.0 & 4 & NA & NA & NA & 15E_4s1d2Wd_1 & 6117A & TDP-182 & 9150235 \\
\hline 26.3 & 0.999 & 0.04500 & 0.050 & 0.189 & 14.2 & $\mathrm{P}$ & NA & 7.49 & 7.65 & 7.73 & 8.00 & 7.20 & 7.00 & NA & NA & NA & NA & NA & NA & 1 & 0.0 & 4 & NA & $\mathrm{NA}$ & NA & 15E_4s1d2Wd_ 1 & 6117A & TDP-182 & 9150236 \\
\hline 26.5 & 0.999 & 0.04500 & 0.050 & 0.187 & 13.0 & $\mathrm{P}$ & NA & 8.18 & 8.38 & 8.48 & 8.80 & 7.20 & 8.25 & NA & NA & NA & NA & NA & NA & 1 & 0.0 & 4 & NA & $\mathrm{NA}$ & NA & 15E_4s1d2Wd_1 1 & 6117A & TDP-182 & 9150237 \\
\hline 26.9 & 0.999 & 0.04500 & 0.050 & 0.187 & 12.2 & $\mathrm{P}$ & NA & 8.70 & 8.92 & 9.04 & 9.40 & 7.20 & 9.25 & NA & NA & NA & NA & NA & NA & 1 & 0.0 & 4 & NA & NA & NA & 15E_4s1d2Wd_1 & 6117A & TDP-182 & 9150238 \\
\hline 27.2 & 0.999 & 0.04500 & 0.050 & 0.189 & 11.4 & $\mathrm{P}$ & NA & 9.26 & 9.50 & 9.63 & 10.00 & 7.20 & 10.50 & NA & NA & NA & NA & $\mathrm{NA}$ & $\mathrm{N}$ & & 0.0 & 4 & NA & NA & NA & 15E_4s1d2Wd_1 & 6117A & TDP-182 & 9150239 \\
\hline 27.9 & 0.998 & 0.04500 & 0.050 & 0.185 & 11.0 & $\mathrm{P}$ & NA & 9.77 & 册 & \begin{tabular}{|l|}
10.18 \\
\end{tabular} & 10.60 & 7.20 & 12.00 & NA & NA & NA & NA & NA & NA & 1 & \begin{tabular}{|l|} 
\\
\end{tabular} & 4 & NA & NA & NA & 15E_4s1d2Wd_1 & $617 \mathrm{~A}$ & TDP-182 & 9150240 \\
\hline 28.3 & 0.998 & 0.04500 & 0.050 & 0.188 & 15.8 & $\mathrm{P}$ & NA & 6.77 & 6.91 & \begin{tabular}{|l|}
6.98 \\
\end{tabular} & 7.20 & 7.20 & 5.75 & NA & NA & NA & NA & NA & NA & NA & n/a & NA & NA & NA & NA & 15E_4S1d2Wd_1 1 & 6117A & TDP-182 & 9150240.1 \\
\hline 28.3 & 0.998 & 0.04500 & 0.050 & 0.188 & 15.8 & $\mathrm{P}$ & NA & 6.77 & 6.91 & \begin{tabular}{|l|}
6.98 \\
\end{tabular} & 7.20 & 7.20 & 5.75 & NA & NA & NA & NA & NA & NA & NA & n/a & NA & NA & NA & NA & 15E_4s1d2Wd_1 & 6117A & TDP-182 & 9150240.2 \\
\hline 28.3 & 0.998 & 0.04500 & 0.050 & 0.188 & 15.8 & $\mathrm{P}$ & NA & 6.77 & 6.91 & 6.98 & 7.20 & 7.20 & 5.75 & NA & NA & NA & NA & NA & NA & NA & na & NA & NA & NA & NA & 15E_4s1d2Wd_1 & 6/17A & TDP-182 & 9150240.3 \\
\hline 28.3 & 0.998 & 0.04500 & 0.050 & 0.188 & 15.8 & $\mathrm{P}$ & NA & 6.77 & 6.91 & 6.98 & 7.20 & 7.20 & 5.75 & NA & NA & NA & NA & NA & NA & $\mathrm{NA}$ & ra & NA & NA & NA & NA & 15E_4sIdZWd_1 & 6117A & TDP-182 & 9150240.4 \\
\hline 28.3 & 0.998 & 0.04500 & 0.050 & 0.188 & 15.8 & $\mathrm{P}$ & NA & 6.77 & 6.91 & 6.98 & 7.20 & 7.20 & 5.75 & NA & NA & NA & NA & NA & NA & $\mathrm{NA}$ & $\mathrm{N} / \mathrm{a}$ & NA & NA & $\mathrm{NA}$ & NA & 15E_4s1d2Wd_1 1 & 6/17A & TDP-182 & 9150240.5 \\
\hline 28.3 & 0.998 & 0.04500 & 0.050 & 0.188 & 15.8 & $\mathrm{P}$ & NA & 6.77 & 6.91 & 6.98 & 7.20 & 7.20 & 5.75 & NA & NA & NA & NA & NA & NA & 1 & n/a & NA & NA & NA & NA & 15E_4s1d2Wd_1 1 & 6117A & TDP-182 & 9150240.6 \\
\hline 28.3 & 0.998 & 0.04500 & 0.050 & 0.188 & 15.8 & $\mathrm{P}$ & NA & 6.77 & 6.91 & 6.98 & 7.20 & 7.20 & 5.75 & NA & NA & NA & NA & NA & $\mathrm{N} / \mathrm{H}$ & $\mathrm{NA}$ & nva & NA & NA & NA & NA & 15E_4s1d2Wd_1 1 & 6117A & TDP-182 & 9150240.7 \\
\hline 28.3 & 0.998 & 0.04500 & 0.050 & 0.188 & 15.8 & $P$ & NA & 6.77 & 6.91 & 6.98 & 7.20 & 7.20 & 5.75 & NA & NA & NA & NA & $\mathrm{NA}$ & NA & $\mathrm{NA}$ & \begin{tabular}{|l|}
3.7 \\
\end{tabular} & 1 & $\mathrm{NA}$ & NA & NA & 15E_4sIdZWd_1 & $6 / 17 \mathrm{~A}$ & TDP-182 & 9150241 \\
\hline 28.3 & 0.998 & 0.04500 & 0.050 & 0.188 & 15.8 & $P$ & NA & 6.77 & 6.91 & 6.98 & 7.20 & 7.20 & 5.75 & NA & NA & $\mathrm{NA}$ & NA & NA & NA & $\mathrm{NA}$ & 1.5 & NA & $\mathrm{NA}$ & $\mathrm{NA}$ & NA & 15E_4s1d2Wd_1 & 6/17A & TDP-182 & 9150242 \\
\hline 28.3 & 0.998 & 0.04500 & 0.050 & 0.188 & 15.8 & $\mathrm{P}$ & NA & 6.77 & 6.91 & 6.98 & 7.20 & 7.20 & 5.75 & NA & NA & NA & NA & NA & NA & NA & 0.7 & $\mathrm{NA}$ & NA & NA & NA & 15E_4s1d2Wd_1 1 & 6117A & TDP-182 & 9150243 \\
\hline 28.3 & 0.998 & 0.04500 & 0.050 & 0.188 & 15.8 & $P$ & NA & 6.77 & 6.91 & 6.98 & 7.20 & 7.20 & 5.75 & NA & NA & $N A$ & $\mathrm{NA}$ & NA & NA & NA & 2.2. & NA & $\mathrm{NA}$ & $N A$ & $\mathrm{NA}$ & 15E_4s1d2Wd_1 1 & 6117A & TDP-182 & 9150244 \\
\hline 28.3 & 0.998 & 0.04500 & 0.050 & 0.188 & 15.8 & $\mathrm{P}$ & NA & 6.77 & 6.91 & 6.98 & 7.20 & 7.20 & 5.75 & NA & NA & NA & NA & NA & NA & NA & 21 & NA & NA & NA & NA & 15E_4sIdZWd_1 & $617 \mathrm{~A}$ & TDP-182 & 9150245 \\
\hline 28.3 & 0.998 & 0.04500 & 0.050 & 0.188 & 15.8 & $\mathrm{P}$ & NA & 6.77 & 6.91 & 6.98 & 7.20 & 7.20 & 5.75 & NA & NA & NA & NA & NA & NA & NA & 22 & NA & $\mathrm{NA}$ & $\mathrm{NA}$ & NA & 15E_4s1d2Wd_1 & 6117A & TDP-182 & 9150246 \\
\hline 28.3 & 0.998 & 0.04500 & 0.050 & 0.188 & 15.8 & $\mathrm{P}$ & NA & 6.77 & 6.91 & 6.98 & 7.20 & 7.20 & 5.75 & NA & NA & NA & NA & NA & NA & NA & 22 & NA & NA & NA & NA & 15E_4s1d2Wd_1 1 & 6/17A & TDP-182 & 9150247 \\
\hline 28.3 & 0.998 & 0.04500 & 0.050 & 0.188 & 15.8 & $\mathrm{P}$ & NA & 6.77 & \begin{tabular}{|l|l|}
6.91 \\
\end{tabular} & \begin{tabular}{|l|}
6.98 \\
\end{tabular} & 7.20 & 7.20 & 5.75 & NA & NA & NA & NA & NA & NA & NA & 3.1 & NA & NA & NA & NA & 15E_4s1d2Wd_1 1 & 6117A & TDP-182 & 9150248 \\
\hline 27.1 & 0.999 & 0.04500 & $\begin{array}{l}\text { undefined } \\
\end{array}$ & 1.000 & infinite & $\mathrm{s}$ & & ra & Na & n/a & 2.00 & 3.00 & 5.63 & NA & NA & NA & $\mathrm{NA}$ & NA & NA & (null) & 20.4 & 1 & $\mathrm{NA}$ & NA & NA & 15E_4s1d2Wa & $6 / 178$ & TDP-182 & 9150249 \\
\hline 27.1 & 0.999 & 0.04500 & $\begin{array}{l}\text { undefined } \\
\end{array}$ & 1.000 & infinite & $\mathrm{s}$ & & ra & $\mathrm{na}$ & ra & 240 & 3.00 & 7.88 & NA & NA & NA & NA & NA & NA & & 7.5 & 1 & NA & NA & NA & 15E_4sidzWa & $6 / 17 \mathrm{~B}$ & TDP-182 & 9150250 \\
\hline 27.2 & 0.998 & 0.04500 & undefined & 1.000 & infinite & $\mathrm{s}$ & 2.79 & na & ra & na & 2.80 & 3.00 & 11.50 & NA & NA & NA & NA & NA & NA & 1 & 4.2 & 1 & NA & NA & NA & 15E_4s1d2Wa & 6/178 & TDP-182 & 9150251 \\
\hline
\end{tabular}


Table B.3. Data from 2008 Tests in Small-Scale Vessel with Elliptical Head A.8

\begin{tabular}{|c|c|c|c|c|c|c|c|c|c|c|c|c|c|c|c|c|c|c|c|c|c|c|c|c|c|c|c|}
\hline $\begin{array}{l}\text { Row } \\
\text { Number }\end{array}$ & Test & Case ID & $\begin{array}{l}\text { Tank } \\
\text { Diameter }\end{array}$ & $\begin{array}{l}\text { Head } \\
\text { Shape }\end{array}$ & \begin{tabular}{|c} 
Dish \\
Height
\end{tabular} & $\begin{array}{l}\text { Dish } \\
\text { Volume }\end{array}$ & $\begin{array}{l}\text { Tank FIII } \\
\text { Height }\end{array}$ & $\begin{array}{c}\text { Retur } \\
\text { Line } \\
\text { Height }\end{array}$ & \begin{tabular}{|c|} 
Nozzle \\
Inner \\
Diameter \\
\end{tabular} & $\begin{array}{l}\text { Nozzle } \\
\text { Stand-off } \\
\text { Distance }\end{array}$ & $\begin{array}{l}\text { Pulse Tube } \\
\text { Configuration }\end{array}$ & $\begin{array}{l}\text { Installed } \\
\text { Nozzles }\end{array}$ & $\begin{array}{l}\text { Outer } \\
\text { Nozzles } \\
\text { Operated }\end{array}$ & $\begin{array}{c}\text { Inner } \\
\text { Noveles } \\
\text { Operated }\end{array}$ & $\begin{array}{c}\text { Pulse Tube } \\
\text { Outer } \\
\text { Diameter }\end{array}$ & $\begin{array}{c}\text { Outer } \\
\text { PMM } \\
\text { Radius }\end{array}$ & $\begin{array}{c}\text { Inner PJM } \\
\text { Radius }\end{array}$ & $\begin{array}{c}\text { "FIO" Outer PJM } \\
\text { Impingement } \\
\text { Angle }\end{array}$ & $\begin{array}{l}\text { "FO' Inner PJM } \\
\text { Impingement Angle }\end{array}$ & $\begin{array}{l}\begin{array}{l}\text { Ratio Outer PJM } \\
\text { to Tank Radius }\end{array} \\
\end{array}$ & \begin{tabular}{|l}
$\begin{array}{c}\text { Ratio Inner PJM } \\
\text { to Tank Radius }\end{array}$ \\
\end{tabular} & Simulant & $\begin{array}{l}\text { Solids } \\
\text { Density }\end{array}$ & $\begin{array}{c}\text { Particle } \\
\text { Diameter d5 }\end{array}$ & \begin{tabular}{c|} 
Particle \\
Diameter d50
\end{tabular} & \begin{tabular}{c|c} 
Patricle \\
Diameter d95
\end{tabular} & $\begin{array}{c}\text { Void } \\
\text { Fraction }\end{array}$ \\
\hline text & text & text & in. & text & in. & in. ${ }^{3}$ & in. & in. & in. & in. & text & number & number & number & in. & in. & in. & deg & deg & nondim & nondim & text & $\mathrm{g} / \mathrm{cm}^{3}$ & $\mathrm{~m}$ & \begin{tabular}{l|}
$\mathrm{m}$ \\
\end{tabular} & $m$ & fraction \\
\hline MSS & MDDX & ID & $\mathrm{D}$ & $\mathrm{HS}$ & Hosh & $V_{\text {dish }}$ & $\mathrm{H}$ & Rn & $d$ & sod & PT & $\mathrm{N}$ & $\mathrm{Nb}$ & $\mathrm{N}$ & $\mathrm{PT}_{\alpha \mathrm{d}}$ & $\mathrm{Ro}_{\mathrm{o}}$ & $R$ & $\theta_{0}$ & $\theta_{1}$ & $\mathrm{Rd} d \mathrm{R}$ & $R / R$ & sxdx & $\rho_{s}$ & $d_{b}$ & $\mathrm{~d}_{60}$ & $d_{65}$ & $\mathrm{vf}$ \\
\hline 9150252 & $6 / 178$ & 15E_4sidd2Wa & $147 / 16$ & $E$ & 3.25 & 354.8 & $341 / 2$ & 30 & 0.126 & 0.189 & HLP.22 & 12 & 8 & 4 & 1.05 & 4.5 & 2.4 & 21.8 & 10.1 & 0.62 & 0.34 & s1d2 & 2.48 & 0.0000569 & 0.0000693 & 0.0000821 & 0.3750 \\
\hline 9150253 & $6 / 178$ & 15E_4s1d2Wa & $147 / 16$ & $E$ & 3.25 & 354.8 & $341 / 2$ & 30 & 0.126 & 0.189 & HLP. 22 & 12 & 8 & 4 & 1.05 & 4.5 & 2.4 & 21.8 & 10.1 & 0.62 & 0.34 & s1d2 & 2.48 & 0.0000569 & $\begin{array}{ll}0.0000693 \\
\end{array}$ & 0.0000821 & 0.3750 \\
\hline 9150254 & $6 / 178$ & 15E_4sidzWa & 147716 & $\mathrm{E}$ & 3.25 & 354.8 & $341 / 2$ & 30 & 0.126 & 0.189 & HLP-22 & 12 & 8 & 4 & 1.05 & 4.5 & 2.4 & 21.8 & 10.1 & 0.62 & 0.34 & s1d2 & 2.48 & 0.0000569 & $\begin{array}{ll}0.0000693 \\
\end{array}$ & 0.0000821 & 0.3750 \\
\hline 9150255 & 6/178 & 15E_4sidzWa & 147116 & $E$ & 3.25 & 354.8 & $341 / 2$ & 30 & 0.126 & 0.189 & HLP 22 & 12 & 8 & 4 & 1.05 & 4.5 & 2.4 & 21.8 & 10.1 & 0.62 & 0.34 & $\mathrm{~s} 1 \mathrm{~d} 2$ & 248 & 0.0000569 & 0.0000693 & 0.0000821 & 0.3750 \\
\hline 9150256 & 61778 & 15E_4sidd2Wa & $147 / 16$ & $E$ & 3.25 & 354.8 & $341 / 2$ & 30 & 0.126 & 0.189 & HLP-22 & 12 & 8 & 4 & 1.05 & 4.5 & 2.4 & 21.8 & 10.1 & 0.62 & 0.34 & s1d2 & 248 & 0.0000569 & 0.0000693 & 0.0000821 & 0.3750 \\
\hline 9150257 & $6 / 17 \mathrm{~B}$ & 15E_4sidd2Wa & $147 / 16$ & $\mathrm{E}$ & 3.25 & 354.8 & $341 / 2$ & 30 & 0.126 & 0.189 & HLP-22 & 12 & 8 & 4 & 1.05 & 4.5 & 2.4 & 21.8 & 10.1 & 0.62 & 0.34 & s1d2 & 248 & 0.0000569 & 0.0000693 & 0.0000821 & 0.3750 \\
\hline 9150258 & 6/178 & 15E_4sidzWa & $147 / 16$ & $E$ & 3.25 & 354.8 & $341 / 2$ & 30 & 0.126 & 0.189 & HLP-22 & 12 & 8 & 4 & 1.05 & 4.5 & 2.4 & 21.8 & 10.1 & 0.62 & 0.34 & s1d2 & 2.48 & 0.0000569 & 0.0000693 & 0.0000821 & 0.3750 \\
\hline 9150259 & $6 / 17 \mathrm{~B}$ & 15E_4sidzWWa & $147 / 16$ & $E$ & 3.25 & 354.8 & $341 / 2$ & 30 & 0.126 & 0.189 & HLP-22 & 12 & 8 & 4 & 1.05 & 4.5 & 2.4 & 21.8 & 10.1 & 0.62 & 0.34 & s1d2 & 2.48 & 0.0000569 & 0.0000693 & 0.0000821 & 0.3750 \\
\hline 9150260 & $6 / 178$ & 15E_4sidd2Wa & 147716 & $E$ & 3.25 & 354.8 & $341 / 2$ & 30 & 0.126 & 0.189 & HLP-22 & 12 & 8 & 4 & 1.05 & 4.5 & 2.4 & 21.8 & 10.1 & 0.62 & 0.34 & s1d2 & 248 & 0.0000569 & 0.0000693 & 0.0000821 & 0.3750 \\
\hline 9150261 & $6 / 17 \mathrm{~B}$ & 15E_4sido2wa & $147 / 16$ & $E$ & 3.25 & 354.8 & $341 / 2$ & 30 & 0.126 & 0.189 & HLP-22 & 12 & 8 & 4 & 1.05 & 4.5 & 24 & 21.8 & 10. & 0.62 & 0.34 & s1d2 & 2.48 & 0.0000569 & 0.0000693 & 0.0000821 & 0.3750 \\
\hline 9150262 & $6 / 178$ & 15E__4sidzWa & 147116 & E & 3.25 & 354.8 & $341 / 2$ & 30 & 0.126 & 0.189 & HLP-22 & 12 & 8 & 4 & 1.05 & 4.5 & 2.4 & 21.8 & 10.1 & 0.62 & 0.34 & s1d2 & 248 & 0.0000569 & 0.0000693 & 0.0000821 & 0.3750 \\
\hline 9150263 & 6/178 & $15 E$ - 4sidewa & $147 / 16$ & E & $\begin{array}{ll}3.25 \\
\end{array}$ & 354.8 & $341 / 2$ & 30 & 0.126 & 0.189 & HLP-22 & 12 & 8 & 4 & 1.05 & 4.5 & 2.4 & 21.8 & 10.1 & 0.62 & 0.34 & s1d2 & 248 & 0.0000569 & $\begin{array}{l}0.0000693 \\
\end{array}$ & 0.0000821 & 0.3750 \\
\hline 9150264 & 6/178 & 15E_4sidd2Wa & $147 / 16$ & $E$ & 3.25 & 354.8 & $341 / 2$ & 30 & 0.126 & 0.189 & HLP-22 & 12 & 8 & 4 & 1.05 & 4.5 & 2.4 & 21.8 & 10.1 & 0.62 & 0.34 & s1d2 & 2.48 & 0.0000569 & 0.0000693 & 0.0000821 & 0.3750 \\
\hline 9150265 & 61178 & 15E_4s1d2Wa & $147 / 16$ & $E$ & 3.25 & 354.8 & $341 / 2$ & 30 & 0.126 & 0.189 & HLP-22 & 12 & 8 & 4 & 105 & 4.5 & 24 & 218 & 10.1 & 0.62 & 0.34 & s1d2 & 248 & 0.0000569 & \begin{tabular}{|c|}
0.0000693 \\
\end{tabular} & 0.0000821 & 0.3750 \\
\hline $9150266 \mathrm{M}$ & 6 6171 & 15E_4s1d2Wc_1 & 147716 & $E$ & 3.25 & 354.8 & $341 / 2$ & 30 & 0.126 & 0.189 & HLP-22 & 12 & 8 & 4 & 1.05 & 4.5 & 2.4 & 21.8 & 10.1 & 0.62 & 0.34 & $\mathrm{~s} 1 \mathrm{~d} 2$ & 248 & 0.0000569 & 0.0000693 & 0.0000821 & 0.3750 \\
\hline 9150267 & $6 / 17 \mathrm{C}$ & 15E_4S1d2WE_ 11 & 147116 & $E$ & 3.25 & 354.8 & $341 / 2$ & 30 & 0.126 & 0.189 & HLP-22 & 12 & 8 & 4 & 1.05 & 4.5 & 2.4 & 21.8 & 10.1 & 0.62 & 0.34 & $\mathrm{~s} 1 \mathrm{~d} 2$ & 2.48 & 0.0000569 & 0.0000693 & 0.0000821 & 0.3750 \\
\hline 9150268 & $6 / 17 \mathrm{C}$ & 15E_4s1d2WC_1 & 147716 & $E$ & 3.25 & 354.8 & $341 / 2$ & 30 & 0.126 & 0.189 & HLP-22 & 12 & 8 & 4 & 1.05 & 4.5 & 2.4 & 21.8 & 10.1 & 0.62 & 0.34 & s1d2 & 2.48 & 0.0000569 & 0.0000693 & 0.0000821 & 0.3750 \\
\hline 9150269 & $6117 \mathrm{C}$ & 15E_4S1d2WE_1 & $147 / 16$ & $E$ & 3.25 & 354.8 & $341 / 2$ & 30 & 0.126 & 0.189 & HLP-22 & 12 & 8 & 4 & 1.05 & 4.5 & 2.4 & 21.8 & 10.1 & 0.62 & 0.34 & s1d2 & 2.48 & 0.0000569 & $\begin{array}{ll}0.0000693 \\
\end{array}$ & 0.0000821 & 0.3750 \\
\hline 9150270 & $6 / 17 \mathrm{C}$ & 15E_4s1d2WC_1 & $147 / 16$ & $E$ & 3.25 & 354.8 & $341 / 2$ & 30 & 0.126 & 0.189 & HLP-22 & 12 & 8 & 4 & 1.05 & 4.5 & 2.4 & 21.8 & 10.1 & 0.62 & 0.34 & $\mathrm{~s} 1 \mathrm{~d} 2$ & 2.48 & 0.0000569 & 0.0000693 & 0.0000821 & 0.3750 \\
\hline 9150271 & $617 \mathrm{C}$ & 15E_4S1d 2WC 1 & $147 / 16$ & E & 3.25 & 354.8 & $341 / 2$ & 30 & 0.126 & 0.189 & HLP-22 & 12 & 8 & 4 & 1.05 & 4.5 & 24 & 21.8 & 10.1 & 0.62 & 0.34 & s1d2 & 2.48 & 0.0000569 & 0.0000693 & 0.0000821 & 0.3750 \\
\hline 9150272 & $6 / 17 \mathrm{C}$ & 15E_4s1d2WC_ 1 & $147 / 16$ & $E$ & 3.25 & 354.8 & $341 / 2$ & 30 & 0.126 & 0.189 & HLP-22 & 12 & 8 & 4 & 1.05 & 4.5 & 2.4 & 21.8 & 10.1 & 0.62 & 0.34 & s1d2 & 248 & 0.0000569 & 0.0000693 & 0.0000821 & 0.3750 \\
\hline 9150273 & $6 / 17 \mathrm{C}$ & 15E_4s1d2WC_1 & $147 / 16$ & $E$ & 3.25 & 354.8 & $341 / 2$ & 30 & 0.126 & 0.189 & HLP-22 & 12 & 8 & 4 & 1.05 & 4.5 & 2.4 & 21.8 & 10.1 & 0.62 & 0.34 & s1d2 & 2.48 & 0.0000569 & 0.0000693 & 0.0000821 & 0.3750 \\
\hline 9150274 & $617 \mathrm{C}$ & 15E_4s1d2WE_1 & $147 / 16$ & $E$ & 3.25 & 354.8 & $341 / 2$ & 30 & 0.126 & 0.189 & HLP.22 & 12 & 8 & 4 & 1.05 & 4.5 & 2.4 & 21.8 & 10. & 0.62 & 0.34 & s1d2 & 2.48 & 0.0000569 & $\begin{array}{ll}0.0000693 \\
\end{array}$ & 0.0000821 & 0.3750 \\
\hline 9150275 & $6 / 17 \mathrm{C}$ & 15E_4SIdZWC_1 & $147 / 16$ & $E$ & 3.25 & 354.8 & $341 / 2$ & 30 & 0.126 & 0.189 & HLP.22 & 12 & 8 & 4 & 1.05 & 4.5 & 2.4 & 21.8 & 10.1 & 0.62 & 0.34 & s1d2 & 2.48 & 0.0000569 & 0.0000693 & 0.0000821 & 0.3750 \\
\hline 9150276 & $6 / 17 \mathrm{C}$ & 15E_4SIdI2WC_1 & $147 / 16$ & $E$ & 3.25 & 354.8 & $341 / 2$ & 30 & 0.126 & 0.189 & HLP-22 & 12 & 8 & 4 & 1.05 & 4.5 & 2.4 & 21.8 & 10.1 & 0.62 & 0.34 & s1d2 & 248 & 0.0000569 & 0.0000693 & 0.0000821 & 0.3750 \\
\hline $91502 \pi$ & $6 / 17 \mathrm{C}$ & 15E_4s1d2WC_1 & $147 / 16$ & $E$ & 3.25 & 354.8 & $341 / 2$ & 30 & 0.126 & 0.189 & HLP-22 & 12 & 8 & 4 & 1.05 & 4.5 & 2.4 & 21.8 & 10.1 & 0.62 & 0.34 & s1d2 & 248 & 0.0000569 & 0.0000693 & 0.0000821 & 0.3750 \\
\hline 9150278 & 61818A & 15E_4s1d2Pc_1 & $147 / 16$ & $E$ & 3.25 & 354.8 & $341 / 2$ & 30 & 0.126 & 0.189 & HLP-22 & 12 & 8 & 4 & 108 & 4.5 & 24 & 218 & 10.1 & 0.62 & 0.34 & s1d2 & 2.48 & 0.0000569 & \begin{tabular}{|c|}
0.0000693 \\
\end{tabular} & 0.0000821 & 0.3750 \\
\hline 9150279 & 6/18A & 15E_4s1d2PC_ 1 & $147 / 16$ & $E$ & 3.25 & 354.8 & $341 / 2$ & 30 & 0.126 & 0.189 & HLP-22 & 12 & 8 & 4 & 1.05 & 4.5 & 2.4 & 21.8 & 10.1 & 0.62 & 0.34 & s1d2 & 2.48 & 0.0000569 & 0.0000693 & 0.0000821 & 0.3750 \\
\hline 9150280 & 6118A & 15E_4s1d2PC_1 & $147 / 16$ & $E$ & 3.25 & 354.8 & $341 / 2$ & 30 & 0.126 & 0.189 & HLP-22 & 12 & 8 & 4 & 1.05 & 4.5 & 2.4 & 21.8 & 10.1 & 0.62 & 0.34 & $\mathrm{sid2}$ & 2.48 & 0.0000569 & 0.0000693 & 0.0000821 & 0.3750 \\
\hline 9150281 & $6 / 18 \mathrm{~A}$ & $15 \mathrm{E}_{4}$ 4s1d2Pc 1 & $147 / 16$ & $E$ & 3.25 & 354.8 & $341 / 2$ & 30 & 0.126 & 0.189 & HLP-22 & 12 & 8 & 4 & 1.05 & 4.5 & 2.4 & 21.8 & 10.1 & 0.62 & 0.34 & s1d2 & 2.48 & 0.0000569 & 0.0000693 & 0.0000821 & 0.3750 \\
\hline 9150282 & 6/18A & 15E_4s1d2Pc_1 & $147 / 16$ & $E$ & 3.25 & 354.8 & $341 / 2$ & 30 & 0.126 & 0.189 & HLP-22 & 12 & 8 & 4 & 1.05 & 4.5 & 2.4 & 21.8 & 10.1 & 0.62 & 0.34 & s1d2 & 2.48 & 0.0000569 & 0.0000693 & 0.0000821 & 0.3750 \\
\hline 9150283 & $6 / 18 \mathrm{~A}$ & 15E_4s $1 \mathrm{~d} 2 \mathrm{Pc} 1$ & $147 / 16$ & $E$ & 3.25 & 354.8 & $341 / 2$ & 30 & 0.126 & 0.189 & HLP-22 & 12 & 8 & 4 & 1.05 & 4.5 & 2.4 & 21.8 & 10.1 & 0.62 & 0.34 & s1d2 & 2.48 & 0.0000569 & 0.0000693 & 0.0000821 & 0.3750 \\
\hline $9150284 \mathrm{M}$ & 6/18A & 15E_4s1d2PC_1 & 147116 & $E$ & 3.25 & 354.8 & $341 / 2$ & 30 & 0.126 & 0.189 & HLP 22 & 12 & 8 & 4 & 1.05 & 4.5 & 2.4 & 21.8 & 10.1 & 0.62 & 0.34 & $\mathrm{sid2}$ & 2.48 & 0.0000569 & 0.0000693 & 0.0000821 & 0.3750 \\
\hline $9150285 \mathrm{M}$ & $6 / 18 \mathrm{~A}$ & $15 \mathrm{E}_{4} 4 \mathrm{~s} 1 \mathrm{~d} 2 \mathrm{Pc} \_1$ & $147 / 16$ & $E$ & 3.25 & 354.8 & $341 / 2$ & 30 & 0.126 & 0.189 & HLP-22 & 12 & 8 & 4 & 1.05 & 4.5 & 2.4 & 21.8 & 10.1 & 0.62 & 0.34 & & 2.48 & 0.0000569 & 0.0000693 & 0.0000821 & 0.3750 \\
\hline $9150286 \mathrm{M}$ & $6 / 18 \mathrm{~A}$ & 15E_4s1d2PC_1 & $147 / 16$ & $E$ & 3.25 & 354.8 & $341 / 2$ & 30 & 0.126 & 0.189 & HLP-22 & 12 & 8 & 4 & 1.05 & 4.5 & 2.4 & 21.8 & 10.1 & 0.62 & 0.34 & $\mathrm{~s} 1 \mathrm{~d} 2$ & 2.48 & 0.0000569 & $\begin{array}{ll}0.0000693 \\
\end{array}$ & 0.0000821 & 0.3750 \\
\hline $9150287 \mathrm{M}$ & $6 / 18 \mathrm{~A}$ & 15E_4s $1 \mathrm{~d} 2 \mathrm{Pc} 1$ & $147 / 16$ & $E$ & 3.25 & 354.8 & $341 / 2$ & 30 & 0.126 & 0.189 & HLP-22 & 12 & 8 & 4 & 1.05 & 4.5 & 2.4 & 21.8 & 10.1 & 0.62 & 0.34 & $\mathrm{~s} 1 \mathrm{~d} 2$ & 2.48 & 0.0000569 & 0.0000693 & 0.0000821 & 0.3750 \\
\hline $9150288 \mathrm{M}$ & 6/18A & 15E_4S1d2PC 1 & $147 / 16$ & $E$ & 3.25 & 354.8 & $341 / 2$ & 30 & 0.126 & 0.189 & HLP 22 & 12 & 8 & 4 & 1.05 & 4.5 & 24 & 21.8 & 10.1 & 0.62 & 0.34 & $\mathrm{sid} 2$ & 2.48 & 0.0000569 & 0.0000693 & 0.0000821 & 0.3750 \\
\hline $9150289 \mathrm{M}$ & 6/18A & 15E_4s1d2PC_1 & 147116 & $\mathrm{E}$ & 3.25 & 354.8 & $341 / 2$ & 30 & 0.126 & 0.189 & HLP-22 & 12 & 8 & 4 & 1.05 & 4.5 & 2.4 & 21.8 & 10.1 & 0.62 & 0.34 & $\mathrm{sid2}$ & 2.48 & 0.0000569 & 0.0000693 & 0.0000821 & 0.3750 \\
\hline $9150290 \mathrm{M}$ & 618A & & $147 / 16$ & $E$ & 3.25 & 354.8 & $341 / 2$ & 30 & 0.126 & 0.189 & & 12 & 8 & - & & 4.5 & 2.4 & & & & & & & & & & \\
\hline 9150290.1 & 6118A & 15E_4s1d2PC_1 & $147 / 16$ & $E$ & 3.25 & 354.8 & $341 / 2$ & 30 & 0.126 & 0.189 & HLP-22 & 12 & 8 & 4 & 1.05 & 4.5 & 2.4 & 21.8 & 10.1 & 0.62 & 0.34 & s1d2 & 2.48 & 0.0000569 & \begin{tabular}{|c|}
0.0000693 \\
\end{tabular} & 0.0000821 & 0.3750 \\
\hline 9150290.2 & 6118A & 15E_4S1d2PC_1 1 & $147 / 16$ & $E$ & 3.25 & 354.8 & $341 / 2$ & 30 & 0.126 & 0.189 & HLP-22 & 12 & 8 & 4 & 1.05 & 4.5 & 2.4 & 218 & 10.1 & 0.62 & 0.34 & s1d2 & 2.48 & $\begin{array}{l}0.0000569 \\
\end{array}$ & 0.0000693 & 0.0000821 & 0.3750 \\
\hline
\end{tabular}


Table B.3. Data from 2008 Tests in Small-Scale Vessel with Elliptical Head B.8

\begin{tabular}{|c|c|c|c|c|c|c|c|c|c|c|c|c|c|c|c|c|c|c|c|c|c|c|c|c|c|c|c|c|c|}
\hline $\begin{array}{l}\text { Tank Water } \\
\text { Temperature }\end{array}$ & \begin{tabular}{|c|} 
Water \\
Density
\end{tabular} & $\begin{array}{c}\text { Solids } \\
\text { Fraction }\end{array}$ & \begin{tabular}{|c|} 
Pulse \\
Vulume \\
Fraction \\
\end{tabular} & \begin{tabular}{|l|} 
Duty \\
Oycle \\
\end{tabular} & $\begin{array}{l}\text { Oyde } \\
\text { Time }\end{array}$ & \begin{tabular}{|l|}
$\begin{array}{l}\text { Pulsed or } \\
\text { Steacy Jet }\end{array}$ \\
Steacy Jet
\end{tabular} & \begin{tabular}{|c|} 
Us \\
Steacy \\
Jet \\
\end{tabular} & $\begin{array}{c}\text { U1 } \\
\text { Pulsin } \\
\text { g Jet }\end{array}$ & $\begin{array}{c}\text { U2 } \\
\text { URMS }\end{array}$ & \begin{tabular}{|c|} 
U3 \\
URNB \\
\end{tabular} & $\begin{array}{l}\text { Discharge } \\
\text { Velocity }\end{array}$ & 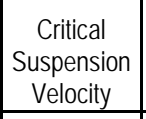 & \begin{tabular}{|c} 
Average Peak \\
doud height
\end{tabular} & \begin{tabular}{|c|} 
uCs \\
Condition
\end{tabular} & $\begin{array}{l}\text { UCS } \\
\text { Method }\end{array}$ & UCS Hag & $\begin{array}{c}\text { UCS Center } \\
\text { Hag }\end{array}$ & $\begin{array}{l}\text { UCSuadv } \\
\text { Flag }\end{array}$ & \begin{tabular}{|c} 
UCS based on \\
Decreasing \\
Velocity
\end{tabular} & $\begin{array}{l}\text { Swreep } \\
\text { Increase / } \\
\text { Decrease }\end{array}$ & \begin{tabular}{|c|} 
UDV \\
Height \\
Bed \\
\end{tabular} & $\begin{array}{l}\text { Patrice } \\
\text { Motion }\end{array}$ & \begin{tabular}{|l|} 
Solids \\
Level
\end{tabular} & \begin{tabular}{|c|} 
Outer \\
Bototom \\
Patem
\end{tabular} & \begin{tabular}{|l|} 
Inner \\
Botomom \\
Patem
\end{tabular} & Case ID & Test & IDP & $\begin{array}{l}\text { Row } \\
\text { Number }\end{array}$ \\
\hline C & $g / \mathrm{cm}^{3}$ & fraction & fraction & fraction & $\mathrm{s}$ & \begin{tabular}{|l|} 
text \\
\end{tabular} & \begin{tabular}{|l|}
$\mathrm{m} / \mathrm{s}$ \\
\end{tabular} & $\mathrm{m} / \mathrm{s}$ & $\mathrm{m} / \mathrm{s}$ & $m / s$ & $\mathrm{~m} / \mathrm{s}$ & \begin{tabular}{|l|}
$\mathrm{m} / \mathrm{s}$ \\
\end{tabular} & $\begin{array}{l}\text { in. } \\
\end{array}$ & $\mathrm{m} / \mathrm{s}$ & text & text & text & \begin{tabular}{|l|} 
text \\
\end{tabular} & m/s & text & \begin{tabular}{|l|}
$\mathrm{m}$ \\
\end{tabular} & text & text & \begin{tabular}{|l|} 
text \\
\end{tabular} & \begin{tabular}{|l|} 
text \\
\end{tabular} & text & text & text & text \\
\hline $\mathrm{T}$ & $\rho$ & $\phi_{\mathrm{s}}$ & $\phi_{\rho}$ & DC & $t_{c}$ & Jet & $U_{s}$ & $\mathrm{U}_{1}$ & $\mathrm{U} 2$ & U3 & $u$ & $u_{\text {ss }}$ & $H_{\mathrm{H}}$ & U Uase & Uasn & \begin{tabular}{l|l} 
Unsvis \\
\end{tabular} & Ussen & Usoudv & $u_{s \leq} \mathrm{D}$ & $\mathrm{s}_{\mathrm{v}}$ & $H_{\text {bed }}$ & PM & sol & SPo & $\mathrm{SP}_{\mathrm{I}}$ & ID & MDDX & TDP & MSS \\
\hline 27.3 & 0.999 & 0.04500 & undefined & 1.000 & infinite & $\mathrm{s}$ & 2.99 & $n / a$ & $\mathrm{na}$ & n/a & 3.00 & 3.00 & 14.50 & 3.00 & udv & UCShis & NA & ucsuav & NA & 1 & 0.0 & 3 & NA & NA & NA & 15E $451 \mathrm{~d} 2 \mathrm{Wa}$ & 6/178 & TDP-182 & 9150252 \\
\hline 27.4 & 0.998 & 0.04500 & undefined & 1.000 & infinite & $\mathrm{s}$ & 2.99 & & na & n/a & 3.00 & 3.00 & 14.50 & NA & NA & UCSvis & NA & NA & NA & (null) & 0.0 & 3 & NA & $\mathrm{NA}$ & NA & 15E_4s1d2Wa & 61178 & TDP-182 & 9150253 \\
\hline 27.4 & 0.998 & 0.04500 & undefined & 1.000 & infinite & $\mathrm{s}$ & 2.99 & $\mathrm{Na}$ & ra & ra & 3.00 & 3.00 & $\begin{array}{l}14.50 \\
\end{array}$ & NA & NA & \begin{tabular}{|l|}
$N A$ \\
$N A$
\end{tabular} & NA & NA & NA & NA & 0.0 & NA & NA & $\mathrm{NA}$ & NA & 15E_4s1d2W Wa & 6/178 & TDP-182 & 9150254 \\
\hline 27.4 & 0.998 & 0.04500 & undefined & 1.000 & infinite & $s$ & 2.99 & nva & $\mathrm{n} / \mathrm{a}$ & rra & 3.00 & 3.00 & 14.50 & NA & NA & NA & NA & NA & NA & NA & 0.7 & NA & NA & NA & NA & 15E_4s1do2Wa & 6/178 & TDP-182 & 9150255 \\
\hline 27.4 & 0.998 & 0.04500 & undefined & 1.000 & & $\mathrm{~s}$ & 2.99 & & na & ra & 3.00 & 3.00 & 14.50 & NA & NA & NA & NA & NA & NA & NA & 0.0 & NA & NA & NA & NA & 15E_4s1d2WWa & $6 / 178$ & TDP-182 & 9150256 \\
\hline 27.4 & 0.998 & 0.04500 & undefined & 1.000 & infinite & $\mathrm{s}$ & 2.99 & Na & ra & ra & 3.00 & 3.00 & 14.50 & NA & NA & NA & NA & NA & NA & NA & 0.0 & NA & $\mathrm{NA}$ & NA & NA & 15E__sid2WWa & $6 / 17 \mathrm{~B}$ & TDP-182 & 9150257 \\
\hline 27.4 & 0.998 & 0.04500 & undefined & 1.000 & infinite & $\mathrm{s}$ & 2.99 & & ra & ra & 3.00 & 3.00 & $\begin{array}{l}14.50 \\
\end{array}$ & NA & NA & NA & NA & NA & NA & $\mathrm{NA}$ & 0.0 & $\mathrm{NA}$ & NA & NA & NA & 15E_4sid2W & 6/178 & TDP-182 & 9150258 \\
\hline 27.4 & 0.998 & 0.04500 & undefined & 1.000 & infininte & $\mathrm{s}$ & 2.99 & & $\mathrm{n} / \mathrm{a}$ & rra & 3.00 & 3.00 & 14.50 & NA & NA & NA & NA & NA & NA & NA & 0.0 & NA & NA & NA & NA & 15E_4s1do2Wa & 6/178 & TDP-182 & 9150259 \\
\hline 27.4 & 0.998 & 0.04500 & undefined & 1.000 & infinite & $\mathrm{s}$ & 2.99 & ra & ra & $\mathrm{n} / \mathrm{a}$ & 3.00 & 3.00 & 14.50 & NA & NA & NA & NA & $\mathrm{NA}$ & NA & $\mathrm{NA}$ & 0.0 & NA & $\mathrm{NA}$ & NA & NA & 15E_4s1d2WWa & $6 / 178$ & TDP-182 & 9150260 \\
\hline 27.4 & 0.998 & 0.04500 & undefined & 1.000 & infinite & $\mathrm{s}$ & 2.99 & & na & n/a & 3.00 & 3.00 & 14.50 & NA & NA & NA & NA & NA & NA & $\mathrm{NA}$ & 0.0 & NA & NA & NA & NA & 15E_4s1d22Wa & 6/178 & TDP-182 & 9150261 \\
\hline 27.4 & 0.998 & 0.04500 & undefined & 1.000 & infinite & $\mathrm{s}$ & 2.99 & na & na & ra & 3.00 & 3.00 & 14.50 & NA & NA & NA & NA & NA & NA & NA & 0.8 & NA & NA & NA & NA & 15E_4s1d2Wa & 6/178 & TDP-182 & 9150262 \\
\hline 27.4 & 0.998 & 0.04500 & undefined & 1.000 & infinite & $\mathrm{s}$ & 2.99 & & $\mathrm{na}$ & na & 3.00 & 3.00 & 14.50 & NA & NA & NA & NA & NA & NA & $\mathrm{NA}$ & 0.0 & NA & NA & NA & NA & 15E_4s1d2Wa & 6/178 & TDP-182 & 9150263 \\
\hline 27.4 & 0.998 & 0.04500 & undefined & 1.000 & infinite & $\mathrm{s}$ & 2.99 & ria & na & ra & 3.00 & 3.00 & 14.50 & NA & NA & NA & NA & NA & NA & NA & 5.2 & NA & NA & NA & NA & 15E_4sido2Wa & 6/178 & TDP-182 & 9150264 \\
\hline 27.7 & 0.998 & 0.04500 & undefined & 1.000 & infinite & $\mathrm{s}$ & 3.12 & $\mathrm{na}$ & na & $n / a$ & 3.10 & 3.00 & 16.00 & NA & NA & NA & NA & NA & NA & NA & 0.0 & 4 & NA & NA & NA & 15E_4s1d2Wa & 6/178 & TDP-182 & 9150265 \\
\hline 28.0 & 0.998 & 0.04500 & 0.050 & 0.337 & 8.0 & $\mathrm{P}$ & NA & 7.40 & 7.59 & 7.69 & 8.00 & 6.50 & 14.50 & NA & NA & $\mathrm{NA}$ & NA & NA & NA & (null) & 0.0 & 4 & NA & $\mathrm{NA}$ & NA & 15E_4s1d2WC_1 & $6 / 17 c$ & TDP-182 & 9150266 \\
\hline 28.0 & 0.998 & 0.04500 & 0.050 & 0.337 & 8.0 & $\mathrm{P}$ & NA & 7.40 & 7.59 & 7.69 & 8.00 & 6.50 & 14.50 & NA & NA & NA & NA & NA & NA & NA & 0.0 & NA & NA & NA & NA & 15E_4s1d2WC_1 & 6117c & TDP-182 & 9150267 \\
\hline 28.0 & 0.998 & 0.04500 & 0.050 & \begin{tabular}{l|l}
0.337 \\
\end{tabular} & 8.0 & $\mathrm{P}$ & NA & 7.40 & 7.59 & 7.69 & 8.00 & 6.50 & 14.50 & NA & NA & $N A$ & $\mathrm{NA}$ & NA & NA & $\mathrm{N} /$ & 0.0 & NA & NA & $\mathrm{NA}$ & $N A$ & 15E_4s1d2WE_1 & $6 / 17 \mathrm{C}$ & TDP-182 & 9150268 \\
\hline 28.0 & 0.998 & 0.04500 & 0.050 & \begin{tabular}{l|l|l|l|}
0.337 \\
\end{tabular} & 8.0 & $\mathrm{P}$ & NA & 7.40 & 7.59 & 7.69 & 8.00 & 6.50 & 14.50 & NA & NA & NA & NA & NA & NA & $\mathrm{NA}$ & 0.0 & NA & NA & NA & NA & 15E_4s1d2WC_ 1 & 6/17c & TDP-182 & 9150269 \\
\hline 28.0 & 0.998 & 0.04500 & 0.050 & 0.337 & 8.0 & $P$ & $\mathrm{NA}$ & 7.40 & 7.59 & 7.69 & 8.00 & 6.50 & 14.50 & NA & NA & NA & NA & NA & NA & NA & 0.0 & NA & $\mathrm{NA}$ & NA & NA & 15E_4s1d2WC_ 1 & $6 / 17 \mathrm{C}$ & TDP-182 & 9150270 \\
\hline 28.0 & 0.998 & 0.04500 & 0.050 & \begin{tabular}{l|l}
0.337 \\
\end{tabular} & 8.0 & $\mathrm{P}$ & $\mathrm{NA}$ & 7.40 & 7.59 & 7.69 & 8.00 & 6.50 & 14.50 & NA & NA & NA & NA & NA & NA & NA & 0.0 & NA & NA & $\mathrm{NA}$ & NA & 15E_4s1d2WE__1 & 6117c & TDP-182 & 9150271 \\
\hline 28.0 & 0.998 & 0.04500 & 0.050 & 0.337 & 8.0 & $\mathrm{P}$ & NA & 7.40 & 7.59 & 7.69 & 8.00 & 6.50 & 14.50 & NA & NA & NA & NA & NA & NA & NA & 0.0 & NA & NA & NA & NA & 15E_4s1d2WC_1 & 6/17c & TDP-182 & 9150272 \\
\hline 28.0 & 0.998 & 0.04500 & 0.050 & \begin{tabular}{l|l|l}
0.337 & \\
\end{tabular} & 8.0 & $\mathrm{P}$ & NA & 7.40 & 7.59 & 7.69 & 8.00 & 6.50 & 14.50 & NA & NA & NA & NA & $\mathrm{NA}$ & $\mathrm{N}$ & $\mathrm{N} /$ & 0.0 & NA & NA & NA & NA & 15E_4s1d2WE_1 & $6117 \mathrm{C}$ & TDP-182 & 9150273 \\
\hline 28.0 & 0.998 & 0.04500 & 0.050 & \begin{tabular}{l|l}
0.337 \\
\end{tabular} & 8.0 & $\mathrm{P}$ & NA & 7.40 & 7.59 & \begin{tabular}{|l|} 
\\
\end{tabular} & 8.00 & 6.50 & 14.50 & NA & NA & NA & NA & NA & NA & $\mathrm{NA}$ & 0.0 & NA & NA & NA & NA & 15E_4s1d2WC_1 & $6117 \mathrm{C}$ & TDP-182 & 9150274 \\
\hline 28.0 & 0.998 & 0.04500 & 0.050 & \begin{tabular}{l|l}
0.337 \\
\end{tabular} & 8.0 & $\mathrm{P}$ & NA & 7.40 & 7.59 & 7.69 & 8.00 & 6.50 & 14.50 & NA & NA & NA & NA & NA & NA & NA & 0.0 & NA & NA & NA & NA & 15E_4S1d2WE_1 & 6117c & TDP-182 & 9150275 \\
\hline 28.0 & 0.998 & 0.04500 & 0.050 & 0.337 & 8.0 & $\mathrm{P}$ & NA & 7.40 & 7.59 & \begin{tabular}{|r|} 
\\
\end{tabular} & 8.00 & 6.50 & 14.50 & NA & NA & NA & NA & NA & NA & $\mathrm{NA}$ & 0.0 & NA & NA & NA & NA & 15E_4s1d2WC_1 & 6/17c & TDP-182 & 9150276 \\
\hline 28.0 & 0.998 & 0.04500 & 0.050 & 0.337 & 8.0 & $\mathrm{P}$ & NA & 7.40 & 7.59 & \begin{tabular}{|l|}
7.69 \\
\end{tabular} & 8.00 & 6.50 & 14.50 & NA & NA & NA & NA & NA & $\mathrm{N}$ & NA & 0.0 & NA & NA & NA & NA & 15E_4s1d2WC_1 & G/17c & TDP-182 & 9150277 \\
\hline 23.3 & 1.000 & 0.06000 & 0.050 & 0.329 & 12.8 & $\mathrm{P}$ & NA & 4.74 & 4.82 & \begin{tabular}{|l|} 
\\
\end{tabular} & 5.00 & 6.20 & 7.25 & NA & NA & NA & NA & NA & NA & (null) & 9.9 & 1 & NA & NA & NA & 15E_4s1d2Pc_1 & 6/18A & TDP-183 & 9150278 \\
\hline 23.3 & 1.000 & 0.06000 & 0.050 & 0.331 & 12.0 & $\mathrm{P}$ & NA & 5.00 & 5.09 & \begin{tabular}{|l|}
5.13 \\
\end{tabular} & 5.30 & 6.20 & 7.75 & NA & NA & NA & NA & NA & NA & 1 & 7.6 & 1 & NA & $\mathrm{NA}$ & NA & 15E_4S1d2PC_ _ & 6/18A & TDP-183 & 9150279 \\
\hline 23.5 & 0.999 & 0.06000 & 0.050 & 0.333 & 11.6 & $\mathrm{P}$ & NA & 5.18 & 5.27 & 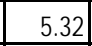 & 5.50 & 6.20 & 7.75 & NA & NA & NA & NA & NA & NA & 1 & 5.4 & 1 & NA & NA & NA & 15E_4s1d2Pc_1 & 6/18A & TDP-183 & 9150280 \\
\hline 23.5 & 0.999 & 0.06000 & 0.050 & 0.332 & 11.2 & $\mathrm{P}$ & NA & 5.39 & 5.48 & 5.53 & 5.70 & 6.20 & 8.25 & NA & NA & $N A$ & $\mathrm{NA}$ & NA & $\mathrm{N} / \mathrm{H}$ & & 4.5 & 1 & NA & $\mathrm{NA}$ & NA & 15E_4s1d2PC_1 & $6 / 18 \mathrm{~A}$ & TDP-183 & 9150281 \\
\hline 23.7 & 0.999 & 0.06000 & 0.050 & 0.333 & 10.8 & $P$ & NA & 5.57 & 5.67 & 5.72 & 5.90 & 6. & 8.75 & NA & NA & NA & NA & NA & NA & 1 & 3.7 & 1 & NA & NA & NA & 15E_4s1d2Pc_1 & 6118A & IDP-183 & 9150282 \\
\hline 23.7 & 1.000 & 0.06000 & 0.050 & 0.334 & 10.6 & $\mathrm{p}$ & NA & 5.67 & 5.77 & 5.82 & 6.00 & 6.20 & 8.75 & NA & NA & NA & NA & NA & NA & 1 & 3.7 & 1 & NA & $\mathrm{NA}$ & NA & 15E_4s1d2Pc_1 & 6/18A & TDP-183 & 9150283 \\
\hline 23.8 & 1.000 & 0.06000 & 0.050 & 0.335 & 10.2 & $P$ & NA & 5.86 & 5.97 & \begin{tabular}{|l|}
6.03 \\
\end{tabular} & 6.20 & 6.20 & 9.25 & \begin{tabular}{|l|}
6.20 \\
\end{tabular} & uad & Ucsis & NA & ucsuav & $\mathrm{NA}$ & 1 & 2.5 & 3 & NA & NA & NA & 15E_4s1d2Pc_1 & 6118A & TDP-183 & 9150284 \\
\hline 24.0 & 0.999 & 0.06000 & 0.050 & 0.337 & 9.8 & $\mathrm{P}$ & NA & 6.05 & 6.16 & 6.22 & 6.40 & 6.20 & 10.00 & NA & NA & NA & NA & NA & NA & 1 & 0.0 & 4 & NA & NA & NA & 15E_4sId2Pc_ 1 & 6/18A & TDP-183 & 9150285 \\
\hline 24.1 & 0.999 & 0.06000 & 0.050 & 0.339 & 9.2 & $\mathrm{P}$ & NA & 6.40 & 6.53 & 6.60 & 6.80 & 6.20 & 10.50 & NA & NA & NA & NA & NA & NA & 1 & 0.0 & 4 & NA & NA & NA & 15E_4sId2PC_1 & 6118A & TDP-183 & 9150286 \\
\hline 24.2 & 0.999 & 0.06000 & 0.050 & 0.336 & 8.8 & $P$ & NA & 6.77 & 6.90 & 6.97 & 7.20 & 6.20 & 13.00 & NA & NA & NA & NA & NA & NA & 1 & 0.0 & 4 & NA & $\mathrm{NA}$ & NA & 15E_4s1d2Pc_1 & 6/18A & TDP-183 & 9150287 \\
\hline 24.3 & 0.999 & 0.06000 & 0.050 & 0.338 & 8.4 & $\mathrm{P}$ & NA & 7.00 & 7.15 & 7.23 & 7.50 & 6.20 & 14.00 & NA & NA & NA & NA & NA & NA & 1 & 0.0 & 4 & NA & NA & $\mathrm{NA}$ & 15E_4s1d2Pc_1 & 6118A & TDP-183 & 9150288 \\
\hline 24.5 & 0.999 & 0.06000 & 0.050 & 0.330 & 8.1 & $\mathrm{P}$ & NA & 7.46 & 7.63 & 7.71 & 8.00 & 6.20 & 16.50 & NA & NA & NA & NA & NA & NA & 1 & 0.0 & 4 & NA & NA & NA & 15E_4s1d2Pc_1 & 6118A & TDP-183 & 9150289 \\
\hline 24.7 & 0.999 & 0.06000 & 0.050 & 0.333 & 7.6 & $\mathrm{P}$ & NA & 7.94 & 8.13 & 8.22 & 8.50 & 6.20 & 19.50 & NA & NA & NA & NA & NA & NA & 1 & 0.0 & 4 & NA & NA & NA & 15E_-SSICPPC 1 & 6/18A & TDP-183 & 9150290 \\
\hline 25.0 & 0.999 & 0.06000 & 0.050 & 0.336 & 10.2 & $P$ & NA & 5.87 & 5.97 & 6.03 & 6.20 & 6.20 & & NA & NA & NA & NA & NA & NA & NA & na & NA & NA & NA & NA & 15E_4sid2PC_ 1 & 618A & TDP-183 & 9150200.1 \\
\hline 25.0 & 0.999 & 0.06000 & \begin{tabular}{|l|}
0.050 \\
\end{tabular} & 0.336 & 10.2 & $P$ & NA & 5.87 & 5.97 & 6.03 & 6.20 & 6.20 & 9.50 & NA & NA & NA & NA & NA & NA & NA & nra & NA & NA & NA & NA & 15E_4s1d2Pc_1 & 6/18A & TDP-183 & 9150290.2 \\
\hline
\end{tabular}


Table B.3. Data from 2008 Tests in Small-Scale Vessel with Elliptical Head A.9

\begin{tabular}{|c|c|c|c|c|c|c|c|c|c|c|c|c|c|c|c|c|c|c|c|c|c|c|c|c|c|c|c|}
\hline $\begin{array}{l}\text { Rov } \\
\text { Number }\end{array}$ & Test & Case ID & $\begin{array}{c}\text { Tank } \\
\text { Diameter }\end{array}$ & $\begin{array}{l}\text { Head } \\
\text { Shape }\end{array}$ & \begin{tabular}{|l} 
Dish \\
Height
\end{tabular} & $\begin{array}{l}\text { Dish } \\
\text { Volume }\end{array}$ & $\begin{array}{c}\text { Tank Fill } \\
\text { Height }\end{array}$ & $\begin{array}{l}\text { Retur } \\
\text { Line } \\
\text { Height }\end{array}$ & \begin{tabular}{c|} 
Nozzle \\
Inner \\
Dianter
\end{tabular} & $\begin{array}{l}\text { Nozzle } \\
\text { Stantoff } \\
\text { Distance }\end{array}$ & $\begin{array}{l}\text { Pulse Tube } \\
\text { Configuration }\end{array}$ & \begin{tabular}{|l} 
Installed \\
Nozzles
\end{tabular} & $\begin{array}{l}\text { Outer } \\
\text { Nozzles } \\
\text { Operated }\end{array}$ & $\begin{array}{l}\text { Inner } \\
\text { Nozzles } \\
\text { Operated }\end{array}$ & $\begin{array}{l}\text { Pulse Tube } \\
\text { Outer } \\
\text { Dianteter }\end{array}$ & $\begin{array}{c}\text { Outer } \\
\text { PMM } \\
\text { Radius }\end{array}$ & $\begin{array}{c}\text { Inner PJM } \\
\text { Radius } \\
\end{array}$ & \begin{tabular}{|c|} 
"FO" Outer PJM \\
Impingement \\
Angle
\end{tabular} & $\begin{array}{c}\text { "FO' Inner PJM } \\
\text { Impingement Angle }\end{array}$ & \begin{tabular}{|l} 
Ratio Outer PJM \\
to Tank Radius
\end{tabular} & $\begin{array}{l}\text { Ratio Inner PJM } \\
\text { to Tank Radius }\end{array}$ & Simulant & \begin{tabular}{|l|} 
Solids \\
Density \\
\end{tabular} & $\begin{array}{c}\text { Particle } \\
\text { Diameter d5 }\end{array}$ & \begin{tabular}{c|} 
Particle \\
Diameter d d50
\end{tabular} & $\begin{array}{c}\text { Particle } \\
\text { Diameter d95 }\end{array}$ & $\begin{array}{l}\text { Void } \\
\text { Fraction }\end{array}$ \\
\hline text & text & text & in. & text & in. & in. $^{3}$ & in. 1 & in. & in. & in. & text & number & number & number & in. & in. & in. & deg & deg & nondim & nondim & text & \begin{tabular}{|l|l|}
$\mathrm{g} / \mathrm{cm}^{3}$ \\
\end{tabular} & $\mathrm{~m}$ & \begin{tabular}{l|}
$\mathrm{m}$ \\
\end{tabular} & $m$ & fraction \\
\hline MSS & MDDX & $\mathrm{ID}$ & $\mathrm{D}$ & HS & Hish & $V_{\text {dish }}$ & $\mathrm{H}$ & $\operatorname{Rin}$ & $d$ & sod & PT & $\mathrm{N}$ & $\mathrm{Nb}$ & $\mathrm{N}$ & $\mathrm{PT}_{\alpha d}$ & $R_{0}$ & $R$ & $\theta_{0}$ & $\theta_{1}$ & $R d R$ & $R / R$ & $\operatorname{sxdx}$ & $\rho_{\mathrm{s}}$ & $d_{b}$ & $d_{60}$ & $d_{65}$ & vf \\
\hline 9150200.3 & 6/18A & 15E_4s1d2Pc_1 & $147 / 16$ & $E$ & 3.25 & 354. & $341 / 2$ & 30 & 0.126 & 0.189 & HLP-22 & 12 & 8 & 4 & 1.05 & 4.5 & 2.4 & 21.8 & 10.1 & 0.62 & 0.34 & s1d2 & 2.48 & 0.0000569 & 0.0000693 & 0.0000821 & 0.3750 \\
\hline $9150291 \mathrm{M}$ & $618 \mathrm{~A}$ & 15E_4s1d2Pc_1 & $147 / 16$ & $E$ & 3.25 & 354.8 & $341 / 2$ & 30 & 0.126 & 0.189 & HLP-22 & 12 & 8 & 4 & 1.05 & 4.5 & 2.4 & 21.8 & 10.1 & 0.62 & 0.34 & $\mathrm{~s} 1 \mathrm{~d} 2$ & 2.48 & 0.0000569 & 0.0000693 & 0.0000821 & 0.3750 \\
\hline $9150291 \mathrm{M}$ & $618 \mathrm{~A}$ & 15E_4s1d2PC_1 & $147 / 16$ & $E$ & 3.25 & 354. & $341 / 2$ & 30 & 0.126 & 0.189 & HLP-22 & 12 & 8 & 4 & 1.05 & 4.5 & 2.4 & 21.8 & 10.1 & 0.62 & 0.34 & s1d2 & 2.48 & 0.0000569 & 0.0000693 & 0.0000821 & 0.3750 \\
\hline 9150292 & 6/18A & 15E_4s1d2Pc_1 & $147 / 16$ & E & 3.25 & 354. & $341 / 2$ & 30 & 0.126 & 0.189 & HLP-22 & 12 & 8 & 4 & 1.05 & 4.5 & 2.4 & 21.8 & 10.1 & 0.62 & 0.34 & $\mathrm{~s} 1 \mathrm{~d} 2$ & 2.48 & 0.0000569 & 0.0000693 & 0.0000821 & 0.3750 \\
\hline 9150293 & 618A & 15E_4s1d2PC_1 & $147 / 16$ & $E$ & 3.25 & 354.8 & $341 / 2$ & 30 & 0.126 & 0.189 & HLP-22 & 12 & 8 & 4 & 1.05 & 4.5 & 2.4 & 21.8 & 10.1 & 0.62 & 0.34 & $\mathrm{~s} 1 \mathrm{~d} 2$ & 2.48 & 0.0000569 & 0.0000693 & 0.0000821 & 0.3750 \\
\hline 9150293.1 & 61818A & 15E_4s1d2Pc_1 & $147 / 16$ & $E$ & 3.25 & 354.8 & $341 / 2$ & 30 & 0.126 & 0.189 & HLP-22 & 12 & 8 & 4 & 1.05 & 4.5 & 2.4 & 21.8 & 10.1 & 0.62 & 0.34 & $\mathrm{~s} 1 \mathrm{~d} 2$ & 2.48 & 0.0000569 & 0.0000693 & 0.0000821 & 0.3750 \\
\hline 9150294 & 618A & 15E_4s1d2PC_1 & $147 / 16$ & $E$ & 3.25 & 354.8 & $341 / 2$ & 30 & 0.126 & 0.189 & HLP-22 & 12 & 8 & 4 & 1.05 & 4.5 & 2.4 & 21.8 & 10.1 & 0.62 & 0.34 & $\mathrm{~s} 1 \mathrm{~d} 2$ & 2.48 & 0.0000569 & 0.0000693 & 0.0000821 & 0.3750 \\
\hline 9150294.1 & 6118A & 15E_4s1d2Pc_1 & $147 / 16$ & E & 3.25 & 354.8 & $341 / 2$ & 30 & 0.126 & 0.189 & HLP-22 & 12 & 8 & 4 & 1.05 & 4.5 & 2.4 & 21.8 & 10.1 & 0.62 & 0.34 & $\mathrm{~s} 1 \mathrm{~d} 2$ & 2.48 & 0.0000569 & 0.0000693 & 0.0000821 & 0.3750 \\
\hline 9150295 & 6/18A & 15E_4s1d2PC_1 & $147 / 16$ & $E$ & 3.25 & 354.8 & $341 / 2$ & 30 & 0.126 & 0.189 & HLP-22 & 12 & 8 & 4 & 1.05 & 4.5 & 2.4 & 21.8 & 10.1 & 0.62 & 0.34 & $\mathrm{~s} 1 \mathrm{~d} 2$ & 2.48 & 0.0000569 & 0.0000693 & 0.0000821 & 0.3750 \\
\hline 9150205.1 & 6/18A & 15E_4s1d2Pc_1 & $147 / 16$ & $E$ & 3.25 & 354. & $341 / 2$ & 30 & 0.126 & 0.189 & HLP-22 & 12 & 8 & 4 & 1.05 & 4.5 & 2.4 & 21.8 & 10.1 & 0.62 & 0.34 & $\mathrm{~s} 1 \mathrm{~d} 2$ & 2.48 & 0.0000569 & 0.0000693 & 0.0000821 & 0.3750 \\
\hline 9150296 & 618A & 15E $4 \mathrm{~S} 1 \mathrm{~d} 2 \mathrm{PC} \mathrm{C}$ & $147 / 16$ & E & 3.25 & 354. & $341 / 2$ & 30 & 0.126 & 0.189 & HLP-22 & 12 & 8 & 4 & 1.05 & 4.5 & 2.4 & 21.8 & 10.1 & 0.62 & 0.34 & $\mathrm{~s} 1 \mathrm{~d} 2$ & 2.48 & 0.0000569 & 0.0000693 & 0.0000821 & 0.3750 \\
\hline 9150296.1 & 6/18A & 15E 4s $1 \mathrm{~d} 2 \mathrm{Pc} 1$ & $147 / 16$ & $\mathrm{E}$ & 3.25 & 354.8 & $341 / 2$ & 30 & 0.126 & 0.189 & HLP-22 & 12 & 8 & 4 & 1.05 & 4.5 & 2.4 & 21.8 & 10.1 & 0.62 & 0.34 & s1d2 & 2.48 & 0.0000569 & 0.0000693 & 0.0000821 & 0.3750 \\
\hline 9150297 & 6/18A & 15E_4s $1 \mathrm{~d} 2 \mathrm{PC} \_1$ & $147 / 16$ & $E$ & 3.25 & 354.8 & $341 / 2$ & 30 & 0.126 & 0.189 & HLP-22 & 12 & 8 & 4 & 1.05 & 4.5 & 2.4 & 21.8 & 10.1 & 0.62 & 0.34 & $\mathrm{~s} 1 \mathrm{~d} 2$ & 2.48 & 0.0000569 & 0.0000693 & 0.0000821 & 0.3750 \\
\hline 9150298 & 61818B & 15E_4s2d27c_1 & $147 / 16$ & $E$ & 3.25 & 354.8 & 35 & 30 & 0.126 & 0.189 & HLP-22 & 12 & 8 & 4 & 1.05 & 4.5 & 2.4 & 21.8 & 10.1 & 0.62 & 0.34 & $\mathrm{~s} 2 \mathrm{~d} 2$ & 4.18 & 0.0000609 & 0.0000756 & 0.0000931 & 0.3684 \\
\hline 9150299 & 6/188 & $15 E_{2} 4 \mathrm{~s} 2 \mathrm{~d} 27 \mathrm{C} \_1$ & $147 / 16$ & $E$ & 3.25 & 354.8 & 35 & 30 & 0.126 & 0.189 & HLP-22 & 12 & 8 & 4 & 1.05 & 4.5 & 2.4 & 21.8 & 10.1 & 0.62 & 0.34 & $\mathrm{~s} 2 \mathrm{~d} 2$ & 4.18 & 0.0000609 & 0.0000756 & 0.0000931 & 0.3684 \\
\hline 9150300 & $618 \mathrm{~B}$ & 15E_4s2d2Zc_1 & $147 / 16$ & $E$ & 3.25 & 354.8 & 35 & 30 & 0.126 & 0.189 & HLP-22 & 12 & 8 & 4 & 1.05 & 4.5 & 2.4 & 21.8 & 10.1 & 0.62 & 0.34 & $\mathrm{~s} 2 \mathrm{~d} 2$ & 4.18 & 0.0000609 & 0.0000756 & 0.0000931 & 0.3684 \\
\hline 9150301 & 6/188 & $15 E_{2} 4 \mathrm{~s} 2 \mathrm{~d} 27 \mathrm{c} 1$ & $147 / 16$ & $E$ & 3.25 & 354.8 & 35 & 30 & 0.126 & 0.189 & HLP-22 & 12 & 8 & 4 & 1.05 & 4.5 & 2.4 & 21.8 & 10.1 & 0.62 & 0.34 & $\mathrm{~s} 2 \mathrm{~d} 2$ & 4.18 & 0.0000609 & 0.0000756 & 0.0000931 & 0.3684 \\
\hline 9150302 & 6/188 & 15E_4s2d2Zc_1 & $147 / 16$ & $\mathrm{E}$ & 3.25 & 354.8 & 35 & 30 & 0.126 & 0.189 & HLP-22 & 12 & 8 & 4 & 1.05 & 4.5 & 2.4 & 21.8 & 10.1 & 0.62 & 0.34 & $\mathrm{~s} 2 \mathrm{~d} 2$ & 4.18 & 0.0000609 & 0.0000756 & 0.0000931 & 0.3684 \\
\hline 9150303 & 6188B & 15E_4s2d227c_1 & $147 / 16$ & $E$ & 3.25 & 354.8 & 35 & 30 & 0.126 & 0.189 & HLP-22 & 12 & 8 & 4 & 1.05 & 4.5 & 2.4 & 21.8 & 10.1 & 0.62 & 0.34 & $\mathrm{~s} 2 \mathrm{~d} 2$ & 4.18 & 0.0000609 & 0.0000756 & 0.0000931 & 0.3684 \\
\hline 9150304 & 6/188 & 15E_4s2d2Zc_1 & $147 / 16$ & $E$ & 3.25 & 354.8 & 35 & 30 & 0.126 & 0.189 & HLP-22 & 12 & 8 & 4 & 1.05 & 4.5 & 2.4 & 21.8 & 10.1 & 0.62 & 0.34 & $\mathrm{~s} 2 \mathrm{~d} 2_{2}$ & 4.18 & 0.0000609 & 0.0000756 & 0.0000931 & 0.3684 \\
\hline 9150305 & 6/18B & 15E_4S2d2Zc_1 & $147 / 16$ & $\mathrm{E}$ & 3.25 & 354. & 35 & 30 & 0.126 & 0.189 & HLP-22 & 12 & 8 & 4 & 1.05 & 4.5 & 2.4 & 21.8 & 10.1 & 0.62 & 0.34 & $\mathrm{~s} 2 \mathrm{~d} 2$ & 4.18 & 0.0000000 & 0.0000756 & 0.0000931 & 0.3684 \\
\hline 9150306 & 6/188 & 15E_4s2d2Zc_1 & $147 / 16$ & $E$ & 3.25 & 354.8 & 35 & 30 & 0.126 & 0.189 & HLP-22 & 12 & 8 & 4 & 1.05 & 4.5 & 2.4 & 21.8 & 10.1 & 0.62 & 0.34 & $\mathrm{~s} 2 \mathrm{~d} 2$ & 4.18 & 0.0000609 & 0.0000756 & 0.0000931 & 0.3684 \\
\hline 9150307M & 61818B & 15E_4s2d2Zc_ _1 & $147 / 16$ & $\mathrm{E}$ & 3.25 & 354. & 35 & 30 & 0.126 & 0.189 & HLP-22 & 12 & 8 & 4 & 1.05 & 4.5 & 2.4 & 21.8 & 10.1 & 0.62 & 0.34 & $\mathrm{~s} 2 \mathrm{~d} 2_{2}$ & 4.18 & 0.0000609 & 0.0000756 & 0.0000931 & 0.3684 \\
\hline $9150308 \mathrm{M}$ & 6/18B & 15E_4s2d2Zc_1 & $147 / 16$ & $E$ & 3.25 & 354.8 & 35 & 30 & 0.126 & 0.189 & HLP-22 & 12 & 8 & 4 & 1.05 & 4.5 & 2.4 & 21.8 & 10.1 & 0.62 & 0.34 & $\mathrm{~s} 2 \mathrm{~d} 2$ & 4.18 & 0.0000609 & 0.0000756 & o.0000931 & 0.3684 \\
\hline $9150309 \mathrm{M}$ & $618 \mathrm{~B}$ & 15E_4s2d2Zc_1 & $147 / 16$ & $E$ & 3.25 & 354. & 35 & 30 & 0.126 & 0.189 & HLP-22 & 12 & 8 & 4 & 1.05 & 4.5 & 2.4 & 21.8 & 10.1 & 0.62 & 0.34 & $\mathrm{~s} 2 \mathrm{~d} 2$ & 4.18 & 0.0000609 & 0.0000756 & 0.0000931 & 0.3684 \\
\hline $9150310 \mathrm{M}$ & 6/18B & 15E_4s2d2Zc_1 & $147 / 16$ & $E$ & 3.25 & 354.8 & 35 & 30 & 0.126 & 0.189 & HLP-22 & 12 & 8 & 4 & 1.05 & 4.5 & 2.4 & 21.8 & 10.1 & 0.62 & 0.34 & $\mathrm{~s} 2 \mathrm{~d} 2$ & 4.18 & 0.0000609 & 0.0000756 & 0.0000931 & 0.3684 \\
\hline 9150311 & 6/19A & 15E_4s2d2Zc_1 & $147 / 16$ & $E$ & 3.25 & 354.8 & 35 & 30 & 0.126 & 0.189 & HLP-22 & 12 & 8 & 4 & 1.05 & 4.5 & 2.4 & 21.8 & 10.1 & 0.62 & 0.34 & $\mathrm{~s} 2 \mathrm{~d} 2$ & 4.18 & 0.00006009 & 0.0000756 & 0.0000931 & 0.3684 \\
\hline 9150312M M & 6/19A & 15E_4s2d2Zc_1 & $147 / 16$ & $E$ & 3.25 & 354.8 & 35 & 30 & 0.126 & 0.189 & HLP-22 & 12 & 8 & 4 & 1.05 & 4.5 & 2.4 & 21.8 & 10.1 & 0.62 & 0.34 & $\mathrm{~s} 2 \mathrm{~d} 2$ & 4.18 & 0.0000609 & 0.0000756 & 0.0000931 & 0.3684 \\
\hline $9150313 \mathrm{M}$ & 6/19A & 15E_4S2d27c_1 & $147 / 16$ & E & 3.25 & 354. & 35 & 30 & 0.126 & 0.189 & HLP-22 & 12 & 8 & 4 & 1.05 & 4.5 & 2.4 & 21.8 & 10.1 & 0.62 & 0.34 & $\mathrm{~s} 2 \mathrm{~d} 2$ & 4.18 & 0.0000600 & 0.0000756 & 0.0000931 & 0.3684 \\
\hline 9150313.1 & $6 / 19 \mathrm{~A}$ & $15 E_{2} 4 \mathrm{~s} 2 \mathrm{~d} 27 \mathrm{c} 1$ & $147 / 16$ & $E$ & 3.25 & 354.8 & 35 & 30 & 0.126 & 0.189 & HLP-22 & 12 & 8 & 4 & 1.05 & 4.5 & 2.4 & 21.8 & 10.1 & 0.62 & 0.34 & $\mathrm{~s} 2 \mathrm{~d} 2$ & 4.18 & 0.0000609 & 0.0000756 & 0.0000931 & 0.3684 \\
\hline 9150313.2 & 6/19A & 15E_4s2d2Z_c_1 & $147 / 16$ & $E$ & 3.25 & 354.8 & 35 & 30 & 0.126 & 0.189 & HLP-22 & 12 & 8 & 4 & 1.05 & 4.5 & 2.4. & 21.8 & 10.1 & 0.62 & 0.34 & $\mathrm{~s} 2 \mathrm{~d} 2$ & 4.18 & 0.0000609 & 0.0000756 & 0.0000931 & 0.3684 \\
\hline 9150313.3 & 619A & 15E_4s2d27c_1 & $147 / 16$ & $E$ & 3.25 & 354.8 & 35 & 30 & 0.126 & 0.189 & HLP-22 & 12 & 8 & 4 & 1.05 & 4.5 & 2.4 & 21.8 & 10.1 & 0.62 & 0.34 & $\mathrm{~s} 2 \mathrm{~d} 2$ & 4.18 & 0.0000609 & 0.0000756 & 0.0000931 & 0.3684 \\
\hline 9150313.4 & 619A & 15E_4S2d2Zc_1 & $147 / 16$ & $\mathrm{E}$ & 3.25 & 354. & 35 & 30 & 0.126 & 0.189 & HLP-22 & 12 & 8 & 4 & 1.05 & 4.5 & 2.4 & 21.8 & 10.1 & 0.62 & 0.34 & $\mathrm{~s} 2 \mathrm{~d} 2$ & 4.18 & 0.0000609 & 0.0000756 & 0.0000931 & 0.3684 \\
\hline 9150313.5 & 619A & $15 E_{2} 4 \mathrm{~s} 2 \mathrm{~d} 27 \mathrm{C} \_1$ & $147 / 16$ & $E$ & 3.25 & 354.8 & 35 & 30 & 0.126 & 0.189 & HLP-22 & 12 & 8 & 4 & 1.05 & 4.5 & 2.4 & 21.8 & 10.1 & 0.62 & 0.34 & $\mathrm{~s} 2 \mathrm{~d} 2$ & 4.18 & 0.0000609 & 0.0000756 & 0.0000931 & 0.3684 \\
\hline $9150314 \mathrm{M}$ & 619A & 15E_4s2d2Z__ 1 & $147 / 16$ & $E$ & 3.25 & 354.8 & 35 & 30 & 0.126 & 0.189 & HLP-22 & 12 & 8 & 4 & 1.05 & 4.5 & 2.4 & 21.8 & 10.1 & 0.62 & 0.34 & $\mathrm{~s} 2 \mathrm{~d} 2$ & 4.18 & 0.0000609 & 0.0000756 & 0.0000931 & 0.3684 \\
\hline 9150315 & 6/19A & $15 E_{2} 4 \mathrm{~s} 2 \mathrm{~d} 27 \mathrm{C} \_1$ & $147 / 16$ & $E$ & 3.25 & 354.8 & 35 & 30 & 0.126 & 0.189 & HLP-22 & 12 & 8 & 4 & 1.05 & 4.5 & 2.4 & 21.8 & 10.1 & 0.62 & 0.34 & $\mathrm{~s} 2 \mathrm{~d} 2$ & 4.18 & 0.0000609 & 0.0000756 & 0.0000931 & 0.3684 \\
\hline 9150316 & 6/19A & 15E_4s2d27c_ _ 1 & $147 / 16$ & $E$ & 3.25 & 354.8 & 35 & 30 & 0.126 & 0.189 & HLP-22 & 12 & 8 & 4 & 1.05 & 4.5 & 2.4 & 21.8 & 10.1 & 0.62 & 0.34 & $\mathrm{~s} 2 \mathrm{~d} 2$ & 4.18 & 0.0000609 & 0.0000756 & 0.0000931 & 0.3684 \\
\hline 9150317 & 6/19A & 15E_4S2d27c_1 & $147 / 16$ & $E$ & 3.25 & 354. & 35 & 30 & 0.126 & 0.189 & HLP-22 & 12 & 8 & 4 & 1.05 & 4.5 & 2.4 & 21.8 & 10.1 & 0.62 & 0.34 & $\mathrm{~s} 2 \mathrm{~d} 2$ & 4.18 & 0.0000609 & 0.0000756 & 0.0000931 & 0.3684 \\
\hline 9150318 & 6/19A & & $147 / 16$ & $E$ & 3.25 & 354.8 & 35 & 30 & 0.126 & 0.189 & HLP-22 & 12 & 8 & 4 & & 4.5 & 2.4 & & & 0.62 & & $\mathrm{~s} 2 \mathrm{~d} 2$ & 4. & & & 0.0000931 & \\
\hline 9150319 & 61919A & $15 \mathrm{E} \_4 \mathrm{~s} 2 \mathrm{~d} 27 \mathrm{c}$-1 & $147 / 16$ & $\mathrm{E}$ & 3.25 & 354.8 & 35 & 30 & 0.126 & 0.189 & HLP-22 & 12 & 8 & 4 & 1.05 & 4.5 & 2.4 & 21.8 & 10.1 & 0.62 & 0.34 & $\mathrm{~s} 2 \mathrm{~d} 2$ & 4.18 & 0.0000609 & 0.0000756 & 0.0000931 & 0.3684 \\
\hline 9150320 & 6/19A & 15E_4s2d2Z__ 1 & $147 / 16$ & $E$ & 3.25 & 354.8 & 35 & 30 & 0.126 & 0.189 & HLP-22 & 12 & 8 & 4 & 1.05 & 4.5 & 2.4 & 21.8 & 10.1 & 0.62 & 0.34 & $\mathrm{~s} 2 \mathrm{~d} 2$ & 4.18 & 0.0000609 & \begin{tabular}{|c|}
0.0000756 \\
\end{tabular} & 0.0000931 & 0.3684 \\
\hline
\end{tabular}


Table B.3. Data from 2008 Tests in Small-Scale Vessel with Elliptical Head B.9

\begin{tabular}{|c|c|c|c|c|c|c|c|c|c|c|c|c|c|c|c|c|c|c|c|c|c|c|c|c|c|c|c|c|c|}
\hline $\begin{array}{l}\text { Tank Water } \\
\text { Temperature }\end{array}$ & \begin{tabular}{|l|} 
Water \\
Density
\end{tabular} & $\begin{array}{l}\text { Solids } \\
\text { Fraction } \\
\end{array}$ & \begin{tabular}{|c|} 
Pulse \\
Volume \\
Fraction \\
\end{tabular} & \begin{tabular}{|l} 
Duty \\
Cycle \\
\end{tabular} & $\begin{array}{l}\text { Cycle } \\
\text { Time }\end{array}$ & \begin{tabular}{|l|} 
Pulsed or \\
Steacy Jet
\end{tabular} & \begin{tabular}{|c|} 
Us \\
Steacy \\
Jet \\
\end{tabular} & \begin{tabular}{|c|} 
U1 \\
Pulsin \\
g Jet \\
\end{tabular} & \begin{tabular}{|c|} 
U2 \\
URMS \\
\end{tabular} & \begin{tabular}{|c|} 
U3 \\
URMB \\
\end{tabular} & \begin{tabular}{|c|} 
Discharge \\
Velocity
\end{tabular} & $\begin{array}{l}\text { Cintical } \\
\text { suspension } \\
\text { velocity } \\
\text { vate }\end{array}$ & 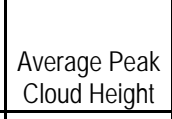 & \begin{tabular}{|l|} 
UnS \\
Condition \\
\end{tabular} & $\begin{array}{l}\text { UCS } \\
\text { Method }\end{array}$ & UCS Fag & $\begin{array}{c}\text { UCS Center } \\
\text { Fag }\end{array}$ & $\begin{array}{c}\text { UCS udv } \\
\text { Flag }\end{array}$ & 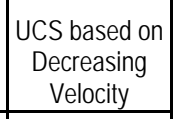 & $\begin{array}{l}\text { Sweep } \\
\text { Increase/ } \\
\text { Decrease }\end{array}$ & \begin{tabular}{|c|} 
UDV \\
Height \\
Bedd \\
\end{tabular} & \begin{tabular}{|l} 
Particle \\
Notion
\end{tabular} & $\begin{array}{l}\text { Solids } \\
\text { Level }\end{array}$ & $\left|\begin{array}{c}\text { Outer } \\
\text { Botoum } \\
\text { Patterm }\end{array}\right|$ & \begin{tabular}{|l|} 
Inner \\
Bottom \\
Patterm \\
\end{tabular} & Case ID & Test & TDP & $\begin{array}{l}\text { Row } \\
\text { Number }\end{array}$ \\
\hline $\mathrm{c}$ & $\mathrm{g} / \mathrm{cm}^{3}$ & fraction & fraction & fraction & $\mathrm{s}$ & \begin{tabular}{|l|} 
text \\
\end{tabular} & \begin{tabular}{|l|l|}
$\mathrm{m} / \mathrm{s}$ \\
\end{tabular} & $\mathrm{m} / \mathrm{s}$ & $\mathrm{m} / \mathrm{s}$ & m/s & \begin{tabular}{|l|}
$\mathrm{m} / \mathrm{s}$ \\
\end{tabular} & \begin{tabular}{|l|}
$\mathrm{m} / \mathrm{s}$ \\
\end{tabular} & in. & $\mathrm{m} / \mathrm{s}$ & text & text & text & \begin{tabular}{|l|} 
text \\
\end{tabular} & \begin{tabular}{|l|}
$\mathrm{ms}$ \\
\end{tabular} & text & $\mathrm{mm}$ & text & text & text & text & text & text & text & text \\
\hline $\mathrm{T}$ & $\rho$ & $\phi_{\mathrm{s}}$ & $\phi_{p}$ & $D C$ & $t_{c}$ & Jet & $u_{s}$ & $\mathrm{U} 1$ & $\mathrm{U} 2$ & U3 & $u$ & $u_{\text {cs }}$ & $\mathrm{H}_{\mathrm{c}}$ & $U_{\text {Cas }}$ & $U_{\text {son }}$ & Ussis & Uscen & Usoudiv & Uss $D$ & $\mathrm{~S}_{\mathrm{w}}$ & $\mathrm{H}_{\text {bed }}$ & $\mathrm{PM}$ & Sol & SPo & $\mathrm{SP}_{\mathrm{P}}$ & ID & MDDX & TDP & MSS \\
\hline 25.0 & 0.999 & 0.06000 & 0.050 & 0.336 & 10.2 & $\mathrm{P}$ & NA & 5.87 & 5.97 & \begin{tabular}{|l|}
6.03 \\
\end{tabular} & 6.20 & 6.20 & 9.50 & NA & NA & NA & NA & NA & NA & NA & ra & NA & NA & NA & NA & 15E_4s1d2Pc_1 & 6/18A & TDP-183 & 9150290.3 \\
\hline 25.0 & 0.999 & 0.06000 & 0.050 & 0.336 & 10.2 & $\mathrm{P}$ & NA & 5.87 & 5.97 & 6.03 & 6.20 & 6.20 & 9.50 & NA & vis dec & ucsis & NA & NA & 6.20 & D & \begin{tabular}{|l|}
3.7 \\
\end{tabular} & 3 & NA & NA & NA & 15E_4s $1 \mathrm{~d} 2 \mathrm{PC} \_1$ & 6/18A & TDP-183 & 9150291 \\
\hline 25.0 & 0.999 & 0.06000 & 0.050 & 0.336 & 10.2 & $\mathrm{P}$ & NA & 5.87 & 5.97 & 6.03 & 6.20 & 6.20 & 9.50 & NA & NA & NA & NA & NA & NA & NA & $\mathrm{r} / \mathrm{a}$ & NA & NA & NA & NA & 15E_4s1d2PC_1 & 6/18A & TDP-183 & 9150291 \\
\hline 25.0 & 0.999 & 0.06000 & 0.050 & 0.336 & 10.2 & $\mathrm{P}$ & NA & 5.87 & 5.97 & 6.03 & 6.20 & 6.20 & 9.50 & NA & NA & NA & NA & NA & NA & NA & \begin{tabular}{|l|}
3.6 \\
\end{tabular} & NA & NA & NA & NA & 15E_4sid2Pc_1 & 6/18A & TDP-183 & 9150292 \\
\hline 25.0 & 0.999 & 0.060000 & 0.050 & 0.336 & 10.2 & $P$ & NA & 5.87 & 5.97 & 6.03 & 6.20 & 6.20 & 9.50 & NA & NA & NA & NA & NA & NA & NA & 3.7 & NA & NA & NA & NA & 15E_4sId2Pc_1 & 6/18A & TDP-183 & 9150293 \\
\hline 25.0 & 0.999 & 0.06000 & 0.050 & 0.336 & 10.2 & $\mathrm{P}$ & NA & 5.87 & 5.97 & \begin{tabular}{|l|}
6.03 \\
\end{tabular} & 6.20 & 6.20 & 9.50 & NA & NA & NA & NA & NA & NA & NA & wa & NA & NA & NA & NA & 15E_4s $1 \mathrm{~d} 2 \mathrm{PC} \_1$ & 6/18A & TDP-183 & 9150293.1 \\
\hline 25.0 & 0.999 & 0.06000 & 0.050 & 0.336 & 10.2 & $\mathrm{P}$ & NA & 5.87 & 5.97 & 6.03 & 6.20 & 6.20 & 9.50 & NA & NA & NA & NA & NA & NA & NA & \begin{tabular}{|l|}
3.7 \\
\end{tabular} & NA & NA & NA & NA & 15E_4sid2Pc_1 & $6 / 18 \mathrm{~A}$ & TDP-183 & 9150294 \\
\hline 25.0 & 0.999 & 0.06000 & 0.050 & 0.336 & 10.2 & $\mathrm{P}$ & NA & 5.87 & 5.97 & 6.03 & 6.20 & 6.20 & 9.50 & NA & NA & NA & NA & NA & NA & NA & nra & NA & NA & NA & NA & 15E_4s $1 \mathrm{~d} 2 \mathrm{PC} \_1$ & $6 / 18 \mathrm{~A}$ & TDP-183 & 9150294.1 \\
\hline 25.0 & 0.999 & 0.06000 & 0.050 & 0.336 & 10.2 & $\mathrm{P}$ & NA & 5.87 & 5.97 & 6.03 & 6.20 & 6.20 & 9.50 & NA & NA & NA & NA & NA & NA & NA & 3.7 & NA & $\mathrm{NA}$ & NA & NA & 15E_4s1d2PC_1 & 6/18A & TDP-183 & 9150295 \\
\hline 25.0 & 0.999 & 0.06000 & 0.050 & 0.336 & 10.2 & $\mathrm{P}$ & NA & 5.87 & 5.97 & 6.03 & 6.20 & 6.20 & 9.50 & NA & NA & NA & NA & NA & NA & NA & na & NA & NA & NA & NA & 15E_4sid2Pc_1 & $6 / 18 \mathrm{~A}$ & TDP-183 & 9150295.1 \\
\hline 25.0 & 0.999 & 0.06000 & 0.050 & 0.336 & 10.2 & $\mathrm{P}$ & NA & 5.87 & 5.97 & 6.03 & 6.20 & 6.20 & 9.50 & NA & NA & NA & NA & NA & NA & NA & \begin{tabular}{|l|} 
\\
\end{tabular} & NA & NA & NA & NA & 15E_4sid2PC_1 & 6/18A & TDP-183 & 9150296 \\
\hline 25.0 & 0.999 & 0.06000 & 0.050 & 0.336 & 10.2 & $\mathrm{P}$ & NA & 5.87 & 5.97 & 6.03 & 6.20 & 6.20 & 9.50 & NA & NA & NA & NA & NA & NA & NA & $\mathrm{n} / \mathrm{a}$ & NA & NA & NA & NA & 15E_4s $1 \mathrm{~d} 2 \mathrm{PC} \_1$ & $6 / 18 \mathrm{~A}$ & TDP-183 & 9150296.1 \\
\hline 25.0 & 0.999 & 0.06000 & 0.050 & 0.336 & 10.2 & $\mathrm{P}$ & NA & 5.87 & 5.97 & 6.03 & 6.20 & 6.20 & 9.50 & NA & NA & NA & NA & NA & NA & NA & \begin{tabular}{|l|}
3.7 \\
\end{tabular} & NA & NA & NA & NA & 15E_4s1d2Pc_1 & 6/18A & TDP-183 & 9150297 \\
\hline 24.5 & 0.999 & 0.00155 & 0.050 & 0.331 & 31.0 & $\mathrm{P}$ & NA & 1.96 & 1.97 & 1.98 & 2.00 & 5.40 & 10.00 & NA & NA & NA & NA & NA & NA & (null) & 14.9 & 1 & NA & NA & NA & 15E_4s2d2Zc_1 & $6 / 18 B$ & TDP-184 & 9150298 \\
\hline 24.7 & 0.999 & 0.00155 & 0.050 & 0.331 & 25.6 & $\mathrm{P}$ & NA & 2.37 & 238 & \begin{tabular}{|l|}
2.38 \\
\end{tabular} & 2.40 & 5.40 & 5.75 & NA & NA & NA & NA & NA & NA & 1 & 13.9 & 1 & NA & NA & NA & 15E_4s2d2Zc_1 & $6 / 188$ & TDP-184 & 9150299 \\
\hline 24.8 & 0.999 & 0.00155 & 0.050 & 0.335 & 21.9 & $\mathrm{P}$ & NA & 2.75 & 2.76 & $2.7 \pi$ & 280 & 5.40 & 4.75 & NA & NA & NA & NA & NA & NA & 1 & 14.1 & 1 & NA & NA & NA & 15E_4S2d27c_1 & 6118B & TDP-184 & 9150300 \\
\hline 25.1 & 0.999 & 0.00155 & 0.050 & 0.335 & 19.2 & $\mathrm{P}$ & NA & 3.13 & 3.15 & 3.16 & 3.20 & 5.40 & 4.50 & NA & NA & $N A$ & NA & NA & NA & 1 & 13.7 & 1 & NA & NA & NA & 15E_4S2027Z__1 & $6 / 188$ & TDP-184 & 9150301 \\
\hline 25.3 & 0.999 & 0.00155 & 0.050 & 0.335 & 17.1 & $\mathrm{P}$ & NA & 3.51 & 3.54 & 3.56 & 3.60 & 5.40 & 4.75 & NA & NA & NA & NA & NA & NA & 1 & 13.1 & 1 & NA & NA & NA & 15E_4s2d2Zc_1 & $6 / 18 \mathrm{~B}$ & IDP-184 & 9150302 \\
\hline 25.5 & 0.999 & 0.00155 & 0.050 & 0.337 & 15.4 & $\mathrm{P}$ & NA & 3.88 & 3.92 & 3.94 & 4.00 & 5.40 & 5.25 & NA & NA & NA & NA & NA & NA & 1 & 11.1 & 1 & NA & NA & NA & 15E_4s2d27c 1 & $6 / 18 B$ & TDP-184 & 9150303 \\
\hline 25.8 & 0.999 & 0.00155 & 0.050 & 0.338 & 14.0 & $\mathrm{P}$ & NA & 4.26 & 4.31 & 4.33 & 4.40 & 5.40 & 5.75 & NA & NA & NA & NA & NA & NA & 1 & 8.5 & 1 & NA & NA & NA & 15E_4s2d2ZC_1 & $6 / 18 B$ & TDP-184 & 9150304 \\
\hline 26.0 & 0.999 & 0.00155 & 0.050 & \begin{tabular}{l|l}
0.337 \\
\end{tabular} & 12.8 & $P$ & NA & 4.62 & 4.68 & 4.71 & 4.80 & 5.40 & 5.75 & NA & NA & NA & NA & NA & NA & 1 & 6.5 & 1 & NA & NA & NA & 15E_4s2d27c_1 & 6118B & TDP-184 & 9150305 \\
\hline 26.3 & 0.999 & 0.00155 & 0.050 & 0.335 & 11.9 & $\mathrm{P}$ & NA & 4.99 & 5.07 & \begin{tabular}{|l|l|}
5.10 \\
\end{tabular} & 5.20 & 5.40 & 6.00 & NA & NA & NA & NA & NA & NA & 1 & 4.2 & 1 & NA & NA & NA & 15E_4S2027c_1 & $6 / 188$ & TDP-184 & 9150306 \\
\hline 26.5 & 0.999 & 0.00155 & 0.050 & 0.337 & 11.5 & $\mathrm{P}$ & NA & 5.18 & 5.26 & 5.30 & 5.40 & 5.40 & 6.75 & 5.46 & udv & NA & NA & ucsudv & NA & 1 & 2.7 & 1 & NA & NA & NA & 15E_4s2d2Zc_1 1 & $6 / 18 B$ & TDP-184 & 9150307 \\
\hline 26.9 & 0.999 & 0.00155 & 0.050 & 0.338 & 11.1 & $\mathrm{P}$ & NA & 5.37 & 5.45 & 5.49 & 5.60 & & 8.25 & NA & NA & ucsis & NA & NA & $\mathrm{N}$ & & 0.0 & 3 & NA & NA & NA & 15E_4s2d27c_1 & $6 / 18 \mathrm{~B}$ & TDP-184 & 9150308 \\
\hline 27.3 & 0.998 & 0.00155 & 0.050 & 0.339 & 10.7 & $\mathrm{P}$ & NA & 5.54 & 5.64 & 5.69 & 5.80 & 5.40 & 9.50 & NA & NA & NA & NA & NA & NA & 1 & 0.0 & 4 & NA & NA & NA & 15E_4s2d27c_1 & 6118B & TDP-184 & 9150309 \\
\hline 27.7 & 0.998 & 0.00155 & 0.050 & 0.336 & 10.0 & $\mathrm{P}$ & NA & 5.90 & 6.01 & 6.06 & 6.20 & 5.40 & 17.00 & NA & NA & NA & NA & NA & NA & 1 & 0.0 & 4 & NA & NA & NA & 15E_4S2d27c_1 & $6 / 188$ & TDP-184 & 9150310 \\
\hline 23.6 & 0.999 & 0.00155 & 0.050 & 0.334 & 12.4 & $\mathrm{P}$ & NA & 4.79 & 4.87 & 4.90 & 5.00 & 5.20 & 6.25 & NA & NA & NA & NA & NA & NA & & 3.2 & 1 & NA & NA & NA & 15E_4s2d27c_1 & 619A & TDP-185 & 9150311 \\
\hline 23.7 & 0.999 & 0.00155 & 0.050 & 0.334 & 12.0 & $\mathrm{P}$ & NA & 4.98 & 5.06 & 5.10 & 5.20 & 5.20 & 6.75 & \begin{tabular}{|l|l|}
5.20 \\
\end{tabular} & udv & NA & NA & ucsudv & NA & 1 & 0.5 & 1 & NA & NA & NA & 15E_4s2d2Zc__1 & 6/19A & TDP-185 & 9150312 \\
\hline 23.9 & 0.999 & 0.00155 & 0.050 & 0.335 & 11.5 & $\mathrm{P}$ & NA & 5.17 & 5.25 & 5.29 & 5.40 & 5.20 & 8.75 & NA & NA & Ucsis & NA & NA & NA & 1 & 0.0 & 3 & NA & NA & NA & 15E_4s2d2Zc_1 & 619A & TDP-185 & 9150313 \\
\hline 24.2 & 0.999 & 0.00155 & 0.050 & 0.335 & 12.0 & $P$ & NA & 4.98 & 5.06 & 5.10 & 5.20 & 5.20 & 7.00 & NA & NA & NA & NA & NA & NA & $\mathrm{NA}$ & na & NA & NA & $\mathrm{NA}$ & $N A$ & 15E_4S2d27c_1 & 6/19A & TDP-185 & 9150313.1 \\
\hline 24.2 & 0.999 & 0.00155 & 0.050 & 0.335 & 12.0 & $P$ & NA & 4.98 & 5.06 & 5.10 & 5.20 & 5.20 & 7.00 & NA & NA & NA & NA & NA & NA & $\mathrm{NA}$ & r/a & $\mathrm{NA}$ & NA & $\mathrm{NA}$ & NA & 15E_4s2d27c_1 & 6/19A & TDP-185 & 9150313.2 \\
\hline 24.2 & 0.999 & 0.00155 & 0.050 & 0.335 & 12.0 & $\mathrm{P}$ & NA & 4.98 & 5.06 & 5.10 & 5.20 & 5.20 & 7.00 & NA & NA & NA & NA & NA & NA & NA & n/a & NA & NA & NA & NA & 15E_4s2d27c_1 & 6/19A & TDP-185 & 9150313.3 \\
\hline 24.2 & 0.999 & 0.00155 & 0.050 & 0.335 & 12.0 & $\mathrm{P}$ & NA & 4.98 & 5.06 & 5.10 & 5.20 & 5.20 & 7.00 & NA & NA & NA & NA & NA & NA & NA & n/a & NA & NA & $\mathrm{NA}$ & NA & 15E_4s2d27c_1 & 619A & TDP-185 & 9150313.4 \\
\hline 24.2 & 0.999 & 0.00155 & 0.050 & 0.335 & 12.0 & $P$ & NA & 4.98 & 5.06 & 5.10 & 5.20 & 5.20 & 7.00 & NA & NA & $N A$ & NA & NA & NA & NA & na & NA & $\mathrm{NA}$ & NA & $\mathrm{NA}$ & 15E_4S2d27c_1 & 6/19A & TDP-185 & 9150313.5 \\
\hline 24.2 & 0.999 & 0.00155 & 0.050 & 0.335 & 12.0 & $\mathrm{P}$ & NA & 4.98 & 5.06 & 5.10 & 5.20 & 5.20 & 7.00 & NA & NA & NA & NA & NA & & & \begin{tabular}{|l|}
1.6 \\
\end{tabular} & & NA & NA & NA & 15E_4s2d2Zc__1 & 619A & TDP-185 & 9150314 \\
\hline 24.2 & 0.999 & 0.00155 & 0.050 & 0.335 & 12.0 & $\mathrm{P}$ & NA & 4.98 & 5.06 & 5.10 & 5.20 & 5.20 & 7.00 & NA & NA & NA & NA & NA & NA & NA & 1.3 & NA & NA & NA & NA & 15E_4s2d27c_1 & 6/19A & TDP-185 & 9150315 \\
\hline 24.2 & 0.999 & 0.00155 & 0.050 & 0.335 & 12.0 & $\mathrm{P}$ & NA & 4.98 & 5.06 & 5.10 & 5.20 & 5.20 & 7.00 & NA & NA & NA & NA & NA & NA & NA & 1.9 & NA & NA & NA & NA & $15 \mathrm{E}_{4} \mathrm{~s} 2 \mathrm{~d} 2 \mathrm{ZC} \_1$ & 6/19A & IDP-185 & 9150316 \\
\hline 24.2 & 0.999 & 0.00155 & 0.050 & 0.335 & 12.0 & $P$ & NA & 4.98 & 5.06 & 5.10 & 5.20 & 5.20 & 7.00 & NA & NA & NA & NA & NA & NA & $\mathrm{NA}$ & 1.9 & NA & NA & NA & NA & 15E_4s2d27c_1 & 6/19A & TDP-185 & 9150317 \\
\hline 24.2 & 0.999 & 0.00155 & 0.050 & 0.335 & 12.0 & $\mathrm{P}$ & NA & 4.98 & 5.06 & 5.10 & 5.20 & 5.20 & 7.00 & NA & NA & NA & NA & NA & NA & NA & 1.9 & NA & NA & NA & NA & 15E_4S2d27c_1 & 6/19A & TDP-185 & 9150318 \\
\hline 24.2 & 0.999 & 0.00155 & 0.050 & 0.335 & 12.0 & $\mathrm{P}$ & NA & 4.98 & 5.06 & 5.10 & & 5.20 & & & NA & NA & NA & & -4 & NA & & NA & & NA & NA & 15E_4S2d27c_1 & 619A & TDP-185 & 9150319 \\
\hline 24.2 & 0.999 & 0.00155 & \begin{tabular}{|l|}
0.050 \\
\end{tabular} & \begin{tabular}{|l|l|} 
& 0.3355 \\
\end{tabular} & 12.0 & $P$ & NA & 4.98 & \begin{tabular}{|l|}
5.06 \\
\end{tabular} & 5.10 & 5.20 & 5.20 & 7.00 & NA & NA & NA & NA & NA & NA & NA & 0.0 & NA & NA & NA & NA & 15E_4S2d2Zc_1 & 6/19A & ITDP-185 & 9150320 \\
\hline
\end{tabular}


Table B.3. Data from 2008 Tests in Small-Scale Vessel with Elliptical Head A.10

\begin{tabular}{|c|c|c|c|c|c|c|c|c|c|c|c|c|c|c|c|c|c|c|c|c|c|c|c|c|c|c|c|}
\hline $\begin{array}{l}\text { Rov } \\
\text { Number }\end{array}$ & Test & Case ID & $\begin{array}{c}\text { Tank } \\
\text { Diameter }\end{array}$ & $\begin{array}{l}\text { Head } \\
\text { Shape }\end{array}$ & \begin{tabular}{|l} 
Dish \\
Height
\end{tabular} & $\begin{array}{l}\text { Dish } \\
\text { Volume }\end{array}$ & $\begin{array}{c}\text { Tank Fill } \\
\text { Height }\end{array}$ & $\begin{array}{l}\text { Retur } \\
\text { Line } \\
\text { Height }\end{array}$ & \begin{tabular}{c|} 
Nozzle \\
Inner \\
Dianter
\end{tabular} & $\begin{array}{l}\text { Nozzle } \\
\text { Stantoff } \\
\text { Distance }\end{array}$ & $\begin{array}{l}\text { Pulse Tube } \\
\text { Configuration }\end{array}$ & \begin{tabular}{|l} 
Installed \\
Nozzles
\end{tabular} & $\begin{array}{l}\text { Outer } \\
\text { Nozzles } \\
\text { Operated }\end{array}$ & $\begin{array}{l}\text { Inner } \\
\text { Nozzles } \\
\text { Operated }\end{array}$ & $\begin{array}{l}\text { Pulse Tube } \\
\text { Outer } \\
\text { Dianteter }\end{array}$ & $\begin{array}{c}\text { Outer } \\
\text { PMM } \\
\text { Radius }\end{array}$ & $\begin{array}{c}\text { Inner PJM } \\
\text { Radius } \\
\end{array}$ & \begin{tabular}{|c|} 
"FO" Outer PJM \\
Impingement \\
Angle
\end{tabular} & $\begin{array}{c}\text { "FO' Inner PJM } \\
\text { Impingement Angle }\end{array}$ & \begin{tabular}{|l} 
Ratio Outer PJM \\
to Tank Radius
\end{tabular} & $\begin{array}{l}\text { Ratio Inner PJM } \\
\text { to Tank Radius }\end{array}$ & Simulant & \begin{tabular}{|l|} 
Solids \\
Density \\
\end{tabular} & $\begin{array}{c}\text { Particle } \\
\text { Diameter d5 }\end{array}$ & \begin{tabular}{c|} 
Particle \\
Diameter d d50
\end{tabular} & $\begin{array}{c}\text { Particle } \\
\text { Diameter d95 }\end{array}$ & $\begin{array}{l}\text { Void } \\
\text { Fraction }\end{array}$ \\
\hline text & text & text & in. & text & in. & in ${ }^{3}$ & in. 1 & in. & in. & in. & text & number & number & number & in. & in. & in. & deg & deg & nondim & nondim & text & \begin{tabular}{|l|l|}
$\mathrm{g} / \mathrm{cm}^{3}$ \\
\end{tabular} & $\mathrm{~m}$ & \begin{tabular}{l|}
$\mathrm{m}$ \\
\end{tabular} & $m$ & fraction \\
\hline MSS & MDDX & $\mathrm{ID}$ & $\mathrm{D}$ & HS & Hish & $V_{\text {dish }}$ & $\mathrm{H}$ & $\operatorname{Rin}$ & $d$ & sod & PT & $\mathrm{N}$ & $\mathrm{Nb}$ & $\mathrm{N}$ & $\mathrm{PT}_{\alpha d}$ & $R_{0}$ & $R$ & $\theta_{0}$ & $\theta_{1}$ & $R d R$ & $R / R$ & $\operatorname{sxdx}$ & $\rho_{\mathrm{s}}$ & $d_{b}$ & $d_{60}$ & $d_{65}$ & vf \\
\hline 9150321 & 6/19A & 15E_4s2d2Zc_1 1 & $147 / 16$ & $E$ & 3.25 & 354.8 & 35 & 30 & 0.126 & 0.189 & HLP-22 & 12 & 8 & 4 & 1.05 & 4.5 & 2.4 & 21.8 & 10.1 & 0.62 & 0.34 & $\mathrm{~s} 2 \mathrm{~d} 2$ & 4.18 & 0.0000609 & 0.0000756 & 0.0000931 & 0.3684 \\
\hline 9150322 & 619AA & 15E_4s2d27c__1 & $147 / 16$ & $E$ & 3.25 & 354.8 & 35 & 30 & 0.126 & 0.189 & HLP-22 & 12 & 8 & 4 & 1.05 & 4.5 & 2.4 & 21.8 & 10.1 & 0.62 & 0.34 & $\mathrm{~s} 2 \mathrm{~d} 2$ & 4.18 & 0.0000609 & 0.0000756 & 0.0000931 & 0.3684 \\
\hline 9150323 & 6/19A & 15E_4s2d2ZZ__1 & $147 / 16$ & $E$ & 3.25 & 354.8 & 35 & 30 & 0.126 & 0.189 & HLP-22 & 12 & 8 & 4 & 1.05 & 4.5 & 2.4 & 21.8 & 10.1 & 0.62 & 0.34 & $\mathrm{~s} 2 \mathrm{~d} 2$ & 4.18 & 0.0000609 & 0.0000756 & 0.0000931 & 0.3684 \\
\hline 9150324 & 6/198 & 15E_4s2d2Zd_1 & $147 / 16$ & E & 3.25 & 354.8 & 35 & 30 & 0.126 & 0.189 & HLP-22 & 12 & 8 & 4 & 1.05 & 4.5 & 2.4 & 21.8 & 10.1 & 0.62 & 0.34 & $\mathrm{~s} 2 \mathrm{~d} 2$ & 4.18 & 0.0000609 & 0.0000756 & 0.0000931 & 0.3684 \\
\hline 9150325 & 6/198 & 15E_4s2d2Zd_1 & $147 / 16$ & $E$ & 3.25 & 354.8 & 35 & 30 & 0.126 & 0.189 & HLP-22 & 12 & 8 & 4 & 1.05 & 4.5 & 2.4 & 21.8 & 10.1 & 0.62 & 0.34 & $\mathrm{~s} 2 \mathrm{~d} 2$ & 4.18 & 0.0000609 & 0.0000756 & 0.0000931 & 0.3684 \\
\hline 9150326 & $6 / 198$ & 15E_4s2d2Zd_1 & $147 / 16$ & $E$ & 3.25 & 354.8 & 35 & 30 & 0.126 & 0.189 & HLP-22 & 12 & 8 & 4 & 1.05 & 4.5 & 2.4 & 21.8 & 10.1 & 0.62 & 0.34 & $\mathrm{~s} 2 \mathrm{~d} 2$ & 4.18 & 0.0000609 & 0.0000756 & o.0000931 & 0.3684 \\
\hline 9150327 & 6/198 & 15E_4s2d2Zd_1 & $147 / 16$ & $E$ & 3.25 & 354.8 & 35 & 30 & 0.126 & 0.189 & HLP-22 & 12 & 8 & 4 & 1.05 & 4.5 & 2.4 & 21.8 & 10.1 & 0.62 & 0.34 & $\mathrm{~s} 2 \mathrm{~d} 2$ & 4.18 & 0.0000609 & 0.0000756 & 0.0000931 & 0.3684 \\
\hline $9150328 \mathrm{M}$ & 6/198 & 15E_4s2d2Zd_1 & $147 / 16$ & $E$ & 3.25 & 354.8 & 35 & 30 & 0.126 & 0.189 & HLP-22 & 12 & 8 & 4 & 1.05 & 4.5 & 2.4 & 21.8 & 10.1 & 0.62 & 0.34 & $\mathrm{~s} 2 \mathrm{~d} 2$ & 4.18 & 0.0000609 & 0.0000756 & 0.0000931 & 0.3684 \\
\hline 9150329M M & 6/19B & 15E_4s2d2Zd_1 & $147 / 16$ & $E$ & 3.25 & 354.8 & 35 & 30 & 0.126 & 0.189 & HLP-22 & 12 & 8 & 4 & 1.05 & 4.5 & 2.4 & 21.8 & 10.1 & 0.62 & 0.34 & $\mathrm{~s} 2 \mathrm{~d} 2$ & 4.18 & 0.0000609 & 0.0000756 & 0.0000931 & 0.3684 \\
\hline $9150330 \mathrm{M}$ & $6 / 198$ & 15E_4s2d2Zd_1 & $147 / 16$ & $E$ & 3.25 & 354.8 & 35 & 30 & 0.126 & 0.189 & HLP-22 & 12 & 8 & 4 & 1.05 & 4.5 & 2.4 & 21.8 & 10.1 & 0.62 & 0.34 & $\mathrm{~s} 2 \mathrm{~d} 2$ & 4.18 & 0.0000609 & 0.0000756 & 0.0000931 & 0.3684 \\
\hline $9150331 \mathrm{M}$ & 6/198 & 15E $4 \mathrm{~s} 2 \mathrm{~d} 2 \mathrm{~d} Z \mathrm{~d} 1$ & $147 / 16$ & E & 3.25 & 354.8 & 35 & 30 & 0.126 & 0.189 & HLP-22 & 12 & 8 & 4 & 1.05 & 4.5 & 2.4 & 21.8 & 10.1 & 0.62 & 0.34 & $\mathrm{~s} 2 \mathrm{~d} 2$ & 4.18 & 0.00006009 & 0.0000756 & 0.0000931 & 0.3684 \\
\hline 9150032M & 6/19B & $15 \mathrm{E} 4 \mathrm{~s} 2 \mathrm{~d} 27 \mathrm{~d} 1$ & $147 / 16$ & $\mathrm{E}$ & 3.25 & 354.8 & 35 & 30 & 0.126 & 0.189 & HLP-22 & 12 & 8 & 4 & 1.05 & 4.5 & 2.4 & 21.8 & 10.1 & 0.62 & 0.34 & $\mathrm{~s} 2 \mathrm{~d} 2$ & 4.18 & 0.0000609 & 0.0000756 & 0.0000931 & 0.3684 \\
\hline 9150333M & 6/19B & 15E_4s2d2Zd_1 & $147 / 16$ & $E$ & 3.25 & 354.8 & 35 & 30 & 0.126 & 0.189 & HLP-22 & 12 & 8 & 4 & 1.05 & 4.5 & 2.4 & 21.8 & 10.1 & 0.62 & 0.34 & $\mathrm{~s} 2 \mathrm{~d} 2$ & 4.18 & 0.0000609 & 0.0000756 & 0.0000931 & 0.3684 \\
\hline $9150334 \mathrm{M}$ & $6 / 19 B$ & 15E_4s2d27d_1 & $147 / 16$ & $E$ & 3.25 & 354.8 & 35 & 30 & 0.126 & 0.189 & HLP-22 & 12 & 8 & 4 & 1.05 & 4.5 & 2.4 & 21.8 & 10.1 & 0.62 & 0.34 & $\mathrm{~s} 2 \mathrm{~d} 2$ & 4.18 & 0.0000609 & 0.0000756 & 0.0000931 & 0.3684 \\
\hline $9150335 \mathrm{M}$ & 6198B & 15E_4s2d2Zd_ 1 & $147 / 16$ & $E$ & 3.25 & 354.8 & 35 & 30 & 0.126 & 0.189 & HLP-22 & 12 & 8 & 4 & 1.05 & 4.5 & 2.4 & 21.8 & 10.1 & 0.62 & 0.34 & $\mathrm{~s} 2 \mathrm{~d} 2$ & 4.18 & 0.0000609 & 0.0000756 & 0.0000931 & 0.3684 \\
\hline 9150336 & $6 / 19 \mathrm{C}$ & 15E_4s2d2Yc_1 & $147 / 16$ & $E$ & 3.25 & 354.8 & 35 & 30 & 0.126 & 0.189 & HLP-22 & 12 & 8 & 4 & 1.05 & 4.5 & 2.4 & 21.8 & 10.1 & 0.62 & 0.34 & $\mathrm{~s} 2 \mathrm{~d} 2$ & 4.18 & 0.0000609 & 0.0000756 & 0.0000931 & 0.3684 \\
\hline 9150337 & 6/19c & $15 \mathrm{E}$-4s2d2Yc_1 & $147 / 16$ & $E$ & 3.25 & 354.8 & 35 & 30 & 0.126 & 0.189 & HLP-22 & 12 & 8 & 4 & 1.05 & 4.5 & 2.4 & 21.8 & 10.1 & 0.62 & 0.34 & $\mathrm{~s} 2 \mathrm{~d} 2$ & 4.18 & 0.0000609 & 0.0000756 & 0.0000931 & 0.3684 \\
\hline 9150338 & $6 / 19 \mathrm{C}$ & 15E_4s2d2Yc_1 & $147 / 16$ & $\mathrm{E}$ & 3.25 & 354.8 & 35 & 30 & 0.126 & 0.189 & HLP-22 & 12 & 8 & 4 & 1.05 & 4.5 & 2.4 & 21.8 & 10.1 & 0.62 & 0.34 & $\mathrm{~s} 2 \mathrm{~d} 2$ & 4.18 & 0.0000609 & 0.0000756 & 0.0000931 & 0.3684 \\
\hline 9150339 & $6 / 19 \mathrm{C}$ & 15E_4s2d2YC_1 & $147 / 16$ & $E$ & 3.25 & 354.8 & 35 & 30 & 0.126 & 0.189 & HLP-22 & 12 & 8 & 4 & 1.05 & 4.5 & 2.4 & 21.8 & 10.1 & 0.62 & 0.34 & $\mathrm{~s} 2 \mathrm{~d} 2$ & 4.18 & 0.0000609 & 0.0000756 & 0.0000931 & 0.3684 \\
\hline 9150340 & $6 / 19 \mathrm{C}$ & 15E_4s2d2Yc_1 & $147 / 16$ & $E$ & 3.25 & 354.8 & 35 & 30 & 0.126 & 0.189 & HLP-22 & 12 & 8 & 4 & 1.05 & 4.5 & 2.4 & 21.8 & 10.1 & 0.62 & 0.34 & $\mathrm{~s} 2 \mathrm{~d} 2_{2}$ & 4.18 & 0.0000609 & 0.0000756 & 0.0000931 & 0.3684 \\
\hline 9150341 & 6/19c & 15E_4s2d2YC_1 & $147 / 16$ & $\mathrm{E}$ & 3.25 & 354.8 & 35 & 30 & 0.126 & 0.189 & HLP-22 & 12 & 8 & 4 & 1.05 & 4.5 & 2.4 & 21.8 & 10.1 & 0.62 & 0.34 & $\mathrm{~s} 2 \mathrm{~d} 2$ & 4.18 & 0.0000000 & 0.0000756 & 0.0000931 & 0.3684 \\
\hline 9150342 & $6 / 19 \mathrm{C}$ & 15E_4s2d2Yc_1 & $147 / 16$ & $E$ & 3.25 & 354.8 & 35 & 30 & 0.126 & 0.189 & HLP-22 & 12 & 8 & 4 & 1.05 & 4.5 & 2.4 & 21.8 & 10.1 & 0.62 & 0.34 & $\mathrm{~s} 2 \mathrm{~d} 2$ & 4.18 & 0.0000609 & 0.0000756 & 0.0000931 & 0.3684 \\
\hline 9150343 & $6 / 19 \mathrm{C}$ & 15E_4s2d2Y__1 & $147 / 16$ & $E$ & 3.25 & 354.8 & 35 & 30 & 0.126 & 0.189 & HLP-22 & 12 & 8 & 4 & 1.05 & 4.5 & 2.4 & 21.8 & 10.1 & 0.62 & 0.34 & $\mathrm{~s} 2 \mathrm{~d} 2_{2}$ & 4.18 & 0.0000609 & 0.0000756 & 0.0000931 & 0.3684 \\
\hline 9150344 & $6 / 19 c$ & 15E_4s2d2Yc_1 & $147 / 16$ & $E$ & 3.25 & 354.8 & 35 & 30 & 0.126 & 0.189 & HLP-22 & 12 & 8 & 4 & 1.05 & 4.5 & 2.4 & 21.8 & 10.1 & 0.62 & 0.34 & $\mathrm{~s} 2 \mathrm{~d} 2$ & 4.18 & 0.0000609 & 0.0000756 & o.0000931 & 0.3684 \\
\hline 9150345M & $6 / 19 \mathrm{C}$ & 15E_4s2d2Yc_1 & $147 / 16$ & $E$ & 3.25 & 354.8 & 35 & 30 & 0.126 & 0.189 & HLP-22 & 12 & 8 & 4 & 1.05 & 4.5 & 2.4 & 21.8 & 10.1 & 0.62 & 0.34 & $\mathrm{~s} 2 \mathrm{~d} 2$ & 4.18 & 0.0000609 & 0.0000756 & 0.0000931 & 0.3684 \\
\hline $9150346 \mathrm{M}$ & 6/19c & 15E_4s2d2Yc_1 & $147 / 16$ & $E$ & 3.25 & 354.8 & 35 & 30 & 0.126 & 0.189 & HLP-22 & 12 & 8 & 4 & 1.05 & 4.5 & 2.4 & 21.8 & 10.1 & 0.62 & 0.34 & $\mathrm{~s} 2 \mathrm{~d} 2$ & 4.18 & 0.0000609 & 0.0000756 & 0.0000931 & 0.3684 \\
\hline $9150347 \mathrm{M}$ & 6/20A & 15E_4s2d2Yc_1 & $147 / 16$ & $E$ & 3.25 & 354.8 & 35 & 30 & 0.126 & 0.189 & HLP-22 & 12 & 8 & 4 & 1.05 & 4.5 & 2.4 & 21.8 & 10.1 & 0.62 & 0.34 & $\mathrm{~s} 2 \mathrm{~d} 2$ & 4.18 & 0.00006009 & 0.0000756 & 0.0000931 & 0.3684 \\
\hline $9150348 \mathrm{M}$ & 6/20A & 15E_4s2d2Yc_1 & $147 / 16$ & $E$ & 3.25 & 354.8 & 35 & 30 & 0.126 & 0.189 & HLP-22 & 12 & 8 & 4 & 1.05 & 4.5 & 2.4 & 21.8 & 10.1 & 0.62 & 0.34 & $\mathrm{~s} 2 \mathrm{~d} 2$ & 4.18 & 0.0000609 & 0.0000756 & 0.0000931 & 0.3684 \\
\hline $9150349 \mathrm{M}$ & 6/20A & 15E_4S2d22YC_1 & $147 / 16$ & E & 3.25 & 354.8 & 35 & 30 & 0.126 & 0.189 & HLP-22 & 12 & 8 & 4 & 1.05 & 4.5 & 2.4 & 21.8 & 10.1 & 0.62 & 0.34 & $\mathrm{~s} 2 \mathrm{~d} 2$ & 4.18 & 0.0000600 & 0.0000756 & 0.0000931 & 0.3684 \\
\hline $9150350 \mathrm{M}$ & 6/20A & $15 E_{4} 4 \mathrm{~s} 2 \mathrm{~d} 2 \mathrm{Yc}-1$ & $147 / 16$ & $E$ & 3.25 & 354.8 & 35 & 30 & 0.126 & 0.189 & HLP-22 & 12 & 8 & 4 & 1.05 & 4.5 & 2.4 & 21.8 & 10.1 & 0.62 & 0.34 & $\mathrm{~s} 2 \mathrm{~d} 2$ & 4.18 & 0.0000609 & 0.0000756 & 0.0000931 & 0.3684 \\
\hline 9150351M & 6/20A & 15E_4s2d22Yc_1 & $147 / 16$ & $E$ & 3.25 & 354.8 & 35 & 30 & 0.126 & 0.189 & HLP-22 & 12 & 8 & 4 & 1.05 & 4.5 & 2.4. & 21.8 & 10.1 & 0.62 & 0.34 & $\mathrm{~s} 2 \mathrm{~d} 2$ & 4.18 & 0.0000609 & 0.0000756 & 0.0000931 & 0.3684 \\
\hline $9150352 \mathrm{M}$ & 6120A & 15E_4s2d2YC_1 & $147 / 16$ & $E$ & 3.25 & 354.8 & 35 & 30 & 0.126 & 0.189 & HLP-22 & 12 & 8 & 4 & 1.05 & 4.5 & 2.4 & 21.8 & 10.1 & 0.62 & 0.34 & $\mathrm{~s} 2 \mathrm{~d} 2$ & 4.18 & 0.0000609 & 0.0000756 & 0.0000931 & 0.3684 \\
\hline 9150353M & 6/20A & 15E_4s2d2Yc_1 & $147 / 16$ & $\mathrm{E}$ & 3.25 & 354.8 & 35 & 30 & 0.126 & 0.189 & HLP-22 & 12 & 8 & 4 & 1.05 & 4.5 & 2.4 & 21.8 & 10.1 & 0.62 & 0.34 & $\mathrm{~s} 2 \mathrm{~d} 2$ & 4.18 & 0.0000609 & 0.0000756 & 0.0000931 & 0.3684 \\
\hline 9150353.1 & 6/20A & $15 E_{4} 4 \mathrm{~s} 2 \mathrm{~d} 2 \mathrm{Yc} \_1$ & $147 / 16$ & $E$ & 3.25 & 354.8 & 35 & 30 & 0.126 & 0.189 & HLP-22 & 12 & 8 & 4 & 1.05 & 4.5 & 2.4 & 21.8 & 10.1 & 0.62 & 0.34 & & 4.18 & 0.0000609 & 0.0000756 & 0.0000931 & 0.3684 \\
\hline 9150353.2 & 6/20A & 15E_4s2d2YC_ 1 & $147 / 16$ & $E$ & 3.25 & 354.8 & 35 & 30 & 0.126 & 0.189 & HLP-22 & 12 & 8 & 4 & 1.05 & 4.5 & 2.4 & 21.8 & 10.1 & 0.62 & 0.34 & $\mathrm{~s} 2 \mathrm{~d} 2$ & 4.18 & 0.0000609 & 0.0000756 & 0.0000931 & 0.3684 \\
\hline 9150353.3 & 6/20A & $15 E_{4} 4 \mathrm{~s} 2 \mathrm{~d} 2 \mathrm{Yc}_{1} 1$ & $147 / 16$ & $E$ & 3.25 & 354.8 & 35 & 30 & 0.126 & 0.189 & HLP-22 & 12 & 8 & 4 & 1.05 & 4.5 & 2.4 & 21.8 & 10.1 & 0.62 & 0.34 & $\mathrm{~s} 2 \mathrm{~d} 2$ & 4.18 & 0.0000609 & 0.0000756 & 0.0000931 & 0.3684 \\
\hline 9150353.4 & 6/20A & 15E_4s2d2YC_1 & $147 / 16$ & $E$ & 3.25 & 354.8 & 35 & 30 & 0.126 & 0.189 & HLP-22 & 12 & 8 & 4 & 1.05 & 4.5 & 2.4 & 21.8 & 10.1 & 0.62 & 0.34 & $\mathrm{~s} 2 \mathrm{~d} 2$ & 4.18 & 0.0000609 & 0.0000756 & 0.0000931 & 0.3684 \\
\hline 9150353.5 & 6/20A & 15E_4S2d2YC_1 & $147 / 16$ & $E$ & 3.25 & 354.8 & 35 & 30 & 0.126 & 0.189 & HLP-22 & 12 & 8 & 4 & 1.05 & 4.5 & 2.4 & 21.8 & 10.1 & 0.62 & 0.34 & $\mathrm{~s} 2 \mathrm{~d} 2$ & 4.18 & 0.0000609 & 0.0000756 & 0.0000931 & 0.3684 \\
\hline $9150354 \mathrm{M}$ & 6/20A & 15E_4s2d2Yc_1 & $147 / 16$ & $E$ & 3.25 & 354.8 & 35 & 30 & 0.126 & 0.189 & HLP-22 & 12 & 8 & 4 & & 4.5 & 2.4 & 21 & & 0.62 & & $\mathrm{~s} 2 \mathrm{~d} 2$ & 4. & & & 0.0000931 & \\
\hline 9150355 & 6/20A & 15E_4s2d2Y__1 & $147 / 16$ & $\mathrm{E}$ & 3.25 & 354.8 & 35 & 30 & 0.126 & 0.189 & HLP-22 & 12 & 8 & 4 & 1.05 & 4.5 & 2.4 & 21.8 & 10.1 & 0.62 & 0.34 & $\mathrm{~s} 2 \mathrm{~d} 2$ & \begin{tabular}{|c|}
4.18 \\
\end{tabular} & 0.0000609 & 0.0000756 & 0.0000931 & 0.3684 \\
\hline 9150356 & 6/20A & 15E_4s2d2YC_1 & $147 / 16$ & $E$ & 3.25 & 354.8 & 35 & 30 & 0.126 & 0.189 & HLP-22 & 12 & 8 & 4 & 1.05 & 4.5 & 2.4 & 21.8 & 10.1 & 0.62 & 0.34 & $\mathrm{~s} 2 \mathrm{~d} 2$ & 4.18 & 0.0000609 & \begin{tabular}{|c|}
0.0000756 \\
\end{tabular} & 0.0000931 & 0.3684 \\
\hline
\end{tabular}


Table B.3. Data from 2008 Tests in Small-Scale Vessel with Elliptical Head B.10

\begin{tabular}{|c|c|c|c|c|c|c|c|c|c|c|c|c|c|c|c|c|c|c|c|c|c|c|c|c|c|c|c|c|c|}
\hline $\begin{array}{l}\text { Tank Water } \\
\text { Temperature }\end{array}$ & $\begin{array}{c}\text { Water } \\
\text { Density }\end{array}$ & $\begin{array}{l}\text { Solids } \\
\text { Fraction }\end{array}$ & $\begin{array}{l}\text { Pulse } \\
\text { Volume } \\
\text { Fraction } \\
\end{array}$ & $\begin{array}{l}\text { Duty } \\
\text { cycle }\end{array}$ & $\begin{array}{l}\text { Cyde } \\
\text { Time }\end{array}$ & $\begin{array}{l}\text { Pulsed or } \\
\text { Steady Jet }\end{array}$ & \begin{tabular}{|c} 
Us \\
Steady \\
Jet
\end{tabular} & $\begin{array}{c}\text { U1 } \\
\text { Pulsin } \\
\text { g Jet }\end{array}$ & $\begin{array}{c}\text { U2 } \\
\text { URMS }\end{array}$ & \begin{tabular}{c|c} 
UB & 1 \\
URMB
\end{tabular} & $\begin{array}{l}\text { Discharge } \\
\text { velocity }\end{array}$ & $\begin{array}{c}\text { Cutical } \\
\text { suspension } \\
\text { velocity }\end{array}$ & $\begin{array}{c}\text { Average Peak } \\
\text { Cloud Height } \\
\end{array}$ & $\begin{array}{c}\text { UCS } \\
\text { Condition }\end{array}$ & $\begin{array}{l}\text { UCS } \\
\text { Method }\end{array}$ & Ucs Hag & $\begin{array}{c}\text { Ucs Center } \\
\text { Flag }\end{array}$ & $\begin{array}{c}\text { Ucs udv } \\
\text { Hag } \\
\end{array}$ & $\begin{array}{c}\text { UCS based on } \\
\text { Decreasing } \\
\text { velocity }\end{array}$ & $\begin{array}{l}\text { Sneep } \\
\text { Increase/ } \\
\text { Decrease }\end{array}$ & $\begin{array}{c}\text { ULV } \\
\text { Height } \\
\text { Bed }\end{array}$ & $\begin{array}{l}\text { Particle } \\
\text { Motion }\end{array}$ & $\begin{array}{l}\text { Solids } \\
\text { Level }\end{array}$ & $\mid$\begin{tabular}{|} 
Oater \\
Bottom \\
Pattem \\
\end{tabular} & $\begin{array}{l}\text { Inner } \\
\text { Bottom } \\
\text { Pattem }\end{array}$ & Case ID & Test & IDP & $\begin{array}{l}\text { Row } \\
\text { Number }\end{array}$ \\
\hline $\mathrm{c}$ & $\mathrm{g} / \mathrm{cm}^{3}$ & fraction & fraction & fraction & \begin{tabular}{l|l}
$\mathrm{s}$ \\
\end{tabular} & text & m/s & $\mathrm{m} / \mathrm{s}$ & m/s & \begin{tabular}{l|l|}
$m / s$ \\
\end{tabular} & m/s & \begin{tabular}{l|}
$\mathrm{m} / \mathrm{s}$ \\
\end{tabular} & \begin{tabular}{|l|} 
in. \\
\end{tabular} & m/s & text & $\begin{array}{ll}\text { text } \\
\end{array}$ & text & text & $\begin{array}{ll}m / s \\
\end{array}$ & text & \begin{tabular}{l|l}
$\mathrm{mm}$ \\
\end{tabular} & text & text & \begin{tabular}{|l|l|} 
text \\
\end{tabular} & text & text & text & text & text \\
\hline$T$ & $\rho$ & $\phi_{\mathrm{s}}$ & $\begin{array}{ll}\phi_{p} \\
\phi_{0}\end{array}$ & $\mathrm{DC}$ & $t_{c}$ & Jet & $u_{s}$ & $U_{1}$ & $\mathrm{U2}$ & us & $u$ & $u_{\text {us }}$ & $\mathrm{Hc}$ & uss & Uosm & Usvis & Uscen & Ussudv & $U_{c S_{2} D}$ & $s_{\mathrm{w}}$ & $H_{\text {Hod }}$ & $\mathrm{PM}$ & Sol & SPo & $\mathrm{SP}_{\mathrm{P}}$ & $\mathrm{ID}$ & MDDX & $\mathrm{TDP}$ & MSS \\
\hline 24.2 & 0.999 & 0.00155 & 0.050 & 0.335 & 12.0 & $P$ & NA & 4.98 & 5.06 & 5.10 & 5.20 & 5.20 & 7.00 & NA & NA & NA & NA & NA & NA & $\mathrm{NA}$ & 1.9 & NA & NA & \begin{tabular}{l|l} 
NA & I \\
I
\end{tabular} & NA & 15E_4s2d27c_1 & 6/19A & IDP-185 & 9150321 \\
\hline 24.2 & 0.999 & 0.00155 & 0.050 & 0.335 & 12.0 & $\mathrm{P}$ & NA & 4.98 & 5.06 & 5.10 & 5.20 & 5.20 & $7.00 \mid$ & NA & NA & NA & NA & NA & $\mathrm{NA}$ & $\mathrm{NA}$ & 1.3 & NA & NA & NA & $\mathrm{NA}$ & 15E_4s2d2Zc__1 & $619 \mathrm{~A}$ & TDP-185 & 9150322 \\
\hline 24.2 & 0.999 & 0.00155 & 0.050 & 0.335 & 120 & $P$ & NA & 4.98 & 5.06 & 5.10 & 5.20 & 5.20 & $7.00 / \mathrm{N}$ & NA & NA & NA & NA & NA & NA & NA & 3.2 & NA & NA & NA & NA & 15E_4s2d27c_ 1 & $619 \mathrm{~A}$ & IDP-185 & 9150323 \\
\hline 24.6 & 0.999 & 0.00155 & 0.050 & 0.183 & 28.4 & $\mathrm{P}$ & NA & 3.86 & 3.90 & 3.93 & 4.00 & 5.40 & 5.25 . & NA & NA & NA & NA & NA & $\mathrm{NA}$ & (null) & 7.9 & 1 & NA & NA & NA & 15E_4s2d27d_1 & $619 \mathrm{~B}$ & TDP-185 & 9150324 \\
\hline 24.7 & 0.999 & 0.00155 & 0.050 & 0.185 & 25.6 & $\mathrm{P}$ & NA & 4.25 & 4.30 & 4.32 & 4.40 & 5.40 & 5.75 . & NA & NA & NA & NA & NA & NA & 1 & 6.0 & 1 & NA & NA & NA & 15E_4s2d2Zd_1 & 6/19B & TDP-185 & 9150325 \\
\hline 24.8 & 0.999 & 0.00155 & 0.050 & 0.186 & 23.4 & $P$ & NA & 4.62 & 4.69 & 4.72 & 4.80 & 5.40 & 6.25 . & NA & NA & NA & NA & NA & $\mathrm{NA}$ & 1 & 4.5 & 1 & NA & NA & NA & 15E_4s2d2Zd_1 & $619 \mathrm{~B}$ & IDP-185 & 9150326 \\
\hline 25.0 & 0.999 & 0.00155 & 0.050 & 0.186 & 21.6 & $\mathrm{P}$ & NA & 4.98 & 5.06 & 5.09 & 5.20 & 5.40 & 6.75 ก & \begin{tabular}{l|l} 
NA & N \\
Nat
\end{tabular} & NA & NA & NA & NA & NA & 1 & 3.3 & 1 & NA & NA & NA & 15E_4s2d27d_1 & 6/98B & TDP-185 & 9150327 \\
\hline 25.1 & 0.999 & 0.00155 & 0.050 & 0.187 & 20.8 & $\mathrm{P}$ & NA & 5.17 & 5.25 & 5.29 & 5.40 & 5.40 & 6.75 & $\left.5.40\right|_{L}$ & udv & NA & NA & ucsuav & $\mathrm{NA}$ & 1 & 1.6 & 1 & NA & NA & NA & 15E 4s2d2Zd 1 & 6/198 & TDP-185 & 9150328 \\
\hline 25.5 & 0.999 & 0.00155 & 0.050 & 0.185 & 20.1 & $\mathrm{P}$ & NA & 5.37 & 5.45 & 5.49 & 5.60 & 5.40 & 7.001 & \begin{tabular}{l|l} 
NA & D \\
nat
\end{tabular} & NA & UCSVis & NA & NA & NA & 1 & 0.0 & 3 & NA & NA & $\mathrm{NA}$ & 15E_4s2d27d_1 & 6/19B & TDP-185 & 9150329 \\
\hline 25.6 & 0.999 & 0.00155 & 0.050 & 0.185 & 19.4 & $\mathrm{P}$ & NA & 5.56 & 5.65 & 5.70 & 5.80 & 5.40 & $7.75 \mid$ & NA & NA & NA & NA & NA & $\mathrm{NA}$ & 1 & 0.0 & 4 & NA & NA & $\mathrm{NA}$ & 15E_4s2d2Zd_1 & 6/19B & TDP-185 & 9150330 \\
\hline 25.8 & 0.999 & 0.00155 & 0.050 & 0.187 & 18.1 & $\mathrm{P}$ & NA & 5.93 & 6.03 & 6.08 & 6.20 & 5.40 & $10.25 \mathrm{n}$ & NA & NA & NA & NA & NA & NA & 1 & 0.0 & 4 & NA & NA & NA & 15E_4s2d27d_1 & $619 \mathrm{~B}$ & IDP-185 & 9150331 \\
\hline 25.9 & 0.998 & 0.00155 & 0.050 & 0.187 & 17.0 & $\mathrm{P}$ & NA & 6.29 & 6.40 & 6.46 & 6.60 & 5.40 & $12.50 \mathrm{~N}$ & NA & NA & NA & $\mathrm{NA}$ & NA & $\mathrm{NA}$ & 1 & 0.0 & 4 & NA & NA & NA & 15E_4s2d2Zd_1 & $619 \mathrm{~B}$ & IDP-185 & 9150332 \\
\hline 26.3 & 0.999 & 0.00155 & 0.050 & 0.188 & 16.0 & $P$ & NA & 6.66 & 6.79 & 6.85 & 7.00 & 5.40 & $13.75 \mathrm{~N}$ & NA & NA & NA & NA & NA & $\mathrm{NA}$ & 1 & 0.0 & 4 & NA & NA & $\mathrm{NA}$ & 15E_4s2d2Zd_1 & 6/19B & TDP-185 & 9150333 \\
\hline 26.5 & 0.998 & 0.00155 & 0.050 & 0.188 & 15.2 & $P$ & NA & 7.04 & 7.18 & 7.25 & 7.40 & 5.40 & $15.75 \mathrm{~A}$ & NA & NA & NA & NA & NA & & 1 & 0.0 & 4 & NA & NA & $\mathrm{NA}$ & 15E_4s2d27d_1 & 6198 & IDP-185 & 9150334 \\
\hline 26.9 & 0.999 & 0.00155 & 0.050 & 0.189 & 14.4 & $\mathrm{P}$ & NA & 7.40 & 7.56 & 7.64 & 7.80 & 5.40 & $18.00 \mid \mathrm{n}$ & NA & NA & NA & NA & NA & $\mathrm{NA}$ & 1 & 0.6 & 4 & $\mathrm{NA}$ & NA & NA & 15E $4 \mathrm{~s} 2 \mathrm{~d} 2 \mathrm{Zd} 1$ & 6/19B & TDP-185 & 9150335 \\
\hline 27.7 & 0.999 & 0.00500 & 0.050 & 0.337 & 124 & $P$ & NA & 4.76 & 4.83 & 4.87 & 5.00 & 7.60 & 3.75 & NA & NA & $\mathrm{NA}$ & NA & $\mathrm{NA}$ & NA & (null) & 11.4 & 1 & NA & NA & $\mathrm{NA}$ & 15E_4s2d2YC_1 & 6/199C & IDP-186 & 9150336 \\
\hline 27.7 & 0.998 & 0.00500 & 0.050 & 0.334 & 11.7 & $\mathrm{P}$ & NA & 5.12 & 5.20 & 5.25 & 5.40 & 7.60 & 4.001 & NA & NA & $\mathrm{NA}$ & NA & NA & $\mathrm{NA}$ & 1 & 10.2 & 1 & NA & NA & $\mathrm{NA}$ & 15E_4s2d2YC_1 & 6/19C & TDP-186 & 9150337 \\
\hline 27.8 & 0.998 & 0.00500 & 0.050 & 0.335 & 10.9 & $\mathrm{P}$ & NA & 5.50 & 5.60 & 5.65 & 5.80 & 7.60 & 4.25 . & NA & NA & NA & $\mathrm{NA}$ & NA & NA & 1 & 7.7 & 1 & NA & NA & $\mathrm{NA}$ & 15E_4s2d2Yc_1 & $6 / 19 \mathrm{C}$ & TDP-186 & 9150338 \\
\hline 27.9 & 0.999 & 0.00500 & 0.050 & 0.335 & 10.2 & $P$ & $N A$ & 5.89 & 6.00 & 6.05 & 6.20 & 7.60 & 4.75 N & NA & $\mathrm{NA}$ & NA & NA & NA & NA & 1 & 6.0 & 1 & NA & NA & NA & 15E_4s2d2YC_1 & 6/19C & IDP-186 & 9150339 \\
\hline 28.0 & 0.999 & 0.00500 & 0.050 & 0.335 & 9.6 & $P$ & NA & 6.25 & 6.37 & 6.43 & 6.60 & 7.60 & 4.75 ก & NA & NA & NA & NA & NA & $\mathrm{NA}$ & 1 & 3.3 & 1 & NA & NA & $\mathrm{NA}$ & 15E_4s2d2Yc_1 & 6/19C & TDP-186 & 9150340 \\
\hline 28.1 & 0.998 & 0.00500 & 0.050 & 0.336 & 9.3 & $P$ & NA & 6.43 & 6.55 & 6.61 & 6.80 & 7.60 & $5.25 \mathrm{~N}$ & NA & NA & NA & NA & NA & $\mathrm{NA}$ & 1 & 3.8 & 1 & NA & NA & $\mathrm{NA}$ & 15E_4s2d2Yc_1 1 & 6/19c & IDP-186 & 9150341 \\
\hline 28.3 & 0.998 & 0.00500 & 0.050 & 0.338 & 9.0 & $\mathrm{P}$ & NA & 6.63 & 6.76 & 6.82 & 7.00 & 7.60 & 5.25 . & NA & NA & NA & NA & NA & $\mathrm{NA}$ & 1 & 3.2 & 1 & NA & NA & NA & 15E_4s2d2Yc_1 & $6 / 19 c$ & TDP-186 & 9150342 \\
\hline 28.4 & 0.998 & 0.00500 & 0.050 & 0.337 & 8.8 & $\mathrm{P}$ & NA & 6.80 & 6.94 & 7.01 & 7.20 & 7.60 & 5.75 . & NA & NA & UCSNis & NA & NA & NA & 1 & 3.2 & 3 & NA & NA & NA & 15E_4s2d2Yc_1 & 6/19c & TDP-186 & 9150343 \\
\hline 28.5 & 0.998 & 0.00500 & 0.050 & 0.334 & 8.6 & $\mathrm{P}$ & NA & 6.99 & 7.13 & 7.20 & 7.40 & 7.60 & 5.75 . & NA & NA & NA & NA & NA & NA & 1 & 3.2 & 4 & NA & NA & NA & 15E_4s2d2Yc_1 & $6 / 19 \mathrm{C}$ & TDP-186 & 9150344 \\
\hline 28.7 & 0.998 & 0.00500 & 0.050 & 0.335 & 8.4 & $\mathrm{P}$ & NA & 7.15 & 7.30 & 7.38 & 7.60 & 7.60 & 6.00 & $\left.7.60\right|_{4}$ & udv & NA & NA & vesuav & NA & 1 & 2.6 & 4 & NA & NA & $\mathrm{NA}$ & 15E_4s2d2Yc_1 1 & 6/19c & TDP-186 & 9150345 \\
\hline 28.8 & 0.998 & 0.00500 & 0.050 & 0.334 & 8.2 & $P$ & NA & 7.34 & 7.50 & 7.58 & 7.80 & 7.60 & 6.25 . & NA & NA & NA & NA & NA & NA & 1 & 0.0 & 4 & NA & NA & NA & 15E_4s2d2Yc_1 & $6 / 19 c$ & TDP-186 & 9150346 \\
\hline 24.3 & 0.999 & 0.00500 & 0.050 & 0.334 & 8.4 & $P$ & NA & 7.17 & 7.32 & 7.40 & 7.60 & 7.60 & \begin{tabular}{l|l}
5.75 \\
\end{tabular} & $7.600_{4}$ & udv & NA & NA & ucsud & NA & (null) & 1.3 & 4 & NA & NA & $\mathrm{NA}$ & 15E_4s2d2YC_1 & $6 / 20 \mathrm{~A}$ & TDP-187 & 9150347 \\
\hline 24.5 & 0.999 & 0.00500 & 0.050 & 0.335 & 8.2 & $P$ & NA & 7.32 & 7.48 & 7.56 & 7.80 & 7.60 & $6.00 \mid$ & 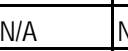 & NA & NA & NA & NA & NA & 1 & 0.0 & 4 & NA & NA & NA & $15 \mathrm{E}-4 \mathrm{~s} 2 \mathrm{~d} 2 \mathrm{Yc} \_1$ & 6/20A & IDP-187 & 9150348 \\
\hline 24.8 & 0.999 & 0.00500 & 0.050 & 0.335 & 7.8 & $\mathrm{P}$ & NA & 7.72 & 7.89 & 7.97 & 8.20 & 7.60 & $6.25 \mathrm{~N}$ & NA & NA & NA & NA & NA & $\mathrm{NA}$ & 1 & 0.0 & 4 & NA & NA & $\mathrm{NA}$ & 15E_4s2d2YC_1 & 6/20A & IDP-187 & 9150349 \\
\hline 24.9 & 0.999 & 0.00500 & 0.050 & 0.336 & 7.4 & $\mathrm{P}$ & NA & 8.08 & 8.27 & 8.36 & 8.60 & 7.60 & $9.00 / \mathrm{n}$ & NA & NA & NA & NA & NA & $\mathrm{NA}$ & 1 & 0.0 & 4 & NA & NA & NA & $15 \mathrm{E}=4 \mathrm{~s} 2 \mathrm{~d} 2 \mathrm{Yc} 1$ & 6/20A & TDP-187 & 9150350 \\
\hline 25.2 & 0.999 & 0.00500 & 0.050 & 0.337 & 7.1 & $\mathrm{P}$ & NA & 8.43 & 8.63 & 8.73 & 9.00 & 7.60 & $12.00 \mid$ & NA & NA & NA & NA & NA & $\mathrm{N} / \mathrm{A}$ & 1 & 0.0 & 4 & NA & NA & NA & 15E_4s2d2Yc_1 & 6/20A & TDP-187 & 9150351 \\
\hline 25.5 & 0.999 & 0.00500 & 0.050 & 0.334 & 6.8 & $\mathrm{P}$ & NA & 8.77 & 8.99 & 9.10 & 9.40 & 7.60 & 14.251 & NA & NA & NA & NA & $\mathrm{NA}$ & NA & 1 & 0.0 & 4 & NA & NA & NA & 15E_ $4 \mathrm{~s} 2 \mathrm{~d} 2 \mathrm{YC} 1$ & 6/20A & IDP-187 & 9150352 \\
\hline 25.7 & 0.999 & 0.00500 & 0.050 & 0.336 & 6.5 & $P$ & NA & 9.14 & 9.38 & $\begin{array}{l}9.50 \\
\end{array}$ & 9.80 & 7.60 & $21.50 \mathrm{~N}$ & NA & NA & NA & NA & $\mathrm{NA}$ & NA & 1 & 0.0 & 4 & NA & NA & NA & 15E_4s22 $2 \mathrm{YC}_{1} 1$ & 6/20A & TDP-187 & 9150353 \\
\hline 26.0 & 0.999 & 0.00500 & 0.050 & 0.334 & 8.4 & $P$ & NA & 7.16 & 7.31 & 7.39 & 7.60 & 7.60 & $6.00 \mathrm{f}$ & NA & $\mathrm{NA}$ & NA & NA & NA & $\mathrm{NA}$ & NA & va & NA & NA & NA & NA & 15E_4s2d2YC_1 & 6/20A & IDP-187 & 9150353.1 \\
\hline 26.0 & 0.999 & 0.00500 & 0.050 & 0.334 & 8.4 & $P$ & NA & 7.16 & 7.31 & 7.39 & 7.60 & 7.60 & $6.00 \mathrm{~T}$ & NA & $\mathrm{NA}$ & NA & NA & NA & NA & NA & na & NA & NA & NA & NA & 15E_4s2d2YC_1 & 6/20A & IDP-187 & 9150353.2 \\
\hline 26.0 & 0.999 & 0.00500 & 0.050 & 0.334 & 8.4 & $\mathrm{P}$ & NA & 7.16 & 7.31 & 7.39 & 7.60 & 7.60 & 6.001 & NA & NA & NA & NA & NA & $\mathrm{NA}$ & $\mathrm{NA}$ & $\mathrm{Na}$ & NA & $\mathrm{NA}$ & NA & NA & 15E_4s2d2YC_1 & 6/20A & IDP-187 & 9150353.3 \\
\hline 26.0 & 0.999 & 0.00500 & 0.050 & 0.334 & 8.4 & $P$ & NA & 7.16 & 7.31 & 7.39 & 7.60 & 7.60 & 6.001 & NA & NA & $\mathrm{NA}$ & NA & $\mathrm{NA}$ & NA & NA & $\mathrm{na}$ & NA & NA & NA & NA & 15E_4s2d2YC 1 & 6/20A & TDP-187 & 9150353.4 \\
\hline 26.0 & 0.999 & 0.00500 & 0.050 & 0.334 & 8.4 & $\mathrm{P}$ & NA & 7.16 & 7.31 & 7.39 & 7.60 & 7.60 & $6.00 \mathrm{~A}$ & NA & NA & $\mathrm{NA}$ & $\mathrm{NA}$ & $\mathrm{NA}$ & NA & NA & na & $\mathrm{NA}$ & NA & NA & $\mathrm{NA}$ & 15E_4s2d2YC_1 1 & 6/20A & IDP-187 & 9150353.5 \\
\hline 26.0 & 0.999 & 0.00500 & 0.050 & 0.334 & 8.4 & $\mathrm{P}$ & NA & 7.16 & 7.31 & 7.39 & 7.60 & 7.60 & $6.00 \mathrm{~N}$ & NA & NA & NA & NA & NA & NA & 1 & 2.6 & 4 & NA & NA & NA & 15E_4s2d2Yc_1 & 6/20A & TDP-187 & 9150354 \\
\hline 26.0 & 0.999 & 0.00500 & 0.050 & 0.334 & 8.4 & $\mathrm{P}$ & $\mathrm{NA}$ & 7.16 & 7.31 & 7.39 & 7.60 & 7.60 & & NA & $\mathrm{NA}$ & NA & NA & NA & NA & NA & & NA & NA & NA & $\mathrm{NA}$ & 15E_4S2d2YC_1 & 6/20A & TDP-187 & 9150355 \\
\hline 26.0 & 0.999 & 0.00500 & 0.050 & 0.334 & 8.4 & $\mathrm{P}$ & NA & 7.16 & 7.31 & 7.39 & 7.60 & 7.60 & $6.00 \mid \mathrm{r}$ & NA & NA & NA & NA & NA & NA & NA & 2.0 & NA & NA & NA & NA & 15E_4s2d2YC_ 1 & 6/20A & TIDP-187 & 9150356 \\
\hline
\end{tabular}


Table B.3. Data from 2008 Tests in Small-Scale Vessel with Elliptical Head A.11

\begin{tabular}{|c|c|c|c|c|c|c|c|c|c|c|c|c|c|c|c|c|c|c|c|c|c|c|c|c|c|c|c|}
\hline $\begin{array}{l}\text { Rov } \\
\text { Number }\end{array}$ & Test & Case ID & $\begin{array}{c}\text { Tank } \\
\text { Diameter }\end{array}$ & $\begin{array}{l}\text { Head } \\
\text { Shape }\end{array}$ & \begin{tabular}{|l} 
Dish \\
Height
\end{tabular} & $\begin{array}{l}\text { Dish } \\
\text { Volume }\end{array}$ & $\begin{array}{c}\text { Tank Fill } \\
\text { Height }\end{array}$ & $\begin{array}{l}\text { Retur } \\
\text { Line } \\
\text { Height }\end{array}$ & \begin{tabular}{c|} 
Nozzle \\
Inner \\
Dianter
\end{tabular} & $\begin{array}{l}\text { Nozzle } \\
\text { Stantoff } \\
\text { Distance }\end{array}$ & $\begin{array}{l}\text { Pulse Tube } \\
\text { Configuration }\end{array}$ & \begin{tabular}{|l} 
Installed \\
Nozzles
\end{tabular} & $\begin{array}{l}\text { Outer } \\
\text { Nozzles } \\
\text { Operated }\end{array}$ & $\begin{array}{l}\text { Inner } \\
\text { Nozzles } \\
\text { Operated }\end{array}$ & $\begin{array}{l}\text { Pulse Tube } \\
\text { Outer } \\
\text { Dianteter }\end{array}$ & $\begin{array}{c}\text { Outer } \\
\text { PMM } \\
\text { Radius }\end{array}$ & $\begin{array}{c}\text { Inner PJM } \\
\text { Radius } \\
\end{array}$ & \begin{tabular}{|c|} 
"FO" Outer PJM \\
Impingement \\
Angle
\end{tabular} & $\begin{array}{c}\text { "FO' Inner PJM } \\
\text { Impingement Angle }\end{array}$ & \begin{tabular}{|l} 
Ratio Outer PJM \\
to Tank Radius
\end{tabular} & $\begin{array}{l}\text { Ratio Inner PJM } \\
\text { to Tank Radius }\end{array}$ & Simulant & \begin{tabular}{|l|} 
Solids \\
Density \\
\end{tabular} & $\begin{array}{c}\text { Particle } \\
\text { Diameter d5 }\end{array}$ & \begin{tabular}{c|} 
Particle \\
Diameter d d50
\end{tabular} & $\begin{array}{c}\text { Particle } \\
\text { Diameter d95 }\end{array}$ & $\begin{array}{l}\text { Void } \\
\text { Fraction }\end{array}$ \\
\hline text & text & text & in. & text & in. & in ${ }^{3}$ & in. 1 & in. & in. & in. & text & number & number & number & in. & in. & in. & deg & deg & nondim & nondim & text & \begin{tabular}{|l|l|}
$\mathrm{g} / \mathrm{cm}^{3}$ \\
\end{tabular} & $\mathrm{~m}$ & \begin{tabular}{l|}
$\mathrm{m}$ \\
\end{tabular} & $m$ & fraction \\
\hline MSS & MDDX & $\mathrm{ID}$ & $\mathrm{D}$ & HS & Hish & $V_{\text {dish }}$ & $\mathrm{H}$ & $\operatorname{Rin}$ & $d$ & sod & PT & $\mathrm{N}$ & $\mathrm{Nb}$ & $\mathrm{N}$ & $\mathrm{PT}_{\alpha d}$ & $R_{0}$ & $R$ & $\theta_{0}$ & $\theta_{1}$ & $R d R$ & $R / R$ & $\operatorname{sxdx}$ & $\rho_{\mathrm{s}}$ & $d_{b}$ & $d_{60}$ & $d_{65}$ & vf \\
\hline 9150357 & 6/20A & 15E_4s2d2Yc_1 & $147 / 16$ & $E$ & 3.25 & 354.8 & 35 & 30 & 0.126 & 0.189 & HLP-22 & 12 & 8 & 4 & 1.05 & 4.5 & 2.4 & 21.8 & 10.1 & 0.62 & 0.34 & $\mathrm{~s} 2 \mathrm{~d} 2$ & 4.18 & 0.0000609 & 0.0000756 & 0.0000931 & 0.3684 \\
\hline 9150358 & $6120 \mathrm{~A}$ & 15E_4s2d2YC_1 & $147 / 16$ & $E$ & 3.25 & 354.8 & 35 & 30 & 0.126 & 0.189 & HLP-22 & 12 & 8 & 4 & 1.05 & 4.5 & 2.4 & 21.8 & 10.1 & 0.62 & 0.34 & $\mathrm{~s} 2 \mathrm{~d} 2$ & 4.18 & 0.0000609 & 0.0000756 & 0.0000931 & 0.3684 \\
\hline 9150359 & 6/20A & 15E_4s2d2YC_1 & $147 / 16$ & $E$ & 3.25 & 354.8 & 35 & 30 & 0.126 & 0.189 & HLP-22 & 12 & 8 & 4 & 1.05 & 4.5 & 2.4 & 21.8 & 10.1 & 0.62 & 0.34 & $\mathrm{~s} 2 \mathrm{~d} 2$ & 4.18 & 0.0000609 & 0.0000756 & 0.0000931 & 0.3684 \\
\hline 9150360 & 6/20A & 15E_4s2d2Yc_1 & $147 / 16$ & E & 3.25 & 354.8 & 35 & 30 & 0.126 & 0.189 & HLP-22 & 12 & 8 & 4 & 1.05 & 4.5 & 2.4 & 21.8 & 10.1 & 0.62 & 0.34 & $\mathrm{~s} 2 \mathrm{~d} 2$ & 4.18 & 0.0000609 & 0.0000756 & 0.0000931 & 0.3684 \\
\hline 9150361 & 6/20A & 15E_4s2d2Yc_1 & $147 / 16$ & $E$ & 3.25 & 354.8 & 35 & 30 & 0.126 & 0.189 & HLP-22 & 12 & 8 & 4 & 1.05 & 4.5 & 2.4 & 21.8 & 10.1 & 0.62 & 0.34 & $\mathrm{~s} 2 \mathrm{~d} 2$ & 4.18 & 0.0000609 & 0.0000756 & 0.0000931 & 0.3684 \\
\hline 9150362 & 6/20A & 15E_4s2d2Yc_1 & $147 / 16$ & $E$ & 3.25 & 354.8 & 35 & 30 & 0.126 & 0.189 & HLP-22 & 12 & 8 & 4 & 1.05 & 4.5 & 2.4 & 21.8 & 10.1 & 0.62 & 0.34 & $\mathrm{~s} 2 \mathrm{~d} 2$ & 4.18 & 0.0000609 & 0.0000756 & o.0000931 & 0.3684 \\
\hline 9150363 & 6/20B & 15E_4s2d2Xc_1 & $147 / 16$ & $E$ & 3.25 & 354.8 & 35 & 30 & 0.126 & 0.189 & HLP-22 & 12 & 8 & 4 & 1.05 & 4.5 & 2.4 & 21.8 & 10.1 & 0.62 & 0.34 & $\mathrm{~s} 2 \mathrm{~d} 2$ & 4.18 & 0.0000609 & 0.0000756 & 0.0000931 & 0.3684 \\
\hline 9150364 & 6/20B & $15 \mathrm{E} \_4 \mathrm{~s} 2 \mathrm{~d} 2 \mathrm{C} \mathrm{C} \_1$ & $147 / 16$ & $E$ & 3.25 & 354.8 & 35 & 30 & 0.126 & 0.189 & HLP-22 & 12 & 8 & 4 & 1.05 & 4.5 & 2.4 & 21.8 & 10.1 & 0.62 & 0.34 & $\mathrm{~s} 2 \mathrm{~d} 2$ & 4.18 & 0.0000609 & 0.0000756 & 0.0000931 & 0.3684 \\
\hline 9150365 & 6/20B & 15E_4s2d2X__1 & $147 / 16$ & $E$ & 3.25 & 354.8 & 35 & 30 & 0.126 & 0.189 & HLP-22 & 12 & 8 & 4 & 1.05 & 4.5 & 2.4 & 21.8 & 10.1 & 0.62 & 0.34 & $\mathrm{~s} 2 \mathrm{~d} 2$ & 4.18 & 0.0000609 & 0.0000756 & 0.0000931 & 0.3684 \\
\hline 9150366 & 6/20B & $15 \mathrm{1} \_4 \mathrm{~s} 2 \mathrm{~d} 2 \mathrm{C} \mathrm{C} \_1$ & $147 / 16$ & $E$ & 3.25 & 354.8 & 35 & 30 & 0.126 & 0.189 & HLP-22 & 12 & 8 & 4 & 1.05 & 4.5 & 2.4 & 21.8 & 10.1 & 0.62 & 0.34 & $\mathrm{~s} 2 \mathrm{~d} 2$ & 4.18 & 0.0000609 & 0.0000756 & 0.0000931 & 0.3684 \\
\hline 9150367 & 6/20B & 15E $4 \mathrm{~s} 2 \mathrm{~d} 2 \mathrm{2} \times \mathrm{c}$. 1 & $147 / 16$ & E & 3.25 & 354.8 & 35 & 30 & 0.126 & 0.189 & HLP-22 & 12 & 8 & 4 & 1.05 & 4.5 & 2.4 & 21.8 & 10.1 & 0.62 & 0.34 & $\mathrm{~s} 2 \mathrm{~d} 2$ & 4.18 & 0.0000609 & 0.0000756 & 0.0000931 & 0.3684 \\
\hline 9150368 & 6/20B & $15 \mathrm{E} 4 \mathrm{~s} 2 \mathrm{~d} 2 \mathrm{x} \mathrm{c} 1$ & $147 / 16$ & $\mathrm{E}$ & 3.25 & 354.8 & 35 & 30 & 0.126 & 0.189 & HLP-22 & 12 & 8 & 4 & 1.05 & 4.5 & 2.4 & 21.8 & 10.1 & 0.62 & 0.34 & $\mathrm{~s} 2 \mathrm{~d} 2$ & 4.18 & 0.0000609 & 0.0000756 & 0.0000931 & 0.3684 \\
\hline 9150369 & $6 / 20 B$ & 15E_4s $2 \mathrm{~d} 2 \mathrm{X}_{\mathrm{C}} 1$ & $147 / 16$ & $E$ & 3.25 & 354.8 & 35 & 30 & 0.126 & 0.189 & HLP-22 & 12 & 8 & 4 & 1.05 & 4.5 & 2.4 & 21.8 & 10.1 & 0.62 & 0.34 & $\mathrm{~s} 2 \mathrm{~d} 2$ & 4.18 & 0.0000609 & 0.0000756 & 0.0000931 & 0.3684 \\
\hline 9150370 & 6/20B & $15 \mathrm{15} \_4 \mathrm{~s} 2 \mathrm{~d} 2 \mathrm{X} \mathrm{C} \_1$ & $147 / 16$ & $E$ & 3.25 & 354.8 & 35 & 30 & 0.126 & 0.189 & HLP-22 & 12 & 8 & 4 & 1.05 & 4.5 & 2.4 & 21.8 & 10.1 & 0.62 & 0.34 & $\mathrm{~s} 2 \mathrm{~d} 2$ & 4.18 & 0.0000600 & 0.0000756 & 0.0000931 & 0.3684 \\
\hline 9150371 & 6/20B & $15 E_{4} 4 \mathrm{~s} 2 \mathrm{~d} 2 \mathrm{Xc} 1$ & $147 / 16$ & $E$ & 3.25 & 354.8 & 35 & 30 & 0.126 & 0.189 & HLP-22 & 12 & 8 & 4 & 1.05 & 4.5 & 2.4 & 21.8 & 10.1 & 0.62 & 0.34 & $\mathrm{~s} 2 \mathrm{~d} 2$ & 4.18 & 0.0000609 & 0.0000756 & 0.0000931 & 0.3684 \\
\hline 9150372 & 6/20B & 15E_4s2d2Xc_1 & $147 / 16$ & $E$ & 3.25 & 354.8 & 35 & 30 & 0.126 & 0.189 & HLP-22 & 12 & 8 & 4 & 1.05 & 4.5 & 2.4 & 21.8 & 10.1 & 0.62 & 0.34 & $\mathrm{~s} 2 \mathrm{~d} 2$ & 4.18 & 0.0000609 & 0.0000756 & 0.0000931 & 0.3684 \\
\hline 9150373 & $6 / 20 B$ & $15 E_{2} 4 \mathrm{~s} 2 \mathrm{~d} 2 \mathrm{Xc} 1$ & $147 / 16$ & $E$ & 3.25 & 354.8 & 35 & 30 & 0.126 & 0.189 & HLP-22 & 12 & 8 & 4 & 1.05 & 4.5 & 2.4 & 21.8 & 10.1 & 0.62 & 0.34 & $\mathrm{~s} 2 \mathrm{~d} 2$ & 4.18 & 0.0000609 & 0.0000756 & 0.0000931 & 0.3684 \\
\hline 9150374 & 6/208 & 15E_4s2d2Xc_1 & $147 / 16$ & $\mathrm{E}$ & 3.25 & 354.8 & 35 & 30 & 0.126 & 0.189 & HLP-22 & 12 & 8 & 4 & 1.05 & 4.5 & 2.4 & 21.8 & 10.1 & 0.62 & 0.34 & $\mathrm{~s} 2 \mathrm{~d} 2$ & 4.18 & 0.0000609 & 0.0000756 & 0.0000931 & 0.3684 \\
\hline 9150375 & 6/20B & $15 \mathrm{E} 4 \mathrm{~s} 2 \mathrm{~d} 2 \mathrm{~d} \mathrm{C}-1$ & $147 / 16$ & $\mathrm{E}$ & 3.25 & 354.8 & 35 & 30 & 0.126 & 0.189 & HLP-22 & 12 & 8 & 4 & 1.05 & 4.5 & 2.4 & 21.8 & 10.1 & 0.62 & 0.34 & $\mathrm{~s} 2 \mathrm{~d} 2$ & 4.18 & 0.0000609 & 0.0000756 & 0.0000931 & 0.3684 \\
\hline 9150376 & 6/20B & 15E_4s2d2Xc_1 & $147 / 16$ & $E$ & 3.25 & 354.8 & 35 & 30 & 0.126 & 0.189 & HLP-22 & 12 & 8 & 4 & 1.05 & 4.5 & 2.4 & 21.8 & 10.1 & 0.62 & 0.34 & $\mathrm{~s} 2 \mathrm{~d} 2_{2}$ & 4.18 & 0.0000609 & 0.0000756 & 0.0000931 & 0.3684 \\
\hline 9150377M & 6/20B & $15 \mathrm{E}-4 \mathrm{~s} 2 \mathrm{~d} 2 \mathrm{C} \mathrm{c} 1$ & $147 / 16$ & $E$ & 3.25 & 354.8 & 35 & 30 & 0.126 & 0.189 & HLP-22 & 12 & 8 & 4 & 1.05 & 4.5 & 2.4 & 21.8 & 10.1 & 0.62 & 0.34 & $\mathrm{~s} 2 \mathrm{~d} 2$ & 4.18 & 0.0000609 & 0.0000756 & 0.0000931 & 0.3684 \\
\hline 9150378M & 6/20B & 15E_4s2d2X__1 & $147 / 16$ & $E$ & 3.25 & 354.8 & 35 & 30 & 0.126 & 0.189 & HLP-22 & 12 & 8 & 4 & 1.05 & 4.5 & 2.4 & 21.8 & 10.1 & 0.62 & 0.34 & $\mathrm{~s} 2 \mathrm{~d} 2$ & 4.18 & 0.0000609 & 0.0000756 & 0.0000931 & 0.3684 \\
\hline 9150378.1 & 6/20B & 15E_4s2d2Xc_1 & $147 / 16$ & $\mathrm{E}$ & 3.25 & 354.8 & 35 & 30 & 0.126 & 0.189 & HLP-22 & 12 & 8 & 4 & 1.05 & 4.5 & 2.4 & 21.8 & 10.1 & 0.62 & 0.34 & $\mathrm{~s} 2 \mathrm{~d} 2_{2}$ & 4.18 & 0.0000609 & 0.0000756 & 0.0000931 & 0.3684 \\
\hline 9150378.2 & 6/20B & 15E_4s2d2X__1 & $147 / 16$ & $E$ & 3.25 & 354.8 & 35 & 30 & 0.126 & 0.189 & HLP-22 & 12 & 8 & 4 & 1.05 & 4.5 & 2.4 & 21.8 & 10.1 & 0.62 & 0.34 & $\mathrm{~s} 2 \mathrm{~d} 2$ & 4.18 & 0.0000609 & 0.0000756 & o.0000931 & 0.3684 \\
\hline 9150378.3 & 6/20B & $15 \mathrm{E} \_4 \mathrm{~s} 2 \mathrm{~d} 2 \mathrm{C} \mathrm{C} \_1$ & $147 / 16$ & $E$ & 3.25 & 354.8 & 35 & 30 & 0.126 & 0.189 & HLP-22 & 12 & 8 & 4 & 1.05 & 4.5 & 2.4 & 21.8 & 10.1 & 0.62 & 0.34 & $\mathrm{~s} 2 \mathrm{~d} 2$ & 4.18 & 0.0000609 & 0.0000756 & 0.0000931 & 0.3684 \\
\hline 9150378.4 & 6/20B & 15E_4s2d2X__1 & $147 / 16$ & $E$ & 3.25 & 354.8 & 35 & 30 & 0.126 & 0.189 & HLP-22 & 12 & 8 & 4 & 1.05 & 4.5 & 2.4 & 21.8 & 10.1 & 0.62 & 0.34 & $\mathrm{~s} 2 \mathrm{~d} 2$ & 4.18 & 0.0000609 & 0.0000756 & 0.0000931 & 0.3684 \\
\hline 9150378.5 & 6/20B & 15E_4s2d2Xc_1 & $147 / 16$ & $E$ & 3.25 & 354.8 & 35 & 30 & 0.126 & 0.189 & HLP-22 & 12 & 8 & 4 & 1.05 & 4.5 & 2.4 & 21.8 & 10.1 & 0.62 & 0.34 & $\mathrm{~s} 2 \mathrm{~d} 2$ & 4.18 & 0.00000009 & 0.0000756 & 0.0000931 & 0.3684 \\
\hline 9150379M & 6/20B & 15E_4s $2 \mathrm{~d} 2 \mathrm{XC}_{\mathrm{C}} 1$ & $147 / 16$ & $E$ & 3.25 & 354.8 & 35 & 30 & 0.126 & 0.189 & HLP-22 & 12 & 8 & 4 & 1.05 & 4.5 & 2.4 & 21.8 & 10.1 & 0.62 & 0.34 & $\mathrm{~s} 2 \mathrm{~d} 2$ & 4.18 & 0.0000609 & 0.0000756 & 0.0000931 & 0.3684 \\
\hline 9150380 & 6/20B & 15E_4S2d2Xc_1 & $147 / 16$ & E & 3.25 & 354.8 & 35 & 30 & 0.126 & 0.189 & HLP-22 & 12 & 8 & 4 & 1.05 & 4.5 & 2.4 & 21.8 & 10.1 & 0.62 & 0.34 & $\mathrm{~s} 2 \mathrm{~d} 2$ & 4.18 & 0.0000609 & 0.0000756 & 0.0000931 & 0.3684 \\
\hline 9150381 & 6/20B & $15 E_{2} 4 \mathrm{~s} 2 \mathrm{~d} 2 \mathrm{Xc} 1$ & $147 / 16$ & $E$ & 3.25 & 354.8 & 35 & 30 & 0.126 & 0.189 & HLP-22 & 12 & 8 & 4 & 1.05 & 4.5 & 2.4 & 21.8 & 10.1 & 0.62 & 0.34 & $\mathrm{~s} 2 \mathrm{~d} 2$ & 4.18 & 0.0000609 & 0.0000756 & 0.0000931 & 0.3684 \\
\hline 9150382 & 6/20B & $15 E_{4} 4 \mathrm{~s} 2 \mathrm{~d} 2 \mathrm{C} \mathrm{c} 1$ & $147 / 16$ & $\mathrm{E}$ & 3.25 & 354.8 & 35 & 30 & 0.126 & 0.189 & HLP-22 & 12 & 8 & 4 & 1.05 & 4.5 & 2.4 & 21.8 & 10.1 & 0.62 & 0.34 & $\mathrm{~s} 2 \mathrm{~d} 2$ & 4.18 & $\begin{array}{l}0.0000609 \\
\end{array}$ & 0.0000756 & 0.0000931 & 0.3684 \\
\hline 9150383 & $6 / 20 B$ & 15E_4s2d2Xc_1 & $147 / 16$ & $E$ & 3.25 & 354.8 & 35 & 30 & 0.126 & 0.189 & HLP-22 & 12 & 8 & 4 & 1.05 & 4.5 & 2.4 & 21.8 & 10.1 & 0.62 & 0.34 & $\mathrm{~s} 2 \mathrm{~d} 2$ & 4.18 & 0.0000609 & 0.0000756 & 0.0000931 & 0.3684 \\
\hline 9150384 & $6 / 20 \mathrm{~B}$ & 15E_4s2d2Xc_1 & $147 / 16$ & $\mathrm{E}$ & 3.25 & 354.8 & 35 & 30 & 0.126 & 0.189 & HLP-22 & 12 & 8 & 4 & 1.05 & 4.5 & 2.4 & 21.8 & 10.1 & 0.62 & 0.34 & $\mathrm{~s} 2 \mathrm{~d} 2$ & 4.18 & 0.0000609 & 0.0000756 & 0.0000931 & 0.3684 \\
\hline 9150385 & $6 / 20 B$ & $15 E_{2} 4 \mathrm{~s} 2 \mathrm{~d} 2 \mathrm{Xc} 1$ & $147 / 16$ & $E$ & 3.25 & 354.8 & 35 & 30 & 0.126 & 0.189 & HLP-22 & 12 & 8 & 4 & 1.05 & 4.5 & 2.4 & 21.8 & 10.1 & 0.62 & 0.34 & & 4.18 & 0.0000609 & 0.0000756 & 0.0000931 & 0.3684 \\
\hline 9150386 & 6/20B & 15E_4s2d2X__ 1 & $147 / 16$ & $E$ & 3.25 & 354.8 & 35 & 30 & 0.126 & 0.189 & HLP-22 & 12 & 8 & 4 & 1.05 & 4.5 & 2.4 & 21.8 & 10.1 & 0.62 & 0.34 & $\mathrm{~s} 2 \mathrm{~d} 2$ & 4.18 & 0.0000609 & 0.0000756 & 0.0000931 & 0.3684 \\
\hline 9150387 & 6/20B & $15 E_{4} 4 \mathrm{~s} 2 \mathrm{~d} 2 \mathrm{Xc} 1$ & $147 / 16$ & $E$ & 3.25 & 354.8 & 35 & 30 & 0.126 & 0.189 & HLP-22 & 12 & 8 & 4 & 1.05 & 4.5 & 2.4 & 21.8 & 10.1 & 0.62 & 0.34 & $\mathrm{~s} 2 \mathrm{~d} 2$ & 4.18 & 0.0000609 & 0.0000756 & 0.0000931 & 0.3684 \\
\hline 9150388 & 6/23A & 15E_4s2d2Xd_1 & $147 / 16$ & $E$ & 3.25 & 354.8 & $331 / 2$ & 30 & 0.126 & 0.189 & HLP-22 & 12 & 8 & 4 & 1.05 & 4.5 & 2.4 & 21.8 & 10.1 & 0.62 & 0.34 & $\mathrm{~s} 2 \mathrm{~d} 2$ & 4.18 & 0.0000609 & 0.0000756 & 0.0000931 & 0.3684 \\
\hline $9150389 \mathrm{M}$ & 6/23A & 15E_4s2d2Xd_1 & $147 / 16$ & $E$ & 3.25 & 354.8 & $331 / 2$ & 30 & 0.126 & 0.189 & HLP-22 & 12 & 8 & 4 & 1.05 & 4.5 & 2.4 & 21.8 & 10.1 & 0.62 & 0.34 & $\mathrm{~s} 2 \mathrm{~d} 2$ & 4.18 & 0.0000609 & 0.0000756 & 0.0000931 & 0.3684 \\
\hline 9150390 & 6/23A & 15E_4s2d2Xd_1 & $147 / 16$ & $E$ & 3.25 & 354.8 & $331 / 2$ & 30 & 0.126 & 0.189 & HLP-22 & 12 & - & 4 & & 4.5 & 2.4 & 21.8 & & 0.62 & & $\mathrm{~s} 2 \mathrm{~d} 2$ & $2 \mathrm{t}$ & & & 0.0000931 & \\
\hline 9150391M & 6/23A & 15E_4s2d2Xd_1 & $147 / 16$ & $\mathrm{E}$ & 3.25 & 354.8 & $331 / 2$ & 30 & 0.126 & 0.189 & HLP-22 & 12 & 8 & 4 & 1.05 & 4.5 & 2.4 & 21.8 & 10.1 & 0.62 & 0.34 & $\mathrm{~s} 2 \mathrm{~d} 2$ & 4.18 & 0.0000609 & 0.0000756 & 0.0000931 & 0.3684 \\
\hline 9150392M & 6/23A & 15E_4s2d2Xd_1 & $147 / 16$ & $E$ & 3.25 & 354.8 & $331 / 2$ & 30 & 0.126 & 0.189 & HLP-22 & 12 & 8 & 4 & 1.05 & 4.5 & 2.4 & 21.8 & 10.1 & 0.62 & 0.34 & $\mathrm{~s} 2 \mathrm{~d} 2$ & 4.18 & 0.0000609 & \begin{tabular}{|c|}
0.0000756 \\
\end{tabular} & 0.0000931 & 0.3684 \\
\hline
\end{tabular}


Table B.3. Data from 2008 Tests in Small-Scale Vessel with Elliptical Head B.11

\begin{tabular}{|c|c|c|c|c|c|c|c|c|c|c|c|c|c|c|c|c|c|c|c|c|c|c|c|c|c|c|c|c|c|}
\hline $\begin{array}{l}\text { Tank Water } \\
\text { Temperature }\end{array}$ & \begin{tabular}{|l} 
Water \\
Density
\end{tabular} & $\begin{array}{l}\text { Solids } \\
\text { Fraction }\end{array}$ & $\begin{array}{l}\text { Pulse } \\
\text { Volume } \\
\text { Fraction } \\
\end{array}$ & $\begin{array}{l}\text { Duty } \\
\text { ayde }\end{array}$ & \begin{tabular}{|l|} 
Cydle \\
Time \\
\end{tabular} & \begin{tabular}{|l} 
Pulsed or \\
Steacy Jet
\end{tabular} & \begin{tabular}{|c} 
Us \\
Steady \\
Jet
\end{tabular} & \begin{tabular}{|l|} 
UI \\
Pulsing \\
Jet \\
\end{tabular} & $\begin{array}{l}\text { U2 } \\
\text { URMS }\end{array}$ & $\begin{array}{c}\text { UR } \\
\text { URNB } \\
\end{array}$ & \begin{tabular}{|l} 
Discharge \\
Velocity
\end{tabular} & $\begin{array}{c}\text { Coritical } \\
\text { suspension } \\
\text { velocity }\end{array}$ & \begin{tabular}{|c|} 
Average Peak \\
Cloud Height \\
\end{tabular} & $\begin{array}{l}\text { UcS } \\
\text { Condition }\end{array}$ & $\begin{array}{l}\text { UCS } \\
\text { Nethod }\end{array}$ & uCs Fag & $\begin{array}{l}\text { Ucs Center } \\
\text { Fag }\end{array}$ & $\begin{array}{c}\text { ucsuad } \\
\text { Hag } \\
\end{array}$ & \begin{tabular}{|c} 
UCS based on \\
Decreasing \\
Velocity
\end{tabular} & \begin{tabular}{|c|} 
sheep \\
Increase/ \\
Decrease
\end{tabular} & \begin{tabular}{|c|} 
UDV \\
Height \\
Bed
\end{tabular} & \begin{tabular}{|l} 
Patricle \\
Motion \\
\end{tabular} & $\begin{array}{l}\text { Solids } \\
\text { Level }\end{array}$ & \begin{tabular}{|c|} 
Outer \\
Botom \\
Patter
\end{tabular} & \begin{tabular}{|l|} 
Inner \\
Botom \\
Pattem \\
\end{tabular} & Case ID & Test & TDP & $\begin{array}{l}\text { Row } \\
\text { Number }\end{array}$ \\
\hline $\mathrm{c}$ & $\mathrm{g} / \mathrm{cm}^{3}$ & fraction & fraction & fraction & $\mathrm{s}$ & text & $\mathrm{m} / \mathrm{s}$ & \begin{tabular}{|l|l}
$\mathrm{m} / \mathrm{s}$ \\
\end{tabular} & $\mathrm{m} / \mathrm{s}$ & $\mathrm{m} / \mathrm{s}$ & $\mathrm{m} / \mathrm{s}$ & $\mathrm{m} / \mathrm{s}$ & \begin{tabular}{|l|} 
in. \\
\end{tabular} & $\mathrm{m} / \mathrm{s}$ & text & text & text & text & $\mathrm{m} / \mathrm{s}$ & \begin{tabular}{|l|l} 
text \\
\end{tabular} & $\mathrm{mm}$ & \begin{tabular}{|l|l|} 
text \\
\end{tabular} & text & \begin{tabular}{|l|} 
text \\
\end{tabular} & text & text & text & text & text \\
\hline $\mathrm{T}$ & $\rho$ & $\phi_{\mathrm{s}}$ & $\phi_{\mathrm{p}}$ & $D C$ & $t_{c}$ & Jet & $u_{s}$ & $\mathrm{U}_{1}$ & $\mathrm{U}_{2}$ & $\mathrm{UB}_{3}$ & $u$ & $u_{\text {ss }}$ & $H_{\mathrm{C}}$ & U USR & Ussu & Ussis & Uscen & Ussudv & $u_{s} \mathrm{D}$ & $\mathrm{S}_{\mathrm{N}}$ & $\mathrm{H}_{\text {od }}$ & $P M$ & sol & $\mathrm{SP}_{\mathrm{o}}$ & $\mathrm{SP}_{1}$ & $\mathrm{ID}$ & MDDX & IDP & MSS \\
\hline 26.0 & 0.999 & 0.00500 & 0.050 & 0.334 & \begin{tabular}{|l|}
8.4 \\
\end{tabular} & $\mathrm{P}$ & NA & 7.16 & 7.31 & 7.39 & 7.60 & 7.60 & 6.001 & NA & NA & NA & NA & NA & NA & NA & 1.9 & $\mathrm{NA}$ & NA & NA & NA & 15E_4S202YC_1 & 6/20A & \begin{tabular}{|l|} 
TDP-187 \\
\end{tabular} & 9150357 \\
\hline 26.0 & 0.999 & 0.00500 & 0.050 & 0.334 & 8.4 & $\mathrm{P}$ & NA & 7.16 & 7.31 & 7.39 & 7.60 & 7.60 & $6.00 / 1$ & & NA & NA & NA & NA & NA & NA & 2.6 & NA & NA & NA & NA & 15E_4S20202C_ 1 & 6/20A & TDP-187 & 9150358 \\
\hline 26.0 & 0.999 & 0.00500 & 0.050 & 0.334 & 8.4 & $\mathrm{P}$ & NA & 7.16 & 7.31 & 7.39 & 7.60 & 7.60 & $6.00 / r$ & NA & NA & NA & NA & NA & NA & NA & 3.2 & NA & NA & NA & NA & 15E_4s2d2Yc_1 & 6/20A & TDP-187 & 9150359 \\
\hline 26.0 & 0.999 & 0.00500 & 0.050 & 0.334 & 8.4 & $\mathrm{P}$ & NA & 7.16 & 7.31 & 7.39 & 7.60 & 7.60 & $6.00 / \mathrm{r}$ & NA & NA & NA & NA & $\mathrm{NA}$ & NA & $\mathrm{NA}$ & 2.6 & $\mathrm{NA}$ & NA & NA & NA & 15E_4S2d2YC_1 & 6/20A & TDP-187 & 9150360 \\
\hline 26.0 & 0.999 & 0.00500 & 0.050 & 0.334 & 8.4 & $P$ & NA & 7.16 & 7.31 & 7.39 & 7.60 & 7.60 & $6.00 / r$ & NA & NA & NA & NA & NA & NA & NA & 3.2 & NA & NA & NA & NA & 15E_4s2d2Yc_1 & 6/20A & IDP-187 & 9150361 \\
\hline 26.0 & 0.999 & 0.00500 & 0.050 & 0.334 & 8.4 & $\mathrm{P}$ & NA & 7.16 & 7.31 & 7.39 & 7.60 & 7.60 & $6.00 / 1$ & NA & NA & NA & NA & NA & $\mathrm{N}$ & NA & 1.9 & $\mathrm{NA}$ & $\mathrm{NA}$ & NA & NA & 15E_4s2d2Yc_1 & 6/20A & TDP-187 & 9150362 \\
\hline 26.6 & 0.999 & 0.01500 & 0.050 & 0.333 & 8.0 & $\mathrm{P}$ & NA & 7.50 & 7.67 & 7.75 & 8.00 & 11.80 & $3.75 \mid$ & NA & NA & NA & NA & NA & NA & (null) & 11.1 & 1 & NA & NA & NA & 15E_4s2d2Xc_1 & 6/20B & TDP-188 & 9150363 \\
\hline 27.2 & 0.999 & 0.01500 & 0.050 & 0.334 & 7.6 & $\mathrm{P}$ & NA & 7.88 & 8.06 & 8.14 & 8.40 & 11.80 & $4.001 \mathrm{r}$ & NA & NA & NA & NA & NA & NA & 1 & 10.2 & 1 & NA & NA & NA & $15 E_{-} 4 \mathrm{~s} 2 \mathrm{~d} 2 \mathrm{C}_{\mathrm{C}_{1}} 1$ & 6/20B & TDP-188 & 9150364 \\
\hline 27.4 & 0.998 & 0.01500 & 0.050 & 0.335 & 7.4 & $\mathrm{P}$ & NA & 8.08 & 8.27 & 8.36 & 8.60 & 11.80 & $4.25 \mathrm{r}$ & NA & NA & NA & NA & NA & NA & 1 & 9.0 & 1 & $\mathrm{NA}$ & NA & NA & 15E_4s2d2Xc_1 & $6 / 20 \mathrm{~B}$ & TDP-188 & 9150365 \\
\hline 27.8 & 0.999 & 0.01500 & 0.050 & 0.335 & 7.1 & $\mathrm{P}$ & NA & 8.39 & 8.60 & 8.71 & 9.00 & 11.80 & 4.25 & NA & NA & NA & NA & NA & NA & 1 & 6.6 & 1 & NA & NA & NA & 15E_4s2d2Xc_1 & 6/20B & TDP-188 & 9150366 \\
\hline 28.0 & 0.999 & 0.01500 & 0.050 & 0.336 & 6.8 & $\mathrm{P}$ & NA & 8.78 & 9.01 & 9.12 & 9.40 & 11.80 & 4.75 & NA & NA & NA & NA & NA & NA & 1 & 6.1 & 1 & NA & NA & NA & 15E_4s2d2X__1 & $6 / 20 \mathrm{~B}$ & TDP-188 & 9150367 \\
\hline 27.8 & 0.998 & 0.01500 & 0.050 & 0.334 & 6.4 & $\mathrm{P}$ & NA & 9.32 & 9.57 & 9.69 & 10.00 & 11.80 & $5.00 /$ & NA & NA & NA & NA & NA & $\mathrm{NA}$ & (null) & 3.4 & 1 & $\mathrm{NA}$ & $\mathrm{NA}$ & NA & $15 \mathrm{E} \_4 \mathrm{~s} 2 \mathrm{~d} 2 \times \mathrm{C} \_1$ & 6/20B & TDP-188 & 9150368 \\
\hline 28.1 & 0.998 & 0.01500 & 0.050 & 0.336 & 6.3 & $\mathrm{P}$ & NA & 9.47 & 9.74 & 9.88 & 10.20 & 11.80 & 5.00 & NA & NA & NA & NA & NA & NA & 1 & 3.6 & 1 & NA & NA & NA & 15E_4s2d2Xc_1 & $6 / 20 \mathrm{~B}$ & IDPP-188 & 9150369 \\
\hline 29.2 & 0.998 & 0.01500 & 0.050 & 0.334 & 6.2 & $\mathrm{P}$ & NA & 9.61 & 9.88 & 10.02 & 10.40 & 11.80 & $5.00 /$ & & NA & ucsis & NA & NA & $\mathrm{N} / \mathrm{H}$ & 1 & 3.2 & 3 & NA & NA & NA & $15 E_{-4} 4 \mathrm{~s} 2 \mathrm{~d} 2 \mathrm{X} \mathrm{c}_{-} 1$ & 6/20B & IDP-188 & 9150370 \\
\hline 29.5 & 0.998 & 0.01500 & 0.050 & 0.334 & 6.1 & $\mathrm{P}$ & NA & 9.77 & 10.06 & 10.21 & 10.60 & 11.80 & 5.251 & NA & NA & NA & NA & NA & NA & 1 & 3.2 & 4 & NA & NA & NA & 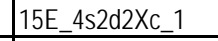 & 6/20B & IDPP-188 & 9150371 \\
\hline 29.7 & 0.998 & 0.01500 & 0.050 & 0.334 & 6.0 & $\mathrm{P}$ & NA & 9.97 & 10.26 & 10.40 & 10.80 & 11.80 & 5.25 & NA & NA & NA & NA & NA & NA & 1 & 3.2. & 4 & NA & NA & NA & $15 \mathrm{E} \_4 \mathrm{~s} 2 \mathrm{~d} 2 \mathrm{XC} \_1$ & $6 / 20 \mathrm{~B}$ & IDP-188 & 9150372 \\
\hline 29.9 & 0.998 & 0.01500 & 0.050 & 0.335 & 5.9 & $\mathrm{P}$ & NA & 10.16 & 10.45 & 10.60 & 11.00 & 11.80 & $5.50 \mathrm{r}$ & $\mathrm{NA}$ & NA & NA & NA & NA & NA & 1 & 2.1. & 4 & $\mathrm{NA}$ & NA & NA & 15E_4S202XC_1 & $6 / 20 \mathrm{~B}$ & IDP-188 & 9150373 \\
\hline 30.2 & 0.998 & 0.01500 & 0.050 & 0.335 & 5.8 & $\mathrm{P}$ & NA & 10.35 & 10.64 & 10.79 & 11.20 & 11.80 & 6.00 & NA & NA & NA & NA & NA & NA & 1 & 2.2. & 4 & NA & NA & NA & $15 \mathrm{E} \_4 \mathrm{~s} 2 \mathrm{~d} 2 \mathrm{XC} \_1$ & 6/208 & IDP-188 & 9150374 \\
\hline 30.6 & 0.998 & 0.01500 & 0.050 & 0.334 & 5.7 & $\mathrm{P}$ & NA & 10.48 & 10.80 & 10.97 & 11.40 & 11.80 & 5.75 & NA & NA & NA & NA & NA & $\mathrm{N}$ & 1 & 1.1. & 4 & NA & NA & NA & $15 E_{-4} 42 \mathrm{~d} 2 \times \mathrm{C}_{1} 1$ & 6/20B & IDP-188 & 9150375 \\
\hline 31.2 & 0.998 & 0.01500 & 0.050 & 0.336 & 5.6 & $\mathrm{P}$ & NA & 10.65 & 10.99 & 11.16 & 11.60 & 11.80 & 5.75 & NA & NA & NA & NA & NA & NA & 1 & 14 & 4 & NA & NA & NA & $155 \_45222 x 2 x c 1$ & 6/20B & IDP-188 & 9150376 \\
\hline 32.1 & 0.998 & 0.01500 & 0.050 & 0.334 & 5.5 & $\mathrm{P}$ & NA & 10.89 & 11.25 & 11.43 & 11.80 & 11.80 & 6.00 & $11.800_{1}$ & uav & NA & NA & ucsudv & NA & 1 & 1.9 & 4 & $\mathrm{NA}$ & NA & NA & 15E_4s2d2X__ 1 & 6/20B & TDP-188 & 915037 \\
\hline 32.7 & 0.997 & 0.01500 & 0.050 & 0.334 & 5.4 & $\mathrm{P}$ & NA & 11.09 & 11.44 & 11.63 & 12.00 & 11.80 & $6.25 \mathrm{r}$ & \begin{tabular}{l|l} 
NA & r
\end{tabular} & NA & NA & NA & NA & NA & 1 & 0.0 & 4 & $\mathrm{NA}$ & NA & NA & $15 E_{4} 4 \mathrm{~s} 2 \mathrm{~d} 2 \times \mathrm{C}_{1} 1$ & 6/200 & TDP-188 & 9150378 \\
\hline 33.4 & 0.997 & 0.01500 & 0.050 & 0.334 & 5.5 & $\mathrm{P}$ & NA & 10.85 & 11.21 & 11.39 & 11.80 & .80 & $6.00 \mid r$ & NA & NA & NA & NA & NA & NA & NA & rra & NA & NA & NA & NA & 15E_4s2d2Xc_1 & 6/200B & TDP-188 & 9150378.1 \\
\hline 33.4 & 0.997 & 0.01500 & 0.050 & 0.334 & 5.5 & $\mathrm{P}$ & NA & 10.85 & 11.21 & 11.39 & 11.80 & & $6.00 \mid r$ & NA & NA & NA & NA & NA & NA & $\mathrm{NA}$ & na & NA & $\mathrm{NA}$ & NA & NA & 15E_4S2d2Xc_1 & $6 / 20 \mathrm{~B}$ & TDP-188 & 9150378.2 \\
\hline 33.4 & 0.997 & 0.01500 & 0.050 & 0.334 & 5.5 & $\mathrm{P}$ & NA & 10.85 & 11.21 & 11.39 & 11.80 & 11.80 & $6.00 / 1$ & NA & $\mathrm{NA}$ & NA & NA & NA & $\mathrm{N}$ & $\mathrm{NA}$ & ra & NA & $\mathrm{NA}$ & $\mathrm{NA}$ & NA & 15E_4S2d2Xc_1 & $6 / 20 \mathrm{~B}$ & TDP-188 & 9150378.3 \\
\hline 33.4 & 0.997 & 0.01500 & 0.050 & 0.334 & 5.5 & $\mathrm{P}$ & NA & 10.85 & 11.21 & 11.39 & 11.80 & 11.80 & $6.001 \mathrm{r}$ & NA & NA & NA & NA & NA & $\mathrm{N}$ & $\mathrm{NA}$ & $\mathrm{N} / \mathrm{a}$ & NA & NA & NA & NA & 15E_4S2d2Xc_1 & $6 / 20 \mathrm{~B}$ & TDP-188 & 9150378.4 \\
\hline 33.4 & 0.997 & 0.01500 & 0.050 & 0.334 & 5.5 & $\mathrm{P}$ & NA & 10.85 & 11.21 & 11.39 & 11.80 & 11.80 & $6.00 / \mathrm{r}$ & NA & NA & NA & NA & NA & $\mathrm{N}$ & $\mathrm{NA}$ & ra & NA & NA & NA & NA & 15E_4s2d2Xc_1 & $6 / 20 \mathrm{~B}$ & TDP-188 & 9150378.5 \\
\hline 33.4 & 0.997 & 0.01500 & 0.050 & 0.334 & 5.5 & $\mathrm{P}$ & NA & 10.85 & 11.21 & 11.39 & 11.80 & & $6.00 \mid r$ & NA & NA & NA & NA & NA & $\mathrm{N}$ & 1 & 3.4 & 4 & NA & NA & NA & $15 E_{4} \_52 \mathrm{~d} 2 \mathrm{X} \mathrm{C}_{\_} 1$ & $6 / 20 B$ & TDP-188 & 9150379 \\
\hline 33.4 & 0.997 & 0.01500 & 0.050 & 0.334 & 5.5 & $\mathrm{P}$ & NA & 10.85 & 11.21 & 11.39 & 11.80 & 11.80 & 6.001 & NA & NA & NA & NA & NA & $\mathrm{N} /$ & NA & 3.3 & NA & NA & NA & NA & 15E_4s2d2Xc_1 & $6 / 20 \mathrm{~B}$ & TDP-188 & 9150380 \\
\hline 33.4 & $\begin{array}{ll}0.997 \\
\end{array}$ & 0.01500 & 0.050 & 0.334 & 5.5 & $\mathrm{P}$ & NA & 10.85 & 11.21 & 11.39 & 11.80 & 11.80 & $6.001 \mathrm{r}$ & $\mathrm{NA}$ & NA & NA & NA & NA & $\mathrm{N}$ & NA & 4.0 & NA & $\mathrm{NA}$ & NA & NA & 15E_4S202XC_1 & $6 / 20 \mathrm{~B}$ & IDP-188 & 9150381 \\
\hline 33.4 & 0.997 & 0.01500 & 0.050 & 0.334 & 5.5 & $\mathrm{P}$ & NA & 10.85 & 11.21 & 11.39 & 11.80 & & $6.00 \mid r$ & NA & NA & NA & NA & NA & $\mathrm{N}$ & & 3.6 & NA & NA & NA & NA & 15E_4s2d2XC_1 & $6 / 20 \mathrm{~B}$ & IDP-188 & 9150382 \\
\hline 33.4 & 0.997 & 0.01500 & 0.050 & 0.334 & 5.5 & $\mathrm{P}$ & NA & 10.85 & 11.21 & 11.39 & 11.80 & 11.80 & $6.001 \mathrm{f}$ & $\mathrm{NA}$ & NA & NA & NA & NA & $\mathrm{N}$ & $\mathrm{NA}$ & 3.7 & NA & NA & NA & NA & 15E_4S202XC_1 & 6/200B & IDP-188 & 9150383 \\
\hline 33.4 & 0.997 & 0.01500 & 0.050 & 0.334 & 5.5 & $\mathrm{P}$ & NA & 10.85 & 11.21 & 11.39 & 11.80 & & $6.00 / \mathrm{r}$ & & NA & NA & NA & NA & $\mathrm{N} /$ & & 3.6 & $\mathrm{NA}$ & NA & NA & NA & $15 E \_4 s 2 d 2 \times c \_1$ & 6/20B & TDP-188 & 9150384 \\
\hline 33.4 & $\begin{array}{ll}0.997 \\
\end{array}$ & 0.01500 & 0.050 & 0.334 & 5.5 & $\mathrm{P}$ & $\mathrm{NA}$ & 10.85 & 11.21 & 11.39 & 11.80 & 11.80 & 6.001 & NA & NA & NA & NA & NA & NA & $\mathrm{NA}$ & 3.4 & NA & NA & $\mathrm{NA}$ & NA & $15 E_{4} 4 \mathrm{~s} 2 \mathrm{~d} 2 \times \mathrm{C}_{1} 1$ & 6/200B & IDP-188 & 9150385 \\
\hline 33.4 & 0.997 & 0.01500 & 0.050 & 0.334 & 5.5 & $\mathrm{P}$ & NA & 10.85 & 11.21 & 11.39 & 11.80 & 11.80 & $6.00 / 1$ & & NA & NA & NA & NA & & & 3.4 & NA & NA & NA & NA & $15 \mathrm{E} \_4 \mathrm{~s} 2 \mathrm{~d} 2 \mathrm{XC} \_1$ & 6/20B & IDP-188 & 9150386 \\
\hline 33.4 & 0.997 & 0.01500 & 0.050 & 0.334 & 5.5 & $\mathrm{P}$ & NA & 10.85 & 11.21 & 11.39 & 11.80 & 11.80 & $6.00 / \mathrm{r}$ & NA & NA & NA & NA & NA & $\mathrm{N} /$ & $\mathrm{NA}$ & 3.7. & NA & NA & NA & NA & 15E_4s2d2Xc_1 & 6/20B & TDP-188 & 9150387 \\
\hline 24.8 & 0.999 & 0.01500 & 0.050 & 0.186 & 11.2 & $\mathrm{P}$ & NA & 9.66 & 9.95 & 10.11 & 10.50 & 10.70 & 4.25 r & NA & NA & NA & NA & NA & NA & (null) & 4.5 & 1 & NA & NA & NA & 15E_4s2d2Xd_1 & 6/23A & IDP-189 & 9150388 \\
\hline 25.2 & 0.999 & 0.01500 & 0.050 & 0.188 & 10.6 & $\mathrm{P}$ & NA & 10.02 & 10.34 & 10.51 & 11.00 & 10.70 & 5.25 & NA & NA & NA & NA & NA & NA & 1 & 4.5 & 4 & NA & NA & NA & 15E_4s2d2Xd_1 & 6/23A & TDP-189 & 9150389 \\
\hline 25.8 & 0.999 & 0.01500 & 0.050 & 0.186 & 11.2 & $\mathrm{P}$ & NA & 9.68 & 9.97 & 10.13 & 10.50 & 10.70 & $4.25 \mathrm{r}$ & NA & NA & NA & NA & NA & NA & $\mathrm{D}$ & 4.7. & 1 & $\mathrm{NA}$ & NA & NA & 15E_4s2d2Xd_1 & 6/23A & TDP-189 & 9150390 \\
\hline & 0.999 & 0.01500 & 0.050 & 0.186 & 10.8 & $\mathrm{P}$ & NA & & 10.21 & 10.37 & 10.70 & & & & & ucsis & & & & & & & & & NA & 15E_4s2d2Xd_1 & 6123A & TDP-189 & 9150391 \\
\hline 26.3 & 0.999 & 0.01500 & 0.050 & \begin{tabular}{|l|}
0.187 \\
\end{tabular} & \begin{tabular}{|l|}
10.6 \\
\end{tabular} & $P$ & NA & 10.11 & $\begin{array}{l}10.43 \\
\end{array}$ & \begin{tabular}{|l|}
10.60 \\
\end{tabular} & \begin{tabular}{|l|}
10.90 \\
\end{tabular} & 10.70 & $4.75 \mid \mathrm{r}$ & NA & NA & NA & NA & NA & NA & & 4.2 & 4 & NA & NA & NA & 15E_4s2d2Xd_1 & 6/23A & TDP-189 & 9150392 \\
\hline
\end{tabular}


Table B.3. Data from 2008 Tests in Small-Scale Vessel with Elliptical Head A.12

\begin{tabular}{|c|c|c|c|c|c|c|c|c|c|c|c|c|c|c|c|c|c|c|c|c|c|c|c|c|c|c|c|}
\hline $\begin{array}{l}\text { Rov } \\
\text { Number }\end{array}$ & Test & Case ID & $\begin{array}{c}\text { Tank } \\
\text { Diameter }\end{array}$ & $\begin{array}{l}\text { Head } \\
\text { Shape }\end{array}$ & \begin{tabular}{|l} 
Dish \\
Height
\end{tabular} & $\begin{array}{l}\text { Dish } \\
\text { Volume }\end{array}$ & $\begin{array}{l}\text { Tank Fill } \\
\text { Height }\end{array}$ & $\begin{array}{c}\text { Retum } \\
\text { Line } \\
\text { Height }\end{array}$ & \begin{tabular}{c|} 
Nozzle \\
Inner \\
Dianter
\end{tabular} & $\begin{array}{l}\text { Nozzle } \\
\text { Stantoff } \\
\text { Distance }\end{array}$ & $\begin{array}{l}\text { Pulse Tube } \\
\text { Configuration }\end{array}$ & \begin{tabular}{|l} 
Installed \\
Nozzles
\end{tabular} & $\begin{array}{l}\text { Outer } \\
\text { Nozzles } \\
\text { Operated }\end{array}$ & $\begin{array}{l}\text { Inner } \\
\text { Nozzles } \\
\text { Operated }\end{array}$ & $\begin{array}{l}\text { Pulse Tube } \\
\text { Outer } \\
\text { Dianteter }\end{array}$ & $\begin{array}{c}\text { Outer } \\
\text { PMM } \\
\text { Radius }\end{array}$ & $\begin{array}{c}\text { Inner PJM } \\
\text { Radius } \\
\end{array}$ & \begin{tabular}{|c|} 
"FO" Outer PJM \\
Impingement \\
Angle
\end{tabular} & $\begin{array}{c}\text { "FO' Inner PJM } \\
\text { Impingement Angle }\end{array}$ & \begin{tabular}{|l} 
Ratio Outer PJM \\
to Tank Radius
\end{tabular} & $\begin{array}{l}\text { Ratio Inner PJM } \\
\text { to Tank Radius }\end{array}$ & Simulant & \begin{tabular}{|l|} 
Solids \\
Density \\
\end{tabular} & $\begin{array}{c}\text { Particle } \\
\text { Diameter d5 }\end{array}$ & \begin{tabular}{c|} 
Particle \\
Diameter d d50
\end{tabular} & $\begin{array}{c}\text { Particle } \\
\text { Diameter d95 }\end{array}$ & $\begin{array}{l}\text { Void } \\
\text { Fraction }\end{array}$ \\
\hline text & text & text & in. & text & in. & in ${ }^{3}$ & in. & in. & in. & in. & text & number & number & number & in. & in. & in. & deg & deg & nondim & nondim & text & \begin{tabular}{|l|l|}
$\mathrm{g} / \mathrm{cm}^{3}$ \\
\end{tabular} & $\mathrm{~m}$ & \begin{tabular}{l|}
$\mathrm{m}$ \\
\end{tabular} & $m$ & fraction \\
\hline MSS & MDDX & $\mathrm{ID}$ & $\mathrm{D}$ & HS & Hish & $V_{\text {dish }}$ & $\mathrm{H}$ & $\mathrm{Rtn}$ & $d$ & sod & PT & $\mathrm{N}$ & $\mathrm{Nb}$ & $\mathrm{N}$ & $\mathrm{PT}_{\alpha d}$ & $R_{0}$ & $R$ & $\theta_{0}$ & $\theta_{1}$ & $R d R$ & $R / R$ & $\operatorname{sxdx}$ & $\rho_{\mathrm{s}}$ & $d_{b}$ & $d_{60}$ & $d_{65}$ & vf \\
\hline $9150393 \mathrm{M}$ & 6/23A & 15E_4s2d2Xd_1 & $147 / 16$ & $E$ & 3.25 & 354.8 & $331 / 2$ & 30 & 0.126 & 0.189 & HLP-22 & 12 & 8 & 4 & 1.05 & 4.5 & 2.4 & 21.8 & 10.1 & 0.62 & 0.34 & $\mathrm{~s} 2 \mathrm{~d} 2$ & 4.18 & 0.0000609 & 0.0000756 & 0.0000931 & 0.3684 \\
\hline 9150394M & 6/23A & 15E_4s2d2Xd_1 & $147 / 16$ & $E$ & 3.25 & 354.8 & $331 / 2$ & 30 & 0.126 & 0.189 & HLP-22 & 12 & 8 & 4 & 1.05 & 4.5 & 2.4 & 21.8 & 10.1 & 0.62 & 0.34 & $\mathrm{~s} 2 \mathrm{~d} 2$ & 4.18 & 0.0000609 & 0.0000756 & 0.0000931 & 0.3684 \\
\hline 9150395M & 6/23A & 15E_4s2d2Xd_1 & $147 / 16$ & $E$ & 3.25 & 354.8 & $331 / 2$ & 30 & 0.126 & 0.189 & HLP-22 & 12 & 8 & 4 & 1.05 & 4.5 & 2.4 & 21.8 & 10.1 & 0.62 & 0.34 & $\mathrm{~s} 2 \mathrm{~d} 2$ & 4.18 & 0.0000609 & 0.0000756 & 0.0000931 & 0.3684 \\
\hline 9150396M & 6/23A & 15E_4s2d2Xd_1 & $147 / 16$ & E & 3.25 & 354.8 & $331 / 2$ & 30 & 0.126 & 0.189 & HLP-22 & 12 & 8 & 4 & 1.05 & 4.5 & 2.4 & 21.8 & 10.1 & 0.62 & 0.34 & $\mathrm{~s} 2 \mathrm{~d} 2$ & 4.18 & 0.0000609 & 0.0000756 & 0.0000931 & 0.3684 \\
\hline 9150397M & 6/23A & 15E_4s2d2Xd_1 & $147 / 16$ & $E$ & 3.25 & 354.8 & $331 / 2$ & 30 & 0.126 & 0.189 & HLP-22 & 12 & 8 & 4 & 1.05 & 4.5 & 2.4 & 21.8 & 10.1 & 0.62 & 0.34 & $\mathrm{~s} 2 \mathrm{~d} 2$ & 4.18 & 0.0000609 & 0.0000756 & 0.0000931 & 0.3684 \\
\hline 9150398M & 6/23A & 15E_4s2d2Xd_1 & $147 / 16$ & $E$ & 3.25 & 354.8 & $331 / 2$ & 30 & 0.126 & 0.189 & HLP-22 & 12 & 8 & 4 & 1.05 & 4.5 & 2.4 & 21.8 & 10.1 & 0.62 & 0.34 & $\mathrm{~s} 2 \mathrm{~d} 2$ & 4.18 & 0.0000609 & 0.0000756 & 0.0000931 & 0.3684 \\
\hline 9150399M & 6/23A & 15E_4s2d2Xd_1 & $147 / 16$ & $E$ & 3.25 & 354.8 & $331 / 2$ & 30 & 0.126 & 0.189 & HLP-22 & 12 & 8 & 4 & 1.05 & 4.5 & 2.4 & 21.8 & 10.1 & 0.62 & 0.34 & $\mathrm{~s} 2 \mathrm{~d} 2$ & 4.18 & 0.0000609 & 0.0000756 & 0.0000931 & 0.3684 \\
\hline 9150400M & 6/23A & 15E_4s2d2Xd_1 & $147 / 16$ & $E$ & 3.25 & 354.8 & $331 / 2$ & 30 & 0.126 & 0.189 & HLP-22 & 12 & 8 & 4 & 1.05 & 4.5 & 2.4 & 21.8 & 10.1 & 0.62 & 0.34 & $\mathrm{~s} 2 \mathrm{~d} 2$ & 4.18 & 0.0000609 & 0.0000756 & 0.0000931 & 0.3684 \\
\hline 9150401M & 6/23A & 15E_4s2d2Xd_1 & $147 / 16$ & $E$ & 3.25 & 354.8 & $331 / 2$ & 30 & 0.126 & 0.189 & HLP-22 & 12 & 8 & 4 & 1.05 & 4.5 & 2.4 & 21.8 & 10.1 & 0.62 & 0.34 & $\mathrm{~s} 2 \mathrm{~d} 2$ & 4.18 & 0.0000609 & 0.0000756 & 0.0000931 & 0.3684 \\
\hline 9150402M & 6/23A & 15E_4s2d2Xd_1 & $147 / 16$ & $E$ & 3.25 & 354.8 & $331 / 2$ & 30 & 0.126 & 0.189 & HLP-22 & 12 & 8 & 4 & 1.05 & 4.5 & 2.4 & 21.8 & 10.1 & 0.62 & 0.34 & $\mathrm{~s} 2 \mathrm{~d} 2$ & 4.18 & 0.0000609 & 0.0000756 & 0.0000931 & 0.3684 \\
\hline 9150403M & 6/23A & 15E_4s2d2Xd 1 & $147 / 16$ & E & 3.25 & 354.8 & $331 / 2$ & 30 & 0.126 & 0.189 & HLP-22 & 12 & 8 & 4 & 1.05 & 4.5 & 2.4 & 21.8 & 10.1 & 0.62 & 0.34 & $\mathrm{~s} 2 \mathrm{~d} 2$ & 4.18 & 0.0000609 & 0.0000756 & 0.0000931 & 0.3684 \\
\hline 9150404M & 6/24A & 15E $452 \mathrm{~d} 2 \times \mathrm{d} 1$ & $147 / 16$ & $\mathrm{E}$ & 3.25 & 354.8 & $351 / 4$ & 30 & 0.126 & 0.189 & HLP-22 & 12 & 8 & 4 & 1.05 & 4.5 & 2.4 & 21.8 & 10.1 & 0.62 & 0.34 & $\mathrm{~s} 2 \mathrm{~d} 2$ & 4.18 & 0.0000609 & 0.0000756 & 0.0000931 & 0.3684 \\
\hline 9150405M & 6/24A & 15E_4s2d2Xd_1 & $147 / 16$ & $E$ & 3.25 & 354.8 & $351 / 4$ & 30 & 0.126 & 0.189 & HLP-22 & 12 & 8 & 4 & 1.05 & 4.5 & 2.4 & 21.8 & 10.1 & 0.62 & 0.34 & $\mathrm{~s} 2 \mathrm{~d} 2$ & 4.18 & 0.0000609 & 0.0000756 & 0.0000931 & 0.3684 \\
\hline 9150406M & 6/24A & 15E_4s2d2Xd_1 & $147 / 16$ & $E$ & 3.25 & 354.8 & $351 / 4$ & 30 & 0.126 & 0.189 & HLP-22 & 12 & 8 & 4 & 1.05 & 4.5 & 2.4 & 21.8 & 10.1 & 0.62 & 0.34 & $\mathrm{~s} 2 \mathrm{~d} 2$ & 4.18 & 0.0000600 & 0.0000756 & 0.0000931 & 0.3684 \\
\hline 9150407M & 6/24A & $15 \mathrm{E}$ 4s $2 \mathrm{~d} 2 \mathrm{~d} \mathrm{~d} \_1$ & $147 / 16$ & $E$ & 3.25 & 354.8 & $351 / 4$ & 30 & 0.126 & 0.189 & HLP-22 & 12 & 8 & 4 & 1.05 & 4.5 & 2.4 & 21.8 & 10.1 & 0.62 & 0.34 & $\mathrm{~s} 2 \mathrm{~d} 2$ & 4.18 & 0.0000609 & 0.0000756 & 0.0000931 & 0.3684 \\
\hline 9150408 & 6/24B & 15E_4s2d2WC_1 & $147 / 16$ & $E$ & 3.25 & 354.8 & $353 / 4$ & 30 & 0.126 & 0.189 & HLP-22 & 12 & 8 & 4 & 1.05 & 4.5 & 2.4 & 21.8 & 10.1 & 0.62 & 0.34 & $\mathrm{~s} 2 \mathrm{~d} 2$ & 4.18 & 0.0000609 & 0.0000756 & 0.0000931 & 0.3684 \\
\hline 9150409 & 6/24B & 15E_4s2d2Wc_1 & $147 / 16$ & $E$ & 3.25 & 354.8 & $353 / 4$ & 30 & 0.126 & 0.189 & HLP-22 & 12 & 8 & 4 & 1.05 & 4.5 & 2.4 & 21.8 & 10.1 & 0.62 & 0.34 & $\mathrm{~s} 2 \mathrm{~d} 2$ & 4.18 & 0.0000609 & 0.0000756 & 0.0000931 & 0.3684 \\
\hline 9150410 & 6/24B & 15E_4s2d2Wc_1 & $147 / 16$ & $\mathrm{E}$ & 3.25 & 354.8 & $353 / 4$ & 30 & 0.126 & 0.189 & HLP-22 & 12 & 8 & 4 & 1.05 & 4.5 & 2.4 & 21.8 & 10.1 & 0.62 & 0.34 & $\mathrm{~s} 2 \mathrm{~d} 2$ & 4.18 & 0.0000609 & 0.0000756 & 0.0000931 & 0.3684 \\
\hline 9150411 & 6/24B & 15E_4s2dzWc_1 & $147 / 16$ & $\mathrm{E}$ & 3.25 & 354.8 & $353 / 4$ & 30 & 0.126 & 0.189 & HLP-22 & 12 & 8 & 4 & 1.05 & 4.5 & 2.4 & 21.8 & 10.1 & 0.62 & 0.34 & $\mathrm{~s} 2 \mathrm{~d} 2$ & 4.18 & 0.0000609 & 0.0000756 & 0.0000931 & 0.3684 \\
\hline 9150412M & 6/24B & 15E_4s2d2Wc_1 & $147 / 16$ & $E$ & 3.25 & 354.8 & $353 / 4$ & 30 & 0.126 & 0.189 & HLP-22 & 12 & 8 & 4 & 1.05 & 4.5 & 2.4 & 21.8 & 10.1 & 0.62 & 0.34 & $\mathrm{~s} 2 \mathrm{~d} 2_{2}$ & 4.18 & 0.0000609 & 0.0000756 & 0.0000931 & 0.3684 \\
\hline $9150413 \mathrm{M}$ & 6/24B & 15E_4s2d2WC_1 & $147 / 16$ & $\mathrm{E}$ & 3.25 & 354.8 & $353 / 4$ & 30 & 0.126 & 0.189 & HLP-22 & 12 & 8 & 4 & 1.05 & 4.5 & 2.4 & 21.8 & 10.1 & 0.62 & 0.34 & $\mathrm{~s} 2 \mathrm{~d} 2$ & 4.18 & 0.0000609 & 0.0000756 & 0.0000931 & 0.3684 \\
\hline 9150414M & $6 / 24 B$ & 15E_4s2d2Wc_1 & $147 / 16$ & $E$ & 3.25 & 354.8 & $353 / 4$ & 30 & 0.126 & 0.189 & HLP-22 & 12 & 8 & 4 & 1.05 & 4.5 & 2.4 & 21.8 & 10.1 & 0.62 & 0.34 & $\mathrm{~s} 2 \mathrm{~d} 2$ & 4.18 & 0.0000609 & 0.0000756 & 0.0000931 & 0.3684 \\
\hline 9150415 & 6/25A & 15E_4s2dzWC_1 & $147 / 16$ & $E$ & 3.25 & 354.8 & $341 / 2$ & 30 & 0.126 & 0.189 & HLP-22 & 12 & 8 & 4 & 1.05 & 4.5 & 2.4 & 21.8 & 10.1 & 0.62 & 0.34 & $\mathrm{~s} 2 \mathrm{~d} 2_{2}$ & 4.18 & 0.0000609 & 0.0000756 & 0.0000931 & 0.3684 \\
\hline 9150416 & 6/25A & 15E_4s2d2Wc_1 & $147 / 16$ & $E$ & 3.25 & 354.8 & $341 / 2$ & 30 & 0.126 & 0.189 & HLP-22 & 12 & 8 & 4 & 1.05 & 4.5 & 2.4 & 21.8 & 10.1 & 0.62 & 0.34 & $\mathrm{~s} 2 \mathrm{~d} 2$ & 4.18 & 0.0000609 & 0.0000756 & o.0000931 & 0.3684 \\
\hline 9150417 & 6/25A & 15E_4s2d2Wc_1 & $147 / 16$ & $E$ & 3.25 & 354.8 & $341 / 2$ & 30 & 0.126 & 0.189 & HLP-22 & 12 & 8 & 4 & 1.05 & 4.5 & 2.4 & 21.8 & 10.1 & 0.62 & 0.34 & $\mathrm{~s} 2 \mathrm{~d} 2$ & 4.18 & 0.0000609 & 0.0000756 & 0.0000931 & 0.3684 \\
\hline 9150418 & 6/25A & 15E_4s2d2Wc_1 & $147 / 16$ & $E$ & 3.25 & 354.8 & $341 / 2$ & 30 & 0.126 & 0.189 & HLP-22 & 12 & 8 & 4 & 1.05 & 4.5 & 2.4 & 21.8 & 10.1 & 0.62 & 0.34 & $\mathrm{~s} 2 \mathrm{~d} 2$ & 4.18 & 0.0000609 & 0.0000756 & 0.0000931 & 0.3684 \\
\hline 9150419M & 6/25A & 15E_4s2d2Wc_1 & $147 / 16$ & $E$ & 3.25 & 354.8 & $341 / 2$ & 30 & 0.126 & 0.189 & HLP-22 & 12 & 8 & 4 & 1.05 & 4.5 & 2.4 & 21.8 & 10.1 & 0.62 & 0.34 & $\mathrm{~s} 2 \mathrm{~d} 2$ & 4.18 & 0.00000009 & 0.0000756 & 0.0000931 & 0.3684 \\
\hline 9150420M & 6/25A & 15E_4s2d2Wc_1 & $147 / 16$ & $E$ & 3.25 & 354.8 & $341 / 2$ & 30 & 0.126 & 0.189 & HLP-22 & 12 & 8 & 4 & 1.05 & 4.5 & 2.4 & 21.8 & 10.1 & 0.62 & 0.34 & $\mathrm{~s} 2 \mathrm{~d} 2$ & 4.18 & 0.0000609 & 0.0000756 & 0.0000931 & 0.3684 \\
\hline $9150421 \mathrm{M}$ & 6/25A & 15E_4S22d2WE_ 1 & $147 / 16$ & E & 3.25 & 354.8 & $341 / 2$ & 30 & 0.126 & 0.189 & HLP-22 & 12 & 8 & 4 & 1.05 & 4.5 & 2.4 & 21.8 & 10.1 & 0.62 & 0.34 & $\mathrm{~s} 2 \mathrm{~d} 2$ & 4.18 & 0.0000609 & 0.0000756 & 0.0000931 & 0.3684 \\
\hline 9150422M & 6/25A & 15E_4s2d2Wc_1 & $147 / 16$ & $E$ & 3.25 & 354.8 & $341 / 2$ & 30 & 0.126 & 0.189 & HLP-22 & 12 & 8 & 4 & 1.05 & 4.5 & 2.4 & 21.8 & 10.1 & 0.62 & 0.34 & $\mathrm{~s} 2 \mathrm{~d} 2$ & 4.18 & 0.0000609 & 0.0000756 & 0.0000931 & 0.3684 \\
\hline $9150423 \mathrm{M}$ & 6/25A & 15E_4s2d2WC_1 & $147 / 16$ & $E$ & 3.25 & 354.8 & $341 / 2$ & 30 & 0.126 & 0.189 & HLP-22 & 12 & 8 & 4 & 1.05 & 4.5 & 2.4. & 21.8 & 10.1 & 0.62 & 0.34 & $\mathrm{~s} 2 \mathrm{~d} 2$ & 4.18 & 0.0000609 & 0.0000756 & 0.0000931 & 0.3684 \\
\hline 9150424 & 6/25B & 15E_4s2d2Pc_1 & $147 / 16$ & $E$ & 3.25 & 354.8 & $341 / 2$ & 30 & 0.126 & 0.189 & HLP-22 & 12 & 8 & 4 & 1.05 & 4.5 & 2.4 & 21.8 & 10.1 & 0.62 & 0.34 & $\mathrm{~s} 2 \mathrm{~d} 2$ & 4.18 & 0.0000609 & 0.0000756 & 0.0000931 & 0.3684 \\
\hline 9150425 & $6 / 25 B$ & 15E_4S2d2Pc_ 1 & $147 / 16$ & $\mathrm{E}$ & 3.25 & 354.8 & $341 / 2$ & 30 & 0.126 & 0.189 & HLP-22 & 12 & 8 & 4 & 1.05 & 4.5 & 2.4 & 21.8 & 10.1 & 0.62 & 0.34 & $\mathrm{~s} 2 \mathrm{~d} 2$ & 4.18 & 0.0000609 & 0.0000756 & 0.0000931 & 0.3684 \\
\hline 9150426 & 6/255B & $15 E_{2} 4 \mathrm{~s} 2 \mathrm{~d} 2 \mathrm{Pc} \_1$ & $147 / 16$ & $E$ & 3.25 & 354.8 & $341 / 2$ & 30 & 0.126 & 0.189 & HLP-22 & 12 & 8 & 4 & 1.05 & 4.5 & 2.4 & 21.8 & 10.1 & 0.62 & & & 4.18 & 0.0000609 & 0.0000756 & 0.0000931 & 0.3684 \\
\hline 9150427 & 6/25B & 15E_4s2d2P__ 1 & $147 / 16$ & $E$ & 3.25 & 354.8 & $341 / 2$ & 30 & 0.126 & 0.189 & HLP-22 & 12 & 8 & 4 & 1.05 & 4.5 & 2.4 & 21.8 & 10.1 & 0.62 & 0.34 & $\mathrm{~s} 2 \mathrm{~d} 2$ & 4.18 & 0.0000609 & 0.0000756 & 0.0000931 & 0.3684 \\
\hline 9150428 & 6/25B & $15 E_{4} 4 \mathrm{~s} 2 \mathrm{~d} 2 \mathrm{Pc} \_1$ & $147 / 16$ & $E$ & 3.25 & 354.8 & $341 / 2$ & 30 & 0.126 & 0.189 & HLP-22 & 12 & 8 & 4 & 1.05 & 4.5 & 2.4 & 21.8 & 10.1 & 0.62 & 0.34 & $\mathrm{~s} 2 \mathrm{~d} 2$ & 4.18 & 0.0000609 & 0.0000756 & 0.0000931 & 0.3684 \\
\hline $9150429 \mathrm{M}$ & 6/25B & 15E_4s2d22PC_ _ & $147 / 16$ & $E$ & 3.25 & 354.8 & $341 / 2$ & 30 & 0.126 & 0.189 & HLP-22 & 12 & 8 & 4 & 1.05 & 4.5 & 2.4 & 21.8 & 10.1 & 0.62 & 0.34 & $\mathrm{~s} 2 \mathrm{~d} 2$ & 4.18 & 0.0000609 & 0.0000756 & 0.0000931 & 0.3684 \\
\hline $9150430 \mathrm{M}$ & 6/25B & 15E_4S2d2PC_1 & $147 / 16$ & $E$ & 3.25 & 354.8 & $341 / 2$ & 30 & 0.126 & 0.189 & HLP-22 & 12 & 8 & 4 & 1.05 & 4.5 & 2.4 & 21.8 & 10.1 & 0.62 & 0.34 & $\mathrm{~s} 2 \mathrm{~d} 2$ & 4.18 & 0.0000609 & 0.0000756 & 0.0000931 & 0.3684 \\
\hline 9150431M & 6/25B & 15E_4s2d2Pc_1 1 & $147 / 16$ & $E$ & 3.25 & 354.8 & $341 / 2$ & 30 & 0.126 & 0.189 & & 12 & 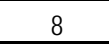 & 4 & & 4.5 & 2.4 & 21. & & 0.62 & & $\mathrm{~s} 2 \mathrm{~d} 2$ & 4. & & & 0.0000931 & \\
\hline 9150432M & 6/25B & 15E_4s2d2PC_1 & $147 / 16$ & $E$ & 3.25 & 354.8 & $341 / 2$ & 30 & 0.126 & 0.189 & HLP-22 & 12 & 8 & 4 & 1.05 & 4.5 & 2.4 & 21.8 & 10.1 & 0.62 & 0.34 & $\mathrm{~s} 2 \mathrm{~d} 2$ & $\begin{array}{l}4.18 \\
\end{array}$ & 0.0000609 & 0.0000756 & 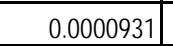 & 0.3684 \\
\hline $33 m$ & 6/25B & 15E 4s2d2P & $147 / 16$ & $E$ & 3.25 & 354.8 & $341 / 2$ & 30 & 0.126 & 0.189 & HLP-22 & 12 & 8 & 4 & 1.05 & 4.5 & 2.4 & 21.8 & 10.1 & 0.62 & 0.34 & $\mathrm{~s} 2 \mathrm{~d} 2$ & 4.18 & $\begin{array}{c}.00000609 \\
\end{array}$ & 0.0000756 & 0.0000931 & 0.3684 \\
\hline
\end{tabular}


Table B.3. Data from 2008 Tests in Small-Scale Vessel with Elliptical Head B.12

\begin{tabular}{|c|c|c|c|c|c|c|c|c|c|c|c|c|c|c|c|c|c|c|c|c|c|c|c|c|c|c|c|c|c|}
\hline $\begin{array}{l}\text { Tank Water } \\
\text { Temperature }\end{array}$ & \begin{tabular}{|l} 
Weter \\
Density
\end{tabular} & $\begin{array}{c}\text { Solidis } \\
\text { Fraction } \\
\text { F }\end{array}$ & $\begin{array}{c}\text { Pulse } \\
\text { Volume } \\
\text { Fraction } \\
\end{array}$ & $\begin{array}{l}\text { Duty } \\
\text { Cyde }\end{array}$ & $\begin{array}{l}\text { Oyde } \\
\text { Time } \\
\end{array}$ & $\begin{array}{l}\text { Pulsed or } \\
\text { Steacy J Jet }\end{array}$ & \begin{tabular}{|c} 
Us \\
Steacy \\
Jet
\end{tabular} & \begin{tabular}{|l} 
U1 \\
Pulsing \\
Jet \\
\end{tabular} & $\begin{array}{l}\text { U2 } \\
\text { URMS }\end{array}$ & \begin{tabular}{c|} 
U3 \\
URNB \\
\end{tabular} & \begin{tabular}{|c|} 
Discharge \\
Velocity \\
\end{tabular} & \begin{tabular}{|c} 
Oritical \\
Suspension \\
velocity
\end{tabular} & \begin{tabular}{|l} 
Average Peak \\
Coud Height
\end{tabular} & $\begin{array}{l}\text { UCS } \\
\text { Condition }\end{array}$ & $\begin{array}{l}\text { UCS } \\
\text { Nethod }\end{array}$ & UCS Hag & $\begin{array}{l}\text { Ucs Center } \\
\text { Hag }\end{array}$ & \begin{tabular}{|c|}
$\begin{array}{c}\text { uessudv } \\
\text { Hag }\end{array}$ \\
\end{tabular} & 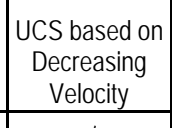 & \begin{tabular}{|c|} 
Sheep \\
Increase/ \\
Decrease \\
\end{tabular} & \begin{tabular}{|c|} 
UDV \\
Height \\
Bed
\end{tabular} & \begin{tabular}{|l} 
Patride \\
Motion \\
\end{tabular} & $\begin{array}{l}\text { Solids } \\
\text { Level }\end{array}$ & $\begin{array}{l}\text { Outer } \\
\text { Botom } \\
\text { Pattem }\end{array}$ & \begin{tabular}{|l|} 
Inner \\
Botom \\
Pattem \\
\end{tabular} & Case ID & Test & TDP & $\begin{array}{r}\text { Raw } \\
\text { Numbe }\end{array}$ \\
\hline \begin{tabular}{l|l}
$\mathrm{c}$ & \\
\end{tabular} & $g / \mathrm{cm}^{3}$ & fraction & fraction & fraction & $\mathrm{s}$ & text & $\mathrm{m} / \mathrm{s}$ & \begin{tabular}{|l|l}
$\mathrm{m} / \mathrm{s}$ \\
\end{tabular} & $\mathrm{m} / \mathrm{s}$ & $\mathrm{m} / \mathrm{s}$ & $\mathrm{m} / \mathrm{s}$ & $\mathrm{m} / \mathrm{s}$ & in. & $\mathrm{m} / \mathrm{s}$ & text & text & text & text & $\mathrm{m} / \mathrm{s}$ & \begin{tabular}{|l|l} 
text \\
\end{tabular} & $\mathrm{mm}$ & text & text & text & text & text & text & text & text \\
\hline $\mathrm{T}$ & $\rho$ & $\phi_{\mathrm{s}}$ & $\phi_{\mathrm{p}}$ & $D C$ & $t_{c}$ & Jet & $u_{s}$ & $\mathrm{U}_{1}$ & $\mathrm{U}_{2}$ & $\mathrm{UB}_{3}$ & $u$ & Uss & $H_{\mathrm{C}}$ & U USR & Ussu & Uasvis & Uscen & Ussudv & Ucs $D$ & $\mathrm{~S}_{\mathrm{N}}$ & $H_{\text {bed }}$ & $\mathrm{PM}$ & Sol & $\mathrm{SP}_{\mathrm{o}}$ & $\mathrm{SP}_{1}$ & $\mathrm{ID}$ & MDDX & IDP & MSS \\
\hline 26.7 & 0.999 & 0.01500 & 0.050 & $\begin{array}{ll}0.187 \\
\end{array}$ & \begin{tabular}{|l|}
10.4 \\
\end{tabular} & $\mathrm{P}$ & NA & 10.31 & 10.62 & 10.79 & 111.10 & 10.70 & 4.75 & $5 /$ NA & NA & NA & NA & NA & NA & 1 & 4.0 & 4 & NA & NA & NA & 15E_4s2d2Xd_1 1 & 6/23A & TDP-189 & 9150393 \\
\hline 27.0 & 0.999 & 0.01500 & 0.050 & 0.188 & 10.2 & $\mathrm{P}$ & NA & 10.45 & 10.79 & 10.97 & 11.30 & 10.70 & 5.00 & & NA & NA & NA & NA & NA & 1 & 3.6 & 4 & NA & NA & NA & 15E_4s2d2Xd_1 & 6/23A & TDP-189 & 9150394 \\
\hline 27.3 & 0.999 & 0.01500 & 0.050 & 0.189 & 10.0 & $\mathrm{P}$ & NA & 10.63 & 10.97 & 11.16 & 11.50 & 10.70 & 5.00 & onA & NA & NA & NA & NA & NA & 1 & 3.5 & 4 & NA & NA & NA & 15E_4s2d2Xd_1 & 6/23A & TDP-189 & 9150395 \\
\hline 27.6 & 0.999 & 0.01500 & 0.050 & 0.189 & 9.8 & $\mathrm{P}$ & NA & 10.85 & 11.19 & 11.37 & 11.70 & 10.70 & 5.00 & NA & NA & NA & NA & NA & NA & $\mathrm{I}$ & 3.4 & 4 & NA & NA & NA & 15E_4s2d2Xd_1 & 6/23A & TDP-189 & 9150396 \\
\hline 28.0 & 0.999 & 0.01500 & 0.050 & 0.178 & 10.2 & $P$ & NA & 11.07| & 11.44 & 11.64 & 11.90 & 10.70 & 5.25 & 5 NA & NA & NA & NA & NA & NA & 1 & 3.6 & 4 & NA & NA & NA & 155 -452d2Xd 1 & 6/23A & IDP-189 & 9150397 \\
\hline 28.3 & 0.998 & 0.01500 & 0.050 & 0.180 & 10.0 & $\mathrm{P}$ & NA & 11.17 & 11.55 & 11.75 & 12.10 & 10.70 & 5.50 & ONA & NA & NA & NA & NA & NA & 1 & 3.3 & 4 & $\mathrm{NA}$ & NA & NA & 15E_4s2d2Xd_1 & 6/23A & TDP-189 & 9150398 \\
\hline 28.5 & 0.998 & 0.01500 & 0.050 & 0.180 & 9.8 & $\mathrm{P}$ & NA & 11.35 & 11.73 & 11.94 & 12.30 & 10.70 & 5.25 & 5. NA & NA & NA & NA & NA & NA & I & 3.5 & 4 & NA & NA & NA & 15E_4s2d2Xd_1 & 6/23A & TDP-189 & 9150399 \\
\hline 28.8 & 0.998 & 0.01500 & 0.050 & 0.180 & 9.6 & $\mathrm{P}$ & NA & 11.50 & 11.89 & 12.10 & 12.50 & 10.70 & 5.25 & NA & NA & NA & NA & NA & NA & 1 & 1.9 & 4 & NA & NA & NA & 15E_4s2d2Xd_1 & $6 / 23 \mathrm{~A}$ & TDP-189 & 9150400 \\
\hline 29.2 & 0.998 & 0.01500 & 0.050 & 0.182 & 9.4 & $\mathrm{P}$ & NA & 11.67 & 12.08 & 12.30 & 12.70 & 10.70 & 5.50 & NA & NA & NA & NA & NA & NA & 1 & 3.4 & 4 & $\mathrm{NA}$ & NA & NA & 15E_4s2d2Xd_1 & $6 / 23 \mathrm{~A}$ & TDP-189 & 9150401 \\
\hline 29.6 & 0.998 & 0.01500 & 0.050 & 0.184 & 9.2 & $\mathrm{P}$ & NA & 11.78 & 12.22 & 12.45 & 12.90 & 10.70 & 5.50 & NA & NA & NA & NA & NA & NA & 1 & 2.6 & 4 & NA & NA & NA & 15E_4s2d2Xd_1 & $6 / 23 \mathrm{~A}$ & TDP-189 & 9150402 \\
\hline 29.9 & 0.998 & 0.01500 & 0.050 & 0.182 & 9.2 & $\mathrm{P}$ & NA & 12.03 & 12.46 & 12.69 & 13.10 & 10.70 & 5.75 & NA & NA & NA & NA & NA & $\mathrm{N}$ & 1 & 1.7. & 4 & NA & NA & NA & 15E_4s2d2Xd_1 & $6 / 23 \mathrm{~A}$ & TDP-189 & 9150403 \\
\hline 25.7 & 0.998 & 0.01500 & 0.050 & 0.179 & 9.2 & $\mathrm{P}$ & NA & 12.21 & 12.63 & 12.86 & 13.10 & 10.70 & 5.50 & NA & NA & NA & NA & NA & $\mathrm{NA}$ & (null) & 3.3 & 4 & $\mathrm{NA}$ & $\mathrm{NA}$ & NA & 15E_4s2d2Xd_1 & $6 / 24 \mathrm{~A}$ & TDP-190 & 9150404 \\
\hline 26.2 & 0.998 & 0.01500 & 0.050 & 0.184 & 8.4 & $\mathrm{P}$ & NA & 13.03 & 13.53 & 13.81 & 14.00 & 10.70 & 5.75 & NA & NA & NA & NA & NA & NA & 1 & 1.8. & 4 & NA & NA & NA & 15E_4s2d2Xd_1 & 6/24A & IDPP-190 & 9150405 \\
\hline 26.6 & 0.999 & 0.01500 & 0.050 & 0.185 & 8.0 & $\mathrm{P}$ & NA & 13.54 & $\begin{array}{ll}14.07 \\
\end{array}$ & 14.36 & 14.50 & 10.70 & 5.75 & NA & $\mathrm{NA}$ & NA & NA & NA & $\mathrm{N} /$ & 1 & 1.0 & 4 & $\mathrm{NA}$ & $\mathrm{NA}$ & NA & 15E_4s2d2Xd_1 & $6 / 24 \mathrm{~A}$ & TDP-190 & 9150406 \\
\hline 27.1 & 0.998 & 0.01500 & 0.050 & 0.186 & 7.8 & $\mathrm{P}$ & NA & 13.80 & 14.34 & 14.64 & 15.00 & 10.70 & 6.00 & DNA & NA & NA & NA & NA & NA & 1 & 0.6 & 4 & NA & NA & NA & 15E_4s2d2Xd_1 & | $/ 24 \mathrm{~A}$ & IDP-190 & 9150407 \\
\hline 26.6 & 0.998 & 0.04500 & 0.050 & 0.326 & 8.0 & $\mathrm{P}$ & NA & 7.70 & 7.83 & 7.91 & 8.00 & 11.50 & 4.25 & NA & NA & NA & NA & NA & NA & (null) & 13.1 & 1 & NA & NA & NA & 15E_4s2d2WC_1 & $6 / 24 \mathrm{~B}$ & IDP-191 & 9150408 \\
\hline 27.0 & 0.999 & 0.04500 & 0.050 & 0.336 & 7.1 & $\mathrm{P}$ & NA & 8.40 & 8.61 & 8.72 & 9.00 & 11.50 & 4.25 & NAA & NA & NA & NA & NA & NA & 1 & 9.1 & 1 & $\mathrm{NA}$ & NA & NA & 15E_4S2d2WC_1 1 & $6 / 24 B$ & IDP-191 & 9150409 \\
\hline 27.1 & 0.999 & 0.04500 & 0.050 & 0.339 & 6.4 & $\mathrm{P}$ & NA & 9.24 & 9.50 & 9.64 & 10.00 & 11.50 & 4.75 & NA & NA & NA & NA & NA & NA & $\mathrm{I}$ & 7.9 & 1 & NA & NA & NA & 15E_4s2d2WC_1 & $6 / 24 B$ & IDP-191 & 9150410 \\
\hline 27.4 & 0.999 & 0.04500 & 0.050 & 0.337 & 5.8 & $\mathrm{P}$ & NA & 10.20 & 10.51 & 10.67 & 11.00 & 11.50 & 5.25 & NA & NA & NA & NA & NA & $\mathrm{N}$ & 1 & 3.6 & 1 & NA & NA & NA & 15E_-4S2d2WC 1 & $6 / 248$ & IDP-191 & 9150411 \\
\hline 27.8 & 0.998 & 0.04500 & 0.050 & 0.333 & 5.7 & $\mathrm{P}$ & NA & 10.61 & 10.93 & 11.09 & 11.50 & 11.50 & 5.50 & | 11.50 & uarv & NA & NA & Jucsudv & $\mathrm{N} / \mathrm{t}$ & $\mathrm{I}$ & 1.1 & 4 & NA & NA & NA & 15E_4s2d2WC_1 & $6 / 24 B$ & IDP-191 & 9150412 \\
\hline 28.5 & 0.998 & 0.04500 & 0.050 & 0.337 & 5.3 & $\mathrm{P}$ & NA & 11.10 & 11.46 & 11.65 & 12.00 & 11.50 & & NA & NA & NA & NA & NA & NA & 1 & 0.0 & 4 & $\mathrm{NA}$ & NA & NA & 15E_4S2d2WWC_1 & 6/24B & TDP-191 & 9150413 \\
\hline 29.1 & 0.998 & 0.04500 & 0.050 & 0.337 & 4.9 & $\mathrm{P}$ & NA & 12.03 & 12.46 & 12.68 & 13.00 & 11.50 & 6.50 & NA & NA & NA & NA & NA & NA & 1 & 0.0 & 4 & NA & NA & NA & 15E_4S2d2WL_1 & $6 / 24 B$ & TDP-191 & 9150414 \\
\hline 24.2 & 0.999 & 0.04500 & 0.050 & 0.329 & 8.0 & $\mathrm{P}$ & NA & 7.61 & 7.78 & 7.87 & 8.00 & .50 & 4.25 & NA & NA & NA & NA & NA & $\mathrm{N} /$ & (null) & 8.5 & 1 & NA & NA & NA & 15E_4s2d2WC_1 & 6/25A & TDP-192 & 9150415 \\
\hline 24.2 & 1.000 & 0.04500 & 0.050 & 0.331 & 6.4 & $\mathrm{P}$ & NA & 9.38 & 9.64 & 9.77 & 10.00 & 1 & 5.25 & NA & NA & NA & NA & NA & $\mathrm{N}$ & 1 & 3.2 & & NA & NA & NA & 15E_4s2d2Wc_1 & 6/25A & TDP-192 & 9150416 \\
\hline 24.4 & 0.999 & 0.04500 & 0.050 & 0.336 & 6.0 & $\mathrm{P}$ & NA & 9.88 & 10.16 & 10.31 & 10.50 & 11.50 & 5.25 & NA & NA & ucsis & NA & NA & NA & 工 & 3.2 & 3 & $\mathrm{NA}$ & $\mathrm{NA}$ & NA & 15E_4S2d2WC_ 1 & $6 / 25 \mathrm{~A}$ & TDP-192 & 9150417 \\
\hline 24.7 & 0.999 & 0.04500 & 0.050 & 0.333 & 5.8 & $\mathrm{P}$ & NA & 10.43 & 10.76 & 10.93 & 11.00 & 11.50 & 5.75 & NA & NA & NA & NA & NA & $\mathrm{N}$ & $\mathrm{I}$ & 1.9 & 4 & NA & NA & NA & 15E_4s2d2Wc_1 & 6/25A & TDP-192 & 9150418 \\
\hline 24.9 & 0.999 & 0.04500 & 0.050 & 0.332 & 5.6 & $\mathrm{P}$ & NA & 10.80 & 11.16 & 11.34 & 11.50 & 11.50 & 6.00 & \begin{tabular}{|l|}
11.50 \\
\end{tabular} & uadv & NA & NA & ucsudv & $\mathrm{N} /$ & 1 & 0.6 & 4 & $\mathrm{NA}$ & NA & NA & 15E_4S2d2WC_ 1 & $6 / 25 \mathrm{~A}$ & TDP-192 & 9150419 \\
\hline 25.2 & 0.999 & 0.04500 & 0.050 & 0.331 & 5.4 & $\mathrm{P}$ & NA & 11.17 & 11.56 & 11.77 & 12.00 & 1 & 6.25 & NA & NA & NA & NA & NA & NA & 1 & 0.0 & 4 & NA & NA & NA & 15E_4s2d2Wc_1 & $6 / 25 \mathrm{~A}$ & TDP-192 & 9150420 \\
\hline 25.6 & 0.999 & 0.04500 & 0.050 & 0.328 & 5.0 & $\mathrm{P}$ & NA & 12.21 & 12.65 & 12.88 & 13.00 & 11.50 & 6.75 & NA & NA & NA & NA & NA & $\mathrm{N} /$ & 1 & 0.0 & 4 & NA & NA & NA & 15E_4s2d2Wc_1 & $6 / 25 \mathrm{~A}$ & TDP-192 & 9150421 \\
\hline 25.9 & 0.999 & 0.04500 & 0.050 & 0.336 & 4.6 & $\mathrm{P}$ & NA & 13.00 & 13.53 & 13.81 & 14.00 & 11.50 & 7.75 & NA & NA & NA & NA & NA & $\mathrm{N}$ & 1 & 0.0 & 4 & NA & NA & NA & 15E_4S2d2WC_1 1 & $6 / 25 \mathrm{~A}$ & IDP-192 & 9150422 \\
\hline 26.3 & 0.999 & 0.04500 & 0.050 & 0.338 & 4.2 & $\mathrm{P}$ & NA & 14.04 & 14.67 & 15.01 & 15.00 & & 9.50 & NA & NA & NA & NA & N/ & $\mathrm{N}$ & $\mathrm{I}$ & 0.0 & 4 & NA & NA & NA & 15E_4s2d2WC_1 & $6 / 25 \mathrm{~A}$ & IDP-192 & 9150423 \\
\hline 26.4 & 0.999 & 0.06000 & 0.050 & 0.330 & 8.1 & $\mathrm{P}$ & NA & 7.50 & 7.68 & 7.78 & 8.00 & 11.50 & 5.25 & NA & NA & NA & NA & NA & $\mathrm{N}$ & (null) & 11.0 & 1 & NA & NA & NA & 15E_4S202PC_1 & $6 / 25 B$ & IDP-193 & 9150424 \\
\hline 26.4 & 0.999 & 0.06000 & 0.050 & 0.335 & 7.2 & $\mathrm{P}$ & NA & 8.34 & 8.55 & 8.66 & 9.00 & & 5.25 & NA & NA & NA & NA & NA & $\mathrm{N} /$ & 1 & 7.3 & 1 & NA & NA & NA & 15E_4s2d2PC_ 1 & 6/25B & TDP-193 & 9150425 \\
\hline 26.5 & 0.999 & 0.06000 & 0.050 & 0.335 & 6.5 & $\mathrm{P}$ & NA & 9.26 & 9.53 & 9.66 & 10.00 & 11.50 & 5.75 & NA & NA & NA & NA & NA & NA & 1 & 3.2 & 1 & NA & NA & NA & 15E_4S222PC_1 & 6/25B & TDP-193 & 9150426 \\
\hline 26.7 & 0.999 & 0.06000 & 0.050 & 0.334 & 6.2 & $\mathrm{P}$ & NA & & 9.99 & 10.13 & 10.50 & & 6.00 & & NA & UCSVis & NA & NA & & 1 & 3.2 & 3 & NA & NA & NA & 15E_4s2d2PC_1 & $6 / 25 \mathrm{~B}$ & IDP-193 & 9150427 \\
\hline 26.9 & 0.999 & 0.06000 & 0.050 & 0.333 & 5.9 & $\mathrm{P}$ & NA & 10.23 & 10.54 & 10.70 & 11.00 & 11.50 & 6.25 & NA & NA & NA & NA & NA & $\mathrm{N} /$ & 1 & 1.0 & 4 & NA & NA & NA & 15E_4s2d2PC_1 & $6 / 25 B$ & IDP-193 & 9150428 \\
\hline 27.1 & 0.999 & 0.06000 & 0.050 & 0.333 & 5.6 & $\mathrm{P}$ & NA & 10.66 & 11.02 & 11.20 & 11.50 & 11.50 & 6.25 & $\mid 11.50$ & uav & NA & NA & ucsuck & NA & 1 & 0.5. & 4 & NA & NA & NA & 15E_4S2d2PC_ 1 & $6 / 25 \mathrm{~B}$ & IDP-193 & 9150429 \\
\hline 27.3 & 0.999 & 0.06000 & 0.050 & 0.334 & 5.2 & $\mathrm{P}$ & NA & 11.53 & 11.67 & 11.76 & 12.00 & 11.50 & 6.75 & NA & NA & NA & NA & NA & NA & 1 & 0.0 & 4 & NA & NA & NA & 15E_4S2d2PC_ 1 & $6 / 25 \mathrm{~B}$ & TDP-193 & 9150430 \\
\hline 27.7 & 0.999 & 0.06000 & 0.050 & 0.333 & 5.0 & $\mathrm{P}$ & NA & 12.01 & 12.43 & 12.64 & 13.00 & 11.50 & 7.75 & NA & NA & NA & NA & NA & NA & 1 & 0.0 & 4 & NA & NA & NA & 15E_4s2d2Pc_1 & $6 / 25 B$ & IDP-193 & 9150431 \\
\hline 27.9 & 0.998 & 0.06000 & 0.050 & 0.339 & 4.6 & $\mathrm{P}$ & NA & 12.88 & 13.36 & 13.61 & 14.00 & 11.50 & & & & & & & 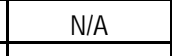 & 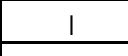 & 0.0 & & & & NA & 15E_4S2d2PC_1 & $6 / 25 \mathrm{~B}$ & TDP-193 & 9150432 \\
\hline 28.3 & 0.999 & 0.06000 & 0.050 & \begin{tabular}{|l|}
0.337 \\
\end{tabular} & 4.3 & $P$ & NA & 13.80 & $\begin{array}{l}14.37 \\
\end{array}$ & 14.66 & $\begin{array}{r}15.00 \\
\end{array}$ & 11.50 & 9.50 & & NA & NA & NA & NA & NA & 1 & 0.0 & 4 & NA & NA & NA & 15E_4S222PC_1 & 6/25B & TDP-193 & 9150433 \\
\hline
\end{tabular}


Table B.3. Data from 2008 Tests in Small-Scale Vessel with Elliptical Head A.13

\begin{tabular}{|c|c|c|c|c|c|c|c|c|c|c|c|c|c|c|c|c|c|c|c|c|c|c|c|c|c|c|c|}
\hline $\begin{array}{l}\text { Rov } \\
\text { Number }\end{array}$ & Test & Case ID & $\begin{array}{c}\text { Tank } \\
\text { Diameter }\end{array}$ & $\begin{array}{l}\text { Head } \\
\text { Shape }\end{array}$ & \begin{tabular}{|l} 
Dish \\
Height
\end{tabular} & $\begin{array}{l}\text { Dish } \\
\text { Volume }\end{array}$ & $\begin{array}{l}\text { Tank Fill } \\
\text { Height }\end{array}$ & $\begin{array}{c}\text { Retum } \\
\text { Line } \\
\text { Height }\end{array}$ & \begin{tabular}{c|} 
Nozzle \\
Inner \\
Dianter
\end{tabular} & $\begin{array}{l}\text { Nozzle } \\
\text { Stantoff } \\
\text { Distance }\end{array}$ & $\begin{array}{l}\text { Pulse Tube } \\
\text { Configuration }\end{array}$ & \begin{tabular}{|l} 
Installed \\
Nozzles
\end{tabular} & $\begin{array}{l}\text { Outer } \\
\text { Nozzles } \\
\text { Operated }\end{array}$ & $\begin{array}{l}\text { Inner } \\
\text { Nozzles } \\
\text { Operated }\end{array}$ & $\begin{array}{l}\text { Pulse Tube } \\
\text { Outer } \\
\text { Dianteter }\end{array}$ & $\begin{array}{c}\text { Outer } \\
\text { PMM } \\
\text { Radius }\end{array}$ & $\begin{array}{c}\text { Inner PJM } \\
\text { Radius } \\
\end{array}$ & \begin{tabular}{|c|} 
"FO" Outer PJM \\
Impingement \\
Angle
\end{tabular} & $\begin{array}{c}\text { "FO' Inner PJM } \\
\text { Impingement Angle }\end{array}$ & \begin{tabular}{|l} 
Ratio Outer PJM \\
to Tank Radius
\end{tabular} & $\begin{array}{l}\text { Ratio Inner PJM } \\
\text { to Tank Radius }\end{array}$ & Simulant & \begin{tabular}{|l|} 
Solids \\
Density \\
\end{tabular} & $\begin{array}{c}\text { Particle } \\
\text { Diameter d5 }\end{array}$ & \begin{tabular}{c|} 
Particle \\
Diameter d d50
\end{tabular} & $\begin{array}{c}\text { Particle } \\
\text { Diameter d95 }\end{array}$ & $\begin{array}{l}\text { Void } \\
\text { Fraction }\end{array}$ \\
\hline text & text & text & in. & text & in. & in ${ }^{3}$ & in. & in. & in. & in. & text & number & number & number & in. & in. & in. & deg & deg & nondim & nondim & text & \begin{tabular}{|l|l|}
$\mathrm{g} / \mathrm{cm}^{3}$ \\
\end{tabular} & $\mathrm{~m}$ & \begin{tabular}{l|}
$\mathrm{m}$ \\
\end{tabular} & $m$ & fraction \\
\hline MSS & MDDX & $\mathrm{ID}$ & $\mathrm{D}$ & HS & Hish & $V_{\text {dish }}$ & $\mathrm{H}$ & $\mathrm{Rtn}$ & $d$ & sod & PT & $\mathrm{N}$ & $\mathrm{Nb}$ & $\mathrm{N}$ & $\mathrm{PT}_{\alpha d}$ & $R_{0}$ & $R$ & $\theta_{0}$ & $\theta_{1}$ & $R d R$ & $R / R$ & $\operatorname{sxdx}$ & $\rho_{\mathrm{s}}$ & $d_{b}$ & $d_{60}$ & $d_{65}$ & vf \\
\hline 9150434 & 6/26A & 15E_4sid17c_1 1 & $147 / 16$ & $E$ & 3.25 & 354.8 & $343 / 4$ & 30 & 0.126 & 0.189 & HLP-22 & 12 & 8 & 4 & 1.05 & 4.5 & 2.4 & 21.8 & 10.1 & 0.62 & 0.34 & s1d1 1 & 2.46 & 0.0001428 & 0.0001664 & 0.0001951 & 0.4118 \\
\hline 9150435 & 6126A & 15E_4sid17c_1 & $147 / 16$ & $E$ & 3.25 & 354.8 & $343 / 4$ & 30 & 0.126 & 0.189 & HLP-22 & 12 & 8 & 4 & 1.05 & 4.5 & 2.4 & 21.8 & 10.1 & 0.62 & 0.34 & sidn 1 & 2.46 & $\begin{array}{ll}0.0001428 \\
\end{array}$ & 0.0001664 & 0.0001951 & 0.4118 \\
\hline 9150436 & 6126A & 15E_4s1d1Z__1 & $147 / 16$ & $E$ & 3.25 & 354.8 & $343 / 4$ & 30 & 0.126 & 0.189 & HLP-22 & 12 & 8 & 4 & 1.05 & 4.5 & 2.4 & 21.8 & 10.1 & 0.62 & 0.34 & s1d1 & 2.46 & $\begin{array}{ll}0.0001428 \\
\end{array}$ & 0.0001664 & 0.0001951 & 0.4118 \\
\hline 9150437 & 6/26A & 15E_4s1d1Zc_1 & $147 / 16$ & E & 3.25 & 354.8 & $343 / 4$ & 30 & 0.126 & 0.189 & HLP-22 & 12 & 8 & 4 & 1.05 & 4.5 & 2.4 & 21.8 & 10.1 & 0.62 & 0.34 & sld1 & 2.46 & 0.0001428 & 0.0001664 & 0.0001951 & 0.4118 \\
\hline 9150438M & 6/26A & 15E_4s1d1Zc_1 & $147 / 16$ & $E$ & 3.25 & 354.8 & $343 / 4$ & 30 & 0.126 & 0.189 & HLP-22 & 12 & 8 & 4 & 1.05 & 4.5 & 2.4 & 21.8 & 10.1 & 0.62 & 0.34 & s1d1 & 2.46 & 0.0001428 & 0.0001664 & 0.0001951 & 0.4118 \\
\hline 9150439M & 6/26A & 15E_4s1d1Zc_1 & $147 / 16$ & $E$ & 3.25 & 354.8 & $343 / 4$ & 30 & 0.126 & 0.189 & HLP-22 & 12 & 8 & 4 & 1.05 & 4.5 & 2.4 & 21.8 & 10.1 & 0.62 & 0.34 & sld1 & 2.46 & 0.0001428 & 0.0001664 & 0.0001951 & 0.4118 \\
\hline 9150440M & 6/26A & 15E_4s1d1Zc_1 & $147 / 16$ & $E$ & 3.25 & 354.8 & $343 / 4$ & 30 & 0.126 & 0.189 & HLP-22 & 12 & 8 & 4 & 1.05 & 4.5 & 2.4 & 21.8 & 10.1 & 0.62 & 0.34 & s1d1 1 & 2.46 & 0.0001428 & 0.0001664 & 0.0001951 & 0.4118 \\
\hline 9150441M & 6/26A & 15E_4s1d1Zc_1 & $147 / 16$ & $E$ & 3.25 & 354.8 & $343 / 4$ & 30 & 0.126 & 0.189 & HLP-22 & 12 & 8 & 4 & 1.05 & 4.5 & 2.4 & 21.8 & 10.1 & 0.62 & 0.34 & s1d1 & 2.46 & 0.0001428 & 0.0001664 & 0.0001951 & 0.4118 \\
\hline 9150442M & 6/26A & 15E_4s1d1Zc_1 & $147 / 16$ & $E$ & 3.25 & 354.8 & $343 / 4$ & 30 & 0.126 & 0.189 & HLP-22 & 12 & 8 & 4 & 1.05 & 4.5 & 2.4 & 21.8 & 10.1 & 0.62 & 0.34 & s1d1 1 & 2.46 & 0.0001428 & 0.0001664 & 0.0001951 & 0.4118 \\
\hline 9150443M & 6/26A & 15E_4sId1Zc_1 1 & $147 / 16$ & $E$ & 3.25 & 354.8 & $343 / 4$ & 30 & 0.126 & 0.189 & HLP-22 & 12 & 8 & 4 & 1.05 & 4.5 & 2.4 & 21.8 & 10.1 & 0.62 & 0.34 & sld1 & 2.46 & 0.0001428 & 0.0001664 & 0.0001951 & 0.4118 \\
\hline $9150444 \mathrm{M}$ & 6/26A & 15E_ 4 sIdIIIC 1 & $147 / 16$ & E & 3.25 & 354.8 & $343 / 4$ & 30 & 0.126 & 0.189 & HLP-22 & 12 & 8 & 4 & 1.05 & 4.5 & 2.4 & 21.8 & 10.1 & 0.62 & 0.34 & sidn & 2.46 & 0.0001428 & 0.0001664 & 0.0001951 & 0.4118 \\
\hline 9150445M & 6/26A & 15E 4sid17c 1 & $147 / 16$ & $\mathrm{E}$ & 3.25 & 354.8 & $343 / 4$ & 30 & 0.126 & 0.189 & HLP-22 & 12 & 8 & 4 & 1.05 & 4.5 & 2.4 & 21.8 & 10.1 & 0.62 & 0.34 & s1d1 & 2.46 & 0.0001428 & 0.0001664 & 0.0001951 & 0.4118 \\
\hline 9150446 & 6/26A & 15E_4sId1Zc_1 & $147 / 16$ & $E$ & 3.25 & 354.8 & $343 / 4$ & 30 & 0.126 & 0.189 & HLP-22 & 12 & 8 & 4 & 1.05 & 4.5 & 2.4 & 21.8 & 10.1 & 0.62 & 0.34 & s1d1 & 2.46 & 0.0001428 & 0.0001664 & 0.0001951 & 0.4118 \\
\hline 9150447 & 6/26A & 15E_4s1d17c_1 & $147 / 16$ & $E$ & 3.25 & 354.8 & $343 / 4$ & 30 & 0.126 & 0.189 & HLP-22 & 12 & 8 & 4 & 1.05 & 4.5 & 2.4 & 21.8 & 10.1 & 0.62 & 0.34 & sld1 & 246 & 0.0001428 & 0.0001664 & 0.0001951 & 0.4118 \\
\hline 9150448 & 6126A & 15E_4sId1Zc_ 1 & $147 / 16$ & $E$ & 3.25 & 354.8 & $343 / 4$ & 30 & 0.126 & 0.189 & HLP-22 & 12 & 8 & 4 & 1.05 & 4.5 & 2.4 & 21.8 & 10.1 & 0.62 & 0.34 & s1d1 & 2.46 & 0.0001428 & 0.0001664 & 0.0001951 & 0.4118 \\
\hline 9150449 & 6/26A & 15E_4s1d1Zc_1 & $147 / 16$ & $E$ & 3.25 & 354.8 & $343 / 4$ & 30 & 0.126 & 0.189 & HLP-22 & 12 & 8 & 4 & 1.05 & 4.5 & 2.4 & 21.8 & 10.1 & 0.62 & 0.34 & s1d1 1 & 2.46 & 0.0001428 & 0.0001664 & 0.0001951 & 0.4118 \\
\hline 9150450 & 6/26A & 15E_4sId1Zc 1 & $147 / 16$ & $E$ & 3.25 & 354.8 & $343 / 4$ & 30 & 0.126 & 0.189 & HLP-22 & 12 & 8 & 4 & 1.05 & 4.5 & 2.4 & 21.8 & 10.1 & 0.62 & 0.34 & s1d1 & 2.46 & 0.0001428 & 0.0001664 & 0.0001951 & 0.4118 \\
\hline 9150451 & 6/26A & 15E_4s1d17c_1 & $147 / 16$ & $\mathrm{E}$ & 3.25 & 354.8 & $343 / 4$ & 30 & 0.126 & 0.189 & HLP-22 & 12 & 8 & 4 & 1.05 & 4.5 & 2.4 & 21.8 & 10.1 & 0.62 & 0.34 & s1d1 & 2.46 & 0.0001428 & 0.0001664 & 0.0001951 & 0.4118 \\
\hline 9150452 & 6126A & 15E_4s1d1Zc_1 & $147 / 16$ & $\mathrm{E}$ & 3.25 & 354.8 & $343 / 4$ & 30 & 0.126 & 0.189 & HLP-22 & 12 & 8 & 4 & 1.05 & 4.5 & 2.4 & 21.8 & 10.1 & 0.62 & 0.34 & s1d1 & 2.46 & 0.0001428 & 0.0001664 & 0.0001951 & 0.4118 \\
\hline 9150453 & 6/26B & 15E_4s1d1Zd_1 & $147 / 16$ & $E$ & 3.25 & 354.8 & $343 / 4$ & 30 & 0.126 & 0.189 & HLP-22 & 12 & 8 & 4 & 1.05 & 4.5 & 2.4 & 21.8 & 10.1 & 0.62 & 0.34 & s1d1 1 & 2.46 & 0.0001428 & 0.0001664 & 0.0001951 & 0.4118 \\
\hline 9150454 & 6/26B & 15E_4sId17d_1 & $147 / 16$ & $\mathrm{E}$ & 3.25 & 354.8 & $343 / 4$ & 30 & 0.126 & 0.189 & HLP-22 & 12 & 8 & 4 & 1.05 & 4.5 & 2.4 & 21.8 & 10.1 & 0.62 & 0.34 & sid1 & 2.46 & 0.0001428 & 0.0001664 & 0.0001951 & 0.4118 \\
\hline 9150455 & 6/26B & 15E_4s1d1Zd_1 & $147 / 16$ & $E$ & 3.25 & 354.8 & $343 / 4$ & 30 & 0.126 & 0.189 & HLP-22 & 12 & 8 & 4 & 1.05 & 4.5 & 2.4 & 21.8 & 10.1 & 0.62 & 0.34 & s1d1 1 & 2.46 & 0.0001428 & 0.0001664 & 0.0001951 & 0.4118 \\
\hline 9150456 & 6/26B & 15E_4s1d1Zd_ 1 & $147 / 16$ & E & 3.25 & 354.8 & $343 / 4$ & 30 & 0.126 & 0.189 & HLP-22 & 12 & 8 & 4 & 1.05 & 4.5 & 2.4 & 21.8 & 10.1 & 0.62 & 0.34 & s1d1 & 2.46 & 0.0001428 & 0.0001664 & 0.0001951 & 0.4118 \\
\hline 9150457 & 6/26B & 15E_4s1d1Zd_1 & $147 / 16$ & $E$ & 3.25 & 354.8 & $343 / 4$ & 30 & 0.126 & 0.189 & HLP-22 & 12 & 8 & 4 & 1.05 & 4.5 & 2.4 & 21.8 & 10.1 & 0.62 & 0.34 & sidn & 2.46 & $\begin{array}{ll}0.0001428 \\
\end{array}$ & 0.0001664 & 0.0001951 & 0.4118 \\
\hline 9150458 & 6/26B & 15E_4s1d1Zd_1 & $147 / 16$ & $E$ & 3.25 & 354.8 & $343 / 4$ & 30 & 0.126 & 0.189 & HLP-22 & 12 & 8 & 4 & 1.05 & 4.5 & 2.4 & 21.8 & 10.1 & 0.62 & 0.34 & sld1 & 2.46 & 0.0001428 & 0.0001664 & 0.0001951 & 0.4118 \\
\hline 9150459 & 6/26B & 15E_4s1d1Zd_1 & $147 / 16$ & $E$ & 3.25 & 354.8 & $343 / 4$ & 30 & 0.126 & 0.189 & HLP-22 & 12 & 8 & 4 & 1.05 & 4.5 & 2.4 & 21.8 & 10.1 & 0.62 & 0.34 & s1d1 & 2.46 & 0.0001428 & 0.0001664 & 0.0001951 & 0.4118 \\
\hline 9150460M & 6/26B & 15E_4sId1Zd_1 & $147 / 16$ & $E$ & 3.25 & 354.8 & $343 / 4$ & 30 & 0.126 & 0.189 & HLP-22 & 12 & 8 & 4 & 1.05 & 4.5 & 2.4 & 21.8 & 10.1 & 0.62 & 0.34 & sld1 & 246 & 0.0001428 & 0.0001664 & 0.0001951 & 0.4118 \\
\hline 9150461M & 6/26B & 15E_4sıIdIZd_1 & $147 / 16$ & $E$ & 3.25 & 354.8 & $343 / 4$ & 30 & 0.126 & 0.189 & HLP-22 & 12 & 8 & 4 & 1.05 & 4.5 & 2.4 & 21.8 & 10.1 & 0.62 & 0.34 & s1d1 & 2.46 & 0.0001428 & 0.0001664 & 0.0001951 & 0.4118 \\
\hline $9150462 \mathrm{M}$ & 6/26B & 15E_4sId17d_1 & $147 / 16$ & E & 3.25 & 354.8 & $343 / 4$ & 30 & 0.126 & 0.189 & HLP-22 & 12 & 8 & 4 & 1.05 & 4.5 & 2.4 & 21.8 & 10.1 & 0.62 & 0.34 & sidn & 246 & 0.0001428 & 0.0001664 & 0.0001951 & 0.4118 \\
\hline 9150463M & 6/26B & 15E_4sıd1Zd_ 1 & $147 / 16$ & $E$ & 3.25 & 354.8 & $343 / 4$ & 30 & 0.126 & 0.189 & HLP-22 & 12 & 8 & 4 & 1.05 & 4.5 & 2.4 & 21.8 & 10.1 & 0.62 & 0.34 & s1d1 & 2.46 & 0.0001428 & 0.0001664 & 0.0001951 & 0.4118 \\
\hline $9150464 \mathrm{M}$ & 6/26B & 15E_4sid12d_1 & $147 / 16$ & $E$ & 3.25 & 354.8 & $343 / 4$ & 30 & 0.126 & 0.189 & HLP-22 & 12 & 8 & 4 & 1.05 & 4.5 & 2.4. & 21.8 & 10.1 & 0.62 & 0.34 & s1d1 & 2.46 & $\begin{array}{ll}0.0001428 \\
\end{array}$ & 0.0001664 & 0.0001951 & 0.4118 \\
\hline $9150465 \mathrm{M}$ & 6/26B & 15E_4sId17d__ 1 & $147 / 16$ & $E$ & 3.25 & 354.8 & $343 / 4$ & 30 & 0.126 & 0.189 & HLP-22 & 12 & 8 & 4 & 1.05 & 4.5 & 2.4 & 21.8 & 10.1 & 0.62 & 0.34 & sidn & 2.46 & 0.0001428 & 0.0001664 & 0.0001951 & 0.4118 \\
\hline 9150466 & 6/27A & 15E_4s1d1Yc_1 & $147 / 16$ & $\mathrm{E}$ & 3.25 & 354.8 & $343 / 4$ & 30 & 0.126 & 0.189 & HLP-22 & 12 & 8 & 4 & 1.05 & 4.5 & 2.4 & 21.8 & 10.1 & 0.62 & 0.34 & s1d1 & 2.46 & 0.0001428 & 0.0001664 & 0.0001951 & 0.4118 \\
\hline 9150467 & 6/27A & 15E_4sId1Yc_ 1 & $147 / 16$ & $E$ & 3.25 & 354.8 & $343 / 4$ & 30 & 0.126 & 0.189 & HLP-22 & 12 & 8 & 4 & 1.05 & 4.5 & 2.4 & 21.8 & 10.1 & 0.62 & 0.34 & & 2.46 & 0.0001428 & 0.0001664 & 0.0001951 & 0.4118 \\
\hline 9150468 & 6127A & 15E_4sId1YC_ 1 & $147 / 16$ & $E$ & 3.25 & 354.8 & $343 / 4$ & 30 & 0.126 & 0.189 & HLP-22 & 12 & 8 & 4 & 1.05 & 4.5 & 2.4 & 21.8 & 10.1 & 0.62 & 0.34 & s1d1 & 2.46 & 0.0001428 & 0.0001664 & 0.0001951 & 0.4118 \\
\hline 9150469 & 6127A & 15E_4sId1Yc_ 1 & $147 / 16$ & $E$ & 3.25 & 354.8 & $343 / 4$ & 30 & 0.126 & 0.189 & HLP-22 & 12 & 8 & 4 & 1.05 & 4.5 & 2.4 & 21.8 & 10.1 & 0.62 & 0.34 & s1d1 & 2.46 & 0.0001428 & 0.0001664 & 0.0001951 & 0.4118 \\
\hline 9150470 & 6/27A & 15E_4sId1YC_1 & $147 / 16$ & $E$ & 3.25 & 354.8 & $343 / 4$ & 30 & 0.126 & 0.189 & HLP-22 & 12 & 8 & 4 & 1.05 & 4.5 & 2.4 & 21.8 & 10.1 & 0.62 & 0.34 & s1d1 & 246 & 0.0001428 & 0.0001664 & 0.0001951 & 0.4118 \\
\hline 9150471 & 6/27A & 15E_4sId1YC_1 & $147 / 16$ & $E$ & 3.25 & 354.8 & $343 / 4$ & 30 & 0.126 & 0.189 & HLP-22 & 12 & 8 & 4 & 1.05 & 4.5 & 2.4 & 21.8 & 10.1 & 0.62 & 0.34 & sidn & 2.46 & 0.0001428 & 0.0001664 & 0.0001951 & 0.4118 \\
\hline 9150472M & 6/27A & 15E_4sid1Yc_1 & $147 / 16$ & $E$ & 3.25 & 354.8 & $343 / 4$ & 30 & 0.126 & 0.189 & HLP & 12 & 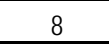 & 4 & & 4.5 & 2.4 & 21 & & 0.62 & & sic & 246 & & & & \\
\hline 9150473M & 6127A & 15E_4SId1Y__1 & $147 / 16$ & $E$ & 3.25 & 354.8 & $343 / 4$ & 30 & 0.126 & 0.189 & HLP-22 & 12 & 8 & 4 & 1.05 & 4.5 & 2.4 & 21.8 & 10.1 & 0.62 & 0.34 & s1d1 & 246 & \begin{tabular}{|c|}
0.0001428 \\
\end{tabular} & 0.0001664 & 0.0001951 & 0.4118 \\
\hline 9150474 & 6/27A & 15E 4sid1Y & $147 / 16$ & $E$ & 3.25 & 354.8 & 34344 & 30 & 0.126 & 0.189 & HLP-22 & 12 & 8 & 4 & 1.05 & 4.5 & 2.4 & 21.8 & 10.1 & 0.62 & 0.34 & sidn & 2.46 & 0.0001428 & 0.0001664 & 0.0001951 & 0.4118 \\
\hline
\end{tabular}


Table B.3. Data from 2008 Tests in Small-Scale Vessel with Elliptical Head B.13

\begin{tabular}{|c|c|c|c|c|c|c|c|c|c|c|c|c|c|c|c|c|c|c|c|c|c|c|c|c|c|c|c|c|c|}
\hline $\begin{array}{l}\text { Tank Water } \\
\text { Temperature }\end{array}$ & \begin{tabular}{|l} 
Water \\
Density
\end{tabular} & $\begin{array}{l}\text { Solids } \\
\text { Fraction } \\
\end{array}$ & $\begin{array}{c}\text { Pulse } \\
\text { Volume } \\
\text { Fraction } \\
\end{array}$ & \begin{tabular}{|l} 
Duty \\
Cycle \\
\end{tabular} & $\begin{array}{l}\text { Cycle } \\
\text { Time }\end{array}$ & \begin{tabular}{|l|}
$\begin{array}{l}\text { Pulsed or } \\
\text { Steacy Jet }\end{array}$ \\
\end{tabular} & \begin{tabular}{|c|} 
Us \\
Steacy \\
Jet \\
\end{tabular} & \begin{tabular}{|c|} 
U1 \\
Pulsin \\
g Jet \\
\end{tabular} & \begin{tabular}{|l|} 
U2 \\
URMS \\
\end{tabular} & $\begin{array}{c}\text { U3 } \\
\text { URMB } \\
\end{array}$ & \begin{tabular}{|c|} 
Discharge \\
Velocity
\end{tabular} & 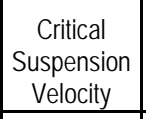 & $\begin{array}{c}\text { Average Peak } \\
\text { Cloud Height }\end{array}$ & \begin{tabular}{|c|} 
UCS \\
Condition \\
\end{tabular} & $\begin{array}{l}\text { UCS } \\
\text { Method }\end{array}$ & UCS Hag & $\begin{array}{c}\text { Ucs Center } \\
\text { Fag }\end{array}$ & $\begin{array}{c}\text { UCS udv } \\
\text { Fag }\end{array}$ & 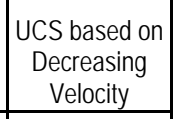 & $\begin{array}{l}\text { Sweep } \\
\text { Increase/ } \\
\text { Decrease }\end{array}$ & \begin{tabular}{|c|} 
UDV \\
Height \\
Bed \\
\end{tabular} & \begin{tabular}{|l} 
Particle \\
Notion
\end{tabular} & $\begin{array}{l}\text { Solids } \\
\text { Level }\end{array}$ & $\begin{array}{l}\text { atter } \\
\text { Botom } \\
\text { Pattem }\end{array}$ & \begin{tabular}{|l|} 
Inner \\
Bottom \\
Patterm \\
\end{tabular} & Case ID & Test & TDP & $\begin{array}{c}\text { Row } \\
\text { Numbe }\end{array}$ \\
\hline c & $\mathrm{g} / \mathrm{cm}^{3}$ & fraction & fraction & fraction & $\mathrm{s}$ & \begin{tabular}{|l|} 
text \\
\end{tabular} & \begin{tabular}{|l|l|}
$\mathrm{m} / \mathrm{s}$ \\
\end{tabular} & $\mathrm{m} / \mathrm{s}$ & $\begin{array}{ll}\mathrm{m} / \mathrm{s} \\
\end{array}$ & m/s & $\mathrm{m} / \mathrm{s}$ & \begin{tabular}{|l|}
$\mathrm{m} / \mathrm{s}$ \\
\end{tabular} & \begin{tabular}{|l|} 
in. \\
\end{tabular} & m/s & text & text & text & \begin{tabular}{|l|} 
text \\
\end{tabular} & \begin{tabular}{|l|}
$\mathrm{ms}$ \\
\end{tabular} & text & \begin{tabular}{|l|}
$\mathrm{mm}$ \\
\end{tabular} & text & text & text & text & text & text & text & text \\
\hline $\mathrm{T}$ & $\rho$ & $\phi_{\mathrm{s}}$ & $\phi_{p}$ & $D C$ & tc & Jet & $u_{s}$ & $\mathrm{U} 1$ & $\mathrm{U} 2$ & U3 & $u$ & Us & $\mathrm{H}_{\mathrm{c}}$ & $U_{\text {Cas }}$ & Ussu & \begin{tabular}{|l|} 
Unsis \\
\end{tabular} & Uscen & $\begin{array}{l}\text { Ussudv } \\
\end{array}$ & Uss $D$ & $\mathrm{~s}_{\mathrm{N}}$ & $H_{\text {bed }}$ & $\mathrm{PM}$ & Sol & SPo & $\mathrm{SP}_{\mathrm{P}}$ & ID & MDDX & TDP & MSS \\
\hline 24.8 & 0.999 & 0.00155 & 0.050 & 0.327 & 20.8 & $\mathrm{P}$ & NA & 2.94 & 2.95 & \begin{tabular}{|l|}
2.96 \\
\end{tabular} & 3.00 & 4.20 & 4.25 & NA & NA & NA & NA & NA & NA & (null) & 11.6 & 1 & NA & NA & NA & 15E_4s1d1Zc_ 1 & 6/26A & TDP-194 & 9150434 \\
\hline 24.9 & 0.999 & 0.00155 & 0.050 & 0.331 & 17.8 & $\mathrm{P}$ & NA & 3.42 & 3.44 & 3.45 & 3.50 & 4.20 & 4.75 & NA & NA & NA & NA & NA & NA & 1 & 8.6 & 1 & NA & NA & NA & 15E_4s1d1Zc_1 & 6/26A & TDP-194 & 9150435 \\
\hline 25.1 & 0.999 & 0.00155 & 0.050 & 0.332 & 16.4 & $\mathrm{P}$ & NA & 3.70 & 3.72 & 3.73 & 3.80 & 4.20 & 5.75 & NA & NA & NA & NA & NA & NA & 1 & 4.8 & 1 & NA & NA & NA & 15E_4s1d1Zc__1 & 6/26A & TDP-194 & 9150436 \\
\hline 25.2 & 0.999 & 0.00155 & 0.050 & 0.332 & 15.6 & $\mathrm{P}$ & NA & 3.90 & 3.92 & 3.94 & 4.00 & 4.20 & 6.25 & NA & NA & NA & NA & NA & NA & 1 & 3.5 & 1 & NA & NA & NA & 15E_4s1d1Zc_1 & 6/26A & TDP-194 & 9150437 \\
\hline 25.2 & 0.999 & 0.00155 & 0.050 & 0.334 & 14.6 & $P$ & NA & 4.10 & 4.13 & 4.15 & 4.20 & 4.20 & 6.25 & \begin{tabular}{|l|}
4.20 \\
\end{tabular} & uav & UCSvis & NA & ucsudv & NA & 1 & 28 & 3 & NA & NA & NA & 15E_4s1d1Zc_1 & 6/26A & TDP-194 & 9150438 \\
\hline 25.4 & 0.999 & 0.00155 & 0.050 & 0.335 & 14.0 & $\mathrm{P}$ & NA & 4.28 & 4.31 & 4.33 & 4.40 & 4.20 & 6.50 & NA & NA & NA & NA & NA & NA & 1 & 0.0 & 4 & NA & NA & NA & 15E_4s1d1Zc_1 & 6/26A & TDP-194 & 9150439 \\
\hline 25.5 & 0.999 & 0.00155 & 0.050 & 0.338 & 12.8 & $\mathrm{P}$ & NA & 4.65 & 4.70 & 4.72 & 4.80 & 4.20 & 10.25 & NA & NA & NA & NA & NA & NA & 1 & 0.0 & 4 & NA & NA & NA & 15E_4sid1Zc_1 & 6/26A & TDP-194 & 9150440 \\
\hline 25.8 & 0.999 & 0.00155 & 0.050 & 0.335 & 11.8 & $\mathrm{P}$ & NA & 5.03 & 5.08 & 5.11 & 5.20 & 4.20 & 13.25 & NA & NA & NA & NA & NA & NA & 1 & 0.0 & 4 & NA & NA & NA & 15E_4sid1Zc_1 & 6/26A & TDP-194 & 9150441 \\
\hline 25.9 & 0.999 & 0.00155 & 0.050 & 0.339 & 11.4 & $\mathrm{P}$ & NA & 5.19 & 5.26 & 5.30 & 5.40 & 4.20 & 15.75 & NA & NA & NA & NA & NA & NA & 1 & 0.0 & 4 & NA & NA & NA & 15E_4sid1Zc_1 & 6/26A & TDP-194 & 9150442 \\
\hline 26.3 & 0.999 & 0.00155 & 0.050 & 0.333 & 11.2 & $\mathrm{P}$ & NA & 5.37 & 5.44 & 5.48 & 5.60 & 4.20 & 16.00 & NA & NA & NA & NA & NA & NA & 1 & 0.0 & 4 & NA & NA & NA & 15E_4sid1Zc_1 & 6/26A & TDP-194 & 9150443 \\
\hline 26.5 & 0.999 & 0.00155 & 0.050 & 0.338 & 10.4 & $\mathrm{P}$ & NA & 5.71 & 5.80 & 5.85 & 6.00 & 4.20 & 18.50 & NA & NA & NA & NA & NA & NA & & 0.0 & 4 & NA & NA & NA & 15E_4sid17z_1 & 6/26A & TDP-194 & 9150444 \\
\hline 26.9 & 0.999 & 0.00155 & 0.050 & 0.334 & 14.6 & $P$ & NA & 4.10 & 4.13 & 4.15 & 4.20 & 4.20 & 6.25 & NA & NA & \begin{tabular}{|l|} 
UCShis \\
\end{tabular} & NA & NA & NA & 1 & 28 & 3 & NA & NA & $\mathrm{NA}$ & 15E_4sid17z_ _ 1 & 6/26A & TDP-194 & 9150445 \\
\hline 26.9 & 0.999 & 0.00155 & 0.050 & 0.334 & 14.6 & $\mathrm{P}$ & NA & 4.10 & 4.13 & 4.15 & 4.20 & 4.20 & 6.25 & NA & NA & NA & NA & NA & NA & $\mathrm{NA}$ & 2.9 & NA & NA & $\mathrm{NA}$ & $N A$ & 15E_4sid1Zc_1 & 6/26A & TDP-194 & 9150446 \\
\hline 26.9 & 0.999 & 0.00155 & 0.050 & 0.334 & 14.6 & $\mathrm{P}$ & NA & 4.10 & 4.13 & 4.15 & 4.20 & 4.20 & 6.25 & NA & NA & NA & NA & NA & NA & NA & 1.4 & NA & NA & NA & NA & 15E_4s1d1Zc_1 & 6/26A & TDP-194 & 9150447 \\
\hline 26.9 & 0.999 & 0.00155 & 0.050 & 0.334 & 14.6 & $\mathrm{P}$ & NA & 4.10 & 4.13 & \begin{tabular}{|l|} 
\\
\end{tabular} & 4.20 & 4.20 & 6.25 & NA & NA & NA & NA & NA & NA & NA & 21 & NA & NA & NA & NA & 15E_4sid1Zc_1 & 6/26A & TDP-194 & 9150448 \\
\hline 26.9 & 0.999 & 0.00155 & 0.050 & 0.334 & 14.6 & $\mathrm{P}$ & NA & 4.10 & 4.13 & 4.15 & 4.20 & 4.20 & 6.25 & NA & NA & NA & NA & NA & NA & NA & 21 & NA & NA & NA & NA & 15E_4sid17z__ 1 & 6/26A & TDP-194 & 9150449 \\
\hline 26.9 & 0.999 & 0.00155 & 0.050 & 0.334 & 14.6 & $\mathrm{P}$ & NA & 4.10 & 4.13 & 4.15 & 4.20 & 4.20 & 6.25 & NA & NA & $N A$ & NA & NA & NA & NA & 1.4 & NA & NA & $\mathrm{NA}$ & $N A$ & 15E_4sid1Zc_1 & 6/26A & TDP-194 & 9150450 \\
\hline 26.9 & 0.999 & 0.00155 & 0.050 & 0.334 & 14.6 & $\mathrm{P}$ & NA & 4.10 & 4.13 & 4.15 & 4.20 & 4.20 & 6.25 & NA & NA & NA & NA & NA & NA & NA & 28 & NA & NA & NA & NA & 15E_4sId1Zc__1 & 6/26A & TDP-194 & 9150451 \\
\hline 26.9 & 0.999 & 0.00155 & 0.050 & 0.334 & 14.6 & $\mathrm{P}$ & NA & 4.10 & 4.13 & \begin{tabular}{|l|} 
\\
\end{tabular} & 4.20 & 4.20 & 6.25 & NA & NA & NA & NA & NA & NA & NA & 14 & NA & NA & NA & NA & 15E_4sid17c 1 & 6/26A & TDP-194 & 9150452 \\
\hline 27.6 & 0.999 & 0.00155 & 0.050 & 0.179 & 35.6 & $\mathrm{P}$ & NA & 3.15 & 3.17 & \begin{tabular}{|l|}
3.18 \\
\end{tabular} & 3.20 & 4.50 & 4.25 & NA & NA & NA & NA & NA & NA & (null) & 8.7 & 1 & NA & NA & NA & 15E__sid172d_1 & 6/26B & TDP-194 & 9150453 \\
\hline 27.7 & 0.998 & 0.00155 & 0.050 & 0.181 & 31.6 & $P$ & NA & 3.52 & 3.55 & 3.56 & 3.60 & 4.50 & 5.25 & NA & NA & NA & NA & NA & NA & 1 & 7.1 & 1 & NA & NA & NA & 15E_4sid17d_1 & 6/26B & TDP-194 & 9150454 \\
\hline 27.9 & 0.999 & 0.00155 & 0.050 & 0.182 & 30.0 & $\mathrm{P}$ & NA & 3.70 & 3.72 & 3.74 & 3.80 & 4.50 & 5.50 & NA & NA & NA & NA & NA & NA & 1 & 4.8 & 1 & NA & NA & NA & 15E_4sid17d_1 1 & $6 / 26 \mathrm{~B}$ & TDP-194 & 9150455 \\
\hline 28.1 & 0.998 & 0.00155 & 0.050 & 0.183 & 28.2 & $\mathrm{P}$ & NA & 3.89 & 3.93 & 3.95 & 4.00 & 4.50 & 6.25 & NA & NA & NA & NA & NA & NA & 1 & 4.1 & 1 & NA & NA & NA & 15E_4s1d1Zd_1 & 6/26B & TDP-194 & 9150456 \\
\hline 28.2 & 0.998 & 0.00155 & 0.050 & 0.183 & 26.8 & $\mathrm{P}$ & NA & 4.07 & 4.11 & 4.13 & 4.20 & 4.50 & 6.50 & NA & NA & NA & NA & NA & $\mathrm{N}$ & & 3.6 & 1 & NA & NA & NA & 15E_4sid12d_1 & $6 / 26 \mathrm{~B}$ & TDP-194 & 9150457 \\
\hline 28.5 & 0.998 & 0.00155 & 0.050 & 0.184 & 25.6 & $\mathrm{P}$ & NA & 4.26 & 4.31 & 4.33 & 4.40 & 4.50 & 6.50 & NA & NA & UCSvis & NA & NA & NA & 1 & 1.4 & 3 & NA & NA & NA & 15E_4sid17d_1 & 6/26B & TDP-194 & 9150458 \\
\hline 28.9 & 0.998 & 0.00155 & 0.050 & 0.185 & 25.6 & $\mathrm{P}$ & NA & 4.26 & 4.31 & 4.33 & 4.40 & 4.50 & 6.75 & NA & NA & UCShis & NA & NA & NA & 1 & 22. & 3 & NA & NA & NA & 15E_4sid1Zd_1 & 6/26B & TDP-194 & 9150459 \\
\hline 29.1 & 0.998 & 0.00155 & 0.050 & 0.185 & 25.0 & $\mathrm{P}$ & NA & 4.35 & 4.40 & 4.43 & 4.50 & 4.50 & 6.75 & \begin{tabular}{|l|} 
\\
\end{tabular} & uav & NA & NA & ucsudv & NA & 1 & 0.7 & 4 & NA & NA & NA & 15E_4sid17d_1 & 6/268 & TDP-194 & 9150460 \\
\hline 29.3 & 0.998 & 0.00155 & 0.050 & 0.184 & 24.0 & $\mathrm{P}$ & NA & 4.52 & 4.59 & 4.62 & 4.70 & 4.50 & 7.50 & NA & NA & NA & NA & NA & NA & 1 & 0.0 & 4 & NA & NA & NA & 15E_4sid1Zd_1 & 6/26B & TDP-194 & 9150461 \\
\hline 29.4 & 0.998 & 0.00155 & 0.050 & 0.185 & 22.6 & $\mathrm{P}$ & NA & 4.81 & 4.87 & 4.90 & 5.00 & 4.50 & 9.75 & NA & NA & NA & NA & NA & NA & 1 & 0.0 & 4 & NA & NA & NA & 15E_4sid17d_1 1 & 6/26B & TDP-194 & 9150462 \\
\hline 29.7 & 0.998 & 0.00155 & 0.050 & 0.186 & 20.6 & $P$ & NA & 5.25 & 5.34 & 5.39 & 5.50 & 4.50 & 13.75 & NA & NA & $N A$ & NA & NA & NA & 1 & 0.0 & 4 & NA & $\mathrm{NA}$ & NA & 15E_4sid1Zd_1 & 6/26B & TDP-194 & 9150463 \\
\hline 29.9 & 0.998 & 0.00155 & 0.050 & 0.188 & 18.8 & $P$ & NA & 5.70 & 5.81 & 5.86 & 6.00 & 4.50 & 16.25 & NA & NA & NA & NA & NA & NA & 1 & 0.0 & 4 & NA & $\mathrm{NA}$ & NA & 15E_4sid17d_1 1 & 6/26B & TDP-194 & 9150464 \\
\hline 30.1 & 0.998 & 0.00155 & 0.050 & 0.187 & 17.4 & $\mathrm{P}$ & NA & 6.14 & 6.27 & 6.33 & 6.50 & 4.50 & 18.50 & NA & NA & NA & NA & NA & NA & 1 & 0.0 & 4 & NA & NA & NA & 15E_4sid12d_1 & 6/26B & TDP-194 & 9150465 \\
\hline 24.3 & 0.999 & 0.00500 & 0.050 & 0.333 & 14.8 & $\mathrm{P}$ & NA & 4.07 & 4.11 & 4.13 & 4.20 & 5.90 & 3.75 & NA & NA & NA & NA & NA & NA & (null) & 9.5 & 1 & NA & $\mathrm{NA}$ & NA & 15E_4sid1YC_1 & 6/27A & TDP-195 & 9150466 \\
\hline 24.6 & 0.999 & 0.00500 & 0.050 & 0.333 & 13.3 & $P$ & NA & 4.53 & 4.59 & 4.62 & 4.70 & 5.90 & 4.50 & NA & NA & $N A$ & NA & NA & NA & 1 & 5.5 & 1 & NA & NA & $\mathrm{NA}$ & 15E__sid1Yc_1 & 6/27A & TDP-195 & 9150467 \\
\hline 24.7 & 0.999 & 0.00500 & 0.050 & 0.338 & 12.5 & $\mathrm{P}$ & NA & 4.76 & 4.85 & 4.89 & 5.00 & 5.90 & 4.75 & NA & NA & NA & NA & NA & & 1 & 4.8 & 1 & NA & NA & NA & 15E_4sid1Yc_1 & 6/27A & TDP-195 & 9150468 \\
\hline 25.0 & 0.999 & 0.00500 & 0.050 & 0.338 & 11.8 & $\mathrm{P}$ & NA & 5.05 & 5.15 & 5.19 & 5.30 & 5.90 & 5.25 & NA & NA & NA & NA & NA & NA & 1 & 4.2 & 1 & NA & NA & NA & 15E_4sid1Yc_1 & 6/27A & TDP-195 & 9150469 \\
\hline 25.2 & 0.999 & 0.00500 & 0.050 & 0.337 & 11.4 & $\mathrm{P}$ & NA & 5.24 & 5.34 & 5.38 & 5.50 & 5.90 & 5.25 & NA & NA & NA & NA & NA & NA & 1 & 3.6 & 1 & NA & NA & NA & 15E_4s1d1Yc_1 & 6/27A & IDP-195 & 9150470 \\
\hline 25.5 & 0.999 & 0.00500 & 0.050 & 0.333 & 11.0 & $P$ & NA & 5.47 & 5.55 & 5.60 & 5.70 & 5.90 & 5.75 & NA & NA & UCSvis & NA & NA & NA & 1 & 29 & 3 & NA & NA & NA & 15E_4sid1Yc_1 & 6/27A & TDP-195 & 9150471 \\
\hline 25.7 & 0.999 & 0.00500 & 0.050 & 0.335 & 10.6 & $\mathrm{P}$ & NA & 5.64 & 5.74 & 5.78 & 5.90 & 5.90 & 5.75 & \begin{tabular}{|l|}
5.90 \\
\end{tabular} & udv & NA & NA & Ucsudv & NA & 1 & 0.6 & 4 & NA & NA & NA & 15E_4s1d1Yc_1 & 6/27A & TDP-195 & 9150472 \\
\hline 25.8 & 0.999 & 0.00500 & 0.050 & 0.338 & 10.4 & $\mathrm{P}$ & NA & 5.70 & 5.81 & 5.86 & & 5.90 & & NA & & NA & NA & & NA & & & & & NA & & 15E_4sid1YC_1 & 6127A & TDP-195 & 9150473 \\
\hline 26.1 & 0.999 & 0.00500 & \begin{tabular}{|l|}
0.050 \\
\end{tabular} & \begin{tabular}{|l|} 
\\
\end{tabular} & 10.1 & $\mathrm{P}$ & NA & 6.02 & 6.11 & \begin{tabular}{|l|l|} 
& \\
\end{tabular} & 6.30 & 5.90 & 6.25 & & NA & NA & NA & NA & NA & 1 & 0.0 & 4 & NA & NA & na & 15E_4sid1Yc_1 & |6/27A & IIDP-195 & 9150474 \\
\hline
\end{tabular}


Table B.3. Data from 2008 Tests in Small-Scale Vessel with Elliptical Head A.14

\begin{tabular}{|c|c|c|c|c|c|c|c|c|c|c|c|c|c|c|c|c|c|c|c|c|c|c|c|c|c|c|c|}
\hline $\begin{array}{l}\text { Rov } \\
\text { Number }\end{array}$ & Test & Case ID & $\begin{array}{c}\text { Tank } \\
\text { Diameter }\end{array}$ & $\begin{array}{l}\text { Head } \\
\text { Shape }\end{array}$ & \begin{tabular}{|l} 
Dish \\
Height
\end{tabular} & $\begin{array}{l}\text { Dish } \\
\text { Volume }\end{array}$ & $\begin{array}{l}\text { Tank Fill } \\
\text { Height }\end{array}$ & $\begin{array}{c}\text { Retum } \\
\text { Line } \\
\text { Height }\end{array}$ & \begin{tabular}{c|} 
Nozzle \\
Inner \\
Dianter
\end{tabular} & $\begin{array}{l}\text { Nozzle } \\
\text { Stantoff } \\
\text { Distance }\end{array}$ & $\begin{array}{l}\text { Pulse Tube } \\
\text { Configuration }\end{array}$ & \begin{tabular}{|l} 
Installed \\
Nozzles
\end{tabular} & $\begin{array}{l}\text { Outer } \\
\text { Nozzles } \\
\text { Operated }\end{array}$ & $\begin{array}{l}\text { Inner } \\
\text { Nozzles } \\
\text { Operated }\end{array}$ & $\begin{array}{l}\text { Pulse Tube } \\
\text { Outer } \\
\text { Dianteter }\end{array}$ & $\begin{array}{c}\text { Outer } \\
\text { PMM } \\
\text { Radius }\end{array}$ & $\begin{array}{c}\text { Inner PJM } \\
\text { Radius } \\
\end{array}$ & \begin{tabular}{|c|} 
"FO" Outer PJM \\
Impingement \\
Angle
\end{tabular} & $\begin{array}{c}\text { "FO' Inner PJM } \\
\text { Impingement Angle }\end{array}$ & \begin{tabular}{|l} 
Ratio Outer PJM \\
to Tank Radius
\end{tabular} & $\begin{array}{l}\text { Ratio Inner PJM } \\
\text { to Tank Radius }\end{array}$ & Simulant & \begin{tabular}{|l|} 
Solids \\
Density \\
\end{tabular} & $\begin{array}{c}\text { Particle } \\
\text { Diameter d5 }\end{array}$ & \begin{tabular}{c|} 
Particle \\
Diameter d d50
\end{tabular} & $\begin{array}{c}\text { Particle } \\
\text { Diameter d95 }\end{array}$ & $\begin{array}{l}\text { Void } \\
\text { Fraction }\end{array}$ \\
\hline text & text & text & in. & text & in. & in. $^{3}$ & in. & in. & in. & in. & text & number & number & number & in. & in. & in. & deg & deg & nondim & nondim & text & \begin{tabular}{|l|l|}
$\mathrm{g} / \mathrm{cm}^{3}$ \\
\end{tabular} & $\mathrm{~m}$ & \begin{tabular}{l|}
$\mathrm{m}$ \\
\end{tabular} & $m$ & fraction \\
\hline MSS & MDDX & $\mathrm{ID}$ & $\mathrm{D}$ & HS & Hish & $V_{\text {dish }}$ & $\mathrm{H}$ & $\operatorname{Rin}$ & $d$ & sod & PT & $\mathrm{N}$ & $\mathrm{Nb}$ & $\mathrm{N}$ & $\mathrm{PT}_{\alpha d}$ & $R_{0}$ & $R$ & $\theta_{0}$ & $\theta_{1}$ & $R d R$ & $R / R$ & $\operatorname{sxdx}$ & $\rho_{\mathrm{s}}$ & $d_{b}$ & $d_{60}$ & $d_{65}$ & vf \\
\hline 9150475M & 6/27A & 15E_4s1d1Yc_1 & $147 / 16$ & $E$ & 3.25 & 354. & $343 / 4$ & 30 & 0.126 & 0.189 & HLP-22 & 12 & 8 & 4 & 1.05 & 4.5 & 2.4 & 21.8 & 10.1 & 0.62 & 0.34 & s1d1 1 & 2.46 & 0.0001428 & 0.0001664 & 0.0001951 & 0.4118 \\
\hline $9150476 \mathrm{M}$ & 6/27A & 15E_4s1d1Yc_1 & $147 / 16$ & $E$ & 3.25 & 354.8 & $343 / 4$ & 30 & 0.126 & 0.189 & HLP-22 & 12 & 8 & 4 & 1.05 & 4.5 & 2.4 & 21.8 & 10.1 & 0.62 & 0.34 & sidn & 2.46 & 0.0001428 & 0.0001664 & 0.0001951 & 0.4118 \\
\hline 9150477M & 6/27A & 15E_4s1d1Y__1 & $147 / 16$ & $E$ & 3.25 & 354. & $343 / 4$ & 30 & 0.126 & 0.189 & HLP-22 & 12 & 8 & 4 & 1.05 & 4.5 & 2.4 & 21.8 & 10.1 & 0.62 & 0.34 & s1d1 & 2.46 & $\begin{array}{ll}0.0001428 \\
\end{array}$ & 0.0001664 & 0.0001951 & 0.4118 \\
\hline 9150478M & 6/27A & 15E_4s1d1Yc_1 & $147 / 16$ & E & 3.25 & 354. & $343 / 4$ & 30 & 0.126 & 0.189 & HLP-22 & 12 & 8 & 4 & 1.05 & 4.5 & 2.4 & 21.8 & 10.1 & 0.62 & 0.34 & sld1 & 2.46 & 0.0001428 & 0.0001664 & 0.0001951 & 0.4118 \\
\hline 9150479M & 6/27A & 15E_4s1d1Yc_1 & $147 / 16$ & $E$ & 3.25 & 354.8 & $343 / 4$ & 30 & 0.126 & 0.189 & HLP-22 & 12 & 8 & 4 & 1.05 & 4.5 & 2.4 & 21.8 & 10.1 & 0.62 & 0.34 & s1d1 & 2.46 & 0.0001428 & 0.0001664 & 0.0001951 & 0.4118 \\
\hline 9150480 & $6 / 278$ & 15E_4s1d1Yd_1 & $147 / 16$ & $E$ & 3.25 & 354.8 & $343 / 4$ & 30 & 0.126 & 0.189 & HLP-22 & 12 & 8 & 4 & 1.05 & 4.5 & 2.4 & 21.8 & 10.1 & 0.62 & 0.34 & sld1 & 2.46 & 0.0001428 & 0.0001664 & 0.0001951 & 0.4118 \\
\hline 9150481 & 6/27B & 15E_4s1d1Yd_1 & $147 / 16$ & $E$ & 3.25 & 354.8 & $343 / 4$ & 30 & 0.126 & 0.189 & HLP-22 & 12 & 8 & 4 & 1.05 & 4.5 & 2.4 & 21.8 & 10.1 & 0.62 & 0.34 & s1d1 1 & 2.46 & 0.0001428 & 0.0001664 & 0.0001951 & 0.4118 \\
\hline 9150482 & $6 / 278$ & 15E_4s1d1Yd_1 & $147 / 16$ & $E$ & 3.25 & 354.8 & $343 / 4$ & 30 & 0.126 & 0.189 & HLP-22 & 12 & 8 & 4 & 1.05 & 4.5 & 2.4 & 21.8 & 10.1 & 0.62 & 0.34 & s1d1 & 2.46 & 0.0001428 & 0.0001664 & 0.0001951 & 0.4118 \\
\hline 9150483 & $6 / 278$ & 15E_4s1d1Yd_1 & $147 / 16$ & $E$ & 3.25 & 354.8 & $343 / 4$ & 30 & 0.126 & 0.189 & HLP-22 & 12 & 8 & 4 & 1.05 & 4.5 & 2.4 & 21.8 & 10.1 & 0.62 & 0.34 & s1d1 1 & 2.46 & 0.0001428 & 0.0001664 & 0.0001951 & 0.4118 \\
\hline 9150484 & $6 / 278$ & 15E_4s1d1Yd_1 & $147 / 16$ & $E$ & 3.25 & 354. & $343 / 4$ & 30 & 0.126 & 0.189 & HLP-22 & 12 & 8 & 4 & 1.05 & 4.5 & 2.4 & 21.8 & 10.1 & 0.62 & 0.34 & sld1 & 2.46 & 0.0001428 & 0.0001664 & 0.0001951 & 0.4118 \\
\hline 9150485 & 6/278 & 15E - 4sId1Yd 1 & $147 / 16$ & E & 3.25 & 354. & $343 / 4$ & 30 & 0.126 & 0.189 & HLP-22 & 12 & 8 & 4 & 1.05 & 4.5 & 2.4 & 21.8 & 10.1 & 0.62 & 0.34 & sidn & 2.46 & 0.0001428 & 0.0001664 & 0.0001951 & 0.4118 \\
\hline 9150486M & 6/278 & 15E 4sidiYd 1 & $147 / 16$ & $\mathrm{E}$ & 3.25 & 354.8 & $343 / 4$ & 30 & 0.126 & 0.189 & HLP-22 & 12 & 8 & 4 & 1.05 & 4.5 & 2.4 & 21.8 & 10.1 & 0.62 & 0.34 & s1d1 & 2.46 & 0.0001428 & 0.0001664 & 0.0001951 & 0.4118 \\
\hline 9150487M & $6 / 27 \mathrm{~B}$ & 15E_4s1d1Yd_1 & $147 / 16$ & $E$ & 3.25 & 354.8 & $343 / 4$ & 30 & 0.126 & 0.189 & HLP-22 & 12 & 8 & 4 & 1.05 & 4.5 & 2.4 & 21.8 & 10.1 & 0.62 & 0.34 & s1d1 & 2.46 & 0.0001428 & 0.0001664 & 0.0001951 & 0.4118 \\
\hline 9150488M & $6 / 27 \mathrm{~B}$ & 15E_4s1d1Yd_1 & $147 / 16$ & $E$ & 3.25 & 354.8 & $343 / 4$ & 30 & 0.126 & 0.189 & HLP-22 & 12 & 8 & 4 & 1.05 & 4.5 & 2.4 & 21.8 & 10.1 & 0.62 & 0.34 & sld1 & 246 & 0.0001428 & 0.0001664 & 0.0001951 & 0.4118 \\
\hline 9150489M & 6/278 & 15E_4s1d1Yd_1 & $147 / 16$ & $E$ & 3.25 & 354.8 & $343 / 4$ & 30 & 0.126 & 0.189 & HLP-22 & 12 & 8 & 4 & 1.05 & 4.5 & 2.4 & 21.8 & 10.1 & 0.62 & 0.34 & s1d1 & 2.46 & 0.0001428 & 0.0001664 & 0.0001951 & 0.4118 \\
\hline 9150490M & 6/278 & 15E_4s1d1Yd_1 & $147 / 16$ & $E$ & 3.25 & 354. & $343 / 4$ & 30 & 0.126 & 0.189 & HLP-22 & 12 & 8 & 4 & 1.05 & 4.5 & 2.4 & 21.8 & 10.1 & 0.62 & 0.34 & s1d1 1 & 2.46 & 0.0001428 & 0.0001664 & 0.0001951 & 0.4118 \\
\hline 9150491M & $6 / 27 \mathrm{~B}$ & 15E_4s1d1Yd_1 & $147 / 16$ & $E$ & 3.25 & 354.8 & $343 / 4$ & 30 & 0.126 & 0.189 & HLP-22 & 12 & 8 & 4 & 1.05 & 4.5 & 2.4 & 21.8 & 10.1 & 0.62 & 0.34 & s1d1 & 2.46 & 0.0001428 & 0.0001664 & 0.0001951 & 0.4118 \\
\hline 9150492M & 6/27B & 15E_4s1d1Yd_1 & $147 / 16$ & $\mathrm{E}$ & 3.25 & 354.8 & $343 / 4$ & 30 & 0.126 & 0.189 & HLP-22 & 12 & 8 & 4 & 1.05 & 4.5 & 2.4 & 21.8 & 10.1 & 0.62 & 0.34 & s1d1 & 2.46 & 0.0001428 & 0.0001664 & 0.0001951 & 0.4118 \\
\hline 9150493M & 6/278 & 15E_4sId1Yd_1 & $147 / 16$ & $\mathrm{E}$ & 3.25 & 354.8 & $343 / 4$ & 30 & 0.126 & 0.189 & HLP-22 & 12 & 8 & 4 & 1.05 & 4.5 & 2.4 & 21.8 & 10.1 & 0.62 & 0.34 & s1d1 & 2.46 & 0.0001428 & 0.0001664 & 0.0001951 & 0.4118 \\
\hline 9150494M & 6/27B & 15E_4s1d1Yd_1 1 & $147 / 16$ & $E$ & 3.25 & 354.8 & $343 / 4$ & 30 & 0.126 & 0.189 & HLP-22 & 12 & 8 & 4 & 1.05 & 4.5 & 2.4 & 21.8 & 10.1 & 0.62 & 0.34 & s1d1 1 & 2.46 & 0.0001428 & 0.0001664 & 0.0001951 & 0.4118 \\
\hline 9150497 & 6/27C & 15E_4s1d1Xc_1 & $147 / 16$ & $\mathrm{E}$ & 3.25 & 354. & $351 / 2$ & 30 & 0.126 & 0.189 & HLP-22 & 12 & 8 & 4 & 1.05 & 4.5 & 2.4 & 21.8 & 10.1 & 0.62 & 0.34 & sid1 & 2.46 & 0.0001428 & 0.0001664 & 0.0001951 & 0.4118 \\
\hline 9150498 & $6 / 27 \mathrm{C}$ & 15E_4s1d1X__1 & $147 / 16$ & $E$ & 3.25 & 354.8 & $351 / 2$ & 30 & 0.126 & 0.189 & HLP-22 & 12 & 8 & 4 & 1.05 & 4.5 & 2.4 & 21.8 & 10.1 & 0.62 & 0.34 & s1d1 1 & 2.46 & 0.0001428 & 0.0001664 & 0.0001951 & 0.4118 \\
\hline 9150499 & 6/27C & 15E_4s1d1Xc_1 & $147 / 16$ & $\mathrm{E}$ & 3.25 & 354. & $351 / 2$ & 30 & 0.126 & 0.189 & HLP-22 & 12 & 8 & 4 & 1.05 & 4.5 & 2.4 & 21.8 & 10.1 & 0.62 & 0.34 & s1d1 & 2.46 & 0.0001428 & 0.0001664 & 0.0001951 & 0.4118 \\
\hline 9150500 & $6 / 27 \mathrm{C}$ & 15E_4s1d1X__1 & $147 / 16$ & $E$ & 3.25 & 354.8 & $351 / 2$ & 30 & 0.126 & 0.189 & HLP-22 & 12 & 8 & 4 & 1.05 & 4.5 & 2.4 & 21.8 & 10.1 & 0.62 & 0.34 & sidn & 2.46 & $\begin{array}{ll}0.0001428 \\
\end{array}$ & 0.0001664 & 0.0001951 & 0.4118 \\
\hline 9150501 & $6 / 27 \mathrm{C}$ & 15E_4s1d1Xc_1 & $147 / 16$ & $E$ & 3.25 & 354. & $351 / 2$ & 30 & 0.126 & 0.189 & HLP-22 & 12 & 8 & 4 & 1.05 & 4.5 & 2.4 & 21.8 & 10.1 & 0.62 & 0.34 & sld1 & 2.46 & 0.0001428 & 0.0001664 & 0.0001951 & 0.4118 \\
\hline 9150502 & $6 / 27 \mathrm{C}$ & 15E_4s1d1X__1 & $147 / 16$ & $E$ & 3.25 & 354.8 & $351 / 2$ & 30 & 0.126 & 0.189 & HLP-22 & 12 & 8 & 4 & 1.05 & 4.5 & 2.4 & 21.8 & 10.1 & 0.62 & 0.34 & s1d1 & 2.46 & 0.0001428 & 0.0001664 & 0.0001951 & 0.4118 \\
\hline 9150503 & $6 / 27 \mathrm{C}$ & 15E_4s1d1Xc_1 & $147 / 16$ & $E$ & 3.25 & 354.8 & $351 / 2$ & 30 & 0.126 & 0.189 & HLP-22 & 12 & 8 & 4 & 1.05 & 4.5 & 2.4 & 21.8 & 10.1 & 0.62 & 0.34 & sld1 & 246 & 0.0001428 & 0.0001664 & 0.0001951 & 0.4118 \\
\hline 9150504 & $6 / 27 \mathrm{C}$ & 15E_4sid1X__1 & $147 / 16$ & $E$ & 3.25 & 354.8 & $351 / 2$ & 30 & 0.126 & 0.189 & HLP-22 & 12 & 8 & 4 & 1.05 & 4.5 & 2.4 & 21.8 & 10.1 & 0.62 & 0.34 & s1d1 & 2.46 & 0.0001428 & 0.0001664 & 0.0001951 & 0.4118 \\
\hline 9150505 & $6 / 27 \mathrm{C}$ & 15E_4sId1Xc_1 & $147 / 16$ & E & 3.25 & 354. & $351 / 2$ & 30 & 0.126 & 0.189 & HLP-22 & 12 & 8 & 4 & 1.05 & 4.5 & 2.4 & 21.8 & 10.1 & 0.62 & 0.34 & sidn & 246 & 0.0001428 & 0.0001664 & 0.0001951 & 0.4118 \\
\hline $9150506 \mathrm{M}$ & $6 / 27 \mathrm{C}$ & 15E_4sId1Xc 1 & $147 / 16$ & $E$ & 3.25 & 354.8 & $351 / 2$ & 30 & 0.126 & 0.189 & HLP-22 & 12 & 8 & 4 & 1.05 & 4.5 & 2.4 & 21.8 & 10.1 & 0.62 & 0.34 & s1d1 & 2.46 & 0.0001428 & 0.0001664 & 0.0001951 & 0.4118 \\
\hline $9150507 \mathrm{M}$ & 6127C & 15E_4s1d1 Xc_1 & $147 / 16$ & $E$ & 3.25 & 354.8 & $351 / 2$ & 30 & 0.126 & 0.189 & HLP-22 & 12 & 8 & 4 & 1.05 & 4.5 & 2.4. & 21.8 & 10.1 & 0.62 & 0.34 & s1d1 & 2.46 & $\begin{array}{ll}0.0001428 \\
\end{array}$ & 0.0001664 & 0.0001951 & 0.4118 \\
\hline $9150508 \mathrm{M}$ & $6 / 27 \mathrm{C}$ & 15E_4s1d1X__1 & $147 / 16$ & $E$ & 3.25 & 354.8 & $351 / 2$ & 30 & 0.126 & 0.189 & HLP-22 & 12 & 8 & 4 & 1.05 & 4.5 & 2.4 & 21.8 & 10.1 & 0.62 & 0.34 & sidn & 2.46 & 0.0001428 & 0.0001664 & 0.0001951 & 0.4118 \\
\hline $9150509 \mathrm{M}$ & 6/27C & 15E_4s1d1X__ 1 & $147 / 16$ & $\mathrm{E}$ & 3.25 & 354. & $351 / 2$ & 30 & 0.126 & 0.189 & HLP-22 & 12 & 8 & 4 & 1.05 & 4.5 & 2.4 & 21.8 & 10.1 & 0.62 & 0.34 & sid1 & 2.46 & 0.0001428 & 0.0001664 & 0.0001951 & 0.4118 \\
\hline 9150510M & $6 / 27 \mathrm{C}$ & 15E_4sId1Xc 1 & $147 / 16$ & $E$ & 3.25 & 354.8 & $351 / 2$ & 30 & 0.126 & 0.189 & HLP-22 & 12 & 8 & 4 & 1.05 & 4.5 & 2.4 & 21.8 & 10.1 & 0.62 & & & 2.46 & 0.0001428 & 0.0001664 & 0.0001951 & 0.4118 \\
\hline 9150512M & $6 / 27 \mathrm{C}$ & 15E_4sId1X__ 1 & $147 / 16$ & $E$ & 3.25 & 354.8 & $351 / 2$ & 30 & 0.126 & 0.189 & HLP-22 & 12 & 8 & 4 & 1.05 & 4.5 & 2.4 & 21.8 & 10.1 & 0.62 & 0.34 & s1d1 & 2.46 & 0.0001428 & 0.0001664 & 0.0001951 & 0.4118 \\
\hline 9150513 & 6/30A & 15E_4sid1Xc_ 1 & $147 / 16$ & $E$ & 3.25 & 354.8 & 35 & 30 & 0.126 & 0.189 & HLP-22 & 12 & 8 & 4 & 1.05 & 4.5 & 2.4 & 21.8 & 10.1 & 0.62 & 0.34 & s1d1 & 2.46 & 0.0001428 & 0.0001664 & 0.0001951 & 0.4118 \\
\hline 9150514 & $6 / 30 \mathrm{~A}$ & 15E_4sId1 Xc_1 & $147 / 16$ & $E$ & 3.25 & 354.8 & 35 & 30 & 0.126 & 0.189 & HLP-22 & 12 & 8 & 4 & 1.05 & 4.5 & 2.4 & 21.8 & 10.1 & 0.62 & 0.34 & s1d1 & 246 & 0.0001428 & 0.0001664 & 0.0001951 & 0.4118 \\
\hline 9150515 & $6 / 30 \mathrm{~A}$ & 15E_4sid1 $1 \times$ __ 1 & $147 / 16$ & $E$ & 3.25 & 354. & 35 & 30 & 0.126 & 0.189 & HLP-22 & 12 & 8 & 4 & 1.05 & 4.5 & 2.4 & 21.8 & 10.1 & 0.62 & 0.34 & sidn & 2.46 & 0.0001428 & 0.0001664 & 0.0001951 & 0.4118 \\
\hline $9150516 \mathrm{M}$ & $630 \mathrm{~A}$ & 15E_4sid1X__1 & $147 / 16$ & $E$ & 3.25 & 354.8 & 35 & 30 & 0.126 & 0.189 & HLP-22 & 12 & 8 & 4 & & 4.5 & 2.4 & 21 & & 0.62 & & sic & 2. & & & & \\
\hline 9150517M & 6/30A & 15E_4sId1X__1 & $147 / 16$ & $\mathrm{E}$ & 3.25 & 354.8 & 35 & 30 & 0.126 & 0.189 & HLP-22 & 12 & 8 & 4 & 1.05 & 4.5 & 2.4 & 21.8 & 10.1 & 0.62 & 0.34 & s1d1 & 2.46 & 0.0001428 & 0.0001664 & 0.0001951 & 0.4118 \\
\hline 915051 & 6/30A & 15E 4s1d1X & $147 / 16$ & $E$ & 3.25 & 354.8 & & 30 & 0.126 & 0.189 & HLP-22 & 12 & 8 & 4 & 1.05 & 4.5 & 2.4 & 21.8 & 10.1 & 0.62 & 0.34 & sidn & 246 & 0.0001428 & 0.0001664 & 0.0001951 & 0.4118 \\
\hline
\end{tabular}


Table B.3. Data from 2008 Tests in Small-Scale Vessel with Elliptical Head B.14

\begin{tabular}{|c|c|c|c|c|c|c|c|c|c|c|c|c|c|c|c|c|c|c|c|c|c|c|c|c|c|c|c|c|c|}
\hline $\begin{array}{l}\text { Tank Water } \\
\text { Temperature }\end{array}$ & $\begin{array}{l}\text { Water } \\
\text { Density }\end{array}$ & $\begin{array}{l}\text { Solids } \\
\text { Fraction }\end{array}$ & $\begin{array}{c}\text { Pulse } \\
\text { Volume } \\
\text { Fraction }\end{array}$ & $\begin{array}{l}\text { Duty } \\
\text { Cycle }\end{array}$ & $\begin{array}{l}\text { Oydle } \\
\text { Time }\end{array}$ & $\begin{array}{c}\text { Pulsed } \\
\text { or } \\
\text { Steady } \\
\text { Jet }\end{array}$ & $\begin{array}{l}\text { Us } \\
\text { Steacady } \\
\text { Jet }\end{array}$ & $\begin{array}{c}\text { U1 } \\
\text { Pulsing } \\
\text { Jet }\end{array}$ & $\begin{array}{c}\text { U2 } \\
\text { URMS }\end{array}$ & $\begin{array}{c}\text { U3 } \\
\text { URMB }\end{array}$ & $\begin{array}{l}\text { Discharge } \\
\text { Velocity }\end{array}$ & $\begin{array}{c}\text { Citical } \\
\text { Suspension } \\
\text { velocity }\end{array}$ & $\begin{array}{c}\text { Average } \\
\text { Peak loud } \\
\text { Height }\end{array}$ & $\begin{array}{c}\text { UCS } \\
\text { Condition }\end{array}$ & $\begin{array}{l}\text { UCS } \\
\text { Method }\end{array}$ & $\begin{array}{l}\text { UCS } \\
\text { Flag }\end{array}$ & $\begin{array}{l}\text { UCS } \\
\text { Center } \\
\text { Flag }\end{array}$ & $\begin{array}{c}\text { UCS udv } \\
\text { Hag }\end{array}$ & $\begin{array}{l}\text { UCS based } \\
\text { on } \\
\text { Decreasing } \\
\text { Velocity }\end{array}$ & $\begin{array}{l}\text { Sweep } \\
\text { Increase I } \\
\text { Decrease }\end{array}$ & $\begin{array}{c}\text { UDV } \\
\text { Height } \\
\text { Bed }\end{array}$ & $\begin{array}{l}\text { Particle } \\
\text { Motion }\end{array}$ & $\begin{array}{l}\text { Solids } \\
\text { Level }\end{array}$ & $\begin{array}{l}\text { Outer } \\
\text { Botomm } \\
\text { Pattem }\end{array}$ & $\begin{array}{l}\text { Inner } \\
\text { Botorom } \\
\text { Pattem }\end{array}$ & Case ID & Test & TDP & $\begin{array}{l}\text { Row } \\
\text { Number }\end{array}$ \\
\hline$c$ & $\mathrm{~g} / \mathrm{cm}^{3}$ & fraction & fraction & fraction & $\mathrm{s}$ & text & $\mathrm{m} / \mathrm{s}$ & $\mathrm{m} / \mathrm{s}$ & ms & $\mathrm{m} / \mathrm{s}$ & $\mathrm{m} / \mathrm{s}$ & $\mathrm{ms}$ & in. & $\mathrm{m} / \mathrm{s}$ & text & text & text & text & $\mathrm{m} / \mathrm{s}$ & text & $\mathrm{mm}$ & text & text & text & text & text & text & text & text \\
\hline$T$ & $\rho$ & $\phi_{\mathrm{s}}$ & $\phi_{p}$ & $D C$ & tc & Jet & $U_{s}$ & $\mathrm{U}_{1}$ & $\mathrm{U}_{2}$ & U3 & $u$ & Us & $H_{c}$ & Usse & Uan & Uosvis & Uscen & Uosuch & Uss D & $\mathrm{s}_{\mathrm{v}}$ & $\mathrm{H}_{\text {bed }}$ & PM & Sol & $\mathrm{SPo}$ & $\mathrm{SP}$ & ID & MDDX & $\mathrm{TDP}$ & MSS \\
\hline 26.4 & 0.999 & 0.00500 & 0.050 & 0.338 & 9.1 & $\mathrm{P}$ & NA & 6.55 & 6.73 & 6.81 & 7.00 & 5.90 & 6.75 & NA & NA & NA & NA & NA & NA & 1 & 0.0 & 4 & NA & NA & NA & 15E_4s1d1Yc_1 & 6/27A & TDP-195 & 9150475 \\
\hline 26.6 & 0.999 & 0.00500 & 0.050 & 0.333 & 8.0 & $P$ & NA & 7.51 & 7.69 & 7.78 & 8.00 & 5.90 & 11.00 & NA & NA & NA & NA & NA & NA & 1 & 0.0 & 4 & NA & NA & NA & 15E_4s1d1YC_ 1 & 6/27A & TDP-195 & 9150476 \\
\hline 26.9 & 0.999 & 0.00500 & 0.050 & 0.337 & 7.5 & $\mathrm{P}$ & NA & 7.97 & 8.17 & 8.27 & 8.50 & 5.90 & 16.50 | & NA & NA & NA & NA & NA & NA & 1 & 0.0 & 4 & NA & NA & $N_{A}$ & 15E 4sid1YY 1 & 6/27A & TDP-195 & 9150477 \\
\hline 27.2 & 0.999 & 0.00500 & 0.050 & 0.337 & 7.1 & $\mathrm{P}$ & NA & 8.41 & 8.63 & 8.74 & 9.00 & 5.90 & 19.25 & NA & NA & NA & NA & NA & NA & 1 & 0.0 & 4 & NA & NA & NA & 15E_4sid1Yc_1 & 6/27A & TDP-195 & 9150478 \\
\hline 27.4 & 0.999 & 0.00500 & 0.050 & 0.330 & 8.5 & $P$ & NA & 7.09 & 7.24 & 7.32 & 7.50 & 5.90 & 7.75 & NA & NA & NA & NA & NA & NA & 1 & 0.0 & 4 & NA & NA & NA & 15E_4s1d1Yc_1 1 & 6/27A & TDP-195 & 9150479 \\
\hline 27.8 & 0.999 & 0.00500 & 0.050 & 0.186 & 25.0 & $\mathrm{P}$ & NA & 4.28 & 4.36 & 4.40 & 4.50 & 6.00 & 3.75 & NA & NA & NA & NA & NA & NA & (null) & 7.3 & 1 & NA & NA & NA & 15E_4s1d1Yd_1 & 6/278 & TDP-195 & 9150480 \\
\hline 27.6 & 0.999 & 0.00500 & 0.050 & 0.188 & 22.5 & $\mathrm{P}$ & NA & 4.74 & 4.83 & 4.88 & 5.00 & 6.00 & 4.75 & NA & NA & NA & NA & NA & NA & 1 & 4.3 & 1 & NA & NA & NA & 15E_4sid1Yd_1 & $6 / 27 \mathrm{~B}$ & TDP-195 & 9150481 \\
\hline 27.7 & 0.999 & 0.00500 & 0.050 & 0.187 & 20.5 & $\mathrm{P}$ & NA & 5.18 & 5.30 & 5.36 & 5.50 & 6.00 & 5.25 & NA & NA & NA & NA & NA & NA & 1 & 4.3 & 1 & NA & NA & $N_{A}$ & 15E 4sid1YY 1 1 & $6 / 27 \mathrm{~B}$ & TDP-195 & 9150482 \\
\hline 27.8 & 0.999 & 0.00500 & 0.050 & 0.188 & 19.4 & $\mathrm{P}$ & NA & 5.45 & 5.59 & 5.65 & 5.80 & 6.00 & 5.50 & NA & NA & UCSis & NA & NA & NA & 1 & 2.1 & 3 & NA & NA & NA & 15E_4s1d1Yd_ 1 & 6/278 & TDP-195 & 9150483 \\
\hline 27.8 & 0.999 & 0.00500 & 0.050 & 0.186 & 20.1 & $\mathrm{P}$ & NA & 5.35 & 5.44 & 5.48 & 5.60 & 6.00 & 5.00 & NA & NA & NA & NA & NA & NA & 1 & 3.6 & 1 & NA & NA & NA & 15E_4sid1Yd_ 1 & $6 / 278$ & TDP-195 & 9150484 \\
\hline 27.9 & 0.998 & 0.00500 & 0.050 & 0.186 & 19.4 & $\mathrm{P}$ & NA & 5.55 & 5.64 & 5.68 & 5.80 & 6.00 & 5.50 & NA & NA & ucsis & NA & NA & NA & 1 & 28 & 3 & NA & NA & NA & 15E_4s1d1Yd_1 & 6/278 & TDP-195 & 9150485 \\
\hline 27.9 & 0.999 & 0.00500 & 0.050 & 0.186 & 18.8 & $\mathrm{P}$ & NA & 5.73 & 5.82 & 5.87 & 6.00 & 6.00 & 5.75 & 6.00 & udv & NA & NA & ucsudv & NA & 1 & 0.7 & 4 & NA & NA & NA & 15E_4s1d1Yd_1 & 6/278 & TDP-195 & 9150486 \\
\hline 28.1 & 0.999 & 0.00500 & 0.050 & 0.187 & 18.2 & $\mathrm{P}$ & NA & 5.93 & 6.03 & 6.08 & 6.20 & 6.00 & 6.00 & NA & NA & NA & NA & NA & NA & 1 & 0.0 & 4 & NA & NA & NA & 15E_4s1d1Yd_ 1 & $6 / 27 \mathrm{~B}$ & TDP-195 & 9150487 \\
\hline 28.2 & 0.998 & 0.00500 & 0.050 & 0.188 & 17.6 & $\mathrm{P}$ & NA & 6.06 & 6.19 & 6.25 & 6.40 & 6.00 & 6.50 & NA & NA & NA & NA & NA & NA & 1 & 0.0 & 4 & NA & NA & NA & 15E_4s1d1Yd_ 1 & 6/278 & TDP-195 & 9150488 \\
\hline 28.3 & 0.999 & 0.00500 & 0.050 & 0.188 & 16.1 & $\mathrm{P}$ & NA & 6.62 & 6.76 & 6.83 & 7.00 & 6.00 & 7.00 & NA & NA & NA & NA & NA & NA & 1 & 0.0 & 4 & NA & NA & NA & 15E_4sid1Yd_ 1 & 6/278 & TDP-195 & 9150489 \\
\hline 28.4 & 0.998 & 0.00500 & 0.050 & 0.187 & 15.2 & $\mathrm{P}$ & NA & 7.02 & 7.16 & 7.23 & 7.40 & 6.00 & 7.50 & NA & NA & NA & NA & NA & NA & 1 & 0.0 & 4 & NA & NA & NA & 15E_4s1d1Yd 1 & 6/278 & TDP-195 & 9150490 \\
\hline 28.5 & 0.998 & 0.00500 & 0.050 & 0.186 & 14.1 & $\mathrm{P}$ & NA & 7.56 & 7.72 & 7.80 & 8.00 & 6.00 & 8.50 & NA & NA & NA & NA & NA & NA & 1 & 0.0 & 4 & NA & NA & NA & 15E_4sid1Yd_ 1 & 6/278 & TDP-195 & 9150491 \\
\hline 28.6 & 0.998 & 0.00500 & 0.050 & 0.188 & 12.5 & $\mathrm{P}$ & NA & 8.45 & 8.65 & 8.75 & 9.00 & 6.00 & 12.25 & NA & NA & NA & NA & NA & NA & 1 & 0.0 & 4 & NA & NA & NA & 15E_4sid1Yd_ 1 & 6/278 & TDP-195 & 9150492 \\
\hline 29.1 & 0.998 & 0.00500 & 0.050 & 0.186 & 11.5 & $\mathrm{P}$ & NA & 9.36 & 9.61 & 9.74 & 10.00 & 6.00 & 15.75 & NA & NA & NA & NA & NA & NA & 1 & 0.0 & 4 & NA & NA & NA & 15E_4s1d1Yd_ 1 & 6/278 & TDP-195 & 9150493 \\
\hline 29.3 & 0.998 & 0.00500 & 0.050 & 0.189 & 10.5 & $\mathrm{P}$ & NA & 10.07 & 10.41 & 10.57 & 11.00 & 6.00 & 19.50 & NA & NA & NA & NA & NA & NA & 1 & 0.0 & 4 & NA & NA & NA & 15E_4sid1Yd_ 1 & 6/278 & TDP-195 & 9150494 \\
\hline 28.9 & 0.998 & 0.01500 & 0.050 & 0.334 & 11.7 & $\mathrm{P}$ & NA & 5.17 & 5.28 & 5.34 & 5.50 & 8.20 & 3.38 & NA & NA & NA & NA & $\mathrm{NA}$ & $\mathrm{NA}$ & (null) & 11.0 & 1 & NA & NA & NA & 15E_4s1d1X__1 & $6 / 27 \mathrm{C}$ & TDP-196 & 9150497 \\
\hline 28.9 & 0.998 & 0.01500 & 0.050 & 0.336 & 10.5 & $\mathrm{P}$ & NA & 5.67 & 5.79 & 5.84 & 6.00 & 8.20 & 3.75 & NA & NA & NA & NA & NA & NA & 1 & 8.8 & 1 & NA & NA & NA & 15E_4s1d1Xc_1 & $6 / 27 \mathrm{C}$ & TDP-196 & 9150498 \\
\hline 28.9 & 0.998 & 0.01500 & 0.050 & 0.337 & 9.7 & $\mathrm{P}$ & NA & 6.09 & 6.24 & 6.31 & 6.50 & 8.20 & 4.25 & NA & NA & NA & NA & NA & NA & 1 & 7.3 & 1 & NA & NA & NA & 15E_4s1d1Xc_1 & $6 / 27 \mathrm{C}$ & TDP-196 & 9150499 \\
\hline 29.0 & 0.998 & 0.01500 & 0.050 & 0.336 & 9.0 & $\mathrm{P}$ & NA & 6.63 & 6.77 & 6.84 & 7.00 & 8.20 & 4.50 & NA & NA & NA & NA & NA & NA & 1 & 4.6 & 1 & NA & NA & NA & 15E_4s1d1Xc_1 & 6/27C & TDP-196 & 9150500 \\
\hline 29.1 & 0.998 & 0.01500 & 0.050 & 0.332 & 8.8 & $\mathrm{P}$ & NA & 6.83 & 6.97 & 7.03 & 7.20 & 8.20 & 4.75 & NA & NA & NA & NA & NA & NA & 1 & 5.0 & 1 & NA & NA & NA & $15 E \_4 s 1 d 1 \times c \_1$ & $6 / 27 \mathrm{C}$ & TDP-196 & 9150501 \\
\hline 29.2 & 0.998 & 0.01500 & 0.050 & 0.338 & 8.6 & $\mathrm{P}$ & NA & 6.92 & 7.09 & 7.18 & 7.40 & 8.20 & 4.75 & NA & NA & ucsis & NA & NA & NA & 1 & 4.6 & 3 & NA & NA & NA & $15 E \_4 s 1 d 1 \times c \_1$ & 6/27C & TDP-196 & 9150502 \\
\hline 29.3 & 0.998 & 0.01500 & 0.050 & 0.333 & 8.4 & $\mathrm{P}$ & NA & 7.16 & 7.32 & 7.40 & 7.60 & & 4.75 & NA & NA & N & NA & NA & $\mathrm{N}$ & 1 & 4.1 & 4 & NA & NA & NA & 15E_4s1d1Xc_1 & $6 / 27 \mathrm{C}$ & TDP-196 & 9150503 \\
\hline 29.4 & 0.998 & 0.01500 & 0.050 & 0.337 & 8.2 & $\mathrm{P}$ & NA & 7.29 & 7.47 & 7.56 & 7.80 & 8.20 & 5.00 & NA & NA & NA & NA & NA & NA & 1 & 14 & 4 & NA & NA & NA & 15E_4s1d1Xc_1 & $6 / 27 \mathrm{C}$ & TDP-196 & 9150504 \\
\hline 29.5 & 0.998 & 0.01500 & 0.050 & 0.337 & 8.0 & $\mathrm{P}$ & NA & 7.47 & 7.67 & 7.76 & 8.00 & 8.20 & 5.25 & NA & NA & NA & NA & NA & NA & 1 & 2.9 & 4 & NA & NA & NA & $15 E \_4 s 1 d 1 \times c \_1$ & $6 / 27 \mathrm{C}$ & TDP-196 & 9150505 \\
\hline 29.6 & 0.998 & 0.01500 & 0.050 & 0.334 & 7.8 & $\mathrm{P}$ & NA & 7.71 & 7.88 & 7.97 & 8.20 & 8.20 & 5.25 & 8.20 & udv & NA & NA & ucsudv & NA & 1 & 0.4 & 4 & NA & NA & NA & 15E_4s1d1Xc_1 & $6 / 27 \mathrm{C}$ & TDP-196 & 9150506 \\
\hline 29.7 & 0.998 & 0.01500 & 0.050 & 0.336 & 7.6 & $\mathrm{P}$ & NA & 7.89 & 8.08 & 8.17 & 8.40 & & 5.50 & NA & NA & $N$ & NA & NA & $\mathrm{NA}$ & 1 & 0.0 & 4 & NA & NA & NA & 15E_4s1d1Xc_1 & $6 / 27 \mathrm{C}$ & TDP-196 & 9150507 \\
\hline 29.9 & 0.998 & 0.01500 & 0.050 & 0.335 & 7.1 & $\mathrm{P}$ & NA & 8.45 & 8.66 & 8.7 & 9 & 8. & 5.75 & NA & $\mathrm{N} / \mathrm{H}$ & $\mathrm{N}$ & NA & N & $\mathrm{N} / \mathrm{H}$ & 1 & 0.0 & 4 & NA & NA & $N$ & $\mathrm{~d} 1 \times \mathrm{c}_{1} 1$ & $6 / 27 \mathrm{C}$ & TDP-196 & 9150508 \\
\hline 30.1 & 0.998 & 0.01500 & 0.050 & 0.336 & 6.4 & $\mathrm{P}$ & NA & 9.35 & 9.59 & 9.71 & 10.00 & 8.20 & 6.25 & NA & NA & NA & NA & NA & NA & 1 & 0.0 & 4 & NA & NA & NA & 15E_4s1d1Xc_1 & $6 / 27 \mathrm{C}$ & TDP-196 & 9150509 \\
\hline 30.2 & 0.998 & 0.01500 & 0.050 & 0.337 & 5.8 & $\mathrm{P}$ & NA & 10.23 & 10.52 & 10.67 & 11. & & 6.50 & NA & Not & & NA & & NA & 1 & 0.0 & 4 & NA & NA & N & $d 1 \times c \_1$ & 6/27C & TDP-196 & 9150510 \\
\hline 30.7 & 0.998 & 0.01500 & 0.050 & 0.337 & 5.4 & $\mathrm{P}$ & NA & 11.07 & 11.44 & 11.62 & 12.00 & 8.20 & 9.50 & NA & NA & NA & NA & NA & NA & 1 & 0.8 & 4 & NA & NA & NA & 15E_4sid1Xc_1 & $6 / 27 \mathrm{C}$ & TDP-196 & 9150512 \\
\hline 28.6 & 0.998 & 0.01500 & 0.050 & 0.329 & 8.1 & $\mathrm{P}$ & NA & 7.52 & 7.69 & 7.78 & 8.00 & & 5.00 & NA & NA & & NA & & & 1 & 1.4 & 4 & NA & NA & NA & & 6/30A & TDP-197 & 9150513 \\
\hline 28.8 & 0.998 & 0.01500 & 0.050 & 0.333 & 7.8 & $\mathrm{P}$ & NA & 7.65 & 7.84 & 7.94 & 8.20 & 8.60 & 5.25 & NA & NA & N/f & NA & NA & NA & 1 & 29 & 4 & NA & NA & NA & E-4sid1Xc_1 & 6/30A & TDP-197 & 9150514 \\
\hline 29.0 & 0.998 & 0.01500 & 0.050 & 0.334 & 7.6 & $\mathrm{P}$ & NA & 7.83 & 8.03 & 8.14 & 8.40 & 8.60 & 5.25 & NA & NA & NA & NA & $N$ & $\mathrm{~N} /$ & 1 & 0.6 & 4 & NA & NA & NA & 15E_4s1d1Xc_1 & 6/30A & TDP-197 & 9150515 \\
\hline 29.1 & 0.998 & 0.01500 & 0.050 & 0.335 & 7.4 & $\mathrm{P}$ & NA & 8.01 & 8.23 & 8.33 & 8.60 & 8.60 & 5.25 & & udv & NA & NA & ucsur & NA & 1 & 1.4 & 4 & NA & NA & NA & $15 E \_4 s 1 d 1 \times c \_1$ & 6/30A & TDP-197 & 9150516 \\
\hline 29.3 & 0.998 & 0.01500 & 0.050 & 0.333 & 7.3 & $P$ & NA & 8.23 & 8.44 & 8.55 & 8.80 & 8.60 & 5.50 & NA & NA & NA & NA & NA & NA & 1 & 0.0 & 4 & NA & NA & NA & 15E_-4sid1 Xc 1 & 6/30A & TDP-197 & 9150517 \\
\hline & & & & & & & & & & & & & & & & & & & & & & & & & & & & & \\
\hline
\end{tabular}


Table B.3. Data from 2008 Tests in Small-Scale Vessel with Elliptical Head A.15

\begin{tabular}{|c|c|c|c|c|c|c|c|c|c|c|c|c|c|c|c|c|c|c|c|c|c|c|c|c|c|c|c|}
\hline $\begin{array}{l}\text { Rov } \\
\text { Number }\end{array}$ & Test & Case ID & $\begin{array}{c}\text { Tank } \\
\text { Diameter }\end{array}$ & $\begin{array}{l}\text { Head } \\
\text { Shape }\end{array}$ & \begin{tabular}{|l} 
Dish \\
Height
\end{tabular} & $\begin{array}{l}\text { Dish } \\
\text { Volume }\end{array}$ & $\begin{array}{c}\text { Tank Fill } \\
\text { Height }\end{array}$ & $\begin{array}{l}\text { Retur } \\
\text { Line } \\
\text { Height }\end{array}$ & \begin{tabular}{c|} 
Nozzle \\
Inner \\
Dianter
\end{tabular} & $\begin{array}{c}\text { Nozzle } \\
\text { Stand-ff } \\
\text { Distance }\end{array}$ & $\begin{array}{l}\text { Pulse Tube } \\
\text { Configuration }\end{array}$ & \begin{tabular}{|l} 
Installed \\
Nozzles
\end{tabular} & $\begin{array}{l}\text { Outer } \\
\text { Nozzles } \\
\text { Operated }\end{array}$ & $\begin{array}{l}\text { Inner } \\
\text { Nozzles } \\
\text { Operated }\end{array}$ & $\begin{array}{l}\text { Pulse Tube } \\
\text { Outer } \\
\text { Dianteter }\end{array}$ & $\begin{array}{c}\text { Outer } \\
\text { PMM } \\
\text { Radius }\end{array}$ & $\begin{array}{c}\text { Inner PJM } \\
\text { Radius } \\
\end{array}$ & \begin{tabular}{|c|} 
"FO" Outer PJM \\
Impingement \\
Angle
\end{tabular} & $\begin{array}{c}\text { "FO' Inner PJM } \\
\text { Impingement Angle }\end{array}$ & \begin{tabular}{|l} 
Ratio Outer PJM \\
to Tank Radius
\end{tabular} & $\begin{array}{l}\text { Ratio Inner PJM } \\
\text { to Tank Radius }\end{array}$ & Simulant & \begin{tabular}{|l|} 
Solids \\
Density \\
\end{tabular} & $\begin{array}{c}\text { Particle } \\
\text { Diameter d5 }\end{array}$ & \begin{tabular}{c|} 
Particle \\
Diameter d d50
\end{tabular} & $\begin{array}{c}\text { Particle } \\
\text { Diameter d95 }\end{array}$ & $\begin{array}{l}\text { Void } \\
\text { Fraction }\end{array}$ \\
\hline text & text & text & in. & text & in. & in ${ }^{3}$ & in. 1 & in. & in. & in. & text & number & number & number & in. & in. & in. & deg & deg & nondim & nondim & text & \begin{tabular}{|l|l|}
$\mathrm{g} / \mathrm{cm}^{3}$ \\
\end{tabular} & $\mathrm{~m}$ & \begin{tabular}{l|}
$\mathrm{m}$ \\
\end{tabular} & $m$ & fraction \\
\hline MSS & MDDX & $\mathrm{ID}$ & $\mathrm{D}$ & HS & Hish & $V_{\text {dish }}$ & $\mathrm{H}$ & $\operatorname{Rin}$ & $d$ & sod & PT & $\mathrm{N}$ & $\mathrm{Nb}$ & $\mathrm{N}$ & $\mathrm{PT}_{\alpha d}$ & $R_{0}$ & $R$ & $\theta_{0}$ & $\theta_{1}$ & $R d R$ & $R / R$ & $\operatorname{sxdx}$ & $\rho_{\mathrm{s}}$ & $d_{b}$ & $d_{60}$ & $d_{65}$ & vf \\
\hline 9150519 & 6/30A & 15E_4sid1Xc_1 & $147 / 16$ & $E$ & 3.25 & 354.8 & 35 & 30 & 0.126 & 0.189 & HLP-22 & 12 & 8 & 4 & 1.05 & 4.5 & 2.4 & 21.8 & 10.1 & 0.62 & 0.34 & s1d1 1 & 2.46 & 0.0001428 & 0.0001664 & 0.0001951 & 0.4118 \\
\hline 9150520 & $630 \mathrm{~A}$ & 15E_4sId1 Xc_1 & $147 / 16$ & $E$ & 3.25 & 354.8 & 35 & 30 & 0.126 & 0.189 & HLP-22 & 12 & 8 & 4 & 1.05 & 4.5 & 2.4 & 21.8 & 10.1 & 0.62 & 0.34 & sidn 1 & 2.46 & $\begin{array}{ll}0.0001428 \\
\end{array}$ & 0.0001664 & 0.0001951 & 0.4118 \\
\hline 9150521 & $6130 \mathrm{~A}$ & 15E_4s1d1X__1 & $147 / 16$ & $E$ & 3.25 & 354.8 & 35 & 30 & 0.126 & 0.189 & HLP-22 & 12 & 8 & 4 & 1.05 & 4.5 & 2.4 & 21.8 & 10.1 & 0.62 & 0.34 & s1d1 & 2.46 & $\begin{array}{ll}0.0001428 \\
\end{array}$ & 0.0001664 & 0.0001951 & 0.4118 \\
\hline 9150522 & $6 / 30 \mathrm{~A}$ & 15E_4s $1 \mathrm{~d} 1 \times \mathrm{C} \_1$ & $147 / 16$ & E & 3.25 & 354.8 & 35 & 30 & 0.126 & 0.189 & HLP-22 & 12 & 8 & 4 & 1.05 & 4.5 & 2.4 & 21.8 & 10.1 & 0.62 & 0.34 & sld1 & 2.46 & 0.0001428 & 0.0001664 & 0.0001951 & 0.4118 \\
\hline 9150523 & $630 \mathrm{~A}$ & 15E_4s1d1X__1 & $147 / 16$ & $E$ & 3.25 & 354.8 & 35 & 30 & 0.126 & 0.189 & HLP-22 & 12 & 8 & 4 & 1.05 & 4.5 & 2.4 & 21.8 & 10.1 & 0.62 & 0.34 & s1d1 & 2.46 & 0.0001428 & 0.0001664 & 0.0001951 & 0.4118 \\
\hline 9150524 & $6 / 30 \mathrm{~A}$ & 15E_4s1d1Xc_1 & $147 / 16$ & $E$ & 3.25 & 354.8 & 35 & 30 & 0.126 & 0.189 & HLP-22 & 12 & 8 & 4 & 1.05 & 4.5 & 2.4 & 21.8 & 10.1 & 0.62 & 0.34 & sld1 & 2.46 & 0.0001428 & 0.0001664 & 0.0001951 & 0.4118 \\
\hline 9150525 & $630 \mathrm{~A}$ & 15E_4s1d1X__1 & $147 / 16$ & $E$ & 3.25 & 354.8 & 35 & 30 & 0.126 & 0.189 & HLP-22 & 12 & 8 & 4 & 1.05 & 4.5 & 2.4 & 21.8 & 10.1 & 0.62 & 0.34 & s1d1 1 & 2.46 & 0.0001428 & 0.0001664 & 0.0001951 & 0.4118 \\
\hline 9150526 & $6 / 30 \mathrm{~B}$ & 15E_4s1d5Zc_1 & $147 / 16$ & $E$ & 3.25 & 354.8 & 35 & 30 & 0.126 & 0.189 & HLP-22 & 12 & 8 & 4 & 1.05 & 4.5 & 2.4 & 21.8 & 10.1 & 0.62 & 0.34 & sid5 & 2.5 & 0.0000328 & 0.0000439 & 0.0000585 & 0.4012 \\
\hline 9150527 & $6 / 30 \mathrm{~B}$ & 15E_4s1d5Zc_1 & $147 / 16$ & $E$ & 3.25 & 354.8 & 35 & 30 & 0.126 & 0.189 & HLP-22 & 12 & 8 & 4 & 1.05 & 4.5 & 2.4 & 21.8 & 10.1 & 0.62 & 0.34 & s1d5 & 2.5 & 0.0000328 & 0.0000439 & 0.0000585 & 0.4012 \\
\hline 9150528 & $6 / 30 \mathrm{~B}$ & 15E_4s1d5Zc_1 & $147 / 16$ & $E$ & 3.25 & 354.8 & 35 & 30 & 0.126 & 0.189 & HLP-22 & 12 & 8 & 4 & 1.05 & 4.5 & 2.4 & 21.8 & 10.1 & 0.62 & 0.34 & sid5 & 2.5 & 0.0000328 & 0.0000439 & 0.0000585 & 0.4012 \\
\hline 9150529 & $6 / 30 \mathrm{~B}$ & 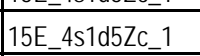 & $147 / 16$ & E & 3.25 & 354.8 & 35 & 30 & 0.126 & 0.189 & HLP-22 & 12 & 8 & 4 & 1.05 & 4.5 & 2.4 & 21.8 & 10.1 & 0.62 & 0.34 & s1d5 & 2.5 & 0.0000328 & 0.0000439 & 0.0000585 & 0.4012 \\
\hline 9150530 & $6 / 30 \mathrm{~B}$ & 15E 4siddszc 1 & $147 / 16$ & $\mathrm{E}$ & 3.25 & 354.8 & 35 & 30 & 0.126 & 0.189 & HLP-22 & 12 & 8 & 4 & 1.05 & 4.5 & 2.4 & 21.8 & 10.1 & 0.62 & 0.34 & s1d5 & 2.5 & 0.0000328 & 0.0000439 & 0.0000585 & 0.4012 \\
\hline 9150531 & $6 / 30 \mathrm{~B}$ & 15E_4s1d5Zc_1 & $147 / 16$ & $E$ & 3.25 & 354.8 & 35 & 30 & 0.126 & 0.189 & HLP-22 & 12 & 8 & 4 & 1.05 & 4.5 & 2.4 & 21.8 & 10.1 & 0.62 & 0.34 & s1d5 & 2.5 & 0.0000328 & 0.0000439 & 0.0000585 & 0.4012 \\
\hline 9150532 & $630 \mathrm{~B}$ & 15E_4s1d5Z__1 & $147 / 16$ & $E$ & 3.25 & 354.8 & 35 & 30 & 0.126 & 0.189 & HLP-22 & 12 & 8 & 4 & 1.05 & 4.5 & 2.4 & 21.8 & 10.1 & 0.62 & 0.34 & s1d5 & 2.5 & 0.0000328 & 0.0000439 & 0.0000585 & 0.4012 \\
\hline 9150533M & $6 / 30 \mathrm{~B}$ & 15E_4s1d5Zc_ 1 & $147 / 16$ & $E$ & 3.25 & 354.8 & 35 & 30 & 0.126 & 0.189 & HLP-22 & 12 & 8 & 4 & 1.05 & 4.5 & 2.4 & 21.8 & 10.1 & 0.62 & 0.34 & s1d5 & 2.5 & 0.0000328 & 0.0000439 & 0.0000585 & 0.4012 \\
\hline $9150534 \mathrm{M}$ & $6130 \mathrm{~B}$ & 15E_4s1d5Zc_1 & $147 / 16$ & $E$ & 3.25 & 354.8 & 35 & 30 & 0.126 & 0.189 & HLP-22 & 12 & 8 & 4 & 1.05 & 4.5 & 2.4 & 21.8 & 10.1 & 0.62 & 0.34 & s1d5 & 2.5 & 0.0000328 & 0.0000439 & 0.0000585 & 0.4012 \\
\hline 9150535M & $6 / 30 B$ & 15E_4s1d5Zc_ 1 & $147 / 16$ & $E$ & 3.25 & 354.8 & 35 & 30 & 0.126 & 0.189 & HLP-22 & 12 & 8 & 4 & 1.05 & 4.5 & 2.4 & 21.8 & 10.1 & 0.62 & 0.34 & s1d5 & 2.5 & 0.0000328 & 0.0000439 & 0.0000585 & 0.4012 \\
\hline $9150536 \mathrm{M}$ & $7 / 1 \mathrm{~A}$ & 15E_4s1d5Zc_1 & $147 / 16$ & $\mathrm{E}$ & 3.25 & 354.8 & 35 & 30 & 0.126 & 0.189 & HLP-22 & 12 & 8 & 4 & 1.05 & 4.5 & 2.4 & 21.8 & 10.1 & 0.62 & 0.34 & s1d5 & 2.5 & 0.0000328 & 0.0000439 & 0.0000585 & 0.4012 \\
\hline $9150537 \mathrm{M}$ & $7 / 1 \mathrm{~A}$ & 15E_4sidszzc_1 & $147 / 16$ & $E$ & 3.25 & 354.8 & 35 & 30 & 0.126 & 0.189 & HLP-22 & 12 & 8 & 4 & 1.05 & 4.5 & 2.4 & 21.8 & 10.1 & 0.62 & 0.34 & s1d5 & 2.5 & 0.0000328 & 0.0000439 & 0.0000585 & 0.4012 \\
\hline $9150538 \mathrm{M}$ & $7 / 1 \mathrm{~A}$ & 15E_4s1d5Zc_1 & $147 / 16$ & $E$ & 3.25 & 354.8 & 35 & 30 & 0.126 & 0.189 & HLP-22 & 12 & 8 & 4 & 1.05 & 4.5 & 2.4 & 21.8 & 10.1 & 0.62 & 0.34 & s1d5 & 2.5 & 0.0000328 & 0.0000439 & 0.0000585 & 0.4012 \\
\hline 9150539 & 7/1A & 15E_4sIda5zc_1 & $147 / 16$ & $\mathrm{E}$ & 3.25 & 354.8 & 35 & 30 & 0.126 & 0.189 & HLP-22 & 12 & 8 & 4 & 1.05 & 4.5 & 2.4 & 21.8 & 10.1 & 0.62 & 0.34 & s1d5 & 2.5 & 0.0000328 & 0.0000439 & 0.0000585 & 0.4012 \\
\hline 9150540 & $7 / 1 \mathrm{~A}$ & 15E_4s1d5Zc_1 & $147 / 16$ & $E$ & 3.25 & 354.8 & 35 & 30 & 0.126 & 0.189 & HLP-22 & 12 & 8 & 4 & 1.05 & 4.5 & 2.4 & 21.8 & 10.1 & 0.62 & 0.34 & s1d5 & 2.5 & 0.0000328 & 0.0000439 & 0.0000585 & 0.4012 \\
\hline 9150541 & $7 / 1 \mathrm{~A}$ & 15E_4s1d5Z__1 & $147 / 16$ & $E$ & 3.25 & 354.8 & 35 & 30 & 0.126 & 0.189 & HLP-22 & 12 & 8 & 4 & 1.05 & 4.5 & 2.4 & 21.8 & 10.1 & 0.62 & 0.34 & s1d5 & 2.5 & 0.0000328 & 0.0000439 & 0.0000585 & 0.4012 \\
\hline 9150542 & 7/1A & 15E_4s1d5Zc_1 & $147 / 16$ & $E$ & 3.25 & 354.8 & 35 & 30 & 0.126 & 0.189 & HLP-22 & 12 & 8 & 4 & 1.05 & 4.5 & 2.4 & 21.8 & 10.1 & 0.62 & 0.34 & s1d5 & 2.5 & 0.0000328 & 0.0000439 & 0.0000585 & 0.4012 \\
\hline 9150543 & $7 / 1 \mathrm{~A}$ & 15E_4s1d5Zc_1 & $147 / 16$ & $E$ & 3.25 & 354.8 & 35 & 30 & 0.126 & 0.189 & HLP-22 & 12 & 8 & 4 & 1.05 & 4.5 & 2.4 & 21.8 & 10.1 & 0.62 & 0.34 & s1d5 & 2.5 & 0.0000328 & 0.0000439 & 0.0000585 & 0.4012 \\
\hline 9150544 & $7 / 1 \mathrm{~A}$ & 15E_4s1d5Zc_1 & $147 / 16$ & $E$ & 3.25 & 354.8 & 35 & 30 & 0.126 & 0.189 & HLP-22 & 12 & 8 & 4 & 1.05 & 4.5 & 2.4 & 21.8 & 10.1 & 0.62 & 0.34 & s1d5 & 2.5 & 0.0000328 & 0.0000439 & 0.0000585 & 0.4012 \\
\hline 9150545 & $7 / 1 \mathrm{~A}$ & 15E_4s1d5Z__1 & $147 / 16$ & $E$ & 3.25 & 354.8 & 35 & 30 & 0.126 & 0.189 & HLP-22 & 12 & 8 & 4 & 1.05 & 4.5 & 2.4 & 21.8 & 10.1 & 0.62 & 0.34 & sid5 & 2.5 & 0.0000328 & 0.0000439 & 0.0000555 & 0.4012 \\
\hline 9150546 & $7 / 1 \mathrm{~A}$ & 15E_4s1d5Zc_1 & $147 / 16$ & $E$ & 3.25 & 354.8 & 35 & 30 & 0.126 & 0.189 & HLP-22 & 12 & 8 & 4 & 1.05 & 4.5 & 2.4 & 21.8 & 10.1 & 0.62 & 0.34 & s1d5 & 2.5 & 0.0000328 & 0.0000439 & 0.0000585 & 0.4012 \\
\hline 9150547 & $7 / 1 \mathrm{~A}$ & 15E_4sidsz_c_1 & $147 / 16$ & E & 3.25 & 354.8 & 35 & 30 & 0.126 & 0.189 & HLP-22 & 12 & 8 & 4 & 1.05 & 4.5 & 2.4 & 21.8 & 10.1 & 0.62 & 0.34 & s1d5 & 2.5 & 0.0000328 & 0.0000439 & 0.0000585 & 0.4012 \\
\hline 9150548 & $7 / 1 \mathrm{~A}$ & 15E_4s1d5Zc_ 1 & $147 / 16$ & $E$ & 3.25 & 354.8 & 35 & 30 & 0.126 & 0.189 & HLP-22 & 12 & 8 & 4 & 1.05 & 4.5 & 2.4 & 21.8 & 10.1 & 0.62 & 0.34 & s1d5 & 2.5 & 0.0000328 & 0.0000439 & 0.0000585 & 0.4012 \\
\hline 9150549 & $7 / 1 \mathrm{~A}$ & 15E_4s1d5z_c_1 & $147 / 16$ & $E$ & 3.25 & 354.8 & 35 & 30 & 0.126 & 0.189 & HLP-22 & 12 & 8 & 4 & 1.05 & 4.5 & 2.4. & 21.8 & 10.1 & 0.62 & 0.34 & s1d5 & 2.5 & $\begin{array}{ll}0.0000328 \\
\end{array}$ & 0.0000439 & 0.0000585 & 0.4012 \\
\hline 9150550 & $7 / 1 \mathrm{~A}$ & 15E_4s1d5ZC__1 & $147 / 16$ & $E$ & 3.25 & 354.8 & 35 & 30 & 0.126 & 0.189 & HLP-22 & 12 & 8 & 4 & 1.05 & 4.5 & 2.4 & 21.8 & 10.1 & 0.62 & 0.34 & s1d5 & 2.5 & 0.0000328 & 0.0000439 & 0.0000585 & 0.4012 \\
\hline 9150551 & $7 / 1 \mathrm{~A}$ & 15E_4s1d5Z__ 1 & $147 / 16$ & $\mathrm{E}$ & 3.25 & 354.8 & 35 & 30 & 0.126 & 0.189 & HLP-22 & 12 & 8 & 4 & 1.05 & 4.5 & 2.4 & 21.8 & 10.1 & 0.62 & 0.34 & s1d5 & 2.5 & 0.0000328 & 0.0000439 & 0.0000585 & 0.4012 \\
\hline 9150552 & $7 / 1 \mathrm{~A}$ & 15E_4s1d5Zc_ 1 & $147 / 16$ & $E$ & 3.25 & 354.8 & 35 & 30 & 0.126 & 0.189 & HLP-22 & 12 & 8 & 4 & 1.05 & 4.5 & 2.4 & 21.8 & 10.1 & 0.62 & 0.34 & & 2.5 & 0.0000328 & 0.0000439 & 0.0000585 & 0.4012 \\
\hline 9150553 & $7 / 1 \mathrm{~A}$ & 15E_4s1d5Z__ 1 & $147 / 16$ & $E$ & 3.25 & 354.8 & 35 & 30 & 0.126 & 0.189 & HLP-22 & 12 & 8 & 4 & 1.05 & 4.5 & 2.4 & 21.8 & 10.1 & 0.62 & 0.34 & s1d5 & 2.5 & 0.0000328 & 0.0000439 & 0.0000585 & 0.4012 \\
\hline 9150554 & $7 / 1 \mathrm{~A}$ & 15E_4s1d5Zc_ 1 & $147 / 16$ & $E$ & 3.25 & 354.8 & 35 & 30 & 0.126 & 0.189 & HLP-22 & 12 & 8 & 4 & 1.05 & 4.5 & 2.4 & 21.8 & 10.1 & 0.62 & 0.34 & s1d5 & 2.5 & 0.0000328 & 0.0000439 & 0.0000585 & 0.4012 \\
\hline 9150555 & $7 / 1 \mathrm{~B}$ & 15E__SIIdSYC_1 & $147 / 16$ & $E$ & 3.25 & 354.8 & 35 & 30 & 0.126 & 0.189 & HLP-22 & 12 & 8 & 4 & 1.05 & 4.5 & 2.4 & 21.8 & 10.1 & 0.62 & 0.34 & s1d5 & 2.5 & 0.0000328 & 0.0000439 & 0.0000585 & 0.4012 \\
\hline 9150556 & $7 / 1 B$ & 15E_4SIddSYC_1 & $147 / 16$ & $E$ & 3.25 & 354.8 & 35 & 30 & 0.126 & 0.189 & HLP-22 & 12 & 8 & 4 & 1.05 & 4.5 & 2.4 & 21.8 & 10.1 & 0.62 & 0.34 & s1d5 & 2.5 & 0.0000328 & 0.0000439 & 0.0000585 & 0.4012 \\
\hline 9150557 & $7 / 1 \mathrm{~B}$ & 15E_4s1d5Yc_1 & & $E$ & 3.25 & 354.8 & 35 & 30 & 0.126 & 0.189 & & 12 & 8 & 4 & & 4.5 & 2.4 & 21. & & 0.62 & & & & & & & \\
\hline 9150558 & $7 / 1 \mathrm{~B}$ & 15E_4s1d5YC_1 & $147 / 16$ & $E$ & 3.25 & 354.8 & 35 & 30 & 0.126 & 0.189 & HLP-22 & 12 & 8 & 4 & 1.05 & 4.5 & 2.4 & 21.8 & 10.1 & 0.62 & 0.34 & s1d5 & 2.5 & 0.0000328 & 0.0000439 & 0.0000585 & 0.4012 \\
\hline $9150559 \mathrm{~N}$ & $7 / 1 \mathrm{~B}$ & 15E_4S1d5YC_ 1 & $147 / 16$ & E & 3.25 & 354.8 & 35 & 30 & 0.126 & 0.189 & HLP-22 & 12 & 8 & 4 & 1.05 & 4.5 & 2.4 & 21.8 & 10.1 & 0.62 & 0.34 & s1d5 & 2.5 & 0.0000328 & 0.0000439 & 0.0000585 & 0.4012 \\
\hline
\end{tabular}


Table B.3. Data from 2008 Tests in Small-Scale Vessel with Elliptical Head B.15

\begin{tabular}{|c|c|c|c|c|c|c|c|c|c|c|c|c|c|c|c|c|c|c|c|c|c|c|c|c|c|c|c|c|c|}
\hline $\begin{array}{l}\text { Tank Water } \\
\text { Temperature }\end{array}$ & \begin{tabular}{|l|} 
Water \\
Density
\end{tabular} & $\begin{array}{l}\text { Solids } \\
\text { Fraction } \\
\end{array}$ & \begin{tabular}{|c|} 
Pulse \\
Volume \\
Fraction \\
\end{tabular} & \begin{tabular}{|l} 
Duty \\
Cycle \\
\end{tabular} & $\begin{array}{l}\text { Cycle } \\
\text { Time }\end{array}$ & \begin{tabular}{|l|} 
Pulsed or \\
Steacy Jet
\end{tabular} & \begin{tabular}{|c|} 
Us \\
Steacy \\
Jet \\
\end{tabular} & \begin{tabular}{|c|} 
U1 \\
Pulsin \\
g Jet \\
\end{tabular} & \begin{tabular}{|l|} 
U2 \\
URMS \\
\end{tabular} & \begin{tabular}{|c|} 
U3 \\
URMB \\
\end{tabular} & \begin{tabular}{|c|} 
Discharge \\
Velocity
\end{tabular} & 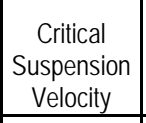 & $\begin{array}{l}\text { Average Peak } \\
\text { Cound Height }\end{array}$ & \begin{tabular}{|l|} 
UnS \\
Condition \\
\end{tabular} & $\begin{array}{l}\text { UCS } \\
\text { Method }\end{array}$ & UCS Fag & \begin{tabular}{|c} 
Ucs Center \\
Fag
\end{tabular} & $\begin{array}{c}\text { Ucsuav } \\
\text { Fag }\end{array}$ & \begin{tabular}{|c|cc} 
UCS based on \\
Decreasing \\
Velocity
\end{tabular} & \begin{tabular}{|} 
Sweep \\
Increase / \\
Decrease
\end{tabular} & \begin{tabular}{|c} 
UDV \\
Height \\
Bed
\end{tabular} & $\begin{array}{l}\text { Particle } \\
\text { Notion }\end{array}$ & $\begin{array}{l}\text { Solids } \\
\text { Level }\end{array}$ & \begin{tabular}{|c|} 
Outer \\
Bottom \\
Patterm
\end{tabular} & \begin{tabular}{|l|} 
IInner \\
Bottom \\
Pattem
\end{tabular} & Case ID & Test & TDP & $\begin{array}{l}\text { Row } \\
\text { Number }\end{array}$ \\
\hline c & $\mathrm{g} / \mathrm{cm}^{3}$ & fraction & fraction & fraction & $\mathrm{s}$ & \begin{tabular}{|l|} 
text \\
\end{tabular} & \begin{tabular}{|l|l|}
$\mathrm{m} / \mathrm{s}$ \\
\end{tabular} & $\mathrm{m} / \mathrm{s}$ & $\begin{array}{ll}\mathrm{m} / \mathrm{s} \\
\end{array}$ & m/s & $\mathrm{m} / \mathrm{s}$ & \begin{tabular}{|l|}
$\mathrm{m} / \mathrm{s}$ \\
\end{tabular} & in. & $\mathrm{m} / \mathrm{s}$ & text & text & text & \begin{tabular}{|l|} 
text \\
\end{tabular} & \begin{tabular}{|l|}
$\mathrm{ms}$ \\
\end{tabular} & text & \begin{tabular}{|l|}
$\mathrm{mm}$ \\
\end{tabular} & text & text & text & text & text & text & text & text \\
\hline $\mathrm{T}$ & $\rho$ & $\phi_{\mathrm{s}}$ & $\phi_{p}$ & $D C$ & $t_{c}$ & Jet & $u_{s}$ & $\mathrm{U} 1$ & $\mathrm{U} 2$ & U3 & $u$ & uss & $\mathrm{H}_{\mathrm{c}}$ & $U_{\text {Cas }}$ & $U_{\text {son }}$ & Ussis & Uscen & Usoudiv & Uss $D$ & $\mathrm{~S}_{\mathrm{w}}$ & $H_{\text {bed }}$ & $\mathrm{PM}$ & Sol & SPo & $\mathrm{SP}_{\mathrm{P}}$ & ID & MDDX & TDP & MSS \\
\hline 29.6 & 0.998 & 0.01500 & 0.050 & 0.335 & 7.4 & $\mathrm{P}$ & NA & 8.03 & 8.24 & \begin{tabular}{|l|}
8.34 \\
\end{tabular} & 8.60 & 8.60 & 5.50 & NA & NA & NA & NA & NA & NA & NA & 0.0 & NA & NA & NA & NA & 15E_4s1d1Xc_ 1 & $6 / 30 \mathrm{~A}$ & TDP-197 & 9150519 \\
\hline 29.6 & 0.998 & 0.01500 & 0.050 & 0.335 & 7.4 & $\mathrm{P}$ & NA & 8.03 & 8.24 & 8.34 & 8.60 & 8.60 & 5.50 & NA & NA & NA & NA & NA & NA & NA & 0.0 & NA & NA & NA & NA & 15E_4s1d1Xc_1 & 6/30A & TDP-197 & 9150520 \\
\hline 29.6 & 0.998 & 0.01500 & 0.050 & 0.335 & 7.4 & $\mathrm{P}$ & NA & 8.03 & 8.24 & 8.34 & 8.60 & 8.60 & 5.50 & NA & NA & NA & NA & NA & NA & NA & 0.0 & NA & NA & NA & NA & 15E_4sId1Xc_1 & 6/30A & TDP-197 & 9150521 \\
\hline 29.6 & 0.998 & 0.01500 & 0.050 & 0.335 & 7.4 & $\mathrm{P}$ & NA & 8.03 & 8.24 & 8.34 & 8.60 & 8.60 & 5.50 & NA & NA & NA & NA & NA & NA & NA & 0.7 & NA & NA & NA & NA & 15E_4s1d1Xc_1 & 6/30A & TDP-197 & 9150522 \\
\hline 29.6 & 0.998 & 0.01500 & 0.050 & 0.335 & 7.4 & $P$ & NA & 8.03 & 8.24 & 8.34 & 8.60 & 8.60 & 5.50 & NA & NA & NA & NA & NA & NA & NA & 0.0 & NA & NA & NA & NA & 15E_4s1d1Xc_1 & 6/30A & TDP-197 & 9150523 \\
\hline 29.6 & 0.998 & 0.01500 & 0.050 & 0.335 & 7.4 & $\mathrm{P}$ & NA & 8.03 & 8.24 & 8.34 & 8.60 & 8.60 & 5.50 & NA & NA & NA & NA & NA & NA & NA & 0.0 & NA & NA & NA & NA & 15E_4s1d1Xc_1 & 6/30A & TDP-197 & 9150524 \\
\hline 29.6 & 0.998 & 0.01500 & 0.050 & 0.335 & 7.4 & $\mathrm{P}$ & NA & 8.03 & 8.24 & 8.34 & 8.60 & 8.60 & 5.50 & NA & NA & NA & NA & NA & NA & NA & 0.7 & NA & NA & NA & NA & 15E_4sid1Xc_1 & 6/30A & TDP-197 & 9150525 \\
\hline 30.3 & 0.998 & 0.00155 & 0.050 & 0.328 & 61.4 & $\mathrm{P}$ & NA & 1.00 & 1.00 & 1.00 & 1.00 & 2.80 & 16.00 & NA & NA & NA & NA & NA & NA & (null) & 14.7 & 1 & NA & NA & NA & 15E_4sid5z__ 1 & $6 / 30 \mathrm{~B}$ & TDP-198 & 9150526 \\
\hline 30.4 & 0.998 & 0.00155 & 0.050 & 0.330 & 43.8 & $\mathrm{P}$ & NA & 1.39 & 1.39 & 1.39 & 1.40 & 2.80 & 10.75 & NA & NA & NA & NA & NA & NA & 1 & 8.7 & 1 & NA & NA & NA & 15E_4sid5Z__1 & $6 / 30 \mathrm{~B}$ & TDP-198 & 9150527 \\
\hline 30.6 & 0.998 & 0.00155 & 0.050 & 0.333 & 34.0 & $\mathrm{P}$ & NA & 1.78 & 1.79 & \begin{tabular}{|l|}
1.79 \\
\end{tabular} & 1.80 & 2.80 & 7.50 & NA & NA & NA & NA & NA & NA & 1 & 11.2 & 1 & NA & NA & NA & 15E_4s1d5Zc_1 & $6 / 30 \mathrm{~B}$ & TDP-198 & 9150528 \\
\hline 30.9 & 0.998 & 0.00155 & 0.050 & 0.333 & 27.8 & $\mathrm{P}$ & NA & 2.17 & 2.17 & 2.18 & 220 & 2.80 & 7.75 & NA & NA & NA & NA & NA & NA & & 6.2 & 1 & NA & NA & NA & 15E_4sid5z__1 & $6 / 30 B$ & TDP-198 & 9150529 \\
\hline 31.0 & 0.998 & 0.00155 & 0.050 & 0.335 & 23.4 & $P$ & NA & 2.56 & 2.57 & \begin{tabular}{|l|}
2.58 \\
\end{tabular} & 260 & 2.80 & 11.00 & NA & NA & NA & NA & NA & NA & 1 & 5.0 & 1 & NA & NA & $\mathrm{NA}$ & 15E_4sidafz__ _ 1 & 6/308 & TDP-198 & 9150530 \\
\hline 31.5 & 0.998 & 0.00155 & 0.050 & 0.336 & 23.4 & $P$ & NA & 2.55 & 2.57 & 2.57 & 260 & 2.80 & 10.50 & NA & NA & $N A$ & NA & NA & NA & 1 & 4.5 & 1 & NA & $\mathrm{NA}$ & $N A$ & 15E_4sid5Zc_1 & $6 / 30 \mathrm{~B}$ & TDP-198 & 9150531 \\
\hline 31.7 & 0.997 & 0.00155 & 0.050 & 0.336 & 22.4 & $\mathrm{P}$ & NA & 2.66 & 2.68 & \begin{tabular}{|l|}
2.68 \\
\end{tabular} & 270 & 2.80 & 12.00 & NA & NA & NA & NA & NA & NA & 1 & 3.7 & 1 & NA & NA & NA & 15E_4s1d5Zc_1 & $6 / 30 \mathrm{~B}$ & TDP-198 & 9150532 \\
\hline 31.9 & 0.997 & 0.00155 & 0.050 & 0.337 & 21.6 & $\mathrm{P}$ & NA & 2.76 & 2.77 & \begin{tabular}{|l|}
2.78 \\
\end{tabular} & 2.80 & 2.80 & 15.50 & 2.80 & uad & Ucsis & NA & Ucsudv & NA & 1 & 0.7 & 3 & NA & NA & NA & 15E_4sid5Zc_1 & $6 / 30 \mathrm{~B}$ & TDP-198 & 9150533 \\
\hline 32.1 & 0.997 & 0.00155 & 0.050 & 0.338 & 20.8 & $\mathrm{P}$ & NA & 2.82 & 2.84 & 2.85 & 2.90 & 2.80 & 18.00 & NA & NA & NA & NA & NA & NA & 1 & 0.0 & 4 & NA & NA & NA & 15E_4sIdIJZ__ _ & 6/30B & TDP-198 & 9150534 \\
\hline 32.2 & 0.997 & 0.00155 & 0.050 & 0.333 & 20.4 & $\mathrm{P}$ & NA & 2.94 & 2.95 & \begin{tabular}{|l|}
2.96 \\
\end{tabular} & 3.00 & 2.80 & 20.75 & NA & NA & NA & NA & NA & NA & 1 & 0.0 & 4 & NA & NA & NA & 15E_4sid5Z__1 & $6 / 30 \mathrm{~B}$ & TDP-198 & 9150535 \\
\hline 28.5 & 0.999 & 0.00155 & 0.050 & 0.334 & 21.7 & $\mathrm{P}$ & NA & 2.76 & 2.77 & \begin{tabular}{|l|} 
\\
\end{tabular} & 280 & 2.80 & 21.00 & NA & NA & Ucsis & NA & NA & NA & (null) & 3.6 & 3 & NA & NA & NA & 15E_4s1d5Zc_1 & $7 / 1 \mathrm{~A}$ & TDP-199 & 9150536 \\
\hline 28.4 & 0.998 & 0.00155 & 0.050 & 0.337 & 21.0 & $P$ & NA & 2.81 & 2.84 & \begin{tabular}{|l|}
2.86 \\
\end{tabular} & 290 & 2.80 & 21.50 & NA & NA & NA & NA & NA & NA & 1 & 0.8 & 4 & NA & NA & NA & 15E_4sid5zc 1 & $7 / 1 \mathrm{~A}$ & TDP-199 & 9150537 \\
\hline 28.5 & 0.999 & 0.00155 & 0.050 & 0.333 & 20.4 & $\mathrm{P}$ & NA & 2.94 & 2.96 & \begin{tabular}{|l|}
2.96 \\
\end{tabular} & 3.00 & 2.80 & 23.50 & NA & NA & NA & NA & NA & NA & 1 & 3.1 & 4 & NA & NA & NA & 15E__4s105z__ 1 & $7 / 1 \mathrm{~A}$ & TDP-199 & 9150538 \\
\hline 28.5 & 0.998 & 0.00155 & 0.050 & 0.331 & 23.6 & $\mathrm{P}$ & NA & 2.55 & 2.57 & \begin{tabular}{|l|}
2.57 \\
\end{tabular} & 260 & 2.80 & 14.50 & NA & NA & NA & NA & NA & NA & 1 & 6.4 & 1 & NA & NA & NA & 15E_4s1d5Zc_1 & 7/1A & TDP-199 & 9150539 \\
\hline 28.6 & 0.998 & 0.00155 & 0.050 & 0.331 & 22.8 & $\mathrm{P}$ & NA & 2.66 & 2.67 & \begin{tabular}{|l|l|}
2.68 \\
\end{tabular} & 2.70 & 2.80 & 18.00 & NA & NA & NA & Ucscen & NA & NA & 1 & 4.5 & 2 & NA & NA & NA & 15E_4sid5Z__1 & 7/1A & TDP-199 & 9150540 \\
\hline 28.9 & 0.998 & 0.00155 & 0.050 & 0.332 & 22.8 & $\mathrm{P}$ & NA & 2.64 & 2.66 & \begin{tabular}{|l|}
2.67 \\
\end{tabular} & 270 & 2.80 & 17.50 & NA & NA & NA & UCScen & NA & NA & (null) & 4.3 & 2 & NA & NA & NA & 15E_4s1d5Zc_1 & $7 / 1 \mathrm{~A}$ & TDP-199 & 9150541 \\
\hline 28.9 & 0.998 & 0.00155 & 0.050 & 0.332 & 22.8 & $\mathrm{P}$ & NA & 2.64 & 2.66 & 2.67 & 270 & 2.80 & 17.50 & NA & NA & NA & NA & NA & NA & NA & 6.3 & NA & NA & NA & NA & 15E_4sid5z__1 & $7 / 1 \mathrm{~A}$ & TDP-199 & 9150542 \\
\hline 28.9 & 0.998 & 0.00155 & 0.050 & 0.332 & 22.8 & $\mathrm{P}$ & NA & 2.64 & 2.66 & 2.67 & 270 & 2.80 & 17.50 & NA & NA & NA & NA & NA & NA & $\mathrm{NA}$ & 3.1. & NA & NA & NA & NA & 15E_4sidafz__ _ & $7 / 1 \mathrm{~A}$ & TDP-199 & 9150543 \\
\hline 28.9 & 0.998 & 0.00155 & 0.050 & 0.332 & 22.8 & $\mathrm{P}$ & NA & 2.64 & 2.66 & 2.67 & 270 & 2.80 & 17.50 & NA & NA & NA & NA & NA & NA & $\mathrm{NA}$ & 22. & NA & NA & NA & NA & 15E_4sid5Z__1 & $7 / 1 \mathrm{~A}$ & TDP-199 & 9150544 \\
\hline 28.9 & 0.998 & 0.00155 & 0.050 & 0.332 & 22.8 & $\mathrm{P}$ & NA & 2.64 & 2.66 & 2.67 & 270 & 2.80 & 17.50 & NA & NA & NA & NA & NA & NA & NA & 3.0 & NA & NA & NA & NA & 15E_4S1d5Z__1 & 7/1A & TDP-199 & 9150545 \\
\hline 28.9 & 0.998 & 0.00155 & 0.050 & 0.332 & 22.8 & $\mathrm{P}$ & NA & 2.64 & 2.66 & 2.67 & 270 & 2.80 & 17.50 & NA & NA & NA & NA & NA & NA & NA & 6.8 & NA & NA & NA & NA & 15E_4s1d5Zc__ & $7 / 1 \mathrm{~A}$ & TDP-199 & 9150546 \\
\hline 28.9 & 0.998 & 0.00155 & 0.050 & 0.332 & 22.8 & $\mathrm{P}$ & NA & 2.64 & 2.66 & 2.67 & 270 & 2.80 & 17.50 & NA & NA & NA & NA & NA & NA & $\mathrm{NA}$ & 4.0 & NA & NA & NA & NA & 15E_4S1d5Z__1 & $7 / 1 \mathrm{~A}$ & TDP-199 & 9150547 \\
\hline 28.9 & 0.998 & 0.00155 & 0.050 & 0.332 & 22.8 & $P$ & NA & 2.64 & 2.66 & 2.67 & 270 & 2.80 & 17.50 & NA & NA & $N A$ & NA & NA & NA & NA & 2.3 & NA & NA & $\mathrm{NA}$ & $N A$ & 15E_4s1d5Z___1 & $7 / 1 \mathrm{~A}$ & TDP-199 & 9150548 \\
\hline 28.9 & 0.998 & 0.00155 & 0.050 & 0.332 & 22.8 & $P$ & NA & 2.64 & 2.66 & 2.67 & 270 & 2.80 & 17.50 & NA & NA & NA & NA & NA & NA & NA & 25 & NA & NA & $\mathrm{NA}$ & NA & 15E_4S1d5Z__1 & $7 / 1 \mathrm{~A}$ & TDP-199 & 9150549 \\
\hline 28.9 & 0.998 & 0.00155 & 0.050 & 0.332 & 22.8 & $\mathrm{P}$ & NA & 2.64 & 2.66 & 2.67 & 270 & 2.80 & 17.50 & NA & NA & NA & NA & NA & NA & NA & 2.2 & NA & NA & NA & NA & 15E_4sid5z__1 & $7 / 1 \mathrm{~A}$ & TDP-199 & 9150550 \\
\hline 28.9 & 0.998 & 0.00155 & 0.050 & 0.332 & 22.8 & $\mathrm{P}$ & NA & 2.64 & 2.66 & 2.67 & 270 & 2.80 & 17.50 & NA & NA & NA & NA & NA & NA & NA & 3.8 & NA & NA & $\mathrm{NA}$ & NA & 15E_4sidsz__1 & $7 / 1 \mathrm{~A}$ & TDP-199 & 9150551 \\
\hline 28.9 & 0.998 & 0.00155 & 0.050 & 0.332 & 22.8 & $P$ & NA & 2.64 & 2.66 & 2.67 & 270 & 2.80 & 17.50 & NA & NA & $N A$ & NA & NA & NA & NA & 1.5 & NA & NA & NA & $\mathrm{NA}$ & 15E_4s1da5zc_1 & $7 / 1 \mathrm{~A}$ & TDP-199 & 9150552 \\
\hline 28.9 & 0.998 & 0.00155 & 0.050 & 0.332 & 22.8 & $\mathrm{P}$ & NA & 2.64 & 2.66 & 2.67 & 270 & 2.80 & 17.50 & NA & NA & NA & NA & NA & & NA & 14.7 & NA & NA & $\mathrm{NA}$ & NA & 15E_4S1d5Z__1 & $7 / 1 \mathrm{~A}$ & TDP-199 & 9150553 \\
\hline 28.9 & 0.998 & 0.00155 & 0.050 & 0.332 & 22.8 & $\mathrm{P}$ & NA & 2.64 & 2.66 & 2.67 & 270 & 2.80 & 17.50 & NA & NA & NA & NA & NA & NA & NA & 13.6 & NA & $\mathrm{NA}$ & NA & NA & 15E_4sidazz_ _ 1 & $7 / 1 \mathrm{~A}$ & TDP-199 & 9150554 \\
\hline 29.4 & 0.998 & 0.00500 & 0.050 & 0.331 & 23.6 & $\mathrm{P}$ & NA & 2.56 & 2.57 & 2.58 & 260 & 3.70 & 3.75 & NA & NA & NA & NA & NA & NA & (null) & 13.4 & 1 & NA & NA & NA & 15E_4s1d5Yc_1 & $7 / 1 \mathrm{~B}$ & IDP-200 & 9150555 \\
\hline 29.5 & 0.998 & 0.00500 & 0.050 & 0.338 & 20.4 & $P$ & NA & 2.88 & 2.92 & 2.94 & 3.00 & 3.70 & 4.75 & NA & NA & NA & NA & NA & NA & 1 & 9.3 & 1 & NA & NA & NA & 15E_4s1d5YC_1 & $7 / 1 \mathrm{~B}$ & TDP-200 & 9150556 \\
\hline 29.6 & 0.998 & 0.00500 & 0.050 & 0.333 & 18.6 & $\mathrm{P}$ & NA & 3.23 & 3.25 & 3.26 & 3.30 & 3.70 & 6.00 & NA & NA & NA & NA & NA & NA & 1 & 4.5 & 1 & NA & NA & NA & 15E_4s1d5YC_1 & $7 / 1 \mathrm{~B}$ & TDP-200 & 9150557 \\
\hline 29.7 & 0.998 & 0.00500 & 0.050 & 0.334 & 17.6 & $\mathrm{P}$ & NA & 3.42 & 3.45 & 3.46 & 3.50 & 3.70 & & & NA & NA & ucscen & & NA & & 23 & & & NA & & 15E_4s1d5YC_1 & $7 / 1 \mathrm{~B}$ & TDP-200 & 9150558 \\
\hline 29.9 & 0.998 & 0.00500 & \begin{tabular}{|l|}
0.050 \\
\end{tabular} & \begin{tabular}{|l|} 
\\
\end{tabular} & 16.6 & $P$ & NA & 3.56 & 3.61 & \begin{tabular}{|l|}
3.63 \\
\end{tabular} & 3.70 & 3.70 & 11.00 & 3.70 & uovi & |ucsis & NA & Ucsudv & NA & & 0.7 & 3 & NA & NA & NA & 15E_4sId5YC_1 & $7 / 1 \mathrm{~B}$ & IDPP-200 & 9150559 \\
\hline
\end{tabular}


Table B.3. Data from 2008 Tests in Small-Scale Vessel with Elliptical Head A.16

\begin{tabular}{|c|c|c|c|c|c|c|c|c|c|c|c|c|c|c|c|c|c|c|c|c|c|c|c|c|c|c|c|}
\hline $\begin{array}{l}\text { Rov } \\
\text { Number }\end{array}$ & Test & Case ID & $\begin{array}{c}\text { Tank } \\
\text { Diameter }\end{array}$ & $\begin{array}{l}\text { Head } \\
\text { Shape }\end{array}$ & \begin{tabular}{|l} 
Dish \\
Height
\end{tabular} & $\begin{array}{l}\text { Dish } \\
\text { Volume }\end{array}$ & $\begin{array}{l}\text { Tank Fill } \\
\text { Height }\end{array}$ & $\begin{array}{l}\text { Retur } \\
\text { Line } \\
\text { Height }\end{array}$ & $\begin{array}{l}\text { Nozzle } \\
\text { Inner } \\
\text { Diameter }\end{array}$ & $\begin{array}{l}\text { Nozzle } \\
\text { Stantoff } \\
\text { Distance }\end{array}$ & $\begin{array}{l}\text { Pulse Tube } \\
\text { Configuration }\end{array}$ & \begin{tabular}{|l} 
Installed \\
Nozzles
\end{tabular} & $\begin{array}{l}\text { Outer } \\
\text { Nozzles } \\
\text { Operated }\end{array}$ & $\begin{array}{l}\text { Inner } \\
\text { Nozzles } \\
\text { Operated }\end{array}$ & $\begin{array}{l}\text { Pulse Tube } \\
\text { Outer } \\
\text { Dianteter }\end{array}$ & $\begin{array}{c}\text { Outer } \\
\text { PMM } \\
\text { Radius }\end{array}$ & $\begin{array}{c}\text { Inner PJM } \\
\text { Radius } \\
\end{array}$ & \begin{tabular}{|c|} 
"FO" Outer PJM \\
Impingement \\
Angle
\end{tabular} & $\begin{array}{c}\text { "FO' Inner PJM } \\
\text { Impingement Angle }\end{array}$ & \begin{tabular}{|l} 
Ratio Outer PJM \\
to Tank Radius
\end{tabular} & $\begin{array}{l}\text { Ratio Inner PJM } \\
\text { to Tank Radius }\end{array}$ & Simulant & \begin{tabular}{|l|} 
Solids \\
Density \\
\end{tabular} & $\begin{array}{c}\text { Particle } \\
\text { Diameter d5 }\end{array}$ & \begin{tabular}{c|} 
Particle \\
Diameter d d50
\end{tabular} & $\begin{array}{c}\text { Particle } \\
\text { Diameter d95 }\end{array}$ & $\begin{array}{l}\text { Void } \\
\text { Fraction }\end{array}$ \\
\hline text & text & text & in. & text & in. & in ${ }^{3}$ & in. & in. & in. & in. & text & number & number & number & in. & in. & in. & deg & deg & nondim & nondim & text & \begin{tabular}{|l|l|}
$\mathrm{g} / \mathrm{cm}^{3}$ \\
\end{tabular} & $\mathrm{~m}$ & \begin{tabular}{l|}
$\mathrm{m}$ \\
\end{tabular} & $m$ & fraction \\
\hline MSS & MDDX & $\mathrm{ID}$ & $\mathrm{D}$ & HS & Hish & $V_{\text {dish }}$ & $\mathrm{H}$ & $\operatorname{Rin}$ & $d$ & sod & PT & $\mathrm{N}$ & $\mathrm{Nb}$ & $\mathrm{N}$ & $\mathrm{PT}_{\alpha d}$ & $R_{0}$ & $R$ & $\theta_{0}$ & $\theta_{1}$ & $R d R$ & $R / R$ & $\operatorname{sxdx}$ & $\rho_{\mathrm{s}}$ & $d_{b}$ & $d_{60}$ & $d_{65}$ & vf \\
\hline $9150560 \mathrm{M}$ & $7 / 1 \mathrm{~B}$ & 15E_4s1d5YC_1 & $147 / 16$ & $E$ & 3.25 & 354.8 & 35 & 30 & 0.126 & 0.189 & HLP-22 & 12 & 8 & 4 & 1.05 & 4.5 & 2.4 & 21.8 & 10.1 & 0.62 & 0.34 & s1d5 & 2.5 & 0.0000328 & 0.0000439 & 0.0000585 & 0.4012 \\
\hline 9150561 & $7 / 1 B$ & 15E_4SIdSTYC_1 & $147 / 16$ & $E$ & 3.25 & 354.8 & 35 & 30 & 0.126 & 0.189 & HLP-22 & 12 & 8 & 4 & 1.05 & 4.5 & 2.4 & 21.8 & 10.1 & 0.62 & 0.34 & sid5 & 2.5 & $\begin{array}{ll}0.0000328 \\
\end{array}$ & 0.0000439 & 0.0000585 & 0.4012 \\
\hline 9150562 & $7 / 1 B$ & 15E_4S1d5YC_1 & $147 / 16$ & $E$ & 3.25 & 354.8 & 35 & 30 & 0.126 & 0.189 & HLP-22 & 12 & 8 & 4 & 1.05 & 4.5 & 2.4 & 21.8 & 10.1 & 0.62 & 0.34 & s1d5 & 2.5 & 0.0000328 & 0.0000439 & 0.0000585 & 0.4012 \\
\hline 9150563 & $7 / 1 \mathrm{~B}$ & 15E_4s1d5Yc_1 & $147 / 16$ & E & 3.25 & 354.8 & 35 & 30 & 0.126 & 0.189 & HLP-22 & 12 & 8 & 4 & 1.05 & 4.5 & 2.4 & 21.8 & 10.1 & 0.62 & 0.34 & s1d5 & 2.5 & 0.0000328 & 0.0000439 & 0.0000585 & 0.4012 \\
\hline 9150564 & $7 / 1 \mathrm{~B}$ & 15E_4s1d5Yc_1 & $147 / 16$ & $E$ & 3.25 & 354.8 & 35 & 30 & 0.126 & 0.189 & HLP-22 & 12 & 8 & 4 & 1.05 & 4.5 & 2.4 & 21.8 & 10.1 & 0.62 & 0.34 & s1d5 & 2.5 & 0.0000328 & 0.0000439 & 0.0000585 & 0.4012 \\
\hline 9150565 & $7 / 1 \mathrm{~B}$ & 15E_4s1d5YC_1 & $147 / 16$ & $E$ & 3.25 & 354.8 & 35 & 30 & 0.126 & 0.189 & HLP-22 & 12 & 8 & 4 & 1.05 & 4.5 & 2.4 & 21.8 & 10.1 & 0.62 & 0.34 & sid5 & 2.5 & 0.0000328 & 0.0000439 & 0.0000585 & 0.4012 \\
\hline 9150566 & $7 / 1 \mathrm{~B}$ & 15E_4s1d5Yc_1 & $147 / 16$ & $E$ & 3.25 & 354.8 & 35 & 30 & 0.126 & 0.189 & HLP-22 & 12 & 8 & 4 & 1.05 & 4.5 & 2.4 & 21.8 & 10.1 & 0.62 & 0.34 & s1d5 & 2.5 & 0.0000328 & 0.0000439 & 0.0000585 & 0.4012 \\
\hline 9150567 & $7 / 1 \mathrm{~B}$ & 15E_4s1d5YC_1 & $147 / 16$ & $E$ & 3.25 & 354.8 & 35 & 30 & 0.126 & 0.189 & HLP-22 & 12 & 8 & 4 & 1.05 & 4.5 & 2.4 & 21.8 & 10.1 & 0.62 & 0.34 & s1d5 & 2.5 & 0.0000328 & 0.0000439 & 0.0000585 & 0.4012 \\
\hline $9150568 \mathrm{M}$ & $7 / 1 B$ & 15E_4s1d5Yc_1 & $147 / 16$ & $E$ & 3.25 & 354.8 & 35 & 30 & 0.126 & 0.189 & HLP-22 & 12 & 8 & 4 & 1.05 & 4.5 & 2.4 & 21.8 & 10.1 & 0.62 & 0.34 & s1d5 & 2.5 & 0.0000328 & 0.0000439 & 0.0000585 & 0.4012 \\
\hline 9150569 & $7 / 2 \mathrm{~A}$ & 15E_4s2d1Tc_1 & $147 / 16$ & $E$ & 3.25 & 354.8 & 36 & 30 & 0.126 & 0.189 & HLP-22 & 12 & 8 & 4 & 1.05 & 4.5 & 2.4 & 21.8 & 10.1 & 0.62 & 0.34 & $\mathrm{~s} 2 \mathrm{~d} 1$ & 4.17 & 0.0001399 & 0.0001642 & 0.0001924 & 0.4000 \\
\hline 9150570 & $7 / 2 \mathrm{~A}$ & 15E_ $4 \mathrm{~S} 2 \mathrm{~d} 1 \mathrm{TC}$. 1 & $147 / 16$ & E & 3.25 & 354.8 & 36 & 30 & 0.126 & 0.189 & HLP-22 & 12 & 8 & 4 & 1.05 & 4.5 & 2.4 & 21.8 & 10.1 & 0.62 & 0.34 & $\mathrm{~s} 2 \mathrm{~d} 1$ & 4.17 & 0.0001399 & 0.0001642 & 0.0001924 & 0.4000 \\
\hline 9150571 & $7 / 2 \mathrm{~A}$ & 15E $4 \mathrm{~s} 2 \mathrm{~d} 1 \mathrm{Tc} 1$ & $147 / 16$ & $\mathrm{E}$ & 3.25 & 354.8 & 36 & 30 & 0.126 & 0.189 & HLP-22 & 12 & 8 & 4 & 1.05 & 4.5 & 2.4 & 21.8 & 10.1 & 0.62 & 0.34 & $\mathrm{~s} 2 \mathrm{~d} 1$ & 4.17 & 0.0001399 & 0.0001642 & 0.0001924 & 0.4000 \\
\hline 9150572 & $7 / 2 \mathrm{~A}$ & 15E_4s2d1Tc_1 1 & $147 / 16$ & $E$ & 3.25 & 354.8 & 36 & 30 & 0.126 & 0.189 & HLP-22 & 12 & 8 & 4 & 1.05 & 4.5 & 2.4 & 21.8 & 10.1 & 0.62 & 0.34 & $\mathrm{~s} 2 \mathrm{~d} 1$ & 4.17 & 0.0001399 & 0.0001642 & 0.0001924 & 0.4000 \\
\hline 9150573M & $7 / 2 A$ & 15E_4s2d1TC_1 & $147 / 16$ & $E$ & 3.25 & 354.8 & 36 & 30 & 0.126 & 0.189 & HLP-22 & 12 & 8 & 4 & 1.05 & 4.5 & 2.4 & 21.8 & 10.1 & 0.62 & 0.34 & $\mathrm{~s} 2 \mathrm{d1}$ & 4.17 & 0.0001399 & 0.0001642 & 0.0001924 & 0.4000 \\
\hline $9150574 \mathrm{M}$ & $7 / 2 \mathrm{~A}$ & 15E_4s2d1Tc_ 1 & $147 / 16$ & $E$ & 3.25 & 354.8 & 36 & 30 & 0.126 & 0.189 & HLP-22 & 12 & 8 & 4 & 1.05 & 4.5 & 2.4 & 21.8 & 10.1 & 0.62 & 0.34 & $\mathrm{~s} 2 \mathrm{~d} 1$ & 4.17 & 0.0001399 & 0.0001642 & 0.0001924 & 0.4000 \\
\hline $9150575 \mathrm{M}$ & $7 / 2 \mathrm{~A}$ & 15E_4s2d1Tc_1 & $147 / 16$ & $E$ & 3.25 & 354.8 & 36 & 30 & 0.126 & 0.189 & HLP-22 & 12 & 8 & 4 & 1.05 & 4.5 & 2.4 & 21.8 & 10.1 & 0.62 & 0.34 & $\mathrm{~s} 2 \mathrm{~d} 1$ & 4.17 & 0.0001399 & 0.0001642 & 0.0001924 & 0.4000 \\
\hline $9150576 \mathrm{M}$ & $7 / 2 \mathrm{~A}$ & 15E_4s2d1Tc_ 1 & $147 / 16$ & $E$ & 3.25 & 354.8 & 36 & 30 & 0.126 & 0.189 & HLP-22 & 12 & 8 & 4 & 1.05 & 4.5 & 2.4 & 21.8 & 10.1 & 0.62 & 0.34 & $\mathrm{~s} 2 \mathrm{~d} 1$ & 4.17 & 0.0001399 & 0.0001642 & 0.0001924 & 0.4000 \\
\hline $915057 \mathrm{MM}$ & $7 / 2 \mathrm{~A}$ & 15E_4s2d1Tc_1 & $147 / 16$ & $\mathrm{E}$ & 3.25 & 354.8 & 36 & 30 & 0.126 & 0.189 & HLP-22 & 12 & 8 & 4 & 1.05 & 4.5 & 2.4 & 21.8 & 10.1 & 0.62 & 0.34 & $\mathrm{~s} 2 \mathrm{~d} 1$ & 4.17 & 0.0001399 & 0.0001642 & 0.0001924 & 0.4000 \\
\hline 9150578 & $7 / 2 B$ & 15E_4s2d17c_1 & $147 / 16$ & $E$ & 3.25 & 354.8 & 36 & 30 & 0.126 & 0.189 & HLP-22 & 12 & 8 & 4 & 1.05 & 4.5 & 2.4 & 21.8 & 10.1 & 0.62 & 0.34 & $\mathrm{~s} 2 \mathrm{~d} 1$ & 4.17 & 0.0001399 & 0.0001642 & $\begin{array}{ll}.0001924 \\
\end{array}$ & 0.4000 \\
\hline 9150579 & $7 / 2 B$ & 15E_4s2d1Zc_1 & $147 / 16$ & $E$ & 3.25 & 354.8 & 36 & 30 & 0.126 & 0.189 & HLP-22 & 12 & 8 & 4 & 1.05 & 4.5 & 2.4 & 21.8 & 10.1 & 0.62 & 0.34 & $\mathrm{~s} 2 \mathrm{~d} 1$ & 4.17 & 0.0001399 & 0.0001642 & 0.0001924 & 0.4000 \\
\hline 9150580 & $7 / 2 B$ & 15E_4S2d17c_1 & $147 / 16$ & $\mathrm{E}$ & 3.25 & 354.8 & 36 & 30 & 0.126 & 0.189 & HLP-22 & 12 & 8 & 4 & 1.05 & 4.5 & 2.4 & 21.8 & 10.1 & 0.62 & 0.34 & $\mathrm{~s} 2 \mathrm{~d} 1$ & 4.17 & 0.0001399 & 0.0001642 & 0.0001924 & 0.4000 \\
\hline 9150581 & $7 / 2 B$ & 15E_4s2d1Zc_1 & $147 / 16$ & $E$ & 3.25 & 354.8 & 36 & 30 & 0.126 & 0.189 & HLP-22 & 12 & 8 & 4 & 1.05 & 4.5 & 2.4 & 21.8 & 10.1 & 0.62 & 0.34 & $\mathrm{~s} 2 \mathrm{~d} 1$ & 4.17 & 0.0001399 & 0.0001642 & 0.0001924 & 0.4000 \\
\hline 9150582 & $7 / 2 B$ & 15E_4s2d1Zc_ 1 & $147 / 16$ & $\mathrm{E}$ & 3.25 & 354.8 & 36 & 30 & 0.126 & 0.189 & HLP-22 & 12 & 8 & 4 & 1.05 & 4.5 & 2.4 & 21.8 & 10.1 & 0.62 & 0.34 & $\mathrm{~s} 2 \mathrm{~d} 1$ & 4.17 & 0.0001399 & 0.0001642 & 0.0001924 & 0.4000 \\
\hline 9150583 & $7 / 2 B$ & 15E_4s2d1Zc_1 & $147 / 16$ & $E$ & 3.25 & 354.8 & 36 & 30 & 0.126 & 0.189 & HLP-22 & 12 & 8 & 4 & 1.05 & 4.5 & 2.4 & 21.8 & 10.1 & 0.62 & 0.34 & $\mathrm{~s} 2 \mathrm{~d} 1$ & 4.17 & 0.0001399 & 0.0001642 & o.0001924 & 0.4000 \\
\hline 9150584 & $7 / 2 \mathrm{~B}$ & 15E_4s2d1Zc_1 & $147 / 16$ & $E$ & 3.25 & 354.8 & 36 & 30 & 0.126 & 0.189 & HLP-22 & 12 & 8 & 4 & 1.05 & 4.5 & 2.4 & 21.8 & 10.1 & 0.62 & 0.34 & $\mathrm{~s} 2 \mathrm{~d} 1$ & 4.17 & 0.0001399 & 0.0001642 & 0.0001924 & 0.4000 \\
\hline 9150525 & $7 / 2 B$ & 15E_4s2d1Zc_1 & $147 / 16$ & $E$ & 3.25 & 354.8 & 36 & 30 & 0.126 & 0.189 & HLP-22 & 12 & 8 & 4 & 1.05 & 4.5 & 2.4 & 21.8 & 10.1 & 0.62 & 0.34 & $\mathrm{~s} 2 \mathrm{~d} 1$ & 4.17 & 0.0001399 & 0.0001642 & 0.0001924 & 0.4000 \\
\hline 9150586 & $7 / 2 \mathrm{~B}$ & 15E_4s2d1Zc_1 & $147 / 16$ & $E$ & 3.25 & 354.8 & 36 & 30 & 0.126 & 0.189 & HLP-22 & 12 & 8 & 4 & 1.05 & 4.5 & 2.4 & 21.8 & 10.1 & 0.62 & 0.34 & $\mathrm{~s} 2 \mathrm{d1}$ & 4.17 & 0.0001399 & 0.0001642 & 0.0001924 & 0.4000 \\
\hline 9150587 & $7 / 2 B$ & 15E_4s2d1Zc_1 & $147 / 16$ & $E$ & 3.25 & 354.8 & 36 & 30 & 0.126 & 0.189 & HLP-22 & 12 & 8 & 4 & 1.05 & 4.5 & 2.4 & 21.8 & 10.1 & 0.62 & 0.34 & $\mathrm{~s} 2 \mathrm{~d} 1$ & 4.17 & 0.0001399 & 0.0001642 & 0.0001924 & 0.4000 \\
\hline $9150588 \mathrm{M}$ & $7 / 2 B$ & 15E_4S2d17c_1 & $147 / 16$ & E & 3.25 & 354.8 & 36 & 30 & 0.126 & 0.189 & HLP-22 & 12 & 8 & 4 & 1.05 & 4.5 & 2.4 & 21.8 & 10.1 & 0.62 & 0.34 & $\mathrm{~s} 2 \mathrm{~d} 1$ & 4.17 & 0.0001399 & 0.0001642 & 0.0001924 & 0.4000 \\
\hline $9150589 \mathrm{M}$ & $7 / 2 B$ & $15 E_{4} 4 \mathrm{~s} 2 \mathrm{~d} 17 \mathrm{c} \_1$ & $147 / 16$ & $E$ & 3.25 & 354.8 & 36 & 30 & 0.126 & 0.189 & HLP-22 & 12 & 8 & 4 & 1.05 & 4.5 & 2.4 & 21.8 & 10.1 & 0.62 & 0.34 & $\mathrm{~s} 2 \mathrm{~d} 1$ & 4.17 & 0.0001399 & 0.0001642 & 0.0001924 & 0.4000 \\
\hline $9150590 \mathrm{M}$ & $7 / 2 B$ & 15E_4s2d17c_1 & $147 / 16$ & $E$ & 3.25 & 354.8 & 36 & 30 & 0.126 & 0.189 & HLP-22 & 12 & 8 & 4 & 1.05 & 4.5 & 2.4. & 21.8 & 10.1 & 0.62 & 0.34 & $\mathrm{~s} 2 \mathrm{~d} 1$ & 4.17 & $\begin{array}{ll}0.0001399 \\
\end{array}$ & 0.0001642 & $\begin{array}{ll}0.0001924 \\
\end{array}$ & 0.4000 \\
\hline $9150591 \mathrm{M}$ & $7 / 2 B$ & 15E_4s2d17c_1 & $147 / 16$ & $E$ & 3.25 & 354.8 & 36 & 30 & 0.126 & 0.189 & HLP-22 & 12 & 8 & 4 & 1.05 & 4.5 & 2.4 & 21.8 & 10.1 & 0.62 & 0.34 & $\mathrm{~s} 2 \mathrm{~d} 1$ & 4.17 & 0.0001399 & 0.0001642 & $\begin{array}{l}0.0001924 \\
\end{array}$ & 0.4000 \\
\hline 9150592M & $7 / 2 B$ & 15E_4s2d17c_1 & $147 / 16$ & $\mathrm{E}$ & 3.25 & 354.8 & 36 & 30 & 0.126 & 0.189 & HLP-22 & 12 & 8 & 4 & 1.05 & 4.5 & 2.4 & 21.8 & 10.1 & 0.62 & 0.34 & $\mathrm{~s} 2 \mathrm{~d} 1$ & 4.17 & 0.0001399 & 0.0001642 & 0.0001924 & 0.4000 \\
\hline 91505921 & $7 / 2 B$ & $15 E_{2} 4 \mathrm{~s} 2 \mathrm{~d} 17 \mathrm{c} \_1$ & $147 / 16$ & $E$ & 3.25 & 354.8 & 36 & 30 & 0.126 & 0.189 & HLP-22 & 12 & 8 & 4 & 1.05 & 4.5 & 2.4 & 21.8 & 10.1 & 0.62 & 0.34 & $\mathrm{~s} 2 \mathrm{~d} 1$ & 4.17 & 0.0001399 & 0.0001642 & 0.0001924 & \\
\hline 91505922 & $7 / 2 B$ & 15E_4s2d17c_1 & $147 / 16$ & $E$ & 3.25 & 354.8 & 36 & 30 & 0.126 & 0.189 & HLP-22 & 12 & 8 & 4 & 1.05 & 4.5 & 2.4 & 21.8 & 10.1 & 0.62 & 0.34 & $\mathrm{~s} 2 \mathrm{~d} 1$ & 4.17 & 0.0001399 & 0.0001642 & 0.0001924 & 0.4000 \\
\hline 91505923 & $7 / 2 B$ & $15 E_{4} 4 \mathrm{~s} 2 \mathrm{~d} 17 \mathrm{c} \_1$ & $147 / 16$ & $E$ & 3.25 & 354.8 & 36 & 30 & 0.126 & 0.189 & HLP-22 & 12 & 8 & 4 & 1.05 & 4.5 & 2.4 & 21.8 & 10.1 & 0.62 & 0.34 & $\mathrm{~s} 2 \mathrm{~d} 1$ & 4.17 & 0.0001399 & 0.0001642 & 0.0001924 & 0.4000 \\
\hline 91505924 & $7 / 2 B$ & 15E_4s2d17c_1 & $147 / 16$ & $E$ & 3.25 & 354.8 & 36 & 30 & 0.126 & 0.189 & HLP-22 & 12 & 8 & 4 & 1.05 & 4.5 & 2.4 & 21.8 & 10.1 & 0.62 & 0.34 & $\mathrm{~s} 2 \mathrm{~d} 1$ & 4.17 & 0.0001399 & 0.0001642 & 0.0001924 & 0.4000 \\
\hline 9150593M & $7 / 2 B$ & 15E_4S2d17c_1 & $147 / 16$ & $E$ & 3.25 & 354.8 & 36 & 30 & 0.126 & 0.189 & HLP-22 & 12 & 8 & 4 & 1.05 & 4.5 & 2.4 & 21.8 & 10.1 & 0.62 & 0.34 & $\mathrm{~s} 2 \mathrm{~d} 1$ & 4.17 & 0.0001399 & 0.0001642 & 0.0001924 & 0.4000 \\
\hline 9150594 & $7 / 2 B$ & 15E_4s2d1Zc_1 & $147 / 16$ & $E$ & 3.25 & 354.8 & 36 & 30 & 0.126 & 0.189 & HLP. & 12 & 8 & 4 & & 4.5 & 2.4 & $21.8 \mathrm{~S}$ & & 0.62 & & $\mathrm{~s} 2 \mathrm{C}$ & & & t & & \\
\hline 9150594.1 & $7 / 2 B$ & 15E_4s2d1Zc_1 & $147 / 16$ & $\mathrm{E}$ & 3.25 & 354.8 & 36 & 30 & 0.126 & 0.189 & HLP-22 & 12 & 8 & 4 & 1.05 & 4.5 & 2.4 & 21.8 & 10.1 & 0.62 & 0.34 & $\mathrm{~s} 2 \mathrm{~d} 1$ & 4.17 & 0.0001399 & 0.0001642 & 0.0001924 & 0.4000 \\
\hline 9150595 & $7 / 2 B$ & 15E_4s2d17c 1 & $147 / 16$ & E & 3.25 & 354.8 & 36 & 30 & 0.126 & 0.189 & HLP-22 & 12 & 8 & 4 & 1.05 & 4.5 & 2.4 & 21.8 & 10.1 & 0.62 & 0.34 & $\mathrm{~s} 2 \mathrm{~d} 1$ & 4.17 & 0.0001399 & 0.0001642 & 0.0001924 & 0.4000 \\
\hline
\end{tabular}


Table B.3. Data from 2008 Tests in Small-Scale Vessel with Elliptical Head B.16

\begin{tabular}{|c|c|c|c|c|c|c|c|c|c|c|c|c|c|c|c|c|c|c|c|c|c|c|c|c|c|c|c|c|c|}
\hline $\begin{array}{l}\text { Tank Water } \\
\text { Temperature }\end{array}$ & \begin{tabular}{|l|} 
Water \\
Density
\end{tabular} & $\begin{array}{l}\text { Solids } \\
\text { Fraction }\end{array}$ & \begin{tabular}{|c|} 
Pulse \\
Volume \\
Fraction \\
\end{tabular} & \begin{tabular}{|l} 
Duty \\
Cycle
\end{tabular} & $\begin{array}{l}\text { oyde } \\
\text { Time }\end{array}$ & \begin{tabular}{|l} 
Pulsed or \\
Steady Je
\end{tabular} & \begin{tabular}{|c} 
Us \\
Steady \\
Jet
\end{tabular} & $\begin{array}{c}\text { UI } \\
\text { Pulsin } \\
\text { g jet }\end{array}$ & $\begin{array}{c}\text { U2 } \\
\text { URMS }\end{array}$ & $\begin{array}{c}\text { UB } \\
\text { URNB }\end{array}$ & \begin{tabular}{|c|} 
Discharge \\
Velocity
\end{tabular} & \begin{tabular}{|c} 
Citical \\
Suspension \\
Velocity
\end{tabular} & \begin{tabular}{|c} 
Average Peak \\
Cound Height
\end{tabular} & \begin{tabular}{|c|} 
UCS \\
Condtion
\end{tabular} & $\begin{array}{l}\text { UCS } \\
\text { Method }\end{array}$ & UCS Hag & $\begin{array}{c}\text { UCS Center } \\
\text { Fag }\end{array}$ & $\begin{array}{l}\text { UCS udv } \\
\text { Hag }\end{array}$ & $\begin{array}{l}\text { UCS based on } \\
\text { Decreasing } \\
\text { Velocity }\end{array}$ & \begin{tabular}{|c} 
Sweep \\
Increase / \\
Decrease
\end{tabular} & \begin{tabular}{|c|} 
uDv \\
Height \\
Bed
\end{tabular} & $\begin{array}{l}\text { Partide } \\
\text { Motion } \\
\end{array}$ & $\begin{array}{l}\text { Solids } \\
\text { Level }\end{array}$ & \begin{tabular}{|c|} 
Outer \\
Botom \\
Pattem
\end{tabular} & \begin{tabular}{|c|} 
Inner \\
Bottom \\
Pattem \\
\end{tabular} & Case ID & Test & IDP & $\begin{array}{l}\text { Row } \\
\text { Number }\end{array}$ \\
\hline c & $9 / \mathrm{cm}^{3}$ & fraction & fraction & \begin{tabular}{|l|l|} 
fraction \\
\end{tabular} & - & text & m/s & $\mathrm{m} / \mathrm{s}$ & m/s & $\mathrm{m} / \mathrm{s}$ & $\mathrm{m} / \mathrm{s}$ & $\mathrm{m} / \mathrm{s}$ & in. & m/s & text & text & text & text & $\mathrm{m} / \mathrm{s}$ & text & $\mathrm{mm}$ & text & text & \begin{tabular}{|l|l|} 
text \\
\end{tabular} & text & text & text & text & text \\
\hline$T$ & $\rho$ & $\phi_{\mathrm{s}}$ & $\phi_{p}$ & $D C$ & $t_{c}$ & Jet & $u_{s}$ & $\mathrm{u}_{1}$ & $\mathrm{U} 2$ & U3 & $u$ & $U_{c s}$ & $\mathrm{H}_{\mathrm{C}}$ & U USR & Uon & Ussis & Ussen & Usurudv & Ucs D & $\mathrm{s}_{\mathrm{w}}$ & $\mathrm{H}_{\text {bod }}$ & PM & Sol & SPo & $\mathrm{SP}_{\mathrm{P}}$ & ID & MDDX & TDP & MSS \\
\hline 30.1 & 0.998 & 0.00500 & 0.050 & 0.339 & 15.8 & $\mathrm{P}$ & NA & 3.76 & 3.81 & 3.83 & 3.90 & 3.70 & 17.00 & NA & NA & NA & NA & NA & NA & 1 & 4.5 & 4 & NA & NA & NA & 15E 4S1d5Yc 1 & $7 / 1 \mathrm{~B}$ & TDP-200 & 9150560 \\
\hline 30.4 & 0.998 & 0.00500 & 0.050 & 0.332 & 17.6 & $\mathrm{P}$ & NA & 3.43 & 3.45 & 3.47 & 3.50 & 3.70 & 8.50 & NA & NA & NA & UCScen & NA & NA & (null) & 0.0 & 2 & NA & $\mathrm{NA}$ & NA & 15E_4s1d5YC_ 1 & $7 / 1 \mathrm{~B}$ & TDP-200 & 9150561 \\
\hline 30.4 & 0.998 & 0.00500 & 0.050 & 0.332 & 17.6 & $\mathrm{P}$ & NA & 3.43 & 3.45 & 3.47 & 3.50 & 3.70 & 8.50 & NA & NA & NA & NA & NA & NA & NA & 0.0 & NA & NA & NA & NA & 15E_4s1d5Yc_1 & $7 / 1 \mathrm{~B}$ & TDP-200 & 9150562 \\
\hline 30.4 & 0.998 & 0.00500 & 0.050 & 0.332 & 17.6 & $\mathrm{P}$ & NA & 3.43 & 3.45 & 3.47 & 3.50 & 3.70 & 8.50 & NA & NA & NA & NA & NA & NA & NA & 0.0 & NA & $\mathrm{NA}$ & NA & NA & 15E_4S1dTYC_1 & $7 / 1 \mathrm{~B}$ & TDP-200 & 9150563 \\
\hline 30.4 & 0.998 & 0.00500 & 0.050 & 0.332 & 17.6 & $\mathrm{P}$ & NA & 3.43 & 3.45 & 3.47 & 3.50 & 3.70 & 8.50 & NA & NA & NA & NA & NA & NA & $\mathrm{NA}$ & 0.0 & NA & NA & NA & NA & 15E_4S1d5YC 1 & $7 / 1 \mathrm{~B}$ & TDP-200 & 9150564 \\
\hline 30.4 & 0.998 & 0.00500 & 0.050 & 0.332 & 17.6 & $\mathrm{P}$ & NA & 3.43 & 3.45 & 3.47 & 3.50 & 3.70 & 8.50 & NA & NA & NA & NA & NA & NA & NA & 0.0 & NA & NA & NA & NA & 15E_4s1da5Y_ _ 1 & $7 / 1 \mathrm{~B}$ & TDP-200 & 9150565 \\
\hline 30.4 & 0.998 & 0.00500 & 0.050 & 0.332 & 17.6 & $\mathrm{P}$ & NA & 3.43 & 3.45 & 3.47 & 3.50 & 3.70 & 8.50 & NA & NA & NA & NA & NA & NA & NA & 0.8 & NA & NA & NA & NA & 15E_4s1d5YC_1 & $7 / 1 \mathrm{~B}$ & TDP-200 & 9150566 \\
\hline 30.4 & 0.998 & 0.00500 & 0.050 & 0.332 & 17.6 & $\mathrm{P}$ & NA & 3.43 & 3.45 & 3.47 & 3.50 & 3.70 & 8.50 & NA & NA & NA & NA & NA & NA & $\mathrm{NA}$ & 0.0 & NA & NA & NA & NA & 15E_4s1d5Yc_1 & $7 / 1 \mathrm{~B}$ & TDP-200 & 9150567 \\
\hline 30.7 & 0.998 & 0.00500 & 0.050 & 0.334 & 15.8 & $\mathrm{P}$ & NA & 3.78 & 3.81 & 3.83 & 3.90 & 3.70 & 16.00 & NA & NA & NA & NA & NA & NA & 1 & 0.0 & 4 & NA & NA & NA & 15E_4s1d5YC 1 & $7 / 1 \mathrm{~B}$ & TDP-200 & 9150568 \\
\hline 27.7 & 0.998 & 0.00050 & 0.050 & 0.327 & 20.5 & $\mathrm{P}$ & NA & 2.94 & 2.97 & 2.98 & 3.00 & 4.70 & 10.00 & NA & NA & NA & NA & NA & NA & D & 5.9 & 1 & NA & NA & NA & 15E_4S2 $2 \mathrm{~d} 1 \mathrm{TC}$ I & $7 / 2 \mathrm{~A}$ & TDP-201 & 9150569 \\
\hline 27.9 & 0.998 & 0.00050 & 0.050 & 0.330 & 17.8 & $P$ & NA & 3.42 & 3.45 & 3.46 & 3.50 & 4.70 & 10.50 & NA & NA & NA & NA & NA & NA & 1 & 7.2 & 1 & NA & NA & NA & 15E_4s2d1Tc 1 & $7 / 2 \mathrm{~A}$ & TDP-201 & 9150570 \\
\hline 28.0 & $\begin{array}{ll}0.998 \\
\end{array}$ & 0.00050 & 0.050 & 0.336 & 15.4 & $P$ & NA & 3.87 & 3.92 & 3.94 & 4.00 & 4.70 & 9.00 & NA & NA & NA & NA & $\mathrm{NA}$ & NA & 1 & 7.4 & 1 & NA & NA & $\mathrm{NA}$ & 15E_4s2d1TC_1 & $7 / 2 \mathrm{~A}$ & TDP-201 & 9150571 \\
\hline 28.2 & 0.998 & 0.00050 & 0.050 & 0.337 & 13.6 & $\mathrm{P}$ & NA & 4.36 & 4.41 & 4.43 & 4.50 & 4.70 & 10.00 & NA & NA & NA & NA & NA & NA & 1 & 2.6 & 1 & NA & NA & NA & 15E_4s2d1TC 1 & $7 / 2 \mathrm{~A}$ & IDP-201 & 9150572 \\
\hline 28.6 & $\begin{array}{ll}0.998 \\
\end{array}$ & 0.00050 & 0.050 & 0.330 & 13.4 & $P$ & NA & 4.52 & 4.59 & 4.62 & 4.70 & 4.70 & 11.25 & 4.76 & udv & ucsis & NA & ucsudv & NA & 1 & 0.6 & 3 & NA & NA & NA & 15E_4s2d1Tc_1 & $7 / 2 \mathrm{~A}$ & TDP-201 & 9150573 \\
\hline 28.9 & 0.998 & 0.00050 & 0.050 & 0.331 & 12.8 & $\mathrm{P}$ & $\mathrm{NA}$ & 4.72 & 4.78 & 4.82 & 4.90 & 4.70 & 12.25 & NA & NA & NA & NA & NA & NA & 1 & 0.0 & 4 & NA & NA & NA & 15E_4S2 $2 \mathrm{~d} 1 \mathrm{~T} \mathrm{~T} \_1$ & $7 / 2 \mathrm{~A}$ & TDP-201 & 9150574 \\
\hline 29.4 & 0.998 & 0.00050 & 0.050 & 0.335 & 11.8 & $\mathrm{P}$ & NA & 5.06 & 5.14 & 5.18 & 5.30 & 4.70 & 14.50 & NA & NA & NA & NA & NA & NA & 1 & 0.0 & 4 & NA & NA & NA & 15E_4S2d1TC_1 & $7 / 2 \mathrm{~A}$ & TDP-201 & 9150575 \\
\hline 29.7 & 0.998 & 0.00050 & 0.050 & 0.335 & 11.2 & $\mathrm{P}$ & NA & 5.36 & 5.45 & 5.49 & 5.60 & 4.70 & 16.75 & NA & NA & NA & NA & NA & NA & 1 & 0.0 & 4 & NA & NA & NA & 15E_4S2 $2 \mathrm{~d} 1 \mathrm{TC}$ 1 & $7 / 2 \mathrm{~A}$ & TDP-201 & 9150576 \\
\hline 29.8 & 0.998 & 0.00050 & 0.050 & 0.337 & 10.6 & $\mathrm{P}$ & NA & 5.63 & 5.72 & $5.7 \pi$ & 5.90 & 4.70 & 19.50 & NA & NA & NA & NA & NA & NA & 1 & 0.0 & 4 & NA & NA & NA & $15 \mathrm{E}-4 \mathrm{~s} 2 \mathrm{~d} 1 \mathrm{TC} 1$ & $7 / 2 \mathrm{~A}$ & TDP-201 & 915057 \\
\hline 30.1 & 0.998 & 0.00155 & 0.050 & 0.329 & 15.6 & $P$ & NA & 3.91 & 3.94 & 3.96 & 4.00 & 6.80 & 5.75 & NA & NA & NA & NA & NA & NA & (null) & 14.5 & 1 & NA & NA & NA & 15E_4s2d17c 1 & $7 / 28$ & TDP-202 & 9150578 \\
\hline 30.4 & 0.998 & 0.00155 & 0.050 & 0.334 & 14.2 & $\mathrm{P}$ & NA & 4.25 & 4.30 & 4.33 & 4.40 & 6.80 & 5.75 & NA & NA & NA & NA & NA & NA & 1 & 14.8 & 1 & NA & $\mathrm{NA}$ & NA & 15E_4s2d17c__1 & $7 / 2 \mathrm{~B}$ & TDP-202 & 9150579 \\
\hline 30.5 & 0.998 & 0.00155 & 0.050 & 0.335 & 13.0 & $\mathrm{P}$ & NA & 4.62 & 4.69 & 4.72 & 4.80 & 6.80 & 6.50 & NA & NA & NA & NA & NA & NA & 1 & \begin{tabular}{|l|}
13.9 \\
\end{tabular} & 1 & NA & NA & NA & 15E_4s2d17c_1 & $7 / 2 \mathrm{~B}$ & TDP-202 & 9150580 \\
\hline 31.4 & 0.998 & 0.00155 & 0.050 & 0.338 & 12.0 & $\mathrm{P}$ & NA & 4.98 & 5.06 & 5.10 & 5.20 & 6.80 & 6.75 & NA & NA & NA & NA & NA & NA & 1 & NA & 1 & NA & NA & NA & 15E_4s2d17c 1 & $7 / 2 \mathrm{~B}$ & TDP-202 & 9150581 \\
\hline 31.8 & 0.997 & 0.00155 & 0.050 & 0.334 & 11.6 & $\mathrm{P}$ & NA & 5.18 & 5.26 & 5.30 & 5.40 & 6.80 & 7.00 & NA & NA & NA & NA & NA & NA & 1 & 8.5 & 1 & NA & NA & NA & 15E_4s2d17c 1 & $7 / 28$ & TDP-202 & 9150582 \\
\hline 32.1 & 0.997 & 0.00155 & 0.050 & 0.336 & 10.8 & $\mathrm{p}$ & NA & 5.54 & 5.63 & 5.67 & 5.80 & 6.80 & 7.25 & NA & NA & NA & NA & NA & $\mathrm{N}$ & 1 & 6.3. & 1 & NA & NA & NA & 15E_ 4s2d17c 1 & $7 / 2 \mathrm{~B}$ & TDP-202 & 9150583 \\
\hline 32.4 & 0.997 & 0.00155 & 0.050 & 0.339 & 10.4 & $\mathrm{P}$ & NA & 5.72 & 5.82 & 5.86 & 6.00 & 6.80 & 7.50 & NA & NA & NA & NA & NA & $\mathrm{N}$ & & 5.1 & 1 & NA & NA & NA & 15E_4s2d17c 1 & $7 / 2 B$ & TDP-202 & 9150584 \\
\hline 32.7 & 0.997 & 0.00155 & 0.050 & 0.337 & 10.0 & $\mathrm{P}$ & NA & 5.91 & 6.01 & 6.06 & 6.20 & 6.80 & 7.50 & NA & NA & NA & NA & NA & NA & 1 & 4.1 & 1 & NA & NA & NA & $15 E$ _s $2 \mathrm{~d} 17 \mathrm{c}$ 1 & $7 / 2 B$ & TDP-202 & 9150585 \\
\hline 32.9 & 0.997 & 0.00155 & 0.050 & 0.333 & 9.8 & $\mathrm{P}$ & NA & 6.09 & 6.20 & 6.25 & 6.40 & 6.80 & 8.00 & NA & NA & NA & NA & NA & NA & 1 & 4.6 & 1 & NA & NA & NA & 15E_4s2d17c 1 & $7 / 2 \mathrm{~B}$ & TDP-202 & 9150586 \\
\hline 33.1 & 0.997 & 0.00155 & 0.050 & 0.335 & 9.5 & $\mathrm{P}$ & NA & 6.29 & 6.40 & 6.45 & 6.60 & 6.80 & 8.50 & NA & NA & NA & NA & NA & NA & 1 & 3.5 & 1 & NA & $\mathrm{NA}$ & NA & 15E_4S2d17c_ _ & $7 / 2 \mathrm{~B}$ & TDP-202 & 9150587 \\
\hline 33.5 & $\begin{array}{ll}0.997 \\
\end{array}$ & 0.00155 & 0.050 & 0.327 & 9.4 & $\mathrm{P}$ & NA & 6.49 & 6.60 & 6.66 & 6.80 & 6.80 & 8.00 & 6.80 & uad & UCSis & NA & uesuav & NA & 1 & 0.4 & 3 & NA & NA & NA & 15E_4s2d17c_1 & $7 / 2 \mathrm{~B}$ & TDP-202 & 9150588 \\
\hline 33.6 & 0.997 & 0.00155 & 0.050 & 0.330 & 9.1 & $\mathrm{P}$ & NA & 6.64 & 6.77 & 6.84 & 7.00 & 6.80 & 8.50 & NA & NA & NA & $\mathrm{NA}$ & NA & NA & 1 & 0.0 & 4 & NA & $\mathrm{NA}$ & NA & 15E_4s2d17c_1 & $7 / 2 B$ & TDP-202 & 9150589 \\
\hline 33.6 & 0.997 & 0.00155 & 0.050 & 0.333 & 8.4 & $\mathrm{P}$ & NA & 7.12 & 7.27 & 7.34 & 7.50 & 6.80 & 10.25 & NA & NA & NA & NA & NA & NA & 1 & 0.0 & 4 & NA & NA & NA & 15E_4s2d17c 1 & $7 / 28$ & TDP-202 & 9150590 \\
\hline 33.8 & 0.997 & 0.00155 & 0.050 & 0.338 & 7.8 & $\mathrm{P}$ & $\mathrm{NA}$ & 7.55 & 7.71 & 7.80 & 8.00 & 6.80 & 13.25 & NA & NA & $\mathrm{NA}$ & NA & NA & NA & 1 & 0.0 & 4 & NA & $\mathrm{NA}$ & NA & 15E_4s2d17c__1 & $7 / 2 B$ & TDP-202 & 9150591 \\
\hline 34.0 & 0.997 & 0.00155 & 0.050 & 0.335 & 7.5 & $\mathrm{P}$ & NA & 7.97 & 8.16 & 8.25 & 8.50 & 6.80 & 16.00 & NA & NA & NA & NA & NA & NA & 1 & 0.0 & 4 & NA & NA & NA & 15E_4s2d17c_1 & $7 / 2 \mathrm{~B}$ & TDP-202 & 9150592 \\
\hline 34.2 & 0.997 & 0.00155 & 0.050 & 0.328 & 9.4 & $P$ & NA & 6.46 & 6.58 & 6.64 & 6.80 & 6.80 & 8.00 & NA & NA & NA & NA & NA & NA & $\mathrm{NA}$ & na & NA & NA & NA & $N A$ & 15E_4s2d17c_1 & $7 / 2 B$ & TDP-202 & 9150592.1 \\
\hline 34.2 & 0.997 & 0.00155 & 0.050 & 0.328 & 9.4 & $\mathrm{P}$ & NA & 6.46 & 6.58 & 6.64 & 6.80 & 6.80 & 8.00 & NA & NA & NA & NA & NA & NA & NA & ra & NA & NA & NA & NA & 15E $4 \mathrm{~s} 2 \mathrm{~d} 2 \mathrm{~d} \mathrm{c} 1$ & $7 / 2 B$ & TDP-202 & 9150592.2 \\
\hline 34.2 & 0.997 & 0.00155 & 0.050 & 0.328 & 9.4 & $\mathrm{P}$ & NA & 6.46 & 6.58 & 6.64 & 6.80 & 6.80 & 8.00 & NA & NA & NA & NA & NA & NA & $\mathrm{NA}$ & $\mathrm{n} / \mathrm{a}$ & NA & NA & NA & NA & 15E_4s2d1Zc_1 & $7 / 2 B$ & TDP-202 & 9150592.3 \\
\hline 34.2 & 0.997 & 0.00155 & 0.050 & 0.328 & 9.4 & $\mathrm{P}$ & NA & 6.46 & 6.58 & 6.64 & 6.80 & 6.80 & 8.00 & NA & NA & NA & NA & NA & $\mathrm{NA}$ & NA & $\mathrm{Na}$ & NA & NA & NA & NA & 15E_4s2d17c_ _ 1 & $7 / 2 \mathrm{~B}$ & TDP-202 & 9150592.4 \\
\hline 34.2 & $\begin{array}{ll}0.997 \\
\end{array}$ & 0.00155 & 0.050 & 0.328 & 9.4 & $P$ & NA & 6.46 & 6.58 & 6.64 & 6.80 & 6.80 & 8.00 & NA & vis dec & ucsis & NA & NA & 6.80 & $\mathrm{D}$ & 1.1 & 3 & NA & NA & NA & 15E_4s2d17c_1 & $7 / 2 \mathrm{~B}$ & TDP-202 & 9150593 \\
\hline 34.2 & 0.997 & 0.00155 & 0.050 & 0.328 & 9.4 & $\mathrm{P}$ & NA & 6.46 & 6.58 & 6.64 & 6.80 & 6.80 & 8.00 & NA & NA & NA & NA & NA & NA & NA & 1.2 & NA & NA & NA & NA & $15 E$ _s $2 \mathrm{~d} 17 \mathrm{c}$ 1 & $7 / 2 B$ & TDP-202 & 9150594 \\
\hline 34.2 & 0.997 & 0.00155 & 0.050 & 0.328 & 9.4 & $\mathrm{P}$ & NA & 6.46 & 6.58 & 6.64 & 6.80 & 6.80 & 8.00 & NA & NA & NA & NA & NA & NA & NA & na & NA & NA & NA & NA & 15E_4S2d17c 1 & $7 / 2 B$ & TDP-202 & 9150594.1 \\
\hline 34.2 & 0.997 & 0.00155 & 0.050 & 0.328 & 9.4 & $\mathrm{P}$ & NA & 6.46 & 6.58 & 6.64 & 6.80 & 6.80 & 8.00 & NA & NA & NA & NA & NA & NA & NA & 0.0 & NA & NA & NA & NA & 15E_4S2d17c_1 & $7 / 28$ & TDP-202 & 9150595 \\
\hline
\end{tabular}


Table B.3. Data from 2008 Tests in Small-Scale Vessel with Elliptical Head A.17

\begin{tabular}{|c|c|c|c|c|c|c|c|c|c|c|c|c|c|c|c|c|c|c|c|c|c|c|c|c|c|c|c|}
\hline $\begin{array}{l}\text { Rov } \\
\text { Number }\end{array}$ & Test & Case ID & $\begin{array}{c}\text { Tank } \\
\text { Diameter }\end{array}$ & $\begin{array}{l}\text { Head } \\
\text { Shape }\end{array}$ & \begin{tabular}{|l} 
Dish \\
Height
\end{tabular} & $\begin{array}{l}\text { Dish } \\
\text { Volume }\end{array}$ & $\begin{array}{c}\text { Tank Fill } \\
\text { Height }\end{array}$ & $\begin{array}{l}\text { Retur } \\
\text { Line } \\
\text { Height }\end{array}$ & \begin{tabular}{c|} 
Nozzle \\
Inner \\
Dianter
\end{tabular} & $\begin{array}{l}\text { Nozzle } \\
\text { Stantoff } \\
\text { Distance }\end{array}$ & $\begin{array}{l}\text { Pulse Tube } \\
\text { Configuration }\end{array}$ & \begin{tabular}{|l} 
Installed \\
Nozzles
\end{tabular} & $\begin{array}{l}\text { Outer } \\
\text { Nozzles } \\
\text { Operated }\end{array}$ & $\begin{array}{l}\text { Inner } \\
\text { Nozzles } \\
\text { Operated }\end{array}$ & $\begin{array}{l}\text { Pulse Tube } \\
\text { Outer } \\
\text { Dianteter }\end{array}$ & $\begin{array}{c}\text { Outer } \\
\text { PMM } \\
\text { Radius }\end{array}$ & $\begin{array}{c}\text { Inner PJM } \\
\text { Radius } \\
\end{array}$ & $\begin{array}{c}\text { "FO" Outer PJM } \\
\text { Impingement } \\
\text { Angle }\end{array}$ & $\begin{array}{c}\text { "FO' Inner PJM } \\
\text { Impingement Angle }\end{array}$ & \begin{tabular}{|l} 
Ratio Outer PJM \\
to Tank Radius
\end{tabular} & $\begin{array}{l}\text { Ratio Inner PJM } \\
\text { to Tank Radius }\end{array}$ & Simulant & \begin{tabular}{|l|} 
Solids \\
Density \\
\end{tabular} & $\begin{array}{c}\text { Particle } \\
\text { Diameter d5 }\end{array}$ & \begin{tabular}{c|} 
Particle \\
Diameter d d50
\end{tabular} & $\begin{array}{c}\text { Particle } \\
\text { Diameter d95 }\end{array}$ & $\begin{array}{l}\text { Void } \\
\text { Fraction }\end{array}$ \\
\hline text & text & text & in. & text & in. & in. $^{3}$ & in. 1 & in. & in. & in. & text & number & number & number & in. & in. & in. & deg & deg & nondim & nondim & text & \begin{tabular}{|l|l|}
$\mathrm{g} / \mathrm{cm}^{3}$ \\
\end{tabular} & $\mathrm{~m}$ & \begin{tabular}{l|}
$\mathrm{m}$ \\
\end{tabular} & $m$ & fraction \\
\hline MSS & MDDX & $\mathrm{ID}$ & $\mathrm{D}$ & HS & Hish & $V_{\text {dish }}$ & $\mathrm{H}$ & $\operatorname{Rin}$ & $d$ & sod & PT & $\mathrm{N}$ & $\mathrm{Nb}$ & $\mathrm{N}$ & $\mathrm{PT}_{\alpha d}$ & $R_{0}$ & $R$ & $\theta_{0}$ & $\theta_{1}$ & $R d R$ & $R / R$ & $\operatorname{sxdx}$ & $\rho_{\mathrm{s}}$ & $d_{b}$ & $d_{60}$ & $\frac{d 65}{d}$ & vf \\
\hline 9150595.1 & $7 / 2 B$ & 15E_4s2d1Zc_1 & $147 / 16$ & $E$ & 3.25 & 354. & 36 & 30 & 0.126 & 0.189 & HLP-22 & 12 & 8 & 4 & 1.05 & 4.5 & 2.4 & 21.8 & 10.1 & 0.62 & 0.34 & $\mathrm{~s} 2 \mathrm{~d} 1$ & 4.17 & 0.0001399 & 0.0001642 & 0.0001924 & 0.4000 \\
\hline 9150596 & $7 / 2 B$ & 15E_4s2d17c_1 & $147 / 16$ & $E$ & 3.25 & 354.8 & 36 & 30 & 0.126 & 0.189 & HLP-22 & 12 & 8 & 4 & 1.05 & 4.5 & 2.4 & 21.8 & 10.1 & 0.62 & 0.34 & $\mathrm{~s} 2 \mathrm{~d} 1$ & 4.17 & 0.0001399 & $\begin{array}{ll}0.0001642 \\
\end{array}$ & $\begin{array}{ll}0.0001924 \\
\end{array}$ & 0.4000 \\
\hline 9150596.1 & $7 / 2 B$ & 15E_4s2d17c_ 1 & $147 / 16$ & $E$ & 3.25 & 354.8 & 36 & 30 & 0.126 & 0.189 & HLP-22 & 12 & 8 & 4 & 1.05 & 4.5 & 2.4 & 21.8 & 10.1 & 0.62 & 0.34 & $\mathrm{~s} 2 \mathrm{~d} 1$ & 4.17 & 0.0001399 & 0.0001642 & 0.0001924 & 0.4000 \\
\hline 9150597 & $7 / 2 \mathrm{~B}$ & 15E_4s2d1Zc_1 & $147 / 16$ & E & 3.25 & 354. & 36 & 30 & 0.126 & 0.189 & HLP-22 & 12 & 8 & 4 & 1.05 & 4.5 & 2.4 & 21.8 & 10.1 & 0.62 & 0.34 & $\mathrm{~s} 2 \mathrm{~d} 1$ & 4.17 & 0.0001399 & 0.0001642 & 0.0001924 & 0.4000 \\
\hline 9150597.1 & $7 / 2 B$ & 15E_4s2d1Zc_1 & $147 / 16$ & $E$ & 3.25 & 354.8 & 36 & 30 & 0.126 & 0.189 & HLP-22 & 12 & 8 & 4 & 1.05 & 4.5 & 2.4 & 21.8 & 10.1 & 0.62 & 0.34 & $\mathrm{~s} 2 \mathrm{~d} 1$ & 4.17 & 0.0001399 & 0.0001642 & 0.0001924 & 0.4000 \\
\hline 9150598 & $7 / 2 \mathrm{~B}$ & 15E_4s2d1Zc_1 & $147 / 16$ & $E$ & 3.25 & 354.8 & 36 & 30 & 0.126 & 0.189 & HLP-22 & 12 & 8 & 4 & 1.05 & 4.5 & 2.4 & 21.8 & 10.1 & 0.62 & 0.34 & $\mathrm{~s} 2 \mathrm{~d} 1$ & 4.17 & 0.0001399 & 0.0001642 & 0.0001924 & 0.4000 \\
\hline 9150599 & $7 / 3 A$ & 15E_4s2d1Yc_1 & $147 / 16$ & $E$ & 3.25 & 354.8 & $351 / 2$ & 30 & 0.126 & 0.189 & HLP-22 & 12 & 8 & 4 & 1.05 & 4.5 & 2.4 & 21.8 & 10.1 & 0.62 & 0.34 & $\mathrm{~s} 2 \mathrm{~d} 1$ & 4.17 & 0.0001399 & 0.0001642 & 0.0001924 & 0.4000 \\
\hline 9150600 & $7 / 3 A$ & 15E_4s2d1Yc_1 & $147 / 16$ & $E$ & 3.25 & 354.8 & $351 / 2$ & 30 & 0.126 & 0.189 & HLP-22 & 12 & 8 & 4 & 1.05 & 4.5 & 2.4 & 21.8 & 10.1 & 0.62 & 0.34 & $\mathrm{~s} 2 \mathrm{~d} 1$ & 4.17 & 0.0001399 & 0.0001642 & 0.0001924 & 0.4000 \\
\hline 9150001 & $7 / 3 A$ & 15E_4s2d1Yc_1 & $147 / 16$ & $E$ & 3.25 & 354.8 & $351 / 2$ & 30 & 0.126 & 0.189 & HLP-22 & 12 & 8 & 4 & 1.05 & 4.5 & 2.4 & 21.8 & 10.1 & 0.62 & 0.34 & $\mathrm{~s} 2 \mathrm{~d} 1$ & 4.17 & 0.0001399 & 0.0001642 & 0.0001924 & 0.4000 \\
\hline 9150602 & $7 / 3 \mathrm{~A}$ & 15E_4s2d1Yc_1 & $147 / 16$ & $E$ & 3.25 & 354. & $351 / 2$ & 30 & 0.126 & 0.189 & HLP-22 & 12 & 8 & 4 & 1.05 & 4.5 & 2.4 & 21.8 & 10.1 & 0.62 & 0.34 & $\mathrm{~s} 2 \mathrm{~d} 1$ & 4.17 & 0.0001399 & 0.0001642 & 0.0001924 & 0.4000 \\
\hline 9150603 & $7 / 3 \mathrm{~A}$ & 15E $4 \mathrm{~S} 2 \mathrm{~d} 1 \mathrm{Yc}$. 1 & $147 / 16$ & E & 3.25 & 354. & $351 / 2$ & 30 & 0.126 & 0.189 & HLP-22 & 12 & 8 & 4 & 1.05 & 4.5 & 2.4 & 21.8 & 10.1 & 0.62 & 0.34 & $\mathrm{~s} 2 \mathrm{~d} 1$ & 4.17 & 0.0001399 & 0.0001642 & 0.0001924 & 0.4000 \\
\hline 9150604 & 7/3A & 15E 4s $2 \mathrm{~d} 1 \mathrm{Yc} 1$ & $147 / 16$ & $\mathrm{E}$ & 3.25 & 354.8 & $351 / 2$ & 30 & 0.126 & 0.1899 & HLP-22 & 12 & 8 & 4 & 1.05 & 4.5 & 2.4 & 21.8 & 10.1 & 0.62 & 0.34 & $\mathrm{~s} 2 \mathrm{~d} 1$ & 4.17 & 0.0001399 & 0.0001642 & 0.0001924 & 0.4000 \\
\hline 9150605 & $7 / 3 A$ & 15E_4s2d1Yc_1 1 & $147 / 16$ & $E$ & 3.25 & 354.8 & $351 / 2$ & 30 & 0.126 & 0.189 & HLP-22 & 12 & 8 & 4 & 1.05 & 4.5 & 2.4 & 21.8 & 10.1 & 0.62 & 0.34 & $\mathrm{~s} 2 \mathrm{~d} 1$ & 4.17 & 0.0001399 & 0.0001642 & 0.0001924 & 0.4000 \\
\hline 9150606 & $7 / 3 A$ & 15E_4s2d1YC_ 1 & $147 / 16$ & $E$ & 3.25 & 354.8 & $351 / 2$ & 30 & 0.126 & 0.189 & HLP-22 & 12 & 8 & 4 & 1.05 & 4.5 & 2.4 & 21.8 & 10.1 & 0.62 & 0.34 & $\mathrm{~s} 2 \mathrm{d1}$ & 4.17 & 0.0001399 & 0.0001642 & 0.0001924 & 0.4000 \\
\hline 9150607 & $7 / 3 A$ & 15E_4s2d1Yc_1 & $147 / 16$ & $E$ & 3.25 & 354.8 & $351 / 2$ & 30 & 0.126 & 0.189 & HLP-22 & 12 & 8 & 4 & 1.05 & 4.5 & 2.4 & 21.8 & 10.1 & 0.62 & 0.34 & $\mathrm{~s} 2 \mathrm{~d} 1$ & 4.17 & 0.0001399 & 0.0001642 & 0.0001924 & 0.4000 \\
\hline 9150608 & $7 / 3 A$ & 15E_4s2d1YC_1 & $147 / 16$ & E & 3.25 & 354. & $351 / 2$ & 30 & 0.126 & 0.189 & HLP-22 & 12 & 8 & 4 & 1.05 & 4.5 & 2.4 & 21.8 & 10.1 & 0.62 & 0.34 & $\mathrm{~s} 2 \mathrm{~d} 1$ & 4.17 & 0.0001399 & 0.0001642 & 0.0001924 & 0.4000 \\
\hline 9150609 & $7 / 3 A$ & 15E_4s2d1Yc_1 & $147 / 16$ & $E$ & 3.25 & 354.8 & $351 / 2$ & 30 & 0.126 & 0.189 & HLP-22 & 12 & 8 & 4 & 1.05 & 4.5 & 2.4 & 21.8 & 10.1 & 0.62 & 0.34 & $\mathrm{~s} 2 \mathrm{~d} 1$ & 4.17 & 0.0001399 & 0.0001642 & 0.0001924 & 0.4000 \\
\hline $9150610 \mathrm{M}$ & $7 / 3 \mathrm{~A}$ & 15E_4s2d1Yc_1 & $147 / 16$ & $\mathrm{E}$ & 3.25 & 354.8 & $351 / 2$ & 30 & 0.126 & 0.189 & HLP-22 & 12 & 8 & 4 & 1.05 & 4.5 & 2.4 & 21.8 & 10.1 & 0.62 & 0.34 & $\mathrm{~s} 2 \mathrm{~d} 1$ & 4.17 & 0.0001399 & 0.0001642 & 0.0001924 & 0.4000 \\
\hline $9150611 \mathrm{M}$ & $7 / 3 \mathrm{~A}$ & 15E 4s2d1Yc 1 & $147 / 16$ & $\mathrm{E}$ & 3.25 & 354.8 & $351 / 2$ & 30 & 0.126 & 0.189 & HLP-22 & 12 & 8 & 4 & 1.05 & 4.5 & 2.4 & 21.8 & 10.1 & 0.62 & 0.34 & $\mathrm{~s} 2 \mathrm{~d} 1$ & 4.17 & 0.0001399 & 0.0001642 & 0.0001924 & 0.4000 \\
\hline 9150612M & $7 / 3 A$ & 15E_4s2d1Yc_1 & $147 / 16$ & $E$ & 3.25 & 354.8 & $351 / 2$ & 30 & 0.126 & 0.189 & HLP-22 & 12 & 8 & 4 & 1.05 & 4.5 & 2.4 & 21.8 & 10.1 & 0.62 & 0.34 & $\mathrm{~s} 2 \mathrm{~d} 1$ & 4.17 & 0.0001399 & 0.0001642 & 0.0001924 & 0.4000 \\
\hline 9150613M & $7 / 3 A$ & 15E_4s2d1YC_1 & $147 / 16$ & $\mathrm{E}$ & 3.25 & 354. & $351 / 2$ & 30 & 0.126 & 0.189 & HLP-22 & 12 & 8 & 4 & 1.05 & 4.5 & 2.4 & 21.8 & 10.1 & 0.62 & 0.34 & $\mathrm{~s} 2 \mathrm{~d} 1$ & 4.17 & 0.0001399 & 0.0001642 & 0.0001924 & 0.4000 \\
\hline $9150614 M$ & $7 / 3 A$ & 15E_4s2d1Yc_1 & $147 / 16$ & $E$ & 3.25 & 354.8 & $351 / 2$ & 30 & 0.126 & 0.189 & HLP-22 & 12 & 8 & 4 & 1.05 & 4.5 & 2.4 & 21.8 & 10.1 & 0.62 & 0.34 & $\mathrm{~s} 2 \mathrm{~d} 1$ & 4.17 & 0.0001399 & 0.0001642 & 0.0001924 & 0.4000 \\
\hline $9150615 \mathrm{M}$ & $7 / 3 \mathrm{~A}$ & 15E_4S2d1YC_1 & $147 / 16$ & $E$ & 3.25 & 354. & $351 / 2$ & 30 & 0.126 & 0.189 & HLP-22 & 12 & 8 & 4 & 1.05 & 4.5 & 2.4 & 21.8 & 10.1 & 0.62 & 0.34 & $\mathrm{~s} 2 \mathrm{~d} 1$ & 4.17 & $\begin{array}{ll}0.0001399 \\
\end{array}$ & $\begin{array}{ll}0.0001642 \\
\end{array}$ & $\begin{array}{ll}0.0001924 \\
\end{array}$ & 0.4000 \\
\hline 9150616 & $7 / 3 B$ & 15E_4s2d1X__1 & $147 / 16$ & $E$ & 3.25 & 354.8 & $351 / 2$ & 30 & 0.126 & 0.189 & HLP-22 & 12 & 8 & 4 & 1.05 & 4.5 & 2.4 & 21.8 & 10.1 & 0.62 & 0.34 & $\mathrm{~s} 2 \mathrm{~d} 1$ & 4.17 & 0.0001399 & 0.0001642 & 0.0001924 & 0.4000 \\
\hline 9150617 & $7 / 3 B$ & $15 \mathrm{15} \_4 \mathrm{~s} 2 \mathrm{~d} 1 \mathrm{Xc} \_1$ & $147 / 16$ & $E$ & 3.25 & 354. & $351 / 2$ & 30 & 0.126 & 0.189 & HLP-22 & 12 & 8 & 4 & 1.05 & 4.5 & 2.4 & 21.8 & 10.1 & 0.62 & 0.34 & $\mathrm{~s} 2 \mathrm{~d} 1$ & 4.17 & 0.0001399 & 0.0001642 & 0.0001924 & 0.4000 \\
\hline $9150618 \mathrm{M}$ & $7 / 3 B$ & 15E_4s2d1Xc_1 & $147 / 16$ & $E$ & 3.25 & 354.8 & $351 / 2$ & 30 & 0.126 & 0.189 & HLP-22 & 12 & 8 & 4 & 1.05 & 4.5 & 2.4 & 21.8 & 10.1 & 0.62 & 0.34 & $\mathrm{~s} 2 \mathrm{~d} 1$ & 4.17 & 0.0001399 & 0.0001642 & 0.0001924 & 0.4000 \\
\hline $9150619 \mathrm{M}$ & $7 / 3 B$ & 15E_4s2d1Xc_1 & $147 / 16$ & $E$ & 3.25 & 354.8 & $351 / 2$ & 30 & 0.126 & 0.189 & HLP-22 & 12 & 8 & 4 & 1.05 & 4.5 & 2.4 & 21.8 & 10.1 & 0.62 & 0.34 & $\mathrm{~s} 2 \mathrm{d1}$ & 4.17 & 0.0001399 & 0.0001642 & 0.0001924 & 0.4000 \\
\hline 9150620M & $7 / 3 B$ & 15E_4s $2 \mathrm{~d} 1 \mathrm{X} \mathrm{C}_{1} 1$ & $147 / 16$ & $E$ & 3.25 & 354.8 & $351 / 2$ & 30 & 0.126 & 0.189 & HLP-22 & 12 & 8 & 4 & 1.05 & 4.5 & 2.4 & 21.8 & 10.1 & 0.62 & 0.34 & $\mathrm{~s} 2 \mathrm{~d} 1$ & 4.17 & 0.0001399 & 0.0001642 & 0.0001924 & 0.4000 \\
\hline $9150621 \mathrm{M}$ & $7 / 3 B$ & 15E_4s2d1Xc_1 & $147 / 16$ & E & 3.25 & 354. & $351 / 2$ & 30 & 0.126 & 0.189 & HLP-22 & 12 & 8 & 4 & 1.05 & 4.5 & 2.4 & 21.8 & 10.1 & 0.62 & 0.34 & $\mathrm{~s} 2 \mathrm{~d} 1$ & 4.17 & 0.0001399 & 0.0001642 & 0.0001924 & 0.4000 \\
\hline 9150622 & $7 / 8 \mathrm{~A}$ & 15E8_6s1d2Zc_1 & $147 / 16$ & $E$ & 3.25 & 354.8 & 35 & 30 & 0.191 & 0.202 & 8TA & 8 & 4 & 4 & 1.05 & 4.9 & 3.6 & 24.4 & 16 & 0.67 & 0.50 & $\mathrm{~s} 1 \mathrm{~d} 2$ & 2.48 & 0.0000569 & 0.0000693 & 0.0000821 & 0.3750 \\
\hline 9150623 & $7 / 8 \mathrm{~A}$ & 15E8_6s1d27c_1 1 & $147 / 16$ & $E$ & 3.25 & 354.8 & 35 & 30 & 0.191 & 0.202 & 8 8TA & 8 & 4 & 4 & 1.05 & 4.9 & 3.6 & 24.4 & 16 & 0.67 & 0.50 & $\mathrm{~s} 1 \mathrm{~d} 2$ & 2.48 & 0.0000569 & $\begin{array}{ll}0.0000693 \\
\end{array}$ & 0.0000821 & 0.3750 \\
\hline $9150624 \mathrm{M}$ & $7 / 8 \mathrm{~A}$ & 15E8_6sid272__1 & $147 / 16$ & $E$ & 3.25 & 354.8 & 35 & 30 & 0.191 & 0.202 & 8TA & 8 & 4 & 4 & 1.05 & 4.9 & 3.6 & 24.4 & 16 & 0.67 & 0.50 & $\mathrm{sid2}$ & 2.48 & 0.0000569 & 0.0000693 & 0.0000821 & 0.3750 \\
\hline $9150625 \mathrm{M}$ & $7 / 8 \mathrm{~A}$ & 15E8__sidd2ZC_1 & $147 / 16$ & $\mathrm{E}$ & 3.25 & 354. & 35 & 30 & 0.191 & 0.202 & 8TA & 8 & 4 & 4 & 1.05 & 4.9 & 3.6 & 24.4 & 16 & 0.67 & 0.50 & $\mathrm{sid} 2$ & 2.48 & 0.0000569 & 0.0000693 & 0.0000821 & 0.3750 \\
\hline $9150626 \mathrm{M}$ & $7 / 8 \mathrm{~A}$ & 15E8_6s1d2Zc_1 & $147 / 16$ & $E$ & 3.25 & 354.8 & 35 & 30 & 0.191 & 0.202 & $8 \mathrm{PTA}$ & 8 & 4 & 4 & 1.05 & 4.9 & 3.6 & 24.4 & 16 & 0.67 & 0.50 & $\mathrm{~s} 1 \mathrm{~d} 2$ & 2.48 & 0.0000569 & 0.0000693 & 0.0000821 & 0.3750 \\
\hline $9150627 \mathrm{M}$ & $7 / 8 \mathrm{~A}$ & 15E8__sid2ZC_ 1 & $147 / 16$ & $E$ & 3.25 & 354.8 & 35 & 30 & 0.191 & 0.202 & 8TA & 8 & 4 & 4 & 1.05 & 4.9 & 3.6 & 24.4 & 16 & 0.67 & 0.50 & $\mathrm{~s} 1 \mathrm{~d} 2$ & 2.48 & 0.0000569 & 0.0000693 & 0.0000821 & 0.3750 \\
\hline 9150628 & $7 / 8 B$ & $15 E 8$ _ss1d2ZC_ 2 & $147 / 16$ & $E$ & 3.25 & 354.8 & 35 & 30 & 0.191 & 0.202 & $8 \mathrm{PTA}$ & 8 & 4 & 4 & 1.05 & 4.9 & 3.6 & 24.4 & 16 & 0.67 & 0.50 & s1d2 & 2.48 & 0.0000569 & 0.0000693 & 0.0000821 & 0.3750 \\
\hline 9150629 & $7 / 88$ & 15E8__ss1d27C 2 & $147 / 16$ & $E$ & 3.25 & 354.8 & 35 & 30 & 0.191 & 0.202 & $8 \mathrm{BA}$ & 8 & 4 & 4 & 1.05 & 4.9 & 3.6 & 24.4 & 16 & 0.67 & 0.50 & s1d2 & 2.48 & 0.0000569 & 0.0000693 & 0.0000821 & 0.3750 \\
\hline 9150630 & $7 / 8 B$ & 15E8__sidd2Z__2 & $147 / 16$ & $E$ & 3.25 & 354. & 35 & 30 & 0.191 & 0.202 & 8TA & 8 & 4 & 4 & 1.05 & 4.9 & 3.6 & 24.4 & 16 & 0.67 & 0.50 & $\mathrm{sid2}$ & 2.48 & 0.0000569 & 0.0000693 & 0.0000821 & 0.3750 \\
\hline 9150631 & $7 / 8 \mathrm{~B}$ & 15E8_6s1d2Zc_2 & $147 / 16$ & $E$ & 3.25 & 354.8 & 35 & 30 & 0.191 & 0.202 & $8 T \mathrm{~A}$ & 8 & 4 & 4 & 1.05 & 4.9 & 3.6 & 24 & & 0.67 & & $\mathrm{~s} 1 \mathrm{~d} 2$ & 1 & & & & \\
\hline 9150632M & $7 / 88$ & $15 E 8$ Gs1d2Zc 2 & $147 / 16$ & $E$ & 3.25 & 354.8 & 35 & 30 & 0.191 & 0.202 & $8 \mathrm{BTA}$ & 8 & 4 & 4 & 1.05 & 4.9 & 3.6 & 24.4 & 16 & 0.67 & 0.50 & s1d2 & 2.48 & 0.0000569 & 0.0000693 & 0.0000821 & 0.3750 \\
\hline $9150633 \mathrm{M}$ & $7 / 88$ & $15 E 8$ _ssid27_ _ 2 & $147 / 16$ & E & 3.25 & 354. & 35 & 30 & 0.191 & 0.202 & BTA & 8 & 4 & 4 & 1.05 & 4.9 & 3.6 & 24.4 & 16 & 0.67 & 0.50 & s1d2 & 248 & 0.0000569 & 0.0000693 & 0.0000821 & 0.3750 \\
\hline
\end{tabular}


Table B.3. Data from 2008 Tests in Small-Scale Vessel with Elliptical Head B.17

\begin{tabular}{|c|c|c|c|c|c|c|c|c|c|c|c|c|c|c|c|c|c|c|c|c|c|c|c|c|c|c|c|c|c|}
\hline $\begin{array}{l}\text { Tank Water } \\
\text { Temperature }\end{array}$ & $\begin{array}{l}\text { Water } \\
\text { Density }\end{array}$ & $\begin{array}{l}\text { Solids } \\
\text { Fraction }\end{array}$ & $\begin{array}{c}\text { Pulse } \\
\text { Volume } \\
\text { Fraction }\end{array}$ & $\begin{array}{l}\text { Duty } \\
\text { adde }\end{array}$ & $\begin{array}{l}\text { Cyde } \\
\text { Time }\end{array}$ & $\begin{array}{c}\text { Pulsed } \\
\text { or } \\
\text { Steacy } \\
\text { Jet }\end{array}$ & $\begin{array}{c}\text { Us } \\
\text { Steacdy } \\
\text { Jet }\end{array}$ & $\begin{array}{c}\text { U1 } \\
\text { Pulsing } \\
\text { Jet }\end{array}$ & $\begin{array}{c}\text { U2 } \\
\text { URMS }\end{array}$ & $\begin{array}{c}\text { U3 } \\
\text { URMB }\end{array}$ & 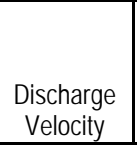 & $\begin{array}{c}\text { Citical } \\
\text { Suspension } \\
\text { Velocity }\end{array}$ & $\begin{array}{c}\text { Average } \\
\text { Peak Coud } \\
\text { Height }\end{array}$ & $\begin{array}{c}\text { UCS } \\
\text { Condition }\end{array}$ & $\begin{array}{l}\text { UCS } \\
\text { Method }\end{array}$ & $\begin{array}{l}\text { ucs } \\
\text { Flag }\end{array}$ & $\begin{array}{l}\text { UCS } \\
\text { Center } \\
\text { Fag }\end{array}$ & $\begin{array}{c}\text { UCS ucv } \\
\text { Hag }\end{array}$ & $\begin{array}{l}\text { UCS based } \\
\text { on } \\
\text { Decreasing } \\
\text { Velocity }\end{array}$ & $\begin{array}{c}\text { Smeep } \\
\text { Increase I } \\
\text { Decrease }\end{array}$ & $\begin{array}{c}\text { UDV } \\
\text { Height } \\
\text { Bedt }\end{array}$ & $\begin{array}{c}\text { Particle } \\
\text { Motion }\end{array}$ & $\begin{array}{l}\text { Solids } \\
\text { Level }\end{array}$ & $\begin{array}{l}\text { Outer } \\
\text { Botom } \\
\text { Pattem }\end{array}$ & $\begin{array}{l}\text { Inner } \\
\text { Bototom } \\
\text { Pattem }\end{array}$ & Case ID & Test & $\mathrm{TDP}$ & $\begin{array}{l}\text { Row } \\
\text { Number }\end{array}$ \\
\hline $\mathrm{c}$ & $\begin{array}{ll}\mathrm{g} / \mathrm{cm}^{3} \\
\end{array}$ & fraction & ffraction & fraction & $\mathrm{s}$ & text & $\mathrm{m} / \mathrm{s}$ & $\begin{array}{ll}\mathrm{m} / \mathrm{s} \\
\end{array}$ & $\begin{array}{ll}\mathrm{ms} \\
\end{array}$ & $\mathrm{m} / \mathrm{s}$ & $\begin{array}{ll}\mathrm{m} / \mathrm{s} \\
\end{array}$ & m/s & in. & $m / s$ & text & text & text & text & $m / s$ & text & \begin{tabular}{l|l|l}
$\mathrm{mm}$ \\
\end{tabular} & text & text & text & text & text & text & text & text \\
\hline$T$ & $\rho$ & $\phi_{\mathrm{s}}$ & $\phi_{p}$ & $\mathrm{DC}$ & tc & Jet & $u_{s}$ & $\mathrm{U}_{1}$ & $\mathrm{U} 2$ & U3 & $u$ & $U_{\text {Us }}$ & $\mathrm{Hc}$ & Uass & Uas & Ucsis & Ussen & Usurur & $U_{\text {Us_D }}$ & $\mathrm{S}_{\mathrm{N}}$ & $\mathrm{H}_{\text {bod }}$ & $\mathrm{PM}$ & Sol & $\mathrm{SP}$ & $\mathrm{SP}_{1}$ & $\mathrm{ID}$ & MDDX & $\mathrm{IDP}$ & MSS \\
\hline 34.2 & 0.997 & 0.00155 & 0.050 & 0.328 & 9.4 & $P$ & NA & 6.46 & 6.58 & 6.64 & $\begin{array}{ll}6.80 \\
\end{array}$ & 6.80 & 8.00 & $\mathrm{NA}$ & $\mathrm{NA}$ & NA & $\mathrm{NA}$ & $\mathrm{NA}$ & NA & NA & $\mathrm{n} / \mathrm{a}$ & NA & $\mathrm{NA}$ & NA & NA & 15E_4s2d17c_1 & $7 / 2 \mathrm{~B}$ & TDP-202 & 9150595.1 \\
\hline 34.2 & 0.997 & 0.00155 & 0.050 & 0.328 & 9.4 & $\mathrm{P}$ & NA & 6.46 & 6.58 & 6.64 & 6.80 & 6.80 & 8.00 & NA & NA & NA & NA & NA & NA & NA & 0.6 & NA & NA & NA & NA & 15E_4s2d1Zc_1 & $7 / 2 B$ & TDP-202 & 9150596 \\
\hline 34.2 & 0.997 & 0.00155 & 0.050 & 0.328 & 9.4 & $\mathrm{P}$ & $\mathrm{NA}$ & 6.46 & 6.58 & 6.64 & 6.80 & 6.80 & 8.00 & NA & NA & $\mathrm{NA}$ & NA & NA & NA & NA & $\mathrm{na}$ & NA & NA & NA & $\mathrm{NA}$ & 15E_4s2d17c_1 & $7 / 2 B$ & TDP-202 & 9150596.1 \\
\hline 34.2 & 0.997 & 0.00155 & 0.050 & 0.328 & 9.4 & $\mathrm{P}$ & NA & 6.46 & 6.58 & 6.64 & 6.80 & 6.80 & 8.00 & NA & NA & NA & NA & NA & NA & NA & 1.9 & NA & NA & NA & NA & $15 E \_4 s 2 d 1 Z c \_1$ & $7 / 2 \mathrm{~B}$ & TDP-202 & 9150597 \\
\hline 34.2 & 0.997 & 0.00155 & 0.050 & 0.328 & 9.4 & $\mathrm{P}$ & NA & 6.46 & 6.58 & 6.64 & 6.80 & 6.80 & 8.00 & NA & NA & NA & NA & NA & NA & NA & na & NA & NA & NA & NA & 15E_4s2d17c_ 1 & $7 / 2 B$ & TDP-202 & 9150597.1 \\
\hline 34.2 & 0.997 & 0.00155 & 0.050 & 0.328 & 9.4 & $\mathrm{P}$ & NA & 6.46 & 6.58 & 6.64 & 6.80 & 6.80 & 8.00 & NA & NA & NA & NA & NA & NA & NA & 0.0 & NA & NA & NA & NA & 15E_4s2d17c_1 & $7 / 2 B$ & TDP-202 & 9150598 \\
\hline 29.1 & 0.998 & 0.00500 & 0.050 & 0.331 & 10.6 & $\mathrm{P}$ & NA & 5.67 & 5.78 & 5.84 & 6.00 & 9.00 & 3.38 & NA & NA & NA & NA & NA & NA & (null) & 16.2 & 1 & NA & NA & NA & 15E_4s2d1Yc_1 & $7 / 3 \mathrm{~A}$ & TDP-203 & 9150599 \\
\hline 29.3 & 0.998 & 0.00500 & 0.050 & 0.333 & 9.4 & $\mathrm{P}$ & NA & 6.44 & 6.56 & 6.62 & 6.80 & 9.00 & 3.75 & NA & NA & NA & NA & NA & NA & 1 & 9.7 & 1 & NA & NA & NA & 15E_4s2d1Yc_1 & $7 / 3 \mathrm{~A}$ & TDP-203 & 9150001 \\
\hline 29.5 & 0.998 & 0.00500 & 0.050 & 0.332 & 8.9 & $\mathrm{P}$ & NA & 6.83 & 6.96 & 7.03 & 7.20 & 9.00 & 4.25 & NA & NA & NA & NA & NA & NA & 1 & 6.7 & 1 & NA & NA & NA & 15E_4s2d1Yc_1 & $7 / 3 \mathrm{~A}$ & TDP-203 & 9150602 \\
\hline 29.6 & 0.998 & 0.00500 & 0.050 & 0.333 & 8.4 & $\mathrm{P}$ & NA & 7.19 & 7.34 & 7.41 & 7.60 & 9.00 & 4.50 & NA & NA & NA & NA & NA & NA & 1 & 5.2 & 1 & NA & NA & NA & 15E_4s2d1Yc_1 & $7 / 3 A$ & TDP-203 & 9150603 \\
\hline 29.9 & 0.998 & 0.00500 & 0.050 & 0.335 & 8.2 & $\mathrm{P}$ & NA & 7.33 & 7.49 & 7.57 & 7.80 & 9.00 & 4.75 & NA & NA & NA & NA & NA & NA & 1 & 3.9 & 1 & NA & NA & NA & 15E_4s2d1Yc_1 & $7 / 3 \mathrm{~A}$ & TDP-203 & 9150004 \\
\hline 30.0 & 0.998 & 0.00500 & 0.050 & 0.335 & 8.0 & $P$ & NA & 7.51 & 7.68 & 7.76 & 8.00 & 9.00 & 4.75 & NA & NA & NA & NA & $\mathrm{NA}$ & NA & 1 & 3.5 & 1 & NA & NA & NA & 15E_4s2d1Yc_1 & $7 / 3 \mathrm{~A}$ & TDP-203 & 9150605 \\
\hline 30.2 & 0.998 & 0.00500 & 0.050 & 0.335 & 7.8 & $\mathrm{P}$ & NA & 7.70 & 7.87 & 7.96 & 8.20 & 9.00 & 5.25 & NA & NA & NA & NA & NA & NA & 1 & 3.6 & 1 & NA & NA & NA & 15E_As2d1YC_1 & 7/3A & TDP-203 & 9150006 \\
\hline 30.4 & 0.998 & 0.00500 & 0.050 & 0.336 & 7.6 & $\mathrm{P}$ & NA & 7.90 & 8.08 & 8.17 & 8.40 & 9.00 & 5.25 & NA & NA & NA & NA & NA & NA & 1 & 2.9 & 1 & NA & NA & NA & 15E_4s2d1Yc_1 & $7 / 3 \mathrm{~A}$ & TDP-203 & 9150607 \\
\hline 30.6 & 0.998 & 0.00500 & 0.050 & 0.335 & 7.4 & $\mathrm{P}$ & NA & 8.07 & 8.27 & 8.36 & 8.60 & 9.00 & 5.50 & NA & NA & NA & NA & NA & NA & 1 & 3.1 & 1 & NA & NA & NA & 15E_4s2d1Yc_1 & $7 / 3 A$ & TDP-203 & 9150608 \\
\hline 30.9 & 0.998 & 0.00500 & 0.050 & 0.338 & 7.2 & $\mathrm{P}$ & NA & 8.26 & 8.46 & 8.55 & 8.80 & 9.00 & 5.75 & NA & NA & UcSis & NA & NA & NA & 1 & 1.3 & 3 & NA & NA & NA & 15E_4s2d1Yc_1 & $7 / 3 A$ & TDP-203 & 9150609 \\
\hline 31.3 & 0.998 & 0.00500 & 0.050 & 0.339 & 7.0 & $\mathrm{P}$ & NA & 8.39 & 8.60 & 8.71 & 9.00 & 9.00 & 5.75 & 9.00 & udv & NA & NA & ucsudv & NA & 1 & 0.7 & 4 & NA & NA & NA & 15E_4s2d1Yc_1 & $7 / 3 \mathrm{~A}$ & TDP-203 & 9150610 \\
\hline 31.5 & 0.998 & 0.00500 & 0.050 & 0.334 & 7.0 & $\mathrm{P}$ & NA & 8.59 & 8.79 & 8.89 & 9.20 & 9.00 & 6.00 & NA & NA & NA & NA & NA & NA & 1 & 0.0 & 4 & NA & NA & NA & 15E_4s2d1Yc_1 & $7 / 3 \mathrm{~A}$ & TDP-203 & 9150611 \\
\hline 31.7 & 0.998 & 0.00500 & 0.050 & 0.337 & 6.6 & $\mathrm{P}$ & NA & 9.04 & 9.30 & 9.43 & 9.70 & 9.00 & 6.25 & NA & NA & NA & NA & NA & NA & 1 & 0.0 & 4 & NA & NA & NA & 15E_4s2d1Yc_1 & $7 / 3 \mathrm{~A}$ & TDP-203 & 9150612 \\
\hline 32.3 & 0.997 & 0.00500 & 0.050 & 0.335 & 5.9 & $\mathrm{P}$ & NA & 10.21 & 10.53 & 10.69 & 11.00 & 9.00 & 7.00 & NA & NA & NA & NA & NA & NA & 1 & 0.0 & 4 & NA & NA & NA & 15E_4s2d1Yc_1 & $7 / 3 \mathrm{~A}$ & TDP-203 & 9150614 \\
\hline 32.5 & 0.998 & 0.00500 & 0.050 & 0.321 & 5.4 & $\mathrm{P}$ & NA & 11.60 & 11.74 & 11.83 & 12.00 & 9.00 & 8.00 & NA & NA & $\mathrm{NA}$ & NA & NA & NA & 1 & 0.0 & 4 & NA & NA & NA & 15E_4s2d1Yc_1 & $7 / 3 \mathrm{~A}$ & TDP-203 & 9150615 \\
\hline 32.4 & 0.997 & 0.01500 & 0.050 & 0.334 & 7.1 & $\mathrm{P}$ & NA & 8.38 & 8.61 & 8.73 & 9.00 & 9.40 & NA & NA & NA & NA & NA & NA & NA & (null) & 3.2 & 1 & NA & NA & NA & $15 E \_4 s 2 d 1 X c \_1$ & $7 / 3 \mathrm{~B}$ & TDP-204 & 9150616 \\
\hline 32.5 & 0.997 & 0.01500 & 0.050 & 0.333 & 7.0 & $\mathrm{P}$ & NA & 8.59 & 8.83 & 8.94 & 9.20 & 9.40 & NA & NA & NA & NA & NA & NA & NA & 1 & 2.9 & 1 & NA & NA & NA & 15E_4s2d1Xc_1 & $7 / 38$ & TDP-204 & 9150617 \\
\hline 32.7 & 0.997 & 0.01500 & 0.050 & 0.336 & 6.8 & $\mathrm{P}$ & NA & 8.79 & 9.04 & 9.16 & 9.40 & 9.40 & 3.25 & 9.40 & udv & UCSis & NA & ucsudv & NA & 1 & 0.4 & 3 & NA & NA & NA & 15E_4s2d1Xc_1 & $7 / 3 B$ & TDP-204 & 9150618 \\
\hline 32.7 & 0.997 & 0.01500 & 0.050 & 0.336 & 6.6 & $\mathrm{P}$ & NA & 8.97 & 9.22 & 9.34 & 9.60 & 9.40 & 3.38 & NA & NA & NA & NA & NA & NA & 1 & 0.0 & 4 & NA & NA & NA & 15E_4s2d1Xc_1 & $7 / 3 B$ & TDP-204 & 9150619 \\
\hline 33.0 & 0.997 & 0.01500 & 0.050 & 0.333 & 5.9 & $P$ & NA & 10.23 & 10.54 & 10.69 & 11.00 & 9.40 & 3.75 & NA & NA & $\mathrm{NA}$ & NA & NA & NA & 1 & 0.0 & 4 & NA & NA & NA & 15E_4s2d1X__1 & $7 / 3 B$ & TDP-204 & 9150620 \\
\hline 33.2 & 0.997 & 0.01500 & 0.050 & 0.337 & 5.4 & $\mathrm{P}$ & NA & 11.06 & 11.42 & 11.60 & 12.00 & 9.40 & 4.25 & NA & NA & NA & NA & NA & NA & 1 & 0.0 & 4 & NA & NA & NA & 15E_4s2d1X__1 & $7 / 3 B$ & IDP-204 & 9150621 \\
\hline 26.4 & 0.999 & 0.00155 & 0.050 & 0.330 & 20.8 & $\mathrm{P}$ & NA & 1.93 & 1.95 & 1.96 & 2.00 & 2.60 & 7.00 & NA & NA & NA & NA & NA & NA & (null) & 10.0 & 1 & NA & NA & NA & 15E8_6sid27z_ 1 & $7 / 8 \mathrm{~A}$ & TDP-205 & 9150622 \\
\hline 26.3 & 0.999 & 0.00155 & 0.050 & 0.333 & 17.3 & $\mathrm{P}$ & NA & 2.32 & 2.34 & 2.35 & 2.40 & 2.60 & 8.50 & NA & NA & NA & NA & NA & NA & 1 & 5.6 & 1 & NA & NA & NA & 15E8__sidd2Zc_1 & $7 / 8 \mathrm{~A}$ & TDP-205 & 9150623 \\
\hline 26.3 & 0.999 & 0.00155 & 0.050 & 0.335 & 16.0 & $\mathrm{P}$ & NA & 2.49 & 2.52 & 2.53 & 2.60 & 2.60 & 9.00 & 2.60 & udv & NA & NA & ucsuav & NA & 1 & 0.0 & 1 & NA & NA & NA & $15 E 8$ _ssid2Zc_ 1 & $7 / 8 \mathrm{~A}$ & TDP-205 & 9150624 \\
\hline 26.4 & 0.999 & 0.00155 & 0.050 & 0.333 & 14.9 & $\mathrm{P}$ & NA & 2.68 & 2.71 & 2.72 & 2.80 & 2.60 & 15.50 & NA & NA & UCSis & NA & NA & NA & 1 & 0.0 & 3 & NA & NA & NA & 15E8_6s1d2Zc_ _ & $7 / 8 \mathrm{~A}$ & TDP-205 & 9150625 \\
\hline 26.5 & 0.999 & 0.00155 & 0.050 & 0.335 & 13.9 & $\mathrm{P}$ & NA & 287 & 2.91 & 2.92 & 3.00 & 2.60 & 19.50 & NA & NA & NA & NA & NA & NA & 1 & 0.0 & 4 & NA & NA & NA & 15E8_6s1d27___1 & $7 / 8 \mathrm{~A}$ & TDP-205 & 9150626 \\
\hline 26.5 & 0.999 & 0.00155 & 0.050 & 0.335 & 13.0 & $\mathrm{P}$ & NA & 3.06 & 3.10 & 3.12 & 3.20 & 2.60 & 22.50 & NA & NA & NA & NA & NA & NA & 1 & 0.7 & 4 & NA & NA & NA & 15E8_6s1d2Zc__ 1 & $7 / 8 \mathrm{~A}$ & TDP-205 & 9150027 \\
\hline 26.7 & 0.999 & 0.00155 & 0.100 & 0.328 & 412 & $\mathrm{P}$ & NA & 1.97 & 1.98 & 1.98 & 2.00 & 280 & 11.00 & NA & NA & NA & NA & NA & NA & (null) & 6.2 & 1 & NA & NA & NA & 15E8_6sid2ZC_2 2 & $7 / 88$ & TDP-205 & 9150628 \\
\hline 26.8 & 0.999 & 0.00155 & 0.101 & 0.329 & 37.5 & $\mathrm{P}$ & NA & 2.16 & 2.17 & 2.18 & 2.20 & 280 & 11.00 & NA & NA & NA & NA & NA & NA & 1 & 9.5 & 1 & NA & NA & NA & $15 E 8$ _6sid2Zz_ 2 & $7 / 8 B$ & TDP-205 & 9150629 \\
\hline 26.8 & 0.999 & 0.00155 & 0.101 & 0.330 & 34.3 & $\mathrm{P}$ & NA & 2.36 & 2.37 & 2.37 & 2.40 & 280 & 13.00 & NA & NA & NA & NA & NA & NA & 1 & 6.9 & 1 & NA & NA & NA & 15E8_6s1d27c_2 2 & $7 / 88$ & TDP-205 & 9150630 \\
\hline 26.8 & 0.999 & 0.00155 & 0.101 & 0.331 & 31.7 & $\mathrm{P}$ & NA & 2.54 & 2.56 & 2.57 & 2.60 & 280 & 13.50 & NA & NA & NA & NA & NA & NA & 1 & 3.8 & 1 & NA & NA & NA & 15E8_6s1d27___2 & $7 / 8 B$ & TDP-205 & 9150631 \\
\hline 26.9 & 0.999 & 0.00155 & 0.100 & 0.332 & 29.2 & $\mathrm{P}$ & NA & 274 & 2.76 & 2.77 & 2.80 & 280 & 16.25 & 2.80 & & Ucsis & NA & NA & NA & 1 & 1.5 & 3 & NA & NA & NA & 15E8_6s1d27c_2 & $7 / 8 \mathrm{~B}$ & TDP-205 & 9150632 \\
\hline 27.1 & 0.999 & 0.00155 & 0.100 & 0.333 & 27.3 & $P$ & $\mathrm{NA}$ & 2.93 & 2.95 & 2.96 & 3.00 & 280 & 21.50 & NA & NA & NA & NA & $\mathrm{NA}$ & NA & 1 & 0.8 & 4 & NA & NA & NA & 15E8_6sid2Zc__2 & $7 / 8 \mathrm{~B}$ & TDP-205 & 9150633 \\
\hline
\end{tabular}


Table B.3. Data from 2008 Tests in Small-Scale Vessel with Elliptical Head A.18

\begin{tabular}{|c|c|c|c|c|c|c|c|c|c|c|c|c|c|c|c|c|c|c|c|c|c|c|c|c|c|c|c|}
\hline $\begin{array}{l}\text { Row } \\
\text { Number }\end{array}$ & Test & Case ID & $\begin{array}{l}\text { Tank } \\
\text { Diameter }\end{array}$ & $\begin{array}{l}\text { Head } \\
\text { Shape }\end{array}$ & $\begin{array}{l}\text { Dish } \\
\text { Height }\end{array}$ & $\begin{array}{c}\text { Dish } \\
\text { Volume }\end{array}$ & $\begin{array}{c}\text { Tank } \\
\text { Fill } \\
\text { Height }\end{array}$ & $\begin{array}{c}\text { Retur } \\
\text { Line } \\
\text { Height } \\
\text { Heign }\end{array}$ & $\begin{array}{c}\text { Nozzle } \\
\text { IInner } \\
\text { Diameter }\end{array}$ & $\begin{array}{l}\text { Nozle } \\
\text { Stanc-off } \\
\text { Distance }\end{array}$ & $\begin{array}{l}\text { Pulse Tube } \\
\text { Configuration }\end{array}$ & $\begin{array}{l}\text { Installed } \\
\text { Nozzles } \\
\text { Nates }\end{array}$ & $\begin{array}{c}\text { Outer } \\
\text { Nozzles } \\
\text { Operated }\end{array}$ & $\begin{array}{c}\text { Inner } \\
\text { Nozzles } \\
\text { Operated }\end{array}$ & $\begin{array}{c}\text { Pulse Tube } \\
\text { Outer } \\
\text { Diameter } \\
\end{array}$ & $\begin{array}{l}\text { Outer } \\
\text { PMM } \\
\text { Radius }\end{array}$ & $\begin{array}{c}\text { Inner } \\
\text { PPM } \\
\text { Radius }\end{array}$ & $\begin{array}{l}\text { "FO" Outer } \\
\text { PJM } \\
\text { Impingement } \\
\text { Angle } \\
\end{array}$ & $\begin{array}{c}\text { "FFO' Inner PJM } \\
\text { Impingement } \\
\text { Angle }\end{array}$ & $\begin{array}{c}\text { Ratio Oter } \\
\text { PJMMto Tank } \\
\text { Radius } \\
\end{array}$ & $\begin{array}{c}\text { Ratio Inner } \\
\text { PJMto Tank } \\
\text { Radius } \\
\end{array}$ & Simulant & $\begin{array}{l}\text { Solids } \\
\text { Density }\end{array}$ & $\begin{array}{l}\text { Particle } \\
\text { Diameter d5 }\end{array}$ & $\begin{array}{c}\text { Particle } \\
\text { Diamter } \\
\text { d50 }\end{array}$ & $\begin{array}{c}\text { Particle } \\
\text { Dianterer } \\
\text { d955 }\end{array}$ & $\begin{array}{c}\text { Void } \\
\text { Fraction } \\
\end{array}$ \\
\hline text & text & text & in. & text & in. & in. ${ }^{3}$ & in. & in. & in. & in. & text & number & number & number & in. & in. & in. & deg & deg & nondim & nondim & text & $\mathrm{g} / \mathrm{cm}^{3}$ & $m$ & $m$ & $m$ & fraction \\
\hline MSS & MDDX & $\mathrm{ID}$ & $\mathrm{D}$ & HS & Hash & $V_{\text {ash }}$ & $\mathrm{H}$ & Rtn & $d$ & sod & PT & $\mathrm{N}$ & $\mathrm{No}$ & $\mathrm{N}$ & $P T_{\alpha 1}$ & $R_{0}$ & $\mathrm{R}$ & $\theta_{0}$ & $\theta_{1}$ & $\mathrm{RdR}$ & $R / R$ & sxdx & $\rho_{\mathrm{s}}$ & $d s$ & $d_{50}$ & des & vf \\
\hline $9150634 \mathrm{M}$ & $7 / 8 \mathrm{~B}$ & 15E8_6s1d27c_2 & $147 / 16$ & $E$ & 3.25 & 354.8 & 35 & 30 & 0.191 & 0.202 & 8TA & 8 & 4 & 4 & 1.05 & 4.9 & 3.6 & 24.4 & 16 & 0.67 & 0.50 & s1d2 & 2.48 & 0.0000569 & 0.0000693 & 0.0000821 & 0.3750 \\
\hline 9150635 & $7 / 8 \mathrm{C}$ & 15E8_6sid2V__1 & $147 / 16$ & $E$ & 3.25 & 354.8 & 36 & 30 & 0.191 & 0.202 & $8 \mathrm{TA}$ & 8 & 4 & 4 & 1.05 & 4.9 & 3.6 & 24.4 & 16 & 0.67 & 0.50 & s1d2 & 2.48 & 0.0000569 & 0.0000693 & 0.0000821 & 0.3750 \\
\hline 9150636 & $7 / 8 \mathrm{C}$ & 15E8_6s1d2Vc_1 & $147 / 16$ & $E$ & 3.25 & 354.8 & 36 & 30 & 0.191 & 0.202 & 8TA & 8 & 4 & 4 & 1.05 & 4.9 & 3.6 & 24.4 & 16 & 0.67 & 0.50 & s1d2 & 2.48 & 0.0000569 & 0.0000693 & 0.0000821 & 0.3750 \\
\hline 9150637 & $7 / 8 \mathrm{C}$ & 15E8_6sid2Vc_1 & $147 / 16$ & E & 3.25 & 354.8 & 36 & 30 & 0.191 & 0.202 & 8TA & 8 & 4 & 4 & 1.05 & 4.9 & 3.6 & 24.4 & 16 & 0.67 & 0.50 & s1d2 & 2.48 & 0.0000569 & 0.0000693 & 0.0000821 & 0.3750 \\
\hline $9150638 \mathrm{M}$ & $7 / 8 \mathrm{C}$ & 15E8_6sid2Vc_1 & $147 / 16$ & E & 3.25 & 354.8 & 36 & 30 & 0.191 & 0.202 & $8 \mathrm{TA}$ & 8 & 4 & 4 & 1.05 & 4.9 & 3.6 & 24.4 & 16 & 0.67 & 0.50 & s1d2 & 2.48 & 0.0000569 & 0.0000693 & 0.0000821 & 0.3750 \\
\hline $9150639 \mathrm{M}$ & $7 / 8 \mathrm{C}$ & 15E8_6s1d2VC_1 & $147 / 16$ & E & 3.25 & 354.8 & 36 & 30 & 0.191 & 0.202 & 8TA & 8 & 4 & 4 & 1.05 & 4.9 & 3.6 & 24.4 & 16 & 0.67 & 0.50 & s1d2 & 2.48 & 0.0000569 & 0.0000693 & 0.0000821 & 0.3750 \\
\hline $9150640 \mathrm{M}$ & $7 / 8 \mathrm{C}$ & 15E8_6sid2V__ 1 & $147 / 16$ & $E$ & 3.25 & 354.8 & 36 & 30 & 0.191 & 0.202 & 8TA & 8 & 4 & 4 & 1.05 & 4.9 & 3.6 & 24.4 & 16 & 0.67 & 0.50 & s1d2 & 2.48 & 0.0000569 & 0.0000693 & 0.0000821 & 0.3750 \\
\hline $9150641 \mathrm{M}$ & $7 / 8 \mathrm{C}$ & 15E8_6s1d2V__1 & $147 / 16$ & $E$ & 3.25 & 354.8 & 36 & 30 & 0.191 & 0.202 & 8TA & 8 & 4 & 4 & 1.05 & 4.9 & 3.6 & 24.4 & 16 & 0.67 & 0.50 & s1d2 & 2.48 & 0.0000569 & 0.0000693 & 0.0000821 & 0.3750 \\
\hline $9150642 \mathrm{M}$ & $7 / 8 \mathrm{C}$ & 15E8_6sid2Vc_1 & $147 / 16$ & E & 3.25 & 354.8 & 36 & 30 & 0.191 & 0.202 & 8TA & 8 & 4 & 4 & 1.05 & 4.9 & 3.6 & 24.4 & 16 & 0.67 & 0.50 & s1d2 & 2.48 & 0.0000569 & 0.0000693 & 0.0000821 & 0.3750 \\
\hline 9150642.19 & $7 / 8 \mathrm{C}$ & 15E8_6sid2V _ 1 1 & $147 / 16$ & E & 3.25 & 354.8 & 36 & 30 & 0.191 & 0.202 & $8 T \mathrm{~A}$ & 8 & 4 & 4 & 1.05 & 4.9 & 3.6 & 24.4 & 16 & 0.67 & 0.50 & s1d2 & 2.48 & 0.0000569 & 0.0000693 & 0.0000821 & 0.3750 \\
\hline 9150642.2 & $7 / 8 \mathrm{C}$ & 15E8_6s1d2Vc_1 & $147 / 16$ & E & 3.25 & 354.8 & 36 & 30 & 0.191 & 0.202 & 8TA & 8 & 4 & 4 & 1.05 & 4.9 & 3.6 & 24.4 & 16 & 0.67 & 0.50 & s1d2 & 2.48 & 0.0000569 & 0.0000693 & 0.0000821 & 0.3750 \\
\hline $9150643 \mathrm{M}$ & $7 / 8 \mathrm{C}$ & 15E8_6sid2V__ 1 & $147 / 16$ & $E$ & 3.25 & 354.8 & 36 & 30 & 0.191 & 0.202 & 8TA & 8 & 4 & 4 & 1.05 & 4.9 & 3.6 & 24.4 & 16 & 0.67 & 0.50 & s1d2 & 2.48 & 0.0000569 & 0.0000693 & 0.0000821 & 0.3750 \\
\hline 9150644 & $7 / 8 \mathrm{C}$ & 15E8_6s1d2V__1 & $147 / 16$ & $E$ & 3.25 & 354.8 & 36 & 30 & 0.191 & 0.202 & 8TA & 8 & 4 & 4 & 1.05 & 4.9 & 3.6 & 24.4 & 16 & 0.67 & 0.50 & s1d2 & 2.48 & 0.0000569 & 0.0000693 & 0.0000821 & 0.3750 \\
\hline 9150645 & $7 / 8 \mathrm{C}$ & 15E8_6sid2Vc_1 & $147 / 16$ & E & 3.25 & 354.8 & 36 & 30 & 0.191 & 0.202 & 8TA & 8 & 4 & 4 & 1.05 & 4.9 & 3.6 & 24.4 & 16 & 0.67 & 0.50 & s1d2 & 2.48 & 0.0000569 & 0.0000693 & 0.0000821 & 0.3750 \\
\hline 9150646 & $7 / 8 \mathrm{C}$ & 15E8_6s1d2Vc_1 & $147 / 16$ & $\mathrm{E}$ & 3.25 & 354.8 & 36 & 30 & 0.191 & 0.202 & 8TA & 8 & 4 & 4 & 1.05 & 4.9 & 3.6 & 24.4 & 16 & 0.67 & 0.50 & s1d2 & 2.48 & 0.0000569 & 0.0000693 & 0.0000821 & 0.3750 \\
\hline 9150646.1 & $7 / 8 \mathrm{C}$ & 15E8_6s1d2Vc_1 & $147 / 16$ & $E$ & 3.25 & 354.8 & 36 & 30 & 0.191 & 0.202 & 8TA & 8 & 4 & 4 & 1.05 & 4.9 & 3.6 & 24.4 & 16 & 0.67 & 0.50 & s1d2 & 2.48 & 0.0000569 & 0.0000693 & 0.0000821 & 0.3750 \\
\hline 9150647 & $7 / 8 \mathrm{C}$ & 15E8_6sid2VV__1 & $147 / 16$ & E & 3.25 & 354.8 & 36 & 30 & 0.191 & 0.202 & 8TA & 8 & 4 & 4 & 1.05 & 4.9 & 3.6 & 24.4 & 16 & 0.67 & 0.50 & s1d2 & 2.48 & 0.0000569 & 0.0000693 & 0.0000821 & 0.3750 \\
\hline 9150647.1 & $7 / 8 \mathrm{C}$ & 15E8_6s1d2V__1 & $147 / 16$ & $E$ & 3.25 & 354.8 & 36 & 30 & 0.191 & 0.202 & 8TA & 8 & 4 & 4 & 1.05 & 4.9 & 3.6 & 24.4 & 16 & 0.67 & 0.50 & s1d2 & 2.48 & 0.0000569 & 0.0000693 & 0.0000821 & 0.3750 \\
\hline 9150648 & $7 / 8 \mathrm{C}$ & 15E8_6s1d2V__1 & $147 / 16$ & E & 3.25 & 354.8 & 36 & 30 & 0.191 & 0.202 & 8TA & 8 & 4 & 4 & 1.05 & 4.9 & 3.6 & 24.4 & 16 & 0.67 & 0.50 & s1d2 & 2.48 & 0.0000569 & 0.0000693 & 0.0000821 & 0.3750 \\
\hline 9150648.1 & $7 / 8 \mathrm{C}$ & 15E8_6sid2Vc_1 & $147 / 16$ & E & 3.25 & 354.8 & 36 & 30 & 0.191 & 0.202 & $8 \mathrm{TA}$ & 8 & 4 & 4 & 1.05 & 4.9 & 3.6 & 24.4 & 16 & 0.67 & 0.50 & s1d2 & 2.48 & 0.0000569 & 0.0000693 & 0.0000821 & 0.3750 \\
\hline 9150649 & $7 / 8 \mathrm{C}$ & 15E8_6s1d2Vc_1 & $147 / 16$ & E & 3.25 & 354.8 & 36 & 30 & 0.191 & 0.202 & 8TA & 8 & 4 & 4 & 1.05 & 4.9 & 3.6 & 24.4 & 16 & 0.67 & 0.50 & s1d2 & 2.48 & 0.0000569 & 0.0000693 & 0.0000821 & 0.3750 \\
\hline 9150649.1 & $7 / 8 \mathrm{C}$ & 15E8_6sid2VV_1 & $147 / 16$ & E & 3.25 & 354.8 & 36 & 30 & 0.191 & 0.202 & 8TA & 8 & 4 & 4 & 1.05 & 4.9 & 3.6 & 24.4 & 16 & 0.67 & 0.50 & s1d2 & 2.48 & 0.0000569 & 0.0000693 & 0.0000821 & 0.3750 \\
\hline 9150650 & $7 / 8 \mathrm{C}$ & 15E8_6s1d2V__1 & $147 / 16$ & $E$ & 3.25 & 354.8 & 36 & 30 & 0.191 & 0.202 & $8 \mathrm{TA}$ & 8 & 4 & 4 & 1.05 & 4.9 & 3.6 & 24.4 & 16 & 0.67 & 0.50 & s1d2 & 2.48 & 0.0000569 & 0.0000693 & 0.0000821 & 0.3750 \\
\hline 9150651 & $7 / 9 A$ & 15E8_6s1d2Vt_2 & $147 / 16$ & E & 3.25 & 354.8 & 36 & 30 & 0.191 & 0.287 & 8TA & 8 & 4 & 4 & 1.05 & 4.9 & 3.6 & 24.4 & 16 & 0.67 & 0.50 & s1d2 & 2.48 & 0.0000569 & 0.0000693 & 0.0000821 & 0.3750 \\
\hline 9150652 & $7 / 9 \mathrm{~A}$ & $15 E 8$ _6s1d2Vc_ 2 & $147 / 16$ & E & 3.25 & 354.8 & 36 & 30 & 0.191 & 0.287 & 8TA & 8 & 4 & 4 & 1.05 & 4.9 & 3.6 & 24.4 & 16 & 0.67 & 0.50 & s1d2 & 2.48 & 0.0000569 & 0.0000693 & 0.0000821 & 0.3750 \\
\hline 9150653M & $7 / 9 \mathrm{~A}$ & 15E8_6sid2Vc_ 2 & $147 / 16$ & E & 3.25 & 354.8 & 36 & 30 & 0.191 & 0.287 & 8TA & 8 & 4 & 4 & 1.05 & 4.9 & 3.6 & 24.4 & 16 & 0.67 & 0.50 & s1d2 & 2.48 & 0.0000569 & 0.0000693 & 0.0000821 & 0.3750 \\
\hline 9150654M & $7 / 9 \mathrm{~A}$ & $15 E 8$ _6sid2VV__2 & $147 / 16$ & E & 3.25 & 354.8 & 36 & 30 & 0.191 & 0.287 & 8TA & 8 & 4 & 4 & 1.05 & 4.9 & 3.6 & 24.4 & 16 & 0.67 & 0.50 & s1d2 & 2.48 & 0.0000569 & 0.0000693 & 0.0000821 & 0.3750 \\
\hline $9150655 \mathrm{M}$ & $7 / 9 \mathrm{~A}$ & 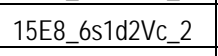 & $147 / 16$ & $E$ & 3.25 & 354.8 & 36 & 30 & 0.191 & 0.287 & 8TA & 8 & 4 & 4 & 1.05 & 4.9 & 3.6 & 24.4 & 16 & 0.67 & 0.50 & s1d2 & 2.48 & 0.0000569 & 0.0000693 & 0.0000821 & 0.3750 \\
\hline $9150656 \mathrm{M}$ & $7 / 9 \mathrm{~A}$ & 15E8_6s1d2Vc_2 & $147 / 16$ & $E$ & 3.25 & 354.8 & 36 & 30 & 0.191 & 0.287 & $8 \mathrm{TA}$ & 8 & 4 & 4 & 1.05 & 4.9 & 3.6 & 24.4 & 16 & 0.67 & 0.50 & s1d2 & 2.48 & 0.0000569 & 0.0000693 & 0.0000821 & 0.3750 \\
\hline 9150657M & $7 / 9 \mathrm{~A}$ & $15 E 8$ _6s1d2Vc_ 2 & $147 / 16$ & E & 3.25 & 354.8 & 36 & 30 & 0.191 & 0.287 & 8TA & 8 & 4 & 4 & 1.05 & 4.9 & 3.6 & 24.4 & 16 & 0.67 & 0.50 & s1d2 & 2.48 & 0.0000569 & 0.0000693 & 0.0000821 & 0.3750 \\
\hline 9150658 & $7 / 9 \mathrm{~B}$ & $15 E 8$ _ssid2Xc_1 & $147 / 16$ & E & 3.25 & 354.8 & 36 & 30 & 0.191 & 0.287 & 8TA & 8 & 4 & 4 & 1.05 & 4.9 & 3.6 & 24.4 & 16 & 0.67 & 0.50 & s1d2 & 2.48 & 0.0000569 & 0.0000693 & 0.0000821 & 0.3750 \\
\hline 9150659 & $7 / 98$ & $15 E 8$ _ssid2Xc_1 & $147 / 16$ & E & 3.25 & 354.8 & 36 & 30 & 0.191 & 0.287 & 8TA & 8 & 4 & 4 & 1.05 & 4.9 & 3.6 & 24.4 & 16 & 0.67 & 0.50 & s1d2 & 2.48 & 0.0000569 & 0.0000693 & 0.0000821 & 0.3750 \\
\hline $9150660 \mathrm{M}$ & $7 / 98$ & $15 E 8$ _6sid $2 \times c_{1} 1$ & $147 / 16$ & $E$ & 3.25 & 354.8 & 36 & 30 & 0.191 & 0.287 & $8 \mathrm{TA}$ & 8 & 4 & 4 & 1.05 & 4.9 & 3.6 & 24.4 & 16 & 0.67 & 0.50 & s1d2 & 2.48 & 0.0000569 & 0.0000693 & 0.0000821 & 0.3750 \\
\hline $9150661 \mathrm{M}$ & $7 / 98$ & 15E8_6sid2Xc_1 & $147 / 16$ & $E$ & 3.25 & 354.8 & 36 & 30 & 0.191 & 0.287 & 8TA & 8 & 4 & 4 & 1.05 & 4.9 & 3.6 & 24.4 & 16 & 0.67 & 0.50 & s1d2 & 248 & 0.0000569 & 0.0000693 & 0.0000821 & 0.3750 \\
\hline $9150662 \mathrm{M}$ & $7 / 9 \mathrm{~B}$ & $15 E 8$ _ssid2Xc_1 & $147 / 16$ & E & 3.25 & 354.8 & 36 & 30 & 0.191 & 0.287 & $8 \mathrm{TA}$ & 8 & 4 & 4 & 1.05 & 4.9 & 3.6 & 24.4 & 16 & 0.67 & 0.50 & s1d2 & 2.48 & 0.0000569 & 0.0000693 & 0.0000821 & 0.3750 \\
\hline 9150663M & $7 / 9 \mathrm{~B}$ & 15E8_6sid2Xc_1 & $147 / 16$ & E & 3.25 & 354.8 & 36 & 30 & 0.191 & 0.287 & 8TA & 8 & 4 & 4 & 1.05 & 4.9 & 3.6 & 24.4 & 16 & 0.67 & 0.50 & $51 \mathrm{~d} 2$ & 2.48 & 0.0000569 & 0.0000693 & 0.0000821 & 0.3750 \\
\hline $9150664 \mathrm{M}$ & $7 / 98$ & $15 E 8 \_$ssid2X__1 & $147 / 16$ & E & 3.25 & 354.8 & 36 & 30 & 0.191 & 0.287 & 8TA & 8 & 4 & 4 & 1.05 & 4.9 & 3.6 & 24.4 & 16 & 0.67 & 0.50 & s1d2 & 2.48 & 0.0000569 & 0.0000693 & 0.0000821 & 0.3750 \\
\hline 9150665M & $7 / 98$ & $15 E 8$ _ssid2X__1 & $147 / 16$ & E & 3.25 & 354.8 & 36 & 30 & 0.191 & 0.287 & $8 T A$ & 8 & 4 & 4 & 1.05 & 4.9 & 3.6 & 24.4 & 16 & 0.67 & 0.50 & s1d2 & 2.48 & 0.0000569 & 0.0000693 & 0.0000821 & 0.3750 \\
\hline 9150665.1 & $7 / 98$ & 15E8_6sid2Xc_1 & $147 / 16$ & E & 3.25 & 354.8 & 36 & 30 & 0.191 & 0.287 & 8TA & 8 & 4 & 4 & 1.05 & 4.9 & 3.6 & 24.4 & 16 & 0.67 & 0.50 & s1d2 & 248 & 0.0000569 & 0.0000693 & 0.0000821 & 0.3750 \\
\hline 9150665.2 & $7 / 98$ & 15E8__sid2Xc_1 & $147 / 16$ & E & 3.25 & 354.8 & 36 & 30 & 0.191 & 0.287 & $8 \mathrm{TA}$ & 8 & 4 & 4 & 1.05 & 4.9 & 3.6 & 24.4 & 16 & 0.67 & 0.50 & s1d2 & 2.48 & 0.0000569 & 0.0000693 & 0.0000821 & 0.3750 \\
\hline 9150665.3 & $7 / 9 \mathrm{~B}$ & $15 E 8$ _ssid2Xc_1 & $147 / 16$ & E & 3.25 & 354.8 & 36 & 30 & 0.191 & 0.287 & 8TA & 8 & 4 & 4 & 1.05 & 4.9 & 3.6 & 24.4 & 16 & 0.67 & 0.50 & $51 d_{2}$ & 2.48 & 0.0000569 & 0.0000693 & 0.0000821 & 0.3750 \\
\hline
\end{tabular}


Table B.3. Data from 2008 Tests in Small-Scale Vessel with Elliptical Head B.18

\begin{tabular}{|c|c|c|c|c|c|c|c|c|c|c|c|c|c|c|c|c|c|c|c|c|c|c|c|c|c|c|c|c|c|}
\hline $\begin{array}{l}\text { Tank Water } \\
\text { Temperature }\end{array}$ & $\begin{array}{l}\text { Water } \\
\text { Density }\end{array}$ & $\begin{array}{l}\text { Solids } \\
\text { Fraction }\end{array}$ & $\begin{array}{l}\text { Pulse } \\
\text { Volume } \\
\text { Fraction }\end{array}$ & $\begin{array}{l}\text { Duty } \\
\text { Qyde }\end{array}$ & $\begin{array}{l}\text { Oyde } \\
\text { Time }\end{array}$ & $\begin{array}{c}\text { Pulsod } \\
\text { or } \\
\text { Steacy } \\
\text { Jet }\end{array}$ & $\begin{array}{c}\text { Us } \\
\text { Steady } \\
\text { Jet }\end{array}$ & $\begin{array}{c}\text { U1 } \\
\text { Pulsing } \\
\text { Jet } \\
\end{array}$ & $\begin{array}{c}\text { U2 } \\
\text { URMS }\end{array}$ & $\begin{array}{c}\text { U3 } \\
\text { URNB }\end{array}$ & $\begin{array}{c}\text { Discharge } \\
\text { Velocity }\end{array}$ & $\begin{array}{c}\text { Citical } \\
\text { Suspension } \\
\text { Velocity }\end{array}$ & $\begin{array}{l}\text { Average } \\
\text { Peak Cloud } \\
\text { Height }\end{array}$ & $\begin{array}{c}\text { Ucs } \\
\text { Condition }\end{array}$ & $\begin{array}{l}\text { UCS } \\
\text { Method }\end{array}$ & $\begin{array}{l}\text { UCS } \\
\text { Fag }\end{array}$ & $\begin{array}{c}\text { UCS } \\
\text { Center } \\
\text { Fag }\end{array}$ & $\begin{array}{c}\text { UcS udv } \\
\text { Hag }\end{array}$ & $\begin{array}{c}\text { UCS based } \\
\text { on } \\
\text { Decreasing } \\
\text { Velocity }\end{array}$ & $\begin{array}{c}\text { Smeep } \\
\text { Increase I } \\
\text { Decrease }\end{array}$ & $\begin{array}{c}\text { UDV } \\
\text { Height } \\
\text { Bed }\end{array}$ & 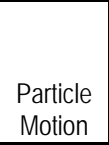 & \begin{tabular}{|l|}
$\begin{array}{l}\text { Solids } \\
\text { Level }\end{array}$ \\
\end{tabular} & \begin{tabular}{|l|} 
Outer \\
Botom \\
Pattem \\
\end{tabular} & $\begin{array}{l}\text { Inner } \\
\text { Bototom } \\
\text { Pattem }\end{array}$ & Case ID & Test & TDP & $\begin{array}{l}\text { Row } \\
\text { Number }\end{array}$ \\
\hline$c$ & $\mathrm{~g} / \mathrm{cm}^{3}$ & fraction & fraction & fraction & $\mathrm{s}$ & text & $\mathrm{m} / \mathrm{s}$ & $\mathrm{ms}$ & $\mathrm{m} / \mathrm{s}$ & ms & $\mathrm{m} / \mathrm{s}$ & $m / s$ & in. & $\mathrm{m} / \mathrm{s}$ & text & text & text & text & \begin{tabular}{|l|}
$\mathrm{m} / \mathrm{s}$ \\
\end{tabular} & text & $\begin{array}{ll}\mathrm{mm} \\
\end{array}$ & text & \begin{tabular}{|l|} 
text \\
\end{tabular} & text & text & text & text & text & text \\
\hline $\mathrm{T}$ & $\rho$ & $\phi_{\mathrm{s}}$ & $\phi_{p_{p}}$ & $D C$ & tc & Jet & $u_{s}$ & $\mathrm{U}_{1}$ & $\mathrm{U} 2$ & U3 & $u$ & Uss & $H_{k}$ & Uosr & Uosn & Ucsis & Usseen & Usuldv & Uos D & $s_{N}$ & $H_{\text {bod }}$ & $\mathrm{PM}$ & Sol & $\mathrm{SPo}_{\mathrm{O}}$ & $\mathrm{SP}$ & ID & MDDX & $\mathrm{IDP}$ & MSS \\
\hline 27.2 & 0.999 & 0.00155 & 0.100 & 0.332 & 25.6 & $P$ & $\mathrm{NA}$ & 3.13 & 3.15 & 3.16 & 3.20 & 280 & 27.00 & $\mathrm{NA}$ & $\mathrm{NA}$ & $\mathrm{NA}$ & NA & NA & NA & 1 & 2.2 & 4 & $\mathrm{NA}$ & NA & $\mathrm{NA}$ & 15E8_Gsid2Zz _ 2 & $7 / 8 B$ & TDP-205 & 9150634 \\
\hline 28.1 & 0.999 & 0.01430 & 0.050 & 0.337 & 10.4 & $\mathrm{P}$ & NA & 3.78 & 3.85 & 3.88 & 4.00 & 4.80 & 6.00 & NA & NA & NA & NA & NA & NA & (null) & 15.6 & 1 & NA & NA & NA & 15E8_6sid2VV_ 1 & $7 / 8 \mathrm{C}$ & TDP-206 & 9150635 \\
\hline 28.4 & 0.999 & 0.01430 & 0.050 & 0.329 & 9.8 & $\mathrm{P}$ & NA & 4.14 & 4.22 & 4.26 & 4.40 & 4.80 & 8.25 & NA & NA & NA & NA & NA & NA & 1 & 3.8 & 1 & NA & NA & NA & 15E8__ss1d2Vc_1 & $7 / 8 \mathrm{C}$ & TDP-206 & 9150636 \\
\hline 28.6 & 0.998 & 0.01430 & 0.050 & 0.332 & 9.2 & $\mathrm{P}$ & NA & 4.31 & 4.40 & 4.45 & 4.60 & 4.80 & 8.75 & NA & NA & NA & NA & NA & NA & $\mathrm{I}$ & 3.6 & 1 & NA & NA & NA & 15E8_Gs1d2Vc_1 & $7 / 8 \mathrm{C}$ & TDP-206 & 9150637 \\
\hline 28.7 & 0.998 & 0.01430 & 0.050 & 0.334 & 8.8 & $\mathrm{P}$ & NA & 4.49 & 4.59 & 4.63 & 4.80 & 4.80 & 9.75 & \begin{tabular}{|l|}
4.80 \\
\end{tabular} & udv & NA & NA & ucsudv & NA & 1 & 0.8 & 1 & NA & NA & NA & 15E8_6sid2Vc_1 & $7 / 8 \mathrm{C}$ & TDP-206 & 9150638 \\
\hline 29.0 & 0.999 & 0.01430 & 0.050 & 0.332 & 8.6 & $P$ & NA & 4.67 & 4.78 & 4.83 & 5.00 & 4.80 & 11.00 & \begin{tabular}{|l|} 
NA \\
\end{tabular} & NA & UCSis & NA & NA & NA & 1 & 0.0 & 3 & NA & NA & NA & 15E8_6sid2VC_1 & $7 / 8 C$ & TDP-206 & 9150639 \\
\hline 29.2 & 0.998 & 0.01430 & 0.050 & 0.331 & 8.3 & $\mathrm{P}$ & NA & 4.85 & 4.96 & 5.01 & 5.20 & 4.80 & 13.00 & NA & NA & NA & NA & NA & NA & 1 & 0.0 & 4 & NA & NA & NA & 15E8_Gs1d2Vc_1 & $7 / 8 \mathrm{C}$ & TDP-206 & 9150640 \\
\hline 29.7 & 0.998 & 0.01430 & 0.050 & 0.332 & 7.2 & $\mathrm{P}$ & NA & 5.54 & 5.70 & 5.7 & 6.00 & 4.80 & 18.50 & NA & NA & NA & NA & NA & NA & 1 & 0.0 & 4 & NA & NA & NA & 15E8_6s1d2Vc_1 & $7 / 8 \mathrm{C}$ & TDP-206 & 9150642 \\
\hline 30.0 & 0.998 & 0.01430 & 0.050 & 0.333 & 8.8 & $\mathrm{P}$ & NA & 4.49 & 4.59 & 4.64 & 4.80 & 4.80 & 9.50 & NA & NA & NA & NA & NA & NA & NA & na & NA & NA & NA & NA & 15E8_6sid2Vc_1 & $7 / 8 \mathrm{C}$ & TDP-206 & 9150642.1 \\
\hline 30.0 & 0.998 & 0.01430 & 0.050 & 0.333 & 8.8 & $P$ & NA & 4.49 & 4.59 & 4.64 & 4.80 & 4.80 & 9.50 & NA & NA & NA & NA & NA & NA & NA & na & NA & NA & NA & NA & 15E8_6sid2V___1 & $7 / 8 C$ & TDP-206 & 9150642.2 \\
\hline 30.0 & 0.998 & 0.01430 & 0.050 & 0.333 & 8.8 & $\mathrm{P}$ & NA & 4.49 & 4.59 & 4.64 & 4.80 & 4.80 & 9.50 & NA & NA & NA & NA & NA & NA & 1 & 0.0 & 1 & NA & NA & NA & 15E8_6sid2VV_ 1 & $7 / 8 \mathrm{C}$ & TDP-206 & 9150643 \\
\hline 30.0 & 0.998 & 0.01430 & 0.050 & 0.333 & 8.8 & $\mathrm{P}$ & NA & 4.49 & 4.59 & 4.64 & 4.80 & 4.80 & 9.50 & NA & NA & NA & NA & NA & NA & NA & 0.0 & NA & NA & NA & NA & 15E8_6s1d2V__ 1 & $7 / 8 \mathrm{C}$ & TDP-206 & 9150644 \\
\hline 30.0 & 0.998 & 0.01430 & 0.050 & 0.333 & 8.8 & $P$ & NA & 4.49 & 4.59 & 4.64 & 4.80 & 4.80 & 9.50 & NA & NA & NA & NA & NA & NA & NA & 0.7 & NA & NA & NA & NA & 15E__6s1d2VV__1 & $7 / 8 \mathrm{C}$ & TDP-206 & 9150645 \\
\hline 30.0 & 0.998 & 0.01430 & 0.050 & 0.333 & 8.8 & $\mathrm{P}$ & NA & 4.49 & 4.59 & 4.64 & 4.80 & 4.80 & 9.50 & NA & NA & NA & NA & NA & NA & NA & 0.7 & NA & NA & NA & NA & 15E8_6sid2Vc_1 & $7 / 8 \mathrm{C}$ & TDP-206 & 9150646 \\
\hline 30.0 & 0.998 & 0.01430 & 0.050 & 0.333 & 8.8 & $\mathrm{P}$ & NA & 4.49 & 4.59 & 4.64 & 4.80 & 4.80 & 9.50 & NA & NA & NA & NA & NA & NA & NA & na & NA & NA & NA & NA & 15E8_6sidaV__1 & $7 / 8 \mathrm{C}$ & TDP-206 & 9150646.1 \\
\hline 30.0 & 0.998 & 0.01430 & 0.050 & 0.333 & 8.8 & $\mathrm{P}$ & NA & 4.49 & 4.59 & 4.64 & 4.80 & 4.80 & 9.50 & NA & NA & NA & NA & NA & NA & NA & 1.6 & NA & NA & NA & NA & 15E8_Gs1d2VC_1 & $7 / 8 \mathrm{C}$ & TDP-206 & 9150647 \\
\hline 30.0 & 0.998 & 0.01430 & 0.050 & 0.333 & 8.8 & $\mathrm{P}$ & $\mathrm{NA}$ & 4.49 & 4.59 & 4.64 & 4.80 & 4.80 & 9.50 & NA & NA & NA & NA & NA & NA & NA & $\mathrm{Na}$ & NA & NA & NA & NA & 15E8_6s1d2V__ 1 & $7 / 8 \mathrm{C}$ & TDP-206 & 9150647.1 \\
\hline 30.0 & 0.998 & 0.01430 & 0.050 & 0.333 & 8.8 & $P$ & NA & 4.49 & 4.59 & 4.64 & 4.80 & 4.80 & 9.50 & NA & NA & NA & NA & NA & NA & NA & 0.7 & NA & NA & NA & NA & 15E8_Gs1d2VC_1 & $7 / 8 \mathrm{C}$ & TDP-206 & 9150648 \\
\hline 30.0 & 0.998 & 0.01430 & 0.050 & 0.333 & 8.8 & $\mathrm{P}$ & NA & 4.49 & 4.59 & 4.64 & 4.80 & 4.80 & 9.50 & NA & NA & NA & NA & NA & NA & NA & $\mathrm{n} / \mathrm{a}$ & NA & NA & NA & NA & 15E8_6s1d2Vc_1 & $7 / 8 \mathrm{C}$ & TDP-206 & 9150648.1 \\
\hline 30.0 & 0.998 & 0.01430 & 0.050 & 0.333 & 8.8 & $\mathrm{P}$ & NA & 4.49 & 4.59 & 4.64 & 4.80 & 4.80 & 9.50 & NA & NA & NA & NA & NA & NA & NA & $\mathrm{na}$ & NA & NA & NA & NA & 15E8_GsIdZVV_1 & $7 / 8 \mathrm{C}$ & TDP-206 & 9150649.1 \\
\hline 30.0 & 0.998 & 0.01430 & 0.050 & 0.333 & 8.8 & $\mathrm{P}$ & $\mathrm{NA}$ & 4.49 & 4.59 & 4.64 & 4.80 & 4.80 & 9.50 & NA & NA & NA & NA & NA & NA & NA & 3.0 & NA & NA & NA & $\mathrm{NA}$ & 15E8_6s1d2V__1 & $7 / 8 \mathrm{C}$ & TDP-206 & 9150650 \\
\hline 27.2 & 0.999 & 0.01430 & 0.099 & 0.328 & 20.7 & $\mathrm{P}$ & NA & 3.89 & 3.92 & 3.94 & 4.00 & 4.40 & 7.50 & NA & NA & NA & NA & NA & NA & D & 7.5 & 1 & NA & NA & NA & 15E8_Gs1d2Vc_2 & $7 / 9 \mathrm{~A}$ & TDP-207 & 9150651 \\
\hline 27.3 & 0.999 & 0.01430 & 0.099 & 0.329 & 19.7 & $\mathrm{P}$ & NA & 4.07 & 4.11 & 4.13 & 4.20 & 4.40 & 8.50 & NA & NA & NA & NA & NA & NA & 1 & 1.5 & 1 & NA & NA & NA & 15E8_6sid2Vc_ 2 & $7 / 9 \mathrm{~A}$ & TDP-207 & 9150652 \\
\hline 27.4 & 0.999 & 0.01430 & 0.100 & 0.331 & 18.8 & $\mathrm{P}$ & NA & 4.26 & 4.31 & 4.33 & 4.40 & 4.40 & 10.00 & 4.40 & udv & NA & NA & Ucsudv & NA & 1 & 0.8 & 1 & NA & NA & NA & 15E8_6s1d2VV_2 & $7 / 9 A$ & TDP-207 & 9150653 \\
\hline 27.6 & 0.999 & 0.01430 & 0.100 & 0.332 & 18.0 & $\mathrm{P}$ & NA & 4.45 & 4.50 & 4.52 & 4.60 & 4.40 & 11.00 & NA & NA & UCsis & NA & NA & NA & 1 & 0.0 & 3 & NA & NA & NA & 15E8_GsIdIVV__ 2 & $7 / 9 \mathrm{~A}$ & TDP-207 & 9150654 \\
\hline 27.7 & 0.999 & 0.01430 & 0.100 & 0.331 & 17.3 & $\mathrm{P}$ & NA & 4.64 & 4.69 & 4.72 & 4.80 & 4.40 & 12.00 & NA & NA & NA & NA & NA & NA & 1 & 0.0 & 4 & NA & NA & $\mathrm{NA}$ & 15E8_Gs1d2VV__ 2 & $7 / 9 A$ & TDP-207 & 9150655 \\
\hline 27.8 & 0.999 & 0.01430 & 0.100 & 0.333 & 16.0 & $\mathrm{P}$ & NA & 5.01 & 5.07 & 5.10 & 5.20 & 4.40 & 14.75 & NA & NA & NA & NA & NA & NA & 1 & 0.0 & 4 & NA & NA & NA & 15E8__sid2Vc__2 & $7 / 9 \mathrm{~A}$ & TDP-207 & 9150656 \\
\hline 28.2 & 0.998 & 0.01430 & 0.100 & 0.331 & 14.9 & $\mathrm{P}$ & NA & 5.39 & 5.47 & 5.50 & 5.60 & 4.40 & 20.00 & NA & NA & NA & NA & NA & NA & 1 & 0.0 & 4 & NA & NA & NA & 15E8_Gs1d2Vc_2 & $7 / 9 \mathrm{~A}$ & TDP-207 & 9150657 \\
\hline 28.4 & 0.999 & 0.01500 & 0.050 & 0.328 & 10.7 & $\mathrm{P}$ & NA & 3.78 & 3.85 & 3.88 & 4.00 & 4.60 & 5.75 & NA & NA & NA & NA & NA & NA & (null) & 16.2 & 1 & NA & NA & NA & 15E8_6sid2X__1 & $7 / 98$ & TDP-208 & 9150658 \\
\hline 28.7 & 0.998 & 0.01500 & 0.050 & 0.333 & 9.7 & $\mathrm{P}$ & NA & 4.13 & 4.22 & 4.26 & 4.40 & 4.60 & 7.75 & NA & NA & NA & NA & NA & NA & 1 & 10.3 & 1 & NA & NA & NA & 15E__6sid2X__ 1 & $7 / 9 B$ & TDP-208 & 9150659 \\
\hline 28.8 & 0.998 & 0.01500 & 0.050 & 0.333 & 9.3 & $\mathrm{P}$ & NA & 4.32 & 4.41 & 4.45 & 4.60 & 4.60 & 8.25 & \begin{tabular}{|l|}
4.60 \\
\end{tabular} & udv & NA & NA & Ucsuav & NA & $\mathrm{I}$ & 0.5 & 1 & NA & NA & NA & 15E8_Gsid2X__1 & $7 / 9 B$ & TDP-208 & 9150660 \\
\hline 28.9 & 0.999 & 0.01500 & 0.050 & 0.333 & 8.9 & $\mathrm{P}$ & NA & 4.49 & 4.59 & 4.64 & 4.80 & 4.60 & 9.50 & NA & NA & NA & NA & NA & NA & 1 & 0.0 & 1 & NA & NA & NA & 15E8_6sid2Xc_1 & $7 / 9 \mathrm{~B}$ & TDP-208 & 9150661 \\
\hline 29.0 & 0.998 & 0.01500 & 0.050 & 0.335 & 8.5 & $\mathrm{P}$ & NA & 4.68 & 4.78 & 4.83 & 5.00 & 4.60 & 10.25 & NA & NA & UCSis & NA & NA & NA & 1 & 0.0 & 3 & NA & NA & NA & 15E8_Gs1d2Xc_1 & $7 / 9 \mathrm{~B}$ & TDP-208 & 9150662 \\
\hline 29.1 & 0.998 & 0.01500 & 0.050 & 0.335 & 8.2 & $\mathrm{P}$ & NA & 4.85 & 4.96 & 5.01 & 5.20 & 4.60 & 11.75 & NA & NA & NA & NA & NA & NA & 1 & 0.0 & 4 & NA & NA & NA & 15E8_6sid2X__1 & $7 / 98$ & TDP-208 & 9150663 \\
\hline 29.3 & 0.998 & 0.01500 & 0.050 & 0.337 & 7.6 & $\mathrm{P}$ & NA & 5.18 & 5.32 & 5.38 & 5.60 & 4.60 & 15.50 & NA & NA & NA & NA & NA & NA & 1 & 0.0 & 4 & NA & NA & NA & 15E__6sid2X__ 1 & $7 / 9 B$ & TDP-208 & 9150664 \\
\hline 29.4 & 0.998 & 0.01500 & 0.050 & 0.336 & 7.1 & $P$ & NA & 5.56 & 5.70 & 5.77 & 6.00 & 4.60 & 19.50 & NA & NA & NA & NA & NA & NA & 1 & 0.0 & 4 & NA & NA & NA & $15 E_{8}$ _ssid2X $\mathrm{C}_{1} 1$ & $7 / 9 B$ & TDP-208 & 9150665 \\
\hline 29.8 & 0.998 & 0.01500 & 0.050 & 0.333 & 9.3 & $P$ & NA & 4.32 & 4.41 & 4.46 & 4.60 & 4.60 & 8.50 & NA & NA & NA & NA & NA & NA & NA & $\mathrm{Na}$ & NA & NA & NA & NA & $15 E 8 \_6 s 1 d 2 \times c \_1$ & $7 / 9 \mathrm{~B}$ & TDP-208 & 9150665.1 \\
\hline 29.8 & 0.998 & 0.01500 & 0.050 & 0.333 & 9.3 & $\mathrm{P}$ & NA & 4.32 & 4.41 & 4.46 & 4.60 & 4.60 & 8.50 & NA & NA & NA & NA & NA & NA & NA & na & NA & NA & NA & NA & 15E8_Gsid2X__1 & $7 / 9 \mathrm{~B}$ & TDP-208 & 9150665.2 \\
\hline 29.8 & 0.998 & 0.01500 & 0.050 & 0.333 & 9.3 & $\mathrm{P}$ & NA & 4.32 & 4.41 & 4.46 & 4.60 & 4.60 & 8.50 & NA & NA & NA & NA & NA & NA & NA & $\mathrm{na}$ & NA & NA & NA & NA & 15E8__sidd2X__1 & $7 / 98$ & TDP-208 & 9150665.3 \\
\hline
\end{tabular}


Table B.3. Data from 2008 Tests in Small-Scale Vessel with Elliptical Head A.19

\begin{tabular}{|c|c|c|c|c|c|c|c|c|c|c|c|c|c|c|c|c|c|c|c|c|c|c|c|c|c|c|c|}
\hline $\begin{array}{l}\text { Row } \\
\text { Number }\end{array}$ & Test & Case ID & $\begin{array}{l}\text { Tank } \\
\text { Diameter }\end{array}$ & $\begin{array}{l}\text { Head } \\
\text { Shape } \\
\end{array}$ & $\begin{array}{l}\text { Dish } \\
\text { Height }\end{array}$ & $\begin{array}{c}\text { Dish } \\
\text { Volume }\end{array}$ & $\begin{array}{c}\text { Tank } \\
\text { Fil } \\
\text { Height }\end{array}$ & $\begin{array}{l}\text { Retum } \\
\text { Lne } \\
\text { Height }\end{array}$ & $\begin{array}{c}\text { Nozzle } \\
\text { IInner } \\
\text { Diameter }\end{array}$ & $\begin{array}{l}\text { Nozle } \\
\text { Stanc-off } \\
\text { Distance }\end{array}$ & $\begin{array}{l}\text { Pulse Tube } \\
\text { Configuration }\end{array}$ & $\begin{array}{l}\text { Installed } \\
\text { Nozzles } \\
\text { Nates }\end{array}$ & $\begin{array}{c}\text { Outer } \\
\text { Nozzles } \\
\text { Operated }\end{array}$ & $\begin{array}{c}\text { Inner } \\
\text { Nozzles } \\
\text { Operated }\end{array}$ & $\begin{array}{c}\text { Pulse Tube } \\
\text { Outer } \\
\text { Diameter } \\
\end{array}$ & $\begin{array}{c}\text { Outer } \\
\text { PMM } \\
\text { Radius }\end{array}$ & $\begin{array}{c}\text { Inner } \\
\text { PPM } \\
\text { Radius }\end{array}$ & $\begin{array}{l}\text { "FO" Outer } \\
\text { PJM } \\
\text { Pmpingement } \\
\text { Angle } \\
\end{array}$ & $\begin{array}{c}\text { "FFO' Inner PJM } \\
\text { Impingement } \\
\text { Angle }\end{array}$ & $\begin{array}{c}\text { Ratio Oter } \\
\text { PJMMto Tank } \\
\text { Radius } \\
\end{array}$ & $\begin{array}{c}\text { Ratio Inner } \\
\text { PJMto Tank } \\
\text { Radius } \\
\end{array}$ & Simulant & $\begin{array}{l}\text { Solids } \\
\text { Density }\end{array}$ & $\begin{array}{l}\text { Particle } \\
\text { Diameter d5 }\end{array}$ & $\begin{array}{c}\text { Particle } \\
\text { Diamter } \\
\text { d50 }\end{array}$ & $\begin{array}{c}\text { Partide } \\
\text { Dianterer } \\
\text { d955 }\end{array}$ & $\begin{array}{c}\text { Void } \\
\text { Fraction } \\
\end{array}$ \\
\hline text & text & text & in. & text & in. & in. ${ }^{3}$ & in. & in. & in. & in. & text & number & number & number & in. & in. & in. & deg & deg & nondim & nondim & text & $\mathrm{g} / \mathrm{cm}^{3}$ & $m$ & $m$ & $m$ & fraction \\
\hline MSS & MDDX & ID & $\mathrm{D}$ & HS & Hish & $V_{\text {ash }}$ & $\mathrm{H}$ & Rtn & $d$ & sod & PT & $\mathrm{N}$ & $\mathrm{No}$ & $\mathrm{N}$ & $\mathrm{PT}_{\alpha \mathrm{d}}$ & $R_{0}$ & $\mathrm{R}$ & $\theta_{0}$ & $\theta_{1}$ & $\mathrm{RdR}$ & $R / R$ & sxdx & $\rho_{\mathrm{s}}$ & $d s$ & $d_{50}$ & des & vf \\
\hline 9150665.4 & $7 / 9 B$ & 15E__6sid2X__1 1 & $147 / 16$ & $E$ & 3.25 & 354.8 & 36 & 30 & 0.191 & 0.287 & 8 8TA & 8 & 4 & 4 & 1.05 & 4.9 & 3.6 & 24.4 & 16 & 0.67 & 0.50 & s1d2 & 2.48 & 0.0000569 & 0.0000693 & 0.0000821 & 0.3750 \\
\hline $9150666 \mathrm{M}$ & $7 / 98$ & $15 E 8$ 6sid $2 X_{c_{1}} 1$ & $147 / 16$ & $E$ & 3.25 & 354.8 & 36 & 30 & 0.191 & 0.287 & $8 \mathrm{TA}$ & 8 & 4 & 4 & 1.05 & 4.9 & 3.6 & 24.4 & 16 & 0.67 & 0.50 & s1d2 & 2.48 & 0.0000569 & 0.0000693 & 0.0000821 & 0.3750 \\
\hline 9150667 & $7 / 9 B$ & 15E8_6s1d2Xc_1 & $147 / 16$ & $E$ & 3.25 & 354.8 & 36 & 30 & 0.191 & 0.287 & $8 \mathrm{TA}$ & 8 & 4 & 4 & 1.05 & 4.9 & 3.6 & 24.4 & 16 & 0.67 & 0.50 & s1d2 & 2.48 & 0.0000569 & 0.0000693 & 0.0000821 & 0.3750 \\
\hline 9150668 & $7 / 9 \mathrm{~B}$ & $15 E 8$ _6s1d2Xc_1 & $147 / 16$ & E & 3.25 & 354.8 & 36 & 30 & 0.191 & 0.287 & 8TA & 8 & 4 & 4 & 1.05 & 4.9 & 3.6 & 24.4 & 16 & 0.67 & 0.50 & s1d2 & 2.48 & 0.0000569 & 0.0000693 & 0.0000021 & 0.3750 \\
\hline 9150668.1 & $7 / 98$ & $15 E 8$ 6sid2 $2 \times 1$ & $147 / 16$ & E & 3.25 & 354.8 & 36 & 30 & 0.191 & 0.287 & $8 \mathrm{TA}$ & 8 & 4 & 4 & 1.05 & 4.9 & 3.6 & 24.4 & 16 & 0.67 & 0.50 & s1d2 & 248 & 0.0000569 & 0.0000693 & 0.0000821 & 0.3750 \\
\hline 9150669 & $7 / 9 \mathrm{~B}$ & 15E8_6s1d2X__1 & 147116 & E & 3.25 & 354.8 & 36 & 30 & 0.191 & 0.287 & 8TA & 8 & 4 & 4 & 1.05 & 4.9 & 3.6 & 24.4 & 16 & 0.67 & 0.50 & s1d2 & 2.48 & 0.0000569 & 0.0000693 & 0.0000821 & 0.3750 \\
\hline 9150669.1 & $7 / 98$ & $15 E 8$ 6sid $2 X_{c} c_{1}$ & $147 / 16$ & $E$ & 3.25 & 354.8 & 36 & 30 & 0.191 & 0.287 & 8TA & 8 & 4 & 4 & 1.05 & 4.9 & 3.6 & 24.4 & 16 & 0.67 & 0.50 & s1d2 & 2.48 & 0.0000569 & 0.0000693 & 0.0000821 & 0.3750 \\
\hline 9150670 & $7 / 98$ & $15 E 8 \_6 s 1 d 2 \times c_{1} 11$ & $147 / 16$ & $E$ & 3.25 & 354.8 & 36 & 30 & 0.191 & 0.287 & 8TA & 8 & 4 & 4 & 1.05 & 4.9 & 3.6 & 24.4 & 16 & 0.67 & 0.50 & s1d2 & 2.48 & 0.0000569 & 0.0000693 & 0.0000821 & 0.3750 \\
\hline 9150670.1 & $7 / 9 B$ & $15 E 8 \_6 s 1 \mathrm{~d} 2 \times \mathrm{C} \_1$ & $147 / 16$ & E & 3.25 & 354.8 & 36 & 30 & 0.191 & 0.287 & 8TA & 8 & 4 & 4 & 1.05 & 4.9 & 3.6 & 24.4 & 16 & 0.67 & 0.50 & s1d2 & 2.48 & 0.0000569 & 0.0000693 & 0.0000021 & 0.3750 \\
\hline 9150671 & $7 / 9 \mathrm{~B}$ & $15 E 8$ _ssid2Xc_1 & $147 / 16$ & E & 3.25 & 354.8 & 36 & 30 & 0.191 & 0.287 & $8 \mathrm{TA}$ & 8 & 4 & 4 & 1.05 & 4.9 & 3.6 & 24.4 & 16 & 0.67 & 0.50 & s1d2 & 248 & 0.0000569 & 0.0000693 & 0.0000821 & 0.3750 \\
\hline 9150671.1 & $7 / 9 \mathrm{~B}$ & 15E8_6sid2X___ 1 & 147116 & E & 3.25 & 354.8 & 36 & 30 & 0.191 & 0.287 & 8TA & 8 & 4 & 4 & 1.05 & 4.9 & 3.6 & 24.4 & 16 & 0.67 & 0.50 & s1d2 & 2.48 & 0.0000569 & 0.0000693 & 0.0000821 & 0.3750 \\
\hline 9150672 & $7 / 9 \mathrm{~B}$ & $15 E 8 \_6 s 1 \mathrm{~d} 2 \times \mathrm{C} \_1$ & $147 / 16$ & E & 3.25 & 354.8 & 36 & 30 & 0.191 & 0.287 & $8 T A$ & 8 & 4 & 4 & 1.05 & 4.9 & 3.6 & 24.4 & 16 & 0.67 & 0.50 & s1d2 & 2.48 & 0.0000569 & 0.0000693 & 0.0000821 & 0.3750 \\
\hline 9150673 & $7 / 90$ & 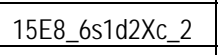 & $147 / 16$ & $E$ & 3.25 & 354.8 & 36 & 30 & 0.191 & 0.287 & $8 \mathrm{TA}$ & 8 & 4 & 4 & 1.05 & 4.9 & 3.6 & 24.4 & 16 & 0.67 & 0.50 & s1d2 & 2.48 & 0.0000569 & 0.0000693 & 0.0000821 & 0.3750 \\
\hline 9150674 & $7 / 9 \mathrm{C}$ & $15 E 8$ _6s1d2Xc_2 2 & $147 / 16$ & E & 3.25 & 354.8 & 36 & 30 & 0.191 & 0.287 & 8TA & 8 & 4 & 4 & 1.05 & 4.9 & 3.6 & 24.4 & 16 & 0.67 & 0.50 & s1d2 & 2.48 & 0.0000569 & 0.0000693 & 0.0000821 & 0.3750 \\
\hline 9150675M & $7 / 9 \mathrm{C}$ & $15 E 8 \_6 s 1 d 2 X c \_2$ & $147 / 16$ & $\mathrm{E}$ & 3.25 & 354.8 & 36 & 30 & 0.191 & 0.287 & $8 \mathrm{TA}$ & 8 & 4 & 4 & 1.05 & 4.9 & 3.6 & 24.4 & 16 & 0.67 & 0.50 & s1d2 & 2.48 & 0.0000569 & 0.0000693 & 0.0000821 & 0.3750 \\
\hline $9150676 \mathrm{M}$ & $7 / 9 \mathrm{C}$ & $15 E 8$ 6sid2Xc 2 & $147 / 16$ & $E$ & 3.25 & 354.8 & 36 & 30 & 0.191 & 0.287 & 8TA & 8 & 4 & 4 & 1.05 & 4.9 & 3.6 & 24.4 & 16 & 0.67 & 0.50 & s1d2 & 2.48 & 0.0000569 & 0.0000693 & 0.0000821 & 0.3750 \\
\hline $915067 \mathrm{M}$ & $7 / 9 \mathrm{C}$ & $15 E 8$ _6s1d2Xc_2 2 & $147 / 16$ & E & 3.25 & 354.8 & 36 & 30 & 0.191 & 0.287 & $8 \mathrm{TA}$ & 8 & 4 & 4 & 1.05 & 4.9 & 3.6 & 24.4 & 16 & 0.67 & 0.50 & s1d2 & 2.48 & 0.0000569 & 0.0000693 & 0.0000821 & 0.3750 \\
\hline $9150678 \mathrm{M}$ & $7 / 90$ & $15 E 8 \_6 s 1 d 2 \times c_{2} 2$ & $147 / 16$ & $E$ & 3.25 & 354.8 & 36 & 30 & 0.191 & 0.287 & 8TA & 8 & 4 & 4 & 1.05 & 4.9 & 3.6 & 24.4 & 16 & 0.67 & 0.50 & s1d2 & 2.48 & 0.0000569 & 0.0000693 & 0.0000821 & 0.3750 \\
\hline $9150679 \mathrm{M}$ & $7 / 90$ & 15E8_6sid2X__2 & $147 / 16$ & E & 3.25 & 354.8 & 36 & 30 & 0.191 & 0.287 & 8TA & 8 & 4 & 4 & 1.05 & 4.9 & 3.6 & 24.4 & 16 & 0.67 & 0.50 & s1d2 & 2.48 & 0.0000569 & 0.0000693 & 0.00000211 & 0.3750 \\
\hline $9150680 \mathrm{M}$ & $7 / 9 \mathrm{C}$ & 15E8_6sid2Xc_2 & $147 / 16$ & E & 3.25 & 354.8 & 36 & 30 & 0.191 & 0.287 & 8TA & 8 & 4 & 4 & 1.05 & 4.9 & 3.6 & 24.4 & 16 & 0.67 & 0.50 & $51 d_{2}$ & 2.48 & 0.0000569 & 0.0000693 & 0.0000821 & 0.3750 \\
\hline 9150681M & $7 / 9 \mathrm{C}$ & $15 E 8 \_6 s 1 \mathrm{~d} 2 \times \mathrm{c} \_2$ & $147 / 16$ & E & 3.25 & 354.8 & 36 & 30 & 0.191 & 0.287 & 8TA & 8 & 4 & 4 & 1.05 & 4.9 & 3.6 & 24.4 & 16 & 0.67 & 0.50 & s1d2 & 2.48 & 0.0000569 & 0.0000693 & 0.0000021 & 0.3750 \\
\hline 9150681.1 & $7 / 9 \mathrm{C}$ & $15 E 8$ _6sid2X__2 & $147 / 16$ & E & 3.25 & 354.8 & 36 & 30 & 0.191 & 0.287 & 8TA & 8 & 4 & 4 & 1.05 & 4.9 & 3.6 & 24.4 & 16 & 0.67 & 0.50 & s1d2 & 248 & 0.0000569 & 0.0000693 & 0.0000821 & 0.3750 \\
\hline 9150681.2 & $7 / 90$ & $15 E 8 \_$_sid2X___ 2 & $147 / 16$ & $E$ & 3.25 & 354.8 & 36 & 30 & 0.191 & 0.287 & 8TA & 8 & 4 & 4 & 1.05 & 4.9 & 3.6 & 24.4 & 16 & 0.67 & 0.50 & s1d2 & 2.48 & 0.0000569 & 0.0000693 & 0.0000821 & 0.3750 \\
\hline 9150681.3 & $7 / 90$ & 15E8_6s1d2X__2 & $147 / 16$ & E & 3.25 & 354.8 & 36 & 30 & 0.191 & 0.287 & 8TA & 8 & 4 & 4 & 1.05 & 4.9 & 3.6 & 24.4 & 16 & 0.67 & 0.50 & s1d2 & 2.48 & 0.0000569 & 0.0000693 & 0.00000211 & 0.3750 \\
\hline 9150682M & $7 / 9 \mathrm{C}$ & $15 E 8 \_6 s 1 d 2 X c \_2$ & $147 / 16$ & $\mathrm{E}$ & 3.25 & 354.8 & 36 & 30 & 0.191 & 0.287 & 8TA & 8 & 4 & 4 & 1.05 & 4.9 & 3.6 & 24.4 & 16 & 0.67 & 0.50 & s1d2 & 2.48 & 0.0000569 & 0.0000693 & 0.0000821 & 0.3750 \\
\hline 9150683 & $7 / 9 \mathrm{C}$ & 15E8_6sid2Xc_ 2 & $147 / 16$ & E & 3.25 & 354.8 & 36 & 30 & 0.191 & 0.287 & 8TA & 8 & 4 & 4 & 1.05 & 4.9 & 3.6 & 24.4 & 16 & 0.67 & 0.50 & 5102 & 248 & 0.0000569 & 0.0000693 & 0.0000821 & 0.3750 \\
\hline 9150684 & $7 / 9 \mathrm{C}$ & $15 E 8$ _6sid2X__2 & $147 / 16$ & E & 3.25 & 354.8 & 36 & 30 & 0.191 & 0.287 & 8TA & 8 & 4 & 4 & 1.05 & 4.9 & 3.6 & 24.4 & 16 & 0.67 & 0.50 & s1d2 & 248 & 0.0000569 & 0.0000693 & 0.0000821 & 0.3750 \\
\hline 9150684.1 & $7 / 9 \mathrm{C}$ & $15 E 8$ _6sid $2 \times \mathrm{C}_{2} 2$ & $147 / 16$ & $\mathrm{E}$ & 3.25 & 354.8 & 36 & 30 & 0.191 & 0.287 & $8 \mathrm{TA}$ & 8 & 4 & 4 & 1.05 & 4.9 & 3.6 & 24.4 & 16 & 0.67 & 0.50 & s1d2 & 248 & 0.0000569 & 0.0000693 & 0.0000821 & 0.3750 \\
\hline 9150685 & $7 / 90$ & 15E8_6s1d2Xc_2 & $147 / 16$ & $E$ & 3.25 & 354.8 & 36 & 30 & 0.191 & 0.287 & $8 \mathrm{TA}$ & 8 & 4 & 4 & 1.05 & 4.9 & 3.6 & 24.4 & 16 & 0.67 & 0.50 & s1d2 & 2.48 & 0.0000569 & 0.0000693 & 0.00000211 & 0.3750 \\
\hline 9150685.1 & $7 / 9 \mathrm{C}$ & $15 E 8$ _6s1d2Xc_2 2 & $147 / 16$ & E & 3.25 & 354.8 & 36 & 30 & 0.191 & 0.287 & 8TA & 8 & 4 & 4 & 1.05 & 4.9 & 3.6 & 24.4 & 16 & 0.67 & 0.50 & 5102 & 2.48 & 0.0000569 & 0.0000693 & 0.0000821 & 0.3750 \\
\hline 9150686 & $7 / 9 \mathrm{C}$ & 15E8_6sid2Xc_ 2 & $147 / 16$ & E & 3.25 & 354.8 & 36 & 30 & 0.191 & 0.287 & 8TA & 8 & 4 & 4 & 1.05 & 4.9 & 3.6 & 24.4 & 16 & 0.67 & 0.50 & 5102 & 2.48 & 0.0000569 & 0.0000693 & 0.0000821 & 0.3750 \\
\hline 9150686.1 & $7 / 9 \mathrm{C}$ & $15 E 8$ _sid2 $2 x_{c} \_2$ & $147 / 16$ & E & 3.25 & 354.8 & 36 & 30 & 0.191 & 0.287 & 8TA & 8 & 4 & 4 & 1.05 & 4.9 & 3.6 & 24.4 & 16 & 0.67 & 0.50 & s1d2 & 2.48 & 0.0000569 & 0.0000693 & 0.0000821 & 0.3750 \\
\hline $\begin{array}{ll}9150687 \\
\end{array}$ & $7 / 9 c$ & $15 E 8$ _6sid $2 \times \mathrm{c}_{2} 2$ & $147 / 16$ & $E$ & 3.25 & 354.8 & 36 & 30 & 0.191 & 0.287 & 8TA & 8 & 4 & 4 & 1.05 & 4.9 & 3.6 & 24.4 & 16 & 0.67 & 0.50 & s1d2 & 248 & 0.0000569 & 0.0000693 & 0.0000821 & 0.3750 \\
\hline 9150687.1 & $7 / 9 \mathrm{C}$ & 15E8_6sid2Xc_2 & $147 / 16$ & $E$ & 3.25 & 354.8 & 36 & 30 & 0.191 & 0.287 & 8TA & 8 & 4 & 4 & 1.05 & 4.9 & 3.6 & 24.4 & 16 & 0.67 & 0.50 & s1d2 & 248 & 0.0000569 & 0.0000693 & 0.0000821 & 0.3750 \\
\hline 9150688 & $7 / 9 \mathrm{C}$ & $15 E 8$ _6s1d2Xc_2 2 & $147 / 16$ & $E$ & 3.25 & 354.8 & 36 & 30 & 0.191 & 0.287 & $8 \mathrm{TA}$ & 8 & 4 & 4 & 1.05 & 4.9 & 3.6 & 24.4 & 16 & 0.67 & 0.50 & s1d2 & 2.48 & 0.0000569 & 0.0000693 & 0.0000821 & 0.3750 \\
\hline 9150689 & $7 / 10 \mathrm{~A}$ & 15E8_Ms1d27c_1 & $147 / 16$ & E & 3.25 & 354.8 & $351 / 2$ & 30 & 0.268 & 0.402 & 8TA & 8 & 4 & 4 & 1.05 & 4.9 & 3.6 & 24.4 & 16 & 0.67 & 0.50 & 5102 & 2.48 & 0.0000569 & 0.0000693 & 0.0000821 & 0.3750 \\
\hline 9150690 & $7 / 10 \mathrm{~A}$ & 15E8_Ms1d2Z__1 & $147 / 16$ & E & 3.25 & 354.8 & $351 / 2$ & 30 & 0.268 & 0.402 & 8 8TA & 8 & 4 & 4 & 1.05 & 4.9 & 3.6 & 24.4 & 16 & 0.67 & 0.50 & 5102 & 2.48 & 0.0000569 & 0.0000693 & 0.0000821 & 0.3750 \\
\hline 9150691M & $7110 \mathrm{~A}$ & 15E8_Ms1d2ZC_1 & $147 / 16$ & E & 3.25 & 354.8 & $351 / 2$ & 30 & 0.268 & 0.402 & $8 T A$ & 8 & 4 & 4 & 1.05 & 4.9 & 3.6 & 24.4 & 16 & 0.67 & 0.50 & s1d2 & 2.48 & 0.0000569 & 0.0000693 & 0.0000821 & 0.3750 \\
\hline $9150692 \mathrm{M}$ & $7 / 10 \mathrm{~A}$ & 15E8_Ms1d27C_1 & 147116 & E & 3.25 & 354.8 & $351 / 2$ & 30 & 0.268 & 0.402 & 8TA & 8 & 4 & 4 & 1.05 & 4.9 & 3.6 & 24.4 & 16 & 0.67 & 0.50 & s1d2 & 2.48 & 0.0000569 & 0.0000693 & 0.0000821 & 0.3750 \\
\hline $9150693 \mathrm{M}$ & $7 / 10 \mathrm{~A}$ & 15E8_Ms1d27__1 & 147116 & E & 3.25 & 354.8 & $351 / 2$ & 30 & 0.268 & 0.402 & $8 \mathrm{TA}$ & 8 & 4 & 4 & 1.05 & 4.9 & 3.6 & 24.4 & 16 & 0.67 & 0.50 & s1d2 & 2.48 & 0.0000569 & 0.0000693 & 0.0000821 & 0.3750 \\
\hline 9150694M & $7 / 10 \mathrm{~A}$ & 15E8_Ms1d27c_1 & $147 / 16$ & E & 3.25 & 354.8 & $351 / 2$ & 30 & 0.268 & 0.402 & 8TA & 8 & 4 & 4 & 1.05 & 4.9 & 3.6 & 24.4 & 16 & 0.67 & 0.50 & 5102 & 2.48 & 0.0000569 & 0.0000693 & 0.0000821 & 0.3750 \\
\hline
\end{tabular}


Table B.3. Data from 2008 Tests in Small-Scale Vessel with Elliptical Head B.19

\begin{tabular}{|c|c|c|c|c|c|c|c|c|c|c|c|c|c|c|c|c|c|c|c|c|c|c|c|c|c|c|c|c|c|}
\hline $\begin{array}{l}\text { Tank Water } \\
\text { Temperature }\end{array}$ & $\begin{array}{l}\text { Water } \\
\text { Density }\end{array}$ & $\begin{array}{l}\text { Solids } \\
\text { Fraction }\end{array}$ & $\begin{array}{l}\text { Pulse } \\
\text { Volume } \\
\text { Fraction }\end{array}$ & $\begin{array}{l}\text { Duty } \\
\text { Qydle }\end{array}$ & $\begin{array}{l}\text { Cycle } \\
\text { Time }\end{array}$ & $\begin{array}{c}\text { Pulsed } \\
\text { or } \\
\text { Steady } \\
\text { Jet }\end{array}$ & $\begin{array}{l}\text { Us } \\
\text { Steacy } \\
\text { Jet }\end{array}$ & $\begin{array}{c}\text { U1 } \\
\text { Pulsing } \\
\text { Jet } \\
\end{array}$ & $\begin{array}{c}\text { U2 } \\
\text { URMS }\end{array}$ & $\begin{array}{c}\text { U3 } \\
\text { URMB }\end{array}$ & $\begin{array}{c}\text { Discharge } \\
\text { Velocity }\end{array}$ & $\begin{array}{c}\text { Citical } \\
\text { Suspension } \\
\text { Velocity }\end{array}$ & $\begin{array}{l}\text { Average } \\
\text { Peak Cloud } \\
\text { Height }\end{array}$ & $\begin{array}{c}\text { UCS } \\
\text { Condition }\end{array}$ & $\begin{array}{c}\text { UCS } \\
\text { Method }\end{array}$ & $\begin{array}{l}\text { UCS } \\
\text { Fag }\end{array}$ & $\begin{array}{l}\text { UCS } \\
\text { Center } \\
\text { Fag }\end{array}$ & $\begin{array}{c}\text { UCS udv } \\
\text { Hag }\end{array}$ & \begin{tabular}{|c|} 
UCS based \\
on \\
Decreasing \\
velocity
\end{tabular} & $\begin{array}{l}\text { Sweep } \\
\text { Increase / } \\
\text { Decrease }\end{array}$ & $\begin{array}{c}\text { UDV } \\
\text { Height } \\
\text { Bed }\end{array}$ & $\begin{array}{l}\text { Particle } \\
\text { Motion }\end{array}$ & \begin{tabular}{|l|} 
Solids \\
Level \\
\end{tabular} & \begin{tabular}{|l|} 
Outer \\
Botom \\
Pattem \\
\end{tabular} & \begin{tabular}{|c|} 
Inner \\
Bottom \\
Pattem \\
\end{tabular} & Case ID & Test & TDP & $\begin{array}{l}\text { Row } \\
\text { Number }\end{array}$ \\
\hline$c$ & $\mathrm{~g} \mathrm{~cm}^{3}$ & fraction & fraction & fraction & $\mathrm{s}$ & text & $\mathrm{m} / \mathrm{s}$ & $\mathrm{m} / \mathrm{s}$ & $\mathrm{m} / \mathrm{s}$ & m/s & m/s & $m / s$ & in. & $\mathrm{ms}$ & text & text & text & $\begin{array}{ll}\text { text } \\
\end{array}$ & \begin{tabular}{|l|}
$\mathrm{m} / \mathrm{s}$ \\
\end{tabular} & text & $\mathrm{mm}$ & text & \begin{tabular}{|l|} 
text \\
\end{tabular} & text & text & text & text & text & text \\
\hline $\mathrm{T}$ & $\rho$ & $\phi_{\mathrm{s}}$ & $\phi_{p}$ & $D C$ & tc & Jet & $u_{s}$ & $\mathrm{U} 1$ & $\mathrm{U} 2$ & U3 & $u$ & Ucs & $\mathrm{He}$ & UosR & Ucsu & Uosvis & Uscen & Usuldv & Ues D & $s_{N}$ & $\mathrm{H}_{\text {bed }}$ & $\mathrm{PM}$ & Sol & $\mathrm{SPo}_{\mathrm{o}}$ & $\mathrm{SP}_{1}$ & $\mathrm{ID}$ & MDDX & $\mathrm{IDP}$ & MSS \\
\hline 29.8 & 0.998 & 0.01500 & 0.050 & 0.333 & 9.3 & $P$ & $\mathrm{NA}$ & 4.32 & 4.41 & 4.46 & 4.60 & 4.60 & 8.50 & NA & NA & NA & NA & NA & NA & NA & $\mathrm{n} / \mathrm{a}$ & NA & $\mathrm{NA}$ & NA & NA & 15E8__sidd2X__1 & $7 / 9 B$ & TDP-208 & 9150665.4 \\
\hline 29.8 & 0.998 & 0.01500 & 0.050 & 0.333 & 9.3 & $\mathrm{P}$ & NA & 4.32 & 4.41 & 4.46 & 4.60 & 4.60 & 8.50 & NA & NA & NA & NA & NA & NA & 1 & 3.3 & 1 & NA & NA & NA & 15E8_Gs1d2Xc_1 & $7 / 98$ & TDP-208 & 9150666 \\
\hline 29.8 & 0.998 & 0.01500 & 0.050 & 0.333 & 9.3 & $\mathrm{P}$ & NA & 4.32 & 4.41 & 4.46 & 4.60 & 4.60 & 8.50 & NA & NA & NA & NA & NA & NA & NA & 3.3 & NA & NA & NA & NA & 15E8_6s1d2X___1 & $7 / 98$ & TDP-208 & 9150667 \\
\hline 29.8 & 0.998 & 0.01500 & 0.050 & 0.333 & 9.3 & $P$ & NA & 4.32 & 4.41 & 4.46 & 4.60 & 4.60 & 8.50 & NA & NA & NA & NA & NA & NA & NA & 3.1 & NA & NA & NA & NA & 15E8_Gsid2X__1 & $7 / 9 B$ & TDP-208 & 9150668 \\
\hline 29.8 & 0.998 & 0.01500 & 0.050 & 0.333 & 9.3 & $\mathrm{P}$ & NA & 4.32 & 4.41 & 4.46 & 4.60 & 4.60 & 8.50 & NA & NA & NA & NA & NA & NA & NA & na & NA & NA & NA & NA & 15E8_6sid2XC_1 & $7 / 98$ & TDP-208 & 9150668.1 \\
\hline 29.8 & 0.998 & 0.01500 & 0.050 & 0.333 & 9.3 & $P$ & NA & 4.32 & 4.41 & 4.46 & 4.60 & 4.60 & 8.50 & NA & NA & NA & NA & NA & NA & NA & 3.3 & NA & NA & NA & NA & 15E8_6sid2X__1 & $7 / 98$ & TDP-208 & 9150669 \\
\hline 29.8 & 0.998 & 0.01500 & 0.050 & 0.333 & 9.3 & $\mathrm{P}$ & NA & 4.32 & 4.41 & 4.46 & 4.60 & 4.60 & 8.50 & NA & NA & NA & NA & NA & NA & NA & $\mathrm{na}$ & NA & NA & NA & NA & 15E8_6sid2X_c1 & $7 / 98$ & TDP-208 & 9150669.1 \\
\hline 29.8 & 0.998 & 0.01500 & 0.050 & 0.333 & 9.3 & $\mathrm{P}$ & NA & 4.32 & 4.41 & 4.46 & 4.60 & 4.60 & 8.50 & NA & NA & NA & NA & NA & NA & NA & $\mathrm{na}$ & NA & NA & NA & NA & 15E8_6s1d2Xc_1 & $7 / 9 B$ & TDP-208 & 9150670.1 \\
\hline 29.8 & 0.998 & 0.01500 & 0.050 & 0.333 & 9.3 & $\mathrm{P}$ & NA & 4.32 & 4.41 & 4.46 & 4.60 & 4.60 & 8.50 & NA & NA & NA & NA & NA & NA & NA & 4.5 & NA & NA & NA & NA & 15E8_6s1d2X__1 & $7 / 9 B$ & TDP-208 & 9150671 \\
\hline 29.8 & 0.998 & 0.01500 & 0.050 & 0.333 & 9.3 & $P$ & NA & 4.32 & 4.41 & 4.46 & 4.60 & 4.60 & 8.50 & NA & NA & NA & NA & NA & NA & NA & $\mathrm{na}$ & NA & NA & NA & NA & 15E8_6sid2X__1 & $7 / 98$ & TDP-208 & 9150671.1 \\
\hline 29.8 & 0.998 & 0.01500 & 0.050 & 0.333 & 9.3 & $\mathrm{P}$ & NA & 4.32 & 4.41 & 4.46 & 4.60 & 4.60 & 8.50 & NA & NA & NA & NA & NA & NA & NA & 4.7 & NA & NA & NA & NA & 15E8_6sid2X__ 1 & $7 / 98$ & TDP-208 & 9150672 \\
\hline 30.3 & 0.998 & 0.01500 & 0.099 & 0.329 & 20.6 & $\mathrm{P}$ & NA & 3.89 & 3.92 & 3.94 & 4.00 & 4.40 & 7.00 & NA & NA & NA & NA & NA & NA & (null) & 7.4 & 1 & NA & NA & NA & 15E8_6s1d2X__2 2 & $7 / 9 \mathrm{C}$ & TDP-208 & 9150673 \\
\hline 30.3 & 0.998 & 0.01500 & 0.099 & 0.330 & 19.6 & $\mathrm{P}$ & NA & 4.08 & 4.12 & 4.14 & 4.20 & 4.40 & 8.00 & NA & NA & NA & NA & NA & NA & 1 & 5.4 & 1 & NA & NA & NA & 15E8_Gsid2X__2 & $7 / 9 C$ & TDP-208 & 9150674 \\
\hline 30.4 & 0.998 & 0.01500 & 0.099 & 0.329 & 18.8 & $\mathrm{P}$ & NA & 4.27 & 4.31 & 4.33 & 4.40 & 4.40 & 8.75 & \begin{tabular}{|l|}
4.40 \\
\end{tabular} & udv & NA & NA & ucsuav & NA & $\mathrm{I}$ & 0.0 & 1 & NA & NA & NA & 15E8_Gs1d2Xc_2 & $7 / 9 C$ & TDP-208 & 9150675 \\
\hline 30.4 & 0.998 & 0.01500 & 0.100 & 0.330 & 18.0 & $\mathrm{P}$ & NA & 4.45 & 4.50 & 4.52 & 4.60 & 4.40 & 9.50 & \begin{tabular}{|l|} 
NA \\
\end{tabular} & NA & NA & NA & NA & NA & 1 & 0.0 & 1 & NA & NA & NA & 15E___sidd2X__2 & $7 / 9 C$ & TDP-208 & 9150676 \\
\hline 30.6 & 0.998 & 0.01500 & 0.100 & 0.332 & 17.2 & $\mathrm{P}$ & NA & 4.64 & 4.69 & 4.71 & 4.80 & 4.40 & 10.75 & NA & NA & Ucsis & NA & NA & NA & 1 & 0.0 & 3 & NA & NA & NA & 15E8_6sid2X__2 2 & $7 / 9 c$ & TDP-208 & 9150677 \\
\hline 30.8 & 0.998 & 0.01500 & 0.100 & 0.332 & 16.6 & $\mathrm{P}$ & $\mathrm{NA}$ & 4.82 & 4.88 & 4.91 & 5.00 & 4.40 & 12.25 & NA & NA & $\mathrm{NA}$ & NA & NA & NA & 1 & 0.0 & 4 & NA & NA & NA & 15E8_6s1d2X__2 2 & $7 / 9 \mathrm{C}$ & TDP-208 & 9150678 \\
\hline 31.0 & 0.998 & 0.01500 & 0.100 & 0.332 & 15.4 & $\mathrm{P}$ & NA & 5.19 & 5.26 & 5.29 & 5.40 & 4.40 & 15.25 & NA & NA & NA & NA & NA & NA & 1 & 0.0 & 4 & NA & NA & NA & 15E8_Gs1d2Xc_2 & $7 / 9 \mathrm{C}$ & TDP-208 & 9150679 \\
\hline 31.2 & 0.998 & 0.01500 & 0.100 & 0.333 & 14.8 & $\mathrm{P}$ & NA & 5.38 & 5.45 & 5.49 & 5.60 & 4.40 & 17.25 & NA & NA & NA & NA & NA & NA & 1 & 0.0 & 4 & NA & NA & NA & $15 E 8$ 6sid2XC_ 2 & $7 / 9 C$ & TDP-208 & 9150680 \\
\hline 31.7 & 0.998 & 0.01500 & 0.100 & 0.329 & 18.8 & $\mathrm{P}$ & NA & 4.27 & 4.31 & 4.33 & 4.40 & 4.40 & 8.50 & NA & NA & NA & NA & NA & NA & NA & $\mathrm{n} / \mathrm{a}$ & NA & NA & NA & NA & 15E8__sidd $2 \times$ C_C $_{2}$ & $7 / 9 \mathrm{C}$ & TDP-208 & 9150681.1. \\
\hline 31.7 & 0.998 & 0.01500 & 0.100 & 0.329 & 18.8 & $\mathrm{P}$ & NA & 4.27 & 4.31 & 4.33 & 4.40 & 4.40 & 8.50 & NA & NA & NA & NA & NA & NA & NA & na & NA & NA & NA & NA & 15E8_Gs1d2Xc_2 & $7 / 9 \mathrm{C}$ & TDP-208 & 9150681.2 \\
\hline 31.7 & 0.998 & 0.01500 & 0.100 & 0.329 & 18.8 & $\mathrm{P}$ & NA & 4.27 & 4.31 & 4.33 & 4.40 & 4.40 & 8.50 & NA & NA & NA & NA & NA & NA & NA & $\mathrm{ra}$ & NA & NA & NA & NA & 15E8_Gs1d2Xc_2 & $7 / 9 \mathrm{C}$ & TDP-208 & 9150681.3 \\
\hline 31.7 & 0.998 & 0.01500 & 0.100 & 0.329 & 18.8 & $\mathrm{P}$ & NA & 4.27 & 4.31 & 4.33 & 4.40 & 4.40 & 8.50 & NA & NA & NA & NA & NA & NA & 1 & 0.7 & 1 & NA & NA & NA & $15 E 8$ 6sidd $2 \times c_{2} 2$ & $7 / 9 \mathrm{C}$ & TDP-208 & 9150682 \\
\hline 31.7 & 0.998 & 0.01500 & 0.100 & 0.329 & 18.8 & $\mathrm{P}$ & NA & 4.27 & 4.31 & 4.33 & 4.40 & 4.40 & 8.50 & NA & NA & NA & NA & NA & NA & NA & 0.6 & NA & NA & NA & NA & 15E8_6sid2X_c_2 & $7 / 9 C$ & TDP-208 & 9150683 \\
\hline 31.7 & 0.998 & 0.01500 & 0.100 & 0.329 & 18.8 & $\mathrm{P}$ & NA & 4.27 & 4.31 & 4.33 & 4.40 & 4.40 & 8.50 & NA & NA & NA & NA & NA & NA & NA & 4.8 & NA & NA & NA & NA & 15E8__sidd $2 \times$ C_C $_{2}$ & $7 / 9 \mathrm{C}$ & TDP-208 & 9150684 \\
\hline 31.7 & 0.998 & 0.01500 & 0.100 & 0.329 & 18.8 & $\mathrm{P}$ & NA & 4.27 & 4.31 & 4.33 & 4.40 & 4.40 & 8.50 & NA & NA & NA & NA & NA & NA & NA & $\mathrm{na}$ & NA & NA & NA & NA & 15E8_Gsid2X__2 & $7 / 9 \mathrm{C}$ & TDP-208 & 9150684.1 \\
\hline 31.7 & 0.998 & 0.01500 & 0.100 & 0.329 & 18.8 & $\mathrm{P}$ & NA & 4.27 & 4.31 & 4.33 & 4.40 & 4.40 & 8.50 & NA & NA & NA & NA & NA & NA & NA & 2.4 & NA & NA & NA & NA & 15E8_Gs1d2Xc_2 & $7 / 9 \mathrm{C}$ & TDP-208 & 9150685 \\
\hline 31.7 & 0.998 & 0.01500 & 0.100 & 0.329 & 18.8 & $\mathrm{P}$ & NA & 4.27 & 4.31 & 4.33 & 4.40 & 4.40 & 8.50 & NA & NA & NA & NA & NA & NA & NA & $\mathrm{na}$ & NA & NA & NA & NA & $15 E 8$ _ssid2Xc_2 & $7 / 9 \mathrm{C}$ & TDP-208 & 9150685.1 \\
\hline 31.7 & 0.998 & 0.01500 & 0.100 & 0.329 & 18.8 & $\mathrm{P}$ & NA & 4.27 & 4.31 & 4.33 & 4.40 & 4.40 & 8.50 & NA & NA & NA & NA & NA & NA & NA & 2.1 & NA & NA & NA & NA & 15E8_6sid2X_c_2 & $7 / 9 C$ & TDP-208 & 9150686 \\
\hline 31.7 & 0.998 & 0.01500 & 0.100 & 0.329 & 18.8 & $\mathrm{P}$ & NA & 4.27 & 4.31 & 4.33 & 4.40 & 4.40 & 8.50 & NA & NA & NA & NA & NA & NA & NA & $\mathrm{na}$ & NA & NA & NA & NA & 15E8_6sid2X_c2 2 & $7 / 9 c$ & TDP-208 & 9150686.1 \\
\hline 31.7 & 0.998 & 0.01500 & 0.100 & 0.329 & 18.8 & $\mathrm{P}$ & NA & 4.27 & 4.31 & 4.33 & 4.40 & 4.40 & 8.50 & NA & NA & NA & NA & NA & NA & NA & 0.7 & NA & NA & NA & NA & 15E8_Gsid2X__2 & $7 / 9 \mathrm{C}$ & TDP-208 & 9150687 \\
\hline 31.7 & 0.998 & 0.01500 & 0.100 & 0.329 & 18.8 & $\mathrm{P}$ & NA & 4.27 & 4.31 & 4.33 & 4.40 & 4.40 & 8.50 & NA & NA & NA & NA & NA & NA & NA & wa & NA & NA & NA & NA & 15E8_6sid2X___2 & $7 / 9 \mathrm{C}$ & TDP-208 & 9150687.1 \\
\hline 31.7 & 0.998 & 0.01500 & 0.100 & 0.329 & 18.8 & $\mathrm{P}$ & NA & 4.27 & 4.31 & 4.33 & 4.40 & 4.40 & 8.50 & NA & NA & NA & NA & NA & NA & NA & 5.6 & NA & NA & NA & NA & $15 E 8$ 6sid2XC_ 2 & $7 / 9 \mathrm{C}$ & TDP-208 & 9150688 \\
\hline 30.2 & 0.998 & 0.00155 & 0.050 & 0.331 & 15.0 & $\mathrm{P}$ & NA & 1.35 & 1.36 & 1.36 & 1.40 & 170 & 14.25 & NA & NA & NA & NA & NA & NA & (null) & 9.2 & 1 & NA & NA & NA & 15E8_Ms1d2ZC_1 & $7110 \mathrm{~A}$ & TDP-209 & 9150689 \\
\hline 30.3 & 0.998 & 0.00155 & 0.050 & 0.335 & 13.0 & $\mathrm{P}$ & NA & 1.54 & 1.55 & 1.56 & 1.60 & 170 & 13.00 & NA & NA & NA & NA & NA & NA & 1 & 4.3 & 1 & NA & NA & NA & 15E8_Ms1d2ZC_ 1 & $7110 \mathrm{~A}$ & TDP-209 & 9150690 \\
\hline 30.5 & 0.998 & 0.00155 & 0.050 & 0.335 & 12.4 & $P$ & NA & 1.62 & 1.64 & 1.65 & 1.70 & 1.70 & 14.00 & \begin{tabular}{|l|}
1.70 \\
\end{tabular} & uav & NA & NA & ucsudv & NA & 1 & 0.0 & 1 & NA & NA & NA & 15E8_Ns1d27c_ 1 & $7 / 10 \mathrm{~A}$ & TDP-209 & 9150691 \\
\hline 30.6 & 0.998 & 0.00155 & 0.050 & 0.335 & 11.6 & $\mathrm{P}$ & NA & 1.72 & 1.74 & 1.75 & 1.80 & 1.70 & 14.25 & NA & NA & NA & NA & NA & NA & 1 & 0.0 & 1 & NA & NA & NA & 15E8_Ms1d27c_1 1 & $7110 \mathrm{~A}$ & TDP-209 & 9150692 \\
\hline 30.7 & 0.998 & 0.00155 & 0.050 & 0.337 & 11.0 & $\mathrm{P}$ & NA & 1.82 & 1.84 & 1.85 & 1.90 & 1.70 & 16.00 & NA & NA & ucsis & NA & NA & NA & $\mathrm{I}$ & 0.0 & 3 & NA & NA & NA & 15E8_Ns1d27c_ 1 & $7110 \mathrm{~A}$ & TDP-209 & 9150693 \\
\hline 30.7 & 0.998 & 0.00155 & 0.050 & 0.338 & 10.4 & $P$ & NA & 1.91 & 1.94 & 1.95 & 2.00 & 1.70 & 17.50 & NA & NA & NA & NA & NA & NA & 1 & 0.0 & 4 & NA & NA & NA & 15E8_Ms1d2Zc_1 & $7110 \mathrm{~A}$ & TDP-209 & 9150694 \\
\hline
\end{tabular}


Table B.3. Data from 2008 Tests in Small-Scale Vessel with Elliptical Head A.20

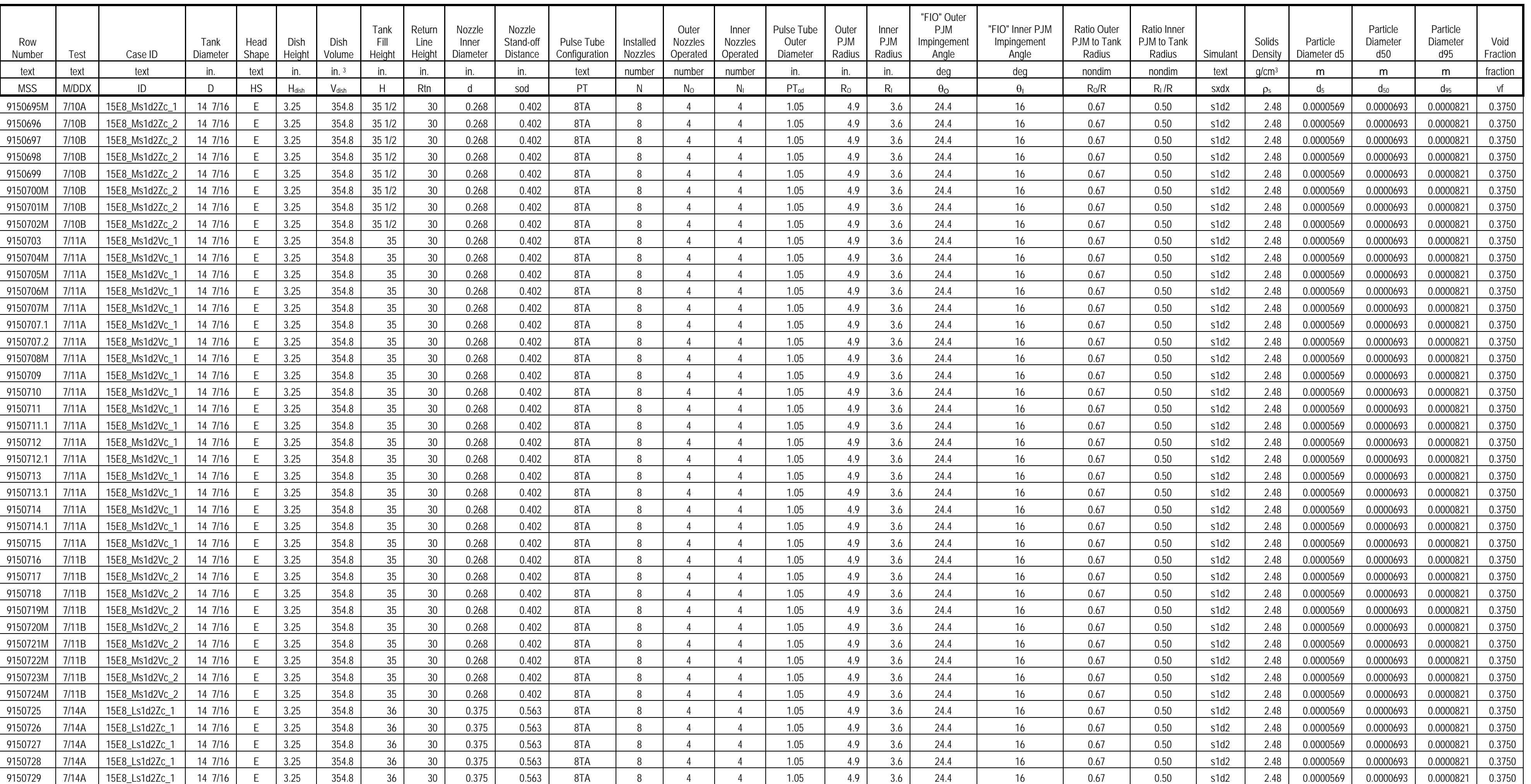


Table B.3. Data from 2008 Tests in Small-Scale Vessel with Elliptical Head B.20

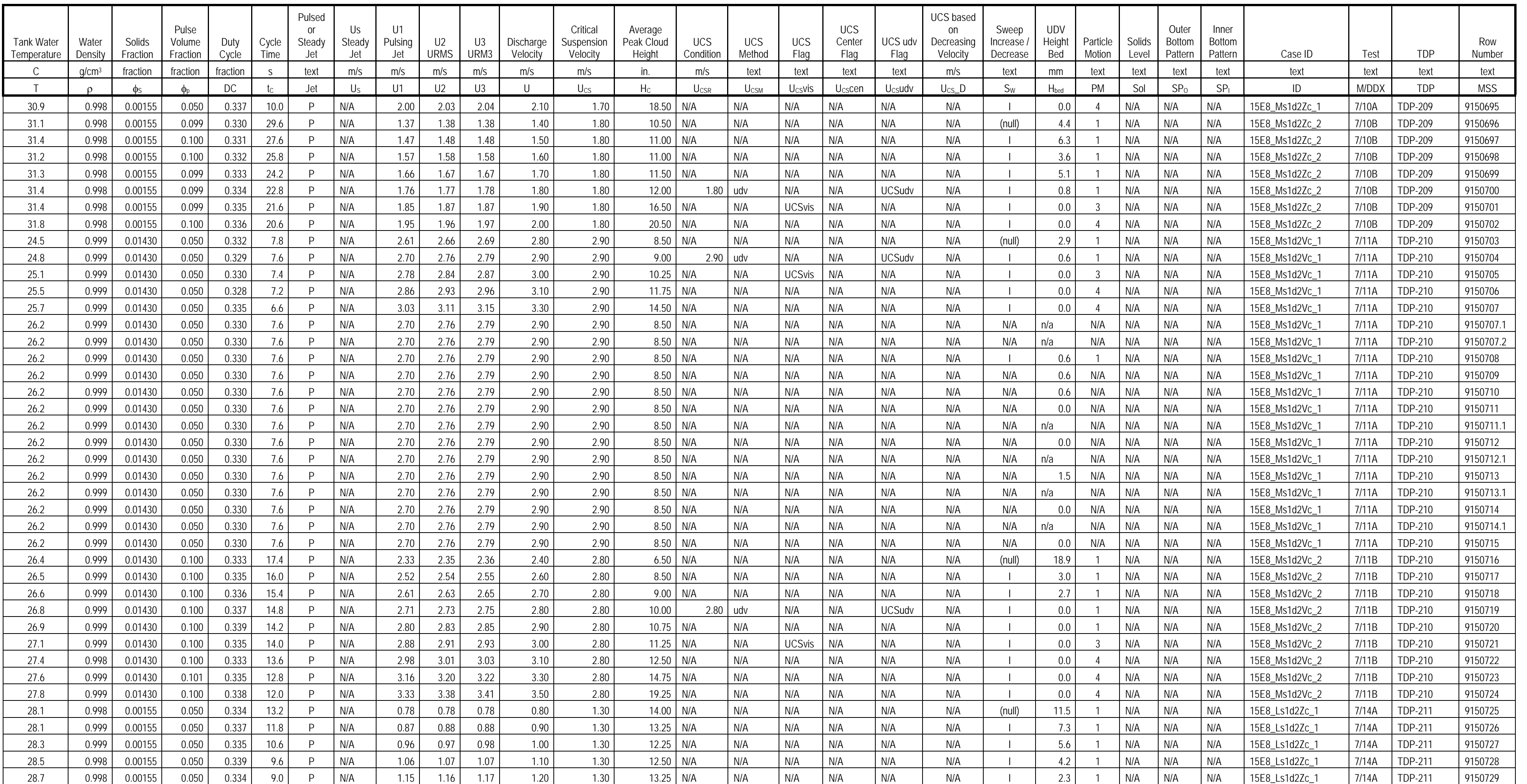


Table B.3. Data from 2008 Tests in Small-Scale Vessel with Elliptical Head A.21

\begin{tabular}{|c|c|c|c|c|c|c|c|c|c|c|c|c|c|c|c|c|c|c|c|c|c|c|c|c|c|c|c|}
\hline Row Number & Test & Case ID & $\begin{array}{c}\text { Tank } \\
\text { Diameter }\end{array}$ & $\begin{array}{l}\text { Head } \\
\text { Shape }\end{array}$ & \begin{tabular}{|l|} 
Dish \\
Height
\end{tabular} & $\begin{array}{c}\text { Dish } \\
\text { Volume }\end{array}$ & $\begin{array}{c}\text { Tank Fill } \\
\text { Height }\end{array}$ & $\begin{array}{l}\text { Retur } \\
\text { Line } \\
\text { Height }\end{array}$ & $\begin{array}{c}\text { Nozzle } \\
\text { Inner } \\
\text { Diameter }\end{array}$ & $\begin{array}{l}\text { Nozzle } \\
\text { Stlancoff } \\
\text { Distance }\end{array}$ & $\begin{array}{l}\text { Pulse Tube } \\
\text { Configuration }\end{array}$ & $\begin{array}{l}\text { Installed } \\
\text { Nozzles }\end{array}$ & $\begin{array}{c}\text { Outer } \\
\text { Nozzles } \\
\text { Operated }\end{array}$ & $\begin{array}{l}\text { Inner } \\
\text { Nozoldes } \\
\text { Operated }\end{array}$ & $\begin{array}{l}\text { Pulse Tube } \\
\text { Outer } \\
\text { Dianter }\end{array}$ & $\begin{array}{c}\text { Outer } \\
\text { PJM } \\
\text { Radius }\end{array}$ & 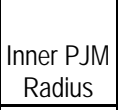 & $\begin{array}{c}\text { "FO" auter PJM } \\
\text { Impingement } \\
\text { Angle }\end{array}$ & $\begin{array}{c}\text { "FO' Inner PJM } \\
\text { Impingement Angle }\end{array}$ & \begin{tabular}{|l}
$\begin{array}{l}\text { Ratio Outer PJM } \\
\text { to Tank Radius }\end{array}$ \\
to Ton
\end{tabular} & $\begin{array}{l}\text { Ratio Inner PJM } \\
\text { to Tank Radius }\end{array}$ & Simulant & $\begin{array}{l}\text { Solids } \\
\text { Density }\end{array}$ & $\begin{array}{c}\text { Particle } \\
\text { Diameter d5 }\end{array}$ & $\begin{array}{c}\text { Particle } \\
\text { Diameter d50 }\end{array}$ & $\begin{array}{c}\text { Particle } \\
\text { Diameter d95 }\end{array}$ & $\begin{array}{l}\text { Void } \\
\text { Fraction }\end{array}$ \\
\hline text & text & text & in. & text & in. & in. ${ }^{3}$ & in. 1 & in. & in. & in. & text & number & number & number & in. & in. & in. & deg & \begin{tabular}{|c|} 
deg \\
\end{tabular} & nondim & nondim & text & $\mathrm{g} / \mathrm{cm}^{3}$ & $\mathrm{~m}$ & $\begin{array}{ll}\mathrm{m} \\
\end{array}$ & $\mathrm{m}$ & fraction \\
\hline MSS & MDDXX & ID & $\mathrm{D}$ & HS & Hish & $V_{\text {dsh }}$ & $\mathrm{H}$ & Rtn & $d$ & sod & PT & $\mathrm{N}$ & $\mathrm{Nb}$ & $\mathrm{N}$ & $\mathrm{PT}_{\alpha \mathrm{d}}$ & $R_{0}$ & $R$ & $\theta_{\circ}$ & $\theta_{1}$ & $R d R$ & $R, \mathbb{R}$ & sxdx & $\rho_{\mathrm{s}}$ & $d_{5}$ & $d_{60}$ & $d_{65}$ & vf \\
\hline $9150730 \mathrm{M}$ & $7 / 14 A$ & 15E8_Ls1d2ZC__1 & $147 / 16$ & $E$ & 3.25 & 354.8 & 36 & 30 & 0.375 & 0.563 & $8 \mathrm{TTA}$ & 8 & 4 & 4 & 1.05 & 4.9 & 3.6 & 24.4 & 16 & 0.67 & 0.50 & $\mathrm{sid2}$ & 2.48 & 0.0000569 & 0.0000693 & 0.0000821 & 0.3750 \\
\hline $9150731 \mathrm{M}$ & $7 / 144$ & 15E8_Ls1d2ZC_1 & $147 / 16$ & $E$ & 3.25 & 354.8 & 36 & 30 & 0.375 & 0.563 & 8TA & 8 & 4 & 4 & 1.05 & 4.9 & 3.6 & 24.4 & 16 & 0.67 & 0.50 & s1d2 & 2.48 & 0.0000569 & $\begin{array}{ll}0.0000693 \\
\end{array}$ & 0.0000821 & 0.3750 \\
\hline 9150732 & $7 / 148$ & 15E8_LSId2VC_1 & $147 / 16$ & $E$ & 3.25 & 354.8 & 36 & 30 & 0.375 & 0.563 & 8TA & 8 & 4 & 4 & 1.05 & 4.9 & 3.6 & 24.4 & 16 & 0.67 & 0.50 & $\mathrm{sid2}$ & 2.48 & 0.0000569 & 0.0000693 & 0.0000821 & 0.3750 \\
\hline 9150733 & $7 / 148$ & 15E8_Ls1d2VC_1 & $147 / 16$ & $E$ & 3.25 & 354.8 & 36 & 30 & 0.375 & 0.563 & 8TA & 8 & 4 & 4 & 1.05 & 4.9 & 3.6 & 24.4 & 16 & 0.67 & 0.50 & s1d2 & 2.48 & 0.0000569 & 0.0000693 & 0.0000821 & 0.3750 \\
\hline 9150734 & $7 / 148$ & 15E8_LsId2VC_1 & $147 / 16$ & $E$ & 3.25 & 354.8 & 36 & 30 & 0.375 & 0.563 & 8TA & 8 & 4 & 4 & 1.05 & 4.9 & 3.6 & 24.4 & 16 & 0.67 & 0.50 & $\mathrm{~s} 1 \mathrm{~d} 2$ & 2.48 & 0.0000569 & 0.0000693 & 0.0000821 & 0.3750 \\
\hline 9150735 & $7 / 148$ & 15E8_Ls1d2VC_1 & $147 / 16$ & $\mathrm{E}$ & 3.25 & 354.8 & 36 & 30 & 0.375 & 0.563 & 8TA & 8 & 4 & 4 & 1.05 & 4.9 & 3.6 & 24.4 & 16 & 0.67 & 0.50 & s1d2 & 2.48 & 0.0000569 & 0.0000693 & 0.0000821 & 0.3750 \\
\hline 9150736 & $7 / 148$ & 15E8_LsId2VC_1 & $147 / 16$ & $E$ & 3.25 & 354.8 & 36 & 30 & 0.375 & 0.563 & 8TA & 8 & 4 & 4 & 1.05 & 4.9 & 3.6 & 24.4 & 16 & 0.67 & 0.50 & s1d2 & 2.48 & 0.0000569 & 0.0000693 & 0.0000821 & 0.3750 \\
\hline 9150737M M & $7 / 14 \mathrm{~B}$ & 15E8_ LS1d2VV_ 1 & $147 / 16$ & $\mathrm{E}$ & 3.25 & 354.8 & 36 & 30 & 0.375 & 0.563 & 8 8TA & 8 & 4 & 4 & 1.05 & 4.9 & 3.6 & 24.4 & 16 & 0.67 & 0.50 & s1d2 & 2.48 & 0.0000569 & 0.0000693 & 0.0000821 & 0.3750 \\
\hline 9150738M & $7 / 148$ & 15E8_Ls1d2V__1 & $147 / 16$ & $E$ & 3.25 & 354.8 & 36 & 30 & 0.375 & 0.563 & $8 T A$ & 8 & 4 & 4 & 1.05 & 4.9 & 3.6 & 24.4 & 16 & 0.67 & 0.50 & s1d2 & 2.48 & 0.0000569 & 0.0000693 & 0.0000821 & 0.3750 \\
\hline 9150738.1 & $7 / 148$ & 15E8_Ls1d2VC_1 & $147 / 16$ & $\mathrm{E}$ & 3.25 & 354.8 & 36 & 30 & 0.375 & 0.563 & 8TA & 8 & 4 & 4 & 1.05 & 4.9 & 3.6 & 24.4 & 16 & 0.67 & 0.50 & $\mathrm{~s} 1 \mathrm{~d} 2$ & 2.48 & 0.0000569 & 0.0000693 & 0.0000821 & 0.3750 \\
\hline 9150738.2 & $7 / 148$ & 15E8_Ls1d2VC_1 & $147 / 16$ & $E$ & 3.25 & 354.8 & 36 & 30 & 0.375 & 0.563 & 8TA & 8 & 4 & 4 & 1.05 & 4.9 & 3.6 & 24.4 & 16 & 0.67 & 0.50 & s1d2 & 2.48 & 0.0000569 & 0.0000693 & 0.0000821 & 0.3750 \\
\hline 9150739M & 7/144B & 15E8 LSII2VC 1 & $147 / 16$ & $\mathrm{E}$ & 3.25 & 354.8 & 36 & 30 & 0.375 & 0.563 & 8TA & 8 & 4 & 4 & 1.05 & 4.99 & 3.6 & 24.4 & 16 & 0.67 & 0.50 & s1d2 & 248 & 0.0000569 & 0.0000693 & 0.0000821 & 0.3750 \\
\hline 9150740 & $7 / 148$ & 15E8_Ls1d2VC_1 & $147 / 16$ & $E$ & 3.25 & 354.8 & 36 & 30 & 0.375 & 0.563 & $8 \mathrm{BTA}$ & 8 & 4 & 4 & 1.05 & 4.9 & 3.6 & 24.4 & 16 & 0.67 & 0.50 & $\mathrm{~s} 1 \mathrm{~d} 2$ & 2.48 & 0.0000569 & 0.0000693 & 0.0000821 & 0.3750 \\
\hline 9150741 & $7 / 148$ & 15E8_LS1d2VC_1 & $147 / 16$ & $E$ & 3.25 & 354.8 & 36 & 30 & 0.375 & 0.563 & $8 \mathrm{BTA}$ & 8 & 4 & 4 & 1.05 & 4.9 & 3.6 & 24.4 & 16 & 0.67 & 0.50 & s1d2 & 248 & 0.0000569 & 0.0000693 & 0.0000821 & 0.3750 \\
\hline 9150742 & $7 / 148$ & 15E8_Ls1d2VC_1 & $147 / 16$ & $E$ & 3.25 & 354.8 & 36 & 30 & 0.375 & 0.563 & 8TA & 8 & 4 & 4 & 1.05 & 4.9 & 3.6 & 24.4 & 16 & 0.67 & 0.50 & s1d2 & 2.48 & 0.0000569 & 0.0000693 & 0.0000821 & 0.3750 \\
\hline 91507421 & $7 / 14 \mathrm{~B}$ & 15E8 LSIdVVV_ 1 & $147 / 16$ & E & 3.25 & 354.8 & 36 & 30 & 0.375 & 0.563 & 8TA & 8 & 4 & 4 & 1.05 & 4.9 & 3.6 & 24.4 & 16 & 0.67 & 0.50 & s1d2 & 2.48 & 0.0000569 & 0.0000693 & 0.0000821 & 0.3750 \\
\hline 9150743 & $7 / 148$ & 15E8_Ls1d2VC_1 & $147 / 16$ & $E$ & 3.25 & 354.8 & 36 & 30 & 0.375 & 0.563 & $8 \mathrm{BA}$ & 8 & 4 & 4 & 1.05 & 4.9 & 3.6 & 24.4 & 16 & 0.67 & 0.50 & $\mathrm{~s} 1 \mathrm{~d} 2$ & 2.48 & 0.0000569 & 0.0000693 & 0.0000821 & 0.3750 \\
\hline 9150743.1 & $7 / 148$ & 15E8_Ls1d2VC_ 1 & $147 / 16$ & $E$ & 3.25 & 354.8 & 36 & 30 & 0.375 & 0.563 & 8TA & 8 & 4 & 4 & 1.05 & 4.9 & 3.6 & 24.4 & 16 & 0.67 & 0.50 & $\mathrm{~s} 1 \mathrm{~d} 2$ & 2.48 & 0.0000569 & 0.0000693 & 0.0000821 & 0.3750 \\
\hline 9150744 & $7 / 148$ & 15E8_LSId2VC_ 1 & $147 / 16$ & $E$ & 3.25 & 354.8 & 36 & 30 & 0.375 & 0.563 & $8 \mathrm{BTA}$ & 8 & 4 & 4 & 1.05 & 4.9 & 3.6 & 24.4 & 16 & 0.67 & 0.50 & s1d2 & 2.48 & 0.0000569 & 0.0000693 & 0.0000821 & 0.3750 \\
\hline 9150744.1 & $7 / 148$ & 15E8_Ls1d2VC_1 & $147 / 16$ & $E$ & 3.25 & 354.8 & 36 & 30 & 0.375 & 0.563 & $8 T A$ & 8 & 4 & 4 & 1.05 & 4.9 & 3.6 & 24.4 & 16 & 0.67 & 0.50 & $\mathrm{~s} 1 \mathrm{~d} 2$ & 2.48 & 0.0000569 & 0.0000693 & 0.0000821 & 0.3750 \\
\hline 9150745 & $7 / 14 \mathrm{~B}$ & 15E8_ LS1d2VV_ 1 & $147 / 16$ & $\mathrm{E}$ & 3.25 & 354.8 & 36 & 30 & 0.375 & 0.563 & 8TA & 8 & 4 & 4 & 1.05 & 4.9 & 3.6 & 24.4 & 16 & 0.67 & 0.50 & s1d2 & 2.48 & 0.0000569 & 0.0000693 & 0.0000821 & 0.3750 \\
\hline 9150745.1 & $7 / 148$ & 15E8_Ls1d2V__1 & $147 / 16$ & $E$ & 3.25 & 354.8 & 36 & 30 & 0.375 & 0.563 & $8 T A$ & 8 & 4 & 4 & 1.05 & 4.9 & 3.6 & 24.4 & 16 & 0.67 & 0.50 & $\mathrm{~s} 1 \mathrm{~d} 2$ & 2.48 & 0.0000569 & 0.0000693 & 0.0000821 & 0.3750 \\
\hline 9150746 & $7 / 14 \mathrm{~B}$ & 15E8_LSId2VC_ 1 & $147 / 16$ & $E$ & 3.25 & 354.8 & 36 & 30 & 0.375 & 0.563 & 8TA & 8 & 4 & 4 & 1.05 & 4.9 & 3.6 & 24.4 & 16 & 0.67 & 0.50 & $\mathrm{~s} 1 \mathrm{~d} 2$ & 2.48 & 0.0000569 & 0.0000693 & 0.0000821 & 0.3750 \\
\hline 9150747 & $7 / 15 \mathrm{~A}$ & 15E8_LsId2VC_ 7 & $147 / 16$ & $E$ & 3.25 & 354.8 & $351 / 2$ & 30 & 0.375 & 0.563 & 8TA & 8 & 4 & 0 & 1.05 & 4.9 & 3.6 & 24.4 & 16 & 0.67 & 0.50 & s1d2 & 2.48 & 0.0000569 & 0.0000693 & 0.0000821 & 0.3750 \\
\hline 9150748 & $7 / 15 \mathrm{~A}$ & 15E8_Ls1d2VC_ 7 & $147 / 16$ & E & 3.25 & 354.8 & $351 / 2$ & 30 & 0.375 & 0.563 & 8TA & 8 & 4 & 0 & 1.05 & 4.9 & 3.6 & 24.4 & 16 & 0.67 & 0.50 & $\mathrm{~s} 1 \mathrm{~d} 2$ & 2.48 & 0.0000569 & 0.0000693 & 0.0000821 & 0.3750 \\
\hline 9150749 & $7 / 15 \mathrm{~A}$ & 15E8_Ls1d2V__ 7 & $147 / 16$ & $E$ & 3.25 & 354.8 & $351 / 2$ & 30 & 0.375 & 0.563 & 8TA & 8 & 4 & 0 & 1.05 & 4.9 & 3.6 & 24.4 & 16 & 0.67 & 0.50 & $\mathrm{~s} 1 \mathrm{~d} 2$ & 2.48 & 0.0000569 & 0.0000693 & 0.0000821 & 0.3750 \\
\hline 9150750 & $7115 \mathrm{~A}$ & 15E8_Ls1d2VC_ 7 & $147 / 16$ & $E$ & 3.25 & 354.8 & $351 / 2$ & 30 & 0.375 & 0.563 & 8TA & 8 & 4 & o & 1.05 & 4.9 & 3.6 & 24.4 & 16 & 0.67 & 0.50 & s1d2 & 248 & 0.0000569 & 0.0000693 & 0.0000821 & 0.3750 \\
\hline 9150751 & $7 / 15 \mathrm{~A}$ & 15E8_Ls1d2VC_ 7 & $147 / 16$ & $\mathrm{E}$ & 3.25 & 354.8 & $351 / 2$ & 30 & 0.375 & 0.563 & $8 T \mathrm{~A}$ & 8 & 4 & 0 & 1.05 & 4.9 & 3.6 & 24.4 & 16 & 0.67 & 0.50 & s1d2 & 2.48 & 0.0000569 & 0.0000693 & 0.0000821 & 0.3750 \\
\hline 9150752 & $7 / 15 \mathrm{~A}$ & 15E8 LSIdVVV .7 & $147 / 16$ & E & 3.25 & 354.8 & $351 / 2$ & 30 & 0.375 & 0.563 & 8TA & 8 & 4 & 0 & 1.05 & 4.9 & 3.6 & 24.4 & 16 & 0.67 & 0.50 & $\mathrm{~s} 1 \mathrm{~d} 2$ & 2.48 & 0.0000569 & 0.0000693 & 0.0000821 & 0.3750 \\
\hline 9150753 & $7 / 15 \mathrm{~A}$ & 15E8_Ls1d2VC_ 7 & $147 / 16$ & $E$ & 3.25 & 354.8 & $351 / 2$ & 30 & 0.375 & 0.563 & $8 \mathrm{BA}$ & 8 & 4 & 0 & 1.05 & 4.9 & 3.6 & 24.4 & 16 & 0.67 & 0.50 & $\mathrm{~s} 1 \mathrm{~d} 2$ & 2.48 & 0.0000569 & 0.0000693 & 0.0000821 & 0.3750 \\
\hline 9150754M & $7 / 15 \mathrm{~A}$ & 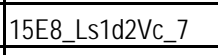 & $147 / 16$ & $E$ & 3.25 & 354.8 & $351 / 2$ & 30 & 0.375 & 0.563 & 8TA & 8 & 4 & 0 & 1.05 & 4.9 & 3.6 & 24.4 & 16 & 0.67 & 0.50 & $\mathrm{~s} 1 \mathrm{~d} 2$ & 2.48 & 0.0000569 & 0.0000693 & 0.0000821 & 0.3750 \\
\hline 9150755M & $7115 \mathrm{~A}$ & 15E8_Ls1d2VC_ 7 & $147 / 16$ & $E$ & 3.25 & 354.8 & $351 / 2$ & 30 & 0.375 & 0.563 & 8TA & 8 & 4 & o & 1.05 & 4.9 & 3.6 & 24.4 & 16 & 0.67 & 0.50 & $\mathrm{sid2}$ & 2.48 & 0.0000569 & 0.0000693 & 0.0000821 & 0.3750 \\
\hline $9150756 \mathrm{M}$ & $7 / 15 \mathrm{~A}$ & 15E8 LS1d2VV . 7 & $147 / 16$ & E & 3.25 & 354.8 & $351 / 2$ & 30 & 0.375 & 0.563 & 8 8TA & 8 & 4 & 0 & 1.05 & 4.9 & 3.6 & 24.4 & 16 & 0.67 & 0.50 & s1d2 & 2.48 & 0.0000569 & 0.0000693 & 0.0000821 & 0.3750 \\
\hline 9150757M & $7 / 15 \mathrm{~A}$ & 15E8_Ls1d2VC_ 7 & $147 / 16$ & $E$ & 3.25 & 354.8 & $351 / 2$ & 30 & 0.375 & 0.563 & $8 \mathrm{PTA}$ & 8 & 4 & 0 & 1.05 & 4.9 & 3.6 & 24.4 & 16 & 0.67 & 0.50 & s1d2 & 2.48 & 0.0000569 & 0.0000693 & 0.0000821 & 0.3750 \\
\hline 9150758M & $7715 \mathrm{~A}$ & 15E8_Ls1d2VC_ 7 & $147 / 16$ & $E$ & 3.25 & 354.8 & $351 / 2$ & 30 & 0.375 & 0.563 & 8TA & 8 & 4 & 0 & 1.05 & 4.9 & 3.6 & 24.4 & 16 & 0.67 & 0.50 & $\mathrm{~s} 1 \mathrm{~d} 2$ & 2.48 & 0.0000569 & \begin{tabular}{|l|}
0.0000693 \\
\end{tabular} & 0.0000821 & 0.3750 \\
\hline 9150758.1 & $7 / 15 \mathrm{~A}$ & 15E8_Ls1d2VC_ 7 & $147 / 16$ & $E$ & 3.25 & 354.8 & $351 / 2$ & 30 & 0.375 & 0.563 & $8 T \mathrm{~A}$ & 8 & 4 & 0 & 1.05 & 4.9 & 3.6 & 24.4 & 16 & 0.67 & 0.50 & s1d2 & 2.48 & 0.0000569 & 0.0000693 & 0.0000821 & 0.3750 \\
\hline 9150759M & $7 / 15 \mathrm{~A}$ & $15 E 8$ LS1d2VV 7 & $147 / 16$ & E & 3.25 & 354.8 & $351 / 2$ & 30 & 0.375 & 0.563 & $8 \mathrm{BA}$ & 8 & 4 & 0 & 1.05 & 4.9 & 3.6 & 24.4 & 16 & 0.67 & 0.50 & $\mathrm{sid2}$ & 2.48 & 0.0000569 & 0.0000693 & 0.0000821 & 0.3750 \\
\hline 9150760 & $7 / 15 \mathrm{~A}$ & 15E8 LS1d2VV. 7 & $147 / 16$ & $E$ & 3.25 & 354.8 & $351 / 2$ & 30 & 0.375 & 0.563 & 8TA & 8 & 4 & 0 & 1.05 & 4.9 & 3.6 & 24.4 & 16 & 0.67 & 0.50 & s1d2 & 2.48 & 0.0000569 & 0.0000693 & 0.0000821 & 0.3750 \\
\hline 9150761 & $7 / 15 \mathrm{~A}$ & 15E8_LS1d2VV 77 & $147 / 16$ & E & 3.25 & 354.8 & $351 / 2$ & 30 & 0.375 & 0.563 & $8 \mathrm{BA}$ & 8 & 4 & 0 & 1.05 & 4.9 & 3.6 & 24. & & 0.67 & & & 2 & & & & \\
\hline 9150762 & $7715 \mathrm{~A}$ & 15E8_LSIId2VC_ 7 & $147 / 16$ & $E$ & 3.25 & 354.8 & $351 / 2$ & 30 & 0.375 & 0.563 & 8TA & 8 & 4 & 0 & 1.05 & 4.9 & 3.6 & 24.4 & 16 & 0.67 & 0.50 & s1d2 & 2.48 & 0.0000569 & 0.0000693 & 0.0000821 & 0.3750 \\
\hline 9150763 & $7 / 15 \mathrm{~A}$ & 15E8 LS1d2V & $147 / 16$ & $E$ & 3.25 & 354.8 & $35_{1 / 2}$ & 30 & 0.375 & 0.563 & 8TA & 8 & 4 & 0 & 1.05 & 4.9 & 3.6 & 24.4 & 16 & 0.67 & 0.50 & s1d2 & 2.48 & 0.0000569 & |0.0000693 & 0.0000821 & 0.3750 \\
\hline
\end{tabular}


Table B.3. Data from 2008 Tests in Small-Scale Vessel with Elliptical Head B.21

\begin{tabular}{|c|c|c|c|c|c|c|c|c|c|c|c|c|c|c|c|c|c|c|c|c|c|c|c|c|c|c|c|c|c|}
\hline $\begin{array}{l}\text { Tank Water } \\
\text { Temperature }\end{array}$ & $\begin{array}{l}\text { Water } \\
\text { Density }\end{array}$ & $\begin{array}{l}\text { Solids } \\
\text { Fraction } \\
\end{array}$ & $\begin{array}{l}\text { Pulse } \\
\text { volume } \\
\text { Fraction } \\
\end{array}$ & $\begin{array}{l}\text { Duty } \\
\text { Oydle }\end{array}$ & $\begin{array}{l}\text { Oyde } \\
\text { Time }\end{array}$ & $\begin{array}{c}\begin{array}{c}\text { Pulsed } \\
\text { Oel } \\
\text { Steacy } \\
\text { Jet }\end{array} \\
\end{array}$ & $\begin{array}{c}\text { Us } \\
\text { Steady } \\
\text { Jet }\end{array}$ & $\begin{array}{c}\text { U1 } \\
\text { Pulsing } \\
\text { Jet }\end{array}$ & $\begin{array}{c}\text { U2 } \\
\text { URMS } \\
\end{array}$ & $\begin{array}{c}\text { U3 } \\
\text { URNB } \\
\end{array}$ & \begin{tabular}{|l|} 
Discharge \\
Velocity \\
\end{tabular} & $\begin{array}{c}\text { Citical } \\
\text { Suspension } \\
\text { velocity } \\
\end{array}$ & $\begin{array}{c}\text { Average } \\
\text { Peak Coloud } \\
\text { Height } \\
\end{array}$ & $\begin{array}{c}\text { Ucs } \\
\text { Condtion }\end{array}$ & $\begin{array}{l}\text { uCS } \\
\text { Nethod }\end{array}$ & $\begin{array}{l}\text { ucs } \\
\text { Hag }\end{array}$ & $\begin{array}{l}\text { Ucs } \\
\text { Center } \\
\text { Hag }\end{array}$ & $\begin{array}{c}\text { ucs udv } \\
\text { Fag } \\
\end{array}$ & \begin{tabular}{|c|} 
Ucs based \\
on \\
Decreasing \\
Velocity \\
\end{tabular} & $\begin{array}{l}\text { Sweepe } \\
\text { Increase } \\
\text { Decrease }\end{array}$ & $\begin{array}{c}\text { UDV } \\
\text { Height } \\
\text { Bed }\end{array}$ & $\begin{array}{c}\text { Particle } \\
\text { Motion } \\
\end{array}$ & \begin{tabular}{|l} 
Solids \\
Level
\end{tabular} & \begin{tabular}{|l} 
Outer \\
Bototom \\
Pater \\
\end{tabular} & $\begin{array}{l}\text { Inner } \\
\text { Bottom } \\
\text { Patterm }\end{array}$ & Case ID & Test & TDP & $\begin{array}{l}\text { Row } \\
\text { Number }\end{array}$ \\
\hline $\mathrm{c}$ & $\mathrm{g} / \mathrm{cm}^{3}$ & fraction & fraction & fraction & $\mathrm{s}$ & text & $\mathrm{m} / \mathrm{s}$ & $\mathrm{m} / \mathrm{s}$ & $\mathrm{m} / \mathrm{s}$ & $\mathrm{m} / \mathrm{s}$ & $\mathrm{m} / \mathrm{s}$ & $\mathrm{m} / \mathrm{s}$ & in. & $\mathrm{m} / \mathrm{s}$ & text & text & text & text & \begin{tabular}{|l|}
$\mathrm{m} / \mathrm{s}$ \\
\end{tabular} & text & $\mathrm{mm}$ & text & text & text & text & text & text & text & text \\
\hline $\mathrm{T}$ & $\rho$ & $\phi_{\mathrm{s}}$ & $\phi_{p}$ & $\mathrm{DC}$ & tc & Jet & $u_{s}$ & $\mathrm{U}_{1}$ & $\mathrm{U} 2$ & U3 & $u$ & Uss & $\mathrm{Hc}$ & USSR & Uan & Unsvis & Uscen & Usuldv & Uss D & $s_{w}$ & $H_{\text {bed }}$ & $\mathrm{PM}$ & Sol & $\mathrm{SP}_{\mathrm{O}}$ & $\mathrm{SP}$ & $\mathrm{ID}$ & MDDX & $\mathrm{IDP}$ & MSS \\
\hline 28.8 & 0.998 & 0.00155 & 0.050 & 0.337 & 8.2 & $\mathrm{P}$ & $\mathrm{NA}$ & 1.24 & 1.25 & 1.26 & 1.30 & 1.30 & $\begin{array}{ll}15.25 \\
\end{array}$ & 1.30 & udv & UCShis & NA & Ucsudv & NA & 1 & 0.0 & 3 & $\mathrm{NA}$ & NA & $\mathrm{NA}$ & 15E8_Ls1d2ZC_1 & $7 / 14 \mathrm{~A}$ & TDP-211 & 9150730 \\
\hline 29.2 & 0.998 & 0.00155 & 0.050 & 0.333 & 7.8 & $\mathrm{P}$ & NA & 1.32 & 1.34 & 1.35 & 1.40 & 1.30 & 18.00 & \begin{tabular}{|l|} 
NA \\
\end{tabular} & NA & NA & NA & NA & NA & 1 & 0.0 & 4 & NA & NA & NA & 15E8_Ls1d27C_1 & $7 / 144 \mathrm{~A}$ & TDP-211 & 9150731 \\
\hline 30.1 & 0.998 & 0.01430 & 0.050 & 0.338 & 6.8 & $\mathrm{P}$ & NA & 1.50 & 1.52 & 1.54 & 1.60 & 190 & 5.50 & NA & NA & NA & NA & NA & NA & (null) & 16.8 & 1 & NA & NA & NA & 15E8_LS1d2VC_1 & $7 / 14 \mathrm{~B}$ & TDP-212 & 9150732 \\
\hline 30.6 & 0.998 & 0.01430 & 0.050 & 0.332 & 6.2 & $\mathrm{P}$ & NA & 1.67 & 1.71 & 1.73 & 1.80 & 1.90 & 8.50 & NA & NA & NA & NA & NA & NA & 1 & 3.6 & 1 & NA & NA & NA & 15E8_LS1d2VC_1 & $7 / 14 \mathrm{~B}$ & TDP-212 & 9150733 \\
\hline 31.1 & 0.997 & 0.01430 & 0.050 & 0.329 & 7.0 & $\mathrm{P}$ & NA & 1.50 & 1.52 & 1.54 & 1.60 & 1.90 & 5.00 & NA & NA & NA & NA & NA & NA & 1 & 18.6 & 1 & NA & NA & NA & 15E8_LsId2VV_ 1 & $7 / 148$ & TDP-212 & 9150734 \\
\hline 31.4 & 0.997 & 0.01430 & 0.050 & 0.332 & 6.6 & $\mathrm{P}$ & NA & 1.58 & 1.61 & 1.62 & 1.70 & 1.90 & 6.50 & NA & NA & NA & NA & NA & NA & 1 & 13.1 & 1 & NA & NA & NA & 15E8_Ls1d2V__ 1 & 71148 & TDP-212 & 9150735 \\
\hline 31.6 & 0.997 & 0.01430 & 0.050 & 0.333 & 6.2 & $\mathrm{P}$ & NA & 1.67 & 1.70 & 1.72 & 1.80 & 1.90 & 8.00 & NA & NA & NA & NA & NA & NA & 1 & 1.1 & 1 & NA & NA & NA & 15E8_Ls1d2VC_1 & $7 / 148$ & TDP-212 & 9150736 \\
\hline 32.2 & 0.998 & 0.01430 & 0.050 & 0.330 & 5.7 & $\mathrm{P}$ & NA & 1.84 & 1.88 & 1.90 & 2.00 & 1.90 & 10.50 & NA & NA & NA & NA & NA & NA & 1 & 0.0 & 4 & NA & NA & NA & 15E8_LSId2VC_1 & $7 / 14 \mathrm{~B}$ & TDP-212 & 9150738 \\
\hline 32.6 & 0.997 & 0.01430 & 0.050 & 0.337 & 5.8 & $\mathrm{P}$ & NA & 1.75 & 1.79 & 1.81 & 1.90 & 1.90 & 9.50 & NA & NA & NA & NA & NA & NA & NA & $\mathrm{na}$ & NA & NA & NA & NA & 15E8_LSIIIVV__1 & $7 / 14 \mathrm{~B}$ & TDP-212 & 9150738.1 \\
\hline 32.6 & 0.997 & 0.01430 & 0.050 & 0.337 & 5.8 & $\mathrm{P}$ & NA & 1.75 & 1.79 & 1.81 & 1.90 & 1.90 & 9.50 & NA & NA & NA & NA & NA & NA & NA & $\mathrm{na}$ & NA & NA & NA & NA & 15E8_Ls1d2V__ 1 & $7 / 148$ & TDP-212 & 9150738.2 \\
\hline 32.6 & 0.997 & 0.01430 & 0.050 & 0.337 & 5.8 & $\mathrm{P}$ & NA & 1.75 & 1.79 & 1.81 & 1.90 & 1.90 & 9.50 & NA & NA & uCsuis & NA & NA & NA & 1 & 0.0 & 3 & NA & NA & NA & 15E8_Ls1d2VC_1 & $7 / 14 \mathrm{~B}$ & TDP-212 & 9150739 \\
\hline 32.6 & 0.997 & 0.01430 & 0.050 & 0.337 & 5.8 & $\mathrm{P}$ & NA & 1.75 & 1.79 & 1.81 & 1.90 & 190 & 9.50 & NA & NA & NA & NA & NA & NA & NA & 0.0 & NA & NA & NA & NA & 15E8_LS1d2VC_1 & $7 / 148$ & TDP-212 & 9150740 \\
\hline 32.6 & 0.997 & 0.01430 & 0.050 & 0.337 & 5.8 & $\mathrm{P}$ & NA & 1.75 & 1.79 & 1.81 & 1.90 & 1.90 & 9.50 & NA & NA & NA & NA & NA & NA & NA & 0.0 & NA & NA & NA & NA & 15E8_Ls1d2V__1 & $7 / 14 \mathrm{~B}$ & TDP-212 & 9150741 \\
\hline 32.6 & 0.997 & 0.01430 & 0.050 & 0.337 & 5.8 & $\mathrm{P}$ & NA & 1.75 & 1.79 & 1.81 & 1.90 & 1.90 & 9.50 & NA & NA & NA & NA & NA & NA & NA & 0.0 & NA & NA & NA & NA & 15E8_LSIIIVV__1 & $7 / 14 \mathrm{~B}$ & TDP-212 & 9150742 \\
\hline 32.6 & 0.997 & 0.01430 & 0.050 & 0.337 & 5.8 & $\mathrm{P}$ & NA & 1.75 & 1.79 & 1.81 & 1.90 & 1.90 & 9.50 & NA & NA & NA & NA & NA & NA & NA & $\mathrm{na}$ & NA & NA & NA & NA & 15E8_LSIdZVV__ 1 & $7 / 148$ & TDP-212 & 9150742.1 \\
\hline 32.6 & 0.997 & 0.01430 & 0.050 & 0.337 & 5.8 & $\mathrm{P}$ & NA & 1.75 & 1.79 & 1.81 & 1.90 & 1.90 & 9.50 & NA & NA & NA & NA & NA & NA & NA & 0.0 & NA & NA & NA & NA & 15E8_Ls1d2VC_1 & $7 / 148$ & TDP-212 & 9150743 \\
\hline 32.6 & 0.997 & 0.01430 & 0.050 & 0.337 & 5.8 & $\mathrm{P}$ & NA & 1.75 & 1.79 & 1.81 & 1.90 & 1.90 & 9.50 & NA & NA & NA & NA & NA & NA & NA & na & NA & NA & NA & NA & 15E8_LS1d2VC_1 & $7 / 14 \mathrm{~B}$ & TDP-212 & 9150743.1 \\
\hline 32.6 & 0.997 & 0.01430 & 0.050 & 0.337 & 5.8 & $\mathrm{P}$ & NA & 1.75 & 1.79 & 1.81 & 1.90 & 1.90 & 9.50 & NA & NA & NA & NA & NA & NA & NA & 0.0 & NA & NA & NA & NA & 15E8_Ls1d2V__1 & $7 / 14 \mathrm{~B}$ & TDP-212 & 9150744 \\
\hline 32.6 & 0.997 & 0.01430 & 0.050 & 0.337 & 5.8 & $\mathrm{P}$ & NA & 1.75 & 1.79 & 1.81 & 1.90 & 1.90 & 9.50 & NA & NA & NA & NA & NA & NA & NA & $\mathrm{na}$ & NA & NA & NA & NA & 15E8_LSIdZVV_ 1 & $7 / 14 \mathrm{~B}$ & TDP-212 & 9150744.1 \\
\hline 32.6 & 0.997 & 0.01430 & 0.050 & 0.337 & 5.8 & $\mathrm{P}$ & NA & 1.75 & 1.79 & 1.81 & 1.90 & 1.90 & 9.50 & NA & NA & NA & NA & NA & NA & NA & $\mathrm{na}$ & NA & NA & NA & NA & 15E8_LS1d2VC_1 & $7 / 14 \mathrm{~B}$ & TDP-212 & 9150745.1 \\
\hline 32.6 & 0.997 & 0.01430 & 0.050 & 0.337 & 5.8 & $\mathrm{P}$ & NA & 1.75 & 1.79 & 1.81 & 1.90 & 1.90 & 9.50 & NA & NA & NA & NA & NA & NA & NA & 0.0 & NA & NA & NA & NA & 15E8_LS1d2VC_1 & $7 / 14 \mathrm{~B}$ & TDP-212 & 9150746 \\
\hline 27.9 & 0.998 & 0.01430 & 0.100 & 0.329 & 26.8 & $\mathrm{P}$ & NA & 1.56 & 1.57 & 1.58 & 1.60 & 250 & 4.50 & NA & NA & NA & NA & NA & NA & (null) & 14.6 & 1 & NA & NA & NA & 15E8_Ls1d2VC_ 7 & $7 / 15 \mathrm{~A}$ & TDP-213 & 9150747 \\
\hline 27.9 & 0.998 & 0.01430 & 0.100 & 0.331 & 23.8 & $\mathrm{P}$ & NA & 1.75 & 1.76 & 1.77 & 1.80 & 250 & 4.75 & NA & NA & NA & NA & NA & NA & 1 & 11.3 & 1 & NA & NA & NA & 15E8 LSIdIVVC 7 & $7125 \mathrm{~A}$ & TDP-213 & 9150748 \\
\hline 28.1 & 0.998 & 0.01430 & 0.100 & 0.331 & 21.4 & $\mathrm{P}$ & NA & 1.95 & 1.96 & 1.97 & 2.00 & 250 & 5.75 & NA & NA & NA & NA & NA & NA & D & 17.6 & 1 & NA & NA & NA & 15E8 LsId2VVC 7 & $7 / 15 \mathrm{~A}$ & TDP-213 & 9150749 \\
\hline 28.2 & 0.999 & 0.01430 & 0.100 & 0.333 & 20.2 & $\mathrm{P}$ & NA & 2.04 & 2.06 & 2.07 & 2.10 & 250 & 6.75 & NA & NA & NA & NA & NA & NA & 1 & 11.8 & 1 & NA & NA & NA & 15E8_Ls1d2VC_ 7 & $7 / 15 \mathrm{~A}$ & TDP-213 & 9150750 \\
\hline 28.3 & 0.998 & 0.01430 & 0.100 & 0.334 & 19.2 & $\mathrm{P}$ & NA & 2.14 & 2.16 & 2.17 & 2.20 & 250 & 8.50 & NA & NA & NA & NA & NA & NA & 1 & 0.0 & 1 & NA & NA & NA & 15E8_LS1d2VC_ 7 & $715 \mathrm{~A}$ & TDP-213 & 9150751 \\
\hline 28.5 & 0.998 & 0.01430 & 0.100 & 0.332 & 18.6 & $\mathrm{P}$ & NA & 2.23 & 2.24 & 2.25 & 2.30 & 2.50 & 9.50 & NA & NA & NA & NA & NA & NA & 1 & 4.0 & 1 & NA & NA & NA & 15E8_Ls1d2VC_ 7 & $7115 \mathrm{~A}$ & TDP-213 & 9150752 \\
\hline 28.6 & 0.998 & 0.01430 & 0.100 & 0.333 & 17.8 & $\mathrm{P}$ & NA & 2.32 & 2.34 & 2.35 & 2.40 & 250 & 10.75 & \begin{tabular}{|l|} 
NA \\
\end{tabular} & NA & NA & NA & $\mathrm{NA}$ & NA & 1 & 2.8 & 1 & NA & NA & NA & 15E8_LS1d2VC_ 7 & $7 / 15 \mathrm{~A}$ & TDP-213 & 9150753 \\
\hline 28.7 & 0.998 & 0.01430 & 0.100 & 0.335 & 17.0 & $\mathrm{P}$ & NA & 241 & 2.43 & 2.45 & 2.50 & 250 & 11.00 & 2.50 & udv & NA & NA & Ucsuav & NA & 1 & 0.0 & 1 & NA & NA & NA & 15E8 LsId2VVC 7 & $7 / 15 \mathrm{~A}$ & TDP-213 & 9150754 \\
\hline 28.9 & 0.998 & 0.01430 & 0.101 & 0.334 & 16.6 & $\mathrm{P}$ & NA & 2.50 & 2.53 & 2.54 & 2.60 & 250 & 12.25 & \begin{tabular}{|l|} 
NA \\
\end{tabular} & NA & UCShis & NA & NA & NA & 1 & 0.0 & 3 & NA & NA & NA & 15E8_Ls1d2VC_ 7 & $7 / 15 \mathrm{~A}$ & TDP-213 & 9150755 \\
\hline 29.0 & 0.998 & 0.01430 & 0.100 & 0.333 & 16.0 & $\mathrm{P}$ & NA & 2.59 & 2.62 & 2.63 & 2.70 & 250 & 13.00 & NA & NA & NA & NA & NA & NA & 1 & 0.0 & 4 & NA & NA & NA & 15E8_LS1d2VC_ 7 & $7115 \mathrm{~A}$ & TDP-213 & 9150756 \\
\hline 29.1 & 0.998 & 0.01430 & 0.100 & 0.336 & 14.8 & $\mathrm{P}$ & NA & 2.78 & 2.81 & 2.83 & 2.90 & 250 & 15.25 & NA & NA & NA & NA & NA & NA & 1 & 0.0 & 4 & NA & NA & NA & 15E8_Ls1d2VC_ 7 & $7 / 15 \mathrm{~A}$ & TDP-213 & 9150757 \\
\hline 29.3 & 0.998 & 0.01430 & 0.100 & 0.335 & 13.8 & $\mathrm{P}$ & NA & 2.98 & 3.01 & 3.03 & 3.10 & 250 & 18.75 & NA & NA & NA & NA & NA & NA & 1 & 0.0 & 4 & NA & NA & NA & 15E8 LSIdIVVC 7 & $7 / 15 \mathrm{~A}$ & TDP-213 & 9150758 \\
\hline 29.5 & 0.998 & 0.01430 & 0.100 & 0.335 & 17.0 & $\mathrm{P}$ & NA & 241 & 2.43 & 2.45 & 2.50 & 250 & 11.50 & NA & NA & NA & NA & NA & NA & NA & $\mathrm{na}$ & NA & NA & NA & NA & 15E8 LSIdIVVC 7 & $7 / 15 \mathrm{~A}$ & TDP-213 & 9150758.1 \\
\hline 29.5 & 0.998 & 0.01430 & 0.100 & 0.335 & 17.0 & $\mathrm{P}$ & NA & 2.41 & 2.43 & 2.45 & 2.50 & & 11.50 & NA & NA & NA & NA & NA & NA & 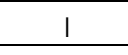 & 1.8 & 1 & NA & NA & NA & 15E8_Ls1d2VC_ 7 & $7 / 15 \mathrm{~A}$ & TDP-213 & 9150759 \\
\hline 29.5 & 0.998 & 0.01430 & 0.100 & 0.335 & 17.0 & $\mathrm{P}$ & NA & 2.41 & 2.43 & 2.45 & 2.50 & 2.50 & 11.50 & NA & NA & NA & NA & NA & NA & NA & 0.0 & NA & NA & NA & NA & 15E8_Ls1d2VC_ 7 & $7115 \mathrm{~A}$ & TDP-213 & 9150760 \\
\hline 29.5 & 0.998 & 0.01430 & 0.100 & 0.335 & 17.0 & $\mathrm{P}$ & NA & 2.41 & 2.43 & 2.45 & 2.50 & 250 & 11.50 & NA & NA & NA & NA & NA & NA & NA & 0.0 & NA & NA & NA & NA & 15E8_LS1d2VC_ 7 & $7115 \mathrm{~A}$ & TDP-213 & 9150761 \\
\hline 29.5 & 0.998 & 0.01430 & 0.100 & 0.335 & 17.0 & $\mathrm{P}$ & NA & 2.41 & 2.43 & 2.45 & 2.50 & 250 & 11.50 & NA & NA & NA & NA & NA & NA & NA & 0.0 & NA & NA & NA & NA & 15E8_LSIdZVV_ 7 & $7 / 15 \mathrm{~A}$ & TDP-213 & 9150762 \\
\hline 29.5 & 0.998 & 0.01430 & 0.100 & 0.335 & 17.0 & $\mathrm{P}$ & NA & 2.41 & 2.43 & 2.45 & 2.50 & 2.50 & 11.50 & NA & NA & NA & NA & NA & NA & NA & 0.0 & NA & & NA & NA & 15E8_Ls1d2VC 7 & $7 / 15 \mathrm{~A}$ & TDP-213 & 9150763 \\
\hline
\end{tabular}


Table B.3. Data from 2008 Tests in Small-Scale Vessel with Elliptical Head A.22

\begin{tabular}{|c|c|c|c|c|c|c|c|c|c|c|c|c|c|c|c|c|c|c|c|c|c|c|c|c|c|c|c|}
\hline $\begin{array}{c}\text { Row } \\
\text { Number }\end{array}$ & Test & Case ID & $\begin{array}{l}\text { Tank } \\
\text { Diameter }\end{array}$ & $\begin{array}{l}\text { Head } \\
\text { Shape }\end{array}$ & $\begin{array}{l}\text { Dish } \\
\text { Height }\end{array}$ & $\begin{array}{l}\text { Dish } \\
\text { Volume }\end{array}$ & $\begin{array}{l}\text { Tank } \\
\text { Fill } \\
\text { Height }\end{array}$ & $\begin{array}{l}\text { Retum } \\
\text { Line } \\
\text { Height }\end{array}$ & $\begin{array}{c}\text { Nozzle } \\
\text { lnner } \\
\text { Diameter }\end{array}$ & $\begin{array}{l}\text { Nozzle } \\
\text { Stanc-off } \\
\text { Distance }\end{array}$ & $\begin{array}{l}\text { Pulse Tube } \\
\text { Configuration }\end{array}$ & $\begin{array}{l}\text { Installed } \\
\text { Nozzles }\end{array}$ & $\begin{array}{c}\text { Outer } \\
\text { Nozzles } \\
\text { Operated }\end{array}$ & $\begin{array}{l}\text { Inner } \\
\text { Nozzles } \\
\text { Operated }\end{array}$ & $\begin{array}{c}\text { Pulse Tube } \\
\text { Outer } \\
\text { Diameter }\end{array}$ & $\begin{array}{c}\text { Outer } \\
\text { PMM } \\
\text { Radius }\end{array}$ & $\begin{array}{c}\text { Inner } \\
\text { PMM } \\
\text { Radius }\end{array}$ & $\begin{array}{c}\text { "FOO' Outer } \\
\text { PJM } \\
\text { Impingement } \\
\text { Angle }\end{array}$ & $\begin{array}{l}\text { "PO' IIner PJM } \\
\text { Impigement } \\
\text { Angle }\end{array}$ & $\begin{array}{c}\text { Ratio Outer } \\
\text { PPMttorank } \\
\text { Radius } \\
\end{array}$ & $\begin{array}{c}\text { Ratioi Inner } \\
\text { PJMtt Tank } \\
\text { Radius } \\
\end{array}$ & Simulant & $\begin{array}{l}\text { Solids } \\
\text { Densiyy }\end{array}$ & $\begin{array}{c}\text { Particle } \\
\text { Diameter d5 }\end{array}$ & $\begin{array}{c}\text { Patide } \\
\text { Diameter } \\
\text { d50 }\end{array}$ & $\begin{array}{c}\text { Particle } \\
\text { Diameter } \\
\text { d95 }\end{array}$ & $\begin{array}{l}\text { Void } \\
\text { Fraction }\end{array}$ \\
\hline text & text & text & in. & text & in. & in. ${ }^{3}$ & in. & in. & in. & in. & text & number & number & number & in. & in. & in. & deg & deg & nondim & nondim & text & $\mathrm{g} / \mathrm{cm}^{3}$ & $\mathrm{~m}$ & $\mathrm{~m}$ & $\mathrm{~m}$ & fraction \\
\hline MSS & MDDX & ID & D & HS & Hosh & $V_{\text {dish }}$ & $\mathrm{H}$ & Rtn & $d$ & sod & PT & $\mathrm{N}$ & $\mathrm{Nb}$ & $\mathrm{N}$ & $\mathrm{PT}_{\alpha d}$ & $R_{0}$ & $\mathrm{R}$ & $\theta_{0}$ & $\theta_{1}$ & $\mathrm{R} d \mathrm{R}$ & $R / R$ & sxdx & $\rho_{\mathrm{s}}$ & $d_{5}$ & $d_{0} 0$ & $d_{65}$ & vf \\
\hline 9150763.1 & $7 / 15 \mathrm{~A}$ & 15E8_Ls1d2VC_ 7 & $147 / 16$ & E & 3.25 & 354.8 & $351 / 2$ & 30 & 0.375 & 0.563 & 8TA & 8 & 4 & 0 & 1.05 & 4.9 & 3.6 & 24.4 & 16 & 0.67 & 0.50 & s1d2 & 2.48 & 0.0000569 & 0.0000693 & 0.0000821 & 0.3750 \\
\hline 9150764 & $7 / 15 \mathrm{~A}$ & 15E8_Ls1d2VC_ 7 & $147 / 16$ & $E$ & 3.25 & 354.8 & $351 / 2$ & 30 & 0.375 & 0.563 & 8TA & 8 & 4 & 0 & 1.05 & 4.9 & 3.6 & 24.4 & 16 & 0.67 & 0.50 & s1d2 & 2.48 & 0.0000569 & 0.0000693 & 0.0000821 & 0.3750 \\
\hline 9150764.1 & $7 / 15 \mathrm{~A}$ & 15E8_Ls1d2VC_ 7 & $147 / 16$ & E & 3.25 & 354.8 & $351 / 2$ & 30 & 0.375 & 0.563 & 8TA & 8 & 4 & 0 & 1.05 & 4.9 & 3.6 & 24.4 & 16 & 0.67 & 0.50 & s1d2 & 2.48 & 0.0000569 & 0.0000693 & 0.0000821 & 0.3750 \\
\hline 9150765 & $7 / 15 \mathrm{~A}$ & 15E8_Ls1d2VC_ 7 & $147 / 16$ & E & 3.25 & 354.8 & $351 / 2$ & 30 & 0.375 & 0.563 & 8TA & 8 & 4 & 0 & 1.05 & 4.9 & 3.6 & 24.4 & 16 & 0.67 & 0.50 & s1d2 & 2.48 & 0.0000569 & 0.0000693 & 0.0000821 & 0.3750 \\
\hline 9150765.1 & $715 \mathrm{~A}$ & 15E8_LSId2VVC 7 & $147 / 16$ & $E$ & 3.25 & $354.8 \mathrm{P}$ & $351 / 2$ & 30 & 0.375 & 0.563 & $8 \mathrm{TA}$ & 8 & 4 & 0 & 1.05 & 4.9 & 3.6 & 24.4 & 16 & 0.67 & 0.50 & sid2 & 248 & 0.0000569 & 0.0000693 & 0.0000821 & 0.3750 \\
\hline 9150766 & $7 / 15 \mathrm{~A}$ & 15E8_Ls1d2VC_ 7 & $147 / 16$ & E & 3.25 & 354.8 & $351 / 2$ & 30 & 0.375 & 0.563 & 8TA & 8 & 4 & 0 & 1.05 & 4.9 & 3.6 & 24.4 & 16 & 0.67 & 0.50 & s1d2 & 2.48 & 0.0000569 & 0.0000693 & 0.0000821 & 0.3750 \\
\hline 9150766.1 & $7 / 15 \mathrm{~A}$ & 15E8_Ls1d2VC_ 7 & $147 / 16$ & $E$ & 3.25 & 354.8 & $351 / 2$ & 30 & 0.375 & 0.563 & $8 \mathrm{TA}$ & 8 & 4 & 0 & 1.05 & 4.9 & 3.6 & 24.4 & 16 & 0.67 & 0.50 & s1d2 & 2.48 & 0.0000569 & 0.0000693 & 0.0000821 & 0.3750 \\
\hline 9150767 & $7 / 15 \mathrm{~A}$ & 15E8_Ls1d2VC_ 7 & $147 / 16$ & E & 3.25 & 354.8 & $351 / 2$ & 30 & 0.375 & 0.563 & 8TA & 8 & 4 & 0 & 1.05 & 4.9 & 3.6 & 24.4 & 16 & 0.67 & 0.50 & s1d2 & 2.48 & 0.0000569 & 0.0000693 & 0.0000821 & 0.3750 \\
\hline 9150768 & $7 / 15 B$ & 15E8_Ls1d2VC__ & $147 / 16$ & $\mathrm{E}$ & 3.25 & 354.8 & $351 / 2$ & 30 & 0.375 & 0.563 & 8TA & 8 & 4 & 4 & 1.05 & 4.9 & 3.6 & 24.4 & 16 & 0.67 & 0.50 & s1d2 & 2.48 & 0.0000569 & 0.0000693 & 0.0000821 & 0.3750 \\
\hline 9150769 & $7 / 15 B$ & 15E8_LS1d2VV__ 2 & $147 / 16$ & $E$ & 3.25 & 354.8 & $351 / 2$ & 30 & 0.375 & 0.563 & 8TA & 8 & 4 & 4 & 1.05 & 4.9 & 3.6 & 24.4 & 16 & 0.67 & 0.50 & s1d2 & 2.48 & 0.0000569 & 0.0000693 & 0.0000821 & 0.3750 \\
\hline 9150770 & $7 / 15 B$ & 15E8_Ls1d2VC__ & $147 / 16$ & E & 3.25 & 354.8 & $351 / 2$ & 30 & 0.375 & 0.563 & 8TA & 8 & 4 & 4 & 1.05 & 4.9 & 3.6 & 24.4 & 16 & 0.67 & 0.50 & s1d2 & 2.48 & 0.0000569 & 0.0000693 & 0.0000821 & 0.3750 \\
\hline $9150771 \mathrm{M}$ & $7 / 15 \mathrm{~B}$ & 15E8_Ls1d2VC_ 2 & 147116 & E & 3.25 & 354.8 & $351 / 2$ & 30 & 0.375 & 0.563 & 8TA & 8 & 4 & 4 & 1.05 & 4.9 & 3.6 & 24.4 & 16 & 0.67 & 0.50 & s1d2 & 2.48 & 0.0000569 & 0.0000693 & 0.0000821 & 0.3750 \\
\hline $9150772 \mathrm{M}$ & $7125 B$ & 15E8_Ls1d2VC__ & $147 / 16$ & E & 3.25 & 354.8 & $351 / 2$ & 30 & 0.375 & 0.563 & 8TA & 8 & 4 & 4 & 1.05 & 4.9 & 3.6 & 24.4 & 16 & 0.67 & 0.50 & s1d2 & 2.48 & 0.0000569 & 0.0000693 & 0.0000821 & 0.3750 \\
\hline 9150773M & $7 / 15 B$ & 15E8_Ls1d2VC__ & $147 / 16$ & $\mathrm{E}$ & 3.25 & 354.8 & $351 / 2$ & 30 & 0.375 & 0.563 & 8TA & 8 & 4 & 4 & 1.05 & 4.9 & 3.6 & 24.4 & 16 & 0.67 & 0.50 & $51 \mathrm{~d} 2$ & 2.48 & 0.0000569 & 0.0000693 & 0.0000821 & 0.3750 \\
\hline 9150744 & $7 / 15 B$ & 15E8_Ls1d2VC__ & $147 / 16$ & $\mathrm{E}$ & 3.25 & 354.8 & $351 / 2$ & 30 & 0.375 & 0.563 & 8TA & 8 & 4 & 4 & 1.05 & 4.9 & 3.6 & 24.4 & 16 & 0.67 & 0.50 & $51 \mathrm{~d} 2$ & 2.48 & 0.0000569 & 0.0000693 & 0.0000821 & 0.3750 \\
\hline 9150775 & $7 / 15 \mathrm{~B}$ & 15E8_Ls1d2VC_ _ & $147 / 16$ & E & 3.25 & 354.8 & $351 / 2$ & 30 & 0.375 & 0.563 & 8TA & 8 & 4 & 4 & 1.05 & 4.9 & 3.6 & 24.4 & 16 & 0.67 & 0.50 & s1d2 & 2.48 & 0.0000569 & 0.0000693 & 0.0000821 & 0.3750 \\
\hline 9150776 & $7 / 15 \mathrm{~B}$ & 15E8_Ls1d2VC__ & $147 / 16$ & $E$ & 3.25 & 354.8 & $351 / 2$ & 30 & 0.375 & 0.563 & $8 \mathrm{TA}$ & 8 & 4 & 4 & 1.05 & 4.9 & 3.6 & 24.4 & 16 & 0.67 & 0.50 & s1d2 & 2.48 & 0.0000569 & 0.0000693 & 0.0000821 & 0.3750 \\
\hline 915077 & $7 / 15 B$ & 15E8_Ls1d2VC__ & $147 / 16$ & E & 3.25 & 354.8 & $351 / 2$ & 30 & 0.375 & 0.563 & 8TA & 8 & 4 & 4 & 1.05 & 4.9 & 3.6 & 24.4 & 16 & 0.67 & 0.50 & s1d2 & 2.48 & 0.0000569 & 0.0000693 & 0.0000821 & 0.3750 \\
\hline 9150778 & $7 / 15 B$ & 15E8_Ls1d2VC__ & $147 / 16$ & $\mathrm{E}$ & 3.25 & 354.8 & $351 / 2$ & 30 & 0.375 & 0.563 & 8TA & 8 & 4 & 4 & 1.05 & 4.9 & 3.6 & 24.4 & 16 & 0.67 & 0.50 & $51 \mathrm{~d} 2$ & 2.48 & 0.0000569 & 0.0000693 & 0.0000821 & 0.3750 \\
\hline 9150778.1 & $7 / 15 B$ & 15E8_LsId2VC__ & $147 / 16$ & E & 3.25 & 354.8 & $351 / 2$ & 30 & 0.375 & 0.563 & 8TA & 8 & 4 & 4 & 1.05 & 4.9 & 3.6 & 24.4 & 16 & 0.67 & 0.50 & s1d2 & 2.48 & 0.0000569 & 0.0000693 & 0.0000821 & 0.3750 \\
\hline 9150779 & $7 / 15 B$ & 15E8_Ls1d2VC_ _ & $147 / 16$ & E & 3.25 & 354.8 & $351 / 2$ & 30 & 0.375 & 0.563 & 8TA & 8 & 4 & 4 & 1.05 & 4.9 & 3.6 & 24.4 & 16 & 0.67 & 0.50 & s1d2 & 2.48 & 0.0000569 & 0.0000693 & 0.0000821 & 0.3750 \\
\hline 9150779.1 & $7 / 15 \mathrm{~B}$ & 15E8_Ls1d2Vc_ 2 & $147 / 16$ & $E$ & 3.25 & 354.8 & $351 / 2$ & 30 & 0.375 & 0.563 & 8TA & 8 & 4 & 4 & 1.05 & 4.9 & 3.6 & 24.4 & 16 & 0.67 & 0.50 & s1d2 & 2.48 & 0.0000569 & 0.0000693 & 0.0000821 & 0.3750 \\
\hline 9150780 & $7 / 15 B$ & 15E8_Ls1d2VC__ & $147 / 16$ & E & 3.25 & 354.8 & $351 / 2$ & 30 & 0.375 & 0.563 & 8TA & 8 & 4 & 4 & 1.05 & 4.9 & 3.6 & 24.4 & 16 & 0.67 & 0.50 & s1d2 & 2.48 & 0.0000569 & 0.0000693 & 0.0000821 & 0.3750 \\
\hline 9150780.1 & $7 / 15 B$ & 15E8_Ls1d2VC__ & $147 / 16$ & E & 3.25 & 354.8 & $351 / 2$ & 30 & 0.375 & 0.563 & 8TA & 8 & 4 & 4 & 1.05 & 4.9 & 3.6 & 24.4 & 16 & 0.67 & 0.50 & $51 \mathrm{~d} 2$ & 2.48 & 0.0000569 & 0.0000693 & 0.0000821 & 0.3750 \\
\hline 9150781 & $7 / 15 \mathrm{~B}$ & 15E8_Ls1d2Vc_ 2 & $147 / 16$ & E & 3.25 & 354.8 & $351 / 2$ & 30 & 0.375 & 0.563 & 8TA & 8 & 4 & 4 & 1.05 & 4.9 & 3.6 & 24.4 & 16 & 0.67 & 0.50 & s1d2 & 2.48 & 0.0000569 & 0.0000693 & 0.0000821 & 0.3750 \\
\hline 9150781.1 & $7 / 15 B$ & 15E8_Ls1d2VC_ _ & $147 / 16$ & E & 3.25 & 354.8 & $351 / 2$ & 30 & 0.375 & 0.563 & 8TA & 8 & 4 & 4 & 1.05 & 4.9 & 3.6 & 24.4 & 16 & 0.67 & 0.50 & s1d2 & 2.48 & 0.0000569 & 0.0000693 & 0.0000821 & 0.3750 \\
\hline 9150782 & $7 / 15 \mathrm{~B}$ & 15E8_Ls1d2Vc_ 2 & $147 / 16$ & $\mathrm{E}$ & 3.25 & 354.8 & $351 / 2$ & 30 & 0.375 & 0.563 & 8TA & 8 & 4 & 4 & 1.05 & 4.9 & 3.6 & 24.4 & 16 & 0.67 & 0.50 & s1d2 & 2.48 & 0.0000569 & 0.0000693 & 0.0000821 & 0.3750 \\
\hline 9150783 & $7 / 15 \mathrm{C}$ & 15E8_Ls1d2VC_ 6 & $147 / 16$ & E & 3.25 & 354.8 & $351 / 2$ & 30 & 0.375 & 0.563 & 8TA & 8 & 4 & 0 & 1.05 & 4.9 & 3.6 & 24.4 & 16 & 0.67 & 0.50 & sid2 & 2.48 & 0.0000569 & 0.0000693 & 0.0000821 & 0.3750 \\
\hline 9150784 & $7 / 15 \mathrm{C}$ & 15E8_Ls1d2VC_ 6 & $147 / 16$ & E & 3.25 & 354.8 & $351 / 2$ & 30 & 0.375 & 0.563 & 8TA & 8 & 4 & 0 & 1.05 & 4.9 & 3.6 & 24.4 & 16 & 0.67 & 0.50 & $51 \mathrm{~d} 2$ & 2.48 & 0.0000569 & 0.0000693 & 0.0000821 & 0.3750 \\
\hline 9150785 & $7 / 15 \mathrm{C}$ & 15E8_LS1d2VI 6 & $147 / 16$ & $E$ & 3.25 & 354.8 & $351 / 2$ & 30 & 0.375 & 0.563 & 8TA & 8 & 4 & 0 & 1.05 & 4.9 & 3.6 & 24.4 & 16 & 0.67 & 0.50 & s1d2 & 2.48 & 0.0000569 & 0.0000693 & 0.0000821 & 0.3750 \\
\hline 9150786 & $7 / 15 \mathrm{C}$ & 15E8_Ls1d2VC_ 6 & 147116 & E & 3.25 & 354.8 & $351 / 2$ & 30 & 0.375 & 0.563 & $8 \mathrm{TA}$ & 8 & 4 & 0 & 1.05 & 4.9 & 3.6 & 24.4 & 16 & 0.67 & 0.50 & s1d2 & 2.48 & 0.0000569 & 0.0000693 & 0.0000821 & 0.3750 \\
\hline 9150787 & $7 / 15 \mathrm{C}$ & 15E8_Ls1d2VC_ 6 & $147 / 16$ & $\mathrm{E}$ & 3.25 & 354.8 & $351 / 2$ & 30 & 0.375 & 0.563 & 8TA & 8 & 4 & 0 & 1.05 & 4.9 & 3.6 & 24.4 & 16 & 0.67 & 0.50 & s1d2 & 2.48 & 0.0000569 & 0.0000693 & 0.0000821 & 0.3750 \\
\hline $9150788 \mathrm{M}$ & $7 / 15 \mathrm{C}$ & 15E8_Ls1d2VC_6 & $147 / 16$ & E & 3.25 & 354.8 & $351 / 2$ & 30 & 0.375 & 0.563 & 8TA & 8 & 4 & 0 & 1.05 & 4.9 & 3.6 & 24.4 & 16 & 0.67 & 0.50 & s1d2 & 2.48 & 0.0000569 & 0.0000693 & 0.0000821 & 0.3750 \\
\hline 9150789M & $7 / 15 \mathrm{C}$ & 15E8_Ls1d2VC_ 6 & $147 / 16$ & E & 3.25 & 354.8 & $351 / 2$ & 30 & 0.375 & 0.563 & 8TA & 8 & 4 & 0 & 1.05 & 4.9 & 3.6 & 24.4 & 16 & 0.67 & 0.50 & $51 \mathrm{~d} 2$ & 2.48 & 0.0000569 & 0.0000693 & 0.0000821 & 0.3750 \\
\hline 9150790 M & $7 / 15 \mathrm{C}$ & 15E8_LSIdT2VC 6 & $147 / 16$ & $E$ & 3.25 & 354.8 & $351 / 2$ & 30 & 0.375 & 0.563 & $8 \mathrm{TA}$ & 8 & 4 & 0 & 1.05 & 4.9 & 3.6 & 24.4 & 16 & 0.67 & 0.50 & s1d2 & 2.48 & 0.0000569 & 0.00006993 & 0.0000821 & 0.3750 \\
\hline 9150791M & $7 / 15 \mathrm{C}$ & 15E8_Ls1d2VC_ 6 & 147116 & E & 3.25 & 354.8 & $351 / 2$ & 30 & 0.375 & 0.563 & 8TA & 8 & 4 & 0 & 1.05 & 4.9 & 3.6 & 24.4 & 16 & 0.67 & 0.50 & s1d2 & 2.48 & 0.0000569 & 0.0000693 & 0.00000821 & 0.3750 \\
\hline 9150792M M & $7 / 15 \mathrm{C}$ & 15E8_Ls1d2Vc_ 6 & $147 / 16$ & $E$ & 3.25 & 354.8 & $351 / 2$ & 30 & 0.375 & 0.563 & 8TA & 8 & 4 & 0 & 1.05 & 4.9 & 3.6 & 24.4 & 16 & 0.67 & 0.50 & s1d2 & 2.48 & 0.0000569 & 0.0000693 & 0.0000821 & 0.3750 \\
\hline 9150793M & $7115 \mathrm{C}$ & 15E8 LLSId2VV 6 & $147 / 16$ & $\mathrm{E}$ & 3.25 & 354.8 & $351 / 2$ & 30 & 0.375 & 0.563 & 8TA & 8 & 4 & 0 & 1.05 & 4.9 & 3.6 & 24.4 & 16 & 0.67 & 0.50 & $\mathrm{~s} 1 \mathrm{~d} 2$ & 2.48 & 0.0000569 & 0.0000693 & 0.0000821 & 0.3750 \\
\hline
\end{tabular}


Table B.3. Data from 2008 Tests in Small-Scale Vessel with Elliptical Head B.22

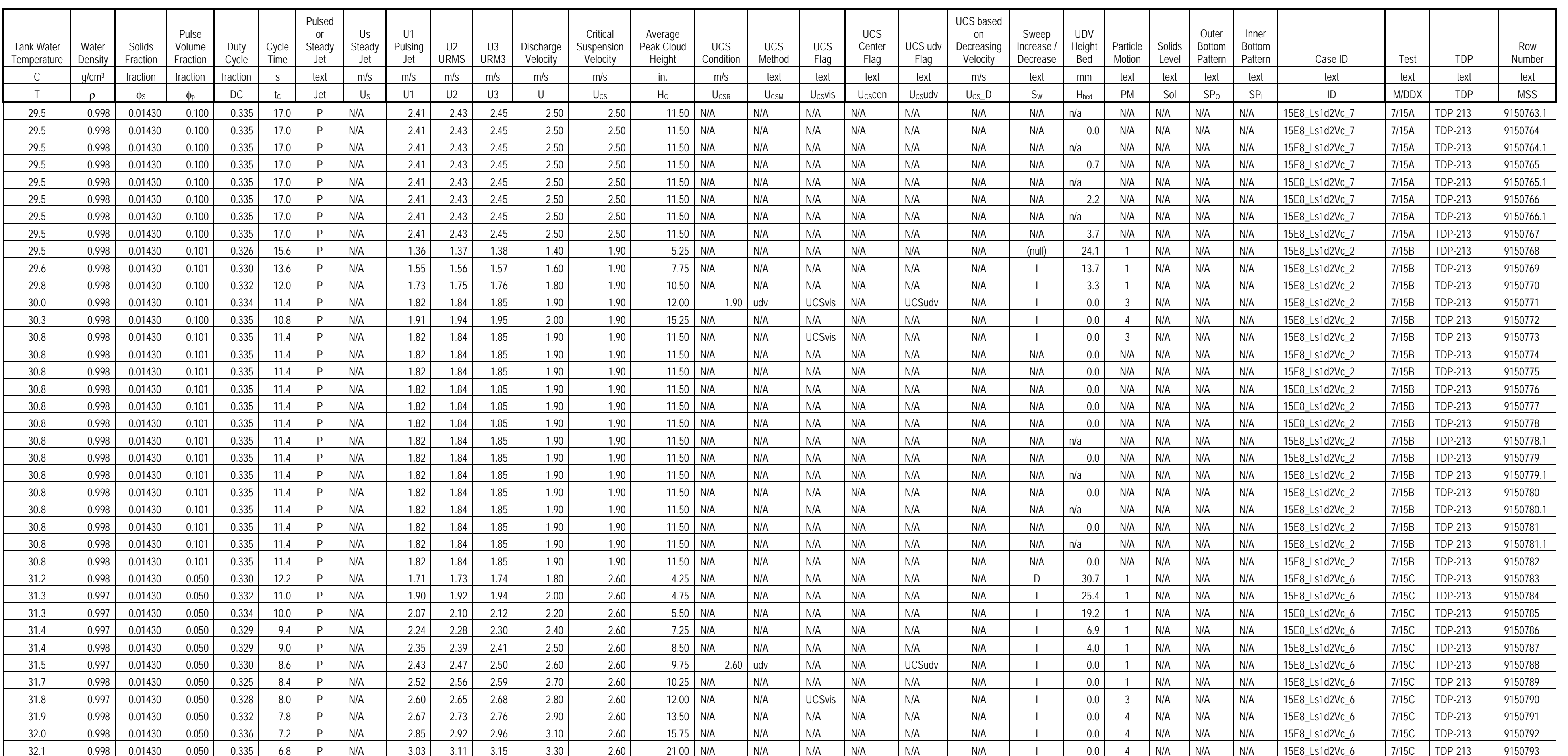


Table B.4. Data from 2008 Tests in Mid-Scale Vessel with Spherical Head A.1

\begin{tabular}{|c|c|c|c|c|c|c|c|c|c|c|c|c|c|c|c|c|c|c|c|c|c|c|c|c|c|c|c|}
\hline $\begin{array}{l}\text { Row } \\
\text { Number }\end{array}$ & Test & Case ID & $\begin{array}{l}\text { Tank } \\
\text { Diameter }\end{array}$ & $\begin{array}{l}\text { Head } \\
\text { Shape }\end{array}$ & $\begin{array}{c}\text { Dish } \\
\text { Height }\end{array}$ & $\begin{array}{c}\text { Dish } \\
\text { Volume }\end{array}$ & $\begin{array}{c}\text { Tank } \\
\text { Fill } \\
\text { Height } \\
\end{array}$ & $\begin{array}{c}\text { Retur } \\
\text { Line } \\
\text { Height } \\
\end{array}$ & $\begin{array}{c}\text { Nozzle } \\
\text { Inner } \\
\text { Diameter }\end{array}$ & $\begin{array}{l}\text { Nozzle } \\
\text { Stand-off } \\
\text { Distance }\end{array}$ & $\begin{array}{l}\text { Pulse Tube } \\
\text { Configuration }\end{array}$ & $\begin{array}{l}\text { Installed } \\
\text { Nozzles } \\
\text { Nates }\end{array}$ & $\begin{array}{c}\text { Outer } \\
\text { Nozzles } \\
\text { Opperated }\end{array}$ & $\begin{array}{c}\text { Inner } \\
\text { Nozzles } \\
\text { Opperated }\end{array}$ & $\begin{array}{c}\text { Pulse Tube } \\
\text { Outer } \\
\text { Diameter }\end{array}$ & $\begin{array}{c}\text { Outer } \\
\text { PJM } \\
\text { Radius } \\
\end{array}$ & \begin{tabular}{c|} 
Inner \\
PJM \\
Radius \\
\end{tabular} & $\begin{array}{c}\text { "FO" Outer PJM } \\
\text { Impingement } \\
\text { Angle }\end{array}$ & $\begin{array}{c}\text { "FIO" Inner PJM } \\
\text { Impingement } \\
\text { Angle }\end{array}$ & $\begin{array}{c}\text { Ratio Outer } \\
\text { PJM to Tank } \\
\text { Radius } \\
\end{array}$ & $\begin{array}{c}\text { Ratio Inner } \\
\text { PJM to Tank } \\
\text { Radius } \\
\end{array}$ & Simulant & $\begin{array}{l}\text { Solids } \\
\text { Density }\end{array}$ & $\begin{array}{c}\begin{array}{c}\text { Paticle } \\
\text { Diameter } \\
\mathrm{d} 5\end{array} \\
\end{array}$ & $\begin{array}{c}\begin{array}{c}\text { Partide } \\
\text { Diameter } \\
\text { d50 }\end{array} \\
\end{array}$ & $\begin{array}{c}\begin{array}{c}\text { Partide } \\
\text { Diameter } \\
\text { de5 }\end{array} \\
\end{array}$ & $\begin{array}{l}\text { Void } \\
\text { Fraction }\end{array}$ \\
\hline text & text & text & in. & text & in. & in. $^{3}$ & in. & in. & in. & in. & text & number & number & number & \begin{tabular}{|l} 
in. \\
\end{tabular} & in. & in. & deg & deg & nondim & nondim & text & $\mathrm{g} / \mathrm{cm}^{3}$ & $\mathrm{~m}$ & $\mathrm{~m}$ & $\mathrm{~m}$ & fraction \\
\hline MSS & MDDX & ID & $\mathrm{D}$ & HS & $H_{\text {tast }}$ & $V_{\text {dish }}$ & $\mathrm{H}$ & $\operatorname{Rin}$ & $d$ & sod & PT & $\mathrm{N}$ & $\mathrm{Nb}_{\mathrm{b}}$ & $\mathrm{N}$ & $\mathrm{PT}_{\mathrm{T}_{\mathrm{d}}}$ & $R_{0}$ & $\mathrm{R}$ & $\theta_{0}$ & $\theta_{1}$ & $\mathrm{RdR}$ & $R / R$ & sxdx & $\rho_{s}$ & $d_{5}$ & $\mathrm{~d}_{60}$ & $d_{65}$ & vf \\
\hline 9340001 & $3 / 5 \mathrm{~A}$ & 345 4s1d12c_1 & $337 / 8$ & $\mathrm{~s}$ & 9 & 4437.4 & 69 & 66 & 0.297 & 0.446 & HLP -22 & 12 & 8 & 4 & 1.9 & 10.5 & 5.7 & 30.8 & 16.1 & 0.62 & 0.33 & sid1 & 2.46 & 0.0001428 & 0.0001664 & 0.0001951 & 0.4118 \\
\hline 9340002M & $3 / 5 \mathrm{~A}$ & $34 \mathrm{~S} \_4 \mathrm{~s} 1 \mathrm{d1Zc} \_1$ & $337 / 8$ & $\mathrm{~s}$ & 9 & 4437.4 & 69 & 66 & 0.297 & 0.446 & HLP -22 & 12 & 8 & 4 & 1.9 & 10.5 & 5.7 & 30.8 & 16.1 & 0.62 & 0.33 & s1d1 & 2.46 & 0.0001428 & 0.0001664 & 0.0001951 & 0.4118 \\
\hline 9340003M & $3 / 5 \mathrm{~A}$ & 345_4sid17c_1 & $337 / 8$ & $\mathrm{~s}$ & 9 & \begin{tabular}{ll|l}
4437.4 \\
\end{tabular} & 69 & 66 & 0.297 & 0.446 & HLP-22 & 12 & 8 & 4 & 1.9 & 10.5 & 5.7 & 30.8 & 16.1 & 0.62 & 0.33 & s1d1 & 2.46 & 0.0001428 & 0.0001664 & 0.0001951 & 0.4118 \\
\hline 9340004 & $3 / 5 \mathrm{~A}$ & 34S_4s1d1Zc_1 & $337 / 8$ & $\mathrm{~s}$ & 9 & \begin{tabular}{ll|l}
4437.4 \\
\end{tabular} & 69 & 66 & 0.297 & 0.446 & HLP-22 & 12 & 8 & 4 & 1.9 & 10.5 & 5.7 & 30.8 & 16.1 & 0.62 & 0.33 & s1d1 & 2.46 & \begin{tabular}{|l|}
0.0001428 \\
\end{tabular} & 0.0001664 & 0.0001951 & 0.4118 \\
\hline 9340005 & $3 / 5 \mathrm{~A}$ & 34__4s1d1Zc_ 1 & $337 / 8$ & $\mathrm{~s}$ & 9 & 4437.4 & 69 & 66 & 0.297 & 0.446 & HLP-22 & 12 & 8 & 4 & 1.9 & 10.5 & 5.7 & 30.8 & 16.1 & 0.62 & 0.33 & sidn & 2.46 & 0.0001428 & 0.0001664 & 0.0001951 & 0.4118 \\
\hline 9340006 & $3 / 5 \mathrm{~A}$ & $345 \_4 \mathrm{~s} 1 \mathrm{~d} 1 \mathrm{Zz} \_1$ & $337 / 8$ & $s$ & 9 & 4437.4 & 69 & 66 & 0.297 & 0.446 & HLP -22 & 12 & 8 & 4 & 1.9 & 10.5 & 5.7 & 30.8 & 16.1 & 0.62 & 0.33 & sid1 & 2.46 & 0.0001428 & 0.0001664 & 0.0001951 & 0.4118 \\
\hline 9340007 & $3 / 5 \mathrm{~A}$ & $34 \mathrm{~S} \_4 \mathrm{~s} 1 \mathrm{d1Zc} \_1$ & $337 / 8$ & $\mathrm{~s}$ & 9 & 4437.4 & 69 & 66 & 0.297 & 0.446 & HLP-22 & 12 & 8 & 4 & 1.9 & 10.5 & 5.7 & 30.8 & 16.1 & 0.62 & 0.33 & s1d1 & 2.46 & 0.0001428 & 0.0001664 & 0.0001951 & 0.4118 \\
\hline 9340008 & $3 / 5 \mathrm{~A}$ & 34S_4s1d17c_ 1 & $337 / 8$ & $\mathrm{~s}$ & 9 & 4437.4 & 69 & 66 & 0.297 & 0.446 & HLP-22 & 12 & 8 & 4 & 1.9 & 10.5 & 5.7 & 30.8 & 16.1 & 0.62 & 0.33 & sidn & 2.46 & 0.0001428 & 0.0001664 & 0.0001951 & 0.4118 \\
\hline 9340009 & $3 / 5 \mathrm{~A}$ & 34S_4s1d1Zc_1 & $337 / 8$ & $s$ & 9 & 4437.4 & 69 & 66 & 0.297 & 0.446 & HLP-22 & 12 & 8 & 4 & 1.9 & 10.5 & 5.7 & 30.8 & 16.1 & 0.62 & 0.33 & sid1 & 2.46 & 0.0001428 & 0.0001664 & 0.0001951 & 0.4118 \\
\hline 9340010 & $3 / 5 \mathrm{~A}$ & $345 \_4 s 1 d 17 c \_1$ & $337 / 8$ & $\mathrm{~s}$ & 9 & 4437.4 & 69 & 66 & 0.297 & 0.446 & HLP-22 & 12 & 8 & 4 & 1.9 & 10.5 & 5.7 & 30.8 & 16.1 & 0.62 & 0.33 & sid1 & 2.46 & 0.0001428 & 0.0001664 & 0.0001951 & 0.4118 \\
\hline 9340011 & $3 / 5 \mathrm{~A}$ & $34 \mathrm{~S} \_4 \mathrm{~s} 1 \mathrm{~d} 12 \mathrm{c} \_1$ & $337 / 8$ & $\mathrm{~s}$ & 9 & 4437.4 & 69 & 66 & 0.297 & 0.446 & HLP-22 & 12 & 8 & 4 & 1.9 & 10.5 & 5.7 & 30.8 & 16.1 & 0.62 & 0.33 & sid1 & 2.46 & 0.0001428 & 0.0001664 & 0.0001951 & 0.4118 \\
\hline 9340012M & $3 / 5 \mathrm{~A}$ & $34 \mathrm{~S} \_4 \mathrm{~s} 1 \mathrm{~d} 1 \mathrm{Zc} \_1$ & $337 / 8$ & $\mathrm{~s}$ & 9 & 4437.4 & 69 & 66 & 0.297 & 0.446 & HLP-22 & 12 & 8 & 4 & 1.9 & 10.5 & 5.7 & 30.8 & 16.1 & 0.62 & 0.33 & s1d1 & 2.46 & 0.0001428 & 0.0001664 & 0.0001951 & 0.4118 \\
\hline 9340013 & $3 / 5 \mathrm{~B}$ & $345 \_4 s 1 d 17 d \_1$ & $337 / 8$ & $\mathrm{~s}$ & 9 & 4437.4 & 69 & 66 & 0.297 & 0.446 & HLP-22 & 12 & 8 & 4 & 1.9 & 10.5 & 5.7 & 30.8 & 16.1 & 0.62 & 0.33 & s1d1 & 246 & 0.0001428 & 0.0001664 & 0.0001951 & 0.4118 \\
\hline 9340014 & $3 / 5 \mathrm{~B}$ & 34S_4s1d1Zd_1 & $337 / 8$ & $s$ & 9 & 4437.4 & 69 & 66 & 0.297 & 0.446 & HLP-22 & 12 & 8 & 4 & 1.9 & 10.5 & 5.7 & 30.8 & 16.1 & 0.62 & 0.33 & sid1 & 246 & 0.0001428 & 0.0001664 & 0.0001951 & 0.4118 \\
\hline $9340015 \mathrm{M}$ & $3 / 5 \mathrm{~B}$ & 34S_4s1d1Zd_1 & $337 / 8$ & $\mathrm{~s}$ & 9 & 4437.4 & 69 & 66 & 0.297 & 0.446 & HLP-22 & 12 & 8 & 4 & 1.9 & 10.5 & 5.7 & 30.8 & 16.1 & 0.62 & 0.33 & sid1 & 2.46 & 0.0001428 & 0.0001664 & 0.0001951 & 0.4118 \\
\hline 9340016M & $3 / 5 \mathrm{~B}$ & 34S_4s1d17d_1 & $337 / 8$ & $s$ & 9 & 4437.4 & 69 & 66 & 0.297 & 0.446 & HLP-22 & 12 & 8 & 4 & 1.9 & 10.5 & 5.7 & 30.8 & 16.1 & 0.62 & 0.33 & s1d1 & 2.46 & 0.0001428 & 0.0001664 & 0.0001951 & 0.4118 \\
\hline $9340017 \mathrm{M}$ & 3/5B & 34S_4s1d17d_1 & $337 / 8$ & $\mathrm{~s}$ & 9 & 4437.4 & 69 & 66 & 0.297 & 0.446 & HLP -22 & 12 & 8 & 4 & 1.9 & 10.5 & 5.7 & 30.8 & 16.1 & 0.62 & 0.33 & s1d1 & 2.46 & 0.0001428 & 0.0001664 & 0.0001951 & 0.4118 \\
\hline 9340018M & $3 / 5 \mathrm{~B}$ & 34S_4s1d1Zd_1 & $337 / 8$ & $\mathrm{~s}$ & 9 & 4437.4 & 69 & 66 & 0.297 & 0.446 & HLP-22 & 12 & 8 & 4 & 1.9 & 10.5 & 5.7 & 30.8 & 16.1 & 0.62 & 0.33 & s1d1 & 2.46 & 0.0001428 & 0.0001664 & 0.0001951 & 0.4118 \\
\hline 9340019 & $3 / 5 \mathrm{C}$ & $34 \mathrm{~S} \_4 \mathrm{~s} 1 \mathrm{~d} 1 \mathrm{Zc} \_2$ & $337 / 8$ & $s$ & 9 & 4437.4 & 69 & 66 & 0.297 & 0.446 & HLP-22 & 12 & 8 & 4 & 1.9 & 10.5 & 5.7 & 30.8 & 16.1 & 0.62 & 0.33 & sidn & 2.46 & 0.0001428 & 0.0001664 & 0.0001951 & 0.4118 \\
\hline 9340021M & $3 / 5 \mathrm{C}$ & $34 \mathrm{~S} \_4 \mathrm{~s} 1 \mathrm{~d} 1 \mathrm{Zc} \_2$ & $337 / 8$ & $\mathrm{~s}$ & 9 & 4437.4 & 69 & 66 & 0.297 & 0.446 & HLP-22 & 12 & 8 & 4 & 1.9 & 10.5 & 5.7 & 30.8 & 16.1 & 0.62 & 0.33 & sidn & 2.46 & 0.0001428 & 0.0001664 & 0.0001951 & 0.4118 \\
\hline 9340022M M & $3 / 5 \mathrm{C}$ & $34 \mathrm{~S} \_4 \mathrm{~s} 1 \mathrm{~d} 1 \mathrm{Zc} \_2$ & $337 / 8$ & $s$ & 9 & 4437.4 & 69 & 66 & 0.297 & 0.446 & HLP-22 & 12 & 8 & 4 & 1.9 & 10.5 & 5.7 & 30.8 & 16.1 & 0.62 & 0.33 & s1d1 & 2.46 & 0.0001428 & 0.0001664 & 0.0001951 & 0.4118 \\
\hline 9340023M & $3 / 5 \mathrm{C}$ & $34 \mathrm{~S}=4 \mathrm{~s} 1 \mathrm{d1Zc} 2$ & $337 / 8$ & $\mathrm{~s}$ & 9 & 4437.4 & 69 & 66 & 0.297 & 0.446 & HLP -22 & 12 & 8 & 4 & 1.9 & 10.5 & 5.7 & 30.8 & 16.1 & 0.62 & 0.33 & s1d1 & 2.46 & 0.0001428 & 0.0001664 & 0.0001951 & 0.4118 \\
\hline 9340024 & $3 / 6 \mathrm{~A}$ & 34S_4s1d1Yc_1 & $337 / 8$ & $\mathrm{~s}$ & 9 & 4437.4 & 69 & 66 & 0.297 & 0.446 & HLP-22 & 12 & 8 & 4 & 1.9 & 10.5 & 5.7 & 30.8 & 16.1 & 0.62 & 0.33 & sid1 & 2.46 & 0.0001428 & 0.0001664 & 0.0001951 & 0.4118 \\
\hline 9340025 & $3 / 6 \mathrm{~A}$ & 34S_4s1d1Yc_1 & $337 / 8$ & $s$ & 9 & 4437.4 & 69 & 66 & 0.297 & 0.446 & HLP-22 & 12 & 8 & 4 & 1.9 & 10.5 & 5.7 & 30.8 & 16.1 & 0.62 & 0.33 & sid1 & 2.46 & 0.0001428 & 0.0001664 & 0.0001951 & 0.4118 \\
\hline 9340026 & $3 / 6 \mathrm{~A}$ & $345 \_4 s 1 d 1 Y c \_1$ & $337 / 8$ & $\mathrm{~s}$ & 9 & 4437.4 & 69 & 66 & 0.297 & 0.446 & HLP-22 & 12 & 8 & 4 & 1.9 & 10.5 & 5.7 & 30.8 & 16.1 & 0.62 & 0.33 & sid1 & 2.46 & 0.0001428 & 0.0001664 & 0.0001951 & 0.4118 \\
\hline 9340027 & $3 / 6 \mathrm{~A}$ & 34S_4s1d1Yc_1 & $337 / 8$ & $s$ & 9 & 4437.4 & 69 & 66 & 0.297 & 0.446 & HLP-22 & 12 & 8 & 4 & 1.9 & 10.5 & 5.7 & 30.8 & 16.1 & 0.62 & 0.33 & s1d1 & 2.46 & 0.0001428 & 0.0001664 & 0.0001951 & 0.4118 \\
\hline 9340028 & $3 / 6 \mathrm{~A}$ & $345 \_4 s 1 d 1 Y c \_1$ & $337 / 8$ & $\mathrm{~s}$ & 9 & 4437.4 & 69 & 66 & 0.297 & 0.446 & HLP-22 & 12 & 8 & 4 & 1.9 & 10.5 & 5.7 & 30.8 & 16.1 & 0.62 & 0.33 & s1d1 & 2.46 & 0.0001428 & 0.0001664 & 0.0001951 & 0.4118 \\
\hline 9340029 & $3 / 6 \mathrm{~A}$ & 34S_4s1d1Yc_1 & $337 / 8$ & $\mathrm{~s}$ & 9 & 4437.4 & 69 & 66 & 0.297 & 0.446 & HLP-22 & 12 & 8 & 4 & 1.9 & 10.5 & 5.7 & 30.8 & 16.1 & 0.62 & 0.33 & sid1 1 & 2.46 & 0.0001428 & 0.0001664 & 0.0001951 & 0.4118 \\
\hline $9340030 \mathrm{M}$ & $3 / 6 \mathrm{~A}$ & 34S_4s1d1Yc_1 & $337 / 8$ & $s$ & 9 & 4437.4 & 69 & 66 & 0.297 & 0.446 & HLP. 22 & 12 & 8 & 4 & 1.9 & 10.5 & 5.7 & 30.8 & 16.1 & 0.62 & 0.33 & sid1 & 2.46 & 0.0001428 & 0.0001664 & 0.0001951 & 0.4118 \\
\hline 9340031M & $3 / 6 \mathrm{~A}$ & $34 S_{-} 4 \mathrm{~s} 1 \mathrm{~d} 1 Y \mathrm{Yc} \_1$ & $337 / 8$ & $\mathrm{~s}$ & 9 & 4437.4 & 69 & 66 & 0.297 & 0.446 & HLP-22 & 12 & 8 & 4 & 1.9 & 10.5 & 5.7 & 30.8 & 16.1 & 0.62 & 0.33 & sid1 & 246 & 0.0001428 & 0.0001664 & 0.0001951 & 0.4118 \\
\hline 9340032M & $3 / 6 \mathrm{~A}$ & 34S_4s1d1Yc_1 & $337 / 8$ & $\mathrm{~s}$ & 9 & 4437.4 & 69 & 66 & 0.297 & 0.446 & HLP-22 & 12 & 8 & 4 & 1.9 & 10.5 & 5.7 & 30.8 & 16.1 & 0.62 & 0.33 & s1d1 & 2.46 & 0.0001428 & 0.0001664 & 0.0001951 & 0.4118 \\
\hline 9340033M & $3 / 6 \mathrm{~A}$ & 34S_4s1d1Yc_1 & $337 / 8$ & $\mathrm{~s}$ & 9 & 4437.4 & 69 & 66 & 0.297 & 0.446 & HLP-22 & 12 & 8 & 4 & 1.9 & 10.5 & 5.7 & 30.8 & 16.1 & 0.62 & 0.33 & s1d1 & 2.46 & 0.0001428 & 0.0001664 & 0.0001951 & 0.4118 \\
\hline 9340034 & $3 / 6 \mathrm{~B}$ & 34S_4s1d1Yd_1 & $337 / 8$ & $\mathrm{~s}$ & 9 & 4437.4 & 69 & 66 & 0.297 & 0.446 & HLP-22 & 12 & 8 & 4 & 1.9 & 10.5 & 5.7 & 30.8 & 16.1 & 0.62 & 0.33 & sid1 & 2.46 & 0.0001428 & 0.0001664 & 0.0001951 & 0.4118 \\
\hline 9340035 & $3 / 6 \mathrm{~B}$ & 34S_4s1d1Yd_1 & $337 / 8$ & $\mathrm{~s}$ & 9 & 4437.4 & 69 & 66 & 0.297 & 0.446 & HLP-22 & 12 & 8 & 4 & 1.9 & 10.5 & 5.7 & 30.8 & 16.1 & 0.62 & 0.33 & sid1 & 2.46 & 0.0001428 & 0.0001664 & 0.0001951 & 0.4118 \\
\hline $9340036 \mathrm{M}$ & 3/6B & 34S_4s1d1Yd_1 & $337 / 8$ & $\mathrm{~s}$ & 9 & 4437.4 & 69 & 66 & 0.297 & 0.446 & HLP-22 & 12 & 8 & 4 & 1.9 & 10.5 & 5.7 & 30.8 & 16.1 & 0.62 & 0.33 & s1d1 & 2.46 & 0.0001428 & 0.0001664 & 0.0001951 & 0.4118 \\
\hline 9340037M & 3/6B & 34S_4s1d1Yd_1 & $337 / 8$ & $s$ & 9 & 4437.4 & 69 & 66 & 0.297 & 0.446 & HLP-22 & 12 & 8 & 4 & 1.9 & 10.5 & 5.7 & 30.8 & 16.1 & 0.62 & 0.33 & sidn & 2.46 & 0.0001428 & 0.0001664 & 0.0001951 & 0.4118 \\
\hline 9340038M M & 3/6B & 34S_4s1d1Yd_1 & $337 / 8$ & $s$ & 9 & 4437.4 & 69 & 66 & 0.297 & 0.446 & HLP-22 & 12 & 8 & 4 & 1.9 & 10.5 & 5.7 & 30.8 & 16.1 & 0.62 & 0.33 & s1d1 & 2.46 & 0.0001428 & 0.0001664 & 0.0001951 & 0.4118 \\
\hline 9340039 & $3 / 6 C$ & $34 \mathrm{~S} \_4 \mathrm{~s} 1 \mathrm{~d} 1 \mathrm{Xc} \_1$ & $337 / 8$ & $\mathrm{~s}$ & 9 & 4437.4 & 69 & 66 & 0.297 & 0.446 & HLP-22 & 12 & 8 & 4 & 1.9 & 10.5 & 5.7 & 30.8 & 16.1 & 0.62 & 0.33 & s1d1 & 2.46 & 0.0001428 & 0.0001664 & 0.0001951 & 0.4118 \\
\hline 9340040 & $3 / 6 \mathrm{C}$ & $345 \_4 s 1 d 1 \times c \_1$ & $337 / 8$ & $\mathrm{~s}$ & 9 & 4437.4 & 69 & 66 & 0.297 & 0.446 & HLP-22 & 12 & 8 & 4 & 1.9 & 10.5 & 5.7 & 30.8 & 16.1 & 0.62 & 0.33 & s1d1 & 246 & 0.0001428 & 0.0001664 & 0.0001951 & 0.4118 \\
\hline $9340041 \mathrm{M}$ & $3 / 6 \mathrm{C}$ & $34 \mathrm{~S} \_4 \mathrm{~s} 1 \mathrm{~d} 1 \mathrm{Xc} \_1$ & $337 / 8$ & $\mathrm{~s}$ & 9 & 4437.4 & 69 & 66 & 0.297 & 0.446 & HLP-22 & 12 & 8 & 4 & 1.9 & 10.5 & 5.7 & 30.8 & 16.1 & 0.62 & 0.33 & s1d1 & 2.46 & 0.0001428 & 0.0001664 & 0.0001951 & \\
\hline $9340042 \mathrm{M}$ & $3 / 6 \mathrm{C}$ & 34S_4s1d1Xc_1 & $337 / 8$ & s & 9 & 4437.4 & 69 & 66 & 0.297 & 0.446 & HLP-22 & 12 & 8 & 4 & 1.9 & 10.5 & 5.7 & 30.8 & 16.1 & 0.62 & 0.33 & s1d1 & 246 & 0.0001428 & 0.0001664 & 0.0001951 & 0.4118 \\
\hline
\end{tabular}


Table B.4. Data from 2008 Tests in Mid-Scale Vessel with Spherical Head B.1

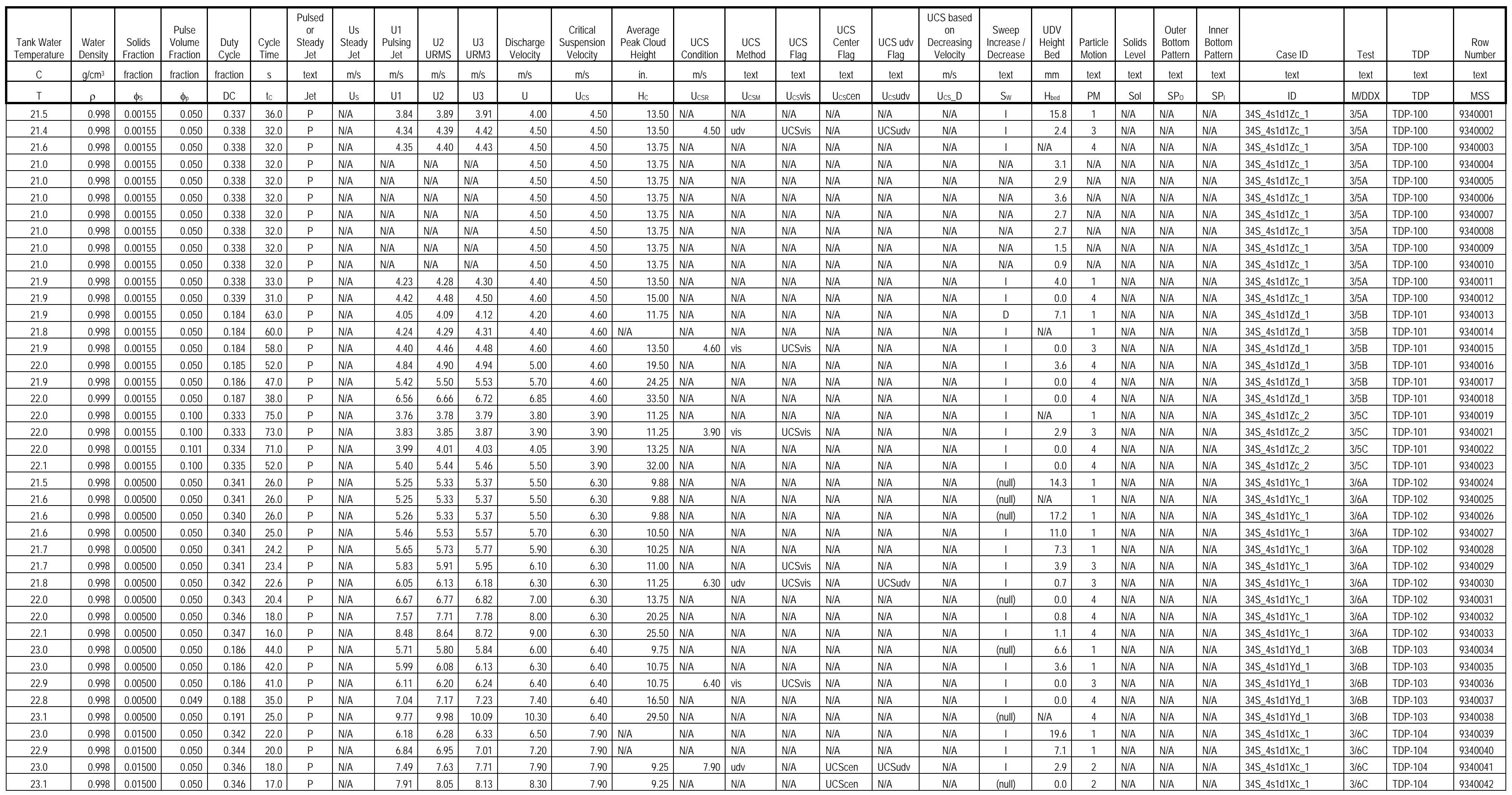


Table B.4. Data from 2008 Tests in Mid-Scale Vessel with Spherical Head A.2

\begin{tabular}{|c|c|c|c|c|c|c|c|c|c|c|c|c|c|c|c|c|c|c|c|c|c|c|c|c|c|c|c|}
\hline $\begin{array}{c}\text { Raw } \\
\text { Number }\end{array}$ & Test & Case ID & $\begin{array}{c}\text { Tank } \\
\text { Diameter }\end{array}$ & $\begin{array}{l}\text { Head } \\
\text { Shape }\end{array}$ & $\begin{array}{l}\text { Dish } \\
\text { Height }\end{array}$ & $\begin{array}{c}\text { Dish } \\
\text { volume }\end{array}$ & $\begin{array}{c}\text { Tank } \\
\text { Fill } \\
\text { Height } \\
\end{array}$ & $\begin{array}{c}\text { Return } \\
\text { Line } \\
\text { Height } \\
\end{array}$ & $\begin{array}{l}\text { Nozzle } \\
\text { Inner } \\
\text { Diameter }\end{array}$ & $\begin{array}{l}\text { Nozzle } \\
\text { Stanc-off } \\
\text { Distance }\end{array}$ & $\begin{array}{l}\text { Pulse Tube } \\
\text { Configuration }\end{array}$ & $\begin{array}{l}\text { Installed } \\
\text { Nozzles }\end{array}$ & $\begin{array}{c}\text { Outer } \\
\text { Nozzles } \\
\text { Operated }\end{array}$ & $\begin{array}{c}\text { Inner } \\
\text { Nozles } \\
\text { Opperated }\end{array}$ & $\begin{array}{c}\text { Pulse Tube } \\
\text { Outer } \\
\text { Diameter }\end{array}$ & $\begin{array}{c}\text { Outer } \\
\text { PJM } \\
\text { Radius } \\
\end{array}$ & \begin{tabular}{r|} 
Inner \\
PJM \\
Radius \\
\end{tabular} & $\begin{array}{c}\text { "FOO" Outer PJM } \\
\text { Impingement } \\
\text { Angle }\end{array}$ & $\begin{array}{c}\text { "FOO' Inner PJM } \\
\text { Impingement } \\
\text { Angle }\end{array}$ & $\begin{array}{c}\text { Ratio Outer } \\
\text { PJM to Tank } \\
\text { Radius } \\
\end{array}$ & $\begin{array}{c}\text { Ratio Inner } \\
\text { PJM to Tank } \\
\text { Radius } \\
\end{array}$ & Simulant & $\begin{array}{l}\text { Solids } \\
\text { Density }\end{array}$ & \begin{tabular}{|c|} 
Particle \\
Diameter \\
d 5 \\
\end{tabular} & $\begin{array}{c}\text { Partide } \\
\text { Diameter } \\
\text { d50 }\end{array}$ & $\begin{array}{c}\begin{array}{c}\text { Patidide } \\
\text { Diameter } \\
\text { d95 }\end{array} \\
\end{array}$ & $\begin{array}{c}\text { Void } \\
\text { Fraction }\end{array}$ \\
\hline text & text & text & in. & text & in. & in. $3^{3}$ & in. & in. & in. & in. & text & number & number & number & in. & in. & in. & deg & deg & nondim & nondim & text & $\mathrm{g} / \mathrm{cm}^{3}$ & $\mathrm{~m}$ & $\mathrm{~m}$ & $\mathrm{~m}$ & fraction \\
\hline MSS & MDDX & $\mathrm{ID}$ & $\mathrm{D}$ & HS & Hosh & $V_{\text {dash }}$ & $\mathrm{H}$ & Rtn & $d$ & sod & PT & $\mathrm{N}$ & $\mathrm{No}_{0}$ & $\mathrm{~N}$ & $\mathrm{PT}_{T_{\alpha}}$ & $\mathrm{Ro}_{0}$ & $R$ & $\theta_{0}$ & $\theta_{1}$ & $\mathrm{RolR}$ & $R / R$ & sxdx & $\rho_{\mathrm{s}}$ & $d_{5}$ & $\mathrm{~d}_{0}$ & $d_{65}$ & vf \\
\hline $9340043 \mathrm{M}$ & $3 / 5 \mathrm{~A}$ & 345_4sid17c_1 & $337 / 8$ & $\mathrm{~s}$ & 9 & 4437.4 & 69 & 66 & 0.297 & 0.446 & HLP-22 & 12 & 8 & 4 & 1.9 & 10.5 & 5.7 & 30.8 & 16.1 & 0.62 & 0.33 & s1d1 & 2.46 & \begin{tabular}{|l|}
0.0001428 \\
\end{tabular} & 0.0001664 & \begin{tabular}{|l|}
0.0001951 \\
\end{tabular} & 0.4118 \\
\hline 9340044M & $3 / 5 \mathrm{~A}$ & $34 S \_4 s 1 d 1 Z c \_1$ & $337 / 8$ & $\mathrm{~s}$ & 9 & 4437.4 & 69 & 66 & 0.297 & 0.446 & HLP-22 & 12 & 8 & 4 & 1.9 & 10.5 & 5.7 & 30.8 & 16.1 & 0.62 & 0.33 & sidn & 2.46 & \begin{tabular}{|l|}
0.0001428 \\
\end{tabular} & \begin{tabular}{|l|l|}
0.0001664 \\
\end{tabular} & \begin{tabular}{|l}
0.0001951 \\
\end{tabular} & 0.4118 \\
\hline $9340045 \mathrm{M}$ & $3 / 5 \mathrm{~A}$ & 34S_4sid17c_ 1 & $337 / 8$ & $\mathrm{~s}$ & 9 & 4437.4 & 69 & 66 & 0.297 & 0.446 & HLP-22 & 12 & 8 & 4 & 1.9 & 10.5 & 5.7 & 30.8 & 16.1 & 0.62 & 0.33 & sid1 & 2.46 & \begin{tabular}{|l|}
0.0001428 \\
\end{tabular} & 0.0001664 & \begin{tabular}{|l|l|}
0.0001951 \\
\end{tabular} & 0.4118 \\
\hline $9340046 \mathrm{M}$ & $3 / 5 \mathrm{~A}$ & $345 \_4 \mathrm{~s} 1 \mathrm{d1Zz} \_1$ & $337 / 8$ & $\mathrm{~s}$ & 9 & \begin{tabular}{ll|l}
4437.4 \\
\end{tabular} & 69 & 66 & 0.297 & 0.446 & HLP-22 & 12 & 8 & 4 & 1.9 & 10.5 & 5.7 & 30.8 & 16.1 & 0.62 & 0.33 & s1d1 & 2.46 & \begin{tabular}{|l|}
0.0001428 \\
\end{tabular} & \begin{tabular}{|l|l|}
0.0001664 \\
\end{tabular} & \begin{tabular}{|l|l|}
0.0001951 \\
\end{tabular} & 0.4118 \\
\hline 9340047 & $3 / 5 \mathrm{~A}$ & $34 S \_4 s 1 d 17 c \_1$ & $337 / 8$ & $s$ & 9 & 4437.4 & 69 & 66 & 0.297 & 0.446 & HLP-22 & 12 & 8 & 4 & 1.9 & 10.5 & 5.7 & 30.8 & 16.1 & 0.62 & 0.33 & s1d1 1 & 2.46 & \begin{tabular}{|l|l|}
0.0001428 \\
\end{tabular} & 0.0001664 & \begin{tabular}{|l|l|}
0.0001951 \\
\end{tabular} & 0.4118 \\
\hline 9340048 & $3 / 5 \mathrm{~A}$ & $345 \_4 \mathrm{~s} 1 \mathrm{~d} 1 \mathrm{Zc} \_1$ & $337 / 8$ & $\mathrm{~s}$ & 9 & 4437.4 & 69 & 66 & 0.297 & 0.446 & HLP-22 & 12 & 8 & 4 & 1.9 & 10.5 & 5.7 & 30.8 & 16.1 & 0.62 & 0.33 & s1d1 & 2.46 & \begin{tabular}{|l|l|}
0.0001428 \\
\end{tabular} & 0.0001664 & \begin{tabular}{|l|l|}
0.0001951 \\
\end{tabular} & 0.4118 \\
\hline 9340049 & $3 / 5 \mathrm{~A}$ & 34S_4sid17c 1 & $337 / 8$ & $\mathrm{~s}$ & 9 & 4437.4 & 69 & 66 & 0.297 & 0.446 & HLP-22 & 12 & 8 & 4 & 1.9 & 10.5 & 5.7 & 30.8 & 16.1 & 0.62 & 0.33 & sid1 & 2.46 & \begin{tabular}{|l|l|}
0.0001428 \\
\end{tabular} & 0.0001664 & \begin{tabular}{|l|l|}
0.0001951 \\
\end{tabular} & 0.4118 \\
\hline $9340050 \mathrm{M}$ & $3 / 5 \mathrm{~A}$ & 345_4s1d17c 1 & $337 / 8$ & $\mathrm{~s}$ & 9 & 4437.4 & 69 & 66 & 0.297 & 0.446 & HLP-22 & 12 & 8 & 4 & 1.9 & 10.5 & 5.7 & 30.8 & 16.1 & 0.62 & 0.33 & s1d1 & 2.46 & \begin{tabular}{|l|}
0.0001428 \\
\end{tabular} & 0.0001664 & \begin{tabular}{|l|l|}
0.0001951 \\
\end{tabular} & 0.4118 \\
\hline 9340051M & $3 / 5 \mathrm{~A}$ & 34S_4sid1zc 1 & $337 / 8$ & $\mathrm{~s}$ & 9 & \begin{tabular}{ll|}
4437.4 \\
\end{tabular} & 69 & 66 & 0.297 & 0.446 & HLP-22 & 12 & 8 & 4 & 1.9 & 10.5 & 5.7 & 30.8 & 16.1 & 0.62 & 0.33 & s1d1 1 & 2.46 & \begin{tabular}{|l|}
0.0001428 \\
\end{tabular} & \begin{tabular}{|l|l|}
0.0001664 \\
\end{tabular} & \begin{tabular}{|l|}
0.0001951 \\
\end{tabular} & 0.4118 \\
\hline 9340052 & $3 / 5 \mathrm{~A}$ & $34 \mathrm{~S} \_4 \mathrm{~s} 1 \mathrm{~d} 1 \mathrm{Zc} \_1$ & $337 / 8$ & $s$ & 9 & 4437.4 & 69 & 66 & 0.297 & 0.446 & HLP-22 & 12 & 8 & 4 & 1.9 & 10.5 & 5.7 & 30.8 & 16.1 & 0.62 & 0.33 & s1d1 & 2.46 & \begin{tabular}{|l|l|}
0.0001428 \\
\end{tabular} & 0.0001664 & 0.0001951 & 0.4118 \\
\hline 9340053 & $3 / 5 \mathrm{~A}$ & 34S_4s1d17c_1 & $337 / 8$ & $\mathrm{~s}$ & 9 & 4437.4 & 69 & 66 & 0.297 & 0.446 & HLP-22 & 12 & 8 & 4 & 1.9 & 10.5 & 5.7 & 30.8 & 16.1 & 0.62 & 0.33 & sld1 & 2.46 & \begin{tabular}{|l|l|} 
& 0.0001428 \\
\end{tabular} & 0.0001664 & 0.0001951 & 0.4118 \\
\hline 9340054 & $3 / 5 \mathrm{~A}$ & $34 \mathrm{~S}$ 4sid17c 1 & $337 / 8$ & $\mathrm{~s}$ & 9 & 4437.4 & 69 & 66 & 0.297 & 0.446 & HLP-22 & 12 & 8 & 4 & 1.9 & 10.5 & 5.7 & 30.8 & 16.1 & 0.62 & 0.33 & sidn & 2.46 & \begin{tabular}{|l|l|}
0.0001428 \\
\end{tabular} & 0.0001664 & \begin{tabular}{|l|l|}
0.0001951 \\
\end{tabular} & 0.4118 \\
\hline $9340055 \mathrm{M}$ & 3/5B & 345_4s1d17d_1 & $337 / 8$ & $\mathrm{~s}$ & 9 & 4437.4 & 69 & 66 & 0.297 & 0.446 & HLP-22 & 12 & 8 & 4 & 1.9 & 10.5 & 5.7 & 30.8 & 16.1 & 0.62 & 0.33 & sidn 1 & 246 & \begin{tabular}{|l|}
0.0001428 \\
\end{tabular} & 0.0001664 & 0.0001951 & 0.4118 \\
\hline $9340056 \mathrm{M}$ & 3/5B & 34S_4sid17d_1 & $337 / 8$ & $\mathrm{~s}$ & 9 & 4437.4 & 69 & 66 & 0.297 & 0.446 & HLP-22 & 12 & 8 & 4 & 1.9 & 10.5 & 5.7 & 30.8 & 16.1 & 0.62 & 0.33 & s1d1 & 2.46 & \begin{tabular}{|l|}
0.0001428 \\
\end{tabular} & 0.0001664 & 0.0001951 & 0.4118 \\
\hline 9340057 & 3/5B & 34S_4sid17d_ 1 & $337 / 8$ & $s$ & 9 & 4437.4 & 69 & 66 & 0.297 & 0.446 & HLP-22 & 12 & 8 & 4 & 1.9 & 10.5 & 5.7 & 30.8 & 16.1 & 0.62 & 0.33 & s1d1 & 2.46 & \begin{tabular}{|l|l|}
0.0001428 \\
\end{tabular} & 0.0001664 & 0.0001951 & 0.4118 \\
\hline 9340058 & 3/5B & 34__4s1d12d_1 & $337 / 8$ & $\mathrm{~s}$ & 9 & 4437.4 & 69 & 66 & 0.297 & 0.446 & HLP-22 & 12 & 8 & 4 & 1.9 & 10.5 & 5.7 & 30.8 & 16.1 & 0.62 & 0.33 & sld1 & 2.46 & \begin{tabular}{|l|l|}
0.0001428 \\
\end{tabular} & 0.0001664 & \begin{tabular}{|l|}
0.0001951 \\
\end{tabular} & 0.4118 \\
\hline 9340059 & $3 / 5 B$ & 34S_4s1d17d_1 & $337 / 8$ & $\mathrm{~s}$ & 9 & 4437.4 & 69 & 66 & 0.297 & 0.446 & HLP-22 & 12 & 8 & 4 & 1.9 & 10.5 & 5.7 & 30.8 & 16.1 & 0.62 & 0.33 & sidn & 2.46 & \begin{tabular}{|l|l|}
0.0001428 \\
\end{tabular} & 0.0001664 & 0.0001951 & 0.4118 \\
\hline 9340060 & 3/5B & 34S_4sid1Zd 1 & $337 / 8$ & $\mathrm{~s}$ & 9 & 4437.4 & 69 & 66 & 0.297 & 0.446 & HLP-22 & 12 & 8 & 4 & 1.9 & 10.5 & 5.7 & 30.8 & 16.1 & 0.62 & 0.33 & sidn & 246 & \begin{tabular}{|l|}
0.0001428 \\
\end{tabular} & 0.0001664 & \begin{tabular}{|l}
0.0001951 \\
\end{tabular} & 0.4118 \\
\hline 9340061 & $3 / 5 \mathrm{C}$ & 345_4s1d17c_2 & $337 / 8$ & $\mathrm{~s}$ & 9 & 4437.4 & 69 & 66 & 0.297 & 0.446 & HLP-22 & 12 & 8 & 4 & 1.9 & 10.5 & 5.7 & 30.8 & 16.1 & 0.62 & 0.33 & s1d1 1 & 2.46 & \begin{tabular}{|l|}
0.0001428 \\
\end{tabular} & \begin{tabular}{|l|l|}
0.0001664 \\
\end{tabular} & \begin{tabular}{|l|}
0.0001951 \\
\end{tabular} & 0.4118 \\
\hline 9340062 & $3 / 5 \mathrm{C}$ & 345 4s1d17c 2 & $337 / 8$ & $\mathrm{~s}$ & 9 & 4437.4 & 69 & 66 & 0.297 & 0.446 & HLP-22 & 12 & 8 & 4 & 1.9 & 10.5 & 5.7 & 30.8 & 16.1 & 0.62 & 0.33 & s1d1 & 2.46 & \begin{tabular}{|l|}
0.0001428 \\
\end{tabular} & 0.0001664 & 0.0001951 & 0.4118 \\
\hline 9340063 & $3 / 5 \mathrm{C}$ & $345 \_4 s 1 d 1 Z c \_2$ & $337 / 8$ & $\mathrm{~s}$ & 9 & 4437.4 & 69 & 66 & 0.297 & 0.446 & HLP-22 & 12 & 8 & 4 & 1.9 & 10.5 & 5.7 & 30.8 & 16.1 & 0.62 & 0.33 & sld1 & 2.46 & 0.0001428 & 0.0001664 & 0.0001951 & 0.4118 \\
\hline 9340064 & $3 / 5 \mathrm{C}$ & 34S_4s1d1Zc_2 & $337 / 8$ & $\mathrm{~s}$ & 9 & 4437.4 & 69 & 66 & 0.297 & 0.446 & HLP-22 & 12 & 8 & 4 & 1.9 & 10.5 & 5.7 & 30.8 & 16.1 & 0.62 & 0.33 & s1d1 1 & 2.46 & \begin{tabular}{|l|}
0.0001428 \\
\end{tabular} & \begin{tabular}{|l|l|}
0.0001664 \\
\end{tabular} & \begin{tabular}{|l|l|}
0.0001951 \\
\end{tabular} & 0.4118 \\
\hline 9340065 & $3 / 6 \mathrm{~A}$ & 345_4s1d1Yc_1 & $337 / 8$ & $\mathrm{~s}$ & 9 & 4437.4 & 69 & 66 & 0.297 & 0.446 & HLP-22 & 12 & 8 & 4 & 1.9 & 10.5 & 5.7 & 30.8 & 16.1 & 0.62 & 0.33 & s1d1 & 246 & \begin{tabular}{|l|}
0.0001428 \\
\end{tabular} & 0.0001664 & \begin{tabular}{|l|l|}
0.0001951 \\
\end{tabular} & 0.4118 \\
\hline 9340066 & $3 / 6 \mathrm{~A}$ & 34S_4sId1Yc_1 & $337 / 8$ & $\mathrm{~s}$ & 9 & 4437.4 & 69 & 66 & 0.297 & 0.446 & HLP-22 & 12 & 8 & 4 & 1.9 & 10.5 & 5.7 & 30.8 & 16.1 & 0.62 & 0.33 & s1d1 1 & 2.46 & \begin{tabular}{|l|}
0.0001428 \\
\end{tabular} & \begin{tabular}{|l|l|}
0.0001664 \\
\end{tabular} & \begin{tabular}{|l|}
0.0001951 \\
\end{tabular} & 0.4118 \\
\hline 9340067M & $3 / 6 \mathrm{~A}$ & 34S_4sid1Yc_1 & $337 / 8$ & $\mathrm{~s}$ & 9 & \begin{tabular}{ll|l}
4437.4 \\
\end{tabular} & 69 & 66 & 0.297 & 0.446 & HLP-22 & 12 & 8 & 4 & 1.9 & 10.5 & 5.7 & 30.8 & 16.1 & 0.62 & 0.33 & s1d1 & 2.46 & \begin{tabular}{|l|}
0.0001428 \\
\end{tabular} & 0.0001664 & 0.0001951 & 0.4118 \\
\hline 9340068 & $3 / 6 \mathrm{~A}$ & 34S_4s1d1Yc_1 & $337 / 8$ & $\mathrm{~s}$ & 9 & 4437.4 & 69 & 66 & 0.297 & 0.446 & HLP-22 & 12 & 8 & 4 & 1.9 & 10.5 & 5.7 & 30.8 & 16.1 & 0.62 & 0.33 & sidn & 2.46 & \begin{tabular}{|l|}
0.0001428 \\
\end{tabular} & 0.0001664 & \begin{tabular}{|l|l|}
0.0001951 \\
\end{tabular} & 0.4118 \\
\hline 9340069M & $3 / 6 \mathrm{~A}$ & 34S_4s1d1Yc_1 & $337 / 8$ & $\mathrm{~s}$ & 9 & 4437.4 & 69 & 66 & 0.297 & 0.446 & HLP-22 & 12 & 8 & 4 & 1.9 & 10.5 & 5.7 & 30.8 & 16.1 & 0.62 & 0.33 & s1d1 & 2.46 & \begin{tabular}{|l|}
0.0001428 \\
\end{tabular} & 0.0001664 & \begin{tabular}{|l|l|}
0.0001951 \\
\end{tabular} & 0.4118 \\
\hline $9340070 \mathrm{M}$ & $3 / 6 \mathrm{~A}$ & 345_4s1d1Yc_1 & $337 / 8$ & $\mathrm{~s}$ & 9 & 4437.4 & 69 & 66 & 0.297 & 0.446 & HLP-22 & 12 & 8 & 4 & 1.9 & 10.5 & 5.7 & 30.8 & 16.1 & 0.62 & 0.33 & sidn & 246 & \begin{tabular}{|l|}
0.0001428 \\
\end{tabular} & 0.0001664 & 0.0001951 & 0.4118 \\
\hline $9340071 \mathrm{M}$ & $3 / 6 \mathrm{~A}$ & 34S_4s1d1Yc 1 & $337 / 8$ & $\mathrm{~s}$ & 9 & 4437.4 & 69 & 66 & 0.297 & 0.446 & HLP-22 & 12 & 8 & 4 & 1.9 & 10.5 & 5.7 & 30.8 & 16.1 & 0.62 & 0.33 & s1d1 1 & 2.46 & \begin{tabular}{|l|}
0.0001428 \\
\end{tabular} & \begin{tabular}{|l|l|}
0.0001664 \\
\end{tabular} & \begin{tabular}{|l|l|}
0.0001951 \\
\end{tabular} & 0.4118 \\
\hline 9340072 & $3 / 6 \mathrm{~A}$ & 34S_4sid1Yc_1 & $337 / 8$ & $\mathrm{~s}$ & 9 & $\begin{array}{ll}4437.4 \\
\end{array}$ & 69 & 66 & 0.297 & 0.446 & HLP-22 & 12 & 8 & 4 & 1.9 & 10.5 & 5.7 & 30.8 & 16.1 & 0.62 & 0.33 & s1d1 & 2.46 & \begin{tabular}{|l|}
0.0001428 \\
\end{tabular} & 0.0001664 & \begin{tabular}{|l|}
0.0001951 \\
\end{tabular} & 0.4118 \\
\hline 9340073 & $3 / 6 \mathrm{~A}$ & 34S_4s1d1Yc_1 & $337 / 8$ & $\mathrm{~s}$ & 9 & 4437.4 & 69 & 66 & 0.297 & 0.446 & HLP-22 & 12 & 8 & 4 & 1.9 & 10.5 & 5.7 & 30.8 & 16.1 & 0.62 & 0.33 & sidn & 2.46 & \begin{tabular}{|l|}
0.0001428 \\
\end{tabular} & 0.0001664 & \begin{tabular}{|l|l|}
0.0001951 \\
\end{tabular} & 0.4118 \\
\hline 9340074M & $3 / 6 \mathrm{~A}$ & $34 \mathrm{~S} 4 \mathrm{~s} 1 \mathrm{~d} 1 \mathrm{Yc} 1$ & $337 / 8$ & $\mathrm{~s}$ & 9 & 4437.4 & 69 & 66 & 0.297 & 0.446 & HLP-22 & 12 & 8 & 4 & 1.9 & 10.5 & 5.7 & 30.8 & 16.1 & 0.62 & 0.33 & s1d1 & 2.46 & \begin{tabular}{|l|l|}
0.0001428 \\
\end{tabular} & \begin{tabular}{|l|l|}
0.0001664 \\
\end{tabular} & \begin{tabular}{|l|l|}
0.0001951 \\
\end{tabular} & 0.4118 \\
\hline 9340075 & $3 / 6 \mathrm{~B}$ & 34S_ 4s1d1Yd 11 & $337 / 8$ & $\mathrm{~s}$ & 9 & 4437.4 & 69 & 66 & 0.297 & 0.446 & HLP-22 & 12 & 8 & 4 & 1.9 & 10.5 & 5.7 & 30.8 & 16.1 & 0.62 & 0.33 & sidn & 2.46 & \begin{tabular}{|l|}
0.0001428 \\
\end{tabular} & 0.0001664 & \begin{tabular}{|l|}
0.0001951 \\
\end{tabular} & 0.4118 \\
\hline 9340076 & $3 / 6 \mathrm{~B}$ & 34S_4sid1Yd_1 & $337 / 8$ & $\mathrm{~s}$ & 9 & 4437.4 & 69 & 66 & 0.297 & 0.446 & HLP-22 & 12 & 8 & 4 & 1.9 & 10.5 & 5.7 & 30.8 & 16.1 & 0.62 & 0.33 & s1d1 1 & 2.46 & \begin{tabular}{|l|}
0.0001428 \\
\end{tabular} & \begin{tabular}{|l|l|}
0.0001664 \\
\end{tabular} & \begin{tabular}{|l|l|}
0.0001951 \\
\end{tabular} & 0.4118 \\
\hline 9340077 & $3 / 68$ & 34S_4sid1Yd_1 & $337 / 8$ & $\mathrm{~s}$ & 9 & $\begin{array}{ll}4437.4 \\
\end{array}$ & 69 & 66 & 0.297 & 0.446 & HLP-22 & 12 & 8 & 4 & 1.9 & 10.5 & 5.7 & 30.8 & 16.1 & 0.62 & 0.33 & s1d1 & 2.46 & \begin{tabular}{|l|}
0.0001428 \\
\end{tabular} & 0.0001664 & \begin{tabular}{|l|}
0.0001951 \\
\end{tabular} & 0.4118 \\
\hline 9340078 & $3 / 6 \mathrm{~B}$ & 34S_4s1d1Yd_1 & $337 / 8$ & $\mathrm{~s}$ & 9 & 4437.4 & 69 & 66 & 0.297 & 0.446 & HLP-22 & 12 & 8 & 4 & 1.9 & 10.5 & 5.7 & 30.8 & 16.1 & 0.62 & 0.33 & sidn & 2.46 & \begin{tabular}{|l|l|}
0.0001428 \\
\end{tabular} & 0.0001664 & \begin{tabular}{|l|l|}
0.0001951 \\
\end{tabular} & 0.4118 \\
\hline 9340079 & $3 / 6 \mathrm{~B}$ & 34S_4sid1Yd_1 & $337 / 8$ & $\mathrm{~s}$ & 9 & 4437.4 & 69 & 66 & 0.297 & 0.446 & HLP-22 & 12 & 8 & 4 & 1.9 & 10.5 & 5.7 & 30.8 & 16.1 & 0.62 & 0.33 & sid1 & 2.46 & \begin{tabular}{|l|l|}
0.0001428 \\
\end{tabular} & \begin{tabular}{|l|l|}
0.0001664 \\
\end{tabular} & \begin{tabular}{|l|l|}
0.0001951 \\
\end{tabular} & 0.4118 \\
\hline 9340080 & $3 / 6 \mathrm{C}$ & 34S_4s1d1Xc_1 & $337 / 8$ & $\mathrm{~s}$ & 9 & 4437.4 & 69 & 66 & 0.297 & 0.446 & HLP -22 & 12 & 8 & 4 & 1.9 & 10.5 & 5.7 & 30.8 & 16.1 & 0.62 & 0.33 & sidn & 2.46 & \begin{tabular}{|l|}
0.0001428 \\
\end{tabular} & 0.0001664 & \begin{tabular}{|l|l|}
0.0001951 \\
\end{tabular} & 0.4118 \\
\hline 9340081 & $3 / 6 \mathrm{C}$ & 34S_4sid1Xc_1 & $337 / 8$ & $\mathrm{~s}$ & 9 & 4437.4 & 69 & 66 & 0.297 & 0.446 & HLP-22 & 12 & 8 & 4 & 1.9 & 10.5 & 5.7 & 30.8 & 16.1 & 0.62 & 0.33 & s1d1 1 & 2.46 & \begin{tabular}{|l|}
0.0001428 \\
\end{tabular} & 0.0001664 & \begin{tabular}{|l|l|}
0.0001951 \\
\end{tabular} & 0.4118 \\
\hline 9340082 & $3 / 6 \mathrm{C}$ & 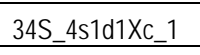 & $337 / 8$ & $\mathrm{~s}$ & 9 & 4437.4 & 69 & 66 & 0.297 & 0.446 & HLP-22 & 12 & 8 & 4 & 1.9 & 10.5 & 5.7 & 30.8 & 16.1 & 0.62 & 0.33 & s1d1 & 2.46 & \begin{tabular}{|l|}
0.0001428 \\
\end{tabular} & 0.0001664 & \begin{tabular}{|l|}
0.0001951 \\
\end{tabular} & 0.4118 \\
\hline 9340083 & $36 \mathrm{C}$ & 34S_4s1d1Xc_1 & $337 / 8$ & $\mathrm{~s}$ & 9 & 4437.4 & 69 & 66 & 0.297 & 0.446 & HLP-22 & 12 & 8 & 4 & 1.9 & 10.5 & 5.7 & 30.8 & 16.1 & 0.62 & 0.33 & s1d1 & 246 & \begin{tabular}{|l|}
0.0001428 \\
\end{tabular} & 0.0001664 & \begin{tabular}{|l|l|}
0.0001951 \\
\end{tabular} & 0.4118 \\
\hline
\end{tabular}


Table B.4. Data from 2008 Tests in Mid-Scale Vessel with Spherical Head B.2

\begin{tabular}{|c|c|c|c|c|c|c|c|c|c|c|c|c|c|c|c|c|c|c|c|c|c|c|c|c|c|c|c|c|c|}
\hline $\begin{array}{l}\text { Tank Water } \\
\text { Temperature }\end{array}$ & $\begin{array}{l}\text { Water } \\
\text { Density }\end{array}$ & $\begin{array}{l}\text { Solids } \\
\text { Fraction }\end{array}$ & $\begin{array}{c}\text { Pulse } \\
\text { Volume } \\
\text { Fraction }\end{array}$ & $\begin{array}{l}\text { Duty } \\
\text { Cycle }\end{array}$ & $\begin{array}{l}\text { Oyde } \\
\text { Time }\end{array}$ & $\begin{array}{c}\text { Pulsed } \\
\text { or } \\
\text { Steady } \\
\text { Jet }\end{array}$ & $\begin{array}{l}\text { Us } \\
\text { Steady } \\
\text { Jet }\end{array}$ & $\begin{array}{c}\text { U1 } \\
\text { Pulsing } \\
\text { Jet }\end{array}$ & $\begin{array}{c}\text { U2 } \\
\text { URNS }\end{array}$ & $\begin{array}{c}\text { U3 } \\
\text { URNB } \\
\end{array}$ & $\begin{array}{l}\text { Discharge } \\
\text { Velocity }\end{array}$ & $\begin{array}{c}\text { Citical } \\
\text { Suspension } \\
\text { velocity }\end{array}$ & $\begin{array}{c}\text { Average } \\
\text { Peek Cloud } \\
\text { Height }\end{array}$ & $\begin{array}{l}\text { UCS } \\
\text { Condition }\end{array}$ & $\begin{array}{l}\text { UCS } \\
\text { Method }\end{array}$ & $\begin{array}{l}\text { UCS } \\
\text { Flag }\end{array}$ & $\begin{array}{l}\text { UCS } \\
\text { Center } \\
\text { Hag }\end{array}$ & $\begin{array}{c}\text { UCS udv } \\
\text { Hag }\end{array}$ & $\begin{array}{l}\text { UCS based } \\
\text { on } \\
\text { Decreasing } \\
\text { Velocity }\end{array}$ & $\begin{array}{c}\text { Sweep } \\
\text { Increase } \\
\text { Decrease }\end{array}$ & $\begin{array}{c}\text { UDV } \\
\text { Height } \\
\text { Bed }\end{array}$ & $\begin{array}{l}\text { Particle } \\
\text { Motion }\end{array}$ & $\begin{array}{l}\text { Solids } \\
\text { Level }\end{array}$ & $\begin{array}{c}\text { Outer } \\
\text { Botom } \\
\text { Pattem }\end{array}$ & $\begin{array}{l}\text { Inner } \\
\text { Botom } \\
\text { Pattem }\end{array}$ & Case ID & Test & TDP & $\begin{array}{l}\text { Row } \\
\text { Number }\end{array}$ \\
\hline c & $\mathrm{g} / \mathrm{cm}^{3}$ & fraction & fraction & fraction & $\mathrm{s}$ & text & $m / s$ & $\mathrm{~m} / \mathrm{s}$ & $\mathrm{ms}$ & $\mathrm{m} / \mathrm{s}$ & $\mathrm{m} / \mathrm{s}$ & $\mathrm{m} / \mathrm{s}$ & in. & $\mathrm{m} / \mathrm{s}$ & text & text & text & text & $\mathrm{m} / \mathrm{s}$ & text & $\mathrm{mm}$ & text & text & text & text & text & text & text & text \\
\hline$T$ & $\rho$ & $\phi_{\mathrm{s}}$ & $\phi_{\mathrm{p}}$ & $D C$ & tc & Jet & $u_{s}$ & $\mathrm{U}_{1}$ & $\mathrm{U} 2$ & U3 & $u$ & Uns & $H_{c}$ & Usse & Uan & Ussis & Usscen & Uosudv & Us_D & $S_{\mathrm{N}}$ & $H_{\text {hed }}$ & $\mathrm{PM}$ & sol & $\mathrm{SPo}$ & SP & ID & MDDX & TDP & MSS \\
\hline 23.4 & 0.998 & 0.01500 & 0.050 & 0.354 & 12.0 & $\mathrm{P}$ & NA & 11.02 & 11.31 & 11.45 & 11.80 & 7.90 & 19.75 & NA & NA & NA & NA & NA & NA & (null) & NA & 4 & NA & NA & NA & $345 \_4 s 1 d 1 X c \_1$ & $3 / 6 \mathrm{C}$ & TDP-104 & 9340043 \\
\hline 23.6 & 0.997 & 0.01500 & 0.050 & 0.357 & 11.0 & $\mathrm{P}$ & NA & 11.99 & 12.33 & 12.50 & 13.00 & 7.90 & 27.00 & NA & NA & NA & NA & NA & NA & 1 & NA & 4 & NA & NA & NA & $34 \mathrm{~S} \_4 \mathrm{~s} 1 \mathrm{~d} 1 \mathrm{X} \mathrm{C} \_1$ & $3 / 6 c$ & TDP-104 & 9340044 \\
\hline 23.8 & 0.998 & 0.01500 & 0.049 & 0.360 & 10.0 & $P$ & NA & 1284 & 13.24 & 13.44 & 14.00 & 7.90 & 33.00 & NA & NA & NA & NA & NA & NA & 1 & NA & 4 & NA & NA & NA & 345 4sid1Xc 1 & $3 / 6 \mathrm{C}$ & TDP-104 & 9340045 \\
\hline 23.6 & 0.998 & 0.01500 & 0.050 & 0.350 & 14.0 & $\mathrm{P}$ & NA & 9.52 & 9.73 & 9.84 & 10.10 & 7.90 & 13.50 & NA & vis dec & UcSis & NA & NA & 10.10 & D & NA & 3 & NA & NA & NA & $345 \_4 s 1 d 1 \times c \_1$ & $3 / 6 \mathrm{C}$ & TDP-104 & 9340046 \\
\hline 18.6 & 0.999 & 0.00015 & 0.050 & 0.333 & 65.0 & $P$ & NA & 2.16 & 2.18 & 2.18 & 220 & NA & 53.50 & NA & NA & UCSTis & NA & NA & NA & (null) & 28.4 & 3 & NA & NA & NA & 34S_ 4s1d2UC_ 1 & $37 / \mathrm{A}$ & TDP-105 & 9340047 \\
\hline 18.5 & 0.999 & 0.00015 & 0.050 & 0.333 & 65.0 & $\mathrm{P}$ & NA & 2.16 & 2.18 & 2.18 & 2.20 & NA & 53.50 & NA & NA & ucsis & NA & NA & NA & (null) & 29.7 & 3 & NA & NA & NA & $345 \_4 s 1 d 2 U c \_1$ & $3 / 7 \mathrm{~A}$ & TDP-105 & 9340048 \\
\hline 19.3 & 0.999 & 0.00050 & 0.050 & 0.333 & 58.0 & $\mathrm{P}$ & NA & 2.42 & 2.44 & 2.45 & 2.50 & 2.75 & 22.25 & NA & NA & NA & NA & NA & NA & (null) & 3.7 & 1 & NA & NA & NA & 34S_4s1d2TC_1 & $3 / 7 \mathrm{~B}$ & TDP-106 & 9340049 \\
\hline 19.7 & 0.999 & 0.00050 & 0.050 & 0.334 & 49.0 & $\mathrm{P}$ & NA & 2.88 & 2.90 & 2.92 & 2.95 & 2.75 & 43.00 & NA & NA & NA & NA & NA & NA & 1 & NA & 4 & NA & NA & NA & 34S_4s1d2Tc_1 & $3 / 7 \mathrm{~B}$ & TDP-106 & 9340051 \\
\hline NA & NA & 0.00050 & 0.049 & 0.332 & 65.0 & $P$ & NA & NA & NA & NA & 2.20 & 2.75 & NA & NA & NA & NA & NA & NA & NA & NA & 37.6 & NA & NA & NA & NA & $34 \mathrm{~S} 4 \mathrm{~s} 1 \mathrm{~d} 2 \mathrm{TC} \mathrm{C}$ & 3/7B & TDP-106 & 9340052 \\
\hline NA & NA & 0.00150 & 0.050 & 0.336 & 40.0 & $\mathrm{P}$ & NA & NA & NA & NA & 3.60 & 3.70 & NA & NA & NA & NA & NA & NA & NA & NA & 0.0 & NA & NA & NA & NA & $34 \mathrm{~S} \_4 \mathrm{~s} 1 \mathrm{~d} 2 \mathrm{Sc} \_1$ & $377 \mathrm{C}$ & TDP-107 & 9340053 \\
\hline 20.2 & 0.999 & 0.00150 & 0.050 & 0.336 & 40.0 & $\mathrm{P}$ & NA & 3.47 & 3.50 & 3.52 & 3.55 & 3.70 & 17.50 & NA & NA & NA & NA & NA & NA & D & NA & 1 & NA & NA & NA & $34 \mathrm{~S} \_4 \mathrm{~s} 1 \mathrm{~d} 2 \mathrm{Sc} \_1$ & $3 / 7 \mathrm{C}$ & TDP-107 & 9340054 \\
\hline 20.2 & 0.999 & 0.00150 & 0.050 & 0.337 & 39.0 & $\mathrm{P}$ & NA & 3.57 & 3.61 & 3.63 & 3.70 & 3.70 & 19.75 & 3.70 & center & NA & UCscen & NA & NA & 1 & 0.0 & 2 & NA & NA & NA & $34 \mathrm{~S} \_4 \mathrm{~s} 1 \mathrm{~d} 2 \mathrm{SC} \_1$ & $37 \mathrm{C}$ & TDP-107 & 9340055 \\
\hline 20.4 & 0.999 & 0.00150 & 0.049 & 0.336 & 36.0 & $\mathrm{P}$ & NA & 3.82 & 3.86 & 3.88 & 3.90 & 3.70 & 25.50 & NA & NA & NA & NA & NA & NA & 1 & NA & 4 & NA & NA & NA & $345 \_4 s 1 d 2 S c \_1$ & $377 \mathrm{C}$ & TDP-107 & 9340056 \\
\hline 20.6 & 0.999 & 0.00150 & 0.050 & 0.335 & 47.0 & $\mathrm{P}$ & NA & 2.96 & 2.99 & 3.00 & 3.00 & 3.70 & 10.75 & NA & NA & NA & NA & NA & NA & D & NA & 1 & NA & NA & NA & 34S_4s1d2SC_1 & $37 \mathrm{C}$ & TDP-107 & 9340057 \\
\hline 20.5 & 0.999 & 0.00150 & 0.050 & 0.336 & 43.0 & $\mathrm{P}$ & NA & 3.22 & 3.25 & 3.27 & 3.30 & 3.70 & 12.25 & NA & NA & NA & NA & NA & NA & 1 & NA & 1 & NA & NA & NA & $34 \mathrm{~S} \_4 \mathrm{~s} 1 \mathrm{~d} 2 \mathrm{Sc} \_1$ & $377 \mathrm{C}$ & TDP-107 & 9340058 \\
\hline 20.5 & 0.999 & 0.00150 & 0.050 & 0.336 & 39.0 & $\mathrm{P}$ & NA & 3.57 & 3.61 & 3.63 & 3.70 & 3.70 & 19.75 & NA & NA & NA & UCScen & NA & NA & 1 & 0.7 & 2 & NA & NA & NA & $34 \mathrm{~S} \_4 \mathrm{~s} 1 \mathrm{~d} 2 \mathrm{SC} \_1$ & $3 / 7 \mathrm{C}$ & TDP-107 & 9340059 \\
\hline 20.5 & 0.999 & 0.00150 & 0.050 & 0.336 & 39.0 & $\mathrm{P}$ & NA & NA & NA & NA & 3.70 & 3.70 & 19.75 & NA & NA & NA & NA & NA & NA & NA & 0.0 & NA & NA & NA & NA & 34S_4s1d2Sc_1 & $37 \mathrm{C}$ & TDP-107 & 9340060 \\
\hline 20.5 & 0.999 & 0.00150 & 0.050 & 0.336 & 39.0 & $\mathrm{P}$ & NA & NA & NA & NA & 3.70 & 3.70 & 19.75 & NA & NA & NA & NA & NA & NA & NA & 0.0 & NA & NA & NA & NA & 34S_4s1d2Sc_1 & $377 \mathrm{C}$ & TDP-107 & 9340061 \\
\hline 20.5 & 0.999 & 0.00150 & 0.050 & 0.336 & 39.0 & $\mathrm{P}$ & NA & NA & NA & NA & 3.70 & 3.70 & 19.75 & NA & NA & NA & NA & NA & NA & NA & 0.0 & NA & NA & NA & NA & 34S_4s1d2SC_1 & $37 \mathrm{C}$ & TDP-107 & 9340062 \\
\hline 20.5 & 0.999 & 0.00150 & 0.050 & 0.336 & 39.0 & $\mathrm{P}$ & NA & NA & NA & NA & 3.70 & 3.70 & 19.75 & NA & NA & NA & NA & NA & NA & NA & 0.0 & NA & NA & NA & NA & $345 \_4 s 1 d 2 S c \_1$ & $3 / 7 \mathrm{C}$ & TDP-107 & 9340064 \\
\hline 21.1 & 0.998 & 0.00500 & 0.050 & 0.339 & 28.0 & $\mathrm{P}$ & NA & 4.91 & 4.97 & 5.01 & 5.05 & 5.10 & 19.50 & NA & NA & NA & UCscen & NA & NA & 1 & 0.0 & 2 & NA & NA & NA & $345 \_4 s 1 \mathrm{~d} 2 \mathrm{YC} \_1$ & $3 / 9 \mathrm{~A}$ & TDP-108 & 9340065 \\
\hline 21.1 & 0.998 & 0.00500 & 0.050 & 0.338 & 29.0 & $\mathrm{P}$ & NA & 4.78 & 4.84 & 4.87 & 4.90 & 5.10 & 14.25 & NA & NA & NA & NA & NA & NA & 1 & 21.1 & 1 & NA & NA & NA & 34S_4s1d2Yc_1 & $3 / 9 \mathrm{~A}$ & TDP-108 & 9340066 \\
\hline 21.3 & 0.998 & 0.00500 & 0.050 & 0.339 & 28.0 & $\mathrm{P}$ & NA & 4.96 & 5.02 & 5.05 & 5.10 & 5.10 & 19.50 & NA & NA & Ucsis & NA & NA & NA & 1 & 0.0 & 3 & NA & NA & NA & $34 \mathrm{~S} \_4 \mathrm{~s} 1 \mathrm{~d} 2 \mathrm{YC} \_1$ & $3 / 9 \mathrm{~A}$ & TDP-108 & 9340067 \\
\hline 21.2 & 0.998 & 0.00500 & 0.050 & 0.339 & 28.4 & $\mathrm{P}$ & NA & 4.88 & 4.94 & 4.97 & 5.00 & 5.10 & 19.00 & NA & udv dec & Ucsis & NA & ucsudv & 5.00 & D & 0.0 & 3 & NA & NA & NA & $34 \mathrm{~S} \_4 \mathrm{~s} 1 \mathrm{~d} 2 \mathrm{Yc} \_1$ & $3 / 9 \mathrm{~A}$ & TDP-108 & 9340068 \\
\hline 21.5 & 0.999 & 0.00500 & 0.050 & 0.336 & 23.0 & $\mathrm{P}$ & NA & 6.03 & 6.12 & 6.17 & 6.25 & 5. & 46.00 & NA & NA & NA & NA & NA & NA & 1 & 0.0 & NA & NA & NA & NA & $34 \mathrm{~S} \_4 \mathrm{~s} 1 \mathrm{~d} 2 \mathrm{Yc} \_1$ & $3 / 9 \mathrm{~A}$ & TDP-108 & 9340069 \\
\hline 21.3 & 0.998 & 0.00500 & 0.050 & 0.335 & 25.0 & $\mathrm{P}$ & NA & 5.58 & 5.66 & 5.70 & 5.80 & 5.10 & 35.00 & NA & NA & NA & NA & NA & NA & D & 19.4 & NA & NA & NA & NA & 34S_4s1d2Yc_1 & $3 / 9 \mathrm{~A}$ & TDP-108 & 9340070 \\
\hline 21.3 & 0.999 & 0.00500 & 0.050 & 0.334 & 27.0 & $\mathrm{P}$ & NA & 5.23 & 5.29 & 5.33 & 5.40 & 5.10 & 24.50 & NA & NA & NA & NA & NA & NA & $\mathrm{D}$ & 0.0 & NA & NA & NA & NA & $345 \_4 s 1 d 2 Y c \_1$ & $3 / 9 \mathrm{~A}$ & TDP-108 & 9340071 \\
\hline 21.4 & 0.998 & 0.00500 & 0.050 & 0.338 & 31.0 & $\mathrm{P}$ & NA & 4.47 & 4.52 & 4.55 & 4.60 & 5.10 & 11.25 & NA & NA & NA & NA & NA & NA & D & 16.7 & NA & NA & NA & NA & $34 \mathrm{~S} \_4 \mathrm{~s} 1 \mathrm{~d} 2 \mathrm{YC} \_1$ & $3 / 9 \mathrm{~A}$ & TDP-108 & 9340072 \\
\hline 21.6 & 0.998 & 0.00500 & 0.050 & 0.335 & 30.0 & $\mathrm{P}$ & NA & 4.66 & 4.72 & 4.75 & 4.80 & 5.10 & 13.00 & NA & NA & NA & NA & NA & NA & 1 & 23.2 & NA & NA & NA & NA & 34S_4s1d2Yc_1 & $3 / 9 \mathrm{~A}$ & TDP-108 & 9340073 \\
\hline 21.4 & 0.998 & 0.00500 & 0.050 & 0.336 & 28.4 & $\mathrm{P}$ & NA & 4.89 & 4.96 & 4.99 & 5.10 & 5.10 & 19.50 & 5.10 & udv & UCSvis & NA & ucsudv & NA & 1 & 0.0 & 3 & NA & NA & NA & $345 \_4 \mathrm{~s} 1 \mathrm{~d} 2 \mathrm{Yc} \_1$ & $3 / 9 \mathrm{~A}$ & TDP-108 & 9340074 \\
\hline 21.4 & 0.998 & 0.00500 & 0.050 & 0.336 & 28.4 & $P$ & NA & NA & NA & NA & 5.10 & 5.10 & 19.50 & NA & NA & NA & NA & NA & NA & NA & 0.0 & NA & NA & NA & NA & $345 \_451222 Y_{1} 1$ & $3 / 9 \mathrm{~A}$ & TDP-108 & 9340075 \\
\hline 21.4 & 0.998 & 0.00500 & 0.050 & 0.336 & 28.4 & $\mathrm{P}$ & NA & NA & NA & NA & 5.10 & 5.10 & 19.50 & NA & NA & NA & NA & NA & NA & NA & 0.0 & NA & NA & NA & NA & $34 S_{-} 4 \mathrm{~s} 1 \mathrm{~d} 2 \mathrm{Yc} \_1$ & 3/9A & TDP-108 & 9340076 \\
\hline 21.4 & 0.998 & 0.00500 & 0.050 & 0.336 & 28.4 & $\mathrm{P}$ & NA & NA & NA & NA & 5.10 & 5.10 & 19.50 & NA & NA & NA & NA & NA & NA & NA & 0.0 & NA & NA & NA & NA & $34 \mathrm{~S} \_4 \mathrm{~s} 1 \mathrm{~d} 2 \mathrm{YC} \_1$ & $3 / 9 \mathrm{~A}$ & TDP-108 & 9340077 \\
\hline 21.4 & 0.998 & 0.00500 & 0.050 & 0.336 & 28.4 & $\mathrm{P}$ & NA & NA & NA & NA & 5.10 & 5.10 & 19.50 & NA & NA & NA & NA & NA & NA & NA & 0.0 & NA & NA & NA & NA & 34S_4s1d2Yc_1 & $3 / 9 \mathrm{~A}$ & TDP-108 & 9340078 \\
\hline 21.4 & 0.998 & 0.00500 & 0.050 & 0.336 & 28.4 & $\mathrm{P}$ & NA & NA & NA & NA & 5.10 & 5.10 & 19.50 & NA & NA & NA & NA & NA & NA & NA & 0.7 & NA & NA & NA & NA & $345 \_4 \mathrm{~s} 1 \mathrm{~d} 2 \mathrm{Yc} \_1$ & $3 / 9 \mathrm{~A}$ & TDP-108 & 9340079 \\
\hline 214 & 0.998 & 0.00500 & 0.050 & 0.336 & 28.4 & $P$ & NA & NA & NA & NA & 5.10 & 5.10 & 19.50 & VA & NA & NA & NA & NA & $\mathrm{NA}$ & NA & 3.7 & NA & NA & NA & NA & $345 \quad 451 d 2 Y Y_{1} 1$ & $3 / 9 \mathrm{~A}$ & TDP-108 & 9340080 \\
\hline 21.7 & 0.999 & 0.00500 & 0.050 & 0.186 & 47.0 & $\mathrm{P}$ & NA & 5.33 & 5.40 & 5.44 & 5.50 & 6.00 & 13.00 & NA & NA & NA & NA & NA & NA & 1 & 41.6 & 1 & NA & NA & NA & 34S_4s1d2Yd_1 & 3/9B & TDP-108 & 9340081 \\
\hline 21.8 & 0.998 & 0.00500 & 0.050 & 0.186 & 45.4 & $P$ & NA & 5.57 & 5.65 & 5.69 & 5.80 & 6.00 & 15.25 & NA & NA & NA & NA & NA & NA & 1 & 19.9 & 1 & NA & NA & NA & $34 \mathrm{~S}$ 4s1d2Yd 1 & 3/9B & TDP-108 & 9340082 \\
\hline
\end{tabular}


Table B.4. Data from 2008 Tests in Mid-Scale Vessel with Spherical Head A.3

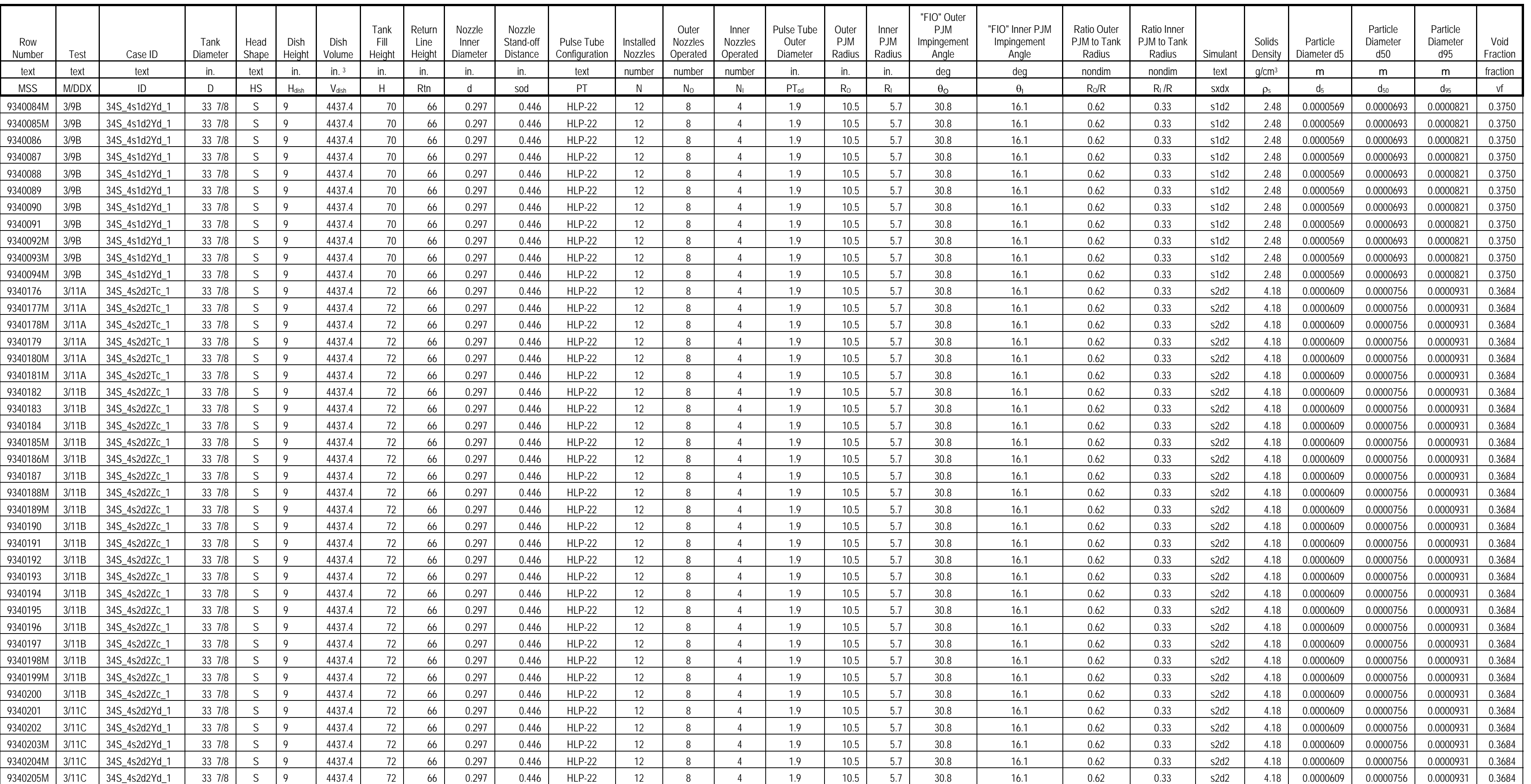


Table B.4. Data from 2008 Tests in Mid-Scale Vessel with Spherical Head B.3

\begin{tabular}{|c|c|c|c|c|c|c|c|c|c|c|c|c|c|c|c|c|c|c|c|c|c|c|c|c|c|c|c|c|c|}
\hline $\begin{array}{l}\text { Tank Water } \\
\text { Temperature }\end{array}$ & $\begin{array}{l}\text { Water } \\
\text { Density }\end{array}$ & $\begin{array}{l}\text { Solids } \\
\text { Fracion }\end{array}$ & $\begin{array}{c}\text { Pulse } \\
\text { Volume } \\
\text { Fraction }\end{array}$ & $\begin{array}{l}\text { Duty } \\
\text { Cycle }\end{array}$ & $\begin{array}{l}\text { Cycle } \\
\text { Time }\end{array}$ & $\begin{array}{c}\begin{array}{c}\text { Pulsed } \\
\text { Oer } \\
\text { Stleay } \\
\text { Jet }\end{array} \\
\end{array}$ & \begin{tabular}{|c|} 
Us \\
Steacy \\
Jet
\end{tabular} & \begin{tabular}{|c} 
U1 \\
Pulsing \\
Jet
\end{tabular} & \begin{tabular}{|c} 
U2 \\
URMS \\
\end{tabular} & $\begin{array}{c}\text { UB } \\
\text { URNB }\end{array}$ & $\begin{array}{c}\text { Discharge } \\
\text { Velocity }\end{array}$ & $\begin{array}{c}\text { Oitical } \\
\text { Suspension } \\
\text { velocity } \\
\end{array}$ & \begin{tabular}{|c} 
Average \\
Peak Coud \\
Height
\end{tabular} & $\begin{array}{c}\text { UCS } \\
\text { Condition }\end{array}$ & $\begin{array}{c}\text { UCS } \\
\text { Method }\end{array}$ & $\begin{array}{l}\text { UCS } \\
\text { Hag }\end{array}$ & $\begin{array}{c}\text { Ues } \\
\text { Center } \\
\text { Hag }\end{array}$ & $\begin{array}{c}\text { ucsuadv } \\
\text { Hag }\end{array}$ & $\begin{array}{l}\text { UCS based } \\
\text { on } \\
\text { Decreasing } \\
\text { Velocity }\end{array}$ & $\begin{array}{l}\text { Inveep } \\
\text { Increase/ } \\
\text { Decrease }\end{array}$ & $\begin{array}{c}\text { UDV } \\
\text { Height } \\
\text { Bed } \\
\end{array}$ & 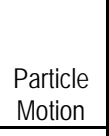 & $\begin{array}{l}\text { Solids } \\
\text { Level } \\
\end{array}$ & $\begin{array}{l}\text { Outer } \\
\text { Bototom } \\
\text { Pattem } \\
\end{array}$ & \begin{tabular}{|l} 
Inner \\
Bototom \\
Patter \\
\end{tabular} & Case ID & Test & IDP & $\begin{array}{c}\text { Row } \\
\text { Number }\end{array}$ \\
\hline$c$ & $\mathrm{~g} / \mathrm{cm}^{3}$ & fraction & fraction & fraction & $\mathrm{s}$ & text & $\mathrm{m} / \mathrm{s}$ & $\mathrm{m} / \mathrm{s}$ & $\mathrm{m} / \mathrm{s}$ & $\mathrm{m} / \mathrm{s}$ & $\mathrm{m} / \mathrm{s}$ & $\mathrm{m} / \mathrm{s}$ & in. & $\mathrm{m} / \mathrm{s}$ & text & text & text & text & $\mathrm{m} / \mathrm{s}$ & text & $\mathrm{mm}$ & text & text & text & text & text & text & text & text \\
\hline $\mathrm{T}$ & $\rho$ & $\phi_{\mathrm{s}}$ & $\phi_{p}$ & $\mathrm{DC}$ & $t_{c}$ & Jet & $U_{\mathrm{s}}$ & $\mathrm{U}_{1}$ & $\mathrm{U} 2$ & U3 & $u$ & $u_{c s}$ & $H_{k}$ & $u_{\text {CSP }}$ & Uosm & Unsis & Uscen & Usoudv & $U_{\text {Cs } D} \mathrm{D}$ & $\mathrm{s}_{\mathrm{w}}$ & Hod & PM & Sol & $\mathrm{SP}_{\mathrm{o}}$ & $\mathrm{SP}_{1}$ & ID & MDDX & $\mathrm{TDP}$ & MSS \\
\hline 21.8 & 0.998 & 0.00500 & 0.050 & 0.186 & 43.4 & $\mathrm{P}$ & NA & 5.80 & 5.89 & 5.93 & 6.00 & 6.00 & 20.25 & 6.00 & udv & NA & NA & ucsuav & $\mathrm{NA}$ & 1 & 2.2 & 4 & NA & $\mathrm{NA}$ & NA & 34S_4s1d2Yd_ 1 & $39 \mathrm{~B}$ & TDP-108 & 9340084 \\
\hline 21.8 & 0.998 & 0.00500 & 0.050 & 0.186 & 42.4 & $\mathrm{P}$ & NA & NA & NA & NA & 6.20 & 6.00 & 21.00 & NA & NA & NA & NA & NA & NA & NA & 0.0 & NA & NA & NA & NA & 34S_4sid2Yd_1 & 3/98 & TDP-108 & 9340086 \\
\hline 21.8 & 0.998 & 0.00500 & 0.050 & 0.186 & 42.4 & $\mathrm{P}$ & NA & NA & NA & NA & 6.20 & 6.00 & 21.00 & NA & NA & NA & NA & NA & NA & NA & 0.0 & NA & NA & NA & NA & 34S_4s1d2Yd 1 & 3/9B & TDP-108 & 9340087 \\
\hline 21.8 & 0.998 & 0.00500 & 0.050 & 0.186 & 42.4 & $\mathrm{P}$ & NA & NA & NA & NA & 6.20 & 6.00 & 21.00 & NA & NA & NA & NA & NA & NA & NA & 0.0 & NA & NA & NA & NA & 34S_4s1d2Yd 1 & $3 / 9 \mathrm{~B}$ & TDP-108 & 9340088 \\
\hline 21.8 & 0.998 & 0.00500 & 0.050 & 0.186 & 42.4 & $\mathrm{P}$ & NA & NA & NA & NA & 6.20 & 6.00 & 21.00 & NA & NA & NA & NA & NA & NA & NA & 0.0 & NA & NA & NA & NA & 34S_4sid2Yd_1 & $3 / 98$ & TDP-108 & 9340009 \\
\hline 21.8 & 0.998 & 0.00500 & 0.050 & 0.186 & 42.4 & $\mathrm{P}$ & NA & NA & NA & NA & 6.20 & 6.00 & 21.00 & NA & NA & NA & NA & NA & $\mathrm{NA}$ & NA & 0.0 & NA & NA & NA & NA & 34S_4sid2Yd_1 1 & $3 / 9 \mathrm{~B}$ & TDP-108 & 9340090 \\
\hline 21.9 & 0.998 & 0.00500 & 0.050 & 0.186 & 40.0 & $\mathrm{P}$ & NA & 6.25 & 6.34 & \begin{tabular}{|l|l|}
6.39 \\
\end{tabular} & 6.50 & 6.00 & 23.00 & NA & NA & NA & NA & NA & NA & 1 & 0.0 & 4 & NA & NA & NA & 34S_4s1d2Yd_1 & 3/9B & TDP-108 & 9340092 \\
\hline 21.9 & 0.999 & 0.00500 & 0.050 & 0.187 & 37.6 & $\mathrm{P}$ & NA & 6.63 & 6.74 & 6.79 & 6.90 & 6.00 & 30.50 & NA & NA & NA & NA & NA & NA & 1 & 0.0 & NA & NA & NA & NA & 34S_4s1d2Yd_1 & $3 / 98$ & TDP-108 & 9340093 \\
\hline 21.9 & 0.998 & 0.00500 & 0.050 & 0.185 & 36.4 & $\mathrm{P}$ & NA & 6.91 & 7.02 & 7.08 & 7.25 & 6.00 & 33.25 & NA & NA & NA & NA & NA & NA & $\mathrm{I}$ & 0.0 & NA & NA & NA & NA & 34S_4s1d2Yd_1 & 3/9B & TDP-108 & 9340094 \\
\hline 12.6 & 1.000 & 0.00050 & 0.050 & 0.331 & 35.8 & $\mathrm{P}$ & NA & 3.82 & 3.86 & 3.88 & 3.95 & 4.05 & 22.50 & NA & NA & NA & NA & NA & NA & $\mathrm{D}$ & 4.6 & 1 & $\mathrm{NA}$ & $\mathrm{NA}$ & NA & 34S_4S2d2T__1 & 3/11A & TDP-112 & 9340176 \\
\hline 12.8 & 1.000 & 0.00050 & 0.050 & 0.332 & 35.0 & $\mathrm{P}$ & NA & 4.03 & 4.08 & 4.10 & 4.20 & 4.05 & 24.50 & NA & NA & NA & Ucscen & NA & NA & 1 & 0.0 & 2 & NA & NA & NA & 34S_4S2d2TC_1 & 3/11A & TDP-112 & 9340177 \\
\hline 13.1 & 1.000 & 0.00050 & 0.050 & 0.332 & 36.0 & $\mathrm{P}$ & NA & 3.93 & 3.97 & 3.99 & 4.05 & 4.05 & 23.00 & \begin{tabular}{|l|}
4.05 \\
\end{tabular} & udv & NA & NA & ucsuav & NA & 1 & 0.7 & 1 & NA & NA & NA & 34S_4S2d2TC_1 & 3/11A & TDP-112 & 9340178 \\
\hline 14.0 & 1.000 & 0.00050 & 0.050 & 0.330 & 49.0 & $\mathrm{P}$ & NA & 2.90 & 2.92 & 2.94 & 3.00 & 4.05 & 20.25 & NA & NA & NA & NA & NA & NA & (null) & NA & $\mathrm{NR}$ & NA & NA & NA & 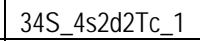 & 3/111A & TDP-112 & 9340179 \\
\hline 14.0 & 1000 & 0.00050 & 0.050 & 0.333 & 32.4 & $\mathrm{P}$ & NA & 4.35 & 4.40 & 4.42 & 4.50 & 4.05 & 43.50 & NA & NA & NA & $\mathrm{NA}$ & NA & NA & 1 & NA & $N R$ & NA & NA & NA & 34S_4s2d2TC 1 & 3/11A & TDP-112 & 9340180 \\
\hline 14.0 & 1.000 & 0.00050 & 0.050 & 0.332 & 32.6 & $\mathrm{P}$ & NA & 4.20 & 4.24 & 4.26 & 4.35 & 4.05 & 37.50 & NA & NA & NA & NA & NA & NA & $\mathrm{D}$ & NA & $\mathrm{NR}$ & $\mathrm{NA}$ & $\mathrm{NA}$ & NA & 34S_4s2d2TC_1 & 3/11A & TDP-112 & 9340181 \\
\hline 15.2 & 1.000 & 0.00155 & 0.050 & 0.332 & 36.0 & $\mathrm{P}$ & NA & 3.91 & 3.96 & 3.98 & 4.10 & 5.60 & 10.00 & NA & NA & NA & NA & NA & NA & (null) & NA & 1 & NA & NA & NA & 34S_4s2d27c_1 & 31118 & TDP-111 & 9340182 \\
\hline 15.2 & 1.000 & 0.00155 & 0.050 & 0.333 & 31.0 & $\mathrm{P}$ & NA & 4.54 & 4.60 & 4.63 & 4.70 & 5.60 & 11.00 & NA & NA & NA & NA & NA & NA & 1 & NA & 1 & NA & NA & NA & 34S_4s2d2ZC_ 1 & $3 / 11 \mathrm{~B}$ & TDP-111 & 9340183 \\
\hline 15.5 & 1.000 & 0.00155 & 0.050 & 0.334 & 29.0 & $\mathrm{P}$ & NA & 4.83 & 4.89 & 4.92 & 5.00 & 5.60 & 11.50 & NA & NA & NA & NA & NA & NA & 1 & 11.8 & 1 & NA & NA & NA & 34S_4s2d2Zc_ 1 & 3/11B & TDP-111 & 9340184 \\
\hline 16.4 & 1.000 & 0.00155 & 0.050 & 0.335 & 26.6 & $\mathrm{P}$ & NA & 5.23 & 5.31 & 5.34 & 5.40 & 5.60 & 13.25 & NA & NA & NA & NA & NA & NA & 1 & 3.5 & 1 & NA & NA & NA & 34S_4S2d27c_1 & $3 / 118$ & TDP-111 & 9340187 \\
\hline 16.6 & 1.000 & 0.00155 & 0.050 & 0.335 & 26.2 & $\mathrm{P}$ & NA & 5.37 & 5.44 & 5.48 & 5.60 & 5.60 & 14.75 & 5.60 & udv & NA & NA & ucsudv & NA & 1 & 1.7 & 1 & NA & NA & NA & 34S_4s2d27c_1 & 3/118 & TDP-111 & 9340188 \\
\hline 17.0 & 1.000 & 0.00155 & 0.050 & 0.335 & 24.9 & $\mathrm{P}$ & NA & 5.37 & 5.45 & 5.48 & 5.60 & 5.60 & 14.00 & NA & NA & NA & NA & ucsudv & NA & (null) & 2.0 & 1 & NA & NA & NA & $34 \mathrm{~S} \_4 \mathrm{~s} 2 \mathrm{~d} 2 \mathrm{Zc}$ & 3/11B & TDP-111 & 9340189 \\
\hline 17.0 & 1.000 & 0.00155 & 0.050 & 0.335 & 24.9 & $\mathrm{P}$ & NA & 5.37 & 5.45 & 5.48 & 5.60 & 5.60 & 14.00 & NA & NA & NA & NA & NA & NA & NA & 1.3 & NA & NA & NA & NA & $34 \mathrm{~S}-4 \mathrm{~s} 2 \mathrm{~d} 27 \mathrm{C}$ & 3/11B & TDP-111 & 9340190 \\
\hline 17.0 & 1.000 & 0.00155 & 0.050 & 0.335 & 24.9 & $\mathrm{P}$ & NA & 5.37 & 5.45 & 5.48 & 5.60 & 5.60 & 14.00 & NA & NA & NA & NA & NA & NA & NA & 1.4 & NA & $\mathrm{NA}$ & NA & NA & $34 \mathrm{~S} 4 \mathrm{~s} 2 \mathrm{~d} 2 \mathrm{ZZ} \mathrm{C}_{1}$ & $3 / 11 \mathrm{~B}$ & TDP-111 & 9340191 \\
\hline 17.0 & 1.000 & 0.00155 & 0.050 & 0.335 & 24.9 & $\mathrm{P}$ & NA & 5.37 & 5.45 & 5.48 & 5.60 & 5.60 & 14.00 & NA & NA & NA & NA & NA & NA & NA & 1.3 & NA & NA & $\mathrm{NA}$ & NA & 34S_4S2d27c_1 & 3/118 & TDP-111 & 9340192 \\
\hline 17.0 & 1.000 & 0.00155 & 0.050 & 0.335 & 24.9 & $\mathrm{P}$ & NA & 5.37 & 5.45 & 5.48 & 5.60 & 5.60 & 14.00 & NA & NA & NA & NA & NA & NA & NA & 0.0 & NA & NA & NA & NA & 34S_4s2d27c_1 & $3 / 11 \mathrm{~B}$ & TDP-111 & 9340193 \\
\hline 17.0 & 1.000 & 0.00155 & 0.050 & 0.335 & 24.9 & $\mathrm{P}$ & NA & 5.37 & 5.45 & 5.48 & 5.60 & 5.60 & 14.00 & NA & NA & NA & $\mathrm{NA}$ & NA & NA & NA & 1.9 & NA & NA & NA & NA & 34S_4S2d27c_1 & 3/118 & TDP-111 & 9340194 \\
\hline 17.0 & 1.000 & 0.00155 & 0.050 & 0.335 & 24.9 & $P$ & NA & 5.37 & 5.45 & 5.48 & 5.60 & 5.60 & 14.00 & NA & NA & NA & NA & NA & NA & NA & 1.3 & NA & NA & $\mathrm{NA}$ & NA & $34 \mathrm{~S} \_4 \mathrm{~s} 2 \mathrm{~d} 2 \mathrm{ZZc} 1$ & 3/118 & TDP-111 & 9340195 \\
\hline 17.0 & 1.000 & 0.00155 & 0.050 & 0.335 & 24.9 & $\mathrm{P}$ & NA & 5.37 & 5.45 & 5.48 & 5.60 & 5.60 & 14.00 & NA & NA & NA & NA & NA & NA & NA & 2.0 & NA & $\mathrm{NA}$ & $\mathrm{NA}$ & NA & $34 \mathrm{~S} 4 \mathrm{~s} 2 \mathrm{~d} 2 \mathrm{ZZ} \mathrm{C}_{1}$ & 3/11B & TDP-111 & 9340196 \\
\hline 17.0 & 1.000 & 0.00155 & 0.050 & 0.335 & 24.9 & $\mathrm{P}$ & NA & 5.37 & 5.45 & 5.48 & 5.60 & 5.60 & 14.00 & NA & NA & NA & NA & NA & NA & NA & 0.0 & NA & NA & NA & NA & 34S_4s2d27c_1 & 3/118 & TDP-111 & 9340197 \\
\hline 17.3 & 0.999 & 0.00155 & 0.050 & 0.335 & 23.6 & $\mathrm{P}$ & NA & 5.92 & 6.00 & 6.04 & 6.10 & 5.60 & 22.75 & NA & NA & NA & NA & NA & NA & $\mathrm{D}$ & 0.0 & 4 & NA & NA & NA & 345_4s2d2ZC_ 1 & 3/118 & TDP-111 & 9340198 \\
\hline 17.3 & 0.999 & 0.00155 & 0.050 & 0.337 & 22.4 & $\mathrm{P}$ & NA & 6.20 & 6.29 & 6.34 & 6.50 & 5.60 & 28.50 & NA & NA & NA & NA & NA & NA & 1 & 0.0 & 4 & NA & NA & NA & 34S_4S2d27c_1 & $3 / 118$ & TDP-111 & 9340199 \\
\hline 17.9 & 0.999 & 0.00155 & 0.050 & 0.335 & 28.1 & $\mathrm{P}$ & NA & 5.36 & 5.43 & 5.47 & 5.60 & 5.60 & NA & NA & NA & NA & NA & NA & NA & (null) & 0.0 & NA & NA & NA & NA & $34 \mathrm{~S} \_4 \mathrm{~s} 2 \mathrm{~d} 2 \mathrm{Z} \mathrm{c} \_1$ & 3/11B & TDP-111 & 9340200 \\
\hline 18.7 & 0.999 & 0.00500 & 0.050 & 0.189 & 30.4 & $\mathrm{P}$ & NA & 8.21 & 8.36 & 8.44 & 8.60 & 9.20 & 12.25 & NA & NA & NA & NA & NA & NA & 1 & 7.8 & 1 & $\mathrm{NA}$ & $\mathrm{NA}$ & NA & 34S_4S2d2Yd_1 & $3 / 11 \mathrm{c}$ & TDP-113 & 9340201 \\
\hline 19.0 & 0.999 & 0.00500 & 0.050 & 0.189 & 29.6 & $\mathrm{P}$ & NA & 8.36 & 8.52 & 8.60 & 8.80 & 9.20 & 12.25 & NA & NA & NA & NA & NA & NA & 1 & 4.3 & 1 & NA & NA & NA & 34S_4S2d2Yd_1 & $3 / 11 \mathrm{c}$ & TDP-113 & 9340202 \\
\hline 19.2 & 0.999 & 0.00500 & 0.050 & 0.185 & 28.8 & $\mathrm{P}$ & NA & 8.75 & 8.92 & 9.01 & 9.20 & 9.20 & 13.00 & 9.20 & udv & NA & NA & ucsuav & NA & $\mathrm{I}$ & 0.7 & 1 & NA & NA & NA & 34S_4s2d2Yd_1 & $3 / 11 \mathrm{C}$ & TDP-113 & 9340203 \\
\hline 19.2 & 0.999 & 0.00500 & 0.050 & 0.185 & 28.0 & $\mathrm{P}$ & NA & 8.97 & 9.15 & 9.24 & 9.40 & 9.20 & 13.00 & NA & NA & Ucsis & NA & NA & NA & 1 & 0.0 & 3 & NA & NA & NA & 34S_4s2d2Yd_1 & $3 / 11 \mathrm{c}$ & TDP-113 & 9340204 \\
\hline 19.4 & 0.999 & 0.00500 & 0.050 & 0.187 & 25.0 & $\mathrm{P}$ & NA & 10.01 & 10.24 & 10.36 & 10.60 & 9.20 & 20.50 & NA & NA & NA & NA & NA & NA & 1 & 0.0 & 4 & NA & NA & NA & 34S_4S2d2Yd_ 1 & $3 / 11 \mathrm{c}$ & TDP-113 & 9340205 \\
\hline
\end{tabular}


Table B.4. Data from 2008 Tests in Mid-Scale Vessel with Spherical Head A.4

\begin{tabular}{|c|c|c|c|c|c|c|c|c|c|c|c|c|c|c|c|c|c|c|c|c|c|c|c|c|c|c|c|}
\hline $\begin{array}{l}\text { Row } \\
\text { Number }\end{array}$ & Test & Case ID & $\begin{array}{l}\text { Tank } \\
\text { Diameter }\end{array}$ & $\begin{array}{l}\text { Head } \\
\text { Shape }\end{array}$ & $\begin{array}{l}\text { Dish } \\
\text { Height }\end{array}$ & $\begin{array}{c}\text { Dish } \\
\text { Volume }\end{array}$ & $\begin{array}{c}\text { Tank } \\
\text { Fill } \\
\text { Height }\end{array}$ & $\begin{array}{l}\text { Retum } \\
\text { Line } \\
\text { Height }\end{array}$ & $\begin{array}{c}\text { Nozzle } \\
\text { Inner } \\
\text { Diameter }\end{array}$ & $\begin{array}{l}\text { Nozzle } \\
\text { Standoff } \\
\text { Distance }\end{array}$ & $\begin{array}{l}\text { Pulse Tube } \\
\text { Configuration }\end{array}$ & $\begin{array}{l}\text { Installed } \\
\text { Nozzles }\end{array}$ & $\begin{array}{l}\text { Outer } \\
\text { Nobzeles } \\
\text { Operated }\end{array}$ & $\begin{array}{l}\text { Inner } \\
\text { Nozzles } \\
\text { Operated }\end{array}$ & $\begin{array}{l}\text { Pulse Tube } \\
\text { Outer } \\
\text { Diamenter }\end{array}$ & $\begin{array}{c}\text { Outer } \\
\text { PJM } \\
\text { Radius }\end{array}$ & $\begin{array}{c}\text { Inner } \\
\text { PMM } \\
\text { Radius }\end{array}$ & $\begin{array}{c}\text { "FO' Outer } \\
\text { PJM } \\
\text { Impingement } \\
\text { Angle }\end{array}$ & $\begin{array}{l}\text { "FO' Inner PJM } \\
\text { Impingement } \\
\text { Angle }\end{array}$ & $\begin{array}{l}\text { Ratio Outer } \\
\text { PJMt to Tank } \\
\text { Radius }\end{array}$ & $\begin{array}{l}\text { Ratio Inner } \\
\text { PJMt to Tank } \\
\text { Radius } \\
\end{array}$ & Simulant & $\begin{array}{l}\text { Solids } \\
\text { Density }\end{array}$ & $\begin{array}{c}\text { Particle } \\
\text { Diameter d5 }\end{array}$ & $\begin{array}{l}\text { Particle } \\
\text { Diameter } \\
\text { d50 }\end{array}$ & $\begin{array}{l}\text { Particle } \\
\text { Diamteter } \\
\text { d955 }\end{array}$ & $\begin{array}{l}\text { Void } \\
\text { Fraction }\end{array}$ \\
\hline text & text & text & in. & text & in. & in. ${ }^{3}$ & in. & in. & in. & in. & text & number & number & number & in. & in. & in. & deg & deg & nondim & nondim & text & $\mathrm{g} / \mathrm{cm}^{3}$ & $m$ & $m$ & $\mathrm{~m}$ & fraction \\
\hline MSS & MDDX & ID & D & HS & Hish & $V_{\text {dath }}$ & $\mathrm{H}$ & Rtn & d & sod & PT & $\mathrm{N}$ & $\mathrm{Nb}$ & $\mathrm{N}$ & $\mathrm{PT}_{\alpha \mathrm{d}}$ & $R_{0}$ & $R$ & $\theta_{\circ}$ & $\theta_{1}$ & $\mathrm{Rol} R$ & $R / R$ & sxdx & $\rho_{\mathrm{s}}$ & $d \mathrm{~d}$ & $\mathrm{~d}_{\mathrm{s}}$ & des & vf \\
\hline 93402060 & $3 / 11 \mathrm{c}$ & $34 S_{3} 4 \mathrm{~s} 2 \mathrm{~d} 2 \mathrm{Yd} \_1$ & $337 / 8$ & $\mathrm{~s}$ & 9 & 4437.4 & 72 & 66 & 0.297 & 0.446 & HLP-22 & 12 & 8 & 4 & 1.9 & 10.5 & 5.7 & 30.8 & 16.1 & 0.62 & 0.33 & $\mathrm{~s} 2 \mathrm{~d} 2$ & 4.18 & 0.0000609 & 0.0000756 & 0.0000931 & 0.3684 \\
\hline 9340207 & $3 / 12 \mathrm{~A}$ & $34 \mathrm{~S} \_4 \mathrm{~s} 2 \mathrm{~d} 2 \mathrm{Yc} \_1$ & $337 / 8$ & $\mathrm{~s}$ & 9 & 4437.4 & 72 & 66 & 0.297 & 0.446 & HLP-22 & 12 & 8 & 4 & 1.9 & 10.5 & 5.7 & 30.8 & 16.1 & 0.62 & 0.33 & $\mathrm{~s} 2 \mathrm{~d} 2$ & 4.18 & 0.0000609 & 0.0000756 & 0.0000931 & 0.3684 \\
\hline 9340208 & $3 / 12 \mathrm{~A}$ & $34 \mathrm{~S} \_4 \mathrm{~s} 2 \mathrm{~d} 2 \mathrm{Yc} \_1$ & $337 / 8$ & $\mathrm{~s}$ & 9 & 4437.4 & 72 & 66 & 0.297 & 0.446 & HLP-22 & 12 & 8 & 4 & 1.9 & 10.5 & 5.7 & 30.8 & 16.1 & 0.62 & 0.33 & $\mathrm{~s} 2 \mathrm{~d} 2$ & 4.18 & 0.0000609 & 0.0000756 & 0.0000931 & 0.3684 \\
\hline 9340209 & $3 / 12 \mathrm{~A}$ & $34 \mathrm{~S} \_4 \mathrm{~s} 2 \mathrm{~d} 2 \mathrm{Yc} \_1$ & $337 / 8$ & $\mathrm{~s}$ & 9 & 4437.4 & 72 & 66 & 0.297 & 0.446 & HLP-22 & 12 & 8 & 4 & 1.9 & 10.5 & 5.7 & 30.8 & 16.1 & 0.62 & 0.33 & $\mathrm{~s} 2 \mathrm{~d} 2$ & 4.18 & 0.0000609 & 0.0000756 & 0.0000931 & 0.3684 \\
\hline $9340210 \mathrm{M}$ & $3 / 12 \mathrm{~A}$ & $34 \mathrm{~S} \_4 \mathrm{~s} 2 \mathrm{~d} 2 \mathrm{Yc} \_1$ & $337 / 8$ & $\mathrm{~s}$ & 9 & 4437.4 & 72 & 66 & 0.297 & 0.446 & HLP-22 & 12 & 8 & 4 & 1.9 & 10.5 & 5.7 & 30.8 & 16.1 & 0.62 & 0.33 & $\mathrm{~s} 2 \mathrm{~d} 2$ & 4.18 & 0.0000609 & 0.0000756 & 0.0000931 & 0.3684 \\
\hline 9340211 & $312 \mathrm{~A}$ & 345_4s2d2YC__1 & $337 / 8$ & $\mathrm{~s}$ & 9 & 4437.4 & 72 & 66 & 0.297 & 0.446 & HLP-22 & 12 & 8 & 4 & 1.9 & 10.5 & 5.7 & 30.8 & 16.1 & 0.62 & 0.33 & $\mathrm{~s} 2 \mathrm{~d} 2$ & 4.18 & 0.0000609 & 0.0000756 & 0.0000931 & 0.3684 \\
\hline 9340212 & $3 / 12 \mathrm{~A}$ & $34 S_{4} 4 \mathrm{~s} 2 \mathrm{~d} 2 \mathrm{YC} \_1$ & $337 / 8$ & $\mathrm{~s}$ & 9 & $\begin{array}{lll}4437.4 \\
\end{array}$ & 72 & 66 & 0.297 & 0.446 & HLP-22 & 12 & 8 & 4 & 1.9 & 10.5 & 5.7 & 30.8 & 16.1 & 0.62 & 0.33 & $\mathrm{~s} 2 \mathrm{~d} 2$ & 4.18 & 0.0000609 & 0.0000756 & 0.0000931 & 0.3684 \\
\hline 9340213 & $3 / 12 \mathrm{~A}$ & $34 \mathrm{~S} \_4 \mathrm{~s} 2 \mathrm{~d} 2 \mathrm{Yc} \_1$ & $337 / 8$ & $\mathrm{~s}$ & 9 & 4437.4 & 72 & 66 & 0.297 & 0.446 & HLP-22 & 12 & 8 & 4 & 1.9 & 10.5 & 5.7 & 30.8 & 16.1 & 0.62 & 0.33 & $\mathrm{~s} 2 \mathrm{~d} 2$ & 4.18 & 0.0000609 & 0.0000756 & 0.0000931 & 0.3684 \\
\hline 9340214 & $3 / 12 \mathrm{~A}$ & $34 \mathrm{~S} \_4 \mathrm{~s} 2 \mathrm{~d} 2 \mathrm{Yc} \_1$ & $337 / 8$ & $\mathrm{~s}$ & 9 & 4437.4 & 72 & 66 & 0.297 & 0.446 & HLP-22 & 12 & 8 & 4 & 1.9 & 10.5 & 5.7 & 30.8 & 16.1 & 0.62 & 0.33 & $\mathrm{~s} 2 \mathrm{~d} 2$ & 4.18 & 0.0000609 & 0.0000756 & 0.0000931 & 0.3684 \\
\hline 9340215 & $3 / 12 \mathrm{~A}$ & $34 \mathrm{~S} \_4 \mathrm{~s} 2 \mathrm{~d} 2 \mathrm{YC} \_1$ & $337 / 8$ & $\mathrm{~s}$ & 9 & 4437.4 & 72 & 66 & 0.297 & 0.446 & HLP-22 & 12 & 8 & 4 & 1.9 & 10.5 & 5.7 & 30.8 & 16.1 & 0.62 & 0.33 & $\mathrm{~s} 2 \mathrm{~d} 2$ & 4.18 & 0.0000609 & 0.0000756 & 0.0000931 & 0.3684 \\
\hline 9340216 & 3/12A & 34S_4s2d2YC_1 & $337 / 8$ & $\mathrm{~s}$ & 9 & 4437.4 & 72 & 66 & 0.297 & 0.446 & HLP-22 & 12 & 8 & 4 & 1.9 & 10.5 & 5.7 & 30.8 & 16.1 & 0.62 & 0.33 & $\mathrm{~s} 2 \mathrm{~d} 2$ & 4.18 & 0.0000609 & 0.0000756 & 0.0000931 & 0.3684 \\
\hline $9340217 \mathrm{M}$ & $3 / 12 \mathrm{~A}$ & 34S_4s2d2YC_1 & $337 / 8$ & $\mathrm{~s}$ & 9 & $\begin{array}{lll}4437.4 \\
\end{array}$ & 72 & 66 & 0.297 & 0.446 & HLP-22 & 12 & 8 & 4 & 1.9 & 10.5 & 5.7 & 30.8 & 16.1 & 0.62 & 0.33 & $\mathrm{~s} 2 \mathrm{~d} 2$ & 4.18 & 0.0000609 & 0.0000756 & 0.0000931 & 0.3684 \\
\hline 9340218M & $3 / 12 \mathrm{~A}$ & $34 \mathrm{~S} \_4 \mathrm{~s} 2 \mathrm{~d} 2 \mathrm{Yc} \_1$ & $337 / 8$ & $\mathrm{~s}$ & 9 & 4437.4 & 72 & 66 & 0.297 & 0.446 & HLP-22 & 12 & 8 & 4 & 1.9 & 10.5 & 5.7 & 30.8 & 16.1 & 0.62 & 0.33 & $\mathrm{~s} 2 \mathrm{~d} 2$ & 4.18 & 0.0000609 & 0.0000756 & 0.0000931 & 0.3684 \\
\hline 9340219 & $3 / 12 \mathrm{C}$ & $34 \mathrm{~S} \_4 \mathrm{~s} 2 \mathrm{~d} 2 \mathrm{X} \_1$ & $337 / 8$ & $\mathrm{~s}$ & 9 & 4437.4 & 72 & 66 & 0.297 & 0.446 & HLP-22 & 12 & 8 & 4 & 1.9 & 10.5 & 5.7 & 30.8 & 16.1 & 0.62 & 0.33 & $\mathrm{~s} 2 \mathrm{~d} 2$ & 4.18 & 0.0000609 & 0.0000756 & 0.0000931 & 0.3684 \\
\hline $9340220 \mathrm{M}$ & $3 / 12 \mathrm{C}$ & $34 \mathrm{~S} \_4 \mathrm{~s} 2 \mathrm{~d} 2 \mathrm{x} \mathrm{C}_{1}$ & $337 / 8$ & $\mathrm{~s}$ & 9 & 4437.4 & 72 & 66 & 0.297 & 0.446 & HLP-22 & 12 & 8 & 4 & 1.9 & 10.5 & 5.7 & 30.8 & 16.1 & 0.62 & 0.33 & $\mathrm{~s} 2 \mathrm{~d} 2$ & 4.18 & 0.0000609 & 0.0000756 & 0.0000931 & 0.3684 \\
\hline 9340221 & $3 / 12 \mathrm{C}$ & $345 \_452 d 2 \times c_{1} 1$ & $337 / 8$ & $\mathrm{~s}$ & 9 & 4437.4 & 72 & 66 & 0.297 & 0.446 & HLP-22 & 12 & 8 & 4 & 1.9 & 10.5 & 5.7 & 30.8 & 16.1 & 0.62 & 0.33 & $\mathrm{~s} 2 \mathrm{~d} 2$ & 4.18 & 0.0000609 & 0.0000756 & 0.0000931 & 0.3684 \\
\hline 9340222 & $3 / 12 \mathrm{C}$ & $34 \mathrm{~S}_{4} 4 \mathrm{~s} 2 \mathrm{~d} 2 \mathrm{2} \times 1$ & $337 / 8$ & $\mathrm{~s}$ & 9 & $\begin{array}{lll}4437.4 \\
\end{array}$ & 72 & 66 & 0.297 & 0.446 & HLP-22 & 12 & 8 & 4 & 1.9 & 10.5 & 5.7 & 30.8 & 16.1 & 0.62 & 0.33 & $\mathrm{~s} 2 \mathrm{~d} 2$ & 4.18 & 0.0000609 & 0.0000756 & 0.0000931 & 0.3684 \\
\hline 9340223 & $3 / 12 \mathrm{C}$ & $34 \mathrm{~S}_{-} 4 \mathrm{~s} 2 \mathrm{~d} 2 \mathrm{X} \mathrm{c}_{-} 1$ & $337 / 8$ & $s$ & 9 & 4437.4 & 72 & 66 & 0.297 & 0.446 & HLP-22 & 12 & 8 & 4 & 1.9 & 10.5 & 5.7 & 30.8 & 16.1 & 0.62 & 0.33 & $\mathrm{~s} 2 \mathrm{~d} 2$ & 4.18 & 0.0000609 & 0.0000756 & 0.0000931 & 0.3684 \\
\hline 9340224 & $3 / 12 \mathrm{C}$ & $345 \_452 d 2 \times{ }_{1} \_1$ & $337 / 8$ & $\mathrm{~s}$ & 9 & 4437.4 & 72 & 66 & 0.297 & 0.446 & HLP-22 & 12 & 8 & 4 & 1.9 & 10.5 & 5.7 & 30.8 & 16.1 & 0.62 & 0.33 & $\mathrm{~s} 2 \mathrm{~d} 2$ & 4.18 & 0.0000609 & 0.0000756 & 0.0000931 & 0.3684 \\
\hline 9340225 & $3 / 12 \mathrm{C}$ & $34 \mathrm{~S} \_4 \mathrm{~s} 2 \mathrm{~d} 2 \times \mathrm{C}_{1} 1$ & $337 / 8$ & $\mathrm{~s}$ & 9 & 4437.4 & 72 & 66 & 0.297 & 0.446 & HLP-22 & 12 & 8 & 4 & 1.9 & 10.5 & 5.7 & 30.8 & 16.1 & 0.62 & 0.33 & $\mathrm{~s} 2 \mathrm{~d} 2$ & 4.18 & 0.0000609 & 0.0000756 & 0.0000931 & 0.3684 \\
\hline 9340226 & $3 / 12 \mathrm{C}$ & $345 \_4 \mathrm{~s} 2 \mathrm{~d} 2 \mathrm{2} \times \mathrm{c}_{1} 1$ & $337 / 8$ & $\mathrm{~s}$ & 9 & 4437.4 & 72 & 66 & 0.297 & 0.446 & HLP-22 & 12 & 8 & 4 & 1.9 & 10.5 & 5.7 & 30.8 & 16.1 & 0.62 & 0.33 & $\mathrm{~s} 2 \mathrm{~d} 2$ & 4.18 & 0.0000609 & 0.0000756 & 0.0000931 & 0.3684 \\
\hline 9340227 & $3 / 12 \mathrm{C}$ & $345 \_4 s 2 d 2 x c_{1} 1$ & $337 / 8$ & $\mathrm{~s}$ & 9 & 4437.4 & 72 & 66 & 0.297 & 0.446 & HLP-22 & 12 & 8 & 4 & 1.9 & 10.5 & 5.7 & 30.8 & 16.1 & 0.62 & 0.33 & $\mathrm{~s} 2 \mathrm{~d} 2$ & 4.18 & 0.0000609 & 0.0000756 & 0.0000931 & 0.3684 \\
\hline $9340228 \mathrm{M}$ & $3 / 12 \mathrm{C}$ & $34 \mathrm{~S}_{4} 4 \mathrm{~s} 2 \mathrm{~d} 2 \times \mathrm{c}_{1} 1$ & $337 / 8$ & $\mathrm{~s}$ & 9 & $\begin{array}{lll}4437.4 \\
\end{array}$ & 72 & 66 & 0.297 & 0.446 & HLP-22 & 12 & 8 & 4 & 1.9 & 10.5 & 5.7 & 30.8 & 16.1 & 0.62 & 0.33 & $\mathrm{~s} 2 \mathrm{~d} 2$ & 4.18 & 0.0000609 & 0.0000756 & 0.0000931 & 0.3684 \\
\hline 9340229 & $3 / 12 \mathrm{C}$ & $345 \_452 d 2 \times{ }_{1} \_1$ & $337 / 8$ & $\mathrm{~s}$ & 9 & 4437.4 & 72 & 66 & 0.297 & 0.446 & HLP-22 & 12 & 8 & 4 & 1.9 & 10.5 & 5.7 & 30.8 & 16.1 & 0.62 & 0.33 & $\mathrm{~s} 2 \mathrm{~d} 2$ & 4.18 & 0.0000609 & 0.0000756 & 0.0000931 & 0.3684 \\
\hline $9340230 \mathrm{M}$ & $3 / 12 \mathrm{C}$ & $34 \mathrm{~S} \_4 \mathrm{~s} 2 \mathrm{~d} 2 \times \mathrm{C}_{1} 1$ & $337 / 8$ & $\mathrm{~s}$ & 9 & 4437.4 & 72 & 66 & 0.297 & 0.446 & HLP-22 & 12 & 8 & 4 & 1.9 & 10.5 & 5.7 & 30.8 & 16.1 & 0.62 & 0.33 & $\mathrm{~s} 2 \mathrm{~d} 2$ & 4.18 & 0.0000609 & 0.0000756 & 0.0000931 & 0.3684 \\
\hline 9340231 & $3 / 12 \mathrm{D}$ & $345 \_4 \mathrm{~s} 2 \mathrm{~d} 2 \mathrm{2} \times \mathrm{c} 2$ & $337 / 8$ & $\mathrm{~s}$ & 9 & 4437.4 & 72 & 66 & 0.297 & 0.446 & HLP-22 & 12 & 8 & 4 & 1.9 & 10.5 & 5.7 & 30.8 & 16.1 & 0.62 & 0.33 & $\mathrm{~s} 2 \mathrm{~d} 2$ & 4.18 & 0.0000609 & 0.0000756 & 0.0000931 & 0.3684 \\
\hline 9340232M & $3 / 12 \mathrm{D}$ & $345 \_4 s 2 d 2 \times c \_2$ & $337 / 8$ & $\mathrm{~s}$ & 9 & 4437.4 & 72 & 66 & 0.297 & 0.446 & HLP-22 & 12 & 8 & 4 & 1.9 & 10.5 & 5.7 & 30.8 & 16.1 & 0.62 & 0.33 & $\mathrm{~s} 2 \mathrm{~d} 2$ & 4.18 & 0.0000609 & 0.0000756 & 0.0000931 & 0.3684 \\
\hline 9340233M & 3/12E & 34S_4s $2 \mathrm{~d} 2 \times \mathrm{b} \_1$ & $337 / 8$ & $s$ & 9 & 4437.4 & 72 & 66 & 0.297 & 0.446 & HLP-22 & 12 & 8 & 4 & 1.9 & 10.5 & 5.7 & 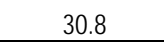 & & 0.62 & 0.33 & & 4.18 & 0.0000609 & 0.0000756 & 0.0000931 & \\
\hline 3340234M & $3 / 12 \mathrm{~F}$ & $=$ & & & 9 & 4437.4 & 70 & 66 & 0.297 & 0.446 & & 12 & & 4 & & 10.5 & 5.7 & 30.8 & & & 0.33 & s2d1 & & 0.0001399 & 0.0001642 & 0.0001924 & \\
\hline
\end{tabular}


Table B.4. Data from 2008 Tests in Mid-Scale Vessel with Spherical Head B.4

\begin{tabular}{|c|c|c|c|c|c|c|c|c|c|c|c|c|c|c|c|c|c|c|c|c|c|c|c|c|c|c|c|c|c|}
\hline $\begin{array}{l}\text { Tank Water } \\
\text { Temperature }\end{array}$ & $\begin{array}{l}\text { Water } \\
\text { Density }\end{array}$ & $\begin{array}{l}\text { Solids } \\
\text { Fraction }\end{array}$ & $\begin{array}{l}\text { Pulse } \\
\text { Volume } \\
\text { Fraction }\end{array}$ & $\begin{array}{l}\text { Duty } \\
\text { Cyde }\end{array}$ & $\begin{array}{l}\text { cycle } \\
\text { Time }\end{array}$ & $\begin{array}{c}\text { Pulsed } \\
\text { or } \\
\text { Steady } \\
\text { Jet } \\
\end{array}$ & $\begin{array}{c}\text { Us } \\
\text { Steacy } \\
\text { Jet }\end{array}$ & $\begin{array}{c}\text { U1 } \\
\text { Pulsing } \\
\text { Jet } \\
\text { Jet }\end{array}$ & $\begin{array}{c}\text { U2 } \\
\text { URMS }\end{array}$ & $\begin{array}{c}\text { U3 } \\
\text { URMB }\end{array}$ & $\begin{array}{c}\text { Discharge } \\
\text { Velocity }\end{array}$ & $\begin{array}{c}\text { Citical } \\
\text { Suspension } \\
\text { Velocity }\end{array}$ & $\begin{array}{c}\text { Average } \\
\text { Peak loud } \\
\text { Height } \\
\end{array}$ & $\begin{array}{c}\text { ucs } \\
\text { Condition }\end{array}$ & $\begin{array}{c}\text { UCS } \\
\text { Method }\end{array}$ & $\begin{array}{l}\text { UCS } \\
\text { Hag }\end{array}$ & $\begin{array}{c}\text { UCS } \\
\text { Center } \\
\text { Flag }\end{array}$ & $\begin{array}{c}\text { ucs udv } \\
\text { Hag }\end{array}$ & $\begin{array}{c}\text { UCS based } \\
\text { on } \\
\text { oceasing } \\
\text { Velocity } \\
\end{array}$ & $\begin{array}{c}\text { Smeep } \\
\text { Increase/ } \\
\text { Decrease }\end{array}$ & $\begin{array}{c}\text { UDV } \\
\text { Height } \\
\text { Bed }\end{array}$ & $\begin{array}{l}\text { Particle } \\
\text { Notion }\end{array}$ & $\begin{array}{l}\text { Solids } \\
\text { Level }\end{array}$ & $\begin{array}{c}\text { Outer } \\
\text { Bototom } \\
\text { Paterm }\end{array}$ & $\begin{array}{c}\text { Inner } \\
\text { Bottom } \\
\text { Patterm }\end{array}$ & Case ID & Test & TDP & $\begin{array}{l}\text { Row } \\
\text { Number }\end{array}$ \\
\hline $\mathrm{C}$ & $\mathrm{g} / \mathrm{cm}^{3}$ & fraction & fraction & fraction & $\mathrm{s}$ & text & $\mathrm{m} / \mathrm{s}$ & $\mathrm{m} / \mathrm{s}$ & $\mathrm{m} / \mathrm{s}$ & $\mathrm{m} / \mathrm{s}$ & $\mathrm{m} / \mathrm{s}$ & $\mathrm{m} / \mathrm{s}$ & in. & m/s & text & text & text & text & $\mathrm{m} / \mathrm{s}$ & text & $\mathrm{mm}$ & text & text & text & text & text & text & text & text \\
\hline$T$ & $\rho$ & $\phi_{\mathrm{s}}$ & $\phi_{p}$ & $\mathrm{DC}$ & $t_{c}$ & Jet & $u_{s}$ & $\mathrm{U}_{1}$ & $\mathrm{U} 2$ & U3 & $u$ & $u_{\text {ss }}$ & $H_{k}$ & Ussp & Usu & Ussis & Uscen & Usoudv & $u_{s} D$ & $S_{w}$ & $H_{\text {tod }}$ & PM & Sol & $\mathrm{SP}_{0}$ & $\mathrm{SP}_{1}$ & ID & MDDX & TDP & MSS \\
\hline 19.5 & 0.999 & 0.00500 & 0.050 & 0.186 & 26.6 & $P$ & $\mathrm{NA}$ & 9.41 & 9.62 & 9.72 & 10.00 & 9.20 & 17.75 & $\mathrm{NA}$ & NA & NA & NA & NA & NA & D & 0.0 & 4 & NA & NA & NA & 34S_4s2d2Yd_1 & $3 / 11 c$ & TDP-113 & 9340206 \\
\hline 19.9 & 0.999 & 0.00500 & 0.050 & 0.336 & 18.1 & $\mathrm{P}$ & NA & 7.59 & 7.74 & 7.81 & 8.00 & 8.60 & 11.25 & NA & NA & NA & NA & NA & NA & (null) & NA & 1 & NA & NA & NA & $345 \_452 \mathrm{~d} 2 \mathrm{YC} \_1$ & $3 / 12 \mathrm{~A}$ & TDP-114 & 9340207 \\
\hline 20.1 & 0.999 & 0.00500 & 0.050 & 0.335 & 18.0 & $P$ & NA & 7.82 & 7.96 & 8.03 & 8.20 & 8.60 & 12.50 & NA & NA & NA & NA & NA & NA & 1 & 5.1 & 1 & NA & NA & NA & $34 \mathrm{~S} \_4 \mathrm{~s} 2 \mathrm{~d} 2 \mathrm{YC} \_1$ & $3 / 12 \mathrm{~A}$ & TDP-114 & 9340208 \\
\hline 20.1 & 0.998 & 0.00500 & 0.050 & 0.335 & 17.6 & $\mathrm{P}$ & NA & 7.98 & 8.13 & 8.21 & 8.40 & 8.60 & 14.25 & NA & NA & NA & NA & NA & NA & 1 & 4.1 & 1 & NA & NA & NA & $34 \mathrm{~S} \_4 \mathrm{~s} 2 \mathrm{~d} 2 \mathrm{YC} \_1$ & $3 / 12 \mathrm{~A}$ & TDP-114 & 9340209 \\
\hline 20.8 & 0.999 & 0.00500 & 0.050 & 0.336 & 17.0 & $\mathrm{P}$ & NA & 8.17 & 8.33 & 8.41 & 8.60 & 8.60 & 18.50 & \begin{tabular}{|l|}
8.60 \\
\end{tabular} & udv & ucsis & NA & ucsudv & NA & (null) & 0.0 & 3 & NA & NA & NA & $345 \_452 \mathrm{~d} 2 \mathrm{Yc} \_1$ & $3 / 12 \mathrm{~A}$ & TDP-114 & 9340210 \\
\hline 20.8 & 0.999 & 0.00500 & 0.050 & 0.336 & 17.0 & $\mathrm{P}$ & NA & 8.17 & 8.33 & 8.41 & 8.60 & 8.60 & 18.50 & \begin{tabular}{|l|} 
NA \\
\end{tabular} & NA & NA & NA & NA & NA & NA & 0.0 & NA & NA & NA & NA & 34S_4s2d2Yc_1 & $3 / 12 \mathrm{~A}$ & TDP-114 & 9340211 \\
\hline 20.8 & 0.999 & 0.00500 & 0.050 & 0.336 & 17.0 & $\mathrm{P}$ & NA & 8.17 & 8.33 & 8.41 & 8.60 & 8.60 & 18.50 & NA & NA & NA & NA & NA & NA & NA & 0.0 & NA & NA & NA & NA & $34 \mathrm{~S} \_4 \mathrm{~s} 2 \mathrm{~d} 2 \mathrm{Yc} \_1$ & 3/12A & TDP-114 & 9340212 \\
\hline 20.8 & 0.999 & 0.00500 & 0.050 & 0.336 & 17.0 & $\mathrm{P}$ & NA & 8.17 & 8.33 & 8.41 & 8.60 & 8.60 & 18.50 & NA & NA & NA & NA & NA & NA & NA & 0.0 & NA & NA & NA & NA & 34S_4s2d2YC_ I & $3 / 12 \mathrm{~A}$ & TDP-114 & 9340213 \\
\hline 20.8 & 0.999 & 0.00500 & 0.050 & 0.336 & 17.0 & $\mathrm{P}$ & NA & 8.17 & 8.33 & 8.41 & 8.60 & 8.60 & 18.50 & NA & NA & NA & NA & NA & NA & NA & 0.0 & NA & NA & NA & NA & 34s_4s $2 \mathrm{~d} 2 \mathrm{YC} \_1$ & $3 / 12 \mathrm{~A}$ & TDP-114 & 9340214 \\
\hline 20.8 & 0.999 & 0.00500 & 0.050 & 0.336 & 17.0 & $\mathrm{P}$ & NA & 8.17 & 8.33 & 8.41 & 8.60 & 8.60 & 18.50 & NA & NA & NA & NA & NA & NA & NA & 0.0 & NA & NA & NA & NA & 34S_4s2d2Yc_1 & $3 / 12 \mathrm{~A}$ & TDP-114 & 9340215 \\
\hline 20.8 & 0.999 & 0.00500 & 0.050 & 0.336 & 17.0 & $\mathrm{P}$ & NA & 8.17 & 8.33 & 8.41 & 8.60 & 8.60 & 18.50 & NA & NA & NA & NA & NA & NA & NA & 0.0 & NA & NA & NA & NA & $34 \mathrm{~S} \_4 \mathrm{~s} 2 \mathrm{~d} 2 \mathrm{Yc} \_1$ & $3 / 12 \mathrm{~A}$ & TDP-114 & 9340216 \\
\hline 21.0 & 0.999 & 0.00500 & 0.050 & 0.337 & 16.4 & $\mathrm{P}$ & NA & 8.53 & 8.70 & 8.78 & 9.00 & 8.60 & 20.75 & NA & NA & NA & NA & NA & NA & 1 & 0.0 & 4 & NA & NA & NA & $34 \mathrm{~S} \_452 \mathrm{~d} 2 \mathrm{Yc} \_1$ & 3/12A & TDP-114 & 9340217 \\
\hline 21.1 & 0.999 & 0.00500 & 0.050 & 0.338 & 15.4 & $P$ & NA & 9.06 & 9.24 & 9.34 & 9.60 & 8.60 & 27.50 & NA & NA & NA & NA & NA & NA & 1 & 0.0 & 4 & NA & NA & NA & 34S_4s2d2YC_1 & $312 \mathrm{~A}$ & TDP-114 & 9340218 \\
\hline 21.5 & 0.999 & 0.01500 & 0.051 & 0.349 & 15.2 & $P$ & NA & NA & NA & NA & 9.80 & 9.80 & NA & NA & NA & NA & NA & UCSudv & NA & NA & 1.3 & NA & NA & $\mathrm{NA}$ & NA & $34 \mathrm{~S}_{4} 4 \mathrm{~s} 2 \mathrm{~d} 2 \times \mathrm{c}_{1} 1$ & $312 \mathrm{C}$ & TDP-115 & 9340219 \\
\hline 21.8 & 0.998 & 0.01500 & 0.050 & 0.339 & 14.8 & $\mathrm{P}$ & NA & $\begin{array}{ll}9.41 \\
\end{array}$ & 9.62 & 9.72 & 10.00 & 9.80 & 10.50 & NA & NA & NA & NA & NA & NA & 1 & 0.0 & 4 & NA & NA & NA & 34S_4s2d2Xc_1 & $312 \mathrm{C}$ & TDP-115 & 9340220 \\
\hline 21.8 & 0.998 & 0.01500 & 0.050 & 0.339 & 14.8 & $\mathrm{P}$ & NA & 9.41 & 9.62 & 9.72 & 10.00 & 9.80 & 10.50 & NA & NA & NA & NA & NA & NA & NA & 0.0 & NA & NA & NA & NA & $34 \mathrm{~S} \_4 \mathrm{~s} 2 \mathrm{~d} 2 \mathrm{Xc} \_1$ & $3 / 12 \mathrm{C}$ & TDP-115 & 9340221 \\
\hline 21.8 & 0.998 & 0.01500 & 0.050 & 0.339 & 14.8 & $\mathrm{P}$ & NA & 9.41 & 9.62 & 9.72 & 10.00 & 9.80 & 10.50 & NA & NA & NA & NA & NA & NA & NA & 0.6 & NA & NA & NA & NA & $34 \mathrm{~S} \_452 \mathrm{~d} 2 \times \mathrm{C}_{1}$ & $3 / 12 \mathrm{C}$ & TDP-115 & 9340222 \\
\hline 21.8 & 0.998 & 0.01500 & 0.050 & 0.339 & 14.8 & $\mathrm{P}$ & NA & 9.41 & 9.62 & 9.72 & 10.00 & 9.80 & 10.50 & NA & NA & NA & NA & NA & NA & NA & 0.0 & NA & NA & NA & NA & 34S_4s2d2Xc_1 & $3 / 12 \mathrm{C}$ & TDP-115 & 9340223 \\
\hline 21.8 & 0.998 & 0.01500 & 0.050 & 0.339 & 14.8 & $\mathrm{P}$ & NA & 9.41 & 9.62 & 9.72 & 10.00 & 9.80 & 10.50 & NA & NA & NA & NA & NA & NA & NA & 0.6 & NA & NA & NA & NA & $345 \_452 \mathrm{~d} 2 \times \mathrm{c}_{1} 1$ & $312 \mathrm{C}$ & TDP-115 & 9340224 \\
\hline 21.8 & 0.998 & 0.01500 & 0.050 & 0.339 & 14.8 & $\mathrm{P}$ & NA & 9.41 & 9.62 & 9.72 & 10.00 & 9.80 & 10.50 & NA & NA & NA & NA & NA & NA & NA & 0.0 & NA & NA & NA & NA & 34S_4s2d2Xc_1 & 3/12C & TDP-115 & 9340227 \\
\hline 22.7 & 0.999 & 0.01500 & 0.050 & 0.337 & 12.8 & $\mathrm{P}$ & NA & 10.80 & 11.06 & 11.20 & 11.60 & 9.80 & 14.75 & NA & NA & NA & NA & NA & NA & 1 & NA & 4 & NA & NA & NA & $34 \mathrm{~S} \_4 \mathrm{~s} 2 \mathrm{~d} 2 \mathrm{Xc} \_1$ & $3 / 12 \mathrm{C}$ & TDP-115 & 9340228 \\
\hline 22.5 & 0.998 & 0.01500 & 0.050 & 0.332 & 16.0 & $\mathrm{P}$ & NA & 8.81 & 8.99 & 9.08 & 9.30 & 9.80 & 9.25 & NA & NA & NA & NA & $\mathrm{NA}$ & NA & $\mathrm{D}$ & 4.0 & 1 & NA & $\mathrm{NA}$ & NA & $34 \mathrm{~S}_{4} 4 \mathrm{~s} 2 \mathrm{~d} 2 \mathrm{2} \times 1$ & $312 \mathrm{C}$ & TDP-115 & 9340229 \\
\hline 22.6 & 0.998 & 0.01500 & 0.050 & 0.333 & 15.2 & $\mathrm{P}$ & NA & 9.23 & 9.43 & 9.53 & 9.80 & 9.80 & 10.00 & \begin{tabular}{|l|}
9.80 \\
\end{tabular} & udv & ucsis & NA & ucsudv & NA & 1 & 2.1 & 3 & NA & NA & NA & $34 \mathrm{~S}_{4} 4 \mathrm{~s} 2 \mathrm{~d} 2 \times \mathrm{c}_{1}$ & $3 / 12 \mathrm{C}$ & TDP-115 & 9340230 \\
\hline 22.6 & 0.998 & 0.01500 & 0.100 & 0.330 & 45.0 & $\mathrm{P}$ & NA & 6.30 & 6.35 & 6.38 & 6.50 & 6.70 & 9.25 & \begin{tabular}{|l|} 
NA \\
\end{tabular} & NA & NA & NA & NA & NA & 1 & 3.7 & 1 & NA & NA & NA & $345 \_4 \mathrm{~s} 2 \mathrm{~d} 2 \times \mathrm{C}_{2} 2$ & 3/12D & TDP-115 & 9340231 \\
\hline 22.7 & 0.998 & 0.01500 & 0.101 & 0.331 & 44.0 & $P$ & NA & 6.48 & 6.54 & 6.57 & 6.70 & 6.70 & 9.25 & \begin{tabular}{|l|}
6.70 \\
\end{tabular} & ur & NA & NA & ucsudv & NA & & 0.6 & 1 & NA & NA & NA & $34 \mathrm{~S} \_4 \mathrm{~s} 2 \mathrm{~d} 2 \times \mathrm{c}_{2}$ & 3/12D & TDP-115 & 9340232 \\
\hline 22.7 & 0.998 & 0.01500 & 0.050 & 0.504 & 11.0 & $\mathrm{P}$ & NA & 8.42 & 8.58 & 8.66 & 8.80 & 8.80 & 12.25 & 8.80 & udv & NA & NA & ucsudv & NA & 1 & 1.3 & 1 & NA & NA & NA & 34S_4s2d2Xb_1 & 3/12E & TDP-115 & 9340233 \\
\hline 13.4 & 1.000 & 0.00500 & 0.050 & 0.340 & 14.0 & $\mathrm{P}$ & NA & 9.83 & 10.04 & 10.15 & 10.40 & 10.40 & 11.75 & 10.40 & udv & UCSis & NA & ucsudv & NA & & 0.0 & 3 & $\mathrm{NA}$ & NA & NA & 34S_4s2d1Yc_1 & 3/12F & TDP-116 & 9340234 \\
\hline
\end{tabular}


Table B.5. Data from 2008 Tests in Large-Scale Vessel with Elliptical Head A.1

\begin{tabular}{|c|c|c|c|c|c|c|c|c|c|c|c|c|c|c|c|c|c|c|c|c|c|c|c|c|c|c|c|}
\hline $\begin{array}{c}\text { Row } \\
\text { Number }\end{array}$ & Test & Case ID & $\begin{array}{l}\text { Tank } \\
\text { Diameter }\end{array}$ & $\begin{array}{l}\text { Head } \\
\text { Shape }\end{array}$ & $\begin{array}{c}\text { Dish } \\
\text { Height }\end{array}$ & $\begin{array}{c}\text { Dish } \\
\text { Volume }\end{array}$ & $\begin{array}{c}\text { Tank } \\
\text { Fill } \\
\text { Height }\end{array}$ & \begin{tabular}{|l} 
Retur \\
Line \\
Height
\end{tabular} & $\begin{array}{c}\text { Nozzle } \\
\text { Inner } \\
\text { Diameter }\end{array}$ & $\begin{array}{l}\text { Nozzle } \\
\text { Stlantoff } \\
\text { Distance }\end{array}$ & $\begin{array}{l}\text { Pulse Tube } \\
\text { Configuration }\end{array}$ & $\begin{array}{l}\text { Installed } \\
\text { Nozzles }\end{array}$ & $\begin{array}{c}\text { Outer } \\
\text { Noztes } \\
\text { Operated }\end{array}$ & $\begin{array}{l}\text { Inner } \\
\text { Nozles } \\
\text { Opperated }\end{array}$ & $\begin{array}{l}\text { Pulse Tube } \\
\text { Outer } \\
\text { Diameter }\end{array}$ & $\begin{array}{c}\text { Outer } \\
\text { PJM } \\
\text { Radius } \\
\text { Pans }\end{array}$ & \begin{tabular}{c|} 
Inner \\
PJM \\
Radius \\
Ratis
\end{tabular} & $\begin{array}{c}\text { "FOC' Outer } \\
\text { PJM } \\
\text { Impingement } \\
\text { Angle } \\
\end{array}$ & $\begin{array}{c}\text { "FIO" Inner PJM } \\
\text { Impingement } \\
\text { Angle }\end{array}$ & $\begin{array}{c}\text { Ratio Outer } \\
\text { PJM to Tank } \\
\text { Radius } \\
\end{array}$ & $\begin{array}{c}\text { Ratio Inner } \\
\text { PJM to Tank } \\
\text { Radius } \\
\end{array}$ & simulant & $\begin{array}{l}\text { Solids } \\
\text { Density }\end{array}$ & $\begin{array}{c}\text { Partice } \\
\text { Diameter d5 }\end{array}$ & $\begin{array}{c}\text { Particle } \\
\text { Dianter } \\
\text { d50 }\end{array}$ & $\begin{array}{c}\text { Particle } \\
\text { Diameter } \\
\text { d95 }\end{array}$ & $\begin{array}{l}\text { Void } \\
\text { Fraction }\end{array}$ \\
\hline text & text & text & in. & text & in. & in. ${ }^{3}$ & in. & in. & in. & in. & text & number & number & number & in. & in. & in. & deg & deg & nondim & nondim & text & $\mathrm{g} / \mathrm{cm}^{3}$ & $\mathrm{~m}$ & $\mathrm{~m}$ & $\mathrm{~m}$ & fraction \\
\hline MSS & MDDX & ID & D & HS & Hosh & $V_{\text {dsh }}$ & $\mathrm{H}$ & $\operatorname{Rtn}$ & $d$ & sod & PT & $\mathrm{N}$ & $\mathrm{Nb}$ & $\mathrm{N}$ & $\mathrm{PT}_{\alpha \mathrm{d}}$ & $R_{0}$ & $R$ & $\theta_{\circ}$ & $\theta_{1}$ & $R d R$ & $R, \mathbb{R}$ & sxdx & $\rho_{\mathrm{s}}$ & $d_{5}$ & $d_{60}$ & $d_{65}$ & vf \\
\hline 9700001 & $5 / 8 \mathrm{~A}$ & 70E_4s1d2ZC 1 & 70 & $E$ & 19 & 4970.7 & 93 & 80 & 0.613 & 0.920 & HLP-22 & 12 & 8 & 4 & 3.5 & 21.9 & 11.5 & 20.3 & 10.5 & 0.62 & 0.33 & $\mathrm{~s} 1 \mathrm{~d} 2$ & 2.48 & 0.0000569 & 0.0000693 & 0.0000821 & 0.3750 \\
\hline 9700002 & $5 / 8 \mathrm{~A}$ & 70E_4s1d2Zc_ 1 & 70 & $\mathrm{E}$ & 19 & 4970.7 & 93 & 80 & 0.613 & 0.920 & HLP-22 & 12 & 8 & 4 & 3.5 & 21.9 & 11.5 & 20.3 & 10.5 & 0.62 & 0.33 & $\mathrm{sid2}$ & 2.48 & 0.0000569 & 0.0000693 & 0.0000821 & 0.3750 \\
\hline 9700003M & $5 / 2 \mathrm{~A}$ & 70E_4s1d2ZC__1 & 70 & E & 19 & 49770.7 & 93 & 80 & 0.613 & 0.920 & HLP-22 & 12 & 8 & 4 & 3.5 & 21.9 & 11.5 & 20.3 & 10.5 & 0.62 & 0.33 & $\mathrm{~s} 1 \mathrm{d2} 2$ & 2.48 & 0.0000569 & 0.00000693 & 0.0000821 & 0.3750 \\
\hline $9700004 \mathrm{M}$ & $5 / 8 \mathrm{~A}$ & 70E_4s1d2ZC_ 1 & 70 & E & 19 & 49770.7 & 93 & 80 & 0.613 & 0.920 & HLP-22 & 12 & 8 & 4 & 3.5 & 21.9 & 11.5 & 20.3 & 10.5 & 0.62 & 0.33 & $\mathrm{~s} 1 \mathrm{~d} 2$ & 2.48 & 0.0000569 & 0.0000693 & 0.0000821 & 0.3750 \\
\hline $9700013 \mathrm{M}$ & $5 / 8 \mathrm{~A}$ & 70E_4s1d27c_ 1 & 70 & $\mathrm{E}$ & 19 & 49770.7 & 93 & 80 & 0.613 & 0.920 & HLP-22 & 12 & 8 & 4 & 3.5 & 21.9 & 11.5 & 20.3 & 10.5 & 0.62 & 0.33 & s1d2 & 2.48 & 0.0000569 & 0.0000693 & 0.0000821 & 0.3750 \\
\hline $9700014 \mathrm{M}$ & $5 / 8 \mathrm{~A}$ & 70E $4 \mathrm{~s} 1 \mathrm{~d} 27 \mathrm{c} 1$ & 70 & E & 19 & 49770.7 & 93 & 80 & 0.613 & 0.920 & HLP-22 & 12 & 8 & 4 & 3.5 & 21.9 & 11.5 & 20.3 & 10.5 & 0.62 & 0.33 & $\mathrm{~s} 1 \mathrm{~d} 2$ & 2.48 & 0.0000569 & 0.0000693 & 0.0000821 & 0.3750 \\
\hline 9700014.1 & $5 / 9 A$ & 70E_4s1d2ZC_1 1 & 70 & E & 19 & 49770.7 & 93 & 80 & 0.613 & 0.920 & HLP-22 & 12 & 8 & 4 & 3.5 & 21.9 & 11.5 & 20.3 & 10.5 & 0.62 & 0.33 & $\mathrm{~s} 1 \mathrm{~d} 2$ & 2.48 & 0.0000569 & 0.0000693 & 0.0000821 & 0.3750 \\
\hline $9700015 \mathrm{M}$ & $5 / 9 A$ & 70E_4s1d2ZC__1 & 70 & E & 19 & 49770.7 & 93 & 80 & 0.613 & 0.920 & HLP-22 & 12 & 8 & 4 & 3.5 & 21.9 & 11.5 & 20.3 & 10.5 & 0.62 & 0.33 & s1d2 & 2.48 & 0.0000569 & 0.0000693 & 0.0000821 & 0.3750 \\
\hline 9700016 & $5 / 9 \mathrm{~A}$ & 70E_4s1d2Zc_ 1 & 70 & $\mathrm{E}$ & 19 & 4970.7 & 93 & 80 & 0.613 & 0.920 & HLP-22 & 12 & 8 & 4 & 3.5 & 21.9 & 11.5 & 20.3 & 10.5 & 0.62 & 0.33 & $\mathrm{~s} 1 \mathrm{~d} 2$ & 2.48 & 0.0000569 & 0.0000693 & 0.0000821 & 0.3750 \\
\hline 9700017 & 5/9A & 70E_4s1d27C_ 1 & 70 & E & 19 & 4970.7 & 93 & 80 & 0.613 & 0.920 & HLP-22 & 12 & 8 & 4 & 3.5 & 21.9 & 11.5 & 20.3 & 10.5 & 0.62 & 0.33 & $\mathrm{sid2}$ & 2.48 & 0.0000569 & 0.0000693 & 0.0000821 & 0.3750 \\
\hline 9700018 & $5 / 9 \mathrm{~A}$ & 70E_4s1d27C__ I & 70 & $\mathrm{E}$ & 19 & 4970.7 & 93 & 80 & 0.613 & 0.920 & HLP-22 & 12 & 8 & 4 & 3.5 & 21.9 & 111.5 & 20.3 & 10.5 & 0.62 & 0.33 & $\mathrm{~s} 1 \mathrm{~d} 2$ & 2.48 & 0.0000569 & 0.0000693 & 0.0000821 & 0.3750 \\
\hline 9700019 & $5 / 9 A$ & 70E_4s1d2Zc_ 1 & 70 & $\mathrm{E}$ & 19 & 49770.7 & 93 & 80 & 0.613 & 0.920 & HLP-22 & 12 & 8 & 4 & 3.5 & 21.9 & 11.5 & 20.3 & 10.5 & 0.62 & 0.33 & $\mathrm{~s} 1 \mathrm{~d} 2$ & 2.48 & 0.0000569 & 0.0000693 & 0.0000821 & 0.3750 \\
\hline 9700020 & $5 / 9 A$ & 70E_4sid2ZC_ 1 & 70 & E & 19 & 49770.7 & 93 & 80 & 0.613 & 0.920 & HLP-22 & 12 & 8 & 4 & 3.5 & 21.9 & 11.5 & 20.3 & 10.5 & 0.62 & 0.33 & $\mathrm{~s} 1 \mathrm{~d} 2$ & 2.48 & 0.0000569 & 0.0000693 & 0.0000821 & 0.3750 \\
\hline 9700021 & $5 / 9 \mathrm{~A}$ & 70E_4s1d2Zc_ 1 & 70 & $\mathrm{E}$ & 19 & 4970.7 & 93 & 80 & 0.613 & 0.920 & HLP-22 & 12 & 8 & 4 & 3.5 & 21.9 & 11.5 & 20.3 & 10.5 & 0.62 & 0.33 & $\mathrm{~s} 1 \mathrm{~d} 2$ & 2.48 & 0.0000569 & 0.0000693 & 0.0000821 & 0.3750 \\
\hline 9700022 & 5/9A & 70E_4s1d27c 1 & 70 & E & 19 & 4970.7 & 93 & 80 & 0.613 & 0.920 & HLP-22 & 12 & 8 & 4 & 3.5 & 21.9 & 11.5 & 20.3 & 10.5 & 0.62 & 0.33 & s1d2 & 2.48 & 0.0000569 & 0.0000693 & 0.0000821 & 0.3750 \\
\hline 9700023 & $5 / 9 \mathrm{~A}$ & 70E_4s1d27__ _ 1 & 70 & $\mathrm{E}$ & 19 & 4970.7 & 93 & 80 & 0.613 & 0.920 & HLP-22 & 12 & 8 & 4 & 3.5 & 21.9 & 11.5 & 20.3 & 10.5 & 0.62 & 0.33 & $\mathrm{sid2}$ & 2.48 & 0.0000569 & 0.0000693 & 0.0000821 & 0.3750 \\
\hline 9700024 & $5 / 9 B$ & 70E_4s1d2Zd_ 1 & 70 & $\mathrm{E}$ & 19 & 49770.7 & 93 & 80 & 0.613 & 0.920 & HLP-22 & 12 & 8 & 4 & 3.5 & 21.9 & 11.5 & 20.3 & 10.5 & 0.62 & 0.33 & $\mathrm{sid2}$ & 2.48 & 0.0000569 & 0.0000693 & 0.0000821 & 0.3750 \\
\hline 9700025 & $5 / 98$ & 70E_4sid2Zd_ 1 & 70 & E & 19 & 49770.7 & 93 & 80 & 0.613 & 0.920 & HLP-22 & 12 & 8 & 4 & 3.5 & 21.9 & 11.5 & 20.3 & 10.5 & 0.62 & 0.33 & $\mathrm{~s} 1 \mathrm{~d} 2$ & 2.48 & 0.0000569 & 0.0000693 & 0.0000821 & 0.3750 \\
\hline 9700026 & $5 / 9 B$ & 70E_4s1d2Zd 1 & 70 & $\mathrm{E}$ & 19 & 4970.7 & 93 & 80 & 0.613 & 0.920 & HLP-22 & 12 & 8 & 4 & 3.5 & 21.9 & 11.5 & 20.3 & 10.5 & 0.62 & 0.33 & $\mathrm{~s} 1 \mathrm{~d} 2$ & 2.48 & 0.0000569 & 0.0000693 & 0.0000821 & 0.3750 \\
\hline $9700027 \mathrm{M}$ & $5 / 98$ & 70E_ 4s1d27d 1 & 70 & E & 19 & 4970.7 & 93 & 80 & 0.613 & 0.920 & HLP-22 & 12 & 8 & 4 & 3.5 & 21.9 & 11.5 & 20.3 & 10.5 & 0.62 & 0.33 & $\mathrm{sid} 2$ & 2.48 & 0.0000569 & 0.0000693 & 0.0000821 & 0.3750 \\
\hline $9700028 \mathrm{M}$ & $5 / 98$ & 70E_4s1d27d_ 1 & 70 & $\mathrm{E}$ & 19 & 4970.7 & 93 & 80 & 0.613 & 0.920 & HLP-22 & 12 & 8 & 4 & 3.5 & 21.9 & 11.5 & 20.3 & 10.5 & 0.62 & 0.33 & $\mathrm{sid2}$ & 2.48 & 0.0000569 & 0.0000693 & 0.0000821 & 0.3750 \\
\hline $9700029 \mathrm{M}$ & $5 / 98$ & 70E_4s1d27d_ 1 & 70 & $\mathrm{E}$ & 19 & 4970.7 & 93 & 80 & 0.613 & 0.920 & HLP-22 & 12 & 8 & 4 & 3.5 & 21.9 & 11.5 & 20.3 & 10.5 & 0.62 & 0.33 & $\mathrm{sid2}$ & 2.48 & 0.0000569 & 0.0000693 & 0.0000821 & 0.3750 \\
\hline $9700030 \mathrm{M}$ & $5 / 98$ & 70E_4sid2Zd_ 1 & 70 & E & 19 & 49770.7 & 93 & 80 & 0.613 & 0.920 & HLP-22 & 12 & 8 & 4 & 3.5 & 21.9 & 11.5 & 20.3 & 10.5 & 0.62 & 0.33 & s1d2 & 2.48 & 0.0000569 & 0.0000693 & 0.0000821 & 0.3750 \\
\hline 9700031 & 5/12A & 70E_4s1d2Yc_ 1 & 70 & $E$ & 19 & 49770.7 & 93 & 80 & 0.613 & 0.920 & HLP-22 & 12 & 8 & 4 & 3.5 & 21.9 & 11.5 & 20.3 & 10.5 & 0.62 & 0.33 & $\mathrm{~s} 1 \mathrm{~d} 2$ & 2.48 & 0.0000569 & 0.0000693 & 0.0000821 & 0.3750 \\
\hline 9700032 & $5 / 12 \mathrm{~A}$ & 70E_4s1d2YC 1 & 70 & E & 19 & 4970.7 & 93 & 80 & 0.613 & 0.920 & HLP-22 & 12 & 8 & 4 & 3.5 & 21.9 & 11.5 & 20.3 & 10.5 & 0.62 & 0.33 & $\mathrm{sid} 2$ & 2.48 & 0.0000569 & 0.0000693 & 0.0000821 & 0.3750 \\
\hline 9700033 & $5 / 12 \mathrm{~A}$ & 70E_4s1d2YC_ 1 & 70 & $\mathrm{E}$ & 19 & 49770.7 & 93 & 80 & 0.613 & 0.920 & HLP-22 & 12 & 8 & 4 & 3.5 & 21.9 & 11.5 & 20.3 & 10.5 & 0.62 & 0.33 & $\mathrm{sid2}$ & 2.48 & 0.0000569 & 0.0000693 & 0.0000821 & 0.3750 \\
\hline 9700034 & 5/12A & 70E_4s1d2Yc_ 1 & 70 & $\mathrm{E}$ & 19 & 49770.7 & 93 & 80 & 0.613 & 0.920 & HLP-22 & 12 & 8 & 4 & 3.5 & 21.9 & 11.5 & 20.3 & 10.5 & 0.62 & 0.33 & $\mathrm{sid2}$ & 2.48 & 0.0000569 & 0.0000693 & 0.0000821 & 0.3750 \\
\hline $9700035 \mathrm{M}$ & 5/2A & 70E_4SId2YC_ 1 & 70 & $E$ & 19 & 4970.7 & 93 & 80 & 0.613 & 0.920 & HLP-22 & 12 & 8 & 4 & 3.5 & 21.9 & 11.5 & 20.3 & 10.5 & 0.62 & 0.33 & $\mathrm{sid2}$ & 2.48 & 0.0000569 & 0.0000693 & 0.0000821 & 0.3750 \\
\hline 9700035.1 & $5 / 12 \mathrm{~A}$ & 70E_ 4s1d2Yc 1 & 70 & $E$ & 19 & 4970.7 & 93 & 80 & 0.613 & 0.920 & HLP-22 & 12 & 8 & 4 & 3.5 & 21.9 & 11.5 & 20.3 & 10.5 & 0.62 & 0.33 & $\mathrm{~s} 1 \mathrm{~d} 2$ & 2.48 & 0.0000569 & 0.0000693 & 0.0000821 & 0.3750 \\
\hline $9700036 \mathrm{M}$ & $5 / 12 \mathrm{~A}$ & 70E_4S1d2YC 1 & 70 & E & 19 & 4970.7 & 93 & 80 & 0.613 & 0.920 & HLP-22 & 12 & 8 & 4 & 3.5 & 21.9 & 11.5 & 20.3 & 10.5 & 0.62 & 0.33 & s1d2 & 2.48 & 0.0000569 & 0.0000693 & 0.0000821 & 0.3750 \\
\hline 9700037 & 5/12A & 70E_4S1d2YC_ 1 & 70 & $\mathrm{E}$ & 19 & 4970.7 & 93 & 80 & 0.613 & 0.920 & HLP-22 & 12 & 8 & 4 & 3.5 & 21.9 & 11.5 & 20.3 & 10.5 & 0.62 & 0.33 & $\mathrm{~s} 1 \mathrm{~d} 2$ & 2.48 & 0.0000569 & 0.0000693 & 0.0000821 & 0.3750 \\
\hline 9700038 & 5/12A & 70E_4S1d2YC__1 & 70 & $\mathrm{E}$ & 19 & 49770.7 & 93 & 80 & 0.613 & 0.920 & HLP-22 & 12 & 8 & 4 & 3.5 & 21.9 & 11.5 & 20.3 & 10.5 & 0.62 & 0.33 & s1d2 & 2.48 & 0.0000569 & 0.0000693 & 0.0000821 & 0.3750 \\
\hline 9700039 & $5 / 12 \mathrm{~A}$ & 70E_4sId2YYC 1 & 70 & $E$ & 19 & 49770.7 & 93 & 80 & 0.613 & 0.920 & HLP-22 & 12 & 8 & 4 & 3.5 & 21.9 & 11.5 & 20.3 & 10.5 & 0.62 & 0.33 & $\mathrm{sid2}$ & 2.48 & 0.0000569 & 0.0000693 & 0.0000821 & 0.3750 \\
\hline 9700040 & $5 / 12 \mathrm{~A}$ & 70E_4s1d2YY__1 & 70 & $E$ & 19 & 4970.7 & 93 & 80 & 0.613 & 0.920 & HLP-22 & 12 & 8 & 4 & 3.5 & 21.9 & 11.5 & 20.3 & 10.5 & 0.62 & 0.33 & s1d2 & 2.48 & 0.0000569 & 0.0000693 & 0.0000821 & 0.3750 \\
\hline 9700041 & $5 / 12 \mathrm{~A}$ & 70E_ $4 \mathrm{~s} 1 \mathrm{~d} 2 \mathrm{VYC} 1$ & 70 & E & 19 & 4970.7 & 93 & 80 & 0.613 & 0.920 & HLP-22 & 12 & 8 & 4 & 3.5 & 21.9 & 11.5 & 20.3 & 10.5 & 0.62 & 0.33 & $\mathrm{sid} 2$ & 2.48 & 0.0000569 & 0.0000693 & 0.0000821 & 0.3750 \\
\hline 9700042 & $5 / 12 \mathrm{~A}$ & 70E_4s1d2YC_ 1 & 70 & $\mathrm{E}$ & 19 & 4970.7 & 93 & 80 & 0.613 & 0.920 & HLP-22 & 12 & 8 & 4 & 3.5 & 21.9 & 11.5 & 20.3 & 10.5 & 0.62 & 0.33 & $\mathrm{sid2}$ & 2.48 & 0.0000569 & 0.0000693 & 0.0000821 & 0.3750 \\
\hline 9700043 & 5/12A & 70E_4S1d2YC__1 & 70 & $\mathrm{E}$ & 19 & 49770.7 & 93 & 80 & 0.613 & 0.920 & HLP-22 & 12 & 8 & 4 & 3.5 & 21.9 & 11.5 & 20.3 & 10.5 & 0.62 & 0.33 & s1d2 & 2.48 & 0.0000569 & 0.0000693 & 0.0000821 & 0.3750 \\
\hline 9700044 & $5 / 12 \mathrm{~A}$ & 70E_4sid2Yc_1 & 70 & E & 19 & 49770.7 & 93 & 80 & 0.613 & 0.920 & HLP-22 & 12 & 8 & 4 & 3.5 & 21.9 & 11.5 & 20.3 & 10.5 & 0.62 & 0.33 & $\mathrm{~s} 1 \mathrm{~d} 2$ & 2.48 & 0.0000569 & 0.0000693 & 0.0000821 & 0.3750 \\
\hline $9700045 \mathrm{M}$ & 5/12A & $70 \mathrm{E}=4 \mathrm{~s} 1 \mathrm{~d} 2 \mathrm{YC} 1$ & 70 & $\mathrm{E}$ & 19 & 4970.7 & 93 & 80 & 0.613 & 0.920 & HLP-22 & 12 & 8 & 4 & 3.5 & 21.9 & 11.5 & 20.3 & 10.5 & 0.62 & 0.33 & $\mathrm{~s} 1 \mathrm{~d} 2$ & 2.48 & 0.0000569 & 0.0000693 & 0.0000821 & 0.3750 \\
\hline $9700046 \mathrm{M}$ & $5 / 12 \mathrm{~A}$ & 70E_ $4 \mathrm{~s} 1 \mathrm{~d}$ d2YC 1 & 70 & E & 19 & 49770.7 & 93 & 80 & 0.613 & 0.920 & HLP-22 & 12 & 8 & 4 & 3.5 & 21.9 & 11.5 & 20.3 & 10.5 & 0.62 & 0.33 & s1d12 & 2.48 & 0.0000569 & 0.0000693 & 0.0000821 & 0.3750 \\
\hline $9700047 \mathrm{M}$ & $5 / 12 \mathrm{~A}$ & $70 \mathrm{E} / \mathrm{4s} 1 \mathrm{~d} 2 \mathrm{YC} 1$ & 70 & $E$ & 19 & 4970.7 & 93 & 80 & 0.613 & 0.920 & HLP-22 & 12 & 8 & 4 & 3.5 & 21.9 & 11.5 & 20.3 & 10.5 & 0.62 & 0.33 & s1d2 & 2.48 & 0.0000569 & 0.0000693 & 0.0000821 & 0.3750 \\
\hline
\end{tabular}


Table B.5. Data from 2008 Tests in Large-Scale Vessel with Elliptical Head B.2

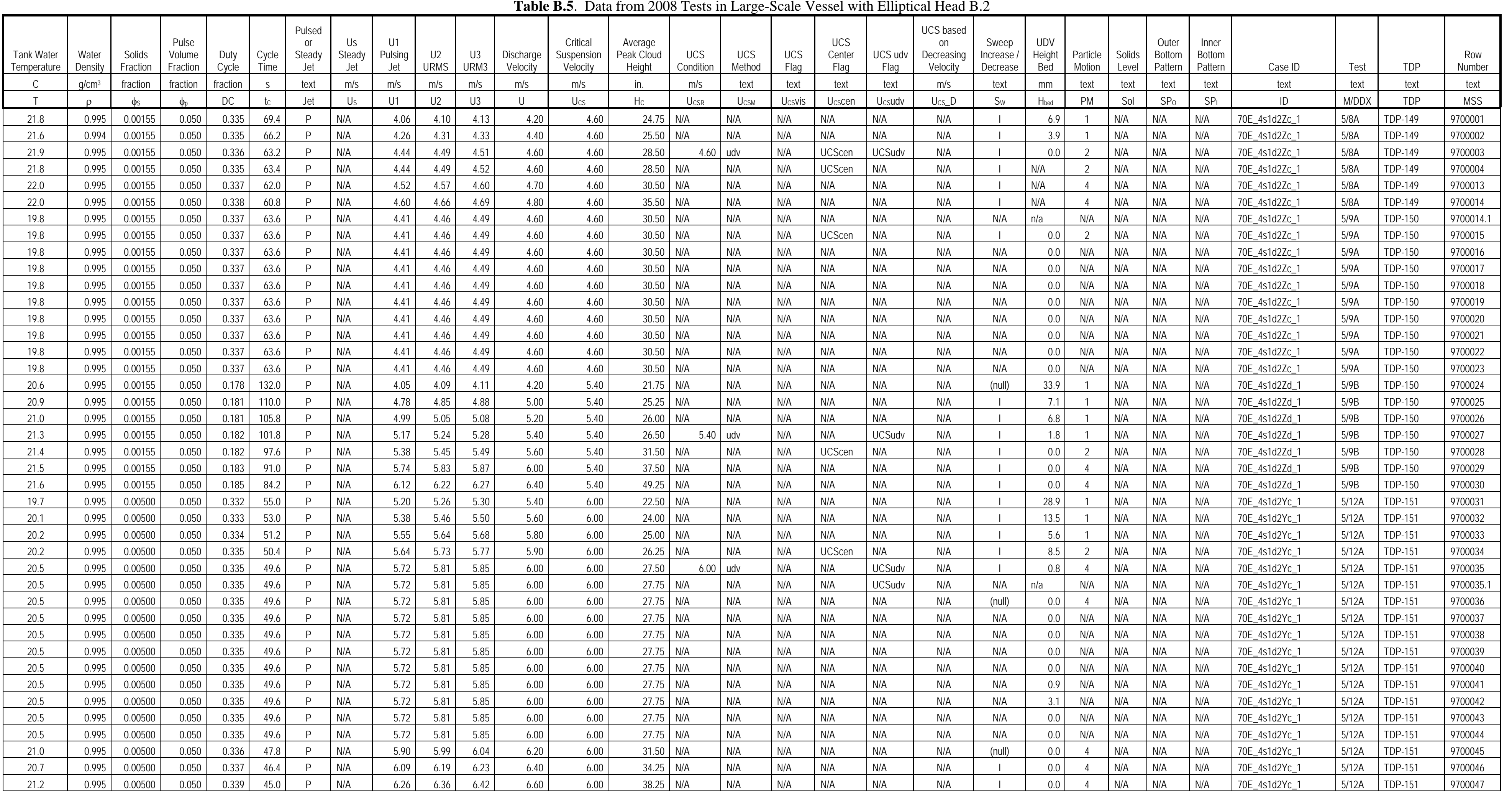


Table B.5. Data from 2008 Tests in Large-Scale Vessel with Elliptical Head A.2

\begin{tabular}{|c|c|c|c|c|c|c|c|c|c|c|c|c|c|c|c|c|c|c|c|c|c|c|c|c|c|c|c|}
\hline Row Numbe & Test & Case ID & $\begin{array}{l}\text { Tank } \\
\text { Diameter }\end{array}$ & \begin{tabular}{|l|} 
Head \\
Shape
\end{tabular} & \begin{tabular}{|l} 
Dish \\
Height
\end{tabular} & \begin{tabular}{|c|} 
Dish \\
Volume \\
\end{tabular} & $\begin{array}{l}\text { Tank FIII } \\
\text { Height }\end{array}$ & $\begin{array}{l}\text { Retum } \\
\text { Line } \\
\text { Height }\end{array}$ & $\begin{array}{l}\text { Nozzle } \\
\text { lnner } \\
\text { Diameter }\end{array}$ & $\begin{array}{c}\text { Nozle } \\
\text { Stand-off } \\
\text { Distance } \\
\end{array}$ & \begin{tabular}{|c|} 
Pulse Tube \\
Configuration \\
\end{tabular} & \begin{tabular}{|l} 
Installed \\
Nozzles
\end{tabular} & 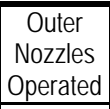 & \begin{tabular}{|c|} 
Inner \\
Nozzles \\
Operated
\end{tabular} & $\begin{array}{c}\text { Pulse Tube } \\
\text { Outer } \\
\text { Diameter }\end{array}$ & $\begin{array}{c}\text { Outer } \\
\text { PMM } \\
\text { Radius }\end{array}$ & $\begin{array}{l}\text { Inner PJM } \\
\text { Radius } \\
\end{array}$ & $\begin{array}{c}\text { "FO'O" Oter JJM } \\
\text { Impingement } \\
\text { Angle }\end{array}$ & $\begin{array}{c}\text { "7FO" Inner PJM } \\
\text { Impingement Angle }\end{array}$ & $\begin{array}{l}\begin{array}{l}\text { Ratio Outer PJn } \\
\text { to Tank Radius }\end{array} \\
\text { (a) }\end{array}$ & $\begin{array}{l}\begin{array}{l}\text { Ratio Inner PJM } \\
\text { to Tank Radius }\end{array} \\
\end{array}$ & simulant & $\begin{array}{l}\text { Solids } \\
\text { Density }\end{array}$ & \begin{tabular}{c|}
$\begin{array}{c}\text { Partide } \\
\text { Diameter d5 }\end{array}$ \\
\end{tabular} & $\begin{array}{c}\text { Particle } \\
\text { Diameter } 050\end{array}$ & \begin{tabular}{c|} 
Particle \\
Diameter d95 \\
\end{tabular} & $\begin{array}{l}\text { Void } \\
\text { Fraction } \\
\end{array}$ \\
\hline text & text & text & in. & text & in. & \begin{tabular}{|l|} 
in. ${ }^{3}$ \\
\end{tabular} & in. & in. & in. & in. & text & number & number & \begin{tabular}{|l|} 
number \\
\end{tabular} & in. & in. & in. & deg & \begin{tabular}{|c|} 
deg \\
\end{tabular} & nondim & \begin{tabular}{|c|} 
nondim \\
\end{tabular} & \begin{tabular}{|l|} 
text \\
\end{tabular} & $\mathrm{g} / \mathrm{cm}^{3}$ & $m$ & \begin{tabular}{l|}
$\mathrm{m}$ \\
\end{tabular} & $\mathrm{m}$ & fraction \\
\hline MSS & MDDX & ID & D & HS & Hash & $V_{\text {dash }}$ & $\mathrm{H}$ & Rtn & $d$ & sod & PT & $\mathrm{N}$ & $\mathrm{Nb}$ & $\mathrm{N}$ & $\mathrm{PT}_{\alpha d}$ & $R_{0}$ & $\mathrm{R}_{\mathrm{P}}$ & $\theta_{\circ}$ & $\theta_{1}$ & $R d R$ & $R / R$ & sxdx & $\rho_{\mathrm{s}}$ & $d_{5}$ & $d_{50}$ & $d_{65}$ & vf \\
\hline 9700048 & $5 / 12 \mathrm{~B}$ & 70E_4sid2Rc_1 & 70 & $E$ & 19 & 49770.7 & 93 & 80 & 0.613 & 0.920 & HLP-22 & 12 & 8 & 4 & 3.5 & 21.9 & 11.5 & 20.3 & 10.5 & 0.62 & 0.33 & $\mathrm{sid2}$ & 2.48 & 0.0000569 & 0.0000693 & 0.0000821 & 0.3750 \\
\hline 9700049 & $5 / 128$ & 70E_4S1d2Rc_1 & 70 & $E$ & 19 & 49770.7 & 93 & 80 & 0.613 & 0.920 & HLP-22 & 12 & 8 & 4 & 3.5 & 21.9 & 11.5 & 20.3 & 10.5 & 0.62 & 0.33 & s1d2 & 248 & 0.0000569 & 0.0000693 & 0.0000821 & 0.3750 \\
\hline 9700050 & $5 / 128$ & 70E_4s1d2Rc_1 & 70 & $E$ & 19 & 49770.7 & 93 & 80 & 0.613 & 0.920 & HLP-22 & 12 & 8 & 4 & 3.5 & 21.9 & 11.5 & 20.3 & 10.5 & 0.62 & 0.33 & s1d2 & 2.48 & 0.0000569 & 0.0000693 & 0.0000821 & 0.3750 \\
\hline $9700051 \mathrm{M}$ & $5 / 128$ & 70E_4s1d2Rc_1 & 70 & $E$ & 19 & 49770.7 & 93 & 80 & 0.613 & 0.920 & HLP-22 & 12 & 8 & 4 & 3.5 & 21.9 & 11.5 & 20.3 & 10.5 & 0.62 & 0.33 & sid2 & 2.48 & 0.0000569 & 0.0000693 & 0.0000821 & 0.3750 \\
\hline $9700052 \mathrm{M}$ & $5 / 13 A$ & 70E_4S1d2Rc__ & 70 & E & 19 & 49770.7 & $921 / 2$ & 80 & 0.613 & 0.920 & HLP.22 & 12 & 8 & 4 & 3.5 & 21.9 & 11.5 & 20.3 & 10.5 & 0.62 & 0.33 & s1d2 & 248 & 0.0000569 & 0.0000693 & 0.0000821 & 0.3750 \\
\hline 9700053M & $5 / 13 \mathrm{~A}$ & 70E_4s1d2Rc_1 & 70 & E & 19 & 49770.7 & $92 \mathrm{1/2}$ & 80 & 0.613 & 0.920 & HLP-22 & 12 & 8 & 4 & 3.5 & 21.9 & 11.5 & 20.3 & 10.5 & 0.62 & 0.33 & sid2 & 248 & 0.0000569 & 0.0000699 & 0.000021 & 0.3750 \\
\hline 9700054 & $5 / 13 \mathrm{~A}$ & 70E_4s1d2Rc_1 & 70 & $E$ & 19 & 49770.7 & $921 / 2$ & 80 & 0.613 & 0.920 & HLP-22 & 12 & 8 & 4 & 3.5 & 21.9 & 11.5 & 20.3 & 10.5 & 0.62 & 0.33 & $\mathrm{~s} 1 \mathrm{~d} 2$ & 248 & 0.0000569 & 0.0000693 & 0.0000821 & 0.3750 \\
\hline 9700055 & 5/13B & 7OE_4s1d2Rd_1 & 70 & E & 19 & 49770.7 & $921 / 2$ & 80 & 0.613 & 0.920 & HLP-22 & 12 & $\varepsilon$ & 4 & 3.5 & 21.9 & 11.5 & 20.3 & 10 & 0.62 & 0.33 & s1d2 & 2.48 & 0.0000569 & 0.0000693 & 0.0000821 & 0.3750 \\
\hline 9700056 & $5 / 138$ & 70E_4s1d2Rd_1 & 70 & $\mathrm{E}$ & 19 & 49770.7 & $921 / 2$ & 80 & 0.613 & 0.920 & HLP-22 & 12 & 8 & 4 & 3.5 & 21.9 & 11.5 & 20.3 & 10.5 & 0.62 & 0.33 & $\mathrm{sid2}$ & 248 & 0.0000569 & 0.0000693 & 0.0000821 & 0.3750 \\
\hline 9700057 & $5 / 138$ & 70E_4s1dRRd_1 & 70 & $E$ & 19 & 49770.7 & $921 / 2$ & 80 & 0.613 & 0.920 & HLP.22 & 12 & 8 & 4 & 3.5 & 21.9 & 11.5 & 20.3 & 10.5 & 0.62 & 0.33 & $\mathrm{sid2}$ & 248 & 0.0000569 & 0.000069 & 0.0000821 & 0.3750 \\
\hline 9700058 & $5 / 13 \mathrm{~B}$ & 70E_4s1d2Rd_1 & 70 & E & 19 & 4970.7 & $921 / 2$ & 80 & 0.613 & 0.920 & HLP-22 & 12 & 8 & 4 & 3.5 & 21.9 & 11.5 & 20.3 & 10.5 & 0.62 & 0.33 & $\mathrm{sid2}$ & 2.48 & 0.0000569 & 0.0000693 & 0.0000821 & 0.3750 \\
\hline 9700059 & $5 / 138$ & 70E_4s1d2Rd_1 & 70 & $E$ & 19 & 49770.7 & $921 / 2$ & 80 & 0.613 & 0.920 & HLP.22 & 12 & 8 & 4 & 3.5 & 21.9 & 11.5 & 20.3 & 10.5 & 0.62 & 0.33 & $\mathrm{~s} 1 \mathrm{~d} 2$ & 248 & 0.0000569 & 0.0000693 & 0.0000821 & 0.3750 \\
\hline $9700060 \mathrm{M}$ & $5 / 138$ & 70E_4s1d2Rd_1 & 70 & $E$ & 19 & 49770.7 & $921 / 2$ & 80 & 0.613 & 0.920 & HLP-22 & 12 & $\varepsilon$ & 4 & 3.5 & 21.9 & 11.5 & 20.3 & 10. & 0.62 & 0.33 & $\mathrm{sid2}$ & 2.48 & 0.0000569 & 0.0000693 & 0.0000821 & 0.3750 \\
\hline 9700061 & $5 / 13 \mathrm{C}$ & 70E_4sid2VC_1 & 70 & $E$ & 19 & 49770.7 & $921 / 2$ & 80 & 0.613 & 0.920 & HLP-22 & 12 & 8 & 4 & 3.5 & 21.9 & 11.5 & 20.3 & 10.5 & 0.62 & 0.33 & s1d2 & 2.48 & 0.0000569 & 0.0000693 & 0.0000821 & 0.3750 \\
\hline 9700062 & $5 / 13 \mathrm{C}$ & 70E_4s1d2Vc_1 & 70 & $E$ & 19 & 49770.7 & $921 / 2$ & 80 & 0.613 & 0.920 & HLP-22 & 12 & 8 & 4 & 3.5 & 21.9 & 11.5 & 20.3 & 10. & 0.62 & 0.33 & $\mathrm{sid2}$ & 2.48 & 0.0000569 & 0.0000693 & 0.0000821 & 0.3750 \\
\hline 9700063 & $5 / 13 c$ & $70 \mathrm{ZE}-4 \mathrm{~s} 1 \mathrm{~d} 2 \mathrm{Vc} \_1$ & 70 & E & 19 & 4970.7 & $921 / 2$ & 80 & 0.613 & 0.920 & HLP-22 & 12 & 8 & 4 & 3.5 & 21.9 & 11.5 & 20.3 & 10.5 & 0.62 & 0.33 & $\mathrm{~s} 1 \mathrm{~d} 2$ & 2.48 & 0.0000569 & 0.0000693 & 0.0000821 & 0.3750 \\
\hline 9700064 & $5 / 13 c$ & $70 \mathrm{7}$ _4s1d2V__1 & 70 & $E$ & 19 & 49770.7 & $921 / 2$ & 80 & 0.613 & 0.920 & HLP-22 & 12 & 8 & 4 & 3.5 & 21.9 & 11.5 & 20.3 & 10.5 & 0.62 & 0.33 & $\mathrm{~s} 1 \mathrm{~d} 2$ & 248 & 0.0000569 & 0.0000693 & 0.0000821 & 0.3750 \\
\hline 9700065 & $5 / 13 \mathrm{C}$ & 70E_4s1d2V__1 & 70 & $E$ & 19 & 49770.7 & $921 / 2$ & 80 & 0.613 & 0.920 & HLP-22 & 1 & $\varepsilon$ & 4 & 3.5 & 21.9 & 11.5 & 20. & 10. & 0.6 & 0.3 & s1d2 & 2.48 & 0.0000569 & 0.0000693 & 0.0000821 & 0.3750 \\
\hline 97000066 & $5 / 14 \mathrm{~A}$ & 70E_4s1d2V__ 1 & 70 & $E$ & 19 & 49770.7 & $921 / 2$ & 80 & 0.613 & 0.920 & HLP-22 & 12 & 8 & 4 & 3.5 & 21.9 & 11.5 & 20.3 & 10.5 & 0.62 & 0.33 & $\mathrm{sid2}$ & 2.48 & 0.0000569 & 0.0000699 & 0.0000821 & 0.3750 \\
\hline 9700067 & 5/14A & 70E_4s1d2VC_ 1 & 70 & $E$ & 19 & 49770.7 & $921 / 2$ & 80 & 0.613 & 0.920 & HLP -22 & 12 & 8 & 4 & 3.5 & 21.9 & 11.5 & 20.3 & 10. & 0.62 & 0.33 & $\mathrm{sid2}$ & 2.48 & 0.0000569 & 0.0000693 & 0.0000821 & 0.3750 \\
\hline $9700068 \mathrm{M}$ & $5 / 14 \mathrm{~A}$ & $70 \mathrm{ZE}-4 \mathrm{~s} 1 \mathrm{~d} 2 \mathrm{Vc} \_1$ & 70 & E & 19 & 4970.7 & $921 / 2$ & 80 & 0.613 & 0.920 & HLP-22 & 12 & 8 & 4 & 3.5 & 21.9 & 11.5 & 20.3 & 10.5 & 0.62 & 0.33 & $\mathrm{~s} 1 \mathrm{~d} 2$ & 2.48 & 0.0000569 & 0.0000693 & 0.0000821 & 0.3750 \\
\hline 9700069 & $5 / 14 \mathrm{~A}$ & 70E_4s1d2Vc_1 & 70 & $E$ & 19 & 49770.7 & $921 / 2$ & 80 & 0.613 & 0.920 & HLP-22 & 12 & 8 & 4 & 3.5 & 21.9 & 11.5 & 20.3 & 10.5 & 0.62 & 0.33 & $\mathrm{~s} 1 \mathrm{~d} 2$ & 2.48 & 0.0000569 & 0.0000693 & 0.0000821 & 0.3750 \\
\hline 9700070 & $5 / 14 \mathrm{~A}$ & $70 E \_4 s 1 d 2 V v_{-} 1$ & 70 & $E$ & 19 & 49770.7 & $921 / 2$ & 80 & 0.613 & 0.920 & HLP-22 & 12 & 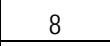 & 4 & 3.5 & 21.9 & 11.5 & 20.3 & 10. & 0.6 & 0.3 & $\mathrm{sid2}$ & 2.48 & 0.0000569 & 0.0000699 & 0.0000821 & 0.3750 \\
\hline 9700070.1 & $5 / 14 A$ & 70E_4s1d2V__1 & 70 & $E$ & 19 & 49770.7 & $921 / 2$ & 80 & 0.613 & 0.920 & HLP-22 & 12 & 8 & 4 & 3.5 & 21.9 & 11.5 & 20.3 & 10.5 & 0.62 & 0.33 & $\mathrm{sid2}$ & 248 & 0.0000569 & 0.0000693 & 0.0000821 & 0.3750 \\
\hline 9700071 & 5/14A & $70 \mathrm{E}_{4} 4 \mathrm{~s} 1 \mathrm{~d} 2 \mathrm{~V} \mathrm{C}_{1}$ & 70 & $E$ & 19 & 49770.7 & $921 / 2$ & 80 & 0.613 & 0.920 & HLP-22 & 12 & 8 & 4 & 3.5 & 21.9 & 11.5 & 20.3 & 10.5 & 0.62 & 0.33 & $\mathrm{sid2}$ & 2.48 & 0.0000569 & 0.0000693 & 0.0000821 & 0.3750 \\
\hline 9700071.1 & $5 / 14 A$ & $70 \mathrm{ZE}-4 \mathrm{~s} 1 \mathrm{~d} 2 \mathrm{Vc} \_1$ & 70 & E & 19 & 49770.7 & $921 / 2$ & 80 & 0.613 & 0.920 & HLP-22 & 12 & 8 & 4 & 3.5 & 21.9 & 11.5 & 20.3 & 10.5 & 0.62 & 0.33 & $\mathrm{~s} 1 \mathrm{~d} 2$ & 248 & 0.0000569 & 0.0000693 & 0.0000821 & 0.3750 \\
\hline 9700072 & $5 / 14 \mathrm{~A}$ & 70E_4s1d2V__1 & 70 & $E$ & 19 & 49770.7 & $921 / 2$ & 80 & 0.613 & 0.920 & HLP-22 & 12 & $\varepsilon$ & 4 & 3.5 & 21.9 & 11.5 & 20.3 & 10 & 0.62 & 0.33 & $\mathrm{~s} 1 \mathrm{~d} 2$ & 2.48 & 0.0000569 & 0.0000693 & 0.0000821 & 0.3750 \\
\hline 9700072.1 & $5 / 14 A$ & 70E_4S1d2VE__1 & 70 & $E$ & 19 & 49770.7 & $92 \mathrm{1/2}$ & 80 & 0.613 & 0.920 & HLP-22 & 12 & 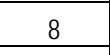 & 4 & 3.5 & 21.9 & 11.5 & 20.3 & 10. & 0.6 & 0.3 & s1d2 & 2.48 & 0.0000569 & 0.0000693 & 0.0000821 & 0.3750 \\
\hline 9700073 & $5 / 14 \mathrm{~A}$ & 70E_4s1d2VE_ 1 & 70 & $E$ & 19 & 49770.7 & $921 / 2$ & 80 & 0.613 & 0.920 & HLP-22 & 12 & $\varepsilon$ & 4 & 3.5 & 21.9 & 11.5 & 20.3 & 10 & 0. & 0.33 & s1d2 & 2.48 & 0.0000569 & 0.0000693 & 0.0000821 & 0.3750 \\
\hline 9700073.1 & 5/14A & 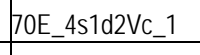 & 70 & $E$ & 19 & 49770.7 & $921 / 2$ & 80 & 0.613 & 0.920 & HLP-22 & 12 & 8 & 4 & 3.5 & 21.9 & 11.5 & 20.3 & 10. & 0.6 & 0.33 & $\mathrm{sid2}$ & 2.48 & 0.0000569 & 0.0000693 & 0.0000821 & 0.3750 \\
\hline 9700074 & $5 / 14 \mathrm{~A}$ & $70 E_{2} 4 \mathrm{~s} 1 \mathrm{~d} 2 \mathrm{~V} \mathrm{v}_{-} 1$ & 70 & $E$ & 19 & 49770.7 & $921 / 2$ & 80 & 0.613 & 0.920 & HLP-22 & 12 & 8 & 4 & 3.5 & 21.9 & 11.5 & 20.3 & & 0.6 & 0.3 & $\mathrm{sid} 2$ & 2.48 & 0.0000569 & 0.0000699 & 0.0000212 & 0.3750 \\
\hline 9700074.1 & $5 / 14 \mathrm{~A}$ & 70E_4S1d2VC_1 & 70 & $E$ & 19 & 49770.7 & $921 / 2$ & 80 & 0.613 & 0.920 & HLP-22 & 12 & 8 & 4 & 3.5 & 21.9 & 11.5 & 20.3 & 10.5 & 0.62 & 0.33 & $\mathrm{~s} 1 \mathrm{~d} 2$ & 2.48 & 0.0000569 & 0.0000693 & 0.0000821 & 0.3750 \\
\hline 9700075 & $5 / 14 A$ & 70E_4S1d2VE__1 & 70 & $E$ & 19 & 49770.7 & $921 / 2$ & 80 & 0.613 & 0.920 & HLP-22 & 1 & $\varepsilon$ & 4 & 3.5 & 21.9 & 11.5 & 20.3 & 10 & & 0.3 & s1d2 & 2.48 & 0.0000569 & 0.0000693 & 0.0000821 & 0.3750 \\
\hline 9700076 & $5 / 14 \mathrm{~A}$ & 70E_4SIIDVV__1 & 70 & $E$ & 19 & 49770.7 & $921 / 2$ & 80 & 0.613 & 0.920 & HLP-22 & 12 & 8 & 4 & 3.5 & 21.9 & 11.5 & 20.3 & 10. & 0.6 & 0.33 & s1d2 & 2.48 & 0.0000569 & 0.0000693 & 0.0000821 & 0.3750 \\
\hline 9700076.1 & $5 / 14 \mathrm{~A}$ & 70E_4sidzVc_1 & 70 & $E$ & 19 & 49770.7 & $921 / 2$ & 80 & 0.613 & 0.920 & HLP-22 & 12 & 8 & 4 & 3.5 & 21.9 & 11.5 & 20.3 & 10.5 & 0.62 & 0.33 & sid2 & 248 & 0.0000569 & 0.0000693 & 0.0000821 & 0.3750 \\
\hline 970007 & $5 / 14 \mathrm{~A}$ & 70E_4sich & 70 & $E$ & 19 & 4970.7 & $921 / 2$ & 80 & 0.613 & 0.920 & & 12 & 8 & 4 & 3.5 & 21.9 & 11.5 & 20.3 & & 0.62 & & $\mathrm{s1d2}$ & 248 & 0.0000560 & 0.0000699 & 0.0000821 & 0.3750 \\
\hline 9700077.1 & $5 / 14 \mathrm{~A}$ & 70E_4s1d2V__1 1 & 70 & $E$ & 19 & 49770.7 & $921 / 2$ & 80 & 0.613 & 0.920 & HLP-22 & 12 & 8 & 4 & 3.5 & 21.9 & 11.5 & 20.3 & 10.5 & 0.62 & 0.33 & s1d2 & 2.48 & 0.0000569 & 0.0000693 & 0.0000821 & 0.3750 \\
\hline 9700078 & $5 / 14 \mathrm{~A}$ & 70E_4s1d2VC_1 & 70 & $E$ & 19 & 49770.7 & $921 / 2$ & 80 & 0.613 & 0.920 & HLP-22 & & & & 3.5 & 21.9 & 11.5 & 20.3 & & & & $\mathrm{~s} 1 \mathrm{~d} 2$ & 2.48 & 0.0000569 & 0.0000699 & 00000821 & 0.3750 \\
\hline 9700078.1 & $5 / 14 \mathrm{~A}$ & 70E_4s1d2V__1 & 70 & $E$ & 19 & 49770.7 & $921 / 2$ & 80 & 0.613 & 0.920 & HLP-22 & 12 & $\varepsilon$ & 4 & 3.5 & 21.9 & 11.5 & 20.3 & 10.5 & 0.62 & 0.33 & $\mathrm{~s} 1 \mathrm{~d} 2$ & 2.48 & 0.0000569 & 0.0000699 & 0.0000821 & 0.3750 \\
\hline 9700079 & $5 / 14 \mathrm{~A}$ & 70E_4sIdZVC_1 & 70 & $E$ & 19 & 49770.7 & $921 / 2$ & 80 & 0.613 & 0.920 & HLP-22 & 12 & 8 & 4 & 3.5 & 21.9 & 11.5 & 20.3 & 10.5 & 0.62 & 0.33 & s1d2 & 2.48 & 0.0000569 & 0.0000693 & 0.0000821 & 0.3750 \\
\hline 700079.1 & $5 / 14 \mathrm{~A}$ & $70 \mathrm{E}_{4} 4 \mathrm{~s} 1 \mathrm{~d} 2 \mathrm{Vc} 1$ & 70 & $E$ & 19 & 49770.7 & $921 / 2$ & 80 & 0.613 & 0.920 & HLP-22 & 12 & 8 & 4 & 3.5 & 21.9 & 11.5 & 20.3 & 10.5 & 0.62 & 0.33 & $\mathrm{sid2}$ & 2.48 & 0.0000569 & 0.0000699 & 0.0000821 & 3.37 \\
\hline
\end{tabular}


Table B.5. Data from 2008 Tests in Large-Scale Vessel with Elliptical Head B.2

\begin{tabular}{|c|c|c|c|c|c|c|c|c|c|c|c|c|c|c|c|c|c|c|c|c|c|c|c|c|c|c|c|c|c|}
\hline $\begin{array}{l}\text { Tank Water } \\
\text { Temperature }\end{array}$ & \begin{tabular}{|l} 
Water \\
Density
\end{tabular} & $\begin{array}{l}\text { Solids } \\
\text { Fraction }\end{array}$ & $\begin{array}{l}\text { Pulse } \\
\text { Volume } \\
\text { Fraction }\end{array}$ & $\begin{array}{l}\text { Duty } \\
\text { cyde }\end{array}$ & $\begin{array}{l}\text { Oyde } \\
\text { Time } \\
\end{array}$ & $\begin{array}{l}\text { Pulsed or } \\
\text { Steacy Jet }\end{array}$ & $\begin{array}{c}\text { Us } \\
\text { Steady } \\
\text { Jet }\end{array}$ & \begin{tabular}{|c|} 
U1 \\
Pulsing \\
Jet \\
\end{tabular} & $\begin{array}{l}\text { U2 } \\
\text { URMS }\end{array}$ & $\begin{array}{c}\text { U3 } \\
\text { URNB3 }\end{array}$ & 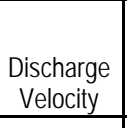 & $\begin{array}{c}\text { Citical } \\
\text { Suspension } \\
\text { Velocity }\end{array}$ & \begin{tabular}{|c|}
$\begin{array}{c}\text { Average Peak } \\
\text { Cloud hlight }\end{array}$ \\
\end{tabular} & $\begin{array}{c}\text { UCS } \\
\text { Condition }\end{array}$ & $\begin{array}{l}\text { UCS } \\
\text { Method }\end{array}$ & UCS Pag & \begin{tabular}{|c} 
Ucs Center \\
Fag
\end{tabular} & $\begin{array}{c}\text { ucs udv } \\
\text { Hag }\end{array}$ & $\begin{array}{c}\text { UCS based on } \\
\text { Decreasing } \\
\text { Velocity }\end{array}$ & \begin{tabular}{|c|} 
Sweep \\
Increase/ \\
Decrease \\
\end{tabular} & \begin{tabular}{|c|} 
UDV \\
Height \\
Bed
\end{tabular} & 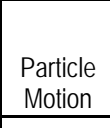 & \begin{tabular}{|l|} 
Solids \\
Level \\
\end{tabular} & \begin{tabular}{|c|} 
Outer \\
Botom \\
Paterem
\end{tabular} & \begin{tabular}{|c|} 
Inner \\
Bottom \\
Pattem \\
\end{tabular} & Case ID & Test & TDP & $\begin{array}{c}\text { Row } \\
\text { Number }\end{array}$ \\
\hline $\mathrm{c}$ & $\mathrm{g} / \mathrm{cm}^{3}$ & fraction & fraction & fraction & $\mathrm{s}$ & text & m/s & \begin{tabular}{|l|}
$\mathrm{m} / \mathrm{s}$ \\
\end{tabular} & m/s & $\mathrm{m} / \mathrm{s}$ & m/s & \begin{tabular}{|l|}
$\mathrm{m} / \mathrm{s}$ \\
\end{tabular} & in. & $\mathrm{m} / \mathrm{s}$ & text & text & text & text & \begin{tabular}{|l|}
$\mathrm{m} / \mathrm{s}$ \\
\end{tabular} & text & $\mathrm{mm}$ & text & text & text & text & text & text & text & text \\
\hline$T$ & $\rho$ & $\phi_{\mathrm{s}}$ & $\phi_{p_{p}}$ & DC & $t_{c}$ & Jet & $u_{s}$ & $\mathrm{U}_{1}$ & $\mathrm{U} 2$ & U3 & $u$ & Uss & $\mathrm{H}_{\mathrm{c}}$ & $u_{\text {ose }}$ & Uasn & Usonis & Uscen & Usuldv & $U_{\text {cs } D} \mathrm{D}$ & $s_{\mathrm{v}}$ & Hocd & $\mathrm{PM}$ & sol & SPo & $\mathrm{SP}_{\mathrm{P}}$ & $\mathrm{ID}$ & MDDX & $\mathrm{TDP}$ & MSS \\
\hline 21.9 & 0.995 & 0.01000 & 0.050 & 0.331 & 47.0 & $\mathrm{P}$ & NA & 6.09 & 6.19 & 6.24 & 6.40 & 7.00 & 24.00 & NA & NA & NA & NA & NA & NA & (null) & 23.6 & 1 & NA & NA & NA & 70E_4s1d2Rc_1 1 & $5 / 12 \mathrm{~B}$ & TDP-152 & 9700048 \\
\hline 21.9 & 0.995 & 0.01000 & 0.050 & 0.332 & 45.6 & $\mathrm{P}$ & NA & 6.29 & 6.38 & 6.43 & 6.60 & 7.00 & 25.50 & & NA & NA & NA & NA & NA & 1 & 19.7 & 1 & NA & NA & NA & 70E_4s1d2Rc_1 & $5 / 128$ & TDP-152 & 9700049 \\
\hline 22.2 & 0.995 & 0.01000 & 0.050 & 0.333 & 44.2 & $\mathrm{P}$ & NA & 6.46 & 6.57 & 6.62 & 6.80 & 7.00 & 27.00 & NA & NA & NA & NA & NA & NA & 1 & 35.5 & 1 & NA & NA & NA & 70E_4s1d2Rc_1 & $5 / 128$ & TDP-152 & 9700050 \\
\hline 22.3 & 0.995 & 0.01000 & 0.050 & 0.334 & 42.8 & $\mathrm{P}$ & NA & 6.64 & 6.75 & 6.81 & 7.00 & 7.00 & 31.50 & NA & NA & NA & NA & NA & $\mathrm{NA}$ & 1 & 9.3 & 1 & NA & NA & NA & 70E_4S1d2R__ I & $5 / 12 B$ & TDP-152 & 9700051 \\
\hline 20.3 & 0.995 & 0.01000 & 0.050 & 0.335 & 41.6 & $\mathrm{P}$ & NA & 6.83 & 6.94 & 7.00 & 7.20 & 7.20 & 35.75 & 7.20 & uad & NA & NA & Ucsudv & NA & 1 & 0.0 & 4 & NA & NA & NA & 70E_ 4sId2Rc 1 & $5 / 13 \mathrm{~A}$ & TDP-153 & 9700052 \\
\hline 20.5 & 0.995 & 0.01000 & 0.050 & 0.337 & 39.6 & $P$ & NA & 7.11 & 7.23 & 7.30 & 7.50 & 7.20 & 42.50 & NA & NA & NA & NA & NA & NA & 1 & 0.0 & 4 & NA & NA & NA & 70E_4s1d2Rc_1 & $5 / 13 \mathrm{~A}$ & TDP-153 & 9700053 \\
\hline 20.6 & 0.995 & 0.01000 & 0.050 & 0.334 & 43.0 & $\mathrm{P}$ & NA & 6.64 & 6.75 & 6.81 & 7.00 & 7.20 & 33.25 & & NA & NA & Ucsoen & NA & NA & 1 & 2.4 & 2 & NA & NA & NA & 70E_4s1d2Rc_1 & $513 \mathrm{~A}$ & TDP-153 & 9700054 \\
\hline 21.3 & 0.995 & 0.01000 & 0.050 & 0.184 & 70.0 & $P$ & NA & 7.37 & 7.51 & 7.58 & 7.80 & 9.80 & 22.00 & NA & NA & NA & NA & NA & NA & 1 & 30.4 & 1 & NA & NA & NA & 70E_4s1d2Rd_1 & $5 / 138$ & TDP-153 & 9700055 \\
\hline 21.5 & 0.995 & 0.01000 & 0.050 & 0.185 & 65.0 & $\mathrm{P}$ & NA & 7.91 & 8.06 & 8.14 & 8.40 & 9.80 & 24.00 & & NA & NA & NA & NA & $\mathrm{NA}$ & 1 & 31.2 & 1 & NA & NA & NA & 70E_4s1d2Rd_ 1 & $5 / 138$ & TDP-153 & 9700056 \\
\hline 21.8 & 0.996 & 0.01000 & 0.050 & 0.186 & 620 & $P$ & NA & 8.29 & 8.46 & 8.54 & 8.80 & 9.80 & 25.75 & NA & NA & NA & NA & NA & NA & 1 & 24.1 & 1 & NA & NA & NA & 70E_4s1d2Rd_1 & $5 / 13 \mathrm{~B}$ & TDP-153 & 9700057 \\
\hline 21.8 & 0.996 & 0.01000 & 0.050 & 0.183 & 59.0 & $\mathrm{P}$ & NA & 8.84 & 9.02 & 9.11 & 9.40 & 9.80 & 31.00 & NA & NA & NA & NA & NA & NA & 1 & 28.5 & 1 & NA & NA & NA & 70E_4s1d2Rd_1 & $5 / 138$ & TDP-153 & 9700058 \\
\hline 21.9 & 0.995 & 0.01000 & 0.050 & 0.184 & 57.8 & $\mathrm{P}$ & NA & 9.01 & 9.20 & 9.30 & 9.60 & 9.80 & 35.50 & NA & NA & NA & Ucscen & NA & NA & 1 & 8.1 & 2 & NA & NA & NA & 70E_4sid2Rd 1 & $5 / 13 \mathrm{~B}$ & TDP-153 & 9700059 \\
\hline 22.0 & 0.995 & 0.01000 & 0.050 & 0.184 & 56.6 & $P$ & NA & 9.20 & 9.39 & 9.49 & 9.80 & 9.80 & 36.50 & 9.80 & udv & NA & NA & Ucsudv & NA & 1 & 1.2 & 4 & NA & NA & NA & 70E_4s1d2Rd_1 & $5 / 13 \mathrm{~B}$ & TDP-153 & 9700060 \\
\hline 22.0 & 0.995 & 0.01430 & 0.050 & 0.329 & 47.4 & $\mathrm{P}$ & NA & 6.12 & 6.20 & 6.25 & 6.40 & 7.80 & 22.50 & NA & NA & NA & NA & NA & $\mathrm{NA}$ & (null) & 28.7 & 1 & NA & NA & NA & 70E_4S1d2V__1 & $5 / 13 \mathrm{C}$ & IDP-154 & 9700061 \\
\hline 22.1 & 0.994 & 0.01430 & 0.050 & 0.332 & 44.6 & $\mathrm{P}$ & NA & 6.46 & 6.56 & 6.61 & 6.80 & 7.80 & 26.00 & NA & NA & NA & NA & NA & NA & 1 & 23.8 & 1 & NA & NA & NA & 70E_4s1d2Vc_1 & $5 / 13 \mathrm{C}$ & TDP-154 & 9700062 \\
\hline 21.3 & 0.995 & 0.01430 & 0.050 & 0.334 & 42.8 & $\mathrm{P}$ & NA & 6.66 & 6.7 & 6.82 & 7.00 & 7.80 & 26.75 & NA & NA & NA & NA & NA & $\mathrm{NA}$ & 1 & 27.3 & 1 & NA & NA & NA & 70E $4 \mathrm{~S} 1 \mathrm{1} 2 \mathrm{VV} \mathrm{V} 1$ & $5 / 13 \mathrm{C}$ & IDP-154 & 9700063 \\
\hline 21.3 & 0.995 & 0.01430 & 0.050 & 0.334 & 42.6 & $\mathrm{P}$ & NA & 6.74 & 6.85 & 6.91 & 7.10 & 7.80 & 27.50 & NA & NA & NA & NA & NA & NA & 1 & 19.2 & 1 & NA & NA & NA & 70E_4S1d2V___ 1 & $5 / 13 \mathrm{C}$ & TDP-154 & 9700064 \\
\hline 21.3 & 0.995 & 0.01430 & 0.050 & 0.337 & 39.8 & $\mathrm{P}$ & NA & 7.10 & 7.23 & 7.29 & 7.50 & 7.80 & 32.00 & NA & NA & NA & NA & NA & NA & 1 & 32.7 & 1 & NA & NA & NA & $70 \mathrm{E}_{4} 4 \mathrm{~s} 1 \mathrm{~d} 2 \mathrm{Vc} \mathrm{C}_{1}$ & $5 / 13 \mathrm{C}$ & TDP-154 & 9700065 \\
\hline 21.0 & 0.995 & 0.01430 & 0.050 & 0.332 & 40.4 & $\mathrm{P}$ & NA & 7.11 & 7.24 & 7.30 & 7.50 & 7.80 & 32.50 & & NA & NA & NA & NA & NA & (null) & 35.1 & 1 & NA & NA & NA & 70E_4S1d2V__1 & $5 / 14 \mathrm{~A}$ & TDP-155 & 9700066 \\
\hline 20.9 & 0.995 & 0.01430 & 0.050 & 0.333 & 39.4 & $\mathrm{P}$ & NA & 7.30 & 7.43 & 7.49 & 7.70 & 7.80 & 38.75 & NA & NA & NA & NA & NA & NA & 1 & 25.9 & 1 & NA & NA & NA & 70E_4s1d2V_C_ 1 & $5 / 14 \mathrm{~A}$ & IDP-155 & 9700067 \\
\hline 21.0 & 0.995 & 0.01430 & 0.050 & 0.333 & 38.8 & $P$ & NA & 7.39 & 7.52 & 7.59 & 7.80 & 7.80 & 41.00 & NA & NA & NA & Ucsoen & NA & $\mathrm{NA}$ & 1 & 2.6 & 2 & NA & NA & NA & 70E_4S1d2V_c 1 & $5 / 14 \mathrm{~A}$ & TDP-155 & 9700068 \\
\hline 20.9 & 0.995 & 0.01430 & 0.050 & 0.333 & 38.8 & $\mathrm{P}$ & NA & 7.39 & 7.52 & 7.59 & 7.80 & 7.80 & 41.00 & 7.80 & eenter & NA & Ucscen & NA & NA & (null) & 0.8 & 2 & NA & NA & NA & 70E_4S1d2VV__1 & $5 / 14 \mathrm{~A}$ & TDP-155 & 9700069 \\
\hline 20.9 & 0.995 & 0.01430 & 0.050 & 0.333 & 38.8 & $P$ & NA & 7.39 & 7.52 & 7.59 & 7.80 & 7.80 & 41.00 & NA & NA & NA & NA & NA & NA & NA & 0.0 & NA & NA & NA & NA & 70E 4s1d2Vc_1 & $5 / 14 \mathrm{~A}$ & TDP-155 & 9700070 \\
\hline 20.9 & 0.995 & 0.01430 & 0.050 & 0.333 & 38.8 & $\mathrm{P}$ & NA & 7.39 & 7.52 & 7.59 & 7.80 & 7.80 & 41.00 & NA & NA & NA & NA & NA & NA & NA & ra & NA & NA & NA & NA & 70E_4s1d2V__1 & $5 / 14 A$ & TDP-155 & 9700070.1 \\
\hline 20.9 & 0.995 & 0.01430 & 0.050 & 0.333 & 38.8 & $\mathrm{P}$ & NA & 7.39 & 7.52 & 7.59 & 7.80 & 7.80 & 41.00 & NA & NA & NA & NA & NA & NA & NA & 0.8 & NA & NA & NA & NA & 70E_4S1d2VEc 1 & $5 / 14 \mathrm{~A}$ & TDP-155 & 9700071 \\
\hline 20.9 & 0.995 & 0.01430 & 0.050 & 0.333 & 38.8 & $\mathrm{P}$ & NA & 7.39 & 7.52 & 7.59 & 7.80 & 7.80 & 41.00 & & NA & NA & NA & NA & NA & NA & Na & NA & NA & NA & NA & 70E_4s1d2V__1 & $5 / 14 \mathrm{~A}$ & TDP-155 & 9700071.1 \\
\hline 20.9 & 0.995 & 0.01430 & 0.050 & 0.333 & 38.8 & $P$ & NA & 7.39 & 7.52 & 7.59 & 7.80 & 7.80 & 41.00 & NA & NA & NA & NA & NA & NA & NA & $\begin{array}{ll}0.0 \\
\end{array}$ & NA & NA & NA & NA & 70E_4s1d2Vc 1 & 5 5/14A & TDP-155 & 9700072 \\
\hline 20.9 & 0.995 & 0.01430 & 0.050 & 0.333 & 38.8 & $P$ & NA & 7.39 & 7.52 & 7.59 & 7.80 & 7.80 & 41.00 & & NA & NA & NA & NA & NA & NA & na & NA & NA & NA & NA & 70E_4s1d2V_C 1 & $5 / 14 \mathrm{~A}$ & TDP-155 & 9700072.1 \\
\hline 20.9 & 0.995 & 0.01430 & 0.050 & 0.333 & 38.8 & $\mathrm{P}$ & NA & 7.39 & 7.52 & 7.59 & 7.80 & 7.80 & 41.00 & NA & NA & NA & NA & NA & NA & NA & 1.0 & NA & NA & NA & NA & $70 \mathrm{E}_{4} \mathrm{~s} 1 \mathrm{~d} 2 \mathrm{~V} \mathrm{VC} 1$ & $5 / 14 \mathrm{~A}$ & TDP-155 & 9700073 \\
\hline 20.9 & 0.995 & 0.01430 & 0.050 & 0.333 & 38.8 & $\mathrm{P}$ & NA & 7.39 & 7.52 & 7.59 & 7.80 & 7.80 & 41.00 & NA & NA & NA & NA & NA & NA & NA & Na & NA & $\mathrm{NA}$ & NA & NA & 70E_4s1d2V__1 & $5 / 14 \mathrm{~A}$ & IDP-155 & 9700073.1. \\
\hline 20.9 & 0.995 & 0.01430 & 0.050 & 0.333 & 38.8 & $\mathrm{P}$ & NA & 7.39 & 7.52 & 7.59 & 7.80 & 7.80 & 41.00 & & NA & NA & NA & NA & $\mathrm{NA}$ & NA & $\begin{array}{l}0.0 \\
\end{array}$ & NA & NA & NA & NA & 70E_4SIIIVV__1 & $5 / 14 \mathrm{~A}$ & TDP-155 & 9700074 \\
\hline 20.9 & 0.995 & 0.01430 & 0.050 & 0.333 & 38.8 & $P$ & NA & 7.39 & 7.52 & 7.59 & 7.80 & 7.80 & 41.00 & NA & NA & NA & NA & NA & NA & NA & $n / a$ & NA & NA & NA & NA & 70E_4s1d2V__1 & $5 / 14 \mathrm{~A}$ & TDP-155 & 9700074.1 \\
\hline 21.0 & 0.995 & 0.01430 & 0.050 & 0.334 & 38.8 & $\mathrm{P}$ & NA & 7.39 & 7.52 & 7.59 & 7.80 & 7.80 & 41.00 & & NA & NA & Ucsoen & NA & NA & (null) & 5.5 & 2 & NA & NA & NA & 70E_4S1d2VLC 1 & $5 / 14 \mathrm{~A}$ & IDP-155 & 9700075 \\
\hline 21.0 & 0.995 & 0.01430 & 0.050 & 0.334 & 38.8 & $P$ & NA & 7.39 & 7.52 & 7.59 & 7.80 & 7.80 & 41.00 & NA & NA & NA & NA & NA & NA & NA & 11.5 & NA & NA & NA & NA & 70E_4S1d22V__ 1 & $5 / 14 \mathrm{~A}$ & TDP-155 & 9700076 \\
\hline 21.0 & 0.995 & 0.01430 & 0.050 & 0.334 & 38.8 & $\mathrm{P}$ & NA & 7.39 & 7.52 & 7.59 & 7.80 & 7.80 & 41.00 & NA & NA & NA & NA & NA & NA & NA & na & NA & NA & NA & NA & 70E_4S1d2VV__1 & $5 / 144$ & TDP-155 & 9700076.1 \\
\hline 21.0 & 0.995 & 0.01430 & 0.050 & 0.334 & 38.8 & $\mathrm{p}$ & NA & 7.39 & 7.52 & 7.59 & 7.80 & 7.80 & 41.00 & & NA & NA & NA & NA & $\mathrm{NA}$ & $\mathrm{NA}$ & 4.4 & NA & NA & NA & NA & 70E_4s1d2V__1 1 & 5 5/14A & TDP-155 & 970007 \\
\hline 21.0 & 0.995 & 0.01430 & 0.050 & 0.334 & 38.8 & $\mathrm{P}$ & NA & 7.39 & 7.52 & 7.59 & 7.80 & 7.80 & 41.00 & NA & NA & NA & NA & NA & NA & NA & na & NA & NA & NA & NA & 70E_4s1d2V_c_1 1 & $5 / 14 \mathrm{~A}$ & IDP-155 & 9700077.1 \\
\hline 21.0 & 0.995 & 0.01430 & 0.050 & 0.334 & 38.8 & $\mathrm{P}$ & NA & 7.39 & 7.52 & 7.59 & 7.80 & 7.80 & 41.00 & & NA & NA & NA & NA & NA & NA & 1.0 & NA & NA & NA & NA & 70E_4S1d2VEc 1 & $5 / 14 \mathrm{~A}$ & TDP-155 & 9700078 \\
\hline 21.0 & 0.995 & 0.01430 & 0.050 & 0.334 & 38.8 & $\mathrm{P}$ & NA & 7.39 & 7.52 & 7.59 & 7.80 & 7.80 & 41.00 & & NA & NA & NA & NA & NA & NA & Na & NA & NA & NA & NA & 70E_4s1d2V__1 & $5 / 14 \mathrm{~A}$ & TDP-155 & 9700078.1 \\
\hline 21.0 & 0.995 & 0.01430 & 0.050 & 0.334 & 38.8 & $\mathrm{P}$ & NA & 7.39 & 7.52 & 7.59 & 7.80 & 7.80 & 41.00 & NA & NA & NA & NA & NA & NA & NA & 3.5 & NA & NA & NA & NA & 70E_4SIII2V__1 & $5 / 14 \mathrm{~A}$ & TDP-155 & 9700079 \\
\hline 21.0 & 0.995 & 0.01430 & 0.050 & 0.334 & 38.8 & $\mathrm{P}$ & NA & 7.39 & 7.52 & 7.59 & 7.80 & 7.80 & 41.00 & NA & NA & NA & NA & NA & NA & NA & na & NA & NA & NA & NA & 70E_4s1d2VC 1 & $5 / 14 \mathrm{~A}$ & TDP-155 & 9700079.1 \\
\hline
\end{tabular}


Table B.5. Data from 2008 Tests in Large-Scale Vessel with Elliptical Head A.3

\begin{tabular}{|c|c|c|c|c|c|c|c|c|c|c|c|c|c|c|c|c|c|c|c|c|c|c|c|c|c|c|c|}
\hline $\begin{array}{c}\text { Row } \\
\text { Number }\end{array}$ & Test & Case ID & $\begin{array}{c}\text { Tank } \\
\text { Diameter }\end{array}$ & $\begin{array}{l}\text { Head } \\
\text { Shape }\end{array}$ & $\begin{array}{l}\text { Dish } \\
\text { Height }\end{array}$ & $\begin{array}{c}\text { Dish } \\
\text { Volume }\end{array}$ & $\begin{array}{c}\text { Tank } \\
\text { FIll } \\
\text { Height }\end{array}$ & $\begin{array}{l}\text { Retum } \\
\text { Lne } \\
\text { Height } \\
\text { Heing }\end{array}$ & $\begin{array}{c}\text { Nozzle } \\
\text { Inner } \\
\text { Diameter }\end{array}$ & $\begin{array}{l}\text { Nozzle } \\
\text { Stand-off } \\
\text { Distance }\end{array}$ & $\begin{array}{l}\text { Pulse Tube } \\
\text { Configuration }\end{array}$ & $\begin{array}{l}\text { Installed } \\
\text { Nozzles }\end{array}$ & $\begin{array}{c}\text { Outer } \\
\text { Nozzles } \\
\text { Opperated } \\
\end{array}$ & $\begin{array}{l}\text { Inner } \\
\text { Nozles } \\
\text { Operated } \\
\end{array}$ & $\begin{array}{c}\text { Pulse Tube } \\
\text { Outer } \\
\text { Diameter } \\
\end{array}$ & $\begin{array}{c}\text { Outer } \\
\text { PJM } \\
\text { Radius } \\
\end{array}$ & $\begin{array}{l}\text { Inner } \\
\text { PJM } \\
\text { Radius } \\
\end{array}$ & $\begin{array}{l}\text { "FO" Outer } \\
\text { PJM } \\
\text { Impingement } \\
\text { Angle }\end{array}$ & $\begin{array}{c}\text { "FO' Inner PJM } \\
\text { Impingement } \\
\text { Angle }\end{array}$ & $\begin{array}{c}\text { Ratio Outer } \\
\text { PJM to Tank } \\
\text { Radius } \\
\end{array}$ & $\begin{array}{c}\text { Ratio Inner } \\
\text { PJM to Tank } \\
\text { Radius } \\
\end{array}$ & Simulant & $\begin{array}{l}\text { Solids } \\
\text { Density }\end{array}$ & $\begin{array}{c}\text { Particle } \\
\text { Diameter d5 }\end{array}$ & $\begin{array}{c}\begin{array}{c}\text { Particle } \\
\text { Diameter } \\
\text { d50 }\end{array} \\
\end{array}$ & $\begin{array}{c}\begin{array}{c}\text { Particle } \\
\text { Diameter } \\
\text { d95 }\end{array} \\
\end{array}$ & $\begin{array}{l}\text { Void } \\
\text { Fraction }\end{array}$ \\
\hline text & text & text & in. & text & in. & in. ${ }^{3}$ & in. & in. & in. & in. & text & number & number & number & in. & in. & in. & deg & deg & nondim & nondim & text & $\mathrm{g} / \mathrm{cm}^{3}$ & $\mathrm{~m}$ & $\mathrm{~m}$ & $\mathrm{~m}$ & fraction \\
\hline MSS & MDDX & ID & D & HS & Hash & $V_{\text {dsh }}$ & $\mathrm{H}$ & Rtn & d & sod & PT & $\mathrm{N}$ & $\mathrm{Nb}$ & $\mathrm{N}$ & $\mathrm{PT}_{\alpha \mathrm{d}}$ & $R_{0}$ & $\mathrm{R}$ & $\theta_{0}$ & $\theta_{1}$ & $R d R$ & $R / R$ & sxdx & $\rho_{\mathrm{s}}$ & $\mathrm{d}_{5}$ & doo & $d_{95}$ & vf \\
\hline 9700080 & $5 / 14 A$ & 70E_4s $1 \mathrm{~d} 2 \mathrm{VC} \_1$ & 70 & E & 19 & 49770.7 & $92 / 2$ & 80 & 0.613 & 0.920 & HLP-22 & 12 & 8 & 4 & 3.5 & 21.9 & 11.5 & 20.3 & 10.5 & 0.62 & 0.33 & s1d2 & 2.48 & 0.0000569 & 0.0000693 & 0.0000821 & 0.3750 \\
\hline 9700080.1. & 5/14A & $70 \mathrm{E} \_4 \mathrm{~s} 1 \mathrm{~d} 2 \mathrm{Vc} \_1$ & 70 & E & 19 & 49770.7 & $921 / 2$ & 80 & 0.613 & 0.920 & HLP-22 & 12 & 8 & 4 & 3.5 & 21.9 & 11.5 & 20.3 & 10.5 & 0.62 & 0.33 & $\mathrm{sid2}$ & 2.48 & 0.0000569 & 0.0000693 & 0.0000821 & 0.3750 \\
\hline 9700081 & $5 / 14 A$ & 70E_4s1d2Vc_1 & 70 & $E$ & 19 & 49770.7 & $92 / 2$ & 80 & 0.613 & 0.920 & HLP-22 & 12 & 8 & 4 & 3.5 & 21.9 & 11.5 & 20.3 & 10.5 & 0.62 & 0.33 & $\mathrm{~s} 1 \mathrm{~d} 2$ & 2.48 & 0.0000569 & 0.0000693 & 0.0000821 & 0.3750 \\
\hline 9700082 & $5 / 14 \mathrm{~A}$ & 70E_4s1d2VC_1 & 70 & E & 19 & 49770.7 & $921 / 2$ & 80 & 0.613 & 0.920 & HLP-22 & 12 & 8 & 4 & 3.5 & 21.9 & 11.5 & 20.3 & 10.5 & 0.62 & 0.33 & s1d2 & 2.48 & 0.0000569 & 0.0000693 & 0.0000821 & 0.3750 \\
\hline 9700082.1 & $5 / 14 \mathrm{~A}$ & 70E_4s $1 \mathrm{~d} 2 \mathrm{Vc} \_1$ & 70 & E & 19 & 49770.7 & $921 / 2$ & 80 & 0.613 & 0.920 & HLP-22 & 12 & 8 & 4 & 3.5 & 21.9 & 11.5 & 20.3 & 10.5 & 0.62 & 0.33 & s1d2 & 2.48 & 0.0000569 & 0.0000693 & 0.0000821 & 0.3750 \\
\hline 9700083 & $5 / 14 \mathrm{~A}$ & 70E_4s1d2Vc_1 & 70 & E & 19 & 49770.7 & $92 / 2$ & 80 & 0.613 & 0.920 & HLP-22 & 12 & 8 & 4 & 3.5 & 21.9 & 11.5 & 20.3 & 10.5 & 0.62 & 0.33 & s1d2 & 2.48 & 0.0000569 & 0.0000693 & 0.0000821 & 0.3750 \\
\hline 9700083.1. & $5 / 14 \mathrm{~A}$ & 70E_4s1d2Vc_1 & 70 & E & 19 & 49770.7 & $921 / 2$ & 80 & 0.613 & 0.920 & HLP-22 & 12 & 8 & 4 & 3.5 & 21.9 & 11.5 & 20.3 & 10.5 & 0.62 & 0.33 & $\mathrm{sid2}$ & 2.48 & 0.0000569 & 0.0000693 & 0.0000821 & 0.3750 \\
\hline 9700084.1 & $5 / 14 \mathrm{~A}$ & 70E_4sid2V__ 1 & 70 & $E$ & 19 & 49770.7 & $921 / 2$ & 80 & 0.613 & 0.920 & HLP-22 & 12 & 8 & 4 & 3.5 & 21.9 & 11.5 & 20.3 & 10.5 & 0.62 & 0.33 & $\mathrm{sid2}$ & 2.48 & 0.0000569 & 0.0000693 & 0.0000821 & 0.3750 \\
\hline 9700085 & $5 / 14 \mathrm{~A}$ & 70E_4s $1 \mathrm{~d} 2 \mathrm{VC} \_1$ & 70 & E & 19 & 49770.7 & $921 / 2$ & 80 & 0.613 & 0.920 & HLP-22 & 12 & 8 & 4 & 3.5 & 21.9 & 11.5 & 20.3 & 10.5 & 0.62 & 0.33 & s1d2 & 2.48 & 0.0000569 & 0.0000693 & 0.0000821 & 0.3750 \\
\hline 97000055.1 & $5 / 14 \mathrm{~A}$ & 70E_4S112VVC 1 & 70 & E & 19 & 49770.7 & $92 / 2$ & 80 & 0.613 & 0.920 & HLP-22 & 12 & 8 & 4 & 3.5 & 21.9 & 11.5 & 20.3 & 10.5 & 0.62 & 0.33 & s1d2 & 2.48 & 0.0000569 & 0.0000693 & 0.0000821 & 0.3750 \\
\hline 9700085.2 & $5 / 14 \mathrm{~A}$ & $70 E_{-} 4 \mathrm{~s} 1 \mathrm{~d} 2 \mathrm{Vc} \_1$ & 70 & E & 19 & 49770.7 & $921 / 2$ & 80 & 0.613 & 0.920 & HLP-22 & 12 & 8 & 4 & 3.5 & 21.9 & 11.5 & 20.3 & 10.5 & 0.62 & 0.33 & s1d2 & 2.48 & 0.0000569 & 0.0000693 & 0.0000821 & 0.3750 \\
\hline 9700005.3. & $5 / 14 \mathrm{~A}$ & 70E_4s1d2V__ _1 & 70 & $E$ & 19 & 49770.7 & $921 / 2$ & 80 & 0.613 & 0.920 & HLP-22 & 12 & 8 & 4 & 3.5 & 21.9 & 11.5 & 20.3 & 10.5 & 0.62 & 0.33 & $\mathrm{~s} 1 \mathrm{~d} 2$ & 2.48 & 0.0000569 & 0.0000693 & 0.0000821 & 0.3750 \\
\hline 9700086 & $5 / 14 B$ & 70E_4s $1 \mathrm{~d} 2 \mathrm{Vd} \_1$ & 70 & E & 19 & 49770.7 & $921 / 2$ & 80 & 0.613 & 0.920 & HLP-22 & 12 & 8 & 4 & 3.5 & 21.9 & 11.5 & 20.3 & 10.5 & 0.62 & 0.33 & $\mathrm{~s} 1 \mathrm{~d} 2$ & 2.48 & 0.0000569 & 0.0000693 & 0.0000821 & 0.3750 \\
\hline 9700087 & $5 / 14 B$ & 70E_4s1d2Vd_1 & 70 & E & 19 & 49770.7 & $921 / 2$ & 80 & 0.613 & 0.920 & HLP-22 & 12 & 8 & 4 & 3.5 & 21.9 & 11.5 & 20.3 & 10.5 & 0.62 & 0.33 & $\mathrm{~s} 1 \mathrm{~d} 2$ & 2.48 & 0.0000569 & 0.0000693 & 0.0000821 & 0.3750 \\
\hline 9700088 & $5 / 148$ & 70E_4s $1 \mathrm{~d} 2 \mathrm{Vd} \_1$ & 70 & E & 19 & 49770.7 & $92 / 2$ & 80 & 0.613 & 0.920 & HLP-22 & 12 & 8 & 4 & 3.5 & 21.9 & 11.5 & 20.3 & 10.5 & 0.62 & 0.33 & s1d2 & 2.48 & 0.0000569 & 0.0000693 & 0.0000821 & 0.3750 \\
\hline 9700089 & $5 / 14 \mathrm{~B}$ & 70E_4s $1 \mathrm{~d} 2 \mathrm{Vd} \_1$ & 70 & E & 19 & 49770.7 & $921 / 2$ & 80 & 0.613 & 0.920 & HLP-22 & 12 & 8 & 4 & 3.5 & 21.9 & 11.5 & 20.3 & 10.5 & 0.62 & 0.33 & $\mathrm{~s} 1 \mathrm{~d} 2$ & 2.48 & 0.0000569 & 0.0000693 & 0.0000821 & 0.3750 \\
\hline 9700090 & $5 / 14 \mathrm{~B}$ & 70E_4s1d2Vd_1 & 70 & E & 19 & 49770.7 & $92 / 2$ & 80 & 0.613 & 0.920 & HLP-22 & 12 & 8 & 4 & 3.5 & 21.9 & 11.5 & 20.3 & 10.5 & 0.62 & 0.33 & s1d2 & 2.48 & 0.0000569 & 0.0000693 & 0.0000821 & 0.3750 \\
\hline 9700091 & $5 / 14 B$ & 70E_4sid2Vd_1 & 70 & $E$ & 19 & 49770.7 & $921 / 2$ & 80 & 0.613 & 0.920 & HLP-22 & 12 & 8 & 4 & 3.5 & 21.9 & 11.5 & 20.3 & 10.5 & 0.62 & 0.33 & $\mathrm{sid2}$ & 2.48 & 0.0000569 & 0.0000693 & 0.0000821 & 0.3750 \\
\hline 9700092 & $5 / 14 B$ & 70E_4s1d2Vd_1 & 70 & E & 19 & 49770.7 & $921 / 2$ & 80 & 0.613 & 0.920 & HLP-22 & 12 & 8 & 4 & 3.5 & 21.9 & 11.5 & 20.3 & 10.5 & 0.62 & 0.33 & $\mathrm{sid2}$ & 2.48 & 0.0000569 & 0.0000693 & 0.0000821 & 0.3750 \\
\hline 9700094M & $5 / 14 \mathrm{~B}$ & 70E_4sid2Vd_1 & 70 & E & 19 & 49770.7 & $921 / 2$ & 80 & 0.613 & 0.920 & HLP-22 & 12 & 8 & 4 & 3.5 & 21.9 & 11.5 & 20.3 & 10.5 & 0.62 & 0.33 & s1d2 & 2.48 & 0.0000569 & 0.0000693 & 0.0000821 & 0.3750 \\
\hline 9700005 M & $5 / 14 \mathrm{~B}$ & 70E_4s $1 \mathrm{~d} 2 \mathrm{Vd} \_1$ & 70 & E & 19 & 49770.7 & $92 / 2$ & 80 & 0.613 & 0.920 & HLP-22 & 12 & 8 & 4 & 3.5 & 21.9 & 11.5 & 20.3 & 10.5 & 0.62 & 0.33 & $\mathrm{~s} 1 \mathrm{~d} 2$ & 2.48 & 0.0000569 & 0.0000693 & 0.0000821 & 0.3750 \\
\hline $9700096 \mathrm{M}$ & $5 / 15 \mathrm{~A}$ & 70E_4sid2Vd_1 & 70 & $E$ & 19 & 4970.7 & $921 / 2$ & 80 & 0.613 & 0.920 & HLP-22 & 12 & 8 & 4 & 3.5 & 21.9 & 11.5 & 20.3 & 10.5 & 0.62 & 0.33 & $\mathrm{~s} 1 \mathrm{~d} 2$ & 2.48 & 0.0000569 & 0.0000693 & 0.0000821 & 0.3750 \\
\hline 9700097 & $5 / 15 \mathrm{~A}$ & 70E_4s $1 \mathrm{~d} 2 \mathrm{Vd} \_1$ & 70 & E & 19 & 49770.7 & $921 / 2$ & 80 & 0.613 & 0.920 & HLP-22 & 12 & 8 & 4 & 3.5 & 21.9 & 11.5 & 20.3 & 10.5 & 0.62 & 0.33 & $\mathrm{~s} 1 \mathrm{~d} 2$ & 2.48 & 0.0000569 & 0.0000693 & 0.0000821 & 0.3750 \\
\hline 9700098 & $5 / 15 \mathrm{~A}$ & 70E_4s1d2Vd_1 & 70 & $E$ & 19 & 49770.7 & $921 / 2$ & 80 & 0.613 & 0.920 & HLP-22 & 12 & 8 & 4 & 3.5 & 21.9 & 11.5 & 20.3 & 10.5 & 0.62 & 0.33 & s1d2 & 2.48 & 0.0000569 & 0.0000693 & 0.0000821 & 0.3750 \\
\hline 9700098.1 & $5 / 15 \mathrm{~A}$ & 70E_4s1d2Vd_1 1 & 70 & E & 19 & 49770.7 & $921 / 2$ & 80 & 0.613 & 0.920 & HLP-22 & 12 & 8 & 4 & 3.5 & 21.9 & 11.5 & 20.3 & 10.5 & 0.62 & 0.33 & s1d2 & 2.48 & 0.0000569 & 0.0000693 & 0.0000821 & 0.3750 \\
\hline 9700099 & $5 / 15 \mathrm{~A}$ & 70E_4s $1 \mathrm{~d} 2 \mathrm{Vd} \_1$ & 70 & E & 19 & 49770.7 & $921 / 2$ & 80 & 0.613 & 0.920 & HLP-22 & 12 & 8 & 4 & 3.5 & 21.9 & 11.5 & 20.3 & 10.5 & 0.6 & 0.33 & s1d2 & 2.48 & 0.0000569 & 0.0000693 & 0.0000821 & 0.3750 \\
\hline 9700099.1 & $5 / 15 \mathrm{~A}$ & 70E_4sid2Vd_1 & 70 & $E$ & 19 & 4970.7 & $921 / 2$ & 80 & 0.613 & 0.920 & HLP-22 & 12 & 8 & 4 & 3.5 & 21.9 & 11.5 & 20.3 & 10.5 & 0.62 & 0.33 & s1d2 & 2.48 & 0.0000569 & 0.0000693 & 0.0000821 & 0.3750 \\
\hline 9700100 & $5 / 15 \mathrm{~A}$ & 70E_4s1d2Vd_1 & 70 & E & 19 & 49770.7 & $921 / 2$ & 80 & 0.613 & 0.920 & HLP-22 & 12 & 8 & 4 & 3.5 & 21.9 & 11.5 & 20.3 & 10.5 & 0.62 & 0.33 & $\mathrm{~s} 1 \mathrm{~d} 2$ & 2.48 & 0.0000569 & 0.0000693 & 0.0000821 & 0.3750 \\
\hline 9700100.1 & $5 / 15 \mathrm{~A}$ & 70E_4s1d2Vd_1 & 70 & $E$ & 19 & 49770.7 & $92 / 2$ & 80 & 0.613 & 0.920 & HLP-22 & 12 & 8 & 4 & 3.5 & 21.9 & 11.5 & 20.3 & 10.5 & 0.62 & 0.33 & s1d2 & 2.48 & 0.0000569 & 0.0000693 & 0.0000821 & 0.3750 \\
\hline 9700101 & $5 / 15 \mathrm{~A}$ & 70E_4s1d2Vd_1 1 & 70 & E & 19 & 49770.7 & $921 / 2$ & 80 & 0.613 & 0.920 & HLP-22 & 12 & 8 & 4 & 3.5 & 21.9 & 11.5 & 20.3 & 10.5 & 0.62 & 0.33 & s1d2 & 2.48 & 0.0000569 & 0.0000693 & 0.0000821 & 0.3750 \\
\hline 9700101.1 . & $5 / 15 \mathrm{~A}$ & 70E_4sid2VId_1 & 70 & E & 19 & 4970.7 & $921 / 2$ & 80 & 0.613 & 0.920 & HLP-22 & 12 & 8 & 4 & 3.5 & 21.9 & 11.5 & 20. & 10.5 & 0.62 & 0.33 & s1d2 & 2.48 & 0.0000569 & 0.0000693 & 0.0000821 & 0.3750 \\
\hline 9700102 & $5 / 15 \mathrm{~A}$ & 70E_4sid2Vd_ 1 & 70 & E & 19 & 49770.7 & $921 / 2$ & 80 & 0.613 & 0.920 & HLP-22 & 12 & 8 & 4 & 3.5 & 21.9 & 11.5 & 20.3 & 10.5 & 0.62 & 0.33 & s1d2 & 2.48 & 0.0000569 & 0.0000693 & 0.0000821 & 0.3750 \\
\hline 9700102.1 & $5 / 15 \mathrm{~A}$ & 70E_4s1d2Vd_1 1 & 70 & E & 19 & 49770.7 & $921 / 2$ & 80 & 0.613 & 0.920 & HLP-22 & 12 & 8 & 4 & 3.5 & 21.9 & 11.5 & 20.3 & 10.5 & 0.62 & 0.33 & $\mathrm{sid2}$ & 2.48 & 0.0000569 & 0.0000693 & 0.0000821 & 0.3750 \\
\hline 9700103M & $5 / 15 \mathrm{~A}$ & 70E_4S112VVd_1 & 70 & E & 19 & 49770.7 & $921 / 2$ & 80 & 0.613 & 0.920 & HLP-22 & 12 & 8 & 4 & 3.5 & 21.9 & 11.5 & 20.3 & 10.5 & 0.62 & 0.33 & s1d2 & 2.48 & 0.0000569 & 0.0000693 & 0.0000821 & 0.3750 \\
\hline 9700104 & $5 / 15 \mathrm{~A}$ & 70E_4s1d2Vd_1 & 70 & E & 19 & 49770.7 & $921 / 2$ & 80 & 0.613 & 0.920 & HLP-22 & 12 & 8 & 4 & 3.5 & 21.9 & 11.5 & 20.3 & 10.5 & 0.62 & 0.33 & $\mathrm{~s} 1 \mathrm{~d} 2$ & 2.48 & 0.0000569 & 0.0000693 & 0.0000821 & 0.3750 \\
\hline 9700105 & $5 / 15 \mathrm{~A}$ & 70E_4s $1 \mathrm{~d} 2 \mathrm{Vd} \_1$ & 70 & E & 19 & 49770.7 & $921 / 2$ & 80 & 0.613 & 0.920 & HLP-22 & 12 & 8 & 4 & 3.5 & 21.9 & 11.5 & 20 & 10.5 & 0.62 & 0.33 & s1d2 & 2.48 & 0.0000569 & 0.0000693 & 0.0000821 & 0.3750 \\
\hline 9700105.1 & $5 / 15 \mathrm{~A}$ & 70E_4sid2Vd_ 1 & 70 & E & 19 & 49770.7 & $921 / 2$ & 80 & 0.613 & 0.920 & HLP-22 & 12 & 8 & 4 & 3.5 & 21.9 & 11.5 & 20.3 & 10.5 & 0.62 & 0.33 & s1d2 & 2.48 & 0.0000569 & 0.0000693 & 0.0000821 & 0.3750 \\
\hline 9700106 & $5 / 15 \mathrm{~A}$ & 70E_4sid2Vd_ 1 & 70 & E & 19 & 4970.7 & $921 / 2$ & 80 & 0.613 & 0.920 & HLP-22 & 12 & 8 & 4 & 3.5 & 21.9 & 11.5 & 20.3 & 10.5 & 0.62 & 0.33 & $\mathrm{~s} 1 \mathrm{~d} 2$ & 2.48 & 0.0000569 & 0.0000693 & 0.0000821 & 0.3750 \\
\hline 9700106.1 & $5 / 15 \mathrm{~A}$ & 70E_4s $1 \mathrm{~d} 2 \mathrm{Vd} \_1$ & 70 & E & 19 & 49770.7 & $92 / 2$ & 80 & 0.613 & 0.920 & HLP-22 & 12 & 8 & 4 & 3.5 & 21.9 & 11.5 & 20.3 & 10.5 & 0.62 & 0.33 & $\mathrm{~s} 1 \mathrm{~d} 2$ & 2.48 & 0.0000569 & 0.0000693 & 0.0000821 & 0.3750 \\
\hline
\end{tabular}


Table B.5. Data from 2008 Tests in Large-Scale Vessel with Elliptical Head B.3

\begin{tabular}{|c|c|c|c|c|c|c|c|c|c|c|c|c|c|c|c|c|c|c|c|c|c|c|c|c|c|c|c|c|c|}
\hline $\begin{array}{l}\text { Tank Water } \\
\text { Temperature }\end{array}$ & $\begin{array}{l}\text { Water } \\
\text { Density }\end{array}$ & $\begin{array}{c}\text { Solids } \\
\text { Fraction }\end{array}$ & $\begin{array}{c}\text { Pulse } \\
\text { Volume } \\
\text { Fraction }\end{array}$ & $\begin{array}{l}\text { Duty } \\
\text { Qyde }\end{array}$ & $\begin{array}{l}\text { Oyde } \\
\text { Time }\end{array}$ & $\begin{array}{c}\text { Pulsed } \\
\text { or } \\
\text { Steady } \\
\text { Jet }\end{array}$ & $\begin{array}{l}\text { Us } \\
\text { Steady } \\
\text { Jet }\end{array}$ & $\begin{array}{c}\text { U1 } \\
\text { Pulsing } \\
\text { Jet } \\
\end{array}$ & $\begin{array}{c}\text { U2 } \\
\text { URMS }\end{array}$ & $\begin{array}{c}\text { U3 } \\
\text { URNB }\end{array}$ & $\begin{array}{l}\text { Discharge } \\
\text { Velocity }\end{array}$ & $\begin{array}{c}\text { Citical } \\
\text { Suspension } \\
\text { velocity }\end{array}$ & $\begin{array}{c}\text { Average } \\
\text { Peak Cloud } \\
\text { Height }\end{array}$ & $\begin{array}{c}\text { UCS } \\
\text { Condition }\end{array}$ & $\begin{array}{l}\text { UCS } \\
\text { Method }\end{array}$ & $\begin{array}{l}\text { UCS } \\
\text { Fag }\end{array}$ & $\begin{array}{c}\text { UCS } \\
\text { Center } \\
\text { Flag }\end{array}$ & $\begin{array}{c}\text { UCS uadv } \\
\text { Hag }\end{array}$ & $\begin{array}{c}\text { UCS based } \\
\text { on } \\
\text { Decreasing } \\
\text { Velocity }\end{array}$ & $\begin{array}{l}\text { Sweep } \\
\text { Increase } \\
\text { Decrease }\end{array}$ & $\begin{array}{c}\text { UDV } \\
\text { Height } \\
\text { Bed }\end{array}$ & $\begin{array}{c}\text { Particle } \\
\text { Motion }\end{array}$ & \begin{tabular}{|l|}
$\begin{array}{l}\text { Solids } \\
\text { Level }\end{array}$ \\
\end{tabular} & \begin{tabular}{|l|} 
Outer \\
Botom \\
Pattem \\
\end{tabular} & $\begin{array}{c}\text { Inner } \\
\text { Botomo } \\
\text { Pattem }\end{array}$ & Case ID & Test & TDP & $\begin{array}{l}\text { Row } \\
\text { Number }\end{array}$ \\
\hline$c$ & $\mathrm{~g} / \mathrm{cm}^{3}$ & fraction & fraction & fraction & $\mathrm{s}$ & text & $\mathrm{m} / \mathrm{s}$ & $\mathrm{m} / \mathrm{s}$ & $m / s$ & $\mathrm{~m} / \mathrm{s}$ & $\mathrm{m} / \mathrm{s}$ & m/s & in. & $\mathrm{m} / \mathrm{s}$ & text & text & text & text & \begin{tabular}{|l|}
$\mathrm{m} / \mathrm{s}$ \\
\end{tabular} & text & $\mathrm{mm}$ & text & text & text & text & text & text & text & text \\
\hline$T$ & $\rho$ & $\phi_{\mathrm{s}}$ & $\phi_{p}$ & $D C$ & tc & Jet & $U_{s}$ & $\mathrm{U1}_{1}$ & $\mathrm{U} 2$ & $U_{3}$ & $u$ & Uos & $\mathrm{H}_{\mathrm{c}}$ & $U_{\text {Csp }}$ & Uosm & Ussis & Usscen & Usoudv & Uos $D$ & $s_{\mathrm{w}}$ & Hod & $\mathrm{PM}$ & Sol & SPo & $\mathrm{SP}_{1}$ & $\mathrm{ID}$ & MDDX & $\mathrm{TDP}$ & MSS \\
\hline 21.0 & 0.995 & 0.01430 & 0.050 & 0.334 & 38.8 & $P$ & $\mathrm{NA}$ & 7.39 & 7.52 & 7.59 & 7.80 & 7.80 & 41.00 & $\mathrm{NA}$ & $\mathrm{NA}$ & $\mathrm{NA}$ & NA & $\mathrm{NA}$ & $\mathrm{NA}$ & NA & 4.1 & NA & $\mathrm{NA}$ & NA & $\mathrm{NA}$ & 70E_4S1d2V__1 & $5 / 14 A$ & TDP-155 & 9700080 \\
\hline 21.0 & 0.995 & 0.01430 & 0.050 & 0.334 & 38.8 & $\mathrm{P}$ & NA & 7.39 & 7.52 & 7.59 & 7.80 & 7.80 & 41.00 & NA & NA & NA & NA & NA & NA & NA & $\mathrm{n} / \mathrm{a}$ & NA & NA & NA & NA & $70 E_{-} 4 \mathrm{~s} 1 \mathrm{~d} 2 \mathrm{Vc} \_1$ & $5 / 14 A$ & TDP-155 & 9700080.1 \\
\hline 21.2 & 0.995 & 0.01430 & 0.050 & 0.334 & 38.8 & $P$ & NA & 7.39 & 7.52 & 7.59 & 7.80 & 7.80 & 41.00 & $\mathrm{NA}$ & NA & NA & UCScen & NA & NA & (null) & 3.9 & 2 & NA & NA & NA & 70E_4s1d2Vc_1 & $5 / 14 \mathrm{~A}$ & TDP-155 & 9700081 \\
\hline 21.2 & 0.995 & 0.01430 & 0.050 & 0.334 & 38.8 & $P$ & NA & 7.39 & 7.52 & 7.59 & 7.80 & 7.80 & 41.00 & NA & NA & NA & NA & NA & NA & NA & 3.8 & NA & NA & NA & NA & 70E_4s1d2V__ 1 & $5 / 14 \mathrm{~A}$ & TDP-155 & 9700082 \\
\hline 21.2 & 0.995 & 0.01430 & 0.050 & 0.334 & 38.8 & $\mathrm{P}$ & NA & 7.39 & 7.52 & 7.59 & 7.80 & 7.80 & 41.00 & NA & NA & NA & NA & NA & NA & NA & $\mathrm{na}$ & NA & NA & NA & NA & 70E_4s $1 \mathrm{~d} 2 \mathrm{VC} \_1$ & $5 / 14 \mathrm{~A}$ & TDP-155 & 9700082.1 \\
\hline 21.2 & 0.995 & 0.01430 & 0.050 & 0.334 & 38.8 & $P$ & NA & 7.39 & 7.52 & 7.59 & 7.80 & 7.80 & 41.00 & NA & NA & NA & NA & NA & NA & NA & 1.2 & NA & NA & NA & NA & 70E_4sId2VC_1 & $5 / 14 \mathrm{~A}$ & TDP-155 & 9700083 \\
\hline 21.2 & 0.995 & 0.01430 & 0.050 & 0.334 & 38.8 & $\mathrm{P}$ & NA & 7.39 & 7.52 & 7.59 & 7.80 & 7.80 & 41.00 & NA & NA & NA & NA & NA & NA & NA & $\mathrm{n} / \mathrm{a}$ & NA & NA & NA & NA & 70E_4sId2Vc_1 & $5 / 14 \mathrm{~A}$ & TDP-155 & 9700083.1 \\
\hline 21.2 & 0.995 & 0.01430 & 0.050 & 0.334 & 38.8 & $\mathrm{P}$ & NA & 7.39 & 7.52 & 7.59 & 7.80 & 7.80 & 41.00 & NA & NA & NA & NA & NA & NA & NA & $\mathrm{na}$ & NA & NA & NA & NA & 70E_4sId2Vc_1 & $5 / 14 \mathrm{~A}$ & TDP-155 & 9700084.1 \\
\hline 21.2 & 0.995 & 0.01430 & 0.050 & 0.334 & 38.8 & $\mathrm{P}$ & NA & 7.39 & 7.52 & 7.59 & 7.80 & 7.80 & 41.00 & NA & NA & NA & NA & NA & NA & NA & 2.5 & NA & NA & NA & NA & 70E_4s1d2Vc_1 & $5 / 14 \mathrm{~A}$ & TDP-155 & 9700085 \\
\hline 21.2 & 0.995 & 0.01430 & 0.050 & 0.334 & 38.8 & $P$ & NA & 7.39 & 7.52 & 7.59 & 7.80 & 7.80 & 41.00 & NA & NA & NA & NA & NA & NA & NA & $\mathrm{na}$ & NA & NA & NA & NA & 70E_4S1d2VV__1 & $5 / 14 \mathrm{~A}$ & TDP-155 & 9700085.1 \\
\hline 21.2 & 0.995 & 0.01430 & 0.050 & 0.334 & 38.8 & $\mathrm{P}$ & NA & 7.39 & 7.52 & 7.59 & 7.80 & 7.80 & 41.00 & NA & NA & NA & NA & NA & NA & NA & $\mathrm{na}$ & NA & NA & NA & NA & 70E_4sid2Vc_1 & $5 / 14 \mathrm{~A}$ & TDP-155 & 9700085.2 \\
\hline 21.2 & 0.995 & 0.01430 & 0.050 & 0.334 & 38.8 & $\mathrm{P}$ & NA & 7.39 & 7.52 & 7.59 & 7.80 & 7.80 & 41.00 & NA & NA & NA & NA & NA & NA & NA & $\mathrm{na}$ & NA & NA & NA & NA & $70 \mathrm{E}=4 \mathrm{~s} 1 \mathrm{~d} 2 \mathrm{Vc} 1$ & $5 / 14 \mathrm{~A}$ & TDP-155 & 9700085.3 \\
\hline 21.8 & 0.995 & 0.01430 & 0.050 & 0.181 & 67.8 & $\mathrm{P}$ & NA & 7.83 & 7.98 & 8.06 & 8.30 & 10.90 & NA & NA & NA & NA & NA & NA & NA & 1 & 25.5 & 1 & NA & NA & NA & 70E_4S1d2Vd_ 1 & $5 / 14 \mathrm{~B}$ & TDP-155 & 9700086 \\
\hline 21.8 & 0.995 & 0.01430 & 0.050 & 0.182 & 65.2 & $\mathrm{P}$ & NA & 8.08 & 8.25 & 8.34 & 8.60 & 10.90 & NA & NA & NA & NA & NA & NA & NA & 1 & 18.0 & 1 & NA & NA & NA & 70E_-4s1d2Vd_1 1 & $5 / 14 \mathrm{~B}$ & TDP-155 & 9700087 \\
\hline 22.0 & 0.995 & 0.01430 & 0.050 & 0.183 & 61.0 & $P$ & NA & 8.56 & 8.74 & 8.83 & 9.10 & 10.90 & 23.50 & NA & NA & NA & NA & NA & NA & 1 & 36.8 & 1 & NA & NA & NA & 70E 4 sId2Vd 1 & $5 / 14 \mathrm{~B}$ & TDP-155 & 9700088 \\
\hline 22.0 & 0.995 & 0.01430 & 0.050 & 0.184 & 57.6 & $\mathrm{P}$ & NA & 9.00 & 9.19 & 9.29 & 9.60 & 10.90 & 25.75 & $\mathrm{NA}$ & NA & NA & NA & NA & NA & 1 & 28.2 & 1 & NA & NA & NA & 70E_4S1d2Vd_1 & $5 / 14 \mathrm{~B}$ & TDP-155 & 9700089 \\
\hline 22.1 & 0.995 & 0.01430 & 0.050 & 0.185 & 55.8 & $\mathrm{P}$ & NA & 9.29 & 9.49 & 9.59 & 9.90 & 10.90 & 28.50 & $\mathrm{NA}$ & NA & NA & NA & NA & NA & 1 & 25.3 & 1 & NA & NA & NA & 70E_4sid2Vd_1 & $5 / 14 \mathrm{~B}$ & TDP-155 & 9700090 \\
\hline 22.5 & 0.994 & 0.01430 & 0.051 & 0.185 & 54.2 & $\mathrm{P}$ & NA & 9.57 & 9.77 & 9.87 & 10.20 & 10.90 & 30.50 & NA & NA & NA & NA & NA & NA & 1 & 20.8 & 1 & NA & NA & NA & 70E_4sid2VV_ 1 & $5 / 14 \mathrm{~B}$ & TDP-155 & 9700091 \\
\hline 22.1 & 0.995 & 0.01430 & 0.050 & 0.186 & 52.4 & $\mathrm{P}$ & NA & 9.74 & 9.95 & 10.05 & 10.40 & 10.90 & 32.50 & NA & NA & NA & NA & NA & NA & 1 & 14.8 & 1 & NA & NA & NA & 70E_4S1d2V__ _ 1 & $5 / 14 \mathrm{~B}$ & TDP-155 & 9700092 \\
\hline 22.5 & 0.995 & 0.01430 & 0.050 & 0.187 & 50.4 & $\mathrm{P}$ & NA & 10.10 & 10.33 & 10.45 & 10.90 & 10.90 & 39.25 & 10.90 & center & NA & UCSoen & NA & NA & 1 & 11.2 & 2 & NA & NA & NA & 70E_4SId2VV__1 & $5 / 14 B$ & TDP-155 & 9700094 \\
\hline 22.8 & 0.995 & 0.01430 & 0.050 & 0.188 & 48.6 & $\mathrm{P}$ & NA & 10.44 & 10.68 & 10.80 & 11.20 & 10.90 & 45.00 & $\mathrm{NA}$ & NA & NA & $\mathrm{NA}$ & NA & NA & 1 & 3.0 & 4 & NA & NA & NA & 70E_4s1d2Vd_1 & $5 / 14 \mathrm{~B}$ & TDP-155 & 9700095 \\
\hline 22.9 & 0.995 & 0.01430 & 0.050 & 0.189 & 48.6 & $\mathrm{P}$ & NA & 10.38 & 10.65 & 10.78 & 11.20 & 10.90 & 45.00 & NA & NA & NA & NA & NA & NA & (null) & 6.3 & 4 & NA & NA & NA & 70E_4S1d2Vd_ 1 & $5 / 15 \mathrm{~A}$ & TDP-156 & 9700096 \\
\hline 22.9 & 0.995 & 0.01430 & 0.050 & 0.189 & 48.6 & $\mathrm{P}$ & NA & 10.38 & 10.65 & 10.78 & 11.20 & 10.90 & 45.00 & NA & NA & NA & NA & NA & NA & NA & 8.3 & NA & NA & NA & NA & 70E_4S1d2V__ _ 1 & $5 / 15 \mathrm{~A}$ & TDP-156 & 9700097 \\
\hline 22.9 & 0.995 & 0.01430 & 0.050 & 0.189 & 48.6 & $\mathrm{P}$ & NA & 10.38 & 10.65 & 10.78 & 11.20 & 10.90 & 45.00 & NA & NA & NA & NA & NA & NA & NA & 11.5 & NA & NA & NA & NA & 70E_4s1d2VV__1 & $5 / 15 \mathrm{~A}$ & TDP-156 & 9700098 \\
\hline 22.9 & 0.995 & 0.01430 & 0.050 & 0.189 & 48.6 & $\mathrm{P}$ & NA & 10.38 & 10.65 & 10.78 & 11.20 & 10.90 & 45.00 & NA & NA & NA & NA & NA & NA & NA & $\mathrm{na}$ & NA & NA & NA & NA & 70E_4SId2VI_1 & $5 / 15 \mathrm{~A}$ & TDP-156 & 9700098.1 \\
\hline 22.9 & 0.995 & 0.01430 & 0.050 & 0.189 & 48.6 & $\mathrm{P}$ & NA & 10.38 & 10.65 & 10.78 & 11.20 & 10.90 & 45.00 & NA & NA & NA & NA & NA & NA & NA & 0.0 & NA & NA & NA & NA & 70E_4sid2Vd_1 1 & 5/15A & TDP-156 & 9700099 \\
\hline 22.9 & 0.995 & 0.01430 & 0.050 & 0.189 & 48.6 & $\mathrm{P}$ & $\mathrm{NA}$ & 10.38 & 10.65 & 10.78 & 11.20 & 10.90 & 45.00 & NA & NA & NA & NA & NA & NA & NA & $\mathrm{n} / \mathrm{a}$ & NA & NA & NA & NA & 70E_4sid2VV _ 1 & $5 / 15 \mathrm{~A}$ & TDP-156 & 9700099.1 \\
\hline 22.9 & 0.995 & 0.01430 & 0.050 & 0.189 & 48.6 & $\mathrm{P}$ & NA & 10.38 & 10.65 & 10.78 & 11.20 & 10.90 & 45.00 & NA & NA & NA & NA & NA & NA & NA & 0.0 & NA & NA & NA & NA & 70E_4S1d2V__ 1 1 & $5 / 15 \mathrm{~A}$ & TDP-156 & 9700100 \\
\hline 22.9 & 0.995 & 0.01430 & 0.050 & 0.189 & 48.6 & $\mathrm{P}$ & NA & 10.38 & 10.65 & 10.78 & 11.20 & 10.90 & 45.00 & NA & NA & NA & NA & NA & NA & NA & na & NA & NA & NA & NA & 70E_4s1d2VI_1 & $5 / 15 \mathrm{~A}$ & TDP-156 & 9700100.1 \\
\hline 22.9 & 0.995 & 0.01430 & 0.050 & 0.189 & 48.6 & $\mathrm{P}$ & NA & 10.38 & 10.65 & 10.78 & 11.20 & 10.90 & 45.00 & NA & NA & NA & NA & NA & NA & NA & 0.0 & NA & NA & NA & NA & 70E_4s1d2Vd_1 & $5 / 15 \mathrm{~A}$ & IDP-156 & 9700101 \\
\hline 22.9 & 0.995 & 0.01430 & 0.050 & 0.189 & 48.6 & $P$ & NA & 10.38 & 10.65 & 10.78 & 11.20 & 10.90 & 45.00 & NA & NA & NA & NA & NA & NA & NA & $\mathrm{na}$ & NA & NA & NA & NA & 70E $4 \mathrm{~s} 1 \mathrm{~d} 2 \mathrm{Vd} 1$ & $5 / 15 \mathrm{~A}$ & TDP-156 & 9700101.1 \\
\hline 22.9 & 0.995 & 0.01430 & 0.050 & 0.189 & 48.6 & $\mathrm{P}$ & NA & 10.38 & 10.65 & 10.78 & 11.20 & 10.90 & 45.00 & NA & NA & NA & NA & NA & NA & NA & 0.0 & NA & NA & NA & NA & 70E_4sid2Vd_ 1 & $5 / 15 \mathrm{~A}$ & TDP-156 & 9700102 \\
\hline 22.9 & 0.995 & 0.01430 & 0.050 & 0.189 & 48.6 & $\mathrm{P}$ & NA & 10.38 & 10.65 & 10.78 & 11.20 & 10.90 & 45.00 & NA & NA & NA & NA & NA & NA & NA & $\mathrm{n} / \mathrm{a}$ & NA & NA & NA & NA & 70E_4S1d2V__ 1 & 5/15A & TDP-156 & 9700102.1 \\
\hline 23.0 & 0.995 & 0.01430 & 0.050 & 0.189 & 48.6 & $\mathrm{P}$ & NA & 10.39 & 10.65 & 10.79 & 11.20 & 10.90 & 45.00 & NA & NA & NA & NA & NA & NA & (null) & 0.0 & 4 & NA & NA & NA & 70E_4s1d2VV__1 & 5/15A & TDP-156 & 9700103 \\
\hline 23.0 & 0.995 & 0.01430 & 0.050 & 0.189 & 48.6 & $\mathrm{P}$ & NA & 10.39 & 10.65 & 10.79 & 11.20 & 10.90 & 45.00 & NA & NA & NA & NA & NA & NA & NA & 0.0 & NA & NA & NA & NA & 70E_4sid2Vd_1 & $5 / 15 \mathrm{~A}$ & TDP-156 & 9700104 \\
\hline 23.0 & 0.995 & 0.01430 & 0.050 & 0.189 & 48.6 & $P$ & NA & 10.39 & 10.65 & 10.79 & 11.20 & 10.90 & 45.00 & NA & NA & NA & NA & NA & NA & NA & 0.0 & NA & NA & NA & NA & 70E_4SId2VV_1 & $5 / 15 \mathrm{~A}$ & TDP-156 & 9700105 \\
\hline 23.0 & 0.995 & 0.01430 & 0.050 & 0.189 & 48.6 & $\mathrm{P}$ & NA & 10.39 & 10.65 & 10.79 & 11.20 & 10.90 & 45.00 & NA & NA & NA & NA & NA & NA & NA & wa & NA & NA & NA & NA & 70E_4sid2VV_ 1 & $5 / 15 \mathrm{~A}$ & TDP-156 & 9700105.1 \\
\hline 23.0 & 0.995 & 0.01430 & 0.050 & 0.189 & 48.6 & $\mathrm{P}$ & NA & 10.39 & 10.65 & 10.79 & 11.20 & 10.90 & 45.00 & NA & NA & NA & NA & NA & NA & NA & 0.0 & NA & NA & NA & NA & 70E_4sId2VI_1 1 & $5 / 15 \mathrm{~A}$ & TDP-156 & 9700106 \\
\hline 23.0 & 0.995 & 0.01430 & 0.050 & 0.189 & 48.6 & $\mathrm{P}$ & NA & 10.39 & 10.65 & 10.79 & 11.20 & 10.90 & 45.00 & NA & NA & NA & NA & NA & NA & NA & na & NA & NA & NA & NA & 70E_4s1d2Vd_1 1 & $5 / 5 \mathrm{~A}$ & TDP-156 & 9700106.1 \\
\hline
\end{tabular}


Table B.5. Data from 2008 Tests in Large-Scale Vessel with Elliptical Head A.4

\begin{tabular}{|c|c|c|c|c|c|c|c|c|c|c|c|c|c|c|c|c|c|c|c|c|c|c|c|c|c|c|c|}
\hline $\begin{array}{l}\text { Row } \\
\text { Number }\end{array}$ & Test & Case ID & $\begin{array}{c}\text { Tank } \\
\text { Diamteter }\end{array}$ & $\begin{array}{l}\text { Head } \\
\text { Shape }\end{array}$ & $\begin{array}{l}\text { Dish } \\
\text { Height }\end{array}$ & $\begin{array}{l}\text { Dish } \\
\text { Volume }\end{array}$ & $\begin{array}{c}\text { Tank } \\
\text { Fll } \\
\text { Height }\end{array}$ & $\begin{array}{c}\text { Retum } \\
\text { Line } \\
\text { Height }\end{array}$ & $\begin{array}{l}\text { Nozzle } \\
\text { Inner } \\
\text { Diameter }\end{array}$ & $\begin{array}{l}\text { Nozzle } \\
\text { Stantoff } \\
\text { Distance }\end{array}$ & $\begin{array}{l}\text { Pulse Tube } \\
\text { Configuration }\end{array}$ & $\begin{array}{l}\text { Installed } \\
\text { Nozzles }\end{array}$ & $\begin{array}{l}\text { Outer } \\
\text { Noztles } \\
\text { Operated }\end{array}$ & $\begin{array}{c}\text { Inner } \\
\text { Nozzles } \\
\text { Operated }\end{array}$ & $\begin{array}{l}\text { Pulse Tube } \\
\text { Outer } \\
\text { Diameter }\end{array}$ & $\begin{array}{c}\text { Outer } \\
\text { PJM } \\
\text { Radius }\end{array}$ & $\begin{array}{c}\text { Inner } \\
\text { PJM } \\
\text { Radius }\end{array}$ & $\begin{array}{l}\text { "FO' Outer } \\
\text { PJM } \\
\text { Impingement } \\
\text { Angle }\end{array}$ & $\begin{array}{l}\text { "FO' Inner PJM } \\
\text { Impingement } \\
\text { Angle }\end{array}$ & $\begin{array}{l}\text { Ratio Outer } \\
\text { PJMto Tank } \\
\text { Radius } \\
\end{array}$ & $\begin{array}{l}\text { Ratio Inner } \\
\text { PJM to Tank } \\
\text { Radius } \\
\end{array}$ & Simulant & $\begin{array}{l}\text { Solids } \\
\text { Density }\end{array}$ & $\begin{array}{c}\text { Particle } \\
\text { Diameter d5 }\end{array}$ & $\begin{array}{l}\text { Paticle } \\
\text { Diameter } \\
\text { d50 }\end{array}$ & $\begin{array}{l}\text { Partide } \\
\text { Diameter } \\
\text { d95 }\end{array}$ & $\begin{array}{c}\text { Void } \\
\text { Fraction }\end{array}$ \\
\hline text & text & text & in. & text & in. & in. ${ }^{3}$ & in. & in. & in. & in. & text & number & number & number & in. & in. & in. & deg & deg & nondim & nondim & text & g/cm & $m$ & $m$ & $\mathrm{~m}$ & fraction \\
\hline MSS & MDDX & ID & D & HS & Hish & $V_{\text {dath }}$ & $\mathrm{H}$ & Rtn & $d$ & sod & PT & $\mathrm{N}$ & $\mathrm{Nb}$ & $\mathrm{N}$ & $\mathrm{PT}_{\alpha \mathrm{d}}$ & $R_{0}$ & $R$ & $\theta_{\circ}$ & $\theta_{1}$ & $\mathrm{RdR}$ & $R / R$ & $\operatorname{sxdx}$ & $\rho_{s}$ & $d \mathrm{~d}$ & $\mathrm{~d}$ bo & des & vf \\
\hline 9700107 & $5 / 15 \mathrm{~A}$ & 70E_4sid2Vd_1 & 70 & $E$ & 19 & 49770.7 & $921 / 2$ & 80 & 0.613 & 0.920 & HLP-22 & 12 & 8 & 4 & 3.5 & 21.9 & 11.5 & 20.3 & 10.5 & 0.62 & 0.33 & $\mathrm{~s} 1 \mathrm{~d} 2$ & 2.48 & 0.0000569 & 0.0000693 & 0.0000821 & 0.3750 \\
\hline 9700107.1 & $5 / 15 \mathrm{~A}$ & 70E_4s1d2Vd_1 1 & 70 & $E$ & 19 & 49770.7 & $921 / 2$ & 80 & 0.613 & 0.920 & HLP-22 & 12 & 8 & 4 & 3.5 & 21.9 & 11.5 & 20.3 & 10.5 & 0.62 & 0.33 & s1d2 & 2.48 & 0.0000569 & 0.0000693 & 0.0000021 & 0.3750 \\
\hline 9700108 & $5 / 15 \mathrm{~A}$ & 70E_4s1d2Vd_1 & 70 & E & 19 & 49770.7 & $921 / 2$ & 80 & 0.613 & 0.920 & HLP-22 & 12 & 8 & 4 & 3.5 & 21.9 & 11.5 & 20.3 & 10.5 & 0.62 & 0.33 & s1d2 & 2.48 & 0.0000569 & 0.0000693 & 0.00000821 & 0.3750 \\
\hline 97000108.1 & $5 / 15 \mathrm{~A}$ & 70E_4s1d2Vd_1 & 70 & $E$ & 19 & 49770.7 & $921 / 2$ & 80 & 0.613 & 0.920 & HLP-22 & 12 & 8 & 4 & 3.5 & 21.9 & 11.5 & 20.3 & 10.5 & 0.62 & 0.33 & $\mathrm{~s} 1 \mathrm{~d} 2$ & 2.48 & 0.0000569 & 0.0000693 & 0.0000821 & 0.3750 \\
\hline 9700109 & $5 / 15 \mathrm{~A}$ & 70E_4s1d2Vd_ 1 & 70 & $E$ & 19 & 49770.7 & $921 / 2$ & 80 & 0.613 & 0.920 & HLP-22 & 12 & 8 & 4 & 3.5 & 21.9 & 11.5 & 20.3 & 10.5 & 0.62 & 0.33 & s1d2 & 2.48 & 0.0000569 & 0.0000693 & 0.0000821 & 0.3750 \\
\hline 9700109.1 & $5 / 15 \mathrm{~A}$ & 70E_4s1d2Vd_1 & 70 & $E$ & 19 & 49770.7 & $921 / 2$ & 80 & 0.613 & 0.920 & HLP-22 & 12 & 8 & 4 & 3.5 & 21.9 & 11.5 & 20.3 & 10.5 & 0.62 & 0.33 & s1d2 & 2.48 & 0.0000569 & 0.0000693 & 0.0000821 & 0.3750 \\
\hline $9700110 \mathrm{M}$ & $5 / 15 \mathrm{~A}$ & 70E_4s1d2Vd_1 & 70 & $E$ & 19 & 49770.7 & $921 / 2$ & 80 & 0.613 & 0.920 & HLP-22 & 12 & 8 & 4 & 3.5 & 21.9 & 11.5 & 20.3 & 10.5 & 0.62 & 0.33 & $\mathrm{~s} 1 \mathrm{~d} 2$ & 2.48 & 0.0000569 & 0.0000693 & 0.0000821 & 0.3750 \\
\hline 9700111 & 5/15A & 70E_4s1d2VI_1 & 70 & $E$ & 19 & 49770.7 & $92 \sqrt{2} / 2$ & 80 & 0.613 & 0.920 & HLP-22 & 12 & 8 & 4 & 3.5 & 21.9 & 11.5 & 20.3 & 10.5 & 0.62 & 0.33 & s1d2 & 2.48 & 0.0000569 & 0.0000693 & 0.0000821 & 0.3750 \\
\hline 9700112 & $5 / 15 \mathrm{~A}$ & 70E_4s1d2Vd_1 & 70 & E & 19 & 49770.7 & $921 / 2$ & 80 & 0.613 & 0.920 & HLP-22 & 12 & 8 & 4 & 3.5 & 21.9 & 11.5 & 20.3 & 10.5 & 0.62 & 0.33 & 51022 & 2.48 & 0.0000569 & 0.0000693 & 0.0000821 & 0.3750 \\
\hline 9700112.1 & $5 / 15 \mathrm{~A}$ & 70E_4s1d2Vd_1 1 & 70 & $E$ & 19 & 49770.7 & $921 / 2$ & 80 & 0.613 & 0.920 & HLP-22 & 12 & 8 & 4 & 3.5 & 21.9 & 11.5 & 20.3 & 10.5 & 0.62 & 0.33 & s1d2 & 2.48 & 0.0000569 & 0.0000693 & 0.0000021 & 0.3750 \\
\hline 9700113 & 5/15A & 70E_4s1d2Vd_1 & 70 & $E$ & 19 & 49770.7 & $921 / 2$ & 80 & 0.613 & 0.920 & HLP-22 & 12 & 8 & 4 & 3.5 & 21.9 & 11.5 & 20.3 & 10.5 & 0.62 & 0.33 & s1d2 & 2.48 & 0.0000569 & 0.0000693 & 0.0000821 & 0.3750 \\
\hline 9700113.1 & 5/15A & 70E_4S1d2Vd_1 & 70 & $E$ & 19 & 49770.7 & $921 / 2$ & 80 & 0.613 & 0.920 & HLP-22 & 12 & 8 & 4 & 3.5 & 21.9 & 11.5 & 20.3 & 10.5 & 0.62 & 0.33 & $\mathrm{~s} 1 \mathrm{~d} 2$ & 2.48 & 0.0000569 & 0.0000693 & 0.0000021 & 0.3750 \\
\hline 9700114 & 5/15A & 70E_4sId2Vd_1 & 70 & $E$ & 19 & 49770.7 & $921 / 2$ & 80 & 0.613 & 0.920 & HLP-22 & 12 & 8 & 4 & 3.5 & 21.9 & 11.5 & 20.3 & 10.5 & 0.62 & 0.33 & s1d2 & 2.48 & 0.0000569 & 0.0000693 & 0.0000821 & 0.3750 \\
\hline 9700014.1 & $5 / 15 \mathrm{~A}$ & 70E_4s1d2Vd_1 & 70 & E & 19 & 49770.7 & $921 / 2$ & 80 & 0.613 & 0.920 & HLP-22 & 12 & 8 & 4 & 3.5 & 21.9 & 11.5 & 20.3 & 10.5 & 0.62 & 0.33 & 5102 & 2.48 & 0.0000569 & 0.0000693 & 0.0000821 & 0.3750 \\
\hline 9700115 & 5/15A & 70E_4s1d2Vd_1 & 70 & E & 19 & 49770.7 & $921 / 2$ & 80 & 0.613 & 0.920 & HLP-22 & 12 & 8 & 4 & 3.5 & 21.9 & 11.5 & 20.3 & 10.5 & 0.62 & 0.33 & $\mathrm{sid2}$ & 2.48 & 0.0000569 & 0.0000693 & 0.0000821 & 0.3750 \\
\hline 9700115.1 & 5/15A & 70E_4sid2Vd_1 & 70 & $E$ & 19 & 49770.7 & $92 \sqrt{1 / 2}$ & 80 & 0.613 & 0.920 & HLP-22 & 12 & 8 & 4 & 3.5 & 21.9 & 11.5 & 20.3 & 10.5 & 0.62 & 0.33 & s1d2 & 2.48 & 0.0000569 & 0.0000693 & 0.0000821 & 0.3750 \\
\hline 9700115.2 & $5 / 15 \mathrm{~A}$ & 70E_4s1d2Vd_1 & 70 & $E$ & 19 & 49770.7 & $921 / 2$ & 80 & 0.613 & 0.920 & HLP-22 & 12 & 8 & 4 & 3.5 & 21.9 & 11.5 & 20.3 & 10.5 & 0.62 & 0.33 & $\mathrm{~s} 1 \mathrm{~d} 2$ & 2.48 & 0.0000569 & 0.0000693 & 0.0000021 & 0.3750 \\
\hline 9700115.3 & 5/15A & 70E_4sId2Vd_1 & 70 & $E$ & 19 & 49770.7 & $92 \sqrt{2} / 2$ & 80 & 0.613 & 0.920 & HLP-22 & 12 & 8 & 4 & 3.5 & 21.9 & 11.5 & 20.3 & 10.5 & 0.62 & 0.33 & s1d2 & 2.48 & 0.0000569 & 0.0000693 & 0.0000821 & 0.3750 \\
\hline 9700116 & 5/15B & 70E_4s1d2Ve_1 & 70 & $E$ & 19 & 49770.7 & $921 / 2$ & 80 & 0.613 & 0.920 & HLP-22 & 12 & 8 & 4 & 3.5 & 21.9 & 11.5 & 20.3 & 10.5 & 0.62 & 0.33 & s1d2 & 2.48 & 0.0000569 & 0.0000693 & 0.0000021 & 0.3750 \\
\hline 9700117M & 5/15B & 70E_4sid2Ve_1 & 70 & E & 19 & 49770.7 & $921 / 2$ & 80 & 0.613 & 0.920 & HLP-22 & 12 & 8 & 4 & 3.5 & 21.9 & 11.5 & 20.3 & 10.5 & 0.62 & 0.33 & $\mathrm{sid2}$ & 2.48 & 0.0000569 & 0.0000693 & 0.0000821 & 0.3750 \\
\hline 9700118 & $5 / 15 \mathrm{C}$ & 70E_4s1d2VC_2 & 70 & $\mathrm{E}$ & 19 & 49770.7 & $921 / 2$ & 80 & 0.613 & 0.920 & HLP-22 & 12 & 8 & 4 & 3.5 & 21.9 & 11.5 & 20.3 & 10.5 & 0.62 & 0.33 & s1d2 & 2.48 & 0.0000569 & 0.0000693 & 0.0000821 & 0.3750 \\
\hline $9700119 \mathrm{M}$ & $5 / 15 \mathrm{C}$ & 70E_4sIdZ2V__2 & 70 & E & 19 & 49770.7 & $921 / 2$ & 80 & 0.613 & 0.920 & HLP-22 & 12 & 8 & 4 & 3.5 & 21.9 & 11.5 & 20.3 & 10.5 & 0.62 & 0.33 & $\mathrm{~s} 1 \mathrm{~d} 2$ & 2.48 & 0.0000569 & 0.0000693 & 0.0000821 & 0.3750 \\
\hline 9700120 & 5/15D & 70E_4sId2Vd_2 & 70 & $E$ & 19 & 49770.7 & $92 \sqrt{2} / 2$ & 80 & 0.613 & 0.920 & HLP-22 & 12 & 8 & 4 & 3.5 & 21.9 & 11.5 & 20.3 & 10.5 & 0.62 & 0.33 & s1d2 & 2.48 & 0.0000569 & 0.0000693 & 0.0000821 & 0.3750 \\
\hline $97000121 \mathrm{M}$ & 5/15D & 70E_4s1d2Vd_2 & 70 & E & 19 & 49770.7 & $921 / 2$ & 80 & 0.613 & 0.920 & HLP-22 & 12 & 8 & 4 & 3.5 & 21.9 & 11.5 & 20.3 & 10.5 & 0.62 & 0.33 & s1d2 & 2.48 & 0.0000569 & 0.0000693 & 0.0000821 & 0.3750 \\
\hline 9700122 & 5/16A & 70E_4sidzVe 2 & 70 & E & 19 & 49770.7 & $921 / 2$ & 80 & 0.613 & 0.920 & HLP-22 & 12 & 8 & 4 & 3.5 & 21.9 & 11.5 & 20.3 & 10.5 & 0.62 & 0.33 & $\mathrm{~s} 1 \mathrm{~d} 2$ & 2.48 & 0.0000569 & 0.0000693 & 0.0000821 & 0.3750 \\
\hline 9700123M & 5/16A & 70E_4sid2Ve_2 & 70 & $\mathrm{E}$ & 19 & 49770.7 & $921 / 2$ & 80 & 0.613 & 0.920 & HLP-22 & 12 & 8 & 4 & 3.5 & 21.9 & 11.5 & 20.3 & 10.5 & 0.62 & 0.33 & s1d2 & 2.48 & 0.0000569 & 0.0000693 & 0.0000821 & 0.3750 \\
\hline 9700124 & 5/16B & 70E_4S1d2VC_4 & 70 & E & 19 & 49770.7 & $921 / 2$ & 80 & 0.613 & 0.920 & HLP-22 & 12 & 8 & 4 & 3.5 & 21.9 & 11.5 & 20.3 & 10.5 & 0.62 & 0.33 & $\mathrm{~s} 1 \mathrm{~d} 2$ & 2.48 & 0.0000569 & 0.0000693 & 0.0000821 & 0.3750 \\
\hline 9700125 & $5 / 16 \mathrm{~B}$ & 70E_4s1d2Vc_4 4 & 70 & $E$ & 19 & 49770.7 & $921 / 2$ & 80 & 0.613 & 0.920 & HLP-22 & 12 & 8 & 4 & 3.5 & 21.9 & 11.5 & 20.3 & 10.5 & 0.62 & 0.33 & $\mathrm{sid2}$ & 2.48 & 0.0000569 & 0.0000693 & 0.0000821 & 0.3750 \\
\hline $9700126 \mathrm{M}$ & 5/16B & 70E_4s1d2V__4 & 70 & E & 19 & 49770.7 & $921 / 2$ & 80 & 0.613 & 0.920 & HLP-22 & 12 & 8 & 4 & 3.5 & 21.9 & 11.5 & 20.3 & 10.5 & 0.62 & 0.33 & s1d2 & 2.48 & 0.0000569 & 0.0000693 & 0.0000821 & 0.3750 \\
\hline 9700127 & 5/16C & 70E_4s1d2Vd_4 & 70 & E & 19 & 49770.7 & $921 / 2$ & 80 & 0.613 & 0.920 & HLP-22 & 12 & 8 & 4 & 3.5 & 21.9 & 11.5 & 20.3 & 10.5 & 0.62 & 0.33 & $\mathrm{sid2}$ & 2.48 & 0.0000569 & 0.0000693 & 0.0000821 & 0.3750 \\
\hline 9700128 & $5 / 16 \mathrm{C}$ & 70E_4s1d2Vd_4 & 70 & $\mathrm{E}$ & 19 & 49770.7 & $921 / 2$ & 80 & 0.613 & 0.920 & HLP-22 & 12 & 8 & 4 & 3.5 & 21.9 & 11.5 & 20.3 & 10.5 & 0.62 & 0.33 & s1d2 & 2.48 & 0.0000569 & 0.0000693 & 0.0000821 & 0.3750 \\
\hline 9700129 & 5/19A & 70E_4SId2VI_ 4 & 70 & E & 19 & 49770.7 & $91 / / 2$ & 80 & 0.613 & 0.920 & HLP-22 & 12 & 8 & 4 & 3.5 & 21.9 & 11.5 & 20.3 & 10.5 & 0.62 & 0.33 & s1d2 & 2.48 & 0.0000569 & 0.0000693 & 0.0000821 & 0.3750 \\
\hline $9700030 \mathrm{M}$ & $5 / 19 \mathrm{~A}$ & 70E_4s1d2Vd_4 4 & 70 & $E$ & 19 & 49770.7 & $911 / 2$ & 80 & 0.613 & 0.920 & HLP-22 & 12 & 8 & 4 & 3.5 & 21.9 & 11.5 & 20.3 & 10.5 & 0.62 & 0.33 & s1d2 & 2.48 & 0.0000569 & 0.0000693 & 0.0000821 & 0.3750 \\
\hline 9700131M & 5/19A & 70E_4sId2Vd_4 & 70 & E & 19 & 49770.7 & $911 / 2$ & 80 & 0.613 & 0.920 & HLP-22 & 12 & 8 & 4 & 3.5 & 21.9 & 11.5 & 20.3 & 10.5 & 0.62 & 0.33 & s1d2 & 2.48 & 0.0000569 & 0.0000693 & 0.0000821 & 0.3750 \\
\hline 9700132 & 5/19B & 70E_4sid2Ve 4 & 70 & E & 19 & 49770.7 & $911 / 2$ & 80 & 0.613 & 0.920 & HLP-22 & 12 & 8 & 4 & 3.5 & 21.9 & 11.5 & 20.3 & 10.5 & 0.62 & 0.33 & $\mathrm{~s} 1 \mathrm{~d} 2$ & 2.48 & 0.0000569 & 0.0000693 & 0.0000821 & 0.3750 \\
\hline 9700133 & 5/19B & 70E_4sid2Ve_4 & 70 & $\mathrm{E}$ & 19 & 49770.7 & $91 / / 2$ & 80 & 0.613 & 0.920 & HLP-22 & 12 & 8 & 4 & 3.5 & 21.9 & 11.5 & 20.3 & 10.5 & 0.62 & 0.33 & s1d2 & 2.48 & 0.0000569 & 0.0000693 & 0.0000821 & 0.3750 \\
\hline 9700134 & $5 / 19 B$ & 70E_4sid2Ve_4 4 & 70 & $E$ & 19 & 49770.7 & $91 / / 2$ & 80 & 0.613 & 0.920 & HLP-22 & 12 & 8 & 4 & 3.5 & 21.9 & 11.5 & 20.3 & 10.5 & 0.62 & 0.33 & s1d2 & 2.48 & 0.0000569 & 0.0000693 & 0.0000821 & 0.3750 \\
\hline 9700135 & $5 / 19 c$ & 70E_4s1d2Xc_1 & 70 & $E$ & 19 & 49770.7 & $91 / 1 / 2$ & 80 & 0.613 & 0.920 & HLP-22 & 12 & 8 & 4 & 3.5 & 21.9 & 11.5 & 20.3 & 10.5 & 0.62 & 0.33 & s1d2 & 2.48 & 0.0000569 & 0.0000693 & 0.0000021 & 0.3750 \\
\hline 9700136 & $5 / 19 \mathrm{C}$ & 70E_4sId2X__1 & 70 & E & 19 & 49770.7 & $911 / 2$ & 80 & 0.613 & 0.920 & HLP-22 & 12 & 8 & 4 & 3.5 & 21.9 & 11.5 & 20.3 & 10.5 & 0.62 & 0.33 & s1d2 & 2.48 & 0.0000569 & 0.0000693 & 0.0000821 & 0.3750 \\
\hline 9700137 & $5 / 19 \mathrm{C}$ & 70E_4s1d2Xc_1 & 70 & E & 19 & 49770.7 & $911 / 2$ & 80 & 0.613 & 0.920 & HLP-22 & 12 & 8 & 4 & 3.5 & 21.9 & 11.5 & 20.3 & 10.5 & 0.62 & 0.33 & $\mathrm{s1d2}$ & 2.48 & 0.0000569 & 0.0000693 & 0.0000821 & 0.3750 \\
\hline 9700138 & $5 / 19 c$ & $70 E_{2} 4 \mathrm{~s} 1 \mathrm{~d} 2 \mathrm{Cc}_{1} 1$ & 70 & $E$ & 19 & 49770.7 & $91 / 2$ & 80 & 0.613 & 0.920 & HLP-22 & 12 & 8 & 4 & 3.5 & 21.9 & 11.5 & 20.3 & 10.5 & 0.62 & 0.33 & s1d2 & 2.48 & 0.0000569 & 0.0000693 & 0.0000821 & 0.3750 \\
\hline
\end{tabular}


Table B.5. Data from 2008 Tests in Large-Scale Vessel with Elliptical Head B.4

\begin{tabular}{|c|c|c|c|c|c|c|c|c|c|c|c|c|c|c|c|c|c|c|c|c|c|c|c|c|c|c|c|c|c|}
\hline $\begin{array}{l}\text { Tank Water } \\
\text { Temperature }\end{array}$ & $\begin{array}{l}\text { Water } \\
\text { Density }\end{array}$ & $\begin{array}{c}\text { Solids } \\
\text { Fraction }\end{array}$ & $\begin{array}{c}\text { Pulse } \\
\text { Volume } \\
\text { Fraction }\end{array}$ & $\begin{array}{l}\text { Duty } \\
\text { Qyde }\end{array}$ & $\begin{array}{l}\text { Oyde } \\
\text { Time }\end{array}$ & $\begin{array}{c}\text { Pulsed } \\
\text { or } \\
\text { Steady } \\
\text { Jet }\end{array}$ & $\begin{array}{l}\text { Us } \\
\text { Steady } \\
\text { Jet }\end{array}$ & $\begin{array}{c}\text { Un } \\
\text { Pulsing } \\
\text { Jet }\end{array}$ & $\begin{array}{l}\text { U2 } \\
\text { URMS }\end{array}$ & $\begin{array}{c}\text { U3 } \\
\text { URNB }\end{array}$ & $\begin{array}{l}\text { Discharge } \\
\text { Velocity }\end{array}$ & $\begin{array}{c}\text { Citical } \\
\text { Suspension } \\
\text { velocity }\end{array}$ & $\begin{array}{c}\text { Average } \\
\text { Peak Cloud } \\
\text { Height }\end{array}$ & $\begin{array}{c}\text { Ucs } \\
\text { Condition }\end{array}$ & $\begin{array}{l}\text { UCS } \\
\text { Method }\end{array}$ & $\begin{array}{l}\text { UCS } \\
\text { Fag }\end{array}$ & $\begin{array}{c}\text { UCS } \\
\text { Center } \\
\text { Flag }\end{array}$ & $\begin{array}{c}\text { UCS uadv } \\
\text { Hag }\end{array}$ & $\begin{array}{c}\text { UCS based } \\
\text { on } \\
\text { Decreasing } \\
\text { Velocity }\end{array}$ & $\begin{array}{l}\text { Sweep } \\
\text { Increase } \\
\text { Decrease }\end{array}$ & $\begin{array}{c}\text { UDV } \\
\text { Height } \\
\text { Bed }\end{array}$ & $\begin{array}{c}\text { Particle } \\
\text { Motion }\end{array}$ & \begin{tabular}{|l|}
$\begin{array}{l}\text { Solids } \\
\text { Level }\end{array}$ \\
\end{tabular} & \begin{tabular}{|l|} 
Outer \\
Botom \\
Pattem \\
\end{tabular} & $\begin{array}{c}\text { Inner } \\
\text { Botomo } \\
\text { Pattem }\end{array}$ & Case ID & Test & TDP & $\begin{array}{l}\text { Row } \\
\text { Number }\end{array}$ \\
\hline $\mathrm{c}$ & $\mathrm{g} / \mathrm{cm}^{3}$ & fraction & fraction & fraction & $\mathrm{s}$ & text & $\mathrm{m} / \mathrm{s}$ & $\mathrm{m} / \mathrm{s}$ & $\mathrm{m} / \mathrm{s}$ & $\mathrm{m} / \mathrm{s}$ & $m / s$ & m/s & in. & $\mathrm{m} / \mathrm{s}$ & text & text & text & text & \begin{tabular}{|l|}
$\mathrm{m} / \mathrm{s}$ \\
\end{tabular} & text & $\mathrm{mm}$ & text & text & text & text & text & text & text & text \\
\hline$T$ & $\rho$ & $\phi_{\mathrm{s}}$ & $\phi_{p}$ & $D C$ & to & Jet & $U_{s}$ & $\mathrm{U} 1$ & $\mathrm{U} 2$ & U3 & $u$ & Uos & $H_{c}$ & $U_{\text {Csp }}$ & Uosm & Ussis & Usscen & Usoudv & Uos $D$ & $S_{w}$ & Hod & $\mathrm{PM}$ & Sol & SPo & $\mathrm{SP}_{1}$ & $\mathrm{ID}$ & MDDX & $\mathrm{TDP}$ & MSS \\
\hline 23.0 & 0.995 & 0.01430 & 0.050 & 0.189 & 48.6 & $\mathrm{P}$ & $\mathrm{NA}$ & 10.39 & 10.65 & 10.79 & 11.20 & 10.90 & 45.00 & NA & $\mathrm{NA}$ & NA & $\mathrm{NA}$ & NA & NA & NA & 6.0 & NA & $\mathrm{NA}$ & NA & $\mathrm{NA}$ & 70E_4s1d2Vd_1 & $5 / 15 \mathrm{~A}$ & TDP-156 & 9700107 \\
\hline 23.0 & 0.995 & 0.01430 & 0.050 & 0.189 & 48.6 & $\mathrm{P}$ & NA & 10.39 & 10.65 & 10.79 & 11.20 & 10.90 & 45.00 & NA & NA & NA & NA & NA & NA & NA & $\mathrm{n} / \mathrm{a}$ & NA & NA & NA & NA & 70E_4s1d2Vd_1 & $5 / 15 \mathrm{~A}$ & TDP-156 & 97000107.1 \\
\hline 23.0 & 0.995 & 0.01430 & 0.050 & 0.189 & 48.6 & $P$ & NA & 10.39 & 10.65 & 10.79 & 11.20 & 10.90 & 45.00 & NA & NA & NA & NA & NA & NA & NA & 0.0 & NA & NA & NA & NA & 70E_4s1d2Vd_1 & $5 / 15 \mathrm{~A}$ & TDP-156 & 9700108 \\
\hline 23.0 & 0.995 & 0.01430 & 0.050 & 0.189 & 48.6 & $P$ & NA & 10.39 & 10.65 & 10.79 & 11.20 & 10.90 & 45.00 & NA & NA & NA & NA & NA & NA & NA & $\mathrm{na}$ & NA & NA & NA & NA & 70E_4sId2Vd_1 & $5 / 15 \mathrm{~A}$ & TDP-156 & 9700108.1 \\
\hline 23.0 & 0.995 & 0.01430 & 0.050 & 0.189 & 48.6 & $\mathrm{P}$ & NA & 10.39 & 10.65 & 10.79 & 11.20 & 10.90 & 45.00 & NA & NA & NA & NA & NA & NA & NA & 4.3 & NA & NA & NA & NA & 70E_4sId2Vd_1 & $5 / 15 \mathrm{~A}$ & TDP-156 & 9700109 \\
\hline 23.0 & 0.995 & 0.01430 & 0.050 & 0.189 & 48.6 & $P$ & NA & 10.39 & 10.65 & 10.79 & 11.20 & 10.90 & 45.00 & NA & NA & NA & NA & NA & NA & NA & $\mathrm{na}$ & NA & NA & NA & NA & 70E_4sId2Vd_1 & $5 / 15 \mathrm{~A}$ & TDP-156 & 9700109.1 \\
\hline 23.3 & 0.995 & 0.01430 & 0.050 & 0.189 & 48.6 & $\mathrm{P}$ & NA & 10.38 & 10.65 & 10.78 & 11.20 & 10.90 & 45.00 & NA & NA & NA & NA & NA & NA & (null) & 0.0 & 4 & NA & NA & NA & 70E_4sId2Vd_1 & $5 / 15 \mathrm{~A}$ & TDP-156 & 9700110 \\
\hline 23.3 & 0.995 & 0.01430 & 0.050 & 0.189 & 48.6 & $P$ & NA & 10.38 & 10.65 & 10.78 & 11.20 & 10.90 & 45.00 & NA & NA & NA & NA & NA & NA & NA & 0.0 & NA & NA & NA & NA & 70E_4s1d2Vd_1 & $5 / 15 \mathrm{~A}$ & TDP-156 & 9700112 \\
\hline 23.3 & 0.995 & 0.01430 & 0.050 & 0.189 & 48.6 & $\mathrm{P}$ & NA & 10.38 & 10.65 & 10.78 & 11.20 & 10.90 & 45.00 & NA & NA & NA & NA & NA & NA & NA & $\mathrm{n} / \mathrm{a}$ & NA & NA & NA & NA & 70E_4sId2Vd_1 1 & $5 / 15 \mathrm{~A}$ & IDP-156 & 9700112.1 \\
\hline 23.3 & 0.995 & 0.01430 & 0.050 & 0.189 & 48.6 & $P$ & NA & 10.38 & 10.65 & 10.78 & 11.20 & 10.90 & 45.00 & NA & NA & NA & NA & NA & NA & NA & 8.8 & NA & NA & NA & NA & 70E_4s1d2Vd_ 1 & $5 / 15 \mathrm{~A}$ & TDP-156 & 9700113 \\
\hline 23.3 & 0.995 & 0.01430 & 0.050 & 0.189 & 48.6 & $\mathrm{P}$ & NA & 10.38 & 10.65 & 10.78 & 11.20 & 10.90 & 45.00 & NA & NA & NA & NA & NA & NA & NA & $\mathrm{na}$ & NA & NA & NA & NA & 70E_4sId2Vd_1 & $5 / 15 \mathrm{~A}$ & TDP-156 & 9700113.1 \\
\hline 23.3 & 0.995 & 0.01430 & 0.050 & 0.189 & 48.6 & $\mathrm{P}$ & NA & 10.38 & 10.65 & 10.78 & 11.20 & 10.90 & 45.00 & NA & NA & NA & NA & NA & NA & NA & 0.0 & NA & NA & NA & $\mathrm{NA}$ & 70E_4s1d2Vd_1 & $5 / 15 \mathrm{~A}$ & TDP-156 & 9700114 \\
\hline 23.3 & 0.995 & 0.01430 & 0.050 & 0.189 & 48.6 & $\mathrm{P}$ & NA & 10.38 & 10.65 & 10.78 & 11.20 & 10.90 & 45.00 & NA & NA & NA & NA & NA & NA & NA & $\mathrm{na}$ & NA & NA & NA & NA & 70E_4S1d2Vd_ 1 & $5 / 15 \mathrm{~A}$ & TDP-156 & 9700114.1 \\
\hline 23.3 & 0.995 & 0.01430 & 0.050 & 0.189 & 48.6 & $\mathrm{P}$ & NA & 10.38 & 10.65 & 10.78 & 11.20 & 10.90 & 45.00 & NA & NA & NA & NA & NA & NA & NA & 2.3 & NA & NA & NA & NA & 70E_4S1d2V___ 1 & $5 / 15 \mathrm{~A}$ & TDP-156 & 9700115 \\
\hline 23.3 & 0.995 & 0.01430 & 0.050 & 0.189 & 48.6 & $P$ & NA & 10.38 & 10.65 & 10.78 & 11.20 & 10.90 & 45.00 & NA & NA & NA & NA & NA & NA & NA & $\mathrm{na}$ & NA & NA & NA & NA & 70E 4 sId2Vd 1 & $5 / 15 \mathrm{~A}$ & TDP-156 & 9700115.1 \\
\hline 23.3 & 0.995 & 0.01430 & 0.050 & 0.189 & 48.6 & $\mathrm{P}$ & NA & 10.38 & 10.65 & 10.78 & 11.20 & 10.90 & 45.00 & NA & NA & NA & NA & NA & NA & NA & $\mathrm{na}$ & NA & NA & NA & NA & 70E_4s1d2Vd_1 & $5 / 15 \mathrm{~A}$ & TDP-156 & 9700115.2 \\
\hline 23.3 & 0.995 & 0.01430 & 0.050 & 0.189 & 48.6 & $\mathrm{P}$ & NA & 10.38 & 10.65 & 10.78 & 11.20 & 10.90 & 45.00 & NA & NA & NA & NA & NA & NA & NA & $\mathrm{Na}$ & NA & NA & NA & NA & 70E_4s1d2Vd_1 & $5 / 15 \mathrm{~A}$ & TDP-156 & 9700115.3 \\
\hline 23.7 & 0.994 & 0.01430 & 0.050 & 0.656 & 32.4 & $\mathrm{P}$ & NA & 4.43 & 4.48 & 4.50 & 4.60 & 4.80 & NA & NA & NA & NA & NA & NA & NA & $\mathrm{D}$ & 26.7 & 1 & NA & NA & NA & 70E_4S1d2Ve_ 1 & $5 / 15 B$ & TDP-156 & 9700116 \\
\hline 23.7 & 0.994 & 0.01430 & 0.050 & 0.662 & 31.0 & $\mathrm{P}$ & NA & 4.62 & 4.68 & 4.71 & 4.80 & 4.80 & 36.25 & 4.80 & udv & NA & UCScen & Ucsudv & NA & 1 & 0.0 & 2 & NA & NA & NA & 70E_4s1d2Ve_1 & $5 / 15 B$ & TDP-156 & 9700117 \\
\hline 24.1 & 0.995 & 0.01430 & 0.101 & 0.332 & 80.0 & $\mathrm{P}$ & NA & 7.19 & 7.26 & 7.29 & 7.40 & 7.40 & 37.50 & 7.40 & udv & NA & UCScen & Ucsudv & NA & 1 & 0.0 & 2 & NA & NA & NA & 70E_4S1d2VV_ 2 & $5 / 15 \mathrm{C}$ & TDP-156 & 9700119 \\
\hline 24.3 & 0.994 & 0.01430 & 0.100 & 0.170 & 136.0 & $\mathrm{P}$ & NA & 8.22 & 8.31 & 8.35 & 8.50 & 8.70 & 28.25 & \begin{tabular}{|l|} 
NA \\
\end{tabular} & NA & NA & UcScen & NA & NA & (null) & 5.1 & 2 & NA & NA & NA & 70E_4s1d2Vd_2 & $5 / 15 \mathrm{D}$ & TDP-156 & 9700120 \\
\hline 24.5 & 0.994 & 0.01430 & 0.101 & 0.182 & 125.0 & $\mathrm{P}$ & NA & 8.44 & 8.52 & 8.57 & 8.70 & 8.70 & 30.50 & 8.70 & udv & NA & NA & ucsudv & NA & (null) & 0.7 & 4 & NA & NA & NA & 70E_4S1d2Vd_2 & $5 / 15 \mathrm{D}$ & TDP-156 & 9700121 \\
\hline 24.1 & 0.994 & 0.01430 & 0.101 & 0.660 & 64.0 & $\mathrm{P}$ & NA & 4.53 & 4.55 & 4.56 & 4.60 & 4.80 & 29.00 & NA & NA & NA & NA & NA & NA & (null) & 7.8 & 1 & NA & NA & NA & 70E_4S1d2Ve_2 & $5 / 16 \mathrm{~A}$ & TDP-157 & 9700122 \\
\hline 24.2 & 0.994 & 0.01430 & 0.100 & 0.663 & 60.6 & $\mathrm{P}$ & NA & 4.72 & 4.75 & 4.76 & 4.80 & 4.80 & 37.25 & 4.80 & udv & NA & Ucscen & Ucsudv & NA & 1 & 0.0 & 2 & NA & NA & NA & 70E_4s1d2Ve_2 & $5 / 16 \mathrm{~A}$ & TDP-157 & 9700123 \\
\hline 24.1 & 0.994 & 0.01430 & 0.150 & 0.330 & 146.6 & $\mathrm{P}$ & NA & 5.88 & 5.91 & 5.93 & 6.00 & 6.60 & 26.50 & NA & NA & NA & NA & NA & NA & (null) & 12.4 & 1 & NA & NA & NA & 70E_4sid2Vc_ 4 & $5 / 16 \mathrm{~B}$ & TDP-157 & 9700124 \\
\hline 24.3 & 0.994 & 0.01430 & 0.150 & 0.331 & 137.4 & $\mathrm{P}$ & NA & 6.29 & 6.33 & 6.35 & 6.40 & 6.60 & 30.25 & \begin{tabular}{|l|}
$N A$ \\
\end{tabular} & NA & NA & Ucscen & NA & NA & (null) & 6.6 & 2 & NA & NA & NA & 70E_4s1d2VE_4 & $5 / 168$ & TDP-157 & 9700125 \\
\hline 24.4 & 0.995 & 0.01430 & 0.151 & 0.331 & 133.2 & $\mathrm{P}$ & $\mathrm{NA}$ & 6.50 & 6.53 & 6.55 & 6.60 & 6.60 & 35.50 & 6.60 & udv & NA & NA & Ucsudv & NA & 1 & 0.0 & 4 & NA & NA & NA & 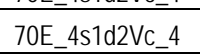 & $5 / 16 \mathrm{~B}$ & TDP-157 & 9700126 \\
\hline 25.0 & 0.995 & 0.01430 & 0.152 & 0.175 & 285.0 & $\mathrm{P}$ & NA & 5.78 & 5.82 & 5.85 & 6.00 & 6.40 & 24.50 & \begin{tabular}{|l|} 
NA \\
\end{tabular} & NA & NA & NA & NA & NA & (null) & 19.4 & 1 & NA & NA & NA & 70E_4S1d2Vd_4 & $5 / 16 \mathrm{C}$ & TDP-157 & 9700127 \\
\hline 25.3 & 0.994 & 0.01430 & 0.150 & 0.175 & 271.0 & $\mathrm{P}$ & NA & 6.00 & 6.04 & 6.06 & 6.20 & 6.40 & 26.00 & NA & NA & NA & NA & NA & NA & (null) & 12.8 & 1 & NA & NA & NA & 70E_4S1d2VV_4 & $5 / 16 \mathrm{C}$ & TDP-157 & 9700128 \\
\hline 24.4 & 0.995 & 0.01430 & 0.152 & 0.175 & 271.0 & $\mathrm{P}$ & NA & 6.10 & 6.13 & 6.15 & 6.20 & 6.40 & 26.50 & \begin{tabular}{|l|} 
NA \\
\end{tabular} & NA & NA & NA & NA & NA & (null) & 5.9 & 1 & NA & NA & NA & 70E_4sid2Vd_4 & $5 / 19 \mathrm{~A}$ & TDP-158 & 9700129 \\
\hline 24.4 & 0.995 & 0.01430 & 0.152 & 0.176 & 2624 & $\mathrm{P}$ & NA & 6.27 & 6.31 & 6.33 & 6.40 & 6.40 & 26.50 & \begin{tabular}{|l|}
6.40 \\
\end{tabular} & udv & NA & UCScen & Ucsudv & NA & 1 & 0.9 & 2 & NA & NA & NA & 70E_4sid2Vd_4 & $5 / 19 A$ & TDP-158 & 9700130 \\
\hline 24.6 & 0.994 & 0.01430 & 0.152 & 0.176 & 254.4 & $\mathrm{P}$ & NA & 6.48 & 6.52 & 6.54 & 6.60 & 6.40 & 27.75 & \begin{tabular}{|l|} 
NA \\
\end{tabular} & NA & NA & NA & NA & NA & 1 & 0.0 & 4 & NA & NA & NA & 70E_4S1d2Vd_4 & $5 / 19 \mathrm{~A}$ & TDP-158 & 9700131 \\
\hline 24.9 & 0.995 & 0.01430 & 0.151 & 0.658 & 100.4 & $\mathrm{P}$ & NA & 4.34 & 4.36 & 4.37 & 4.40 & 4.50 & NA & NA & NA & NA & NA & NA & NA & (null) & 7.4 & 1 & NA & NA & NA & 70E_4S1d2Ve_4 4 & $5 / 198$ & TDP-158 & 9700132 \\
\hline 24.8 & 0.994 & 0.01430 & 0.151 & 0.659 & 98.2 & $\mathrm{P}$ & NA & 4.44 & 4.46 & 4.47 & 4.50 & 4.50 & NA & 4.50 & udv & NA & UCscen & Ucsudv & NA & 1 & 1.8 & 2 & NA & NA & NA & 70E_4s1d2Ve_4 & $5 / 198$ & TDP-158 & 9700133 \\
\hline 24.9 & 0.994 & 0.01430 & 0.151 & 0.660 & 94.0 & $\mathrm{P}$ & NA & 4.64 & 4.65 & 4.67 & 4.70 & 4.50 & NA & NA & NA & NA & NA & NA & NA & 1 & 0.0 & 4 & NA & NA & NA & 70E_4sidzVe_4 & $5 / 198$ & TDP-158 & 9700134 \\
\hline 25.1 & 0.995 & 0.01500 & 0.050 & 0.330 & 43.2 & $P$ & NA & 6.64 & 6.76 & 6.81 & 7.00 & 8.50 & 24.00 & NA & NA & NA & NA & NA & NA & (null) & 17.2 & 1 & NA & NA & NA & 70E_4sid2Xc_1 & $5 / 19 \mathrm{C}$ & TDP-159 & 9700135 \\
\hline 25.1 & 0.994 & 0.01500 & 0.050 & 0.331 & 40.8 & $\mathrm{P}$ & NA & 7.01 & 7.13 & 7.19 & 7.40 & 8.50 & 26.00 & NA & NA & NA & NA & NA & NA & 1 & 26.2 & 1 & NA & NA & NA & 70E_4sid2XC_ 1 & $5 / 19 \mathrm{C}$ & TDP-159 & 9700136 \\
\hline 25.2 & 0.994 & 0.01500 & 0.050 & 0.333 & 38.8 & $\mathrm{P}$ & NA & 7.39 & 7.52 & 7.59 & 7.80 & 8.50 & 28.25 & NA & NA & NA & NA & NA & NA & 1 & 30.9 & 1 & NA & NA & NA & 70E_4s1d2Xc_1 & $5 / 19 \mathrm{C}$ & TDP-159 & 9700137 \\
\hline 25.3 & 0.995 & 0.01500 & 0.050 & 0.334 & 37.8 & $P$ & NA & 7.58 & 7.71 & 7.78 & 8.00 & 8.50 & 32.25 & NA & NA & NA & NA & NA & NA & 1 & 28.2 & 1 & NA & NA & NA & 70E_4s1d2X__1 & $5 / 19 \mathrm{C}$ & TDP-159 & 9700138 \\
\hline
\end{tabular}


Table B.5. Data from 2008 Tests in Large-Scale Vessel with Elliptical Head A.5

\begin{tabular}{|c|c|c|c|c|c|c|c|c|c|c|c|c|c|c|c|c|c|c|c|c|c|c|c|c|c|c|c|}
\hline $\begin{array}{l}\text { Row } \\
\text { Number }\end{array}$ & Test & Case ID & $\begin{array}{c}\text { Tank } \\
\text { Diamteter }\end{array}$ & $\begin{array}{l}\text { Head } \\
\text { Shape }\end{array}$ & $\begin{array}{l}\text { Dish } \\
\text { Height }\end{array}$ & $\begin{array}{l}\text { Dish } \\
\text { Volume }\end{array}$ & $\begin{array}{c}\text { Tank } \\
\text { Fll } \\
\text { Height }\end{array}$ & $\begin{array}{l}\text { Return } \\
\text { Line } \\
\text { Height }\end{array}$ & $\begin{array}{l}\text { Nozzle } \\
\text { Inner } \\
\text { Diameter }\end{array}$ & $\begin{array}{l}\text { Nozzle } \\
\text { Stantoff } \\
\text { Distance }\end{array}$ & $\begin{array}{l}\text { Pulse Tube } \\
\text { Configuration }\end{array}$ & $\begin{array}{l}\text { Installed } \\
\text { Nozzles }\end{array}$ & $\begin{array}{l}\text { Outer } \\
\text { Noztles } \\
\text { Operated }\end{array}$ & $\begin{array}{c}\text { Inner } \\
\text { Nozzles } \\
\text { Operated }\end{array}$ & $\begin{array}{l}\text { Pulse Tube } \\
\text { Outer } \\
\text { Diameter }\end{array}$ & $\begin{array}{c}\text { Outer } \\
\text { PJM } \\
\text { Radius }\end{array}$ & $\begin{array}{c}\text { Inner } \\
\text { PJM } \\
\text { Radius }\end{array}$ & $\begin{array}{l}\text { "FO' Outer } \\
\text { PJM } \\
\text { Impingement } \\
\text { Angle }\end{array}$ & $\begin{array}{l}\text { "FO' Inner PJM } \\
\text { Impingement } \\
\text { Angle }\end{array}$ & $\begin{array}{l}\text { Ratio Outer } \\
\text { PJMto Tank } \\
\text { Radius } \\
\end{array}$ & $\begin{array}{l}\text { Ratio Inner } \\
\text { PJM to Tank } \\
\text { Radius } \\
\end{array}$ & Simulant & $\begin{array}{l}\text { Solids } \\
\text { Density }\end{array}$ & $\begin{array}{c}\text { Particle } \\
\text { Diameter d5 }\end{array}$ & $\begin{array}{l}\text { Paticle } \\
\text { Diameter } \\
\text { d50 }\end{array}$ & $\begin{array}{l}\text { Partide } \\
\text { Diameter } \\
\text { d95 }\end{array}$ & $\begin{array}{c}\text { Void } \\
\text { Fraction }\end{array}$ \\
\hline text & text & text & in. & text & in. & in. ${ }^{3}$ & in. & in. & in. & in. & text & number & number & number & in. & in. & in. & deg & deg & nondim & nondim & text & g/cm & $m$ & $m$ & $\mathrm{~m}$ & fraction \\
\hline MSS & MDDX & ID & D & HS & Hish & $V_{\text {dath }}$ & $\mathrm{H}$ & Rtn & $d$ & sod & PT & $\mathrm{N}$ & $\mathrm{Nb}$ & $\mathrm{N}$ & $\mathrm{PT}_{\alpha \mathrm{d}}$ & $R_{0}$ & $R$ & $\theta_{\circ}$ & $\theta_{1}$ & $\mathrm{RdR}$ & $R / R$ & $\operatorname{sxdx}$ & $\rho_{s}$ & $d \mathrm{~d}$ & $\mathrm{~d}$ bo & des & vf \\
\hline 9700139 & $5 / 19 \mathrm{C}$ & 70E_4s1d2Xc_1 & 70 & $E$ & 19 & 49770.7 & $911 / 2$ & 80 & 0.613 & 0.920 & HLP-22 & 12 & 8 & 4 & 3.5 & 21.9 & 11.5 & 20.3 & 10.5 & 0.62 & 0.33 & $\mathrm{~s} 1 \mathrm{~d} 2$ & 2.48 & 0.0000569 & 0.0000693 & 0.0000821 & 0.3750 \\
\hline 9700140 & $5 / 19 \mathrm{C}$ & $70 E_{-} 4 \mathrm{~s} 1 \mathrm{~d} 2 \times \mathrm{C}_{\mathrm{c}} 1$ & 70 & $E$ & 19 & 49770.7 & $91 / / 2$ & 80 & 0.613 & 0.920 & HLP-22 & 12 & 8 & 4 & 3.5 & 21.9 & 11.5 & 20.3 & 10.5 & 0.62 & 0.33 & s1d2 & 2.48 & 0.0000569 & 0.0000693 & 0.0000021 & 0.3750 \\
\hline 9700141 & $5 / 20 \mathrm{~A}$ & $70 E_{-} 4 \mathrm{~s} 1 \mathrm{~d} 2 \mathrm{X} \mathrm{c} \_1$ & 70 & E & 19 & 49770.7 & $911 / 2$ & 80 & 0.613 & 0.920 & HLP-22 & 12 & 8 & 4 & 3.5 & 21.9 & 11.5 & 20.3 & 10.5 & 0.62 & 0.33 & s1d2 & 2.48 & 0.0000569 & 0.0000693 & 0.00000821 & 0.3750 \\
\hline 9700142 & $5 / 20 \mathrm{~A}$ & 70E_4s1d2X__ 1 & 70 & E & 19 & 49770.7 & $91 / / 2$ & 80 & 0.613 & 0.920 & HLP-22 & 12 & 8 & 4 & 3.5 & 21.9 & 11.5 & 20.3 & 10.5 & 0.62 & 0.33 & s1d2 & 2.48 & 0.0000569 & 0.0000693 & 0.0000821 & 0.3750 \\
\hline 9700143 & $5 / 20 \mathrm{~A}$ & $70 E_{-} 4 \mathrm{~s} 1 \mathrm{~d} 2 \times \mathrm{C}_{-} 1$ & 70 & $E$ & 19 & 49770.7 & $91 / / 2$ & 80 & 0.613 & 0.920 & HLP-22 & 12 & 8 & 4 & 3.5 & 21.9 & 11.5 & 20.3 & 10.5 & 0.62 & 0.33 & $\mathrm{~s} 1 \mathrm{~d} 2$ & 2.48 & 0.0000569 & 0.0000693 & 0.0000821 & 0.3750 \\
\hline $9700144 \mathrm{M}$ & $5 / 20 A$ & 70E_4S1d2Xc_1 & 70 & $E$ & 19 & 49770.7 & $91 / / 2$ & 80 & 0.613 & 0.920 & HLP-22 & 12 & 8 & 4 & 3.5 & 21.9 & 11.5 & 20.3 & 10.5 & 0.62 & 0.33 & s1d2 & 2.48 & 0.0000569 & 0.0000693 & 0.0000821 & 0.3750 \\
\hline 9700145M & 5/20A & 70E_4s1d2X__1 & 70 & $E$ & 19 & 49770.7 & $91 / / 2$ & 80 & 0.613 & 0.920 & HLP-22 & 12 & 8 & 4 & 3.5 & 21.9 & 11.5 & 20.3 & 10.5 & 0.62 & 0.33 & $\mathrm{~s} 1 \mathrm{~d} 2$ & 2.48 & 0.0000569 & 0.0000693 & 0.0000821 & 0.3750 \\
\hline 9700146 & 5/20A & 70E_4s1d2Xc_1 & 70 & $E$ & 19 & 49770.7 & $911 / 2$ & 80 & 0.613 & 0.920 & HLP-22 & 12 & 8 & 4 & 3.5 & 21.9 & 11.5 & 20.3 & 10.5 & 0.62 & 0.33 & s1d2 & 2.48 & 0.0000569 & 0.0000693 & 0.0000821 & 0.3750 \\
\hline 9700147 & $5 / 20 \mathrm{~A}$ & 70E_4s1d2Xc_1 & 70 & E & 19 & 49770.7 & $911 / 2$ & 80 & 0.613 & 0.920 & HLP-22 & 12 & 8 & 4 & 3.5 & 21.9 & 11.5 & 20.3 & 10.5 & 0.62 & 0.33 & 5102 & 2.48 & 0.0000569 & 0.0000693 & 0.0000821 & 0.3750 \\
\hline 9700147.1 & 5/20A & 70E_4s $1 \mathrm{~d} 2 \times \mathrm{X} \_1$ & 70 & $E$ & 19 & 49770.7 & $91 / / 2$ & 80 & 0.613 & 0.920 & HLP-22 & 12 & 8 & 4 & 3.5 & 21.9 & 11.5 & 20.3 & 10.5 & 0.62 & 0.33 & s1d2 & 2.48 & 0.0000569 & 0.0000693 & 0.0000021 & 0.3750 \\
\hline 9700148 & 5/20A & 70E_4S1d2Xc_1 & 70 & $E$ & 19 & 49770.7 & $91 / / 2$ & 80 & 0.613 & 0.920 & HLP-22 & 12 & 8 & 4 & 3.5 & 21.9 & 11.5 & 20.3 & 10.5 & 0.62 & 0.33 & s1d2 & 2.48 & 0.0000569 & 0.0000693 & 0.0000821 & 0.3750 \\
\hline 9700148.1 & 5/20A & $70 \mathrm{Z} \_4 \mathrm{~s} 1 \mathrm{~d} 2 \mathrm{XC} \_1$ & 70 & $\mathrm{E}$ & 19 & 49770.7 & $91 / / 2$ & 80 & 0.613 & 0.920 & HLP-22 & 12 & 8 & 4 & 3.5 & 21.9 & 11.5 & 20.3 & 10.5 & 0.62 & 0.33 & $\mathrm{~s} 1 \mathrm{~d} 2$ & 2.48 & 0.0000569 & 0.0000693 & 0.0000821 & 0.3750 \\
\hline 9700149 & 5/20A & 70E_4s1d2Xc_1 & 70 & $E$ & 19 & 49770.7 & $911 / 2$ & 80 & 0.613 & 0.920 & HLP-22 & 12 & 8 & 4 & 3.5 & 21.9 & 11.5 & 20.3 & 10.5 & 0.62 & 0.33 & s1d2 & 2.48 & 0.0000569 & 0.0000693 & 0.0000821 & 0.3750 \\
\hline 9700149.1 & $5 / 20 \mathrm{~A}$ & 70E_4s1d2Xc_1 & 70 & E & 19 & 49770.7 & $911 / 2$ & 80 & 0.613 & 0.920 & HLP-22 & 12 & 8 & 4 & 3.5 & 21.9 & 11.5 & 20.3 & 10.5 & 0.62 & 0.33 & 5102 & 2.48 & 0.0000569 & 0.0000693 & 0.0000821 & 0.3750 \\
\hline 9700150 & 5/20A & 70E_4s1d2Xc_ 1 & 70 & E & 19 & 49770.7 & $911 / 2$ & 80 & 0.613 & 0.920 & HLP-22 & 12 & 8 & 4 & 3.5 & 21.9 & 11.5 & 20.3 & 10.5 & 0.62 & 0.33 & $\mathrm{sid2}$ & 2.48 & 0.0000569 & 0.0000693 & 0.0000821 & 0.3750 \\
\hline 9700150.1 & 5/20A & 70E_4sid2Xc_1 & 70 & $E$ & 19 & 49770.7 & $91 / / 2$ & 80 & 0.613 & 0.920 & HLP-22 & 12 & 8 & 4 & 3.5 & 21.9 & 11.5 & 20.3 & 10.5 & 0.62 & 0.33 & s1d2 & 2.48 & 0.0000569 & 0.0000693 & 0.0000821 & 0.3750 \\
\hline 9700151 & 5/20A & $70 E_{4} 4 \mathrm{~s} 1 \mathrm{~d} 2 \times \mathrm{C} \_1$ & 70 & $E$ & 19 & 49770.7 & $911 / 2$ & 80 & 0.613 & 0.920 & HLP-22 & 12 & 8 & 4 & 3.5 & 21.9 & 11.5 & 20.3 & 10.5 & 0.62 & 0.33 & $\mathrm{~s} 1 \mathrm{~d} 2$ & 2.48 & 0.0000569 & 0.0000693 & 0.0000021 & 0.3750 \\
\hline 9700151.1 & $5 / 20 \mathrm{~A}$ & 70E_4s1d2Xc_1 & 70 & $E$ & 19 & 49770.7 & $911 / 2$ & 80 & 0.613 & 0.920 & HLP-22 & 12 & 8 & 4 & 3.5 & 21.9 & 11.5 & 20.3 & 10.5 & 0.62 & 0.33 & s1d2 & 2.48 & 0.0000569 & 0.0000693 & 0.0000821 & 0.3750 \\
\hline 9700152 & 5/20A & 70E_4s1d2Xc_1 & 70 & $E$ & 19 & 49770.7 & $911 / 2$ & 80 & 0.613 & 0.920 & HLP-22 & 12 & 8 & 4 & 3.5 & 21.9 & 11.5 & 20.3 & 10.5 & 0.62 & 0.33 & s1d2 & 2.48 & 0.0000569 & 0.0000693 & 0.0000821 & 0.3750 \\
\hline 9700153 & $5 / 20 \mathrm{~A}$ & 70E_4s1d2Xc_1 & 70 & E & 19 & 49770.7 & $911 / 2$ & 80 & 0.613 & 0.920 & HLP-22 & 12 & 8 & 4 & 3.5 & 21.9 & 11.5 & 20.3 & 10.5 & 0.62 & 0.33 & $\mathrm{sid2}$ & 2.48 & 0.0000569 & 0.0000693 & 0.0000821 & 0.3750 \\
\hline 9700154 & 5/20A & 70E_4s1d2Xc_1 & 70 & $\mathrm{E}$ & 19 & 49770.7 & $911 / 2$ & 80 & 0.613 & 0.920 & HLP-22 & 12 & 8 & 4 & 3.5 & 21.9 & 11.5 & 20.3 & 10.5 & 0.62 & 0.33 & s1d2 & 2.48 & 0.0000569 & 0.0000693 & 0.0000821 & 0.3750 \\
\hline 9700154.1 & $5 / 20 \mathrm{~A}$ & $70 E \_4 s 1 d 2 \times c \_1$ & 70 & E & 19 & 49770.7 & $911 / 2$ & 80 & 0.613 & 0.920 & HLP-22 & 12 & 8 & 4 & 3.5 & 21.9 & 11.5 & 20.3 & 10.5 & 0.62 & 0.33 & $\mathrm{~s} 1 \mathrm{~d} 2$ & 2.48 & 0.0000569 & 0.0000693 & 0.0000821 & 0.3750 \\
\hline 9700155 & 5/20A & 70E_4sid2Xc_1 & 70 & $E$ & 19 & 49770.7 & $911 / 2$ & 80 & 0.613 & 0.920 & HLP-22 & 12 & 8 & 4 & 3.5 & 21.9 & 11.5 & 20.3 & 10.5 & 0.62 & 0.33 & s1d2 & 2.48 & 0.0000569 & 0.0000693 & 0.0000821 & 0.3750 \\
\hline 9700155.1 & 5/20A & 70E_4s $1 \mathrm{~d} 2 X \mathrm{C} \_1$ & 70 & E & 19 & 49770.7 & $911 / 2$ & 80 & 0.613 & 0.920 & HLP-22 & 12 & 8 & 4 & 3.5 & 21.9 & 11.5 & 20.3 & 10.5 & 0.62 & 0.33 & s1d2 & 2.48 & 0.0000569 & 0.0000693 & 0.0000821 & 0.3750 \\
\hline 9700156 & 5/20A & 70E_4s1d2Xc_ 1 & 70 & E & 19 & 49770.7 & $911 / 2$ & 80 & 0.613 & 0.920 & HLP-22 & 12 & 8 & 4 & 3.5 & 21.9 & 11.5 & 20.3 & 10.5 & 0.62 & 0.33 & $\mathrm{sid2}$ & 2.48 & 0.0000569 & 0.0000693 & 0.0000821 & 0.3750 \\
\hline 9700156.1 & 5/20A & 70E_4S1d2Xc_1 & 70 & $\mathrm{E}$ & 19 & 49770.7 & $91 / / 2$ & 80 & 0.613 & 0.920 & HLP-22 & 12 & 8 & 4 & 3.5 & 21.9 & 11.5 & 20.3 & 10.5 & 0.62 & 0.33 & s1d2 & 2.48 & 0.0000569 & 0.0000693 & 0.0000821 & 0.3750 \\
\hline 9700157 & $5 / 20 \mathrm{~A}$ & $70 E \_451 \mathrm{~d} 2 \times \mathrm{C} \_1$ & 70 & E & 19 & 49770.7 & $91 / / 2$ & 80 & 0.613 & 0.920 & HLP-22 & 12 & 8 & 4 & 3.5 & 21.9 & 11.5 & 20.3 & 10.5 & 0.62 & 0.33 & $\mathrm{~s} 1 \mathrm{~d} 2$ & 2.48 & 0.0000569 & 0.0000693 & 0.0000821 & 0.3750 \\
\hline 9700157.1 & 5/20A & 70E_4s $1 \mathrm{~d} 2 X \mathrm{X} \_1$ & 70 & $E$ & 19 & 49770.7 & $911 / 2$ & 80 & 0.613 & 0.920 & HLP-22 & 12 & 8 & 4 & 3.5 & 21.9 & 11.5 & 20.3 & 10.5 & 0.62 & 0.33 & $\mathrm{sid2}$ & 2.48 & 0.0000569 & 0.0000693 & 0.0000821 & 0.3750 \\
\hline 9700158 & 5/20A & 70E_4sid2X__1 & 70 & E & 19 & 49770.7 & $911 / 2$ & 80 & 0.613 & 0.920 & HLP-22 & 12 & 8 & 4 & 3.5 & 21.9 & 11.5 & 20.3 & 10.5 & 0.62 & 0.33 & s1d2 & 2.48 & 0.0000569 & 0.0000693 & 0.0000821 & 0.3750 \\
\hline 9700158.1 & 5/20A & 70E_4s1d2Xc_1 & 70 & E & 19 & 49770.7 & $911 / 2$ & 80 & 0.613 & 0.920 & HLP-22 & 12 & 8 & 4 & 3.5 & 21.9 & 11.5 & 20.3 & 10.5 & 0.62 & 0.33 & $\mathrm{sid2}$ & 2.48 & 0.0000569 & 0.0000693 & 0.0000821 & 0.3750 \\
\hline 9700159 & 5/20A & 70E_4S1d2Xc_1 & 70 & $\mathrm{E}$ & 19 & 49770.7 & $91 / / 2$ & 80 & 0.613 & 0.920 & HLP-22 & 12 & 8 & 4 & 3.5 & 21.9 & 11.5 & 20.3 & 10.5 & 0.62 & 0.33 & s1d2 & 2.48 & 0.0000569 & 0.0000693 & 0.0000821 & 0.3750 \\
\hline 9700160 & 5/20A & 70E_4s1d2Xc_1 & 70 & E & 19 & 49770.7 & $91 / / 2$ & 80 & 0.613 & 0.920 & HLP-22 & 12 & 8 & 4 & 3.5 & 21.9 & 11.5 & 20.3 & 10.5 & 0.62 & 0.33 & s1d2 & 2.48 & 0.0000569 & 0.0000693 & 0.0000821 & 0.3750 \\
\hline 9700161 & $5 / 20 \mathrm{~A}$ & 70E_4s $1 \mathrm{~d} 2 \times \mathrm{X} \_1$ & 70 & $E$ & 19 & 49770.7 & $911 / 2$ & 80 & 0.613 & 0.920 & HLP-22 & 12 & 8 & 4 & 3.5 & 21.9 & 11.5 & 20.3 & 10.5 & 0.62 & 0.33 & $\mathrm{~s} 1 \mathrm{~d} 2$ & 2.48 & 0.0000569 & 0.0000693 & 0.0000821 & 0.3750 \\
\hline 9700161.1 & 5/20A & 70E_4sId2X__1 & 70 & E & 19 & 49770.7 & $911 / 2$ & 80 & 0.613 & 0.920 & HLP-22 & 12 & 8 & 4 & 3.5 & 21.9 & 11.5 & 20.3 & 10.5 & 0.62 & 0.33 & s1d2 & 2.48 & 0.0000569 & 0.0000693 & 0.0000821 & 0.3750 \\
\hline 9700162 & 5/20A & 70E_4s1d2Xc_1 & 70 & E & 19 & 49770.7 & $911 / 2$ & 80 & 0.613 & 0.920 & HLP-22 & 12 & 8 & 4 & 3.5 & 21.9 & 11.5 & 20.3 & 10.5 & 0.62 & 0.33 & $\mathrm{sid2}$ & 2.48 & 0.0000569 & 0.0000693 & 0.0000821 & 0.3750 \\
\hline 9700162.1 & $5 / 20 \mathrm{~A}$ & 70E_4S1d2Xc_1 & 70 & $\mathrm{E}$ & 19 & 49770.7 & $91 / / 2$ & 80 & 0.613 & 0.920 & HLP-22 & 12 & 8 & 4 & 3.5 & 21.9 & 11.5 & 20.3 & 10.5 & 0.62 & 0.33 & s1d2 & 2.48 & 0.0000569 & 0.0000693 & 0.0000821 & 0.3750 \\
\hline 9700163 & $5 / 20 \mathrm{~A}$ & 70E_4s1d2Xc_1 & 70 & $E$ & 19 & 49770.7 & $91 / / 2$ & 80 & 0.613 & 0.920 & HLP-22 & 12 & 8 & 4 & 3.5 & 21.9 & 11.5 & 20.3 & 10.5 & 0.62 & 0.33 & s1d2 & 2.48 & 0.0000569 & 0.0000693 & 0.0000821 & 0.3750 \\
\hline 9700163.1 & 5/20A & 70E_4s1d2Xc_1 & 70 & $E$ & 19 & 49770.7 & $91 / 1 / 2$ & 80 & 0.613 & 0.920 & HLP-22 & 12 & 8 & 4 & 3.5 & 21.9 & 11.5 & 20.3 & 10.5 & 0.62 & 0.33 & s1d2 & 2.48 & 0.0000569 & 0.0000693 & 0.0000021 & 0.3750 \\
\hline 9700164 & 5/20A & 70E_4sId2X__1 & 70 & E & 19 & 49770.7 & $911 / 2$ & 80 & 0.613 & 0.920 & HLP-22 & 12 & 8 & 4 & 3.5 & 21.9 & 11.5 & 20.3 & 10.5 & 0.62 & 0.33 & s1d2 & 2.48 & 0.0000569 & 0.0000693 & 0.0000821 & 0.3750 \\
\hline 9700164.1 & $5 / 20 \mathrm{~A}$ & 70E_4s1d2Xc_1 & 70 & E & 19 & 49770.7 & $911 / 2$ & 80 & 0.613 & 0.920 & HLP-22 & 12 & 8 & 4 & 3.5 & 21.9 & 11.5 & 20.3 & 10.5 & 0.62 & 0.33 & $\mathrm{s1d2}$ & 2.48 & 0.0000569 & 0.0000693 & 0.0000821 & 0.3750 \\
\hline 9700164.2 & 5/20A & $70 E_{2} 4 \mathrm{~s} 1 \mathrm{~d} 2 \mathrm{Cc}_{1} 1$ & 70 & $E$ & 19 & 49770.7 & $91 / 2$ & 80 & 0.613 & 0.920 & HLP-22 & 12 & 8 & 4 & 3.5 & 21.9 & 11.5 & 20.3 & 10.5 & 0.62 & 0.33 & s1d2 & 2.48 & 0.0000569 & 0.0000693 & 0.0000821 & 0.3750 \\
\hline
\end{tabular}


Table B.5. Data from 2008 Tests in Large-Scale Vessel with Elliptical Head B.5

\begin{tabular}{|c|c|c|c|c|c|c|c|c|c|c|c|c|c|c|c|c|c|c|c|c|c|c|c|c|c|c|c|c|c|}
\hline $\begin{array}{l}\text { Tank Water } \\
\text { Temperature }\end{array}$ & $\begin{array}{l}\text { Water } \\
\text { Density }\end{array}$ & $\begin{array}{c}\text { Solids } \\
\text { Fraction }\end{array}$ & $\begin{array}{c}\text { Pulse } \\
\text { Volume } \\
\text { Fraction }\end{array}$ & $\begin{array}{l}\text { Duty } \\
\text { Qyde }\end{array}$ & $\begin{array}{l}\text { Cycle } \\
\text { Time }\end{array}$ & $\begin{array}{c}\text { Pulsed } \\
\text { or } \\
\text { Steady } \\
\text { Jet }\end{array}$ & $\begin{array}{l}\text { Us } \\
\text { Steady } \\
\text { Jet }\end{array}$ & $\begin{array}{c}\text { U1 } \\
\text { Pulsing } \\
\text { Jet } \\
\end{array}$ & $\begin{array}{l}\text { U2 } \\
\text { URMS }\end{array}$ & $\begin{array}{c}\text { U3 } \\
\text { URNB }\end{array}$ & $\begin{array}{c}\text { Discharge } \\
\text { Velocity }\end{array}$ & $\begin{array}{c}\text { Citical } \\
\text { Suspension } \\
\text { velocity }\end{array}$ & $\begin{array}{c}\text { Average } \\
\text { Peak Cloud } \\
\text { Height }\end{array}$ & $\begin{array}{c}\text { UCS } \\
\text { Condition }\end{array}$ & $\begin{array}{l}\text { UCS } \\
\text { Method }\end{array}$ & $\begin{array}{l}\text { UCS } \\
\text { Fag }\end{array}$ & $\begin{array}{c}\text { UCS } \\
\text { Center } \\
\text { Fag }\end{array}$ & $\begin{array}{c}\text { UCS uadv } \\
\text { Hag }\end{array}$ & $\begin{array}{c}\text { UCS based } \\
\text { on } \\
\text { Decreasing } \\
\text { Velocity }\end{array}$ & $\begin{array}{l}\text { Sweep } \\
\text { Increase } \\
\text { Decrease }\end{array}$ & $\begin{array}{c}\text { UDV } \\
\text { Height } \\
\text { Bed }\end{array}$ & $\begin{array}{l}\text { Particle } \\
\text { Motion }\end{array}$ & \begin{tabular}{|l|}
$\begin{array}{l}\text { Solids } \\
\text { Level }\end{array}$ \\
\end{tabular} & \begin{tabular}{|l|} 
Outer \\
Botom \\
Pattem \\
\end{tabular} & $\begin{array}{c}\text { Inner } \\
\text { Botomo } \\
\text { Pattem }\end{array}$ & Case ID & Test & TDP & $\begin{array}{l}\text { Row } \\
\text { Number }\end{array}$ \\
\hline$c$ & $\mathrm{~g} / \mathrm{cm}^{3}$ & fraction & ffraction & fraction & $\mathrm{s}$ & text & m/s & $\mathrm{m} / \mathrm{s}$ & m/s & $\mathrm{ms}$ & $\mathrm{m} / \mathrm{s}$ & m/s & in. & $\mathrm{m} / \mathrm{s}$ & text & text & text & text & \begin{tabular}{|l|}
$\mathrm{m} / \mathrm{s}$ \\
\end{tabular} & text & $\begin{array}{ll}\mathrm{mm} \\
\end{array}$ & text & \begin{tabular}{|l|} 
text \\
\end{tabular} & text & text & text & text & text & text \\
\hline$T$ & $\rho$ & $\phi_{\mathrm{s}}$ & $\phi_{p}$ & $D C$ & tc & Jet & $U_{s}$ & $\mathrm{U}_{1}$ & $\mathrm{U} 2$ & $U_{3}$ & $u$ & Uos & $H_{c}$ & U Cose & Uasn & Ussis & Usscen & Usoudv & Uos $D$ & $s_{\mathrm{w}}$ & Hod & $\mathrm{PM}$ & Sol & SPo & $\mathrm{SP}_{1}$ & $\mathrm{ID}$ & MDDX & $\mathrm{TDP}$ & MSS \\
\hline 25.3 & 0.994 & 0.01500 & 0.050 & 0.335 & 36.8 & $P$ & $\mathrm{NA}$ & 7.75 & 7.89 & 7.97 & 8.20 & 8.50 & 40.00 & $\mathrm{NA}$ & $\mathrm{NA}$ & $\mathrm{NA}$ & NA & $\mathrm{NA}$ & $\mathrm{NA}$ & 1 & 9.4 & 1 & NA & NA & $\mathrm{NA}$ & 70E_4s1d2Xc_1 & $5 / 19 \mathrm{C}$ & TDP-159 & 9700139 \\
\hline 25.5 & 0.994 & 0.01500 & 0.051 & 0.336 & 36.0 & $\mathrm{P}$ & NA & 7.94 & 8.09 & 8.17 & 8.40 & 8.50 & NA & NA & NA & NA & NA & NA & NA & 1 & 0.0 & 4 & NA & NA & NA & $70 E_{-} 4 \mathrm{~s} 1 \mathrm{~d} 2 \times \mathrm{C}_{-} 1$ & $5 / 19 \mathrm{C}$ & TDP-159 & 9700140 \\
\hline 26.5 & 0.994 & 0.01500 & 0.050 & 0.335 & 36.8 & $\mathrm{P}$ & NA & 7.76 & 7.90 & 7.97 & 8.20 & 8.50 & 35.75 & $\mathrm{NA}$ & NA & NA & NA & NA & NA & (null) & 25.5 & 1 & NA & NA & NA & 70E_4s1d2Xc_1 & $5 / 20 \mathrm{~A}$ & TDP-160 & 9700141 \\
\hline 26.7 & 0.994 & 0.01500 & 0.050 & 0.336 & 36.4 & $P$ & NA & 7.85 & 8.00 & 8.07 & 8.30 & 8.50 & 39.00 & NA & NA & NA & NA & NA & NA & 1 & 16.2 & 1 & NA & NA & NA & 70E_4s1d2X__ 1 & $5 / 20 \mathrm{~A}$ & TDP-160 & 9700142 \\
\hline 26.7 & 0.994 & 0.01500 & 0.050 & 0.336 & 35.8 & $\mathrm{P}$ & NA & 7.94 & 8.09 & 8.17 & 8.40 & 8.50 & 41.00 & NA & NA & NA & Ucscen & NA & NA & 1 & 3.5 & 2 & NA & NA & NA & 70E_4sId2X__1 & $5 / 20 \mathrm{~A}$ & TDP-160 & 9700143 \\
\hline 26.7 & 0.994 & 0.01500 & 0.050 & 0.337 & 35.4 & $P$ & NA & 8.03 & 8.18 & 8.26 & 8.50 & 8.50 & 41.50 & 8.50 & udv & NA & NA & ucsudv & NA & 1 & 1.0 & 4 & NA & NA & NA & 70 E $4 \mathrm{~s} 1 \mathrm{~d} 2 \mathrm{XC} \_1$ & $5 / 20 \mathrm{~A}$ & TDP-160 & 9700144 \\
\hline 26.6 & 0.994 & 0.01500 & 0.050 & 0.337 & 35.4 & $\mathrm{P}$ & NA & 8.03 & 8.18 & 8.26 & 8.50 & 8.50 & 41.00 & NA & NA & NA & NA & NA & NA & 1 & 0.0 & 4 & NA & NA & NA & 70E_4s1d2Xc_1 & $5 / 20 \mathrm{~A}$ & TDP-160 & 9700145 \\
\hline 26.6 & 0.994 & 0.01500 & 0.050 & 0.337 & 35.4 & $\mathrm{P}$ & NA & 8.03 & 8.18 & 8.26 & 8.50 & 8.50 & 41.00 & NA & NA & NA & NA & NA & NA & NA & 0.0 & NA & NA & NA & NA & 70E_4sid2X__1 & $5 / 20 \mathrm{~A}$ & TDP-160 & 9700147 \\
\hline 26.6 & 0.994 & 0.01500 & 0.050 & 0.337 & 35.4 & $\mathrm{P}$ & NA & 8.03 & 8.18 & 8.26 & 8.50 & 8.50 & 41.00 & NA & NA & NA & NA & NA & NA & NA & $\mathrm{n} / \mathrm{a}$ & NA & NA & NA & NA & 70E_4s1d2Xc_1 & $5 / 20 \mathrm{~A}$ & TDP-160 & 9700147.1 \\
\hline 26.6 & 0.994 & 0.01500 & 0.050 & 0.337 & 35.4 & $P$ & NA & 8.03 & 8.18 & 8.26 & 8.50 & 8.50 & 41.00 & NA & NA & NA & NA & NA & NA & NA & 0.0 & NA & NA & NA & NA & 70 _ $4 \mathrm{~s} 1 \mathrm{~d} 2 \mathrm{XC}$ & 5/20A & TDP-160 & 9700148 \\
\hline 26.6 & 0.994 & 0.01500 & 0.050 & 0.337 & 35.4 & $\mathrm{P}$ & NA & 8.03 & 8.18 & 8.26 & 8.50 & 8.50 & 41.00 & NA & NA & NA & NA & NA & NA & NA & $\mathrm{na}$ & NA & NA & NA & NA & 70E_4sId2X__ 1 & $5 / 20 \mathrm{~A}$ & TDP-160 & 9700148.1 \\
\hline 26.6 & 0.994 & 0.01500 & 0.050 & 0.337 & 35.4 & $\mathrm{P}$ & NA & 8.03 & 8.18 & 8.26 & 8.50 & 8.50 & 41.00 & NA & NA & NA & NA & NA & NA & NA & 0.0 & NA & NA & NA & NA & 70E_4sid2Xc_1 & $5 / 20 \mathrm{~A}$ & TDP-160 & 9700149 \\
\hline 26.6 & 0.994 & 0.01500 & 0.050 & 0.337 & 35.4 & $\mathrm{P}$ & NA & 8.03 & 8.18 & 8.26 & 8.50 & 8.50 & 41.00 & NA & NA & NA & NA & NA & NA & NA & $\mathrm{na}$ & NA & NA & NA & NA & 70E_4S1d2XC 1 & $5 / 20 \mathrm{~A}$ & TDP-160 & 9700149.1 \\
\hline 26.6 & 0.994 & 0.01500 & 0.050 & 0.337 & 35.4 & $\mathrm{P}$ & NA & 8.03 & 8.18 & 8.26 & 8.50 & 8.50 & 41.00 & NA & NA & NA & NA & NA & NA & NA & 0.0 & NA & NA & NA & NA & 70E_-4S102X__ 1 & $5 / 20 \mathrm{~A}$ & TDP-160 & 9700150 \\
\hline 26.6 & 0.994 & 0.01500 & 0.050 & 0.337 & 35.4 & $P$ & NA & 8.03 & 8.18 & 8.26 & 8.50 & 8.50 & 41.00 & NA & NA & NA & NA & NA & NA & NA & $\mathrm{na}$ & NA & NA & NA & NA & 70 _ $4 \mathrm{~s} 1 \mathrm{~d} 2 \mathrm{X} \mathrm{C}$ & $5 / 20 \mathrm{~A}$ & TDP-160 & 9700150.1 \\
\hline 26.6 & 0.994 & 0.01500 & 0.050 & 0.337 & 35.4 & $\mathrm{P}$ & NA & 8.03 & 8.18 & 8.26 & 8.50 & 8.50 & 41.00 & NA & NA & NA & NA & NA & NA & NA & 0.0 & NA & NA & NA & NA & 70E_4sId2X__ 1 & $5 / 20 \mathrm{~A}$ & TDP-160 & 9700151 \\
\hline 26.6 & 0.994 & 0.01500 & 0.050 & 0.337 & 35.4 & $\mathrm{P}$ & NA & 8.03 & 8.18 & 8.26 & 8.50 & 8.50 & 41.00 & NA & NA & NA & NA & NA & NA & NA & $\mathrm{Na}$ & NA & NA & NA & NA & 70E_4sid2Xc_1 & $5 / 20 \mathrm{~A}$ & TDP-160 & 9700151.1 \\
\hline 26.6 & 0.994 & 0.01500 & 0.050 & 0.337 & 35.4 & $\mathrm{P}$ & NA & 8.03 & 8.18 & 8.25 & 8.50 & 8.50 & 41.50 & NA & NA & NA & NA & NA & NA & (null) & 0.0 & 4 & NA & NA & NA & 70E_4S1d2XC_ 1 & $5 / 20 \mathrm{~A}$ & TDP-160 & 9700152 \\
\hline 26.6 & 0.994 & 0.01500 & 0.050 & 0.337 & 35.4 & $\mathrm{P}$ & NA & 8.03 & 8.18 & 8.25 & 8.50 & 8.50 & 41.50 & NA & NA & NA & NA & NA & NA & NA & 0.0 & NA & NA & NA & NA & 70E_-4S1d2X__ 1 & $5 / 20 \mathrm{~A}$ & TDP-160 & 9700153 \\
\hline 26.6 & 0.994 & 0.01500 & 0.050 & 0.337 & 35.4 & $\mathrm{P}$ & NA & 8.03 & 8.18 & 8.25 & 8.50 & 8.50 & 41.50 & NA & NA & NA & NA & NA & NA & NA & $\mathrm{na}$ & NA & NA & NA & NA & 70E_4sId2X__ 1 & $5 / 20 \mathrm{~A}$ & TDP-160 & 9700154.1 \\
\hline 26.6 & 0.994 & 0.01500 & 0.050 & 0.337 & 35.4 & $\mathrm{P}$ & NA & 8.03 & 8.18 & 8.25 & 8.50 & 8.50 & 41.50 & $\mathrm{NA}$ & NA & NA & NA & NA & NA & NA & 0.0 & NA & NA & NA & NA & 70E_4sid2Xc_1 & $5 / 20 \mathrm{~A}$ & TDP-160 & 9700155 \\
\hline 26.6 & 0.994 & 0.01500 & 0.050 & 0.337 & 35.4 & $\mathrm{P}$ & NA & 8.03 & 8.18 & 8.25 & 8.50 & 8.50 & 41.50 & NA & NA & NA & NA & NA & NA & NA & $\mathrm{na}$ & NA & NA & NA & NA & 70E_4S1d2XC 1 & $5 / 20 \mathrm{~A}$ & TDP-160 & 9700155.1 \\
\hline 26.6 & 0.994 & 0.01500 & 0.050 & 0.337 & 35.4 & $\mathrm{P}$ & NA & 8.03 & 8.18 & 8.25 & 8.50 & 8.50 & 41.50 & NA & NA & NA & NA & NA & NA & NA & 0.0 & NA & NA & NA & NA & 70E_-4s1d2X__ 1 & $5 / 20 \mathrm{~A}$ & TDP-160 & 9700156 \\
\hline 26.6 & 0.994 & 0.01500 & 0.050 & 0.337 & 35.4 & $\mathrm{P}$ & NA & 8.03 & 8.18 & 8.25 & 8.50 & 8.50 & 41.50 & NA & NA & NA & NA & NA & NA & NA & na & NA & NA & NA & NA & 70E_4s1d2X___ & $5 / 20 \mathrm{~A}$ & TDP-160 & 9700156.1 \\
\hline 26.6 & 0.994 & 0.01500 & 0.050 & 0.337 & 35.4 & $\mathrm{P}$ & NA & 8.03 & 8.18 & 8.25 & 8.50 & 8.50 & 41.50 & NA & NA & NA & NA & NA & NA & NA & 0.0 & NA & NA & NA & NA & 70E_4sId2X__ 1 & $5 / 20 \mathrm{~A}$ & TDP-160 & 9700157 \\
\hline 26.6 & 0.994 & 0.01500 & 0.050 & 0.337 & 35.4 & $\mathrm{P}$ & NA & 8.03 & 8.18 & 8.25 & 8.50 & 8.50 & 41.50 & NA & NA & NA & NA & NA & NA & NA & $\mathrm{n} / \mathrm{a}$ & NA & NA & NA & NA & 70E_4s1d2Xc_1 & $5 / 20 \mathrm{~A}$ & TDP-160 & 9700157.1 \\
\hline 26.6 & 0.994 & 0.01500 & 0.050 & 0.337 & 35.4 & $\mathrm{P}$ & $\mathrm{NA}$ & 8.03 & 8.18 & 8.25 & 8.50 & 8.50 & 41.50 & NA & NA & NA & NA & NA & NA & NA & 0.0 & NA & NA & NA & NA & 70E_4S1d2XC 1 & $5 / 20 \mathrm{~A}$ & TDP-160 & 9700158 \\
\hline 26.6 & 0.994 & 0.01500 & 0.050 & 0.337 & 35.4 & $\mathrm{P}$ & NA & 8.03 & 8.18 & 8.25 & 8.50 & 8.50 & 41.50 & NA & NA & NA & NA & NA & NA & NA & $\mathrm{na}$ & NA & NA & NA & NA & 70E_4s1d2X__ _ 1 & $5 / 20 \mathrm{~A}$ & TDP-160 & 9700158.1 \\
\hline 26.7 & 0.994 & 0.01500 & 0.050 & 0.337 & 35.4 & $\mathrm{P}$ & NA & 8.04 & 8.19 & 8.26 & 8.50 & 8.50 & 41.50 & NA & NA & NA & NA & NA & NA & (null) & 0.0 & 4 & NA & NA & NA & 70E_4s1d2X___ & $5 / 20 \mathrm{~A}$ & TDP-160 & 9700159 \\
\hline 26.7 & 0.994 & 0.01500 & 0.050 & 0.337 & 35.4 & $\mathrm{P}$ & NA & 8.04 & 8.19 & 8.26 & 8.50 & 8.50 & 41.50 & NA & NA & NA & NA & NA & NA & NA & 0.0 & NA & NA & NA & NA & 70E_4sid2X__ 1 & $5 / 20 \mathrm{~A}$ & TDP-160 & 9700160 \\
\hline 26.7 & 0.994 & 0.01500 & 0.050 & 0.337 & 35.4 & $\mathrm{P}$ & NA & 8.04 & 8.19 & 8.26 & 8.50 & 8.50 & 41.50 & NA & NA & NA & NA & NA & NA & NA & 0.0 & NA & NA & NA & NA & 70E_4sid2Xc_1 & $5 / 20 \mathrm{~A}$ & TDP-160 & 9700161 \\
\hline 26.7 & 0.994 & 0.01500 & 0.050 & 0.337 & 35.4 & $\mathrm{P}$ & NA & 8.04 & 8.19 & 8.26 & 8.50 & 8.50 & 41.50 & NA & NA & NA & NA & NA & NA & NA & $\mathrm{na}$ & NA & NA & NA & NA & 70E_4sid2XC_ 1 & $5 / 20 \mathrm{~A}$ & TDP-160 & 9700161.1 \\
\hline 26.7 & 0.994 & 0.01500 & 0.050 & 0.337 & 35.4 & $\mathrm{P}$ & NA & 8.04 & 8.19 & 8.26 & 8.50 & 8.50 & 41.50 & NA & NA & NA & NA & NA & NA & NA & 2.8 & NA & NA & NA & NA & 70E_-4s1d2X__ 1 & $5 / 20 \mathrm{~A}$ & TDP-160 & 9700162 \\
\hline 26.7 & 0.994 & 0.01500 & 0.050 & 0.337 & 35.4 & $\mathrm{P}$ & NA & 8.04 & 8.19 & 8.26 & 8.50 & 8.50 & 41.50 & NA & NA & NA & NA & NA & NA & NA & na & NA & NA & NA & NA & 70E_4s1d2X___ & $5 / 20 \mathrm{~A}$ & TDP-160 & 9700162.1 \\
\hline 26.7 & 0.994 & 0.01500 & 0.050 & 0.337 & 35.4 & $\mathrm{P}$ & NA & 8.04 & 8.19 & 8.26 & 8.50 & 8.50 & 41.50 & NA & NA & NA & NA & NA & NA & NA & 0.0 & NA & NA & NA & NA & 70E_4sid2X__1 & $5 / 20 \mathrm{~A}$ & TDP-160 & 9700163 \\
\hline 26.7 & 0.994 & 0.01500 & 0.050 & 0.337 & 35.4 & $P$ & NA & 8.04 & 8.19 & 8.26 & 8.50 & 8.50 & 41.50 & NA & NA & NA & NA & NA & NA & NA & Na & NA & NA & NA & NA & 70E_4S1d2X__1 & $5 / 20 \mathrm{~A}$ & TDP-160 & 9700163.1 \\
\hline 26.7 & 0.994 & 0.01500 & 0.050 & 0.337 & 35.4 & $\mathrm{P}$ & NA & 8.04 & 8.19 & 8.26 & 8.50 & 8.50 & 41.50 & NA & NA & NA & NA & NA & NA & NA & 0.0 & NA & NA & NA & NA & 70E_4sid2XC_ 1 & $5 / 20 \mathrm{~A}$ & TDP-160 & 9700164 \\
\hline 26.7 & 0.994 & 0.01500 & 0.050 & 0.337 & 35.4 & $\mathrm{P}$ & NA & 8.04 & 8.19 & 8.26 & 8.50 & 8.50 & 41.50 & NA & $\mathrm{NA}$ & NA & NA & NA & NA & NA & $\mathrm{ra}$ & NA & NA & NA & NA & 70E_4S1d2Xc_ 1 & $5 / 20 \mathrm{~A}$ & TDP-160 & 9700164.1 \\
\hline 26.7 & 0.994 & 0.01500 & 0.050 & 0.337 & 35.4 & $\mathrm{P}$ & NA & 8.04 & 8.19 & 8.26 & 8.50 & 8.50 & 41.50 & NA & NA & NA & NA & NA & NA & NA & na & NA & NA & NA & NA & 70E_4s1d2X__1 & $5 / 20 \mathrm{~A}$ & TDP-160 & 9700164.2 \\
\hline
\end{tabular}


Table B.5. Data from 2008 Tests in Large-Scale Vessel with Elliptical Head A.6

\begin{tabular}{|c|c|c|c|c|c|c|c|c|c|c|c|c|c|c|c|c|c|c|c|c|c|c|c|c|c|c|c|}
\hline $\begin{array}{l}\text { Row } \\
\text { Number }\end{array}$ & Test & Case ID & $\begin{array}{c}\text { Tank } \\
\text { Diameter }\end{array}$ & $\begin{array}{l}\text { Head } \\
\text { Shape }\end{array}$ & $\begin{array}{l}\text { Dish } \\
\text { Height }\end{array}$ & $\begin{array}{l}\text { Dish } \\
\text { Volume }\end{array}$ & $\begin{array}{l}\text { Tank } \\
\text { Fil } \\
\text { Height }\end{array}$ & $\begin{array}{l}\text { Returm } \\
\text { Line } \\
\text { Height }\end{array}$ & $\begin{array}{c}\text { Nozzle } \\
\text { lnmer } \\
\text { Diameter }\end{array}$ & $\begin{array}{l}\text { Nozzle } \\
\text { Stand-off } \\
\text { Distance }\end{array}$ & \begin{tabular}{|l} 
Pulse Tube \\
Configuration
\end{tabular} & $\begin{array}{l}\text { Installed } \\
\text { Nozzles }\end{array}$ & $\begin{array}{c}\text { Oater } \\
\text { Nozzles } \\
\text { Operated }\end{array}$ & $\begin{array}{c}\text { Inner } \\
\text { Nozeles } \\
\text { Operated }\end{array}$ & \begin{tabular}{|l} 
Pulse Tube \\
OOter \\
Dianeter
\end{tabular} & $\begin{array}{c}\text { Outer } \\
\text { PJM } \\
\text { Radius }\end{array}$ & $\begin{array}{c}\text { Inner } \\
\text { PMM } \\
\text { Radius }\end{array}$ & $\begin{array}{l}\text { "FO' Outer } \\
\text { PJM } \\
\text { Impingement } \\
\text { Angle }\end{array}$ & $\begin{array}{l}\text { "FIO' Inner PJM } \\
\text { IImpingerent } \\
\text { Angle }\end{array}$ & $\begin{array}{c}\text { Ratio Outer } \\
\text { PPMto Tank } \\
\text { Radius } \\
\end{array}$ & $\begin{array}{c}\text { Ratio Inner } \\
\text { PPMtoT Tank } \\
\text { Radius } \\
\end{array}$ & Simulant & \begin{tabular}{|l|} 
Solids \\
Density \\
\end{tabular} & $\begin{array}{c}\text { Particle } \\
\text { Diameter } d 5\end{array}$ & $\begin{array}{c}\text { Particle } \\
\text { Diantert } \\
\text { d50 }\end{array}$ & $\begin{array}{c}\text { Particle } \\
\text { Diameter } \\
\text { d95 }\end{array}$ & $\begin{array}{c}\text { Void } \\
\text { Fraction }\end{array}$ \\
\hline text & text & text & in. & text & in. & in. ${ }^{3}$ & in. & in. & in. & in. & text & number & number & number & in. & in. & in. & deg & deg & nondim & nondim & text & $\mathrm{g} / \mathrm{cm}^{3}$ & $\mathrm{~m}$ & $\mathrm{~m}$ & $\mathrm{~m}$ & fraction \\
\hline MSS & MDDX & ID & $\mathrm{D}$ & HS & Hoss & $V_{\text {dsh }}$ & $\mathrm{H}$ & Rtn & $d$ & sod & PT & $\mathrm{N}$ & $\mathrm{Nb}$ & $\mathrm{N}$ & $\mathrm{PT}_{\alpha \mathrm{d}}$ & $\mathrm{Ro}_{\mathrm{o}}$ & $\mathrm{R}$ & $\theta_{\circ}$ & $\theta_{1}$ & $\mathrm{RdR}$ & $R / R$ & $\operatorname{sxdx}$ & $\rho_{\mathrm{s}}$ & $\frac{d_{5}}{3}$ & $d_{60}$ & $d_{65}$ & vf \\
\hline 9700164.3 & $5 / 20 \mathrm{~A}$ & $70 \mathrm{E} \_4 \mathrm{~s} 1 \mathrm{~d} 2 \mathrm{XC} \_1$ & 70 & E & 19 & 49770.7 & $911 / 2$ & 80 & 0.613 & 0.920 & HLP-22 & 12 & 8 & 4 & 3.5 & 21.9 & 11.5 & 20.3 & 10.5 & 0.62 & 0.33 & $\mathrm{~s} 1 \mathrm{~d} 2$ & 2.48 & 0.0000569 & 0.0000693 & 0.0000821 & 0.3750 \\
\hline 9700165 & $5 / 20 \mathrm{~A}$ & $70 \mathrm{E} \_4 \mathrm{~s} 1 \mathrm{~d} 2 \mathrm{Xc} \_1$ & 70 & E & 19 & 49770.7 & $911 / 2$ & 80 & 0.613 & 0.920 & HLP-22 & 12 & 8 & 4 & 3.5 & 21.9 & 11.5 & 20.3 & 10.5 & 0.62 & 0.33 & s1d2 & 2.48 & 0.0000569 & 0.0000693 & 0.0000821 & 0.3750 \\
\hline 9700166 & $5 / 20 \mathrm{~A}$ & 70E_4s1d2Xc_1 & 70 & E & 19 & 49770.7 & $911 / 2$ & 80 & 0.613 & 0.920 & HLP-22 & 12 & 8 & 4 & 3.5 & 21.9 & 11.5 & 20.3 & 10.5 & 0.62 & 0.33 & sid2 & 2.48 & 0.0000569 & 0.0000693 & 0.0000821 & 0.3750 \\
\hline 9700167 & 5/20A & 70E_4S1d2Xc 1 & 70 & E & 19 & 49770.7 & $911 / 2$ & 80 & 0.613 & 0.920 & HLP-22 & 12 & 8 & 4 & 3.5 & 21.9 & 11.5 & 20.3 & 10.5 & 0.62 & 0.33 & $\mathrm{~s} 1 \mathrm{~d} 2$ & 2.48 & 0.0000569 & 0.0000693 & 0.0000821 & 0.3750 \\
\hline 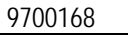 & $5 / 20 \mathrm{~A}$ & $70 E_{4} 451 d 2 \times C_{1} 1$ & 70 & E & 19 & 49770.7 & $911 / 2$ & 80 & 0.613 & 0.920 & HLP-22 & 12 & 8 & 4 & 3.5 & 21.9 & 11.5 & 20.3 & 10.5 & 0.62 & 0.33 & s1d2 & 2.48 & 0.0000569 & 0.0000693 & 0.0000821 & 0.3750 \\
\hline 9700169 & 5/20A & $70 \mathrm{E} \_4 \mathrm{~s} 1 \mathrm{~d} 2 \mathrm{XC} \_1$ & 70 & E & 19 & 49770.7 & $911 / 2$ & 80 & 0.613 & 0.920 & HLP-22 & 12 & 8 & 4 & 3.5 & 21.9 & 11.5 & 20.3 & 10.5 & 0.62 & 0.33 & $\mathrm{sid2}$ & 2.48 & 0.0000569 & 0.0000693 & 0.0000821 & 0.3750 \\
\hline 9700170 & $5 / 20 \mathrm{~A}$ & $70 \mathrm{E} \_4 \mathrm{~s} 1 \mathrm{~d} 2 \mathrm{XC} \_1$ & 70 & E & 19 & 49770.7 & $911 / 2$ & 80 & 0.613 & 0.920 & HLP-22 & 12 & 8 & 4 & 3.5 & 21.9 & 11.5 & 20.3 & 10.5 & 0.62 & 0.33 & $\mathrm{~s} 1 \mathrm{~d} 2$ & 2.48 & 0.0000569 & 0.0000693 & 0.0000821 & 0.3750 \\
\hline 9700171 & $5 / 20 \mathrm{~A}$ & 70E_4s1d2Xc_1 & 70 & E & 19 & 49770.7 & $911 / 2$ & 80 & 0.613 & 0.920 & HLP-22 & 12 & 8 & 4 & 3.5 & 21.9 & 11.5 & 20.3 & 10.5 & 0.62 & 0.33 & s1d2 & 2.48 & 0.0000569 & 0.0000693 & 0.0000821 & 0.3750 \\
\hline 9700172 & $5 / 20 \mathrm{~A}$ & $70 \mathrm{E} \_4 \mathrm{~s} 1 \mathrm{~d} 2 \mathrm{XC} \_1$ & 70 & $\mathrm{E}$ & 19 & 49770.7 & $911 / 2$ & 80 & 0.613 & 0.920 & HLP-22 & 12 & 8 & 4 & 3.5 & 21.9 & 11.5 & 20.3 & 10.5 & 0.62 & 0.33 & $\mathrm{sid2}$ & 2.48 & 0.0000569 & 0.0000693 & 0.0000821 & 0.3750 \\
\hline 9700173 & $5 / 20 A$ & $70 E_{4} 451022 x_{C} 1$ & 70 & E & 19 & 49770.7 & $911 / 2$ & 80 & 0.613 & 0.920 & HLP-22 & 12 & 8 & 4 & 3.5 & 21.9 & 11.5 & 20.3 & 10.5 & 0.62 & 0.33 & s1d2 & 2.48 & 0.0000569 & 0.0000693 & 0.00000821 & 0.3750 \\
\hline 9700174 & $5 / 20 \mathrm{~A}$ & 70E_4s1d2XC_ 1 & 70 & E & 19 & 4970.7 & $911 / 2$ & 80 & 0.613 & 0.920 & HLP-22 & 12 & 8 & 4 & 3.5 & 21.9 & 11.5 & 20.3 & 10.5 & 0.62 & 0.33 & $\mathrm{sid2}$ & 2.48 & 0.0000569 & 0.0000693 & 0.0000821 & 0.3750 \\
\hline 9700174.1 & $5 / 20 \mathrm{~A}$ & $70 \mathrm{E} \_4 \mathrm{~s} 1 \mathrm{~d} 2 \mathrm{XC} \_1$ & 70 & E & 19 & 49770.7 & $911 / 2$ & 80 & 0.613 & 0.920 & HLP-22 & 12 & 8 & 4 & 3.5 & 21.9 & 11.5 & 20.3 & 10.5 & 0.62 & 0.33 & s1d2 & 2.48 & 0.0000569 & 0.0000693 & 0.0000821 & 0.3750 \\
\hline 9700174.2 & $5 / 20 A$ & 70E_4sida2Xc__ & 70 & $E$ & 19 & 49770.7 & $911 / 2$ & 80 & 0.613 & 0.920 & HLP-22 & 12 & 8 & 4 & 3.5 & 21.9 & 11.5 & 20.3 & 10.5 & 0.62 & 0.33 & $\mathrm{~s} 1 \mathrm{~d} 2 \mathrm{P}$ & 2.48 & 0.0000569 & 0.0000693 & 0.0000821 & 0.3750 \\
\hline 9700174.3 & $5 / 20 \mathrm{~A}$ & $70 \mathrm{E} \_4 \mathrm{~s} 1 \mathrm{~d} 2 \mathrm{XC} \_1$ & 70 & $\mathrm{E}$ & 19 & 4970.7 & $911 / 2$ & 80 & 0.613 & 0.920 & HLP-22 & 12 & 8 & 4 & 3.5 & 21.9 & 11.5 & 20.3 & 10.5 & 0.62 & 0.33 & $\mathrm{sid2}$ & 2.48 & 0.0000569 & 0.0000693 & 0.0000821 & 0.3750 \\
\hline 97000174.4 & $5 / 20 \mathrm{~A}$ & 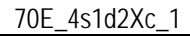 & 70 & E & 19 & 49770.7 & $911 / 2$ & 80 & 0.613 & 0.920 & HLP-22 & 12 & 8 & 4 & 3.5 & 21.9 & 11.5 & 20.3 & 10.5 & 0.62 & 0.33 & $\mathrm{s1d2}$ & 2.48 & 0.0000569 & 0.0000693 & 0.0000821 & 0.3750 \\
\hline 9700174.5 & $5 / 20 \mathrm{~A}$ & $70 \mathrm{E} \_4 \mathrm{~s} 1 \mathrm{~d} 2 \mathrm{XC} \_1$ & 70 & E & 19 & 49770.7 & $911 / 2$ & 80 & 0.613 & 0.920 & HLP-22 & 12 & 8 & 4 & 3.5 & 21.9 & 11.5 & 20.3 & 10.5 & 0.62 & 0.33 & $\mathrm{sid2}$ & 2.48 & 0.0000569 & 0.0000693 & 0.0000821 & 0.3750 \\
\hline 9700175 & $5 / 20 \mathrm{~A}$ & $70 \mathrm{E} \_4 \mathrm{~s} 1 \mathrm{~d} 2 \times \mathrm{C} \_1$ & 70 & E & 19 & 49770.7 & $911 / 2$ & 80 & 0.613 & 0.920 & HLP-22 & 12 & 8 & 4 & 3.5 & 21.9 & 11.5 & 20.3 & 10.5 & 0.62 & 0.33 & s1d2 & 2.48 & 0.0000569 & 0.0000693 & 0.0000821 & 0.3750 \\
\hline 9700176 & $5 / 20 \mathrm{~A}$ & 70E_4s1d2Xc_1 & 70 & E & 19 & 49770.7 & $911 / 2$ & 80 & 0.613 & 0.920 & HLP-22 & 12 & 8 & 4 & 3.5 & 21.9 & 11.5 & 20.3 & 10.5 & 0.62 & 0.33 & sid2 & 2.48 & 0.0000569 & 0.0000693 & 0.0000821 & 0.3750 \\
\hline 970017 & $5 / 20 \mathrm{~A}$ & 70E_4s1d2Xc_ 1 & 70 & $\mathrm{E}$ & 19 & 4970.7 & $911 / 2$ & 80 & 0.613 & 0.920 & HLP-22 & 12 & 8 & 4 & 3.5 & 21.9 & 11.5 & 20.3 & 10.5 & 0.62 & 0.33 & $\mathrm{sid2}$ & 2.48 & 0.0000569 & 0.0000693 & 0.0000821 & 0.3750 \\
\hline 9700178 & $5 / 20 \mathrm{~A}$ & $70 E_{4} 451 d 2 \times C_{1}$ & 70 & $E$ & 19 & 49770.7 & $911 / 2$ & 80 & 0.613 & 0.920 & HLP-22 & 12 & 8 & 4 & 3.5 & 21.9 & 11.5 & 20.3 & 10.5 & 0.62 & 0.33 & $\mathrm{~s} 1 \mathrm{~d} 2$ & 2.48 & 0.0000569 & 0.0000693 & 0.0000821 & 0.3750 \\
\hline 9700179 & $5 / 20 \mathrm{~A}$ & $70 \mathrm{E} \_4 \mathrm{~s} 1 \mathrm{~d} 2 \mathrm{XC} \_1$ & 70 & E & 19 & 4970.7 & $911 / 2$ & 80 & 0.613 & 0.920 & HLP-22 & 12 & 8 & 4 & 3.5 & 21.9 & 11.5 & 20.3 & 10.5 & 0.62 & 0.33 & $\mathrm{sid2}$ & 2.48 & 0.0000569 & 0.0000693 & 0.0000821 & 0.3750 \\
\hline 9700180 & $5 / 20 \mathrm{~A}$ & 70E_4s1d $2 \times \mathrm{XC} \_1$ & 70 & E & 19 & 4970.7 & $911 / 2$ & 80 & 0.613 & 0.920 & HLP-22 & 12 & 8 & 4 & 3.5 & 21.9 & 11.5 & 20.3 & 10.5 & 0.62 & 0.33 & s1d2 & 2.48 & 0.0000569 & 0.0000693 & 0.0000821 & 0.3750 \\
\hline 9700181 & $5 / 20 \mathrm{~A}$ & 70E_4s1d2Xc_1 & 70 & E & 19 & 4970.7 & $911 / 2$ & 80 & 0.613 & 0.920 & HLP-22 & 12 & 8 & 4 & 3.5 & 21.9 & 11.5 & 20.3 & 10.5 & 0.62 & 0.33 & sid2 & 2.48 & 0.0000569 & 0.0000693 & 0.0000821 & 0.3750 \\
\hline 9700182 & $5 / 20 B$ & 70E_4sid2Xd_1 & 70 & $\mathrm{E}$ & 19 & 4970.7 & $911 / 2$ & 80 & 0.613 & 0.920 & HLP-22 & 12 & 8 & 4 & 3.5 & 21.9 & 11.5 & 20.3 & 10.5 & 0.62 & 0.33 & $\mathrm{sid2}$ & 2.48 & 0.0000569 & 0.0000693 & 0.0000821 & 0.3750 \\
\hline 9700183 & $5 / 20 B$ & $70 E_{4}-4 \mathrm{~s} 1 \mathrm{~d} 2 \mathrm{Xd}=1$ & 70 & $E$ & 19 & 49770.7 & $911 / 2$ & 80 & 0.613 & 0.920 & HLP-22 & 12 & 8 & 4 & 3.5 & 21.9 & 11.5 & 20.3 & 10.5 & 0.62 & 0.33 & $\mathrm{~s} 1 \mathrm{~d} 2$ & 2.48 & 0.0000569 & 0.0000693 & 0.0000821 & 0.3750 \\
\hline 9700184 & $5 / 20 B$ & 70E_4sId $2 X \mathrm{~d} \_1$ & 70 & E & 19 & 4970.7 & $911 / 2$ & 80 & 0.613 & 0.920 & HLP-22 & 12 & 8 & 4 & 3.5 & 21.9 & 11.5 & 20.3 & 10.5 & 0.62 & 0.33 & $\mathrm{sid2}$ & 2.48 & 0.0000569 & 0.0000693 & 0.0000821 & 0.3750 \\
\hline 9700185 & $5 / 20 B$ & 70E_4s1d2Xd_1 & 70 & E & 19 & 4970.7 & $911 / 2$ & 80 & 0.613 & 0.920 & HLP -22 & 12 & 8 & 4 & 3.5 & 21.9 & 11.5 & 20.3 & 10.5 & 0.62 & 0.33 & $\mathrm{sid2}$ & 2.48 & 0.0000569 & 0.0000693 & 0.0000821 & 0.3750 \\
\hline 9700186 & $5 / 20 B$ & $70 E \_4 s 1 \mathrm{~d} 2 \mathrm{Xd} \_1$ & 70 & E & 19 & 4970.7 & $911 / 2$ & 80 & 0.613 & 0.920 & HLP -22 & 12 & 8 & 4 & 3.5 & 21.9 & 11.5 & 20.3 & 10.5 & 0.62 & 0.33 & $\mathrm{sid2}$ & 2.48 & 0.0000569 & 0.0000693 & 0.0000821 & 0.3750 \\
\hline 9700187 & $5 / 20 B$ & 70E_4sid2Xd_1 & 70 & $\mathrm{E}$ & 19 & 4970.7 & $911 / 2$ & 80 & 0.613 & 0.920 & HLP-22 & 12 & 8 & 4 & 3.5 & 21.9 & 11.5 & 20.3 & 10.5 & 0.62 & 0.33 & $\mathrm{sid2}$ & 2.48 & 0.0000569 & 0.0000693 & 0.0000821 & 0.3750 \\
\hline 9700188 & $5 / 20 B$ & 70E_4s1d2Xd_1 & 70 & E & 19 & 4970.7 & $911 / 2$ & 80 & 0.613 & 0.920 & HLP-22 & 12 & 8 & 4 & 3.5 & 21.9 & 11.5 & 20.3 & 10.5 & 0.62 & 0.33 & $\mathrm{sid2}$ & 2.48 & 0.0000569 & 0.0000693 & 0.0000821 & 0.3750 \\
\hline 9700189 & $5 / 20 \mathrm{~B}$ & 70E_4sid2Xd_1 & 70 & E & 19 & 4970.7 & $911 / 2$ & 80 & 0.613 & 0.920 & HLP-22 & 12 & 8 & 4 & 3.5 & 21.9 & 11.5 & 20.3 & 10.5 & 0.62 & 0.33 & s1d2 & 2.48 & 0.0000569 & 0.0000693 & 0.0000821 & 0.3750 \\
\hline 9700190 & $5 / 21 \mathrm{~A}$ & 70E_4s1d2Xd_1 & 70 & E & 19 & 4970.7 & 91 & 80 & 0.613 & 0.920 & HLP-22 & 12 & 8 & 4 & 3.5 & 21.9 & 11.5 & 20.3 & 10.5 & 0.62 & 0.33 & s1d2 & 2.48 & 0.0000569 & 0.0000693 & 0.0000821 & 0.3750 \\
\hline 9700191 & $5 / 21 \mathrm{~A}$ & 70E_4sid2Xd_1 & 70 & E & 19 & 4970.7 & 91 & 80 & 0.613 & 0.920 & HLP -22 & 12 & 8 & 4 & 3.5 & 21.9 & 111.5 & 20.3 & 10.5 & 0.62 & 0.33 & $\mathrm{sid}_{2}$ & 2.48 & 0.0000569 & 0.0000693 & 0.00000821 & 0.3750 \\
\hline 9700192 & $5 / 21 \mathrm{~A}$ & $70 \mathrm{E} \_4 \mathrm{~s} 1 \mathrm{~d} 2 \mathrm{Xd} \_1$ & 70 & E & 19 & 4970.7 & 91 & 80 & 0.613 & 0.920 & HLP-22 & 12 & 8 & 4 & 3.5 & 21.9 & 11.5 & 20.3 & 10.5 & 0.62 & 0.33 & $\mathrm{sid2}$ & 2.48 & 0.0000569 & 0.0000693 & 0.0000821 & 0.3750 \\
\hline 9700193 & $5 / 21 \mathrm{~A}$ & $70 \mathrm{E} \_4 \mathrm{~s} 1 \mathrm{~d} 2 \mathrm{Xd} \_1$ & 70 & E & 19 & 4970.7 & 91 & 80 & 0.613 & 0.920 & HLP-22 & 12 & 8 & 4 & 3.5 & 21.9 & 11.5 & 20.3 & 10.5 & 0.62 & 0.33 & s1d2 & 2.48 & 0.0000569 & 0.0000693 & 0.0000821 & 0.3750 \\
\hline 9700194 & $5 / 21 \mathrm{~A}$ & 70E_4s1d2Xd_1 & 70 & $E$ & 19 & 4970.7 & 91 & 80 & 0.613 & 0.920 & HLP-22 & 12 & 8 & 4 & 3.5 & 21.9 & 11.5 & 20.3 & 10.5 & 0.62 & 0.33 & s1d2 & 2.48 & 0.0000569 & 0.0000693 & 0.0000821 & 0.3750 \\
\hline 9700195M & $5 / 21 \mathrm{~A}$ & 70E_4s1d2Xd_1 & 70 & E & 19 & 4970.7 & 91 & 80 & 0.613 & 0.920 & HLP -22 & 12 & 8 & 4 & 3.5 & 21.9 & 11.5 & 20.3 & 10.5 & 0.62 & 0.33 & $\mathrm{sid2}$ & 2.48 & 0.0000569 & 0.0000693 & 0.0000821 & 0.3750 \\
\hline $9700196 \mathrm{M}$ & $5 / 21 \mathrm{~A}$ & 70E_4sId2Xd_1 & 70 & E & 19 & 4970.7 & 91 & 80 & 0.613 & 0.920 & HLP-22 & 12 & 8 & 4 & 3.5 & 21.9 & 11.5 & 20.3 & 10.5 & 0.62 & 0.33 & $\mathrm{sid}_{2}$ & 2.48 & 0.0000569 & 0.0000693 & 0.0000821 & 0.3750 \\
\hline 9700197 & $5 / 21 \mathrm{~B}$ & 70E_4s1d2Xa & 70 & E & 19 & 4970.7 & 91 & 80 & 0.613 & 0.920 & HLP-22 & 12 & 8 & 4 & 3.5 & 21.9 & 11.5 & 20.3 & 10.5 & 0.62 & 0.33 & $\mathrm{~s} 1 \mathrm{~d} 2$ & 2.48 & 0.0000569 & 0.0000693 & 0.0000821 & 0.3750 \\
\hline 9700198 & $5 / 22 \mathrm{~A}$ & $70 E_{4} 452027 \mathrm{C} 1$ & 70 & E & 19 & 49770.7 & $921 / 2$ & 80 & 0.613 & 0.920 & HLP-22 & 12 & 8 & 4 & 3.5 & 21.9 & 11.5 & 20.3 & 10.5 & 0.62 & 0.33 & $\mathrm{~s} 2 \mathrm{~d} 2$ & 4.18 & 0.0000609 & 0.0000756 & 0.0000931 & 0.3684 \\
\hline 9700199 & $5 / 22 \mathrm{~A}$ & 70E_4s2d2Zc_ 1 & 70 & $E$ & 19 & 49770.7 & $921 / 2$ & 80 & 0.613 & 0.920 & HLP-22 & 12 & 8 & 4 & 3.5 & 21.9 & 11.5 & 20.3 & 10.5 & 0.62 & 0.33 & $\mathrm{~s} 2 \mathrm{~d} 2$ & 4.18 & 0.0000609 & 0.0000756 & 0.0000931 & 0.3684 \\
\hline
\end{tabular}


Table B.5. Data from 2008 Tests in Large-Scale Vessel with Elliptical Head B.6

\begin{tabular}{|c|c|c|c|c|c|c|c|c|c|c|c|c|c|c|c|c|c|c|c|c|c|c|c|c|c|c|c|c|c|}
\hline $\begin{array}{l}\text { Tank Water } \\
\text { Temperature }\end{array}$ & $\begin{array}{c}\text { Water } \\
\text { Densiyy }\end{array}$ & $\begin{array}{l}\text { Solids } \\
\text { Fraction }\end{array}$ & $\begin{array}{l}\text { Pulse } \\
\text { Volume } \\
\text { Fraction }\end{array}$ & $\begin{array}{l}\text { Duty } \\
\text { cycle }\end{array}$ & $\begin{array}{l}\text { Oyde } \\
\text { Time }\end{array}$ & $\begin{array}{c}\text { Pulsed } \\
\text { or } \\
\text { Steacy } \\
\text { Jet }\end{array}$ & $\begin{array}{c}\text { Us } \\
\text { Steacy } \\
\text { Jet } \\
\text { Jet }\end{array}$ & $\begin{array}{c}\text { U1 } \\
\text { Pulsing } \\
\text { Jet } \\
\end{array}$ & $\begin{array}{l}\text { U2 } \\
\text { URMS }\end{array}$ & $\begin{array}{c}\text { U3 } \\
\text { URNB }\end{array}$ & $\begin{array}{l}\text { Discharge } \\
\text { Velocity }\end{array}$ & $\begin{array}{c}\text { Citical } \\
\text { Suspension } \\
\text { Velocity }\end{array}$ & $\begin{array}{c}\text { Average } \\
\text { Peak Coloud } \\
\text { Height }\end{array}$ & $\begin{array}{c}\text { Ucs } \\
\text { Condition }\end{array}$ & $\begin{array}{l}\text { UCS } \\
\text { Method }\end{array}$ & $\begin{array}{l}\text { UCS } \\
\text { Flag }\end{array}$ & $\begin{array}{l}\text { UCS } \\
\text { Center } \\
\text { Flag }\end{array}$ & $\begin{array}{c}\text { ucs uad } \\
\text { Hag }\end{array}$ & $\begin{array}{c}\text { UCS based } \\
\text { on } \\
\text { Decreasing } \\
\text { velocity }\end{array}$ & $\begin{array}{l}\text { Smeep } \\
\text { Increase I } \\
\text { Decrease }\end{array}$ & $\begin{array}{c}\text { UDV } \\
\text { Height } \\
\text { Bed }\end{array}$ & $\begin{array}{c}\text { Particle } \\
\text { Motion }\end{array}$ & \begin{tabular}{|l|} 
Solids \\
Level \\
\end{tabular} & \begin{tabular}{|l|} 
Outer \\
Botom \\
Pattem \\
\end{tabular} & $\begin{array}{l}\text { Inner } \\
\text { Bototom } \\
\text { Patem }\end{array}$ & Case ID & Test & $\mathrm{TDP}$ & $\begin{array}{c}\text { Row } \\
\text { Number }\end{array}$ \\
\hline$c$ & $\begin{array}{ll}g / \mathrm{cm}^{3} \\
\end{array}$ & fraction & fraction & fraction & $\mathrm{s}$ & text & $\mathrm{m} / \mathrm{s}$ & $\mathrm{m} / \mathrm{s}$ & m/s & m/s & $m / s$ & $\mathrm{~m} / \mathrm{s}$ & \begin{tabular}{|l|} 
in. \\
\end{tabular} & $\mathrm{m} / \mathrm{s}$ & text & text & text & text & \begin{tabular}{|l|}
$\mathrm{m} / \mathrm{s}$ \\
\end{tabular} & text & $\begin{array}{ll}\mathrm{mm} \\
\mathrm{n}\end{array}$ & text & \begin{tabular}{|l|} 
text \\
\end{tabular} & text & text & text & text & text & text \\
\hline$T$ & $\rho$ & $\phi_{\mathrm{s}}$ & $\phi_{p}$ & $\mathrm{DC}$ & tc & Jet & $u_{s}$ & $\mathrm{U}_{1}$ & $\mathrm{U} 2$ & 43 & $u$ & Uos & $\mathrm{Hc}$ & Uosr & Ucsn & Uosvis & Usoen & Usuldv & Uos_D & $s_{\mathrm{N}}$ & $H_{\text {oed }}$ & $\mathrm{PM}$ & Sol & $\mathrm{SPO}$ & $\mathrm{SP}_{1}$ & ID & MDDX & $\mathrm{IDP}$ & MSS \\
\hline 26.7 & 0.994 & 0.01500 & 0.050 & 0.337 & 35.4 & $P$ & $\mathrm{NA}$ & 8.04 & 8.19 & 8.26 & 8.50 & 8.50 & 41.50 & NA & NA & NA & NA & NA & $\mathrm{NA}$ & NA & $\mathrm{na}$ & NA & $\mathrm{NA}$ & NA & $\mathrm{NA}$ & 70E_4sid2X__1 & $5 / 20 \mathrm{~A}$ & TDP-160 & 9700164.3 \\
\hline 27.1 & 0.994 & 0.01500 & 0.050 & 0.336 & 35.4 & $\mathrm{P}$ & $\mathrm{NA}$ & 8.04 & 8.19 & 8.26 & 8.50 & 8.50 & NA & NA & NA & NA & NA & NA & NA & 1 & 30.9 & $\mathrm{n} / \mathrm{a}$ & NA & NA & NA & 70E_4sid2Xc_1 & $5 / 20 \mathrm{~A}$ & TDP-160 & 9700165 \\
\hline 26.8 & 0.994 & 0.01500 & 0.050 & 0.337 & 35.4 & $\mathrm{P}$ & NA & 8.03 & 8.18 & 8.25 & 8.50 & 8.50 & NA & NA & NA & NA & NA & NA & NA & 1 & 20.6 & na & NA & NA & NA & $70 E \_4 s 1 d 2 X c \_1$ & $5 / 20 \mathrm{~A}$ & TDP-160 & 9700166 \\
\hline 27.0 & 0.994 & 0.01500 & 0.050 & 0.337 & 35.4 & $\mathrm{P}$ & NA & 8.04 & 8.19 & 8.27 & 8.50 & 8.50 & NA & NA & NA & NA & NA & NA & NA & 1 & NA & na & NA & NA & NA & 70E_4s1d2Xc_1 & $5 / 20 \mathrm{~A}$ & TDP-160 & 9700167 \\
\hline 26.7 & 0.994 & 0.01500 & 0.050 & 0.337 & 35.4 & $\mathrm{P}$ & NA & 8.03 & 8.19 & 8.26 & 8.50 & 8.50 & NA & NA & NA & NA & NA & NA & NA & 1 & 21.1 & na & NA & NA & NA & 70E_4S102X__1 & 5/20A & TDP-160 & 9700168 \\
\hline 26.7 & 0.994 & 0.01500 & 0.050 & \begin{tabular}{l|l}
0.337 \\
\end{tabular} & 35.4 & $P$ & NA & 8.02 & 8.17 & 8.25 & 8.50 & 8.50 & NA & NA & NA & NA & NA & NA & NA & 1 & 7.0 & na & NA & NA & NA & 70E_4sid2X___ 1 & $5 / 20 \mathrm{~A}$ & TDP-160 & 9700169 \\
\hline 26.8 & 0.994 & 0.01500 & 0.050 & 0.337 & 35.4 & $\mathrm{P}$ & NA & 8.04 & 8.19 & 8.27 & 8.50 & 8.50 & NA & NA & NA & NA & NA & NA & NA & 1 & 3.8 & $\mathrm{n} / \mathrm{a}$ & NA & NA & NA & 70E_4s1d2X__1 & $5 / 20 \mathrm{~A}$ & TDP-160 & 9700170 \\
\hline 26.9 & 0.994 & 0.01500 & 0.050 & $\begin{array}{ll}0.337 \\
\end{array}$ & 35.4 & $\mathrm{P}$ & NA & 8.03 & 8.19 & 8.27 & 8.50 & 8.50 & NA & NA & NA & NA & NA & NA & NA & 1 & 0.0 & na & NA & NA & NA & $70 E \_4 \mathrm{~s} 1 \mathrm{~d} 2 \mathrm{C}_{\mathrm{C}} 1$ & $5 / 20 \mathrm{~A}$ & TDP-160 & 9700172 \\
\hline 26.9 & 0.994 & 0.01500 & 0.050 & 0.337 & 35.4 & $\mathrm{P}$ & NA & 8.03 & 8.18 & 8.26 & 8.50 & 8.50 & NA & NA & NA & NA & NA & NA & NA & 1 & 0.0 & na & NA & NA & NA & 70E_4S1d2X___ 1 & $5 / 20 \mathrm{~A}$ & TDP-160 & 9700173 \\
\hline 26.9 & 0.994 & 0.01500 & 0.050 & \begin{tabular}{l|l}
0.337 \\
\end{tabular} & 35.4 & $P$ & NA & 8.04 & 8.19 & 8.27 & 8.50 & 8.50 & NA & NA & NA & NA & NA & NA & NA & 1 & NA & na & NA & NA & NA & 70E_4sid2X___ 1 & $5 / 20 \mathrm{~A}$ & TDP-160 & 9700174 \\
\hline 26.7 & 0.994 & 0.01500 & 0.050 & 0.329 & 44.6 & $\mathrm{P}$ & NA & 6.46 & 6.57 & 6.62 & 6.80 & 8.50 & 22.00 & NA & NA & NA & NA & NA & NA & NA & $\mathrm{n} / \mathrm{a}$ & NA & NA & NA & NA & 70E_4sid2 $2 \mathrm{c}_{1} 1$ & 5/20A & TDP-160 & 9700174.1 \\
\hline 26.7 & 0.994 & 0.01500 & 0.050 & 0.329 & 44.6 & $\mathrm{P}$ & NA & 6.46 & 6.57 & 6.62 & 6.80 & 8.50 & 22.00 & NA & NA & NA & NA & NA & NA & NA & na & NA & NA & NA & NA & 70E_4sid2X__1 & $5 / 20 \mathrm{~A}$ & TDP-160 & 9700174.2 \\
\hline 26.7 & 0.994 & 0.01500 & 0.050 & 0.329 & 4.6 & $P$ & NA & 6.46 & 6.57 & 6.62 & 6.80 & 8.50 & 22.00 & NA & NA & NA & NA & NA & NA & NA & $\mathrm{na}$ & NA & NA & NA & NA & 70E_4S102Xc_1 & 5/20A & TDP-160 & 9700174.3 \\
\hline 26.7 & 0.994 & 0.01500 & 0.050 & 0.329 & 44.6 & $\mathrm{P}$ & NA & 6.46 & 6.57 & 6.62 & 6.80 & 8.50 & 22.00 & NA & NA & NA & NA & NA & NA & NA & na & NA & NA & NA & NA & $70 E_{-} 4 \mathrm{~s} 1 \mathrm{~d} 2 \times \mathrm{C} \_1$ & $5 / 20 \mathrm{~A}$ & TDP-160 & 9700174.4 \\
\hline 26.7 & 0.994 & 0.01500 & 0.050 & 0.329 & 44.6 & $\mathrm{P}$ & NA & 6.46 & 6.57 & 6.62 & 6.80 & 8.50 & 22.00 & NA & NA & NA & NA & NA & NA & NA & $\mathrm{na}$ & NA & NA & NA & NA & 70E_4sid2X__1 & $5 / 20 \mathrm{~A}$ & TDP-160 & 9700174.5 \\
\hline 26.7 & 0.994 & 0.01500 & 0.050 & 0.329 & 44.6 & $\mathrm{P}$ & NA & 6.46 & 6.57 & 6.62 & 6.80 & 8.50 & 22.00 & NA & NA & NA & NA & NA & NA & (null) & 30.3 & 1 & NA & NA & NA & 70E_4sid2X__1 & $5 / 20 \mathrm{~A}$ & TDP-160 & 9700175 \\
\hline 26.7 & 0.994 & 0.01500 & 0.050 & 0.329 & 44.6 & $\mathrm{P}$ & $\mathrm{NA}$ & 6.46 & 6.57 & 6.62 & 6.80 & 8.50 & 22.00 & NA & NA & NA & NA & NA & NA & $\mathrm{NA}$ & 35.5 & NA & NA & NA & NA & 70E_4s1d2Xc_1 & $5 / 20 \mathrm{~A}$ & TDP-160 & 9700176 \\
\hline 26.7 & 0.994 & 0.01500 & 0.050 & 0.329 & 44.6 & $P$ & NA & 6.46 & 6.57 & 6.62 & 6.80 & 8.50 & 22.00 & NA & NA & NA & NA & NA & NA & NA & 26.4 & NA & NA & NA & NA & 70E_4s1d2Xc_1 & $5 / 20 \mathrm{~A}$ & TDP-160 & 9700177 \\
\hline 26.7 & 0.994 & 0.01500 & 0.050 & 0.329 & 44.6 & $\mathrm{P}$ & NA & 6.46 & 6.57 & 6.62 & 6.80 & 8.50 & 22.00 & NA & NA & NA & NA & NA & NA & NA & 21.4 & NA & NA & NA & NA & 70E_4sid2X_ 1 & $5 / 20 \mathrm{~A}$ & TDP-160 & 9700178 \\
\hline 26.7 & 0.994 & 0.01500 & 0.050 & 0.329 & 44.6 & $\mathrm{P}$ & NA & 6.46 & 6.57 & 6.62 & 6.80 & 8.50 & 22.00 & NA & NA & NA & NA & NA & NA & NA & 27.8 & NA & NA & NA & NA & 70E_4sid2X__1 & $5 / 20 \mathrm{~A}$ & TDP-160 & 9700180 \\
\hline 26.7 & 0.994 & 0.01500 & 0.050 & 0.329 & 44.6 & $\mathrm{P}$ & NA & 6.46 & 6.57 & 6.62 & 6.80 & 8.50 & 22.00 & NA & NA & NA & NA & NA & NA & NA & 31.3 & NA & NA & NA & NA & 70E_4s1d2X__1 & $5 / 20 \mathrm{~A}$ & TDP-160 & 9700181 \\
\hline 26.7 & 0.994 & 0.01500 & 0.050 & 0.187 & 57.4 & $\mathrm{P}$ & NA & 8.90 & 9.09 & 9.18 & 9.50 & 11.60 & 23.75 & NA & NA & NA & NA & NA & NA & 1 & 32.6 & 1 & NA & NA & NA & 70E_4sid2Xd_1 & $5 / 20 B$ & TDP-160 & 9700182 \\
\hline 26.6 & 0.994 & 0.01500 & 0.050 & 0.183 & 56.0 & $\mathrm{P}$ & NA & 9.17 & 9.37 & 9.47 & 9.80 & 11.60 & 24.50 & NA & NA & NA & NA & NA & NA & 1 & 28.9 & 1 & NA & NA & NA & 70E_4sid2Xd_1 & 5/20B & TDP-160 & 9700183 \\
\hline 26.8 & 0.994 & 0.01500 & 0.050 & 0.184 & 54.8 & $\mathrm{P}$ & NA & 9.37 & 9.57 & 9.68 & 10.00 & 11.60 & 25.50 & NA & NA & NA & NA & NA & NA & 1 & 25.5 & 1 & NA & NA & NA & 70E_4s1d2Xd_1 & $5 / 20 B$ & TDP-160 & 9700184 \\
\hline 27.1 & 0.994 & 0.01500 & 0.050 & 0.185 & 53.6 & $\mathrm{P}$ & NA & 9.54 & 9.76 & 9.87 & 10.20 & 11.60 & 25.25 & NA & NA & NA & NA & NA & NA & 1 & 21.1 & 1 & NA & NA & NA & 70E_4sid2Xd_1 & $5 / 20 \mathrm{~B}$ & TDP-160 & 9700185 \\
\hline 26.9 & 0.994 & 0.01500 & 0.050 & 0.185 & 52.6 & $\mathrm{P}$ & NA & 9.74 & 9.95 & 10.06 & 10.40 & 11.60 & 26.50 & NA & NA & NA & NA & NA & NA & 1 & 18.9 & 1 & NA & NA & NA & 70E_4s1d2Xd_1 & $5 / 20 \mathrm{~B}$ & TDP-160 & 9700186 \\
\hline 26.8 & 0.994 & 0.01500 & 0.050 & 0.185 & 52.0 & $\mathrm{P}$ & NA & 9.83 & 10.05 & 10.16 & 10.50 & 11.60 & 27.00 & NA & NA & NA & UCsoen & NA & NA & 1 & 16.5 & 2 & NA & NA & NA & 70E_4sid2Xd_1 & $5 / 208$ & TDP-160 & 9700187 \\
\hline 27.0 & 0.993 & 0.01500 & 0.050 & 0.186 & 51.0 & $\mathrm{P}$ & NA & 10.00 & 10.23 & 10.35 & 10.70 & 11.60 & 28.75 & NA & NA & NA & NA & NA & NA & 1 & 13.5 & 4 & NA & NA & NA & 70E_4sid2Xd_1 & $5 / 20 B$ & TDP-160 & 9700188 \\
\hline 27.1 & 0.994 & 0.01500 & 0.050 & 0.187 & 49.0 & $\mathrm{P}$ & NA & 10.45 & 10.70 & 10.82 & 11.20 & 11.60 & 36.25 & NA & NA & NA & NA & NA & NA & 1 & 4.3 & 4 & NA & NA & NA & 70E_4s1d2Xd_1 & $5 / 208$ & TDP-160 & 9700189 \\
\hline 25.4 & 0.994 & 0.01500 & 0.050 & 0.185 & 52.6 & $\mathrm{P}$ & NA & 9.82 & 10.04 & 10.15 & 10.50 & 11.60 & 28.75 & NA & NA & NA & NA & NA & NA & (null) & 12.1 & 1 & NA & NA & NA & 70E_4sid2X__ 1 & $5 / 21 \mathrm{~A}$ & TDP-161 & 9700190 \\
\hline 25.4 & 0.994 & 0.01500 & 0.050 & 0.185 & 51.6 & $\mathrm{P}$ & NA & 9.99 & 10.21 & 10.33 & 10.70 & 11.60 & 29.25 & NA & NA & NA & UCSoen & NA & NA & 1 & 2 & 2 & NA & $\mathrm{NA}$ & NA & 70E_4s1d2Xd_1 & $5 / 21 \mathrm{~A}$ & TDP-161 & 9700191 \\
\hline 25.5 & 0.993 & 0.01500 & 0.050 & 0.186 & 50.6 & $\mathrm{P}$ & NA & 10.14 & 10.38 & 10.50 & 10.90 & 11.60 & 33.75 & NA & $\mathrm{NA}$ & NA & NA & NA & $\mathrm{NA}$ & 1 & 5.2 & 4 & NA & NA & NA & 70E_4s1d2Xd_1 & $5 / 21 \mathrm{~A}$ & TDP-161 & 9700192 \\
\hline 25.5 & 0.994 & 0.01500 & 0.050 & 0.186 & 49.6 & $\mathrm{P}$ & NA & 10.36 & 10.60 & 10.72 & 11.10 & 11.60 & 37.25 & NA & NA & NA & NA & NA & NA & 1 & 4.7 & 4 & NA & NA & NA & 70E_4sid2Xd_1 & $5 / 21 \mathrm{~A}$ & TDP-161 & 9700193 \\
\hline 25.6 & 0.994 & 0.01500 & 0.050 & \begin{tabular}{l|l}
.187 \\
\end{tabular} & 48.6 & $\mathrm{P}$ & NA & 10.53 & 10.78 & 10.90 & 11.30 & 11.60 & 39.25 & NA & NA & NA & NA & NA & NA & 1 & 4.3 & 4 & NA & NA & NA & 70E_4sid2Xd_1 & $5 / 21 \mathrm{~A}$ & TDP-161 & 9700194 \\
\hline 25.7 & 0.994 & 0.01500 & 0.050 & 0.184 & 47.8 & $\mathrm{P}$ & NA & 10.81 & 11.07 & 11.20 & 11.60 & 11.60 & 43.00 & 11.60 & udv & NA & NA & Ucsuav & NA & 1 & 0.8 & 4 & NA & NA & NA & 70E_4sid2Xd_1 1 & $5 / 21 \mathrm{~A}$ & TDP-161 & 9700195 \\
\hline 25.6 & 0.994 & 0.01500 & 0.050 & 0.184 & 46.6 & $\mathrm{P}$ & NA & 11.04 & 11.31 & 11.45 & 11.90 & 11.60 & 43.75 & NA & NA & NA & NA & NA & NA & 1 & 0.0 & 4 & NA & NA & NA & 70E_4s1d2Xd_1 & $5 / 21 \mathrm{~A}$ & TDP-161 & 9700196 \\
\hline 25.3 & 0.994 & 0.01500 & undefined & 1.000 & infinite & $\mathrm{s}$ & 3.49 & na & $\mathrm{na}$ & na & 3.50 & & NA & NA & NA & NA & NA & NA & NA & (null) & 0.0 & 1 & NA & NA & NA & 70E_4s1d2Xa & $5 / 218$ & TDP-161 & 9700197 \\
\hline 24.4 & 0.994 & 0.00155 & 0.050 & 0.330 & 53.8 & $\mathrm{P}$ & NA & 5.38 & 5.44 & 5.48 & 5.60 & 8.40 & & NA & NA & NA & NA & NA & NA & (null) & 25.7 & 1 & NA & NA & NA & 70E_4S2d27c_1 1 & $5 / 22 \mathrm{~A}$ & TDP-162 & 9700198 \\
\hline 24.7 & 0.994 & $\begin{array}{ll}0.00155 \\
\end{array}$ & 0.050 & 0.334 & 49.4 & $\mathrm{P}$ & NA & 5.82 & 5.91 & 5.95 & 6.10 & 8.40 & 21.50 & NA & NA & NA & NA & NA & NA & (null) & 16.9 & 1 & NA & NA & NA & POE_4s22027C_1 & 5/22A & TDP-162 & 9700199 \\
\hline
\end{tabular}


Table B.5. Data from 2008 Tests in Large-Scale Vessel with Elliptical Head A.7

\begin{tabular}{|c|c|c|c|c|c|c|c|c|c|c|c|c|c|c|c|c|c|c|c|c|c|c|c|c|c|c|c|}
\hline Row Number & Test & Case ID & $\begin{array}{c}\text { Tank } \\
\text { Diameter }\end{array}$ & $\begin{array}{l}\text { Head } \\
\text { Shape } \\
\end{array}$ & \begin{tabular}{|c} 
Dish \\
Height
\end{tabular} & $\begin{array}{l}\text { Dish } \\
\text { Volume }\end{array}$ & $\begin{array}{r}\text { Tank FIII } \\
\text { Height } \\
\end{array}$ & $\begin{array}{l}\text { Return } \\
\text { Line } \\
\text { Height }\end{array}$ & $\begin{array}{c}\text { Nozzle } \\
\text { IInner } \\
\text { Diameter }\end{array}$ & $\begin{array}{l}\text { Nozzle } \\
\text { Stanc-off } \\
\text { Distance }\end{array}$ & $\begin{array}{l}\text { Pulse Tube } \\
\text { Configuration }\end{array}$ & $\begin{array}{l}\text { Installed } \\
\text { Nozzles }\end{array}$ & $\begin{array}{c}\text { Outer } \\
\text { Nozzles } \\
\text { Operated }\end{array}$ & \begin{tabular}{|c|} 
Inner \\
Nozzles \\
Operate \\
de
\end{tabular} & $\begin{array}{c}\text { Pulse Tube } \\
\text { Outer } \\
\text { Diameter }\end{array}$ & $\begin{array}{c}\text { Outer } \\
\text { PMM } \\
\text { Radius }\end{array}$ & \begin{tabular}{|c|} 
Inner PJM \\
Radius \\
\end{tabular} & \begin{tabular}{|c|c|} 
"FOO" Outer PJM \\
impingement \\
Angle
\end{tabular} & $\begin{array}{l}\text { "FlO" Inner PJM } \\
\text { Impingement Angle }\end{array}$ & $\begin{array}{l}\text { Ratio Outer PJM } \\
\text { to Tank Radius }\end{array}$ & $\begin{array}{l}\text { Ratio Inner PJM } \\
\text { to Tank Radius }\end{array}$ & Simulant & \begin{tabular}{|l|} 
Solids \\
Density
\end{tabular} & $\begin{array}{c}\text { Particle } \\
\text { Diameter d5 }\end{array}$ & $\begin{array}{c}\text { Particle } \\
\text { Diamter } 150 \\
\end{array}$ & \begin{tabular}{|c} 
Particle \\
Diameter d95
\end{tabular} & $\begin{array}{c}\text { Void } \\
\text { Fraction }\end{array}$ \\
\hline text & text & text & in. & \begin{tabular}{|l|} 
text \\
\end{tabular} & in. & in. 3 & in. & in. & in. & in. & text & number & number & number & in. & in. & in. & \begin{tabular}{|l} 
deg \\
\end{tabular} & deg & nondim & nondim & text & $\mathrm{g} / \mathrm{cm}^{3}$ & $\mathrm{~m}$ & $\mathrm{~m}$ & $\mathrm{~m}$ & fraction \\
\hline MSS & MDDX & $\mathrm{ID}$ & $\mathrm{D}$ & $\mathrm{HS}$ & $H_{\text {bst }}$ & $V_{\text {dsh }}$ & $\mathrm{H}$ & $\mathrm{Rtn}$ & $d$ & sod & PT & $\mathrm{N}$ & $\mathrm{Nb}$ & $\mathrm{N}$ & $\mathrm{PT}_{\alpha \mathrm{d}}$ & $\mathrm{Ro}_{\mathrm{o}}$ & $R$ & $\theta_{0}$ & $\theta_{1}$ & $R d / R$ & $R / R$ & $\operatorname{sxdx}$ & $\rho_{\mathrm{s}}$ & $d_{5}$ & $d_{60}$ & $d_{65}$ & $\mathrm{vf}$ \\
\hline 9700200 & $5 / 22 \mathrm{~A}$ & 70E_4s2d2Zc_ 1 & 70 & $E$ & 19 & 49770.7 & $921 / 2$ & 80 & 0.613 & 0.920 & HLP -22 & 12 & 8 & 4 & 3.5 & 21.9 & 11.5 & 20.3 & 10.5 & 0.62 & 0.33 & $\mathrm{~s} 2 \mathrm{~d} 2$ & 4.18 & 0.0000609 & 0.0000756 & 0.0000931 & 0.3684 \\
\hline 9700201 & 5/22A & $70 E \_4 s 2 d 27 \mathrm{c} \_1$ & 70 & $E$ & 19 & 49770.7 & $921 / 2$ & $8 x$ & 0.613 & 0.920 & HLP-22 & 12 & 8 & 4 & 3.5 & 21.9 & 11.5 & 20.3 & 10.5 & 0.62 & 0.33 & $\mathrm{~s} 2 \mathrm{~d} 2$ & 4.18 & $\begin{array}{l}0.0000609 \\
\end{array}$ & 0.0000756 & 0.00000931 & 0.3684 \\
\hline 9700202 & |5/22A & 70E -452d27c 1 & 70 & E & 19 & 49770.7 & $921 / 2$ & 80 & 0.613 & 0.920 & HLP. 22 & 12 & 8 & 4 & 3.5 & 21.9 & 11.5 & 20.3 & 10.5 & 0.62 & 0.33 & $\mathrm{~s} 2 \mathrm{~d} 2$ & 4.18 & 0.0000609 & 0.0000756 & 0.0000931 & 0.3684 \\
\hline 9700203 & 5/22A & $70 E \_4 s 2 d 27 \mathrm{c} \_1$ & 70 & $\mathrm{E}$ & 19 & 49770.7 & $921 / 2$ & $8 x$ & 0.613 & 0.920 & HLP-22 & 12 & 8 & 4 & 3.5 & 21.9 & 11.5 & 20.3 & 10.5 & 0.62 & 0.33 & $\mathrm{~s} 2 \mathrm{~d} 2$ & 4.18 & 0.0000609 & 0.0000756 & 0.0000931 & 0.3684 \\
\hline 9700204 & 5/22A & 70E_4s2d2Zc_ 1 & 70 & $\mathrm{E}$ & 19 & 49770.7 & $921 / 2$ & 80 & 0.613 & 0.920 & HLP-22 & 12 & 8 & 4 & 3.5 & 21.9 & 11.5 & 20.3 & 10.5 & 0.62 & 0.33 & $\mathrm{~s} 2 \mathrm{~d} 2$ & 4.18 & 0.0000609 & 0.0000756 & 0.0000931 & 0.3684 \\
\hline 9700205 & 5/22A & $70 \mathrm{E} 4 \mathrm{~s} 2 \mathrm{~d} 27 \mathrm{c} 1$ & 70 & $\mathrm{E}$ & 19 & 49770.7 & $921 / 2$ & 80 & 0.613 & 0.920 & HLP. 22 & 12 & 8 & 4 & 3.5 & 21.9 & 11.5 & 20.3 & 10.5 & 0.62 & 0.33 & $\mathrm{~s} 2 \mathrm{~d}_{2}$ & 4.18 & 0.0000609 & 0.0000756 & 0.0000931 & 0.3684 \\
\hline 9700206M & |5/22A & 70E $4 \mathrm{~s} 2 \mathrm{~d} 227 \mathrm{c} 1$ & 70 & E & 19 & 49770.7 & $921 / 2$ & 80 & 0.613 & 0.920 & HLP. 22 & 12 & 8 & 4 & 3.5 & 21.9 & 11.5 & 20.3 & 10.5 & 0.62 & 0.33 & $\mathrm{~s} 2 \mathrm{~d}_{2}$ & 4.18 & 0.0000609 & 0.0000756 & 0.00009311 & 0.3684 \\
\hline $9700207 \mathrm{M}$ & $5 / 22 \mathrm{~A}$ & $70 \mathrm{E}$ 4 $4 \mathrm{~s} 2 \mathrm{~d} 2 \mathrm{Zc} \_1$ & 70 & $E$ & 19 & 49770.7 & $921 / 2$ & 80 & 0.613 & 0.920 & HLP-22 & 12 & 8 & 4 & 3.5 & 21.9 & 11.5 & 20.3 & 10.5 & 0.62 & 0.33 & $\mathrm{~s} 2 \mathrm{~d} 2$ & 4.18 & 0.0000609 & 0.0000756 & 0.0000931 & 0.3684 \\
\hline 9700208M & $5 / 22 \mathrm{~A}$ & $70 \mathrm{E} \_4 \mathrm{~s} 2 \mathrm{~d} 27 \mathrm{C} \_1$ & 70 & $\mathrm{E}$ & 19 & 49770.7 & $921 / 2$ & 80 & 0.613 & 0.920 & HLP-22 & 12 & 8 & 4 & 3.5 & 21.9 & 11.5 & 20.3 & 10.5 & 0.62 & 0.33 & $\mathrm{~s} 2 \mathrm{~d} 2$ & 4.18 & 0.0000609 & 0.0000756 & 0.0000931 & 0.3684 \\
\hline 9700208.1 & 5/27A & 70E_4s2d2Zc_1 1 & 70 & $\mathrm{E}$ & 19 & 49770.7 & 92 & $8 x$ & 0.613 & 0.920 & HLP-22 & 12 & 8 & 4 & 3.5 & 21.9 & 11.5 & 20.3 & 10.5 & 0.62 & 0.33 & $\mathrm{~s} 2 \mathrm{~d} 2$ & 4.18 & 0.0000609 & 0.0000756 & 0.00000931 & 0.3684 \\
\hline 9700208.2 & 5/27A & 70E $4 \mathrm{~s} 20227 \mathrm{c} 1$ & 70 & $\mathrm{E}$ & 19 & 49770.7 & 92 & 80 & 0.613 & 0.920 & HLP-22 & 12 & 8 & 4 & 3.5 & 21.9 & 11.5 & 20.3 & 10.5 & 0.62 & 0.33 & $\mathrm{~s} 2 \mathrm{~d} 2$ & 4.18 & 0.0000609 & 0.0000756 & 0.0000931 & 0.3684 \\
\hline 9700209 & 5/27A & 70E_4s2d2Zc_1 1 & 70 & $\mathrm{E}$ & 19 & 49770.7 & 92 & 80 & 0.613 & 0.920 & HLP-22 & 12 & 8 & 4 & 3.5 & 21.9 & 11.5 & 20.3 & 10.5 & 0.62 & 0.33 & $\mathrm{~s} 2 \mathrm{~d} 2$ & 4.18 & 0.0000609 & 0.0000756 & 0.0000931 & 0.3684 \\
\hline 9700210M & 5/27A & 70E_4s2d2Zc_ 1 & 70 & E & 19 & 49770.7 & 92 & $8 x$ & 0.613 & 0.920 & HLP-22 & 12 & 8 & 4 & 3.5 & 21.9 & 11.5 & 20.3 & 10.5 & 0.62 & 0.33 & $\mathrm{~s} 2 \mathrm{~d} 2$ & 4.18 & 0.0000609 & 0.0000756 & 0.0000931 & 0.3684 \\
\hline 9700211 & 5/27/A & 70E_4S2d272_ 1 & 70 & $E$ & 19 & 49770.7 & 92 & $8 x$ & 0.613 & 0.920 & HLP-22 & 12 & 8 & 4 & 3.5 & 21.9 & 11.5 & 20.3 & 10.5 & 0.62 & 0.33 & $\mathrm{~s} 2 \mathrm{~d} 2$ & 4.18 & 0.0000609 & 0.0000756 & 0.0000931 & 0.3684 \\
\hline 9700212 & 5/27A & $70 \mathrm{E} \_4 \mathrm{~s} 2 \mathrm{~d} 27 \mathrm{c} \_1$ & 70 & $E$ & 19 & 49770.7 & 92 & $8 x$ & 0.613 & 0.920 & HLP-22 & 12 & 8 & 4 & 3.5 & 21.9 & 11.5 & 20.3 & 10.5 & 0.62 & 0.33 & $\mathrm{~s} 2 \mathrm{~d} 2$ & 4.18 & 0.0000609 & 0.0000756 & 0.00000931 & 0.3684 \\
\hline 9700213 & 5/27A & 70E_-4s2d27c 1 & 70 & $\mathrm{E}$ & 19 & 49770.7 & 92 & $8 x>>>$ & 0.613 & 0.920 & HLP-22 & 12 & 8 & 4 & 3.5 & 21.9 & 11.5 & 20.3 & 10.5 & 0.62 & 0.33 & $\mathrm{~s} 2 \mathrm{~d} 2$ & 4.18 & 0.0000609 & 0.0000756 & 0.0000931 & 0.3684 \\
\hline 9700214 & 5/27A & $70 \mathrm{E} \_4 \mathrm{~s} 2 \mathrm{~d} 27 \mathrm{c} \_1$ & 70 & $E$ & 19 & 49770.7 & 92 & $8 x$ & 0.613 & 0.920 & HLP-22 & 12 & 8 & 4 & 3.5 & 21.9 & 11.5 & 20.3 & 10.5 & 0.62 & 0.33 & $\mathrm{~s} 2 \mathrm{~d} 2$ & 4.18 & 0.0000609 & 0.0000756 & 0.0000931 & 0.368 \\
\hline 9700215 & 5/27A & 70E_4s2d27c_1 & 70 & $E$ & 19 & 49770.7 & 92 & 80 & 0.613 & 0.920 & HLP-22 & 12 & 8 & 4 & 3.5 & 21.9 & 11.5 & 20.3 & 10.5 & 0.62 & 0.33 & $\mathrm{~s} 2 \mathrm{~d} 2$ & 4.18 & 0.0000609 & 0.0000756 & 0.0000931 & 0.3684 \\
\hline 9700216 & 5/27A & $70 \mathrm{70} \_4 \mathrm{~s} 2 \mathrm{~d} 2 \mathrm{Z} \mathrm{c} \_1$ & 70 & $\mathrm{E}$ & 19 & 49770.7 & 92 & $8 x$ & 0.613 & 0.920 & HLP-22 & 12 & 8 & 4 & 3.5 & 21.9 & 11.5 & 20.3 & 10.5 & 0.62 & 0.33 & $\mathrm{~s} 2 \mathrm{~d} 2$ & 4.18 & 0.0000609 & 0.0000756 & 0.0000931 & 0.3684 \\
\hline 9700217 & |5/27A & 70E $4 \mathrm{~s} 2 \mathrm{~d} 227 \mathrm{c} 1$ & 70 & E & 19 & 49770.7 & 92 & 80 & 0.613 & 0.920 & HLP. 22 & 12 & 8 & 4 & 3.5 & 21.9 & 11.5 & 20.3 & 10.5 & 0.62 & 0.33 & $\mathrm{~s} 2 \mathrm{~d}_{2}$ & 4.18 & 0.0000609 & 0.0000756 & 0.00009311 & 0.368 \\
\hline 9700218 & 5/27A & $70 E \_4 s 2 d 27 \mathrm{c} \_1$ & 70 & $E$ & 19 & 49770.7 & 92 & $8 x$ & 0.613 & 0.920 & HLP-22 & 12 & 8 & 4 & 3.5 & 21.9 & 11.5 & 20.3 & 10.5 & 0.62 & 0.33 & $\mathrm{~s} 2 \mathrm{~d} 2$ & 4.18 & 0.0000609 & 0.0000756 & 0.0000931 & 0.3684 \\
\hline 9700219 & 5/27A & 70E $4 \mathrm{~s} 2 \mathrm{~d} 227 \mathrm{c} 1$ & 70 & E & 19 & 49770.7 & 92 & $8 x$ & 0.613 & 0.920 & HLP-22 & 12 & 8 & 4 & 3.5 & 21.9 & 11.5 & 20.3 & 10.5 & 0.62 & 0.33 & $\mathrm{~s} 2 \mathrm{~d} 2$ & 4.18 & 0.0000609 & 0.0000756 & 0.0000931 & 0.368 \\
\hline 9700220 & 5/278 & 70E_4s2d2Yd_1 & 70 & $E$ & 19 & 49770.7 & 92 & $8 x$ & 0.613 & 0.920 & HLP-22 & 12 & 8 & 4 & 3.5 & 21.9 & 11.5 & 20.3 & 10.5 & 0.62 & 0.33 & $\mathrm{~s} 2 \mathrm{~d} 2$ & 4.18 & 0.0000609 & 0.0000756 & 0.0000931 & 0.3684 \\
\hline 9700221 & $5 / 278$ & 70E_4s2d2Yd_1 & 70 & $\mathrm{E}$ & 19 & 49770.7 & 92 & 80 & 0.613 & 0.920 & HLP-22 & 12 & 8 & 4 & 3.5 & 21.9 & 11.5 & 20.3 & 10.5 & 0.62 & 0.33 & $\mathrm{~s} 2 \mathrm{~d} 2$ & 4.18 & 0.0000609 & 0.0000756 & 0.0000931 & 0.3684 \\
\hline 9700222 & 5/278 & 70E_4s2d2Yd_1 & 70 & $E$ & 19 & 49770.7 & 92 & 80 & 0.613 & 0.920 & HLP-22 & 12 & 8 & 4 & 3.5 & 21.9 & 11.5 & 20.3 & 10.5 & 0.62 & 0.33 & $\mathrm{~s} 2 \mathrm{~d} 2$ & 4.18 & 0.0000609 & 0.0000756 & 0.0000931 & 0.3684 \\
\hline 9700223 & $5 / 278$ & 70 _. $4 \mathrm{~s} 2 \mathrm{~d} 2 \mathrm{Yd} \_1$ & 70 & E & 19 & 49770.7 & 92 & 80 & 0.613 & 0.920 & HLP-22 & 12 & 8 & 4 & 3.5 & 21.9 & 11.5 & 20.3 & 10.5 & 0.62 & 0.33 & $\mathrm{~s} 2 \mathrm{~d} 2$ & 4.18 & 0.0000609 & 0.0000756 & 0.0000931 & 0.3684 \\
\hline $9700224 \mathrm{M}$ & $5 / 278$ & 70E_4s2d2Yd_1 & 70 & $E$ & 19 & 49770.7 & 92 & 80 & 0.613 & 0.920 & HLP-22 & 12 & 8 & 4 & 3.5 & 21.9 & 11.5 & 20.3 & 10.5 & 0.62 & 0.33 & $\mathrm{~s} 2 \mathrm{~d} 2$ & 4.18 & 0.0000609 & 0.0000756 & 0.0000931 & 0.3684 \\
\hline 9700225M & $5 / 278$ & 70E_4s2d2Yd_1 & 70 & E & 19 & 49770.7 & 92 & $8 x$ & 0.613 & 0.920 & HLP-22 & 12 & 8 & 4 & 3.5 & 21.9 & 11.5 & 20.3 & 10.5 & 0.62 & 0.33 & $\mathrm{~s} 2 \mathrm{~d} 2$ & 4.18 & 0.0000609 & 0.0000756 & 0.0000931 & 0.3684 \\
\hline $9700226 \mathrm{M}$ & $5 / 278$ & 70E_4s2d2Yd_1 & 70 & E & 19 & 49770.7 & 92 & $8 c$ & 0.613 & 0.920 & HLP-22 & 12 & 8 & 4 & 3.5 & 21.9 & 11.5 & 20.3 & 10.5 & 0.62 & 0.33 & $\mathrm{~s} 2 \mathrm{~d} 2$ & 4.18 & 0.0000609 & 0.0000756 & 0.0000931 & 0.3684 \\
\hline 9700227 & $5 / 27 \mathrm{C}$ & 70E_4s2d2Yc_1 & 70 & $E$ & 19 & 49770.7 & 92 & $8 x$ & 0.613 & 0.920 & HLP-22 & 12 & 8 & 4 & 3.5 & 21.9 & 11.5 & 20.3 & 10.5 & 0.62 & 0.33 & $\mathrm{~s} 2 \mathrm{~d} 2$ & 4.18 & 0.0000609 & 0.0000756 & 0.0000931 & 0.3684 \\
\hline 9700228 & $5 / 27 \mathrm{C}$ & 70E_4s2d2YC_1 & 70 & E & 19 & 49770.7 & 92 & 80 & 0.613 & 0.920 & HLP-22 & 12 & 8 & 4 & 3.5 & 21.9 & 11.5 & 20.3 & 10.5 & 0.62 & 0.33 & $\mathrm{~s} 2 \mathrm{~d} 2$ & 4.18 & 0.0000609 & 0.0000756 & 0.0000931 & 0.3684 \\
\hline 9700229M & $5 / 27 \mathrm{C}$ & 70E_4s2d2Yc_1 & 70 & E & 19 & 49770.7 & 92 & $8 x$ & 0.613 & 0.920 & HLP-22 & 12 & 8 & 4 & 3.5 & 21.9 & 11.5 & 20.3 & 10.5 & 0.62 & 0.33 & $\mathrm{~s} 2 \mathrm{~d} 2$ & 4.18 & 0.0000609 & 0.0000756 & 0.0000931 & 0.3684 \\
\hline $9700230 \mathrm{M}$ & $5 / 27 \mathrm{C}$ & $70 \mathrm{E} \_4 \mathrm{~s} 2 \mathrm{~d} 2 \mathrm{YC} \_1$ & 70 & E & 19 & 49770.7 & 92 & 80 & 0.613 & 0.920 & HLP-22 & 12 & 8 & 4 & 3.5 & 21.9 & 11.5 & 20.3 & 10.5 & 0.62 & 0.33 & $\mathrm{~s} 2 \mathrm{~d} 2$ & 4.18 & 0.0000609 & 0.0000756 & 0.0000931 & 0.3684 \\
\hline 9700230.1 & $5 / 28 \mathrm{~A}$ & 70E_4s2d2Yc_1 & 70 & $E$ & 19 & 49770.7 & 92 & $8 x$ & 0.613 & 0.920 & HLP-22 & 12 & 8 & 4 & 3.5 & 21.9 & 11.5 & 20.3 & 10.5 & 0.62 & 0.33 & $\mathrm{~s} 2 \mathrm{~d} 2$ & 4.18 & 0.0000609 & 0.0000756 & 0.0000931 & 0.3684 \\
\hline 9700230.2 & $5 / 28 \mathrm{~A}$ & $70 \mathrm{E} \_4 \mathrm{~s} 2 \mathrm{~d} 2 \mathrm{YC} \_1$ & 70 & E & 19 & 49770.7 & 92 & 80 & 0.613 & 0.920 & HLP-22 & 12 & 8 & 4 & 3.5 & 21.9 & 11.5 & 20.3 & 10.5 & 0.62 & 0.33 & $\mathrm{~s} 2 \mathrm{~d} 2$ & 4.18 & 0.0000609 & 0.0000756 & 0.0000931 & 0.3684 \\
\hline 9700230.3 & $5 / 28 \mathrm{~A}$ & 70E_4s2d2Yc_1 & 70 & $E$ & 19 & 49770.7 & 92 & 8 & 0.613 & 0.920 & HLP -22 & 12 & 8 & 4 & 3.5 & 21.9 & 11.5 & 20.3 & 10.5 & 0.62 & 0.33 & $\mathrm{~s} 2 \mathrm{~d} 2$ & 4.18 & 0.0000609 & 0.0000756 & 0.0000931 & 0.3684 \\
\hline 9700231 & $5 / 28 \mathrm{~A}$ & $70 \mathrm{E} \_4 \mathrm{~s} 2 \mathrm{~d} 2 \mathrm{YC} \_1$ & 70 & $\mathrm{E}$ & 19 & 49770.7 & 92 & 80 & 0.613 & 0.920 & HLP-22 & 12 & 8 & 4 & 3.5 & 21.9 & 11.5 & 20.3 & 10.5 & 0.62 & 0.33 & $\mathrm{~s} 2 \mathrm{~d} 2$ & 4.18 & 0.0000609 & 0.0000756 & 0.0000931 & 0.3684 \\
\hline 9700232 & $5 / 28 \mathrm{~A}$ & 70E_4s2d2Yc_1 & 70 & $E$ & 19 & 49770.7 & 92 & $8 x$ & 0.613 & 0.920 & HLP-22 & 12 & 8 & 4 & 3.5 & 21.9 & 11.5 & 20.3 & & & & $\mathrm{~s} 2 \mathrm{~d} 2$ & 4.18 & 0.0000609 & 0.0000756 & 0.0000931 & \\
\hline 9700233 & $5 / 28 \mathrm{~A}$ & 70E_4s2d2YC_1 & 70 & $E$ & 19 & 49770.7 & 92 & $8 x$ & 0.613 & 0.920 & HLP-22 & 12 & 8 & 4 & 3.5 & 21.9 & 11.5 & 20.3 & 10.5 & 0.62 & 0.33 & $\mathrm{~s} 2 \mathrm{~d} 2$ & 4.18 & 0.0000609 & 0.0000756 & 0.0000931 & 0.3684 \\
\hline 9700234 & 5/28A & 70E_4s2d2YC_1 & 70 & $E$ & 19 & 49770.7 & 92 & 80 & 0.613 & 0.920 & HLP-22 & 12 & 8 & 4 & 3.5 & 21.9 & 11.5 & 20.3 & 10.5 & 0.62 & 0.33 & $\mathrm{~s} 2 \mathrm{~d} 2$ & 4.18 & 0.0000609 & 0.0000756 & 0.0000931 & 0.3684 \\
\hline 9700235 & 5/28A & $70 E_{4} 4 \mathrm{~s} 2 \mathrm{~d} 2 \mathrm{Yc}_{1} 1$ & 70 & $E$ & 19 & 49770.7 & 92 & $8 \mathrm{8c}$ & 0.613 & 0.920 & HLP-22 & 12 & 8 & 4 & 3.5 & 21.9 & 11.5 & 20.3 & 10.5 & 0.62 & 0.33 & $\mathrm{~s} 2 \mathrm{~d} 2$ & 4.18 & \begin{tabular}{|c|}
0.0000609 \\
\end{tabular} & 0.0000756 & 0.0000931 & 0.30 \\
\hline
\end{tabular}


Table B.5. Data from 2008 Tests in Large-Scale Vessel with Elliptical Head B.7

\begin{tabular}{|c|c|c|c|c|c|c|c|c|c|c|c|c|c|c|c|c|c|c|c|c|c|c|c|c|c|c|c|c|c|}
\hline $\begin{array}{l}\text { Tank Water } \\
\text { Temperature }\end{array}$ & $\begin{array}{l}\text { Water } \\
\text { Density }\end{array}$ & $\begin{array}{l}\text { Solids } \\
\text { Fraction }\end{array}$ & $\begin{array}{l}\text { Pulse } \\
\text { Volume } \\
\text { Fraction }\end{array}$ & $\begin{array}{l}\text { Duty } \\
\text { Qydle }\end{array}$ & $\begin{array}{l}\text { Cycle } \\
\text { Time }\end{array}$ & $\begin{array}{c}\text { Pulsed } \\
\text { or } \\
\text { Steady } \\
\text { Jet }\end{array}$ & $\begin{array}{l}\text { Us } \\
\text { Steacy } \\
\text { Jet }\end{array}$ & $\begin{array}{c}\text { U1 } \\
\text { Pulsing } \\
\text { Jet } \\
\end{array}$ & $\begin{array}{l}\text { U2 } \\
\text { URMS }\end{array}$ & $\begin{array}{c}\text { U3 } \\
\text { URMB }\end{array}$ & $\begin{array}{l}\text { Discharge } \\
\text { Velocity }\end{array}$ & $\begin{array}{c}\text { Citical } \\
\text { Suspension } \\
\text { velocity }\end{array}$ & $\begin{array}{l}\text { Average } \\
\text { Peak Cloud } \\
\text { Height }\end{array}$ & $\begin{array}{c}\text { UCS } \\
\text { Condition }\end{array}$ & $\begin{array}{c}\text { UCS } \\
\text { Method }\end{array}$ & $\begin{array}{l}\text { UCS } \\
\text { Fag }\end{array}$ & $\begin{array}{l}\text { UCS } \\
\text { Center } \\
\text { Fag }\end{array}$ & $\begin{array}{c}\text { UCS udv } \\
\text { Hag }\end{array}$ & \begin{tabular}{|c|} 
UCS based \\
on \\
Decreasing \\
velocity
\end{tabular} & $\begin{array}{l}\text { Sweep } \\
\text { Increase / } \\
\text { Decrease }\end{array}$ & $\begin{array}{c}\text { UDV } \\
\text { Height } \\
\text { Bed }\end{array}$ & $\begin{array}{l}\text { Particle } \\
\text { Motion }\end{array}$ & \begin{tabular}{|l|} 
Solids \\
Level \\
\end{tabular} & \begin{tabular}{|l|} 
Outer \\
Botom \\
Pattem \\
\end{tabular} & \begin{tabular}{|c|} 
Inner \\
Bottom \\
Pattem \\
\end{tabular} & Case ID & Test & TDP & $\begin{array}{l}\text { Rav } \\
\text { Number }\end{array}$ \\
\hline$c$ & $\mathrm{~g} \mathrm{~cm}^{3}$ & fraction & ffraction & fraction & $\mathrm{s}$ & text & $\mathrm{m} / \mathrm{s}$ & $\mathrm{m} / \mathrm{s}$ & $\mathrm{m} / \mathrm{s}$ & m/s & m/s & $m / s$ & in. & $\mathrm{ms}$ & text & text & text & $\begin{array}{ll}\text { text } \\
\end{array}$ & \begin{tabular}{|l|}
$\mathrm{m} / \mathrm{s}$ \\
\end{tabular} & text & $\mathrm{mm}$ & text & \begin{tabular}{|l|} 
text \\
\end{tabular} & text & text & text & text & text & text \\
\hline $\mathrm{T}$ & $\rho$ & $\phi_{\mathrm{s}}$ & $\phi_{p}$ & $D C$ & tc & Jet & $u_{s}$ & $\mathrm{U} 1$ & $\mathrm{U} 2$ & U3 & $u$ & Ucs & $\mathrm{He}$ & UosR & Ucsu & Uosvis & Uscen & Usuldv & Ues D & $s_{N}$ & $H_{\text {ood }}$ & $\mathrm{PM}$ & Sol & $\mathrm{SPo}_{\mathrm{o}}$ & $\mathrm{SP}_{1}$ & $\mathrm{ID}$ & MDDX & $\mathrm{IDP}$ & MSS \\
\hline 24.5 & 0.995 & 0.00155 & 0.050 & 0.336 & 46.0 & $P$ & $\mathrm{NA}$ & 6.19 & 6.28 & 6.33 & 6.50 & 8.40 & 22.50 & NA & NA & NA & NA & NA & $\mathrm{NA}$ & 1 & 34.1 & 1 & $\mathrm{NA}$ & NA & NA & 70E_4S2d27c_1 & $5 / 22 \mathrm{~A}$ & TDP-162 & 9700200 \\
\hline 24.6 & 0.994 & 0.00155 & 0.050 & 0.338 & 42.6 & $\mathrm{P}$ & NA & 6.64 & 6.75 & 6.81 & 7.00 & 8.40 & 24.25 & NA & NA & NA & NA & NA & NA & $\mathrm{I}$ & 23.7 & 1 & NA & NA & NA & 70E_4s2d2Zc_ 1 & $5 / 22 \mathrm{~A}$ & TDP-162 & 9700201 \\
\hline 24.8 & 0.994 & 0.00155 & 0.050 & 0.335 & 39.8 & $\mathrm{P}$ & NA & 7.09 & 7.21 & 7.28 & 7.50 & 8.40 & 24.75 & NA & NA & NA & NA & NA & NA & 1 & 16.6 & 1 & NA & NA & NA & 70E_4s2d27c_1 & $5 / 22 \mathrm{~A}$ & TDP-162 & 9700202 \\
\hline 24.5 & 0.994 & 0.00155 & 0.050 & 0.335 & 38.8 & $P$ & NA & 7.29 & 7.41 & 7.48 & 7.70 & 8.40 & 26.00 & NA & NA & NA & NA & NA & NA & 1 & 11.5 & 1 & NA & NA & NA & 70E_4s2d2Zc_ 1 & $5 / 22 \mathrm{~A}$ & TDP-162 & 9700203 \\
\hline 24.8 & 0.994 & 0.00155 & 0.051 & 0.337 & 37.4 & $\mathrm{P}$ & NA & 7.63 & 7.77 & 7.84 & 8.00 & 8.40 & 27.25 & NA & NA & NA & NA & NA & NA & 1 & 7.3 & 1 & NA & NA & NA & 70E_4S2027c_ 1 & $5 / 22 \mathrm{~A}$ & TDP-162 & 9700204 \\
\hline 24.8 & 0.994 & 0.00155 & 0.050 & 0.338 & 36.4 & $P$ & NA & 7.79 & 7.93 & 8.00 & 8.20 & 8.40 & 27.00 & NA & NA & NA & NA & NA & NA & 1 & 2.1 & 1 & NA & NA & NA & 70E_4S2d27c__1 & $5 / 22 \mathrm{~A}$ & TDP-162 & 9700205 \\
\hline 24.8 & 0.994 & 0.00155 & 0.050 & 0.339 & 35.4 & $\mathrm{P}$ & $\mathrm{NA}$ & 7.94 & 8.09 & 8.17 & 8.40 & 8.40 & 28.50 & \begin{tabular}{|l|}
8.40 \\
\end{tabular} & udv & NA & UCScen & ucsudv & NA & 1 & 0.0 & 2 & NA & NA & NA & 70E_4S2d27c_1 1 & $5 / 22 \mathrm{~A}$ & TDP-162 & 9700206 \\
\hline 24.6 & 0.994 & 0.00155 & 0.049 & 0.331 & 33.2 & $\mathrm{P}$ & NA & 8.55 & 8.72 & 8.81 & 9.10 & 8.40 & 38.25 & NA & NA & NA & NA & NA & NA & D & 0.0 & 4 & NA & NA & NA & 70E_4s2d27c_1 & $5 / 22 \mathrm{~A}$ & TDP-162 & 9700208 \\
\hline 21.8 & 0.995 & 0.00155 & 0.050 & 0.339 & 35.6 & $\mathrm{P}$ & NA & 7.95 & 8.10 & 8.17 & 8.40 & 8.40 & 28.50 & NA & NA & NA & NA & NA & NA & NA & $n / a$ & NA & NA & NA & NA & 70E_4s2d2Zc_1 & $5 / 27 \mathrm{~A}$ & TDP-163 & 9700208.1 \\
\hline 21.8 & 0.995 & 0.00155 & 0.050 & 0.339 & 35.6 & $P$ & NA & 7.95 & 8.10 & 8.17 & 8.40 & 8.40 & 28.50 & NA & NA & NA & NA & NA & NA & NA & $\mathrm{na}$ & NA & NA & NA & NA & 70E_4S2027c__1 & 5/27A & TDP-163 & 9700208.2 \\
\hline 22.0 & 0.995 & 0.00155 & 0.050 & 0.338 & 36.4 & $\mathrm{P}$ & NA & 7.76 & 7.90 & 7.97 & 8.20 & 8.40 & 27.50 & NA & NA & NA & UCScen & NA & NA & (null) & 0.0 & 2 & NA & NA & NA & 70E_4S2d27c_1 & 5/27A & TDP-163 & 9700209 \\
\hline 21.8 & 0.995 & 0.00155 & 0.050 & 0.339 & 35.6 & $\mathrm{P}$ & NA & 7.95 & 8.10 & 8.17 & 8.40 & 8.40 & 28.50 & NA & NA & NA & NA & NA & NA & 1 & 0.0 & 4 & NA & NA & NA & 70E_4S2027c_1 & $5 / 27 \mathrm{~A}$ & TDP-163 & 9700210 \\
\hline 21.8 & 0.995 & 0.00155 & 0.050 & 0.339 & 35.6 & $\mathrm{P}$ & NA & 7.95 & 8.10 & 8.17 & 8.40 & 8.40 & 28.50 & NA & NA & NA & NA & NA & NA & NA & 0.0 & NA & NA & NA & NA & 70E_452027c_1 & 5/27A & TDP-163 & 9700211 \\
\hline 21.8 & 0.995 & 0.00155 & 0.050 & 0.339 & 35.6 & $\mathrm{P}$ & NA & 7.95 & 8.10 & 8.17 & 8.40 & 8.40 & 28.50 & NA & NA & NA & NA & NA & NA & NA & 3.7 & NA & NA & NA & NA & 70E_4s2d2ZC_1 & 5/27A & TDP-163 & 9700212 \\
\hline 21.8 & 0.995 & 0.00155 & 0.050 & 0.339 & 35.6 & $\mathrm{P}$ & NA & 7.95 & 8.10 & 8.17 & 8.40 & 8.40 & 28.50 & NA & NA & NA & NA & NA & NA & NA & 0.0 & NA & NA & NA & NA & 70E_4S2d27c_1 & 5/27A & TDP-163 & 9700213 \\
\hline 21.8 & 0.995 & 0.00155 & 0.050 & 0.339 & 35.6 & $\mathrm{P}$ & NA & 7.95 & 8.10 & 8.17 & 8.40 & 8.40 & 28.50 & NA & NA & NA & NA & NA & NA & NA & 0.0 & NA & NA & NA & NA & 70E_4S2d27c_1 & $5 / 27 \mathrm{~A}$ & TDP-163 & 9700214 \\
\hline 21.8 & 0.995 & 0.00155 & 0.050 & 0.339 & 35.6 & $\mathrm{P}$ & $\mathrm{NA}$ & 7.95 & 8.10 & 8.17 & 8.40 & 8.40 & 28.50 & NA & NA & NA & NA & NA & NA & NA & 0.0 & NA & NA & NA & NA & 70E_4S2d27c_1 & $5 / 27 \mathrm{~A}$ & TDP-163 & 9700215 \\
\hline 21.8 & 0.995 & 0.00155 & 0.050 & 0.339 & 35.6 & $\mathrm{P}$ & NA & 7.95 & 8.10 & 8.17 & 8.40 & 8.40 & 28.50 & NA & NA & NA & NA & NA & NA & NA & 1.0 & NA & NA & NA & NA & 70E_4S2027c_1 & 5/27A & TDP-163 & 9700216 \\
\hline 21.8 & 0.995 & 0.00155 & 0.050 & 0.339 & 35.6 & $\mathrm{P}$ & NA & 7.95 & 8.10 & 8.17 & 8.40 & 8.40 & 28.50 & NA & NA & NA & NA & NA & NA & NA & 0.0 & NA & NA & NA & NA & 70E_4S2027c 1 & $5 / 27 \mathrm{~A}$ & TDP-163 & 9700217 \\
\hline 21.8 & 0.995 & 0.00155 & 0.050 & 0.339 & 35.6 & $\mathrm{P}$ & NA & 7.95 & 8.10 & 8.17 & 8.40 & 8.40 & 28.50 & NA & NA & NA & NA & NA & NA & NA & 0.0 & NA & NA & NA & NA & 70E_4S2d27c_1 & $5 / 27 \mathrm{~A}$ & TDP-163 & 9700219 \\
\hline 23.8 & 0.994 & 0.00500 & 0.050 & 0.184 & 47.2 & $\mathrm{P}$ & NA & 10.97 & 11.27 & 11.42 & 11.90 & 14.00 & 22.00 & NA & NA & NA & NA & NA & NA & 1 & 24.0 & 1 & NA & NA & NA & 70E_4S2d2Yd_1 & $5 / 278$ & TDP-163 & 9700220 \\
\hline 23.7 & 0.995 & 0.00500 & 0.050 & 0.186 & 45.0 & $\mathrm{P}$ & NA & 11.38 & 11.71 & 11.87 & 12.40 & 14.00 & 22.50 & NA & NA & NA & NA & NA & NA & 1 & 17.0 & 1 & NA & NA & NA & 70E_4s2d2Yd_1 & $5 / 27 \mathrm{~B}$ & TDP-163 & 9700221 \\
\hline 24.3 & 0.995 & 0.00500 & 0.050 & 0.187 & 43.0 & $\mathrm{P}$ & NA & 11.82 & 12.17 & 12.34 & 12.90 & 14.00 & 23.50 & NA & NA & NA & NA & NA & NA & $\mathrm{I}$ & 13.1 & 1 & NA & NA & NA & 70E_4s2d2Yd_ 1 & $5 / 27 \mathrm{~B}$ & TDP-163 & 9700222 \\
\hline 24.2 & 0.995 & 0.00500 & 0.050 & 0.184 & 41.2 & $\mathrm{P}$ & NA & 12.49 & 1288 & 13.08 & 13.70 & 14.00 & 25.50 & NA & NA & NA & Ucscen & NA & NA & 1 & 1.8 & 2 & NA & NA & NA & 70E_4S2d2Yd_1 & $5 / 27 \mathrm{~B}$ & TDP-163 & 9700223 \\
\hline 24.4 & 0.994 & 0.00500 & 0.050 & 0.184 & 40.4 & $\mathrm{P}$ & NA & 12.76 & 13.16 & 13.37 & 14.00 & 14.00 & 26.25 & 14.00 & udv & NA & NA & ucsuav & NA & 1 & 0.9 & 4 & NA & NA & NA & 70E_4S2d2Yd_1 1 & $5 / 27 \mathrm{~B}$ & TDP-163 & 9700224 \\
\hline 24.4 & 0.995 & 0.00500 & 0.049 & 0.186 & 37.2 & $\mathrm{P}$ & NA & 13.57 & 14.03 & 14.26 & 15.00 & 14.00 & 26.00 & NA & NA & NA & NA & NA & NA & $\mathrm{I}$ & NA & 4 & NA & NA & NA & 70E_4S2d2Yd_1 & $5 / 278$ & TDP-163 & 9700225 \\
\hline 24.5 & 0.995 & 0.00500 & 0.050 & 0.188 & 34.6 & $\mathrm{P}$ & NA & 14.68 & 15.13 & 15.36 & 16.10 & 14.00 & 28.50 & NA & NA & NA & NA & NA & NA & 1 & 0.0 & 4 & NA & NA & NA & 70E_4S2d2Yd_1 & $5 / 278$ & TDP-163 & 9700226 \\
\hline 24.9 & 0.994 & 0.00500 & 0.050 & 0.336 & 26.2 & $\mathrm{P}$ & NA & 10.74 & 10.97 & 11.09 & 11.50 & 1250 & 22.50 & NA & NA & NA & NA & NA & NA & 1 & 10.3 & 1 & NA & NA & NA & 70E_4S202Yc_1 & $5 / 27 \mathrm{C}$ & TDP-163 & 9700227 \\
\hline 25.1 & 0.995 & 0.00500 & 0.050 & 0.340 & 25.0 & $\mathrm{P}$ & NA & 11.13 & 11.40 & 11.54 & 12.00 & 12.50 & 25.50 & NA & NA & NA & ucscen & NA & NA & 1 & 3.2 & 2 & NA & NA & NA & 70E_4S2202Y__1 & $5 / 27 \mathrm{C}$ & TDP-163 & 9700228 \\
\hline 25.2 & 0.994 & 0.00500 & 0.050 & 0.336 & 24.4 & $\mathrm{P}$ & NA & 11.56 & 11.86 & 12.01 & 12.50 & 1250 & 25.50 & 12.50 & udv & NA & NA & ucsudv & NA & 1 & 0.0 & 4 & NA & NA & NA & 70E_4S2202Y__ 1 & $5 / 27 \mathrm{C}$ & TDP-163 & 9700229 \\
\hline 25.4 & 0.995 & 0.00500 & 0.050 & 0.333 & 22.6 & $\mathrm{P}$ & NA & 12.59 & 12.94 & 13.12 & 13.70 & 1250 & 34.50 & NA & NA & NA & NA & NA & NA & $\mathrm{I}$ & 0.3 & 4 & NA & NA & NA & 70E_4s2d2Yc_1 & $5 / 27 \mathrm{C}$ & TDP-163 & 9700230 \\
\hline 23.5 & 0.994 & 0.00500 & 0.050 & 0.328 & 26.0 & $\mathrm{P}$ & NA & 11.16 & 11.43 & 11.57 & 12.00 & 12.50 & 25.50 & NA & NA & NA & NA & NA & NA & NA & $\mathrm{n} / \mathrm{a}$ & NA & NA & NA & NA & 70E_4S2d2YC_1 & $5 / 28 \mathrm{~A}$ & TDP-164 & 9700230.1 \\
\hline 23.5 & 0.994 & 0.00500 & 0.050 & 0.328 & 26.0 & $\mathrm{P}$ & NA & 11.16 & 11.43 & 11.57 & 12.00 & 1250 & 25.50 & NA & NA & NA & NA & NA & NA & NA & na & NA & NA & NA & NA & 70E_4S202Yc_1 & 5/28A & TDP-164 & 9700230.2 \\
\hline 23.5 & 0.994 & 0.00500 & 0.050 & 0.328 & 26.0 & $\mathrm{P}$ & NA & 11.16 & 11.43 & 11.57 & 12.00 & 12.50 & 25.50 & NA & NA & NA & NA & NA & NA & NA & $\mathrm{na}$ & NA & NA & NA & NA & 70E_4S2202Y__1 & $5 / 28 \mathrm{~A}$ & TDP-164 & 9700230.3 \\
\hline 23.5 & 0.994 & 0.00500 & 0.050 & 0.328 & 26.0 & $\mathrm{P}$ & NA & 11.16 & 11.43 & 11.57 & 12.00 & 1250 & 25.50 & NA & NA & NA & UcScen & NA & NA & (null) & 0.0 & 2 & NA & NA & NA & 70E_4S2022YC_ 1 & $5 / 28 \mathrm{~A}$ & TDP-164 & 9700231 \\
\hline 23.5 & 0.994 & 0.00500 & 0.050 & 0.328 & 26.0 & $P$ & NA & 11.16 & 11.43 & 11.57 & 12.00 & 12.50 & 25.50 & NA & NA & NA & NA & NA & NA & NA & 0.0 & NA & NA & NA & NA & 70E_4S2222Y__1 & $5 / 28 \mathrm{~A}$ & TDP-164 & 9700232 \\
\hline 23.5 & 0.994 & 0.00500 & 0.050 & 0.328 & 26.0 & $\mathrm{P}$ & NA & 11.16 & 11.43 & 11.57 & 12.00 & 12.50 & 25.50 & NA & NA & NA & NA & NA & NA & NA & 0.0 & NA & NA & NA & NA & 70E_4S2d2YC_1 & $5 / 28 \mathrm{~A}$ & TDP-164 & 9700233 \\
\hline 23.5 & 0.994 & 0.00500 & 0.050 & 0.328 & 26.0 & $\mathrm{P}$ & NA & 11.16 & 11.43 & 11.57 & 12.00 & 12.50 & 25.50 & NA & NA & NA & NA & NA & NA & NA & 0.0 & NA & NA & NA & NA & 70E_4s2d2YC_1 & $5 / 28 \mathrm{~A}$ & TDP-164 & 9700234 \\
\hline 23.5 & 0.994 & 0.00500 & 0.050 & 0.328 & 26.0 & $P$ & NA & 11.16 & 11.43 & 11.57 & 12.00 & 12.50 & 25.50 & NA & NA & NA & NA & NA & NA & NA & 0.0 & NA & NA & NA & NA & 70E_4S2d2YC_1 & $5 / 28 \mathrm{~A}$ & TDP-164 & 9700235 \\
\hline
\end{tabular}


Table B.5. Data from 2008 Tests in Large-Scale Vessel with Elliptical Head A.8

\begin{tabular}{|c|c|c|c|c|c|c|c|c|c|c|c|c|c|c|c|c|c|c|c|c|c|c|c|c|c|c|c|}
\hline $\begin{array}{l}\text { Row } \\
\text { Number }\end{array}$ & Test & Case ID & $\begin{array}{c}\text { Tank } \\
\text { Diameter }\end{array}$ & $\begin{array}{l}\text { Head } \\
\text { Shape }\end{array}$ & $\begin{array}{l}\text { Dish } \\
\text { Height }\end{array}$ & $\begin{array}{c}\text { Dish } \\
\text { Volume }\end{array}$ & $\begin{array}{l}\text { Tank } \\
\text { Fill } \\
\text { Height }\end{array}$ & $\begin{array}{l}\text { Retum } \\
\text { Line } \\
\text { Height }\end{array}$ & $\begin{array}{l}\text { Nozzle } \\
\text { Inner } \\
\text { Diameter }\end{array}$ & $\begin{array}{l}\text { Nozzle } \\
\text { Stand-of } \\
\text { Distance }\end{array}$ & $\begin{array}{l}\text { Pulse Tube } \\
\text { Configuration }\end{array}$ & $\begin{array}{l}\text { Installed } \\
\text { Nozzles }\end{array}$ & $\begin{array}{c}\text { Outer } \\
\text { Nozzles } \\
\text { Operated }\end{array}$ & $\begin{array}{c}\text { Inner } \\
\text { Nozzles } \\
\text { Operated }\end{array}$ & $\begin{array}{c}\text { Pulse Tube } \\
\text { Outer } \\
\text { Diameter }\end{array}$ & $\begin{array}{c}\text { Outer } \\
\text { PMM } \\
\text { Radius }\end{array}$ & $\begin{array}{c}\text { Inner } \\
\text { PMM } \\
\text { Radius } \\
\end{array}$ & $\begin{array}{c}\text { "FO' Outer } \\
\text { PJM } \\
\text { Impingement } \\
\text { Angle }\end{array}$ & $\begin{array}{l}\text { "FO" Inner PJM } \\
\text { Impingement } \\
\text { Angle }\end{array}$ & $\begin{array}{l}\text { Ratio Outer } \\
\text { PJMt to Tank } \\
\text { Radius }\end{array}$ & $\begin{array}{l}\text { Ratio Inner } \\
\text { PJMto Tank } \\
\text { Radius } \\
\end{array}$ & Simulant & $\begin{array}{l}\text { Solids } \\
\text { Density }\end{array}$ & $\begin{array}{l}\text { Particle } \\
\text { Diameter d5 }\end{array}$ & $\begin{array}{l}\text { Particle } \\
\text { Diamter } \\
\text { d50 }\end{array}$ & $\begin{array}{l}\text { Particle } \\
\text { Diamtert } \\
\text { d955 }\end{array}$ & $\begin{array}{l}\text { Void } \\
\text { Fraction }\end{array}$ \\
\hline text & text & text & in. & text & in. & in. 3 & in. & in. & in. & in. & text & number & number & number & in. & in. & in. & deg & deg & nondim & \begin{tabular}{l|l|} 
nondim \\
\end{tabular} & text & $\mathrm{g} / \mathrm{cm}^{3}$ & $m$ & $m$ & $m$ & fraction \\
\hline MSS & MDDX & $\mathrm{ID}$ & D & HS & Hish & $V_{\text {dash }}$ & $\mathrm{H}$ & Rtn & $d$ & sod & PT & $\mathrm{N}$ & $\mathrm{No}$ & $\mathrm{N}$ & $\mathrm{PT}_{\alpha \mathrm{d}}$ & $R_{0}$ & $R$ & $\theta_{\circ}$ & $\theta_{1}$ & $R d R$ & $R / R$ & sxdx & $\rho_{\mathrm{s}}$ & $d s$ & $\mathrm{~d}_{\mathrm{b}}$ & dos & vf \\
\hline 9700236 & $5 / 28 \mathrm{~A}$ & 70E_4s2d2YC_1 & 70 & $E$ & 19 & 49770.7 & 92 & 80 & 0.613 & 0.920 & HLP-22 & 12 & 8 & 4 & 3.5 & 21.9 & 11.5 & 20.3 & 10.5 & 0.62 & 0.33 & $\mathrm{~s} 2 \mathrm{~d} 2$ & 4.18 & 0.0000609 & 0.0000756 & 0.0000931 & 0.3684 \\
\hline 9700237 & $5 / 28 \mathrm{~A}$ & 70E_4s2d2Yc_1 & 70 & $E$ & 19 & 49770.7 & 92 & 80 & 0.613 & 0.920 & HLP. 22 & 12 & 8 & 4 & 3.5 & 21.9 & 11.5 & 20.3 & 10.5 & 0.62 & 0.33 & $\mathrm{~s} 2 \mathrm{~d} 2$ & 4.18 & 0.0000609 & 0.0000756 & 0.0000931 & 0.3684 \\
\hline 9700238 & $5 / 28 \mathrm{~A}$ & $70 \mathrm{E} \_4 \mathrm{~s} 2 \mathrm{~d} 2 \mathrm{Yc} \_1$ & 70 & E & 19 & 49770.7 & 92 & 80 & 0.613 & 0.920 & HLP-22 & 12 & 8 & 4 & 3.5 & 21.9 & 11.5 & 20.3 & 10.5 & 0.62 & 0.33 & $\mathrm{~s} 2 \mathrm{~d} 2$ & 4.18 & 0.0000609 & 0.0000756 & 0.0000931 & 0.3684 \\
\hline 9700239 & $5 / 28 \mathrm{~A}$ & 70E_4s2d2Yc_1 & 70 & $E$ & 19 & 49770.7 & 92 & 80 & 0.613 & 0.920 & HLP.22 & 12 & 8 & 4 & 3.5 & 21.9 & 11.5 & 20.3 & 10.5 & 0.62 & 0.33 & $\mathrm{~s} 2 \mathrm{~d} 2$ & 4.18 & 0.0000609 & 0.0000756 & 0.0000931 & 0.3684 \\
\hline 9700239.1 & $5 / 28 \mathrm{~A}$ & $70 \mathrm{E} \_4 \mathrm{~s} 2 \mathrm{~d} 2 \mathrm{Yc} \_1$ & 70 & $E$ & 19 & 49770.7 & 92 & 80 & 0.613 & 0.920 & HLP-22 & 12 & 8 & 4 & 3.5 & 21.9 & 11.5 & 20.3 & 10.5 & 0.62 & 0.33 & $\mathrm{~s} 2 \mathrm{~d} 2$ & 4.18 & 0.0000609 & 0.0000756 & 0.0000931 & 0.3684 \\
\hline 9700239.2 & $5 / 28 \mathrm{~A}$ & 70E_4s2d2YC_1 & 70 & $\mathrm{E}$ & 19 & 49770.7 & 92 & 80 & 0.613 & 0.920 & HLP-22 & 12 & 8 & 4 & 3.5 & 21.9 & 111.5 & 20.3 & 10.5 & 0.62 & 0.33 & $\mathrm{~s} 2 \mathrm{~d} 2$ & 4.18 & 0.0000609 & 0.0000756 & 0.0000931 & 0.3684 \\
\hline 9700239.3 & 5/28A & 70E_4s2d2Yc_1 & 70 & $\mathrm{E}$ & 19 & 49770.7 & 92 & 80 & 0.613 & 0.920 & HLP-22 & 12 & 8 & 4 & 3.5 & 21.9 & 11.5 & 20.3 & 10.5 & 0.62 & 0.33 & $\mathrm{~s} 2 \mathrm{~d} 2$ & 4.18 & 0.0000609 & 0.0000756 & 0.0000931 & 0.3684 \\
\hline 9700240 & $5 / 28 \mathrm{~A}$ & 70E_4s2d2Yc_1 & 70 & $E$ & 19 & 49770.7 & 92 & 80 & 0.613 & 0.920 & HLP-22 & 12 & 8 & 4 & 3.5 & 21.9 & 11.5 & 20.3 & 10.5 & 0.62 & 0.33 & $\mathrm{~s} 2 \mathrm{d2}$ & 4.18 & 0.0000609 & 0.0000756 & 0.0000931 & 0.3684 \\
\hline 9700241 & $5 / 28 \mathrm{~A}$ & 70E_4s2d2Yc_1 & 70 & $E$ & 19 & 49770.7 & 92 & 80 & 0.613 & 0.920 & HLP.22 & 12 & 8 & 4 & 3.5 & 21.9 & 11.5 & 20.3 & 10.5 & 0.62 & 0.33 & $\mathrm{~s} 2 \mathrm{~d} 2$ & 4.18 & 0.0000609 & 0.0000756 & 0.0000931 & 0.3684 \\
\hline 9700242 & $5 / 28 \mathrm{~A}$ & 70E_452d2YC_ 1 & 70 & $E$ & 19 & 49770.7 & 92 & 80 & 0.613 & 0.920 & HLP.22 & 12 & 8 & 4 & 3.5 & 21.9 & 11.5 & 20.3 & 10.5 & 0.62 & 0.33 & $\mathrm{~s} 2 \mathrm{~d} 2$ & 4.18 & 0.0000609 & 0.0000756 & 0.0000931 & 0.3684 \\
\hline 9700243 & $5 / 28 \mathrm{~A}$ & 70E_4s2d2YC_1 & 70 & $\mathrm{E}$ & 19 & 49770.7 & 92 & 80 & 0.613 & 0.920 & HLP.22 & 12 & 8 & 4 & 3.5 & 21.9 & 111.5 & 20.3 & 10.5 & 0.62 & 0.33 & $\mathrm{~s} 2 \mathrm{~d} 2$ & 4.18 & 0.0000609 & 0.0000756 & 0.0000931 & 0.3684 \\
\hline 9700244 & $5 / 28 \mathrm{~A}$ & 70E_4s2d2YC_1 & 70 & $E$ & 19 & 49770.7 & 92 & 80 & 0.613 & 0.920 & HLP-22 & 12 & 8 & 4 & 3.5 & 21.9 & 11.5 & 20.3 & 10.5 & 0.62 & 0.33 & $\mathrm{~s} 2 \mathrm{~d} 2$ & 4.18 & 0.0000609 & 0.0000756 & 0.0000931 & 0.3684 \\
\hline 9700245 & $5 / 28 \mathrm{~A}$ & 70E_4s2d2Yc_1 & 70 & $E$ & 19 & 49770.7 & 92 & 80 & 0.613 & 0.920 & HLP-22 & 12 & 8 & 4 & 3.5 & 21.9 & 11.5 & 20.3 & 10.5 & 0.62 & 0.33 & $\mathrm{~s} 2 \mathrm{d2}$ & 4.18 & 0.0000609 & 0.0000756 & 0.0000931 & 0.3684 \\
\hline 9700246 & $5 / 28 \mathrm{~A}$ & 70E_4s2d2Yc_1 & 70 & E & 19 & 49770.7 & 92 & 80 & 0.613 & 0.920 & HLP.22 & 12 & 8 & 4 & 3.5 & 21.9 & 11.5 & 20.3 & 10.5 & 0.62 & 0.33 & $\mathrm{~s} 2 \mathrm{~d} 2$ & 4.18 & 0.0000609 & 0.0000756 & 0.0000931 & 0.3684 \\
\hline 9700247 & $5 / 28 \mathrm{~A}$ & 70E_452d2YC_ 1 & 70 & $E$ & 19 & 49770.7 & 92 & 80 & 0.613 & 0.920 & HLP.22 & 12 & 8 & 4 & 3.5 & 21.9 & 11.5 & 20.3 & 10.5 & 0.62 & 0.33 & $\mathrm{~s} 2 \mathrm{~d} 2$ & 4.18 & 0.0000609 & 0.0000756 & 0.0000931 & 0.3684 \\
\hline 9700247.1 & $5 / 28 \mathrm{~A}$ & $70 E_{4} 452 \mathrm{~d} 2 \mathrm{YC}_{1} 1$ & 70 & $E$ & 19 & 49770.7 & 92 & 80 & 0.613 & 0.920 & HLP-22 & 12 & 8 & 4 & 3.5 & 21.9 & 11.5 & 20.3 & 10.5 & 0.62 & 0.33 & $\mathrm{~s} 2 \mathrm{~d} 2$ & 4.18 & 0.0000609 & 0.0000756 & 0.0000931 & 0.3684 \\
\hline 9700247.2 & 5/28A & $70 E_{4} 4 \mathrm{~s} 2 \mathrm{~d} 2 \mathrm{YC} \_1$ & 70 & $E$ & 19 & 49770.7 & 92 & 80 & 0.613 & 0.920 & HLP-22 & 12 & 8 & 4 & 3.5 & 21.9 & 11.5 & 20.3 & 10.5 & 0.62 & 0.33 & $\mathrm{~s} 2 \mathrm{~d} 2$ & 4.18 & 0.0000609 & 0.0000756 & 0.0000931 & 0.3684 \\
\hline 9700247.3 & $5 / 28 \mathrm{~A}$ & 70E_4s2d2Yc_1 & 70 & $E$ & 19 & 49770.7 & 92 & 80 & 0.613 & 0.920 & HLP. 22 & 12 & 8 & 4 & 3.5 & 21.9 & 11.5 & 20.3 & 10.5 & 0.62 & 0.33 & $\mathrm{~s} 2 \mathrm{d2}$ & 4.18 & 0.0000609 & 0.0000756 & 0.0000931 & 0.3684 \\
\hline 9700247.4 & $5 / 28 \mathrm{~A}$ & 70E_4s2d2Yc_1 & 70 & E & 19 & 49770.7 & 92 & 80 & 0.613 & 0.920 & HLP-22 & 12 & 8 & 4 & 3.5 & 21.9 & 11.5 & 20.3 & 10.5 & 0.62 & 0.33 & $\mathrm{~s} 2 \mathrm{~d} 2$ & 4.18 & 0.0000609 & 0.0000756 & 0.0000931 & 0.3684 \\
\hline 9700248 & $5 / 28 \mathrm{~A}$ & 70E_4s2d2YC_ 1 & 70 & E & 19 & 49770.7 & 92 & 80 & 0.613 & 0.920 & HLP.22 & 12 & 8 & 4 & 3.5 & 21.9 & 11.5 & 20.3 & 10.5 & 0.62 & 0.33 & $\mathrm{~s} 2 \mathrm{~d} 2$ & 4.18 & 0.0000609 & 0.0000756 & 0.0000931 & 0.3684 \\
\hline 9700249 & $5 / 28 \mathrm{~A}$ & 70E_4s2d2YC_1 & 70 & E & 19 & 49770.7 & 92 & 80 & 0.613 & 0.920 & HLP-22 & 12 & 8 & 4 & 3.5 & 21.9 & 11.5 & 20.3 & 10.5 & 0.62 & 0.33 & $\mathrm{~s} 2 \mathrm{d2} 2$ & 4.18 & 0.0000609 & 0.0000756 & 0.0000931 & 0.3684 \\
\hline 9700250 & $5 / 28 \mathrm{~A}$ & $70 \mathrm{E} \_4 \mathrm{~s} 2 \mathrm{~d} 2 \mathrm{YC} \_1$ & 70 & E & 19 & 49770.7 & 92 & 80 & 0.613 & 0.920 & HLP. 22 & 12 & 8 & 4 & 3.5 & 21.9 & 111.5 & 20.3 & 10.5 & 0.62 & 0.33 & $\mathrm{~s} 2 \mathrm{~d} 2$ & 4.18 & 0.0000609 & 0.0000756 & 0.0000931 & 0.3684 \\
\hline 9700251 & $5 / 28 \mathrm{~A}$ & 70E_4s2d2Yc_1 & 70 & $E$ & 19 & 49770.7 & 92 & 80 & 0.613 & 0.920 & HLP. 22 & 12 & 8 & 4 & 3.5 & 21.9 & 11.5 & 20.3 & 10.5 & 0.62 & 0.33 & $\mathrm{~s} 2 \mathrm{d2}$ & 4.18 & 0.0000609 & 0.0000756 & 0.0000931 & 0.3684 \\
\hline 9700252 & $5 / 28 \mathrm{~A}$ & 70E_4s2d2YC_1 & 70 & E & 19 & 49770.7 & 92 & 80 & 0.613 & 0.920 & HLP-22 & 12 & 8 & 4 & 3.5 & 21.9 & 11.5 & 20.3 & 10.5 & 0.62 & 0.33 & $\mathrm{~s} 2 \mathrm{~d} 2$ & 4.18 & 0.0000609 & 0.0000756 & 0.0000931 & 0.3684 \\
\hline 9700253 & $5 / 28 \mathrm{~A}$ & 70E_4s2d2YC_ 1 & 70 & E & 19 & 49770.7 & 92 & 80 & 0.613 & 0.920 & HLP-22 & 12 & 8 & 4 & 3.5 & 21.9 & 11.5 & 20.3 & 10.5 & 0.62 & 0.33 & $\mathrm{~s} 2 \mathrm{~d} 2$ & 4.18 & 0.0000609 & 0.0000756 & 0.0000931 & 0.3684 \\
\hline 9700254 & $5 / 28 \mathrm{~A}$ & 70E_4s2d2YC_1 & 70 & E & 19 & 49770.7 & 92 & 80 & 0.613 & 0.920 & HLP-22 & 12 & 8 & 4 & 3.5 & 21.9 & 11.5 & 20.3 & 10.5 & 0.62 & 0.33 & $\mathrm{~s} 2 \mathrm{d2} 2$ & 4.18 & 0.0000609 & 0.0000756 & 0.0000931 & 0.3684 \\
\hline 9700254.1 & $5 / 28 \mathrm{~A}$ & $70 E_{4} 4 \mathrm{~s} 2 \mathrm{~d} 2 \mathrm{YC} \_1$ & 70 & E & 19 & 49770.7 & 92 & 80 & 0.613 & 0.920 & HLP-22 & 12 & 8 & 4 & 3.5 & 21.9 & 111.5 & 20.3 & 10.5 & 0.62 & 0.33 & $\mathrm{~s} 2 \mathrm{~d} 2$ & 4.18 & 0.0000609 & 0.0000756 & 0.0000931 & 0.3684 \\
\hline 9700254.2 & $5 / 28 \mathrm{~A}$ & 70E_4s2d2YC_1 & 70 & $E$ & 19 & 49770.7 & 92 & 80 & 0.613 & 0.920 & HLP. 22 & 12 & 8 & 4 & 3.5 & 21.9 & 11.5 & 20.3 & 10.5 & 0.62 & 0.33 & $\mathrm{~s} 2 \mathrm{d2} 2$ & 4.18 & 0.0000609 & 0.0000756 & 0.0000931 & 0.3684 \\
\hline 9700255 & $5 / 29 \mathrm{~A}$ & 70E_4s1d12d_1 & 70 & E & 19 & 49770.7 & 92 & 80 & 0.613 & 0.920 & HLP-22 & 12 & 8 & 4 & 3.5 & 21.9 & 11.5 & 20.3 & 10.5 & 0.62 & 0.33 & sidn & 2.46 & 0.0001428 & 0.0001664 & 0.0001951 & 0.4118 \\
\hline 9700256 & $5 / 29 \mathrm{~A}$ & 70E_4s1d17d_1 & 70 & $E$ & 19 & 49770.7 & 92 & 80 & 0.613 & 0.920 & HLP.22 & 12 & 8 & 4 & 3.5 & 21.9 & 11.5 & 20.3 & 10.5 & 0.62 & 0.33 & s1d1 & 2.46 & 0.0001428 & 0.0001664 & 0.0001951 & 0.4118 \\
\hline 9700257 & $5 / 29 A$ & 70E_4s1d12d_1 & 70 & $\mathrm{E}$ & 19 & 49770.7 & 92 & 80 & 0.613 & 0.920 & HLP. 22 & 12 & 8 & 4 & 3.5 & 21.9 & 111.5 & 20.3 & 10.5 & 0.62 & 0.33 & sidn & 2.46 & 0.0001428 & 0.0001664 & 0.0001951 & 0.4118 \\
\hline 9700258 & $5 / 29 \mathrm{~A}$ & 70E_4sId1Zd_1 & 70 & E & 19 & 49770.7 & 92 & 80 & 0.613 & 0.920 & HLP-22 & 12 & 8 & 4 & 3.5 & 21.9 & 11.5 & 20.3 & 10.5 & 0.62 & 0.33 & s1d1 & 2.46 & 0.0001428 & 0.0001664 & 0.0001951 & 0.4118 \\
\hline $9700259 \mathrm{M}$ & 5/29A & 70E_4s1d12d_1 & 70 & $E$ & 19 & 49770.7 & 92 & 80 & 0.613 & 0.920 & HLP-22 & 12 & 8 & 4 & 3.5 & 21.9 & 11.5 & 20.3 & 10.5 & 0.62 & 0.33 & sidn & 2.46 & 0.0001428 & 0.0001664 & 0.0001951 & 0.4118 \\
\hline $9700260 \mathrm{M}$ & 5/29A & 70E_4s1d17d_1 & 70 & E & 19 & 49770.7 & 92 & 80 & 0.613 & 0.920 & HLP-22 & 12 & 8 & 4 & 3.5 & 21.9 & 11.5 & 20.3 & 10.5 & 0.62 & 0.33 & s1d1 & 2.46 & 0.0001428 & 0.0001664 & 0.0001951 & 0.4118 \\
\hline $9700261 \mathrm{M}$ & 5/29A & 70E_4s1d17d_1 & 70 & E & 19 & 49770.7 & 92 & 80 & 0.613 & 0.920 & HLP-22 & 12 & 8 & 4 & 3.5 & 21.9 & 11.5 & 20.3 & 10.5 & 0.62 & 0.33 & s1d1 & 246 & 0.0001428 & 0.0001664 & 0.0001951 & 0.4118 \\
\hline 9700262 & 5/29B & 70E_4s1d1Zc_1 & 70 & $\mathrm{E}$ & 19 & 49770.7 & 92 & 80 & 0.613 & 0.920 & HLP -22 & 12 & 8 & 4 & 3.5 & 21.9 & 111.5 & 20.3 & 10.5 & 0.62 & 0.33 & sidn & 2.46 & 0.0001428 & 0.0001664 & 0.0001951 & 0.4118 \\
\hline 9700263 & 5/298 & 70E_4sId1ZC_1 & 70 & E & 19 & 49770.7 & 92 & 80 & 0.613 & 0.920 & HLP-22 & 12 & 8 & 4 & 3.5 & 21.9 & 11.5 & 20.3 & 10.5 & 0.62 & 0.33 & s1d1 & 2.46 & 0.0001428 & 0.0001664 & 0.0001951 & 0.4118 \\
\hline $9700264 \mathrm{M}$ & 5/298 & 70E_4s1d17c_1 & 70 & $E$ & 19 & 49770.7 & 92 & 80 & 0.613 & 0.920 & HLP-22 & 12 & 8 & 4 & 3.5 & 21.9 & 11.5 & 20.3 & 10.5 & 0.62 & 0.33 & sld1 & 2.46 & 0.0001428 & 0.0001664 & 0.0001951 & 0.4118 \\
\hline $9700265 \mathrm{M}$ & 5/29B & 70E_4s1d12c_1 & 70 & E & 19 & 49770.7 & 92 & 80 & 0.613 & 0.920 & HLP-22 & 12 & 8 & 4 & 3.5 & 21.9 & 11.5 & 20.3 & 10.5 & 0.62 & 0.33 & s1d1 & 2.46 & 0.0001428 & 0.0001664 & 0.0001951 & 0.4118 \\
\hline $9700266 \mathrm{M}$ & 5/29B & 70E_4s1d17c_ 1 & 70 & E & 19 & 49770.7 & 92 & 80 & 0.613 & 0.920 & HLP-22 & 12 & 8 & 4 & 3.5 & 21.9 & 11.5 & 20.3 & 10.5 & 0.62 & 0.33 & sidn & 2.46 & 0.0001428 & 0.0001664 & 0.0001951 & 0.4118 \\
\hline $9700267 \mathrm{M}$ & 5/29B & 70 .4s1d17c 1 & 70 & $E$ & 19 & 49770.7 & 92 & 80 & 0.613 & 0.920 & HLP-22 & 12 & 8 & 4 & 3.5 & 21.9 & 111.5 & 20.3 & 10.5 & 0.62 & 0.33 & sidn & 2.46 & 0.0001428 & 0.0001664 & 0.0001951 & 0.4118 \\
\hline
\end{tabular}


Table B.5. Data from 2008 Tests in Large-Scale Vessel with Elliptical Head B.8

\begin{tabular}{|c|c|c|c|c|c|c|c|c|c|c|c|c|c|c|c|c|c|c|c|c|c|c|c|c|c|c|c|c|c|}
\hline $\begin{array}{l}\text { Tank Water } \\
\text { Temperature }\end{array}$ & $\begin{array}{l}\text { Water } \\
\text { Density }\end{array}$ & $\begin{array}{c}\text { Solids } \\
\text { Fraction }\end{array}$ & $\begin{array}{c}\text { Pulse } \\
\text { Volume } \\
\text { Fraction }\end{array}$ & $\begin{array}{l}\text { Duty } \\
\text { Qyde }\end{array}$ & $\begin{array}{l}\text { Cycle } \\
\text { Time }\end{array}$ & $\begin{array}{c}\text { Pulsed } \\
\text { or } \\
\text { Steady } \\
\text { Jet }\end{array}$ & $\begin{array}{l}\text { Us } \\
\text { Steady } \\
\text { Jet }\end{array}$ & $\begin{array}{c}\text { U1 } \\
\text { Pulsing } \\
\text { Jet } \\
\end{array}$ & $\begin{array}{c}\text { U2 } \\
\text { URMS }\end{array}$ & $\begin{array}{c}\text { U3 } \\
\text { URNB }\end{array}$ & $\begin{array}{c}\text { Discharge } \\
\text { Velocity }\end{array}$ & $\begin{array}{c}\text { Oitical } \\
\text { suspension } \\
\text { velocity }\end{array}$ & $\begin{array}{l}\text { Average } \\
\text { Peak Cloud } \\
\text { Height }\end{array}$ & $\begin{array}{c}\text { Ucs } \\
\text { Condition }\end{array}$ & $\begin{array}{l}\text { UCS } \\
\text { Method }\end{array}$ & $\begin{array}{l}\text { UCS } \\
\text { Fag }\end{array}$ & $\begin{array}{c}\text { UCS } \\
\text { Center } \\
\text { Flag }\end{array}$ & $\begin{array}{c}\text { UCS uadv } \\
\text { Hag }\end{array}$ & $\begin{array}{c}\text { UCS based } \\
\text { on } \\
\text { Decreasing } \\
\text { Velocity }\end{array}$ & $\begin{array}{l}\text { Sweep } \\
\text { Increase } \\
\text { Decrease }\end{array}$ & $\begin{array}{c}\text { UDV } \\
\text { Height } \\
\text { Bed }\end{array}$ & $\begin{array}{c}\text { Particle } \\
\text { Motion }\end{array}$ & \begin{tabular}{|l|}
$\begin{array}{l}\text { Solids } \\
\text { Level }\end{array}$ \\
\end{tabular} & \begin{tabular}{|l|} 
Outer \\
Botom \\
Pattem \\
\end{tabular} & $\begin{array}{c}\text { Inner } \\
\text { Botomo } \\
\text { Pattem }\end{array}$ & Case ID & Test & TDP & $\begin{array}{l}\text { Row } \\
\text { Number }\end{array}$ \\
\hline$c$ & $\mathrm{~g} / \mathrm{cm}^{3}$ & fraction & ffraction & fraction & $\mathrm{s}$ & text & m/s & $\mathrm{m} / \mathrm{s}$ & m/s & m/s & $\mathrm{m} / \mathrm{s}$ & m/s & in. & $\mathrm{m} / \mathrm{s}$ & text & text & text & text & \begin{tabular}{|l|}
$\mathrm{m} / \mathrm{s}$ \\
\end{tabular} & text & $\begin{array}{ll}\mathrm{mm} \\
\end{array}$ & text & \begin{tabular}{|l|} 
text \\
\end{tabular} & text & text & text & text & text & text \\
\hline$T$ & $\rho$ & $\phi_{\mathrm{s}}$ & $\phi_{p}$ & $D C$ & tc & Jet & $U_{s}$ & $\mathrm{U} 1$ & $\mathrm{U} 2$ & U3 & $u$ & Uos & $H_{c}$ & $U_{\text {Csp }}$ & Uosm & Ussis & Usscen & Usoudv & Uos $D$ & $S_{w}$ & Hod & $\mathrm{PM}$ & Sol & SPo & $\mathrm{SP}_{1}$ & $\mathrm{ID}$ & MDDX & $\mathrm{TDP}$ & MSS \\
\hline 23.5 & 0.994 & 0.00500 & 0.050 & 0.328 & 26.0 & $P$ & $\mathrm{NA}$ & 11.16 & 11.43 & 11.57 & 12.00 & 12.50 & 25.50 & $\mathrm{NA}$ & $\mathrm{NA}$ & $\mathrm{NA}$ & NA & $\mathrm{NA}$ & $\mathrm{NA}$ & NA & 0.0 & NA & $\mathrm{NA}$ & NA & $\mathrm{NA}$ & 70E_4S2d2YC_1 & $5 / 28 \mathrm{~A}$ & IDP-164 & 9700236 \\
\hline 23.5 & 0.994 & 0.00500 & 0.050 & 0.328 & 26.0 & $\mathrm{P}$ & NA & 11.16 & 11.43 & 11.57 & 12.00 & 1250 & 25.50 & NA & NA & NA & NA & NA & NA & NA & 0.0 & NA & NA & NA & NA & 70E_4s2d2Yc_1 & $5 / 28 \mathrm{~A}$ & TDP-164 & 9700237 \\
\hline 23.5 & 0.994 & 0.00500 & 0.050 & 0.328 & 26.0 & $P$ & NA & 11.16 & 1143 & 11.57 & 12.00 & 12.50 & 25.50 & NA & NA & NA & NA & NA & NA & NA & 0.0 & NA & NA & NA & NA & $70 \mathrm{E} \_4 \mathrm{~s} 2 \mathrm{~d} 2 \mathrm{Yc} \_1$ & $5 / 28 \mathrm{~A}$ & TDP-164 & 9700238 \\
\hline 23.5 & 0.994 & 0.00500 & 0.050 & 0.328 & 26.0 & $P$ & NA & 11.16 & 11.43 & 11.57 & 12.00 & 1250 & 25.50 & NA & NA & NA & NA & NA & NA & NA & 0.0 & NA & NA & NA & NA & 70E_4s2d2Yc_1 & $5 / 28 \mathrm{~A}$ & TDP-164 & 9700239 \\
\hline 23.8 & 0.994 & 0.00500 & 0.050 & 0.328 & 26.0 & $\mathrm{P}$ & NA & 11.16 & 1143 & 11.56 & 12.00 & 1250 & 25.50 & NA & NA & NA & NA & NA & NA & NA & $\mathrm{na}$ & NA & NA & NA & NA & 70E_4s2d2Yc_1 & $5 / 28 \mathrm{~A}$ & TDP-164 & 9700239.1 \\
\hline 23.8 & 0.994 & 0.00500 & 0.050 & 0.328 & 26.0 & $P$ & NA & 11.16 & 1143 & 11.56 & 12.00 & 1250 & 25.50 & NA & NA & NA & NA & NA & NA & NA & $\mathrm{na}$ & NA & NA & NA & NA & $70 E_{15} 4 \mathrm{~s} 2 \mathrm{~d} 2 \mathrm{YC} \_1$ & $5 / 28 \mathrm{~A}$ & TDP-164 & 9700239.2 \\
\hline 23.8 & 0.994 & 0.00500 & 0.050 & 0.328 & 26.0 & $\mathrm{P}$ & NA & 11.16 & 11.43 & 11.56 & 12.00 & 1250 & 25.50 & NA & NA & NA & NA & NA & NA & NA & n/a & NA & NA & NA & NA & 70E_4s2d2YC_1 & $5 / 28 \mathrm{~A}$ & TDP-164 & 9700239.3 \\
\hline 23.8 & 0.994 & 0.00500 & 0.050 & 0.328 & 26.0 & $\mathrm{P}$ & NA & 11.16 & 11.43 & 11.56 & 12.00 & 12.50 & 25.50 & NA & NA & NA & NA & NA & NA & NA & 0.0 & NA & NA & NA & NA & 70E_4s2d2Yc_1 1 & $5 / 28 \mathrm{~A}$ & TDP-164 & 9700241 \\
\hline 23.8 & 0.994 & 0.00500 & 0.050 & 0.328 & 26.0 & $\mathrm{P}$ & NA & 11.16 & 1143 & 11.56 & 12.00 & 1250 & 25.50 & NA & NA & NA & NA & NA & NA & NA & 0.0 & NA & NA & NA & NA & 70E_4s2d2YC_1 & $5 / 28 \mathrm{~A}$ & IDP-164 & 9700242 \\
\hline 23.8 & 0.994 & 0.00500 & 0.050 & 0.328 & 26.0 & $P$ & NA & 11.16 & 1143 & 11.56 & 12.00 & 12.50 & 25.50 & NA & NA & NA & NA & NA & NA & NA & 0.0 & NA & NA & NA & NA & 70 _ $4 \mathrm{~s} 2 \mathrm{~d} 2 \mathrm{YC}$ & $5 / 28 \mathrm{~A}$ & TDP-164 & 9700243 \\
\hline 23.8 & 0.994 & 0.00500 & 0.050 & 0.328 & 26.0 & $\mathrm{P}$ & NA & 11.16 & 1143 & 11.56 & 12.00 & 1250 & 25.50 & NA & NA & NA & NA & NA & NA & NA & 0.0 & NA & NA & NA & NA & 70E_4s2d2YC_1 & $5 / 28 \mathrm{~A}$ & TDP-164 & 9700244 \\
\hline 23.8 & 0.994 & 0.00500 & 0.050 & 0.328 & 26.0 & $\mathrm{P}$ & NA & 11.16 & 1143 & 11.56 & 12.00 & 12.50 & 25.50 & NA & NA & NA & NA & NA & NA & NA & 0.0 & NA & NA & NA & NA & $70 \mathrm{E}=4 \mathrm{~s} 2 \mathrm{~d} 2 \mathrm{Yc} 1$ & $5 / 28 \mathrm{~A}$ & TDP-164 & 9700245 \\
\hline 23.8 & 0.994 & 0.00500 & 0.050 & 0.328 & 26.0 & $\mathrm{P}$ & NA & 11.16 & 11.43 & 11.56 & 12.00 & 1250 & 25.50 & NA & NA & NA & NA & NA & NA & NA & 0.0 & NA & NA & NA & NA & 70E_4S2d2YC 1 1 & $5 / 28 \mathrm{~A}$ & TDP-164 & 9700246 \\
\hline 23.8 & 0.994 & 0.00500 & 0.050 & 0.328 & 26.0 & $\mathrm{P}$ & NA & 11.16 & 11.43 & 11.56 & 12.00 & 12.50 & 25.50 & NA & NA & NA & NA & NA & NA & NA & 0.0 & NA & NA & NA & NA & 70E_-4S2202YC_1 & $5 / 28 \mathrm{~A}$ & TDP-164 & 9700247 \\
\hline 23.8 & 0.994 & 0.00500 & 0.050 & 0.328 & 26.0 & $P$ & NA & 11.16 & 1143 & 11.56 & 12.00 & 12.50 & 25.50 & NA & NA & NA & NA & NA & NA & NA & $\mathrm{na}$ & NA & NA & NA & NA & 70 _ $4 \mathrm{~s} 2 \mathrm{~d} 2 \mathrm{YC} 1$ & $5 / 28 \mathrm{~A}$ & TDP-164 & 9700247.1 \\
\hline 23.9 & 0.994 & 0.00500 & 0.050 & 0.328 & 26.0 & $\mathrm{P}$ & NA & 11.15 & 1142 & 11.56 & 12.00 & 1250 & 25.50 & NA & NA & NA & NA & NA & NA & NA & $\mathrm{na}$ & NA & NA & NA & NA & 70E_4s2d2YC_1 & $5 / 28 \mathrm{~A}$ & TDP-164 & 9700247.2 \\
\hline 23.9 & 0.994 & 0.00500 & 0.050 & 0.328 & 26.0 & $\mathrm{P}$ & NA & 11.15 & 11.42 & 11.56 & 12.00 & 12.50 & 25.50 & NA & NA & NA & NA & NA & NA & NA & $\mathrm{na}$ & NA & NA & NA & NA & $70 \mathrm{E}_{4} \mathrm{~s} 2 \mathrm{~d} 2 \mathrm{YC} 1$ & $5 / 28 \mathrm{~A}$ & TDP-164 & 9700247.3 \\
\hline 23.9 & 0.994 & 0.00500 & 0.050 & 0.328 & 26.0 & $\mathrm{P}$ & NA & 11.15 & 11.42 & 11.56 & 12.00 & 1250 & 25.50 & NA & NA & NA & NA & NA & NA & NA & $\mathrm{n} / \mathrm{a}$ & NA & NA & NA & NA & 70E_4S2d2YC_ 1 & $5 / 28 \mathrm{~A}$ & TDP-164 & 9700247.4 \\
\hline 23.9 & 0.994 & 0.00500 & 0.050 & 0.328 & 26.0 & $\mathrm{P}$ & NA & 11.15 & 11.42 & 11.56 & 12.00 & 12.50 & 25.50 & NA & NA & NA & UCScen & NA & NA & (null) & 0.0 & 2 & NA & NA & NA & 70E_-4S2202YC_1 & $5 / 28 \mathrm{~A}$ & TDP-164 & 9700248 \\
\hline 23.9 & 0.994 & 0.00500 & 0.050 & 0.328 & 26.0 & $\mathrm{P}$ & NA & 11.15 & 1142 & 11.56 & 12.00 & 1250 & 25.50 & NA & NA & NA & NA & NA & NA & NA & 0.0 & NA & NA & NA & NA & 70E_4s2d2YC_1 & $5 / 28 \mathrm{~A}$ & TDP-164 & 9700250 \\
\hline 23.9 & 0.994 & 0.00500 & 0.050 & 0.328 & 26.0 & $\mathrm{P}$ & NA & 11.15 & 1142 & 11.56 & 12.00 & 12.50 & 25.50 & NA & NA & NA & NA & NA & NA & NA & 0.0 & NA & NA & NA & NA & 70E_4S2d2YC_1 & $5 / 28 \mathrm{~A}$ & TDP-164 & 9700251 \\
\hline 23.9 & 0.994 & 0.00500 & 0.050 & 0.328 & 26.0 & $\mathrm{P}$ & NA & 11.15 & 1142 & 11.56 & 12.00 & 1250 & 25.50 & NA & NA & NA & NA & NA & NA & NA & 0.0 & NA & NA & NA & NA & 70E_4S2d2YC 1 1 & $5 / 28 \mathrm{~A}$ & TDP-164 & 9700252 \\
\hline 23.9 & 0.994 & 0.00500 & 0.050 & 0.328 & 26.0 & $\mathrm{P}$ & NA & 11.15 & 11.42 & 11.56 & 12.00 & 1250 & 25.50 & NA & NA & NA & NA & NA & NA & NA & 0.0 & NA & NA & NA & NA & 70E_-4S2202YC_1 & $5 / 28 \mathrm{~A}$ & TDP-164 & 9700253 \\
\hline 23.9 & 0.994 & 0.00500 & 0.050 & 0.328 & 26.0 & $\mathrm{P}$ & NA & 11.15 & 1142 & 11.56 & 12.00 & 12.50 & 25.50 & NA & NA & NA & NA & NA & NA & NA & 0.0 & NA & NA & NA & NA & 70E_4S2202YC_1 & $5 / 28 \mathrm{~A}$ & TDP-164 & 9700254 \\
\hline 23.9 & 0.994 & 0.00500 & 0.050 & 0.328 & 26.0 & $\mathrm{P}$ & NA & 11.15 & 11.42 & 11.56 & 12.00 & 1250 & 25.50 & NA & NA & NA & NA & NA & NA & NA & $\mathrm{ra}$ & NA & NA & NA & NA & 70E_4s2d2YC_1 & $5 / 28 \mathrm{~A}$ & IDP-164 & 9700254.1 \\
\hline 23.9 & 0.994 & 0.00500 & 0.050 & 0.328 & 26.0 & $\mathrm{P}$ & NA & 11.15 & 1142 & 11.56 & 12.00 & 1250 & 25.50 & NA & NA & NA & NA & NA & NA & NA & $\mathrm{na}$ & NA & NA & NA & NA & 70E__S22d2Yc_1 & $5 / 28 \mathrm{~A}$ & TDP-164 & 9700254.2 \\
\hline 17.3 & 0.996 & 0.00155 & 0.050 & 0.181 & 97.6 & $\mathrm{P}$ & $\mathrm{NA}$ & 5.42 & 5.50 & 5.55 & 5.70 & 7.10 & 24.00 & NA & NA & NA & NA & NA & NA & 1 & 31.8 & 1 & NA & NA & NA & 70E 4 sid17d 1 & $5 / 29 \mathrm{~A}$ & TDP-165 & 9700255 \\
\hline 17.6 & 0.996 & 0.00155 & 0.050 & 0.183 & 85.6 & $\mathrm{P}$ & NA & 6.09 & 6.19 & 6.24 & 6.40 & 7.10 & 28.00 & NA & NA & NA & NA & NA & NA & 1 & 18.0 & 1 & NA & NA & NA & 70E_4s1d17d_ 1 & $5 / 29 \mathrm{~A}$ & TDP-165 & 9700256 \\
\hline 17.6 & 0.996 & 0.00155 & 0.050 & 0.184 & 80.4 & $\mathrm{P}$ & NA & 6.48 & 6.58 & 6.64 & 6.80 & 7.10 & 27.75 & NA & NA & NA & NA & NA & NA & 1 & 7.4 & 1 & NA & NA & NA & \begin{tabular}{|l|l} 
70E_4sid17d_1 \\
\end{tabular} & $5 / 29 \mathrm{~A}$ & TDP-165 & 9700257 \\
\hline 17.9 & 0.995 & 0.00155 & 0.050 & 0.185 & 78.0 & $\mathrm{P}$ & NA & 6.64 & 6.75 & 6.81 & 7.00 & 7.10 & 29.50 & \begin{tabular}{|l|} 
NA \\
\end{tabular} & NA & NA & UCscen & NA & NA & 1 & 5.7 & 2 & NA & NA & NA & 70E_4sidIZ__ _ 1 & $5 / 29 \mathrm{~A}$ & TDP-165 & 9700258 \\
\hline 18.3 & 0.996 & 0.00155 & 0.050 & 0.185 & 76.8 & $P$ & NA & 6.72 & 6.84 & 6.90 & 7.10 & 7.10 & 30.50 & 7.10 & udv & NA & NA & ucsuav & NA & 1 & 2.0 & 4 & NA & NA & NA & 70 _4s1d17d 1 & $5 / 29 \mathrm{~A}$ & TDP-165 & 9700259 \\
\hline 18.4 & 0.996 & 0.00155 & 0.050 & 0.182 & 68.0 & $\mathrm{P}$ & NA & 7.65 & 7.80 & 7.87 & 8.10 & 7.10 & 40.50 & \begin{tabular}{|l|} 
NA \\
\end{tabular} & NA & NA & NA & NA & NA & 1 & 0.0 & 4 & NA & NA & NA & 70E_4sid17d 1 & $5 / 29 \mathrm{~A}$ & TDP-165 & 9700260 \\
\hline 18.5 & 0.996 & 0.00155 & 0.050 & 0.181 & 72.4 & $\mathrm{P}$ & NA & 7.30 & 7.43 & 7.50 & 7.70 & 7.10 & 34.75 & NA & NA & NA & NA & NA & NA & D & 0.0 & 4 & NA & NA & NA & 70E_-4s1d17d_ 1 & $5 / 29 A$ & TDP-165 & 9700261 \\
\hline 18.7 & 0.996 & 0.00155 & 0.050 & 0.331 & 46.6 & $\mathrm{P}$ & NA & 6.18 & 6.28 & 6.33 & 6.50 & 7.10 & 27.75 & NA & NA & NA & NA & NA & NA & D & 13.9 & 1 & NA & NA & NA & 70E_4s1d17c__1 & $5 / 298$ & TDP-165 & 9700262 \\
\hline 18.9 & 0.996 & 0.00155 & 0.050 & 0.333 & 43.8 & $\mathrm{P}$ & NA & 6.54 & 6.65 & 6.71 & 6.90 & 7.10 & 30.25 & NA & NA & NA & UCScen & NA & NA & 1 & 5.4 & 2 & NA & NA & NA & 70E_4sid17c_1 & $5 / 298$ & TDP-165 & 9700263 \\
\hline 18.9 & 0.996 & 0.00155 & 0.050 & 0.334 & 42.6 & $P$ & NA & 6.74 & 6.85 & 6.91 & 7.10 & 7.10 & 32.75 & \begin{tabular}{|l|}
7.10 \\
\end{tabular} & udv & NA & NA & Ucsuav & NA & 1 & 0.7 & 4 & NA & NA & NA & 70E_4sid17c_1 & $5 / 298$ & TDP-165 & 9700264 \\
\hline 19.0 & 0.996 & 0.00155 & 0.050 & 0.337 & 39.8 & $\mathrm{P}$ & NA & 7.12 & 7.25 & 7.31 & 7.50 & 7.10 & 33.50 & NA & NA & NA & NA & NA & NA & 1 & 0.0 & 4 & NA & NA & NA & 70E_4sid17c 1 & $5 / 29 \mathrm{~B}$ & TDP-165 & 9700265 \\
\hline 19.0 & 0.996 & 0.00155 & 0.050 & 0.340 & 37.2 & $\mathrm{P}$ & NA & 7.48 & 7.62 & 7.69 & 7.90 & 7.10 & 44.50 & NA & NA & NA & NA & NA & NA & D & 0.0 & 4 & NA & NA & NA & 70E_4sid17c_ 1 & $5 / 298$ & TDP-165 & 9700266 \\
\hline 19.3 & 0.996 & 0.00155 & 0.050 & 0.336 & 40.8 & $\mathrm{P}$ & NA & 6.92 & 7.04 & 7.10 & 7.30 & 7.10 & 31.50 & NA & NA & NA & NA & NA & NA & $\mathrm{D}$ & 0.0 & 4 & NA & NA & NA & 70E_4s1d17c_1 1 & 5/29B & TDP-165 & 9700267 \\
\hline
\end{tabular}


Table B.5. Data from 2008 Tests in Large-Scale Vessel with Elliptical Head A.9

\begin{tabular}{|c|c|c|c|c|c|c|c|c|c|c|c|c|c|c|c|c|c|c|c|c|c|c|c|c|c|c|c|}
\hline $\begin{array}{c}\text { Row } \\
\text { Number }\end{array}$ & Test & Case ID & $\begin{array}{c}\text { Tank } \\
\text { Diameter }\end{array}$ & $\begin{array}{l}\text { Head } \\
\text { Shape }\end{array}$ & $\begin{array}{l}\text { Dish } \\
\text { Height }\end{array}$ & $\begin{array}{c}\text { Dish } \\
\text { Volume }\end{array}$ & $\begin{array}{c}\text { Tank } \\
\text { Fill } \\
\text { Height }\end{array}$ & $\begin{array}{l}\text { Retum } \\
\text { Line } \\
\text { Height }\end{array}$ & $\begin{array}{c}\text { Nozzle } \\
\text { Inner } \\
\text { Diamter }\end{array}$ & $\begin{array}{l}\text { Nozzle } \\
\text { Stand-off } \\
\text { Distance }\end{array}$ & $\begin{array}{l}\text { Pulse Tube } \\
\text { Configuration }\end{array}$ & $\begin{array}{l}\text { Installed } \\
\text { Nozzles }\end{array}$ & $\begin{array}{l}\text { Outer } \\
\text { Nozzles } \\
\text { Operated }\end{array}$ & $\begin{array}{c}\text { Inner } \\
\text { Nozzles } \\
\text { Operated }\end{array}$ & $\begin{array}{c}\text { Pulse Tube } \\
\text { Outur } \\
\text { Dianeter }\end{array}$ & $\begin{array}{c}\text { Outer } \\
\text { PJM } \\
\text { Radius }\end{array}$ & $\begin{array}{l}\text { Inner } \\
\text { PJM } \\
\text { Radius }\end{array}$ & $\begin{array}{l}\text { "FO" Outer } \\
\text { PJM } \\
\text { Impingement } \\
\text { Angle }\end{array}$ & $\begin{array}{l}\text { "FO" Inner PJM } \\
\text { Impingement } \\
\text { Angle }\end{array}$ & $\begin{array}{l}\text { Ratio Outer } \\
\text { PJMtt Tank } \\
\text { Radius } \\
\end{array}$ & $\begin{array}{l}\text { Ratio Inner } \\
\text { PJMt torark } \\
\text { Radius } \\
\end{array}$ & Simulant & $\begin{array}{l}\text { Solids } \\
\text { Density }\end{array}$ & $\begin{array}{c}\text { Particle } \\
\text { Diameter d5 }\end{array}$ & $\begin{array}{c}\text { Particle } \\
\text { Diameter } \\
\text { d50 }\end{array}$ & $\begin{array}{l}\text { Particle } \\
\text { Diameter } \\
\text { d955 }\end{array}$ & $\begin{array}{c}\text { Void } \\
\text { Fraction }\end{array}$ \\
\hline text & text & text & in. & text & in. & in. ${ }^{3}$ & in. & in. & in. & in. & text & number & number & number & in. & in. & in. & deg & deg & nondim & nondim & text & $\mathrm{g} / \mathrm{mm}^{3}$ & $\mathrm{~m}$ & $\mathrm{~m}$ & $m$ & fraction \\
\hline MSS & MDDX & $\mathrm{ID}$ & $\mathrm{D}$ & HS & Hosh & $V_{\text {dath }}$ & $\mathrm{H}$ & $\mathrm{Rtn}$ & $d$ & sod & PT & $\mathrm{N}$ & $\mathrm{Nb}$ & $\mathrm{N}$ & $\mathrm{PTT_{ \alpha 1 }}$ & $R_{0}$ & $R$ & $\theta_{\circ}$ & $\theta_{1}$ & RdR & $R / R$ & sxdx & $\rho_{\mathrm{s}}$ & $\mathrm{d}_{\mathrm{d}}$ & $d_{60}$ & des & vf \\
\hline 9700268 & $5 / 29 B$ & 70E_4s1d1Zc_1 & 70 & $E$ & 19 & 49770.7 & 92 & 80 & 0.613 & 0.920 & HLP-22 & 12 & 8 & 4 & 3.5 & 21.9 & 11.5 & 20.3 & 10.5 & 0.62 & 0.33 & s1d1 & 2.46 & 0.0001428 & 0.0001664 & 0.0001951 & 0.4118 \\
\hline 9700268.1 & $5 / 30 \mathrm{~A}$ & 70E_4s1d17c_1 1 & 70 & $E$ & 19 & 49770.7 & 92 & 80 & 0.613 & 0.920 & HLP-22 & 12 & 8 & 4 & 3.5 & 21.9 & 11.5 & 20.3 & 10.5 & 0.62 & 0.33 & sid1 & 2.46 & 0.0001428 & 0.0001664 & 0.0001951 & 0.4118 \\
\hline 9700268.2 & $5 / 30 A$ & 70E_4s1d17c_1 1 & 70 & $E$ & 19 & 49770.7 & 92 & 80 & 0.613 & 0.920 & HLP-22 & 12 & 8 & 4 & 3.5 & 21.9 & 11.5 & 20.3 & 10.5 & 0.62 & 0.33 & sidn & 2.46 & 0.0001428 & 0.0001664 & 0.0001951 & 0.4118 \\
\hline 9700269M & $5 / 30 \mathrm{~A}$ & 70E_4s1d1Zc_1 1 & 70 & E & 19 & 49770.7 & 92 & 80 & 0.613 & 0.920 & HLP-22 & 12 & 8 & 4 & 3.5 & 21.9 & 11.5 & 20.3 & 10.5 & 0.62 & 0.33 & sld1 & 2.46 & 0.0001428 & 0.00001664 & 0.0001951 & 0.4118 \\
\hline 9700270 & 5/30A & 70E_4sid12c_1 & 70 & $E$ & 19 & 49770.7 & 92 & 80 & 0.613 & 0.920 & HLP-22 & 12 & 8 & 4 & 3.5 & 21.9 & 11.5 & 20.3 & 10.5 & 0.62 & 0.33 & sld1 & 2.46 & 0.0001428 & 0.0001664 & 0.0001951 & 0.4118 \\
\hline 9700271 & $5 / 30 \mathrm{~A}$ & 70E_4s1d17c_1 & 70 & E & 19 & 49770.7 & 92 & 80 & 0.613 & 0.920 & HLP-22 & 12 & 8 & 4 & 3.5 & 21.9 & 11.5 & 20.3 & 10.5 & 0.62 & 0.33 & s1d1 & 2.46 & 0.0001428 & 0.0001664 & 0.0001951 & 0.4118 \\
\hline 9700272 & 5/30A & 70E_4s1d17z_1 1 & 70 & $\mathrm{E}$ & 19 & 49770.7 & 92 & 80 & 0.613 & 0.920 & HLP-22 & 12 & 8 & 4 & 3.5 & 21.9 & 11.5 & 20.3 & 10.5 & 0.62 & 0.33 & s1d1 & 2.46 & 0.0001428 & 0.0001664 & 0.0001951 & 0.4118 \\
\hline 9700273 & $5 / 30 \mathrm{~A}$ & 70E_4s1d17c_1 1 & 70 & $E$ & 19 & 49770.7 & 92 & 80 & 0.613 & 0.920 & HLP-22 & 12 & 8 & 4 & 3.5 & 21.9 & 11.5 & 20.3 & 10.5 & 0.62 & 0.33 & sidn & 2.46 & 0.0001428 & 0.0001664 & 0.0001951 & 0.4118 \\
\hline 9700274 & 5/30A & 70E_4s1d1Zc_1 & 70 & E & 19 & 49770.7 & 92 & 80 & 0.613 & 0.920 & HLP-22 & 12 & 8 & 4 & 3.5 & 21.9 & 11.5 & 20.3 & 10.5 & 0.62 & 0.33 & sld1 & 2.46 & 0.0001428 & 0.00001664 & 0.0001951 & 0.4118 \\
\hline 9700275 & $5 / 30 \mathrm{~A}$ & 70E_4s1d17c__ 1 & 70 & $E$ & 19 & 49770.7 & 92 & 80 & 0.613 & 0.920 & HLP-22 & 12 & 8 & 4 & 3.5 & 21.9 & 11.5 & 20.3 & 10.5 & 0.62 & 0.33 & s1d1 & 2.46 & 0.0001428 & 0.0001664 & 0.0001951 & 0.4118 \\
\hline 9700276 & $5 / 30 \mathrm{~A}$ & 70E_4sid17c_1 & 70 & $\mathrm{E}$ & 19 & 49770.7 & 92 & 80 & 0.613 & 0.920 & HLP-22 & 12 & 8 & 4 & 3.5 & 21.9 & 11.5 & 20.3 & 10.5 & 0.62 & 0.33 & s1d1 & 2.46 & 0.0001428 & 0.0001664 & 0.0001951 & 0.4118 \\
\hline 9700277 & 5/30A & 70E_4s1d17c_1 & 70 & $\mathrm{E}$ & 19 & 49770.7 & 92 & 80 & 0.613 & 0.920 & HLP-22 & 12 & 8 & 4 & 3.5 & 21.9 & 11.5 & 20.3 & 10.5 & 0.62 & 0.33 & s1d1 & 2.46 & 0.0001428 & 0.0001664 & 0.0001951 & 0.4118 \\
\hline 9700278 & 5/30A & 70E_4s1d1Zc_1 & 70 & $E$ & 19 & \begin{tabular}{|l|l|}
49770.7 \\
\end{tabular} & 92 & 80 & 0.613 & 0.920 & HLP-22 & 12 & 8 & 4 & 3.5 & 21.9 & 11.5 & 20.3 & 10.5 & 0.62 & 0.33 & s1d1 & 2.46 & 0.0001428 & 0.0001664 & 0.0001951 & 0.4118 \\
\hline 9700278.1 & $5 / 30 \mathrm{~A}$ & 70E_4s1d1Zc_1 1 & 70 & E & 19 & 49770.7 & 92 & 80 & 0.613 & 0.920 & HLP-22 & 12 & 8 & 4 & 3.5 & 21.9 & 11.5 & 20.3 & 10.5 & 0.62 & 0.33 & s1d1 & 2.46 & 0.0001428 & 0.0001664 & 0.0001951 & 0.4118 \\
\hline 9700278.2 & $5 / 30 \mathrm{~A}$ & 70E_4sid17c_1 & 70 & $E$ & 19 & 49770.7 & 92 & 80 & 0.613 & 0.920 & HLP-22 & 12 & 8 & 4 & 3.5 & 21.9 & 11.5 & 20.3 & 10.5 & 0.62 & 0.33 & sld1 1 & 2.46 & 0.0001428 & 0.0001664 & 0.0001951 & 0.4118 \\
\hline 9700279M & $5 / 30 \mathrm{~A}$ & 70E_4s1d1Zc_1 1 & 70 & $E$ & 19 & 49770.7 & 92 & 80 & 0.613 & 0.920 & HLP-22 & 12 & 8 & 4 & 3.5 & 21.9 & 11.5 & 20.3 & 10.5 & 0.62 & 0.33 & sld1 1 & 2.46 & 0.0001428 & 0.0001664 & 0.0001951 & 0.4118 \\
\hline 9700280 & $5 / 30 \mathrm{~A}$ & 70E_4s1d17z_1 1 & 70 & $E$ & 19 & 49770.7 & 92 & 80 & 0.613 & 0.920 & HLP-22 & 12 & 8 & 4 & 3.5 & 21.9 & 11.5 & 20.3 & 10.5 & 0.62 & 0.33 & s1d1 1 & 2.46 & 0.0001428 & 0.0001664 & 0.0001951 & 0.4118 \\
\hline 9700281 & 5/30A & 70E_4s1d17c_1 & 70 & $E$ & 19 & \begin{tabular}{ll|}
49770.7 \\
\end{tabular} & 92 & 80 & 0.613 & 0.920 & HLP-22 & 12 & 8 & 4 & 3.5 & 21.9 & 11.5 & 20.3 & 10.5 & 0.62 & 0.33 & s1d1 & 2.46 & 0.0001428 & 0.0001664 & 0.0001951 & 0.4118 \\
\hline 9700282 & $5 / 30 \mathrm{~A}$ & 70E_4s1d1Zc_1 & 70 & E & 19 & 49770.7 & 92 & 80 & 0.613 & 0.920 & HLP-22 & 12 & 8 & 4 & 3.5 & 21.9 & 11.5 & 20.3 & 10.5 & 0.62 & 0.33 & sidn & 2.46 & 0.0001428 & 0.0001664 & 0.0001951 & 0.4118 \\
\hline 9700283 & $5 / 30 \mathrm{~A}$ & 70E_4sid17c_1 & 70 & $E$ & 19 & 49770.7 & 92 & 80 & 0.613 & 0.920 & HLP-22 & 12 & 8 & 4 & 3.5 & 21.9 & 11.5 & 20.3 & 10.5 & 0.62 & 0.33 & s1d1 & 2.46 & 0.0001428 & 0.0001664 & 0.0001951 & 0.4118 \\
\hline 9700284 & $5 / 30 A$ & 70E_4s1d1Zc_1 & 70 & $E$ & 19 & 49770.7 & 92 & 80 & 0.613 & 0.920 & HLP-22 & 12 & 8 & 4 & 3.5 & 21.9 & 11.5 & 20.3 & 10.5 & 0.62 & 0.33 & sidn & 2.46 & 0.0001428 & 0.0001664 & 0.0001951 & 0.4118 \\
\hline 9700285 & $5 / 30 \mathrm{~A}$ & 70E_4sid17c_1 & 70 & $\mathrm{E}$ & 19 & 49770.7 & 92 & 80 & 0.613 & 0.920 & HLP-22 & 12 & 8 & 4 & 3.5 & 21.9 & 11.5 & 20.3 & 10.5 & 0.62 & 0.33 & sidn & 2.46 & 0.0001428 & 0.0001664 & 0.0001951 & 0.4118 \\
\hline 9700286 & 5/30A & 70E_4s1d1Zc_1 & 70 & $E$ & 19 & \begin{tabular}{|l|l|}
49770.7 \\
\end{tabular} & 92 & 80 & 0.613 & 0.920 & HLP-22 & 12 & 8 & 4 & 3.5 & 21.9 & 11.5 & 20.3 & 10.5 & 0.62 & 0.33 & s1d1 & 2.46 & 0.0001428 & 0.0001664 & 0.0001951 & 0.4118 \\
\hline 9700287 & $5 / 30 \mathrm{~A}$ & 70E_4s1d17c_1 & 70 & E & 19 & 49770.7 & 92 & 80 & 0.613 & 0.920 & HLP-22 & 12 & 8 & 4 & 3.5 & 21.9 & 11.5 & 20.3 & 10.5 & 0.62 & 0.33 & sidn & 2.46 & 0.0001428 & 0.0001664 & 0.0001951 & 0.4118 \\
\hline 9700288 & $5 / 30 \mathrm{~A}$ & 70E_4sid17c_1 & 70 & $E$ & 19 & 49770.7 & 92 & 80 & 0.613 & 0.920 & HLP-22 & 12 & 8 & 4 & 3.5 & 21.9 & 11.5 & 20.3 & 10.5 & 0.62 & 0.33 & sld1 & 2.46 & 0.0001428 & 0.0001664 & 0.0001951 & 0.4118 \\
\hline 9700288.1 & $5 / 30 A$ & 70E_4s1d1Zc_1 & 70 & $E$ & 19 & 49770.7 & 92 & 80 & 0.613 & 0.920 & HLP-22 & 12 & 8 & 4 & 3.5 & 21.9 & 11.5 & 20.3 & 10.5 & 0.62 & 0.33 & s1d1 & 2.46 & 0.0001428 & 0.0001664 & 0.0001951 & 0.4118 \\
\hline 9700288.2 & $5 / 30 \mathrm{~A}$ & 70E_4sid17c_1 & 70 & $\mathrm{E}$ & 19 & 49770.7 & 92 & 80 & 0.613 & 0.920 & HLP-22 & 12 & 8 & 4 & 3.5 & 21.9 & 11.5 & 20.3 & 10.5 & 0.62 & 0.33 & sidn & 2.46 & 0.0001428 & 0.0001664 & 0.0001951 & 0.4118 \\
\hline $9700289 \mathrm{M}$ & $5 / 30 A$ & 70E_4s1d1Zc_1 & 70 & $E$ & 19 & \begin{tabular}{|l|l|}
49770.7 \\
\end{tabular} & 92 & 80 & 0.613 & 0.920 & HLP-22 & 12 & 8 & 4 & 3.5 & 21.9 & 11.5 & 20.3 & 10.5 & 0.62 & 0.33 & s1d1 & 2.46 & 0.0001428 & 0.0001664 & 0.0001951 & 0.4118 \\
\hline 9700290 & $5 / 30 \mathrm{~A}$ & 70E_4s1d1Zc_1 & 70 & E & 19 & 49770.7 & 92 & 80 & 0.613 & 0.920 & HLP-22 & 12 & 8 & 4 & 3.5 & 21.9 & 11.5 & 20.3 & 10.5 & 0.62 & 0.33 & s1d1 & 2.46 & 0.0001428 & 0.0001664 & 0.0001951 & 0.4118 \\
\hline 9700291 & $5 / 30 \mathrm{~A}$ & 70E_4sid17c_1 & 70 & $E$ & 19 & 49770.7 & 92 & 80 & 0.613 & 0.920 & HLP-22 & 12 & 8 & 4 & 3.5 & 21.9 & 11.5 & 20.3 & 10.5 & 0.62 & 0.33 & s1d1 & 2.46 & 0.0001428 & 0.0001664 & 0.0001951 & 0.4118 \\
\hline 9700292 & $5 / 30 \mathrm{~A}$ & 70E_4s1d1Zc_1 & 70 & $\mathrm{E}$ & 19 & 49770.7 & 92 & 80 & 0.613 & 0.920 & HLP-22 & 12 & 8 & 4 & 3.5 & 21.9 & 11.5 & 20.3 & 10.5 & 0.62 & 0.33 & sidn 1 & 2.46 & 0.0001428 & 0.0001664 & 0.0001951 & 0.4118 \\
\hline 9700293 & 5/30A & 70E_4s1d1Zc_1 & 70 & $\mathrm{E}$ & 19 & 49770.7 & 92 & 80 & 0.613 & 0.920 & HLP-22 & 12 & 8 & 4 & 3.5 & 21.9 & 11.5 & 20.3 & 10.5 & 0.62 & 0.33 & s1d1 & 2.46 & 0.0001428 & 0.0001664 & 0.0001951 & 0.4118 \\
\hline 9700294 & $5 / 30 \mathrm{~A}$ & 70E_4sIdIZC_1 & 70 & $E$ & 19 & \begin{tabular}{|l|l|}
49770.7 \\
\end{tabular} & 92 & 80 & 0.613 & 0.920 & HLP-22 & 12 & 8 & 4 & 3.5 & 21.9 & 11.5 & 20.3 & 10.5 & 0.62 & 0.33 & s1d1 1 & 2.46 & 0.0001428 & 0.0001664 & 0.0001951 & 0.4118 \\
\hline 9700295 & $5 / 30 \mathrm{~A}$ & 70E_4s1d1Zc_1 & 70 & E & 19 & 49770.7 & 92 & 80 & 0.613 & 0.920 & HLP-22 & 12 & 8 & 4 & 3.5 & 21.9 & 11.5 & 20.3 & 10.5 & 0.62 & 0.33 & sld1 & 2.46 & 0.0001428 & 0.0001664 & 0.0001951 & 0.4118 \\
\hline 9700295.1 & $5 / 30 \mathrm{~A}$ & 70E_4s1d1Zc_ 1 & 70 & $E$ & 19 & 49770.7 & 92 & 80 & 0.613 & 0.920 & HLP-22 & 12 & 8 & 4 & 3.5 & 21.9 & 11.5 & 20.3 & 10.5 & 0.62 & 0.33 & s1d1 & 2.46 & 0.0001428 & 0.0001664 & 0.0001951 & 0.4118 \\
\hline 9700295.2 & $5 / 30 \mathrm{~A}$ & 70E_4s1d12c_1 & 70 & $E$ & 19 & 49770.7 & 92 & 80 & 0.613 & 0.920 & HLP-22 & 12 & 8 & 4 & 3.5 & 21.9 & 11.5 & 20.3 & 10.5 & 0.62 & 0.33 & sidn & 2.46 & 0.0001428 & 0.0001664 & 0.0001951 & 0.4118 \\
\hline 9700295.3 & 5/30A & 70E_4s1d1Zc_1 & 70 & $\mathrm{E}$ & 19 & 49770.7 & 92 & 80 & 0.613 & 0.920 & HLP-22 & 12 & 8 & 4 & 3.5 & 21.9 & 11.5 & 20.3 & 10.5 & 0.62 & 0.33 & sidn & 2.46 & 0.0001428 & 0.0001664 & 0.0001951 & 0.4118 \\
\hline 9700296 & 7/177A & 70E8_6sid27c_1 & 70 & $E$ & 19 & \begin{tabular}{|l|l|}
49770.7 \\
\end{tabular} & 93 & 80 & 0.92 & 1.380 & 8TA & 8 & 4 & 4 & 3.5 & 23.5 & 17.5 & 21.9 & 16.1 & 0.67 & 0.50 & $\mathrm{~s} 1 \mathrm{~d} 2$ & 2.48 & 0.0000569 & 0.0000693 & 0.0000821 & 0.3750 \\
\hline 9700297 & $7117 \mathrm{~A}$ & 70E8_6s1d2Zc__1 & 70 & E & 19 & 49770.7 & 93 & 80 & 0.92 & 1.380 & 8TA & 8 & 4 & 4 & 3.5 & 23.5 & 17.5 & 21.9 & 16.1 & 0.67 & 0.50 & $\mathrm{~s} 1 \mathrm{~d} 2$ & 2.48 & 0.0000569 & 0.0000693 & 0.0000821 & 0.3750 \\
\hline 9700298 & $7117 \mathrm{~A}$ & 70E8_6s1d2Zc__1 & 70 & E & 19 & 49770.7 & 93 & 80 & 0.92 & 1.380 & 8TA & 8 & 4 & 4 & 3.5 & 23.5 & 17.5 & 21.9 & 16.1 & 0.67 & 0.50 & $\mathrm{~s} 1 \mathrm{~d} 2$ & 2.48 & 0.0000569 & 0.0000693 & 0.0000821 & 0.3750 \\
\hline 9700299 & $7 / 17 \mathrm{~A}$ & $70 E 8$ 6sida27c 1 & 70 & E & 19 & 49770.7 & 93 & 80 & 0.92 & 1.380 & 8TA & 8 & 4 & 4 & 3.5 & 23.5 & 17.5 & 21.9 & 16.1 & 0.67 & 0.50 & s1d2 & 2.48 & 0.0000569 & 0.0000693 & 0.0000821 & 0.3750 \\
\hline
\end{tabular}


Table B.5. Data from 2008 Tests in Large-Scale Vessel with Elliptical Head B.9

\begin{tabular}{|c|c|c|c|c|c|c|c|c|c|c|c|c|c|c|c|c|c|c|c|c|c|c|c|c|c|c|c|c|c|}
\hline $\begin{array}{l}\text { Tank Water } \\
\text { Temperature }\end{array}$ & $\begin{array}{l}\text { Water } \\
\text { Density }\end{array}$ & $\begin{array}{l}\text { Solids } \\
\text { Fraction }\end{array}$ & $\begin{array}{c}\text { Pulse } \\
\text { Volume } \\
\text { Fraction }\end{array}$ & $\begin{array}{l}\text { Duty } \\
\text { cycle }\end{array}$ & $\begin{array}{l}\text { Cyde } \\
\text { Time }\end{array}$ & $\begin{array}{c}\text { Pulsed } \\
\text { or } \\
\text { Steacy } \\
\text { Jet } \\
\end{array}$ & \begin{tabular}{|c} 
Us \\
Steacy \\
Jet
\end{tabular} & $\begin{array}{c}\text { U1 } \\
\text { Pulsing } \\
\text { Jet }\end{array}$ & $\begin{array}{l}\text { U2 } \\
\text { URMS }\end{array}$ & $\begin{array}{c}\text { U3 } \\
\text { URNB }\end{array}$ & $\begin{array}{l}\text { Discharge } \\
\text { Velocity }\end{array}$ & $\begin{array}{c}\text { Citical } \\
\text { Suspension } \\
\text { Velocity } \\
\text { velate }\end{array}$ & $\begin{array}{c}\text { Average } \\
\text { Peak Cloud } \\
\text { Height }\end{array}$ & $\begin{array}{c}\text { UCS } \\
\text { Condition }\end{array}$ & $\begin{array}{c}\text { UCS } \\
\text { Method }\end{array}$ & $\begin{array}{l}\text { UCS } \\
\text { Hag }\end{array}$ & $\begin{array}{l}\text { Ucs } \\
\text { Center } \\
\text { Hag } \\
\end{array}$ & $\begin{array}{c}\text { UCS udv } \\
\text { Hag }\end{array}$ & \begin{tabular}{|c|} 
UCS based \\
on \\
Decreasing \\
Velocity \\
\end{tabular} & $\begin{array}{l}\text { Sweep } \\
\text { Increase } \\
\text { Decrease }\end{array}$ & \begin{tabular}{|c|} 
uDV \\
Height \\
Bed \\
Bed
\end{tabular} & $\begin{array}{l}\text { Particle } \\
\text { Motion }\end{array}$ & \begin{tabular}{|l|} 
Solids \\
Level \\
\end{tabular} & $\begin{array}{l}\text { Outer } \\
\text { Bottom } \\
\text { Pattem }\end{array}$ & $\begin{array}{l}\text { Inner } \\
\text { Botomo } \\
\text { Pattem }\end{array}$ & Case ID & Test & TDP & $\begin{array}{c}\text { Row } \\
\text { Number }\end{array}$ \\
\hline$c$ & $\mathrm{~g} / \mathrm{cm}^{3}$ & fraction & fraction & fraction & $\mathrm{s}$ & text & $\mathrm{m} / \mathrm{s}$ & $\mathrm{m} / \mathrm{s}$ & $\mathrm{m} / \mathrm{s}$ & $\mathrm{m} / \mathrm{s}$ & $\mathrm{m} / \mathrm{s}$ & $\mathrm{m} / \mathrm{s}$ & in. & $\mathrm{ms}$ & text & text & text & text & \begin{tabular}{|l|}
$\mathrm{m} / \mathrm{s}$ \\
\end{tabular} & text & $\mathrm{mm}$ & text & text & text & text & text & text & text & text \\
\hline$T$ & $\rho$ & $\phi_{\mathrm{s}}$ & $\phi_{p}$ & $D C$ & $t_{c}$ & Jet & $U_{s}$ & $\mathrm{U}_{1}$ & $\mathrm{U} 2$ & $U_{3}$ & $u$ & Uss & $H_{k}$ & Uosr & Usan & Uosis & Ussen & Usuldr & Uss D & $S_{w}$ & $H_{\text {bod }}$ & $P M$ & Sol & $\mathrm{SPo}$ & $\mathrm{SP}$ & ID & MDDX & $\mathrm{TDP}$ & MSS \\
\hline 19.2 & 0.996 & 0.00155 & 0.050 & 0.332 & 45.0 & $P$ & $\mathrm{NA}$ & 6.37 & 6.47 & 6.52 & 6.70 & 7.10 & 29.25 & $\mathrm{NA}$ & $\mathrm{NA}$ & NA & NA & NA & NA & D & 8.8 & 1 & NA & NA & NA & 70E_4s1d1Zc_1 1 & $5 / 29 \mathrm{~B}$ & TDP-165 & 9700268 \\
\hline 19.8 & 0.995 & 0.00155 & 0.050 & 0.334 & 42.6 & $\mathrm{P}$ & NA & 6.72 & 6.84 & 6.89 & 7.10 & 7.10 & 30.75 & NA & NA & NA & NA & NA & NA & NA & $\mathrm{n} / \mathrm{a}$ & NA & NA & NA & NA & 70E_4s1d1Zc_1 1 & $5 / 30 \mathrm{~A}$ & TDP-166 & 9700268.1 \\
\hline 19.8 & 0.995 & 0.00155 & 0.050 & 0.334 & 42.6 & $\mathrm{P}$ & NA & 6.72 & 6.84 & 6.89 & 7.10 & 7.10 & 30.75 & NA & NA & NA & NA & NA & NA & NA & $\mathrm{na}$ & NA & NA & NA & NA & $70 \mathrm{E} \_4 \mathrm{~s} 1 \mathrm{~d} 1 \mathrm{Zc} \_1$ & $5 / 30 \mathrm{~A}$ & TDP-166 & 9700268.2 \\
\hline 19.8 & 0.995 & 0.00155 & 0.050 & 0.334 & 42.6 & $\mathrm{P}$ & NA & 6.72 & 6.84 & 6.89 & 7.10 & 7.10 & 30.75 & NA & NA & NA & NA & NA & NA & (null) & 0.0 & 4 & NA & NA & NA & 70E_4s1d1Zc_1 1 & $5 / 30 \mathrm{~A}$ & TDP-166 & 9700269 \\
\hline 19.8 & 0.995 & 0.00155 & 0.050 & 0.334 & 42.6 & $\mathrm{P}$ & NA & 6.72 & 6.84 & 6.89 & 7.10 & 7.10 & 30.75 & NA & NA & NA & NA & NA & NA & NA & 0.0 & NA & NA & NA & NA & 70E_4s1d17c_ 1 & $5 / 30 \mathrm{~A}$ & TDP-166 & 9700270 \\
\hline 19.8 & 0.995 & 0.00155 & 0.050 & 0.334 & 42.6 & $\mathrm{P}$ & NA & 6.72 & 6.84 & 6.89 & 7.10 & 7.10 & 30.75 & NA & NA & NA & NA & NA & NA & NA & 0.0 & NA & NA & NA & NA & 70E_4s1d1Zc_1 1 & $5 / 30 \mathrm{~A}$ & TDP-166 & 9700271 \\
\hline 19.8 & 0.995 & 0.00155 & 0.050 & 0.334 & 42.6 & $\mathrm{P}$ & NA & 6.72 & 6.84 & 6.89 & 7.10 & 7.10 & 30.75 & NA & NA & NA & NA & NA & NA & NA & 1.4 & NA & NA & NA & NA & $70 \mathrm{E} \_4 \mathrm{~s} 1 \mathrm{~d} 1 \mathrm{Zc} \_1$ & $5 / 30 A$ & TDP-166 & 9700272 \\
\hline 19.8 & 0.995 & 0.00155 & 0.050 & 0.334 & 42.6 & $\mathrm{P}$ & NA & 6.72 & 6.84 & 6.89 & 7.10 & 7.10 & 30.75 & NA & NA & NA & NA & NA & NA & NA & 0.7 & NA & NA & NA & NA & 70E_4s1d1Zc_ 1 & $5 / 30 \mathrm{~A}$ & TDP-166 & 9700274 \\
\hline 19.8 & 0.995 & 0.00155 & 0.050 & 0.334 & 42.6 & $\mathrm{P}$ & NA & 6.72 & 6.84 & 6.89 & 7.10 & 7.10 & 30.75 & NA & NA & NA & NA & NA & NA & NA & 0.7 & NA & NA & NA & NA & 70E_4sId17c_ 1 & $5 / 30 \mathrm{~A}$ & TDP-166 & 9700275 \\
\hline 19.8 & 0.995 & 0.00155 & 0.050 & 0.334 & 42.6 & $\mathrm{P}$ & NA & 6.72 & 6.84 & 6.89 & 7.10 & 7.10 & 30.75 & NA & NA & NA & NA & NA & NA & NA & 0.7 & NA & NA & NA & NA & 70E_4s1d17c_ 1 & $5 / 30 \mathrm{~A}$ & TDP-166 & 9700276 \\
\hline 19.8 & 0.995 & 0.00155 & 0.050 & 0.334 & 42.6 & $\mathrm{P}$ & NA & 6.72 & 6.84 & 6.89 & 7.10 & 7.10 & 30.75 & NA & NA & NA & NA & NA & NA & NA & 0.7 & NA & NA & NA & NA & 70E_4sid17c_1 & $5 / 30 \mathrm{~A}$ & TDP-166 & 970027 \\
\hline 19.8 & 0.995 & 0.00155 & 0.050 & 0.334 & 42.6 & $\mathrm{P}$ & NA & 6.72 & 6.84 & 6.89 & 7.10 & 7.10 & 30.75 & NA & NA & NA & NA & NA & NA & NA & 1.6 & NA & NA & NA & NA & 70E_4s1d17c_ 1 & $5 / 30 \mathrm{~A}$ & TDP-166 & 9700278 \\
\hline 20.1 & 0.995 & 0.00155 & 0.050 & 0.334 & 42.6 & $\mathrm{P}$ & NA & 6.72 & 6.83 & 6.89 & 7.10 & 7.10 & 30.75 & NA & NA & NA & NA & NA & NA & NA & $\mathrm{n} / \mathrm{a}$ & NA & NA & NA & NA & 70E_4s1d1Zc_ 1 & $5 / 30 \mathrm{~A}$ & TDP-166 & 9700278.1 \\
\hline 20.1 & 0.995 & 0.00155 & 0.050 & 0.334 & 42.6 & $\mathrm{P}$ & NA & 6.72 & 6.83 & 6.89 & 7.10 & 7.10 & 30.75 & NA & NA & NA & NA & NA & NA & NA & $\mathrm{na}$ & NA & NA & NA & NA & 70E_4s1d17c_1 1 & $5 / 30 \mathrm{~A}$ & TDP-166 & 9700278.2 \\
\hline 20.1 & 0.995 & 0.00155 & 0.050 & 0.334 & 42.6 & $\mathrm{P}$ & NA & 6.72 & 6.83 & 6.89 & 7.10 & 7.10 & 30.25 & NA & NA & NA & NA & NA & NA & (null) & 0.9 & 4 & NA & NA & NA & 70E_4s1d17c_ 1 & $5 / 30 \mathrm{~A}$ & TDP-166 & 9700279 \\
\hline 20.1 & 0.995 & 0.00155 & 0.050 & 0.334 & 42.6 & $\mathrm{P}$ & NA & 6.72 & 6.83 & 6.89 & 7.10 & 7.10 & 30.25 & NA & NA & NA & NA & NA & NA & NA & 1.8 & NA & NA & NA & NA & 70E_4sid17c_1 & $5 / 30 \mathrm{~A}$ & TDP-166 & 9700280 \\
\hline 20.1 & 0.995 & 0.00155 & 0.050 & 0.334 & 42.6 & $\mathrm{P}$ & NA & 6.72 & 6.83 & 6.89 & 7.10 & 7.10 & 30.25 & NA & NA & NA & NA & NA & NA & NA & 0.0 & NA & NA & NA & NA & 70E_4s1d17c_ 1 & $5 / 30 \mathrm{~A}$ & TDP-166 & 9700281 \\
\hline 20.1 & 0.995 & 0.00155 & 0.050 & 0.334 & 42.6 & $\mathrm{P}$ & NA & 6.72 & 6.83 & 6.89 & 7.10 & 7.10 & 30.25 & NA & NA & NA & NA & NA & NA & NA & 0.0 & NA & NA & NA & NA & 70E_4s1d1Zc_ 1 & $5 / 30 \mathrm{~A}$ & TDP-166 & 9700282 \\
\hline 20.1 & 0.995 & 0.00155 & 0.050 & 0.334 & 42.6 & $\mathrm{P}$ & NA & 6.72 & 6.83 & 6.89 & 7.10 & 7.10 & 30.25 & NA & NA & NA & NA & NA & NA & NA & 1.8 & NA & NA & NA & NA & 70E_4sId17c_ 1 & $5 / 30 \mathrm{~A}$ & TDP-166 & 9700283 \\
\hline 20.1 & 0.995 & 0.00155 & 0.050 & 0.334 & 42.6 & $\mathrm{P}$ & NA & 6.72 & 6.83 & 6.89 & 7.10 & 7.10 & 30.25 & NA & NA & NA & NA & NA & NA & NA & 0.0 & NA & NA & NA & NA & 70E_4sIdIZ__1 & $5 / 30 \mathrm{~A}$ & TDP-166 & 9700285 \\
\hline 20.1 & 0.995 & 0.00155 & 0.050 & 0.334 & 42.6 & $\mathrm{P}$ & NA & 6.72 & 6.83 & 6.89 & 7.10 & 7.10 & 30.25 & NA & NA & NA & NA & NA & NA & NA & 1.4 & NA & NA & NA & NA & 70E_4s1d17c_ 1 & $5 / 30 \mathrm{~A}$ & TDP-166 & 9700286 \\
\hline 20.1 & 0.995 & 0.00155 & 0.050 & 0.334 & 42.6 & $\mathrm{P}$ & NA & 6.72 & 6.83 & 6.89 & 7.10 & 7.10 & 30.25 & NA & NA & NA & NA & NA & NA & NA & 0.7 & NA & NA & NA & NA & 70E_4sId1Zc_ 1 & $5 / 30 \mathrm{~A}$ & TDP-166 & 9700287 \\
\hline 20.1 & 0.995 & 0.00155 & 0.050 & 0.334 & 42.6 & $\mathrm{P}$ & NA & 6.72 & 6.83 & 6.89 & 7.10 & 7.10 & 30.25 & NA & NA & NA & NA & NA & NA & NA & 1.6 & NA & NA & NA & NA & 70E_4s1d17c_ 1 & $5 / 30 \mathrm{~A}$ & TDP-166 & 9700288 \\
\hline 20.2 & 0.995 & 0.00155 & 0.050 & 0.334 & 42.6 & $\mathrm{P}$ & NA & 6.72 & 6.83 & 6.89 & 7.10 & 7.10 & 30.25 & NA & NA & NA & NA & NA & NA & NA & $n / a$ & NA & NA & NA & NA & 70E_4s1d17c_ 1 & $5 / 30 \mathrm{~A}$ & TDP-166 & 9700288.1 \\
\hline 20.2 & 0.995 & 0.00155 & 0.050 & 0.334 & 42.6 & $\mathrm{P}$ & NA & 6.72 & 6.83 & 6.89 & 7.10 & 7.10 & 30.25 & NA & NA & NA & NA & NA & NA & NA & $\mathrm{n} / \mathrm{a}$ & NA & NA & NA & NA & 70E_4sid17c_1 & $5 / 30 \mathrm{~A}$ & TDP-166 & 9700288.2 \\
\hline 20.2 & 0.995 & 0.00155 & 0.050 & 0.334 & 42.6 & $\mathrm{P}$ & NA & 6.72 & 6.83 & 6.89 & 7.10 & 7.10 & 30.75 & NA & NA & NA & NA & NA & NA & (null) & 1.6 & 4 & NA & NA & $\mathrm{NA}$ & 70E_4sid17c_ 1 & $5 / 30 \mathrm{~A}$ & TDP-166 & 9700289 \\
\hline 20.2 & 0.995 & 0.00155 & 0.050 & 0.334 & 42.6 & $\mathrm{P}$ & NA & 6.72 & 6.83 & 6.89 & 7.10 & 7.10 & 30.75 & NA & NA & NA & NA & NA & NA & NA & 0.8 & NA & NA & NA & NA & 70E_4s1d17c__ 1 & $5 / 30 \mathrm{~A}$ & TDP-166 & 9700290 \\
\hline 20.2 & 0.995 & 0.00155 & 0.050 & 0.334 & 42.6 & $\mathrm{P}$ & NA & 6.72 & 6.83 & 6.89 & 7.10 & 7.10 & 30.75 & NA & NA & NA & NA & NA & NA & NA & 0.9 & NA & NA & NA & NA & 70E_4s1d12c_1 1 & $5 / 30 \mathrm{~A}$ & TDP-166 & 9700291 \\
\hline 20.2 & 0.995 & 0.00155 & 0.050 & 0.334 & 42.6 & $\mathrm{P}$ & NA & 6.72 & 6.83 & 6.89 & 7.10 & 7.10 & 30.75 & NA & NA & NA & NA & NA & NA & NA & 1.9 & NA & NA & NA & NA & 70E_4s1d17c_1 1 & $5 / 30 \mathrm{~A}$ & TDP-166 & 9700292 \\
\hline 20.2 & 0.995 & 0.00155 & 0.050 & 0.334 & 42.6 & $\mathrm{P}$ & NA & 6.72 & 6.83 & 6.89 & 7.10 & 7.10 & 30.75 & NA & NA & NA & NA & NA & NA & NA & 0.0 & NA & NA & NA & NA & 70E_4sid12__1 & $5 / 30 \mathrm{~A}$ & TDP-166 & 9700293 \\
\hline 20.2 & 0.995 & 0.00155 & 0.050 & 0.334 & 42.6 & $\mathrm{P}$ & NA & 6.72 & 6.83 & 6.89 & 7.10 & 7.10 & 30.75 & NA & NA & NA & NA & NA & NA & NA & 1.9 & NA & NA & NA & $\mathrm{NA}$ & 70E_4sid17c_ 1 & $5 / 30 \mathrm{~A}$ & TDP-166 & 9700294 \\
\hline 20.2 & 0.995 & 0.00155 & 0.050 & 0.334 & 42.6 & $P$ & NA & 6.72 & 6.83 & 6.89 & 7.10 & 7.10 & 30.75 & NA & NA & NA & NA & NA & NA & NA & 0.7 & NA & NA & NA & NA & \begin{tabular}{|l|l} 
70E_4s1d17c__ \\
\end{tabular} & $5 / 30 \mathrm{~A}$ & TDP-166 & 9700295 \\
\hline 20.2 & 0.995 & 0.00155 & 0.050 & 0.334 & 42.6 & $\mathrm{P}$ & NA & 6.72 & 6.83 & 6.89 & 7.10 & 7.10 & 30.75 & NA & NA & NA & NA & NA & NA & NA & $\mathrm{n} / \mathrm{a}$ & NA & NA & NA & NA & 70E_4sId17c 1 & $5 / 30 \mathrm{~A}$ & TDP-166 & 9700295.1 \\
\hline 20.2 & 0.995 & 0.00155 & 0.050 & 0.334 & 42.6 & $\mathrm{P}$ & NA & 6.72 & 6.83 & 6.89 & 7.10 & 7.10 & 30.75 & NA & NA & NA & NA & NA & NA & NA & $\mathrm{na}$ & NA & NA & NA & NA & 70E_4sid17c_1 & $5 / 30 \mathrm{~A}$ & TDP-166 & 9700295.2 \\
\hline 20.2 & 0.995 & 0.00155 & 0.050 & 0.334 & 42.6 & $\mathrm{P}$ & NA & 6.72 & 6.83 & 6.89 & 7.10 & 7.10 & 30.75 & & NA & $\mathrm{NA}$ & NA & NA & NA & NA & & NA & NA & NA & NA & 70E_4s1d12c_1 & $5 / 30 \mathrm{~A}$ & TDP-166 & 9700295.3 \\
\hline 25.6 & 0.994 & 0.00155 & 0.050 & 0.332 & 67.0 & $\mathrm{P}$ & NA & 285 & 2.90 & 2.92 & 3.00 & 4.40 & 29.00 & NA & NA & NA & NA & NA & NA & (null) & 16.7 & 1 & NA & NA & NA & $70 E 8$ 6s1d27c _ 1 & $7117 \mathrm{~A}$ & TDP-168 & 9700296 \\
\hline 25.7 & 0.994 & 0.00155 & 0.050 & 0.332 & 59.2 & $P$ & NA & 3.24 & 3.29 & 3.31 & 3.40 & 4.40 & 34.25 & NA & NA & NA & NA & NA & NA & 1 & 16.6 & 1 & $\mathrm{NA}$ & NA & NA & 70E8_6s1d27zc_1 & $717 \mathrm{~A}$ & TDP-168 & 9700297 \\
\hline 25.8 & 0.994 & 0.00155 & 0.050 & 0.335 & 53.0 & $\mathrm{P}$ & NA & 3.57 & 3.63 & 3.66 & 3.80 & 4.40 & 43.25 & & NA & NA & NA & NA & NA & 1 & 16.5 & 1 & NA & NA & NA & $70 E 8$ 6s1d27c _ 1 & $7177 \mathrm{~A}$ & TDP-168 & 9700298 \\
\hline 25.8 & 0.994 & 0.00155 & 0.050 & 0.334 & 50.4 & $\mathrm{P}$ & NA & 3.78 & 3.84 & 3.88 & 4.00 & 4.40 & 62.00 & NA & NA & NA & NA & NA & NA & 1 & 20.9 & 1 & NA & NA & NA & 70E8_6s1d27c_1 & $7 / 17 \mathrm{~A}$ & TDP-168 & 9700299 \\
\hline
\end{tabular}


Table B.5. Data from 2008 Tests in Large-Scale Vessel with Elliptical Head A.10

\begin{tabular}{|c|c|c|c|c|c|c|c|c|c|c|c|c|c|c|c|c|c|c|c|c|c|c|c|c|c|c|c|}
\hline $\begin{array}{l}\text { Row } \\
\text { Number }\end{array}$ & Test & Case ID & $\begin{array}{l}\text { Tank } \\
\text { Diameter }\end{array}$ & $\begin{array}{l}\text { Head } \\
\text { Shape }\end{array}$ & $\begin{array}{l}\text { Dish } \\
\text { Height }\end{array}$ & $\begin{array}{c}\text { Dish } \\
\text { Volume }\end{array}$ & $\begin{array}{l}\text { Tank } \\
\text { Fill } \\
\text { Height }\end{array}$ & $\begin{array}{l}\text { Retum } \\
\text { Line } \\
\text { Height }\end{array}$ & $\begin{array}{c}\text { Nozzle } \\
\text { IInner } \\
\text { Diameter }\end{array}$ & $\begin{array}{l}\text { Nozzle } \\
\text { Stand-off } \\
\text { Distance }\end{array}$ & $\begin{array}{l}\text { Pulse Tube } \\
\text { Configuration }\end{array}$ & $\begin{array}{l}\text { Installed } \\
\text { Nozzles }\end{array}$ & $\begin{array}{l}\text { Outer } \\
\text { Novzles } \\
\text { Operated }\end{array}$ & $\begin{array}{c}\text { Inner } \\
\text { Nozoldes } \\
\text { Operated }\end{array}$ & $\begin{array}{c}\text { Pulse Tube } \\
\text { Outer } \\
\text { Diameter }\end{array}$ & $\begin{array}{l}\text { Outer } \\
\text { PJM } \\
\text { Radius }\end{array}$ & $\begin{array}{c}\text { Inner } \\
\text { PMM } \\
\text { Radius }\end{array}$ & $\begin{array}{l}\text { "FO' Outer } \\
\text { PJM } \\
\text { Impingement } \\
\text { Angle }\end{array}$ & $\begin{array}{l}\text { "FO' IIner PJM } \\
\text { Impingement } \\
\text { Angle }\end{array}$ & $\begin{array}{l}\text { Ratio Outer } \\
\text { PJMto Tank } \\
\text { Radius }\end{array}$ & $\begin{array}{l}\text { Ratio Inner } \\
\text { PJMt torakk } \\
\text { Radius } \\
\end{array}$ & Simulant & $\begin{array}{l}\text { Solids } \\
\text { Density }\end{array}$ & $\begin{array}{c}\text { Particle } \\
\text { Diameter d5 }\end{array}$ & $\begin{array}{c}\text { Particle } \\
\text { Diameter } \\
\text { d50 }\end{array}$ & $\begin{array}{c}\text { Particle } \\
\text { Diameter } \\
\text { d95 }\end{array}$ & $\begin{array}{l}\text { Void } \\
\text { Fraction }\end{array}$ \\
\hline text & text & text & in. & text & in. & in. 3 & in. & in. & in. & in. & text & number & number & number & in. & in. & in. & deg & deg & nondim & nondim & text & $\mathrm{g} / \mathrm{cm}^{3}$ & $m$ & $m$ & $m$ & fraction \\
\hline MSS & MDDX & ID & D & HS & Hesh & $V_{\text {ash }}$ & $\mathrm{H}$ & Rtn & $d$ & sod & PT & $\mathrm{N}$ & $\mathrm{Nb}$ & $\mathrm{N}$ & $\mathrm{PT}_{\alpha \mathrm{d}}$ & $R_{0}$ & $R$ & $\theta_{0}$ & $\theta_{1}$ & $\mathrm{RdR}$ & $R / R$ & $\operatorname{sxdx}$ & $\rho_{\mathrm{s}}$ & $d_{5}$ & $d b_{0}$ & des & vf \\
\hline 9700300 & $7 / 17 \mathrm{~A}$ & 70E8_6sid27c_1 & 70 & $E$ & 19 & 49770.7 & 93 & 80 & 0.92 & 1.380 & 8 8TA & 8 & 4 & 4 & 3.5 & 23.5 & 17.5 & 21.9 & 16.1 & 0.67 & 0.50 & $\mathrm{~s} 1 \mathrm{~d} 2$ & 2.48 & 0.0000569 & 0.0000693 & 0.0000821 & 0.3750 \\
\hline 9700301 & $7117 \mathrm{~A}$ & 70E8_6sid27c_ 1 & 70 & $E$ & 19 & 49770.7 & 93 & 80 & 0.92 & 1.380 & 8TA & 8 & 4 & 4 & 3.5 & 23.5 & 17.5 & 21.9 & 16.1 & 0.67 & 0.50 & $\mathrm{~s} 1 \mathrm{~d} 2$ & 2.48 & 0.0000569 & 0.0000693 & 0.0000821 & 0.3750 \\
\hline 9700302M & $7117 \mathrm{~A}$ & 70E8_6sid27z__1 & 70 & $E$ & 19 & 49770.7 & 93 & 80 & 0.92 & 1.380 & 8TA & 8 & 4 & 4 & 3.5 & 23.5 & 17.5 & 21.9 & 16.1 & 0.67 & 0.50 & $\mathrm{~s} 1 \mathrm{~d} 2$ & 2.48 & 0.0000569 & 0.0000693 & 0.0000821 & 0.3750 \\
\hline 9700303 & $7117 \mathrm{~B}$ & 70E8_6s1d2Zc__2 & 70 & E & 19 & 49770.7 & 93 & 80 & 0.92 & 1380 & 8TA & 8 & 4 & 4 & 3.5 & 23.5 & 17.5 & 21.9 & 16.1 & 0.67 & 0.50 & sid2 & 2.48 & 0.0000569 & 0.0000693 & 0.0000821 & 0.3750 \\
\hline 9700304 & $7 / 17 \mathrm{~B}$ & 70E8_6sid27c_2 & 70 & E & 19 & 49770.7 & 93 & 80 & 0.92 & 1.330 & 8TA & 8 & 4 & 4 & 3.5 & 23.5 & 17.5 & 21.9 & 16.1 & 0.67 & 0.50 & $\mathrm{~s} 1 \mathrm{~d} 2$ & 2.48 & 0.0000569 & 0.0000693 & 0.0000821 & 0.3750 \\
\hline 9700305 & $7 / 17 \mathrm{~B}$ & 70E8_6s1d2Zc__2 & 70 & E & 19 & 49770.7 & 93 & 80 & 0.92 & 1380 & 8TA & 8 & 4 & 4 & 3.5 & 23.5 & 17.5 & 21.9 & 16.1 & 0.67 & 0.50 & s1d2 & 2.48 & 0.0000569 & 0.0000693 & 0.0000821 & 0.3750 \\
\hline 9700306 & $7 / 17 \mathrm{~B}$ & 70E8_6sid2Zc_ 2 & 70 & E & 19 & 49770.7 & 93 & 80 & 0.92 & 1.380 & 8TA & 8 & 4 & 4 & 3.5 & 23.5 & 17.5 & 21.9 & 16.1 & 0.67 & 0.50 & $51 \mathrm{~d} 2$ & 2.48 & 0.0000569 & 0.0000693 & 0.0000821 & 0.3750 \\
\hline 9700307 & $7 / 178$ & 70E8_6sid27z__2 & 70 & $E$ & 19 & 49770.7 & 93 & 80 & 0.92 & 1.380 & 8TA & 8 & 4 & 4 & 3.5 & 23.5 & 17.5 & 21.9 & 16.1 & 0.67 & 0.50 & $\mathrm{~s} 1 \mathrm{~d} 2$ & 2.48 & 0.0000569 & 0.0000693 & 0.0000821 & 0.3750 \\
\hline 9700308M & $7117 \mathrm{~B}$ & 70E8_6s1d2Zc__2 & 70 & E & 19 & 49770.7 & 93 & 80 & 0.92 & 1.380 & 8TA & 8 & 4 & 4 & 3.5 & 23.5 & 17.5 & 21.9 & 16.1 & 0.67 & 0.50 & sid2 & 2.48 & 0.0000569 & 0.0000693 & 0.0000821 & 0.3750 \\
\hline 9700309 & $7 / 18 \mathrm{~A}$ & 70E8_6sid2Vc_1 & 70 & $E$ & 19 & 49770.7 & 94 & 80 & 0.92 & 1330 & 8TA & 8 & 4 & 4 & 3.5 & 23.5 & 17.5 & 21.9 & 16.1 & 0.67 & 0.50 & $\mathrm{~s} 1 \mathrm{~d} 2$ & 2.48 & 0.0000569 & 0.0000693 & 0.0000821 & 0.3750 \\
\hline 9700310 & 7/18A & 70E8_6sId2VC_1 & 70 & E & 19 & 49770.7 & 94 & 80 & 0.92 & 1380 & 8TA & 8 & 4 & 4 & 3.5 & 23.5 & 17.5 & 21.9 & 16.1 & 0.67 & 0.50 & s1d2 & 2.48 & 0.0000569 & 0.0000693 & 0.0000821 & 0.3750 \\
\hline 9700311 & $7 / 18 \mathrm{~A}$ & 70E8_6s1d2VC_1 & 70 & E & 19 & 49770.7 & 94 & 80 & 0.92 & 1.380 & 8TA & 8 & 4 & 4 & 3.5 & 23.5 & 17.5 & 21.9 & 16.1 & 0.67 & 0.50 & $\mathrm{sid2}$ & 2.48 & 0.0000569 & 0.0000693 & 0.0000821 & 0.3750 \\
\hline 9700312 & $7 / 18 \mathrm{~A}$ & 70E8_6sid2V__1 & 70 & $E$ & 19 & 49770.7 & 94 & 80 & 0.92 & 1.380 & 8TA & 8 & 4 & 4 & 3.5 & 23.5 & 17.5 & 21.9 & 16.1 & 0.67 & 0.50 & $\mathrm{~s} 1 \mathrm{~d} 2$ & 2.48 & 0.0000569 & 0.0000693 & 0.0000821 & 0.3750 \\
\hline 9700313M & $7118 \mathrm{~A}$ & 70E8_6s1d2VC_1 & 70 & E & 19 & 49770.7 & 94 & 80 & 0.92 & 1.380 & 8TA & 8 & 4 & 4 & 3.5 & 23.5 & 17.5 & 21.9 & 16.1 & 0.67 & 0.50 & sid2 & 2.48 & 0.0000569 & 0.0000693 & 0.0000821 & 0.3750 \\
\hline $9700314 \mathrm{M}$ & $7 / 18 \mathrm{~A}$ & 70E8_6sid2V _ _ 1 & 70 & $E$ & 19 & 49770.7 & 94 & 80 & 0.92 & 1.380 & 8TA & 8 & 4 & 4 & 3.5 & 23.5 & 17.5 & 21.9 & 16.1 & 0.67 & 0.50 & $\mathrm{~s} 1 \mathrm{~d} 2$ & 2.48 & 0.0000569 & 0.0000693 & 0.0000821 & 0.3750 \\
\hline 9700315 & $7118 \mathrm{~A}$ & 70E8_6s1d2Vc_1 & 70 & $E$ & 19 & 49770.7 & 94 & 80 & 0.92 & 1.380 & 8TA & 8 & 4 & 4 & 3.5 & 23.5 & 17.5 & 21.9 & 16.1 & 0.67 & 0.50 & $\mathrm{~s} 1 \mathrm{~d} 2$ & 2.48 & 0.0000569 & 0.0000693 & 0.0000821 & 0.3750 \\
\hline 9700315.1 & $7118 \mathrm{~A}$ & 70E8_6s1d2VC_1 & 70 & E & 19 & 49770.7 & 94 & 80 & 0.92 & 1.380 & 8TA & 8 & 4 & 4 & 3.5 & 23.5 & 17.5 & 21.9 & 16.1 & 0.67 & 0.50 & $51 \mathrm{~d} 2$ & 2.48 & 0.0000569 & 0.0000693 & 0.0000821 & 0.3750 \\
\hline 9700316 & $7118 \mathrm{~A}$ & 70E8_6sid2V__1 & 70 & $E$ & 19 & 49770.7 & 94 & 80 & 0.92 & 1.380 & 8TA & 8 & 4 & 4 & 3.5 & 23.5 & 17.5 & 21.9 & 16.1 & 0.67 & 0.50 & $\mathrm{~s} 1 \mathrm{~d} 2$ & 2.48 & 0.0000569 & 0.0000693 & 0.0000821 & 0.3750 \\
\hline 9700316.1 & $7118 \mathrm{~A}$ & 70E8_6sid2V__1 & 70 & E & 19 & 49770.7 & 94 & 80 & 0.92 & 1.380 & 8TA & 8 & 4 & 4 & 3.5 & 23.5 & 17.5 & 21.9 & 16.1 & 0.67 & 0.50 & s1d2 & 2.48 & 0.0000569 & 0.0000693 & 0.0000821 & 0.3750 \\
\hline 9700316.2 & $7118 \mathrm{~A}$ & 70E8_6sid2Vc_1 & 70 & E & 19 & 49770.7 & 94 & 80 & 0.92 & 1330 & 8TA & 8 & 4 & 4 & 3.5 & 23.5 & 17.5 & 21.9 & 16.1 & 0.67 & 0.50 & $\mathrm{~s} 1 \mathrm{~d} 2$ & 2.48 & 0.0000569 & 0.0000693 & 0.0000821 & 0.3750 \\
\hline 9700317 & $7118 \mathrm{~A}$ & 70E8_6sid2VC_1 & 70 & E & 19 & 49770.7 & 94 & 80 & 0.92 & 1.380 & 8TA & 8 & 4 & 4 & 3.5 & 23.5 & 17.5 & 21.9 & 16.1 & 0.67 & 0.50 & s1d2 & 2.48 & 0.0000569 & 0.0000693 & 0.00000821 & 0.3750 \\
\hline 9700317.1 & $7118 \mathrm{~A}$ & 70E8_6s1d2VC_1 & 70 & E & 19 & 49770.7 & 94 & 80 & 0.92 & 1.380 & 8TA & 8 & 4 & 4 & 3.5 & 23.5 & 17.5 & 21.9 & 16.1 & 0.67 & 0.50 & $\mathrm{sid2}$ & 2.48 & 0.0000569 & 0.0000693 & 0.0000821 & 0.3750 \\
\hline 9700317.2 & $7118 \mathrm{~A}$ & 70E8_6sid2V__1 & 70 & $E$ & 19 & 49770.7 & 94 & 80 & 0.92 & 1380 & 8TA & 8 & 4 & 4 & 3.5 & 23.5 & 17.5 & 21.9 & 16.1 & 0.67 & 0.50 & s1d2 & 2.48 & 0.0000569 & 0.0000693 & 0.0000821 & 0.3750 \\
\hline 9700317.3 & $7118 \mathrm{~A}$ & 70E8_6sid2V__1 & 70 & E & 19 & 49770.7 & 94 & 80 & 0.92 & 1.380 & 8TA & 8 & 4 & 4 & 3.5 & 23.5 & 17.5 & 21.9 & 16.1 & 0.67 & 0.50 & s1d2 & 2.48 & 0.0000569 & 0.0000693 & 0.0000821 & 0.3750 \\
\hline 9700318 & $7 / 18 \mathrm{~A}$ & 70E8_6sid2VC_1 & 70 & E & 19 & 49770.7 & 94 & 80 & 0.92 & 1330 & 8TA & 8 & 4 & 4 & 3.5 & 23.5 & 17.5 & 21.9 & 16.1 & 0.67 & 0.50 & $\mathrm{sid2}$ & 2.48 & 0.0000569 & 0.0000693 & 0.0000821 & 0.3750 \\
\hline 9700318.1 & $7 / 18 \mathrm{~A}$ & 70E8_6sid2VC_1 & 70 & E & 19 & 4970.7 & 94 & 80 & 0.92 & 1.380 & 8TA & 8 & 4 & 4 & 3.5 & 23.5 & 17.5 & 21.9 & 16.1 & 0.67 & 0.50 & $\mathrm{sid2}$ & 2.48 & 0.0000569 & 0.0000693 & 0.0000821 & 0.3750 \\
\hline 9700319 & $7 / 18 \mathrm{~A}$ & 70E8_6sid2V_c_1 & 70 & $E$ & 19 & 49770.7 & 94 & 80 & 0.92 & 1380 & $8 \mathrm{BA}$ & 8 & 4 & 4 & 3.5 & 23.5 & 17.5 & 21.9 & 16.1 & 0.67 & 0.50 & s1d2 & 2.48 & 0.0000569 & 0.0000693 & 0.0000821 & 0.3750 \\
\hline 9700320 & $7 / 18 \mathrm{~A}$ & 70E8_6s1d2V__ 1 & 70 & $E$ & 19 & 49770.7 & 94 & 80 & 0.92 & 1.380 & 8TA & 8 & 4 & 4 & 3.5 & 23.5 & 17.5 & 21.9 & 16.1 & 0.67 & 0.50 & s1d2 & 2.48 & 0.0000569 & 0.0000693 & 0.0000821 & 0.3750 \\
\hline 9700321 & $7 / 188$ & 70E8_Gs1d2V__2 & 70 & E & 19 & 49770.7 & 94 & 80 & 0.92 & 1.380 & 8TA & 8 & 4 & 4 & 3.5 & 23.5 & 17.5 & 21.9 & 16.1 & 0.67 & 0.50 & sid2 & 2.48 & 0.0000569 & 0.0000693 & 0.0000821 & 0.3750 \\
\hline 9700322 & $7 / 188$ & $70 E 8$ 6sid2Vc 2 & 70 & $E$ & 19 & 49770.7 & 94 & 80 & 0.92 & 1330 & 8TA & 8 & 4 & 4 & 3.5 & 23.5 & 17.5 & 21.9 & 16.1 & 0.67 & 0.50 & $\mathrm{sid2}$ & 2.48 & 0.0000569 & 0.0000693 & 0.0000821 & 0.3750 \\
\hline 9700323 & 7/18B & 70E8__ss1d2Vc_2 & 70 & E & 19 & 49770.7 & 94 & 80 & 0.92 & 1.380 & 8TA & 8 & 4 & 4 & 3.5 & 23.5 & 17.5 & 21.9 & 16.1 & 0.67 & 0.50 & $\mathrm{sid2}$ & 2.48 & 0.0000569 & 0.0000693 & 0.0000821 & 0.3750 \\
\hline $9700324 \mathrm{M}$ & $7 / 18 \mathrm{~B}$ & 70E8__ssid2VV__2 & 70 & $E$ & 19 & 49770.7 & 94 & 80 & 0.92 & 1380 & $8 \mathrm{TA}$ & 8 & 4 & 4 & 3.5 & 23.5 & 17.5 & 21.9 & 16.1 & 0.67 & 0.50 & s1d2 & 2.48 & 0.0000569 & 0.0000693 & 0.0000821 & 0.3750 \\
\hline $9700325 \mathrm{M}$ & $7118 \mathrm{~B}$ & 70E8_6s1d2V___ 2 & 70 & $E$ & 19 & 49770.7 & 94 & 80 & 0.92 & 1.380 & 8TA & 8 & 4 & 4 & 3.5 & 23.5 & 17.5 & 21.9 & 16.1 & 0.67 & 0.50 & s1d2 & 2.48 & 0.0000569 & 0.0000693 & 0.0000821 & 0.3750 \\
\hline 9700326 & 71188 & 70E8_6s1d2V___2 & 70 & E & 19 & 49770.7 & 94 & 80 & 0.92 & 1.380 & 8TA & 8 & 4 & 4 & 3.5 & 23.5 & 17.5 & 21.9 & 16.1 & 0.67 & 0.50 & s1d2 & 2.48 & 0.0000569 & 0.0000693 & 0.0000821 & 0.3750 \\
\hline 9700326.1 & $7 / 18 \mathrm{~B}$ & $70 E 8$ 6sid2Vc_2 & 70 & E & 19 & 49770.7 & 94 & 80 & 0.92 & 1330 & 8TA & 8 & 4 & 4 & 3.5 & 23.5 & 17.5 & 21.9 & 16.1 & 0.67 & 0.50 & 5102 & 2.48 & 0.0000569 & 0.0000693 & 0.0000821 & 0.3750 \\
\hline 9700327 & 7/18B & 70E8__ss1d2Vc_2 & 70 & E & 19 & 49770.7 & 94 & 80 & 0.92 & 1.380 & 8TA & 8 & 4 & 4 & 3.5 & 23.5 & 17.5 & 21.9 & 16.1 & 0.67 & 0.50 & $\mathrm{sid2}$ & 2.48 & 0.0000569 & 0.0000693 & 0.0000821 & 0.3750 \\
\hline 9700327.1 & 7/18B & 70E8__ssidaVV__2 & 70 & E & 19 & 49770.7 & 94 & 80 & 0.92 & 1.380 & 8TA & 8 & 4 & 4 & 3.5 & 23.5 & 17.5 & 21.9 & 16.1 & 0.67 & 0.50 & $\mathrm{sid2}$ & 2.48 & 0.0000569 & 0.0000693 & 0.0000821 & 0.3750 \\
\hline 9700327.2 & $7118 \mathrm{~B}$ & $70 E 8$ 6s1d2VV_ 2 & 70 & $E$ & 19 & 4970.7 & 94 & 80 & 0.92 & 1.380 & 8TA & 8 & 4 & 4 & 3.5 & 23.5 & 17.5 & 21.9 & 16.1 & 0.67 & 0.50 & s1d2 & 2.48 & 0.0000569 & 0.0000693 & 0.0000821 & 0.3750 \\
\hline 9700328 & 71188 & 70E8_6s1d2V___2 & 70 & E & 19 & 49770.7 & 94 & 80 & 0.92 & 1.380 & 8TA & 8 & 4 & 4 & 3.5 & 23.5 & 17.5 & 21.9 & 16.1 & 0.67 & 0.50 & $\mathrm{sid2}$ & 2.48 & 0.0000569 & 0.0000693 & 0.0000821 & 0.3750 \\
\hline 9700328.1 & $7 / 188$ & $70 E 8$ 6sid2Vc_2 & 70 & $E$ & 19 & 49770.7 & 94 & 80 & 0.92 & 1.380 & $8 \mathrm{TA}$ & 8 & 4 & 4 & 3.5 & 23.5 & 17.5 & 21.9 & 16.1 & 0.67 & 0.50 & sid2 & 2.48 & 0.0000569 & 0.0000693 & 0.0000821 & 0.3750 \\
\hline
\end{tabular}


Table B.5. Data from 2008 Tests in Large-Scale Vessel with Elliptical Head B.10

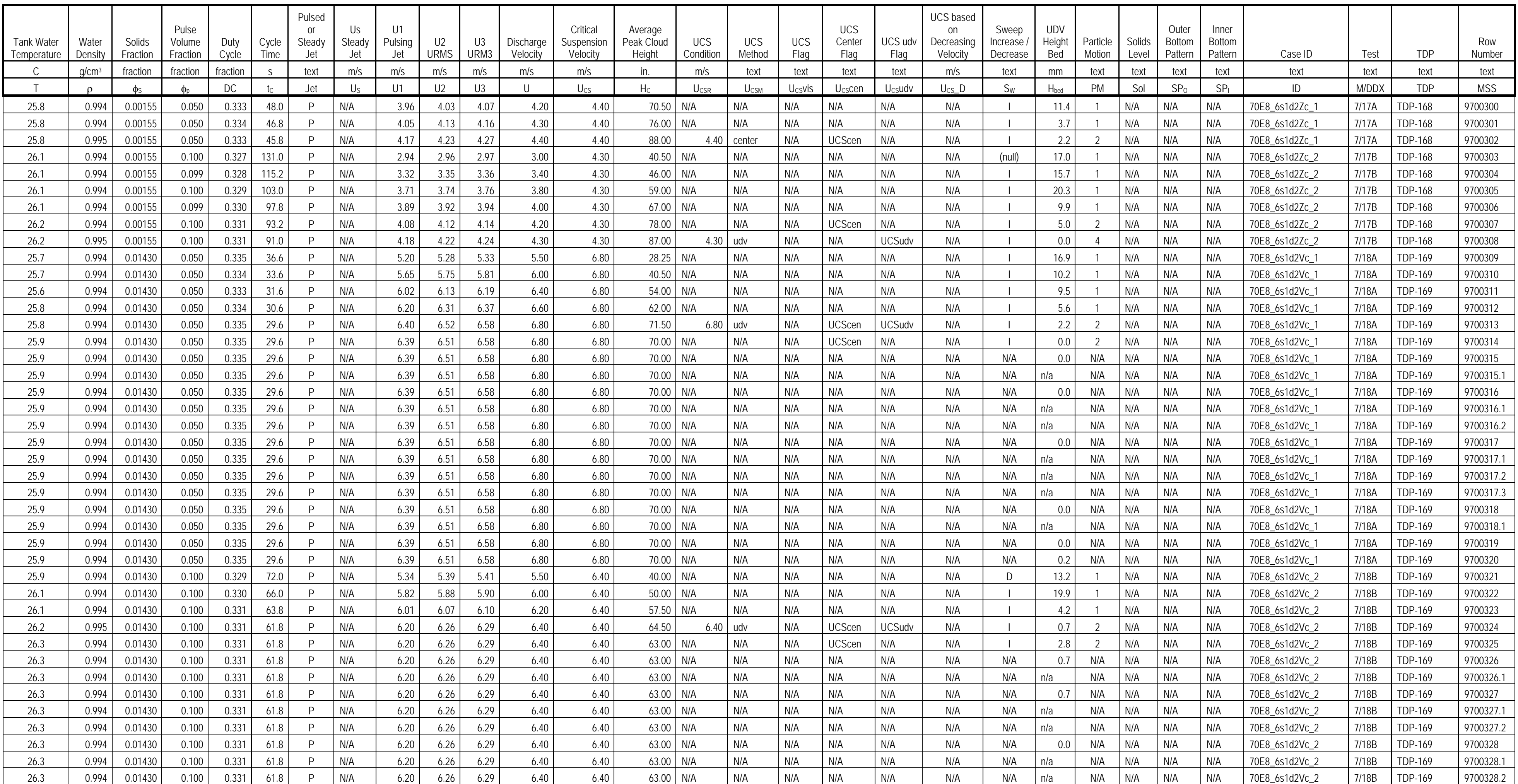


Table B.5. Data from 2008 Tests in Large-Scale Vessel with Elliptical Head A.11

\begin{tabular}{|c|c|c|c|c|c|c|c|c|c|c|c|c|c|c|c|c|c|c|c|c|c|c|c|c|c|c|c|}
\hline $\begin{array}{c}\text { Rav } \\
\text { Number }\end{array}$ & Test & Case ID & $\begin{array}{l}\text { Tank } \\
\text { Diameter }\end{array}$ & $\begin{array}{l}\text { Head } \\
\text { Shape }\end{array}$ & $\begin{array}{c}\text { Dish } \\
\text { Height }\end{array}$ & $\begin{array}{l}\text { Dish } \\
\text { Volume }\end{array}$ & $\begin{array}{l}\text { Tank } \\
\text { Fill } \\
\text { Height }\end{array}$ & $\begin{array}{l}\text { Retum } \\
\text { Line } \\
\text { Height }\end{array}$ & $\begin{array}{c}\text { Nozzle } \\
\text { lnner } \\
\text { Dianter }\end{array}$ & $\begin{array}{l}\text { Nozzle } \\
\text { Sland-of } \\
\text { Distance }\end{array}$ & $\begin{array}{l}\text { Pulse Tube } \\
\text { Configuration }\end{array}$ & $\begin{array}{l}\text { Installed } \\
\text { Nozzles }\end{array}$ & $\begin{array}{l}\text { Outer } \\
\text { Nozzles } \\
\text { Operated }\end{array}$ & $\begin{array}{l}\text { Inner } \\
\text { Nobles } \\
\text { Operated }\end{array}$ & $\begin{array}{c}\text { Pulse Tube } \\
\text { Outer } \\
\text { Diameter }\end{array}$ & $\begin{array}{c}\text { Outer } \\
\text { PJM } \\
\text { Radius }\end{array}$ & $\begin{array}{l}\text { Inner } \\
\text { PJM } \\
\text { Radius }\end{array}$ & $\begin{array}{c}\text { "FO" Outer } \\
\text { PJM } \\
\text { Impingement } \\
\text { Angle } \\
\end{array}$ & $\begin{array}{l}\text { "FOO" Inner PJM } \\
\text { Impingement } \\
\text { Angle }\end{array}$ & $\begin{array}{l}\text { Ratio Outer } \\
\text { PJM to Tank } \\
\text { Radius } \\
\end{array}$ & $\begin{array}{c}\text { Ratio Inner } \\
\text { PJM to Tank } \\
\text { Radius } \\
\end{array}$ & Simulant & $\begin{array}{l}\text { Solids } \\
\text { Density }\end{array}$ & $\begin{array}{c}\text { Particle } \\
\text { Diameter d5 }\end{array}$ & $\begin{array}{l}\text { Partide } \\
\text { Dianter } \\
\text { d50 }\end{array}$ & $\begin{array}{c}\text { Particle } \\
\text { Diameter } \\
\text { d95 } \\
\end{array}$ & $\begin{array}{c}\text { Void } \\
\text { Fraction }\end{array}$ \\
\hline text & text & text & in. & text & in. & in. ${ }^{3}$ & in. & in. & in. & in. & text & number & number & number & in. & in. & in. & deg & deg & nondim & nondim & text & $g / \mathrm{m}^{3}$ & $\mathrm{~m}$ & $\mathrm{~m}$ & $\mathrm{~m}$ & fraction \\
\hline MSS & MDDX & ID & D & $\mathrm{HS}$ & Hesh & $V_{\text {dath }}$ & $\mathrm{H}$ & $\mathrm{Rtn}$ & $d$ & sod & PT & $\mathrm{N}$ & $\mathrm{Nb}$ & $\mathrm{N}$ & $P \mathrm{PT}_{\alpha \mathrm{d}}$ & $R_{0}$ & $R$ & $\theta_{0}$ & $\theta_{1}$ & $\mathrm{Rd} / \mathrm{R}$ & $R / R$ & sxdx & $\rho_{\mathrm{s}}$ & $d_{b}$ & $d_{50}$ & $d_{65}$ & $\mathrm{vf}$ \\
\hline 9700328.3 & $7 / 18 B$ & 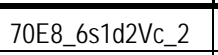 & 70 & $E$ & 19 & 49770.7 & 94 & 80 & 0.92 & 1.380 & 8TA & 8 & 4 & 4 & 3.5 & 23.5 & 17.5 & 21.9 & 16.1 & 0.67 & 0.50 & $\mathrm{~s} 1 \mathrm{~d} 2$ & 2.48 & 0.0000569 & 0.0000693 & 0.0000821 & 0.3750 \\
\hline 9700329 & 71188 & 70EE_6siddVV__2 & 70 & $E$ & 19 & 49770.7 & 94 & 80 & 0.92 & 1.380 & 8TA & 8 & 4 & 4 & 3.5 & 23.5 & 17.5 & 21.9 & 16.1 & 0.67 & 0.50 & $\mathrm{~s} 1 \mathrm{~d} 2$ & 2.48 & 0.0000569 & 0.0000693 & 0.0000821 & 0.3750 \\
\hline 9700329.1 & $7 / 188$ & $70 E_{8}$ _6sidzVV_2 & 70 & $\mathrm{E}$ & 19 & 49770.7 & 94 & 80 & 0.92 & 1.380 & 8TA & 8 & 4 & 4 & 3.5 & 23.5 & 17.5 & 21.9 & 16.1 & 0.67 & 0.50 & s1d2 & 2.48 & 0.0000569 & 0.0000693 & 0.0000821 & 0.3750 \\
\hline 9700330 & 71188 & 70E8_Gs1d2Vc_ 2 & 70 & E & 19 & 49770.7 & 94 & 80 & 0.92 & 1.380 & 8TA & 8 & 4 & 4 & 3.5 & 23.5 & 17.5 & 21.9 & 16.1 & 0.67 & 0.50 & $\mathrm{~s} 1 \mathrm{~d} 2$ & 2.48 & 0.0000569 & 0.0000693 & 0.0000821 & 0.3750 \\
\hline 9700331 & 71188 & 70E8_6sid2V___2 & 70 & E & 19 & 49770.7 & 94 & 80 & 0.92 & 1.380 & 8TA & 8 & 4 & 4 & 3.5 & 23.5 & 17.5 & 21.9 & 16.1 & 0.67 & 0.50 & $\mathrm{~s} 1 \mathrm{~d} 2$ & 2.48 & 0.0000569 & 0.0000693 & 0.0000821 & 0.3750 \\
\hline 9700332 & 7/188C & $70 E 8$ 6s1d2Vc_ 7 & 70 & E & 19 & 49770.7 & 94 & 80 & 0.92 & 1.380 & 8TA & 8 & 4 & 0 & 3.5 & 23.5 & 17.5 & 21.9 & 16.1 & 0.67 & 0.50 & $\mathrm{~s} 1 \mathrm{~d} 2$ & 2.48 & 0.0000569 & 0.0000693 & 0.0000821 & 0.3750 \\
\hline 9700333 & $7 / 18 \mathrm{C}$ & 70EE_6siddVV__ 7 & 70 & E & 19 & 49770.7 & 94 & 80 & 0.92 & 1.380 & 8TA & 8 & 4 & 0 & 3.5 & 23.5 & 17.5 & 21.9 & 16.1 & 0.67 & 0.50 & $\mathrm{~s} 1 \mathrm{~d} 2$ & 2.48 & 0.0000569 & 0.0000693 & 0.0000821 & 0.3750 \\
\hline 9700334 & $7 / 18 \mathrm{C}$ & $70 E_{8}$ 6sidzVV_ 7 & 70 & $\mathrm{E}$ & 19 & 49770.7 & 94 & 80 & 0.92 & 1.380 & 8TA & 8 & 4 & 0 & 3.5 & 23.5 & 17.5 & 21.9 & 16.1 & 0.67 & 0.50 & s1d2 & 2.48 & 0.0000569 & 0.0000693 & 0.0000821 & 0.3750 \\
\hline 9700335 & $7118 \mathrm{C}$ & 70E8_6s1d2V__ 7 & 70 & E & 19 & 49770.7 & 94 & 80 & 0.92 & 1.380 & 8TA & 8 & 4 & 0 & 3.5 & 23.5 & 17.5 & 21.9 & 16.1 & 0.67 & 0.50 & s1d2 & 2.48 & 0.0000569 & 0.0000693 & 0.0000821 & 0.3750 \\
\hline 9700336 & $7 / 18 \mathrm{C}$ & 70E8_6s1d2VV__7 & 70 & E & 19 & 49770.7 & 94 & 80 & 0.92 & 1.380 & 8TA & 8 & 4 & 0 & 3.5 & 23.5 & 17.5 & 21.9 & 16.1 & 0.67 & 0.50 & s1d2 & 2.48 & 0.0000569 & 0.0000693 & 0.0000821 & 0.3750 \\
\hline 9700337M & $7 / 18 \mathrm{C}$ & 70E8_6s1d2V__ 7 & 70 & $\mathrm{E}$ & 19 & 49770.7 & 94 & 80 & 0.92 & 1.380 & 8TA & 8 & 4 & 0 & 3.5 & 23.5 & 17.5 & 21.9 & 16.1 & 0.67 & 0.50 & $\mathrm{~s} 1 \mathrm{~d} 2$ & 2.48 & 0.0000569 & 0.00006993 & 0.0000821 & 0.3750 \\
\hline $9700338 \mathrm{M}$ & $7 / 18 \mathrm{C}$ & 70EE_6siddVV__7 & 70 & $E$ & 19 & 49770.7 & 94 & 80 & 0.92 & 1.380 & 8 8TA & 8 & 4 & 0 & 3.5 & 23.5 & 17.5 & 21.9 & 16.1 & 0.67 & 0.50 & $\mathrm{~s} 1 \mathrm{~d} 2$ & 2.48 & 0.0000569 & 0.0000693 & 0.0000821 & 0.3750 \\
\hline
\end{tabular}


Table B.5. Data from 2008 Tests in Large-Scale Vessel with Elliptical Head B.11

\begin{tabular}{|c|c|c|c|c|c|c|c|c|c|c|c|c|c|c|c|c|c|c|c|c|c|c|c|c|c|c|c|c|c|}
\hline $\begin{array}{l}\text { Tank Water } \\
\text { Temperature }\end{array}$ & $\begin{array}{l}\text { Water } \\
\text { Density }\end{array}$ & $\begin{array}{l}\text { Solids } \\
\text { Fraction } \\
\end{array}$ & $\begin{array}{l}\text { Pulse } \\
\text { Volume } \\
\text { Fraction }\end{array}$ & $\begin{array}{l}\text { Duty } \\
\text { Cycle }\end{array}$ & $\begin{array}{l}\text { Oyde } \\
\text { Time }\end{array}$ & 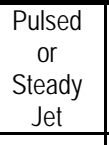 & \begin{tabular}{|c} 
Us \\
Steacy \\
Jet
\end{tabular} & $\begin{array}{c}\text { U1 } \\
\text { Pulsing } \\
\text { Jet }\end{array}$ & $\begin{array}{l}\text { U2 } \\
\text { URMS }\end{array}$ & $\begin{array}{c}\text { U3 } \\
\text { URNB } \\
\end{array}$ & $\begin{array}{l}\text { Discharge } \\
\text { velocity }\end{array}$ & $\begin{array}{c}\text { Citical } \\
\text { Suspension } \\
\text { Velocity }\end{array}$ & $\begin{array}{c}\text { Average } \\
\text { Peak Cound } \\
\text { Height }\end{array}$ & $\begin{array}{c}\text { UCS } \\
\text { Condition } \\
\end{array}$ & $\begin{array}{c}\text { uCS } \\
\text { Method }\end{array}$ & $\begin{array}{l}\text { UCs } \\
\text { Hag }\end{array}$ & $\begin{array}{l}\text { UCS } \\
\text { Center } \\
\text { Hag }\end{array}$ & $\begin{array}{c}\text { UcS uav } \\
\text { Hag } \\
\end{array}$ & \begin{tabular}{|c|} 
UCS based \\
on \\
Dereasing \\
Velocity \\
\end{tabular} & 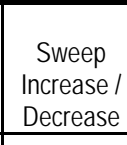 & \begin{tabular}{|c|} 
UDV \\
Height \\
Bed \\
\end{tabular} & $\begin{array}{l}\begin{array}{c}\text { Patricle } \\
\text { Motion }\end{array} \\
\text {. }\end{array}$ & \begin{tabular}{|l|}
$\begin{array}{l}\text { Solids } \\
\text { Level }\end{array}$ \\
\end{tabular} & \begin{tabular}{|l} 
Outer \\
Botom \\
Patterm
\end{tabular} & \begin{tabular}{|l|} 
IInner \\
Bottom \\
Pattem \\
\end{tabular} & Case ID & Test & TDP & $\begin{array}{c}\text { Row } \\
\text { Number }\end{array}$ \\
\hline $\mathrm{c}$ & $\mathrm{g} / \mathrm{cm}^{3}$ & fraction & fraction & fraction & $\mathrm{s}$ & $\begin{array}{ll}\text { text } \\
\end{array}$ & m/s & $\mathrm{ms}$ & $\mathrm{m} / \mathrm{s}$ & $\begin{array}{ll}\mathrm{m} / \mathrm{s} \\
\end{array}$ & $\mathrm{m} / \mathrm{s}$ & $m / s$ & in. & $\mathrm{m} / \mathrm{s}$ & text & text & text & text & $\begin{array}{ll}\mathrm{m} / \mathrm{s} \\
\end{array}$ & text & $\mathrm{mm}$ & text & \begin{tabular}{|l|} 
text \\
\end{tabular} & text & \begin{tabular}{|l|} 
text \\
\end{tabular} & text & text & text & text \\
\hline $\mathrm{T}$ & $\rho$ & $\phi_{\mathrm{s}}$ & $\phi_{p}$ & $D C$ & $t_{c}$ & Jet & $U_{s}$ & $\mathrm{U} 1$ & $\mathrm{U} 2$ & U3 & $u$ & Uss & $H_{\mathrm{c}}$ & Usse & Uasn & Uosvis & Uscen & Usuldv & $u_{s s} \mathrm{D}$ & $\mathrm{s}_{\mathrm{v}}$ & $H_{\text {bed }}$ & $\mathrm{PM}$ & Sol & $\mathrm{SP}$ & $\mathrm{SP}_{1}$ & $1 D$ & MDDX & IDP & MSS \\
\hline 26.3 & 0.994 & 0.01430 & 0.100 & 0.331 & 61.8 & $\mathrm{P}$ & NA & 6.20 & 6.26 & 6.29 & 6.40 & 6.40 & 63.00 & NA & NA & $\mathrm{NA}$ & NA & NA & NA & NA & n/a & NA & $\mathrm{NA}$ & NA & NA & 70E8_6sid2VC_2 & $7 / 18 B$ & TDP-169 & 9700328.3 \\
\hline 26.3 & 0.994 & 0.01430 & 0.100 & 0.331 & 61.8 & $\mathrm{P}$ & NA & 6.20 & 6.26 & 6.29 & 6.40 & 6.40 & 63.00 & NA & $\mathrm{NA}$ & NA & NA & NA & NA & NA & 0.0 & NA & $\mathrm{NA}$ & $\mathrm{NA}$ & NA & 70E__6s1d2Vc_2 2 & $7 / 188$ & TDP-169 & 9700329 \\
\hline 26.3 & 0.994 & 0.01430 & 0.100 & 0.331 & 61.8 & $\mathrm{P}$ & NA & 6.20 & 6.26 & 6.29 & 6.40 & 6.40 & 63.00 & NA & NA & NA & NA & NA & NA & NA & raa & NA & NA & NA & NA & 70E8_6s1d2Vc_2 & $7 / 188$ & TDP-169 & 9700329.1 \\
\hline 26.3 & 0.994 & 0.01430 & 0.100 & 0.331 & 61.8 & $\mathrm{P}$ & NA & 6.20 & 6.26 & 6.29 & 6.40 & 6.40 & 63.00 & NA & NA & NA & NA & NA & NA & NA & 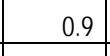 & NA & NA & NA & NA & 70E8_6sidzVc_2 & $7 / 188$ & TDP-169 & 9700330 \\
\hline 26.3 & 0.994 & 0.01430 & 0.100 & 0.331 & 61.8 & $\mathrm{P}$ & NA & 6.20 & 6.26 & 6.29 & 6.40 & 6.40 & 63.00 & NA & NA & NA & NA & NA & NA & NA & 0.0 & NA & NA & NA & NA & 70E8_6s1d2Vc_2 & $7 / 188$ & TDP-169 & 9700331 \\
\hline 26.6 & 0.994 & 0.01430 & 0.100 & 0.324 & 132.0 & $\mathrm{P}$ & NA & 5.93 & 5.95 & 5.97 & 6.00 & 8.20 & 23.00 & NA & NA & NA & NA & NA & NA & $\mathrm{D}$ & 12.2 & 1 & NA & NA & NA & 70E8_6sid2VC_7 & $7 / 18 \mathrm{C}$ & TDP-169 & 9700332 \\
\hline 26.5 & 0.994 & 0.01430 & 0.100 & 0.325 & 113.0 & $\mathrm{P}$ & NA & 6.88 & 6.91 & 6.93 & 7.00 & 8.20 & 29.75 & NA & $\mathrm{NA}$ & NA & NA & NA & NA & 1 & 10.5 & 1 & NA & NA & NA & 70E8_6s1d2VV_ 7 & $7 / 18 \mathrm{C}$ & TDP-169 & 9700333 \\
\hline 26.6 & 0.994 & 0.01430 & 0.100 & 0.326 & 99.0 & $\mathrm{P}$ & NA & 7.87 & 7.91 & 7.93 & 8.00 & 8.20 & 45.50 & NA & NA & NA & NA & NA & NA & 1 & 9.7 & 1 & NA & NA & NA & 70E8_6s1d2VC_ 7 & $7 / 18 \mathrm{C}$ & TDP-169 & 9700335 \\
\hline 26.8 & 0.994 & 0.01430 & 0.100 & 0.326 & 99.0 & $\mathrm{P}$ & NA & 7.87 & 7.90 & 7.93 & 8.00 & 8.20 & 47.00 & & NA & NA & NA & NA & NA & D & 5 & & NA & NA & NA & $70 E 8$ _6s1d2V $\_7$ & $7 / 18 \mathrm{C}$ & TDP-169 & 9700336 \\
\hline 26.7 & 0.994 & 0.01430 & 0.101 & 0.326 & 96.6 & $\mathrm{P}$ & NA & 8.08 & 8.12 & 8.14 & 8.20 & 8. & 49. & 8.20 & & NA & & ucsudv & NA & 1 & 0.0 & 1 & NA & NA & NA & $70 E 8$ 6sid2Vc_ 7 & $7 / 18 \mathrm{C}$ & TDP-169 & 9700337 \\
\hline 26.8 & 0.994 & 0.01430 & 0.101 & 0.327 & 94.2 & $\mathrm{P}$ & NA & 8.27 & 8.32 & 8.34 & 8.40 & 8.20 & 52.50 & NA & NA & NA & Ucscen & NA & NA & 1 & 0.0 & 2 & NA & NA & NA & 70E__6s1d2VC_ 7 & $7 / 18 \mathrm{C}$ & \begin{tabular}{|l|l|} 
TDP-169 \\
\end{tabular} & 9700338 \\
\hline
\end{tabular}


Table B.6. Data from 2008 in Large-Scale Vessel with Flanged and Dished Head A.1

\begin{tabular}{|c|c|c|c|c|c|c|c|c|c|c|c|c|c|c|c|c|c|c|c|c|c|c|c|c|c|c|c|}
\hline Row Number & Test & Case ID & $\begin{array}{c}\text { Tank } \\
\text { Diameter }\end{array}$ & $\begin{array}{l}\text { Head } \\
\text { Shape }\end{array}$ & \begin{tabular}{|c|} 
Dish \\
Height
\end{tabular} & $\begin{array}{l}\text { Dish } \\
\text { Volume }\end{array}$ & $\begin{array}{l}\text { Tank FIII } \\
\text { Height }\end{array}$ & $\begin{array}{l}\text { Retum } \\
\text { Lne } \\
\text { Height }\end{array}$ & $\begin{array}{l}\text { Nozzle } \\
\text { Inner } \\
\text { Diameter }\end{array}$ & $\begin{array}{l}\text { Nozzle } \\
\text { Stand-of } \\
\text { Distance }\end{array}$ & $\begin{array}{l}\text { Pulse Tube } \\
\text { Configuration }\end{array}$ & $\begin{array}{l}\text { Installed } \\
\text { Nozzles }\end{array}$ & $\begin{array}{c}\text { Outer } \\
\text { Nolzele } \\
\text { Operate } \\
d \\
d\end{array}$ & $\begin{array}{c}\text { IIner } \\
\text { Nozzles } \\
\text { Operate } \\
d\end{array}$ & $\begin{array}{c}\text { Pulse Tube } \\
\text { Outer } \\
\text { Diameter }\end{array}$ & $\begin{array}{c}\text { Outer } \\
\text { PMM } \\
\text { Radius }\end{array}$ & $\begin{array}{c}\text { Inner } \\
\text { PMM } \\
\text { Radius }\end{array}$ & $\begin{array}{l}\text { "FO" Outer PJN } \\
\text { Impingement } \\
\text { Angle }\end{array}$ & \begin{tabular}{|c|} 
"FOO" Inner PJM \\
Impingement \\
Angle
\end{tabular} & $\begin{array}{l}\text { Ratio Oter } \\
\text { PJMto Tank } \\
\text { Radius }\end{array}$ & $\begin{array}{l}\text { Ratio Inner } \\
\text { PJMtt Tarkk } \\
\text { Radius }\end{array}$ & Simulant & $\begin{array}{l}\text { Solids } \\
\text { Density }\end{array}$ & $\begin{array}{c}\text { Particle } \\
\text { Diameter d5 }\end{array}$ & $\begin{array}{c}\text { Particle } \\
\text { Diameter } 050\end{array}$ & $\begin{array}{c}\text { Particle } \\
\text { Diameter d95 }\end{array}$ & $\begin{array}{l}\text { Void } \\
\text { Fraction }\end{array}$ \\
\hline text & text & text & in. & text & in. & in. ${ }^{3}$ & in. & in. & in. & in. & text & number & number & number & in. & in. & in. & deg & deg & nondim & nondim & text & $\mathrm{g} / \mathrm{cm}^{3}$ & $\mathrm{~m}$ & $\mathrm{~m}$ & $\mathrm{~m}$ & fraction \\
\hline MSS & MDDX & ID & $\mathrm{D}$ & HS & $H_{\text {osh }}$ & $V_{\text {dish }}$ & $\mathrm{H}$ & Rtn & $d$ & sod & PT & $\mathrm{N}$ & $\mathrm{Nb}_{\mathrm{B}}$ & $\mathrm{N}$ & $\mathrm{PT}_{\mathrm{od}}$ & $R_{0}$ & $\mathrm{R}$ & $\theta_{0}$ & $\theta_{1}$ & $\mathrm{R} d \mathrm{R}$ & $R / R$ & sxdx & $\rho_{\mathrm{s}}$ & $d_{5}$ & $d_{50}$ & $d_{65}$ & vf \\
\hline 700204 & $47 \mathrm{~A}$ & 70F_6s2d2YC_1_FMO1 ${ }^{1}$ & 70 & $\overline{F D}$ & 127 & 30569.0 & 88 & 83518 & 0.92 & 1.380 & HLP-22 & 12 & 8 & 4 & 3.5 & 26.4 & 1117 & 22.4 & 9.7 & 0.75 & 0.33 & $\mathrm{~s} 2 \mathrm{~d} 2$ & 4.18 & 0.00000009 & 0.0000756 & 0.0000931 & 0.368 \\
\hline 700205 & $47 / \mathrm{A}$ & 70F_6S2d2YC_1 1 FNO1 & 70 & $\mathrm{FD}$ & 12.7 & 30569.0 & 88 & $835 / 8$ & 0.92 & 1.380 & HLP-22 & 12 & 8 & 4 & 3.5 & 26.4 & 11.7 & 22.4 & 9.7 & 0.75 & 0.33 & $\mathrm{~s} 2 \mathrm{~d} 2$ & 4.18 & 0.00000009 & 0.0000756 & 0.0000931 & 0.36 \\
\hline 700206 & $477 \mathrm{~A}$ & 70F_6S2d2YC_ 1 FNO1 & 70 & $\mathrm{FD}$ & 12.7 & 30569.0 & 88 & $835 / 8$ & 0.92 & 1.380 & HLP-22 & 12 & 8 & 4 & 3.5 & 26.4 & 11.7 & 22.4 & 9.7 & 0.75 & 0.33 & $\mathrm{~s} 2 \mathrm{~d} 2$ & 4.18 & 0.0000609 & 0.0000756 & 0.0000931 & 0.3684 \\
\hline 700207 & $47 \mathrm{~A}$ & 70F_6S2d2YC_1 FNO1 & 70 & $\mathrm{FD}$ & 127 & 30569.0 & 88 & $835 / 8$ & 0.92 & 1.380 & HLP-22 & 12 & 8 & 4 & 3.5 & 26.4 & 11.7 & 22.4 & 9.7 & 0.75 & 0.33 & $\mathrm{~s} 2 \mathrm{~d} 2$ & 4.18 & 0.0000609 & 0.0000756 & 0.0000931 & \\
\hline $700208 \mathrm{M}$ & $4 / 7 \mathrm{~A}$ & 70F_652d2YC_1 FNO1 & 70 & $\mathrm{FD}$ & 12.7 & 30569.0 & 88 & $835 / 8$ & 0.92 & 1.380 & HLP-22 & 12 & 8 & 4 & 3.5 & 26.4 & 11.7 & 22.4 & 9.7 & 0.75 & 0.33 & $\mathrm{~s} 2 \mathrm{~d} 2$ & 4.18 & 0.0000609 & 0.0000756 & 0.0000931 & 0.36 \\
\hline 700208.1 & $4 / 7 \mathrm{~A}$ & 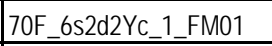 & 70 & $\mathrm{FD}$ & 12.7 & 30569.0 & 88 & $835 / 8$ & 0.92 & 1.380 & HLP-22 & 12 & 8 & 4 & 3.5 & 26.4 & 11.7 & 22.4 & 9.7 & 0.75 & 0.33 & $\mathrm{~s} 2 \mathrm{~d} 2$ & 4.18 & 0.0000609 & 0.0000756 & 0.0000931 & 0.3684 \\
\hline 700208.2 & $4 / 7 \mathrm{~A}$ & 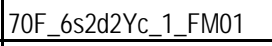 & 70 & $\mathrm{FD}$ & 12.7 & 30569.0 & 88 & $835 / 8$ & 0.92 & 1.380 & HLP-22 & 12 & 8 & 4 & 3.5 & 26.4 & 11.7 & 22.4 & 9.7 & 0.75 & 0.33 & $\mathrm{~s} 2 \mathrm{~d} 2$ & 4.18 & 0.0000609 & 0.0000756 & 0.0000931 & \\
\hline 700209 & $47 \mathrm{~A}$ & 70F_6S2d2YC_1 FN01 & 70 & $\mathrm{FD}$ & 12.7 & 30569.0 & 88 & $835 / 8$ & 0.92 & 1.380 & HLP-22 & 12 & 8 & 4 & 3.5 & 26.4 & 11.7 & 22.4 & 9.7 & 0.75 & 0.33 & $\mathrm{~s} 2 \mathrm{~d} 2$ & 4.18 & 0.0000609 & 0.0000756 & 0.0000931 & 0.3684 \\
\hline 700210 & $4 / 7 \mathrm{~A}$ & 70F_652d2YC_1 FNO1 & 70 & $\mathrm{FD}$ & 12.7 & 30569.0 & 88 & $835 / 8$ & 0.92 & 1.380 & HLP-22 & 12 & 8 & 4 & 3.5 & 26.4 & 11.7 & 22.4 & 9.7 & 0.75 & 0.33 & $\mathrm{~s} 2 \mathrm{~d} 2$ & 4.18 & 0.0000609 & 0.0000756 & 0.0000931 & \\
\hline 700211 & $4 / 7 \mathrm{~A}$ & 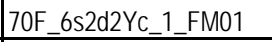 & 70 & $\mathrm{FD}$ & 12.7 & 30569.0 & 88 & $835 / 8$ & 0.92 & 1.380 & HLP-22 & 12 & 8 & 4 & 3.5 & 26.4 & 11.7 & 22.4 & 9.7 & 0.75 & 0.33 & $\mathrm{~s} 2 \mathrm{~d} 2$ & 4.18 & 0.0000609 & 0.0000756 & 0.0000931 & 0.3684 \\
\hline 700211.1 & $47 / \mathrm{A}$ & 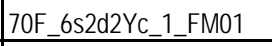 & 70 & $\mathrm{FD}$ & 12.7 & 30569.0 & 88 & $835 / 8$ & 0.92 & 1.380 & HLP-22 & 12 & 8 & 4 & 3.5 & 26.4 & 11.7 & 22.4 & 9.7 & 0.75 & 0.33 & $\mathrm{~s} 2 \mathrm{~d} 2$ & 4.18 & 0.0000609 & 0.0000756 & 0.0000931 & 0.3684 \\
\hline 700212 & $477 \mathrm{~A}$ & 70F_6S2d2YC_ 1FNO1 & 70 & $\mathrm{FD}$ & 12.7 & 30569.0 & 88 & $835 / 8$ & 0.92 & 1.380 & HLP-22 & 12 & 8 & 4 & 3.5 & 26.4 & 11.7 & 22.4 & 9.7 & 0.75 & 0.33 & $\mathrm{~s} 2 \mathrm{~d} 2$ & 4.18 & 0.0000609 & 0.0000756 & 0.0000931 & \\
\hline 700212.1 & $47 / \mathrm{A}$ & 70F_652d2YC_1FNO1 & 70 & $\mathrm{FD}$ & 12.7 & 30569.0 & 88 & $835 / 8$ & 0.92 & 1.380 & HLP-22 & 12 & 8 & 4 & 3.5 & 26.4 & 11.7 & 22.4 & 9.7 & 0.75 & 0.33 & $\mathrm{~s} 2 \mathrm{~d} 2$ & 4.18 & 0.0000609 & 0.0000756 & 0.0000931 & 0.3684 \\
\hline 700213 & $47 \mathrm{~A}$ & 70F_6s2d2YYC 1 FNO1 & 70 & $\mathrm{FD}$ & 12.7 & 30569.0 & 88 & $835 / 8$ & 0.92 & 1.380 & HLP-22 & 12 & 8 & 4 & 3.5 & 26.4 & 11.7 & 22.4 & 9.7 & 0.75 & 0.33 & $\mathrm{~s} 2 \mathrm{~d} 2$ & 4.18 & 0.0000009 & 0.000056 & 0.00009311 & \\
\hline 700214 & $47 \mathrm{~A}$ & 70F_652d2YC_1FN01 & 70 & $\mathrm{FD}$ & 12.7 & 30569.0 & 88 & $835 / 8$ & 0.92 & 1.380 & HLP-22 & 12 & 8 & 4 & 3.5 & 26.4 & 11.7 & 22.4 & 9.7 & 0.75 & 0.33 & $\mathrm{~s} 2 \mathrm{~d} 2$ & 4.18 & 0.0000609 & 0.0000756 & 0.0000931 & \\
\hline $700215 \mathrm{M}$ & $47 \mathrm{~A}$ & 70F_66202YC_ 1 FN01 & 70 & $\mathrm{FD}$ & 12.7 & 30569.0 & 88 & $835 / 8$ & 0.92 & 1.380 & HLP-22 & 12 & 8 & 4 & 3.5 & 26.4 & 11.7 & 22.4 & 9.7 & 0.75 & 0.33 & $\mathrm{~s} 2 \mathrm{~d} 2$ & 4.18 & 0.0000609 & 0.0000756 & 0.0000931 & 0.36 \\
\hline $700216 \mathrm{M}$ & $4 / 7 \mathrm{~A}$ & 70F_6S2d2YC_1_FN01 & 70 & $\mathrm{FD}$ & 12.7 & 30569.0 & 88 & $835 / 8$ & 0.92 & 1.380 & HLP-22 & 12 & 8 & 4 & 3.5 & 26.4 & 11.7 & 22.4 & 9.7 & 0.75 & 0.33 & $\mathrm{~s} 2 \mathrm{~d} 2$ & 4.18 & 0.0000609 & 0.0000756 & 0.0000931 & \\
\hline $700218 \mathrm{M}$ & 4/8A & $70 F\left[652 \mathrm{~d} 2 \mathrm{M} \_1\right.$ & 70 & $\mathrm{FD}$ & 12.7 & 30569.0 & 89 & $835 / 8$ & 0.92 & 1.380 & HLP-22 & 12 & 8 & 4 & 3.5 & 26.4 & 11.7 & 22.4 & 9.7 & 0.75 & 0.33 & $\mathrm{~s} 2 \mathrm{~d} 2$ & 4.18 & 0.0000609 & 0.0000756 & 0.0000931 & 0.3684 \\
\hline 700220 & $4 / 8 \mathrm{~A}$ & 70F_6s2d2Yg 1 & 70 & $\mathrm{FD}$ & 12.7 & 30569.0 & 89 & $835 / 8$ & 0.92 & 1.380 & HLP-22 & 12 & 8 & 4 & 3.5 & 26.4 & 11.7 & 22.4 & 9.7 & 0.75 & 0.33 & $\mathrm{~s} 2 \mathrm{~d} 2$ & 4.18 & 0.0000609 & 0.0000756 & 0.0000931 & \\
\hline 700223 & $4110 \mathrm{~A}$ & 70F_4s2d2YI_1 & 70 & $\mathrm{FD}$ & 12.7 & 30569.0 & $901 / 2$ & $835 / 8$ & 0.613 & 0.920 & HLP-22 & 12 & 8 & 4 & 3.5 & 26.4 & 11.7 & 22.4 & 9.7 & 0.75 & 0.33 & $\mathrm{~s} 2 \mathrm{~d} 2$ & 4.18 & 0.0000609 & 0.0000756 & 0.0000931 & \\
\hline $700224 \mathrm{M}$ & $410 \mathrm{~A}$ & 70F_4s2d2Yc_1 & 70 & $\mathrm{FD}$ & 12.7 & 30569.0 & $901 / 2$ & $835 / 8$ & 0.613 & 0.920 & HLP-22 & 12 & 8 & 4 & 3.5 & 26.4 & 11.7 & 22.4 & 9.7 & 0.75 & 0.33 & $\mathrm{~s} 2 \mathrm{~d} 2$ & 4.18 & 0.0000609 & 0.0000756 & 0.0000931 & 0.3684 \\
\hline $700227 \mathrm{M}$ & $410 \mathrm{~B}$ & $70 F-4 \mathrm{~s} 2 \mathrm{~d} 2 \mathrm{Yk} \_1$ & 70 & $\mathrm{FD}$ & 12.7 & 30569.0 & $901 / 2$ & $835 / 8$ & 0.613 & 0.920 & HLP-22 & 12 & 8 & 4 & 3.5 & 26.4 & 11.7 & 22.4 & 9.7 & 0.75 & 0.33 & $\mathrm{~s} 2 \mathrm{~d} 2$ & 4.18 & 0.0000609 & 0.0000756 & 0.0000931 & \\
\hline $700228 \mathrm{M}$ & $4 / 10 \mathrm{~B}$ & 70F_4s2d2Yd_1 & 70 & $\mathrm{FD}$ & 12.7 & 30569.0 & $901 / 2$ & $835 / 8$ & 0.613 & 0.920 & HLP-22 & 12 & 8 & 4 & 3.5 & 26.4 & 11.7 & 22.4 & 9.7 & 0.75 & 0.33 & $\mathrm{~s} 2 \mathrm{~d} 2$ & 4.18 & 0.0000609 & 0.0000756 & 0.0000931 & \\
\hline $700229 \mathrm{M}$ & $4 / 10 \mathrm{~B}$ & 70F_4s2d2Yd_1 & 70 & $\mathrm{FD}$ & 12.7 & 30569.0 & $901 / 2$ & $835 / 8$ & 0.613 & 0.920 & HLP-22 & 12 & 8 & 4 & 3.5 & 26.4 & 11.7 & 22.4 & 9.7 & 0.75 & 0.33 & $\mathrm{~s} 2 \mathrm{~d} 2$ & 4.18 & 0.0000609 & 0.0000756 & 0.0000931 & 0.3684 \\
\hline 700230 & $4110 \mathrm{C}$ & 70F_4s2d2Yc_1 & 70 & $\mathrm{FD}$ & 127 & 30569.0 & $901 / 2$ & $835 / 8$ & 0.613 & 0.920 & HLP-22 & 12 & 8 & 4 & 3.5 & 26.4 & 11.7 & 22.4 & 9.7 & 0.75 & 0.33 & $\mathrm{~s} 2 \mathrm{~d} 2$ & 4.18 & 0.0000609 & 0.0000756 & 0.0000931 & \\
\hline 700231 & $4110 \mathrm{C}$ & 70F_4s2d2Yc_1 & 70 & $\mathrm{FD}$ & 12.7 & 30569.0 & $901 / 2$ & $835 / 8$ & 0.613 & 0.920 & HLP-22 & 12 & 8 & 4 & 3.5 & 26.4 & 11.7 & 22.4 & 9.7 & 0.75 & 0.33 & $\mathrm{~s} 2 \mathrm{~d} 2$ & 4.18 & 0.0000609 & 0.0000756 & 0.0000931 & 0.36 \\
\hline 700232 & $4 / 10 \mathrm{C}$ & 70F_452d2YC_ 1 & 70 & $\mathrm{FD}$ & 12.7 & 30569.0 & $901 / 2$ & $835 / 8$ & 0.613 & 0.920 & HLP-22 & 12 & 8 & 4 & 3.5 & 26.4 & 11.7 & 22.4 & 9.7 & 0.75 & 0.33 & $\mathrm{~s} 2 \mathrm{~d} 2$ & 4.18 & 0.0000609 & 0.0000756 & 0.0000931 & \\
\hline 700233 & $4 / 10 \mathrm{C}$ & 70F_4s2d2Yc_1 1 & 70 & $\mathrm{FD}$ & 12.7 & 30569.0 & $901 / 2$ & $835 / 8$ & 0.613 & 0.920 & HLP-22 & 12 & 8 & 4 & 3.5 & 26.4 & 11.7. & 22.4 & 9.7 & 0.75 & 0.33 & $\mathrm{~s} 2 \mathrm{~d} 2$ & 4.18 & 0.0000609 & 0.0000756 & 0.0000931 & \\
\hline 700234 & 4144 & 70F_4s1d1Zc_1 & 70 & $\mathrm{FD}$ & 12.7 & 30569.0 & 89 & $835 / 8$ & 0.613 & 0.920 & HLP-22 & 12 & 8 & 4 & 3.5 & 26.4 & 11.7 & 22.4 & 9.7 & 0.75 & 0.33 & sid1 & 2.46 & 0.0001428 & 0.0001664 & 0.0001951 & 0.4118 \\
\hline 700235 & $4114 \mathrm{~A}$ & 70F_4s1d17c_1 1 & 70 & $\mathrm{FD}$ & 127 & 30569.0 & 89 & $835 / 8$ & 0.613 & 0.920 & HLP-22 & 12 & 8 & 4 & 3.5 & 26.4 & 11.7 & 22.4 & 9.7 & 0.75 & 0.33 & s1d1 & 2.46 & 0.0001428 & 0.0001664 & 0.0001951 & \\
\hline 700236 & $414 \mathrm{~A}$ & 70F_4s1d1Zc_1 & 70 & $\mathrm{FD}$ & 12.7 & 30569.0 & 89 & $835 / 8$ & 0.613 & 0.920 & HLP-22 & 12 & 8 & 4 & 3.5 & 26.4 & 11.7 & 22.4 & 9.7 & 0.75 & 0.33 & s1d1 & 2.46 & 0.0001428 & 0.0001664 & 0.0001951 & \\
\hline $700237 \mathrm{M}$ & $4 / 14 A$ & 70F_4s1d17c_1 & 70 & $\mathrm{FD}$ & 12.7 & 30569.0 & 89 & $835 / 8$ & 0.613 & 0.920 & HLP-22 & 12 & 8 & 4 & 3.5 & 26.4 & 11.7 & 22.4 & 9.7 & 0.75 & 0.33 & s1d1 & 2.46 & 0.0001428 & 0.0001664 & 0.0001951 & \\
\hline 700238 & $414 \mathrm{~A}$ & 70F_4sidizc_1 1 & 70 & $\mathrm{FD}$ & 12.7 & 30569.0 & 89 & $835 / 8$ & 0.613 & 0.920 & HLP-22 & 12 & 8 & 4 & 3.5 & 26.4 & 11.7 & 22.4 & 9.7 & 0.75 & 0.33 & s1d1 & 2.46 & $\begin{array}{ll}0.0001428 \\
\end{array}$ & 0.0001664 & 0.0001951 & \\
\hline 700239 & $4 / 14 \mathrm{~A}$ & 70F_4sid1zc_1 & 70 & $\mathrm{FD}$ & 12.7 & 30569.0 & 89 & $835 / 8$ & 0.613 & 0.920 & HLP-22 & 12 & 8 & 4 & 3.5 & 26.4 & 11.7 & 22.4 & 9.7 & 0.75 & 0.33 & s1d1 & 2.46 & 0.0001428 & 0.0001664 & 0.0001951 & 0.4118 \\
\hline 700240 & 4144 & 70F_4s1d1Zc_1 & 70 & $\mathrm{FD}$ & 12.7 & 30569.0 & 89 & $835 / 8$ & 0.613 & 0.920 & HLP-22 & 12 & 8 & 4 & 3.5 & 26.4 & 11.7 & 22.4 & 9.7 & 0.75 & 0.33 & sid1 & 2.46 & 0.00001428 & 0.0001664 & 0.0001951 & \\
\hline 700241 & $4114 \mathrm{~A}$ & 70F_4sid1Zc_ 1 & 70 & $F D$ & 12.7 & 30569.0 & 89 & $835 / 8$ & 0.613 & 0.920 & HLP-22 & 12 & 8 & 4 & 3.5 & 26.4 & 11.7 & 22.4 & 9.7 & 0.75 & 0.33 & sid1 & 2.46 & 0.0001428 & 0.0001664 & 0.0001951 & \\
\hline 700242 & $4 / 14 \mathrm{~A}$ & 70F_4s1d1Zc_1 & 70 & $\mathrm{FD}$ & 12.7 & 30569.0 & 89 & $835 / 8$ & 0.613 & 0.920 & HLP-22 & 12 & 8 & 4 & 3.5 & 26.4 & 11.7 & 22.4 & 9.7 & 0.75 & 0.33 & s1d1 & 2.46 & 0.0001428 & 0.0001664 & 0.0001951 & 0.4118 \\
\hline 700243 & $4 / 144$ & 70F_4s1d17c_1 & 70 & $\mathrm{FD}$ & 127 & 30569.0 & 89 & $835 / 8$ & 0.613 & 0.920 & HLP-22 & 12 & 8 & 4 & 3.5 & 26.4 & 11.7 & 22.4 & & 0.75 & & s1d1 & 2.46 & 0.0001428 & 0.0001664 & 0.0001951 & \\
\hline 700244 & $4 / 14 \mathrm{~A}$ & 70F_4s1d1Zc_1 & 70 & $\mathrm{FD}$ & 12.7 & 30569.0 & 89 & $835 / 8$ & 0.613 & 0.920 & HLP-22 & 12 & 8 & 4 & 3.5 & 26.4 & 11.7 & 22.4 & 9.7 & 0.75 & 0.33 & s1d1 & 2.46 & 0.0001428 & 0.0001664 & 0.0001951 & 4118 \\
\hline 700244.1 & $4 / 14 \mathrm{~A}$ & 70F_4s1d17c_ 1 & 70 & $\mathrm{FD}$ & 12.7 & 30569.0 & 89 & $835 / 8$ & 0.613 & 0.920 & HLP-22 & 12 & 8 & 4 & 3.5 & 26.4 & 11.7 & 22.4 & 9.7 & 0.75 & 0.33 & s1d1 & 2.46 & $\begin{array}{ll}0.0001428 \\
\end{array}$ & 0.0001664 & 0.0001951 & \\
\hline 700244.2 & $4 / 14 A$ & 70F_4sid1zc_1 1 & 70 & $\mathrm{FD}$ & 12.7 & 30569.0 & 89 & $835 / 8$ & 0.613 & 0.920 & HLP-22 & 12 & 8 & 4 & 3.5 & 26.4 & 111.7 & 22.4 & 9.7 & 0.75 & 0.33 & s1d1 & 2.46 & \begin{tabular}{|c|}
0.0001428 \\
\end{tabular} & 0001664 & 0.0001951 & \\
\hline
\end{tabular}

FM01 indicates flow meter time constant of 0.1 instead of 0.01 . 
Table B.6. Data from 2008 in Large-Scale Vessel with Flanged and Dished Head B.1

\begin{tabular}{|c|c|c|c|c|c|c|c|c|c|c|c|c|c|c|c|c|c|c|c|c|c|c|c|c|c|c|c|c|c|}
\hline $\begin{array}{l}\text { Tank Water } \\
\text { Temperature }\end{array}$ & $\begin{array}{l}\text { Water } \\
\text { Density }\end{array}$ & $\begin{array}{l}\text { Solids } \\
\text { Fraction } \\
\end{array}$ & $\begin{array}{c}\text { Pulse } \\
\text { Volume } \\
\text { Fraction }\end{array}$ & $\begin{array}{l}\text { Duty } \\
\text { Qydde }\end{array}$ & $\begin{array}{l}\text { Cyde } \\
\text { Time }\end{array}$ & $\begin{array}{c}\text { Pulsed } \\
\text { or } \\
\text { Steady } \\
\text { Jet } \\
\end{array}$ & $\begin{array}{c}\text { Us } \\
\text { Steady } \\
\text { Jet }\end{array}$ & $\begin{array}{c}\text { II } \\
\text { Pulsing } \\
\text { Jet }\end{array}$ & $\begin{array}{l}\text { U2 } \\
\text { URMS }\end{array}$ & $\begin{array}{c}\text { U3 } \\
\text { URNB } \\
\end{array}$ & $\begin{array}{l}\text { Discharge } \\
\text { Velocity }\end{array}$ & $\begin{array}{c}\text { Citical } \\
\text { Suspension } \\
\text { Velocity }\end{array}$ & $\begin{array}{c}\text { Average } \\
\text { Peeak Cloud } \\
\text { Height } \\
\end{array}$ & $\begin{array}{c}\text { UCs } \\
\text { Condition }\end{array}$ & $\begin{array}{l}\text { UCS } \\
\text { Nethod }\end{array}$ & $\begin{array}{l}\text { UCS } \\
\text { Hag }\end{array}$ & $\begin{array}{c}\text { Ues } \\
\text { Center } \\
\text { Hag }\end{array}$ & $\begin{array}{c}\text { UcS udy } \\
\text { Hag }\end{array}$ & $\begin{array}{c}\text { UCS based } \\
\text { on } \\
\text { Decreasing } \\
\text { Velocity } \\
\end{array}$ & $\begin{array}{l}\text { Sweep } \\
\text { Increase I } \\
\text { Decrease }\end{array}$ & \begin{tabular}{|c|} 
UDV \\
Height \\
Bed \\
\end{tabular} & $\begin{array}{l}\text { Particle } \\
\text { Motion }\end{array}$ & \begin{tabular}{|l|} 
Solids \\
Level \\
\end{tabular} & \begin{tabular}{|l|} 
Outer \\
Bototom \\
Patter \\
\end{tabular} & \begin{tabular}{|l|} 
Inner \\
Bottom \\
Pattem \\
\end{tabular} & Case ID & Test & IDP & $\begin{array}{l}\text { Row } \\
\text { Number }\end{array}$ \\
\hline $\mathrm{C}$ & $\mathrm{g} / \mathrm{cm}^{3}$ & fraction & fraction & fraction & $\mathrm{s}$ & text & $\mathrm{m} / \mathrm{s}$ & $\mathrm{m} / \mathrm{s}$ & $\mathrm{m} / \mathrm{s}$ & $\mathrm{m} / \mathrm{s}$ & $\mathrm{m} / \mathrm{s}$ & $\mathrm{m} / \mathrm{s}$ & in. & $\mathrm{m} / \mathrm{s}$ & text & text & text & text & $\mathrm{m} / \mathrm{s}$ & text & $\mathrm{mm}$ & text & text & text & text & text & text & text & text \\
\hline $\mathrm{T}$ & $\rho$ & $\phi_{\mathrm{s}}$ & $\phi_{\rho}$ & $\mathrm{DC}$ & tc & Jet & Us & $\mathrm{U}_{1}$ & $\mathrm{U}_{2}$ & U3 & $u$ & Uss & $H_{c}$ & U Usp & Unsm & Uosvis & Ussen & Ussudv & Us_D & $\mathrm{s}_{\mathrm{w}}$ & $\mathrm{H}_{\text {bed }}$ & $\mathrm{PM}$ & Sol & $\mathrm{SPo}$ & $\mathrm{SP}$ & ID & MDDX & $\mathrm{IDP}$ & MSS \\
\hline 20.8 & 0.995 & 0.00500 & 0.049 & 0.332 & 22.5 & $\mathrm{P}$ & NA & 5.56 & 5.75 & 5.85 & 6.20 & 6.70 & $\mathrm{NA}$ & NA & NA & NA & NA & NA & $\mathrm{NA}$ & 1 & 9.4 & 1 & NA & NA & NA & 70F_652d2YC___FNO1 & $47 \mathrm{~A}$ & TDP-133 & 700204 \\
\hline 20.6 & 0.995 & 0.00500 & 0.050 & 0.338 & 21.7 & $\mathrm{P}$ & NA & 5.74 & 5.92 & 6.01 & 6.40 & 6.70 & NA & NA & NA & NA & NA & NA & NA & 1 & 5.4 & 1 & NA & NA & NA & 70F_6s2d2YC__ FNO1 & $4 / 7 \mathrm{~A}$ & TDP-133 & 700205 \\
\hline 20.7 & 0.995 & 0.00500 & 0.050 & 0.341 & 20.8 & $\mathrm{P}$ & NA & 5.95 & 6.13 & 6.24 & 6.60 & 6.70 & NA & NA & NA & NA & NA & NA & NA & 1 & 3.2 & 1 & NA & NA & NA & 70F_6s2d2YC__ FNO1 & $4 / 7 \mathrm{~A}$ & TDP-133 & 700206 \\
\hline 20.7 & 0.995 & 0.00500 & 0.050 & 0.336 & 21.2 & $\mathrm{P}$ & NA & 5.94 & 6.13 & 6.23 & 6.60 & 6.70 & 22.00 & NA & NA & NA & NA & NA & NA & 1 & 4.0 & 1 & NA & NA & NA & 70F_652d2YC___FNO1 & $477 \mathrm{~A}$ & TDP-133 & 700207 \\
\hline 20.7 & 0.995 & 0.00500 & 0.050 & 0.338 & 20.6 & $\mathrm{P}$ & NA & 6.06 & 6.25 & 6.36 & 6.70 & 6.70 & 22.00 & \begin{tabular}{|l|}
6.70 \\
\end{tabular} & udv & NA & Ucscen & ucsudv & NA & 1 & 0.0 & 2 & NA & NA & NA & 70F_6s2d2YC_1_FNO1 & $47 \mathrm{~A}$ & TDP-133 & 700208 \\
\hline 20.7 & 0.995 & 0.00500 & 0.050 & 0.338 & 20.6 & $\mathrm{P}$ & NA & 6.06 & 6.25 & 6.36 & 6.70 & 6.70 & NA & NA & NA & NA & NA & NA & NA & NA & naa & NA & NA & NA & NA & 70F_6S2d2YC___FNO1 & $4 / 7 \mathrm{~A}$ & TDP-133 & 700208.1 \\
\hline 20.7 & 0.995 & 0.00500 & 0.050 & 0.338 & 20.6 & $\mathrm{P}$ & NA & 6.06 & 6.25 & 6.36 & 6.70 & 6.70 & NA & NA & NA & NA & NA & NA & NA & NA & na & NA & NA & NA & NA & 70F_6s2d2YC_1 FNO1 & $4 / 7 \mathrm{~A}$ & TDP-133 & 700208.2 \\
\hline 20.7 & 0.995 & 0.00500 & 0.050 & 0.338 & 20.6 & $\mathrm{P}$ & NA & 6.06 & 6.25 & 6.36 & 6.70 & 6.70 & NA & NA & NA & NA & NA & NA & NA & 1 & 0.0 & NA & NA & NA & NA & 70F_6s2d2YC_1_FNO1 & $47 \mathrm{~A}$ & TDP-133 & 700209 \\
\hline 20.7 & 0.995 & 0.00500 & 0.050 & 0.338 & 20.6 & $\mathrm{P}$ & NA & 6.06 & 6.25 & 6.36 & 6.70 & 6.70 & NA & NA & NA & NA & NA & NA & NA & NA & 0.6 & NA & NA & NA & NA & 70F_652d2YC_1_FNO1 & $4 / 7 \mathrm{~A}$ & TDP-133 & 700210 \\
\hline 20.7 & 0.995 & 0.00500 & 0.050 & 0.338 & 20.6 & $\mathrm{P}$ & NA & 6.06 & 6.25 & 6.36 & 6.70 & 6.70 & NA & NA & NA & NA & NA & NA & NA & NA & 0.0 & NA & NA & NA & NA & 70F_6s2d2YC_1_FNO1 & $4 / 7 \mathrm{~A}$ & TDP-133 & 700211 \\
\hline 20.7 & 0.995 & 0.00500 & 0.050 & 0.338 & 20.6 & $\mathrm{P}$ & NA & 6.06 & 6.25 & 6.36 & 6.70 & 6.70 & NA & NA & NA & NA & NA & NA & NA & NA & naa & NA & NA & NA & NA & 70F_6S2d2YC___FNO1 & $4 / 7 \mathrm{~A}$ & TDP-133 & 700211.1 \\
\hline 20.7 & 0.995 & 0.00500 & 0.050 & 0.338 & 20.6 & $\mathrm{P}$ & NA & 6.06 & 6.25 & 6.36 & 6.70 & 6.70 & NA & NA & NA & NA & NA & NA & NA & NA & 1.3 & NA & NA & NA & NA & 70F_6s2d2YC___FNO1 & $47 \mathrm{~A}$ & TDP-133 & 700212 \\
\hline 20.7 & 0.995 & 0.00500 & 0.050 & 0.338 & 20.6 & $\mathrm{P}$ & NA & 6.06 & 6.25 & 6.36 & 6.70 & 6.70 & NA & NA & NA & NA & NA & NA & NA & NA & na & NA & NA & NA & NA & 70F_6s2d2YC_1_FNO1 & $47 \mathrm{~A}$ & TDP-133 & 700212.1 \\
\hline 20.7 & 0.995 & 0.00500 & 0.050 & 0.338 & 20.6 & $\mathrm{P}$ & NA & 6.06 & 6.25 & 6.36 & 6.70 & 6.70 & NA & NA & NA & NA & NA & NA & NA & NA & 2.5 & NA & NA & NA & NA & 70F_GS2d2YC___FNO1 & $4 / 7 \mathrm{~A}$ & TDP-133 & 700213 \\
\hline 20.7 & 0.995 & 0.00500 & 0.050 & 0.338 & 20.6 & $\mathrm{P}$ & NA & 6.06 & 6.25 & 6.36 & 6.70 & 6.70 & NA & NA & NA & NA & NA & NA & NA & NA & 1.9 & NA & NA & NA & NA & 70F_6s2d2YC_1 FNO1 & $4 / 7 \mathrm{~A}$ & TDP-133 & 700214 \\
\hline 21.0 & 0.995 & 0.00500 & 0.050 & 0.339 & 18.4 & $\mathrm{P}$ & NA & 6.73 & 6.97 & 7.10 & 7.60 & 6.70 & 36.00 & NA & NA & NA & NA & NA & NA & 1 & 0.0 & 4 & NA & $\mathrm{NA}$ & NA & 70F_6s2d2YC___ FNO1 & $4 / 7 \mathrm{~A}$ & TDP-133 & 700215 \\
\hline 20.8 & 0.995 & 0.00500 & 0.049 & 0.315 & 20.2 & $\mathrm{P}$ & NA & 6.57 & 6.76 & 6.86 & 7.20 & 6.70 & 29.50 & NA & NA & NA & NA & NA & NA & D & 0.0 & 4 & NA & NA & NA & 70F_6s2d2YC___FNO1 & $4 / 7 \mathrm{~A}$ & TDP-133 & 700216 \\
\hline 22.5 & 0.995 & 0.00500 & 0.050 & 0.237 & 26.6 & $\mathrm{P}$ & NA & 6.70 & 6.94 & 7.07 & 7.50 & 7.50 & 24.00 & \begin{tabular}{|l|}
7.50 \\
\end{tabular} & center & NA & UCscen & NA & NA & (null) & 4.1 & 2 & NA & NA & NA & 70F_6s2d2 $2 \mathrm{~W} \_1$ & $4 / 8 \mathrm{~A}$ & TDP-134 & 700218 \\
\hline 22.8 & 0.996 & 0.00500 & 0.050 & 0.220 & 24.0 & $\mathrm{P}$ & NA & 7.95 & 8.29 & 8.48 & 9.10 & NA & 30.25 & NA & NA & NA & NA & NA & NA & 1 & 1.0 & 4 & NA & NA & NA & 70F_6s2d2Yg 1 & 4/8A & TDP-134 & 700220 \\
\hline 21.4 & 0.995 & 0.00500 & 0.054 & 0.278 & 37.0 & $\mathrm{P}$ & NA & 10.02 & 10.22 & 10.32 & 10.60 & NA & 23.25 & NA & NA & NA & NA & NA & NA & (null) & 0.6 & 1 & NA & NA & NA & 70F_4s2d2YI 1 & $410 \mathrm{~A}$ & TDP-135 & 700223 \\
\hline 21.5 & 0.995 & 0.00500 & 0.050 & 0.334 & 28.4 & $\mathrm{P}$ & NA & 9.95 & 10.17 & 10.28 & 10.60 & 10.60 & 23.50 & 10.60 & udv & NA & Ucsoen & ucsudv & NA & (null) & 1.7 & 2 & NA & NA & NA & 70F_4s2d2Yc_1 & $4 / 10 \mathrm{~A}$ & TDP-135 & 700224 \\
\hline 21.8 & 0.995 & 0.00500 & 0.050 & 0.143 & 620 & $\mathrm{P}$ & NA & 10.67 & 10.92 & 11.05 & 11.40 & 11.40 & 22.50 & 11.40 & udv & NA & NA & ucsudv & NA & (null) & 9.8 & 1 & NA & NA & NA & 70F_4s2d2Yk_1 & $4 / 10 B$ & TDP-135 & 700227 \\
\hline 21.9 & 0.995 & 0.00500 & 0.050 & 0.183 & 49.0 & $\mathrm{P}$ & NA & 10.67 & 10.92 & 11.05 & 11.40 & 11.40 & 23.00 & 11.40 & udv & NA & NA & ucsudv & NA & (null) & 3.5 & 1 & NA & NA & NA & 70F_4s2d2Yd_1 & $4 / 10 B$ & TDP-135 & 700228 \\
\hline 22.1 & 0.995 & 0.00500 & 0.050 & 0.184 & 48.0 & $\mathrm{P}$ & NA & 10.84 & 11.10 & 11.23 & 11.60 & 11.40 & 23.00 & NA & NA & NA & UCScen & NA & NA & 1 & 2.0 & 2 & NA & NA & NA & 70F_4s2d2Yd_1 & $410 \mathrm{~B}$ & TDP-135 & 700229 \\
\hline 22.3 & 0.995 & 0.00500 & 0.050 & 0.338 & 26.4 & $\mathrm{P}$ & NA & 10.70 & 10.95 & 11.08 & 11.50 & NA & 28.00 & NA & NA & NA & NA & NA & NA & $\mathrm{D}$ & NA & 4 & NA & NA & NA & 70F_4s2d2Yc_1 & $410 \mathrm{C}$ & TDP-135 & 700230 \\
\hline 22.4 & 0.995 & 0.00500 & 0.050 & 0.337 & 25.4 & $\mathrm{P}$ & NA & 11.13 & 11.40 & 11.54 & 12.00 & NA & 29.75 & NA & NA & NA & NA & NA & NA & 1 & NA & 4 & NA & NA & NA & 70F_4s2d2Yc_1 & $410 \mathrm{C}$ & TDP-135 & 700231 \\
\hline 22.5 & 0.994 & 0.00500 & 0.050 & 0.335 & 24.4 & $\mathrm{P}$ & NA & 11.59 & 11.89 & 12.04 & 12.50 & NA & 45.75 & NA & NA & NA & NA & NA & NA & 1 & NA & 4 & NA & NA & NA & 70F_4s2d2Yc_1 & $410 \mathrm{C}$ & TDP-135 & 700232 \\
\hline 22.4 & 0.995 & 0.00500 & 0.050 & 0.333 & 25.4 & $\mathrm{P}$ & NA & 11.28 & 11.56 & 11.71 & 12.20 & NA & 32.00 & NA & NA & NA & NA & NA & NA & D & NA & 4 & NA & NA & NA & 70F_4s2d2Yc_ 1 & $4 / 10 \mathrm{C}$ & TDP-135 & 700233 \\
\hline 25.0 & 0.994 & 0.00155 & 0.050 & 0.321 & 70.0 & $\mathrm{P}$ & NA & NA & NA & NA & 4.40 & 6.70 & 21.50 & NA & NA & NA & NA & NA & NA & (null) & 0.0 & 1 & NA & NA & NA & 70F_4sid17c_1 & 4114A & TDP-136 & 700234 \\
\hline 25.1 & 0.994 & 0.00155 & 0.050 & 0.327 & 53.0 & $\mathrm{P}$ & NA & 5.45 & 5.53 & 5.57 & 5.70 & 6.70 & 22.50 & NA & $\mathrm{NA}$ & NA & NA & NA & NA & 1 & 16.3 & 1 & NA & $\mathrm{NA}$ & NA & 70F_4s1d17c_1 & $4114 \mathrm{~A}$ & TDP-136 & 700235 \\
\hline 25.0 & 0.994 & 0.00155 & $\begin{array}{ll}0.051 \\
\end{array}$ & 0.331 & 47.0 & $\mathrm{P}$ & NA & 6.17 & 6.27 & 6.32 & 6.50 & 6.70 & 25.25 & NA & NA & NA & Ucsoen & NA & NA & 1 & 2.5 & 2 & NA & NA & NA & 70F_4s1d17c_1 & 4/14A & TDP-136 & 700236 \\
\hline 24.6 & 0.994 & 0.00155 & 0.050 & 0.332 & 45.4 & $\mathrm{P}$ & NA & 6.35 & 6.45 & 6.51 & 6.70 & 6.70 & 25.50 & \begin{tabular}{|l|}
6.70 \\
\end{tabular} & udv & NA & Ucscen & ucsudv & NA & 1 & 1.5 & 2 & NA & NA & NA & 70F_4s1d12c_ 1 & 4/14A & TDP-136 & 700237 \\
\hline 24.6 & 0.994 & 0.00155 & 0.050 & 0.332 & 45.4 & $\mathrm{P}$ & NA & 6.35 & 6.45 & 6.51 & 6.70 & 6.70 & 25.50 & NA & NA & NA & NA & NA & NA & NA & 1.3 & NA & NA & NA & NA & 70F_4s1d12c_ 1 & $4 / 14 \mathrm{~A}$ & TDP-136 & 700238 \\
\hline 24.6 & 0.994 & 0.00155 & 0.050 & 0.332 & 45.4 & $\mathrm{P}$ & NA & 6.35 & 6.45 & 6.51 & 6.70 & 6.70 & 25.50 & NA & NA & NA & NA & NA & NA & NA & 0.0 & NA & NA & NA & NA & 70F_4s1d17c_1 & 4/14A & TDP-136 & 700239 \\
\hline 24.6 & 0.994 & 0.00155 & 0.050 & 0.332 & 45.4 & $\mathrm{P}$ & NA & 6.35 & 6.45 & 6.51 & 6.70 & 6.70 & 25.50 & NA & NA & NA & NA & NA & NA & NA & 0.0 & NA & NA & $\mathrm{NA}$ & NA & 70F_4sid17c_1 & $4114 \mathrm{~A}$ & TDP-136 & 700240 \\
\hline 24.6 & 0.994 & 0.00155 & 0.050 & 0.332 & 45.4 & $\mathrm{P}$ & NA & 6.35 & 6.45 & 6.51 & 6.70 & 6.70 & 25.50 & NA & NA & NA & NA & NA & NA & NA & 0.0 & NA & NA & NA & NA & 70F_4s1d17c_1 & 4/14A & TDP-136 & 700241 \\
\hline 24.6 & 0.994 & 0.00155 & 0.050 & 0.332 & 45.4 & $\mathrm{P}$ & NA & 6.35 & 6.45 & 6.51 & 6.70 & 6.70 & 25.50 & NA & NA & NA & NA & NA & NA & NA & 0.6 & NA & NA & NA & NA & 70F_4sid17c_1 & 4/14A & TDP-136 & 700242 \\
\hline 24.6 & 0.994 & 0.00155 & 0.050 & 0.332 & 45.4 & $\mathrm{P}$ & NA & 6.35 & 6.45 & 6.51 & 6.70 & 6.70 & 25.50 & & & NA & & NA & NA & NA & 0.0 & NA & NA & NA & NA & & & TDP-136 & 700243 \\
\hline 24.6 & 0.994 & 0.00155 & 0.050 & 0.332 & 45.4 & $\mathrm{P}$ & NA & 6.35 & 6.45 & 6.51 & 6.70 & 6.70 & 25.50 & NA & NA & NA & NA & NA & NA & NA & 0.6 & NA & NA & NA & NA & 70F_4sid12c_1 & 4/14A & TDP-136 & 700244 \\
\hline 24.6 & 0.994 & 0.00155 & 0.050 & 0.332 & 45.4 & $\mathrm{P}$ & NA & 6.35 & 6.45 & 6.51 & 6.70 & 6.70 & 25.50 & NA & NA & NA & NA & NA & NA & NA & na & NA & NA & NA & NA & 70F_4s1d17c_1 & $4 / 14 \mathrm{~A}$ & TDP-136 & 700244.1 \\
\hline
\end{tabular}


Table B.6. Data from 2008 in Large-Scale Vessel with Flanged and Dished Head A.2

\begin{tabular}{|c|c|c|c|c|c|c|c|c|c|c|c|c|c|c|c|c|c|c|c|c|c|c|c|c|c|c|c|}
\hline $\begin{array}{c}\text { Rav } \\
\text { Number }\end{array}$ & Test & Case ID & $\begin{array}{c}\text { Tank } \\
\text { Diameter }\end{array}$ & $\begin{array}{l}\text { Head } \\
\text { Shape }\end{array}$ & $\begin{array}{l}\text { Dish } \\
\text { Height }\end{array}$ & $\begin{array}{c}\text { Dish } \\
\text { Volume }\end{array}$ & $\begin{array}{c}\text { Tank } \\
\text { Fill } \\
\text { Height }\end{array}$ & $\begin{array}{l}\text { Reum } \\
\text { Line } \\
\text { Height }\end{array}$ & $\begin{array}{c}\text { Nozzle } \\
\text { IInner } \\
\text { Diameter }\end{array}$ & $\begin{array}{l}\text { Nozzle } \\
\text { Stand- } \\
\text { off } \\
\text { Distance }\end{array}$ & $\begin{array}{l}\text { Pulse Tube } \\
\text { Configuration }\end{array}$ & $\begin{array}{l}\text { Installed } \\
\text { Nozzles }\end{array}$ & $\begin{array}{c}\text { Outer } \\
\text { Nozzles } \\
\text { Operated }\end{array}$ & $\begin{array}{c}\text { Inner } \\
\text { Nozzles } \\
\text { Opperated }\end{array}$ & $\begin{array}{c}\text { Pulse Tube } \\
\text { Outer } \\
\text { Diamter }\end{array}$ & $\begin{array}{c}\text { Outer } \\
\text { PMM } \\
\text { Radius }\end{array}$ & $\begin{array}{c}\text { Inner } \\
\text { PMM } \\
\text { Radius }\end{array}$ & $\begin{array}{l}\text { "FO" Outer } \\
\text { PJM } \\
\text { Impingement } \\
\text { Angle }\end{array}$ & $\begin{array}{l}\text { "FO" Inner } \\
\text { PJM } \\
\text { Impingement } \\
\text { Angle }\end{array}$ & $\begin{array}{c}\text { Ratio Outer } \\
\text { PJM to } \\
\text { Tank } \\
\text { Radius } \\
\end{array}$ & $\begin{array}{c}\text { Ratio Inner } \\
\text { PJM to } \\
\text { Tank } \\
\text { Radius } \\
\end{array}$ & Simulant & $\begin{array}{l}\text { Solids } \\
\text { Density }\end{array}$ & $\begin{array}{c}\text { Particle } \\
\text { Diameter d5 }\end{array}$ & $\begin{array}{c}\text { Partide } \\
\text { Diameter } \\
\text { d50 }\end{array}$ & $\begin{array}{c}\text { Particle } \\
\text { Diameter } \\
\text { d95 }\end{array}$ & $\begin{array}{c}\text { Void } \\
\text { Fraction }\end{array}$ \\
\hline text & text & text & in. & text & in. & in. 3 & in. & in. & in. & in. & text & number & number & number & in. & in. & in. & deg & deg & nondim & nondim & text & $g / \mathrm{cm}^{\beta}$ & $m$ & $\mathrm{~m}$ & $m$ & fraction \\
\hline MSS & MDDX & ID & $\mathrm{D}$ & $\mathrm{HS}$ & Hosh & $V_{\text {ast }}$ & $\mathrm{H}$ & $\operatorname{Rtn}$ & $d$ & sod & PT & $\mathrm{N}$ & $\mathrm{No}$ & $\mathrm{N}$ & $P \mathrm{PT}_{\alpha \mathrm{l}}$ & $\mathrm{Ro}_{\mathrm{o}}$ & $R$ & $\theta_{\circ}$ & $\theta_{1}$ & RodR & $R / R$ & sxdx & $\rho_{\mathrm{s}}$ & $\mathrm{ds}$ & deo & des & vf \\
\hline $700245 \mathrm{M}$ & $4 / 14 \mathrm{~A}$ & 70F_4s1d17c_1 1 & 70 & $\mathrm{FD}$ & 12.7 & 30569.0 & 89 & $835 / 8$ & 0.613 & 0.920 & HLP -22 & 12 & 8 & 4 & 3.5 & 26.4 & 11.7 & 22.4 & 9.7 & 0.75 & 0.33 & s1d1 & 2.46 & 0.0001428 & 0.0001664 & 0.0001951 & 0.4118 \\
\hline $700246 \mathrm{M}$ & $4 / 14 A$ & 70F_4sId1Zc_1 1 & 70 & $\mathrm{FD}$ & 12.7 & 30569.0 & 89 & $835 / 8$ & 0.613 & 0.920 & HLP-22 & 12 & 8 & 4 & 3.5 & 26.4 & 11.7 & 22.4 & 9.7 & 0.75 & 0.33 & s1d1 & 2.46 & 0.0001428 & 0.0001664 & 0.0001951 & 0.4118 \\
\hline $700247 \mathrm{M}$ & $4 / 14 \mathrm{~A}$ & 70F_4s1d17c_1 & 70 & $\mathrm{FD}$ & 12.7 & 30569.0 & 89 & $835 / 8$ & 0.613 & 0.920 & HLP-22 & 12 & 8 & 4 & 3.5 & 26.4 & 11.7 & 22.4 & 9.7 & 0.75 & 0.33 & sld1 & 2.46 & 0.0001428 & 0.0001664 & 0.0001951 & 0.4118 \\
\hline 700248 & 4/15A & 70F_4s1d1Zc_2 2 & 70 & $\mathrm{FD}$ & 12.7 & 30569.0 & 88 & $835 / 8$ & 0.613 & 0.920 & HLP-22 & 12 & 8 & 4 & 3.5 & 26.4 & 11.7 & 22.4 & 9.7 & 0.75 & 0.33 & sidn & 2.46 & 0.0001428 & 0.0001664 & 0.0001951 & 0.4118 \\
\hline 700249 & 4/15A & 70F_4sid17c 2 & 70 & $F D$ & 12.7 & 30569.0 & 88 & $835 / 8$ & 0.613 & 0.920 & HLP-22 & 12 & 8 & 4 & 3.5 & 26.4 & 11.7 & 22.4 & 9.7 & 0.75 & 0.33 & s1d1 & 2.46 & 0.0001428 & 0.0001664 & 0.0001951 & 0.4118 \\
\hline 700250 & 4/15A & 70F_4s1d17c_2 2 & 70 & $\mathrm{FD}$ & 12.7 & 30569.0 & 88 & $835 / 8$ & 0.613 & 0.920 & HLP-22 & 12 & 8 & 4 & 3.5 & 26.4 & 11.7 & 22.4 & 9.7 & 0.75 & 0.33 & s1d1 & 2.46 & 0.0001428 & 0.0001664 & 0.0001951 & 0.4118 \\
\hline 700251 & 4/15A & 70F_4s1d1Zc_2 2 & 70 & $\mathrm{FD}$ & 12.7 & 30569.0 & 88 & $835 / 8$ & 0.613 & 0.920 & HLP-22 & 12 & 8 & 4 & 3.5 & 26.4 & 11.7 & 22.4 & 9.7 & 0.75 & 0.33 & s1d1 & 2.46 & 0.0001428 & 0.0001664 & 0.0001951 & 0.4118 \\
\hline 700252M & $4 / 15 \mathrm{~A}$ & 70F_4s1d17c_2 2 & 70 & $\mathrm{FD}$ & 12.7 & 30569.0 & 88 & $835 / 8$ & 0.613 & 0.920 & HLP-22 & 12 & 8 & 4 & 3.5 & 26.4 & 11.7 & 22.4 & 9.7 & 0.75 & 0.33 & sld1 & 2.46 & 0.0001428 & 0.0001664 & 0.0001951 & 0.4118 \\
\hline 700253M & 4/15A & 70F_4s1d17c_2 2 & 70 & FD & 12.7 & 30569.0 & 88 & $835 / 8$ & 0.613 & 0.920 & HLP-22 & 12 & 8 & 4 & 3.5 & 26.4 & 11.7 & 22.4 & 9.7 & 0.75 & 0.33 & sid1 & 2.46 & 0.0001428 & 0.0001664 & 0.0001951 & 0.4118 \\
\hline $700254 \mathrm{M}$ & 4/15A & 70F_4s1d17c 2 & 70 & $F D$ & 12.7 & 30569.0 & 88 & $835 / 8$ & 0.613 & 0.920 & HLP-22 & 12 & 8 & 4 & 3.5 & 26.4 & 11.7 & 22.4 & 9.7 & 0.75 & 0.33 & sidn & 2.46 & 0.0001428 & 0.0001664 & 0.0001951 & 0.4118 \\
\hline 700255 & 4/15B & 70F_4s1d12c_4 4 & 70 & $\mathrm{FD}$ & 12.7 & 30569.0 & $881 / 2$ & $835 / 8$ & 0.613 & 0.920 & HLP-22 & 12 & 8 & 4 & 3.5 & 26.4 & 11.7 & 22.4 & 9.7 & 0.75 & 0.33 & s1d1 & 2.46 & 0.0001428 & 0.0001664 & 0.0001951 & 0.4118 \\
\hline 700256 & 4/15B & 70F_4s1d1Zc_4 & 70 & FD & 12.7 & 30569.0 & $881 / 2$ & $835 / 8$ & 0.613 & 0.920 & HLP-22 & 12 & 8 & 4 & 3.5 & 26.4 & 11.7 & 22.4 & 9.7 & 0.75 & 0.33 & sid1 & 2.46 & 0.0001428 & 0.0001664 & 0.0001951 & 0.4118 \\
\hline 700257 & 4/15B & 70F_4s1d17c_4 4 & 70 & $\mathrm{FD}$ & 12.7 & 30569.0 & $881 / 2$ & $835 / 8$ & 0.613 & 0.920 & HLP-22 & 12 & 8 & 4 & 3.5 & 26.4 & 11.7 & 22.4 & 9.7 & 0.75 & 0.33 & sld1 & 2.46 & 0.0001428 & 0.0001664 & 0.0001951 & 0.4118 \\
\hline 700258 & 4/15B & 70F_4s1d17c_4 & 70 & FD & 12.7 & 30569.0 & $881 / 2$ & $835 / 8$ & 0.613 & 0.920 & HLP-22 & 12 & 8 & 4 & 3.5 & 26.4 & 11.7 & 22.4 & 9.7 & 0.75 & 0.33 & sidn & 2.46 & 0.0001428 & 0.0001664 & 0.0001951 & 0.4118 \\
\hline $700259 \mathrm{~m}$ & 4/15B & 70F_4sid12c_4 4 & 70 & $\mathrm{FD}$ & 12.7 & 30569.0 & $881 / 2$ & $835 / 8$ & 0.613 & 0.920 & HLP-22 & 12 & 8 & 4 & 3.5 & 26.4 & 11.7 & 22.4 & 9.7 & 0.75 & 0.33 & sid1 & 2.46 & 0.0001428 & 0.0001664 & 0.0001951 & 0.4118 \\
\hline 700260M & 4/15B & 70F_4s1d17c 4 & 70 & $F D$ & 12.7 & 30569.0 & $881 / 2$ & $835 / 8$ & 0.613 & 0.920 & HLP-22 & 12 & 8 & 4 & 3.5 & 26.4 & 11.7 & 22.4 & 9.7 & 0.75 & 0.33 & sld1 & 2.46 & 0.0001428 & 0.0001664 & 0.0001951 & 0.4118 \\
\hline $700261 \mathrm{M}$ & 4/15B & 70F_4s1d12c_4 & 70 & FD & 12.7 & 30569.0 & $881 / 2$ & $835 / 8$ & 0.613 & 0.920 & HLP-22 & 12 & 8 & 4 & 3.5 & 26.4 & 11.7 & 22.4 & 9.7 & 0.75 & 0.33 & sid1 & 2.46 & 0.0001428 & 0.0001664 & 0.0001951 & 0.4118 \\
\hline 700262 & $4 / 15 \mathrm{C}$ & 70F_4s1d17c_ 2 & 70 & $\mathrm{FD}$ & 12.7 & 30569.0 & $881 / 2$ & $835 / 8$ & 0.613 & 0.920 & HLP-22 & 12 & 8 & 4 & 3.5 & 26.4 & 11.7 & 22.4 & 9.7 & 0.75 & 0.33 & sidn & 2.46 & 0.0001428 & 0.0001664 & 0.0001951 & 0.4118 \\
\hline 700263 & $4 / 15 \mathrm{C}$ & 70F_4s1d17c_2 2 & 70 & FD & 12.7 & 30569.0 & $881 / 2$ & $835 / 8$ & 0.613 & 0.920 & HLP-22 & 12 & 8 & 4 & 3.5 & 26.4 & 11.7 & 22.4 & 9.7 & 0.75 & 0.33 & sid1 & 2.46 & 0.0001428 & 0.0001664 & 0.0001951 & 0.4118 \\
\hline 700264 & $4 / 15 \mathrm{C}$ & 70F_4s1d17c_2 2 & 70 & $\mathrm{FD}$ & 12.7 & 30569.0 & $881 / 2$ & $835 / 8$ & 0.613 & 0.920 & HLP-22 & 12 & 8 & 4 & 3.5 & 26.4 & 11.7 & 22.4 & 9.7 & 0.75 & 0.33 & s1d1 & 2.46 & 0.0001428 & 0.0001664 & 0.0001951 & 0.4118 \\
\hline 700265 & $4 / 15 \mathrm{C}$ & 70F_4s1d17c_2 2 & 70 & $\mathrm{FD}$ & 12.7 & 30569.0 & $881 / 2$ & $835 / 8$ & 0.613 & 0.920 & HLP-22 & 12 & 8 & 4 & 3.5 & 26.4 & 11.7 & 22.4 & 9.7 & 0.75 & 0.33 & sld1 & 2.46 & 0.0001428 & 0.0001664 & 0.00001951 & 0.4118 \\
\hline 700266 & $4 / 15 \mathrm{C}$ & 70F_4s1d1Zc_2 & 70 & FD & 12.7 & 30569.0 & $881 / 2$ & $835 / 8$ & 0.613 & 0.920 & HLP-22 & 12 & 8 & 4 & 3.5 & 26.4 & 11.7 & 22.4 & 9.7 & 0.75 & 0.33 & s1d1 & 2.46 & 0.0001428 & 0.0001664 & 0.0001951 & 0.4118 \\
\hline 700267 & $4 / 15 \mathrm{C}$ & 70F_4s1d17c_2 2 & 70 & $\mathrm{FD}$ & 12.7 & 30569.0 & $881 / 2$ & $835 / 8$ & 0.613 & 0.920 & HLP.22 & 12 & 8 & 4 & 3.5 & 26.4 & 11.7 & 22.4 & 9.7 & 0.75 & 0.33 & s1d1 & 2.46 & 0.0001428 & 0.0001664 & 0.00001951 & 0.4118 \\
\hline 700268 & $4 / 15 \mathrm{C}$ & 70F_4s1d17c_ 2 & 70 & FD & 12.7 & 30569.0 & $881 / 2$ & $835 / 8$ & 0.613 & 0.920 & HLP-22 & 12 & 8 & 4 & 3.5 & 26.4 & 11.7 & 22.4 & 9.7 & 0.75 & 0.33 & s1d1 & 2.46 & 0.0001428 & 0.0001664 & 0.00001951 & 0.4118 \\
\hline 700269 & $4 / 15 \mathrm{C}$ & 70F_4s1d17c_2 2 & 70 & $\mathrm{FD}$ & 12.7 & 30569.0 & $881 / 2$ & $835 / 8$ & 0.613 & 0.920 & HLP-22 & 12 & 8 & 4 & 3.5 & 26.4 & 11.7 & 22.4 & 9.7 & 0.75 & 0.33 & sld1 & 2.46 & 0.0001428 & 0.0001664 & 0.00001951 & 0.4118 \\
\hline 700270 & $4 / 15 \mathrm{C}$ & 70F_4s1d17c_2 & 70 & $\mathrm{FD}$ & 12.7 & 30569.0 & $881 / 2$ & $835 / 8$ & 0.613 & 0.920 & HLP-22 & 12 & 8 & 4 & 3.5 & 26.4 & 11.7 & 22.4 & 9.7 & 0.75 & 0.33 & s1d1 & 2.46 & 0.0001428 & 0.0001664 & 0.0001951 & 0.4118 \\
\hline 700271 & $4 / 15 \mathrm{C}$ & 70F_4s1d1Zc_2 2 & 70 & FD & 12.7 & 30569.0 & $881 / 2$ & $835 / 8$ & 0.613 & 0.920 & HLP-22 & 12 & 8 & 4 & 3.5 & 26.4 & 11.7 & 22.4 & 9.7 & 0.75 & 0.33 & s1d1 & 2.46 & 0.0001428 & 0.0001664 & 0.0001951 & 0.4118 \\
\hline 700272 & $4 / 16 \mathrm{~A}$ & 70F_4s1d27c_1 & 70 & $\mathrm{FD}$ & 12.7 & 30569.0 & $881 / 2$ & $835 / 8$ & 0.613 & 0.920 & HLP-22 & 12 & 8 & 4 & 3.5 & 26.4 & 11.7 & 22.4 & 9.7 & 0.75 & 0.33 & s1d2 & 2.48 & 0.0000569 & 0.0000693 & 0.0000821 & 0.3750 \\
\hline 700273M & $4 / 16 \mathrm{~A}$ & 70F_4s1d2Zc_1 & 70 & $\mathrm{FD}$ & 12.7 & 30569.0 & $881 / 2$ & $835 / 8$ & 0.613 & 0.920 & HLP-22 & 12 & 8 & 4 & 3.5 & 26.4 & 11.7 & 22.4 & 9.7 & 0.75 & 0.33 & s1d2 & 2.48 & 0.0000569 & 0.0000693 & 0.0000021 & 0.3750 \\
\hline $700274 \mathrm{M}$ & $416 \mathrm{~A}$ & 70F_4s1d27c_1 & 70 & $\mathrm{FD}$ & 12.7 & 30569.0 & $881 / 2$ & $835 / 8$ & 0.613 & 0.920 & HLP-22 & 12 & 8 & 4 & 3.5 & 26.4 & 11.7 & 22.4 & 9.7 & 0.75 & 0.33 & s1d2 & 2.48 & 0.0000569 & 0.0000693 & 0.0000021 & 0.3750 \\
\hline 700275 & $4 / 16 \mathrm{~A}$ & 70F_4s1d27c_1 & 70 & $F D$ & 12.7 & 30569.0 & $881 / 2$ & $835 / 8$ & 0.613 & 0.920 & HLP-22 & 12 & 8 & 4 & 3.5 & 26.4 & 11.7 & 22.4 & 9.7 & 0.75 & 0.33 & s1d2 & 2.48 & 0.0000569 & 0.0000693 & 0.0000821 & 0.3750 \\
\hline $700276 \mathrm{M}$ & $4 / 16 \mathrm{~A}$ & 70F_4s1d2Zc_1 & 70 & $\mathrm{FD}$ & 12.7 & 30569.0 & $881 / 2$ & $835 / 8$ & 0.613 & 0.920 & HLP-22 & 12 & 8 & 4 & 3.5 & 26.4 & 11.7 & 22.4 & 9.7 & 0.75 & 0.33 & s1d2 & 2.48 & 0.0000569 & 0.0000693 & 0.0000821 & 0.3750 \\
\hline 700276.1 & $4 / 17 \mathrm{~A}$ & 70F_4s1d27c_1 & 70 & $\mathrm{FD}$ & 12.7 & 30569.0 & $871 / 2$ & $835 / 8$ & 0.613 & 0.920 & HLP-22 & 12 & 8 & 4 & 3.5 & 26.4 & 11.7 & 22.4 & 9.7 & 0.75 & 0.33 & s1d2 & 2.48 & 0.0000569 & 0.0000693 & 0.0000821 & 0.3750 \\
\hline $70027 \mathrm{M}$ & 4/17A & 70F_4s1d2Z__1 1 & 70 & $\mathrm{FD}$ & 12.7 & 30569.0 & $871 / 2$ & $835 / 8$ & 0.613 & 0.920 & HLP-22 & 12 & 8 & 4 & 3.5 & 26.4 & 11.7 & 22.4 & 9.7 & 0.75 & 0.33 & s1d2 & 2.48 & 0.0000569 & 0.0000693 & 0.0000821 & 0.3750 \\
\hline 700278 & $4 / 17 \mathrm{~A}$ & 70F_4s1d27c_1 & 70 & $\mathrm{FD}$ & 12.7 & 30569.0 & $871 / 2$ & $835 / 8$ & 0.613 & 0.920 & HLP-22 & 12 & 8 & 4 & 3.5 & 26.4 & 11.7 & 22.4 & 9.7 & 0.75 & 0.33 & s1d2 & 2.48 & 0.0000569 & 0.0000693 & 0.00000211 & 0.3750 \\
\hline 700279 & $4177 \mathrm{~A}$ & $70 F \_4 s 1 d 27 \mathrm{c} \_1$ & 70 & FD & 12.7 & 30569.0 & $871 / 2$ & $835 / 8$ & 0.613 & 0.920 & HLP-22 & 12 & 8 & 4 & 3.5 & 26.4 & 11.7 & 22.4 & 9.7 & 0.75 & 0.33 & s1d2 & 2.48 & 0.0000569 & 0.0000693 & 0.0000821 & 0.3750 \\
\hline 700280 & 4/177A & 70F_4s1d27c_1 1 & 70 & $\mathrm{FD}$ & 12.7 & 30569.0 & $871 / 2$ & $835 / 8$ & 0.613 & 0.920 & HLP 22 & 12 & 8 & 4 & 3.5 & 26.4 & 11.7 & 22.4 & 9.7 & 0.75 & 0.33 & s1d2 & 2.48 & 0.0000569 & 0.0000693 & 0.0000821 & 0.3750 \\
\hline 700281 & $417 \mathrm{~A}$ & 70F_4s1d27c_1 1 & 70 & $F D$ & 12.7 & 30569.0 & $871 / 2$ & $835 / 8$ & 0.613 & 0.920 & HLP-22 & 12 & 8 & 4 & 3.5 & 26.4 & 11.7 & 22.4 & 9.7 & 0.75 & 0.33 & s1d2 & 2.48 & 0.0000569 & 0.0000693 & 0.0000821 & 0.3750 \\
\hline 700282 & 4/17A & 70F_4s1d27Z__1 & 70 & $\mathrm{FD}$ & 12.7 & 30569.0 & $871 / 2$ & $835 / 8$ & 0.613 & 0.920 & HLP-22 & 12 & 8 & 4 & 3.5 & 26.4 & 11.7 & 22.4 & 9.7 & 0.75 & 0.33 & s1d2 & 2.48 & 0.0000569 & 0.0000693 & 0.0000821 & 0.3750 \\
\hline 700283 & 4/17A & 70F_4s1d27c_1 & 70 & $\mathrm{FD}$ & 12.7 & 30569.0 & $871 / 2$ & $835 / 8$ & 0.613 & 0.920 & HLP-22 & 12 & 8 & 4 & 3.5 & 26.4 & 11.7 & 22.4 & 9.7 & 0.75 & 0.33 & s1d2 & 2.48 & 0.0000569 & 0.0000693 & 0.0000021 & 0.3750 \\
\hline 700284 & $4 / 17 \mathrm{~A}$ & 70F_4s1d2Zc_1 & 70 & $\mathrm{FD}$ & 12.7 & 30569.0 & $871 / 2$ & $835 / 8$ & 0.613 & 0.920 & HLP-22 & 12 & 8 & 4 & 3.5 & 26.4 & 11.7 & 22.4 & 9.7 & 0.75 & 0.33 & s1d2 & 2.48 & 0.0000569 & 0.0000693 & 0.0000021 & 0.3750 \\
\hline
\end{tabular}


Table B.6. Data from 2008 in Large-Scale Vessel with Flanged and Dished Head B.2

\begin{tabular}{|c|c|c|c|c|c|c|c|c|c|c|c|c|c|c|c|c|c|c|c|c|c|c|c|c|c|c|c|c|c|}
\hline $\begin{array}{l}\text { Tank Water } \\
\text { Temperature }\end{array}$ & $\begin{array}{c}\text { Water } \\
\text { Density }\end{array}$ & $\begin{array}{c}\text { Solids } \\
\text { Fraction }\end{array}$ & \begin{tabular}{c|} 
Pulse \\
Volume \\
Fraction \\
\end{tabular} & $\begin{array}{l}\text { Duty } \\
\text { adde }\end{array}$ & $\begin{array}{l}\text { cyde } \\
\text { Time }\end{array}$ & $\begin{array}{c}\text { Pulsed } \\
\text { or } \\
\text { Steacy } \\
\text { Jet } \\
\end{array}$ & $\begin{array}{c}\text { Us } \\
\text { Steacy } \\
\text { Jet }\end{array}$ & $\begin{array}{c}\text { U1 } \\
\text { Pulsing } \\
\text { Jet }\end{array}$ & $\begin{array}{l}\text { U2 } \\
\text { URMS }\end{array}$ & $\begin{array}{c}\text { U3 } \\
\text { URNB }\end{array}$ & $\begin{array}{l}\text { Discharge } \\
\text { Velocity }\end{array}$ & $\begin{array}{c}\text { Citical } \\
\text { Suspension } \\
\text { Velocity } \\
\end{array}$ & $\begin{array}{c}\text { Average } \\
\text { Peak Cloud } \\
\text { Height } \\
\end{array}$ & $\begin{array}{c}\text { ucs } \\
\text { Condition }\end{array}$ & $\begin{array}{c}\text { UCS } \\
\text { Nethod }\end{array}$ & $\begin{array}{l}\text { Ucs } \\
\text { Hag }\end{array}$ & $\begin{array}{c}\text { ucs } \\
\text { Center } \\
\text { Flag }\end{array}$ & $\begin{array}{c}\text { Ucs udv } \\
\text { Hag }\end{array}$ & $\begin{array}{l}\text { UcS based } \\
\text { on } \\
\text { Decreasing } \\
\text { velocity } \\
\end{array}$ & \begin{tabular}{|c|} 
Sweep \\
Increase/ \\
Decrease
\end{tabular} & \begin{tabular}{c|} 
UDV \\
Height \\
Bed
\end{tabular} & \begin{tabular}{|c|} 
Particle \\
Motion \\
\end{tabular} & $\begin{array}{l}\text { Solids } \\
\text { Level } \\
\end{array}$ & $\begin{array}{l}\text { Outer } \\
\text { Botom } \\
\text { Pataltem }\end{array}$ & $\begin{array}{l}\text { Inner } \\
\text { Botom } \\
\text { Patatem }\end{array}$ & Case ID & Test & $\mathrm{TDP}$ & $\begin{array}{c}\text { Row } \\
\text { Number }\end{array}$ \\
\hline $\mathrm{c}$ & $g \mathrm{gcm} \mathrm{cm}^{2}$ & fraction & fraction & fraction & $\mathrm{s}$ & text & $\mathrm{m} / \mathrm{s}$ & $\mathrm{m} / \mathrm{s}$ & $\mathrm{m} / \mathrm{s}$ & $\mathrm{m} / \mathrm{s}$ & m/s & m/s & \begin{tabular}{|l|} 
in. \\
\end{tabular} & \begin{tabular}{|l|}
$\mathrm{m} / \mathrm{s}$ \\
\end{tabular} & text & text & text & text & m/s & text & $\mathrm{mm}$ & text & text & text & text & text & text & text & text \\
\hline$T$ & $\rho$ & $\phi_{\mathrm{s}}$ & $\phi_{p}$ & $\mathrm{DC}$ & tc & Jet & $u_{s}$ & $\mathrm{U}_{1}$ & $\mathrm{U} 2$ & U3 & $u$ & $U_{\text {cs }}$ & $H_{k}$ & USSR & Uson & Ussis & Ussen & Uosudv & Ucs $D$ & $s_{\mathrm{N}}$ & $\mathrm{H}_{\text {bed }}$ & $\mathrm{PM}$ & sol & $\mathrm{SPo}$ & $\mathrm{SP}$ & $\mathrm{ID}$ & MDDX & $\mathrm{IDP}$ & MSS \\
\hline 24.7 & 0.994 & 0.00155 & 0.050 & 0.336 & 41.0 & $\mathrm{P}$ & $\mathrm{NA}$ & 6.93 & 7.05 & 7.11 & 7.30 & 6.70 & 28.50 & NA & NA & NA & NA & NA & NA & 1 & NA & 4 & NA & NA & NA & 70F_4sid12_ 1 & $4 / 14 A$ & TDP-136 & 700245 \\
\hline 24.8 & 0.994 & 0.00155 & 0.050 & 0.335 & 38.0 & $\mathrm{P}$ & NA & 7.49 & 7.62 & 7.69 & 7.90 & 6.70 & 33.00 & NA & NA & NA & NA & NA & NA & 1 & NA & 4 & NA & NA & NA & 70F_4sid17c_1 & $4 / 14 \mathrm{~A}$ & TDP-136 & 700246 \\
\hline 24.8 & 0.995 & 0.00155 & 0.050 & 0.336 & 36.6 & $P$ & NA & 7.72 & 7.86 & 7.94 & 8.20 & 6.70 & 39.50 & NA & NA & NA & NA & NA & NA & 1 & NA & 4 & NA & $\mathrm{NA}$ & NA & 70F_4sid17c__ 1 & $4144 \mathrm{~A}$ & TDP-136 & 700247 \\
\hline 24.3 & 0.994 & 0.00155 & 0.100 & 0.332 & 127.0 & $\mathrm{P}$ & NA & 4.51 & 4.54 & 4.56 & 4.60 & 5.80 & 20.00 & NA & NA & NA & NA & NA & NA & 1 & 34.9 & 1 & NA & NA & NA & 70F_4s1d17c 2 & $415 \mathrm{~A}$ & TDP-137 & 700248 \\
\hline 24.0 & 0.995 & 0.00155 & 0.100 & 0.333 & 116.8 & $\mathrm{P}$ & NA & 4.90 & 4.94 & 4.95 & 5.00 & 5.80 & 22.50 & NA & NA & NA & NA & NA & NA & 1 & 21.4 & 1 & NA & NA & NA & 70F_4sid17c_ 2 & $4 / 15 \mathrm{~A}$ & TDP-137 & 700249 \\
\hline 24.0 & 0.994 & 0.00155 & 0.101 & 0.334 & 108.2 & $\mathrm{P}$ & NA & 5.30 & 5.34 & 5.36 & 5.40 & 5.80 & 24.50 & NA & NA & NA & NA & NA & NA & 1 & 111.3 & 1 & NA & NA & NA & 70F_4sid17c_2 & $4 / 15 \mathrm{~A}$ & TDP-137 & 700250 \\
\hline 24.1 & 0.994 & 0.00155 & 0.100 & 0.334 & 104.4 & $\mathrm{P}$ & NA & 5.47 & 5.51 & 5.53 & 5.60 & 5.80 & 25.50 & NA & NA & NA & NA & NA & NA & 1 & 6.1 & 1 & NA & NA & NA & 70F_4s1d17c_ 2 & 4/15A & TDP-137 & 700251 \\
\hline 24.0 & 0.994 & 0.00155 & 0.101 & 0.334 & 100.8 & $\mathrm{P}$ & NA & 5.67 & 5.71 & 5.73 & 5.80 & 5.80 & 26.00 & 5.80 & uav & NA & UCScen & ucsudv & NA & 1 & 0.0 & 2 & NA & NA & NA & 70F_4s1d17c_ 2 & $415 \mathrm{~A}$ & TDP-137 & 700252 \\
\hline 24.0 & 0.994 & 0.00155 & 0.101 & 0.336 & 91.2 & $\mathrm{P}$ & NA & 6.26 & 6.31 & 6.34 & 6.40 & 5.80 & 33.00 & NA & NA & NA & NA & NA & NA & 1 & 0.0 & 4 & NA & NA & NA & 70F_4s1d12c_2 2 & $415 \mathrm{~A}$ & TDP-137 & 700253 \\
\hline 23.8 & 0.994 & 0.00155 & 0.100 & 0.333 & 87.2 & $\mathrm{P}$ & NA & 6.53 & 6.59 & 6.62 & 6.70 & 5.80 & 40.00 & NA & NA & NA & NA & NA & NA & 1 & 0.0 & 4 & NA & NA & NA & 70F_4sid1Zc 2 & $4 / 15 \mathrm{~A}$ & TDP-137 & 700254 \\
\hline 23.8 & $\begin{array}{ll}0.994 \\
\end{array}$ & 0.00155 & 0.150 & 0.328 & 191.0 & $\mathrm{P}$ & NA & 4.55 & 4.57 & 4.58 & 4.60 & 5.60 & 21.50 & NA & NA & NA & NA & NA & NA & (null) & 28.4 & 1 & NA & NA & NA & 70F_4s1d1Zc_4 4 & $415 \mathrm{~B}$ & TDP-137 & 700255 \\
\hline 23.9 & $\begin{array}{ll}0.994 \\
\end{array}$ & 0.00155 & 0.151 & 0.329 & 175.8 & $\mathrm{P}$ & NA & 4.96 & 4.99 & 5.00 & 5.00 & 5.60 & 26.00 & NA & NA & NA & NA & NA & NA & 1 & 15.1 & 1 & NA & NA & NA & 70F_4s1d12C_4 4 & $4 / 15 B$ & TDP-137 & 700256 \\
\hline 23.8 & 0.995 & 0.00155 & 0.150 & 0.329 & 169.0 & $\mathrm{P}$ & NA & 5.15 & 5.17 & 5.19 & 5.20 & 5.60 & 26.75 & NA & NA & NA & NA & NA & NA & 1 & 10.2 & 1 & NA & NA & NA & 70F_4sid1Zc 4 & 4/15B & TDP-137 & 700257 \\
\hline 23.7 & 0.994 & 0.00155 & 0.150 & 0.329 & 162.8 & $\mathrm{P}$ & NA & 5.33 & 5.35 & 5.36 & 5.40 & 5.60 & 28.00 & NA & NA & NA & NA & NA & NA & 1 & 7.1 & 1 & NA & NA & NA & 70F_4sid1Zc_4 4 & 4/15B & TDP-137 & 700258 \\
\hline 23.7 & 0.994 & 0.00155 & 0.150 & 0.329 & 157.0 & $\mathrm{P}$ & NA & 5.51 & 5.54 & 5.55 & 5.60 & 5.60 & 29.75 & 5.60 & uav & NA & Ucscen & ucsudv & NA & 1 & 0.0 & 2 & NA & NA & NA & 70F_4sId1Zc_ 4 & $415 \mathrm{~B}$ & TDP-137 & 700259 \\
\hline 23.7 & $\begin{array}{ll}0.994 \\
\end{array}$ & 0.00155 & 0.151 & 0.330 & 146.6 & $\mathrm{P}$ & NA & 5.92 & 5.95 & 5.97 & 6.00 & 5.60 & 36.75 & NA & NA & NA & NA & NA & NA & 1 & 0.0 & 4 & NA & NA & NA & 70F_4s1d121__4 & 4/15B & TDP-137 & 700260 \\
\hline 23.8 & 0.994 & 0.00155 & 0.151 & 0.331 & 137.4 & $\mathrm{P}$ & NA & 6.30 & 6.34 & 6.36 & 6.40 & 5.60 & 48.00 & NA & NA & NA & NA & NA & NA & 1 & 0.0 & 4 & NA & NA & NA & 70F_4sid1Zc_4 4 & 4/15B & TDP-137 & 700261 \\
\hline 23.7 & 0.994 & 0.00155 & 0.101 & 0.335 & 100.8 & $\mathrm{P}$ & NA & 5.67 & 5.71 & 5.73 & 5.80 & 5.80 & 26.00 & NA & NA & NA & NA & NA & NA & (null) & 0.6 & NA & NA & NA & NA & 70F_4sid17c_ 2 & $4 / 15 \mathrm{C}$ & TDP-137 & 700262 \\
\hline 23.7 & 0.994 & 0.00155 & 0.101 & 0.335 & 100.8 & $\mathrm{P}$ & NA & 5.67 & 5.71 & 5.73 & 5.80 & 5.80 & 26.00 & NA & NA & NA & NA & NA & NA & NA & 0.7 & NA & NA & NA & NA & 70F_4sid17c_2 2 & $4 / 15 \mathrm{C}$ & TDP-137 & 700263 \\
\hline 23.7 & $\begin{array}{ll}0.994 \\
\end{array}$ & 0.00155 & 0.101 & 0.335 & 100.8 & $\mathrm{P}$ & NA & 5.67 & 5.71 & 5.73 & 5.80 & 5.80 & 26.00 & NA & NA & NA & NA & NA & NA & NA & 24 & NA & NA & NA & NA & 70F_4sid1Zc_2 & $4 / 15 \mathrm{C}$ & TDP-137 & 700264 \\
\hline 23.7 & 0.994 & 0.00155 & 0.101 & 0.335 & 100.8 & $\mathrm{P}$ & NA & 5.67 & 5.71 & 5.73 & 5.80 & 5.80 & 26.00 & NA & NA & NA & NA & NA & NA & NA & 1.2 & NA & NA & NA & NA & 70F_4sidizc 2 & $4 / 15 \mathrm{C}$ & TDP-137 & 700265 \\
\hline 23.7 & 0.994 & 0.00155 & 0.101 & 0.335 & 100.8 & $\mathrm{P}$ & NA & 5.67 & 5.71 & 5.73 & 5.80 & 5.80 & 26.00 & NA & NA & NA & NA & NA & NA & NA & 0.0 & NA & NA & NA & NA & 70F_4sid17c_2 & $4 / 15 \mathrm{C}$ & TDP-137 & 700266 \\
\hline 23.7 & 0.994 & 0.00155 & 0.101 & 0.335 & 100.8 & $\mathrm{P}$ & NA & 5.67 & 5.71 & 5.73 & 5.80 & 5.80 & 26.00 & NA & NA & NA & NA & NA & NA & NA & 0.7 & NA & NA & NA & NA & 70F_4sid17c_2 & $4 / 15 \mathrm{C}$ & TDP-137 & 700267 \\
\hline 23.7 & 0.994 & 0.00155 & 0.101 & 0.335 & 100.8 & $\mathrm{P}$ & NA & 5.67 & 5.71 & 5.73 & 5.80 & 5.80 & 26.00 & NA & NA & NA & NA & NA & NA & NA & 0.7 & NA & NA & NA & NA & 70F_4sidizc 2 & $4 / 15 \mathrm{C}$ & TDP-137 & 700268 \\
\hline 23.7 & 0.994 & 0.00155 & 0.101 & 0.335 & 100.8 & $\mathrm{P}$ & NA & 5.67 & 5.71 & 5.73 & 5.80 & 5.80 & 26.00 & NA & NA & NA & NA & NA & NA & NA & 0.0 & NA & NA & NA & NA & 70F_4sidizc 2 & $4 / 15 \mathrm{C}$ & TDP-137 & 700269 \\
\hline 23.7 & $\begin{array}{ll}0.994 \\
\end{array}$ & 0.00155 & 0.101 & 0.335 & 100.8 & $P$ & NA & 5.67 & 5.71 & 5.73 & 5.80 & 5.80 & 26.00 & NA & NA & NA & NA & NA & NA & NA & 0.7 & NA & NA & NA & NA & 70F_4sid17c_2 & $4 / 15 \mathrm{C}$ & TDP-137 & 700270 \\
\hline 23.7 & 0.994 & 0.00155 & 0.101 & 0.335 & 100.8 & $\mathrm{P}$ & NA & 5.67 & 5.71 & 5.73 & 5.80 & 5.80 & 26.00 & NA & NA & NA & NA & NA & NA & NA & 1.5 & NA & NA & NA & NA & 70F_4sid1Zc 2 & $4 / 15 \mathrm{C}$ & TDP-137 & 700271 \\
\hline 21.3 & 0.995 & 0.00155 & 0.050 & 0.333 & 77.0 & $\mathrm{P}$ & NA & $\mathrm{na}$ & $\mathrm{na}$ & na & 3.80 & 4.40 & 21.75 & NA & NA & NA & NA & NA & NA & $\mathrm{D}$ & 17.7 & 1 & NA & NA & NA & 70F_4s1d227c_1 & $4 / 16 \mathrm{~A}$ & TDP-138 & 700272 \\
\hline 21.4 & 0.995 & 0.00155 & 0.050 & 0.336 & 68.0 & $\mathrm{P}$ & NA & 4.18 & 4.23 & 4.26 & 4.40 & 4.40 & 27.75 & 4.40 & udv & NA & Ucsoen & UCSudv & NA & 1 & 1.9 & 2 & NA & NA & NA & 70F_4s1d227c_1 & $416 \mathrm{~A}$ & TDP-138 & 700273 \\
\hline 21.6 & 0.995 & 0.00155 & 0.050 & 0.335 & 63.6 & $\mathrm{P}$ & NA & 4.50 & 4.56 & 4.59 & 4.70 & 4.40 & 36.50 & NA & NA & NA & NA & NA & NA & 1 & 0.0 & 4 & NA & NA & NA & 70F_4sid22Z_ 1 & $416 \mathrm{~A}$ & TDP-138 & 700274 \\
\hline 21.6 & 0.995 & 0.00155 & 0.050 & 0.331 & 712 & $\mathrm{P}$ & NA & $\mathrm{na}$ & $\mathrm{na}$ & $\mathrm{Na}$ & 4.20 & 4.40 & 25.75 & NA & NA & NA & NA & NA & NA & $\mathrm{D}$ & 3.5 & 1 & NA & NA & NA & 70F_4s1d227__1 & $4116 \mathrm{~A}$ & TDP-138 & 700275 \\
\hline 21.4 & 0.995 & 0.00155 & 0.050 & 0.334 & 62.4 & $\mathrm{P}$ & NA & 4.60 & 4.66 & 4.69 & 4.80 & 4.40 & 42.50 & NA & NA & NA & NA & NA & NA & 1 & 0.0 & 4 & NA & NA & NA & 70F_4s1d227c_1 & $4 / 16 \mathrm{~A}$ & TDP-138 & 700276 \\
\hline 22.3 & 0.995 & 0.00155 & 0.050 & 0.336 & 67.4 & $\mathrm{P}$ & NA & 4.21 & 4.27 & 4.30 & 4.40 & 4.40 & 28.25 & NA & NA & NA & NA & NA & NA & NA & na & NA & NA & NA & NA & 70F_4s1d27c_1 1 & $4177 \mathrm{~A}$ & TDP-139 & 700276.1 \\
\hline 22.3 & 0.995 & 0.00155 & 0.050 & 0.336 & 67.4 & $\mathrm{P}$ & NA & 4.21 & 4.27 & 4.30 & 4.40 & 4.40 & 28.25 & NA & NA & NA & NA & NA & NA & (null) & 0.0 & 4 & NA & NA & NA & 70F_4s1d227c_1 & $4177 \mathrm{~A}$ & TDP-139 & 700277 \\
\hline 22.3 & 0.995 & 0.00155 & 0.050 & 0.336 & 67.4 & $\mathrm{P}$ & NA & 4.21 & 4.27 & 4.30 & 4.40 & 4.40 & 28.25 & NA & NA & NA & NA & NA & NA & NA & 0.0 & NA & NA & NA & NA & 70F_4s1d227c_1 & $4177 \mathrm{~A}$ & TDP-139 & 700278 \\
\hline 22.3 & 0.995 & 0.00155 & 0.050 & 0.336 & 67.4 & $\mathrm{P}$ & NA & 4.21 & 4.27 & 4.30 & 4.40 & 4.40 & 28.25 & NA & NA & NA & NA & NA & NA & NA & 0.0 & NA & NA & NA & NA & 70F_4sid2ZC 1 & $4177 \mathrm{~A}$ & TDP-139 & 700279 \\
\hline 22.3 & 0.995 & 0.00155 & 0.050 & 0.336 & 67.4 & $\mathrm{P}$ & NA & 4.21 & 4.27 & 4.30 & 4.40 & 4.40 & 28.25 & NA & NA & NA & NA & NA & NA & NA & 0.0 & NA & NA & NA & NA & 70F_4s1d227c_1 & $4 / 17 \mathrm{~A}$ & TDP-139 & 700280 \\
\hline 22.3 & 0.995 & 0.00155 & 0.050 & 0.336 & 67.4 & $\mathrm{P}$ & NA & 4.21 & 4.27 & 4.30 & 4.40 & 4.40 & 28.25 & NA & NA & NA & NA & NA & NA & NA & 0.0 & NA & NA & NA & NA & 70F_4sId2ZZ_ 1 & $4 / 17 \mathrm{~A}$ & TDP-139 & 700281 \\
\hline 22.3 & 0.995 & 0.00155 & 0.050 & 0.336 & \begin{tabular}{ll|}
67.4 \\
\end{tabular} & $P$ & NA & 4.21 & 4.27 & 4.30 & 4.40 & 4.40 & 28.25 & NA & NA & NA & NA & NA & NA & NA & 0.0 & NA & NA & NA & NA & 70F_4s1d227c_1 & $4177 \mathrm{~A}$ & TDP-139 & 700282 \\
\hline 22.3 & 0.995 & 0.00155 & 0.050 & 0.336 & 67.4 & $\mathrm{P}$ & NA & 4.21 & 4.27 & 4.30 & 4.40 & 4.40 & 28.25 & NA & NA & NA & NA & NA & NA & NA & 0.0 & NA & NA & NA & NA & 70F_4s1d227c_1 & $4177 \mathrm{~A}$ & TDP-139 & 700283 \\
\hline 22.3 & 0.995 & 0.00155 & 0.050 & 0.336 & 67.4 & $\mathrm{P}$ & NA & 4.21 & 4.27 & 4.30 & 4.40 & 4.40 & 28.25 & NA & NA & NA & NA & NA & NA & NA & 0.0 & NA & NA & NA & NA & 70F_4s1d227c_1 & $41717 \mathrm{~A}$ & TDP-139 & 700284 \\
\hline
\end{tabular}


Table B.6. Data from 2008 in Large-Scale Vessel with Flanged and Dished Head A.3

\begin{tabular}{|c|c|c|c|c|c|c|c|c|c|c|c|c|c|c|c|c|c|c|c|c|c|c|c|c|c|c|c|}
\hline $\begin{array}{c}\text { Row } \\
\text { Number }\end{array}$ & Test & Case ID & $\begin{array}{c}\text { Tank } \\
\text { Diameter }\end{array}$ & $\begin{array}{l}\text { Head } \\
\text { Shape }\end{array}$ & $\begin{array}{l}\text { Dish } \\
\text { Height }\end{array}$ & $\begin{array}{l}\text { Dish } \\
\text { Volume }\end{array}$ & $\begin{array}{c}\text { Tank } \\
\text { Filn } \\
\text { Height }\end{array}$ & $\begin{array}{c}\text { Retur } \\
\text { Line } \\
\text { Height } \\
\text { Heignt }\end{array}$ & $\begin{array}{c}\text { Nozzle } \\
\text { Inner } \\
\text { Diameter }\end{array}$ & $\begin{array}{c}\text { Nozzle } \\
\text { Stanct } \\
\text { off } \\
\text { Distance }\end{array}$ & $\begin{array}{l}\text { Pulse Tube } \\
\text { Configuration }\end{array}$ & $\begin{array}{l}\text { Installed } \\
\text { Nozzles }\end{array}$ & $\begin{array}{c}\text { OOter } \\
\text { Nozeldes } \\
\text { Operated }\end{array}$ & $\begin{array}{c}\text { Inner } \\
\text { Nozeles } \\
\text { Operated }\end{array}$ & $\begin{array}{c}\text { Pulse Tube } \\
\text { Outer } \\
\text { Diameter }\end{array}$ & $\begin{array}{c}\text { Outer } \\
\text { PJM } \\
\text { Radius }\end{array}$ & $\begin{array}{c}\text { Inner } \\
\text { PPM } \\
\text { Radius }\end{array}$ & $\begin{array}{l}\text { "FOC' Outer } \\
\text { PJM } \\
\text { Impingement } \\
\text { Angle }\end{array}$ & $\begin{array}{l}\text { "FO' Inner } \\
\text { PJM } \\
\text { Impingement } \\
\text { Angle }\end{array}$ & $\begin{array}{c}\text { Ratio Outer } \\
\text { PJM to } \\
\text { Tank } \\
\text { Radius } \\
\end{array}$ & $\begin{array}{c}\text { Ratio Inner } \\
\text { PJMto } \\
\text { Tank } \\
\text { Radius } \\
\end{array}$ & Simulant & $\begin{array}{l}\text { Solids } \\
\text { Density }\end{array}$ & $\begin{array}{c}\text { Particle } \\
\text { Diameter } 55\end{array}$ & $\begin{array}{c}\text { Particle } \\
\text { Diameter } \\
\text { d50 }\end{array}$ & $\begin{array}{c}\text { Patidice } \\
\text { Diameter } \\
\text { d95 }\end{array}$ & $\begin{array}{c}\text { Void } \\
\text { Fraction }\end{array}$ \\
\hline text & text & text & in. & text & in. & in. ${ }^{3}$ & in. & in. & in. & in. & text & number & number & number & in. & in. & in. & deg & deg & nondim & nondim & text & $\mathrm{g} / \mathrm{cm}^{3}$ & $\mathrm{~m}$ & $\mathrm{~m}$ & $\mathrm{~m}$ & fraction \\
\hline MSS & MDDX & $\mathrm{ID}$ & $\mathrm{D}$ & $\mathrm{HS}$ & Hash & $V_{\text {dsh }}$ & $\mathrm{H}$ & $\mathrm{Rn}$ & $d$ & sod & PT & $\mathrm{N}$ & $\mathrm{Nb}$ & $\mathrm{N}$ & $\mathrm{PT}_{\alpha \mathrm{d}}$ & $\mathrm{Ro}_{0}$ & $R$ & $\theta_{\circ}$ & $\theta_{1}$ & $R d R$ & $R / R$ & $\operatorname{sxdx}$ & $\rho_{s}$ & $d s$ & $\mathrm{~d}_{\mathrm{s}}$ & $\frac{d 65}{d}$ & vf \\
\hline 700285 & $4117 \mathrm{~A}$ & 70F_4s1d27c_1 & 70 & $\mathrm{FD}$ & 12.7 & 30569.0 & $871 / 2$ & $835 / 8$ & 0.613 & 0.920 & HLP-22 & 12 & 8 & 4 & 3.5 & 26.4 & 11.7 & 22.4 & 9.7 & 0.75 & 0.33 & s1d2 & 2.48 & 0.0000569 & 0.0000693 & 0.0000821 & 0.3750 \\
\hline 700286 & $4118 \mathrm{~A}$ & 70F_4s1d2Yc_1 & 70 & $F D$ & 12.7 & 30569.0 & $871 / 2$ & $835 / 8$ & 0.613 & 0.920 & HLP-22 & 12 & 8 & 4 & 3.5 & 26.4 & 11.7 & 22.4 & 9.7 & 0.75 & 0.33 & s1d2 & 2.48 & 0.0000569 & 0.0000693 & 0.0000821 & 0.3750 \\
\hline 700287 & $4118 \mathrm{~A}$ & 70F_4s1d2Yc_1 & 70 & $F D$ & 12.7 & 30569.0 & $871 / 2$ & $835 / 8$ & 0.613 & 0.920 & HLP-22 & 12 & 8 & 4 & 3.5 & 26.4 & 11.7 & 22.4 & 9.7 & 0.75 & 0.33 & s1d2 & 2.48 & 0.0000569 & 0.0000693 & 0.0000821 & 0.3750 \\
\hline $700288 \mathrm{M}$ & $4 / 18 \mathrm{~A}$ & 70F_4s1d22Y__ 1 & 70 & FD & 12.7 & 30569.0 & $871 / 2$ & $835 / 8$ & 0.613 & 0.920 & HLP-22 & 12 & 8 & 4 & 3.5 & 26.4 & 11.7 & 22.4 & 9.7 & 0.75 & 0.33 & $\mathrm{sid2}$ & 2.48 & 0.0000569 & 0.0000693 & 0.0000821 & 0.3750 \\
\hline 700288.1 & $418 \mathrm{~A}$ & 70F_4s1d2YC_1 & 70 & $\mathrm{FD}$ & 12.7 & 30569.0 & $871 / 2$ & $835 / 8$ & 0.613 & 0.920 & HLP-22 & 12 & 8 & 4 & 3.5 & 26.4 & 11.7 & 22.4 & 9.7 & 0.75 & 0.33 & s1d2 & 2.48 & 0.0000569 & 0.0000693 & 0.0000821 & 0.3750 \\
\hline 700288.2 & 4/18A & 70F_4s1d2Yc_1 & 70 & $F D$ & 12.7 & 30569.0 & $871 / 2$ & $835 / 8$ & 0.613 & 0.920 & HLP-22 & 12 & 8 & 4 & 3.5 & 26.4 & 11.7 & 22.4 & 9.7 & 0.75 & 0.33 & $\mathrm{sid2}$ & 2.48 & 0.0000569 & 0.0000693 & 0.0000821 & 0.3750 \\
\hline $700289 \mathrm{M}$ & $4118 \mathrm{~A}$ & 70F_4s1d2Yc_1 & 70 & $F D$ & 12.7 & 30569.0 & $871 / 2$ & $835 / 8$ & 0.613 & 0.920 & HLP-22 & 12 & 8 & 4 & 3.5 & 26.4 & 11.7 & 22.4 & 9.7 & 0.75 & 0.33 & s1d2 & 2.48 & 0.0000569 & 0.0000693 & 0.0000821 & 0.3750 \\
\hline 700290 & 4/18A & 70F_4s1d2Yc_1 & 70 & $F D$ & 12.7 & 30569.0 & $871 / 2$ & $835 / 8$ & 0.613 & 0.920 & HLP-22 & 12 & 8 & 4 & 3.5 & 26.4 & 11.7 & 22.4 & 9.7 & 0.75 & 0.33 & s1d2 & 2.48 & 0.0000569 & 0.0000693 & 0.0000821 & 0.3750 \\
\hline 700291 & $4118 \mathrm{~A}$ & $70 F \_4 s 1 d 2 Y c \_1$ & 70 & $F D$ & 12.7 & 30569.0 & $871 / 2$ & $835 / 8$ & 0.613 & 0.920 & HLP-22 & 12 & 8 & 4 & 3.5 & 26.4 & 11.7 & 22.4 & 9.7 & 0.75 & 0.33 & s1d2 & 2.48 & 0.0000569 & 0.0000693 & 0.0000821 & 0.3750 \\
\hline 700292 & 4/18A & $70 \mathrm{~F} \_4 \mathrm{~s} 1 \mathrm{~d} 2 \mathrm{Yc} \_1$ & 70 & $F D$ & 12.7 & 30569.0 & $871 / 2$ & $835 / 8$ & 0.613 & 0.920 & HLP-22 & 12 & 8 & 4 & 3.5 & 26.4 & 11.7 & 22.4 & 9.7 & 0.75 & 0.33 & $51 \mathrm{~d} 2$ & 2.48 & 0.0000569 & 0.0000693 & 0.0000821 & 0.3750 \\
\hline 700293 & $4118 \mathrm{~A}$ & 70F_4s1d2Yc_1 & 70 & $F D$ & 12.7 & 30569.0 & $871 / 2$ & $835 / 8$ & 0.613 & 0.920 & HLP-22 & 12 & 8 & 4 & 3.5 & 26.4 & 11.7 & 22.4 & 9.7 & 0.75 & 0.33 & $\mathrm{sid2}$ & 2.48 & 0.0000569 & 0.0000693 & 0.0000821 & 0.3750 \\
\hline 700294 & $418 \mathrm{~A}$ & 70F_4s1d2Yc_1 & 70 & $F$ & 12.7 & 30569.0 & $871 / 2$ & $835 / 8$ & 0.613 & 0.920 & HLP-22 & 12 & 8 & 4 & 3.5 & 26.4 & 11.7 & 22.4 & 9.7 & 0.75 & 0.33 & s1d2 & 2.48 & 0.0000569 & 0.0000693 & 0.0000821 & 0.3750 \\
\hline 700295 & $4118 \mathrm{~A}$ & 70F_4s1d2Yc_1 & 70 & $F D$ & 12.7 & 30569.0 & $871 / 2$ & $835 / 8$ & 0.613 & 0.920 & HLP-22 & 12 & 8 & 4 & 3.5 & 26.4 & 11.7 & 22.4 & 9.7 & 0.75 & 0.33 & $51 \mathrm{~d} 2$ & 2.48 & 0.0000569 & 0.0000693 & 0.0000821 & 0.3750 \\
\hline 700296 & 4/18A & $70 F \_451 \mathrm{~d} 2 \mathrm{Yc} \_1$ & 70 & $F D$ & 12.7 & 30569.0 & $871 / 2$ & $835 / 8$ & 0.613 & 0.920 & HLP-22 & 12 & 8 & 4 & 3.5 & 26.4 & 11.7 & 22.4 & 9.7 & 0.75 & 0.33 & $\mathrm{~s} 1 \mathrm{~d} 2$ & 2.48 & 0.0000569 & 0.0000693 & 0.0000821 & 0.3750 \\
\hline $700297 \mathrm{M}$ & $4118 \mathrm{~A}$ & 70F_4s1d2Yc_1 & 70 & $F D$ & 12.7 & 30569.0 & $871 / 2$ & $835 / 8$ & 0.613 & 0.920 & HLP-22 & 12 & 8 & 4 & 3.5 & 26.4 & 11.7 & 22.4 & 9.7 & 0.75 & 0.33 & $\mathrm{sid2}$ & 2.48 & 0.0000569 & 0.0000693 & 0.0000821 & 0.3750 \\
\hline 700298M & $4118 \mathrm{~A}$ & 70F_4s1d2Yc_1 & 70 & $F D$ & 12.7 & 30569.0 & $871 / 2$ & $835 / 8$ & 0.613 & 0.920 & HLP-22 & 12 & 8 & 4 & 3.5 & 26.4 & 11.7 & 22.4 & 9.7 & 0.75 & 0.33 & $51 \mathrm{~d} 2$ & 2.48 & 0.0000569 & 0.0000693 & 0.0000821 & 0.3750 \\
\hline $700299 \mathrm{M}$ & $4118 \mathrm{~A}$ & 70F_4s1d2Yc_1 & 70 & $F D$ & 12.7 & 30569.0 & $871 / 2$ & $835 / 8$ & 0.613 & 0.920 & HLP-22 & 12 & 8 & 4 & 3.5 & 26.4 & 11.7 & 22.4 & 9.7 & 0.75 & 0.33 & sid2 2 & 2.48 & 0.0000569 & 0.0000693 & 0.0000821 & 0.3750 \\
\hline 700300 & $4 / 18 B$ & 70F_4s1d2Rc_1 & 70 & $F D$ & 12.7 & 30569.0 & $871 / 2$ & $835 / 8$ & 0.613 & 0.920 & HLP-22 & 12 & 8 & 4 & 3.5 & 26.4 & 11.7 & 22.4 & 9.7 & 0.75 & 0.33 & $51 \mathrm{~d} 2$ & 2.48 & 0.0000569 & 0.0000693 & 0.0000821 & 0.3750 \\
\hline $700301 \mathrm{M}$ & 4/18B & 70F_4s1d2Rc_1 & 70 & $F D$ & 12.7 & 30569.0 & $871 / 2$ & $835 / 8$ & 0.613 & 0.920 & HLP-22 & 12 & 8 & 4 & 3.5 & 26.4 & 11.7 & 22.4 & 9.7 & 0.75 & 0.33 & $\mathrm{sid2}$ & 2.48 & 0.0000569 & 0.0000693 & 0.0000821 & 0.3750 \\
\hline 700301.1 & 41188 & 70F_4s1d2Rc_1 & 70 & $F D$ & 12.7 & 30569.0 & $871 / 2$ & $835 / 8$ & 0.613 & 0.920 & HLP-22 & 12 & 8 & 4 & 3.5 & 26.4 & 11.7 & 22.4 & 9.7 & 0.75 & 0.33 & sid2 & 2.48 & 0.0000569 & 0.0000693 & 0.0000821 & 0.3750 \\
\hline 700301.2 & $4 / 18 B$ & 70F_4s1d2Rc_1 & 70 & $\mathrm{FD}$ & 12.7 & 30569.0 & $871 / 2$ & $835 / 8$ & 0.613 & 0.920 & HLP.22 & 12 & 8 & 4 & 3.5 & 26.4 & 11.7 & 22.4 & 9.7 & 0.75 & 0.33 & $51 \mathrm{~d} 2$ & 2.48 & 0.0000569 & 0.0000693 & 0.0000821 & 0.3750 \\
\hline $700302 \mathrm{M}$ & 41188 & 70F_4s1d2Rc_1 & 70 & $F$ & 12.7 & 30569.0 & $871 / 2$ & $835 / 8$ & 0.613 & 0.920 & HLP-22 & 12 & 8 & 4 & 3.5 & 26.4 & 11.7 & 22.4 & 9.7 & 0.75 & 0.33 & sid2 2 & 2.48 & 0.0000569 & 0.0000693 & 0.0000821 & 0.3750 \\
\hline 700303 & $4118 B$ & 70F_4s1d2Rc_1 & 70 & $F D$ & 12.7 & 30569.0 & $871 / 2$ & $835 / 8$ & 0.613 & 0.920 & HLP-22 & 12 & 8 & 4 & 3.5 & 26.4 & 11.7 & 22.4 & 9.7 & 0.75 & 0.33 & $51 \mathrm{~d} 2$ & 2.48 & 0.0000569 & 0.0000693 & 0.0000821 & 0.3750 \\
\hline 700304 & $4118 \mathrm{~B}$ & 70F_4s1d2Rc_1 & 70 & $\mathrm{FD}$ & 12.7 & 30569.0 & $871 / 2$ & $835 / 8$ & 0.613 & 0.920 & HLP-22 & 12 & 8 & 4 & 3.5 & 26.4 & 11.7 & 22.4 & 9.7 & 0.75 & 0.33 & s1d2 & 2.48 & 0.0000569 & 0.0000693 & 0.0000821 & 0.3750 \\
\hline 700305 & 41188 & 70F_4s1d2Rc_1 & 70 & $F D$ & 12.7 & 30569.0 & $871 / 2$ & $835 / 8$ & 0.613 & 0.920 & HLP-22 & 12 & 8 & 4 & 3.5 & 26.4 & 11.7 & 22.4 & 9.7 & 0.75 & 0.33 & sid2 & 2.48 & 0.0000569 & 0.0000693 & 0.0000821 & 0.3750 \\
\hline 700306 & $4 / 18 B$ & 70F_4s1d2Rc_1 & 70 & $F D$ & 12.7 & 30569.0 & $871 / 2$ & $835 / 8$ & 0.613 & 0.920 & HLP.22 & 12 & 8 & 4 & 3.5 & 26.4 & 11.7 & 22.4 & 9.7 & 0.75 & 0.33 & $\mathrm{~s} 1 \mathrm{~d} 2$ & 2.48 & 0.0000569 & 0.0000693 & 0.0000821 & 0.3750 \\
\hline 700307 & 41188 & 70F_4s1d2Rc_1 & 70 & $F D$ & 12.7 & 30569.0 & $871 / 2$ & $835 / 8$ & 0.613 & 0.920 & HLP-22 & 12 & 8 & 4 & 3.5 & 26.4 & 11.7 & 22.4 & 9.7 & 0.75 & 0.33 & sid2 2 & 2.48 & 0.0000569 & 0.0000693 & 0.0000821 & 0.3750 \\
\hline 700308 & $4118 B$ & 70F_4s1d2Rc_1 & 70 & $F D$ & 12.7 & 30569.0 & $871 / 2$ & $835 / 8$ & 0.613 & 0.920 & HLP-22 & 12 & 8 & 4 & 3.5 & 26.4 & 11.7 & 22.4 & 9.7 & 0.75 & 0.33 & $51 \mathrm{~d} 2$ & 2.48 & 0.0000569 & 0.0000693 & 0.0000821 & 0.3750 \\
\hline 700309 & 41188 & 70F_4s1d2Rc_1 & 70 & $F D$ & 12.7 & 30569.0 & $871 / 2$ & $835 / 8$ & 0.613 & 0.920 & HLP-22 & 12 & 8 & 4 & 3.5 & 26.4 & 11.7 & 22.4 & 9.7 & 0.75 & 0.33 & s1d2 & 2.48 & 0.0000569 & 0.0000693 & 0.0000821 & 0.3750 \\
\hline $700310 \mathrm{M}$ & 41188 & 70F_4s1d2Rc_1 & 70 & $F D$ & 12.7 & 30569.0 & $871 / 2$ & $835 / 8$ & 0.613 & 0.920 & HLP-22 & 12 & 8 & 4 & 3.5 & 26.4 & 11.7 & 22.4 & 9.7 & 0.75 & 0.33 & sid2 & 2.48 & 0.0000569 & 0.0000693 & 0.0000821 & 0.3750 \\
\hline $700311 \mathrm{M}$ & $4 / 18 B$ & 70F_4s1d2Rc_1 & 70 & $F D$ & 12.7 & 30569.0 & $871 / 2$ & $835 / 8$ & 0.613 & 0.920 & HLP-22 & 12 & 8 & 4 & 3.5 & 26.4 & 11.7 & 22.4 & 9.7 & 0.75 & 0.33 & $\mathrm{~s} 1 \mathrm{~d} 2$ & 2.48 & 0.0000569 & 0.0000693 & 0.0000821 & 0.3750 \\
\hline $700312 \mathrm{M}$ & 41188 & 70F_4s1d2Rc_1 & 70 & $F$ & 12.7 & 30569.0 & $871 / 2$ & $835 / 8$ & 0.613 & 0.920 & HLP-22 & 12 & 8 & 4 & 3.5 & 26.4 & 11.7 & 22.4 & 9.7 & 0.75 & 0.33 & sid2 2 & 2.48 & 0.0000569 & 0.0000693 & 0.0000821 & 0.3750 \\
\hline 700313M & $4 / 18 B$ & 70F_4s1d2Rc_1 & 70 & $F D$ & 12.7 & 30569.0 & $871 / 2$ & $835 / 8$ & 0.613 & 0.920 & HLP-22 & 12 & 8 & 4 & 3.5 & 26.4 & 11.7 & 22.4 & 9.7 & 0.75 & 0.33 & $51 \mathrm{~d} 2$ & 2.48 & 0.0000569 & 0.0000693 & 0.0000821 & 0.3750 \\
\hline 700314M & 41188 & 70F_4s1d2Rc_1 & 70 & $\mathrm{FD}$ & 12.7 & 30569.0 & $871 / 2$ & $835 / 8$ & 0.613 & 0.920 & HLP-22 & 12 & 8 & 4 & 3.5 & 26.4 & 11.7 & 22.4 & 9.7 & 0.75 & 0.33 & s1d2 & 2.48 & 0.0000569 & 0.0000693 & 0.0000821 & 0.3750 \\
\hline 700315 & 4/21A & 70F_4s1d2Vc_1 & 70 & $F D$ & 12.7 & 30569.0 & $871 / 2$ & $835 / 8$ & 0.613 & 0.920 & HLP-22 & 12 & 8 & 4 & 3.5 & 26.4 & 11.7 & 22.4 & 9.7 & 0.75 & 0.33 & s1d2 & 2.48 & 0.0000569 & 0.0000693 & 0.0000821 & 0.3750 \\
\hline 700316 & 4/21A & 70F_4s1d2Vc_1 & 70 & FD & 12.7 & 30569.0 & $871 / 2$ & $835 / 8$ & 0.613 & 0.920 & HLP-22 & 12 & 8 & 4 & 3.5 & 26.4 & 11.7 & 22.4 & 9.7 & 0.75 & 0.33 & s1d2 & 2.48 & 0.0000569 & 0.0000693 & 0.0000821 & 0.3750 \\
\hline 700317 & 4/21A & 70F_4s $1 \mathrm{~d} 2 \mathrm{Vc} \_1$ & 70 & $F D$ & 12.7 & 30569.0 & $871 / 2$ & $835 / 8$ & 0.613 & 0.920 & HLP-22 & 12 & 8 & 4 & 3.5 & 26.4 & 11.7 & 22.4 & 9.7 & 0.75 & 0.33 & sid2 2 & 2.48 & 0.0000569 & 0.0000693 & 0.0000821 & 0.3750 \\
\hline 700318 & 4/21A & 70F_4s1d2VC_1 & 70 & $F$ & 12.7 & 30569.0 & $871 / 2$ & $835 / 8$ & 0.613 & 0.920 & HLP-22 & 12 & 8 & 4 & 3.5 & 26.4 & 11.7 & 22.4 & 9.7 & 0.75 & 0.33 & sid2 2 & 2.48 & 0.0000569 & 0.0000693 & 0.0000821 & 0.3750 \\
\hline 700319M & 4/21A & 70F_4s1d2Vc_1 & 70 & FD & 12.7 & 30569.0 & $871 / 2$ & $835 / 8$ & 0.613 & 0.920 & HLP-22 & 12 & 8 & 4 & 3.5 & 26.4 & 11.7 & 22.4 & 9.7 & 0.75 & 0.33 & s1d2 & 2.48 & 0.0000569 & 0.0000693 & 0.0000821 & 0.3750 \\
\hline $700320 \mathrm{M}$ & 4/21A & 70F_4s1d2Vc_1 & 70 & $F D$ & 12.7 & 30569.0 & $871 / 2$ & 83518 & 0.613 & 0.920 & HLP-22 & 12 & 8 & 4 & 3.5 & 26.4 & 11.7 & 22.4 & 9.7 & 0.75 & 0.33 & s1d2 & 2.48 & 0.0000569 & 0.0000693 & 0.0000821 & 0.3750 \\
\hline 700321 & 4/21A & 70F_4s1d2Vc_1 & 70 & $\mathrm{FD}$ & 12.7 & 30569.0 & $871 / 2$ & $835 / 8$ & 0.613 & 0.920 & HLP-22 & 12 & 8 & 4 & 3.5 & 26.4 & 11.7 & 22.4 & 9.7 & 0.75 & 0.33 & $\mathrm{~s} 1 \mathrm{~d} 2$ & 2.48 & 0.0000569 & 0.0000693 & 0.0000821 & 0.3750 \\
\hline
\end{tabular}


Table B.6. Data from 2008 in Large-Scale Vessel with Flanged and Dished Head B.3

\begin{tabular}{|c|c|c|c|c|c|c|c|c|c|c|c|c|c|c|c|c|c|c|c|c|c|c|c|c|c|c|c|c|c|}
\hline $\begin{array}{l}\text { Tank Water } \\
\text { Temperature }\end{array}$ & $\begin{array}{l}\text { Water } \\
\text { Density }\end{array}$ & $\begin{array}{l}\text { Solids } \\
\text { Fraction } \\
\end{array}$ & $\begin{array}{c}\text { Pulse } \\
\text { Volume } \\
\text { Fraction } \\
\end{array}$ & $\begin{array}{l}\text { Dury } \\
\text { Cyde }\end{array}$ & $\begin{array}{l}\text { Oyde } \\
\text { Time }\end{array}$ & $\begin{array}{c}\text { Pulsed } \\
\text { or } \\
\text { Steady } \\
\text { Jet } \\
\end{array}$ & $\begin{array}{c}\text { Us } \\
\text { Steacy } \\
\text { Jet }\end{array}$ & $\begin{array}{c}\text { U1 } \\
\text { Pulsing } \\
\text { Jet } \\
\end{array}$ & $\begin{array}{l}\text { U2 } \\
\text { URNS }\end{array}$ & $\begin{array}{c}\text { UR } \\
\text { URNB } \\
\end{array}$ & $\begin{array}{l}\text { Discharge } \\
\text { Velocity }\end{array}$ & $\begin{array}{c}\text { Oitical } \\
\text { Suspension } \\
\text { Velocity } \\
\end{array}$ & $\begin{array}{c}\text { Average } \\
\text { Peak Cloud } \\
\text { Height } \\
\end{array}$ & $\begin{array}{c}\text { UCS } \\
\text { Condtion } \\
\end{array}$ & $\begin{array}{l}\text { uCS } \\
\text { Method }\end{array}$ & $\begin{array}{l}\text { UCS } \\
\text { Hag }\end{array}$ & $\begin{array}{c}\text { UCS } \\
\text { Center } \\
\text { Hag } \\
\end{array}$ & $\begin{array}{c}\text { Ucs ucrv } \\
\text { Flag } \\
\end{array}$ & $\begin{array}{c}\text { UCS based } \\
\text { on } \\
\text { Decreasing } \\
\text { velocity } \\
\end{array}$ & \begin{tabular}{|c|} 
Sweep \\
Increase/ \\
Decrease \\
\end{tabular} & $\begin{array}{c}\text { UDV } \\
\text { Height } \\
\text { Bed }\end{array}$ & $\begin{array}{c}\text { Patricle } \\
\text { Motion } \\
\end{array}$ & \begin{tabular}{|l|}
$\begin{array}{l}\text { Solids } \\
\text { Level }\end{array}$ \\
\end{tabular} & \begin{tabular}{|l} 
Outer \\
Botom \\
Pattem \\
\end{tabular} & \begin{tabular}{|c|} 
Inner \\
Bottom \\
Pattem \\
\end{tabular} & Case ID & Test & TDP & $\begin{array}{c}\text { Row } \\
\text { Number }\end{array}$ \\
\hline $\mathrm{C}$ & $\mathrm{g} / \mathrm{cm}^{3}$ & fraction & fraction & fraction & $\mathrm{s}$ & text & $\mathrm{m} / \mathrm{s}$ & $\mathrm{m} / \mathrm{s}$ & $\mathrm{m} / \mathrm{s}$ & $\mathrm{m} / \mathrm{s}$ & $\mathrm{m} / \mathrm{s}$ & $\mathrm{m} / \mathrm{s}$ & in. & m/s & text & text & text & text & $\mathrm{m} / \mathrm{s}$ & \begin{tabular}{|l|} 
text \\
\end{tabular} & $\mathrm{mm}$ & text & \begin{tabular}{|l|} 
text \\
\end{tabular} & text & text & text & text & text & text \\
\hline $\mathrm{T}$ & $\rho$ & $\phi_{\mathrm{s}}$ & $\phi_{p}$ & $\mathrm{DC}$ & tc & Jet & $u_{s}$ & $\mathrm{U}_{1}$ & $\mathrm{U} 2$ & $U_{3}$ & $u$ & Uos & $H_{k}$ & U Usp & Uan & Ussis & Usscen & Usulur & Us_D & $s_{w}$ & $\mathrm{H}_{\mathrm{Hed}}$ & $\mathrm{PM}$ & sol & SPo & $\mathrm{SP}$ & ID & MDDX & $\mathrm{TDP}$ & MSS \\
\hline 22.3 & 0.995 & 0.00155 & 0.050 & 0.336 & 67.4 & $\mathrm{P}$ & $\mathrm{NA}$ & 4.21 & 4.27 & 4.30 & 4.40 & 4.40 & 28.25 & $\mathrm{NA}$ & $\mathrm{NA}$ & $\mathrm{NA}$ & NA & $\mathrm{NA}$ & NA & NA & 1.0 & NA & $\mathrm{NA}$ & NA & NA & 70F_4s1d27c_1 & $417 \mathrm{~A}$ & TDP-139 & 700285 \\
\hline 23.0 & 0.994 & 0.00500 & 0.050 & 0.332 & 55.0 & $\mathrm{P}$ & NA & 5.16 & 5.24 & 5.28 & 5.40 & 5.80 & 19.50 & NA & NA & NA & NA & NA & NA & 1 & 9.0 & 1 & NA & NA & NA & 70F_4s1d2Yc_1 & $4 / 18 \mathrm{~A}$ & TDP-140 & 700286 \\
\hline 22.8 & 0.994 & 0.00500 & 0.050 & 0.333 & 53.0 & $\mathrm{P}$ & NA & 5.38 & 5.46 & 5.50 & 5.60 & 5.80 & 21.75 & NA & NA & NA & NA & NA & NA & 1 & 3.8 & 1 & NA & NA & NA & 70F_4s1d2Yc_1 & 4/18A & TDP-140 & 700287 \\
\hline 22.8 & 0.995 & 0.00500 & 0.050 & 0.334 & 51.0 & $\mathrm{P}$ & NA & 5.54 & 5.62 & 5.66 & 5.80 & 5.80 & 23.25 & 5.80 & udv & NA & ucscen & ucsudv & NA & 1 & 0.0 & 2 & NA & NA & NA & 70F_4s1d2YC_ 1 & 4/18A & TDP-140 & 700288 \\
\hline 22.9 & 0.994 & 0.00500 & 0.050 & 0.335 & 51.0 & $\mathrm{P}$ & NA & 5.53 & 5.62 & 5.66 & 5.80 & 5.80 & 23.00 & NA & NA & NA & NA & NA & NA & NA & $n / a$ & NA & NA & NA & NA & 70F_4sid2YC_ 1 & $4118 \mathrm{~A}$ & TDP-140 & 700288.1 \\
\hline 22.9 & 0.994 & 0.00500 & 0.050 & 0.335 & 51.0 & $\mathrm{P}$ & NA & 5.53 & 5.62 & 5.66 & 5.80 & 5.80 & 23.00 & NA & NA & NA & NA & NA & NA & NA & $\mathrm{na}$ & NA & NA & NA & NA & 70F_4s1d2YY__1 & $4118 \mathrm{~A}$ & TDP-140 & 700288.2 \\
\hline 22.9 & 0.994 & 0.00500 & 0.050 & 0.335 & 51.0 & $\mathrm{P}$ & NA & 5.53 & 5.62 & 5.66 & 5.80 & 5.80 & 23.00 & NA & NA & NA & ucscen & NA & NA & 1 & 0.0 & 2 & NA & NA & NA & 70F_4s1d2YC_ 1 & $4118 \mathrm{~A}$ & TDP-140 & 700289 \\
\hline 22.9 & 0.994 & 0.00500 & 0.050 & 0.335 & 51.0 & $\mathrm{P}$ & NA & 5.53 & 5.62 & 5.66 & 5.80 & 5.80 & 23.00 & NA & NA & NA & NA & NA & NA & NA & 0.0 & NA & NA & NA & NA & $70 F \_4 s 1 d 2 Y c \_1$ & 4/18A & TDP-140 & 700291 \\
\hline 22.9 & 0.994 & 0.00500 & 0.050 & 0.335 & 51.0 & $\mathrm{P}$ & NA & 5.53 & 5.62 & 5.66 & 5.80 & 5.80 & 23.00 & NA & NA & NA & NA & NA & NA & NA & 0.0 & NA & NA & NA & NA & 70F_4sid2YC_ 1 & $418 \mathrm{~A}$ & TDP-140 & 700292 \\
\hline 22.9 & 0.994 & 0.00500 & 0.050 & 0.335 & 51.0 & $\mathrm{P}$ & NA & 5.53 & 5.62 & 5.66 & 5.80 & 5.80 & 23.00 & NA & NA & NA & NA & NA & NA & NA & 0.0 & NA & NA & NA & NA & 70F_4s1d2YC_1 & $4 / 18 \mathrm{~A}$ & TDP-140 & 700293 \\
\hline 22.9 & 0.994 & 0.00500 & 0.050 & 0.335 & 51.0 & $\mathrm{P}$ & NA & 5.53 & 5.62 & 5.66 & 5.80 & 5.80 & 23.00 & NA & NA & NA & NA & NA & NA & NA & 0.0 & NA & NA & NA & NA & 70F_4sid2YC_1 & $4118 \mathrm{~A}$ & TDP-140 & 700294 \\
\hline 22.9 & 0.994 & 0.00500 & 0.050 & 0.335 & 51.0 & $\mathrm{P}$ & NA & 5.53 & 5.62 & 5.66 & 5.80 & 5.80 & 23.00 & NA & NA & NA & NA & NA & NA & NA & 0.0 & NA & NA & NA & NA & 70F_4sid2Yc_1 & $4118 \mathrm{~A}$ & TDP-140 & 700295 \\
\hline 22.9 & 0.994 & 0.00500 & 0.050 & 0.335 & 51.0 & $\mathrm{P}$ & NA & 5.53 & 5.62 & 5.66 & 5.80 & 5.80 & 23.00 & NA & NA & NA & NA & NA & NA & NA & 0.0 & NA & NA & NA & NA & 70F_4sid2Yc_1 & 4/18A & TDP-140 & 700296 \\
\hline 22.9 & 0.994 & 0.00500 & 0.050 & 0.337 & 47.6 & $\mathrm{P}$ & NA & 5.91 & 6.00 & 6.05 & 6.20 & 5.80 & 32.75 & NA & NA & NA & NA & NA & NA & (null) & 0.0 & 4 & NA & NA & NA & 70F_4sid2YC_ 1 & 4/18A & TDP-140 & 700297 \\
\hline 23.0 & 0.995 & 0.00500 & 0.050 & 0.338 & 46.0 & $P$ & NA & 6.10 & 6.19 & 6.24 & 6.40 & 5.80 & 41.25 & NA & NA & NA & NA & NA & NA & 1 & 0.0 & 4 & NA & NA & NA & 70F_4S1d2YC_1 & $4118 \mathrm{~A}$ & TDP-140 & 700298 \\
\hline 22.8 & 0.994 & 0.00500 & 0.050 & 0.335 & 49.0 & $\mathrm{P}$ & NA & 5.75 & 5.83 & 5.87 & 6.00 & 5.80 & 27.75 & NA & NA & NA & NA & NA & NA & $\mathrm{D}$ & 0.0 & 4 & NA & NA & NA & 70F_4s1d2YC_1 & $4 / 18 \mathrm{~A}$ & TDP-140 & 700299 \\
\hline 22.9 & 0.995 & 0.01000 & 0.050 & 0.338 & 46.0 & $\mathrm{P}$ & NA & 6.11 & 6.21 & 6.26 & 6.40 & 6.60 & 22.50 & NA & NA & NA & NA & NA & NA & 1 & 10.1 & 1 & NA & NA & NA & 70F_4s1d2Rc_1 & $4118 \mathrm{~B}$ & TDP-141 & 700300 \\
\hline 22.9 & 0.994 & 0.01000 & 0.050 & 0.339 & 44.6 & $\mathrm{P}$ & NA & 6.28 & 6.38 & 6.44 & 6.60 & 6.60 & 23.00 & \begin{tabular}{|l|}
6.60 \\
\end{tabular} & udv & NA & UCScen & ucsudv & NA & 1 & 0.0 & 2 & NA & NA & NA & 70F_4s1d2Rc_1 & 4/18B & TDP-141 & 700301 \\
\hline 22.9 & 0.995 & 0.01000 & 0.050 & 0.339 & 44.6 & $\mathrm{P}$ & NA & 6.29 & 6.39 & 6.44 & 6.60 & 6.60 & 23.00 & NA & NA & NA & NA & NA & NA & NA & na & NA & NA & NA & NA & 70F_4sid2Rc_1 & 4/18B & TDP-141 & 700301.1 \\
\hline 22.9 & 0.995 & 0.01000 & 0.050 & 0.339 & 44.6 & $\mathrm{P}$ & NA & 6.29 & 6.39 & 6.44 & 6.60 & 6.60 & 23.00 & NA & NA & NA & UCScen & NA & NA & (null) & 1.9 & 2 & NA & NA & NA & 70F_4s1d2Rc_1 & 4/18B & TDP-141 & 700302 \\
\hline 22.9 & 0.995 & 0.01000 & 0.050 & 0.339 & 44.6 & $\mathrm{P}$ & NA & 6.29 & 6.39 & 6.44 & 6.60 & 6.60 & 23.00 & NA & NA & NA & NA & NA & NA & NA & 0.0 & NA & NA & NA & NA & 70F_4s1d2Rc_1 & $4118 \mathrm{~B}$ & TDP-141 & 700303 \\
\hline 22.9 & 0.995 & 0.01000 & 0.050 & 0.339 & 44.6 & $\mathrm{P}$ & NA & 6.29 & 6.39 & 6.44 & 6.60 & 6.60 & 23.00 & NA & NA & NA & NA & NA & NA & NA & 0.0 & NA & NA & NA & NA & 70F_4s1d2Rc_1 & 4/18B & TDP-141 & 700304 \\
\hline 22.9 & 0.995 & 0.01000 & 0.050 & 0.339 & 44.6 & $\mathrm{P}$ & NA & 6.29 & 6.39 & 6.44 & 6.60 & 6.60 & 23.00 & NA & NA & NA & NA & NA & NA & NA & 8.2 & NA & NA & NA & NA & 70F_4sid2Rc_1 & $4188 \mathrm{~B}$ & TDP-141 & 700305 \\
\hline 22.9 & 0.995 & 0.01000 & 0.050 & 0.339 & 44.6 & $\mathrm{P}$ & NA & 6.29 & 6.39 & 6.44 & 6.60 & 6.60 & 23.00 & NA & NA & NA & NA & NA & NA & NA & 2.9 & NA & NA & NA & NA & 70F_4s1d2Rc_1 & $4118 \mathrm{~B}$ & TDP-141 & 700306 \\
\hline 22.9 & 0.995 & 0.01000 & 0.050 & 0.339 & 44.6 & $\mathrm{P}$ & NA & 6.29 & 6.39 & 6.44 & 6.60 & 6.60 & 23.00 & NA & NA & NA & NA & NA & NA & NA & 0.0 & NA & NA & NA & NA & 70F_4s1d2Rc_1 & 4/188 & TDP-141 & 700307 \\
\hline 22.9 & 0.995 & 0.01000 & 0.050 & 0.339 & 44.6 & $\mathrm{P}$ & NA & 6.29 & 6.39 & 6.44 & 6.60 & 6.60 & 23.00 & NA & NA & NA & NA & NA & NA & NA & 0.0 & NA & NA & NA & NA & 70F_4s1d2Rc_1 & $4118 \mathrm{~B}$ & TDP-141 & 700308 \\
\hline 22.9 & 0.995 & 0.01000 & 0.050 & 0.339 & 44.6 & $\mathrm{P}$ & NA & 6.29 & 6.39 & 6.44 & 6.60 & 6.60 & 23.00 & NA & NA & NA & NA & NA & NA & NA & 0.7 & NA & NA & NA & NA & 70F_4s1d2Rc_ 1 & 4/18B & TDP-141 & 700309 \\
\hline 22.7 & 0.995 & 0.01000 & 0.050 & 0.340 & 43.2 & $\mathrm{P}$ & NA & 6.47 & 6.58 & 6.63 & 6.80 & 6.60 & 27.50 & NA & NA & NA & NA & NA & NA & (null) & 0.0 & 4 & NA & NA & NA & 70F_4s1d2Rc_1 & $4188 \mathrm{~B}$ & TDP-141 & 700310 \\
\hline 22.9 & 0.995 & 0.01000 & 0.050 & 0.334 & 43.2 & $\mathrm{P}$ & NA & 6.63 & 6.74 & 6.80 & 7.00 & 6.60 & 27.75 & NA & NA & NA & NA & $\mathrm{NA}$ & NA & 1 & 0.0 & 4 & NA & NA & NA & 70F_4s1d2Rc_1 & $4118 \mathrm{~B}$ & TDP-141 & 700311 \\
\hline 23.0 & 0.994 & 0.01000 & 0.050 & 0.335 & 42.0 & $\mathrm{P}$ & NA & 6.81 & 6.92 & 6.98 & 7.20 & 6.60 & 30.25 & NA & NA & NA & NA & NA & NA & 1 & 0.0 & 4 & NA & NA & NA & 70F_4s1d2Rc_1 & $4 / 188$ & TDP-141 & 700312 \\
\hline 23.0 & 0.994 & 0.01000 & 0.050 & 0.336 & 40.0 & $\mathrm{P}$ & NA & 7.10 & 7.23 & 7.29 & 7.50 & 6.60 & 38.00 & NA & NA & NA & NA & NA & NA & 1 & 0.0 & 4 & NA & NA & NA & 70F_4s1d2Rc_1 & $4118 \mathrm{~B}$ & TDP-141 & 700313 \\
\hline 23.2 & 0.994 & 0.01000 & 0.050 & 0.338 & 38.6 & $\mathrm{P}$ & NA & 7.27 & 7.40 & 7.47 & 7.70 & 6.60 & 51.50 & NA & NA & NA & NA & NA & NA & 1 & 0.0 & 4 & NA & NA & NA & 70F_4s1d2Rc_ 1 & 4/18B & TDP-141 & 700314 \\
\hline 20.4 & 0.995 & 0.01430 & 0.050 & 0.332 & 47.4 & $\mathrm{P}$ & NA & 6.10 & 6.20 & 6.25 & 6.40 & 7.10 & 22.00 & NA & NA & NA & NA & NA & NA & 1 & 32.9 & 1 & NA & NA & NA & 70F_4sid2Vc_1 & $4 / 21 \mathrm{~A}$ & TDP-142 & 700315 \\
\hline 20.4 & 0.995 & 0.01430 & 0.050 & 0.334 & 44.4 & $\mathrm{P}$ & NA & 6.48 & 6.58 & 6.63 & 6.80 & 7.10 & 24.50 & NA & NA & NA & NA & $\mathrm{NA}$ & NA & 1 & 10.5 & 1 & NA & NA & NA & 70F_4s1d2VC_1 & 4/21A & TDP-142 & 700316 \\
\hline 21.0 & 0.995 & 0.01430 & 0.050 & 0.334 & 44.4 & $\mathrm{P}$ & NA & 6.47 & 6.57 & 6.63 & 6.80 & 7.10 & 25.00 & NA & NA & NA & NA & NA & NA & (null) & 16.2 & 1 & NA & NA & NA & 70F_4s1d2VC_1 & $4 / 21 \mathrm{~A}$ & TDP-142 & 700317 \\
\hline 21.2 & 0.995 & 0.01430 & 0.050 & 0.335 & 43.0 & $\mathrm{P}$ & NA & 6.64 & 6.75 & 6.81 & 7.00 & 7.10 & 28.00 & NA & NA & NA & NA & NA & NA & 1 & 4.1 & 1 & NA & NA & NA & 70F_4s1d2VC_1 & $4 / 21 \mathrm{~A}$ & TDP-142 & 700318 \\
\hline 21.1 & 0.995 & 0.01430 & 0.050 & 0.336 & 42.2 & $\mathrm{P}$ & NA & 6.75 & 6.86 & 6.92 & 7.10 & 7.10 & 30.50 & 7.10 & uav & NA & Ucscen & ucsudv & NA & 1 & 0.0 & 2 & NA & NA & NA & 70F_4s1d2V _ 1 & 4/21A & TDP-142 & 700319 \\
\hline 21.0 & 0.995 & 0.01430 & 0.050 & 0.336 & 42.2 & $\mathrm{P}$ & NA & 6.74 & 6.86 & 6.91 & 7.10 & 7.10 & 30.00 & NA & NA & NA & Ucscen & NA & NA & 1 & 0.0 & 2 & NA & NA & NA & 70F_4s1d2V__1 & $4 / 21 \mathrm{~A}$ & TDP-142 & 700320 \\
\hline 21.0 & 0.995 & & 0.050 & 0.336 & 42.2 & $P$ & NA & 6.74 & 6.86 & 6.91 & 7.10 & 7.10 & 30.00 & NA & NA & NA & NA & NA & NA & NA & 1.5 & NA & NA & NA & NA & 705010 & & TDP-142 & 700321 \\
\hline
\end{tabular}


Table B.6. Data from 2008 in Large-Scale Vessel with Flanged and Dished Head A.4

\begin{tabular}{|c|c|c|c|c|c|c|c|c|c|c|c|c|c|c|c|c|c|c|c|c|c|c|c|c|c|c|c|}
\hline $\begin{array}{c}\text { Row } \\
\text { Number }\end{array}$ & Test & Case ID & \begin{tabular}{c|} 
Tank \\
Diameter
\end{tabular} & $\begin{array}{l}\text { Head } \\
\text { Shape }\end{array}$ & $\begin{array}{l}\text { Dish } \\
\text { Height }\end{array}$ & $\begin{array}{l}\text { Dish } \\
\text { Volume }\end{array}$ & $\begin{array}{c}\text { Tank } \\
\text { Filn } \\
\text { Height }\end{array}$ & $\begin{array}{c}\text { Retur } \\
\text { Line } \\
\text { Height } \\
\text { Heignt }\end{array}$ & $\begin{array}{c}\text { Nozzle } \\
\text { Inner } \\
\text { Diameter }\end{array}$ & $\begin{array}{c}\text { Nozzle } \\
\text { Stanct } \\
\text { off } \\
\text { Distance }\end{array}$ & $\begin{array}{l}\text { Pulse Tube } \\
\text { Configuration }\end{array}$ & $\begin{array}{l}\text { Installed } \\
\text { Nozzles }\end{array}$ & $\begin{array}{c}\text { OOter } \\
\text { Nozeldes } \\
\text { Operated }\end{array}$ & $\begin{array}{c}\text { Inner } \\
\text { Nozeles } \\
\text { Operated }\end{array}$ & $\begin{array}{c}\text { Pulse Tube } \\
\text { Outer } \\
\text { Diameter }\end{array}$ & $\begin{array}{c}\text { Outer } \\
\text { PJM } \\
\text { Radius }\end{array}$ & $\begin{array}{c}\text { Inner } \\
\text { PPM } \\
\text { Radius }\end{array}$ & $\begin{array}{l}\text { "FOC' Outer } \\
\text { PJM } \\
\text { Impingement } \\
\text { Angle }\end{array}$ & $\begin{array}{l}\text { "FO' Inner } \\
\text { PJM } \\
\text { Impingement } \\
\text { Angle }\end{array}$ & $\begin{array}{c}\text { Ratio Outer } \\
\text { PJM to } \\
\text { Tank } \\
\text { Radius } \\
\end{array}$ & $\begin{array}{c}\text { Ratio Inner } \\
\text { PJMto } \\
\text { Tank } \\
\text { Radius } \\
\end{array}$ & Simulant & $\begin{array}{l}\text { Solids } \\
\text { Density }\end{array}$ & $\begin{array}{c}\text { Particle } \\
\text { Diameter } 55\end{array}$ & $\begin{array}{c}\text { Particle } \\
\text { Diameter } \\
\text { d50 }\end{array}$ & $\begin{array}{c}\text { Patidice } \\
\text { Diameter } \\
\text { d95 }\end{array}$ & $\begin{array}{c}\text { Void } \\
\text { Fraction }\end{array}$ \\
\hline text & text & text & in. & text & in. & in. ${ }^{3}$ & in. & in. & in. & in. & text & number & number & number & in. & in. & in. & deg & deg & nondim & nondim & text & $\mathrm{g} / \mathrm{cm}^{3}$ & $\mathrm{~m}$ & $\mathrm{~m}$ & $\mathrm{~m}$ & fraction \\
\hline MSS & MDDX & $\mathrm{ID}$ & $\mathrm{D}$ & $\mathrm{HS}$ & Hash & $V_{\text {dsh }}$ & $\mathrm{H}$ & $\mathrm{Rn}$ & $d$ & sod & PT & $\mathrm{N}$ & $\mathrm{Nb}$ & $\mathrm{N}$ & $\mathrm{PT}_{\alpha \mathrm{d}}$ & $\mathrm{Ro}_{0}$ & $R$ & $\theta_{\circ}$ & $\theta_{1}$ & $R d R$ & $R / R$ & $\operatorname{sxdx}$ & $\rho_{s}$ & $d s$ & $\mathrm{~d}_{\mathrm{s}}$ & $\frac{d 65}{d}$ & vf \\
\hline 700322 & 4/21A & 70F_4s1d2VC_1 & 70 & $\mathrm{FD}$ & 12.7 & 30569.0 & $871 / 2$ & $835 / 8$ & 0.613 & 0.920 & HLP-22 & 12 & 8 & 4 & 3.5 & 26.4 & 11.7 & 22.4 & 9.7 & 0.75 & 0.33 & s1d2 & 2.48 & 0.0000569 & 0.0000693 & 0.0000821 & 0.3750 \\
\hline 700323 & 4/21A & 70F_4s1d2Vc_1 & 70 & $F D$ & 12.7 & 30569.0 & $871 / 2$ & $835 / 8$ & 0.613 & 0.920 & HLP-22 & 12 & 8 & 4 & 3.5 & 26.4 & 11.7 & 22.4 & 9.7 & 0.75 & 0.33 & s1d2 & 2.48 & 0.0000569 & 0.0000693 & 0.0000821 & 0.3750 \\
\hline 700324 & 4/21A & 70F_4s1d2Vc_1 & 70 & $F D$ & 12.7 & 30569.0 & $871 / 2$ & $835 / 8$ & 0.613 & 0.920 & HLP-22 & 12 & 8 & 4 & 3.5 & 26.4 & 11.7 & 22.4 & 9.7 & 0.75 & 0.33 & s1d2 & 2.48 & 0.0000569 & 0.0000693 & 0.0000821 & 0.3750 \\
\hline 700325 & 4/21A & 70F_4s1d2VC_1 & 70 & FD & 12.7 & 30569.0 & $871 / 2$ & $835 / 8$ & 0.613 & 0.920 & HLP-22 & 12 & 8 & 4 & 3.5 & 26.4 & 11.7 & 22.4 & 9.7 & 0.75 & 0.33 & $\mathrm{sid2}$ & 2.48 & 0.0000569 & 0.0000693 & 0.0000821 & 0.3750 \\
\hline 700326 & 4/21A & 70F_4sidzVc_1 & 70 & $\mathrm{FD}$ & 12.7 & 30569.0 & $871 / 2$ & $835 / 8$ & 0.613 & 0.920 & HLP-22 & 12 & 8 & 4 & 3.5 & 26.4 & 11.7 & 22.4 & 9.7 & 0.75 & 0.33 & s1d2 & 2.48 & 0.0000569 & 0.0000693 & 0.0000821 & 0.3750 \\
\hline 700327 & 4/21A & 70F_4s1d2Vc_1 & 70 & $F D$ & 12.7 & 30569.0 & $871 / 2$ & $835 / 8$ & 0.613 & 0.920 & HLP-22 & 12 & 8 & 4 & 3.5 & 26.4 & 11.7 & 22.4 & 9.7 & 0.75 & 0.33 & $\mathrm{sid2}$ & 2.48 & 0.0000569 & 0.0000693 & 0.0000821 & 0.3750 \\
\hline 700328 & 4/21A & 70F_4s1d2Vc_1 & 70 & $F D$ & 12.7 & 30569.0 & $871 / 2$ & $835 / 8$ & 0.613 & 0.920 & HLP-22 & 12 & 8 & 4 & 3.5 & 26.4 & 11.7 & 22.4 & 9.7 & 0.75 & 0.33 & s1d2 & 2.48 & 0.0000569 & 0.0000693 & 0.0000821 & 0.3750 \\
\hline 700329 & 4/21A & 70F_4s1d2Vc_1 & 70 & $F D$ & 12.7 & 30569.0 & $871 / 2$ & $835 / 8$ & 0.613 & 0.920 & HLP-22 & 12 & 8 & 4 & 3.5 & 26.4 & 11.7 & 22.4 & 9.7 & 0.75 & 0.33 & s1d2 & 2.48 & 0.0000569 & 0.0000693 & 0.0000821 & 0.3750 \\
\hline 700330M & 4/21A & 70F_4s1d2VC_1 1 & 70 & $F D$ & 12.7 & 30569.0 & $871 / 2$ & $835 / 8$ & 0.613 & 0.920 & HLP-22 & 12 & 8 & 4 & 3.5 & 26.4 & 11.7 & 22.4 & 9.7 & 0.75 & 0.33 & $\mathrm{sid2}$ & 2.48 & 0.0000569 & 0.0000693 & 0.0000821 & 0.3750 \\
\hline 700331 & 4/21A & 70F_4s1d2Vc_1 & 70 & $F D$ & 12.7 & 30569.0 & $871 / 2$ & $835 / 8$ & 0.613 & 0.920 & HLP-22 & 12 & 8 & 4 & 3.5 & 26.4 & 11.7 & 22.4 & 9.7 & 0.75 & 0.33 & $51 \mathrm{~d} 2$ & 2.48 & 0.0000569 & 0.0000693 & 0.0000821 & 0.3750 \\
\hline 700332 & 4/21A & 70F_4s1d2Vc_1 & 70 & $F D$ & 12.7 & 30569.0 & $871 / 2$ & $835 / 8$ & 0.613 & 0.920 & HLP-22 & 12 & 8 & 4 & 3.5 & 26.4 & 11.7 & 22.4 & 9.7 & 0.75 & 0.33 & $\mathrm{sid2}$ & 2.48 & 0.0000569 & 0.0000693 & 0.0000821 & 0.3750 \\
\hline 700333 & 4/21A & 70F_4s1d2Vc_1 & 70 & $F$ & 12.7 & 30569.0 & $871 / 2$ & $835 / 8$ & 0.613 & 0.920 & HLP-22 & 12 & 8 & 4 & 3.5 & 26.4 & 11.7 & 22.4 & 9.7 & 0.75 & 0.33 & s1d2 & 2.48 & 0.0000569 & 0.0000693 & 0.0000821 & 0.3750 \\
\hline 700334 & 4/21A & 70F_4s1d2Vc_1 & 70 & $F D$ & 12.7 & 30569.0 & $871 / 2$ & $835 / 8$ & 0.613 & 0.920 & HLP-22 & 12 & 8 & 4 & 3.5 & 26.4 & 11.7 & 22.4 & 9.7 & 0.75 & 0.33 & $51 \mathrm{~d} 2$ & 2.48 & 0.0000569 & 0.0000693 & 0.0000821 & 0.3750 \\
\hline 700335 & 4/21A & 70F_4s1d2V__1 1 & 70 & $F D$ & 12.7 & 30569.0 & $871 / 2$ & $835 / 8$ & 0.613 & 0.920 & HLP-22 & 12 & 8 & 4 & 3.5 & 26.4 & 11.7 & 22.4 & 9.7 & 0.75 & 0.33 & $\mathrm{~s} 1 \mathrm{~d} 2$ & 2.48 & 0.0000569 & 0.0000693 & 0.0000821 & 0.3750 \\
\hline 700336 & 4/21A & 70F_4s1d2Vc_1 & 70 & $F D$ & 12.7 & 30569.0 & $871 / 2$ & $835 / 8$ & 0.613 & 0.920 & HLP-22 & 12 & 8 & 4 & 3.5 & 26.4 & 11.7 & 22.4 & 9.7 & 0.75 & 0.33 & $\mathrm{sid2}$ & 2.48 & 0.0000569 & 0.0000693 & 0.0000821 & 0.3750 \\
\hline 700337 & 4/21A & 70F_4s1d2Vc_1 & 70 & $F D$ & 12.7 & 30569.0 & $871 / 2$ & $835 / 8$ & 0.613 & 0.920 & HLP-22 & 12 & 8 & 4 & 3.5 & 26.4 & 11.7 & 22.4 & 9.7 & 0.75 & 0.33 & $51 \mathrm{~d} 2$ & 2.48 & 0.0000569 & 0.0000693 & 0.0000821 & 0.3750 \\
\hline 700338 & 4/21A & 70F_4s1d2Vc_1 & 70 & $F D$ & 12.7 & 30569.0 & $871 / 2$ & $835 / 8$ & 0.613 & 0.920 & HLP-22 & 12 & 8 & 4 & 3.5 & 26.4 & 11.7 & 22.4 & 9.7 & 0.75 & 0.33 & sid2 2 & 2.48 & 0.0000569 & 0.0000693 & 0.0000821 & 0.3750 \\
\hline 700339 & 4/21A & 70F_4s1d2Vc_1 & 70 & $F D$ & 12.7 & 30569.0 & $871 / 2$ & $835 / 8$ & 0.613 & 0.920 & HLP-22 & 12 & 8 & 4 & 3.5 & 26.4 & 11.7 & 22.4 & 9.7 & 0.75 & 0.33 & $51 \mathrm{~d} 2$ & 2.48 & 0.0000569 & 0.0000693 & 0.0000821 & 0.3750 \\
\hline 700340M & 4/21A & 70F_4s1d2Vc_ 1 & 70 & $F D$ & 12.7 & 30569.0 & $871 / 2$ & $835 / 8$ & 0.613 & 0.920 & HLP-22 & 12 & 8 & 4 & 3.5 & 26.4 & 11.7 & 22.4 & 9.7 & 0.75 & 0.33 & $\mathrm{sid2}$ & 2.48 & 0.0000569 & 0.0000693 & 0.0000821 & 0.3750 \\
\hline 700341 & 4/21A & 70F_4s1d2VC_1 & 70 & $\mathrm{FD}$ & 12.7 & 30569.0 & $871 / 2$ & $835 / 8$ & 0.613 & 0.920 & HLP-22 & 12 & 8 & 4 & 3.5 & 26.4 & 111.7 & 22.4 & 9.7 & 0.75 & 0.33 & $\mathrm{~s} 1 \mathrm{~d} 2$ & 2.48 & 0.0000569 & 0.0000693 & 0.0000821 & 0.3750 \\
\hline 700342 & 4/21A & 70F_4s1d2Vc_1 & 70 & $\mathrm{FD}$ & 12.7 & 30569.0 & $871 / 2$ & $835 / 8$ & 0.613 & 0.920 & HLP.22 & 12 & 8 & 4 & 3.5 & 26.4 & 11.7 & 22.4 & 9.7 & 0.75 & 0.33 & $51 \mathrm{~d} 2$ & 2.48 & 0.0000569 & 0.0000693 & 0.0000821 & 0.3750 \\
\hline 700343 & 4/21A & 70F_4s1d2Vc_1 & 70 & $F$ & 12.7 & 30569.0 & $871 / 2$ & $835 / 8$ & 0.613 & 0.920 & HLP-22 & 12 & 8 & 4 & 3.5 & 26.4 & 11.7 & 22.4 & 9.7 & 0.75 & 0.33 & sid2 2 & 2.48 & 0.0000569 & 0.0000693 & 0.0000821 & 0.3750 \\
\hline 700344 & 4/21A & 70F_4s1d2Vc_1 & 70 & $F D$ & 12.7 & 30569.0 & $871 / 2$ & $835 / 8$ & 0.613 & 0.920 & HLP-22 & 12 & 8 & 4 & 3.5 & 26.4 & 11.7 & 22.4 & 9.7 & 0.75 & 0.33 & $51 \mathrm{~d} 2$ & 2.48 & 0.0000569 & 0.0000693 & 0.0000821 & 0.3750 \\
\hline 700345 & 4/21A & $70 F \_4 s 1 d 2 \mathrm{Vc} \_1$ & 70 & $\mathrm{FD}$ & 12.7 & 30569.0 & $871 / 2$ & $835 / 8$ & 0.613 & 0.920 & HLP-22 & 12 & 8 & 4 & 3.5 & 26.4 & 11.7 & 22.4 & 9.7 & 0.75 & 0.33 & s1d2 & 2.48 & 0.0000569 & 0.0000693 & 0.0000821 & 0.3750 \\
\hline 700346 & 4/21A & 70F_4sid2VC_1 & 70 & $\mathrm{FD}$ & 12.7 & 30569.0 & $871 / 2$ & $835 / 8$ & 0.613 & 0.920 & HLP-22 & 12 & 8 & 4 & 3.5 & 26.4 & 11.7 & 22.4 & 9.7 & 0.75 & 0.33 & s1d2 & 2.48 & 0.0000569 & 0.0000693 & 0.0000821 & 0.3750 \\
\hline 700347 & 4/21A & 70F_4s1d2Vc_1 & 70 & $F D$ & 12.7 & 30569.0 & $871 / 2$ & $835 / 8$ & 0.613 & 0.920 & HLP.22 & 12 & 8 & 4 & 3.5 & 26.4 & 11.7 & 22.4 & 9.7 & 0.75 & 0.33 & $\mathrm{~s} 1 \mathrm{~d} 2$ & 2.48 & 0.0000569 & 0.0000693 & 0.0000821 & 0.3750 \\
\hline 700347.1 & 4/21A & $70 F \_4 s 1 d 2 \mathrm{Vc} \_1$ & 70 & $F D$ & 12.7 & 30569.0 & $871 / 2$ & $835 / 8$ & 0.613 & 0.920 & HLP-22 & 12 & 8 & 4 & 3.5 & 26.4 & 11.7 & 22.4 & 9.7 & 0.75 & 0.33 & sid2 2 & 2.48 & 0.0000569 & 0.0000693 & 0.0000821 & 0.3750 \\
\hline 700347.2 & 4/21A & 70F_4s1d2Vc_1 & 70 & $F D$ & 12.7 & 30569.0 & $871 / 2$ & $835 / 8$ & 0.613 & 0.920 & HLP-22 & 12 & 8 & 4 & 3.5 & 26.4 & 11.7 & 22.4 & 9.7 & 0.75 & 0.33 & $51 \mathrm{~d} 2$ & 2.48 & 0.0000569 & 0.0000693 & 0.0000821 & 0.3750 \\
\hline 700348M & 4/21A & $70 F \_4 \mathrm{~s} 1 \mathrm{~d} 2 \mathrm{Vc} \_1$ & 70 & $F D$ & 12.7 & 30569.0 & $871 / 2$ & $835 / 8$ & 0.613 & 0.920 & HLP-22 & 12 & 8 & 4 & 3.5 & 26.4 & 11.7 & 22.4 & 9.7 & 0.75 & 0.33 & s1d2 & 2.48 & 0.0000569 & 0.0000693 & 0.0000821 & 0.3750 \\
\hline $700349 \mathrm{M}$ & 4/21A & 70F_4S1d2VC_1 & 70 & $\mathrm{FD}$ & 12.7 & 30569.0 & $871 / 2$ & $835 / 8$ & 0.613 & 0.920 & HLP-22 & 12 & 8 & 4 & 3.5 & 26.4 & 111.7 & 22.4 & 9.7 & 0.75 & 0.33 & s1d2 & 2.48 & 0.0000569 & 0.0000693 & 0.0000821 & 0.3750 \\
\hline 700350M & 4/21A & 70F_4s1d2Vc_1 & 70 & $F D$ & 12.7 & 30569.0 & $871 / 2$ & $835 / 8$ & 0.613 & 0.920 & HLP-22 & 12 & 8 & 4 & 3.5 & 26.4 & 11.7 & 22.4 & 9.7 & 0.75 & 0.33 & $\mathrm{~s} 1 \mathrm{~d} 2$ & 2.48 & 0.0000569 & 0.0000693 & 0.0000821 & 0.3750 \\
\hline 700351 & $4 / 22 \mathrm{~A}$ & 70F_4s1d2Vd_1 & 70 & $F D$ & 12.7 & 30569.0 & 88 & $835 / 8$ & 0.613 & 0.920 & HLP-22 & 12 & 8 & 4 & 3.5 & 26.4 & 11.7 & 22.4 & 9.7 & 0.75 & 0.33 & sid2 2 & 2.48 & 0.0000569 & 0.0000693 & 0.0000821 & 0.3750 \\
\hline 700352 & 4/22A & 70F_4s1d2Vd_1 & 70 & $F D$ & 12.7 & 30569.0 & 88 & $835 / 8$ & 0.613 & 0.920 & HLP-22 & 12 & 8 & 4 & 3.5 & 26.4 & 11.7 & 22.4 & 9.7 & 0.75 & 0.33 & $51 \mathrm{~d} 2$ & 2.48 & 0.0000569 & 0.0000693 & 0.0000821 & 0.3750 \\
\hline 700353 & 4/22A & 70F_4s1d2Vd_1 & 70 & $F D$ & 12.7 & 30569.0 & 88 & $835 / 8$ & 0.613 & 0.920 & HLP-22 & 12 & 8 & 4 & 3.5 & 26.4 & 11.7 & 22.4 & 9.7 & 0.75 & 0.33 & s1d2 & 2.48 & 0.0000569 & 0.0000693 & 0.0000821 & 0.3750 \\
\hline 700354 & 4/22A & 70F_4sid2Vd_1 & 70 & $F D$ & 12.7 & 30569.0 & 88 & $835 / 8$ & 0.613 & 0.920 & HLP-22 & 12 & 8 & 4 & 3.5 & 26.4 & 11.7 & 22.4 & 9.7 & 0.75 & 0.33 & s1d2 & 2.48 & 0.0000569 & 0.0000693 & 0.0000821 & 0.3750 \\
\hline 700355 & 4/22A & 70F_4s1d2Vd_1 & 70 & FD & 12.7 & 30569.0 & 88 & $835 / 8$ & 0.613 & 0.920 & HLP-22 & 12 & 8 & 4 & 3.5 & 26.4 & 11.7 & 22.4 & 9.7 & 0.75 & 0.33 & s1d2 & 2.48 & 0.0000569 & 0.0000693 & 0.0000821 & 0.3750 \\
\hline $700356 \mathrm{M}$ & $4 / 22 \mathrm{~A}$ & 70F_4s1d2Vd_1 & 70 & $F D$ & 12.7 & 30569.0 & 88 & $835 / 8$ & 0.613 & 0.920 & HLP-22 & 12 & 8 & 4 & 3.5 & 26.4 & 11.7 & 22.4 & 9.7 & 0.75 & 0.33 & sid2 2 & 2.48 & 0.0000569 & 0.0000693 & 0.0000821 & 0.3750 \\
\hline 700356.1 & 4/22A & 70F_4s1d2Vd_1 & 70 & $F D$ & 12.7 & 30569.0 & 88 & $835 / 8$ & 0.613 & 0.920 & HLP-22 & 12 & 8 & 4 & 3.5 & 26.4 & 11.7 & 22.4 & 9.7 & 0.75 & 0.33 & s1d2 2 & 2.48 & 0.0000569 & 0.0000693 & 0.0000821 & 0.3750 \\
\hline 700357M & 4/22A & 70F_4s1d2Vd_1 & 70 & FD & 12.7 & 30569.0 & 88 & $835 / 8$ & 0.613 & 0.920 & HLP-22 & 12 & 8 & 4 & 3.5 & 26.4 & 11.7 & 22.4 & 9.7 & 0.75 & 0.33 & s1d2 & 2.48 & 0.0000569 & 0.0000693 & 0.0000821 & 0.3750 \\
\hline 700358 & 4/22A & 70F_4s1d2Vd_1 & 70 & $F D$ & 12.7 & 30569.0 & 88 & 83518 & 0.613 & 0.920 & HLP-22 & 12 & 8 & 4 & 3.5 & 26.4 & 11.7 & 22.4 & 9.7 & 0.75 & 0.33 & s1d2 & 2.48 & 0.0000569 & 0.0000693 & 0.0000821 & 0.3750 \\
\hline 700359 & $4 / 22 \mathrm{~A}$ & 70F_4sid2Vd_1 & 70 & $\mathrm{FD}$ & 12.7 & 30569.0 & 88 & $835 / 8$ & 0.613 & 0.920 & HLP-22 & 12 & 8 & 4 & 3.5 & 26.4 & 11.7 & 22.4 & 9.7 & 0.75 & 0.33 & $\mathrm{~s} 1 \mathrm{~d} 2$ & 2.48 & 0.0000569 & 0.0000693 & 0.0000821 & 0.3750 \\
\hline
\end{tabular}


Table B.6. Data from 2008 in Large-Scale Vessel with Flanged and Dished Head B.4

\begin{tabular}{|c|c|c|c|c|c|c|c|c|c|c|c|c|c|c|c|c|c|c|c|c|c|c|c|c|c|c|c|c|c|}
\hline $\begin{array}{l}\text { Tank Water } \\
\text { Temperature }\end{array}$ & $\begin{array}{l}\text { Water } \\
\text { Density }\end{array}$ & $\begin{array}{l}\text { Solids } \\
\text { Fraction }\end{array}$ & $\begin{array}{c}\text { Pulse } \\
\text { Volume } \\
\text { Fraction }\end{array}$ & $\begin{array}{l}\text { Duty } \\
\text { Cydle }\end{array}$ & $\begin{array}{l}\text { Oyde } \\
\text { Time }\end{array}$ & $\begin{array}{c}\text { Pulsed } \\
\text { or } \\
\text { Steady } \\
\text { Jet }\end{array}$ & $\begin{array}{l}\text { Us } \\
\text { Steacdy } \\
\text { Jet }\end{array}$ & $\begin{array}{c}\text { U1 } \\
\text { Pulsing } \\
\text { Jet } \\
\text { Jut }\end{array}$ & $\begin{array}{c}\text { U2 } \\
\text { URMS }\end{array}$ & $\begin{array}{c}\text { UB } \\
\text { URNB }\end{array}$ & $\begin{array}{c}\text { Discharge } \\
\text { Velocity }\end{array}$ & $\begin{array}{c}\text { Citical } \\
\text { Suspension } \\
\text { velocity }\end{array}$ & 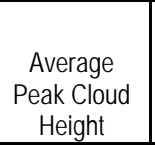 & $\begin{array}{c}\text { UCS } \\
\text { Condition }\end{array}$ & $\begin{array}{l}\text { UCS } \\
\text { Nethod }\end{array}$ & $\begin{array}{l}\text { UCS } \\
\text { Fag }\end{array}$ & $\begin{array}{l}\text { UCS } \\
\text { Center } \\
\text { Hag }\end{array}$ & $\begin{array}{c}\text { UCS udv } \\
\text { Hag }\end{array}$ & $\begin{array}{l}\text { UCS based } \\
\text { on } \\
\text { Decreasing } \\
\text { Velocity }\end{array}$ & $\begin{array}{l}\text { Sweep } \\
\text { Increase I } \\
\text { Decrease }\end{array}$ & $\begin{array}{c}\text { UDV } \\
\text { Height } \\
\text { Bed }\end{array}$ & $\begin{array}{c}\text { Particle } \\
\text { Motion }\end{array}$ & $\begin{array}{l}\text { Solids } \\
\text { Level }\end{array}$ & $\begin{array}{c}\text { Outer } \\
\text { Bottom } \\
\text { Pattem }\end{array}$ & $\begin{array}{l}\text { Inner } \\
\text { Bototom } \\
\text { Pattem }\end{array}$ & CaselD & Test & TDP & $\begin{array}{l}\text { Row } \\
\text { Number }\end{array}$ \\
\hline$c$ & $\mathrm{~g} / \mathrm{cm}^{3}$ & fraction & fraction & fraction & $\mathrm{s}$ & text & $\mathrm{m} / \mathrm{s}$ & $\begin{array}{ll}\mathrm{m} / \mathrm{s} \\
\end{array}$ & $m / s$ & ms & \begin{tabular}{l|}
$\mathrm{m} / \mathrm{s}$ \\
\end{tabular} & $\begin{array}{ll}\mathrm{ms} \\
\end{array}$ & in. & $\mathrm{ms}$ & text & text & text & text & $m / s$ & text & $\mathrm{mm}$ & $\begin{array}{ll}\text { text } \\
\end{array}$ & text & text & text & text & text & text & text \\
\hline$T$ & $\rho$ & $\phi_{\mathrm{s}}$ & $\phi_{\phi_{p}}$ & $\mathrm{DC}$ & tc & Jet & $u_{s}$ & $\mathrm{U}_{1}$ & $\mathrm{U} 2$ & U3 & $u$ & Uas & $H_{k}$ & U Uss & Usom & Uosvis & Ussen & Usururv & $U_{\text {Us_D }}$ & $s_{\mathrm{w}}$ & Hoad & $\mathrm{PM}$ & Sol & $\mathrm{SPo}$ & SP & $\mathrm{ID}$ & MDDX & $\mathrm{TDP}$ & MSS \\
\hline 21.0 & 0.995 & 0.01430 & 0.050 & 0.336 & 42.2 & $P$ & $\mathrm{NA}$ & 6.74 & 6.86 & 6.91 & 7.10 & 7.10 & 30.00 & $\mathrm{NA}$ & $\mathrm{NA}$ & NA & NA & $\mathrm{NA}$ & NA & $\mathrm{NA}$ & 0.0 & NA & NA & NA & NA & 70F_4s1d2V__1 & $4 / 21 \mathrm{~A}$ & TDP-142 & 700322 \\
\hline 21.0 & 0.995 & 0.01430 & 0.050 & 0.336 & 42.2 & $P$ & $\mathrm{NA}$ & 6.74 & 6.86 & 6.91 & 7.10 & 7.10 & 30.00 & NA & NA & NA & NA & NA & NA & NA & 0.6 & NA & NA & NA & NA & 70F_4s1d2Vc_1 & 4/21A & TDP-142 & 700323 \\
\hline 21.0 & 0.995 & 0.01430 & 0.050 & 0.336 & 42.2 & $\mathrm{P}$ & NA & 6.74 & 6.86 & 6.91 & 7.10 & 7.10 & 30.00 & NA & NA & NA & NA & NA & NA & NA & 0.0 & NA & NA & NA & NA & 70F_4s1d2Vc_1 & 4/21A & TDP-142 & 700324 \\
\hline 21.0 & 0.995 & 0.01430 & 0.050 & 0.336 & 42.2 & $\mathrm{P}$ & NA & 6.74 & 6.86 & 6.91 & 7.10 & 7.10 & 30.00 & NA & NA & NA & NA & NA & NA & NA & 0.0 & NA & NA & NA & NA & $70 \mathrm{~F} \_4 \mathrm{~s} 1 \mathrm{~d} 2 \mathrm{Vc} \_1$ & 4/21A & TDP-142 & 700325 \\
\hline 21.0 & 0.995 & 0.01430 & 0.050 & 0.336 & 42.2 & $\mathrm{P}$ & NA & 6.74 & 6.86 & 6.91 & 7.10 & 7.10 & 30.00 & NA & NA & NA & NA & NA & NA & NA & 0.0 & NA & NA & NA & NA & 70F_4s1d22 _ 1 & $4 / 21 \mathrm{~A}$ & TDP-142 & 700326 \\
\hline 21.0 & 0.995 & 0.01430 & 0.050 & 0.336 & 42.2 & $\mathrm{P}$ & NA & 6.74 & 6.86 & 6.91 & 7.10 & 7.10 & 30.00 & NA & NA & NA & NA & NA & NA & NA & 0.0 & NA & NA & NA & NA & 70F_4s1d2VE__ 1 & 4/21A & TDP-142 & 700327 \\
\hline 21.0 & 0.995 & 0.01430 & 0.050 & 0.336 & 42.2 & $\mathrm{P}$ & NA & 6.74 & 6.86 & 6.91 & 7.10 & 7.10 & 30.00 & NA & NA & NA & NA & NA & NA & NA & 0.0 & NA & NA & NA & NA & 70F_4s1d2Vc_1 & 4/21A & TDP-142 & 700328 \\
\hline 21.1 & 0.995 & 0.01430 & 0.050 & 0.336 & 42.2 & $\mathrm{P}$ & NA & 6.75 & 6.86 & 6.92 & 7.10 & 7.10 & 29.50 & NA & NA & NA & Ucssen & NA & NA & (null) & 0.0 & 2 & NA & NA & NA & 70F_4s1d2Vc_1 & $4 / 21 \mathrm{~A}$ & TDP-142 & 700330 \\
\hline 21.1 & 0.995 & 0.01430 & 0.050 & 0.336 & 42.2 & $\mathrm{P}$ & NA & 6.75 & 6.86 & 6.92 & 7.10 & 7.10 & 29.50 & NA & NA & NA & NA & NA & NA & NA & 0.0 & NA & NA & NA & NA & 70F_4s1d2Vc_1 & 4/21A & TDP-142 & 700331 \\
\hline 21.1 & 0.995 & 0.01430 & 0.050 & 0.336 & 42.2 & $\mathrm{P}$ & NA & 6.75 & 6.86 & 6.92 & 7.10 & 7.10 & 29.50 & NA & NA & NA & NA & NA & NA & NA & 0.0 & NA & NA & NA & NA & 70F_4s1d2VE__1 & 4/21A & TDP-142 & 700332 \\
\hline 21.1 & 0.995 & 0.01430 & 0.050 & 0.336 & 42.2 & $\mathrm{P}$ & NA & 6.75 & 6.86 & 6.92 & 7.10 & 7.10 & 29.50 & NA & NA & NA & NA & NA & NA & NA & 0.0 & NA & NA & NA & NA & 70F_4s1d2Vc_1 & 4/21A & TDP-142 & 700333 \\
\hline 21.1 & 0.995 & 0.01430 & 0.050 & 0.336 & 42.2 & $\mathrm{P}$ & $\mathrm{NA}$ & 6.75 & 6.86 & 6.92 & 7.10 & 7.10 & 29.50 & NA & NA & NA & NA & NA & NA & NA & 0.0 & NA & NA & NA & NA & 70F_4s1d2Vc_1 & 4/21A & TDP-142 & 700334 \\
\hline 21.1 & 0.995 & 0.01430 & 0.050 & 0.336 & 42.2 & $\mathrm{P}$ & NA & 6.75 & 6.86 & 6.92 & 7.10 & 7.10 & 29.50 & NA & NA & NA & NA & NA & NA & NA & 0.0 & NA & NA & NA & NA & 7OF_4S1d2VV_ 1 & 4/21A & TDP-142 & 700335 \\
\hline 21.1 & 0.995 & 0.01430 & 0.050 & 0.336 & 42.2 & $\mathrm{P}$ & NA & 6.75 & 6.86 & 6.92 & 7.10 & 7.10 & 29.50 & NA & NA & NA & NA & NA & NA & NA & 0.0 & NA & NA & NA & NA & 70F_4s1d2Vc_1 & 4/21A & TDP-142 & 700336 \\
\hline 21.1 & 0.995 & 0.01430 & 0.050 & 0.336 & 42.2 & $\mathrm{P}$ & NA & 6.75 & 6.86 & 6.92 & 7.10 & 7.10 & 29.50 & NA & NA & NA & NA & NA & NA & NA & 0.0 & NA & NA & NA & NA & 70F_4sid2VC_ 1 & $4 / 21 \mathrm{~A}$ & TDP-142 & 700337 \\
\hline 21.1 & 0.995 & 0.01430 & 0.050 & 0.336 & 42.2 & $\mathrm{P}$ & $\mathrm{NA}$ & 6.75 & 6.86 & 6.92 & 7.10 & 7.10 & 29.50 & NA & NA & NA & NA & NA & NA & NA & 0.0 & NA & NA & NA & NA & 70F_4s1d2Vc_1 & 4/21A & TDP-142 & 700338 \\
\hline 21.1 & 0.995 & 0.01430 & 0.050 & 0.336 & 42.2 & $\mathrm{P}$ & NA & 6.75 & 6.86 & 6.92 & 7.10 & 7.10 & 29.50 & NA & NA & NA & $\mathrm{NA}$ & NA & NA & NA & 0.0 & NA & NA & NA & NA & 70F_4s1d2Vc_1 & 4/21A & TDP-142 & 700339 \\
\hline 21.2 & 0.995 & 0.01430 & 0.050 & 0.336 & 42.2 & $\mathrm{P}$ & NA & 6.75 & 6.86 & 6.92 & 7.10 & 7.10 & 30.00 & NA & NA & NA & Ucscen & NA & NA & (null) & 1.5 & 2 & NA & NA & NA & 70F_4s1d2Vc_1 & 4/21A & TDP-142 & 700340 \\
\hline 21.2 & 0.995 & 0.01430 & 0.050 & 0.336 & 42.2 & $\mathrm{P}$ & NA & 6.75 & 6.86 & 6.92 & 7.10 & 7.10 & 30.00 & NA & NA & NA & NA & NA & NA & NA & 3.3 & NA & NA & NA & NA & 70F_4s1d2Vc_1 & 4/21A & TDP-142 & 700341 \\
\hline 21.2 & 0.995 & 0.01430 & 0.050 & 0.336 & 42.2 & $\mathrm{P}$ & NA & 6.75 & 6.86 & 6.92 & 7.10 & 7.10 & 30.00 & NA & NA & NA & NA & NA & NA & NA & 0.0 & NA & NA & NA & NA & 70F_4s1d2Vc_1 & 4/21A & TDP-142 & 700343 \\
\hline 21.2 & 0.995 & 0.01430 & 0.050 & 0.336 & 42.2 & $\mathrm{P}$ & NA & 6.75 & 6.86 & 6.92 & 7.10 & 7.10 & 30.00 & NA & NA & NA & NA & NA & NA & NA & 0.0 & NA & NA & NA & NA & 70F_4s1d2V__1 & 4/21A & TDP-142 & 700344 \\
\hline 21.2 & 0.995 & 0.01430 & 0.050 & 0.336 & 42.2 & $\mathrm{P}$ & NA & 6.75 & 6.86 & 6.92 & 7.10 & 7.10 & 30.00 & NA & NA & NA & NA & NA & NA & NA & 0.0 & NA & NA & NA & NA & 70F_4s1d2Vc_1 & 4/21A & TDP-142 & 700345 \\
\hline 21.2 & 0.995 & 0.01430 & 0.050 & 0.336 & 42.2 & $\mathrm{P}$ & NA & 6.75 & 6.86 & 6.92 & 7.10 & 7.10 & 30.00 & NA & NA & NA & NA & NA & NA & NA & 0.0 & NA & NA & NA & NA & 70F_4s1d2VE_1 & 4/21A & TDP-142 & 700346 \\
\hline 21.2 & 0.995 & 0.01430 & 0.050 & 0.336 & 42.2 & $\mathrm{P}$ & NA & 6.75 & 6.86 & 6.92 & 7.10 & 7.10 & 30.00 & NA & NA & NA & NA & NA & NA & NA & 0.7 & NA & NA & NA & NA & 70F_4s1d2Vc_1 & 4/21A & TDP-142 & 700347 \\
\hline 21.2 & 0.995 & 0.01430 & 0.050 & 0.336 & 42.2 & $\mathrm{P}$ & $\mathrm{NA}$ & 6.75 & 6.86 & 6.92 & 7.10 & 7.10 & 30.00 & NA & NA & NA & NA & NA & NA & NA & $\mathrm{na}$ & NA & NA & NA & NA & 70F_4s1d2VE_1 & $4 / 21 \mathrm{~A}$ & TDP-142 & 700347.1 \\
\hline 21.2 & 0.995 & 0.01430 & 0.050 & 0.336 & 42.2 & $\mathrm{P}$ & NA & 6.75 & 6.86 & 6.92 & 7.10 & 7.10 & 30.00 & NA & NA & NA & NA & NA & NA & NA & $n / a$ & NA & NA & NA & NA & 70F_4s1d2V__1 & 4/21A & TDP-142 & 700347.2 \\
\hline 21.3 & 0.994 & 0.01430 & 0.050 & 0.336 & 41.0 & $\mathrm{P}$ & NA & 6.93 & 7.05 & 7.11 & 7.30 & 7.10 & 33.50 & NA & NA & NA & NA & NA & NA & (null) & 0.0 & 4 & NA & NA & NA & 70F_4s1d2Vc_1 & 4/21A & TDP-142 & 700348 \\
\hline 21.2 & 0.995 & 0.01430 & 0.050 & 0.338 & 39.6 & $\mathrm{P}$ & NA & 7.10 & 7.22 & 7.29 & 7.50 & 7.10 & 35.50 & NA & NA & NA & NA & NA & NA & 1 & 0.0 & 4 & NA & NA & NA & 70F_4s1d2Vc_ 1 & $4 / 21 \mathrm{~A}$ & TDP-142 & 700349 \\
\hline 21.3 & 0.995 & 0.01430 & 0.050 & 0.339 & 38.4 & $\mathrm{P}$ & NA & 7.28 & 7.42 & 7.48 & 7.70 & 7.10 & 40.50 & NA & NA & NA & NA & NA & NA & 1 & 0.0 & 4 & NA & NA & NA & 70F_4s1d2VV__ 1 & $4 / 21 \mathrm{~A}$ & TDP-142 & 700350 \\
\hline 21.9 & 0.995 & 0.01430 & 0.050 & 0.183 & 72.8 & $\mathrm{P}$ & NA & 7.20 & 7.33 & 7.40 & 7.60 & 9.90 & 19.25 & NA & NA & NA & NA & NA & NA & 1 & NA & 1 & NA & NA & NA & 70F_4sid2Vd_1 & $4 / 22 \mathrm{~A}$ & TDP-143 & 700351 \\
\hline 22.1 & 0.995 & 0.01430 & 0.050 & 0.185 & 65.8 & $\mathrm{P}$ & $\mathrm{NA}$ & 7.87 & 8.02 & 8.10 & 8.30 & 9.90 & 21.50 & NA & NA & NA & NA & NA & NA & 1 & 22.1 & 1 & NA & NA & NA & 70F_4s1d2Vd_1 1 & $4 / 22 \mathrm{~A}$ & TDP-143 & 700352 \\
\hline 22.3 & 0.995 & 0.01430 & 0.050 & 0.184 & 63.4 & $\mathrm{P}$ & NA & 8.13 & 8.29 & 8.37 & 8.60 & 9.90 & 22.75 & NA & NA & NA & NA & NA & NA & 1 & 19.9 & 1 & NA & NA & NA & 70F_4s1d2Vd_1 & $4 / 22 A$ & TDP-143 & 700353 \\
\hline 22.4 & 0.995 & 0.01430 & 0.050 & 0.185 & 59.8 & $\mathrm{P}$ & NA & 8.58 & 8.75 & 8.84 & 9.10 & 9.90 & 24.25 & NA & NA & NA & NA & NA & NA & 1 & 18.6 & 1 & NA & NA & NA & 70F_4s1d2Vd_1 & $4 / 22 \mathrm{~A}$ & TDP-143 & 700354 \\
\hline 22.5 & 0.994 & 0.01430 & 0.050 & 0.186 & 56.6 & $\mathrm{P}$ & NA & 9.00 & 9.19 & 9.29 & 9.60 & 9.90 & 27.00 & NA & NA & NA & UCscen & NA & NA & 1 & 123 & 2 & NA & NA & NA & 70F_4sId2VI_1 & $4 / 22 \mathrm{~A}$ & TDP-143 & 700355 \\
\hline 22.7 & 0.994 & 0.01430 & 0.050 & 0.185 & 54.8 & $\mathrm{P}$ & NA & 9.30 & 9.50 & 9.60 & 9.90 & 9.90 & 27.75 & 9.90 & udv & NA & NA & ucsudv & NA & 1 & 0.7 & 4 & NA & NA & NA & 70F_4s1d2VI_1 & $4 / 22 \mathrm{~A}$ & TDP-143 & 700356 \\
\hline 22.6 & 0.995 & 0.01430 & 0.050 & 0.185 & 54.8 & $\mathrm{P}$ & NA & 9.29 & 9.49 & 9.59 & 9.90 & 9.90 & 27.50 & NA & NA & NA & NA & NA & NA & NA & na & NA & NA & NA & NA & 70F_4s1d2Vd_1 & 4/22A & TDP-143 & 700356.1 \\
\hline 22.6 & 0.995 & 0.01430 & 0.050 & 0.185 & 54.8 & $\mathrm{P}$ & NA & 9.29 & 9.49 & 9.59 & 9.90 & 9.90 & 27.50 & NA & NA & NA & NA & NA & NA & (null) & 4.5 & 4 & NA & NA & NA & 70F_4s1d2Vd_1 & $4 / 22 \mathrm{~A}$ & TDP-143 & 700357 \\
\hline 22.6 & 0.995 & 0.01430 & 0.050 & 0.185 & 54.8 & $\mathrm{P}$ & NA & 9.29 & 9.49 & 9.59 & 9.90 & 9.90 & 27.50 & NA & NA & NA & NA & NA & NA & NA & 0.0 & NA & NA & NA & NA & 70F_4s1d2Vd_1 1 & 4/22A & TDP-143 & 700358 \\
\hline 22.6 & 0.995 & 0.01430 & 0.050 & 0.185 & 54.8 & $\mathrm{P}$ & $\mathrm{NA}$ & 9.29 & 9.49 & 9.59 & 9.90 & 9.90 & 27.50 & NA & $\mathrm{NA}$ & $\mathrm{NA}$ & NA & NA & NA & NA & 0.0 & NA & NA & NA & NA & 70F_4s1d2Vd_1 & $4 / 22 \mathrm{~A}$ & TDP-143 & 700359 \\
\hline
\end{tabular}


Table B.6. Data from 2008 in Large-Scale Vessel with Flanged and Dished Head A.5

\begin{tabular}{|c|c|c|c|c|c|c|c|c|c|c|c|c|c|c|c|c|c|c|c|c|c|c|c|c|c|c|c|}
\hline $\begin{array}{c}\text { Row } \\
\text { Number }\end{array}$ & Test & Case ID & \begin{tabular}{c|} 
Tank \\
Diameter
\end{tabular} & $\begin{array}{l}\text { Head } \\
\text { Shape }\end{array}$ & $\begin{array}{l}\text { Dish } \\
\text { Height }\end{array}$ & $\begin{array}{l}\text { Dish } \\
\text { Volume }\end{array}$ & $\begin{array}{c}\text { Tank } \\
\text { Filn } \\
\text { Height }\end{array}$ & $\begin{array}{c}\text { Retur } \\
\text { Line } \\
\text { Height } \\
\text { Heignt }\end{array}$ & $\begin{array}{c}\text { Nozzle } \\
\text { Inner } \\
\text { Diameter }\end{array}$ & $\begin{array}{c}\text { Nozzle } \\
\text { Stanct } \\
\text { off } \\
\text { Distance }\end{array}$ & $\begin{array}{l}\text { Pulse Tube } \\
\text { Configuration }\end{array}$ & $\begin{array}{l}\text { Installed } \\
\text { Nozzles }\end{array}$ & $\begin{array}{c}\text { OOter } \\
\text { Nozeldes } \\
\text { Operated }\end{array}$ & $\begin{array}{c}\text { Inner } \\
\text { Nozeles } \\
\text { Operated }\end{array}$ & $\begin{array}{c}\text { Pulse Tube } \\
\text { Outer } \\
\text { Diameter }\end{array}$ & $\begin{array}{c}\text { Outer } \\
\text { PJM } \\
\text { Radius }\end{array}$ & $\begin{array}{c}\text { Inner } \\
\text { PPM } \\
\text { Radius }\end{array}$ & $\begin{array}{l}\text { "FOC' Outer } \\
\text { PJM } \\
\text { Impingement } \\
\text { Angle }\end{array}$ & $\begin{array}{l}\text { "FO' Inner } \\
\text { PJM } \\
\text { Impingement } \\
\text { Angle }\end{array}$ & $\begin{array}{c}\text { Ratio Outer } \\
\text { PJM to } \\
\text { Tank } \\
\text { Radius } \\
\end{array}$ & $\begin{array}{c}\text { Ratio Inner } \\
\text { PJMto } \\
\text { Tank } \\
\text { Radius } \\
\end{array}$ & Simulant & $\begin{array}{l}\text { Solids } \\
\text { Density }\end{array}$ & $\begin{array}{c}\text { Particle } \\
\text { Diameter } 55\end{array}$ & $\begin{array}{c}\text { Particle } \\
\text { Diameter } \\
\text { d50 }\end{array}$ & $\begin{array}{c}\text { Patidice } \\
\text { Diameter } \\
\text { d95 }\end{array}$ & $\begin{array}{c}\text { Void } \\
\text { Fraction }\end{array}$ \\
\hline text & text & text & in. & text & in. & in. ${ }^{3}$ & in. & in. & in. & in. & text & number & number & number & in. & in. & in. & deg & deg & nondim & nondim & text & $\mathrm{g} / \mathrm{cm}^{3}$ & $\mathrm{~m}$ & $\mathrm{~m}$ & $\mathrm{~m}$ & fraction \\
\hline MSS & MDDX & $\mathrm{ID}$ & $\mathrm{D}$ & $\mathrm{HS}$ & Hash & $V_{\text {dsh }}$ & $\mathrm{H}$ & $\mathrm{Rn}$ & $d$ & sod & PT & $\mathrm{N}$ & $\mathrm{Nb}$ & $\mathrm{N}$ & $\mathrm{PT}_{\alpha \mathrm{d}}$ & $\mathrm{Ro}_{0}$ & $R$ & $\theta_{\circ}$ & $\theta_{1}$ & $R d R$ & $R / R$ & $\operatorname{sxdx}$ & $\rho_{s}$ & $d s$ & $\mathrm{~d}_{\mathrm{s}}$ & $\frac{d 65}{d}$ & vf \\
\hline 700360 & $4 / 22 \mathrm{~A}$ & 70F_4s1d2Vd_1 & 70 & $\mathrm{FD}$ & 12.7 & 30569.0 & 88 & $835 / 8$ & 0.613 & 0.920 & HLP-22 & 12 & 8 & 4 & 3.5 & 26.4 & 11.7 & 22.4 & 9.7 & 0.75 & 0.33 & s1d2 & 2.48 & 0.0000569 & 0.0000693 & 0.0000821 & 0.3750 \\
\hline 700361 & $4 / 22 \mathrm{~A}$ & 70F_4s1d2Vd_1 & 70 & $F D$ & 12.7 & 30569.0 & 88 & $835 / 8$ & 0.613 & 0.920 & HLP-22 & 12 & 8 & 4 & 3.5 & 26.4 & 11.7 & 22.4 & 9.7 & 0.75 & 0.33 & s1d2 & 2.48 & 0.0000569 & 0.0000693 & 0.0000821 & 0.3750 \\
\hline 700362 & 4/22A & 70F_4s1d2Vd_1 & 70 & $F D$ & 12.7 & 30569.0 & 88 & $835 / 8$ & 0.613 & 0.920 & HLP-22 & 12 & 8 & 4 & 3.5 & 26.4 & 11.7 & 22.4 & 9.7 & 0.75 & 0.33 & s1d2 & 2.48 & 0.0000569 & 0.0000693 & 0.0000821 & 0.3750 \\
\hline 700363 & 4/22A & 70F_4s1d2Vd_1 1 & 70 & FD & 12.7 & 30569.0 & 88 & $835 / 8$ & 0.613 & 0.920 & HLP-22 & 12 & 8 & 4 & 3.5 & 26.4 & 11.7 & 22.4 & 9.7 & 0.75 & 0.33 & $\mathrm{sid2}$ & 2.48 & 0.0000569 & 0.0000693 & 0.0000821 & 0.3750 \\
\hline 700364 & 4/22A & 70F_4sid2Vd_1 & 70 & $F D$ & 12.7 & 30569.0 & 88 & $835 / 8$ & 0.613 & 0.920 & HLP-22 & 12 & 8 & 4 & 3.5 & 26.4 & 11.7 & 22.4 & 9.7 & 0.75 & 0.33 & s1d2 & 2.48 & 0.0000569 & 0.0000693 & 0.0000821 & 0.3750 \\
\hline 700365 & 4/22A & 70F_4s1d2Vd_1 & 70 & FD & 12.7 & 30569.0 & 88 & $835 / 8$ & 0.613 & 0.920 & HLP-22 & 12 & 8 & 4 & 3.5 & 26.4 & 11.7 & 22.4 & 9.7 & 0.75 & 0.33 & $\mathrm{sid2}$ & 2.48 & 0.0000569 & 0.0000693 & 0.0000821 & 0.3750 \\
\hline $700366 \mathrm{M}$ & 4/22A & 70F_4s1d2Vd_1 & 70 & $F D$ & 12.7 & 30569.0 & 88 & $835 / 8$ & 0.613 & 0.920 & HLP-22 & 12 & 8 & 4 & 3.5 & 26.4 & 11.7 & 22.4 & 9.7 & 0.75 & 0.33 & s1d2 & 2.48 & 0.0000569 & 0.0000693 & 0.0000821 & 0.3750 \\
\hline $700367 \mathrm{M}$ & 4/22A & 70F_4s1d2Vd_1 & 70 & $F D$ & 12.7 & 30569.0 & 88 & $835 / 8$ & 0.613 & 0.920 & HLP-22 & 12 & 8 & 4 & 3.5 & 26.4 & 11.7 & 22.4 & 9.7 & 0.75 & 0.33 & s1d2 & 2.48 & 0.0000569 & 0.0000693 & 0.0000821 & 0.3750 \\
\hline $700368 \mathrm{M}$ & $4 / 228$ & 70F_4s1d2Vc_ 2 & 70 & $F D$ & 12.7 & 30569.0 & $871 / 2$ & $835 / 8$ & 0.613 & 0.920 & HLP-22 & 12 & 8 & 4 & 3.5 & 26.4 & 11.7 & 22.4 & 9.7 & 0.75 & 0.33 & $\mathrm{sid2}$ & 2.48 & 0.0000569 & 0.0000693 & 0.0000821 & 0.3750 \\
\hline 700369 & 4/23A & 70F_4s1d2Ve_1 & 70 & $F D$ & 12.7 & 30569.0 & $871 / 2$ & $835 / 8$ & 0.613 & 0.920 & HLP-22 & 12 & 8 & 4 & 3.5 & 26.4 & 11.7 & 22.4 & 9.7 & 0.75 & 0.33 & $51 \mathrm{~d} 2$ & 2.48 & 0.0000569 & 0.0000693 & 0.0000821 & 0.3750 \\
\hline $700370 \mathrm{M}$ & 4/23A & 70F_4s1d2Ve_1 & 70 & FD & 12.7 & 30569.0 & $871 / 2$ & $835 / 8$ & 0.613 & 0.920 & HLP-22 & 12 & 8 & 4 & 3.5 & 26.4 & 11.7 & 22.4 & 9.7 & 0.75 & 0.33 & $\mathrm{sid2}$ & 2.48 & 0.0000569 & 0.0000693 & 0.0000821 & 0.3750 \\
\hline 700371 & 4/23B & 70F_4s1d2Ve_2 & 70 & $F D$ & 12.7 & 30569.0 & $871 / 2$ & $835 / 8$ & 0.613 & 0.920 & HLP-22 & 12 & 8 & 4 & 3.5 & 26.4 & 11.7 & 22.4 & 9.7 & 0.75 & 0.33 & s1d2 & 2.48 & 0.0000569 & 0.0000693 & 0.0000821 & 0.3750 \\
\hline $700372 \mathrm{M}$ & $4 / 23 B$ & 70F_4s1d2Ve_2 & 70 & $F D$ & 12.7 & 30569.0 & $871 / 2$ & $835 / 8$ & 0.613 & 0.920 & HLP-22 & 12 & 8 & 4 & 3.5 & 26.4 & 11.7 & 22.4 & 9.7 & 0.75 & 0.33 & $51 \mathrm{~d} 2$ & 2.48 & 0.0000569 & 0.0000693 & 0.0000821 & 0.3750 \\
\hline 700373 & $4 / 23 \mathrm{C}$ & 70F_4s1d2Ve_4 4 & 70 & $F D$ & 12.7 & 30569.0 & 88 & $835 / 8$ & 0.613 & 0.920 & HLP-22 & 12 & 8 & 4 & 3.5 & 26.4 & 11.7 & 22.4 & 9.7 & 0.75 & 0.33 & s1d2 & 2.48 & 0.0000569 & 0.0000693 & 0.0000821 & 0.3750 \\
\hline 700374M & $4 / 23 \mathrm{C}$ & 70F_4s1d2Ve_4 & 70 & $F D$ & 12.7 & 30569.0 & 88 & $835 / 8$ & 0.613 & 0.920 & HLP-22 & 12 & 8 & 4 & 3.5 & 26.4 & 11.7 & 22.4 & 9.7 & 0.75 & 0.33 & $\mathrm{sid2}$ & 2.48 & 0.0000569 & 0.0000693 & 0.0000821 & 0.3750 \\
\hline 700375 & 4/24A & 70F_4s1d2Vc_4 & 70 & $F D$ & 12.7 & 30569.0 & 88 & $835 / 8$ & 0.613 & 0.920 & HLP-22 & 12 & 8 & 4 & 3.5 & 26.4 & 11.7 & 22.4 & 9.7 & 0.75 & 0.33 & $51 \mathrm{~d} 2$ & 2.48 & 0.0000569 & 0.0000693 & 0.0000821 & 0.3750 \\
\hline 700376 & 4/24A & 70F_4s1d2Vc_4 & 70 & $F D$ & 12.7 & 30569.0 & 88 & $835 / 8$ & 0.613 & 0.920 & HLP-22 & 12 & 8 & 4 & 3.5 & 26.4 & 11.7 & 22.4 & 9.7 & 0.75 & 0.33 & sid2 2 & 2.48 & 0.0000569 & 0.0000693 & 0.0000821 & 0.3750 \\
\hline 700377 & $4 / 24 \mathrm{~A}$ & 70F_4s1d2Vc_4 & 70 & $F D$ & 12.7 & 30569.0 & 88 & $835 / 8$ & 0.613 & 0.920 & HLP-22 & 12 & 8 & 4 & 3.5 & 26.4 & 11.7 & 22.4 & 9.7 & 0.75 & 0.33 & $51 \mathrm{~d} 2$ & 2.48 & 0.0000569 & 0.0000693 & 0.0000821 & 0.3750 \\
\hline 700378 & 4/24A & 70F_4s1d2Vc_4 & 70 & $F D$ & 12.7 & 30569.0 & 88 & $835 / 8$ & 0.613 & 0.920 & HLP-22 & 12 & 8 & 4 & 3.5 & 26.4 & 11.7 & 22.4 & 9.7 & 0.75 & 0.33 & s1d2 & 2.48 & 0.0000569 & 0.0000693 & 0.0000821 & 0.3750 \\
\hline 700379 & $4 / 24 A$ & 70F_4s1d2VC_4 & 70 & $\mathrm{FD}$ & 12.7 & 30569.0 & 88 & $835 / 8$ & 0.613 & 0.920 & HLP-22 & 12 & 8 & 4 & 3.5 & 26.4 & 11.7 & 22.4 & 9.7 & 0.75 & 0.33 & $\mathrm{~s} 1 \mathrm{~d} 2$ & 2.48 & 0.0000569 & 0.0000693 & 0.0000821 & 0.3750 \\
\hline $700380 \mathrm{M}$ & 4/24A & 70F_4s1d2Vc_4 & 70 & $\mathrm{FD}$ & 12.7 & 30569.0 & 88 & $835 / 8$ & 0.613 & 0.920 & HLP.22 & 12 & 8 & 4 & 3.5 & 26.4 & 11.7 & 22.4 & 9.7 & 0.75 & 0.33 & $51 \mathrm{~d} 2$ & 2.48 & 0.0000569 & 0.0000693 & 0.0000821 & 0.3750 \\
\hline 700381 & 4/24B & 70F_4s1d2Vd_2 & 70 & $F D$ & 12.7 & 30569.0 & 88 & $835 / 8$ & 0.613 & 0.920 & HLP-22 & 12 & 8 & 4 & 3.5 & 26.4 & 11.7 & 22.4 & 9.7 & 0.75 & 0.33 & sid2 2 & 2.48 & 0.0000569 & 0.0000693 & 0.0000821 & 0.3750 \\
\hline 700382 & $4 / 24 B$ & 70F_4s1d2Vd_2 & 70 & $F D$ & 12.7 & 30569.0 & 88 & $835 / 8$ & 0.613 & 0.920 & HLP-22 & 12 & 8 & 4 & 3.5 & 26.4 & 11.7 & 22.4 & 9.7 & 0.75 & 0.33 & $51 \mathrm{~d} 2$ & 2.48 & 0.0000569 & 0.0000693 & 0.0000821 & 0.3750 \\
\hline 700383 & 4/24B & $70 F \_4 s 1 d 2 V d \_2$ & 70 & $F D$ & 12.7 & 30569.0 & 88 & $835 / 8$ & 0.613 & 0.920 & HLP-22 & 12 & 8 & 4 & 3.5 & 26.4 & 11.7 & 22.4 & 9.7 & 0.75 & 0.33 & s1d2 & 2.48 & 0.0000569 & 0.0000693 & 0.0000821 & 0.3750 \\
\hline $700384 \mathrm{M}$ & $4 / 24 B$ & 70F_4sidzVd_2 & 70 & $F D$ & 12.7 & 30569.0 & 88 & $835 / 8$ & 0.613 & 0.920 & HLP-22 & 12 & 8 & 4 & 3.5 & 26.4 & 11.7 & 22.4 & 9.7 & 0.75 & 0.33 & s1d2 & 2.48 & 0.0000569 & 0.0000693 & 0.0000821 & 0.3750 \\
\hline 700385 & $4 / 25 \mathrm{~A}$ & 70F_4s1d2Vd_4 & 70 & $\mathrm{FD}$ & 12.7 & 30569.0 & $871 / 2$ & $835 / 8$ & 0.613 & 0.920 & HLP. 22 & 12 & 8 & 4 & 3.5 & 26.4 & 11.7 & 22.4 & 9.7 & 0.75 & 0.33 & $\mathrm{~s} 1 \mathrm{~d} 2$ & 2.48 & 0.0000569 & 0.0000693 & 0.0000821 & 0.3750 \\
\hline 700386 & $425 \mathrm{~A}$ & 70F_4s1d2Vd_4 & 70 & $F D$ & 12.7 & 30569.0 & $871 / 2$ & $835 / 8$ & 0.613 & 0.920 & HLP-22 & 12 & 8 & 4 & 3.5 & 26.4 & 11.7 & 22.4 & 9.7 & 0.75 & 0.33 & sid2 2 & 2.48 & 0.0000569 & 0.0000693 & 0.0000821 & 0.3750 \\
\hline 700387M & $4 / 25 \mathrm{~A}$ & 70F_4s1d2Vd_4 & 70 & $F D$ & 12.7 & 30569.0 & $871 / 2$ & $835 / 8$ & 0.613 & 0.920 & HLP. 22 & 12 & 8 & 4 & 3.5 & 26.4 & 11.7 & 22.4 & 9.7 & 0.75 & 0.33 & $51 \mathrm{~d} 2$ & 2.48 & 0.0000569 & 0.0000693 & 0.0000821 & 0.3750 \\
\hline 700388M & 4/25B & 70F_4s1d2Ve_1 & 70 & $F D$ & 12.7 & 30569.0 & $871 / 2$ & $835 / 8$ & 0.613 & 0.920 & HLP-22 & 12 & 8 & 4 & 3.5 & 26.4 & 11.7 & 22.4 & 9.7 & 0.75 & 0.33 & s1d2 & 2.48 & 0.0000569 & 0.0000693 & 0.0000821 & 0.3750 \\
\hline 700389 & $4 / 25 \mathrm{~B}$ & 70F_4sidzVe_1 & 70 & $\mathrm{FD}$ & 12.7 & 30569.0 & $871 / 2$ & $835 / 8$ & 0.613 & 0.920 & HLP-22 & 12 & 8 & 4 & 3.5 & 26.4 & 11.7 & 22.4 & 9.7 & 0.75 & 0.33 & s1d2 & 2.48 & 0.0000569 & 0.0000693 & 0.0000821 & 0.3750 \\
\hline 700339.1 & $4 / 25 B$ & 70F_4s1d2Ve_1 & 70 & $\mathrm{FD}$ & 12.7 & 30569.0 & $871 / 2$ & $835 / 8$ & 0.613 & 0.920 & HLP-22 & 12 & 8 & 4 & 3.5 & 26.4 & 11.7 & 22.4 & 9.7 & 0.75 & 0.33 & $\mathrm{~s} 1 \mathrm{~d} 2$ & 2.48 & 0.0000569 & 0.0000693 & 0.0000821 & 0.3750 \\
\hline 700390 & $425 B$ & 70F_4s1d2Ve_1 & 70 & $F D$ & 12.7 & 30569.0 & $871 / 2$ & $835 / 8$ & 0.613 & 0.920 & HLP-22 & 12 & 8 & 4 & 3.5 & 26.4 & 11.7 & 22.4 & 9.7 & 0.75 & 0.33 & sid2 2 & 2.48 & 0.0000569 & 0.0000693 & 0.0000821 & 0.3750 \\
\hline 700390.1 & $4 / 25 B$ & 70F_4s1d2Ve_1 & 70 & $F D$ & 12.7 & 30569.0 & $871 / 2$ & $835 / 8$ & 0.613 & 0.920 & HLP-22 & 12 & 8 & 4 & 3.5 & 26.4 & 11.7 & 22.4 & 9.7 & 0.75 & 0.33 & $51 \mathrm{~d} 2$ & 2.48 & 0.0000569 & 0.0000693 & 0.0000821 & 0.3750 \\
\hline 700391 & 4/25B & 70F_4s1d2Ve_1 & 70 & $F D$ & 12.7 & 30569.0 & $871 / 2$ & $835 / 8$ & 0.613 & 0.920 & HLP-22 & 12 & 8 & 4 & 3.5 & 26.4 & 11.7 & 22.4 & 9.7 & 0.75 & 0.33 & sid2 & 2.48 & 0.0000569 & 0.0000693 & 0.00000821 & 0.3750 \\
\hline 700391.1 & $4 / 25 B$ & 70F_4s1d2Ve_1 & 70 & $F D$ & 12.7 & 30569.0 & $871 / 2$ & $835 / 8$ & 0.613 & 0.920 & HLP-22 & 12 & 8 & 4 & 3.5 & 26.4 & 11.7 & 22.4 & 9.7 & 0.75 & 0.33 & s1d2 & 2.48 & 0.0000569 & 0.0000693 & 0.0000821 & 0.3750 \\
\hline 700392 & $4 / 25 B$ & 70F_4s1d2Ve_1 & 70 & FD & 12.7 & 30569.0 & $871 / 2$ & $835 / 8$ & 0.613 & 0.920 & HLP-22 & 12 & 8 & 4 & 3.5 & 26.4 & 11.7 & 22.4 & 9.7 & 0.75 & 0.33 & s1d2 & 2.48 & 0.0000569 & 0.0000693 & 0.0000821 & 0.3750 \\
\hline 700392.1 & $425 B$ & 70F_4s1d2Ve_1 & 70 & $F D$ & 12.7 & 30569.0 & $871 / 2$ & $835 / 8$ & 0.613 & 0.920 & HLP-22 & 12 & 8 & 4 & 3.5 & 26.4 & 11.7 & 22.4 & 9.7 & 0.75 & 0.33 & sid2 2 & 2.48 & 0.0000569 & 0.0000693 & 0.0000821 & 0.3750 \\
\hline 700393 & $4 / 25 B$ & 70F_4s1d2Ve_1 & 70 & $F D$ & 12.7 & 30569.0 & $871 / 2$ & $835 / 8$ & 0.613 & 0.920 & HLP-22 & 12 & 8 & 4 & 3.5 & 26.4 & 11.7 & 22.4 & 9.7 & 0.75 & 0.33 & s1d2 2 & 2.48 & 0.0000569 & 0.0000693 & 0.0000821 & 0.3750 \\
\hline 700393.1 & 4/25B & 70F_4s1d2Ve_1 & 70 & FD & 12.7 & 30569.0 & $871 / 2$ & $835 / 8$ & 0.613 & 0.920 & HLP-22 & 12 & 8 & 4 & 3.5 & 26.4 & 11.7 & 22.4 & 9.7 & 0.75 & 0.33 & s1d2 & 2.48 & 0.0000569 & 0.0000693 & 0.0000821 & 0.3750 \\
\hline 700393.2 & $4 / 25 \mathrm{C}$ & $70 \mathrm{~F} \_4 \mathrm{~s} 1 \mathrm{~d} 2 \mathrm{Vc} \_2$ & 70 & $F D$ & 12.7 & 30569.0 & $871 / 2$ & 83518 & 0.613 & 0.920 & HLP-22 & 12 & 8 & 4 & 3.5 & 26.4 & 11.7 & 22.4 & 9.7 & 0.75 & 0.33 & s1d2 & 2.48 & 0.0000569 & 0.0000693 & 0.0000821 & 0.3750 \\
\hline $700394 \mathrm{M}$ & $4 / 25 \mathrm{C}$ & $70 F \_4 s 1 d 2 \mathrm{Vc} \_2$ & 70 & $\mathrm{FD}$ & 12.7 & 30569.0 & $871 / 2$ & $835 / 8$ & 0.613 & 0.920 & HLP-22 & 12 & 8 & 4 & 3.5 & 26.4 & 11.7 & 22.4 & 9.7 & 0.75 & 0.33 & $\mathrm{~s} 1 \mathrm{~d} 2$ & 2.48 & 0.0000569 & 0.0000693 & 0.0000821 & 0.3750 \\
\hline
\end{tabular}


Table B.6. Data from 2008 in Large-Scale Vessel with Flanged and Dished Head B.5

\begin{tabular}{|c|c|c|c|c|c|c|c|c|c|c|c|c|c|c|c|c|c|c|c|c|c|c|c|c|c|c|c|c|c|}
\hline $\begin{array}{l}\text { Tank Water } \\
\text { Temperature }\end{array}$ & $\begin{array}{c}\text { Water } \\
\text { Density }\end{array}$ & $\begin{array}{l}\text { Solids } \\
\text { Fraction } \\
\end{array}$ & $\begin{array}{c}\text { Pulse } \\
\text { Volume } \\
\text { Fraction } \\
\end{array}$ & $\begin{array}{l}\text { Duty } \\
\text { ayde }\end{array}$ & $\begin{array}{l}\text { Cyde } \\
\text { Time } \\
\end{array}$ & $\begin{array}{c}\text { Pulsed } \\
\text { or } \\
\text { Steacy } \\
\text { Jet } \\
\end{array}$ & $\begin{array}{c}\text { Us } \\
\text { Steacy } \\
\text { Jet } \\
\end{array}$ & $\begin{array}{c}\text { U1 } \\
\text { Pulsing } \\
\text { Jet }\end{array}$ & $\begin{array}{l}\text { U2 } \\
\text { URMS }\end{array}$ & $\begin{array}{l}\text { U3 } \\
\text { URNB }\end{array}$ & $\begin{array}{c}\text { Discharge } \\
\text { Velocity }\end{array}$ & $\begin{array}{c}\text { Critical } \\
\text { Suspension } \\
\text { velocity }\end{array}$ & $\begin{array}{c}\text { Average } \\
\text { Peak Koud } \\
\text { Height } \\
\end{array}$ & $\begin{array}{c}\text { UCS } \\
\text { Condition } \\
\end{array}$ & $\begin{array}{c}\text { UCS } \\
\text { Method }\end{array}$ & $\begin{array}{l}\text { UCS } \\
\text { Flag }\end{array}$ & $\begin{array}{c}\text { ucs } \\
\text { Center } \\
\text { Hag }\end{array}$ & $\begin{array}{c}\text { ucs udv } \\
\text { Hag }\end{array}$ & $\begin{array}{c}\text { UCS based } \\
\text { on } \\
\text { Decreasing } \\
\text { velocity } \\
\end{array}$ & $\begin{array}{l}\text { Sweep } \\
\text { Increase I } \\
\text { Decrease }\end{array}$ & \begin{tabular}{|c|} 
UDV \\
Height \\
Bed \\
\end{tabular} & $\begin{array}{l}\text { Particle } \\
\text { Mation }\end{array}$ & $\begin{array}{l}\text { Solids } \\
\text { Level }\end{array}$ & $\begin{array}{l}\text { Outer } \\
\text { Bottom } \\
\text { Patterm }\end{array}$ & $\begin{array}{l}\text { Inner } \\
\text { Bototom } \\
\text { Paterm }\end{array}$ & Case ID & Test & TDP & $\begin{array}{l}\text { Row } \\
\text { Number }\end{array}$ \\
\hline $\mathrm{C}$ & $\mathrm{g} / \mathrm{cm}^{\beta}$ & fraction & fraction & fraction & $\mathrm{s}$ & text & $\mathrm{m} / \mathrm{s}$ & $\mathrm{m} / \mathrm{s}$ & $\mathrm{m} / \mathrm{s}$ & $\mathrm{m} / \mathrm{s}$ & $\mathrm{m} / \mathrm{s}$ & $\mathrm{m} / \mathrm{s}$ & in. & m/s & text & text & text & text & $\mathrm{m} / \mathrm{s}$ & text & $\mathrm{mm}$ & text & text & text & text & text & text & text & text \\
\hline $\mathrm{T}$ & $\rho$ & $\phi_{\mathrm{s}}$ & $\phi_{p}$ & $D C$ & tc & Jet & $u_{s}$ & $\mathrm{u}_{1}$ & $\mathrm{U} 2$ & $\mathrm{U}_{3}$ & $u$ & $u_{\text {us }}$ & $H_{c}$ & U Uss & Uan & Ussis & Usceen & Usuldr & Us_D & $s_{\mathrm{N}}$ & Hed & $\mathrm{PM}$ & Sol & $\mathrm{SPo}_{\mathrm{O}}$ & SP & $\mathrm{ID}$ & MDDX & $\mathrm{IDP}$ & MSS \\
\hline 22.6 & 0.995 & 0.01430 & 0.050 & 0.185 & 54.8 & $\mathrm{P}$ & NA & 9.29 & 9.49 & 9.59 & 9.90 & 9.90 & 27.50 & NA & NA & $\mathrm{NA}$ & NA & NA & NA & NA & 0.2 & NA & $\mathrm{NA}$ & NA & $\mathrm{NA}$ & 70F_4s1d2V _ I 1 & 4/22A & TDP-143 & 700360 \\
\hline 22.6 & 0.995 & 0.01430 & 0.050 & 0.185 & 54.8 & $\mathrm{P}$ & NA & 9.29 & 9.49 & 9.59 & 9.90 & 9.90 & 27.50 & NA & NA & NA & NA & NA & NA & NA & 0.0 & NA & NA & NA & NA & 70F_4s1d2Vd_1 & $4 / 22 \mathrm{~A}$ & TDP-143 & 700361 \\
\hline 22.6 & 0.995 & 0.01430 & 0.050 & 0.185 & 54.8 & $\mathrm{P}$ & NA & 9.29 & 9.49 & 9.59 & 9.90 & 9.90 & 27.50 & NA & NA & NA & NA & NA & NA & NA & 0.0 & NA & NA & NA & NA & 70F_4s1d2Vd_1 & $422 \mathrm{~A}$ & IDP-143 & 700362 \\
\hline 22.6 & 0.995 & 0.01430 & 0.050 & 0.185 & 54.8 & $\mathrm{P}$ & NA & 9.29 & 9.49 & 9.59 & 9.90 & 9.90 & 27.50 & NA & NA & NA & NA & NA & NA & NA & 0.0 & NA & NA & NA & NA & 70F_4sid2Vd_1 & $422 \mathrm{~A}$ & TDP-143 & 700363 \\
\hline 22.6 & 0.995 & 0.01430 & 0.050 & 0.185 & 54.8 & $\mathrm{P}$ & NA & 9.29 & 9.49 & 9.59 & 9.90 & 9.90 & 27.50 & NA & NA & NA & NA & NA & NA & NA & 0.0 & NA & NA & NA & NA & 70F_4s1d2VI_1 & $4222 \mathrm{~A}$ & TDP-143 & 700364 \\
\hline 22.6 & 0.995 & 0.01430 & 0.050 & 0.185 & 54.8 & $\mathrm{P}$ & NA & 9.29 & 9.49 & 9.59 & 9.90 & 9.90 & 27.50 & NA & NA & NA & NA & NA & NA & NA & 0.0 & NA & NA & NA & NA & 70F_4s1d2VI_1 & $422 \mathrm{~A}$ & TDP-143 & 700365 \\
\hline 22.8 & 0.995 & 0.01430 & 0.050 & 0.184 & 52.0 & $\mathrm{P}$ & NA & 9.91 & 10.13 & 10.24 & 10.60 & 9.90 & 36.75 & NA & NA & NA & NA & NA & NA & 1 & NA & 4 & NA & NA & NA & 70F_4s1d2Vd_1 & $4 / 22 \mathrm{~A}$ & IDP-143 & 700366 \\
\hline 23.1 & 0.994 & 0.01430 & 0.099 & 0.327 & 90.0 & $\mathrm{P}$ & NA & 6.42 & 6.47 & 6.50 & 6.00 & 6.60 & 29.00 & NA & center dec & NA & UCscen & NA & 6.60 & D & 4.7 & 2 & NA & NA & NA & 70F_4s1d2V__ 2 & $4 / 22 B$ & TDP-143 & 700368 \\
\hline 23.3 & 0.994 & 0.01430 & 0.050 & 0.666 & 32.6 & $\mathrm{P}$ & NA & 4.40 & 4.45 & 4.48 & 4.60 & 4.80 & 28.00 & NA & \begin{tabular}{|l|} 
NA \\
\end{tabular} & NA & NA & NA & NA & D & 12.8 & 1 & NA & NA & NA & 70F_4s1d2Ve_1 & 4/23A & TDP-144 & 700369 \\
\hline 23.4 & 0.994 & 0.01430 & 0.050 & 0.669 & 31.2 & $\mathrm{P}$ & NA & 4.59 & 4.65 & 4.68 & 4.80 & 4.80 & 33.50 & 4.80 & udv & NA & UCScen & UCsudv & NA & 1 & 0.0 & 2 & NA & NA & NA & 70F_4sidzVe_1 & 4/23A & TDP-144 & 700370 \\
\hline 23.6 & 0.994 & 0.01430 & 0.100 & 0.660 & 67.0 & $\mathrm{P}$ & NA & 4.31 & 4.34 & 4.35 & 4.40 & 4.60 & 26.00 & NA & NA & NA & NA & NA & NA & (null) & 13.8 & 1 & NA & NA & NA & 70F_4s1d2Ve_2 & 4/23B & TDP-144 & 700371 \\
\hline 23.4 & 0.994 & 0.01430 & 0.100 & 0.661 & 64.0 & $\mathrm{P}$ & NA & 4.50 & 4.53 & 4.54 & 4.60 & 4.60 & 32.50 & \begin{tabular}{|l|}
4.60 \\
\end{tabular} & udv & NA & Ucseen & ucsudv & NA & (null) & 0.0 & 2 & NA & NA & NA & 70F_4sidzVe_2 & 4/23B & IDP-144 & 700372 \\
\hline 23.3 & 0.995 & 0.01430 & 0.150 & 0.662 & 101.0 & $\mathrm{P}$ & NA & 4.25 & 4.27 & 4.27 & 4.30 & 4.50 & 27.00 & NA & NA & NA & NA & NA & NA & 1 & 6.9 & 1 & NA & NA & NA & 70F_4s1d2Ve_4 & $4 / 23 \mathrm{C}$ & TDP-144 & 700373 \\
\hline 23.3 & 0.995 & 0.01430 & 0.149 & 0.664 & 96.0 & $\mathrm{P}$ & NA & 4.43 & 4.45 & 4.46 & 4.50 & 4.50 & 33.75 & 4.50 & center & NA & UCScen & NA & NA & 1 & 2.3 & 2 & NA & NA & NA & 70F_4sidzVe 4 & $4 / 23 \mathrm{C}$ & TDP-144 & 700374 \\
\hline 23.0 & 0.994 & 0.01430 & 0.150 & 0.331 & 194.0 & $\mathrm{P}$ & NA & 4.44 & 4.46 & 4.47 & 4.50 & 6.10 & 18.50 & NA & NA & NA & NA & NA & NA & (null) & 39.3 & 1 & NA & NA & NA & 70F_451d2VC_4 & $4 / 24 A$ & TDP-145 & 700375 \\
\hline 23.2 & 0.994 & 0.01430 & 0.150 & 0.332 & 185.6 & $\mathrm{P}$ & NA & 4.64 & 4.66 & 4.67 & 4.70 & 6.10 & 19.50 & NA & NA & NA & $\mathrm{NA}$ & NA & NA & (null) & 37.6 & 1 & NA & NA & NA & 70F_4s1d2VC_4 & $4 / 24 A$ & TDP-145 & 700376 \\
\hline 23.2 & 0.995 & 0.01430 & 0.150 & 0.333 & 171.0 & $\mathrm{P}$ & NA & 5.02 & 5.05 & 5.06 & 5.10 & 6.10 & 21.50 & NA & NA & NA & NA & NA & NA & (null) & 27.3 & 1 & NA & NA & NA & 70F_4s1d2Vc_4 & $4 / 24 \mathrm{~A}$ & IDP-145 & 700377 \\
\hline 23.2 & 0.994 & 0.01430 & 0.150 & 0.333 & 158.6 & $\mathrm{P}$ & NA & 5.41 & 5.44 & 5.45 & 5.50 & 6.10 & 24.00 & NA & NA & NA & NA & NA & NA & 1 & 20.1 & 1 & NA & NA & NA & 70F_4s1d2V__ 4 & $4 / 24 \mathrm{~A}$ & TDP-145 & 700378 \\
\hline 23.1 & 0.994 & 0.01430 & 0.150 & 0.334 & 147.8 & $\mathrm{P}$ & NA & 5.78 & 5.81 & 5.83 & 5.90 & 6.10 & 26.25 & NA & NA & NA & NA & NA & NA & 1 & 15.4 & 1 & NA & NA & NA & 70F_4s1d2VC_4 & $4 / 24 A$ & TDP-145 & 700379 \\
\hline 23.0 & 0.994 & 0.01430 & 0.100 & 0.185 & 154.0 & $\mathrm{P}$ & NA & 6.69 & 6.75 & 6.79 & 6.90 & 8.50 & 20.25 & NA & NA & NA & NA & NA & NA & 1 & 16.7 & 1 & NA & NA & NA & 70F_4s1d2Vd_2 & 4/24B & TDP-145 & 700381 \\
\hline 23.2 & 0.994 & 0.01430 & 0.100 & 0.186 & 145.0 & $\mathrm{P}$ & NA & 7.09 & 7.15 & 7.18 & 7.30 & 8.50 & 21.00 & NA & NA & NA & NA & NA & NA & 1 & 12.8 & 1 & NA & NA & NA & 70F_4s1d2Vd_ 2 & $4 / 24 B$ & TDP-145 & 700382 \\
\hline 23.2 & 0.994 & 0.01430 & 0.101 & 0.186 & 141.0 & $\mathrm{P}$ & NA & 7.30 & 7.36 & 7.40 & 7.50 & 8.50 & 22.25 & NA & NA & NA & NA & NA & NA & 1 & 10.0 & 1 & NA & NA & NA & 70F_4s1d2Vd_2 & $4 / 24 B$ & TDP-145 & 700383 \\
\hline 23.1 & 0.995 & 0.01430 & 0.100 & 0.188 & 123.0 & $\mathrm{P}$ & NA & 8.26 & 8.34 & 8.38 & 8.50 & 8.50 & 27.25 & \begin{tabular}{|l|} 
\\
\end{tabular} & udv & NA & Ucssen & ucsudv & NA & 1 & 0.0 & 2 & NA & NA & NA & 70F_4sIdzVd_ 2 & 4/24B & TDP-145 & 700384 \\
\hline 23.3 & 0.994 & 0.01430 & 0.150 & 0.182 & 252.0 & $\mathrm{P}$ & NA & 6.21 & 6.24 & 6.26 & 6.30 & 6.80 & 27.00 & NA & NA & NA & NA & NA & NA & D & 10.0 & 1 & NA & NA & NA & 70F_4s1d2VV_ 4 & $4 / 25 \mathrm{~A}$ & TDP-146 & 700385 \\
\hline 23.2 & 0.995 & 0.01430 & 0.149 & 0.182 & 244.0 & $\mathrm{P}$ & NA & 6.40 & 6.44 & 6.45 & 6.50 & 6.80 & 27.75 & NA & NA & NA & UCScen & $\mathrm{NA}$ & NA & 1 & 7.3 & 2 & NA & NA & NA & 70F_4s1d2Vd_4 & $4 / 25 \mathrm{~A}$ & IDP-146 & 700386 \\
\hline 23.2 & 0.995 & 0.01430 & 0.150 & 0.182 & 234.0 & $\mathrm{P}$ & NA & 6.69 & 6.73 & 6.75 & 6.80 & 6.80 & 29.50 & \begin{tabular}{|l|}
6.80 \\
\end{tabular} & udv & NA & NA & ucsudv & NA & 1 & 0.7 & 4 & NA & NA & NA & 70F_4s1d2Vd_4 4 & $4 / 25 \mathrm{~A}$ & IDP-146 & 700387 \\
\hline 23.2 & 0.994 & 0.01430 & 0.050 & 0.666 & 31.2 & $\mathrm{P}$ & NA & 4.59 & 4.64 & 4.67 & 4.80 & 4.80 & 35.75 & NA & NA & NA & UCScen & NA & NA & (null) & 0.0 & 2 & NA & NA & NA & 70F_4sid2Ve_1 & 4/25B & IDP-146 & 700388 \\
\hline 23.2 & 0.994 & 0.01430 & 0.050 & 0.666 & 31.2 & $\mathrm{P}$ & NA & 4.59 & 4.64 & 4.67 & 4.80 & 4.80 & 35.75 & NA & NA & NA & NA & NA & NA & NA & 0.0 & NA & NA & NA & NA & 70F_4s1d2Ve_1 & $425 B$ & TDP-146 & 700389 \\
\hline 23.2 & 0.994 & 0.01430 & 0.050 & 0.666 & 31.2 & $\mathrm{P}$ & NA & 4.59 & 4.64 & 4.67 & 4.80 & 4.80 & 35.75 & NA & NA & NA & NA & NA & NA & NA & $\mathrm{na}$ & NA & NA & NA & NA & 70F_4sIdZ2Ve_1 & 4/25B & TDP-146 & 700389.1 \\
\hline 23.2 & 0.994 & 0.01430 & 0.050 & 0.666 & 31.2 & $\mathrm{P}$ & NA & 4.59 & 4.64 & 4.67 & 4.80 & 4.80 & 35.75 & NA & NA & NA & NA & NA & NA & NA & 0.0 & NA & NA & NA & NA & 70F_4s1d2Ve_1 & 4/25B & IDP-146 & 700390 \\
\hline 23.2 & 0.994 & 0.01430 & 0.050 & 0.666 & 31.2 & $\mathrm{P}$ & NA & 4.59 & 4.64 & 4.67 & 4.80 & 4.80 & 35.75 & NA & NA & NA & NA & NA & NA & NA & naa & NA & NA & NA & NA & 70F_4s1d2Ve_1 & $425 \mathrm{~B}$ & TDP-146 & 700390.1 \\
\hline 23.2 & 0.994 & 0.01430 & 0.050 & 0.666 & 31.2 & $\mathrm{P}$ & NA & 4.59 & 4.64 & 4.67 & 4.80 & 4.80 & 35.75 & NA & NA & NA & NA & NA & NA & NA & 0.0 & NA & NA & NA & NA & 70F_4s1d2Ve_1 & 4/25B & TDP-146 & 700391 \\
\hline 23.2 & 0.994 & 0.01430 & 0.050 & 0.666 & 31.2 & $\mathrm{P}$ & NA & 4.59 & 4.64 & 4.67 & 4.80 & 4.80 & 35.75 & NA & $\mathrm{NA}$ & NA & NA & NA & NA & NA & na & NA & NA & NA & NA & 70F_4s1d2Ve_1 & 4/25B & TDP-146 & 700391.1 \\
\hline 23.2 & 0.994 & 0.01430 & 0.050 & 0.666 & 31.2 & $\mathrm{P}$ & NA & 4.59 & 4.64 & 4.67 & 4.80 & 4.80 & 35.75 & NA & NA & NA & NA & NA & NA & NA & 0.0 & NA & NA & NA & NA & 70F_4s1d2Ve_1 & 4/25B & TDP-146 & 700392 \\
\hline 23.2 & 0.994 & 0.01430 & 0.050 & 0.666 & 31.2 & $\mathrm{P}$ & NA & 4.59 & 4.64 & 4.67 & 4.80 & 4.80 & 35.75 & NA & NA & NA & NA & NA & NA & NA & ra & NA & NA & NA & NA & 70F_4s1d2Ve_1 & 4/25B & IDP-146 & 700392.1 \\
\hline 23.2 & 0.994 & 0.01430 & 0.050 & 0.666 & 31.2 & $\mathrm{P}$ & NA & 4.59 & 4.64 & 4.67 & 4.80 & 4.80 & 35.75 & NA & NA & NA & NA & NA & NA & NA & 0.0 & NA & NA & NA & NA & 70F_4s1d2Ve_1 & $425 B$ & TDP-146 & 700393 \\
\hline 23.2 & 0.994 & 0.01430 & 0.050 & 0.666 & 31.2 & $\mathrm{P}$ & NA & 4.59 & 4.64 & 4.67 & 4.80 & 4.80 & 35.75 & NA & NA & NA & NA & NA & $\mathrm{N} / \mathrm{H}$ & NA & $\mathrm{na}$ & NA & NA & NA & NA & 70F_4sidzVe_1 & 4/25B & TDP-146 & 700393.1 \\
\hline 23.1 & 0.995 & 0.01430 & 0.100 & 0.327 & 90.0 & $\mathrm{P}$ & NA & 6.46 & 6.51 & 6.54 & 6.60 & 6.60 & 28.50 & NA & NA & NA & NA & NA & NA & NA & na & NA & NA & NA & NA & 70F_4s1d2VC_2 & $4 / 25 \mathrm{C}$ & TDP-146 & 700393.2 \\
\hline & 0.995 & 0.01430 & 0.100 & 0.327 & 90.0 & $P$ & NA & 6.46 & 6.51 & 6.54 & 6.60 & 6.60 & 28.50 & 6 & oenter & NA & ucsce & NA & NA & (null) & 7.8 & & NA & NA & NA & 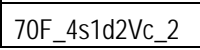 & 4/255 & TDP-146 & 700394 \\
\hline
\end{tabular}


Table B.6. Data from 2008 in Large-Scale Vessel with Flanged and Dished Head A.6

\begin{tabular}{|c|c|c|c|c|c|c|c|c|c|c|c|c|c|c|c|c|c|c|c|c|c|c|c|c|c|c|c|}
\hline Row Number & Test & Case ID & \begin{tabular}{l|} 
Tank \\
Diameter \\
\end{tabular} & \begin{tabular}{|l} 
Head \\
Shape
\end{tabular} & \begin{tabular}{|c} 
Dish \\
Height
\end{tabular} & $\begin{array}{c}\text { Dish } \\
\text { Volume }\end{array}$ & $\begin{array}{c}\text { Tank Fill } \\
\text { Height }\end{array}$ & $\begin{array}{l}\text { Return } \\
\text { Line } \\
\text { Height }\end{array}$ & $\begin{array}{l}\text { Nozzle } \\
\text { onner } \\
\text { Diameter }\end{array}$ & $\begin{array}{c}\text { Nonle } \\
\text { Stand-off } \\
\text { Distance }\end{array}$ & $\begin{array}{l}\text { Pulse Tube } \\
\text { Configuration }\end{array}$ & \begin{tabular}{|l|}
$\begin{array}{l}\text { Installed } \\
\text { Nozzles }\end{array}$ \\
\end{tabular} & $\begin{array}{l}\text { Outer } \\
\text { Nozles } \\
\text { Operated }\end{array}$ & \begin{tabular}{|l|} 
Inner \\
Nozeles \\
Operated
\end{tabular} & $\begin{array}{c}\text { Pulse Tube } \\
\text { Outer } \\
\text { Diameter }\end{array}$ & $\begin{array}{c}\text { Outer } \\
\text { PMM } \\
\text { Radius }\end{array}$ & $\begin{array}{c}\text { IInner } \\
\text { PJM } \\
\text { Radius }\end{array}$ & $\begin{array}{c}\text { "FO' O' Oter JJM } \\
\text { Impingenent } \\
\text { Angle }\end{array}$ & \begin{tabular}{|l}
$\mid \begin{array}{l}\text { "Fo' IInner JuM } \\
\text { Impingement } \\
\text { Angle }\end{array}$ \\
\end{tabular} & \begin{tabular}{|c} 
Ratio Outer \\
PJMto torank \\
Radius \\
\end{tabular} & \begin{tabular}{|l}
$\begin{array}{l}\text { Ratio Inner PJM } \\
\text { to Tank Radius }\end{array}$ \\
to
\end{tabular} & Simulant & $\begin{array}{l}\text { Solidis } \\
\text { Density }\end{array}$ & 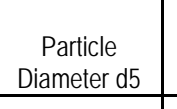 & \begin{tabular}{|c|} 
Particle \\
Diameter d50 \\
\end{tabular} & \begin{tabular}{|c|}
$\begin{array}{c}\text { Particle } \\
\text { Diameter d95 }\end{array}$ \\
\end{tabular} & \begin{tabular}{|c} 
Void \\
Fraction \\
\end{tabular} \\
\hline text & text & text & in. & text & in. & in. ${ }^{3}$ & in. & in. & in. & in. & text & number & number & number & in. & in. & in. & deg & deg & nondim & nondim & text & $\mathrm{g} / \mathrm{cm}^{3}$ & $\mathrm{~m}$ & $\mathrm{~m}$ & $\mathrm{~m}$ & fraction \\
\hline MSS & MDDX & ID & D & $\mathrm{HS}$ & Hosh & $V_{\text {dsh }}$ & $\mathrm{H}$ & $\operatorname{Rn}$ & $d$ & sod & PT & $\mathrm{N}$ & $\mathrm{Nb}_{\mathrm{b}}$ & $\mathrm{N}$ & $\mathrm{PT}_{\alpha \mathrm{d}}$ & $R_{0}$ & $R_{1}$ & $\theta_{0}$ & $\theta_{1}$ & $\mathrm{R} d \mathrm{R}$ & $R, R$ & sxdx & $\rho_{\mathrm{s}}$ & $d s$ & $d_{60}$ & dos & vf \\
\hline 700395 & $4 / 25 \mathrm{C}$ & 7oF_4s1d2VC_ 2 & 70 & $F$ & 12.7 & 30569.0 & $871 / 2$ & $835 / 8$ & 0.613 & 0.920 & HLP-22 & 12 & 8 & 4 & 3.5 & 26.4 & 11.7 & 22.4 & 9.7 & 0.75 & 0.33 & s1d2 & 2.48 & 0.0000569 & 0.0000693 & 0.0000821 & 0.3750 \\
\hline 700396 & $4 / 25 \mathrm{C}$ & 7OF_4s1d2VC_ 2 & 70 & $\mathrm{FD}$ & 12.7 & 30569.0 & $871 / 2$ & $835 / 8$ & 0.613 & 0.920 & HLP-22 & 12 & 8 & 4 & 3.5 & 26.4 & 11.7 & 22.4 & 9.7 & 0.75 & 0.33 & s1d2 & 2.48 & 0.0000569 & 0.0000693 & 0.0000821 & 0.3750 \\
\hline 700397 & $4 / 25 \mathrm{C}$ & 7OF_4s1d2Vc_2 & 70 & $F D$ & 12.7 & 30569. & $871 / 2$ & $835 / 8$ & 0.613 & 0.920 & HLP-22 & 12 & 8 & 4 & 3.5 & 26.4 & 11.7 & 22.4 & 9.7 & 0.75 & 0.33 & s1d2 & 2.48 & 0.0000569 & 0.0000693 & 0.0000821 & 0.3750 \\
\hline 700398 & $4 / 25 \mathrm{C}$ & 7OF_4s1dd2Vc_2 & 70 & $F D$ & 12.7 & 30569.0 & $871 / 2$ & $835 / 8$ & 0.613 & 0.920 & HLP-22 & 12 & 8 & 4 & 3.5 & 26.4 & 11.7 & 22.4 & 9.7 & 0.75 & 0.33 & s1d2 & 248 & 0.0000569 & 0.0000693 & 0.0000821 & 0.3750 \\
\hline 700399 & $4 / 25 \mathrm{C}$ & 7oF_4s1d2Vc__2 & 70 & $\mathrm{FD}$ & 12.7 & 30569. 0 & $871 / 2$ & $835 / 8$ & 0.613 & 0.920 & HLP-22 & 12 & 8 & 4 & 3.5 & 26.4 & 11.7 & 22.4 & 9.7 & 0.75 & 0.33 & s1d2 & 2.48 & 0.0000569 & 0.0000693 & 0.0000821 & 0.3750 \\
\hline 700400 & $4 / 25 \mathrm{C}$ & TOF_4s1d2vc_2 & 70 & $F D$ & 12.7 & 30569. & $871 / 2$ & $835 / 8$ & 0.613 & 0.920 & HLP.22 & 12 & 8 & 4 & 3.5 & 26.4 & 111.7 & 22.4 & 9.7 & 0.75 & 0.33 & s1d2 & 248 & 0.0000569 & 0.0000693 & 0.0000827 & 0.3750 \\
\hline 700401 & $4 / 25 \mathrm{C}$ & TOF_4s1d2VC_ 2 & 70 & $F D$ & 12.7 & 30569.0 & $871 / 2$ & $835 / 8$ & 0.613 & 0.920 & HLP-22 & 12 & 8 & 4 & 3.5 & 26.4 & 11.7 & 22.4 & 9.7 & 0.75 & 0.33 & s1d2 & 2.48 & 0.0000569 & 0.0000693 & 0.0000821 & 0.3750 \\
\hline 700402 & $4 / 25 \mathrm{C}$ & ToF_4s1d2vc_2 2 & 70 & $F D$ & 12.7 & 30569. & $871 / 2$ & $835 / 8$ & 0.613 & 0.920 & HLP -22 & 12 & 8 & 4 & 3.5 & 26.4 & 111.7 & 22.4 & 9.7 & 0.75 & 0.33 & s1d2 & 2.48 & 0.0000569 & 0.0000693 & 0.0000821 & 0.3750 \\
\hline 700403 & $4 / 28 \mathrm{~A}$ & TOF_4s1d2Vd_1 1 & 70 & $F D$ & 12.7 & 30569.0 & $891 / 2$ & $835 / 8$ & 0.613 & 0.920 & HLP-22 & 12 & 8 & 4 & 3.5 & 26.4 & 11.7 & 22.4 & 9.7 & 0.75 & 0.33 & s1d2 & 2.48 & 0.0000569 & 0.0000693 & 0.0000821 & 0.3750 \\
\hline 700404 & $4 / 28 \mathrm{~A}$ & 7OF_4s1ddVVd_1 & 70 & $\mathrm{FD}$ & 12.7 & 30569.0 & $89 \mathrm{1/2}$ & $835 / 8$ & 0.613 & 0.920 & HLP-22 & 12 & 8 & 4 & 3.5 & 26.4 & 11.7 & 22.4 & 9.7 & 0.75 & 0.33 & s1d2 & 2.48 & 0.0000569 & 0.0000693 & 0.0000821 & 0.3750 \\
\hline 700405 & $4 / 28 \mathrm{~A}$ & 7OF_4s1d2Vd_1 1 & 70 & $F D$ & 12.7 & 30569.0 & $891 / 2$ & $835 / 8$ & 0.613 & 0.920 & HLP-22 & 12 & 8 & 4 & 3.5 & 26.4 & 11.7 & 22.4 & 9.7 & 0.75 & 0.33 & s1d2 & 2.48 & 0.0000569 & 0.0000693 & 0.0000821 & 0.3750 \\
\hline 700405.1 & $4 / 28 \mathrm{~A}$ & 70F_4s1di2Vd_1 & 70 & $\mathrm{FD}$ & 12.7 & 30569.0 & $891 / 2$ & $835 / 8$ & 0.613 & 0.920 & HLP-22 & 12 & 8 & 4 & 3.5 & 26.4 & 11.7 & 22.4 & 9.7 & 0.75 & 0.33 & s1d2 & 2.48 & 0.0000569 & 0.0000693 & 0.0000821 & 0.3750 \\
\hline 700405.2 & $4 / 28 \mathrm{~A}$ & 70F_4s1d2Vd_1 1 & 70 & $F D$ & 12.7 & 30569. & $89 \mathrm{1/2}$ & $835 / 8$ & 0.613 & 0.920 & HLP-22 & 12 & 8 & 4 & 3.5 & 26.4 & 11.7 & 22.4 & 9.7 & 0.75 & 0.33 & s1d2 & 2.48 & 0.0000569 & 0.0000693 & 0.0000821 & 0.3750 \\
\hline 700406 & 4/28A & TOF_4s1d2Vd_1 & 70 & $F D$ & 12.7 & 30569. & $891 / 2$ & $835 / 8$ & 0.613 & 0.920 & HLP-22 & 12 & 8 & 4 & 3.5 & 26.4 & 111.7 & & 9.7 & & & s1d2 & 248 & 0.0000569 & 0.0000693 & 0.0000827 & 0.3750 \\
\hline 700407 & $4 / 28 \mathrm{~A}$ & 7oF_4s1d2Vd_1 1 & 70 & $F$ & 12.7 & 30569.0 & $89 \mathrm{1/2}$ & $835 / 8$ & 0.613 & 0.920 & HLP-22 & 12 & 8 & 4 & 3.5 & 26.4 & 11.7 & 22.4 & 9.7 & 0.75 & 0.33 & s1d2 & 248 & 0.0000569 & 0.0000693 & 0.0000821 & 0.3750 \\
\hline 700408 & $4 / 28 \mathrm{~A}$ & 70F_4s1da2vd_1 & 70 & $\mathrm{FD}$ & 12.7 & 30569.0 & $891 / 2$ & $835 / 8$ & 0.613 & 0.920 & HLP-22 & 12 & 8 & 4 & 3.5 & 26.4 & 11.7 & 22.4 & 9.7 & 0.75 & 0.33 & s1d2 & 2.48 & 0.0000569 & 0.0000693 & 0.0000821 & 0.3750 \\
\hline 700409 & $4 / 28 \mathrm{~A}$ & 7OF_4s1d2Vd_1 1 & 70 & $F D$ & 12.7 & 30569.0 & $891 / 2$ & $835 / 8$ & 0.613 & 0.920 & HLP-22 & 12 & 8 & 4 & 3.5 & 26.4 & 11.7 & 22.4 & 9.7 & 0.75 & 0.33 & s1d2 & 2.48 & 0.0000569 & 0.0000693 & 0.0000821 & 0.3750 \\
\hline 700410 & $4 / 28 \mathrm{~A}$ & 7OF_4s1dd2Vd_1 & 70 & $F D$ & 12.7 & 30569.0 & $891 / 2$ & $835 / 8$ & 0.613 & 0.920 & HLP-22 & 12 & 8 & 4 & 3.5 & 26.4 & 117 & 22.4 & 9.7 & 0.75 & 0.33 & s1d2 & 248 & 0.0000569 & 0.0000693 & 0.0000821 & 0.3750 \\
\hline 700411 & $4 / 28 \mathrm{~A}$ & 7OF_4s1d2Vd_1 & 70 & $F$ & 12.7 & 30569.0 & $891 / 2$ & $835 / 8$ & 0.613 & 0.920 & HLP-22 & 12 & 8 & 4 & 3.5 & 26.4 & 11.7 & 22.4 & 9.7 & 0.75 & 0.33 & s1d2 & 2.48 & 0.0000569 & 0.0000693 & 0.0000821 & 0.3750 \\
\hline 700412 & 4/28A & ToF_4s1d2Vd_1 & 70 & $F D$ & 12.7 & 30569. & $891 / 2$ & $835 / 8$ & 0.613 & 0.920 & HLP-22 & 12 & 8 & 4 & 3.5 & 26.4 & 111.7 & 22.4 & 9.7 & 0.7 & 0.3 & s1d2 & 248 & 0.0000569 & 0.0000693 & 0.0000821 & 0.3750 \\
\hline 700413 & $4 / 28 \mathrm{~A}$ & 7OF_4s1d2Vd_1 1 & 70 & $F D$ & 12.7 & 30569.0 & $89 \mathrm{1/2}$ & $835 / 8$ & 0.613 & 0.920 & HLP-22 & 12 & 8 & 4 & 3.5 & 26.4 & 11.7 & 22.4 & 9.7 & 0.75 & 0.33 & s1d2 & 2.48 & 0.0000569 & 0.0000693 & 0.0000821 & 0.3750 \\
\hline 700414 & $428 \mathrm{~A}$ & 70F_4s1d2VVd_1 & 70 & $\mathrm{FD}$ & 12.7 & 30569.0 & $891 / 2$ & $835 / 8$ & 0.613 & 0.920 & HLP-22 & 12 & 8 & 4 & 3.5 & 26.4 & 11.7 & 22.4 & 9.7 & 0.75 & 0.3 & s1d2 & 2.48 & 0.0000569 & 0.0000693 & 0.0000821 & 0.3750 \\
\hline 700415M & $4 / 28 A$ & TOF_4s1d2Vd_1 & 70 & $F D$ & 12.7 & 30569. & $89 \mathrm{1/2}$ & $835 / 8$ & 0.613 & 0.920 & HLP-22 & 12 & 8 & 4 & 3.5 & 26.4 & 11.7 & 22.4 & 9.7 & 0.7 & 0.33 & s1d2 & 2.48 & 0.0000569 & 0.0000693 & 0.0000821 & 0.3750 \\
\hline 700415.1 & $428 \mathrm{~A}$ & 70F_4s1da2vd_1 & 70 & $\mathrm{FD}$ & 12.7 & 30569.0 & $891 / 2$ & $835 / 8$ & 0.613 & 0.920 & HLP-22 & 12 & 8 & 4 & 3.5 & 26.4 & 11.7 & 22.4 & 9.7 & 0.75 & 0.33 & s1d2 & 2.48 & 0.0000569 & 0.0000693 & 0.0000821 & 0.3750 \\
\hline $700416 \mathrm{M}$ & $428 \mathrm{~A}$ & TOF_4s1d2Vd_1 & 70 & $P D$ & 12.7 & 30569.9 & $891 / 2$ & $835 / 8$ & 0.613 & 0.920 & HLP-22 & 12 & 8 & 4 & 3.5 & 26.4 & 11.7 & 22.4 & 9.7 & 0.75 & 0.33 & s1d2 & 2.48 & 0.0000569 & 0.0000693 & 0.0000821 & 0.3750 \\
\hline 700417 & $4 / 28 \mathrm{~A}$ & 70F_4s1da2vd_1 & 70 & $\mathrm{FD}$ & 12.7 & 30569.0 & $891 / 2$ & $835 / 8$ & 0.613 & 0.920 & HLP-22 & 12 & 8 & 4 & 3.5 & 26.4 & 11.7 & 22.4 & 9.7 & 0.75 & 0.33 & s1d2 & 2.48 & 0.0000569 & 0.0000693 & 0.0000821 & 0.3750 \\
\hline 700418 & $428 \mathrm{~A}$ & TOF_4s1d2Vd_1 & 70 & $F D$ & 12.7 & 30569.9 & $891 / 2$ & $835 / 8$ & 0.613 & 0.920 & HLP-22 & 12 & 8 & 4 & 3.5 & 26.4 & 11.7 & 22.4 & 9.7 & 0.75 & 0.33 & s1d2 & 2.48 & 0.0000569 & 0.0000693 & 0.0000821 & 0.3750 \\
\hline 700419 & $4 / 28 \mathrm{~A}$ & 7oF_4s1d2Vd_1 & 70 & $F D$ & 12.7 & 30569. & $891 / 2$ & $835 / 8$ & 0.613 & 0.920 & HLP. 22 & 12 & 8 & 4 & 3.5 & 26.4 & 1117 & 22.4 & 9.7 & 0.75 & 0.33 & s1d2 & 248 & 0.0000569 & 0.0000693 & 0.0000821 & 0.3750 \\
\hline 700420 & $4 / 28 \mathrm{~A}$ & 7oF_4sid2Vd_1 1 & 70 & $F$ & 12.7 & 30569.0 & $891 / 2$ & $835 / 8$ & 0.613 & 0.920 & HLP-22 & 12 & 8 & 4 & 3.5 & 26.4 & 11.7 & 22.4 & 9.7 & 0.7 & 0.33 & s1d2 & 2.48 & 0.0000569 & 0.0000693 & 0.0000827 & 0.3750 \\
\hline 700421 & $4 / 28 \mathrm{~A}$ & ToF_4s1d2Vd_1 & 70 & $F D$ & 12.7 & 30569. & $891 / 2$ & $835 / 8$ & 0.613 & 0.920 & HLP-22 & 12 & 8 & 4 & 3.5 & 26.4 & 11.7 & 22.4 & 9.7 & 0.7 & 0.5 & s1d2 & 248 & 0.0000569 & 0.0000693 & 0.0000821 & 0.3750 \\
\hline 700422 & $4 / 28 A$ & 7oF_4s1d2vd_1 1 & 70 & $F$ & 12.7 & 30569. & $891 / 2$ & $835 / 8$ & 0.613 & 0.920 & HLP-22 & 12 & 8 & 4 & 3.5 & 26.4 & 11.7 & 22.4 & 9.7 & 0.75 & 0.38 & s1d2 & 2.48 & 0.0000569 & 0.0000693 & 0.0000822 & 0.3750 \\
\hline 700423 & $4 / 28 \mathrm{~A}$ & 7OF_4s1d2Vd_1 & 70 & $\mathrm{FD}$ & 12.7 & 30569.0 & $891 / 2$ & $835 / 8$ & 0.613 & 0.920 & HLP-22 & 12 & 8 & 4 & 3.5 & 26.4 & 11.7 & 22.4 & 9.7 & 0.7 & 0.3 & s1d2 & 2.48 & 0.0000569 & 0.0000693 & 0.0000821 & 0.3750 \\
\hline 700424 & $4 / 28 \mathrm{~A}$ & 70F_4s1d2Vd_1 & 70 & $F D$ & 12.7 & 30569. & $89 \mathrm{1/2}$ & $835 / 8$ & 0.613 & 0.920 & HLP-22 & 12 & 8 & 4 & 3.5 & 26.4 & 11.7 & 22.4 & 9.7 & 0.75 & 0.33 & s1d2 & 2.48 & 0.0000569 & 0.0000693 & 0.0000821 & 0.3750 \\
\hline $700425 \mathrm{M}$ & $4 / 28 \mathrm{~A}$ & 7OF_4s1d2VV__1 & 70 & $F$ & 12.7 & 30569.0 & $891 / 2$ & $835 / 8$ & 0.613 & 0.920 & HLP-22 & 12 & 8 & 4 & 3.5 & 26.4 & 11.7 & 22.4 & 9.7 & 0.75 & 0.33 & $s 1 \mathrm{~d} 2$ & 248 & 0.0000569 & 0.0000693 & 0.0000821 & 0.3750 \\
\hline $700426 \mathrm{M}$ & 4/28A & 70F_4sid2Vd_1 & 70 & $F D$ & 12.7 & 30569.9 & $891 / 2$ & $835 / 8$ & 0.613 & 0.920 & HLP-22 & 12 & 8 & 4 & 3.5 & 26.4 & 11.7 & 22.4 & 9.7 & o. & & sid2 & 2.48 & 0.0000569 & 0.0000693 & 0.0000822 & 0.3750 \\
\hline 700427 & $4 / 29 \mathrm{~A}$ & 7OF_4s1d2Vc_1 & 70 & $\mathrm{FD}$ & 12.7 & 30569.0 & 89 & $835 / 8$ & 0.613 & 0.920 & HLP-22 & 12 & 8 & 4 & 3.5 & 26.4 & 11.7 & 22.4 & 9.7 & 0.75 & 0.33 & s1d2 & 2.48 & 0.0000569 & 0.0000693 & 0.0000821 & 0.3750 \\
\hline 700428 & 4/29A & TOF_4s1d2Vc_1 & 70 & $F D$ & 12.7 & 30569.9 & 89 & $835 / 8$ & 0.613 & 0.920 & HLP-22 & 12 & 8 & 4 & 3.5 & 26.4 & 11.7 & 22.4 & 9.7 & 0.7 & 0.33 & s1d2 & 2.48 & 0.0000569 & 0.0000693 & 0.0000821 & 0.3750 \\
\hline 700429 & $4 / 29 A$ & TOF_4s1d2Vc_1 & 70 & $F D$ & 12.7 & 30569. & 89 & $835 / 8$ & 0.613 & 0.920 & HLP-22 & 12 & 8 & 4 & 3.5 & 26.4 & 111.7 & 22.4 & 9.7 & 0.75 & 0.33 & $\mathrm{~s} 1 \mathrm{~d} 2$ & 2.48 & 0.0000569 & 0.0000693 & 0.0000821 & 0.3750 \\
\hline 700430M & 4/29A & 7OF_4s1d2Vc_1 & 70 & $P D$ & 12.7 & 30569.9 & 89 & $835 / 8$ & 0.613 & 0.920 & HLP-22 & 12 & 8 & 4 & 3.5 & 26.4 & 11.7 & 22.4 & 9.7 & 0.75 & 0.33 & s1d2 & 2.48 & 0.0000569 & 0.0000693 & 0.0000821 & 0.3750 \\
\hline $700431 \mathrm{M}$ & $429 A$ & TOF_4s1d2Vc_1 & 70 & 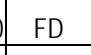 & & 30569.0 & 89 & $835 / 8$ & 0.613 & 0.920 & HLP-22 & 12 & 8 & & 3.5 & 26.4 & & 22.4 & 9.7 & 0.15 & 0.33 & 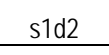 & 2.48 & 0.0000569 & 0.0000693 & 0.0000821 & \\
\hline & & & & & 127 & & & & & 0020 & & & & & & & & & & & & & & & & & \\
\hline
\end{tabular}


Table B.6. Data from 2008 in Large-Scale Vessel with Flanged and Dished Head B.6

\begin{tabular}{|c|c|c|c|c|c|c|c|c|c|c|c|c|c|c|c|c|c|c|c|c|c|c|c|c|c|c|c|c|c|}
\hline $\begin{array}{l}\text { Tank Water } \\
\text { Temperature }\end{array}$ & $\begin{array}{l}\text { Water } \\
\text { Density }\end{array}$ & $\begin{array}{l}\text { Solids } \\
\text { Fraction }\end{array}$ & $\begin{array}{l}\text { Pulse } \\
\text { Volume } \\
\text { Fraction } \\
\end{array}$ & $\begin{array}{l}\text { Duty } \\
\text { cyde }\end{array}$ & $\begin{array}{l}\text { Cydle } \\
\text { Time }\end{array}$ & $\begin{array}{l}\text { Pulsed or } \\
\text { Steacy Jet }\end{array}$ & \begin{tabular}{|l|} 
Us \\
Steady \\
Jet \\
\end{tabular} & \begin{tabular}{|c} 
U1 \\
Pulsing \\
Jet
\end{tabular} & $\begin{array}{l}\text { U2 } \\
\text { URMS } \\
\end{array}$ & $\begin{array}{c}\text { U3 } \\
\text { URNB } \\
\end{array}$ & \begin{tabular}{|c} 
Discharge \\
Velocity \\
\end{tabular} & \begin{tabular}{|c|} 
Citical \\
Suspension \\
Velocity \\
\end{tabular} & $\begin{array}{c}\text { Average Peak } \\
\text { Cloud hlight }\end{array}$ & $\begin{array}{l}\text { UcS } \\
\text { Condtion }\end{array}$ & $\begin{array}{l}\text { ucs } \\
\text { Method }\end{array}$ & UCS Hag & $\begin{array}{c}\text { Ucs Center } \\
\text { Hag }\end{array}$ & $\begin{array}{c}\text { UCS uov } \\
\text { Hag }\end{array}$ & $\begin{array}{c}\text { UCS based on } \\
\text { Decreasing } \\
\text { velocity }\end{array}$ & $\begin{array}{l}\text { Sweep } \\
\text { Increase/ } \\
\text { Decrease }\end{array}$ & \begin{tabular}{|c|} 
UDV \\
Height \\
Bed
\end{tabular} & \begin{tabular}{|l|}
$\begin{array}{l}\text { Patidicle } \\
\text { Motion }\end{array}$ \\
\end{tabular} & \begin{tabular}{|l|} 
Solids \\
Level \\
\end{tabular} & \begin{tabular}{|l|} 
Outer \\
Bototo \\
Pattem \\
\end{tabular} & \begin{tabular}{|l} 
Inner \\
Botom \\
Pattem
\end{tabular} & Case ID & Test & IDP & $\begin{array}{r}\text { Row } \\
\text { Numbe }\end{array}$ \\
\hline $\mathrm{c}$ & $\mathrm{g} / \mathrm{cm}^{3}$ & fraction & fraction & fraction & $\mathrm{s}$ & text & m/s & $m / s$ & $\mathrm{~m} / \mathrm{s}$ & m/s & \begin{tabular}{|l|}
$\mathrm{m} / \mathrm{s}$ \\
\end{tabular} & \begin{tabular}{|l|}
$\mathrm{m} / \mathrm{s}$ \\
\end{tabular} & in. & m/s & text & text & text & text & \begin{tabular}{|l|}
$\mathrm{m} / \mathrm{s}$ \\
\end{tabular} & text & $\mathrm{mm}$ & text & text & text & text & text & text & text & text \\
\hline $\mathrm{T}$ & $\rho$ & $\phi_{\mathrm{s}}$ & $\phi_{p}$ & $\mathrm{DC}$ & $t_{\mathrm{tc}}$ & Jet & $u_{\mathrm{s}}$ & $\mathrm{U}_{1}$ & $\mathrm{U} 2$ & U3 & $u$ & uss & $\mathrm{Hc}$ & $U_{\text {CSR }}$ & Ussu & \begin{tabular}{|l|} 
Ussvis \\
\end{tabular} & Usscen & Usoudv & $U_{c s} \mathrm{D}$ & $\mathrm{S}_{\mathrm{N}}$ & $H_{\text {bod }}$ & $\mathrm{PM}$ & Sol & $\mathrm{SPo}$ & $\mathrm{SP}_{\mathrm{P}}$ & $1 \mathrm{DD}$ & MDDX & $\mathrm{TDP}$ & MSS \\
\hline 23.1 & 0.995 & 0.01430 & 0.100 & \begin{tabular}{l|l|}
0.327 \\
\end{tabular} & 90.0 & $P$ & NA & 6.46 & $\begin{array}{l}6.51 \\
\end{array}$ & 6.54 & 6.60 & 6.60 & \multicolumn{2}{|c|}{$28.50 \mathrm{NA}$} & NA & NA & NA & NA & $\mathrm{NA}$ & NA & 8.0 & NA & NA & $\frac{N A}{N A}$ & NA & 70F_4s1d2VV__2 & $425 \mathrm{C}$ & TDP-146 & 700395 \\
\hline 23.1 & 0.995 & 0.01430 & 0.100 & 0.327 & 90.0 & $\mathrm{P}$ & NA & 6.46 & 6.51 & 6.54 & 6.60 & 6.60 & \multicolumn{2}{|c|}{28.50 NA } & NA & NA & NA & NA & NA & NA & 8.0 & NA & NA & NA & NA & 70F_4s1d2Vc_ 2 & $4 / 25 \mathrm{C}$ & TDP-146 & 700396 \\
\hline 23.1 & 0.995 & 0.01430 & 0.100 & \begin{tabular}{l|l}
0.327 \\
\end{tabular} & 90.0 & $\mathrm{P}$ & NA & 6.46 & 6.51 & 6.54 & 6.60 & 6.60 & \multirow{2}{*}{\multicolumn{2}{|c|}{$\begin{array}{l}28.50 \mid \mathrm{NA} \\
28.50 \mathrm{NA}\end{array}$}} & NA & $N A$ & NA & NA & NA & NA & 7.8 & NA & NA & NA & NA & 70F_4s1d2Vc_2 & $4 / 25 \mathrm{C}$ & TDP-146 & 700397 \\
\hline 23.1 & 0.995 & 0.01430 & 0.100 & 0.327 & 90.0 & $\mathrm{P}$ & NA & 6.46 & 6.51 & 6.54 & 6.60 & 6.60 & & & NA & NA & NA & NA & NA & NA & 7.5 & NA & NA & NA & NA & 7OF_4sid2Vc_2 & $4 / 25 \mathrm{C}$ & TDP-146 & 700398 \\
\hline 23.1 & 0.995 & 0.01430 & 0.100 & 0.327 & 90.0 & $\mathrm{P}$ & NA & 6.46 & 6.51 & 6.54 & 6.60 & 6.60 & \multicolumn{2}{|c|}{$28.50 \mathrm{NA}$} & NA & NA & NA & NA & NA & NA & 6.7 & NA & NA & NA & $\mathrm{NA}$ & 70F_4s1d2VV__2 & $4 / 25 \mathrm{C}$ & TDP-146 & 700399 \\
\hline 23.1 & 0.995 & 0.01430 & 0.100 & 0.327 & 90.0 & $\mathrm{P}$ & NA & 6.46 & 6.51 & 6.54 & 6.60 & 6.60 & \multirow{2}{*}{\multicolumn{2}{|c|}{$\begin{array}{l}28.50 \text { NA } \\
28.50 \text { NA }\end{array}$}} & NA & NA & NA & NA & NA & NA & 6.4 & NA & NA & NA & NA & 70F_4s1d2Vc_2 & $4 / 25 \mathrm{C}$ & TDP-146 & 700400 \\
\hline 23.1 & 0.995 & 0.01430 & 0.100 & 0.327 & 90.0 & $\mathrm{P}$ & NA & 6.46 & 6.51 & 6.54 & 6.60 & 6.60 & & & NA & NA & NA & NA & NA & NA & 8.4 & NA & NA & NA & NA & $70 F_{4} 4 \mathrm{~s} 1 \mathrm{~d} 2 \mathrm{Vc} \mathrm{c}_{2}$ & $4 / 25 \mathrm{C}$ & TDP-146 & 700401 \\
\hline 23.1 & 0.995 & 0.01430 & 0.100 & 0.327 & 90.0 & $\mathrm{P}$ & NA & 6.46 & 6.51 & 6.54 & 6.60 & 6.60 & \multicolumn{2}{|c|}{$28.50 \mathrm{NA}$} & NA & NA & NA & NA & NA & NA & 8.7 & NA & NA & NA & $\mathrm{NA}$ & 70F_4s1d2Vc 2 & $4 / 25 \mathrm{C}$ & TDP-146 & 700402 \\
\hline 22.5 & 0.995 & 0.01430 & 0.050 & 0.185 & 60.4 & $\mathrm{P}$ & NA & 8.57 & 8.73 & 8.82 & 9.10 & 9.80 & \multicolumn{2}{|c|}{\begin{tabular}{l|l|l}
24.25 & $\mathrm{NA}$ \\
\end{tabular}} & NA & NA & NA & NA & NA & (null) & 28.7 & 1 & NA & NA & NA & 70F_4s1d2Vd 1 & 4/28A & TDP-147 & 700403 \\
\hline 22.6 & 0.995 & 0.01430 & 0.050 & 0.186 & 58.0 & $\mathrm{P}$ & NA & 8.87 & 9.04 & 9.13 & 9.40 & 9.80 & \multirow{2}{*}{\multicolumn{2}{|c|}{$\begin{array}{l}25.75 \text { NA } \\
26.75 \text { NA }\end{array}$}} & NA & NA & NA & NA & NA & 1 & 20.8 & 1 & NA & NA & NA & 70F_4s1d2Vd_1 & 4/28A & IDP-147 & 700404 \\
\hline 22.7 & 0.995 & 0.01430 & 0.050 & 0.187 & 56.4 & $\mathrm{P}$ & NA & 9.06 & 9.24 & 9.33 & 9.60 & 9.80 & & & NA & NA & UCScen & NA & NA & $\mathrm{I}$ & 2.8 & 2 & NA & NA & NA & 70F_4s1d2Vd_1 & 4/28A & TDP-147 & 700405 \\
\hline 22.9 & 0.994 & 0.01430 & 0.050 & 0.187 & 56.4 & $\mathrm{P}$ & NA & 9.05 & 9.23 & 9.32 & 9.60 & 9.80 & \multicolumn{2}{|c|}{$26.25 \mathrm{NA}$} & NA & NA & NA & NA & NA & NA & naa & NA & NA & $\mathrm{NA}$ & $\mathrm{NA}$ & 70F_4s1d2Vd_ 1 & 4/28A & TDP-147 & 700405 \\
\hline 22.9 & 0.994 & 0.01430 & 0.050 & 0.187 & 56.4 & $\mathrm{p}$ & NA & 9.05 & 9.23 & 9.32 & 9.60 & 9.80 & \multicolumn{2}{|c|}{\begin{tabular}{l|l|l}
26.25 & $\mathrm{NA}$ \\
\end{tabular}} & NA & NA & NA & NA & NA & NA & $\mathrm{N} / \mathrm{a}$ & NA & NA & NA & NA & 70F_4s1d2Vd_ 1 & 4/28A & TDP-147 & 700405 \\
\hline 22.9 & 0.994 & 0.01430 & 0.050 & 0.187 & 56.4 & $\mathrm{P}$ & NA & 9.05 & 9.23 & 9.32 & 9.60 & 9.80 & \multirow{2}{*}{\multicolumn{2}{|c|}{$\begin{array}{l}26.25 / \mathrm{NA} \\
26.25 / \mathrm{NA}\end{array}$}} & NA & NA & UCScen & NA & NA & (null) & \begin{tabular}{|l|l|}
19.7 \\
\end{tabular} & 2 & NA & $\mathrm{NA}$ & $\mathrm{NA}$ & 70F_4sid2VI_ 1 & 4/28A & TDP-147 & 700406 \\
\hline 22.9 & 0.994 & 0.01430 & 0.050 & \begin{tabular}{l|l}
0.187 \\
\end{tabular} & 56.4 & $\mathrm{P}$ & NA & 9.05 & 9.23 & 9.32 & 9.60 & 9.80 & & & NA & NA & NA & NA & NA & NA & 13.5 & NA & NA & $\mathrm{NA}$ & NA & 70F_4s1d2Vd_1 & 4/28A & TDP-147 & 700407 \\
\hline 22.9 & 0.994 & 0.01430 & 0.050 & 0.187 & 56.4 & $\mathrm{P}$ & NA & 9.05 & 9.23 & 9.32 & 9.60 & 9.80 & \multicolumn{2}{|c|}{$26.25 \mathrm{NA}$} & NA & NA & NA & NA & NA & NA & 11.0 & NA & NA & NA & NA & 70F_4s1d2VI_ 1 & $4 / 23 \mathrm{~A}$ & TDP-147 & 700408 \\
\hline 22.9 & 0.994 & 0.01430 & 0.050 & 0.187 & 56.4 & $\mathrm{P}$ & NA & 9.05 & 9.23 & 9.32 & 9.60 & 9.80 & 26.25 & & NA & NA & NA & NA & NA & NA & 14.2 & NA & NA & NA & NA & 70F_4s1d2Vd_ 1 & $4 / 28 \mathrm{~A}$ & TDP-147 & 700409 \\
\hline 22.9 & 0.994 & 0.01430 & 0.050 & 0.187 & 56.4 & $\mathrm{P}$ & NA & 9.05 & 9.23 & 9.32 & 9.60 & 9.80 & 26.25 & & NA & NA & NA & NA & NA & NA & 14.4 & NA & NA & NA & $\mathrm{NA}$ & 70F_4sid2Vd_1 & $4 / 28 \mathrm{~A}$ & TDP-147 & 700410 \\
\hline 22.9 & 0.994 & 0.01430 & 0.050 & \begin{tabular}{l|l}
0.187 \\
\end{tabular} & 56.4 & $\mathrm{P}$ & NA & 9.05 & 9.23 & 9.32 & 9.60 & 9.80 & 26.25 & NA & NA & NA & NA & NA & NA & NA & 17.2 & NA & NA & NA & NA & 70F_4s1d2Vd_1 & $4 / 28 \mathrm{~A}$ & TDP-147 & 700411 \\
\hline 22.9 & 0.994 & 0.01430 & 0.050 & \begin{tabular}{l|l|l|l|l|}
0.187 & \\
\end{tabular} & 56.4 & $\mathrm{P}$ & NA & 9.05 & 9.23 & 9.32 & 9.60 & 9.80 & 26.25 & NA & NA & NA & NA & NA & NA & NA & 15.0 & NA & NA & NA & NA & 70F_4s1d2Vd_1 & 4/28A & TDP-147 & 700412 \\
\hline 22.9 & 0.994 & 0.01430 & 0.050 & 0.187 & 56.4 & $\mathrm{P}$ & NA & 9.05 & 9.23 & 9.32 & 9.60 & 9.80 & 26.25 & & NA & NA & NA & NA & NA & NA & 19.0 & NA & NA & NA & $\mathrm{NA}$ & 70F_4s1d2Vd_ 1 & 4/28A & TDP-147 & 700413 \\
\hline 23.3 & 0.995 & 0.01430 & 0.050 & 0.186 & 56.8 & $\mathrm{P}$ & NA & 9.04 & 9.22 & 9.32 & 9.60 & 9.80 & 26.50 & NA & NA & NA & Ucscen & NA & NA & 1 & 13.8 & 2 & NA & NA & NA & 70F_4sId2Vd_1 & 4/28A & TDP-147 & 700414 \\
\hline 23.5 & 0.995 & 0.01430 & 0.050 & 0.187 & 55.6 & $\mathrm{P}$ & NA & 9.21 & 9.40 & 9.50 & 9.80 & 9.80 & 27.75 & 9.80 & uav & NA & Ucscen & ucsudv & NA & $\mathrm{I}$ & 3.7 & 2 & NA & NA & NA & 70F_4s1d2Vd_1 & 4/28A & TDP-147 & 700415 \\
\hline 23.7 & 0.995 & 0.01430 & 0.050 & 0.187 & 55.6 & $\mathrm{P}$ & NA & 9.20 & \begin{tabular}{|c|}
9.39 \\
\end{tabular} & 9.49 & 9.80 & 9.80 & 28.00 & NA & NA & NA & NA & NA & NA & NA & wa & NA & NA & NA & NA & 70F_4s1d2Vd 1 & 4/28A & TDP-147 & 700415 \\
\hline 23.7 & 0.995 & 0.01430 & 0.050 & 0.187 & 55.6 & $\mathrm{p}$ & NA & 9.20 & 9.39 & 9.49 & 9.80 & 9.80 & 28.00 & & NA & NA & ucsoen & NA & $\mathrm{NA}$ & 1 & 0.7 & 2 & NA & NA & NA & 70F_4sidd2V__1 & $4 / 28 \mathrm{~A}$ & DDP-147 & 700416 \\
\hline 23.7 & 0.995 & 0.01430 & 0.050 & 0.187 & 55.6 & $\mathrm{P}$ & NA & 9.20 & 9.39 & 9.49 & 9.80 & 9.80 & 28.00 & & NA & NA & NA & NA & NA & $\mathrm{NA}$ & 0.7 & NA & NA & $\mathrm{NA}$ & NA & 70F_4s1d2Vd_1 & $4 / 28 \mathrm{~A}$ & TDP-147 & 700417 \\
\hline 23.7 & 0.995 & 0.01430 & 0.050 & 0.187 & 55.6 & $\mathrm{P}$ & NA & 9.20 & 9.39 & 9.49 & 9.80 & 9.80 & 28.00 & NA & NA & NA & NA & NA & NA & NA & 3.0 & NA & NA & $\mathrm{NA}$ & $\mathrm{NA}$ & 70F_4sIdd2Vd_ 1 & $4 / 28 \mathrm{~A}$ & TDP-147 & 700418 \\
\hline 23.7 & 0.995 & 0.01430 & 0.050 & \begin{tabular}{l|l}
0.187 \\
\end{tabular} & 55.6 & $P$ & NA & 9.20 & 9.39 & 9.49 & 9.80 & 9.80 & 28.00 & & NA & NA & NA & NA & NA & NA & 3.7. & NA & $\mathrm{NA}$ & $\mathrm{NA}$ & $\mathrm{NA}$ & 7OF_4s1d2VI__1 & $4 / 28 \mathrm{~A}$ & TDP-147 & 700419 \\
\hline 23.7 & 0.995 & 0.01430 & 0.050 & 0.187 & 55.6 & $\mathrm{P}$ & NA & 9.20 & 9.39 & 9.49 & 9.80 & 9.80 & 28.00 & NA & NA & NA & NA & NA & NA & NA & 3.0 & NA & NA & NA & $\mathrm{NA}$ & 70F_ 4 s1d2VVd 11 & $4 / 28 \mathrm{~A}$ & IDP-147 & 700420 \\
\hline 23.7 & 0.995 & 0.01430 & 0.050 & 0.187 & 55.6 & $\mathrm{p}$ & NA & 9.20 & \begin{tabular}{|c|}
9.39 \\
\end{tabular} & 9.49 & 9.80 & 9.80 & 28.00 & NA & NA & NA & NA & NA & NA & $\mathrm{NA}$ & 3.2 & NA & NA & NA & NA & 70F_4s1d2Vd_1 & $428 \mathrm{~A}$ & IDP-147 & 700421 \\
\hline 23.7 & 0.995 & 0.01430 & 0.050 & 0.187 & 55.6 & $\mathrm{P}$ & NA & 9.20 & 9.39 & 9.49 & 9.80 & 9.80 & 28.00 & & NA & NA & NA & NA & NA & $\mathrm{NA}$ & 3.9 & NA & NA & $\mathrm{NA}$ & $\mathrm{NA}$ & 70F_4sIdd2Vd_ 1 & $4 / 28 \mathrm{~A}$ & TDP-147 & 700422 \\
\hline 23.7 & 0.995 & 0.01430 & 0.050 & 0.187 & 55.6 & $\mathrm{P}$ & NA & 9.20 & 9.39 & 9.49 & 9.80 & 9.80 & 28.00 & NA & NA & NA & NA & NA & NA & NA & 3.0 & NA & NA & NA & NA & 70F_4s1d2Vd_1 & $4 / 28 \mathrm{~A}$ & IDP-147 & 700423 \\
\hline 23.7 & 0.995 & 0.01430 & 0.050 & 0.187 & 55.6 & $\mathrm{P}$ & NA & 9.20 & 9.39 & 9.49 & 9.80 & 9.80 & 28.00 & & NA & NA & NA & NA & NA & $\mathrm{NA}$ & 3.1 & NA & NA & NA & NA & 70F_4s1d2Vd_1 & $4 / 28 \mathrm{~A}$ & IDP-147 & 700424 \\
\hline 24.0 & 0.994 & 0.01430 & 0.050 & 0.183 & 53.0 & $\mathrm{P}$ & NA & 9.84 & 10.05 & 10.17 & 10.50 & 9.80 & 33.00 & NA & NA & NA & NA & NA & NA & 1 & 0.0 & 4 & NA & NA & NA & 70F_4s1d2Vd_ 11 & 4/28A & TDP-147 & 700425 \\
\hline 24.1 & 0.995 & 0.01430 & 0.050 & 0.184 & 51.0 & $\mathrm{P}$ & NA & 10.13 & 10.36 & 10.47 & 10.80 & 9.80 & 39.00 & & NA & NA & NA & NA & NA & 1 & 0.0 & 4 & NA & NA & NA & 70F_4sId2Vd_1 & 4/28A & TDP-147 & 700426 \\
\hline 23.2 & 0.994 & 0.01430 & 0.050 & 0.333 & 45.4 & $\mathrm{P}$ & NA & 6.29 & 6.39 & 6.44 & 6.60 & 7.30 & 22.50 & & NA & NA & NA & NA & NA & 1 & 40.2 & 1 & $\mathrm{NA}$ & NA & NA & 70F_4s1d2V__1 & 4/29A & TDP-148 & 700427 \\
\hline 23.0 & 0.995 & 0.01430 & 0.050 & 0.335 & 42.8 & $\mathrm{P}$ & NA & 6.65 & 6.76 & 6.82 & 7.00 & 7.30 & 27.00 & NA & NA & NA & NA & NA & NA & 1 & 10.8 & 1 & NA & NA & NA & 70F_4s1d2VC_ 1 & 4/29A & TDP-148 & 700428 \\
\hline 23.2 & 0.995 & 0.01430 & 0.050 & 0.336 & 41.6 & $\mathrm{P}$ & NA & 6.83 & 6.95 & 7.01 & 7.20 & 7.30 & 29.50 & NA & NA & NA & NA & NA & NA & 1 & 2.6 & 1 & NA & NA & NA & 70F_4sid2VV_ 1 & 4/29A & TDP-148 & 700429 \\
\hline 23.2 & 0.995 & 0.01430 & 0.050 & 0.336 & 41.2 & $\mathrm{P}$ & NA & 6.92 & 7.03 & 7.09 & 7.30 & 7.30 & 32.00 & 7.30 & uav & NA & ucscen & ucsuav & NA & (null) & 3.0 & 2 & NA & NA & NA & 70F_4s1d2V__ _ 1 & 4/29A & TDP-148 & 700430 \\
\hline 23.1 & 0.995 & 0.01430 & 0.050 & 0.335 & 40.0 & $P$ & NA & 7.11 & 7.24 & 7.30 & 7.50 & 7.30 & & & 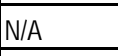 & NA & NAB & NA & NA & & 4 & 4 & NA & NA & NA & 7OF_4sid2VV__1 & 4/29A & TDP-148 & 700431 \\
\hline 23.3 & 0.995 & 0.01430 & 0.050 & 0.335 & 37.6 & $\mathrm{P}$ & NA & 7.58 & 7.71 & 7.78 & 8.00 & 7.30 & 44.00 & & NA & NA & NA & NA & NA & 1 & 0.0 & 4 & NA & NA & NA & 70F_4s1d2VV__1 & $4 / 29 A$ & TDP-148 & 700432 \\
\hline
\end{tabular}


Table B.6. Data from 2008 in Large-Scale Vessel with Flanged and Dished Head A.7

\begin{tabular}{|c|c|c|c|c|c|c|c|c|c|c|c|c|c|c|c|c|c|c|c|c|c|c|c|c|c|c|c|}
\hline $\begin{array}{l}\text { Row } \\
\text { Number }\end{array}$ & Test & Case ID & $\begin{array}{l}\text { Tank } \\
\text { Diameter }\end{array}$ & $\begin{array}{l}\text { Head } \\
\text { Shape }\end{array}$ & $\begin{array}{c}\text { Dish } \\
\text { Height }\end{array}$ & $\begin{array}{c}\text { Dish } \\
\text { Volume }\end{array}$ & $\begin{array}{c}\text { Tank } \\
\text { Fill } \\
\text { Height }\end{array}$ & $\begin{array}{l}\text { Retum } \\
\text { Line } \\
\text { Height }\end{array}$ & $\begin{array}{c}\text { Nozzle } \\
\text { Inner } \\
\text { Diameter }\end{array}$ & $\begin{array}{c}\text { Nozzle } \\
\text { Stanct } \\
\text { off } \\
\text { Distance }\end{array}$ & $\begin{array}{l}\text { Pulse Tube } \\
\text { Configuration }\end{array}$ & $\begin{array}{l}\text { Installed } \\
\text { Nozzles }\end{array}$ & $\begin{array}{l}\text { Outer } \\
\text { Nozzles } \\
\text { Operated }\end{array}$ & $\begin{array}{c}\text { Inner } \\
\text { Nozzles } \\
\text { Operated }\end{array}$ & $\begin{array}{l}\text { Pulse Tube } \\
\text { Outer } \\
\text { Dianteter }\end{array}$ & $\begin{array}{l}\text { Outer } \\
\text { PJM } \\
\text { Radius }\end{array}$ & $\begin{array}{l}\text { Inner } \\
\text { PJM } \\
\text { Radius }\end{array}$ & $\begin{array}{l}\text { "FOO" Outer } \\
\text { PJM } \\
\text { Impingement } \\
\text { Angle }\end{array}$ & $\begin{array}{c}\text { "FO' IIner } \\
\text { PJM } \\
\text { Impingement } \\
\text { Angle }\end{array}$ & $\begin{array}{c}\text { Ratio Outer } \\
\text { PJMto } \\
\text { Tank } \\
\text { Radius }\end{array}$ & $\begin{array}{c}\text { Ratio Inner } \\
\text { PJMto } \\
\text { Tank } \\
\text { Radius }\end{array}$ & Simulant & $\begin{array}{l}\text { Solids } \\
\text { Density }\end{array}$ & $\begin{array}{c}\text { Particle } \\
\text { Diameter d5 }\end{array}$ & $\begin{array}{l}\text { Paticle } \\
\text { Diameter } \\
\text { d50 }\end{array}$ & $\begin{array}{l}\text { Paticle } \\
\text { Diamtert } \\
\text { d955 }\end{array}$ & $\begin{array}{l}\text { Void } \\
\text { Fraction }\end{array}$ \\
\hline text & text & text & in. & text & in. & in. 3 & in. & in. & in. & in. & text & number & number & number & in. & in. & in. & deg & deg & nondim & nondim & text & $\mathrm{g} / \mathrm{cm}^{3}$ & $m$ & $\mathrm{~m}$ & $\mathrm{~m}$ & fraction \\
\hline MSS & MDDX & ID & D & $\mathrm{HS}$ & Hosh & $V_{\text {dish }}$ & $\mathrm{H}$ & $\operatorname{Rin}$ & $d$ & sod & PT & $\mathrm{N}$ & $\mathrm{No}$ & $\mathrm{N}$ & $\mathrm{PT}_{\alpha \mathrm{d}}$ & $R_{0}$ & $R$ & $\theta_{0}$ & $\theta_{1}$ & RolR & $R / R$ & $\operatorname{sxdx}$ & $\rho_{\mathrm{s}}$ & $d_{5}$ & $d_{50}$ & dos & $\mathrm{vf}$ \\
\hline $700433 \mathrm{M}$ & $429 \mathrm{~A}$ & 70F_4s1d2VE_1 & 70 & $\mathrm{FD}$ & 12.7 & 30569.0 & 89 & 83518 & 0.613 & 0.920 & HLP-22 & 12 & 8 & 4 & 3.5 & 26.4 & 11.7 & 22.4 & 9.7 & 0.75 & 0.33 & $\mathrm{~s} 1 \mathrm{~d} 2$ & 2.48 & 0.0000569 & 0.0000693 & 0.0000821 & 0.3750 \\
\hline 700434 & 4/20A & 70F_4s1d2Vc_1 & 70 & $F D$ & 12.7 & 30569.0 & 89 & $835 / 8$ & 0.613 & 0.920 & HLP-22 & 12 & 8 & 4 & 3.5 & 26.4 & 11.7 & 22.4 & 9.7 & 0.75 & 0.33 & s1d2 & 2.48 & 0.0000569 & 0.0000693 & 0.0000021 & 0.3750 \\
\hline 700435 & 4/29A & $70 F_{4} 4 \mathrm{~s} 1 \mathrm{~d} 2 \mathrm{Vc} 1$ & 70 & $\mathrm{FD}$ & 12.7 & 30569.0 & 89 & $835 / 8$ & 0.613 & 0.920 & HLP-22 & 12 & 8 & 4 & 3.5 & 26.4 & 11.7 & 22.4 & 9.7 & 0.75 & 0.33 & s1d2 & 2.48 & 0.0000569 & 0.0000693 & 0.0000821 & 0.3750 \\
\hline 700436 & $429 \mathrm{~A}$ & 70F_4s1d2V__1 & 70 & $\mathrm{FD}$ & 12.7 & 30569.0 & 89 & $835 / 8$ & 0.613 & 0.920 & HLP.22 & 12 & 8 & 4 & 3.5 & 26.4 & 11.7 & 22.4 & 9.7 & 0.75 & 0.33 & s1d2 & 2.48 & 0.0000569 & 0.0000693 & 0.0000821 & 0.3750 \\
\hline 700437 & 4/29A & $70 F \_4 s 1 d 2 V v_{-} 1$ & 70 & $F D$ & 12.7 & 30569.0 & 89 & $835 / 8$ & 0.613 & 0.920 & HLP-22 & 12 & 8 & 4 & 3.5 & 26.4 & 11.7 & 22.4 & 9.7 & 0.75 & 0.33 & s1d2 & 2.48 & 0.0000569 & 0.0000693 & 0.0000821 & 0.3750 \\
\hline 700438 & $429 \mathrm{~A}$ & 70F_4sId2VV__1 & 70 & $F D$ & 12.7 & 30569.0 & 89 & $835 / 8$ & 0.613 & 0.920 & HLP-22 & 12 & 8 & 4 & 3.5 & 26.4 & 11.7 & 22.4 & 9.7 & 0.75 & 0.33 & s1d2 & 2.48 & 0.0000569 & 0.0000693 & 0.0000821 & 0.3750 \\
\hline $700439 \mathrm{M}$ & 4/20A & 70F_4sid2VE_1 & 70 & $\mathrm{FD}$ & 12.7 & 30569.0 & 89 & $835 / 8$ & 0.613 & 0.920 & HLP-22 & 12 & 8 & 4 & 3.5 & 26.4 & 11.7 & 22.4 & 9.7 & 0.75 & 0.33 & s1d2 & 2.48 & 0.0000569 & 0.0000693 & 0.0000021 & 0.3750 \\
\hline 700440 & 4/298 & 70F_4sId2V__1 & 70 & $\mathrm{FD}$ & 12.7 & 30569.0 & 89 & $835 / 8$ & 0.613 & 0.920 & HLP-22 & 12 & 8 & 4 & 3.5 & 26.4 & 11.7 & 22.4 & 9.7 & 0.75 & 0.33 & $\mathrm{~s} 1 \mathrm{~d} 2$ & 2.48 & 0.0000569 & 0.0000693 & 0.0000821 & 0.3750 \\
\hline 700441 & 4/29B & 70F_4s1d2VY_1 & 70 & FD & 12.7 & 30569.0 & 89 & $835 / 8$ & 0.613 & 0.920 & HLP-22 & 12 & 8 & 4 & 3.5 & 26.4 & 11.7 & 22.4 & 9.7 & 0.75 & 0.33 & s1d2 & 2.48 & 0.0000569 & 0.0000693 & 0.00000821 & 0.3750 \\
\hline 700442 & $4 / 298$ & 70F_4s1d2V__1 & 70 & $F D$ & 12.7 & 30569.0 & 89 & $835 / 8$ & 0.613 & 0.920 & HLP-22 & 12 & 8 & 4 & 3.5 & 26.4 & 11.7 & 22.4 & 9.7 & 0.75 & 0.33 & $\mathrm{sid2}$ & 2.48 & 0.0000569 & 0.0000693 & 0.0000821 & 0.3750 \\
\hline 700444 & 4298 & 70F_4s1d2V__1 & 70 & $\mathrm{FD}$ & 12.7 & 30569.0 & 89 & $835 / 8$ & 0.613 & 0.920 & HLP-22 & 12 & 8 & 4 & 3.5 & 26.4 & 11.7 & 22.4 & 9.7 & 0.75 & 0.33 & s1d2 & 2.48 & 0.0000569 & 0.0000693 & 0.0000821 & 0.3750 \\
\hline 700445M & 4/20B & 70F_4s1d2VI_1 & 70 & FD & 12.7 & 30569.0 & 89 & $835 / 8$ & 0.613 & 0.920 & HLP-22 & 12 & 8 & 4 & 3.5 & 26.4 & 11.7 & 22.4 & 9.7 & 0.75 & 0.33 & s1d2 & 2.48 & 0.0000569 & 0.0000693 & 0.0000821 & 0.3750 \\
\hline $700446 \mathrm{M}$ & 4/29B & 70F_4s1d2Vf_1 & 70 & $\mathrm{FD}$ & 12.7 & 30569.0 & 89 & $835 / 8$ & 0.613 & 0.920 & HLP-22 & 12 & 8 & 4 & 3.5 & 26.4 & 11.7 & 22.4 & 9.7 & 0.75 & 0.33 & s1d2 & 2.48 & 0.0000569 & 0.0000693 & 0.0000821 & 0.3750 \\
\hline
\end{tabular}


Table B.6. Data from 2008 in Large-Scale Vessel with Flanged and Dished Head B.7

\begin{tabular}{|c|c|c|c|c|c|c|c|c|c|c|c|c|c|c|c|c|c|c|c|c|c|c|c|c|c|c|c|c|c|}
\hline $\begin{array}{l}\text { Tank Water } \\
\text { Temperature }\end{array}$ & $\begin{array}{l}\text { Water } \\
\text { Density }\end{array}$ & $\begin{array}{c}\text { Solids } \\
\text { Fraction }\end{array}$ & $\begin{array}{l}\text { Pulse } \\
\text { Volume } \\
\text { Fraction }\end{array}$ & $\begin{array}{l}\text { Duty } \\
\text { Cydle }\end{array}$ & $\begin{array}{l}\text { Cycle } \\
\text { Time }\end{array}$ & $\begin{array}{c}\text { Pulsed } \\
\text { or } \\
\text { Steacy } \\
\text { Jet } \\
\end{array}$ & $\begin{array}{c}\text { Us } \\
\text { Steacy } \\
\text { Jet }\end{array}$ & $\begin{array}{c}\text { U1 } \\
\text { Pulsing } \\
\text { Jet }\end{array}$ & $\begin{array}{c}\text { U2 } \\
\text { URNS }\end{array}$ & $\begin{array}{l}\text { UB } \\
\text { URNB }\end{array}$ & \begin{tabular}{|c} 
Discharge \\
Velocity
\end{tabular} & $\begin{array}{c}\text { Citical } \\
\text { Suspension } \\
\text { Velocity } \\
\end{array}$ & $\begin{array}{c}\text { Average } \\
\text { Peak Coud } \\
\text { Height }\end{array}$ & $\begin{array}{c}\text { UCS } \\
\text { Condition }\end{array}$ & $\begin{array}{c}\text { UCS } \\
\text { Method }\end{array}$ & $\begin{array}{l}\text { ucs } \\
\text { Flag }\end{array}$ & $\begin{array}{l}\text { UCS } \\
\text { Center } \\
\text { Hag }\end{array}$ & $\begin{array}{c}\text { Ucs sudv } \\
\text { Hag }\end{array}$ & $\begin{array}{c}\text { UCS based } \\
\text { on } \\
\text { Decreasing } \\
\text { Velocity }\end{array}$ & $\begin{array}{l}\text { Sweep } \\
\text { Increase I } \\
\text { Decrease }\end{array}$ & $\begin{array}{c}\text { UDV } \\
\text { Height } \\
\text { Bed }\end{array}$ & $\begin{array}{l}\text { Particle } \\
\text { Motion } \\
\end{array}$ & $\begin{array}{l}\text { Solids } \\
\text { Level }\end{array}$ & \begin{tabular}{|c|} 
Outer \\
Botom \\
Pattem
\end{tabular} & \begin{tabular}{|c|} 
Inner \\
Botom \\
Pattem \\
\end{tabular} & Case ID & Test & $\mathrm{TDP}$ & $\begin{array}{r}\text { Row } \\
\text { Numbe }\end{array}$ \\
\hline $\mathrm{c}$ & $\mathrm{g} / \mathrm{cm}^{3}$ & fraction & fraction & fraction & $\mathrm{s}$ & text & $\mathrm{m} / \mathrm{s}$ & $\mathrm{m} / \mathrm{s}$ & $\mathrm{m} / \mathrm{s}$ & $\mathrm{m} / \mathrm{s}$ & $\mathrm{m} / \mathrm{s}$ & $\mathrm{m} / \mathrm{s}$ & in. & $\mathrm{m} / \mathrm{s}$ & text & text & text & text & $\mathrm{m} / \mathrm{s}$ & text & $\mathrm{mm}$ & text & text & text & text & text & text & text & text \\
\hline$T$ & $\rho$ & $\phi_{\mathrm{s}}$ & $\phi_{p}$ & $D C$ & $t_{c}$ & Jet & $u_{\mathrm{s}}$ & U1 & $\mathrm{U} 2$ & U3 & $u$ & Uos & $\mathrm{Hc}$ & $U_{\text {CSR }}$ & $U_{\text {com }}$ & Ussis & Usscen & Usulud & $U_{\text {Cs_ }} \mathrm{D}$ & $\mathrm{s}_{\mathrm{N}}$ & $\mathrm{H}_{\text {bod }}$ & $\mathrm{PM}$ & Sol & $\mathrm{SPo}_{\mathrm{o}}$ & $\mathrm{SP}_{\mathrm{P}}$ & ID & MDDX & $\mathrm{TDP}$ & MSS \\
\hline 23.3 & 0.994 & 0.01430 & 0.050 & 0.336 & 41.2 & $P$ & NA & 6.91 & 7.03 & 7.09 & 7.30 & 7.30 & 31.00 & NA & NA & NA & UCScen & NA & NA & (null) & 3.7 & 2 & NA & NA & NA & 70F_4s1d2VV_ 1 & $4 / 29 \mathrm{~A}$ & TDP-148 & 700433 \\
\hline 23.3 & 0.994 & 0.01430 & 0.050 & 0.336 & 41.2 & $\mathrm{P}$ & NA & 6.91 & 7.03 & 7.09 & 7.30 & 7.30 & 31.00 & $\mathrm{NA}$ & NA & NA & NA & NA & $\mathrm{NA}$ & NA & 2.3 & NA & NA & NA & NA & 70F_4s1d2V__ 1 & $4 / 29 A$ & TDP-148 & 700434 \\
\hline 23.3 & 0.994 & 0.01430 & 0.050 & 0.336 & 41.2 & $\mathrm{P}$ & NA & 6.91 & 7.03 & 7.09 & 7.30 & 7.30 & 31.00 & NA & NA & NA & NA & NA & NA & NA & 4.0 & NA & NA & NA & NA & 70F_4s1d2Vc_1 & $429 A$ & TDP-148 & 700435 \\
\hline 23.3 & 0.994 & 0.01430 & 0.050 & 0.336 & 41.2 & $P$ & NA & 6.91 & 7.03 & 7.09 & 7.30 & 7.30 & 31.00 & NA & NA & NA & NA & NA & NA & NA & 3.8 & NA & NA & NA & NA & 70F_4sid2Vc_1 & $4 / 29 \mathrm{~A}$ & TDP-148 & 700436 \\
\hline 23.3 & 0.994 & 0.01430 & 0.050 & 0.336 & 41.2 & $\mathrm{P}$ & NA & 6.91 & 7.03 & 7.09 & 7.30 & 7.30 & 31.00 & NA & NA & NA & NA & NA & NA & NA & 1.5 & NA & NA & NA & NA & 70F_4s1d2VV_ 1 & 4/29A & TDP-148 & 700437 \\
\hline 23.3 & 0.994 & 0.01430 & 0.050 & 0.336 & 41.2 & $\mathrm{P}$ & NA & 6.91 & 7.03 & 7.09 & 7.30 & 7.30 & 31.00 & NA & NA & NA & NA & NA & NA & NA & 3.2 & NA & NA & NA & NA & 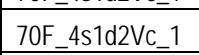 & 4/29A & TDP-148 & 700438 \\
\hline 23.8 & 0.995 & 0.01430 & 0.050 & 0.336 & 39.4 & $\mathrm{P}$ & NA & 7.23 & 7.35 & 7.42 & 7.60 & 7.30 & 34.75 & $\mathrm{NA}$ & NA & NA & NA & NA & NA & $\mathrm{D}$ & 0.0 & 4 & NA & NA & NA & 70F_4s1d2V__ 1 & $4 / 29 A$ & TDP-148 & 700439 \\
\hline 23.6 & 0.994 & 0.01430 & 0.050 & 0.252 & 51.6 & $\mathrm{P}$ & NA & 7.30 & 7.44 & 7.50 & 7.70 & 8.80 & 22.75 & NA & NA & NA & NA & NA & NA & 1 & 29.2 & 1 & NA & NA & NA & 70F_4s1d2VI_1 & $429 \mathrm{~B}$ & TDP-148 & 700440 \\
\hline 23.7 & 0.995 & 0.01430 & 0.050 & 0.254 & 49.0 & $P$ & NA & 7.66 & 7.80 & 7.87 & 8.10 & 8.80 & 25.75 & NA & NA & NA & NA & NA & NA & 1 & 26.5 & 1 & NA & NA & NA & 70F_4S1d2VI_1 & 4/29B & TDP-148 & 700441 \\
\hline 23.7 & 0.994 & 0.01430 & 0.050 & 0.254 & 47.8 & $\mathrm{P}$ & NA & 7.86 & 8.00 & 8.08 & 8.30 & 8.80 & 27.25 & NA & NA & NA & NA & NA & NA & 1 & 10.0 & 1 & NA & NA & NA & 70F_4sid2VI_ 1 & 4/29B & TDP-148 & 700442 \\
\hline 23.7 & 0.995 & 0.01430 & 0.050 & 0.255 & 46.2 & $\mathrm{P}$ & NA & 8.13 & 8.28 & 8.36 & 8.60 & 8.80 & 29.75 & NA & NA & NA & UCScen & NA & NA & 1 & 2.5 & 2 & NA & NA & NA & 70F_4sid2VI_ 1 & 4/298 & TDP-148 & 700444 \\
\hline 23.8 & 0.994 & 0.01430 & 0.050 & 0.256 & 45.2 & $\mathrm{P}$ & NA & 8.29 & 8.45 & 8.53 & 8.80 & 8.80 & 32.50 & 8.80 & udv & NA & UCScen & ucsudv & NA & 1 & 0.7 & 2 & NA & NA & NA & 70F_4s1d2VI_ _ & 4/29B & TDP-148 & 700445 \\
\hline 23.9 & 0.994 & 0.01430 & 0.050 & 0.256 & 42.2 & $\mathrm{P}$ & NA & 8.78 & 8.96 & 9.05 & 9.35 & 8.80 & 43.00 & NA & NA & NA & NA & NA & NA & 1 & 0.0 & 4 & NA & NA & NA & 70F_4s1d2Vf_1 & $4 / 29 B$ & TDP-148 & 700446 \\
\hline
\end{tabular}


Table B.7. Data from July 2007 Tests in Mid-Scale Vessel with Spherical Head A1

\begin{tabular}{|c|c|c|c|c|c|c|c|c|c|c|c|c|c|c|c|c|c|c|c|c|c|c|c|c|c|c|c|}
\hline $\begin{array}{l}\text { Row } \\
\text { Number }\end{array}$ & Test & Case ID & $\begin{array}{l}\text { Tank } \\
\text { Diameter }\end{array}$ & $\begin{array}{l}\text { Head } \\
\text { Shape }\end{array}$ & $\begin{array}{c}\text { Dish } \\
\text { Height }\end{array}$ & $\begin{array}{l}\text { Dish } \\
\text { Volume }\end{array}$ & $\begin{array}{l}\text { Tank } \\
\text { Fill } \\
\text { Height }\end{array}$ & $\begin{array}{l}\text { Retum } \\
\text { Line } \\
\text { Height }\end{array}$ & $\begin{array}{l}\text { Nozzle } \\
\text { Inner } \\
\text { Diameter }\end{array}$ & $\begin{array}{c}\text { Nozzle } \\
\text { Stand- } \\
\text { off } \\
\text { Distance }\end{array}$ & $\begin{array}{l}\text { Pulse Tube } \\
\text { Configuration }\end{array}$ & $\begin{array}{l}\text { Installed } \\
\text { Nozzles }\end{array}$ & $\begin{array}{c}\text { Outer } \\
\text { Nozeles } \\
\text { Opperated }\end{array}$ & $\begin{array}{c}\text { Inner } \\
\text { Nozzles } \\
\text { Operated }\end{array}$ & $\begin{array}{l}\text { Pulse Tube } \\
\text { Outer } \\
\text { Diameter }\end{array}$ & $\begin{array}{c}\text { Outer } \\
\text { PJM } \\
\text { Radius }\end{array}$ & $\begin{array}{c}\text { Inner } \\
\text { PJM } \\
\text { Radius }\end{array}$ & $\begin{array}{c}\text { "FlO' Outer } \\
\text { PJM } \\
\text { Impingement } \\
\text { Angle }\end{array}$ & \begin{tabular}{|c|} 
"FIO" Inner \\
PMM \\
Impingement \\
Angle
\end{tabular} & $\begin{array}{l}\text { Ratio Outer } \\
\text { PJMto } \\
\text { Tank } \\
\text { Radius }\end{array}$ & $\begin{array}{c}\text { Ratio Inner } \\
\text { PJMto } \\
\text { Tank } \\
\text { Radius }\end{array}$ & Simulant & $\begin{array}{l}\text { Solids } \\
\text { Density }\end{array}$ & $\begin{array}{c}\text { Particle } \\
\text { Diameter d5 }\end{array}$ & $\begin{array}{l}\text { Particle } \\
\text { Diameter } \\
\text { d50 }\end{array}$ & $\begin{array}{l}\text { Particle } \\
\text { Diameter } \\
\text { d95 }\end{array}$ & $\begin{array}{c}\text { Void } \\
\text { Fraction }\end{array}$ \\
\hline text & text & text & in. & text & in. & in. ${ }^{3}$ & in. & in. & in. & in. & text & number & number & number & in. & in. & in. & deg & deg & nondim & nondim & text & $\mathrm{g} / \mathrm{cm}^{3}$ & $\mathrm{~m}$ & $\mathrm{~m}$ & $\mathrm{~m}$ & fraction \\
\hline MSS & MDDX & $\mathrm{ID}$ & $\mathrm{D}$ & $\mathrm{HS}$ & Hosh & $v_{\text {dat }}$ & $\mathrm{H}$ & Rtn & $d$ & sod & $\begin{array}{l}\text { PT } \\
\end{array}$ & $\mathrm{N}$ & $\mathrm{Nb}$ & $\mathrm{N}$ & $\mathrm{PT}_{\alpha \mathrm{T}}$ & $\mathrm{R}_{0}$ & $R$ & $\theta_{\circ}$ & $\theta_{1}$ & $R d R$ & $R, / R$ & sxdx & $\rho_{s}$ & $d_{b}$ & $d_{60}$ & $\mathrm{~d}_{65}$ & vf \\
\hline 20070019 & $7116 \mathrm{~A} 1$ & 34s_4p1d/ra & $337 / 8$ & $\mathrm{~s}$ & 9 & 4437.4 & $711 / 8$ & 62 & 0.297 & 0.446 & HLP-22 & 12 & 8 & 4 & 1.9 & 10.5 & 5.7 & 30.8 & 16.1 & 0.62 & 0.33 & p1d7 & 2.45 & 0.0001213 & 0.0001780 & 0.0002606 & 0.4277 \\
\hline 20070027 & $7116 \mathrm{Al}$ & 34s_4p1dTra & $337 / 8$ & $\mathrm{~s}$ & 9 & 4437.4 & $711 / 8$ & 62 & 0.297 & 0.446 & HLP-22 & 12 & 8 & 4 & 1.9 & 10.5 & 5.7 & 30.8 & 16.1 & 0.62 & 0.33 & p1d7 & 2.45 & 0.0001213 & 0.0001780 & 0.0002606 & $0.42 \pi 7$ \\
\hline 20070031 & $7 / 16 \mathrm{Al}$ & 34s _ppldr/ra & $337 / 8$ & $\mathrm{~s}$ & 9 & 4437.4 & $711 / 8$ & 62 & 0.297 & 0.446 & HLP-22 & 12 & 8 & 4 & 1.9 & 10.5 & 5.7 & 30.8 & 16.1 & 0.62 & 0.33 & p1d7 & 2.45 & 0.0001213 & 0.0001780 & 0.0002606 & 0.4277 \\
\hline 20070038 & $7 / 16 \mathrm{Al}$ & 34s_4p1dTra & $337 / 8$ & $s$ & 9 & 4437.4 & $711 / 8$ & 62 & 0.297 & 0.446 & HLP-22 & 12 & 8 & 4 & 1.9 & 10.5 & 5.7 & 30.8 & 16.1 & 0.62 & 0.33 & p1d7 & 2.45 & 0.0001213 & 0.0001780 & 0.0002606 & 0.4277 \\
\hline 20070042 & $7 / 16 \mathrm{Al}$ & 34s_4p1dTra & $337 / 8$ & $\mathrm{~s}$ & 9 & 4437.4 & $711 / 8$ & 62 & 0.297 & 0.446 & HLP-22 & 12 & 8 & 4 & 1.9 & 10.5 & 5.7 & 30.8 & 16.1 & 0.62 & 0.33 & pld7 & 2.45 & 0.0001213 & 0.0001780 & 0.0002606 & $0.42 \pi$ \\
\hline 20070048 & $7116 \mathrm{Al}$ & 34s_apldr/a & $337 / 8$ & $\mathrm{~s}$ & 9 & 4437.4 & $711 / 8$ & 62 & 0.297 & 0.446 & HLP-22 & 12 & 8 & 4 & 1.9 & 10.5 & 5.7 & 30.8 & 16.1 & 0.62 & 0.33 & p1d7 & 2.45 & 0.0001213 & 0.0001780 & 0.0002606 & 0.4277 \\
\hline 20070051 & $7116 \mathrm{Al}$ & 34S_4p1dTra & $337 / 8$ & $\mathrm{~s}$ & 9 & 4437.4 & $711 / 8$ & 62 & 0.297 & 0.446 & HLP-22 & 12 & 8 & 4 & 1.9 & 10.5 & 5.7 & 30.8 & 16.1 & 0.62 & 0.33 & p1d7 & 2.45 & 0.0001213 & 0.0001780 & 0.0002606 & $0.42 \pi 7$ \\
\hline 20070057 & $7 / 16 \mathrm{Al}$ & 34S_4p1d/ra & $337 / 8$ & $\mathrm{~s}$ & 9 & 4437.4 & $711 / 8$ & 62 & 0.297 & 0.446 & HLP-22 & 12 & 8 & 4 & 1.9 & 10.5 & 5.7 & 30.8 & 16.1 & 0.62 & 0.33 & pld7 & 2.45 & 0.0001213 & 0.0001780 & 0.0002606 & 0.4277 \\
\hline 20070059 & $7 / 16 \mathrm{Al}$ & 34s_4p1dTra & $337 / 8$ & $s$ & 9 & 4437.4 & $711 / 8$ & 62 & 0.297 & 0.446 & HLP-22 & 12 & 8 & 4 & 1.9 & 10.5 & 5.7 & 30.8 & 16.1 & 0.62 & 0.33 & pld7 & 2.45 & 0.0001213 & 0.0001780 & 0.0002606 & 0.4277 \\
\hline 20070061 & $716 \mathrm{Al}$ & 34S_4p1dr/ra & $337 / 8$ & $s$ & 9 & 4437.4 & $711 / 8$ & 62 & 0.297 & 0.446 & HLP-22 & 12 & 8 & 4 & 1.9 & 10.5 & 5.7 & 30.8 & 16.1 & 0.62 & 0.33 & p1d7 & 2.45 & 0.0001213 & 0.0001780 & 0.0002606 & 0.4277 \\
\hline 20070063 & $7116 \mathrm{Al}$ & 34s_4pldr/a & $337 / 8$ & $\mathrm{~s}$ & 9 & 4437.4 & $711 / 8$ & 62 & 0.297 & 0.446 & HLP-22 & 12 & 8 & 4 & 1.9 & 10.5 & 5.7 & 30.8 & 16.1 & 0.62 & 0.33 & p1d7 & 2.45 & 0.0001213 & 0.0001780 & 0.0002606 & 0.4277 \\
\hline 20070065 & $7116 \mathrm{Al}$ & 34S_4p1drra & $337 / 8$ & $\mathrm{~s}$ & 9 & 4437.4 & $711 / 8$ & 62 & 0.297 & 0.446 & HLP-22 & 12 & 8 & 4 & 1.9 & 10.5 & 5.7 & 30.8 & 16.1 & 0.62 & 0.33 & p1d7 & 2.45 & 0.0001213 & 0.0001780 & 0.0002606 & $0.42 \pi$ \\
\hline 20070068 & $7 / 16 \mathrm{Al}$ & 34S_4p1dr/ra & $337 / 8$ & $\mathrm{~s}$ & 9 & 4437.4 & $711 / 8$ & 62 & 0.297 & 0.446 & HLP-22 & 12 & 8 & 4 & 1.9 & 10.5 & 5.7 & 30.8 & 16.1 & 0.62 & 0.33 & p1d7 & 2.45 & 0.0001213 & 0.0001780 & 0.0002606 & $0.42 \pi 7$ \\
\hline 20070073 & $7 / 16 \mathrm{A1}$ & 34S_4p1dTra & $337 / 8$ & $\mathrm{~s}$ & 9 & 4437.4 & $711 / 8$ & 62 & 0.297 & 0.446 & HLP-22 & 12 & 8 & 4 & 1.9 & 10.5 & 5.7 & 30.8 & 16.1 & 0.62 & 0.33 & pld7 & 2.45 & 0.0001213 & 0.0001780 & 0.0002606 & 0.4277 \\
\hline 20070081 & $7116 \mathrm{A2}$ & $34 \mathrm{~S}$ 4p1dT/C_ 8 & $337 / 8$ & $\mathrm{~s}$ & 9 & 4437.4 & $711 / 8$ & 62 & 0.297 & 0.446 & HLP.22 & 12 & 8 & 4 & 1.9 & 10.5 & 5.7 & 30.8 & 16.1 & 0.62 & 0.33 & p1d7 & 2.45 & 0.0001213 & 0.0001780 & 0.0002606 & 0.4277 \\
\hline 20070099 & $7116 \mathrm{Az}$ & 345_4p1drrc 8 & $337 / 8$ & $\mathrm{~s}$ & 9 & 4437.4 & $711 / 8$ & 62 & 0.297 & 0.446 & HLP-22 & 12 & 8 & 4 & 1.9 & 10.5 & 5.7 & 30.8 & 16.1 & 0.62 & 0.33 & pld7 & 2.45 & 0.0001213 & 0.0001780 & 0.0002606 & 0.4277 \\
\hline 20070097 & $7116 \mathrm{A2}$ & 345_4p1dTrc 8 & $337 / 8$ & $\mathrm{~s}$ & 9 & 4437.4 & $711 / 8$ & 62 & 0.297 & 0.446 & HLP-22 & 12 & 8 & 4 & 1.9 & 10.5 & 5.7 & 30.8 & 16.1 & 0.62 & 0.33 & p1d7 & 2.45 & 0.0001213 & 0.0001780 & 0.0002606 & $0.42 \pi 7$ \\
\hline $20070105 \mathrm{M}$ & $716 \mathrm{Az}$ & $34 \mathrm{~S} \_4 \mathrm{p} 1 \mathrm{~d} / \mathrm{YC} \_8$ & $337 / 8$ & $\mathrm{~s}$ & 9 & 4437.4 & $711 / 8$ & 62 & 0.297 & 0.446 & HLP-22 & 12 & 8 & 4 & 1.9 & 10.5 & 5.7 & 30.8 & 16.1 & 0.62 & 0.33 & pld7 & 2.45 & 0.0001213 & 0.0001780 & 0.0002606 & $0.42 \pi 7$ \\
\hline $20070109 \mathrm{M}$ & $7 / 16 \mathrm{A2}$ & $345 \_4 p 1 d r y c 8$ & $337 / 8$ & $\mathrm{~s}$ & 9 & 4437.4 & $711 / 8$ & 62 & 0.297 & 0.446 & HLP-22 & 12 & 8 & 4 & 1.9 & 10.5 & 5.7 & 30.8 & 16.1 & 0.62 & 0.33 & p1d7 & 2.45 & 0.0001213 & 0.0001780 & 0.0002606 & $0.42 \pi 7$ \\
\hline $20070114 \mathrm{M}$ & $7 / 16 \mathrm{A2}$ & 345 4p1dTrc_ 8 & $337 / 8$ & $\mathrm{~s}$ & 9 & 4437.4 & $711 / 8$ & 62 & 0.297 & 0.446 & HLP-22 & 12 & 8 & 4 & 1.9 & 10.5 & 5.7 & 30.8 & 16.1 & 0.62 & 0.33 & $\mathrm{p} 1 \mathrm{~d} 7 \mathrm{7}$ & 2.45 & 0.0001213 & 0.0001780 & 0.0002606 & 0.4277 \\
\hline 20070127 & $7117 \mathrm{~A} 1$ & 34s_4p1d7xa & $337 / 8$ & $\mathrm{~s}$ & 9 & 4437.4 & $661 / 8$ & 62 & 0.297 & 0.446 & HLP-22 & 12 & 8 & 4 & 1.9 & 10.5 & 5.7 & 30.8 & 16.1 & 0.62 & 0.33 & p1d7 & 2.45 & 0.0001213 & 0.0001780 & 0.0002606 & 0.4277 \\
\hline 20070131 & $7117 \mathrm{~A} 1$ & 34s_4p1d7xa & $337 / 8$ & $\mathrm{~s}$ & 9 & 4437.4 & $661 / 8$ & 62 & 0.297 & 0.446 & HLP-22 & 12 & 8 & 4 & 1.9 & 10.5 & 5.7 & 30.8 & 16.1 & 0.62 & 0.33 & p1d7 & 2.45 & 0.0001213 & 0.0001780 & 0.0002606 & 0.4277 \\
\hline 20070135 & $7117 \mathrm{~A} 1$ & 34s_4pldixa & $337 / 8$ & $\mathrm{~s}$ & 9 & 4437.4 & $661 / 8$ & 62 & 0.297 & 0.446 & HLP-22 & 12 & 8 & 4 & 1.9 & 10.5 & 5.7 & 30.8 & 16.1 & 0.62 & 0.33 & pld7 & 2.45 & 0.0001213 & 0.0001780 & 0.0002606 & $0.42 \pi 7$ \\
\hline 20070142 & $7 / 17 \mathrm{~A} 1$ & 34__ppld7xa & $337 / 8$ & $\mathrm{~s}$ & 9 & 4437.4 & $661 / 8$ & 62 & 0.297 & 0.446 & HLP-22 & 12 & 8 & 4 & 1.9 & 10.5 & 5.7 & 30.8 & 16.1 & 0.62 & 0.33 & p1d7 & 2.45 & 0.0001213 & 0.0001780 & 0.0002606 & $0.42 \pi 7$ \\
\hline 20070146 & $7 / 17 \mathrm{~A} 1$ & 34s_apldrXa & $337 / 8$ & $\mathrm{~s}$ & 9 & 4437.4 & $661 / 8$ & 62 & 0.297 & 0.446 & HLP-22 & 12 & 8 & 4 & 1.9 & 10.5 & 5.7 & 30.8 & 16.1 & 0.62 & 0.33 & p1d7 & 2.45 & 0.0001213 & 0.0001780 & 0.0002606 & $0.42 \pi$ \\
\hline 20070151 & $7117 \mathrm{~A} 1$ & 34s_4pldrxa & $337 / 8$ & $\mathrm{~s}$ & 9 & 4437.4 & $661 / 8$ & 62 & 0.297 & 0.446 & HLP-22 & 12 & 8 & 4 & 1.9 & 10.5 & 5.7 & 30.8 & 16.1 & 0.62 & 0.33 & p1d7 & 2.45 & 0.0001213 & 0.0001780 & 0.0002606 & 0.4277 \\
\hline 20070155 & $7117 \mathrm{~A} 1$ & 34s_4pldr/Xa & $337 / 8$ & $\mathrm{~s}$ & 9 & 4437.4 & $661 / 8$ & 62 & 0.297 & 0.446 & HLP-22 & 12 & 8 & 4 & 1.9 & 10.5 & 5.7 & 30.8 & 16.1 & 0.62 & 0.33 & p1d7 & 2.45 & 0.0001213 & 0.0001780 & 0.0002606 & 0.4277 \\
\hline 20070161 & $7117 \mathrm{Al}$ & 34S_4p1d7xa & $337 / 8$ & $\mathrm{~s}$ & 9 & 4437.4 & $661 / 8$ & 62 & 0.297 & 0.446 & HLP-22 & 12 & 8 & 4 & 1.9 & 10.5 & 5.7 & 30.8 & 16.1 & 0.62 & 0.33 & pldr & 2.45 & 0.0001213 & 0.0001780 & 0.0002606 & $0.42 \pi 7$ \\
\hline 20070168 & $7 / 17 \mathrm{Al}$ & 34S_4p1d7xa & $337 / 8$ & $\mathrm{~s}$ & 9 & 4437.4 & $661 / 8$ & 62 & 0.297 & 0.446 & HLP-22 & 12 & 8 & 4 & 1.9 & 10.5 & 5.7 & 30.8 & 16.1 & 0.62 & 0.33 & $\mathrm{pld7}$ & 2.45 & 0.0001213 & 0.0001780 & 0.0002606 & 0.4277 \\
\hline 20070171 & $7117 \mathrm{~A} 1$ & 34s_4pld7Xa & $337 / 8$ & $\mathrm{~s}$ & 9 & 4437.4 & $661 / 8$ & 62 & 0.297 & 0.446 & HLP-22 & 12 & 8 & 4 & 1.9 & 10.5 & 5.7 & 30.8 & 16.1 & 0.62 & 0.33 & p1d7 & 2.45 & 0.0001213 & 0.0001780 & 0.0002606 & $0.42 \pi$ \\
\hline 20070174 & $7117 \mathrm{~A} 1$ & 34s _ppldr Xa & $337 / 8$ & $\mathrm{~s}$ & 9 & 4437.4 & $661 / 8$ & 62 & 0.297 & 0.446 & HLP-22 & 12 & 8 & 4 & 1.9 & 10.5 & 5.7 & 30.8 & 16.1 & 0.62 & 0.33 & p1d7 & 2.45 & 0.0001213 & 0.0001780 & 0.0002606 & 0.4277 \\
\hline 20070179 & $7117 \mathrm{Al}$ & 34s_4p1d7Xa & $337 / 8$ & $\mathrm{~s}$ & 9 & 4437.4 & $661 / 8$ & 62 & 0.297 & 0.446 & HLP-22 & 12 & 8 & 4 & 1.9 & 10.5 & 5.7 & 30.8 & 16.1 & 0.62 & 0.33 & p1d7 & 2.45 & 0.0001213 & 0.0001780 & 0.0002606 & $0.42 \pi$ \\
\hline 20070183 & $7 / 17 \mathrm{Al}$ & 34s_4pldixa & $337 / 8$ & $\mathrm{~s}$ & 9 & 4437.4 & $661 / 8$ & 62 & 0.297 & 0.446 & HLP-22 & 12 & 8 & 4 & 1.9 & 10.5 & 5.7 & 30.8 & 16.1 & 0.62 & 0.33 & pld7 & 2.45 & 0.0001213 & 0.0001780 & 0.0002606 & \\
\hline 20070200 & $7117 \mathrm{A2}$ & $345 \_4 p 1 d 7 \times c_{8} 8$ & $337 / 8$ & $\mathrm{~s}$ & 9 & 4437.4 & $661 / 8$ & 62 & 0.297 & 0.446 & HLP-22 & 12 & 8 & 4 & 1.9 & 10.5 & 5.7 & 30.8 & 16.1 & 0.62 & 0.33 & p1d7 & 2.45 & 0.0001213 & 0.0001780 & 0.0002606 & $0.42 \pi 7$ \\
\hline 20070206 & $7117 \mathrm{AL}$ & 345 4p1d7Xc_8 8 & $337 / 8$ & $\mathrm{~s}$ & 9 & 4437.4 & $661 / 8$ & 62 & 0.297 & 0.446 & HLP-22 & 12 & 8 & 4 & 1.9 & 10.5 & 5.7 & 30.8 & 16.1 & 0.62 & 0.33 & p1d7 & 2.45 & 0.0001213 & 0.0001780 & 0.0002606 & $0.42 \pi$ \\
\hline 20070211 & $7117 \mathrm{A2}$ & 345 4p1d $7 \times \mathrm{c} 8$ & $337 / 8$ & $\mathrm{~s}$ & 9 & 4437.4 & $661 / 8$ & 62 & 0.297 & 0.446 & HLP-22 & 12 & 8 & 4 & 1.9 & 10.5 & 5.7 & 30.8 & 16.1 & 0.62 & 0.33 & p1d7 & 2.45 & 0.0001213 & 0.0001780 & 0.0002606 & $0.42 \pi 7$ \\
\hline 20070217 & $7117 \AA 2$ & 345_4p1d7 $7 \mathrm{c} 8$ & $337 / 8$ & $\mathrm{~s}$ & 9 & 4437.4 & $661 / 8$ & 62 & 0.297 & 0.446 & HLP-22 & 12 & 8 & 4 & 1.9 & 10.5 & 5.7 & 30.8 & 16.1 & 0.62 & 0.33 & p1d7 & 2.45 & 0.0001213 & 0.0001780 & 0.0002606 & $0.42 \pi$ \\
\hline 20070228 & $7117 \mathrm{A2}$ & 34__4p1d7Xc_8 8 & $337 / 8$ & $\mathrm{~s}$ & 9 & 4437.4 & $661 / 8$ & 62 & 0.297 & 0.446 & HLP-22 & 12 & 8 & 4 & 1.9 & 10.5 & 5.7 & 30.8 & 16.1 & 0.62 & 0.33 & p1d7 & 2.45 & 0.0001213 & 0.0001780 & 0.0002606 & $0.42 \pi 7$ \\
\hline 20070233 & $7117 \AA 2$ & $345 \_4 p 1 d 7 \times c_{8} 8$ & $337 / 8$ & $\mathrm{~s}$ & 9 & 4437.4 & $661 / 8$ & 62 & 0.297 & 0.446 & HLP-22 & 12 & 8 & 4 & 1.9 & 10.5 & 5.7 & 30.8 & 16.1 & 0.62 & 0.33 & p1d7 & 2.45 & 0.0001213 & 0.0001780 & 0.0002606 & 0.4277 \\
\hline $20070234 \mathrm{M}$ & $7117 \mathrm{AL}$ & $345 \_4 p 1 d 7 \times x_{8} 8$ & $337 / 8$ & $\mathrm{~s}$ & 9 & 4437.4 & $661 / 8$ & 62 & 0.297 & 0.446 & HLP-22 & 12 & 8 & 4 & 1.9 & 10.5 & 5.7 & 30.8 & 16.1 & 0.62 & 0.33 & $\mathrm{p} 1 \mathrm{~d} 7 \mathrm{~F}$ & 2.45 & 0.0001213 & 0.0001780 & 0.0002606 & 0.4277 \\
\hline $20070236 \mathrm{M}$ & $7117 \AA 2$ & $345 \_4 p 1 d 7 \times x_{C} 8$ & $337 / 8$ & $\mathrm{~s}$ & 9 & 4437.4 & $661 / 8$ & 62 & 0.297 & 0.446 & HLP-22 & 12 & 8 & 4 & 1.9 & 10.5 & 5.7 & 30.8 & 16.1 & 0.62 & 0.33 & p1d7 & 2.45 & 0.0001213 & 0.0001780 & 0.0002606 & $0.42 \pi 7$ \\
\hline
\end{tabular}


Table B.7. Data from July 2007 Tests in Mid-Scale Vessel with Spherical Head B.1

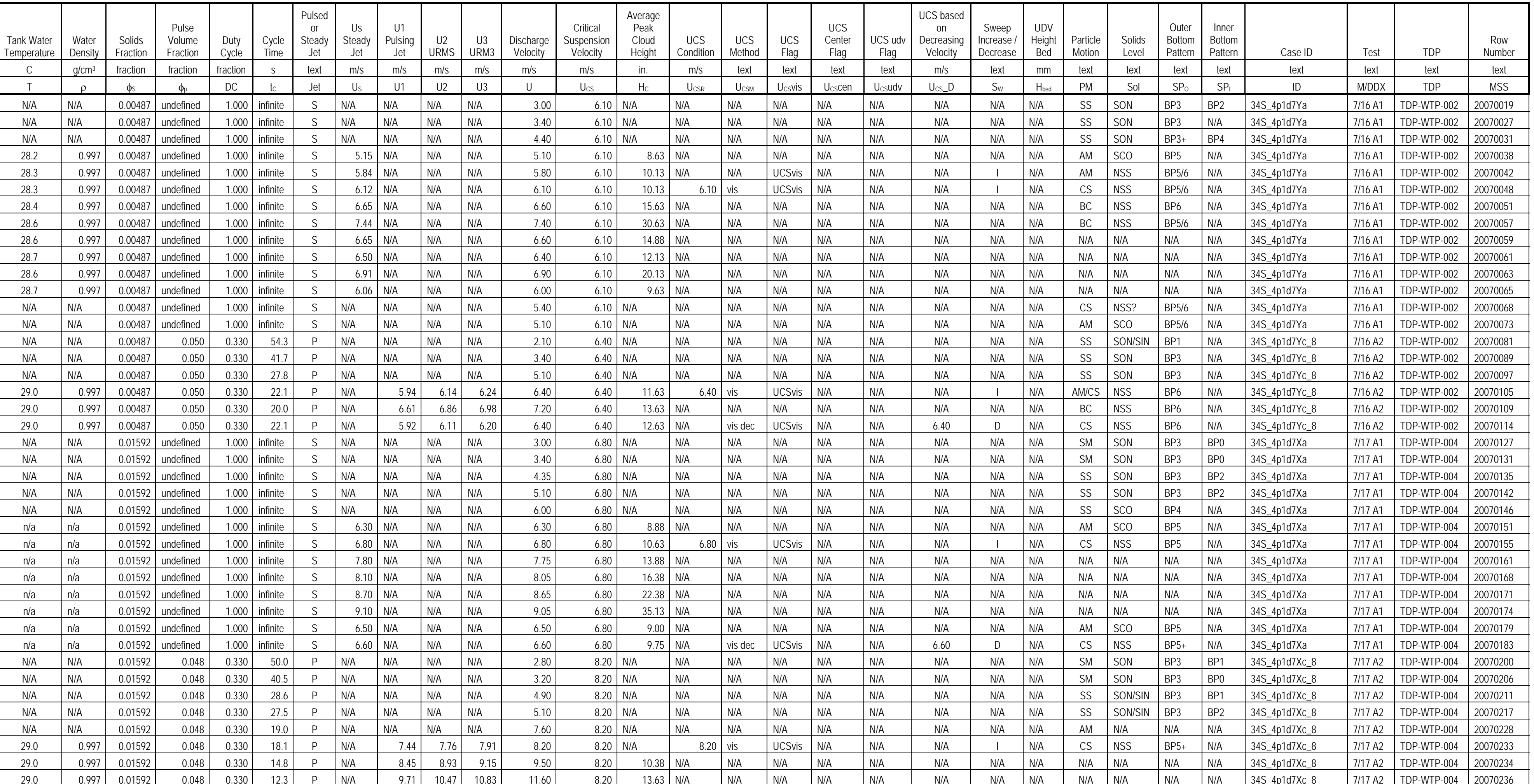


Table B.7. Data from July 2007 Tests in Mid-Scale Vessel with Spherical Head A.2

\begin{tabular}{|c|c|c|c|c|c|c|c|c|c|c|c|c|c|c|c|c|c|c|c|c|c|c|c|c|c|c|c|}
\hline $\begin{array}{c}\text { Row } \\
\text { Number }\end{array}$ & Test & Case ID & $\begin{array}{l}\text { Tank } \\
\text { Diameter }\end{array}$ & $\begin{array}{l}\text { Head } \\
\text { Shape }\end{array}$ & $\begin{array}{l}\text { Dish } \\
\text { Height }\end{array}$ & $\begin{array}{c}\text { Dish } \\
\text { Volume }\end{array}$ & $\begin{array}{c}\text { Tank } \\
\text { Fill } \\
\text { Height }\end{array}$ & $\begin{array}{l}\text { Retur } \\
\text { Line } \\
\text { Height }\end{array}$ & $\begin{array}{c}\text { Nozzle } \\
\text { lmerer } \\
\text { Diameter }\end{array}$ & $\begin{array}{c}\text { Nozzle } \\
\text { Stland } \\
\text { off } \\
\text { Distance }\end{array}$ & $\begin{array}{l}\text { Pulse Tube } \\
\text { Configuration }\end{array}$ & \begin{tabular}{|l|} 
Installed \\
Nozzles \\
\end{tabular} & $\begin{array}{c}\text { Outer } \\
\text { Noviles } \\
\text { Operated }\end{array}$ & $\begin{array}{l}\text { Inner } \\
\text { Nozzldes } \\
\text { Operated }\end{array}$ & $\begin{array}{c}\text { Pulse Tube } \\
\text { Outur } \\
\text { Dianeter }\end{array}$ & $\begin{array}{c}\text { Outer } \\
\text { PJM } \\
\text { Radius } \\
\end{array}$ & \begin{tabular}{|l|} 
Inner \\
PJM \\
Radius \\
\end{tabular} & \begin{tabular}{|c|c} 
"FOO" Outer \\
PJM \\
Impingement \\
Angle \\
\end{tabular} & \begin{tabular}{|c} 
"FoO' Inner \\
PJMM \\
Impingement \\
Angle
\end{tabular} & $\begin{array}{c}\text { Ratio Outer } \\
\text { PJM to } \\
\text { Tank } \\
\text { Radius } \\
\end{array}$ & $\begin{array}{c}\text { Ratio Inner } \\
\text { PJM to } \\
\text { Tank } \\
\text { Radius } \\
\end{array}$ & Simulant & $\begin{array}{l}\text { Solids } \\
\text { Density }\end{array}$ & \begin{tabular}{|c|c} 
Particle \\
Diameter 15
\end{tabular} & $\begin{array}{c}\text { Partice } \\
\text { Diameter } \\
\text { a50 }\end{array}$ & $\begin{array}{c}\text { Patidice } \\
\text { Dianeter } \\
\text { d95 }\end{array}$ & $\begin{array}{c}\text { Void } \\
\text { Fraction }\end{array}$ \\
\hline text & text & text & in. & text & in. & in. ${ }^{3}$ & in. & in. & in. & in. & text & number & number & number & in. & in. & in. & deg & deg & nondim & nondim & text & $\mathrm{g} / \mathrm{cm}^{3}$ & $\mathrm{~m}$ & $m$ & $\mathrm{~m}$ & fraction \\
\hline MSS & MDDX & $1 \mathrm{ID}$ & $\mathrm{D}$ & $\mathrm{HS}$ & Hash & $V_{\text {dath }}$ & $\mathrm{H}$ & Rtn & $d$ & sod & PT & $\mathrm{N}$ & $\mathrm{Nb}$ & $\mathrm{N}$ & $\mathrm{PT}_{\mathrm{Td}}$ & $\mathrm{Ro}_{\mathrm{o}}$ & $R$ & $\theta_{\circ}$ & $\theta_{1}$ & RdR & $R / R$ & sxdx & $\rho_{s}$ & $d_{5}$ & $\mathrm{c}_{\mathrm{d} 0}$ & $\frac{d \text { des }}{d}$ & $\mathrm{vf}$ \\
\hline $20070238 \mathrm{M}$ & $7 / 17 A^{2}$ & 345 4p1d $7 \times X_{1} 88$ & $337 / 8$ & $\mathrm{~s}$ & 9 & 4437.4 & $661 / 8$ & 62 & 0.297 & 0.446 & HLP-22 & 12 & 8 & 4 & 1.9 & 10.5 & 5.7 & 30.8 & 16.1 & 0.62 & 0.33 & p1d7 & 2.45 & 0.0001213 & 0.0001780 & 0.0002606 & 0.4277 \\
\hline $20070241 \mathrm{M}$ & $7 / 17 \mathrm{~A}^{2}$ & 34S_4p1d7X__ 8 & $337 / 8$ & $\mathrm{~s}$ & 9 & 4437.4 & $661 / 8$ & 62 & 0.297 & 0.446 & HLP-22 & 12 & 8 & 4 & 1.9 & 10.5 & 5.7 & 30.8 & 16.1 & 0.62 & 0.33 & p1d7 & 2.45 & 0.0001213 & 0.0001780 & 0.0002606 & 0.4277 \\
\hline 20070245 & $7 / 17 \mathrm{~A} 2^{2}$ & $34 S_{-} 4 \mathrm{p} 1 \mathrm{~d} / \mathrm{X} \mathrm{c}_{2} 8$ & $337 / 8$ & $s$ & 9 & 4437.4 & $661 / 8$ & 62 & 0.297 & 0.446 & HLP-22 & 12 & 8 & 4 & 1.9 & 10.5 & 5.7 & 30.8 & 16.1 & 0.62 & 0.33 & pld7 & 2.45 & 0.0001213 & 0.0001780 & 0.0002606 & 0.4277 \\
\hline 20070253 & $7 / 17$ A2 & $34 \mathrm{~S} \_\mathrm{pld} 7 \mathrm{XC} \_8$ & $337 / 8$ & $s$ & 9 & 4437.4 & $655 / 6$ & 62 & 0.297 & 0.446 & HLP-22 & 12 & 8 & 4 & 1.9 & 10.5 & 5.7 & 30.8 & 16.1 & 0.62 & 0.33 & p1d7 & 2.45 & 0.0001213 & 0.0001780 & 0.0002606 & 0.4277 \\
\hline 20070255 & $7 / 17$ A2 & 34S_4p1d7Xc_8 8 & $337 / 8$ & $\mathrm{~s}$ & 9 & 4437.4 & $655 / 6$ & 62 & 0.297 & 0.446 & HLP-22 & 12 & 8 & 4 & 1.9 & 10.5 & 5.7 & 30.8 & 16.1 & 0.62 & 0.33 & p1d7 & 2.45 & 0.0001213 & 0.0001780 & 0.0002606 & 0.4277 \\
\hline 20070257 & $7 / 17 \mathrm{A2}$ & $34 S_{-} 4 \mathrm{p} 1 \mathrm{~d} / \mathrm{Xc} \_8$ & $337 / 8$ & $\mathrm{~s}$ & 9 & 4437.4 & $655 / 6$ & 62 & 0.297 & 0.446 & HLP-22 & 12 & 8 & 4 & 1.9 & 10.5 & 5.7 & 30.8 & 16.1 & 0.62 & 0.33 & p1d7 & 2.45 & 0.0001213 & 0.0001780 & 0.0002606 & 0.4277 \\
\hline 20070258 & $7 / 17 \mathrm{~A}^{2}$ & 345_4p1d7Xc 8 & $337 / 8$ & $\mathrm{~s}$ & 9 & 4437.4 & $655 / 6$ & 62 & 0.297 & 0.446 & HLP-22 & 12 & 8 & 4 & 1.9 & 10.5 & 5.7 & 30.8 & 16.1 & 0.62 & 0.33 & p1d7 & 2.45 & 0.0001213 & 0.0001780 & 0.0002606 & 0.4277 \\
\hline 20070283 & 7/18A1 & $34 \mathrm{~S} \_4 \mathrm{p} 1 \mathrm{~d} / \mathrm{XC \textrm {C }} 8$ & $337 / 8$ & $\mathrm{~s}$ & 9 & 4437.4 & $761 / 8$ & 62 & 0.297 & 0.446 & HLP-22 & 12 & 8 & 4 & 1.9 & 10.5 & 5.7 & 30.8 & 16.1 & 0.62 & 0.33 & pld7 & 2.45 & 0.0001213 & 0.0001780 & 0.0002606 & 0.4277 \\
\hline $20070286 \mathrm{M}$ & 7/18A1 & $34 \mathrm{~S} \_\mathrm{pld} 7 \mathrm{XC} \_8$ & $337 / 8$ & $s$ & 9 & 4437.4 & $761 / 8$ & 62 & 0.297 & 0.446 & HLP-22 & 12 & 8 & 4 & 1.9 & 10.5 & 5.7 & 30.8 & 16.1 & 0.62 & 0.33 & p1d7 & 2.45 & 0.0001213 & 0.0001780 & 0.0002606 & 0.4277 \\
\hline $20070291 \mathrm{M}$ & $7 / 18 \mathrm{~A} 1$ & $345 \_4 p 1 d 7 \times X_{8} 8$ & $337 / 8$ & $\mathrm{~s}$ & 9 & 4437.4 & $761 / 8$ & 62 & 0.297 & 0.446 & HLP-22 & 12 & 8 & 4 & 1.9 & 10.5 & 5.7 & 30.8 & 16.1 & 0.62 & 0.33 & p1d7 & 2.45 & 0.0001213 & 0.0001780 & 0.0002606 & 0.4277 \\
\hline $20070293 \mathrm{M}$ & 7/18A1 & 34S_4p1d7X__8 & $337 / 8$ & $\mathrm{~s}$ & 9 & 4437.4 & $761 / 8$ & 62 & 0.297 & 0.446 & HLP-22 & 12 & 8 & 4 & 1.9 & 10.5 & 5.7 & 30.8 & 16.1 & 0.62 & 0.33 & p1d7 & 2.45 & 0.0001213 & 0.0001780 & 0.0002606 & 0.4277 \\
\hline $20070296 \mathrm{M}$ & $7 / 18 \mathrm{~A} 1$ & 345_4p1d7Xc 8 & $337 / 8$ & $\mathrm{~s}$ & 9 & 4437.4 & $761 / 8$ & 62 & 0.297 & 0.446 & HLP-22 & 12 & 8 & 4 & 1.9 & 10.5 & 5.7 & 30.8 & 16.1 & 0.62 & 0.33 & p1d7 & 2.45 & 0.0001213 & 0.0001780 & 0.0002606 & 0.4277 \\
\hline $20070299 \mathrm{M}$ & 7/18A1 & $34 \mathrm{~S} \_4 \mathrm{p} 1 \mathrm{~d} / \mathrm{XC \textrm {C }} 8$ & $337 / 8$ & $\mathrm{~s}$ & 9 & 4437.4 & $761 / 8$ & 62 & 0.297 & 0.446 & HLP-22 & 12 & 8 & 4 & 1.9 & 10.5 & 5.7 & 30.8 & 16.1 & 0.62 & 0.33 & p1d7 & 2.45 & 0.0001213 & 0.0001780 & 0.0002606 & 0.4277 \\
\hline 20070309 & 7/18A1 & 34S_4p1d $7 \times x_{8} 8$ & $337 / 8$ & $\mathrm{~s}$ & 9 & 4437.4 & $761 / 8$ & 62 & 0.297 & 0.446 & HLP-22 & 12 & 8 & 4 & 1.9 & 10.5 & 5.7 & 30.8 & 16.1 & 0.62 & 0.33 & p1d7 & 2.45 & 0.0001213 & 0.0001780 & 0.0002606 & 0.4277 \\
\hline 20070314 & 7/18A1 & 34S $4 \mathrm{p} 1 \mathrm{~d} / \mathrm{XC} \_8$ & $337 / 8$ & $\mathrm{~s}$ & 9 & 4437.4 & $761 / 8$ & 62 & 0.297 & 0.446 & HLP-22 & 12 & 8 & 4 & 1.9 & 10.5 & 5.7 & 30.8 & 16.1 & 0.62 & 0.33 & p1d7 & 2.45 & 0.0001213 & 0.0001780 & 0.0002606 & 0.4277 \\
\hline $20070335 \mathrm{M}$ & $7 / 18 \mathrm{A2}$ & $34 \mathrm{~S}$ 4p1d7Xc_2 & $337 / 8$ & $\mathrm{~s}$ & 9 & 4437.4 & $761 / 8$ & 62 & 0.297 & 0.446 & HLP-22 & 12 & 8 & 4 & 1.9 & 10.5 & 5.7 & 30.8 & 16.1 & 0.62 & 0.33 & p1d7 & 2.45 & 0.0001213 & 0.0001780 & 0.0002606 & 0.4277 \\
\hline 20070339 & $7 / 18 \mathrm{~A}^{2}$ & 34S_4p1d7X__2 & $337 / 8$ & $\mathrm{~s}$ & 9 & 4437.4 & $761 / 8$ & 62 & 0.297 & 0.446 & HLP-22 & 12 & 8 & 4 & 1.9 & 10.5 & 5.7 & 30.8 & 16.1 & 0.62 & 0.33 & p1d7 & 2.45 & 0.0001213 & 0.0001780 & 0.0002606 & 0.4277 \\
\hline 20070344 & $7 / 18 \mathrm{A2}$ & $34 \mathrm{~S}_{4} 4 \mathrm{pld} / \mathrm{X} \mathrm{C}_{2} 2$ & $337 / 8$ & $\mathrm{~s}$ & 9 & 4437.4 & $761 / 8$ & 62 & 0.297 & 0.446 & HLP-22 & 12 & 8 & 4 & 1.9 & 10.5 & 5.7 & 30.8 & 16.1 & 0.62 & 0.33 & p1d7 & 2.45 & 0.0001213 & 0.0001780 & 0.0002606 & 0.4277 \\
\hline 20070347 & $7 / 18 \mathrm{A2}$ & 34S_4p1d7X__ 2 & $337 / 8$ & $\mathrm{~s}$ & 9 & 4437.4 & $761 / 8$ & 62 & 0.297 & 0.446 & HLP-22 & 12 & 8 & 4 & 1.9 & 10.5 & 5.7 & 30.8 & 16.1 & 0.62 & 0.33 & p1d7 & 2.45 & 0.0001213 & 0.0001780 & 0.0002606 & 0.4277 \\
\hline 20070352 & $7 / 18 \mathrm{Az}$ & $34 \mathrm{~S} \_4 \mathrm{pld} / \mathrm{XC} \mathrm{c}_{2}$ & $337 / 8$ & $\mathrm{~s}$ & 9 & 4437.4 & $761 / 8$ & 62 & 0.297 & 0.446 & HLP-22 & 12 & 8 & 4 & 1.9 & 10.5 & 5.7 & 30.8 & 16.1 & 0.62 & 0.33 & p1d7 & 2.45 & 0.0001213 & 0.0001780 & 0.0002606 & 0.4277 \\
\hline 20070357 & 7/18A2 & 34S_4p1d7Xc_2 2 & $337 / 8$ & $\mathrm{~s}$ & 9 & 4437.4 & $761 / 8$ & 62 & 0.297 & 0.446 & HLP-22 & 12 & 8 & 4 & 1.9 & 10.5 & 5.7 & 30.8 & 16.1 & 0.62 & 0.33 & p1d7 & 2.45 & 0.0001213 & 0.0001780 & 0.0002606 & 0.4277 \\
\hline $20070362 \mathrm{M}$ & 7/18A2 & 34S_ $4 \mathrm{p} 1 \mathrm{~d} 7 \mathrm{X} \mathrm{C}_{2} 2$ & $337 / 8$ & $\mathrm{~s}$ & 9 & 4437.4 & $761 / 8$ & 62 & 0.297 & 0.446 & HLP-22 & 12 & 8 & 4 & 1.9 & 10.5 & 5.7 & 30.8 & 16.1 & 0.62 & 0.33 & p1d7 & 2.45 & 0.0001213 & 0.0001780 & 0.0002606 & 0.4277 \\
\hline $20070369 \mathrm{M}$ & $7 / 18 \mathrm{A2}$ & $345 \_4 p 1 d 7 \times x_{2} 2$ & $337 / 8$ & $\mathrm{~s}$ & 9 & 4437.4 & $761 / 8$ & 62 & 0.297 & 0.446 & HLP-22 & 12 & 8 & 4 & 1.9 & 10.5 & 5.7 & 30.8 & 16.1 & 0.62 & 0.33 & p1d7 & 2.45 & 0.0001213 & 0.0001780 & 0.0002606 & 0.4277 \\
\hline $20070372 \mathrm{M}$ & $7 / 18 \mathrm{A2}$ & 34S_4p1d7X__ 2 & $337 / 8$ & $\mathrm{~s}$ & 9 & 4437.4 & $761 / 8$ & 62 & 0.297 & 0.446 & HLP-22 & 12 & 8 & 4 & 1.9 & 10.5 & 5.7 & 30.8 & 16.1 & 0.62 & 0.33 & p1d7 & 2.45 & 0.0001213 & 0.0001780 & 0.0002606 & 0.4277 \\
\hline 20070384 & 7/19A1 & 34S_4p1d/rc_ 8 & $337 / 8$ & $\mathrm{~s}$ & 9 & 4437.4 & $675 / 8$ & 62 & 0.297 & 0.446 & HLP-22 & 12 & 8 & 4 & 1.9 & 10.5 & 5.7 & 30.8 & 16.1 & 0.62 & 0.33 & $\mathrm{p} 1 \mathrm{dr}$ & 2.45 & 0.0001213 & 0.0001780 & 0.0002606 & 0.4277 \\
\hline $20070387 \mathrm{M}$ & 7/19A1 & 34S_4p1dTrc_ 8 & $337 / 8$ & $\mathrm{~s}$ & 9 & 4437.4 & $675 / 8$ & 62 & 0.297 & 0.446 & HLP-22 & 12 & 8 & 4 & 1.9 & 10.5 & 5.7 & 30.8 & 16.1 & 0.62 & 0.33 & p1d7 & 2.45 & 0.0001213 & 0.0001780 & 0.0002606 & 0.4277 \\
\hline $20070392 \mathrm{M}$ & 7/19A1 & 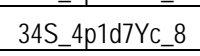 & $337 / 8$ & $\mathrm{~s}$ & 9 & 4437.4 & $675 / 8$ & 62 & 0.297 & 0.446 & HLP-22 & 12 & 8 & 4 & 1.9 & 10.5 & 5.7 & 30.8 & 16.1 & 0.62 & 0.33 & p1d7 & 2.45 & 0.0001213 & 0.0001780 & 0.0002606 & 0.4277 \\
\hline $20070395 \mathrm{M}$ & $7 / 19 \mathrm{~A} 1$ & 345 4p1d/rc 8 & $337 / 8$ & $\mathrm{~s}$ & 9 & 4437.4 & $675 / 8$ & 62 & 0.297 & 0.446 & HLP-22 & 12 & 8 & 4 & 1.9 & 10.5 & 5.7 & 30.8 & 16.1 & 0.62 & 0.33 & p1d7 & 2.45 & 0.0001213 & 0.0001780 & 0.0002606 & 0.4277 \\
\hline $20070398 \mathrm{M}$ & $7 / 19 \mathrm{~A} 1$ & 34S_4p1dTrc_ 8 & $337 / 8$ & $s$ & 9 & 4437.4 & $675 / 8$ & 62 & 0.297 & 0.446 & HLP-22 & 12 & 8 & 4 & 1.9 & 10.5 & 5.7 & 30.8 & 16.1 & 0.62 & 0.33 & p1d7 & 2.45 & 0.0001213 & 0.0001780 & 0.0002606 & 0.4277 \\
\hline $20070401 \mathrm{M}$ & $7 / 19 \mathrm{~A} 1$ & $34 S_{-} 4 \mathrm{p} 1 \mathrm{~d} T \mathrm{Yc} \_8$ & $337 / 8$ & $\mathrm{~s}$ & 9 & 4437.4 & $675 / 8$ & 62 & 0.297 & 0.446 & HLP-22 & 12 & 8 & 4 & 1.9 & 10.5 & 5.7 & 30.8 & 16.1 & 0.62 & 0.33 & p1d7 & 2.45 & 0.0001213 & 0.0001780 & 0.0002606 & 0.4277 \\
\hline $20070403 \mathrm{M}$ & 7/19A1 & 34S_4p1dTrc_ 8 & $337 / 8$ & $\mathrm{~s}$ & 9 & 4437.4 & $675 / 8$ & 62 & 0.297 & 0.446 & HLP-22 & 12 & 8 & 4 & 1.9 & 10.5 & 5.7 & 30.8 & 16.1 & 0.62 & 0.33 & p1d7 & 2.45 & 0.0001213 & 0.0001780 & 0.0002606 & 0.4277 \\
\hline $20070411 \mathrm{M}$ & $7 / 19 \mathrm{~A}_{1}$ & 345 _p1d/rc 8 & $337 / 8$ & $\mathrm{~s}$ & 9 & 4437.4 & $675 / 8$ & 62 & 0.297 & 0.446 & HLP-22 & 12 & 8 & 4 & 1.9 & 10.5 & 5.7 & 30.8 & 16.1 & 0.62 & 0.33 & p1d7 & 2.45 & 0.0001213 & 0.0001780 & 0.0002606 & 0.4277 \\
\hline 20070417 & $7 / 19 \mathrm{~A}^{2}$ & 34S_4p1drra & $337 / 8$ & $\mathrm{~s}$ & 9 & 4437.4 & $675 / 8$ & 62 & 0.297 & 0.446 & HLP-22 & 12 & 8 & 4 & 1.9 & 10.5 & 5.7 & 30.8 & 16.1 & 0.62 & 0.33 & p1d7 & 2.45 & 0.0001213 & 0.0001780 & 0.0002606 & 0.4277 \\
\hline $20070423 \mathrm{M}$ & $7 / 19 A 3$ & 34S_4p1dTrc_ 2 & $337 / 8$ & $\mathrm{~s}$ & 9 & 4437.4 & $675 / 8$ & 62 & 0.297 & 0.446 & HLP-22 & 12 & 8 & 4 & 1.9 & 10.5 & 5.7 & 30.8 & 16.1 & 0.62 & 0.33 & p1d7 & 2.45 & 0.0001213 & 0.0001780 & 0.0002606 & 0.4277 \\
\hline $20070426 \mathrm{M}$ & 7/19A3 & 34S_4p1d/Yc_ 2 & $337 / 8$ & $\mathrm{~s}$ & 9 & 4437.4 & $675 / 8$ & 62 & 0.297 & 0.446 & HLP-22 & 12 & 8 & 4 & 1.9 & 10.5 & 5.7 & 30.8 & 16.1 & 0.62 & 0.33 & pld7 & 2.45 & 0.0001213 & 0.0001780 & 0.0002606 & 0.4277 \\
\hline $20070428 \mathrm{M}$ & 7/19A3 & 34S_4p1dTrc_ 2 & $337 / 8$ & $\mathrm{~s}$ & 9 & 4437.4 & $675 / 8$ & 62 & 0.297 & 0.446 & HLP-22 & 12 & 8 & 4 & 1.9 & 10.5 & 5.7 & 30.8 & 16.1 & 0.62 & 0.33 & p1d7 & 2.45 & 0.0001213 & 0.0001780 & 0.0002606 & 0.4277 \\
\hline $20070432 \mathrm{M}$ & $7 / 19 A^{3}$ & 345 _tp1d/rc 22 & $337 / 8$ & $\mathrm{~s}$ & 9 & 4437.4 & $675 / 8$ & 62 & 0.297 & 0.446 & HLP-22 & 12 & 8 & 4 & 1.9 & 10.5 & 5.7 & 30.8 & 16.1 & 0.62 & 0.33 & p1d7 & 2.45 & 0.0001213 & 0.0001780 & 0.0002606 & 0.4277 \\
\hline 20070434 & 7/19A3 & $345 \_4 p 1 d / Y C 22$ & $337 / 8$ & $\mathrm{~s}$ & 9 & 4437.4 & $675 / 8$ & 62 & 0.297 & 0.446 & HLP-22 & 12 & 8 & 4 & 1.9 & 10.5 & 5.7 & 30.8 & 16.1 & 0.62 & 0.33 & p1d7 & 2.45 & 0.0001213 & 0.0001780 & 0.0002606 & 0.4277 \\
\hline 20070438 & 7/19A4 & 34S_4p1dT/d_ 8 & $337 / 8$ & $\mathrm{~s}$ & 9 & 4437.4 & $675 / 8$ & 62 & 0.297 & 0.446 & & 12 & 8 & 4 & 1.9 & 10.5 & 5.7 & 30.8 & 16.1 & 0.62 & 0.33 & pld7 & 2.45 & 0.0001213 & 0.0001780 & 0.0002606 & \\
\hline $20070441 \mathrm{M}$ & $7 / 19 \mathrm{AA}$ & $345 \_4 p 1 d / r d d 8$ & $337 / 8$ & $\mathrm{~s}$ & 9 & 4437.4 & $675 / 8$ & 62 & 0.297 & 0.446 & HLP-22 & 12 & 8 & 4 & 1.9 & 10.5 & 5.7 & 30.8 & 16.1 & 0.62 & 0.33 & p1d7 & 2.45 & 0.0001213 & 0.0001780 & 0.0002606 & 0.4277 \\
\hline $20070445 \mathrm{M}$ & 7/19 A4 & 34S 4 p1dTrd 8 & $337 / 8$ & $\mathrm{~s}$ & 9 & 4437.4 & $675 / 8$ & 62 & 0.297 & 0.446 & HLP-22 & 12 & 8 & 4 & 1.9 & 10.5 & 5.7 & 30.8 & 16.1 & 0.62 & 0.33 & p1d7 & 2.45 & 0.0001213 & 0.0001780 & 0.0002606 & 0.4277 \\
\hline
\end{tabular}


Table B.7. Data from July 2007 Tests in Mid-Scale Vessel with Spherical Head B.2

\begin{tabular}{|c|c|c|c|c|c|c|c|c|c|c|c|c|c|c|c|c|c|c|c|c|c|c|c|c|c|c|c|c|c|}
\hline $\begin{array}{l}\text { Tank Water } \\
\text { Temperature }\end{array}$ & $\begin{array}{l}\text { Water } \\
\text { Density }\end{array}$ & $\begin{array}{l}\text { Solids } \\
\text { Fraction }\end{array}$ & $\begin{array}{l}\text { Pulse } \\
\text { Volume } \\
\text { Fraction }\end{array}$ & $\begin{array}{l}\text { Duty } \\
\text { Qycle }\end{array}$ & $\begin{array}{l}\text { Oyde } \\
\text { Time }\end{array}$ & $\begin{array}{c}\text { Pulsed } \\
\text { or } \\
\text { Steady } \\
\text { Jet }\end{array}$ & $\begin{array}{c}\text { Us } \\
\text { Steacy } \\
\text { Jet }\end{array}$ & $\begin{array}{c}\text { U1 } \\
\text { Pulsing } \\
\text { Jet }\end{array}$ & $\begin{array}{c}\text { U2 } \\
\text { URMS }\end{array}$ & $\begin{array}{l}\text { UB } \\
\text { URNB }\end{array}$ & $\begin{array}{l}\text { Discharge } \\
\text { Velocity }\end{array}$ & $\begin{array}{c}\text { Critical } \\
\text { Suspension } \\
\text { Velocity }\end{array}$ & $\begin{array}{c}\text { Average } \\
\text { Peakk } \\
\text { Cloud } \\
\text { Height } \\
\end{array}$ & $\begin{array}{l}\text { UCS } \\
\text { Condition }\end{array}$ & $\begin{array}{c}\text { UCS } \\
\text { Nethod }\end{array}$ & $\begin{array}{l}\text { UCS } \\
\text { Flag }\end{array}$ & $\begin{array}{c}\text { UCS } \\
\text { Center } \\
\text { Flag }\end{array}$ & $\begin{array}{c}\text { ucsuav } \\
\text { Hag } \\
\end{array}$ & $\begin{array}{l}\text { UCS based } \\
\text { on } \\
\text { Decreasing } \\
\text { Velocity }\end{array}$ & $\begin{array}{l}\text { Sweep } \\
\text { Innerase I } \\
\text { Decrease }\end{array}$ & $\begin{array}{c}\text { UDV } \\
\text { Hhight } \\
\text { Bed } \\
\text { Bed }\end{array}$ & $\begin{array}{l}\text { Particle } \\
\text { Motion }\end{array}$ & $\begin{array}{l}\text { Solids } \\
\text { Level }\end{array}$ & $\begin{array}{c}\text { Outer } \\
\text { Bottom } \\
\text { Pattem }\end{array}$ & $\begin{array}{l}\text { Inner } \\
\text { Bototom } \\
\text { Patterm }\end{array}$ & Case ID & Test & TDP & $\begin{array}{l}\text { Rav } \\
\text { Number }\end{array}$ \\
\hline$c$ & $g / \mathrm{cm}^{3}$ & fraction & ffraction & fraction & $\mathrm{s}$ & text & $\mathrm{m} / \mathrm{s}$ & $\mathrm{m} / \mathrm{s}$ & $\mathrm{m} / \mathrm{s}$ & m/s & $m / s$ & $m / s$ & in. & $m / s$ & text & text & text & text & $m / s$ & text & $\mathrm{mm}$ & text & text & text & text & text & text & text & text \\
\hline$T$ & $\rho$ & $\phi_{s}$ & $\phi_{p}$ & $\mathrm{DC}$ & tc & Jet & $u_{\mathrm{s}}$ & $\mathrm{U} 1$ & $\mathrm{U} 2$ & U3 & $u$ & Uss & $\mathrm{Hc}$ & uss & Uan & Uosvis & Usscen & Usuack & Uos_D & $\mathrm{S}_{\mathrm{N}}$ & $H_{\text {oed }}$ & $\mathrm{PM}$ & sol & $\mathrm{SPo}_{\mathrm{O}}$ & $\mathrm{SP}_{1}$ & $\mathrm{ID}$ & MDDX & $\mathrm{TDP}$ & MSS \\
\hline 29.0 & 0.997 & 0.01592 & 0.048 & 0.330 & 1.0 & $P$ & $\mathrm{NA}$ & 10.76 & 11.92 & 12.48 & 15.20 & 8.20 & 22.63 & NA & NA & $\mathrm{NA}$ & $\mathrm{NA}$ & $\mathrm{NA}$ & $\mathrm{NA}$ & NA & $\mathrm{NA}$ & NA & $\mathrm{NA}$ & $\mathrm{NA}$ & $\mathrm{NA}$ & $34 S_{4} 4 \mathrm{p} 1 \mathrm{~d} 7 \times \mathrm{C}_{1} 8$ & $7 / 17 \mathrm{A2}$ & TDP-WIP-004 & 20070238 \\
\hline 29.0 & 0.997 & 0.01592 & 0.048 & 0.330 & 1.1 & $\mathrm{P}$ & NA & 10.95 & 11.86 & 12.29 & 13.30 & 8.20 & 19.13 & NA & NA & NA & NA & NA & NA & NA & NA & NA & NA & NA & NA & $345 \_4 p 1 d 7 \times c \_8$ & $7 / 17 \mathrm{A2}$ & TDP-WIP-004 & 20070241 \\
\hline NA & NA & 0.01592 & 0.048 & 0.330 & 16.7 & $\mathrm{P}$ & NA & NA & NA & NA & 8.60 & 8.20 & NA & NA & NA & NA & NA & NA & NA & NA & NA & NA & NA & NA & NA & $345 \_4 p 1 d 7 \times c \_8$ & $7 / 17 \mathrm{A2}$ & TDP-WIP-004 & 20070245 \\
\hline NA & NA & 0.01592 & 0.048 & 0.330 & 33.3 & $\mathrm{P}$ & NA & NA & NA & NA & 9.40 & 8.20 & NA & NA & NA & NA & NA & NA & NA & NA & NA & NA & NA & NA & NA & $34 S_{-} 4 p 1 d 7 \times x_{c} 8$ & $7 / 17 \mathrm{A2}$ & TDP-WIP-005 & 20070253 \\
\hline NA & NA & 0.01592 & 0.048 & 0.330 & 29.2 & $\mathrm{P}$ & NA & NA & NA & NA & 10.25 & 8.20 & NA & NA & NA & NA & NA & NA & NA & NA & NA & NA & NA & NA & NA & $345 \_4 p 1 d 7 \times x_{0} 8$ & $7 / 17$ A2 & TDP-WIP-005 & 20070255 \\
\hline NA & NA & 0.01592 & 0.048 & 0.330 & 29.5 & $P$ & NA & NA & NA & NA & 11.45 & 8.20 & NA & NA & NA & NA & NA & $\mathrm{NA}$ & NA & NA & NA & NA & NA & NA & NA & 34S_4p1d7Xc_8 & $7117 \mathrm{A2}$ & TDP-WIP-005 & 20070257 \\
\hline NA & NA & 0.01592 & 0.048 & 0.330 & 23.6 & $\mathrm{P}$ & NA & NA & NA & NA & 13.55 & 8.20 & NA & NA & NA & NA & NA & NA & NA & NA & NA & NA & NA & NA & NA & $345 \_4 p 1 d 7 \times x_{1} 8$ & $7117 \mathrm{A2}$ & TDP-WIP-005 & 20070258 \\
\hline 27.0 & 0.998 & 0.01592 & 0.048 & 0.330 & 18.1 & $\mathrm{P}$ & NA & 7.50 & 7.81 & 7.95 & 8.10 & 8.10 & 9.13 & \begin{tabular}{|l|}
8.10 \\
\end{tabular} & vis & ucsis & NA & NA & NA & 1 & NA & cs & NSS & BP6 & NA & $345 \_4 p 1 d 7 \times c \_8$ & $7 / 18 \mathrm{~A} 1$ & TDP-WIP-006 & 20070286 \\
\hline 27.0 & 0.998 & 0.01592 & 0.048 & 0.330 & 13.4 & $\mathrm{P}$ & NA & 8.25 & 9.02 & 9.36 & 10.24 & 8.10 & 11.63 & NA & NA & NA & NA & NA & NA & NA & NA & NA & NA & NA & NA & 345_4p1d $7 \times \mathrm{c} 8$ & $7 / 18 \mathrm{~A} 1$ & TDP-WIP-006 & 20070291 \\
\hline 27.0 & 0.998 & 0.01592 & 0.048 & 0.330 & 13.4 & $P$ & NA & 8.72 & 9.49 & 9.84 & 10.70 & 8.10 & 11.88 & NA & NA & NA & NA & $\mathrm{NA}$ & NA & NA & NA & $\mathrm{BC}$ & NSS & BP6 & NA & 345_4p1d7Xc_8 & $7 / 18 \mathrm{~A} 1$ & TDP-WIP-006 & 20070293 \\
\hline 27.0 & 0.998 & 0.01592 & 0.048 & 0.330 & 11.1 & $\mathrm{P}$ & NA & 11.43 & 1281 & 13.48 & 15.20 & 8.10 & 26.13 & NA & NA & NA & NA & NA & NA & NA & NA & NA & NA & NA & NA & $34 \mathrm{~S} \_4 \mathrm{p} 1 \mathrm{~d} 7 \mathrm{Xc}_{\mathrm{c}} 8$ & $7 / 18 \mathrm{~A} 1$ & TDP-WIP-006 & 20070296 \\
\hline 27.0 & 0.998 & 0.01592 & 0.048 & 0.330 & 11.8 & $\mathrm{P}$ & NA & 10.12 & 11.14 & 11.62 & 12.70 & 8.10 & 17.13 & NA & $\mathrm{NA}$ & NA & NA & $\mathrm{NA}$ & NA & NA & NA & NA & NA & NA & $\mathrm{NA}$ & $345 \_4 p 1 d 7 \times x_{8} 8$ & $7 / 18 \mathrm{~A} 1$ & TDP-WIP-006 & 20070299 \\
\hline 27.0 & 0.998 & 0.01592 & 0.048 & 0.330 & 18.3 & $\mathrm{P}$ & NA & 7.00 & 7.43 & 7.61 & 8.00 & 8.10 & 9.13 & NA & vis dec & UCSis & NA & NA & 8.00 & $\mathrm{D}$ & NA & $\operatorname{cs}$ & NSS & $\mathrm{BPO}$ & NA & 345 4p1d7Xc_ 8 & $7 / 18 \mathrm{~A} 1$ & TDP-WIP-006 & 20070309 \\
\hline NA & NA & 0.01592 & 0.048 & 0.330 & 18.6 & $\mathrm{P}$ & NA & NA & NA & NA & 7.90 & 8.10 & NA & NA & NA & NA & NA & NA & NA & NA & NA & $A M$ & soo & BP5/6 & NA & 345_4p1d7Xc 8 & $7 / 18 \mathrm{~A} 1$ & TDP-WIP-006 & 20070314 \\
\hline 27.0 & 0.998 & 0.01592 & 0.100 & 0.330 & 33.3 & $\mathrm{P}$ & NA & 8.39 & 8.70 & 8.83 & 9.10 & 8.50 & 12.38 & NA & NA & NA & NA & $\mathrm{NA}$ & NA & NA & NA & CS & NSS & BP6 & $\mathrm{NA}$ & $345 \_4 p 1 d 7 \times c_{2} 2$ & $7 / 18 \mathrm{A2}$ & TDP-WIP-007 & 20070335 \\
\hline 27.0 & 0.998 & 0.01592 & 0.100 & 0.330 & 35.6 & $\mathrm{P}$ & NA & 7.69 & 7.94 & 8.05 & 8.25 & 8.50 & 11.38 & NA & vis dec & UCSvis & NA & NA & 8.25 & $\mathrm{D}$ & NA & cs & NSS & BP6 & NA & $34 \mathrm{~S} \_4 \mathrm{p} 1 \mathrm{~d} 7 \mathrm{XC}_{\mathrm{c}} 2$ & $7 / 18 A 2$ & TDP-WIP-007 & 20070339 \\
\hline 27.0 & 0.998 & 0.01592 & 0.100 & 0.330 & 43.5 & $\mathrm{P}$ & NA & 6.45 & 6.55 & 6.59 & 6.70 & 8.50 & 8.63 & NA & NA & $\mathrm{NA}$ & NA & $\mathrm{NA}$ & NA & NA & NA & $A M$ & 500 & BP5 & $\mathrm{NA}$ & $345 \_4 p 1 d 7 \times x_{2} 2$ & $7 / 18 \mathrm{A2}$ & TDP-WIP-007 & 20070344 \\
\hline 27.0 & 0.998 & 0.01592 & 0.100 & 0.330 & 40.8 & $\mathrm{P}$ & NA & 6.99 & 7.11 & 7.17 & 7.25 & 8.50 & 9.63 & NA & NA & NA & NA & NA & NA & NA & NA & AM & soo & BP5 & NA & $345 \_4 p 1 d 7 \times c \_2$ & $7118 \mathrm{A2}$ & TDP-WIP-007 & 20070347 \\
\hline 27.0 & 0.998 & 0.01592 & 0.100 & 0.330 & 39.4 & $\mathrm{P}$ & NA & 7.36 & 7.49 & 7.55 & 7.60 & 8.50 & 10.38 & NA & NA & NA & NA & NA & $\mathrm{NA}$ & NA & NA & $A M$ & soo & BP5/6 & NA & $345 \_4 p 1 d 7 \times c_{2} 2$ & $7118 \mathrm{A2}$ & TDP-WIP-007 & 20070352 \\
\hline 27.0 & 0.998 & 0.01592 & 0.100 & 0.330 & 36.1 & $\mathrm{P}$ & NA & 7.93 & 8.20 & 8.31 & 8.50 & 8.50 & 11.63 & & vis & UCSvis & NA & NA & NA & 1 & NA & cs & NSS & BP6 & NA & $345 \_4 p 1 d 7 \times c_{2} 2$ & $7 / 18 \mathrm{A2}$ & TDP-WIP-007 & 20070362 \\
\hline 27.0 & 0.998 & 0.01592 & 0.100 & 0.330 & 30.3 & $\mathrm{P}$ & NA & 9.13 & 9.48 & 9.64 & 10.00 & 8.50 & 14.38 & NA & NA & NA & NA & $\mathrm{NA}$ & $\mathrm{NA}$ & NA & NA & NA & NA & NA & $\mathrm{NA}$ & $345 \_4 p 1 d 7 \times c_{2} 2$ & $7 / 18 \mathrm{A2}$ & TDP-WIP-007 & 20070369 \\
\hline 27.0 & 0.998 & 0.01592 & 0.100 & 0.330 & 22.7 & $\mathrm{P}$ & NA & 11.19 & 11.79 & 12.06 & 12.60 & 8.50 & 22.13 & NA & NA & NA & NA & NA & NA & NA & NA & NA & NA & NA & NA & $34 \mathrm{~S} \_4 \mathrm{p} 1 \mathrm{~d} / \mathrm{X} \mathrm{c}_{2} 2$ & $7 / 18 \mathrm{A2}$ & TDP-WIP-007 & 20070372 \\
\hline 23.0 & 0.999 & 0.00487 & 0.048 & 0.330 & 24.3 & $\mathrm{P}$ & NA & 5.60 & 5.77 & 5.84 & 6.00 & 6.20 & 11.88 & NA & NA & NA & NA & NA & $\mathrm{NA}$ & NA & NA & $A M$ & NA & BP5 & NA & $345 \_4 p 1 d r / c \_8$ & $7 / 19 \mathrm{~A} 1$ & TDP-WIP-008 & 20070384 \\
\hline 23.0 & 0.999 & 0.00487 & 0.048 & 0.330 & 24.3 & $\mathrm{P}$ & NA & 5.80 & 5.98 & 6.06 & 6.20 & 6.20 & 12.63 & 6.20 & vis & ucsvis & NA & NA & NA & 1 & NA & cs & NA & BP6 & $\mathrm{NA}$ & 345_4p1dr/C_ 8 & $7 / 19 \mathrm{~A} 1$ & TDP-WIP-008 & 20070387 \\
\hline 23.0 & 0.999 & 0.00487 & 0.048 & 0.330 & 21.1 & $\mathrm{P}$ & NA & 6.45 & 6.68 & 6.78 & 7.00 & 6.20 & 13.38 & NA & NA & NA & NA & NA & NA & NA & NA & $\mathrm{BC}$ & NA & BP6 & NA & $345 \_$_pldrrc 8 & $7 / 19 \mathrm{~A} 1$ & TDP-WIP-008 & 20070392 \\
\hline 23.0 & 0.999 & 0.00487 & 0.048 & 0.330 & 18.3 & $\mathrm{P}$ & NA & 7.23 & 7.54 & 7.68 & 8.00 & 6.20 & 16.63 & NA & NA & NA & NA & $\mathrm{NA}$ & $\mathrm{NA}$ & NA & NA & $\mathrm{BC}$ & NA & NA & $\mathrm{NA}$ & $345 \_4 p 1 d / r c \_8$ & $7 / 19 \mathrm{~A} 1$ & TDP-WIP-008 & 20070395 \\
\hline 23.0 & 0.999 & 0.00487 & 0.048 & 0.330 & 16.1 & $\mathrm{P}$ & NA & 7.56 & 8.14 & 8.40 & 9.00 & 6.20 & 22.79 & NA & A & NA & NA & NA & NA & NA & NA & $B C$ & NA & NA & NA & $34 \mathrm{~S} \_4 \mathrm{p} 1 \mathrm{~d} / \mathrm{Tc} \_8$ & $7 / 19 \mathrm{~A} 1$ & TDP-WIP-008 & 20070398 \\
\hline 23.0 & 0.999 & 0.00487 & 0.048 & 0.330 & 17.1 & $\mathrm{P}$ & NA & 7.38 & 7.84 & 8.05 & 8.50 & 6.20 & 20.63 & NA & NA & NA & NA & NA & NA & NA & NA & $\mathrm{BC}$ & NA & BP6 & NA & 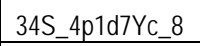 & $7 / 19 \mathrm{~A} 1$ & TDP-WIP-008 & 20070401 \\
\hline 23.0 & 0.999 & 0.00487 & 0.048 & 0.330 & 19.2 & $\mathrm{P}$ & NA & 6.80 & 7.08 & 7.21 & 7.50 & 6.20 & 15.13 & NA & NA & NA & NA & NA & NA & NA & NA & $\mathrm{BC}$ & NA & BP6 & $\mathrm{NA}$ & 345_4p1dr/C_ 8 & $7 / 19 \mathrm{~A} 1$ & TDP-WIP-008 & 20070403 \\
\hline 23.0 & 0.999 & 0.00487 & 0.048 & 0.330 & 22.7 & $\mathrm{P}$ & NA & 5.77 & 5.95 & 6.03 & 6.20 & 6.20 & 11.63 & NA & vis dec & UCSvis & NA & NA & 6.20 & $\mathrm{D}$ & NA & cs & NA & BP5 & NA & $345 \_4 p 1 d 7 Y c \_8$ & $7 / 19 \mathrm{~A} 1$ & TDP-WIP-008 & 20070411 \\
\hline 24.1 & 0.998 & 0.00487 & Indefined & 1.000 & infinite & $\mathrm{s}$ & 7.09 & $\mathrm{NA}$ & NA & NA & 7.00 & NA & 38.63 & NA & NA & NA & NA & $\mathrm{NA}$ & NA & NA & NA & NA & NA & NA & $\mathrm{NA}$ & 345_4p1d7ra & $7 / 19 A 2$ & TDP-WIP-008 & 20070417 \\
\hline 25.0 & 0.998 & 0.00487 & 0.100 & 0.330 & NA & $\mathrm{P}$ & NA & 5.48 & 5.55 & 5.58 & 5.70 & 5.70 & 9.63 & 5.70 & vis & UCSvis & NA & NA & NA & 1 & NA & cs & NA & NA & NA & $34 S_{2} 4 \mathrm{p} 1 \mathrm{~d} / \mathrm{Tc} \_2$ & $7 / 19 A^{3}$ & DP-WTP-008 & 20070423 \\
\hline 25.0 & 0.998 & 0.00487 & 0.100 & 0.330 & 48.8 & $\mathrm{P}$ & NA & 5.95 & 6.04 & 6.08 & 6.10 & 5.70 & 12.63 & NA & NA & $\mathrm{NA}$ & NA & NA & NA & NA & NA & $\mathrm{BC}$ & NA & NA & NA & $34 \mathrm{~S} \_\mathrm{pp} 1 \mathrm{~d} / \mathrm{Yc} \_2$ & $7 / 19 A_{3}$ & TDP-WIP-008 & 20070426 \\
\hline 25.0 & 0.998 & 0.00487 & 0.100 & 0.330 & 35.8 & $\mathrm{P}$ & NA & 7.67 & 7.84 & 7.92 & 8.00 & 5.70 & 23.63 & NA & NA & NA & NA & NA & NA & NA & NA & $\mathrm{BC}$ & NA & NA & NA & 34S_4p1dTrc_2 & $7 / 19 A^{3}$ & TDP-WIP-008 & 20070428 \\
\hline 25.0 & 0.998 & 0.00487 & 0.100 & 0.330 & 42.2 & $\mathrm{P}$ & NA & 6.54 & 6.66 & 6.71 & 6.80 & 5.70 & 16.63 & NA & NA & NA & NA & NA & NA & NA & NA & $\mathrm{BC}$ & NA & NA & NA & $345 \_4 p 1 d 7 r c 2$ & $7 / 19 A_{3}$ & TDP-WIP-008 & 20070432 \\
\hline 25.0 & 0.998 & 0.00487 & 0.100 & 0.330 & 51.0 & $\mathrm{P}$ & NA & 5.38 & 5.46 & 5.49 & 5.60 & 5.70 & 10.13 & NA & NA & NA & NA & NA & NA & NA & NA & AM & NA & NA & $\mathrm{NA}$ & $34 \mathrm{~S}$ 4p1d/rc 2 & $7 / 19 A^{3}$ & PP-WIP-008 & 20070434 \\
\hline 25.0 & 0.998 & 0.00487 & 0.048 & 0.180 & 41.7 & $\mathrm{P}$ & NA & 5.83 & 6.01 & 6.09 & 6.30 & 6.40 & 11.88 & NA & NA & NA & NA & NA & NA & NA & NA & AM & NA & NA & NA & 34S_4p1dTrd_8 & $7 / 19 \mathrm{AA}$ & TDP-WIP-008 & 20070438 \\
\hline 25.0 & 0.998 & 0.00487 & 0.048 & 0.180 & 40.0 & $\mathrm{P}$ & NA & 5.96 & 6.15 & 6.23 & 6.40 & 6.40 & 13.63 & 6.40 & & UCSVis & NA & NA & NA & & NA & CS & NA & NA & NA & 34S_4p1drrd 8 & $7 / 19 \mathrm{AA}$ & TDP-WIP-008 & 20070441 \\
\hline 25.0 & 0.998 & 0.00487 & 0.048 & 0.180 & 32.8 & $P$ & NA & 7.25 & 7.56 & 7.71 & 8.00 & 6.40 & 16.63 & NA & NA & NA & NA & NA & NA & NA & NA & $\mathrm{BC}$ & NA & NA & NA & 345_4p1dTrd 8 & $7 / 19 \mathrm{AA}$ & TDP-WIP-008 & 20070445 \\
\hline
\end{tabular}


Table B.7. Data from July 2007 Tests in Mid-Scale Vessel with Spherical Head A.3

\begin{tabular}{|c|c|c|c|c|c|c|c|c|c|c|c|c|c|c|c|c|c|c|c|c|c|c|c|c|c|c|c|}
\hline $\begin{array}{l}\text { Row } \\
\text { Number }\end{array}$ & Test & Case ID & $\begin{array}{c}\text { Tank } \\
\text { Diameter }\end{array}$ & $\begin{array}{l}\text { Head } \\
\text { Shape }\end{array}$ & $\begin{array}{l}\text { Dish } \\
\text { Height }\end{array}$ & $\begin{array}{c}\text { Dish } \\
\text { Volume }\end{array}$ & $\begin{array}{l}\text { Tank } \\
\text { Fill } \\
\text { Height }\end{array}$ & $\begin{array}{l}\text { Retum } \\
\text { Line } \\
\text { Height }\end{array}$ & $\begin{array}{c}\text { Nozzle } \\
\text { Inner } \\
\text { Diameter }\end{array}$ & $\begin{array}{l}\text { Nozzle } \\
\text { Stand- } \\
\text { off } \\
\text { Distance }\end{array}$ & $\begin{array}{l}\text { Pulse Tube } \\
\text { Configuration }\end{array}$ & $\begin{array}{l}\text { Installed } \\
\text { Nozzles }\end{array}$ & $\begin{array}{c}\text { Outer } \\
\text { Nozzles } \\
\text { Operated }\end{array}$ & $\begin{array}{l}\text { IInner } \\
\text { Nozbles } \\
\text { Operated }\end{array}$ & $\begin{array}{l}\text { Pulse Tube } \\
\text { Outer } \\
\text { Diameter }\end{array}$ & $\begin{array}{c}\text { Outer } \\
\text { PMM } \\
\text { Radius }\end{array}$ & $\begin{array}{c}\text { Inner } \\
\text { PMM } \\
\text { Radius }\end{array}$ & $\begin{array}{l}\text { "FO" Outer } \\
\text { PJM } \\
\text { Impingement } \\
\text { Angle }\end{array}$ & $\begin{array}{c}\text { "FO"' Inner } \\
\text { PJM } \\
\text { Impingement } \\
\text { Angle }\end{array}$ & $\begin{array}{c}\text { Ratio Outer } \\
\text { PJMto } \\
\text { Tank } \\
\text { Radius } \\
\end{array}$ & $\begin{array}{c}\text { Ratio Inner } \\
\text { PJM to } \\
\text { Tank } \\
\text { Radius }\end{array}$ & Simulant & $\begin{array}{l}\text { Solids } \\
\text { Density }\end{array}$ & $\begin{array}{c}\text { Particle } \\
\text { Diameter d5 }\end{array}$ & $\begin{array}{l}\text { Particle } \\
\text { Diameter } \\
\text { d50 }\end{array}$ & $\begin{array}{l}\text { Particle } \\
\text { Diameter } \\
\text { d95 }\end{array}$ & $\begin{array}{c}\text { Void } \\
\text { Fraction }\end{array}$ \\
\hline text & text & text & in. & text & in. & in. ${ }^{3}$ & in. & in. & in. & in. & text & number & number & number & in. & in. & in. & deg & deg & nondim & nondim & text & $\mathrm{g} / \mathrm{cm}^{3}$ & $\mathrm{~m}$ & $\mathrm{~m}$ & $\mathrm{~m}$ & fraction \\
\hline MSS & MDDX & ID & $\mathrm{D}$ & $\mathrm{HS}$ & Hash & $V_{\text {dsh }}$ & $\mathrm{H}$ & Rtn & $d$ & sod & PT & $\mathrm{N}$ & $\mathrm{Nb}$ & $\mathrm{N}$ & $\mathrm{PT}_{\alpha d}$ & $R_{0}$ & $R$ & $\theta_{0}$ & $\theta_{1}$ & $R d R$ & $R / R$ & sxdx & $\rho_{\mathrm{s}}$ & $d_{5}$ & $d \leq 0$ & des & vf \\
\hline $20070449 \mathrm{M}$ & $7 / 19 \mathrm{AA}$ & 34S_4p1dTrd_8 8 & $337 / 8$ & $s$ & 9 & 4437.4 & $675 / 8$ & 62 & 0.297 & 0.446 & HLP.22 & 12 & 8 & 4 & 1.9 & 10.5 & 5.7 & 30.8 & 16.1 & 0.62 & 0.33 & pld & 2.45 & 0.0001213 & 0.0001780 & 0.0002606 & 0.4277 \\
\hline 20070453 & $7 / 19 \mathrm{AA}$ & $34 S \_4 p 1 d T Y d \_8$ & $337 / 8$ & $\mathrm{~s}$ & 9 & 4437.4 & $675 / 8$ & 62 & 0.297 & 0.446 & HLP-22 & 12 & 8 & 4 & 1.9 & 10.5 & 5.7 & 30.8 & 16.1 & 0.62 & 0.33 & pld7 & 2.45 & 0.0001213 & 0.0001780 & 0.0002606 & 0.4277 \\
\hline 20070471 & $7 / 20 \mathrm{~A} 1$ & $345 \_4 p 1 d / 7 b \_8$ & $337 / 8$ & s & 9 & 4437.4 & $675 / 8$ & 62 & 0.297 & 0.446 & HLP-22 & 12 & 8 & 4 & 1.9 & 10.5 & 5.7 & 30.8 & 16.1 & 0.62 & 0.33 & pld7 & 2.45 & 0.0001213 & 0.0001780 & 0.0002606 & 0.4277 \\
\hline 20070478 & $7 / 20 \mathrm{~A} 1$ & $34 S \_4 p 1 d / 7 b \_8$ & $337 / 8$ & $\mathrm{~s}$ & 9 & 4437.4 & $675 / 8$ & 62 & 0.297 & 0.446 & HLP-22 & 12 & 8 & 4 & 1.9 & 10.5 & 5.7 & 30.8 & 16.1 & 0.62 & 0.33 & pld & 2.45 & 0.0001213 & 0.0001780 & 0.0002606 & 0.4277 \\
\hline 20070482 & $7 / 20 \mathrm{~A} 1$ & $345 \_4 p 1 d 7 / m b 8$ & $337 / 8$ & $\mathrm{~s}$ & 9 & 4437.4 & $675 / 8$ & 62 & 0.297 & 0.446 & HLP-22 & 12 & 8 & 4 & 1.9 & 10.5 & 5.7 & 30.8 & 16.1 & 0.62 & 0.33 & pld7 & 2.45 & 0.0001213 & 0.0001780 & 0.0002606 & 0.4277 \\
\hline 20070484 & $7 / 20 \mathrm{~A} 1$ & 34S_4p1d7rb_8 8 & $337 / 8$ & $s$ & 9 & 4437.4 & $675 / 8$ & 62 & 0.297 & 0.446 & HLP.22 & 12 & 8 & 4 & 1.9 & 10.5 & 5.7 & 30.8 & 16.1 & 0.62 & 0.33 & pldr & 2.45 & 0.0001213 & 0.0001780 & 0.0002606 & 0.4277 \\
\hline $20070489 \mathrm{M}$ & $7 / 20 \mathrm{~A} 1$ & $34 S_{2} 4 p 1 d / 7 b \_8$ & $337 / 8$ & $\mathrm{~s}$ & 9 & 4437.4 & $675 / 8$ & 62 & 0.297 & 0.446 & HLP-22 & 12 & 8 & 4 & 1.9 & 10.5 & 5.7 & 30.8 & 16.1 & 0.62 & 0.33 & pld & 2.45 & 0.0001213 & 0.0001780 & 0.0002606 & 0.4277 \\
\hline $20070495 \mathrm{M}$ & $7 / 20 \mathrm{~A} 1$ & 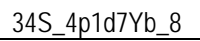 & $337 / 8$ & $s$ & 9 & 4437.4 & $675 / 8$ & 62 & 0.297 & 0.446 & HLP-22 & 12 & 8 & 4 & 1.9 & 10.5 & 5.7 & 30.8 & 16.1 & 0.62 & 0.33 & pld & 2.45 & 0.0001213 & 0.0001780 & 0.0002606 & 0.4277 \\
\hline $20070497 \mathrm{M}$ & $7 / 20 \mathrm{~A} 1$ & 34S_4p1d/7b_8 & $337 / 8$ & $\mathrm{~s}$ & 9 & 4437.4 & $675 / 8$ & 62 & 0.297 & 0.446 & HLP-22 & 12 & 8 & 4 & 19 & 10.5 & 5.7 & 30.8 & 16.1 & 0.62 & 0.33 & pld7 & 2.45 & 0.0001213 & 0.0001780 & 0.0002606 & 0.4277 \\
\hline $20070502 \mathrm{M}$ & $7 / 20 \mathrm{~A} 1$ & $345 \_4 p 1 d 7 / m b 8$ & $337 / 8$ & $\mathrm{~s}$ & 9 & 4437.4 & $675 / 8$ & 62 & 0.297 & 0.446 & HLP-22 & 12 & 8 & 4 & 1.9 & 10.5 & 5.7 & 30.8 & 16.1 & 0.62 & 0.33 & pld & 2.45 & 0.0001213 & 0.0001780 & 0.0002606 & 0.4277 \\
\hline $20070508 \mathrm{M}$ & $7 / 20 \mathrm{~A} 1$ & 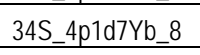 & $337 / 8$ & $\mathrm{~s}$ & 9 & 4437.4 & $675 / 8$ & 62 & 0.297 & 0.446 & HLP.22 & 12 & 8 & 4 & 1.9 & 10.5 & 5.7 & 30.8 & 16.1 & 0.62 & 0.33 & pld & 2.45 & 0.0001213 & 0.0001780 & 0.0002606 & 0.4277 \\
\hline $20070512 \mathrm{M}$ & $7 / 20 \mathrm{~A} 1$ & $34 S_{2} 4 p 1 d / 7 b_{B} 8$ & $337 / 8$ & $s$ & 9 & 4437.4 & $675 / 8$ & 62 & 0.297 & 0.446 & HLP-22 & 12 & 8 & 4 & 1.9 & 10.5 & 5.7 & 30.8 & 16.1 & 0.62 & 0.33 & pld & 2.45 & 0.0001213 & 0.0001780 & 0.0002606 & 0.4277 \\
\hline $20070519 \mathrm{M}$ & $7 / 20 \mathrm{~A} 1$ & $34 \mathrm{~S} \_4 p 1 d / 7 b \quad 8$ & $337 / 8$ & $\mathrm{~s}$ & 9 & 4437.4 & $675 / 8$ & 62 & 0.297 & 0.446 & HLP-22 & 12 & 8 & 4 & 1.9 & 10.5 & 5.7 & 30.8 & 16.1 & 0.62 & 0.33 & pld7 & 2.45 & 0.0001213 & 0.0001780 & 0.0002606 & 0.4277 \\
\hline $20070524 \mathrm{M}$ & $7 / 20 \mathrm{~A} 1$ & 345 4p1drro 8 & $337 / 8$ & $\mathrm{~s}$ & 9 & 4437.4 & $675 / 8$ & 62 & 0.297 & 0.446 & HLP-22 & 12 & 8 & 4 & 1.9 & 10.5 & 5.7 & 30.8 & 16.1 & 0.62 & 0.33 & p1d7 & 2.45 & 0.0001213 & 0.0001780 & 0.0002606 & 0.4277 \\
\hline 20070535 & $7 / 20 \mathrm{A2}$ & $34 S_{-} 4 p 1 d T Y c_{-} 3$ & $337 / 8$ & $\mathrm{~s}$ & 9 & 4437.4 & $675 / 8$ & 62 & 0.297 & 0.446 & HLP-22 & 12 & 8 & 4 & 1.9 & 10.5 & 5.7 & 30.8 & 16.1 & 0.62 & 0.33 & pld7 & 2.45 & 0.0001213 & 0.0001780 & 0.0002606 & 0.4277 \\
\hline 20070539 & $7 / 20 \mathrm{~A}^{2}$ & $34 \mathrm{~S} 4 \mathrm{p} 1 \mathrm{~d} / \mathrm{Yc} 3$ & $337 / 8$ & $\mathrm{~s}$ & 9 & 4437.4 & $675 / 8$ & 62 & 0.297 & 0.446 & HLP 22 & 12 & 8 & 4 & 19 & 10.5 & 5.7 & 30.8 & 16.1 & 0.62 & 0.33 & pld7 & 2.45 & 0.0001213 & 0.0001780 & 0.0002606 & 0.4277 \\
\hline $20070547 \mathrm{M}$ & $7 / 20 \mathrm{~A}^{2}$ & $34 S_{-} 4 p 1 d T / Y c_{3} 3$ & $337 / 8$ & $s$ & 9 & 4437.4 & $675 / 8$ & 62 & 0.297 & 0.446 & HLP.22 & 12 & 8 & 4 & 1.9 & 10.5 & 5.7 & 30.8 & 16.1 & 0.62 & 0.33 & pld7 & 2.45 & 0.0001213 & 0.0001780 & 0.0002606 & 0.4277 \\
\hline $20070552 \mathrm{M}$ & $7 / 20 \mathrm{A2}$ & $345 \_4 p 1 d T r c \_3$ & $337 / 8$ & $\mathrm{~s}$ & 9 & 4437.4 & $675 / 8$ & 62 & 0.297 & 0.446 & HLP-22 & 12 & 8 & 4 & 1.9 & 10.5 & 5.7 & 30.8 & 16.1 & 0.62 & 0.33 & p1d7 & 2.45 & 0.0001213 & 0.0001780 & 0.0002606 & $0.42 \pi$ \\
\hline $20070557 \mathrm{M}$ & $7 / 20 \mathrm{~A} 2$ & 345 4p1drrc 3 & $337 / 8$ & $\mathrm{~s}$ & 9 & 4437.4 & $675 / 8$ & 62 & 0.297 & 0.446 & HLP-22 & 12 & 8 & 4 & 1.9 & 10.5 & 5.7 & 30.8 & 16.1 & 0.62 & 0.33 & p1d7 & 2.45 & 0.0001213 & 0.0001780 & 0.0002606 & 0.4277 \\
\hline $20070562 \mathrm{M}$ & $7 / 20 \mathrm{~A}^{2}$ & $34 S_{-} 4 p 1 d T Y c \_3$ & $337 / 8$ & $\mathrm{~s}$ & 9 & 4437.4 & $675 / 8$ & 62 & 0.297 & 0.446 & HLP-22 & 12 & 8 & 4 & 1.9 & 10.5 & 5.7 & 30.8 & 16.1 & 0.62 & 0.33 & pld7 & 2.45 & 0.0001213 & 0.0001780 & 0.0002606 & 0.4277 \\
\hline $20070571 \mathrm{M}$ & $7 / 20 \mathrm{~A}^{2}$ & 34S_4p1dTrc_ 3 & $337 / 8$ & $s$ & 9 & 4437.4 & $675 / 8$ & 62 & 0.297 & 0.446 & HLP.22 & 12 & 8 & 4 & 1.9 & 10.5 & 5.7 & 30.8 & 16.1 & 0.62 & 0.33 & pld7 & 2.45 & 0.0001213 & 0.0001780 & 0.0002606 & 0.4277 \\
\hline 20070584 & $7 / 21 \mathrm{~A} 1$ & 34S_6p1d/ra & $337 / 8$ & $s$ & 9 & 4437.4 & $683 / 8$ & 62 & 0.446 & 0.669 & HLP.22 & 12 & 8 & 4 & 1.9 & 10.5 & 5.7 & 30.8 & 16.1 & 0.62 & 0.33 & pld7 & 2.45 & 0.0001213 & 0.0001780 & 0.0002606 & 0.4277 \\
\hline 20070587 & $7 / 21 \mathrm{~A} 1$ & 34S fopldrra & $337 / 8$ & $\mathrm{~s}$ & 9 & 4437.4 & $683 / 8$ & 62 & 0.446 & 0.669 & HLP-22 & 12 & 8 & 4 & 1.9 & 10.5 & 5.7 & 30.8 & 16.1 & 0.62 & 0.33 & pld7 & 2.45 & 0.0001213 & 0.0001780 & 0.0002606 & $0.42 \pi$ \\
\hline 20070591 & $7 / 21 \mathrm{~A} 1$ & 34s_opldrva & $337 / 8$ & $\mathrm{~s}$ & 9 & 4437.4 & $683 / 8$ & 62 & 0.446 & 0.669 & HLP-22 & 12 & 8 & 4 & 1.9 & 10.5 & 5.7 & 30.8 & 16.1 & 0.62 & 0.33 & p1d7 & 2.45 & 0.0001213 & 0.0001780 & 0.0002606 & $0.42 \pi$ \\
\hline 20070593 & $7 / 21 \mathrm{~A} 1$ & 34s_fpldr/ra & $337 / 8$ & $\mathrm{~s}$ & 9 & 4437.4 & $683 / 8$ & 62 & 0.446 & 0.669 & HLP-22 & 12 & 8 & 4 & 1.9 & 10.5 & 5.7 & 30.8 & 16.1 & 0.62 & 0.33 & pld7 & 2.45 & 0.0001213 & 0.0001780 & 0.0002606 & 0.4277 \\
\hline 20070598 & $7 / 21 \mathrm{~A} 1$ & 345_6pldrra & $337 / 8$ & $s$ & 9 & 4437.4 & $683 / 8$ & 62 & 0.446 & 0.669 & HLP-22 & 12 & 8 & 4 & 1.9 & 10.5 & 5.7 & 30.8 & 16.1 & 0.62 & 0.33 & pld7 & 2.45 & 0.0001213 & 0.0001780 & 0.0002606 & 0.4277 \\
\hline 20070601 & $7 / 21 \mathrm{~A} 1$ & 34s_fplddra & $337 / 8$ & $s$ & 9 & 4437.4 & $683 / 8$ & 62 & 0.446 & 0.669 & HLP.22 & 12 & 8 & 4 & 1.9 & 10.5 & 5.7 & 30.8 & 16.1 & 0.62 & 0.33 & pld7 & 2.45 & 0.0001213 & 0.0001780 & 0.0002606 & 0.4277 \\
\hline 20070605 & $7 / 21 \mathrm{~A} 1$ & 34S fopldr/ra & $337 / 8$ & $\mathrm{~s}$ & 9 & 4437.4 & $683 / 8$ & 62 & 0.446 & 0.669 & HLP-22 & 12 & 8 & 4 & 1.9 & 10.5 & 5.7 & 30.8 & 16.1 & 0.62 & 0.33 & pld7 & 2.45 & 0.0001213 & 0.0001780 & 0.0002606 & $0.42 \pi 7$ \\
\hline 20070609 & $7 / 21 \mathrm{A2}$ & 345 6p1dTrc 8 & $337 / 8$ & $\mathrm{~s}$ & 9 & 4437.4 & $683 / 8$ & 62 & 0.446 & 0.669 & HLP-22 & 12 & 8 & 4 & 1.9 & 10.5 & 5.7 & 30.8 & 16.1 & 0.62 & 0.33 & p1d7 & 2.45 & 0.0001213 & 0.0001780 & 0.0002606 & 0.4277 \\
\hline 20070613 & $7 / 21 \mathrm{A2}$ & 345_6p1d/rc 8 & $337 / 8$ & $\mathrm{~s}$ & 9 & 4437.4 & $683 / 8$ & 62 & 0.446 & 0.669 & HLP-22 & 12 & 8 & 4 & 1.9 & 10.5 & 5.7 & 30.8 & 16.1 & 0.62 & 0.33 & p1d7 & 2.45 & 0.0001213 & 0.0001780 & 0.0002606 & 0.4277 \\
\hline 20070615 & $7 / 21 \mathrm{~A} 2^{2}$ & 34S_6p1d/Yc_ 8 & $337 / 8$ & $\mathrm{~s}$ & 9 & 4437.4 & $683 / 8$ & 62 & 0.446 & 0.669 & HLP-22 & 12 & 8 & 4 & 1.9 & 10.5 & 5.7 & 30.8 & 16.1 & 0.62 & 0.33 & pld7 & 2.45 & 0.0001213 & 0.0001780 & 0.0002606 & $0.42 \pi$ \\
\hline 20070617 & $7 / 21 \mathrm{~A}^{2}$ & 34S_6p1dTrc_8 8 & $337 / 8$ & $s$ & 9 & 4437.4 & $683 / 8$ & 62 & 0.446 & 0.669 & HLP-22 & 12 & 8 & 4 & 1.9 & 10.5 & 5.7 & 30.8 & 16.1 & 0.62 & 0.33 & pld7 & 2.45 & 0.0001213 & 0.0001780 & 0.0002606 & 0.4277 \\
\hline 20070620 & $7 / 21 \mathrm{~A} 2^{2}$ & 34S_6p1d/rc_ 8 & $337 / 8$ & $\mathrm{~s}$ & 9 & 4437.4 & $683 / 8$ & 62 & 0.446 & 0.669 & HLP-22 & 12 & 8 & 4 & 1.9 & 10.5 & 5.7 & 30.8 & 16.1 & 0.62 & 0.33 & pld7 & 2.45 & 0.0001213 & 0.0001780 & 0.0002606 & $0.42 \pi$ \\
\hline 20070625 & $7 / 21 \mathrm{~A} 2^{2}$ & 34S_6p1dTrc_ 8 & $337 / 8$ & $s$ & 9 & 4437.4 & $683 / 8$ & 62 & 0.446 & 0.669 & HLP-22 & 12 & 8 & 4 & 1.9 & 10.5 & 5.7 & 30.8 & 16.1 & 0.62 & 0.33 & pld7 & 2.45 & 0.0001213 & 0.0001780 & 0.0002606 & $0.42 \pi$ \\
\hline $20070627 \mathrm{M}$ & $7 / 21 \mathrm{A2}$ & 345_6p1dTrc 8 & $337 / 8$ & $\mathrm{~s}$ & 9 & 4437.4 & $683 / 8$ & 62 & 0.446 & 0.669 & HLP-22 & 12 & 8 & 4 & 1.9 & 10.5 & 5.7 & 30.8 & 16.1 & 0.62 & 0.33 & pld7 & 2.45 & 0.0001213 & 0.0001780 & 0.0002606 & 0.4277 \\
\hline $20070633 \mathrm{M}$ & $7 / 21 \mathrm{~A} 2^{2}$ & 34S_6p1dTrc 88 & $337 / 8$ & $\mathrm{~s}$ & 9 & 4437.4 & $683 / 8$ & 62 & 0.446 & 0.669 & HLP-22 & 12 & 8 & 4 & 1.9 & 10.5 & 5.7 & 30.8 & 16.1 & 0.62 & 0.33 & p1d7 & 2.45 & 0.0001213 & 0.0001780 & 0.0002606 & 0.4277 \\
\hline $20070636 \mathrm{M}$ & $7 / 21 \mathrm{~A}^{2}$ & 34S_6p1dTrc_8 8 & $337 / 8$ & $s$ & 9 & 4437.4 & $683 / 8$ & 62 & 0.446 & 0.669 & HLP-22 & 12 & 8 & 4 & 1.9 & 10.5 & 5.7 & 30.8 & 16.1 & 0.62 & 0.33 & pld7 & 2.45 & 0.0001213 & 0.0001780 & 0.0002606 & 0.4277 \\
\hline $20070639 \mathrm{M}$ & $7 / 21 A^{2}$ & 345 6p1d/ry 8 & $337 / 8$ & $\mathrm{~s}$ & 9 & 4437.4 & $683 / 8$ & 62 & 0.446 & 0.669 & HLP-22 & 12 & 8 & 4 & 1.9 & 10.5 & 5.7 & 30.8 & 16.1 & 0.62 & 0.33 & pld7 & 2.45 & 0.0001213 & 0.0001780 & 0.0002606 & 0.4277 \\
\hline $20070641 \mathrm{M}$ & $7 / 21 \mathrm{A2}$ & 345 6p1dr/rc 8 & $337 / 8$ & $\mathrm{~s}$ & 9 & 4437.4 & $683 / 8$ & 62 & 0.446 & 0.669 & HLP-22 & 12 & 8 & 4 & 1.9 & 10.5 & 5.7 & 30.8 & 16.1 & 0.62 & 0.33 & p1d7 & 2.45 & 0.0001213 & 0.0001780 & 0.0002606 & $0.42 \pi$ \\
\hline $20070645 \mathrm{M}$ & $7 / 21 \mathrm{~A}^{2}$ & 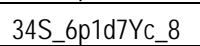 & $337 / 8$ & $\mathrm{~s}$ & 9 & 4437.4 & $683 / 8$ & 62 & 0.446 & 0.669 & HLP-22 & 12 & 8 & 4 & 1.9 & 10.5 & 5.7 & 30.8 & 16.1 & 0.62 & 0.33 & p1d7 & 2.45 & 0.0001213 & 0.0001780 & 0.0002606 & 0.4277 \\
\hline 20070648 & $7 / 21 \mathrm{~A}^{2}$ & 34S_6p1d/rc_ 8 & $337 / 8$ & $\mathrm{~s}$ & 9 & 4437.4 & $683 / 8$ & 62 & 0.446 & 0.669 & HLP-22 & 12 & 8 & 4 & 1.9 & 10.5 & 5.7 & 30.8 & 16.1 & 0.62 & 0.33 & p1d7 & 2.45 & 0.0001213 & 0.0001780 & 0.0002606 & 0.4277 \\
\hline
\end{tabular}


Table B.7. Data from July 2007 Tests in Mid-Scale Vessel with Spherical Head B.3

\begin{tabular}{|c|c|c|c|c|c|c|c|c|c|c|c|c|c|c|c|c|c|c|c|c|c|c|c|c|c|c|c|c|c|}
\hline $\begin{array}{l}\text { Tank Water } \\
\text { Temperature }\end{array}$ & $\begin{array}{l}\text { Water } \\
\text { Density }\end{array}$ & $\begin{array}{l}\text { Solids } \\
\text { Fraction }\end{array}$ & $\begin{array}{l}\text { Pulse } \\
\text { Volume } \\
\text { Fraction }\end{array}$ & $\begin{array}{l}\text { Duty } \\
\text { Cycle }\end{array}$ & $\begin{array}{l}\text { cydle } \\
\text { Time }\end{array}$ & $\begin{array}{c}\text { Pulsed } \\
\text { orady } \\
\text { Sheady } \\
\text { Jet }\end{array}$ & $\begin{array}{l}\text { Steacady } \\
\text { Jet }\end{array}$ & $\begin{array}{c}\text { Pulsing } \\
\text { Jet } \\
\end{array}$ & \begin{tabular}{|c} 
U2 \\
URNS \\
\end{tabular} & $\begin{array}{c}\text { UI } \\
\text { URNB } \\
\end{array}$ & $\begin{array}{l}\text { Discharge } \\
\text { Velocity }\end{array}$ & $\begin{array}{c}\text { Cintical } \\
\text { Suspension } \\
\text { Velocity }\end{array}$ & $\begin{array}{l}\text { Average } \\
\text { Peak } \\
\text { Cloud } \\
\text { Height } \\
\end{array}$ & $\begin{array}{c}\text { UCS } \\
\text { Condition }\end{array}$ & \begin{tabular}{|c|} 
UCS \\
Nethod \\
\end{tabular} & $\begin{array}{l}\text { UCS } \\
\text { Hag }\end{array}$ & $\begin{array}{c}\text { UCS } \\
\text { Center } \\
\text { Hag }\end{array}$ & \begin{tabular}{|c|} 
ucs udv \\
Hag
\end{tabular} & \begin{tabular}{|c} 
UCS based \\
on \\
Decreasing \\
Velocity \\
\end{tabular} & \begin{tabular}{|c|} 
Inceep \\
Increase/ \\
Decrease
\end{tabular} & \begin{tabular}{|c} 
UDV \\
Height \\
Bed
\end{tabular} & $\begin{array}{l}\text { Patricle } \\
\text { Motion } \\
\end{array}$ & $\begin{array}{l}\text { Solids } \\
\text { Level }\end{array}$ & \begin{tabular}{|l|} 
Outer \\
Bototom \\
Patem \\
\end{tabular} & \begin{tabular}{|l|} 
Inner \\
Bototom \\
Pattem \\
\end{tabular} & Case ID & Test & TDP & $\begin{array}{l}\text { Row } \\
\text { Number }\end{array}$ \\
\hline c & $\mathrm{g} / \mathrm{cm}^{3}$ & fraction & fraction & fraction & $\mathrm{s}$ & text & $\mathrm{m} / \mathrm{s}$ & $\mathrm{m} / \mathrm{s}$ & $\mathrm{m} / \mathrm{s}$ & $\mathrm{m} / \mathrm{s}$ & $\mathrm{m} / \mathrm{s}$ & m/s & in. & $\mathrm{m} / \mathrm{s}$ & text & text & text & text & \begin{tabular}{|l}
$\mathrm{m} / \mathrm{s}$ \\
\end{tabular} & \begin{tabular}{|l} 
text \\
\end{tabular} & $\mathrm{mm}$ & text & text & text & text & text & text & text & text \\
\hline $\mathrm{T}$ & $\rho$ & $\phi_{\mathrm{s}}$ & $\phi_{\mathrm{p}}$ & $\mathrm{DC}$ & $t_{c}$ & Jet & $u_{s}$ & $\mathrm{U1}$ & $\mathrm{U} 2$ & U3 & $u$ & Ucs & $H_{\mathrm{c}}$ & U Cos & Uan & Uosvis & Ussen & Usuldv & Uos_D & $\mathrm{S}_{\mathrm{N}}$ & $\mathrm{H}_{\text {ocd }}$ & $\mathrm{PM}$ & sol & $\mathrm{SPo}$ & $S P_{1}$ & ID & MDDX & $\mathrm{IDP}$ & MSS \\
\hline 25.0 & 0.998 & 0.00487 & 0.048 & 0.180 & 40.8 & $\mathrm{P}$ & NA & 5.97 & 6.16 & 6.24 & 6.40 & 6.40 & 13.13 & NA & vis dec & ucsis & NA & NA & 6.40 & D & NA & cs & NA & NA & NA & 34s_4p1dr/rd_8 & $7 / 19 \mathrm{AA}$ & TDP-WTP-008 & 20070449 \\
\hline 25.0 & 0.998 & 0.00487 & 0.048 & 0.180 & 43.5 & $\mathrm{P}$ & NA & 5.62 & 5.79 & 5.87 & 6.00 & 6.40 & 10.13 & NA & NA & NA & NA & NA & NA & NA & NA & $A M$ & $\mathrm{NA}$ & NA & NA & 34S _4pldr/d 8 & 7/19AA & TDP-WTP-008 & 20070453 \\
\hline 25.0 & 0.998 & 0.00487 & 0.048 & 0.500 & 19.0 & $\mathrm{P}$ & NA & 4.79 & 4.89 & 4.94 & 5.00 & 6.00 & 11.13 & NA & NA & NA & NA & NA & NA & NA & NA & $A M$ & NA & NA & NA & $34 \mathrm{~S} \_4 \mathrm{pld} / \mathrm{Mb} \_8$ & $7 / 20 \mathrm{~A} 1$ & TDP-WIP-010 & 20070471 \\
\hline 25.0 & 0.998 & 0.00487 & 0.048 & 0.500 & 17.4 & $\mathrm{P}$ & NA & 5.31 & 5.45 & 5.51 & 5.50 & 6.00 & 12.46 & NA & NA & NA & NA & NA & NA & NA & NA & $A M+$ & NA & NA & NA & $34 \mathrm{~S}=4 \mathrm{pld} / \mathrm{Mb} \_8$ & $7 / 20 \mathrm{~A}_{1}$ & TDP-WTP-010 & 20070478 \\
\hline 25.0 & 0.998 & 0.00487 & 0.048 & 0.500 & 16.7 & $P$ & NA & 5.53 & 5.68 & 5.75 & 5.80 & 6.00 & 1229 & NA & NA & NA & NA & NA & NA & NA & NA & $A M$ & NA & NA & NA & 34S 4 ppldrob 8 & 7/20A1 & TDP-WIP-010 & 20070482 \\
\hline 25.0 & 0.998 & 0.00487 & 0.048 & 0.500 & 16.7 & $\mathrm{P}$ & NA & 5.53 & 5.68 & 5.75 & 5.80 & 6.00 & 12.29 & NA & NA & NA & NA & NA & NA & NA & NA & cs. & NA & NA & NA & 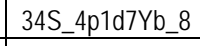 & $7 / 20 \mathrm{~A} 1$ & TDP-WIP-010 & 20070484 \\
\hline 25.0 & 0.998 & 0.00487 & 0.048 & 0.500 & 15.9 & $\mathrm{P}$ & NA & 5.66 & 5.82 & 5.90 & 6.00 & 6.00 & 12.63 & 6.00 & vis & ucsis & NA & NA & NA & 1 & NA & cs & NA & NA & NA & 34s_4p1d/rob 8 & $7 / 20 \mathrm{~A}_{1}$ & TDP-WTP-010 & 20070489 \\
\hline 25.0 & 0.998 & 0.00487 & 0.048 & 0.500 & 14.7 & $\mathrm{P}$ & NA & 6.07 & 6.27 & 6.36 & 6.50 & 6.00 & 13.79 & NA & NA & NA & NA & NA & NA & NA & NA & cs & NA & NA & NA & $34 \mathrm{~s}=4 \mathrm{pld} 7 \mathrm{Yb}=8$ & $7 / 20 \mathrm{~A} 1$ & TDP-WIP-010 & 20070497 \\
\hline 25.0 & 0.998 & 0.00487 & 0.048 & 0.500 & 13.7 & $\mathrm{P}$ & NA & 6.52 & 6.75 & 6.85 & 7.00 & 6.00 & 14.38 & NA & NA & NA & NA & NA & NA & NA & NA & $B C$ & NA & NA & NA & $34 \mathrm{~S} \_\mathrm{p} 1 \mathrm{~d} / \mathrm{Mb} \_8$ & 7/20A1 & TDP-WIP-010 & 20070502 \\
\hline 25.0 & 0.998 & 0.00487 & 0.048 & 0.500 & 12.1 & $\mathrm{P}$ & NA & 7.32 & 7.63 & 7.77 & 8.00 & 6.00 & 18.88 & NA & NA & NA & NA & NA & NA & NA & NA & $B C$ & NA & NA & NA & $34 \mathrm{~S}-4 \mathrm{p} 1 \mathrm{~d} / \mathrm{Yr} \_8$ & $7 / 20 \mathrm{~A} 1$ & TDP-WIP-010 & 20070508 \\
\hline 25.0 & 0.998 & 0.00487 & 0.048 & 0.500 & 11.2 & $\mathrm{P}$ & NA & 8.11 & 8.51 & 8.70 & 9.00 & 6.00 & 30.38 & NA & NA & NA & NA & NA & NA & NA & NA & $B C$ & NA & NA & NA & $34 \mathrm{~S} \_\mathrm{pld} / \mathrm{Mb}=8$ & $7 / 20 \mathrm{~A}_{1}$ & TDP-WTP-010 & 20070512 \\
\hline 25.0 & 0.998 & 0.00487 & 0.048 & 0.500 & 14.7 & $\mathrm{P}$ & NA & 6.11 & 6.30 & 6.39 & 6.50 & 6.00 & 12.63 & NA & NA & NA & NA & NA & NA & NA & NA & NA & NA & NA & NA & 34S_4p1dTrb_ 8 & $7 / 20 A_{1}$ & TDP-WIP-010 & 20070519 \\
\hline 25.0 & 0.998 & 0.00487 & 0.048 & 0.500 & 15.9 & $\mathrm{P}$ & NA & 5.70 & 5.87 & 5.94 & 6.00 & 6.00 & 12.13 & NA & vis dec & ucsis & NA & NA & 6.00 & $\mathrm{D}$ & NA & NA & NA & NA & NA & $34 \mathrm{~s} \quad 4 \mathrm{pld} 7 \mathrm{Yb}=8$ & $7 / 20 \mathrm{~A}_{1}$ & TDP-WIP-010 & 20070524 \\
\hline 25.0 & 0.998 & 0.00487 & 0.025 & 0.330 & 15.2 & $\mathrm{P}$ & NA & 4.59 & 4.78 & 4.87 & 5.00 & 6.90 & 11.63 & NA & NA & NA & NA & NA & NA & NA & NA & AM- & NA & NA & NA & $34 S_{4} 4 \mathrm{pld} 7 \mathrm{Yc} \_3$ & $7 / 20 \mathrm{~A} 2$ & TDP-WIP-010 & 20070535 \\
\hline 25.0 & 0.998 & 0.00487 & 0.025 & 0.330 & 13.3 & $\mathrm{P}$ & NA & 5.41 & 5.68 & 5.81 & 6.00 & 6.90 & 12.88 & NA & NA & NA & NA & NA & NA & NA & NA & $A M$ & NA & NA & NA & $34 \mathrm{~S}-4 \mathrm{pld} 7 \mathrm{Yc} \_3$ & $7 / 20 \mathrm{AZ}^{2}$ & TDP-WIP-010 & 20070539 \\
\hline 25.0 & 0.998 & 0.00487 & 0.025 & 0.330 & 12.0 & $\mathrm{P}$ & NA & 6.10 & 6.47 & 6.65 & 6.90 & 6.90 & 13.38 & 6.90 & vis & ucsis & NA & NA & NA & 1 & NA & cs & NA & NA & NA & $34 \mathrm{~S} 4 \mathrm{p} 1 \mathrm{~d} / \mathrm{Yc} \_3$ & $7 / 20 \mathrm{~A} 2$ & TDP-WIP-010 & 20070547 \\
\hline 25.0 & 0.998 & 0.00487 & 0.025 & 0.330 & 10.3 & $\mathrm{P}$ & NA & 6.83 & 7.35 & 7.59 & 8.00 & 6.90 & 12.63 & NA & NA & NA & NA & NA & NA & NA & NA & NA & NA & NA & NA & $34 S_{4} 4 \mathrm{pld} 7 \mathrm{Yc} \_3$ & $7 / 20 \mathrm{~A} 2$ & TDP-WIP-010 & 20070552 \\
\hline 25.0 & 0.998 & 0.00487 & 0.025 & 0.330 & 9.5 & $\mathrm{P}$ & NA & 7.48 & 8.13 & 8.45 & 9.00 & 6.90 & 14.63 & NA & NA & NA & NA & NA & NA & NA & NA & NA & NA & NA & NA & $34 \mathrm{~s}, 4 \mathrm{pld} 7 \mathrm{Yc} \_3$ & $7 / 20 \mathrm{~A}^{2}$ & TDP-WIP-010 & 20070557 \\
\hline 25.0 & 0.998 & 0.00487 & 0.025 & 0.330 & 8.4 & $\mathrm{P}$ & NA & 7.75 & 8.56 & 8.96 & 10.00 & 6.90 & 26.13 & NA & NA & NA & NA & NA & NA & NA & NA & NA & NA & NA & NA & $34 S_{4} 4 \mathrm{p} 1 \mathrm{~d} / \mathrm{Yc} \_3$ & $7 / 20 \mathrm{~A}^{2}$ & TDP-WIP-010 & 20070562 \\
\hline NA & NA & 0.00487 & undefined & 1.000 & infinite & $\mathrm{s}$ & NA & NA & NA & NA & 2.70 & 3.30 & NA & NA & NA & NA & NA & NA & NA & NA & NA & ss & NA & NA & NA & 34s_6p1d7ra & $7 / 21 \mathrm{~A} 1$ & TDP-WIP-011 & 20070584 \\
\hline 25.2 & 0.998 & 0.00487 & undefined & 1.000 & infinite & $\mathrm{s}$ & 3.02 & NA & NA & NA & 3.00 & 3.30 & \begin{tabular}{|l|}
9.13 \\
\end{tabular} & NA & NA & NA & NA & NA & NA & NA & NA & $A M$ & NA & NA & NA & 34s_opldrva & $7 / 21 \mathrm{~A} 1$ & TDP-WIP-011 & 20070587 \\
\hline 25.2 & 0.998 & 0.00487 & undefined & 1.000 & infinite & $\mathrm{s}$ & 3.20 & NA & NA & NA & 3.20 & 3.30 & 10.13 & NA & NA & NA & NA & NA & NA & NA & NA & $A M$ & NA & NA & NA & 345_opldrya & $7 / 21 \mathrm{~A} 1$ & TDP-WIP-011 & 20070591 \\
\hline 25.2 & 0.998 & 0.00487 & undefined & 1.000 & infinite & $s$ & 3.32 & NA & NA & NA & 3.30 & 3.30 & 10.38 & 3.30 & vis & UCSvis & NA & NA & NA & 1 & NA & cs & NA & NA & NA & 34s 6p1dr/ra & $7 / 21 \mathrm{~A} 1$ & TDP-WIP-011 & 20070593 \\
\hline 25.2 & 0.998 & 0.00487 & undefined & 1.000 & infinite & $\mathrm{s}$ & 3.99 & NA & NA & NA & 4.00 & 3.30 & 28.13 & NA & NA & NA & NA & NA & NA & NA & NA & $B C$ & NA & NA & NA & 345 bpldrra & $7 / 21 \mathrm{~A} 1$ & TDP-WIP-011 & 20070598 \\
\hline 25.3 & 0.998 & 0.00487 & undefined & 1.000 & infinite & $\mathrm{s}$ & 3.51 & NA & NA & NA & 3.50 & 3.30 & 11.63 & NA & NA & NA & NA & NA & NA & NA & NA & $B C$ & NA & NA & NA & 345_opldrva & $7 / 21 \mathrm{~A} 1$ & TDP-WTP-011 & 20070601 \\
\hline 25.3 & 0.998 & 0.00487 & undefined & 1.000 & infinite & $\mathrm{s}$ & 3.71 & NA & NA & NA & 3.70 & 3.30 & 16.63 & NA & NA & NA & NA & NA & NA & NA & NA & $B C$ & NA & NA & NA & 345_6p1dTra & $7 / 21 \mathrm{~A} 1$ & TDP-WTP-011 & 20070605 \\
\hline 25.0 & 0.998 & 0.00487 & 0.048 & 0.330 & 22.7 & $\mathrm{P}$ & NA & 2.44 & 2.52 & \begin{tabular}{|l|}
2.56 \\
\end{tabular} & 2.70 & 4.00 & 9.88 & NA & NA & NA & NA & NA & NA & NA & NA & ss & NA & NA & NA & 34s_6pld7rc_ 8 & $7 / 21 \mathrm{A2}$ & TDP-WIP-011 & 20070609 \\
\hline 25.0 & 0.998 & 0.00487 & 0.048 & 0.330 & 20.8 & $\mathrm{P}$ & NA & 2.68 & 2.78 & 2.82 & 3.00 & 4.00 & 11.88 & NA & NA & NA & NA & NA & NA & NA & NA & ss & NA & NA & NA & 34s_6p1d7rc 8 & $7 / 21 \mathrm{A2}$ & TDP-WIP-011 & 20070613 \\
\hline 25.0 & 0.998 & 0.00487 & 0.048 & 0.330 & 18.9 & $\mathrm{P}$ & NA & 2.92 & 3.05 & 3.11 & 3.35 & 4.00 & 12.13 & NA & NA & NA & NA & NA & NA & NA & NA & $A M$ & NA & NA & NA & 34s_6p1d7rc_ 8 & $7 / 21 \mathrm{A2}$ & TDP-WIP-011 & 20070615 \\
\hline 25.0 & 0.998 & 0.00487 & 0.048 & 0.330 & 18.2 & $\mathrm{P}$ & NA & 3.03 & 3.19 & 3.26 & 3.50 & 4.00 & 12.38 & NA & NA & NA & NA & NA & NA & NA & NA & $A M$ & NA & NA & NA & 34s_6p1d7rc_ 8 & $7 / 21 \mathrm{A2}$ & TDP-WIP-011 & 20070617 \\
\hline 25.0 & 0.998 & 0.00487 & 0.048 & 0.330 & 17.7 & $\mathrm{P}$ & NA & 3.18 & 3.34 & 3.41 & 3.70 & 4.00 & 13.38 & NA & NA & NA & NA & NA & NA & NA & NA & $A M++$ & NA & NA & NA & 34S_6pldTrc_8 & $7 / 21 \mathrm{~A} 2^{2}$ & TDP-WTP-011 & 20070620 \\
\hline 25.0 & 0.998 & 0.00487 & 0.048 & 0.330 & 16.9 & $\mathrm{P}$ & NA & 3.35 & 3.52 & 3.60 & 3.90 & 4.00 & 13.63 & NA & NA & NA & NA & NA & NA & NA & NA & AM & NA & NA & NA & 34s_6p1dr/rc_8 & $7 / 21 \mathrm{A2}$ & TDP-WTP-011 & 20070625 \\
\hline 25.0 & 0.998 & 0.00487 & 0.048 & 0.330 & 16.5 & $\mathrm{P}$ & NA & 3.42 & 3.62 & 3.71 & 4.00 & 4.00 & 13.63 & 4.00 & vis & ucsis & NA & NA & NA & 1 & NA & cs & NA & NA & NA & 34s_6pld $6 \mathrm{rc} \_8$ & $7 / 21 \mathrm{A2}$ & TDP-WTP-011 & 20070627 \\
\hline 25.0 & 0.998 & 0.00487 & 0.048 & 0.330 & 14.6 & $\mathrm{P}$ & NA & 3.69 & 3.97 & 4.09 & 4.50 & 4.00 & 14.38 & NA & NA & NA & $n$ & NA & NA & NA & NA & $\mathrm{BC}$ & NA & NA & NA & 34s_6pld7rc_8 & $7 / 21 \mathrm{A2}$ & TDP-WTP-011 & 20070633 \\
\hline 25.0 & 0.998 & 0.00487 & 0.048 & 0.330 & 13.2 & $\mathrm{P}$ & NA & 3.81 & 4.23 & 4.41 & 5.00 & 4.00 & 14.63 & NA & NA & NA & NA & NA & NA & NA & NA & $B C$ & NA & NA & NA & 34s_6p1drrc_ 8 & $7 / 21 \mathrm{A2}$ & TDP-WTP-011 & 20070636 \\
\hline 25.0 & 0.998 & 0.00487 & 0.048 & 0.330 & 12.3 & $\mathrm{P}$ & NA & 4.14 & 4.63 & 4.85 & 5.50 & 4.00 & 15.38 & NA & NA & NA & NA & NA & NA & NA & NA & $\mathrm{BC}$ & NA & NA & NA & 34S_6pldrrc_8 & $7 / 21 \mathrm{A2}$ & TDP-WIP-011 & 20070639 \\
\hline 25.0 & 0.998 & 0.00487 & 0.048 & 0.330 & 11.3 & $\mathrm{P}$ & NA & 4.42 & 5.00 & 5.26 & 6.00 & 4.00 & 24.13 & NA & NA & NA & NA & NA & NA & NA & NA & $B C$ & NA & NA & NA & 34s_6p1d7rc_ 8 & $7 / 21 \mathrm{~A} 2$ & TDP-WTP-011 & 20070641 \\
\hline 25.0 & 0.998 & 0.00487 & 0.048 & 0.330 & 16.3 & $P$ & NA & 3.41 & 3.61 & 3.70 & 4.00 & 4.00 & 13.88 & NA & vis dec & UCSvis & NA & NA & 4.00 & D & NA & cs & NA & NA & NA & 345 _ppldr/re 8 & $7 / 21 \mathrm{~A} 2^{2}$ & TDP-WTP-011 & 20070645 \\
\hline 25.0 & 0.998 & 0.00487 & 0.048 & 0.330 & 16.9 & $P$ & $\mathrm{NA}$ & 3.35 & 3.52 & 3.60 & 3.90 & 4.00 & 13.38 & 3.90 & NA & Ucsis & NA & NA & NA & $\mathrm{D}$ & $N A$ & $A M$ & $\mathrm{NA}$ & $\mathrm{NA}$ & NA & 34S 6p1d/res 8 & $7 / 21 \mathrm{~A} 2^{2}$ & TDP-WIP-011 & 200070648 \\
\hline
\end{tabular}


Table B.7. Data from July 2007 Tests in Mid-Scale Vessel with Spherical Head A.4

\begin{tabular}{|c|c|c|c|c|c|c|c|c|c|c|c|c|c|c|c|c|c|c|c|c|c|c|c|c|c|c|c|}
\hline $\begin{array}{l}\text { Row } \\
\text { Number }\end{array}$ & Test & Case ID & $\begin{array}{c}\text { Tank } \\
\text { Diameter }\end{array}$ & $\begin{array}{l}\text { Head } \\
\text { Shape }\end{array}$ & $\begin{array}{l}\text { Dish } \\
\text { Height }\end{array}$ & $\begin{array}{c}\text { Dish } \\
\text { Volume }\end{array}$ & $\begin{array}{l}\text { Tank } \\
\text { Fill } \\
\text { Height }\end{array}$ & $\begin{array}{c}\text { Retum } \\
\text { Line } \\
\text { Height }\end{array}$ & $\begin{array}{c}\text { Nozzle } \\
\text { Inner } \\
\text { Diameter }\end{array}$ & $\begin{array}{l}\text { Nozzle } \\
\text { Stand- } \\
\text { off } \\
\text { Distance }\end{array}$ & $\begin{array}{l}\text { Pulse Tube } \\
\text { Configuration }\end{array}$ & $\begin{array}{l}\text { Installed } \\
\text { Nozzles }\end{array}$ & $\begin{array}{c}\text { Outer } \\
\text { Nozzles } \\
\text { Operated }\end{array}$ & $\begin{array}{l}\text { IInner } \\
\text { Nozbles } \\
\text { Operated }\end{array}$ & $\begin{array}{l}\text { Pulse Tube } \\
\text { Outer } \\
\text { Diameter }\end{array}$ & $\begin{array}{c}\text { Outer } \\
\text { PMM } \\
\text { Radius }\end{array}$ & $\begin{array}{c}\text { Inner } \\
\text { PMM } \\
\text { Radius }\end{array}$ & $\begin{array}{l}\text { "FO" Outer } \\
\text { PJM } \\
\text { Impingement } \\
\text { Angle }\end{array}$ & $\begin{array}{c}\text { "FO"' Inner } \\
\text { PJM } \\
\text { Impingement } \\
\text { Angle }\end{array}$ & $\begin{array}{c}\text { Ratio Outer } \\
\text { PJMto } \\
\text { Tank } \\
\text { Radius } \\
\end{array}$ & $\begin{array}{c}\text { Ratio Inner } \\
\text { PJM to } \\
\text { Tank } \\
\text { Radius }\end{array}$ & Simulant & $\begin{array}{l}\text { Solids } \\
\text { Density }\end{array}$ & $\begin{array}{c}\text { Particle } \\
\text { Diameter d5 }\end{array}$ & $\begin{array}{l}\text { Particle } \\
\text { Diameter } \\
\text { d50 }\end{array}$ & $\begin{array}{l}\text { Particle } \\
\text { Diameter } \\
\text { d95 }\end{array}$ & $\begin{array}{c}\text { Void } \\
\text { Fraction }\end{array}$ \\
\hline text & text & text & in. & text & in. & in. ${ }^{3}$ & in. & in. & in. & in. & text & number & number & number & in. & in. & in. & deg & deg & nondim & nondim & text & $\mathrm{g} / \mathrm{cm}^{3}$ & $\mathrm{~m}$ & $\mathrm{~m}$ & $\mathrm{~m}$ & fraction \\
\hline MSS & MDDX & ID & $\mathrm{D}$ & $\mathrm{HS}$ & Hash & $V_{\text {dsh }}$ & $\mathrm{H}$ & Rtn & $d$ & sod & PT & $\mathrm{N}$ & $\mathrm{Nb}$ & $\mathrm{N}$ & $\mathrm{PT}_{\alpha d}$ & $R_{0}$ & $R$ & $\theta_{0}$ & $\theta_{1}$ & $R d R$ & $R / R$ & sxdx & $\rho_{\mathrm{s}}$ & $d_{5}$ & $d \leq 0$ & des & vf \\
\hline 20070655 & $7 / 23 \mathrm{~A} 1$ & 34S_6p1d/rd_ 8 & $337 / 8$ & $s$ & 9 & 4437.4 & $677 / 8$ & 62 & 0.446 & 0.669 & HLP.22 & 12 & 8 & 4 & 1.9 & 10.5 & 5.7 & 30.8 & 16.1 & 0.62 & 0.33 & pld & 2.45 & 0.0001213 & 0.0001780 & 0.0002606 & 0.4277 \\
\hline 20070658 & $7 / 23 \mathrm{~A} 1$ & 34S_6p1dTrd_8 8 & $337 / 8$ & $\mathrm{~s}$ & 9 & 4437.4 & $677 / 8$ & 62 & 0.446 & 0.669 & HLP-22 & 12 & 8 & 4 & 1.9 & 10.5 & 5.7 & 30.8 & 16.1 & 0.62 & 0.33 & pld7 & 2.45 & 0.0001213 & 0.0001780 & 0.0002606 & 0.4277 \\
\hline 20070662 & $7 / 23 \mathrm{~A} 1$ & 34S_6p1dTYd_8 8 & $337 / 8$ & s & 9 & 4437.4 & $677 / 8$ & 62 & 0.446 & 0.669 & HLP-22 & 12 & 8 & 4 & 1.9 & 10.5 & 5.7 & 30.8 & 16.1 & 0.62 & 0.33 & pld7 & 2.45 & 0.0001213 & 0.0001780 & 0.0002606 & 0.4277 \\
\hline 20070668 & $7 / 23 \mathrm{~A} 1$ & 34S_6p1d/rd__8 & $337 / 8$ & $\mathrm{~s}$ & 9 & 4437.4 & $677 / 8$ & 62 & 0.446 & 0.669 & HLP-22 & 12 & 8 & 4 & 1.9 & 10.5 & 5.7 & 30.8 & 16.1 & 0.62 & 0.33 & pld & 2.45 & 0.0001213 & 0.00001780 & 0.0002606 & 0.4277 \\
\hline 20070672 & $7 / 23 \mathrm{~A} 1$ & 34S_6p1dTYd_8 8 & $337 / 8$ & $\mathrm{~s}$ & 9 & 4437.4 & $677 / 8$ & 62 & 0.446 & 0.669 & HLP-22 & 12 & 8 & 4 & 1.9 & 10.5 & 5.7 & 30.8 & 16.1 & 0.62 & 0.33 & pld7 & 2.45 & 0.0001213 & 0.0001780 & 0.0002606 & 0.4277 \\
\hline $20070677 \mathrm{M}$ & $7 / 23 \mathrm{~A} 1$ & 34S_6p1dryd_8 8 & $337 / 8$ & $s$ & 9 & 4437.4 & $677 / 8$ & 62 & 0.446 & 0.669 & HLP.22 & 12 & 8 & 4 & 1.9 & 10.5 & 5.7 & 30.8 & 16.1 & 0.62 & 0.33 & pldr & 2.45 & 0.0001213 & 0.0001780 & 0.0002606 & 0.4277 \\
\hline 20070683 & $7 / 23 \mathrm{~A} 1$ & 34S_6p1dTrd_8 8 & $337 / 8$ & $\mathrm{~s}$ & 9 & 4437.4 & $677 / 8$ & 62 & 0.446 & 0.669 & HLP-22 & 12 & 8 & 4 & 1.9 & 10.5 & 5.7 & 30.8 & 16.1 & 0.62 & 0.33 & pld & 2.45 & 0.0001213 & 0.0001780 & 0.0002606 & 0.4277 \\
\hline $20070686 \mathrm{M}$ & $7 / 23 \mathrm{~A} 1$ & 34s fopldryd 8 & $337 / 8$ & $\mathrm{~s}$ & 9 & 4437.4 & $677 / 8$ & 62 & 0.446 & 0.669 & HLP-22 & 12 & 8 & 4 & 1.9 & 10.5 & 5.7 & 30.8 & 16.1 & 0.62 & 0.33 & pld & 2.45 & 0.0001213 & 0.0001780 & 0.0002606 & 0.4277 \\
\hline $20070690 \mathrm{M}$ & $7 / 23 \mathrm{~A} 1$ & 34S_6p1dTrd_8 & $337 / 8$ & $\mathrm{~s}$ & 9 & 4437.4 & $677 / 8$ & 62 & 0.446 & 0.669 & HLP-22 & 12 & 8 & 4 & 19 & 10.5 & 5.7 & 30.8 & 16.1 & 0.62 & 0.33 & pld7 & 2.45 & 0.0001213 & 0.0001780 & 0.0002606 & 0.4277 \\
\hline $20070695 \mathrm{M}$ & $7 / 23 \mathrm{~A} 1$ & 34S_6p1d/rd_8 8 & $337 / 8$ & $\mathrm{~s}$ & 9 & 4437.4 & $677 / 8$ & 62 & 0.446 & 0.669 & HLP-22 & 12 & 8 & 4 & 1.9 & 10.5 & 5.7 & 30.8 & 16.1 & 0.62 & 0.33 & pld & 2.45 & 0.0001213 & 0.0001780 & 0.0002606 & 0.4277 \\
\hline $20070699 \mathrm{M}$ & $7 / 23 \mathrm{~A} 1$ & 34S_6p1d/rd_8 8 & $337 / 8$ & $\mathrm{~s}$ & 9 & 4437.4 & $677 / 8$ & 62 & 0.446 & 0.669 & HLP-22 & 12 & 8 & 4 & 1.9 & 10.5 & 5.7 & 30.8 & 16.1 & 0.62 & 0.33 & pldr & 2.45 & 0.0001213 & 0.0001780 & 0.0002606 & 0.4277 \\
\hline $20070704 \mathrm{M}$ & $7 / 23 \mathrm{~A} 1$ & 34s_6p1dTrd_8 8 & $337 / 8$ & $s$ & 9 & 4437.4 & $677 / 8$ & 62 & 0.446 & 0.669 & HLP-22 & 12 & 8 & 4 & 1.9 & 10.5 & 5.7 & 30.8 & 16.1 & 0.62 & 0.33 & pld & 2.45 & 0.0001213 & 0.0001780 & 0.0002606 & 0.4277 \\
\hline $20070709 \mathrm{M}$ & $7 / 23 \mathrm{~A} 1$ & 34S_6p1drrd_ 8 & $337 / 8$ & $\mathrm{~s}$ & 9 & 4437.4 & $677 / 8$ & 62 & 0.446 & 0.669 & HLP-22 & 12 & 8 & 4 & 1.9 & 10.5 & 5.7 & 30.8 & 16.1 & 0.62 & 0.33 & pld7 & 2.45 & 0.0001213 & 0.0001780 & 0.0002606 & 0.4277 \\
\hline 20070714 & $7 / 23 \mathrm{~A} 1$ & 345_6p1dr/d 8 & $337 / 8$ & $\mathrm{~s}$ & 9 & 4437.4 & $677 / 8$ & 62 & 0.446 & 0.669 & HLP-22 & 12 & 8 & 4 & 1.9 & 10.5 & 5.7 & 30.8 & 16.1 & 0.62 & 0.33 & p1d7 & 2.45 & 0.0001213 & 0.0001780 & 0.0002606 & 0.4277 \\
\hline 20070718 & $7 / 23 \mathrm{~A} 1$ & 34S_6p1d/rd_8 8 & $337 / 8$ & $\mathrm{~s}$ & 9 & 4437.4 & $677 / 8$ & 62 & 0.446 & 0.669 & HLP-22 & 12 & 8 & 4 & 1.9 & 10.5 & 5.7 & 30.8 & 16.1 & 0.62 & 0.33 & pld7 & 2.45 & 0.0001213 & 0.0001780 & 0.0002606 & 0.4277 \\
\hline 20070724 & $7 / 23 \mathrm{~A}_{1}$ & 34S_6p1d/Yd 8 & $337 / 8$ & $\mathrm{~s}$ & 9 & 4437.4 & $677 / 8$ & 62 & 0.446 & 0.669 & HLP 22 & 12 & 8 & 4 & 19 & 10.5 & 5.7 & 30.8 & 16.1 & 0.62 & 0.33 & pld7 & 2.45 & 0.0001213 & 0.0001780 & 0.0002606 & 0.4277 \\
\hline 20070729 & $7 / 23 \mathrm{~A} 1$ & 34s_6p1dTrd_8 8 & $337 / 8$ & $s$ & 9 & 4437.4 & $677 / 8$ & 62 & 0.446 & 0.669 & HLP.22 & 12 & 8 & 4 & 1.9 & 10.5 & 5.7 & 30.8 & 16.1 & 0.62 & 0.33 & pld & 2.45 & 0.0001213 & 0.0001780 & 0.0002606 & 0.4277 \\
\hline 20070736 & $7 / 23 \mathrm{~A} 1$ & 34S_6p1drrd_ 8 & $337 / 8$ & $\mathrm{~s}$ & 9 & 4437.4 & $677 / 8$ & 62 & 0.446 & 0.669 & HLP -22 & 12 & 8 & 4 & 1.9 & 10.5 & 5.7 & 30.8 & 16.1 & 0.62 & 0.33 & pld7 & 2.45 & 0.0001213 & 0.0001780 & 0.0002606 & $0.42 \pi$ \\
\hline 20070742 & $7 / 23 \mathrm{~A} 1$ & 34S_6p1dTrd 8 & $337 / 8$ & $\mathrm{~s}$ & 9 & 4437.4 & $677 / 8$ & 62 & 0.446 & 0.669 & HLP-22 & 12 & 8 & 4 & 1.9 & 10.5 & 5.7 & 30.8 & 16.1 & 0.62 & 0.33 & p1d7 & 2.45 & 0.0001213 & 0.0001780 & 0.0002606 & 0.4277 \\
\hline 20070747 & $7 / 23 \mathrm{~A} 1$ & 34S_6p1d/rdd_8 & $337 / 8$ & $\mathrm{~s}$ & 9 & 4437.4 & $677 / 8$ & 62 & 0.446 & 0.669 & HLP-22 & 12 & 8 & 4 & 1.9 & 10.5 & 5.7 & 30.8 & 16.1 & 0.62 & 0.33 & pld & 2.45 & 0.0001213 & 0.0001780 & 0.0002606 & 0.4277 \\
\hline $20070750 \mathrm{M}$ & $7 / 23 \mathrm{~A} 1$ & 34 _6p1d/rd_8 8 & $337 / 8$ & $s$ & 9 & 4437.4 & $677 / 8$ & 62 & 0.446 & 0.669 & HLP.22 & 12 & 8 & 4 & 1.9 & 10.5 & 5.7 & 30.8 & 16.1 & 0.62 & 0.33 & pldr & 2.45 & 0.0001213 & 0.0001780 & 0.0002606 & 0.4277 \\
\hline $20070760 \mathrm{M}$ & $7 / 23 \mathrm{~A}_{2}$ & 34S_6p1d/rd_ 2 & $337 / 8$ & $s$ & 9 & 4437.4 & $677 / 8$ & 62 & 0.446 & 0.669 & HLP.22 & 12 & 8 & 4 & 1.9 & 10.5 & 5.7 & 30.8 & 16.1 & 0.62 & 0.33 & pld & 2.45 & 0.0001213 & 0.0001780 & 0.0002606 & 0.4277 \\
\hline 20070765 & $7 / 23 \mathrm{~A}^{2}$ & 34S_6p1drrd_2 2 & $337 / 8$ & $\mathrm{~s}$ & 9 & 4437.4 & $677 / 8$ & 62 & 0.446 & 0.669 & HLP-22 & 12 & 8 & 4 & 1.9 & 10.5 & 5.7 & 30.8 & 16.1 & 0.62 & 0.33 & pldr & 2.45 & 0.0001213 & 0.0001780 & 0.0002606 & $0.42 \pi$ \\
\hline 20070769 & $7 / 23 \mathrm{A2}$ & 34S_6p1dryd 2 & $337 / 8$ & $\mathrm{~s}$ & 9 & 4437.4 & $677 / 8$ & 62 & 0.446 & 0.669 & HLP-22 & 12 & 8 & 4 & 1.9 & 10.5 & 5.7 & 30.8 & 16.1 & 0.62 & 0.33 & p1d7 & 2.45 & 0.0001213 & 0.0001780 & 0.0002606 & $0.42 \pi$ \\
\hline $20070770 \mathrm{M}$ & $7 / 23 \mathrm{~A}_{2}$ & 34S_6p1d/rdd 2 & $337 / 8$ & $\mathrm{~s}$ & 9 & 4437.4 & $677 / 8$ & 62 & 0.446 & 0.669 & HLP-22 & 12 & 8 & 4 & 1.9 & 10.5 & 5.7 & 30.8 & 16.1 & 0.62 & 0.33 & pld & 2.45 & 0.0001213 & 0.0001780 & 0.0002606 & 0.4277 \\
\hline $20070774 \mathrm{M}$ & $7 / 23 \mathrm{~A}^{2}$ & 34S_6pld/rd_2 & $337 / 8$ & $s$ & 9 & 4437.4 & $677 / 8$ & 62 & 0.446 & 0.669 & HLP-22 & 12 & 8 & 4 & 1.9 & 10.5 & 5.7 & 30.8 & 16.1 & 0.62 & 0.33 & p1d7 & 2.45 & 0.0001213 & 0.0001780 & 0.0002606 & 0.4277 \\
\hline $20070778 \mathrm{M}$ & $7 / 23 \mathrm{~A}_{2}$ & 34S_6p1d/rd_ 2 & $337 / 8$ & $s$ & 9 & 4437.4 & $677 / 8$ & 62 & 0.446 & 0.669 & HLP.22 & 12 & 8 & 4 & 1.9 & 10.5 & 5.7 & 30.8 & 16.1 & 0.62 & 0.33 & pld & 2.45 & 0.0001213 & 0.0001780 & 0.0002606 & 0.4277 \\
\hline $20070782 \mathrm{M}$ & $7 / 23 \mathrm{~A}^{2}$ & $34 \mathrm{~S}$ 6p1drrd_2 2 & $337 / 8$ & $\mathrm{~s}$ & 9 & 4437.4 & $677 / 8$ & 62 & 0.446 & 0.669 & HLP-22 & 12 & 8 & 4 & 1.9 & 10.5 & 5.7 & 30.8 & 16.1 & 0.62 & 0.33 & pld7 & 2.45 & 0.0001213 & 0.0001780 & 0.0002606 & $0.42 \pi 7$ \\
\hline $20070787 \mathrm{M}$ & $7 / 23 \mathrm{A2}$ & 34S 6p1dr/d 2 & $337 / 8$ & $\mathrm{~s}$ & 9 & 4437.4 & $677 / 8$ & 62 & 0.446 & 0.669 & HLP-22 & 12 & 8 & 4 & 1.9 & 10.5 & 5.7 & 30.8 & 16.1 & 0.62 & 0.33 & p1d7 & 2.45 & 0.0001213 & 0.0001780 & 0.0002606 & 0.4277 \\
\hline $20070791 \mathrm{M}$ & $7 / 23 \mathrm{~A}_{2}$ & 34S_6p1d/rd_2 & $337 / 8$ & $\mathrm{~s}$ & 9 & 4437.4 & $677 / 8$ & 62 & 0.446 & 0.669 & HLP-22 & 12 & 8 & 4 & 1.9 & 10.5 & 5.7 & 30.8 & 16.1 & 0.62 & 0.33 & p1d7 & 2.45 & 0.0001213 & 0.0001780 & 0.0002606 & 0.4277 \\
\hline 20070794 & $7 / 23 \mathrm{~A}^{2}$ & 34S_6pld/rd_2 & $337 / 8$ & $\mathrm{~s}$ & 9 & 4437.4 & $677 / 8$ & 62 & 0.446 & 0.669 & HLP-22 & 12 & 8 & 4 & 1.9 & 10.5 & 5.7 & 30.8 & 16.1 & 0.62 & 0.33 & pldr & 2.45 & 0.0001213 & 0.0001780 & 0.0002606 & $0.42 \pi$ \\
\hline 20070800 & $7 / 23 A 3$ & 34S_6p1dTrc_2 2 & $337 / 8$ & $s$ & 9 & 4437.4 & $677 / 8$ & 62 & 0.446 & 0.669 & HLP-22 & 12 & 8 & 4 & 1.9 & 10.5 & 5.7 & 30.8 & 16.1 & 0.62 & 0.33 & pld7 & 2.45 & 0.0001213 & 0.0001780 & 0.0002606 & 0.4277 \\
\hline 20070803 & $7 / 23 \mathrm{AB}$ & 34S_6p1d/rc_ 2 & $337 / 8$ & $\mathrm{~s}$ & 9 & 4437.4 & $677 / 8$ & 62 & 0.446 & 0.669 & HLP-22 & 12 & 8 & 4 & 1.9 & 10.5 & 5.7 & 30.8 & 16.1 & 0.62 & 0.33 & pld7 & 2.45 & 0.0001213 & 0.0001780 & 0.0002606 & $0.42 \pi$ \\
\hline $20070807 \mathrm{M}$ & $7 / 23 \mathrm{AB}$ & 34S_6p1dTrc_ 2 & $337 / 8$ & $\mathrm{~s}$ & 9 & 4437.4 & $677 / 8$ & 62 & 0.446 & 0.669 & HLP-22 & 12 & 8 & 4 & 1.9 & 10.5 & 5.7 & 30.8 & 16.1 & 0.62 & 0.33 & pld7 & 2.45 & 0.0001213 & 0.0001780 & 0.0002606 & $0.42 \pi$ \\
\hline $20070812 \mathrm{M}$ & $7 / 23 A 3$ & 345 6p1drYc 2 & $337 / 8$ & $\mathrm{~s}$ & 9 & 4437.4 & $677 / 8$ & 62 & 0.446 & 0.669 & HLP-22 & 12 & 8 & 4 & 1.9 & 10.5 & 5.7 & 30.8 & 16.1 & 0.62 & 0.33 & pld7 & 2.45 & 0.0001213 & 0.0001780 & 0.0002606 & 0.4277 \\
\hline $20070816 \mathrm{M}$ & $7 / 23 \mathrm{AB}$ & 34S_6p1dTrc 2 & $337 / 8$ & $\mathrm{~s}$ & 9 & 4437.4 & $677 / 8$ & 62 & 0.446 & 0.669 & HLP-22 & 12 & 8 & 4 & 1.9 & 10.5 & 5.7 & 30.8 & 16.1 & 0.62 & 0.33 & p1d7 & 2.45 & 0.0001213 & 0.0001780 & 0.0002606 & 0.4277 \\
\hline $20070820 \mathrm{M}$ & $7 / 23 A 3$ & 34S_6p1dTrc_2 2 & $337 / 8$ & $s$ & 9 & 4437.4 & $677 / 8$ & 62 & 0.446 & 0.669 & HLP-22 & 12 & 8 & 4 & 1.9 & 10.5 & 5.7 & 30.8 & 16.1 & 0.62 & 0.33 & pld7 & 2.45 & 0.0001213 & 0.0001780 & 0.0002606 & 0.4277 \\
\hline $20070823 \mathrm{M}$ & $7 / 23 \mathrm{~A}_{3}$ & 34 s gpldrec 2 & $337 / 8$ & $\mathrm{~s}$ & 9 & 4437.4 & $677 / 8$ & 62 & 0.446 & 0.669 & HLP-22 & 12 & 8 & 4 & 1.9 & 10.5 & 5.7 & 30.8 & 16.1 & 0.62 & 0.33 & pld7 & 2.45 & 0.0001213 & 0.0001780 & 0.0002606 & 0.4277 \\
\hline 20070827 & $7 / 23 \mathrm{AB}$ & 34S_6p1d/Yc_ 2 & $337 / 8$ & $\mathrm{~s}$ & 9 & 4437.4 & $677 / 8$ & 62 & 0.446 & 0.669 & HLP-22 & 12 & 8 & 4 & 1.9 & 10.5 & 5.7 & 30.8 & 16.1 & 0.62 & 0.33 & pld7 & 2.45 & 0.0001213 & 0.0001780 & 0.0002606 & $0.42 \pi 7$ \\
\hline 20070033 & $7 / 23 \mathrm{A4}$ & 345 6p1d/rc 3 & $337 / 8$ & $\mathrm{~s}$ & 9 & 4437.4 & $677 / 8$ & 62 & 0.446 & 0.669 & HLP-22 & 12 & 8 & 4 & 1.9 & 10.5 & 5.7 & 30.8 & 16.1 & 0.62 & 0.33 & p1d7 & 2.45 & 0.0001213 & 0.0001780 & 0.0002606 & 0.4277 \\
\hline 20070037 & $7 / 23 \mathrm{~A}$ & $34 \mathrm{~s} 6 \mathrm{p} 1 \mathrm{~d} / \mathrm{Yc} 3$ & $337 / 8$ & $\mathrm{~s}$ & 9 & 4437.4 & $677 / 8$ & 62 & 0.446 & 0.669 & HLP-22 & 12 & 8 & 4 & 1.9 & 10.5 & 5.7 & 30.8 & 16.1 & 0.62 & 0.33 & p1d7 & 2.45 & 0.0001213 & 0.0001780 & 0.0002606 & 0.4277 \\
\hline
\end{tabular}


Table B.7. Data from July 2007 Tests in Mid-Scale Vessel with Spherical Head B.4

\begin{tabular}{|c|c|c|c|c|c|c|c|c|c|c|c|c|c|c|c|c|c|c|c|c|c|c|c|c|c|c|c|c|c|}
\hline $\begin{array}{l}\text { Tank Water } \\
\text { Temperature }\end{array}$ & $\begin{array}{l}\text { Water } \\
\text { Density }\end{array}$ & $\begin{array}{c}\text { Solids } \\
\text { Fraction }\end{array}$ & $\begin{array}{l}\text { Pulse } \\
\text { Volume } \\
\text { Fraction }\end{array}$ & $\begin{array}{l}\text { Duty } \\
\text { Cydle }\end{array}$ & $\begin{array}{l}\text { Cycle } \\
\text { Time }\end{array}$ & $\begin{array}{c}\begin{array}{c}\text { Pulsed } \\
\text { or } \\
\text { Steacy } \\
\text { Jet }\end{array} \\
\end{array}$ & \begin{tabular}{|c} 
Us \\
Steacy \\
Jet
\end{tabular} & $\begin{array}{c}\text { U1 } \\
\text { Pulsing } \\
\text { Jet }\end{array}$ & $\begin{array}{c}\text { U2 } \\
\text { URMS }\end{array}$ & $\begin{array}{c}\text { U3 } \\
\text { URNB }\end{array}$ & $\begin{array}{c}\text { Discharge } \\
\text { Velocity }\end{array}$ & $\begin{array}{c}\text { Cintical } \\
\text { Suspension } \\
\text { Velocity }\end{array}$ & \begin{tabular}{|c|} 
Average \\
Peak \\
Cloud \\
Height \\
\end{tabular} & $\begin{array}{c}\text { UCS } \\
\text { Condition }\end{array}$ & $\begin{array}{c}\text { UCS } \\
\text { Nethod }\end{array}$ & $\begin{array}{l}\text { UCS } \\
\text { Hag }\end{array}$ & $\begin{array}{l}\text { Ues } \\
\text { Center } \\
\text { Hag }\end{array}$ & $\begin{array}{c}\text { Ucs udv } \\
\text { Fag }\end{array}$ & \begin{tabular}{|c} 
UCS based \\
on \\
Decreasing \\
Velocity \\
\end{tabular} & \begin{tabular}{|} 
Isceep \\
Inncrease/ \\
Decrease
\end{tabular} & $\begin{array}{c}\text { UDV } \\
\text { Height } \\
\text { Bed }\end{array}$ & $\begin{array}{l}\text { Partide } \\
\text { Motion } \\
\end{array}$ & $\begin{array}{l}\text { Solids } \\
\text { Level }\end{array}$ & \begin{tabular}{|l} 
Outer \\
Bototom \\
Patem
\end{tabular} & $\begin{array}{l}\text { Inner } \\
\text { Botorom } \\
\text { Patter }\end{array}$ & Case ID & Test & IDP & $\begin{array}{l}\text { Row } \\
\text { Number }\end{array}$ \\
\hline C & $\mathrm{g} / \mathrm{cm}^{3}$ & fraction & fraction & fraction & $s$ & text & m/s & $\mathrm{m} / \mathrm{s}$ & $\mathrm{m} / \mathrm{s}$ & $\mathrm{m} / \mathrm{s}$ & $\mathrm{m} / \mathrm{s}$ & $\mathrm{m} / \mathrm{s}$ & in. & $\mathrm{m} / \mathrm{s}$ & text & text & text & \begin{tabular}{|l|} 
text \\
\end{tabular} & $\mathrm{m} / \mathrm{s}$ & text & $\mathrm{mm}$ & text & text & text & text & text & text & text & text \\
\hline $\mathrm{T}$ & $\rho$ & $\phi_{\mathrm{s}}$ & $\phi_{p}$ & $D C$ & $t_{c}$ & Jet & $U_{\mathrm{s}}$ & $\mathrm{UI}_{1}$ & $\mathrm{U} 2$ & U3 & $u$ & $u_{\text {us }}$ & $H_{\mathrm{c}}$ & $u_{\text {SsR }}$ & $U_{\text {ssm }}$ & Usvis & Usceen & Usuldv & $U_{\text {Cs } D} D$ & $\mathrm{~s}_{\mathrm{w}}$ & $\mathrm{H}_{\text {bed }}$ & $\mathrm{PM}$ & Sol & SPo & $\mathrm{SP}_{\mathrm{I}}$ & ID & MDDX & TDP & MSS \\
\hline NA & NA & 0.00487 & 0.048 & 0.180 & 33.3 & $\mathrm{P}$ & NA & $\mathrm{NA}$ & NA & NA & 3.60 & 4.10 & NA & NA & NA & NA & NA & NA & NA & NA & NA & AMt & NA & NA & $\mathrm{NA}$ & 34S_6pldr/da_ 8 & $7 / 23 \mathrm{~A} 1$ & TDP-WIP-012 & 20070655 \\
\hline NA & NA & 0.00487 & 0.048 & 0.180 & 27.0 & $\mathrm{P}$ & NA & NA & NA & NA & 4.60 & 4.10 & NA & NA & NA & NA & NA & NA & NA & NA & NA & AMt & NA & NA & NA & 34S_6pldr/rd_8 & 7/23A1 & TDP-WIP-012 & 20070662 \\
\hline NA & NA & 0.00487 & 0.048 & 0.180 & 35.7 & $\mathrm{P}$ & NA & NA & NA & NA & 3.50 & 4.10 & NA & NA & NA & NA & NA & NA & NA & NA & NA & AMt & NA & NA & NA & 34S_6p1drrd_8 & 7/23 A1 & TDP-WIP-012 & 20070668 \\
\hline NA & NA & 0.00487 & 0.048 & 0.180 & 30.8 & $\mathrm{P}$ & NA & NA & NA & NA & 4.00 & 4.10 & NA & NA & NA & NA & NA & NA & NA & NA & NA & $A M$ & NA & NA & NA & 34S_6pldrYd 8 & 7/23A1 & TDP-WTP-012 & 20070672 \\
\hline 28.0 & 0.998 & 0.00487 & 0.048 & 0.180 & 29.8 & $\mathrm{P}$ & NA & 3.61 & 3.79 & \begin{tabular}{|l|l|}
3.87 \\
\end{tabular} & 4.10 & 4.10 & 14.63 & NA & NA & ucsis & NA & NA & NA & 1 & NA & cs & NA & NA & NA & 34S_6pldr/d_ 8 & 7/23A1 & TDP-WIP-012 & 2007067 \\
\hline NA & NA & 0.00487 & 0.048 & 0.180 & 29.0 & $\mathrm{P}$ & NA & NA & NA & NA & 4.25 & 4.10 & NA & NA & NA & NA & NA & NA & NA & NA & NA & cs & NA & NA & NA & 34S_6pldr/rd_8 & 7/23A1 & TDP-WIP-012 & 20070683 \\
\hline 28.0 & 0.998 & 0.00487 & 0.048 & 0.180 & 24.5 & $\mathrm{P}$ & NA & 4.23 & 4.49 & 4.61 & 5.00 & 4.10 & 14.63 & NA & NA & NA & NA & NA & NA & NA & NA & NA & NA & NA & NA & 34S_6pldrrd_8 & 7/23A1 & TDP-WTP-012 & 20070690 \\
\hline 28.0 & 0.998 & 0.00487 & 0.048 & 0.180 & 22.5 & $\mathrm{P}$ & NA & 4.49 & 4.83 & 4.99 & 5.50 & 4.10 & 15.13 & NA & NA & NA & NA & NA & NA & NA & NA & NA & NA & NA & NA & 34s_6pldrrd_8 & 7/23 A1 & TDP-WTP-012 & 20070695 \\
\hline 28.0 & 0.998 & 0.00487 & 0.048 & 0.180 & 20.4 & $\mathrm{P}$ & NA & 4.81 & 5.23 & 5.43 & 6.00 & 4.10 & 19.88 & NA & NA & NA & NA & NA & NA & NA & NA & NA & NA & NA & NA & 34S 6p1d/rd_ 8 & $7 / 23 \mathrm{~A} 1$ & TDP-WIP-012 & 20070699 \\
\hline 28.0 & 0.998 & 0.00487 & 0.048 & 0.180 & 19.4 & $\mathrm{P}$ & $\mathrm{NA}$ & 5.15 & 5.63 & 5.87 & 6.50 & 4.10 & 25.63 & NA & NA & NA & NA & NA & NA & NA & $\mathrm{NA}$ & NA & NA & NA & NA & 34S_6pld/rd_ 8 & 7/23A1 & TDP-WIP-012 & 20070704 \\
\hline 28.0 & 0.998 & 0.00487 & 0.048 & 0.180 & 18.2 & $\mathrm{P}$ & NA & 5.39 & 5.95 & 6.22 & 7.00 & 4.10 & 29.63 & NA & NA & NA & NA & NA & NA & NA & NA & NA & NA & NA & NA & 34S_6pldr/d_ _ 8 & 7/23A1 & TDP-WIP-012 & 20070709 \\
\hline 28.0 & 0.998 & 0.00487 & 0.048 & 0.180 & 30.8 & $\mathrm{P}$ & NA & 3.52 & 3.69 & 3.77 & 4.00 & 4.10 & 14.63 & NA & vis dec & UCSis & NA & NA & 4.00 & $\mathrm{D}$ & NA & cs & NA & NA & NA & 345_6pldrrd_8 8 & 7/23A1 & TDP-WIP-012 & 20070714 \\
\hline NA & NA & 0.00487 & 0.048 & 0.180 & 35.7 & $\mathrm{P}$ & NA & NA & NA & NA & 3.50 & 4.10 & 12.63 & NA & NA & NA & NA & NA & NA & NA & NA & AMt & NA & NA & NA & $34 \mathrm{~S} 6 \mathrm{pld} / \mathrm{rd} 8$ & 7/23A1 & TDP-WTP-012 & 20070718 \\
\hline 28.0 & 0.998 & 0.00487 & 0.048 & 0.180 & 37.0 & $P$ & NA & 2.95 & 3.06 & 3.12 & 3.25 & 4.10 & 11.63 & NA & NA & NA & NA & NA & NA & NA & $\mathrm{NA}$ & $A M-$ & NA & NA & NA & 345_6pld/rd_ 8 & 7/23A1 & TDP-WIP-012 & 20070724 \\
\hline 28.0 & 0.998 & 0.00487 & 0.048 & 0.180 & 40.0 & $\mathrm{P}$ & NA & 2.70 & 2.79 & 2.83 & 3.00 & 4.10 & 11.63 & NA & NA & NA & NA & NA & NA & NA & NA & AMt & NA & NA & NA & 34S_6pld/rd_ 8 & 7/23A1 & TDP-WIP-012 & 20070729 \\
\hline 28.0 & 0.998 & 0.00487 & 0.048 & 0.180 & 30.8 & $\mathrm{P}$ & NA & 3.27 & 3.42 & 3.49 & 3.70 & 4.10 & 12.63 & NA & NA & NA & NA & NA & NA & NA & NA & AM+ & NA & NA & NA & 34S_6pldr/rd_8 & 7/23A1 & TDP-WIP-012 & 20070736 \\
\hline 28.0 & 0.998 & 0.00487 & 0.048 & 0.180 & 31.3 & $\mathrm{P}$ & NA & 3.43 & 3.59 & 3.67 & 3.90 & 4.10 & \begin{tabular}{|l|l|}
13.13 \\
\end{tabular} & NA & NA & NA & NA & NA & NA & NA & NA & $A M++$ & NA & NA & NA & 345_6pldTrd_8 8 & 7/23A1 & TDP-WIP-012 & 20070742 \\
\hline 28.0 & 0.998 & 0.00487 & 0.048 & 0.180 & 31.3 & $\mathrm{P}$ & NA & 3.51 & 3.68 & 3.76 & 4.00 & 4.10 & NA & NA & NA & ucsis & NA & NA & NA & 1 & NA & cs- & NA & NA & NA & 34s_6p1drrd_8 & 7/23A1 & TDP-WTP-012 & 20070747 \\
\hline 29.0 & 0.997 & 0.00487 & 0.100 & 0.180 & 82.0 & $\mathrm{P}$ & NA & 2.84 & 2.88 & 2.91 & 3.00 & 3.40 & $\begin{array}{ll}9.63 \\
\end{array}$ & NA & NA & NA & NA & NA & NA & NA & NA & AMt & NA & NA & NA & 34S_6pldr/rd_2 & $7 / 23 \mathrm{~A}_{2}$ & TDP-WIP-012 & 20070765 \\
\hline 29.0 & 0.997 & 0.00487 & 0.100 & 0.180 & 77.0 & $\mathrm{P}$ & NA & 3.12 & 3.18 & 3.21 & 3.30 & 3.40 & 10.13 & 3.30 & NA & ucsis & NA & NA & NA & 1 & NA & CS. & NA & NA & NA & 345_6p1drrd_2 & $7 / 23 \mathrm{Az}$ & TDP-WIP-012 & 20070769 \\
\hline 29.0 & 0.997 & 0.00487 & 0.100 & 0.180 & 72.5 & $P$ & NA & 3.22 & 3.28 & 3.31 & 3.40 & 3.40 & 12.13 & 3.40 & vis & ucsis & NA & NA & NA & 1 & NA & cs & NA & NA & NA & 34S_6pldr/Yd_2 & $7 / 23$ A2 & TDP-WIP-012 & 20070770 \\
\hline 29.0 & 0.997 & 0.00487 & 0.100 & 0.180 & 61.7 & $\mathrm{P}$ & NA & 3.80 & 3.90 & 3.94 & 4.00 & 3.40 & 14.63 & NA & NA & NA & NA & NA & NA & NA & NA & NA & NA & NA & NA & 345_6p1drrd_2 2 & $7 / 23 A_{2}$ & TDP-WIP-012 & 20070774 \\
\hline 29.0 & 0.997 & 0.00487 & 0.100 & 0.180 & 47.6 & $\mathrm{P}$ & NA & 4.56 & 4.72 & 4.80 & 5.00 & 3.40 & 21.13 & NA & NA & NA & NA & NA & NA & NA & NA & NA & NA & NA & NA & 34S_6pldr/d_ 2 2 & $7 / 23 \mathrm{~A}_{2}$ & TDP-WTP-012 & 20070778 \\
\hline 29.0 & 0.997 & 0.00487 & 0.100 & 0.180 & 40.0 & $\mathrm{P}$ & NA & 5.41 & 5.65 & 5.75 & 6.00 & 3.40 & 29.63 & NA & NA & NA & NA & NA & NA & NA & NA & NA & NA & NA & NA & 34S_6pldr/rd_2 & $7 / 23 \mathrm{~A}_{2}$ & TDP-WIP-012 & 20070782 \\
\hline 29.0 & 0.997 & 0.00487 & 0.100 & 0.180 & 66.7 & $\mathrm{P}$ & NA & 3.42 & 3.49 & 3.52 & 3.60 & 3.40 & 12.63 & NA & NA & NA & NA & NA & NA & NA & NA & NA & NA & NA & NA & 34S_6p1drrd_2 & $7 / 23 \mathrm{~A}^{2}$ & TDP-WIP-012 & 20070787 \\
\hline 29.0 & 0.997 & 0.00487 & 0.100 & 0.180 & 71.4 & $\mathrm{P}$ & NA & 3.22 & 3.28 & 3.31 & 3.40 & 3.40 & 11.63 & NA & vis dec & ucsis & NA & NA & 3.40 & D & NA & NA & NA & NA & NA & 34S_6pldrrd 2 & $7 / 23 \mathrm{A2}$ & TDP-WIP-012 & 20070791 \\
\hline 29.0 & 0.997 & 0.00487 & 0.100 & 0.180 & 74.1 & $\mathrm{P}$ & NA & 3.07 & 3.12 & 3.15 & 3.20 & 3.40 & \begin{tabular}{ll|}
11.13 \\
\end{tabular} & NA & vis dec & UCSis & NA & NA & 3.20 & $\mathrm{D}$ & NA & cs & NA & NA & NA & 34S_6pldrrd_2 2 & $7 / 23 A 2$ & TDP-WIP-012 & 20070794 \\
\hline 29.0 & 0.997 & 0.00487 & 0.100 & 0.330 & 41.7 & $\mathrm{P}$ & NA & 3.07 & 3.13 & 3.16 & 3.20 & 3.45 & 10.13 & NA & NA & NA & NA & NA & NA & NA & NA & $A M+$ & NA & NA & NA & 34S_6pldr/rc_2 & $7 / 23 \mathrm{AB}$ & TDP-WIP-012 & 20070800 \\
\hline 29.0 & 0.997 & 0.00487 & 0.100 & 0.330 & 39.1 & $P$ & NA & 3.20 & 3.27 & 3.30 & 3.40 & 3.45 & 11.13 & NA & NA & NA & NA & NA & NA & NA & NA & cs & NA & NA & NA & 34S_6pld/rc_2 2 & $723 A_{3}$ & TDP-WIP-012 & 20070803 \\
\hline 29.0 & 0.997 & 0.00487 & 0.100 & 0.330 & 38.5 & $\mathrm{P}$ & NA & 3.27 & 3.33 & 3.36 & 3.45 & 3.45 & 11.63 & 3.45 & vis & Ucsis & NA & NA & NA & & NA & cs & NA & NA & NA & 345 6plddrc_ 2 & $7 / 23 \mathrm{AB}$ & TDP-WIP-012 & 20070807 \\
\hline 29.0 & 0.997 & 0.00487 & 0.100 & 0.330 & 32.3 & $P$ & NA & 3.50 & 3.58 & 3.62 & 4.00 & 3.45 & 13.63 & NA & NA & NA & NA & NA & NA & NA & NA & NA & NA & NA & NA & 34S_6pldr/rc_2 2 & $7 / 23 A 3$ & TDP-WIP-012 & 20070812 \\
\hline 29.0 & 0.997 & 0.00487 & 0.100 & 0.330 & 26.3 & $\mathrm{P}$ & NA & 4.56 & 4.73 & 4.80 & 5.00 & 3.45 & 22.63 & NA & NA & NA & NA & NA & NA & NA & NA & NA & NA & NA & NA & 34S_6p1dTrc 2 & $7 / 23 A 3$ & TDP-WIP-012 & 20070816 \\
\hline 29.0 & 0.997 & 0.00487 & 0.100 & 0.330 & 22.0 & $\mathrm{P}$ & NA & 5.42 & 5.66 & 5.77 & 6.00 & 3.45 & 32.13 & NA & NA & NA & NA & NA & NA & NA & NA & NA & NA & NA & NA & 34S_6pld/rc_ 2 & $7 / 23 A 3$ & \begin{tabular}{|l|} 
TDP-WIP-012 \\
\end{tabular} & 20070820 \\
\hline 30.0 & 0.997 & 0.00487 & 0.100 & 0.330 & 37.7 & $\mathrm{P}$ & NA & 3.31 & 3.38 & 3.41 & 3.50 & 3.45 & 12.13 & NA & vis dec & Ucsis & NA & NA & 3.50 & $D$ & NA & CSt & NA & NA & NA & 34S_6pld/rc_2 2 & $7 / 23 A 3$ & TDP-WIP-012 & 20070823 \\
\hline 30.0 & 0.997 & 0.00487 & 0.100 & 0.330 & 41.7 & $\mathrm{P}$ & NA & 3.13 & 3.18 & 3.21 & 3.30 & 3.45 & 10.38 & NA & vis dec & UCSis & NA & NA & 3.30 & - & NA & CS & $\mathrm{NA}$ & NA & NA & 345 6pld $/ \mathrm{rc} 2$ & $7 / 23 \mathrm{AB}$ & TDP-WIP-012 & \begin{tabular}{|l|l|}
20070827 \\
\end{tabular} \\
\hline 30.0 & 0.997 & 0.00487 & 0.025 & 0.330 & 11.1 & $\mathrm{P}$ & NA & 2.72 & 2.90 & 2.99 & 3.30 & 4.70 & 10.13 & NA & NA & NA & NA & NA & NA & NA & NA & AM- & NA & NA & NA & 34S_6p1dTrc_3 & 7/23 A4 & TDP-WIP-012 & 20070833 \\
\hline 30.0 & 0.997 & 0.00487 & 0.025 & 0.330 & 10.3 & $\mathrm{P}$ & NA & 2.85 & 3.06 & 3.16 & 3.50 & 4.70 & 11.63 & NA & NA & NA & NA & NA & NA & NA & NA & AM & NA & NA & NA & 345_6p1drrc_3 3 & $7 / 23 \mathrm{~A} 4$ & TDP-WIP-012 & 20070837 \\
\hline
\end{tabular}


Table B.7. Data from July 2007 Tests in Mid-Scale Vessel with Spherical Head A.5

\begin{tabular}{|c|c|c|c|c|c|c|c|c|c|c|c|c|c|c|c|c|c|c|c|c|c|c|c|c|c|c|c|}
\hline Rownumber & Test & Case ID & Tank Diameter & $\begin{array}{l}\text { Head } \\
\text { Shape }\end{array}$ & \begin{tabular}{|c} 
Dish \\
Height
\end{tabular} & $\begin{array}{c}\text { Dish } \\
\text { volume }\end{array}$ & $\begin{array}{c}\text { Tank Fill } \\
\text { Height }\end{array}$ & $\begin{array}{c}\begin{array}{c}\text { Retum Line } \\
\text { Height }\end{array} \\
\end{array}$ & $\begin{array}{c}\text { Nozzle } \\
\text { Inner } \\
\text { Diameter }\end{array}$ & $\begin{array}{c}\text { Nozzle } \\
\text { Stand-of } \\
\text { Distance }\end{array}$ & $\begin{array}{l}\text { Pulse Tube } \\
\text { Configuration } \\
\end{array}$ & $\begin{array}{l}\text { Installed } \\
\text { Nozzles }\end{array}$ & \begin{tabular}{|c} 
Outer Nozzles \\
pperated
\end{tabular} & $\begin{array}{c}\text { Inner } \\
\text { Nozzles } \\
\text { Opperated }\end{array}$ & $\begin{array}{c}\text { Pulse Tube } \\
\text { Outer } \\
\text { Diameter }\end{array}$ & \begin{tabular}{|c|}
$\begin{array}{c}\text { Outer PJMM } \\
\text { Radius }\end{array}$ \\
\end{tabular} & \begin{tabular}{|l|} 
Inner \\
PJM \\
Radius \\
\end{tabular} & \begin{tabular}{|c|} 
"PO" Outer PJM \\
Impingement \\
Angle
\end{tabular} & \begin{tabular}{|c|} 
"FO" Inner \\
PJM \\
Impingement \\
Angle \\
\end{tabular} & $\begin{array}{l}\text { Ratio Outer PJM } \\
\text { to Tank Radius }\end{array}$ & \begin{tabular}{|c|} 
Ratio Inner \\
PJMt to Tank \\
Radius \\
\end{tabular} & Simulant & $\begin{array}{l}\text { Solids } \\
\text { Density } \\
\end{array}$ & \begin{tabular}{|c|} 
Particle \\
Diameter d5
\end{tabular} & $\begin{array}{c}\text { Partide } \\
\text { Diameter a } 50\end{array}$ & $\begin{array}{c}\text { Particle } \\
\text { Diameter } 995\end{array}$ & $\begin{array}{c}\text { Void } \\
\text { Fraction } \\
\end{array}$ \\
\hline text & text & text & in. & text & in. & in. ${ }^{3}$ & in. & \begin{tabular}{|l|} 
in. \\
\end{tabular} & in. & in. & \begin{tabular}{|l} 
text \\
\end{tabular} & number & number & number & in. & in. & \begin{tabular}{|l|} 
in. \\
\end{tabular} & \begin{tabular}{|l|} 
deg \\
\end{tabular} & deg & \begin{tabular}{|l} 
nondim \\
\end{tabular} & nondim & text & $\mathrm{g} / \mathrm{cm}^{3}$ & $\mathrm{~m}$ & $\mathrm{~m}$ & $\mathrm{~m}$ & \begin{tabular}{|l|} 
fraction \\
\end{tabular} \\
\hline MSS & MDDX & ID & $\mathrm{D}$ & HS & $H_{\text {sish }}$ & $V_{\text {dsh }}$ & $\mathrm{H}$ & $\mathrm{Rin}$ & $d$ & sod & PT & $\mathrm{N}$ & $\mathrm{No}$ & $\mathrm{N}$ & $\mathrm{PT}_{\alpha \mathrm{T}}$ & $R_{0}$ & $R$ & $\theta_{0}$ & $\theta_{1}$ & $R d R$ & $R / R$ & $\operatorname{sxdx}$ & $\rho_{\mathrm{s}}$ & $d_{5}$ & $d_{0}$ & $d_{65}$ & vf \\
\hline 20070841 & $7 / 23 \mathrm{AA} 3$ & 34 __6p1dTrc_3 3 & $337 / 8$ & $\mathrm{~s}$ & 9 & 4437.4 & $677 / 8$ & 62 & 0.446 & 0.669 & HLP-22 & 12 & 8 & 4 & 1.9 & 10.5 & 5.7 & 30.8 & 16.1 & 0.62 & 0.33 & p1d7 & 245 & 0.0001213 & 0.0001780 & 0.0002600 & $0.42 \pi 7$ \\
\hline 20070846 & $723 \mathrm{AA} 3$ & 345 _6pldrrc_ 3 & 33718 & $\mathrm{~s}$ & 9 & 4437.4 & $677 / 8$ & 62 & 0.446 & 0.669 & HLP-22 & 12 & 8 & 4 & 1.9 & 10.5 & 5.7 & 30.8 & 16.1 & 0.62 & 0.33 & pld7 & 2.45 & 0.0001213 & 0.0001780 & 0.0002600 & $0.42 \pi 7$ \\
\hline 20070850 & $7 / 23 \mathrm{AA} 3$ & 34S_6p1dTrc 3 & $337 / 8$ & $\mathrm{~s}$ & 9 & 4437.4 & $677 / 8$ & 62 & 0.446 & 0.669 & HLP-22 & 12 & 8 & 4 & 1.9 & 10.5 & 5.7 & 30.8 & 16.1 & 0.62 & 0.33 & p1d7 & 2.45 & 0.0001213 & 0.0001780 & 0.0002600 & $0.42 \pi 7$ \\
\hline 20070855 & $7 / 23 \mathrm{AA} 3$ & $34 \mathrm{~S}$ _6p1drrc_3 3 & 33718 & $\mathrm{~s}$ & 9 & 4437.4 & $677 / 8$ & 62 & 0.446 & 0.669 & HLP-22 & 12 & 8 & 4 & 1.9 & 10.5 & 5.7 & 30.8 & 16.1 & 0.62 & 0.33 & pld7 & 2.45 & 0.0001213 & 0.0001780 & 0.0002600 & $0.42 \pi$ \\
\hline 20070860 & $7 / 23 \mathrm{AA} 3$ & 34S_6p1d/Yc_3 3 & 33718 & $\mathrm{~s}$ & 9 & 4437.4 & $677 / 8$ & 62 & 0.446 & 0.669 & HLP-22 & 12 & 8 & 4 & 1.9 & 10.5 & 5.7 & 30.8 & 16.1 & 0.62 & 0.33 & pld7 & 2.45 & 0.0001213 & 0.0001780 & 0.0002600 & 0.4277 \\
\hline $20070864 \mathrm{M}$ & $723 \mathrm{AA} 3$ & 34S_6pldTrc_3 3 & 33718 & $\mathrm{~s}$ & 9 & 4437.4 & $677 / 8$ & 62 & 0.446 & 0.669 & HLP-22 & 12 & 8 & 4 & 1.9 & 10.5 & 5.7 & 30.8 & 16.1 & 0.62 & 0.33 & pld7 & 2.45 & 0.0001213 & 0.0001780 & 0.0002600 & $0.42 \pi 7$ \\
\hline $20070868 \mathrm{M}$ & $723 \mathrm{AA} 3$ & 345 _6pldrrc_ 3 & $337 / 8$ & $\mathrm{~s}$ & 9 & 4437.4 & $677 / 8$ & 62 & 0.446 & 0.669 & HLP-22 & 12 & 8 & 4 & 1.9 & 10.5 & 5.7 & 30.8 & 16.1 & 0.62 & 0.33 & pld7 & 2.45 & 0.0001213 & $0.000178 \mathrm{~d}$ & 0.0002600 & $0.42 \pi 7$ \\
\hline $20070872 \mathrm{M}$ & $7 / 23 \mathrm{AA} 3$ & 34S_6p1dTrc 3 & $337 / 8$ & $\mathrm{~s}$ & 9 & 4437.4 & $677 / 8$ & 62 & 0.446 & 0.669 & HLP-22 & 12 & 8 & 4 & 1.9 & 10.5 & 5.7 & 30.8 & 16.1 & 0.62 & 0.33 & p1d7 & 2.45 & 0.0001213 & 0.0001780 & 0.0002600 & $0.42 \pi 7$ \\
\hline $20070877 \mathrm{M}$ & $7 / 23 \mathrm{AA} 3$ & 34S_6p1dTrc_3 3 & 33718 & $\mathrm{~s}$ & 9 & 4437.4 & $677 / 8$ & 62 & 0.446 & 0.669 & HLP-22 & 12 & 8 & 4 & 1.9 & 10.5 & 5.7 & 30.8 & 16.1 & 0.62 & 0.33 & pld7 & 2.45 & 0.0001213 & 0.0001780 & 0.0002600 & $0.42 \pi 7$ \\
\hline 20070882M & $7 / 23 \mathrm{~A}_{4} 3$ & 34S_6p1d7Yc_3 3 & $337 / 8$ & $\mathrm{~s}$ & 9 & 4437.4 & $677 / 8$ & 62 & 0.446 & 0.669 & HLP-22 & 12 & 8 & 4 & 1.9 & 10.5 & 5.7 & 30.8 & 16.1 & 0.62 & 0.33 & pld7 & 2.45 & 0.0001213 & 0.0001780 & 0.0002600 & 0.4277 \\
\hline 20070886 & $7 / 23 \mathrm{~A}_{4} 3$ & 34S_6p1d/7r__ 3 & $337 / 8$ & $\mathrm{~s}$ & 9 & 4437.4 & $677 / 8$ & 62 & 0.446 & 0.669 & HLP-22 & 12 & 8 & 4 & 1.9 & 10.5 & 5.7 & 30.8 & 16.1 & 0.62 & 0.33 & pld7 & 2.45 & 0.0001213 & 0.0001780 & 0.0002600 & $0.42 \pi 7$ \\
\hline 20070891 & 723235 & 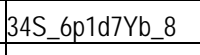 & $337 / 8$ & $\mathrm{~s}$ & 9 & 4437.4 & $677 / 8$ & 62 & 0.446 & 0.669 & HLP-22 & 12 & 8 & 4 & 1.9 & 10.5 & 5.7 & 30.8 & 16.1 & 0.62 & 0.33 & pld7 & 2.45 & 0.0001213 & 0.0001780 & 0.0002600 & $0.42 \pi 7$ \\
\hline 20070896 & $7 / 23 A 53$ & 34S_6p1drrb_8 8 & $337 / 8$ & $\mathrm{~s}$ & 9 & 4437.4 & $677 / 8$ & 62 & 0.446 & 0.669 & HLP-22 & 12 & 8 & 4 & 1.9 & 10.5 & 5.7 & 30.8 & 16.1 & 0.62 & 0.33 & p1d7 & 2.45 & 0.0001213 & 0.0001780 & 0.0002600 & $0.42 \pi 7$ \\
\hline 20070099 & $7 / 23 A 53$ & 34S_6p1drrb_8 8 & 33718 & $\mathrm{~s}$ & 9 & 4437.4 & $677 / 8$ & 62 & 0.446 & 0.669 & HLP-22 & 12 & 8 & 4 & 1.9 & 10.5 & 5.7 & 30.8 & 16.1 & 0.62 & 0.33 & pld7 & 2.45 & 0.0001213 & 0.0001780 & 0.0002600 & $0.42 \pi 7$ \\
\hline $20070904 \mathrm{M}$ & $7 / 23 A 53$ & $34 S_{\text {S6pldrob } 8} 8$ & $337 / 8$ & $\mathrm{~s}$ & 9 & 4437.4 & $677 / 8$ & 62 & 0.446 & 0.669 & HLP-22 & 12 & 8 & 4 & 1.9 & 10.5 & 5.7 & 30.8 & 16.1 & 0.62 & 0.33 & pld7 & 2.45 & 0.0001213 & 0.0001780 & 0.0002600 & 0.4277 \\
\hline $20070909 \mathrm{M}$ & $7 / 23$ A5 3 & 34S_6p1d7/b_8 8 & $337 / 8$ & $\mathrm{~s}$ & 9 & 4437.4 & $677 / 8$ & 62 & 0.446 & 0.669 & HLP-22 & 12 & 8 & 4 & 1.9 & 10.5 & 5.7 & 30.8 & 16.1 & 0.62 & 0.33 & pld7 & 2.45 & 0.0001213 & 0.0001780 & 0.0002600 & 0.4277 \\
\hline $20070912 \mathrm{M}$ & $7 / 23$ A5 3 & 34 _6pldrro 8 & $337 / 8$ & $\mathrm{~s}$ & 9 & 4437.4 & $677 / 8$ & 62 & 0.446 & 0.669 & HLP-22 & 12 & 8 & 4 & 1.9 & 10.5 & 5.7 & 30.8 & 16.1 & 0.62 & 0.33 & pld7 & 2.45 & 0.0001213 & 0.0001780 & 0.0002600 & $0.42 \pi 7$ \\
\hline $20070916 \mathrm{M}$ & $7 / 23 A 53$ & 34S_6p1drrb_8 8 & $337 / 8$ & $\mathrm{~s}$ & 9 & 4437.4 & $677 / 8$ & 62 & 0.446 & 0.669 & HLP-22 & 12 & 8 & 4 & 1.9 & 10.5 & 5.7 & 30.8 & 16.1 & 0.62 & 0.33 & p1d7 & 2.45 & 0.0001213 & 0.0001780 & 0.0002600 & $0.42 \pi 7$ \\
\hline $20070920 \mathrm{M}$ & $7 / 23 A 53$ & 34S_6pldrrb_8 8 & 33718 & $\mathrm{~s}$ & 9 & 4437.4 & $677 / 8$ & 62 & 0.446 & 0.669 & HLP-22 & 12 & 8 & 4 & 1.9 & 10.5 & 5.7 & 30.8 & 16.1 & 0.62 & 0.33 & pld7 & 2.45 & 0.0001213 & 0.0001780 & 0.0002600 & $0.42 \pi 7$ \\
\hline 20070924 & $7123 A 5=$ & 34S_6p1dTrb_8 & $337 / 8$ & $s$ & 9 & 4437.4 & $677 / 8$ & 62 & 0.446 & 0.669 & HLP-22 & 12 & 8 & 4 & 1.9 & 10.5 & 5.7 & 30.8 & 16.1 & 0.62 & 0.33 & pld7 & 2.45 & 0.0001213 & 0.0001780 & 0.0002600 & 0.4277 \\
\hline 20070932 & $7 / 24 \mathrm{~A} 1:=$ & 34S_6p1d7Xa & $337 / 8$ & $\mathrm{~s}$ & 9 & 4437.4 & $677 / 8$ & 62 & 0.446 & 0.669 & HLP-22 & 12 & 8 & 4 & 1.9 & 10.5 & 5.7 & 30.8 & 16.1 & 0.62 & 0.33 & pld7 & 2.45 & 0.0001213 & 0.00001780 & 0.0002600 & $0.42 \pi 7$ \\
\hline 20070935 & $7 / 24 \mathrm{~A} 1:=$ & 34s_6pldr/Xa & $337 / 8$ & $s$ & 9 & 4437.4 & $677 / 8$ & 62 & 0.446 & 0.669 & HLP-22 & 12 & 8 & 4 & 1.9 & 10.5 & 5.7 & 30.8 & 16.1 & 0.62 & 0.33 & p1d7 & 2.45 & 0.0001213 & 0.0001780 & 0.0002600 & $0.42 \pi 7$ \\
\hline 20070936 & $7 / 24 \mathrm{~A} 1=$ & 34s_fpld $\times X_{a}$ & $337 / 8$ & $\mathrm{~s}$ & 9 & 4437.4 & $677 / 8$ & 62 & 0.446 & 0.669 & HLP-22 & 12 & 8 & 4 & 1.9 & 10.5 & 5.7 & 30.8 & 16.1 & 0.62 & 0.33 & p1d7 & 2.45 & 0.0001213 & 0.0001780 & 0.0002600 & $0.42 \pi 7$ \\
\hline 20070938 & $7 / 24 A 1=$ & 345_spldixa & $337 / 8$ & $\mathrm{~s}$ & 9 & 4437.4 & $677 / 8$ & 62 & 0.446 & 0.669 & HLP-22 & 12 & 8 & 4 & 1.9 & 10.5 & 5.7 & 30.8 & 16.1 & 0.62 & 0.33 & pld7 & 2.45 & 0.0001213 & 0.0001780 & 0.0002600 & $0.42 \pi 7$ \\
\hline 20070940 & $7 / 24 \mathrm{~A} 1=$ & 34S_6pldidxa & 33718 & $\mathrm{~s}$ & 9 & 4437.4 & $677 / 8$ & 62 & 0.446 & 0.669 & HLP-22 & 12 & 8 & 4 & 1.9 & 10.5 & 5.7 & 30.8 & 16.1 & 0.62 & 0.33 & pld7 & 2.45 & 0.0001213 & 0.00001780 & 0.0002600 & 0.4277 \\
\hline 20070941 & $7 / 24 \mathrm{~A} 1:=$ & 34s_fplddXa & $337 / 8$ & $s$ & 9 & 4437.4 & $677 / 8$ & 62 & 0.446 & 0.669 & HLP-22 & 12 & 8 & 4 & 1.9 & 10.5 & 5.7 & 30.8 & 16.1 & 0.62 & 0.33 & pld7 & 2.45 & 0.0001213 & 0.00001780 & 0.0002600 & $0.42 \pi 7$ \\
\hline 20070944 & $7 / 24 \mathrm{~A} 1:=$ & 34s_opldr Xa & $337 / 8$ & $s$ & 9 & 4437.4 & $677 / 8$ & 62 & 0.446 & 0.669 & HLP-22 & 12 & 8 & 4 & 1.9 & 10.5 & 5.7 & 30.8 & 16.1 & 0.62 & 0.33 & p1d7 & 2.45 & 0.0001213 & 0.0001780 & 0.0002600 & $0.42 \pi 7$ \\
\hline 20070947 & $7 / 24 \mathrm{A1}=$ & 34s_fopdd $\times x_{a}$ & $337 / 8$ & $\mathrm{~s}$ & 9 & 4437.4 & $677 / 8$ & 62 & 0.446 & 0.669 & HLP-22 & 12 & 8 & 4 & 1.9 & 10.5 & 5.7 & 30.8 & 16.1 & 0.62 & 0.33 & p1d7 & 2.45 & 0.0001213 & 0.0001780 & 0.0002600 & $0.42 \pi$ \\
\hline 20070948 & $7 / 24 A 1=$ & 345_ppldixa & 33718 & $\mathrm{~s}$ & 9 & 4437.4 & $677 / 8$ & 62 & 0.446 & 0.669 & HLP-22 & 12 & 8 & 4 & 1.9 & 10.5 & 5.7 & 30.8 & 16.1 & 0.62 & 0.33 & pldr & 2.45 & 0.0001213 & 0.0001780 & 0.0002600 & $0.42 \pi 7$ \\
\hline 20070951 & $7 / 24 \mathrm{~A} 1=$ & 34S 6ppldixa & $337 / 8$ & $\mathrm{~s}$ & 9 & 4437.4 & $677 / 8$ & 62 & 0.446 & 0.669 & HLP-22 & 12 & 8 & 4 & 1.9 & 10.5 & 5.7 & 30.8 & 16.1 & 0.62 & 0.33 & p1d7 & 2.45 & 0.0001213 & 0.00001780 & 0.0002600 & \\
\hline 20070956 & $7 / 24 \mathrm{~A} 1=$ & 345_fpldd Xa & $337 / 8$ & $s$ & 9 & 4437.4 & $677 / 8$ & 62 & 0.446 & 0.669 & HLP-22 & 12 & 8 & 4 & 1.9 & 10.5 & 5.7 & 30.8 & 16.1 & 0.62 & 0.33 & pld7 & 2.45 & 0.0001213 & 0.0001780 & 0.0002600 & $0.42 \pi 7$ \\
\hline 20070959 & $7 / 24 \mathrm{~A} 1:=$ & 34s_opld $7 \times a$ & $337 / 8$ & $s$ & 9 & 4437.4 & $677 / 8$ & 62 & 0.446 & 0.669 & HLP-22 & 12 & 8 & 4 & 1.9 & 10.5 & 5.7 & 30.8 & 16.1 & 0.62 & 0.33 & p1d7 & 2.45 & 0.0001213 & 0.0001780 & 0.0002600 & $0.427 \pi$ \\
\hline 20070961 & $7 / 24 \mathrm{A1}:=$ & 34S_opldi $\times a$ & $337 / 8$ & $\mathrm{~s}$ & 9 & 4437.4 & $677 / 8$ & 62 & 0.446 & 0.669 & HLP-22 & 12 & 8 & 4 & 1.9 & 10.5 & 5.7 & 30.8 & 16.1 & 0.62 & 0.33 & p1d7 & 2.45 & 0.0001213 & 0.0001780 & 0.0002600 & $0.42 \pi$ \\
\hline 20070964 & $7 / 24 A 1=$ & 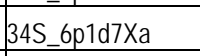 & $337 / 8$ & $\mathrm{~s}$ & 9 & 4437.4 & $677 / 8$ & 62 & 0.446 & 0.669 & HLP-22 & 12 & 8 & 4 & 1.9 & 10.5 & 5.7 & 30.8 & 16.1 & 0.62 & 0.33 & pldr & 2.45 & 0.0001213 & 0.0001780 & 0.0002600 & $0.42 \pi 7$ \\
\hline 20070967 & $7 / 24 \mathrm{~A} 1=$ & 34S_6pldidxa & 33718 & $\mathrm{~s}$ & 9 & 4437.4 & $677 / 8$ & 62 & 0.446 & 0.669 & HLP-22 & 12 & 8 & 4 & 1.9 & 10.5 & 5.7 & 30.8 & 16.1 & 0.62 & 0.33 & pld7 & 2.45 & 0.0001213 & 0.0001780 & 0.0002600 & 0.4277 \\
\hline 20070970 & $7 / 24 \mathrm{~A} 1=$ & 34s_6p1d7Xa & $337 / 8$ & $s$ & 9 & 4437.4 & $677 / 8$ & 62 & 0.446 & 0.669 & HLP-22 & 12 & 8 & 4 & 1.9 & 10.5 & 5.7 & 30.8 & 16.1 & 0.62 & 0.33 & pld7 & 2.45 & 0.0001213 & 0.0001780 & 0.0002600 & 0.4277 \\
\hline 20070974 & $7 / 24 \mathrm{B1}=$ & 34S_6p1d7Xd_8 & $337 / 8$ & $\mathrm{~s}$ & 9 & 4437.4 & $677 / 8$ & 62 & 0.446 & 0.669 & HLP-22 & 12 & 8 & 4 & 1.9 & 10.5 & 5.7 & 30.8 & 16.1 & 0.62 & 0.33 & p1d7 & 2.45 & 0.0001213 & 0.0001780 & 0.0002600 & \\
\hline 2007097 & $7 / 24 \mathrm{~B} 1:=$ & 34S_6p1d7Xd_8 & $337 / 8$ & $\mathrm{~s}$ & 9 & 4437.4 & $677 / 8$ & 62 & 0.446 & 0.669 & HLP-22 & 12 & 8 & 4 & 1.9 & 10.5 & 5.7 & 30.8 & 16.1 & 0.62 & 0.33 & pld7 & 2.45 & 0.0001213 & 0.0001780 & 0.0002600 & 0.4277 \\
\hline 20070979 & $7 / 24 \mathrm{~B} 1=$ & 34S_6p1d7Xd_8 & $337 / 8$ & $\mathrm{~s}$ & 9 & 4437.4 & $677 / 8$ & 62 & 0.446 & 0.669 & HLP-22 & 12 & 8 & 4 & 1.9 & 10.5 & 5.7 & 30.8 & 16.1 & 0.62 & 0.33 & p1d7 & 2.45 & 0.0001213 & 0.0001780 & 0.0002600 & $0.42 \pi 7$ \\
\hline 20070982 & $7 / 24 \mathrm{~B} 1=$ & 34S_6pld7Xd_8 & 33718 & $\mathrm{~s}$ & 9 & 4437.4 & $677 / 8$ & 62 & 0.446 & 0.669 & HLP-22 & 12 & 8 & 4 & 1.9 & 10.5 & 5.7 & 30.8 & 16.1 & 0.62 & 0.33 & pld7 & 2.45 & 0.0001213 & 0.0001780 & 0.0002600 & $0.42 \pi 7$ \\
\hline 20070986 & $7 / 24 \mathrm{~B} 1 \mathrm{:}$ & 34S_6p1d7Xd_8 8 & $337 / 8$ & $s$ & 9 & 4437.4 & $677 / 8$ & 62 & 0.446 & 0.669 & HLP-22 & 12 & 8 & 4 & 1.9 & 10.5 & 5.7 & 30.8 & 16.1 & 0.62 & 0.33 & pld7 & 2.45 & 0.0001213 & 0.0001780 & 0.0002600 & $0.42 \pi 7$ \\
\hline
\end{tabular}


Table B.7. Data from July 2007 Tests in Mid-Scale Vessel with Spherical Head B.5

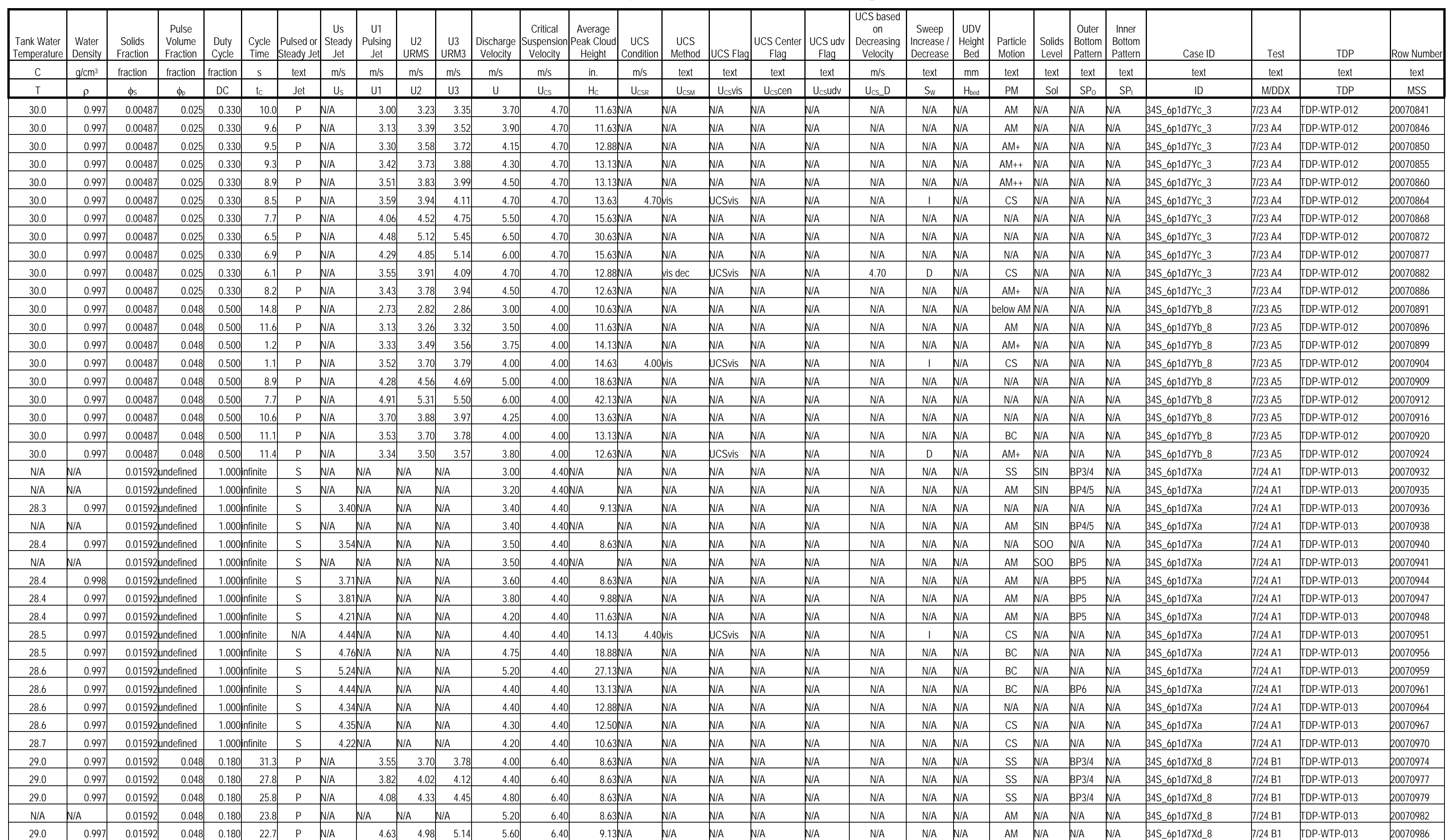


Table B.7. Data from July 2007 Tests in Mid-Scale Vessel with Spherical Head A.6

\begin{tabular}{|c|c|c|c|c|c|c|c|c|c|c|c|c|c|c|c|c|c|c|c|c|c|c|c|c|c|c|c|}
\hline $\begin{array}{c}\text { Row } \\
\text { Number }\end{array}$ & Test & Case ID & $\begin{array}{c}\text { Tank } \\
\text { Diameter }\end{array}$ & $\begin{array}{l}\text { Head } \\
\text { Shape }\end{array}$ & $\begin{array}{l}\text { Dish } \\
\text { Height }\end{array}$ & $\begin{array}{c}\text { Dish } \\
\text { volume }\end{array}$ & $\begin{array}{c}\text { Tank } \\
\text { Fill } \\
\text { Height }\end{array}$ & $\begin{array}{l}\text { Retum } \\
\text { Line } \\
\text { Height }\end{array}$ & $\begin{array}{c}\text { Nozzle } \\
\text { Inner } \\
\text { Dianeter }\end{array}$ & $\begin{array}{c}\text { Nozzle } \\
\text { Stand } \\
\text { of } \\
\text { Distance } \\
\end{array}$ & $\begin{array}{l}\text { Pulse Tube } \\
\text { Configuration }\end{array}$ & \begin{tabular}{|l|} 
Installed \\
Nozzles \\
\end{tabular} & $\begin{array}{c}\text { Outer } \\
\text { Nozles } \\
\text { Operated }\end{array}$ & $\begin{array}{c}\text { Inner } \\
\text { Nozzles } \\
\text { Opperated }\end{array}$ & \begin{tabular}{|c|c} 
Pulse Tube \\
Outur \\
Diameter
\end{tabular} & \begin{tabular}{|c|} 
Outer \\
PJM \\
Radius \\
\end{tabular} & \begin{tabular}{|c|} 
Inner \\
PJM \\
Radius \\
\end{tabular} & \begin{tabular}{|l} 
"FOO" "uter \\
PJMM \\
Impingement \\
Angle
\end{tabular} & \begin{tabular}{|c|} 
"FO' Inner \\
IIMM \\
Impingement \\
Angle
\end{tabular} & $\begin{array}{l}\text { Ratio Outer } \\
\text { PJMto } \\
\text { Tank } \\
\text { Radius } \\
\end{array}$ & $\begin{array}{l}\text { Radioi Inner } \\
\text { PJMto } \\
\text { Tank } \\
\text { Radius } \\
\end{array}$ & Simulant & \begin{tabular}{|l|} 
Solids \\
Density \\
\end{tabular} & $\begin{array}{c}\text { Particle } \\
\text { Diameter d5 }\end{array}$ & $\begin{array}{c}\text { Particle } \\
\text { Diameter } \\
\text { d50 }\end{array}$ & $\begin{array}{l}\text { Particle } \\
\text { Dianeter } \\
\text { d95 }\end{array}$ & $\begin{array}{c}\text { Void } \\
\text { Fraction }\end{array}$ \\
\hline text & text & text & in. & text & in. & in. ${ }^{3}$ & in. & in. & in. & in. & text & \begin{tabular}{|l|} 
number \\
\end{tabular} & number & number & in. & in. & in. & deg & deg & nondim & nondim & text & $\mathrm{g} / \mathrm{cm}^{3}$ & $\mathrm{~m}$ & $\mathrm{~m}$ & $\mathrm{~m}$ & fraction \\
\hline MSS & MDDX & ID & D & HS & Hesh & $V_{\text {dash }}$ & $\mathrm{H}$ & Rtn & $d$ & sod & PT & $\mathrm{N}$ & $N_{b}$ & $\mathrm{~N}$ & $\mathrm{PT}_{\mathrm{od}}$ & $R_{0}$ & $R_{1}$ & $\theta_{0}$ & $\theta_{1}$ & $R d R$ & $\mathrm{R} / \mathrm{R}$ & $\operatorname{sxdx}$ & $\rho_{\mathrm{s}}$ & $d_{5}$ & $\mathrm{~d}_{0}$ & $d_{65}$ & uf \\
\hline 20070999 & $7 / 24 \mathrm{~B} 1$ & 34S_6p1d7Xd 88 & $337 / 8$ & $\mathrm{~s}$ & 9 & 4437.4 & $677 / 8$ & 62 & 0.446 & 0.669 & HLP-22 & 12 & 8 & 4 & 1.9 & 10.5 & 5.7 & 30.8 & 16.1 & 0.62 & 0.33 & p1d7 & 2.45 & 0.0001213 & 0.0001780 & 0.0002606 & 0.4277 \\
\hline 20070993 & $7 / 24 \mathrm{B1}$ & 34S_6p1d $7 \times d \_8$ & $337 / 8$ & $\mathrm{~s}$ & 9 & 4437.4 & $677 / 8$ & 62 & 0.446 & 0.669 & HLP-22 & 12 & 8 & 4 & 19 & 10.5 & 5.7 & 30.8 & 16.1 & 0.62 & 0.33 & p1d7 & 2.45 & 0.0001213 & 0.0001780 & 0.0002606 & 0.4277 \\
\hline 20070995M & $7 / 24 \mathrm{B1}$ & 34s_6p1d7Xd_8 & $337 / 8$ & $s$ & 9 & 4437.4 & $677 / 8$ & 62 & 0.446 & 0.669 & HLP-22 & 12 & 8 & 4 & 19 & 10.5 & 5.7 & 30.8 & 16.1 & 0.62 & 0.33 & pld 7 & 2.45 & 0.0001213 & 0.0001780 & 0.0002606 & 0.427 \\
\hline $20070998 \mathrm{M}$ & $7 / 24 \mathrm{~B} 1$ & 34s_6p1d7Xd_8 & $337 / 8$ & $\mathrm{~s}$ & 9 & 4437.4 & $677 / 8$ & 62 & 0.446 & 0.669 & HLP-22 & 12 & 8 & 4 & 19 & 10.5 & 5.7 & 30.8 & 16.1 & 0.62 & 0.33 & p1d7 & 2.45 & 0.0001213 & 0.0001780 & 0.0002606 & 0.4277 \\
\hline $20071001 \mathrm{M}$ & $7 / 24 \mathrm{~B} 1$ & 34s_6p1d7Xd_8 & $337 / 8$ & $\mathrm{~s}$ & 9 & 4437.4 & $677 / 8$ & 62 & 0.446 & 0.669 & HLP-22 & 12 & 8 & 4 & 19 & 10.5 & 5.7 & 30.8 & 16.1 & 0.62 & 0.33 & p1d7 & 2.45 & 0.0001213 & 0.0001780 & 0.0002606 & 0.4277 \\
\hline $20071005 \mathrm{M}$ & $7 / 24 \mathrm{~B} 1$ & 345_6p1d7Xd_8 8 & $337 / 8$ & $\mathrm{~s}$ & 9 & 4437.4 & $677 / 8$ & 62 & 0.446 & 0.669 & HLP-22 & 12 & 8 & 4 & 19 & 10.5 & 5.7 & 30.8 & 16.1 & 0.62 & 0.33 & p1d7 & 2.45 & 0.0001213 & 0.0001780 & 0.0002606 & $0.42 \pi$ \\
\hline $20071010 \mathrm{M}$ & $7 / 24 \mathrm{~B} 1$ & 34S_6p1d7Xd_8 8 & $337 / 8$ & $\mathrm{~s}$ & 9 & 4437.4 & $677 / 8$ & 62 & 0.446 & 0.669 & HLP-22 & 12 & 8 & 4 & 19 & 10.5 & 5.7 & 30.8 & 16.1 & 0.62 & 0.33 & p1d7 & 2.45 & 0.0001213 & 0.0001780 & 0.0002606 & 0.427 \\
\hline 20071014M & $7 / 24 \mathrm{~B} 1$ & 34s_6p1d7Xd_8 & $337 / 8$ & $\mathrm{~s}$ & 9 & 4437.4 & $677 / 8$ & 62 & 0.446 & 0.669 & HLP-22 & 12 & 8 & 4 & 19 & 10.5 & 5.7 & 30.8 & 16.1 & 0.62 & 0.33 & pld7 & 2.45 & 0.0001213 & 0.0001780 & 0.0002606 & 0.427 \\
\hline $20071016 \mathrm{M}$ & $7 / 24 \mathrm{~B} 1$ & 34s_6p1d7Xd_8 & $337 / 8$ & $\mathrm{~s}$ & 9 & 4437.4 & $677 / 8$ & 62 & 0.446 & 0.669 & HLP-22 & 12 & 8 & 4 & 19 & 10.5 & 5.7 & 30.8 & 16.1 & 0.62 & 0.33 & p1d7 & 2.45 & 0.0001213 & 0.0001780 & 0.0002606 & 0.4277 \\
\hline $20071020 \mathrm{M}$ & $7 / 24 \mathrm{~B} 1$ & 34s_6p1d7Xd_8 & $337 / 8$ & $\mathrm{~s}$ & 9 & 4437.4 & $677 / 8$ & 62 & 0.446 & 0.669 & HLP-22 & 12 & 8 & 4 & 19 & 10.5 & 5.7 & 30.8 & 16.1 & 0.62 & 0.33 & pld7 & 2.45 & 0.0001213 & 0.0001780 & 0.0002606 & 0.427 \\
\hline $20071025 \mathrm{M}$ & $7 / 24 \mathrm{~B} 1$ & 345_6p1d7Xd_8 8 & $337 / 8$ & $\mathrm{~s}$ & 9 & 4437.4 & $677 / 8$ & 62 & 0.446 & 0.669 & HLP-22 & 12 & 8 & 4 & 19 & 10.5 & 5.7 & 30.8 & 16.1 & 0.62 & 0.33 & p1d7 & 2.45 & 0.0001213 & 0.0001780 & 0.0002606 & 0.4277 \\
\hline $20071028 \mathrm{M}$ & $7 / 24 \mathrm{~B} 1$ & 34S_6p1d $7 \times d \_8$ & $337 / 8$ & $\mathrm{~s}$ & 9 & 4437.4 & $677 / 8$ & 62 & 0.446 & 0.669 & HLP-22 & 12 & 8 & 4 & 19 & 10.5 & 5.7 & 30.8 & 16.1 & 0.62 & 0.33 & p1d7 & 2.45 & 0.0001213 & 0.0001780 & 0.0002606 & 0.4277 \\
\hline 20071032M & $7 / 24 \mathrm{~B} 1$ & 34s_6p1d7Xd_8 & $337 / 8$ & $\mathrm{~s}$ & 9 & 4437.4 & $677 / 8$ & 62 & 0.446 & 0.669 & HLP-22 & 12 & 8 & 4 & 19 & 10.5 & 5.7 & 30.8 & 16.1 & 0.62 & 0.33 & p1d7 & 2.45 & 0.0001213 & 0.0001780 & 0.0002606 & 0.4277 \\
\hline $20071036 \mathrm{M}$ & $7 / 24 \mathrm{~B} 1$ & 34s_6p1d7Xd_8 & $337 / 8$ & $\mathrm{~s}$ & 9 & 4437.4 & $677 / 8$ & 62 & 0.446 & 0.669 & HLP-22 & 12 & 8 & 4 & 19 & 10.5 & 5.7 & 30.8 & 16.1 & 0.62 & 0.33 & p1d7 & 2.45 & 0.0001213 & 0.0001780 & 0.0002606 & $0.42 \pi$ \\
\hline 20071038 & $7 / 24 \mathrm{~B} 1$ & 34S_6p1d7Xd_8 & $337 / 8$ & $\mathrm{~s}$ & 9 & 4437.4 & $677 / 8$ & 62 & 0.446 & 0.669 & HLP -22 & 12 & 8 & 4 & 19 & 10.5 & 5.7 & 30.8 & 16.1 & 0.62 & 0.33 & p1d7 & 2.45 & 0.0001213 & 0.0001780 & 0.0002606 & 0.4277 \\
\hline $20071042 \mathrm{M}$ & $7 / 24 \mathrm{~B} 1$ & 34S_6p1d7Xd_8 8 & $337 / 8$ & $\mathrm{~s}$ & 9 & 4437.4 & $677 / 8$ & 62 & 0.446 & 0.669 & HLP-22 & 12 & 8 & 4 & 19 & 10.5 & 5.7 & 30.8 & 16.1 & 0.62 & 0.33 & p1d7 & 2.45 & 0.0001213 & 0.0001780 & 0.0002606 & 0.4277 \\
\hline 20071067 & $7 / 24 \mathrm{B1}$ & 34S_6p1d $7 \times d \_8$ & $337 / 8$ & $\mathrm{~s}$ & 9 & 4437.4 & $677 / 8$ & 62 & 0.446 & 0.669 & HLP-22 & 12 & 8 & 4 & 19 & 10.5 & 5.7 & 30.8 & 16.1 & 0.62 & 0.33 & p1d7 & 2.45 & 0.0001213 & 0.0001780 & 0.0002606 & 0.4277 \\
\hline $20071070 \mathrm{M}$ & $7 / 24 \mathrm{B1}$ & 34S_6p1d7Xd_8 8 & $337 / 8$ & $\mathrm{~s}$ & 9 & 4437.4 & $677 / 8$ & 62 & 0.446 & 0.669 & HLP-22 & 12 & 8 & 4 & 19 & 10.5 & 5.7 & 30.8 & 16.1 & 0.62 & 0.33 & p1d7 & 2.45 & 0.0001213 & 0.0001780 & 0.0002606 & 0.427 \\
\hline 20071074 & $7 / 25 \mathrm{Al}_{1}$ & 34S_6p2dGYa & $337 / 8$ & $\mathrm{~s}$ & 9 & 4437.4 & $681 / 8$ & 62 & 0.446 & 0.669 & HLP - 22 & 12 & 8 & 4 & 19 & 10.5 & 5.7 & 30.8 & 16.1 & 0.62 & 0.33 & $\mathrm{p} 2 \mathrm{~d} 6$ & 2.46 & 0.0005184 & 0.0007662 & 0.0011729 & 0.4080 \\
\hline 20071075 & $7 / 25 A_{1}$ & 345_6p2d6ra & $337 / 8$ & $\mathrm{~s}$ & 9 & 4437.4 & $68 \mathrm{y} / 8$ & 62 & 0.446 & 0.669 & HLP-22 & 12 & 8 & 4 & 19 & 10.5 & 5.7 & 30.8 & 16.1 & 0.62 & 0.33 & p2d6 & 2.46 & 0.0005184 & 0.0007662 & 0.0011729 & 0.4080 \\
\hline 20071076 & $7 / 25 \mathrm{~A}_{1}$ & $345.6 p 2 d 6 Y a$ & $337 / 8$ & $\mathrm{~s}$ & 9 & 4437.4 & $681 / 8$ & 62 & 0.446 & 0.669 & HLP-22 & 12 & 8 & 4 & 19 & 10.5 & 5.7 & 30.8 & 16.1 & 0.62 & 0.33 & p2d6 & 2.46 & 0.0005184 & 0.0007662 & 0.0011729 & 0.4080 \\
\hline 20071080 & $7 / 25 \mathrm{~A} 1$ & 345_6p2dora & $337 / 8$ & $\mathrm{~s}$ & 9 & 4437.4 & $681 / 8$ & 62 & 0.446 & 0.669 & HLP-22 & 12 & 8 & 4 & 19 & 10.5 & 5.7 & 30.8 & 16.1 & 0.62 & 0.33 & p2d6 & 2.46 & 0.0005184 & 0.0007662 & 0.0011729 & 0.4080 \\
\hline 20071085 & $7 / 25 \mathrm{~A} 1$ & 345_6p2016Ya & $337 / 8$ & $s$ & 9 & 4437.4 & $68 \mathrm{y} / 8$ & 62 & 0.446 & 0.669 & HLP-22 & 12 & 8 & 4 & 19 & 10.5 & 5.7 & 30.8 & 16.1 & 0.62 & 0.33 & p2d6 & 2.46 & 0.0005184 & 0.0007662 & 0.0011729 & 0.4080 \\
\hline 20071088 & $7 / 25 \mathrm{~A}_{1}$ & 345_6p2d6YYa & $337 / 8$ & $\mathrm{~s}$ & 9 & 4437.4 & $681 / 8$ & 62 & 0.446 & 0.669 & HLP-22 & 12 & 8 & 4 & 19 & 10.5 & 5.7 & 30.8 & 16.1 & 0.62 & 0.33 & $\mathrm{p} 2 \mathrm{~d} 6$ & 2.46 & 0.0005184 & 0.0007662 & 0.0011729 & 0.4080 \\
\hline 20071092 & $7 / 25 \mathrm{~A}_{1}$ & 345_6p2d6ra & $337 / 8$ & $\mathrm{~s}$ & 9 & 4437.4 & $681 / 8$ & 62 & 0.446 & 0.669 & HLP -22 & 12 & 8 & 4 & 19 & 10.5 & 5.7 & 30.8 & 16.1 & 0.62 & 0.33 & p2d6 & 2.46 & 0.0005184 & 0.0007662 & 0.0011729 & 0.4080 \\
\hline 20071095 & $7 / 25 \mathrm{~A} 1$ & 345 6p2016Ya & $337 / 8$ & $\mathrm{~s}$ & 9 & 4437.4 & $681 / 8$ & 62 & 0.446 & 0.669 & HLP-22 & 12 & 8 & 4 & 19 & 10.5 & 5.7 & 30.8 & 16.1 & 0.62 & 0.33 & $\mathrm{p} 2 \mathrm{~d} 6$ & 2.46 & 0.0005184 & 0.0007662 & 0.0011729 & 0.4080 \\
\hline 20071101 & $7 / 25 \mathrm{~A} 1$ & 345_6p206ra & $337 / 8$ & $\mathrm{~s}$ & 9 & 4437.4 & $681 / 8$ & 62 & 0.446 & 0.669 & HLP-22 & 12 & 8 & 4 & 19 & 10.5 & 5.7 & 30.8 & 16.1 & 0.62 & 0.33 & p2d6 & 2.46 & 0.0005184 & 0.0007662 & 0.0011729 & 0.4080 \\
\hline 20071104 & $7 / 25 \mathrm{~A} 1$ & 345_6p2067\% & $337 / 8$ & $\mathrm{~s}$ & 9 & 4437.4 & $681 / 8$ & 62 & 0.446 & 0.669 & HLP-22 & 12 & 8 & 4 & 19 & 10.5 & 5.7 & 30.8 & 16.1 & 0.62 & 0.33 & p2d6 & 2.46 & 0.0005184 & 0.0007662 & 0.0011729 & 0.4080 \\
\hline 20071108 & $7 / 25 \mathrm{~A}_{1}$ & 345_6p2d6YYa & $337 / 8$ & $\mathrm{~s}$ & 9 & 4437.4 & $681 / 8$ & 62 & 0.446 & 0.669 & HLP-22 & 12 & 8 & 4 & 19 & 10.5 & 5.7 & 30.8 & 16.1 & 0.62 & 0.33 & $\mathrm{p} 2 \mathrm{~d} 6$ & 2.46 & 0.0005184 & 0.0007662 & 0.0011729 & 0.4080 \\
\hline 20071112 & $7 / 25 \mathrm{~A}_{1}$ & 345 .pp2d6YYa & $337 / 8$ & $\mathrm{~s}$ & 9 & 4437.4 & $681 / 8$ & 62 & 0.446 & 0.669 & HLP-22 & 12 & 8 & 4 & 19 & 10.5 & 5.7 & 30.8 & 16.1 & 0.62 & 0.33 & $\mathrm{p} 2 \mathrm{~d} 6$ & 2.46 & 0.0005184 & 0.0007662 & 0.0011729 & 0.4080 \\
\hline 200711115 & $7 / 25 \mathrm{~A} 1$ & $345.6 p 2016 Y a$ & $337 / 8$ & $\mathrm{~s}$ & 9 & 4437.4 & $681 / 8$ & 62 & 0.446 & 0.669 & HLP-22 & 12 & 8 & 4 & 19 & 10.5 & 5.7 & 30.8 & 16.1 & 0.62 & 0.33 & p2d6 & 2.46 & 0.0005184 & 0.0007662 & 0.0011729 & 0.4080 \\
\hline 20071121 & $7 / 25 \mathrm{~A} 1$ & 345_6p206ra & $337 / 8$ & $\mathrm{~s}$ & 9 & 4437.4 & $681 / 8$ & 62 & 0.446 & 0.669 & HLP-22 & 12 & 8 & 4 & 19 & 10.5 & 5.7 & 30.8 & 16.1 & 0.62 & 0.33 & $\mathrm{p} 2 \mathrm{~d} 6$ & 2.46 & 0.0005184 & 0.0007662 & 0.0011729 & 0.4080 \\
\hline 20071123 & $7 / 25 \mathrm{~A} 1$ & 345_6p2067\% & $337 / 8$ & $\mathrm{~s}$ & 9 & 4437.4 & $681 / 8$ & 62 & 0.446 & 0.669 & HLP-22 & 12 & 8 & 4 & 1.9 & 10.5 & 5.7 & 30.8 & 16.1 & 0.62 & 0.33 & $\mathrm{p} 2 \mathrm{~d} 6$ & 2.46 & 0.0005184 & 0.0007662 & 0.0011729 & 0.4080 \\
\hline 20071129 & $7 / 25 \mathrm{~A} 1$ & 345 6p2016Ya & $337 / 8$ & $\mathrm{~s}$ & 9 & 4437.4 & $681 / 8$ & 62 & 0.446 & 0.669 & HLP-22 & 12 & 8 & 4 & 19 & 10.5 & 5.7 & 30.8 & 16.1 & 0.62 & 0.33 & $\mathrm{p} 2 \mathrm{~d} 6$ & 2.46 & 0.0005184 & 0.0007662 & 0.0011729 & 0.4080 \\
\hline 20071133 & $7 / 25 \mathrm{~A}_{1}$ & 34s_6p2d6Ya & $337 / 8$ & $\mathrm{~s}$ & 9 & 4437.4 & $68 \mathrm{y} / 8$ & 62 & 0.446 & 0.669 & HLP -22 & 12 & 8 & 4 & 19 & 10.5 & 5.7 & 30.8 & 16.1 & 0.62 & 0.33 & $\mathrm{p} 2 \mathrm{~d} 6$ & 2.46 & 0.0005184 & 0.0007662 & 0.0011729 & 0.4080 \\
\hline 20071139 & $7 / 25 \mathrm{~B} 1$ & $34 \mathrm{~S} \_602 \mathrm{~d} 6 \mathrm{Yd} \_8$ & $337 / 8$ & $\mathrm{~s}$ & 9 & 4437.4 & $68 \mathrm{I} / 8$ & 62 & 0.446 & 0.669 & HLP -22 & 12 & 8 & 4 & 19 & 10.5 & 5.7 & 30.8 & 16.1 & 0.62 & 0.33 & $\mathrm{p} 2 \mathrm{~d} 6$ & 2.46 & 0.0005184 & 0.0007662 & 0.0011729 & 0.4080 \\
\hline 20071142 & $7 / 25 \mathrm{~B} 1$ & 34S_6p2d6Yd_ 8 & $337 / 8$ & $\mathrm{~s}$ & 9 & 4437.4 & $681 / 8$ & 62 & 0.446 & 0.669 & HLP-22 & 12 & 8 & 4 & 19 & 10.5 & 5.7 & 30.8 & 16.1 & 0.62 & 0.33 & $\mathrm{p} 2 \mathrm{~d} 6$ & 2.46 & 0.0005184 & 0.0007662 & 0.0011729 & 0.4080 \\
\hline 20071143 & $7 / 25 \mathrm{~B} 1$ & 34S_6p2d6Yd_8 8 & $337 / 8$ & $\mathrm{~s}$ & 9 & 4437.4 & $681 / 8$ & 62 & 0.446 & 0.669 & HLP-22 & 12 & 8 & 4 & 19 & 10.5 & 5.7 & 30.8 & 16.1 & 0.62 & 0.33 & $\mathrm{p} 2 \mathrm{~d} 6$ & 2.46 & 0.0005184 & 0.0007662 & 0.0011729 & 0.4080 \\
\hline 20071146 & $7 / 25 \mathrm{~B} 1$ & $34 \mathrm{~S} 6 \mathrm{pp} 2 \mathrm{~d} 6 \mathrm{Yd} \_8$ & $337 / 8$ & $\mathrm{~s}$ & 9 & 4437.4 & $681 / 8$ & 62 & 0.446 & 0.669 & HLP-22 & 12 & 8 & 4 & 1.9 & 10.5 & 5.7 & 30.8 & 16.1 & 0.62 & 0.33 & $\mathrm{p} 2 \mathrm{~d} 6$ & 2.46 & 0.0005184 & 0.0007662 & 0.0011729 & 0.4080 \\
\hline 20071148 & $7 / 25 \mathrm{~B} 1$ & 34s_6p2d6Yd_8 & $337 / 8$ & $\mathrm{~s}$ & 9 & 4437.4 & $681 / 8$ & 62 & 0.446 & 0.669 & HLP-22 & 12 & 8 & 4 & 19 & 10.5 & 5.7 & 30.8 & 16.1 & 0.62 & 0.33 & $\mathrm{p} 2 \mathrm{~d} 6$ & 2.46 & & 0.0007662 & 0.0011729 & 0.4080 \\
\hline $20071150 \mathrm{M}$ & $725 \mathrm{B1}$ & 34s_6p2d6Yd_8 & $337 / 8$ & $\mathrm{~s}$ & 9 & 4437.4 & $681 / 8$ & 62 & 0.446 & 0.669 & HLP - 22 & 12 & 8 & 4 & 1.9 & 10.5 & 5.7 & 30.8 & 16.1 & 0.62 & 0.33 & $\mathrm{p} 2 \mathrm{~d} 6$ & 2.46 & 0.0005184 & 0.0007662 & 0.0011729 & 0.4080 \\
\hline
\end{tabular}


Table B.7. Data from July 2007 Tests in Mid-Scale Vessel with Spherical Head B.6

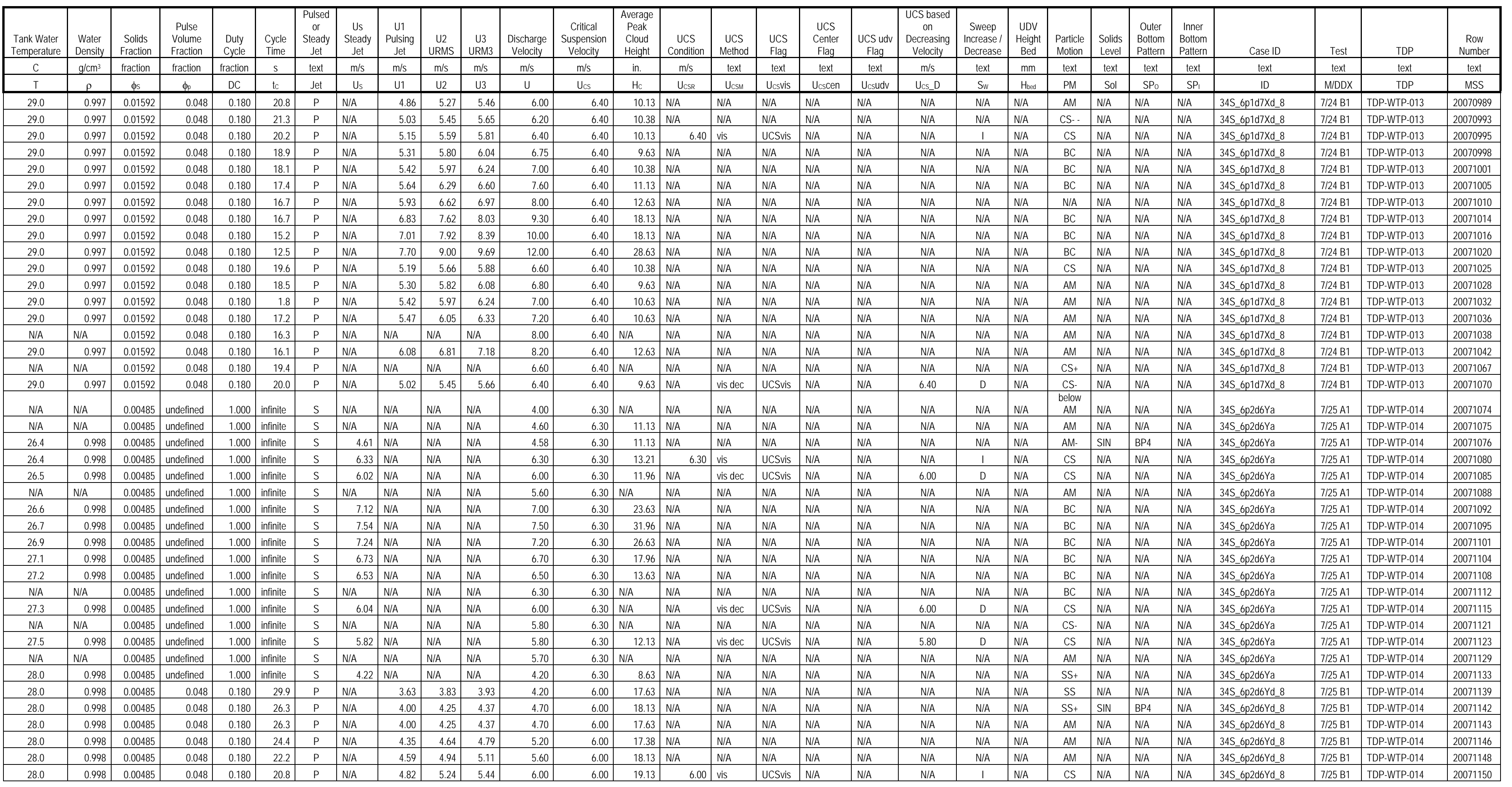


Table B.7. Data from July 2007 Tests in Mid-Scale Vessel with Spherical Head A.7

\begin{tabular}{|c|c|c|c|c|c|c|c|c|c|c|c|c|c|c|c|c|c|c|c|c|c|c|c|c|c|c|c|}
\hline $\begin{array}{c}\text { Row } \\
\text { Number }\end{array}$ & Test & Case ID & \begin{tabular}{c|} 
Tank \\
Diameter
\end{tabular} & $\begin{array}{l}\text { Head } \\
\text { Shape }\end{array}$ & $\begin{array}{l}\text { Dish } \\
\text { Height }\end{array}$ & $\begin{array}{c}\text { Dish } \\
\text { Volume } \\
\end{array}$ & $\begin{array}{l}\text { Tank } \\
\text { Fill } \\
\text { Height }\end{array}$ & $\begin{array}{l}\text { Retum } \\
\text { Line } \\
\text { Height }\end{array}$ & $\begin{array}{l}\text { Nozzle } \\
\text { Inner } \\
\text { Diameter }\end{array}$ & \begin{tabular}{c|}
$\begin{array}{c}\text { Nozzle } \\
\text { Stand- } \\
\text { off } \\
\text { Distance }\end{array}$ \\
\end{tabular} & $\begin{array}{l}\text { Pulse Tube } \\
\text { Configuration }\end{array}$ & $\begin{array}{l}\text { Installed } \\
\text { Nozzles } \\
\text { Nates }\end{array}$ & $\begin{array}{c}\text { Outer } \\
\text { Nozzles } \\
\text { Operated }\end{array}$ & $\begin{array}{c}\text { Inner } \\
\text { Nozzles } \\
\text { Operated }\end{array}$ & $\begin{array}{c}\text { Pulse Tube } \\
\text { Outer } \\
\text { Diameter }\end{array}$ & $\begin{array}{c}\text { Outer } \\
\text { PMM } \\
\text { Radius } \\
\end{array}$ & $\begin{array}{c}\text { Inner } \\
\text { PJM } \\
\text { Radius } \\
\end{array}$ & $\begin{array}{l}\text { "FO" Outer } \\
\text { PJM } \\
\text { Imingement } \\
\text { Angle }\end{array}$ & $\begin{array}{c}\text { "FO" Inner } \\
\text { PJM } \\
\text { Impigement } \\
\text { Angle } \\
\end{array}$ & $\begin{array}{c}\text { Ratio Outer } \\
\text { PJM to } \\
\text { Tank } \\
\text { Radius } \\
\end{array}$ & $\begin{array}{c}\text { Ratio Inner } \\
\text { PJM to } \\
\text { Tank } \\
\text { Radius } \\
\end{array}$ & Simulant & $\begin{array}{l}\text { Solids } \\
\text { Density }\end{array}$ & $\begin{array}{c}\text { Paticle } \\
\text { Diameter d5 }\end{array}$ & $\begin{array}{c}\text { Particle } \\
\text { Diamter } \\
\text { d50 }\end{array}$ & $\begin{array}{c}\text { Particle } \\
\text { Diameter } \\
\text { d955 }\end{array}$ & $\begin{array}{l}\text { Void } \\
\text { Fraction }\end{array}$ \\
\hline text & text & text & in. & text & in. & in. ${ }^{3}$ & in. & in. & in. & in. & text & number & number & number & in. & in. & in. & deg & deg & nondim & nondim & text & $\mathrm{g} / \mathrm{cm}^{3}$ & $m$ & $\mathrm{~m}$ & $m$ & fraction \\
\hline MSS & MDDX & $\mathrm{ID}$ & D & $\mathrm{HS}$ & Hish & $V_{\text {ast }}$ & $\mathrm{H}$ & $\operatorname{Rtn}$ & d & sod & PT & $\mathrm{N}$ & $\mathrm{Nb}$ & $\mathrm{N}$ & $\mathrm{PT}_{\alpha d}$ & $R_{0}$ & $\mathrm{R}$ & $\theta_{0}$ & $\theta_{1}$ & $\mathrm{R} d \mathrm{R}$ & $R / R$ & sxdx & $\rho_{\mathrm{s}}$ & $d_{5}$ & $\mathrm{~d}_{\mathrm{c} 0}$ & $d_{65}$ & vf \\
\hline $20071155 \mathrm{M}$ & $7 / 25 \mathrm{B1}$ & 34S_6p2d6Yd_8 & $337 / 8$ & $s$ & 9 & 4437.4 & $681 / 8$ & 62 & 0.446 & 0.669 & HLP-22 & 12 & 8 & 4 & 1.9 & 10.5 & 5.7 & 30.8 & 16.1 & 0.62 & 0.33 & $\mathrm{p} 2 \mathrm{~d} 6$ & 2.46 & 0.0005184 & 0.0007662 & 0.0011729 & 0.4080 \\
\hline $20071159 \mathrm{M}$ & $7 / 25 \mathrm{~B} 1$ & 34S_6p2d6Yd_8 & $337 / 8$ & $\mathrm{~s}$ & 9 & \begin{tabular}{ll|}
4437.4 \\
\end{tabular} & $681 / 8$ & 62 & 0.446 & 0.669 & HLP-22 & 12 & 8 & 4 & 19 & 10.5 & 5.7 & 30.8 & 16.1 & 0.62 & 0.33 & $\mathrm{p} 2 \mathrm{~d} 6$ & 2.46 & 0.0005184 & 0.0007662 & 0.0011729 & 0.4080 \\
\hline 20071160M & $7 / 25 \mathrm{~B} 1$ & 34S_6p2d6Yd_8 & $337 / 8$ & $\mathrm{~s}$ & 9 & 4437.4 & $681 / 8$ & 62 & 0.446 & 0.669 & HLP-22 & 12 & 8 & 4 & 19 & 10.5 & 5.7 & 30.8 & 16.1 & 0.62 & 0.33 & $\mathrm{p} 2 \mathrm{~d} 6$ & 2.46 & 0.0005184 & 0.0007662 & 0.0011729 & 0.4080 \\
\hline $20071165 \mathrm{M}$ & $7 / 25 \mathrm{B1}$ & 34S_6p2d6Yd_8 & $337 / 8$ & $\mathrm{~s}$ & 9 & 4437.4 & $681 / 8$ & 62 & 0.446 & 0.669 & HLP-22 & 12 & 8 & 4 & 19 & 10.5 & 5.7 & 30.8 & 16.1 & 0.62 & 0.33 & p2d6 & 2.46 & 0.0005184 & 0.0007662 & 0.0011729 & 0.4080 \\
\hline $20071168 \mathrm{M}$ & $7 / 25 \mathrm{B1}$ & 34S_6p2d6Yd_8 & $337 / 8$ & s & 9 & 4437.4 & $681 / 8$ & 62 & 0.446 & 0.669 & HLP-22 & 12 & 8 & 4 & 19 & 10.5 & 5.7 & 30.8 & 16.1 & 0.62 & 0.33 & p2d6 & 2.46 & 0.0005184 & 0.0007662 & 0.0011729 & 0.4080 \\
\hline $20071171 \mathrm{M}$ & $7 / 25 \mathrm{~B} 1$ & $34 \mathrm{~S}$ 6p2d6Yd 8 & $337 / 8$ & $\mathrm{~s}$ & 9 & \begin{tabular}{ll|}
4437.4 \\
\end{tabular} & $681 / 8$ & 62 & 0.446 & 0.669 & HLP-22 & 12 & 8 & 4 & 19 & 10.5 & 5.7 & 30.8 & 16.1 & 0.62 & 0.33 & $\mathrm{p} 2 \mathrm{~d} 6$ & 2.46 & 0.0005184 & 0.0007662 & 0.0011729 & 0.4080 \\
\hline $20071176 \mathrm{M}$ & $7 / 25 \mathrm{~B} 1$ & 34S_6p2d6Yd_8 & $337 / 8$ & $\mathrm{~s}$ & 9 & 4437.4 & $681 / 8$ & 62 & 0.446 & 0.669 & HLP-22 & 12 & 8 & 4 & 19 & 10.5 & 5.7 & 30.8 & 16.1 & 0.62 & 0.33 & $\mathrm{p} 2 \mathrm{~d} 6$ & 2.46 & 0.0005184 & 0.0007662 & 0.0011729 & 0.4080 \\
\hline 20071180M & $7 / 25 \mathrm{~B} 1$ & 34S_6p2d6Yd_8 & $337 / 8$ & $\mathrm{~s}$ & 9 & 4437.4 & $681 / 8$ & 62 & 0.446 & 0.669 & HLP-22 & 12 & 8 & 4 & 19 & 10.5 & 5.7 & 30.8 & 16.1 & 0.62 & 0.33 & $\mathrm{p} 2 \mathrm{~d} 6$ & 2.46 & 0.0005184 & 0.0007662 & 0.0011729 & 0.4080 \\
\hline $20071182 \mathrm{M}$ & $7 / 25 \mathrm{~B} 1$ & 34S_6p2d6Yd_8 & $337 / 8$ & s & 9 & 4437.4 & $681 / 8$ & 62 & 0.446 & 0.669 & HLP-22 & 12 & 8 & 4 & 19 & 10.5 & 5.7 & 30.8 & 16.1 & 0.62 & 0.33 & $\mathrm{p} 2 \mathrm{~d} 6$ & 2.46 & 0.0005184 & 0.00007662 & 0.0011729 & 0.4080 \\
\hline 20071185M & $7 / 25 \mathrm{B1}$ & 34S_6p2d6Yd_8 & $337 / 8$ & s & 9 & 4437.4 & $681 / 8$ & 62 & 0.446 & 0.669 & HLP-22 & 12 & 8 & 4 & 19 & 10.5 & 5.7 & 30.8 & 16.1 & 0.62 & 0.33 & $\mathrm{p} 2 \mathrm{~d} 6$ & 2.46 & 0.0005184 & 0.0007662 & 0.0011729 & 0.4080 \\
\hline $20071187 \mathrm{M}$ & $7 / 25 \mathrm{~B} 1$ & 34S_6p2d6Yd_8 & $337 / 8$ & $\mathrm{~s}$ & 9 & 4437.4 & $681 / 8$ & 62 & 0.446 & 0.669 & HLP-22 & 12 & 8 & 4 & 19 & 10.5 & 5.7 & 30.8 & 16.1 & 0.62 & 0.33 & $\mathrm{p} 2 \mathrm{~d} 6$ & 2.46 & 0.0005184 & 0.0007662 & 0.0011729 & 0.4080 \\
\hline $20071193 \mathrm{M}$ & $7 / 25 \mathrm{~B} 1$ & 34S_6p2d6Yd_8 & $337 / 8$ & $\mathrm{~s}$ & 9 & \begin{tabular}{ll|}
4437.4 \\
\end{tabular} & $681 / 8$ & 62 & 0.446 & 0.669 & HLP-22 & 12 & 8 & 4 & 19 & 10.5 & 5.7 & 30.8 & 16.1 & 0.62 & 0.33 & $\mathrm{p} 2 \mathrm{~d} 6$ & 2.46 & 0.0005184 & 0.0007662 & 0.0011729 & 0.4080 \\
\hline 20071200 & $7 / 26 \mathrm{Al}$ & 345_6p1d8Ya & $337 / 8$ & $\mathrm{~s}$ & 9 & 4437.4 & $687 / 8$ & 62 & 0.446 & 0.669 & HLP-22 & 12 & 8 & 4 & 19 & 10.5 & 5.7 & 30.8 & 16.1 & 0.62 & 0.33 & pld8 & 2.45 & 0.0000605 & 0.0000895 & 0.0001320 & 0.4269 \\
\hline 20071203 & $7 / 26 \mathrm{A1}$ & 34s__pp1d8Ya & $337 / 8$ & $\mathrm{~s}$ & 9 & 4437.4 & $687 / 8$ & 62 & 0.446 & 0.669 & HLP-22 & 12 & 8 & 4 & 19 & 10.5 & 5.7 & 30.8 & 16.1 & 0.62 & 0.33 & pld8 & 2.45 & 0.0000605 & 0.0000895 & 0.0001320 & 0.4269 \\
\hline 20071205 & $7 / 26 \mathrm{~A} 1$ & 345_6p1daYYa & $337 / 8$ & $\mathrm{~s}$ & 9 & 4437.4 & $687 / 8$ & 62 & 0.446 & 0.669 & HLP-22 & 12 & 8 & 4 & 19 & 10.5 & 5.7 & 30.8 & 16.1 & 0.62 & 0.33 & p1d8 & 2.45 & 0.0000605 & 0.0000895 & 0.0001320 & 0.4269 \\
\hline 20071209 & $7 / 26 \mathrm{Al}$ & 34S_6p1daYa & $337 / 8$ & $\mathrm{~s}$ & 9 & 4437.4 & $687 / 8$ & 62 & 0.446 & 0.669 & HLP-22 & 12 & 8 & 4 & 19 & 10.5 & 5.7 & 30.8 & 16.1 & 0.62 & 0.33 & p1d8 & 2.45 & 0.0000605 & 0.0000895 & 0.0001320 & 0.4269 \\
\hline 20071212 & $7 / 26 \mathrm{Al}$ & 34S_6p1d8Ya & $337 / 8$ & $\mathrm{~s}$ & 9 & \begin{tabular}{ll|}
4437.4 \\
\end{tabular} & $687 / 8$ & 62 & 0.446 & 0.669 & HLP-22 & 12 & 8 & 4 & 19 & 10.5 & 5.7 & 30.8 & 16.1 & 0.62 & 0.33 & pld8 & 2.45 & 0.0000605 & 0.0000895 & 0.0001320 & 0.4269 \\
\hline 20071213 & $7 / 26 \mathrm{Al}$ & 34S_fpldarya & $337 / 8$ & $\mathrm{~s}$ & 9 & 4437.4 & $687 / 8$ & 62 & 0.446 & 0.669 & HLP-22 & 12 & 8 & 4 & 19 & 10.5 & 5.7 & 30.8 & 16.1 & 0.62 & 0.33 & p1d8 & 2.45 & 0.0000605 & 0.0000895 & 0.0001320 & 0.4269 \\
\hline 20071216 & $7 / 26 \mathrm{A1}$ & 34S_6pldigYa & $337 / 8$ & $\mathrm{~s}$ & 9 & 4437.4 & $687 / 8$ & 62 & 0.446 & 0.669 & HLP-22 & 12 & 8 & 4 & 19 & 10.5 & 5.7 & 30.8 & 16.1 & 0.62 & 0.33 & p1d8 & 2.45 & 0.0000605 & 0.0000895 & 0.0001320 & 0.4269 \\
\hline 20071219 & $7 / 26 \mathrm{A1}$ & 34S_6p1d8Ya & $337 / 8$ & $\mathrm{~s}$ & 9 & 4437.4 & $687 / 8$ & 62 & 0.446 & 0.669 & HLP-22 & 12 & 8 & 4 & 19 & 10.5 & 5.7 & 30.8 & 16.1 & 0.62 & 0.33 & p1d8 & 2.45 & 0.0000605 & 0.0000095 & 0.0001320 & 0.4269 \\
\hline 20071222 & $7 / 26 \mathrm{Al}$ & 345_splddYa & $337 / 8$ & $\mathrm{~s}$ & 9 & 4437.4 & $687 / 8$ & 62 & 0.446 & 0.669 & HLP-22 & 12 & 8 & 4 & 19 & 10.5 & 5.7 & 30.8 & 16.1 & 0.62 & 0.33 & p1d8 & 2.45 & 0.0000605 & 0.0000895 & 0.0001320 & 0.4269 \\
\hline 20071225 & $7 / 26 \mathrm{Al}$ & 34S_6p1d8Ya & $337 / 8$ & $\mathrm{~s}$ & 9 & \begin{tabular}{ll|l}
4437.4 \\
\end{tabular} & $687 / 8$ & 62 & 0.446 & 0.669 & HLP-22 & 12 & 8 & 4 & 19 & 10.5 & 5.7 & 30.8 & 16.1 & 0.62 & 0.33 & pld8 & 2.45 & 0.0000605 & 0.0000895 & 0.0001320 & 0.4269 \\
\hline 20071229 & $7 / 26 \mathrm{B1}$ & 34S_6p1d8Yd_8 8 & $337 / 8$ & $\mathrm{~s}$ & 9 & 4437.4 & $687 / 8$ & 62 & 0.446 & 0.669 & HLP-22 & 12 & 8 & 4 & 19 & 10.5 & 5.7 & 30.8 & 16.1 & 0.62 & 0.33 & pld8 & 2.45 & 0.0000605 & 0.0000895 & 0.0001320 & 0.4269 \\
\hline 20071235 & $7 / 26 \mathrm{B1}$ & 34S_6p1d8Yd_8 & $337 / 8$ & $\mathrm{~s}$ & 9 & 4437.4 & $687 / 8$ & 62 & 0.446 & 0.669 & HLP-22 & 12 & 8 & 4 & 19 & 10.5 & 5.7 & 30.8 & 16.1 & 0.62 & 0.33 & plds & 2.45 & 0.0000605 & 0.0000895 & 0.0001320 & 0.4269 \\
\hline 20071238 & $7 / 26 \mathrm{B1}$ & 34S_6p1d8Yd_8 & $337 / 8$ & $\mathrm{~s}$ & 9 & 4437.4 & $687 / 8$ & 62 & 0.446 & 0.669 & HLP-22 & 12 & 8 & 4 & 19 & 10.5 & 5.7 & 30.8 & 16.1 & 0.62 & 0.33 & p1d8 & 2.45 & 0.0000605 & 0.0000095 & 0.0001320 & 0.4269 \\
\hline 20071241 & $7 / 26 \mathrm{B1}$ & 34S_6p1d8Yd_8 & $337 / 8$ & $\mathrm{~s}$ & 9 & 4437.4 & $687 / 8$ & 62 & 0.446 & 0.669 & HLP-22 & 12 & 8 & 4 & 19 & 10.5 & 5.7 & 30.8 & 16.1 & 0.62 & 0.33 & pld8 & 2.45 & 0.0000605 & 0.0000895 & 0.0001320 & 0.4269 \\
\hline 20071244 & $7 / 26 \mathrm{B1}$ & 34S_6p1d8Yd_8 & $337 / 8$ & $\mathrm{~s}$ & 9 & \begin{tabular}{ll|l}
4437.4 \\
\end{tabular} & $687 / 8$ & 62 & 0.446 & 0.669 & HLP-22 & 12 & 8 & 4 & 19 & 10.5 & 5.7 & 30.8 & 16.1 & 0.62 & 0.33 & p1d8 & 2.45 & 0.0000605 & 0.0000895 & 0.0001320 & 0.4269 \\
\hline 20071246 & $7 / 26 \mathrm{~B} 1$ & 34S_6p1d8Yd_8 & $337 / 8$ & $\mathrm{~s}$ & 9 & 4437.4 & $687 / 8$ & 62 & 0.446 & 0.669 & HLP-22 & 12 & 8 & 4 & 19 & 10.5 & 5.7 & 30.8 & 16.1 & 0.62 & 0.33 & $\mathrm{p} 1 \mathrm{~d} 8$ & 2.45 & 0.0000605 & 0.0000895 & 0.0001320 & 0.4269 \\
\hline 20071248 & $7 / 26 \mathrm{B1}$ & 34S_6p1d8Yd_8 & $337 / 8$ & $\mathrm{~s}$ & 9 & 4437.4 & $687 / 8$ & 62 & 0.446 & 0.669 & HLP-22 & 12 & 8 & 4 & 19 & 10.5 & 5.7 & 30.8 & 16.1 & 0.62 & 0.33 & pld8 & 2.45 & 0.0000605 & 0.0000895 & 0.0001320 & 0.4269 \\
\hline 20071250 & $7 / 26 \mathrm{B1}$ & 34s_6p1d8Yd 8 & $337 / 8$ & $\mathrm{~s}$ & 9 & 4437.4 & $687 / 8$ & 62 & 0.446 & 0.669 & HLP-22 & 12 & 8 & 4 & 19 & 10.5 & 5.7 & 30.8 & 16.1 & 0.62 & 0.33 & p1d8 & 2.45 & 0.0000605 & 0.0000095 & 0.0001320 & 0.4269 \\
\hline 20071253 & $7 / 26 \mathrm{~B} 1$ & 34S_6p1d8Yd_ 8 & $337 / 8$ & $\mathrm{~s}$ & 9 & 4437.4 & $687 / 8$ & 62 & 0.446 & 0.669 & HLP-22 & 12 & 8 & 4 & 19 & 10.5 & 5.7 & 30.8 & 16.1 & 0.62 & 0.33 & p1d8 & 2.45 & 0.0000605 & 0.0000895 & 0.0001320 & 0.4269 \\
\hline 20071256 & $7 / 26 \mathrm{B1}$ & 34S_6p1d8Yd_8 & $337 / 8$ & $\mathrm{~s}$ & 9 & \begin{tabular}{ll|}
4437.4 \\
\end{tabular} & $687 / 8$ & 62 & 0.446 & 0.669 & HLP-22 & 12 & 8 & 4 & 19 & 10.5 & 5.7 & 30.8 & 16.1 & 0.62 & 0.33 & p1d8 & 2.45 & 0.0000605 & 0.0000895 & 0.0001320 & 0.4269 \\
\hline 20071261 & $7 / 26 \mathrm{B1}$ & 34S_6p1d8Yd_8 & $337 / 8$ & $\mathrm{~s}$ & 9 & 4437.4 & $687 / 8$ & 62 & 0.446 & 0.669 & HLP-22 & 12 & 8 & 4 & 19 & 10.5 & 5.7 & 30.8 & 16.1 & 0.62 & 0.33 & $\mathrm{p} 1 \mathrm{~d} 8$ & 2.45 & 0.0000605 & 0.0000895 & 0.0001320 & 0.4269 \\
\hline 20071264 & $7 / 26 \mathrm{B1}$ & 34s_6p1d8Yd_8 8 & $337 / 8$ & $\mathrm{~s}$ & 9 & 4437.4 & $687 / 8$ & 62 & 0.446 & 0.669 & HLP-22 & 12 & 8 & 4 & 19 & 10.5 & 5.7 & 30.8 & 16.1 & 0.62 & 0.33 & pld8 & 2.45 & 0.0000605 & 0.0000895 & 0.0001320 & 0.4269 \\
\hline 20071267 & $7 / 26 \mathrm{B1}$ & 34S_6p1d8Yd_8 & $337 / 8$ & $\mathrm{~s}$ & 9 & 4437.4 & $687 / 8$ & 62 & 0.446 & 0.669 & HLP-22 & 12 & 8 & 4 & 19 & 10.5 & 5.7 & 30.8 & 16.1 & 0.62 & 0.33 & pld8 & 2.45 & 0.0000605 & 0.0000895 & 0.0001320 & 0.4269 \\
\hline 20071270 & $7 / 26 \mathrm{B1}$ & 34S_6p1d8Yd_8 & $337 / 8$ & $\mathrm{~s}$ & 9 & 4437.4 & $687 / 8$ & 62 & 0.446 & 0.669 & HLP-22 & 12 & 8 & 4 & 19 & 10.5 & 5.7 & 30.8 & 16.1 & 0.62 & 0.33 & pld8 & 2.45 & 0.0000605 & 0.0000895 & 0.0001320 & 0.4269 \\
\hline $20071272 \mathrm{M}$ & $7 / 26 \mathrm{~B} 1$ & 34S_6p1d8Yd_8 & $337 / 8$ & $\mathrm{~s}$ & 9 & \begin{tabular}{ll|}
4437.4 \\
\end{tabular} & $687 / 8$ & 62 & 0.446 & 0.669 & HLP-22 & 12 & 8 & 4 & 19 & 10.5 & 5.7 & 30.8 & 16.1 & 0.62 & 0.33 & pld8 & 2.45 & 0.0000605 & 0.0000895 & 0.0001320 & 0.4269 \\
\hline $20071275 \mathrm{M}$ & $7 / 26 \mathrm{~B} 1$ & 34S_6p1d8Yd_8 & $337 / 8$ & $\mathrm{~s}$ & 9 & 4437.4 & $687 / 8$ & 62 & 0.446 & 0.669 & HLP-22 & 12 & 8 & 4 & 19 & 10.5 & 5.7 & 30.8 & 16.1 & 0.62 & 0.33 & pld8 & 2.45 & 0.0000605 & 0.0000895 & 0.0001320 & 0.4269 \\
\hline $20071276 \mathrm{M}$ & $7 / 26 \mathrm{B1}$ & 34S_6p1d8Yd_ 8 & $337 / 8$ & $\mathrm{~s}$ & 9 & 4437.4 & $687 / 8$ & 62 & 0.446 & 0.669 & HLP-22 & 12 & 8 & 4 & 1.9 & 10.5 & 5.7 & 30.8 & 16.1 & 0.62 & 0.33 & p1d8 & 2.45 & 0.0000605 & 0.0000895 & 0.0001320 & 0.4269 \\
\hline $20071279 \mathrm{M}$ & $7 / 26 \mathrm{B1}$ & 34S_6p1d8Yd_8 8 & $337 / 8$ & $s$ & 9 & 4437.4 & $687 / 8$ & 62 & 0.446 & 0.669 & HLP-22 & 12 & 8 & 4 & 19 & 10.5 & 5.7 & 30.8 & 16.1 & 0.62 & $0 . \infty$ & pld8 & 2.45 & 0.0000605 & 0.0000895 & 0.0001320 & \\
\hline $20071280 \mathrm{M}$ & $7 / 26 \mathrm{B1}$ & 34S_6p1d8Yd_8 8 & $337 / 8$ & $s$ & 9 & 4437.4 & $687 / 8$ & 62 & 0.446 & 0.669 & HLP-22 & 12 & 8 & 4 & 19 & 10.5 & 5.7 & 30.8 & 16.1 & 0.62 & 0.33 & $\mathrm{p} 1 \mathrm{~d} 8$ & 2.45 & 0.0000605 & 0.0000895 & 0.0001320 & 0.4269 \\
\hline
\end{tabular}


Table B.7. Data from July 2007 Tests in Mid-Scale Vessel with Spherical Head B.7

\begin{tabular}{|c|c|c|c|c|c|c|c|c|c|c|c|c|c|c|c|c|c|c|c|c|c|c|c|c|c|c|c|c|c|}
\hline $\begin{array}{l}\text { Tank Water } \\
\text { Temperature }\end{array}$ & $\begin{array}{l}\text { Water } \\
\text { Density }\end{array}$ & $\begin{array}{l}\text { Solids } \\
\text { Fraction }\end{array}$ & $\begin{array}{l}\text { Pulse } \\
\text { Volume } \\
\text { Fraction }\end{array}$ & $\begin{array}{l}\text { Duty } \\
\text { Oyde }\end{array}$ & $\begin{array}{l}\text { cycle } \\
\text { Time }\end{array}$ & $\begin{array}{c}\text { Pulsed } \\
\text { or } \\
\text { Steacy } \\
\text { Jet } \\
\end{array}$ & $\begin{array}{c}\text { Us } \\
\text { Steacy } \\
\text { Jet } \\
\end{array}$ & 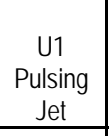 & $\begin{array}{l}\text { U2 } \\
\text { URMS } \\
\end{array}$ & $\begin{array}{l}\text { UR } \\
\text { URNB } \\
\end{array}$ & $\begin{array}{l}\text { Discharge } \\
\text { Velocity }\end{array}$ & $\begin{array}{c}\text { Oitical } \\
\text { Suspension } \\
\text { Velocity }\end{array}$ & $\begin{array}{c}\text { Average } \\
\text { Peak } \\
\text { Cloud } \\
\text { Height } \\
\end{array}$ & $\begin{array}{c}\text { UCS } \\
\text { Condition }\end{array}$ & $\begin{array}{l}\text { UeS } \\
\text { Nethod }\end{array}$ & $\begin{array}{l}\text { UCS } \\
\text { Flag }\end{array}$ & $\begin{array}{c}\text { UCS } \\
\text { Center } \\
\text { Flag }\end{array}$ & $\begin{array}{c}\text { UcSudv } \\
\text { Fag }\end{array}$ & \begin{tabular}{|c|} 
Ucs based \\
on \\
Decreasing \\
Velocity
\end{tabular} & $\begin{array}{c}\text { Sweep } \\
\text { Increase } \\
\text { Decrease }\end{array}$ & $\begin{array}{c}\text { UDV } \\
\text { Height } \\
\text { Bed } \\
\end{array}$ & $\begin{array}{c}\begin{array}{c}\text { Patrice } \\
\text { Motion }\end{array} \\
\end{array}$ & $\begin{array}{l}\text { Solids } \\
\text { Level }\end{array}$ & $\begin{array}{l}\text { Outer } \\
\text { Botomom } \\
\text { Pattem }\end{array}$ & \begin{tabular}{|l|} 
Inner \\
Bototom \\
Paterm \\
\end{tabular} & Case ID & Test & TDP & $\begin{array}{l}\text { Raw } \\
\text { Number }\end{array}$ \\
\hline C & $\mathrm{g} / \mathrm{cm}^{3}$ & fraction & fraction & fraction & $\mathrm{s}$ & text & $\mathrm{m} / \mathrm{s}$ & $\mathrm{m} / \mathrm{s}$ & $\mathrm{m} / \mathrm{s}$ & $\mathrm{m} / \mathrm{s}$ & $\mathrm{m} / \mathrm{s}$ & $\mathrm{m} / \mathrm{s}$ & in. & $\mathrm{m} / \mathrm{s}$ & text & text & text & text & \begin{tabular}{|l|}
$\mathrm{m} / \mathrm{s}$ \\
\end{tabular} & text & $\mathrm{mm}$ & text & text & text & text & text & text & text & text \\
\hline$T$ & $\rho$ & $\phi_{\mathrm{s}}$ & $\phi_{p}$ & $\mathrm{DC}$ & $t_{c}$ & Jet & $u_{s}$ & $\mathrm{U}_{1}$ & $\mathrm{U} 2$ & U3 & $u$ & Uos & $\mathrm{H}_{\mathrm{C}}$ & U Uss & Unsu & Uosvis & Uscen & Ussudv & Uss D & $\mathrm{s}_{\mathrm{w}}$ & $\mathrm{H}_{\text {bed }}$ & PM & sol & SPo & $\mathrm{SP}_{1}$ & ID & MDDX & $\mathrm{TDP}$ & MSS \\
\hline 28.0 & 0.998 & 0.00485 & 0.048 & 0.180 & 20.3 & $\mathrm{P}$ & NA & 5.21 & 5.67 & 5.88 & 6.50 & 6.00 & 18.63 & NA & NA & NA & NA & NA & NA & NA & NA & $\mathrm{BC}$ & NA & NA & NA & 34S_6p2d6Yd_8 & $7 / 25 \mathrm{B1}$ & TDP-WIP-014 & 20071155 \\
\hline 28.0 & 0.998 & 0.00485 & 0.048 & 0.180 & 18.2 & $\mathrm{P}$ & NA & 5.40 & 5.95 & 6.22 & 7.00 & 6.00 & 19.63 & NA & NA & NA & NA & NA & NA & NA & NA & $B C$ & NA & NA & NA & 345 6p2d6rd 8 & 7/25B & IDP-WIP-014 & 20071159 \\
\hline 28.0 & 0.998 & 0.00485 & 0.048 & 0.180 & 17.2 & $\mathrm{P}$ & NA & 5.61 & 6.22 & 6.53 & 7.50 & 6.00 & 20.38 & NA & NA & NA & NA & NA & NA & NA & NA & $B C$ & NA & NA & NA & 34S_6p2dGYd_8 & $7 / 25 \mathrm{~B} 1$ & TDP-WIP-014 & 20071160 \\
\hline 28.0 & 0.998 & 0.00485 & 0.048 & 0.180 & 19.4 & $\mathrm{P}$ & NA & 5.10 & 5.58 & 5.82 & 6.50 & 6.00 & 17.63 & NA & NA & NA & NA & NA & NA & NA & NA & $B C$ & NA & NA & NA & 34S_6p2d6Yd_8 & $7 / 25 \mathrm{~B} 1$ & TDP-WIP-014 & 20071165 \\
\hline 28.0 & 0.998 & 0.00485 & 0.048 & 0.180 & 20.4 & $P$ & NA & 4.87 & 5.32 & 5.53 & 6.20 & 6.00 & 16.88 & NA & NA & NA & $N A$ & NA & NA & NA & NA & $B C$ & NA & NA & NA & 34S 6p2d6rd 8 & 7/25 B1 & TDP-WIP-014 & 20071168 \\
\hline 28.0 & 0.998 & 0.00485 & 0.048 & 0.180 & 20.4 & $\mathrm{P}$ & NA & 4.83 & 5.25 & 5.45 & 6.00 & 6.00 & 17.63 & NA & vis dec & UCSuis & NA & NA & 6.00 & D & NA & CS & NA & NA & NA & 34S_6p2d6Yd_8 & $7 / 25 \mathrm{~B} 1$ & TDP-WIP-014 & 20071171 \\
\hline 28.0 & 0.998 & 0.00485 & 0.048 & 0.180 & 14.3 & $\mathrm{P}$ & NA & 5.95 & 6.79 & 7.22 & 8.60 & 6.00 & 20.63 & NA & NA & NA & NA & NA & NA & NA & NA & $\mathrm{BC}$ & NA & NA & NA & 34S_6p2d6Yd_8 & $7 / 25 \mathrm{B1}$ & TDP-WIP-014 & 20071176 \\
\hline 28.0 & 0.998 & 0.00485 & 0.048 & 0.180 & 13.8 & $\mathrm{P}$ & NA & 6.20 & 7.08 & 7.54 & 9.00 & 6.00 & 25.88 & NA & NA & NA & NA & NA & NA & NA & NA & $\mathrm{BC}$ & NA & NA & NA & 34S_6p2d6Yd_8 & $7 / 25 \mathrm{~B} 1$ & TDP-WIP-014 & 20071182 \\
\hline 28.0 & 0.998 & 0.00485 & 0.048 & 0.180 & NA & $\mathrm{P}$ & NA & 6.38 & 7.30 & 7.79 & 9.60 & 6.00 & 27.63 & NA & NA & NA & NA & NA & NA & NA & NA & $\mathrm{BC}$ & NA & NA & NA & 34S_6p2d6Yd_8 & $7 / 25 \mathrm{B1}$ & TDP-WIP-014 & 20071185 \\
\hline 28.0 & 0.998 & 0.00485 & 0.048 & 0.180 & 13.1 & $\mathrm{P}$ & NA & 6.81 & 7.85 & 8.39 & 10.30 & 6.00 & 35.63 & NA & NA & NA & NA & NA & NA & NA & NA & $\mathrm{BC}$ & NA & NA & NA & 34S_6p2d6Yd_8 & $7 / 25 \mathrm{B1}$ & TDP-WIP-014 & 20071187 \\
\hline 28.0 & 0.998 & 0.00485 & 0.048 & 0.180 & 16.3 & $\mathrm{P}$ & NA & 6.05 & 6.75 & 7.10 & 8.30 & 6.00 & 20.63 & NA & NA & NA & NA & NA & NA & NA & NA & $B C$ & NA & NA & NA & 34S_6p2d6Yd_8 & $7 / 25 \mathrm{B1}$ & TDP-WIP-014 & 20071193 \\
\hline 22.0 & 0.999 & 0.00487 & undefined & 1.000 & infinite & s & 1.90 & NA & NA & NA & 1.90 & 2.00 & 13.63 & NA & NA & NA & NA & NA & NA & NA & NA & $A M$ & NA & NA & NA & 34S_6p1d8Ya & $7 / 26 \mathrm{A1}$ & TDP-WIP-015 & 20071200 \\
\hline 22.1 & 0.999 & 0.00487 & undefined & 1.000 & infinite & $\mathrm{s}$ & 2.04 & NA & NA & NA & 2.00 & 2.00 & 25.63 & NA & NA & NA & NA & NA & NA & NA & NA & $A M$ & NA & NA & NA & 34s_.6p1darYa & $7 / 26 \mathrm{A1}$ & TDP-WIP-015 & 20071203 \\
\hline 22.3 & 0.999 & 0.00487 & undefined & 1.000 & infinite & $\mathrm{s}$ & 2.20 & NA & NA & NA & 2.20 & 2.00 & 32.63 & NA & NA & NA & NA & NA & NA & NA & NA & AM & NA & NA & NA & 345_6p1dorya & $7 / 26 \mathrm{A1}$ & TDP-WIP-015 & 20071205 \\
\hline 22.4 & 0.999 & 0.00487 & undefined & 1.000 & infinite & $\mathrm{s}$ & 1.50 & NA & NA & NA & 1.50 & 2.00 & 8.63 & NA & NA & NA & NA & NA & NA & NA & NA & ss & NA & NA & NA & 34S_.pp1d8Ya & $7 / 26 \mathrm{A1}$ & TDP-WTP-015 & 20071209 \\
\hline 22.7 & 0.999 & 0.00487 & undefined & 1.000 & infinite & $\mathrm{s}$ & 1.68 & NA & NA & NA & 1.70 & 2.00 & 9.63 & NA & NA & NA & NA & NA & NA & NA & NA & ss & NA & NA & NA & 34S_fplddYra & $7 / 26 \mathrm{A1}$ & TDP-WIP-015 & 20071212 \\
\hline 22.8 & 0.999 & 0.00487 & undefined & 1.000 & infinite & $\mathrm{s}$ & 1.96 & NA & NA & NA & 1.95 & 2.00 & 18.63 & NA & NA & NA & NA & NA & NA & NA & NA & $A M$ & NA & NA & NA & 34s_fpldaYa & $7 / 26 \mathrm{A1}$ & TDP-WIP-015 & 20071213 \\
\hline 23.1 & 0.999 & 0.00487 & undefined & 1.000 & infinite & $\mathrm{s}$ & 2.07 & NA & NA & NA & 2.05 & 2.00 & 27.63 & NA & NA & NA & NA & NA & NA & NA & NA & $A M$ & NA & NA & NA & 34s_.6p1darYa & $7 / 26 \mathrm{A1}$ & TDP-WIP-015 & 20071216 \\
\hline 23.4 & 0.998 & 0.00487 & undefined & 1.000 & infinite & $\mathrm{s}$ & 2.10 & NA & NA & NA & 2.08 & 2.00 & 26.63 & NA & NA & NA & NA & NA & NA & NA & NA & AM & NA & NA & NA & 34S_fpp1dBYa & $7 / 26 \mathrm{A1}$ & TDP-WIP-015 & 20071219 \\
\hline 23.9 & 0.998 & 0.00487 & undefined & 1.000 & infinite & s & 2.06 & NA & NA & NA & 2.00 & 2.00 & 26.63 & NA & vis dec & Ucsis & NA & NA & 2.00 & $\mathrm{D}$ & NA & CS & NA & NA & NA & 34S_.ppldirya & $7 / 26 \mathrm{A1}$ & TDP-WIP-015 & 20071225 \\
\hline 25.0 & 0.998 & 0.00487 & 0.048 & 0.180 & 62.5 & $\mathrm{P}$ & NA & 1.80 & 1.83 & 1.85 & 1.90 & 4.00 & 9.13 & NA & NA & NA & NA & NA & NA & NA & NA & ss & NA & NA & NA & 34S_6p1d8Yd_8 & $7 / 26 \mathrm{~B} 1$ & TDP-WIP-015 & 20071229 \\
\hline 25.0 & 0.998 & 0.00487 & 0.048 & 0.180 & 58.8 & $\mathrm{P}$ & NA & 1.92 & 1.96 & 1.98 & 2.00 & 4.00 & 9.13 & NA & NA & NA & NA & NA & NA & NA & NA & ss & NA & NA & NA & 34S_6p1d8Yd_8 & $7 / 26 \mathrm{B1}$ & TDP-WIP-015 & 20071235 \\
\hline 25.0 & 0.998 & 0.00487 & 0.048 & 0.180 & 54.9 & $\mathrm{P}$ & NA & 2.00 & 2.04 & 2.06 & 2.10 & 4.00 & 9.63 & NA & NA & NA & NA & NA & NA & NA & NA & ss & NA & NA & NA & 34S_6p1d8Yd_8 & $7 / 26 \mathrm{B1}$ & TDP-WIP-015 & 20071238 \\
\hline 25.0 & 0.998 & 0.00487 & 0.048 & 0.180 & 54.1 & $\mathrm{P}$ & NA & 2.07 & 2.11 & 2.13 & 2.20 & 4.00 & 9.63 & NA & NA & NA & NA & NA & NA & NA & NA & ss & NA & NA & NA & 34S_6p1d8Yd_8 & $7 / 26 \mathrm{B1}$ & TDP-WTP-015 & 20071241 \\
\hline 25.0 & 0.998 & 0.00487 & 0.048 & 0.180 & 51.3 & $\mathrm{P}$ & NA & 2.17 & 2.22 & 2.25 & 2.32 & 4.00 & 9.63 & NA & NA & NA & NA & NA & NA & NA & NA & ss & NA & NA & NA & 34S_6p1d8Yd_ 8 & $7 / 26 \mathrm{B1}$ & TDP-WIP-015 & 20071244 \\
\hline 25.0 & 0.998 & 0.00487 & 0.048 & 0.180 & 47.6 & $\mathrm{P}$ & NA & 2.37 & 2.44 & 2.47 & 2.55 & 4.00 & 10.63 & NA & NA & NA & NA & NA & NA & NA & NA & ss & NA & NA & NA & 34S_6p1d8Yd_ 8 & $7 / 26 \mathrm{~B} 1$ & TDP-WIP-015 & 20071246 \\
\hline NA & NA & 0.00487 & 0.048 & 0.180 & 47.6 & $\mathrm{P}$ & NA & NA & NA & NA & 2.50 & 4.00 & 10.63 & NA & NA & NA & NA & NA & NA & NA & NA & NA & NA & NA & NA & 34S_6p1d8Yd_8 & $7 / 26 \mathrm{B1}$ & TDP-WIP-015 & 20071248 \\
\hline 25.0 & 0.998 & 0.00487 & 0.048 & 0.180 & 43.5 & $\mathrm{P}$ & NA & 2.59 & 2.67 & 2.71 & 2.80 & 4.00 & 11.13 & NA & NA & NA & NA & NA & NA & NA & NA & ss & NA & NA & NA & 34S_6p1d8Yd_8 & $7 / 26 \mathrm{B1}$ & TDP-WIP-015 & 20071250 \\
\hline 25.0 & 0.998 & 0.00487 & 0.048 & 0.180 & 41.7 & $\mathrm{P}$ & NA & 2.71 & 2.80 & 2.84 & 3.00 & 4.00 & 11.63 & NA & NA & NA & NA & NA & NA & NA & NA & ss & NA & NA & NA & 34S_6p1d8Yd_8 & $7 / 26 \mathrm{B1}$ & TDP-WIP-015 & 20071253 \\
\hline NA & NA & 0.00487 & 0.048 & 0.180 & 37.0 & $\mathrm{P}$ & NA & NA & NA & NA & 3.25 & 4.00 & 11.63 & NA & NA & NA & NA & NA & NA & NA & NA & ss & NA & NA & NA & 34S_6p1d8Yd_8 8 & $7 / 26 \mathrm{B1}$ & TDP-WIP-015 & 20071256 \\
\hline NA & NA & 0.00487 & 0.048 & 0.180 & 35.1 & $\mathrm{P}$ & NA & NA & NA & NA & 3.50 & 4.00 & 12.63 & NA & NA & NA & NA & NA & NA & NA & NA & ss & NA & NA & NA & 34S_6p1d8Yd_ 8 & $7 / 26 \mathrm{~B} 1$ & TDP-WIP-015 & 20071261 \\
\hline 25.0 & 0.998 & 0.00487 & 0.048 & 0.180 & 32.8 & $\mathrm{P}$ & NA & 3.34 & 3.50 & 3.58 & 3.80 & 4.00 & 13.63 & NA & NA & NA & NA & NA & NA & NA & NA & $A M$ & NA & NA & NA & s $6 p 1 d 8 Y$ Y 8 & $7 / 26 \mathrm{B1}$ & TDP-WIP-015 & 20071264 \\
\hline NA & NA & 0.00487 & 0.048 & 0.180 & 31.3 & $\mathrm{P}$ & NA & NA & NA & NA & 3.90 & 4.00 & 13.63 & NA & NA & NA & NA & NA & NA & NA & NA & $A M$ & NA & NA & NA & 34S_6p1d8Yd_8 & $7 / 26 \mathrm{B1}$ & TDP-WIP-015 & 20071267 \\
\hline 25.0 & 0.998 & 0.00487 & 0.048 & 0.180 & 30.5 & $\mathrm{P}$ & NA & 3.50 & 3.68 & 3.76 & 4.00 & 4.00 & 14.63 & 4.00 & & Ucsuis & NA & NA & & & NA & CS & NA & NA & NA & 34S_6p1d8Yd_8 & $7 / 26 \mathrm{~B} 1$ & TDP-WIP-015 & 20071270 \\
\hline 25.0 & 0.998 & 0.00487 & 0.048 & 0.180 & 26.2 & $\mathrm{P}$ & NA & 3.92 & 4.15 & 4.26 & 4.50 & 4.00 & 15.63 & NA & NA & NA & NA & NA & NA & NA & NA & $B C$ & NA & NA & NA & 34S_6p1d8Yd_8 8 & $7 / 26 \mathrm{B1}$ & TDP-WIP-015 & 20071272 \\
\hline 25.0 & 0.998 & 0.00487 & 0.048 & 0.180 & 25.6 & $\mathrm{P}$ & NA & 4.20 & 4.48 & 4.61 & 5.00 & 4.00 & 24.63 & NA & NA & NA & NA & NA & NA & NA & NA & $B C$ & NA & NA & NA & 34S_6p1d8Yd_8 8 & $7 / 26 \mathrm{~B} 1$ & TDP-WIP-015 & 20071275 \\
\hline 25.0 & 0.998 & 0.00487 & 0.048 & 0.180 & 26.3 & $\mathrm{P}$ & NA & 4.13 & 4.37 & 4.49 & 4.80 & 4.00 & 21.63 & NA & NA & NA & NA & NA & NA & NA & NA & $B C$ & NA & NA & NA & 34S_6p1d8Yd_8 & $7 / 26 \mathrm{~B} 1$ & TDP-WIP-015 & 20071276 \\
\hline 25.0 & 0.998 & 0.00487 & 0.048 & 0.180 & 23.8 & $\mathrm{P}$ & NA & 4.40 & 4.72 & 4.87 & 5.30 & 4.00 & 28.63 & NA & NA & NA & NA & NA & NA & NA & NA & $\mathrm{BC}$ & NA & NA & NA & 34S_6p1d8Yd_8 & $7 / 26 \mathrm{~B} 1$ & TDP-WIP-015 & 20071279 \\
\hline 25.0 & 0.998 & 0.00487 & 0.048 & 0.180 & 26.0 & $P$ & NA & 3.92 & 4.16 & 4.28 & 4.63 & 4.00 & 17.63 & NA & NA & $N A$ & NA & NA & NA & NA & NA & $B C$ & NA & NA & NA & 34S_6p1d8Yd_ 8 & 7726 B1 & TDP-WIP-015 & 20071280 \\
\hline
\end{tabular}


Table B.7. Data from July 2007 Tests in Mid-Scale Vessel with Spherical Head A.8

\begin{tabular}{|c|c|c|c|c|c|c|c|c|c|c|c|c|c|c|c|c|c|c|c|c|c|c|c|c|c|c|c|}
\hline $\begin{array}{c}\text { Row } \\
\text { Number }\end{array}$ & Test & Case ID & $\begin{array}{c}\text { Tank } \\
\text { Diameter }\end{array}$ & $\begin{array}{l}\text { Head } \\
\text { Shape }\end{array}$ & $\begin{array}{l}\text { Dish } \\
\text { Height }\end{array}$ & $\begin{array}{c}\text { Dish } \\
\text { volume }\end{array}$ & $\begin{array}{c}\text { Tank } \\
\text { Fill } \\
\text { Height }\end{array}$ & $\begin{array}{l}\text { Retum } \\
\text { Line } \\
\text { Height }\end{array}$ & $\begin{array}{c}\text { Nozzle } \\
\text { Inner } \\
\text { Dianeter }\end{array}$ & $\begin{array}{c}\text { Nozzle } \\
\text { Stand } \\
\text { of } \\
\text { Distance } \\
\end{array}$ & $\begin{array}{l}\text { Pulse Tube } \\
\text { Configuration }\end{array}$ & \begin{tabular}{|l|} 
Installed \\
Nozzles \\
\end{tabular} & $\begin{array}{c}\text { Outer } \\
\text { Nozles } \\
\text { Operated }\end{array}$ & $\begin{array}{c}\text { Inner } \\
\text { Nozzles } \\
\text { Opperated }\end{array}$ & \begin{tabular}{|c|c} 
Pulse Tube \\
Outur \\
Diameter
\end{tabular} & \begin{tabular}{|c|} 
Outer \\
PJM \\
Radius \\
\end{tabular} & \begin{tabular}{|c|} 
Inner \\
PJM \\
Radius \\
\end{tabular} & \begin{tabular}{|l} 
"FOO" "uter \\
PJMM \\
Impingement \\
Angle
\end{tabular} & \begin{tabular}{|c|} 
"FO' Inner \\
IIMM \\
Impingement \\
Angle
\end{tabular} & $\begin{array}{l}\text { Ratio Outer } \\
\text { PJMto } \\
\text { Tank } \\
\text { Radius } \\
\end{array}$ & $\begin{array}{l}\text { Radioi Inner } \\
\text { PJMto } \\
\text { Tank } \\
\text { Radius } \\
\end{array}$ & Simulant & \begin{tabular}{|l|} 
Solids \\
Density \\
\end{tabular} & $\begin{array}{c}\text { Particle } \\
\text { Diameter d5 }\end{array}$ & $\begin{array}{c}\text { Particle } \\
\text { Diameter } \\
\text { d50 }\end{array}$ & $\begin{array}{l}\text { Particle } \\
\text { Dianeter } \\
\text { d95 }\end{array}$ & $\begin{array}{c}\text { Void } \\
\text { Fraction }\end{array}$ \\
\hline text & text & text & in. & text & in. & in. ${ }^{3}$ & in. & in. & in. & in. & text & \begin{tabular}{|l|} 
number \\
\end{tabular} & number & number & in. & in. & in. & deg & deg & nondim & nondim & text & $\mathrm{g} / \mathrm{cm}^{3}$ & $\mathrm{~m}$ & $\mathrm{~m}$ & $\mathrm{~m}$ & fraction \\
\hline MSS & MDDX & ID & D & HS & Hesh & $V_{\text {dash }}$ & $\mathrm{H}$ & Rtn & $d$ & sod & PT & $\mathrm{N}$ & $N_{b}$ & $\mathrm{~N}$ & $\mathrm{PT}_{\mathrm{od}}$ & $R_{0}$ & $R_{1}$ & $\theta_{0}$ & $\theta_{1}$ & $R d R$ & $\mathrm{R} / \mathrm{R}$ & $\operatorname{sxdx}$ & $\rho_{\mathrm{s}}$ & $d_{5}$ & $\mathrm{~d}_{0}$ & $d_{65}$ & uf \\
\hline $20071283 \mathrm{M}$ & $7 / 26 \mathrm{~B} 1$ & 34S_6p1d8Yd 88 & $337 / 8$ & $\mathrm{~s}$ & 9 & 4437.4 & $687 / 8$ & 62 & 0.446 & 0.669 & HLP-22 & 12 & 8 & 4 & 1.9 & 10.5 & 5.7 & 30.8 & 16.1 & 0.62 & 0.33 & p1d8 & 2.45 & 0.0000605 & 0.0000895 & 0.0001320 & 0.4269 \\
\hline 20071285 & $7 / 26 \mathrm{B1}$ & 34S_6p1d8Yd_8 8 & $337 / 8$ & $\mathrm{~s}$ & 9 & 4437.4 & $687 / 8$ & 62 & 0.446 & 0.669 & HLP-22 & 12 & 8 & 4 & 19 & 10.5 & 5.7 & 30.8 & 16.1 & 0.62 & 0.33 & p1d8 & 2.45 & 0.0000605 & 0.0000895 & 0.0001320 & 0.4269 \\
\hline 20071288 & $7 / 26 \mathrm{~B} 1$ & 34s_6p1d8Yd_8 & $337 / 8$ & $s$ & 9 & 4437.4 & $687 / 8$ & 62 & 0.446 & 0.669 & HLP-22 & 12 & 8 & 4 & 19 & 10.5 & 5.7 & 30.8 & 16.1 & 0.62 & 0.33 & pld8 & 2.45 & 0.0000605 & 0.0000895 & 0.0001320 & 0.4269 \\
\hline 20071291 & $7 / 26 \mathrm{~B} 1$ & 34S_6p1d8Yd_8 & $337 / 8$ & $\mathrm{~s}$ & 9 & 4437.4 & $687 / 8$ & 62 & 0.446 & 0.669 & HLP-22 & 12 & 8 & 4 & 19 & 10.5 & 5.7 & 30.8 & 16.1 & 0.62 & 0.33 & plds & 2.45 & 0.0000605 & 0.0000895 & 0.0001320 & 0.4269 \\
\hline 20071302 & $7 / 27 \mathrm{~A}_{1}$ & 34S_6p1d8Yd_8 & $337 / 8$ & $\mathrm{~s}$ & 9 & 4437.4 & 68778 & 62 & 0.446 & 0.669 & HLP - 22 & 12 & 8 & 4 & 19 & 10.5 & 5.7 & 30.8 & 16.1 & 0.62 & 0.33 & plds & 2.45 & 0.0000605 & 0.0000895 & 0.0001320 & 0.4269 \\
\hline 20071305 & $7 / 27 \mathrm{~A}_{1}$ & 34S_6p1d8Yd 88 & $337 / 8$ & $\mathrm{~s}$ & 9 & 4437.4 & $687 / 8$ & 62 & 0.446 & 0.669 & HLP-22 & 12 & 8 & 4 & 19 & 10.5 & 5.7 & 30.8 & 16.1 & 0.62 & 0.33 & p1d8 & 2.45 & 0.0000605 & 0.0000895 & 0.0001320 & 0.4269 \\
\hline 20071308 & $7 / 27 \mathrm{~A} 1$ & 34S_6p1d8Yd_8 8 & $337 / 8$ & $\mathrm{~s}$ & 9 & 4437.4 & $687 / 8$ & 62 & 0.446 & 0.669 & HLP-22 & 12 & 8 & 4 & 19 & 10.5 & 5.7 & 30.8 & 16.1 & 0.62 & 0.33 & p1d8 & 2.45 & 0.0000605 & 0.0000895 & 0.0001320 & 0.4269 \\
\hline 20071311 & $7 / 27 \mathrm{~A}_{1}$ & 345_6p1d8Yd_8 & $337 / 8$ & $\mathrm{~s}$ & 9 & 4437.4 & $687 / 8$ & 62 & 0.446 & 0.669 & HLP-22 & 12 & 8 & 4 & 19 & 10.5 & 5.7 & 30.8 & 16.1 & 0.62 & 0.33 & pld8 & 2.45 & 0.0000605 & 0.0000895 & 0.0001320 & 0.4269 \\
\hline 20071313 & $7 / 27 \mathrm{~B} 1$ & 34s_6p1d8Yc_8 & $337 / 8$ & $\mathrm{~s}$ & 9 & 4437.4 & $687 / 8$ & 62 & 0.446 & 0.669 & HLP-22 & 12 & 8 & 4 & 1.9 & 10.5 & 5.7 & 30.8 & 16.1 & 0.62 & 0.33 & $\mathrm{p} 1 \mathrm{~d} 8$ & 2.45 & 0.0000605 & 0.0000895 & 0.0001320 & 0.4269 \\
\hline 20071315 & $7 / 27 \mathrm{~B} 1$ & 34S_6p1d8Yc_8 & $337 / 8$ & $\mathrm{~s}$ & 9 & 4437.4 & $687 / 8$ & 62 & 0.446 & 0.669 & HLP -22 & 12 & 8 & 4 & 19 & 10.5 & 5.7 & 30.8 & 16.1 & 0.62 & 0.33 & p1d8 & 2.45 & 0.0000605 & 0.0000895 & 0.0001320 & 0.4269 \\
\hline 20071318 & $7 / 27 \mathrm{~B} 1$ & 345 6p1d8Yc 8 & $337 / 8$ & $\mathrm{~s}$ & 9 & 4437.4 & $687 / 8$ & 62 & 0.446 & 0.669 & HLP-22 & 12 & 8 & 4 & 1.9 & 10.5 & 5.7 & 30.8 & 16.1 & 0.62 & 0.33 & p1d8 & 2.45 & 0.0000605 & 0.0000895 & 0.0001320 & 0.4269 \\
\hline 20071321 & $7 / 27 \mathrm{B1}$ & 34S_6p1d8Yc 8 & $337 / 8$ & $\mathrm{~s}$ & 9 & 4437.4 & $687 / 8$ & 62 & 0.446 & 0.669 & HLP-22 & 12 & 8 & 4 & 1.9 & 10.5 & 5.7 & 30.8 & 16.1 & 0.62 & 0.33 & p1d8 & 2.45 & 0.0000605 & 0.0000895 & 0.0001320 & 0.4269 \\
\hline 20071323 & $7 / 27 \mathrm{~B} 1$ & 345_6p1d8Yc_8 & $337 / 8$ & $\mathrm{~s}$ & 9 & 4437.4 & $687 / 8$ & 62 & 0.446 & 0.669 & HLP-22 & 12 & 8 & 4 & 19 & 10.5 & 5.7 & 30.8 & 16.1 & 0.62 & 0.33 & p1d8 & 2.45 & 0.0000605 & 0.0000895 & 0.0001320 & 0.4269 \\
\hline 20071325 & $7127 \mathrm{B1}$ & 34s_6p1d8Yc_8 8 & $337 / 8$ & $\mathrm{~s}$ & 9 & 4437.4 & $687 / 8$ & 62 & 0.446 & 0.669 & HLP-22 & 12 & 8 & 4 & 1.9 & 10.5 & 5.7 & 30.8 & 16.1 & 0.62 & 0.33 & $\mathrm{p} 1 \mathrm{~d} 8$ & 2.45 & 0.0000605 & 0.0000095 & 0.0001320 & 0.4269 \\
\hline $20071327 \mathrm{M}$ & $7127 \mathrm{B1}$ & 34S_6p1d8Yc_8 8 & $337 / 8$ & $\mathrm{~s}$ & 9 & 4437.4 & $687 / 8$ & 62 & 0.446 & 0.669 & HLP-22 & 12 & 8 & 4 & 19 & 10.5 & 5.7 & 30.8 & 16.1 & 0.62 & 0.33 & p1d8 & 2.45 & 0.0000605 & 0.0000895 & 0.0001320 & 0.4269 \\
\hline 20071331 & $7 / 27 \mathrm{C1}$ & 345_6p2d6rd_ 88 & $337 / 8$ & $\mathrm{~s}$ & 9 & 4437.4 & $681 / 8$ & 62 & 0.446 & 0.669 & HLP-22 & 12 & 8 & 4 & 19 & 10.5 & 5.7 & 30.8 & 16.1 & 0.62 & 0.33 & p2d6 & 2.46 & 0.0005184 & 0.0007662 & 0.0011729 & 0.4080 \\
\hline 20071335 & $7 / 27 \mathrm{Cl}$ & 34S_6p2d6Yd_ 8 & $337 / 8$ & $\mathrm{~s}$ & 9 & 4437.4 & $681 / 8$ & 62 & 0.446 & 0.669 & HLP-22 & 12 & 8 & 4 & 19 & 10.5 & 5.7 & 30.8 & 16.1 & 0.62 & 0.33 & p2d6 & 2.46 & 0.0005184 & 0.0007662 & 0.0011729 & 0.4080 \\
\hline 20071338 & $7 / 27 \mathrm{Cl}$ & 34S_6p2d6Yd_8 8 & $337 / 8$ & $\mathrm{~s}$ & 9 & 4437.4 & $68 \mathrm{y} / 8$ & 62 & 0.446 & 0.669 & HLP-22 & 12 & 8 & 4 & 19 & 10.5 & 5.7 & 30.8 & 16.1 & 0.62 & 0.33 & p2d6 & 2.46 & 0.0005184 & 0.0007662 & 0.0011729 & 0.4080 \\
\hline 20071343 & $7 / 27 \mathrm{Cl}$ & $34 \mathrm{~S} 602 \mathrm{~d} 6 \mathrm{Yd} \_8$ & $337 / 8$ & $\mathrm{~s}$ & 9 & 4437.4 & $681 / 8$ & 62 & 0.446 & 0.669 & HLP - 22 & 12 & 8 & 4 & 19 & 10.5 & 5.7 & 30.8 & 16.1 & 0.62 & 0.33 & $\mathrm{p} 2 \mathrm{~d} 6$ & 2.46 & 0.0005184 & 0.0007662 & 0.0011729 & 0.4080 \\
\hline 20071344 & $7 / 27 \mathrm{Cl}$ & $34 \mathrm{~S} \_602 \mathrm{~d} 6 \mathrm{Yd} \_8$ & $337 / 8$ & $\mathrm{~s}$ & 9 & 4437.4 & $68 \mathrm{y} / 8$ & 62 & 0.446 & 0.669 & HLP -22 & 12 & 8 & 4 & 19 & 10.5 & 5.7 & 30.8 & 16.1 & 0.62 & 0.33 & p2d6 & 2.46 & 0.0005184 & 0.0007662 & 0.0011729 & 0.4080 \\
\hline 20071347 & $7 / 27 \mathrm{Cl}$ & $345 \_602 d 6 \gamma d \_8$ & $337 / 8$ & $\mathrm{~s}$ & 9 & 4437.4 & $681 / 8$ & 62 & 0.446 & 0.669 & HLP-22 & 12 & 8 & 4 & 19 & 10.5 & 5.7 & 30.8 & 16.1 & 0.62 & 0.33 & p2d6 & 2.46 & 0.0005184 & 0.0007662 & 0.0011729 & 0.4080 \\
\hline 20071350 & $7 / 27 \mathrm{Cl}$ & 34S_6p2d6Yd_ 8 & $337 / 8$ & $\mathrm{~s}$ & 9 & 4437.4 & $681 / 8$ & 62 & 0.446 & 0.669 & HLP-22 & 12 & 8 & 4 & 19 & 10.5 & 5.7 & 30.8 & 16.1 & 0.62 & 0.33 & p2d6 & 2.46 & 0.0005184 & 0.0007662 & 0.0011729 & 0.4080 \\
\hline 20071353 & $7 / 27 \mathrm{Cl}$ & 34S_6p2d6Yd_8 8 & $337 / 8$ & $\mathrm{~s}$ & 9 & 4437.4 & $68 \mathrm{y} / 8$ & 62 & 0.446 & 0.669 & HLP-22 & 12 & 8 & 4 & 19 & 10.5 & 5.7 & 30.8 & 16.1 & 0.62 & 0.33 & p2d6 & 2.46 & 0.0005184 & 0.0007662 & 0.0011729 & 0.4080 \\
\hline 20071356 & $7 / 27 \mathrm{D} 1$ & $345602066 Y c 8$ & $337 / 8$ & $\mathrm{~s}$ & 9 & 4437.4 & $681 / 8$ & 62 & 0.446 & 0.669 & HLP - 22 & 12 & 8 & 4 & 19 & 10.5 & 5.7 & 30.8 & 16.1 & 0.62 & 0.33 & p2d6 & 2.46 & 0.0005184 & 0.0007662 & 0.0011729 & 0.4080 \\
\hline 20071358 & $7 / 27 \mathrm{D} 1$ & $34 \mathrm{~S} \_6 \mathrm{p} 2 \mathrm{~d} 6 \mathrm{Yc} \_8$ & $337 / 8$ & $\mathrm{~s}$ & 9 & 4437.4 & $68 \mathrm{y} / 8$ & 62 & 0.446 & 0.669 & HLP -22 & 12 & 8 & 4 & 19 & 10.5 & 5.7 & 30.8 & 16.1 & 0.62 & 0.33 & p2d6 & 2.46 & 0.0005184 & 0.0007662 & 0.0011729 & 0.4080 \\
\hline 20071360 & $7 / 27 \mathrm{D} 1$ & $34 \mathrm{~S} \_602 \mathrm{~d} 6 \mathrm{YC} \_8$ & $337 / 8$ & $\mathrm{~s}$ & 9 & 4437.4 & $681 / 8$ & 62 & 0.446 & 0.669 & HLP-22 & 12 & 8 & 4 & 19 & 10.5 & 5.7 & 30.8 & 16.1 & 0.62 & 0.33 & p2d6 & 2.46 & 0.0005184 & 0.0007662 & 0.0011729 & 0.4080 \\
\hline 20071362 & $7 / 27 \mathrm{D} 1$ & 345 6p2026YC 8 & $337 / 8$ & $\mathrm{~s}$ & 9 & 4437.4 & $681 / 8$ & 62 & 0.446 & 0.669 & HLP-22 & 12 & 8 & 4 & 1.9 & 10.5 & 5.7 & 30.8 & 16.1 & 0.62 & 0.33 & p2d6 & 2.46 & 0.0005184 & 0.0007662 & 0.0011729 & 0.4080 \\
\hline 20071367 & $7 / 27 \mathrm{D1}$ & 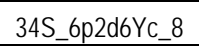 & $337 / 8$ & $\mathrm{~s}$ & 9 & 4437.4 & $681 / 8$ & 62 & 0.446 & 0.669 & HLP-22 & 12 & 8 & 4 & 1.9 & 10.5 & 5.7 & 30.8 & 16.1 & 0.62 & 0.33 & p2d6 & 2.46 & 0.0005184 & 0.0007662 & 0.0011729 & 0.4080 \\
\hline 20071369 & $7 / 27 \mathrm{D} 1$ & $34 \mathrm{~S} 6 \mathrm{p} 2 \mathrm{~d} 6 \mathrm{Yc} \_8$ & $337 / 8$ & $\mathrm{~s}$ & 9 & 4437.4 & $681 / 8$ & 62 & 0.446 & 0.669 & HLP - 22 & 12 & 8 & 4 & 19 & 10.5 & 5.7 & 30.8 & 16.1 & 0.62 & 0.33 & $\mathrm{p} 2 \mathrm{~d} 6$ & 2.46 & 0.0005184 & 0.0007662 & 0.0011729 & 0.4080 \\
\hline 20071371 & $7 / 27 \mathrm{D} 1$ & $345,602067 c 8$ & $337 / 8$ & $\mathrm{~s}$ & 9 & 4437.4 & $681 / 8$ & 62 & 0.446 & 0.669 & HLP -22 & 12 & 8 & 4 & 1.9 & 10.5 & 5.7 & 30.8 & 16.1 & 0.62 & 0.33 & $\mathrm{p} 2 \mathrm{~d} 6$ & 2.46 & 0.0005184 & 0.0007662 & 0.0011729 & 0.4080 \\
\hline 20071374 & $7 / 27 \mathrm{D} 1$ & $34 \mathrm{~S} \_60206 \mathrm{YC} \_8$ & $337 / 8$ & $\mathrm{~s}$ & 9 & 4437.4 & $681 / 8$ & 62 & 0.446 & 0.669 & HLP-22 & 12 & 8 & 4 & 1.9 & 10.5 & 5.7 & 30.8 & 16.1 & 0.62 & 0.33 & p2d6 & 2.46 & 0.0005184 & 0.0007662 & 0.0011729 & 0.4080 \\
\hline 2007137 & $7 / 27 \mathrm{D} 1$ & $345 \_60206 Y_{C} \_8$ & $337 / 8$ & $\mathrm{~s}$ & 9 & 4437.4 & $681 / 8$ & 62 & 0.446 & 0.669 & HLP-22 & 12 & 8 & 4 & 1.9 & 10.5 & 5.7 & 30.8 & 16.1 & 0.62 & 0.33 & $\mathrm{p} 2 \mathrm{~d} 6$ & 2.46 & 0.0005184 & 0.0007662 & 0.0011729 & 0.4080 \\
\hline 20071381 & $7 / 27 \mathrm{DI}$ & 34S_6p206rc 8 & $337 / 8$ & $\mathrm{~s}$ & 9 & 4437.4 & $681 / 8$ & 62 & 0.446 & 0.669 & HLP-22 & 12 & 8 & 4 & 1.9 & 10.5 & 5.7 & 30.8 & 16.1 & 0.62 & 0.33 & $\mathrm{p} 2 \mathrm{~d} 6$ & 2.46 & 0.0005184 & 0.0007662 & 0.0011729 & 0.4080 \\
\hline 20071382 & $7 / 27 \mathrm{D1}$ & $345602206 Y_{c} 8$ & $337 / 8$ & $\mathrm{~s}$ & 9 & 4437.4 & $681 / 8$ & 62 & 0.446 & 0.669 & HLP-22 & 12 & 8 & 4 & 1.9 & 10.5 & 5.7 & 30.8 & 16.1 & 0.62 & 0.33 & $\mathrm{p} 2 \mathrm{~d} 6$ & 2.46 & 0.0005184 & 0.0007662 & 0.0011729 & 0.4080 \\
\hline 20071383 & $7 / 27 \mathrm{D} 1$ & 34s_6p2d6Yc_8 & $337 / 8$ & $s$ & 9 & 4437.4 & $681 / 8$ & 62 & 0.446 & 0.669 & HLP-22 & 12 & 8 & 4 & 1.9 & 10.5 & 5.7 & 30.8 & 16.1 & 0.62 & 0.33 & $\mathrm{p} 2 \mathrm{~d} 6$ & 2.46 & 0.0005184 & 0.0007662 & 0.0011729 & 0.4080 \\
\hline 20071387 & $7 / 27 \mathrm{~B} 2$ & 34S_6p2d6Ya & $337 / 8$ & $\mathrm{~s}$ & 9 & 4437.4 & $68 \mathrm{I} / 8$ & 62 & 0.446 & 0.669 & HLP -22 & 12 & 8 & 4 & 19 & 10.5 & 5.7 & 30.8 & 16.1 & 0.62 & 0.33 & $\mathrm{p} 2 \mathrm{~d} 6$ & 2.46 & 0.0005184 & 0.0007662 & 0.0011729 & 0.4080 \\
\hline 20071339 & $7 / 27 \mathrm{~B} 2$ & 345_6p206ra & $337 / 8$ & $\mathrm{~s}$ & 9 & 4437.4 & $681 / 8$ & 62 & 0.446 & 0.669 & HLP-22 & 12 & 8 & 4 & 19 & 10.5 & 5.7 & 30.8 & 16.1 & 0.62 & 0.33 & $\mathrm{p} 2 \mathrm{~d} 6$ & 2.46 & 0.0005184 & 0.0007662 & 0.0011729 & 0.4080 \\
\hline 20071390 & $7 / 27 \mathrm{~B} 2$ & 345_6p206ra & $337 / 8$ & $\mathrm{~s}$ & 9 & 4437.4 & $681 / 8$ & 62 & 0.446 & 0.669 & HLP-22 & 12 & 8 & 4 & 19 & 10.5 & 5.7 & 30.8 & 16.1 & 0.62 & 0.33 & $\mathrm{p} 2 \mathrm{~d} 6$ & 2.46 & 0.0005184 & 0.0007662 & 0.0011729 & 0.4080 \\
\hline 20071394 & $7 / 27 \mathrm{~B} 2$ & 345 6p2016Ya & $337 / 8$ & $\mathrm{~s}$ & 9 & 4437.4 & $681 / 8$ & 62 & 0.446 & 0.669 & HLP-22 & 12 & 8 & 4 & 1.9 & 10.5 & 5.7 & 30.8 & 16.1 & 0.62 & 0.33 & $\mathrm{p} 2 \mathrm{~d} 6$ & 2.46 & 0.0005184 & 0.0007662 & 0.0011729 & 0.4080 \\
\hline 20071397 & $7 / 27 \mathrm{~B} 2$ & 345_6p2d6YYa & $337 / 8$ & $\mathrm{~s}$ & 9 & 4437.4 & $681 / 8$ & 62 & 0.446 & 0.669 & HLP-22 & 12 & 8 & 4 & 19 & 10.5 & 5.7 & 30.8 & 16.1 & 0.62 & 0.33 & $\mathrm{p} 2 \mathrm{~d} 6$ & 2.46 & 0.0005184 & 0.0007662 & 0.0011729 & 0.4080 \\
\hline 20071401 & $7 / 27 \mathrm{~B} 2$ & 345_6p2d6ra & $337 / 8$ & $\mathrm{~s}$ & 9 & 4437.4 & $681 / 8$ & 62 & 0.446 & 0.669 & HLP-22 & 12 & 8 & 4 & 1.9 & 10.5 & 5.7 & 30.8 & 16.1 & 0.62 & 0.33 & $\mathrm{p} 2 \mathrm{~d} 6$ & 2.46 & 0.0005184 & 0.0007662 & 0.0011729 & 0.4080 \\
\hline
\end{tabular}


Table B.7. Data from July 2007 Tests in Mid-Scale Vessel with Spherical Head B.8

\begin{tabular}{|c|c|c|c|c|c|c|c|c|c|c|c|c|c|c|c|c|c|c|c|c|c|c|c|c|c|c|c|c|c|}
\hline $\begin{array}{l}\text { Tank Water } \\
\text { Temperature }\end{array}$ & $\begin{array}{l}\text { Water } \\
\text { Density }\end{array}$ & $\begin{array}{l}\text { Solids } \\
\text { Fraction }\end{array}$ & $\begin{array}{l}\text { Pulse } \\
\text { Volume } \\
\text { Fraction }\end{array}$ & $\begin{array}{l}\text { Duty } \\
\text { Cycle }\end{array}$ & $\begin{array}{l}\text { Cyde } \\
\text { Time }\end{array}$ & $\begin{array}{l}\text { Pulsed } \\
\text { Steady } \\
\text { Seet } \\
\text { Jet }\end{array}$ & $\begin{array}{l}\text { Steacady } \\
\text { Jet }\end{array}$ & \begin{tabular}{|c|} 
Pulsing \\
Jet
\end{tabular} & \begin{tabular}{|c} 
U2 \\
URNS \\
\end{tabular} & $\begin{array}{c}\text { U3 } \\
\text { URNB } \\
\end{array}$ & $\begin{array}{l}\text { Discharge } \\
\text { Velocity }\end{array}$ & $\begin{array}{c}\text { Coritical } \\
\text { Suspension } \\
\text { Velocity }\end{array}$ & \begin{tabular}{|c|} 
Average \\
Peak \\
Cloud \\
Height \\
\end{tabular} & $\begin{array}{l}\text { UCS } \\
\text { Condition }\end{array}$ & \begin{tabular}{|c|} 
UCS \\
Nethod \\
\end{tabular} & $\begin{array}{l}\text { UCS } \\
\text { Hag }\end{array}$ & $\begin{array}{c}\text { UCS } \\
\text { Center } \\
\text { Hag }\end{array}$ & \begin{tabular}{|c|} 
ucs udv \\
Hag
\end{tabular} & \begin{tabular}{|c} 
UCS based \\
on \\
Decreasing \\
Velocity \\
\end{tabular} & \begin{tabular}{|c|} 
Inceep \\
Increase/ \\
Decrease
\end{tabular} & \begin{tabular}{|c} 
UDV \\
Height \\
Bed
\end{tabular} & \begin{tabular}{|c|} 
Particle \\
Mboion \\
\end{tabular} & $\begin{array}{l}\text { Solids } \\
\text { Level }\end{array}$ & \begin{tabular}{|l|} 
Outer \\
Bototom \\
Patem \\
\end{tabular} & \begin{tabular}{|} 
Inner \\
Botom \\
Patem \\
Patem
\end{tabular} & Case ID & Test & TDP & $\begin{array}{l}\text { Row } \\
\text { Number }\end{array}$ \\
\hline c & $\mathrm{g} / \mathrm{cm}^{3}$ & fraction & fraction & fraction & $\mathrm{s}$ & text & $\mathrm{m} / \mathrm{s}$ & $\mathrm{m} / \mathrm{s}$ & $\mathrm{m} / \mathrm{s}$ & $\mathrm{m} / \mathrm{s}$ & $\mathrm{m} / \mathrm{s}$ & m/s & in. & $\mathrm{m} / \mathrm{s}$ & text & text & text & text & \begin{tabular}{|l}
$\mathrm{m} / \mathrm{s}$ \\
\end{tabular} & \begin{tabular}{|l} 
text \\
\end{tabular} & $\mathrm{mm}$ & text & text & text & text & text & text & text & text \\
\hline $\mathrm{T}$ & $\rho$ & $\phi_{\mathrm{s}}$ & $\phi_{\mathrm{p}}$ & $\mathrm{DC}$ & $t_{c}$ & Jet & $u_{s}$ & $\mathrm{u}_{1}$ & $\mathrm{U} 2$ & $U_{3}$ & $u$ & Ucs & $H_{c}$ & U Cos & Uan & Uosvis & Ussen & Usuldv & Uos_D & $S_{w}$ & $\mathrm{H}_{\text {bed }}$ & PM & sol & $\mathrm{SPo}$ & $S P_{1}$ & ID & MDDX & $\mathrm{IDP}$ & MSS \\
\hline 25.0 & 0.998 & 0.00487 & 0.048 & 0.180 & 21.9 & $\mathrm{P}$ & NA & 4.52 & 4.87 & 5.04 & 5.50 & 4.00 & 33.63 & NA & NA & NA & NA & NA & NA & NA & NA & $\mathrm{BC}$ & NA & NA & NA & 34s_6p1d8Yd_8 & $7 / 26 \mathrm{~B} 1$ & TDP-WIP-015 & 20071283 \\
\hline NA & NA & 0.00487 & 0.048 & 0.180 & 27.8 & $\mathrm{P}$ & NA & NA & NA & NA & 4.50 & 4.00 & NA & NA & NA & NA & NA & NA & NA & NA & NA & $\mathrm{BC}$ & NA & NA & NA & 34S_6p1d8Yd_8 & $7 / 26 \mathrm{~B} 1$ & TDP-WTP-015 & 20071285 \\
\hline NA & NA & 0.00487 & 0.048 & 0.180 & NA & $\mathrm{P}$ & NA & NA & NA & NA & 4.10 & 4.00 & NA & NA & NA & NA & NA & NA & NA & NA & NA & $B C$ & NA & NA & NA & 34S_6plddYY__ 8 & $7 / 26 \mathrm{~B} 1$ & TDP-WTP-015 & 20071288 \\
\hline 25.0 & 0.998 & 0.00487 & 0.048 & 0.180 & 29.4 & $\mathrm{P}$ & NA & \begin{tabular}{|l|}
3.51 \\
\end{tabular} & 3.68 & $\begin{array}{l}3.76 \\
\end{array}$ & 4.00 & 4.00 & NA & NA & vis dec & ucsis & NA & NA & 4.00 & D & NA & cs & NA & NA & NA & 34s_6p1d8Yd_8 & $7 / 26 \mathrm{~B} 1$ & TDP-WTP-015 & 20071291 \\
\hline 27.0 & 0.998 & 0.00487 & 0.048 & 0.180 & 30.6 & $\mathrm{P}$ & NA & 3.51 & 3.68 & 3.77 & 4.00 & 4.00 & NA & 4.00 & vis & ucsis & NA & NA & NA & 1 & NA & cs & NA & NA & NA & 34S_6p1d8Yd_8 & $7 / 27 \mathrm{~A}_{1}$ & TDP-WIP-016 & 20071302 \\
\hline NA & NA & 0.00487 & 0.048 & 0.180 & 32.8 & $\mathrm{P}$ & NA & NA & NA & NA & 3.80 & 4.00 & NA & NA & NA & NA & NA & NA & NA & NA & NA & SSIAM & NA & NA & NA & 34s_6p1d8Yd_8 & $7 / 27 \mathrm{~A} 1$ & TDP-WIP-016 & 20071305 \\
\hline NA & NA & 0.00487 & 0.048 & 0.180 & NA & $\mathrm{P}$ & NA & NA & NA & NA & 4.50 & 4.00 & NA & NA & NA & NA & NA & NA & NA & NA & NA & $\mathrm{BC}$ & NA & NA & NA & 34s_6p1d8Yd_8 & $7 / 27 \mathrm{~A} 1$ & TDP-WTP-016 & 20071308 \\
\hline NA & NA & 0.00487 & 0.048 & 0.330 & 21.0 & $\mathrm{P}$ & NA & NA & NA & NA & 3.20 & 3.60 & NA & NA & NA & NA & NA & NA & NA & NA & NA & $A M$ & NA & NA & NA & 34s_6p1d8Yc_ 8 & $7 / 27 \mathrm{~B} 1$ & TDP-WIP-016 & 20071313 \\
\hline NA & NA & 0.00487 & 0.048 & 0.330 & 19.2 & $P$ & NA & NA & NA & NA & 3.50 & 3.60 & NA & NA & NA & NA & NA & NA & NA & NA & NA & $A M$ & NA & NA & NA & 34S_6ppldaYc 8 & $7 / 27 \mathrm{~B} 1$ & TDP-WIP-016 & 20071315 \\
\hline 27.0 & \begin{tabular}{|l|l|} 
& 0.998 \\
\end{tabular} & 0.00487 & 0.048 & 0.330 & 18.5 & $\mathrm{P}$ & NA & \begin{tabular}{|l|}
.19 \\
\end{tabular} & 3.32 & $\begin{array}{r}3.39 \\
\end{array}$ & 3.60 & 3.60 & NA & 3.60 & vis & UCSuis & NA & NA & NA & 1 & NA & cs & NA & NA & NA & 34s_6p1d8Yc_8 & $7 / 27 \mathrm{~B} 1$ & TDP-WTP-016 & 20071318 \\
\hline NA & NA & 0.00487 & 0.048 & 0.330 & 16.1 & $\mathrm{P}$ & NA & NA & NA & NA & 4.50 & 3.60 & NA & NA & NA & NA & NA & NA & NA & NA & NA & NA & NA & NA & NA & 34s_6p1d8Yc 8 & $7 / 27 \mathrm{~B} 1$ & TDP-WTP-016 & 20071321 \\
\hline NA & NA & 0.00487 & 0.048 & 0.330 & 16.1 & $\mathrm{P}$ & NA & NA & NA & NA & 4.45 & 3.60 & NA & NA & NA & NA & NA & NA & NA & NA & NA & $B C$ & NA & NA & NA & 34s_6pld8Yc_8 & $7 / 27 \mathrm{~B} 1$ & TDP-WIP-016 & 20071323 \\
\hline NA & NA & 0.00487 & 0.048 & 0.330 & 17.4 & $\mathrm{P}$ & NA & NA & NA & NA & 3.80 & 3.60 & NA & NA & NA & NA & NA & NA & NA & NA & NA & $B C$ & NA & NA & NA & 34s_6p1d8Yc_ 8 & $7 / 27 \mathrm{~B} 1$ & TDP-WIP-016 & 20071325 \\
\hline 27.0 & 0.998 & 0.00487 & 0.048 & 0.330 & 18.7 & $\mathrm{P}$ & NA & \begin{tabular}{|l|}
3.18 \\
\end{tabular} & 3.33 & $\begin{array}{r}3.39 \\
\end{array}$ & 3.60 & 3.60 & 12.63 & NA & vis dec & ucsis & NA & NA & 3.60 & $\mathrm{D}$ & NA & cs & NA & NA & NA & 34S_6pld8Yc_8 & $7 / 27 \mathrm{~B} 1$ & TDP-WIP-016 & 20071327 \\
\hline NA & NA & 0.00485 & 0.048 & 0.180 & 22.2 & $\mathrm{P}$ & NA & NA & NA & NA & 5.50 & 6.00 & NA & NA & NA & NA & NA & NA & NA & NA & NA & $A M$ & NA & NA & NA & 34s_6p2d6Yd_8 & $7 / 27 \mathrm{Cl}$ & TDP-WTP-017 & 20071331 \\
\hline NA & NA & 0.00485 & 0.048 & 0.180 & 21.5 & $\mathrm{P}$ & NA & NA & NA & NA & 5.70 & 6.00 & NA & NA & NA & NA & NA & NA & NA & NA & NA & $A M$ & NA & NA & NA & 34s_6p2d6Yd_8 & $7 / 27 \mathrm{Cl}$ & TDP-WIP-017 & 20071335 \\
\hline 23.0 & 0.999 & 0.00485 & 0.048 & 0.180 & 20.8 & $\mathrm{P}$ & NA & 4.75 & 5.17 & 5.37 & 6.00 & 6.00 & NA & 6.00 & vis & ucsis & NA & NA & NA & 1 & NA & cs & NA & NA & NA & 34S_6p2d6Yd_8 8 & $7 / 27 \mathrm{Cl}_{1}$ & TDP-WIP-017 & 20071338 \\
\hline NA & NA & 0.00485 & 0.048 & 0.180 & 19.7 & $\mathrm{P}$ & NA & NA & NA & NA & 6.58 & 6.00 & NA & NA & NA & NA & NA & NA & NA & NA & NA & $B C$ & NA & NA & NA & 34s_6p2d6Yd_8 & $7 / 27 \mathrm{Cl}$ & TDP-WIP-017 & 20071343 \\
\hline NA & NA & 0.00485 & 0.048 & 0.180 & 19.7 & $P$ & NA & NA & NA & NA & 6.60 & 6.00 & NA & NA & NA & NA & NA & NA & NA & NA & NA & $B C$ & NA & NA & NA & 345 6p2dord 8 & $7 / 27 \mathrm{Cl}$ & TDP-WIP-017 & 20071344 \\
\hline NA & NA & 0.00485 & 0.048 & 0.180 & 20.8 & $\mathrm{P}$ & NA & NA & NA & NA & 6.10 & 6.00 & NA & NA & NA & NA & NA & NA & NA & NA & NA & $B C$ & NA & NA & NA & 34s_6p2d6Yd_8 & $7 / 27 \mathrm{Cl}$ & TDP-WIP-017 & 20071350 \\
\hline 23.0 & 0.999 & 0.00485 & 0.048 & 0.180 & 21.1 & $\mathrm{P}$ & NA & \begin{tabular}{|l|}
4.79 \\
\end{tabular} & 5.20 & \begin{tabular}{|l}
5.39 \\
\end{tabular} & 6.00 & 6.00 & NA & NA & vis dec & ucsis & NA & NA & 6.00 & D & NA & cs & NA & NA & NA & 34S_6p2d6Yd_8 8 & $7 / 27 \mathrm{C} 1$ & TDP-WTP-017 & 20071353 \\
\hline NA & NA & 0.00485 & 0.048 & 0.330 & 14.9 & $\mathrm{P}$ & NA & NA & NA & NA & 4.35 & 6.00 & NA & NA & NA & NA & NA & NA & NA & NA & NA & ss & NA & NA & NA & 34s_6p2d6Yc 8 & $7 / 27 \mathrm{D} 1$ & TDP-WIP-017 & 20071356 \\
\hline NA & NA & 0.00485 & 0.048 & 0.330 & NA & $P$ & NA & NA & NA & NA & 4.10 & 6.00 & NA & NA & NA & NA & NA & NA & NA & NA & NA & ss & NA & NA & NA & 345 6p2dorc 8 & $7 / 27 \mathrm{D} 1$ & TDP-WIP-017 & 20071358 \\
\hline NA & NA & 0.00485 & 0.048 & 0.330 & NA & $\mathrm{P}$ & NA & NA & NA & NA & 5.00 & 6.00 & NA & NA & NA & NA & NA & NA & NA & NA & NA & ss & NA & NA & NA & $34 \mathrm{~S} 6 \mathrm{p} 2 \mathrm{~d} 6 \mathrm{Yc} \_8$ & $7 / 27 \mathrm{D} 1$ & TDP-WIP-017 & 20071360 \\
\hline NA & NA & 0.00485 & 0.048 & 0.330 & 12.6 & $\mathrm{P}$ & NA & NA & NA & NA & 5.50 & 6.00 & NA & NA & NA & NA & NA & NA & NA & NA & NA & $A M$ & NA & NA & NA & 34s_6p2d6Yc 8 & $7 / 27 \mathrm{D} 1$ & TDP-WIP-017 & 20071362 \\
\hline NA & NA & 0.00485 & 0.048 & 0.330 & 12.1 & $\mathrm{P}$ & NA & NA & NA & NA & 5.75 & 6.00 & NA & NA & NA & NA & NA & NA & NA & NA & NA & $A M$ & NA & NA & NA & 34S_6p2d6rс_ 8 & $7 / 27 \mathrm{D} 1$ & TDP-WTP-017 & 20071367 \\
\hline 23.0 & 0.999 & 0.00485 & 0.048 & 0.330 & 11.6 & $\mathrm{P}$ & NA & 4.74 & 5.17 & \begin{tabular}{|l|} 
\\
\end{tabular} & 6.00 & 6.00 & NA & 6.00 & vis & UCSuis & NA & NA & NA & 1 & NA & cs & NA & NA & NA & $34 \mathrm{~s} 6 \mathrm{p} 2 \mathrm{~d} 6 \mathrm{Yc} \_8$ & $7 / 27 \mathrm{D} 1$ & TDP-WIP-017 & 20071369 \\
\hline NA & NA & 0.00485 & 0.048 & 0.330 & 10.6 & $P$ & NA & NA & NA & NA & 6.60 & 6.00 & NA & NA & NA & $\mathrm{NA}$ & NA & NA & NA & NA & NA & $B C$ & NA & NA & NA & 345 6p2doYc 8 & $7 / 27 \mathrm{D} 1$ & TDP-WIP-017 & 20071371 \\
\hline NA & NA & 0.00485 & 0.048 & 0.330 & 10.7 & $\mathrm{P}$ & NA & NA & NA & NA & 6.10 & 6.00 & NA & NA & NA & NA & NA & NA & NA & NA & NA & $B C$ & NA & NA & NA & 34S_6p2d6Yc_8 & $7 / 27 \mathrm{D} 1$ & TDP-WIP-017 & 20071374 \\
\hline 23.0 & 0.999 & 0.00485 & 0.048 & 0.330 & 11.6 & $\mathrm{P}$ & NA & \begin{tabular}{|l|}
4.72 \\
\end{tabular} & 5.16 & \begin{tabular}{|l}
5.36 \\
\end{tabular} & 6.00 & 6.00 & NA & NA & vis dec & ucsis & NA & NA & 6.00 & D & NA & cs & NA & NA & NA & 34s_6p2d6Yc 8 & $7 / 27 \mathrm{D} 1$ & TDP-WIP-017 & 2007137 \\
\hline NA & NA & 0.00485 & 0.048 & 0.330 & 11.7 & $\mathrm{P}$ & NA & NA & NA & NA & 5.80 & 6.00 & NA & NA & NA & NA & NA & NA & NA & NA & NA & $A M$ & NA & NA & NA & 34S_6p2d6rс_ 8 & $7 / 27 \mathrm{D} 1$ & TDP-WTP-017 & 20071381 \\
\hline NA & NA & 0.00485 & 0.048 & 0.330 & 11.7 & $\mathrm{P}$ & NA & NA & NA & NA & 5.85 & 6.00 & NA & NA & NA & NA & NA & NA & NA & NA & NA & $A M$ & NA & NA & NA & 34s_6p2d6Yc_8 & $7 / 27 \mathrm{D} 1$ & TDP-WIP-017 & 20071382 \\
\hline NA & NA & 0.00485 & 0.048 & 0.330 & NA & $\mathrm{P}$ & NA & NA & NA & NA & 1.55 & 6.00 & NA & NA & NA & NA & NA & NA & NA & NA & NA & NA & NA & NA & NA & $34 \mathrm{~s} 6 \mathrm{p} 2 \mathrm{~d} 6 \mathrm{Yc} \_8$ & $7 / 27 \mathrm{D} 1$ & TDP-WTP-017 & 20071383 \\
\hline NA & NA & 0.00485 & undefined & 1.000 & infinite & $\mathrm{s}$ & NA & NA & NA & NA & 4.06 & 5.75 & NA & NA & NA & NA & NA & NA & NA & NA & NA & ss & NA & NA & NA & 34s_6p2d6Ya & $7 / 27 \mathrm{~B} 2$ & TDP-WIP-017 & 20071387 \\
\hline NA & NA & 0.00485 & undefined & 1.000 & infinite & $\mathrm{s}$ & NA & NA & NA & NA & 4.00 & 5.75 & NA & NA & NA & NA & NA & NA & NA & NA & NA & ss & NA & NA & NA & 34__fp2d6Ya & $7 / 27 \mathrm{~B} 2$ & TDP-WIP-017 & 20071389 \\
\hline NA & NA & 0.00485 & undefined & 1.000 & infinite & $\mathrm{s}$ & NA & NA & NA & NA & 5.00 & 5.75 & NA & NA & NA & NA & NA & NA & NA & NA & NA & ss & NA & NA & NA & 34__fp2d6Ya & $7 / 27 \mathrm{~B} 2$ & TDP-WIP-017 & 20071390 \\
\hline NA & NA & 0.00485 & defined & 1.000 & infinite & $\mathrm{s}$ & NA & NA & NA & NA & 5.50 & 5.75 & NA & NA & NA & NA & NA & NA & NA & NA & NA & $A M$ & NA & NA & NA & 345_6p2d6Ya & $7 / 27 \mathrm{~B} 2$ & TDP-WTP-017 & 20071394 \\
\hline 24.7 & 0.998 & 0.00485 & undefined & 1.000 & infinite & $s$ & 5.75 & NA & NA & NA & 5.75 & 5.75 & NA & 5.75 & vis & UCSvis & NA & NA & NA & NA & NA & cs & NA & NA & NA & 34s_6p2d6Ya & $7 / 27 \mathrm{~B} 2$ & TDP-WIP-017 & 20071397 \\
\hline 24.8 & 0.998 & 0.00485 & undefined & 1.000 & infinite & $\mathrm{s}$ & 5.53 & NA & NA & $N A$ & 5.50 & 5.75 & NA & NA & $N A$ & NA & NA & NA & NA & NA & $N A$ & $A M$ & $\mathrm{NA}$ & $\mathrm{NA}$ & NA & 345_ 6p2d6ra & $7 / 27 \mathrm{~B} 2$ & TDP-WIP-017 & 200714001 \\
\hline
\end{tabular}


Table B.8. Data from Fall 2007 Tests in Mid-Scale Vessel with Spherical Head A.1

\begin{tabular}{|c|c|c|c|c|c|c|c|c|c|c|c|c|c|c|c|c|c|c|c|c|c|c|c|c|c|c|c|}
\hline $\begin{array}{l}\text { Row } \\
\text { Number }\end{array}$ & Test & Case ID & \begin{tabular}{c|} 
Tank \\
Diameter
\end{tabular} & $\begin{array}{l}\text { Head } \\
\text { Shape }\end{array}$ & $\begin{array}{l}\text { Dish } \\
\text { Height }\end{array}$ & $\begin{array}{l}\text { Dish } \\
\text { Volume }\end{array}$ & $\begin{array}{l}\text { Tank } \\
\text { Fill } \\
\text { Height }\end{array}$ & $\begin{array}{c}\text { Retum } \\
\text { Line } \\
\text { Height } \\
\end{array}$ & $\begin{array}{c}\text { Nozzle } \\
\text { Inner } \\
\text { Diameter }\end{array}$ & \begin{tabular}{|c|} 
Nozzle \\
Stanch \\
of \\
Distance \\
\end{tabular} & $\begin{array}{l}\text { Pulse Tube } \\
\text { Configuration }\end{array}$ & $\begin{array}{l}\text { Installed } \\
\text { Nozzles }\end{array}$ & $\begin{array}{c}\text { Outer } \\
\text { Nozzles } \\
\text { Opperated }\end{array}$ & $\begin{array}{c}\text { Inner } \\
\text { Nozzles } \\
\text { Opperated }\end{array}$ & $\begin{array}{c}\text { Pulse Tube } \\
\text { Outer } \\
\text { Diameter }\end{array}$ & \begin{tabular}{|c} 
Outer \\
PJM \\
Radius \\
\end{tabular} & $\begin{array}{c}\text { Inner } \\
\text { PJM } \\
\text { Radius } \\
\text { Ratis }\end{array}$ & $\begin{array}{c}\text { "FO' Outer } \\
\text { PJM } \\
\text { PJingenent } \\
\text { Angle }\end{array}$ & $\begin{array}{c}\text { "FO" Inner } \\
\text { PJM } \\
\text { Impingement } \\
\text { Angle } \\
\end{array}$ & $\begin{array}{c}\text { Ratio Outer } \\
\text { PJM to } \\
\text { Tank } \\
\text { Radius } \\
\end{array}$ & $\begin{array}{c}\text { Ratio Inner } \\
\text { PJM to } \\
\text { Tank } \\
\text { Radius } \\
\end{array}$ & Simulant & $\begin{array}{l}\text { Solids } \\
\text { Density }\end{array}$ & $\begin{array}{c}\text { Particle } \\
\text { Diameter } 05\end{array}$ & $\begin{array}{c}\text { Particle } \\
\text { Diameter } \\
\text { d50 } \\
\end{array}$ & $\begin{array}{c}\text { Particle } \\
\text { Diameter } \\
\text { d95 } \\
\end{array}$ & $\begin{array}{l}\text { Void } \\
\text { Fraction }\end{array}$ \\
\hline text & text & text & in. & text & in. & in. ${ }^{3}$ & in. & in. & in. & in. & text & number & number & $\begin{array}{ll}\text { number } \\
\end{array}$ & in. & in. & in. & deg & deg & nondim & nondim & text & $g / \mathrm{cm}^{3}$ & $\mathrm{~m}$ & $\mathrm{~m}$ & $\mathrm{~m}$ & fraction \\
\hline MSS & MDDX & ID & $\mathrm{D}$ & $\mathrm{HS}$ & Hosh & $V_{\text {dish }}$ & $\mathrm{H}$ & Rin & $d$ & sod & PT & $\mathrm{N}$ & $\mathrm{Nb}$ & $\mathrm{N}$ & $\mathrm{PT}_{\alpha \mathrm{d}}$ & $R_{0}$ & $R$ & $\theta_{0}$ & $\theta_{1}$ & RdR & $R / R$ & sxdx & $\rho_{\mathrm{s}}$ & $d_{5}$ & $d_{60}$ & $d_{65}$ & vf \\
\hline 7090002 & $1017 \mathrm{~A} 1$ & 34S_6p1dr/ra-80 & $337 / 8$ & $\mathrm{~s}$ & 9 & 4437.4 & $673 / 4$ & $613 / 4$ & 0.446 & 0.669 & HLP-22 & 12 & 8 & 0 & 1.9 & 10.5 & 5.7 & 30.8 & 16.1 & 0.62 & 0.33 & p1d7 & 2.45 & 0.0001213 & 0.0001780 & 0.0002606 & 0.4277 \\
\hline 7090004 & $1017 \mathrm{~A} 1$ & 34S_6p1dTra-80 & $337 / 8$ & $\mathrm{~s}$ & 9 & 4437.4 & $673 / 4$ & $613 / 4$ & 0.446 & 0.669 & HLP-22 & 12 & 8 & 0 & 1.9 & 10.5 & 5.7 & 30.8 & 16.1 & 0.62 & 0.33 & p1d7 & 2.45 & 0.0001213 & 0.0001780 & 0.0002606 & 0.4277 \\
\hline 7090006 & $1017 \mathrm{~A} 1$ & 345_6p1dTra-80 & $337 / 8$ & $\mathrm{~s}$ & 9 & 4437.4 & $673 / 4$ & $613 / 4$ & 0.446 & 0.669 & HLP-22 & 12 & 8 & 0 & 1.9 & 10.5 & 5.7 & 30.8 & 16.1 & 0.62 & 0.33 & p1d7 & 2.45 & 0.0001213 & 0.0001780 & 0.0002606 & 0.4277 \\
\hline 7090008 & $1017 \mathrm{~A} 1$ & 34S_6p1d7ra-80 & $337 / 8$ & $\mathrm{~s}$ & 9 & 4437.4 & $673 / 4$ & $613 / 4$ & 0.446 & 0.669 & HLP-22 & 12 & 8 & 0 & 1.9 & 10.5 & 5.7 & 30.8 & 16.1 & 0.62 & 0.33 & pld & 2.45 & 0.0001213 & 0.0001780 & 0.0002606 & 0.4277 \\
\hline 70900012 & $1017 \mathrm{~A} 1$ & 34S_6p1d7ra-80 & $337 / 8$ & $\mathrm{~s}$ & 9 & 4437.4 & $673 / 4$ & $613 / 4$ & 0.446 & 0.669 & HLP-22 & 12 & 8 & 0 & 1.9 & 10.5 & 5.7 & 30.8 & 16.1 & 0.62 & 0.33 & pld & 2.45 & 0.0001213 & 0.0001780 & 0.0002606 & 0.4277 \\
\hline 7090015 & $1017 \mathrm{~A} 1$ & 34S_6p1drra-80 & $337 / 8$ & $\mathrm{~s}$ & 9 & 4437.4 & $673 / 4$ & $613 / 4$ & 0.446 & 0.669 & HLP-22 & 12 & 8 & 0 & 1.9 & 10.5 & 5.7 & 30.8 & 16.1 & 0.62 & 0.33 & p1d7 & 2.45 & 0.0001213 & 0.0001780 & 0.0002606 & 0.4277 \\
\hline 7090019 & 10177A & 34S_6p1dTra-80 & $337 / 8$ & $\mathrm{~s}$ & 9 & 4437.4 & $673 / 4$ & $613 / 4$ & 0.446 & 0.669 & HLP-22 & 12 & 8 & 0 & 1.9 & 10.5 & 5.7 & 30.8 & 16.1 & 0.62 & 0.33 & p1d7 & 2.45 & 0.0001213 & 0.0001780 & 0.0002606 & 0.4277 \\
\hline 7090023 & $10177 \mathrm{~A} 2$ & 34S_6pldrrd_5 5 & $337 / 8$ & $\mathrm{~s}$ & 9 & 4437.4 & $673 / 4$ & $613 / 4$ & 0.446 & 0.669 & HLP-22 & 12 & 8 & 0 & 1.9 & 10.5 & 5.7 & 30.8 & 16.1 & 0.62 & 0.33 & p1d7 & 2.45 & 0.0001213 & 0.0001780 & 0.0002606 & 0.4277 \\
\hline 7090026 & $10177 \mathrm{~A} 2$ & 34s_6p1dTrd_5 5 & $337 / 8$ & $\mathrm{~s}$ & 9 & 4437.4 & $673 / 4$ & $613 / 4$ & 0.446 & 0.669 & HLP-22 & 12 & 8 & 0 & 1.9 & 10.5 & 5.7 & 30.8 & 16.1 & 0.62 & 0.33 & p1d7 & 2.45 & 0.00001213 & 0.0001780 & 0.0002606 & 0.4277 \\
\hline 7090029 & $10177 \mathrm{~A} 2$ & 34 S6p1drYd_ 5 & $337 / 8$ & $\mathrm{~s}$ & 9 & 4437.4 & $673 / 4$ & $613 / 4$ & 0.446 & 0.669 & HLP-22 & 12 & 8 & 0 & 1.9 & 10.5 & 5.7 & 30.8 & 16.1 & 0.62 & 0.33 & p1d7 & 2.45 & 0.0001213 & 0.0001780 & 0.0002606 & 0.4277 \\
\hline 7090032 & $10177 \mathrm{~A} 2$ & 34S_6p1dTYd_5 & $337 / 8$ & $\mathrm{~s}$ & 9 & 4437.4 & $673 / 4$ & $613 / 4$ & 0.446 & 0.669 & HLP-22 & 12 & 8 & 0 & 1.9 & 10.5 & 5.7 & 30.8 & 16.1 & 0.62 & 0.33 & p1d7 & 2.45 & 0.0001213 & 0.0001780 & 0.0002606 & 0.4277 \\
\hline 7090035 & $1017 \mathrm{~A} 2$ & 34S_6p1dTrd 5 5 & $337 / 8$ & $\mathrm{~s}$ & 9 & 4437.4 & $673 / 4$ & $613 / 4$ & 0.446 & 0.669 & HLP-22 & 12 & 8 & 0 & 1.9 & 10.5 & 5.7 & 30.8 & 16.1 & 0.62 & 0.33 & p1d7 & 2.45 & 0.0001213 & 0.0001780 & 0.0002606 & 0.4277 \\
\hline 7090038 & $10177 \mathrm{~A} 2$ & 34S_6pld7Yd_ 5 & $337 / 8$ & $s$ & 9 & 4437.4 & $673 / 4$ & $613 / 4$ & 0.446 & 0.669 & HLP-22 & 12 & 8 & 0 & 1.9 & 10.5 & 5.7 & 30.8 & 16.1 & 0.62 & 0.33 & p1d & 2.45 & 0.0001213 & 0.0001780 & 0.0002606 & 0.4277 \\
\hline 7090040 & $10177 \mathrm{~A} 2$ & 34s_6p1dryd_5 5 & $337 / 8$ & $\mathrm{~s}$ & 9 & 4437.4 & $673 / 4$ & $613 / 4$ & 0.446 & 0.669 & HLP-22 & 12 & 8 & 0 & 1.9 & 10.5 & 5.7 & 30.8 & 16.1 & 0.62 & 0.33 & p1d7 & 2.45 & 0.00001213 & 0.0001780 & 0.0002606 & 0.4277 \\
\hline 7090043 & $10177 \mathrm{A2}$ & 34S_6p1dTrd_5 5 & $337 / 8$ & $\mathrm{~s}$ & 9 & 4437.4 & $673 / 4$ & $613 / 4$ & 0.446 & 0.669 & HLP-22 & 12 & 8 & 0 & 1.9 & 10.5 & 5.7 & 30.8 & 16.1 & 0.62 & 0.33 & p1d7 & 2.45 & 0.0001213 & 0.0001780 & 0.0002606 & 0.4277 \\
\hline 7090046 & $1017 \mathrm{~A} 2$ & 345 6p1dTrd 5 & $337 / 8$ & $\mathrm{~s}$ & 9 & 4437.4 & $673 / 4$ & $613 / 4$ & 0.446 & 0.669 & HLP-22 & 12 & 8 & 0 & 1.9 & 10.5 & 5.7 & 30.8 & 16.1 & 0.62 & 0.33 & p1d7 & 2.45 & 0.0001213 & 0.0001780 & 0.0002606 & 0.4277 \\
\hline 7090048 & $1017 \mathrm{~A} 2$ & 34S_6p1dTrd 5 5 & $337 / 8$ & $\mathrm{~s}$ & 9 & 4437.4 & $673 / 4$ & $613 / 4$ & 0.446 & 0.669 & HLP-22 & 12 & 8 & 0 & 1.9 & 10.5 & 5.7 & 30.8 & 16.1 & 0.62 & 0.33 & p1d7 & 2.45 & 0.0001213 & 0.0001780 & 0.0002606 & 0.4277 \\
\hline 7090052 & $10177 \mathrm{~A} 2$ & 34S_6pld7Yd_ 5 & $337 / 8$ & $s$ & 9 & 4437.4 & $673 / 4$ & $613 / 4$ & 0.446 & 0.669 & HLP-22 & 12 & 8 & 0 & 1.9 & 10.5 & 5.7 & 30.8 & 16.1 & 0.62 & 0.33 & pld & 2.45 & 0.0001213 & 0.0001780 & 0.0002606 & 0.4277 \\
\hline $7090054 M$ & $10 / 17 \mathrm{AP}$ & 34S_6pldrrd_5 5 & $337 / 8$ & $\mathrm{~s}$ & 9 & 4437.4 & $673 / 4$ & $613 / 4$ & 0.446 & 0.669 & HLP-22 & 12 & 8 & 0 & 1.9 & 10.5 & 5.7 & 30.8 & 16.1 & 0.62 & 0.33 & p1d7 & 2.45 & 0.0001213 & 0.0001780 & 0.0002606 & $0.42 \pi$ \\
\hline 7090056 & $10 / 18 A 1$ & 34s_6p1drra-44 & $337 / 8$ & $\mathrm{~s}$ & 9 & 4437.4 & $673 / 4$ & $613 / 4$ & 0.446 & 0.669 & HLP-22 & 12 & 4 & 4 & 1.9 & 10.5 & 5.7 & 30.8 & 16.1 & 0.62 & 0.33 & pld & 2.45 & 0.0001213 & 0.0001780 & 0.0002606 & 0.4277 \\
\hline 7090059 & $1018 \mathrm{~A} 1$ & 34S_6p1dr/a-44 & $337 / 8$ & $\mathrm{~s}$ & 9 & 4437.4 & $673 / 4$ & $613 / 4$ & 0.446 & 0.669 & HLP-22 & 12 & 4 & 4 & 1.9 & 10.5 & 5.7 & 30.8 & 16.1 & 0.62 & 0.33 & p1d7 & 2.45 & 0.0001213 & 0.0001780 & 0.0002606 & 0.4277 \\
\hline 7090063 & $1018 \mathrm{~A} 1$ & 34S_6pldrra-44 & $337 / 8$ & $\mathrm{~s}$ & 9 & 4437.4 & $673 / 4$ & $613 / 4$ & 0.446 & 0.669 & HLP-22 & 12 & 4 & 4 & 1.9 & 10.5 & 5.7 & 30.8 & 16.1 & 0.62 & 0.33 & p1d7 & 2.45 & 0.0001213 & 0.0001780 & 0.0002606 & 0.4277 \\
\hline 7090066 & $1018 \mathrm{~A} 1$ & 34s_6p1dr/ra-44 & $337 / 8$ & $s$ & 9 & 4437.4 & $673 / 4$ & $613 / 4$ & 0.446 & 0.669 & HLP-22 & 12 & 4 & 4 & 1.9 & 10.5 & 5.7 & 30.8 & 16.1 & 0.62 & 0.33 & pld & 2.45 & 0.0001213 & 0.0001780 & 0.0002606 & 0.4277 \\
\hline 7090068 & $1018 \mathrm{~A} 1$ & 34s_6p1drra-44 & $337 / 8$ & $\mathrm{~s}$ & 9 & 4437.4 & $673 / 4$ & $613 / 4$ & 0.446 & 0.669 & HLP-22 & 12 & 4 & 4 & 1.9 & 10.5 & 5.7 & 30.8 & 16.1 & 0.62 & 0.33 & p1d7 & 2.45 & 0.0001213 & 0.0001780 & 0.0002606 & $0.42 \pi$ \\
\hline 7090071 & $1018 \mathrm{~A} 2$ & 34__6p1dr/rdo 0 & $337 / 8$ & $\mathrm{~s}$ & 9 & 4437.4 & $673 / 4$ & $613 / 4$ & 0.446 & 0.669 & HLP-22 & 12 & 4 & 4 & 1.9 & 10.5 & 5.7 & 30.8 & 16.1 & 0.62 & 0.33 & p1d7 & 2.45 & 0.0001213 & 0.0001780 & 0.0002606 & $0.42 \pi$ \\
\hline 70900074 & $1018 \mathrm{~A} 2$ & 34S_6p1dTYd_O & $337 / 8$ & $\mathrm{~s}$ & 9 & 4437.4 & $673 / 4$ & $613 / 4$ & 0.446 & 0.669 & HLP-22 & 12 & 4 & 4 & 1.9 & 10.5 & 5.7 & 30.8 & 16.1 & 0.62 & 0.33 & p1d7 & 2.45 & 0.0001213 & 0.0001780 & 0.0002606 & 0.4277 \\
\hline 70900077 & $1018 \mathrm{~A} 2$ & 34S_6p1dTYd_o & $337 / 8$ & $\mathrm{~s}$ & 9 & 4437.4 & $673 / 4$ & $613 / 4$ & 0.446 & 0.669 & HLP-22 & 12 & 4 & 4 & 1.9 & 10.5 & 5.7 & 30.8 & 16.1 & 0.62 & 0.33 & p1d7 & 2.45 & 0.0001213 & 0.0001780 & 0.0002606 & 0.4277 \\
\hline 7090081 & $1018 \mathrm{~A} 2$ & 34s_6p1dTrd_o & $337 / 8$ & $\mathrm{~s}$ & 9 & 4437.4 & $673 / 4$ & $613 / 4$ & 0.446 & 0.669 & HLP-22 & 12 & 4 & 4 & 1.9 & 10.5 & 5.7 & 30.8 & 16.1 & 0.62 & 0.33 & p1d7 & 2.45 & 0.0001213 & 0.0001780 & 0.0002606 & 0.4277 \\
\hline 7090005 & $1018 \mathrm{~A} 2$ & 34S_6p1d7Yd_O 0 & $337 / 8$ & $s$ & 9 & 4437.4 & $673 / 4$ & $613 / 4$ & 0.446 & 0.669 & HLP-22 & 12 & 4 & 4 & 1.9 & 10.5 & 5.7 & 30.8 & 16.1 & 0.62 & 0.33 & p1d7 & 2.45 & 0.0001213 & 0.0001780 & 0.0002606 & $0.42 \pi$ \\
\hline 7090089 & $10 / 18 A 2$ & 34S_6p1dryd_o & $337 / 8$ & $\mathrm{~s}$ & 9 & 4437.4 & $673 / 4$ & $613 / 4$ & 0.446 & 0.669 & HLP-22 & 12 & 4 & 4 & 1.9 & 10.5 & 5.7 & 30.8 & 16.1 & 0.62 & 0.33 & pld & 2.45 & 0.0001213 & 0.0001780 & 0.0002606 & $0.42 \pi$ \\
\hline $7090095 \mathrm{M}$ & $10 / 18 A 2$ & 34S_6pldryd_o & $337 / 8$ & $\mathrm{~s}$ & 9 & 4437.4 & $673 / 4$ & $613 / 4$ & 0.446 & 0.669 & HLP-22 & 12 & 4 & 4 & 1.9 & 10.5 & 5.7 & 30.8 & 16.1 & 0.62 & 0.33 & p1d7 & 2.45 & 0.0001213 & 0.0001780 & 0.0002606 & 0.4277 \\
\hline 7090097 & 10/18B1 & 34S_6pldrra-40 & $337 / 8$ & $\mathrm{~s}$ & 9 & 4437.4 & $673 / 4$ & $613 / 4$ & 0.446 & 0.669 & HLP-22 & 12 & 4 & 0 & 1.9 & 10.5 & 5.7 & 30.8 & 16.1 & 0.62 & 0.33 & p1d7 & 2.45 & 0.0001213 & 0.0001780 & 0.0002606 & 0.4277 \\
\hline 7090101 & 101881 & 34s_6pldrra-40 & $337 / 8$ & $\mathrm{~s}$ & 9 & 4437.4 & $673 / 4$ & $613 / 4$ & 0.446 & 0.669 & HLP-22 & 12 & 4 & 0 & 1.9 & 10.5 & 5.7 & 30.8 & 16.1 & 0.62 & 0.33 & pld & 2.45 & 0.0001213 & 0.0001780 & 0.0002606 & 0.4277 \\
\hline 7090105 & 101881 & 345_6p1drra-40 & $337 / 8$ & $s$ & 9 & 4437.4 & $673 / 4$ & $613 / 4$ & 0.446 & 0.669 & HLP-22 & 12 & 4 & 0 & 1.9 & 10.5 & 5.7 & 30.8 & 16.1 & 0.62 & 0.33 & p1d7 & 2.45 & 0.0001213 & 0.0001780 & 0.0002606 & $0.42 \pi$ \\
\hline 7090111 & 10188B1 & 345_6pldr/ra-40 & $337 / 8$ & $\mathrm{~s}$ & 9 & 4437.4 & $673 / 4$ & $613 / 4$ & 0.446 & 0.669 & HLP-22 & 12 & 4 & 0 & 1.9 & 10.5 & 5.7 & 30.8 & 16.1 & 0.62 & 0.33 & p1d7 & 2.45 & 0.0001213 & 0.0001780 & 0.0002606 & 0.4277 \\
\hline 7090113 & $1018 \mathrm{~B} 2$ & 34S_6p1dr/Yd_6 & $337 / 8$ & $\mathrm{~s}$ & 9 & 4437.4 & $673 / 4$ & $613 / 4$ & 0.446 & 0.669 & HLP-22 & 12 & 4 & 0 & 1.9 & 10.5 & 5.7 & 30.8 & 16.1 & 0.62 & 0.33 & p1dr & 2.45 & 0.0001213 & 0.0001780 & 0.0002606 & 0.4277 \\
\hline 7090116 & 101882 & 34S_6p1dTYd_6 & $337 / 8$ & $\mathrm{~s}$ & 9 & 4437.4 & $673 / 4$ & $613 / 4$ & 0.446 & 0.669 & HLP-22 & 12 & 4 & 0 & 1.9 & 10.5 & 5.7 & 30.8 & 16.1 & 0.62 & 0.33 & p1d7 & 2.45 & 0.0001213 & 0.0001780 & 0.0002606 & 0.4277 \\
\hline 7090119 & 101882 & 34S_6p1dTrd_6 6 & $337 / 8$ & $s$ & 9 & 4437.4 & $673 / 4$ & $613 / 4$ & 0.446 & 0.669 & HLP-22 & 12 & 4 & 0 & 1.9 & 10.5 & 5.7 & 30.8 & 16.1 & 0.62 & 0.33 & p1d7 & 2.45 & 0.0001213 & 0.0001780 & 0.0002606 & 0.4277 \\
\hline 7090122 & $1018 \mathrm{~B} 2$ & 34S_6p1dTrd_6 6 & $337 / 8$ & $\mathrm{~s}$ & 9 & 4437.4 & $673 / 4$ & $613 / 4$ & 0.446 & 0.669 & HLP-22 & 12 & 4 & 0 & 1.9 & 10.5 & 5.7 & 30.8 & 16.1 & 0.62 & 0.33 & p1d7 & 2.45 & 0.0001213 & 0.0001780 & 0.0002606 & $0.42 \pi$ \\
\hline 7090126 & 101882 & 34s_6p1dr/d_ 6 & $337 / 8$ & $\mathrm{~s}$ & 9 & 4437.4 & $673 / 4$ & $613 / 4$ & 0.446 & 0.669 & HLP-22 & 12 & 4 & 0 & 1.9 & 10.5 & 5.7 & 30.8 & 16.1 & 0.62 & 0.33 & p1d7 & 2.45 & 0.0001213 & 0.0001780 & 0.0002606 & $0.42 \pi$ \\
\hline 7090130 & $1018 \mathrm{~B} 2$ & 34S_6p1dTYd_6 & $337 / 8$ & $\mathrm{~s}$ & 9 & 4437.4 & $673 / 4$ & $613 / 4$ & 0.446 & 0.669 & HLP-22 & 12 & 4 & 0 & 1.9 & 10.5 & 5.7 & 30.8 & 16.1 & 0.62 & 0.33 & p1dr & 2.45 & 0.0001213 & 0.0001780 & 0.0002606 & 0.4277 \\
\hline
\end{tabular}


Table B.8. Data from Fall 2007 Tests in Mid-Scale Vessel with Spherical Head B.1

\begin{tabular}{|c|c|c|c|c|c|c|c|c|c|c|c|c|c|c|c|c|c|c|c|c|c|c|c|c|c|c|c|c|c|}
\hline $\begin{array}{l}\text { Tank Water } \\
\text { Temperature }\end{array}$ & $\begin{array}{l}\text { Water } \\
\text { Density }\end{array}$ & $\begin{array}{l}\text { Solids } \\
\text { Fraction }\end{array}$ & $\begin{array}{l}\text { Pulse } \\
\text { Volume } \\
\text { Fraction }\end{array}$ & $\begin{array}{l}\text { Duty } \\
\text { Oydle }\end{array}$ & $\begin{array}{l}\text { Oyde } \\
\text { Time }\end{array}$ & $\begin{array}{c}\begin{array}{c}\text { Pulsod } \\
\text { Sorac } \\
\text { Steay } \\
\text { Jet }\end{array} \\
\end{array}$ & $\begin{array}{c}\text { Us } \\
\text { Steacy } \\
\text { Jet }\end{array}$ & $\begin{array}{l}\text { U1 } \\
\text { Pulsing } \\
\text { Jet }\end{array}$ & \begin{tabular}{|l} 
U2 \\
URMS \\
\end{tabular} & \begin{tabular}{|c|} 
UR \\
URNB \\
\end{tabular} & $\begin{array}{l}\text { Discharge } \\
\text { Velocity }\end{array}$ & $\begin{array}{c}\text { Citical } \\
\text { Suspension } \\
\text { Velocity }\end{array}$ & $\begin{array}{c}\text { Average } \\
\text { Peak } \\
\text { Coud } \\
\text { Height } \\
\end{array}$ & $\begin{array}{c}\text { UCs } \\
\text { Condition } \\
\end{array}$ & $\begin{array}{l}\text { UCS } \\
\text { Method }\end{array}$ & $\begin{array}{l}\text { UCS } \\
\text { Flag }\end{array}$ & $\begin{array}{c}\text { UCS } \\
\text { Center } \\
\text { Hag }\end{array}$ & $\begin{array}{c}\text { UcS udv } \\
\text { Hag }\end{array}$ & $\begin{array}{l}\text { UcS based } \\
\text { on } \\
\text { Deceasing } \\
\text { Velocity }\end{array}$ & $\begin{array}{l}\text { Sweep } \\
\text { Increase/ } \\
\text { Decrease }\end{array}$ & $\begin{array}{c}\text { UDV } \\
\text { Height } \\
\text { Bed }\end{array}$ & $\begin{array}{l}\text { Particle } \\
\text { Notion }\end{array}$ & $\begin{array}{l}\text { Solids } \\
\text { Level }\end{array}$ & $\begin{array}{l}\text { Outer } \\
\text { Botom } \\
\text { Pattem }\end{array}$ & $\begin{array}{l}\text { Inner } \\
\text { Botom } \\
\text { Patem } \\
\text { Patem }\end{array}$ & Case ID & Test & TDP & $\begin{array}{l}\text { Row } \\
\text { Number }\end{array}$ \\
\hline $\mathrm{c}$ & $\mathrm{g} / \mathrm{cm}^{3}$ & fraction & fraction & fraction & $\mathrm{s}$ & text & $\mathrm{m} / \mathrm{s}$ & $\mathrm{m} / \mathrm{s}$ & m/s & $\mathrm{m} / \mathrm{s}$ & $\mathrm{m} / \mathrm{s}$ & $\mathrm{m} / \mathrm{s}$ & in. & $\mathrm{m} / \mathrm{s}$ & text & text & text & text & $\mathrm{m} / \mathrm{s}$ & text & $\mathrm{mm}$ & text & text & text & text & text & text & text & text \\
\hline $\mathrm{T}$ & $\rho$ & $\phi_{\mathrm{s}}$ & $\phi_{p}$ & $\mathrm{DC}$ & $t_{c}$ & Jet & $u_{s}$ & $\mathrm{U} 1$ & $\mathrm{U} 2$ & U3 & $u$ & Us & $H_{c}$ & U USR & Ussm & Uosis & Usceen & Usosudv & $U_{c s} D$ & $\mathrm{~s}_{\mathrm{v}}$ & $H_{\text {bed }}$ & $\mathrm{PM}$ & Sol & $\mathrm{SP} \mathrm{P}_{\mathrm{O}}$ & $\mathrm{SP}_{1}$ & ID & MDDX & TDP & MSS \\
\hline 21.2 & 0.999 & 0.00487 & undefined & 1.000 & infinite & $\mathrm{s}$ & 3.04 & NA & NA & NA & 3.00 & 4.50 & 8.63 & NA & NA & NA & NA & NA & NA & 1 & NA & ss & NA & NA & NA & 345_6p1d7/Ya-80 & 10/17A1 & TDP-WIP-033 & 7090002 \\
\hline 21.3 & 0.999 & 0.00487 & undefined & 1.000 & infinite & $\mathrm{s}$ & 3.30 & NA & NA & NA & 3.30 & 4.50 & 9.13 & NA & NA & NA & NA & NA & NA & 1 & NA & ss & NA & NA & NA & 34S_6p1d/Ya-80 & 10/17A1 & TDP-WIP-033 & 7090004 \\
\hline 21.2 & 0.999 & 0.00487 & undefined & 1.000 & infinite & $\mathrm{s}$ & 3.74 & NA & NA & NA & 3.70 & 4.50 & 10.13 & NA & NA & NA & NA & NA & NA & 1 & NA & ss & NA & NA & NA & 34s_6p1d7/a-80 & 10/17A1 & TDP-WIP-033 & 7090006 \\
\hline 21.3 & 0.999 & 0.00487 & undefined & 1.000 & infinite & $\mathrm{s}$ & 4.14 & NA & NA & NA & 4.10 & 4.50 & 19.63 & NA & NA & NA & NA & NA & NA & 1 & NA & ss & $\mathrm{sco}$ & BP5 & NA & 34s_6p1d/ra-80 & $1017 \mathrm{AA} 1$ & TDP-WIP-033 & 7090008 \\
\hline 21.3 & 0.999 & 0.00487 & undefined & 1.000 & infrinite & $\mathrm{s}$ & 4.33 & NA & NA & NA & 4.30 & 4.50 & 24.29 & NA & NA & NA & NA & NA & NA & 1 & NA & $A M$ & soo & BP6 & NA & 345_6p1dr/ra-80 & 10/17A 1 & TDP-WTP-033 & 7090012 \\
\hline 21.3 & 0.999 & 0.00487 & undefined & 1.000 & infinite & $\mathrm{s}$ & 4.46 & NA & NA & NA & 4.50 & 4.50 & 31.29 & \begin{tabular}{|l|}
4.50 \\
\end{tabular} & vis & ucsis & NA & NA & NA & 1 & NA & cs & NSS & BP6 & NA & 345_6p1d/7a-80 & 10177A & TDP-WTP-033 & 7090015 \\
\hline 21.3 & 0.999 & 0.00487 & undefined & 1.000 & infinite & $\mathrm{s}$ & 4.40 & NA & NA & NA & 4.40 & 4.50 & 28.29 & NA & vis dec & ucsis & NA & NA & 4.40 & D & NA & cs & NSS & BP6 & NA & 34S_6p1d/Ya-80 & $10177 \mathrm{~A} 1$ & TDP-WIP-033 & 7090019 \\
\hline 21.0 & 0.999 & 0.00487 & 0.053 & 0.180 & 62.5 & $\mathrm{P}$ & NA & 2.91 & 2.95 & 296 & 3.00 & 6.60 & 9.46 & NA & NA & NA & NA & NA & NA & D & NA & ss & NA & NA & NA & 34S_6p1d7Yd_55 & $10177 A^{2}$ & TDP-WIP-033 & 7090023 \\
\hline 21.0 & 0.999 & 0.00487 & 0.060 & 0.180 & 57.1 & $\mathrm{P}$ & NA & 3.41 & 3.45 & 3.48 & 3.50 & 6.60 & 9.96 & NA & NA & NA & NA & NA & NA & 1 & NA & ss & NA & NA & NA & 34S_6p1d7Yd_5 5 & 10/17A2 & TDP-WIP-033 & 7090026 \\
\hline 21.0 & 0.999 & 0.00487 & 0.057 & 0.180 & 48.8 & $\mathrm{P}$ & NA & 3.60 & 3.79 & 3.87 & 4.00 & 6.60 & 11.63 & NA & NA & NA & NA & NA & NA & 1 & NA & ss & NA & NA & NA & 34S_6p1d7Yd_5 & 10/17A2 & TDP-WIP-033 & 7090029 \\
\hline 21.0 & 0.999 & 0.00487 & 0.056 & 0.180 & 40.0 & $\mathrm{P}$ & NA & 3.89 & 4.15 & 4.26 & 4.50 & 6.60 & 11.96 & NA & NA & NA & NA & NA & NA & 1 & NA & ss & NA & NA & NA & 34S_6p1d7Yd_5 & 10117A2 & TDP-WTP-033 & 7090032 \\
\hline 21.0 & 0.999 & 0.00487 & 0.052 & 0.180 & 35.7 & $\mathrm{P}$ & NA & 4.10 & 4.47 & 4.63 & 5.00 & 6.60 & 12.96 & NA & NA & NA & NA & NA & NA & 1 & NA & ss & NA & NA & NA & 34S_6p1d7rd_5 & $10 / 17 \mathrm{~A}^{2}$ & TDP-WIP-033 & 7090035 \\
\hline 21.0 & 0.999 & 0.00487 & 0.053 & 0.180 & 32.3 & $\mathrm{P}$ & NA & 4.24 & 4.75 & 4.97 & 5.50 & 6.60 & 14.63 & NA & NA & NA & NA & NA & NA & 1 & NA & ss & NA & NA & NA & 34S_6p1d7Yd_5 & 10/17A2 & TDP-WTP-033 & 7090038 \\
\hline 21.0 & 0.999 & 0.00487 & 0.051 & 0.180 & 30.2 & $\mathrm{P}$ & NA & 4.19 & 4.82 & 5.10 & 5.80 & 6.60 & 17.13 & NA & NA & NA & NA & NA & NA & 1 & NA & SS+ & $\mathrm{sco}$ & BP5 & NA & 34S_6p1d7Yd_5 5 & 10/17A & TDP-WIP-033 & 7090040 \\
\hline 21.0 & 0.999 & 0.00487 & 0.051 & 0.180 & 29.1 & $\mathrm{P}$ & NA & 4.18 & 4.88 & 5.20 & 6.00 & 6.60 & 19.13 & NA & NA & NA & NA & NA & NA & 1 & NA & $A M$ & sco & BP5 & NA & 34S_6p1d7Yd_5 5 & 10/17A2 & TDP-WIP-033 & 7090043 \\
\hline 21.0 & 0.999 & 0.00487 & 0.053 & 0.180 & 28.7 & $\mathrm{P}$ & NA & 4.12 & 4.93 & 5.30 & 6.20 & 6.60 & 21.63 & NA & NA & NA & NA & NA & NA & 1 & NA & $A M$ & $\mathrm{sco}$ & BP5 & NA & 34S_6p1d7Yd_5 & 10/17A2 & TDP-WIP-033 & 7090046 \\
\hline 21.0 & 0.999 & 0.00487 & 0.051 & 0.180 & 27.0 & $\mathrm{P}$ & NA & 3.97 & 4.88 & 5.30 & 6.40 & 6.60 & 21.63 & NA & NA & NA & NA & NA & NA & 1 & NA & $A M+$ & $\mathrm{sco}$ & BP5 & NA & 34S_6p1d7rd_5 5 & $10 / 17 \mathrm{~A}^{2}$ & TDP-WIP-033 & 7090048 \\
\hline 21.0 & 0.999 & 0.00487 & 0.052 & 0.180 & 27.0 & $\mathrm{P}$ & NA & 3.88 & 4.86 & 5.31 & 6.50 & 6.60 & 22.63 & NA & NA & NA & NA & NA & NA & 1 & NA & $A M$ & sco & BP5 & NA & 34s_6pldr/Yd_5 5 & 10/17A2 & TDP-WIP-033 & 7090052 \\
\hline 21.0 & 0.999 & 0.00487 & 0.053 & 0.180 & 27.0 & $\mathrm{P}$ & NA & 4.24 & 5.14 & 5.55 & 6.60 & 6.60 & 23.63 & \begin{tabular}{|l|}
6.60 \\
\end{tabular} & vis & ucsis & NA & NA & NA & 1 & NA & cs & NSS & BP6 & NA & 34s_6p1d7/Yd_5 5 & $10117 \mathrm{~A} 2$ & TDP-WIP-033 & 7090054 \\
\hline 21.4 & 0.999 & 0.00487 & undefined & 1.000 & infinite & $\mathrm{s}$ & 3.52 & NA & NA & NA & 3.50 & 5.50 & NA & NA & NA & NA & NA & NA & NA & 1 & NA & ss & NA & NA & NA & 34s_6p1d/Ya-44 & 10/18A1 & TDP-WIP-038 & 7090056 \\
\hline 21.4 & 0.999 & 0.00487 & undefined & 1.000 & infinite & $\mathrm{s}$ & 4.02 & NA & NA & NA & 4.00 & 5.50 & 10.00 & NA & NA & NA & NA & NA & NA & 1 & NA & $A M$ & NA & NA & NA & 34s_6p1dr/ra-44 & 10/18A1 & TDP-WTP-038 & 7090059 \\
\hline 21.5 & 0.999 & 0.00487 & undefined & 1.000 & infinite & $\mathrm{s}$ & 4.51 & NA & NA & NA & 4.50 & 5.50 & 16.00 & NA & NA & NA & NA & NA & NA & 1 & NA & AM & NA & NA & NA & 34S_6p1drya-44 & $10 / 18 \mathrm{~A} 1$ & TDP-WIP-038 & 7090063 \\
\hline 21.5 & 0.999 & 0.00487 & undefined & 1.000 & infrinite & $\mathrm{s}$ & 5.01 & NA & NA & NA & 5.00 & 5.50 & 31.00 & NA & NA & NA & NA & NA & NA & 1 & NA & AM & NA & NA & NA & 34s_6p1d7ra-44 & 10/18A1 & TDP-WIP-038 & 7090066 \\
\hline 21.5 & 0.999 & 0.00487 & undefined & 1.000 & infinite & $\mathrm{s}$ & 5.52 & NA & NA & NA & 5.50 & 5.50 & 47.50 & \begin{tabular}{|l|}
5.50 \\
\end{tabular} & vis & ucsis & NA & NA & NA & 1 & NA & cs & NA & NA & NA & 345_6p1drya-44 & 10/18A1 & TDP-WIP-038 & 7090068 \\
\hline 22.0 & 0.999 & 0.00487 & 0.053 & 0.180 & 48.8 & $\mathrm{P}$ & NA & 3.73 & 3.85 & 3.90 & 4.00 & 6.10 & 9.00 & NA & NA & NA & NA & NA & NA & NA & NA & ss & NA & NA & NA & 34s_6p1d7/Yd_0 & 10/18A2 & TDP-WIP-038 & 7090071 \\
\hline 22.0 & 0.999 & 0.00487 & 0.052 & 0.180 & 40.0 & $\mathrm{P}$ & NA & 3.99 & 4.20 & 4.29 & 4.50 & 6.10 & 10.50 & NA & NA & NA & NA & NA & NA & 1 & NA & $A M$ & NA & NA & NA & 34S_6p1d7Yd_0 & 10/18A2 & TDP-WTP-038 & 7090074 \\
\hline 22.0 & 0.999 & 0.00487 & 0.054 & 0.180 & 36.4 & $\mathrm{P}$ & NA & 4.24 & 4.57 & 4.70 & 5.00 & 6.10 & 13.83 & NA & NA & NA & NA & NA & NA & 1 & NA & AM & NA & NA & NA & 34S_6p1d7rd_0 0 & $10 / 18 \mathrm{~A}^{2}$ & TDP-WIP-038 & 7090077 \\
\hline 22.0 & 0.999 & 0.00487 & 0.054 & 0.180 & 33.3 & $\mathrm{P}$ & NA & 4.36 & 4.82 & 5.01 & 5.50 & 6.10 & 15.67 & NA & NA & NA & NA & NA & NA & 1 & NA & AM & NA & NA & NA & 34s_6p1d7/Yd_0 0 & $10 / 18 \mathrm{~A} 2$ & TDP-WTP-038 & 7090081 \\
\hline 22.0 & 0.999 & 0.00487 & 0.051 & 0.180 & 30.8 & $\mathrm{P}$ & NA & 4.43 & 4.93 & 5.15 & 5.70 & 6.10 & 16.67 & NA & NA & NA & NA & NA & NA & 1 & NA & $A M$ & NA & NA & NA & 34s_6p1d7/Yd_0 & $10 / 18 \mathrm{~A} 2$ & TDP-WIP-038 & 7090085 \\
\hline 22.0 & 0.999 & 0.00487 & 0.052 & 0.180 & 30.3 & $\mathrm{P}$ & NA & 4.43 & 5.02 & 5.27 & 5.90 & 6.10 & 17.33 & NA & NA & NA & NA & NA & NA & 1 & NA & AM & NA & NA & NA & 34S_6p1d7rd_0 0 & 10/18A2 & TDP-WIP-038 & 7090089 \\
\hline 22.0 & 0.999 & 0.00487 & 0.052 & 0.180 & 29.4 & $\mathrm{P}$ & NA & 4.46 & 5.11 & 5.39 & 6.10 & 6.10 & 18.83 & \begin{tabular}{|l|}
6.10 \\
\end{tabular} & vis & ucsis & NA & NA & NA & 1 & NA & cs & NA & NA & NA & 34S_6p1d7Yrd_0 & $10 / 18 \mathrm{~A} 2$ & TDP-WTP-038 & 7090095 \\
\hline 21.7 & 0.999 & 0.00487 & undefined & 1.000 & infinite & $\mathrm{s}$ & 5.05 & NA & NA & NA & 5.00 & 5.90 & 11.00 & NA & NA & NA & NA & NA & NA & 1 & NA & ss & NA & NA & NA & 34s_6p1d7/ra-40 & 10/18B1 & TDP-WIP-038 & 7090097 \\
\hline 21.8 & 0.999 & 0.00487 & undefined & 1.000 & infinite & $\mathrm{s}$ & 5.52 & NA & NA & NA & 5.50 & 5.90 & 13.17 & NA & NA & NA & NA & NA & NA & 1 & NA & $A M$ & NA & NA & NA & 34s__ppldrva-40 & 10/18B1 & TDP-WTP-038 & 7090101 \\
\hline 21.8 & 0.999 & 0.00487 & undefined & 1.000 & infinite & $\mathrm{s}$ & 5.72 & NA & NA & NA & 5.70 & 5.90 & 20.33 & NA & NA & NA & NA & NA & NA & 1 & NA & $A M+$ & NA & NA & NA & 345_6p1d7ra-40 & $10 / 18 B 1$ & TDP-WIP-038 & 7090105 \\
\hline 21.8 & 0.999 & 0.00487 & undefined & 1.000 & infinite & $\mathrm{s}$ & 5.93 & NA & NA & NA & 5.90 & 5.90 & 23.33 & 5.90 & vis & UcSis & NA & NA & NA & 1 & NA & cs & NA & NA & NA & 34s_6p1drya-40 & 10/18B1 & TDP-WIP-038 & 7090111 \\
\hline 22.0 & 0.999 & 0.00487 & 0.037 & 0.180 & 87.0 & $\mathrm{P}$ & NA & 3.98 & 4.04 & 4.07 & 4.00 & 6.40 & 9.17 & NA & NA & NA & NA & NA & NA & D & NA & ss & NA & NA & NA & 34S_6p1dTrd_6 6 & 10/18B2 & TDP-WIP-038 & 7090113 \\
\hline 22.0 & 0.999 & 0.00487 & 0.054 & 0.180 & 80.0 & $\mathrm{P}$ & NA & 4.41 & 4.45 & 4.47 & 4.50 & 6.40 & 9.33 & NA & NA & NA & NA & NA & NA & 1 & NA & ss & NA & NA & NA & 34S_6p1d7rd_6 & 10/18B2 & TDP-WIP-038 & 7090116 \\
\hline 22.0 & 0.999 & 0.00487 & 0.054 & 0.180 & 71.4 & $\mathrm{P}$ & NA & 4.92 & 4.97 & 4.99 & 5.00 & 6.40 & 9.50 & NA & NA & NA & NA & NA & NA & 1 & NA & ss & NA & NA & NA & 34s_6p1dTrd_6 6 & 10/18B2 & TDP-WIP-038 & 7090119 \\
\hline 22.0 & 0.999 & 0.00487 & 0.051 & 0.180 & 64.5 & $\mathrm{P}$ & NA & 5.38 & 5.44 & 5.46 & 5.50 & 6.40 & 10.33 & NA & NA & NA & NA & NA & NA & 1 & NA & ss & NA & NA & NA & 34S_6p1d7Yd_6 6 & $10 / 1882$ & TDP-WIP-038 & 7090122 \\
\hline 22.0 & 0.999 & 0.00487 & 0.052 & 0.180 & 58.8 & $\mathrm{P}$ & NA & 5.84 & 5.91 & 5.95 & 6.00 & 6.40 & 11.33 & NA & NA & NA & NA & NA & NA & 1 & NA & AM & NA & NA & NA & $34 S \_6 p 1 d 7 Y d \_6$ & 10/18B2 & TDP-WTP-038 & 7090126 \\
\hline 22.0 & 0.999 & 0.00487 & 0.051 & 0.180 & 57.1 & $P$ & NA & 6.01 & 6.09 & 6.13 & 6.20 & 6.40 & 12.00 & NA & NA & NA & $N A$ & NA & NA & 1 & NA & $A M$ & NA & NA & NA & 34S_6p1dryd_6 6 & 101882 & TDP-WIP-038 & 7090130 \\
\hline
\end{tabular}


Table B.8. Data from Fall 2007 Tests in Mid-Scale Vessel with Spherical Head A.2

\begin{tabular}{|c|c|c|c|c|c|c|c|c|c|c|c|c|c|c|c|c|c|c|c|c|c|c|c|c|c|c|c|}
\hline $\begin{array}{l}\text { Row } \\
\text { Number }\end{array}$ & Test & Case ID & $\begin{array}{c}\text { Tank } \\
\text { Diameter }\end{array}$ & $\begin{array}{l}\text { Head } \\
\text { Shape }\end{array}$ & $\begin{array}{c}\text { Dish } \\
\text { Height }\end{array}$ & $\begin{array}{c}\text { Dish } \\
\text { Volume }\end{array}$ & $\begin{array}{c}\text { Tank Fill } \\
\text { Height }\end{array}$ & $\begin{array}{l}\text { Return } \\
\text { Line } \\
\text { Height }\end{array}$ & $\begin{array}{l}\text { Nozzle } \\
\text { Inner } \\
\text { Dianneter }\end{array}$ & $\begin{array}{l}\text { Nozzle } \\
\text { Stanc-off } \\
\text { Distance }\end{array}$ & $\begin{array}{l}\text { Pulse Tube } \\
\text { Configuration }\end{array}$ & $\begin{array}{l}\text { Installed } \\
\text { Nozzles }\end{array}$ & $\begin{array}{c}\text { Outur } \\
\text { Nozzles } \\
\text { Operate } \\
\text { cat } \\
\end{array}$ & $\begin{array}{c}\text { Inner } \\
\text { Nozzles } \\
\text { Operate } \\
\text { cer }\end{array}$ & $\begin{array}{c}\text { Pulse Tube } \\
\text { Outer } \\
\text { Diameter }\end{array}$ & $\begin{array}{c}\text { Outer } \\
\text { PMM } \\
\text { Radius }\end{array}$ & $\begin{array}{l}\text { Inner } \\
\text { PPM } \\
\text { Radius }\end{array}$ & $\begin{array}{c}\text { "FO" Outer PJM } \\
\text { Impingement } \\
\text { Angle }\end{array}$ & \begin{tabular}{|c|} 
"FO' Inner PJM \\
Impingement \\
Anglele
\end{tabular} & $\begin{array}{l}\text { Ratio Outer } \\
\text { PJMto Tank } \\
\text { Radius } \\
\end{array}$ & $\begin{array}{c}\text { Ratio Inner } \\
\text { PJMt to Tank } \\
\text { Radius } \\
\end{array}$ & Simulant & $\begin{array}{l}\text { Solids } \\
\text { Density }\end{array}$ & $\begin{array}{c}\text { Particle } \\
\text { Diameter d5 }\end{array}$ & $\begin{array}{c}\text { Particle } \\
\text { Diameter } 450\end{array}$ & $\begin{array}{c}\text { Particle } \\
\text { Diameter d95 }\end{array}$ & $\begin{array}{c}\text { Void } \\
\text { Fraction }\end{array}$ \\
\hline text & text & text & in. & text & in. & in. $3^{3}$ & in. & in. & in. & in. & text & number & number | & number & in. & in. & in. & \begin{tabular}{|l} 
deg \\
\end{tabular} & \begin{tabular}{|l} 
deg \\
\end{tabular} & nondim & nondim & text & $g / \mathrm{cm}^{\beta}$ & $m$ & $\mathrm{~m}$ & $\mathrm{~m}$ & fraction \\
\hline MSS & MDDX & ID & $\mathrm{D}$ & HS & Hosh & Vash & $\mathrm{H}$ & $\operatorname{Rtn}$ & $d$ & sod & PT & $\mathrm{N}$ & $\mathrm{No}$ & $\mathrm{N}$ & $\mathrm{PT}_{\alpha \mathrm{d}}$ & $R_{0}$ & $R$ & $\theta_{\circ}$ & $\theta_{1}$ & $R d R$ & $R / R$ & sxdx & $\rho_{\mathrm{s}}$ & $d \mathrm{~d}$ & $d_{0} 0$ & des & vf \\
\hline $7090136 \mathrm{M}$ & $10 / 1882$ & 34S_6p1dTrd_6 6 & $337 / 8$ & $s$ & 9 & 4437.4 & $673 / 4$ & $613 / 4$ & 0.446 & 0.669 & HLP-22 & 12 & 4 & 0 & 1.9 & 10.5 & 5.7 & 30.8 & 16.1 & 0.62 & 0.33 & p1d7 & 2.45 & 0.0001213 & 0.0001780 & 0.0002606 & 0.427 \\
\hline 7090142 & 10/19A1 & 34S_fp1d/ra-04 & $337 / 8$ & $\mathrm{~s}$ & 9 & 4437.4 & $673 / 4$ & $613 / 4$ & 0.446 & 0.669 & HLP-22 & 12 & 0 & 4 & 1.9 & 10.5 & 5.7 & 30.8 & 16.1 & 0.62 & 0.33 & p1d7 & 2.45 & 0.0001213 & 0.0001780 & 0.0002606 & 0.427 \\
\hline 7090144 & 10/19A1 & 34S_6p1dtra-04 & $337 / 8$ & $\mathrm{~s}$ & 9 & 4437.4 & $673 / 4$ & $613 / 4$ & 0.446 & 0.669 & HLP.22 & 12 & 0 & 4 & 1.9 & 10.5 & 5.7 & 30.8 & 16.1 & 0.62 & 0.33 & p1d7 & 2.45 & 0.0001213 & 0.00001780 & 0.0002606 & 0.427 \\
\hline 7090146 & 10/19A1 & 34S 6p1drra-04 & $337 / 8$ & $\mathrm{~s}$ & 9 & 4437.4 & $673 / 4$ & 61344 & 0.446 & 0.669 & HLP -22 & 12 & 0 & 4 & 1.9 & 10.5 & 5.7 & 30.8 & 16.1 & 0.62 & 0.33 & pld7 & 2.45 & 0.0001213 & 0.00001780 & 0.0002606 & \\
\hline 7090149 & 10/19A1 & 34S_6p1dtra-04 & $337 / 8$ & $\mathrm{~s}$ & 9 & 4437.4 & $673 / 4$ & $613 / 4$ & 0.446 & 0.669 & HLP-22 & 12 & 0 & 4 & 1.9 & 10.5 & 5.7 & 30.8 & 16.1 & 0.62 & 0.33 & p1d7 & 2.45 & 0.0001213 & 0.0001780 & 0.0002606 & 0.427 \\
\hline 7090152 & 10/19A1 & 34S_6pldrra-04 & $337 / 8$ & $\mathrm{~s}$ & 9 & 4437.4 & $673 / 4$ & $613 / 4$ & 0.446 & 0.669 & HLP-22 & 12 & 0 & 4 & 1.9 & 10.5 & 5.7 & 30.8 & 16.1 & 0.62 & 0.33 & pld7 & 2.45 & 0.0001213 & 0.0001780 & 0.0002606 & \\
\hline 7090158 & 10/19A1 & 34__6p1drra-04 & $337 / 8$ & $\mathrm{~s}$ & 9 & 4437.4 & $673 / 4$ & $613 / 4$ & 0.446 & 0.669 & HLP-22 & 12 & 0 & 4 & 1.9 & 10.5 & 5.7 & 30.8 & 16.1 & 0.62 & 0.33 & pld7 & 2.45 & 0.0001213 & 0.0001780 & 0.0002606 & 0.427 \\
\hline 7090161 & 10/19A1 & 34S_6pld7ra-04 & $337 / 8$ & $s$ & 9 & 4437.4 & $673 / 4$ & $613 / 4$ & 0.446 & 0.669 & HLP-22 & 12 & 0 & 4 & 1.9 & 10.5 & 5.7 & 30.8 & 16.1 & 0.62 & 0.33 & pld7 & 2.45 & 0.0001213 & 0.00001780 & 0.0002606 & \\
\hline 7090165 & 10/19A1 & 34__6p1drra-04 & $337 / 8$ & $\mathrm{~s}$ & 9 & 4437.4 & $673 / 4$ & $613 / 4$ & 0.446 & 0.669 & HLP-22 & 12 & 0 & 4 & 1.9 & 10.5 & 5.7 & 30.8 & 16.1 & 0.62 & 0.33 & pld7 & 2.45 & 0.0001213 & 0.0001780 & 0.0002606 & 0.427 \\
\hline 7090167 & 10/19A2 & 34S_6p1drYd_ 9 & $337 / 8$ & $\mathrm{~s}$ & 9 & 4437.4 & $673 / 4$ & $613 / 4$ & 0.446 & 0.669 & HLP-22 & 12 & 0 & 4 & 1.9 & 10.5 & 5.7 & 30.8 & 16.1 & 0.62 & 0.33 & pld7 & 2.45 & 0.0001213 & 0.00001780 & 0.0002606 & 0.427 \\
\hline 7090169 & 10/19A2 & 34S_6p1drrd_9 & $337 / 8$ & $\mathrm{~s}$ & 9 & 4437.4 & $673 / 4$ & 6134 & 0.446 & 0.669 & HLP -22 & 12 & 0 & 4 & 1.9 & 10.5 & 5.7 & 30.8 & 16.1 & 0.62 & 0.33 & p1d7 & 2.45 & 0.0001213 & 0.0001780 & 0.0002606 & \\
\hline 7090172 & 10/19A2 & 34S_6p1drYd_ 9 & $337 / 8$ & $s$ & 9 & 4437.4 & $673 / 4$ & $613 / 4$ & 0.446 & 0.669 & HLP-22 & 12 & 0 & 4 & 1.9 & 10.5 & 5.7 & 30.8 & 16.1 & 0.62 & 0.33 & pld7 & 2.45 & 0.0001213 & 0.00001780 & 0.0002606 & 0.427 \\
\hline 7090174 & 10/19A2 & 34S_6p1drYd_9 & $337 / 8$ & $\mathrm{~s}$ & 9 & 4437.4 & $673 / 4$ & $613 / 4$ & 0.446 & 0.669 & HLP-22 & 12 & 0 & 4 & 1.9 & 10.5 & 5.7 & 30.8 & 16.1 & 0.62 & & $\mathrm{p} 1 \mathrm{~d} 7$ & 2.45 & 0.0001213 & 0.0001780 & 0.0002606 & \\
\hline 709017 & $1019 A^{2}$ & 34S_fpldtrd 9 & $337 / 8$ & $\mathrm{~s}$ & 9 & 4437.4 & $673 / 4$ & 6134 & 0.446 & 0.669 & HLP-22 & 12 & 0 & 4 & 1.9 & 10.5 & 5.7 & 30.8 & 16.1 & 0.62 & 0.33 & p1d7 & 2.45 & 0.0001213 & 0.0001780 & 0.0002606 & 0.427 \\
\hline 7090180 & 10/19A2 & 34S_6p1d7Yd_99 & $337 / 8$ & $\mathrm{~s}$ & 9 & 4437.4 & $673 / 4$ & $613 / 4$ & 0.446 & 0.669 & HLP-22 & 12 & 0 & 4 & 1.9 & 10.5 & 5.7 & 30.8 & 16.1 & 0.62 & 0.33 & pld7 & 2.45 & 0.0001213 & 0.0001780 & 0.0002606 & 0.427 \\
\hline 7090184M & $10 / 19 A^{2}$ & 34S_6p1d7Yd_9 9 & $337 / 8$ & $\mathrm{~s}$ & 9 & 4437.4 & $673 / 4$ & $613 / 4$ & 0.446 & 0.669 & HLP-22 & 12 & 0 & 4 & 1.9 & 10.5 & 5.7 & 30.8 & 16.1 & 0.62 & 0.33 & pld7 & 2.45 & 0.0001213 & 0.0001780 & 0.0002606 & \\
\hline 7090186 & 10/26A1 & 34s_6p1dTra & $337 / 8$ & $\mathrm{~s}$ & 9 & 4437.4 & $673 / 4$ & $653 / 4$ & 0.446 & 0.669 & HLP-22 & 12 & 8 & 4 & 1.9 & 10.5 & 5.7 & 30.8 & 16.1 & 0.62 & 0.33 & p1d7 & 2.45 & 0.0001213 & 0.00001780 & 0.0002606 & 0.4277 \\
\hline 7090189 & 10/26A1 & 345_.6p1d/ra & $337 / 8$ & $\mathrm{~s}$ & 9 & 4437.4 & $673 / 4$ & $653 / 4$ & 0.446 & 0.669 & HLP-22 & 12 & 8 & 4 & 1.9 & 10.5 & 5.7 & 30.8 & 16.1 & 0.62 & 0.3 & p1d7 & 2.45 & 0.0001213 & 0.0001780 & 0.0002606 & $0.42 \pi$ \\
\hline 7090198 & 10/26A2 & 34S_6p1d/Yrd_1 & $337 / 8$ & $\mathrm{~s}$ & 9 & 4437.4 & $673 / 4$ & $653 / 4$ & 0.446 & 0.669 & HLP-22 & 12 & 8 & 4 & 1.9 & 10.5 & 5.7 & 30.8 & 16.1 & 0.62 & 0.33 & pld7 & 2.45 & 0.0001213 & 0.0001780 & 0.0002606 & \\
\hline 7090201 & 10/26A2 & 34S_6p1d7rd_1 & $337 / 8$ & $\mathrm{~s}$ & 9 & 4437.4. & $673 / 4$ & $653 / 4$ & 0.446 & 0.669 & HLP-22 & 12 & 8 & 4 & 1.9 & 10.5 & 5.7 & 30.8 & 16.1 & 0.62 & 0.33 & pld7 & 2.45 & 0.0001213 & 0.0001780 & 0.0002606 & $0.4 .4-4.4$ \\
\hline 7090204 & 10/26A2 & 34S_6p1dTrd_1 1 & $337 / 8$ & $\mathrm{~s}$ & 9 & 4437.4 & $673 / 4$ & $653 / 4$ & 0.446 & 0.669 & HLP-22 & 12 & 8 & 4 & 1.9 & 10.5 & 5.7 & 30.8 & 16.1 & 0.62 & $0.3=$ & pld7 & 2.45 & 0.0001213 & 0.00001780 & 0.0002606 & \\
\hline $7000200 \mathrm{n} n$ & 10/26A2 & 34S_6p1drrd_1 1 & $337 / 8$ & $\mathrm{~s}$ & 9 & 4437.4 & $673 / 4$ & $653 / 4$ & 0.446 & 0.669 & HLP -22 & 12 & 8 & 4 & 1.9 & 10.5 & 5.7 & 30.8 & 16.1 & 0.62 & 0.33 & p1d7 & 2.45 & 0.0001213 & 0.0001780 & 0.0002606 & \\
\hline 7090210 & 10/26B1 & 34S_6p1drra-44 & $337 / 8$ & $s$ & 9 & 4437.4 & $673 / 4$ & $653 / 4$ & 0.446 & 0.669 & HLP-22 & 12 & 4 & 4 & 1.9 & 10.5 & 5.7 & 30.8 & 16.1 & 0.62 & 0.33 & pld7 & 2.45 & 0.0001213 & 0.00001780 & 0.0002606 & 0.427 \\
\hline 7090213 & 10/26B1 & 34__6p1drYa-44 & $337 / 8$ & $\mathrm{~s}$ & 9 & 4437.4 & $673 / 4$ & $653 / 4$ & 0.446 & 0.669 & HLP-22 & 12 & 4 & 4 & 1.9 & 10.5 & 5.7 & 30.8 & 16.1 & 0.62 & 0.33 & pld7 & 2.45 & 0.0001213 & 0.0001780 & 0.0002606 & \\
\hline 7090217 & 10/26B1 & 34S 6p1drra-44 & $337 / 8$ & $s$ & 9 & 4437.4 & $673 / 4$ & $653 / 4$ & 0.446 & 0.669 & HLP-22 & 12 & 4 & 4 & 1.9 & 10.5 & 5.7 & 30.8 & 16.1 & 0.62 & 0.33 & pld7 & 2.45 & 0.0001213 & 0.0001780 & 0.0002606 & \\
\hline 7090219 & 10/26B1 & 34S_6p1drra-44 & $337 / 8$ & $\mathrm{~s}$ & 9 & 4437.4 & $673 / 4$ & $653 / 4$ & 0.446 & 0.669 & HLP-22 & 12 & 4 & 4 & 1.9 & 10.5 & 5.7 & 30.8 & 16.1 & 0.62 & 0.33 & pld7 & 2.45 & 0.00001213 & 0.0001780 & 0.0002606 & \\
\hline 7090223 & 10/26B1 & 34S_6pld/ra-44 & $337 / 8$ & $\mathrm{~s}$ & 9 & 4437.4 & $673 / 4$ & $653 / 4$ & 0.446 & 0.669 & HLP-22 & 12 & 4 & 4 & 1.9 & 10.5 & 5.7 & 30.8 & 16.1 & 0.62 & 0.33 & pld7 & 2.45 & 0.0001213 & 0.00001780 & 0.0002606 & \\
\hline 7090225 & 10/26B2 & 34s_6p1drYd_o & $337 / 8$ & $\mathrm{~s}$ & 9 & 4437.4 & $673 / 4$ & $653 / 4$ & 0.446 & 0.669 & HLP-22 & 12 & 4 & 4 & 1.9 & 10.5 & 5.7 & 30.8 & 16.1 & 0.62 & 0.33 & pld7 & 2.45 & 0.0001213 & 0.0001780 & 0.0002606 & $0.4 .4>0$ \\
\hline 7090228 & 10/26B2 & 34S_6p1dTYd_O 0 & $337 / 8$ & $\mathrm{~s}$ & 9 & 4437.4 & $673 / 4$ & $653 / 4$ & 0.446 & 0.669 & HLP-22 & 12 & 4 & 4 & 1.9 & 10.5 & 5.7 & 30.8 & 16.1 & 0.62 & 0.33 & pld7 & 2.45 & 0.0001213 & 0.0001780 & 0.0002606 & \\
\hline 7090231 & 10/26B2 & 34S_6pldTrd_o & $337 / 8$ & $\mathrm{~s}$ & 9 & 4437.4 & $673 / 4$ & $653 / 4$ & 0.446 & 0.669 & HLP-22 & 12 & 4 & 4 & 1.9 & 10.5 & 5.7 & 30.8 & 16.1 & 0.62 & 0.3 & p1d7 & 2.45 & 0.0001213 & 0.00001780 & 0.0002606 & \\
\hline 7090234 & 10/26B2 & 34S_6pldrrd_ 0 & $337 / 8$ & $\mathrm{~s}$ & 9 & 4437.4 & $673 / 4$ & $653 / 4$ & 0.446 & 0.669 & HLP-22 & 12 & 4 & 4 & 1.9 & 10.5 & 5.7 & 30.8 & 16.1 & 0.62 & 0.33 & p1d7 & 2.45 & 0.0001213 & 0.0001780 & 0.0002606 & 0.4 \\
\hline 7090237 & 10/26B2 & 34S_6pld7Yd_o & $337 / 8$ & $s$ & 9 & 4437.4 & $673 / 4$ & $653 / 4$ & 0.446 & 0.669 & HLP-22 & 12 & 4 & 4 & 1.9 & 10.5 & 5.7 & 30.8 & & 0.62 & & pld7 & 2.45 & 0.0001213 & 0.00001780 & 0.0002606 & \\
\hline 7090240 & 10/26B2 & 34S_6p1drYd_0 & $337 / 8$ & $\mathrm{~s}$ & 9 & 4437.4 & $673 / 4$ & $653 / 4$ & 0.446 & 0.669 & HLP-22 & 12 & 4 & 4 & 1.9 & 10.5 & 5.7 & 30.8 & 16.1 & 0.62 & 0.33 & pld7 & 2.45 & 0.0001213 & 0.0001780 & 0.0002606 & 0.4 \\
\hline $7000244 n x$ & 10/26B2 & 34S_6pldTYd_o & $337 / 8$ & $s$ & 9 & 4437.4 & $673 / 4$ & $653 / 4$ & 0.446 & 0.669 & HLP-22 & 12 & 4 & 4 & 1.9 & 10.5 & 5.7 & 30.8 & 16.1 & 0.62 & 0.33 & pld7 & 2.45 & 0.0001213 & 0.00001780 & 0.0002606 & 0.427 \\
\hline 7090247 & 10/29A1 & 34S_6p1drra-04 & $337 / 8$ & $\mathrm{~s}$ & 9 & 4437.4 & $673 / 4$ & $653 / 4$ & 0.446 & 0.669 & HLP-22 & 12 & 0 & 4 & 1.9 & 10.5 & 5.7 & 30.8 & 16.1 & 0.62 & 0.33 & p1d7 & 2.45 & \begin{tabular}{ll|l}
0.0001213 \\
\end{tabular} & 0.0001780 & 0.0002606 & \\
\hline 7090250 & 10/29A1 & 34S_6p1d/ra-04 & $337 / 8$ & $s$ & 9 & 4437.4 & $673 / 4$ & $653 / 4$ & 0.446 & 0.669 & HLP-22 & 12 & 0 & 4 & 1.9 & 10.5 & 5.7 & 30.8 & 16.1 & 0.62 & 0.33 & pld7 & 2.45 & 0.0001213 & 0.0001780 & 0.0002606 & 0.427 \\
\hline 000252 & IVI/ZGAL & 34S_6p1drYa-04 & $337 / 8$ & $s$ & & 4437.4 & $673 / 4$ & $653 / 4$ & 0.446 & 0.669 & HLP-22 & & 0 & & 15 & 10.5 & 5.7 & 30.8 & & 0.02 & & pid7 & 2.45 & & & & \\
\hline
\end{tabular}


Table B.8. Data from Fall 2007 Tests in Mid-Scale Vessel with Spherical Head B.2

\begin{tabular}{|c|c|c|c|c|c|c|c|c|c|c|c|c|c|c|c|c|c|c|c|c|c|c|c|c|c|c|c|c|c|}
\hline $\begin{array}{l}\text { Tank Water } \\
\text { Temperature }\end{array}$ & $\begin{array}{l}\text { Water } \\
\text { Density }\end{array}$ & $\begin{array}{l}\text { Solids } \\
\text { Fraction }\end{array}$ & $\begin{array}{l}\text { Pulse } \\
\text { Volume } \\
\text { Fraction }\end{array}$ & $\begin{array}{l}\text { Duty } \\
\text { Oydle }\end{array}$ & $\begin{array}{l}\text { Oyde } \\
\text { Time }\end{array}$ & 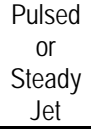 & $\begin{array}{c}\text { Us } \\
\text { Steacy } \\
\text { Jet }\end{array}$ & $\begin{array}{l}\text { U1 } \\
\text { Pulsing } \\
\text { Jet }\end{array}$ & \begin{tabular}{|l} 
U2 \\
URMS \\
\end{tabular} & \begin{tabular}{|c|} 
UR \\
URNB \\
\end{tabular} & $\begin{array}{l}\text { Discharge } \\
\text { Velocity }\end{array}$ & $\begin{array}{c}\text { Citical } \\
\text { Suspension } \\
\text { Velocity }\end{array}$ & $\begin{array}{c}\text { Average } \\
\text { Peak } \\
\text { Coud } \\
\text { Height } \\
\end{array}$ & $\begin{array}{c}\text { UCs } \\
\text { Condition } \\
\end{array}$ & $\begin{array}{l}\text { UCS } \\
\text { Method }\end{array}$ & $\begin{array}{l}\text { UCS } \\
\text { Flag }\end{array}$ & $\begin{array}{c}\text { UCS } \\
\text { Center } \\
\text { Hag }\end{array}$ & $\begin{array}{c}\text { UcS udv } \\
\text { Hag }\end{array}$ & $\begin{array}{l}\text { UcS based } \\
\text { on } \\
\text { Deceasing } \\
\text { Velocity }\end{array}$ & $\begin{array}{l}\text { Sweep } \\
\text { Increase/ } \\
\text { Decrease }\end{array}$ & $\begin{array}{c}\text { UDV } \\
\text { Height } \\
\text { Bed }\end{array}$ & $\begin{array}{l}\text { Particle } \\
\text { Notion }\end{array}$ & $\begin{array}{l}\text { Solids } \\
\text { Level }\end{array}$ & $\begin{array}{l}\text { Outer } \\
\text { Botom } \\
\text { Pattem }\end{array}$ & $\begin{array}{l}\text { Inner } \\
\text { Botom } \\
\text { Patem } \\
\text { Patem }\end{array}$ & Case ID & Test & TDP & $\begin{array}{l}\text { Row } \\
\text { Number }\end{array}$ \\
\hline $\mathrm{C}$ & $\mathrm{g} \mathrm{cm}^{3}$ & fraction & fraction & fraction & $\mathrm{s}$ & text & $\mathrm{m} / \mathrm{s}$ & m/s & $\mathrm{m} / \mathrm{s}$ & $\mathrm{m} / \mathrm{s}$ & m/s & m/s & in. & $\mathrm{m} / \mathrm{s}$ & text & text & text & text & $\mathrm{m} / \mathrm{s}$ & text & $\mathrm{mm}$ & text & text & text & text & text & text & text & text \\
\hline $\mathrm{T}$ & $\rho$ & $\phi_{\mathrm{s}}$ & $\phi_{p}$ & $\mathrm{DC}$ & $t_{c}$ & Jet & $U_{s}$ & $\mathrm{U}_{1}$ & $\mathrm{U} 2$ & U3 & $u$ & Us & $H_{c}$ & $u_{\text {asp }}$ & Ussm & Uosis & Usceen & Usosudv & $U_{c s} D$ & $S_{\mathrm{N}}$ & $H_{\text {bed }}$ & $\mathrm{PM}$ & Sol & $\mathrm{SP} \mathrm{P}_{\mathrm{O}}$ & $\mathrm{SP}_{1}$ & ID & MDDX & $\mathrm{TDP}$ & MSS \\
\hline 22.0 & 0.999 & 0.00487 & 0.051 & 0.180 & 54.9 & $\mathrm{P}$ & NA & 6.22 & 6.31 & 6.35 & 6.40 & 6.40 & 13.00 & 6.40 & vis & ucsis & NA & NA & NA & 1 & NA & cs & NA & NA & NA & 34S_6p1d7Yd_6 6 & 10/18B2 & TDP-WIP-038 & 7090136 \\
\hline 22.0 & 0.999 & 0.00487 & 0.051 & 0.180 & 54.1 & $\mathrm{P}$ & NA & 6.41 & 6.50 & 6.55 & 6.60 & 6.40 & 16.00 & NA & NA & NA & NA & NA & NA & 1 & NA & $B C$ & NA & NA & NA & 34S_6p1d7rd_6 6 & 10/18B2 & TDP-WIP-038 & 7090138 \\
\hline 21.8 & 0.999 & 0.00487 & undefined & 1.000 & infinite & $\mathrm{s}$ & 4.06 & NA & NA & NA & 4.00 & 8.00 & 9.00 & NA & NA & NA & NA & NA & NA & 1 & NA & ss & NA & NA & NA & 34S_6pldtra-04 & 10/19A1 & TDP-WIP-034 & 7090142 \\
\hline 21.7 & 0.999 & 0.00487 & undefined & 1.000 & infinite & $\mathrm{s}$ & 4.52 & NA & NA & NA & 4.50 & 8.00 & 10.00 & NA & NA & NA & NA & NA & NA & 1 & NA & ss & NA & NA & NA & 34s_6p1drya-04 & 10/19A1 & TDP-WIP-034 & 7090144 \\
\hline 21.8 & 0.999 & 0.00487 & undefined & 1.000 & infinite & $\mathrm{s}$ & 5.02 & NA & NA & NA & 5.00 & 8.00 & 12.00 & NA & NA & NA & NA & NA & NA & 1 & NA & ss & NA & BP5 & NA & 34S_6p1d/Ya-04 & 10/19A1 & IDP-WIP-034 & 7090146 \\
\hline 21.8 & 0.999 & 0.00487 & undefined & 1.000 & infinite & $\mathrm{s}$ & 5.11 & NA & NA & NA & 5.50 & 8.00 & 15.50 & NA & NA & NA & NA & NA & NA & 1 & NA & AM & NA & BP5 & NA & 34s_6p1dr/Ya-04 & 10/19A1 & TDP-WIP-034 & 7090149 \\
\hline 21.8 & 0.999 & 0.00487 & undefined & 1.000 & infinite & $\mathrm{s}$ & 6.01 & NA & NA & NA & 6.00 & 8.00 & 18.50 & NA & NA & NA & NA & NA & NA & 1 & NA & $A M$ & NA & BP5 & NA & 34s_6p1d7/ra-04 & 10/19A1 & IDP-WIP-034 & 7090152 \\
\hline 21.8 & 0.999 & 0.00487 & undefined & 1.000 & infinite & $\mathrm{s}$ & 6.55 & NA & NA & NA & 6.50 & 8.00 & 24.00 & NA & NA & NA & NA & NA & NA & 1 & NA & $A M$ & NA & BP5 & NA & 34s_6p1d7/ra-04 & 10/19A1 & TDP-WIP-034 & 7090156 \\
\hline 21.8 & 0.999 & 0.00487 & undefined & 1.000 & infinite & $\mathrm{s}$ & 7.01 & NA & NA & NA & 7.00 & 8.00 & 33.00 & NA & NA & NA & NA & NA & NA & 1 & NA & $A M+$ & NA & BP5 & NA & 34s_6p1d7/Ya-04 & 10/19A1 & TDP-WIP-034 & 7090158 \\
\hline 21.9 & 0.999 & 0.00487 & undefined & 1.000 & infinite & $\mathrm{s}$ & 7.51 & NA & NA & NA & 7.50 & 8.00 & 40.00 & NA & NA & NA & NA & NA & NA & 1 & NA & $\mathrm{AM}+$ & NA & BP5 & NA & 34s_6p1dr/ra-04 & 10/19A1 & TDP-WTP-034 & 7090161 \\
\hline 21.9 & 0.999 & 0.00487 & undefined & 1.000 & infinite & $\mathrm{s}$ & 8.02 & NA & NA & NA & 8.00 & 8.00 & 50.00 & \begin{tabular}{|l|}
8.00 \\
\end{tabular} & vis & ucsis & NA & NA & NA & 1 & NA & cs & NA & BP6 & NA & 34s_6p1d/ra-04 & 10/19A1 & TDP-WIP-034 & 7090165 \\
\hline 22.0 & 0.999 & 0.00487 & 0.049 & 0.180 & 87.0 & $\mathrm{P}$ & NA & 4.09 & 4.13 & 4.15 & 4.00 & 8.50 & 9.00 & NA & NA & NA & NA & NA & NA & 1 & NA & ss & NA & NA & NA & 34S_6p1d7/Yd_9 9 & 10/19A2 & TDP-WIP-034 & 7090167 \\
\hline 22.0 & 0.999 & 0.00487 & 0.052 & 0.180 & 71.4 & $\mathrm{P}$ & NA & 4.95 & 5.00 & 5.02 & 5.00 & 8.50 & 12.50 & NA & NA & NA & NA & NA & NA & 1 & NA & ss & NA & NA & NA & 34S_6p1d7Yd_9 9 & 10/19A2 & TDP-WIP-034 & 7090169 \\
\hline 22.0 & 0.999 & 0.00487 & 0.053 & 0.180 & 58.8 & $\mathrm{P}$ & NA & 5.85 & 5.92 & 5.96 & 6.00 & 8.50 & 16.00 & NA & NA & NA & NA & NA & NA & 1 & NA & ss & NA & BP4 & NA & 34S_6p1d7Yd_99 & 10/19A2 & TDP-WIP-034 & 7090172 \\
\hline 22.0 & 0.999 & 0.00487 & 0.054 & 0.180 & 51.3 & $\mathrm{P}$ & NA & 6.23 & 6.58 & 6.72 & 7.00 & 8.50 & 19.50 & NA & NA & NA & NA & NA & NA & 1 & NA & $A M$ & NA & BP5 & NA & 34S_6p1d7Yd_9 9 & 10/19A2 & TDP-WIP-034 & 7090174 \\
\hline 22.0 & 0.999 & 0.00487 & 0.051 & 0.180 & 46.5 & $\mathrm{P}$ & NA & 6.32 & 6.83 & 7.04 & 7.50 & 8.50 & 23.00 & NA & NA & NA & NA & NA & NA & 1 & NA & $\mathrm{AM}+$ & NA & BP5 & NA & 34S_6p1d7Yd_9 9 & $10 / 19 A^{2}$ & TDP-WIP-034 & 7090177 \\
\hline 22.0 & 0.999 & 0.00487 & 0.052 & 0.180 & 43.5 & $\mathrm{P}$ & NA & 6.72 & 7.29 & 7.52 & 8.00 & 8.50 & 25.50 & NA & NA & NA & NA & NA & NA & 1 & NA & $A M+$ & NA & BP6 & NA & 34S_6p1d7rd_9 9 & 10/19A2 & TDP-WIP-034 & 7090180 \\
\hline 22.0 & 0.999 & 0.00487 & 0.050 & 0.180 & 40.0 & $\mathrm{P}$ & NA & 6.76 & 7.51 & 7.83 & 8.50 & 8.50 & 29.00 & \begin{tabular}{|l|}
8.50 \\
\end{tabular} & vis & ucsis & NA & NA & NA & 1 & NA & $c s$ & NA & BP6 & NA & 34S_6p1d7Yd_9 & 10/19A2 & TDP-WIP-034 & 7090184 \\
\hline 20.8 & 0.999 & 0.00487 & undefined & 1.000 & infinite & $\mathrm{s}$ & 2.51 & NA & NA & NA & 2.50 & 3.20 & 8.50 & NA & NA & NA & NA & NA & NA & 1 & NA & sSt+ & NA & NA & NA & 34s_6p1d7/a & 10/26A1 & TDP-WIP-039 & 7090186 \\
\hline 20.7 & 0.999 & 0.00487 & undefined & 1.000 & infinite & $\mathrm{s}$ & 3.02 & NA & NA & NA & 3.00 & 3.20 & 10.00 & NA & NA & NA & NA & NA & NA & 1 & NA & AMt & NA & NA & NA & 34s__ppldrTa & 10/26A1 & TDP-WIP-039 & 7090189 \\
\hline 20.7 & 0.999 & 0.00487 & undefined & 1.000 & infinite & $\mathrm{s}$ & 3.21 & NA & NA & NA & 3.20 & 3.20 & 10.75 & \begin{tabular}{|l|}
3.20 \\
\end{tabular} & vis & ucsis & NA & NA & NA & 1 & NA & cs & NA & NA & NA & 34s .0p1drva & 10/26A1 & TDP-WTP-039 & 7090193 \\
\hline 21.0 & 0.999 & 0.00487 & 0.045 & 0.180 & 40.0 & $\mathrm{P}$ & NA & 2.74 & 2.85 & 290 & 3.00 & 4.00 & 9.75 & NA & NA & NA & NA & NA & NA & D & NA & $A M$ & NA & NA & NA & 34S_6p1d/rd_1 1 & 10/26A2 & TDP-WIP-039 & 7090195 \\
\hline 21.0 & 0.999 & 0.00487 & 0.050 & 0.180 & 37.0 & $\mathrm{P}$ & NA & 2.92 & 3.02 & 3.07 & 3.20 & 4.00 & 11.00 & NA & NA & NA & NA & NA & NA & 1 & NA & $A M$ & NA & NA & NA & 34S_6p1d7Yd_1 & 10/26A2 & TDP-WIP-039 & 7090198 \\
\hline 21.0 & 0.999 & 0.00487 & 0.051 & 0.180 & 35.5 & $\mathrm{P}$ & NA & 3.02 & 3.15 & 3.22 & 3.40 & 4.00 & 11.00 & NA & NA & NA & NA & NA & NA & 1 & NA & $A M+$ & NA & NA & NA & 34S_6p1d7Yd_1 1 & 10/26A2 & TDP-WIP-039 & 7090201 \\
\hline 21.0 & 0.999 & 0.00487 & 0.052 & 0.180 & 33.0 & $\mathrm{P}$ & NA & 3.06 & 3.27 & 3.36 & 3.60 & 4.00 & 11.00 & NA & NA & NA & NA & NA & NA & 1 & NA & AMt & NA & NA & NA & 34S_6p1d7rd_1 & 10/26A2 & TDP-WIP-039 & 7090204 \\
\hline 21.0 & 0.999 & 0.00487 & 0.051 & 0.180 & 29.5 & $\mathrm{P}$ & NA & 3.23 & 3.53 & 3.67 & 4.00 & 4.00 & 1200 & \begin{tabular}{|l|}
4.00 \\
\end{tabular} & vis & ucsis & NA & NA & NA & 1 & NA & cs & NA & NA & NA & 34S_6p1d7Yd_1 1 & $10 / 26 A^{2}$ & TDP-WTP-039 & 7090208 \\
\hline 20.8 & 0.999 & 0.00487 & undefined & 1.000 & infinite & $\mathrm{s}$ & 3.40 & NA & NA & NA & 3.40 & 4.60 & NA & NA & NA & NA & NA & NA & NA & 1 & NA & ss & NA & NA & NA & 34s_6p1d7/ra-44 & 10/26B1 & TDP-WIP-039 & 7090210 \\
\hline 20.8 & 0.999 & 0.00487 & undefined & 1.000 & infinite & $\mathrm{s}$ & 3.82 & NA & NA & NA & 3.80 & 4.60 & 9.00 & NA & NA & NA & NA & NA & NA & 1 & NA & AM & NA & NA & NA & 34s_6p1d7ra-44 & 10/26B1 & TDP-WIP-039 & 7090213 \\
\hline 20.8 & 0.999 & 0.00487 & undefined & 1.000 & infinite & $\mathrm{s}$ & 4.22 & NA & NA & NA & 4.20 & 4.60 & 12.00 & NA & NA & NA & UCScen & NA & NA & 1 & NA & $A M$ & NA & NA & NA & 345_6p1drya-44 & $10 / 26 B 1$ & TDP-WIP-039 & 7090217 \\
\hline 20.8 & 0.999 & 0.00487 & undefined & 1.000 & infinite & $\mathrm{s}$ & 4.42 & NA & NA & NA & 4.40 & 4.60 & 17.00 & NA & NA & NA & NA & NA & NA & 1 & NA & $A M+$ & NA & NA & NA & 34s_6p1drya-44 & 10/26B1 & TDP-WIP-039 & 7090219 \\
\hline 20.9 & 0.999 & 0.00487 & undefined & 1.000 & infinite & $\mathrm{s}$ & 4.61 & NA & NA & NA & 4.60 & 4.60 & 21.00 & \begin{tabular}{|l|}
4.60 \\
\end{tabular} & vis & ucsis & NA & NA & NA & 1 & NA & cs & NA & NA & NA & 34s_6p1d7/ra-44 & 10/26B1 & TDP-WTP-039 & 7090223 \\
\hline 21.0 & 0.999 & 0.00487 & 0.045 & 0.180 & 45.0 & $\mathrm{P}$ & NA & 3.69 & \begin{tabular}{|l}
3.79 \\
\end{tabular} & 3.84 & 4.00 & 6.10 & 9.00 & NA & NA & NA & NA & NA & NA & D & NA & SS+ & NA & NA & NA & 34S_6p1dTrd_0 0 & 10/26B2 & TDP-WIP-039 & 7090225 \\
\hline 21.0 & 0.999 & 0.00487 & 0.051 & 0.180 & 40.5 & $\mathrm{P}$ & NA & 4.04 & 4.18 & 4.24 & 4.40 & 6.10 & 10.00 & NA & NA & NA & NA & NA & NA & 1 & NA & sst & NA & NA & NA & 34S_6p1dTYd_0 & 10/26B2 & TDP-WTP-039 & 7090228 \\
\hline 21.0 & 0.999 & 0.00487 & 0.051 & 0.180 & 37.5 & $\mathrm{P}$ & NA & 4.14 & 4.40 & 4.51 & 4.80 & 6.10 & 12.50 & NA & NA & NA & NA & NA & NA & 1 & NA & $A M$ & NA & NA & NA & 34S_6p1d7YYd_0 & 10/26B2 & TDP-WIP-039 & 7090231 \\
\hline 21.0 & 0.999 & 0.00487 & 0.050 & 0.180 & 34.0 & $\mathrm{P}$ & NA & 4.41 & 4.72 & 4.86 & 5.20 & 6.10 & 14.00 & NA & NA & NA & NA & NA & NA & 1 & NA & $A M$ & NA & NA & NA & 34S_6p1d7rd_0 0 & 10/26B2 & TDP-WIP-039 & 7090234 \\
\hline 21.0 & 0.999 & 0.00487 & 0.050 & 0.180 & 31.5 & $\mathrm{P}$ & NA & 4.52 & 4.94 & 5.12 & 5.60 & 6.10 & 14.75 & NA & NA & NA & NA & NA & NA & 1 & NA & $\mathrm{AM}+$ & NA & NA & NA & 34S_6p1d7Yd_0 0 & 10/26B2 & TDP-WIP-039 & 7090237 \\
\hline 21.0 & 0.999 & 0.00487 & 0.050 & 0.180 & 29.0 & $\mathrm{P}$ & NA & 4.64 & 5.19 & 5.43 & 6.00 & 6.10 & 16.50 & NA & NA & NA & NA & NA & NA & 1 & NA & CS & NA & NA & NA & 34S_6p1d7rd_0 0 & 10/26B2 & TDP-WIP-039 & 7090240 \\
\hline 21.0 & 0.999 & 0.00487 & 0.050 & 0.180 & 28.5 & $\mathrm{P}$ & NA & 4.66 & 5.23 & 5.47 & 6.10 & 6.10 & 18.00 & \begin{tabular}{|l|}
6.10 \\
\end{tabular} & vis & ucsis & NA & NA & NA & 1 & NA & cs & NA & NA & NA & 34S_6p1drTd__o & 10/26B2 & TDP-WIP-039 & 7090244 \\
\hline 20.9 & 0.999 & 0.00487 & undefined & 1.000 & infinite & $\mathrm{s}$ & 4.01 & NA & NA & NA & 4.00 & 6.00 & 10.75 & NA & NA & NA & NA & NA & NA & 1 & NA & ss & NA & NA & NA & 34s_6p1dr/Ya-04 & 10/29A1 & TDP-WIP-040 & 7090247 \\
\hline 20.9 & 0.999 & 0.00487 & undefined & 1.000 & infinite & $\mathrm{s}$ & 4.50 & NA & NA & NA & 4.50 & 6.00 & 13.50 & NA & NA & NA & NA & NA & NA & 1 & NA & ss & NA & NA & NA & 34s_6pld7ra-04 & 10/29A1 & TDP-WIP-040 & 7090250 \\
\hline 20.9 & 0.999 & 0.00487 & undefined & 1.000 & infinite & $s$ & 5.00 & NA & NA & NA & 5.00 & 6.00 & 16.75 & NA & NA & NA & $N A$ & NA & NA & 1 & NA & $A M$ & NA & NA & NA & 34s_6p1drra-04 & 10/29A1 & TDP-WIP-040 & 7090252 \\
\hline
\end{tabular}


Table B.8. Data from Fall 2007 Tests in Mid-Scale Vessel with Spherical Head A.3

\begin{tabular}{|c|c|c|c|c|c|c|c|c|c|c|c|c|c|c|c|c|c|c|c|c|c|c|c|c|c|c|c|}
\hline $\begin{array}{c}\text { Row } \\
\text { Number }\end{array}$ & Test & Case ID & $\begin{array}{c}\text { Tank } \\
\text { Diameter }\end{array}$ & $\begin{array}{l}\text { Head } \\
\text { Shape }\end{array}$ & \begin{tabular}{|c} 
Dish \\
Height
\end{tabular} & $\begin{array}{l}\text { Dish } \\
\text { Volume }\end{array}$ & $\begin{array}{c}\text { Tank Fill } \\
\text { Height }\end{array}$ & $\begin{array}{l}\text { Retum } \\
\text { Line } \\
\text { Height }\end{array}$ & $\begin{array}{c}\text { Nozzle } \\
\text { Inner } \\
\text { Diameter }\end{array}$ & $\begin{array}{l}\text { Nozde } \\
\text { Sland-off } \\
\text { Distance }\end{array}$ & $\begin{array}{l}\text { Pulse Tube } \\
\text { Configuration }\end{array}$ & $\begin{array}{l}\text { Installed } \\
\text { Nozzles }\end{array}$ & $\begin{array}{c}\text { Outer } \\
\text { Nozzles } \\
\text { Opperate } \\
d\end{array}$ & $\begin{array}{c}\text { Inner } \\
\text { Nozzles } \\
\text { Operate } \\
\text { d } \\
\end{array}$ & $\begin{array}{l}\text { Pulse Tube } \\
\text { OAter } \\
\text { Dianneter }\end{array}$ & $\begin{array}{l}\text { Outer } \\
\text { PMM } \\
\text { Radius }\end{array}$ & $\begin{array}{c}\text { Inner } \\
\text { PMM } \\
\text { Radius }\end{array}$ & $\begin{array}{l}\text { "FO' Outer PJM } \\
\text { IInpinement } \\
\text { Angle }\end{array}$ & \begin{tabular}{|c|} 
"FO' Inner PJM \\
Impigement \\
Angle
\end{tabular} & $\begin{array}{l}\text { Ratio Outer } \\
\text { PJMMto Tank } \\
\text { Radius } \\
\end{array}$ & $\begin{array}{c}\text { Ratioi Inner } \\
\text { PJMto Tank } \\
\text { Radius } \\
\end{array}$ & Simulant & $\begin{array}{l}\text { Solids } \\
\text { Density }\end{array}$ & $\begin{array}{c}\text { Particle } \\
\text { Diameter } 0\end{array}$ & $\begin{array}{c}\text { Particle } \\
\text { Diameter } 550\end{array}$ & $\begin{array}{c}\text { Particle } \\
\text { Diameter d95 }\end{array}$ & $\begin{array}{l}\text { Void } \\
\text { Fraction }\end{array}$ \\
\hline text & text & text & in. & text & in. & in. ${ }^{3}$ & in. & in. & in. & in. & text & number & number & number & in. & in. & in. & $\begin{array}{l}\text { deg } \\
\end{array}$ & deg & nondim & nondim & text & $\mathrm{g} / \mathrm{cm}^{3}$ & $\mathrm{~m}$ & $m$ & $\mathrm{~m}$ & fraction \\
\hline MSS & MDDX & $\mathrm{ID}$ & $\mathrm{D}$ & $\mathrm{HS}$ & Hosh & $V_{\text {ash }}$ & $\mathrm{H}$ & $\operatorname{Rtn}$ & $d$ & sod & PT & $\mathrm{N}$ & $\mathrm{Nb}$ & $\mathrm{N}$ & $\mathrm{PT}_{\alpha \mathrm{d}}$ & $\mathrm{Ro}_{\mathrm{o}}$ & $R$ & $\theta_{0}$ & $\theta_{1}$ & $\mathrm{RdR}$ & $R / R$ & sxdx & $\rho_{\mathrm{s}}$ & $d \mathrm{dg}$ & d doo & des & vf \\
\hline 7090256 & $10 / 20 A 1$ & 34S_6p1drra-04 & $337 / 8$ & $\mathrm{~s}$ & 9 & 4437.4 & $673 / 4$ & $653 / 4$ & 0.446 & 0.669 & HLP-22 & 12 & 0 & 4 & 1.9 & 10.5 & 5.7 & 30.8 & 16.1 & 0.62 & 0.33 & pld7 & 2.45 & 0.0001213 & 0.0001780 & 0.0002606 & 0.4277 \\
\hline 7090261 & 10/29A1 & 345_6p1d/ra-04 & $337 / 8$ & $s$ & 9 & 4437.4 & $673 / 4$ & $653 / 4$ & 0.446 & 0.669 & HLP-22 & 12 & 0 & 4 & 1.9 & 10.5 & 5.7 & 30.8 & 16.1 & 0.62 & 0.33 & pldr & 2.45 & 0.0001213 & 0.0001780 & 0.0002606 & 0.4277 \\
\hline 7090265 & 10/29A1 & 345_6p1dr/a-04 & $337 / 8$ & $\mathrm{~s}$ & 9 & 4437.4 & $673 / 4$ & $653 / 4$ & 0.446 & 0.669 & HLP-22 & 12 & 0 & 4 & 1.9 & 10.5 & 5.7 & 30.8 & 16.1 & 0.62 & 0.33 & p1d7 & 2.45 & 0.0001213 & 0.0001780 & 0.0002606 & 0.4277 \\
\hline 7090268 & 10/29A2 & 34S 6p1dr/rm 9 & $337 / 8$ & $s$ & 9 & 4437.4 & $673 / 4$ & $653 / 4$ & 0.446 & 0.669 & HLP-22 & 12 & 0 & 4 & 1.9 & 10.5 & 5.7 & 30.8 & 16.1 & 0.62 & 0.33 & p1d7 & 2.45 & $\begin{array}{ll}0.0001213 \\
\end{array}$ & 0.0001780 & 0.0002606 & \\
\hline $7000271 \mathrm{Nx}$ & 10/29A2 & 34s_6p1d/rm_ 9 & $337 / 8$ & $s$ & 9 & 4437.4 & $673 / 4$ & $653 / 4$ & 0.446 & 0.669 & HLP-22 & 12 & 0 & 4 & 1.9 & 10.5 & 5.7 & 30.8 & 16.1 & 0.62 & 0.33 & p1d7 & 2.45 & 0.0001213 & 0.0001780 & 0.0002606 & 0.4277 \\
\hline $7000274 \mathrm{Nx}$ & 10/29A2 & 34S_6p1dT/rm 9 & $337 / 8$ & $s$ & 9 & 4437.4 & $673 / 4$ & $653 / 4$ & 0.446 & 0.669 & HLP-22 & 12 & 0 & 4 & 1.9 & 10.5 & 5.7 & 30.8 & 16.1 & 0.62 & 0.33 & p1d7 & 2.45 & $\begin{array}{ll}0.0001213 \\
\end{array}$ & 0.0001780 & 0.0002606 & 0.42 \\
\hline 7090279 & 10/2981 & 34S_6p1dTra-40 & $337 / 8$ & $\mathrm{~s}$ & 9 & 4437.4 & $673 / 4$ & $653 / 4$ & 0.446 & 0.669 & HLP-22 & 12 & 4 & 0 & 1.9 & 10.5 & 5.7 & 30.8 & 16.1 & 0.62 & 0.33 & p1d7 & 2.45 & $\begin{array}{ll}0.0001213 \\
\end{array}$ & 0.0001780 & 0.0002606 & 0.4277 \\
\hline 7000283 & 10/2981 & 34S_6p1dr/ra-40 & $337 / 8$ & $s$ & 9 & 4437.4 & $673 / 4$ & $653 / 4$ & 0.446 & 0.669 & HLP.22 & 12 & 4 & 0 & 1.9 & 10.5 & 5.7 & 30.8 & 16.1 & 0.62 & 0.33 & p1d7 & 2.45 & 0.0001213 & 0.0001780 & 0.0002606 & \\
\hline 7090225 & 10/2981 & 34S_6pldrra-40 & $337 / 8$ & s & 9 & 4437.4 & $673 / 4$ & $653 / 4$ & 0.446 & 0.669 & HLP-22 & 12 & 4 & 0 & 1.9 & 10.5 & 5.7 & 30.8 & 16.1 & 0.62 & 0.33 & p1d7 & 2.45 & 0.0001213 & 0.0001780 & 0.0002606 & 0.4277 \\
\hline 7090288 & 10/2982 & 34S_6p1dr/d_ 6 & $337 / 8$ & $\mathrm{~s}$ & 9 & 4437.4 & $673 / 4$ & $653 / 4$ & 0.446 & 0.669 & HLP-22 & 12 & 4 & 0 & 1.9 & 10.5 & 5.7 & 30.8 & 16.1 & 0.62 & 0.33 & pld7 & 2.45 & 0.0001213 & 0.0001780 & 0.0002606 & 0.4277 \\
\hline 7090291 & 10/29832 & 34S_6p1drYd_ 6 & $337 / 8$ & $s$ & 9 & 4437.4 & $673 / 4$ & $653 / 4$ & 0.446 & 0.669 & HLP-22 & 12 & 4 & 0 & 1.9 & 10.5 & 5.7 & 30.8 & 16.1 & 0.62 & 0.33 & p1d7 & 2.45 & $\begin{array}{ll}0.0001213 \\
\end{array}$ & 0.0001780 & 0.0002606 & \\
\hline 7090294 & 10/2982 & 34S_6p1d/rd_6 6 & $337 / 8$ & $s$ & 9 & 4437.4 & $673 / 4$ & $653 / 4$ & 0.446 & 0.669 & HLP-22 & 12 & 4 & 0 & 1.9 & 10.5 & 5.7 & 30.8 & 16.1 & 0.62 & 0.33 & p1d7 & 2.45 & 0.0001213 & 0.0001780 & 0.0002606 & 0.4277 \\
\hline $7090298 \mathrm{nx}$ & 10/2982 & 34 Sopldrrd_6 6 & $337 / 8$ & $s$ & 9 & 4437.4 & $673 / 4$ & $653 / 4$ & 0.446 & 0.669 & HLP-22 & 12 & 4 & 0 & 1.9 & 10.5 & 5.7 & 30.8 & 16.1 & 0.62 & 0.33 & p1d7 & 2.45 & $\begin{array}{ll}0.0001213 \\
\end{array}$ & 0.0001780 & 0.0002606 & 0.42 \\
\hline 7090300n $x$ & 10/2982 & 34S_6p1dTrd_6 6 & $337 / 8$ & $s$ & 9 & 4437.4 & $673 / 4$ & $653 / 4$ & 0.446 & 0.669 & HLP-22 & 12 & 4 & 0 & 1.9 & 10.5 & 5.7 & 30.8 & 16.1 & 0.62 & 0.33 & p1d7 & 2.45 & \begin{tabular}{|l|l|}
0.0001213 \\
\end{tabular} & 0.0001780 & 0.0002606 & 0.4277 \\
\hline 7090303 & 10/30A1 & 34S 6p1d7Ya & $337 / 8$ & $\mathrm{~s}$ & 9 & 4437.4 & $673 / 4$ & $653 / 4$ & 0.446 & 0.669 & HLP-22 & 12 & 8 & 4 & 1.9 & 10.5 & 5.7 & 30.8 & 16.1 & 0.62 & 0.33 & p1d7 & 2.45 & \begin{tabular}{|l|l|}
0.0001213 \\
\end{tabular} & 0.0001780 & 0.0002606 & 0.4277 \\
\hline 7090306 & 10/30A1 & 34S fopldrra & $337 / 8$ & $\mathrm{~s}$ & 9 & 4437.4 & $673 / 4$ & $653 / 4$ & 0.446 & 0.669 & HLP-22 & 12 & 8 & 4 & 1.9 & 10.5 & 5.7 & 30.8 & 16.1 & 0.62 & 0.33 & p1d7 & 2.45 & 0.0001213 & 0.0001780 & 0.0002606 & \\
\hline 7090310 & 10/30A1 & 34s_.6pldr/Ya & $337 / 8$ & s & 9 & 4437.4 & $673 / 4$ & $653 / 4$ & 0.446 & 0.669 & HLP-22 & 12 & 8 & 4 & 1.9 & 10.5 & 5.7 & 30.8 & 16.1 & 0.62 & 0.33 & pld7 & 2.45 & 0.0001213 & 0.0001780 & 0.0002606 & 0.4277 \\
\hline 7090313 & 10/30A1 & 34S _ppldr/ra & $337 / 8$ & $\mathrm{~s}$ & 9 & 4437.4 & $673 / 4$ & $653 / 4$ & 0.446 & 0.669 & HLP-22 & 12 & 8 & 4 & 1.9 & 10.5 & 5.7 & 30.8 & 16.1 & 0.62 & 0.33 & pldr & 2.45 & 0.0001213 & 0.0001780 & 0.0002606 & 0.4277 \\
\hline 7000321 & 10/30A2 & 34S_6p1d/rd_1 1 & $337 / 8$ & $\mathrm{~s}$ & 9 & 4437.4 & $673 / 4$ & $653 / 4$ & 0.446 & 0.669 & HLP-22 & 12 & 8 & 4 & 1.9 & 10.5 & 5.7 & 30.8 & 16.1 & 0.62 & 0.33 & p1d7 & 2.45 & 0.0001213 & 0.0001780 & 0.0002606 & 0.42 \\
\hline 7090324 & 10/30A2 & 34S_6p1dTrd_1 & $337 / 8$ & s & 9 & 4437.4 & $673 / 4$ & $653 / 4$ & 0.446 & 0.669 & HLP-22 & 12 & 8 & 4 & 1.9 & 10.5 & 5.7 & 30.8 & 16.1 & 0.62 & 0.33 & pld7 & 2.45 & 0.0001213 & 0.0001780 & 0.0002606 & 0.4277 \\
\hline $7090328 \mathrm{Mx}$ & 10/30A2 & 34__fopldryd_1 1 & $337 / 8$ & s & 9 & 4437.4 & $673 / 4$ & $653 / 4$ & 0.446 & 0.669 & HLP-22 & 12 & 8 & 4 & 1.9 & 10.5 & 5.7 & 30.8 & 16.1 & 0.62 & 0.33 & p1d7 & 2.45 & 0.0001213 & 0.0001780 & 0.0002606 & 0.427 \\
\hline 7090333 & $10 / 30 C_{1}$ & 345_6p1drra-04 & $337 / 8$ & $\mathrm{~s}$ & 9 & 4437.4 & $673 / 4$ & $653 / 4$ & 0.446 & 0.669 & HLP-22 & 12 & 0 & 4 & 1.9 & 10.5 & 5.7 & 30.8 & 16.1 & 0.62 & 0.33 & p1d7 & 2.45 & 0.0001213 & 0.0001780 & 0.0002606 & \\
\hline 7000335 & $10 / 30 C_{1}$ & 34S_6p1drra-04 & $337 / 8$ & $s$ & 9 & 4437.4 & $673 / 4$ & $653 / 4$ & 0.446 & 0.669 & HLP.22 & 12 & 0 & 4 & 1.9 & 10.5 & 5.7 & 30.8 & 16.1 & 0.62 & 0.33 & pld7 & 2.45 & 0.0001213 & 0.0001780 & 0.0002606 & 0.4277 \\
\hline 7090338 & $10 / 30 \mathrm{C1}$ & 345_6p1drra-04 & $337 / 8$ & $s$ & 9 & 4437.4 & $673 / 4$ & $653 / 4$ & 0.446 & 0.669 & HLP-22 & 12 & 0 & 4 & 1.9 & 10.5 & 5.7 & 30.8 & 16.1 & 0.62 & 0.33 & p1d7 & 2.45 & \begin{tabular}{l|l}
0.0001213 \\
\end{tabular} & 0.0001780 & 0.0002606 & 0.42 \\
\hline 7090341 & $10 / 30 \mathrm{Cl}$ & 345_6p1drra-04 & $337 / 8$ & $s$ & 9 & 4437.4 & $673 / 4$ & $653 / 4$ & 0.446 & 0.669 & HLP-22 & 12 & 0 & 4 & 1.9 & 10.5 & 5.7 & 30.8 & 16.1 & 0.62 & 0.33 & p1dr & 2.45 & \begin{tabular}{|l|l|}
0.0001213 \\
\end{tabular} & 0.0001780 & 0.0002606 & \\
\hline 7090344 & $10 / 30 C 1$ & 34__6p1dTra-04 & $337 / 8$ & $\mathrm{~s}$ & 9 & 4437.4 & $673 / 4$ & $653 / 4$ & 0.446 & 0.669 & HLP-22 & 12 & 0 & 4 & 1.9 & 10.5 & 5.7 & 30.8 & 16.1 & 0.62 & 0.33 & p1d7 & 2.45 & $\begin{array}{ll}0.0001213 \\
\end{array}$ & 0.0001780 & 0.0002606 & 0.4277 \\
\hline 7090348 & $10130 c_{2}$ & 34S_6p1dr/dd_9 & $337 / 8$ & $s$ & 9 & 4437.4 & $673 / 4$ & $653 / 4$ & 0.446 & 0.669 & HLP-22 & 12 & 0 & 4 & 19 & 10.5 & 5.7 & 30.8 & 16.1 & 0.62 & 0.33 & pld & 2.45 & 0.0001213 & 0.0001780 & 0.0002606 & \\
\hline 7000350 & 10/30c2 & 34S_6p1dTrd_99 & $337 / 8$ & s & 9 & 4437.4 & $673 / 4$ & $653 / 4$ & 0.446 & 0.669 & HLP-22 & 12 & 0 & 4 & 1.9 & 10.5 & 5.7 & 30.8 & 16.1 & 0.62 & 0.33 & pld7 & 2.45 & 0.0001213 & 0.0001780 & 0.0002606 & 0.4277 \\
\hline 7000353 & 10/30c2 & 34S_6p1d/rd_99 & $337 / 8$ & $s$ & 9 & 4437.4 & $673 / 4$ & $653 / 4$ & 0.446 & 0.669 & HLP-22 & 12 & 0 & 4 & 1.9 & 10.5 & 5.7 & 30.8 & 16.1 & 0.62 & 0.33 & pldr & 2.45 & 0.0001213 & 0.0001780 & 0.0002606 & 0.4277 \\
\hline 7090357 & $101300^{2}$ & 34S_6p1dTrd_9 9 & $337 / 8$ & $s$ & 9 & 4437.4 & $673 / 4$ & $653 / 4$ & 0.446 & 0.669 & HLP-22 & 12 & 0 & 4 & 1.9 & 10.5 & 5.7 & 30.8 & 16.1 & 0.62 & 0.33 & p1d7 & 2.45 & 0.0001213 & 0.0001780 & 0.0002606 & \\
\hline $7090360 \mathrm{n} x$ & $10 / 30 C_{2}$ & 34S_6pldr/d_ 9 & $337 / 8$ & $s$ & 9 & 4437.4 & $673 / 4$ & $653 / 4$ & 0.446 & 0.669 & HLP-22 & 12 & 0 & 4 & 1.9 & 10.5 & 5.7 & 30.8 & 16.1 & 0.62 & 0.33 & p1d7 & 2.45 & 0.0001213 & 0.0001780 & 0.0002606 & 0.4277 \\
\hline $7090362 \mathrm{Nx}$ & $10130 \mathrm{CZ}^{2}$ & 34S_6pldr/d_ 9 & $337 / 8$ & $s$ & 9 & 4437.4 & $673 / 4$ & $653 / 4$ & 0.446 & 0.669 & HLP-22 & 12 & 0 & 4 & 1.9 & 10.5 & 5.7 & 30.8 & 16.1 & 0.62 & 0.33 & p1d7 & 2.45 & $\begin{array}{ll}0.0001213 \\
\end{array}$ & 0.0001780 & 0.0002606 & 0.4277 \\
\hline 7090368 & 10/31A1 & 34s .ppldr/ra & $337 / 8$ & $s$ & 9 & 4437.4 & $337 / 8$ & $317 / 8$ & 0.446 & 0.669 & HLP-22 & 12 & 8 & 4 & 1.9 & 10.5 & 5.7 & 30.8 & 16.1 & 0.62 & 0.33 & pld7 & 2.45 & 0.0001213 & 0.0001780 & 0.0002606 & 0.4277 \\
\hline 7090371 & 10/31A1 & 34S _ppldr/ra & $337 / 8$ & $\mathrm{~s}$ & 9 & 4437.4 & $337 / 8$ & $317 / 8$ & 0.446 & 0.669 & HLP-22 & 12 & 8 & 4 & 1.9 & 10.5 & 5.7 & 30.8 & 16.1 & 0.62 & 0.33 & p1d7 & 2.45 & 0.0001213 & 0.0001780 & 0.0002606 & 0.4277 \\
\hline 7090374 & 10/31A1 & 34S fopldrra & $337 / 8$ & $\mathrm{~s}$ & 9 & 4437.4 & $337 / 8$ & $317 / 8$ & 0.446 & 0.669 & HLP-22 & 12 & 8 & 4 & 1.9 & 10.5 & 5.7 & & & 0.62 & 0.33 & & 2.45 & 0.0001213 & 0.0001780 & 0.0002606 & \\
\hline 7090376 & 10/31A1 & 345_6pldr/ra & $337 / 8$ & $\mathrm{~s}$ & 9 & \begin{tabular}{ll|}
4437.4 \\
\end{tabular} & $337 / 8$ & $317 / 8$ & 0.446 & 0.669 & HLP-22 & 12 & 8 & 4 & 1.9 & 10.5 & 5.7 & 30.8 & 16.1 & 0.62 & 0.33 & pld7 & 2.45 & 0.0001213 & 0.0001780 & 0.0002606 & 0.4277 \\
\hline 7090379 & 10/31/A2 & $34 \mathrm{~s}$ 6p1drTd 1 & $337 / 8$ & $\mathrm{~s}$ & 9 & 4437.4 & $337 / 8$ & $317 / 8$ & 0.446 & 0.669 & HLP-22 & 12 & 8 & 4 & 1.9 & 10.5 & 5.7 & 30.8 & 16.1 & 0.62 & 0.33 & p1d7 & 2.45 & 0.0001213 & 0.0001780 & 0.0002606 & 0.427 \\
\hline
\end{tabular}


Table B.8. Data from Fall 2007 Tests in Mid-Scale Vessel with Spherical Head B.3

\begin{tabular}{|c|c|c|c|c|c|c|c|c|c|c|c|c|c|c|c|c|c|c|c|c|c|c|c|c|c|c|c|c|c|}
\hline $\begin{array}{l}\text { Tank Water } \\
\text { Temperature }\end{array}$ & $\begin{array}{l}\text { Water } \\
\text { Density }\end{array}$ & $\begin{array}{l}\text { Solids } \\
\text { Fraction }\end{array}$ & $\begin{array}{l}\text { Pulse } \\
\text { Volume } \\
\text { Fraction }\end{array}$ & $\begin{array}{l}\text { Duty } \\
\text { Cycle }\end{array}$ & $\begin{array}{l}\text { Cyde } \\
\text { Time }\end{array}$ & $\begin{array}{c}\text { Pulsed } \\
\text { ord } \\
\text { Steady } \\
\text { Jet }\end{array}$ & $\begin{array}{l}\text { Steacady } \\
\text { Jet }\end{array}$ & \begin{tabular}{|c} 
Pulsing \\
Jet
\end{tabular} & $\begin{array}{l}\text { U2 } \\
\text { URNS } \\
\end{array}$ & $\begin{array}{l}\text { U3 } \\
\text { URMB } \\
\end{array}$ & \begin{tabular}{|c} 
Discharge \\
Velocity
\end{tabular} & \begin{tabular}{|c} 
Cortiteal \\
Suspension \\
Velocity
\end{tabular} & $\begin{array}{l}\text { Average } \\
\text { Peak } \\
\text { Cloud } \\
\text { Height } \\
\end{array}$ & $\begin{array}{l}\text { UCS } \\
\text { Condition }\end{array}$ & \begin{tabular}{|c} 
UCS \\
Method
\end{tabular} & $\begin{array}{l}\text { UCS } \\
\text { Hag }\end{array}$ & $\begin{array}{l}\text { UCS } \\
\text { Center } \\
\text { Flag }\end{array}$ & $\begin{array}{c}\text { UCS udv } \\
\text { Hag }\end{array}$ & $\begin{array}{l}\text { UCS based } \\
\text { on } \\
\text { Decreasing } \\
\text { Velocity }\end{array}$ & \begin{tabular}{|c|} 
Inceep \\
Increase/ \\
Decrease
\end{tabular} & \begin{tabular}{|c} 
UDV \\
Height \\
Bed
\end{tabular} & \begin{tabular}{|l|} 
Partide \\
Motion \\
\end{tabular} & $\begin{array}{l}\text { Solids } \\
\text { Level }\end{array}$ & \begin{tabular}{|l|} 
Outer \\
Botomom \\
Pattem \\
\end{tabular} & $\begin{array}{l}\text { Inner } \\
\text { Botomom } \\
\text { Pattem }\end{array}$ & Case ID & Test & IDP & $\begin{array}{c}\text { Row } \\
\text { Number }\end{array}$ \\
\hline c & $\mathrm{g} / \mathrm{cm}^{3}$ & fraction & fraction & fraction & $s$ & text & $\mathrm{m} / \mathrm{s}$ & $m / s$ & $\mathrm{~m} / \mathrm{s}$ & $\mathrm{m} / \mathrm{s}$ & $\mathrm{m} / \mathrm{s}$ & m/s & in. & $\mathrm{m} / \mathrm{s}$ & text & text & text & text & \begin{tabular}{|l}
$\mathrm{m} / \mathrm{s}$ \\
\end{tabular} & text & $\mathrm{mm}$ & text & text & text & text & text & text & text & text \\
\hline $\mathrm{T}$ & $\rho$ & $\phi_{\mathrm{s}}$ & $\phi_{p}$ & DC & $t_{c}$ & Jet & Us & $\mathrm{U}_{1}$ & $\mathrm{U} 2$ & $U_{3}$ & $u$ & Uss & $H_{c}$ & U Uss & Unan & Uosvis & Uscen & Usuldv & Uos D & $S_{w}$ & $\mathrm{H}_{\mathrm{kad}}$ & $\mathrm{PM}$ & sol & SPo & $S P_{1}$ & $\mathrm{ID}$ & MDDX & $\mathrm{IDP}$ & MSS \\
\hline 20.9 & 0.999 & 0.00487 & undefined & 1.000 & infinite & $s$ & 5.40 & NA & NA & NA & 5.40 & 6.00 & 19.50 & NA & NA & NA & NA & NA & NA & 1 & NA & $A M$ & NA & NA & NA & 34s_6p1d/ra-04 & 10/29A1 & TDP-WTP-040 & 7090256 \\
\hline 20.9 & 0.999 & 0.00487 & undefined & 1.000 & infinite & $\mathrm{s}$ & 5.60 & NA & NA & NA & 5.60 & 6.00 & 21.50 & NA & NA & NA & NA & NA & NA & 1 & NA & AMt & $\mathrm{NA}$ & NA & NA & 345 6p1dr/ra-04 & 10/29A1 & TDP-WIP-040 & 7090258 \\
\hline 20.9 & 0.999 & 0.0448 & undefined & 1.000 & infinite & s & 5.80 & NA & NA & NA & 5.80 & 6.00 & 23.00 & NA & NA & NA & NA & NA & NA & 1 & NA & $c s$ & NA & NA & NA & 34s_6p1dr/ra-04 & 10/29A1 & TDP-WIP-040 & 7090261 \\
\hline 20.9 & 0.999 & 0.00487 & undefined & 1.000 & infinite & $\mathrm{s}$ & 5.99 & NA & NA & NA & 6.00 & 6.00 & 24.50 & \begin{tabular}{|l}
.00 \\
\end{tabular} & vis & ucsis & NA & NA & NA & 1 & NA & cs & NA & NA & NA & 34s_6p1d/ra-04 & 10/29A1 & TDP-WTP-040 & 7090265 \\
\hline 210 & 0.999 & 0.00487 & 0.046 & 0.196 & 45.0 & $P$ & NA & 6.11 & 6.53 & \begin{tabular}{|l|l|}
6.70 \\
\end{tabular} & 7.00 & 7.50 & 24.50 & NA & NA & NA & NA & NA & NA & 1 & NA & $A M$ & NA & NA & NA & 34s_6pld/r/m_9 & $10 / 29 A^{2}$ & TDP-WIP-040 & 7090268 \\
\hline 21.0 & 0.999 & 0.00487 & 0.049 & 0.203 & 45.0 & $\mathrm{P}$ & NA & 6.44 & 6.92 & 7.12 & 7.50 & 7.50 & 27.00 & $\begin{array}{l}7.50 \\
\end{array}$ & vis & UCsis & NA & NA & NA & 1 & NA & CS & NA & NA & NA & 34s_6p1d $/ 7 \mathrm{rm}=9$ & 10/29A2 & TDP-WIP-040 & 7090271 \\
\hline 21.0 & 0.999 & 0.00487 & 0.051 & 0.198 & 45.0 & $\mathrm{P}$ & NA & 6.62 & 7.10 & 7.30 & 7.70 & 7.50 & 28.00 & NA & NA & NA & NA & NA & NA & 1 & NA & $B C$ & NA & NA & NA & 34s_6p1d $7 / \mathrm{m}$ _ 9 & 10/29A2 & TDP-WIP-040 & 7090274 \\
\hline 21.0 & 0.999 & 0.00487 & undefined & 1.000 & infinite & s & 4.99 & NA & NA & NA & 5.00 & 5.50 & 11.50 & NA & NA & NA & NA & NA & NA & 1 & NA & AMt & NA & NA & NA & 34s_6p1d/ra-40 & 10/29B1 & TDP-WIP-040 & 7090279 \\
\hline 21.1 & 0.999 & 0.00487 & undefined & 1.000 & infinite & $\mathrm{s}$ & 5.50 & NA & NA & NA & 5.50 & 5.50 & 21.25 & \begin{tabular}{|l|}
5.50 \\
\end{tabular} & vis & ucsis & NA & NA & NA & 1 & NA & cs & NA & NA & NA & 34s_6p1d/ra-40 & 10/2981 & TDP-WIP-040 & 7090283 \\
\hline 21.0 & 0.999 & 0.00487 & undefined & 1.000 & infinite & $\mathrm{s}$ & 5.70 & NA & NA & NA & 5.70 & 5.50 & 25.00 & NA & NA & NA & NA & NA & NA & 1 & NA & $B C$ & NA & NA & NA & 34s_6p1d/ra-40 & 10/29B1 & TDP-WIP-040 & 7090285 \\
\hline 21.0 & 0.999 & 0.00487 & 0.050 & 0.180 & 70.0 & $\mathrm{P}$ & NA & 4.90 & 4.95 & 4.98 & 5.00 & 6.20 & 9.75 & NA & NA & NA & NA & NA & NA & D & NA & ss & NA & NA & NA & 34S_6p1d/rd_6 6 & 10/2982 & TDP-WIP-040 & 7090288 \\
\hline 21.0 & 0.999 & 0.00487 & 0.050 & 0.180 & 63.0 & $\mathrm{P}$ & NA & 5.39 & 5.45 & 5.48 & 5.50 & 6.20 & 11.50 & NA & NA & NA & NA & NA & NA & 1 & NA & sst & NA & NA & NA & 34S_6p1dT/Yd_6 & 10/29B2 & TDP-WIP-040 & 7090291 \\
\hline 21.0 & 0.999 & 0.00487 & 0.055 & 0.180 & 58.0 & $\mathrm{P}$ & NA & 5.83 & 5.90 & 5.93 & 6.00 & 6.20 & 14.00 & NA & NA & NA & NA & NA & NA & 1 & NA & $A M+$ & NA & NA & NA & 34s_6p1d7Yd_6 & 10/29B2 & TDP-WTP-040 & 7090294 \\
\hline 21.0 & 0.999 & 0.00487 & 0.050 & 0.180 & 56.0 & $\mathrm{P}$ & NA & 6.06 & 6.14 & 6.17 & 6.20 & 6.20 & 16.00 & $\begin{array}{l}6.20 \\
\end{array}$ & vis & ucsis & NA & NA & NA & 1 & NA & CS & NA & NA & NA & 34s_6pldryd_6 & $10 / 29 B 2$ & TDP-WIP-040 & 7090298 \\
\hline 21.0 & 0.999 & 0.00487 & 0.050 & 0.180 & 53.0 & $\mathrm{P}$ & NA & 6.23 & 6.32 & 6.37 & 6.40 & 6.20 & 17.25 & NA & NA & NA & NA & NA & NA & 1 & NA & $B C$ & NA & NA & NA & 34s_6pldryd 6 & 10/2982 & TDP-WTP-040 & 7090300 \\
\hline 21.1 & 0.999 & 0.00487 & undefined & 1.000 & infinite & $\mathrm{s}$ & 2.02 & NA & NA & NA & 2.00 & 3.20 & NA & NA & NA & NA & NA & NA & NA & NA & NA & ss & NA & NA & NA & 34s_6p1d/ra & 1030A1 & TDP-WIP-041 & 7090303 \\
\hline 21.1 & 0.999 & 0.00487 & undefined & 1.000 & infinite & s & 2.50 & NA & NA & NA & 2.50 & 3.20 & 9.00 & NA & NA & NA & NA & NA & NA & 1 & NA & sst & NA & NA & NA & 34s_ppldrra & 1030A1 & TDP-WIP-041 & 7090306 \\
\hline 21.1 & 0.999 & 0.00487 & undefined & 1.000 & infinite & s & 3.01 & NA & NA & NA & 3.00 & 3.20 & 10.25 & NA & NA & NA & NA & NA & NA & 1 & NA & $A M$ & NA & NA & NA & 345_opldrra & $1030 \mathrm{~A}_{1}$ & TDP-WIP-041 & 7090310 \\
\hline 21.1 & 0.999 & 0.00487 & undefined & 1.000 & infinite & $\mathrm{s}$ & 3.23 & NA & NA & NA & 3.20 & 3.20 & 17.75 & $\begin{array}{l}3.20 \\
\end{array}$ & vis & ucsis & NA & NA & NA & 1 & NA & cs & NA & NA & NA & 345_6pldrva & 10/30A1 & TDP-WIP-041 & 7090313 \\
\hline 21.0 & 0.999 & 0.00487 & 0.050 & 0.180 & 39.5 & $\mathrm{P}$ & NA & 2.78 & 2.86 & 2.90 & 3.00 & 3.60 & 11.00 & NA & NA & NA & NA & NA & NA & 1 & NA & sst & NA & NA & NA & 34s_6pldryd_1 & $1030 \mathrm{~A}^{2}$ & TDP-WTP-041 & 7090318 \\
\hline 21.0 & 0.999 & 0.0448 & 0.051 & 0.180 & 37.0 & $\mathrm{P}$ & NA & 2.94 & 3.04 & 3.09 & 3.20 & 3.60 & 11.75 & NA & NA & NA & NA & NA & NA & 1 & NA & $A M$ & NA & NA & NA & 34S_6p1d/rd_1 1 & 103012 & TDP-WIP-041 & 7090321 \\
\hline 21.0 & 0.999 & 0.00487 & 0.051 & 0.180 & 35.0 & $\mathrm{P}$ & NA & 3.06 & 3.18 & 3.24 & 3.40 & 3.60 & 12.50 & NA & NA & NA & NA & NA & NA & 1 & NA & $A M+$ & NA & NA & NA & 34s_6p1d7Yd_1 & $1030 \mathrm{~A}^{2}$ & TDP-WTP-041 & 7090324 \\
\hline 21.0 & 0.999 & 0.00487 & 0.051 & 0.180 & 33.0 & $\mathrm{P}$ & NA & 3.09 & 3.25 & 3.33 & 3.60 & 3.60 & 12.75 & 3.60 & vis & ucsis & NA & NA & NA & 1 & NA & CS & NA & NA & NA & 34s_6p1d/rdd_1 & $1030 \mathrm{AZ}$ & TDP-WIP-041 & 7090328 \\
\hline 21.3 & 0.999 & 0.00487 & undefined & 1.000 & infinite & $\mathrm{s}$ & 4.02 & NA & NA & NA & 4.00 & NA & 11.25 & NA & NA & NA & NA & NA & NA & 1 & NA & ss & NA & NA & NA & 34s_6p1d/ra-04 & $10 / 30 \mathrm{C1}$ & TDP-WIP-041 & 7090333 \\
\hline 21.3 & 0.999 & 0.00487 & undefined & 1.000 & infinite & $\mathrm{s}$ & 4.51 & NA & NA & NA & 4.50 & NA & 14.00 & NA & NA & NA & NA & NA & NA & 1 & NA & $A M$ & NA & NA & NA & 34s_6p1d/7a-04 & $1030 \mathrm{C1}$ & TDP-WTP-041 & 7090335 \\
\hline 21.3 & 0.999 & 0.00487 & undefined & 1.000 & infinite & $\mathrm{s}$ & 5.02 & NA & NA & NA & 5.00 & NA & 16.75 & NA & NA & NA & NA & NA & NA & 1 & NA & $A M$ & NA & NA & NA & 34S_6p1d/7ra.04 & $10 / 30 \mathrm{C} 1$ & TDP-WIP-041 & 7090338 \\
\hline 21.4 & 0.999 & 0.00487 & undefined & 1.000 & infinite & $\mathrm{s}$ & 5.52 & NA & NA & NA & 5.50 & NA & 20.50 & NA & NA & NA & NA & NA & NA & 1 & NA & $A M+$ & NA & NA & NA & 34s_6p1d/ra-04 & $1030 \mathrm{C1}$ & TDP-WIP-041 & 7090341 \\
\hline 21.4 & 0.999 & 0.00487 & undefined & 1.000 & infinite & $\mathrm{s}$ & 5.74 & NA & NA & NA & 5.70 & NA & 23.50 & NA & NA & NA & NA & NA & NA & 1 & NA & CS & NA & NA & NA & 34s_6pld/ra-04 & $1030 \mathrm{Cl}$ & TDP-WIP-041 & 7090344 \\
\hline 21.0 & 0.999 & 0.00487 & 0.046 & 0.180 & 70.0 & $\mathrm{P}$ & NA & 4.87 & \begin{tabular}{|l|} 
\\
\end{tabular} & 4.96 & 5.00 & 6.70 & 15.50 & NA & NA & NA & NA & NA & NA & $\mathrm{D}$ & NA & sst & NA & NA & NA & 34s_6p1d/rd_ 9 & $1030 \mathrm{C2}$ & TDP-WIP-041 & 7090348 \\
\hline 21.0 & 0.999 & 0.00487 & 0.050 & 0.180 & 63.5 & $\mathrm{P}$ & NA & 5.37 & 5.44 & 5.48 & 5.50 & 6.70 & 18.25 & NA & NA & NA & NA & NA & NA & 1 & NA & $A M$ & NA & NA & NA & 34S_6p1d/rd_99 & $1030 \mathrm{CZ} 2$ & TDP-WIP-041 & 7090350 \\
\hline 21.0 & 0.999 & 0.00487 & 0.050 & 0.180 & 57.5 & $\mathrm{P}$ & NA & 5.86 & 5.95 & 5.99 & 6.00 & 6.70 & 20.50 & NA & NA & NA & NA & NA & NA & 1 & NA & $A M$ & NA & NA & NA & 34S_6p1dryd_9 & $1030 \mathrm{C2}$ & TDP-WIP-041 & 7090353 \\
\hline 21.0 & 0.999 & 0.00487 & 0.051 & 0.180 & 54.0 & $\mathrm{P}$ & NA & 6.25 & 6.38 & 6.44 & 6.50 & 6.70 & 22.25 & NA & NA & NA & NA & NA & NA & 1 & NA & $A M+$ & NA & NA & NA & 34s_6p1d/rd_ 9 & $1030 \mathrm{C2}$ & TDP-WTP-041 & 7090357 \\
\hline 21.0 & 0.999 & 0.00487 & 0.050 & 0.180 & 51.5 & $P$ & NA & 6.37 & 6.54 & 6.62 & 6.70 & 6.70 & 24.50 & 6.70 & vis & ucsis & NA & NA & NA & 1 & NA & cs & NA & NA & NA & 34S_6p1d/rd_99 & $1030 \mathrm{CZ} 2$ & TDP-WIP-041 & 7090360 \\
\hline 21.0 & 0.999 & 0.00487 & 0.051 & 0.180 & 50.5 & $\mathrm{P}$ & NA & 6.12 & 6.49 & 6.64 & 6.90 & & 25.50 & NA & NA & NA & & NA & NA & 1 & NA & $\mathrm{BC}$ & NA & NA & NA & 34s_6pldryd_9 & $10 / 30 \mathrm{C2}$ & TDP-WIP-041 & 7090362 \\
\hline 21.5 & 0.999 & 0.00487 & undefined & 1.000 & infinite & $\mathrm{s}$ & 281 & NA & NA & NA & 2.80 & 3.00 & 10.50 & NA & NA & NA & NA & NA & NA & 1 & NA & $A M$ & NA & NA & NA & 34s_6p1d/ra & 10/31A1 & TDP-WIP-042 & 7090368 \\
\hline 214 & 0.999 & 0.00487 & undefined & 1.000 & infinite & s & 2.42 & NA & NA & NA & 2.40 & 3.00 & 9.50 & NA & NA & NA & NA & NA & NA & D & NA & ss & NA & NA & NA & 34s_opldrva & 10/31A1 & TDP-WIP-042 & 7090371 \\
\hline 214 & 0.999 & 0.00487 & undefined & 1.000 & infinite & $s$ & 3.01 & NA & NA & NA & 3.00 & 3.00 & 16.50 & 3.00 & vis & UCSis & $\mathrm{N}$ & NA & NA & 1 & NA & cs & NA & NA & NA & 34s 6pldrva & 10/31A1 & TDP-WIP-042 & 7090374 \\
\hline 21.4 & 0.999 & 0.00487 & undefined & 1.000 & infinite & $\mathrm{s}$ & 3.22 & NA & NA & NA & 3.20 & 3.00 & 26.00 & NA & NA & NA & NA & NA & NA & 1 & NA & $B C$ & NA & NA & NA & 345_opldrva & 10/31A1 & TDP-WIP-042 & 7090376 \\
\hline 210 & 0.999 & 0.00487 & 0.050 & 0.180 & 48.0 & $P$ & NA & 2.35 & 2.39 & 2.41 & 2.50 & 3.40 & 11.00 & NAA & $\mathrm{NA}$ & NA & NA & NA & NA & $D$ & NA & ss & $\mathrm{NA}$ & NA & NA & 34S Gp1d/Td _ 1 & 10/31A2 & TDP-WIP-042 & 7090379 \\
\hline
\end{tabular}


Table B.8. Data from Fall 2007 Tests in Mid-Scale Vessel with Spherical Head A.4

\begin{tabular}{|c|c|c|c|c|c|c|c|c|c|c|c|c|c|c|c|c|c|c|c|c|c|c|c|c|c|c|c|}
\hline $\begin{array}{c}\text { Row } \\
\text { Number }\end{array}$ & Test & Case ID & $\begin{array}{c}\text { Tank } \\
\text { Diameter }\end{array}$ & $\begin{array}{l}\text { Head } \\
\text { Shape }\end{array}$ & $\begin{array}{c}\text { Dish } \\
\text { Height }\end{array}$ & $\begin{array}{l}\text { Dish } \\
\text { Volume }\end{array}$ & $\begin{array}{l}\text { Tank } \\
\text { Fill } \\
\text { Height }\end{array}$ & \begin{tabular}{|l} 
Returm \\
Line \\
Height
\end{tabular} & $\begin{array}{c}\text { Nozzle } \\
\text { Inner } \\
\text { Dianeter }\end{array}$ & $\begin{array}{c}\text { Nozzle } \\
\text { Stand- } \\
\text { off } \\
\text { Distance }\end{array}$ & $\begin{array}{l}\text { Pulse Tube } \\
\text { Configuration }\end{array}$ & $\begin{array}{l}\text { Installed } \\
\text { Nozzles } \\
\text { Nets }\end{array}$ & \begin{tabular}{|c} 
Outur \\
Nozles \\
Operated \\
\end{tabular} & $\begin{array}{c}\text { Inner } \\
\text { Nozzles } \\
\text { Opperated }\end{array}$ & $\begin{array}{l}\text { Pulse Tube } \\
\text { Outer } \\
\text { Diameter }\end{array}$ & $\begin{array}{c}\text { Outer } \\
\text { PJM } \\
\text { Radius }\end{array}$ & $\begin{array}{c}\text { Inner } \\
\text { PJM } \\
\text { Radius }\end{array}$ & $\begin{array}{l}\text { "FO' Outer } \\
\text { PJM } \\
\text { Impingement } \\
\text { Angle }\end{array}$ & $\begin{array}{l}\text { "FO' Inner } \\
\text { PJM } \\
\text { Impingement } \\
\text { Angle }\end{array}$ & $\begin{array}{c}\text { Ratio Outer } \\
\text { PJMto } \\
\text { Tank } \\
\text { Radius } \\
\end{array}$ & $\begin{array}{c}\text { Ratio Inner } \\
\text { PJM to } \\
\text { Tank } \\
\text { Radius } \\
\end{array}$ & Simulant & $\begin{array}{l}\text { Solids } \\
\text { Density }\end{array}$ & $\begin{array}{c}\text { Particle } \\
\text { Diameter d5 }\end{array}$ & $\begin{array}{c}\text { Partide } \\
\text { Dianeter } \\
\text { d50 }\end{array}$ & $\begin{array}{c}\text { Particle } \\
\text { Diameter } \\
\text { d95 }\end{array}$ & $\begin{array}{c}\text { Void } \\
\text { Fraction }\end{array}$ \\
\hline text & text & text & in. & text & in. & in. ${ }^{3}$ & in. & in. & in. & in. & text & number & \begin{tabular}{|l} 
number \\
\end{tabular} & number & in. & in. & in. & deg & deg & nondim & nondim & text & $\mathrm{g} / \mathrm{cm}^{3}$ & $\mathrm{~m}$ & $\mathrm{~m}$ & $\mathrm{~m}$ & fraction \\
\hline MSS & MDDX & ID & $\mathrm{D}$ & HS & Hess & $V_{\text {dsh }}$ & $\mathrm{H}$ & Rtn & $d$ & sod & PT & $\mathrm{N}$ & $\mathrm{Nb}$ & $\mathrm{N}$ & $\mathrm{PT}_{\alpha \mathrm{d}}$ & $\mathrm{R}_{0}$ & $\mathrm{R}_{4}$ & $\theta_{0}$ & $\theta_{1}$ & $\mathrm{RdR}$ & $R / R$ & $\operatorname{sxdx}$ & $\rho_{\mathrm{s}}$ & $\frac{d}{b}$ & $d_{50}$ & $d_{65}$ & vf \\
\hline 7090382 & $10 / 31 / A_{2}$ & 34s_6p1d/Yd_1 1 & $337 / 8$ & $\mathrm{~s}$ & 9 & 4437.4 & $337 / 8$ & $317 / 8$ & 0.446 & 0.669 & HLP-22 & 12 & 8 & 4 & 1.9 & 10.5 & 5.7 & 30.8 & 16.1 & 0.62 & 0.33 & pldr & 2.45 & 0.0001213 & 0.0001780 & 0.0002606 & 0.4277 \\
\hline 7090385 & 10/31A2 & 34s gpldr/rd 1 & $337 / 8$ & $\mathrm{~s}$ & 9 & 4437.4 & $337 / 8$ & $317 / 8$ & 0.446 & 0.669 & HLP. 22 & 12 & 8 & 4 & 1.9 & 10.5 & 5.7 & 30.8 & 16.1 & 0.62 & 0.33 & p1d7 & 2.45 & 0.0001213 & 0.0001780 & 0.0002606 & $0.42 \pi 7$ \\
\hline 7090389 & 10/31A2 & 34S_6p1d7Yd_1 1 & $337 / 8$ & $\mathrm{~s}$ & 9 & 4437.4 & $337 / 8$ & $317 / 8$ & 0.446 & 0.669 & HLP-22 & 12 & 8 & 4 & 1.9 & 10.5 & 5.7 & 30.8 & 16.1 & 0.62 & 0.33 & p1d7 & 2.45 & 0.0001213 & 0.0001780 & 0.0002606 & 0.4277 \\
\hline 7090391 & $10 / 31 A_{2}$ & 34s_6p1d/rd_1 1 & $337 / 8$ & $\mathrm{~s}$ & 9 & 4437.4 & $337 / 8$ & $317 / 8$ & 0.446 & 0.669 & HLP-22 & 12 & 8 & 4 & 1.9 & 10.5 & 5.7 & 30.8 & 16.1 & 0.62 & 0.33 & pld 7 & 2.45 & 0.0001213 & 0.0001780 & 0.0002606 & 0.4277 \\
\hline 7090395 & $11 / 2 A 1$ & 34s_ 6p1d/ra-80 & $337 / 8$ & $s$ & 9 & 4437.4 & $337 / 8$ & $317 / 8$ & 0.446 & 0.669 & HLP-22 & 12 & 8 & 0 & 19 & 10.5 & 5.7 & 30.8 & 16.1 & 0.62 & 0.33 & p1d7 & 2.45 & 0.0001213 & 0.0001780 & 0.0002606 & 0.4277 \\
\hline 7090398 & $11 / 2 \mathrm{~A} 1$ & 34s_6p1d/7a-80 & $337 / 8$ & $s$ & 9 & 4437.4 & $337 / 8$ & $317 / 8$ & 0.446 & 0.669 & HLP-22 & 12 & 8 & 0 & 19 & 10.5 & 5.7 & 30.8 & 16.1 & 0.62 & 0.33 & pldr & 2.45 & 0.0001213 & 0.0001780 & 0.0002606 & 0.4277 \\
\hline 7090401 & 11/2A2 & 34S_6p1d7rd_5 5 & $337 / 8$ & $\mathrm{~s}$ & 9 & 4437.4 & $337 / 8$ & $317 / 8$ & 0.446 & 0.669 & HLP. 22 & 12 & 8 & 0 & 1.9 & 10.5 & 5.7 & 30.8 & 16.1 & 0.62 & 0.33 & p1d7 & 2.45 & 0.0001213 & 0.0001780 & 0.0002606 & $0.42 \pi 7$ \\
\hline 7090403 & $11 / 2 A_{2}$ & 34S_6p1d7Yd_5 5 & $337 / 8$ & $\mathrm{~s}$ & 9 & 4437.4 & $337 / 8$ & $317 / 8$ & 0.446 & 0.669 & HLP-22 & 12 & 8 & 0 & 1.9 & 10.5 & 5.7 & 30.8 & 16.1 & 0.62 & 0.33 & p1dr & 2.45 & 0.0001213 & 0.0001780 & 0.0002606 & 0.4277 \\
\hline 7090406 & $11 / 2 \mathrm{~A} 2$ & 34s_6p1d7rd_5 5 & $337 / 8$ & $\mathrm{~s}$ & 9 & 4437.4 & $337 / 8$ & $317 / 8$ & 0.446 & 0.669 & HLP-22 & 12 & 8 & 0 & 1.9 & 10.5 & 5.7 & 30.8 & 16.1 & 0.62 & 0.33 & p1d7 & 2.45 & 0.0001213 & 0.0001780 & 0.0002606 & 0.4277 \\
\hline 7090409 & $11 / 2 A^{2}$ & 34S_6pldT/d 5 & $337 / 8$ & $s$ & 9 & 4437.4 & $337 / 8$ & $317 / 8$ & 0.446 & 0.669 & HLP-22 & 12 & 8 & 0 & 1.9 & 10.5 & 5.7 & 30.8 & 16.1 & 0.62 & 0.33 & p1d7 & 2.45 & 0.0001213 & 0.0001780 & 0.0002606 & 0.4277 \\
\hline 7090413 & $11 / 2 \mathrm{~A} 2$ & 34s_6p1d7/d_5 5 & $337 / 8$ & $\mathrm{~s}$ & 9 & 4437.4 & $337 / 8$ & $317 / 8$ & 0.446 & 0.669 & HLP-22 & 12 & 8 & 0 & 1.9 & 10.5 & 5.7 & 30.8 & 16.1 & 0.62 & 0.33 & pldr & 2.45 & 0.0001213 & 0.0001780 & 0.0002606 & 0.4277 \\
\hline 7090416 & $11 / 5 \mathrm{~A} 1$ & 34s_6p1d/7a-44 & $337 / 8$ & $\mathrm{~s}$ & 9 & 4437.4 & $337 / 8$ & $317 / 8$ & 0.446 & 0.669 & HLP-22 & 12 & 4 & 4 & 19 & 10.5 & 5.7 & 30.8 & 16.1 & 0.62 & 0.33 & p1d7 & 2.45 & 0.0001213 & 0.0001780 & 0.0002606 & 0.4277 \\
\hline 7090419 & 11/5A1 & 34s_6p1d7/ra-44 & $337 / 8$ & $\mathrm{~s}$ & 9 & 4437.4 & $337 / 8$ & $317 / 8$ & 0.446 & 0.669 & HLP-22 & 12 & 4 & 4 & 19 & 10.5 & 5.7 & 30.8 & 16.1 & 0.62 & 0.33 & p1d7 & 2.45 & 0.0001213 & 0.0001780 & 0.0002606 & 0.4277 \\
\hline 7090421 & 11/5A1 & 34s_6p1d7/Ya-44 & $337 / 8$ & $\mathrm{~s}$ & 9 & 4437.4 & $337 / 8$ & $317 / 8$ & 0.446 & 0.669 & HLP-22 & 12 & 4 & 4 & 19 & 10.5 & 5.7 & 30.8 & 16.1 & 0.62 & 0.33 & p1d7 & 2.45 & 0.0001213 & 0.0001780 & 0.0002606 & 0.4277 \\
\hline 7090424 & $11 / 5 \mathrm{~A} 1$ & 34s_ 6p1dr/ra-44 & $337 / 8$ & $\mathrm{~s}$ & 9 & 4437.4 & $337 / 8$ & $317 / 8$ & 0.446 & 0.669 & HLP-22 & 12 & 4 & 4 & 19 & 10.5 & 5.7 & 30.8 & 16.1 & 0.62 & 0.33 & p1d7 & 2.45 & 0.0001213 & 0.0001780 & 0.0002606 & 0.4277 \\
\hline 7090428 & $11 / 5 \mathrm{~A} 1$ & 34s_6p1d/7a-44 & $337 / 8$ & $\mathrm{~s}$ & 9 & 4437.4 & $337 / 8$ & $317 / 8$ & 0.446 & 0.669 & HLP-22 & 12 & 4 & 4 & 1.9 & 10.5 & 5.7 & 30.8 & 16.1 & 0.62 & 0.33 & pld7 & 2.45 & 0.0001213 & 0.0001780 & 0.0002606 & 0.4277 \\
\hline 7090430 & $11 / 5 \mathrm{~A} 1$ & 34s_6p1d/7a-44 & $337 / 8$ & $\mathrm{~s}$ & 9 & 4437.4 & $337 / 8$ & $317 / 8$ & 0.446 & 0.669 & HLP-22 & 12 & 4 & 4 & 19 & 10.5 & 5.7 & 30.8 & 16.1 & 0.62 & 0.33 & pld 7 & 2.45 & 0.0001213 & 0.0001780 & 0.0002606 & 0.4277 \\
\hline 7090434 & $11 / 5 \mathrm{~A} 2$ & 34s_6p1d/7d_0 0 & $337 / 8$ & $\mathrm{~s}$ & 9 & 4437.4 & $337 / 8$ & $317 / 8$ & 0.446 & 0.669 & HLP-22 & 12 & 4 & 4 & 1.9 & 10.5 & 5.7 & 30.8 & 16.1 & 0.62 & 0.33 & p1d7 & 2.45 & 0.0001213 & 0.0001780 & 0.0002606 & 0.4277 \\
\hline 7090436 & $11 / 5 \mathrm{~A} 2$ & 34s_6p1d/7d_0 0 & $337 / 8$ & $\mathrm{~s}$ & 9 & 4437.4 & $337 / 8$ & $317 / 8$ & 0.446 & 0.669 & HLP-22 & 12 & 4 & 4 & 1.9 & 10.5 & 5.7 & 30.8 & 16.1 & 0.62 & 0.33 & p1d7 & 2.45 & 0.0001213 & 0.0001780 & 0.0002606 & 0.4277 \\
\hline 7090439 & $11 / 5 \mathrm{~A} 2$ & 34S 6p1dr/d o 0 & $337 / 8$ & $s$ & 9 & 4437.4 & $337 / 8$ & $317 / 8$ & 0.446 & 0.669 & HLP-22 & 12 & 4 & 4 & 1.9 & 10.5 & 5.7 & 30.8 & 16.1 & 0.62 & 0.33 & $\mathrm{p} 1 \mathrm{~d} 7 \mathrm{P}$ & 2.45 & 0.0001213 & 0.0001780 & 0.0002606 & 0.4277 \\
\hline 7090443 & $11 / 5 \mathrm{~A} 2$ & 34s_6p1d7Yd_0 0 & $337 / 8$ & $\mathrm{~s}$ & 9 & 4437.4 & $337 / 8$ & $317 / 8$ & 0.446 & 0.669 & HLP-22 & 12 & 4 & 4 & 1.9 & 10.5 & 5.7 & 30.8 & 16.1 & 0.62 & 0.33 & pldr & 2.45 & 0.0001213 & 0.0001780 & 0.0002606 & 0.4277 \\
\hline 7090445 & $11 / 5 \mathrm{~A} 2$ & 34S_6p1d7rd_0 0 & $337 / 8$ & $\mathrm{~s}$ & 9 & 4437.4 & $337 / 8$ & $317 / 8$ & 0.446 & 0.669 & HLP-22 & 12 & 4 & 4 & 1.9 & 10.5 & 5.7 & 30.8 & 16.1 & 0.62 & 0.33 & pld 7 & 2.45 & 0.0001213 & 0.0001780 & 0.0002606 & 0.4277 \\
\hline 7090448 & $11 / 5 A^{2}$ & 34S_6p1d7rd_0 0 & $337 / 8$ & $\mathrm{~s}$ & 9 & 4437.4 & $337 / 8$ & $317 / 8$ & 0.446 & 0.669 & HLP-22 & 12 & 4 & 4 & 1.9 & 10.5 & 5.7 & 30.8 & 16.1 & 0.62 & 0.33 & p1dr & 2.45 & 0.0001213 & 0.0001780 & 0.0002606 & 0.4277 \\
\hline 7090451 & $11 / 5 A 2$ & 34s_6p1d7rd_0 0 & $337 / 8$ & $\mathrm{~s}$ & 9 & 4437.4 & $337 / 8$ & $317 / 8$ & 0.446 & 0.669 & HLP-22 & 12 & 4 & 4 & 1.9 & 10.5 & 5.7 & 30.8 & 16.1 & 0.62 & 0.33 & p1d7 & 2.45 & 0.0001213 & 0.0001780 & 0.0002606 & 0.4277 \\
\hline 7090454 & $11 / 5 \mathrm{~A} 2$ & 34S 6p1dr/dd o 0 & $337 / 8$ & $s$ & 9 & 4437.4 & $337 / 8$ & $317 / 8$ & 0.446 & 0.669 & HLP-22 & 12 & 4 & 4 & 1.9 & 10.5 & 5.7 & 30.8 & 16.1 & 0.62 & 0.33 & $\mathrm{p} 1 \mathrm{dr}$ & 2.45 & 0.0001213 & 0.0001780 & 0.0002606 & 0.4277 \\
\hline 7090458 & $11 / 5 \mathrm{~A} 2$ & 34s_6p1d7Yd_0 0 & $337 / 8$ & $\mathrm{~s}$ & 9 & 4437.4 & $337 / 8$ & $317 / 8$ & 0.446 & 0.669 & HLP-22 & 12 & 4 & 4 & 1.9 & 10.5 & 5.7 & 30.8 & 16.1 & 0.62 & 0.33 & pldr & 2.45 & 0.0001213 & 0.0001780 & 0.0002606 & 0.4277 \\
\hline 7090461 & $11 / 5 \mathrm{~B} 1$ & 34S_6p1d/7a-04 & $337 / 8$ & $\mathrm{~s}$ & 9 & 4437.4 & $337 / 8$ & $317 / 8$ & 0.446 & 0.669 & HLP-22 & 12 & 0 & 4 & 19 & 10.5 & 5.7 & 30.8 & 16.1 & 0.62 & 0.33 & pld 7 & 2.45 & 0.0001213 & 0.0001780 & 0.0002606 & 0.4277 \\
\hline 7090464 & $11 / 5 \mathrm{~B} 1$ & 34S_6p1d/7a-04 & $337 / 8$ & $\mathrm{~s}$ & 9 & 4437.4 & $337 / 8$ & $317 / 8$ & 0.446 & 0.669 & HLP-22 & 12 & 0 & 4 & 19 & 10.5 & 5.7 & 30.8 & 16.1 & 0.62 & 0.33 & p1d7 & 2.45 & 0.0001213 & 0.0001780 & 0.0002606 & 0.4277 \\
\hline 7090466 & $11 / 5 B 1$ & 34s_6p1d7/ra-04 & $337 / 8$ & $\mathrm{~s}$ & 9 & 4437.4 & $337 / 8$ & $317 / 8$ & 0.446 & 0.669 & HLP-22 & 12 & 0 & 4 & 19 & 10.5 & 5.7 & 30.8 & 16.1 & 0.62 & 0.33 & p1d7 & 2.45 & 0.0001213 & 0.0001780 & 0.0002606 & 0.4277 \\
\hline 7090469 & $11 / 5 \mathrm{~B} 1$ & 34S_6p1d/7a-04 & $337 / 8$ & $\mathrm{~s}$ & 9 & 4437.4 & $337 / 8$ & $317 / 8$ & 0.446 & 0.669 & HLP-22 & 12 & 0 & 4 & 19 & 10.5 & 5.7 & 30.8 & 16.1 & 0.62 & 0.33 & p1d7 & 2.45 & 0.0001213 & 0.0001780 & 0.0002606 & 0.4277 \\
\hline 7090473 & $11 / 5 \mathrm{~B} 1$ & 34s_6p1d $7 /$ Ya-04 & $337 / 8$ & $\mathrm{~s}$ & 9 & 4437.4 & $337 / 8$ & $317 / 8$ & 0.446 & 0.669 & HLP-22 & 12 & 0 & 4 & 19 & 10.5 & 5.7 & 30.8 & 16.1 & 0.62 & 0.33 & pld7 & 2.45 & 0.0001213 & 0.0001780 & 0.0002606 & 0.4277 \\
\hline 7090476 & $11 / 5 \mathrm{~B} 2$ & 34S_6p1d/7d_9 9 & $337 / 8$ & $\mathrm{~s}$ & 9 & 4437.4 & $337 / 8$ & $317 / 8$ & 0.446 & 0.669 & HLP-22 & 12 & 0 & 4 & 1.9 & 10.5 & 5.7 & 30.8 & 16.1 & 0.62 & 0.33 & pld 7 & 2.45 & 0.0001213 & 0.0001780 & 0.0002606 & 0.4277 \\
\hline 7090479 & $11 / 5 \mathrm{~B} 2$ & 345 6p1d/rd 9 & $337 / 8$ & $s$ & 9 & 4437.4 & $337 / 8$ & $317 / 8$ & 0.446 & 0.669 & HLP-22 & 12 & 0 & 4 & 1.9 & 10.5 & 5.7 & 30.8 & 16.1 & 0.62 & 0.33 & p1d7 & 2.45 & 0.0001213 & 0.0001780 & 0.0002606 & $0.42 \pi$ \\
\hline 7090481 & $11 / 5 \mathrm{~B} 2$ & 34S_6p1d/rd_9 9 & $337 / 8$ & $\mathrm{~s}$ & 9 & 4437.4 & $337 / 8$ & $317 / 8$ & 0.446 & 0.669 & HLP-22 & 12 & 0 & 4 & 1.9 & 10.5 & 5.7 & 30.8 & 16.1 & 0.62 & 0.33 & p1d7 & 2.45 & 0.0001213 & 0.0001780 & 0.0002606 & 0.4277 \\
\hline 7090484 & $11 / 5 \mathrm{~B} 2$ & 34S_6p1d/rd 9 & $337 / 8$ & $\mathrm{~s}$ & 9 & 4437.4 & $337 / 8$ & $317 / 8$ & 0.446 & 0.669 & HLP-22 & 12 & 0 & 4 & 1.9 & 10.5 & 5.7 & 30.8 & 16.1 & 0.62 & 0.33 & p1d7 & 2.45 & 0.0001213 & 0.0001780 & 0.0002606 & 0.4277 \\
\hline 7090487 & $11 / 5 \mathrm{~B} 2$ & 34S_6p1d/Yd_ 9 & $337 / 8$ & $\mathrm{~s}$ & 9 & 4437.4 & $337 / 8$ & $317 / 8$ & 0.446 & 0.669 & HLP-22 & 12 & 0 & 4 & 1.9 & 10.5 & 5.7 & 30.8 & 16.1 & 0.62 & 0.33 & pldr & 2.45 & 0.0001213 & 0.0001780 & 0.0002606 & 0.4277 \\
\hline 7090491 & $11 / 5 \mathrm{~B} 2$ & 34S_6p1d/rd_9 9 & $337 / 8$ & $\mathrm{~s}$ & 9 & 4437.4 & $337 / 8$ & $317 / 8$ & 0.446 & 0.669 & HLP-22 & 12 & 0 & 4 & 1.9 & 10.5 & 5.7 & 30.8 & 16.1 & 0.62 & 0.33 & p1d7 & 2.45 & 0.0001213 & 0.0001780 & 0.0002606 & 0.4277 \\
\hline 7090493 & $11 / 6 \mathrm{~A} 1$ & 345_6p1dr/ra-40 & $337 / 8$ & $\mathrm{~s}$ & 9 & 4437.4 & $337 / 8$ & 31778 & 0.446 & 0.669 & HLP-22 & 12 & 4 & 0 & 19 & 10.5 & 5.7 & 30.8 & 16.1 & 0.62 & 0.33 & $\mathrm{pld} 7$ & 2.45 & 0.0001213 & 0.0001780 & 0.0002606 & 0.4277 \\
\hline 7090496 & $11 / 6 \mathrm{~A} 1$ & 34s_6p1d $7 / 7 a-40$ & $337 / 8$ & $\mathrm{~s}$ & 9 & 4437.4 & $337 / 8$ & 3178 & 0.446 & 0.669 & HLP-22 & 12 & 4 & 0 & 19 & 10.5 & 5.7 & 30.8 & 16.1 & 0.62 & 0.33 & p1d7 & 2.45 & 0.0001213 & 0.0001780 & 0.0002606 & 0.4277 \\
\hline 7090499 & $11 / 6 \mathrm{A1}$ & 34s_6p1d7/Ya-40 & $337 / 8$ & $\mathrm{~s}$ & 9 & 4437.4 & $337 / 8$ & 3178 & 0.446 & 0.669 & HLP-22 & 12 & 4 & 0 & 1.9 & 10.5 & 5.7 & 30.8 & 16.1 & 0.62 & 0.33 & p1d7 & 2.45 & 0.0001213 & 0.0001780 & 0.0002606 & 0.4277 \\
\hline 7090503 & $11 / 6 \mathrm{~A} 1$ & $345 \_6 p 1 d 7 / Y a-40$ & $337 / 8$ & $\mathrm{~s}$ & 9 & 4437.4 & $337 / 8$ & 3178 & 0.446 & 0.669 & HLP. 22 & 12 & 4 & 0 & 1.9 & 10.5 & 5.7 & 30.8 & 16.1 & 0.62 & 0.33 & p1d7 & 2.45 & 0.0001213 & 0.0001780 & 0.0002606 & 0.4277 \\
\hline
\end{tabular}


Table B.8. Data from Fall 2007 Tests in Mid-Scale Vessel with Spherical Head B.4

\begin{tabular}{|c|c|c|c|c|c|c|c|c|c|c|c|c|c|c|c|c|c|c|c|c|c|c|c|c|c|c|c|c|c|}
\hline $\begin{array}{l}\text { Tank Water } \\
\text { Temperature }\end{array}$ & $\begin{array}{l}\text { Water } \\
\text { Density }\end{array}$ & $\begin{array}{l}\text { Solids } \\
\text { Fraction }\end{array}$ & $\begin{array}{l}\text { Pulse } \\
\text { Volume } \\
\text { Fraction }\end{array}$ & $\begin{array}{l}\text { Duty } \\
\text { Cyde }\end{array}$ & $\begin{array}{l}\text { Cycle } \\
\text { Time }\end{array}$ & $\begin{array}{c}\text { Pulsed } \\
\text { Oer } \\
\text { Steacy } \\
\text { Jet } \\
\end{array}$ & $\begin{array}{c}\text { Us } \\
\text { Steacy } \\
\text { Jet }\end{array}$ & $\begin{array}{c}\text { II } \\
\text { Pulsing } \\
\text { Jet } \\
\end{array}$ & \begin{tabular}{|l} 
U2 \\
URNS \\
\end{tabular} & $\begin{array}{c}\text { U3 } \\
\text { URMB } \\
\end{array}$ & $\begin{array}{c}\text { Discharge } \\
\text { Velocity }\end{array}$ & $\begin{array}{c}\text { Citical } \\
\text { Suspension } \\
\text { Velocity }\end{array}$ & $\begin{array}{c}\text { Average } \\
\text { Peak } \\
\text { Cloud } \\
\text { Height } \\
\end{array}$ & $\begin{array}{c}\text { UCS } \\
\text { Condition } \\
\end{array}$ & \begin{tabular}{|c|} 
UCS \\
Nethod \\
\end{tabular} & $\begin{array}{l}\text { UCS } \\
\text { Flag }\end{array}$ & $\begin{array}{c}\text { UCS } \\
\text { Center } \\
\text { Flag }\end{array}$ & $\begin{array}{c}\text { ucsuav } \\
\text { Flag }\end{array}$ & $\begin{array}{l}\text { UcS based } \\
\text { on } \\
\text { Dereasing } \\
\text { Velocity }\end{array}$ & $\begin{array}{l}\text { Sweep } \\
\text { Increase I } \\
\text { Decrease }\end{array}$ & \begin{tabular}{|c|} 
UDV \\
Height \\
Bed \\
\end{tabular} & $\begin{array}{c}\text { Paticice } \\
\text { Notion } \\
\end{array}$ & $\begin{array}{l}\text { Solids } \\
\text { Level }\end{array}$ & \begin{tabular}{|l|} 
Outer \\
Bototom \\
Pattem \\
\end{tabular} & \begin{tabular}{|c|} 
Inner \\
Bottom \\
Pattem \\
\end{tabular} & Case ID & Test & TDP & $\begin{array}{l}\text { Row } \\
\text { Number }\end{array}$ \\
\hline C & $\mathrm{g} / \mathrm{cm}^{3}$ & fraction & fraction & fraction & $\mathrm{s}$ & text & $\mathrm{m} / \mathrm{s}$ & $\mathrm{m} / \mathrm{s}$ & $\mathrm{m} / \mathrm{s}$ & $\mathrm{m} / \mathrm{s}$ & $\mathrm{m} / \mathrm{s}$ & $\mathrm{m} / \mathrm{s}$ & in. & $\mathrm{m} / \mathrm{s}$ & text & text & text & text & $\mathrm{m} / \mathrm{s}$ & text & $\mathrm{mm}$ & text & text & text & text & text & text & text & text \\
\hline $\mathrm{T}$ & $\rho$ & $\phi_{\mathrm{s}}$ & $\phi_{p}$ & $\mathrm{DC}$ & $t_{c}$ & Jet & $u_{s}$ & $\mathrm{U}_{1}$ & $\mathrm{U} 2$ & U3 & $u$ & Uss & $H_{c}$ & $U_{\text {SRR }}$ & $u_{\text {son }}$ & Uosvis & Ussoen & Usuldv & Uss_D & $S_{\mathrm{N}}$ & $\mathrm{H}_{\mathrm{hed}}$ & PM & Sol & SPo & $\mathrm{SP}_{\mathrm{P}_{1}}$ & ID & MDDX & $\mathrm{TDP}$ & MSS \\
\hline 21.0 & 0.999 & 0.00487 & 0.052 & 0.180 & 40.0 & $\mathrm{P}$ & NA & 2.80 & 2.87 & 290 & 3.00 & 3.40 & 12.50 & NA & NA & NA & NA & NA & NA & 1 & NA & AM & NA & NA & NA & 34S_6p1d7Yd_1 1 & $10311_{12}$ & TDP-WIP-042 & 7090382 \\
\hline 21.0 & 0.999 & 0.00487 & 0.050 & 0.180 & 37.5 & $\mathrm{P}$ & NA & 2.97 & 3.04 & 3.08 & 3.20 & 3.40 & 13.00 & NA & NA & NA & NA & NA & NA & 1 & NA & $\mathrm{AMN}_{\mathrm{H}} \mathrm{C}$ & NA & NA & NA & 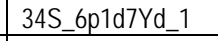 & 10131/A2 & IDP-WIP-042 & 7090385 \\
\hline 21.0 & 0.999 & 0.00487 & 0.050 & 0.180 & 35.0 & $\mathrm{P}$ & NA & 3.13 & 3.22 & 3.26 & 3.40 & 3.40 & 13.50 & 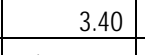 & vis & ucsis & NA & NA & NA & 1 & NA & cs & NA & NA & NA & 34S_6pldr/rd_1 & 10/31A2 & TDP-WIP-042 & 7090389 \\
\hline 21.0 & 0.999 & 0.00487 & 0.050 & 0.180 & 33.0 & $\mathrm{P}$ & NA & 3.29 & 3.39 & 3.44 & 3.60 & 3.40 & 14.25 & NA & NA & NA & NA & NA & NA & 1 & NA & $\mathrm{BC}$ & NA & NA & NA & 34S_6p1d7Yd_1 1 & 10/31/A2 & TDP-WIP-042 & 7090391 \\
\hline 24.0 & 0.999 & 0.00487 & undefined & 1.000 & inffinite & $\mathrm{s}$ & 5.00 & NA & NA & NA & 5.00 & 5.30 & 13.50 & NA & NA & NA & NA & NA & NA & 1 & NA & ss & NA & NA & NA & 34S_6p1d7Ya-80 & $11 / 2 \mathrm{~A} 1$ & TDP-WIP-043 & 7090395 \\
\hline 24.0 & 0.999 & 0.00487 & undefined & 1.000 & infinite & $\mathrm{s}$ & 5.29 & NA & NA & NA & 5.30 & 5.30 & 23.50 & \begin{tabular}{|l|}
5.30 \\
\end{tabular} & vis & UCSuis & NA & NA & NA & 1 & NA & CS & NA & NA & NA & 34S_6p1d7/Ya-80 & 11/2A1 & TDP-WIP-043 & 7090398 \\
\hline 24.0 & 0.999 & 0.00487 & 0.051 & 0.180 & 30.0 & $\mathrm{P}$ & NA & 5.05 & 5.40 & 5.55 & 5.90 & 6.60 & 14.25 & NA & NA & NA & NA & NA & NA & 1 & NA & ss & NA & NA & NA & 34S_6p1d7rd_5 5 & $11 / 2 A_{2}$ & TDP-WIP-043 & 7090401 \\
\hline 24.0 & 0.999 & 0.00487 & 0.051 & 0.180 & 28.0 & $\mathrm{P}$ & NA & 5.04 & 5.57 & 5.80 & 6.30 & 6.60 & 16.75 & NA & NA & NA & NA & NA & NA & 1 & NA & AM & NA & NA & NA & 34S_6p1d7Yd_5 5 & $11 / 2 A 2$ & TDP-WTP-043 & 7090406 \\
\hline 24.0 & 0.999 & 0.00487 & 0.051 & 0.180 & 27.0 & $\mathrm{P}$ & NA & 5.15 & 5.70 & 5.95 & 6.50 & 6.60 & 18.50 & NA & NA & NA & NA & NA & NA & 1 & NA & AMt & NA & NA & NA & 34S_6p1d7Yd_5 5 & $11 / 2 A 2$ & TDP-WIP-043 & 7090409 \\
\hline 24.0 & 0.999 & 0.00487 & 0.051 & 0.180 & 26.5 & $\mathrm{P}$ & NA & 5.15 & 5.74 & 6.00 & 6.60 & 6.60 & 19.00 & \begin{tabular}{|r|} 
\\
\end{tabular} & vis & UCShis & NA & NA & NA & 1 & NA & CS & NA & NA & NA & 34S_6p1d7Yd_5 5 & $11 / 2 A 2$ & TDP-WIP-043 & 7090413 \\
\hline 20.8 & 0.999 & 0.00487 & undefined & 1.000 & infinite & s & 3.13 & NA & NA & NA & 3.00 & 4.60 & NA & NA & NA & NA & NA & NA & NA & 1 & NA & ss & NA & NA & NA & 345_6p1d/ra-44 & $1115 \mathrm{~A} 1$ & TDP-WIP-044 & 7090416 \\
\hline 20.9 & 0.999 & 0.00487 & undefined & 1.000 & infinite & $\mathrm{s}$ & 3.53 & NA & NA & NA & 3.50 & 4.60 & NA & NA & NA & NA & NA & NA & NA & 1 & NA & ss & NA & NA & NA & 34s_6p1dr/a-44 & $11 / 5 A_{1}$ & TDP-WIP-044 & 7090419 \\
\hline 20.9 & 0.999 & 0.00487 & undefined & 1.000 & infinite & $\mathrm{s}$ & 4.01 & NA & NA & NA & 4.00 & 4.60 & 9.25 & NA & NA & NA & UCScen & NA & NA & 1 & NA & AM & NA & NA & NA & 345_6p1d7ra-44 & $1115 \mathrm{~A} 1$ & TDP-WTP-044 & 7000421 \\
\hline 0.0 & 0.999 & 0.00487 & undefined & 1.000 & infinite & $\mathrm{s}$ & NA & NA & NA & NA & 4.40 & 4.60 & 12.25 & NA & NA & NA & NA & NA & NA & 1 & NA & AMt & NA & NA & NA & 34s_6p1d7ra-44 & $115 \mathrm{~A} 1$ & TDP-WTP-044 & 7090424 \\
\hline 20.9 & 0.999 & 0.00487 & undefined & 1.000 & infinite & $\mathrm{s}$ & 4.65 & NA & NA & NA & 4.60 & 4.60 & 15.25 & \begin{tabular}{|l|} 
\\
\end{tabular} & vis & UCSuis & NA & NA & NA & 1 & NA & CS & NA & NA & NA & 34s_6pld7/Ya-44 & $115 \mathrm{~A} 1$ & TDP-WTP-044 & 7090428 \\
\hline 21.0 & 0.999 & 0.00487 & undefined & 1.000 & infinite & $\mathrm{s}$ & 4.80 & NA & NA & NA & 4.80 & 4.60 & 18.50 & NA & NA & NA & NA & NA & NA & 1 & NA & $B C$ & NA & NA & NA & 345_6p1d7/Ya-44 & $1115 \mathrm{~A} 1$ & TDP-WTP-044 & 7090430 \\
\hline 21.0 & 0.999 & 0.00487 & 0.050 & 0.180 & 42.0 & $\mathrm{P}$ & NA & 4.04 & 4.12 & 4.16 & 4.00 & 6.30 & 9.00 & NA & NA & NA & NA & NA & NA & D & NA & ss & NA & NA & NA & 34S_6p1dTrd_0 & $1115 A 2$ & TDP-WIP-044 & 7090434 \\
\hline 21.0 & 0.999 & 0.00487 & 0.051 & 0.180 & 39.5 & $\mathrm{P}$ & NA & 4.24 & 4.35 & 4.39 & 4.50 & 6.30 & 9.50 & NA & NA & NA & NA & NA & NA & 1 & NA & $A M$ & NA & NA & NA & 34S_6p1d7Yd_0 0 & $1115 \mathrm{~A}_{2}$ & TDP-WTP-044 & 7090436 \\
\hline 21.0 & 0.999 & 0.00487 & 0.051 & 0.180 & 36.5 & $\mathrm{P}$ & NA & 4.60 & 4.72 & 4.78 & 4.90 & 6.30 & 10.25 & NA & NA & NA & NA & NA & NA & 1 & NA & $A M$ & NA & NA & NA & 34S_6p1d7Yd_0 & $115 \mathrm{AA}_{2}$ & TDP-WIP-044 & 7090439 \\
\hline 21.0 & 0.999 & 0.00487 & 0.051 & 0.180 & 32.0 & $\mathrm{P}$ & NA & 5.09 & 5.25 & 5.33 & 5.50 & 6.30 & 13.00 & NA & NA & NA & NA & NA & NA & 1 & NA & $A M+$ & NA & NA & NA & 34S_6p1d7Yd_0 0 & $1115 \mathrm{~A}^{2}$ & TDP-WTP-044 & 7090445 \\
\hline 21.0 & 0.999 & 0.00487 & 0.051 & 0.180 & 31.0 & $\mathrm{P}$ & NA & 5.12 & 5.35 & 5.46 & 5.70 & 6.30 & 13.75 & NA & NA & NA & NA & NA & NA & 1 & NA & AMt & NA & NA & NA & 34S_6p1dTrd_o & $115 \mathrm{AL}^{2}$ & TDP-WIP-044 & 7090448 \\
\hline 21.0 & 0.999 & 0.00487 & 0.051 & 0.180 & 30.0 & $\mathrm{P}$ & NA & 5.15 & 5.46 & 5.60 & 5.90 & 6.30 & 14.75 & NA & NA & NA & NA & NA & NA & 1 & NA & $A M+$ & NA & NA & NA & 34S_6p1d7Yd_0 0 & $1115 \mathrm{~A} 2$ & TDP-WTP-044 & 7090451 \\
\hline 21.0 & 0.999 & 0.00487 & 0.051 & 0.180 & 28.8 & $\mathrm{P}$ & NA & 5.22 & 5.59 & 5.75 & 6.10 & 6.30 & 16.00 & NA & NA & NA & NA & NA & NA & 1 & NA & AMt & NA & NA & NA & 34S_6p1d7Yd_O 0 & $115 \mathrm{AA2}$ & TDP-WIP-044 & 7090454 \\
\hline 21.0 & 0.999 & 0.00487 & 0.051 & 0.180 & 27.8 & $\mathrm{P}$ & NA & 5.23 & 5.67 & 5.86 & 6.30 & 6.30 & 16.50 & 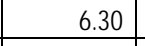 & vis & UCSuis & NA & NA & NA & 1 & NA & cs & NA & NA & NA & 34s_6p1d7Yd_0 0 & $115 \mathrm{~A}_{2}$ & TDP-WTP-044 & 7090458 \\
\hline 21.3 & 0.999 & 0.00487 & undefined & 1.000 & infinite & $\mathrm{s}$ & 4.52 & NA & NA & NA & 4.50 & 6.50 & 9.50 & NA & NA & NA & NA & NA & NA & D & NA & ss & NA & NA & NA & 34S_6p1d7/Ya-04 & $1115 \mathrm{BB}$ & TDP-WTP-044 & 7090461 \\
\hline 21.3 & 0.999 & 0.00487 & undefined & 1.000 & infinite & $\mathrm{s}$ & 5.00 & NA & NA & NA & 5.00 & 6.50 & 11.25 & NA & NA & NA & NA & NA & NA & 1 & NA & sst & NA & NA & NA & 34s_6pldtra-04 & $1115 \mathrm{~B} 1$ & TDP-WIP-044 & 7090464 \\
\hline 21.4 & 0.999 & 0.00487 & undefined & 1.000 & infinite & $\mathrm{s}$ & 5.57 & NA & NA & NA & 5.50 & 6.50 & 13.75 & NA & NA & NA & NA & NA & NA & 1 & NA & AM & NA & NA & NA & 34s_6p1d7ra-04 & $11 / 5 \mathrm{~B} 1$ & TDP-WIP-044 & 7090466 \\
\hline 21.4 & 0.999 & 0.00487 & undefined & 1.000 & infinite & $\mathrm{s}$ & 6.04 & NA & NA & NA & 6.00 & 6.50 & 16.00 & NA & NA & NA & NA & NA & NA & 1 & NA & AMt & NA & NA & NA & 34s_6p1d7ra-04 & $11 / 5 B 1$ & TDP-WIP-044 & 7090469 \\
\hline 21.4 & 0.999 & 0.00487 & undefined & 1.000 & infinite & $\mathrm{s}$ & 6.53 & NA & NA & NA & 6.50 & 6.50 & 19.50 & \begin{tabular}{|r|}
6.50 \\
\end{tabular} & vis & UCSuis & NA & NA & NA & 1 & NA & cs & NA & NA & NA & 34s_6p1d7ra-04 & $115 \mathrm{BB} 1$ & TDP-WIP-044 & 7090473 \\
\hline 21.0 & 0.999 & 0.00487 & 0.047 & 0.180 & 62.0 & $\mathrm{P}$ & NA & 5.51 & 5.59 & 5.63 & 5.50 & 7.80 & 12.50 & NA & NA & NA & NA & NA & NA & D & NA & ss & NA & NA & NA & 34S_6p1d/rd_ 9 & $115 \mathrm{BB} 2$ & TDP-WIP-044 & 7090476 \\
\hline 21.0 & 0.999 & 0.00487 & 0.052 & 0.180 & 58.5 & $\mathrm{P}$ & NA & 5.99 & 6.08 & 6.12 & 6.00 & 7.80 & 14.25 & NA & NA & NA & NA & NA & NA & 1 & NA & AMt & NA & NA & NA & 34S_6pldr/rd_9 9 & $11 / 5 \mathrm{~B} 2$ & TDP-WIP-044 & 7090479 \\
\hline 21.0 & 0.999 & 0.00487 & 0.052 & 0.180 & 54.0 & $\mathrm{P}$ & NA & 6.40 & 6.50 & 6.55 & 6.50 & 7.80 & 15.75 & NA & NA & NA & NA & NA & NA & 1 & NA & AM & NA & NA & NA & is 6p1d/Yd_ 9 & $11 / 5 \mathrm{~B} 2$ & TDP-WIP-044 & 7090481 \\
\hline 21.0 & 0.999 & 0.00487 & 0.051 & 0.180 & 49.5 & $P$ & NA & 6.89 & 7.01 & 7.07 & 7.00 & 7.80 & 17.25 & NA & NA & NA & NA & NA & NA & 1 & NA & AMt & NA & NA & NA & 34S_6p1dTrd_9 9 & $115 \mathrm{BB} 2$ & TDP-WIP-044 & 7090484 \\
\hline 21.0 & 0.999 & 0.00487 & 0.050 & 0.180 & 46.5 & $\mathrm{P}$ & NA & 7.04 & 7.26 & 7.36 & 7.40 & 7.80 & 19.00 & NA & NA & NA & NA & NA & NA & 1 & NA & AMt & NA & NA & NA & 34S_6p1d7Yd_9 9 & $115 \mathrm{BB} 2$ & TDP-WIP-044 & 7090487 \\
\hline 21.0 & 0.999 & 0.00487 & 0.051 & 0.180 & 44.3 & $\mathrm{P}$ & NA & 7.26 & 7.57 & 7.70 & 7.80 & 7.80 & 20.25 & 7.80 & vis & ucsis & NA & NA & NA & 1 & NA & CS & NA & NA & NA & 34S_6p1d7/rd_9 & $1115 \mathrm{BB} 2$ & TDP-WIP-044 & 7090491 \\
\hline 20.6 & 0.999 & 0.00487 & undefined & 1.000 & infinite & $\mathrm{s}$ & 5.48 & NA & NA & NA & 5.50 & 6.40 & NA & NA & NA & NA & NA & NA & NA & 1 & NA & ss & NA & NA & NA & 345_6p1drYa-40 & $11 / 6 A_{1}$ & TDP-WIP-049 & 7090493 \\
\hline 20.7 & 0.999 & 0.00487 & & 1.000 & infinite & $\mathrm{s}$ & 5.99 & NA & NA & NA & 6.00 & 6.40 & 10.50 & NA & NA & NA & NA & NA & NA & 1 & NA & $A M$ & NA & NA & NA & 345_6p1d7/ra-40 & 116 A 1 & TDP-WIP-049 & 7090496 \\
\hline 20.7 & 0.999 & 0.00487 & undefined & 1.000 & infinite & $\mathrm{s}$ & 6.20 & NA & NA & NA & 6.20 & 6.40 & 17.00 & NA & NA & NA & NA & NA & NA & 1 & NA & AMt & NA & NA & NA & 34s_6p1dr/ra-40 & 11/6A1 & TDP-WIP-049 & 7090499 \\
\hline 20.8 & 0.999 & 0.00487 & lefined & 1.000 & infinite & $s$ & 6.42 & NA & NA & NA & 6.40 & 6.40 & 21.00 & 6.40 & vis & UCShis & NA & $N A$ & NA & 1 & NA & $c s$ & NA & $N A$ & NA & 34S_6p1drra-40 & 11/6A1 & TDP-WIP-049 & 7090503 \\
\hline
\end{tabular}


Table B.8. Data from Fall 2007 Tests in Mid-Scale Vessel with Spherical Head A.5

\begin{tabular}{|c|c|c|c|c|c|c|c|c|c|c|c|c|c|c|c|c|c|c|c|c|c|c|c|c|c|c|c|}
\hline $\begin{array}{c}\text { Row } \\
\text { Number }\end{array}$ & Test & Case ID & $\begin{array}{c}\text { Tank } \\
\text { Diameter }\end{array}$ & $\begin{array}{l}\text { Head } \\
\text { Shape }\end{array}$ & $\begin{array}{c}\text { Dish } \\
\text { Height }\end{array}$ & $\begin{array}{l}\text { Dish } \\
\text { Volume }\end{array}$ & $\begin{array}{l}\text { Tank } \\
\text { Fill } \\
\text { Height }\end{array}$ & \begin{tabular}{|l} 
Returm \\
Line \\
Height
\end{tabular} & $\begin{array}{c}\text { Nozzle } \\
\text { Inner } \\
\text { Dianeter }\end{array}$ & $\begin{array}{c}\text { Nozzle } \\
\text { Stand- } \\
\text { off } \\
\text { Distance }\end{array}$ & $\begin{array}{l}\text { Pulse Tube } \\
\text { Configuration }\end{array}$ & $\begin{array}{l}\text { Installed } \\
\text { Nozzles } \\
\text { Nets }\end{array}$ & \begin{tabular}{|c} 
Outur \\
Nozles \\
Operated \\
\end{tabular} & $\begin{array}{c}\text { Inner } \\
\text { Nozzles } \\
\text { Opperated }\end{array}$ & $\begin{array}{l}\text { Pulse Tube } \\
\text { Outer } \\
\text { Diameter }\end{array}$ & $\begin{array}{c}\text { Outer } \\
\text { PJM } \\
\text { Radius }\end{array}$ & $\begin{array}{c}\text { Inner } \\
\text { PJM } \\
\text { Radius }\end{array}$ & $\begin{array}{l}\text { "FO' Outer } \\
\text { PJM } \\
\text { Impingement } \\
\text { Angle }\end{array}$ & $\begin{array}{l}\text { "FO' Inner } \\
\text { PJM } \\
\text { Impingement } \\
\text { Angle }\end{array}$ & $\begin{array}{c}\text { Ratio Outer } \\
\text { PJMto } \\
\text { Tank } \\
\text { Radius } \\
\end{array}$ & $\begin{array}{c}\text { Ratio Inner } \\
\text { PJM to } \\
\text { Tank } \\
\text { Radius } \\
\end{array}$ & Simulant & $\begin{array}{l}\text { Solids } \\
\text { Density }\end{array}$ & $\begin{array}{c}\text { Particle } \\
\text { Diameter d5 }\end{array}$ & $\begin{array}{c}\text { Partide } \\
\text { Dianeter } \\
\text { d50 }\end{array}$ & $\begin{array}{c}\text { Particle } \\
\text { Diameter } \\
\text { d95 }\end{array}$ & $\begin{array}{c}\text { Void } \\
\text { Fraction }\end{array}$ \\
\hline text & text & text & in. & text & in. & in. ${ }^{3}$ & in. & in. & in. & in. & text & number & \begin{tabular}{|l} 
number \\
\end{tabular} & number & in. & in. & in. & deg & deg & nondim & nondim & text & $\mathrm{g} / \mathrm{cm}^{3}$ & $\mathrm{~m}$ & $\mathrm{~m}$ & $\mathrm{~m}$ & fraction \\
\hline MSS & MDDX & ID & $\mathrm{D}$ & HS & Hess & $V_{\text {dsh }}$ & $\mathrm{H}$ & Rtn & $d$ & sod & PT & $\mathrm{N}$ & $\mathrm{Nb}$ & $\mathrm{N}$ & $\mathrm{PT}_{\alpha \mathrm{d}}$ & $\mathrm{R}_{0}$ & $\mathrm{R}_{4}$ & $\theta_{0}$ & $\theta_{1}$ & $\mathrm{RdR}$ & $R / R$ & $\operatorname{sxdx}$ & $\rho_{\mathrm{s}}$ & $\frac{d}{b}$ & $d_{50}$ & $d_{65}$ & vf \\
\hline 7090506 & $11 / 6 \mathrm{A1}$ & 34s_6p1d $7 / 7 a-40$ & $337 / 8$ & $\mathrm{~s}$ & 9 & 4437.4 & $337 / 8$ & $317 / 8$ & 0.446 & 0.669 & HLP-22 & 12 & 4 & 0 & 1.9 & 10.5 & 5.7 & 30.8 & 16.1 & 0.62 & 0.33 & pldr & 2.45 & 0.0001213 & 0.0001780 & 0.0002606 & 0.4277 \\
\hline 7090508 & $11 / 6 \mathrm{~A} 2$ & 34s gp1dr/d 66 & $337 / 8$ & $\mathrm{~s}$ & 9 & 4437.4 & $337 / 8$ & $317 / 8$ & 0.446 & 0.669 & HLP. 22 & 12 & 4 & 0 & 1.9 & 10.5 & 5.7 & 30.8 & 16.1 & 0.62 & 0.33 & p1d7 & 2.45 & 0.0001213 & 0.0001780 & 0.0002606 & $0.42 \pi 7$ \\
\hline 7090511 & $11 / 6 A_{2}$ & 34S_6p1d7Yd_6 6 & $337 / 8$ & $\mathrm{~s}$ & 9 & 4437.4 & $337 / 8$ & $317 / 8$ & 0.446 & 0.669 & HLP-22 & 12 & 4 & 0 & 1.9 & 10.5 & 5.7 & 30.8 & 16.1 & 0.62 & 0.33 & p1dr & 2.45 & 0.0001213 & 0.0001780 & 0.0002606 & 0.4277 \\
\hline 7090514 & $11 / 6 \mathrm{A2}$ & $34 S \_6 p 1 d 7 / d d 6$ & $337 / 8$ & $\mathrm{~s}$ & 9 & 4437.4 & $337 / 8$ & $317 / 8$ & 0.446 & 0.669 & HLP-22 & 12 & 4 & 0 & 1.9 & 10.5 & 5.7 & 30.8 & 16.1 & 0.62 & 0.33 & pld 7 & 2.45 & 0.0001213 & 0.0001780 & 0.0002606 & 0.4277 \\
\hline 7090518 & $11 / 6 \mathrm{~A} 2$ & 34s 6p1dr/rd 6 & $337 / 8$ & $s$ & 9 & 4437.4 & $337 / 8$ & $317 / 8$ & 0.446 & 0.669 & HLP-22 & 12 & 4 & 0 & 1.9 & 10.5 & 5.7 & 30.8 & 16.1 & 0.62 & 0.33 & p1d7 & 2.45 & 0.0001213 & 0.0001780 & 0.0002606 & 0.4277 \\
\hline 7090520 & $11 / 6 A_{2}$ & 34S_6p1d/Yd_6 6 & $337 / 8$ & $s$ & 9 & 4437.4 & $337 / 8$ & $317 / 8$ & 0.446 & 0.669 & HLP-22 & 12 & 4 & 0 & 1.9 & 10.5 & 5.7 & 30.8 & 16.1 & 0.62 & 0.33 & pldr & 2.45 & 0.0001213 & 0.0001780 & 0.0002606 & 0.4277 \\
\hline 7090523 & $11 / 7 \mathrm{~A} 1$ & 34s_6pld/ra & $337 / 8$ & $\mathrm{~s}$ & 9 & 4437.4 & $235 / 7$ & $215 / 7$ & 0.446 & 0.669 & HLP. 22 & 12 & 8 & 4 & 1.9 & 10.5 & 5.7 & 30.8 & 16.1 & 0.62 & 0.33 & p1d7 & 2.45 & 0.0001213 & 0.0001780 & 0.0002606 & $0.42 \pi 7$ \\
\hline 7090526 & $11 / 7 \mathrm{~A} 1$ & 345_ppldrva & $337 / 8$ & $\mathrm{~s}$ & 9 & 4437.4 & 23577 & $215 / 7$ & 0.446 & 0.669 & HLP-22 & 12 & 8 & 4 & 1.9 & 10.5 & 5.7 & 30.8 & 16.1 & 0.62 & 0.33 & p1d7 & 2.45 & 0.0001213 & 0.0001780 & 0.0002606 & 0.4277 \\
\hline 7090529 & $11 / 7 \mathrm{~A} 1$ & 34s gpldrya & $337 / 8$ & $\mathrm{~s}$ & 9 & 4437.4 & 2357 & $215 / 7$ & 0.446 & 0.669 & HLP -22 & 12 & 8 & 4 & 1.9 & 10.5 & 5.7 & 30.8 & 16.1 & 0.62 & 0.33 & p1d7 & 2.45 & 0.0001213 & 0.0001780 & 0.0002606 & 0.4277 \\
\hline 7090532 & $11 / 7 \mathrm{~A} 1$ & 345_ppldTra & $337 / 8$ & $s$ & 9 & 4437.4 & $235 / 7$ & $215 / 7$ & 0.446 & 0.669 & HLP-22 & 12 & 8 & 4 & 1.9 & 10.5 & 5.7 & 30.8 & 16.1 & 0.62 & 0.33 & p1d7 & 2.45 & 0.0001213 & 0.0001780 & 0.0002606 & 0.4277 \\
\hline 7090536 & 11/7A1 & 345 gpldrya & $337 / 8$ & $\mathrm{~s}$ & 9 & 4437.4 & 23577 & $215 / 7$ & 0.446 & 0.669 & HLP-22 & 12 & 8 & 4 & 1.9 & 10.5 & 5.7 & 30.8 & 16.1 & 0.62 & 0.33 & p1d7 & 2.45 & 0.0001213 & 0.0001780 & 0.0002606 & 0.4277 \\
\hline 7090538 & $11 / 7 \mathrm{~A} 1$ & 34s_6p1d7/a & $337 / 8$ & $\mathrm{~s}$ & 9 & 4437.4 & 23577 & $215 / 7$ & 0.446 & 0.669 & HLP-22 & 12 & 8 & 4 & 1.9 & 10.5 & 5.7 & 30.8 & 16.1 & 0.62 & 0.33 & p1d7 & 2.45 & 0.0001213 & 0.0001780 & 0.0002606 & 0.4277 \\
\hline 7090542 & $11 / 7 \mathrm{A2}$ & 34S_6p1d7rd_1 & $337 / 8$ & $\mathrm{~s}$ & 9 & 4437.4 & $235 / 7$ & 21577 & 0.446 & 0.669 & HLP-22 & 12 & 8 & 4 & 1.9 & 10.5 & 5.7 & 30.8 & 16.1 & 0.62 & 0.33 & p1d 7 & 2.45 & 0.0001213 & 0.0001780 & 0.0002606 & 0.4277 \\
\hline 7090544 & 11/7A2 & 34s_6p1d/rd_1 1 & $337 / 8$ & $\mathrm{~s}$ & 9 & 4437.4 & 2357 & $215 / 7$ & 0.446 & 0.669 & HLP-22 & 12 & 8 & 4 & 1.9 & 10.5 & 5.7 & 30.8 & 16.1 & 0.62 & 0.33 & p1d7 & 2.45 & 0.0001213 & 0.0001780 & 0.0002606 & 0.4277 \\
\hline 7090547 & $11 / 7 \mathrm{~A}^{2}$ & 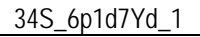 & $337 / 8$ & $\mathrm{~s}$ & 9 & 4437.4 & $235 / 7$ & $215 / 7$ & 0.446 & 0.669 & HLP-22 & 12 & 8 & 4 & 1.9 & 10.5 & 5.7 & 30.8 & 16.1 & 0.62 & 0.33 & p1d7 & 2.45 & 0.0001213 & 0.0001780 & 0.0002606 & 0.4277 \\
\hline 7090551 & 11/7A2 & 34s_6p1d/7d_1 1 & $337 / 8$ & $\mathrm{~s}$ & 9 & 4437.4 & 23577 & $215 / 7$ & 0.446 & 0.669 & HLP-22 & 12 & 8 & 4 & 1.9 & 10.5 & 5.7 & 30.8 & 16.1 & 0.62 & 0.33 & pldr & 2.45 & 0.0001213 & 0.0001780 & 0.0002606 & 0.4277 \\
\hline 7090553 & $11 / 7 \mathrm{~B} 1$ & 34s_6p1d/7a-44 & $337 / 8$ & $\mathrm{~s}$ & 9 & 4437.4 & 2357 & $215 / 7$ & 0.446 & 0.669 & HLP-22 & 12 & 4 & 4 & 19 & 10.5 & 5.7 & 30.8 & 16.1 & 0.62 & 0.33 & pld 7 & 2.45 & 0.0001213 & 0.0001780 & 0.0002606 & 0.4277 \\
\hline 7090557 & $11 / 7 \mathrm{~B} 1$ & 34s_6p1d/7a-44 & $337 / 8$ & $\mathrm{~s}$ & 9 & 4437.4 & 2357 & $215 / 7$ & 0.446 & 0.669 & HLP-22 & 12 & 4 & 4 & 19 & 10.5 & 5.7 & 30.8 & 16.1 & 0.62 & 0.33 & p1d7 & 2.45 & 0.0001213 & 0.0001780 & 0.0002606 & 0.4277 \\
\hline 7090560 & $11 / 7 \mathrm{~B} 1$ & 34s_6p1d7/Ya-44 & $337 / 8$ & $\mathrm{~s}$ & 9 & 4437.4 & 2357 & $215 / 7$ & 0.446 & 0.669 & HLP-22 & 12 & 4 & 4 & 19 & 10.5 & 5.7 & 30.8 & 16.1 & 0.62 & 0.33 & p1d7 & 2.45 & 0.0001213 & 0.0001780 & 0.0002606 & 0.4277 \\
\hline 7090562 & 11/7B1 & 345 6p1d/ra-44 & $337 / 8$ & $s$ & 9 & 4437.4 & 23577 & $215 / 7$ & 0.446 & 0.669 & HLP-22 & 12 & 4 & 4 & 19 & 10.5 & 5.7 & 30.8 & 16.1 & 0.62 & 0.33 & $\mathrm{p} 1 \mathrm{~d} 7 \mathrm{P}$ & 2.45 & 0.0001213 & 0.0001780 & 0.0002606 & 0.4277 \\
\hline 7090566 & 11/7B1 & 34s_6p1d/7a-44 & $337 / 8$ & $\mathrm{~s}$ & 9 & 4437.4 & 23577 & $215 / 7$ & 0.446 & 0.669 & HLP-22 & 12 & 4 & 4 & 19 & 10.5 & 5.7 & 30.8 & 16.1 & 0.62 & 0.33 & pld7 & 2.45 & 0.0001213 & 0.0001780 & 0.0002606 & 0.4277 \\
\hline 7090569 & $11 / 7 \mathrm{~B} 2$ & 34S_6p1d7rd_0 0 & $337 / 8$ & $\mathrm{~s}$ & 9 & 4437.4 & 2357 & $215 / 7$ & 0.446 & 0.669 & HLP-22 & 12 & 4 & 4 & 1.9 & 10.5 & 5.7 & 30.8 & 16.1 & 0.62 & 0.33 & pld 7 & 2.45 & 0.0001213 & 0.0001780 & 0.0002606 & 0.4277 \\
\hline 7090571 & $11 / 7 \mathrm{~B} 2$ & 34S_6p1d7rd_0 0 & $337 / 8$ & $\mathrm{~s}$ & 9 & 4437.4 & 2357 & $215 / 7$ & 0.446 & 0.669 & HLP-22 & 12 & 4 & 4 & 1.9 & 10.5 & 5.7 & 30.8 & 16.1 & 0.62 & 0.33 & p1dr & 2.45 & 0.0001213 & 0.0001780 & 0.0002606 & 0.4277 \\
\hline 7090574 & $11 / 7 \mathrm{~B} 2$ & 34s_6p1d7rd_0 0 & $337 / 8$ & $\mathrm{~s}$ & 9 & 4437.4 & 2357 & $215 / 7$ & 0.446 & 0.669 & HLP-22 & 12 & 4 & 4 & 1.9 & 10.5 & 5.7 & 30.8 & 16.1 & 0.62 & 0.33 & p1d7 & 2.45 & 0.0001213 & 0.0001780 & 0.0002606 & 0.4277 \\
\hline 709057 & $11 / 7 \mathrm{~B} 2$ & 34S 6p1dr/dd o 0 & $337 / 8$ & $s$ & 9 & 4437.4 & 23577 & $215 / 7$ & 0.446 & 0.669 & HLP-22 & 12 & 4 & 4 & 1.9 & 10.5 & 5.7 & 30.8 & 16.1 & 0.62 & 0.33 & $\mathrm{p} 1 \mathrm{dr}$ & 2.45 & 0.0001213 & 0.0001780 & 0.0002606 & 0.4277 \\
\hline 7090580 & 11/7B2 & 34s_6p1d7Yd_0 0 & $337 / 8$ & $\mathrm{~s}$ & 9 & 4437.4 & 23577 & $215 / 7$ & 0.446 & 0.669 & HLP-22 & 12 & 4 & 4 & 1.9 & 10.5 & 5.7 & 30.8 & 16.1 & 0.62 & 0.33 & pldr & 2.45 & 0.0001213 & 0.0001780 & 0.0002606 & 0.4277 \\
\hline 7090583 & $11 / 7 \mathrm{~B} 2$ & 34S_6p1d/rd_0 0 & $337 / 8$ & $\mathrm{~s}$ & 9 & 4437.4 & 2357 & $215 / 7$ & 0.446 & 0.669 & HLP-22 & 12 & 4 & 4 & 1.9 & 10.5 & 5.7 & 30.8 & 16.1 & 0.62 & 0.33 & pld 7 & 2.45 & 0.0001213 & 0.0001780 & 0.0002606 & 0.4277 \\
\hline 7090587 & $11 / 7 \mathrm{~B} 2$ & 34S_6p1d/rd_0 & $337 / 8$ & $\mathrm{~s}$ & 9 & 4437.4 & 2357 & $215 / 7$ & 0.446 & 0.669 & HLP-22 & 12 & 4 & 4 & 1.9 & 10.5 & 5.7 & 30.8 & 16.1 & 0.62 & 0.33 & p1d7 & 2.45 & 0.0001213 & 0.0001780 & 0.0002606 & 0.4277 \\
\hline 7090591 & 11/8A2 & 34S_6p1d/rd_9 9 & $337 / 8$ & $\mathrm{~s}$ & 9 & 4437.4 & 2357 & $215 / 7$ & 0.446 & 0.669 & HLP-22 & 12 & 0 & 4 & 1.9 & 10.5 & 5.7 & 30.8 & 16.1 & 0.62 & 0.33 & p1d7 & 2.45 & 0.0001213 & 0.0001780 & 0.0002606 & 0.4277 \\
\hline 7090594 & $11 / 8 \mathrm{~A} 2$ & 34S_6p1d7rd_9 9 & $337 / 8$ & $\mathrm{~s}$ & 9 & 4437.4 & 23577 & $215 / 7$ & 0.446 & 0.669 & HLP-22 & 12 & 0 & 4 & 1.9 & 10.5 & 5.7 & 30.8 & 16.1 & 0.62 & 0.33 & p1d7 & 2.45 & 0.0001213 & 0.0001780 & 0.0002606 & 0.4277 \\
\hline 7090596 & 11/8A2 & 34s_6p1d/Yd_ 9 & $337 / 8$ & $\mathrm{~s}$ & 9 & 4437.4 & 23577 & $215 / 7$ & 0.446 & 0.669 & HLP-22 & 12 & 0 & 4 & 1.9 & 10.5 & 5.7 & 30.8 & 16.1 & 0.62 & 0.33 & p1d7 & 2.45 & 0.0001213 & 0.0001780 & 0.0002606 & 0.4277 \\
\hline 7090599 & $11 / 8 \mathrm{~A} 2$ & 34S_6p1d/rd 99 & $337 / 8$ & $\mathrm{~s}$ & 9 & 4437.4 & 23577 & $215 / 7$ & 0.446 & 0.669 & HLP-22 & 12 & 0 & 4 & 1.9 & 10.5 & 5.7 & 30.8 & 16.1 & 0.62 & 0.33 & pld 7 & 2.45 & 0.0001213 & 0.0001780 & 0.0002606 & 0.4277 \\
\hline 7090002 & $11 / 8 A_{2}$ & 345 6p1d/rd 9 & $337 / 8$ & $s$ & 9 & 4437.4 & 2357 & $215 / 7$ & 0.446 & 0.669 & HLP-22 & 12 & 0 & 4 & 1.9 & 10.5 & 5.7 & 30.8 & 16.1 & 0.62 & 0.33 & p1d7 & 2.45 & 0.0001213 & 0.0001780 & 0.0002606 & $0.42 \pi$ \\
\hline 7090605 & $11 / 8 \mathrm{~A} 2$ & 34S_6p1d/Yd_ 9 & $337 / 8$ & $\mathrm{~s}$ & 9 & 4437.4 & 23577 & 2157 & 0.446 & 0.669 & HLP-22 & 12 & 0 & 4 & 1.9 & 10.5 & 5.7 & 30.8 & 16.1 & 0.62 & 0.33 & p1d7 & 2.45 & 0.0001213 & 0.0001780 & 0.0002606 & 0.4277 \\
\hline 7090608 & $11 / 8 \mathrm{~A} 2$ & 34S_6p1d/rd 9 & $337 / 8$ & $\mathrm{~s}$ & 9 & 4437.4 & 23577 & $215 / 7$ & 0.446 & 0.669 & HLP-22 & 12 & 0 & 4 & 1.9 & 10.5 & 5.7 & 30.8 & 16.1 & 0.62 & 0.33 & p1d7 & 2.45 & 0.0001213 & 0.0001780 & 0.0002606 & 0.4277 \\
\hline 7090612 & $11 / 8 \mathrm{~A} 2$ & 34S_6p1d/Yd_ 9 & $337 / 8$ & $\mathrm{~s}$ & 9 & 4437.4 & 23577 & $215 / 7$ & 0.446 & 0.669 & HLP-22 & 12 & 0 & 4 & 1.9 & 10.5 & 5.7 & 30.8 & 16.1 & 0.62 & 0.33 & pldr & 2.45 & 0.0001213 & 0.0001780 & 0.0002606 & 0.4277 \\
\hline 7090616 & $11 / 8 \mathrm{C} 1$ & 34s_6p1d7ra & $337 / 8$ & $\mathrm{~s}$ & 9 & 4437.4 & $337 / 8$ & $317 / 8$ & 0.446 & 0.669 & HLP-22 & 12 & 8 & 4 & 1.9 & 10.5 & 5.7 & 30.8 & 16.1 & 0.62 & 0.33 & p1d7 & 2.45 & 0.0001213 & 0.0001780 & 0.0002606 & 0.4277 \\
\hline 7090619 & $11 / 8 \mathrm{CC}$ & 34s_ppldrra & $337 / 8$ & $\mathrm{~s}$ & 9 & 4437.4 & $337 / 8$ & 31778 & 0.446 & 0.669 & HLP-22 & 12 & 8 & 4 & 1.9 & 10.5 & 5.7 & 30.8 & 16.1 & 0.62 & 0.33 & $\mathrm{p} 1 \mathrm{~d} 7$ & 2.45 & 0.0001213 & 0.0001780 & 0.0002606 & 0.4277 \\
\hline 7090622 & $11 / 8 \mathrm{C} 1$ & 345 gpldrra & $337 / 8$ & $\mathrm{~s}$ & 9 & 4437.4 & $337 / 8$ & 3178 & 0.446 & 0.669 & HLP-22 & 12 & 8 & 4 & 1.9 & 10.5 & 5.7 & 30.8 & 16.1 & 0.62 & 0.33 & $\mathrm{p} 1 \mathrm{~d} 7$ & 2.45 & 0.0001213 & 0.0001780 & 0.0002606 & 0.4277 \\
\hline 7090626 & $11 / 8 \mathrm{CC}$ & 34s_6p1d7Ya & $337 / 8$ & $\mathrm{~s}$ & 9 & 4437.4 & $337 / 8$ & 3178 & 0.446 & 0.669 & HLP-22 & 12 & 8 & 4 & 1.9 & 10.5 & 5.7 & 30.8 & 16.1 & 0.62 & 0.33 & p1d7 & 2.45 & 0.0001213 & 0.0001780 & 0.0002606 & 0.4277 \\
\hline 7090628 & $11 / 8 \mathrm{C} 2$ & 34S_6p1d/rd__1 & $337 / 8$ & $\mathrm{~s}$ & 9 & 4437.4 & $337 / 8$ & 3178 & 0.446 & 0.669 & HLP. 22 & 12 & 8 & 4 & 1.9 & 10.5 & 5.7 & 30.8 & 16.1 & 0.62 & 0.33 & p1d7 & 2.45 & 0.0001213 & 0.0001780 & 0.0002606 & 0.4277 \\
\hline
\end{tabular}


Table B.8. Data from Fall 2007 Tests in Mid-Scale Vessel with Spherical Head B.5

\begin{tabular}{|c|c|c|c|c|c|c|c|c|c|c|c|c|c|c|c|c|c|c|c|c|c|c|c|c|c|c|c|c|c|}
\hline $\begin{array}{l}\text { Tank Water } \\
\text { Temperature }\end{array}$ & $\begin{array}{l}\text { Water } \\
\text { Density }\end{array}$ & $\begin{array}{l}\text { Solids } \\
\text { Fraction }\end{array}$ & $\begin{array}{l}\text { Pulse } \\
\text { Volume } \\
\text { Fraction }\end{array}$ & $\begin{array}{l}\text { Duty } \\
\text { Oyde }\end{array}$ & $\begin{array}{l}\text { Cycle } \\
\text { Time }\end{array}$ & $\begin{array}{c}\text { Pulsed } \\
\text { Or } \\
\text { Steacy } \\
\text { Jet } \\
\end{array}$ & $\begin{array}{c}\text { Us } \\
\text { Steady } \\
\text { Jet }\end{array}$ & $\begin{array}{c}\text { U1 } \\
\text { Pulsing } \\
\text { Jet }\end{array}$ & $\begin{array}{l}\text { U2 } \\
\text { URNS } \\
\end{array}$ & $\begin{array}{c}\text { UI } \\
\text { URMB } \\
\end{array}$ & $\begin{array}{c}\text { Discharge } \\
\text { Velocity }\end{array}$ & $\begin{array}{c}\text { Citical } \\
\text { Suspension } \\
\text { Velocity }\end{array}$ & $\begin{array}{c}\text { Average } \\
\text { Peak } \\
\text { Cloud } \\
\text { Height } \\
\end{array}$ & $\begin{array}{c}\text { UCS } \\
\text { Condition }\end{array}$ & \begin{tabular}{|c|} 
UCS \\
Method
\end{tabular} & $\begin{array}{l}\text { UCS } \\
\text { Flag }\end{array}$ & $\begin{array}{c}\text { UCS } \\
\text { Center } \\
\text { Flag }\end{array}$ & $\begin{array}{c}\text { ucsuav } \\
\text { Hag } \\
\end{array}$ & $\begin{array}{l}\text { UcS based } \\
\text { on } \\
\text { Dereasing } \\
\text { Velocity } \\
\end{array}$ & $\begin{array}{c}\text { Sweep } \\
\text { Increase I } \\
\text { Decrease }\end{array}$ & \begin{tabular}{|c|} 
UDV \\
Height \\
Bed \\
\end{tabular} & $\begin{array}{c}\text { Paticice } \\
\text { Nation } \\
\end{array}$ & \begin{tabular}{|l} 
Solids \\
Level
\end{tabular} & \begin{tabular}{|l|} 
Outer \\
Bototom \\
Pattem \\
\end{tabular} & \begin{tabular}{|c|} 
Inner \\
Bottom \\
Pattem \\
\end{tabular} & Case ID & Test & TDP & $\begin{array}{l}\text { Row } \\
\text { Number }\end{array}$ \\
\hline$c$ & $\mathrm{~g} / \mathrm{cm}^{3}$ & fraction & fraction & fraction & $\mathrm{s}$ & text & $\mathrm{m} / \mathrm{s}$ & $\mathrm{m} / \mathrm{s}$ & $\mathrm{m} / \mathrm{s}$ & $\mathrm{m} / \mathrm{s}$ & $\mathrm{m} / \mathrm{s}$ & $\mathrm{m} / \mathrm{s}$ & in. & $\mathrm{m} / \mathrm{s}$ & text & text & text & text & m/s & text & $\mathrm{mm}$ & text & text & text & text & text & text & text & text \\
\hline $\mathrm{T}$ & $\rho$ & $\phi_{\mathrm{s}}$ & $\phi_{p}$ & $\mathrm{DC}$ & $t_{c}$ & Jet & $U_{s}$ & $\mathrm{U}_{1}$ & $\mathrm{U} 2$ & U3 & $u$ & Uss & $H_{k}$ & Ussp & $u_{\text {som }}$ & Ussis & Ussoen & Usuldv & $U_{\text {ss }} \mathrm{D}$ & $S_{w}$ & $\mathrm{H}_{\mathrm{hed}}$ & PM & Sol & SPo & $\mathrm{SP}_{1}$ & ID & MDDX & $\mathrm{TDP}$ & MSS \\
\hline 20.7 & 0.999 & 0.00487 & undefined & 1.000 & infinite & $s$ & 6.59 & NA & NA & NA & 6.60 & 6.40 & 24.00 & NA & NA & NA & NA & NA & NA & 1 & NA & $B C$ & NA & NA & NA & 34s_opldrra-40 & $11 / 6 \mathrm{~A} 1$ & TDP-WTP-049 & 7090506 \\
\hline 21.0 & 0.999 & 0.00487 & 0.051 & 0.180 & 58.0 & $\mathrm{P}$ & NA & 5.91 & \begin{tabular}{|l|l|}
5.98 \\
\end{tabular} & \begin{tabular}{|l|l|} 
& 6.01 \\
\end{tabular} & 6.00 & 7.30 & 10.00 & NA & NA & NA & NA & NA & NA & 1 & NA & ss & NA & NA & NA & 34s Gp1dr/d 6 & $1116 \mathrm{AA2}$ & TDP-WIP-049 & 7090508 \\
\hline 21.0 & 0.999 & 0.00487 & 0.051 & 0.180 & 54.0 & $\mathrm{P}$ & NA & 6.34 & 6.42 & 6.46 & 6.50 & 7.30 & 10.75 & NA & NA & NA & NA & NA & NA & 1 & NA & sSt & NA & NA & NA & 34S_6p1dTrd_6 6 & $11 / 6 \mathrm{AL}^{2}$ & TDP-WIP-049 & 7090511 \\
\hline 21.0 & 0.999 & 0.00487 & 0.051 & 0.180 & 50.0 & $\mathrm{P}$ & NA & 6.61 & 6.80 & 6.89 & 7.00 & 7.30 & 11.50 & NA & NA & NA & NA & NA & NA & 1 & NA & $A M$ & NA & NA & NA & 34S_6p1dTrd_6 6 & $11 / 6 A^{2}$ & TDP-WTP-049 & 7090514 \\
\hline 21.0 & 0.999 & 0.00487 & 0.050 & 0.180 & 47.3 & $P$ & NA & 6.84 & 7.07 & 7.17 & 7.30 & 7.30 & 13.50 & \begin{tabular}{|l|} 
\\
\end{tabular} & vis & UCSuis & NA & NA & NA & 1 & NA & CS & NA & NA & NA & 34S_6p1dTrd_6 6 & $11 / 6 \mathrm{A2}$ & TDP-WIP-049 & 7090518 \\
\hline 21.0 & 0.999 & 0.00487 & 0.050 & 0.180 & 45.3 & $\mathrm{P}$ & NA & 6.95 & 7.26 & 7.39 & 7.60 & 7.30 & 15.50 & \begin{tabular}{|l|l} 
NAA \\
\end{tabular} & NA & NA & NA & NA & NA & 1 & NA & $B C$ & NA & NA & NA & 34S_6p1d7rd_6 6 & 11/6A2 & TDP-WTP-049 & 7090520 \\
\hline 20.9 & 0.999 & 0.00487 & undefined & 1.000 & infinite & $\mathrm{s}$ & 2.62 & NA & NA & NA & 2.60 & 3.40 & NA & NA & NA & NA & NA & NA & NA & D & NA & SS+ & NA & NA & NA & 34S_6p1d/ra & $11 / 7 A_{1}$ & TDP-WTP-050 & 7090523 \\
\hline 21.0 & 0.999 & 0.00487 & undefined & 1.000 & infinite & $\mathrm{s}$ & 3.02 & NA & NA & NA & 3.00 & 3.40 & 9.50 & NA & NA & NA & NA & NA & NA & 1 & NA & $A M$ & NA & NA & NA & 34s gpldrTa & $11 / 7 \mathrm{~A} 1$ & TDP-WIP-050 & 7000529 \\
\hline 20.9 & 0.999 & 0.00487 & undefined & 1.000 & infinite & $\mathrm{s}$ & 3.22 & NA & NA & NA & 3.20 & 3.40 & 10.00 & NA & NA & NA & NA & NA & NA & 1 & NA & AMt & NA & NA & NA & 34s_ppldrTa & 11/7A1 & TDP-WIP-050 & 7090532 \\
\hline 21.0 & 0.999 & 0.00487 & undefined & 1.000 & infinite & $\mathrm{s}$ & 3.38 & NA & NA & NA & 3.40 & 3.40 & 11.00 & \begin{tabular}{|r|}
.40 \\
\end{tabular} & vis & UCSis & NA & NA & NA & 1 & NA & cs & NA & NA & NA & 345 6p1drTa & 11/7A1 & TDP-WIP-050 & 7090536 \\
\hline 21.0 & 0.999 & 0.00487 & undefined & 1.000 & infinite & $\mathrm{s}$ & 3.60 & NA & NA & NA & 3.60 & 3.40 & 15.00 & \begin{tabular}{|l|} 
NA \\
\end{tabular} & NA & NA & NA & NA & NA & 1 & NA & $B C$ & NA & NA & NA & 34s_6p1d/ra & $11 / 7 \mathrm{~A} 1$ & TDP-WIP-050 & 7090538 \\
\hline 21.0 & 0.999 & 0.00487 & 0.050 & 0.180 & 39.0 & $\mathrm{P}$ & NA & 283 & 2.92 & 296 & 3.00 & 4.20 & 8.75 & NA & NA & NA & NA & NA & NA & D & NA & ss & NA & NA & NA & 34S_6p1dT/d__1 & 11/7A2 & TDP-WIP-050 & 7090542 \\
\hline 21.0 & 0.999 & 0.00487 & 0.051 & 0.180 & 35.3 & $\mathrm{P}$ & NA & 3.11 & 3.21 & 3.26 & 3.40 & 4.20 & 10.00 & NA & NA & NA & NA & NA & NA & 1 & NA & sst & NA & NA & NA & 34S_6p1dTrd_1 1 & $11 / 7 \mathrm{~A} 2$ & TDP-WTP-050 & 7000544 \\
\hline 21.0 & 0.999 & 0.00487 & 0.051 & 0.180 & 31.0 & $\mathrm{P}$ & NA & 3.37 & 3.52 & 3.59 & 3.80 & 4.20 & 11.00 & NA & NA & NA & NA & NA & NA & 1 & NA & AM- & NA & NA & NA & 34S_6p1dTrd_1 & 11/7A2 & TDP-WIP-050 & 7090547 \\
\hline 21.0 & 0.999 & 0.00487 & 0.050 & 0.180 & 28.0 & $\mathrm{P}$ & NA & 3.49 & \begin{tabular}{|l|l|} 
& 3.76 \\
\end{tabular} & 3.88 & 4.20 & 4.20 & 11.75 & \begin{tabular}{|l|} 
\\
\end{tabular} & vis & uCsis & NA & NA & NA & 1 & NA & Cs & NA & NA & NA & 34s_6p1dTrd_1 1 & $11 / 7 A 2$ & TDP-WIP-050 & 7090551 \\
\hline 21.1 & 0.999 & 0.00487 & undefined & 1.000 & infinite & $\mathrm{s}$ & 3.99 & NA & NA & NA & 4.00 & 4.80 & 8.75 & NA & NA & NA & NA & NA & NA & D & NA & $A M$ & NA & NA & NA & 34S_6p1d/ra-44 & $11 / 7 \mathrm{~B} 1$ & TDP-WIP-050 & 7090553 \\
\hline 21.1 & 0.999 & 0.00487 & undefined & 1.000 & infinite & $\mathrm{s}$ & 4.18 & NA & NA & NA & 4.20 & 4.80 & 9.50 & NA & NA & NA & NA & NA & NA & 1 & NA & $A M$ & NA & NA & NA & 34S_6p1d/ra-44 & $11 / 7 \mathrm{~B} 1$ & TDP-WIP-050 & 7090557 \\
\hline 21.2 & 0.999 & 0.00487 & undefined & 1.000 & infinite & $\mathrm{s}$ & 4.41 & NA & NA & NA & 4.40 & 4.80 & 11.00 & NA & NA & NA & NA & NA & NA & 1 & NA & $A M$ & NA & NA & NA & 34__6p1dr/ra-44 & $11 / 7 \mathrm{B1}$ & TDP-WIP-050 & 7000560 \\
\hline 21.2 & 0.999 & 0.00487 & undefined & 1.000 & infinite & $\mathrm{s}$ & 4.62 & NA & NA & NA & 4.60 & 4.80 & 13.25 & NA & NA & NA & NA & NA & NA & 1 & NA & AMt & NA & NA & NA & 34s_6p1dTra-44 & $11 / 7 \mathrm{~B} 1$ & TDP-WIP-050 & 7090562 \\
\hline 21.0 & 0.999 & 0.00487 & 0.048 & 0.180 & \begin{tabular}{|l|}
39.5 \\
\end{tabular} & $\mathrm{P}$ & NA & 4.18 & 4.30 & \begin{tabular}{|l|l|} 
& 4.35 \\
\end{tabular} & 4.50 & 6.20 & 9.25 & \begin{tabular}{|l|} 
NA \\
\end{tabular} & NA & NA & NA & NA & NA & $\mathrm{D}$ & NA & ss & NA & NA & NA & 34s_6p1dTrd_0 0 & $117 \mathrm{~B} 2$ & TDP-WIP-050 & 7090569 \\
\hline 21.0 & 0.999 & 0.00487 & 0.050 & 0.180 & 35.3 & $\mathrm{P}$ & NA & 4.58 & 4.74 & 4.81 & 5.00 & 6.20 & 11.00 & NA & NA & NA & NA & NA & NA & 1 & NA & $A M$ & NA & NA & NA & 34S_6p1dTrd_o & $11 / 7 \mathrm{~B} 2$ & TDP-WIP-050 & 7090571 \\
\hline 21.0 & 0.999 & 0.00487 & 0.050 & 0.180 & 32.5 & $\mathrm{P}$ & NA & 4.65 & 4.95 & 5.08 & 5.40 & 6.20 & 12.75 & NA & NA & NA & NA & NA & NA & 1 & NA & AM+ & NA & NA & NA & 34S_6pldr/rd_o & $11 / 7 \mathrm{~B} 2$ & TDP-WIP-050 & 7000574 \\
\hline 21.0 & 0.999 & 0.00487 & 0.050 & 0.180 & 31.5 & $\mathrm{P}$ & NA & 4.77 & 5.10 & 5.24 & 5.60 & 6.20 & 14.00 & NA & NA & NA & NA & NA & NA & 1 & NA & AMt & NA & NA & NA & 34S_6p1dTrd_o 0 & $11 / 7 \mathrm{~B} 2$ & TDP-WIP-050 & 709057 \\
\hline 21.0 & 0.999 & 0.00487 & 0.050 & 0.180 & 30.0 & $\mathrm{P}$ & NA & 4.85 & 5.23 & 5.40 & 5.80 & 6.20 & 14.50 & NA & NA & NA & NA & NA & NA & 1 & NA & $A M+$ & NA & NA & NA & 34s_6p1dTrd_0 0 & $11 / 7 \mathrm{~B} 2$ & TDP-WIP-050 & 7090580 \\
\hline 21.0 & 0.999 & 0.00487 & 0.050 & 0.180 & 29.0 & $\mathrm{P}$ & NA & 4.96 & 5.37 & 5.55 & 6.00 & 6.20 & 15.75 & NA & NA & NA & NA & NA & NA & 1 & NA & $A M+$ & NA & NA & NA & 34S_6p1d/rd_0 0 & $11 / 7 \mathrm{~B} 2$ & TDP-WIP-050 & 7090583 \\
\hline 21.0 & 0.999 & 0.00487 & 0.050 & 0.180 & 28.0 & $\mathrm{P}$ & NA & 5.07 & 5.52 & 5.72 & 6.20 & 6.20 & 16.00 & \begin{tabular}{|l|}
6.20 \\
\end{tabular} & vis & ucsis & NA & NA & NA & 1 & NA & cs & NA & NA & NA & 34s_6p1dr/d__o & $11 / 7 \mathrm{~B} 2$ & TDP-WIP-050 & 7000587 \\
\hline 21.0 & 0.999 & 0.00487 & 0.046 & 0.180 & 63.0 & $\mathrm{P}$ & NA & 5.38 & 5.46 & 5.49 & 5.50 & 8.40 & 12.75 & \begin{tabular}{|l|} 
NA \\
\end{tabular} & NA & NA & NA & NA & NA & $\mathrm{D}$ & NA & ss & NA & NA & NA & 34S_6pldr/rd 9 & $11 / 8 A 2$ & TDP-WIP-051 & 7090591 \\
\hline 21.0 & 0.999 & 0.00487 & 0.051 & 0.180 & 58.5 & $\mathrm{P}$ & NA & 5.85 & 5.92 & 5.95 & 6.00 & 8.40 & 15.00 & NA & NA & NA & NA & NA & NA & 1 & NA & sSt & NA & NA & NA & 34 _6p1dr/d 9 & $11 / 8 A 2$ & TDP-WIP-051 & 7090594 \\
\hline 21.0 & 0.999 & 0.00487 & 0.051 & 0.180 & 55.0 & $\mathrm{P}$ & NA & 6.23 & 6.31 & 6.35 & 6.40 & 8.40 & 15.25 & NA & NA & NA & NA & NA & NA & 1 & NA & $A M$ & NA & NA & NA & 34S_6p1d/rd 9 & $11 / 8 A 2$ & TDP-WIP-051 & 7090596 \\
\hline 21.0 & 0.999 & 0.00487 & 0.051 & 0.180 & 51.5 & $\mathrm{P}$ & NA & 6.59 & 6.69 & 6.74 & 6.80 & 8.40 & 17.00 & NA & NA & NA & NA & NA & NA & 1 & NA & $A M$ & NA & NA & NA & 34S_6p1d/rd_9 9 & $11 / 8 A 2$ & TDP-WIP-051 & 7090599 \\
\hline 21.0 & 0.999 & 0.00487 & 0.050 & 0.180 & 48.5 & $\mathrm{P}$ & NA & 6.91 & 7.05 & 7.11 & 7.20 & 8.40 & 18.25 & NA & NA & NA & NA & NA & NA & 1 & NA & AM & NA & NA & NA & 34S_6p1dTrd_a & $11 / 8 A 2$ & TDP-WIP-051 & 7090602 \\
\hline 21.0 & 0.999 & 0.00487 & 0.050 & 0.180 & 45.5 & $\mathrm{P}$ & NA & 6.99 & 7.29 & 7.42 & 7.60 & 8.40 & 20.25 & NA & NA & NA & NA & NA & NA & 1 & NA & AMt & NA & NA & NA & 34S_6p1dr/d 9 & $11 / 8 A 2$ & TDP-WIP-051 & 7090605 \\
\hline 21.0 & 0.999 & 0.00487 & 0.049 & 0.180 & 43.5 & $\mathrm{P}$ & NA & 7.20 & 7.56 & 7.71 & 8.00 & 8.40 & 21.00 & NA & NA & NA & NA & NA & NA & 1 & NA & AMt & NA & NA & NA & 34S_6p1dTrd_9 9 & $11 / 8 A 2$ & TDP-WIP-051 & 7090608 \\
\hline 21.0 & 0.999 & 0.00487 & 0.050 & 0.180 & 41.0 & $\mathrm{P}$ & NA & 7.47 & 7.88 & \begin{tabular}{|l|l|} 
& 8.06 \\
\end{tabular} & 8.40 & 8.40 & 22.25 & \begin{tabular}{|l|}
8.40 \\
\end{tabular} & vis & UCSuis & & NA & & 1 & NA & cs & NA & NA & NA & 34S_6p1d/rd_ 9 & $11 / 8 A 2$ & TDP-WTP-051 & 7090612 \\
\hline 20.9 & 0.999 & 0.00487 & undefined & 1.000 & infinite & $\mathrm{s}$ & 2.51 & NA & NA & NA & 2.50 & 2.60 & \begin{tabular}{l|l} 
NA \\
\end{tabular} & NA & NA & NA & NA & NA & NA & 1 & NA & ss & NA & NA & NA & 34s_opldr/ra & $11 / 8 \mathrm{C}_{1}$ & TDP-WTP-051 & 7090616 \\
\hline 20.9 & 0.999 & 0.00487 & undefined & 1.000 & infinite & $\mathrm{s}$ & 3.01 & NA & NA & NA & 3.00 & 3.40 & 9.25 & NA & NA & NA & NA & NA & NA & 1 & NA & $A M$ & NA & NA & NA & 34s_ppldrra & $11 / 8 \mathrm{Cl}_{1}$ & TDP-WIP-051 & 7000619 \\
\hline 20.9 & 0.999 & 0.00487 & undefined & 1.000 & infinite & $\mathrm{s}$ & 3.23 & NA & NA & NA & 3.20 & 3.40 & 9.75 & NA & NA & NA & NA & NA & NA & 1 & NA & cs & NA & NA & NA & 345_6pldrra & $11 / 8 \mathrm{CC}$ & TDP-WIP-051 & 7090622 \\
\hline 20.9 & 0.999 & 0.00487 & undefined & 1.000 & infinite & $\mathrm{s}$ & 3.39 & NA & NA & NA & 3.40 & 3.40 & 11.00 & 3.40 & vis & ucsis & NA & NA & NA & 1 & NA & cs & NA & NA & NA & 34S_fpldr/ra & $11 / 8 \mathrm{CC} 1$ & TDP-WIP-051 & 7090626 \\
\hline 21.0 & 0.999 & 0.00487 & 0.051 & 0.180 & 34.0 & $\mathrm{P}$ & NA & 3.18 & \begin{tabular}{|l|}
3.30 \\
\end{tabular} & \begin{tabular}{|l|}
3.36 \\
\end{tabular} & 3.50 & 4.40 & 9.75 & \begin{tabular}{|l|l} 
NA \\
\end{tabular} & NA & NA & NA & NA & NA & s & NA & ss+ & NA & NA & NA & 34S_6pldr/Yd_1 1 & 111/8C2 & TDP-WIP-051 & 7090628 \\
\hline
\end{tabular}


Table B.8. Data from Fall 2007 Tests in Mid-Scale Vessel with Spherical Head A.6

\begin{tabular}{|c|c|c|c|c|c|c|c|c|c|c|c|c|c|c|c|c|c|c|c|c|c|c|c|c|c|c|c|}
\hline $\begin{array}{c}\text { Row } \\
\text { Number }\end{array}$ & Test & Case ID & $\begin{array}{c}\text { Tank } \\
\text { Diameter }\end{array}$ & $\begin{array}{l}\text { Head } \\
\text { Shape }\end{array}$ & $\begin{array}{c}\text { Dish } \\
\text { Height }\end{array}$ & $\begin{array}{l}\text { Dish } \\
\text { Volume }\end{array}$ & $\begin{array}{l}\text { Tank } \\
\text { Fill } \\
\text { Height }\end{array}$ & \begin{tabular}{|l} 
Returm \\
Line \\
Height
\end{tabular} & $\begin{array}{c}\text { Nozzle } \\
\text { Inner } \\
\text { Dianeter }\end{array}$ & $\begin{array}{c}\text { Nozzle } \\
\text { Stand- } \\
\text { off } \\
\text { Distance }\end{array}$ & $\begin{array}{l}\text { Pulse Tube } \\
\text { Configuration }\end{array}$ & $\begin{array}{l}\text { Installed } \\
\text { Nozzles } \\
\text { Nets }\end{array}$ & $\begin{array}{c}\text { Oater } \\
\text { Nozeles } \\
\text { Operated }\end{array}$ & $\begin{array}{c}\text { Inner } \\
\text { Nozzles } \\
\text { Opperated }\end{array}$ & $\begin{array}{l}\text { Pulse Tube } \\
\text { Outer } \\
\text { Diameter }\end{array}$ & $\begin{array}{c}\text { Outer } \\
\text { PJM } \\
\text { Radius }\end{array}$ & $\begin{array}{c}\text { Inner } \\
\text { PJM } \\
\text { Radius }\end{array}$ & $\begin{array}{l}\text { "FO' Outer } \\
\text { PJM } \\
\text { Impingement } \\
\text { Angle }\end{array}$ & $\begin{array}{l}\text { "FO' Inner } \\
\text { PJM } \\
\text { Impingement } \\
\text { Angle }\end{array}$ & $\begin{array}{c}\text { Ratio Outer } \\
\text { PJMto } \\
\text { Tank } \\
\text { Radius } \\
\end{array}$ & $\begin{array}{c}\text { Ratio Inner } \\
\text { PJM to } \\
\text { Tank } \\
\text { Radius } \\
\end{array}$ & Simulant & $\begin{array}{l}\text { Solids } \\
\text { Density }\end{array}$ & $\begin{array}{c}\text { Particle } \\
\text { Diameter d5 }\end{array}$ & $\begin{array}{c}\text { Partide } \\
\text { Dianeter } \\
\text { d50 }\end{array}$ & $\begin{array}{c}\text { Particle } \\
\text { Diameter } \\
\text { d95 }\end{array}$ & $\begin{array}{c}\text { Void } \\
\text { Fraction }\end{array}$ \\
\hline text & text & text & in. & text & in. & in. ${ }^{3}$ & in. & in. & in. & in. & text & number & number & number & in. & in. & in. & deg & deg & nondim & nondim & text & $\mathrm{g} / \mathrm{cm}^{3}$ & $\mathrm{~m}$ & $\mathrm{~m}$ & $\mathrm{~m}$ & fraction \\
\hline MSS & MDDX & ID & $\mathrm{D}$ & HS & Hess & $V_{\text {dsh }}$ & $\mathrm{H}$ & Rtn & $d$ & sod & PT & $\mathrm{N}$ & $\mathrm{Nb}$ & $\mathrm{N}$ & $\mathrm{PT}_{\alpha \mathrm{d}}$ & $\mathrm{R}_{0}$ & $\mathrm{R}_{4}$ & $\theta_{0}$ & $\theta_{1}$ & $\mathrm{RdR}$ & $R / R$ & $\operatorname{sxdx}$ & $\rho_{\mathrm{s}}$ & $\frac{d}{b}$ & $d_{50}$ & $d_{65}$ & vf \\
\hline 7090631 & $11 / 8 \mathrm{C} 2$ & 34s_6p1d/Yd_1 1 & $337 / 8$ & $\mathrm{~s}$ & 9 & 4437.4 & $337 / 8$ & $317 / 8$ & 0.446 & 0.669 & HLP-22 & 12 & 8 & 4 & 1.9 & 10.5 & 5.7 & 30.8 & 16.1 & 0.62 & 0.33 & pldr & 2.45 & 0.0001213 & 0.0001780 & 0.0002606 & 0.4277 \\
\hline 7090634 & $11 / 8 \mathrm{C}_{2}$ & 34s gpldr/rd 1 & $337 / 8$ & $\mathrm{~s}$ & 9 & 4437.4 & $337 / 8$ & $317 / 8$ & 0.446 & 0.669 & HLP. 22 & 12 & 8 & 4 & 1.9 & 10.5 & 5.7 & 30.8 & 16.1 & 0.62 & 0.33 & p1d7 & 2.45 & 0.0001213 & 0.0001780 & 0.0002606 & $0.42 \pi 7$ \\
\hline 7090637 & $11 / 8 \mathrm{C} 2$ & 34S_6p1d7Yd_1 1 & $337 / 8$ & $\mathrm{~s}$ & 9 & 4437.4 & $337 / 8$ & $317 / 8$ & 0.446 & 0.669 & HLP-22 & 12 & 8 & 4 & 1.9 & 10.5 & 5.7 & 30.8 & 16.1 & 0.62 & 0.33 & p1dr & 245 & 0.0001213 & 0.0001780 & 0.0002606 & 0.4277 \\
\hline 7090641 & $11 / 8 \mathrm{C} 2$ & 34s_6p1d/rd_1 1 & $337 / 8$ & $\mathrm{~s}$ & 9 & 4437.4 & $337 / 8$ & $317 / 8$ & 0.446 & 0.669 & HLP-22 & 12 & 8 & 4 & 1.9 & 10.5 & 5.7 & 30.8 & 16.1 & 0.62 & 0.33 & pld 7 & 2.45 & 0.0001213 & 0.0001780 & 0.0002606 & 0.4277 \\
\hline 7090643 & $11 / 8 \mathrm{C} 2$ & 34s 6p1dr/rd 1 1 & $337 / 8$ & $s$ & 9 & 4437.4 & $337 / 8$ & $317 / 8$ & 0.446 & 0.669 & HLP-22 & 12 & 8 & 4 & 1.9 & 10.5 & 5.7 & 30.8 & 16.1 & 0.62 & 0.33 & p1d7 & 2.45 & 0.0001213 & 0.0001780 & 0.0002606 & 0.4277 \\
\hline 7090648 & $11 / 8 \mathrm{D} 2$ & 34s_6p1d/Yd_0 0 & $337 / 8$ & $s$ & 9 & 4437.4 & $337 / 8$ & $317 / 8$ & 0.446 & 0.669 & HLP-22 & 12 & 4 & 4 & 1.9 & 10.5 & 5.7 & 30.8 & 16.1 & 0.62 & 0.33 & pldr & 245 & 0.0001213 & 0.0001780 & 0.0002606 & 0.4277 \\
\hline 7090650 & $11 / 8 \mathrm{D} 2$ & 34S_6p1d7rd_0 0 & $337 / 8$ & $\mathrm{~s}$ & 9 & 4437.4 & $337 / 8$ & $317 / 8$ & 0.446 & 0.669 & HLP. 22 & 12 & 4 & 4 & 1.9 & 10.5 & 5.7 & 30.8 & 16.1 & 0.62 & 0.33 & p1d7 & 2.45 & 0.0001213 & 0.0001780 & 0.0002606 & $0.42 \pi 7$ \\
\hline 7090653 & $11 / 8 \mathrm{D} 2$ & 34S_6p1d7rd_0 0 & $337 / 8$ & $\mathrm{~s}$ & 9 & 4437.4 & $337 / 8$ & $317 / 8$ & 0.446 & 0.669 & HLP-22 & 12 & 4 & 4 & 1.9 & 10.5 & 5.7 & 30.8 & 16.1 & 0.62 & 0.33 & p1dr & 2.45 & 0.0001213 & 0.0001780 & 0.0002606 & 0.4277 \\
\hline 7090656 & $11 / 802$ & 34s_6p1d/rd_0 0 & $337 / 8$ & $\mathrm{~s}$ & 9 & 4437.4 & $337 / 8$ & $317 / 8$ & 0.446 & 0.669 & HLP -22 & 12 & 4 & 4 & 1.9 & 10.5 & 5.7 & 30.8 & 16.1 & 0.62 & 0.33 & p1d7 & 2.45 & 0.0001213 & 0.0001780 & 0.0002606 & 0.4277 \\
\hline 7090659 & $11 / 8 D 2$ & 34S_6p1dTrd_o 0 & $337 / 8$ & $s$ & 9 & 4437.4 & $337 / 8$ & $317 / 8$ & 0.446 & 0.669 & HLP-22 & 12 & 4 & 4 & 1.9 & 10.5 & 5.7 & 30.8 & 16.1 & 0.62 & 0.33 & p1d7 & 2.45 & 0.0001213 & 0.0001780 & 0.0002606 & 0.4277 \\
\hline 7090662 & $11 / 8 \mathrm{D} 2$ & 34s_6p1d7rd_0 0 & $337 / 8$ & $\mathrm{~s}$ & 9 & 4437.4 & $337 / 8$ & $317 / 8$ & 0.446 & 0.669 & HLP-22 & 12 & 4 & 4 & 1.9 & 10.5 & 5.7 & 30.8 & 16.1 & 0.62 & 0.33 & pldr & 2.45 & 0.0001213 & 0.0001780 & 0.0002606 & 0.4277 \\
\hline 7090665 & $11 / 8 \mathrm{D} 2$ & 34S_6p1d/rd_0 0 & $337 / 8$ & $\mathrm{~s}$ & 9 & 4437.4 & $337 / 8$ & $317 / 8$ & 0.446 & 0.669 & HLP-22 & 12 & 4 & 4 & 1.9 & 10.5 & 5.7 & 30.8 & 16.1 & 0.62 & 0.33 & p1d7 & 2.45 & 0.0001213 & 0.0001780 & 0.0002606 & 0.4277 \\
\hline 7090668 & $11 / 8 \mathrm{D} 2$ & 34s_6p1d/7d_0 0 & $337 / 8$ & $\mathrm{~s}$ & 9 & 4437.4 & $337 / 8$ & $317 / 8$ & 0.446 & 0.669 & HLP-22 & 12 & 4 & 4 & 1.9 & 10.5 & 5.7 & 30.8 & 16.1 & 0.62 & 0.33 & p1d 7 & 2.45 & 0.0001213 & 0.0001780 & 0.0002606 & 0.4277 \\
\hline 7090671 & $11 / 802$ & 34s_6p1d/rd_0 0 & $337 / 8$ & $\mathrm{~s}$ & 9 & 4437.4 & $337 / 8$ & $317 / 8$ & 0.446 & 0.669 & HLP-22 & 12 & 4 & 4 & 1.9 & 10.5 & 5.7 & 30.8 & 16.1 & 0.62 & 0.33 & p1d7 & 245 & 0.0001213 & 0.0001780 & 0.0002606 & 0.4277 \\
\hline 7090674 & $11 / 8 \mathrm{D} 2$ & 34S_spldr/rd o 0 & $337 / 8$ & $\mathrm{~s}$ & 9 & 4437.4 & $337 / 8$ & $317 / 8$ & 0.446 & 0.669 & HLP-22 & 12 & 4 & 4 & 1.9 & 10.5 & 5.7 & 30.8 & 16.1 & 0.62 & 0.33 & p1d7 & 2.45 & 0.0001213 & 0.0001780 & 0.0002606 & 0.4277 \\
\hline 7090678 & $11 / 8 \mathrm{D} 2$ & 34s_6p1d7rd_0 0 & $337 / 8$ & $\mathrm{~s}$ & 9 & 4437.4 & $337 / 8$ & $317 / 8$ & 0.446 & 0.669 & HLP-22 & 12 & 4 & 4 & 1.9 & 10.5 & 5.7 & 30.8 & 16.1 & 0.62 & 0.33 & pldr & 245 & 0.0001213 & 0.0001780 & 0.0002606 & 0.4277 \\
\hline 7090681 & 11/9A1 & 34S_6p1d/7a-04 & $337 / 8$ & $\mathrm{~s}$ & 9 & 4437.4 & $337 / 8$ & $317 / 8$ & 0.446 & 0.669 & HLP-22 & 12 & 0 & 4 & 19 & 10.5 & 5.7 & 30.8 & 16.1 & 0.62 & 0.33 & pld 7 & 2.45 & 0.0001213 & 0.0001780 & 0.0002606 & 0.4277 \\
\hline 7090684 & 11/9A1 & 34s_6p1d/7a-04 & $337 / 8$ & $\mathrm{~s}$ & 9 & 4437.4 & $337 / 8$ & $317 / 8$ & 0.446 & 0.669 & HLP-22 & 12 & 0 & 4 & 19 & 10.5 & 5.7 & 30.8 & 16.1 & 0.62 & 0.33 & p1d7 & 2.45 & 0.0001213 & 0.0001780 & 0.0002606 & 0.4277 \\
\hline 7090687 & 11/9A1 & $345 \_6 p 1 d 7 / 7 a-04$ & $337 / 8$ & $\mathrm{~s}$ & 9 & 4437.4 & $337 / 8$ & $317 / 8$ & 0.446 & 0.669 & HLP-22 & 12 & 0 & 4 & 19 & 10.5 & 5.7 & 30.8 & 16.1 & 0.62 & 0.33 & p1d7 & 2.45 & 0.0001213 & 0.0001780 & 0.0002606 & 0.4277 \\
\hline 7090690 & 11/9A1 & 345 6p1d/ra-04 & $337 / 8$ & $s$ & 9 & 4437.4 & $337 / 8$ & $317 / 8$ & 0.446 & 0.669 & HLP-22 & 12 & 0 & 4 & 19 & 10.5 & 5.7 & 30.8 & 16.1 & 0.62 & 0.33 & $\mathrm{p} 1 \mathrm{~d} 7 \mathrm{P}$ & 2.45 & 0.0001213 & 0.0001780 & 0.0002606 & 0.4277 \\
\hline 7090692 & 11/9A1 & 34s_6p1d7/Ya-04 & $337 / 8$ & $\mathrm{~s}$ & 9 & 4437.4 & $337 / 8$ & $317 / 8$ & 0.446 & 0.669 & HLP-22 & 12 & 0 & 4 & 19 & 10.5 & 5.7 & 30.8 & 16.1 & 0.62 & 0.33 & pld7 & 245 & 0.0001213 & 0.0001780 & 0.0002606 & 0.4277 \\
\hline 7090696 & 11/9A1 & 34S_6p1d/7a-04 & $337 / 8$ & $\mathrm{~s}$ & 9 & 4437.4 & $337 / 8$ & $317 / 8$ & 0.446 & 0.669 & HLP-22 & 12 & 0 & 4 & 19 & 10.5 & 5.7 & 30.8 & 16.1 & 0.62 & 0.33 & pld 7 & 2.45 & 0.0001213 & 0.0001780 & 0.0002606 & 0.4277 \\
\hline 7090698 & 11/9A1 & 34s_6p1d/7a-04 & $337 / 8$ & $\mathrm{~s}$ & 9 & 4437.4 & $337 / 8$ & $317 / 8$ & 0.446 & 0.669 & HLP-22 & 12 & 0 & 4 & 19 & 10.5 & 5.7 & 30.8 & 16.1 & 0.62 & 0.33 & p1d7 & 2.45 & 0.0001213 & 0.0001780 & 0.0002606 & 0.4277 \\
\hline 7090702 & 11/9A1 & 34s_6p1d7/Ya-04 & $337 / 8$ & $\mathrm{~s}$ & 9 & 4437.4 & $337 / 8$ & $317 / 8$ & 0.446 & 0.669 & HLP-22 & 12 & 0 & 4 & 19 & 10.5 & 5.7 & 30.8 & 16.1 & 0.62 & 0.33 & p1d7 & 2.45 & 0.0001213 & 0.0001780 & 0.0002606 & 0.4277 \\
\hline 7090705 & $11 / 9 A^{2}$ & 34S 6p1dr/d 9 & $337 / 8$ & $s$ & 9 & 4437.4 & $337 / 8$ & $317 / 8$ & 0.446 & 0.669 & HLP-22 & 12 & 0 & 4 & 1.9 & 10.5 & 5.7 & 30.8 & 16.1 & 0.62 & 0.33 & $\mathrm{p} 1 \mathrm{dr}$ & 2.45 & 0.0001213 & 0.0001780 & 0.0002606 & 0.4277 \\
\hline 7090708 & 11/9A2 & 34S_6p1d/7d_9 9 & $337 / 8$ & $\mathrm{~s}$ & 9 & 4437.4 & $337 / 8$ & $317 / 8$ & 0.446 & 0.669 & HLP-22 & 12 & 0 & 4 & 1.9 & 10.5 & 5.7 & 30.8 & 16.1 & 0.62 & 0.33 & pldr & 245 & 0.0001213 & 0.0001780 & 0.0002606 & 0.4277 \\
\hline 7090710 & $11 / 9 \mathrm{~A}^{2}$ & 34S_6p1d/7d_9 9 & $337 / 8$ & $\mathrm{~s}$ & 9 & 4437.4 & $337 / 8$ & $317 / 8$ & 0.446 & 0.669 & HLP-22 & 12 & 0 & 4 & 1.9 & 10.5 & 5.7 & 30.8 & 16.1 & 0.62 & 0.33 & pld 7 & 2.45 & 0.0001213 & 0.0001780 & 0.0002606 & 0.4277 \\
\hline 7090713 & $11 / 9 \mathrm{~A}^{2}$ & 34S_6p1d7Yd_9 9 & $337 / 8$ & $\mathrm{~s}$ & 9 & 4437.4 & $337 / 8$ & $317 / 8$ & 0.446 & 0.669 & HLP-22 & 12 & 0 & 4 & 1.9 & 10.5 & 5.7 & 30.8 & 16.1 & 0.62 & 0.33 & p1d7 & 2.45 & 0.0001213 & 0.0001780 & 0.0002606 & $0.42 \pi$ \\
\hline 7090716 & $11 / 9 A^{2}$ & 34S_6p1d/rd_9 9 & $337 / 8$ & $\mathrm{~s}$ & 9 & 4437.4 & $337 / 8$ & $317 / 8$ & 0.446 & 0.669 & HLP-22 & 12 & 0 & 4 & 1.9 & 10.5 & 5.7 & 30.8 & 16.1 & 0.62 & 0.33 & p1d7 & 2.45 & 0.0001213 & 0.0001780 & 0.0002606 & 0.4277 \\
\hline 7090719 & $11 / 9 A^{2}$ & 34S_6p1d7rd_9 9 & $337 / 8$ & $\mathrm{~s}$ & 9 & 4437.4 & $337 / 8$ & $317 / 8$ & 0.446 & 0.669 & HLP-22 & 12 & 0 & 4 & 1.9 & 10.5 & 5.7 & 30.8 & 16.1 & 0.62 & 0.33 & p1d7 & 2.45 & 0.0001213 & 0.0001780 & 0.0002606 & 0.4277 \\
\hline 7090722 & $11 / 9 A^{2}$ & 34s_6p1d/Yd_ 9 & $337 / 8$ & $\mathrm{~s}$ & 9 & 4437.4 & $337 / 8$ & $317 / 8$ & 0.446 & 0.669 & HLP-22 & 12 & 0 & 4 & 1.9 & 10.5 & 5.7 & 30.8 & 16.1 & 0.62 & 0.33 & p1d7 & 2.45 & 0.0001213 & 0.0001780 & 0.0002606 & 0.4277 \\
\hline 7090725 & 11/9A2 & 34S_6p1d/rd 99 & $337 / 8$ & $\mathrm{~s}$ & 9 & 4437.4 & $337 / 8$ & $317 / 8$ & 0.446 & 0.669 & HLP-22 & 12 & 0 & 4 & 1.9 & 10.5 & 5.7 & 30.8 & 16.1 & 0.62 & 0.33 & pld 7 & 2.45 & 0.0001213 & 0.0001780 & 0.0002606 & 0.4277 \\
\hline 7090728 & $11 / 9 A^{2}$ & 34S_6p1d/Yd_ 9 & $337 / 8$ & $\mathrm{~s}$ & 9 & 4437.4 & $337 / 8$ & $317 / 8$ & 0.446 & 0.669 & HLP-22 & 12 & 0 & 4 & 1.9 & 10.5 & 5.7 & 30.8 & 16.1 & 0.62 & 0.33 & p1d7 & 2.45 & 0.0001213 & 0.0001780 & 0.0002606 & 0.4277 \\
\hline 7090732 & $119 \mathrm{AA}_{2}$ & 34S_6p1d/rd_9 9 & $337 / 8$ & $\mathrm{~s}$ & 9 & 4437.4 & $337 / 8$ & $317 / 8$ & 0.446 & 0.669 & HLP-22 & 12 & 0 & 4 & 1.9 & 10.5 & 5.7 & 30.8 & 16.1 & 0.62 & 0.33 & p1d7 & 245 & 0.0001213 & 0.0001780 & 0.0002606 & 0.4277 \\
\hline 7090737 & $11 / 14 A 1$ & 34s_6p1d/7a-44 & $337 / 8$ & $\mathrm{~s}$ & 9 & 4437.4 & $673 / 4$ & $653 / 4$ & 0.446 & 0.669 & HLP-22 & 12 & 4 & 4 & 1.9 & 10.5 & 5.7 & 30.8 & 16.1 & 0.62 & 0.33 & p1d7 & 2.45 & 0.0001213 & 0.0001780 & 0.0002606 & 0.4277 \\
\hline 7090740 & $11 / 14 A 2$ & 34S_6p1d7Yd_0 0 & $337 / 8$ & $\mathrm{~s}$ & 9 & 4437.4 & $673 / 4$ & $653 / 4$ & 0.446 & 0.669 & HLP-22 & 12 & 4 & 4 & 1.9 & 10.5 & 5.7 & 30.8 & 16.1 & 0.62 & 0.33 & pld7 & 2.45 & 0.0001213 & 0.0001780 & 0.0002606 & 0.4277 \\
\hline 7090742 & $11 / 14 A_{2}$ & 34S_6p1d/rd_0 0 & $337 / 8$ & $\mathrm{~s}$ & 9 & 4437.4 & $673 / 4$ & $653 / 4$ & 0.446 & 0.669 & HLP-22 & 12 & 4 & 4 & 1.9 & 10.5 & 5.7 & 30.8 & 16.1 & 0.62 & 0.33 & p1d7 & 2.45 & 0.0001213 & 0.0001780 & 0.0002606 & 0.4277 \\
\hline 7090745 & $1 / 1 / 14 A 2$ & 34S_6p1dr/Yd_0 & $337 / 8$ & $\mathrm{~s}$ & 9 & 4437.4 & $673 / 4$ & $653 / 4$ & 0.446 & 0.669 & HLP-22 & 12 & 4 & 4 & 1.9 & 10.5 & 5.7 & 30.8 & 16.1 & 0.62 & 0.33 & $\mathrm{p} 1 \mathrm{~d} 7$ & 2.45 & 0.0001213 & 0.0001780 & 0.0002606 & 0.4277 \\
\hline 7090748 & $11 / 14 A 2$ & 34S_6p1d $7 / \mathrm{dd} \_0$ & $337 / 8$ & $\mathrm{~s}$ & 9 & 4437.4 & $673 / 4$ & $653 / 4$ & 0.446 & 0.669 & HLP-22 & 12 & 4 & 4 & 1.9 & 10.5 & 5.7 & 30.8 & 16.1 & 0.62 & 0.33 & $\mathrm{p} 1 \mathrm{~d} 7$ & 2.45 & 0.0001213 & 0.0001780 & 0.0002606 & 0.4277 \\
\hline 7090751 & $11 / 14 A 2$ & 34s_6p1d7rd_0 0 & $337 / 8$ & $\mathrm{~s}$ & 9 & 4437.4 & $673 / 4$ & $653 / 4$ & 0.446 & 0.669 & HLP-22 & 12 & 4 & 4 & 1.9 & 10.5 & 5.7 & 30.8 & 16.1 & 0.62 & 0.33 & p1d7 & 245 & 0.0001213 & 0.0001780 & 0.0002606 & 0.4277 \\
\hline 7090754 & $11 / 14 A 2$ & 34S_6p1d/Ydd_ 0 & $337 / 8$ & $\mathrm{~s}$ & 9 & 4437.4 & $673 / 4$ & $653 / 4$ & 0.446 & 0.669 & HLP. 22 & 12 & 4 & 4 & 1.9 & 10.5 & 5.7 & 30.8 & 16.1 & 0.62 & 0.33 & p1d7 & 2.45 & 0.0001213 & 0.0001780 & 0.0002606 & 0.4277 \\
\hline
\end{tabular}


Table B.8. Data from Fall 2007 Tests in Mid-Scale Vessel with Spherical Head B.6

\begin{tabular}{|c|c|c|c|c|c|c|c|c|c|c|c|c|c|c|c|c|c|c|c|c|c|c|c|c|c|c|c|c|c|}
\hline $\begin{array}{l}\text { Tank Water } \\
\text { Temperature }\end{array}$ & $\begin{array}{l}\text { Water } \\
\text { Density }\end{array}$ & $\begin{array}{l}\text { Solids } \\
\text { Fraction }\end{array}$ & $\begin{array}{l}\text { Pulse } \\
\text { Volume } \\
\text { Fraction }\end{array}$ & $\begin{array}{l}\text { Duty } \\
\text { Cycle }\end{array}$ & $\begin{array}{l}\text { Oyde } \\
\text { Time }\end{array}$ & \begin{tabular}{|c|} 
Pulsed \\
or \\
Steacy \\
Jet \\
\end{tabular} & $\begin{array}{c}\text { Us } \\
\text { Steacady } \\
\text { Jet }\end{array}$ & $\begin{array}{c}\text { U1 } \\
\text { Pulsing } \\
\text { Jet }\end{array}$ & \begin{tabular}{|c|} 
U2 \\
URMS \\
\end{tabular} & $\begin{array}{c}\text { U3 } \\
\text { URNB }\end{array}$ & $\begin{array}{l}\text { Discharge } \\
\text { Velocity }\end{array}$ & $\begin{array}{c}\text { Citical } \\
\text { Suspension } \\
\text { Velocity }\end{array}$ & \begin{tabular}{|c|} 
Average \\
Peak \\
Cloud \\
Height \\
\end{tabular} & $\begin{array}{c}\text { ves } \\
\text { Condition }\end{array}$ & \begin{tabular}{|c|} 
UCS \\
Nethod \\
\end{tabular} & $\begin{array}{l}\text { ucs } \\
\text { Hag }\end{array}$ & $\begin{array}{c}\text { ucs } \\
\text { center } \\
\text { Hag }\end{array}$ & $\begin{array}{c}\text { UCS udv } \\
\text { Hag }\end{array}$ & \begin{tabular}{|c|} 
UCS based \\
on \\
Decreasing \\
Velocity \\
\end{tabular} & $\begin{array}{c}\text { Sweep } \\
\text { Increase / } \\
\text { Decrease }\end{array}$ & \begin{tabular}{|c|} 
UDV \\
Height \\
Bed \\
\end{tabular} & $\begin{array}{l}\begin{array}{l}\text { Patricle } \\
\text { Motion }\end{array} \\
\text { M }\end{array}$ & \begin{tabular}{|l|}
$\begin{array}{l}\text { Solids } \\
\text { Level }\end{array}$ \\
\end{tabular} & \begin{tabular}{|c|} 
Outer \\
Botom \\
Pattem \\
\end{tabular} & \begin{tabular}{|l} 
Inner \\
Bototom \\
Pattem \\
\end{tabular} & Case ID & Test & $\mathrm{TDP}$ & $\begin{array}{l}\text { Row } \\
\text { Number }\end{array}$ \\
\hline $\mathrm{c}$ & $\mathrm{g} / \mathrm{cm}^{3}$ & fraction & fraction & fraction & \begin{tabular}{l|l}
$\mathrm{s}$ \\
\end{tabular} & text & m/s & m/s & m/s & $\mathrm{m} / \mathrm{s}$ & $m / s$ & \begin{tabular}{|l|}
$\mathrm{m} / \mathrm{s}$ \\
\end{tabular} & in. & m/s & text & text & text & text & \begin{tabular}{|l|}
$m / s$ \\
\end{tabular} & \begin{tabular}{|l|} 
text \\
\end{tabular} & $\mathrm{mm}$ & text & \begin{tabular}{|l|} 
text \\
\end{tabular} & text & text & text & text & text & text \\
\hline$T$ & $\rho$ & $\phi_{\mathrm{s}}$ & $\phi_{p}$ & $D C$ & $t_{c}$ & Jet & $U_{s}$ & $\mathrm{U}_{1}$ & $\mathrm{U} 2$ & U3 & $u$ & Uss & $\mathrm{Hc}_{\mathrm{c}}$ & $u_{\text {Cor }}$ & Uasm & Usvis & Usceen & Usoudv & $U_{\text {cs }} \mathrm{D}$ & $s_{w}$ & $\mathrm{H}_{\text {bed }}$ & $\mathrm{PM}$ & Sol & $\mathrm{SPo}$ & $\mathrm{SP}_{1}$ & ID & MDDX & $\mathrm{TDP}$ & MSS \\
\hline 21.0 & 0.999 & $\begin{array}{ll}0.0487 \\
\end{array}$ & 0.050 & 0.180 & 31.3 & $\mathrm{P}$ & $\mathrm{NA}$ & 3.43 & 3.56 & 3.63 & 3.80 & 4.40 & 10.50 & NA & $\mathrm{NA}$ & NA & NA & NA & NA & 1 & NA & $A M$ & $\mathrm{NA}$ & NA & NA & $34 \mathrm{~s} 6 \mathrm{p} 1 \mathrm{~d} / \mathrm{d} \mathrm{d} 1$ & $11 / 8 \mathrm{CC} 2$ & TDP-WIP-051 & 7090631 \\
\hline 21.0 & 0.999 & 0.00487 & 0.050 & 0.180 & 29.5 & $P$ & NA & 3.41 & 3.63 & 3.73 & 4.00 & 4.40 & 11.25 & NA & NA & NA & NA & NA & NA & $\mathrm{I}$ & NA & $A M$ & NA & NA & NA & 34S_6p1d/Yd_1 1 & $11 / 8 \mathrm{CC} 2$ & TDP-WIP-051 & 7090634 \\
\hline 21.0 & 0.999 & 0.00487 & 0.050 & 0.180 & 28.3 & $\mathrm{P}$ & NA & 3.58 & 3.81 & 3.92 & 4.20 & 4.40 & 11.50 & NA & NA & NA & NA & NA & NA & 1 & NA & AMt & NA & NA & NA & 34S_6p1dTYd_1 & $11 / 8 \mathrm{CC} 2$ & TDP-WIP-051 & 7090637 \\
\hline 21.0 & 0.999 & $\begin{array}{ll}0.00487 \\
\end{array}$ & 0.050 & 0.180 & 26.8 & $\mathrm{P}$ & NA & 3.62 & 3.92 & 4.05 & 4.40 & 4.40 & 12.50 & \begin{tabular}{|l|}
4.40 \\
\end{tabular} & vis & UCShis & $\mathrm{NA}$ & NA & NA & 1 & NA & cs & NA & NA & NA & 34S_6p1dTrd_1 & $11 / 8 \mathrm{CC} 2$ & TDP-WIP-051 & 7090641 \\
\hline 21.0 & 0.999 & 0.00487 & 0.049 & 0.180 & 25.5 & $P$ & NA & 3.64 & 4.01 & 4.18 & 4.60 & 4.40 & 12.75 & NA & NA & NA & NA & NA & NA & 1 & NA & $\mathrm{BC}$ & NA & NA & NA & 34S_6p1dr/d 1 & $11 / 8 \mathrm{CC} 2$ & TDP-WTP-051 & 7090643 \\
\hline 21.0 & 0.999 & 0.00487 & 0.050 & 0.180 & 44.0 & $\mathrm{P}$ & NA & 3.83 & 3.90 & 3.93 & 4.00 & 7.20 & 9.50 & NA & NA & NA & NA & NA & NA & D & NA & ss & NA & NA & NA & 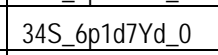 & $11 / 8 \mathrm{DD} 2$ & TDP-WIP-051 & 7090648 \\
\hline 21.0 & 0.999 & 0.00487 & 0.051 & 0.180 & 38.0 & $P$ & NA & 4.28 & 4.37 & 4.41 & 4.50 & 7.20 & 9.50 & NA & NA & NA & NA & NA & NA & 1 & NA & AMt & NA & NA & NA & 34S_6p1d7rd_o 0 & $11 / 8 \mathrm{D} 2$ & TDP-WIP-051 & 7090650 \\
\hline 21.0 & 0.999 & $\begin{array}{ll}0.00487 \\
\end{array}$ & 0.050 & 0.180 & 34.5 & $\mathrm{P}$ & $\mathrm{NA}$ & 4.69 & 4.85 & 4.92 & 5.10 & 7.20 & 11.50 & NA & NA & NA & NA & NA & NA & 1 & NA & $A M$ & NA & NA & NA & 34S_6p1dTrd_O & $11 / 8 \mathrm{DD} 2$ & TDP-WIP-051 & 7090656 \\
\hline 21.0 & 0.999 & 0.00487 & 0.050 & 0.180 & 32.5 & $\mathrm{P}$ & NA & 4.71 & 4.99 & 5.11 & 5.40 & 7.20 & 12.25 & NA & NA & NA & NA & NA & NA & 1 & NA & $A M$ & NA & NA & NA & 34S 6p1dryd o 0 & $11 / 8 \mathrm{DD} 2$ & TDP-WTP-051 & 7090659 \\
\hline 21.0 & 0.999 & 0.00487 & 0.050 & 0.180 & 30.8 & $\mathrm{P}$ & NA & 4.83 & 5.17 & 5.32 & 5.70 & 7.20 & 13.25 & NA & NA & NA & NA & NA & NA & 1 & NA & $A M$ & NA & NA & NA & 345_fpldr/rd 0 & $11 / 8 \mathrm{DD} 2$ & TDP-WIP-051 & 7090662 \\
\hline 21.0 & 0.999 & $\begin{array}{ll}.00487 \\
\end{array}$ & 0.050 & 0.180 & 29.0 & $\mathrm{P}$ & NA & 4.96 & 5.38 & 5.56 & 6.00 & 7.20 & 14.75 & NA & NA & NA & NA & NA & NA & 1 & NA & AM+ & NA & NA & NA & 34S_6p1dTYd_O & $11 / 8 \mathrm{DD} 2$ & TDP-WIP-051 & 7090665 \\
\hline 21.0 & 0.999 & 0.00487 & 0.050 & 0.180 & 27.3 & $\mathrm{P}$ & NA & 4.99 & 5.52 & 5.75 & 6.30 & 7.20 & 16.00 & NA & NA & NA & NA & NA & NA & 1 & NA & AMt & NA & NA & NA & 34S_6p1dTYd_o & $11 / 8 \mathrm{DD} 2$ & TDP-WIP-051 & 7090668 \\
\hline 21.0 & 0.999 & $\begin{array}{ll}0.00487 \\
\end{array}$ & 0.050 & 0.180 & 26.0 & $\mathrm{P}$ & NA & 4.99 & 5.62 & 5.89 & 6.60 & 7.20 & 17.00 & NA & $\mathrm{NA}$ & NA & NA & NA & NA & 1 & NA & AMt & NA & NA & NA & 34S_6p1dr/d_ 0 & $11 / 8 \mathrm{D} 2$ & TDP-WIP-051 & 7090671 \\
\hline 21.0 & 0.999 & 0.00487 & 0.049 & 0.180 & 24.5 & $\mathrm{P}$ & NA & 4.80 & 5.62 & 5.98 & 6.90 & 7.20 & 17.50 & NA & NA & NA & NA & NA & NA & 1 & NA & cs & NA & NA & NA & 34S_6p1drYd o 0 & $11 / 8 \mathrm{DD} 2$ & TDP-WTP-051 & 7090674 \\
\hline 21.0 & 0.999 & 0.00487 & 0.049 & 0.180 & 23.0 & $\mathrm{P}$ & NA & 4.57 & 5.57 & 6.03 & 7.20 & 7.20 & 18.00 & 7.20 & vis & Ucsis & NA & NA & NA & 1 & NA & cs & NA & NA & NA & 345_6p1drYd_ O & $1118 \mathrm{DD} 2$ & TDP-WTP-051 & 7090678 \\
\hline 21.4 & 0.999 & $\begin{array}{ll}.00487 \\
\end{array}$ & undefined & 1.000 & infinite & $\mathrm{s}$ & 3.63 & NA & NA & NA & 3.60 & 7.00 & NA & NA & NA & NA & UCScen & NA & NA & 1 & NA & SSt+ & NA & NA & NA & 34s_6p1drra-04 & 11/9A1 & TDP-WIP-052 & 7090681 \\
\hline 21.5 & 0.999 & 0.00487 & undefined & 1.000 & infinite & $\mathrm{s}$ & 4.00 & NA & NA & NA & 4.00 & 7.00 & 8.50 & NA & NA & NA & NA & NA & NA & 1 & NA & ss & NA & NA & NA & 34s_6p1d7ra-04 & 11/9A1 & TDP-WIP-052 & 7090684 \\
\hline 21.4 & 0.999 & $\begin{array}{ll}0.00487 \\
\end{array}$ & undefined & 1.000 & infinite & $\mathrm{s}$ & 4.52 & NA & NA & NA & 4.50 & 7.00 & 9.25 & NA & NA & NA & NA & NA & NA & 1 & NA & AM- & NA & NA & NA & 34s_6p1dr/ra-04 & 11/9A1 & TDP-WIP-052 & 7090687 \\
\hline 21.5 & 0.999 & $\begin{array}{ll}0.00487 \\
\end{array}$ & undefined & 1.000 & infinite & $\mathrm{s}$ & 5.02 & NA & NA & NA & 5.00 & 7.00 & 11.00 & NA & NA & NA & NA & NA & NA & 1 & NA & AM & NA & NA & NA & 34s_6p1drra-04 & 11/9A1 & TDP-WIP-052 & 7090690 \\
\hline 21.5 & 0.999 & $\begin{array}{ll}.00487 \\
\end{array}$ & undefined & 1.000 & infinite & $\mathrm{s}$ & 6.03 & NA & NA & NA & 6.00 & 7.00 & 16.00 & NA & NA & NA & NA & NA & NA & 1 & NA & $A M$ & NA & NA & NA & 34s_6pidrra-04 & 11/9A1 & TDP-WIP-052 & 7090696 \\
\hline 21.5 & 0.999 & 0.00487 & undefined & 1.000 & infinite & $\mathrm{s}$ & 6.54 & NA & NA & NA & 6.50 & 7.00 & 19.25 & NA & NA & NA & NA & NA & NA & $\mathrm{I}$ & NA & AMt & NA & NA & NA & 34s_6p1d7ra-04 & 11/9A1 & TDP-WIP-052 & 7090698 \\
\hline 21.5 & 0.999 & $\begin{array}{ll}0.00487 \\
\end{array}$ & undefined & 1.000 & infinite & $\mathrm{s}$ & 7.01 & $\mathrm{NA}$ & NA & NA & 7.00 & 7.00 & 22.50 & \begin{tabular}{|l|}
7.00 \\
\end{tabular} & vis & Ucsis & NA & NA & NA & 1 & NA & cs & $\mathrm{NA}$ & NA & NA & 345_6p1dr/ra-04 & $11 / 9 A 1$ & TDP-WIP-052 & 7090702 \\
\hline 22.0 & 0.999 & 0.00487 & 0.051 & 0.180 & 91.0 & $\mathrm{P}$ & NA & 3.80 & 3.83 & 3.84 & 3.80 & 8.50 & NA & NA & NA & NA & Ucscen & NA & NA & 1 & NA & ss & NA & NA & NA & 34S_6p1dr/d 99 & $11 / 9 A^{2}$ & TDP-WTP-052 & 7090705 \\
\hline 22.0 & 0.999 & 0.00487 & 0.050 & 0.180 & 77.5 & $\mathrm{P}$ & NA & 4.46 & 4.49 & 4.50 & 4.50 & 8.50 & 9.25 & NA & NA & NA & NA & NA & NA & 1 & NA & AMt & NA & NA & NA & 345_6p1dr/d_99 & $11 / 9 A^{2}$ & TDP-WIP-052 & 7090708 \\
\hline 22.0 & 0.999 & $\begin{array}{ll}.00487 \\
\end{array}$ & 0.049 & 0.180 & 70.0 & $\mathrm{P}$ & NA & 4.95 & 4.99 & 5.01 & 5.00 & 8.50 & 11.00 & NA & NA & NA & NA & NA & NA & 1 & NA & $A M$ & NA & NA & NA & 34S_6p1d7Yd_ 9 & $11 / 9 A^{2}$ & TDP-WIP-052 & 7090710 \\
\hline 22.0 & 0.999 & $\begin{array}{ll}0.00487 \\
\end{array}$ & 0.050 & 0.180 & 63.0 & $P$ & NA & 5.44 & 5.49 & 5.52 & 5.50 & 8.50 & 12.75 & NA & NA & NA & NA & NA & NA & 1 & NA & AM & NA & NA & NA & 34S_6p1dr/d_ 9 & $11 / 9 A^{2}$ & TDP-WIP-052 & 7090713 \\
\hline 22.0 & 0.999 & $\begin{array}{ll}0.00487 \\
\end{array}$ & 0.050 & 0.180 & 58.0 & $\mathrm{P}$ & NA & 5.84 & 5.93 & 5.97 & 6.00 & 8.50 & 14.50 & NA & NA & NA & NA & NA & NA & 1 & NA & $A M$ & NA & NA & NA & 34 _opldr/rd_9 & $11 / 9 A 2$ & TDP-WIP-052 & 7090716 \\
\hline 22.0 & 0.999 & 0.00487 & 0.051 & 0.180 & 53.5 & $\mathrm{P}$ & NA & 6.32 & 6.42 & 6.47 & 6.50 & 8.50 & 16.50 & NA & NA & NA & NA & NA & NA & 1 & NA & AM & NA & NA & NA & 34S_6p1dr/d 99 & $11 / 9 \mathrm{AP}$ & TDP-WIP-052 & 7090719 \\
\hline 22.0 & 0.999 & 0.00487 & 0.050 & 0.180 & 49.5 & $\mathrm{P}$ & NA & 6.70 & 6.86 & 6.94 & 7.00 & 8.50 & 17.75 & NA & NA & NA & NA & NA & NA & 1 & NA & $A M$ & NA & NA & NA & 345_6p1dr/d_99 & $11 / 9 \mathrm{AP}^{2}$ & TDP-WIP-052 & 7090722 \\
\hline 22.0 & 0.999 & 0.00487 & 0.050 & 0.180 & 46.0 & $\mathrm{P}$ & NA & 6.71 & 7.07 & 7.22 & 7.50 & 8.50 & 20.00 & NA & NA & NA & NA & NA & NA & 1 & NA & AM+ & NA & NA & NA & 345_6p1dr/Yd 9 & $11 / 9 A 2$ & TDP-WIP-052 & 7090725 \\
\hline 22.0 & 0.999 & $\begin{array}{ll}0.00487 \\
\end{array}$ & 0.051 & 0.180 & 43.0 & $\mathrm{P}$ & NA & 7.12 & 7.53 & 7.71 & 8.00 & 8.50 & 21.50 & NA & NA & NA & NA & NA & NA & 1 & $\mathrm{NA}$ & AMt & $\mathrm{NA}$ & NA & NA & 34S_6p1dryd_9 & $11 / 9 A^{2}$ & TDP-WIP-052 & 7090728 \\
\hline 22.0 & 0.999 & $\begin{array}{ll}0.00487 \\
\end{array}$ & 0.051 & 0.180 & 40.5 & $\mathrm{P}$ & NA & 7.37 & 7.87 & 8.09 & 8.50 & 8.50 & 22.75 & \begin{tabular}{|l|}
8.50 \\
\end{tabular} & vis & ucsis & NA & NA & NA & 1 & NA & CS & NA & NA & NA & 34S_6p1d/rd_9 9 & $1199 A^{2}$ & \begin{tabular}{|l} 
TDP-WTP-052 \\
\end{tabular} & 7090732 \\
\hline 22.9 & 0.999 & $\begin{array}{ll}0.00487 \\
\end{array}$ & undefined & 1.000 & infinite & $\mathrm{s}$ & 3.40 & NA & NA & NA & 3.40 & NA & NA & NA & NA & NA & UCSsoen & NA & NA & 1 & NA & ss & NA & NA & NA & 345_6p1drra-44 & $11 / 14 A 1$ & \begin{tabular}{|l|} 
TDP-WIP-063 \\
\end{tabular} & 7090737 \\
\hline 23.0 & 0.999 & 0.00487 & 0.051 & 0.180 & 44.0 & $\mathrm{P}$ & NA & 3.82 & 3.90 & 3.94 & 4.00 & 7.00 & 8.50 & NA & NA & NA & UCscen & NA & NA & 1 & NA & sst+ & NA & NA & NA & 34S_6p1dr/d__o & $11 / 14 A 2$ & \begin{tabular}{|l|} 
TDP-WIP-063 \\
\end{tabular} & 7090740 \\
\hline 23.0 & 0.999 & $\begin{array}{ll}0.00487 \\
\end{array}$ & 0.051 & 0.180 & 39.5 & $\mathrm{P}$ & NA & 4.18 & 4.30 & 4.35 & 4.50 & & 9.25 & NA & NA & NA & NA & NA & NA & 1 & NA & AM & NA & NA & NA & 345_6p1dTrd_OO & $11 / 14 A 2$ & \begin{tabular}{|l|} 
TDP-WIP-063 \\
\end{tabular} & 7090742 \\
\hline 23.0 & 0.999 & $\begin{array}{ll}0.00487 \\
\end{array}$ & 0.051 & 0.180 & 35.3 & $\mathrm{P}$ & NA & 4.52 & 4.71 & 4.80 & 5.00 & 7.00 & 10.75 & NA & NA & NA & NA & NA & NA & 1 & NA & AM & NA & NA & NA & 34S_6p1dTYd_O & $11 / 14 A 2$ & \begin{tabular}{|l|} 
TDP-WIP-063 \\
\end{tabular} & 7090745 \\
\hline 23.0 & 0.999 & $\begin{array}{ll}0.00487 \\
\end{array}$ & 0.050 & 0.180 & 32.0 & $\mathrm{P}$ & NA & 4.69 & 5.01 & 5.15 & 5.50 & 7.00 & 13.00 & NA & NA & NA & NA & NA & NA & 1 & NA & $A M$ & $\mathrm{NA}$ & NA & NA & 34S_6p1dTrd_o & $11 / 14 A 2$ & \begin{tabular}{|l|} 
TDP-WIP-063 \\
\end{tabular} & 7090748 \\
\hline 23.0 & 0.999 & 0.00487 & 0.051 & 0.180 & 29.0 & $\mathrm{P}$ & NA & 4.83 & 5.30 & 5.50 & 6.00 & 7.00 & 15.75 & NA & NA & NA & NA & NA & NA & 1 & NA & AMt & NA & NA & NA & 34S_6p1dTrd o 0 & $11 / 14 A 2$ & \begin{tabular}{|l|} 
TDP-WIP-063 \\
\end{tabular} & 7090751 \\
\hline 23.0 & 0.999 & 0.00487 & 0.050 & 0.180 & 26.3 & $\mathrm{P}$ & NA & 4.88 & 5.53 & 5.81 & 6.50 & 7.00 & 17.00 & NA & NA & NA & NA & NA & NA & 1 & NA & AMt & NA & NA & NA & 34S_fpldr/rd 0 & $11 / 14 A 2$ & \begin{tabular}{|l|} 
TDP-WIP-063 \\
\end{tabular} & 7090754 \\
\hline
\end{tabular}


Table B.8. Data from Fall 2007 Tests in Mid-Scale Vessel with Spherical Head A.7

\begin{tabular}{|c|c|c|c|c|c|c|c|c|c|c|c|c|c|c|c|c|c|c|c|c|c|c|c|c|c|c|c|}
\hline $\begin{array}{l}\text { Raw } \\
\text { Number }\end{array}$ & Test & Case ID & $\begin{array}{l}\text { Tank } \\
\text { Diameter }\end{array}$ & $\begin{array}{l}\text { Head } \\
\text { Shape }\end{array}$ & $\begin{array}{l}\text { Dish } \\
\text { Height }\end{array}$ & $\begin{array}{l}\text { Dish } \\
\text { Volume }\end{array}$ & $\begin{array}{c}\text { Tank } \\
\text { Fill } \\
\text { Height }\end{array}$ & $\begin{array}{l}\text { Retum } \\
\text { Line } \\
\text { Height }\end{array}$ & $\begin{array}{c}\text { Nozzle } \\
\text { Inner } \\
\text { Diameter }\end{array}$ & \begin{tabular}{|c|} 
Nozzle \\
Stann- \\
of \\
Distance \\
\end{tabular} & $\begin{array}{l}\text { Pulse Tube } \\
\text { Configuration }\end{array}$ & $\begin{array}{l}\text { Installed } \\
\text { Nozzles }\end{array}$ & $\begin{array}{c}\text { Outer } \\
\text { Nozzles } \\
\text { Operated }\end{array}$ & $\begin{array}{c}\text { Inner } \\
\text { Nozzles } \\
\text { Operated }\end{array}$ & $\begin{array}{l}\text { Pulse Tube } \\
\text { Outer } \\
\text { Diameter }\end{array}$ & $\begin{array}{c}\text { Outer } \\
\text { PJM } \\
\text { Radius }\end{array}$ & $\begin{array}{c}\text { Inner } \\
\text { PPM } \\
\text { Radius }\end{array}$ & $\begin{array}{l}\text { "FO' Outer } \\
\text { PJM } \\
\text { Pimigement } \\
\text { Angle }\end{array}$ & $\begin{array}{c}\text { "FO" Inner } \\
\text { PJM } \\
\text { Impigement } \\
\text { Angle } \\
\end{array}$ & $\begin{array}{c}\text { Ratio Outer } \\
\text { PJM to } \\
\text { Tank } \\
\text { Radius } \\
\end{array}$ & $\begin{array}{c}\text { Ratio Inner } \\
\text { PJM to } \\
\text { Tank } \\
\text { Radius } \\
\end{array}$ & Simulant & $\begin{array}{l}\text { Solids } \\
\text { Density }\end{array}$ & $\begin{array}{c}\text { Particle } \\
\text { Diameter d } 5\end{array}$ & $\begin{array}{c}\text { Partide } \\
\text { Diantert } \\
\text { d50 }\end{array}$ & $\begin{array}{c}\text { Particle } \\
\text { Diameter } \\
\text { d95 }\end{array}$ & $\begin{array}{l}\text { Void } \\
\text { Fraction }\end{array}$ \\
\hline text & text & text & in. & text & in. & in. ${ }^{3}$ & in. & in. & in. & in. & text & number & number & number & in. & in. & in. & deg & deg & nondim & nondim & text & $\mathrm{g} / \mathrm{cm}^{3}$ & $m$ & $m$ & $\mathrm{~m}$ & fraction \\
\hline MSS & MDDX & ID & $\mathrm{D}$ & $\mathrm{HS}$ & Hosh & $V_{\text {dash }}$ & $\mathrm{H}$ & Rtn & $d$ & sod & PT & $\mathrm{N}$ & $\mathrm{No}$ & $\mathrm{N}$ & $\mathrm{PT}_{\alpha \mathrm{d}}$ & $\mathrm{Ro}_{0}$ & $R$ & $\theta_{\circ}$ & $\theta_{1}$ & $\mathrm{RdR}$ & $R / R$ & sxdx & $\rho_{\mathrm{s}}$ & $c_{b}$ & $\mathrm{~d}_{60}$ & $d_{65}$ & vf \\
\hline $7090758 \mathrm{Mx}$ & $11 / 14 A^{2}$ & 34S_6pldr/dd_o & $337 / 8$ & $\mathrm{~s}$ & 9 & 4437.4 & $673 / 4$ & $653 / 4$ & 0.446 & 0.669 & HLP-22 & 12 & 4 & 4 & 1.9 & 10.5 & 5.7 & 30.8 & 16.1 & 0.62 & 0.33 & p1d7 & 2.45 & 0.0001213 & 0.0001780 & 0.0002606 & 0.4277 \\
\hline 7090761 & $11 / 14 \mathrm{BB}$ & 34__6p1d/ra-44 & $337 / 8$ & $\mathrm{~s}$ & 9 & 4437.4 & $673 / 4$ & $613 / 4$ & 0.446 & 0.669 & HLP-22 & 12 & 4 & 4 & 1.9 & 10.5 & 5.7 & 30.8 & 16.1 & 0.62 & 0.33 & p1d7 & 2.45 & 0.0001213 & 0.0001780 & 0.0002606 & 0.4277 \\
\hline 7090764 & $11 / 1482$ & 34S_6pldTrd_0 & $337 / 8$ & $s$ & 9 & 4437.4 & $673 / 4$ & $613 / 4$ & 0.446 & 0.669 & HLP-22 & 12 & 4 & 4 & 1.9 & 10.5 & 5.7 & 30.8 & 16.1 & 0.62 & 0.33 & p1d7 & 2.45 & 0.0001213 & 0.0001780 & 0.0002606 & 0.4277 \\
\hline 7090766 & $11 / 14 \mathrm{Cl}$ & 34s_6p1d7/ra-04 & $337 / 8$ & $\mathrm{~s}$ & 9 & 4437.4 & $673 / 4$ & $613 / 4$ & 0.446 & 0.669 & HLP-22 & 12 & 0 & 4 & 1.9 & 10.5 & 5.7 & 30.8 & 16.1 & 0.62 & 0.33 & p1d7 & 2.45 & 0.0001213 & 0.0001780 & 0.0002606 & $0.42 \pi 7$ \\
\hline 709072 & $111 / 4 C 2$ & 34s_6p1d/rd_a & $337 / 8$ & $\mathrm{~s}$ & 9 & 4437.4 & $673 / 4$ & $613 / 4$ & 0.446 & 0.669 & HLP.22 & 12 & 0 & 4 & 1.9 & 10.5 & 5.7 & 30.8 & 16.1 & 0.62 & 0.33 & $\mathrm{pld} 7$ & 2.45 & 0.0001213 & 0.0001780 & 0.0002606 & 0.4277 \\
\hline 7090776 & $11 / 14 \mathrm{DI}$ & 345 6p1drve_1 & $337 / 8$ & $\mathrm{~s}$ & 9 & 4437.4 & $673 / 4$ & $613 / 4$ & 0.446 & 0.669 & HLP-22 & 12 & 8 & 4 & 1.9 & 10.5 & 5.7 & 30.8 & 16.1 & 0.62 & 0.33 & p1d7 & 2.45 & 0.0001213 & 0.0001780 & 0.0002606 & 0.4277 \\
\hline $7090779 \mathrm{M}$ & $11 / 14 \mathrm{DI}$ & 345 6p1dTrc_1 1 & $337 / 8$ & $\mathrm{~s}$ & 9 & 4437.4 & $673 / 4$ & $613 / 4$ & 0.446 & 0.669 & HLP-22 & 12 & 8 & 4 & 1.9 & 10.5 & 5.7 & 30.8 & 16.1 & 0.62 & 0.33 & p1d7 & 2.45 & 0.0001213 & 0.0001780 & 0.0002606 & 0.4277 \\
\hline 7090781M & $11 / 14 \mathrm{D} 1$ & 34s_6pldTrc_1 & $337 / 8$ & $s$ & 9 & 4437.4 & $673 / 4$ & $613 / 4$ & 0.446 & 0.669 & HLP-22 & 12 & 8 & 4 & 1.9 & 10.5 & 5.7 & 30.8 & 16.1 & 0.62 & 0.33 & p1d7 & 2.45 & 0.0001213 & 0.0001780 & 0.0002606 & 0.4277 \\
\hline 7090785 & $11 / 15 \mathrm{~A} 1$ & 34s_6p1d/rc_o & $337 / 8$ & $s$ & 9 & 4437.4 & $673 / 4$ & $613 / 4$ & 0.446 & 0.669 & HLP-22 & 12 & 4 & 4 & 1.9 & 10.5 & 5.7 & 30.8 & 16.1 & 0.62 & 0.33 & p1d7 & 2.45 & 0.0001213 & 0.0001780 & 0.0002606 & 0.4277 \\
\hline 7090787 & $1 / 15 \mathrm{~A}_{1}$ & $34 \mathrm{~s} \_$ $6 \mathrm{p} 1 \mathrm{~d} / \mathrm{rc} \_0$ & $337 / 8$ & $\mathrm{~s}$ & 9 & 4437.4 & $673 / 4$ & $613 / 4$ & 0.446 & 0.669 & HLP-22 & 12 & 4 & 4 & 1.9 & 10.5 & 5.7 & 30.8 & 16.1 & 0.62 & 0.33 & pld7 & 2.45 & 0.0001213 & 0.0001780 & 0.0002606 & 0.4277 \\
\hline 7090790 & $11 / 15 \mathrm{~A} 1$ & 345 spldr/rc 0 & $337 / 8$ & $\mathrm{~s}$ & 9 & 4437.4 & $673 / 4$ & $613 / 4$ & 0.446 & 0.669 & HLP-22 & 12 & 4 & 4 & 1.9 & 10.5 & 5.7 & 30.8 & 16.1 & 0.62 & 0.33 & p1d7 & 2.45 & 0.0001213 & 0.0001780 & 0.0002606 & 0.4277 \\
\hline 7090793 & $11 / 15 \mathrm{~A}$ & $345 \_6 p 1 d \gamma / c \_0$ & $337 / 8$ & $\mathrm{~s}$ & 9 & 4437.4 & $673 / 4$ & $613 / 4$ & 0.446 & 0.669 & HLP-22 & 12 & 4 & 4 & 1.9 & 10.5 & 5.7 & 30.8 & 16.1 & 0.62 & 0.33 & p1d7 & 2.45 & 0.0001213 & 0.0001780 & 0.0002606 & 0.4277 \\
\hline 7090796 & $11 / 15 \mathrm{~A}$ & 34S_6p1dTrc_0 0 & $337 / 8$ & $s$ & 9 & 4437.4 & $673 / 4$ & $613 / 4$ & 0.446 & 0.669 & HLP-22 & 12 & 4 & 4 & 1.9 & 10.5 & 5.7 & 30.8 & 16.1 & 0.62 & 0.33 & p1d7 & 2.45 & 0.0001213 & 0.0001780 & 0.0002606 & 0.4277 \\
\hline 7090799 & $11 / 15 \mathrm{~A}$ & 34s_6p1d/rc_o & $337 / 8$ & $\mathrm{~s}$ & 9 & 4437.4 & $673 / 4$ & $613 / 4$ & 0.446 & 0.669 & HLP-22 & 12 & 4 & 4 & 1.9 & 10.5 & 5.7 & 30.8 & 16.1 & 0.62 & 0.33 & p1d7 & 245 & 0.0001213 & 0.0001780 & 0.0002606 & 0.4277 \\
\hline 7090802 & $11 / 15 \mathrm{~A}_{1}$ & $34 \mathrm{~s} \_\mathrm{pp} 1 \mathrm{~d} / \mathrm{rc} \_0$ & $337 / 8$ & $\mathrm{~s}$ & 9 & 4437.4 & $673 / 4$ & $613 / 4$ & 0.446 & 0.669 & HLP-22 & 12 & 4 & 4 & 1.9 & 10.5 & 5.7 & 30.8 & 16.1 & 0.62 & 0.33 & p1d7 & 2.45 & 0.0001213 & 0.0001780 & 0.0002606 & 0.4277 \\
\hline $7090006 \mathrm{M}$ & $17 / 15 \mathrm{~A} 1$ & $345 \_6 p 1 d / r c \_0$ & $337 / 8$ & $\mathrm{~s}$ & 9 & 4437.4 & $673 / 4$ & $613 / 4$ & 0.446 & 0.669 & HLP-22 & 12 & 4 & 4 & 1.9 & 10.5 & 5.7 & 30.8 & 16.1 & 0.62 & 0.33 & p1d7 & 2.45 & 0.0001213 & 0.0001780 & 0.0002606 & 0.4277 \\
\hline $7090808 \mathrm{M}$ & $1715 \mathrm{~A} 1$ & $345 \_6 p 1 d / r c \_0$ & $337 / 8$ & $\mathrm{~s}$ & 9 & 4437.4 & $673 / 4$ & $613 / 4$ & 0.446 & 0.669 & HLP-22 & 12 & 4 & 4 & 1.9 & 10.5 & 5.7 & 30.8 & 16.1 & 0.62 & 0.33 & p1d7 & 2.45 & 0.0001213 & 0.0001780 & 0.0002606 & 0.4277 \\
\hline 7090812 & $11 / 15 B 1$ & 34s_6p1dTrc_9 9 & $337 / 8$ & $\mathrm{~s}$ & 9 & 4437.4 & $673 / 4$ & $613 / 4$ & 0.446 & 0.669 & HLP-22 & 12 & 0 & 4 & 1.9 & 10.5 & 5.7 & 30.8 & 16.1 & 0.62 & 0.33 & p1d7 & 2.45 & 0.0001213 & 0.0001780 & 0.0002606 & 0.4277 \\
\hline 7090814 & $11 / 15 \mathrm{BB}$ & $34 \mathrm{~s}$ 6p1dr/c_ 9 & $337 / 8$ & $\mathrm{~s}$ & 9 & 4437.4 & $673 / 4$ & $613 / 4$ & 0.446 & 0.669 & HLP-22 & 12 & 0 & 4 & 1.9 & 10.5 & 5.7 & 30.8 & 16.1 & 0.62 & 0.33 & p1d7 & 2.45 & 0.0001213 & 0.0001780 & 0.0002606 & 0.4277 \\
\hline 7090816 & $11 / 15 \mathrm{BB}$ & 34s_6p1dr/rc 9 & $337 / 8$ & $\mathrm{~s}$ & 9 & 4437.4 & $673 / 4$ & $613 / 4$ & 0.446 & 0.669 & HLP-22 & 12 & 0 & 4 & 1.9 & 10.5 & 5.7 & 30.8 & 16.1 & 0.62 & 0.33 & pld 7 & 2.45 & 0.0001213 & 0.0001780 & 0.0002606 & 0.4277 \\
\hline 7090819 & $11 / 15 \mathrm{BB}$ & 345 6p1drrc 9 & $337 / 8$ & $\mathrm{~s}$ & 9 & 4437.4 & $673 / 4$ & $613 / 4$ & 0.446 & 0.669 & HLP-22 & 12 & 0 & 4 & 1.9 & 10.5 & 5.7 & 30.8 & 16.1 & 0.62 & 0.33 & p1d7 & 2.45 & 0.0001213 & 0.0001780 & 0.0002606 & $0.42 \pi 7$ \\
\hline 7090822 & $11 / 15 \mathrm{BB}$ & 345 6p1dTrc_9 & $337 / 8$ & $\mathrm{~s}$ & 9 & 4437.4 & $673 / 4$ & $613 / 4$ & 0.446 & 0.669 & HLP-22 & 12 & 0 & 4 & 1.9 & 10.5 & 5.7 & 30.8 & 16.1 & 0.62 & 0.33 & p1d7 & 2.45 & 0.0001213 & 0.0001780 & 0.0002606 & 0.4277 \\
\hline 7090825 & 11/15B1 & 34s_6p1dTrc_9 9 & $337 / 8$ & $\mathrm{~s}$ & 9 & 4437.4 & $673 / 4$ & $613 / 4$ & 0.446 & 0.669 & HLP-22 & 12 & 0 & 4 & 1.9 & 10.5 & 5.7 & 30.8 & 16.1 & 0.62 & 0.33 & p1d7 & 2.45 & 0.0001213 & 0.0001780 & 0.0002606 & $0.42 \pi$ \\
\hline 7090828 & $11 / 15 \mathrm{BB}$ & $34 \mathrm{~s}$ 6p1dr/ce 9 & $337 / 8$ & $\mathrm{~s}$ & 9 & 4437.4 & $673 / 4$ & $613 / 4$ & 0.446 & 0.669 & HLP-22 & 12 & 0 & 4 & 1.9 & 10.5 & 5.7 & 30.8 & 16.1 & 0.62 & 0.33 & p1d7 & 2.45 & 0.0001213 & 0.0001780 & 0.0002606 & 0.4277 \\
\hline 7090831 & $1 / 15 \mathrm{BB} 1$ & 34s_opldr/rc_a 9 & $337 / 8$ & $\mathrm{~s}$ & 9 & 4437.4 & $673 / 4$ & $613 / 4$ & 0.446 & 0.669 & HLP-22 & 12 & 0 & 4 & 1.9 & 10.5 & 5.7 & 30.8 & 16.1 & 0.62 & 0.33 & pld 7 & 2.45 & 0.0001213 & 0.0001780 & 0.0002606 & 0.4277 \\
\hline 7090835M & $11 / 15 \mathrm{BB}$ & $345 \_6 p 1 d 7 / \mathrm{c} \_9$ & $337 / 8$ & $\mathrm{~s}$ & 9 & 4437.4 & $673 / 4$ & $613 / 4$ & 0.446 & 0.669 & HLP-22 & 12 & 0 & 4 & 1.9 & 10.5 & 5.7 & 30.8 & 16.1 & 0.62 & 0.33 & p1d7 & 2.45 & 0.0001213 & 0.0001780 & 0.0002606 & $0.42 \pi 7$ \\
\hline 7090837M & $11 / 15 \mathrm{BB}$ & 345 6p1dTrc_9 9 & $337 / 8$ & $\mathrm{~s}$ & 9 & 4437.4 & $673 / 4$ & $613 / 4$ & 0.446 & 0.669 & HLP-22 & 12 & 0 & 4 & 1.9 & 10.5 & 5.7 & 30.8 & 16.1 & 0.62 & 0.33 & p1d7 & 2.45 & 0.0001213 & 0.0001780 & 0.0002606 & 0.4277 \\
\hline 7090840 & $11 / 15 \mathrm{Cl}$ & $345 \_6 p 1 d \gamma / c \_6$ & $337 / 8$ & $\mathrm{~s}$ & 9 & 4437.4 & $673 / 4$ & $613 / 4$ & 0.446 & 0.669 & HLP-22 & 12 & 4 & 0 & 1.9 & 10.5 & 5.7 & 30.8 & 16.1 & 0.62 & 0.33 & p1d7 & 2.45 & 0.0001213 & 0.0001780 & 0.0002606 & 0.4277 \\
\hline 7090842 & $11 / 15 \mathrm{Cl}$ & $34 \mathrm{~s}$ 6p1dr/ce 6 & $337 / 8$ & $\mathrm{~s}$ & 9 & 4437.4 & $673 / 4$ & $613 / 4$ & 0.446 & 0.669 & HLP-22 & 12 & 4 & 0 & 1.9 & 10.5 & 5.7 & 30.8 & 16.1 & 0.62 & 0.33 & p1d7 & 2.45 & 0.0001213 & 0.0001780 & 0.0002606 & $0.42 \pi$ \\
\hline 7000844 & $11 / 15 \mathrm{C} 1$ & $34 \mathrm{~S}$ 6p1dr/c 6 & $337 / 8$ & $\mathrm{~s}$ & 9 & 4437.4 & $673 / 4$ & $613 / 4$ & 0.446 & 0.669 & HLP-22 & 12 & 4 & 0 & 1.9 & 10.5 & 5.7 & 30.8 & 16.1 & 0.62 & 0.33 & pld7 & 2.45 & 0.0001213 & 0.0001780 & 0.0002606 & 0.4277 \\
\hline 7090847 & $11 / 15 \mathrm{Cl}_{1}$ & $34 \mathrm{~S} \_$Gp1dr/c_ 6 & $337 / 8$ & $\mathrm{~s}$ & 9 & 4437.4 & $673 / 4$ & $613 / 4$ & 0.446 & 0.669 & HLP-22 & 12 & 4 & 0 & 1.9 & 10.5 & 5.7 & 30.8 & 16.1 & 0.62 & 0.33 & p1d7 & 2.45 & 0.0001213 & 0.0001780 & 0.0002606 & $0.42 \pi 7$ \\
\hline 7090850 & $11 / 15 \mathrm{Cl}$ & $345 \_6 p 1 d r c \_6$ & $337 / 8$ & $\mathrm{~s}$ & 9 & 4437.4 & $673 / 4$ & $613 / 4$ & 0.446 & 0.669 & HLP-22 & 12 & 4 & 0 & 1.9 & 10.5 & 5.7 & 30.8 & 16.1 & 0.62 & 0.33 & p1d7 & 2.45 & 0.0001213 & 0.0001780 & 0.0002606 & 0.4277 \\
\hline $7090854 \mathrm{M}$ & $11 / 15 \mathrm{Cl}$ & $345 \_6 p 1 d \gamma / c \_6$ & $337 / 8$ & $\mathrm{~s}$ & 9 & 4437.4 & $673 / 4$ & $613 / 4$ & 0.446 & 0.669 & HLP-22 & 12 & 4 & 0 & 1.9 & 10.5 & 5.7 & 30.8 & 16.1 & 0.62 & 0.33 & p1d7 & 2.45 & 0.0001213 & 0.0001780 & 0.0002606 & $0.42 \pi$ \\
\hline $7090856 \mathrm{M}$ & $11 / 15 \mathrm{Cl}$ & 345 6p1drrc 6 & $337 / 8$ & $\mathrm{~s}$ & 9 & 4437.4 & $673 / 4$ & $613 / 4$ & 0.446 & 0.669 & HLP-22 & 12 & 4 & 0 & 1.9 & 10.5 & 5.7 & 30.8 & 16.1 & 0.62 & 0.33 & p1d7 & 2.45 & 0.0001213 & 0.0001780 & 0.0002606 & 0.4277 \\
\hline 7090859 & $1 / 19 \mathrm{~A}_{1}$ & 34s_4p1dr/ra & $337 / 8$ & $\mathrm{~s}$ & 9 & 4437.4 & $673 / 4$ & $613 / 4$ & 0.297 & 0.446 & HLP-22 & 12 & 8 & 4 & 1.9 & 10.5 & 5.7 & 30.8 & 16.1 & 0.62 & 0.33 & p1d7 & 2.45 & 0.0001213 & 0.0001780 & 0.0002606 & $0.42 \pi$ \\
\hline 7090863 & $1 / 1 / 19 A_{1}$ & 34s_.p1drTra & $337 / 8$ & $\mathrm{~s}$ & 9 & 4437.4 & $673 / 4$ & $613 / 4$ & 0.297 & 0.446 & HLP -22 & 12 & 8 & 4 & 1.9 & 10.5 & 5.7 & 30.8 & 16.1 & 0.62 & 0.33 & p1d7 & 2.45 & 0.0001213 & 0.0001780 & 0.0002606 & 0.4277 \\
\hline 7090865 & $1 / 19 \mathrm{~A}_{1}$ & 34S_4p1drra & $337 / 8$ & $\mathrm{~s}$ & 9 & 4437.4 & $673 / 4$ & $613 / 4$ & 0.297 & 0.446 & HLP-22 & 12 & 8 & 4 & 1.9 & 10.5 & 5.7 & 30.8 & 16.1 & 0.62 & 0.33 & pld7 & 2.45 & 0.0001213 & 0.0001780 & 0.0002606 & 0.4277 \\
\hline 7090869 & $1 / 19 A^{2}$ & 34S_4p1dTYd_1 & $337 / 8$ & $\mathrm{~s}$ & 9 & 4437.4 & $673 / 4$ & $613 / 4$ & 0.297 & 0.446 & HLP-22 & 12 & 8 & 4 & 1.9 & 10.5 & 5.7 & 30.8 & 16.1 & 0.62 & 0.33 & pld7 & 2.45 & 0.0001213 & 0.0001780 & 0.0002606 & $0.42 \pi$ \\
\hline 7090871 & $11 / 19 A^{2}$ & 34s_4p1drdd_1 & $337 / 8$ & $\mathrm{~s}$ & 9 & 4437.4 & $673 / 4$ & $613 / 4$ & 0.297 & 0.446 & HLP-22 & 12 & 8 & 4 & 1.9 & 10.5 & 5.7 & 30.8 & 16.1 & 0.62 & 0.33 & p1d7 & 2.45 & 0.0001213 & 0.0001780 & 0.0002606 & 0.4277 \\
\hline $7090875 \mathrm{M}$ & $11 / 19 \mathrm{~A} 2$ & 34s_4p1dr/d__1 & $337 / 8$ & $s$ & 9 & 4437.4 & $673 / 4$ & $613 / 4$ & 0.297 & 0.446 & & 12 & 8 & 4 & 1.9 & 10.5 & 5.1 & 30.8 & 16.1 & 0.62 & 0.33 & p1d7 & 2.45 & 0.0001213 & 0.0001780 & 0.0002606 & \\
\hline $7090877 \mathrm{M}$ & $11 / 19 A^{2}$ & 34S_4p1d/rd_1 1 & $337 / 8$ & $\mathrm{~s}$ & 9 & 4437.4 & $673 / 4$ & $613 / 4$ & 0.297 & 0.446 & HLP-22 & 12 & 8 & 4 & 1.9 & 10.5 & 5.7 & 30.8 & 16.1 & 0.62 & 0.33 & p1d7 & 2.45 & 0.0001213 & 0.0001780 & 0.0002606 & 0.4277 \\
\hline
\end{tabular}


Table B.8. Data from Fall 2007 Tests in Mid-Scale Vessel with Spherical Head B.7

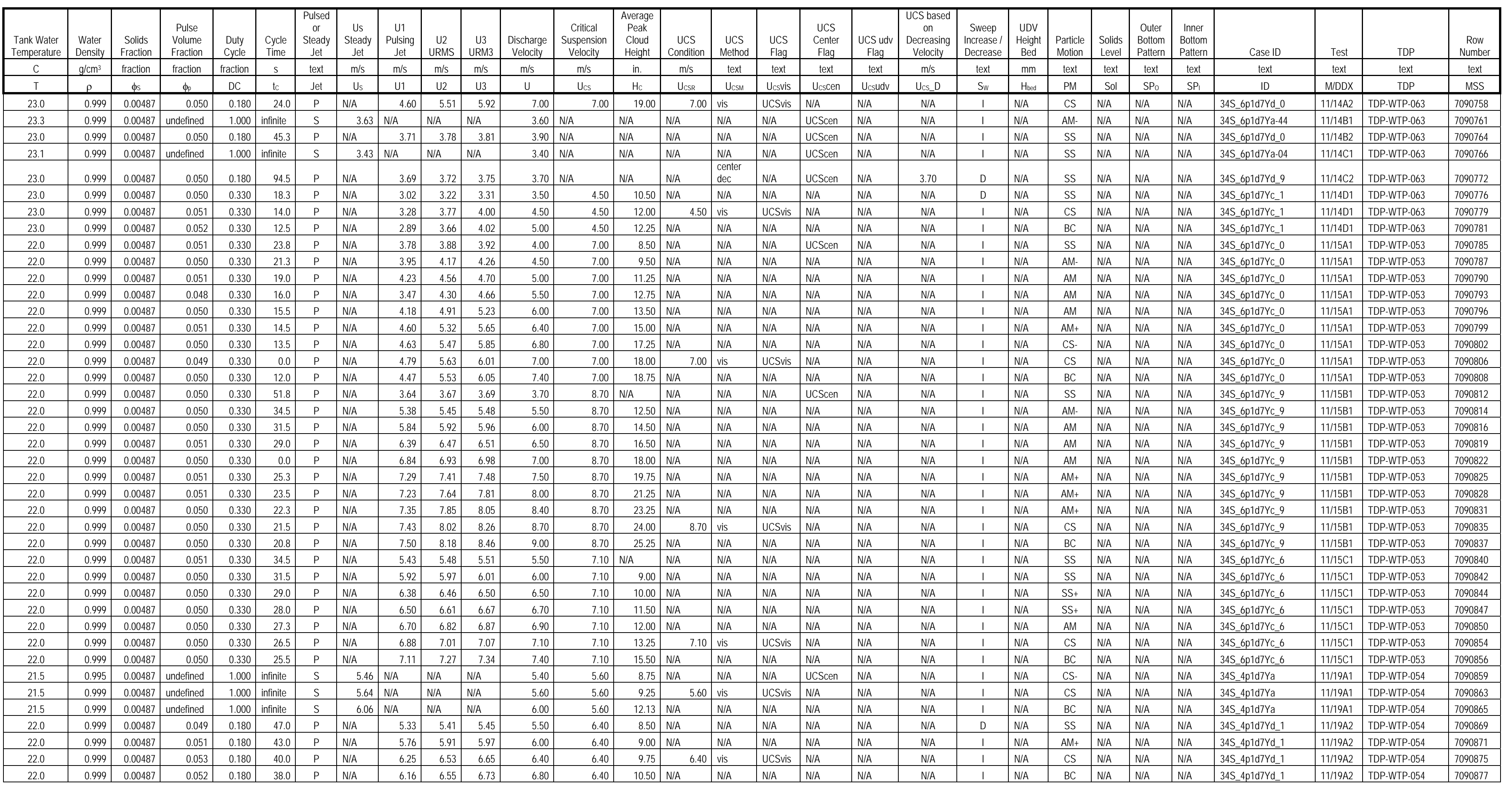


Table B.8. Data from Fall 2007 Tests in Mid-Scale Vessel with Spherical Head A.8

\begin{tabular}{|c|c|c|c|c|c|c|c|c|c|c|c|c|c|c|c|c|c|c|c|c|c|c|c|c|c|c|c|}
\hline $\begin{array}{c}\text { Row } \\
\text { Number }\end{array}$ & Test & Case ID & $\begin{array}{c}\text { Tank } \\
\text { Diameter }\end{array}$ & \begin{tabular}{|l} 
Head \\
Shape
\end{tabular} & \begin{tabular}{|c|}
$\begin{array}{c}\text { Dish } \\
\text { Height }\end{array}$ \\
\end{tabular} & \begin{tabular}{|c|}
$\begin{array}{c}\text { Dish } \\
\text { Volume } \\
\end{array}$ \\
\end{tabular} & $\begin{array}{c}\text { Tank FIII } \\
\text { Height }\end{array}$ & $\begin{array}{l}\text { Return } \\
\text { Line } \\
\text { Height }\end{array}$ & \begin{tabular}{|c|} 
Nozzer \\
Inner \\
Diamter
\end{tabular} & \begin{tabular}{|l} 
Nozzle \\
Stand-off \\
Distance \\
\end{tabular} & \begin{tabular}{|l} 
Pulse Tube \\
Configuration
\end{tabular} & \begin{tabular}{|l} 
Installed \\
Nozzles
\end{tabular} & \begin{tabular}{|l} 
Outer \\
Nozzles \\
operated
\end{tabular} & 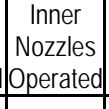 & \begin{tabular}{|c} 
Pulse entube \\
Outur \\
Diameter
\end{tabular} & \begin{tabular}{|c|} 
Outer \\
PJM \\
Radius
\end{tabular} & \begin{tabular}{|c|} 
Inner \\
PJM \\
Radius \\
\end{tabular} & $\begin{array}{l}\text { "Fo' Outer PN } \\
\text { impingerent } \\
\text { Angle }\end{array}$ & 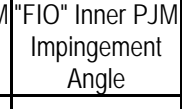 & \begin{tabular}{|l} 
Paiai outer \\
PJMto trank \\
Radius
\end{tabular} & \begin{tabular}{|c|c|} 
Ratio Inner \\
PaMto Tark \\
Radius \\
\end{tabular} & simulant & \begin{tabular}{|l|} 
Solids \\
Densily \\
\end{tabular} & \begin{tabular}{|c} 
Partide \\
Diameter 15 \\
\end{tabular} & \begin{tabular}{|l|} 
Particle \\
Diameter 550 \\
\end{tabular} & \begin{tabular}{|c|} 
Particle \\
Diameter d95 \\
\end{tabular} & \begin{tabular}{|c} 
Void \\
Fraction \\
\end{tabular} \\
\hline text & text & text & in. & text & in. & \begin{tabular}{|l|} 
in. $^{3}$ \\
\end{tabular} & in. & \begin{tabular}{|l|} 
in. \\
\end{tabular} & \begin{tabular}{|l|} 
in. \\
\end{tabular} & in. & text & \begin{tabular}{|l|l} 
number \\
\end{tabular} & number & number & in. & \begin{tabular}{|l|} 
in. \\
\end{tabular} & in. & deg & \begin{tabular}{|l|} 
deg \\
\end{tabular} & nondim & nondim & text & $g / \mathrm{cm}^{3}$ & $\mathrm{~m}$ & \begin{tabular}{|l|}
$\mathrm{m}$ \\
\end{tabular} & \begin{tabular}{|l|}
$\mathrm{m}$ \\
\end{tabular} & fraction \\
\hline MSS & MDDX & $\mathrm{ID}$ & $\mathrm{D}$ & $\mathrm{HS}$ & $H_{\text {sst }}$ & $V_{\text {dath }}$ & $\mathrm{H}$ & Rin & $d$ & sod & PT & $\mathrm{N}$ & $\mathrm{N}_{\mathrm{N}}$ & $\mathrm{N}$ & $\mathrm{PT}_{\alpha \mathrm{d}}$ & $\mathrm{Ro}_{0}$ & $\mathrm{R}$ & $\theta_{0}$ & $\theta_{1}$ & RdR & $R / R$ & sxdx & $\rho_{\mathrm{s}}$ & $d_{5}$ & $\mathrm{~d}_{\mathrm{so}}$ & $d_{65}$ & vf \\
\hline 7090881 & $11 / 20 A 1$ & 34S_4p1drra-44 & $337 / 8$ & $\mathrm{~s}$ & 9 & 4437.4 & $673 / 4$ & $613 / 4$ & 0.297 & 0.446 & HLP-22 & 12 & 4 & 4 & 1.9 & 10.5 & 5.7 & 30.8 & 16.1 & 0.62 & 0.33 & p1d7 & 2.45 & 0.0001213 & 0.0001780 & 0.0002606 & 0.42 \\
\hline 7090883 & 11/20A1 & 34S_4p1drra-44 & $337 / 8$ & $\mathrm{~s}$ & 9 & 4437.4 & $673 / 4$ & $613 / 4$ & 0.297 & 0.446 & HLP-22 & 12 & 4 & 4 & 1.9 & 10.5 & 5.7 & 30.8 & 16.1 & 0.62 & 0.33 & p1d7 & 2.45 & 0.0001213 & 0.0001780 & 0.0002606 & $0.427 \pi$ \\
\hline 7000836 & 11/20A1 & 34S_4p1d7/ra-44 & $337 / 8$ & $s$ & 9 & 4437.4 & $673 / 4$ & $613 / 4$ & 0.297 & 0.446 & HLP-22 & 12 & 4 & 4 & 1.9 & 10.5 & 5.7 & 30.8 & 16.1 & 0.62 & 0.33 & p1d7 & 2.45 & 0.0001213 & 0.0001780 & 0.0002606 & 0.4277 \\
\hline 7090889 & $11 / 20 \mathrm{~A} 1$ & 34S_4p1d/ra-44 & $337 / 8$ & $\mathrm{~s}$ & 9 & 4437.4 & $673 / 4$ & $613 / 4$ & 0.297 & 0.446 & HLP-22 & 12 & 4 & 4 & 1.9 & 10.5 & 5.7 & 30.8 & 16.1 & 0.62 & 0.33 & pld7 & 2.45 & 0.0001213 & 0.0001780 & 0.0002600 & 0.4277 \\
\hline 7090892 & 11200A1 & 34S_4p1d/ra-44 & $337 / 8$ & $\mathrm{~s}$ & 9 & 4437.4 & $673 / 4$ & 61344 & 0.297 & 0.446 & HLP-22 & 12 & 4 & 4 & 1.9 & 10.5 & 5.7 & 30.8 & 16.1 & 0.62 & 0.33 & p1d7 & 2.45 & 0.0001213 & 0.0001780 & 0.0002600 & 0.4277 \\
\hline 7090895 & $1120{ }^{2} 1$ & 34s_4p1dr/ra-44 & $337 / 8$ & $\mathrm{~s}$ & 9 & 4437.4 & $673 / 4$ & $613 / 4$ & 0.297 & 0.446 & HLP-22 & 12 & 4 & 4 & 1.9 & 10.5 & 5.7 & 30.8 & 16.1 & 0.62 & 0.33 & p1d7 & 2.45 & 0.0001213 & 0.0001780 & 0.0002600 & 0.4277 \\
\hline 7090899 & 11/20A1 & 345_4p1drra-44 & $337 / 8$ & $\mathrm{~s}$ & 9 & 4437.4 & $673 / 4$ & $613 / 4$ & 0.297 & 0.446 & HLP-22 & 12 & 4 & 4 & 1.9 & 10.5 & 5.7 & 30.8 & 16.1 & 0.62 & 0.33 & p1d7 & 2.45 & 0.0001213 & 0.0001780 & 0.0002606 & 0.4277 \\
\hline 7090901 & $11 / 20 \mathrm{~A} 1$ & 34S_4p1d/ra-44 & $337 / 8$ & $s$ & 9 & 4437.4 & $673 / 4$ & $613 / 4$ & 0.297 & 0.446 & HLP-22 & 12 & 4 & 4 & 1.9 & 10.5 & 5.7 & 30.8 & 16.1 & 0.62 & 0.33 & p1d7 & 2.45 & 0.0001213 & 0.0001780 & 0.0002606 & \\
\hline 7000905 & $1120 \mathrm{~A}^{2}$ & 34S_4p1dTrd_0 & $337 / 8$ & $\mathrm{~s}$ & 9 & 4437.4 & $673 / 4$ & $613 / 4$ & 0.297 & 0.446 & HLP-22 & 12 & 4 & 4 & 1.9 & 10.5 & 5.7 & 30.8 & 16.1 & 0.62 & 0.33 & p1d7 & 2.45 & 0.0001213 & 0.0001780 & 0.0002600 & 0.4277 \\
\hline 7000908 & $1120 \mathrm{~A}^{2}$ & 34S_4p1dTYd_O 0 & $337 / 8$ & $\mathrm{~s}$ & 9 & 4437.4 & $673 / 4$ & $613 / 4$ & 0.297 & 0.446 & HLP-22 & 12 & 4 & 4 & 1.9 & 10.5 & 5.7 & 30.8 & 16.1 & 0.62 & 0.33 & p1d 7 & 2.45 & 0.0001213 & 0.0001780 & 0.0002606 & $0.427 \pi$ \\
\hline 7090910 & $1120 \mathrm{~A}^{2}$ & 34S_4p1drrd_o & $337 / 8$ & $\mathrm{~s}$ & 9 & 4437.4 & $673 / 4$ & $613 / 4$ & 0.297 & 0.446 & HLP-22 & 12 & 4 & 4 & 1.9 & 10.5 & 5.7 & 30.8 & 16.1 & 0.62 & 0.33 & p1d7 & 2.45 & 0.0001213 & 0.0001780 & 0.0002600 & 0.4277 \\
\hline 7090913 & $11 / 20 \mathrm{~A} 2$ & 34S_4p1dTrd_O 0 & $337 / 8$ & $\mathrm{~s}$ & 9 & 4437.4 & $673 / 4$ & $613 / 4$ & 0.297 & 0.446 & HLP-22 & 12 & 4 & 4 & 1.9 & 10.5 & 5.7 & 30.8 & 16.1 & 0.62 & 0.33 & p1d7 & 2.45 & 0.0001213 & 0.0001780 & 0.0002606 & 0.4277 \\
\hline 7000916 & 11/20A2 & $34 \mathrm{~S}$ 4p1dTrd 0 & $337 / 8$ & $\mathrm{~s}$ & 9 & 4437.4 & $673 / 4$ & $613 / 4$ & 0.297 & 0.446 & HLP-22 & 12 & 4 & 4 & 1.9 & 10.5 & 5.7 & 30.8 & 16.1 & 0.62 & & $\mathrm{p} 1 \mathrm{~d} 7$ & 2.45 & 0.0001213 & 0.0001780 & 0.0002606 & \\
\hline 7090919 & 11/20A2 & 34S_4p1dTYd_ 0 & $337 / 8$ & $\mathrm{~s}$ & 9 & 4437.4 & $673 / 4$ & 6134 & 0.297 & 0.446 & HLP-22 & 12 & 4 & 4 & 1.9 & 10.5 & 5.7 & 30.8 & 16.1 & 0.62 & 0.33 & p1d7 & 2.45 & 0.0001213 & 0.0001780 & 0.0002600 & 0.4277 \\
\hline 7090922 & $11 / 20 \mathrm{~A}^{2}$ & 34S_4p1dTrd_O 0 & $337 / 8$ & $\mathrm{~s}$ & 9 & 4437.4 & $673 / 4$ & $613 / 4$ & 0.297 & 0.446 & HLP-22 & 12 & 4 & 4 & 1.9 & 10.5 & 5.7 & 30.8 & 16.1 & 0.62 & 0.33 & p1d7 & 2.45 & 0.0001213 & 0.0001780 & 0.0002806 & $0.427 \pi$ \\
\hline 7090925 & $11 / 20 \mathrm{~A}^{2}$ & 34S_4p1drrd_o & $337 / 8$ & $s$ & 9 & 4437.4 & $673 / 4$ & $613 / 4$ & 0.297 & 0.446 & HLP-22 & 12 & 4 & 4 & 1.9 & 10.5 & 5.7 & 30.8 & 16.1 & 0.62 & 0.33 & p1d7 & 2.45 & 0.0001213 & 0.0001780 & 0.0002600 & 0.4277 \\
\hline 7090928 & $11 / 20 A^{2}$ & 34S_4p1dTrd_o & $337 / 8$ & $\mathrm{~s}$ & 9 & 4437.4 & $673 / 4$ & $613 / 4$ & 0.297 & 0.446 & HLP-22 & 12 & 4 & 4 & 1.9 & 10.5 & 5.7 & 30.8 & 16.1 & 0.62 & 0.33 & p1d7 & 2.45 & 0.0001213 & 0.0001780 & 0.0002600 & 0.4277 \\
\hline $7090932 \mathrm{M}$ & $11 / 20 A^{2}$ & 34S_4p1dTYd_O & $337 / 8$ & $\mathrm{~s}$ & 9 & 4437.4 & $673 / 4$ & $613 / 4$ & 0.297 & 0.446 & HLP-22 & 12 & 4 & 4 & 1.9 & 10.5 & 5.7 & 30.8 & 16.1 & 0.62 & 0.33 & p1d7 & 2.45 & 0.0001213 & 0.0001780 & 0.0002606 & 0.427 \\
\hline $7090934 \mathrm{M}$ & $11 / 20 A^{2}$ & $34 \mathrm{~S} \_$_pldr/rd 0 & $337 / 8$ & $\mathrm{~s}$ & 9 & 4437.4 & $673 / 4$ & 6134 & 0.297 & 0.446 & HLP-22 & 12 & 4 & 4 & 1.9 & 10.5 & 5.7 & 30.8 & 16.1 & 0.62 & 0.33 & p1d7 & 2.45 & 0.0001213 & 0.0001780 & 0.0002600 & 0.4277 \\
\hline 7090938 & $11 / 20 B 1$ & 34s_4p1dr/ra-04 & $337 / 8$ & $\mathrm{~s}$ & 9 & 4437.4 & $673 / 4$ & 6134 & 0.297 & 0.446 & HLP-22 & 12 & 0 & 4 & 1.9 & 10.5 & 5.7 & 30.8 & 16.1 & 0.62 & 0.3 & p1d7 & 2.45 & 0.0001213 & 0.0001780 & 0.0002600 & 0.427 \\
\hline 7090941 & 112001 & 34S_4p1drra-04 & $337 / 8$ & $\mathrm{~s}$ & 9 & 4437.4 & $673 / 4$ & $613 / 4$ & 0.297 & 0.446 & HLP-22 & 12 & 0 & 4 & 1.9 & 10.5 & 5.7 & 30.8 & 16.1 & 0.62 & 0.33 & p1d7 & 2.45 & 0.0001213 & 0.0001780 & 0.0002600 & 0.427 \\
\hline 7090943 & $11 / 2081$ & 34S_4p1drra-04 & $337 / 8$ & $\mathrm{~s}$ & 9 & 4437.4 & $673 / 4$ & $613 / 4$ & 0.297 & 0.446 & HLP-22 & 12 & 0 & 4 & 1.9 & 10.5 & 5.7 & 30.8 & 16.1 & 0.62 & 0.33 & p1d7 & 2.45 & 0.0001213 & 0.0001780 & 0.0002600 & 0.427 \\
\hline 7090946 & $11 / 20 \mathrm{~B} 1$ & 34S_4p1d7/Ya-04 & $337 / 8$ & $\mathrm{~s}$ & 9 & 4437.4 & $673 / 4$ & $613 / 4$ & 0.297 & 0.446 & HLP-22 & 12 & 0 & 4 & 1.9 & 10.5 & 5.7 & 30.8 & 16.1 & 0.62 & 0.3 & p1d7 & 2.45 & 0.0001213 & 0.0001780 & 0.0002606 & 0.427 \\
\hline 7000949 & $11 / 20 B 1$ & 34s_4p1dr/ra-04 & $337 / 8$ & $\mathrm{~s}$ & 9 & 4437.4 & $673 / 4$ & 6134 & 0.297 & 0.446 & HLP-22 & 12 & 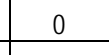 & 4 & 1.9 & 10.5 & 5.7 & 30.8 & 16.1 & 0.62 & & p1d7 & 2.45 & 0.0001213 & 0.0001780 & 0.0002600 & 0.4277 \\
\hline 7000952 & $11 / 20 B 1$ & 34S_4p1dTra-04 & $337 / 8$ & $\mathrm{~s}$ & 9 & 4437.4 & $673 / 4$ & $613 / 4$ & 0.297 & 0.446 & HLP-22 & 12 & c & 4 & 1.9 & 10.5 & 5.7 & 30.8 & 16.1 & 0.62 & 0.33 & p1d7 & 2.45 & 0.0001213 & 0.0001780 & 0.0002806 & $0.427 \pi$ \\
\hline 7090956 & 112001 & 34s_4p1drra-04 & $337 / 8$ & $\mathrm{~s}$ & 9 & 4437.4 & $673 / 4$ & 6134 & 0.297 & 0.446 & HLP-22 & 12 & 0 & 4 & 1.9 & 10.5 & 5.7 & 30.8 & 16.1 & 0.62 & 0.33 & p1d7 & 2.45 & 0.0001213 & 0.0001780 & 0.0002600 & 0.4277 \\
\hline 7090958 & 11/20B1 & 34S_4p1dr/ra-04 & $337 / 8$ & $\mathrm{~s}$ & 9 & 4437.4 & $673 / 4$ & $613 / 4$ & 0.297 & 0.446 & HLP-22 & 12 & 0 & 4 & 1.9 & 10.5 & 5.7 & 30.8 & 16.1 & 0.62 & 0.33 & p1d7 & 2.45 & 0.0001213 & 0.0001780 & 0.0002606 & 0.427 \\
\hline 7090962 & $11 / 20 \mathrm{~B} 2$ & 34S_4p1drTd_9 9 & $337 / 8$ & $s$ & 9 & 4437.4 & $673 / 4$ & 6134 & 0.297 & 0.446 & HLP-22 & 12 & 0 & 4 & 1.9 & 10.5 & 5.7 & 30.8 & 16.1 & 0.62 & 0.33 & p1d7 & 2.45 & 0.0001213 & 0.0001780 & 0.0002806 & 0.427 \\
\hline 7000965 & $11 / 20 B 2$ & 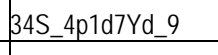 & $337 / 8$ & $\mathrm{~s}$ & 9 & 4437.4 & $673 / 4$ & 6134 & 0.297 & 0.446 & HLP-22 & 12 & 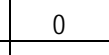 & 4 & 1.9 & 10.5 & 5.7 & 30.8 & 16. & 0.6. & 0.3 & p1d7 & 2.45 & 0.0001213 & 0.0001780 & 0.0002600 & 0.4277 \\
\hline 7000967 & 11/20B2 & 34S_4p1dTrd_ 9 & $337 / 8$ & $\mathrm{~s}$ & 9 & 4437.4 & $673 / 4$ & 6134 & 0.297 & 0.446 & HLP -22 & 12 & 0 & 4 & 1.9 & 10.5 & 5.7 & 30.8 & 16.1 & 0.62 & 0.3 & p1d7 & 2.45 & 0.0001213 & 0.0001780 & 0.0002600 & 0.427 \\
\hline 7090970 & 11/20B2 & 34S_ 4 pldr/Yd 9 & $337 / 8$ & $\mathrm{~s}$ & 9 & 4437.4 & $673 / 4$ & 6134 & 0.297 & 0.446 & HLP-22 & 12 & 0 & 4 & 1.9 & 10.5 & 5.7 & 30.8 & 16.1 & 0.62 & & p1d7 & 2.45 & 0.0001213 & 0.0001780 & 0.0002600 & 0.427 \\
\hline 7090973 & $11 / 20 \mathrm{~B} 2$ & $34 \mathrm{~S}$ 4p1dTrd_9 & $337 / 8$ & $\mathrm{~s}$ & 9 & 4437.4 & $673 / 4$ & $613 / 4$ & 0.297 & 0.446 & HLP-22 & 12 & 0 & 4 & 1.9 & 10.5 & 5.7 & 30.8 & 16.1 & 0.62 & 0.33 & p1d7 & 2.45 & 0.0001213 & 0.0001780 & 0.0002606 & 0.4277 \\
\hline $7090977 \mathrm{M}$ & $11 / 20 \mathrm{BB} 2$ & 34S_4p1dTYd_9 & $337 / 8$ & $\mathrm{~s}$ & 9 & 4437.4 & $673 / 4$ & 6134 & 0.297 & 0.446 & HLP-22 & 12 & 0 & 4 & 1.9 & 10.5 & 5.7 & 30.8 & 16.1 & 0.62 & & p1d7 & 2.45 & 0.0001213 & 0.0001780 & 0.0002606 & \\
\hline $7090979 \mathrm{M}$ & $11 / 20 \mathrm{~B} 2$ & $34 \mathrm{~S}, 4 \mathrm{p} 1 \mathrm{~d} / \mathrm{rd} \_9$ & $337 / 8$ & $s$ & 9 & 4437.4 & $673 / 4$ & $613 / 4$ & 0.297 & 0.446 & HLP-22 & 12 & 0 & 4 & 1.9 & 10.5 & 5.7 & 30.8 & 16.1 & 0.62 & 0.33 & p1d7 & 2.45 & 0.0001213 & 0.0001780 & 0.0002606 & 0.427 \\
\hline 7090982 & $11 / 26 \mathrm{~A} 1$ & 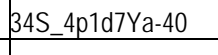 & $337 / 8$ & $\mathrm{~s}$ & 9 & 4437.4 & $673 / 4$ & 6134 & 0.297 & 0.446 & & 12 & 4 & 0 & 1.9 & 10.5 & 5.7 & 30.8 & 16.1 & & & p10 & 2.45 & 0.0001213 & 0.0001780 & 0.0002600 & \\
\hline 7009985 & $11 / 26 \mathrm{A1}$ & 34S_4p1drra-40 & $337 / 8$ & $\mathrm{~s}$ & 9 & 4437.4 & $673 / 4$ & 6134 & 0.297 & 0.446 & HLP-22 & 12 & 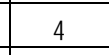 & 0 & 1.5 & 10.5 & 5.7 & 30.8 & 16.1 & 0.62 & 0.33 & p1d7 & 2.45 & 0.0001213 & 0.0001780 & 0.0002600 & 0.4277 \\
\hline 7090989 & $11 / 26 \mathrm{A1}$ & 34S_4p1dr/ra-40 & $337 / 8$ & $s$ & & 4437.4 & $673 / 4$ & $613 / 4$ & 0.297 & 0.446 & HLP-22 & 12 & 4 & 0 & 1.9 & 10.5 & 5.7 & 30.8 & 16.1 & 0.62 & 0.33 & p1d7 & 2.45 & 0.0001213 & 0.0001780 & 0.0002606 & 0.4277 \\
\hline 7090991 & 11/26A1 & 34S_4p1dTra-40 & $337 / 8$ & $\mathrm{~s}$ & 9 & 4437.4 & $673 / 4$ & 6134 & 0.297 & 0.446 & & 12 & 4 & $c^{-1}$ & 1.9 & 10.5 & 5.7 & 30.8 & 10.1 & 0.62 & $-x$ & p1d7 & 2.45 & 0.0001213 & 0.0001780 & 0.0002600 & \\
\hline 7090994 & $11 / 26 \mathrm{A1}$ & 34s_4p1drra 40 & $337 / 8$ & $s$ & & 4437.4 & $673 / 4$ & $613 / 4$ & 0.297 & 0.446 & HLP-22 & 12 & 4 & 0 & 1.9 & 10.5 & 5.7 & 30.8 & 16.1 & 0.62 & 0.33 & $\mathrm{p} 1 \mathrm{~d} 7$ & 2.45 & 0.0001213 & 0.0001780 & 0.0002606 & 0.427 \\
\hline 7000996 & $11 / 26 A_{1}$ & 34 S & & $s$ & & & & & 0.297 & & & & & 0 & & 10.5 & 5.7 & & & & & & & & & & \\
\hline 7090998 & $11 / 26 \mathrm{A1}$ & 34s_4p1drra-40 & $337 / 8$ & $s$ & & 4437.4 & $673 / 4$ & $613 / 4$ & 0.297 & 0.446 & HLP-22 & 12 & 4 & 0 & 1.9 & 10.5 & 5.7 & 30.8 & 16.1 & 0.62 & 0.33 & p1d7 & 2.45 & 0.0001213 & 0.0001780 & 0.0002606 & \\
\hline
\end{tabular}


Table B.8. Data from Fall 2007 Tests in Mid-Scale Vessel with Spherical Head B.8

\begin{tabular}{|c|c|c|c|c|c|c|c|c|c|c|c|c|c|c|c|c|c|c|c|c|c|c|c|c|c|c|c|c|c|}
\hline $\begin{array}{l}\text { Tank Water } \\
\text { Temperature }\end{array}$ & $\begin{array}{l}\text { Water } \\
\text { Density }\end{array}$ & $\begin{array}{l}\text { Solids } \\
\text { Fraction }\end{array}$ & $\begin{array}{l}\text { Pulse } \\
\text { Volume } \\
\text { Fraction }\end{array}$ & $\begin{array}{l}\text { Duty } \\
\text { cydle }\end{array}$ & $\begin{array}{l}\text { Cycle } \\
\text { Time }\end{array}$ & $\begin{array}{c}\text { Pulsed } \\
\text { or } \\
\text { Steady } \\
\text { Jet } \\
\end{array}$ & $\begin{array}{c}\text { Us } \\
\text { Steacy } \\
\text { Jet }\end{array}$ & \begin{tabular}{|c|} 
U1 \\
Pulsing \\
Jet
\end{tabular} & \begin{tabular}{|c|} 
UR \\
URNS \\
\end{tabular} & \begin{tabular}{|c} 
U3 \\
URMB \\
\end{tabular} & \begin{tabular}{|l} 
Discharge \\
Velocity
\end{tabular} & $\begin{array}{c}\text { Citical } \\
\text { Suspension } \\
\text { Velocity }\end{array}$ & $\begin{array}{c}\text { Average } \\
\text { Peak } \\
\text { Cloud } \\
\text { Height } \\
\end{array}$ & $\begin{array}{c}\text { UCS } \\
\text { Condition }\end{array}$ & $\begin{array}{c}\text { UCS } \\
\text { Method }\end{array}$ & $\begin{array}{l}\text { UCS } \\
\text { Hag }\end{array}$ & $\begin{array}{c}\text { Ues } \\
\text { Center } \\
\text { Hag }\end{array}$ & $\begin{array}{c}\text { ues udv } \\
\text { Hag }\end{array}$ & \begin{tabular}{|c|c|} 
UCS based \\
on \\
Decreasing \\
Velocity \\
\end{tabular} & \begin{tabular}{|c|} 
Snceep \\
Inncrease/ \\
Decrease
\end{tabular} & \begin{tabular}{|c} 
UDV \\
Height \\
Bed \\
\end{tabular} & \begin{tabular}{|l} 
Particle \\
Motion
\end{tabular} & \begin{tabular}{|l|} 
Solids \\
Level \\
\end{tabular} & $\begin{array}{l}\text { Outer } \\
\text { Bototom } \\
\text { Patterm }\end{array}$ & \begin{tabular}{|l} 
Inner \\
Bototom \\
Pattem \\
\end{tabular} & Case ID & Test & IDP & $\begin{array}{c}\text { Row } \\
\text { Numbe }\end{array}$ \\
\hline$c$ & $\mathrm{~g} / \mathrm{cm}^{3}$ & ffraction & fraction & fraction & $\mathrm{s}$ & text & m/s & \begin{tabular}{|l|}
$\mathrm{m} / \mathrm{s}$ \\
\end{tabular} & \begin{tabular}{|l|l|}
$\mathrm{m} / \mathrm{s}$ \\
\end{tabular} & $\mathrm{m} / \mathrm{s}$ & $\mathrm{m} / \mathrm{s}$ & $\mathrm{m} / \mathrm{s}$ & in. & $\mathrm{m} / \mathrm{s}$ & text & text & text & text & $\mathrm{m} / \mathrm{s}$ & text & $\mathrm{mm}$ & text & text & text & text & text & text & text & text \\
\hline $\mathrm{T}$ & $\rho$ & $\phi_{\mathrm{s}}$ & $\phi_{p}$ & $D C$ & $t_{c}$ & Jet & $u_{s}$ & $\mathrm{U} 1$ & $\mathrm{U2}$ & U3 & $u$ & Uss & $H_{k}$ & $U_{\text {CSR }}$ & Uasn & Usvis & Uscen & Usulde & $U_{\text {CS } D}$ & $\mathrm{~s}_{\mathrm{v}}$ & $H_{\text {hod }}$ & $\mathrm{PM}$ & Sol & $\mathrm{SP}_{\mathrm{o}}$ & $\mathrm{SP}_{1}$ & $\mathrm{ID}$ & MDDX & $\mathrm{TDP}$ & MSS \\
\hline 21.4 & 0.999 & 0.00487 & undefined & 1.000 & infinite & $\mathrm{s}$ & 5.55 & NA & NA & NA & 5.50 & 8.50 & NA & NA & NA & NA & UCScen & NA & NA & 1 & NA & SS+ & NA & NA & NA & 345_4p1dTra-44 & $11 / 20 \mathrm{~A} 1$ & TDP-WIP-055 & 7090881 \\
\hline 21.4 & 0.999 & 0.00487 & undefined & 1.000 & infinite & $\mathrm{s}$ & 6.04 & NA & NA & NA & 6.00 & 8.50 & NA & NA & NA & NA & NA & NA & NA & 1 & NA & $A M$ & NA & NA & NA & 34S_4p1dTra-44 & 11/20A1 & TDP-WIP-055 & 7090883 \\
\hline 21.5 & 0.999 & 0.00487 & undefined & 1.000 & infinite & $\mathrm{s}$ & 6.53 & NA & NA & NA & 6.50 & 8.50 & 8.75 & NA & NA & NA & NA & NA & NA & 1 & NA & $A M$ & NA & NA & NA & 34s_4p1d7ra-44 & 11/20A1 & TDP-WIP-055 & 7090836 \\
\hline 21.5 & 0.999 & 0.00487 & undefined & 1.000 & infinite & $\mathrm{s}$ & 7.06 & NA & NA & NA & 7.00 & 8.50 & 10.00 & NA & NA & NA & NA & NA & NA & 1 & NA & $A M$ & NA & NA & NA & 34S_4p1dTra-44 & 11/20A1 & TDP-WIP-055 & 7090889 \\
\hline 21.5 & 0.999 & 0.00487 & undefined & 1.000 & infinite & $\mathrm{s}$ & 7.55 & NA & NA & NA & 7.50 & 8.50 & 13.25 & NA & NA & NA & NA & NA & NA & 1 & NA & $A M+$ & NA & NA & NA & 34s_4p1d7ra-44 & 11/20A1 & TDP-WIP-055 & 7090092 \\
\hline 21.5 & 0.999 & 0.00487 & undefined & 1.000 & infinite & $\mathrm{s}$ & 8.05 & NA & NA & NA & 8.00 & 8.50 & 20.50 & NA & NA & NA & NA & NA & NA & 1 & NA & AMt & NA & NA & NA & 345_4p1dTra-44 & 11/20A1 & TDP-WIP-055 & 7090095 \\
\hline 21.5 & 0.999 & 0.00487 & undefined & 1.000 & infinite & $\mathrm{s}$ & 8.60 & NA & NA & NA & 8.50 & 8.50 & 30.00 & \begin{tabular}{|l}
8.50 \\
\end{tabular} & vis & Ucsis & NA & NA & NA & 1 & NA & cs & NA & NA & NA & 345_4p1dTra-44 & 11/20A1 & TDP-WIP-055 & 7090099 \\
\hline 21.6 & 0.999 & \begin{tabular}{l|l|}
0.00487 \\
\end{tabular} & undefined & 1.000 & infinite & $\mathrm{s}$ & 9.03 & NA & NA & NA & 9.00 & 8.50 & 36.75 & NA & NA & NA & NA & NA & NA & 1 & NA & $B C-$ & NA & NA & NA & 34S_4p1dTra-44 & 11/20A1 & TDP-WIP-055 & 7090901 \\
\hline 22.0 & 0.999 & 0.00487 & 0.049 & 0.180 & 71.0 & $\mathrm{P}$ & NA & 5.58 & 5.64 & 5.68 & 5.50 & 11.00 & NA & NA & $\begin{array}{l}\text { center } \\
\text { dec }\end{array}$ & NA & Ucsoen & NA & 5.50 & $\mathrm{D}$ & NA & ss & NA & NA & NA & 34S_4p1d/rdd 0 & $11 / 20 \mathrm{~A}^{2}$ & TDP-WIP-055 & 7090905 \\
\hline 22.0 & 0.999 & $\begin{array}{ll}0.00487 \\
\end{array}$ & 0.051 & 0.180 & 64.5 & $P$ & NA & 6.10 & 6.18 & 6.23 & 6.00 & 11.00 & NA & NA & NA & NA & NA & NA & NA & 1 & NA & AM- & NA & NA & NA & 34S_4p1dTYd_OO & 11/20A2 & TDP-WIP-055 & 7090908 \\
\hline 22.0 & 0.999 & 0.00487 & 0.051 & 0.180 & 55.0 & $\mathrm{P}$ & NA & 7.10 & 7.21 & 7.27 & 7.00 & 11.00 & 9.25 & NA & NA & NA & NA & NA & NA & 1 & NA & $A M$ & NA & NA & NA & 34S_4p1dTrd_o & 11/20A2 & TDP-WIP-055 & 7090910 \\
\hline 22.0 & 0.999 & 0.00487 & 0.051 & 0.180 & 47.0 & $\mathrm{P}$ & NA & 8.11 & 8.26 & 8.35 & 8.00 & 11.00 & 11.25 & NA & NA & NA & NA & NA & NA & 1 & NA & $A M$ & NA & NA & NA & 34S_4p1dTYd_O & 11/20A2 & TDP-WIP-055 & 7090913 \\
\hline 22.0 & 0.999 & $\begin{array}{ll}0.00487 \\
\end{array}$ & 0.050 & 0.180 & 44.5 & $\mathrm{P}$ & NA & 8.18 & 8.50 & 8.65 & 8.50 & 11.00 & 12.00 & NA & NA & NA & NA & NA & NA & $\mathrm{I}$ & NA & AM & NA & NA & NA & 34S_4p1dTrd_O 0 & $11 / 20 \mathrm{~A}^{2}$ & TDP-WIP-055 & 7090916 \\
\hline 22.0 & 0.999 & $\begin{array}{ll}0.00487 \\
\end{array}$ & 0.051 & 0.180 & 41.5 & $\mathrm{P}$ & NA & 8.46 & 8.92 & 9.14 & 9.00 & 11.00 & 14.25 & NA & NA & NA & NA & NA & NA & 1 & NA & AM & NA & NA & NA & 34S__pldr/rd_o & $11 / 20 A 2$ & TDP-WIP-055 & 7090919 \\
\hline 22.0 & 0.999 & $\begin{array}{ll}0.00487 \\
\end{array}$ & 0.051 & 0.180 & 40.0 & $\mathrm{P}$ & NA & \begin{tabular}{l|l}
9.02 \\
\end{tabular} & 9.44 & 9.64 & 9.50 & 11.00 & 15.75 & NA & NA & NA & NA & NA & NA & 1 & NA & $A M+$ & NA & NA & NA & 34S__pldTrd_OO & $11 / 20 A 2$ & TDP-WIP-055 & 7090922 \\
\hline 22.0 & 0.999 & 0.00487 & 0.051 & 0.180 & 37.5 & $\mathrm{P}$ & NA & 9.33 & 9.85 & 10.09 & 10.00 & 11.00 & 16.63 & NA & NA & NA & NA & NA & NA & 1 & NA & $A M+$ & NA & NA & NA & 34S_4p1d/YYd_O & 11/20A2 & TDP-WIP-055 & 7090925 \\
\hline 22.0 & 0.999 & 0.00487 & 0.051 & 0.180 & 35.5 & $\mathrm{P}$ & NA & 9.57 & 10.20 & 10.50 & 10.50 & 11.00 & 19.00 & NA & NA & NA & NA & NA & NA & 1 & NA & $A M+$ & NA & NA & NA & 34S_4p1d/Yd_ 0 & 11/20A2 & TDP-WIP-055 & 7090928 \\
\hline 22.0 & 0.999 & 0.00487 & 0.050 & 0.180 & 33.5 & $P$ & NA & 9.80 & 10.56 & 10.92 & 11.00 & 11.00 & 19.50 & 11.00 & vis & Ucsis & NA & NA & NA & 1 & NA & cs & NA & NA & NA & 34S_4p1dTrd_O & $11 / 20 A 2$ & TDP-WIP-055 & 7090932 \\
\hline 22.0 & 0.999 & 0.00487 & 0.050 & 0.180 & \begin{tabular}{|l|}
30.7 \\
\end{tabular} & $\mathrm{P}$ & NA & 11.69 & \begin{tabular}{|l|l|}
12.18 \\
\end{tabular} & 12.43 & 12.00 & 11.00 & 22.00 & NA & NA & NA & NA & NA & NA & 1 & NA & $\mathrm{BC}$ & NA & NA & NA & 34S_4p1dTrd _O & $11 / 20 \mathrm{~A}^{2}$ & TDP-WIP-055 & 7090934 \\
\hline 22.2 & 0.999 & 0.00487 & undefined & 1.000 & infinite & $\mathrm{s}$ & 6.02 & NA & NA & NA & 6.00 & 12.00 & NA & NA & NA & NA & Ucscen & NA & NA & $\mathrm{I}$ & NA & ss & NA & NA & NA & 34s_4p1d7ra-04 & 11/20B1 & TDP-WIP-055 & 7090938 \\
\hline 22.2 & 0.999 & 0.00487 & undefined & 1.000 & infinite & $\mathrm{s}$ & 7.01 & NA & NA & NA & 7.00 & 12.00 & 8.75 & NA & NA & NA & NA & NA & NA & 1 & NA & sSt & NA & NA & NA & 34S_4p1d7ra-04 & 11/20B1 & TDP-WIP-055 & 7090941 \\
\hline 22.3 & 0.999 & 0.00487 & undefined & 1.000 & infinite & $s$ & 7.98 & NA & NA & NA & 8.00 & 12.00 & 10.50 & NA & NA & NA & NA & NA & NA & 1 & NA & $A M$ & NA & NA & NA & 34S_4p1d7ra-04 & 11/20B1 & TDP-WIP-055 & 7090943 \\
\hline 22.3 & 0.999 & $\begin{array}{ll}0.00487 \\
\end{array}$ & undefined & 1.000 & infinite & $\mathrm{s}$ & 9.01 & NA & NA & NA & 9.00 & 12.00 & 13.25 & NA & NA & NA & NA & NA & NA & 1 & NA & AM & NA & NA & NA & 345_4p1dTra-04 & $11 / 2081$ & TDP-WIP-055 & 7090946 \\
\hline 22.3 & 0.999 & \begin{tabular}{l|l|}
0.00487 \\
\end{tabular} & undefined & 1.000 & infinite & $\mathrm{s}$ & 10.06 & NA & NA & NA & 10.00 & 12.00 & 16.50 & NA & NA & NA & NA & NA & NA & 1 & NA & AM & NA & NA & NA & 345_4p1d/ra-04 & $11 / 2081$ & TDP-WIP-055 & 7090949 \\
\hline 22.2 & 0.999 & 0.00487 & undefined & 1.000 & infinite & $\mathrm{s}$ & 11.05 & NA & NA & NA & 11.00 & 12.00 & 21.00 & NA & NA & NA & NA & NA & NA & 1 & NA & $A M+$ & NA & NA & NA & 34S_4p1d7ra-04 & $11 / 20 \mathrm{~B} 1$ & TDP-WIP-055 & 7090952 \\
\hline 22.3 & 0.999 & 0.00487 & undefined & 1.000 & infinite & $\mathrm{s}$ & 12.11 & NA & NA & NA & 12.00 & 12.00 & 29.50 & \begin{tabular}{|l}
12.00 \\
\end{tabular} & vis & ucsis & NA & NA & NA & 1 & NA & cs & NA & NA & NA & 34S_4p1dTra-04 & 11/20B1 & TDP-WIP-055 & 7090956 \\
\hline 22.3 & 0.999 & 0.00487 & undefined & 1.000 & inffinite & $\mathrm{s}$ & 13.06 & NA & NA & NA & 13.00 & 12.00 & 39.25 & NA & NA & NA & NA & NA & NA & 1 & NA & $B C$ & NA & NA & NA & 34S_4p1d7ra-04 & $11 / 20 B 1$ & TDP-WIP-055 & 7090958 \\
\hline 22.0 & 0.999 & \begin{tabular}{ll|}
0.00487 \\
\end{tabular} & \begin{tabular}{|l|}
0.052 \\
\end{tabular} & 0.180 & 100.0 & $\mathrm{P}$ & NA & 8.15 & \begin{tabular}{|l|}
8.32 \\
\end{tabular} & 8.54 & 7.70 & 14.00 & 10.00 & NA & NA & NA & NA & NA & NA & $\mathrm{D}$ & NA & ss & NA & NA & NA & 34S_4p1dTYd_99 & $11 / 20 \mathrm{~B} 2$ & TDP-WIP-055 & 7090962 \\
\hline 22.0 & 0.999 & $\begin{array}{l}0.00487 \\
\end{array}$ & 0.051 & 0.180 & 85.5 & $\mathrm{P}$ & NA & 9.31 & 9.52 & 9.77 & 9.00 & 14.00 & 12.75 & NA & NA & NA & NA & NA & NA & 1 & NA & sst & NA & NA & NA & 34S_4p1d/Yd 99 & $11 / 20 \mathrm{~B} 2$ & TDP-WIP-055 & 7090965 \\
\hline 22.0 & 0.999 & 0.00487 & 0.052 & 0.180 & 77.0 & $P$ & NA & 10.37 & 10.61 & 10.90 & 10.00 & 14.00 & 15.50 & NA & NA & NA & NA & NA & NA & 1 & NA & AM & NA & NA & NA & 34S_4p1d/Yd_ 9 & $11 / 20 \mathrm{~B} 2$ & TDP-WIP-055 & 7090967 \\
\hline 22.0 & 0.999 & 0.00487 & 0.052 & 0.180 & 63.5 & $\mathrm{P}$ & NA & 12.50 & 12.81 & 13.16 & 12.00 & 14.00 & 18.75 & NA & NA & NA & NA & NA & NA & $\mathrm{I}$ & NA & AM & NA & NA & NA & 34S_4p1dTYd_ 9 & 11/20B2 & TDP-WIP-055 & 7090970 \\
\hline 22.0 & 0.999 & 0.00487 & 0.051 & 0.180 & 57.5 & $\mathrm{P}$ & NA & 13.57 & \begin{tabular}{|l|l|}
13.92 \\
\end{tabular} & 14.31 & 13.00 & 14.00 & 20.50 & NA & NA & NA & NA & NA & NA & 1 & NA & $A M+$ & NA & NA & NA & 34S_4p1d/Yd 9 & 11/20B2 & TDP-WIP-055 & 7090973 \\
\hline 22.0 & 0.999 & 0.00487 & 0.051 & 0.180 & 53.3 & $\mathrm{P}$ & NA & 14.55 & \begin{tabular}{|l|l|}
14.97 & \\
\end{tabular} & 15.40 & 14.00 & 14.00 & 23.00 & 14.00 & vis & Ucsis & NA & NA & NA & 1 & NA & cs & NA & NA & NA & 34S_4p1d7Yd_99 & 11/20B2 & TDP-WIP-055 & 7090977 \\
\hline 22.0 & 0.999 & \begin{tabular}{l|l|}
0.00487 \\
\end{tabular} & 0.051 & 0.180 & 48.5 & $\mathrm{P}$ & NA & 15.90 & \begin{tabular}{|l|l|}
16.35 \\
\end{tabular} & 16.84 & 15.00 & 14.00 & 26.25 & NA & NA & NA & NA & NA & NA & 1 & NA & $\mathrm{BC}$ & NA & NA & NA & 34S_4p1dTYd 9 & 11/20B2 & TDP-WIP-055 & 7090979 \\
\hline 20.5 & 0.999 & \begin{tabular}{l|l|}
0.00487 \\
\end{tabular} & undefined & 1.000 & inffinite & $\mathrm{s}$ & 9.06 & NA & NA & NA & 9.00 & 9.50 & NA & NA & NA & NA & NA & NA & NA & 1 & NA & sSt & NA & NA & NA & 34S_4p1d7ra-40 & 11/26A1 & TDP-WIP-064 & 7090982 \\
\hline 20.5 & 0.999 & 0.00487 & undefined & 1.000 & infinite & $\mathrm{s}$ & 10.06 & NA & NA & NA & 10.00 & 9.50 & 21.50 & NA & NA & NA & NA & NA & NA & 1 & NA & $\mathrm{BC}$ & NA & NA & NA & 345_4p1dTra-40 & 111/26A1 & TDP-WIP-064 & 7090985 \\
\hline 20.5 & 0.999 & 0.00487 & undefined & 1.000 & infinite & $\mathrm{s}$ & 9.62 & NA & NA & NA & 9.50 & 9.50 & 17.50 & NA & vis dec & UCsis & NA & NA & 9.50 & D & NA & cs & NA & NA & NA & 34S_4p1dr/ra-40 & 11/26A1 & TDP-WIP-064 & 7090989 \\
\hline 20.5 & 0.999 & 0.00487 & \begin{tabular}{|l|} 
undefined \\
\end{tabular} & 1.000 & infinite & $\mathrm{s}$ & 9.03 & NA & NA & NA & 9.00 & 9.50 & NA & NA & NA & NA & NA & NA & NA & $\mathrm{D}$ & NA & sSt & NA & NA & NA & 345_4p1drra-40 & 111/26A1 & TDP-WIP-064 & 7090991 \\
\hline 20.6 & 0.999 & \begin{tabular}{l|l|}
0.00487 \\
\end{tabular} & \begin{tabular}{|l|} 
undefined \\
\end{tabular} & 1.000 & infinite & $\mathrm{s}$ & 9.42 & NA & NA & NA & 9.25 & 9.50 & 9.25 & NA & NA & NA & NA & NA & NA & 1 & NA & AM & NA & NA & NA & 345_4p1d/ra-40 & $11 / 26 A 1$ & TDP-WIP-064 & 7090994 \\
\hline 20.6 & 0.999 & \begin{tabular}{l|l|}
0.00487 \\
\end{tabular} & undefined & 1.000 & infinite & $\mathrm{s}$ & 9.42 & NA & NA & NA & 9.30 & 9.50 & 9.25 & NA & NA & NA & NA & NA & NA & 1 & NA & NA & NA & NA & NA & 34__4p1dTra-40 & $11 / 26 \mathrm{A1}$ & TDP-WIP-064 & 7090996 \\
\hline 20.5 & 0.999 & 0.00487 & undefined & 1.000 & infinite & $\mathrm{s}$ & 9.60 & NA & NA & NA & 9.50 & 9.50 & 13.75 & 9.50 & vis & ucsis & NA & NA & NA & 1 & NA & cs & NA & NA & NA & 345_4p1dTra-40 & 111/26A1 & TDP-WIP-064 & 7090998 \\
\hline
\end{tabular}


Table B.8. Data from Fall 2007 Tests in Mid-Scale Vessel with Spherical Head A.9

\begin{tabular}{|c|c|c|c|c|c|c|c|c|c|c|c|c|c|c|c|c|c|c|c|c|c|c|c|c|c|c|c|}
\hline $\begin{array}{l}\text { Row } \\
\text { Number }\end{array}$ & Test & Case ID & $\begin{array}{c}\text { Tank } \\
\text { Diameter }\end{array}$ & $\begin{array}{l}\text { Head } \\
\text { Shape }\end{array}$ & $\begin{array}{c}\text { Dish } \\
\text { Height }\end{array}$ & $\begin{array}{l}\text { Dish } \\
\text { Volume }\end{array}$ & $\begin{array}{l}\text { Tank } \\
\text { Fil } \\
\text { Height }\end{array}$ & $\begin{array}{l}\text { Retum } \\
\text { Line } \\
\text { Height }\end{array}$ & $\begin{array}{c}\text { Nozle } \\
\text { Inner } \\
\text { Diameter }\end{array}$ & $\begin{array}{c}\text { Nozzle } \\
\text { Stanct- } \\
\text { of } \\
\text { Distance } \\
\end{array}$ & $\begin{array}{l}\text { Pulse Tube } \\
\text { Configuration }\end{array}$ & $\begin{array}{l}\text { Installed } \\
\text { Nozzles }\end{array}$ & $\begin{array}{c}\text { Outer } \\
\text { Nozzles } \\
\text { Operated }\end{array}$ & $\begin{array}{c}\text { Inner } \\
\text { Nozzles } \\
\text { Operated }\end{array}$ & $\begin{array}{l}\text { Pulse Tube } \\
\text { Outer } \\
\text { Diameter }\end{array}$ & $\begin{array}{c}\text { Outer } \\
\text { PMM } \\
\text { Radius }\end{array}$ & $\begin{array}{c}\text { Inner } \\
\text { PMM } \\
\text { Radius }\end{array}$ & $\begin{array}{l}\text { "FIO" Outer } \\
\text { PJM } \\
\text { Impingement } \\
\text { Angle }\end{array}$ & $\begin{array}{c}\text { "FO' Inner } \\
\text { PJM } \\
\text { Impingement } \\
\text { Angle }\end{array}$ & $\begin{array}{c}\text { Ratio Outer } \\
\text { PJM to } \\
\text { Tank } \\
\text { Radius } \\
\end{array}$ & $\begin{array}{c}\text { Ratio Inner } \\
\text { PJM to } \\
\text { Tank } \\
\text { Radius } \\
\end{array}$ & Simulant & $\begin{array}{l}\text { Solids } \\
\text { Density }\end{array}$ & $\begin{array}{c}\text { Particle } \\
\text { Diameter d5 }\end{array}$ & $\begin{array}{c}\text { Patidide } \\
\text { Diamter } \\
\text { d50 }\end{array}$ & $\begin{array}{c}\text { Particle } \\
\text { Diantert } \\
\text { d95 }\end{array}$ & $\begin{array}{l}\text { Void } \\
\text { Fraction }\end{array}$ \\
\hline text & text & text & in. & text & in. & in. ${ }^{3}$ & in. & in. & in. & in. & text & number & number & number & in. & in. & in. & deg & deg & nondim & nondim & text & $\mathrm{g} / \mathrm{cm}^{3}$ & $\mathrm{~m}$ & $m$ & $m$ & fraction \\
\hline MSS & MDDX & ID & $\mathrm{D}$ & HS & Hash & $V_{\text {dash }}$ & $\mathrm{H}$ & Rtin & $d$ & sod & PT & $\mathrm{N}$ & $\mathrm{Nb}_{\mathrm{b}}$ & $N$ & $\mathrm{PT}_{\infty \mathrm{d}}$ & $\mathrm{R}_{0}$ & $R$ & $\theta_{0}$ & $\theta_{1}$ & $R d R$ & $R / R$ & sxdx & $\rho_{\mathrm{s}}$ & $d_{5}$ & $\mathrm{~d}_{60}$ & $d_{65}$ & vf \\
\hline 7091000 & $11 / 26 \mathrm{~A}$ & 34S_4p1drra-40 & $337 / 8$ & $s$ & 9 & 4437.4 & $673 / 4$ & $613 / 4$ & 0.297 & 0.446 & HLP-22 & 12 & 4 & 0 & 1.9 & 10.5 & 5.7 & 30.8 & 16.1 & 0.62 & 0.33 & pld7 & 2.45 & 0.0001213 & 0.0001780 & 0.0002606 & 0.4277 \\
\hline 7091003 & $11 / 26 A 2$ & $34 \mathrm{~S} \triangle 4 \mathrm{p} 1 \mathrm{~d} / \mathrm{Yd} \_6$ & $337 / 8$ & $\mathrm{~s}$ & 9 & 4437.4 & $673 / 4$ & $613 / 4$ & 0.297 & 0.446 & HLP-22 & 12 & 4 & 0 & 1.9 & 10.5 & 5.7 & 30.8 & 16.1 & 0.62 & 0.33 & pld7 & 2.45 & 0.0001213 & 0.0001780 & 0.0002606 & 0.4277 \\
\hline 7091006 & $11 / 26 \mathrm{AZ}$ & $34 \mathrm{~S} \_4 \mathrm{p} 1 \mathrm{~d} / \mathrm{d} d \_6$ & $337 / 8$ & $\mathrm{~s}$ & 9 & 4437.4 & $673 / 4$ & $613 / 4$ & 0.297 & 0.446 & HLP-22 & 12 & 4 & 0 & 1.9 & 10.5 & 5.7 & 30.8 & 16.1 & 0.62 & 0.33 & pldr & 2.45 & 0.0001213 & 0.0001780 & 0.0002606 & 0.4277 \\
\hline 7091010M & $11 / 26 A^{2}$ & $34 \mathrm{~S} \_4 \mathrm{p} 1 \mathrm{~d} / \mathrm{d} \mathrm{d} \_6$ & $337 / 8$ & $\mathrm{~s}$ & 9 & 4437.4 & $673 / 4$ & $613 / 4$ & 0.297 & 0.446 & HLP-22 & 12 & 4 & 0 & 1.9 & 10.5 & 5.7 & 30.8 & 16.1 & 0.62 & 0.33 & pld7 & 2.45 & 0.0001213 & 0.0001780 & 0.0002606 & 0.4277 \\
\hline 7091012M & $1126 A^{2}$ & 34S_4p1d7/Yd_6 & $337 / 8$ & $\mathrm{~s}$ & 9 & 4437.4 & $673 / 4$ & $613 / 4$ & 0.297 & 0.446 & HLP-22 & 12 & 4 & 0 & 1.9 & 10.5 & 5.7 & 30.8 & 16.1 & 0.62 & 0.33 & pld7 & 2.45 & 0.0001213 & 0.0001780 & 0.0002606 & 0.4277 \\
\hline 7091015M & $11 / 26 \mathrm{A2}$ & 34S_4p1d7/Yd_6 & $337 / 8$ & $\mathrm{~s}$ & 9 & 4437.4 & $673 / 4$ & $613 / 4$ & 0.297 & 0.446 & HLP-22 & 12 & 4 & 0 & 1.9 & 10.5 & 5.7 & 30.8 & 16.1 & 0.62 & 0.33 & pld7 & 2.45 & 0.0001213 & 0.0001780 & 0.0002606 & 0.4277 \\
\hline 7091018 & 11/26B1 & $34 \mathrm{~S} \_4 \mathrm{p} 1 \mathrm{~d} / \mathrm{YC} \_1$ & $337 / 8$ & $\mathrm{~s}$ & 9 & 4437.4 & $673 / 4$ & $613 / 4$ & 0.297 & 0.446 & HLP-22 & 12 & 8 & 4 & 1.9 & 10.5 & 5.7 & 30.8 & 16.1 & 0.62 & 0.33 & pld7 & 2.45 & 0.0001213 & 0.0001780 & 0.0002606 & 0.4277 \\
\hline 7091022 & 11/26B1 & 34S_4p1dT/Yc_1 & $337 / 8$ & $\mathrm{~s}$ & 9 & 4437.4 & $673 / 4$ & $613 / 4$ & 0.297 & 0.446 & HLP-22 & 12 & 8 & 4 & 1.9 & 10.5 & 5.7 & 30.8 & 16.1 & 0.62 & 0.33 & pld & 2.45 & 0.0001213 & 0.0001780 & 0.0002606 & 0.4277 \\
\hline 7091025M & $11 / 2681$ & 34S_4p1d/7c__1 & $337 / 8$ & $\mathrm{~s}$ & 9 & 4437.4 & $673 / 4$ & $613 / 4$ & 0.297 & 0.446 & HLP-22 & 12 & 8 & 4 & 1.9 & 10.5 & 5.7 & 30.8 & 16.1 & 0.62 & 0.33 & pld7 & 2.45 & 0.0001213 & 0.0001780 & 0.0002606 & 0.4277 \\
\hline 7091027M & $11 / 26 B 1$ & $34 \mathrm{~S} \_4 \mathrm{p} 1 \mathrm{~d} / \mathrm{Yc} \_1$ & $337 / 8$ & $\mathrm{~s}$ & 9 & 4437.4 & $673 / 4$ & $613 / 4$ & 0.297 & 0.446 & HLP-22 & 12 & 8 & 4 & 1.9 & 10.5 & 5.7 & 30.8 & 16.1 & 0.62 & 0.33 & pld7 & 2.45 & 0.0001213 & 0.0001780 & 0.0002606 & 0.4277 \\
\hline 7091030 & $11 / 26 \mathrm{C1}$ & 34S_4p1d/YYc $\_0$ & $337 / 8$ & $\mathrm{~s}$ & 9 & 4437.4 & $673 / 4$ & $613 / 4$ & 0.297 & 0.446 & HLP-22 & 12 & 4 & 4 & 1.9 & 10.5 & 5.7 & 30.8 & 16.1 & 0.62 & 0.33 & pldr & 2.45 & 0.0001213 & 0.0001780 & 0.0002606 & 0.4277 \\
\hline 7091033 & $11 / 26 \mathrm{C} 1$ & $34 S \_4 p 1 d 7 / Y c \_0$ & $337 / 8$ & $\mathrm{~s}$ & 9 & 4437.4 & $673 / 4$ & $613 / 4$ & 0.297 & 0.446 & HLP-22 & 12 & 4 & 4 & 1.9 & 10.5 & 5.7 & 30.8 & 16.1 & 0.62 & 0.33 & pld7 & 2.45 & 0.0001213 & 0.0001780 & 0.0002606 & 0.4277 \\
\hline 7091036 & $11 / 26 \mathrm{C1}$ & 34S_4p1d/Yc_O 0 & $337 / 8$ & $\mathrm{~s}$ & 9 & 4437.4 & $673 / 4$ & $613 / 4$ & 0.297 & 0.446 & HLP-22 & 12 & 4 & 4 & 1.9 & 10.5 & 5.7 & 30.8 & 16.1 & 0.62 & 0.33 & pld & 2.45 & 0.0001213 & 0.0001780 & 0.0002606 & 0.4277 \\
\hline 7091039 & $11 / 26 \mathrm{C} 1$ & 34S_4p1dTrc_o & $337 / 8$ & $\mathrm{~s}$ & 9 & 4437.4 & $673 / 4$ & $613 / 4$ & 0.297 & 0.446 & HLP-22 & 12 & 4 & 4 & 1.9 & 10.5 & 5.7 & 30.8 & 16.1 & 0.62 & 0.33 & pld & 2.45 & 0.0001213 & 0.0001780 & 0.0002606 & 0.4277 \\
\hline 7091042 & $11 / 26 \mathrm{CC}$ & $345 \_4 p 1 d \gamma / \gamma \_0$ & $337 / 8$ & $\mathrm{~s}$ & 9 & \begin{tabular}{ll|l|}
4437.4 \\
\end{tabular} & $673 / 4$ & $613 / 4$ & 0.297 & 0.446 & HLP-22 & 12 & 4 & 4 & 1.9 & 10.5 & 5.7 & 30.8 & 16.1 & 0.62 & 0.33 & p1d7 & 2.45 & 0.0001213 & 0.0001780 & 0.0002606 & 0.4277 \\
\hline 7091046M & $11 / 26 \mathrm{C1}$ & 34S_4p1d7/Yc $\_0$ & $337 / 8$ & $\mathrm{~s}$ & 9 & 4437.4 & $673 / 4$ & $613 / 4$ & 0.297 & 0.446 & HLP-22 & 12 & 4 & 4 & 1.9 & 10.5 & 5.7 & 30.8 & 16.1 & 0.62 & 0.33 & pld7 & 2.45 & 0.0001213 & 0.0001780 & 0.0002606 & 0.4277 \\
\hline 7091048M & $11 / 26 \mathrm{Cl}$ & $34 S \_4 p 1 d 7 / Y c \_0$ & $337 / 8$ & $s$ & 9 & 4437.4 & $673 / 4$ & $613 / 4$ & 0.297 & 0.446 & HLP-22 & 12 & 4 & 4 & 1.9 & 10.5 & 5.7 & 30.8 & 16.1 & 0.62 & 0.33 & pld7 & 2.45 & 0.0001213 & 0.0001780 & 0.0002606 & $0.42 \pi$ \\
\hline 7091052 & $11 / 2601$ & 34S_4p1dTrd_9 & $337 / 8$ & $\mathrm{~s}$ & 9 & 4437.4 & $673 / 4$ & $613 / 4$ & 0.297 & 0.446 & HLP-22 & 12 & 0 & 4 & 1.9 & 10.5 & 5.7 & 30.8 & 16.1 & 0.62 & 0.33 & pld & 2.45 & 0.0001213 & 0.0001780 & 0.0002606 & $0.42 \pi$ \\
\hline 7091055 & $11 / 2602$ & 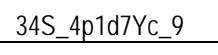 & $337 / 8$ & $\mathrm{~s}$ & 9 & 4437.4 & $673 / 4$ & $613 / 4$ & 0.297 & 0.446 & HLP-22 & 12 & 0 & 4 & 1.9 & 10.5 & 5.7 & 30.8 & 16.1 & 0.62 & 0.33 & pld7 & 2.45 & 0.0001213 & 0.0001780 & 0.0002606 & $0.42 \pi$ \\
\hline 7091058 & $11 / 26 \mathrm{D} 2$ & $34 S \_4 p 1 d 7 / Y c \_9$ & $337 / 8$ & $\mathrm{~s}$ & 9 & 4437.4 & $673 / 4$ & $613 / 4$ & 0.297 & 0.446 & HLP-22 & 12 & 0 & 4 & 1.9 & 10.5 & 5.7 & 30.8 & 16.1 & 0.62 & 0.33 & pld7 & 2.45 & 0.0001213 & 0.0001780 & 0.0002606 & 0.4277 \\
\hline 7091063 & $11 / 2602$ & 34S_4p1dT/Y_ 99 & $337 / 8$ & $\mathrm{~s}$ & 9 & 4437.4 & $673 / 4$ & $613 / 4$ & 0.297 & 0.446 & HLP-22 & 12 & 0 & 4 & 1.9 & 10.5 & 5.7 & 30.8 & 16.1 & 0.62 & 0.33 & pld & 2.45 & 0.0001213 & 0.0001780 & 0.0002606 & 0.4277 \\
\hline 7091065 & $11 / 26 \mathrm{D} 2$ & $34 S \_4 p 1 d 7 / Y c \_9$ & $337 / 8$ & $\mathrm{~s}$ & 9 & 4437.4 & $673 / 4$ & $613 / 4$ & 0.297 & 0.446 & HLP-22 & 12 & 0 & 4 & 1.9 & 10.5 & 5.7 & 30.8 & 16.1 & 0.62 & 0.33 & pld7 & 2.45 & 0.0001213 & 0.0001780 & 0.0002606 & $0.42 \pi$ \\
\hline 7091070 & $11 / 26 \mathrm{D} 2$ & 34S_4p1dTYc_9 9 & $337 / 8$ & $\mathrm{~s}$ & 9 & 4437.4 & $673 / 4$ & $613 / 4$ & 0.297 & 0.446 & HLP-22 & 12 & 0 & 4 & 1.9 & 10.5 & 5.7 & 30.8 & 16.1 & 0.62 & 0.33 & pld7 & 2.45 & 0.0001213 & 0.0001780 & 0.0002606 & $0.42 \pi$ \\
\hline 7091075M & $11 / 26 \mathrm{D} 2$ & 34S_4p1d7/Y_ $\_9$ & $337 / 8$ & $\mathrm{~s}$ & 9 & 4437.4 & $673 / 4$ & $613 / 4$ & 0.297 & 0.446 & HLP-22 & 12 & 0 & 4 & 1.9 & 10.5 & 5.7 & 30.8 & 16.1 & 0.62 & 0.33 & pld7 & 2.45 & 0.0001213 & 0.0001780 & 0.0002606 & 0.4277 \\
\hline 7091077M & $11 / 26 \mathrm{D} 2$ & $34 S \_4 p 1 d 7 / Y c \_9$ & $337 / 8$ & $\mathrm{~s}$ & 9 & 4437.4 & $673 / 4$ & $613 / 4$ & 0.297 & 0.446 & HLP-22 & 12 & 0 & 4 & 1.9 & 10.5 & 5.7 & 30.8 & 16.1 & 0.62 & 0.33 & pld7 & 2.45 & 0.0001213 & 0.0001780 & 0.0002606 & 0.4277 \\
\hline 7091081M & $11 / 26 \mathrm{D} 2$ & 34S_4p1d7/Yc_9 9 & $337 / 8$ & $\mathrm{~s}$ & 9 & 4437.4 & $673 / 4$ & $613 / 4$ & 0.297 & 0.446 & HLP-22 & 12 & 0 & 4 & 1.9 & 10.5 & 5.7 & 30.8 & 16.1 & 0.62 & 0.33 & pld7 & 2.45 & 0.0001213 & 0.0001780 & 0.0002606 & 0.4277 \\
\hline 7091005 & 11/27A1 & $34 \mathrm{~S} \_4 \mathrm{p} 1 \mathrm{~d} / \mathrm{YC} \_6$ & $337 / 8$ & $s$ & 9 & 4437.4 & $673 / 4$ & $613 / 4$ & 0.297 & 0.446 & HLP-22 & 12 & 4 & 0 & 1.9 & 10.5 & 5.7 & 30.8 & 16.1 & 0.62 & 0.33 & pld7 & 2.45 & 0.0001213 & 0.0001780 & 0.0002606 & $0.42 \pi$ \\
\hline 7091088 & $11 / 27 \mathrm{~A} 1$ & $34 S \_4 p 1 d T / Y c \_6$ & $337 / 8$ & $\mathrm{~s}$ & 9 & 4437.4 & $673 / 4$ & $613 / 4$ & 0.297 & 0.446 & HLP-22 & 12 & 4 & 0 & 1.9 & 10.5 & 5.7 & 30.8 & 16.1 & 0.62 & 0.33 & pld7 & 2.45 & 0.0001213 & 0.0001780 & 0.0002606 & 0.4277 \\
\hline 7091091 & $11 / 27 \mathrm{~A} 1$ & 34S_4p1d/Yc_ 6 & $337 / 8$ & $\mathrm{~s}$ & 9 & 4437.4 & $673 / 4$ & $613 / 4$ & 0.297 & 0.446 & HLP-22 & 12 & 4 & 0 & 1.9 & 10.5 & 5.7 & 30.8 & 16.1 & 0.62 & 0.33 & pld7 & 2.45 & 0.0001213 & 0.0001780 & 0.0002606 & 0.4277 \\
\hline 7091095M & $11 / 27 A_{1}$ & $34 \mathrm{~S} \_\mathrm{pp} 1 \mathrm{~d} / \mathrm{\gamma c} \_6$ & $337 / 8$ & $\mathrm{~s}$ & 9 & 4437.4 & $673 / 4$ & $613 / 4$ & 0.297 & 0.446 & HLP-22 & 12 & 4 & 0 & 1.9 & 10.5 & 5.7 & 30.8 & 16.1 & 0.62 & 0.33 & pld7 & 2.45 & 0.0001213 & 0.0001780 & 0.0002606 & 0.4277 \\
\hline 7091097M & $11 / 27 A_{1}$ & 34S_4p1d7/C_ 6 & $337 / 8$ & $\mathrm{~s}$ & 9 & 4437.4 & $673 / 4$ & $613 / 4$ & 0.297 & 0.446 & HLP-22 & 12 & 4 & 0 & 1.9 & 10.5 & 5.7 & 30.8 & 16.1 & 0.62 & 0.33 & p1d7 & 2.45 & 0.0001213 & 0.0001780 & 0.0002606 & 0.4277 \\
\hline 7091100 & 11/2781 & 34S_4p1dTraz80 & $337 / 8$ & $\mathrm{~s}$ & 9 & \begin{tabular}{ll|l}
4437.4 \\
\end{tabular} & $673 / 4$ & $613 / 4$ & 0.297 & \begin{tabular}{l|l|l}
0.446 \\
\end{tabular} & HLP-22 & 12 & 8 & 0 & 1.9 & 10.5 & 5.7 & 30.8 & 16.1 & 0.62 & 0.33 & p1d7 & 2.45 & 0.0001213 & 0.0001780 & 0.0002606 & $0.42 \pi$ \\
\hline 7091103 & 11/2781 & 34S_4p1dTra-80 & $337 / 8$ & $\mathrm{~s}$ & 9 & 4437.4 & $673 / 4$ & $613 / 4$ & 0.297 & 0.446 & HLP-22 & 12 & 8 & 0 & 1.9 & 10.5 & 5.7 & 30.8 & 16.1 & 0.62 & 0.33 & p1d7 & 2.45 & 0.0001213 & 0.0001780 & 0.0002606 & 0.4277 \\
\hline 7091106 & $11 / 2781$ & 34S_4p1d7ra-80 & $337 / 8$ & $s$ & 9 & 4437.4 & $673 / 4$ & $613 / 4$ & 0.297 & 0.446 & HLP-22 & 12 & 8 & 0 & 1.9 & 10.5 & 5.7 & 30.8 & 16.1 & 0.62 & 0.33 & pld7 & 2.45 & 0.0001213 & 0.0001780 & 0.0002606 & 0.4277 \\
\hline 7091109 & $11 / 2781$ & 34S_4p1d7ra-80 & $337 / 8$ & $s$ & 9 & 4437.4 & $673 / 4$ & $613 / 4$ & 0.297 & 0.446 & HLP-22 & 12 & 8 & 0 & 1.9 & 10.5 & 5.7 & 30.8 & 16.1 & 0.62 & 0.33 & pld7 & 2.45 & 0.0001213 & 0.0001780 & 0.0002606 & 0.4277 \\
\hline 7091113 & $11 / 27 B 1$ & $34 \mathrm{~S} 4 \mathrm{pp} 1 \mathrm{~d} / \mathrm{Ya}-80$ & $337 / 8$ & $\mathrm{~s}$ & 9 & 4437.4 & $673 / 4$ & $613 / 4$ & 0.297 & 0.446 & HLP-22 & 12 & 8 & 0 & 1.9 & 10.5 & 5.7 & 30.8 & 16.1 & 0.62 & 0.33 & pld7 & 2.45 & 0.0001213 & 0.0001780 & 0.0002606 & 0.4277 \\
\hline 7091115 & 11/2781 & 34S_4p1drra-80 & $337 / 8$ & $\mathrm{~s}$ & 9 & \begin{tabular}{ll|l}
4437.4 \\
\end{tabular} & $673 / 4$ & $613 / 4$ & 0.297 & 0.446 & HLP-22 & 12 & 8 & 0 & 1.9 & 10.5 & 5.7 & 30.8 & 16.1 & 0.62 & 0.33 & p1d7 & 2.45 & 0.0001213 & 0.0001780 & 0.0002606 & $0.42 \pi$ \\
\hline 7091118 & $11 / 2782$ & 34S_4p1dTrd_5 & $337 / 8$ & $\mathrm{~s}$ & 9 & 4437.4 & $673 / 4$ & $613 / 4$ & 0.297 & 0.446 & HLP-22 & 12 & 8 & 0 & 1.9 & 10.5 & 5.7 & 30.8 & 16.1 & 0.62 & 0.33 & pld7 & 2.45 & 0.0001213 & 0.0001780 & 0.0002606 & $0.42 \pi$ \\
\hline 7091121 & 1112782 & 34S_4p1d7Yd_5 & & $\mathrm{s}$ & 9 & 4437.4 & $673 / 4$ & $613 / 4$ & 0.297 & & $A[P=-22$ & 12 & 8 & 0 & 1.9 & 10.5 & 5.7 & 30.8 & 16.1 & 0.62 & & pldr & 2.45 & 0.0001213 & 0.0001780 & 0.0002606 & \\
\hline 7091124 & $11 / 2782$ & 34S_4p1dTrd 5 & $337 / 8$ & $\mathrm{~s}$ & 9 & 4437.4 & $673 / 4$ & $613 / 4$ & 0.297 & 0.446 & HLP-22 & 12 & 8 & 0 & 1.9 & 10.5 & 5.7 & 30.8 & 16.1 & 0.62 & 0.33 & pld7 & 2.45 & 0.0001213 & 0.0001780 & 0.0002606 & 0.4277 \\
\hline 7091127 & $11 / 2782$ & 34S_4p1d/7d_ 5 & $337 / 8$ & $s$ & 9 & 4437.4 & $673 / 4$ & $613 / 4$ & 0.297 & 0.446 & HLP-22 & 12 & 8 & 0 & 1.9 & 10.5 & 5.7 & 30.8 & 16.1 & 0.62 & 0.33 & pld7 & 2.45 & 0.0001213 & 0.0001780 & 0.0002606 & 0.4277 \\
\hline
\end{tabular}


Table B.8. Data from Fall 2007 Tests in Mid-Scale Vessel with Spherical Head B.9

\begin{tabular}{|c|c|c|c|c|c|c|c|c|c|c|c|c|c|c|c|c|c|c|c|c|c|c|c|c|c|c|c|c|c|}
\hline $\begin{array}{l}\text { Tank Water } \\
\text { Temperature }\end{array}$ & $\begin{array}{l}\text { Water } \\
\text { Density }\end{array}$ & $\begin{array}{c}\text { Solids } \\
\text { Fraction }\end{array}$ & $\begin{array}{l}\text { Pulse } \\
\text { Volume } \\
\text { Fraction }\end{array}$ & $\begin{array}{l}\text { Duty } \\
\text { Cyde }\end{array}$ & $\begin{array}{l}\text { Cyde } \\
\text { Time }\end{array}$ & $\begin{array}{c}\begin{array}{c}\text { Pulsed } \\
\text { or } \\
\text { Steacy } \\
\text { Jet }\end{array} \\
\end{array}$ & \begin{tabular}{|c|c} 
Us \\
Steacdy \\
Jet
\end{tabular} & $\begin{array}{c}\text { U1 } \\
\text { Pulsing } \\
\text { Jet }\end{array}$ & \begin{tabular}{|l} 
UR \\
URMS \\
\end{tabular} & $\begin{array}{c}\text { U3 } \\
\text { URNB } \\
\end{array}$ & $\begin{array}{l}\text { Discharge } \\
\text { Velocity } \\
\end{array}$ & $\begin{array}{c}\text { Citical } \\
\text { Suspension } \\
\text { Velocity }\end{array}$ & \begin{tabular}{|c|} 
Average \\
Peak \\
Cloud \\
Height \\
\end{tabular} & $\begin{array}{c}\text { Ucs } \\
\text { Condition }\end{array}$ & \begin{tabular}{|c|} 
UCS \\
Method
\end{tabular} & $\begin{array}{l}\text { UCS } \\
\text { Flag }\end{array}$ & $\begin{array}{l}\text { ucs } \\
\text { Center } \\
\text { Hag }\end{array}$ & $\begin{array}{l}\text { Ucs udv } \\
\text { Fag }\end{array}$ & \begin{tabular}{|c|} 
UCS based \\
on \\
Deceasing \\
Velocity
\end{tabular} & $\begin{array}{l}\text { Sweep } \\
\text { Increase/ } \\
\text { Decrease }\end{array}$ & \begin{tabular}{|c|} 
UDV \\
Height \\
Bed \\
\end{tabular} & 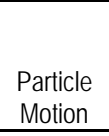 & \begin{tabular}{|l|}
$\begin{array}{l}\text { Solids } \\
\text { Level }\end{array}$ \\
\end{tabular} & \begin{tabular}{|c|} 
Outer \\
Botom \\
Patter \\
\end{tabular} & $\begin{array}{l}\text { Inner } \\
\text { Bottom } \\
\text { Patterm }\end{array}$ & Case ID & Test & TDP & $\begin{array}{c}\text { Row } \\
\text { Number }\end{array}$ \\
\hline C & $\mathrm{g} / \mathrm{cm}^{3}$ & fraction & fraction & fraction & $\mathrm{s}$ & text & $m / s$ & $\mathrm{~m} / \mathrm{s}$ & $\mathrm{m} / \mathrm{s}$ & $\mathrm{m} / \mathrm{s}$ & $\mathrm{m} / \mathrm{s}$ & $\mathrm{m} / \mathrm{s}$ & in. & $\mathrm{ms}$ & text & text & text & text & \begin{tabular}{|l|}
$\mathrm{m} / \mathrm{s}$ \\
\end{tabular} & text & $\mathrm{mm}$ & text & \begin{tabular}{|l|} 
text \\
\end{tabular} & text & text & text & text & text & text \\
\hline $\mathrm{T}$ & $\rho$ & $\phi_{\mathrm{s}}$ & $\phi_{p}$ & $\mathrm{DC}$ & $t_{c}$ & Jet & $U_{s}$ & $\mathrm{U}_{1}$ & $\mathrm{U} 2$ & U3 & $u$ & Uss & $H_{c}$ & Uspe & Uasn & Usvis & Usceen & Usudv & $U_{\text {cs_D }}$ & $\mathrm{S}_{\mathrm{N}}$ & $H_{\text {bed }}$ & $\mathrm{PM}$ & Sol & $\mathrm{SP}$ & $\mathrm{SP}_{1}$ & ID & MDDX & $\mathrm{IDP}$ & MSS \\
\hline 20.5 & 0.999 & 0.00487 & undefined & 1.000 & infinite & $\mathrm{s}$ & 10.60 & NA & NA & NA & 10.50 & 9.50 & 26.75 & NA & NA & NA & NA & NA & NA & 1 & NA & $\mathrm{BC}$ & NA & NA & NA & 345_4p1dTra-40 & $11 / 26 \mathrm{~A} 1$ & TDP-WIP-064 & 7091000 \\
\hline 21.0 & 0.999 & 0.00487 & 0.049 & 0.180 & 0.0 & $\mathrm{P}$ & NA & 10.05 & 10.34 & 10.66 & 9.50 & 10.50 & \begin{tabular}{|l|l|} 
& \\
\end{tabular} & NA & NA & NA & NA & NA & NA & D & NA & sst & NA & NA & NA & 34S_4p1d/rd_6 6 & $11 / 26 A_{2}$ & TDP-WIP-064 & 7091003 \\
\hline 21.0 & 0.999 & 0.00487 & 0.052 & 0.180 & 0.0 & $\mathrm{P}$ & NA & 10.59 & 10.86 & 11.17 & 10.00 & 10.50 & \begin{tabular}{|l|}
9.50 \\
\end{tabular} & NA & NA & NA & NA & NA & NA & $\mathrm{I}$ & NA & $A M$ & NA & NA & NA & 34S_4p1dTrd_ 6 & $11 / 26 \mathrm{A2}$ & TDP-WIP-064 & 7091006 \\
\hline 21.0 & 0.999 & 0.00487 & 0.052 & 0.180 & 0.0 & $\mathrm{P}$ & NA & 11.15 & 11.39 & 11.71 & 10.50 & 10.50 & 12.50 & \begin{tabular}{|l|}
10.50 \\
\end{tabular} & vis & ucsis & NA & NA & NA & 1 & NA & CS & NA & NA & NA & $34 S \_4 p 1 d T Y d \_6$ & $11 / 26 A 2$ & TDP-WIP-064 & 7091010 \\
\hline 21.0 & 0.999 & 0.00487 & 0.052 & 0.180 & 0.0 & $\mathrm{P}$ & NA & 1150 & 11.81 & 12.16 & 11.00 & 10.50 & 15.00 & NA & NA & NA & NA & NA & NA & 1 & NA & $\mathrm{BC}-$ & NA & NA & NA & $345 \_4 p 1 d 7 \gamma d \_6$ & $11 / 26 A 2$ & TDP-WIP-064 & 7091012 \\
\hline 21.0 & 0.999 & 0.00487 & 0.051 & 0.180 & 0.0 & $\mathrm{P}$ & NA & 12.21 & 12.55 & 12.94 & 11.50 & 10.50 & 16.50 & NA & NA & NA & NA & NA & NA & 1 & NA & $B C$ & NA & NA & NA & $34 S \_4 p 1 d T Y d \_6$ & $11 / 26 A 2$ & TDP-WIP-064 & 7091015 \\
\hline 21.0 & 0.999 & 0.00487 & 0.046 & 0.330 & 0.0 & $\mathrm{P}$ & NA & 4.92 & 5.00 & 5.03 & 5.00 & 6.50 & NA & NA & NA & NA & NA & NA & NA & D & NA & ss & NA & NA & NA & 34S_4p1d/YYc_1 & $11 / 2681$ & TDP-WIP-064 & 7091018 \\
\hline 21.0 & 0.999 & 0.00487 & 0.051 & 0.330 & 0.0 & $\mathrm{P}$ & NA & 6.31 & 6.43 & 6.49 & 6.50 & 6.50 & 9.75 & \begin{tabular}{|l|}
6.50 \\
\end{tabular} & vis & Ucsis & NA & NA & NA & 1 & NA & cs & NA & NA & NA & 34S_4p1dTrc_1 & $11 / 26 \mathrm{~B} 1$ & IDP-WIP-064 & 7091025 \\
\hline 21.0 & 0.999 & 0.00487 & 0.051 & 0.330 & 0.0 & $\mathrm{P}$ & NA & 6.82 & 6.96 & 7.02 & 7.00 & 6.50 & 11.25 & NA & NA & NA & NA & NA & NA & 1 & NA & $B C$ & NA & NA & NA & 34S_4p1dTYc_1 & $11 / 26 \mathrm{~B} 1$ & TDP-WIP-064 & 7091027 \\
\hline 21.0 & 0.999 & 0.00487 & 0.051 & 0.330 & 0.0 & $\mathrm{P}$ & NA & 6.12 & 6.20 & 6.25 & 6.00 & 11.00 & NA & NA & NA & NA & Ucscen & NA & NA & 1 & NA & AMt & NA & NA & NA & $34 S \_4 p 1 d T Y c \_0$ & $11 / 26 \mathrm{Cl}$ & TDP-WIP-064 & 7091030 \\
\hline 21.0 & 0.999 & 0.00487 & 0.051 & 0.330 & 0.0 & $\mathrm{P}$ & NA & 7.04 & 7.17 & 7.24 & 7.00 & 11.00 & \begin{tabular}{|l|}
.25 \\
\end{tabular} & NA & NA & NA & NA & NA & NA & 1 & NA & $A M$ & NA & NA & NA & 34s_4p1d/YYc_0 & $11 / 26 \mathrm{C1}$ & TDP-WIP-064 & 7091033 \\
\hline 210 & 0.999 & 0.00487 & 0.051 & 0.330 & 0.0 & $\mathrm{P}$ & NA & 8.06 & 8.21 & 8.30 & 8.00 & 11.00 & 11.25 & NA & NA & NA & NA & NA & NA & 1 & NA & AM & NA & NA & NA & $34 \mathrm{~S}, 4 \mathrm{p} 1 \mathrm{~d} / \mathrm{rc} \_0$ & $11 / 26 C 1$ & TDP-WTP-064 & 7091036 \\
\hline 21.0 & 0.999 & 0.00487 & 0.051 & 0.330 & 0.0 & $\mathrm{P}$ & NA & 9.15 & 9.48 & 9.65 & 9.00 & 11.00 & 15.00 & NA & NA & NA & NA & NA & NA & 1 & NA & $A M$ & NA & NA & NA & 34S_Ap1dTrc_ 0 & $11 / 26 \mathrm{CI}$ & TDP-WIP-064 & 7091039 \\
\hline 21.0 & 0.999 & 0.00487 & 0.051 & 0.330 & 0.0 & $\mathrm{P}$ & NA & 9.36 & 9.89 & 10.15 & 10.00 & 11.00 & 18.00 & NA & NA & NA & NA & NA & NA & $\mathrm{I}$ & NA & AM+ & NA & NA & NA & $345 \_4 p 1 d / Y c \_0$ & $11 / 26 \mathrm{CI}$ & TDP-WIP-064 & 7091042 \\
\hline 21.0 & 0.999 & 0.00487 & 0.051 & 0.330 & 0.0 & $\mathrm{P}$ & NA & 9.83 & 10.60 & 10.97 & 11.00 & 11.00 & 21.25 & \begin{tabular}{|l|}
11.00 \\
\end{tabular} & vis & ucsis & NA & NA & NA & 1 & NA & cs & NA & NA & NA & $34 S \_4 p 1 d T r c \_0$ & $11 / 26 \mathrm{Cl}$ & TDP-WIP-064 & 7091046 \\
\hline 21.0 & 0.999 & 0.00487 & 0.052 & 0.330 & 0.0 & $\mathrm{P}$ & NA & 10.81 & 11.69 & 12.11 & 12.00 & 11.00 & 27.00 & NA & NA & NA & NA & NA & NA & 1 & NA & $\mathrm{BC}$ & NA & NA & NA & 34s_4p1d/YYc_0 & $11 / 26 \mathrm{Cl}$ & TDP-WIP-064 & 7091048 \\
\hline 22.0 & 0.999 & 0.00487 & 0.057 & 0.180 & 0.0 & $\mathrm{P}$ & NA & 5.90 & 6.04 & 6.22 & 5.70 & NA & \begin{tabular}{|l|l|} 
NA & \\
\end{tabular} & NA & NA & NA & UCScen & NA & NA & NA & NA & ss & NA & NA & NA & $345,4 p 1 d / \gamma d a$ & $11 / 26 \mathrm{D} 1$ & TDP-WTP-064 & 7091052 \\
\hline 22.0 & 0.999 & 0.00487 & 0.051 & 0.330 & 0.0 & $\mathrm{P}$ & NA & 6.03 & 6.17 & 6.35 & 5.70 & 13.00 & NA & NA & NA & NA & UCscen & NA & NA & 1 & NA & ss & NA & NA & NA & 34S_4p1dTrc_ 9 & $11 / 26 \mathrm{DD} 2$ & TDP-WIP-064 & 7091055 \\
\hline 22.0 & 0.999 & 0.00487 & 0.050 & 0.330 & 0.0 & $P$ & NA & 7.14 & 7.30 & 7.52 & 7.00 & 13.00 & 8.75 & NA & NA & NA & NA & NA & NA & 1 & NA & ss & NA & NA & NA & $345 \_4 p 1 d r r c 9$ & 11/26D2 & TDP-WIP-064 & 7091058 \\
\hline 22.0 & 0.999 & 0.00487 & 0.050 & 0.330 & 0.0 & $P$ & NA & 11.52 & 11.83 & 12.19 & 11.00 & 13.00 & 18.17 & NA & NA & NA & NA & NA & NA & $\mathrm{I}$ & NA & $A M$ & NA & NA & NA & $34 S \_4 p 1 d 7 Y c \_9$ & $11 / 26 \mathrm{D} 2$ & TDP-WTP-064 & 7091065 \\
\hline 22.0 & 0.999 & 0.00487 & 0.050 & 0.330 & 0.0 & $\mathrm{P}$ & NA & 12.48 & 12.83 & 13.24 & 12.00 & 13.00 & 20.00 & NA & NA & NA & NA & NA & NA & $\mathrm{I}$ & NA & AM+ & NA & NA & NA & 34S_4p1d/rc_ 9 & $11 / 26 \mathrm{D} 2$ & TDP-WIP-064 & 7091070 \\
\hline 22.0 & 0.999 & 0.00487 & 0.050 & 0.330 & 0.0 & $\mathrm{P}$ & NA & 13.47 & 13.86 & 14.30 & 13.00 & 13.00 & 21.33 & 13.00 & vis & Ucsis & NA & NA & NA & 1 & NA & cs & NA & NA & NA & 34S_4p1dTrc_ 9 & $11 / 26 \mathrm{DD} 2$ & TDP-WIP-064 & 7091075 \\
\hline 22.0 & 0.999 & 0.00487 & 0.050 & 0.330 & 0.0 & $P$ & NA & 14.59 & 15.03 & 15.54 & 14.00 & 13.00 & 23.83 & NA & NA & NA & NA & NA & NA & 1 & NA & $B C-$ & NA & NA & NA & $345 \_4 p 1 d r r c 9$ & 11/26D2 & TDP-WIP-064 & 7091077 \\
\hline 22.0 & 0.999 & 0.00487 & 0.050 & 0.330 & 0.0 & $\mathrm{P}$ & NA & 15.48 & 16.07 & 16.67 & 15.00 & 13.00 & 28.83 & NA & NA & NA & NA & NA & NA & 1 & NA & $B C$ & NA & NA & NA & 34S_4p1dTrc_ 9 & $11 / 26 \mathrm{D} 2$ & TDP-WIP-064 & 7091081 \\
\hline 22.0 & 0.999 & 0.00487 & 0.052 & 0.330 & 0.0 & $\mathrm{P}$ & NA & 9.50 & 9.75 & 10.06 & 9.00 & 11.00 & 8.50 & NA & NA & NA & NA & NA & NA & $\mathrm{I}$ & NA & ss & NA & NA & NA & $34 S \_4 p 1 d 7 Y c \_6$ & $11 / 27 \mathrm{~A} 1$ & TDP-WTP-065 & 7091085 \\
\hline 22.0 & 0.999 & 0.00487 & 0.051 & 0.330 & 0.0 & $\mathrm{P}$ & NA & 10.63 & 10.89 & 11.24 & 10.00 & 11.00 & 10.00 & NA & NA & NA & NA & NA & NA & 1 & NA & $A M$ & NA & NA & NA & $34 \mathrm{~S} \_4 \mathrm{p} 1 \mathrm{~d} / \mathrm{rc} \_6$ & $11 / 27 \mathrm{~A} 1$ & TDP-WIP-065 & 7091088 \\
\hline 22.0 & 0.999 & 0.00487 & 0.051 & 0.330 & 0.0 & $\mathrm{P}$ & NA & 11.08 & 11.39 & 11.77 & 10.50 & 11.00 & 11.50 & NA & NA & NA & UCseen & NA & NA & 1 & NA & AM+ & NA & NA & NA & 34S_4p1dTrc 6 & 11/27A1 & TDP-WIP-065 & 7091091 \\
\hline 22.0 & 0.999 & 0.00487 & 0.051 & 0.330 & 0.0 & $\mathrm{P}$ & NA & 11.7 & 12.08 & 12.47 & 11.00 & 11.00 & 14.25 & 11.00 & vis & Ucsis & NA & NA & NA & 1 & NA & CS & NA & NA & NA & $345 \_4 p 1 d r r c 6$ & 11/27A1 & TDP-WIP-065 & 7091095 \\
\hline 22.0 & 0.999 & 0.00487 & 0.051 & 0.330 & 0.0 & $\mathrm{P}$ & NA & 12.68 & \begin{tabular}{|l|l|}
13.01 \\
\end{tabular} & \begin{tabular}{ll|}
13.44 \\
\end{tabular} & 12.00 & 11.00 & 20.00 & NA & NA & NA & NA & NA & NA & 1 & NA & $B C$ & NA & NA & $\mathrm{NA}$ & 34S_4p1d/rc_6 6 & $11 / 27 \mathrm{~A} 1$ & TDP-WIP-065 & 7091097 \\
\hline 21.9 & 0.999 & 0.00487 & undefined & 1.000 & infinite & $s$ & 7.57 & NA & NA & NA & 7.50 & 9.50 & 8.75 & NA & NA & NA & NA & NA & NA & NA & NA & ss & NA & NA & NA & 34S_4p1d7/ra-80 & $11 / 2781$ & TDP-WIP-065 & 7091100 \\
\hline 21.8 & 0.999 & 0.00487 & undefined & 1.000 & infinite & $\mathrm{s}$ & 8.11 & NA & NA & NA & 8.00 & 9.50 & 9.00 & NA & NA & NA & NA & NA & NA & 1 & NA & ss & NA & NA & NA & 34s_4p1dr/ra-80 & $11 / 27 \mathrm{B1}$ & TDP-WTP-065 & 7091103 \\
\hline 21.8 & 0.999 & 0.00487 & undefined & 1.000 & infinite & $\mathrm{s}$ & 8.53 & NA & NA & NA & 8.50 & 9.50 & 10.50 & NA & NA & NA & NA & NA & NA & 1 & NA & ss & NA & NA & NA & 34S_4p1d/ra-80 & $11 / 27 \mathrm{B1}$ & TDP-WIP-065 & 7091106 \\
\hline 21.9 & 0.999 & 0.00487 & undefined & 1.000 & infinite & $\mathrm{s}$ & 9.06 & NA & NA & NA & 9.00 & 9.50 & 18.63 & NA & NA & NA & NA & NA & NA & 1 & NA & $A M$ & NA & NA & NA & 34S_4p1drraso 80 & $11 / 27 \mathrm{B1}$ & TDP-WIP-065 & 7091109 \\
\hline 21.9 & 0.999 & 0.00487 & undefined & 1.000 & infinite & $\mathrm{s}$ & 9.57 & NA & NA & NA & 9.50 & & 29.25 & \begin{tabular}{|l|}
9.50 \\
\end{tabular} & vis & ucsis & NA & NA & NA & 1 & NA & cs & NA & NA & NA & 34S_4p1dr/raso 80 & $11 / 27 \mathrm{B1}$ & TDP-WIP-065 & 7091113 \\
\hline 21.8 & 0.999 & 0.00487 & undefined & 1.000 & infinite & $s$ & 10.01 & $\mathrm{NA}$ & $\mathrm{NA}$ & NA & 10.00 & 9.50 & 38.50 & NA & NA & NA & NA & NA & NA & 1 & $\mathrm{NA}$ & $\mathrm{BC}$ & NA & NA & NA & 34S_4p1drra-80 & $11 / 27 \mathrm{B1}$ & TDP-WIP-065 & 7091115 \\
\hline 220 & 0.999 & 0.00487 & 0.053 & 0.180 & 0.0 & $P$ & NA & 7.06 & 7.15 & 7.20 & 7.00 & 10.00 & 9.00 & NA & NA & NA & NA & NA & NA & NA & NA & ss & NA & NA & NA & $34 \mathrm{~S}=4 \mathrm{p} 1 \mathrm{dr} / \mathrm{d} \_5$ & $11 / 27 \mathrm{~B} 2$ & TDP-WIP-065 & 7091118 \\
\hline 220 & 0.999 & 0.00487 & 0.051 & 0.180 & 0.0 & $\mathrm{P}$ & NA & 8.09 & 8.22 & 8.28 & 8.00 & 10.00 & 11.75 & NA & NA & NA & NA & NA & NA & 1 & NA & ss & NA & NA & NA & 34S_4p1drYd 5 & $11 / 2782$ & TDP-WIP-065 & 7091121 \\
\hline 22.0 & 0.999 & 0.00487 & 0.054 & 0.180 & 0.0 & $\mathrm{P}$ & NA & 9.72 & $\begin{array}{ll}9.88 \\
\end{array}$ & 9.96 & 9.00 & 10.00 & 17.00 & NA & NA & NA & NA & NA & NA & 1 & NA & sst & NA & NA & NA & 34S_4p1dTrd 5 & $11 / 27 \mathrm{~B} 2$ & TDP-WIP-065 & 7091124 \\
\hline 22.0 & 0.999 & 0.00487 & 0.052 & 0.180 & 0.0 & $\mathrm{P}$ & NA & 9.57 & 9.90 & 10.07 & 9.50 & 10.00 & 19.25 & NA & NA & NA & NA & NA & NA & 1 & NA & $A M$ & NA & NA & NA & 34S_4p1dr/d_ 5 & $11 / 2782$ & TDP-WIP-065 & 7091127 \\
\hline
\end{tabular}


Table B.8. Data from Fall 2007 Tests in Mid-Scale Vessel with Spherical Head A.10

\begin{tabular}{|c|c|c|c|c|c|c|c|c|c|c|c|c|c|c|c|c|c|c|c|c|c|c|c|c|c|c|c|}
\hline $\begin{array}{l}\text { Row } \\
\text { Number }\end{array}$ & Test & Case ID & $\begin{array}{c}\text { Tank } \\
\text { Diameter }\end{array}$ & $\begin{array}{l}\text { Head } \\
\text { Shape }\end{array}$ & $\begin{array}{c}\text { Dish } \\
\text { Height }\end{array}$ & $\begin{array}{l}\text { Dish } \\
\text { Volume }\end{array}$ & $\begin{array}{l}\text { Tank } \\
\text { Fill } \\
\text { Height }\end{array}$ & $\begin{array}{l}\text { Return } \\
\text { Line } \\
\text { Height }\end{array}$ & $\begin{array}{c}\text { Nozzle } \\
\text { Inner } \\
\text { Diameter }\end{array}$ & $\begin{array}{c}\text { Nozzle } \\
\text { Stanct- } \\
\text { of } \\
\text { Distance } \\
\end{array}$ & $\begin{array}{l}\text { Pulse Tube } \\
\text { Configuration }\end{array}$ & $\begin{array}{l}\text { Installed } \\
\text { Nozzles }\end{array}$ & $\begin{array}{c}\text { Outer } \\
\text { Nozzles } \\
\text { Operated }\end{array}$ & $\begin{array}{c}\text { Inner } \\
\text { Nozzles } \\
\text { Operated }\end{array}$ & $\begin{array}{l}\text { Pulse Tube } \\
\text { Outer } \\
\text { Diameter }\end{array}$ & $\begin{array}{c}\text { Outer } \\
\text { PJM } \\
\text { Radius }\end{array}$ & $\begin{array}{c}\text { Inner } \\
\text { PJM } \\
\text { Radius }\end{array}$ & $\begin{array}{c}\text { "FlO" Outer } \\
\text { PJM } \\
\text { Impingement } \\
\text { Angle }\end{array}$ & $\begin{array}{c}\text { "FO' Inner } \\
\text { PJM } \\
\text { Impingement } \\
\text { Angle } \\
\end{array}$ & $\begin{array}{c}\text { Ratio Outer } \\
\text { PJM to } \\
\text { Tank } \\
\text { Radius } \\
\end{array}$ & $\begin{array}{c}\text { Ratio Inner } \\
\text { PJM to } \\
\text { Tank } \\
\text { Radius } \\
\end{array}$ & Simulant & $\begin{array}{l}\text { Solids } \\
\text { Density }\end{array}$ & $\begin{array}{c}\text { Particle } \\
\text { Diameter d5 }\end{array}$ & $\begin{array}{l}\text { Particle } \\
\text { Diameter } \\
\text { d50 }\end{array}$ & $\begin{array}{c}\text { Particle } \\
\text { Diantert } \\
\text { d95 }\end{array}$ & $\begin{array}{l}\text { Void } \\
\text { Fraction }\end{array}$ \\
\hline text & text & text & in. & text & in. & in. ${ }^{3}$ & in. & in. & in. & in. & text & number & number & number & in. & in. & in. & deg & deg & nondim & nondim & text & $\mathrm{g} / \mathrm{cm}^{3}$ & $\mathrm{~m}$ & $\mathrm{~m}$ & $\mathrm{~m}$ & fraction \\
\hline MSS & MDDX & $\mathrm{ID}$ & $\mathrm{D}$ & $\mathrm{HS}$ & $H_{\text {stat }}$ & $V_{\text {dath }}$ & $\mathrm{H}$ & Rin & $d$ & sod & PT & $\mathrm{N}$ & $\mathrm{N}_{\mathrm{b}}$ & $\mathrm{N}$ & $\mathrm{PT}_{\alpha \mathrm{d}}$ & $\mathrm{R}_{0}$ & $R_{1}$ & $\theta_{0}$ & $\theta_{1}$ & RdR & $R / R$ & sxdx & $\rho_{\mathrm{s}}$ & $c_{b}$ & $\mathrm{~d}_{60}$ & $d_{65}$ & vf \\
\hline 7091131M & $11 / 2782$ & 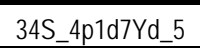 & $337 / 8$ & $\mathrm{~s}$ & 9 & 4437.4 & $673 / 4$ & 6134 & 0.297 & 0.446 & HLP-22 & 12 & 8 & 0 & 1.9 & 10.5 & 5.7 & 30.8 & 16.1 & 0.62 & 0.33 & p1d7 & 2.45 & 0.0001213 & 0.0001780 & 0.0002606 & 0.4277 \\
\hline 7091134M & $11 / 2782$ & 34S_4p1d7Yd_5 5 & $337 / 8$ & $\mathrm{~s}$ & 9 & 4437.4 & $673 / 4$ & $613 / 4$ & 0.297 & 0.446 & HLP-22 & 12 & 8 & 0 & 1.9 & 10.5 & 5.7 & 30.8 & 16.1 & 0.62 & 0.33 & pld7 & 2.45 & 0.0001213 & 0.0001780 & 0.0002606 & 0.4277 \\
\hline 7091136M & $11 / 27 \mathrm{~B} 2$ & 34s_4p1d7Yd_5 & $337 / 8$ & $\mathrm{~s}$ & 9 & 4437.4 & $673 / 4$ & 6134 & 0.297 & 0.446 & HLP-22 & 12 & 8 & 0 & 19 & 10.5 & 5.7 & 30.8 & 16.1 & 0.62 & 0.33 & pld7 & 2.45 & 0.0001213 & 0.0001780 & 0.0002606 & $0.42 \pi$ \\
\hline 7091139 & $11 / 2783$ & $34 \mathrm{~S}=4 \mathrm{p} 1 \mathrm{~d} / \mathrm{Yc}=5$ & $337 / 8$ & $\mathrm{~s}$ & 9 & 4437.4 & $673 / 4$ & 6134 & 0.297 & 0.446 & HLP-22 & 12 & 8 & 0 & 1.9 & 10.5 & 5.7 & 30.8 & 16.1 & 0.62 & 0.33 & pld & 2.45 & 0.0001213 & 0.0001780 & 0.0002606 & $0.42 \pi$ \\
\hline 7091142 & $11 / 27 B 3$ & 34S_4p1d7Yc_ 5 & $337 / 8$ & $s$ & 9 & 4437.4 & $673 / 4$ & $613 / 4$ & 0.297 & 0.446 & HLP-22 & 12 & 8 & 0 & 1.9 & 10.5 & 5.7 & 30.8 & 16.1 & 0.62 & 0.33 & pld7 & 2.45 & 0.0001213 & 0.0001780 & 0.0002606 & 0.4277 \\
\hline 7091145 & $11 / 2783$ & $345 \_4 p 1 d / Y c \_5$ & $337 / 8$ & $s$ & 9 & 4437.4 & $673 / 4$ & $613 / 4$ & 0.297 & 0.446 & HLP-22 & 12 & 8 & 0 & 1.9 & 10.5 & 5.7 & 30.8 & 16.1 & 0.62 & 0.33 & pld & 2.45 & 0.0001213 & 0.0001780 & 0.0002606 & 0.4277 \\
\hline 7091149M & $11 / 2783$ & 34S_4p1d7Yc_5 5 & $337 / 8$ & $\mathrm{~s}$ & 9 & 4437.4 & $673 / 4$ & $613 / 4$ & 0.297 & 0.446 & HLP-22 & 12 & 8 & 0 & 1.9 & 10.5 & 5.7 & 30.8 & 16.1 & 0.62 & 0.33 & pld7 & 2.45 & 0.0001213 & 0.0001780 & 0.0002606 & $0.42 \pi$ \\
\hline 7091151M & $11 / 2783$ & $34 S \_4 p 1 d 7 / c \_5$ & $337 / 8$ & $s$ & 9 & 4437.4 & $673 / 4$ & $613 / 4$ & 0.297 & 0.446 & HLP-22 & 12 & 8 & 0 & 1.9 & 10.5 & 5.7 & 30.8 & 16.1 & 0.62 & 0.33 & pld7 & 2.45 & 0.0001213 & 0.0001780 & 0.0002606 & 0.4277 \\
\hline 7091154 & $11 / 30 A^{1}$ & 34S_4p1d8Ya & $337 / 8$ & $\mathrm{~s}$ & 9 & 4437.4 & $673 / 4$ & 6134 & 0.297 & 0.446 & HLP-22 & 12 & 8 & 4 & 1.9 & 10.5 & 5.7 & 30.8 & 16.1 & 0.62 & 0.33 & plds & 2.45 & 0.0000605 & 0.0000895 & 0.0001320 & 0.4269 \\
\hline 7091158 & $11 / 30 \mathrm{~A} 1$ & 34S_4p1d8Ya & $337 / 8$ & $\mathrm{~s}$ & 9 & 4437.4 & $673 / 4$ & $613 / 4$ & 0.297 & 0.446 & HLP-22 & 12 & 8 & 4 & 1.9 & 10.5 & 5.7 & 30.8 & 16.1 & 0.62 & 0.33 & p1d8 & 2.45 & 0.0000605 & 0.0000895 & 0.0001320 & 0.4269 \\
\hline 7091161 & $11 / 30 A_{1}$ & 34S_4p1d8Ya & $337 / 8$ & $\mathrm{~s}$ & 9 & 4437.4 & $673 / 4$ & 6134 & 0.297 & 0.446 & HLP-22 & 12 & 8 & 4 & 1.9 & 10.5 & 5.7 & 30.8 & 16.1 & 0.62 & 0.33 & p1d8 & 2.45 & 0.0000605 & 0.0000895 & 0.0001320 & 0.4269 \\
\hline 7091164 & $11 / 30 \mathrm{~A} 1$ & 345_4p1d8Ya & $337 / 8$ & $\mathrm{~s}$ & 9 & 4437.4 & $673 / 4$ & $613 / 4$ & 0.297 & 0.446 & HLP-22 & 12 & 8 & 4 & 1.9 & 10.5 & 5.7 & 30.8 & 16.1 & 0.62 & 0.33 & p1d8 & 2.45 & 0.0000605 & 0.0000895 & 0.0001320 & 0.4269 \\
\hline 7091167 & $11 / 30 \mathrm{~A} 1$ & 34S_4p1d8Ya & $337 / 8$ & $s$ & 9 & 4437.4 & $673 / 4$ & $613 / 4$ & 0.297 & 0.446 & HLP-22 & 12 & 8 & 4 & 1.9 & 10.5 & 5.7 & 30.8 & 16.1 & 0.62 & 0.33 & pld8 & 2.45 & 0.0000605 & 0.0000895 & 0.0001320 & 0.4269 \\
\hline 7091169 & $11 / 30 \mathrm{~A} 1$ & 34S_4pidBYa & $337 / 8$ & $\mathrm{~s}$ & 9 & 4437.4 & $673 / 4$ & 6134 & 0.297 & 0.446 & HLP-22 & 12 & 8 & 4 & 1.9 & 10.5 & 5.7 & 30.8 & 16.1 & 0.62 & 0.33 & pld8 & 2.45 & 0.0000605 & 0.0000895 & 0.0001320 & 0.4269 \\
\hline 7091172 & $11 / 30 A^{2}$ & 34S_4p1d8Yd_1 & $337 / 8$ & $\mathrm{~s}$ & 9 & 4437.4 & $673 / 4$ & $613 / 4$ & 0.297 & 0.446 & HLP-22 & 12 & 8 & 4 & 1.9 & 10.5 & 5.7 & 30.8 & 16.1 & 0.62 & 0.33 & pld8 & 2.45 & 0.0000605 & 0.0000895 & 0.0001320 & 0.4269 \\
\hline 7091175 & $11 / 30 A^{2}$ & 34s_4p1d8Yd_1 & $337 / 8$ & $\mathrm{~s}$ & 9 & 4437.4 & $673 / 4$ & 6134 & 0.297 & 0.446 & HLP-22 & 12 & 8 & 4 & 1.9 & 10.5 & 5.7 & 30.8 & 16.1 & 0.62 & 0.33 & p1d8 & 2.45 & 0.0000605 & 0.0000895 & 0.0001320 & 0.4269 \\
\hline 7091178 & $11 / 30 A^{2}$ & 34S_4p1d8Yd_1 & $337 / 8$ & $\mathrm{~s}$ & 9 & 4437.4 & $673 / 4$ & $613 / 4$ & 0.297 & 0.446 & HLP-22 & 12 & 8 & 4 & 1.9 & 10.5 & 5.7 & 30.8 & 16.1 & 0.62 & 0.33 & p1d8 & 2.45 & 0.0000605 & 0.0000895 & 0.0001320 & 0.4269 \\
\hline 7091181 & $11 / 30 A^{2}$ & 34S_4p1d8Yd_1 & $337 / 8$ & $\mathrm{~s}$ & 9 & 4437.4 & $673 / 4$ & 6134 & 0.297 & 0.446 & HLP-22 & 12 & 8 & 4 & 1.9 & 10.5 & 5.7 & 30.8 & 16.1 & 0.62 & 0.33 & p1d8 & 2.45 & 0.0000605 & 0.0000895 & 0.0001320 & 0.4269 \\
\hline 7091185M M & $11 / 30 A^{2}$ & 34S_4p1d8Yd_1 & $337 / 8$ & $\mathrm{~s}$ & 9 & 4437.4 & $673 / 4$ & 6134 & 0.297 & 0.446 & HLP-22 & 12 & 8 & 4 & 1.9 & 10.5 & 5.7 & 30.8 & 16.1 & 0.62 & 0.33 & pld8 & 2.45 & 0.0000605 & 0.0000895 & 0.0001320 & 0.4269 \\
\hline 7091187M & $11 / 30 A^{2}$ & 34S_4p1d8Yd_1 & $337 / 8$ & $s$ & 9 & 4437.4 & $673 / 4$ & $613 / 4$ & 0.297 & 0.446 & HLP-22 & 12 & 8 & 4 & 1.9 & 10.5 & 5.7 & 30.8 & 16.1 & 0.62 & 0.33 & p1d8 & 2.45 & 0.0000605 & 0.0000895 & 0.0001320 & 0.4269 \\
\hline 7091191 & 11/30B1 & 34S_4p1d8Yc_1 & $337 / 8$ & $\mathrm{~s}$ & 9 & 4437.4 & $673 / 4$ & $613 / 4$ & 0.297 & 0.446 & HLP-22 & 12 & 8 & 4 & 1.9 & 10.5 & 5.7 & 30.8 & 16.1 & 0.62 & 0.33 & p1d8 & 2.45 & 0.0000605 & 0.0000895 & 0.0001320 & 0.4269 \\
\hline 7091193 & $11 / 30 B 1$ & 34S_4p1d8Yc_1 1 & $337 / 8$ & $s$ & 9 & 4437.4 & $673 / 4$ & $613 / 4$ & 0.297 & 0.446 & HLP-22 & 12 & 8 & 4 & 1.9 & 10.5 & 5.7 & 30.8 & 16.1 & 0.62 & 0.33 & p1d8 & 2.45 & 0.0000605 & 0.0000895 & 0.0001320 & 0.4269 \\
\hline 7091197 & $11 / 30 \mathrm{B1}$ & 34S_4p1d8Yc_1 1 & $337 / 8$ & $\mathrm{~s}$ & 9 & 4437.4 & $673 / 4$ & $613 / 4$ & 0.297 & 0.446 & HLP-22 & 12 & 8 & 4 & 1.9 & 10.5 & 5.7 & 30.8 & 16.1 & 0.62 & 0.33 & p1d8 & 2.45 & 0.0000605 & 0.0000895 & 0.0001320 & 0.4269 \\
\hline 7091200M & 11/30B1 & $34 \mathrm{~S} \_4 \mathrm{pld} 1 \mathrm{Yrc} \_1$ & $337 / 8$ & $\mathrm{~s}$ & 9 & 4437.4 & $673 / 4$ & $613 / 4$ & 0.297 & 0.446 & HLP-22 & 12 & 8 & 4 & 1.9 & 10.5 & 5.7 & 30.8 & 16.1 & 0.62 & 0.33 & p1d8 & 2.45 & 0.0000605 & 0.0000895 & 0.0001320 & 0.4269 \\
\hline 7091202M & 11/30B1 & 34S_4p1d8Yc_1 1 & $337 / 8$ & $s$ & 9 & 4437.4 & $673 / 4$ & $613 / 4$ & 0.297 & 0.446 & HLP-22 & 12 & 8 & 4 & 1.9 & 10.5 & 5.7 & 30.8 & 16.1 & 0.62 & 0.33 & p1d8 & 2.45 & 0.0000605 & 0.0000895 & 0.0001320 & 0.4269 \\
\hline 7091206 & $11 / 30 \mathrm{C1}$ & 34S_4p1d8Ya-44 & $337 / 8$ & $\mathrm{~s}$ & 9 & 4437.4 & $673 / 4$ & 6134 & 0.297 & 0.446 & HLP-22 & 12 & 4 & 4 & 1.9 & 10.5 & 5.7 & 30.8 & 16.1 & 0.62 & 0.33 & p1d8 & 2.45 & 0.0000605 & 0.0000895 & 0.0001320 & 0.4269 \\
\hline 7091209 & $11 / 30 \mathrm{Cl}$ & 34__4p1d8Ya-44 & $337 / 8$ & $\mathrm{~s}$ & 9 & 4437.4 & $673 / 4$ & $613 / 4$ & 0.297 & 0.446 & HLP-22 & 12 & 4 & 4 & 1.9 & 10.5 & 5.7 & 30.8 & 16.1 & 0.62 & 0.33 & p1d8 & 2.45 & 0.0000605 & 0.0000895 & 0.0001320 & 0.4269 \\
\hline 7091212 & $11 / 30 \mathrm{Cl}$ & 34S_4p1d8Ya-44 & $337 / 8$ & $\mathrm{~s}$ & 9 & 4437.4 & $673 / 4$ & $613 / 4$ & 0.297 & 0.446 & HLP-22 & 12 & 4 & 4 & 1.9 & 10.5 & 5.7 & 30.8 & 16.1 & 0.62 & 0.33 & p1d8 & 2.45 & 0.0000605 & 0.0000895 & 0.0001320 & 0.4269 \\
\hline 7091215 & $11 / 30 \mathrm{Cl}$ & 34S_4p1d8Ya-44 & $337 / 8$ & $\mathrm{~s}$ & 9 & 4437.4 & $673 / 4$ & $613 / 4$ & 0.297 & 0.446 & HLP-22 & 12 & 4 & 4 & 1.9 & 10.5 & 5.7 & 30.8 & 16.1 & 0.62 & 0.33 & p1d8 & 2.45 & 0.0000605 & 0.0000895 & 0.0001320 & 0.4269 \\
\hline 7091217 & $11 / 30 \mathrm{C1}$ & 34S $4 \mathrm{p} 1 \mathrm{~d} 8 \mathrm{Ya}-44$ & $337 / 8$ & $\mathrm{~s}$ & 9 & 4437.4 & $673 / 4$ & $613 / 4$ & 0.297 & 0.446 & HLP-22 & 12 & 4 & 4 & 1.9 & 10.5 & 5.7 & 30.8 & 16.1 & 0.62 & 0.33 & p1d8 & 2.45 & 0.0000605 & 0.0000895 & 0.0001320 & 0.4269 \\
\hline 7091221 & $11 / 30 \mathrm{C1}$ & 34S_4p1d8Ya-44 & $337 / 8$ & $\mathrm{~s}$ & 9 & 4437.4 & $673 / 4$ & 6134 & 0.297 & 0.446 & HLP-22 & 12 & 4 & 4 & 1.9 & 10.5 & 5.7 & 30.8 & 16.1 & 0.62 & 0.33 & p1d8 & 2.45 & 0.0000605 & 0.0000895 & 0.0001320 & 0.4269 \\
\hline 7091224 & $11 / 30 c_{2}$ & 34S_4p1d8Yd_O & $337 / 8$ & $\mathrm{~s}$ & 9 & 4437.4 & $673 / 4$ & $613 / 4$ & 0.297 & 0.446 & HLP-22 & 12 & 4 & 4 & 1.9 & 10.5 & 5.7 & 30.8 & 16.1 & 0.62 & 0.33 & p1d8 & 2.45 & 0.0000605 & 0.0000895 & 0.0001320 & 0.4269 \\
\hline 7091226 & $11 / 30 \mathrm{C2}$ & 34S_4p1d8Yd_O & $337 / 8$ & $\mathrm{~s}$ & 9 & 4437.4 & $673 / 4$ & $613 / 4$ & 0.297 & 0.446 & HLP-22 & 12 & 4 & 4 & 1.9 & 10.5 & 5.7 & 30.8 & 16.1 & 0.62 & 0.33 & p1d8 & 2.45 & 0.0000605 & 0.0000895 & 0.0001320 & 0.4269 \\
\hline 7091229 & $11 / 30 C_{2}$ & Spld8Yd 0 & $337 / 8$ & $\mathrm{~s}$ & 9 & 4437.4 & $673 / 4$ & $613 / 4$ & 0.297 & 0.446 & HLP-22 & 12 & 4 & 4 & 1.9 & 10.5 & 5.7 & 30.8 & 16.1 & 0.62 & 0.33 & p1d8 & 2.45 & 0.0000605 & 0.0000895 & 0.0001320 & 0.4269 \\
\hline 7091232 & $11 / 30 c 2$ & 34S_4p1d8Yd_0 & $337 / 8$ & $\mathrm{~s}$ & 9 & 4437.4 & $673 / 4$ & $613 / 4$ & 0.297 & 0.446 & HLP-22 & 12 & 4 & 4 & 1.9 & 10.5 & 5.7 & 30.8 & 16.1 & 0.62 & 0.33 & pld8 & 2.45 & 0.0000605 & 0.0000895 & 0.0001320 & 0.4269 \\
\hline 7091236 & $11 / 30 C_{2}$ & 34S_4p1d8Yd_0 & $337 / 8$ & $\mathrm{~s}$ & 9 & 4437.4 & $673 / 4$ & 6134 & 0.297 & 0.446 & HLP-22 & 12 & 4 & 4 & 1.9 & 10.5 & 5.7 & 30.8 & 16.1 & 0.62 & 0.33 & p1d8 & 2.45 & 0.0000605 & 0.0000895 & 0.0001320 & 0.4269 \\
\hline 7091240 & $11 / 30 c_{2}$ & 34S_4p1d8Yd_O & $337 / 8$ & $\mathrm{~s}$ & 9 & 4437.4 & $673 / 4$ & $613 / 4$ & 0.297 & 0.446 & HLP-22 & 12 & 4 & 4 & 1.9 & 10.5 & 5.7 & 30.8 & 16.1 & 0.62 & 0.33 & p1d8 & 2.45 & 0.0000605 & 0.0000895 & 0.0001320 & 0.4269 \\
\hline 7091243 & $11 / 30 \mathrm{C2}$ & 34S_4p1d8Yd_O & $337 / 8$ & $\mathrm{~s}$ & 9 & 4437.4 & $673 / 4$ & $613 / 4$ & 0.297 & 0.446 & HLP-22 & 12 & 4 & 4 & 1.9 & 10.5 & 5.7 & 30.8 & 16.1 & 0.62 & 0.33 & p1d8 & 2.45 & 0.0000605 & 0.0000895 & 0.0001320 & 0.4269 \\
\hline 7091246 & $11 / 30 C_{2}$ & & & $\mathrm{~s}$ & 9 & 4437.4 & $673 / 4$ & 6134 & 0.297 & 0.446 & HLP-22 & 12 & 4 & 4 & 1.9 & 10.5 & 5.7 & 30.8 & 16.1 & 0.62 & 0.33 & p1d8 & 2.45 & 0.0000605 & 0.0000895 & 0.0001320 & 0.4269 \\
\hline 7091249 & $11 / 30 C_{2}$ & 34S_4p1d8Yd_O & $337 / 8$ & $\mathrm{~s}$ & 9 & 4437.4 & $673 / 4$ & $613 / 4$ & 0.297 & 0.446 & HLP-22 & 12 & 4 & 4 & 1.9 & 10.5 & 5.7 & 30.8 & 16.1 & 0.62 & 0.33 & pld8 & 2.45 & 0.0000605 & 0.0000895 & 0.0001320 & 0.4269 \\
\hline 7091253M & $11 / 30 c 2$ & 34S_4p1d8Yd _O & $337 / 8$ & $\mathrm{~s}$ & 9 & 4437.4 & $673 / 4$ & 6134 & 0.297 & 0.446 & HLP-22 & 12 & 4 & 4 & 1.9 & 10.5 & 5.7 & 30.8 & 16.1 & 0.62 & 0.33 & pld8 & 2.45 & 0.0000605 & 0.0000895 & 0.0001320 & 0.4269 \\
\hline
\end{tabular}


Table B.8. Data from Fall 2007 Tests in Mid-Scale Vessel with Spherical Head B.10

\begin{tabular}{|c|c|c|c|c|c|c|c|c|c|c|c|c|c|c|c|c|c|c|c|c|c|c|c|c|c|c|c|c|c|}
\hline $\begin{array}{l}\text { Tank Water } \\
\text { Temperature }\end{array}$ & $\begin{array}{l}\text { Water } \\
\text { Density }\end{array}$ & $\begin{array}{l}\text { Solids } \\
\text { Fraction }\end{array}$ & $\begin{array}{l}\text { Pulse } \\
\text { Volume } \\
\text { Fraction }\end{array}$ & $\begin{array}{l}\text { Duty } \\
\text { Cycle }\end{array}$ & $\begin{array}{l}\text { Cyde } \\
\text { Time }\end{array}$ & $\begin{array}{c}\text { Pulsed } \\
\text { or } \\
\text { Steacdy } \\
\text { Jet } \\
\end{array}$ & $\begin{array}{c}\text { Us } \\
\text { Steacady } \\
\text { Jet }\end{array}$ & \begin{tabular}{|c|} 
U1 \\
Pulsing \\
Jet
\end{tabular} & $\begin{array}{c}\text { U2 } \\
\text { URMS }\end{array}$ & \begin{tabular}{|c|} 
UB \\
URNB \\
\end{tabular} & $\begin{array}{c}\text { Discharge } \\
\text { Velocity }\end{array}$ & $\begin{array}{c}\text { Citical } \\
\text { Suspension } \\
\text { velocily }\end{array}$ & \begin{tabular}{|c|} 
Average \\
Peak \\
Cloud \\
Height \\
\end{tabular} & $\begin{array}{c}\text { UCS } \\
\text { Condition }\end{array}$ & $\begin{array}{c}\text { UCS } \\
\text { Nethod }\end{array}$ & $\begin{array}{l}\text { UCS } \\
\text { Fag }\end{array}$ & $\begin{array}{c}\text { UCs } \\
\text { Center } \\
\text { Flag }\end{array}$ & $\begin{array}{c}\text { UcS udv } \\
\text { Hag }\end{array}$ & \begin{tabular}{|c|} 
UCS based \\
on \\
Decreasing \\
Velocity \\
\end{tabular} & $\begin{array}{l}\text { Sweep } \\
\text { Inncrease/ } \\
\text { Decrease }\end{array}$ & $\begin{array}{c}\text { UDV } \\
\text { Height } \\
\text { Bed } \\
\end{array}$ & \begin{tabular}{|l|}
$\begin{array}{l}\text { Particle } \\
\text { Motion }\end{array}$ \\
\end{tabular} & $\begin{array}{l}\text { Solids } \\
\text { Level } \\
\end{array}$ & $\begin{array}{l}\text { Outer } \\
\text { Bottom } \\
\text { Patem }\end{array}$ & \begin{tabular}{|l} 
Inner \\
Botomom \\
Pattem \\
\end{tabular} & Case ID & Test & TDP & $\begin{array}{c}\text { Rav } \\
\text { Number }\end{array}$ \\
\hline $\mathrm{C}$ & $\mathrm{g} / \mathrm{cm}^{3}$ & fraction & fraction & fraction & $\mathrm{s}$ & text & $\mathrm{m} / \mathrm{s}$ & $\mathrm{m} / \mathrm{s}$ & $\mathrm{m} / \mathrm{s}$ & $\mathrm{m} / \mathrm{s}$ & $\mathrm{m} / \mathrm{s}$ & $\mathrm{m} / \mathrm{s}$ & in. & $\mathrm{m} / \mathrm{s}$ & text & text & text & text & m/s & text & $\mathrm{mm}$ & text & text & text & text & text & text & text & text \\
\hline $\mathrm{T}$ & $\rho$ & $\phi_{\mathrm{s}}$ & $\phi_{p}$ & $\mathrm{DC}$ & $t_{c}$ & Jet & $u_{s}$ & $\mathrm{U}_{1}$ & $\mathrm{U} 2$ & U3 & $u$ & Uss & $H_{c}$ & Uase & Uosn & Ussis & Uscen & Usoudur & $U_{c s} D$ & $\mathrm{~s}_{\mathrm{v}}$ & $H_{\text {bed }}$ & $\mathrm{PM}$ & Sol & $\mathrm{SPo}$ & $\mathrm{SP}_{1}$ & ID & MDDX & $\mathrm{TDP}$ & MSS \\
\hline 22.0 & 0.999 & 0.00487 & 0.052 & 0.180 & 0.0 & $\mathrm{P}$ & $\mathrm{NA}$ & 9.72 & 10.20 & 10.44 & 10.00 & 10.00 & 21.25 & 10.00 & vis & ucsis & NA & NA & NA & 1 & $\mathrm{NA}$ & cs & NA & $\mathrm{NA}$ & NA & 34S_4p1d/Yd_ 5 & $11 / 2782$ & TDP-WIP-065 & 7091131 \\
\hline 22.0 & 0.999 & 0.00487 & 0.051 & 0.180 & 0.0 & $\mathrm{P}$ & NA & 9.73 & 10.32 & 10.60 & 10.50 & 10.00 & 21.75 & NA & NA & NA & NA & NA & NA & 1 & NA & $\mathrm{BC}-$ & NA & NA & NA & 34S_4p1d/Ydd 5 & $11 / 27 \mathrm{~B} 2$ & TDP-WTP-065 & 7091134 \\
\hline 22.0 & 0.999 & 0.00487 & 0.051 & 0.180 & 0.0 & $P$ & NA & 9.89 & 10.59 & 10.92 & 11.00 & 10.00 & 23.25 & NA & NA & NA & NA & NA & NA & 1 & NA & $\mathrm{BC}$ & NA & NA & NA & 34S_4p1dTYd_5 & $11 / 27 B 2$ & TDP-WIP-065 & 7091136 \\
\hline 22.0 & 0.999 & 0.00487 & 0.051 & 0.330 & 0.0 & $\mathrm{P}$ & NA & 7.99 & 8.14 & 8.22 & 8.00 & 10.00 & 12.25 & NA & NA & NA & NA & NA & NA & $\mathrm{I}$ & NA & ss & NA & NA & NA & $34 \mathrm{~S} \_4 \mathrm{p} 1 \mathrm{~d} / \mathrm{YCC}, 5$ & $11 / 2783$ & TDP-WIP-065 & 7091139 \\
\hline 22.0 & 0.999 & 0.00487 & 0.056 & 0.330 & 0.0 & $\mathrm{P}$ & NA & 9.99 & 10.19 & 10.29 & 9.00 & 10.00 & 16.25 & NA & NA & NA & NA & NA & NA & 1 & NA & sst+ & NA & NA & NA & 34S_4p1d/rc_5 5 & $11 / 2783$ & TDP-WIP-065 & 7091142 \\
\hline 22.0 & 0.999 & 0.00487 & 0.051 & 0.330 & 0.0 & $\mathrm{P}$ & NA & 9.45 & 9.70 & 9.84 & 9.50 & 10.00 & 19.50 & NA & NA & NA & NA & NA & NA & $\mathrm{I}$ & NA & AM & NA & NA & NA & $34 \mathrm{~S}=4 \mathrm{p} 1 \mathrm{~d} / \mathrm{YC}$ & $11 / 2783$ & TDP-WIP-065 & 7091145 \\
\hline 22.0 & 0.999 & 0.00487 & 0.050 & 0.330 & 0.0 & $\mathrm{P}$ & NA & 9.86 & 10.14 & 10.28 & 10.00 & 10.00 & 21.25 & \begin{tabular}{|l|}
10.00 \\
\end{tabular} & vis & ucsis & NA & NA & NA & 1 & NA & cs & NA & NA & NA & 34S_4p1dTrc_ 5 & $11 / 2783$ & TDP-WIP-065 & 7091149 \\
\hline 220 & 0.999 & 0.00487 & 0.050 & 0.330 & 0.0 & $\mathrm{P}$ & NA & \begin{tabular}{|l|}
10.29 \\
\end{tabular} & 10.83 & 11.08 & 11.00 & 10.00 & \begin{tabular}{|l|}
26.75 \\
\end{tabular} & NA & NA & NA & NA & NA & NA & 1 & NA & $B C$ & NA & NA & NA & 34S_4p1dTYC_5 & $11 / 2783$ & TDP-WIP-065 & 7091151 \\
\hline 21.0 & 0.999 & 0.00487 & undefined & 1.000 & infinite & $s$ & 1.99 & \begin{tabular}{|l|l} 
NA & \\
\end{tabular} & NA & NA & 2.00 & 3.90 & \begin{tabular}{|l|l|} 
NA \\
\end{tabular} & NA & NA & NA & NA & NA & NA & NA & NA & ss & NA & NA & NA & 34S_4p1d8Ya & 11/30A1 & TDP-WIP-066 & 7091154 \\
\hline 20.9 & 0.999 & 0.00487 & undefined & 1.000 & infinite & $s$ & 3.05 & NA & NA & NA & 3.00 & 3.90 & NA & NA & NA & NA & NA & NA & NA & 1 & NA & $A M$ & NA & NA & NA & 34S_4p1dBYa & 1130A1 & TDP-WIP-066 & 7091158 \\
\hline 20.9 & 0.999 & 0.00487 & undefined & 1.000 & infinite & $\mathrm{s}$ & 3.52 & NA & NA & NA & 3.50 & 3.90 & \begin{tabular}{|l|}
14.50 \\
\end{tabular} & NA & NA & NA & UCSoen & NA & NA & $\mathrm{I}$ & NA & $A M$ & NA & NA & NA & 34S _pp1dBYa & 11/30A1 & TDP-WIP-066 & 7091161 \\
\hline 21.0 & 0.999 & 0.00487 & undefined & 1.000 & infinite & $\mathrm{s}$ & 3.72 & NA & NA & NA & 3.70 & 3.90 & 24.50 & NA & NA & NA & NA & NA & NA & 1 & NA & AMt & NA & NA & NA & 34S_4p1dBYa & $1130 \mathrm{~A} 1$ & TDP-WIP-066 & 7091164 \\
\hline 21.0 & 0.999 & 0.00487 & undefined & 1.000 & infinite & $\mathrm{s}$ & 3.96 & NA & NA & NA & 3.90 & 3.90 & 33.50 & 3.90 & vis & ucsis & NA & NA & NA & 1 & NA & cs & NA & NA & NA & 34S_4p1dBYa & 11/30A1 & TDP-WIP-066 & 7091167 \\
\hline 21.0 & 0.999 & 0.00487 & undefined & 1.000 & infinite & $s$ & 4.12 & NA & NA & NA & 4.10 & 3.90 & 42.50 & NA & NA & NA & NA & NA & NA & $\mathrm{I}$ & NA & $\mathrm{BC}$ & NA & NA & NA & 34S_4p1d8Ya & 11/30A1 & TDP-WIP-066 & 7091169 \\
\hline 21.0 & 0.999 & 0.00487 & 0.050 & 0.180 & 0.0 & $\mathrm{P}$ & NA & \begin{tabular}{|l|} 
\\
\end{tabular} & 3.95 & \begin{tabular}{|l|}
3.97 \\
\end{tabular} & 4.00 & 6.00 & NA & NA & NA & NA & NA & NA & NA & 1 & NA & ss & NA & NA & NA & 34S_4p1d8Yd_1 & $1130 \mathrm{~A}^{2}$ & TDP-WIP-066 & 7091172 \\
\hline 21.0 & 0.999 & 0.00487 & 0.050 & 0.180 & 0.0 & $\mathrm{P}$ & NA & 4.44 & 4.48 & 4.50 & 4.50 & 6.00 & 9.00 & NA & NA & NA & NA & NA & NA & $\mathrm{I}$ & NA & AMt & NA & NA & NA & 34S_4p1d8Yd_1 & $1130 \mathrm{~A}^{2}$ & TDP-WIP-066 & 7091175 \\
\hline 21.0 & 0.999 & 0.00487 & 0.049 & 0.180 & 0.0 & $\mathrm{P}$ & NA & 4.85 & 4.90 & 4.93 & 5.00 & 6.00 & 9.75 & NA & NA & NA & NA & NA & NA & 1 & NA & $A M$ & NA & NA & NA & 34S_4p1d8Yd 1 & $1130 \mathrm{AZ}^{2}$ & TDP-WIP-066 & 7091178 \\
\hline 21.0 & 0.999 & 0.00487 & 0.050 & 0.180 & 0.0 & $\mathrm{P}$ & NA & 5.38 & 5.45 & 5.49 & 5.50 & 6.00 & 11.25 & NA & NA & NA & NA & NA & NA & 1 & NA & AMt & NA & NA & NA & 34S_4p1d8Yd_1 & $11 / 30 \mathrm{~A} 2$ & TDP-WIP-066 & 7091181 \\
\hline 21.0 & 0.999 & 0.00487 & 0.050 & 0.180 & 0.0 & $\mathrm{P}$ & NA & 5.86 & 5.95 & 5.99 & 6.00 & 6.00 & 12.50 & \begin{tabular}{|l|}
6.00 \\
\end{tabular} & vis & UCSis & NA & NA & NA & $\mathrm{I}$ & NA & cs & NA & NA & NA & 34S_4p1d8Yd_1 & $11 / 30 \mathrm{~A} 2$ & TDP-WIP-066 & 7091185 \\
\hline 21.0 & 0.999 & 0.00487 & 0.050 & 0.180 & 0.0 & $\mathrm{P}$ & NA & 6.37 & 6.48 & 6.53 & 6.50 & 6.00 & 16.75 & NA & NA & NA & NA & NA & NA & 1 & NA & $B C$ & NA & NA & NA & 34S_4p1d8Yd_ 1 & $1130 \mathrm{AZ}$ & TDP-WIP-066 & 7091187 \\
\hline 21.0 & 0.999 & 0.00487 & 0.050 & 0.330 & 0.0 & $\mathrm{P}$ & NA & 3.89 & 3.93 & 3.95 & 4.00 & 5.30 & 8.50 & NA & NA & NA & NA & NA & NA & D & NA & ss & NA & NA & NA & 34S_4p1d8Yc_1 1 & 11/30B1 & TDP-WIP-066 & 7091191 \\
\hline 21.0 & 0.999 & 0.00487 & 0.050 & 0.330 & 0.0 & $\mathrm{P}$ & NA & 4.43 & 4.48 & 4.50 & 4.50 & 5.30 & 9.75 & NA & NA & NA & NA & NA & NA & 1 & NA & sSt & NA & NA & NA & 34S_4p1d8Yc_1 & 113081 & TDP-WIP-066 & 7091193 \\
\hline 21.0 & 0.999 & 0.00487 & 0.052 & 0.330 & 0.0 & $\mathrm{P}$ & NA & 4.87 & 4.94 & 4.97 & 5.00 & 5.30 & 10.75 & NA & NA & NA & NA & NA & NA & 1 & NA & AM & NA & NA & NA & 34S_4p1d8Yc_1 & $11 / 30 \mathrm{B1}$ & TDP-WIP-066 & 7091197 \\
\hline 21.0 & 0.999 & 0.00487 & 0.050 & 0.330 & 0.0 & $\mathrm{P}$ & NA & 5.16 & 5.22 & 5.25 & 5.30 & 5.30 & 12.50 & 5.30 & vis & Uesvis & NA & NA & NA & 1 & NA & Cs & NA & NA & NA & 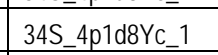 & $11 / 30 \mathrm{~B} 1$ & TDP-WIP-066 & 7091200 \\
\hline 21.0 & 0.999 & 0.00487 & 0.050 & 0.330 & 0.0 & $\mathrm{P}$ & NA & 5.52 & 5.59 & \begin{tabular}{|l|}
5.62 \\
\end{tabular} & 5.60 & 5.30 & 17.50 & NA & NA & NA & NA & NA & NA & 1 & NA & $\mathrm{BC}$ & NA & NA & NA & 34S_4p1d8Yc_1 & 11/3081 & TDP-WIP-066 & 7091202 \\
\hline 21.3 & 0.999 & 0.00487 & undefined & 1.000 & infinite & $\mathrm{s}$ & 3.53 & \begin{tabular}{|l|l} 
NA & \\
\end{tabular} & NA & \begin{tabular}{|l|l|} 
NA \\
\end{tabular} & 3.50 & 5.50 & NA & NA & NA & NA & NA & NA & NA & $\mathrm{I}$ & NA & ss & NA & NA & NA & 34S_4p1d8Ya-44 & $11 / 30 \mathrm{Cl}$ & TDP-WIP-066 & 7091206 \\
\hline 21.2 & 0.999 & 0.00487 & undefined & 1.000 & infinite & $s$ & 3.70 & NA & NA & NA & 3.70 & 5.50 & NA & NA & NA & NA & UCscen & NA & NA & 1 & NA & ss & NA & NA & NA & 34S_4p1d8Ya-44 & $11 / 30 \mathrm{C1}$ & TDP-WIP-066 & 7091209 \\
\hline 21.3 & 0.999 & 0.00487 & undefined & 1.000 & infinite & $\mathrm{s}$ & 4.04 & NA & NA & NA & 4.00 & 5.50 & 9.50 & NA & NA & NA & NA & NA & NA & 1 & NA & AM & NA & NA & NA & 34S_4p1d8Ya-44 & $11 / 30 \mathrm{C1}$ & TDP-WIP-066 & 7091212 \\
\hline 21.3 & 0.999 & 0.00487 & undefined & 1.000 & infinite & $\mathrm{s}$ & 4.54 & NA & NA & NA & 4.50 & 5.50 & 14.25 & NA & NA & NA & NA & NA & NA & 1 & NA & AM & NA & NA & NA & 34__4p1d8Ya-44 & $11 / 30 \mathrm{CC}$ & TDP-WIP-066 & 7091215 \\
\hline 21.3 & 0.999 & 0.00487 & undefined & 1.000 & infinite & $\mathrm{s}$ & 5.03 & NA & NA & NA & 5.00 & 5.50 & 29.25 & NA & NA & NA & NA & NA & NA & 1 & NA & AM+ & NA & NA & NA & 345_4p1d8Ya-44 & $11 / 30 C_{1}$ & TDP-WIP-066 & 7091217 \\
\hline 21.3 & 0.999 & 0.00487 & undefined & 1.000 & infinite & $\mathrm{s}$ & 5.55 & NA & NA & NA & 5.50 & 5.50 & 43.75 & 5.50 & vis & UCSis & NA & NA & NA & $\mathrm{I}$ & NA & CS & NA & NA & NA & 34S_4p1d8Ya-44 & $11 / 30 \mathrm{Cl}$ & TDP-WIP-066 & 7091221 \\
\hline 21.0 & 0.999 & 0.00487 & 0.051 & 0.180 & 87.0 & $\mathrm{P}$ & NA & \begin{tabular}{|r|}
4.55 \\
\end{tabular} & 4.60 & \begin{tabular}{|l|}
4.63 \\
\end{tabular} & 4.50 & 9.00 & \begin{tabular}{|l|l|} 
NA \\
\end{tabular} & NA & NA & NA & Ucscen & NA & NA & 1 & NA & ss & NA & NA & NA & 34S_4p1d8Yd_O 0 & $11 / 30 \mathrm{C2} 2$ & TDP-WIP-066 & 7091224 \\
\hline 21.0 & 0.999 & 0.00487 & 0.051 & 0.180 & 78.0 & $\mathrm{P}$ & NA & 5.06 & 5.10 & 5.14 & 5.00 & 9.00 & 9.50 & NA & NA & NA & NA & NA & NA & 1 & NA & AM & NA & NA & NA & 345 4p1d8Yd 0 & $11 / 30 C_{2}$ & TDP-WIP-066 & 7091226 \\
\hline 21.0 & 0.999 & 0.00487 & 0.051 & 0.180 & 70.0 & $\mathrm{P}$ & NA & 5.61 & 5.67 & 5.71 & 5.50 & 9.00 & 11.00 & NA & NA & NA & NA & NA & NA & 1 & NA & AM & NA & NA & NA & 34S_4p1d8Yd 0 & $11 / 30 \mathrm{CC} 2$ & TDP-WIP-066 & 7091229 \\
\hline 21.0 & 0.999 & 0.00487 & 0.050 & 0.180 & 64.0 & $\mathrm{P}$ & NA & 6.10 & 6.16 & 6.21 & 6.00 & 9.00 & 12.83 & NA & NA & NA & NA & NA & NA & 1 & NA & AM & NA & NA & NA & 345_4p1d8Yd_O & $11 / 30 C_{2}$ & TDP-WIP-066 & 7091232 \\
\hline 21.0 & 0.999 & 0.00487 & 0.050 & 0.180 & 59.0 & $\mathrm{P}$ & NA & 6.58 & 6.65 & 6.71 & & 9.00 & 15.00 & NA & NA & NA & NA & NA & NA & $\mathrm{I}$ & NA & AM & NA & NA & NA & 34S_4p1d8Yd_O 0 & $11 / 30 C_{2}$ & IDP-WIP-066 & 7091236 \\
\hline 21.0 & 0.999 & 0.00487 & 0.051 & 0.180 & 54.0 & $\mathrm{P}$ & NA & 7.15 & 7.23 & 7.29 & 7.00 & 9.00 & 15.50 & NA & NA & NA & NA & NA & NA & 1 & NA & AM+ & $\mathrm{NA}$ & NA & NA & 34S_4p1d8Yd_O & $11 / 30 C_{2}$ & TDP-WIP-066 & 7091240 \\
\hline 21.0 & 0.999 & 0.00487 & 0.050 & 0.180 & 50.5 & $\mathrm{P}$ & NA & 7.55 & 7.66 & 7.74 & 7.50 & 9.00 & 17.63 & NA & NA & NA & NA & NA & NA & 1 & NA & AMt & NA & NA & NA & 34S_4p1d8Yd_O & $1130 \mathrm{C2}$ & TDP-WIP-066 & 7091243 \\
\hline 21.0 & 0.999 & 0.00487 & 0.046 & 0.180 & 47.0 & $\mathrm{P}$ & NA & 8.16 & 8.28 & 8.37 & 8.00 & 9.00 & 20.25 & NA & NA & NA & NA & NA & NA & 1 & NA & $\mathrm{AM+}$ & NA & NA & NA & 34S $4 \mathrm{p} 1 \mathrm{~d}$ dird 0 & $11330 \mathrm{C2}$ & TDP-WIP-066 & 7091246 \\
\hline 21.0 & 0.999 & 0.00487 & 0.050 & 0.180 & 45.0 & $P$ & NA & 8.58 & 8.69 & 8.76 & 8.50 & 9.00 & 22.25 & NA & NA & NA & NA & NA & NA & 1 & NA & AMt & NA & NA & NA & 34S_4p1d8Yd_O & $11 / 30 C_{2}$ & TDP-WIP-066 & 7091249 \\
\hline 21.0 & 0.999 & 0.00487 & 0.051 & 0.180 & 42.5 & $\mathrm{P}$ & NA & 9.10 & 9.24 & 9.33 & 9.00 & 9.00 & 25.88 & 9.00 & vis & UCSis & NA & NA & NA & 1 & NA & cs & NA & NA & NA & 34S_ 4 P1d8YY 0 & $11 / 30 C_{2}$ & TDP-WIP-066 & 7091253 \\
\hline
\end{tabular}


Table B.8. Data from Fall 2007 Tests in Mid-Scale Vessel with Spherical Head A.11

\begin{tabular}{|c|c|c|c|c|c|c|c|c|c|c|c|c|c|c|c|c|c|c|c|c|c|c|c|c|c|c|c|}
\hline $\begin{array}{l}\text { Row } \\
\text { Number }\end{array}$ & Test & Case ID & $\begin{array}{c}\text { Tank } \\
\text { Diameter }\end{array}$ & $\begin{array}{l}\text { Head } \\
\text { Shape }\end{array}$ & $\begin{array}{c}\text { Dish } \\
\text { Height }\end{array}$ & $\begin{array}{l}\text { Dish } \\
\text { Volume }\end{array}$ & $\begin{array}{l}\text { Tank } \\
\text { Fill } \\
\text { Height }\end{array}$ & $\begin{array}{l}\text { Return } \\
\text { Line } \\
\text { Height }\end{array}$ & $\begin{array}{c}\text { Nozzle } \\
\text { Inner } \\
\text { Diameter }\end{array}$ & $\begin{array}{c}\text { Nozzle } \\
\text { Stanct- } \\
\text { of } \\
\text { Distance } \\
\end{array}$ & $\begin{array}{l}\text { Pulse Tube } \\
\text { Configuration }\end{array}$ & $\begin{array}{l}\text { Installed } \\
\text { Nozzles }\end{array}$ & $\begin{array}{c}\text { Outer } \\
\text { Nozzles } \\
\text { Operated }\end{array}$ & $\begin{array}{c}\text { Inner } \\
\text { Nozzles } \\
\text { Operated }\end{array}$ & $\begin{array}{l}\text { Pulse Tube } \\
\text { Outer } \\
\text { Diameter }\end{array}$ & $\begin{array}{c}\text { Outer } \\
\text { PJM } \\
\text { Radius }\end{array}$ & $\begin{array}{c}\text { Inner } \\
\text { PJM } \\
\text { Radius }\end{array}$ & $\begin{array}{c}\text { "FlO" Outer } \\
\text { PJM } \\
\text { Impingement } \\
\text { Angle }\end{array}$ & $\begin{array}{c}\text { "FO' Inner } \\
\text { PJM } \\
\text { Impingement } \\
\text { Angle } \\
\end{array}$ & $\begin{array}{c}\text { Ratio Outer } \\
\text { PJM to } \\
\text { Tank } \\
\text { Radius } \\
\end{array}$ & $\begin{array}{c}\text { Ratio Inner } \\
\text { PJM to } \\
\text { Tank } \\
\text { Radius } \\
\end{array}$ & Simulant & $\begin{array}{l}\text { Solids } \\
\text { Density }\end{array}$ & $\begin{array}{c}\text { Particle } \\
\text { Diameter d5 }\end{array}$ & $\begin{array}{l}\text { Particle } \\
\text { Diameter } \\
\text { d50 }\end{array}$ & $\begin{array}{c}\text { Particle } \\
\text { Diantert } \\
\text { d95 }\end{array}$ & $\begin{array}{l}\text { Void } \\
\text { Fraction }\end{array}$ \\
\hline text & text & text & in. & text & in. & in. ${ }^{3}$ & in. & in. & in. & in. & text & number & number & number & in. & in. & in. & deg & deg & nondim & nondim & text & $\mathrm{g} / \mathrm{cm}^{3}$ & $\mathrm{~m}$ & $\mathrm{~m}$ & $\mathrm{~m}$ & fraction \\
\hline MSS & MDDX & $\mathrm{ID}$ & $\mathrm{D}$ & $\mathrm{HS}$ & $H_{\text {stat }}$ & $V_{\text {dath }}$ & $\mathrm{H}$ & Rin & $d$ & sod & PT & $\mathrm{N}$ & $\mathrm{N}_{\mathrm{b}}$ & $\mathrm{N}$ & $\mathrm{PT}_{\alpha \mathrm{d}}$ & $\mathrm{R}_{0}$ & $R_{1}$ & $\theta_{0}$ & $\theta_{1}$ & RdR & $R / R$ & sxdx & $\rho_{\mathrm{s}}$ & $d_{5}$ & $d_{0}$ & $d_{65}$ & vf \\
\hline 7092256 & $12 / 3 A 1$ & $345,4 p 1 d 8 Y c \_0$ & $337 / 8$ & $\mathrm{~s}$ & 9 & 4437.4 & $673 / 4$ & $613 / 4$ & 0.297 & 0.446 & HLP-22 & 12 & 4 & 4 & 1.9 & 10.5 & 5.7 & 30.8 & 16.1 & 0.62 & 0.33 & $\mathrm{p} 1 \mathrm{~d} 8$ & 2.45 & 0.0000605 & 0.0000895 & 0.0001320 & 0.4269 \\
\hline 7091259 & 12/3A1 & 34S_4p1d8Yc_0 0 & $337 / 8$ & $\mathrm{~s}$ & 9 & 4437.4 & $673 / 4$ & $613 / 4$ & 0.297 & 0.446 & HLP-22 & 12 & 4 & 4 & 1.9 & 10.5 & 5.7 & 30.8 & 16.1 & 0.62 & 0.33 & p1d8 & 2.45 & 0.0000605 & 0.00000895 & 0.0001320 & 0.4269 \\
\hline 7091261 & 12/3A1 & 34S_4p1d8Yc_0 & $337 / 8$ & $\mathrm{~s}$ & 9 & 4437.4 & $673 / 4$ & $613 / 4$ & 0.297 & 0.446 & HLP-22 & 12 & 4 & 4 & 1.9 & 10.5 & 5.7 & 30.8 & 16.1 & 0.62 & 0.33 & p1d8 & 2.45 & 0.0000605 & 0.0000895 & 0.0001320 & 0.4269 \\
\hline 7091265 & $12 / 3 \mathrm{~A} 1$ & 34S_4p1d8Yc_0 & $337 / 8$ & $\mathrm{~s}$ & 9 & 4437.4 & $673 / 4$ & 6134 & 0.297 & 0.446 & HLP-22 & 12 & 4 & 4 & 1.9 & 10.5 & 5.7 & 30.8 & 16.1 & 0.62 & 0.33 & plds & 2.45 & 0.0000605 & 0.0000895 & 0.0001320 & 0.4269 \\
\hline 7091268M & 12/3A1 & $34 S \_4 p 1 d 8 Y c \_0$ & $337 / 8$ & $s$ & 9 & 4437.4 & $673 / 4$ & $613 / 4$ & 0.297 & 0.446 & HLP-22 & 12 & 4 & 4 & 1.9 & 10.5 & 5.7 & 30.8 & 16.1 & 0.62 & 0.33 & p1d8 & 2.45 & 0.0000605 & 0.0000895 & 0.0001320 & 0.4269 \\
\hline 7091270M & $12 / 3 \mathrm{~A} 1$ & 34S_4p1d8Yc_0 & $337 / 8$ & $s$ & 9 & 4437.4 & $673 / 4$ & $613 / 4$ & 0.297 & 0.446 & HLP-22 & 12 & 4 & 4 & 1.9 & 10.5 & 5.7 & 30.8 & 16.1 & 0.62 & 0.33 & p1d8 & 2.45 & 0.0000605 & 0.0000895 & 0.0001320 & 0.4269 \\
\hline 7091274 & 12/3B1 & 34S_4p1d8Ya-04 & $337 / 8$ & $\mathrm{~s}$ & 9 & 4437.4 & $673 / 4$ & $613 / 4$ & 0.297 & 0.446 & HLP-22 & 12 & 0 & 4 & 1.9 & 10.5 & 5.7 & 30.8 & 16.1 & 0.62 & 0.33 & p1d8 & 2.45 & 0.0000605 & 0.0000895 & 0.0001320 & 0.4269 \\
\hline $70912 \pi$ & $12 / 3 \mathrm{~B} 1$ & 34S_4p1d8Ya-04 & $337 / 8$ & $s$ & 9 & 4437.4 & $673 / 4$ & $613 / 4$ & 0.297 & 0.446 & HLP-22 & 12 & 0 & 4 & 1.9 & 10.5 & 5.7 & 30.8 & 16.1 & 0.62 & 0.33 & p1d8 & 2.45 & 0.0000605 & 0.0000895 & 0.0001320 & 0.4269 \\
\hline 7091279 & $12 / 3 \mathrm{~B} 1$ & 34S_4p1d8Ya-04 & $337 / 8$ & $\mathrm{~s}$ & 9 & 4437.4 & $673 / 4$ & $613 / 4$ & 0.297 & 0.446 & HLP-22 & 12 & 0 & 4 & 1.9 & 10.5 & 5.7 & 30.8 & 16.1 & 0.62 & 0.33 & pld8 & 2.45 & 0.0000605 & 0.0000895 & 0.0001320 & 0.4269 \\
\hline 7091283 & 12/3B1 & 34S_4p1d8Ya-04 & $337 / 8$ & $\mathrm{~s}$ & 9 & 4437.4 & $673 / 4$ & $613 / 4$ & 0.297 & 0.446 & HLP-22 & 12 & 0 & 4 & 1.9 & 10.5 & 5.7 & 30.8 & 16.1 & 0.62 & 0.33 & p1d8 & 2.45 & 0.0000605 & 0.0000895 & 0.0001320 & 0.4269 \\
\hline 7091286 & $12 / 3 \mathrm{~B} 1$ & 34S_4p1d8Ya-04 & $337 / 8$ & $\mathrm{~s}$ & 9 & 4437.4 & $673 / 4$ & 6134 & 0.297 & 0.446 & HLP-22 & 12 & 0 & 4 & 1.9 & 10.5 & 5.7 & 30.8 & 16.1 & 0.62 & 0.33 & p1d8 & 2.45 & 0.0000605 & 0.0000895 & 0.0001320 & 0.4269 \\
\hline 7091289 & $12 / 3 \mathrm{~B} 2$ & 34S_4p1d8Yd_9 9 & $337 / 8$ & $\mathrm{~s}$ & 9 & 4437.4 & $673 / 4$ & $613 / 4$ & 0.297 & 0.446 & HLP-22 & 12 & 0 & 4 & 1.9 & 10.5 & 5.7 & 30.8 & 16.1 & 0.62 & 0.33 & p1d8 & 2.45 & 0.0000605 & 0.0000895 & 0.0001320 & 0.4269 \\
\hline 7091291 & $12 / 3 \mathrm{~B} 2$ & 34S_4p1d8Yd_9 & $337 / 8$ & $s$ & 9 & 4437.4 & $673 / 4$ & 6134 & 0.297 & 0.446 & HLP-22 & 12 & 0 & 4 & 1.9 & 10.5 & 5.7 & 30.8 & 16.1 & 0.62 & 0.33 & pld8 & 2.45 & 0.0000605 & 0.0000895 & 0.0001320 & 0.4269 \\
\hline 7091294 & $12 / 3 \mathrm{~B} 2$ & 34S_4p1d8Yd_9 & $337 / 8$ & $\mathrm{~s}$ & 9 & 4437.4 & $673 / 4$ & 6134 & 0.297 & 0.446 & HLP-22 & 12 & 0 & 4 & 19 & 10.5 & 5.7 & 30.8 & 16.1 & 0.62 & 0.33 & p1d8 & 2.45 & 0.0000605 & 0.0000895 & 0.0001320 & 0.4269 \\
\hline 7091297 & $12 / 3 \mathrm{~B} 2$ & 34S_4p1d8Yd_9 9 & $337 / 8$ & $\mathrm{~s}$ & 9 & 4437.4 & $673 / 4$ & 6134 & 0.297 & 0.446 & HLP-22 & 12 & 0 & 4 & 1.9 & 10.5 & 5.7 & 30.8 & 16.1 & 0.62 & 0.33 & pld8 & 2.45 & 0.0000605 & 0.0000895 & 0.0001320 & 0.4269 \\
\hline 7091300 & $12 / 3 \mathrm{~B} 2$ & 34S_4p1d8Yd_9 9 & $337 / 8$ & $\mathrm{~s}$ & 9 & 4437.4 & $673 / 4$ & 6134 & 0.297 & 0.446 & HLP-22 & 12 & 0 & 4 & 19 & 10.5 & 5.7 & 30.8 & 16.1 & 0.62 & 0.33 & p1d8 & 2.45 & 0.0000605 & 0.0000895 & 0.0001320 & 0.4269 \\
\hline 7091303 & $12 / 3 \mathrm{~B} 2$ & 34S_4p1d8Yd_9 & $337 / 8$ & $\mathrm{~s}$ & 9 & 4437.4 & $673 / 4$ & $613 / 4$ & 0.297 & 0.446 & HLP-22 & 12 & 0 & 4 & 1.9 & 10.5 & 5.7 & 30.8 & 16.1 & 0.62 & 0.33 & p1d8 & 2.45 & 0.0000605 & 0.0000895 & 0.0001320 & 0.4269 \\
\hline 7091306 & $12 / 3 \mathrm{~B} 2$ & 34S_4p1d8Yd_9 & $337 / 8$ & $\mathrm{~s}$ & 9 & 4437.4 & $673 / 4$ & 6134 & 0.297 & 0.446 & HLP-22 & 12 & 0 & 4 & 19 & 10.5 & 5.7 & 30.8 & 16.1 & 0.62 & 0.33 & p1d8 & 2.45 & 0.0000605 & 0.0000895 & 0.0001320 & 0.4269 \\
\hline 7091310m & $12 / 3 \mathrm{~B} 2$ & 34S_4p1d8Yd_9 & $337 / 8$ & $\mathrm{~s}$ & 9 & 4437.4 & $673 / 4$ & 6134 & 0.297 & 0.446 & HLP-22 & 12 & 0 & 4 & 1.9 & 10.5 & 5.7 & 30.8 & 16.1 & 0.62 & 0.33 & pld8 & 2.45 & 0.0000605 & 0.0000895 & 0.0001320 & 0.4269 \\
\hline 7091312M & 12/382 & 34S_4p1d8Yd_9 9 & $337 / 8$ & $s$ & 9 & 4437.4 & $673 / 4$ & $613 / 4$ & 0.297 & 0.446 & HLP-22 & 12 & 0 & 4 & 1.9 & 10.5 & 5.7 & 30.8 & 16.1 & 0.62 & 0.33 & p1d8 & 2.45 & 0.0000605 & 0.0000895 & 0.0001320 & 0.4269 \\
\hline 7091316 & $12 / 3 \mathrm{C} 1$ & 34S_4p1d8Yc_9 9 & $337 / 8$ & $\mathrm{~s}$ & 9 & 4437.4 & $673 / 4$ & $613 / 4$ & 0.297 & 0.446 & HLP-22 & 12 & 0 & 4 & 1.9 & 10.5 & 5.7 & 30.8 & 16.1 & 0.62 & 0.33 & p1d8 & 2.45 & 0.0000605 & 0.0000895 & 0.0001320 & 0.4269 \\
\hline 7091318 & $12 / 3 \mathrm{C} 1$ & $345 \_4 p 1 d 8 Y c \_9$ & $337 / 8$ & $s$ & 9 & 4437.4 & $673 / 4$ & $613 / 4$ & 0.297 & 0.446 & HLP-22 & 12 & 0 & 4 & 1.9 & 10.5 & 5.7 & 30.8 & 16.1 & 0.62 & 0.33 & p1d8 & 2.45 & 0.0000605 & 0.0000895 & 0.0001320 & 0.4269 \\
\hline 7091321 & $12 / 3 \mathrm{C} 1$ & 34S_4p1d8Yc_9 9 & $337 / 8$ & $\mathrm{~s}$ & 9 & 4437.4 & $673 / 4$ & $613 / 4$ & 0.297 & 0.446 & HLP-22 & 12 & 0 & 4 & 1.9 & 10.5 & 5.7 & 30.8 & 16.1 & 0.62 & 0.33 & p1d8 & 2.45 & 0.0000605 & 0.0000895 & 0.0001320 & 0.4269 \\
\hline 7091324 & $12 / 3 \mathrm{C} 1$ & 34S_4p1d8Yc_9 & $337 / 8$ & $\mathrm{~s}$ & 9 & 4437.4 & $673 / 4$ & $613 / 4$ & 0.297 & 0.446 & HLP-22 & 12 & 0 & 4 & 1.9 & 10.5 & 5.7 & 30.8 & 16.1 & 0.62 & 0.33 & p1d8 & 2.45 & 0.0000605 & 0.0000895 & 0.0001320 & 0.4269 \\
\hline 7091328M & $12 / 3 \mathrm{C} 1$ & 34S_4p1d8Yc_9 9 & $337 / 8$ & $s$ & 9 & 4437.4 & $673 / 4$ & $613 / 4$ & 0.297 & 0.446 & HLP-22 & 12 & 0 & 4 & 1.9 & 10.5 & 5.7 & 30.8 & 16.1 & 0.62 & 0.33 & p1d8 & 2.45 & 0.0000605 & 0.0000895 & 0.0001320 & 0.4269 \\
\hline 7091330M & $12 / 3 \mathrm{C} 1$ & 34S_4p1d8Yc_9 9 & $337 / 8$ & $\mathrm{~s}$ & 9 & 4437.4 & $673 / 4$ & $613 / 4$ & 0.297 & 0.446 & HLP-22 & 12 & 0 & 4 & 1.9 & 10.5 & 5.7 & 30.8 & 16.1 & 0.62 & 0.33 & p1d8 & 2.45 & 0.0000605 & 0.0000895 & 0.0001320 & 0.4269 \\
\hline 7091333 & 12/4A1 & 34__4p1d8Ya-40 & $337 / 8$ & $\mathrm{~s}$ & 9 & 4437.4 & $673 / 4$ & $613 / 4$ & 0.297 & 0.446 & HLP-22 & 12 & 4 & 0 & 1.9 & 10.5 & 5.7 & 30.8 & 16.1 & 0.62 & 0.33 & p1d8 & 2.45 & 0.0000605 & 0.0000895 & 0.0001320 & 0.4269 \\
\hline 7091336 & 12/4A1 & 34S_4p1d8Ya-40 & $337 / 8$ & $\mathrm{~s}$ & 9 & 4437.4 & $673 / 4$ & $613 / 4$ & 0.297 & 0.446 & HLP-22 & 12 & 4 & 0 & 1.9 & 10.5 & 5.7 & 30.8 & 16.1 & 0.62 & 0.33 & p1d8 & 2.45 & 0.0000605 & 0.0000895 & 0.0001320 & 0.4269 \\
\hline 7091339 & 12/4A1 & 34s_4p1d8Ya-40 & $337 / 8$ & $\mathrm{~s}$ & 9 & 4437.4 & $673 / 4$ & $613 / 4$ & 0.297 & 0.446 & HLP-22 & 12 & 4 & 0 & 1.9 & 10.5 & 5.7 & 30.8 & 16.1 & 0.62 & 0.33 & p1d8 & 2.45 & 0.0000605 & 0.0000895 & 0.0001320 & 0.4269 \\
\hline 7091342 & $12 / 4 A 1$ & $34 \mathrm{~S}$ 4p1d8Ya-40 & $337 / 8$ & $\mathrm{~s}$ & 9 & 4437.4 & $673 / 4$ & 6134 & 0.297 & 0.446 & HLP-22 & 12 & 4 & 0 & 1.9 & 10.5 & 5.7 & 30.8 & 16.1 & 0.62 & 0.33 & p1d8 & 2.45 & 0.0000605 & 0.0000895 & 0.0001320 & 0.4269 \\
\hline 7091346 & 12/4A1 & 34S_4p1d8Ya-40 & $337 / 8$ & $\mathrm{~s}$ & 9 & 4437.4 & $673 / 4$ & 6134 & 0.297 & 0.446 & HLP-22 & 12 & 4 & 0 & 1.9 & 10.5 & 5.7 & 30.8 & 16.1 & 0.62 & 0.33 & p1d8 & 2.45 & 0.0000605 & 0.0000895 & 0.0001320 & 0.4269 \\
\hline 7091348 & 12/4A1 & 34S_4p1d8Ya-40 & $337 / 8$ & $\mathrm{~s}$ & 9 & 4437.4 & $673 / 4$ & $613 / 4$ & 0.297 & 0.446 & HLP-22 & 12 & 4 & 0 & 1.9 & 10.5 & 5.7 & 30.8 & 16.1 & 0.62 & 0.33 & p1d8 & 2.45 & 0.0000605 & 0.0000895 & 0.0001320 & 0.4269 \\
\hline 7091351 & $12 / 442$ & 34S_4p1d8Yd_6 6 & $337 / 8$ & $\mathrm{~s}$ & 9 & 4437.4 & $673 / 4$ & $613 / 4$ & 0.297 & 0.446 & HLP-22 & 12 & 4 & 0 & 1.9 & 10.5 & 5.7 & 30.8 & 16.1 & 0.62 & 0.33 & p1d8 & 2.45 & 0.0000605 & 0.0000895 & 0.0001320 & 0.4269 \\
\hline 7091354 & $12 / 4 A 2$ & 34S_4p1d8Yd_6 6 & $337 / 8$ & $\mathrm{~s}$ & 9 & 4437.4 & $673 / 4$ & $613 / 4$ & 0.297 & 0.446 & HLP-22 & 12 & 4 & 0 & 1.9 & 10.5 & 5.7 & 30.8 & 16.1 & 0.62 & 0.33 & p1d8 & 2.45 & 0.0000605 & 0.0000895 & 0.0001320 & 0.4269 \\
\hline 7091357 & $12 / 4 A 2$ & $345 \_4 p 1 d 8 Y d 6$ & $337 / 8$ & $\mathrm{~s}$ & 9 & 4437.4 & $673 / 4$ & 6134 & 0.297 & 0.446 & HLP -22 & 12 & 4 & 0 & 1.9 & 10.5 & 5.7 & 30.8 & 16.1 & 0.62 & 0.33 & p1d8 & 2.45 & 0.0000605 & 0.0000895 & 0.0001320 & 0.4269 \\
\hline 7091360 & 12/4A2 & $34 S \_4 p 1 d 8 Y d \_6$ & $337 / 8$ & $\mathrm{~s}$ & 9 & 4437.4 & $673 / 4$ & 6134 & 0.297 & 0.446 & HLP-22 & 12 & 4 & 0 & 1.9 & 10.5 & 5.7 & 30.8 & 16.1 & 0.62 & 0.33 & p1d8 & 2.45 & 0.0000605 & 0.0000895 & 0.0001320 & 0.4269 \\
\hline $7091364 \mathrm{M}$ & $12 / 442$ & 34S_4p1d8Yd_6 & $337 / 8$ & $\mathrm{~s}$ & 9 & 4437.4 & $673 / 4$ & $613 / 4$ & 0.297 & 0.446 & HLP-22 & 12 & 4 & 0 & 1.9 & 10.5 & 5.7 & 30.8 & 16.1 & 0.62 & 0.33 & p1d8 & 2.45 & 0.0000605 & 0.0000895 & 0.0001320 & 0.4269 \\
\hline $7091366 \mathrm{M}$ & 12/4A2 & 34S_4p1d8Yd_6 6 & $337 / 8$ & $\mathrm{~s}$ & 9 & 4437.4 & $673 / 4$ & $613 / 4$ & 0.297 & 0.446 & HLP-22 & 12 & 4 & 0 & 1.9 & 10.5 & 5.7 & 30.8 & 16.1 & 0.62 & 0.33 & p1d8 & 2.45 & 0.0000605 & 0.0000895 & 0.0001320 & 0.4269 \\
\hline 7091369 & 12/4B1 & & & $\mathrm{s}$ & 9 & 4437.4 & $673 / 4$ & 6134 & 0.297 & 0.446 & HLP-22 & 12 & 4 & 0 & 1.9 & 10.5 & 5.7 & 30.8 & 16.1 & 0.62 & 0.33 & p1d8 & 2.45 & 0.0000605 & 0.0000895 & 0.0001320 & 0.4269 \\
\hline 7091372 & 12/4B1 & 34S_4p1d8Yc_6 6 & $337 / 8$ & $\mathrm{~s}$ & 9 & 4437.4 & $673 / 4$ & $613 / 4$ & 0.297 & 0.446 & HLP-22 & 12 & 4 & 0 & 1.9 & 10.5 & 5.7 & 30.8 & 16.1 & 0.62 & 0.33 & p1d8 & 2.45 & 0.0000605 & 0.0000895 & 0.0001320 & 0.4269 \\
\hline 7091375 & 12/4B1 & $34 \mathrm{~S}$ 4p1d8Yc 6 & $337 / 8$ & $\mathrm{~s}$ & 9 & 4437.4 & $673 / 4$ & $613 / 4$ & 0.297 & 0.446 & HLP-22 & 12 & 4 & 0 & 1.9 & 10.5 & 5.7 & 30.8 & 16.1 & 0.62 & 0.33 & pld8 & 2.45 & 0.0000605 & 0.0000895 & 0.0001320 & 0.4269 \\
\hline
\end{tabular}


Table B.8. Data from Fall 2007 Tests in Mid-Scale Vessel with Spherical Head B.11

\begin{tabular}{|c|c|c|c|c|c|c|c|c|c|c|c|c|c|c|c|c|c|c|c|c|c|c|c|c|c|c|c|c|c|}
\hline $\begin{array}{l}\text { Tank Water } \\
\text { Temperature }\end{array}$ & $\begin{array}{l}\text { Water } \\
\text { Density }\end{array}$ & $\begin{array}{l}\text { Solids } \\
\text { Fraction }\end{array}$ & $\begin{array}{l}\text { Pulse } \\
\text { Volume } \\
\text { Fraction }\end{array}$ & $\begin{array}{l}\text { Duty } \\
\text { Cydle }\end{array}$ & $\begin{array}{l}\text { Oyde } \\
\text { Time }\end{array}$ & $\begin{array}{c}\begin{array}{c}\text { Pulsed } \\
\text { or } \\
\text { Steady } \\
\text { Jet }\end{array} \\
\end{array}$ & $\begin{array}{c}\text { Us } \\
\text { Sueacy } \\
\text { Jet }\end{array}$ & \begin{tabular}{|c|} 
U1 \\
Pulsing \\
Jet
\end{tabular} & $\begin{array}{c}\text { U2 } \\
\text { URMS }\end{array}$ & \begin{tabular}{|c} 
UB \\
URNB \\
\end{tabular} & $\begin{array}{l}\text { Discharge } \\
\text { Velocity }\end{array}$ & $\begin{array}{c}\text { Qitical } \\
\text { Suspension } \\
\text { velocity } \\
\end{array}$ & $\begin{array}{l}\text { Average } \\
\text { Peak } \\
\text { Cloud } \\
\text { Height } \\
\end{array}$ & $\begin{array}{c}\text { UCS } \\
\text { Condition }\end{array}$ & $\begin{array}{c}\text { UcS } \\
\text { Method }\end{array}$ & $\begin{array}{l}\text { Ucs } \\
\text { Hag }\end{array}$ & $\begin{array}{l}\text { Ues } \\
\text { Center } \\
\text { Hag } \\
\end{array}$ & $\begin{array}{l}\text { Ucs udv } \\
\text { Hag }\end{array}$ & \begin{tabular}{|c} 
UCS based \\
on \\
Decreasing \\
Velocity
\end{tabular} & \begin{tabular}{|c|} 
Shreep \\
Increase/ \\
Decrease
\end{tabular} & \begin{tabular}{|l} 
UDV \\
Height \\
Bed \\
\end{tabular} & \begin{tabular}{|l|} 
Particle \\
Motion
\end{tabular} & \begin{tabular}{|l|} 
Solids \\
Level \\
\end{tabular} & $\begin{array}{l}\text { Outer } \\
\text { Botom } \\
\text { Pattem }\end{array}$ & \begin{tabular}{|l|} 
Inner \\
BBotom \\
Pattem \\
\end{tabular} & Case ID & Test & TDP & $\begin{array}{r}\text { Row } \\
\text { Numbe }\end{array}$ \\
\hline C & $\mathrm{g} / \mathrm{cm}^{3}$ & fraction & fraction & fraction & $\mathrm{s}$ & text & $\mathrm{m} / \mathrm{s}$ & $\mathrm{m} / \mathrm{s}$ & $\mathrm{m} / \mathrm{s}$ & $\mathrm{m} / \mathrm{s}$ & $\mathrm{m} / \mathrm{s}$ & $\mathrm{m} / \mathrm{s}$ & in. & $\mathrm{m} / \mathrm{s}$ & text & text & text & text & $\mathrm{m} / \mathrm{s}$ & text & $\mathrm{mm}$ & text & text & text & text & text & text & text & text \\
\hline $\mathrm{T}$ & $\rho$ & $\phi_{\mathrm{s}}$ & $\phi_{p_{0}}$ & $D C$ & $t_{c}$ & Jet & $U_{\mathrm{s}}$ & $\mathrm{U}_{1}$ & $\mathrm{U} 2$ & U3 & $u$ & $U_{c s}$ & $\mathrm{H}_{\mathrm{c}}$ & $u_{\text {CsR }}$ & $U_{\text {son }}$ & Ussis & Usscen & Usoudv & Uss D & $\mathrm{s}_{\mathrm{w}}$ & $\mathrm{H}_{\text {bed }}$ & $\mathrm{PM}$ & Sol & $\mathrm{SP}_{\mathrm{o}}$ & $\mathrm{SP}_{\mathrm{P}}$ & $1 \mathrm{ID}$ & MDDX & $\mathrm{TDP}$ & MSS \\
\hline 21.0 & 0.999 & 0.00487 & 0.050 & 0.330 & 47.0 & $\mathrm{P}$ & $\mathrm{NA}$ & 4.53 & 4.58 & 4.62 & 4.50 & 7.30 & NA & NA & NA & NA & NA & NA & NA & 1 & NA & ss & NA & NA & NA & 34S_4p1d8Y_ $\_0$ & $12 / 3 \mathrm{~A} A$ & TDP-WIP-067 & 7091256 \\
\hline 21.0 & 0.999 & 0.00487 & 0.051 & 0.330 & 42.0 & $\mathrm{P}$ & NA & 5.12 & 5.16 & 5.20 & 5.00 & 7.30 & 9.25 & NA & NA & NA & UCScen & NA & NA & $\mathrm{I}$ & NA & ss & NA & NA & NA & 34S__p1dBYc_0 & 122/3A1 & TDP-WIP-067 & 7091259 \\
\hline 21.0 & 0.999 & 0.00487 & 0.051 & 0.330 & 35.0 & $\mathrm{P}$ & NA & 6.08 & 6.16 & 6.21 & 6.00 & 7.30 & 13.50 & NA & NA & NA & NA & NA & NA & $\mathrm{D}$ & NA & AM & NA & NA & NA & 34S_4p1d8YC_O & 12/3A1 & TDP-WIP-067 & 7091261 \\
\hline 21.0 & 0.999 & 0.00487 & 0.051 & 0.330 & 30.0 & $\mathrm{P}$ & NA & 7.03 & 7.14 & 7.22 & 7.00 & 7.30 & 17.50 & NA & NA & NA & NA & NA & NA & 1 & NA & $A M$ & NA & NA & NA & 34S__pldaYc_o & 12/3A1 & TDP-WIP-067 & 7091265 \\
\hline 21.0 & 0.999 & 0.00487 & 0.051 & 0.330 & 28.8 & $\mathrm{P}$ & NA & 7.33 & 7.44 & 7.51 & 7.30 & 7.30 & 20.50 & \begin{tabular}{|l}
7.30 \\
\end{tabular} & vis & ucsis & NA & NA & NA & 1 & NA & cs & NA & NA & NA & $34 \mathrm{~S} \triangle 4 \mathrm{pld} 8 \mathrm{Yc} \_0$ & 12/3A1 & TDP-WIP-067 & 7091268 \\
\hline 21.0 & 0.999 & 0.00487 & 0.050 & 0.330 & 26.0 & $\mathrm{P}$ & NA & \begin{tabular}{|l|} 
\\
\end{tabular} & \begin{tabular}{|l|l|} 
& 8.22 \\
\end{tabular} & \begin{tabular}{|l|} 
\\
\end{tabular} & 8.00 & 7.30 & 31.25 & NA & NA & NA & NA & NA & NA & 1 & NA & $B C$ & NA & NA & NA & 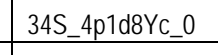 & 12/3A1 & TDP-WIP-067 & 7091270 \\
\hline 21.3 & 0.999 & 0.00487 & undefined & 1.000 & infinite & $\mathrm{s}$ & 4.54 & NA & NA & NA & 4.50 & 8.00 & NA & NA & NA & NA & UCScen & NA & NA & 1 & NA & ss & NA & NA & NA & 34S_4p1d8Ya-04 & 122/3B1 & TDP-WIP-067 & 7091274 \\
\hline 21.3 & 0.999 & $\begin{array}{ll}0.00487 \\
\end{array}$ & undefined & 1.000 & infinite & $\mathrm{s}$ & 5.03 & NA & NA & NA & 5.00 & 8.00 & 8.75 & NA & NA & NA & NA & NA & NA & 1 & NA & ss & NA & NA & NA & 345_4p1d8Ya-04 & 12/3B1 & TDP-WIP-067 & 7091277 \\
\hline 21.3 & 0.999 & 0.00487 & undefined & 1.000 & infinite & $\mathrm{s}$ & 6.04 & NA & NA & NA & 6.00 & 8.00 & 14.25 & NA & NA & NA & NA & NA & NA & 1 & NA & $A M$ & NA & NA & NA & 34__4p1d8Ya-04 & $12 / 3 \mathrm{~B} 1$ & TDP-WIP-067 & 7091279 \\
\hline 21.3 & 0.999 & 0.00487 & undefined & 1.000 & infinite & $\mathrm{s}$ & 7.04 & NA & NA & NA & 7.00 & 8.00 & 22.75 & NA & NA & NA & NA & NA & NA & 1 & NA & $A M$ & NA & NA & NA & 34S_4p1d8Ya04 & 12/3B1 & TDP-WIP-067 & 7091283 \\
\hline 21.3 & 0.999 & 0.00487 & undefined & 1.000 & infinite & $\mathrm{s}$ & 8.02 & NA & NA & NA & 8.00 & 8.00 & 42.50 & 8.00 & vis & Ucsis & NA & NA & NA & 1 & NA & cs & NA & NA & NA & 345_4p1d8Ya-04 & $122 / 3 B 1$ & TDP-WIP-067 & 7091286 \\
\hline 22.0 & 0.999 & 0.00487 & 0.049 & 0.180 & 190.0 & $\mathrm{P}$ & NA & 4.03 & 4.15 & 4.38 & 4.00 & 12.00 & NA & NA & \begin{tabular}{|l} 
center \\
dec
\end{tabular} & NA & Ucsoen & NA & 4.00 & D & NA & ss & NA & NA & NA & 34S_4p1d8Yd 9 & $12 / 3 \mathrm{~B} 2$ & TDP-WIP-067 & 7091289 \\
\hline 22.0 & 0.999 & $\begin{array}{ll}0.00487 \\
\end{array}$ & 0.049 & 0.180 & 127.0 & $\mathrm{P}$ & NA & 6.05 & 6.20 & 6.46 & 6.00 & 12.00 & $\begin{array}{l}11.00 \\
\end{array}$ & NA & NA & NA & NA & NA & NA & 1 & NA & AM- & NA & NA & NA & 34S_4p1d8Yd 99 & 12/3B2 & TDP-WIP-067 & 7091291 \\
\hline 22.0 & 0.999 & 0.00487 & 0.048 & 0.180 & 105.0 & $\mathrm{P}$ & NA & 7.17 & 7.37 & 7.67 & 7.00 & 12.00 & 13.50 & NA & NA & NA & NA & NA & NA & $\mathrm{I}$ & NA & $A M$ & NA & NA & NA & 34S_4p1d8Yd_99 & 122/3B2 & TDP-WIP-067 & 7091294 \\
\hline 22.0 & 0.999 & 0.00487 & 0.049 & 0.180 & 92.8 & $\mathrm{P}$ & NA & 8.17 & 8.40 & 8.75 & 8.00 & 12.00 & 16.75 & NA & NA & NA & NA & NA & NA & 1 & NA & $A M$ & NA & NA & NA & 34S_4p1dBYd_99 & 12/3B2 & TDP-WIP-067 & 7091297 \\
\hline 22.0 & 0.999 & 0.00487 & 0.049 & 0.180 & 80.0 & $\mathrm{P}$ & NA & 9.29 & 9.57 & 9.96 & 9.00 & 12.00 & 19.75 & NA & NA & NA & NA & NA & NA & $\mathrm{I}$ & NA & $A M$ & NA & NA & NA & 34S_4p1d8Yd 9 & $12 / 3 \mathrm{~B} 2$ & TDP-WIP-067 & 7091300 \\
\hline 22.0 & 0.999 & 0.00487 & 0.048 & 0.180 & 72.5 & $\mathrm{P}$ & NA & 10.20 & 10.50 & 10.92 & 10.00 & 12.00 & 20.25 & NA & NA & NA & NA & NA & NA & 1 & NA & $A M+$ & NA & NA & NA & 34S_4p1d8Yd_9 & $12 / 3 \mathrm{~B} 2$ & TDP-WIP-067 & 7091303 \\
\hline 22.0 & 0.999 & 0.00487 & 0.048 & 0.180 & 66.0 & $\mathrm{P}$ & NA & 11.19 & 11.53 & 12.00 & 11.00 & 12.00 & 22.50 & NA & NA & NA & NA & NA & NA & 1 & NA & $A M+$ & NA & NA & NA & 34S_4p1daYd 99 & $122 / 3 \mathrm{~B} 2$ & TDP-WIP-067 & 7091306 \\
\hline 22.0 & 0.999 & 0.00487 & 0.049 & 0.180 & 60.5 & $\mathrm{P}$ & NA & 12.31 & 12.73 & 13.27 & 1200 & 12.00 & 27.25 & \begin{tabular}{|l|l|}
12.00 \\
\end{tabular} & vis & Ucsis & NA & NA & NA & 1 & NA & cs & NA & NA & NA & 34S_4p1d8Yd_99 & 122/3B2 & TDP-WIP-067 & 7091310 \\
\hline 22.0 & 0.999 & 0.00487 & 0.049 & 0.180 & 56.0 & $\mathrm{P}$ & NA & 13.43 & 13.91 & \begin{tabular}{ll|}
14.51 \\
\end{tabular} & 13.00 & 12.00 & 31.75 & NA & NA & NA & NA & NA & NA & 1 & NA & $\mathrm{BC}-$ & NA & NA & NA & 34S_4p1d8Yd_99 & 12/3B2 & TDP-WIP-067 & 7091312 \\
\hline 22.0 & 0.999 & 0.00487 & 0.047 & 0.330 & 93.0 & $\mathrm{P}$ & NA & 4.51 & 4.63 & 4.83 & 4.50 & 10.50 & NA & NA & NA & NA & Ucsoen & NA & NA & $\mathrm{I}$ & NA & ss & NA & NA & NA & 34S_4p1d8Yc_ 9 & $12 / 3 \mathrm{C} 1$ & TDP-WIP-067 & 7091316 \\
\hline 22.0 & 0.999 & 0.00487 & 0.050 & 0.330 & 59.0 & $\mathrm{P}$ & NA & 7.20 & 7.36 & 7.61 & 7.00 & 10.50 & \begin{tabular}{|l|l|}
14.00 \\
\end{tabular} & NA & NA & NA & NA & NA & NA & 1 & NA & AMt & NA & NA & NA & 34S_4p1d8Yc 99 & $12 / 3 \mathrm{C} 1$ & IDP-WIP-067 & 7091318 \\
\hline 22.0 & 0.999 & 0.00487 & 0.049 & 0.330 & 51.5 & $\mathrm{P}$ & NA & 8.12 & 8.32 & 8.59 & 8.00 & 10.50 & 16.00 & NA & NA & NA & NA & NA & NA & 1 & NA & AM & NA & NA & NA & 34S_4p1d8Yc_ 9 & $12 / 3 \mathrm{Cl}$ & TDP-WIP-067 & 7091321 \\
\hline 22.0 & 0.999 & 0.00487 & 0.050 & 0.330 & 41.0 & $\mathrm{P}$ & NA & 10.29 & 10.54 & 10.90 & 10.00 & 10.50 & 22.50 & NA & NA & NA & NA & NA & NA & 1 & NA & $A M+$ & NA & NA & NA & 34S_ $4 \mathrm{p} 1 \mathrm{~d}$ YYc $\_9$ & $122 / 3 C_{1}$ & IDP-WIP-067 & 7091324 \\
\hline 22.0 & 0.999 & 0.00487 & 0.049 & 0.330 & 38.5 & $\mathrm{P}$ & NA & 10.7 & \begin{tabular}{|l|l|}
11.06 \\
\end{tabular} & 11.44 & 10.50 & 10.50 & 26.75 & 10.50 & vis & Ucsis & NA & NA & NA & 1 & NA & cs & NA & NA & NA & 34S_4p1d8Yc_99 & $122 / 3 C 1_{1}$ & TDP-WIP-067 & 7091328 \\
\hline 22.0 & 0.999 & 0.00487 & 0.049 & 0.330 & 35.0 & $\mathrm{P}$ & NA & 11.78 & \begin{tabular}{|l|l|}
12.14 \\
\end{tabular} & \begin{tabular}{|l|}
12.57 \\
\end{tabular} & 11.50 & 10.50 & \begin{tabular}{|l|l}
34.50 \\
\end{tabular} & NA & NA & NA & NA & NA & NA & 1 & NA & $\mathrm{BC}$ & NA & NA & NA & 34S_4p1d8Yc 9 & $12 / 3 \mathrm{Cl}$ & TDP-WIP-067 & 7091330 \\
\hline 21.7 & 0.999 & 0.00487 & undefined & 1.000 & infinite & $\mathrm{s}$ & 5.09 & \begin{tabular}{|l|l|} 
NA \\
\end{tabular} & NA & NA & 5.00 & 7.00 & NA & NA & NA & NA & NA & NA & NA & $\mathrm{D}$ & NA & ss & NA & NA & NA & 34S_4p1d8Ya-40 & $12 / 4 A 1$ & TDP-WTP-068 & 7091333 \\
\hline 21.7 & 0.998 & 0.00487 & undefined & 1.000 & infinite & $\mathrm{s}$ & 5.56 & NA & NA & NA & 5.50 & 7.00 & 10.00 & NA & NA & NA & NA & NA & NA & 1 & NA & ss & NA & NA & NA & \begin{tabular}{|l|l|}
345 4p1d8Ya-40 \\
\end{tabular} & 12/4A1 & TDP-WTP-068 & 7091336 \\
\hline 21.7 & 0.998 & 0.00487 & undefined & 1.000 & infinite & $\mathrm{s}$ & 6.04 & NA & NA & NA & 6.00 & 7.00 & 13.25 & NA & NA & NA & NA & NA & NA & 1 & NA & $A M$ & NA & NA & NA & 345_4p1d8Ya-40 & 12/4AA1 & TDP-WTP-068 & 7091339 \\
\hline 21.7 & 0.998 & $\begin{array}{ll}0.00487 \\
\end{array}$ & undefined & 1.000 & infinite & $\mathrm{s}$ & 6.54 & NA & NA & NA & 6.50 & 7.00 & 22.50 & NA & NA & NA & UCSoen & NA & NA & 1 & NA & cs & NA & NA & NA & 34S_4p1d8Ya-40 & 12/4A1 & TDP-WIP-068 & 7091342 \\
\hline 21.7 & 0.998 & 0.00487 & undefined & 1.000 & infinite & $\mathrm{s}$ & 7.04 & NA & NA & NA & 7.00 & 7.00 & 30.00 & 7.00 & vis & Ucsis & NA & NA & NA & 1 & NA & cs & NA & NA & NA & 345_4p1d8Ya-40 & 12/4A1 & TDP-WIP-068 & 7091346 \\
\hline 21.7 & 0.998 & 0.00487 & undefined & 1.000 & infinite & $\mathrm{s}$ & 7.60 & NA & NA & NA & 7.50 & 7.00 & 40.50 & NA & NA & NA & NA & NA & NA & 1 & NA & $B C$ & NA & NA & NA & 34__4p1d8Ya-40 & $12 / 4 A 1$ & TDP-WIP-068 & 7091348 \\
\hline 22.0 & 0.999 & 0.00487 & 0.050 & 0.180 & 152.0 & $\mathrm{P}$ & NA & \begin{tabular}{|l|l|}
5.12 \\
\end{tabular} & \begin{tabular}{|l|}
5.24 \\
\end{tabular} & 5.43 & 5.00 & 9.00 & 9.50 & NA & NA & NA & NA & NA & NA & NA & NA & ss & NA & NA & NA & 34S_4p1d8Yd_6 6 & $12 / 4 A_{2}$ & TDP-WTP-068 & 7091351 \\
\hline 22.0 & 0.999 & 0.00487 & 0.049 & 0.180 & 125.0 & $\mathrm{P}$ & NA & 6.12 & 6.25 & 6.47 & 6.00 & 9.00 & 11.00 & NA & NA & NA & NA & NA & NA & 1 & NA & ss & NA & NA & NA & 34S_4p1d8Yd 66 & $12 / 4 A 2$ & TDP-WIP-068 & 7091354 \\
\hline 22.0 & 0.999 & 0.00487 & 0.050 & 0.180 & 107.0 & $\mathrm{P}$ & NA & 7.23 & 7.40 & 7.65 & 7.00 & 9.00 & 14.50 & NA & NA & NA & NA & NA & NA & 1 & NA & ss & NA & NA & NA & 34S_4p1d8Yd_6 6 & $12 / 4 A 2$ & TDP-WTP-068 & 7091357 \\
\hline 22.0 & 0.999 & 0.00487 & 0.049 & 0.180 & 92.0 & $\mathrm{P}$ & NA & 8.19 & 8.42 & 8.72 & 8.00 & 9.00 & 17.50 & NA & NA & NA & NA & NA & NA & $\mathrm{I}$ & NA & AMt & NA & NA & NA & 34S_4p1d8Yd_6 & $12 / 4 A_{2}$ & TDP-WTP-068 & 7091360 \\
\hline 22.0 & 0.999 & 0.00487 & 0.049 & 0.180 & 82.0 & $\mathrm{P}$ & NA & 9.30 & 9.52 & 9.83 & 9.00 & 9.00 & 22.00 & 9. & vis & ucsuis & NA & NA & NA & 1 & NA & cs & NA & NA & NA & 34S_4p1d8Yd_6 6 & $12 / 4 A 2$ & TDP-WIP-068 & 7091364 \\
\hline 22.0 & 0.999 & 0.00487 & 0.049 & 0.180 & 74.0 & $\mathrm{P}$ & NA & 10.39 & 10.68 & 11.08 & 10.00 & 9.00 & 24.75 & NA & NA & NA & NA & NA & NA & 1 & NA & $B C$ & NA & NA & NA & 34S_4p1d8Yd_ 6 & $12 / 4 A 2$ & TDP-WTP-068 & 7091366 \\
\hline 22.0 & 0.999 & 0.00487 & 0.049 & 0.330 & 68.0 & $\mathrm{P}$ & NA & 6.11 & 6.27 & 6.50 & 6.00 & 9.00 & 11.00 & NA & NA & NA & NA & NA & NA & $\mathrm{NA}$ & NA & ss & NA & NA & NA & 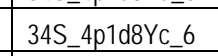 & $12 / 4 \mathrm{~B} 1$ & TDP-WIP-068 & 7091369 \\
\hline 22.0 & 0.999 & 0.00487 & 0.049 & 0.330 & 58.0 & $\mathrm{P}$ & NA & 7.14 & 7.33 & 7.60 & 7.00 & 9.00 & 13.75 & NA & NA & NA & NA & NA & NA & 1 & NA & ss & NA & NA & NA & 34S_4p1d8YC_6 6 & 12/4B1 & TDP-WTP-068 & 7091372 \\
\hline 22.0 & 0.999 & 0.00487 & 0.050 & 0.330 & 50.8 & $\mathrm{P}$ & NA & 8.21 & 8.42 & 8.72 & 8.00 & 9.00 & 19.00 & NA & NA & NA & NA & NA & NA & $\mathrm{I}$ & NA & AMt & NA & NA & NA & 34S_4p1d8YC_ 6 & $12 / 4 \mathrm{~B} 1$ & TDP-WIP-068 & 7091375 \\
\hline
\end{tabular}


Table B.8. Data from Fall 2007 Tests in Mid-Scale Vessel with Spherical Head A.12

\begin{tabular}{|c|c|c|c|c|c|c|c|c|c|c|c|c|c|c|c|c|c|c|c|c|c|c|c|c|c|c|c|}
\hline $\begin{array}{l}\text { Row } \\
\text { Number }\end{array}$ & Test & Case ID & $\begin{array}{l}\text { Tank } \\
\text { Diameter }\end{array}$ & $\begin{array}{l}\text { Head } \\
\text { Shape }\end{array}$ & $\begin{array}{l}\text { Dish } \\
\text { Height }\end{array}$ & $\begin{array}{c}\text { Dish } \\
\text { Volume }\end{array}$ & $\begin{array}{c}\text { Tank } \\
\text { Fill } \\
\text { Height }\end{array}$ & $\begin{array}{l}\text { Retum } \\
\text { Line } \\
\text { Height }\end{array}$ & $\begin{array}{c}\text { Nozzle } \\
\text { Inner } \\
\text { Dianeter }\end{array}$ & $\begin{array}{c}\text { Noztle } \\
\text { Sttanc } \\
\text { off } \\
\text { Distance } \\
\end{array}$ & $\begin{array}{l}\text { Pulse Tube } \\
\text { Configuration }\end{array}$ & $\begin{array}{l}\text { Installed } \\
\text { Nozzles }\end{array}$ & $\begin{array}{c}\text { Outer } \\
\text { Nozzles } \\
\text { Operated }\end{array}$ & $\begin{array}{c}\text { Inner } \\
\text { Nozzles } \\
\text { Operated }\end{array}$ & $\begin{array}{c}\text { Pulse Tube } \\
\text { Outer } \\
\text { Diameter }\end{array}$ & $\begin{array}{c}\text { Outer } \\
\text { PMM } \\
\text { Radius }\end{array}$ & $\begin{array}{c}\text { Inner } \\
\text { PMM } \\
\text { Radius }\end{array}$ & $\begin{array}{c}\text { "FOO" Outer } \\
\text { PJMM } \\
\text { Imingement } \\
\text { Angle }\end{array}$ & $\begin{array}{c}\text { "FO' Inner } \\
\text { PJM } \\
\text { Imingement } \\
\text { Angle } \\
\end{array}$ & $\begin{array}{c}\text { Ratio Outer } \\
\text { PJM to } \\
\text { Tank } \\
\text { Radius } \\
\end{array}$ & $\begin{array}{c}\text { Ratio Inner } \\
\text { PJM to } \\
\text { Tank } \\
\text { Radius } \\
\end{array}$ & Simulant & $\begin{array}{l}\text { Solids } \\
\text { Density }\end{array}$ & $\begin{array}{c}\text { Particle } \\
\text { Diameter d5 }\end{array}$ & $\begin{array}{c}\text { Particle } \\
\text { Diantert } \\
\text { d50 }\end{array}$ & $\begin{array}{c}\text { Particle } \\
\text { Diameter } \\
\text { d95 }\end{array}$ & $\begin{array}{l}\text { Void } \\
\text { Fraction }\end{array}$ \\
\hline text & text & text & in. & text & in. & in. ${ }^{3}$ & in. & in. & in. & in. & text & number & number & number & in. & in. & in. & deg & deg & nondim & nondim & text & $\mathrm{g} / \mathrm{cm}^{3}$ & $m$ & $\mathrm{~m}$ & $\mathrm{~m}$ & fraction \\
\hline MSS & MDDX & ID & D & $\mathrm{HS}$ & Hest & $V_{\text {ast }}$ & $\mathrm{H}$ & $\operatorname{Rtn}$ & $d$ & sod & PT & $\mathrm{N}$ & $\mathrm{Nb}$ & $\mathrm{N}$ & $\mathrm{PT}_{\infty}$ & $R_{0}$ & $\mathrm{R}$ & $\theta_{0}$ & $\theta_{1}$ & $R d R$ & $R / R$ & sxdx & $\rho_{\mathrm{s}}$ & $d_{5}$ & $d_{60}$ & $d_{65}$ & vf \\
\hline 7091379M & 12/4B1 & $34 S_{4} 4 \mathrm{p} 1 \mathrm{~d} 8 \mathrm{YC} \_6$ & $337 / 8$ & $\mathrm{~s}$ & 9 & \begin{tabular}{ll|}
4437.4 \\
\end{tabular} & $673 / 4$ & $613 / 4$ & 0.297 & 0.446 & HLP-22 & 12 & 4 & 0 & 1.9 & 10.5 & 5.7 & 30.8 & 16.1 & 0.62 & 0.33 & p1d8 & 2.45 & 0.0000605 & 0.0000895 & 0.0001320 & 0.4269 \\
\hline 7091381M & $12 / 4 \mathrm{~B} 1$ & 34S_4p1d8Yc_6 & $337 / 8$ & $s$ & 9 & 4437.4 & $673 / 4$ & $613 / 4$ & 0.297 & 0.446 & HLP-22 & 12 & 4 & 0 & 1.9 & 10.5 & 5.7 & 30.8 & 16.1 & 0.62 & 0.33 & p1d8 & 2.45 & 0.0000605 & 0.0000895 & 0.0001320 & 0.4269 \\
\hline 7091384 & $12 / 4 \mathrm{Cl}$ & 34S_4p1d8Ya-80 & $337 / 8$ & $\mathrm{~s}$ & 9 & 4437.4 & $673 / 4$ & $613 / 4$ & 0.297 & 0.446 & HLP-22 & 12 & 8 & 0 & 1.9 & 10.5 & 5.7 & 30.8 & 16.1 & 0.62 & 0.33 & p1d8 & 2.45 & 0.0000605 & 0.0000095 & 0.0001320 & 0.4269 \\
\hline 7091388 & $12 / 4 \mathrm{Cl}_{1}$ & 34S_4p1d8Ya-80 & $337 / 8$ & s & 9 & 4437.4 & $673 / 4$ & $613 / 4$ & 0.297 & 0.446 & HLP-22 & 12 & 8 & 0 & 1.9 & 10.5 & 5.7 & 30.8 & 16.1 & 0.62 & 0.33 & p1d8 & 2.45 & 0.0000605 & 0.0000095 & 0.0001320 & 0.4269 \\
\hline 7091391 & $12 / 4 \mathrm{Cl}_{1}$ & 34S $4 p 1 d 8 Y a-80$ & $337 / 8$ & $\mathrm{~s}$ & 9 & 4437.4 & $673 / 4$ & $613 / 4$ & 0.297 & 0.446 & HLP-22 & 12 & 8 & 0 & 1.9 & 10.5 & 5.7 & 30.8 & 16.1 & 0.62 & 0.33 & pld8 & 2.45 & 0.0000605 & 0.0000095 & 0.0001320 & 0.4269 \\
\hline 7091393 & $12 / 4 \mathrm{CZ}$ & 34S_4p1d8Yd_5 & $337 / 8$ & $\mathrm{~s}$ & 9 & \begin{tabular}{l|l}
4437.4 \\
\end{tabular} & $673 / 4$ & $613 / 4$ & 0.297 & 0.446 & HLP-22 & 12 & 8 & 0 & 1.9 & 10.5 & 5.7 & 30.8 & 16.1 & 0.62 & 0.33 & p1d8 & 2.45 & 0.0000605 & 0.0000095 & 0.0001320 & 0.4269 \\
\hline 7091396 & $12 / 4 \mathrm{CZ}_{2}$ & 34S_4p1d8Yd_5 & $337 / 8$ & $s$ & 9 & 4437.4 & $673 / 4$ & $613 / 4$ & 0.297 & 0.446 & HLP-22 & 12 & 8 & 0 & 1.9 & 10.5 & 5.7 & 30.8 & 16.1 & 0.62 & 0.33 & p1d8 & 2.45 & 0.0000605 & 0.0000095 & 0.0001320 & 0.4269 \\
\hline 7091399 & $12 / 4 \mathrm{CZ}^{2}$ & 34S_4p1d8Yd_5 & $337 / 8$ & $\mathrm{~s}$ & 9 & 4437.4 & $673 / 4$ & $613 / 4$ & 0.297 & 0.446 & HLP-22 & 12 & 8 & 0 & 1.9 & 10.5 & 5.7 & 30.8 & 16.1 & 0.62 & 0.33 & p1d8 & 2.45 & 0.0000605 & 0.0000895 & 0.0001320 & 0.4269 \\
\hline 7091402 & $12 / 4 \mathrm{CZ}_{2}$ & 34S_4p1d8Yd 5 & $337 / 8$ & $\mathrm{~s}$ & 9 & 4437.4 & $673 / 4$ & $613 / 4$ & 0.297 & 0.446 & HLP-22 & 12 & 8 & 0 & 1.9 & 10.5 & 5.7 & 30.8 & 16.1 & 0.62 & 0.33 & p1d8 & 2.45 & 0.0000605 & 0.0000895 & 0.0001320 & 0.4269 \\
\hline 7091405 & $12 / 4 \mathrm{CC} 2$ & 34S_4p1d8Yd_5 & $337 / 8$ & $s$ & 9 & 4437.4 & $673 / 4$ & $613 / 4$ & 0.297 & 0.446 & HLP-22 & 12 & 8 & 0 & 1.9 & 10.5 & 5.7 & 30.8 & 16.1 & 0.62 & 0.33 & p1d8 & 2.45 & 0.0000605 & 0.0000095 & 0.0001320 & 0.4269 \\
\hline 7091409M & $12 / 4 \mathrm{CL}^{2}$ & 34S_4p1d8Yd 5 & $337 / 8$ & $\mathrm{~s}$ & 9 & 4437.4 & $673 / 4$ & $613 / 4$ & 0.297 & 0.446 & HLP-22 & 12 & 8 & 0 & 1.9 & 10.5 & 5.7 & 30.8 & 16.1 & 0.62 & 0.33 & plds & 2.45 & 0.0000605 & 0.0000095 & 0.0001320 & 0.4269 \\
\hline 7091411M & $12 / 4 \mathrm{CZ}$ & 34S_4p1d8Yd_5 & $337 / 8$ & $\mathrm{~s}$ & 9 & \begin{tabular}{l|l}
4437.4 \\
\end{tabular} & $673 / 4$ & $613 / 4$ & 0.297 & 0.446 & HLP-22 & 12 & 8 & 0 & 1.9 & 10.5 & 5.7 & 30.8 & 16.1 & 0.62 & 0.33 & p1d8 & 2.45 & 0.0000605 & 0.0000895 & 0.0001320 & 0.4269 \\
\hline 7091414 & 12/4D1 & 34S_4p1d8Yc_5 & $337 / 8$ & $\mathrm{~s}$ & 9 & \begin{tabular}{l|l}
4437.4 \\
\end{tabular} & $673 / 4$ & $613 / 4$ & 0.297 & 0.446 & HLP-22 & 12 & 8 & 0 & 1.9 & 10.5 & 5.7 & 30.8 & 16.1 & 0.62 & 0.33 & p1d8 & 2.45 & 0.0000605 & 0.0000895 & 0.0001320 & 0.4269 \\
\hline 7091417 & 12/4D1 & 345 4p1d8rc 5 & $337 / 8$ & $\mathrm{~s}$ & 9 & 4437.4 & $673 / 4$ & $613 / 4$ & 0.297 & 0.446 & HLP-22 & 12 & 8 & 0 & 1.9 & 10.5 & 5.7 & 30.8 & 16.1 & 0.62 & 0.33 & p1d8 & 2.45 & 0.0000605 & 0.0000095 & 0.0001320 & 0.4269 \\
\hline 7091421M & $12 / 4 \mathrm{D} 1$ & $345 \_4 p 1 d 8 Y c \_5$ & $337 / 8$ & $\mathrm{~s}$ & 9 & 4437.4 & $673 / 4$ & $613 / 4$ & 0.297 & 0.446 & HLP-22 & 12 & 8 & 0 & 1.9 & 10.5 & 5.7 & 30.8 & 16.1 & 0.62 & 0.33 & pld8 & 2.45 & 0.0000605 & 0.0000095 & 0.0001320 & 0.4269 \\
\hline 7091423M & 12/4D1 & 34S_4p1d8Yc_5 & $337 / 8$ & $s$ & 9 & 4437.4 & $673 / 4$ & $613 / 4$ & 0.297 & 0.446 & HLP-22 & 12 & 8 & 0 & 1.9 & 10.5 & 5.7 & 30.8 & 16.1 & 0.62 & 0.33 & p1d8 & 2.45 & 0.0000605 & 0.0000095 & 0.0001320 & 0.4269 \\
\hline
\end{tabular}


Table B.8. Data from Fall 2007 Tests in Mid-Scale Vessel with Spherical Head B.12

\begin{tabular}{|c|c|c|c|c|c|c|c|c|c|c|c|c|c|c|c|c|c|c|c|c|c|c|c|c|c|c|c|c|c|}
\hline $\begin{array}{l}\text { Tank Water } \\
\text { Temperature }\end{array}$ & $\begin{array}{l}\text { Water } \\
\text { Density }\end{array}$ & $\begin{array}{l}\text { Solids } \\
\text { Fraction }\end{array}$ & $\begin{array}{l}\text { Pulse } \\
\text { Volume } \\
\text { Fraction }\end{array}$ & $\begin{array}{l}\text { Duty } \\
\text { Cydle }\end{array}$ & $\begin{array}{l}\text { Oyde } \\
\text { Time }\end{array}$ & $\begin{array}{c}\text { Pulsed } \\
\text { or } \\
\text { Steacy } \\
\text { Jet }\end{array}$ & $\begin{array}{c}\text { Us } \\
\text { Steacy } \\
\text { Jet }\end{array}$ & $\begin{array}{c}\text { U1 } \\
\text { Pulsing } \\
\text { Jet }\end{array}$ & $\begin{array}{l}\text { U2 } \\
\text { URMS } \\
\end{array}$ & $\begin{array}{l}\text { U3 } \\
\text { URNB }\end{array}$ & $\begin{array}{c}\text { Discharge } \\
\text { Velocity }\end{array}$ & $\begin{array}{c}\text { Citical } \\
\text { SSispension } \\
\text { Velocity }\end{array}$ & $\begin{array}{c}\text { Average } \\
\text { Peak } \\
\text { Coud } \\
\text { Height } \\
\end{array}$ & $\begin{array}{l}\text { UCS } \\
\text { Condition }\end{array}$ & $\begin{array}{l}\text { UCS } \\
\text { Method }\end{array}$ & $\begin{array}{l}\text { UCS } \\
\text { Fag }\end{array}$ & $\begin{array}{c}\text { UCS } \\
\text { Center } \\
\text { Flag }\end{array}$ & $\begin{array}{l}\text { ucs } \\
\text { unv } \\
\text { Hag }\end{array}$ & $\begin{array}{c}\text { UcS } \\
\text { besed on } \\
\text { Decreasing } \\
\text { velocity }\end{array}$ & $\begin{array}{c}\text { Sweep } \\
\text { Increase } \\
1 \\
\text { Decrease }\end{array}$ & $\begin{array}{c}\text { UDV } \\
\text { Height } \\
\text { Bed } \\
\end{array}$ & $\begin{array}{l}\text { Particie } \\
\text { Motion }\end{array}$ & $\begin{array}{l}\text { Solids } \\
\text { Level }\end{array}$ & $\begin{array}{l}\text { Outer } \\
\text { Botoman } \\
\text { Pattem }\end{array}$ & $\begin{array}{l}\text { Inner } \\
\text { Bottom } \\
\text { Pattem }\end{array}$ & Case ID & Test & TDP & $\begin{array}{l}\text { Row } \\
\text { Number }\end{array}$ \\
\hline $\mathrm{C}$ & $\mathrm{g} / \mathrm{cm}^{3}$ & fraction & fraction & fraction & $\mathrm{s}$ & text & $\mathrm{m} / \mathrm{s}$ & $\mathrm{m} / \mathrm{s}$ & $\mathrm{m} / \mathrm{s}$ & $\mathrm{m} / \mathrm{s}$ & $\mathrm{m} / \mathrm{s}$ & m/s & in. & $\mathrm{m} / \mathrm{s}$ & text & text & text & text & m/s & text & $\mathrm{mm}$ & text & text & text & text & text & text & text & text \\
\hline $\mathrm{T}$ & $\rho$ & $\phi_{\mathrm{s}}$ & $\phi_{p}$ & $\mathrm{DC}$ & $t_{c}$ & Jet & $u_{s}$ & $\mathrm{un}_{1}$ & $\mathrm{U} 2$ & U3 & $u$ & $U_{c s}$ & $H_{c}$ & $U_{\text {CsR }}$ & $U_{\text {san }}$ & Ussis & Ussen & Ussudv & $U_{\text {cs_ }} \mathrm{D}$ & $s_{N}$ & $H_{\text {bed }}$ & PM & Sol & $\mathrm{SP}_{\mathrm{O}}$ & $S P_{1}$ & ID & MDDX & $\mathrm{TDP}$ & MSS \\
\hline 22.0 & 0.999 & 0.00487 & 0.049 & 0.330 & 45.0 & $\mathrm{P}$ & NA & 9.27 & 9.53 & 9.88 & 9.00 & 9.00 & 25.63 & 9.00 & vis & UCShis & NA & NA & NA & 1 & NA & cs & NA & NA & NA & $34 \mathrm{~S} \_4 \mathrm{p} 1 \mathrm{~d} 8 \mathrm{YC} \_6$ & $12 / 4 \mathrm{~B} 1$ & TDP-WTP-068 & 7091379 \\
\hline 22.0 & 0.999 & 0.00487 & 0.050 & 0.330 & 41.0 & $\mathrm{P}$ & NA & 10.29 & 10.57 & 10.97 & 10.00 & 9.00 & 34.00 & NA & NA & $\mathrm{NA}$ & NA & NA & NA & 1 & NA & $\mathrm{BC}$ & NA & NA & NA & 34S_4p1d8Yc 6 & $12 / 4 \mathrm{~B} 1$ & TDP-WTP-068 & 7091381 \\
\hline 22.1 & 0.998 & 0.00487 & undefined & 1.000 & infinite & $\mathrm{s}$ & 4.07 & NA & NA & NA & 4.00 & 5.20 & 17.00 & NA & NA & NA & NA & NA & NA & NA & NA & ss & NA & NA & NA & 34S_4p1d8Ya-80 & $12 / 4 \mathrm{CI}$ & TDP-WIP-068 & 7091384 \\
\hline 22.1 & 0.998 & 0.00487 & undefined & 1.000 & infinite & $\mathrm{s}$ & 5.05 & NA & NA & NA & 5.00 & 5.20 & 4200 & NA & NA & NA & NA & NA & NA & 1 & NA & AM & NA & NA & NA & 34S_4p1d8Ya-80 & $12 / 4 \mathrm{CC}$ & TDP-WIP-068 & 7091388 \\
\hline 22.2 & 0.998 & 0.00487 & undefined & 1.000 & infinite & $\mathrm{s}$ & 5.30 & NA & NA & NA & 5.20 & 5.20 & 51.00 & 5.20 & vis & UCShis & NA & NA & NA & 1 & NA & CS & NA & NA & NA & 34S_4p1d8Ya-80 & $12 / 4 \mathrm{CC}$ & TDP-WTP-068 & 7091391 \\
\hline 22.0 & 0.999 & 0.00487 & 0.049 & 0.180 & 76.0 & $\mathrm{P}$ & NA & 4.97 & 5.03 & 5.06 & 5.00 & 9.00 & 14.25 & NA & NA & NA & NA & NA & NA & NA & NA & ss & NA & NA & NA & 34S_4p1d8Yd_5 5 & $12 / 4 \mathrm{CC} 2$ & TDP-WIP-068 & 7091393 \\
\hline 22.0 & 0.999 & 0.00487 & 0.049 & 0.180 & 63.5 & $\mathrm{P}$ & NA & 5.97 & 6.04 & 6.09 & 6.00 & 9.00 & 16.75 & NA & NA & NA & NA & NA & NA & 1 & NA & ss & NA & NA & NA & 34S_4p1d8Yd_5 5 & $12 / 4 \mathrm{C} 2$ & TDP-WIP-068 & 7091396 \\
\hline 22.0 & 0.999 & 0.00487 & 0.050 & 0.180 & 54.5 & $\mathrm{P}$ & NA & 6.95 & 7.05 & 7.11 & 7.00 & 9.00 & 20.25 & NA & NA & NA & NA & NA & NA & 1 & NA & ss & NA & NA & NA & 34S_4p1d8Yd_5 5 & $12 / 4 \mathrm{C}_{2}$ & TDP-WIP-068 & 7091399 \\
\hline 22.0 & 0.999 & 0.00487 & 0.049 & 0.180 & 47.8 & $\mathrm{P}$ & NA & 7.88 & 8.00 & 8.07 & 8.00 & 9.00 & 26.13 & NA & NA & NA & NA & NA & NA & 1 & NA & ss & NA & NA & NA & 34S_4p1d8Yd_5 5 & $12 / 4 \mathrm{CC} 2$ & TDP-WTP-068 & 7091402 \\
\hline 22.0 & 0.999 & 0.00487 & 0.050 & 0.180 & 45.0 & $\mathrm{P}$ & NA & 8.43 & 8.58 & 8.67 & 8.50 & 9.00 & 28.00 & NA & NA & NA & NA & NA & NA & 1 & NA & sst & NA & NA & NA & 34S_4p1d8Yd_5 & $12 / 4 \mathrm{CC}$ & TDP-WIP-068 & 7091405 \\
\hline 22.0 & 0.999 & 0.00487 & 0.049 & 0.180 & 41.0 & $\mathrm{P}$ & NA & 9.00 & 9.12 & 9.21 & 9.00 & 9.00 & 37.50 & 9.00 & vis & UCSis & NA & NA & NA & 1 & NA & cs & NA & NA & NA & 34S_4p1d8Yd_5 & $12 / 4 \mathrm{CZ}$ & TDP-WIP-068 & 7091409 \\
\hline 22.0 & 0.999 & 0.00487 & 0.049 & 0.180 & 40.0 & $\mathrm{P}$ & NA & 9.41 & 9.60 & 9.71 & 9.50 & 9.00 & 47.75 & NA & NA & NA & NA & NA & NA & 1 & NA & $\mathrm{BC}$ & NA & NA & NA & 34S_4p1d8Yd_5 & $12 / 4 \mathrm{CC}$ & TDP-WIP-068 & 7091411 \\
\hline 22.0 & 0.999 & 0.00487 & 0.050 & 0.330 & 35.0 & $\mathrm{P}$ & NA & 5.98 & 6.04 & 6.09 & 6.00 & 7.50 & 18.75 & NA & NA & NA & NA & NA & NA & NA & NA & ss & NA & NA & NA & $34 \mathrm{~S} \_4 \mathrm{p} 1 \mathrm{dBYc} \_5$ & 12/4D1 & TDP-WIP-068 & 7091414 \\
\hline 22.0 & 0.999 & 0.00487 & 0.049 & 0.330 & 29.5 & $\mathrm{P}$ & NA & 7.04 & 7.11 & 7.15 & 7.00 & 7.50 & 29.75 & NA & NA & NA & NA & NA & NA & 1 & NA & sSt & NA & NA & NA & $345 \_4 p 1 d 8 Y C=5$ & 12/4D1 & TDP-WTP-068 & 7091417 \\
\hline 22.0 & 0.999 & 0.00487 & 0.049 & 0.330 & 27.5 & $\mathrm{P}$ & NA & 7.51 & 7.61 & 7.67 & 7.50 & 7.50 & 38.00 & 7.50 & vis & UCSis & NA & NA & NA & 1 & NA & CS & NA & NA & NA & 34S_4p1d8Yc_5 5 & 12/4D1 & TDP-WTP-068 & 7091421 \\
\hline 22.0 & 0.999 & 0.00487 & 0.049 & 0.330 & 26.0 & $\mathrm{P}$ & NA & 7.92 & 8.03 & 8.09 & 8.00 & 7.50 & $\begin{array}{ll}48.00 \\
\end{array}$ & NA & NA & NA & NA & NA & NA & 1 & NA & $B C$ & NA & NA & NA & $34 \mathrm{~S}$ 4p1d8Yc 5 & 12/4D1 & TDP-WIP-068 & 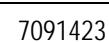 \\
\hline
\end{tabular}



Appendix C

Concentration Profile Data 



\section{Appendix C}

\section{Figures}

C.1 0.367-m- (14 7/16-in.-) diameter tank, 0.320-cm- (0.126-in.-) diameter nozzle; solids nominal diameter $69.3 \mu \mathrm{m}, 2.48 \mathrm{~g} / \mathrm{cm}^{3}$ density; 0.00155 nominal solids fraction; 33.2\% duty cycle, cycle time $22.0 \mathrm{~s}$, pulse volume fraction $0.050, \mathrm{U}_{\mathrm{CS}}$ velocity $2.8 \mathrm{~m} / \mathrm{s}$, target nozzle exit velocity $2.8 \mathrm{~m} / \mathrm{s}$; peak cloud height upper bound $0.184 \mathrm{~m}$ (7.25 in.). Case ID 15E_4s1d2Zc_1..

C.2 0.367-m- (14 7/16-in.-) diameter tank, 0.320-cm- (0.126-in-) diameter nozzle; solids nominal diameter $69.3 \mu \mathrm{m}, 2.48 \mathrm{~g} / \mathrm{cm}^{3}$ density, 0.005 nominal solids fraction, 33.0\% duty cycle, cycle time $15.0 \mathrm{~s}$, pulse volume fraction 0.050 , $\mathrm{U}_{\mathrm{CS}}$ velocity $4.3 \mathrm{~m} / \mathrm{s}$, target nozzle exit velocity $4.2 \mathrm{~m} / \mathrm{s}$; peak cloud height upper bound $0.140 \mathrm{~m}$ (5.5 in.) Case ID 15E_4s1d2Yc_1

C.3 0.367-m- (14 7/16-in.-) diameter tank, 0.320-cm- (0.126-in-) diameter nozzle, solids nominal diameter $69.3 \mu \mathrm{m}, 2.48 \mathrm{~g} / \mathrm{cm}^{3}$ density; 0.015 nominal solids fraction, $18.4 \%$ duty cycle, cycle time $16.0 \mathrm{~s}$, pulse volume fraction 0.050 , $\mathrm{U}_{\mathrm{CS}}$ velocity $7.2 \mathrm{~m} / \mathrm{s}$, target nozzle exit velocity $7.2 \mathrm{~m} / \mathrm{s}$; peak cloud height upper bound $0.152 \mathrm{~m}$ (6 in.). Case ID 15E_4s1d2Xd_1

C.4 0.367-m- (14 7/16-in.-) diameter tank, 0.320-cm- (0.126-in-) diameter nozzle; solids nominal diameter $69.3 \mu \mathrm{m}, 2.48 \mathrm{~g} / \mathrm{cm}^{3}$ density; 0.015 nominal solids fraction, $33.0 \%$ duty cycle, cycle time $11.0 \mathrm{~s}$, pulse volume fraction $0.050 ; \mathrm{U}_{\mathrm{CS}}$ velocity $5.8 \mathrm{~m} / \mathrm{s}$, target nozzle exit velocity $5.8 \mathrm{~m} / \mathrm{s}$; peak cloud height upper bound $0.178 \mathrm{~m}$ (7 in.). Case ID 15E_4s1d2Xc_1

C.5 0.367-m- (14 7/16-in.-) diameter tank, 0.320-cm- (0.126-in-) diameter nozzle; solids nominal diameter $69.3 \mu \mathrm{m}, 2.48 \mathrm{~g} / \mathrm{cm}^{3}$ density; 0.015 nominal solids fraction, $66.7 \%$ duty cycle, cycle time $8.0 \mathrm{~s}$, pulse volume fraction 0.050 , $\mathrm{U}_{\mathrm{CS}}$ velocity $3.9 \mathrm{~m} / \mathrm{s}$, target nozzle exit velocity $3.9 \mathrm{~m} / \mathrm{s}$; peak cloud height upper bound $0.191 \mathrm{~m}$ (7.5 in.). Case ID 15E_4s1d2Xe_1

C.6 0.367-m- (14 7/16-in.-) diameter tank, 0.320-cm- (0.126-in-) diameter nozzle; solids nominal diameter $69.3 \mu \mathrm{m}, 2.48 \mathrm{~g} / \mathrm{cm}^{3}$ density, 0.045 nominal solids fraction; $18.8 \%$ duty cycle, cycle time $15.8 \mathrm{~s}$, pulse volume fraction 0.050 , $\mathrm{U}_{\mathrm{CS}}$ velocity $7.2 \mathrm{~m} / \mathrm{s}$, target nozzle exit velocity $7.2 \mathrm{~m} / \mathrm{s}$; peak cloud height upper bound $0.152 \mathrm{~m}$ (6 in.). Case ID 15E_4s1d2Wd_1

C.7 0.367-m- (14 7/16-in.-) diameter tank, 0.320-cm- (0.126-in-) diameter nozzle; solids nominal diameter $69.3 \mu \mathrm{m}, 2.48 \mathrm{~g} / \mathrm{cm}^{3}$ density; 0.045 nominal solids fraction; 33.2\% duty cycle, cycle time $9.8 \mathrm{~s}$, pulse volume fraction 0.050 ; $\mathrm{U}_{\mathrm{CS}}$ velocity $6.5 \mathrm{~m} / \mathrm{s}$, target nozzle exit velocity $6.5 \mathrm{~m} / \mathrm{s}$; peak cloud height upper bound $0.203 \mathrm{~m}$ (8 in.). Case ID 15E_4s1d2Wc_1

C.8 0.367-m- (14 7/16-in.-) diameter tank, 0.320-cm- (0.126-in-) diameter nozzle; solids nominal diameter $69.3 \mu \mathrm{m}, 2.48 \mathrm{~g} / \mathrm{cm}^{3}$ density; 0.045 nominal solids fraction; $100.0 \%$ duty cycle, cycle time infinite, pulse volume fraction undefined, $\mathrm{U}_{\mathrm{CS}}$ velocity $3 \mathrm{~m} / \mathrm{s}$, target nozzle exit velocity $3 \mathrm{~m} / \mathrm{s}$; peak cloud height upper bound $0.381 \mathrm{~m}$ (15 in.) Case ID 15E_4s1d2Wa....

C.9 0.367-m- (14 7/16-in.-) diameter tank, 0.320-cm- (0.126-in-) diameter nozzle; solids nominal diameter $69.3 \mu \mathrm{m}, 2.48 \mathrm{~g} / \mathrm{cm}^{3}$ density; 0.045 nominal solids fraction; $33.7 \%$ duty 
cycle, cycle time $8.0 \mathrm{~s}$, pulse volume fraction 0.050 , $\mathrm{U}_{\mathrm{CS}}$ velocity $6.5 \mathrm{~m} / \mathrm{s}$, target nozzle exit velocity $8 \mathrm{~m} / \mathrm{s}$; peak cloud height upper bound $0.381 \mathrm{~m}$ (15 in.). Case ID 15E_4s1d2Wc_1

C.10 0.367-m- (14 7/16-in.-) diameter tank, 0.320-cm- (0.126-in-) diameter nozzle; solids nominal diameter $69.3 \mu \mathrm{m}, 2.48 \mathrm{~g} / \mathrm{cm}^{3}$ density; 0.06 nominal solids fraction; 33.6\% duty cycle, cycle time $10.2 \mathrm{~s}$, pulse volume fraction $0.050, \mathrm{U}_{\mathrm{CS}}$ velocity $6.2 \mathrm{~m} / \mathrm{s}$, target nozzle exit velocity $6.2 \mathrm{~m} / \mathrm{s}$; peak cloud height upper bound $0.241 \mathrm{~m}$ (9.5 in.). Case ID 15E_4s1d2Pc_1

C.11 0.367-m- (14 7/16-in.-) diameter tank, 0.320-cm- (0.126-in-) diameter nozzle; solids nominal diameter $75.6 \mu \mathrm{m}, 4.18 \mathrm{~g} / \mathrm{cm}^{3}$ density; 0.00155 nominal solids fraction; $33.5 \%$ duty cycle, cycle time $12.0 \mathrm{~s}$, pulse volume fraction 0.050 , $\mathrm{U}_{\mathrm{CS}}$ velocity $5.2 \mathrm{~m} / \mathrm{s}$, target nozzle exit velocity $5.2 \mathrm{~m} / \mathrm{s}$; peak cloud height upper bound $0.191 \mathrm{~m}$ (7.5 in.). Case ID 15E_4s2d2Zc_1.

C.12 0.367-m- (14 7/16-in.-) diameter tank, 0.320-cm- (0.126-in-) diameter nozzle; solids nominal diameter $75.6 \mu \mathrm{m}, 4.18 \mathrm{~g} / \mathrm{cm}^{3}$ density; 0.015 nominal solids fraction; $33.4 \%$ duty cycle, cycle time $5.5 \mathrm{~s}$, pulse volume fraction 0.050 , $\mathrm{U}_{\mathrm{CS}}$ velocity $11.8 \mathrm{~m} / \mathrm{s}$, target nozzle exit velocity $11.8 \mathrm{~m} / \mathrm{s}$; peak cloud height upper bound $0.165 \mathrm{~m}$ (6.5 in.). Case ID 15E_4s2d2Xc_1

C.13 0.367-m- (14 7/16-in.-) diameter tank, 0.320-cm- (0.126-in-) diameter nozzle; solids nominal diameter $75.6 \mu \mathrm{m}, 4.18 \mathrm{~g} / \mathrm{cm}^{3}$ density; 0.005 nominal solids fraction; $33.4 \%$ duty cycle, cycle time $8.4 \mathrm{~s}$, pulse volume fraction 0.050 , $\mathrm{U}_{\mathrm{CS}}$ velocity $7.6 \mathrm{~m} / \mathrm{s}$, target nozzle exit velocity $7.6 \mathrm{~m} / \mathrm{s}$; peak cloud height upper bound $0.165 \mathrm{~m}$ (6.5 in.). Case ID 15E_4s2d2Yc_1

C.14 0.367-m- (14 7/16-in.-) diameter tank, 0.320-cm- (0.126-in-) diameter nozzle; solids nominal diameter $166.4 \mu \mathrm{m}, 2.46 \mathrm{~g} / \mathrm{cm}^{3}$ density; 0.00155 nominal solids fraction; 33.4\% duty cycle, cycle time $14.6 \mathrm{~s}$, pulse volume fraction $0.050, \mathrm{U}_{\mathrm{CS}}$ velocity $4.2 \mathrm{~m} / \mathrm{s}$, target nozzle exit velocity $4.2 \mathrm{~m} / \mathrm{s}$; peak cloud height upper bound $0.165 \mathrm{~m}$ (6.5 in.). Case ID 15E_4s1d1Zc_1.

C.15 0.367-m- (14 7/16-in.-) diameter tank, 0.320-cm- (0.126-in-) diameter nozzle; solids nominal diameter $166.4 \mu \mathrm{m}, 2.46 \mathrm{~g} / \mathrm{cm}^{3}$ density; 0.015 nominal solids fraction; $33.5 \%$ duty cycle, cycle time $7.4 \mathrm{~s}$, pulse volume fraction 0.050 , $\mathrm{U}_{\mathrm{CS}}$ velocity $8.6 \mathrm{~m} / \mathrm{s}$, target nozzle exit velocity $8.6 \mathrm{~m} / \mathrm{s}$; peak cloud height upper bound $0.152 \mathrm{~m}$ (6 in.). Case ID 15E_4s1d1Xc_1

C.16 0.367-m- (14 7/16-in.-) diameter tank, 0.320-cm- (0.126-in-) diameter nozzle; solids nominal diameter $43.9 \mu \mathrm{m}, 2.5 \mathrm{~g} / \mathrm{cm}^{3}$ density; 0.005 nominal solids fraction; 33.2\% duty cycle, cycle time $17.6 \mathrm{~s}$, pulse volume fraction 0.050 , $\mathrm{U}_{\mathrm{CS}}$ velocity $3.7 \mathrm{~m} / \mathrm{s}$, target nozzle exit velocity $3.5 \mathrm{~m} / \mathrm{s}$; peak cloud height upper bound $0.229 \mathrm{~m}$ (9 in.). Case ID 15E_4s1d5Yc_1

C.17 0.367-m- (14 7/16-in.-) diameter tank, 0.320-cm- (0.126-in-) diameter nozzle; solids nominal diameter $164.2 \mu \mathrm{m}, 4.17 \mathrm{~g} / \mathrm{cm}^{3}$ density; 0.00155 nominal solids fraction; $32.8 \%$ duty cycle, cycle time $9.4 \mathrm{~s}$, pulse volume fraction 0.050 , $\mathrm{U}_{\mathrm{Cs}}$ velocity $6.8 \mathrm{~m} / \mathrm{s}$, target nozzle exit velocity $6.8 \mathrm{~m} / \mathrm{s}$; peak cloud height upper bound $0.216 \mathrm{~m}$ (8.5 in.). Case ID 15E_4s2d1Zc_1

C.18 0.367-m- (14 7/16-in.-) diameter tank, 0.485-cm- (0.191-in-) diameter nozzle; solids nominal diameter $69.3 \mu \mathrm{m}, 2.48 \mathrm{~g} / \mathrm{cm}^{3}$ density; 0.0143 nominal solids fraction; $33.3 \%$ duty cycle, cycle time $8.8 \mathrm{~s}$, pulse volume fraction 0.050 , $\mathrm{U}_{\mathrm{CS}}$ velocity $4.8 \mathrm{~m} / \mathrm{s}$, target nozzle exit velocity $4.8 \mathrm{~m} / \mathrm{s}$; peak cloud height upper bound 0.254 (10 in.). Case ID 15E_6s1d2Vc_1 ..

C.19 0.367-m- (14 7/16-in.-) diameter tank, 0.485-cm- (0.191-in-) diameter nozzle; solids nominal diameter $69.3 \mu \mathrm{m}, 2.48 \mathrm{~g} / \mathrm{cm}^{3}$ density; 0.015 nominal solids fraction; 33.3\% duty 
cycle, cycle time $9.3 \mathrm{~s}$, pulse volume fraction 0.050 , $\mathrm{U}_{\mathrm{CS}}$ velocity $4.6 \mathrm{~m} / \mathrm{s}$, target nozzle exit velocity $4.6 \mathrm{~m} / \mathrm{s}$; peak cloud height upper bound $0.229 \mathrm{~m}$ (9 in.). Case ID 15E_6s1d2Xc_1

C.20 0.367-m- (14 7/16-in.-) diameter tank, 0.485-cm- (0.191-in-) diameter nozzle; solids nominal diameter $69.3 \mu \mathrm{m}, 2.48 \mathrm{~g} / \mathrm{cm}^{3}$ density; 0.015 nominal solids fraction, $32.9 \%$ duty cycle, cycle time $18.8 \mathrm{~s}$, pulse volume fraction $0.100, \mathrm{U}_{\mathrm{CS}}$ velocity $4.4 \mathrm{~m} / \mathrm{s}$, target nozzle exit velocity $4.4 \mathrm{~m} / \mathrm{s}$; peak cloud height upper bound $0.229 \mathrm{~m}$ (9 in.). Case ID 15E_6s1d2Xc_2

C.21 0.367-m- (14 7/16-in.-) diameter tank, 0.681-cm- (0.268-in-) diameter nozzle; solids nominal diameter $69.3 \mu \mathrm{m}, 2.48 \mathrm{~g} / \mathrm{cm}^{3}$ density; 0.0143 nominal solids fraction; $33.0 \%$ duty cycle, cycle time $7.6 \mathrm{~s}$, pulse volume fraction 0.050 , $\mathrm{U}_{\mathrm{CS}}$ velocity $2.9 \mathrm{~m} / \mathrm{s}$, target nozzle exit velocity $2.9 \mathrm{~m} / \mathrm{s}$; peak cloud height upper bound $0.229 \mathrm{~m}$ (9 in.). Case ID 15E_Ms1d2Vc_1

C.22 0.367-m- (14 7/16-in.-) diameter tank, 0.953-cm- (0.375-in-) diameter nozzle; solids nominal diameter $69.3 \mu \mathrm{m}, 2.48 \mathrm{~g} / \mathrm{cm}^{3}$ density; 0.0143 nominal solids fraction; $33.7 \%$ duty cycle, cycle time $5.8 \mathrm{~s}$, pulse volume fraction 0.050 , $\mathrm{U}_{\mathrm{Cs}}$ velocity $1.9 \mathrm{~m} / \mathrm{s}$, target nozzle exit velocity $1.9 \mathrm{~m} / \mathrm{s}$; peak cloud height upper bound $0.254 \mathrm{~m}$ (10 in.). Case ID 15E_Ls1d2Vc_1

C.23 0.367-m- (14 7/16-in.-) diameter tank, 0.953-cm- (0.375-in-) diameter nozzle; solids nominal diameter $69.3 \mu \mathrm{m}, 2.48 \mathrm{~g} / \mathrm{cm}^{3}$ density; 0.0143 nominal solids fraction; 33.5\% duty cycle, cycle time $11.4 \mathrm{~s}$, pulse volume fraction 0.101 , $\mathrm{U}_{\mathrm{CS}}$ velocity $1.9 \mathrm{~m} / \mathrm{s}$, target nozzle exit velocity $1.9 \mathrm{~m} / \mathrm{s}$; peak cloud height upper bound $0.305 \mathrm{~m}$ (12 in.). Case ID 15E_Ls1d2Vc_2.

C.24 0.367-m- (14 7/16-in.-) diameter tank, 0.953-cm- (0.375-in-) diameter nozzle; solids nominal diameter $69.3 \mu \mathrm{m}, 2.48 \mathrm{~g} / \mathrm{cm}^{3}$ density; 0.0143 nominal solids fraction; $33.5 \%$ duty cycle, cycle time $17.0 \mathrm{~s}$, pulse volume fraction 0.100 , $\mathrm{U}_{\mathrm{CS}}$ velocity $2.5 \mathrm{~m} / \mathrm{s}$, target nozzle exit velocity $2.5 \mathrm{~m} / \mathrm{s}$; peak cloud height upper bound $0.305 \mathrm{~m}$ (12 in.). Case ID 15E_Ls1d2Vc_7.

C.25 0.860-m- (33 7/8-in.-) diameter tank, 0.754-cm- (0.297-in-) diameter nozzle; solids nominal diameter $166.4 \mu \mathrm{m}, 2.46 \mathrm{~g} / \mathrm{cm}^{3}$ density; 0.00155 nominal solids fraction; 33.8\% duty cycle, cycle time $32.0 \mathrm{~s}$, pulse volume fraction 0.050 , $\mathrm{U}_{\mathrm{CS}}$ velocity $4.5 \mathrm{~m} / \mathrm{s}$, target nozzle exit velocity $4.5 \mathrm{~m} / \mathrm{s}$; peak cloud height upper bound $0.356 \mathrm{~m}$ (14 in.). Case ID 34E_4s1d1Zc_1

C.26 0.860-m- (33 7/8-in.-) diameter tank, 0.754-cm- (0.297-in-) diameter nozzle; solids nominal diameter $69.3 \mu \mathrm{m}, 2.48 \mathrm{~g} / \mathrm{cm}^{3}$ density; 0.0015 nominal solids fraction; 33.6\% duty cycle, cycle time $39.0 \mathrm{~s}$, pulse volume fraction 0.050 , $\mathrm{U}_{\mathrm{CS}}$ velocity $3.7 \mathrm{~m} / \mathrm{s}$, target nozzle exit velocity $3.7 \mathrm{~m} / \mathrm{s}$; peak cloud height upper bound $0.533 \mathrm{~m}$ (21 in.). Case ID 34E_4s1d2Sc_1

C.27 0.860-m- (33 7/8-in.-) diameter tank, 0.754-cm- (0.297-in-) diameter nozzle; solids nominal diameter $69.3 \mu \mathrm{m}, 2.48 \mathrm{~g} / \mathrm{cm}^{3}$ density; 0.005 nominal solids fraction; 33.6\% duty cycle, cycle time $28.4 \mathrm{~s}$, pulse volume fraction $0.050, \mathrm{U}_{\mathrm{CS}}$ velocity $5.1 \mathrm{~m} / \mathrm{s}$, target nozzle exit velocity $5.1 \mathrm{~m} / \mathrm{s}$; peak cloud height upper bound $0.508 \mathrm{~m}$ (20 in.). Case ID 34E_4s1d2Yc_1

C.28 0.860-m- (33 7/8-in.-) diameter tank, 0.754-cm- (0.297-in-) diameter nozzle; solids nominal diameter $69.3 \mu \mathrm{m}, 2.48 \mathrm{~g} / \mathrm{cm}^{3}$ density; 0.005 nominal solids fraction; $18.6 \%$ duty cycle, cycle time $42.4 \mathrm{~s}$, pulse volume fraction 0.050 , $\mathrm{U}_{\mathrm{CS}}$ velocity $6 \mathrm{~m} / \mathrm{s}$, target nozzle exit velocity $6.2 \mathrm{~m} / \mathrm{s}$; peak cloud height upper bound $0.559 \mathrm{~m}$ (22 in.). Case ID 34E_4s1d2Yd_1

C.29 0.860-m- (33 7/8-in.-) diameter tank, 0.754-cm- (0.297-in-) diameter nozzle; solids nominal diameter $75.6 \mu \mathrm{m}, 4.18 \mathrm{~g} / \mathrm{cm}^{3}$ density; 0.00155 nominal solids fraction; 33.5\% duty cycle, 
cycle time $24.9 \mathrm{~s}$, pulse volume fraction 0.050 , $\mathrm{U}_{\mathrm{CS}}$ velocity $5.6 \mathrm{~m} / \mathrm{s}$, target nozzle exit velocity $5.6 \mathrm{~m} / \mathrm{s}$; peak cloud height upper bound $0.368 \mathrm{~m}$ (14.5 in.). Case ID

34E_4s2d2Zc_1

C.30 0.860-m- (33 7/8-in.-) diameter tank, 0.754-cm- (0.297-in-) diameter nozzle; solids nominal diameter $75.6 \mu \mathrm{m}, 4.18 \mathrm{~g} / \mathrm{cm}^{3}$ density; 0.015 nominal solids fraction; $33.9 \%$ duty cycle, cycle time $14.8 \mathrm{~s}$, pulse volume fraction 0.050 , $\mathrm{U}_{\mathrm{CS}}$ velocity $9.8 \mathrm{~m} / \mathrm{s}$, target nozzle exit velocity $10 \mathrm{~m} / \mathrm{s}$; peak cloud height upper bound $0.279 \mathrm{~m}$ (11 in.). Case ID 34E_4s2d2Xc_1

C.31 0.860-m- (33 7/8-in.-) diameter tank, 0.754-cm- (0.297-in-) diameter nozzle; solids nominal diameter $75.6 \mu \mathrm{m}, 4.18 \mathrm{~g} / \mathrm{cm}^{3}$ density; 0.005 nominal solids fraction; 33.6\% duty cycle, cycle time $17.0 \mathrm{~s}$, pulse volume fraction $0.050, \mathrm{U}_{\mathrm{CS}}$ velocity $8.6 \mathrm{~m} / \mathrm{s}$, target nozzle exit velocity $8.6 \mathrm{~m} / \mathrm{s}$; peak cloud height upper bound $0.483 \mathrm{~m}$ (19 in.). Case ID 34E_4s2d2Yc_1

C.32 1.778-m- (70-in.-) diameter tank, 1.557-cm- (0.613-in.-) diameter nozzle; solids nominal diameter $166.4 \mu \mathrm{m}, 2.46 \mathrm{~g} / \mathrm{cm}^{3}$ density; 0.00155 nominal solids fraction; 33.2\% duty cycle, cycle time $45.4 \mathrm{~s}$, pulse volume fraction 0.050 , $\mathrm{U}_{\mathrm{CS}}$ velocity $6.7 \mathrm{~m} / \mathrm{s}$, target nozzle exit velocity $6.7 \mathrm{~m} / \mathrm{s}$; peak cloud height upper bound $0.660 \mathrm{~m}$ (26 in.). Case ID 70F_4s1d1Zc_1

C.33 1.778-m- (70-in.-) diameter tank, 1.557-cm- (0.613-in.-) diameter nozzle; solids nominal diameter $166.4 \mu \mathrm{m}, 2.46 \mathrm{~g} / \mathrm{cm}^{3}$ density; 0.00155 nominal solids fraction; 33.5\% duty cycle, cycle time $100.8 \mathrm{~s}$, pulse volume fraction 0.101 , $\mathrm{U}_{\mathrm{CS}}$ velocity $5.8 \mathrm{~m} / \mathrm{s}$, target nozzle exit velocity $5.8 \mathrm{~m} / \mathrm{s}$; peak cloud height upper bound $0.660 \mathrm{~m}$ (26 in.). Case ID 70F_4s1d1Zc_2

C.34 1.778-m- (70-in.-) diameter tank, 1.557-cm- (0.613-in.-) diameter nozzle; solids nominal diameter $69.3 \mu \mathrm{m}, 2.48 \mathrm{~g} / \mathrm{cm}^{3}$ density; 0.00155 nominal solids fraction; 33.6\% duty cycle, cycle time $67.4 \mathrm{~s}$, pulse volume fraction $0.050, \mathrm{U}_{\mathrm{CS}}$ velocity $4.4 \mathrm{~m} / \mathrm{s}$, target nozzle exit velocity $4.4 \mathrm{~m} / \mathrm{s}$; peak cloud height upper bound $0.749 \mathrm{~m}$ (29.5 in.). Case ID 70F_4s1d2Zc_1

C.35 1.778-m- (70-in.-) diameter tank, 1.557-cm- (0.613-in.-) diameter nozzle; solids nominal diameter $69.3 \mu \mathrm{m}, 2.48 \mathrm{~g} / \mathrm{cm}^{3}$ density; 0.01 nominal solids fraction; 33.9\% duty cycle, cycle time $44.6 \mathrm{~s}$, pulse volume fraction 0.050 , $\mathrm{U}_{\mathrm{CS}}$ velocity $6.6 \mathrm{~m} / \mathrm{s}$, target nozzle exit velocity $6.6 \mathrm{~m} / \mathrm{s}$; peak cloud height upper bound $0.610 \mathrm{~m}$ (24 in.). Case ID 70F_4s1d2Rc_1.

C.36 1.778-m- (70-in.-) diameter tank, 1.557-cm- (0.613-in.-) diameter nozzle; solids nominal diameter $69.3 \mu \mathrm{m}, 2.48 \mathrm{~g} / \mathrm{cm}^{3}$ density; 0.005 nominal solids fraction; 33.5\% duty cycle, cycle time $51.0 \mathrm{~s}$, pulse volume fraction $0.050, \mathrm{U}_{\mathrm{CS}}$ velocity $5.8 \mathrm{~m} / \mathrm{s}$, target nozzle exit velocity $5.8 \mathrm{~m} / \mathrm{s}$; peak cloud height upper bound $0.597 \mathrm{~m}$ (23.5 in.). Case ID 70F_4s1d2Yc_1

C.37 1.778-m- (70-in.-) diameter tank, 1.557-cm- (0.613-in.-) diameter nozzle; solids nominal diameter $69.3 \mu \mathrm{m}, 2.48 \mathrm{~g} / \mathrm{cm}^{3}$ density; 0.0143 nominal solids fraction; 33.6\% duty cycle, cycle time $42.2 \mathrm{~s}$, pulse volume fraction $0.050, \mathrm{U}_{\mathrm{CS}}$ velocity $7.1 \mathrm{~m} / \mathrm{s}$, target nozzle exit velocity $7.1 \mathrm{~m} / \mathrm{s}$; peak cloud height upper bound $0.787 \mathrm{~m}$ (31 in.). Case ID 70F_4s1d2Vc_1

C.38 1.778-m- (70-in.-) diameter tank, 1.557-cm- (0.613-in.-) diameter nozzle; solids nominal diameter $69.3 \mu \mathrm{m}, 2.48 \mathrm{~g} / \mathrm{cm}^{3}$ density; 0.0143 nominal solids fraction; 33.6\% duty cycle, cycle time $42.2 \mathrm{~s}$, pulse volume fraction $0.050, \mathrm{U}_{\mathrm{CS}}$ velocity $7.1 \mathrm{~m} / \mathrm{s}$, target nozzle exit velocity $7.1 \mathrm{~m} / \mathrm{s}$; peak cloud height upper bound $0.787 \mathrm{~m}$ (31 in.). Case ID 70F_4s1d2Vc_1

C.39 1.778-m- (70-in.-) diameter tank, 1.557-cm- (0.613-in.-) diameter nozzle; solids nominal diameter $69.3 \mu \mathrm{m}, 2.48 \mathrm{~g} / \mathrm{cm}^{3}$ density; 0.0143 nominal solids fraction; 33.6\% duty cycle, cycle time $42.2 \mathrm{~s}$, pulse volume fraction $0.050, \mathrm{U}_{\mathrm{CS}}$ velocity $7.1 \mathrm{~m} / \mathrm{s}$, target nozzle exit 
velocity $7.1 \mathrm{~m} / \mathrm{s}$; peak cloud height upper bound $0.787 \mathrm{~m}$ (31 in.). Case ID

70F_4s1d2Vc_1

C.40 1.778-m- (70-in.-) diameter tank, 1.557-cm- (0.613-in.-) diameter nozzle; solids nominal diameter $69.3 \mu \mathrm{m}, 2.48 \mathrm{~g} / \mathrm{cm}^{3}$ density; 0.0143 nominal solids fraction; $18.7 \%$ duty cycle, cycle time $56.4 \mathrm{~s}$, pulse volume fraction 0.050 , $\mathrm{U}_{\mathrm{CS}}$ velocity $9.8 \mathrm{~m} / \mathrm{s}$, target nozzle exit velocity $9.6 \mathrm{~m} / \mathrm{s}$; peak cloud height upper bound $0.673 \mathrm{~m}$ (26.5 in.). Case ID 70F_4s1d2Vd_1

C.41 1.778-m- (70-in.-) diameter tank, 1.557-cm- (0.613-in.-) diameter nozzle; solids nominal diameter $69.3 \mu \mathrm{m}, 2.48 \mathrm{~g} / \mathrm{cm}^{3}$ density; 0.0143 nominal solids fraction; $18.7 \%$ duty cycle, cycle time $55.6 \mathrm{~s}$, pulse volume fraction 0.050 , $\mathrm{U}_{\mathrm{CS}}$ condition $9.8 \mathrm{~m} / \mathrm{s}$, target nozzle exit velocity $9.8 \mathrm{~m} / \mathrm{s}$; peak cloud height upper bound $0.724 \mathrm{~m}$ (28.5 in.). Case ID 70F_4s1d2Vd_1

C.42 1.778-m- (70-in.-) diameter tank, 1.557-cm- (0.613-in.-) diameter nozzle; solids nominal diameter $69.3 \mu \mathrm{m}, 2.48 \mathrm{~g} / \mathrm{cm}^{3}$ density; 0.0143 nominal solids fraction; $18.5 \%$ duty cycle, cycle time $54.8 \mathrm{~s}$, pulse volume fraction 0.050 , U $\mathrm{U}_{\mathrm{CS}}$ velocity $9.9 \mathrm{~m} / \mathrm{s}$, target nozzle exit velocity $9.9 \mathrm{~m} / \mathrm{s}$; peak cloud height upper bound $0.711 \mathrm{~m}$ (28 in.). Case ID 70F_4s1d2Vd_1

C.43 1.778-m- (70-in.-) diameter tank, 1.557-cm- (0.613-in.-) diameter nozzle; solids nominal diameter $69.3 \mu \mathrm{m}, 2.48 \mathrm{~g} / \mathrm{cm}^{3}$ density; 0.0143 nominal solids fraction; 33.6\% duty cycle, cycle time $41.2 \mathrm{~s}$, pulse volume fraction 0.050 , $\mathrm{U}_{\mathrm{CS}}$ velocity $7.3 \mathrm{~m} / \mathrm{s}$, target nozzle exit velocity $7.3 \mathrm{~m} / \mathrm{s}$; peak cloud height upper bound $0.813 \mathrm{~m}$ (32 in.). Case ID 70F_4s1d2Vc_1

C.44 1.778-m- (70-in.-) diameter tank, 1.557-cm- (0.613-in.-) diameter nozzle; solids nominal diameter $69.3 \mu \mathrm{m}, 2.48 \mathrm{~g} / \mathrm{cm}^{3}$ density; 0.0143 nominal solids fraction; $66.6 \%$ duty cycle, cycle time $31.2 \mathrm{~s}$, pulse volume fraction 0.050 , $\mathrm{U}_{\mathrm{CS}}$ velocity $4.8 \mathrm{~m} / \mathrm{s}$, target nozzle exit velocity $4.8 \mathrm{~m} / \mathrm{s}$; peak cloud height upper bound $0.927 \mathrm{~m}$ (36.5 in.). Case ID 70F_4s1d2Ve_1

C.45 1.778-m- (70-in.-) diameter tank, 1.557-cm- (0.613-in.-) diameter nozzle; solids nominal diameter $69.3 \mu \mathrm{m}, 2.48 \mathrm{~g} / \mathrm{cm}^{3}$ density; 0.0143 nominal solids fraction; 32.7\% duty cycle, cycle time $90.0 \mathrm{~s}$, pulse volume fraction $0.100, \mathrm{U}_{\mathrm{CS}}$ velocity $6.6 \mathrm{~m} / \mathrm{s}$, target nozzle exit velocity $6.6 \mathrm{~m} / \mathrm{s}$; peak cloud height upper bound $0.749 \mathrm{~m}$ (29.5 in.). Case ID 70F_4s1d2Vc_2

C.46 1.778-m- (70-in.-) diameter tank, 1.557-cm- (0.613-in.-) diameter nozzle; solids nominal diameter $69.3 \mu \mathrm{m}, 2.48 \mathrm{~g} / \mathrm{cm}^{3}$ density; 0.00155 nominal solids fraction; 33.7\% duty cycle, cycle time $63.6 \mathrm{~s}$, pulse volume fraction 0.050 ; $\mathrm{U}_{\mathrm{CS}}$ velocity $4.6 \mathrm{~m} / \mathrm{s}$, target nozzle exit velocity $4.6 \mathrm{~m} / \mathrm{s}$; peak cloud height upper bound $0.787 \mathrm{~m}$ (31 in.). Case ID 70E_4s1d2Zc_1.

C.47 1.778-m- (70-in.-) diameter tank, 1.557-cm- (0.613-in.-) diameter nozzle; solids nominal diameter $69.3 \mu \mathrm{m}, 2.48 \mathrm{~g} / \mathrm{cm}^{3}$ density; 0.005 nominal solids fraction; 33.5\% duty cycle, cycle time $49.6 \mathrm{~s}$, pulse volume fraction 0.050 , $\mathrm{U}_{\mathrm{CS}}$ velocity $6 \mathrm{~m} / \mathrm{s}$, target nozzle exit velocity $6 \mathrm{~m} / \mathrm{s}$; peak cloud height upper bound $0.724 \mathrm{~m}$ (28.5 in.). Case ID 70E_4s1d2Yc_1

C.48 1.778-m- (70-in.-) diameter tank, 1.557-cm- (0.613-in.-) diameter nozzle; solids nominal diameter $69.3 \mu \mathrm{m}, 2.48 \mathrm{~g} / \mathrm{cm}^{3}$ density; 0.0143 nominal solids fraction; $18.9 \%$ duty cycle, cycle time $48.6 \mathrm{~s}$, pulse volume fraction 0.050 , $\mathrm{U}_{\mathrm{Cs}}$ velocity $10.9 \mathrm{~m} / \mathrm{s}$, target nozzle exit velocity $11.2 \mathrm{~m} / \mathrm{s}$; peak cloud height upper bound $1.168 \mathrm{~m}$ (46 in.). Case ID 70E_4s1d2Vd_1 
C.49 1.778-m- (70-in.-) diameter tank, 1.557-cm- (0.613-in.-) diameter nozzle; solids nominal diameter $69.3 \mu \mathrm{m}, 2.48 \mathrm{~g} / \mathrm{cm}^{3}$ density; 0.0143 nominal solids fraction; 18.9\% duty cycle, cycle time $48.6 \mathrm{~s}$, pulse volume fraction 0.050 , $\mathrm{U}_{\mathrm{CS}}$ velocity $10.9 \mathrm{~m} / \mathrm{s}$, target nozzle exit velocity $11.2 \mathrm{~m} / \mathrm{s}$; peak cloud height upper bound $1.168 \mathrm{~m}$ (46 in.). Case ID 70E_4s1d2Vd_1

C.50 1.778-m- (70-in.-) diameter tank, 1.557-cm- (0.613-in.-) diameter nozzle; solids nominal diameter $69.3 \mu \mathrm{m}, 2.48 \mathrm{~g} / \mathrm{cm}^{3}$ density; 0.0143 nominal solids fraction; 18.9\% duty cycle, cycle time $48.6 \mathrm{~s}$, pulse volume fraction 0.050 , $\mathrm{U}_{\mathrm{CS}}$ velocity $10.9 \mathrm{~m} / \mathrm{s}$, target nozzle exit velocity $11.2 \mathrm{~m} / \mathrm{s}$; peak cloud height upper bound $1.168 \mathrm{~m}$ (46 in.). Case ID 70E_4s1d2Vd_1

C.51 1.778-m- (70-in.-) diameter tank, 1.557-cm- (0.613-in.-) diameter nozzle; solids nominal diameter $69.3 \mu \mathrm{m}, 2.48 \mathrm{~g} / \mathrm{cm}^{3}$ density; 0.0143 nominal solids fraction; 33.3\% duty cycle, cycle time $38.8 \mathrm{~s}$, pulse volume fraction $0.050, \mathrm{U}_{\mathrm{CS}}$ velocity $7.8 \mathrm{~m} / \mathrm{s}$, target nozzle exit velocity $7.8 \mathrm{~m} / \mathrm{s}$; peak cloud height upper bound $1.041 \mathrm{~m}$ (41 in.). Case ID 70E_4s1d2Vc_1

C.52 1.778-m- (70-in.-) diameter tank, 1.557-cm- (0.613-in.-) diameter nozzle; solids nominal diameter $69.3 \mu \mathrm{m}, 2.48 \mathrm{~g} / \mathrm{cm}^{3}$ density; 0.0143 nominal solids fraction; 33.3\% duty cycle, cycle time $38.8 \mathrm{~s}$, pulse volume fraction $0.050, \mathrm{U}_{\mathrm{CS}}$ velocity $7.8 \mathrm{~m} / \mathrm{s}$, target nozzle exit velocity $7.8 \mathrm{~m} / \mathrm{s}$; peak cloud height upper bound $1.041 \mathrm{~m}$ (41 in.). Case ID 70E_4s1d2Vc_1

C.53 1.778-m- (70-in.-) diameter tank, 1.557-cm- (0.613-in.-) diameter nozzle; solids nominal diameter $69.3 \mu \mathrm{m}, 2.48 \mathrm{~g} / \mathrm{cm}^{3}$ density; 0.0143 nominal solids fraction; 33.3\% duty cycle, cycle time $38.8 \mathrm{~s}$, pulse volume fraction $0.050, \mathrm{U}_{\mathrm{CS}}$ velocity $7.8 \mathrm{~m} / \mathrm{s}$, target nozzle exit velocity $7.8 \mathrm{~m} / \mathrm{s}$; peak cloud height upper bound $1.041 \mathrm{~m}$ (41 in.). Case ID 70E_4s1d2Vc_1

C.54 1.778-m- (70-in.-) diameter tank, 1.557-cm- (0.613-in.-) diameter nozzle; solids nominal diameter $69.3 \mu \mathrm{m}, 2.48 \mathrm{~g} / \mathrm{cm}^{3}$ density; 0.015 nominal solids fraction; $32.9 \%$ duty cycle, cycle time $44.6 \mathrm{~s}$, pulse volume fraction 0.050 , $\mathrm{U}_{\mathrm{CS}}$ velocity $8.5 \mathrm{~m} / \mathrm{s}$, target nozzle exit velocity $6.8 \mathrm{~m} / \mathrm{s}$; peak cloud height upper bound $0.572 \mathrm{~m}$ (22.5 in.). Case ID 70E_4s1d2Xc_1

C.55 1.778-m- (70-in.-) diameter tank, 1.557-cm- (0.613-in.-) diameter nozzle; solids nominal diameter $69.3 \mu \mathrm{m}, 2.48 \mathrm{~g} / \mathrm{cm}^{3}$ density; 0.015 nominal solids fraction; 33.7\% duty cycle, cycle time $35.4 \mathrm{~s}$, pulse volume fraction 0.050 , $\mathrm{U}_{\mathrm{CS}}$ velocity $8.5 \mathrm{~m} / \mathrm{s}$, target nozzle exit velocity $8.5 \mathrm{~m} / \mathrm{s}$; peak cloud height upper bound $1.067 \mathrm{~m}$ (42 in.). Case ID 70E_4s1d2Xc_1

C.56 1.778-m- (70-in.-) diameter tank, 1.557-cm- (0.613-in.-) diameter nozzle; solids nominal diameter $69.3 \mu \mathrm{m}, 2.48 \mathrm{~g} / \mathrm{cm}^{3}$ density; 0.015 nominal solids fraction; 33.7\% duty cycle, cycle time $35.4 \mathrm{~s}$, pulse volume fraction $0.050, \mathrm{U}_{\mathrm{CS}}$ velocity $8.5 \mathrm{~m} / \mathrm{s}$, target nozzle exit velocity $8.5 \mathrm{~m} / \mathrm{s}$; peak cloud height upper bound $1.067 \mathrm{~m}$ (42 in.). Case ID 70E_4s1d2Xc_1

C.57 1.778-m- (70-in.-) diameter tank, 1.557-cm- (0.613-in.-) diameter nozzle; solids nominal diameter $69.3 \mu \mathrm{m}, 2.48 \mathrm{~g} / \mathrm{cm}^{3}$ density; 0.015 nominal solids fraction; 33.7\% duty cycle, cycle time $35.4 \mathrm{~s}$, pulse volume fraction 0.050 , $\mathrm{U}_{\mathrm{CS}}$ velocity $8.5 \mathrm{~m} / \mathrm{s}$, target nozzle exit velocity $8.5 \mathrm{~m} / \mathrm{s}$; peak cloud height upper bound $1.067 \mathrm{~m}$ (42 in.). Case ID 70E_4s1d2Xc_1

C.58 1.778-m- (70-in.-) diameter tank, 1.557-cm- (0.613-in.-) diameter nozzle; solids nominal diameter $75.6 \mu \mathrm{m}, 4.18 \mathrm{~g} / \mathrm{cm}^{3}$ density; 0.00155 nominal solids fraction; 33.9\% duty cycle, 
cycle time $35.6 \mathrm{~s}$, pulse volume fraction 0.050 , $\mathrm{U}_{\mathrm{CS}}$ velocity $8.4 \mathrm{~m} / \mathrm{s}$, target nozzle exit velocity $8.4 \mathrm{~m} / \mathrm{s}$; peak cloud height upper bound $0.737 \mathrm{~m}$ (29 in.). Case ID

70E_4s2d2Zc_1.

C.59 1.778-m- (70-in.-) diameter tank, 1.557-cm- (0.613-in.-) diameter nozzle; solids nominal diameter $75.6 \mu \mathrm{m}, 4.18 \mathrm{~g} / \mathrm{cm}^{3}$ density; 0.005 nominal solids fraction; $32.8 \%$ duty cycle, cycle time $26.0 \mathrm{~s}$, pulse volume fraction $0.050, \mathrm{U}_{\mathrm{CS}}$ velocity $12.5 \mathrm{~m} / \mathrm{s}$, target nozzle exit velocity $12 \mathrm{~m} / \mathrm{s}$; peak cloud height upper bound $0.660 \mathrm{~m}$ (26 in.). Case ID 70E_4s2d2Yc_1

C.60 1.778-m- (70-in.-) diameter tank, 1.557-cm- (0.613-in.-) diameter nozzle; solids nominal diameter $75.6 \mu \mathrm{m}, 4.18 \mathrm{~g} / \mathrm{cm}^{3}$ density; 0.005 nominal solids fraction, $32.8 \%$ duty cycle, cycle time $26.0 \mathrm{~s}$, pulse volume fraction 0.050 , $\mathrm{U}_{\mathrm{CS}}$ velocity $12.5 \mathrm{~m} / \mathrm{s}$, target nozzle exit velocity $12 \mathrm{~m} / \mathrm{s}$; peak cloud height upper bound $0.660 \mathrm{~m}$ (26 in.). Case ID 70E_4s2d2Yc_1

C.61 1.778-m- (70-in.-) diameter tank, 1.557-cm- (0.613-in.-) diameter nozzle; solids nominal diameter $75.6 \mu \mathrm{m}, 4.18 \mathrm{~g} / \mathrm{cm}^{3}$ density; 0.005 nominal solids fraction; 32.8\% duty cycle, cycle time $26.0 \mathrm{~s}$, pulse volume fraction $0.050, \mathrm{U}_{\mathrm{CS}}$ velocity $12.5 \mathrm{~m} / \mathrm{s}$, target nozzle exit velocity $12 \mathrm{~m} / \mathrm{s}$; peak cloud height upper bound $0.660 \mathrm{~m}$ (26 in.). Case ID 70E_4s2d2Yc_1

C.62 1.778-m- (70-in.-) diameter tank, 1.557-cm- (0.613-in.-) diameter nozzle; solids nominal diameter $166.4 \mu \mathrm{m}, 2.46 \mathrm{~g} / \mathrm{cm}^{3}$ density; 0.00155 nominal solids fraction; 33.4\% duty cycle, cycle time $42.6 \mathrm{~s}$, pulse volume fraction 0.050 , $\mathrm{U}_{\mathrm{CS}}$ velocity $7.1 \mathrm{~m} / \mathrm{s}$, target nozzle exit velocity $7.1 \mathrm{~m} / \mathrm{s}$; peak cloud height upper bound $0.800 \mathrm{~m}$ (31.5 in.). Case ID 70E_4s1d1Zc_1.

C.63 1.778-m- (70-in.-) diameter tank, 1.557-cm- (0.613-in.-) diameter nozzle; solids nominal diameter $166.4 \mu \mathrm{m}, 2.46 \mathrm{~g} / \mathrm{cm}^{3}$ density; 0.00155 nominal solids fraction; 33.4\% duty cycle, cycle time $42.6 \mathrm{~s}$, pulse volume fraction 0.050 , $\mathrm{U}_{\mathrm{CS}}$ velocity $7.1 \mathrm{~m} / \mathrm{s}$, target nozzle exit velocity $7.1 \mathrm{~m} / \mathrm{s}$; peak cloud height upper bound $0.800 \mathrm{~m}$ (31.5 in.). Case ID 70E_4s1d1Zc_1.

C.64 1.778-m- (70-in.-) diameter tank, 1.557-cm- (0.613-in.-) diameter nozzle; solids nominal diameter $166.4 \mu \mathrm{m}, 2.46 \mathrm{~g} / \mathrm{cm}^{3}$ density; 0.00155 nominal solids fraction; 33.4\% duty cycle, cycle time $42.6 \mathrm{~s}$, pulse volume fraction 0.050 , $\mathrm{U}_{\mathrm{CS}}$ velocity $7.1 \mathrm{~m} / \mathrm{s}$, target nozzle exit velocity $7.1 \mathrm{~m} / \mathrm{s}$; peak cloud height upper bound $0.800 \mathrm{~m}$ (31.5 in.). Case ID 70E_4s1d1Zc_1.

C.65 1.778-m- (70-in.-) diameter tank, 2.337-cm- (0.92-in.-) diameter nozzle; solids nominal diameter $69.3 \mu \mathrm{m}, 2.48 \mathrm{~g} / \mathrm{cm}^{3}$ density; 0.0143 nominal solids fraction; 33.5\% duty cycle, cycle time $29.6 \mathrm{~s}$, pulse volume fraction 0.050 , $\mathrm{U}_{\mathrm{CS}}$ velocity $6.8 \mathrm{~m} / \mathrm{s}$, target nozzle exit velocity $6.8 \mathrm{~m} / \mathrm{s}$; peak cloud height upper bound $1.829 \mathrm{~m}$ (72 in.). Case ID 70E_6s1d2Vc_1

C.66 1.778-m- (70-in.-) diameter tank, 2.337-cm- (0.92-in.-) diameter nozzle; solids nominal diameter $69.3 \mu \mathrm{m}, 2.48 \mathrm{~g} / \mathrm{cm}^{3}$ density; 0.0143 nominal solids fraction; 33.1\% duty cycle, cycle time $61.8 \mathrm{~s}$, pulse volume fraction 0.100 , $\mathrm{U}_{\mathrm{CS}}$ velocity $6.4 \mathrm{~m} / \mathrm{s}$, target nozzle exit velocity $6.4 \mathrm{~m} / \mathrm{s}$; peak cloud height upper bound $1.626 \mathrm{~m}$ (64 in.). Case ID 70E_6s1d2Vc_2.

\section{Tables}

C.1 Summary of Concentration Profile Cases. 



\section{Acronyms}

\section{Symbols}

D diameter of tank

DC duty cycle

d diameter of jet nozzle

$\mathrm{d}_{50}$ mean particle diameter

H fluid height, normal fill level

$\mathrm{H}_{\mathrm{C}}$ average peak cloud height

HS head shape

$\mathrm{N}_{\mathrm{I}}$ number of jets operating in the inner ring

$\mathrm{N}_{\mathrm{O}}$ number of jets operating in the outer ring

$\mathrm{R}$ tank radius

$\mathrm{U}$ jet velocity

$\mathrm{U}_{\mathrm{CS}}$ critical-suspension velocity

$\mathrm{V}_{\mathrm{P}}$ volume of pulse

$\mathrm{V}_{\mathrm{REF}}$ reference volume based on the volume of a right circular cylinder of diameter $\mathrm{D}$ where height equals diameter, $\mathrm{V}_{\mathrm{REF}}=\left(\pi \mathrm{D}^{3}\right) / 4$

$\mathrm{V}_{\mathrm{S}}$ volume of solid particulate

Z elevation

\section{Greek Symbols}

$\phi_{\mathrm{p}} \quad$ pulse volume fraction $=\left(\mathrm{N}_{\mathrm{I}}+\mathrm{N}_{\mathrm{O}}\right) \mathrm{V}_{\mathrm{P}} / \mathrm{V}_{\mathrm{REF}}$

$\phi_{\mathrm{S}}$ solids volume fraction: ratio of volume of solid particulate to reference volume $=V_{S} /\left(\pi D^{3}\right) / 4$

$\rho_{\mathrm{s}} \quad$ solids density

C.ix 



\section{Appendix C - Concentration Profile Data}

Solid concentration by volume profile measurements in the cloud of suspended particles were obtained using the ultrasonic concentration probe described in Appendix A. The probe was inserted into the tank to a radial elevation and position within the cloud where the probe measured the ultrasonic signal attenuation in real time during the pulse of the fluid in the volume. The signal attenuation was used to determine the local concentration between the transducers of the concentration probe.

A list of the profiles measured, operating conditions, and velocity and cloud height data for each profile is provided in Table C.1. The table shows the test parameters and radial position of the probe. The first column lists the figure number where the data is found in Appendix C. The second column lists the test Case ID. The Case ID provides a quick summary of major test conditions, and the components of the Case ID are described in Table B.2. The next columns list the operating parameters for the test. The measurements were taken at elevations within the cloud. For some tests in the large-scale tank, profiles were obtained at three radial locations: tank center [0R], half way between the center and the wall [0.5R], and near the wall [0.9R] where $\mathrm{R}$ is the tank radius. Table C.1 lists the "highest concentration test measurement location" associated with the measurement at that radial location. This is the nondimensional elevation within the cloud where a measurement was taken. Above this location the cloud was not visible. The "highest concentration test measurement location" is provided at the three radial measurement locations where data was taken. This information is followed by the velocity, the critical suspension velocity and the cloud height associated with the profile. The last column lists the test which shows the date of the measurement followed by the sequence during the day. If the entry in the velocity column is shown in italics, the profile was taken at a velocity below $\mathrm{U}_{\mathrm{CS}}$; if the entry in the velocity column is shown in bold, the profile was taken at a velocity above $\mathrm{U}_{\mathrm{CS}}$. Most measurements were taken at the critical suspension velocity.

Concentration profiles taken in the small-scale tank are shown in Figures C.1 through C.24. Concentration profiles taken in the mid-scale tank are shown in Figures C.25 through C.31. Concentration profiles taken in the large-scale tank with the flange and dish bottom are shown in Figures C.32 through C.45, and concentration profiles taken in the large-scale tank with the elliptical bottom are shown in Figures C.46 through C.66. When profiles were taken at multiple radii the profile at the tank center [0R] is listed first, the profile half way between the center and the wall [0.5R] is listed second, and near the wall [0.9R] where $\mathrm{R}$ is the tank radius is listed last. 
Table C.1. Summary of Concentration Profile Cases

\begin{tabular}{|c|c|c|c|c|c|c|c|c|c|c|c|c|c|c|c|c|c|c|}
\hline \multirow[b]{2}{*}{ Figure } & \multirow[b]{2}{*}{ Case ID } & \multirow{2}{*}{$\begin{array}{c}\text { Tank } \\
\text { Diameter } \\
\text { D } \\
\end{array}$} & \multirow{2}{*}{$\begin{array}{c}\text { Head } \\
\text { Shape } \\
\text { HS } \\
\end{array}$} & \multirow{2}{*}{\begin{tabular}{|c} 
Nozzle \\
Diameter \\
$\mathrm{d}$
\end{tabular}} & \multicolumn{2}{|c|}{$\begin{array}{c}\text { Number of } \\
\text { Nozzles } \\
\text { Operated }\end{array}$} & \multirow[b]{2}{*}{$\begin{array}{c}\text { Density } \\
\rho_{\mathrm{s}}\end{array}$} & \multirow{2}{*}{\begin{tabular}{|c|}
$\begin{array}{c}\text { Particle } \\
\text { Diameter }\end{array}$ \\
\\
$\mathrm{d}_{50}$ \\
\end{tabular}} & \multirow{2}{*}{$\begin{array}{c}\text { Concentration } \\
\phi_{\mathrm{S}}\end{array}$} & \multirow{2}{*}{$\begin{array}{c}\text { Duty } \\
\text { Cycle } \\
\text { DC }\end{array}$} & \multirow{2}{*}{$\begin{array}{c}\text { Pulse } \\
\text { Volume } \\
\phi_{p} \\
\end{array}$} & \multicolumn{3}{|c|}{$\begin{array}{l}\text { Highest Concentration } \\
\text { Measurement Location }\end{array}$} & \multirow[b]{2}{*}{$\begin{array}{c}\text { Velocity } \\
\mathrm{U}\end{array}$} & \multirow[b]{2}{*}{$\begin{array}{l}\text { Velocity } \\
\text { at } U_{C S}\end{array}$} & \multirow{2}{*}{$\begin{array}{c}\text { Average } \\
\text { Peak } \\
\text { Cloud } \\
\text { Height } \\
\mathrm{H}_{\mathrm{C}} \\
\end{array}$} & \multirow[b]{2}{*}{ Test } \\
\hline & & & & & $\begin{array}{l}\text { Outer } \\
N_{0}\end{array}$ & $\begin{array}{c}\ln _{2} \text { nner } \\
\mathrm{N}_{1}\end{array}$ & & & & & & at $0 \mathrm{R}$ & at $0.5 \mathrm{R}$ & at $0.9 \mathrm{R}$ & & & & \\
\hline text & text & in. & text & in. & integer & integer & $\mathrm{g} / \mathrm{cm}^{3}$ & $\mu \mathrm{m}$ & volume fraction & fraction & fraction & $Z / D$ & Z/D & Z/D & $\mathrm{m} / \mathrm{s}$ & $\mathrm{m} / \mathrm{s}$ & In. & text \\
\hline C.1 & 15E_4s1d2Zc_1 & $147 / 16$ & E & 0.126 & 8 & 4 & 2.48 & 69.3 & 0.00155 & 0.33 & 0.05 & 0.5 & $n / a$ & $\mathrm{n} / \mathrm{a}$ & 2.8 & 2.8 & 6.88 & $6 / 6 \mathrm{~A}$ \\
\hline C. 2 & 15E_4s1d2Yc_1 & $147 / 16$ & $\mathrm{E}$ & 0.126 & 8 & 4 & 2.48 & 69.3 & 0.005 & 0.33 & 0.05 & 0.4 & $\mathrm{n} / \mathrm{a}$ & $n / a$ & 4.2 & 4.3 & 5 & $6 / 9 \mathrm{~A}$ \\
\hline C.3 & 15E_4s1d2Xd_1 & $147 / 16$ & $\mathrm{E}$ & 0.126 & 8 & 4 & 2.48 & 69.3 & 0.015 & 0.18 & 0.05 & 0.4 & $n / a$ & $n / a$ & 7.2 & 7.2 & 5.75 & $6 / 11 \mathrm{~A}$ \\
\hline C. 4 & 15E_4s1d2Xc_1 & $147 / 16$ & $\mathrm{E}$ & 0.126 & 8 & 4 & 2.48 & 69.3 & 0.015 & 0.33 & 0.05 & 0.45 & $n / a$ & $n / a$ & 5.8 & 5.8 & 6.62 & $6 / 10 B$ \\
\hline C.5 & 15E_4s1d2Xe_1 & $147 / 16$ & $E$ & 0.126 & 8 & 4 & 2.48 & 69.3 & 0.015 & 0.67 & 0.05 & 0.55 & $\mathrm{n} / \mathrm{a}$ & $\mathrm{n} / \mathrm{a}$ & 3.9 & 3.9 & 7.25 & $6 / 12 \mathrm{~A}$ \\
\hline C.6 & 15E_4s1d2Wd_1 & $147 / 16$ & $E$ & 0.126 & 8 & 4 & 2.48 & 69.3 & 0.045 & 0.19 & 0.05 & 0.45 & $\mathrm{n} / \mathrm{a}$ & $\mathrm{n} / \mathrm{a}$ & 7.2 & 7.2 & 5.75 & $6 / 17 \mathrm{~A}$ \\
\hline C. 7 & 15E_4s1d2Wc_1 & $147 / 16$ & $\mathrm{E}$ & 0.126 & 8 & 4 & 2.48 & 69.3 & 0.045 & 0.33 & 0.05 & 0.55 & $n / a$ & $n / a$ & 6.5 & 6.5 & 7.5 & $6 / 16 B$ \\
\hline C. 8 & $15 \mathrm{E} \_4 \mathrm{~s} 1 \mathrm{~d} 2 \mathrm{Wa}$ & $147 / 16$ & $\mathrm{E}$ & 0.126 & 8 & 4 & 2.48 & 69.3 & 0.045 & 1.00 & undefined & 1 & $\mathrm{n} / \mathrm{a}$ & $\mathrm{n} / \mathrm{a}$ & 3 & 3 & 14.5 & $6 / 17 \mathrm{~B}$ \\
\hline C.9 & 15E_4s1d2Wc_1 & $147 / 16$ & $E$ & 0.126 & 8 & 4 & 2.48 & 69.3 & 0.045 & 0.34 & 0.05 & 1 & $\mathrm{n} / \mathrm{a}$ & $\mathrm{n} / \mathrm{a}$ & 8 & 6.5 & 14.5 & $6 / 17 \mathrm{C}$ \\
\hline C.10 & 15E_4s1d2Pc_1 & $147 / 16$ & $E$ & 0.126 & 8 & 4 & 2.48 & 69.3 & 0.06 & 0.34 & 0.05 & 0.7 & $\mathrm{n} / \mathrm{a}$ & $\mathrm{n} / \mathrm{a}$ & 6.2 & 6.2 & 9.5 & $6 / 18 \mathrm{~A}$ \\
\hline C.11 & 15E_4s2d2Zc_1 & $147 / 16$ & $\mathrm{E}$ & 0.126 & 8 & 4 & 4.18 & 75.6 & 0.00155 & 0.34 & 0.05 & 0.45 & $n / a$ & $\mathrm{n} / \mathrm{a}$ & 5.2 & 5.2 & 7 & $6 / 19 A$ \\
\hline C.12 & 15E_4s2d2Xc_1 & $147 / 16$ & $\mathrm{E}$ & 0.126 & 8 & 4 & 4.18 & 75.6 & 0.015 & 0.33 & 0.05 & 0.4 & $n / a$ & $n / a$ & 11.8 & 11.8 & 6 & $6 / 20 \mathrm{~B}$ \\
\hline C.13 & 15E_4s2d2Yc_1 & $147 / 16$ & $\mathrm{E}$ & 0.126 & 8 & 4 & 4.18 & 75.6 & 0.005 & 0.33 & 0.05 & 0.4 & $\mathrm{n} / \mathrm{a}$ & $\mathrm{n} / \mathrm{a}$ & 7.6 & 7.6 & 6 & $6 / 20 \mathrm{~A}$ \\
\hline C.14 & 15E_4s1d1Zc_1 & $147 / 16$ & $E$ & 0.126 & 8 & 4 & 2.46 & 166.4 & 0.00155 & 0.33 & 0.05 & 0.45 & $\mathrm{n} / \mathrm{a}$ & $\mathrm{n} / \mathrm{a}$ & 4.2 & 4.2 & 6.25 & $6 / 26 \mathrm{~A}$ \\
\hline C. 15 & 15E_4s1d1Xc_1 & $147 / 16$ & E & 0.126 & 8 & 4 & 2.46 & 166.4 & 0.015 & 0.34 & 0.05 & 0.35 & $n / a$ & $n / a$ & 8.6 & 8.6 & 5.5 & $6 / 30 \mathrm{~A}$ \\
\hline C.16 & 15E_4s1d5Yc_1 & $147 / 16$ & $E$ & 0.126 & 8 & 4 & 2.5 & 43.9 & 0.005 & 0.33 & 0.05 & 0.6 & $\mathrm{n} / \mathrm{a}$ & $\mathrm{n} / \mathrm{a}$ & 3.5 & 3.7 & 8.5 & $7 / 1 \mathrm{~B}$ \\
\hline C. 17 & 15E_4s2d1Zc_1 & $147 / 16$ & $E$ & 0.126 & 8 & 4 & 4.17 & 164.2 & 0.00155 & 0.33 & 0.05 & 0.6 & $\mathrm{n} / \mathrm{a}$ & $\mathrm{n} / \mathrm{a}$ & 6.8 & 6.8 & 8 & $7 / 2 \mathrm{~B}$ \\
\hline C.18 & 15E_6s1d2Vc_1 & $147 / 16$ & E & 0.191 & 4 & 4 & 2.48 & 69.3 & 0.0143 & 0.33 & 0.05 & 0.7 & $n / a$ & $n / a$ & 4.8 & 4.8 & 9.5 & $7 / 8 \mathrm{C}$ \\
\hline C.19 & 15E_6s1d2Xc_1 & $147 / 16$ & $E$ & 0.191 & 4 & 4 & 2.48 & 69.3 & 0.015 & 0.33 & 0.05 & 0.6 & $\mathrm{n} / \mathrm{a}$ & $\mathrm{n} / \mathrm{a}$ & 4.6 & 4.6 & 8.5 & $7 / 9 \mathrm{~B}$ \\
\hline C. 20 & 15E_6s1d2Xc_2 & $147 / 16$ & $\mathrm{E}$ & 0.191 & 4 & 4 & 2.48 & 69.3 & 0.015 & 0.33 & 0.10 & 0.7 & $\mathrm{n} / \mathrm{a}$ & $\mathrm{n} / \mathrm{a}$ & 4.4 & 4.4 & 8.5 & $7 / 9 C$ \\
\hline C. 21 & 15E_Ms1d2Vc_1 & $147 / 16$ & $E$ & 0.268 & 4 & 4 & 2.48 & 69.3 & 0.0143 & 0.33 & 0.05 & 0.8 & $\mathrm{n} / \mathrm{a}$ & $\mathrm{n} / \mathrm{a}$ & 2.9 & 2.9 & 8.5 & $7 / 11 \mathrm{~A}$ \\
\hline C.22 & 15E_Ls1d2Vc_1 & $147 / 16$ & E & 0.375 & 4 & 4 & 2.48 & 69.3 & 0.0143 & 0.34 & 0.05 & 0.7 & $n / a$ & $\mathrm{n} / \mathrm{a}$ & 1.9 & 1.9 & 9.5 & 7/14B \\
\hline C.23 & 15E_Ls1d2Vc_2 & $147 / 16$ & $E$ & 0.375 & 4 & 4 & 2.48 & 69.3 & 0.0143 & 0.33 & 0.10 & 0.9 & $\mathrm{n} / \mathrm{a}$ & $n / a$ & 1.9 & 1.9 & 11.5 & $7 / 15 \mathrm{~B}$ \\
\hline C. 24 & 15E_Ls1d2Vc_7 & $147 / 16$ & $E$ & 0.375 & 4 & 0 & 2.48 & 69.3 & 0.0143 & 0.34 & 0.10 & 0.9 & $\mathrm{n} / \mathrm{a}$ & $\mathrm{n} / \mathrm{a}$ & 2.5 & 2.5 & 11.5 & $7 / 15 \mathrm{~A}$ \\
\hline C. 25 & 34E_4s1d1Zc_1 & $337 / 8$ & $\mathrm{~S}$ & 0.297 & 8 & 4 & 2.46 & 166.4 & 0.00155 & 0.34 & 0.05 & 0.4 & $\mathrm{n} / \mathrm{a}$ & $\mathrm{n} / \mathrm{a}$ & 4.5 & 4.5 & 13.75 & $3 / 5 \mathrm{~A}$ \\
\hline C.26 & 34E_4s1d2Sc_1 & $337 / 8$ & $\mathrm{~s}$ & 0.297 & 8 & 4 & 2.48 & 69.3 & 0.0015 & 0.34 & 0.05 & 0.6 & $n / a$ & $n / a$ & 3.7 & 3.7 & 19.75 & $3 / 7 \mathrm{C}$ \\
\hline C. 27 & 34E_4s1d2Yc_1 & $337 / 8$ & $S$ & 0.297 & 8 & 4 & 2.48 & 69.3 & 0.005 & 0.34 & 0.05 & 0.7 & $\mathrm{n} / \mathrm{a}$ & $\mathrm{n} / \mathrm{a}$ & 5.1 & 5.1 & 19.5 & $3 / 9 \mathrm{~A}$ \\
\hline C. 28 & 34E_4s1d2Yd_1 & $337 / 8$ & $\mathrm{~S}$ & 0.297 & 8 & 4 & 2.48 & 69.3 & 0.005 & 0.19 & 0.05 & 0.6 & $\mathrm{n} / \mathrm{a}$ & $\mathrm{n} / \mathrm{a}$ & 6.2 & 6 & 21 & $3 / 9 \mathrm{~B}$ \\
\hline C. 29 & 34E_4s2d2Zc_1 & $337 / 8$ & $\mathrm{~s}$ & 0.297 & 8 & 4 & 4.18 & 75.6 & 0.00155 & 0.33 & 0.05 & 0.45 & $n / a$ & $n / a$ & 5.6 & 5.6 & 14 & $3 / 11 B$ \\
\hline C. 30 & 34E_4s2d2Xc_1 & $337 / 8$ & $\mathrm{~s}$ & 0.297 & 8 & 4 & 4.18 & 75.6 & 0.015 & 0.34 & 0.05 & 0.35 & $\mathrm{n} / \mathrm{a}$ & $\mathrm{n} / \mathrm{a}$ & 10 & 9.8 & 10.5 & $3 / 12 \mathrm{C}$ \\
\hline C.31 & 34E_4s2d2Yc_1 & $337 / 8$ & $\mathrm{~s}$ & 0.297 & 8 & 4 & 4.18 & 75.6 & 0.005 & 0.34 & 0.05 & 0.6 & $\mathrm{n} / \mathrm{a}$ & $\mathrm{n} / \mathrm{a}$ & 8.6 & 8.6 & 18.5 & $3 / 12 \mathrm{~A}$ \\
\hline
\end{tabular}


Table C.1. Summary of Concentration Profile Cases (continued)

\begin{tabular}{|c|c|c|c|c|c|c|c|c|c|c|c|c|c|c|c|c|c|c|}
\hline \multirow[b]{2}{*}{ Figure } & \multirow[b]{2}{*}{ Case ID } & \multirow{2}{*}{$\begin{array}{c}\text { Tank } \\
\text { Diameter } \\
\text { D } \\
\end{array}$} & \multirow{2}{*}{$\begin{array}{c}\text { Head } \\
\text { Shape } \\
\text { HS }\end{array}$} & \multirow{2}{*}{\begin{tabular}{|c} 
Nozzle \\
Diameter \\
$\mathrm{d}$
\end{tabular}} & \multicolumn{2}{|c|}{$\begin{array}{c}\text { Number of } \\
\text { Nozzles } \\
\text { Operated }\end{array}$} & \multirow[b]{2}{*}{$\begin{array}{c}\text { Density } \\
\rho_{\mathrm{s}}\end{array}$} & \multirow{2}{*}{\begin{tabular}{|c|}
$\begin{array}{c}\text { Particle } \\
\text { Diameter }\end{array}$ \\
\\
$\mathrm{d}_{50}$ \\
\end{tabular}} & \multirow{2}{*}{$\begin{array}{c}\text { Concentration } \\
\phi_{\mathrm{S}}\end{array}$} & \multirow{2}{*}{\begin{tabular}{|c} 
Duty \\
Cycle \\
DC
\end{tabular}} & \multirow{2}{*}{$\begin{array}{c}\text { Pulse } \\
\text { Volume } \\
\phi_{\mathrm{p}}\end{array}$} & \multicolumn{3}{|c|}{$\begin{array}{l}\text { Highest Concentration } \\
\text { Measurement Location }\end{array}$} & \multirow[b]{2}{*}{$\begin{array}{c}\text { Velocity } \\
U\end{array}$} & \multirow{2}{*}{$\begin{array}{c}\text { Velocity } \\
\text { at } U_{C S}\end{array}$} & \multirow{2}{*}{\begin{tabular}{|c|} 
Average \\
Peak \\
Cloud \\
Height \\
$\mathrm{H}_{\mathrm{C}}$ \\
\end{tabular}} & \multirow[b]{2}{*}{ Test } \\
\hline & & & & & $\begin{array}{c}\text { Outer } \\
N_{0}\end{array}$ & $\begin{array}{c}\text { Inner } \\
\mathrm{N}_{\mathrm{I}}\end{array}$ & & & & & & at $0 \mathrm{R}$ & at $0.5 \mathrm{R}$ & at $0.9 \mathrm{R}$ & & & & \\
\hline text & text & in. & text & in. & integer & integer & $\mathrm{g} / \mathrm{cm}^{3}$ & $\mu \mathrm{m}$ & volume fraction & fraction & fraction & Z/D & Z/D & Z/D & $\mathrm{m} / \mathrm{s}$ & $\mathrm{m} / \mathrm{s}$ & $\mathrm{m}$ & text \\
\hline C.32 & 70F_4s1d1Zc_1 & 70 & FD & 0.613 & 8 & 4 & 2.46 & 166.4 & 0.00155 & 0.33 & 0.05 & 0.4 & $\mathrm{n} / \mathrm{a}$ & $n / a$ & 6.7 & 6.7 & 25.5 & $4 / 14 \mathrm{~A}$ \\
\hline C. 33 & 70F_4s1d1Zc_2 & 70 & FD & 0.613 & 8 & 4 & 2.46 & 166.4 & 0.00155 & 0.33 & 0.10 & 0.5 & $n / a$ & $n / a$ & 5.8 & 5.8 & 26 & $4 / 15 \mathrm{C}$ \\
\hline C. 34 & 70F_4s1d2Zc_1 & 70 & FD & 0.613 & 8 & 4 & 2.48 & 69.3 & 0.00155 & 0.34 & 0.05 & 0.45 & $\mathrm{n} / \mathrm{a}$ & $\mathrm{n} / \mathrm{a}$ & 4.4 & 4.4 & 28.25 & 4/17A \\
\hline C. 35 & 70F_4s1d2Rc_1 & 70 & FD & 0.613 & 8 & 4 & 2.48 & 69.3 & 0.01 & 0.34 & 0.05 & 0.4 & $\mathrm{n} / \mathrm{a}$ & $n / a$ & 6.6 & 6.6 & 23 & $4 / 18 B$ \\
\hline C.36 & 70F_4s1d2Yc_1 & 70 & FD & 0.613 & 8 & 4 & 2.48 & 69.3 & 0.005 & 0.33 & 0.05 & 0.35 & $\mathrm{n} / \mathrm{a}$ & $\mathrm{n} / \mathrm{a}$ & 5.8 & 5.8 & 23 & $4 / 18 \mathrm{~A}$ \\
\hline C. 37 & 70F_4s1d2Vc_1 & 70 & FD & 0.613 & 8 & 4 & 2.48 & 69.3 & 0.0143 & 0.34 & 0.05 & 0.45 & $\mathrm{n} / \mathrm{a}$ & $n / a$ & 7.1 & 7.1 & 30 & $4 / 21 \mathrm{~A}$ \\
\hline C. 38 & 70F_4s1d2Vc_1 & 70 & FD & 0.613 & 8 & 4 & 2.48 & 69.3 & 0.0143 & 0.34 & 0.05 & $\mathrm{n} / \mathrm{a}$ & 0.4 & $n / a$ & 7.1 & 7.1 & 30 & $4 / 21 \mathrm{~A}$ \\
\hline C.39 & 70F_4s1d2Vc_1 & 70 & FD & 0.613 & 8 & 4 & 2.48 & 69.3 & 0.0143 & 0.34 & 0.05 & $n / a$ & $n / a$ & 0.4 & 7.1 & 7.1 & 30 & $4 / 21 \mathrm{~A}$ \\
\hline C. 40 & 70F_4s1d2Vd_1 & 70 & FD & 0.613 & 8 & 4 & 2.48 & 69.3 & 0.0143 & 0.19 & 0.05 & 0.4 & $\mathrm{n} / \mathrm{a}$ & $\mathrm{n} / \mathrm{a}$ & 9.6 & 9.8 & 26.25 & $4 / 28 \mathrm{~A}$ \\
\hline C.41 & 70F_4s1d2Vd_1 & 70 & FD & 0.613 & 8 & 4 & 2.48 & 69.3 & 0.0143 & 0.19 & 0.05 & 0.4 & $\mathrm{n} / \mathrm{a}$ & $\mathrm{n} / \mathrm{a}$ & 9.8 & 9.8 & 28 & $4 / 28 \mathrm{~A}$ \\
\hline C. 42 & 70F_4s1d2Vd_1 & 70 & $\mathrm{FD}$ & 0.613 & 8 & 4 & 2.48 & 69.3 & 0.0143 & 0.19 & 0.05 & 0.45 & $n / a$ & $n / a$ & 9.9 & 9.9 & 27.5 & $4 / 22 \mathrm{~A}$ \\
\hline C. 43 & 70F_4s1d2Vc_1 & 70 & FD & 0.613 & 8 & 4 & 2.48 & 69.3 & 0.0143 & 0.34 & 0.05 & 0.45 & $\mathrm{n} / \mathrm{a}$ & $n / a$ & 7.3 & 7.3 & 31 & $4 / 29 A$ \\
\hline C. 44 & 70F_4s1d2Ve_1 & 70 & FD & 0.613 & 8 & 4 & 2.48 & 69.3 & 0.0143 & 0.67 & 0.05 & 0.6 & $\mathrm{n} / \mathrm{a}$ & $\mathrm{n} / \mathrm{a}$ & 4.8 & 4.8 & 35.75 & $4 / 25 B$ \\
\hline C. 45 & 70F_4s1d2Vc_2 & 70 & FD & 0.613 & 8 & 4 & 2.48 & 69.3 & 0.0143 & 0.33 & 0.10 & 0.45 & $\mathrm{n} / \mathrm{a}$ & $\mathrm{n} / \mathrm{a}$ & 6.6 & 6.6 & 28.5 & $4 / 25 \mathrm{C}$ \\
\hline C. 46 & 70E_4s1d2Zc_1 & 70 & $\mathrm{E}$ & 0.613 & 8 & 4 & 2.48 & 69.3 & 0.00155 & 0.34 & 0.05 & 0.45 & $n / a$ & $n / a$ & 4.6 & 4.6 & 30.5 & $5 / 9 \mathrm{~A}$ \\
\hline C. 47 & 70E_4s1d2Yc_1 & 70 & $\mathrm{E}$ & 0.613 & 8 & 4 & 2.48 & 69.3 & 0.005 & 0.34 & 0.05 & 0.45 & $\mathrm{n} / \mathrm{a}$ & $n / a$ & 6 & 6 & 27.75 & $5 / 12 A$ \\
\hline C. 48 & 70E_4s1d2Vd_1 & 70 & $\mathrm{E}$ & 0.613 & 8 & 4 & 2.48 & 69.3 & 0.0143 & 0.19 & 0.05 & 0.6 & $\mathrm{n} / \mathrm{a}$ & $\mathrm{n} / \mathrm{a}$ & 11.2 & 10.9 & 45 & $5 / 15 \mathrm{~A}$ \\
\hline C. 49 & 70E_4s1d2Vd_1 & 70 & $\mathrm{E}$ & 0.613 & 8 & 4 & 2.48 & 69.3 & 0.0143 & 0.19 & 0.05 & $\mathrm{n} / \mathrm{a}$ & 0.6 & $\mathrm{n} / \mathrm{a}$ & 11.2 & 10.9 & 45 & $5 / 15 \mathrm{~A}$ \\
\hline C. 50 & 70E_4s1d2Vd_1 & 70 & $\mathrm{E}$ & 0.613 & 8 & 4 & 2.48 & 69.3 & 0.0143 & 0.19 & 0.05 & $n / a$ & $n / a$ & 0.6 & 11.2 & 10.9 & 45 & $5 / 15 \mathrm{~A}$ \\
\hline C. 51 & 70E_4s1d2Vc_1 & 70 & E & 0.613 & 8 & 4 & 2.48 & 69.3 & 0.0143 & 0.33 & 0.05 & 0.6 & $\mathrm{n} / \mathrm{a}$ & $\mathrm{n} / \mathrm{a}$ & 7.8 & 7.8 & 41 & $5 / 14 \mathrm{~A}$ \\
\hline C. 52 & 70E_4s1d2Vc_1 & 70 & E & 0.613 & 8 & 4 & 2.48 & 69.3 & 0.0143 & 0.33 & 0.05 & n/a & 0.6 & $n / a$ & 7.8 & 7.8 & 41 & $5 / 14 \mathrm{~A}$ \\
\hline C.53 & 70E_4s1d2Vc_1 & 70 & $E$ & 0.613 & 8 & 4 & 2.48 & 69.3 & 0.0143 & 0.33 & 0.05 & $n / a$ & $\mathrm{n} / \mathrm{a}$ & 0.6 & 7.8 & 7.8 & 41 & $5 / 14 \mathrm{~A}$ \\
\hline C. 54 & 70E_4s1d2Xc_1 & 70 & E & 0.613 & 8 & 4 & 2.48 & 69.3 & 0.015 & 0.33 & 0.05 & 0.35 & $n / a$ & $\mathrm{n} / \mathrm{a}$ & 6.8 & 8.5 & 22 & $5 / 20 \mathrm{~A}$ \\
\hline C.55 & 70E_4s1d2Xc_1 & 70 & $E$ & 0.613 & 8 & 4 & 2.48 & 69.3 & 0.015 & 0.34 & 0.05 & 0.7 & $\mathrm{n} / \mathrm{a}$ & $\mathrm{n} / \mathrm{a}$ & 8.5 & 8.5 & 41 & $5 / 20 \mathrm{~A}$ \\
\hline C. 56 & 70E_4s1d2Xc_1 & 70 & $\mathrm{E}$ & 0.613 & 8 & 4 & 2.48 & 69.3 & 0.015 & 0.34 & 0.05 & $\mathrm{n} / \mathrm{a}$ & 0.6 & $\mathrm{n} / \mathrm{a}$ & 8.5 & 8.5 & 41 & $5 / 20 \mathrm{~A}$ \\
\hline C. 57 & 70E_4s1d2Xc_1 & 70 & $\mathrm{E}$ & 0.613 & 8 & 4 & 2.48 & 69.3 & 0.015 & 0.34 & 0.05 & n/a & $\mathrm{n} / \mathrm{a}$ & 0.7 & 8.5 & 8.5 & 41 & $5 / 20 \mathrm{~A}$ \\
\hline C. 58 & 70E_4s2d2Zc_1 & 70 & E & 0.613 & 8 & 4 & 4.18 & 75.6 & 0.00155 & 0.34 & 0.05 & 0.45 & $\mathrm{n} / \mathrm{a}$ & $\mathrm{n} / \mathrm{a}$ & 8.4 & 8.4 & 28.5 & $5 / 27 \mathrm{~A}$ \\
\hline C.59 & 70E_4s2d2Yc_1 & 70 & $\mathrm{E}$ & 0.613 & 8 & 4 & 4.18 & 75.6 & 0.005 & 0.33 & 0.05 & 0.4 & $\mathrm{n} / \mathrm{a}$ & $\mathrm{n} / \mathrm{a}$ & 12 & 12.5 & 25.5 & $5 / 28 \mathrm{~A}$ \\
\hline C. 60 & 70E_4s2d2Yc_1 & 70 & $E$ & 0.613 & 8 & 4 & 4.18 & 75.6 & 0.005 & 0.33 & 0.05 & $\mathrm{n} / \mathrm{a}$ & 0.35 & $\mathrm{n} / \mathrm{a}$ & 12 & 12.5 & 25.5 & $5 / 28 \mathrm{~A}$ \\
\hline C. 61 & 70E_4s2d2Yc_1 & 70 & $\mathrm{E}$ & 0.613 & 8 & 4 & 4.18 & 75.6 & 0.005 & 0.33 & 0.05 & $\mathrm{n} / \mathrm{a}$ & $\mathrm{n} / \mathrm{a}$ & 0.35 & 12 & 12.5 & 25.5 & $5 / 28 \mathrm{~A}$ \\
\hline C.62 & 70E_4s1d1Zc_1 & 70 & $E$ & 0.613 & 8 & 4 & 2.46 & 166.4 & 0.00155 & 0.33 & 0.05 & 0.4 & $\mathrm{n} / \mathrm{a}$ & $\mathrm{n} / \mathrm{a}$ & 7.1 & 7.1 & 30.75 & $5 / 30 \mathrm{~A}$ \\
\hline C.63 & 70E_4s1d1Zc_1 & 70 & $\mathrm{E}$ & 0.613 & 8 & 4 & 2.46 & 166.4 & 0.00155 & 0.33 & 0.05 & $\mathrm{n} / \mathrm{a}$ & 0.4 & $\mathrm{n} / \mathrm{a}$ & 7.1 & 7.1 & 30.75 & $5 / 30 \mathrm{~A}$ \\
\hline C.64 & 70E_4s1d1Zc_1 & 70 & $\mathrm{E}$ & 0.613 & 8 & 4 & 2.46 & 166.4 & 0.00155 & 0.33 & 0.05 & $\mathrm{n} / \mathrm{a}$ & $\mathrm{n} / \mathrm{a}$ & 0.4 & 7.1 & 7.1 & 30.75 & $5 / 30 \mathrm{~A}$ \\
\hline C. 65 & 70E_6s1d2Vc_1 & 70 & E & 0.92 & 4 & 4 & 2.48 & 69.3 & 0.0143 & 0.34 & 0.05 & 0.85 & $\mathrm{n} / \mathrm{a}$ & $\mathrm{n} / \mathrm{a}$ & 6.8 & 6.8 & 70 & $7 / 18 \mathrm{~A}$ \\
\hline C. 66 & 70E_6s1d2Vc_2 & 70 & E & 0.92 & 4 & 4 & 2.48 & 69.3 & 0.0143 & 0.33 & 0.10 & 0.8 & $n / a$ & $n / a$ & 6.4 & 6.4 & 63 & $7 / 18 \mathrm{~B}$ \\
\hline
\end{tabular}


In the small-scale tank, 24 concentration profiles were measured and are shown in Figures C.1 through C.24. This test platform provided the broadest range of test conditions, which are listed below grouped by simulant:

- s1d2

- 10 profiles were obtained in the HLP-22 12 tube array vessel configuration[8/4]

- 3 profiles were obtained in the 8TA (eight tube array) configuration [4/4] with a 6-in. full-scale nozzle

- 1 profile was obtained in the 8TA configuration [4/4] using an 8.5 in. full-scale nozzle ( $\mathrm{M}$ in the Case ID)

- 2 profiles were obtained in the 8TA configuration [4/4] using an 11.8-in. full-scale nozzle (L in the Case ID)

- 1 profile was obtained in the 8TA configuration using an 11.8-in. full-scale nozzle with only the four outer tubes operating [4/0]

- $\operatorname{s} 1 \mathrm{~d} 2$

- 3 profiles were obtained in the HLP-22 vessel configuration

- s1d1

- 2 profiles were obtained in the HLP-22 vessel configuration

- $\operatorname{s} 1 \mathrm{~d} 5$

- 1 profile was obtained in the HLP-22 vessel configuration

- s2d1

- 1 profile was obtained in the HLP-22 vessel configuration

In the mid-scale tank seven concentration profiles were measured, which are shown in Figures C.25 through C.31. The profiles were all conducted in the HLP-22 vessel configuration and are grouped by simulant.

- $\operatorname{s} 1 \mathrm{~d} 2$

- 3 profiles

- s1d1

- 1 profile

- $\mathrm{s} 2 \mathrm{~d} 2$

- 3 profiles

In the large-scale tank with the flange and dish bottom, 14 concentration profiles were measured and are shown in Figures C.32 through C.45. The profiles were all conducted in the HLP-22 vessel configuration and are grouped by simulant.

- $\operatorname{s} 1 \mathrm{~d} 2$

- 10 profiles at $\mathrm{R}=0 ; 1$ profile at $\mathrm{R}=0.5 ; 1$ profile at $\mathrm{R}=0.9$

- s1d1

- 2 profiles at $\mathrm{R}=0$

In the large-scale tank with the elliptical bottom, 21 concentration profiles were measured and are shown in Figures C.46 through C.66.

- $\operatorname{s1d} 2$

- 6 profiles at $\mathrm{R}=0 ; 3$ profile at $\mathrm{R}=0.5 ; 3$ profile at $\mathrm{R}=0.9$ in the HLP-22 vessel configuration

- 2 profiles at $\mathrm{R}=0$ were obtained in the 8TA configuration using a 6 in. full-scale nozzle 
- s1d1

- 1 profile at $\mathrm{R}=0 ; 1$ profile at $\mathrm{R}=0.5 ; 1$ profile at $\mathrm{R}=0.9$ were obtained in the HLP-22 vessel configuration

- $\mathrm{s} 2 \mathrm{~d} 2$

- $\quad 2$ profiles at $\mathrm{R}=0 ; 1$ profile at $\mathrm{R}=0.5 ; 1$ profile at $\mathrm{R}=0.9$ were obtained in the HLP-22 vessel configuration

The first solid concentration by volume profile shown in Figure C.1 for Case ID 15E_4s1d2Zc-1 is used to describe the types of information provided for each profile. For each profile the data are plotted dimensionally in the upper row of five plots and nondimensionally in the lower row of five plots. For pulsating flow, each data set consists of a series of 10 plots. The upper row presents the dimensional data; the lower row presents the nondimensional data. The first plot shows the minimum (circle symbol), average (triangle symbol), and maximum (square symbol) concentration at each elevation throughout the entire pulse cycle. The second plot shows the minimum, average, and maximum concentration at each elevation during the drive portion of the cycle, when fluid is flowing through the pulse tubes. The third plot shows the minimum, average, and maximum concentration at each elevation through the non-drive portion of the cycle, when there is no flow through the pulse tubes. The fourth plot shows the average concentration at each elevation at fractional cycle time increments (slices) during the drive portion of the cycle corresponding to 0.00 (the profile at the start of the pulse), 0.25 (the profile one-quarter of the way through the pulse, 0.50 (the profile half-way through the pulse), 0.75 (the profile three-quarters of the way through the pulse) and 1.00 (the profile at the end of the pulse). The fifth plot shows similar fractional cycle time increments (slices) during the non-drive portion of the cycle. Time 0.00 corresponds to the beginning of the nondrive portion of the pulse and is equivalent to time 1.00 shown in the drive portion of the pulse in the fourth plot. Time 1.00 corresponds to the end of the non-drive portion of the pulse and is equivalent to the time 0.00 at the start of the next pulse.

The accompanying Figure C.1A shows the concentration transient during the pulse at each elevation. Each profile measurement at a specified location captured the concentration transient over duration of one cycle. The measurement started at the beginning of the pulse and ended at the completion of the cycle. Data obtained for up to five pulses were averaged to obtain the transient plots shown in each Figure C.1A. The number of pulses in the average is shown in parenthesis as the last number in each chart heading. For example in Figure C.1A the heading of the first plot is 15E_4s1d2Zc_1 H 0.1D R 0R 15_06_06_2008_10_31 (5). 15E_4s1d2Zc_1 is the Case ID. H $0.1 \mathrm{D}$ shows the probe elevation $[\mathrm{H}=0.1 \mathrm{D}]$. $\mathrm{R}$ 0R shows the probe radial location $[\mathrm{R}=0 \mathrm{R}]$, the center of the tank. 15_06_06_2008_10_31 shows the vessel diameter (15) followed by the date (06-06-2008) followed by the time (10:31), and (5) shows the number of pulses averaged for this plot. At each elevation the averaged data were analyzed to determine the average minimum concentration, average maximum concentration, and average concentration, which are shown in plots C.1 (a) minimum concentration, C.1 (b) average concentration, and C.1 (c) maximum concentration.

If photographs were taken for these conditions they are shown "for information only" above the first row of figures. The photos are arranged in the following order: The first photo shows the maximum cloud height observed during the pulse. The second photo shows the cloud at the start of the drive portion of the pulse. The third photo shows the cloud at the middle of the drive portion of the pulse. The fourth photo shows the cloud at the end of the drive portion of the pulse. The fifth photo shows the cloud at the middle of the non-drive portion of the pulse. 


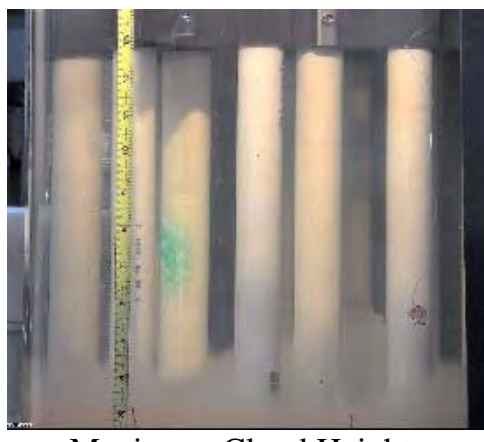

Maximum Cloud Height

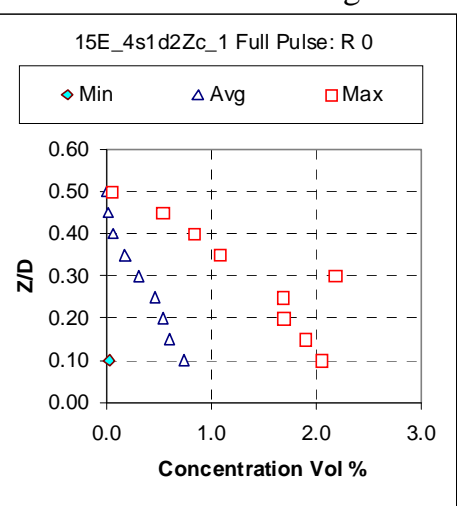

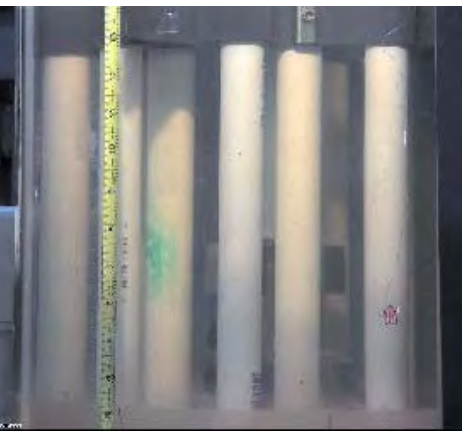

Start of Drive

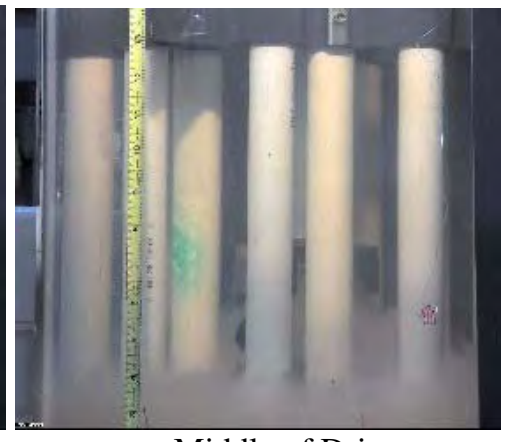

Middle of Drive

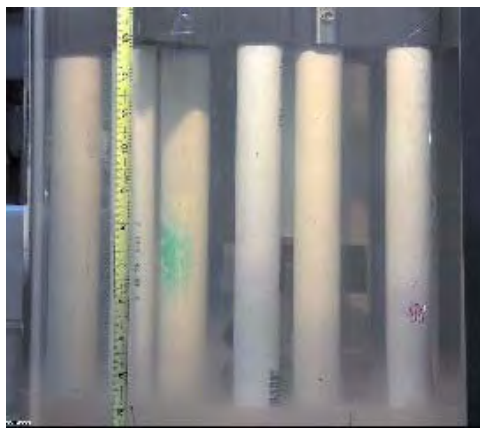

End of Drive
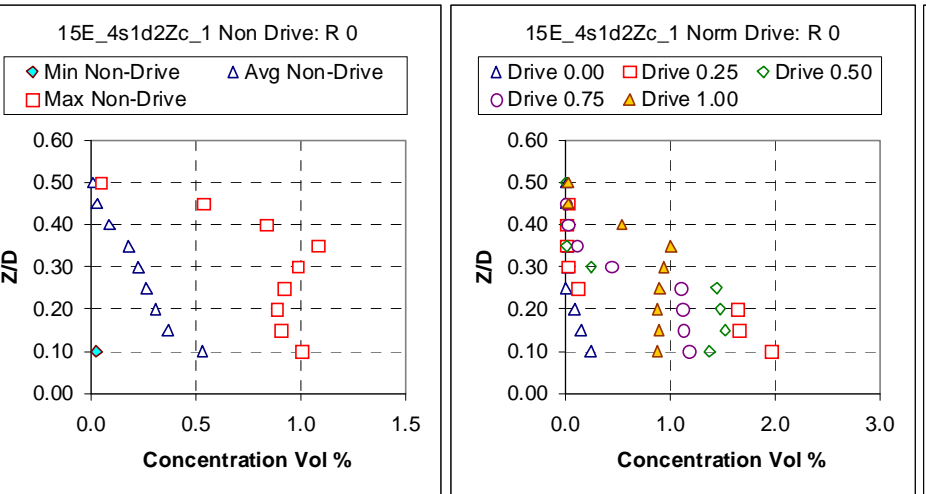

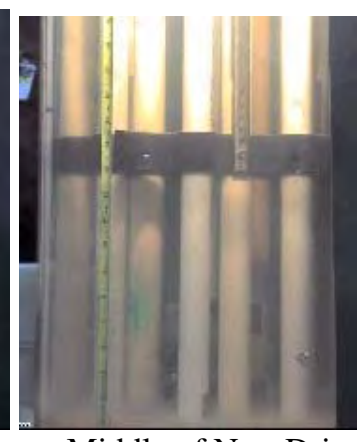

Middle of Non-Drive

15E_4s1d2Zc_1 Norm Non-Drive: R 0 $\begin{array}{ll}\Delta \text { Non-Drive } 0.00 & \square \text { Non-Drive } 0.25 \\ \diamond \text { Non-Drive } 0.50 & \text { ONon-Drive } 0.75\end{array}$

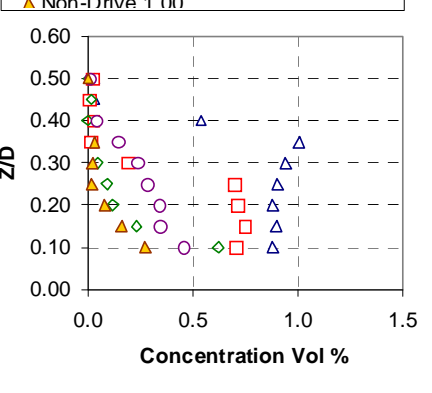

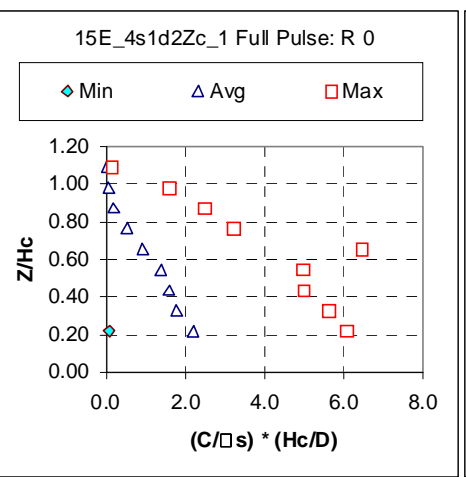
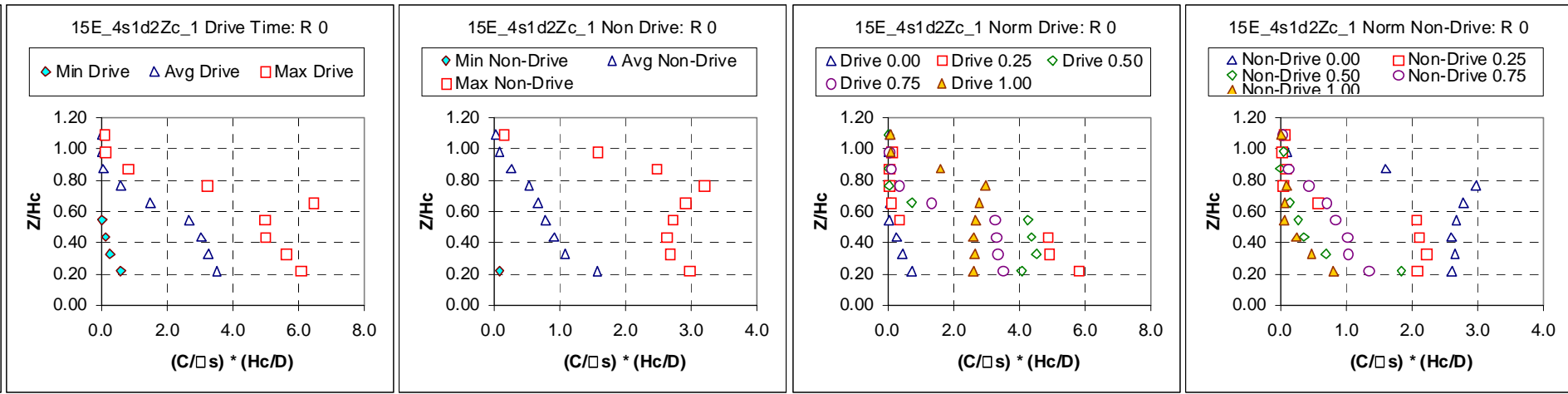

Figure C.1. 0.367-m- (14 7/16-in.-) diameter tank, 0.320-cm- (0.126-in.-) diameter nozzle; solids nominal diameter $69.3 \mu \mathrm{m}, 2.48 \mathrm{~g} / \mathrm{cm}^{3}$ density; 0.00155 nominal solids fraction; $33.2 \%$ duty cycle, cycle time $22.0 \mathrm{~s}$, pulse volume fraction 0.050 , $\mathrm{U}_{\mathrm{Cs}}$ velocity $2.8 \mathrm{~m} / \mathrm{s}$, target nozzle exit velocity $2.8 \mathrm{~m} / \mathrm{s}$; peak cloud height upper bound $0.184 \mathrm{~m}$ (7.25 in.). Case ID 15E_4s1d2Zc_1. 

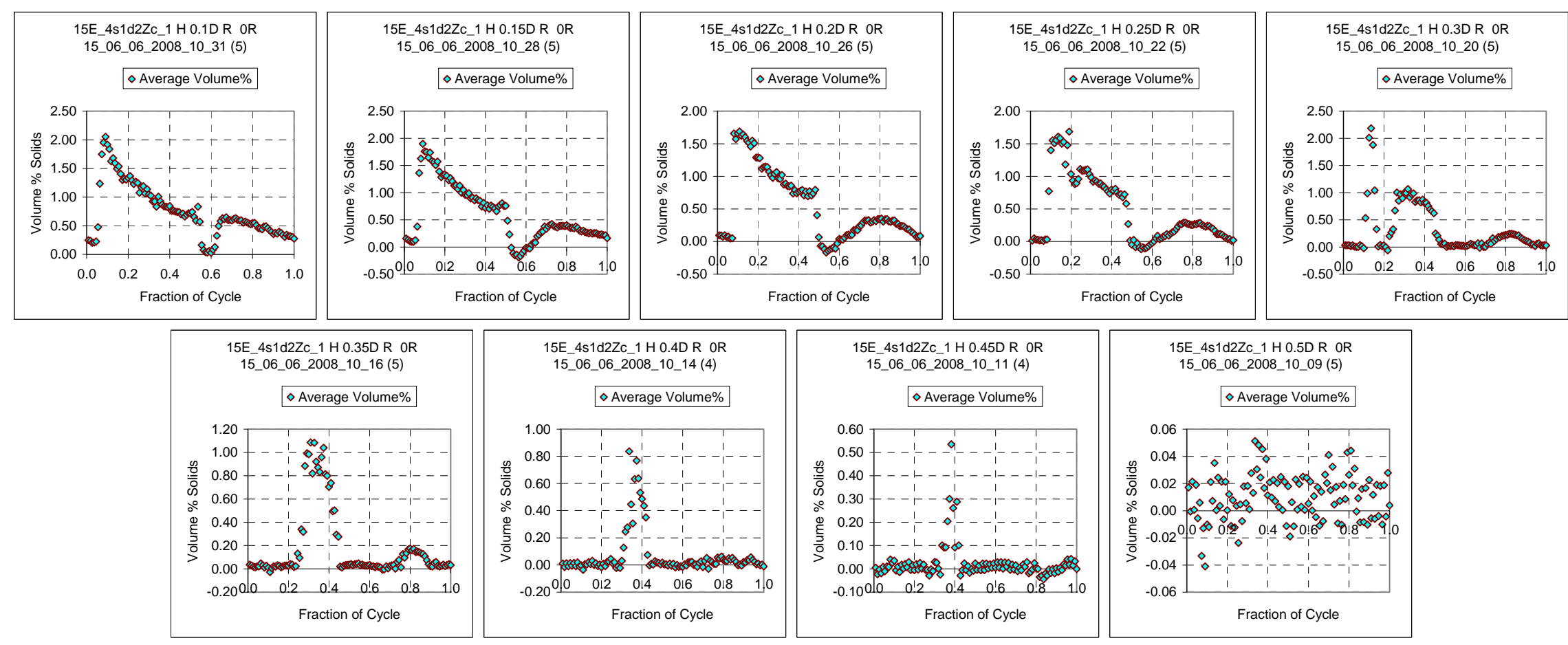

Figure C.1A. Case ID 15E_4s1d2Zc_1 Concentration Variation During the Cycle

The plots in Figure C.1 show the first profile using simulant s1d2 in the small-scale tank. The solids fraction is 0.00155 . The $\mathrm{U}_{\mathrm{CS}}$ velocity is $2.8 \mathrm{~m} / \mathrm{s}$. The data in Figure C.1 show that the cloud height rose to an elevation of $\sim$ half the tank diameter. The cloud height is 7.25 in. The transient data in Figure C1.A shows that at $\mathrm{H}=0.1 \mathrm{D}$ the maximum concentration occurred at $\sim 0.1$ cycle. The maximum concentration at $\mathrm{H}=0.45 \mathrm{D}$ occurred at $\sim 0.4$ cycle. This time lag shows the effect of the pulse upon the solids concentration at that elevation. The concentration in the cloud at $0.1 \mathrm{Z} / \mathrm{D}$ was on average $<1$ vol\% solids and at the maximum $>2$ vol\% solids. 


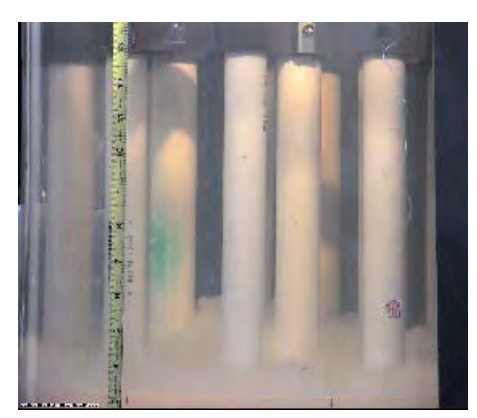

Maximum Cloud Height
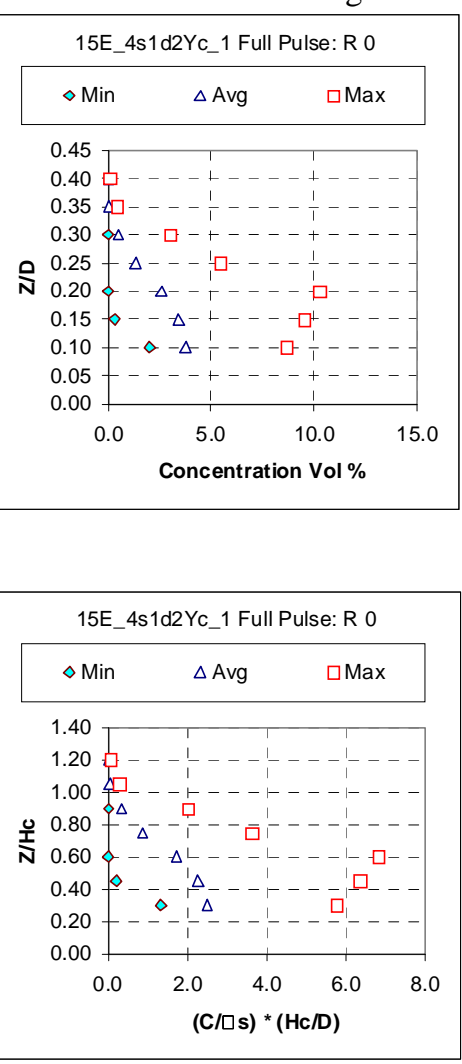

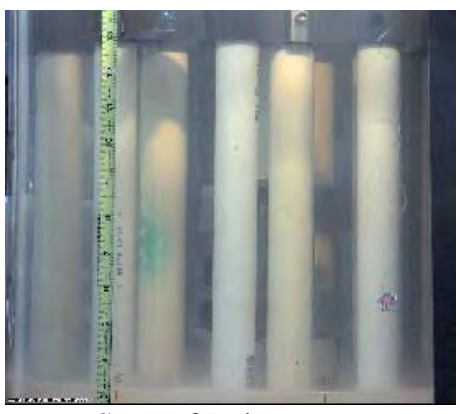

Start of Drive

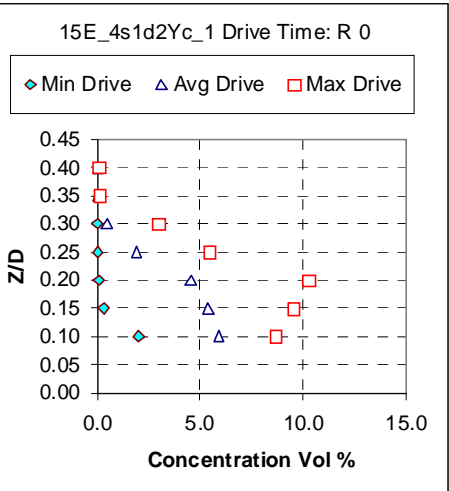

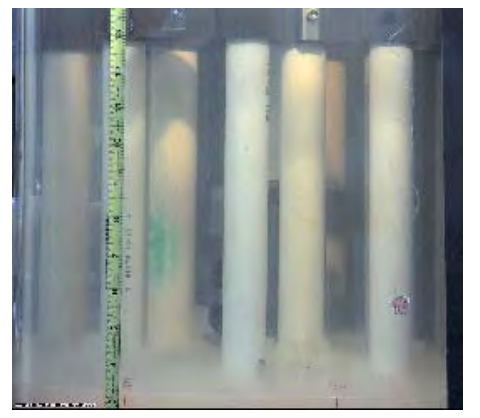

Middle of Drive

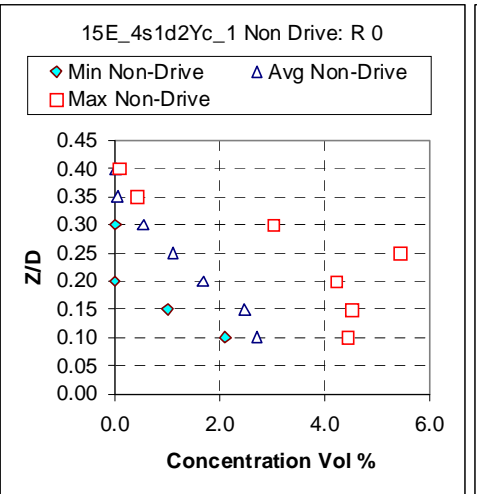

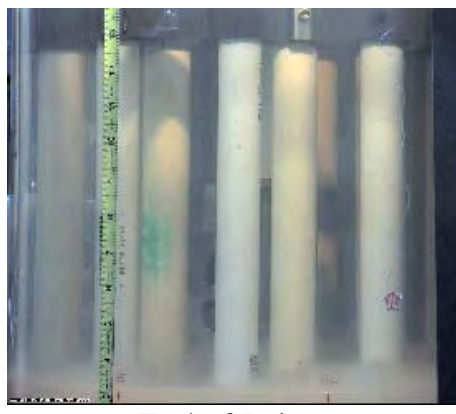

End of Drive

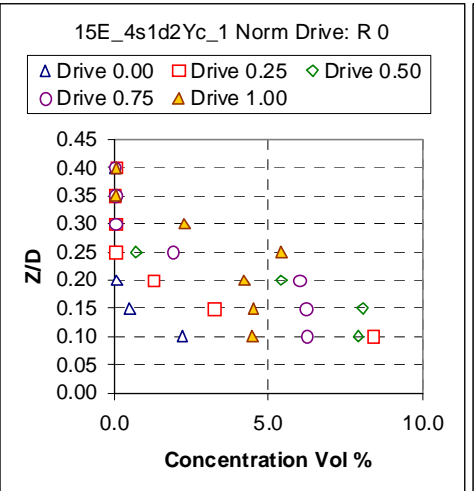

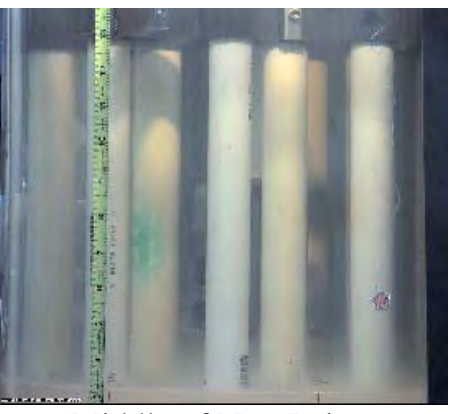

Middle of Non-Drive
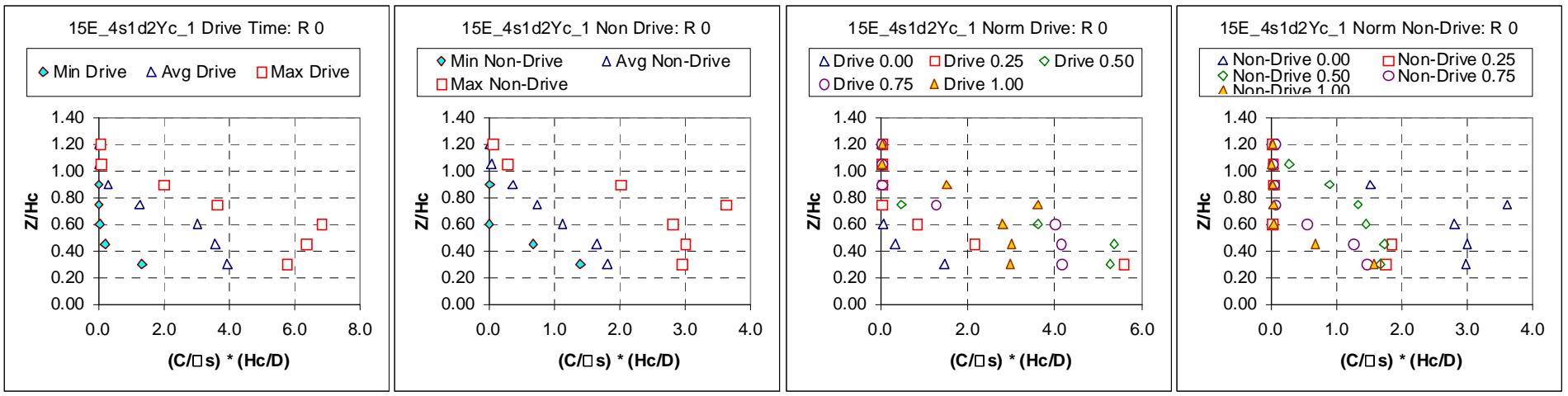

Figure C.2. $0.367-\mathrm{m}$ - (14 7/16-in.-) diameter tank, 0.320-cm- (0.126-in-) diameter nozzle; solids nominal diameter $69.3 \mu \mathrm{m}, 2.48 \mathrm{~g} / \mathrm{cm}^{3} \mathrm{density}$, 0.005 nominal solids fraction, $33.0 \%$ duty cycle, cycle time $15.0 \mathrm{~s}$, pulse volume fraction $0.050, \mathrm{U}_{\mathrm{CS}}$ velocity $4.3 \mathrm{~m} / \mathrm{s}$, target nozzle exit velocity $4.2 \mathrm{~m} / \mathrm{s}$; peak cloud height upper bound $0.140 \mathrm{~m}$ (5.5 in.) Case ID 15E_4s1d2Yc_1. 

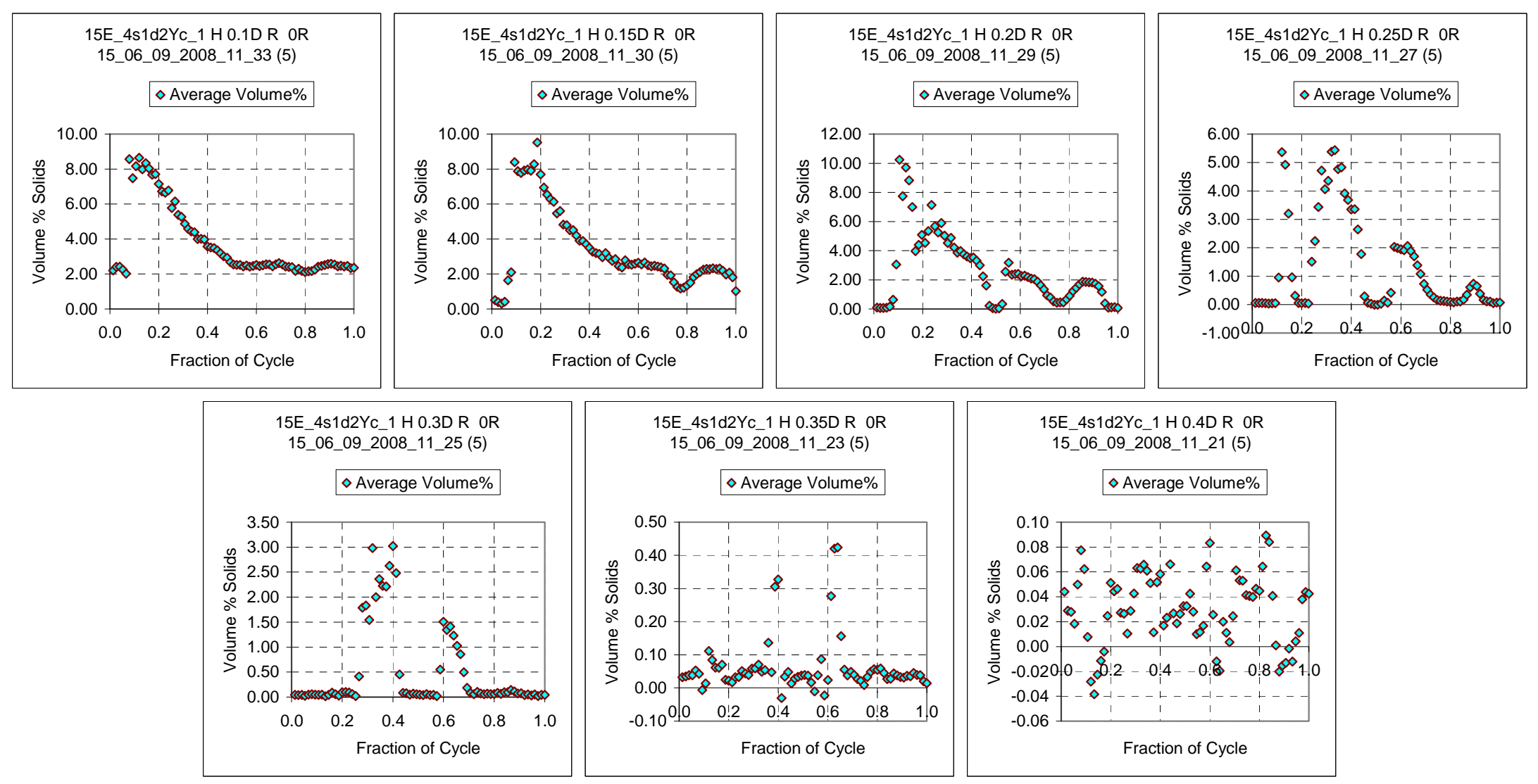

Figure C.2A. Case ID 15E_4s1d2Yc_1 Concentration Variation During the Cycle

This is the second profile shown using simulant s1d2 in the small-scale tank. The solids fraction has increased $\sim$ five times, from 0.00155 in

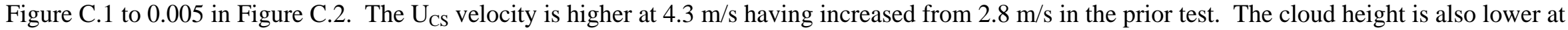
$5.5 \mathrm{in}$. compared to $7.25 \mathrm{in}$. in the prior test. The transient data in Figure C2.A shows that at $\mathrm{H}=0.1 \mathrm{D}$ the maximum concentration occurred at 0.1 cycle as in the prior test. The maximum concentration at $\mathrm{H}=0.3 \mathrm{D}$ occurred at 0.4 cycle with a second smaller peak observed at 0.6 cycle. The maximum concentration transient of 10 vol\% occurred at $\mathrm{H}=0.2 \mathrm{D}$ at 0.1 cycle. 


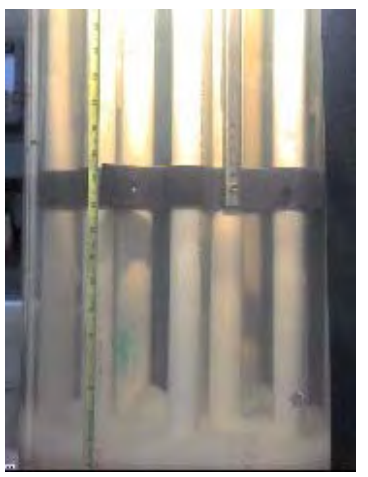

Maximum Cloud Height

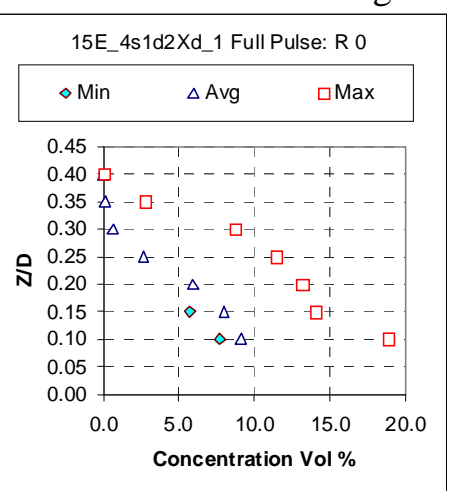

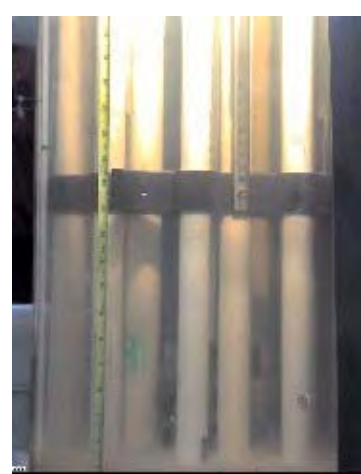

Start of Drive

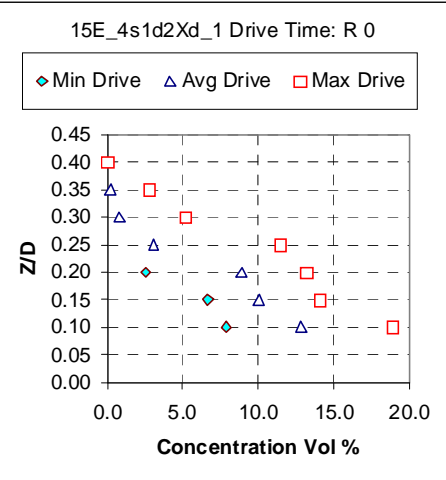

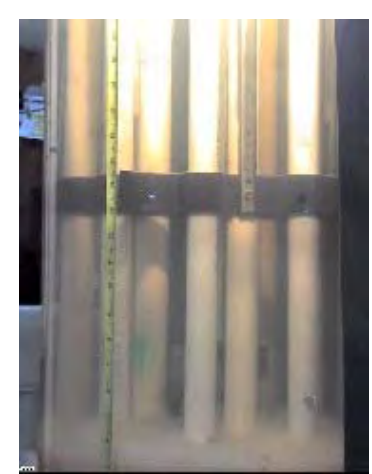

Middle of Drive

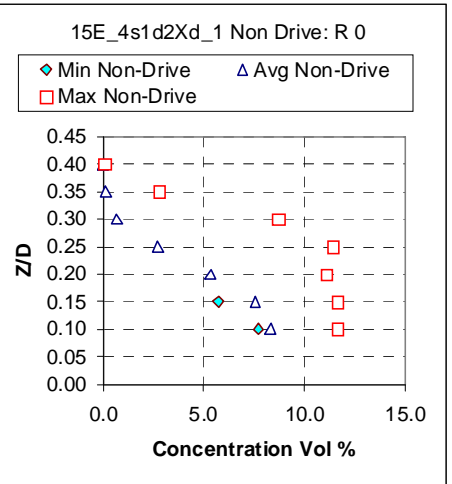

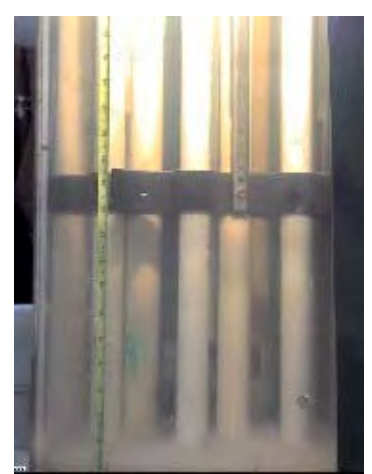

End of Drive

15E_4s1d2Xd_1 Norm Drive: R 0 $\Delta$ Drive $0.00 \square$ Drive $0.25 \diamond$ Drive 0.50 ODrive $0.75 \triangle$ Drive 1.00

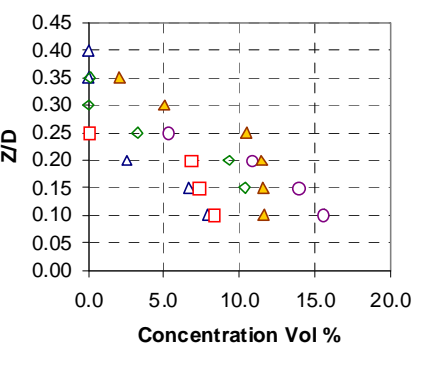

$$
0.40
$$$$
0.35 \Delta \Delta--\ldots
$$

0.15 - - - $0.0-\Delta-0-$

0.10 Concentration Vol $\%$

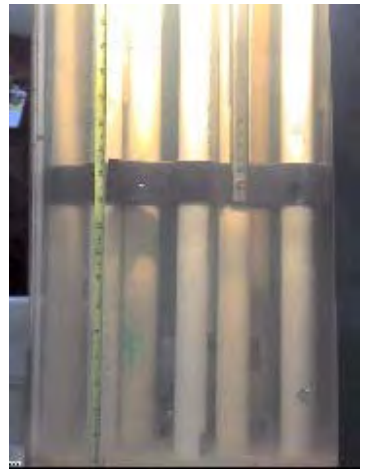

Middle of Non-Drive

15E_4s1d2Xd_1 Norm Non-Drive: R 0 $\begin{array}{ll}\Delta \text { Non-Drive } 0.00 & \square \text { Non-Drive } 0.25 \\ \diamond \text { Non-Drive } 0.50 & \text { ONon-Drive } 0.75\end{array}$

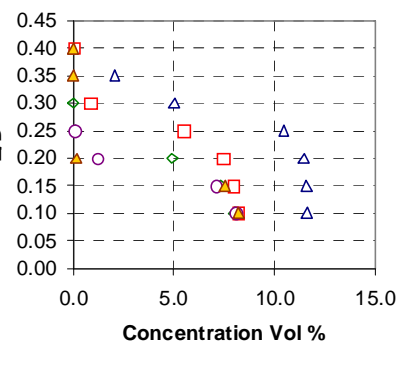

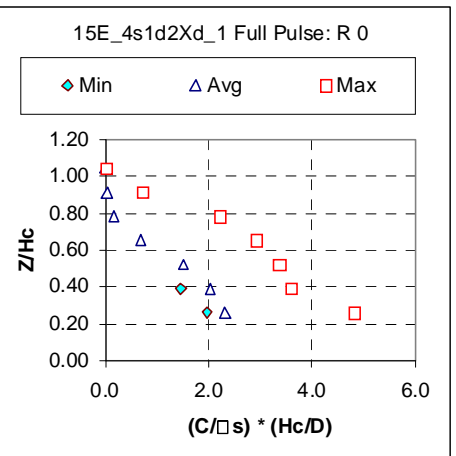
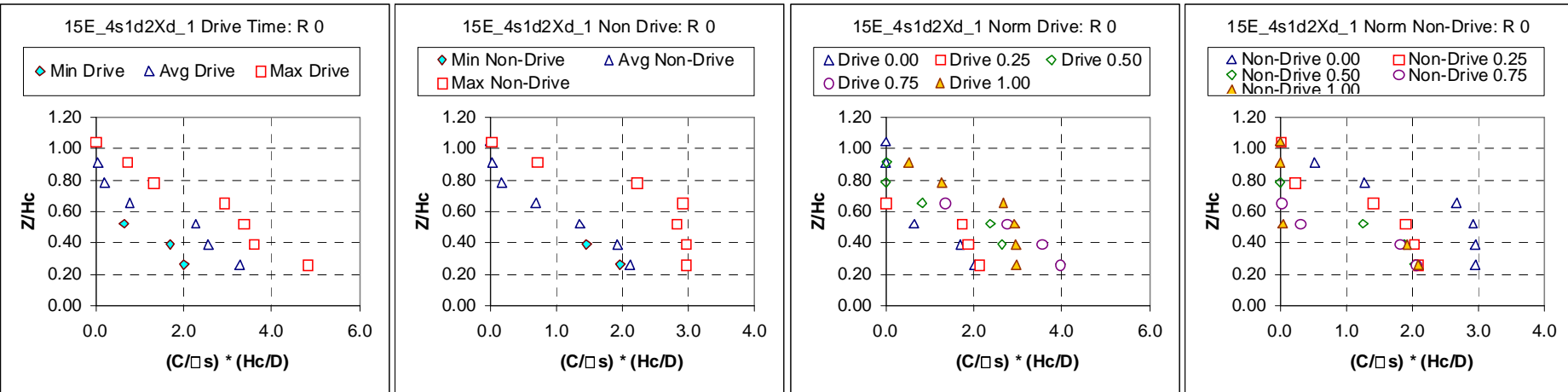

Figure C.3. 0.367-m- (14 7/16-in.-) diameter tank, 0.320-cm- (0.126-in-) diameter nozzle, solids nominal diameter $69.3 \mu \mathrm{m}, 2.48$ g/cm ${ }^{3}$ density; 0.015 nominal solids fraction, $18.4 \%$ duty cycle, cycle time $16.0 \mathrm{~s}$, pulse volume fraction 0.050 , $\mathrm{U}_{\mathrm{CS}}$ velocity $7.2 \mathrm{~m} / \mathrm{s}$, target nozzle exit velocity $7.2 \mathrm{~m} / \mathrm{s}$; peak cloud height upper bound $0.152 \mathrm{~m}$ (6 in.). Case ID 15E_4s1d2Xd_1. 

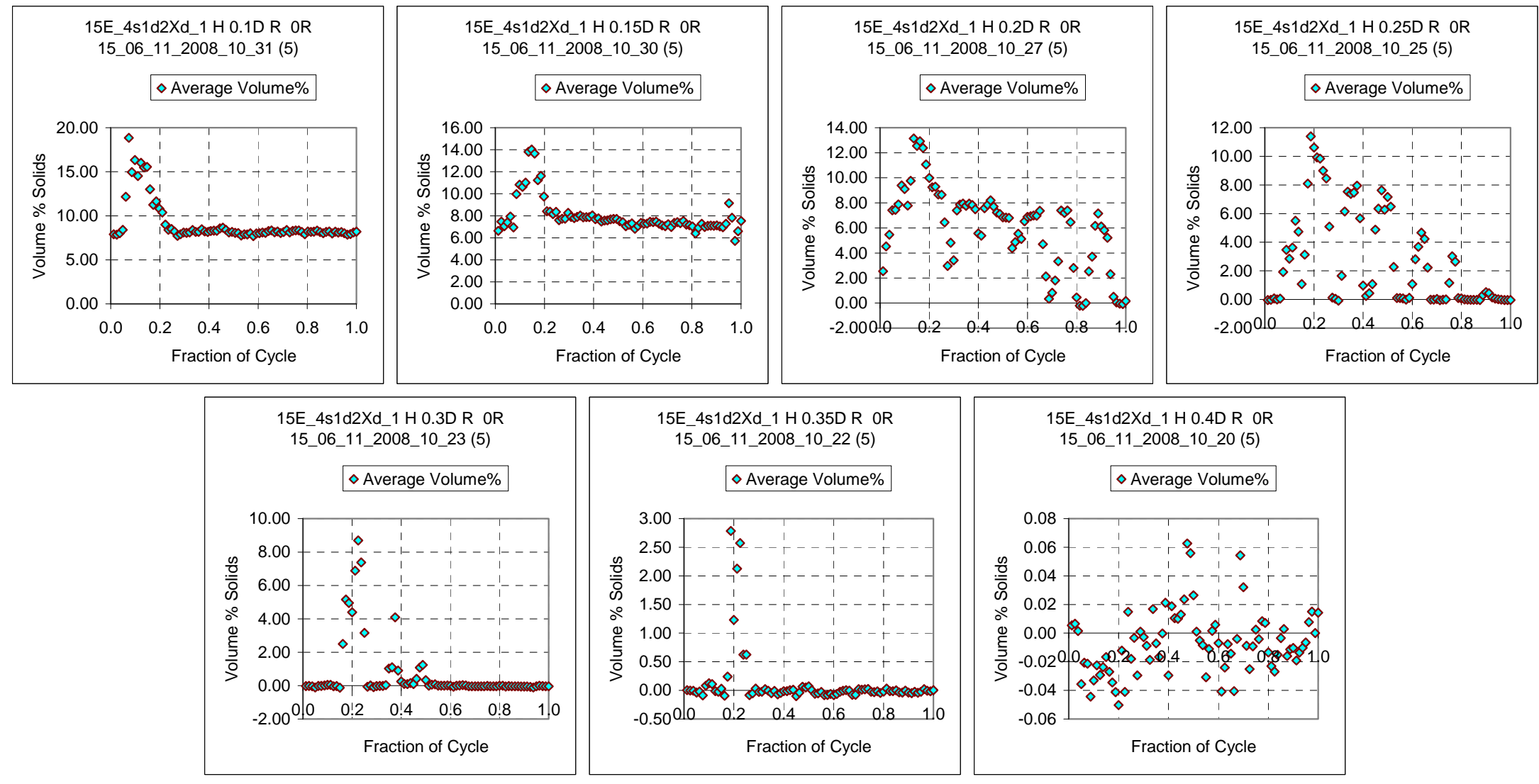

Figure C.3A. Case ID 15E_4s1d2Xd_1 Concentration Variation During the Cycle

This is the third profile shown using simulant s1d2 in the small-scale tank. The solids fraction has increased $\sim$ three times, from 0.005 in Figure C.2 to 0.015 in Figure C.3. The $U_{C s}$ velocity is higher at $7.2 \mathrm{~m} / \mathrm{s}$ having increased from $4.3 \mathrm{~m} / \mathrm{s}$ in the prior test. The cloud height is slightly higher at 6.0 in. instead of $5.5 \mathrm{in}$. in the prior test. In addition the duty cycle has changed to $18.4 \%$ from $33.0 \%$ in the prior test. The transient data in Figure C3.A shows that at $\mathrm{H}=0.1 \mathrm{D}$ the maximum concentration occurred at $\sim 0.1$ cycle as in the prior two tests. The maximum concentration at $\mathrm{H}=0.35 \mathrm{D}$ occurred at 0.2 cycle. In the prior test with a DC of 33.0 this peak was observed at $\sim 0.4$ cycle. The maximum concentration transient of 19 vol\% occurred at $\mathrm{H}=0.1 \mathrm{D}$ at $\sim 0.1$ cycle. 

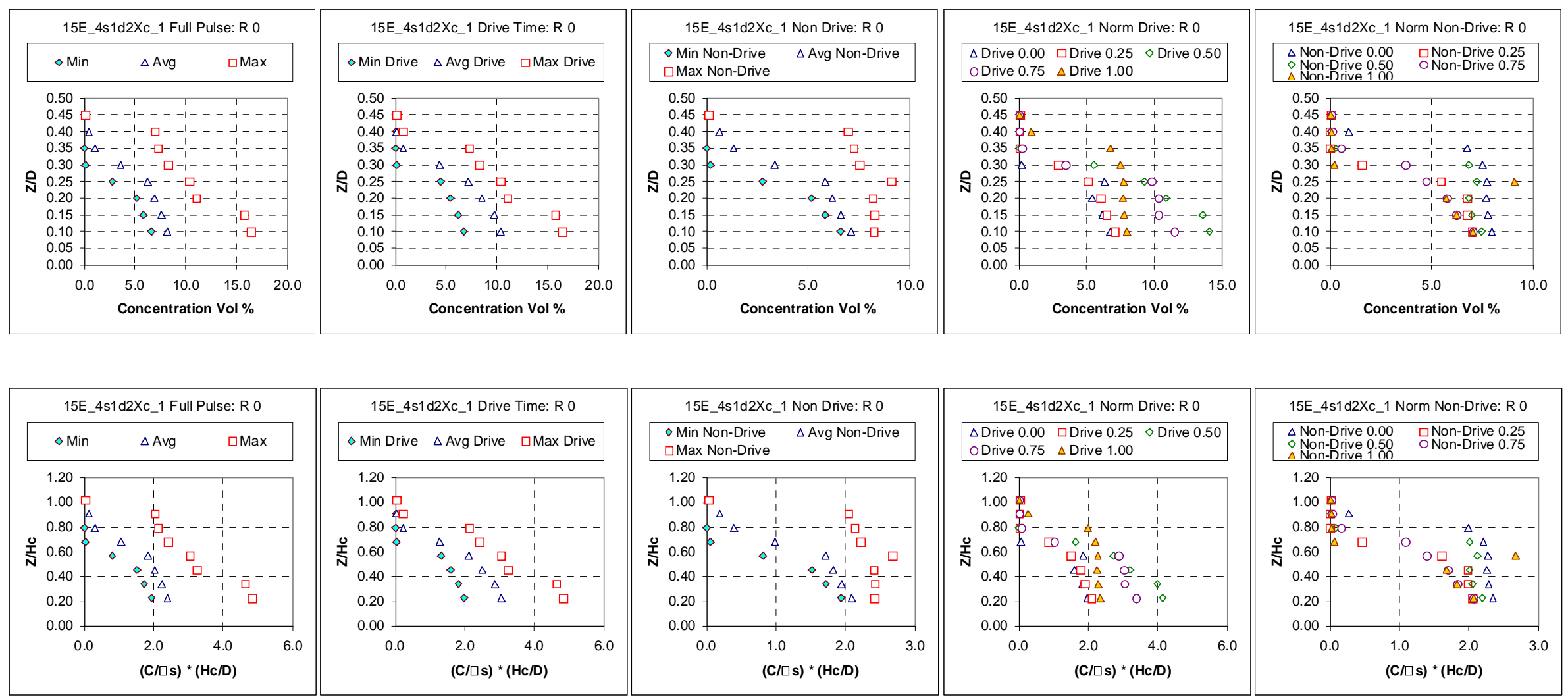

Figure C.4. 0.367-m- (14 7/16-in.-) diameter tank, 0.320-cm- (0.126-in-) diameter nozzle; solids nominal diameter $69.3 \mu \mathrm{m}, 2.48 \mathrm{~g} / \mathrm{cm}^{3}$ density; 0.015 nominal solids fraction, $33.0 \%$ duty cycle, cycle time $11.0 \mathrm{~s}$, pulse volume fraction 0.050 ; $\mathrm{U}_{\mathrm{CS}}$ velocity $5.8 \mathrm{~m} / \mathrm{s}$, target nozzle exit velocity $5.8 \mathrm{~m} / \mathrm{s}$; peak cloud height upper bound $0.178 \mathrm{~m}$ (7 in.). Case ID 15E_4s1d2Xc_1. 

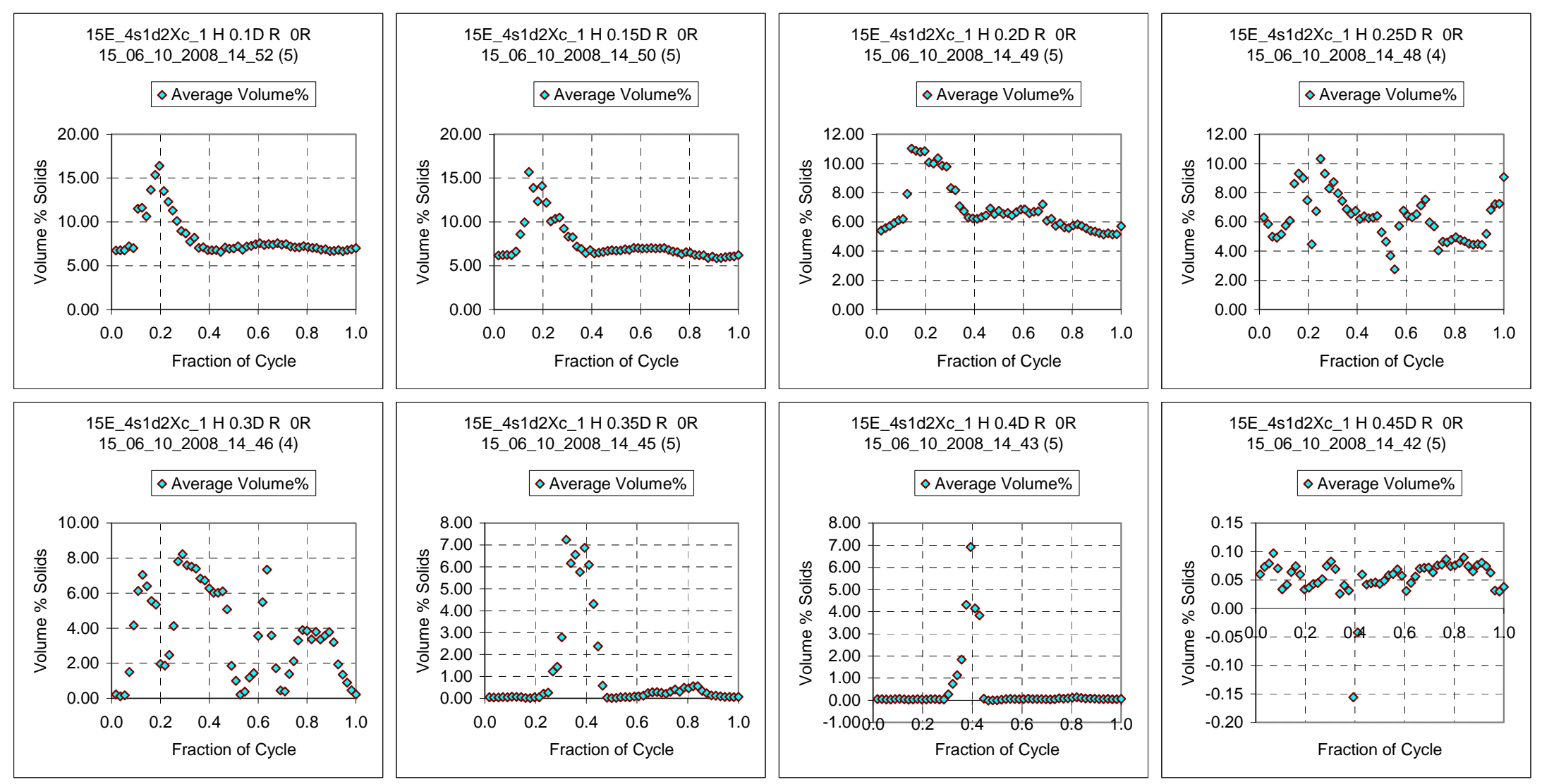

Figure C.4A. Case ID 15E_4s1d2Xc_1 Concentration Variation During the Cycle

This is the fourth profile shown using simulant s1d2 in the small-scale tank. The solids fraction remains at 0.005 , the same as in the prior test shown in Figure C.3. The duty cycle has changed to $33.0 \%$ from $18.4 \%$ in the prior test. The $\mathrm{U}_{\mathrm{Cs}}$ velocity is lower at $5.8 \mathrm{~m} / \mathrm{s}$ having increased from $7.2 \mathrm{~m} / \mathrm{s}$ in the prior test. The cloud height is slightly higher at $7.0 \mathrm{in}$. instead of $6.0 \mathrm{in}$. in the prior test. The transient data in Figure $\mathrm{C} 4$. A shows that at $\mathrm{H}=0.1 \mathrm{D}$ the maximum concentration occurred at 0.2 cycle, later than in the prior two tests. The maximum concentration at $\mathrm{H}=0.4 \mathrm{D}$ occurred at 0.4 cycle. In Figure C2.A a prior test with a DC of 33.0 this peak was also observed at 0.4 cycle. The maximum concentration transient of 16 vol\% occurred at $\mathrm{H}=0.1 \mathrm{D}$ at 0.2 cycle. Some additional peaks perhaps due to simulant sloshing are observed at elevations of $\mathrm{H}=0.25 \mathrm{D}$ and $0.3 \mathrm{D}$. 


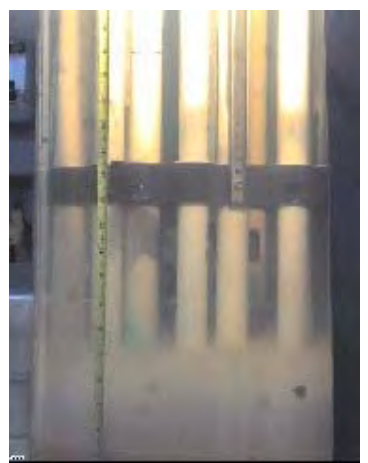

Maximum Cloud Height
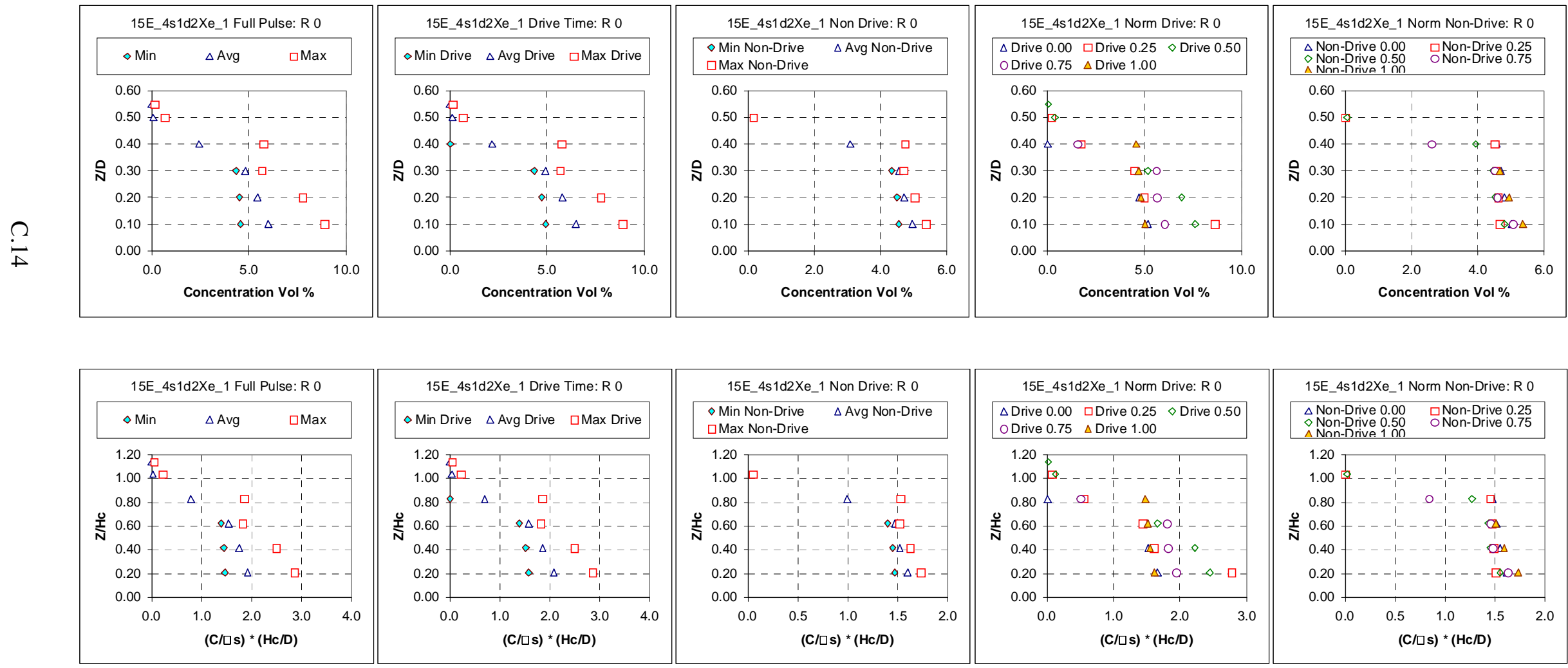

Figure C.5. 0.367-m- (14 7/16-in.-) diameter tank, 0.320-cm- (0.126-in-) diameter nozzle; solids nominal diameter $69.3 \mu \mathrm{m}, 2.48 \mathrm{~g} / \mathrm{cm}^{3}$ density; 0.015 nominal solids fraction, $66.7 \%$ duty cycle, cycle time $8.0 \mathrm{~s}$, pulse volume fraction 0.050 , $\mathrm{U}_{\mathrm{CS}}$ velocity $3.9 \mathrm{~m} / \mathrm{s}$, target nozzle exit velocity $3.9 \mathrm{~m} / \mathrm{s}$; peak cloud height upper bound $0.191 \mathrm{~m}$ (7.5 in.). Case ID 15E_4s1d2Xe_1. 

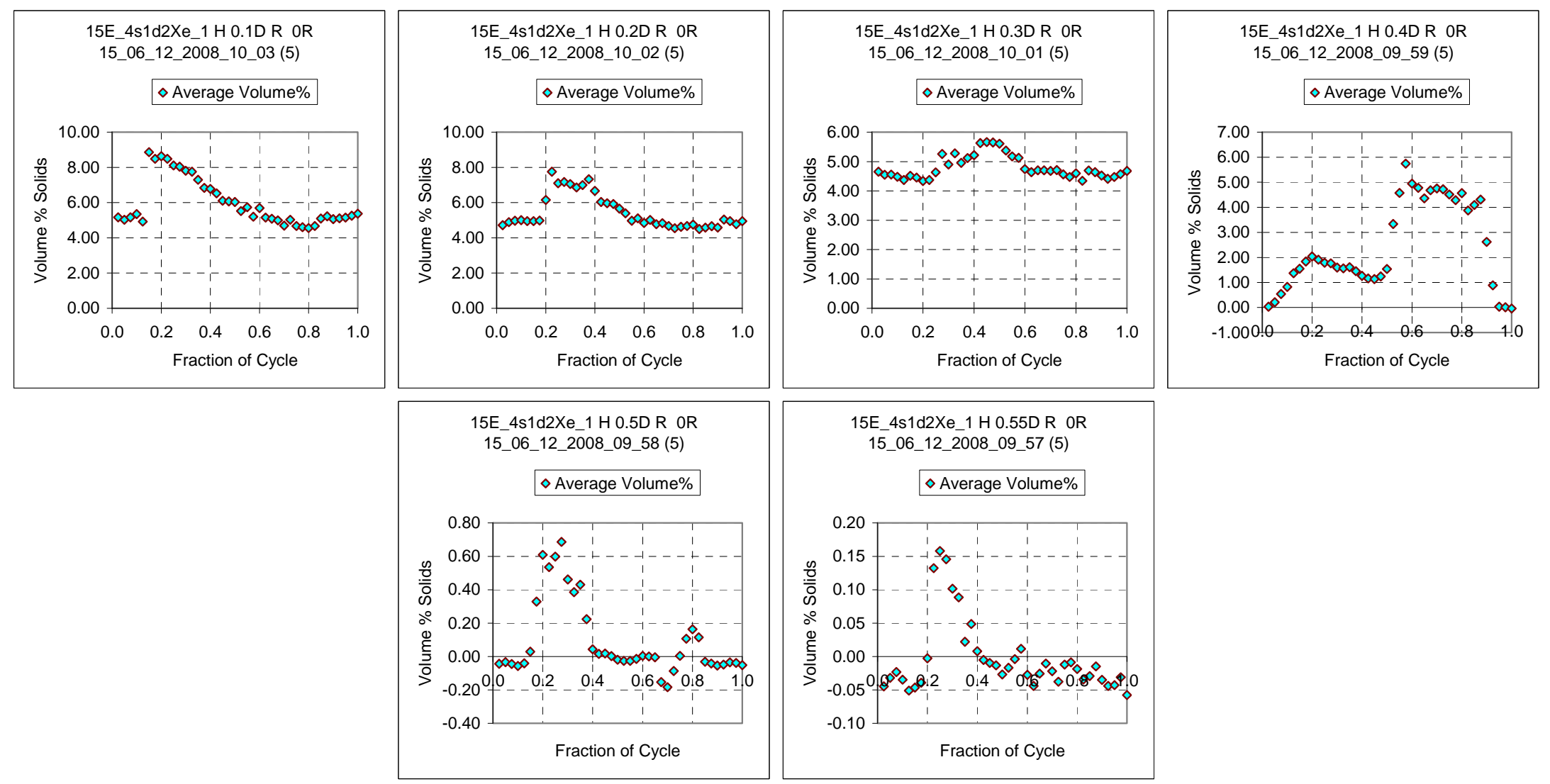

Figure C.5A. Case ID 15E_4s1d2Xe_1 Concentration Variation During the Cycle

This is the fifth profile shown using simulant s1d2 in the small-scale tank. The solids fraction remains at 0.005 , the same as in the prior two tests shown in Figures C.3 and C.4. The $U_{C S}$ velocity is lower at 3.9 m/s, having decreased from $5.8 \mathrm{~m} / \mathrm{s}$ in Figure C.4 and $7.2 \mathrm{~m} / \mathrm{s}$ in Figure C.3. The cloud height is slightly higher at 7.5 in. instead of 7.0 in. in Figure C.4 and 6.0 in. in Figure C.3. In addition the duty cycle has changed to $66.7 \%$ from $33.0 \%$ in Figure C.4 and 18.4\% in Figure C.3. The pulse jet is approaching a steady jet. In Figure C.5 the average concentration profile is more vertical than before, indicating a more uniform concentration up to an elevation of $\mathrm{Z}=0.3 \mathrm{D}$. The transient data in Figure C5.A shows that at $\mathrm{H}=0.1 \mathrm{D}$ the maximum concentration occurred at 0.1 cycle, with a broader peak than in the prior two tests. The maximum concentration at $\mathrm{H}=0.5 \mathrm{D}$ occurred at $\sim 0.3$ cycle. In The maximum concentration transient of 9 vol\% occurred at $\mathrm{H}=0.1 \mathrm{D}$ at $\sim 0.15$ cycle. 


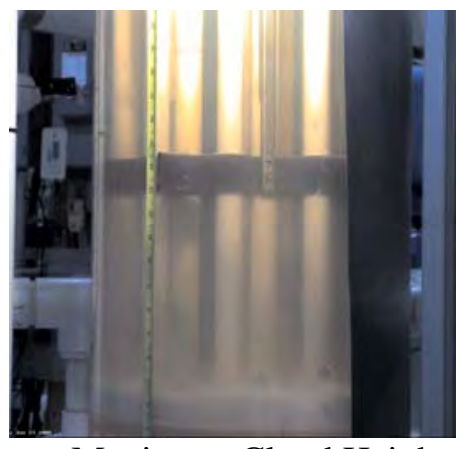

Maximum Cloud Height
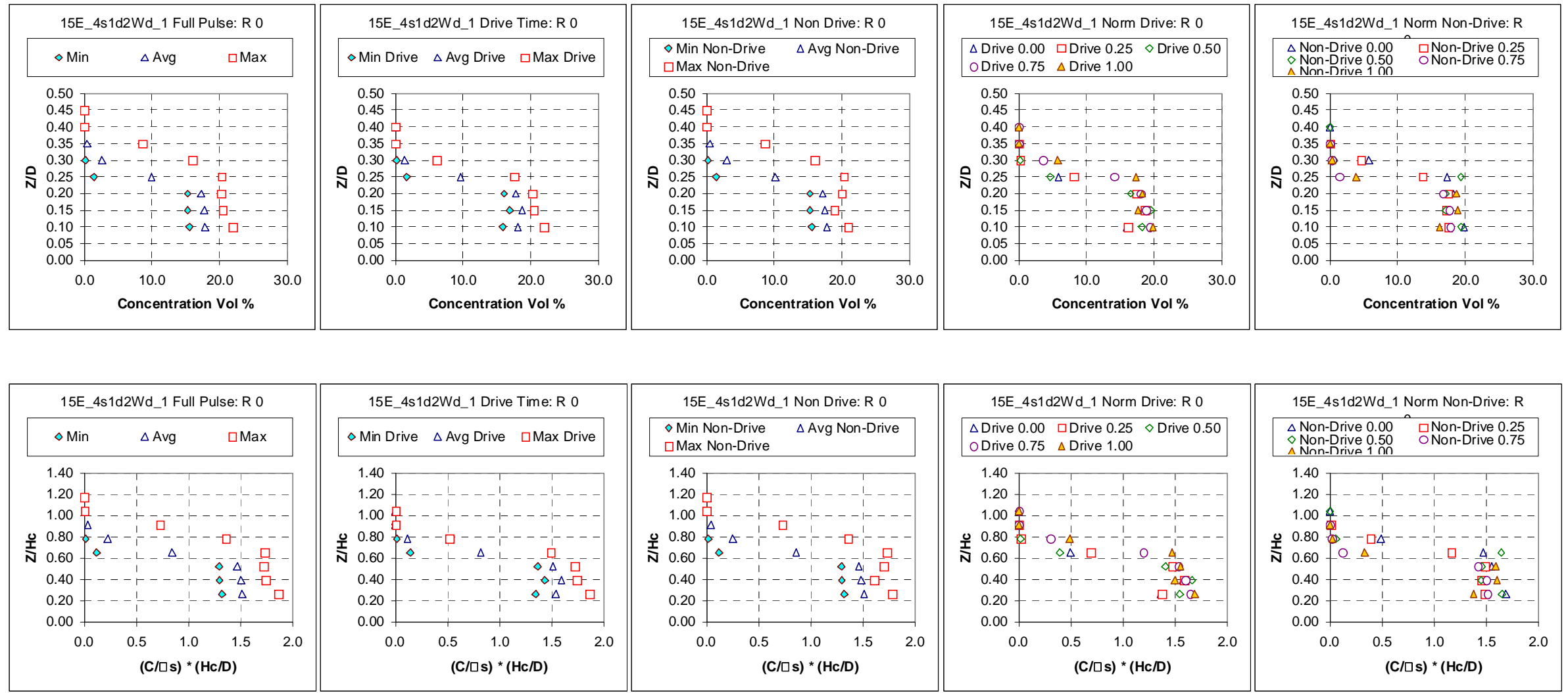

Figure C.6. $0.367-\mathrm{m}$ - (14 7/16-in.-) diameter tank, 0.320-cm- (0.126-in-) diameter nozzle; solids nominal diameter $69.3 \mu \mathrm{m}, 2.48$ g/cm³ density, 0.045 nominal solids fraction; $18.8 \%$ duty cycle, cycle time $15.8 \mathrm{~s}$, pulse volume fraction 0.050 , $\mathrm{U}_{\mathrm{Cs}}$ velocity $7.2 \mathrm{~m} / \mathrm{s}$, target nozzle exit velocity $7.2 \mathrm{~m} / \mathrm{s}$; peak cloud height upper bound $0.152 \mathrm{~m}$ (6 in.). Case ID 15E_4s1d2Wd_1. 

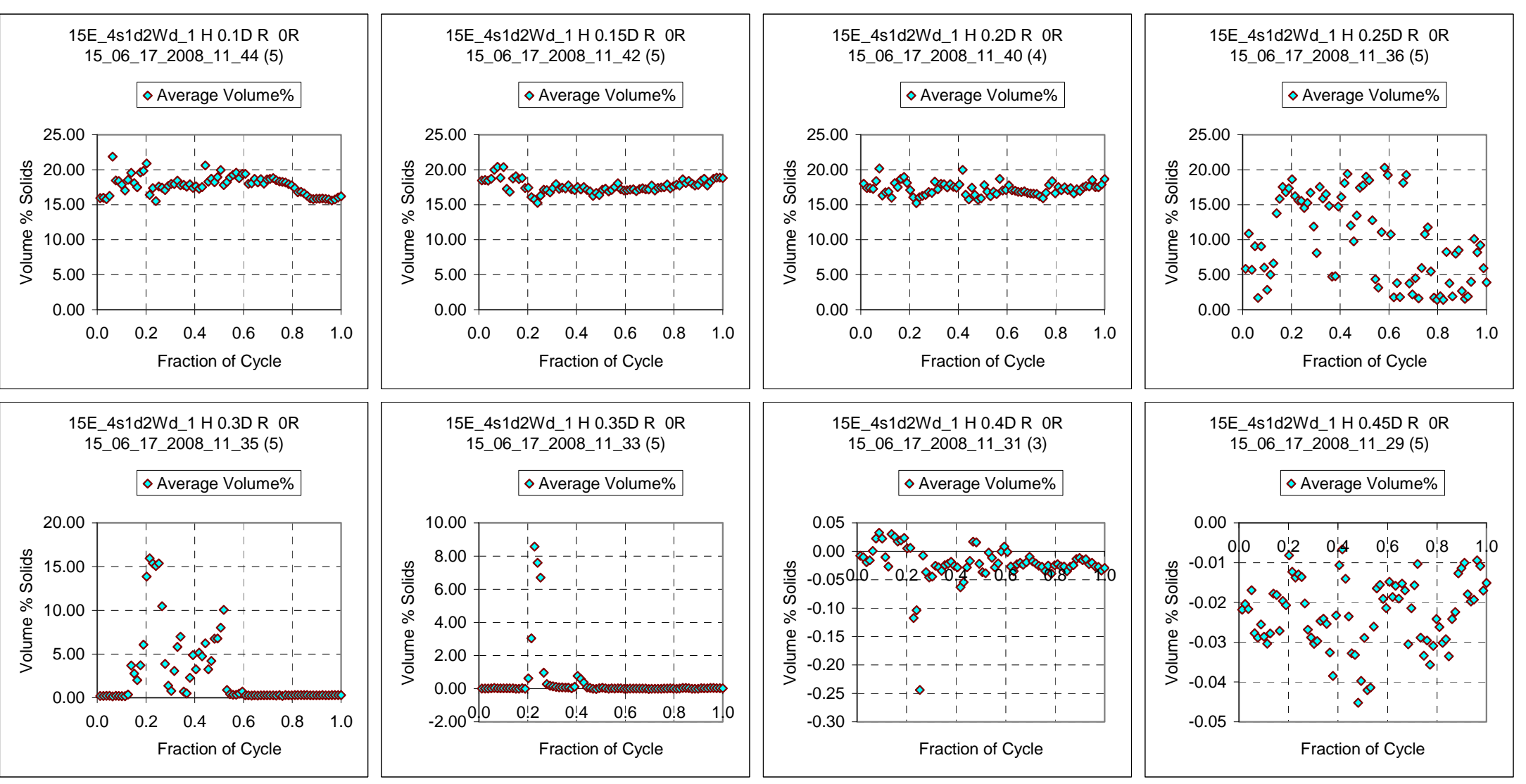

Figure C.6A. Case ID 15E_4s1d2Wd_1 Concentration Variation During the Cycle

This is the sixth profile shown using simulant s1d2 in the small-scale tank. The solids fraction increased $\sim 9$ times, to 0.045 from 0.005 in the prior three tests shown in Figures C.3, C.4 and C.5. The $\mathrm{U}_{\mathrm{CS}}$ velocity occurs $7.2 \mathrm{~m} / \mathrm{s}$, the same as was observed in Figure C.3. The cloud height is 6.0 in., the same as was observed in Figure C.3. In addition the duty cycle is $18.8 \%$, essentially the same as the $18.4 \%$ in Figure C.3. In Figure C.5 the average concentration profile is more vertical than before, indicating a more uniform concentration up to an elevation of $\mathrm{Z}=0.2 \mathrm{D}$. The transient data in Figure C5.A shows that in the range of $\mathrm{H}=0.1 \mathrm{D}$ to $\mathrm{H}=0.2 \mathrm{D}$ concentration is relatively constant throughout the cycle. At higher elevation, the maximum concentration transient of 9 vol\% occurred at $\mathrm{H}=0.35 \mathrm{D}$ at 0.25 cycle. 


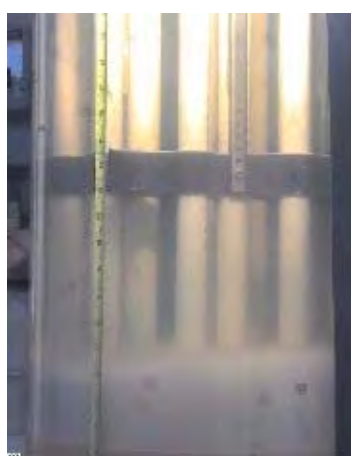

\section{Maximum Cloud Height}

\begin{tabular}{|c|c|c|c|}
\hline \multicolumn{4}{|c|}{ 15E_4s1d2Wc_1 Full Pulse: $R 0$} \\
\hline$\diamond \operatorname{Min}$ & $\triangle A v g$ & ㅁ & \\
\hline \multicolumn{4}{|l|}{$0.60_{1}$} \\
\hline \multicolumn{4}{|l|}{$0.50 \mathrm{C}$} \\
\hline \multicolumn{4}{|l|}{$0.40 \mathrm{~A}^{\mathrm{s}}$} \\
\hline \multicolumn{4}{|l|}{0.30} \\
\hline \multicolumn{4}{|l|}{0.20} \\
\hline \multicolumn{4}{|c|}{$-\Delta \Delta \square$} \\
\hline \multicolumn{4}{|l|}{0.00} \\
\hline 0.0 & 10.0 & 0.0 & 30.0 \\
\hline \multicolumn{4}{|c|}{ Concentration Vol \% } \\
\hline
\end{tabular}
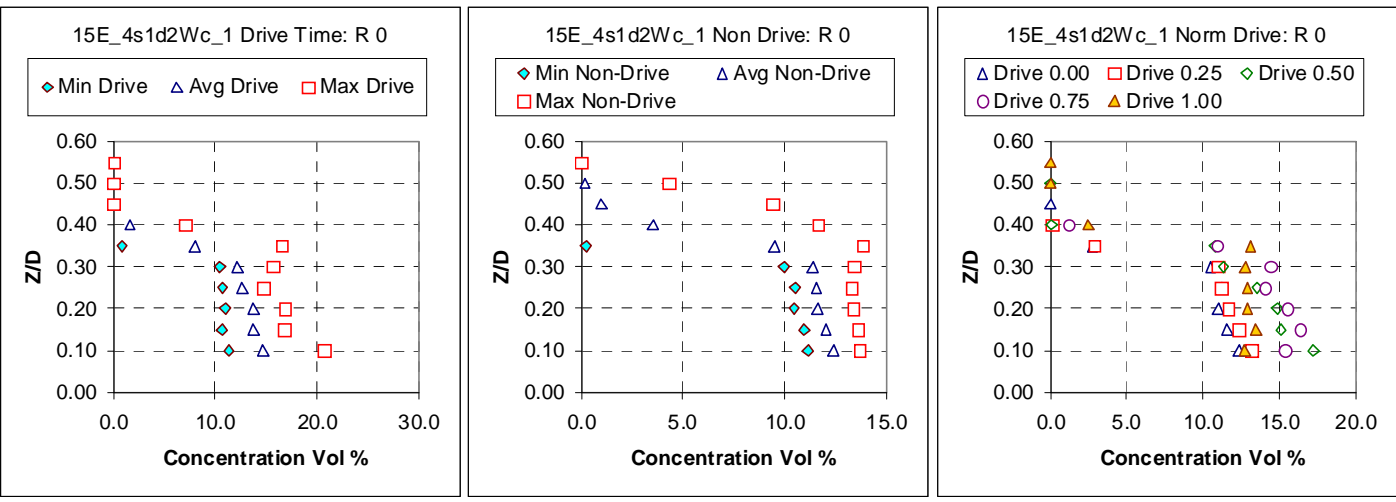

15E_4s1d2Wc_1 Norm Non-Drive: $R$ \begin{tabular}{|ll|}
\hline $\begin{array}{l}\Delta \text { Non-Drive } 0.00 \\
\Delta \text { Non-Drive } 0.50\end{array}$ & a Non-Drive 0.25 \\
$\Delta$ Nnn-Drive 1 nn & onon-Drive 0.75 \\
\hline
\end{tabular}
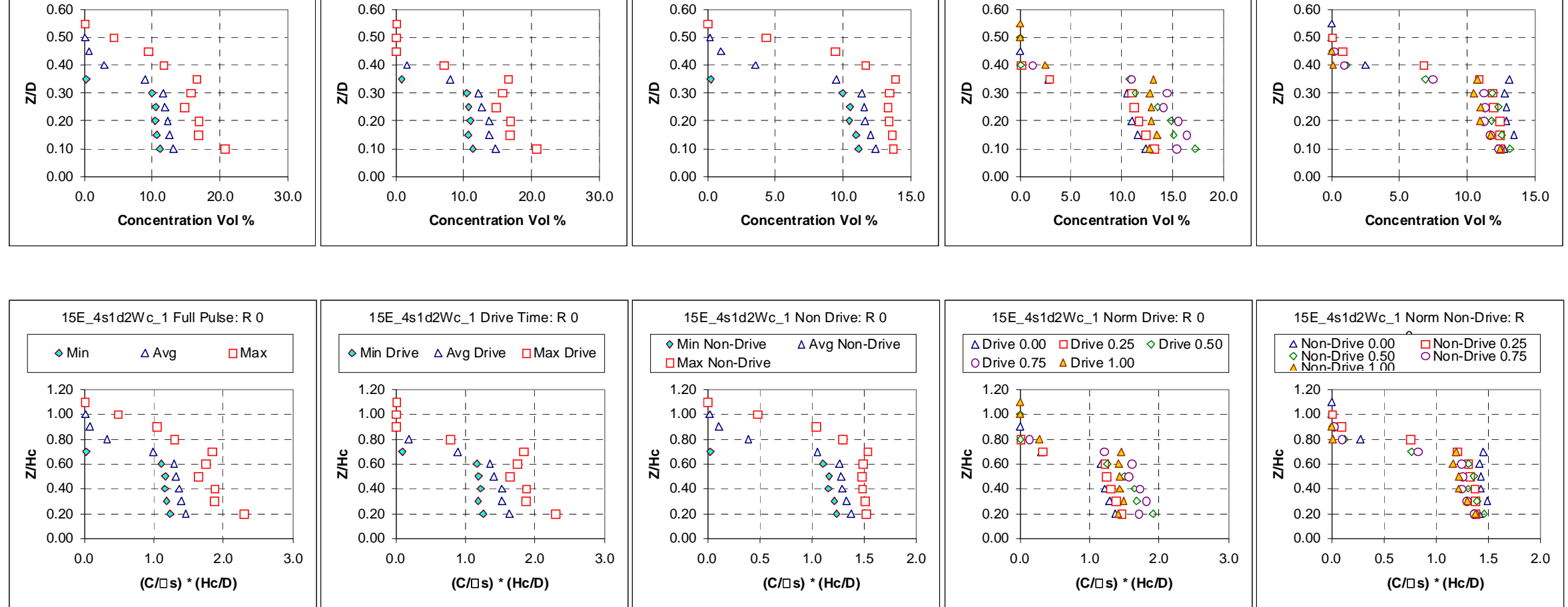

Figure C.7. 0.367-m- (14 7/16-in.-) diameter tank, 0.320-cm- (0.126-in-) diameter nozzle; solids nominal diameter $69.3 \mu \mathrm{m}, 2.48 \mathrm{~g} / \mathrm{cm}^{3}$ density; 0.045 nominal solids fraction; $33.2 \%$ duty cycle, cycle time $9.8 \mathrm{~s}$, pulse volume fraction 0.050 ; $\mathrm{U}_{\mathrm{CS}}$ velocity $6.5 \mathrm{~m} / \mathrm{s}$, target nozzle exit velocity $6.5 \mathrm{~m} / \mathrm{s}$; peak cloud height upper bound $0.203 \mathrm{~m}$ (8 in.). Case ID 15E_4s1d2Wc_1. 

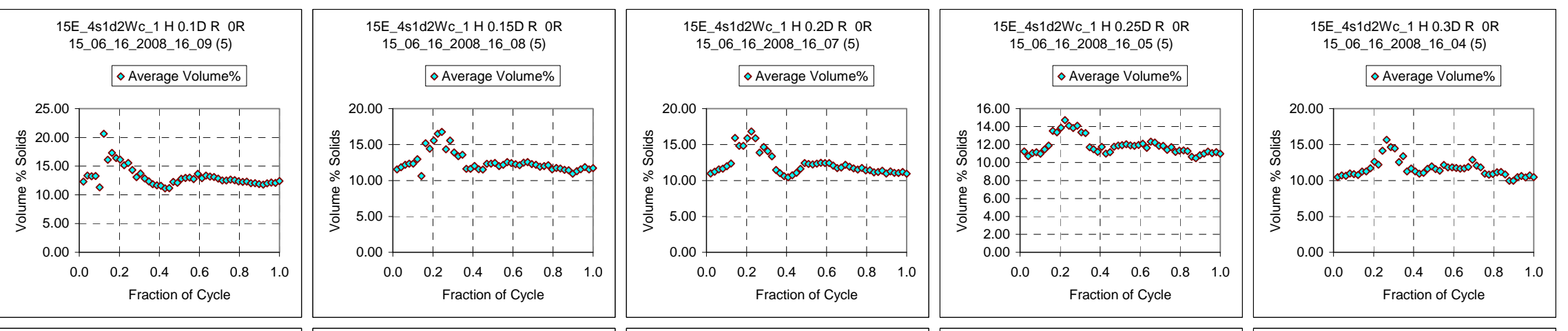
15E_4s1d2Wc_1 H $0.35 \mathrm{D} R$ OR
15 06 $16 \_2008$ 16 02 (5)
$\diamond$ Average Volume $\%$

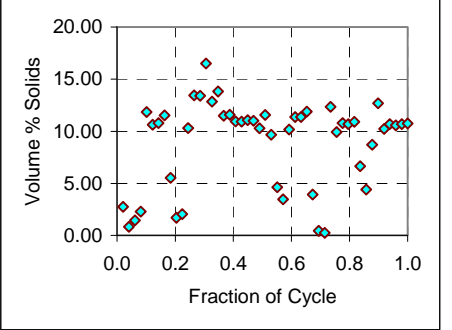

5E_-4sid2Wc_1 H O.4D R OR

$\diamond$ Average Volume $\%$

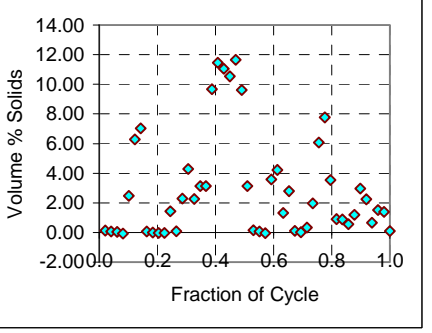

15E_4s $1 \mathrm{~d} 2 \mathrm{Wc} \_1 \mathrm{H} 0.45 \mathrm{D} R$ OR

$\diamond$ Average Volume $\%$

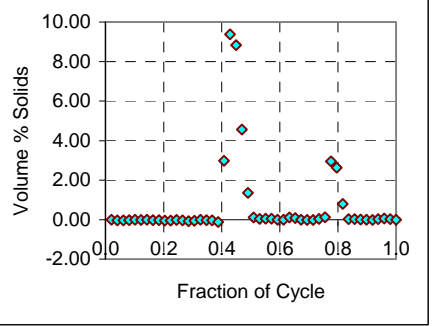

15E_4s1d2Wc_1 H 0.5D R OR

$\triangle$ Average Volume $\%$

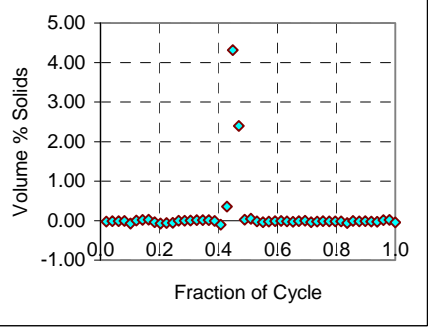

15E_4s 1 d2Wc_1 H 0.55D R OR $\diamond$ Average Volume $\%$

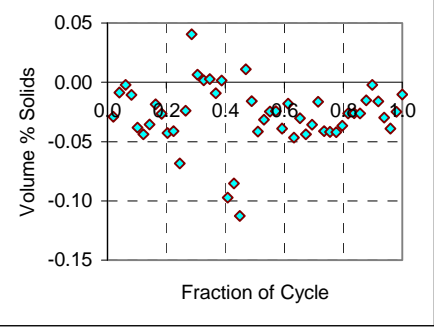

Figure C.7A. Case ID 15E_4s1d2Wc_1 Concentration Variation During the Cycle

This is the seventh profile shown using simulant s1d2 in the small-scale tank. The solids fraction remained constant at 0.045 ; however, the duty cycle increased to $33.2 \%$ from $18.8 \%$ in Figure C.6. The $\mathrm{U}_{\mathrm{CS}}$ velocity occurred $6.5 \mathrm{~m} / \mathrm{s}$, slightly less than $7.2 \mathrm{~m} / \mathrm{s}$ that was observed in Figure C.6. The cloud height is 8.0 in., slightly higher than the 6 in. observed in Figure C.6. In Figure C.7 the average concentration profile is relatively vertical, indicating a more uniform concentration up to an elevation of $\mathrm{Z}=0.3 \mathrm{D}$. The transient data in Figure C5.A show that at in the range of $\mathrm{H}=0.1 \mathrm{D}$ to $\mathrm{H}=0.3 \mathrm{D}$ concentration is relatively constant throughout the cycle. At higher elevation, the maximum concentration transient of 9 vol\% occurred at $\mathrm{H}=0.45 \mathrm{D}$ at 0.45 cycle.

The eighth profile shown using simulant s1d2 is shown in Figure C.8. The solids fraction remained constant at 0.45 ; however, the system was operated as a steady jet. In this case the concentration is essentially constant to an elevation of $\mathrm{Z}=0.8 \mathrm{D}$. 


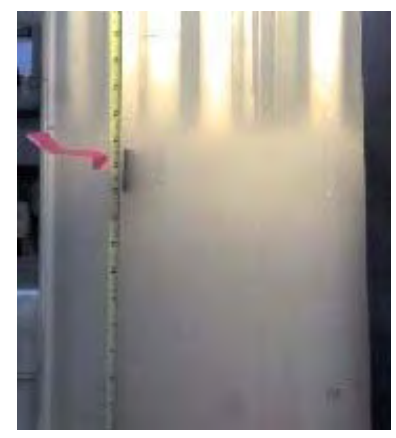

Maximum Cloud Height

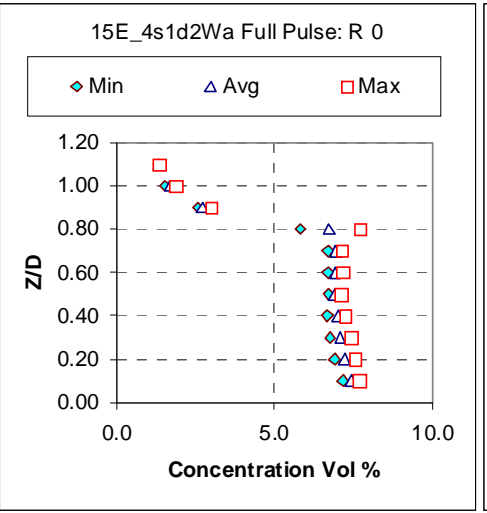
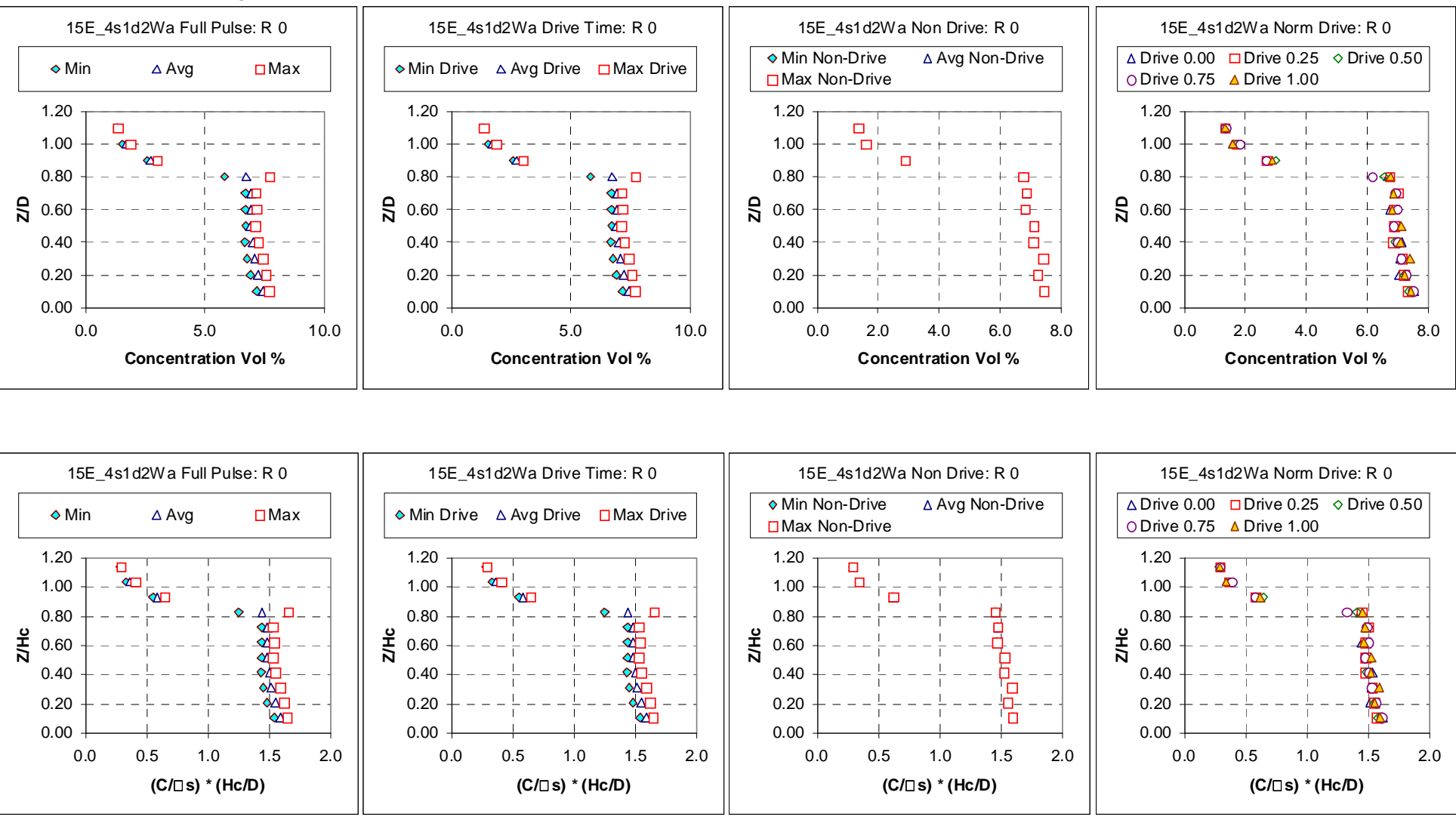

Figure C.8. $0.367-\mathrm{m}$ - (14 7/16-in.-) diameter tank, 0.320-cm- (0.126-in-) diameter nozzle; solids nominal diameter $69.3 \mu \mathrm{m}, 2.48 \mathrm{~g} / \mathrm{cm}^{3}$ density; 0.045 nominal solids fraction; $100.0 \%$ duty cycle, cycle time infinite, pulse volume fraction undefined, $\mathrm{U}_{\mathrm{CS}}$ velocity $3 \mathrm{~m} / \mathrm{s}$, target nozzle exit velocity $3 \mathrm{~m} / \mathrm{s}$; peak cloud height upper bound $0.381 \mathrm{~m}$ (15 in.) Case ID 15E_4s1d2Wa. 

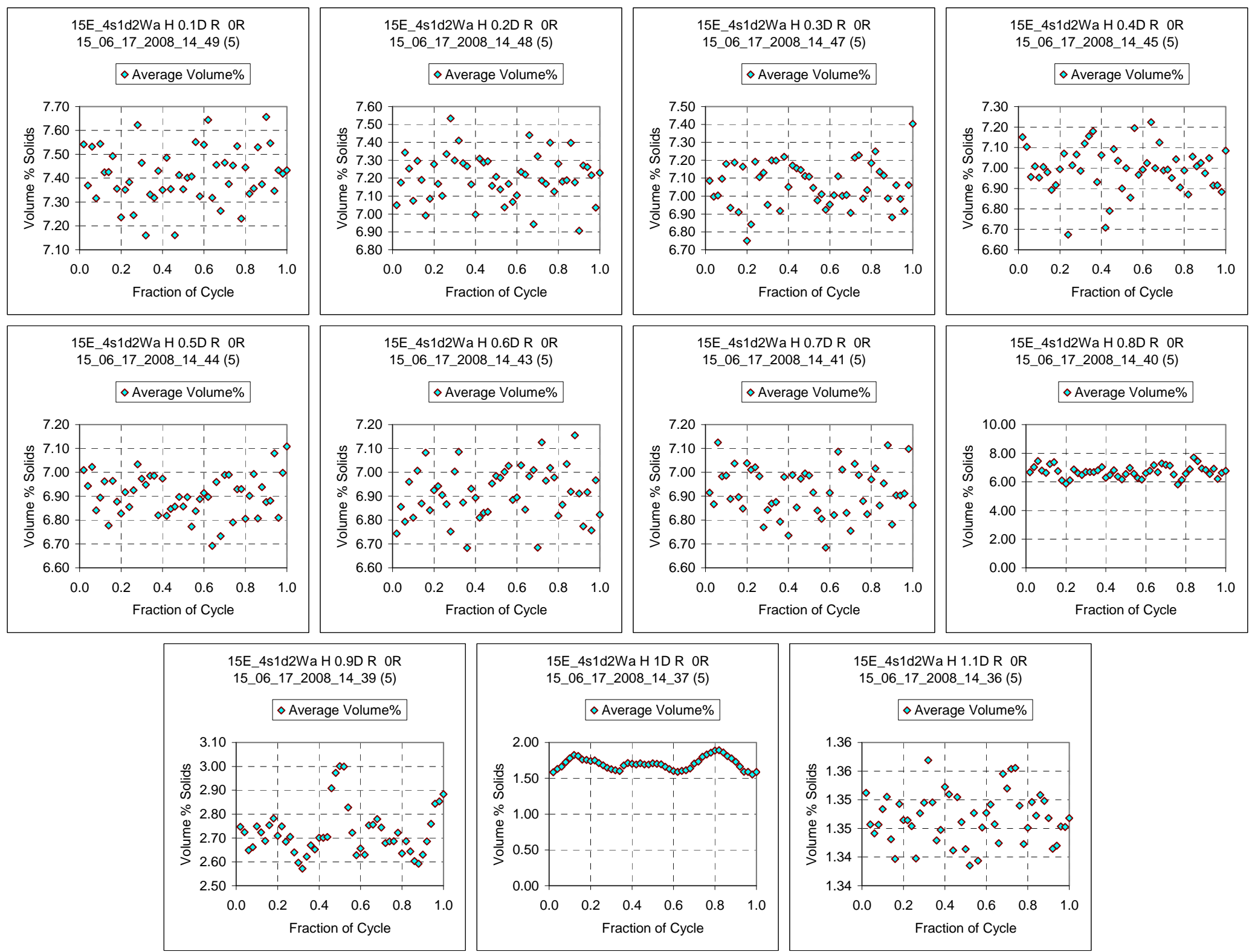

Figure C.8A. Case ID 15E_4s1d2Wa Concentration Variation During the Cycle 


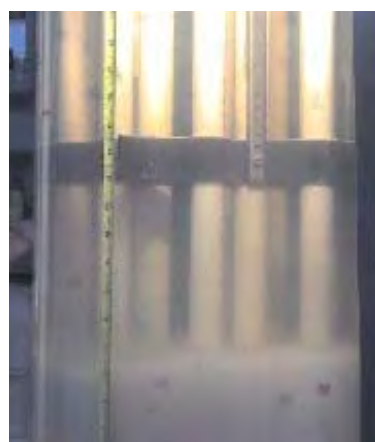

Maximum Cloud Height

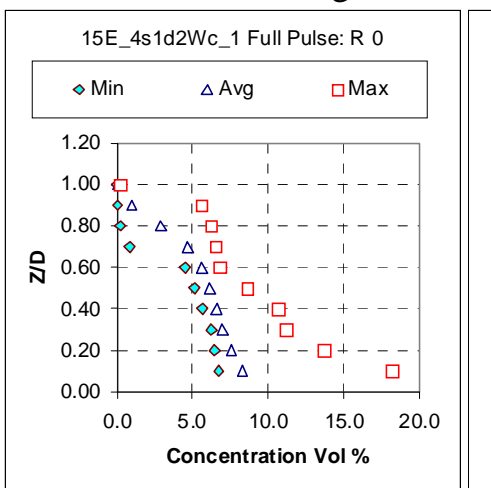
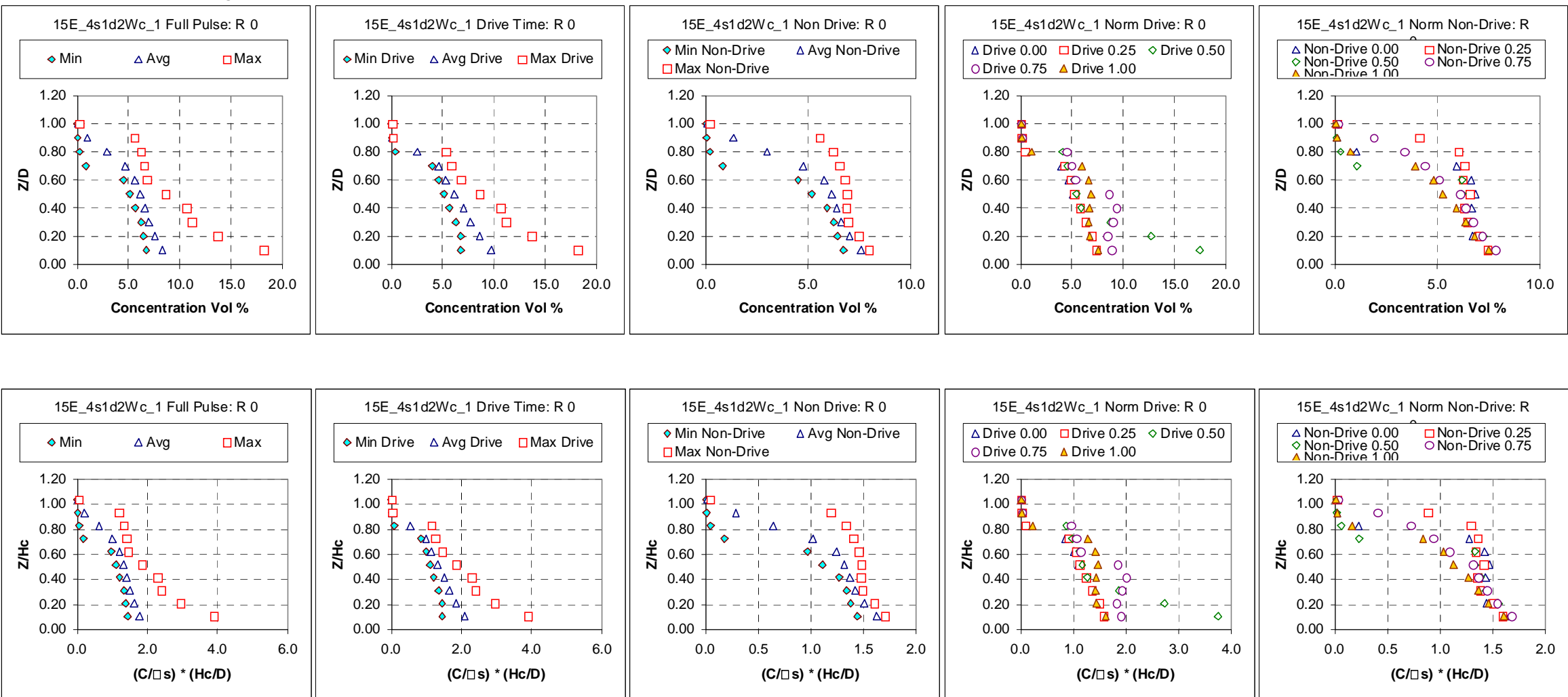

15E_4s1d2Wc_1 Norm Non-Drive: $R$

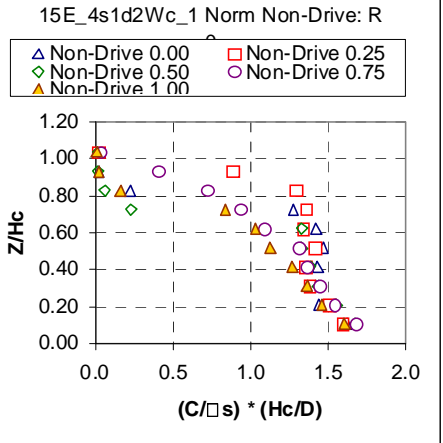

Figure C.9. 0.367-m- (14 7/16-in.-) diameter tank, 0.320-cm- (0.126-in-) diameter nozzle; solids nominal diameter $69.3 \mu \mathrm{m}, 2.48$ g/cm ${ }^{3}$ density; 0.045 nominal solids fraction; $33.7 \%$ duty cycle, cycle time $8.0 \mathrm{~s}$, pulse volume fraction 0.050 , $\mathrm{U}_{\mathrm{CS}}$ velocity $6.5 \mathrm{~m} / \mathrm{s}$, target nozzle exit velocity $8 \mathrm{~m} / \mathrm{s}$; peak cloud height upper bound $0.381 \mathrm{~m}$ (15 in.). Case ID 15E_4s1d2Wc_1. 

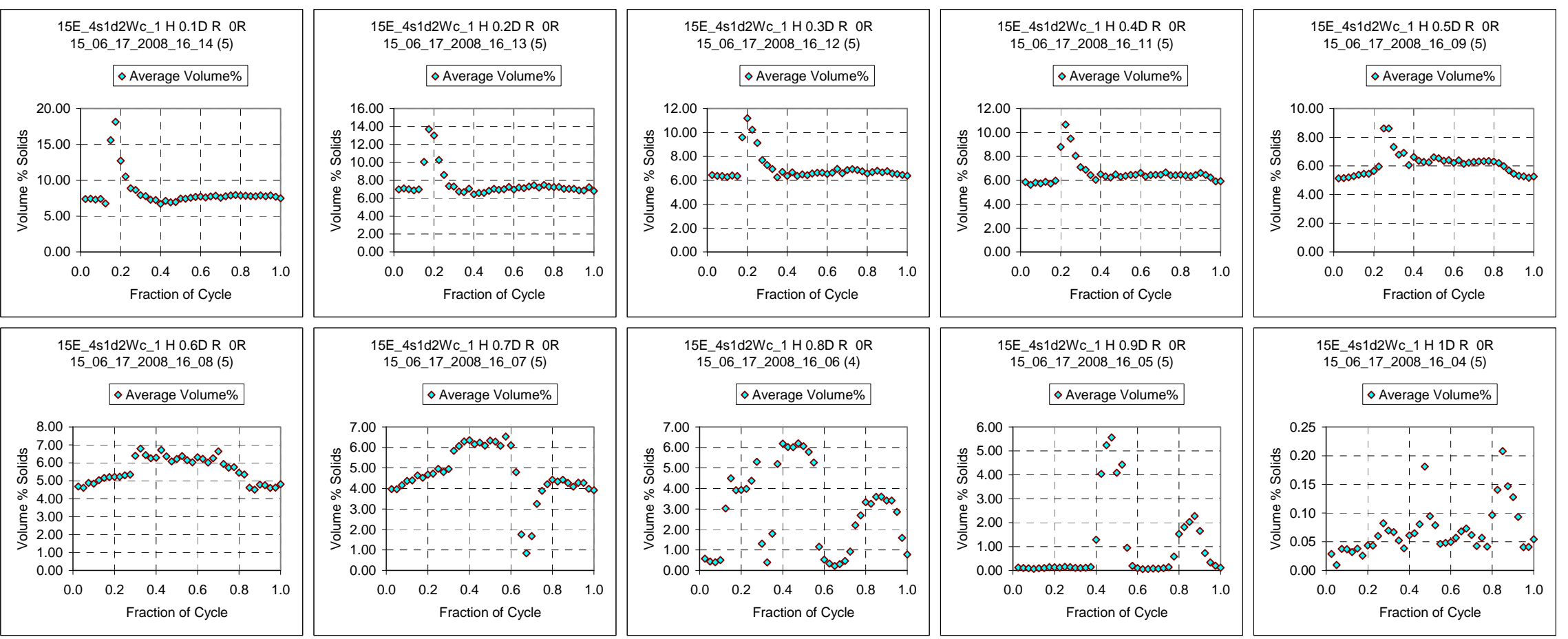

Figure C.9A. Case ID 15E_4s1d2Wc_1 Concentration Variation During the Cycle

This is the ninth profile shown using simulant s1d2 in the small-scale tank. This is first test with a velocity above $\mathrm{U}_{\mathrm{CS}}$. The conditions match those in Figure C.7 except for nozzle exit velocity. The solids fraction remained constant at 0.045 ; the duty cycle remained essentially constant at $33.7 \%$ from $33.2 \%$ in Figure C.7. The nozzle exit velocity of $8 \mathrm{~m} / \mathrm{s}$ was $>\mathrm{U}_{\mathrm{Cs}}$ velocity, which occurred at $6.5 \mathrm{~m} / \mathrm{s}$. The cloud height is 15.0 in., much higher than the 8 in. observed in Figure C.7. In Figure C.9 the average concentration profile is relatively vertical, indicating a more uniform concentration up to an elevation of $\mathrm{Z}=0.7 \mathrm{D}$, more than twice the height obtained at $\mathrm{U}_{\mathrm{CS}}$ in Figure C.7. This change shows that an increase in concentration uniformity was obtained when operating at velocities above $\mathrm{U}_{\mathrm{CS}}$. 


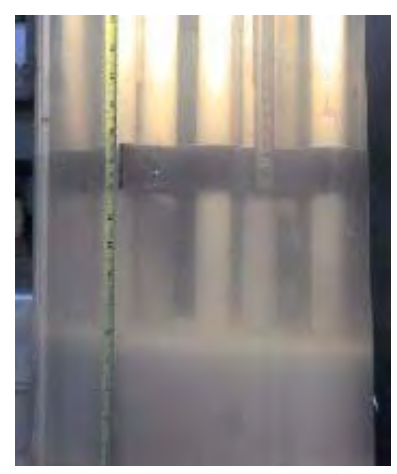

Maximum Cloud Height

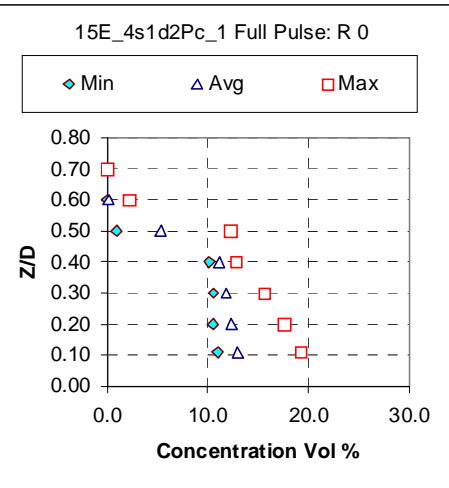

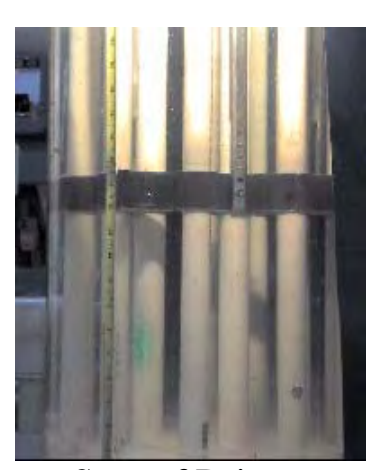

Start of Drive

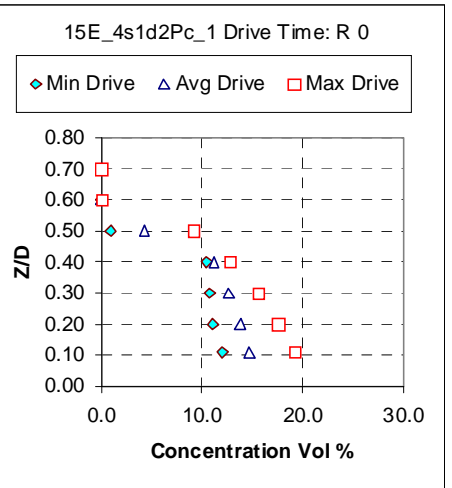

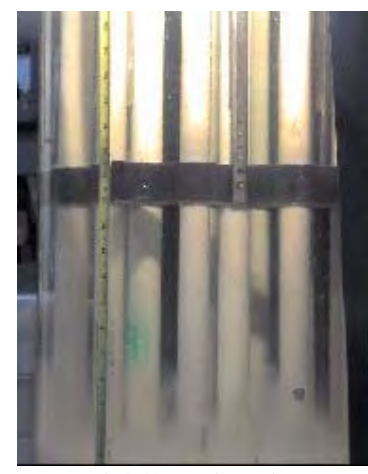

Middle of Drive

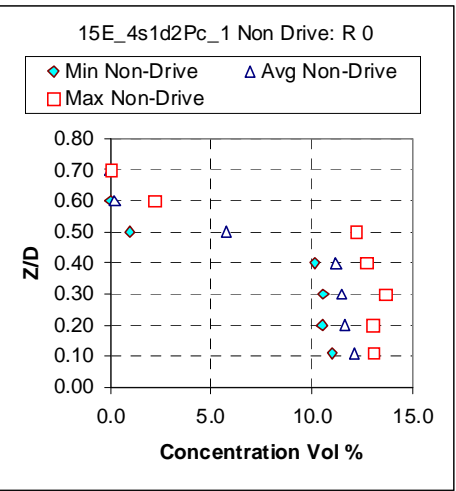

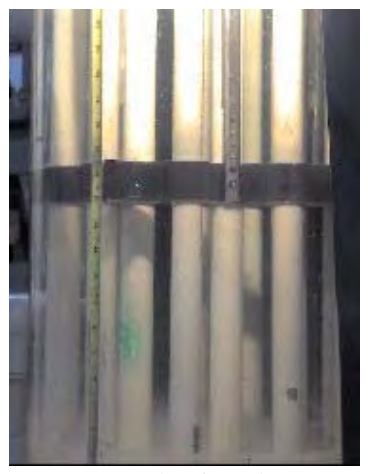

End of Drive

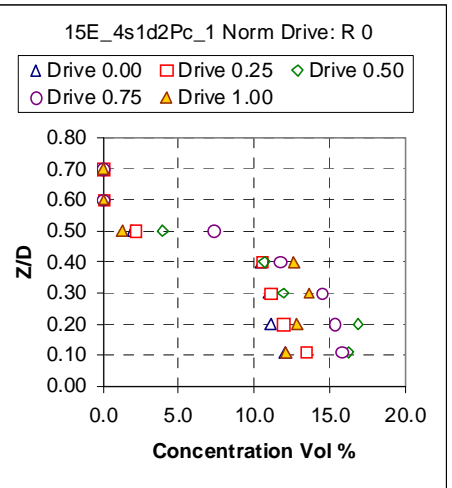

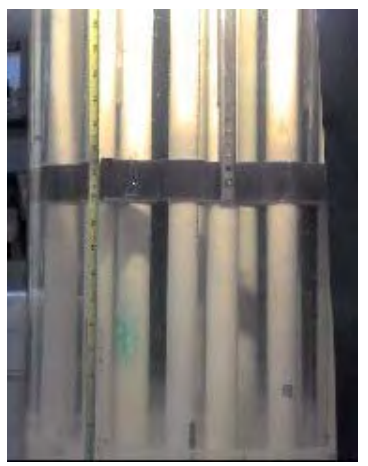

Middle of Non-Drive

\section{E_4s1d2Pc_1 Norm Non-Drive: R 0} $\begin{array}{ll}\Delta \text { Non-Drive } 0.00 & \text { a Non-Drive 0.25 } \\ \diamond \text { Non-Drive } 0.50 & \text { ONon-Drive } 0.75\end{array}$ 0.80 0.70 ․․ $\ldots . \ldots \ldots \ldots$ 0.60 마 $0.50-\Delta-\cdots-\cdots-\infty \square--$ $\curvearrowright 0.40-\cdots-\cdots-\otimes-\square \Delta-$ $0.30-\cdots-\cdots---\Delta$ $0.20-\quad \Delta \quad \Delta \nabla \Delta$ $0.10 \ldots \ldots-\ldots, \Delta \Delta \Delta$ $0.00 \quad 5.0 \quad 100$ Concentration Vol \%
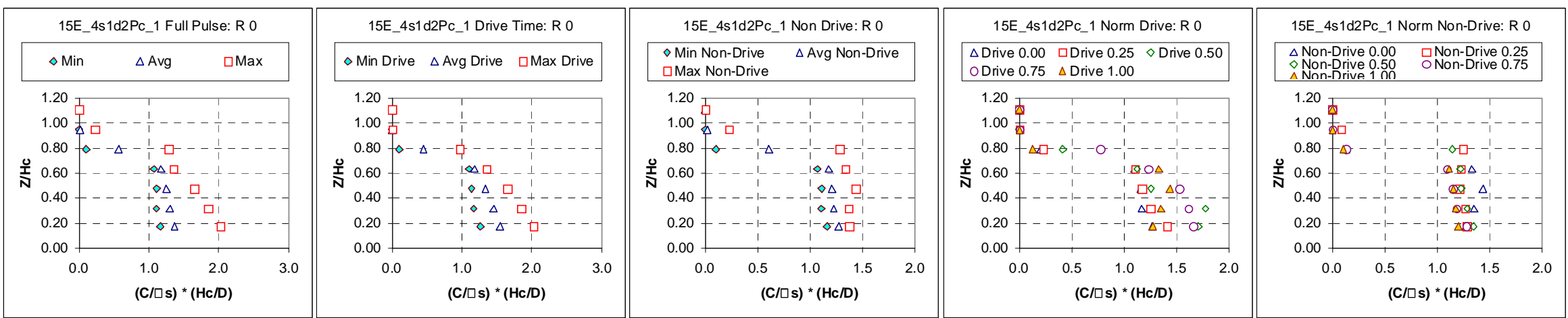

Figure C.10. $\quad 0.367-\mathrm{m}$ - (14 7/16-in.-) diameter tank, 0.320-cm- (0.126-in-) diameter nozzle; solids nominal diameter $69.3 \mu \mathrm{m}, 2.48 \mathrm{~g} / \mathrm{cm}^{3}$ density; 0.06 nominal solids fraction; $33.6 \%$ duty cycle, cycle time $10.2 \mathrm{~s}$, pulse volume fraction 0.050 , $\mathrm{U}_{\mathrm{CS}}$ velocity $6.2 \mathrm{~m} / \mathrm{s}$, target nozzle exit velocity $6.2 \mathrm{~m} / \mathrm{s}$; peak cloud height upper bound $0.241 \mathrm{~m}$ (9.5 in.). Case ID 15E_4s1d2Pc_1. 

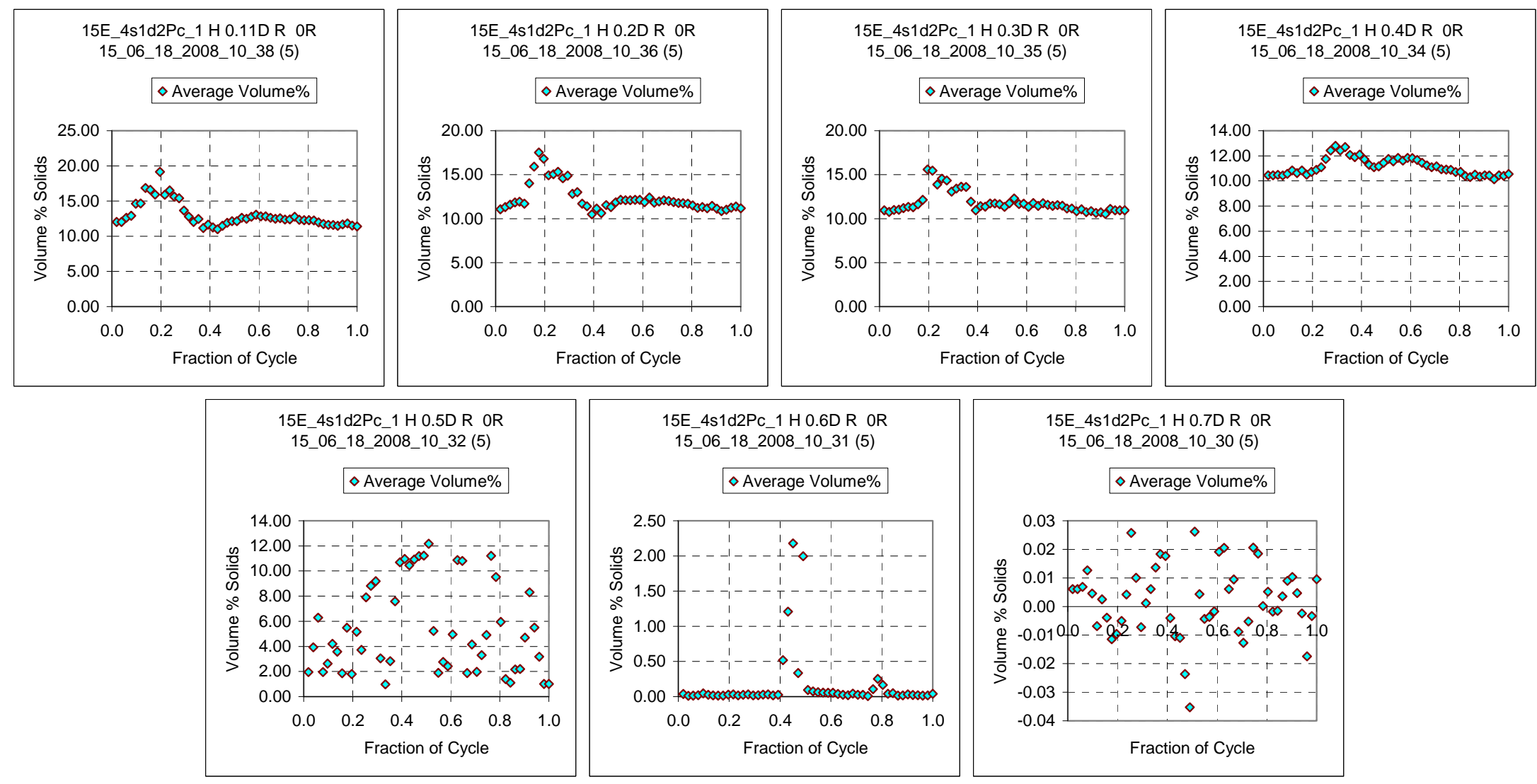

Figure C.10A. Case ID 15E_4s1d2Pc_1 Concentration Variation During the Cycle

This is the tenth profile shown using simulant s1d2 in the small-scale tank. This is highest solids concentration tested. The solids fraction increased to 0.06 from 0.045 in the prior four tests; the duty cycle remained essentially constant at $33.6 \%$ from $33.2 \%$ in Figure C.7. The $U_{\mathrm{CS}}$ velocity occurred at $6.2 \mathrm{~m} / \mathrm{s}$, slightly less than $6.5 \mathrm{~m} / \mathrm{s}$ that was observed in Figure C.7. The cloud height is 9.5 in., slightly higher than the 8 in. observed in Figure C.7. In Figure C.10 the average concentration profile is relatively vertical, indicating a more uniform concentration up to an elevation of $\mathrm{Z}=0.4 \mathrm{D}$. The transient data in Figure C10.A show that at $\mathrm{H}=0.1 \mathrm{D}$ the maximum concentration of $\sim 20$ vol\% solids occurred at 0.2 cycle 


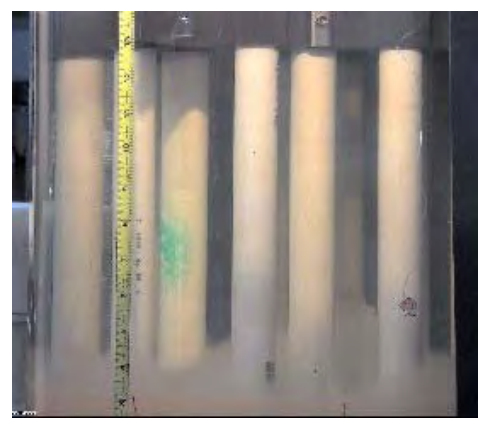

Maximum Cloud Height
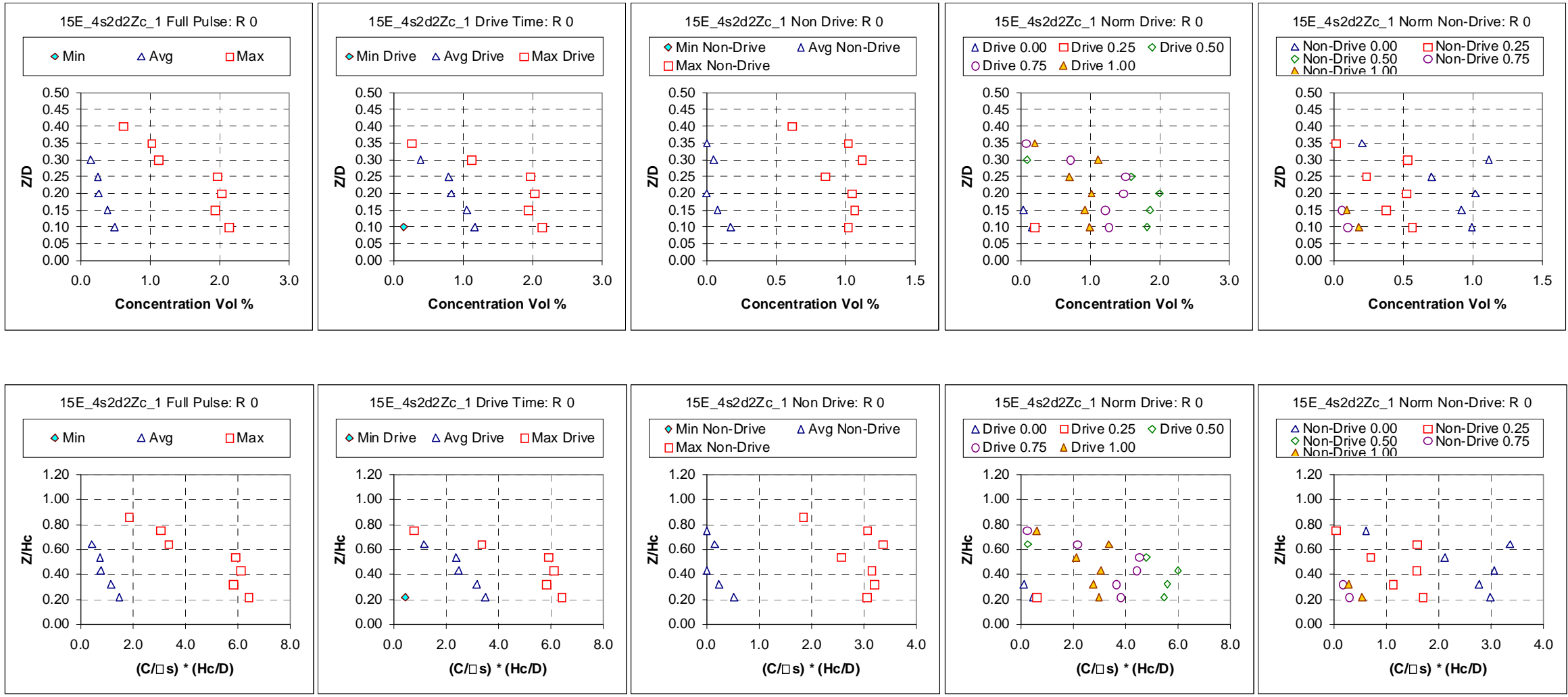

Figure C.11. 0.367-m- (14 7/16-in.-) diameter tank, 0.320-cm- (0.126-in-) diameter nozzle; solids nominal diameter $75.6 \mu \mathrm{m}, 4.18 \mathrm{~g} / \mathrm{cm}^{3}$ density; 0.00155 nominal solids fraction; 33.5\% duty cycle, cycle time $12.0 \mathrm{~s}$, pulse volume fraction 0.050 , $\mathrm{U}_{\mathrm{CS}}$ velocity $5.2 \mathrm{~m} / \mathrm{s}$, target nozzle exit velocity $5.2 \mathrm{~m} / \mathrm{s}$; peak cloud height upper bound $0.191 \mathrm{~m}$ (7.5 in.). Case ID 15E_4s2d2Zc_1. 

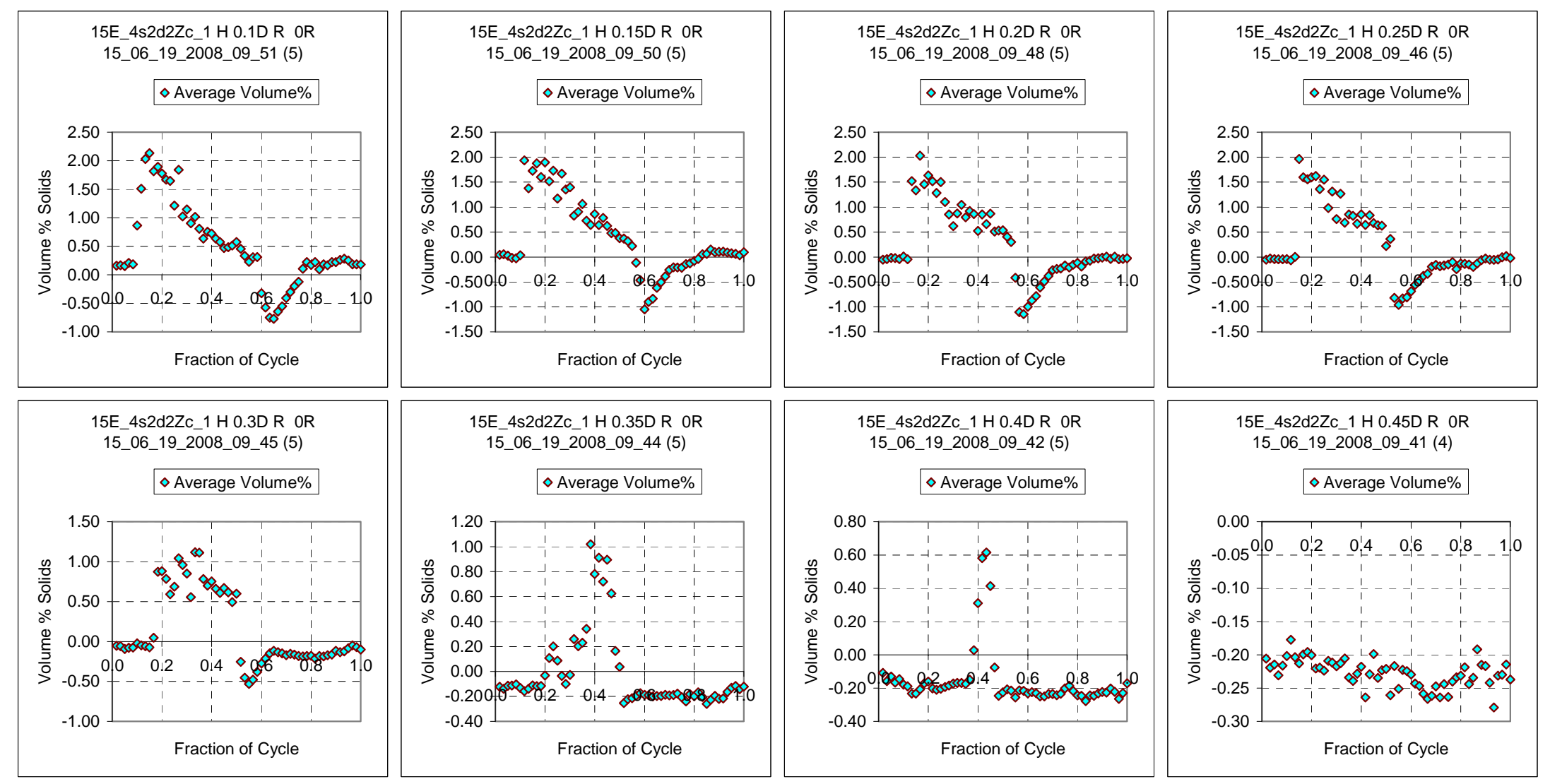

Figure C.11A. Case ID 15E_4s2d2Zc_1 Concentration Variation During the Cycle

This is the first of three profiles using simulant s2d2 in the small-scale tank. This solids concentration of 0.00155 is the lowest tested. During the three tests the duty cycle remained essentially constant at $33.5 \%$, and the pulse volume fraction was constant at 0.050 . The $\mathrm{U}_{\mathrm{CS}}$ velocity occurred at $5.2 \mathrm{~m} / \mathrm{s}$. The cloud height is $7.5 \mathrm{in}$. The conditions during this profile match those shown in Figure C.1, which used simulant s1d2-which has a lower density than s2d2 and similar particle size. There the $U_{C S}$ velocity is $2.8 \mathrm{~m} / \mathrm{s}$. The cloud height is $7.25 \mathrm{in}$. With the denser particulate the $U_{C S}$ velocity occurred at a higher velocity; however, the cloud height was essentially the same in both profiles. 


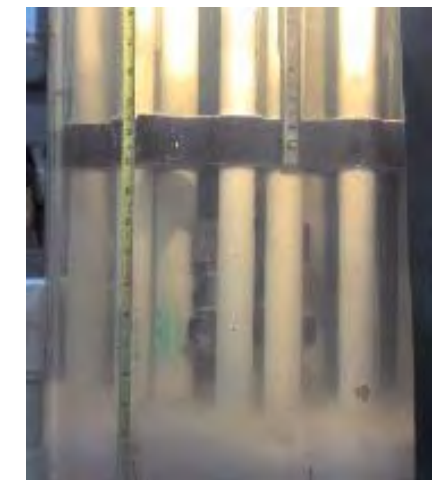

Maximum Cloud Height

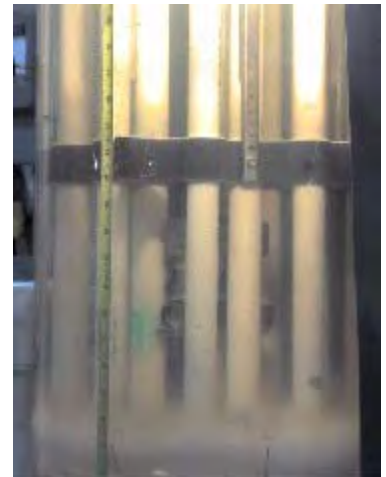

Start of Drive

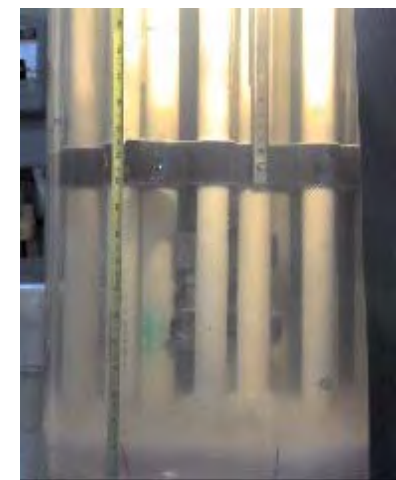

Middle of Drive

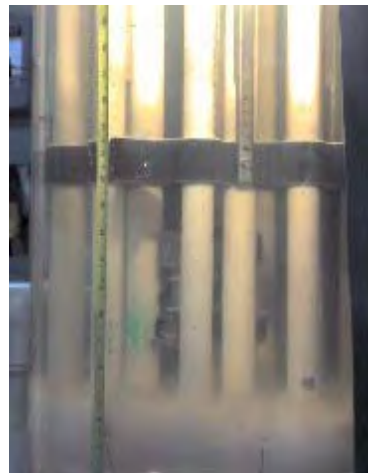

End of Drive

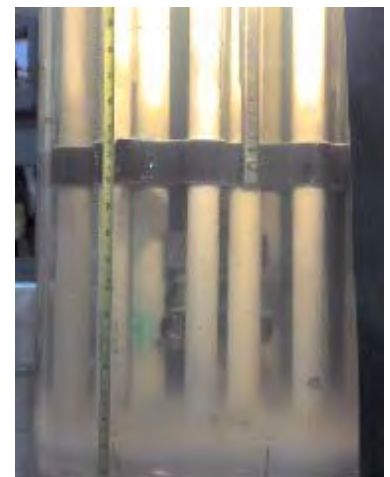

Middle of Non-Drive
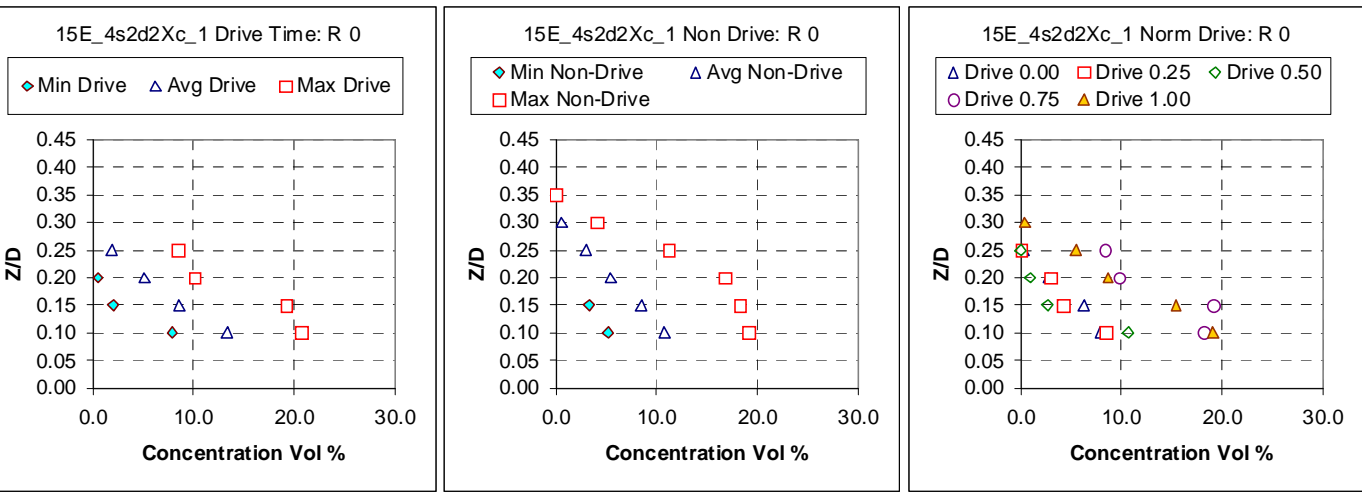

15E_4s2d2Xc_1 Norm Non-Drive: R 0 $\begin{array}{ll}\Delta \text { Non-Drive } 0.00 & \square \text { Non-Drive } 0.25 \\ \diamond \text { Non-Drive } 0.50 & \text { ONon-Drive } 0.75\end{array}$

0.45

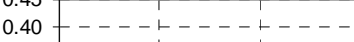

0.35

$0.25-\Delta-$

Q $\square \Delta$

$0.15-0 \Delta \diamond \square$

$0.10--O \Delta \Delta-\square-\Delta---$

0.05

$\begin{array}{llll}0.0 & 10.0 & 20.0 & 30.0\end{array}$

$\begin{array}{ccc}0.0 & 10.0 & 20.0 \\ \text { Concentration Vol \% }\end{array}$
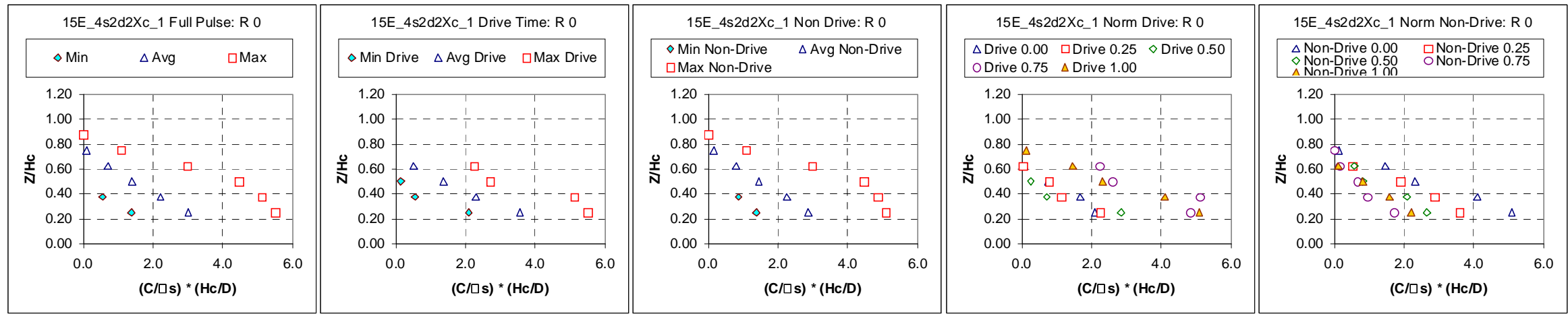

Figure C.12. $\quad 0.367-\mathrm{m}$ - (14 7/16-in.-) diameter tank, 0.320-cm- (0.126-in-) diameter nozzle; solids nominal diameter $75.6 \mu \mathrm{m}, 4.18 \mathrm{~g} / \mathrm{cm}^{3}$ density; 0.015 nominal solids fraction; $33.4 \%$ duty cycle, cycle time $5.5 \mathrm{~s}$, pulse volume fraction 0.050 , $\mathrm{U}_{\mathrm{CS}}$ velocity $11.8 \mathrm{~m} / \mathrm{s}$, target nozzle exit velocity $11.8 \mathrm{~m} / \mathrm{s}$; peak cloud height upper bound $0.165 \mathrm{~m}$ (6.5 in.). Case ID 15E_4s2d2Xc_1. 

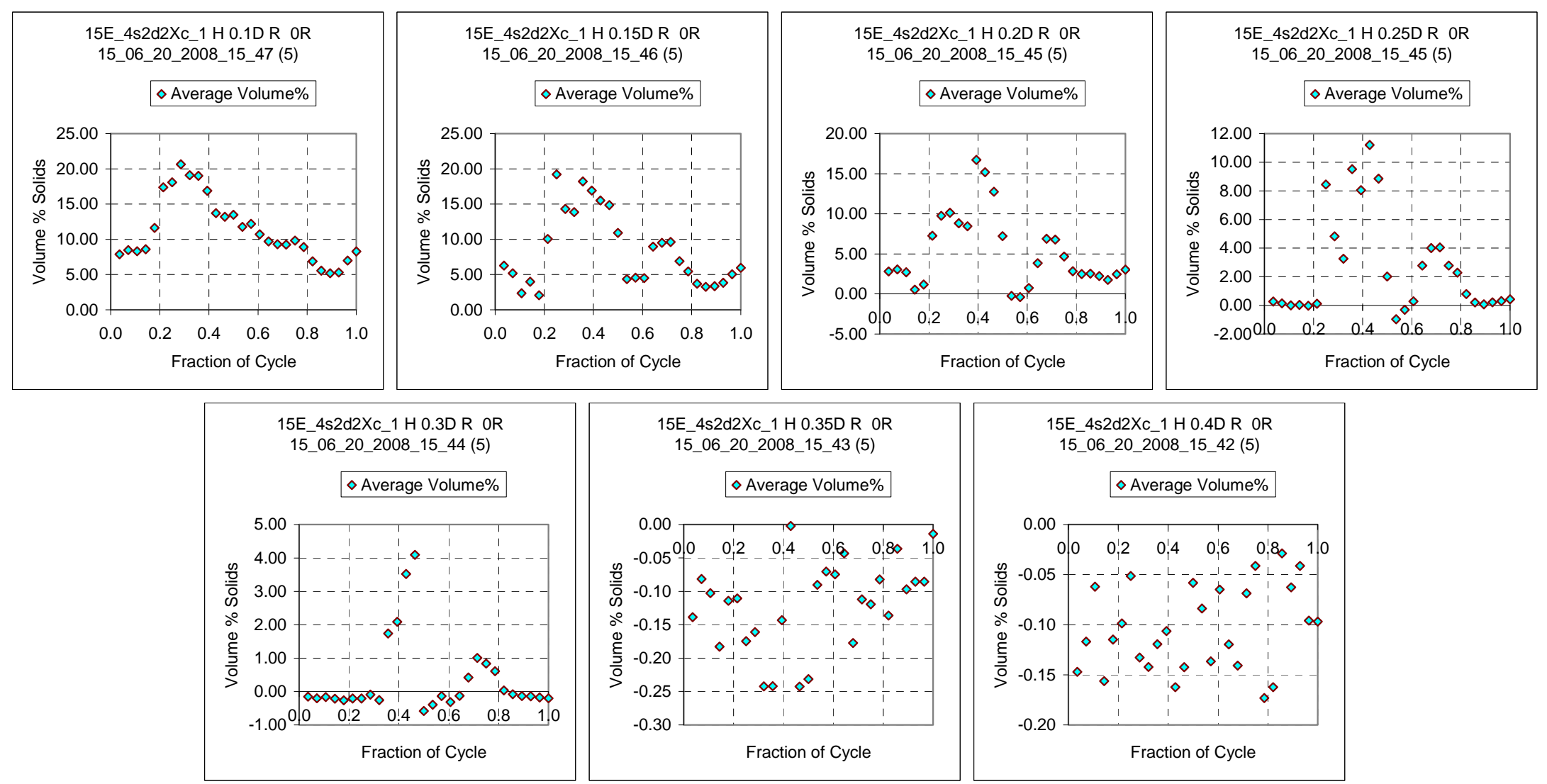

Figure C.12A. Case ID 15E_4s2d2Xc_1 Concentration Variation During the Cycle

This is the second of three profiles shown using simulant s2d2 in the small-scale tank. This solids fraction increased $\sim 10$ times to 0.015 from 0.00155 from the first profile. During the three tests the duty cycle remained essentially constant at 33.5\%, and the pulse volume fraction was constant at 0.050 . The $U_{C S}$ velocity occurred at $11.8 \mathrm{~m} / \mathrm{s}$, an increase from the prior test which was $5.2 \mathrm{~m} / \mathrm{s}$. The cloud height is $6.5 \mathrm{in}$., a decrease from $7.5 \mathrm{in}$. in the prior test. The conditions during this profile match those shown in Figure C.4, which used simulant s1d2-which has a lower density than s2d2. There the $U_{C S}$ velocity is $5.8 \mathrm{~m} / \mathrm{s}$. The cloud height is 7 in. With the denser particulate the $U_{C s}$ velocity occurred at a higher velocity; however, the cloud height was essentially the same. 


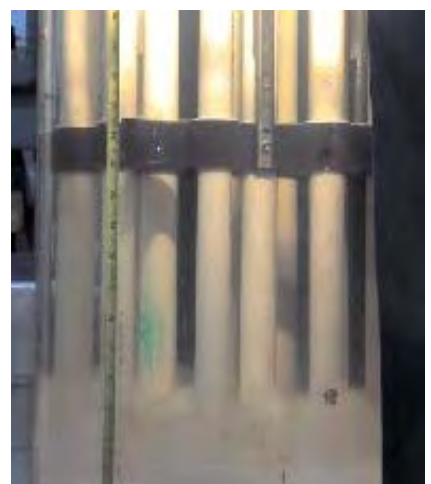

Maximum Cloud Height

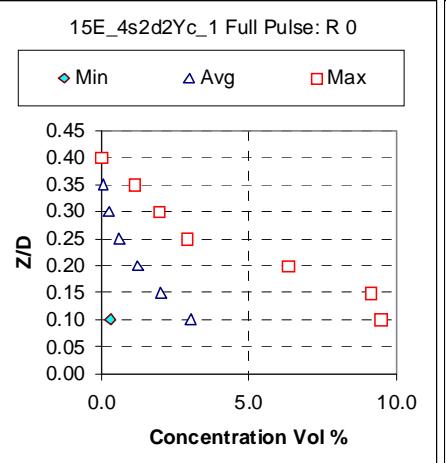

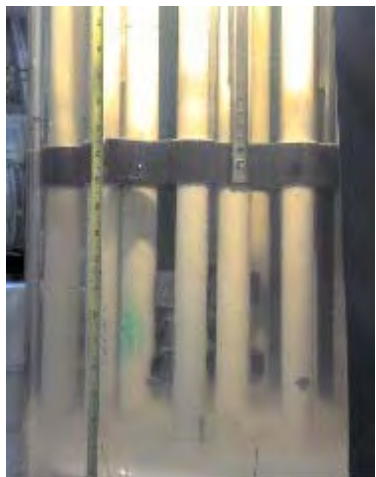

Start of Drive

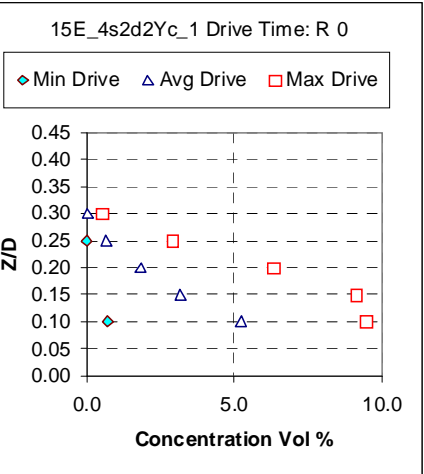

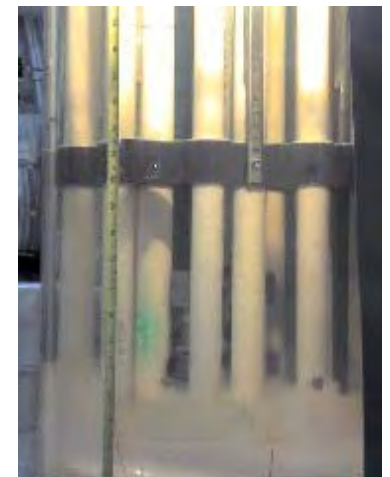

Middle of Drive

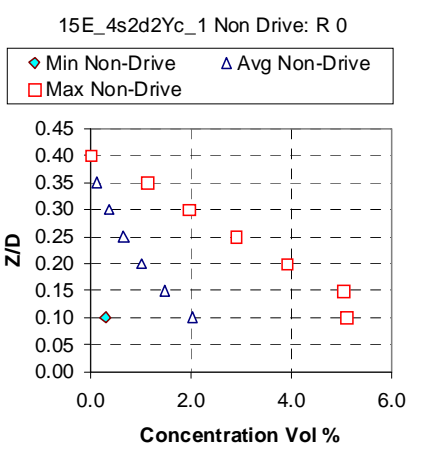

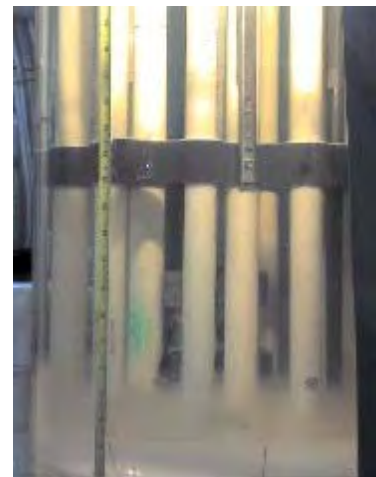

End of Drive

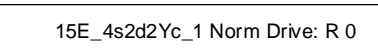

$\Delta$ Drive $0.00 \square$ Drive $0.25 \diamond$ Drive 0.50 ODrive $0.75 \Delta$ Drive 1.00

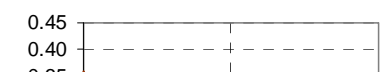

$0.40-$

$0.30 \triangle \Delta-$

N 0.25 P $0.20-\Delta$

0.15 ㅁ- - - $\Delta \mathrm{O}-----\theta---$

0.05

0.00

0.0

Concentration Vol \%

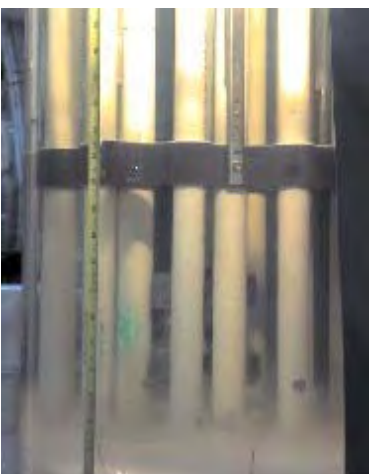

Middle of Non-Drive

15E_4s2d2Yc_1 Norm Non-Drive: R 0 \begin{tabular}{ll|}
\hline$\triangle$ Non-Drive 0.00 & aNon-Drive 0.25 \\
$\triangleright$ Non-Drive 0.50 & ONon-Drive 0.75 \\
$\wedge$ Non-Drive 100 &
\end{tabular}

0.45

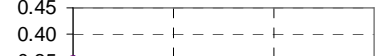

0.350

$0.30 \mathrm{AO \Delta}-\ldots-\ldots$

$0.20-\Delta 0 \quad \Delta$

$0.15--0 \square \sigma--\Delta-\cdots--$

$0.10-$

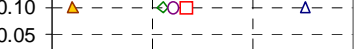

0.00

$\begin{array}{llll}0.0 & 2.0 & 4.0 & 6.0\end{array}$

Concentration Vol \%
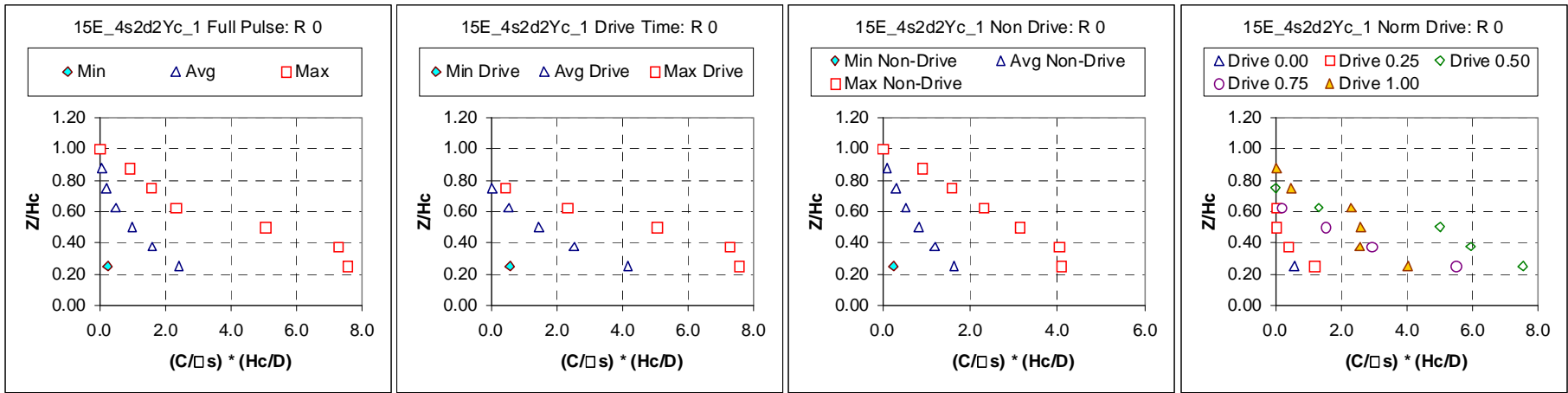

15E_4s2d2Yc_1 Norm Non-Drive: R 0 \begin{tabular}{|ll|}
\hline$\Delta$ Non-Drive 0.00 & aNon-Drive 0.25 \\
$\Delta$ Non-Drive 0.50 & onon-Drive 0.75 \\
$\triangle$ Non-Drive 100 &
\end{tabular}

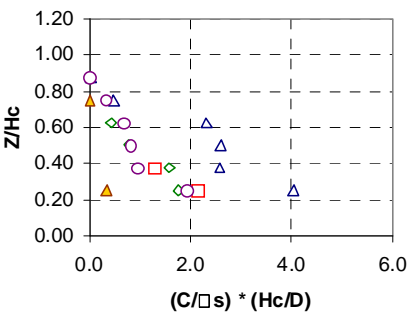

Figure C.13. 0.367-m- (14 7/16-in.-) diameter tank, 0.320-cm- (0.126-in-) diameter nozzle; solids nominal diameter $75.6 \mu \mathrm{m}, 4.18 \mathrm{~g} / \mathrm{cm}^{3}$ density; 0.005 nominal solids fraction; $33.4 \%$ duty cycle, cycle time $8.4 \mathrm{~s}$, pulse volume fraction 0.050 , $\mathrm{U}_{\mathrm{CS}}$ velocity $7.6 \mathrm{~m} / \mathrm{s}$, target nozzle exit velocity $7.6 \mathrm{~m} / \mathrm{s}$; peak cloud height upper bound 0.165 m (6.5 in.). Case ID 15E_4s2d2Yc_1. 

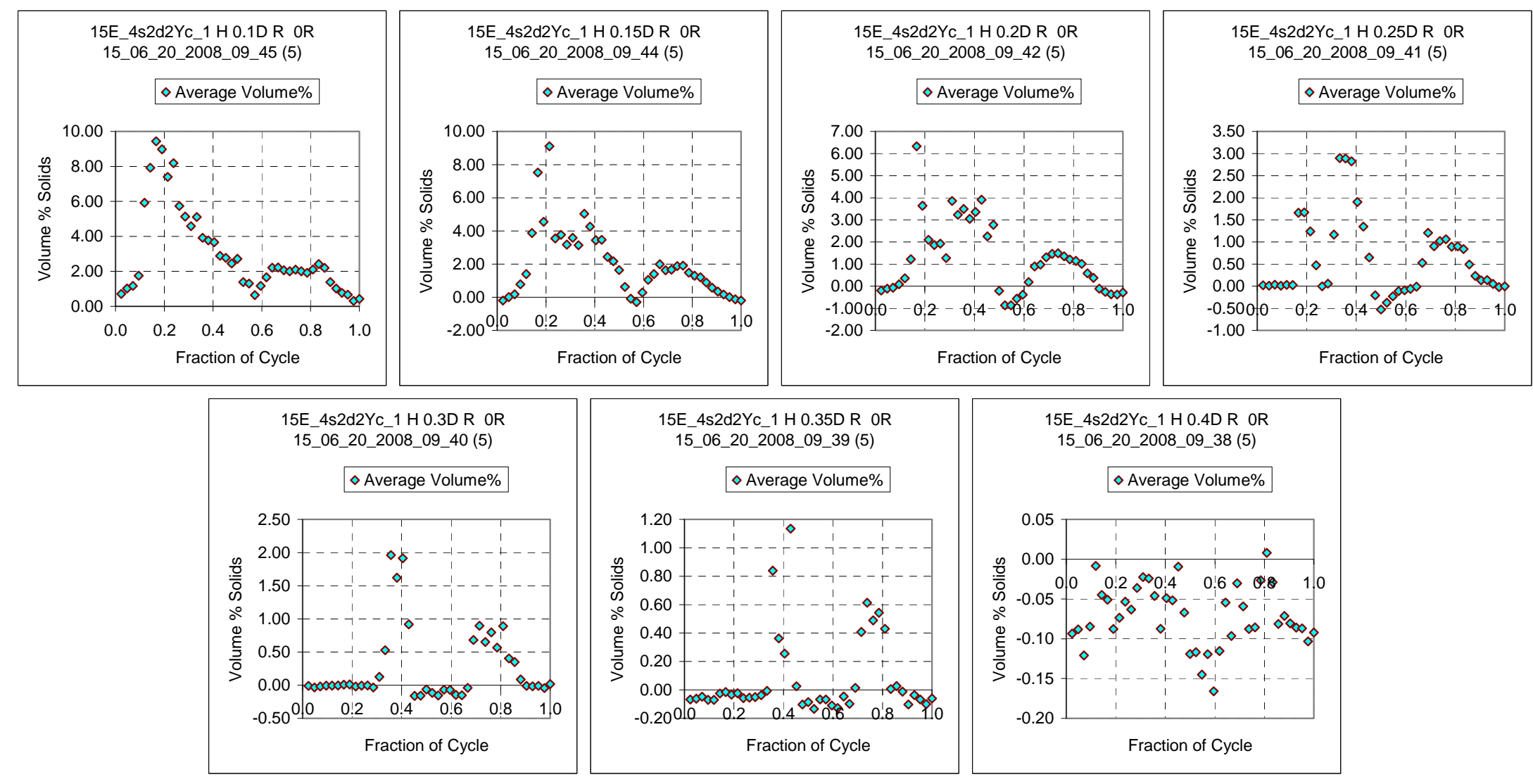

Figure C.13A. Case ID 15E_4s2d2Yc_1 Concentration Variation During the Cycle

This is the third of three profiles using simulant s2d2 in the small-scale tank. This solids fraction decreased to 0.005 from 0.015 . During the three tests the duty cycle remained essentially constant at $33.5 \%$, and the pulse volume fraction was constant at 0.050 . The $\mathrm{U}_{\mathrm{CS}}$ velocity occurred at $7.6 \mathrm{~m} / \mathrm{s}$, a decrease from the prior test, which was $11.8 \mathrm{~m} / \mathrm{s}$. The cloud height is $6.5 \mathrm{in}$., the same as the prior test. The conditions during this profile match those shown in Figure C.2, which used simulant s1d2-which has a lower density than s2d2. There the $\mathrm{U}_{\mathrm{CS}}$ velocity is $4.3 \mathrm{~m} / \mathrm{s}$. The cloud height is 5.5 in. With the denser particulate the $\mathrm{U}_{\mathrm{CS}}$ velocity occurred at a higher velocity; the cloud height was slightly higher. 

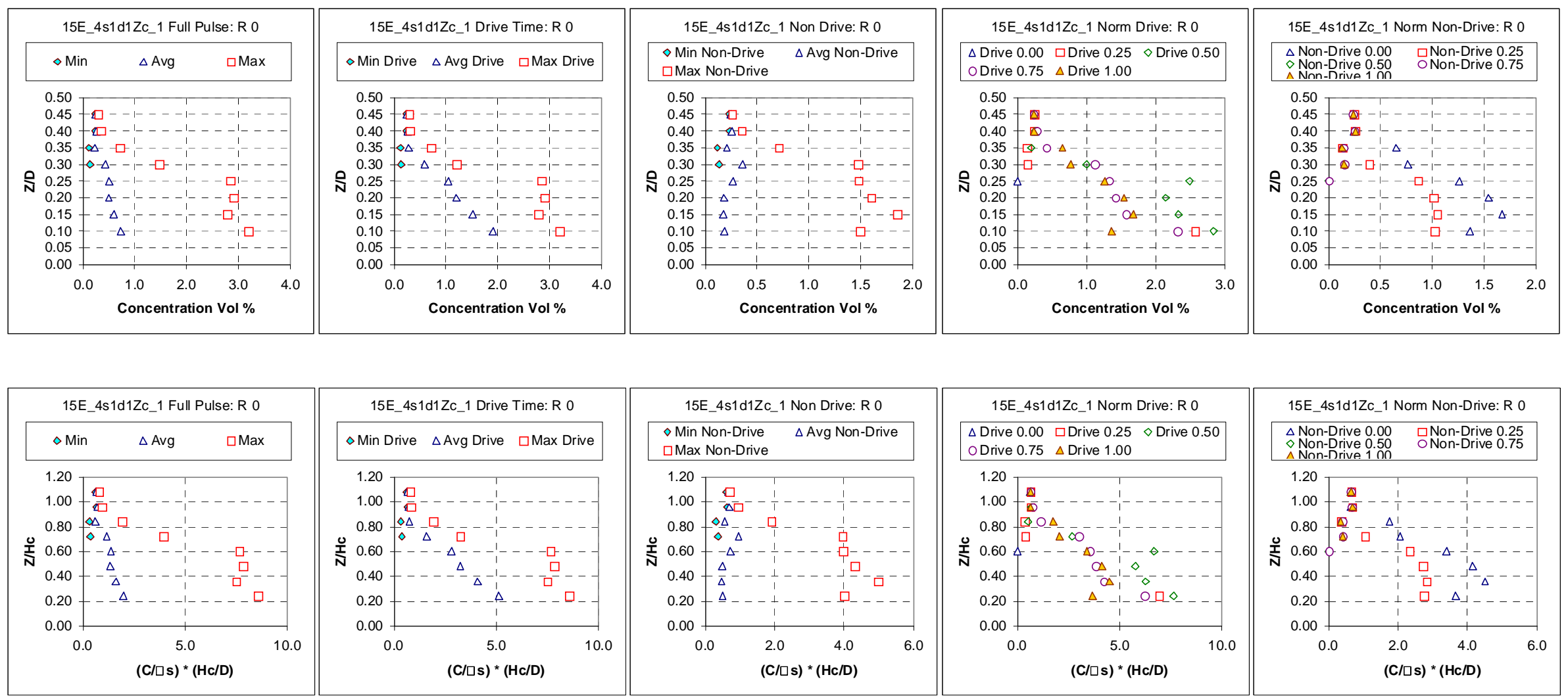

Figure C.14. $\quad$ 0.367-m- (14 7/16-in.-) diameter tank, 0.320-cm- (0.126-in-) diameter nozzle; solids nominal diameter $166.4 \mu \mathrm{m}, 2.46 \mathrm{~g} / \mathrm{cm}^{3} \mathrm{density}$; 0.00155 nominal solids fraction; $33.4 \%$ duty cycle, cycle time $14.6 \mathrm{~s}$, pulse volume fraction 0.050 , $\mathrm{U}_{\mathrm{CS}}$ velocity $4.2 \mathrm{~m} / \mathrm{s}$, target nozzle exit velocity $4.2 \mathrm{~m} / \mathrm{s}$; peak cloud height upper bound 0.165 m (6.5 in.). Case ID 15E_4s1d1Zc_1. 

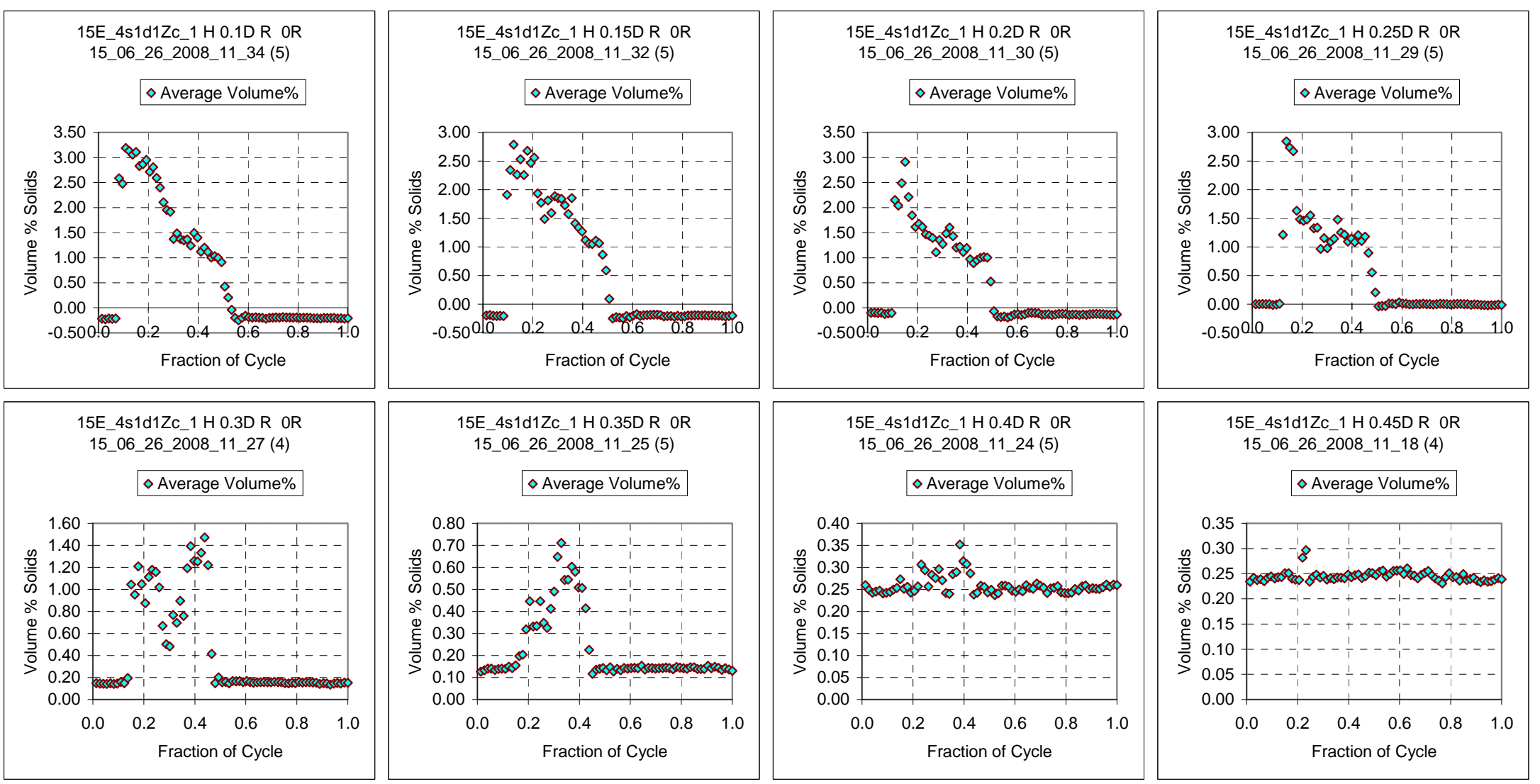

Figure C.14A. Case ID 15E_4s1d1Zc_1 Concentration Variation During the Cycle

This is the first of two profiles using simulant s1d1 in the small-scale tank. This solids fraction is 0.00155 . During the two tests the duty cycle remained essentially constant at $33.4 \%$, and the pulse volume fraction was constant at 0.050 . The $\mathrm{U}_{\mathrm{CS}}$ velocity occurred at $4.2 \mathrm{~m} / \mathrm{s}$. The cloud height is 6.5 in. The conditions during this profile match those shown in Figure C.1, which used simulant s1d2-which has a smaller diameter particle than s1d1. There the $\mathrm{U}_{\mathrm{CS}}$ velocity is $2.8 \mathrm{~m} / \mathrm{s}$. The cloud height is $7.25 \mathrm{in}$. With the larger particulate the $\mathrm{U}_{\mathrm{CS}}$ velocity occurred at a higher velocity; the cloud height was slightly lower. 


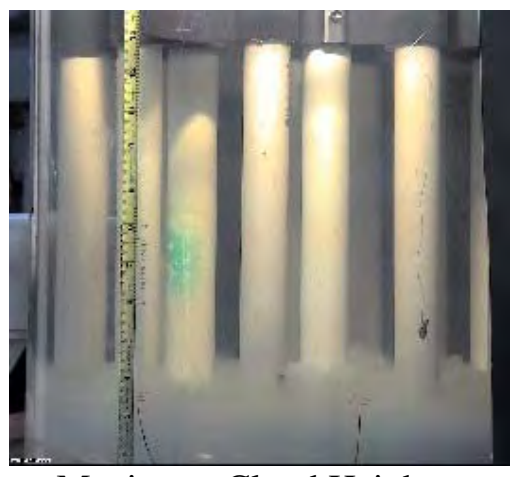

Maximum Cloud Height

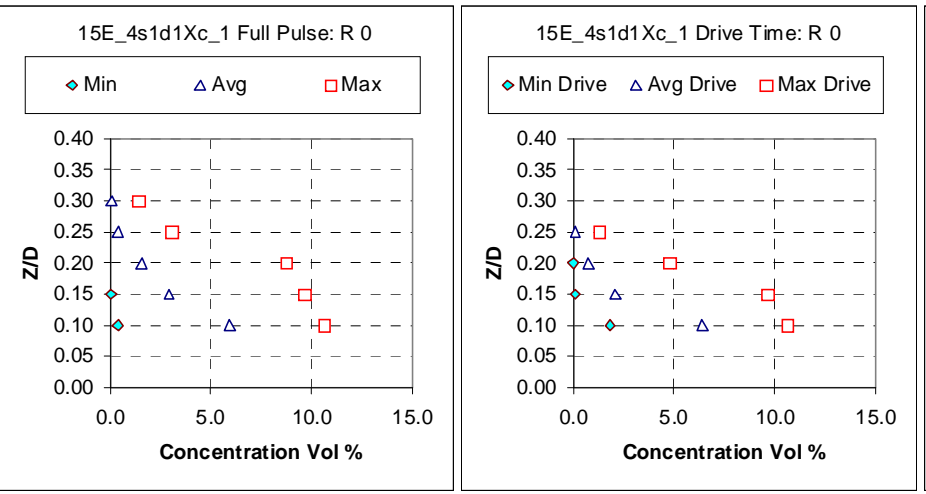
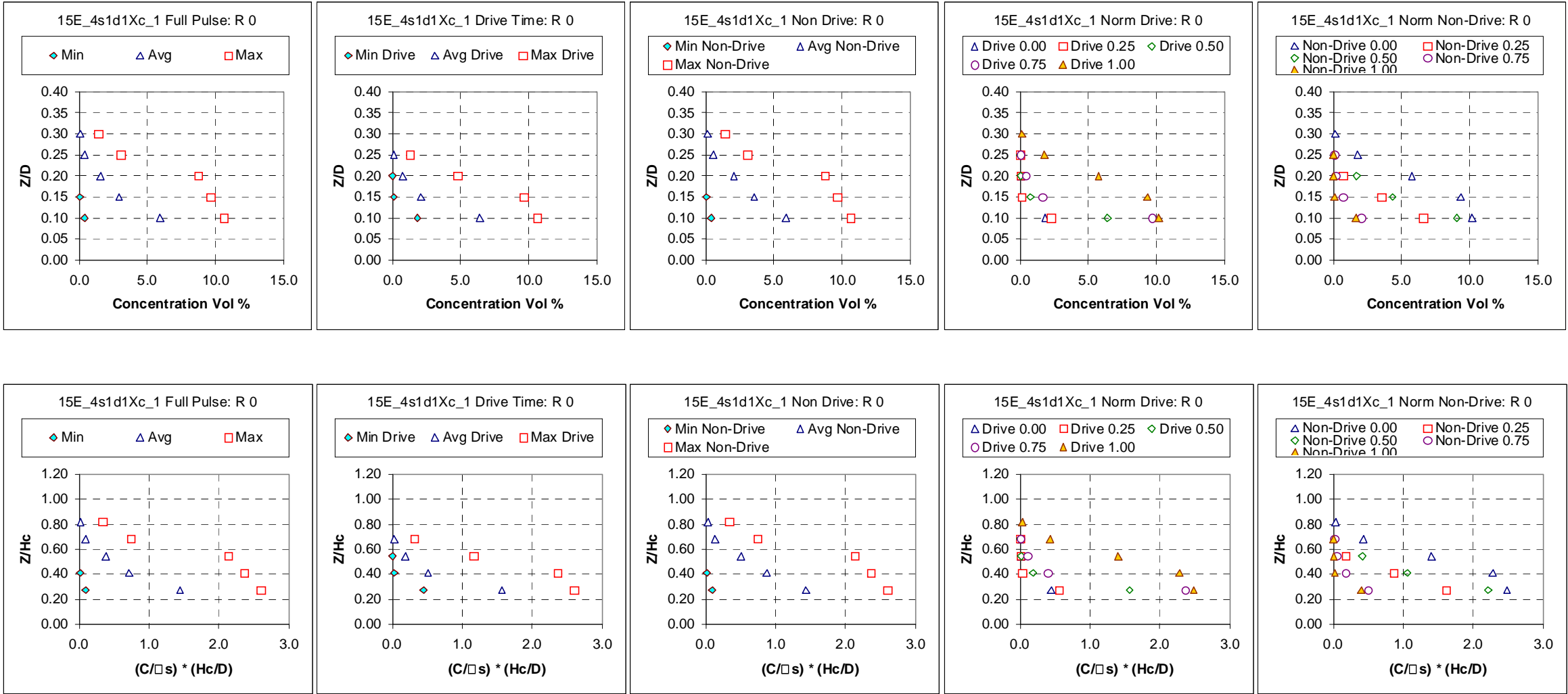

Figure C.15. 0.367-m- (14 7/16-in.-) diameter tank, 0.320-cm- (0.126-in-) diameter nozzle; solids nominal diameter $166.4 \mu \mathrm{m}$, $2.46 \mathrm{~g} / \mathrm{cm}^{3}$ density; 0.015 nominal solids fraction; $33.5 \%$ duty cycle, cycle time $7.4 \mathrm{~s}$, pulse volume fraction $0.050, \mathrm{U}_{\mathrm{CS}}$ velocity $8.6 \mathrm{~m} / \mathrm{s}$, target nozzle exit velocity $8.6 \mathrm{~m} / \mathrm{s}$; peak cloud height upper bound $0.152 \mathrm{~m}$ (6 in.). Case ID 15E_4s1d1Xc_1. 

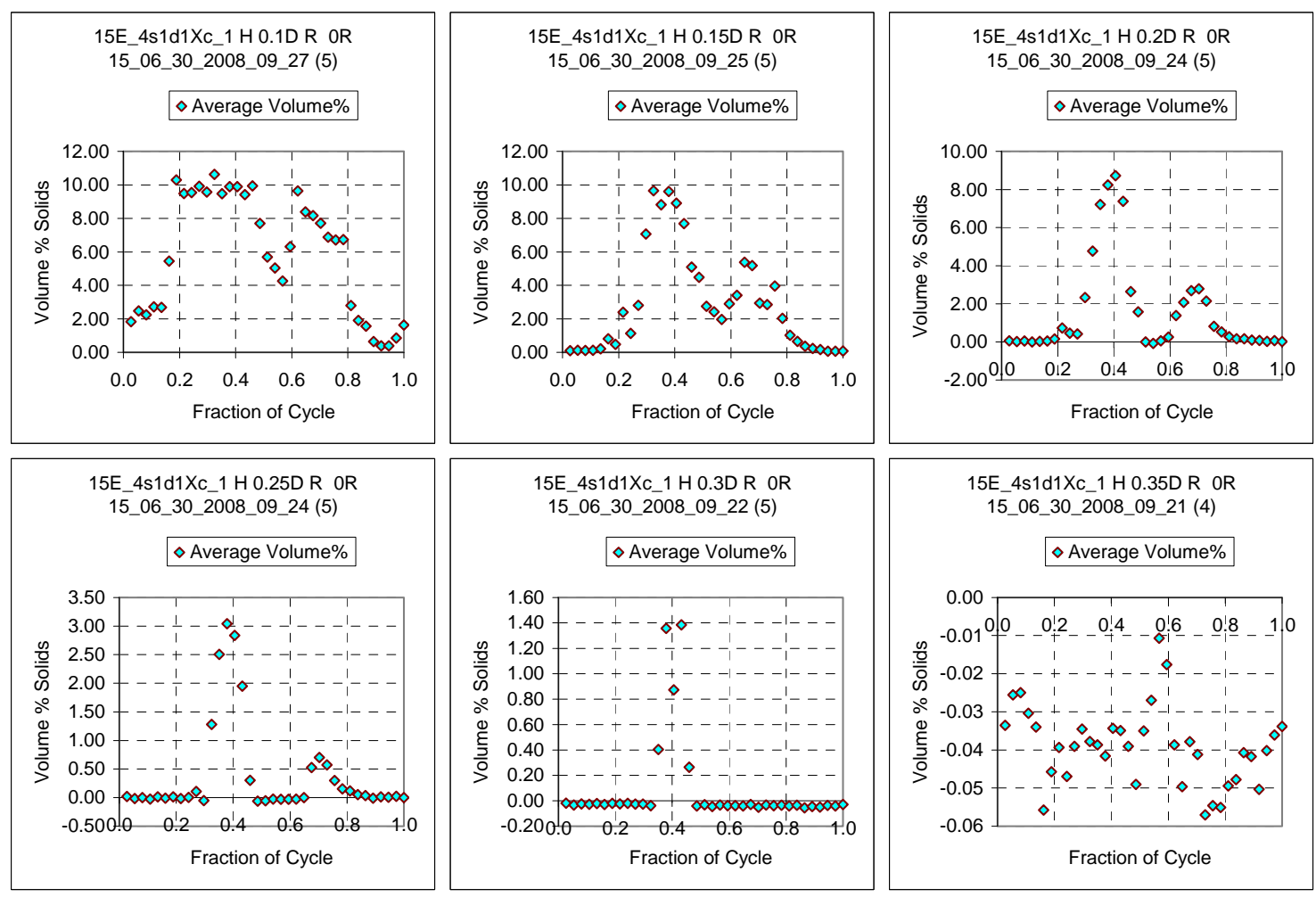

Figure C.15A. Case ID 15E_4s1d1Xc_1 Concentration Variation During the Cycle

This is the second of two profiles using simulant s1d1 in the small-scale tank. This solids fraction increased $~ 10$ times to 0.015 from 0.00155 . During the three tests the duty cycle remained essentially constant at 33.5\%, and the pulse volume fraction was constant at 0.050 . The $\mathrm{U}_{\mathrm{CS}}$ velocity occurred at $8.6 \mathrm{~m} / \mathrm{s}$, an increase from the prior test, which was $4.2 \mathrm{~m} / \mathrm{s}$. The cloud height is $6.0 \mathrm{in}$., slightly lower than the 6.5 in. from the prior test. The conditions during this profile match those shown in Figure C.3 that used simulant s1d2, which has a smaller diameter particle than s1d1. There the $\mathrm{U}_{\mathrm{CS}}$ velocity is $7.2 \mathrm{~m} / \mathrm{s}$. The cloud height is 6.0 in. With the larger particulate the $\mathrm{U}_{\mathrm{Cs}}$ velocity occurred at a higher velocity; the cloud height was essentially the same. 


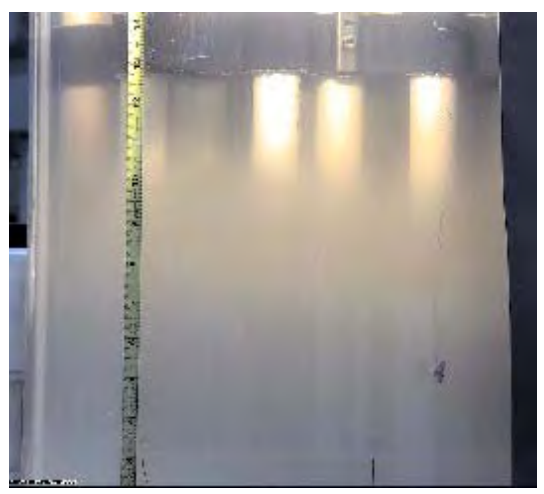

Maximum Cloud Height

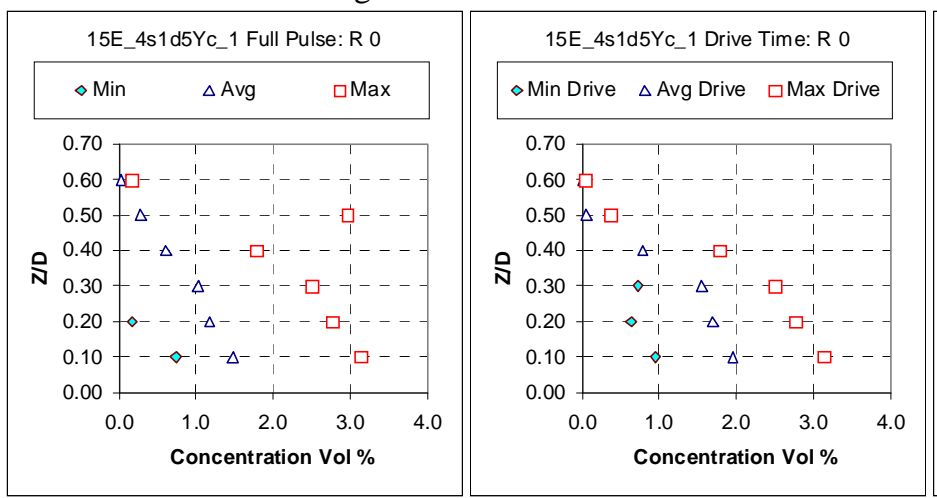
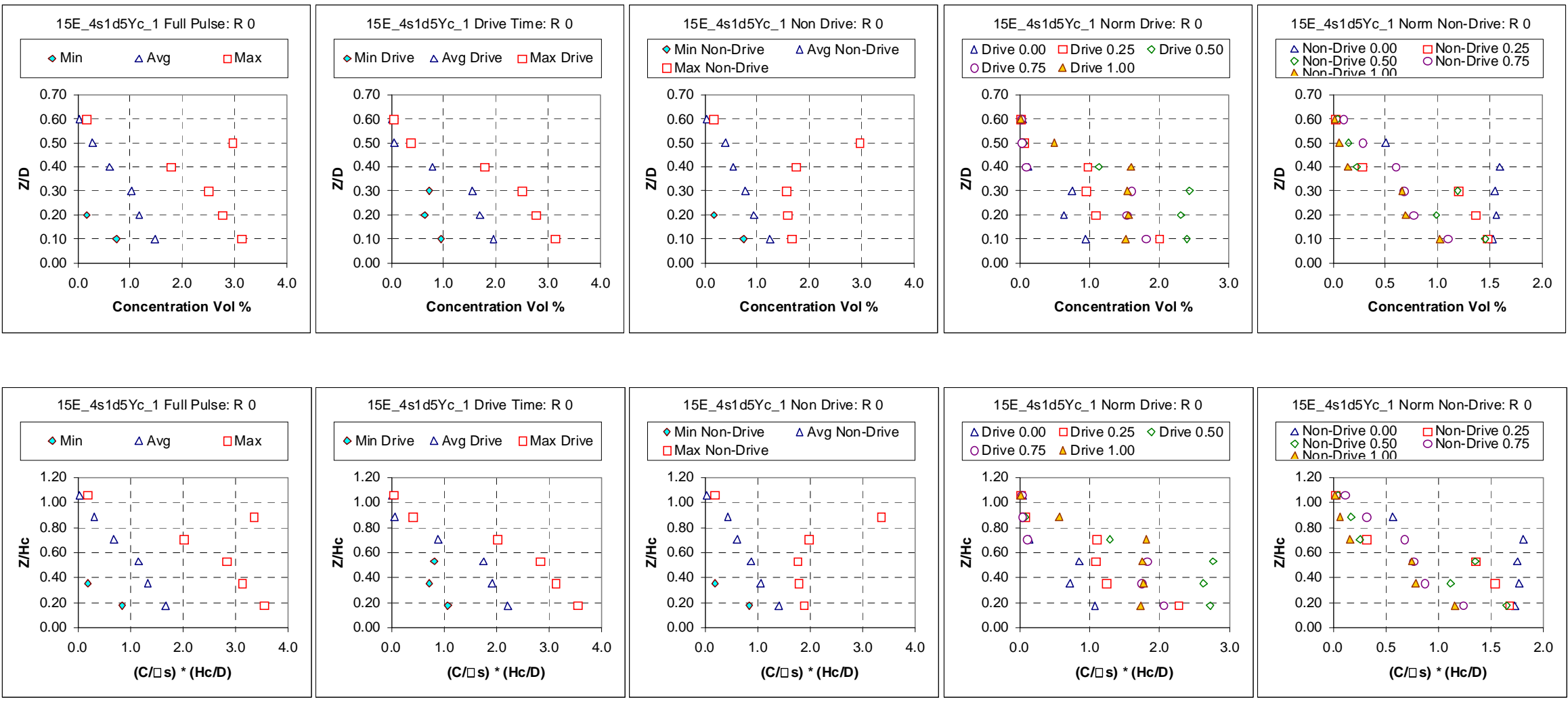

Figure C.16. $\quad 0.367-\mathrm{m}$ - (14 7/16-in.-) diameter tank, 0.320-cm- (0.126-in-) diameter nozzle; solids nominal diameter $43.9 \mu \mathrm{m}, 2.5 \mathrm{~g} / \mathrm{cm}^{3} \mathrm{density}$; 0.005 nominal solids fraction; $33.2 \%$ duty cycle, cycle time $17.6 \mathrm{~s}$, pulse volume fraction 0.050 , $\mathrm{U}_{\mathrm{CS}}$ velocity $3.7 \mathrm{~m} / \mathrm{s}$, target nozzle exit velocity $3.5 \mathrm{~m} / \mathrm{s}$; peak cloud height upper bound $0.229 \mathrm{~m}$ (9 in.). Case ID 15E_4s1d5Yc_1. 

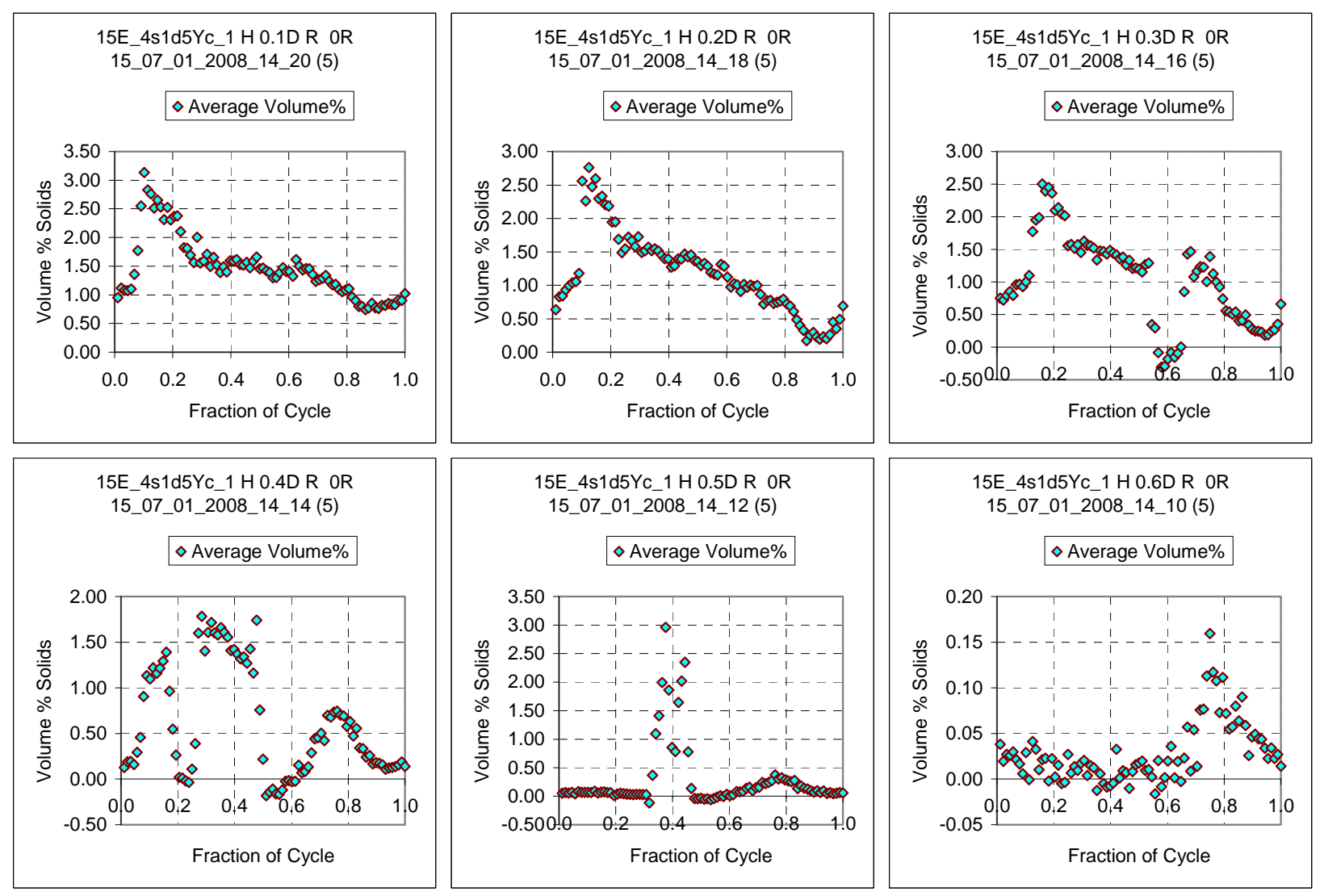

Figure C.16A. Case ID 15E_4s1d5Yc_1 Concentration Variation During the Cycle

Figure C.16 is the only profile shown using simulant s1d5 in the small-scale tank. This solids fraction is 0.005 . During the test the duty cycle was $33.2 \%$, and the pulse volume fraction was constant at 0.050 . The $U_{\mathrm{CS}}$ velocity occurred at $3.7 \mathrm{~m} / \mathrm{s}$. The cloud height is 9 in. The conditions during this profile match those shown in Figure C.2 that used simulant s1d2, which has a larger diameter particle than s1d5 and similar density. There the $\mathrm{U}_{\mathrm{CS}}$ velocity is $4.3 \mathrm{~m} / \mathrm{s}$. The cloud height is $5.5 \mathrm{in}$. With the smaller particulate the $\mathrm{U}_{\mathrm{CS}}$ velocity occurred at a lower velocity; the cloud height was much higher too. 

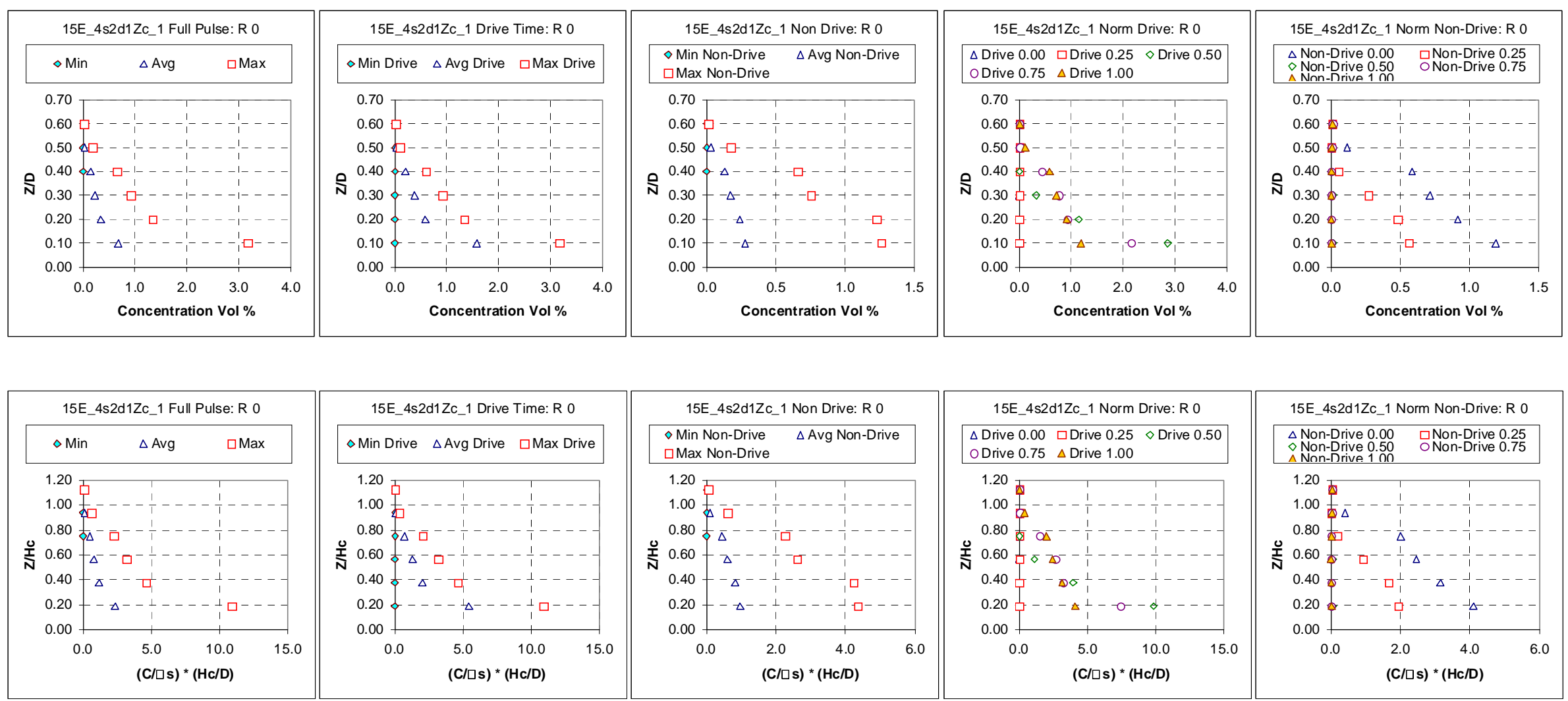

Figure C.17. $\quad$ 0.367-m- (14 7/16-in.-) diameter tank, 0.320-cm- (0.126-in-) diameter nozzle; solids nominal diameter $164.2 \mu \mathrm{m}, 4.17 \mathrm{~g} / \mathrm{cm}^{3}$ density; 0.00155 nominal solids fraction; $32.8 \%$ duty cycle, cycle time $9.4 \mathrm{~s}$, pulse volume fraction 0.050 , $\mathrm{U}_{\mathrm{CS}}$ velocity $6.8 \mathrm{~m} / \mathrm{s}$, target nozzle exit velocity $6.8 \mathrm{~m} / \mathrm{s}$; peak cloud height upper bound $0.216 \mathrm{~m}$ (8.5 in.). Case ID 15E_4s2d1Zc_1. 

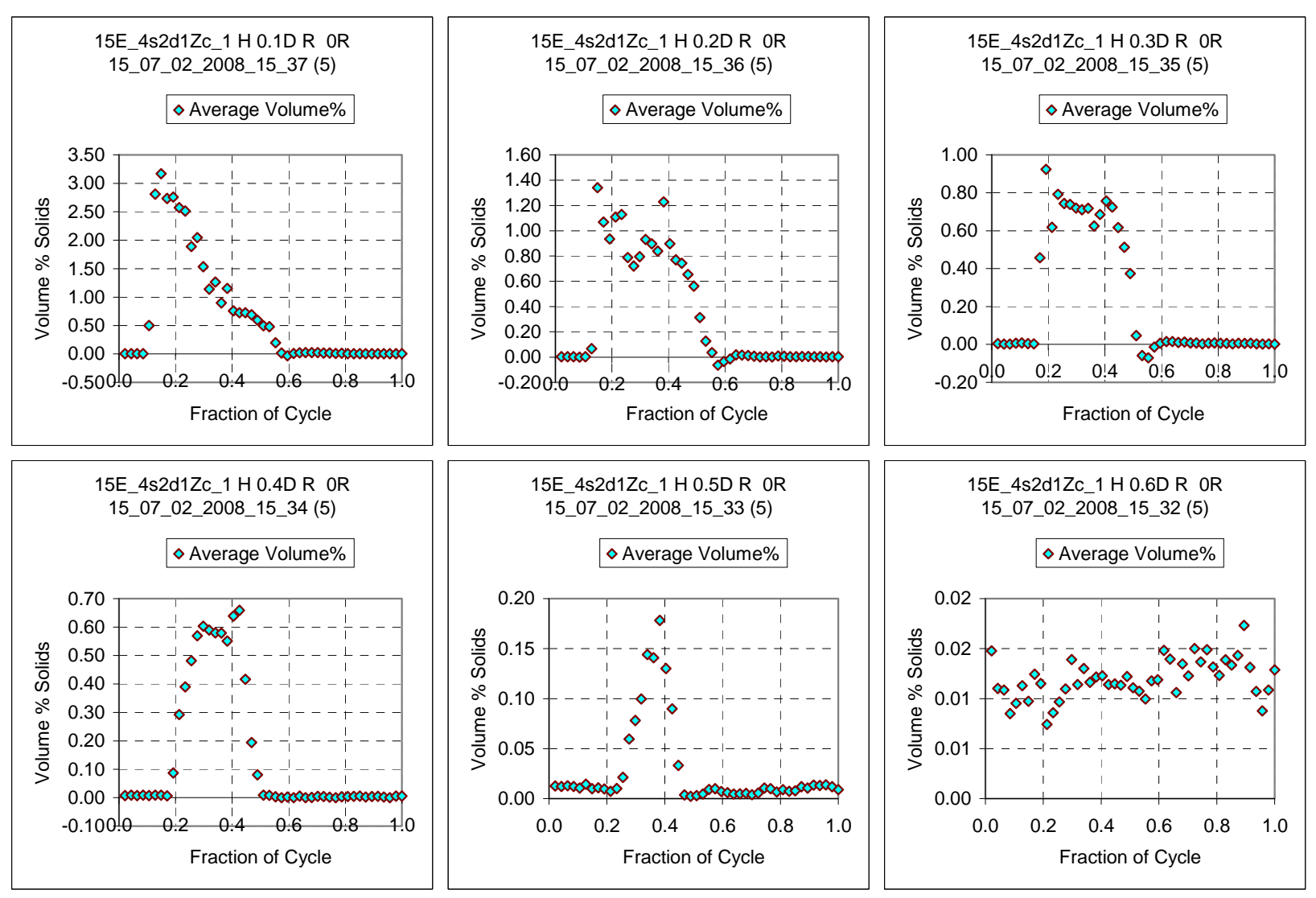

Figure C.17A. Case ID 15E_4s2d1Zc_1 Concentration Variation During the Cycle

Figure C.17 is the only profile shown using simulant s2d1 in the small-scale tank. This solids fraction is 0.000155 . The duty cycle was $32.8 \%$ and the pulse volume fraction was constant at 0.050 . The $U_{\mathrm{CS}}$ velocity occurred at $6.8 \mathrm{~m} / \mathrm{s}$. The cloud height is $8.5 \mathrm{in}$. The conditions during this profile match those shown in Figure C.11 that used simulant s2d2, which has a smaller diameter particle than s2d1 and a similar density. There the $\mathrm{U}_{\mathrm{CS}}$ velocity is $5.2 \mathrm{~m} / \mathrm{s}$. The cloud height is $7.5 \mathrm{in}$. With the larger particulate the $U_{\mathrm{CS}}$ velocity occurred at a higher velocity; the cloud height was slightly higher too. 

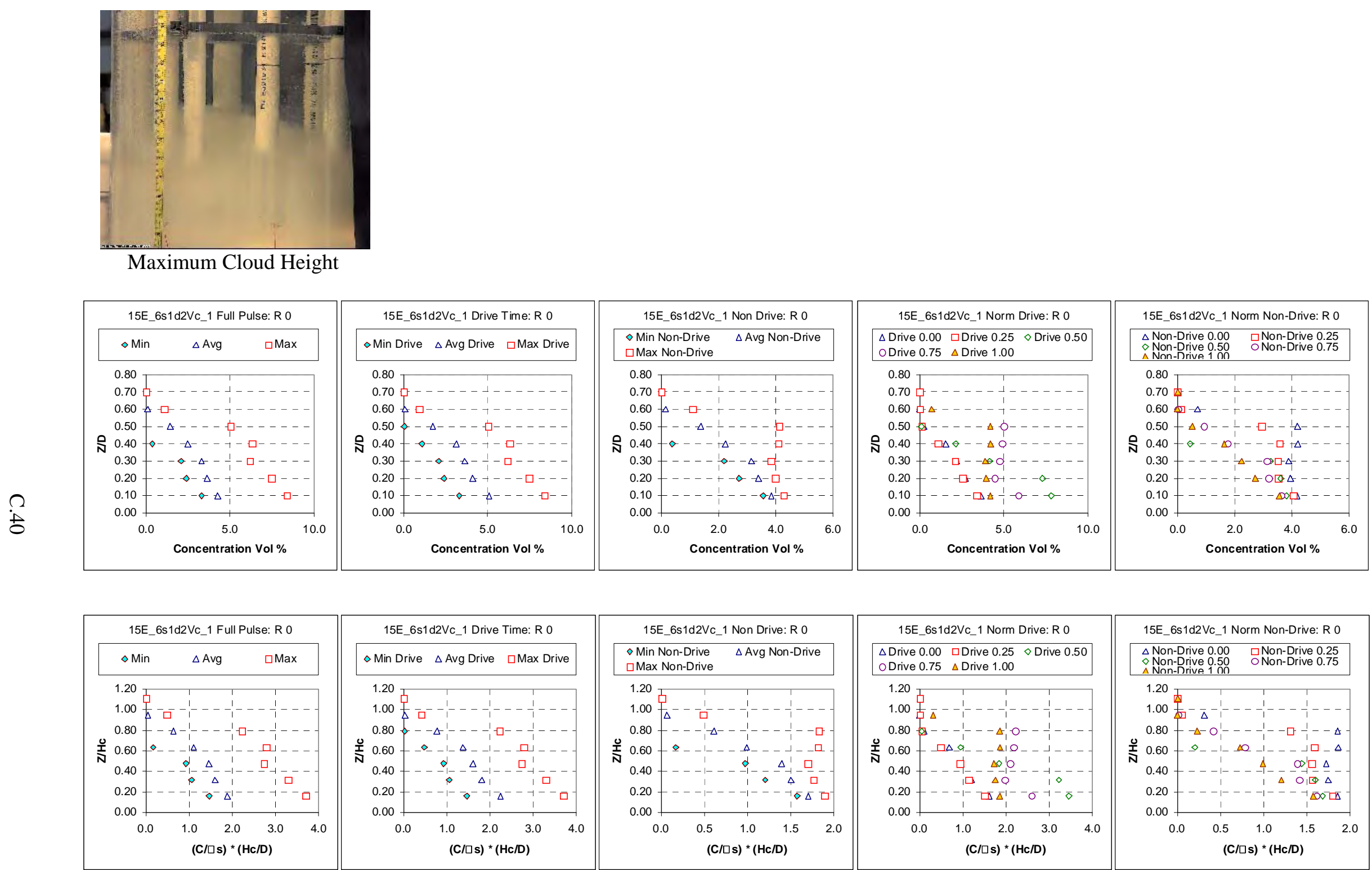

Figure C.18. $\quad 0.367-\mathrm{m}$ - (14 7/16-in.-) diameter tank, 0.485-cm- (0.191-in-) diameter nozzle; solids nominal diameter $69.3 \mu \mathrm{m}, 2.48 \mathrm{~g} / \mathrm{cm}^{3}$ density; 0.0143 nominal solids fraction; $33.3 \%$ duty cycle, cycle time $8.8 \mathrm{~s}$, pulse volume fraction 0.050 , $\mathrm{U}_{\mathrm{CS}}$ velocity $4.8 \mathrm{~m} / \mathrm{s}$, target nozzle exit velocity $4.8 \mathrm{~m} / \mathrm{s}$; peak cloud height upper bound 0.254 (10 in.). Case ID 15E_6s1d2Vc_1. 

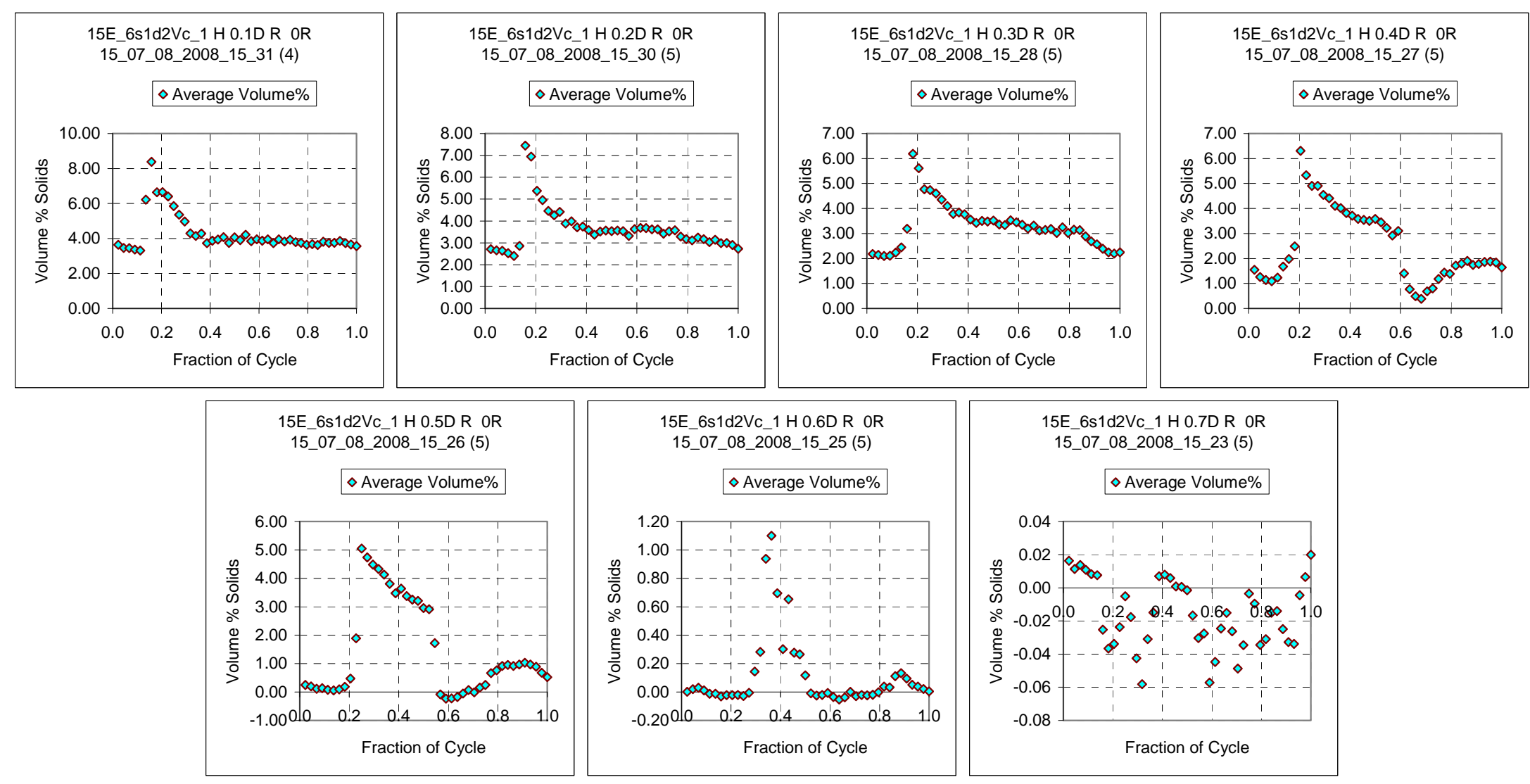

Figure C.18A. Case ID 15E_6s1d2Vc_1 Concentration Variation During the Cycle

Figure C.18 is the first of three profiles shown using simulant s1d2 in the small-scale tank using the 8TA vessel configuration with four pulse tubes in the outer ring and four in the inner ring. The solids fraction is 0.0143 . The duty cycle was $33.3 \%$ and the pulse volume fraction was constant at 0.050 . The $\mathrm{U}_{\mathrm{CS}}$ velocity occurred at $4.8 \mathrm{~m} / \mathrm{s}$. The cloud height is $10 \mathrm{in}$. 


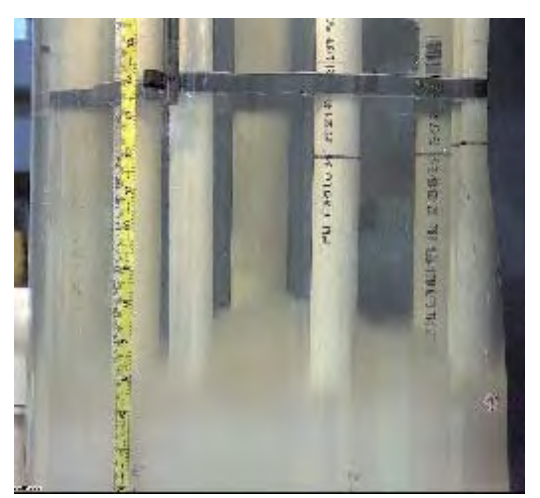

Maximum Cloud Height

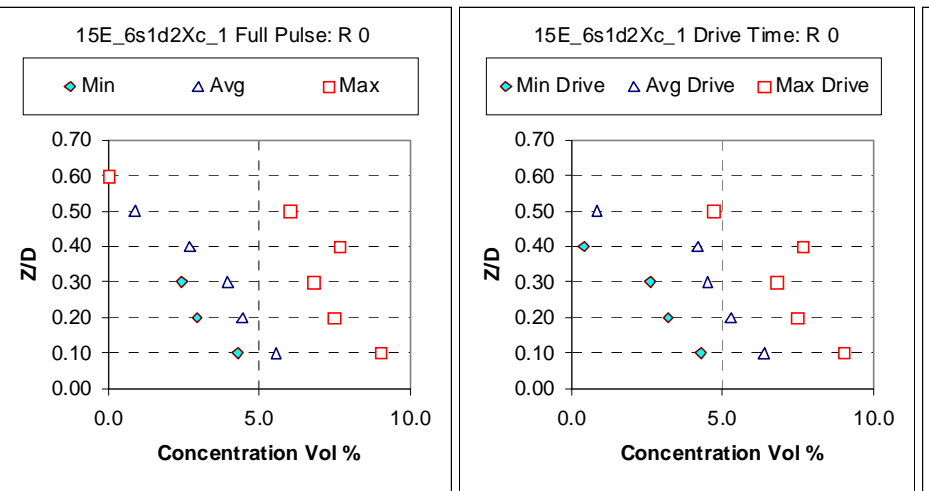
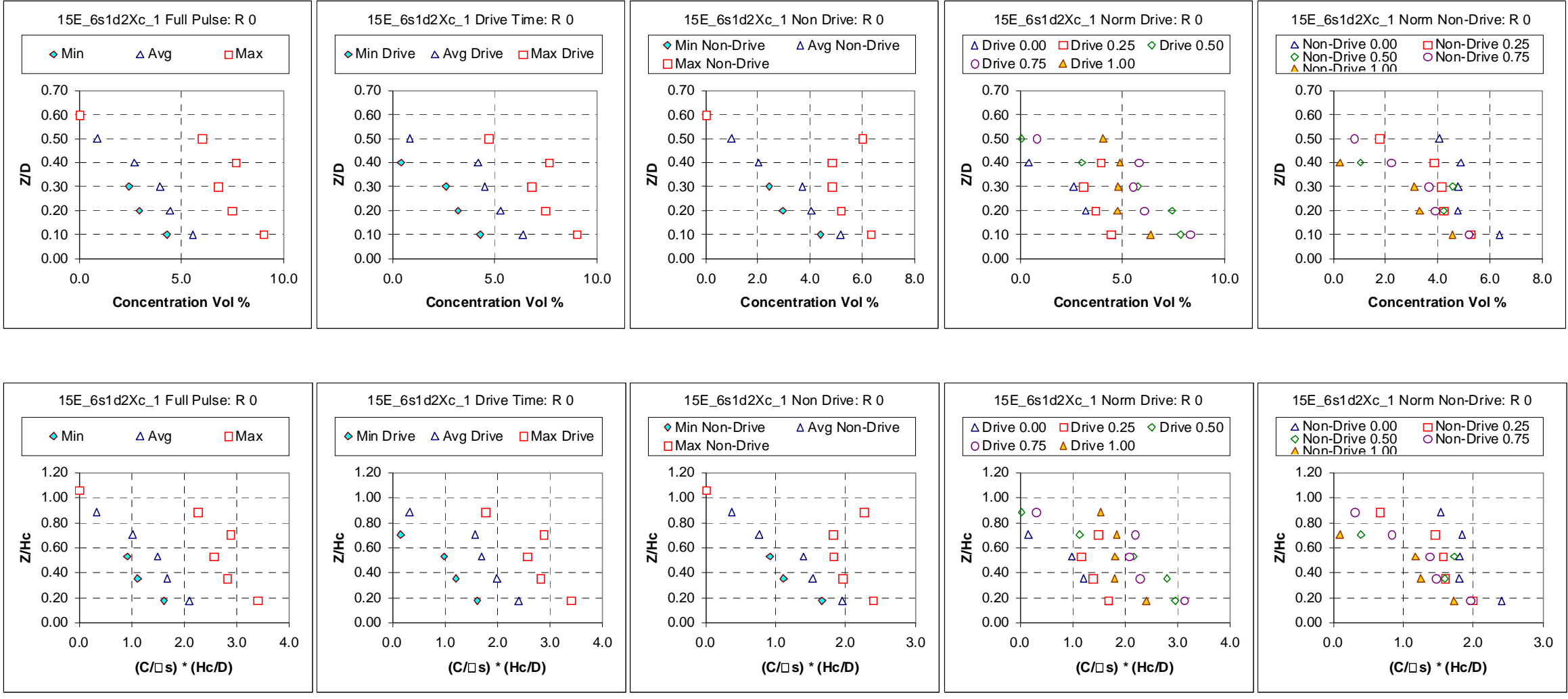

Figure C.19. 0.367-m- (14 7/16-in.-) diameter tank, 0.485-cm- (0.191-in-) diameter nozzle; solids nominal diameter $69.3 \mu \mathrm{m}, 2.48$ g/cm ${ }^{3}$ density; 0.015 nominal solids fraction; 33.3\% duty cycle, cycle time $9.3 \mathrm{~s}$, pulse volume fraction 0.050 , $\mathrm{U}_{\mathrm{CS}}$ velocity $4.6 \mathrm{~m} / \mathrm{s}$, target nozzle exit velocity $4.6 \mathrm{~m} / \mathrm{s}$; peak cloud height upper bound $0.229 \mathrm{~m}$ (9 in.). Case ID 15E_6s1d2Xc_1. 

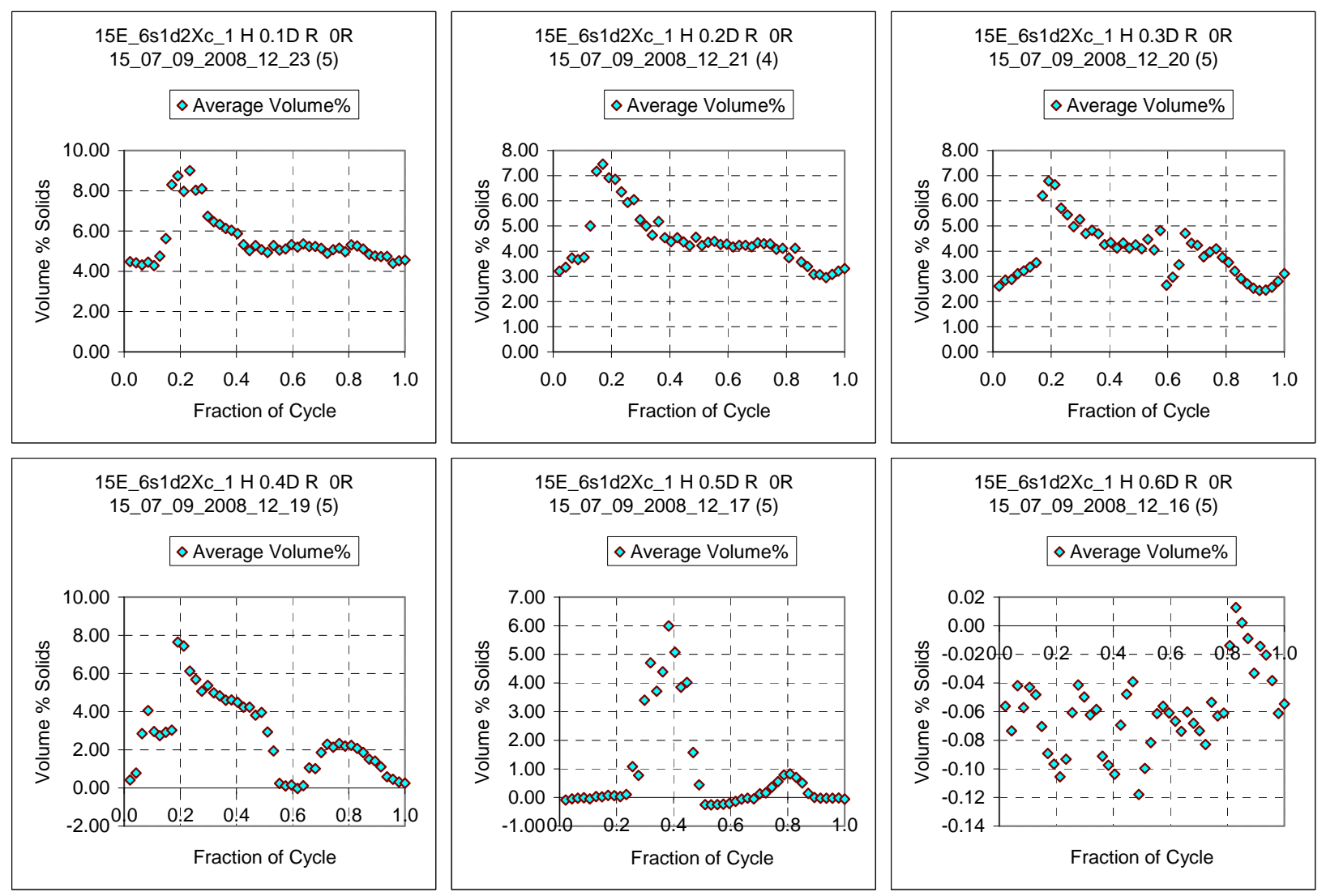

Figure C.19A. Case ID 15E_6s1d2Xc_1 Concentration Variation During the Cycle

Figure C.19 is the second of three profiles shown using simulant s1d2 in the small-scale tank using the 8TA vessel configuration. The solids fraction is increased to 0.015 from 0.0143 during the prior test. The duty cycle was $33.3 \%$ and the pulse volume fraction was constant at 0.050 . The $\mathrm{U}_{\mathrm{CS}}$ velocity occurred at $4.6 \mathrm{~m} / \mathrm{s}$, slightly lower than $4.8 \mathrm{~m} / \mathrm{s}$ for the prior test. The cloud height is 9 in., slightly lower than 10 in. for the prior test. 


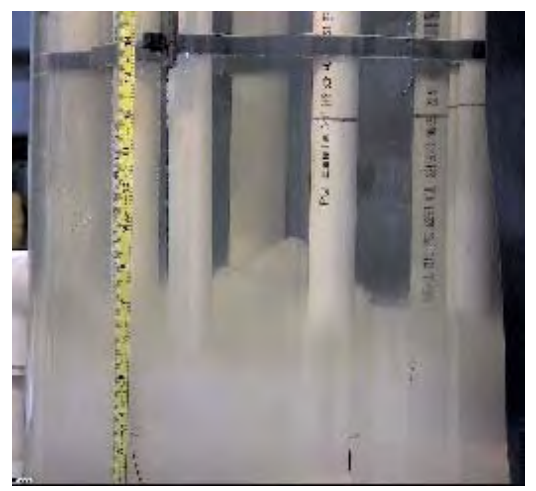

Maximum Cloud Height

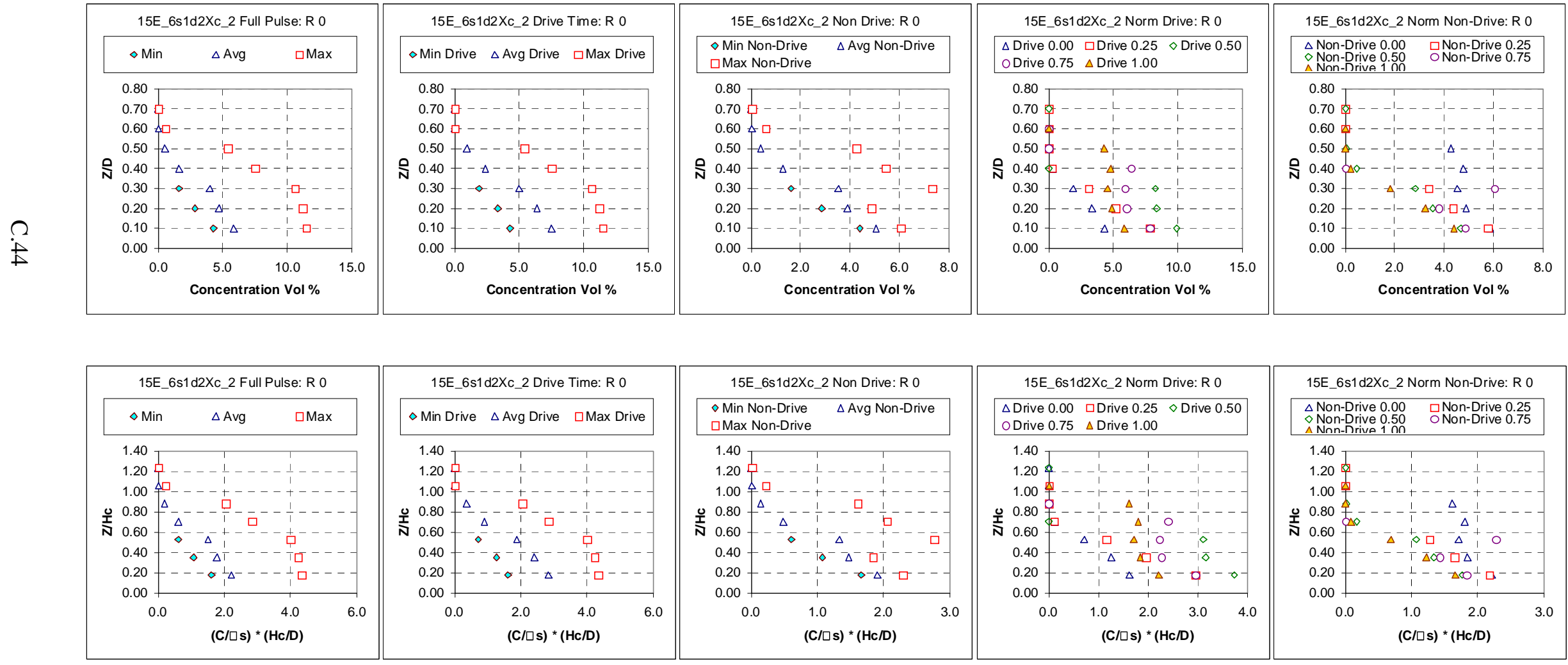

Figure C.20. $\quad 0.367-\mathrm{m}$ - (14 7/16-in.-) diameter tank, 0.485-cm- (0.191-in-) diameter nozzle; solids nominal diameter $69.3 \mu \mathrm{m}, 2.48 \mathrm{~g} / \mathrm{cm}^{3}$ density; 0.015 nominal solids fraction, $32.9 \%$ duty cycle, cycle time $18.8 \mathrm{~s}$, pulse volume fraction $0.100, \mathrm{U}_{\mathrm{CS}}$ velocity $4.4 \mathrm{~m} / \mathrm{s}$, target nozzle exit velocity $4.4 \mathrm{~m} / \mathrm{s}$; peak cloud height upper bound $0.229 \mathrm{~m}$ (9 in.). Case ID 15E_6s1d2Xc_2. 

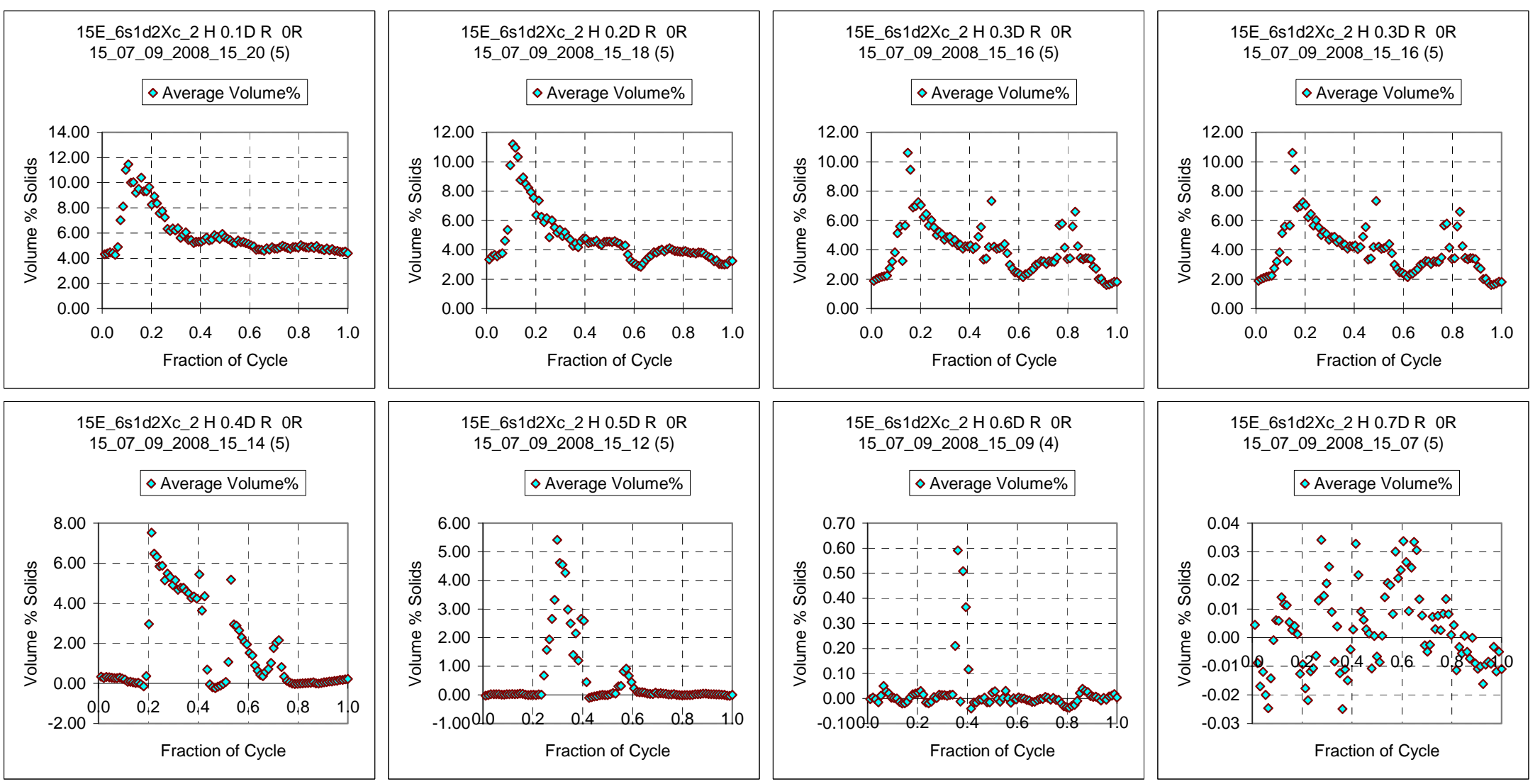

Figure C.20A. Case ID 15E_6s1d2Xc_2 Concentration Variation During the Cycle

Figure C.20 is the third of three profiles shown using simulant s1d2 in the small-scale tank using the 8TA vessel configuration. The solids fraction is unchanged from the prior test at 0.015 . The duty cycle was $32.9 \%$ and the pulse volume fraction was constant at 0.1 , an increase from 0.050 from the prior test. The $U_{\mathrm{CS}}$ velocity occurred at $4.4 \mathrm{~m} / \mathrm{s}$, slightly lower than $4.6 \mathrm{~m} / \mathrm{s}$ for the prior test. The cloud height is 9 in., no change from the prior test. 


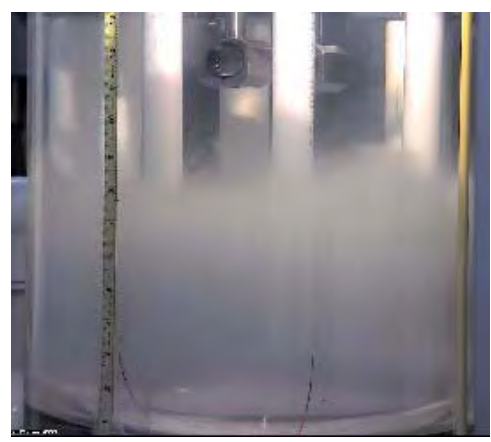

Maximum Cloud Height
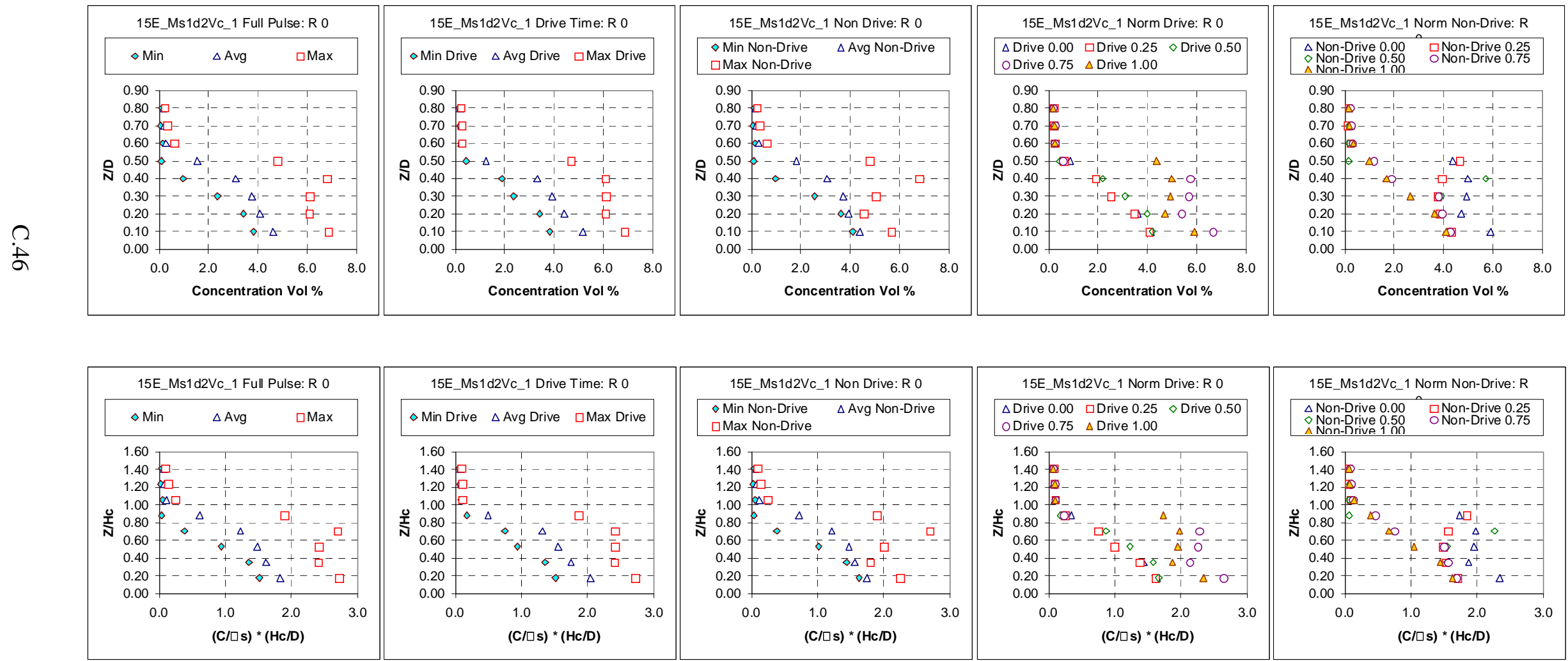

Figure C.21. 0.367-m- (14 7/16-in.-) diameter tank, 0.681-cm- (0.268-in-) diameter nozzle; solids nominal diameter $69.3 \mu \mathrm{m}, 2.48 \mathrm{~g} / \mathrm{cm}^{3}$ density; 0.0143 nominal solids fraction; $33.0 \%$ duty cycle, cycle time $7.6 \mathrm{~s}$, pulse volume fraction 0.050 , $\mathrm{U}_{\mathrm{CS}}$ velocity $2.9 \mathrm{~m} / \mathrm{s}$, target nozzle exit velocity $2.9 \mathrm{~m} / \mathrm{s}$; peak cloud height upper bound $0.229 \mathrm{~m}$ (9 in.). Case ID 15E_Ms1d2Vc_1. 

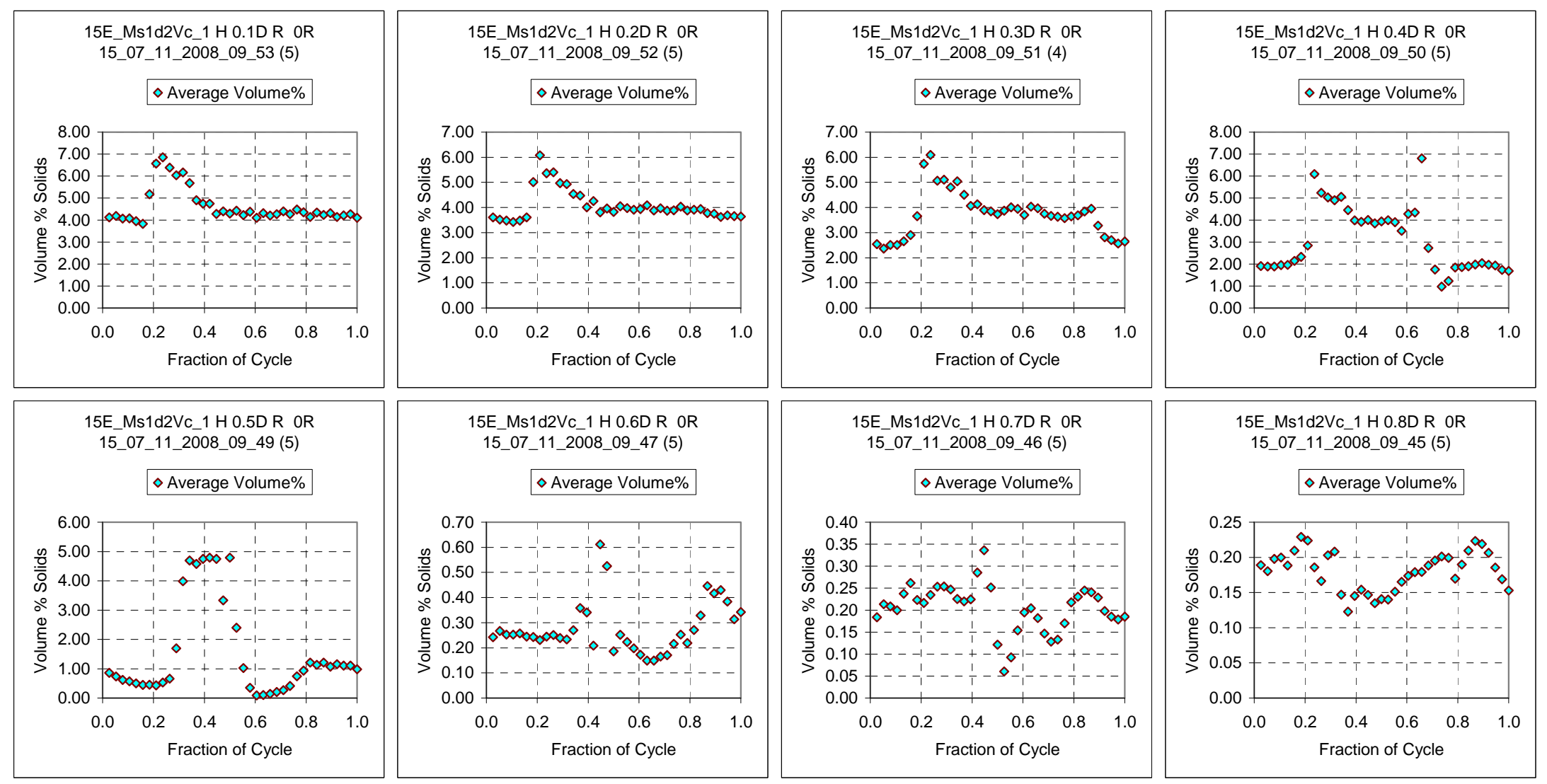

Figure C.21A. Case ID 15E_Ms1d2Vc_1 Concentration Variation During the Cycle

Figure C.21 is the only profile shown using simulant s1d2 in the small-scale tank using the 8TA vessel configuration with a full-scale nozzle diameter of $8.5 \mathrm{in}$. The solids fraction is 0.0143 . The duty cycle was $33.0 \%$ and the pulse volume fraction was 0.050 . This profile can be compared with that shown in Figure C.18 with similar conditions but using a 6 in. full-scale nozzle. The $U_{\text {CS }}$ velocity occurred at $2.9 \mathrm{~m} / \mathrm{s}$, slightly lower than $4.8 \mathrm{~m} / \mathrm{s}$ for that test. The cloud height is 9 in. while the cloud height for Figure C.18 was $10 \mathrm{in}$. 


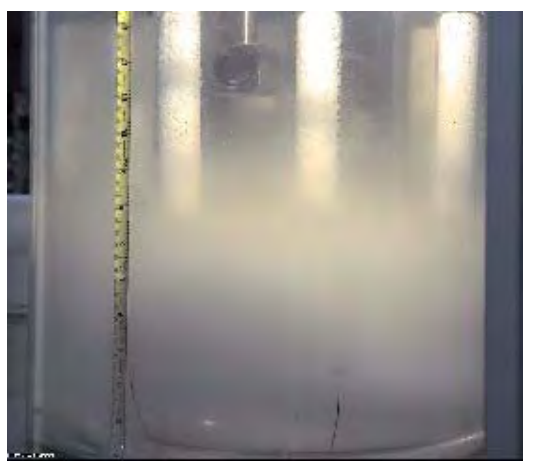

Maximum Cloud Height

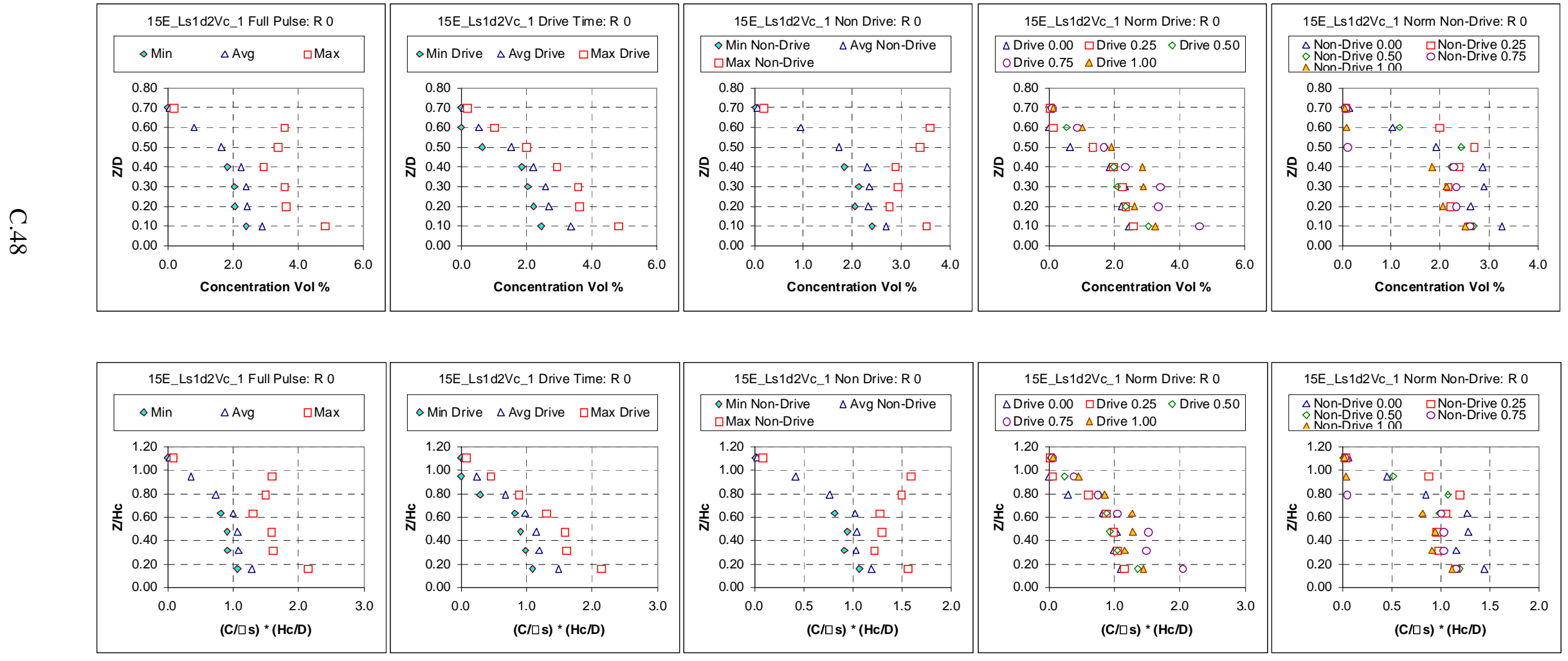

Figure C.22. 0.367-m- (14 7/16-in.-) diameter tank, 0.953-cm- (0.375-in-) diameter nozzle; solids nominal diameter $69.3 \mu \mathrm{m}, 2.48 \mathrm{~g} / \mathrm{cm}^{3}$ density; 0.0143 nominal solids fraction; $33.7 \%$ duty cycle, cycle time $5.8 \mathrm{~s}$, pulse volume fraction 0.050 , $\mathrm{U}_{\mathrm{CS}}$ velocity $1.9 \mathrm{~m} / \mathrm{s}$, target nozzle exit velocity $1.9 \mathrm{~m} / \mathrm{s}$; peak cloud height upper bound $0.254 \mathrm{~m}$ (10 in.). Case ID 15E_Ls1d2Vc_1. 

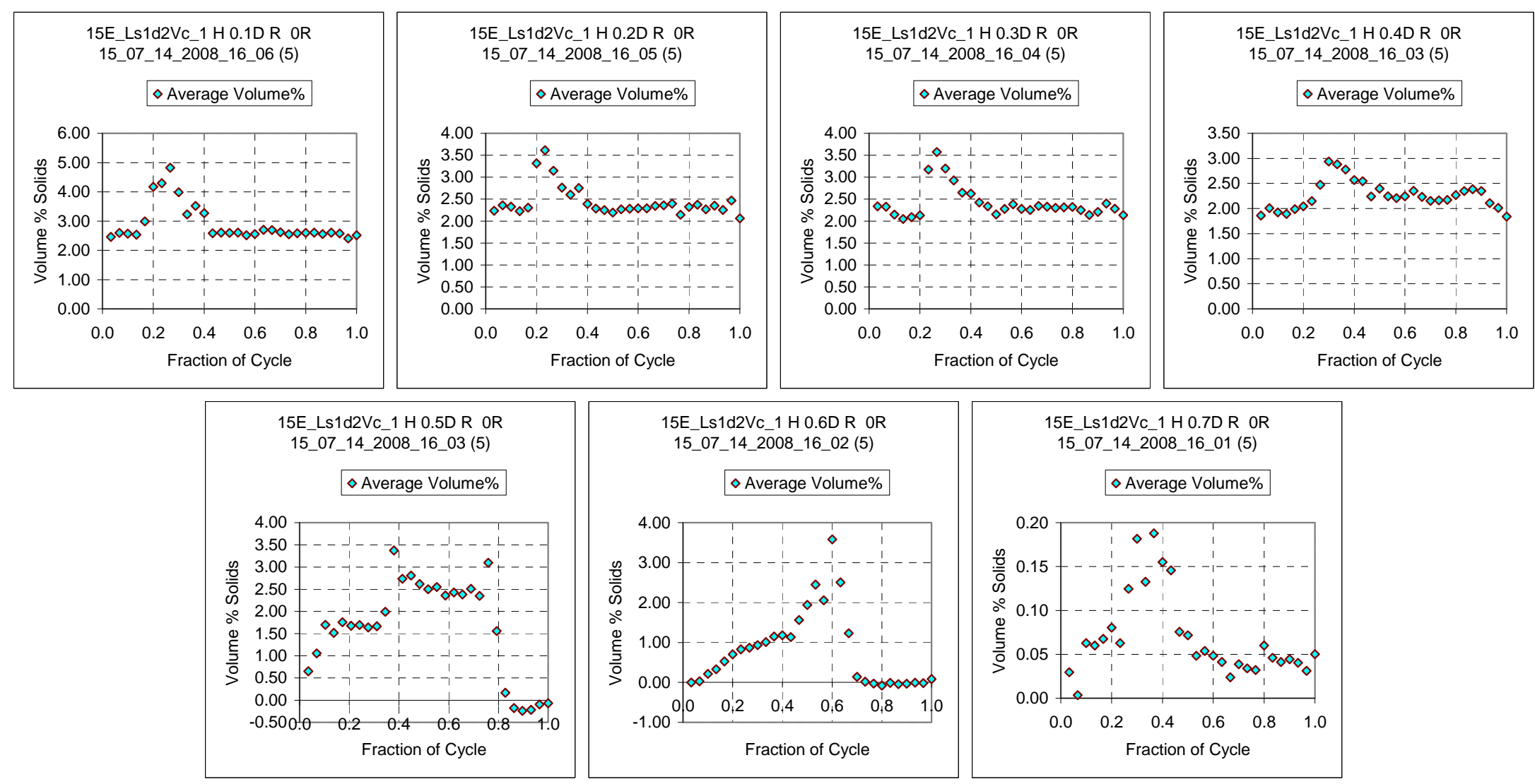

Figure C.22A. Case ID 15E_Ls1d2Vc_1 Concentration Variation During the Cycle

Figure C.22 is the first of three profiles shown using simulant s1d2 in the small-scale tank using the 8TA vessel configuration with a full-scale nozzle diameter of $11.8 \mathrm{in}$. The solids fraction is 0.0143 . The duty cycle was $33.7 \%$ and the pulse volume fraction was 0.050 . The $\mathrm{U}_{\mathrm{CS}}$ velocity occurred at $1.9 \mathrm{~m} / \mathrm{s}$. The cloud height was $10 \mathrm{in}$. 


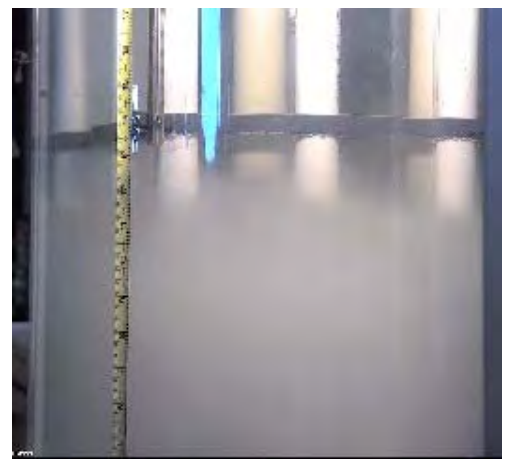

Maximum Cloud Height

\begin{tabular}{|c|c|c|c|c|c|c|}
\hline \multicolumn{3}{|c|}{ 15E_Ls1d2Vc_2 Full Pulse: R 0} & 15E_Ls1d2Vc_2 Drive Time: R 0 & 15E_Ls1d2Vc_2 Non Drive: R 0 & 15E_Ls1d2Vc_2 Norm Drive: R 0 & 15E_Ls1d2Vc_2 Norm Non-Drive: R 0 \\
\hline$\diamond \operatorname{Min}$ & $\triangle \mathrm{Avg}$ & $\square \operatorname{Max}$ & $\diamond$ Min Drive $\quad \Delta$ Avg Drive $\quad \square$ Max Drive & $\begin{array}{l}\diamond \text { Min Non-Drive } \quad \Delta \text { Avg Non-Drive } \\
\square \text { Max Non-Drive }\end{array}$ & $\begin{array}{ll}\Delta \text { Drive } 0.00 & \square \text { Drive } 0.25 \diamond \text { Drive } 0.50 \\
\text { ODrive } 0.75 & \Delta \text { Drive } 1.00\end{array}$ & $\begin{array}{ll}\Delta \text { Non-Drive 0.00 } & \text { Non-Drive 0.25 } \\
\diamond \text { Non-Divive 0.50 } & \text { O Non-Drive 0.75 } \\
\text { A Non-Drive 1 nn } & \end{array}$ \\
\hline \multicolumn{3}{|l|}{1.00} & 1.00 & \multirow{3}{*}{$\begin{array}{l}1.00 \\
0.90 \\
0.80 \\
070-\cdots\end{array}$} & \multirow{2}{*}{$0.90 \quad-1 .-\cdots-\cdots$} & \multirow{2}{*}{0.9000} \\
\hline \multirow{2}{*}{\multicolumn{3}{|c|}{0.90}} & \multirow{2}{*}{ 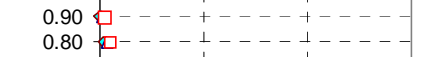 } & & & \\
\hline & & & & & \multirow{2}{*}{$0.70-0-\Delta--$} & 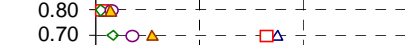 \\
\hline \multicolumn{3}{|l|}{$\begin{array}{l}0.70 \\
0.60\end{array}$} & $0.70+\diamond \Delta--\square--$ & $0.60---\Delta--\Delta-\uparrow--\square-$ & & $0.60+---\Delta--\infty \square--\Delta-$ \\
\hline$\stackrel{\bigcirc}{N} 0.50$ & $\diamond-\Delta-$ & & $--\diamond--\Delta^{-}--\square$ & $----\neg-\Delta+-\square--$ & \multirow{2}{*}{ 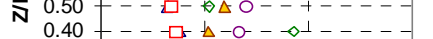 } & \multirow{2}{*}{ 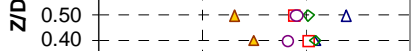 } \\
\hline 0.40 & $\rightarrow-\Delta-$ & - - - - - & $--\infty-\Delta$ & $\ldots--\leadsto-\Delta \square$ & & \\
\hline \multirow{2}{*}{\multicolumn{3}{|c|}{$--\square---$}} & $0.30+---\Delta-\Delta-\cdots$ & $\begin{array}{l}----\Delta \Delta-\square \\
-\cdots--\Delta-\square \square\end{array}$ & $\begin{array}{l}---\square-\Delta-O--\diamond \\
---\square \Delta-O-\diamond-\end{array}$ & $\begin{array}{l}0.30 \\
0.20\end{array}$ \\
\hline & & & 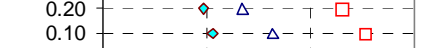 & \multirow{2}{*}{$-\cdots-\cdots-\Delta-\Delta$} & 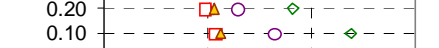 & $-\cdots+--480$ \\
\hline \multicolumn{3}{|l|}{$0.00 \mp$} & $----\diamond--\Delta----\square--$ & & 0.00 & \\
\hline 0.0 & 2.0 & 4.0 & $2.0 \quad 4.0$ & $1.0 \quad 2.0$ & 2.0 & 0.0 \\
\hline \multicolumn{3}{|c|}{ Concentration Vol \% } & Concentration Vol \% & Concentration Vol \% & Concentration Vol \% & Concentration Vol \% \\
\hline
\end{tabular}
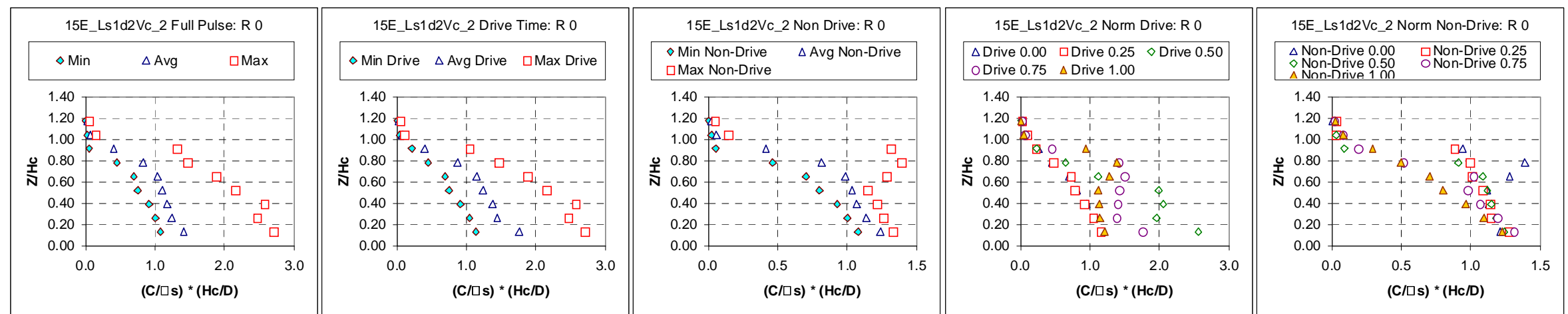

Figure C.23. 0.367-m- (14 7/16-in.-) diameter tank, 0.953-cm- (0.375-in-) diameter nozzle; solids nominal diameter $69.3 \mu \mathrm{m}, 2.48 \mathrm{~g} / \mathrm{cm}^{3}$ density; 0.0143 nominal solids fraction; $33.5 \%$ duty cycle, cycle time $11.4 \mathrm{~s}$, pulse volume fraction 0.101 , $\mathrm{U}_{\mathrm{CS}}$ velocity $1.9 \mathrm{~m} / \mathrm{s}$, target nozzle exit velocity $1.9 \mathrm{~m} / \mathrm{s}$; peak cloud height upper bound 0.305 m (12 in.). Case ID 15E_Ls1d2Vc_2. 

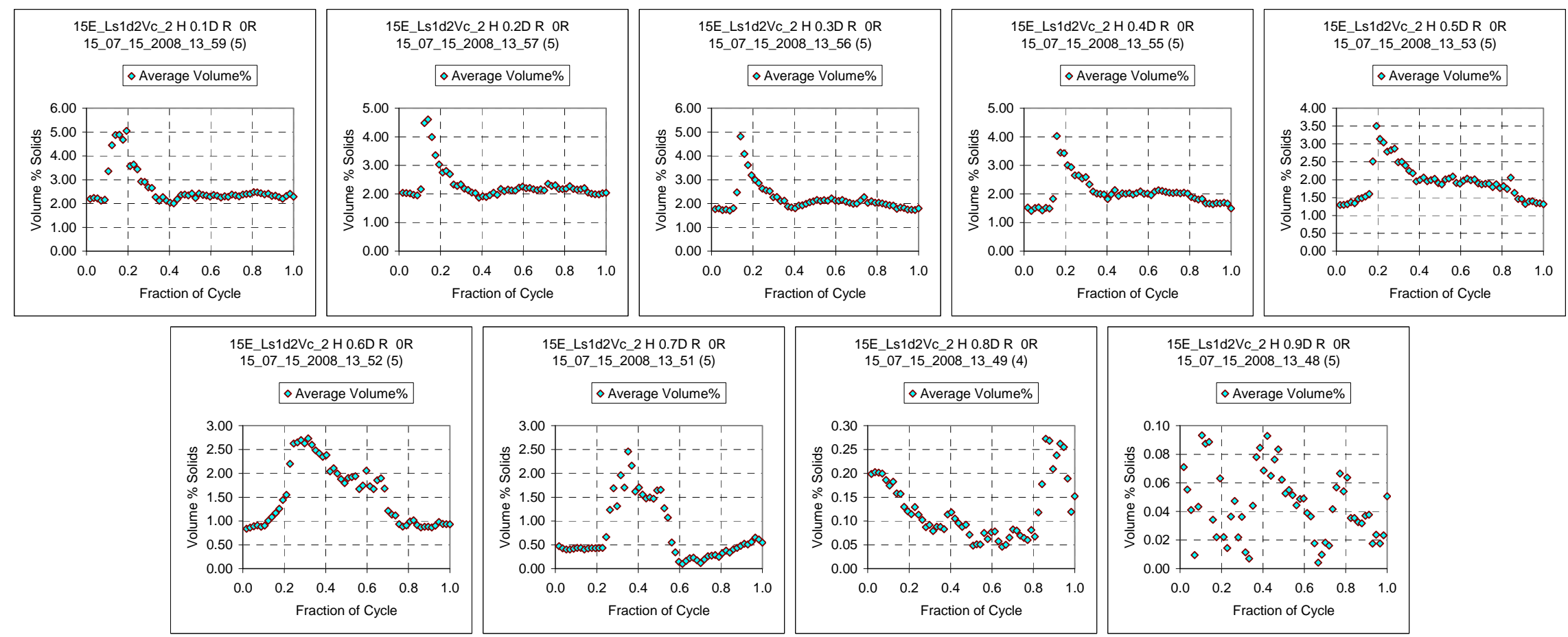

Figure C.23A. Case ID 15E_Ls1d2Vc_2 Concentration Variation During the Cycle

Figure C.23 is the second of three profiles shown using simulant s1d2 in the small-scale tank using the 8TA vessel configuration with a full-scale nozzle diameter of $11.8 \mathrm{in}$. The solids fraction is 0.0143 . The duty cycle was $33.5 \%$ and the pulse volume fraction was 0.10 , a change from 0.050 in the prior test. The $\mathrm{U}_{\mathrm{CS}}$ velocity occurred at $1.9 \mathrm{~m} / \mathrm{s}$, the same as for the prior test. The cloud height is $12 \mathrm{in}$. while the cloud height for the prior test was 10 in. 


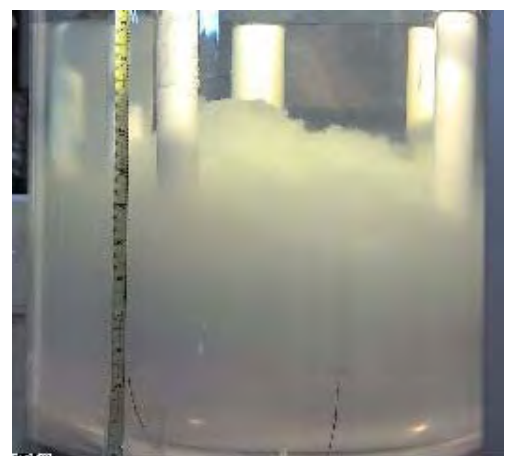

Maximum Cloud Height

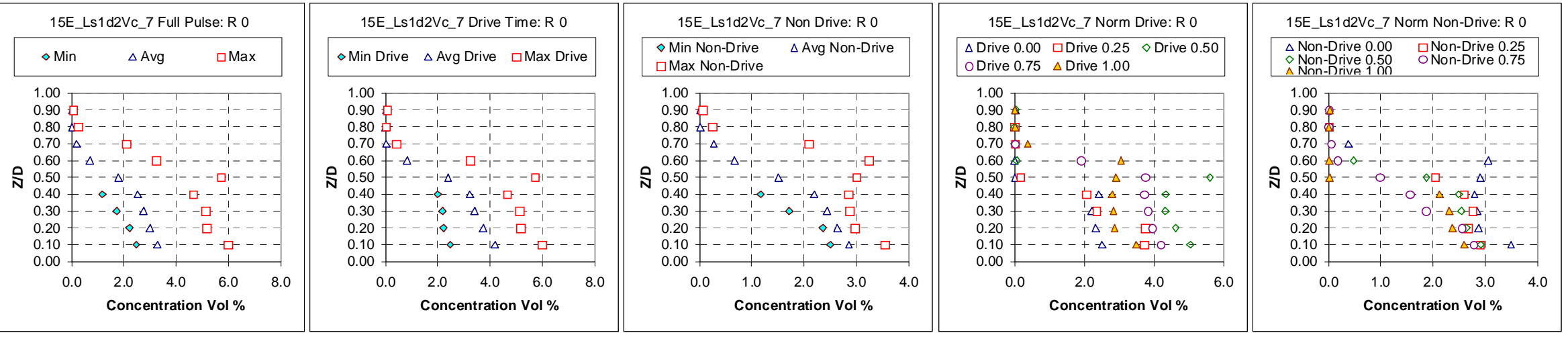
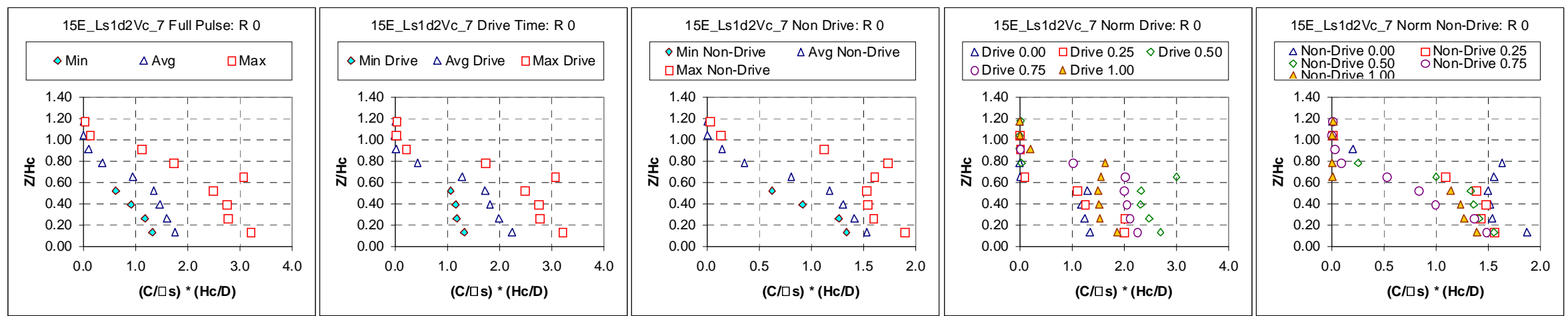

Figure C.24. 0.367-m- (14 7/16-in.-) diameter tank, 0.953-cm- (0.375-in-) diameter nozzle; solids nominal diameter $69.3 \mu \mathrm{m}, 2.48 \mathrm{~g} / \mathrm{cm}^{3}$ density; 0.0143 nominal solids fraction; $33.5 \%$ duty cycle, cycle time $17.0 \mathrm{~s}$, pulse volume fraction 0.100 , $\mathrm{U}_{\mathrm{Cs}}$ velocity $2.5 \mathrm{~m} / \mathrm{s}$, target nozzle exit velocity $2.5 \mathrm{~m} / \mathrm{s}$; peak cloud height upper bound $0.305 \mathrm{~m}$ (12 in.). Case ID 15E_Ls1d2Vc_7. 

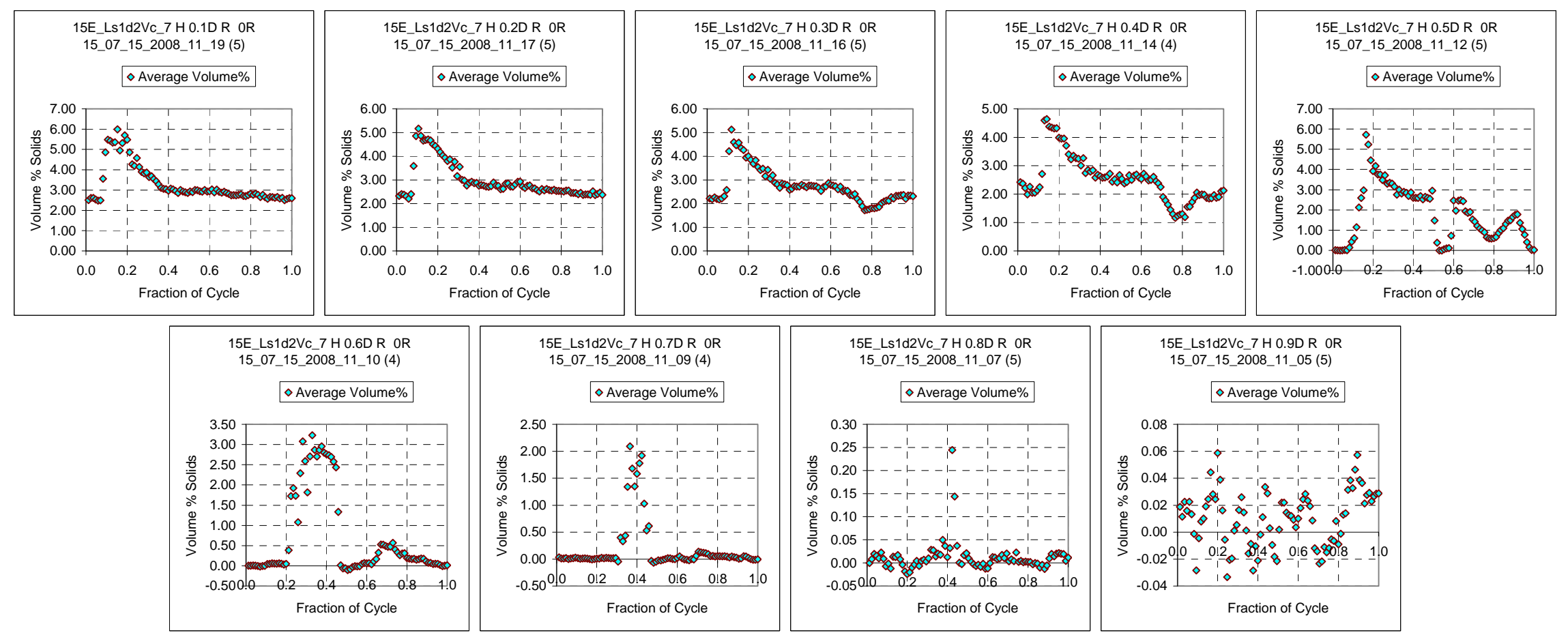

Figure C.24A. Case ID 15E_Ls1d2Vc_7 Concentration Variation During the Cycle

Figure C.24 is the third of three profiles shown using simulant s1d2 in the small-scale tank using the 8TA vessel configuration with a full-scale nozzle diameter of $11.8 \mathrm{in}$. The solids fraction is 0.0143 . The duty cycle was $33.5 \%$ and the pulse volume fraction was 0.10 , no change from the prior test. In this test only the four outer pulse tubes were operated. The $U_{\mathrm{CS}}$ velocity occurred at $2.5 \mathrm{~m} / \mathrm{s}$, an increase from $1.9 \mathrm{~m} / \mathrm{s}$ for the prior test with all eight pulse tubes operating. The cloud height is 12 in., unchanged from the prior test. 


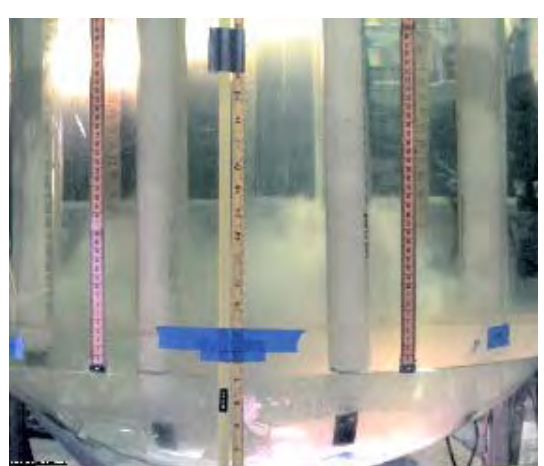

Maximum Cloud Height

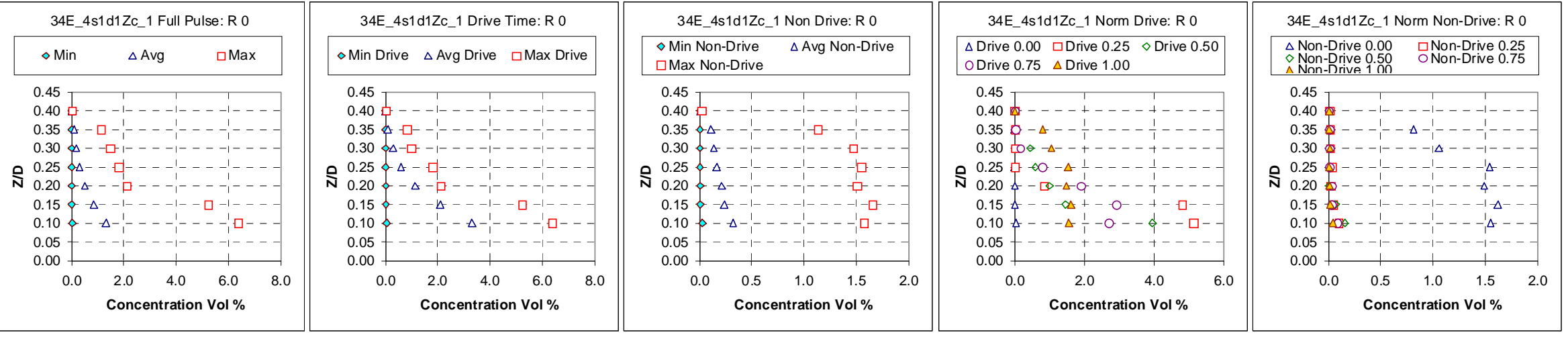
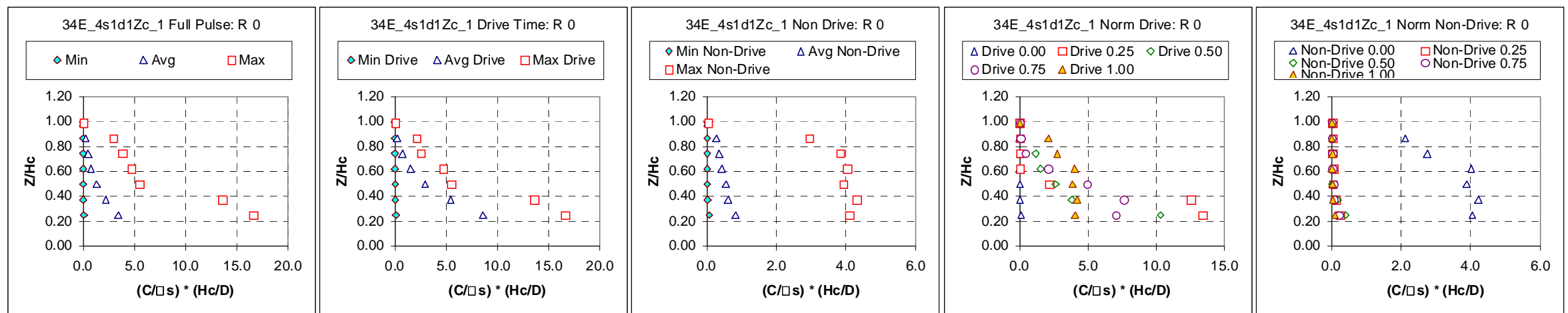

Figure C.25. 0.860-m- (33 7/8-in.-) diameter tank, 0.754-cm- (0.297-in-) diameter nozzle; solids nominal diameter $166.4 \mu \mathrm{m}, 2.46$ g/cm ${ }^{3}$ density; 0.00155 nominal solids fraction; $33.8 \%$ duty cycle, cycle time $32.0 \mathrm{~s}$, pulse volume fraction 0.050 , $\mathrm{U}_{\mathrm{CS}}$ velocity $4.5 \mathrm{~m} / \mathrm{s}$, target nozzle exit velocity $4.5 \mathrm{~m} / \mathrm{s}$; peak cloud height upper bound $0.356 \mathrm{~m}$ (14 in.). Case ID 34E_4s1d1Zc_1. 

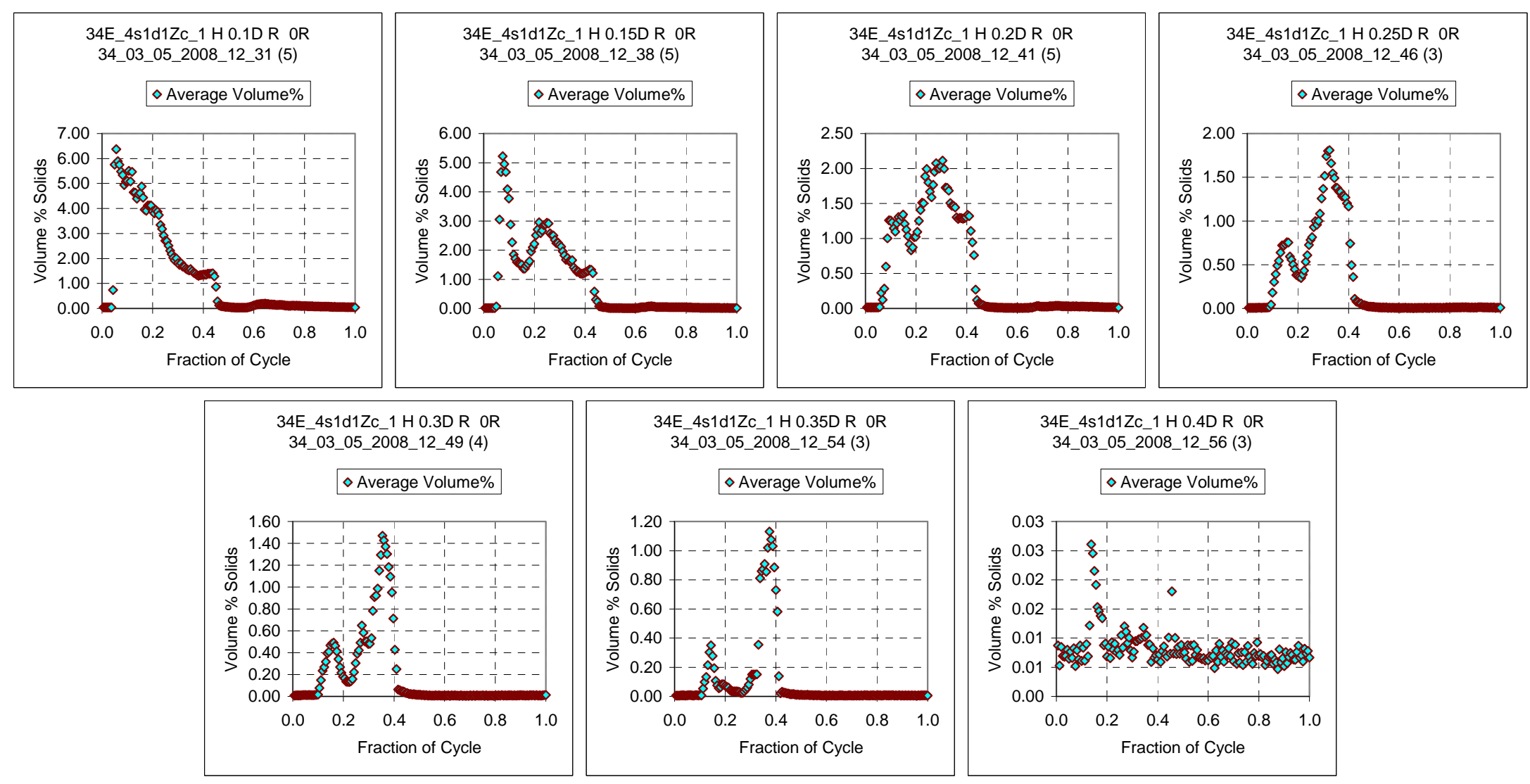

Figure C.25A. Case ID 34E_4s1d1Zc_1 Concentration Variation During the Cycle

Figure C. 25 is the only profile shown using simulant s1d1 in the mid-scale tank. The solids fraction is 0.00155 . The duty cycle was $33.8 \%$ and the pulse volume fraction was 0.050 . The $\mathrm{U}_{\mathrm{CS}}$ velocity occurred at $4.5 \mathrm{~m} / \mathrm{s}$. The cloud height is $14 \mathrm{in}$. 

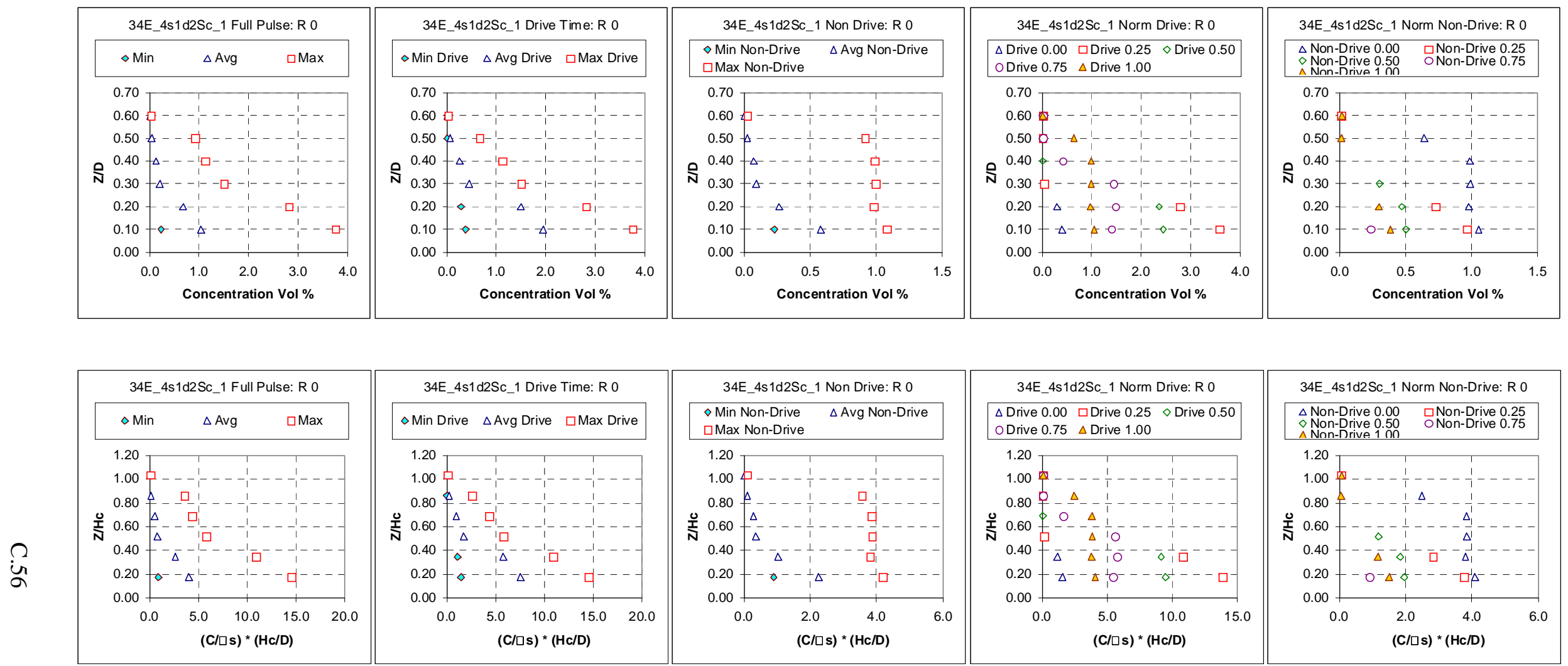

Figure C.26. $\quad$ 0.860-m- (33 7/8-in.-) diameter tank, 0.754-cm- (0.297-in-) diameter nozzle; solids nominal diameter $69.3 \mu \mathrm{m}, 2.48 \mathrm{~g} / \mathrm{cm}^{3}$ density; 0.0015 nominal solids fraction; $33.6 \%$ duty cycle, cycle time $39.0 \mathrm{~s}$, pulse volume fraction 0.050 , $\mathrm{U}_{\mathrm{Cs}}$ velocity $3.7 \mathrm{~m} / \mathrm{s}$, target nozzle exit velocity $3.7 \mathrm{~m} / \mathrm{s}$; peak cloud height upper bound $0.533 \mathrm{~m}$ (21 in.). Case ID 34E_4s1d2Sc_1. 

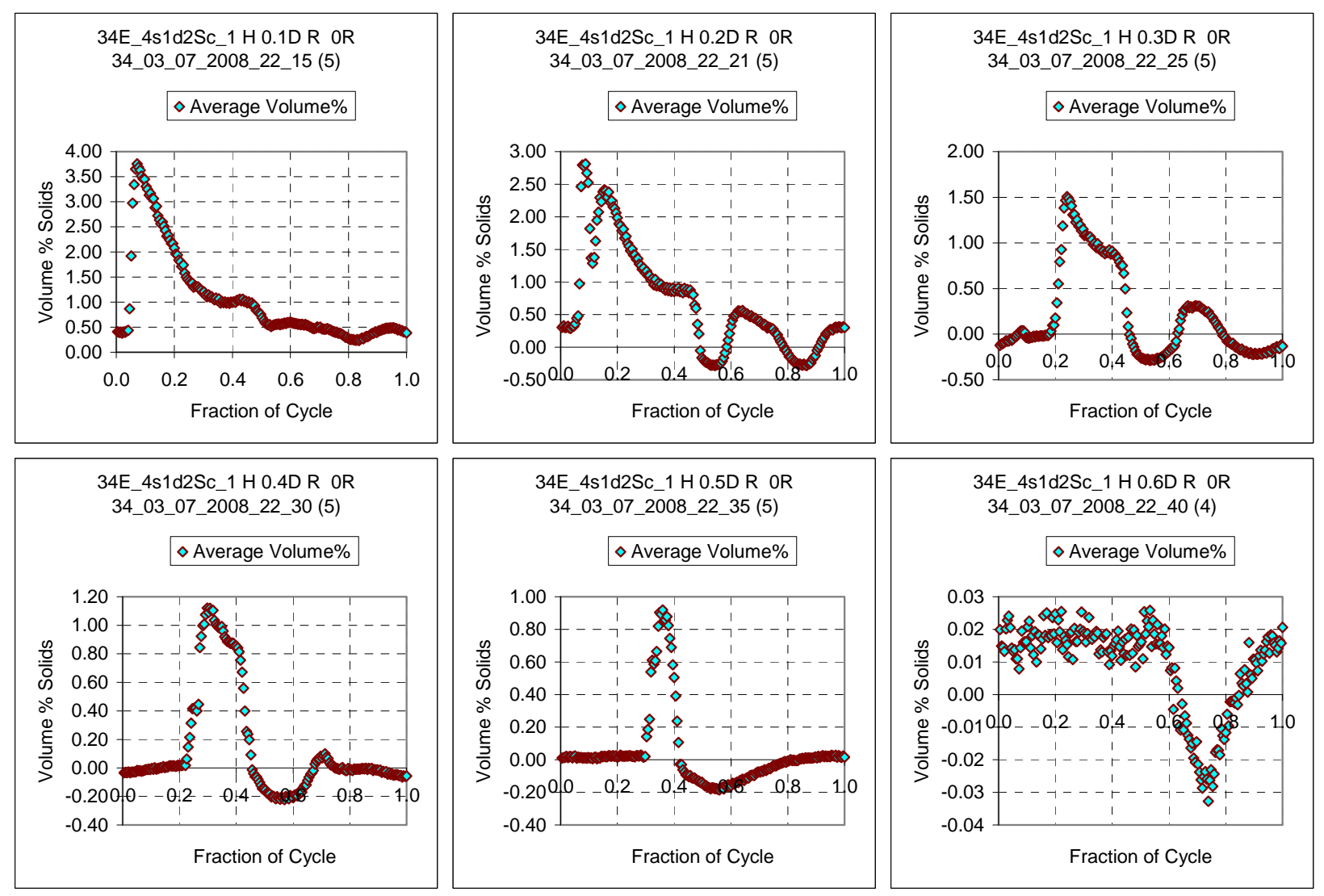

Figure C.26A. Case ID 34E_4s1d2Sc_1 Concentration Variation During the Cycle

Figure C.26 is the first of three profiles shown using simulant s1d2 in the mid-scale tank. The solids fraction is 0.0015 . The duty cycle was $33.6 \%$ and the pulse volume fraction was 0.050 . The $U_{\mathrm{CS}}$ velocity occurred at $3.7 \mathrm{~m} / \mathrm{s}$. The cloud height is $21 \mathrm{in}$. 

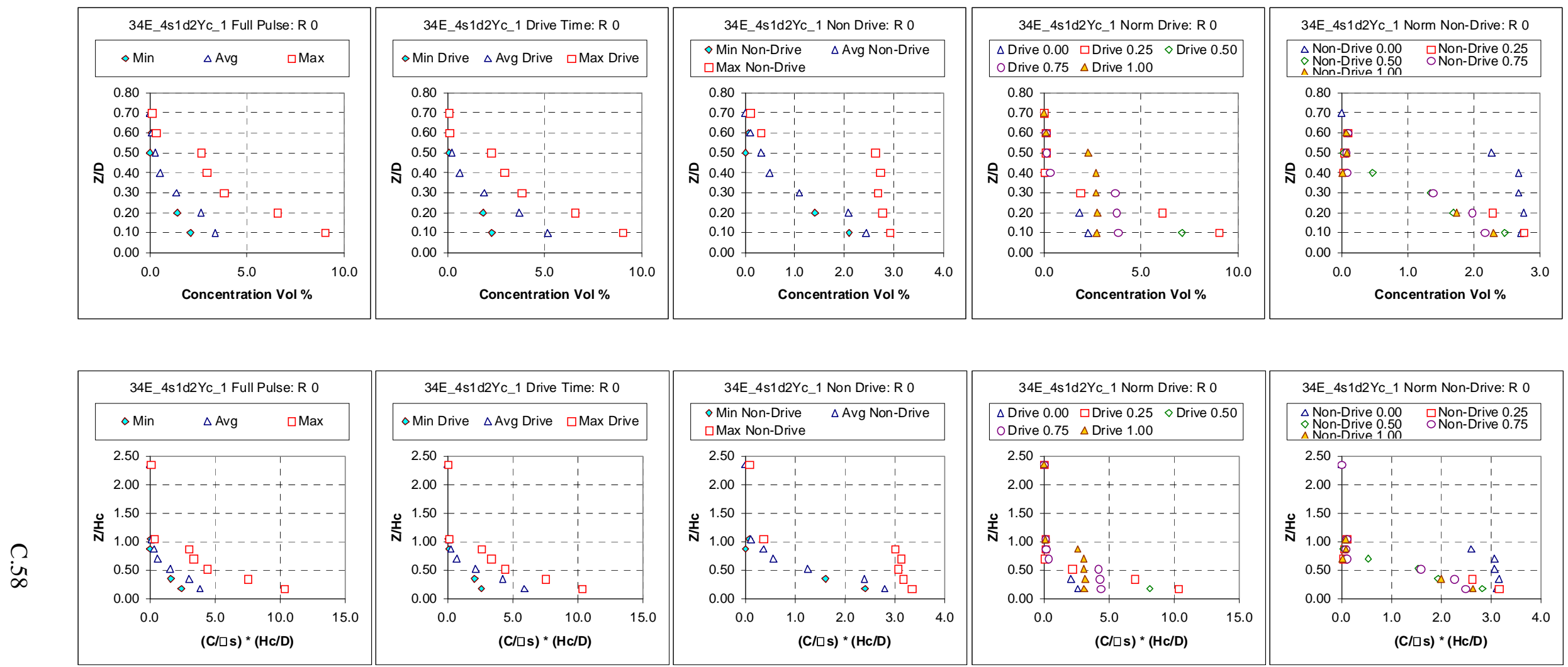

Figure C.27. 0.860-m- (33 7/8-in.-) diameter tank, 0.754-cm- (0.297-in-) diameter nozzle; solids nominal diameter $69.3 \mu \mathrm{m}, 2.48$ g/cm³ density; 0.005 nominal solids fraction; 33.6\% duty cycle, cycle time $28.4 \mathrm{~s}$, pulse volume fraction 0.050 , $\mathrm{U}_{\mathrm{CS}}$ velocity $5.1 \mathrm{~m} / \mathrm{s}$, target nozzle exit velocity $5.1 \mathrm{~m} / \mathrm{s}$; peak cloud height upper bound $0.508 \mathrm{~m}$ (20 in.). Case ID 34E_4s1d2Yc_1. 

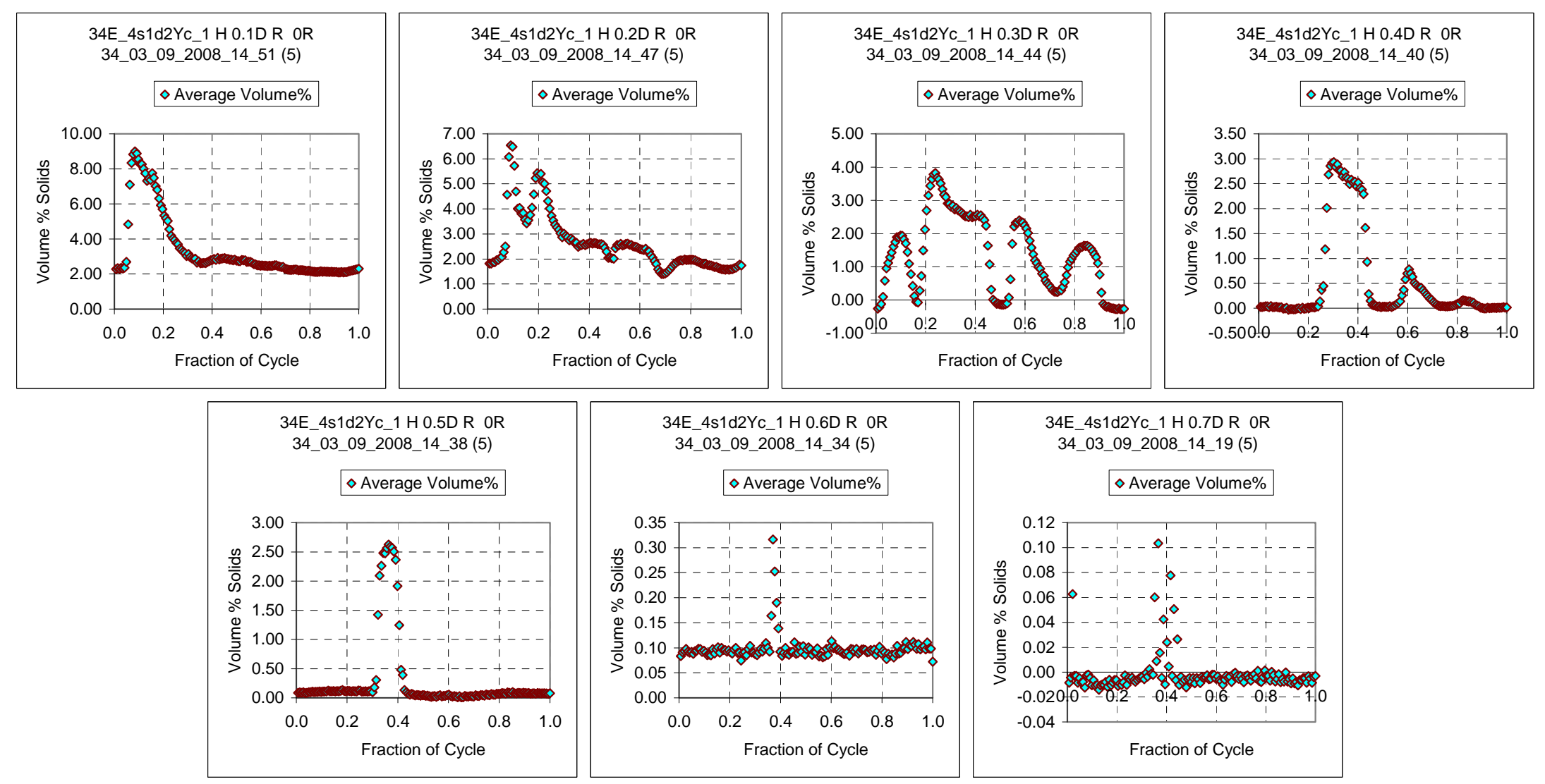

Figure C.27A. Case ID 34E_4s1d2Yc_1 Concentration Variation During the Cycle

Figure C.27 is the second of three profiles shown using simulant s1d2 in the mid-scale tank. The solids fraction is 0.005 , an increase from 0.0015 in the prior test. The duty cycle was $33.6 \%$ and the pulse volume fraction was 0.050 . The $\mathrm{U}_{\mathrm{CS}}$ velocity occurred at 5.1 , an increase from $3.7 \mathrm{~m} / \mathrm{s}$ from the prior test. The cloud height is $20 \mathrm{in}$., a slight decrease from $21 \mathrm{in.}$ in the prior test. In the transient plots significant fluctuations in vol\% solids are observed, especially at an elevation of 0.3D. 

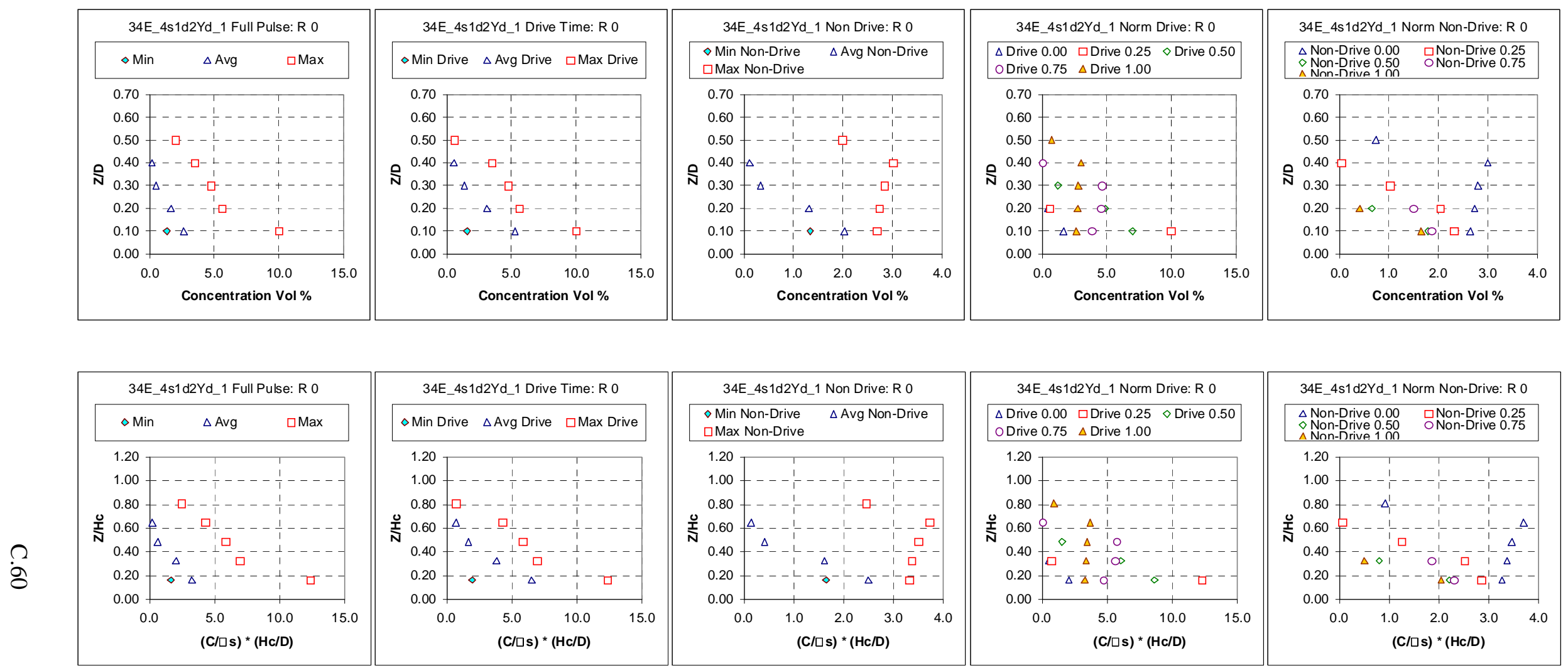

Figure C.28. $\quad$ 0.860-m- (33 7/8-in.-) diameter tank, 0.754-cm- (0.297-in-) diameter nozzle; solids nominal diameter $69.3 \mu \mathrm{m}, 2.48$ g/cm³ density; 0.005 nominal solids fraction; $18.6 \%$ duty cycle, cycle time $42.4 \mathrm{~s}$, pulse volume fraction 0.050 , $\mathrm{U}_{\mathrm{CS}}$ velocity $6 \mathrm{~m} / \mathrm{s}$, target nozzle exit velocity $6.2 \mathrm{~m} / \mathrm{s}$; peak cloud height upper bound $0.559 \mathrm{~m}$ (22 in.). Case ID 34E_4s1d2Yd_1. 

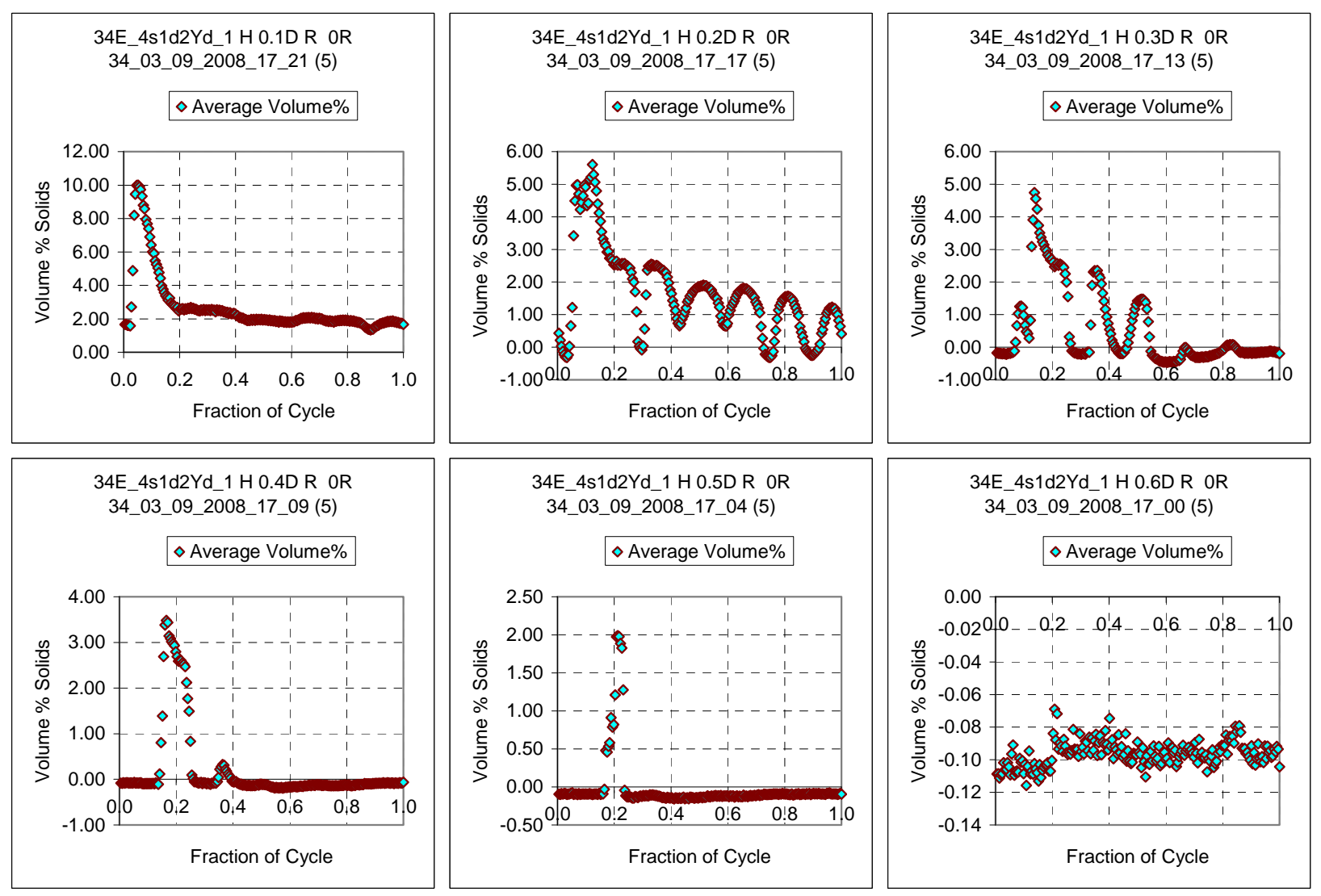

Figure C.28A. Case ID 34E_4s1d2Yd_1 Concentration Variation During the Cycle

Figure C.28 is the third of three profiles shown using simulant s1d2 in the mid-scale tank. The solids fraction is 0.005 unchanged from the prior test. The duty cycle was $18.6 \%$ changed from $33.6 \%$ in the prior test and the pulse volume fraction was 0.050 , no change from the prior test. The $\mathrm{U}_{\mathrm{CS}}$

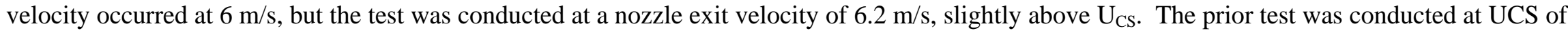
$5.1 \mathrm{~m} / \mathrm{s}$. The cloud height is $22 \mathrm{in}$., a slight increase from $20 \mathrm{in}$. in the prior test. In the transient plots significant fluctuations in vol\% solids are observed, especially at an elevation of $0.2 \mathrm{D}$. 

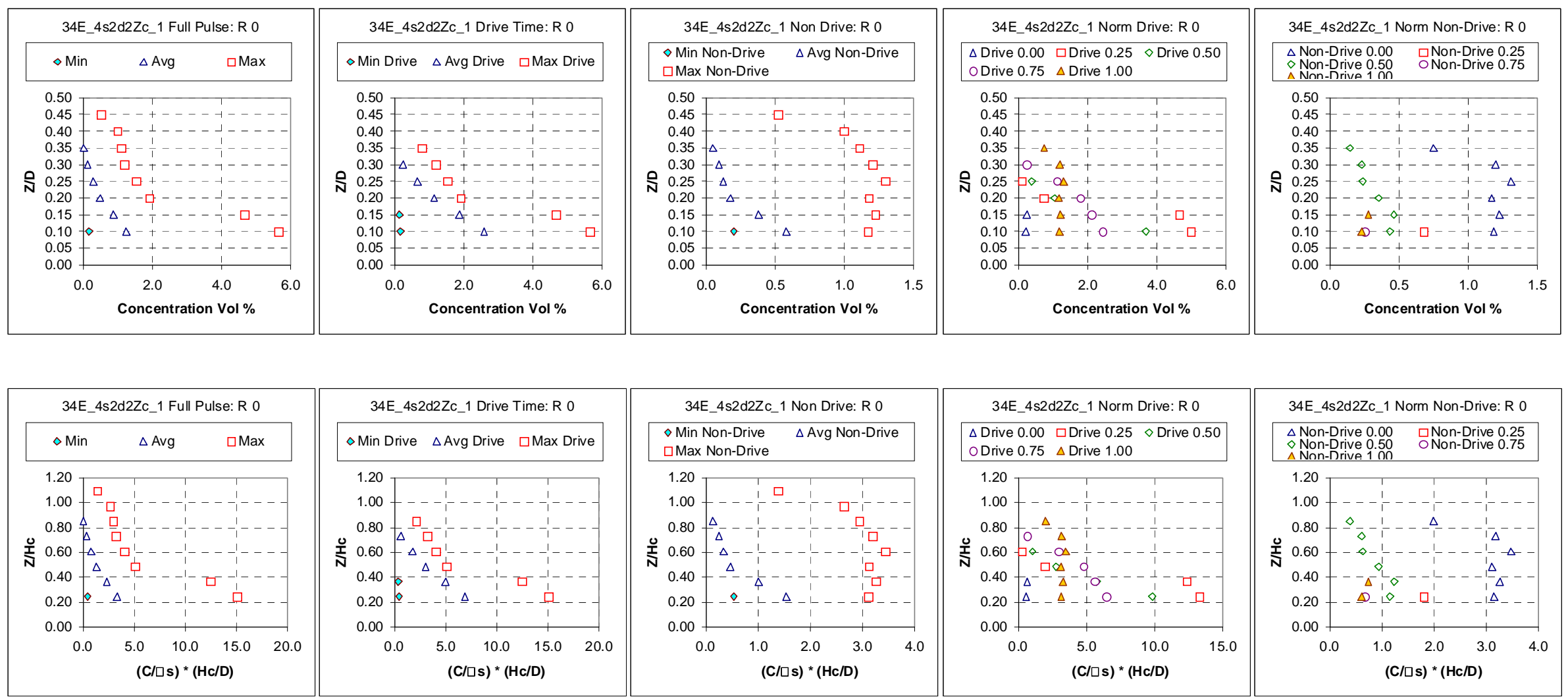

Figure C.29. 0.860-m- (33 7/8-in.-) diameter tank, 0.754-cm- (0.297-in-) diameter nozzle; solids nominal diameter $75.6 \mu \mathrm{m}, 4.18 \mathrm{~g} / \mathrm{cm}^{3} \mathrm{density}$; 0.00155 nominal solids fraction; $33.5 \%$ duty cycle, cycle time $24.9 \mathrm{~s}$, pulse volume fraction 0.050 , $\mathrm{U}_{\mathrm{Cs}}$ velocity $5.6 \mathrm{~m} / \mathrm{s}$, target nozzle exit velocity $5.6 \mathrm{~m} / \mathrm{s}$; peak cloud height upper bound $0.368 \mathrm{~m}$ (14.5 in.). Case ID 34E_4s2d2Zc_1. 

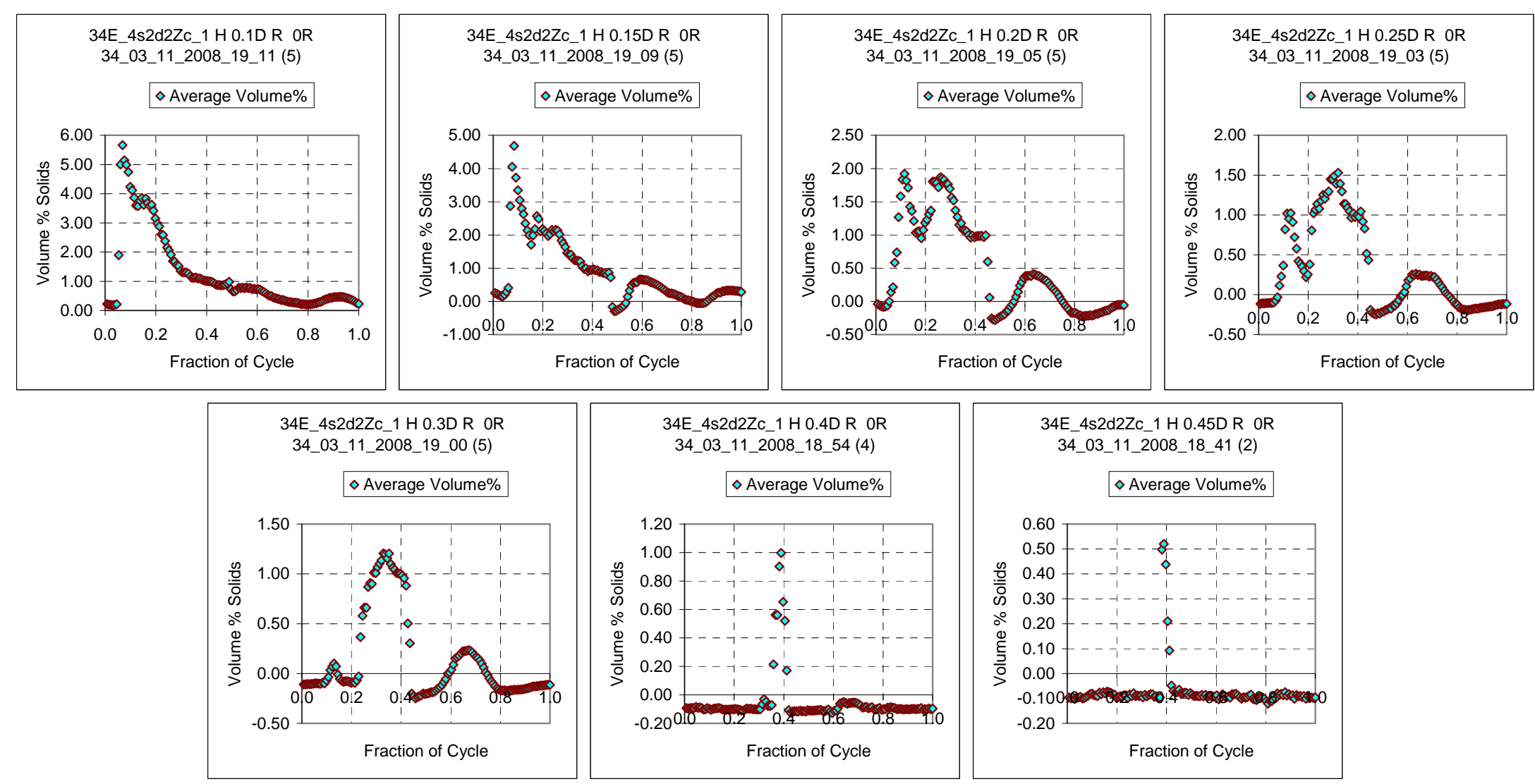

Figure C.29A. Case ID 34E_4s2d2Zc_1 Concentration Variation During the Cycle

Figure C.29 is the first of three profiles shown using simulant s2d2 in the mid-scale tank. The solids fraction is 0.00155 . The duty cycle was $33.5 \%$, and the pulse volume fraction was 0.050 . The $\mathrm{U}_{\mathrm{CS}}$ velocity occurred at $5.6 \mathrm{~m} / \mathrm{s}$; the cloud height is 14.5 in. This test can be compared with Figure C.25, which was conducted with the same conditions except for simulant s1d1. In the prior test the particle diameter was larger and less dense. In Figure C.25 the $U_{C S}$ velocity occurred at $4.5 \mathrm{~m} / \mathrm{s}$ and the cloud height was $14 \mathrm{in}$. As expected, the denser, larger particle had a higher critical-suspension velocity. 

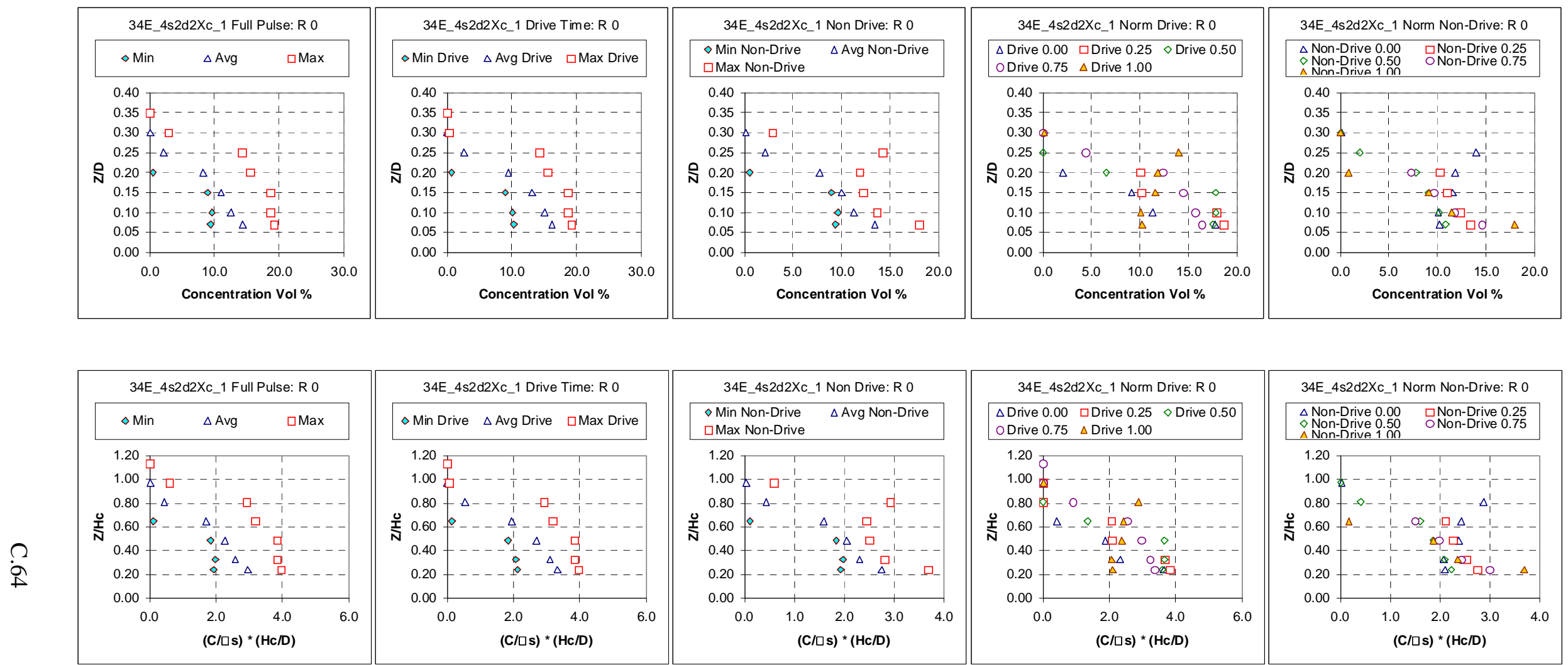

Figure C.30. $\quad$ 0.860-m- (33 7/8-in.-) diameter tank, 0.754-cm- (0.297-in-) diameter nozzle; solids nominal diameter $75.6 \mu \mathrm{m}, 4.18$ g/cm³ density; 0.015 nominal solids fraction; $33.9 \%$ duty cycle, cycle time $14.8 \mathrm{~s}$, pulse volume fraction $0.050, \mathrm{U}_{\mathrm{CS}}$ velocity $9.8 \mathrm{~m} / \mathrm{s}$, target nozzle exit velocity $10 \mathrm{~m} / \mathrm{s}$; peak cloud height upper bound $0.279 \mathrm{~m}$ (11 in.). Case ID 34E_4s2d2Xc_1. 

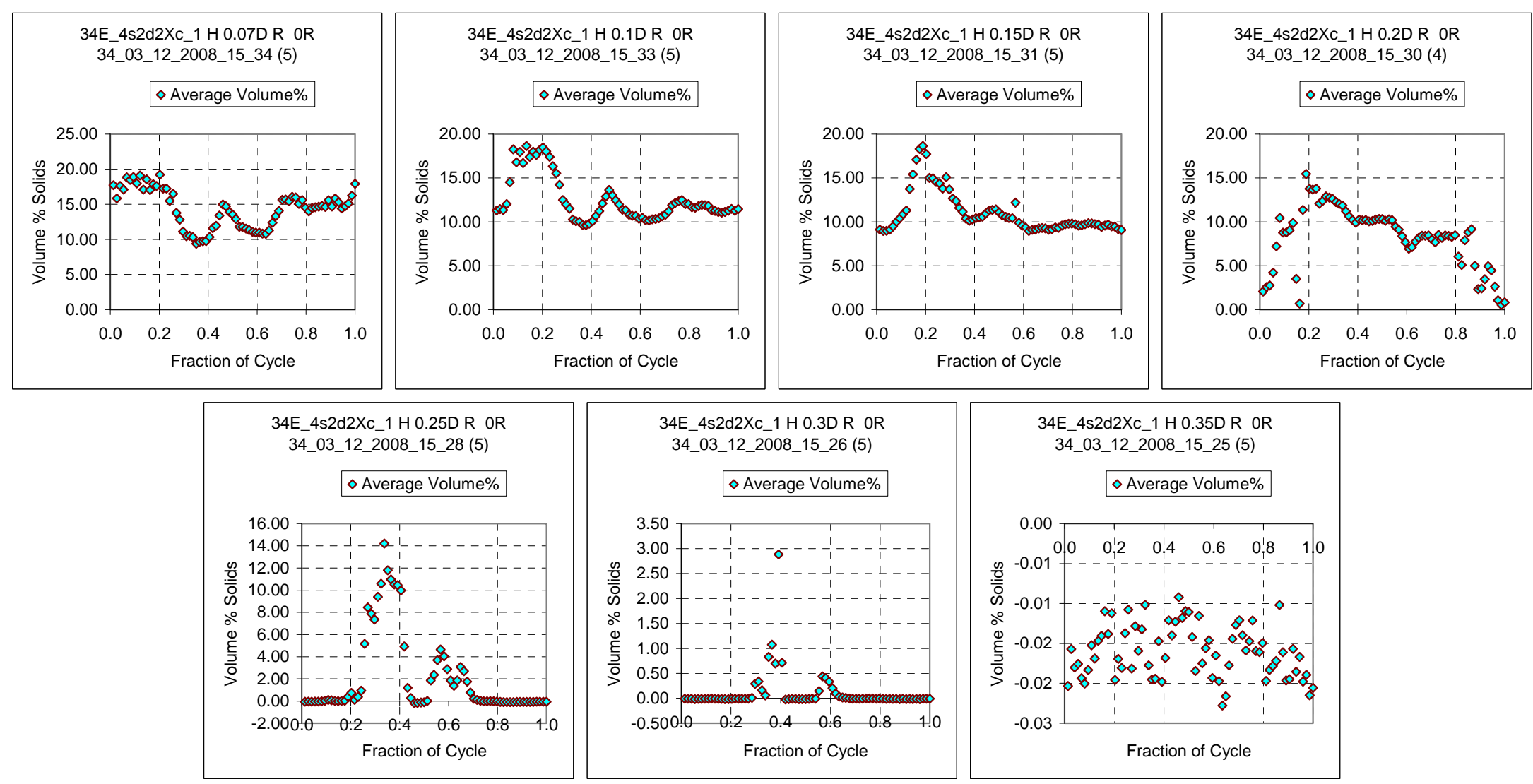

Figure C.30A. Case ID 34E_4s2d2Xc_1 Concentration Variation During the Cycle

Figure C.30 is the second of three profiles shown using simulant s2d2 in the mid-scale tank. The solids fraction is 0.015 , an increase from 0.00155 in the prior test. The duty cycle was $33.9 \%$, changed from $33.5 \%$ in the prior test, and the pulse volume fraction was 0.050 , no change from the prior test. The $\mathrm{U}_{\mathrm{CS}}$ velocity occurred at $9.8 \mathrm{~m} / \mathrm{s}$, an increase from $5.6 \mathrm{~m} / \mathrm{s}$ in the prior test. The cloud height is 11.0 in., a decrease from 14.5 in the prior test. 

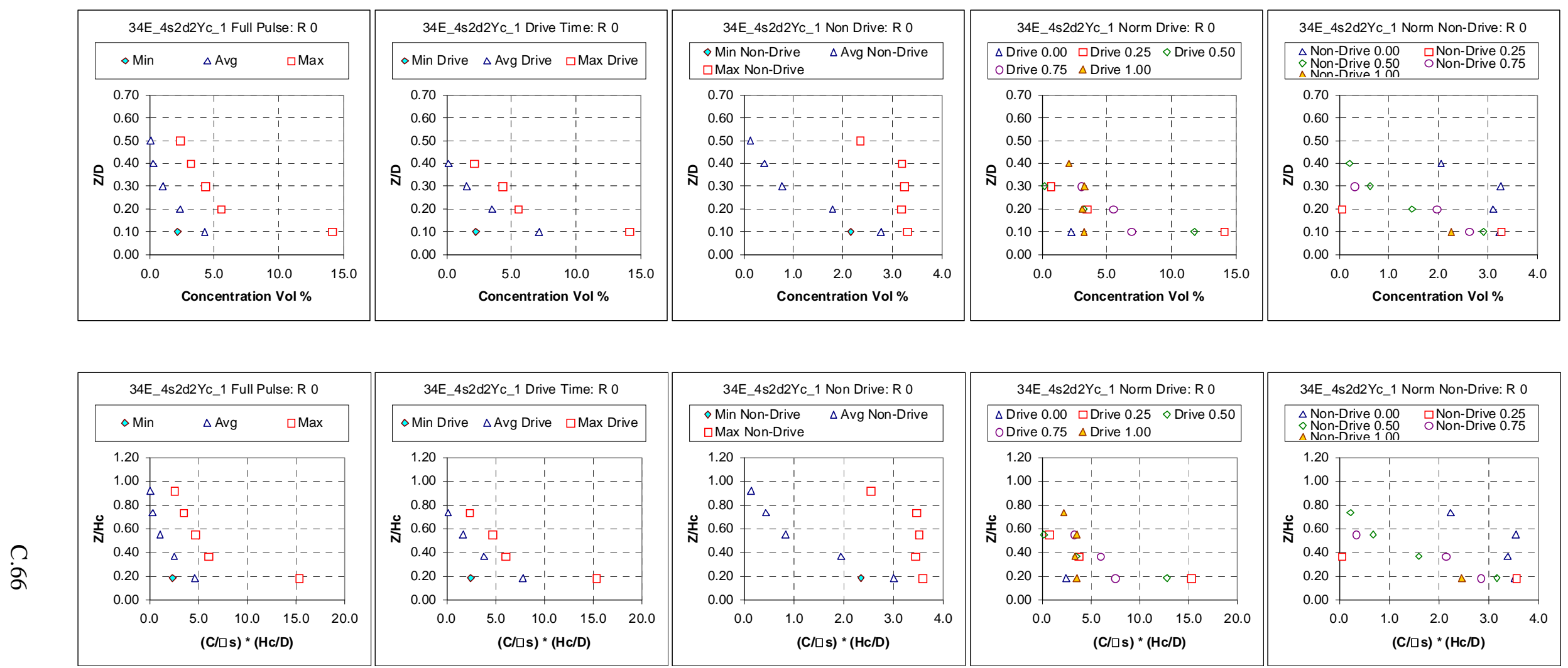

Figure C.31. 0.860-m- (33 7/8-in.-) diameter tank, 0.754-cm- (0.297-in-) diameter nozzle; solids nominal diameter $75.6 \mu \mathrm{m}, 4.18$ g/cm³ density; 0.005 nominal solids fraction; $33.6 \%$ duty cycle, cycle time $17.0 \mathrm{~s}$, pulse volume fraction 0.050 , $\mathrm{U}_{\mathrm{CS}}$ velocity $8.6 \mathrm{~m} / \mathrm{s}$, target nozzle exit velocity $8.6 \mathrm{~m} / \mathrm{s}$; peak cloud height upper bound $0.483 \mathrm{~m}$ (19 in.). Case ID 34E_4s2d2Yc_1. 

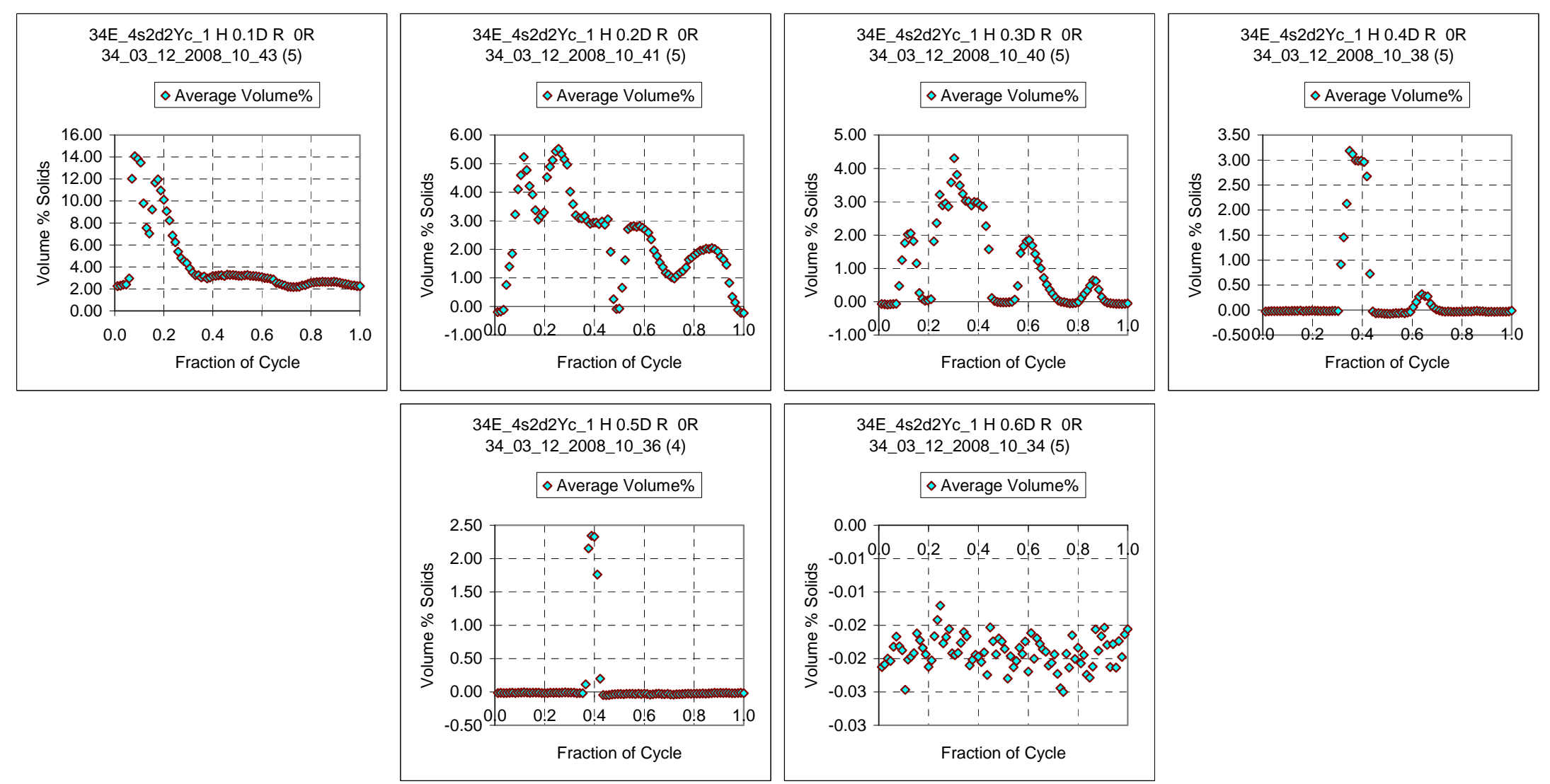

Figure C.31A. Case ID 34E_4s2d2Yc_1 Concentration Variation During the Cycle

Figure C.31 is the third of three profiles shown using simulant s2d2 in the mid-scale tank. The solids fraction is 0.005 , a decrease from 0.015 in the prior test. The duty cycle was $33.6 \%$, changed from $33.9 \%$ in the prior test, and the pulse volume fraction was 0.050 , no change from the prior test. The $\mathrm{U}_{\mathrm{CS}}$ velocity occurred at $8.6 \mathrm{~m} / \mathrm{s}$, a decrease from $9.8 \mathrm{~m} / \mathrm{s}$ in the prior test. The cloud height is $19.0 \mathrm{in}$., an increase from 11.0 in the prior test. 


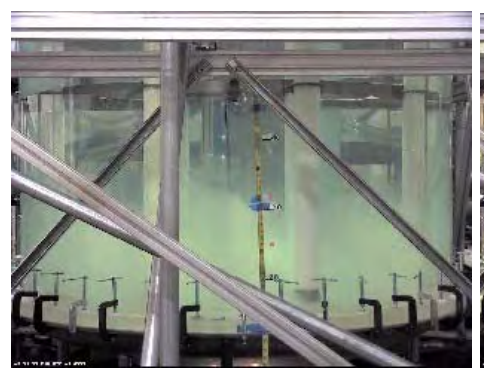

Maximum Cloud Height
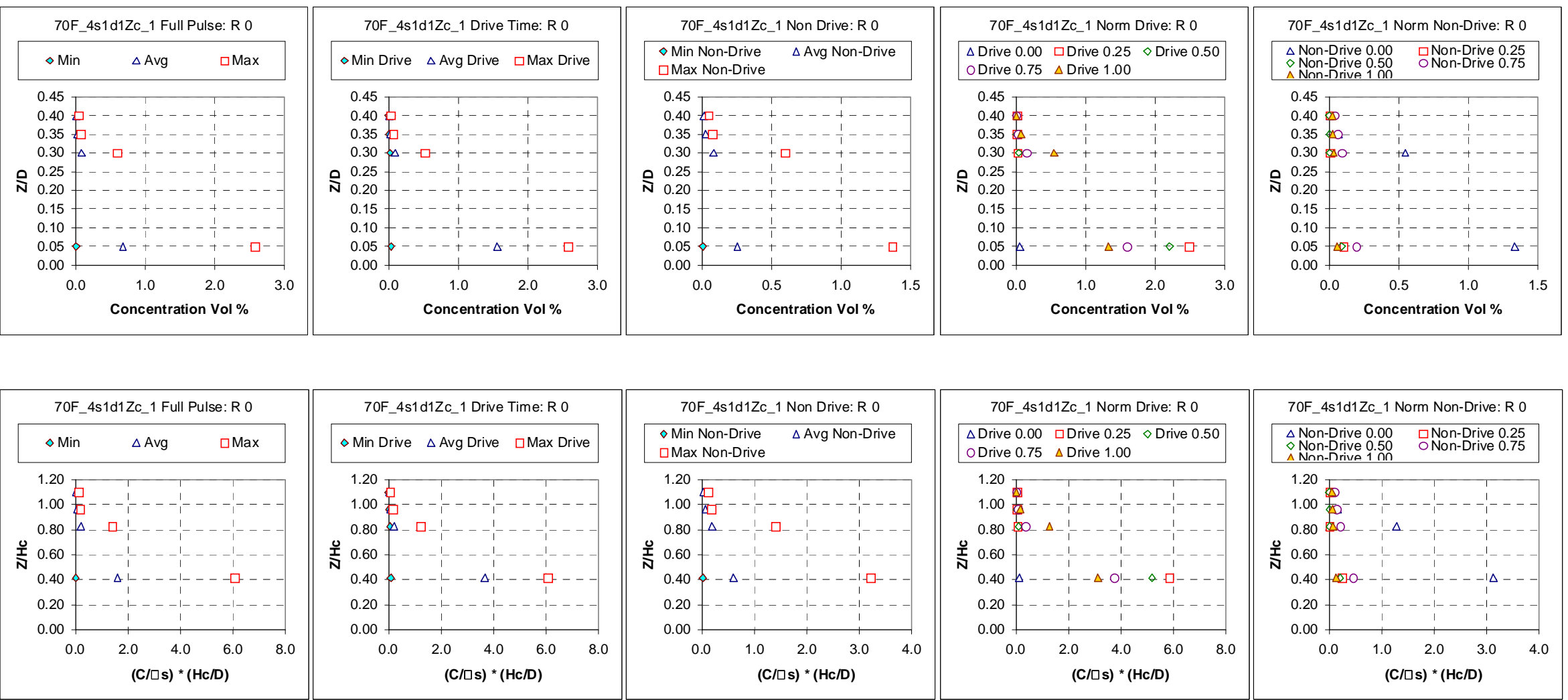

70F_4s1d1Zc_1 Norm Non-Drive: R 0 \begin{tabular}{|ll|}
\hline Non-Drive 0.00 & DNNon-Drive 0.25 \\
$\diamond$ Non-Drive 0.50 & ONon-Drive 0.75 \\
A Nnn-Drive 1 nn &
\end{tabular} 1.20

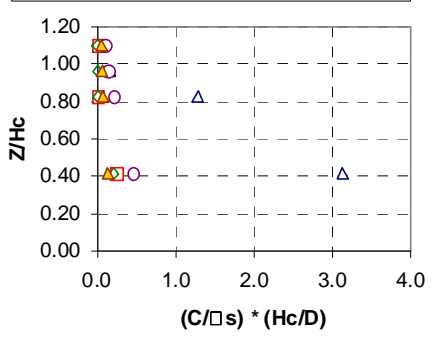

Figure C.32. 1.778-m- (70-in.-) diameter tank, 1.557-cm- (0.613-in.-) diameter nozzle; solids nominal diameter $166.4 \mu \mathrm{m}, 2.46$ g/cm ${ }^{3}$ density; 0.00155 nominal solids fraction; 33.2\% duty cycle, cycle time $45.4 \mathrm{~s}$, pulse volume fraction 0.050 , $\mathrm{U}_{\mathrm{CS}}$ velocity $6.7 \mathrm{~m} / \mathrm{s}$, target nozzle exit velocity $6.7 \mathrm{~m} / \mathrm{s}$; peak cloud height upper bound $0.660 \mathrm{~m}$ (26 in.). Case ID 70F_4s1d1Zc_1. 

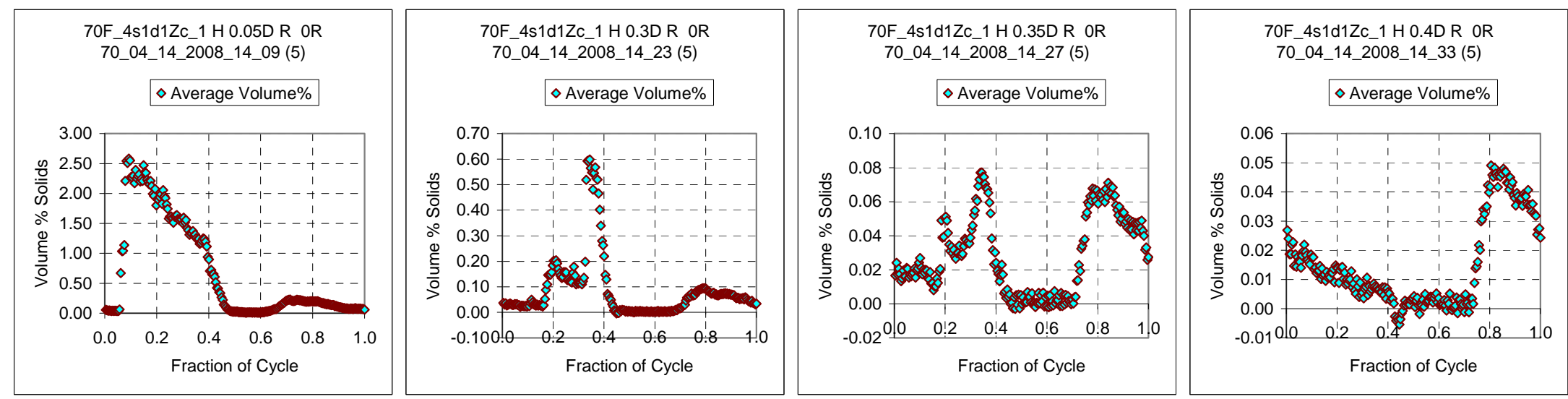

Figure C.32A. Case ID 70F_4s1d1Zc_1 Concentration Variation During the Cycle

Figure C.32 is the first of two profiles shown using simulant s1d1 in the large-scale tank with the flange and dish bottom. The solids fraction is 0.00155. The duty cycle was $33.2 \%$ and the pulse volume fraction was 0.050 . The $\mathrm{U}_{\mathrm{CS}}$ velocity occurred at $6.7 \mathrm{~m} / \mathrm{s}$. The cloud height is 26 in. Data 


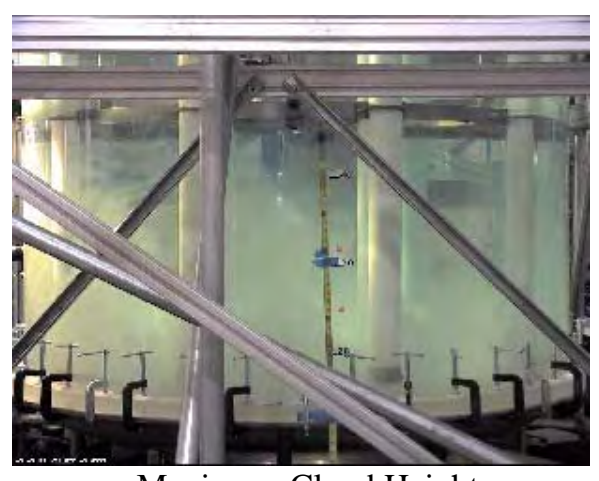

Maximum Cloud Height

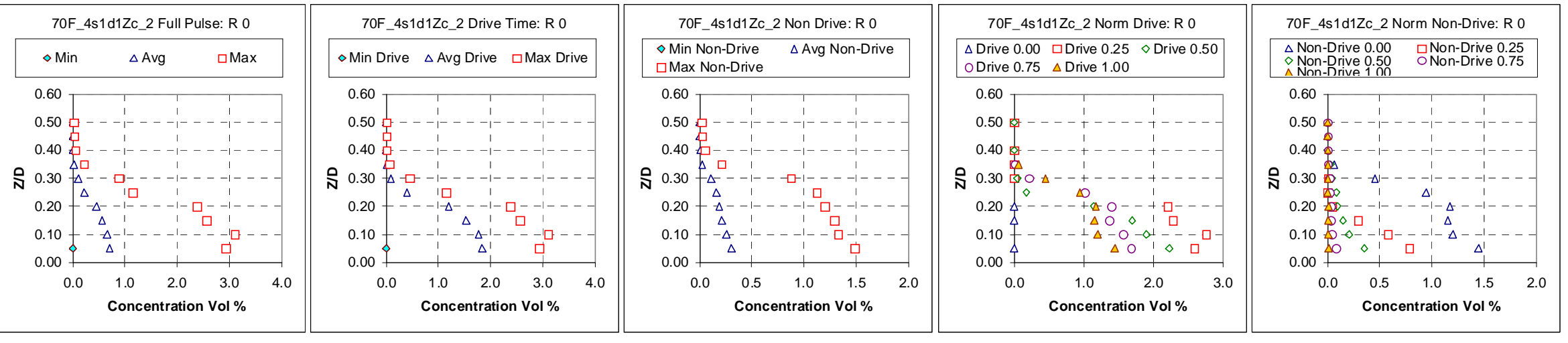
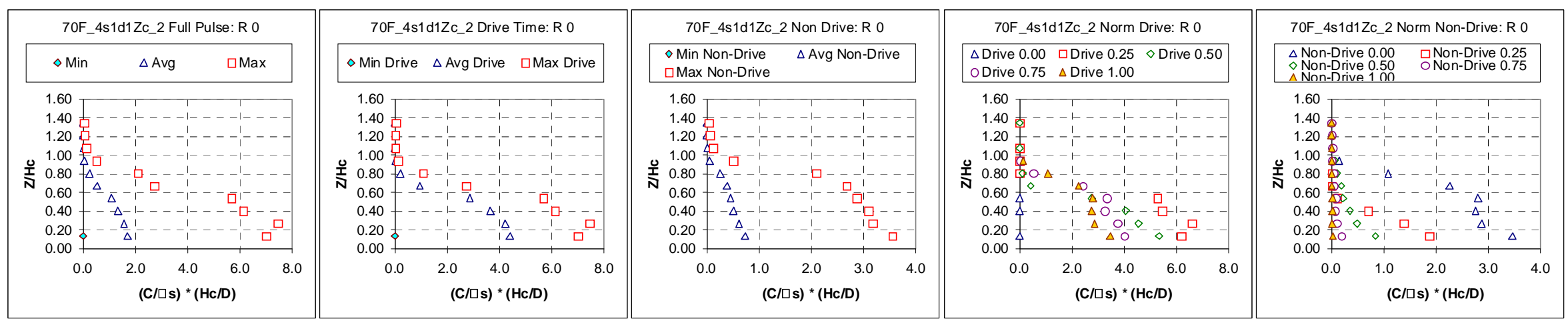

Figure C.33. 1.778-m- (70-in.-) diameter tank, 1.557-cm- (0.613-in.-) diameter nozzle; solids nominal diameter $166.4 \mu \mathrm{m}, 2.46 \mathrm{~g} / \mathrm{cm}^{3} \mathrm{density}$; 0.00155 nominal solids fraction; $33.5 \%$ duty cycle, cycle time $100.8 \mathrm{~s}$, pulse volume fraction 0.101 , $\mathrm{U}_{\mathrm{CS}}$ velocity $5.8 \mathrm{~m} / \mathrm{s}$, target nozzle exit velocity $5.8 \mathrm{~m} / \mathrm{s}$; peak cloud height upper bound $0.660 \mathrm{~m}$ (26 in.). Case ID 70F_4s1d1Zc_2. 

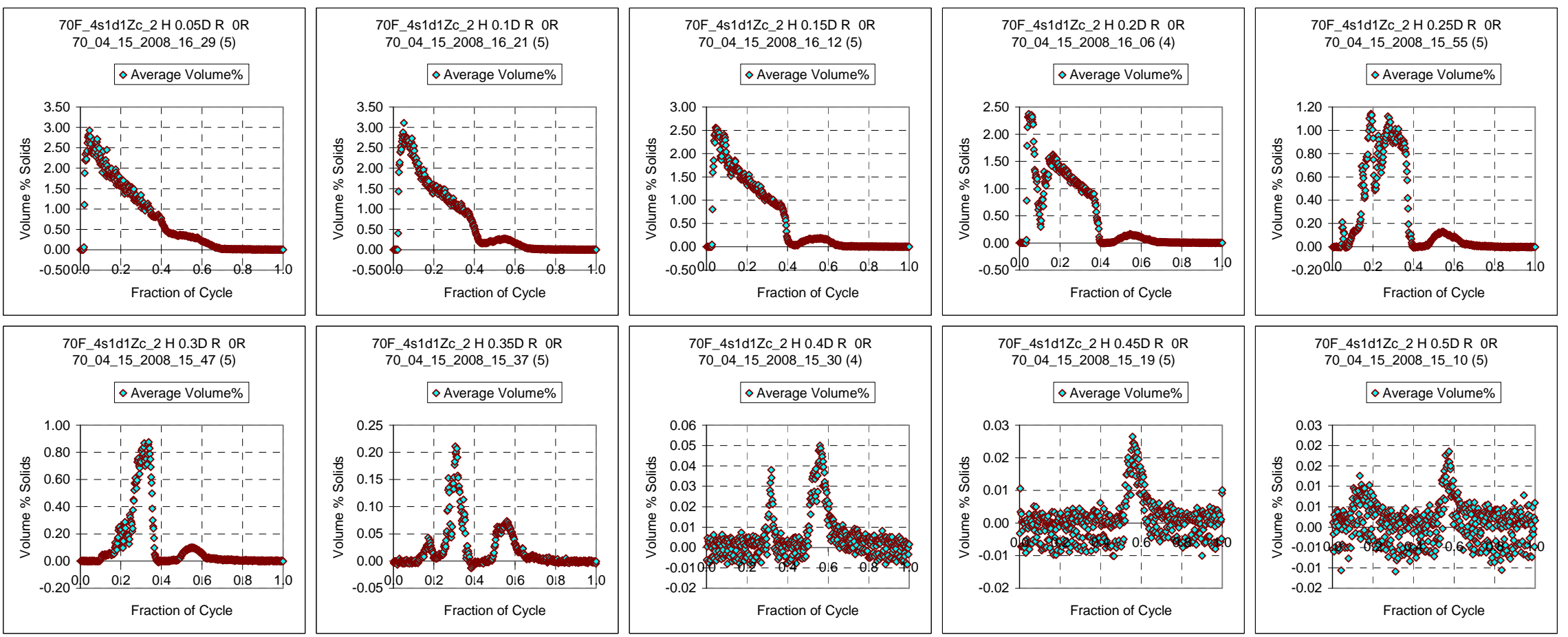

Figure C.33A. Case ID 70F_4s1d1Zc_2 Concentration Variation During the Cycle

Figure C.33 is the second of two profiles shown using simulant s1d1 in the large-scale tank with the flange and dish bottom. The solids fraction is 0.00155 , the same as in the prior test. The duty cycle was $33.5 \%$, unchanged from $33.2 \%$ in the prior test, and the pulse volume fraction was 0.10 , an increase from 0.050 in the prior test. The $U_{C s}$ velocity occurred at $5.8 \mathrm{~m} / \mathrm{s}$, a decrease from $6.7 \mathrm{~m} / \mathrm{s}$ in the prior test. The cloud height is 26 in., the same as in the prior test. The increased pulse volume fraction caused the $\mathrm{U}_{\mathrm{CS}}$ to decrease; however, the cloud height remained unchanged. 

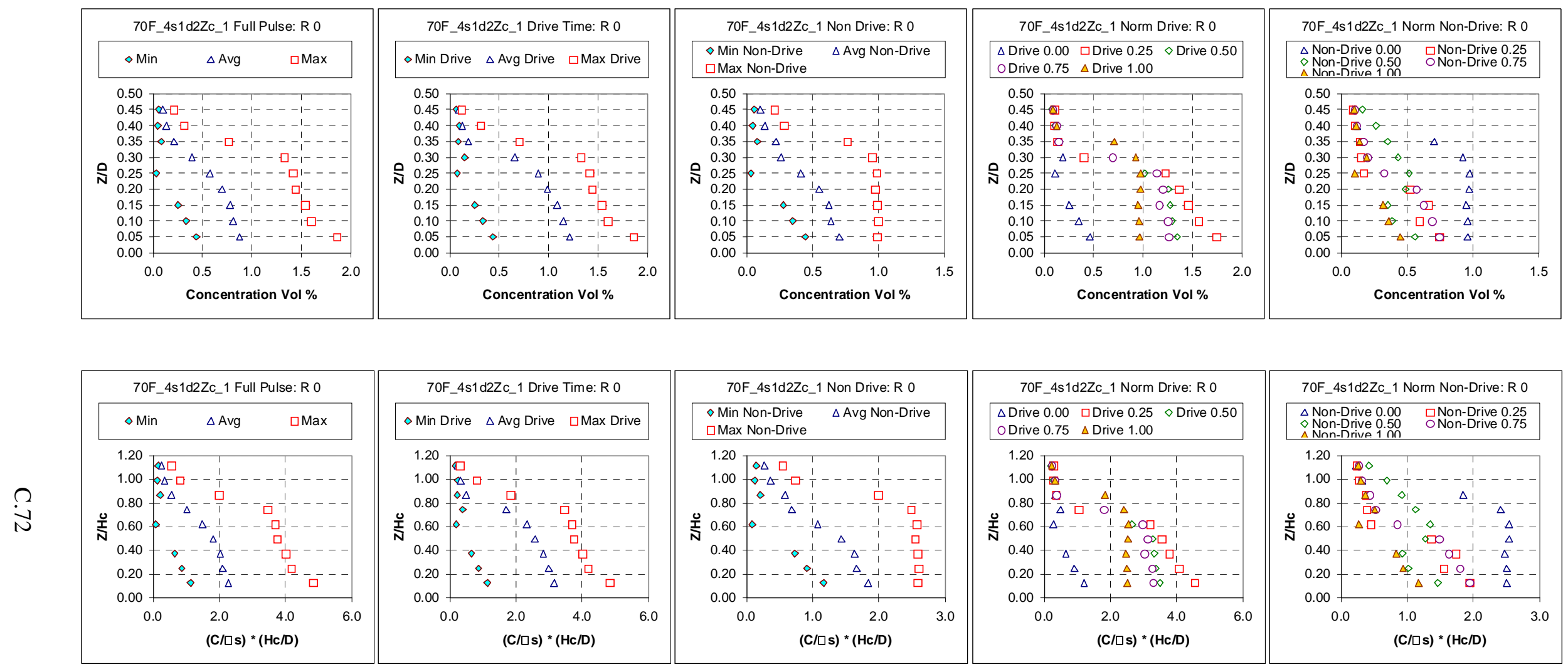

Figure C.34. 1.778-m- (70-in.-) diameter tank, 1.557-cm- (0.613-in.-) diameter nozzle; solids nominal diameter $69.3 \mu \mathrm{m}, 2.48 \mathrm{~g} / \mathrm{cm}^{3}$ density; 0.00155 nominal solids fraction; $33.6 \%$ duty cycle, cycle time $67.4 \mathrm{~s}$, pulse volume fraction 0.050 , $\mathrm{U}_{\mathrm{CS}}$ velocity $4.4 \mathrm{~m} / \mathrm{s}$, target nozzle exit velocity $4.4 \mathrm{~m} / \mathrm{s}$; peak cloud height upper bound $0.749 \mathrm{~m}$ (29.5 in.). Case ID 70F_4s1d2Zc_1. 

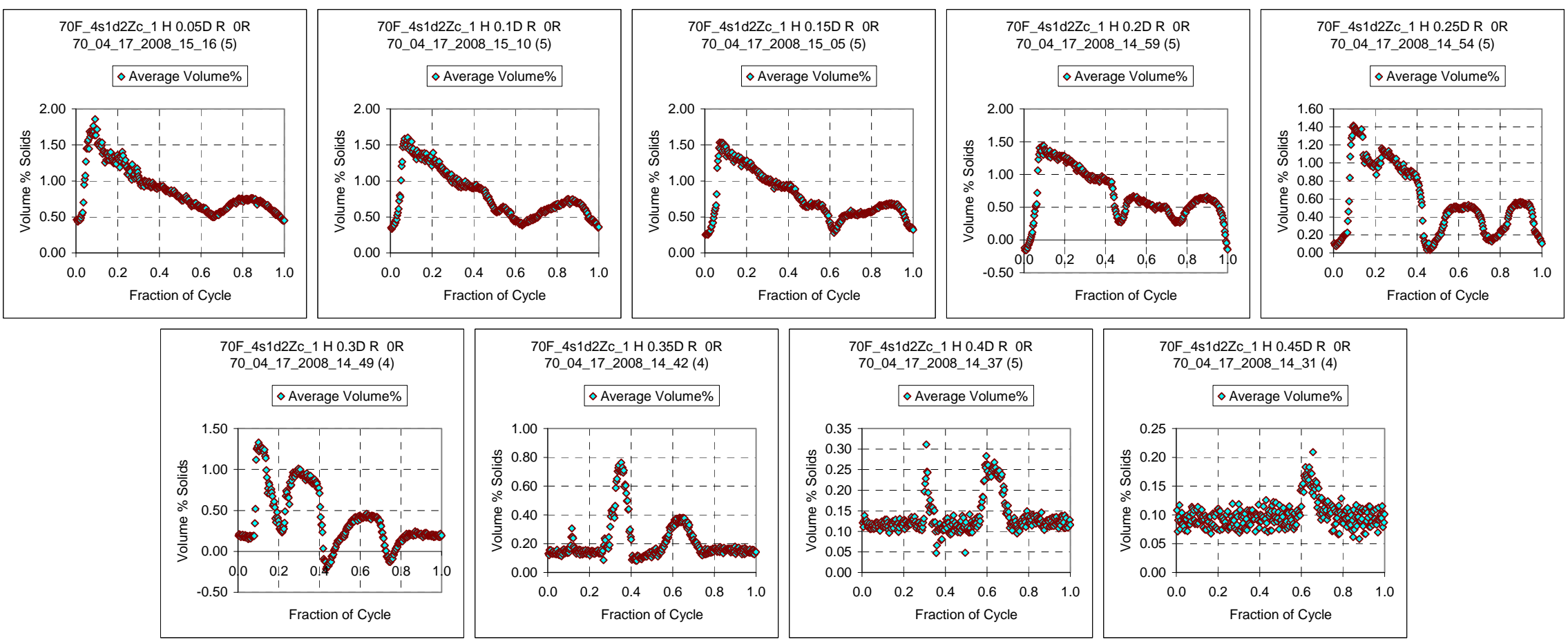

Figure C.34A. Case ID 70F_4s1d2Zc_1 Concentration Variation During the Cycle

Figure C.34 is the first of 12 profiles shown using simulant s1d2 in the large-scale tank with the flange and dish bottom. The solids fraction is 0.00155 , the same as in the prior test. The duty cycle was $33.6 \%$, unchanged from $33.2 \%$ in the prior test, and the pulse volume fraction was 0.050 , an increase from 0.050 in the prior test. The $U_{C S}$ velocity occurred at $4.4 \mathrm{~m} / \mathrm{s}$, a decrease from $6.7 \mathrm{~m} / \mathrm{s}$ in the prior test. The cloud height is 29.5 in., the same as in the prior test. The increased pulse volume fraction caused the $\mathrm{U}_{\mathrm{CS}}$ to decrease; however, the cloud height remained unchanged. 

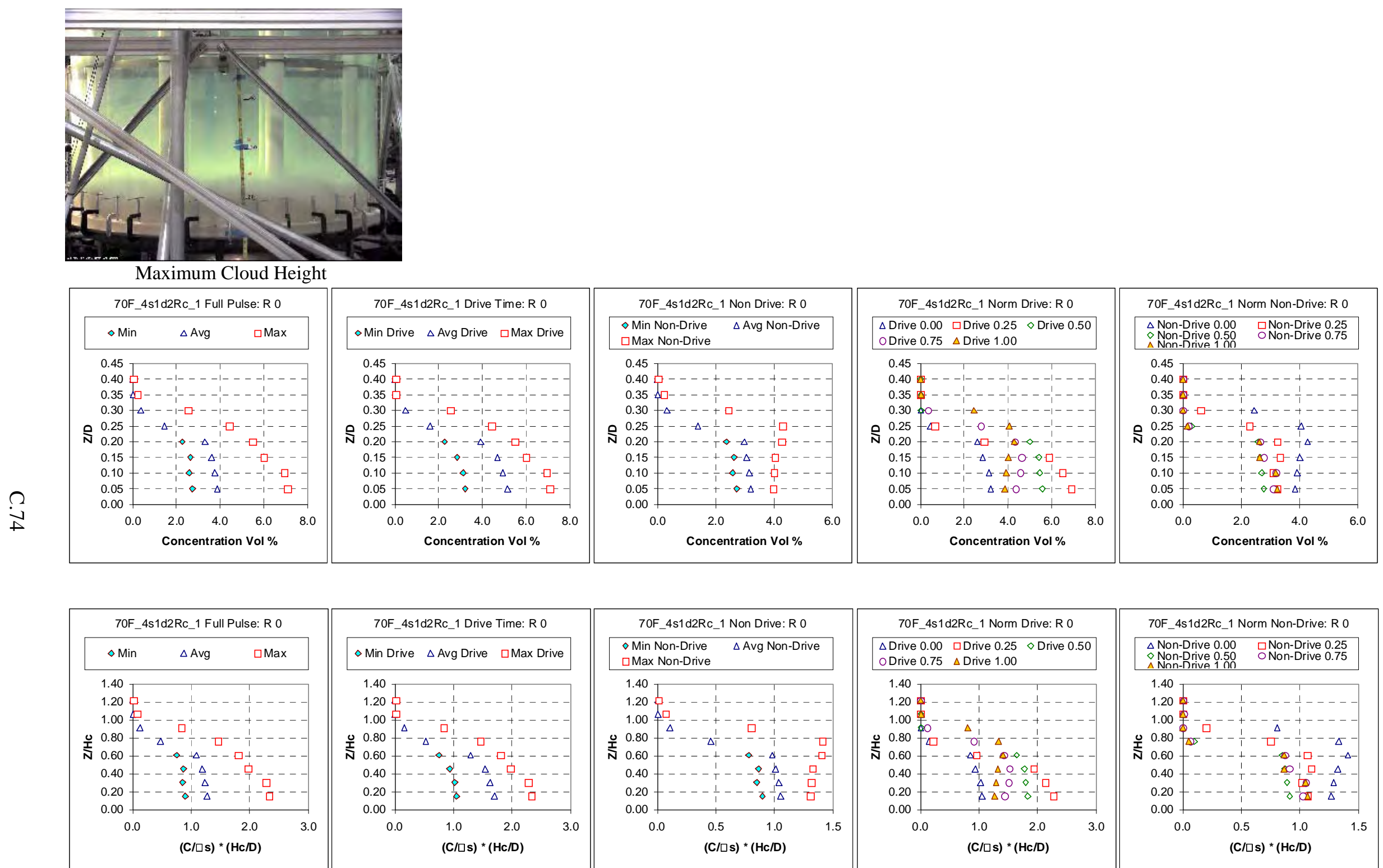

Figure C.35. 1.778-m- (70-in.-) diameter tank, 1.557-cm- (0.613-in.-) diameter nozzle; solids nominal diameter $69.3 \mu \mathrm{m}, 2.48$ g/cm³ density; 0.01 nominal solids fraction; $33.9 \%$ duty cycle, cycle time $44.6 \mathrm{~s}$, pulse volume fraction 0.050 , $\mathrm{U}_{\mathrm{CS}}$ velocity $6.6 \mathrm{~m} / \mathrm{s}$, target nozzle exit velocity $6.6 \mathrm{~m} / \mathrm{s}$; peak cloud height upper bound $0.610 \mathrm{~m}$ (24 in.). Case ID 70F_4s1d2Rc_1. 

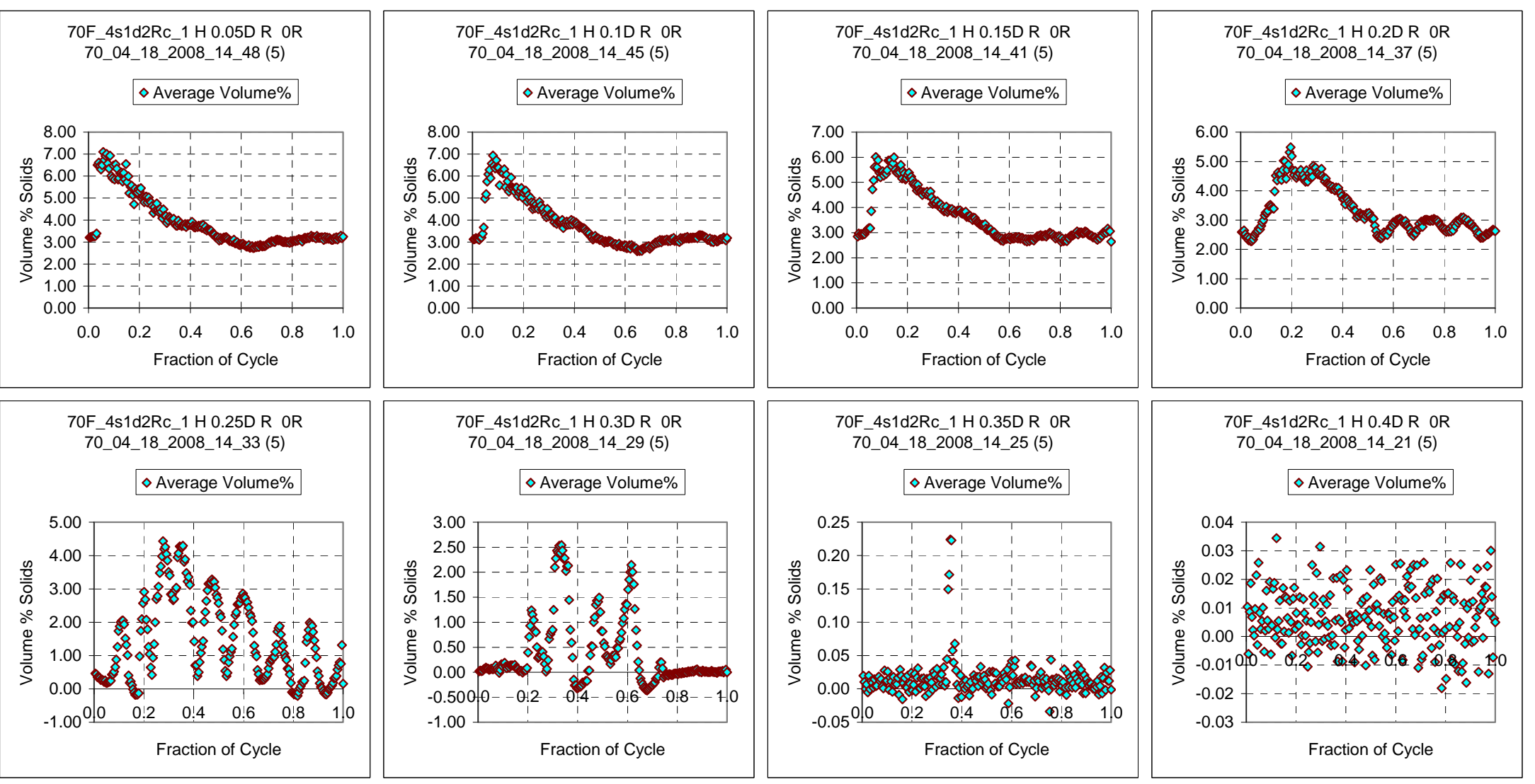

Figure C.35A. Case ID 70F_4s1d2Rc_1 Concentration Variation During the Cycle

Figure C. 35 is the second of 12 profiles shown using simulant s1d2 in the large-scale tank with the flange and dish bottom. The solids fraction is 0.01 , increased from the prior test. The duty cycle was $34 \%$, unchanged from $34.6 \%$ in the prior test , and the pulse volume fraction was 0.050 , the same as in the prior test. The $U_{\mathrm{CS}}$ velocity occurred at $4.4 \mathrm{~m} / \mathrm{s}$, a decrease from $5.8 \mathrm{~m} / \mathrm{s}$ in the prior test. The cloud height is $24 \mathrm{in}$., a decrease from, $29.5 \mathrm{in}$. in the prior test. The increased concentration caused the $\mathrm{U}_{\mathrm{CS}}$ to decrease; however, the cloud height remained unchanged. 

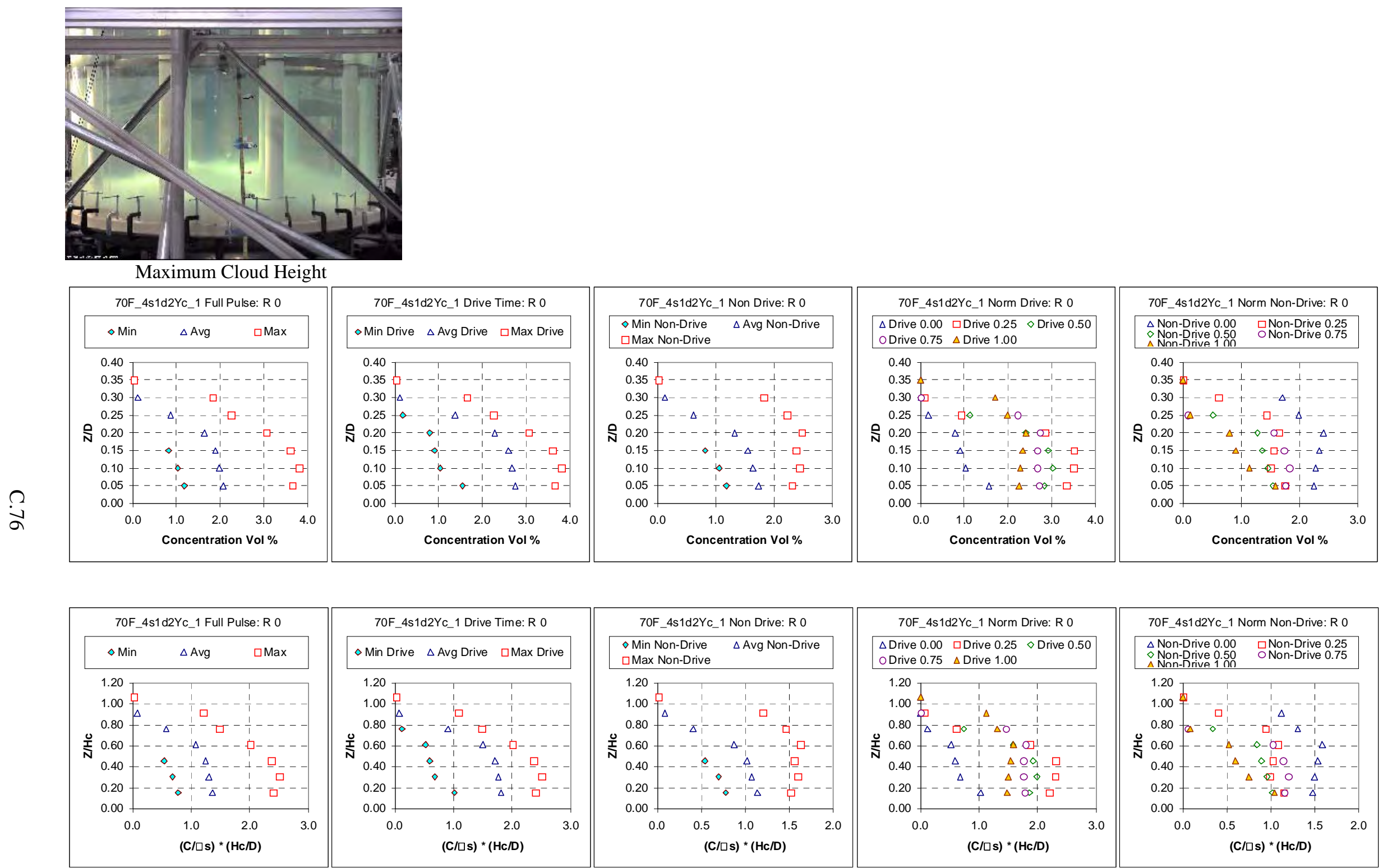

Figure C.36. 1.778-m- (70-in.-) diameter tank, 1.557-cm- (0.613-in.-) diameter nozzle; solids nominal diameter $69.3 \mu \mathrm{m}, 2.48$ g/cm ${ }^{3}$ density; 0.005 nominal solids fraction; $33.5 \%$ duty cycle, cycle time $51.0 \mathrm{~s}$, pulse volume fraction 0.050 , $\mathrm{U}_{\mathrm{CS}}$ velocity $5.8 \mathrm{~m} / \mathrm{s}$, target nozzle exit velocity $5.8 \mathrm{~m} / \mathrm{s}$; peak cloud height upper bound $0.597 \mathrm{~m}$ (23.5 in.). Case ID 70F_4s1d2Yc_1. 

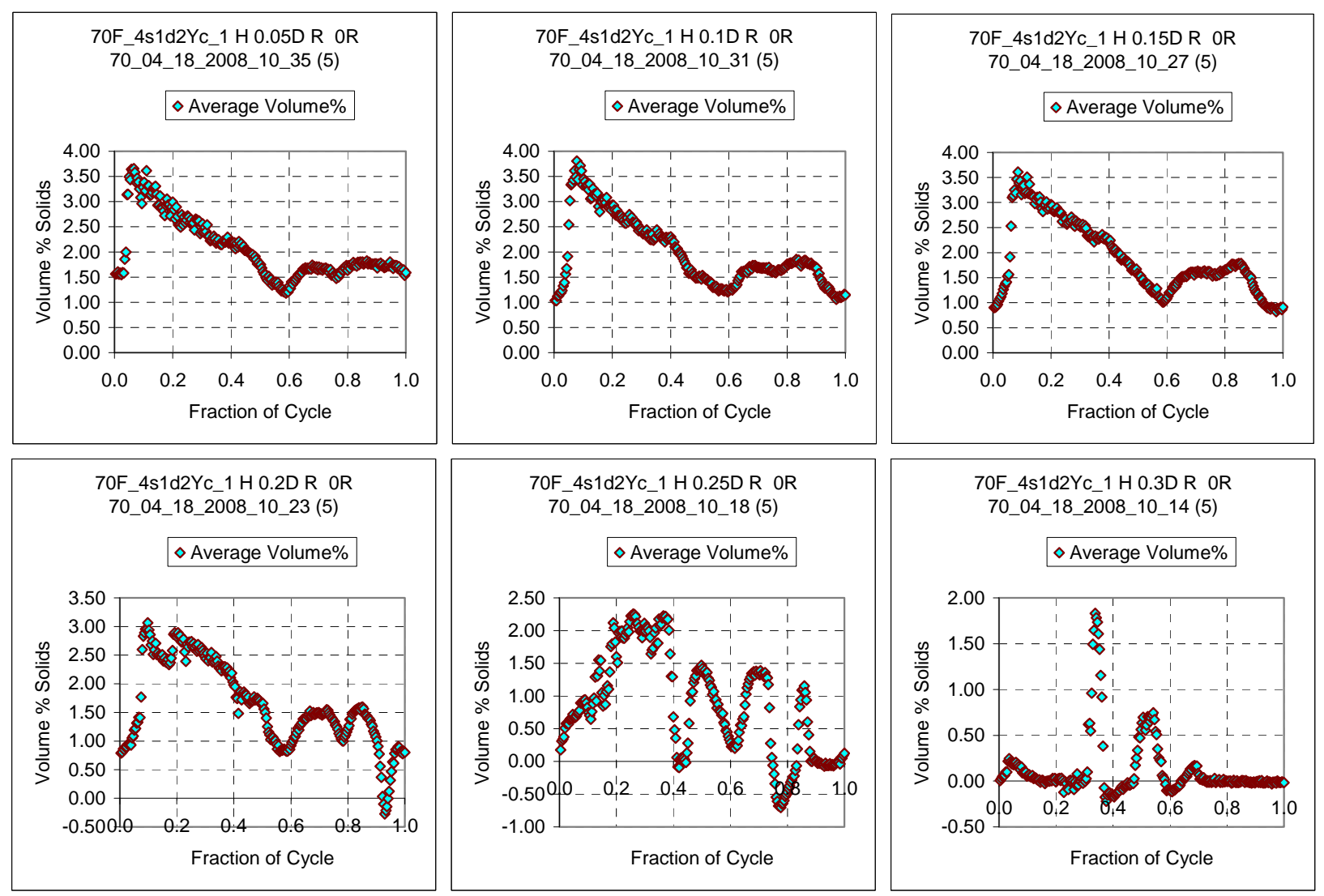

Figure C.36A. Case ID 70F_4s1d2Yc_1 Concentration Variation During the Cycle

Figure C.36 is the third of 12 profiles shown using simulant s1d2 in the large-scale tank with the flange and dish bottom. The solids fraction is 0.005 , decreased from the prior test. The duty cycle was $33.5 \%$, unchanged from $34 \%$ in the prior test, and the pulse volume fraction was 0.050 , the same as in the prior test. The $U_{C S}$ velocity occurred at $5.8 \mathrm{~m} / \mathrm{s}$, a decrease from $6.6 \mathrm{~m} / \mathrm{s}$ in the prior test. The cloud height is 23.5 in., a slight decrease from $24 \mathrm{in}$. in the prior test. The decreased concentration caused the $\mathrm{U}_{\mathrm{CS}}$ to decrease; however, the cloud height remained relatively constant. 


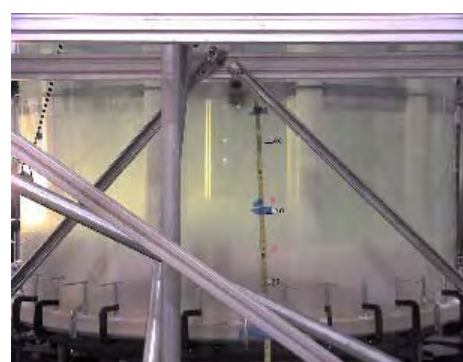

Maximum Cloud Height
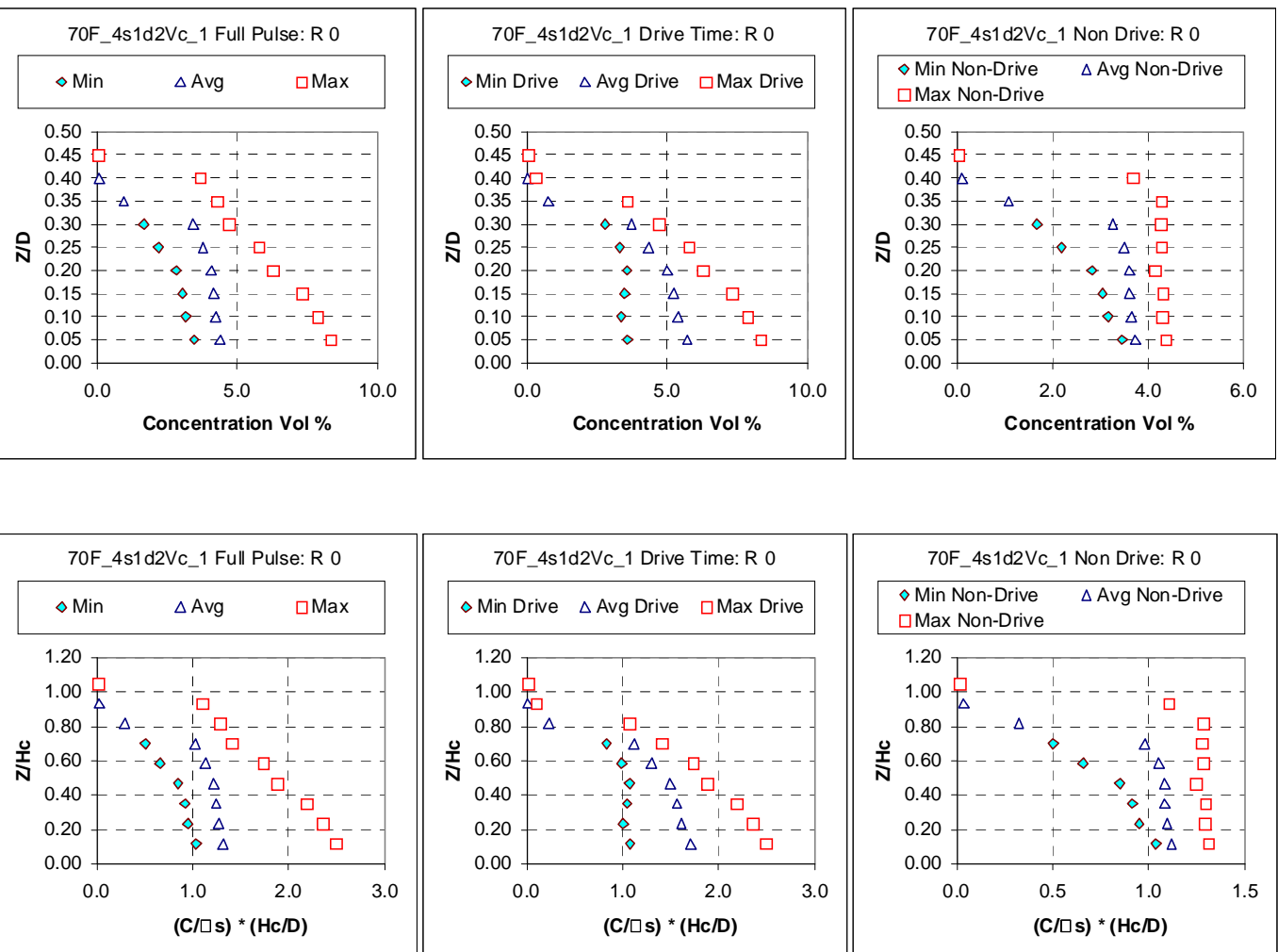

70F_4s1d2Vc_1 Drive Time: R 0
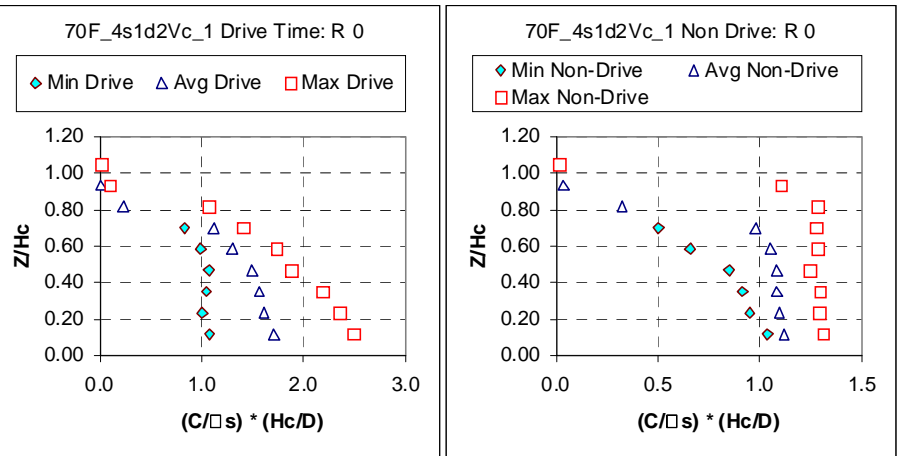

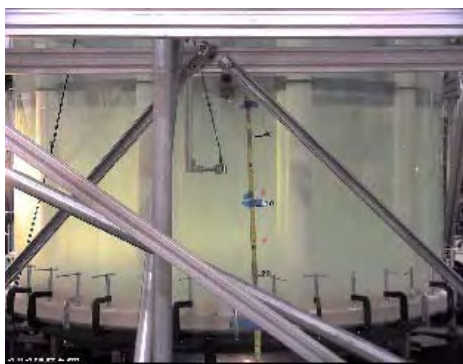

End of Drive
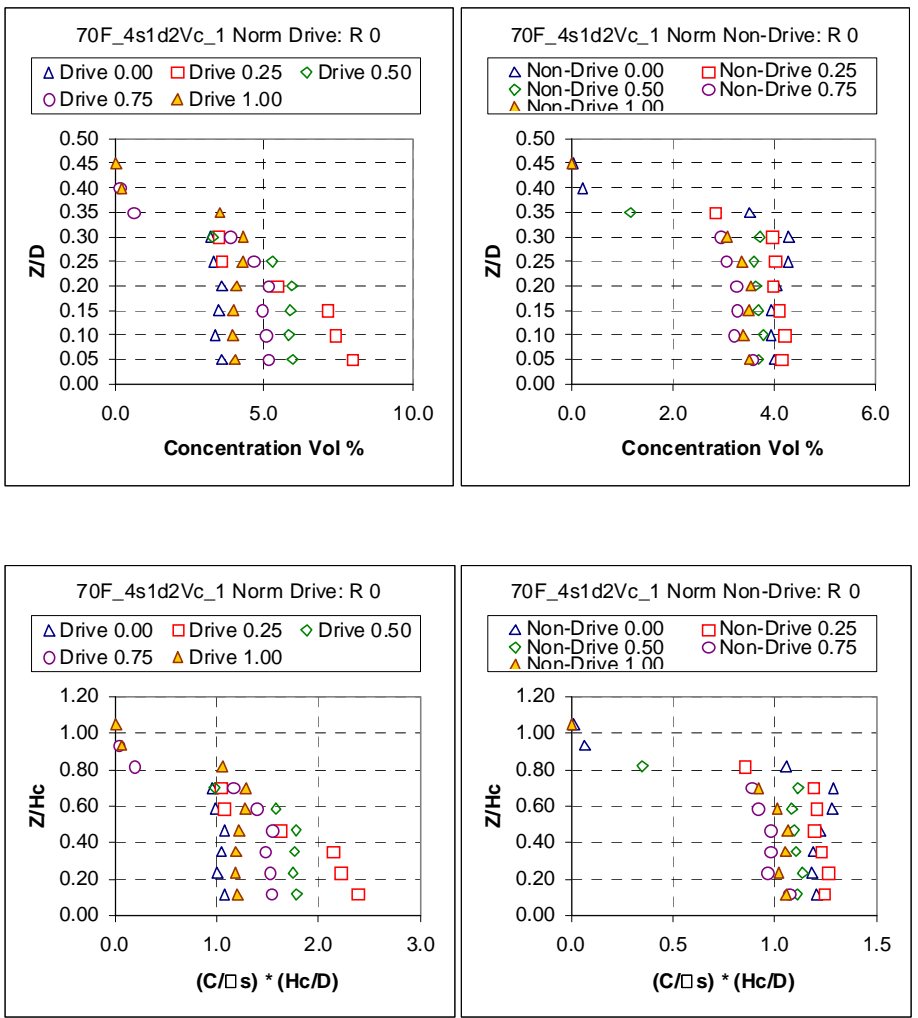

Figure C.37. 1.778-m- (70-in.-) diameter tank, 1.557-cm- (0.613-in.-) diameter nozzle; solids nominal diameter $69.3 \mu \mathrm{m}, 2.48 \mathrm{~g} / \mathrm{cm}^{3}$ density; 0.0143 nominal solids fraction; $33.6 \%$ duty cycle, cycle time $42.2 \mathrm{~s}$, pulse volume fraction $0.050, \mathrm{U}_{\mathrm{CS}}$ velocity $7.1 \mathrm{~m} / \mathrm{s}$, target nozzle exit velocity $7.1 \mathrm{~m} / \mathrm{s}$; peak cloud height upper bound $0.787 \mathrm{~m}$ (31 in.). Case ID 70F_4s1d2Vc_1. 

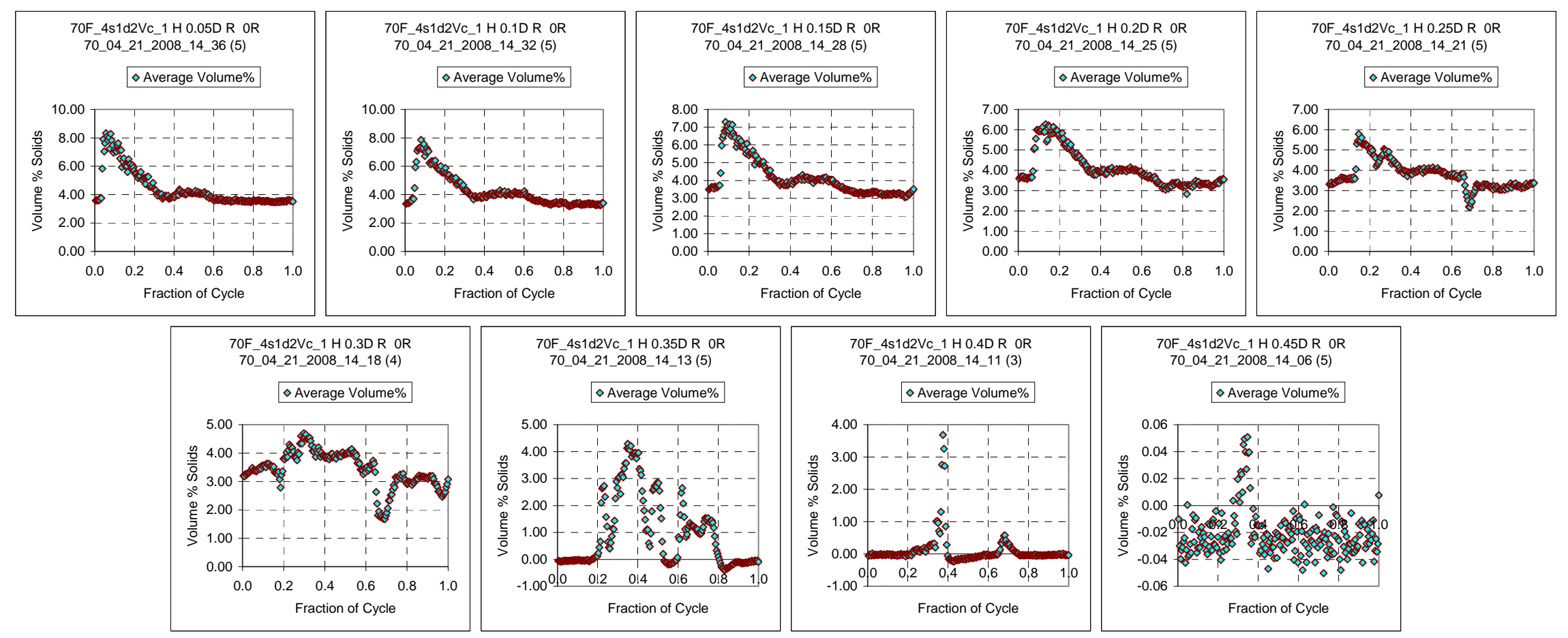

Figure C.37A. Case ID 70F_4s1d2Vc_1 Concentration Variation During the Cycle

Figure C.37 is the fourth of 12 profiles shown using simulant s1d2 in the large-scale tank with the flange and dish bottom. Figures C.37, C.38, and C.39 are a group of three profiles taken at the same flow conditions and differing radial locations. Figure C.37 shows a profile at the center of the tank with $\mathrm{R}=0$. The solids fraction is 0.0143 . The duty cycle is $33.6 \%$, unchanged from $34 \%$ in the prior test, and the pulse volume fraction is 0.050 . The $\mathrm{U}_{\mathrm{CS}}$ velocity occurred at $7.1 \mathrm{~m} / \mathrm{s}$. The cloud height is $31 \mathrm{in}$. When the radial profiles are compared the profile is at a relatively constant concentration to a height of $\mathrm{Z} / \mathrm{D}=0.3$ with concentrations of $\sim 4 \mathrm{vol} \%$ solids at $\mathrm{R}=0$ and $\mathrm{R}=0.5$ and $\sim 3.5 \mathrm{vol} \%$ solids at $\mathrm{R}=0.9$. This shows that the concentration in the tank is relatively constant in these three radial locations. 

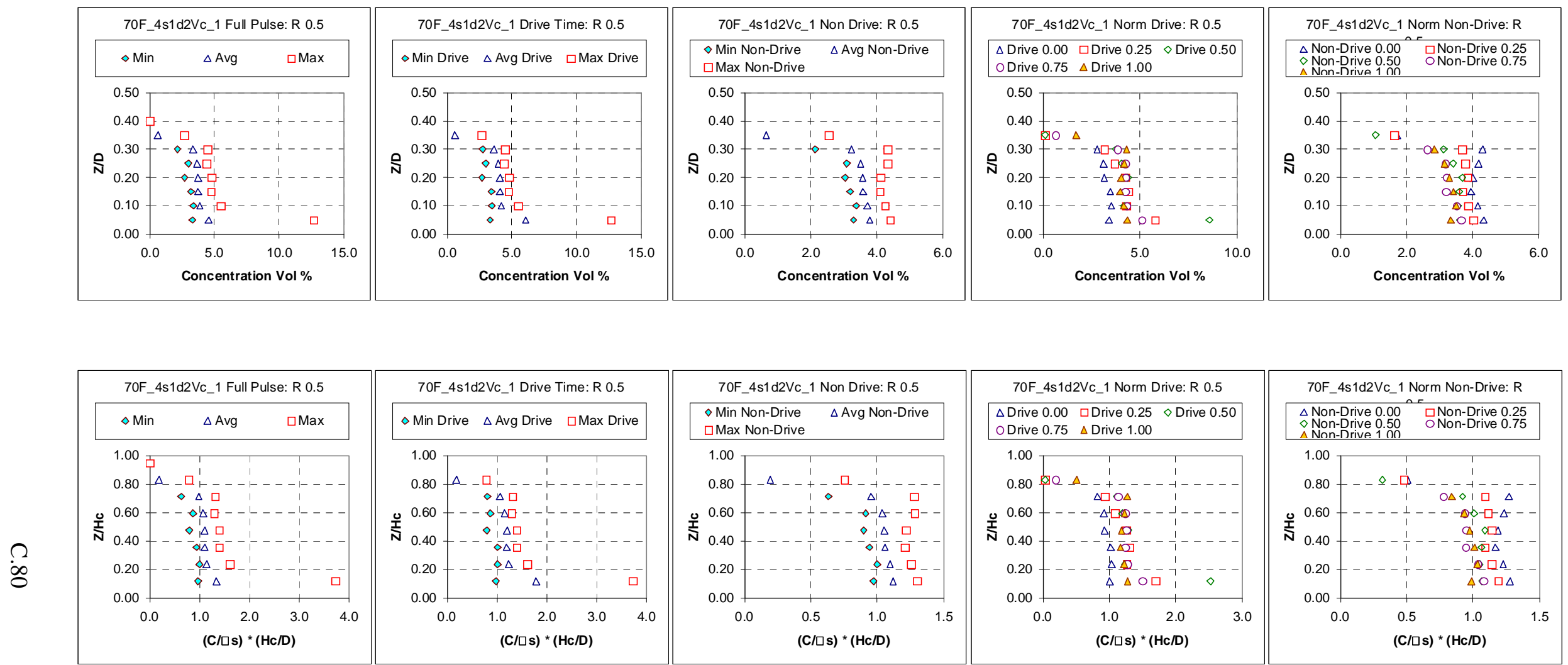

Figure C.38. 1.778-m- (70-in.-) diameter tank, 1.557-cm- (0.613-in.-) diameter nozzle; solids nominal diameter $69.3 \mu \mathrm{m}, 2.48 \mathrm{~g} / \mathrm{cm}^{3} \mathrm{density}$; 0.0143 nominal solids fraction; $33.6 \%$ duty cycle, cycle time $42.2 \mathrm{~s}$, pulse volume fraction $0.050, \mathrm{U}_{\mathrm{CS}}$ velocity $7.1 \mathrm{~m} / \mathrm{s}$, target nozzle exit velocity $7.1 \mathrm{~m} / \mathrm{s}$; peak cloud height upper bound $0.787 \mathrm{~m}$ (31 in.). Case ID 70F_4s1d2Vc_1. 

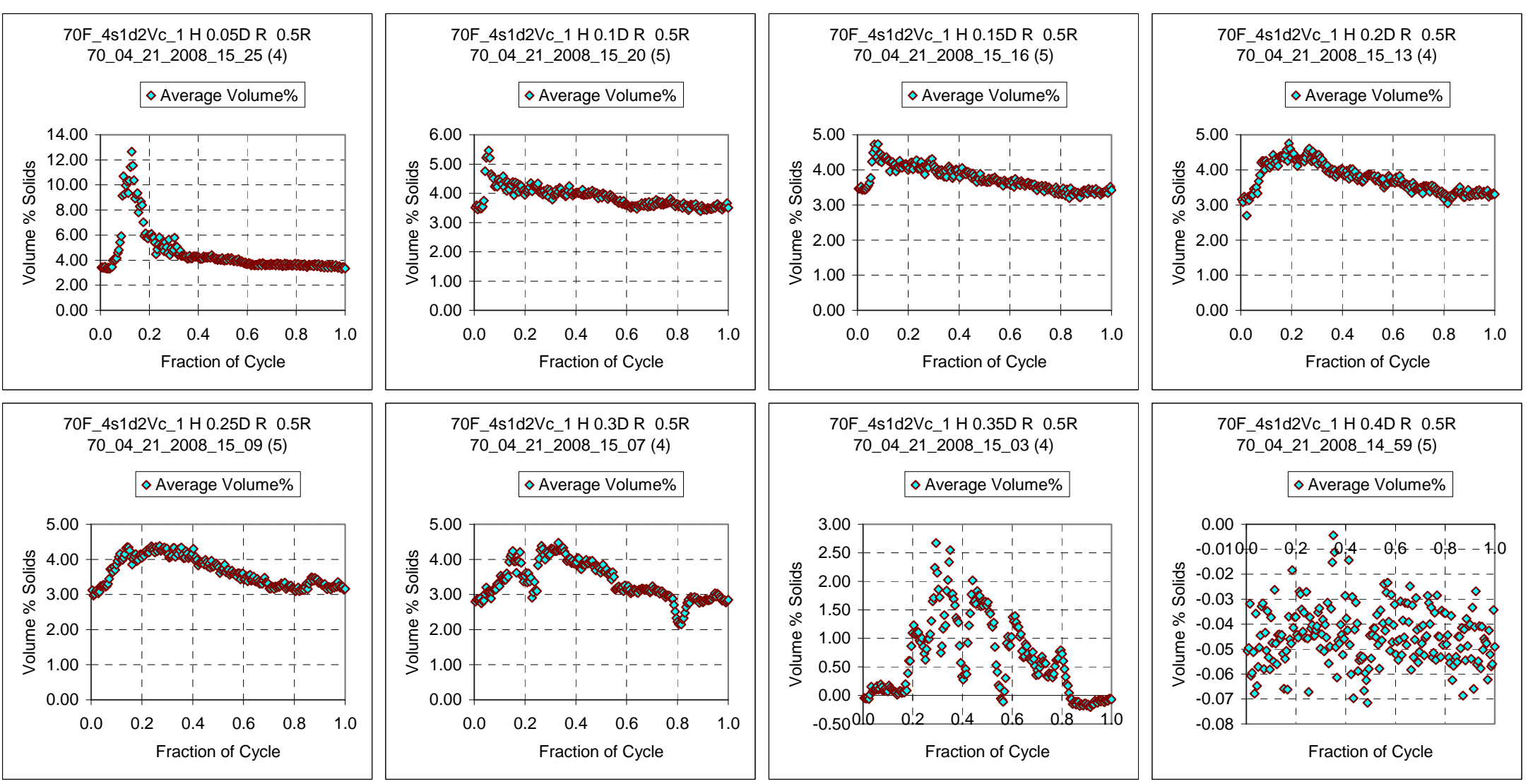

Figure C.38A. Case ID 70F_4s1d2Vc_1 Concentration Variation During the Cycle 

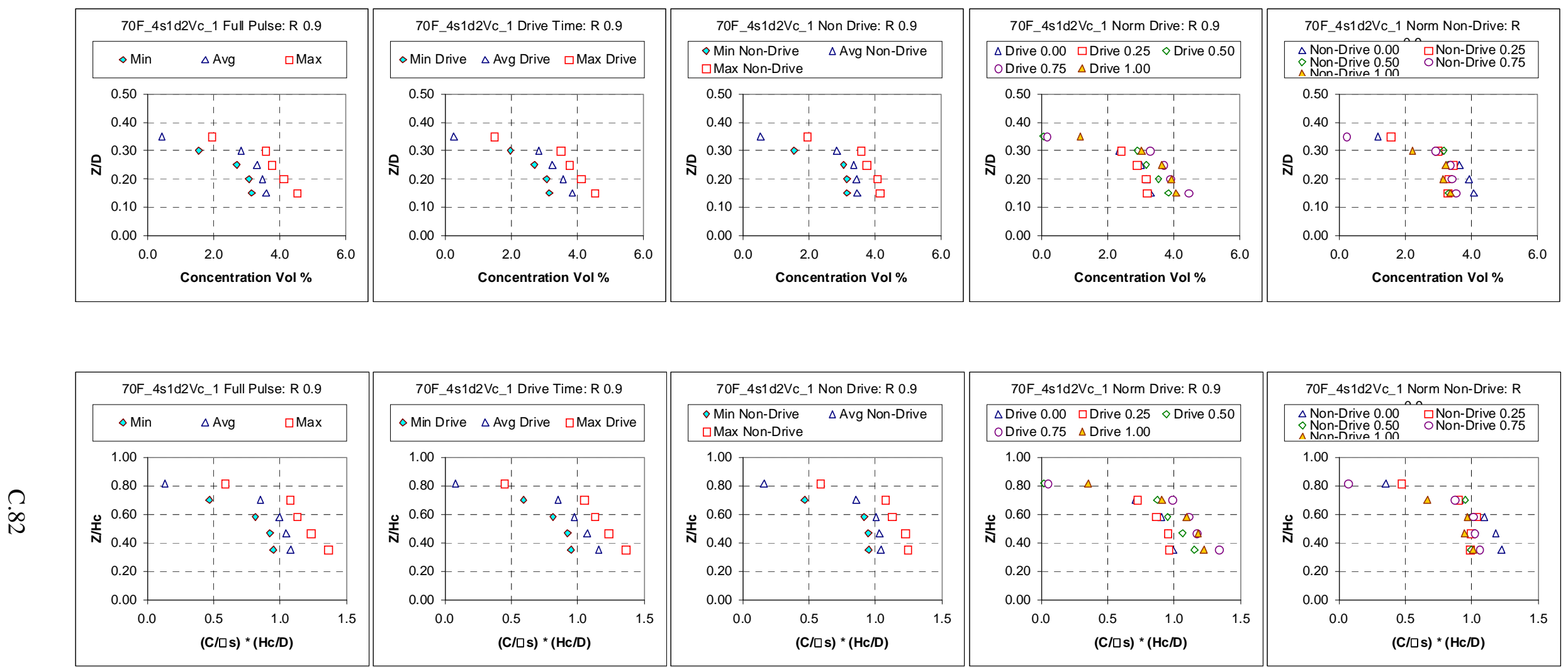

Figure C.39. 1.778-m- (70-in.-) diameter tank, 1.557-cm- (0.613-in.-) diameter nozzle; solids nominal diameter $69.3 \mu \mathrm{m}, 2.48 \mathrm{~g} / \mathrm{cm}^{3} \mathrm{density}$; 0.0143 nominal solids fraction; $33.6 \%$ duty cycle, cycle time $42.2 \mathrm{~s}$, pulse volume fraction $0.050, \mathrm{U}_{\mathrm{CS}}$ velocity $7.1 \mathrm{~m} / \mathrm{s}$, target nozzle exit velocity $7.1 \mathrm{~m} / \mathrm{s}$; peak cloud height upper bound $0.787 \mathrm{~m}$ (31 in.). Case ID 70F_4s1d2Vc_1. 

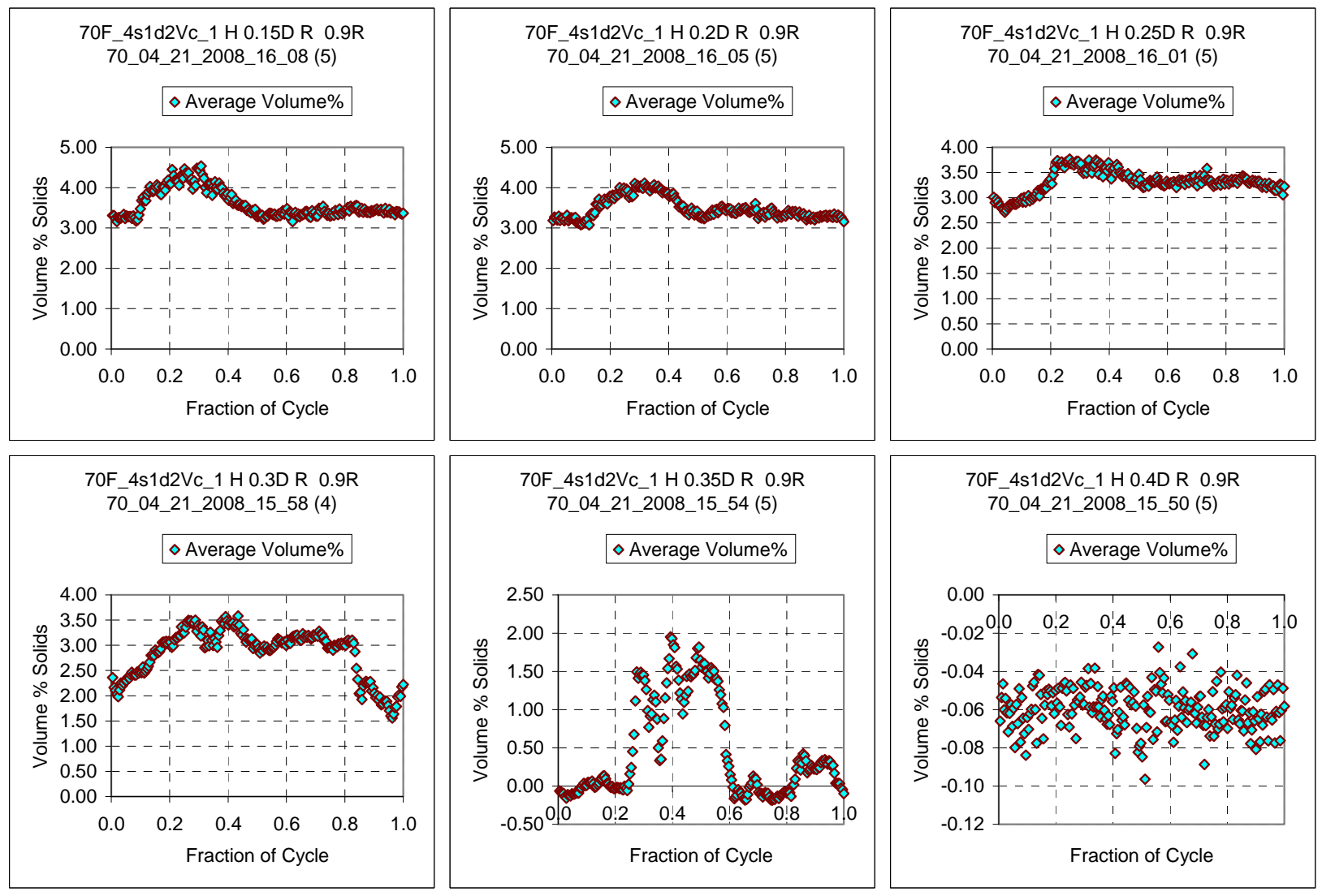

Figure C.39A. Case ID 70F_4s1d2Vc_1 Concentration Variation During the Cycle 


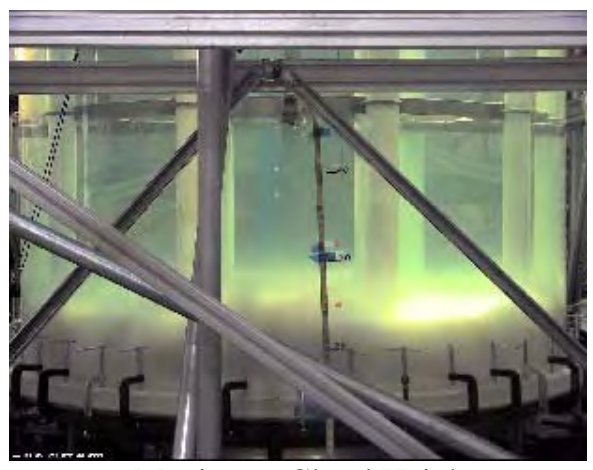

Maximum Cloud Height

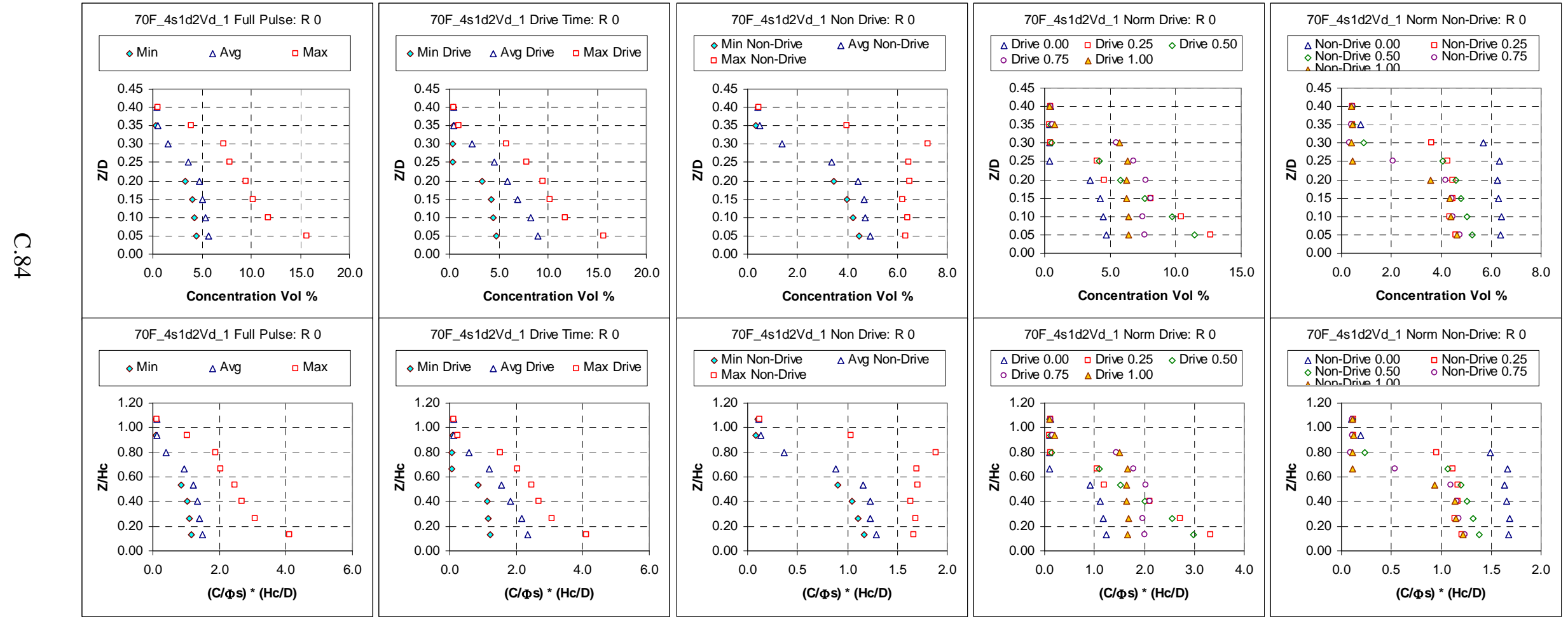

Figure C.40. 1.778-m- (70-in.-) diameter tank, 1.557-cm- (0.613-in.-) diameter nozzle; solids nominal diameter $69.3 \mu \mathrm{m}, 2.48$ g/cm³ density; 0.0143 nominal solids fraction; $18.7 \%$ duty cycle, cycle time $56.4 \mathrm{~s}$, pulse volume fraction 0.050 , $\mathrm{U}_{\mathrm{CS}}$ velocity $9.8 \mathrm{~m} / \mathrm{s}$, target nozzle exit velocity $9.6 \mathrm{~m} / \mathrm{s}$; peak cloud height upper bound $0.673 \mathrm{~m}$ (26.5 in.). Case ID 70F_4s1d2Vd_1. 

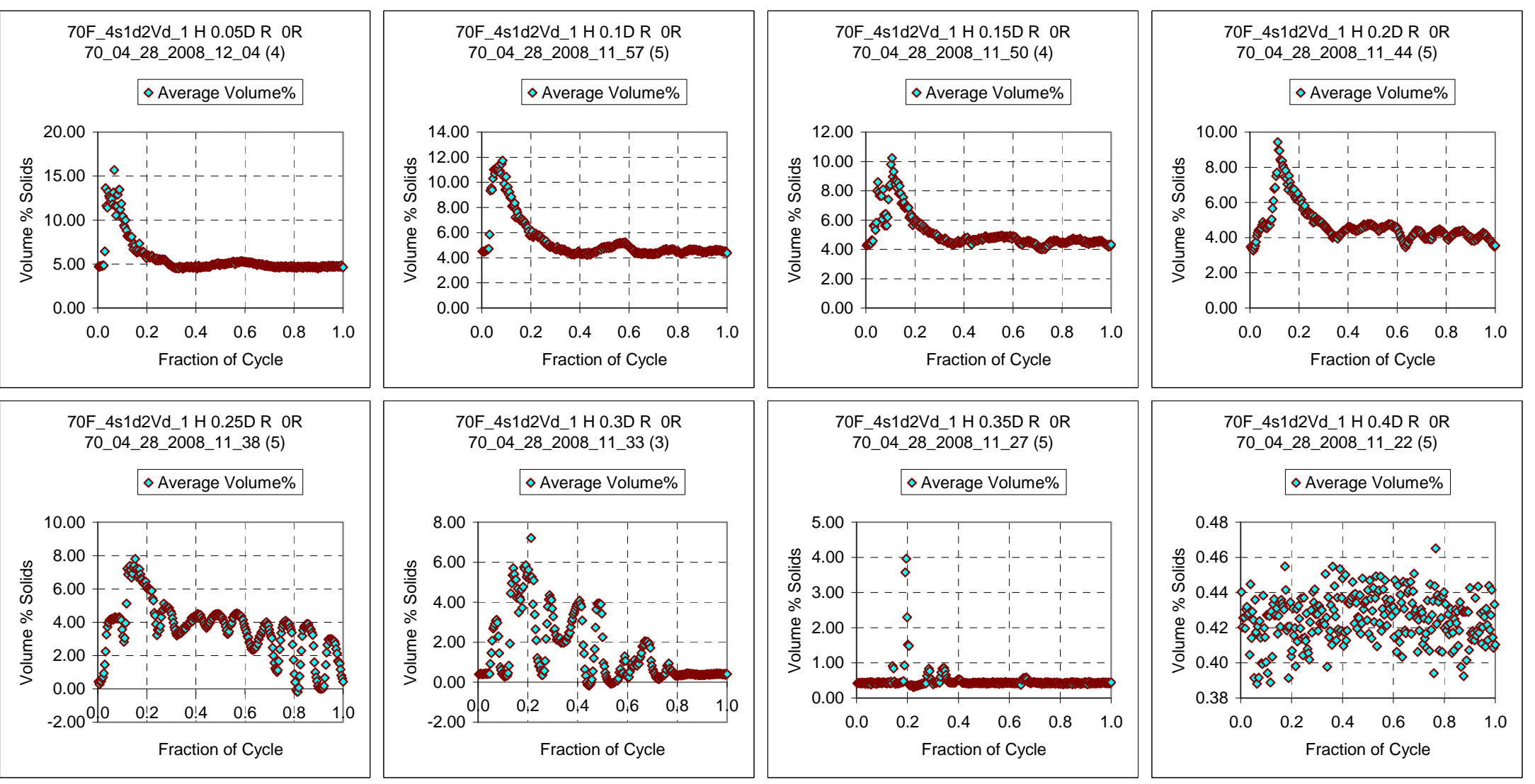

Figure C.40A. Case ID 70F_4s1d2Vd_1 Concentration Variation During the Cycle

Figure C.40 is the seventh of 12 profiles shown using simulant s1d2 in the large-scale tank with the flange and dish bottom. The solids fraction is 0.0143 . The duty cycle is $18.7 \%$. The pulse volume fraction is 0.050 . The $\mathrm{U}_{\mathrm{CS}}$ velocity occurred at $9.8 \mathrm{~m} / \mathrm{s}$. The measurements were taken at a velocity of $9.6 \mathrm{~m} / \mathrm{s}$, slightly below $U_{\mathrm{CS}}$. The cloud height is $26.5 \mathrm{in}$. From the concentration profile the average concentration as a function of elevation and the minimum concentration as a function of elevation are quite similar. 


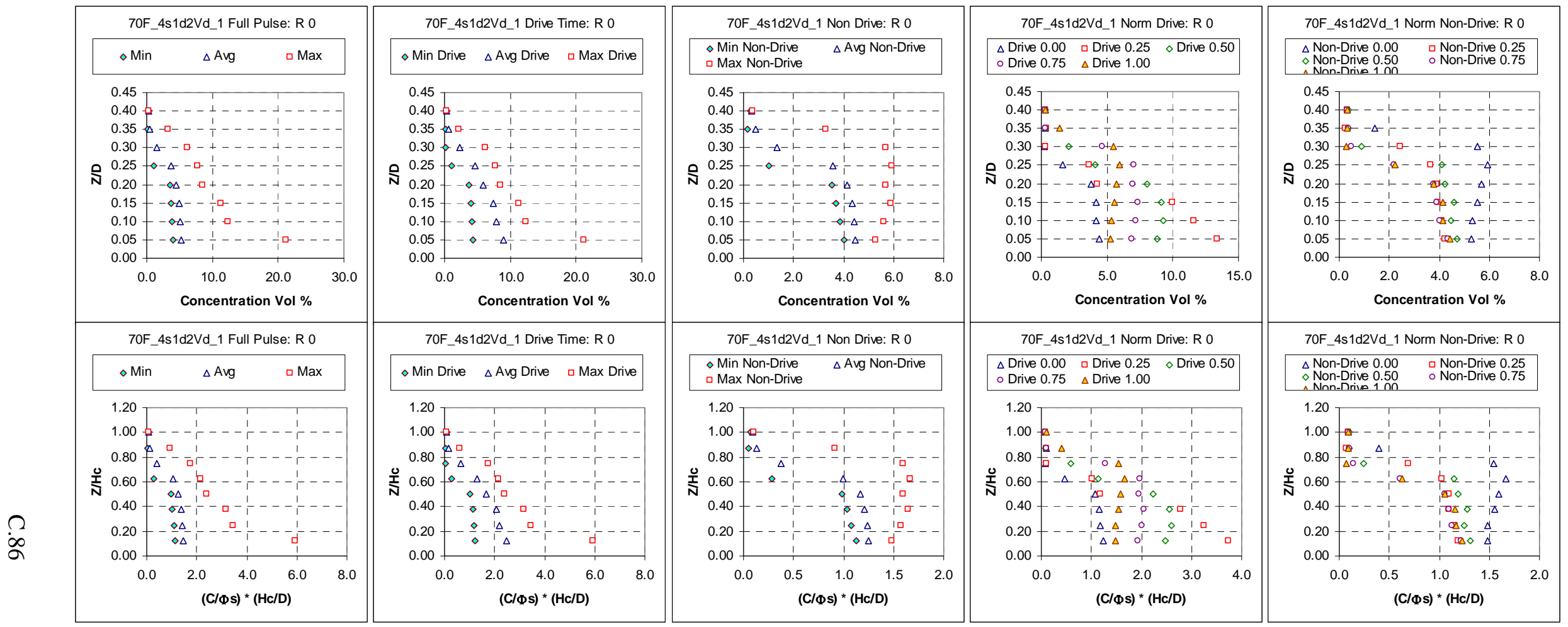

Figure C.41. 1.778-m- (70-in.-) diameter tank, 1.557-cm- (0.613-in.-) diameter nozzle; solids nominal diameter $69.3 \mu \mathrm{m}, 2.48$ g/cm³ density; 0.0143 nominal solids fraction; $18.7 \%$ duty cycle, cycle time $55.6 \mathrm{~s}$, pulse volume fraction 0.050 , $\mathrm{U}_{\mathrm{CS}}$ condition $9.8 \mathrm{~m} / \mathrm{s}$, target nozzle exit velocity $9.8 \mathrm{~m} / \mathrm{s}$; peak cloud height upper bound $0.724 \mathrm{~m}$ (28.5 in.). Case ID 70F_4s1d2Vd_1. 

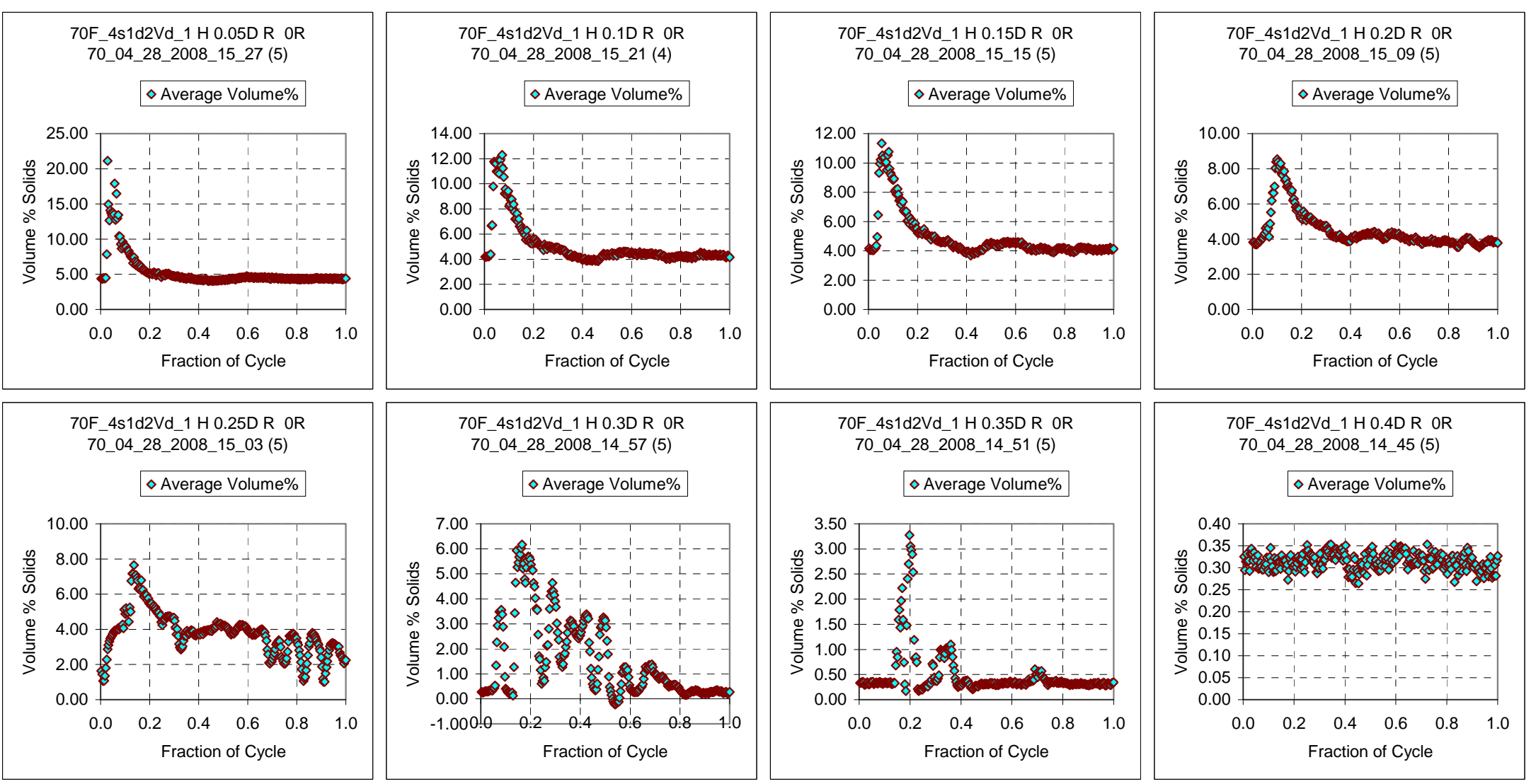

Figure C.41A. Case ID 70F_4s1d2Vd_1 Concentration Variation During the Cycle

Figure C. 41 is the eighth of 12 profiles shown using simulant s1d2 in the large-scale tank with the flange and dish bottom. The solids fraction is 0.0143 . The duty cycle is $18.7 \%$. The pulse volume fraction is 0.050 . The $U_{\text {CS }}$ velocity occurred at $9.8 \mathrm{~m} / \mathrm{s}$. The cloud height is 28.5 in., an increase from $26.5 \mathrm{in}$. in the prior test. As in the prior test, from the concentration profile the average concentration as a function of elevation and the minimum concentration as a function of elevation are quite similar. 


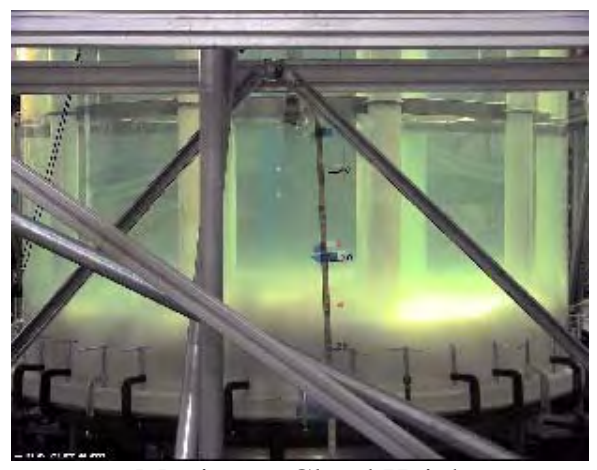

Maximum Cloud Height

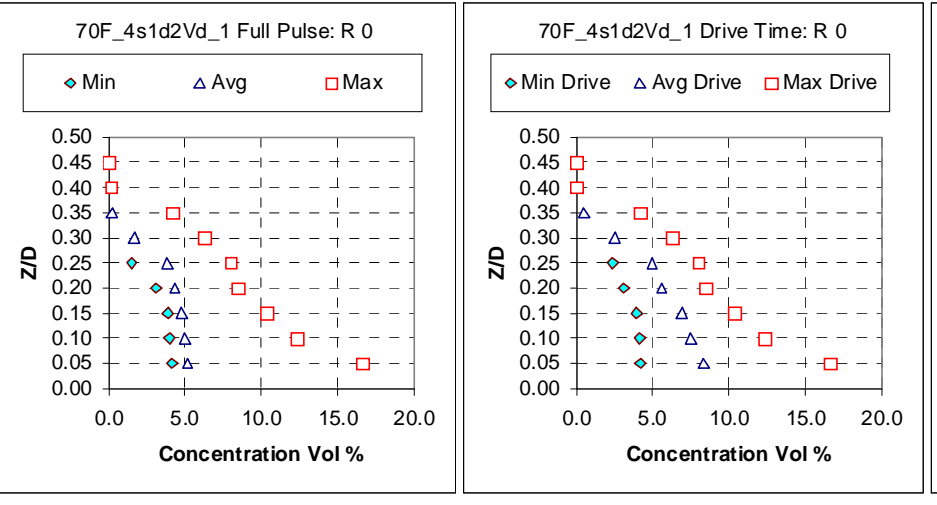
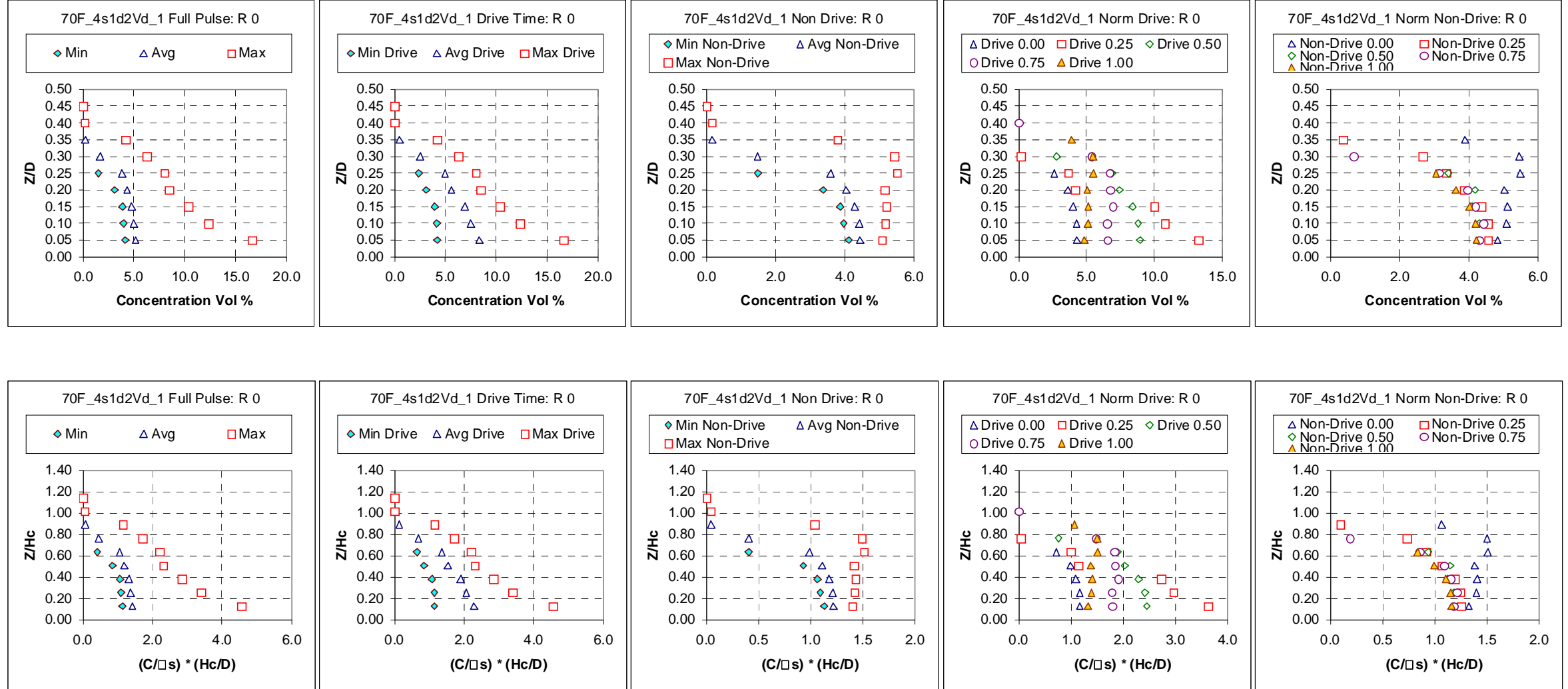

Figure C.42. 1.778-m- (70-in.-) diameter tank, 1.557-cm- (0.613-in.-) diameter nozzle; solids nominal diameter $69.3 \mu \mathrm{m}, 2.48$ g/cm³ density; 0.0143 nominal solids fraction; $18.5 \%$ duty cycle, cycle time $54.8 \mathrm{~s}$, pulse volume fraction 0.050 , $\mathrm{U}_{\mathrm{CS}}$ velocity $9.9 \mathrm{~m} / \mathrm{s}$, target nozzle exit velocity $9.9 \mathrm{~m} / \mathrm{s}$; peak cloud height upper bound $0.711 \mathrm{~m}$ (28 in.). Case ID 70F_4s1d2Vd_1. 

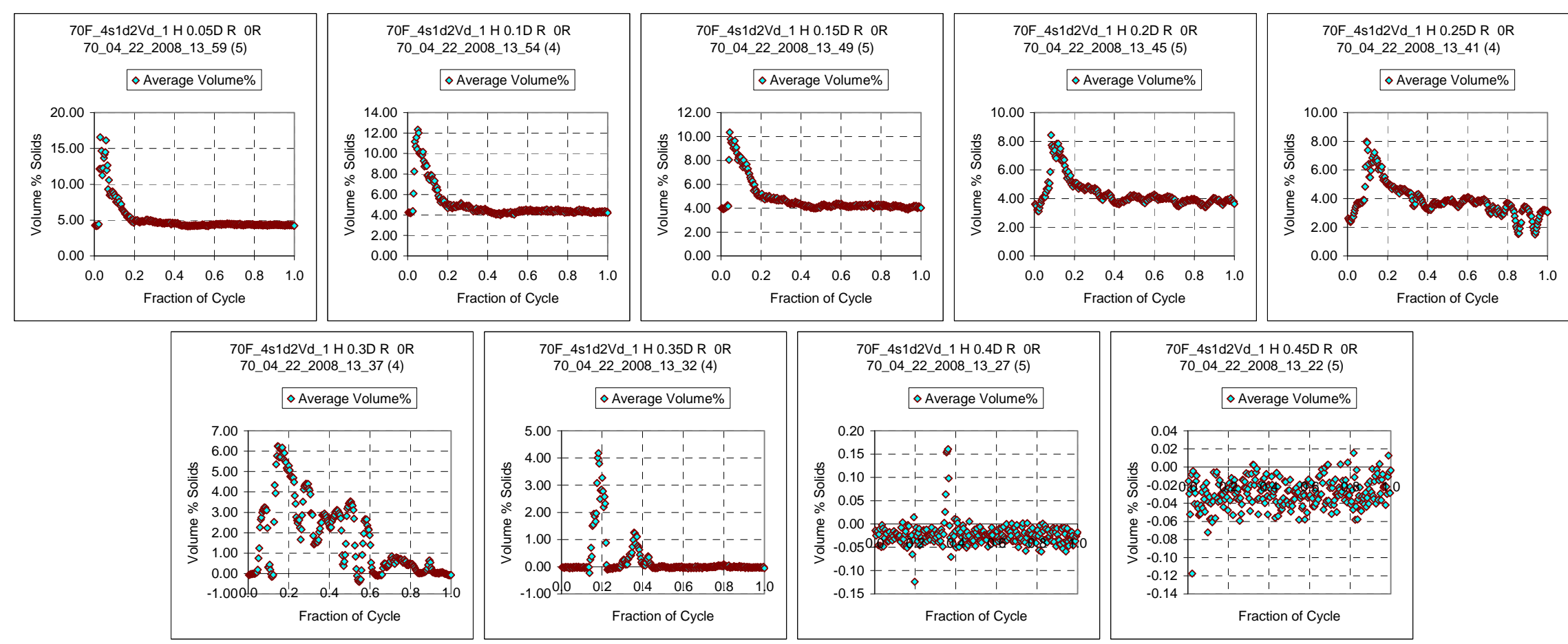

Figure C.42A. Case ID 70F_4s1d2Vd_1 Concentration Variation During the Cycle

Figure C. 42 is the $9^{\text {th }}$ of 12 profiles shown using simulant s1d2 in the large-scale tank with the flange and dish bottom. The solids fraction is 0.0143 . The duty cycle is $18.5 \%$. The pulse volume fraction is 0.050 . The $U_{\mathrm{CS}}$ velocity occurred at $9.9 \mathrm{~m} / \mathrm{s}$. This profile and the one shown in Figure C.41 are for the same test condition both at $\mathrm{U}_{\mathrm{CS}}$. The profiles both show the same features. 


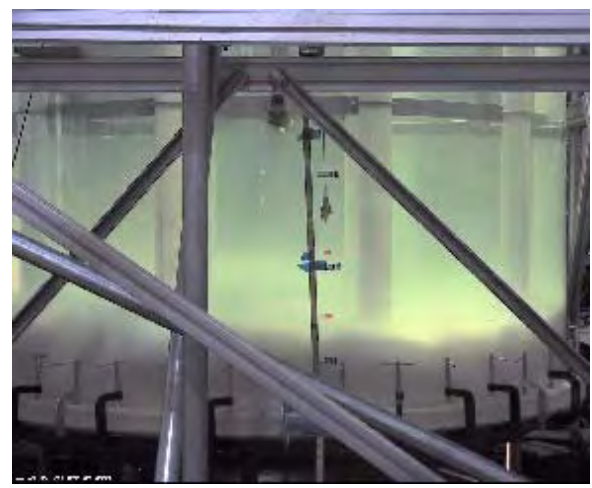

Maximum Cloud Height

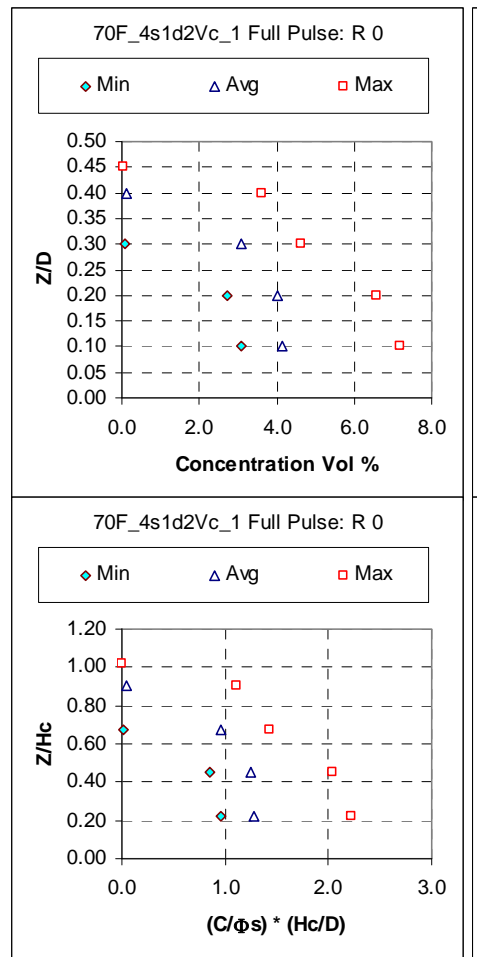
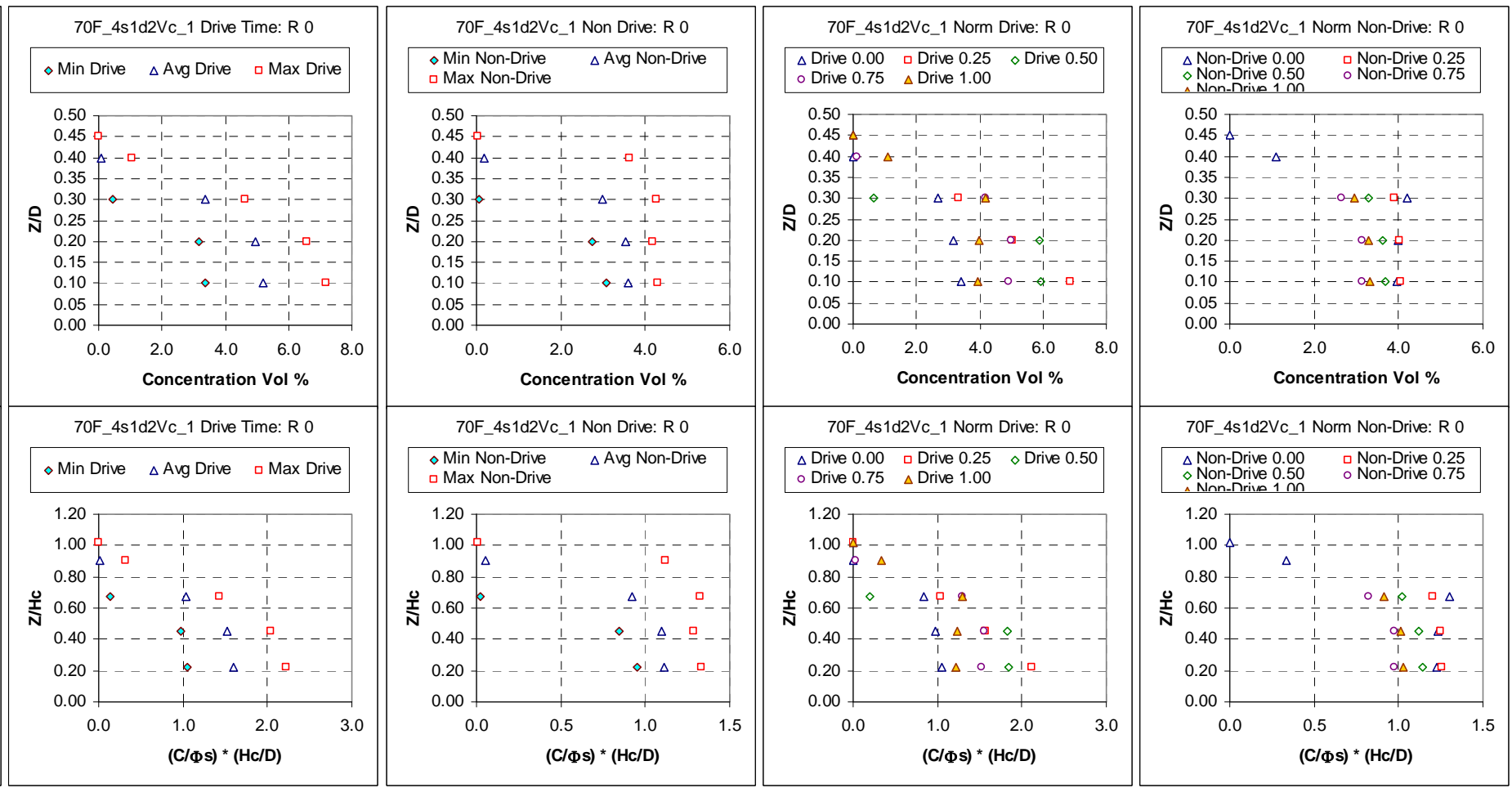

Figure C.43. 1.778-m- (70-in.-) diameter tank, 1.557-cm- (0.613-in.-) diameter nozzle; solids nominal diameter $69.3 \mu \mathrm{m}, 2.48$ g/cm³ density; 0.0143 nominal solids fraction; $33.6 \%$ duty cycle, cycle time $41.2 \mathrm{~s}$, pulse volume fraction $0.050, \mathrm{U}_{\mathrm{CS}}$ velocity $7.3 \mathrm{~m} / \mathrm{s}$, target nozzle exit velocity $7.3 \mathrm{~m} / \mathrm{s}$; peak cloud height upper bound $0.813 \mathrm{~m}$ (32 in.). Case ID 70F_4s1d2Vc_1. 

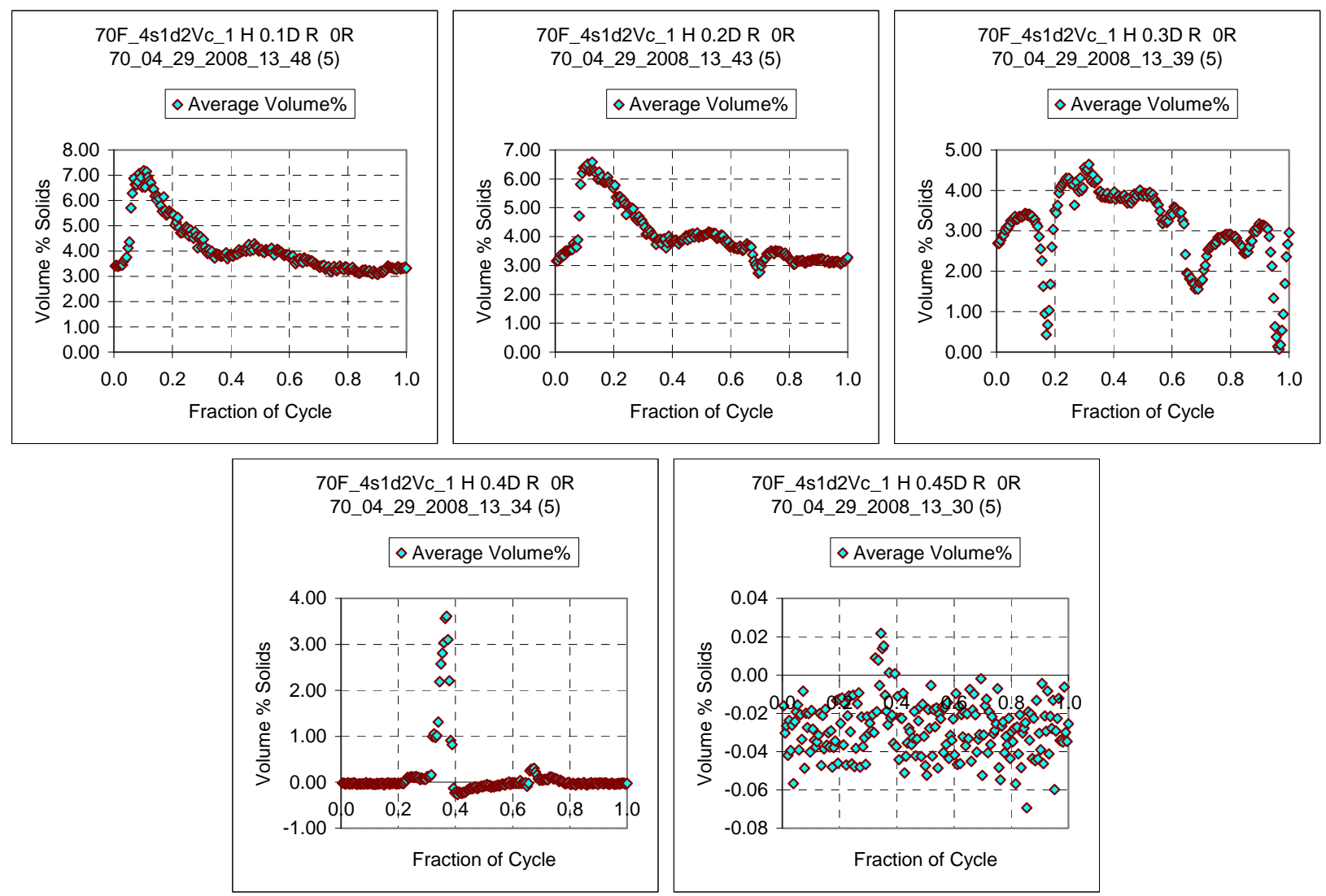

Figure C.43A. Case ID 70F_4s1d2Vc_1 Concentration Variation During the Cycle

Figure C. 43 is the tenth of 12 profiles shown using simulant s1d2 in the large-scale tank with the flange and dish bottom. The solids fraction is 0.0143. The duty cycle is $33.6 \%$ increased from $18.5 \%$ shown in the prior profile. The pulse volume fraction is unchanged at 0.050 . The $\mathrm{U}_{\mathrm{CS}}$ velocity occurred at $7.3 \mathrm{~m} / \mathrm{s}$, a decrease from $9.9 \mathrm{~m} / \mathrm{s}$ shown in the prior profile. 

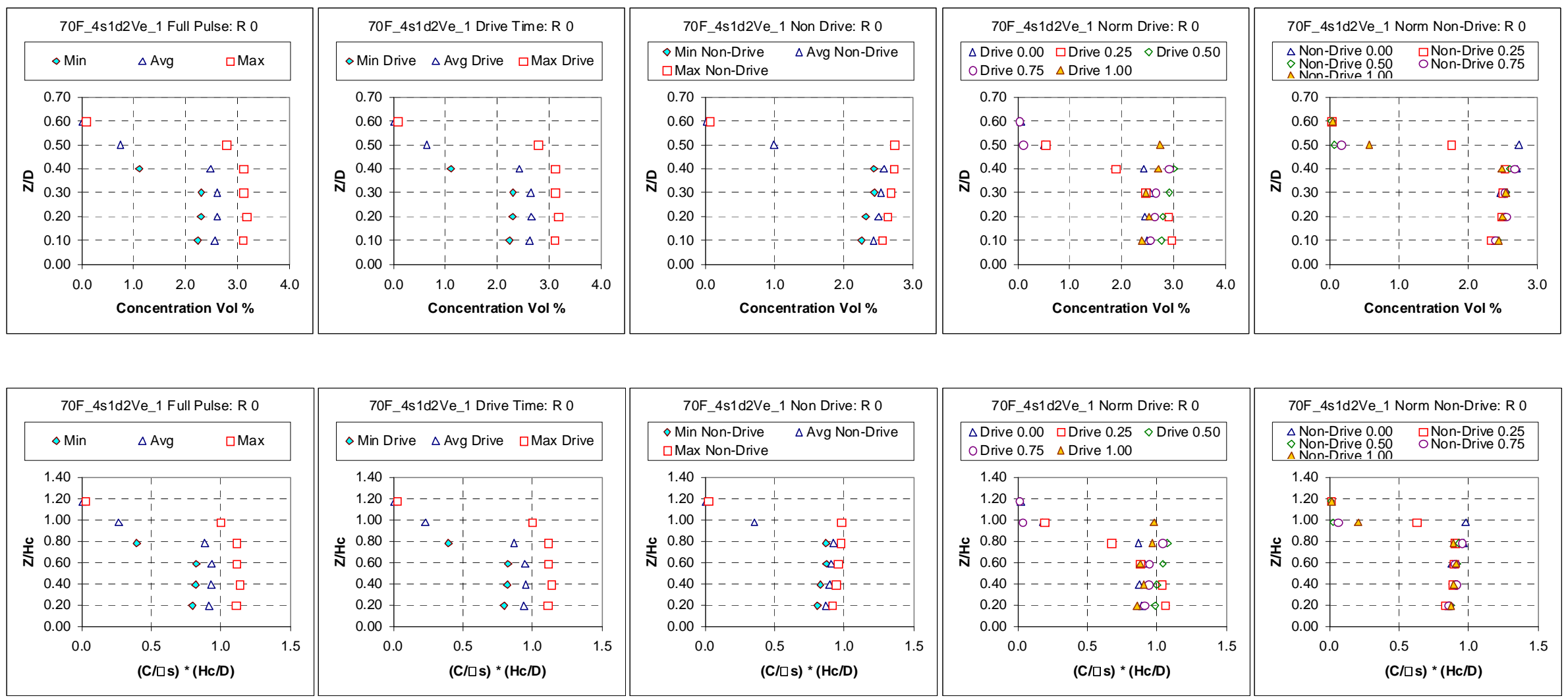

Figure C.44. 1.778-m- (70-in.-) diameter tank, 1.557-cm- (0.613-in.-) diameter nozzle; solids nominal diameter $69.3 \mu \mathrm{m}, 2.48$ g/cm³ density; 0.0143 nominal solids fraction; $66.6 \%$ duty cycle, cycle time $31.2 \mathrm{~s}$, pulse volume fraction 0.050 , $\mathrm{U}_{\mathrm{CS}}$ velocity $4.8 \mathrm{~m} / \mathrm{s}$, target nozzle exit velocity $4.8 \mathrm{~m} / \mathrm{s}$; peak cloud height upper bound $0.927 \mathrm{~m}$ (36.5 in.). Case ID 70F_4s1d2Ve_1. 

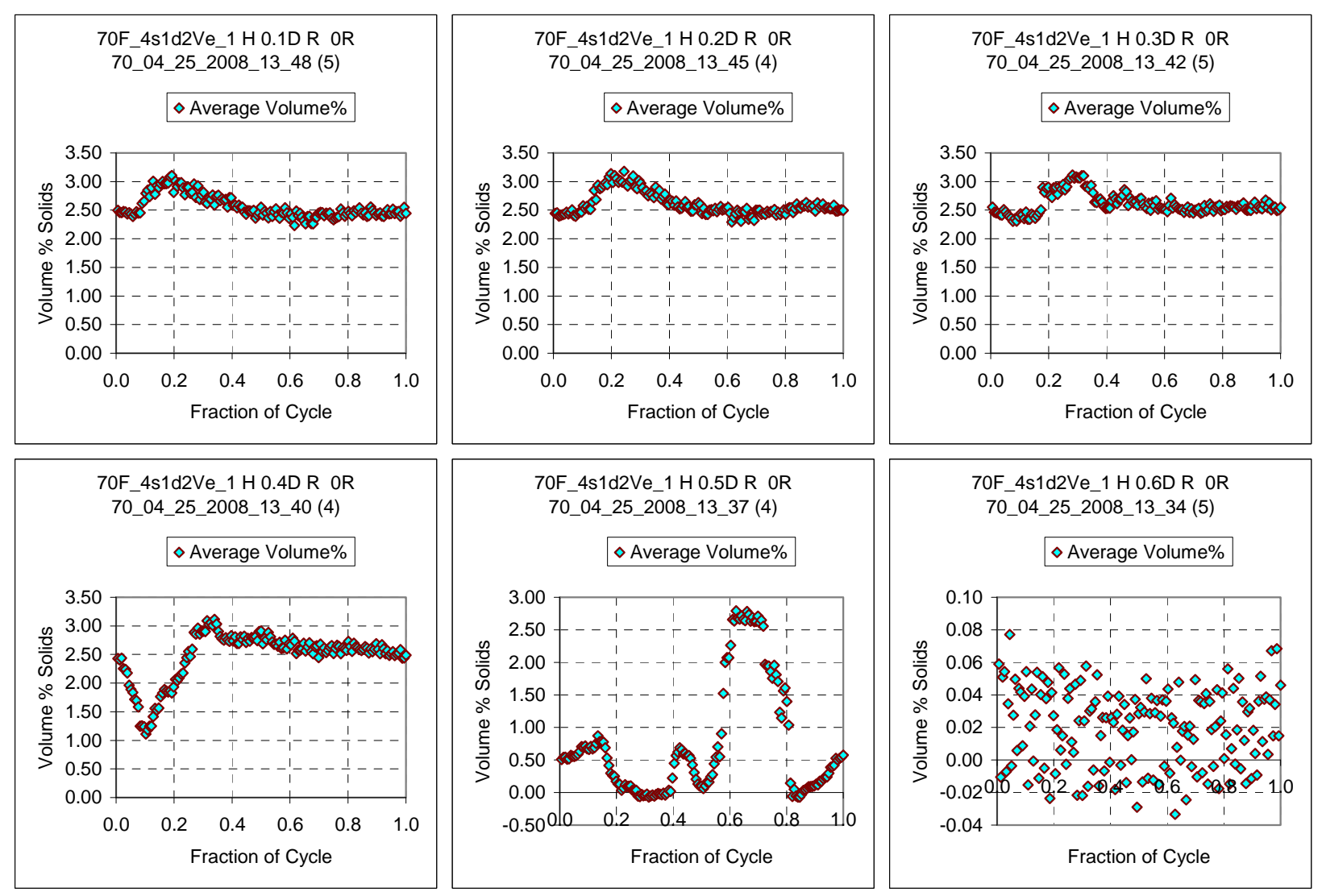

Figure C.44A. Case ID 70F_4s1d2Ve_1 Concentration Variation During the Cycle

Figure C.44 is the eleventh of 12 profiles shown using simulant s1d2 in the large-scale tank with the flange and dish bottom. The solids fraction is 0.0143. The duty cycle is $66.6 \%$, increased from $33.6 \%$ in the prior profile and from $18.5 \%$ shown in Figure C.42. The pulse volume fraction is unchanged at 0.050 . The $U_{\mathrm{CS}}$ velocity occurred at $4.8 \mathrm{~m} / \mathrm{s}$, a decrease from $7.3 \mathrm{~m} / \mathrm{s}$ shown in the prior profile and a decrease from $9.9 \mathrm{~m} / \mathrm{s}$ shown in Figure C.42. The average concentration profile is essentially constant at $\sim 2.5 \mathrm{vol} \%$ to an elevation of $\mathrm{Z} / \mathrm{D}=0.4$. This is an increase in cloud height and region of constant concentration from the prior two profiles. 

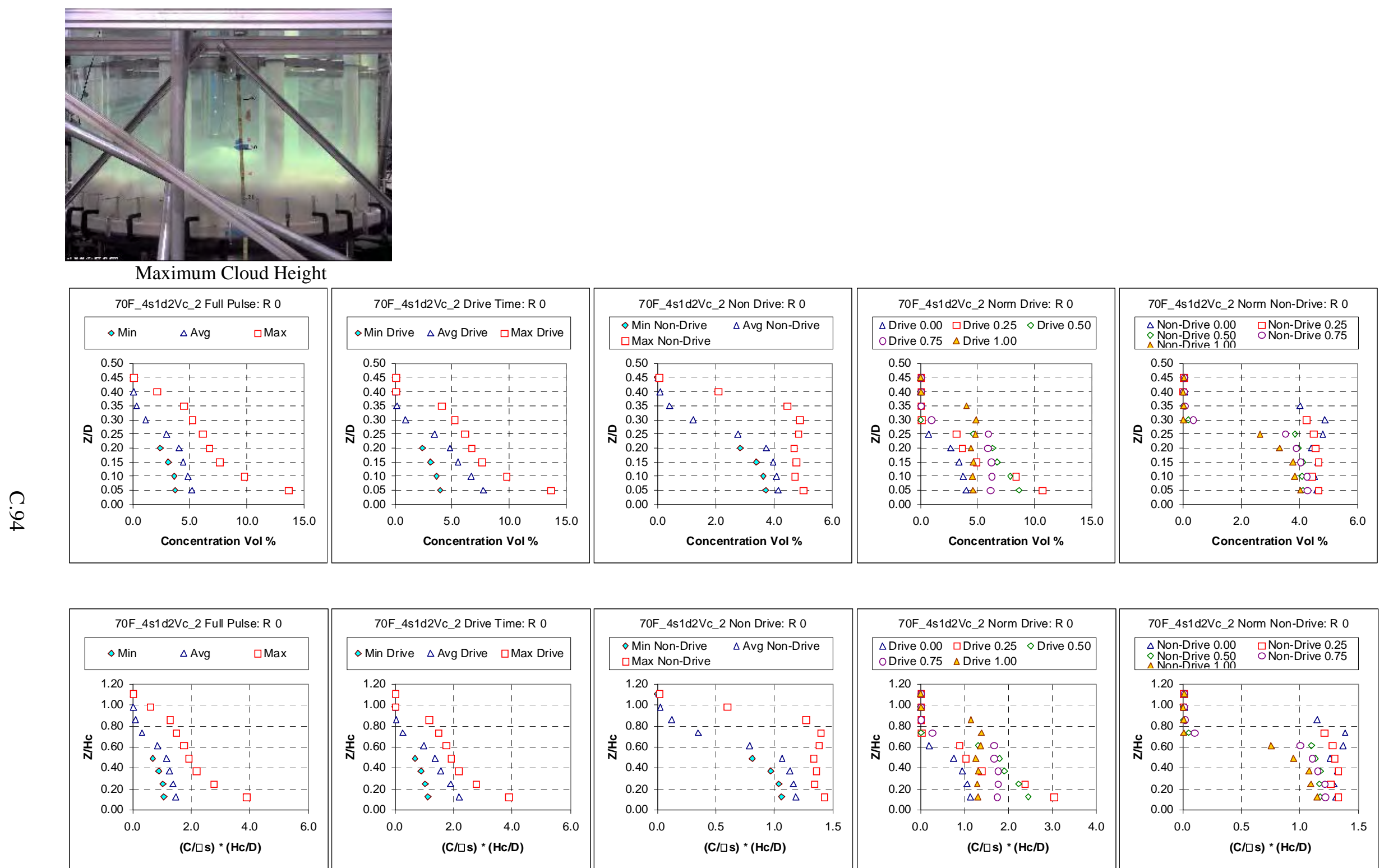

Figure C.45. 1.778-m- (70-in.-) diameter tank, 1.557-cm- (0.613-in.-) diameter nozzle; solids nominal diameter $69.3 \mu \mathrm{m}, 2.48 \mathrm{~g} / \mathrm{cm}^{3} \mathrm{density}$; 0.0143 nominal solids fraction; $32.7 \%$ duty cycle, cycle time $90.0 \mathrm{~s}$, pulse volume fraction 0.100 , $\mathrm{U}_{\mathrm{CS}}$ velocity $6.6 \mathrm{~m} / \mathrm{s}$, target nozzle exit velocity $6.6 \mathrm{~m} / \mathrm{s}$; peak cloud height upper bound $0.749 \mathrm{~m}$ (29.5 in.). Case ID 70F_4s1d2Vc_2. 

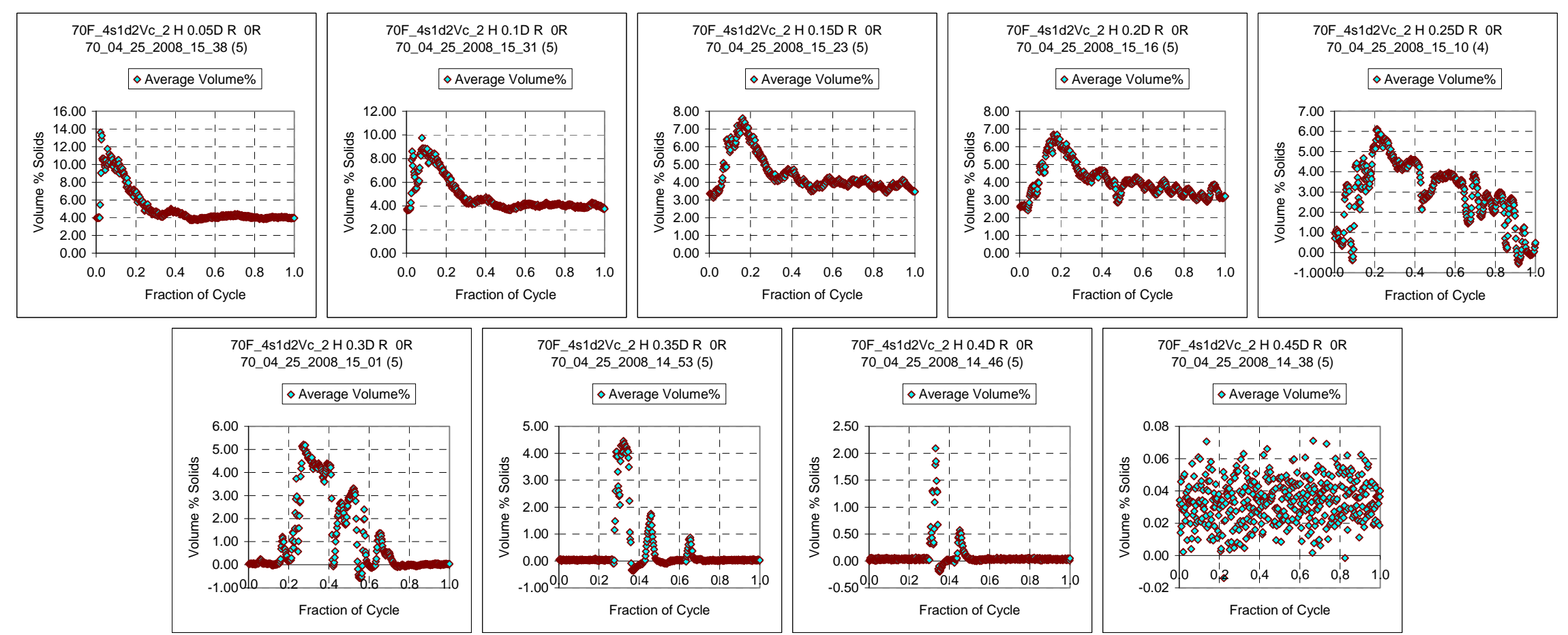

Figure C.45A. Case ID 70F_4s1d2Vc_2 Concentration Variation During the Cycle

Figure C. 45 is the last of 12 profiles shown using simulant s1d2 in the large-scale tank with the flange and dish bottom. The solids fraction is 0.0143. The duty cycle is $32.7 \%$, the same as shown in Figure C. 43 of $33.6 \%$. The pulse volume fraction is increased to 0.10 from 0.050 shown in Figure C.43. The $\mathrm{U}_{\mathrm{CS}}$ velocity occurred at $6.6 \mathrm{~m} / \mathrm{s}$, a decrease from $9.9 \mathrm{~m} / \mathrm{s}$ shown in Figure C.43. The average concentration at Z/D = 0.5 starts at $\sim 5 \mathrm{vol} \%$ and decreases with elevation to $\sim 0$ at $\mathrm{Z} / \mathrm{D}=0.4$. In comparison the profile shown in Figure C. 42 starts at $\sim 4$ vol\% at $\mathrm{Z} / \mathrm{D}=0.5$ and decreases with elevation to $\sim 0$ at $\mathrm{Z} / \mathrm{D}=0.4$. 

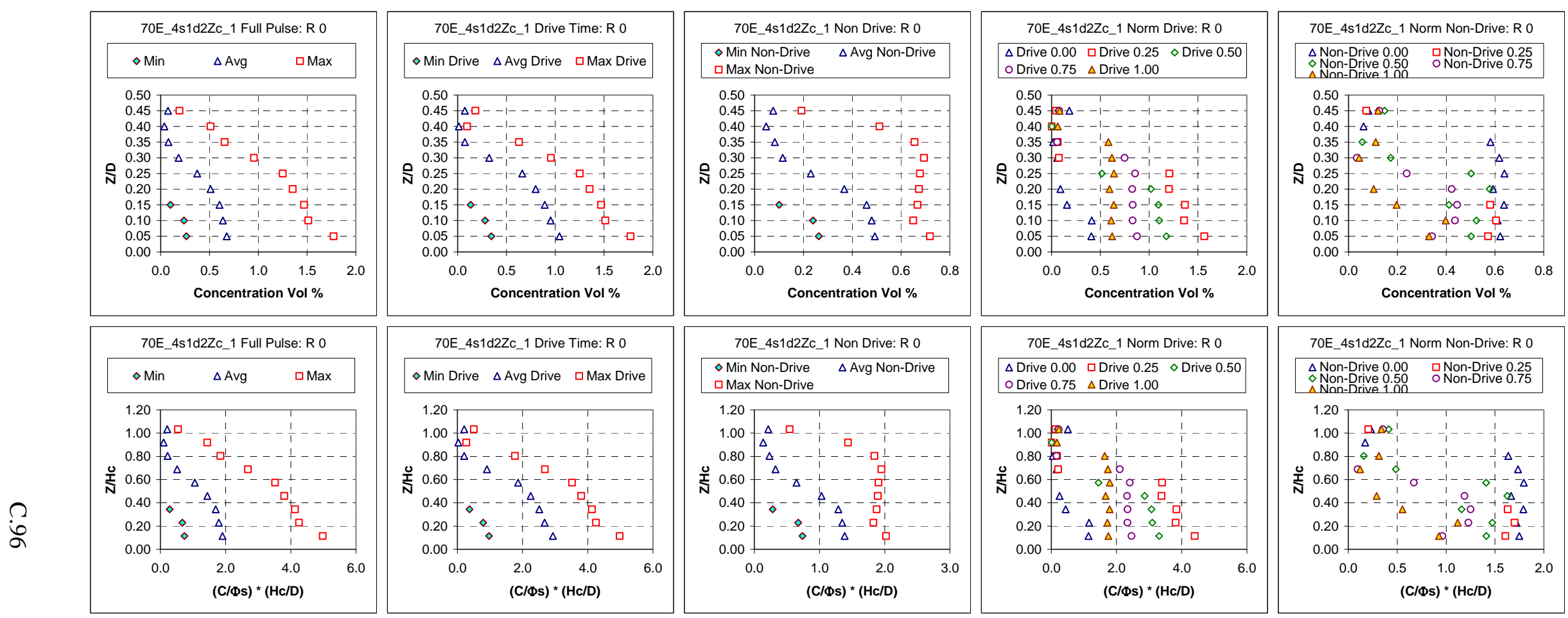

Figure C.46. 1.778-m- (70-in.-) diameter tank, 1.557-cm- (0.613-in.-) diameter nozzle; solids nominal diameter $69.3 \mu \mathrm{m}, 2.48$ g/cm³ density; 0.00155 nominal solids fraction; $33.7 \%$ duty cycle, cycle time $63.6 \mathrm{~s}$, pulse volume fraction 0.050 ; $\mathrm{U}_{\mathrm{CS}}$ velocity $4.6 \mathrm{~m} / \mathrm{s}$, target nozzle exit velocity $4.6 \mathrm{~m} / \mathrm{s}$; peak cloud height upper bound $0.787 \mathrm{~m}$ (31 in.). Case ID 70E_4s1d2Zc_1. 

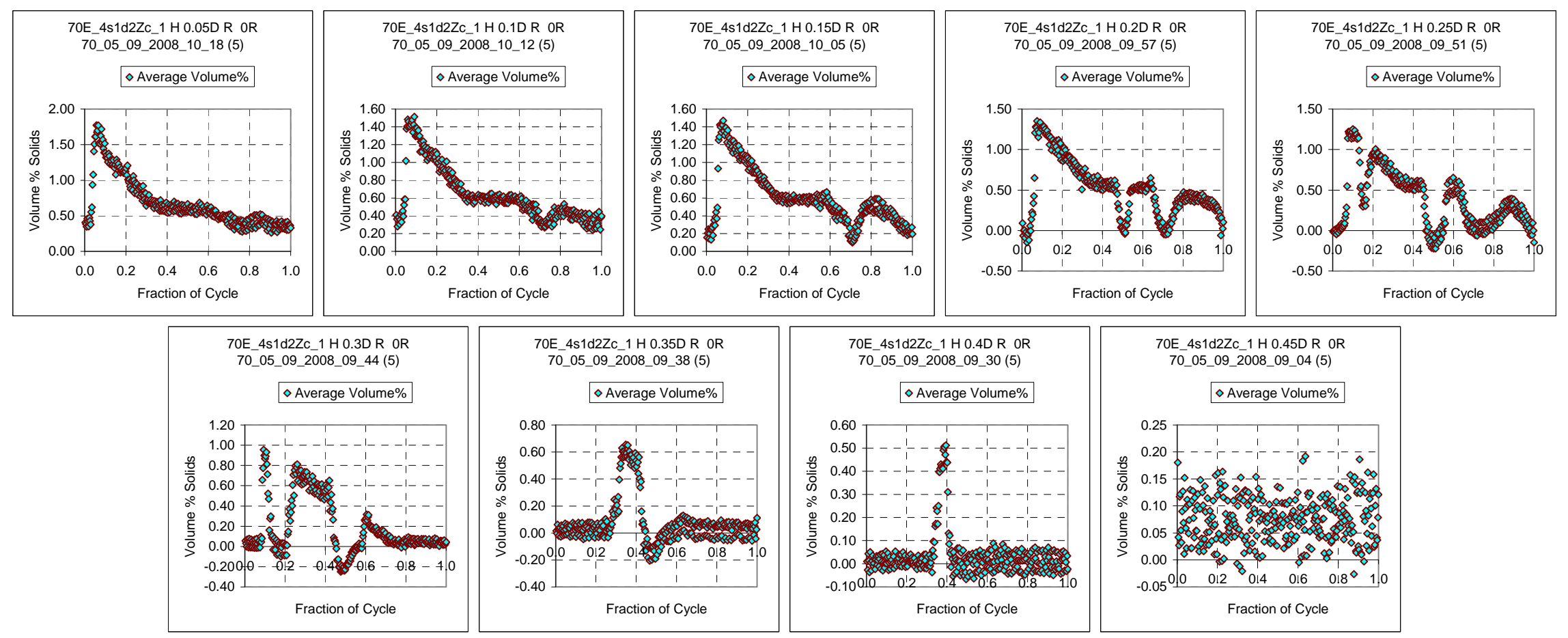

Figure C.46A. Case ID 70E_4s1d2Zc_1 Concentration Variation During the Cycle

Figure C.46 is the first of 12 profiles shown using simulant s1d2 in the large-scale tank with the elliptical bottom. The solids fraction is 0.00155.

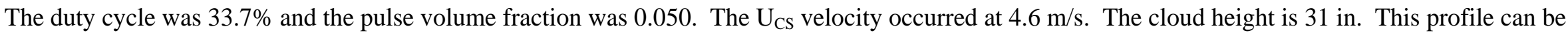
compared with that shown in Figure C.34, which was conducted at similar conditions in the large-scale tank with the flanged and dished bottom. The profiles are very similar with the one with the elliptical bottom showing slightly reduced average concentrations as a function of elevation. 


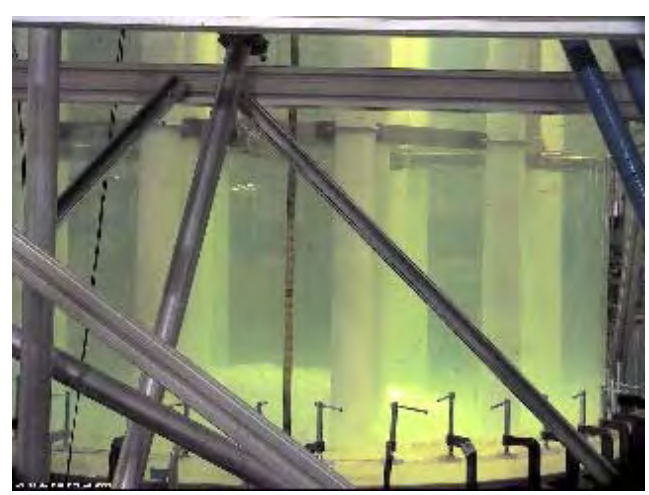

Maximum Cloud Height
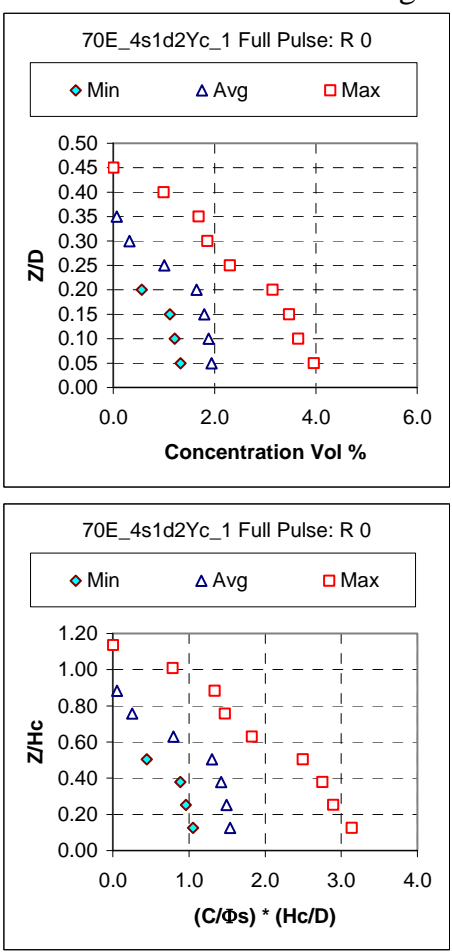

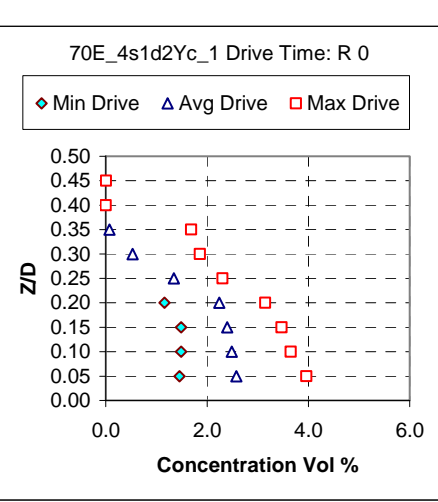

70E_4s1d2Yc_1 Drive Time: R 0
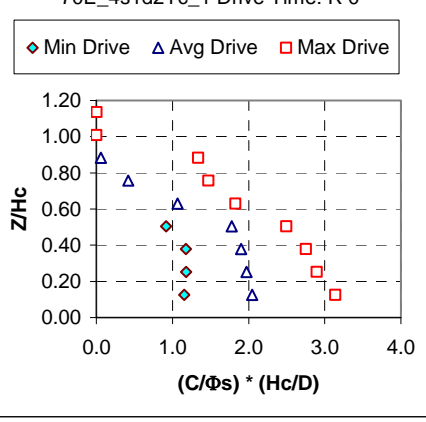

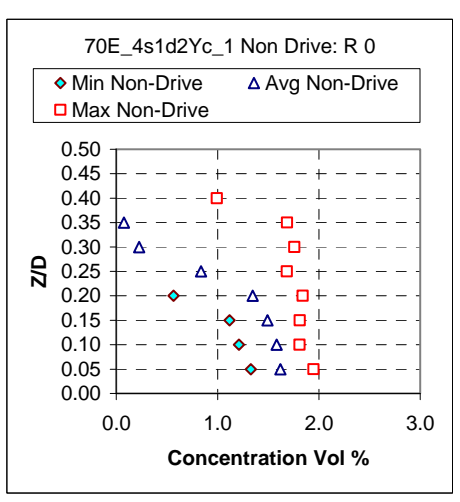

70E_4s1d2Yc_1 Non Drive: R 0

\begin{tabular}{ll|}
$\diamond$ Min Non-Drive & $\triangle$ Avg Non-Drive \\
$\square$ Max Non-Drive &
\end{tabular}

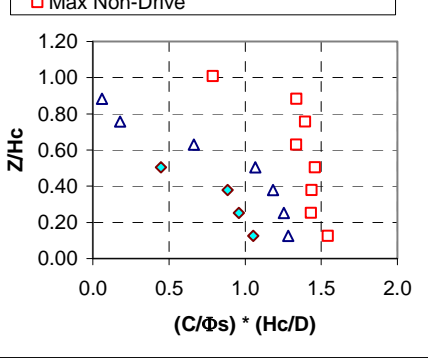

70E 4s1d2Yc_1 Norm Drive: R 0 $\Delta$ Drive $0.00 \quad \square$ Drive $0.25 \diamond$ Drive 0.50 $\circ$ Drive $0.75 \Delta$ Drive 1.00

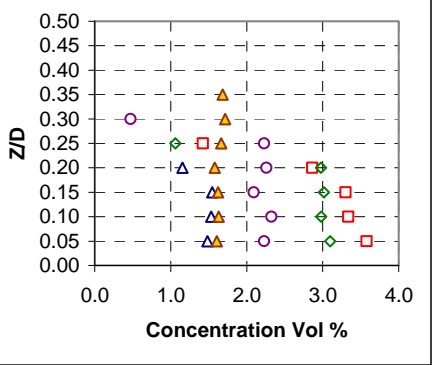

70E_4s1d2Yc_1 Norm Drive: R 0

$\Delta$ Drive $0.00 \quad \square$ Drive $0.25 \diamond$ Drive 0.50 ODrive $0.75 \Delta$ Drive 1.00

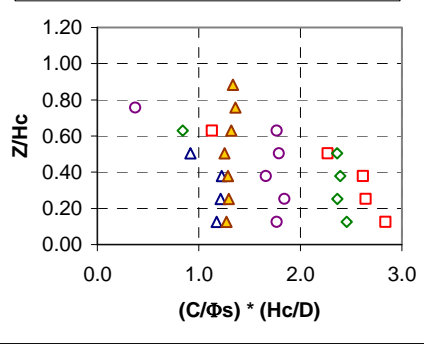

70 _ 4 s1d2Yc 1 Norm Non-Drive: R 0 \begin{tabular}{ll}
$\Delta$ Non-Drive 0.00 & a Non-Drive 0.25 \\
$\diamond$ Non-Drive 0.50 & o Non-Drive 0.75 \\
\hline
\end{tabular} ^Nan-Drive 10

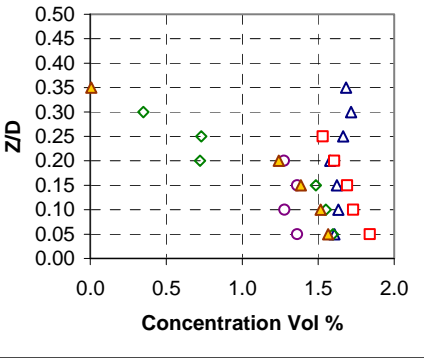

70E_4s1d2Yc_1 Norm Non-Drive: R 0 \begin{tabular}{ll}
$\Delta$ Non-Drive 0.00 & a Non-Drive 0.25 \\
$\diamond$ Non-Drive 0.50 & o Non-Drive 0.75 \\
\hline Non-Dive 1.50 &
\end{tabular}

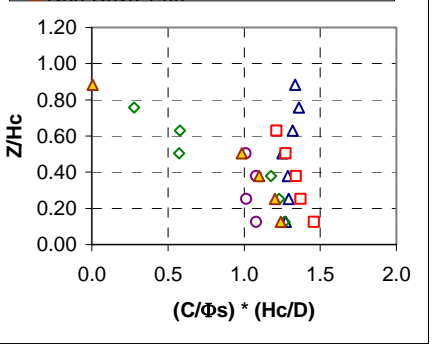

Figure C.47. 1.778-m- (70-in.-) diameter tank, 1.557-cm- (0.613-in.-) diameter nozzle; solids nominal diameter $69.3 \mu \mathrm{m}, 2.48 \mathrm{~g} / \mathrm{cm}^{3}$ density; 0.005 nominal solids fraction; $33.5 \%$ duty cycle, cycle time $49.6 \mathrm{~s}$, pulse volume fraction 0.050 , $\mathrm{U}_{\mathrm{CS}}$ velocity $6 \mathrm{~m} / \mathrm{s}$, target nozzle exit velocity $6 \mathrm{~m} / \mathrm{s}$; peak cloud height upper bound $0.724 \mathrm{~m}$ (28.5 in.). Case ID 70E_4s1d2Yc_1. 

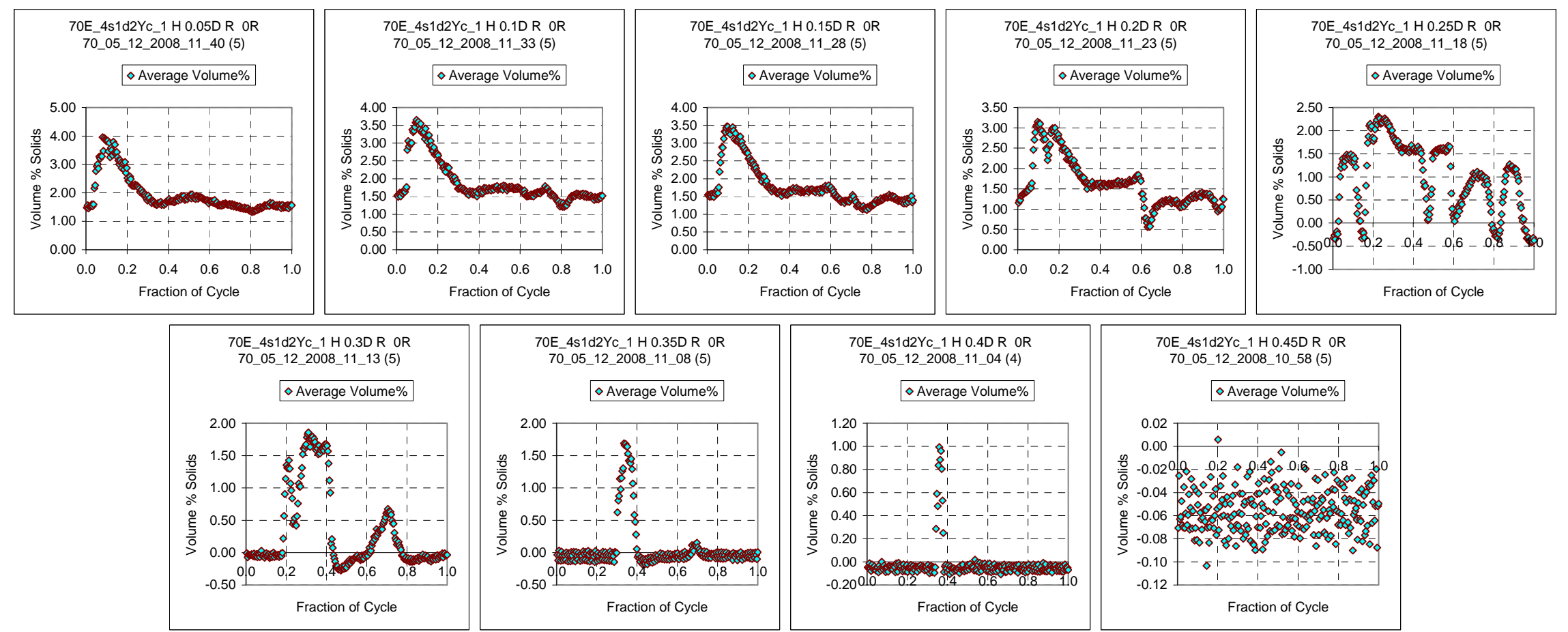

Figure C.47A. Case ID 70E_4s1d2Yc_1 Concentration Variation During the Cycle

Figure C.47 is the second of 12 profiles shown using simulant s1d2 in the large-scale tank with the elliptical bottom. The solids fraction is 0.005 , an increase from 0.00155 shown in Figure C.46. The duty cycle was $33.5 \%$ and the pulse volume fraction was 0.050 . The $\mathrm{U}_{\mathrm{Cs}}$ velocity occurred at $6 \mathrm{~m} / \mathrm{s}$, an increase from $4.6 \mathrm{~m} / \mathrm{s}$ from the prior test. The cloud height is $28.5 \mathrm{in}$., a decrease from $31 \mathrm{in}$. in the prior test. This vertical profile is relatively constant at slightly below 2 vol\% solids over the range from $\mathrm{Z} / \mathrm{D}=0.5$ to $\mathrm{Z} / \mathrm{D}=2$. 

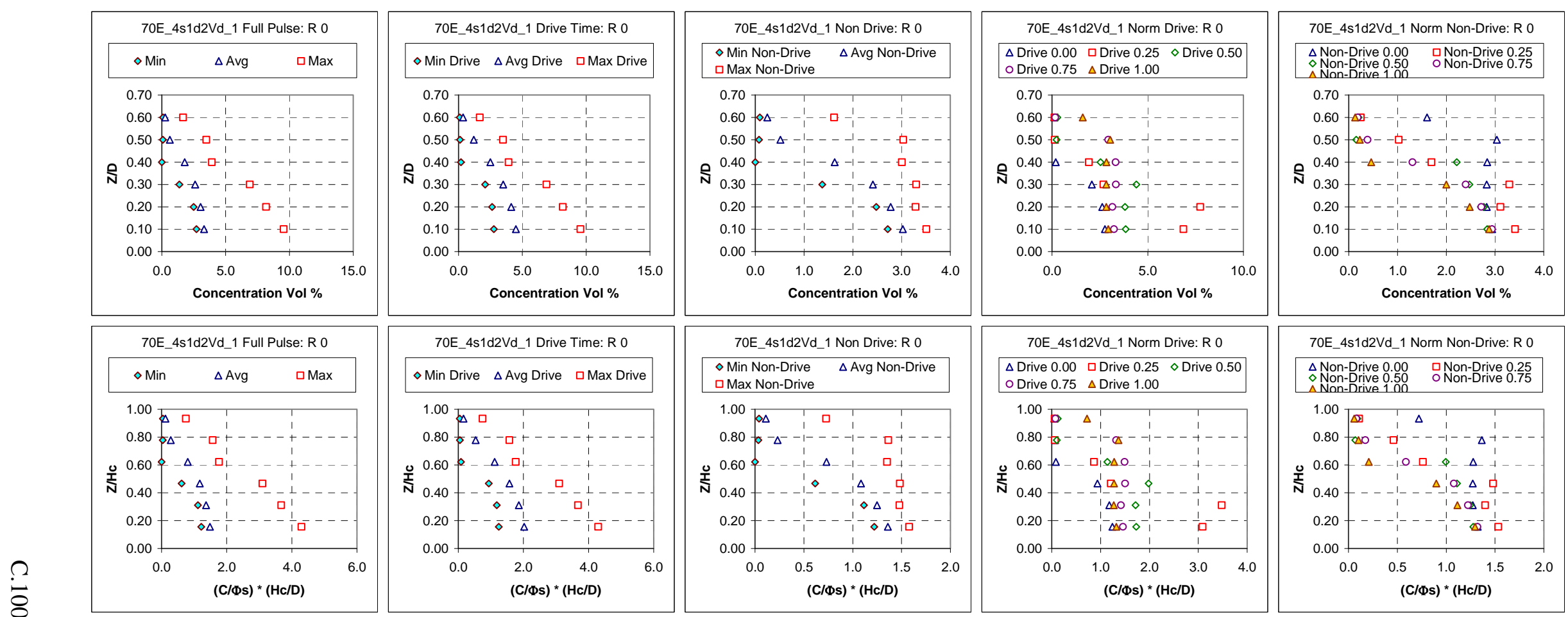

Figure C.48. 1.778-m- (70-in.-) diameter tank, 1.557-cm- (0.613-in.-) diameter nozzle; solids nominal diameter $69.3 \mu \mathrm{m}, 2.48$ g/cm ${ }^{3}$ density; 0.0143 nominal solids fraction; $18.9 \%$ duty cycle, cycle time $48.6 \mathrm{~s}$, pulse volume fraction 0.050 , $\mathrm{U}_{\mathrm{CS}}$ velocity $10.9 \mathrm{~m} / \mathrm{s}$, target nozzle exit velocity $11.2 \mathrm{~m} / \mathrm{s}$; peak cloud height upper bound $1.168 \mathrm{~m}$ (46 in.). Case ID 70E_4s1d2Vd_1. 

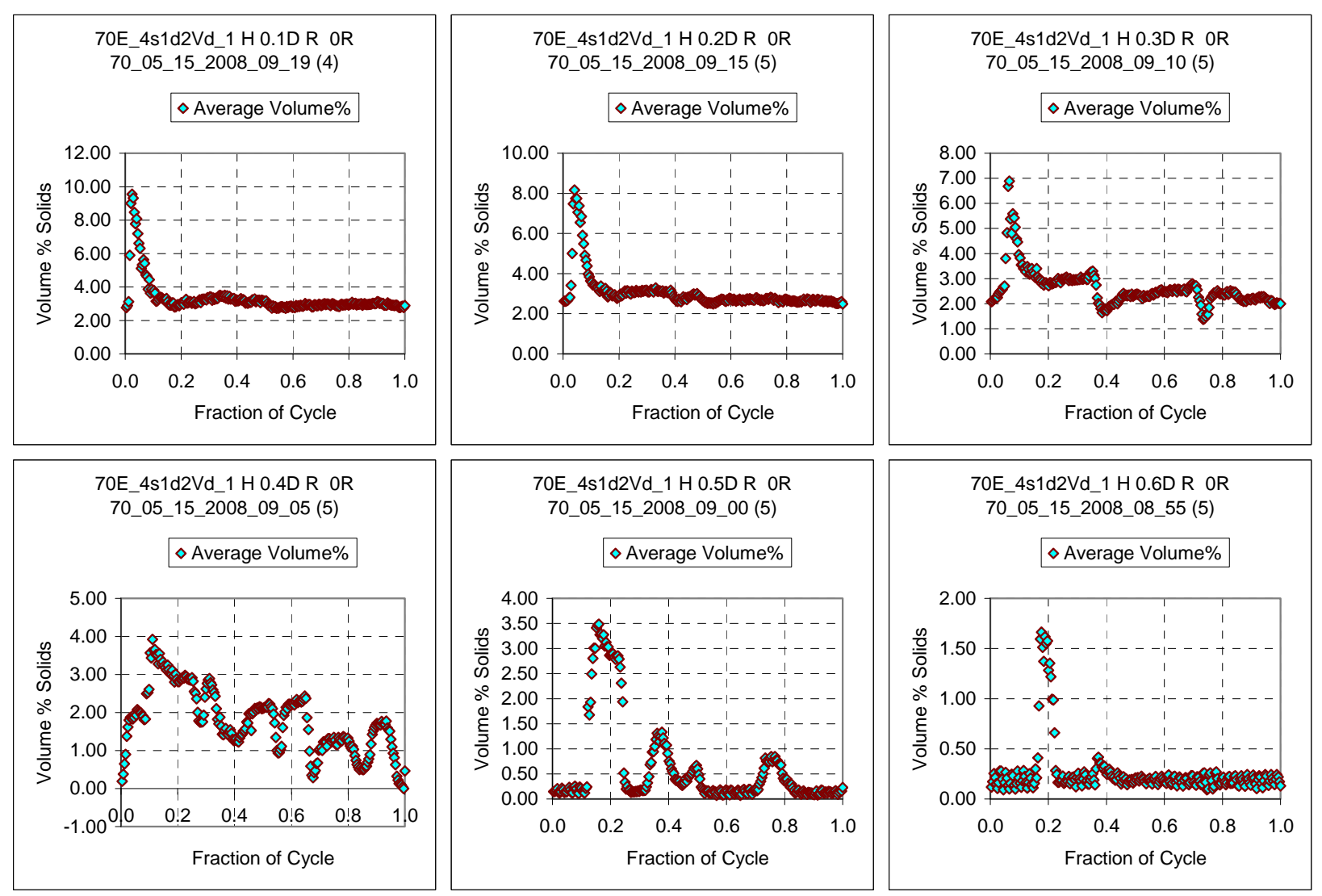

Figure C.48A. Case ID 70E_4s1d2Vd_1 R 0 Concentration Variation During the Cycle

Figure C.48 is the third of 12 profiles shown using simulant s1d2 in the large-scale tank with the elliptical bottom. Figures C.48, C.49, and C.50 are a group of three profiles taken at the same flow conditions and differing radial locations. Figure C.48 shows a profile at the center of the tank with $\mathrm{R}=0$. The solids fraction is 0.0143 . The duty cycle is $18.9 \%$. The $\mathrm{U}_{\mathrm{CS}}$ velocity occurred at 10.9 , and these measurements were taken above $\mathrm{U}_{\mathrm{CS}}$ at a velocity of $11.2 \mathrm{~m} / \mathrm{s}$. The cloud height is $46 \mathrm{in}$. When the radial profiles are compared the profiles are shown to decline slightly with radius. The profile at $\mathrm{R}=0$ reaches $\mathrm{Z} / \mathrm{D}=0.6$; the profile at $\mathrm{R}=0.5$ reaches $\mathrm{Z} / \mathrm{D}=0.5$; and the profile at $\mathrm{Z} / \mathrm{D}=0.9$ reaches 0.5 . The concentration decreases with elevation in all three radial locations. Since the velocity is greater than the critical suspension velocity, a more constant concentration with height was expected; however, instead of maintaining a more constant profile, the additional velocity above the critical suspension velocity may have produced a higher cloud height. 


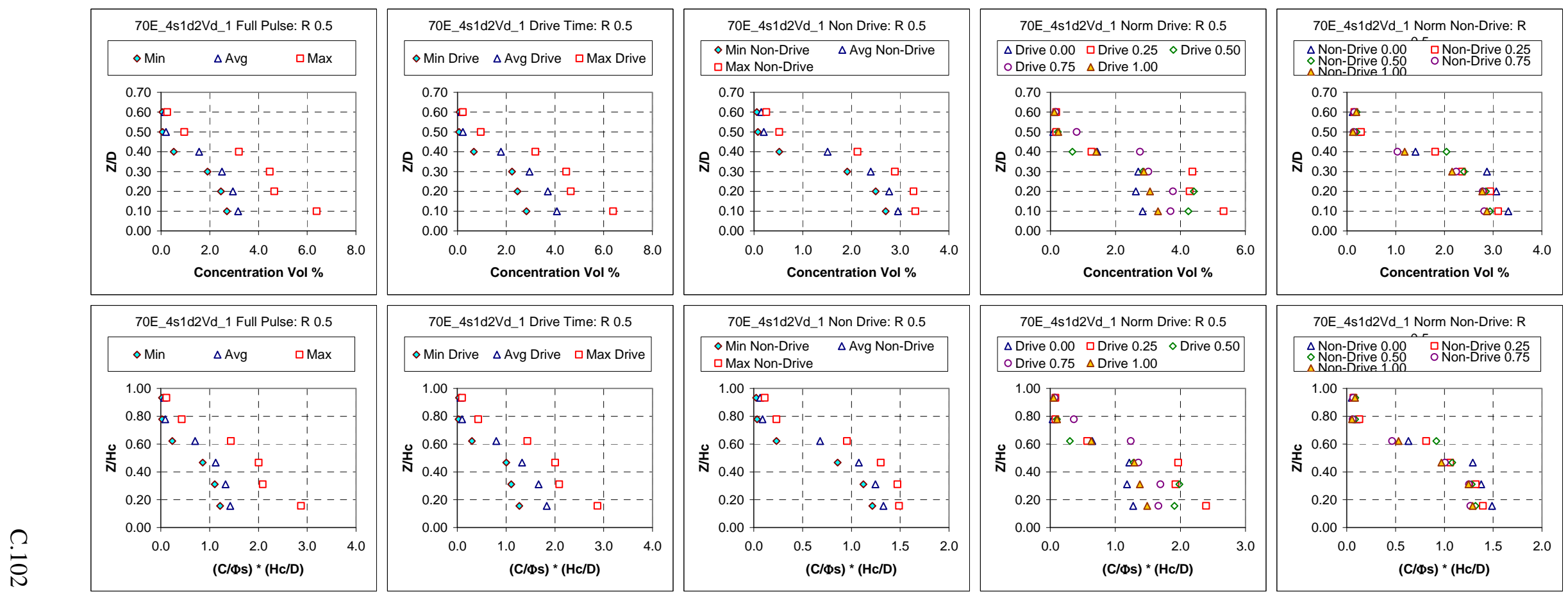

Figure C.49. 1.778-m- (70-in.-) diameter tank, 1.557-cm- (0.613-in.-) diameter nozzle; solids nominal diameter $69.3 \mu \mathrm{m}, 2.48$ g/cm³ density; 0.0143 nominal solids fraction; $18.9 \%$ duty cycle, cycle time $48.6 \mathrm{~s}$, pulse volume fraction 0.050 , $\mathrm{U}_{\mathrm{CS}}$ velocity $10.9 \mathrm{~m} / \mathrm{s}$, target nozzle exit velocity $11.2 \mathrm{~m} / \mathrm{s}$; peak cloud height upper bound 1.168 m (46 in.). Case ID 70E_4s1d2Vd_1. 

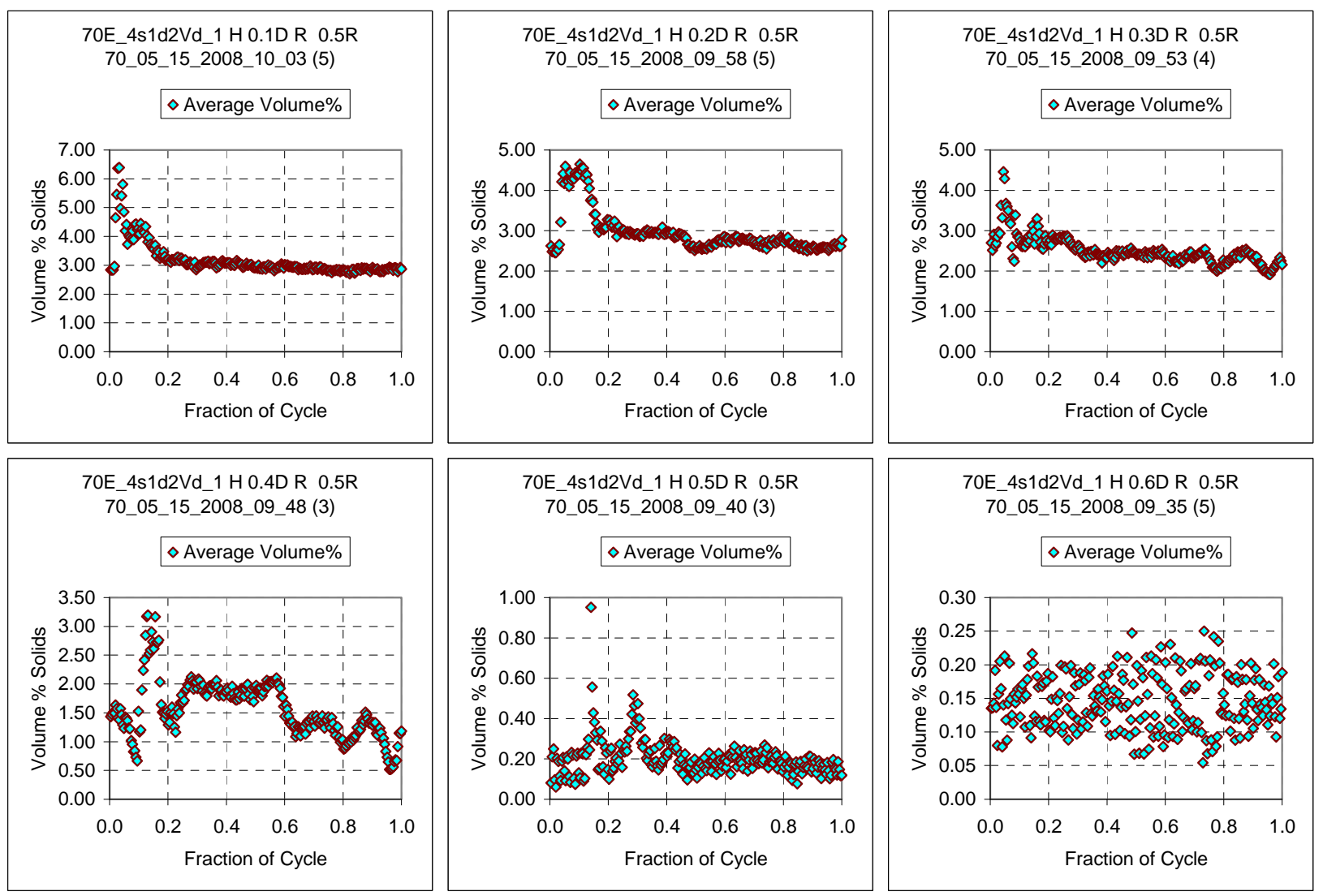

Figure C.49A. Case ID 70E_4s1d2Vd_1 R 0.5 Concentration Variation During the Cycle 


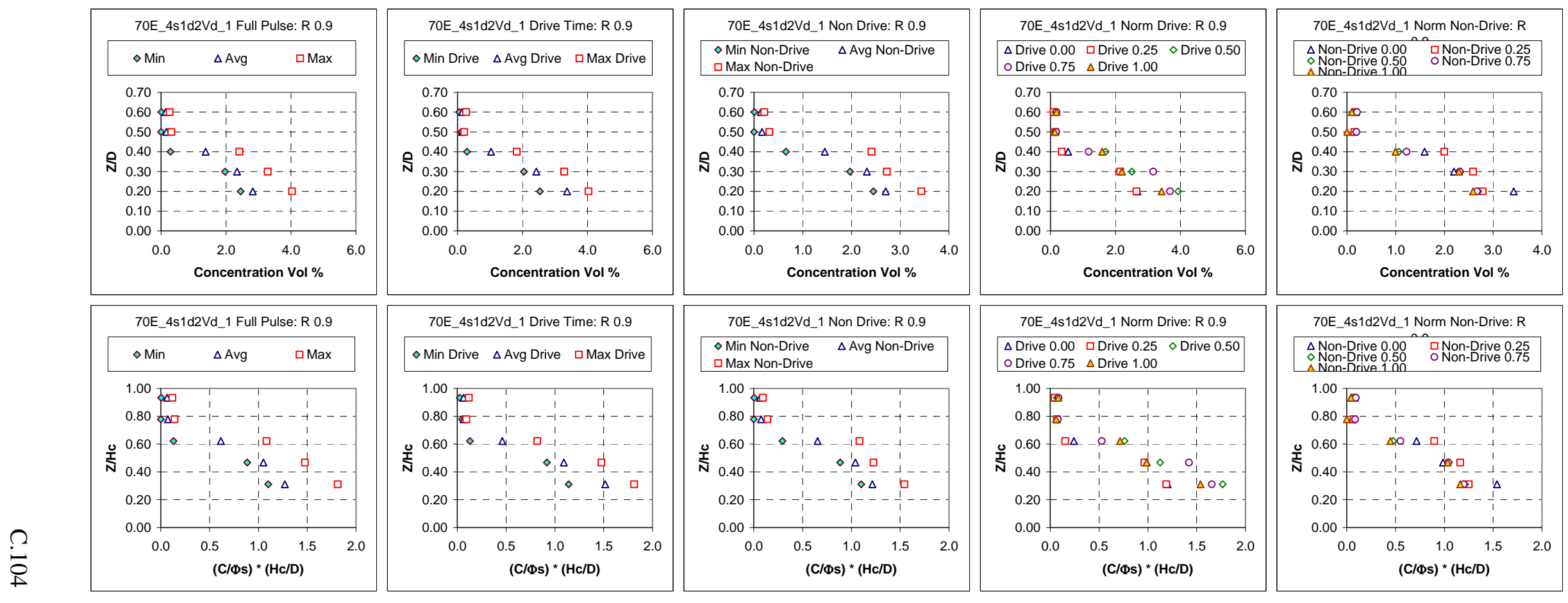

Figure C.50. 1.778-m- (70-in.-) diameter tank, 1.557-cm- (0.613-in.-) diameter nozzle; solids nominal diameter $69.3 \mu \mathrm{m}, 2.48$ g/cm³ density; 0.0143 nominal solids fraction; $18.9 \%$ duty cycle, cycle time $48.6 \mathrm{~s}$, pulse volume fraction $0.050, \mathrm{U}_{\mathrm{CS}}$ velocity $10.9 \mathrm{~m} / \mathrm{s}$, target nozzle exit velocity $11.2 \mathrm{~m} / \mathrm{s}$; peak cloud height upper bound 1.168 m (46 in.). Case ID 70E_4s1d2Vd_1. 

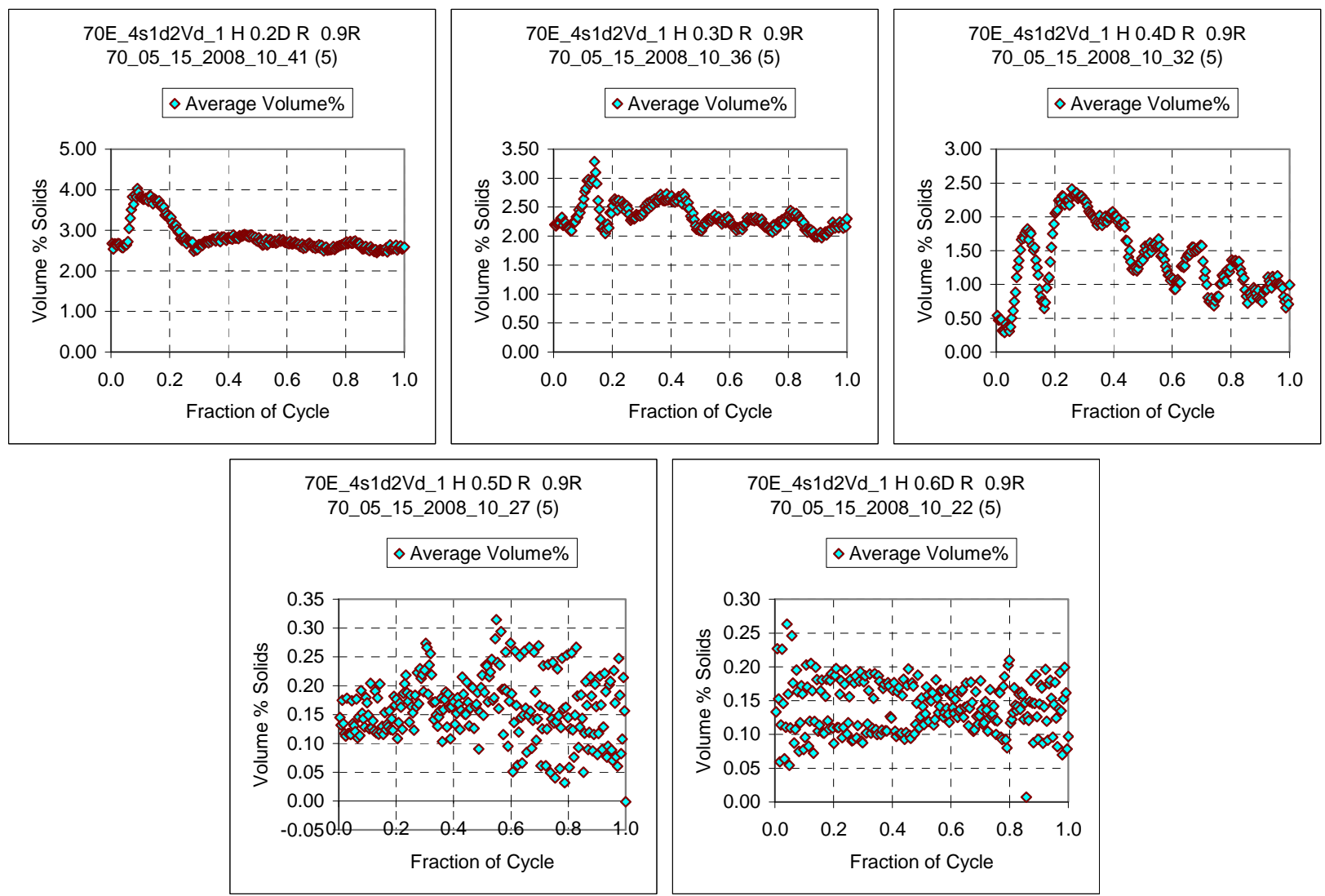

Figure C.50A. Case ID 70E_4s1d2Vd_1 R 0.9 Concentration Variation During the Cycle 


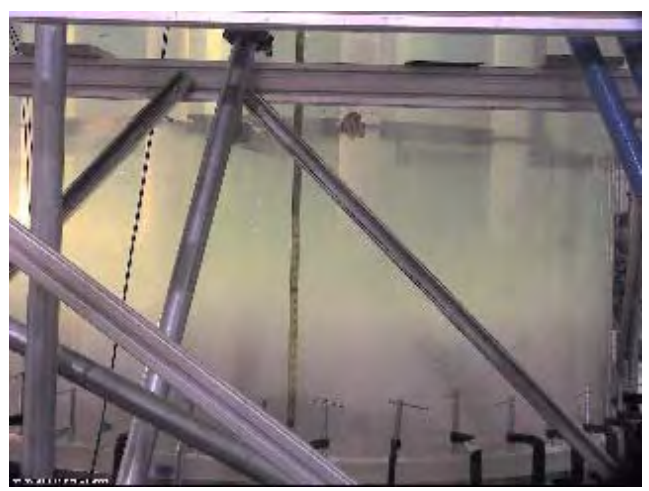

Maximum Cloud Height
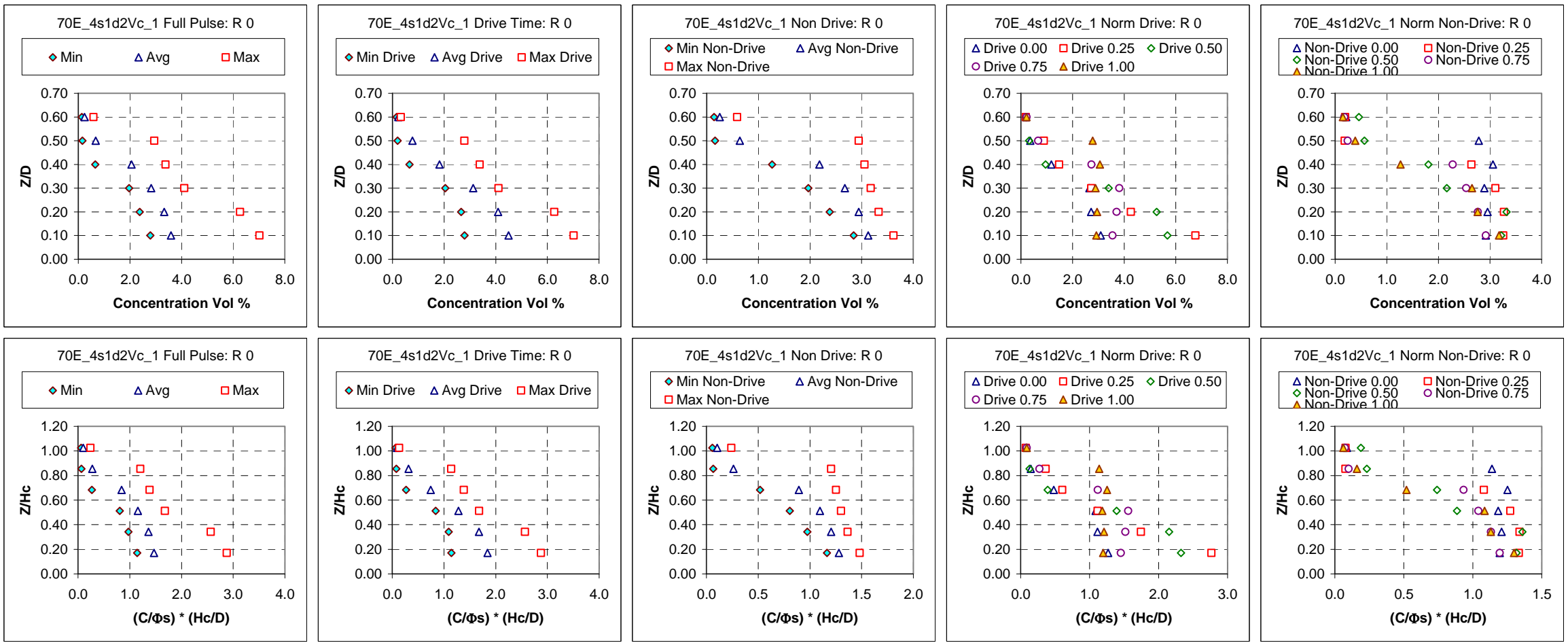

Figure C.51. 1.778-m- (70-in.-) diameter tank, 1.557-cm- (0.613-in.-) diameter nozzle; solids nominal diameter $69.3 \mu \mathrm{m}, 2.48 \mathrm{~g} / \mathrm{cm}^{3}$ density; 0.0143 nominal solids fraction; $33.3 \%$ duty cycle, cycle time $38.8 \mathrm{~s}$, pulse volume fraction 0.050 , $\mathrm{U}_{\mathrm{CS}}$ velocity $7.8 \mathrm{~m} / \mathrm{s}$, target nozzle exit velocity $7.8 \mathrm{~m} / \mathrm{s}$; peak cloud height upper bound $1.041 \mathrm{~m}$ (41 in.). Case ID 70E_4s1d2Vc_1. 

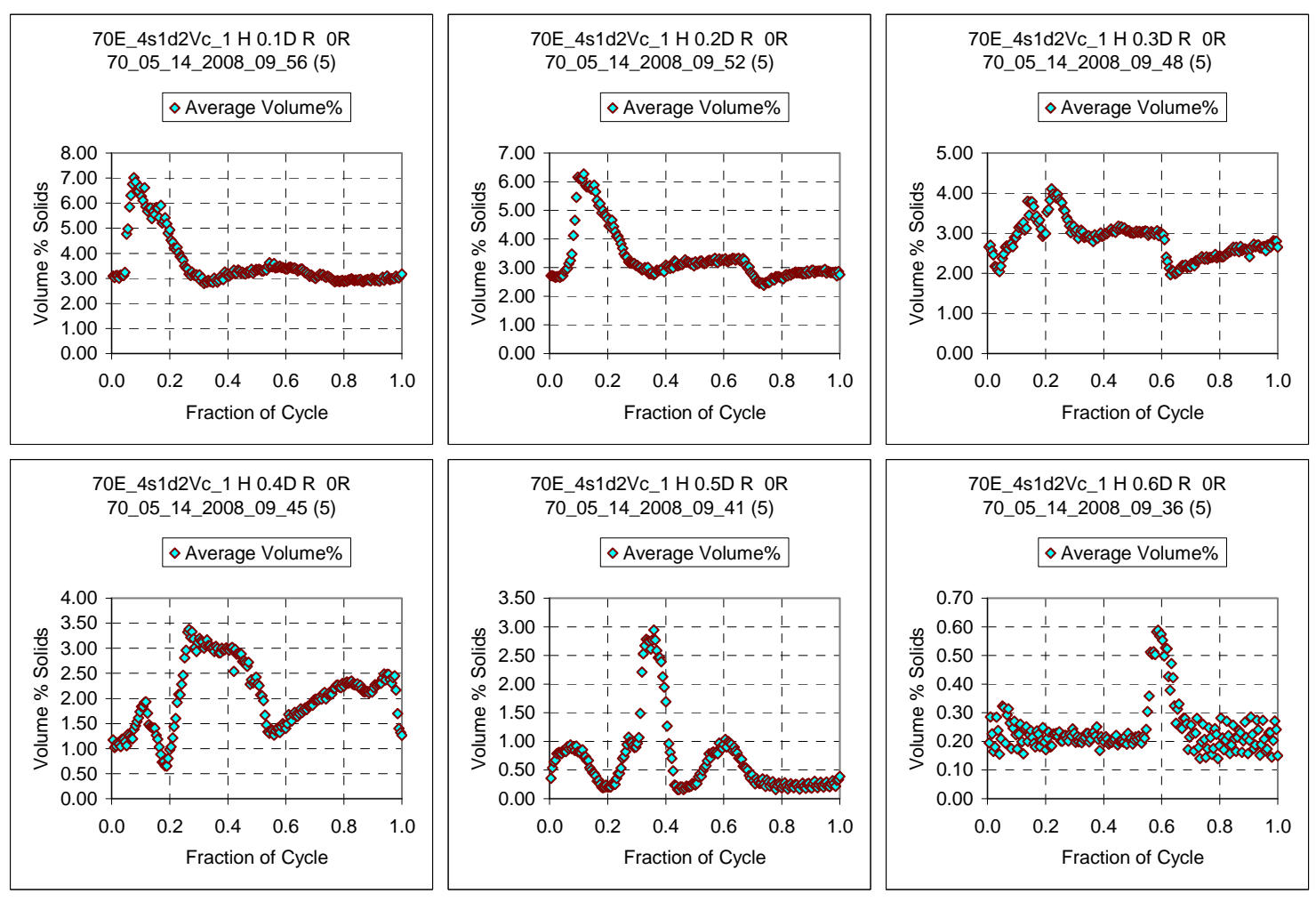

Figure C.51A. Case ID 70E_4s1d2Vc_1 Concentration Variation During the Cycle

Figure C.51 is the sixth of 12 profiles shown using simulant s1d2 in the large-scale tank with the elliptical bottom. Figures C.51, C.52, and C.53 are a group of three profiles taken at the same flow conditions and differing radial locations. Figure C.51 shows a profile at the center of the tank with $\mathrm{R}=0$. The solids fraction is 0.0143 . The duty cycle is $33.3 \%$, an increase from $18.9 \%$ shown in Figures C.48, C.49, and C.50, also a set of three radial profiles. The $U_{C S}$ velocity occurred at $7.8 \mathrm{~m} / \mathrm{s}$, a decrease from $10.9 \mathrm{~m} / \mathrm{s}$ shown for the prior three profiles. These measurements were taken at $U_{\text {CS. }}$ The cloud height is $41 \mathrm{in.} \mathrm{When} \mathrm{the} \mathrm{radial} \mathrm{profiles} \mathrm{are} \mathrm{compared} \mathrm{the} \mathrm{profiles} \mathrm{are} \mathrm{shown} \mathrm{to} \mathrm{decline} \mathrm{slightly} \mathrm{with} \mathrm{radius.} \mathrm{The} \mathrm{profiles} \mathrm{show} \mathrm{the} \mathrm{same} \mathrm{trends} \mathrm{exhibited}$ in the prior three profiles. The profile at $\mathrm{R}=0$ reaches $\mathrm{Z} / \mathrm{D}=0.6$; the profile at $\mathrm{R}=0.5$ reaches $\mathrm{Z} / \mathrm{D}=0.5$; and the profile at $\mathrm{Z} / \mathrm{D}=0.9$ reaches 0.5 . The concentration decreases with elevation in all three radial locations. 


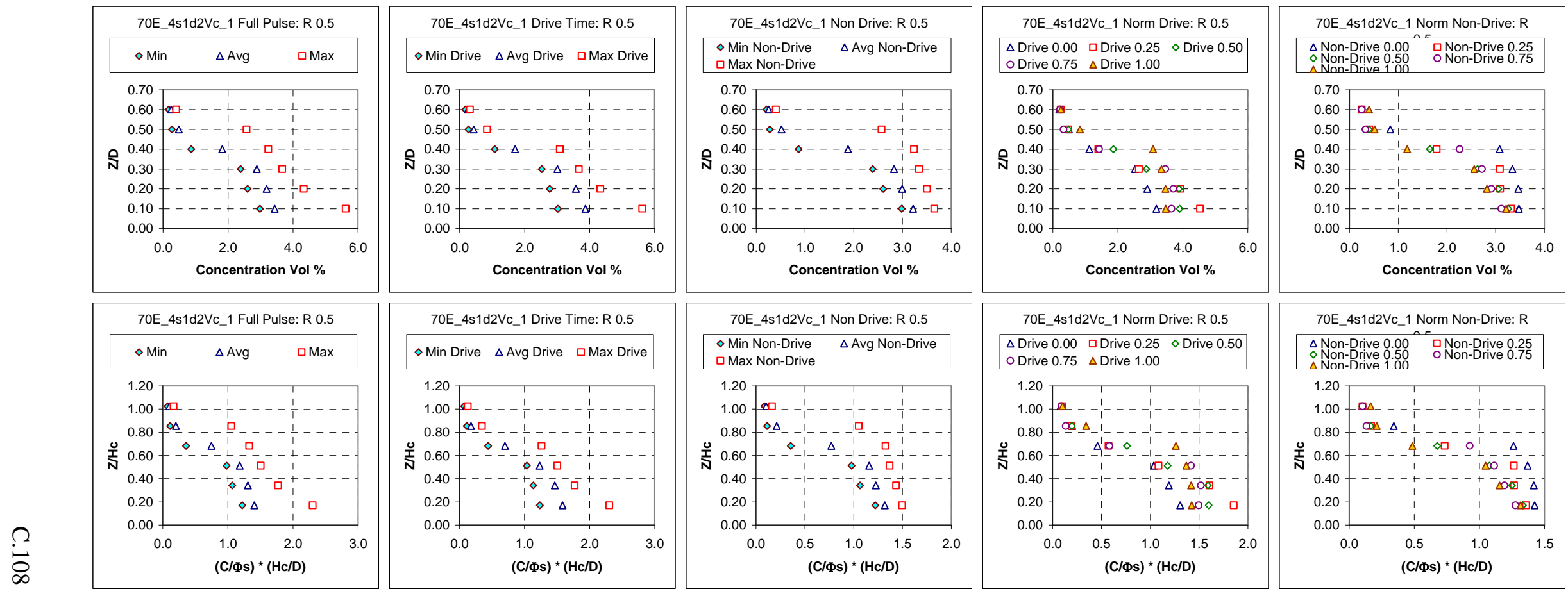

Figure C.52. 1.778-m- (70-in.-) diameter tank, 1.557-cm- (0.613-in.-) diameter nozzle; solids nominal diameter $69.3 \mu \mathrm{m}, 2.48$ g/cm³ density; 0.0143 nominal solids fraction; $33.3 \%$ duty cycle, cycle time $38.8 \mathrm{~s}$, pulse volume fraction $0.050, \mathrm{U}_{\mathrm{CS}}$ velocity $7.8 \mathrm{~m} / \mathrm{s}$, target nozzle exit velocity $7.8 \mathrm{~m} / \mathrm{s}$; peak cloud height upper bound $1.041 \mathrm{~m}$ (41 in.). Case ID 70E_4s1d2Vc_1. 

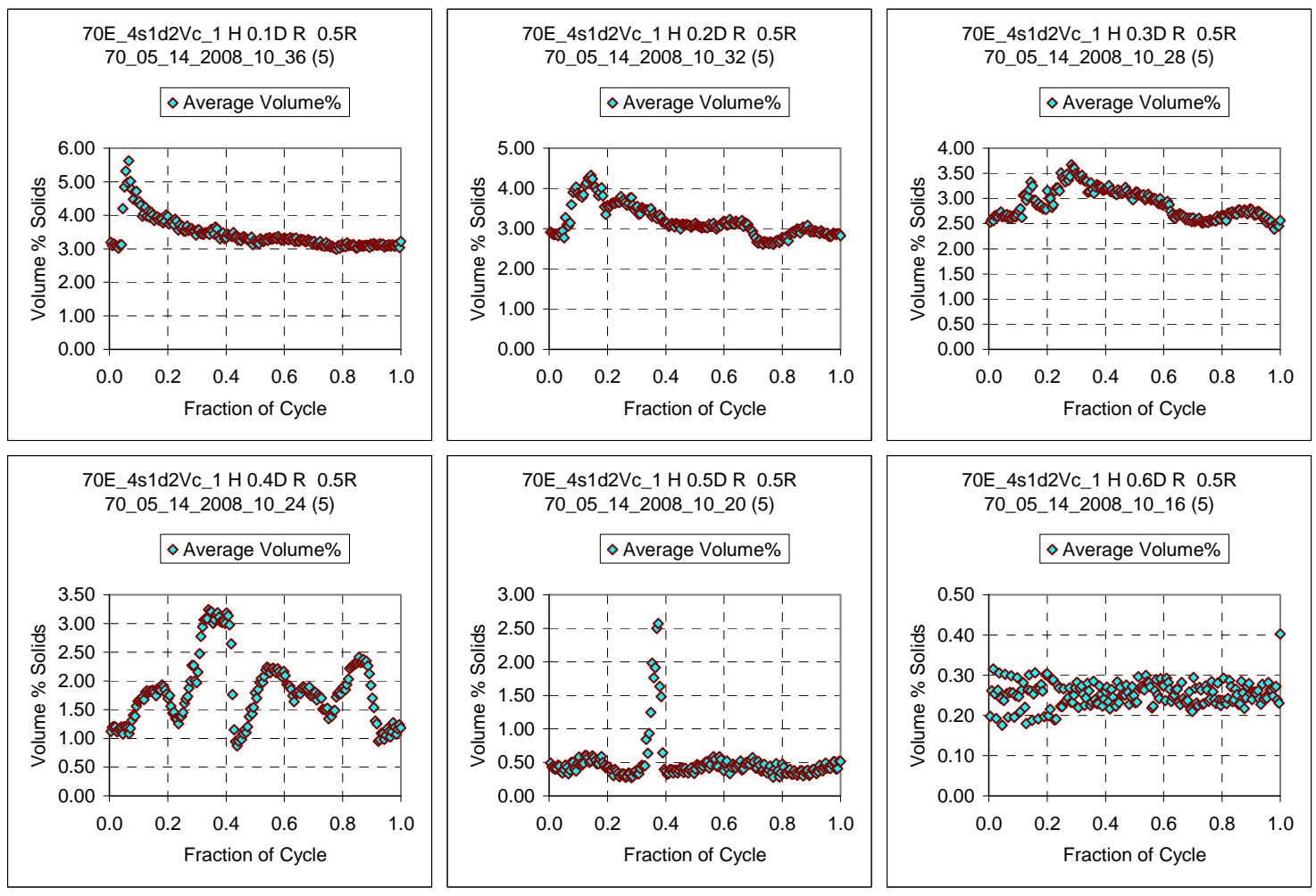

Figure C.52A. Case ID 70E_4s1d2Vc_1 Concentration Variation During the Cycle 

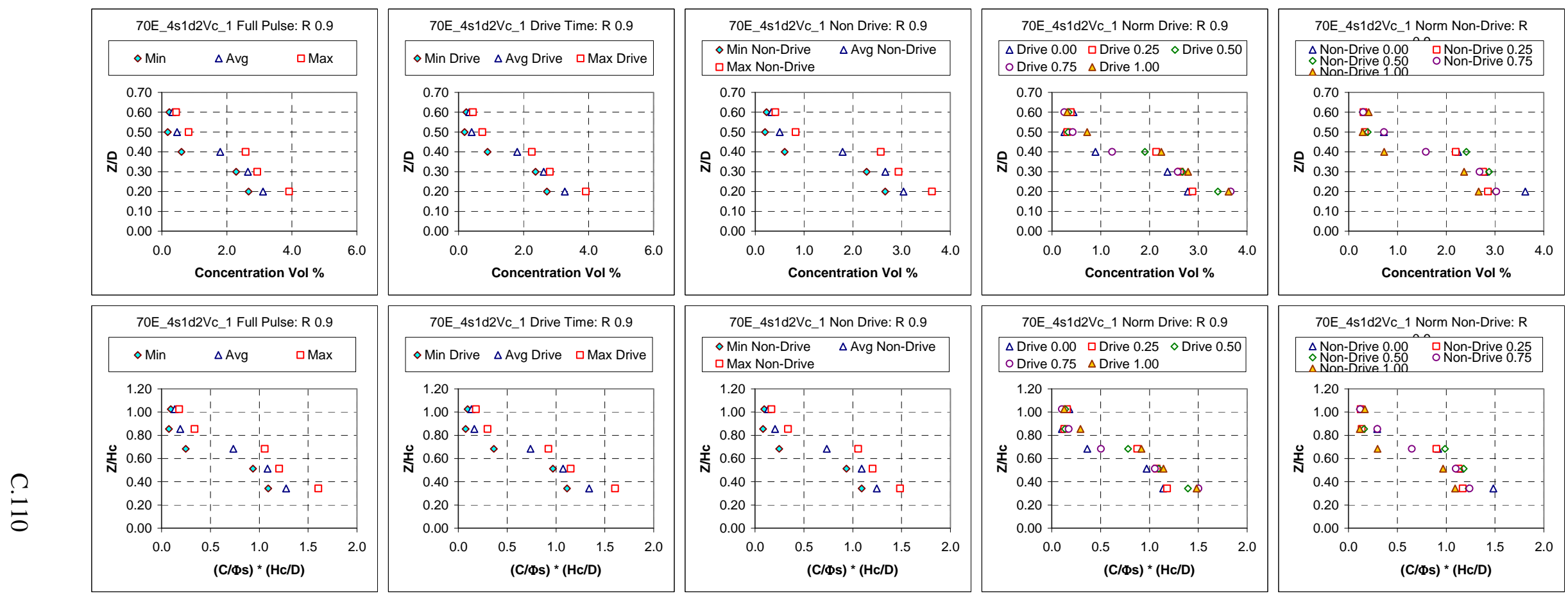

70E_4s1d2Vc_1 Norm Drive: R 0.9 $\Delta$ Drive $0.00 \quad \square$ Drive $0.25 \diamond$ Drive 0.50 $\circ$ Drive $0.75 \Delta$ Drive 1.00

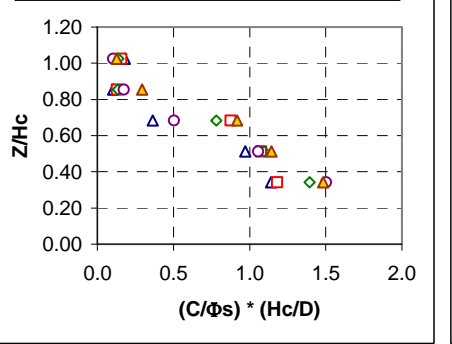

70E_4s1d2Vc_1 Norm Non-Drive: R

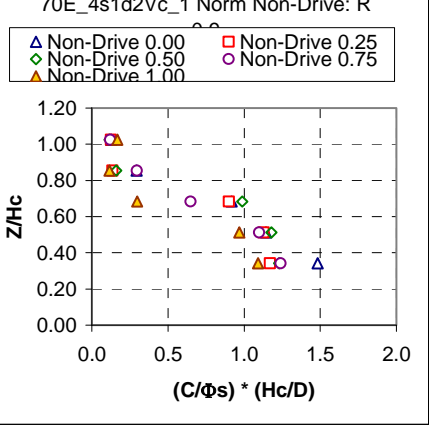

Figure C.53. 1.778-m- (70-in.-) diameter tank, 1.557-cm- (0.613-in.-) diameter nozzle; solids nominal diameter $69.3 \mu \mathrm{m}, 2.48$ g/cm ${ }^{3}$ density; 0.0143 nominal solids fraction; $33.3 \%$ duty cycle, cycle time $38.8 \mathrm{~s}$, pulse volume fraction $0.050, \mathrm{U}_{\mathrm{CS}}$ velocity $7.8 \mathrm{~m} / \mathrm{s}$, target nozzle exit velocity $7.8 \mathrm{~m} / \mathrm{s}$; peak cloud height upper bound $1.041 \mathrm{~m}$ (41 in.). Case ID 70E_4s1d2Vc_1. 

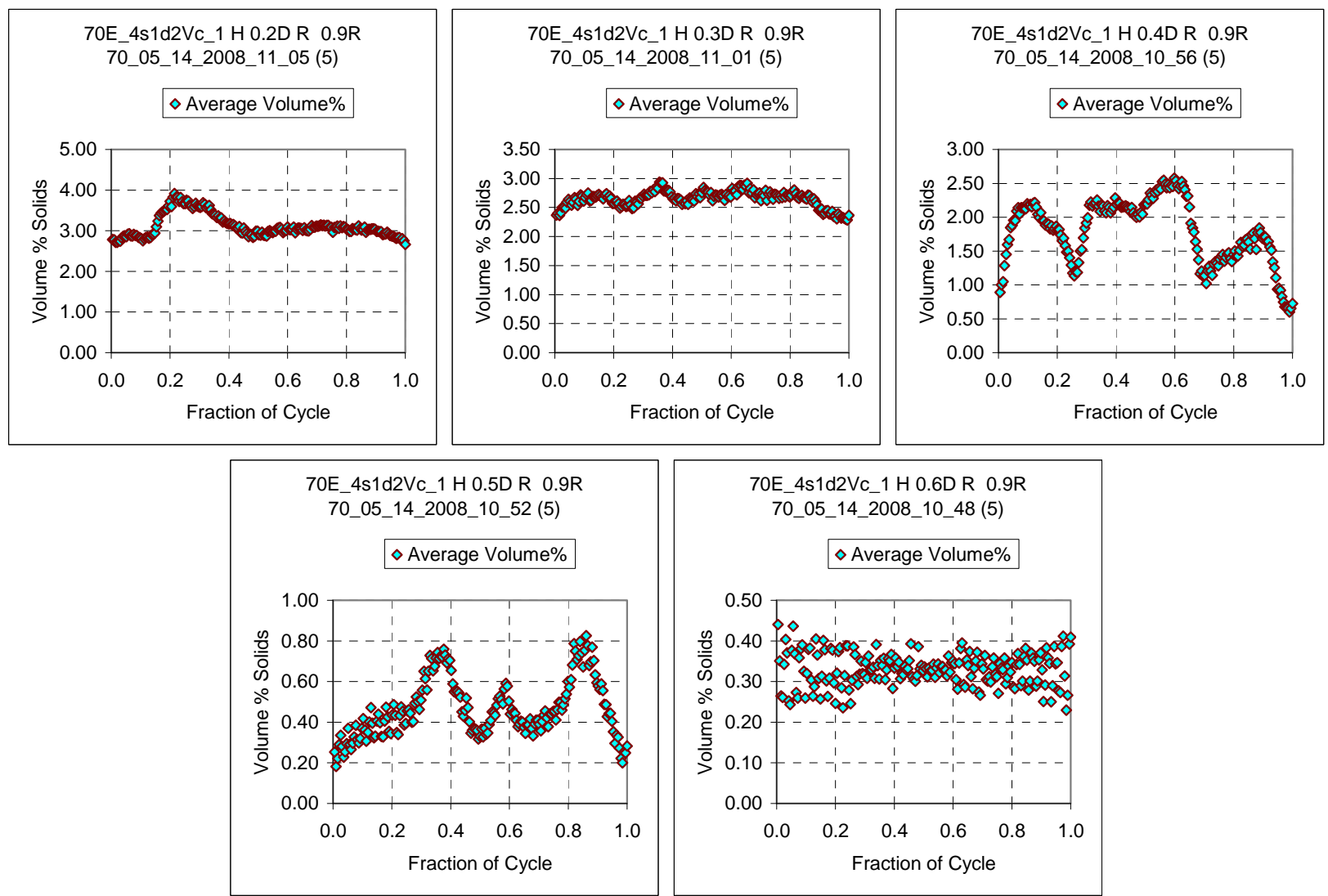

Figure C.53A. Case ID 70E_4s1d2Vc_1 Concentration Variation During the Cycle 


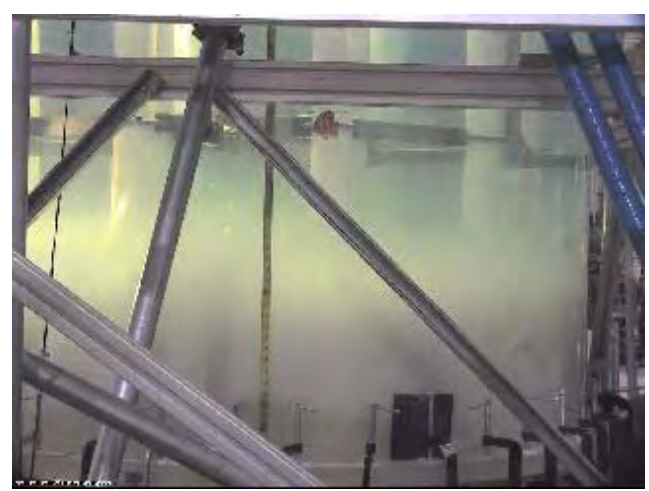

Maximum Cloud Height
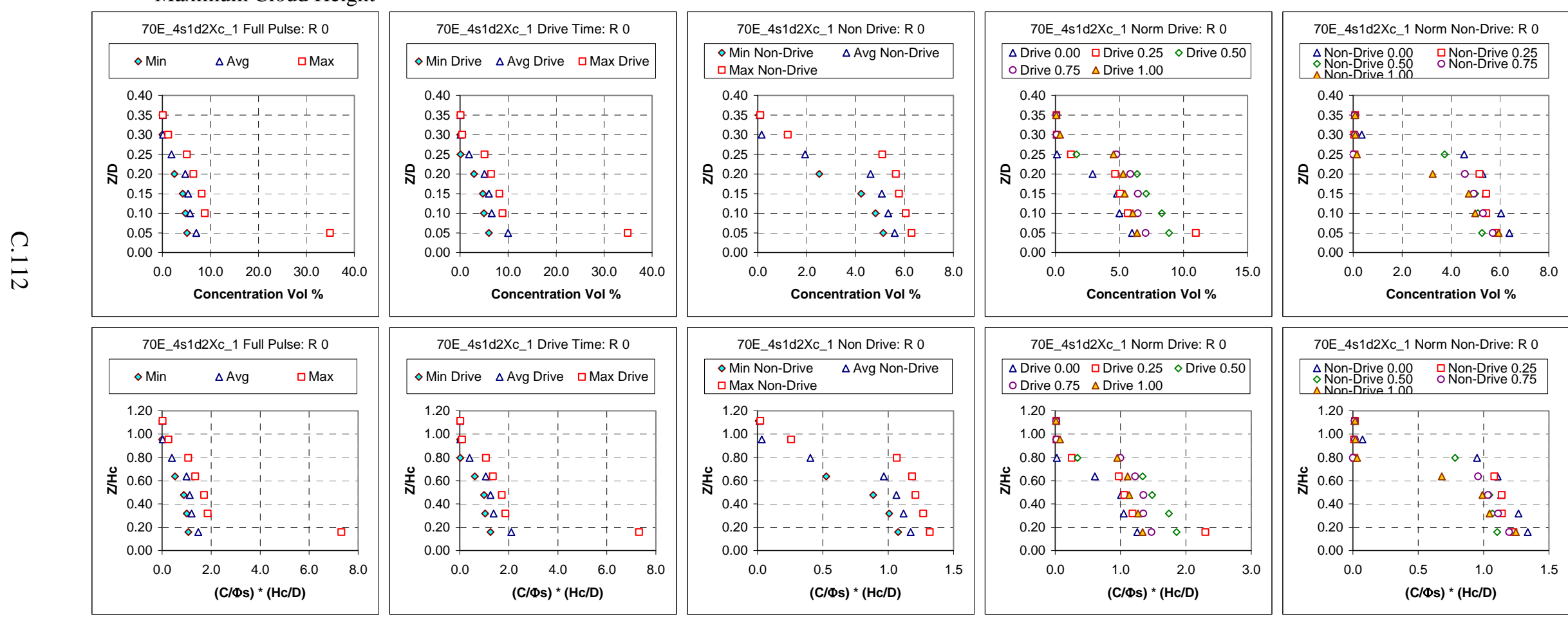

70E_4s1d2Xc_1 Norm Non-Drive: R 0 \begin{tabular}{ll}
$\Delta$ Non-Drive 0.00 & a Non-Drive 0.25 \\
$\diamond$ Non-Drive 0.50 & o Non-Drive 0.75 \\
\hline Non-Dive 1.50 &
\end{tabular}

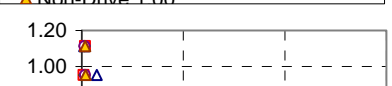
$0.800-\ldots--\frac{1}{1}-\infty-\Delta \frac{1}{1}-\ldots$ 尌 $0.60 \ldots \ldots .+\ldots$ $0.40-\ldots .+\ldots+\ldots$

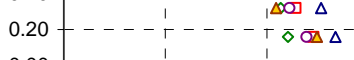

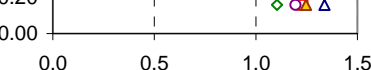

$(\mathrm{C} / \Phi \mathrm{s}) *(\mathrm{HC} / \mathrm{D})$

Figure C.54. 1.778-m- (70-in.-) diameter tank, 1.557-cm- (0.613-in.-) diameter nozzle; solids nominal diameter $69.3 \mu \mathrm{m}, 2.48$ g/cm ${ }^{3}$ density; 0.015 nominal solids fraction; $32.9 \%$ duty cycle, cycle time $44.6 \mathrm{~s}$, pulse volume fraction 0.050 , $\mathrm{U}_{\mathrm{CS}}$ velocity $8.5 \mathrm{~m} / \mathrm{s}$, target nozzle exit velocity $6.8 \mathrm{~m} / \mathrm{s}$; peak cloud height upper bound $0.572 \mathrm{~m}$ (22.5 in.). Case ID 70E_4s1d2Xc_1. 

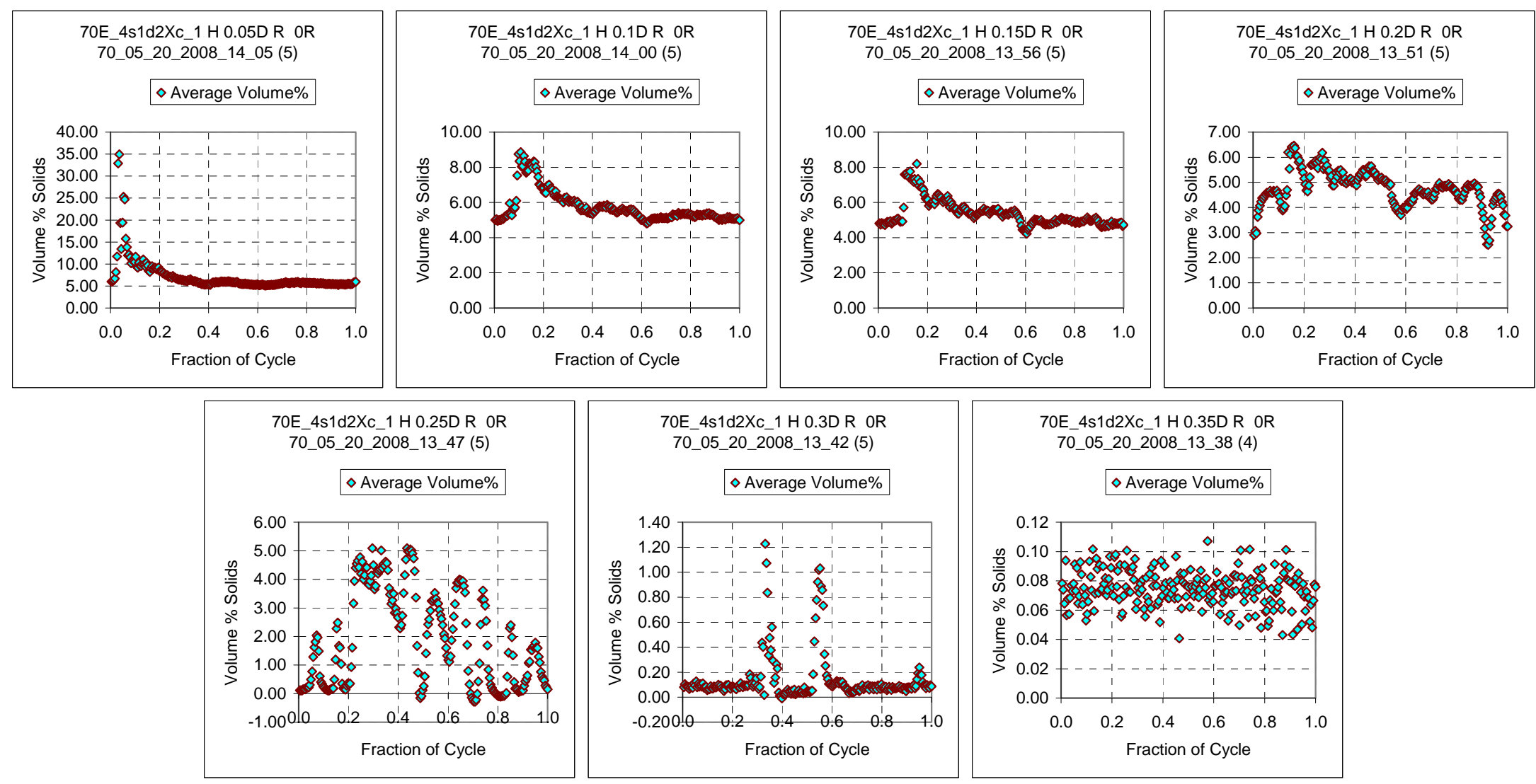

Figure C.54A. Case ID 70E_4s1d2Xc_1 Concentration Variation During the Cycle

Figure C.54 is the ninth of 12 profiles shown using simulant s1d2 in the large-scale tank with the elliptical bottom. This profile occurs at a velocity of $6.8 \mathrm{~m} / \mathrm{s}$, below the $U_{\mathrm{CS}}$ velocity of $8.5 \mathrm{~m} / \mathrm{s}$. Figures C.55, C.56, and C.57 are a group of three profiles taken at the same conditions but at the $\mathrm{U}_{\mathrm{CS}}$ velocity. The solids fraction is 0.015 . The duty cycle is $32.9 \%$, similar to that shown in the following group of three profiles $35.4 \%$. The cloud height is 22.5 in. below the 42 in. obtained at $\mathrm{U}_{\mathrm{CS}}$. 

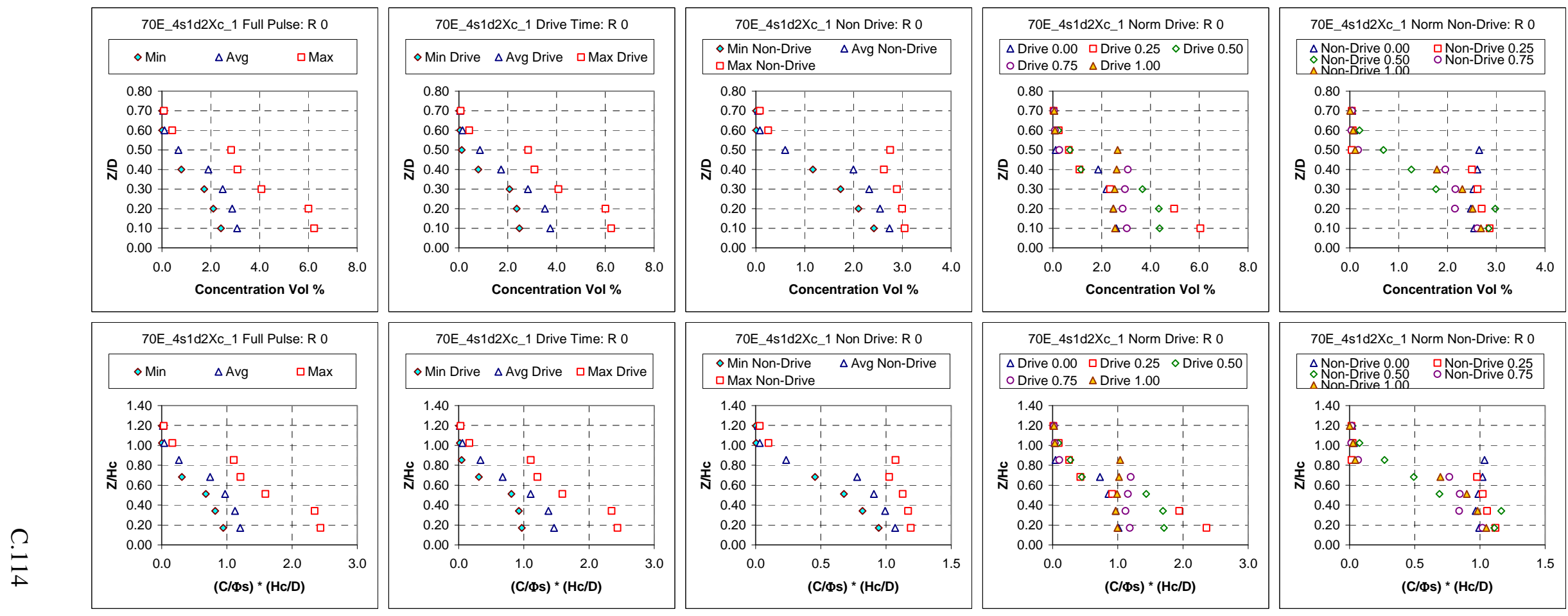

Figure C.55. 1.778-m- (70-in.-) diameter tank, 1.557-cm- (0.613-in.-) diameter nozzle; solids nominal diameter $69.3 \mu \mathrm{m}, 2.48 \mathrm{~g} / \mathrm{cm}^{3}$ density; 0.015 nominal solids fraction; $33.7 \%$ duty cycle, cycle time $35.4 \mathrm{~s}$, pulse volume fraction $0.050, \mathrm{U}_{\mathrm{CS}}$ velocity $8.5 \mathrm{~m} / \mathrm{s}$, target nozzle exit velocity $8.5 \mathrm{~m} / \mathrm{s}$; peak cloud height upper bound 1.067 m (42 in.). Case ID 70E_4s1d2Xc_1. 

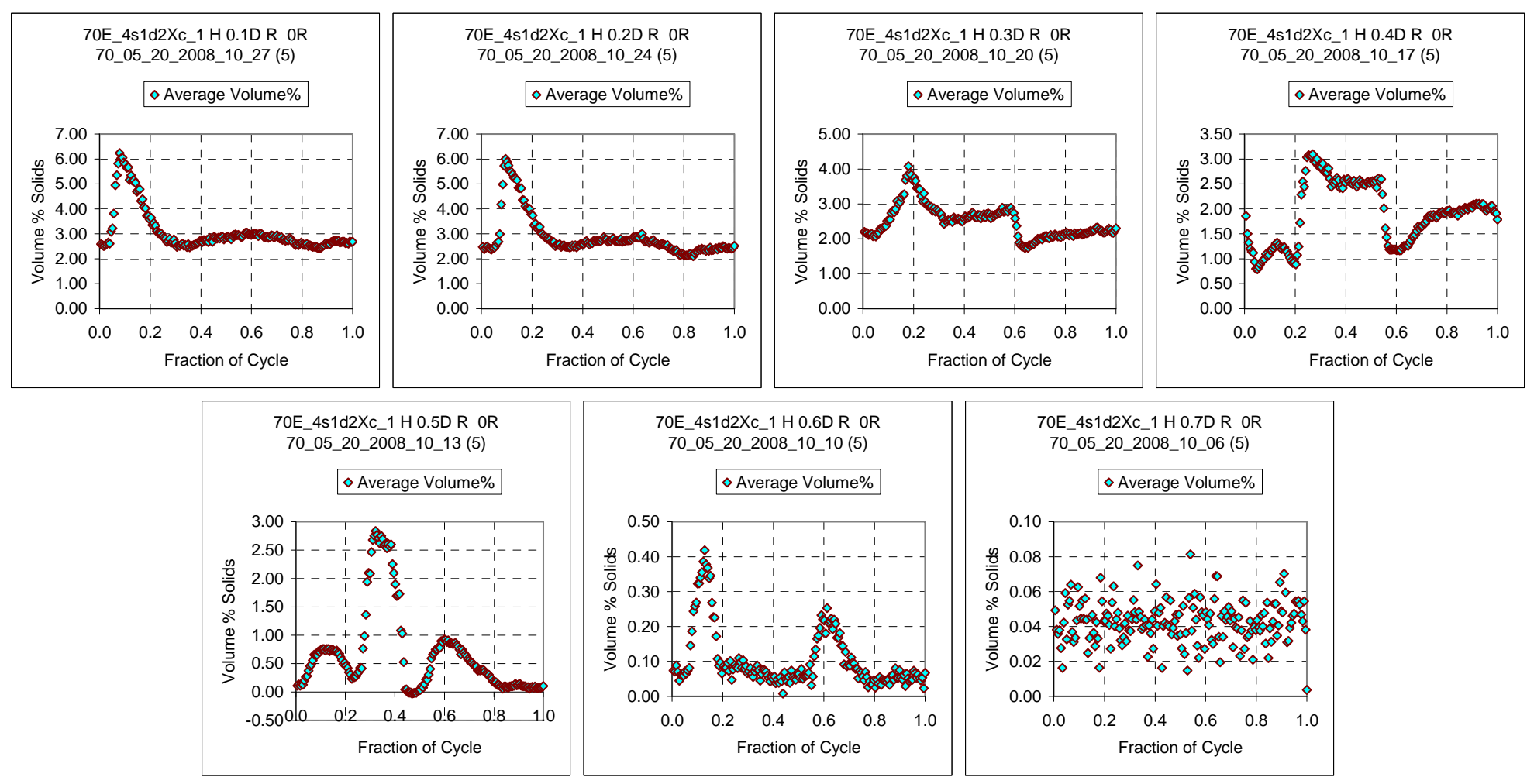

Figure C.55A. Case ID 70E_4s1d2Xc_1 R 0 Concentration Variation During the Cycle

Figure C.55 is the tenth of 12 profiles shown using simulant s1d2 in the large-scale tank with the elliptical bottom. Figures C.55, C.56, and C.57 are a group of three profiles taken at the same flow conditions and differing radial locations. Figure C.55 shows a profile at the center of the tank with $\mathrm{R}=0$. The solids fraction is 0.015 , a slight increase from 0.0143 shown in the prior profile groups. The duty cycle is $33.7 \%$, similar to the $33.3 \%$ shown in Figures C.51, C.52, and C.53, also a set of three radial profiles. The $U_{C S}$ velocity occurred at $8.5 \mathrm{~m} / \mathrm{s}$, a slight increase from $7.8 \mathrm{~m} / \mathrm{s}$ shown for the prior three profiles. These measurements were taken at $\mathrm{U}_{\mathrm{CS}}$. The cloud height is $42 \mathrm{in}$. When the radial profiles are compared the profiles are shown to decline slightly with radius. The profiles show the same trends exhibited in the prior three profiles. The profile at $\mathrm{R}=0$ reaches $\mathrm{Z} / \mathrm{D}=0.6$; the profile at $\mathrm{R}=0.5$ reaches $\mathrm{Z} / \mathrm{D}=0.5$; and the profile at $\mathrm{Z} / \mathrm{D}=0.9$ reaches 0.5 . The concentration decreases with elevation in all three radial locations and the concentration at $\mathrm{R}=0.9$ is lower than at $\mathrm{R}=0.5$ which is lower than at $\mathrm{R}=0$ when concentrations at the same elevations are compared. 


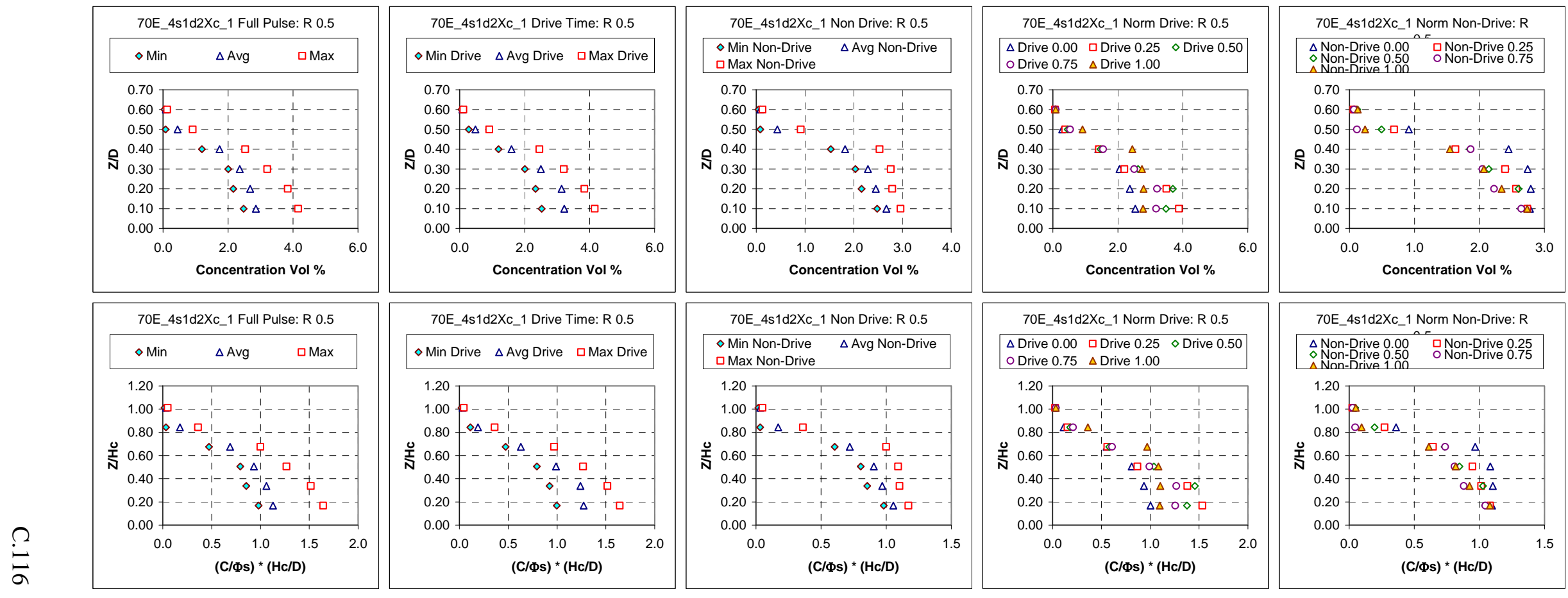

Figure C.56. 1.778-m- (70-in.-) diameter tank, 1.557-cm- (0.613-in.-) diameter nozzle; solids nominal diameter $69.3 \mu \mathrm{m}, 2.48$ g/cm³ density; 0.015 nominal solids fraction; $33.7 \%$ duty cycle, cycle time $35.4 \mathrm{~s}$, pulse volume fraction 0.050 , $\mathrm{U}_{\mathrm{CS}}$ velocity $8.5 \mathrm{~m} / \mathrm{s}$, target nozzle exit velocity $8.5 \mathrm{~m} / \mathrm{s}$; peak cloud height upper bound $1.067 \mathrm{~m}$ (42 in.). Case ID 70E_4s1d2Xc_1. 

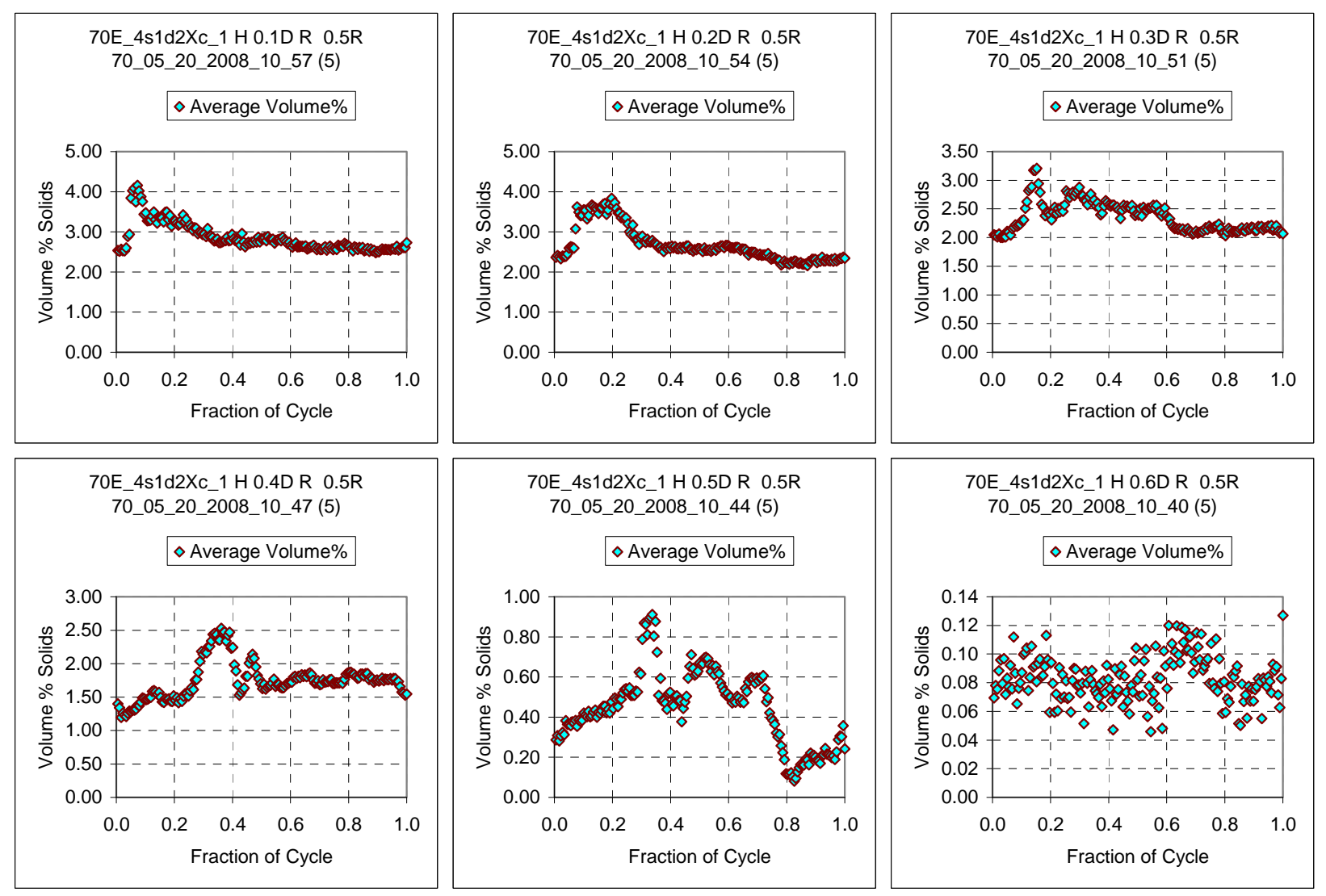

Figure C.56A. Case ID 70E_4s1d2Xc_1 R 0.5 Concentration Variation During the Cycle 


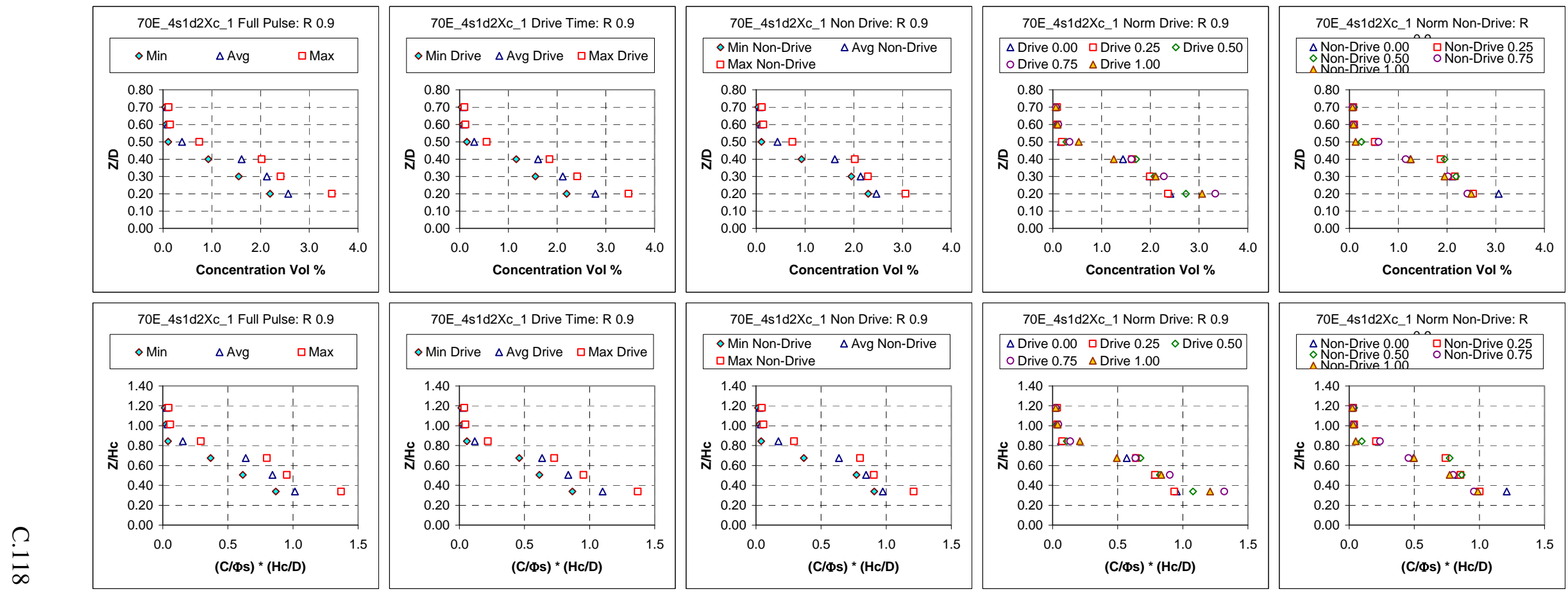

Figure C.57. 1.778-m- (70-in.-) diameter tank, 1.557-cm- (0.613-in.-) diameter nozzle; solids nominal diameter $69.3 \mu \mathrm{m}, 2.48 \mathrm{~g} / \mathrm{cm}^{3} \mathrm{density}$; 0.015 nominal solids fraction; $33.7 \%$ duty cycle, cycle time $35.4 \mathrm{~s}$, pulse volume fraction 0.050 , $\mathrm{U}_{\mathrm{CS}}$ velocity $8.5 \mathrm{~m} / \mathrm{s}$, target nozzle exit velocity $8.5 \mathrm{~m} / \mathrm{s}$; peak cloud height upper bound $1.067 \mathrm{~m}$ (42 in.). Case ID 70E_4s1d2Xc_1. 

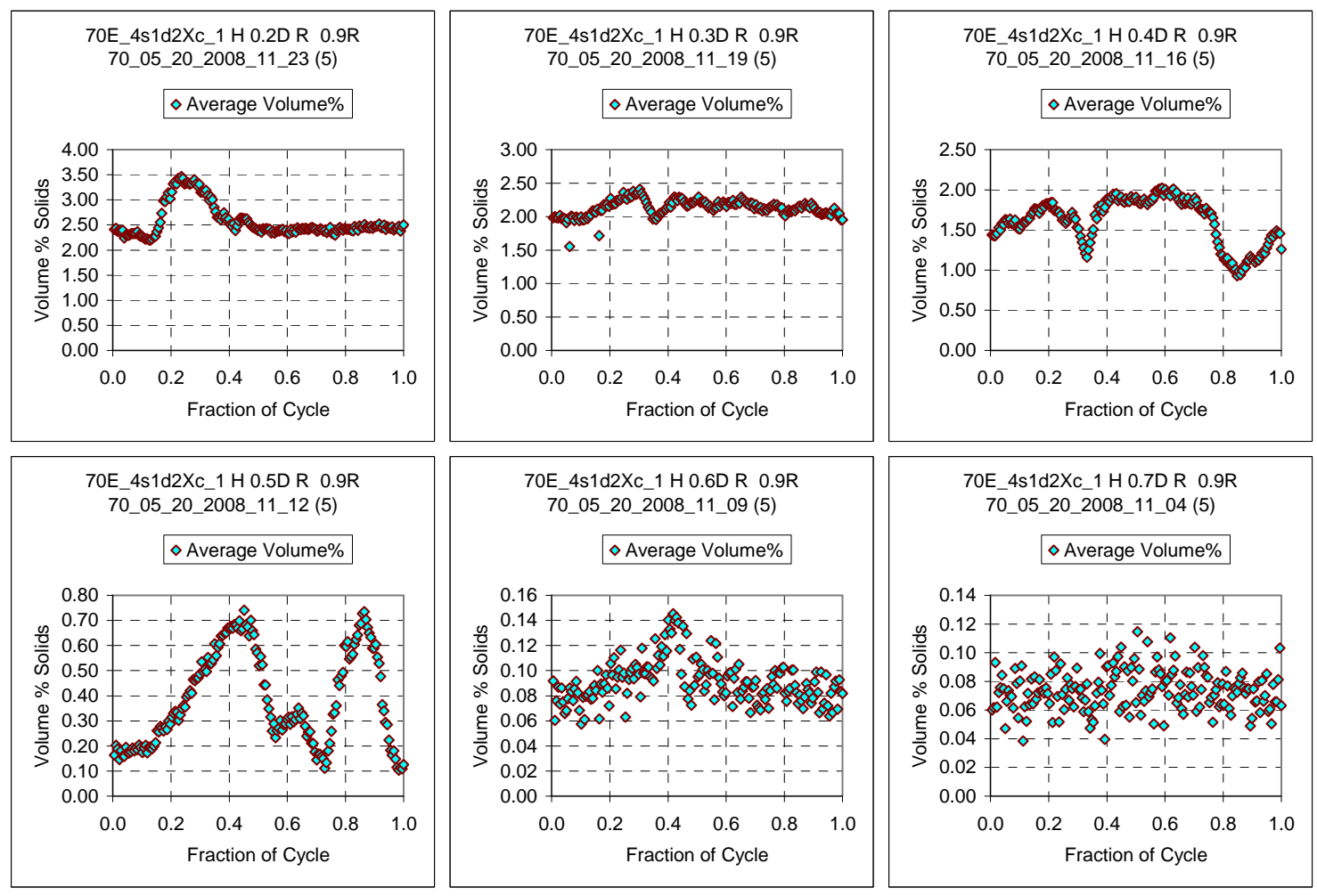

Figure C.57A. Case ID 70E_4s1d2Xc_1 R 0.9 Concentration Variation During the Cycle 

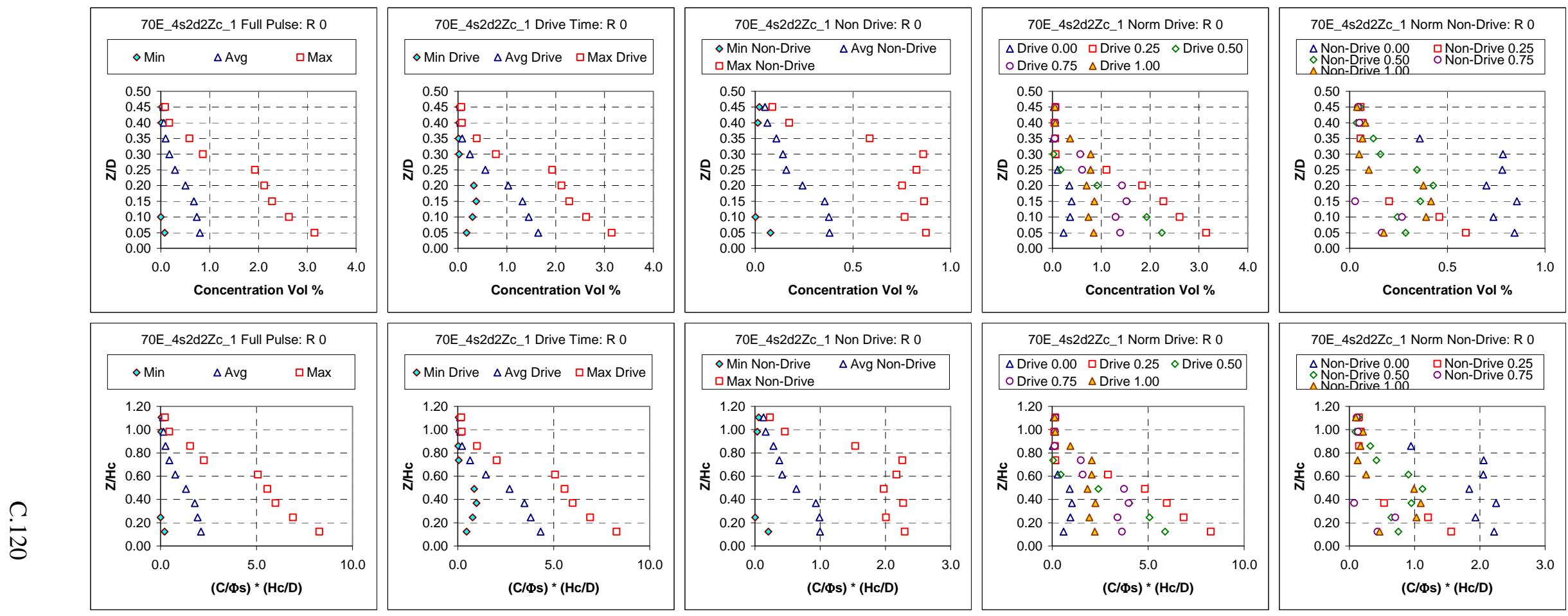
\begin{tabular}{|l|l|} 
70E_4s2d2Zc_1 Norm Drive: R 0 \\
\hline \begin{tabular}{lll|}
$\Delta$ Drive 0.00 & 口 Drive 0.25 & $\diamond$ Drive 0.50 \\
ODrive 0.75 & $\Delta$ Drive 1.00
\end{tabular} \\
\hline
\end{tabular}

70E_4s2d2Z__1 Norm Non-Drive: R 0
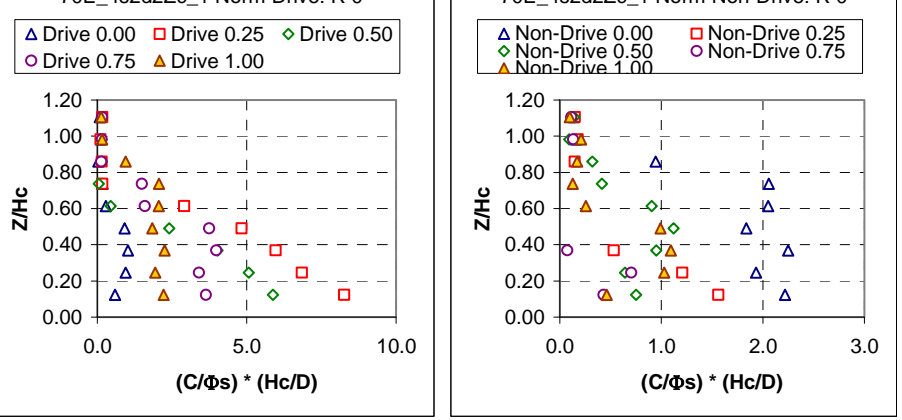

Figure C.58. 1.778-m- (70-in.-) diameter tank, 1.557-cm- (0.613-in.-) diameter nozzle; solids nominal diameter $75.6 \mu \mathrm{m}, 4.18$ g/cm³ density; 0.00155 nominal solids fraction; $33.9 \%$ duty cycle, cycle time $35.6 \mathrm{~s}$, pulse volume fraction $0.050, \mathrm{U}_{\mathrm{CS}}$ velocity $8.4 \mathrm{~m} / \mathrm{s}$, target nozzle exit velocity $8.4 \mathrm{~m} / \mathrm{s}$; peak cloud height upper bound $0.737 \mathrm{~m}$ (29 in.). Case ID 70E_4s2d2Zc_1. 

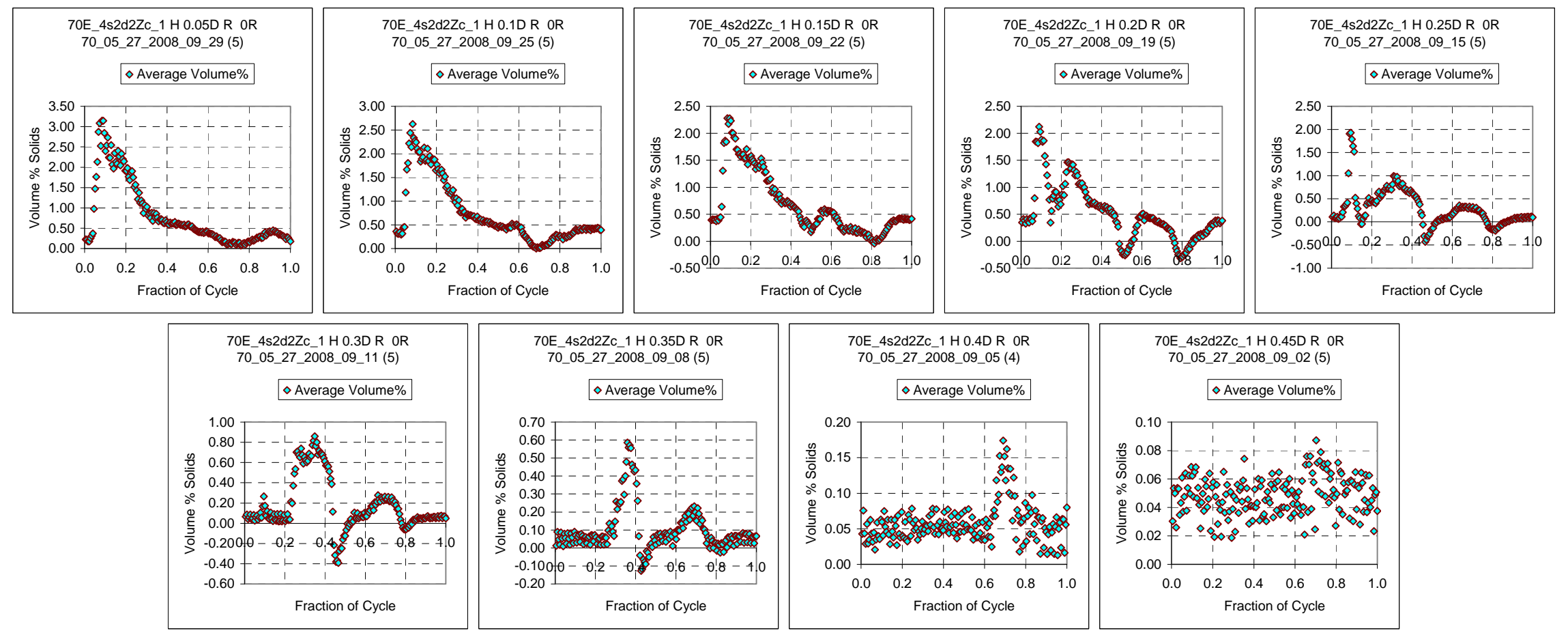

Figure C.58A. Case ID 70E_4s2d2Zc_1 Concentration Variation During the Cycle

Figure C.58 is the first of four profiles shown using simulant s2d2 in the large-scale tank with the elliptical bottom. Figures C.59, C.60, and C.61 are a group of three profiles taken at the same flow conditions and differing radial locations. Figure C.58 shows a profile at the center of the tank with $\mathrm{R}=0$. The solids fraction is 0.00155 . The duty cycle is $33.9 \%$. The $U_{C S}$ velocity occurred at $8.4 \mathrm{~m} / \mathrm{s}$ where the profile was taken. The cloud height is 29 in. This profile can be compared with Figure C.46, which had similar conditions using simulant s1d2. There the $\mathrm{U}_{\mathrm{CS}}$ velocity was $6 \mathrm{~m} / \mathrm{s}$, the target nozzle exit velocity was $6 \mathrm{~m} / \mathrm{s}$; and the peak cloud height upper bound was $28.5 \mathrm{in}$. The profiles for the two cases are very similar. 

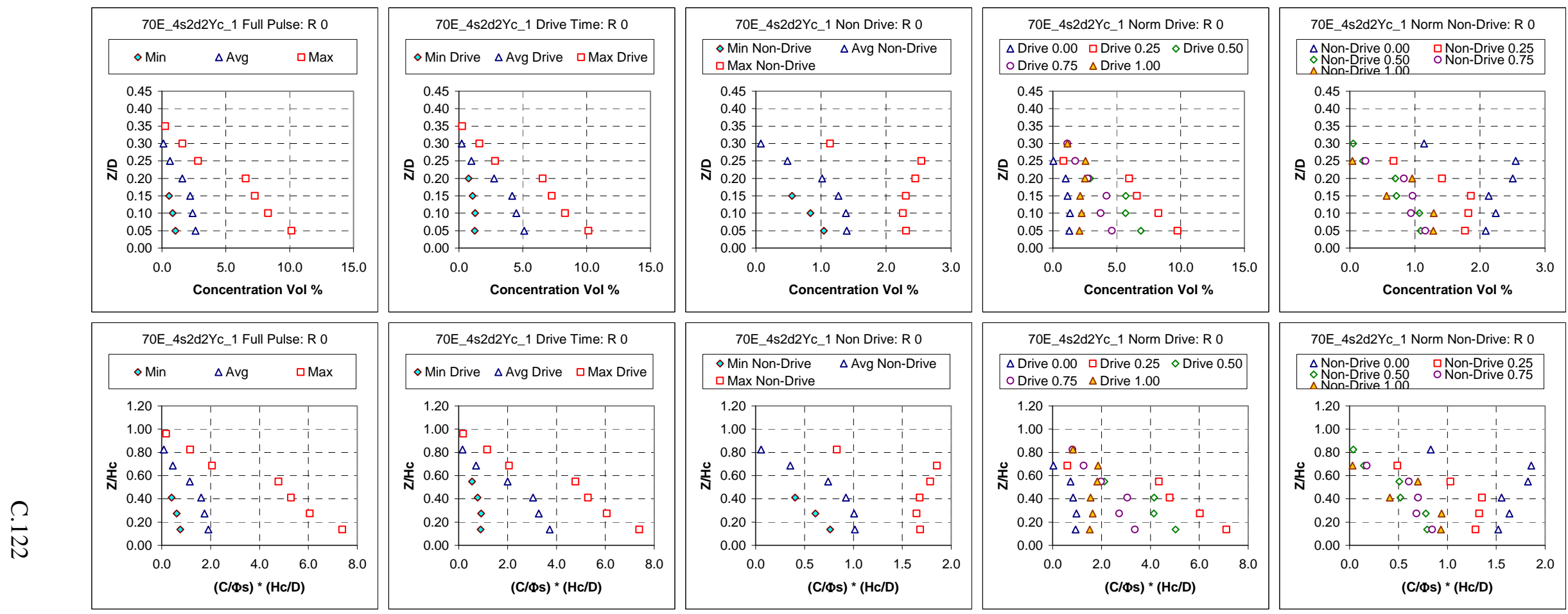
70E_4s2d2Yc_1 Norm Drive: R 0 $\triangle$ Drive $0.00 \quad \square$ Drive $0.25 \diamond$ Drive 0.50 ODrive $0.75 \Delta$ Drive 1.00
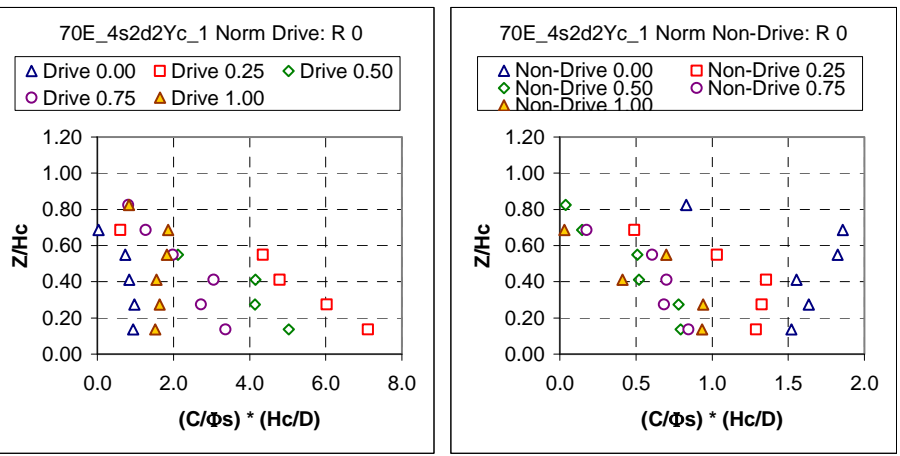

Figure C.59. 1.778-m- (70-in.-) diameter tank, 1.557-cm- (0.613-in.-) diameter nozzle; solids nominal diameter $75.6 \mu \mathrm{m}, 4.18 \mathrm{~g} / \mathrm{cm}^{3}$ density; 0.005 nominal solids fraction; $32.8 \%$ duty cycle, cycle time $26.0 \mathrm{~s}$, pulse volume fraction 0.050 , $\mathrm{U}_{\mathrm{CS}}$ velocity $12.5 \mathrm{~m} / \mathrm{s}$, target nozzle exit velocity $12 \mathrm{~m} / \mathrm{s}$; peak cloud height upper bound $0.660 \mathrm{~m}$ (26 in.). Case ID 70E_4s2d2Yc_1. 

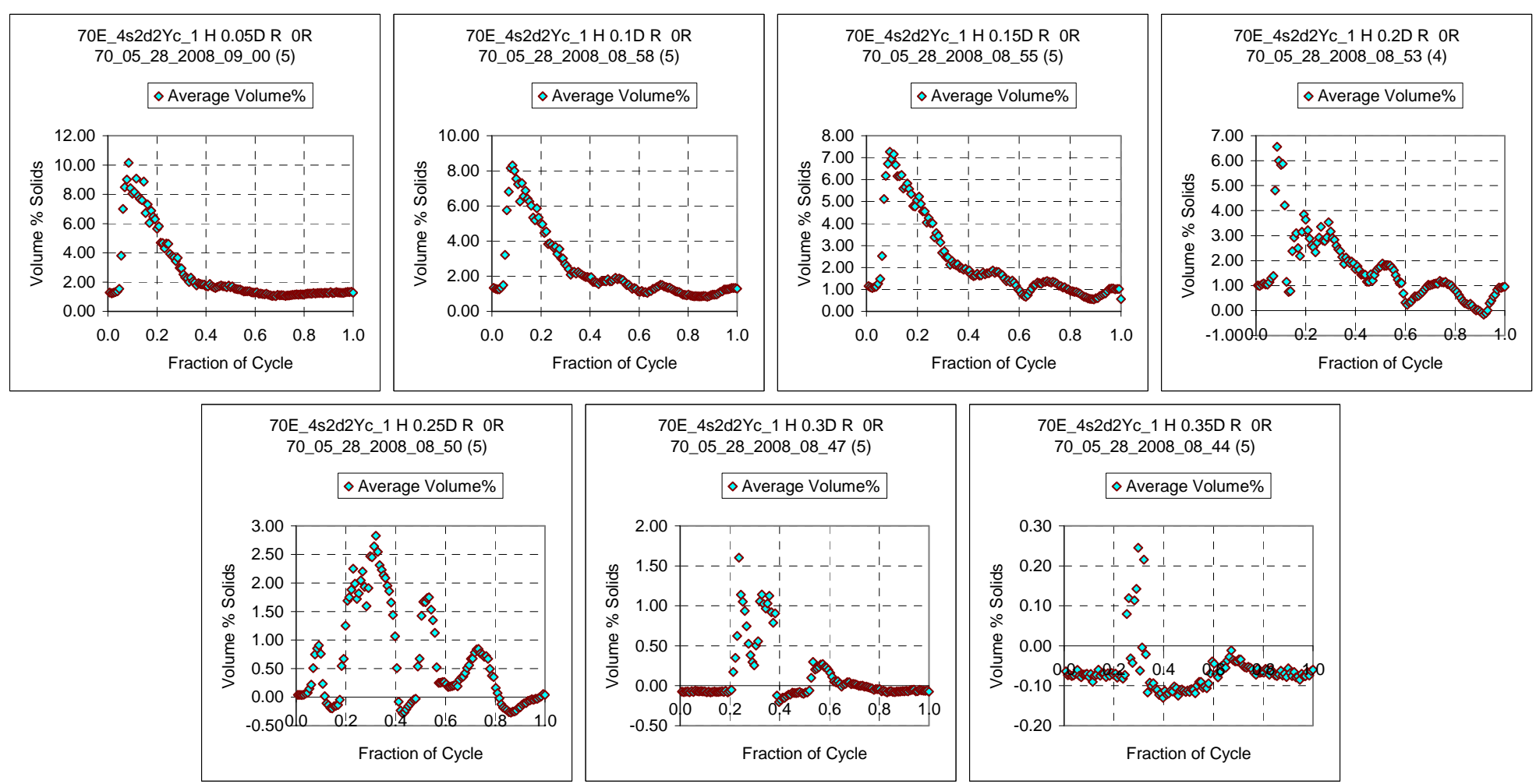

Figure C.59A. Case ID 70E_4s2d2Yc_1 R 0 Concentration Variation During the Cycle

Figure C.59 is the second of four profiles shown using simulant s2d2 in the large-scale tank with the elliptical bottom. Figures C.59, C.60, and C.61 are a group of three profiles taken at the same flow conditions and differing radial locations. Figure C.50 shows a profile at the center of the tank with $\mathrm{R}$ $=0$. The solids fraction is 0.005 . The duty cycle is $32.8 \%$. The $U_{\mathrm{CS}}$ velocity occurred at $12.5 \mathrm{~m} / \mathrm{s}$; however, the velocity for these profiles was $12 \mathrm{~m} / \mathrm{s}$, slightly below $\mathrm{U}_{\mathrm{CS}}$. The cloud height is 26 in. When the radial profiles are compared the concentration is seen to decrease as radius increases. At $\mathrm{Z} / \mathrm{D}=$ 0.05 , the concentration is $\sim 2.5$ vol\% solids at $\mathrm{R}=0, \sim 1.8 \mathrm{vol} \%$ solids at $\mathrm{R}=0.5$, and $\sim 1.4 \mathrm{vol} \%$ solids at $\mathrm{R}=0.9$. This trend continues as elevation increases. 


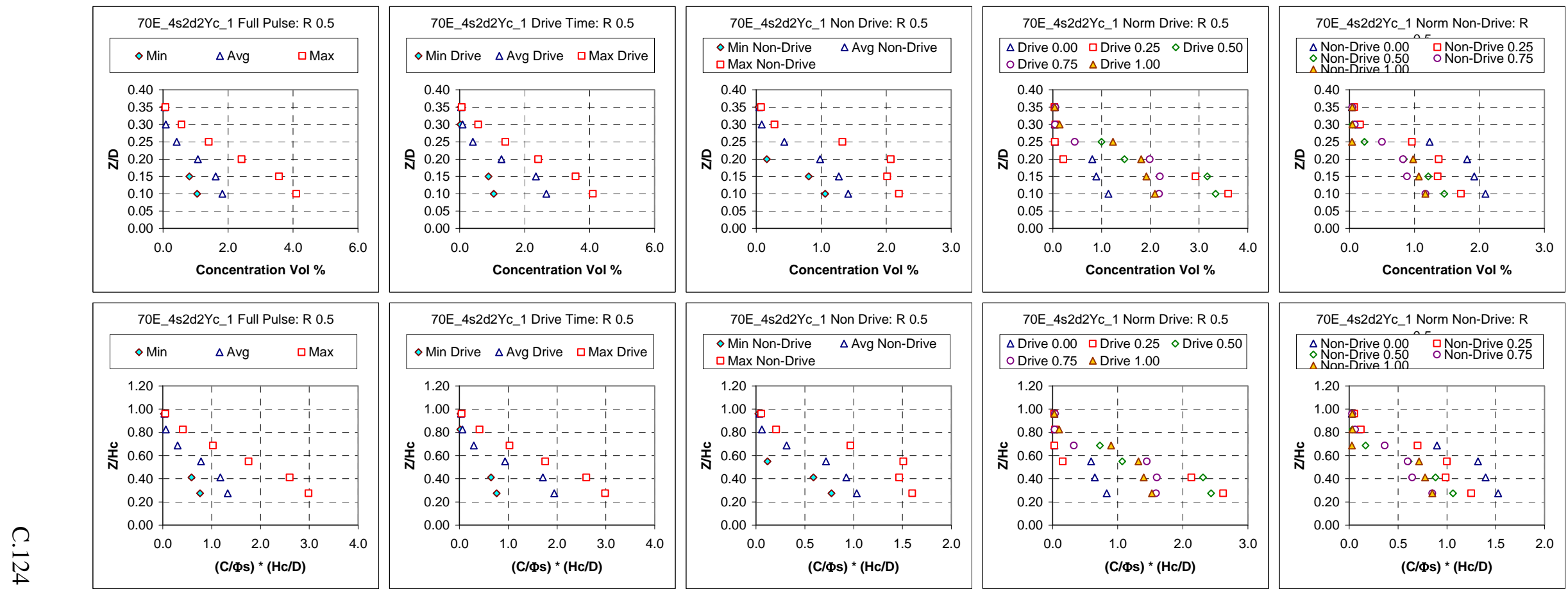

Figure C.60. 1.778-m- (70-in.-) diameter tank, 1.557-cm- (0.613-in.-) diameter nozzle; solids nominal diameter $75.6 \mu \mathrm{m}, 4.18 \mathrm{~g} / \mathrm{cm}^{3} \mathrm{density}$; 0.005 nominal solids fraction, $32.8 \%$ duty cycle, cycle time $26.0 \mathrm{~s}$, pulse volume fraction $0.050, \mathrm{U}_{\mathrm{CS}}$ velocity $12.5 \mathrm{~m} / \mathrm{s}$, target nozzle exit velocity $12 \mathrm{~m} / \mathrm{s}$; peak cloud height upper bound $0.660 \mathrm{~m}$ (26 in.). Case ID 70E_4s2d2Yc_1. 


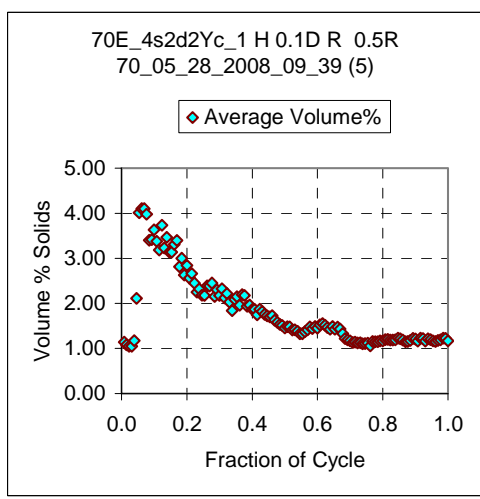

\section{E_4s2d2Yc_1 H 0.25D R $0.5 \mathrm{R}$ 70_05_28_2008_09_29 (5)}

$\diamond$ Average Volume $\%$

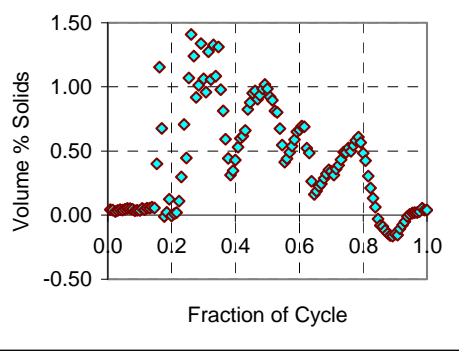

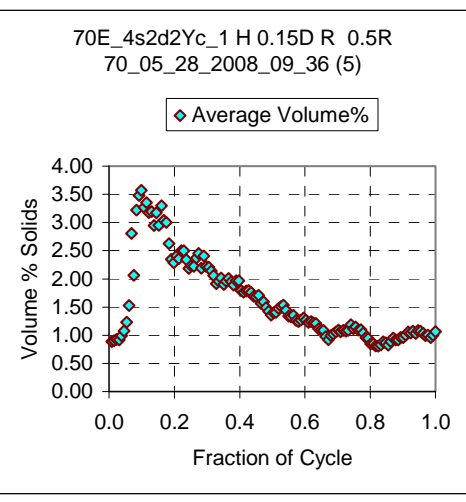

70E_4s2d2Yc_1 H 0.3D R $0.5 R$ 70_05_28_2008_09_26 (5)

$\diamond$ Average Volume $\%$

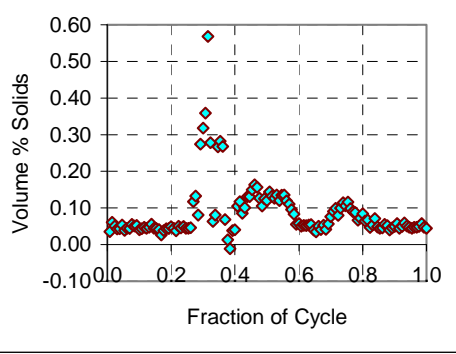

70E_4s2d2Yc_1 H $0.2 \mathrm{D} \mathrm{R} 0.5 \mathrm{R}$

_05_28_2008_09_32 (5)

$\diamond$ Average Volume $\%$

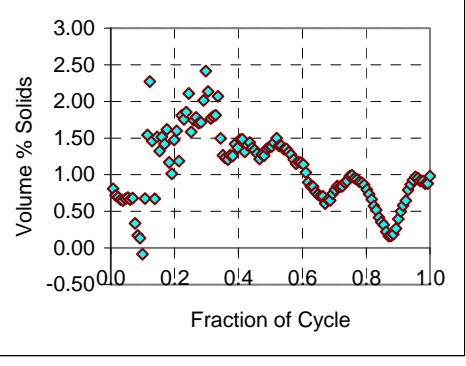

$70 \mathrm{E}_{-} 4 \mathrm{~s} 2 \mathrm{~d} 2 \mathrm{YC} \_1 \mathrm{H} 0.35 \mathrm{D} \mathrm{R} 0.5 \mathrm{R}$ 70_05_28_2008_09_23 (5)

$\diamond$ Average Volume $\%$

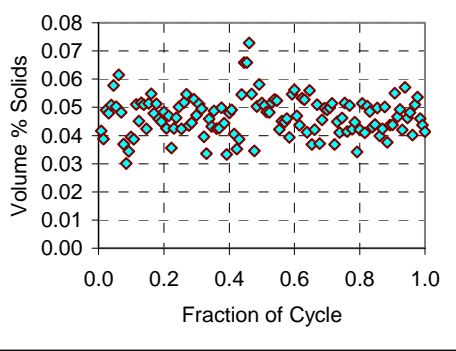

Figure C.60A. Case ID 70E_4s2d2Yc_1 R 0.5 Concentration Variation During the Cycle 

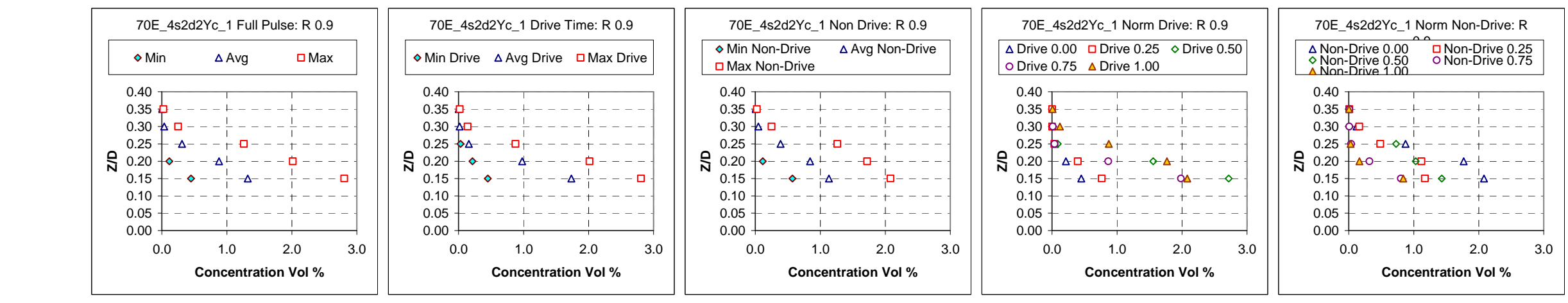

\begin{tabular}{|llr|}
\hline \multicolumn{1}{l}{ 70E_4s2d2Yc_1 Full Pulse: $\mathrm{R} 0.9$} \\
\hline$\diamond$ Min & $\Delta$ Avg & $\square \operatorname{Max}$ \\
\hline
\end{tabular}
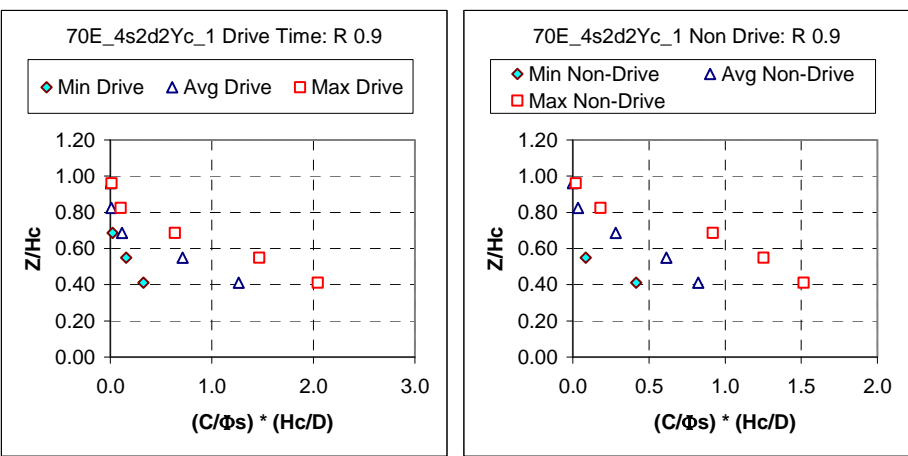
70E_4s2d2Yc_1 Norm Drive: R 0.9 $\Delta$ Drive 0.00 口 Drive $0.25 \diamond$ Drive 0.50 ODrive $0.75 \Delta$ Drive 1.00

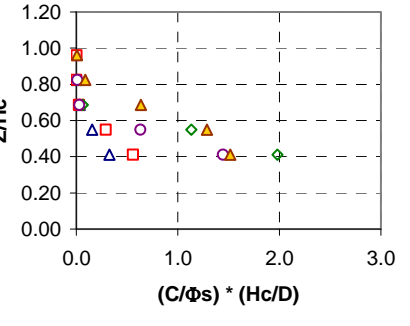

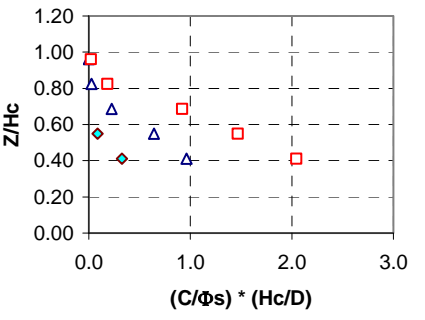

70E_4s2d2Yc_1 Norm Non-Drive: R $\begin{array}{ll}\Delta \text { Non-Drive } 0.00 & \text { a Non-Drive } 0.25 \\ \Delta \text { Non-Drive } 0.50 & \text { o Non-Drive } 0.75 \\ \text { N Non-Drive } 100 & \end{array}$

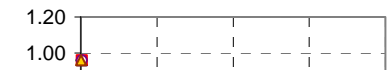
0.80 年 -

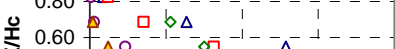

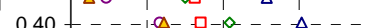
\begin{tabular}{ccc}
$0.20-\ldots$ & 1 \\
0.00 & 1 \\
\hline & 0.5
\end{tabular} $\begin{array}{ccccc}0.0 & 0.5 & 1.0 & 1.5 & 2.0 \\ & (\mathbf{C} / \Phi \mathbf{S}) *(\mathbf{H C} / \mathrm{D}) & \end{array}$

Figure C.61. 1.778-m- (70-in.-) diameter tank, 1.557-cm- (0.613-in.-) diameter nozzle; solids nominal diameter $75.6 \mu \mathrm{m}, 4.18 \mathrm{~g} / \mathrm{cm}^{3}$ density; 0.005 nominal solids fraction; $32.8 \%$ duty cycle, cycle time $26.0 \mathrm{~s}$, pulse volume fraction $0.050, \mathrm{U}_{\mathrm{Cs}}$ velocity $12.5 \mathrm{~m} / \mathrm{s}$, target nozzle exit velocity $12 \mathrm{~m} / \mathrm{s}$; peak cloud height upper bound $0.660 \mathrm{~m}$ (26 in.). Case ID 70E_4s2d2Yc_1. 

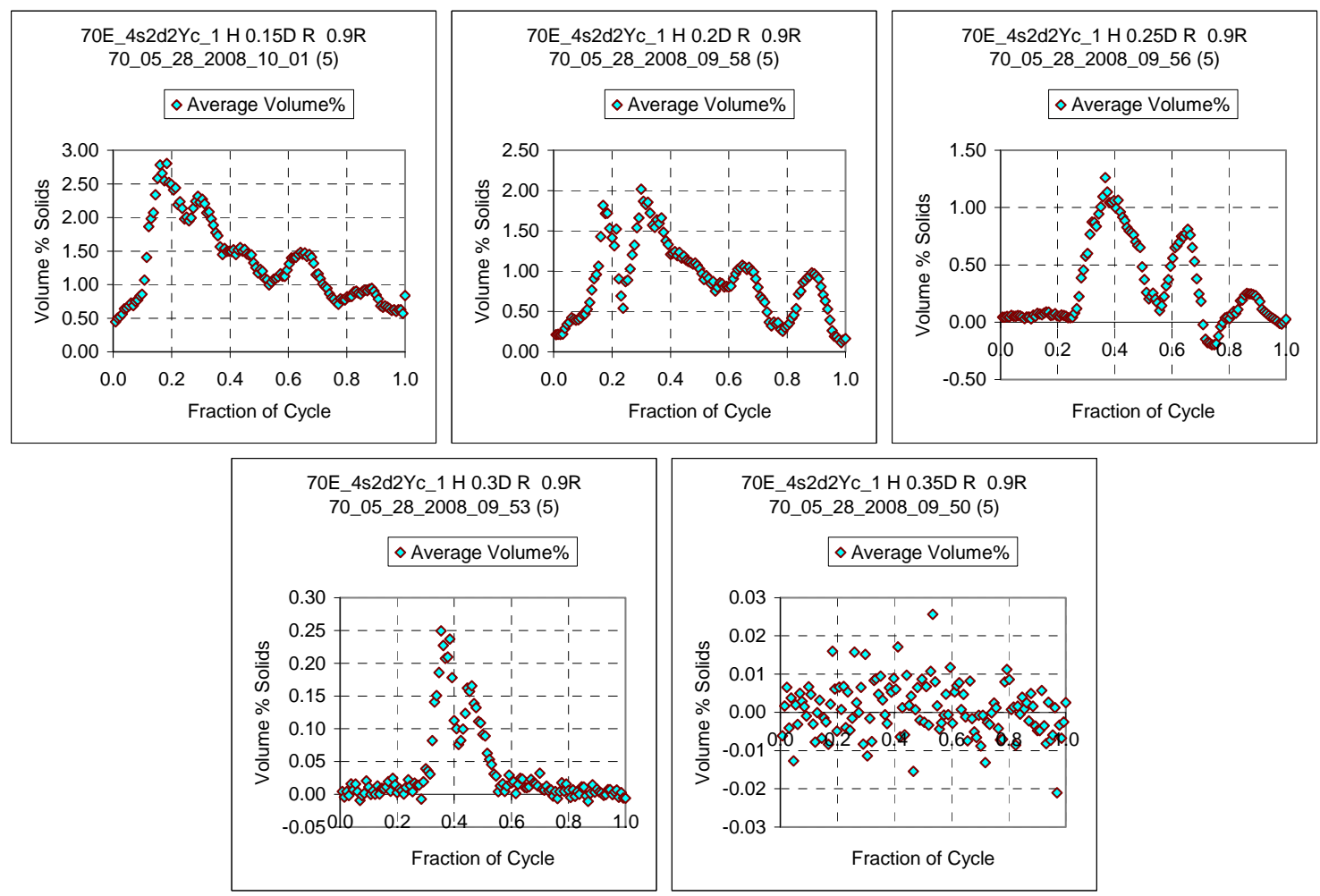

Figure C.61A. Case ID 70E_4s2d2Yc_1 R 0.9 Concentration Variation During the Cycle 

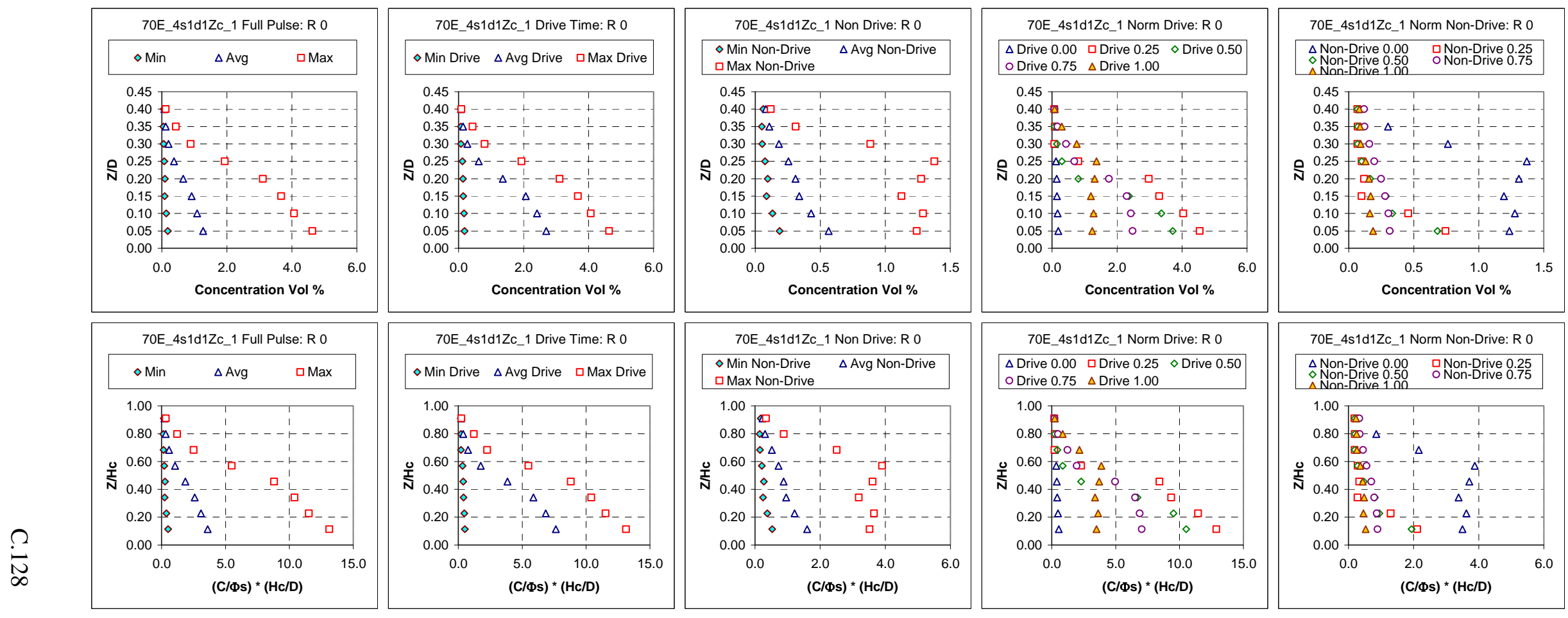

Figure C.62. 1.778-m- (70-in.-) diameter tank, 1.557-cm- (0.613-in.-) diameter nozzle; solids nominal diameter $166.4 \mu \mathrm{m}, 2.46$ g/cm ${ }^{3}$ density; 0.00155 nominal solids fraction; $33.4 \%$ duty cycle, cycle time $42.6 \mathrm{~s}$, pulse volume fraction 0.050 , $\mathrm{U}_{\mathrm{Cs}}$ velocity $7.1 \mathrm{~m} / \mathrm{s}$, target nozzle exit velocity $7.1 \mathrm{~m} / \mathrm{s}$; peak cloud height upper bound $0.800 \mathrm{~m}$ (31.5 in.). Case ID 70E_4s1d1Zc_1. 

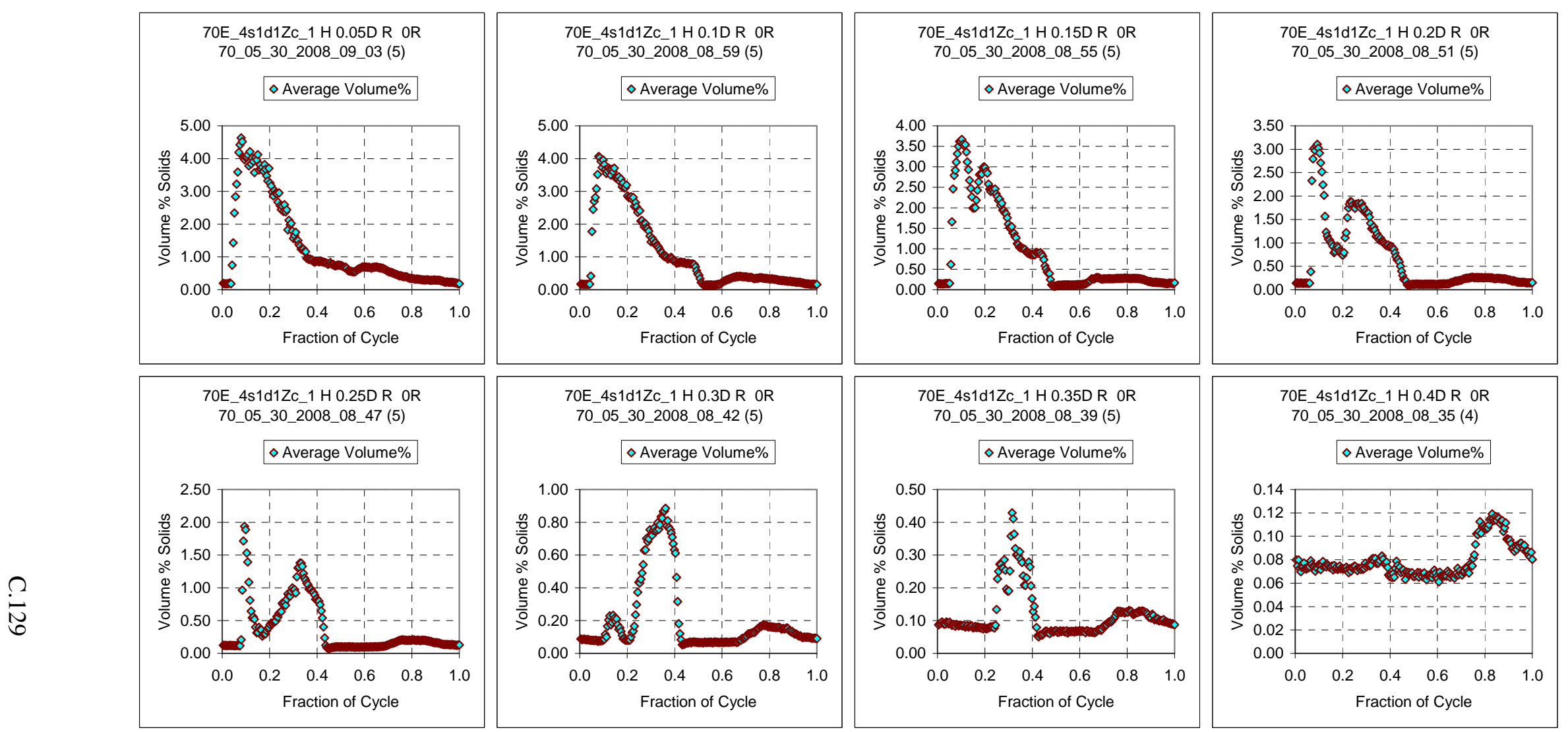

Figure C.62A. Case ID 70E_4s1d1Zc_1 R 0 Concentration Variation During the Cycle

Figure C.62 is the first of three profiles shown using simulant s1d1 in the large-scale tank with the elliptical bottom. Figures C.62, C.63, and C.64 are a group of three profiles taken at the same flow conditions and differing radial locations. Figure C.62 shows a profile at the center of the tank with $\mathrm{R}$ $=0$. The solids fraction is 0.00155 . The duty cycle is $33.4 \%$. The $U_{C S}$ velocity occurred at $7.1 \mathrm{~m} / \mathrm{s}$ and these measurements were made at $U_{\text {CS }}$. The cloud height is $31.5 \mathrm{in}$. When the radial profiles are compared the concentration is seen to decrease as radius increases. At Z/D $=0.05$ the concentration is $\sim 1.3$ vol\% solids at $\mathrm{R}=0, \sim 0.8$ vol\% solids at $\mathrm{R}=0.5$, and $\sim 0.3 \mathrm{vol} \%$ solids at $\mathrm{R}=0.9$. This trend continues as elevation increases with more of the solids concentration towards the tank center. 

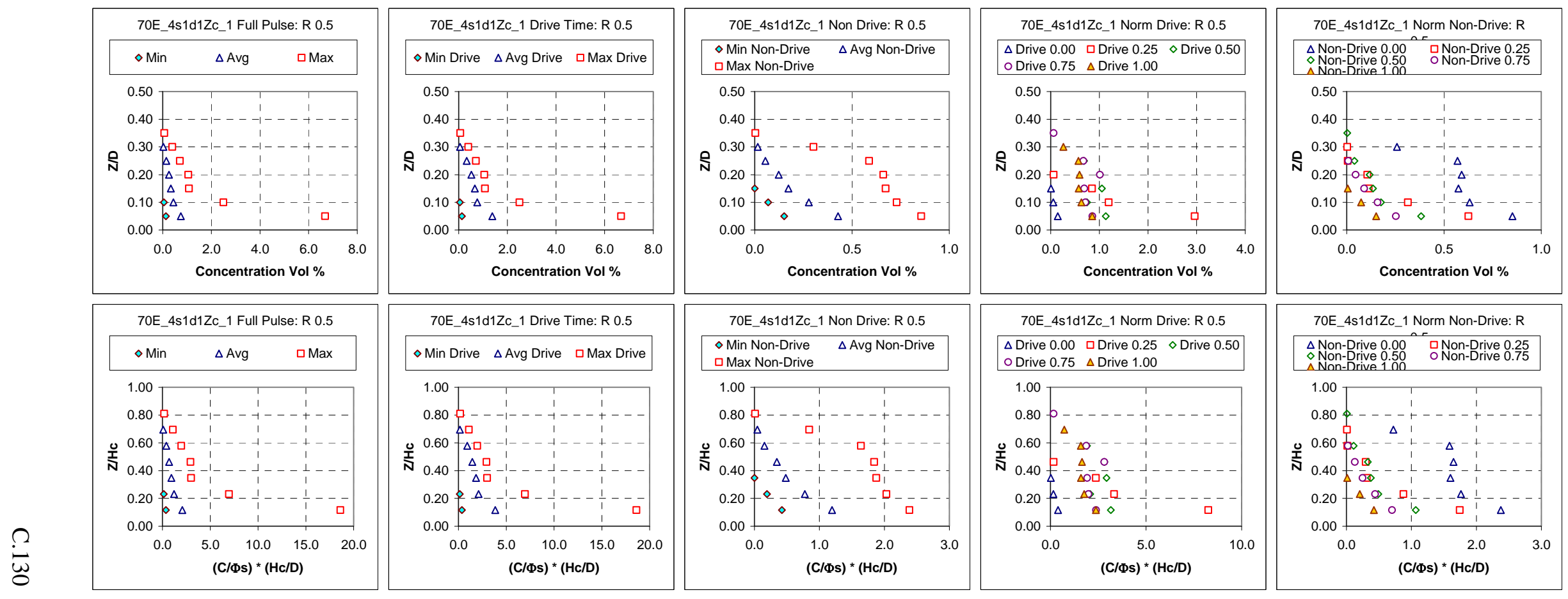

Figure C.63. 1.778-m- (70-in.-) diameter tank, 1.557-cm- (0.613-in.-) diameter nozzle; solids nominal diameter $166.4 \mu \mathrm{m}, 2.46$ g/cm ${ }^{3}$ density; 0.00155 nominal solids fraction; $33.4 \%$ duty cycle, cycle time $42.6 \mathrm{~s}$, pulse volume fraction 0.050 , $\mathrm{U}_{\mathrm{CS}}$ velocity $7.1 \mathrm{~m} / \mathrm{s}$, target nozzle exit velocity $7.1 \mathrm{~m} / \mathrm{s}$; peak cloud height upper bound $0.800 \mathrm{~m}$ (31.5 in.). Case ID 70E_4s1d1Zc_1. 

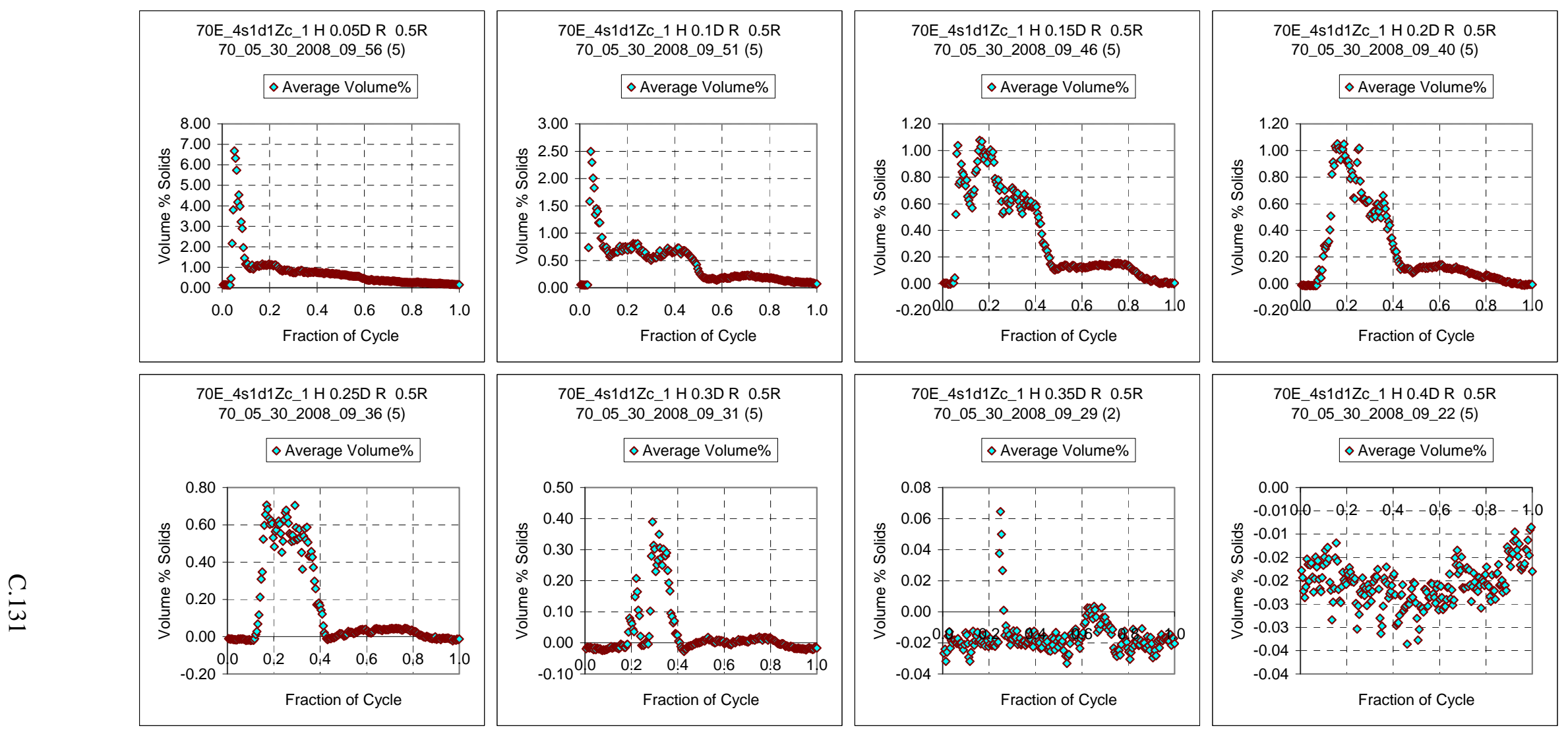

Figure C.63A. Case ID 70E_4s1d1Zc_1 R 0.5 Concentration Variation During the Cycle 

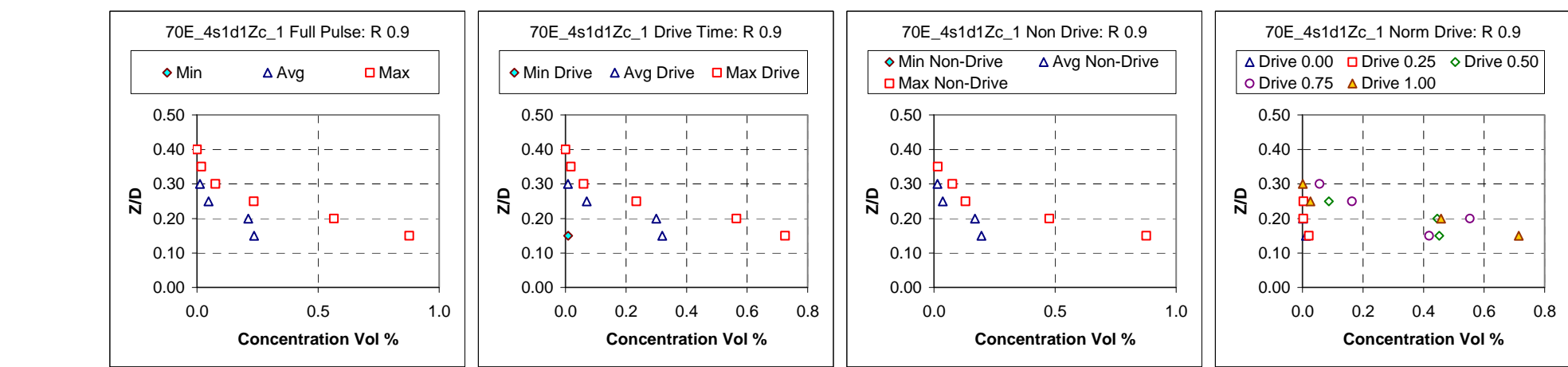

70E_4s1d1Zc_1 Norm Non-Drive: $R$
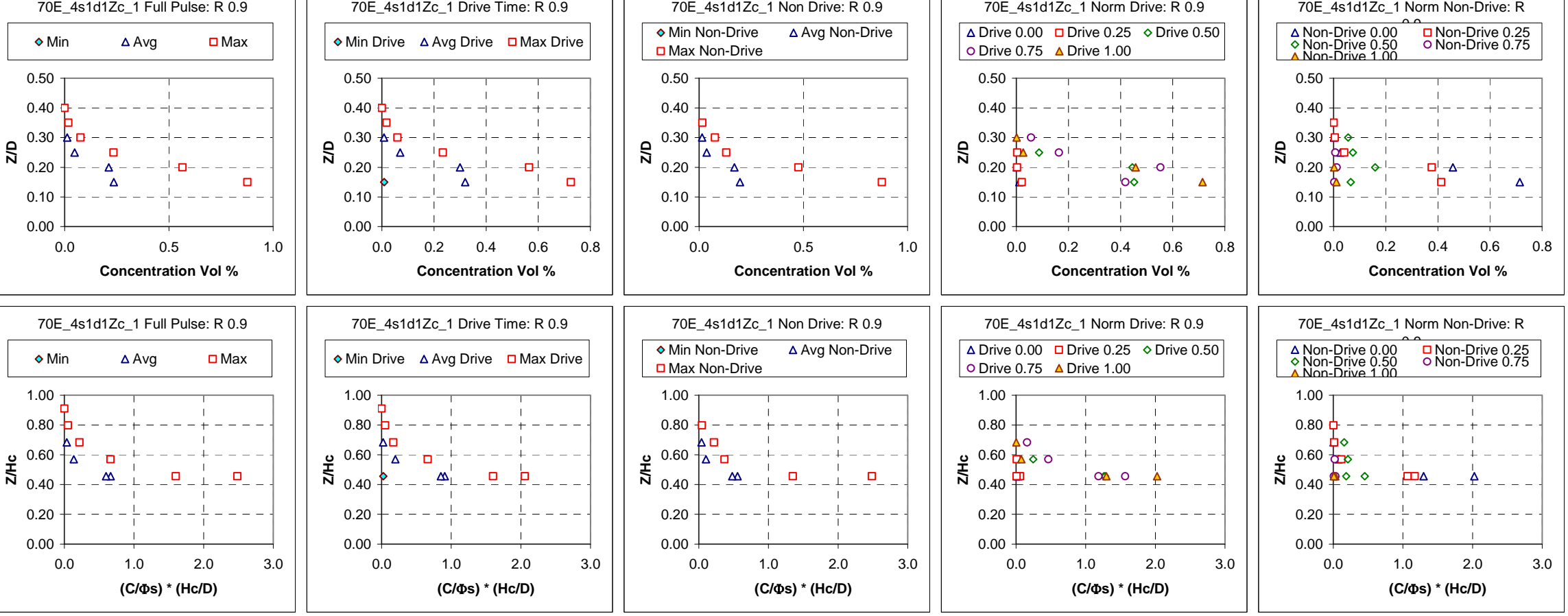

70E_4s1d1Zc_1 Norm Non-Drive: $R$ \begin{tabular}{|l|l|}
\hline $\begin{array}{l}\text { Non-Drive } 0.00 \\
\text { Non- } 0 \text { DNive } 0.50\end{array}$ & on-Drive 0.25 \\
ANan-Drive 100 & o Non-Drive 0.75 \\
\hline
\end{tabular}

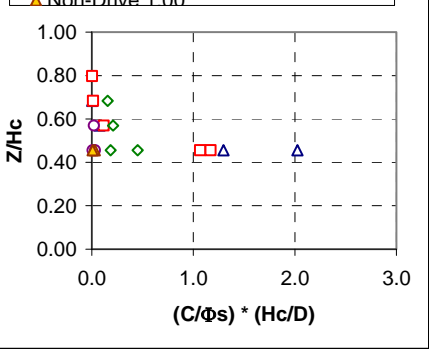

Figure C.64. 1.778-m- (70-in.-) diameter tank, 1.557-cm- (0.613-in.-) diameter nozzle; solids nominal diameter $166.4 \mu \mathrm{m}, 2.46$ g/cm ${ }^{3}$ density; 0.00155 nominal solids fraction; $33.4 \%$ duty cycle, cycle time $42.6 \mathrm{~s}$, pulse volume fraction 0.050 , $\mathrm{U}_{\mathrm{CS}}$ velocity $7.1 \mathrm{~m} / \mathrm{s}$, target nozzle exit velocity $7.1 \mathrm{~m} / \mathrm{s}$; peak cloud height upper bound $0.800 \mathrm{~m}$ (31.5 in.). Case ID 70E_4s1d1Zc_1. 

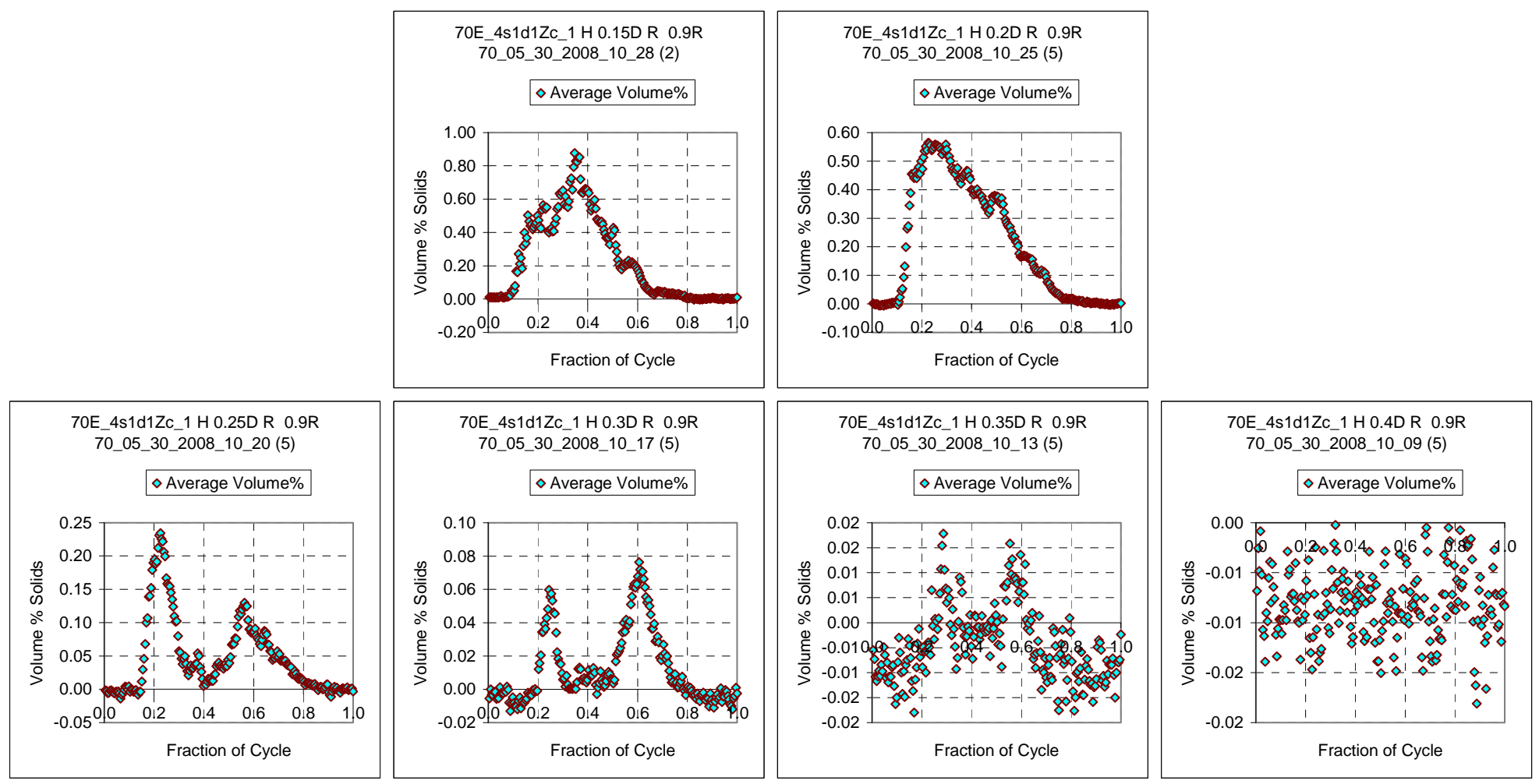

Figure C.64A. Case ID 70E_4s1d1Zc_1 R 0.9 Concentration Variation During the Cycle 


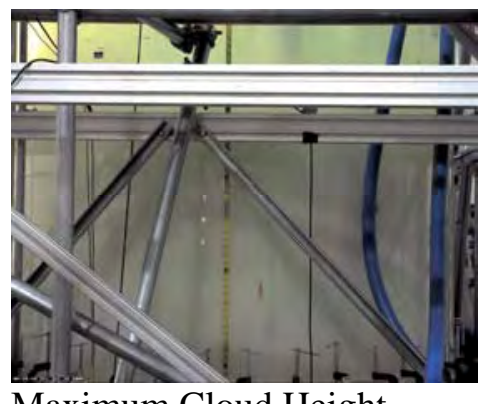

Maximum Cloud Height
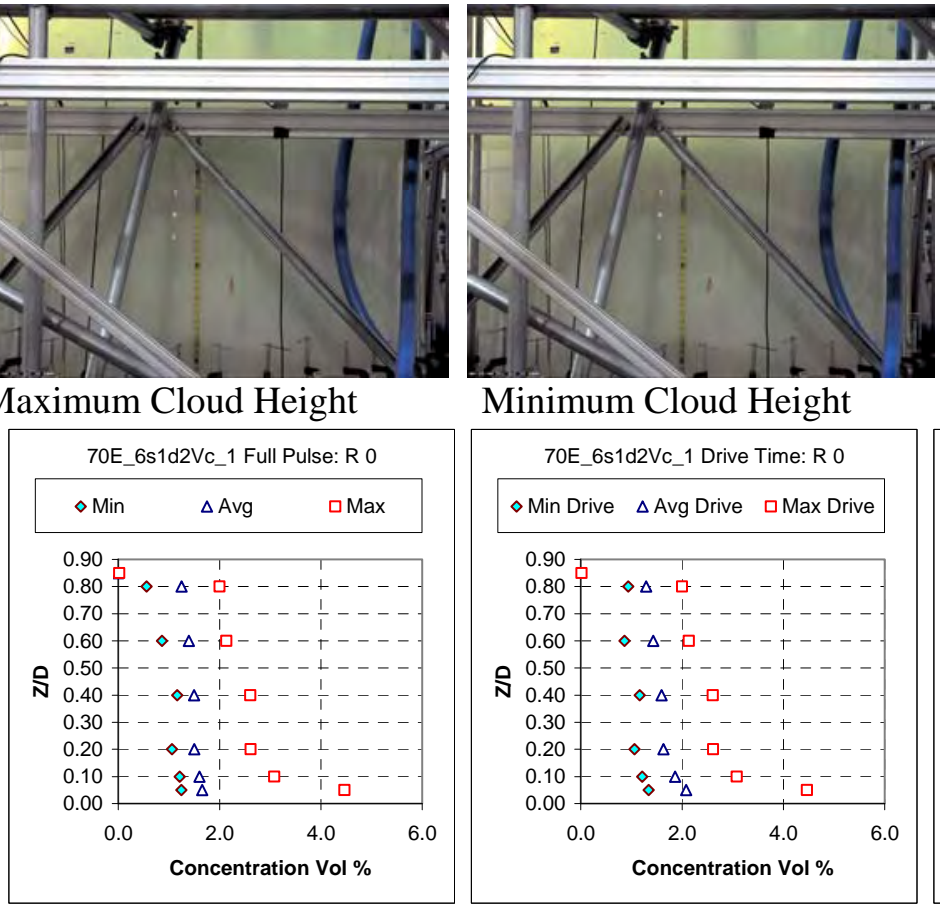

Minimum Cloud Height
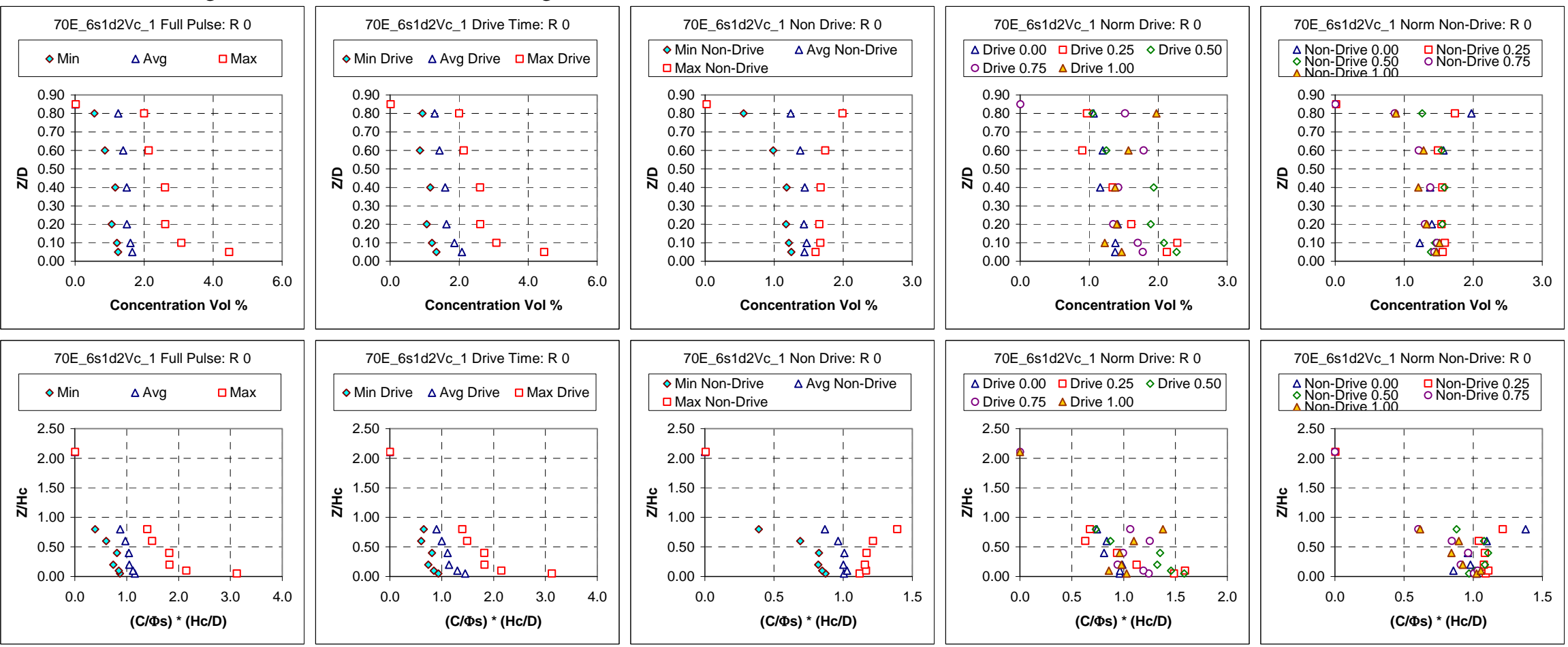

Figure C.65. 1.778-m- (70-in.-) diameter tank, 2.337-cm- (0.92-in.-) diameter nozzle; solids nominal diameter $69.3 \mu \mathrm{m}, 2.48$ g/cm ${ }^{3}$ density; 0.0143 nominal solids fraction; $33.5 \%$ duty cycle, cycle time $29.6 \mathrm{~s}$, pulse volume fraction 0.050 , $\mathrm{U}_{\mathrm{CS}}$ velocity $6.8 \mathrm{~m} / \mathrm{s}$, target nozzle exit velocity $6.8 \mathrm{~m} / \mathrm{s}$; peak cloud height upper bound $1.829 \mathrm{~m}$ (72 in.). Case ID 70E_6s1d2Vc_1. 

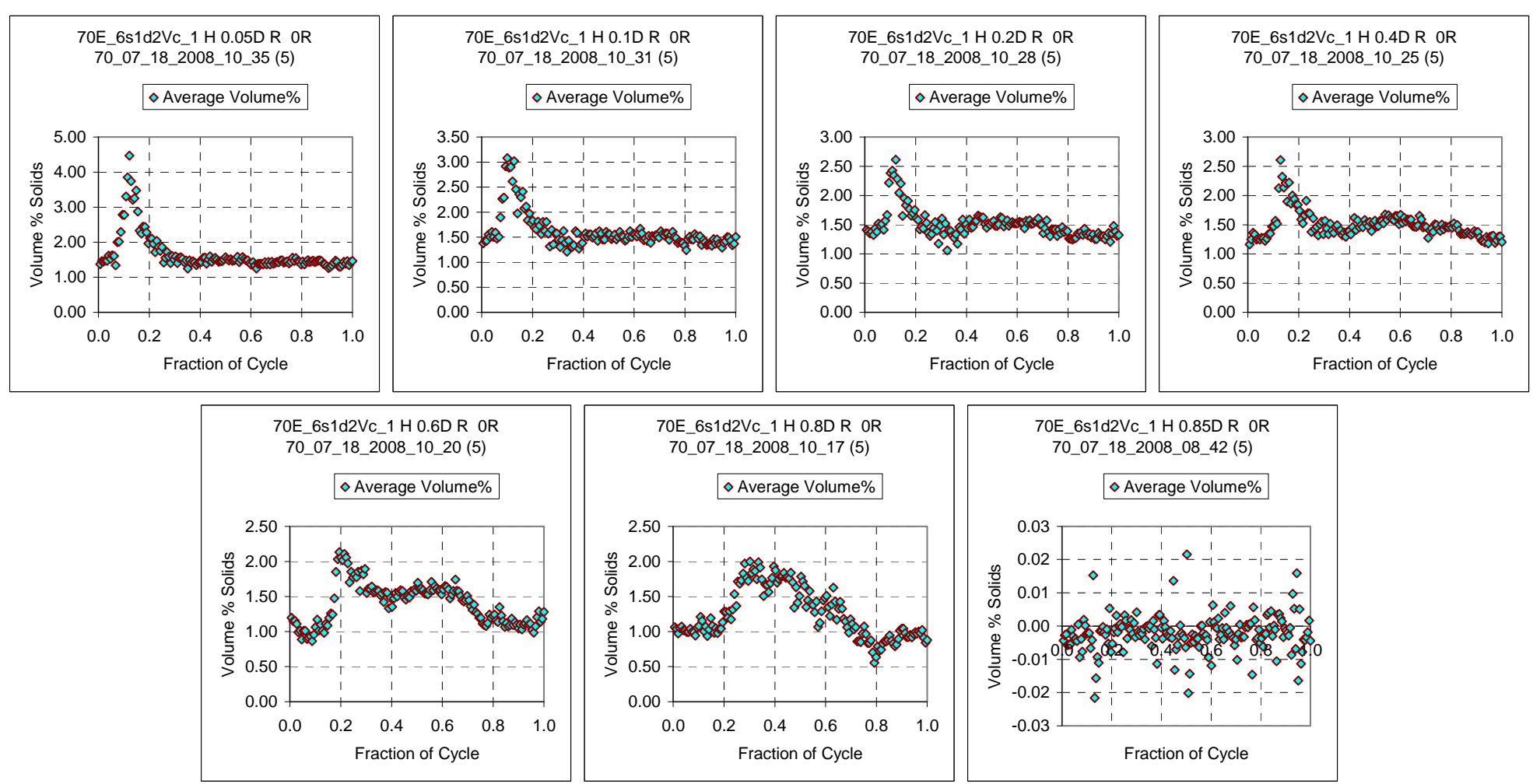

Figure C.65A. Case ID 70E_6s1d2Vc_1 Concentration Variation During the Cycle

Figure C.65 is the first of two profiles shown using simulant s1d2 in the large-scale tank with the elliptical bottom configured with the 8TA pulse tube design, with four pulse tubes in the outer ring and four pulse tubes in the inner and a nozzle diameter of 6 in. full scale. The solids fraction is 0.0143. The duty cycle was $33.5 \%$ and the pulse volume fraction was 0.050 . The $U_{C S}$ velocity occurred at $6.8 \mathrm{~m} / \mathrm{s}$ and the profile was conducted at $U_{C S}$. The cloud height is 26 in. This profile can be compared with the profile shown in Figure C. 51, configured for the HLP-22 pulse tube design with 12 pulse tubes in the outer ring and four pulse tubes in the inner ring and a nozzle diameter of 4 in. full scale. In the 8TA test the solids concentration at $\mathrm{R}=$ 0 is nearly vertical at $\sim 1.8$ vol\% solids up to an elevation of $\mathrm{Z} / \mathrm{D}=0.8$. The profile shown in Figure C.51 does not show quite the same vertical behavior. The solids concentration at $\mathrm{R}=0$ is $\sim 3.6$ vol\% solids at $\mathrm{Z} / \mathrm{D}=0.05$ and drops to $\sim 2 \mathrm{vol} \%$ solids at $\mathrm{Z} / \mathrm{D}=0.4$ and approaches 0 vol\% solids at $\mathrm{Z} / \mathrm{D}=0.6$. 

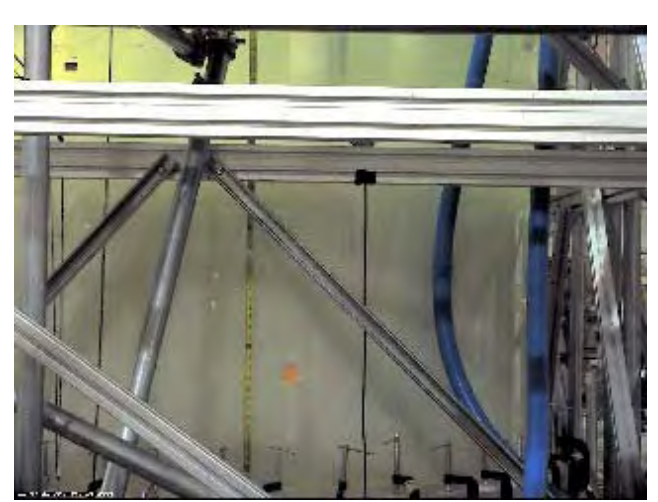

Maximum Cloud Height
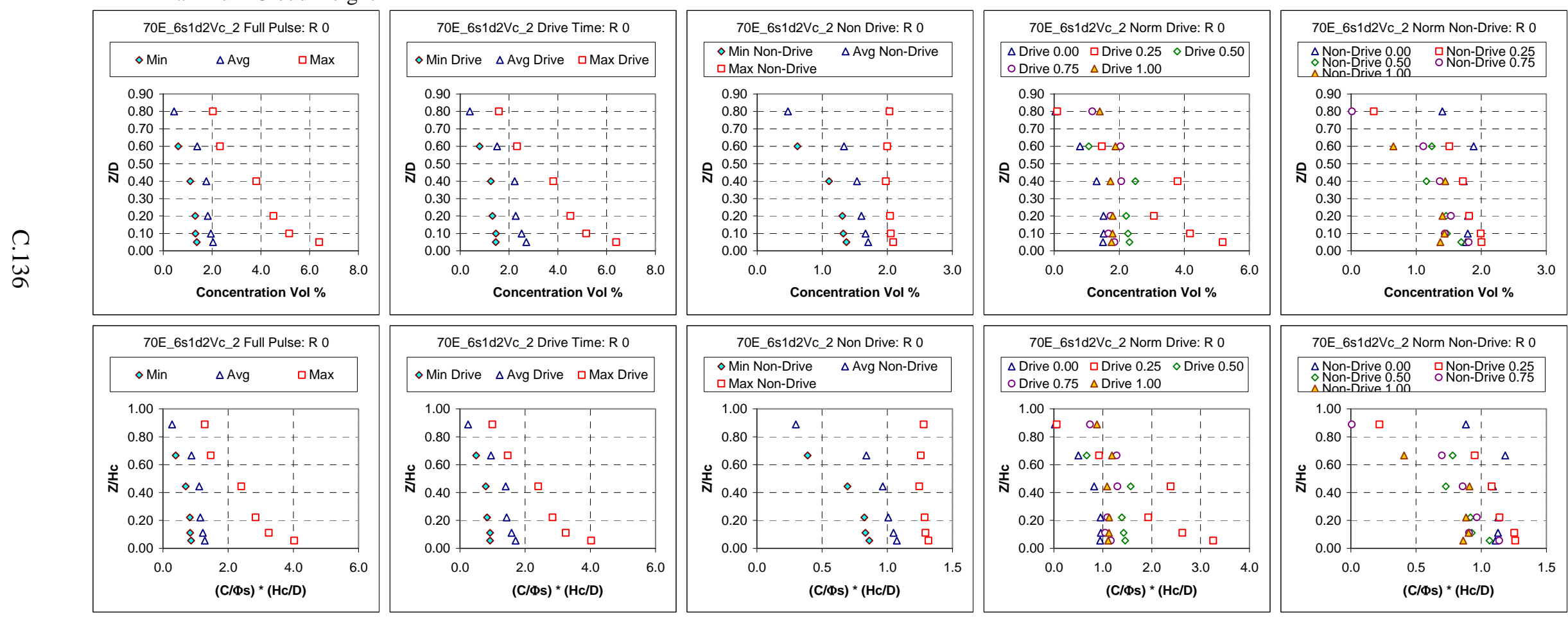

70E_6s1d2Vc_2 Norm Non-Drive: R 0 \begin{tabular}{|ll|}
\hline$\Delta$ Non-Drive 0.00 & a Non-Drive 0.25 \\
N Non-Drive 0.50 & o Non-Drive 0.75 \\
$\Delta$ Non-Drive 100
\end{tabular}

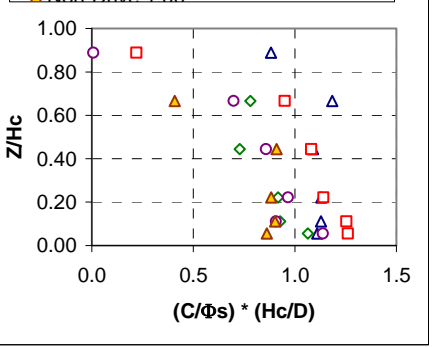

Figure C.66. 1.778-m- (70-in.-) diameter tank, 2.337-cm- (0.92-in.-) diameter nozzle; solids nominal diameter $69.3 \mu \mathrm{m}, 2.48 \mathrm{~g} / \mathrm{cm}^{3} \mathrm{density;} 0.0143$ nominal solids fraction; $33.1 \%$ duty cycle, cycle time $61.8 \mathrm{~s}$, pulse volume fraction 0.100 , $\mathrm{U}_{\mathrm{CS}}$ velocity $6.4 \mathrm{~m} / \mathrm{s}$, target nozzle exit velocity $6.4 \mathrm{~m} / \mathrm{s}$; peak cloud height upper bound $1.626 \mathrm{~m}$ (64 in.). Case ID 70E_6s1d2Vc_2. 

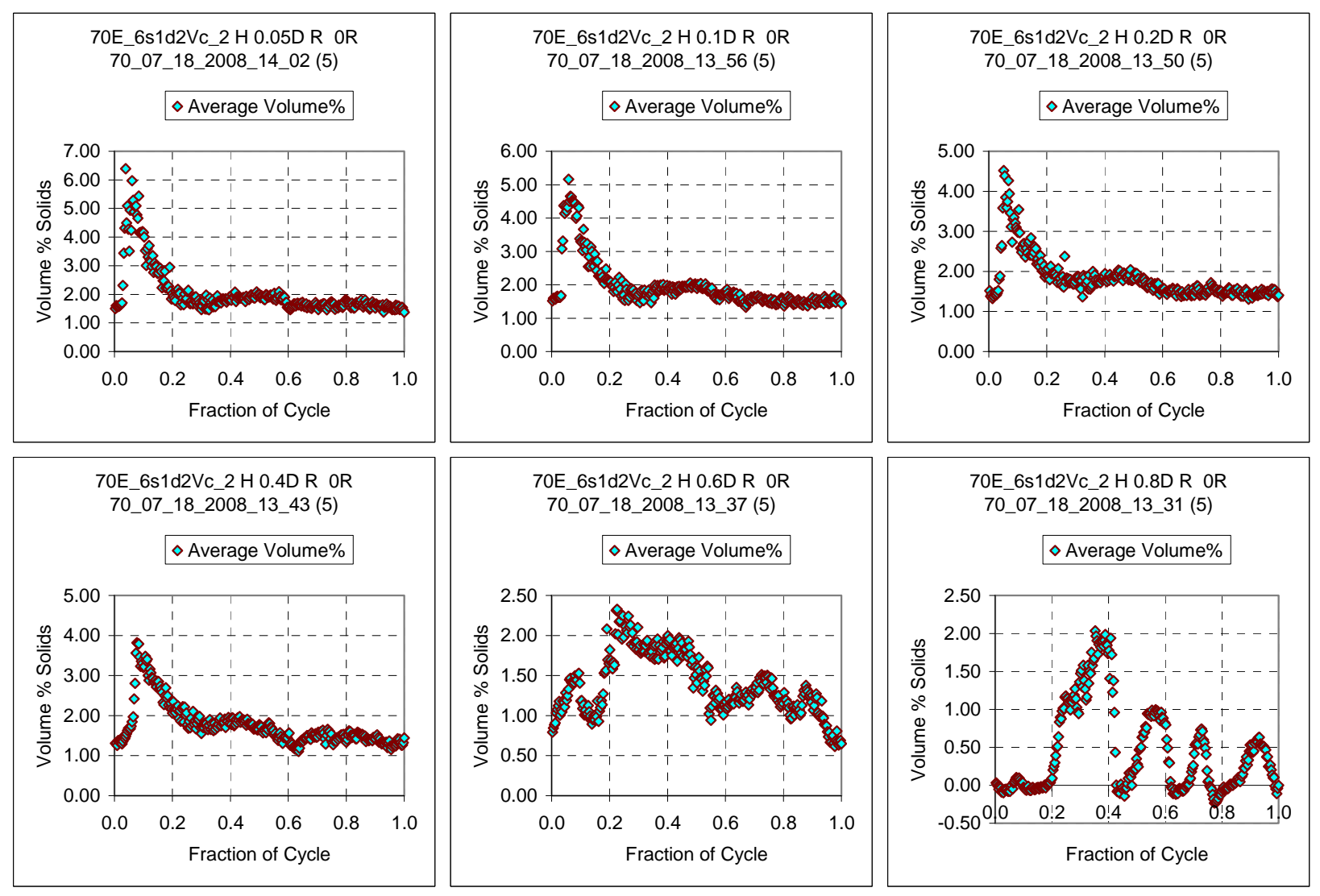

Figure C.66A. Case ID 70E_6s1d2Vc_2 Concentration Variation During the Cycle

Figure C.66 is the second of two profiles shown using simulant s1d2 in the large-scale tank with the elliptical bottom configured with the 8TA pulse tube design with four pulse tubes in the outer ring and four pulse tubes in the inner and a nozzle diameter of 6 in. full scale. The solids fraction is 0.0143 . The duty cycle was $33.1 \%$ and the pulse volume fraction was 0.1 , increased from 0.05 from the prior test. The $\mathrm{U}_{\mathrm{CS}}$ velocity occurred at $6.4 \mathrm{~m} / \mathrm{s}$, a decrease from $6.8 \mathrm{~m} / \mathrm{s}$ for the prior test. The cloud height is $64 \mathrm{in}$., an increase from $26 \mathrm{in}$. in the prior test. The solids concentration at $\mathrm{R}=0$ is not quite as constant as the profile in the prior test, which showed vertical at $\sim 1.8$ vol\% solids up to an elevation of $\mathrm{Z} / \mathrm{D}=0.8$. The solids concentration at $\mathrm{R}=0$ is $\sim 2$ vol\% solids at $\mathrm{Z} / \mathrm{D}=0.05$, drops to $\sim 1.4$ vol\% solids at $\mathrm{Z} / \mathrm{D}=0.6$, and drops to $\sim 0.5$ vol\% solids at $\mathrm{Z} / \mathrm{D}=0.8$. 



\section{Appendix D}

\section{Statistical Methods Used to Develop, Evaluate, and Validate Multiple-Regression Models}

GF Piepel 



\section{Appendix D}

\section{Contents}

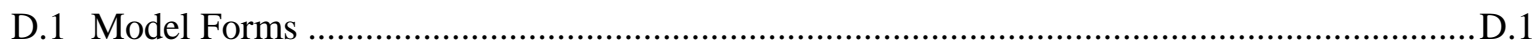

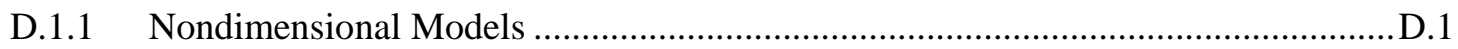

D.1.2 Multiple-Regression Model Forms .................................................................... $\mathrm{D} .2$

D.1.3 Spurious Correlation .....................................................................................

D.2 Linear and Nonlinear Least-Squares Regression Methods and Assumptions for Fitting

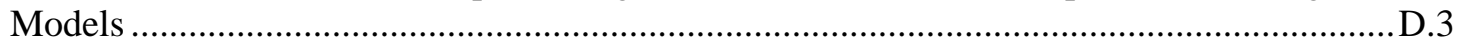

D.2.1 Linear and Nonlinear Regression .................................................................... D.4

D.2.2 Ordinary and Weighted Least Squares Regression ............................................ D.5

D.3 Statistical Methods for Model Evaluation .................................................................... D.7

D.3.1 Notation for Regression Model Evaluation and Validation .................................... . .7

D.3.2 Methods for Evaluating Regression Models Fit to Experimental Data..................... D.8

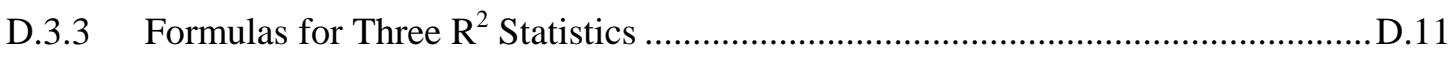

D.4 Statistical Methods for Model Reduction and Augmentation .......................................... D.13

D.4.1 Statistical Methods for Reducing Regression Models ......................................... D.13

D.4.2 Statistical Methods for Adding Terms to Models ................................................ D.13

D.5 Statistical Methods for Model Validation..................................................................... D.14

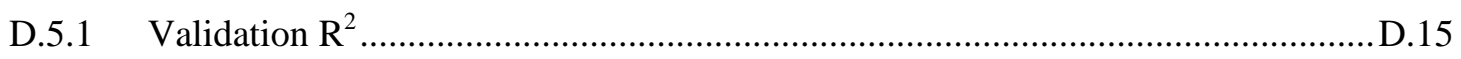

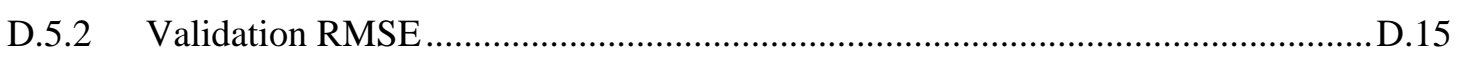

D.5.3 Predicted Versus Measured Plots for Validation ................................................. D.16

D.6 Statistical Intervals for Quantifying Uncertainties in Model Predictions ............................D.16

D.6.1 One-Sided Confidence Intervals .................................................................. D.17

D.6.2 Two-Sided Confidence Interval .................................................................... D.18

D.6.3 Two-Sided Prediction Interval ...................................................................... 19

D.6.4 Simultaneous Confidence Intervals.................................................................. D.20

D.6.5 Statistical Intervals in Transformed and Untransformed Units ............................. D.20

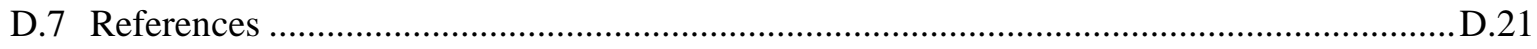




\section{Acronyms}

$\begin{array}{ll}\text { CV } & \text { coefficient of variation } \\ \text { GLS } & \text { generalized least squares } \\ \mathrm{H}_{\mathrm{C}} & \text { cloud height } \\ \text { LOF } & \text { lack-of-fit } \\ \text { LR } & \text { linear regression } \\ \text { MR } & \text { multiple regression } \\ \text { MSE } & \text { mean squared error } \\ \text { NLR } & \text { nonlinear regression } \\ \text { OLS } & \text { ordinary (unweighted) least squares } \\ \text { PI } & \text { prediction interval } \\ \text { PvM } & \text { predicted-versus-measured } \\ \text { RMSE } & \text { root-mean-squared error } \\ \text { SCI } & \text { simultaneous confidence interval } \\ \text { SSE } & \text { sum of squares error } \\ \text { SSPE } & \text { sum of squares pure error } \\ \text { UCI } & \text { upper confidence interval } \\ \text { U } & \text { critical suspension velocity } \\ \text { WLS } & \text { weighted least squares } \\ \text { Y } & \text { nondimensional response variable }\end{array}$

\section{Symbols}

$\mathbf{a}^{\mathrm{T}}$

$\mathbf{A}^{\mathrm{T}}$

$\mathrm{C}_{\mathrm{U}}$

$\mathrm{C}_{\mathrm{W}}$

$\mathrm{f}(\mathbf{)}$

g( )

$\mathrm{h}(\mathbf{)}$

$\mathrm{k}$

$\mathrm{n}$

$\mathrm{p}$

transpose of the vector $\mathbf{x}$ of predictor-variable values expanded in the form of the model transpose of data matrix of predictor-variable values, expanded in the form of the model estimated variance-covariance matrix for the estimated coefficients of model fit by OLS regression

estimated variance-covariance matrix for the estimated coefficients of model fit by WLS regression

function of predictor variables inside the parentheses, which may include constant coefficients and unknown coefficients to be estimated using experimental data function of variables inside the parentheses, which may include constant coefficients function of variables inside the parentheses, which may include constant coefficients and unknown coefficients to be estimated using experimental data

multiplicative coefficient

number of data points used to fit a model

number of parameters (coefficients) in a model form estimated via regression on the data 
$\mathrm{r}_{\mathrm{i}}$

$\mathrm{t}_{1-\alpha}(\mathrm{n}-\mathrm{p})$

$\mathrm{t}(\mathrm{y})$

$\mathbf{W}$

$\mathrm{W}_{\mathrm{i}}$

$\mathrm{X}_{\mathrm{j}}$

$\mathrm{X}_{\mathrm{j}}$

$\left\{X_{j}\right\}_{j \in A}$

$\left\{X_{j}\right\}_{j \in B}$

$\mathrm{y}$

$\mathrm{y}_{\mathrm{i}}$

$\hat{y}_{i}$

$\hat{\mathrm{y}}_{(\mathrm{i})}$

$\overline{\mathrm{y}}$

$\overline{\mathrm{y}}_{\mathrm{w}}$

$\hat{y}(\mathbf{x})$

residual for the $\mathrm{i}^{\text {th }}$ data point $=\mathrm{y}_{\mathrm{i}}-\hat{\mathrm{y}}_{\mathrm{i}}$

100(1- $\alpha)$-percentile of the Student's t-distribution with $n-p$ degrees of freedom

mathematical transformation of the response variable y, which could be the identity transformation, a logarithmic transformation, or some other transformation

an $n \times n$ diagonal weight matrix with entries $\mathrm{w}_{\mathrm{i}}, \mathrm{i}=1,2, \ldots, \mathrm{n}$

weight applied to $i^{\text {th }}$ data point in cases where WLS regression is used

$\mathrm{j}^{\text {th }}$ nondimensional or dimensional predictor variable, $\mathrm{j}=1,2, \ldots, \mathrm{p}$

$\mathrm{j}^{\text {th }}$ nondimensional predictor variable

subset $\mathrm{A}$ of the nondimensional predictor variables

set B (which could be all or a subset) of the nondimensional predictor variables

response variable

measured response for the $\mathrm{i}^{\text {th }}$ data point

predicted response value for $\mathrm{i}^{\text {th }}$ data point made using the model fit to all data points

predicted response value for the $\mathrm{i}^{\text {th }}$ data point, made using a model fit to all $\mathrm{n}$ data points except the $\mathrm{i}^{\text {th }}$ data point

unweighted average (mean) of the $n$ measured response values (mathematically

transformed if appropriate for the model form used)

weighted average (mean) of the $\mathrm{n}$ measured response values (mathematically transformed if appropriate for the model form used)

model predicted value at a set of predictor-variable values $\mathbf{x}$

\section{Greek Symbols}

$\alpha_{j} \quad$ coefficient of the $j^{\text {th }}$ term in the model

$\varepsilon$

random experimental and measurement error

multiplicative random experimental and measurement error assumed to be normally

distributed with mean 0 and standard deviation yo

D.iii 



\section{Appendix D}

\section{Statistical Methods Used to Develop, Evaluate, and Validate Multiple Regression Models}

This appendix summarizes statistical methods used for developing, evaluating, and validating empirical or semi-empirical models obtained using multiple regression. The text was adapted from Appendix C of Piepel et al. (2007), so much of it is written in a general manner. Applications of the methods discussed in this appendix to develop, evaluate, and validate models for predicting slurry mixing response variables as functions of mixing test variables are discussed in Appendix F.

Section D.1 discusses terminology, mathematical forms of models, and issues related to the form of the model. Section D.2 discusses the least-squares regression methods used to fit models to data and the corresponding assumptions. Section D.3 discusses the statistical methods and summary statistics used to evaluate a model based on the data used to fit it. Section D.4 discusses statistical methods for model augmentation (i.e., adding terms to a model) and model reduction (i.e., removing unneeded terms from a model). Section D.5 discusses the statistical methods and summary statistics used for model validation based on data not used to fit a model. Section D.6 discusses several statistical intervals used to quantify uncertainties in model predictions.

\section{D.1 Model Forms}

In many areas of application, experimental data are used to develop an equation relating a response variable to one or more predictor variables. Such an equation enables making predictions of the response variable for combinations of the predictor variables not tested in experiments. Statistical methods for developing these equations provide for quantifying the uncertainty in predicted response values.

When experimental data are used to develop this type of equation, it is referred to as a correlation in many disciplines. In statistics and other disciplines, these equations are referred to as empirical or semiempirical models. The term semi-empirical model is used when the mathematical form of the equation is based on subject-matter theory or first principles, and the coefficients of the equation are estimated using experimental data. The term empirical model is used when the general mathematical form (e.g., powerlaw, polynomial, etc.) is provided or assumed, while the specific form and coefficients of the equation are determined using experimental data. In statistics, the term "correlation" has a specific meaning with specific formulas to measure its magnitude, which is why statisticians prefer the empirical or semiempirical model terms. Correlation is sometimes uses in the slurry mixing field and other disciplines. However, in this appendix, the general term "model" is used to avoid confusion with statistical uses of the word correlation. The term model includes both empirical and semi-empirical models.

\section{D.1.1 Nondimensional Models}

It is traditional in some disciplines to develop models using nondimensional variables as the response variable and predictor variables. This is common in engineering models because 1) they must be dimensionally consistent to represent physical relationships, 2) it is common to derive theoretical forms for models from dimensionless forms of the controlling physical laws, and 3) it is always possible to 
reduce a set of dimensional variables to a physically equivalent set of fewer dimensionless groups. Formulating such models in terms of dimensionless groups both ensures dimensional consistency and provides a model with coefficients with magnitudes that are independent of the choice of dimensional units. Often the response variable consequently is combined with one or more predictor variables in a dimensionless group. In such cases, one or more nondimensional predictor variables appear on both sides of the equation. This is denoted by

$$
g\left(Y,\left\{X_{j}\right\}_{j \in A}\right)=h\left(\left\{X_{j}\right\}_{j \in B}\right)
$$

where

$\mathrm{Y}=$ nondimensional response variable

$\mathrm{X}_{\mathrm{j}}=\mathrm{j}^{\text {th }}$ nondimensional predictor variable

$g()=$ function (i.e., mathematical expression) of the variables inside the parentheses, which may include constant coefficients

$h()=$ function (i.e., mathematical expression) of the variables inside the parentheses, which may include constant coefficients and unknown coefficients to be estimated (fit) using experimental data

$\left\{\mathrm{X}_{\mathrm{j}}\right\}_{\mathrm{j} \in \mathrm{A}}=$ subset $\mathrm{A}$ of the nondimensional predictor variables

$\left\{\mathrm{X}_{\mathrm{j}}\right\}_{\mathrm{j} \in \mathrm{B}}=$ set $\mathrm{B}$ (which could be all or a subset) of the nondimensional predictor variables.

In Eq. (D.1), typically only a subset of the full set of predictor variables appears on the left side of the equation, but the full set or a subset of the predictor variables can appear on the right side of the equation.

\section{D.1.2 Multiple-Regression Model Forms}

In many disciplines, it is traditional to develop models with only the response variable on the left side of the equation, and all predictor variables on the right side of the equation. These are often called multiple-regression (MR) models and are denoted in general by

$$
t(y)=f\left(x_{j}, j=1,2, \ldots, p\right)
$$

where

$\mathrm{t}(\mathrm{y})=$ mathematical transformation of the response variable $\mathrm{y}$, which could be the identity transformation, a logarithmic transformation, or some other transformation

$\mathrm{x}_{\mathrm{j}}=\mathrm{j}^{\text {th }}$ nondimensional or dimensional predictor variable, $\mathrm{j}=1,2, \ldots, \mathrm{p}$

$\mathrm{f}(\mathrm{)}=$ function (i.e., mathematical expression) of the predictor variables inside the parentheses, which may include constant coefficients and unknown coefficients to be estimated (fit) using experimental data.

The predictor variables could be dimensional or nondimensional variables that are functions of dimensional predictor variables. Having the same dimensional predictor variable appear in more than one nondimensional predictor variable can induce correlations among nondimensional predictor variables. This makes it harder for regression (model fitting) routines to separate the effects of the variables and can also inflate the uncertainties of model predictions. Hence, it can be worthwhile to gather predictor 
variables together in separate terms to the extent possible. This also makes it easier to investigate interactive effects among predictor variables.

For many nondimensional models of the form in Eq. (D.1), it is possible to move all predictor variables from the left to the right side to obtain a mathematically equivalent model of the form in Eq. (D.2). This form of model is consistent with least-squares regression methods, as discussed in Section D.2. Models of the form in Eq. (D.2) also have the advantage of not being affected by spurious correlation (see Section D.1.3).

\section{D.1.3 Spurious Correlation}

If one or more nondimensional predictor variables, $\mathrm{X}_{\mathrm{i}}$, appear on both the left and right sides of a model such as that represented by Eq. (D.1), a phenomenon known as spurious self-correlation (or spurious correlation) can occur. Including the same predictor variables on both sides of an equation can artificially inflate the apparent relationship and measures of relationship (such as $\mathrm{R}^{2}$, see Section D.3.3). Research in the literature using randomly generated (and thus unrelated) values for the predictor variables and response variable has shown it is possible to obtain very strong correlations ( $\mathrm{R}^{2}$ approaching 1.0) despite the lack of relationship between the response and predictor variables (Kenney 1982, Brett 2004).

The degree of spurious correlation in a nondimensional model depends on 1) the true strength of relationship between the response variable and predictor variables and 2) the magnitudes of the coefficients of variation $(\mathrm{CV})^{(1)}$ of predictor variables that appear on both sides of the equation (common variables) relative to the $\mathrm{CV}$ of the response variable. If the $\mathrm{CV}$ of one or more common variables is large relative to the $\mathrm{CV}$ of the response variable, some degree of spurious correlation will occur and will increase if more of the common predictor variables have large CVs relative to the CV of the response variable. However, an otherwise very strong correlation may have little spurious correlation resulting from including the same predictor variables on both sides of the model equation.

\section{D.2 Linear and Nonlinear Least-Squares Regression Methods and Assumptions for Fitting Models}

Empirical or semi-empirical models (models, for simplicity) are typically fit to data sets using leastsquares regression methods. Depending on whether the mathematical form of the model being fit is linear or nonlinear in the model coefficients, linear regression (LR) or nonlinear regression (NLR) methods and software can be used. LR methods give a one-step solution to estimating the model coefficients, whereas NLR methods involve an iterative algorithm that must converge to a solution for the estimated model coefficients. Depending on the structure of uncertainties in the response variable being regressed against predictor variables, ordinary (unweighted) least squares (OLS) regression or weighted least squares (WLS) regression methods can be applied with both the LR and NLR. Section D.2.1 discusses LR and NLR, while Section D.2.2 discusses OLS and WLS regression. Draper and Smith (1998) and Montgomery et al. (2001) provide additional discussion of LR and NLR, implemented via OLS or WLS.

(1) The CV of a variable is defined as its standard deviation divided by its mean. 


\section{D.2.1 Linear and Nonlinear Regression}

Different methods are required to fit regression models to data depending on whether the model form is linear or nonlinear in the coefficients to be estimated (fit) using the data. A linear regression model has the general form

$$
t(y)=\sum_{j=1}^{p} \alpha_{j} x_{j}+\varepsilon
$$

where

$$
\begin{aligned}
& \mathrm{t}(\mathrm{y})=\text { a mathematical transformation of the response variable } \mathrm{y} \text {, which could be the identity } \\
& \text { transformation, a logarithmic transformation, or some other transformation } \\
& \mathrm{x}_{\mathrm{j}}=\mathrm{j}^{\text {th }} \text { predictor variable in the model, } \mathrm{j}=1,2, \ldots, \mathrm{p} \text {. An } \mathrm{x}_{\mathrm{j}} \text { could be one (1) so the model } \\
& \text { includes a constant term; a test variable that was changed in experimental work; a } \\
& \text { transformation of a test variable [e.g., } \ln \left(\mathrm{x}_{\mathrm{j}}\right) \text { or } \mathrm{x}_{\mathrm{j}}{ }^{2} \text { ], or a function of two or more test variables } \\
& \text { (e.g., } \left.x_{j} x_{k}\right) \\
& \alpha_{j}=\text { coefficient of the } j^{\text {th }} \text { term in the model } \\
& \varepsilon=\text { random experimental and measurement error. The } \mathrm{n} \text {-dimensional vector of these errors for } \\
& \text { the } \mathrm{n} \text { data points used to fit the model is assumed to be normally distributed with mean vector } \\
& 0 \text { and } n \times n \text { variance-covariance matrix } \mathbf{V} \text {. If } \mathbf{V}=\sigma^{2} \mathbf{I} \text { (where } \mathbf{I} \text { is an } n \times n \text { matrix with ones } \\
& \text { on the diagonal and zeros off-diagonal), then OLS is applicable. If } \mathbf{V} \text { is a diagonal matrix } \\
& \text { with } \sigma_{\mathrm{i}}{ }^{2} \text { in the } \mathrm{i}^{\text {th }} \text { diagonal position, then WLS is applicable. The OLS and WLS } \\
& \text { assumptions are further discussed in Section D.2.2. }
\end{aligned}
$$

A linear regression model can include nonlinear functions of the predictor variables but is linear in its coefficients.

A nonlinear regression model is any equation that is not linear in at least one coefficient. In this report, power-law models are an example of a nonlinear regression model. A basic power-law model with multiplicative error structure has the general form

$$
y=k \prod_{j=1}^{p} x_{j}^{a_{j}} \delta
$$

where

$$
\mathrm{y}=\text { response variable }
$$

$\mathrm{k}=$ multiplicative coefficient

$\mathrm{x}_{\mathrm{j}}=\mathrm{j}^{\text {th }}$ predictor variable in the model, $\mathrm{j}=1,2, \ldots, \mathrm{p}$. An $\mathrm{x}_{\mathrm{j}}$ could be one so that the model includes a constant term, a test variable changed in experimental work, a transformation of a test variable [e.g., $\ln \left(\mathrm{x}_{\mathrm{j}}\right)$ or $\mathrm{x}_{\mathrm{j}}^{2}$ ], or a function of two or more test variables (e.g., $\mathrm{x}_{\mathrm{j}} \mathrm{x}_{\mathrm{k}}$ )

$\alpha_{\mathrm{j}}=$ exponent coefficient of the $\mathrm{j}^{\text {th }}$ term in the model

$\delta=$ multiplicative random experimental and measurement error assumed to be normally distributed with mean 0 and standard deviation yo. Hence, the magnitude of experimental and measurement uncertainties increases in proportion to the magnitude of the response variable. This error structure requires the use of WLS regression (see Section D.2.2). 
Some nonlinear regression models can be linearized by transforming both sides of the model. For example, taking the natural logarithm of both sides of the power-law model in Eq. (D.4) yields

$$
\ln (\mathrm{y})=\ln (\mathrm{k})+\sum_{\mathrm{i}=1}^{\mathrm{p}} \mathrm{a}_{\mathrm{i}} \ln \left(\mathrm{z}_{\mathrm{i}}\right)+\ln (\delta)=\mathrm{a}_{0}+\sum_{\mathrm{i}=1}^{\mathrm{p}} \mathrm{a}_{\mathrm{i}} \ln \left(\mathrm{z}_{\mathrm{i}}\right)+\varepsilon
$$

which is linear in the coefficients $\mathrm{a}_{0}=\ln (\mathrm{k})$ and $\mathrm{a}_{1}, \mathrm{a}_{2}, \ldots, \mathrm{a}_{\mathrm{p}}$. Taking the natural logarithm of both sides also transforms the multiplicative random error term in Eq. (D.4), which was dependent on the magnitude of $\mathrm{y}$, to an additive random error term that is independent of the magnitude of $\mathrm{y}$. This enables OLS linear regression to be used for Eq. (D.5) instead of WLS nonlinear regression for Eq. (D.4).

\section{D.2.2 Ordinary and Weighted Least Squares Regression}

The underlying assumptions of OLS and WLS regression are:

1) The predictor-variable values are known or measured without uncertainty or the uncertainty is small relative to the uncertainty in response-variable values.

2) The testing and/or measurement errors in a response variable over a model development data set are independently distributed (i.e., the errors are not correlated). For OLS regression, the additional assumption is made that the errors are identically distributed (i.e., with zero mean and the same variance). For WLS regression, the errors are also assumed to have zero mean, but the variance can be different for different data points.

3) The errors from (2) are normally (Gaussian) distributed.

Regarding assumption (1), the true values of predictor variables in an experimental data set for developing models for mixing response variables are generally not known. Target values or measured values of the predictor variables are typically used. However, the uncertainties in these values were judged to be small enough that use of least-squares regression methods is acceptable.

The portion of assumption (2) that has to do with the independence of errors in testing and measuring response variables may not be completely satisfied when model development data sets comprise subsets of data generated at different times or locations. There is a potential for errors in testing and measuring response variables to vary for different subsets of data and be more alike within the same subset of data. Data were generated at different times or locations for the M3 mixing work conducted in the three experimental campaigns: July 2007, Fall 2007, and 2008.

The portion of assumption (2) having to do with independence of errors can also be violated if experimental data are collected with a restricted order of experimental tests rather than a randomized order of tests. Restricted order of testing typically occurs when one or more test variables are harder to change than other test variables (Myers and Montgomery 1995). In the M3 mixing tests, all tests with a given tank size had to be performed in the same block of days. Other test variables (e.g., simulant) also had restrictions on the order of testing. These types of restrictions in the order of testing can have two effects: different uncertainties in response variables for different subsets of data and correlated uncertainties for different subsets of data. Experiments with restrictions on the order of testing are referred to as split-plot, split-split-plot, etc., experiments in the statistics literature. Generalized least squares (GLS) methods exist to account for different uncertainties and correlation structure for different subsets of data (Myers and Montgomery 1995). However, it was beyond the scope of the data analysis effort to (i) determine whether the uncertainty structure actually confounds regression analyses of any of 
the data, or (ii) develop models for mixing response variables that account for the complicated uncertainty structure corresponding to the way the mixing data were collected in the different test campaigns (July 2007, Fall 2007, and 2008).

The identically distributed portion of assumption (2) for OLS regression is not valid for any response variable where the variance of errors in testing and measurement depends on the value of the response variable. For example, the variances of critical suspension velocity $\left(\mathrm{U}_{\mathrm{CS}}\right)$ and cloud height $\left(\mathrm{H}_{\mathrm{C}}\right)$ tend to increase as the values of these responses increase. In such cases where the identically distributed (equal variance) assumption is violated, it can often be remedied by applying an appropriate mathematical transformation to the values of the response values (e.g., a logarithmic transformation). The Box-Cox family of transformations contains transformations (including the logarithmic transformation) appropriate for many models (see Draper and Smith 1998). Such transformations also often yield better-fitting models. In some cases, a response-variable transformation used in a particular model form may be preferred for some reason (e.g., provides a better fit), but does not satisfy the constant variance assumption of (2). Or it may be that the difference in variances across response values in the data set cannot be rectified by a response transformation. In such cases, other regression methods such as WLS regression or generalized linear models (Myers et al. 2002) could be applied.

The assumption of normally distributed measurement and testing errors in the measured response variable values allows the use of normal-theory significance tests and uncertainty equations associated with the fitted regression model. For example, confidence intervals and prediction intervals based on normal-distribution theory can be used (see Section D.6).

As discussed, OLS regression requires that all response values for the model development data have constant variance (i.e., uncertainty). WLS regression accounts for response values having different variances by using a weight for each data point $\left(\mathrm{w}_{\mathrm{i}}\right)$. Often, $\mathrm{w}_{\mathrm{i}}$ is chosen to be proportional to the reciprocal of the variance (squared standard deviation) of the response for the $\mathrm{i}^{\text {th }}$ data point $\left(\mathrm{y}_{\mathrm{i}}\right)$ :

$$
\mathrm{w}_{\mathrm{i}}=\frac{\lambda}{\operatorname{Var}\left(\mathrm{y}_{\mathrm{i}}\right)}=\frac{\lambda}{\left[\operatorname{SD}\left(\mathrm{y}_{\mathrm{i}}\right)\right]^{2}}
$$

where $\lambda$ is a proportionality constant (which could be 1 ). In such a WLS regression the weighted response values $\sqrt{w_{i}} y_{i}$ then have equal variance. However, other methods for selecting weights can be applicable for various situations.

In summary, assumptions of OLS regression may not be completely satisfied for a given mixing response variable and corresponding data set. Violations of the constant-variance assumption for response values over a data set can sometimes be addressed by appropriate response transformations so that OLS regression may be used. Other violations may be small enough that OLS regression methods can still be used without significant consequence. However, if there are large enough differences in variances of response values across a modeling data set that cannot be addressed by a response transformation, WLS regression methods should be used. If there are correlations among uncertainties for response values in a regression data set, GLS methods could be used. 


\section{D.3 Statistical Methods for Model Evaluation}

There are many statistical methods (both numerical and graphical) for assessing models. Evaluation methods assess a model with the data used to develop the model. Such data are referred to as modeldevelopment data and are used to assess 1) how well a model fits the data used to develop it, 2) how well the least-squares or other regression method assumptions are satisfied (see Section D.2), and 3) whether there are any outlying or influential data points that significantly affect the fitted model. Problems detected by model evaluation such as violation of assumptions, detection of outlying data points, or detection of model inadequacy require implementing various remedies in the model development process until the problem(s) are corrected. When the model being evaluated acceptably fits the data used to develop it, model-validation methods should be applied using data not used to develop the model. Such data are referred to as model-validation data. If model-validation data are not available, cross-validation methods can be applied using the model-development data. Cross-validation methods leave out one or more data points at a time, so some of the data are used for model fitting and some for model validation. Such methods are also referred to as data-splitting validation methods, where part of the data is used for model fitting and evaluation, while the other part is used for model validation. Draper and Smith (1998) and Montgomery et al. (2001) discuss statistical methods for evaluating and validating regression models.

Model evaluation techniques include predicted-versus-measured (PvM) plots for a response variable, standardized residual plots, outlier diagnostics, three $\mathrm{R}^{2}$ statistics, root-mean-squared error (RMSE), and statistical lack-of-fit (LOF) tests. Each of these is explained briefly in Section D.3.2. First, the relevant notation used in the subsequent descriptions and definitions is defined in Section D.3.1.

\section{D.3.1 Notation for Regression Model Evaluation and Validation}

The following notation is used subsequently in this appendix in formulas for methods to evaluate regression models fit to experimental data.

$\mathrm{n}=$ number of data points used to fit a model

$\mathrm{p} \quad=$ number of parameters (coefficients) in a model form estimated via regression on the data

$\mathrm{y}_{\mathrm{i}}=$ measured response value (mathematically transformed, if appropriate for the model form used) for the $\mathrm{i}^{\text {th }}$ data point

$\hat{\mathrm{y}}_{\mathrm{i}}=$ predicted response value (mathematically transformed, if appropriate for the model form used) for the $i^{\text {th }}$ data point made, using the model fit to all $n$ data points

$\mathrm{r}_{\mathrm{i}}=$ residual for the $\mathrm{i}^{\text {th }}$ data point $=\mathrm{y}_{\mathrm{i}}-\hat{\mathrm{y}}_{\mathrm{i}}$

$\hat{y}_{(i)}=$ predicted response value (mathematically transformed, if appropriate for the model form used) for the $\mathrm{i}^{\text {th }}$ data point, made using a model fit to all $\mathrm{n}$ data points except the $\mathrm{i}^{\text {th }}$ data point

$\mathrm{w}_{\mathrm{i}}=$ weight applied to the $\mathrm{i}^{\text {th }}$ data point in cases where WLS regression is used. Typically, $\mathrm{w}_{\mathrm{i}}$ is proportional to the reciprocal of the variance of the response variable for the $\mathrm{i}^{\text {th }}$ data point

$\overline{\mathrm{y}}=$ unweighted average (mean) of the $\mathrm{n}$ measured response values (mathematically transformed, if appropriate for the model form used)

$\overline{\mathrm{y}}_{\mathrm{w}}=$ weighted average (mean) of the $\mathrm{n}$ measured response values (mathematically transformed if appropriate for the model form used) 


$$
\bar{y}_{w}=\frac{\sum_{i=1}^{n} w_{i} y_{i}}{\sum_{i=1}^{n} w_{i}}
$$

\section{D.3.2 Methods for Evaluating Regression Models Fit to Experimental Data}

Methods for evaluating models fit to experimental data using least-squares regression are briefly described in the following:

- Predicted-versus-measured (PvM) plots show how well model predicted values $\hat{y}_{i}$ compare to the measured values $\mathrm{y}_{\mathrm{i}}$ for the data points in the model-development data set. Predicted response values $\hat{y}_{i}$ are plotted on the $y$-axis and measured response values $y_{i}$ are plotted on the $x$-axis. A line with a slope of one is included in the plot for reference purposes, and represents the ideal of predicted response values equaling measured response values. Plotted points falling above this line correspond to data points for which the model over-predicts the response, while plotted points falling below this line represent data points for which the model under-predicts the response. A preponderance of plotted points in a portion of the PvM plot falling above or below the line indicates that the model tends to yield biased predictions for that range of response values. Plotted points far from the line are outlying or potentially influential data points.

For WLS regression, an ordinary (unweighted) PvM plot of $\hat{y}_{i}$ versus $y_{i}$ could be viewed as is done for OLS regression. Or a weighted PvM plot of $\sqrt{w_{i}} \hat{y}_{i}$ versus $\sqrt{w_{i}} y_{i}$ could be viewed. The ordinary (unweighted) PvM plot has the advantage of retaining the units of the response (or its transformation), but the disadvantage that points with smaller weights (i.e., higher uncertainties) may appear farther from the line with slope one. However, rather than considering this a disadvantage, it may be better thought of as showing the penalty paid in obtaining predictions having more uncertainty for modeling data points with smaller weights (i.e., higher uncertainty). The weighted PvM plot would show the model predictive performance for the modeling data points after accounting for (i.e., removing the scatter due to) the differing weights (i.e., uncertainties).

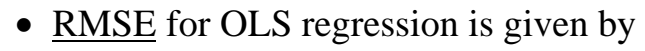

$$
\operatorname{RMSE}_{U}=\sqrt{\frac{\sum_{i=1}^{n}\left(\hat{y}_{i}-y_{i}\right)^{2}}{n-p}}
$$

and for WLS regression by

$$
\operatorname{RMSE}_{\mathrm{W}}=\sqrt{\frac{\sum_{\mathrm{i}=1}^{\mathrm{n}} \mathrm{w}_{\mathrm{i}}\left(\hat{\mathrm{y}}_{\mathrm{i}}-\mathrm{y}_{\mathrm{i}}\right)^{2}}{\mathrm{n}-\mathrm{p}}},
$$

where the subscripts on $\mathrm{RMSE}_{\mathrm{U}}$ and $\mathrm{RMSE}_{\mathrm{W}}$ denote "unweighted" and "weighted" least squares (i.e., OLS and WLS). If the fitted model is adequate and does not have a statistically significant lack-offit, this statistic provides an estimate of the experimental and measurement uncertainty standard 
deviation associated with performing a test and measuring the associated response. The statistic RMSE is included as standard output in most regression software, and has units the same as the response values $\mathrm{y}_{\mathrm{i}}$ (including any mathematical transformation of the response in the model form) for OLS regression and the units of $\sqrt{\mathrm{w}_{\mathrm{i}}} \mathrm{y}_{\mathrm{i}}$ for WLS regression.

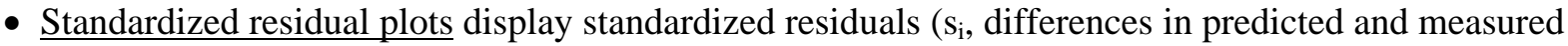
response values divided by their standard deviations) versus various quantities, such as predictor variables $\left(\mathrm{x}_{\mathrm{i}}\right)$ or predicted response values $\left(\hat{\mathrm{y}}_{\mathrm{i}}\right)$. The formula for a standardized residual is given by

$$
\mathrm{s}_{\mathrm{i}}=\frac{\mathrm{r}_{\mathrm{i}}}{\operatorname{RMSE}_{\mathrm{U}}\left[1-\mathbf{a}_{\mathrm{i}}^{\mathrm{T}}\left(\mathbf{A}^{\mathrm{T}} \mathbf{A}\right)^{-1} \mathbf{a}_{\mathrm{i}}\right]^{0.5}}
$$

for OLS regression and by

$$
\mathrm{s}_{\mathrm{i}}=\frac{\sqrt{\mathrm{w}_{\mathrm{i}}} \mathrm{r}_{\mathrm{i}}}{\operatorname{RMSE}_{\mathrm{W}}\left[1-\mathrm{w}_{\mathrm{i}} \mathbf{a}_{\mathrm{i}}^{\mathrm{T}}\left(\mathbf{A}^{\mathrm{T}} \mathbf{W A}\right)^{-1} \mathbf{a}_{\mathrm{i}}\right]^{0.5}}
$$

for WLS regression. In Eq. (D.9a), (D.9b): $\mathrm{s}_{\mathrm{i}}, \mathrm{w}_{\mathrm{i}}$, and $\mathrm{r}_{\mathrm{i}}$ are as previously described; $\mathrm{RMSE}_{\mathrm{U}}$ and RMSE $_{\mathrm{W}}$ are given respectively by Eq. (D.8a) and (D.8b); $\mathbf{a}_{\mathrm{i}}$ is the column vector of predictor-variable values for the $\mathrm{i}^{\text {th }}$ modeling data point expanded in the form of the model; $\mathbf{A}$ is an $n \times p$ matrix of the predictor-variable values in the modeling data set expanded in the form of the model; $\mathbf{W}$ is an $\mathrm{n} \times \mathrm{n}$ matrix with the weights $\mathrm{w}_{\mathrm{i}}$ along the main diagonal, and zeros elsewhere.

Patterns in the $s_{i}$ versus $\hat{y}_{i}$ plot can indicate a violation of the least squares regression assumptions and suggest a response transformation to remedy the situation. Patterns in the $s_{i}$ versus $x_{i}$ plots can indicate inadequacies of the model or least-squares assumptions. Patterns in $\mathrm{s}_{\mathrm{i}}$ versus data indices can indicate subsets of the data for which a model may be inadequate (e.g., yield biased predictions). Standardized residuals are typically used in residual plots because the majority should fall within the range of \pm 2.0 and almost all should fall within \pm 3.0 . Comparing standardized residuals to such a range provides an easy criterion for judging whether a data point is outlying.

- Normality plots display normal scores versus the ordered (from smallest to largest) standardized residuals (from Eq. (D.9a) and (D.9b) for OLS and WLS regression, respectively) for the $n$ data points used to fit the model being assessed. Normal scores are the expected values of a sample of size $\mathrm{n}$ from standard normal distribution (with mean 0 and standard deviation 1 ). The plotted points are compared to the ideal of a straight line corresponding to a normal distribution. A straight middle portion of the plot with curved "tails" on each end of the plot indicate the presence of outlying data points, which cause a heavier-tailed distribution than the normal distribution.

- Outlier diagnostics and plots indicate data points that are outlying or influential with respect to response-variable or predictor-variable values. There are too many of these diagnostics and plots to discuss here, but several produced by the R software (Ihaka and Gentleman 1996, R Development Core Team 2006) were considered in this work. Draper and Smith (1998) and Montgomery et al. (2001) discuss outlier diagnostics and plots for OLS regression, but software such as R produces the appropriate versions of diagnostics and plots for WLS regression as well. 
- $\underline{\mathrm{R}^{2} \text { statistics }}$ quantify the proportion of variation in the response values $\mathrm{y}_{\mathrm{i}}$ (for OLS regression) or weighted response values $\sqrt{\mathrm{w}_{\mathrm{i}}} \mathrm{y}_{\mathrm{i}}$ (for WLS regression) accounted for by the fitted model. Three $\mathrm{R}^{2}$ statistics are used, as discussed later in this section.

- An LOF test checks whether the differences (for OLS regression) or weighted differences (for WLS regression) between measured and predicted response values from a fitted model are larger than expected based on the experimental and measurement uncertainty in the data. If the predicted-versusmeasured differences are larger than data uncertainty at a high enough statistical confidence (greater than $90 \%$ ), the model is said to have a statistically significant LOF. Replicate data points containing all applicable sources of experimental and measurement uncertainty ${ }^{(1)}$ are required to perform

statistical LOF tests. This process is conducted using a LOF F-test given by

$$
\begin{aligned}
F & =\frac{(S S E-S S P E) /(n-p-f)}{S S P E / f} \\
& =\frac{\left[\left(\sum_{i=1}^{n}\left(\hat{y}_{i}-y_{i}\right)^{2}-\sum_{k=1}^{K} \sum_{j=1}^{m_{k}}\left(y_{k j}-\bar{y}_{k}\right)^{2}\right) /(n-p-f)\right]}{\sum_{k=1}^{K} \sum_{j=1}^{m_{k}}\left(y_{k j}-\bar{y}_{k}\right)^{2} / f}
\end{aligned}
$$

for OLS regression and by

$$
\begin{aligned}
F & =\frac{(\text { SSE }- \text { SSPE }) /(n-p-f)}{\text { SSPE } / f} \\
= & \frac{\left[\left(\sum_{i=1}^{n} w_{i}\left(\hat{y}_{i}-y_{i}\right)^{2}-\sum_{k=1}^{K} \sum_{j=1}^{m_{k}} w_{j}\left(y_{k j}-\bar{y}_{k}\right)^{2}\right) /(n-p-f)\right]}{\sum_{k=1}^{K} \sum_{j=1}^{m_{k}} w_{j}\left(y_{k j}-\bar{y}_{k}\right)^{2} / f}
\end{aligned}
$$

for WLS regression. In Eq. (D.10a) and D.10b), SSE = sum of squares error; SSPE = sum of squared pure error (i.e., from replicates); $n$ and $p$ are as described previously such that $n-p$ is the degrees of freedom for SSE; and the degrees of freedom for pure error is given by $f=\sum_{k=1}^{K}\left(m_{k}-1\right)$, where $m_{k}$ is the number of replicate data points in the $\mathrm{k}^{\text {th }}$ replicate set, $\mathrm{k}=1,2, \ldots, \mathrm{K}$. In practice, if the F-test is statistically significant at a significance level (often referred to as a p-value) of 0.05 or smaller (i.e., $95 \%$ confidence or higher), then it is concluded that the fitted model has a statistically significant LOF for the modeling data set. See Draper and Smith (1998) or Montgomery et al. (2001) for additional discussion of the statistical test for model LOF.

Even when a fitted model has a statistically significant LOF, the LOF may not be practically significant. An example of such a situation is when a fitted model yields biased predictions for higher and/or

(1) To be appropriate replicate data points, two or more tests with exactly the same test variables must be tested and the corresponding response variables measured at different times. It is insufficient, for example, to set up a mixing test once, and run it and measure its responses several times (because uncertainties in setting up and performing the test at different times are not included in the data). Similarly, replicate samples should not be measured at the same time (or close in time) because all sources of measurement uncertainty will not be included in the data. 
lower values of a response or in a particular subregion of predictor-variable space, but the model will not be applied to such areas in practice. Another example is when the model fits the data very well (e.g., $\mathrm{R}^{2}>$ 0.95) without bias over the model's region of validity, but the LOF is statistically significant because the experimental and measurement uncertainty is very small (e.g., because experimental tests are very reproducible). Finally, a statistically significant LOF may not be practically significant if the uncertainty in model predictions is considerably smaller than uncertainty that can be tolerated and still satisfy requirements.

The model evaluation techniques discussed in the preceding bullets are included in or can be obtained from the output of the R software (Ihaka and Gentleman 1996, R Development Core Team 2006). See Draper and Smith (1998) or Montgomery et al. (2001) for further discussion of the concepts.

\section{D.3.3 Formulas for Three $\mathrm{R}^{2}$ Statistics}

Three different $\mathrm{R}^{2}$ statistics are useful in evaluating models fit to experimental data. These are denoted as $\mathrm{R}^{2}, \mathrm{R}_{\mathrm{A}}^{2}$, and $\mathrm{R}_{\mathrm{P}}^{2}$, which are discussed subsequently. Formulas for these statistics are given when models are fit by OLS or WLS.

The (ordinary) $\mathrm{R}^{2}$ statistic is given by

$$
R^{2}=1-\frac{\sum_{i=1}^{n}\left(\hat{y}_{i}-y_{i}\right)^{2}}{\sum_{i=1}^{n}\left(y_{i}-\bar{y}\right)^{2}}
$$

for OLS regression and by

$$
R^{2}=1-\frac{\sum_{i=1}^{n} w_{i}\left(\hat{y}_{i}-y_{i}\right)^{2}}{\sum_{i=1}^{n} w_{i}\left(y_{i}-\bar{y}_{w}\right)^{2}}
$$

for WLS regression, where $\bar{y}_{w}$ in Eq. (D.11b) is the weighted mean whose formula is given in Eq. (D.7). $\mathrm{R}^{2}$ is interpreted as the fraction of variability in the unweighted (for OLS regression) or weighted (for WLS regression) response data (transformed if appropriate) accounted for by the fit model. The adjusted $\mathrm{R}^{2}$ statistic is given by

$$
\mathrm{R}_{\mathrm{A}}^{2}=1-\frac{\sum_{\mathrm{i}=1}^{\mathrm{n}}\left(\hat{\mathrm{y}}_{\mathrm{i}}-\mathrm{y}_{\mathrm{i}}\right)^{2} /(\mathrm{n}-\mathrm{p})}{\sum_{\mathrm{i}=1}^{\mathrm{n}}\left(\mathrm{y}_{\mathrm{i}}-\overline{\mathrm{y}}\right)^{2} /(\mathrm{n}-1)}
$$

for OLS regression and by 


$$
\mathrm{R}_{\mathrm{A}}^{2}=1-\frac{\sum_{\mathrm{i}=1}^{\mathrm{n}} \mathrm{w}_{\mathrm{i}}\left(\hat{\mathrm{y}}_{\mathrm{i}}-\mathrm{y}_{\mathrm{i}}\right)^{2} /(\mathrm{n}-\mathrm{p})}{\sum_{\mathrm{i}=1}^{\mathrm{n}} \mathrm{w}_{\mathrm{i}}\left(\mathrm{y}_{\mathrm{i}}-\overline{\mathrm{y}}_{\mathrm{w}}\right)^{2} /(\mathrm{n}-1)}
$$

for WLS regression. $\mathrm{R}_{\mathrm{A}}^{2}$ is interpreted as the adjusted fraction of variability in the unweighted or weighted response data (transformed if appropriate) accounted for by the fitted model. The adjustment is for the number of coefficients (p) and number of data points (n) used in fitting the model.

The predicted- $\mathrm{R}^{2}$ statistic is given by

$$
\mathrm{R}_{\mathrm{P}}^{2}=1-\frac{\sum_{\mathrm{i}=1}^{\mathrm{n}}\left(\hat{\mathrm{y}}_{(\mathrm{i})}-\mathrm{y}_{\mathrm{i}}\right)^{2}}{\sum_{\mathrm{i}=1}^{\mathrm{n}}\left(\mathrm{y}_{\mathrm{i}}-\overline{\mathrm{y}}\right)^{2}}
$$

for OLS regression and by

$$
\mathrm{R}_{\mathrm{P}}^{2}=1-\frac{\sum_{\mathrm{i}=1}^{\mathrm{n}} \mathrm{w}_{\mathrm{i}}\left(\hat{\mathrm{y}}_{(\mathrm{i})}-\mathrm{y}_{\mathrm{i}}\right)^{2}}{\sum_{\mathrm{i}=1}^{\mathrm{n}} \mathrm{w}_{\mathrm{i}}\left(\mathrm{y}_{\mathrm{i}}-\overline{\mathrm{y}}_{\mathrm{w}}\right)^{2}}
$$

for WLS regression. $\mathrm{R}_{\mathrm{P}}^{2}$ is interpreted as the leave-one-out cross-validation fraction of variability in the unweighted or weighted response data (transformed if appropriate) accounted for by the fitted model. This statistic is calculated by a method equivalent to leaving each data point out of the model fit and then evaluating how well the model predicts the response for that data point. $\mathrm{R}_{\mathrm{P}}^{2}$ estimates the fraction of variability that would be explained in predicting new observations drawn from the same predictorvariable space. However, computational simplifications for OLS and WLS regression do not require refitting a model with each data point removed.

Generally $\mathrm{R}^{2}$ statistics take values between 0 and 1 . However, $\mathrm{R}_{\mathrm{A}}^{2}$ and $\mathrm{R}_{\mathrm{P}}^{2}$ can take negative values for a poor-fitting model, a model that contains many more terms than needed to fit the data, or a model fit to data with one or more very influential data points. Among the three $\mathrm{R}^{2}$ statistics, typically $\mathrm{R}^{2}>\mathrm{R}_{\mathrm{A}}^{2}>$ $\mathrm{R}_{\mathrm{P}}^{2}$. More than a minor difference between $\mathrm{R}^{2}$ and $\mathrm{R}_{\mathrm{A}}^{2}$ indicates that the model may contain more terms than needed to achieve the same goodness of fit. A substantial difference between $R^{2}$ and $R_{P}^{2}$ is indicative of one or more data points being very influential in determining the fit of the model. Some reduction from $\mathrm{R}^{2}$ to $\mathrm{R}_{\mathrm{P}}^{2}$ is expected because $\mathrm{R}^{2}$ corresponds to using all data to fit the model, whereas $\mathrm{R}_{\mathrm{P}}^{2}$ corresponds to leaving each data point out of the fit when evaluating the performance of the model for that point. In general, a model will tend to predict better for data used to fit it than for data not used to fit it. $\mathrm{R}_{\mathrm{P}}^{2}$ is a cross-validation evaluation method. 


\section{D.4 Statistical Methods for Model Reduction and Augmentation}

Section D.4.1 discusses methods for identifying and removing unnecessary terms from models fit to experimental data. Section D.4.2 discusses methods for augmenting initial models with additional terms.

\section{D.4.1 Statistical Methods for Reducing Regression Models}

In evaluating a fitted regression model, it may often be determined that there are unnecessary terms in the model. Such terms may not improve and can even degrade the predictive performance of the model in applications to data not used to develop the model.

The most basic statistical method for identifying unnecessary terms in a model is a t-test, which corresponds to a hypothesis test of whether a particular model term has a significant effect. Depending on the nature of the term, a nonsignificant effect could correspond to a hypothesis of its coefficient being zero (for a coefficient on an additive term) or one (a coefficient that is an exponent, such as in a powerlaw model). The t-test computes a t-statistic equal to

$$
\mathrm{t}-\text { statistic }=\frac{\text { coefficient }- \text { hypothesized value }}{\text { standard deviation of coefficient }}
$$

The t-statistic is then compared to the Student-t probability distribution to determine the probability of getting a t-statistic at least that large. The resulting probability is referred to as a p-value and represents the probability of incorrectly deciding a coefficient is significantly different from its hypothesized value. Most regression software outputs estimated model coefficients, coefficient standard deviations, tstatistics, and p-values when the hypothesized value of the coefficient is zero. However, the more general form of t-test in Eq. (D.14) can also be implemented. Typically, practitioners require a p-value to be smaller than 0.05 or 0.01 as strong evidence that the coefficient is significantly different from its hypothesized value, and thus that the corresponding model term is needed. If there are not too many potentially unnecessary terms in a model, a practitioner can assess the t-statistics and p-values for the coefficients in a "full" model, and remove the model term whose coefficient is least statistically significant. Then the model would be refit without that term, and the t-statistics and p-values again considered, deleting the model term with the least statistically significant coefficient. This process continues until all terms in the model have p-values lower than 0.05. This process, known as backward elimination (Draper and Smith 1998, Montgomery et al. 2001), is a widely used statistical method for removing unneeded terms from a model. This method basically automates the process just described, where the practitioner sets a stopping criterion.

\section{D.4.2 Statistical Methods for Adding Terms to Models}

It is often desirable to add additional terms to a starting model in the hopes of improving its predictive performance. For example, a model linear in the predictor variables, or a power-law model, may be considered a starting model. If it has a significant LOF, adding interaction terms may be considered to improve the predictive performance of the model. Stepwise regression is the most commonly used method to add terms to an existing starting model. In stepwise regression, certain terms can be forced into the model, and a candidate list of possible terms to add is identified. The procedure identifies the term from the candidate list that, if added to the model, would yield the greatest reduction in the error sum of squares (i.e., the sum of squared differences in measured and model-predicted values across the 
modeling data set). If the reduction is statistically significant, that term is added to the model. Stepwise regression proceeds in stages, with one additional term being added at each stage unless the user-selected stopping criterion is reached. After adding a term, stepwise regression checks all other terms in the model to assess whether they are still statistically significant. If not, a term can be removed during a stage.

The stepwise-regression algorithm requires that a significance level be specified for terms to enter the model and that a significance level be specified for terms to remain in the model. In each iteration of a stepwise-regression application, t-tests are conducted for each term already in the model and for terms being considered for inclusion in the model. To describe the results of these t-tests, a p-value is calculated for each of the terms. Loosely speaking, the p-values represent the probability that the respective model terms do not make a significant contribution to the predictive ability of the model. Terms whose corresponding p-values are small (often $<0.05$ is considered sufficiently small) are deemed important in the model. The significance levels specified for the stepwise-regression algorithm indicate how small pvalues must be for the corresponding terms to be included in the model. The statistical literature generally indicates that the stepwise algorithm is somewhat liberal in allowing terms into models (i.e., may over-fit the data and add too many terms). However, models containing unnecessary terms are undesirable because they tend to have inflated prediction variance. Thus, it is typically advisable to use tight significance levels such as 0.05 or 0.01 when applying the stepwise-regression algorithm. Draper and Smith (1998) and Montgomery et al. (2001) have further discussion and details on stepwise regression.

\section{D.5 Statistical Methods for Model Validation}

Model validation methods assess how well a fitted model predicts response values for data not used in fitting the model. A validation data set could be separate from the modeling data set or could be a subset obtained by splitting or partitioning the modeling data set into modeling and validation subsets.

The data used for validation ideally should be in the same predictor-variable region as the data used to fit the model being validated. This is because, in general, fitted empirical and semi-empirical models should not be used to extrapolate much beyond the region covered by the modeling data. Also, ideally the validation data should be evenly distributed over the region of model validity ${ }^{(1)}$ to properly assess predictive ability over the region. These ideals can generally be achieved when splitting or partitioning the modeling data set into modeling and validation subsets. However, they can be difficult to achieve in practice for a separate validation data set because such data are typically not designed but often consist of whatever extra or older data are available.

Validation generally consists of using a fitted model to predict response values for a set of validation data, and then comparing the predicted response values to the measured values from the validation database. The following subsections describe several methods for comparing predicted and measured values of response variables.

(1) A model validity region is the region of predictor-variable combinations where a model has been determined to be valid. 


\section{D.5.1 Validation $\mathbf{R}^{2}$}

Statistical summary comparisons of predicted and measured response values are also useful to see whether differences are larger than their expected uncertainties. One such comparison is the validation $\mathrm{R}^{2}$ $\left(\mathrm{R}_{\mathrm{V}}^{2}\right.$ ) statistic, which in general is given by

$$
\mathrm{R}_{\mathrm{V}}^{2}=1-\frac{\sum_{\mathrm{i}=1}^{\mathrm{n}}\left(\hat{\mathrm{y}}_{\mathrm{i}}-\mathrm{y}_{\mathrm{i}}\right)^{2}}{\sum_{\mathrm{i}=1}^{\mathrm{n}}\left(\mathrm{y}_{\mathrm{i}}-\overline{\mathrm{y}}\right)^{2}}
$$

However, in cases where WLS regression is used to fit the model and corresponding weights are available for the validation data set, a weighted version of the validation $\mathrm{R}^{2}$ statistics is given by

$$
\mathrm{R}_{V}^{2}=1-\frac{\sum_{\mathrm{i}=1}^{\mathrm{n}} \mathrm{w}_{\mathrm{i}}\left(\hat{\mathrm{y}}_{\mathrm{i}}-\mathrm{y}_{\mathrm{i}}\right)^{2}}{\sum_{\mathrm{i}=1}^{\mathrm{n}} \mathrm{w}_{\mathrm{i}}\left(\mathrm{y}_{\mathrm{i}}-\overline{\mathrm{y}}_{\mathrm{w}}\right)^{2}}
$$

If weights are not available for the validation data set in the WLS case, weights $\mathrm{w}_{\mathrm{i}}=1$ can be used, which is equivalent to using Eq. (D.15a) instead of Eq. (D.15b). $\mathrm{R}_{\mathrm{V}}^{2}$ is interpreted as the fraction of variability in the unweighted or weighted response values (transformed if appropriate) in the validation data accounted for by the fitted model. Note that $\mathrm{R}_{\mathrm{V}}^{2}$ is defined exactly the same as the ordinary $\mathrm{R}^{2}$ defined in Eq. (D.11a) and (D.11b), except that model-validation data are used to assess model predictive performance instead of the model-development data. Hence, the $\mathrm{y}_{\mathrm{i}}, \hat{\mathrm{y}}_{\mathrm{i}}, \overline{\mathrm{y}}, \mathrm{w}_{\mathrm{i}}$, and $\overline{\mathrm{y}}_{\mathrm{w}}$ values in Eq. (D.15a) and (D.15b) correspond to the model validation data.

Generally, $\mathrm{R}_{\mathrm{V}}^{2} \leq \mathrm{R}_{\mathrm{P}}^{2} \leq \mathrm{R}_{\mathrm{A}}^{2} \leq \mathrm{R}^{2} \leq 1$. However, $\mathrm{R}_{\mathrm{V}}^{2}$ can take negative values (when a model predicts a validation set very poorly) and can take values larger than $\mathrm{R}_{\mathrm{P}}^{2}, \mathrm{R}_{\mathrm{A}}^{2}$, or $\mathrm{R}^{2}$ (when a model predicts a particular validation data set better than estimated by these statistics based on the modeling data).

\section{D.5.2 Validation RMSE}

Another useful summary statistic for model validation is validation RMSE $\left(\mathrm{RMSE}_{\mathrm{V}}\right)$. This statistic is calculated by

$$
\operatorname{RMSE}_{\mathrm{V}}=\sqrt{\frac{\sum_{\mathrm{i}=1}^{\mathrm{n}}\left(\hat{\mathrm{y}}_{\mathrm{i}}-\mathrm{y}_{\mathrm{i}}\right)^{2}}{\mathrm{n}_{\mathrm{V}}}}
$$

for OLS-fitted models and by 


$$
\operatorname{RMSE}_{\mathrm{V}}=\sqrt{\frac{\sum_{\mathrm{i}=1}^{\mathrm{n}} \mathrm{w}_{\mathrm{i}}\left(\hat{\mathrm{y}}_{\mathrm{i}}-\mathrm{y}_{\mathrm{i}}\right)^{2}}{\mathrm{n}_{\mathrm{V}}}}
$$

for WLS-fitted models. For the WLS case, if weights are not available for the validation data set, weights $\mathrm{w}_{\mathrm{i}}=1$ are used. This is equivalent to using Eq. (D.16a) instead of Eq. (D.16b).

In Eq. (D.16a) and (D.16b), the denominator $\mathrm{n}_{\mathrm{V}}$ is the number of observations in the validation data set. The denominator is different from the $\mathrm{n}-\mathrm{p}$ denominator for the modeling RMSE given in Eq. (D.8a) and (D.8b), where $\mathrm{n}$ is the number of observations in the modeling data set and $\mathrm{p}$ is the number of model coefficients estimated using the modeling data set. In Eq. (D.8a) and (D.8b), the $n-p$ denominator accounts for estimating the $\mathrm{p}$ model coefficients using the $\mathrm{n}$ observations in the modeling data set. However, because no model coefficients are estimated from a validation data set, the denominator in Eq. (D.16a) and (D.16b) is $n_{V}$ rather than $n-p$.

In general, RMSE $\mathrm{V}_{\mathrm{V}}$ calculated by Eq. (D.16a) and (D.16b) is expected to be larger than RMSE calculated by Eq. (D.8a) and (D.8b) because the validation subset was not used to fit the model. The difference can be larger when the validation data set is small relative to the modeling data set, so that $n_{V}$ is much smaller than $n-p$. The difference between RMSE and RMSE $E_{V}$ depends not only on how well a model predicts for the validation data set, but also on the distribution of points in the validation data set relative to the distribution in the modeling data set. The non-representativeness of a smaller validation data set can thus cause a larger difference between RMSE and RMSE ${ }_{\mathrm{V}}$.

\section{D.5.3 Predicted Versus Measured Plots for Validation}

Predicted and measured values for a model validation data set can be compared by plotting the predicted versus the measured response values for each data point. Such predicted versus measured plots are the same as described in Section D.3.2, except model validation data are used instead of model development data. Also, similarly as described in Section D.3.2, unweighted or weighted PvM plots may be produced and viewed to validate models fit by WLS regression.

Optionally, error bars consisting of 95\% two-sided prediction intervals (PIs) on the predicted values can be included in the predicted-versus-measured plot for validation. Then, if the error bar for a given validation data point overlaps a line with slope one superimposed on the PvM plot, the model is validated for that data point. Draper and Smith (1998) and Montgomery et al. (2001) provide additional discussion of 95\% PIs for regression models. The formulas for a 95\% two-sided PI in the OLS and WLS cases are given in Section D.6.3.

\section{D.6 Statistical Intervals for Quantifying Uncertainties in Model Predictions}

Several types of statistical intervals are available to describe the uncertainty associated with model predictions. Each type of statistical interval has a particular interpretation. A common assumption for all statistical intervals based on regression models is that the model represents the true underlying response surface without a statistically significant lack of fit. 
The following subsections present the formulas for one-sided upper (or lower) confidence intervals (Section D.6.1), two-sided confidence intervals (Section D.6.2), and two-sided prediction intervals (Section D.6.3). These types of statistical intervals are used to describe the uncertainty associated with model predictions at a single, specific set of predictor-variable values. Section D.6.4 presents the formulas for simultaneous confidence intervals, which are used to describe the uncertainty associated with model predictions at many different sets of predictor-variable values. The formulas for these types of statistical intervals are given in each subsection for the OLS and WLS cases. Section D.6.5 discusses aspects of using the statistical intervals.

\section{D.6.1 One-Sided Confidence Intervals}

Formulas for one-sided upper and one-sided lower confidence intervals are presented in subsections D.6.1.1 and D.6.1.2, respectively.

\section{D.6.1.1 One-Sided Upper Confidence Interval}

A 100(1- $\alpha) \%$ upper confidence interval (UCI) for the true mean response value for a given set of predictor-variable values $\mathbf{x}=\left(\mathrm{x}_{1}, \mathrm{x}_{2}, \ldots, \mathrm{x}_{\mathrm{q}}\right)$ is given by

$$
\begin{aligned}
\hat{y}(\mathbf{x})+t_{1-\alpha}(n-p) \sqrt{\mathbf{a}^{\mathrm{T}} \mathbf{C}_{U} \mathbf{a}} & =\hat{y}(\mathbf{x})+t_{1-\alpha}(n-p) \sqrt{\mathbf{a}^{\mathrm{T}}\left[\left(\mathbf{A}^{\mathrm{T}} \mathbf{A}\right)^{-1} \mathrm{MSE}_{\mathrm{U}}\right] \mathbf{a}} \\
& =\hat{y}(\mathbf{x})+t_{1-\alpha}(n-p) \operatorname{RMSE}_{U} \sqrt{\mathbf{a}^{\mathrm{T}}\left(\mathbf{A}^{\mathrm{T}} \mathbf{A}\right)^{-1} \mathbf{a}}
\end{aligned}
$$

for OLS regression and by

$$
\begin{aligned}
\hat{y}(\mathbf{x})+t_{1-\alpha}(n-p) \sqrt{\mathbf{a}^{\mathrm{T}} \mathbf{C}_{\mathrm{W}} \mathbf{a}} & =\hat{y}(\mathbf{x})+t_{1-\alpha}(n-p) \sqrt{\mathbf{a}^{\mathrm{T}}\left[\left(\mathbf{A}^{\mathrm{T}} \mathbf{W A}\right)^{-1} \mathrm{MSE}_{\mathrm{W}}\right] \mathbf{a}} \\
& =\hat{y}(\mathbf{x})+t_{1-\alpha}(n-p) \operatorname{RMSE}_{\mathrm{W}} \sqrt{\mathbf{a}^{\mathrm{T}}\left(\mathbf{A}^{\mathrm{T}} \mathbf{W A}\right)^{-1} \mathbf{a}}
\end{aligned}
$$

for WLS regression. The notations in Eq. (D.17a) and (D.17b) are defined as follows:

$$
\begin{aligned}
& \hat{\mathrm{y}}(\mathbf{x})=\text { model predicted value at a set of predictor-variable values } \mathrm{x} \\
& 100(1-\alpha)=\text { desired confidence (e.g., } 90 \%) \text { for the confidence interval, where } \alpha \text { denotes the } \\
& \text { significance level (e.g., } \alpha=0.10 \text { for } 90 \% \text { confidence) } \\
& \mathrm{t}_{1-\alpha}(\mathrm{n}-\mathrm{p})=100(1-\alpha) \text {-percentile of the Student's t-distribution with } \mathrm{n}-\mathrm{p} \text { degrees of freedom } \\
& \mathrm{n}=\text { number of data points used to fit the model } \\
& \mathrm{p}=\text { number of coefficients estimated in the model } \\
& \mathrm{C}_{\mathrm{U}}=\text { estimated variance-covariance matrix for the estimated coefficients of a model } \\
& \text { fit by OLS regression }\left(\mathbf{A}^{\mathrm{T}} \mathbf{A}\right)^{-1} \mathrm{MSE}_{\mathrm{U}} \\
& \mathrm{C}_{\mathrm{W}}=\text { estimated variance-covariance matrix for the estimated coefficients of a model } \\
& \text { fit by WLS regression }=\left(\mathbf{A}^{\mathrm{T}} \mathbf{W A}\right)^{-1} \mathrm{MSE}_{\mathrm{W}} \\
& \mathbf{a}^{\mathrm{T}}=\text { transpose of the vector } \mathbf{x} \text { of predictor-variable values expanded in the form of the } \\
& \text { model }
\end{aligned}
$$




$$
\begin{aligned}
\mathbf{A}^{\mathrm{T}}= & \begin{array}{l}
\text { transpose of the data matrix of predictor-variable values, expanded in the form of } \\
\text { the model }
\end{array} \\
\mathbf{W}= & \begin{array}{l}
\text { an } \mathrm{n} \times \mathrm{n} \text { diagonal weight matrix with entries } \mathrm{w}_{\mathrm{i}}, \mathrm{i}=1,2, \ldots, \mathrm{n} \text { (i.e., the weights } \\
\text { associated with the model-development set of } \mathrm{n} \text { data points) }
\end{array} \\
\mathrm{MSE}= & \begin{array}{l}
\text { mean squared error, which is obtained from the OLS }\left(\mathrm{MSE}_{\mathrm{U}}\right) \text { or WLS }\left(\mathrm{MSE}_{\mathrm{W}}\right) \\
\text { regression fit of the model }
\end{array} \\
\text { RMSE = } & \begin{array}{l}
\text { the root mean squared error }=\sqrt{\mathrm{MSE}}, \text { with } \mathrm{RMSE}_{\mathrm{U}} \text { and } \mathrm{RMSE}_{\mathrm{W}} \text { resulting } \\
\text { from OLS and WLS regression fits of a model, respectively. }
\end{array}
\end{aligned}
$$

A $100(1-\alpha) \%$ UCI, as given by Eq. (D.17a) and (D.17b), is appropriate when an uncertainty statement is desired about the true mean response for a given set of predictor-variable values $\mathbf{x}$.

\section{D.6.1.2 One-Sided Lower Confidence Interval}

The formulas for a one-sided lower confidence interval are the same as in Eq. (D.17a) and (D.17b) except the plus signs following $\hat{y}(\mathbf{x})$ are changed to minus signs. Thus, a $100(1-\alpha) \%$ lower confidence interval (LCI) for the true mean response value for a given set of predictor-variable values $\mathbf{x}=\left(\mathrm{x}_{1}, \mathrm{x}_{2}, \ldots\right.$, $\mathrm{x}_{\mathrm{q}}$ ) is given by

$$
\begin{aligned}
\hat{\mathrm{y}}(\mathbf{x})-\mathrm{t}_{1-\alpha}(\mathrm{n}-\mathrm{p}) \sqrt{\mathbf{a}^{\mathrm{T}} \mathbf{C}_{\mathrm{U}} \mathbf{a}} & =\hat{\mathrm{y}}(\mathbf{x})-\mathrm{t}_{1-\alpha}(\mathrm{n}-\mathrm{p}) \sqrt{\mathbf{a}^{\mathrm{T}}\left[\left(\mathbf{A}^{\mathrm{T}} \mathbf{A}\right)^{-1} \mathrm{MSE}_{\mathrm{U}}\right] \mathbf{a}} \\
& =\hat{y}(\mathbf{x})-\mathrm{t}_{1-\alpha}(\mathrm{n}-\mathrm{p}) \mathrm{RMSE}_{\mathrm{U}} \sqrt{\mathbf{a}^{\mathrm{T}}\left(\mathbf{A}^{\mathrm{T}} \mathbf{A}\right)^{-1} \mathbf{a}}
\end{aligned}
$$

for OLS regression and by

$$
\begin{aligned}
\hat{y}(\mathbf{x})-t_{1-\alpha}(n-p) \sqrt{\mathbf{a}^{\mathrm{T}} \mathbf{C}_{\mathrm{W}} \mathbf{a}} & =\hat{y}(\mathbf{x})-\mathrm{t}_{1-\alpha}(\mathrm{n}-\mathrm{p}) \sqrt{\mathbf{a}^{\mathrm{T}}\left[\left(\mathbf{A}^{\mathrm{T}} \mathbf{W A}\right)^{-1} \mathrm{MSE}_{\mathrm{W}}\right] \mathbf{a}} \\
& =\hat{y}(\mathbf{x})-\mathrm{t}_{1-\alpha}(\mathrm{n}-\mathrm{p}) \mathrm{RMSE}_{\mathrm{W}} \sqrt{\mathbf{a}^{\mathrm{T}}\left(\mathbf{A}^{\mathrm{T}} \mathbf{W A}\right)^{-1} \mathbf{a}}
\end{aligned}
$$

for WLS regression. The notation is as previously defined.

\section{D.6.2 Two-Sided Confidence Interval}

A $100(1-\alpha) \%$ two-sided confidence interval (CI) for the true mean response value for a given set of predictor variables $\mathbf{x}=\left(\mathrm{x}_{1}, \mathrm{x}_{2}, \ldots, \mathrm{x}_{\mathrm{q}}\right)$ is given by

$$
\begin{aligned}
\hat{\mathrm{y}}(\mathbf{x}) \mp \mathrm{t}_{1-\alpha / 2}(\mathrm{n}-\mathrm{p}) \sqrt{\mathbf{a}^{\mathrm{T}} \mathbf{C}_{\mathrm{U}} \mathbf{a}} & =\hat{\mathrm{y}}(\mathbf{x}) \mp \mathrm{t}_{1-\alpha / 2}(\mathrm{n}-\mathrm{p}) \sqrt{\mathbf{a}^{\mathrm{T}}\left[\left(\mathbf{A}^{\mathrm{T}} \mathbf{A}\right)^{-1} \mathrm{MSE}_{\mathrm{U}}\right] \mathbf{a}} \\
& =\hat{y}(\mathbf{x}) \mp \mathrm{t}_{1-\alpha / 2}(\mathrm{n}-\mathrm{p}) \mathrm{RMSE}_{\mathrm{U}} \sqrt{\mathbf{a}^{\mathrm{T}}\left(\mathbf{A}^{\mathrm{T}} \mathbf{A}\right)^{-1} \mathbf{a}}
\end{aligned}
$$

for OLS regression and by 


$$
\begin{aligned}
\hat{\mathrm{y}}(\mathbf{x}) \mp \mathrm{t}_{1-\alpha / 2}(\mathrm{n}-\mathrm{p}) \sqrt{\mathbf{a}^{\mathrm{T}} \mathbf{C}_{\mathrm{W}} \mathbf{a}} & =\hat{\mathrm{y}}(\mathbf{x}) \mp \mathrm{t}_{1-\alpha / 2}(\mathrm{n}-\mathrm{p}) \sqrt{\mathbf{a}^{\mathrm{T}}\left[\left(\mathbf{A}^{\mathrm{T}} \mathbf{W A}\right)^{-1} \mathrm{MSE}_{\mathrm{W}}\right] \mathbf{a}} \\
& =\hat{\mathrm{y}}(\mathbf{x}) \mp \mathrm{t}_{1-\alpha / 2}(\mathrm{n}-\mathrm{p}) \mathrm{RMSE}_{\mathrm{W}} \sqrt{\mathbf{a}^{\mathrm{T}}\left(\mathbf{A}^{\mathrm{T}} \mathbf{W A}\right)^{-1} \mathbf{a}}
\end{aligned}
$$

for WLS regression. In Eq. (D.19a) and (D.19b), the notation is all the same as described in Section D.6.1 except that $t_{1-\alpha / 2}(n-p)$ denotes the $100(1-\alpha / 2)$-percentile of the Student t-distribution with $n-p$ degrees of freedom.

\section{D.6.3 Two-Sided Prediction Interval}

A 100(1- $\alpha) \%$ two-sided prediction interval (PI) for an individual response value for a given set of predictor-variable values $\mathbf{x}$ is given by

$$
\begin{aligned}
& \hat{\mathrm{y}}(\mathbf{x}) \mp \mathrm{t}_{1-\alpha / 2}(\mathrm{n}-\mathrm{p}) \sqrt{\mathrm{MSE}_{\mathrm{U}}+\mathbf{a}^{\mathrm{T}} \mathbf{C}_{\mathrm{U}} \mathbf{a}} \\
& \quad=\hat{\mathrm{y}}(\mathbf{x}) \mp \mathrm{t}_{1-\alpha / 2}(\mathrm{n}-\mathrm{p}) \operatorname{RMSE}_{\mathrm{U}} \sqrt{1+\mathbf{a}^{\mathrm{T}}\left(\mathbf{A}^{\mathrm{T}} \mathbf{A}\right)^{-1} \mathbf{a}}
\end{aligned}
$$

for OLS regression and by

$$
\begin{aligned}
& \hat{\mathrm{y}}(\mathbf{x}) \mp \mathrm{t}_{1-\alpha / 2}(\mathrm{n}-\mathrm{p}) \sqrt{\frac{\mathrm{MSE}_{\mathrm{W}}}{\mathrm{w}_{\mathrm{i}}}+\mathbf{a}^{\mathrm{T}} \mathbf{C}_{\mathrm{W}} \mathbf{a}} \\
& \quad=\hat{\mathrm{y}}(\mathbf{x}) \mp \mathrm{t}_{1-\alpha / 2}(\mathrm{n}-\mathrm{p}) \mathrm{RMSE}_{\mathrm{W}} \sqrt{\frac{1}{\mathrm{w}_{\mathrm{i}}}+\mathbf{a}^{\mathrm{T}}\left(\mathbf{A}^{\mathrm{T}} \mathbf{W A}\right)^{-1} \mathbf{a}}
\end{aligned}
$$

for WLS regression. The notations in Eq. (D.20a) and (D.20b) are defined as given following the UCI formulas in Section D.6.1.

The preceding equations for $100(1-\alpha) \%$ two-sided PIs are easily converted to $100(1-\alpha) \%$ one-sided PIs by replacing “ $\mp$ ” with “-” or “+”, replacing $t_{1-\alpha / 2}(n-p)$ with $t_{1-\alpha}(n-p)$, and replacing $\mathrm{t}_{1-\alpha / 2}\left(\mathrm{n}_{\mathrm{g}}-\mathrm{p}_{\mathrm{g}}\right)$ with $\mathrm{t}_{1-\alpha}\left(\mathrm{n}_{\mathrm{g}}-\mathrm{p}_{\mathrm{g}}\right)$.

In Eq. (D.20b) the $\mathrm{w}_{\mathrm{i}}$ under the square root applies when PIs are calculated for modeling data, validation data, or application data (i.e., data used in applying the models and PIs) with weights. In situations where validation or application data do not have weights, $\mathrm{w}_{\mathrm{i}}$ should be set to 1 .

A $100(1-\alpha) \%$ PI is appropriately used when comparing a model predicted response value for a given set of predictor-variable values to an individual measurement of the response for that same set of predictor-variable values. This type of application arises in validating the predictive performance of a model for one or more sets of predictor-variable values not used to fit the model. Specifically, Eq. (D.20a) and (D.20b) can be used to produce 95\% PIs displayed as error bars in PvM plots for validation data, as described in Section D.5.3. 


\section{D.6.4 Simultaneous Confidence Intervals}

At times it is desirable to describe the uncertainty associated with predictions obtained for many sets of predictor-variable values. For example, a statement may be desired that indicates with high confidence that the predicted response value for every set of predictor-variable values $\mathbf{x}$ in a specified region meets requirements. A simultaneous confidence interval provides such a statistical statement. The formula for a 100(1- $\alpha) \%$ simultaneous confidence interval (SCI) associated with predictions on an unlimited number of sets of predictor variables $\mathbf{x}$ is given by

$$
\begin{aligned}
& \hat{\mathrm{y}}(\mathbf{x}) \pm \sqrt{\mathrm{pF}_{1-\alpha}(\mathrm{p}, \mathrm{n}-\mathrm{p})} \sqrt{\mathbf{a}^{\mathrm{T}} \mathbf{C}_{\mathrm{U}} \mathbf{a}} \\
& \quad=\hat{\mathrm{y}}(\mathbf{x}) \pm \operatorname{RMSE}_{\mathrm{U}} \sqrt{\mathrm{pF}_{1-\alpha}(\mathrm{p}, \mathrm{n}-\mathrm{p})} \sqrt{\mathbf{a}^{\mathrm{T}}\left(\mathbf{A}^{\mathrm{T}} \mathbf{A}\right)^{-1} \mathbf{a}}
\end{aligned}
$$

for OLS regression and by

$$
\begin{aligned}
& \hat{\mathrm{y}}(\mathbf{x}) \pm \sqrt{\mathrm{pF}_{1-\alpha}(\mathrm{p}, \mathrm{n}-\mathrm{p})} \sqrt{\mathbf{a}^{\mathrm{T}} \mathbf{C}_{\mathrm{W}} \mathbf{a}} \\
& \quad=\hat{\mathrm{y}}(\mathbf{x}) \pm \operatorname{RMSE}_{\mathrm{W}} \sqrt{\mathrm{pF}_{1-\alpha}(\mathrm{p}, \mathrm{n}-\mathrm{p})} \sqrt{\mathbf{a}^{\mathrm{T}}\left(\mathbf{A}^{\mathrm{T}} \mathbf{W A}\right)^{-1} \mathbf{a}}
\end{aligned}
$$

for WLS regression. In Eq. (D.21a) and (D.21b) $F_{1-\alpha}(p, n-p)=100(1-\alpha)$-percentile of the statistical F-distribution with $\mathrm{p}$ and $\mathrm{n}-\mathrm{p}$ degrees of freedom. The remaining notations were defined previously.

\section{D.6.5 Statistical Intervals in Transformed and Untransformed Units}

Eq. (D.17) to (D.21) yield statistical intervals in transformed units when a transformed response is modeled. For example, a natural logarithm transformation of a response y [i.e., $\ln (\mathrm{y})$ ] is often used for models of responses with experimental and measurement uncertainty proportional to the magnitude of the response. In such cases, the statistical intervals calculated using the preceding equations would be in $\ln (y)$ units. The statistical intervals can be transformed back to the original units of y by exponentiating the endpoint(s) of the statistical interval. However, the process of back-transforming (exponentiating) a statistical interval can change its interpretation. For example, if a $90 \% \mathrm{UCI}$ in $\ln (\mathrm{y})$ units has the value v, the back-transformed 90\% UCI in the original units of y is given by $\mathrm{e}^{\mathrm{v}}$. The $90 \% \mathrm{UCI}$ in units of $\ln (\mathrm{y})$ is a statement about the true mean response in $\ln (\mathrm{y})$ units for a given set of predictor-variable values $\mathbf{x}$. However, the resulting back-transformed interval is a 90\% UCI on the true median response value for the given set of predictor-variable values $\mathbf{x}$ under the assumption that experimental errors in the data used to develop the model are lognormally distributed. This assumption corresponds to the assumption of the natural-log-transformed response data being normally distributed. This change in interpretation occurs because the mean and median of a normal distribution are the same, but the mean of a lognormal distribution is larger than the median of a lognormal distribution.

Hence, back-transforming a $100(1-\alpha) \%$ UCI on a mean response (in ln-units) for a given set of predictor-variable values $\mathbf{x}$ (see Section D.6.1) yields a $100(1-\alpha) \%$ UCI on the median response (in original units) for the given set of predictor-variable values $\mathbf{x}$. This then underestimates a $100(1-\alpha) \%$ UCI on the mean response (in original units) for a given set of predictor-variable values $\mathbf{x}$. Similar interpretations hold for 100(1- $\alpha$ )\% LCIs (see Section D.6.1) and CIs (see Section D.6.2). Backtransforming 100(1- $\alpha) \%$ SCIs (see Section D.6.4) given in ln-transformed units has a similar change in 
interpretation. Whereas the original $100(1-\alpha) \%$ SCIs are statements about the true mean values of responses in ln-transformed response units for multiple sets of predictor-variable values $\mathbf{x}$, the backtransformed $100(1-\alpha) \%$ SCIs are statements about the true median values of responses in original response units for multiple sets of predictor-variable values x. However, a 100(1- $\alpha) \%$ PI (Section D.6.3) in ln-transformed units does not have a change in interpretation when back-transforming because the original statement (in ln-transformed units) and the back-transformed statement (in original units) are both about a true individual response value.

Alternatives exist to using normal-theory-based Eq. (D.17) to (D.21) and back-transforming them when a transformed response variable is modeled. One alternative is to modify the statistical interval equations so the statistical statement is about the true mean response value in the original units for a given set of predictor-variable values $\mathbf{x}$ (e.g., Eq. D.17 for an UCI) or multiple sets of predictor-variable values $\mathbf{x}$ (e.g., Eq. D.21 for a SCI). Although this type of alternative is discussed in the literature for nonregression problems (e.g., Gilbert 1987), no references were found for the regression context. Another alternative, the generalized linear model regression approach (Myers et al. 2002), avoids directly transforming the response variable and instead uses the transformation indirectly. These alternative approaches were not pursued in this work, but the interested reader may refer to the references given.

Note that Eq. (D.17) to (D.21) require knowledge of the variance-covariance matrix of the regression coefficients, denoted $\mathbf{C}_{\mathbf{U}}=\operatorname{MSE}_{\mathrm{U}}\left(\mathbf{A}^{\mathrm{T}} \mathbf{A}\right)^{-1}$ for OLS regression and $\mathbf{C}_{\mathrm{W}}=\operatorname{MSE}_{\mathrm{W}}\left(\mathbf{A}^{\mathrm{T}} \mathbf{W A}\right)^{-1}$ for WLS regression. The $M S E_{U}$ and $M S E_{W}$ are mean-squared errors equal to the squares of $R_{M S E}$ and $R M S E_{W}$ given by Eq. (D.8a) and (D.8b). This information is included in the OLS or WLS regression software output that comes with the estimates of the $p$ model coefficients. A variance-covariance matrix is a $\mathrm{p} \times \mathrm{p}$ matrix with coefficient variances along the diagonal and covariances between coefficient pairs in the offdiagonal entries.

\section{D.7 References}

Brett MT. 2004. “When is a Correlation Between Non-Independent Variables ‘Spurious’?” Oikos 105(3):647-656.

Draper NR and H Smith. 1998. Applied Regression Analysis, Third Edition. John Wiley and Sons, New York.

Gilbert RO. 1987. Statistical Methods for Environmental Pollution Monitoring. Van Nostrand Reinhold, New York.

Ihaka R and R Gentleman. 1996. "R: A Language for Data Analysis and Graphics." Journal of Computational and Graphical Statistics 5:299-314.

Kenney BC. 1982. “Beware of Spurious Self-Correlations!” Water Resources Research 18(4):10411048.

Montgomery DC, EA Peck, and GG Vining. 2001. Introduction to Linear Regression Analysis, Third Edition. John Wiley and Sons, New York.

Myers RH, and DC Montgomery. 1995. Response Surface Methodology: Process and Product Optimization Using Designed Experiments, John Wiley and Sons, New York. 
Myers RH, DC Montgomery, and GG Vining. 2002. Generalized Linear Models: With Applications in Engineering and the Sciences. John Wiley and Sons, New York.

Piepel GF, SK Cooley, I Muller, H Gan, I Joseph, and IL Pegg. June 2007. ILAW PCT, VHT, Viscosity and Electrical Conductivity Model Development. VSL-07R1230-1, Vitreous State Laboratory, The Catholic University of America, Washington, D.C.

R Development Core Team. 2006. R: A Language and Environment for Statistical Computing. R Foundation for Statistical Computing, Vienna. http://www.R-project.org. 


\title{
Appendix E
}

\section{Data Assessment and Analysis to Support Developing}

Multiple Regression Models for Mixing Responses

\author{
GF Piepel \\ BG Amidan \\ A Heredia-Langner
}





\section{Contents}

E.1 Assessment of Data for Developing Mixing Models......................................................... E.1

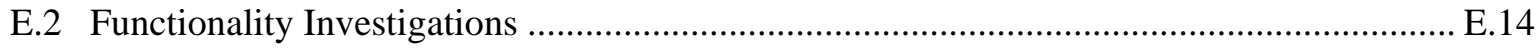

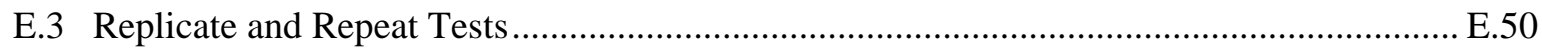

\section{Figures}

E.1 Dot Plots Showing Distributions of Potential Predictor Variables for $\mathrm{U}_{\mathrm{CS}}$ and $\mathrm{H}_{\mathrm{C}}$ Mixing

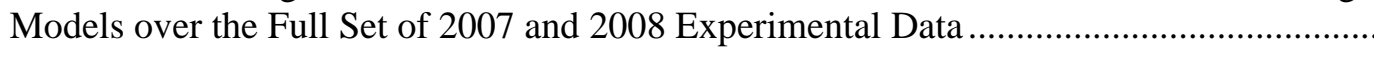

E.2 Dot Plots Showing Distributions of Potential Predictor Variables for $\mathrm{U}_{\mathrm{CS}}$ and $\mathrm{H}_{\mathrm{C}}$ Mixing Models over the Trimmed Set of July 2007, Fall 2007, and 2008 Experimental Data...

E.3 Scatterplot Matrix Plot of Pairwise Distributions of Predictor Variable Values for $\mathrm{U}_{\mathrm{CS}}$ and $\mathrm{H}_{\mathrm{C}}$ Mixing Models over the Full Set of July 2007 (o), Fall 2007 ( $\Delta$ ), and $2008(\times)$

Experimental Data

E.4 Scatterplot Matrix Plot of Pairwise Distributions of Predictor Variable Values for $U_{\mathrm{CS}}$ and $\mathrm{H}_{\mathrm{C}}$ Mixing Models over the Trimmed Set of July 2007 (o), Fall 2007 ( $\Delta$ ), and $2008(\times$ ) Experimental Data

E.5 Scatterplots of Pairwise Distributions of $U_{T H}$ and $U_{T}$ Values for $U_{C S}$ and $H_{C}$ Mixing Models over the Full and Trimmed Sets of July 2007 (o), Fall $2007(\Delta)$, and $2008(\times)$ Experimental Data

E.6 Log-Log Plot of the Functional Relationship Between Critical Suspension Velocity $\left(\mathrm{U}_{\mathrm{CS}}\right)$ and Tank Diameter (D) for Constant Sets of Values of Other Test Variables...

E.7 Log-Log Plot of the Functional Relationship Between Critical Suspension Velocity $\left(\mathrm{U}_{\mathrm{CS}}\right)$ and Number of Pulse Jets $\left(\mathrm{N}_{\mathrm{J}}\right)$ for Constant Sets of Values of Other Test Variables

E.8 Log-Log Plot of the Functional Relationship Between Critical Suspension Velocity $\left(\mathrm{U}_{\mathrm{CS}}\right)$ and Jet Nozzle Diameter (d) for Constant Sets of Values of Other Test Variables

E.9 Log-Log Plot of the Functional Relationship Between Critical Suspension Velocity $\left(\mathrm{U}_{\mathrm{CS}}\right)$ and Jet Density $\left(\phi_{\mathrm{J}}\right.$ ) for Constant Sets of Values of Other Test Variables.

E.10 Log-Log Plot of the Functional Relationship Between Critical Suspension Velocity $\left(\mathrm{U}_{\mathrm{CS}}\right)$ and Pulse Volume Fraction $\left(\phi_{\mathrm{p}}\right)$ for Constant Sets of Values of Other Test Variables.

E.11 Log-Log Plot of the Functional Relationship Between Critical Suspension Velocity $\left(\mathrm{U}_{\mathrm{CS}}\right)$ and Duty Cycle (DC) for Constant Sets of Values of Other Test Variables.

E.12 Log-Log Plot of the Functional Relationship Between Critical Suspension Velocity $\left(\mathrm{U}_{\mathrm{CS}}\right)$ and Solids Volume Fraction $\left(\phi_{\mathrm{S}}\right)$ for Constant Sets of Values of Other Test Variables

E.13 Log-Log Plot of the Functional Relationship Between Critical Suspension Velocity ( $\left.\mathrm{U}_{\mathrm{CS}}\right)$ and Solids Particle Diameter $\left(d_{s}=d_{50}\right)$ for Constant Sets of Values of Other Test Variables

E.14 Log-Log Plot of the Functional Relationship Between Critical Suspension Velocity $\left(\mathrm{U}_{\mathrm{CS}}\right)$ and Density Ratio (s) for Constant Sets of Values of Other Test Variables... 
E.15 Log-Categorical Plot of Functional Relationship Between Critical Suspension Velocity $\left(\mathrm{U}_{\mathrm{CS}}\right)$ and Head Shape (HS) for Constant Sets of Values of Other Test Variables.

E.16 Log-Log Plot of the Functional Relationship Between Critical Suspension Velocity $\left(\mathrm{U}_{\mathrm{CS}}\right)$ and unhindered terminal settling velocity $\left(\mathrm{U}_{\mathrm{T}}\right)$ for Constant Sets of Values of Other Test Variables

E.17 Log-Log Plot of the Functional Relationship Between Cloud Height $\left(\mathrm{H}_{\mathrm{C}}\right)$ and Velocity

(U) for Each Set of Test Conditions in the July 2007 Data Set

E.18 Log-Log Plot of the Functional Relationship Between Cloud Height $\left(\mathrm{H}_{\mathrm{C}}\right)$ and Velocity

(U) for Each Set of Test Conditions in the Fall 2007 Data Set.

E.19 Log-Log Plot of the Functional Relationship Between Cloud Height $\left(\mathrm{H}_{\mathrm{C}}\right)$ and Velocity

(U) for Each Set of 15-in. Tank Test Conditions in the 2008 Data Set

E.20 Log-Log Plot of the Functional Relationship Between Cloud Height $\left(\mathrm{H}_{\mathrm{C}}\right)$ and Velocity

(U) for Each Set of D = 0.860 m ( 34-in.) Tank Test Conditions in the 2008 Data Set

E.21 Log-Log Plot of the Functional Relationship Between Cloud Height $\left(\mathrm{H}_{\mathrm{C}}\right)$ and Velocity

(U) for Each Set of 70-in. Tank Test Conditions in the 2008 Data Set

E.22 Log-Log Plot of Functional Relationship Between Cloud Height at Critical Suspension Velocity $\left(\mathrm{H}_{\mathrm{CS}}\right)$ and Tank Diameter (D) for Constant Sets of Values of Other Test Variables

E.23 Log-Log Plot of Functional Relationship Between Cloud Height at Critical Suspension Velocity $\left(\mathrm{H}_{\mathrm{CS}}\right)$ and Number of Pulse Jets $\left(\mathrm{N}_{\mathrm{J}}\right)$ for Constant Sets of Values of Other Test Variables

E.24 Log-Log Plot of Functional Relationship Between Cloud Height at Critical Suspension Velocity $\left(\mathrm{H}_{\mathrm{CS}}\right)$ and Jet Nozzle Diameter (d) for Constant Sets of Values of Other Test Variables

E.25 Log-Log Plot of the Functional Relationship Between Cloud Height at Critical

Suspension Velocity $\left(\mathrm{H}_{\mathrm{CS}}\right)$ and Jet Density $\left(\phi_{\mathrm{J}}\right.$ ) for Constant Sets of Values of Other Test Variables

E.26 Log-Log Plot of Functional Relationship Between Cloud Height at Critical Suspension Velocity $\left(\mathrm{H}_{\mathrm{CS}}\right)$ and Pulse Volume Fraction $\left(\phi_{\mathrm{p}}\right)$ for Constant Sets of Values of Other

Test Variables

E.27 Log-Log Plot of the Functional Relationship Between Cloud Height at Critical Suspension Velocity $\left(\mathrm{H}_{\mathrm{CS}}\right)$ and Duty Cycle (DC) for Constant Sets of Values of Other Test Variables

E.28 Log-Log Plot of Functional Relationship Between Cloud Height at Critical Suspension Velocity $\left(\mathrm{H}_{\mathrm{CS}}\right)$ and Solids Volume Fraction $\left(\phi_{\mathrm{S}}\right)$ for Constant Sets of Values of Other Test Variables

E.29 Log-Log Plot of Functional Relationship Between Cloud Height at Critical Suspension Velocity $\left(\mathrm{H}_{\mathrm{CS}}\right)$ and Solids Particle Diameter $\left(\mathrm{d}_{\mathrm{S}}=\mathrm{d}_{50}\right)$ for Constant Sets of Values of Other Test Variables

E.30 Log-Log Plot of Functional Relationship Between Cloud Height at Critical Suspension Velocity $\left(\mathrm{H}_{\mathrm{CS}}\right)$ and Density Ratio (s) for Constant Sets of Values of Other Test Variables....

E.31 Log-Categorical Plot of the Functional Relationship Between Cloud Height at Critical Suspension Velocity $\left(\mathrm{H}_{\mathrm{CS}}\right)$ and Head Shape (HS) for Constant Sets of Values of Other Test Variables 
E.32 Log-Log Plot of Functional Relationship Between Cloud Height at Critical Suspension Velocity $\left(\mathrm{H}_{\mathrm{CS}}\right)$ and Unhindered Terminal Settling Velocity $\left(\mathrm{U}_{\mathrm{T}}\right)$ for Constant Sets of Values of Other Test Variables

E.33 Cloud Height $\left(\mathrm{H}_{\mathrm{C}}\right)$ Versus Target Velocity (U) Values for the 70E and 70F Head Shapes with $\mathrm{s}=2.48, \mathrm{~d}_{50}=6.93 \times 10^{-5}, \phi_{\mathrm{p}}=0.05, \phi_{\mathrm{s}}=0.00155$ and $\mathrm{DC}=0.33$.

E.34 Cloud Height $\left(\mathrm{H}_{\mathrm{C}}\right)$ Versus Target Velocity (U) Values for the 70E and 70F Head Shapes with $\mathrm{s}=2.48, \mathrm{~d}_{50}=6.93 \times 10^{-5}, \phi_{\mathrm{p}}=0.05, \phi_{\mathrm{S}}=0.005$ and $\mathrm{DC}=0.33$.

E.35 Cloud Height $\left(\mathrm{H}_{\mathrm{C}}\right)$ Versus Target Velocity $(\mathrm{U})$ Values for the 70E and 70F Head Shapes with $\mathrm{s}=2.48, \mathrm{~d}_{50}=6.93 \times 10^{-5}, \phi_{\mathrm{p}}=0.05, \phi_{\mathrm{S}}=0.01$ and $\mathrm{DC}=0.33$.

E.36 Cloud Height $\left(\mathrm{H}_{\mathrm{C}}\right)$ Versus Target Velocity $(\mathrm{U})$ Values for the $70 \mathrm{E}$ and $70 \mathrm{~F}$ Head Shapes with $\mathrm{s}=2.48, \mathrm{~d}_{50}=6.93 \times 10^{-5}, \phi_{\mathrm{p}}=0.05, \phi_{\mathrm{s}}=0.0143$ and $\mathrm{DC}=0.18$.

E.37 Cloud Height $\left(\mathrm{H}_{\mathrm{C}}\right)$ Versus Target Velocity (U) Values for the 70E and 70F Head Shapes with $\mathrm{s}=2.48, \mathrm{~d}_{50}=6.93 \times 10^{-5}, \phi_{\mathrm{p}}=0.05, \phi_{\mathrm{S}}=0.0143$ and $\mathrm{DC}=0.33$.

E.38 Cloud Height $\left(\mathrm{H}_{\mathrm{C}}\right)$ Versus Target Velocity $(\mathrm{U})$ Values for the $70 \mathrm{E}$ and $70 \mathrm{~F}$ Head Shapes with $\mathrm{s}=2.48, \mathrm{~d}_{50}=6.93 \times 10^{-5}, \phi_{\mathrm{p}}=0.05, \phi_{\mathrm{S}}=0.0143$ and $\mathrm{DC}=0.66$.

E.39 Cloud Height $\left(\mathrm{H}_{\mathrm{C}}\right)$ Versus Target Velocity (U) Values for the 70E and 70F Head Shapes with $\mathrm{s}=2.48, \mathrm{~d}_{50}=6.93 \times 10^{-5}, \phi_{\mathrm{p}}=0.10, \phi_{\mathrm{S}}=0.0143$ and $\mathrm{DC}=0.18$.

E.40 Cloud Height $\left(\mathrm{H}_{\mathrm{C}}\right)$ Versus Target Velocity $(\mathrm{U})$ Values for the 70E and 70F Head Shapes with $\mathrm{s}=2.48, \mathrm{~d}_{50}=6.93 \times 10^{-5}, \phi_{\mathrm{p}}=0.10, \phi_{\mathrm{S}}=0.0143$ and $\mathrm{DC}=0.33$.

E.41 Cloud Height $\left(\mathrm{H}_{\mathrm{C}}\right)$ Versus Target Velocity $(\mathrm{U})$ Values for the 70E and 70F Head Shapes with $\mathrm{s}=2.48, \mathrm{~d}_{50}=6.93 \times 10^{-5}, \phi_{\mathrm{p}}=0.10, \phi_{\mathrm{S}}=0.0143$ and $\mathrm{DC}=0.66$.

E.42 Cloud Height $\left(\mathrm{H}_{\mathrm{C}}\right)$ Versus Target Velocity (U) Values for the 70E and 70F Head Shapes with $\mathrm{s}=2.48, \mathrm{~d}_{50}=6.93 \times 10^{-5}, \phi_{\mathrm{p}}=0.15, \phi_{\mathrm{s}}=0.0143$ and $\mathrm{DC}=0.18$.

E.43 Cloud Height $\left(\mathrm{H}_{\mathrm{C}}\right)$ Versus Target Velocity (U) Values for the 70E and 70F Head Shapes with $\mathrm{s}=2.48, \mathrm{~d}_{50}=6.93 \times 10^{-5}, \phi_{\mathrm{p}}=0.15, \phi_{\mathrm{s}}=0.0143$ and $\mathrm{DC}=0.33$.

E.44 Cloud Height $\left(\mathrm{H}_{\mathrm{C}}\right)$ Versus Target Velocity (U) Values for the 70E and 70F Head Shapes with $\mathrm{s}=2.46, \mathrm{~d}_{50}=1.664 \times 10^{-4}, \phi_{\mathrm{p}}=0.05, \phi_{\mathrm{S}}=0.00155$ and $\mathrm{DC}=0.33$.

E.45 Cloud Height $\left(\mathrm{H}_{\mathrm{C}}\right)$ Versus Target Velocity (U) Values for the 70E and 70F Head Shapes with $\mathrm{s}=4.18, \mathrm{~d}_{50}=7.56 \times 10^{-5}, \phi_{\mathrm{p}}=0.05, \phi_{\mathrm{S}}=0.005$ and $\mathrm{DC}=0.18$

E.46 Cloud Height $\left(\mathrm{H}_{\mathrm{C}}\right)$ Versus Target Velocity (U) Values for the 70E and 70F Head Shapes with $\mathrm{s}=4.18, \mathrm{~d}_{50}=7.56 \times 10^{-5}, \phi_{\mathrm{p}}=0.05, \phi_{\mathrm{S}}=0.005$ and $\mathrm{DC}=0.33$.

\section{Tables}

E.1 Potential Predictor Variables for Developing Models of UCS and HC Response Variables ..

E.2 Comparison of $U_{C s}$ and $H_{C S}$ Data from 2008 Tests with Two Head Shapes (E and FD) on 70-in. Tanks .....

E.3 Near-Replicate and Near-Repeat Tests at Critical Suspension Conditions.

E.1 UCS and HCS Values, SDs, and \%RSDs for Near-Replicate Sets of M3 Mixing Tests. E.53

E.2 UCS and HCS Values, \%RSDs, and Standard Deviations for Near-Repeat Sets of M3 Mixing Tests 



\section{Appendix E}

\section{Data Assessment and Analysis to Support Developing Multiple Regression Models for Mixing Responses}

This appendix discusses the data assessments and analyses performed to support development of empirical and semi-empirical models between key mixing variables (response variables) and nondimensional or dimensional explanatory variables (predictor variables). The response variables of interest include critical suspension velocity $\left(\mathrm{U}_{\mathrm{CS}}\right)$ and cloud height $\left(\mathrm{H}_{\mathrm{C}}\right)$. The predictor variables are generally test variables or functions of test variables.

Section E.1 presents and discusses plots to assess how well the data support developing empirical or semi-empirical models (henceforth, models) for mixing response variables. Section E.2 presents the results of investigations to understand the functionality between mixing response variables and test variables. Section E.3 briefly discusses uncertainty estimates based on limited near-replicate and nearrepeat sets of test data.

\section{E.1 Assessment of Data for Developing Mixing Models}

This section presents and discusses plots of the data available for developing models for the mixing response variables $\mathrm{U}_{\mathrm{CS}}$ and $\mathrm{H}_{\mathrm{C}}$. The intent of these plots is to assess the degree of support the data provide for including potential predictor variables or interactions of predictor variables in models. Oneand two-dimensional plots of the potential predictor variables (listed in Table E.3) are presented and discussed in Sections E.1.1 and E.1.2, respectively.

Table E.3. Potential Predictor Variables for Developing Models of UCS and HC Response Variables

\begin{tabular}{cl}
\hline Variable & \multicolumn{1}{c}{ Definition } \\
\hline $\mathrm{D}$ & tank diameter $(\mathrm{m})$ \\
$\mathrm{N}_{\mathrm{O}}$ & number of operating pulse jets on outer ring \\
$\mathrm{N}_{\mathrm{I}}$ & number of operating pulse jets on inner ring \\
$\mathrm{N}_{\mathrm{J}}$ & $\mathrm{N}_{\mathrm{J}}=\mathrm{N}_{\mathrm{O}}+\mathrm{N}_{\mathrm{I}}=$ number of operating pulse jets (number) \\
$\mathrm{d}$ & jet nozzle diameter $(\mathrm{m})$ \\
$\phi_{\mathrm{J}}$ & phiJ = jet density $=\mathrm{N}_{\mathrm{J}}(\mathrm{d} / \mathrm{D})^{2}$ (nondimensional) \\
$\phi_{\mathrm{p}}$ & phiP = pulse volume fraction (nondimensional) \\
$\mathrm{DC}$ & duty cycle (nondimensional) \\
$\mathrm{S}$ & density ratio of solids to liquid (nondimensional) \\
$\phi_{\mathrm{S}}$ & phiS = solids volume fraction (nondimensional) \\
$\mathrm{d}_{\mathrm{S}}$ & solids particle diameter $=\mathrm{d}_{50}=$ median particle diameter $(\mathrm{m})$ \\
$\mathrm{HS}$ & head shape $(\mathrm{E}=$ elliptical, FD = flange and dish, $\mathrm{S}=$ spherical) \\
$\mathrm{U}_{\mathrm{T}}$ & unhindered terminal settling velocity (m/s) \\
$\mathrm{U}_{\mathrm{TH}}$ & hindered terminal settling velocity $(\mathrm{m} / \mathrm{s})$ \\
\hline
\end{tabular}


In Sections E.1.1 and E.1.2, the predictor variable values are plotted using data from the $\mathrm{U}_{\mathrm{CS}}$ data set combined from the July 2007, Fall 2007, and 2008 test campaigns. Only the pulsed data (i.e., DC < 1) were used for the plots in this section because the mixing models discussed in Appendix F were only developed for pulsed data. Insufficient steady-state $(\mathrm{DC}=1)$ data were collected to include for model development purposes.

The $\mathrm{U}_{\mathrm{CS}}$ data set was used for the plots in this section because the $\mathrm{H}_{\mathrm{C}}$ data set would contain multiples of predictor-variable combinations, corresponding to measuring $\mathrm{H}_{\mathrm{C}}$ at each of several target velocities (U) for each set of test conditions. However, the distribution and scatter plots in this section apply to both $\mathrm{U}_{\mathrm{CS}}$ and $\mathrm{H}_{\mathrm{C}}$. The functionality plots for $\mathrm{H}_{\mathrm{C}}$ versus $\mathrm{U}$ (in Section E.2.3) show the distribution of target velocity values for each set of test conditions. Hence, $\mathrm{U}$ is not included in the plots in Section E.1.

\section{E.1.1 One-Dimensional Dot Plots of Potential Predictor Variables}

One-dimensional dot plots are used to assess the distribution of values for each potential predictor variable over its data range. Plots showing outlying values or limited data in a subrange of a predictor variable suggest caution in using such data to develop models. Outlying data, or sparse data over a subrange of the predictor variable, can be very influential when fitting a model to data. Further, the functional relationship between a response variable and a predictor variable can change over a wider range of the predictor variable. In addition, interactive effects between two (or more) predictor variables are more likely to be significant over wider ranges of the predictor variables. Thus, it can be difficult to develop and fit more complicated relationships over wider ranges of predictor variables when there are outlying or sparse data in subranges of one or more predictor variables. Model fits over wider ranges of predictor variables when there are outlying or sparse values may be degraded or have much higher uncertainty compared with model fits over subranges where predictor-variable values are better distributed.

However, when models must be used to extrapolate, the existence of few data that lie closer to the state to which one must extrapolate represent particularly useful information. Consider the hypothetical situation where numerous experimental data exist from scaled experiments at several closely-distributed length scales, and a few data exist for the actual, full-scale system of interest. In a statistical sense, these latter data are outliers that can unduly influence the fit to the data that ultimately is used to predict the behavior of the actual system. But in an engineering sense, the few data available for the actual system ought to be highly influential in predicting the behavior of the system because they are the only measurements made that require no extrapolation. Then if the few data are not at the actual scale but at a scale significantly closer to actual scale than for the majority of the data, their high influence on a fitted model used for extrapolation might be beneficial.

Figure E.1 shows dot plots for the potential predictor variables listed in Table E.3, using the combined July 2007, Fall 2007, and 2008 data described at the end of Section E.1. The number of data points represented by a dot is shown on the right of each dot plot in Figure E.1. Fractional-size dots are used to represent fewer than the number of data points indicated for full-size dots. The following observations are made regarding distributions of values of potential model predictor variables over their experimental ranges. Although not shown in the dot plots, the observations include information on the number of data points from each of the three test campaigns. 


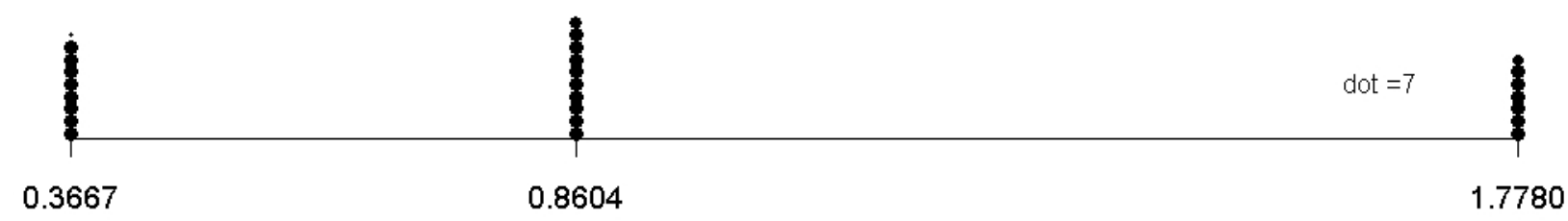

\section{$D(m)$}

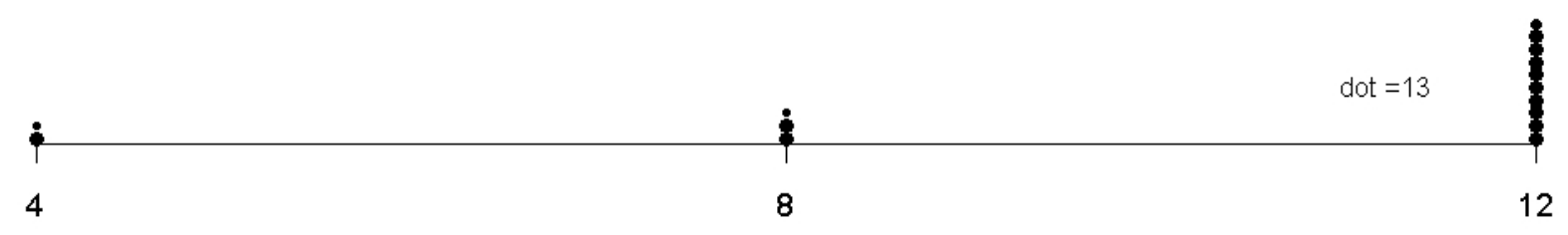

$\mathrm{Nj}$

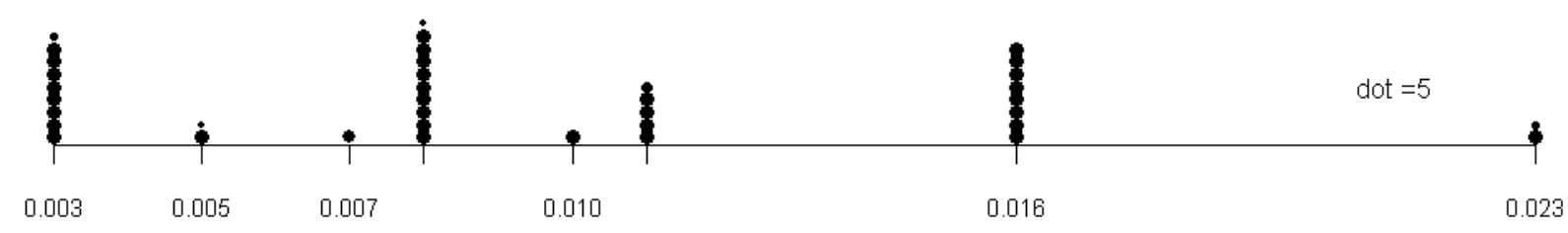

$d(m)$

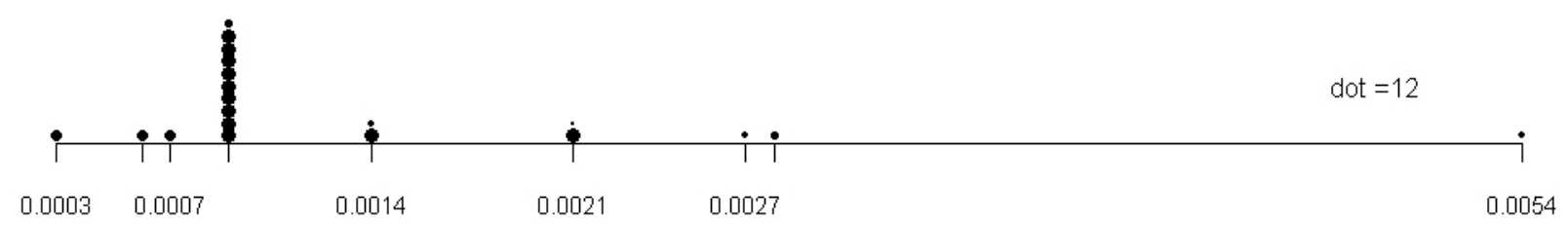

phiJ
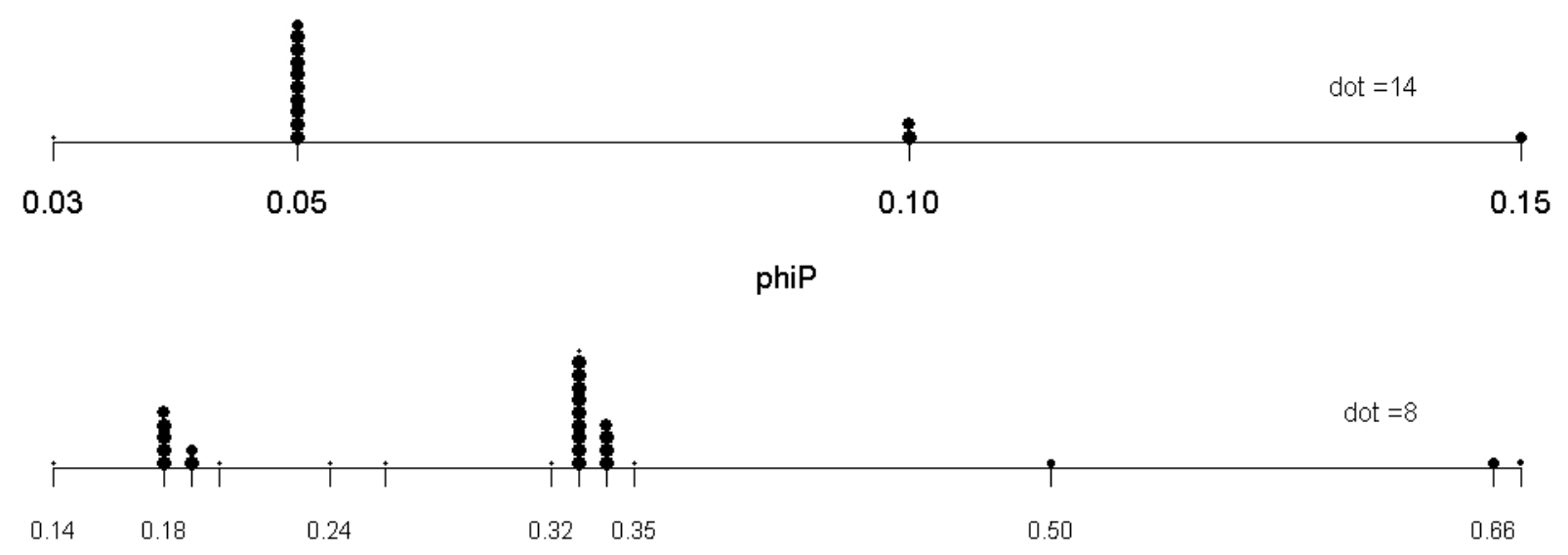

DC

Figure E.1. Dot Plots Showing Distributions of Potential Predictor Variables for $\mathrm{U}_{\mathrm{CS}}$ and $\mathrm{H}_{\mathrm{C}}$ Mixing Models over the Full Set of 2007 and 2008 Experimental Data. The number of data points represented by a dot is shown on the right of each dot plot. Fractional-size dots represent fewer than the indicated number of data points. 


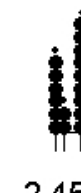

$\operatorname{dot}=8$

s
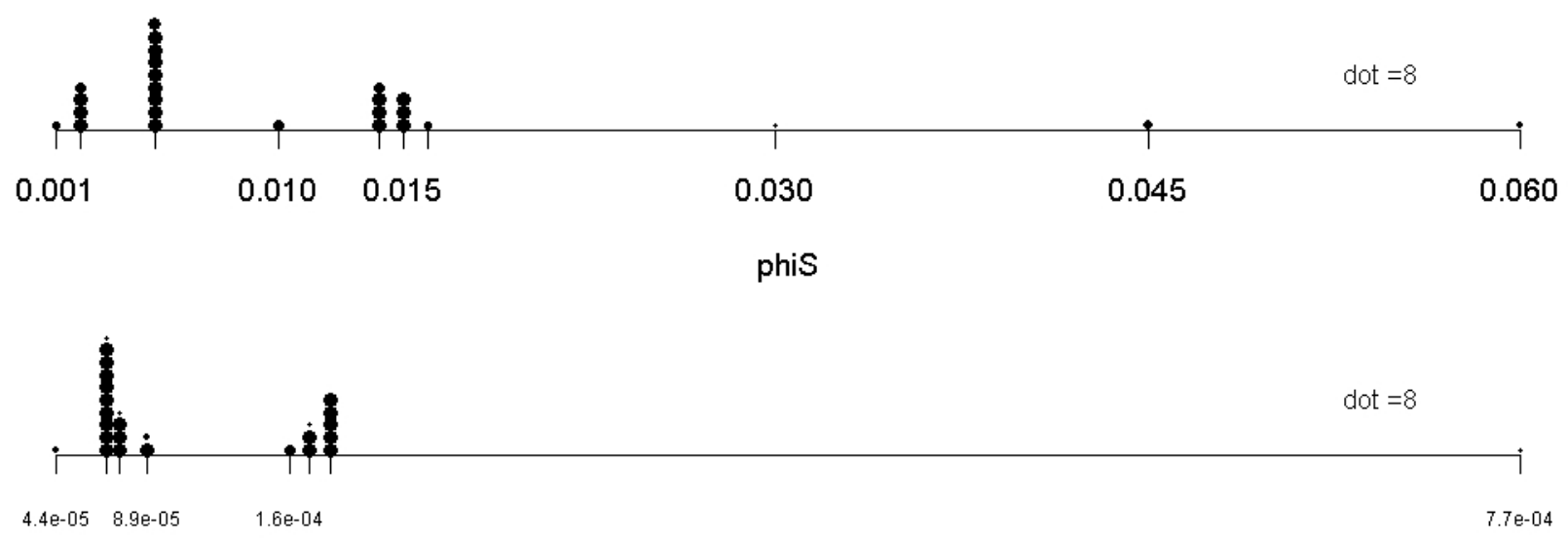

ds (m)

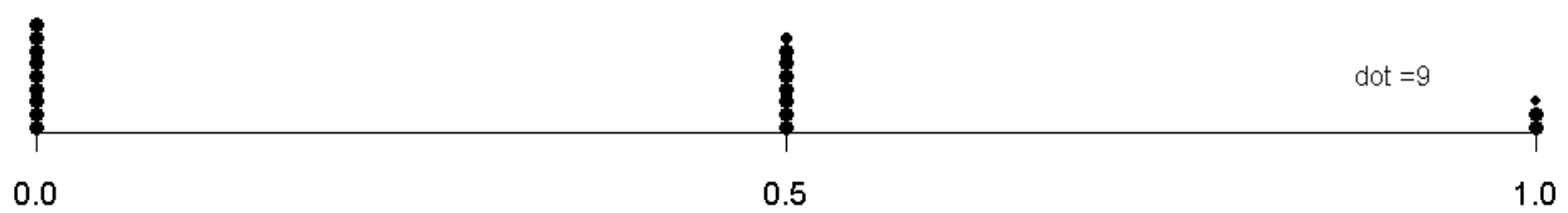

Head $(0=E, 0.5=S, 1=F D)$

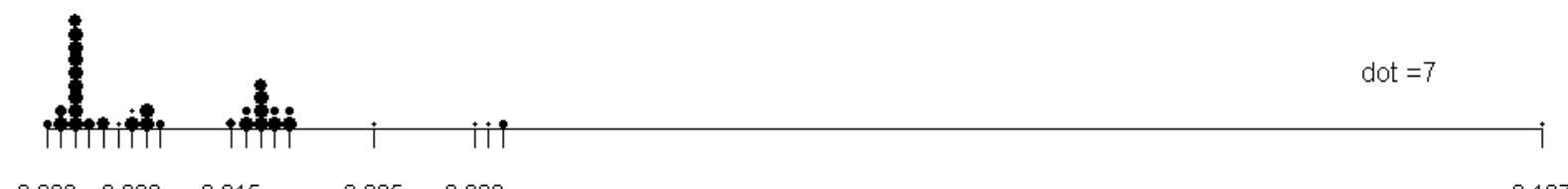

Ut $(\mathrm{m} / \mathrm{s})$

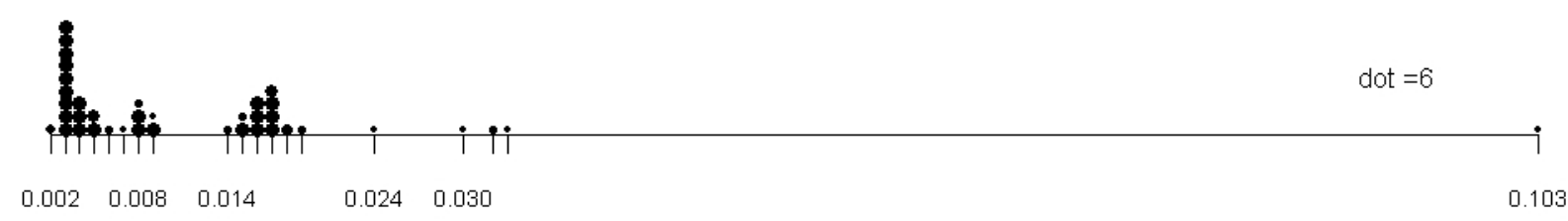

Uth $(\mathrm{m} / \mathrm{s})$

Figure E.1. (contd) Dot Plots Showing Distributions of Potential Predictor Variables for $\mathrm{U}_{\mathrm{CS}}$ and $\mathrm{H}_{\mathrm{C}}$ Mixing Models over the Full Set of 2007 and 2008 Experimental Data. The number of data points represented by a dot is shown on the right of each dot plot. Fractional-size dots represent fewer than the indicated number of data points. 


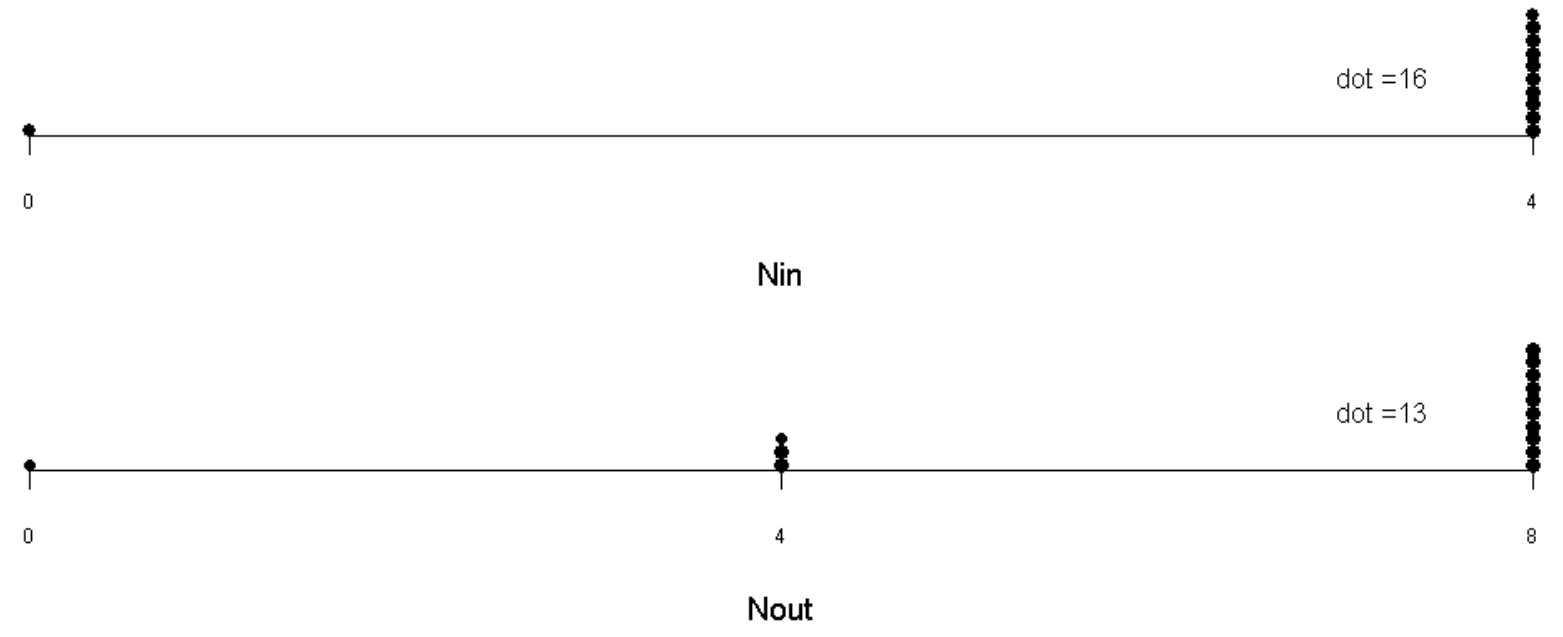

Figure E.1. (contd) Dot Plots Showing Distributions of Potential Predictor Variables for $\mathrm{U}_{\mathrm{CS}}$ and $\mathrm{H}_{\mathrm{C}}$ Mixing Models over the Full Set of 2007 and 2008 Experimental Data. The number of data points represented by a dot is shown on the right of each dot plot. Fractional-size dots represent fewer than the indicated number of data points.

The $\mathrm{U}_{\mathrm{CS}}$ data set contained 186 rows after the steady-state $(\mathrm{DC}=1)$ data were removed, as discussed in Section E.1. In addition, 11 rows were removed because the return-line height was less than D; these included the limited Fall 2007 data in which fill height was varied. Finally, two rows were removed because of questionable $U_{C S}$ values (the $U_{C S}$ values were greater than the target velocity for the row). These changes resulted in a full data set of 173 rows, which is the same data set used to develop the physical-based models for $\mathrm{U}_{\mathrm{CS}}$ in Section 7.3.2.

\section{Diameter of tank, D (m)}
a. 57 of 173 values are 14.44 in. $(0.367 \mathrm{~m})$, all from 2008
b. 69 of 173 values are 33.88 in. (0.860 m), 16 from July 2007, 35 from Fall 2007, and 18 from 2008
c. 47 of 173 values are 70 in. (1.778 m), all from 2008 .

\section{Number of operating pulse jets, $\mathbf{N}_{J}$}
a. 18 of 173 values are 4 ( 15 from Fall 2007, 3 from 2008)
b. 30 of 173 values are 8 (13 from Fall 2007, 17 from 2008)
c. 125 of 173 values are 12 (16 from July 2007, 7 from Fall 2007, and 102 from 2008).

\section{Jet nozzle diameter, $d(m)$}
a. Values range from 0.0032 to $0.0234 \mathrm{~m}$
b. There are 7 values at $0.0234 \mathrm{~m}$, and the rest are $\leq 0.0156 \mathrm{~m}$.

\section{Jet density, $\phi_{\mathrm{J}}$ (nondimensional)}
a. Values range from approximately 0.0003 to 0.0054
b. There are 3 values $~ 0.0054$ and 6 values $\sim 0.0027$ or 0.0028 (all 2008)
c. 164 of the 173 values are $\leq 0.0021$ approximately. 


\section{Pulse Volume Fraction, $\phi_{\mathrm{p}}$ (nondimensional)}
d. 2 of 173 values are $~ 0.03$ (all from July 2007)
b. 136 of 173 values are 0.05 (10 from July 2007, 35 from Fall 2007, 91 from 2008)
c. 26 of 173 values are $~ 0.10$ (4 from July 2007, 22 from 2008)
d. 9 of 173 values are $~ 0.15$ (all from 2008).

\section{Duty Cycle, DC (nondimensional)}
a. 162 of 173 values are $\leq 0.40$
b. 3 of 173 range from $~ 0.47$ to 0.54 (2 from July 2007, 1 from 2008)
c. 8 of $173 \sim 0.66$ (all from 2008).

\section{Density Ratio, s (nondimensional)}
a. 143 of 173 have s 2.45 - 2.50 (15 from July 2007, 46 from Fall 2007, 92 from 2008)
b. 30 of 173 have $\mathrm{s} \sim 4.17$ or 4.18 (all from 2008).

12. Solids Volume Fraction, $\phi_{\mathrm{S}}$ (nondimensional)
a. 166 of 173 values are $\leq 0.016$ (16 from July 2007, 35 from Fall 2007, 115 from 2008)
e. 1 of 173 values $=0.03(2008)$
f. $\quad 4$ of 173 values $=0.045$ (all from 2008)
g. 2 of 173 values $=0.06$ (all from 2008).

13. Median particle size diameter, $d_{S}=d_{50}(\mathrm{~m})$
a. 110 of 173 values range from 4.4E-05 to 8.9E-05 (10 from Fall 2007, 100 from 2008)
b. 62 of 173 values range from 1.4E-04 to 1.8E-04 (15 from July 2007, 25 from Fall 2007, 22 from 2008)
c. 1 of 173 values 7.7E-04 (July 2007).

\section{Head Shape, HS (E, S, or FD)}
a. 81 of 173 are "E" (all from 2008)
b. 69 of 173 are "S" (16 from July 2007, 35 from Fall 2007, 18 from 2008)
c. 23 of 173 are "FD" (all for tests in 70-in. tank in 2008).

\section{Unhindered terminal settling velocity, $U_{T}(\mathrm{~m} / \mathrm{s})$}
a. 167 of 173 values are $\leq 0.017$ approximately (15 from July 2007, 35 from Fall 2007,
b. 117 from 2008)
c. 5 of $173 \sim 0.028$ (all 2008)
d. 1 of $173 \sim 0.102$ (July 2007).

\section{Hindered terminal settling velocity, $U_{T H}(\mathrm{~m} / \mathrm{s})$}
a. 167 of 173 values are $\leq 0.019$ approximately (15 from July 2007, 35 from Fall 2007, 117 from 2008)
b. 5 of 173 range from $\sim 0.024$ to 0.033 (all 2008)
c. 1 of $173 \sim 0.103$ (Fall 2007).

Several of the preceding observations show that some test variables have outlying or limited data that significantly expand the ranges of those variables. As is noted in Section E.1.1, such data can be very influential when developing empirical or semi-empirical models, yielding model coefficients that are very uncertain because of being mostly determined by the outlying or limited data. Hence, in addition to the 
full data set, it was decided to form a "trimmed" data set that eliminates these outlying data points in predictor-variable space. Specifically, the ranges of predictor variables eliminated in forming the trimmed data set include:

- DC $>0.41$ (eliminates 11 of 173 test conditions)

- $\phi_{\mathrm{S}}>0.016$ (eliminates 7 of 173 test conditions)

- $\mathrm{d}_{\mathrm{S}}\left(\mathrm{d}_{50}\right)>1.8 \mathrm{E}-04$ (eliminates 1 of 173 test conditions).

Hence, the trimmed data set for $\mathrm{U}_{\mathrm{CS}}$ consists of 154 rows of data.

However, as is noted in Section E.1.1, these trimmed data lie in the direction of the expected values for the system to which models developed from the data must be extrapolated. Hence, models for mixing responses $\left(\mathrm{U}_{\mathrm{CS}}\right.$ and $\mathrm{H}_{\mathrm{C}}$ ) were developed for both the full and trimmed data sets (see Appendix $\mathrm{F}$ ). In the case of models fit to the full data set, caution will need to be exercised regarding the limited number and influential nature of the outlying data.

Note that the test condition eliminated by the $\mathrm{d}_{\mathrm{S}}\left(\mathrm{d}_{50}\right)>1.8 \mathrm{E}-04$ constraint is the same test condition with extreme values of $U_{\mathrm{T}}$ and $\mathrm{U}_{\mathrm{TH}}$. It was decided not to eliminate the five data points with $\phi_{\mathrm{J}} \sim 0.0054$, even though they roughly double the range of that variable (the next closest values are $\sim 0.0027$ ). The values of $\mathrm{N}_{\mathrm{J}}$, $\mathrm{d}$, and D used to calculate $\phi_{\mathrm{J}}$ (the formula is given in Table E.3) for these three data points are not extreme within their ranges. Hence, they were not eliminated in forming the trimmed data set.

Figure E.2 shows another set of dot plots for the trimmed data set, which provides for visualizing the distribution of predictor variable values over the ranges where the vast majority of data points fall. The trimmed data set also provides a more stable basis for developing models for mixing response variables.

\section{E.1.2 Two-Dimensional Scatterplots of Potential Predictor Variables}

Two-dimensional scatterplots are used to assess the bivariate distributions of two predictor variables over the rectangular space determined by their respective ranges. Scatterplot matrix plots display in a single figure all possible pairwise scatterplots for a set of predictor variables. The size of individual scatterplots of pairs of predictor variables are reduced in such plots, but are sufficient for the intended purpose. Specifically, scatterplot matrix plots are useful for identifying 1) highly correlated predictor variables, and 2) subregions of predictor-variable combinations that are not represented, or are only sparsely represented, in the data.

When two predictor variables are very highly correlated, it will usually be inappropriate to include both in a model. Rather, only one of the predictor variables should be included in the model, and it should be kept in mind that the one predictor variable is representing the combined effects of the highlycorrelated pair of variables. 


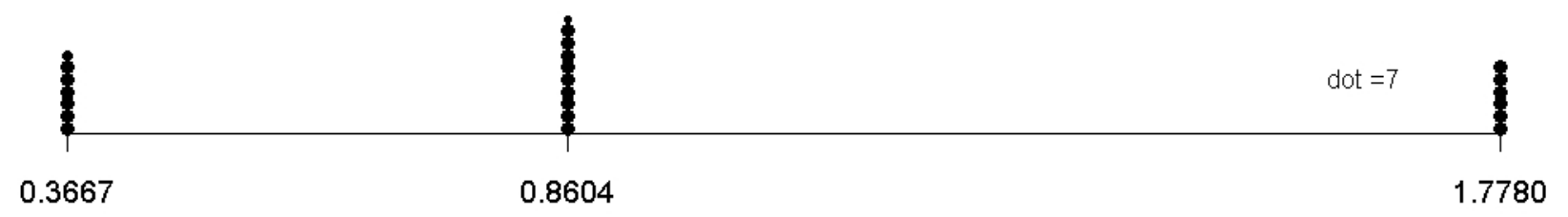

$D(m)$

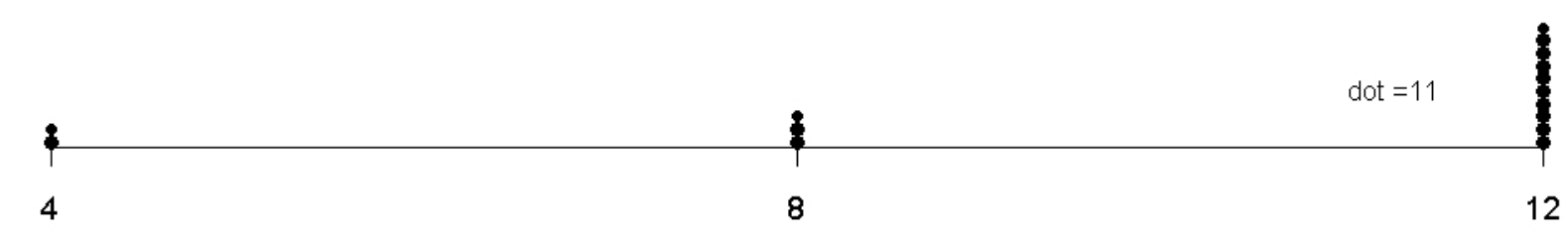

$\mathrm{Nj}$

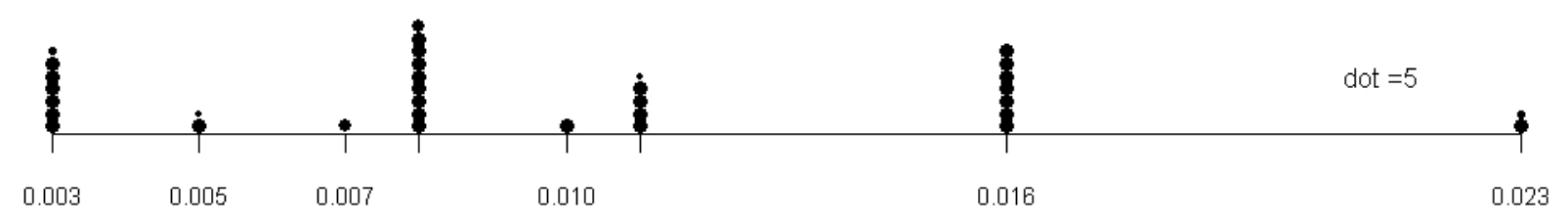

$d(m)$

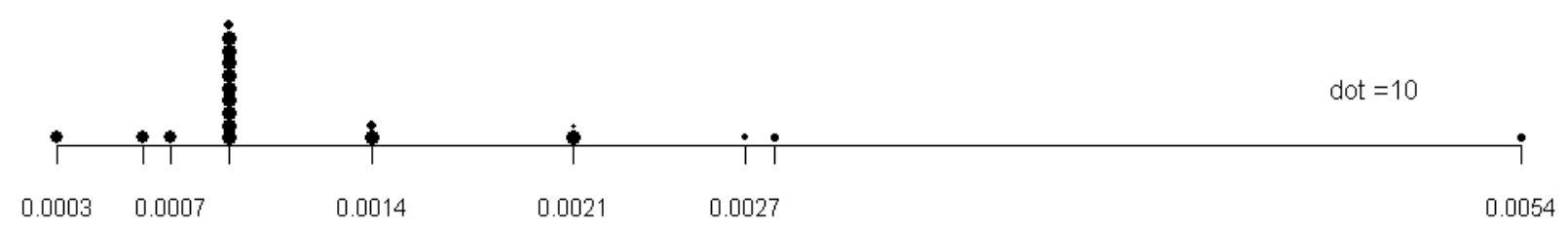

phiJ

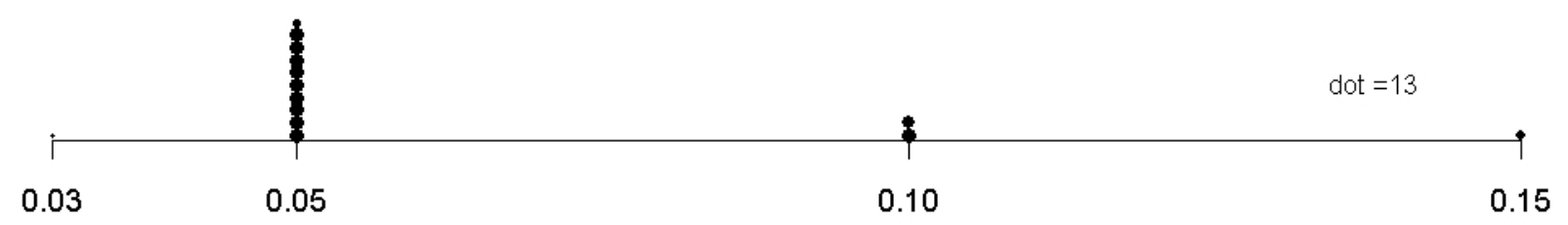

phiP

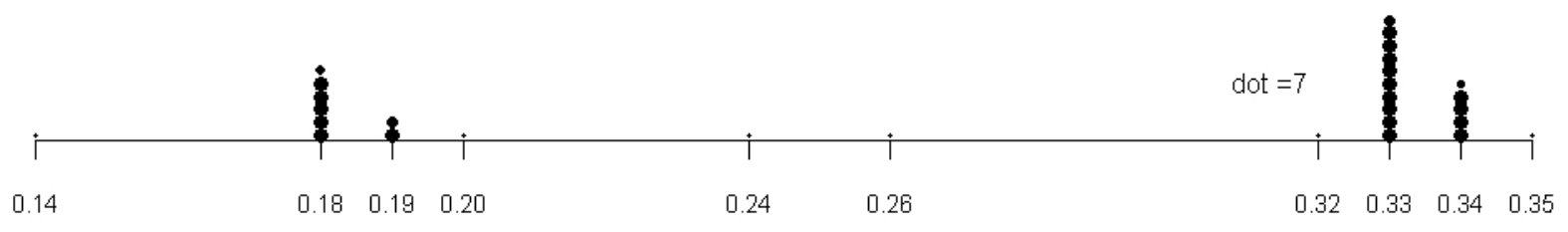

Duty Cycle

Figure E.2. Dot Plots Showing Distributions of Potential Predictor Variables for $\mathrm{U}_{\mathrm{CS}}$ and $\mathrm{H}_{\mathrm{C}}$ Mixing Models over the Trimmed Set of July 2007, Fall 2007, and 2008 Experimental Data. The number of data points represented by a dot is shown on the right of each dot plot. Fractionalsize dots represent fewer than the indicated number of data points. 


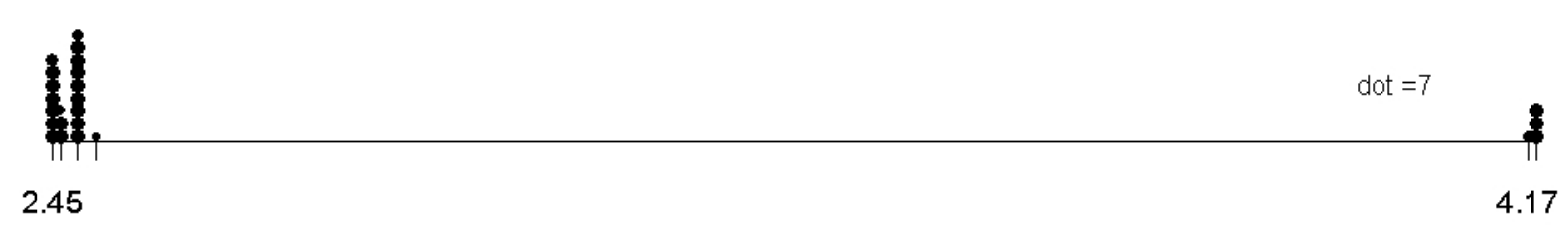

s
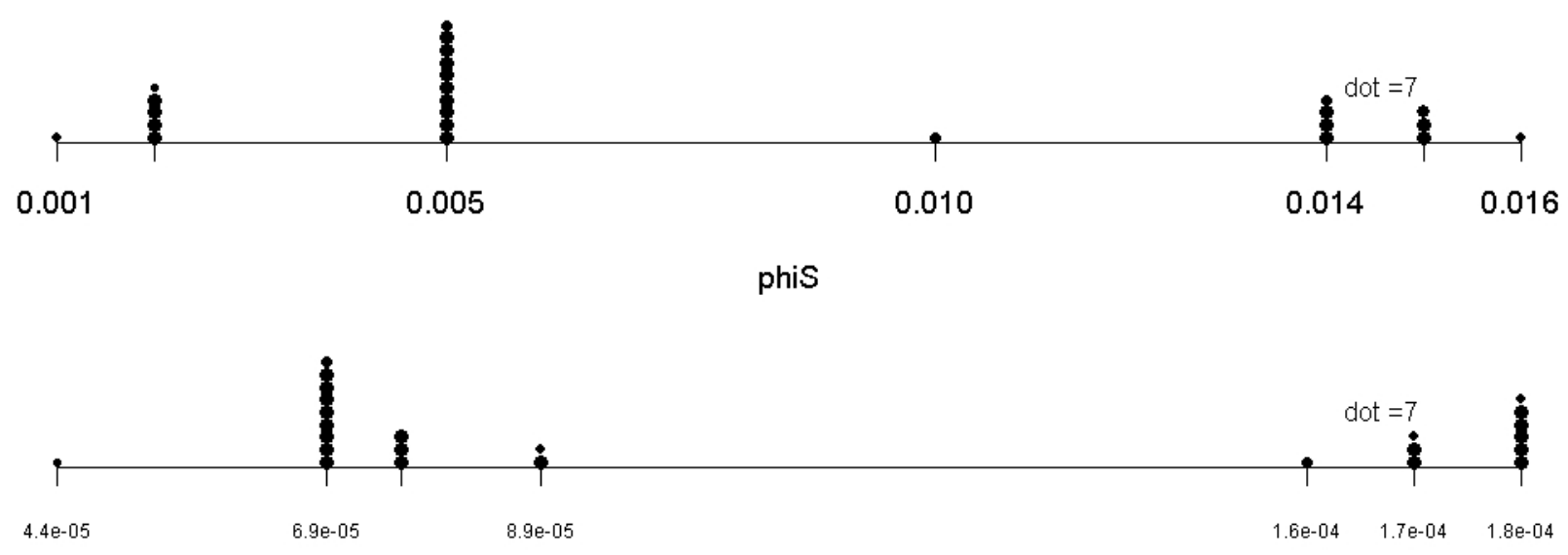

ds (m)

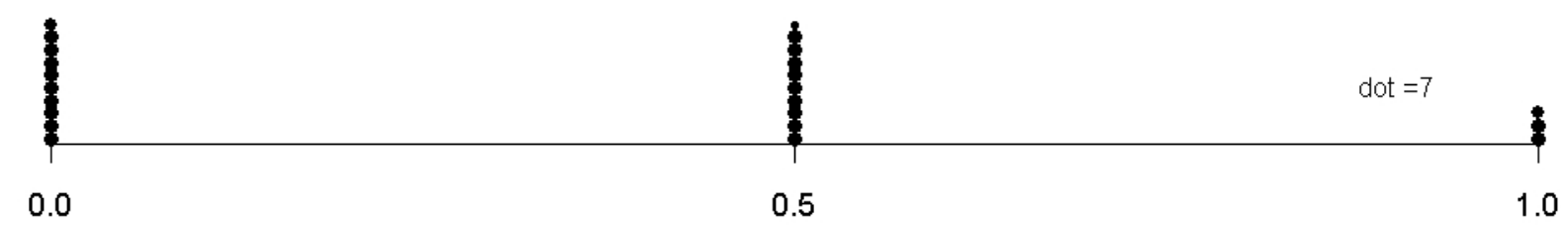

Head $(0=E, 0.5=S, 1=F D)$

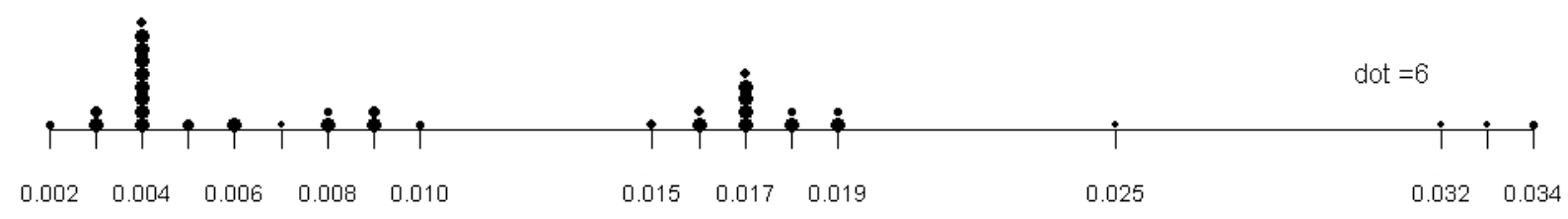

Ut $(\mathrm{m} / \mathrm{s})$

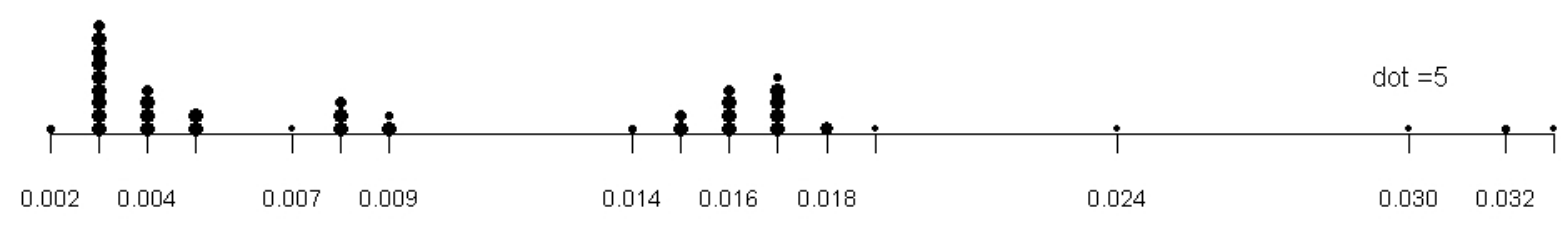

Uth $(\mathrm{m} / \mathrm{s})$

Figure E.2. (contd) Dot Plots Showing Distributions of Potential Predictor Variables for $\mathrm{U}_{\mathrm{CS}}$ and $\mathrm{H}_{\mathrm{C}}$ Mixing Models over the Trimmed Set of July 2007, Fall 2007, and 2008 Experimental Data. The number of data points represented by a dot is shown on the right of each dot plot. Fractional-size dots represent fewer than the indicated number of data points. 

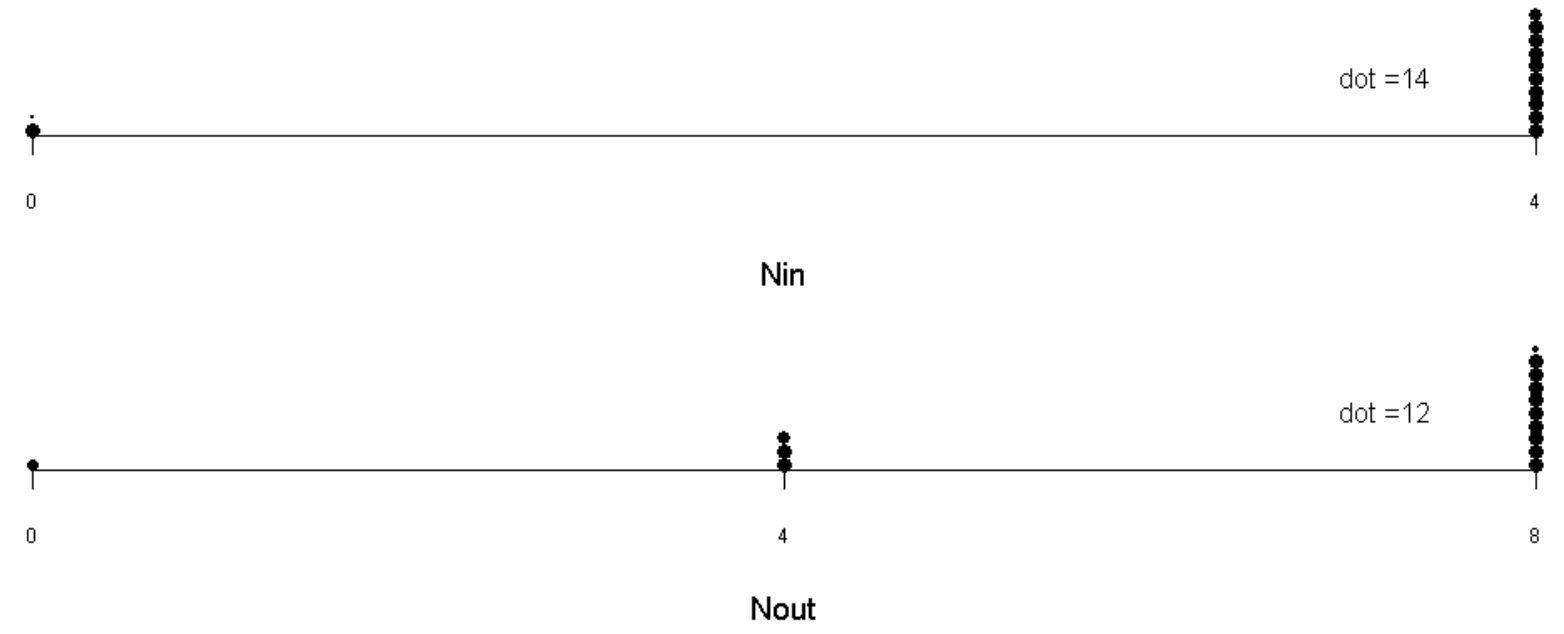

Figure E.2. (contd) Dot Plots Showing Distributions of Potential Predictor Variables for $\mathrm{U}_{\mathrm{CS}}$ and $\mathrm{H}_{\mathrm{C}}$ Mixing Models over the Trimmed Set of July 2007, Fall 2007, and 2008 Experimental Data. The number of data points represented by a dot is shown on the right of each dot plot. Fractional-size dots represent fewer than the indicated number of data points.

A scatterplot of two predictor variables should ideally have data points well distributed over the rectangle representing combinations of values of the two variables over their ranges. Patterns in the shape of an "L" (in any orientation) or "+" indicate that each variable was only varied at a single value (or a small range of similar values) of the other variable. Data with such patterns do not support assessing whether there is an interactive effect of the two variables. A corner of a scatterplot (e.g., both variables at their highest values at the same time) with no data indicates that the corresponding variable combinations were not investigated in the testing. Such data patterns can limit the ability to assess interactive effects of the pair of variables.

Figure E.3 displays the scatterplot matrix for the variables listed in Table E.3 using the full data set of 173 points described at the end of Section E.1 and Section E.1.1. Figure E.4 shows the scatterplot matrix for the trimmed data set of 154 points discussed in Section E.1.1. Although the individual scatterplots in these figures are small, they are sufficient for the intended purpose of seeing strong correlations, outliers, or untested combinations of pairs of predictor variables. Figure E.5 displays a separate scatterplot of $U_{\mathrm{TH}}$ versus $\mathrm{U}_{\mathrm{T}}$. The following observations are made based on Figures E.3 to E.5.

- D and d are strongly positively correlated for the full (Figure E.3) and trimmed (Figure E.4) data sets. This suggests that it may not be appropriate to include both in a model for $\mathrm{U}_{\mathrm{CS}}$ or $\mathrm{H}_{\mathrm{C}}$. Also, because $\phi_{\mathrm{J}}=\mathrm{N}_{\mathrm{J}}(\mathrm{d} / \mathrm{D})^{2}$, the strong correlation between $\mathrm{D}$ and $\mathrm{d}$ means that the resulting value of $\phi_{\mathrm{J}}$ will be strongly determined by $\mathrm{N}_{\mathrm{J}}$. Further, on a log-log basis $\phi_{\mathrm{J}}$ would be redundant given $\mathrm{N}_{\mathrm{J}}$, d, and $\mathrm{D}$.

- Terminal settling velocity $\left(\mathrm{U}_{\mathrm{T}}\right)$ and hindered terminal settling velocity $\left(\mathrm{U}_{\mathrm{TH}}\right)$ are strongly correlated for the full and trimmed data sets (Figure E.5). Figure E.5 shows some differences for $U_{T H}$ versus $U_{T}$ for the outlying data points dropped from the full data set to form the trimmed data set. However, there may not be enough of those data points to show the merit of using $U_{T H}$ instead of $U_{T}$ in $U_{C S}$ and $\mathrm{H}_{\mathrm{C}}$ modeling work (in Appendix F). Hence, it is not clear whether there is any advantage (for these data sets) to use $\mathrm{U}_{\mathrm{TH}}$ instead of $\mathrm{U}_{\mathrm{T}}$ in developing multiple-regression models for mixing response 


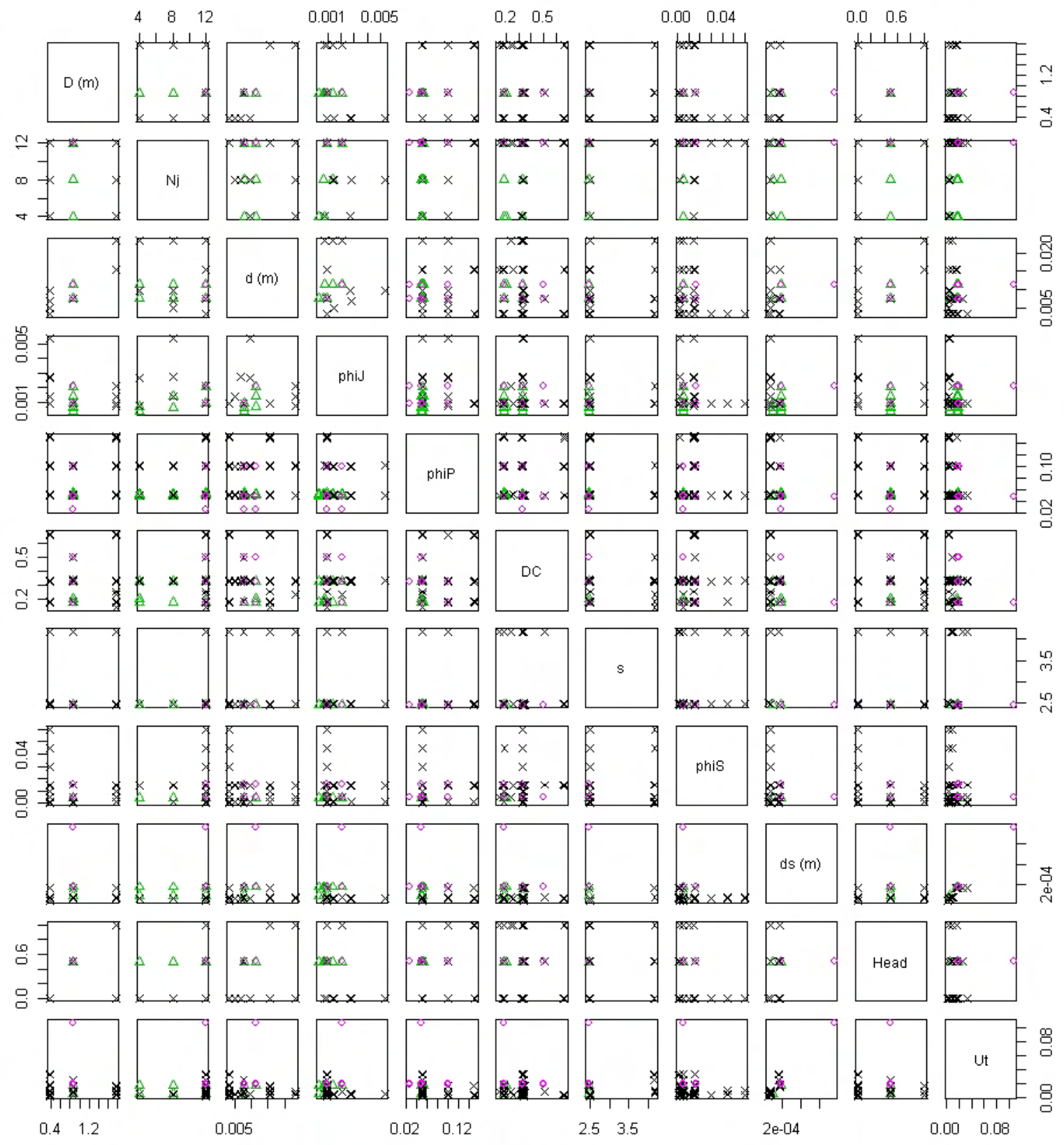

Figure E.3. Scatterplot Matrix Plot of Pairwise Distributions of Predictor Variable Values for $\mathrm{U}_{\mathrm{CS}}$ and $\mathrm{H}_{\mathrm{C}}$ Mixing Models over the Full Set of July 2007 (o), Fall 2007 ( $\triangle$ ), and $2008(\times)$ Experimental Data. Note that for HS (Head), $0=\mathrm{E}$ and $1=$ FD. 


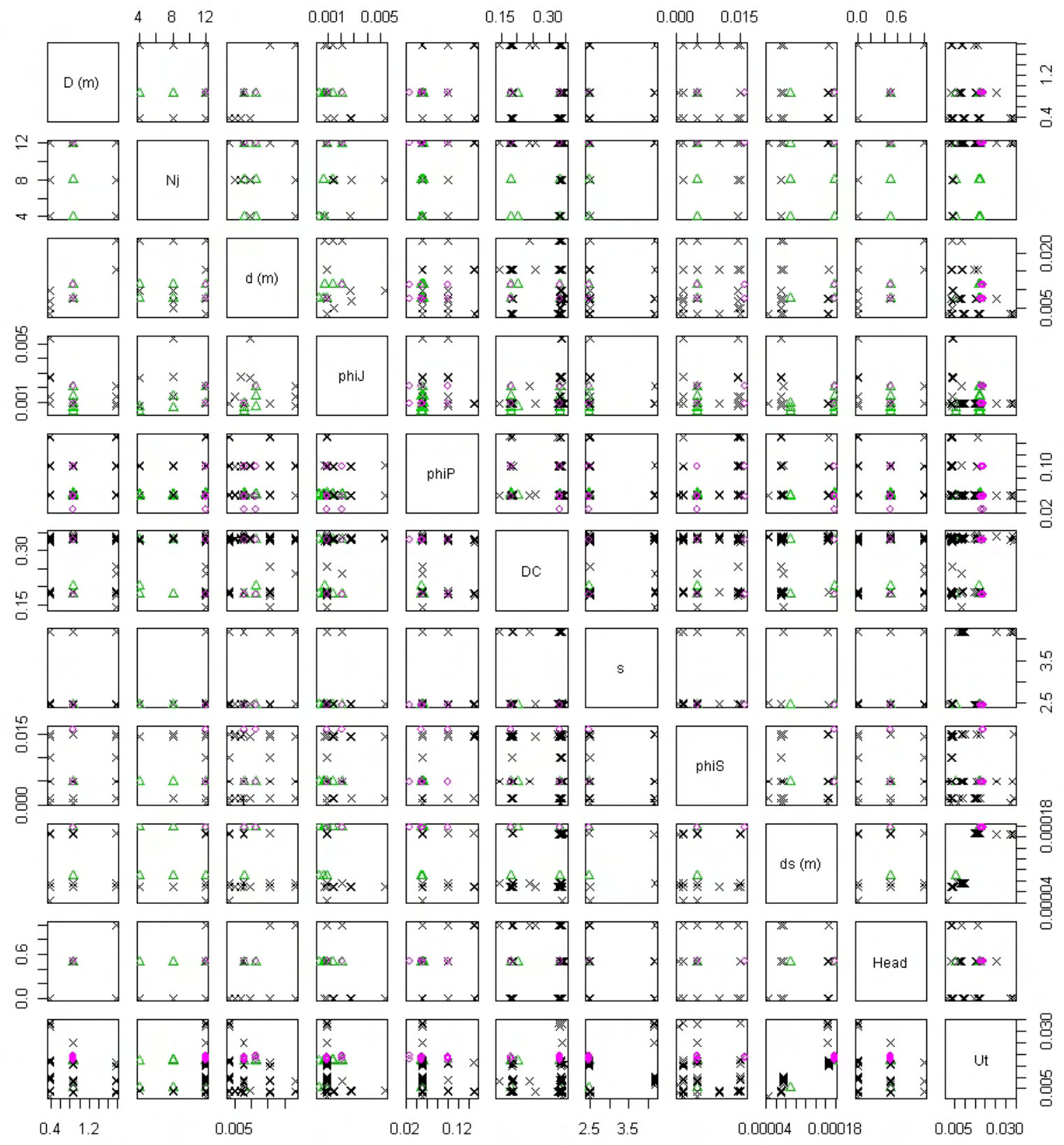

Figure E.4. Scatterplot Matrix Plot of Pairwise Distributions of Predictor Variable Values for $\mathrm{U}_{\mathrm{Cs}}$ and $\mathrm{H}_{\mathrm{C}}$ Mixing Models over the Trimmed Set of July 2007 (o), Fall 2007 ( $\triangle$ ), and $2008(\times)$ Experimental Data. Note that for HS (Head), $0=\mathrm{E}$ and $1=\mathrm{FD}$. 

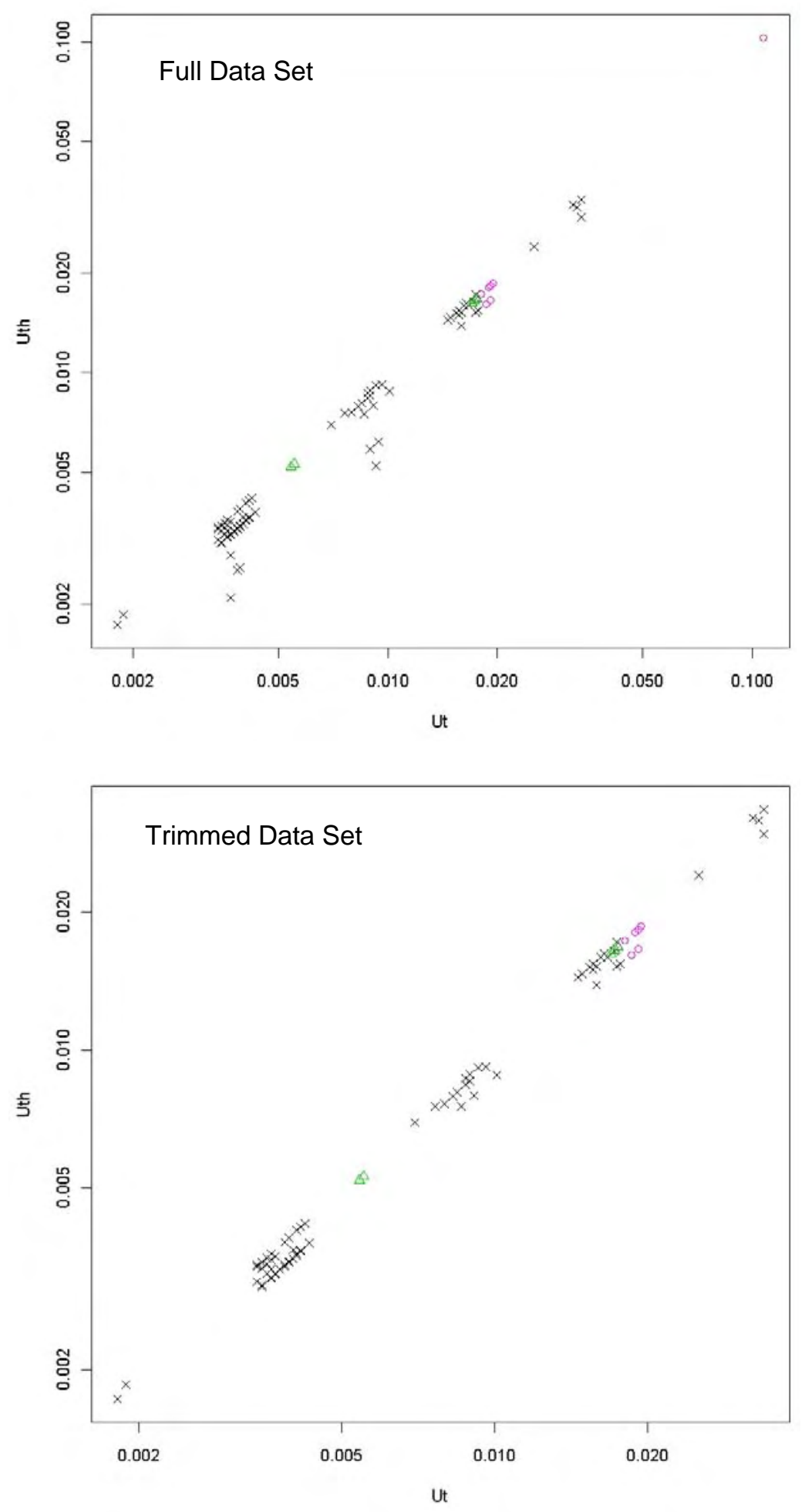

Figure E.5. Scatterplots of Pairwise Distributions of $U_{T H}$ and $U_{T}$ Values for $U_{C s}$ and $H_{C}$ Mixing Models over the Full and Trimmed Sets of July 2007 (o), Fall 2007 ( $\triangle$ ), and 2008 (×) Experimental Data. 
variables. Further, $\mathrm{U}_{\mathrm{T}}$ is associated physically with only the materials used in a test (the particles and the liquid in which they settle). However, $\mathrm{U}_{\mathrm{TH}}$ also depends strongly on the local particle concentration, which varies profoundly over space and time during a pulse cycle. Consequently it may be difficult to physically interpret any apparent correlation of the response variables with $U_{\mathrm{TH}}$ compared to (or in addition to) the correlation with $\mathrm{U}_{\mathrm{T}}$.

- The variable $d_{S}\left(d_{50}\right)$ is very strongly correlated with $U_{T}$ for the full data set (Figure E.3), and still strongly correlated for the trimmed data set (Figure E.4). The latter correlation is very strong except for a few data points (seen in the upper right portions of the $d_{S}$ vs. $U_{T}$ scatterplot), which weakened the overall correlation somewhat. This observation suggests that it may be of limited benefit to include both $\mathrm{d}_{\mathrm{S}}$ and $\mathrm{U}_{\mathrm{T}}$ (or $\mathrm{U}_{\mathrm{TH}}$ ) in a multiple-regression model for mixing response variables. Further, the only anticipated effect of $d_{S}$ on the behavior of the system is through its effect on $U_{T}$. Hence, a priori there is a physical reason not to include $d_{S}$ in addition to $U_{T}$.

- The $\phi_{\mathrm{J}}$ vs. s, $\phi_{\mathrm{J}}$ vs. $\mathrm{d}_{\mathrm{s}}$, and $\phi_{\mathrm{J}}$ vs. HS scatterplots in Figures E.3 and E.4 have less than complete rectangular distributions of points, indicating somewhat limited bases for assessing interactive effects of those pairs of predictor variables.

- The s vs. $\mathrm{N}_{J}$ scatterplots in Figures E.3 and E.4 show that tests with the high value of s ( 4.17) were only performed with 12-jet configurations. Hence, there is no basis for assessing whether s and $\mathrm{N}_{\mathrm{J}}$ have an interactive effect.

- Several scatterplots of $\phi_{\mathrm{S}}$ with other variables in Figure E.3 (full data set) have less than complete rectangular distributions of points, indicating a lack of support for quantifying interactive effects of these variables over the full range of $\phi_{\mathrm{S}}$. The issue is resolved in Figure E.4 for the trimmed data set.

- Several scatterplots of HS with other variables in Figures E.3 and E.4 have less than complete rectangular distributions of points. This is because tests with HS = FD were only performed in the 70 -inch tank ( $\mathrm{D}=1.778 \mathrm{~m})$ with 12 -jet $\left(\mathrm{N}_{\mathrm{J}}=12\right)$ configurations, and with only partial ranges of some other test variables. These observations indicate a lack of support for quantifying interactive effects of $\mathrm{D}$ and $\mathrm{N}_{\mathrm{J}}$ with $\mathrm{HS}$, and limited support for interactive effects of some other variables with HS.

- The scatterplots of $U_{T}$ with other variables in Figure E.3 show limited or no support for interactive effects because of the outlying value of $U_{T}\left(d_{S}\right)$. The situation is improved for the trimmed data set in Figure E.4, although there is still less than complete rectangular distributions of points in the scatterplots of some variables with $\mathrm{U}_{\mathrm{T}}$. This indicates some limitations on support for interactive effects of some other variables with $\mathrm{U}_{\mathrm{T}}$ (or $\mathrm{U}_{\mathrm{TH}}$ ).

These observations were factored into the process of developing and confirming multiple-regression models for $\mathrm{U}_{\mathrm{Cs}}$ and $\mathrm{H}_{\mathrm{C}}$, as discussed in Appendix $\mathrm{F}$.

\section{E.2 Functionality Investigations}

This section presents plots that provide information on the functional relationships between the mixing response variables and test variables. Such plots are referred to simply as functionality plots. Several test variables were varied in the test runs, with each one potentially impacting the value of a given mixing response variable observed for a given set of test variable values. Hence, plots of all the data with a response variable on the $y$-axis and each test variable on the $x$-axis typically are not very informative. 
The reason for this is that the effect on the response variable of the test variable on the x-axis is obscured by the effects of the many other test variables. Thus, functionality plots described in more detail in the subsequent subsection were investigated.

\section{E.2.1 Functionality Plots}

In subsequent subsections, functionality plots are shown for a response variable (y-axis) versus each test variable (x-axis) for subsets of the data. All test runs with two or more values of the test variable on the $\mathrm{x}$-axis, and a set of constant values for the remaining test variables, are included in a given functionality plot. For each set of constant values of the remaining test variables, a different plotting symbol is used. The same plotting symbols for the two or more values of the test variable on the $\mathrm{x}$-axis are joined by line segments to aid in visualizing how the relationship between a response variable and the test variable on the $\mathrm{x}$-axis depends on the different sets of constant values for the other test variables.

A challenge in constructing functionality plots is that several test variables have close but not exactly the same values for different tests. This makes it difficult for the functionality plot of a given variable to obtain sets of constant values for the remaining test variables. Thus, it was necessary to do some rounding and grouping of test variable values to be able to obtain sets of constant values for the remaining test variables. The following adjustments were made to the test variable values to yield the functionality plots presented in Sections E.2.2 and E.2.3.

- $\mathrm{d}$ values were not used in determining sets of constant values because of the larger number of values it has, and also because there is a strong correlation between $\mathrm{d}$ and D (see Figures E.3 and E.4).

- $\phi_{\mathrm{p}}$ values close to $0.05,0.10$, and 0.15 were rounded to these values.

- DC values close to $0.18,0.33$, and 0.66 were grouped at these values.

- $\mathrm{s}$ values close to 2.48 and 4.18 were rounded to these values.

- $\mathrm{d}_{\mathrm{S}}=\mathrm{d}_{50}$ values $\sim 0.00006$ and $\sim 0.00007$ were grouped as 0.00007 , values $\sim 0.00008$ and 0.00009 were grouped as 0.00008 , and values around 0.00016 were grouped at this value.

However, these adjustments to test variable values were only used for obtaining sets of constant values of the remaining variables for the functionality plot of a given variable. The actual values of a variable were used on the x-axis for that variable's functionality plot.

The $x-y$ functionality plots in this section are presented with logarithmic scales on each axis, corresponding to the belief that many relationships between the mixing response variables and a test variable may be represented (or adequately approximated) by a power-law equation:

$$
\mathrm{y}=\mathrm{a} \mathrm{x}^{\mathrm{b}}
$$

On a log-log plot, the power-law model in Eq. (E.1) is represented by a line

$$
\log (\mathrm{y})=\log (\mathrm{a})+\mathrm{b} \log (\mathrm{x})
$$

with intercept $\log (\mathrm{a})$ and slope b. Other forms of plots (original-original, log-original, and original-log) corresponding to other functional relationships were also investigated. While there were some indications 
other functional relationships besides the power-law might be appropriate for some variables, the powerlaw relationships were best for a substantial majority of cases.

Curvature in a log-log plot indicates a departure from a power-law relationship between the mixing response variable $y$ and the test variable $\mathrm{x}$. Non-parallelism in the $\mathrm{x}$-y relationship for different sets of constant values of the remaining test variables indicates that one or more of the other test variables and the test variable on the $x$-axis of a functionality plot have an interactive effect on the mixing response variable y. Non-parallelism in a log-log plot corresponds to different values of the slope $b$ for different values of the interacting test variable(s). In turn, this means that the exponent $\mathrm{b}$ in the power-law model in Eq. (E.1) is a function of one or more other test variables.

Note that interactions identified by statistical methods do not necessarily indicate physically meaningful interactions between the involved variables. This can occur when a set of variables are correlated, so that correlated variables are identified as interacting rather than variables having physically meaningful interactions. However, this is not an issue in the subsequent functionality plots because all data points in a given plot have approximately constant values for all other variables. Statistical methods might also identify variable interactions that are not physically meaningful if the form of the model [e.g., power-law in Eq. (E.1) and (E.2)] is incorrect. However, this possibility was addressed in this appendix by considering other forms of functionality plots (as discussed previously). Ultimately, interactions identified as statistically significant during model development work should be assessed as to whether they are physically meaningful by subject-matter experts. This topic is addressed in Appendix F.

Finally, it must be recognized that the functionality plots presented subsequently display only a fraction of the test data. This is because the functionality plot of a given variable displays only groups of data points with constant values for the remaining test variables. Many of the test combinations performed in the M3 mixing study did not have corresponding tests meeting this condition. This is a result of the large number of possible combinations of many test variables varied at two or more levels in the M3 mixing study. Ultimately, the functionality plots displayed subsequently should be considered with caution, since the relationships shown may or may not hold for other combinations of test variables where there were insufficient data for those data to appear in the plots.

\section{E.2.2 Functionality Plots for Critical Suspension Velocity}

Figures E.6 to E.16 show functionality plots using the full set of July 2007, Fall 2007, and 2008 data for critical suspension velocity $\left(\mathrm{U}_{\mathrm{CS}}\right.$ ) versus $\mathrm{D}, \mathrm{N}_{\mathrm{J}}, \mathrm{d}, \phi_{\mathrm{J}}, \phi_{\mathrm{p}}$, DC, $\mathrm{s}, \phi_{\mathrm{S}}, \mathrm{d}_{\mathrm{S}}, \mathrm{HS}$, and $\mathrm{U}_{\mathrm{T}}$, where these variables are defined in Table E.3. The following observations are made regarding linearity and parallelism in the relationships for different sets of constant values of the remaining variables in each $\mathrm{U}_{\mathrm{CS}}$ functionality plot.

- D (Figure E.6): Increasing D tends to increase $\mathrm{U}_{\mathrm{CS}}$. The relationships are roughly linear with weak to moderate curvature in a few cases. Some non-parallelism is apparent, suggesting some interactive effects of D with other variables. The effects of D and HS are confounded in this plot because including HS as a variable to define the groups would result in no $\mathrm{D}=0.860$ data being plotted. 


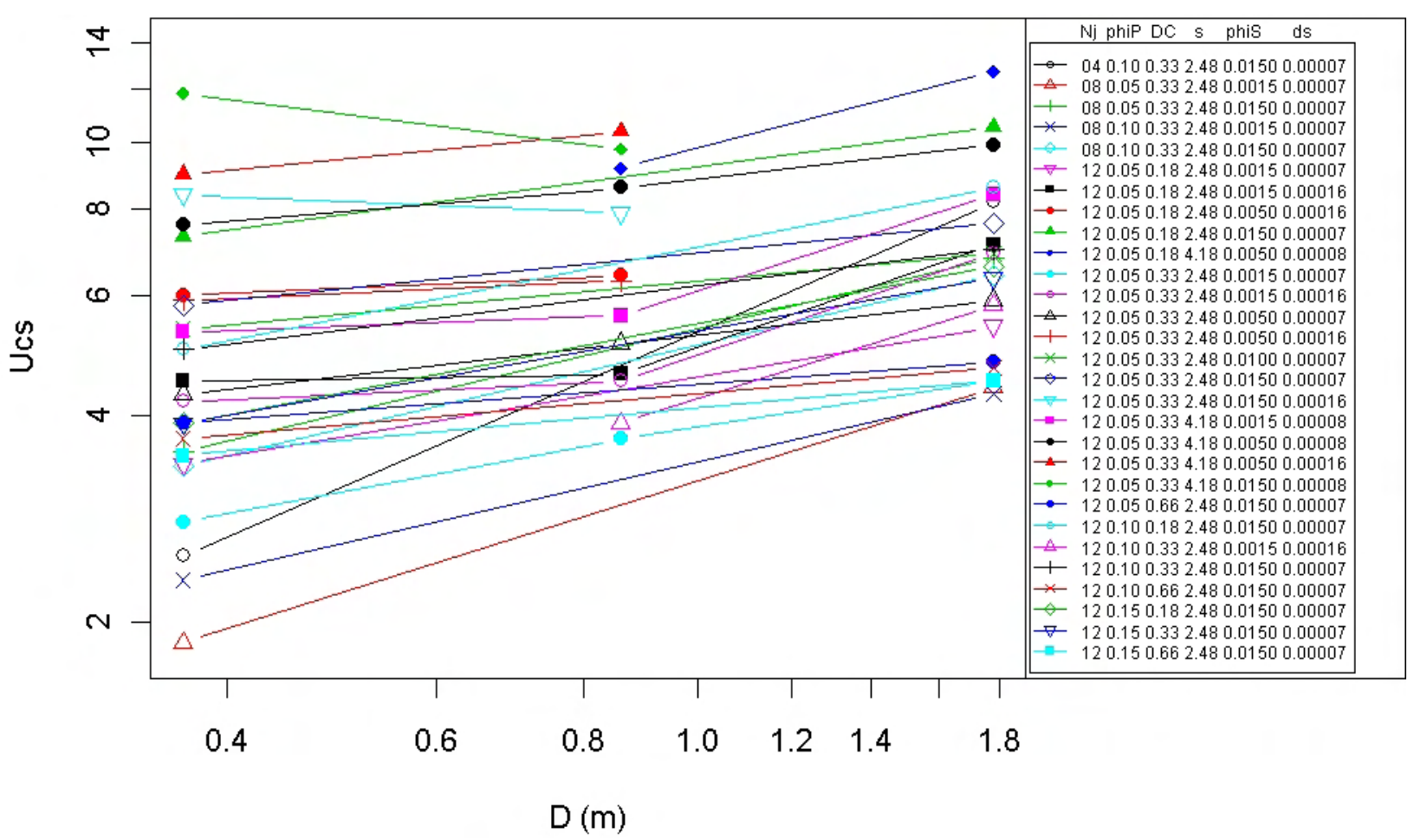

Figure E.6. Log-Log Plot of the Functional Relationship Between Critical Suspension Velocity ( $\left.\mathrm{U}_{\mathrm{CS}}\right)$ and Tank Diameter (D) for Constant Sets of Values of Other Test Variables. The head shape (HS) variable was not used to define the groups, otherwise no $\mathrm{D}=0.860$ data would have plotted (since that was the only test tank with a spherical head shape). Hence, the effect of head shape as well as tank diameter is shown in the plot.

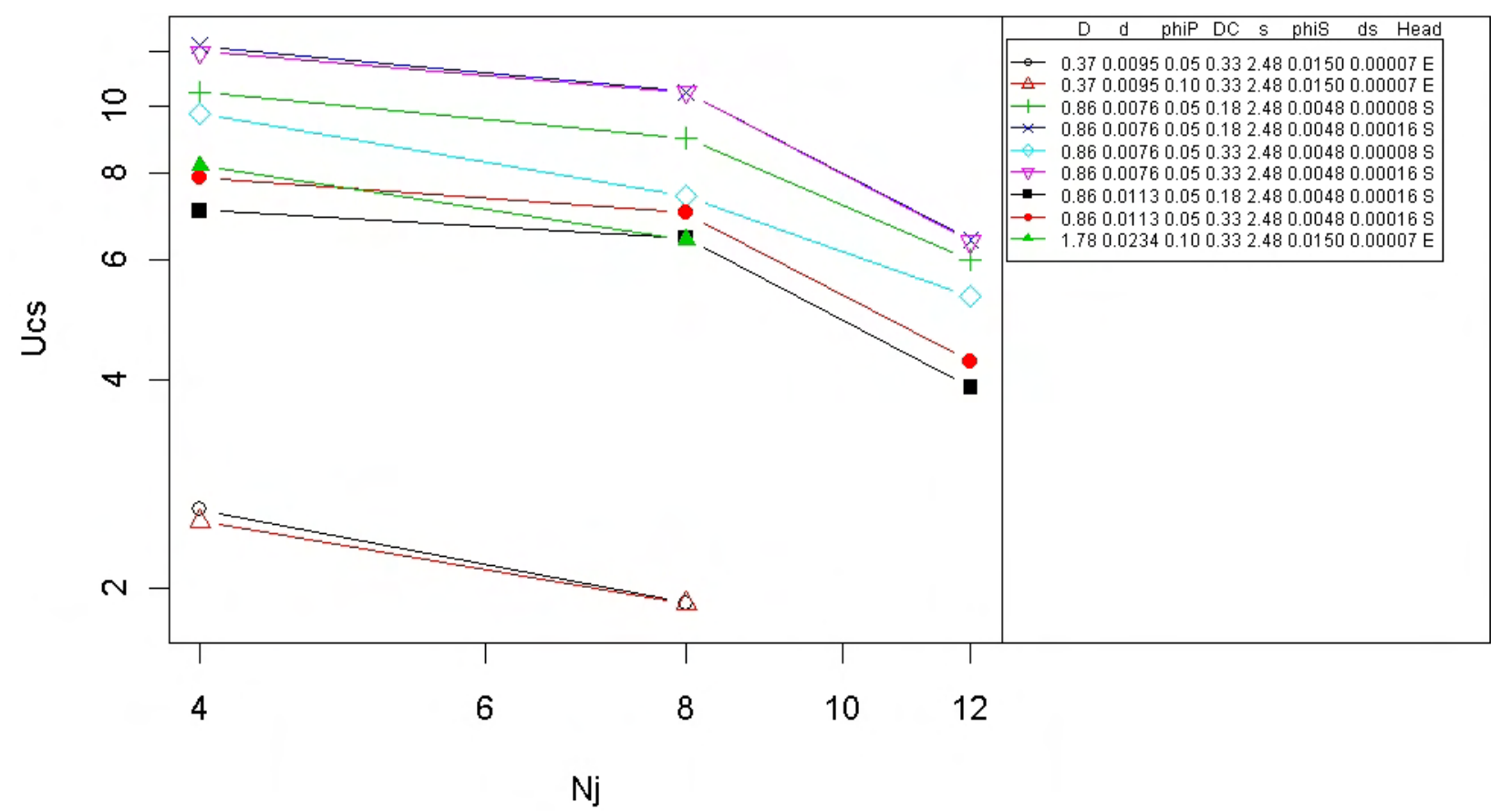

Figure E.7. Log-Log Plot of the Functional Relationship Between Critical Suspension Velocity ( $\left.\mathrm{U}_{\mathrm{CS}}\right)$ and Number of Pulse Jets $\left(\mathrm{N}_{\mathrm{J}}\right)$ for Constant Sets of Values of Other Test Variables 


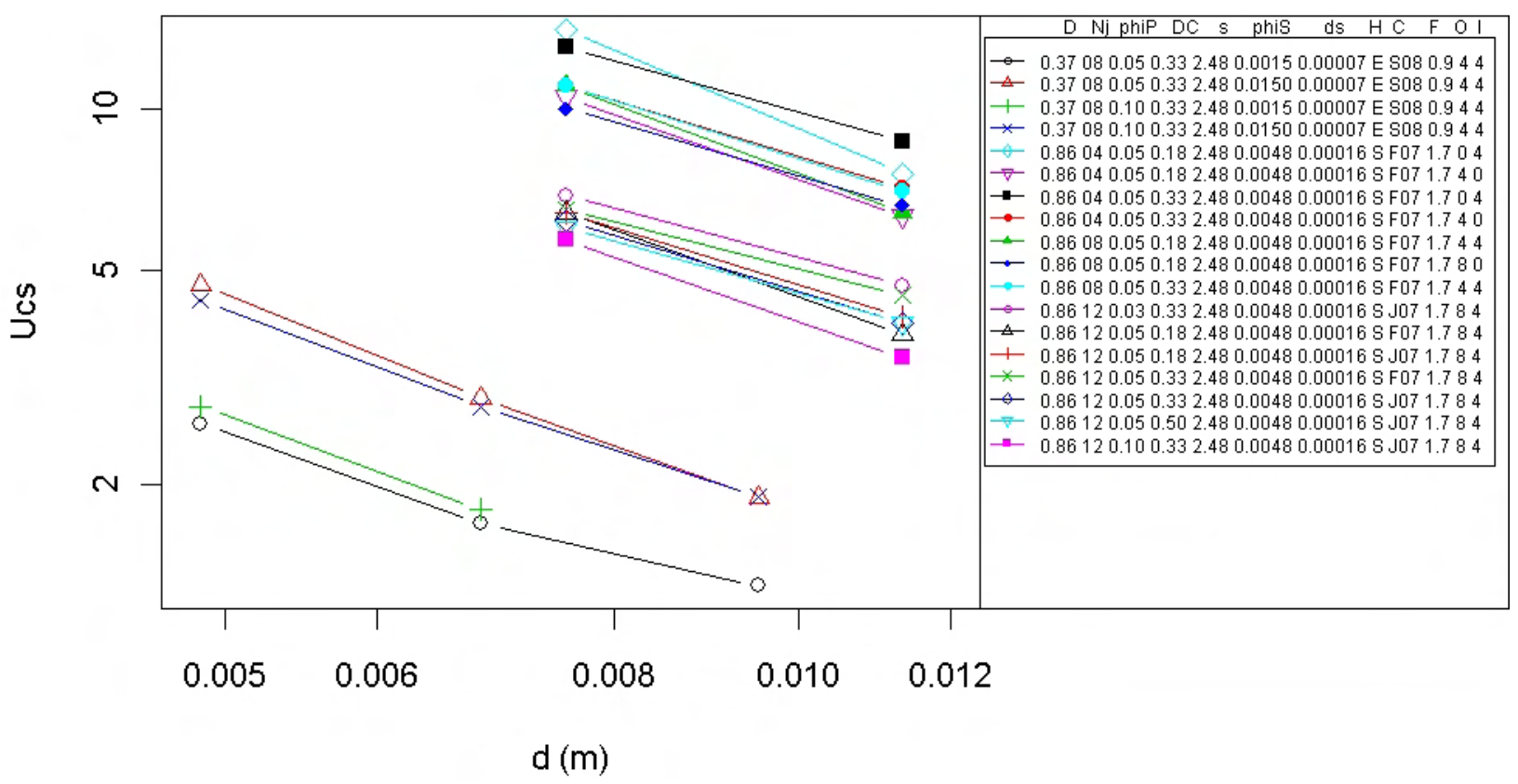

Figure E.8. Log-Log Plot of the Functional Relationship Between Critical Suspension Velocity ( $\left.\mathrm{U}_{\mathrm{CS}}\right)$ and Jet Nozzle Diameter (d) for Constant Sets of Values of Other Test Variables. Variables in the legend include $\mathrm{H}$ = head, $\mathrm{C}=$ test campaign, $\mathrm{F}=$ vessel fill height $(\mathrm{m}), \mathrm{O}=$ number of outer nozzles operating, and $\mathrm{I}=$ number of inner nozzles operating.

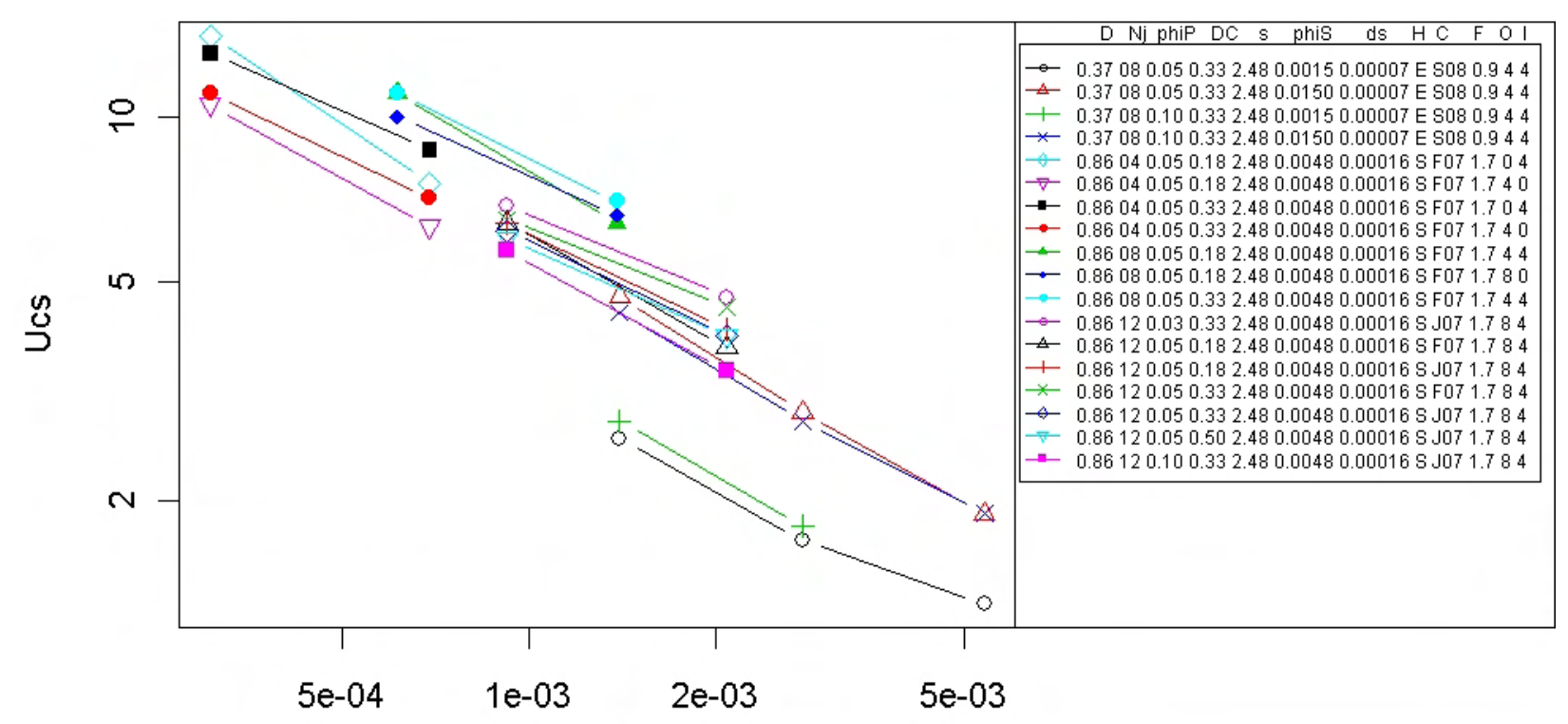

phiJ

Figure E.9. Log-Log Plot of the Functional Relationship Between Critical Suspension Velocity ( $\left.\mathrm{U}_{\mathrm{CS}}\right)$ and Jet Density $\left(\phi_{\mathrm{J}}\right)$ for Constant Sets of Values of Other Test Variables. Variables in the legend include $\mathrm{H}=$ head, $\mathrm{C}$ = test campaign, $\mathrm{F}$ = vessel fill height $(\mathrm{m}), \mathrm{O}=$ number of outer nozzles operating, and $\mathrm{I}=$ number of inner nozzles operating. 


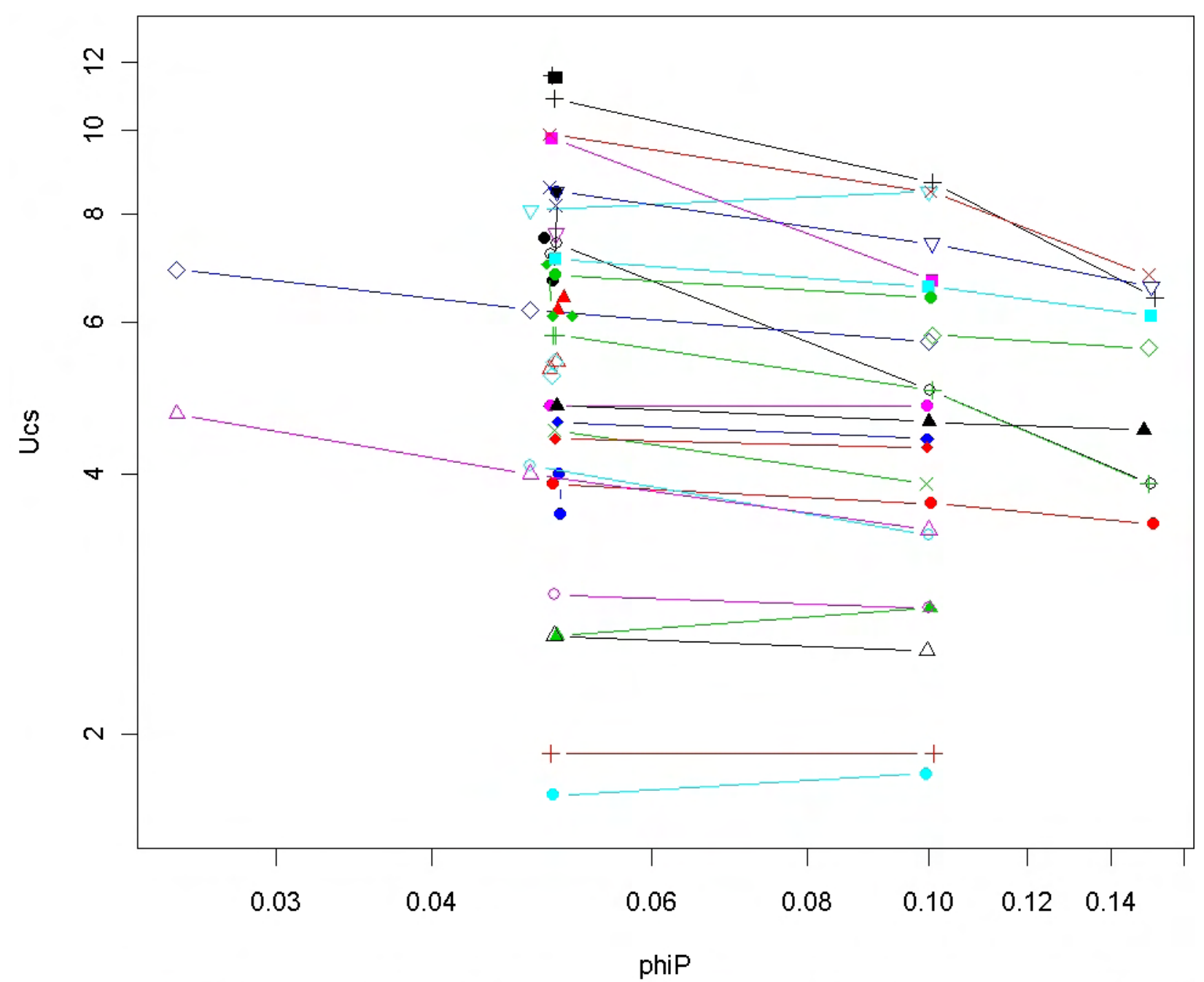

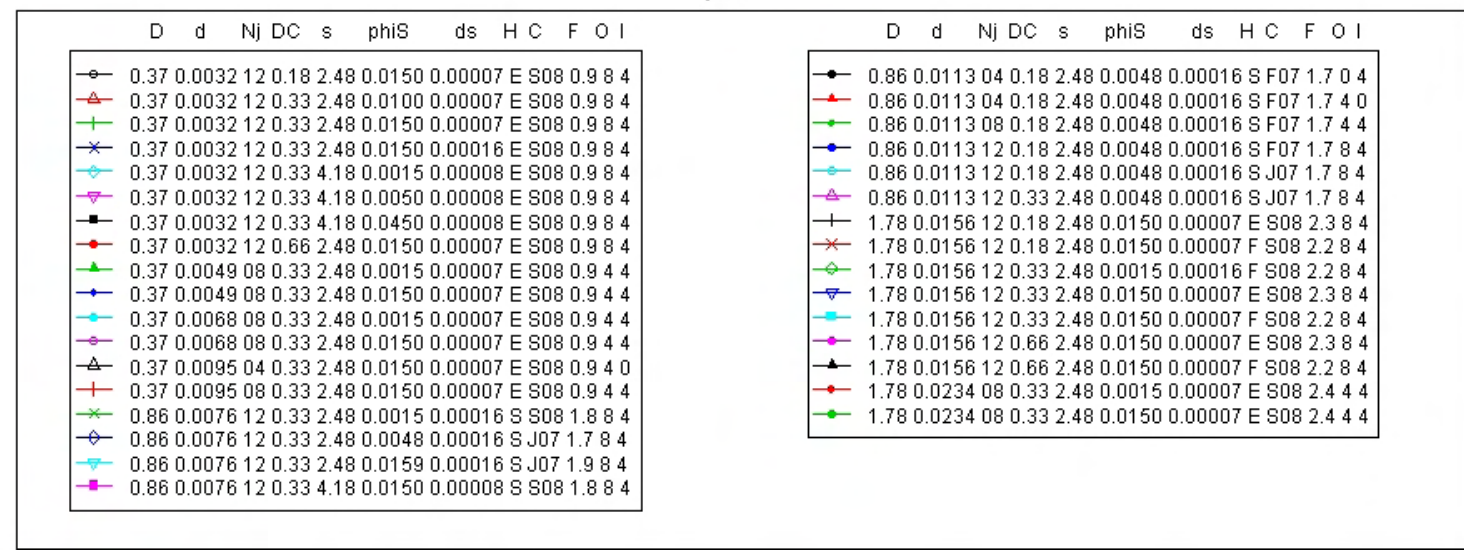

Figure E.10. Log-Log Plot of the Functional Relationship Between Critical Suspension Velocity (U $\left.\mathrm{U}_{\mathrm{CS}}\right)$ and Pulse Volume Fraction $\left(\phi_{\mathrm{p}}\right)$ for Constant Sets of Values of Other Test Variables.

Variables in the legend include $\mathrm{H}=$ head, $\mathrm{C}$ = test campaign, $\mathrm{F}$ = vessel fill height (m), $\mathrm{O}=$ number of outer nozzles operating, and $\mathrm{I}=$ number of inner nozzles operating. 


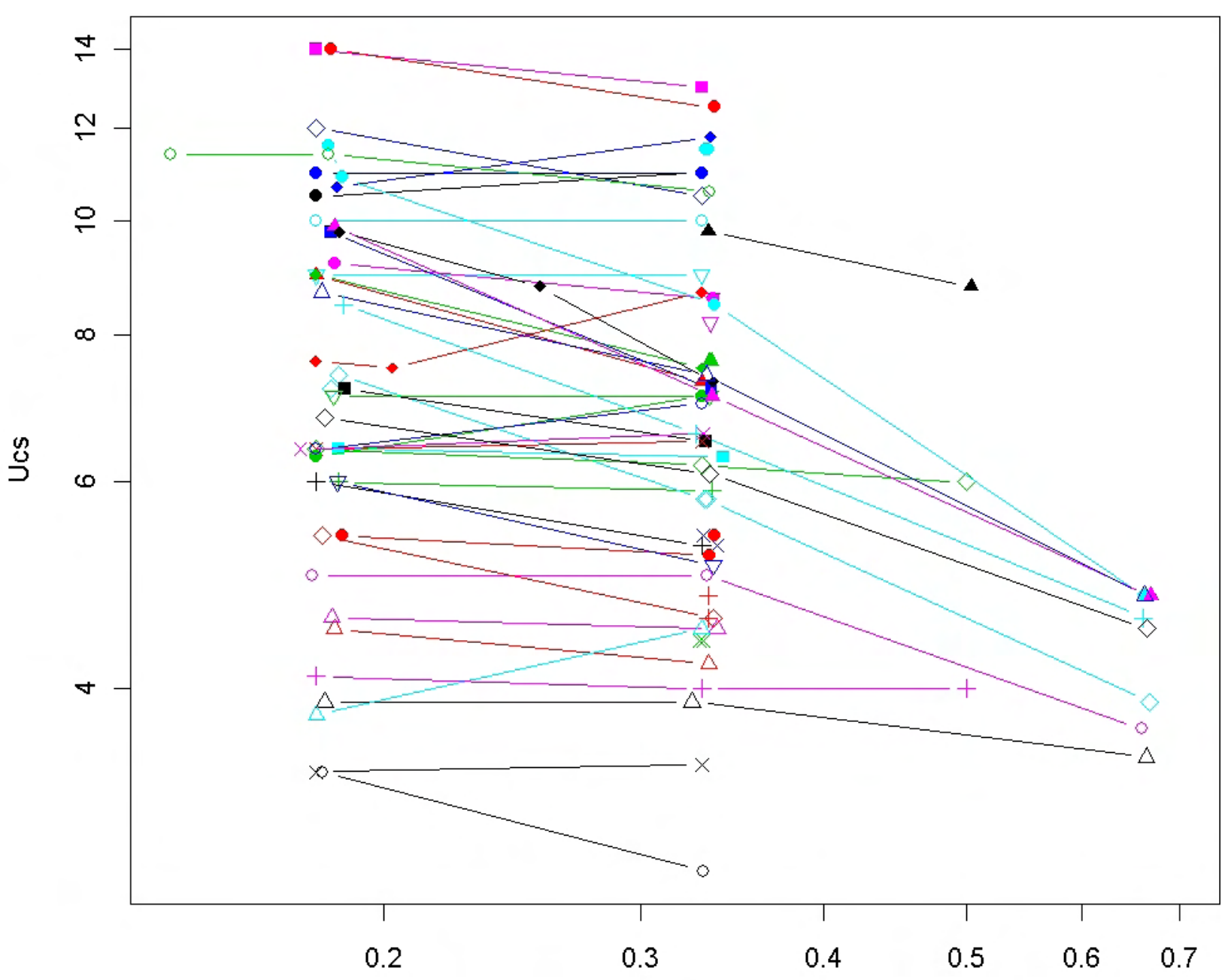

DC

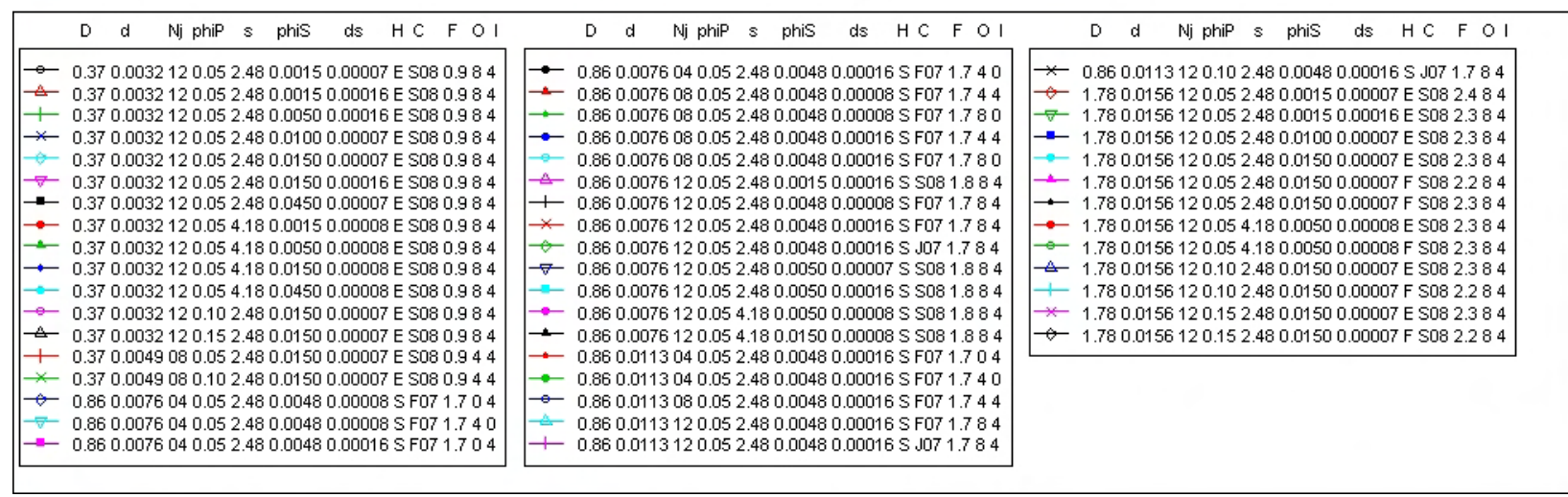

Figure E.11. Log-Log Plot of the Functional Relationship Between Critical Suspension Velocity ( $\mathrm{U}_{\mathrm{CS}}$ ) and Duty Cycle (DC) for Constant Sets of Values of Other Test Variables. Variables in the legend include $\mathrm{H}=$ head, $\mathrm{C}=$ test campaign, $\mathrm{F}$ = vessel fill height $(\mathrm{m}), \mathrm{O}=$ number of outer nozzles operating, and $\mathrm{I}=$ number of inner nozzles operating. 


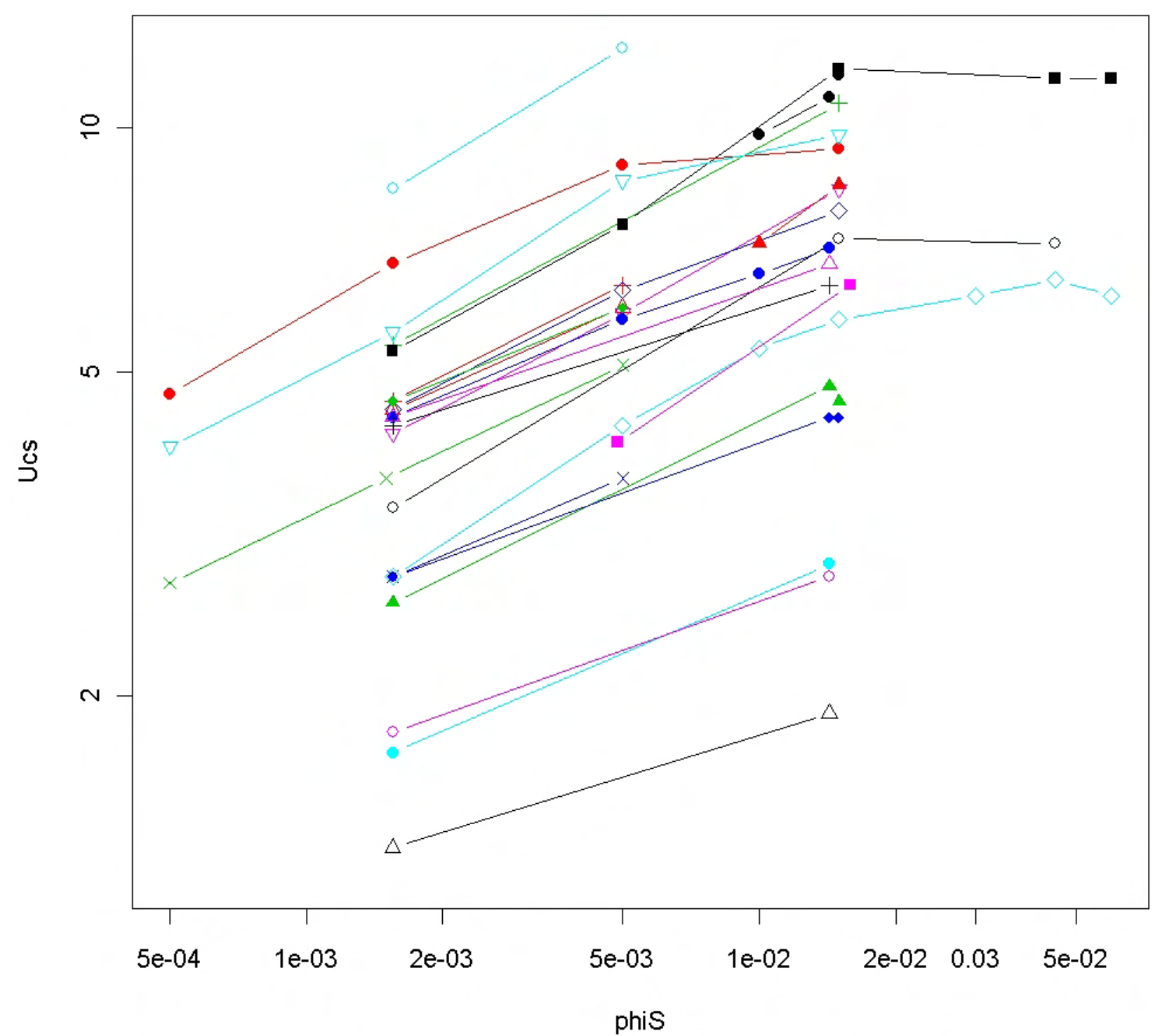

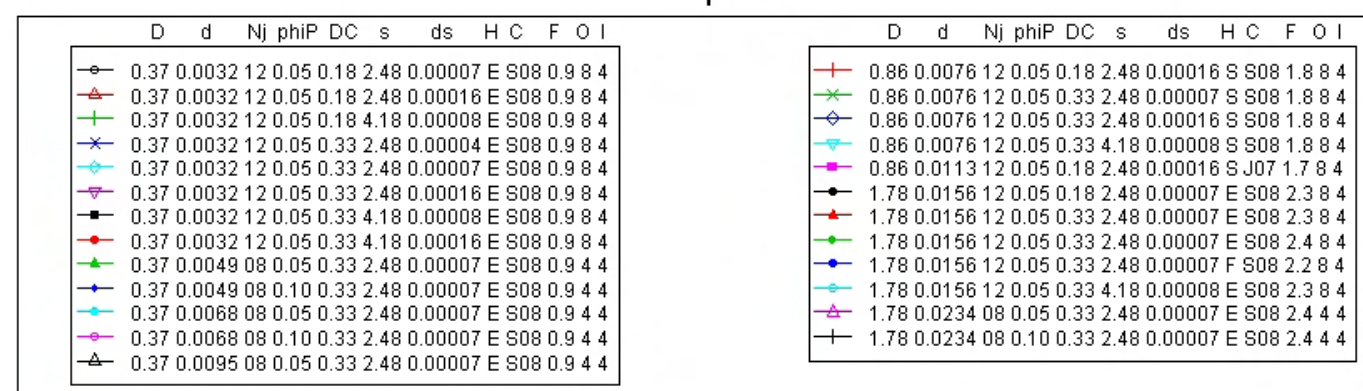

Figure E.12. Log-Log Plot of the Functional Relationship Between Critical Suspension Velocity (U $\left.\mathrm{U}_{\mathrm{CS}}\right)$ and Solids Volume Fraction $\left(\phi_{\mathrm{S}}\right.$ ) for Constant Sets of Values of Other Test Variables.

Variables in the legend include $\mathrm{H}=$ head, $\mathrm{C}=$ test campaign, $\mathrm{F}=$ vessel fill height (m), $\mathrm{O}=$ number of outer nozzles operating, and $\mathrm{I}=$ number of inner nozzles operating. 


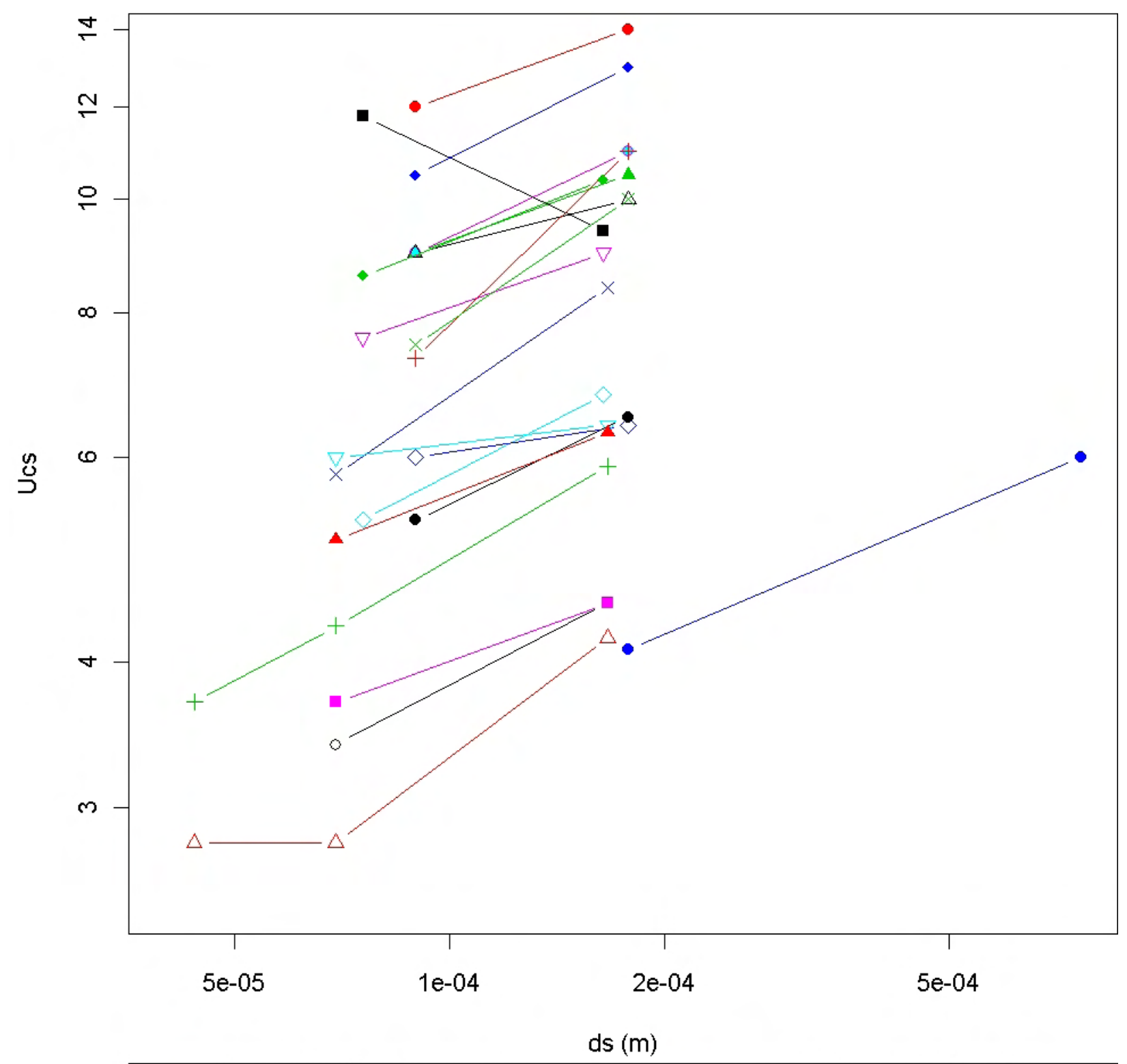

\begin{tabular}{|c|c|}
\hline 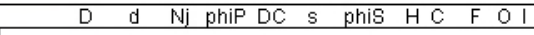 & 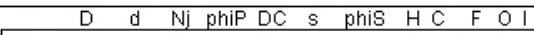 \\
\hline$\rightarrow 0.370 .0032120 .050 .182 .480 .0015 E S 080.984$ & $\because-0.860 .0076040 .050 .332 .480 .0048 \mathrm{SF} 071.740$ \\
\hline$\triangle \quad 0.370 .0032120 .050 .332 .480 .0015 E S 080.984$ & $-\quad 0.860 .0076080 .050 .182 .480 .0048 \mathrm{SF} 071.744$ \\
\hline$+\quad 0.370 .0032120 .050 .332 .480 .0050$ E S08 0.984 & $\triangle \quad 0.860 .0076080 .050 .182 .480 .0048 \mathrm{SF} 071.780$ \\
\hline$\star * \quad 0.370 .0032120 .050 .332 .480 .0150$ E $S 080.984$ & $+-0.860 .0076080 .050 .332 .480 .0048 \mathrm{SF}$ F07 1.744 \\
\hline$-\quad 0.370 .0032120 .050 .334 .180 .0015$ E S08 0.984 & $\rightarrow \quad 0.860 .0076080 .050 .332 .480 .0048 \mathrm{SF} 071.780$ \\
\hline$\rightarrow \quad 0.370 .0032120 .050 .334 .180 .0050$ E S08 0.984 & $\triangle \quad 0.860 .0076120 .050 .182 .480 .0048 \mathrm{SF} 071.784$ \\
\hline$=0.370 .0032120 .050 .334 .180 .0150 \mathrm{E} S 080.984$ & $-\bar{\nabla}-0.860 .0076120 .050 .182 .480 .0050 S 5081.884$ \\
\hline$\rightarrow \quad 0.860 .0076040 .050 .182 .480 .0048 \mathrm{SF} 071.704$ & $=0.860 .0076120 .050 .332 .480 .0015 S 5081.884$ \\
\hline$-\quad 0.860 .0076040 .050 .182 .480 .0048 \mathrm{SF} 071.740$ & $\rightarrow-0.860 .0076120 .050 .332 .480 .0048 \mathrm{SF} F 71.784$ \\
\hline$\rightarrow \quad 0.860 .0076040 .050 .332 .480 .0048 \mathrm{SF} 071.704$ & $\rightarrow \quad 0.860 .0076120 .050 .332 .480 .0050 \mathrm{~S} 5081.884$ \\
\hline & $\begin{array}{lll}\rightarrow & 0.860 .0076120 .050 .334 .180 .0050 S S 081.884 \\
\rightarrow & 0.860 .0113120 .050 .182 .480 .0048 S . J 071.784\end{array}$ \\
\hline
\end{tabular}

Figure E.13. Log-Log Plot of the Functional Relationship Between Critical Suspension Velocity ( $\left.\mathrm{U}_{\mathrm{CS}}\right)$ and Solids Particle Diameter $\left(\mathrm{d}_{\mathrm{S}}=\mathrm{d}_{50}\right)$ for Constant Sets of Values of Other Test Variables. Variables in the legend include $\mathrm{H}=$ head, $\mathrm{C}=$ test campaign, $\mathrm{F}=$ vessel fill height $(\mathrm{m}), \mathrm{O}=$ number of outer nozzles operating, and $\mathrm{I}=$ number of inner nozzles operating. 


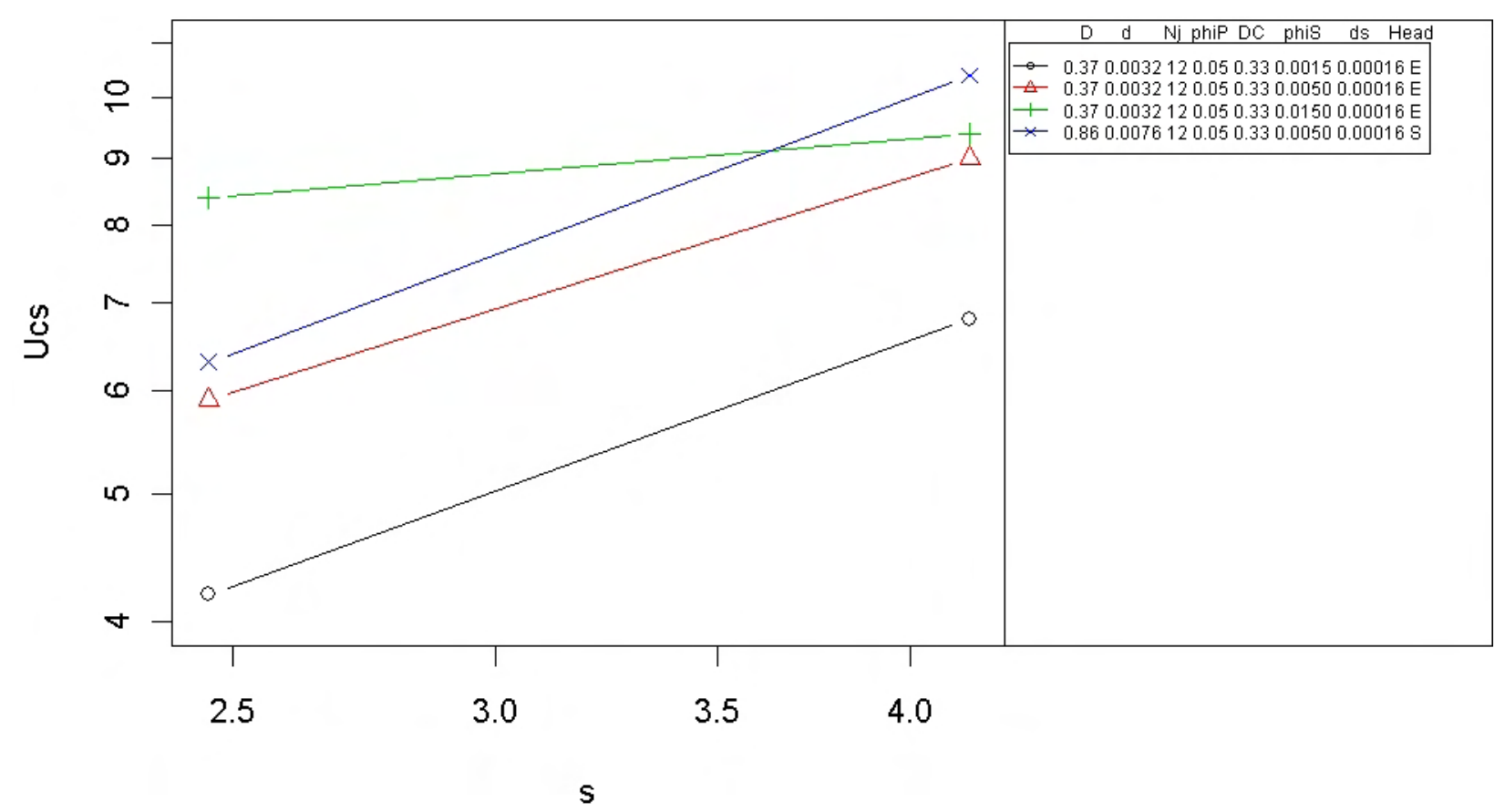

Figure E.14. Log-Log Plot of the Functional Relationship Between Critical Suspension Velocity ( $\left.\mathrm{U}_{\mathrm{CS}}\right)$ and Density Ratio (s) for Constant Sets of Values of Other Test Variables

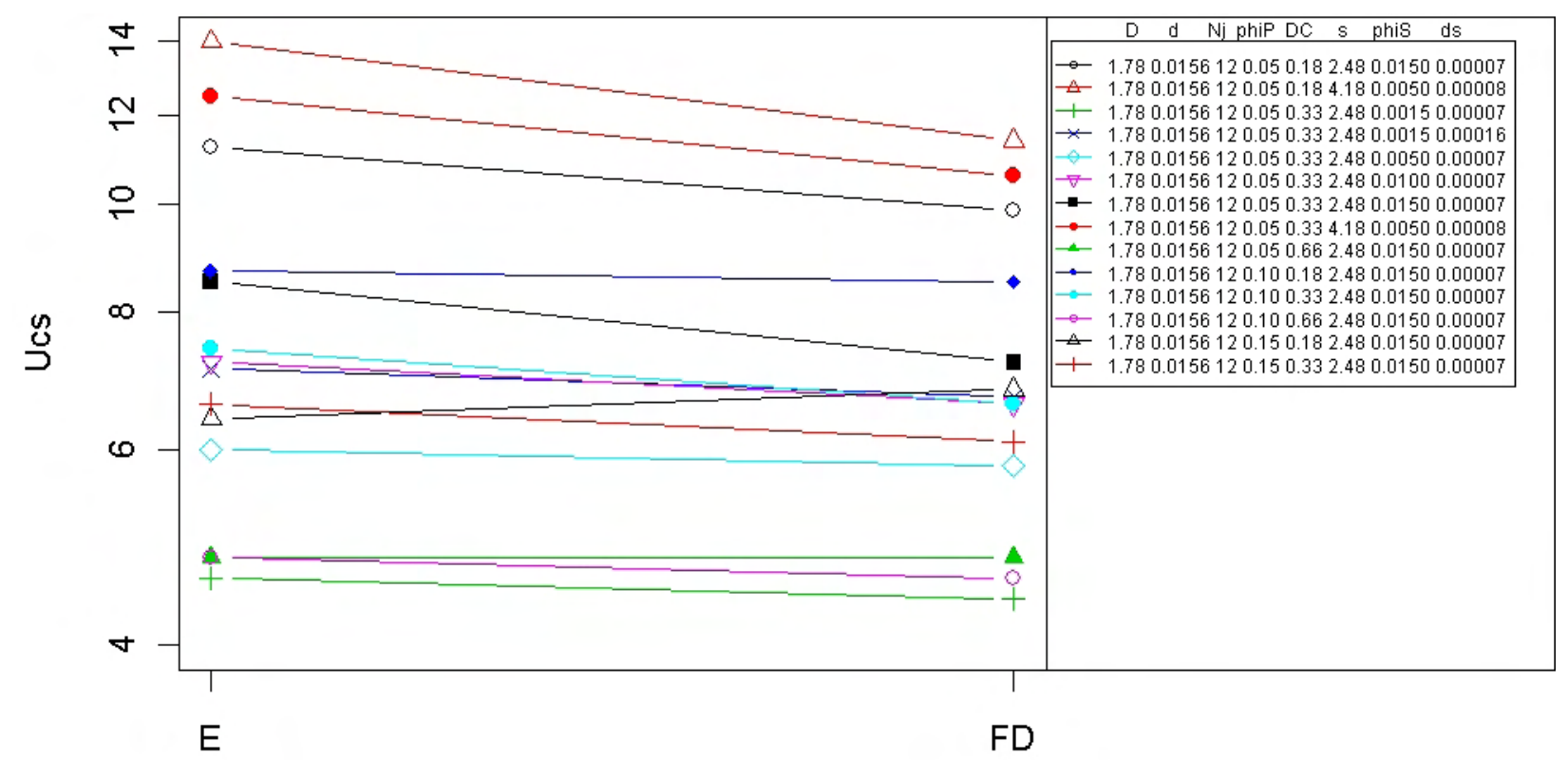

Head

Figure E.15. Log-Categorical Plot of Functional Relationship Between Critical Suspension Velocity $\left(U_{C S}\right)$ and Head Shape (HS) for Constant Sets of Values of Other Test Variables. No data are plotted for the spherical head shape (S), because it was only used in the $\mathrm{D}=0.860 \mathrm{~m}$ tank. 


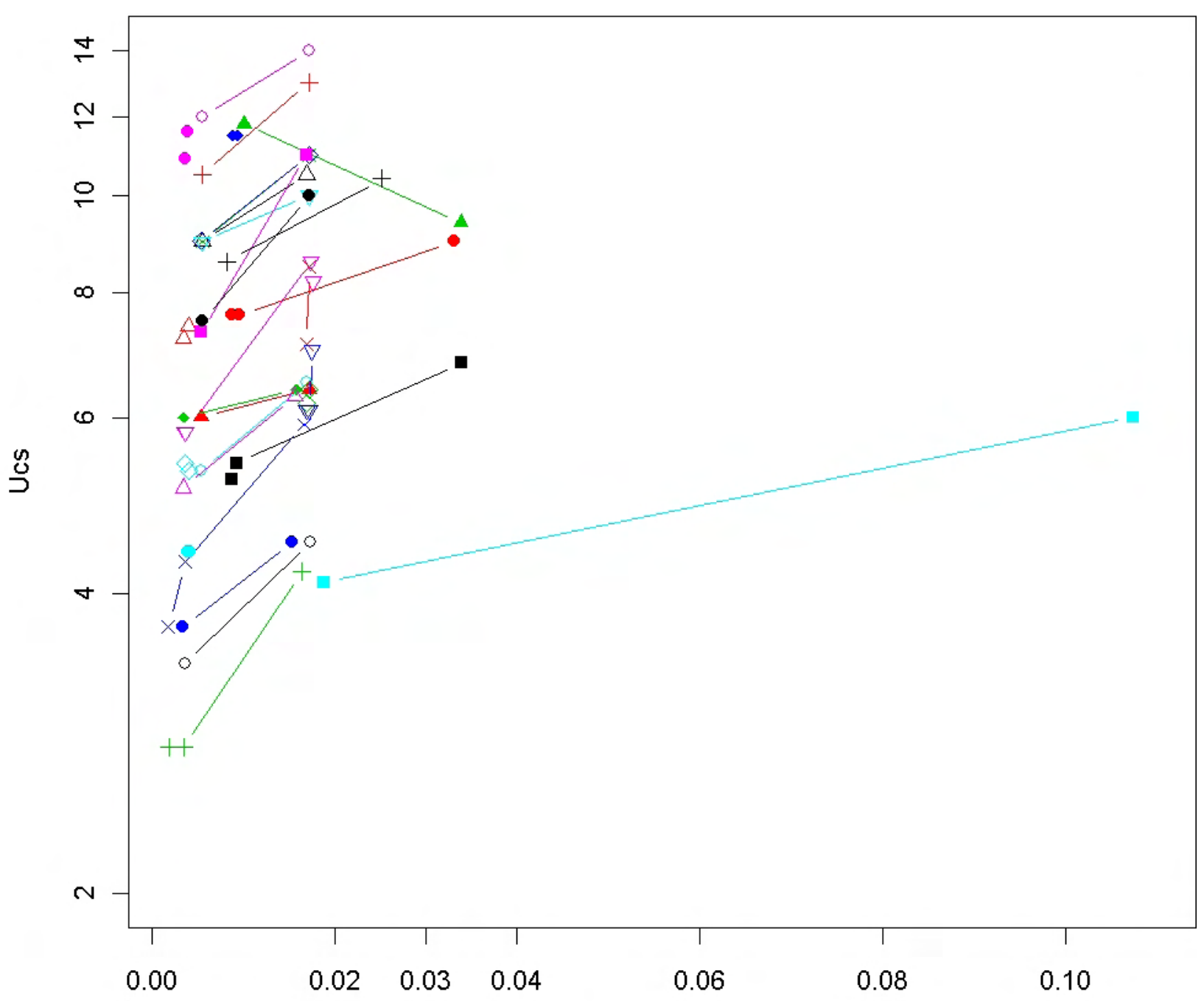

Ut $(\mathrm{m} / \mathrm{s})$

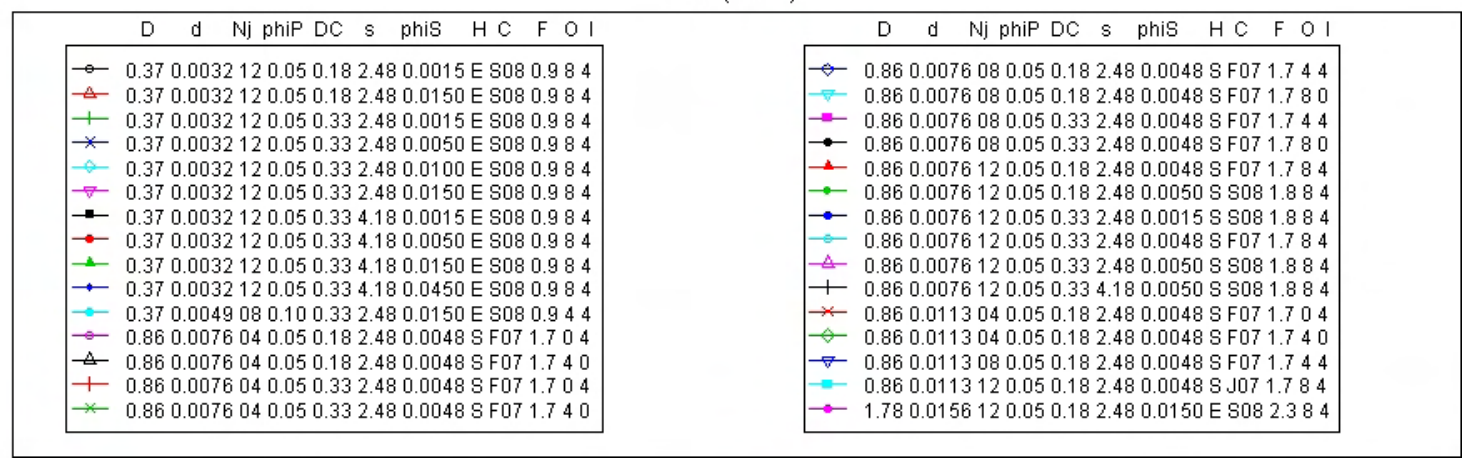

Figure E.16. Log-Log Plot of the Functional Relationship Between Critical Suspension Velocity $\left(\mathrm{U}_{\mathrm{CS}}\right)$ and unhindered terminal settling velocity $\left(\mathrm{U}_{\mathrm{T}}\right)$ for Constant Sets of Values of Other Test Variables. Because $U_{T}$ is calculated as a function of $d_{S}$ and $(s-1), d_{S}$ was not used to define the plotting sets in the legend. Hence, the effects of $U_{T}$ and $d_{S}$ are confounded in the plot. 
- $\mathrm{N}_{\mathrm{J}}$ (Figure E.7): Increasing the number of operating jets decreases $\mathrm{U}_{\mathrm{CS}}$ with the increase from 8 to 12 jets, causing a larger decrease in $U_{\mathrm{CS}}$ than from 4 to 8 jets. Curvature is apparent in several relationships with similar patterns. For these conditions, there is no strong indication of interactive effects with $\mathrm{N}_{\mathrm{J}}$.

- $d$ (Figure E.8): Increasing $d$ tends to decrease $U_{C s}$. In the three cases where there are sufficient data to assess curvature, the relationships are roughly linear. Although there are some differences in slopes (indicating some possible interactive effects), the slopes tend to vary around an average slope.

- $\phi_{\mathrm{J}}$ (Figure E.9): Increasing $\phi_{\mathrm{J}}$ tends to decrease $\mathrm{U}_{\mathrm{CS}}$. In the three cases where there are sufficient data to assess curvature, the relationships are roughly linear. Although there are some differences in slopes (indicating some possible interactive effects of other variables with $\phi_{\mathrm{J}}$ ), the slopes tend to have limited variation around an average slope.

- $\phi_{\mathrm{p}}$ (Figure E.10): For $\phi_{\mathrm{p}} \geq 0.05$, increasing $\phi_{\mathrm{p}}$ has effects ranging from weakly increasing $\mathrm{U}_{\mathrm{CS}}$ to significantly decreasing $U_{\mathrm{CS}}$. The relationships are roughly linear, with weak curvature for two cases. Non-parallelism is apparent, indicating some interactive effects of $\phi_{\mathrm{p}}$ with other variables.

- DC (Figure E.11): $\mathrm{U}_{\mathrm{CS}}$ tends to decrease with DC, although some cases show increases (indicating interactive effects). Some relationships display slight to moderate curvature, as a result of $\mathrm{U}_{\mathrm{CS}}$ generally decreasing as DC increases from $\sim 0.33$ to $\sim 0.66$.

- $\phi_{\mathrm{S}}$ (Figure E.12): The relationships are roughly linear for $\phi_{\mathrm{S}} \leq 0.015$, with $\mathrm{U}_{\mathrm{CS}}$ increasing as $\phi_{\mathrm{S}}$ increases. However, there is a flattening-out of the three relationships that have data for $\phi_{\mathrm{S}}>0.015$. This flattening-out behavior starts at lower $\phi_{\mathrm{S}}$ values for one case.

- $\mathrm{d}_{\mathrm{S}}$ (Figure E.13): Increasing the median solids particle size from $~ 0.00007$ to $\sim 0.00016$ increases $\mathrm{U}_{\mathrm{CS}}$ for many cases, but $\mathrm{U}_{\mathrm{CS}}$ decreases for one case. There are noticeable differences in slope, indicating possible interactive effects. For the two cases with data for $\mathrm{d}_{\mathrm{S}}$ increasing from $\sim 0.00004$ to $\sim 0.00007, \mathrm{U}_{\mathrm{CS}}$ increased (one case) or had a negligible change (other case). Only the latter case showed curvature over the tested range of $d_{\mathrm{S}}$. For the one case where $d_{\mathrm{S}}$ ranged from $\sim 0.00018$ to $\sim 0.00077$, the positive slope was within the range of slopes for the other cases with smaller $d_{S}$ values.

- s (Figure E.14): Increasing s tends to increase $\mathrm{U}_{\mathrm{CS}}$. The slope of the relationship is similar for several cases, but there is one different slope indicating possible interactive effects. Only having data for four conditions in this plot limits the general conclusions that can be made.

- HS (Figure E.15): The flange and dish (FD) head shape tends to yield smaller $\mathrm{U}_{\mathrm{CS}}$ values than the elliptical (E) head shape. See Section E.2.4 for additional discussion. No data are plotted for the spherical (S) head shape, because that shape was only used in tests with the $\mathrm{D}=0.860 \mathrm{~m}$ ( 34-in.) tank, and thus there are no sets of conditions with values for E, FD, and S head shapes.

- $\mathrm{U}_{\mathrm{T}}$ (Figure E.16): Increasing $\mathrm{U}_{\mathrm{T}}$ tends to increase $\mathrm{U}_{\mathrm{CS}}$, except for one case. The rate of increase in $\mathrm{U}_{\mathrm{CS}}$ appears to decrease as $\mathrm{U}_{\mathrm{T}}$ increases. For $\mathrm{U}_{\mathrm{T}}$ up to $\sim 0.035$, the slopes vary enough to suggest possible interactive effects with other variables. However, because $U_{T}$ is calculated as a function of $d_{S}$ and $s-1$, the $d_{s}$ variable was not used in the plotting groups shown in the legend of the figure. Hence, the effects of $U_{T}$ and $d_{S}$ on $U_{C S}$ are confounded, and any statements made here may be as much due to $\mathrm{d}_{\mathrm{S}}$ effects as $\mathrm{U}_{\mathrm{T}}$ effects on $\mathrm{U}_{\mathrm{CS}}$. 
These observations and the functionality plots they are based on serve as a basis for assessing multipleregression models developed for $\mathrm{U}_{\mathrm{CS}}$ in Section F.2, Appendix F.

\section{E.2.3 Functionality Plots for Cloud Height}

Figures E.17 to E.21 show the functionality plots of cloud height $\left(\mathrm{H}_{\mathrm{C}}\right)$ versus target velocity $(\mathrm{U})$ for each set of test conditions in the "full" set of July 2007, Fall 2007, and 2008 data. Each plot is shown with logarithmic scales on both axes. Only target velocity values greater than or equal to the critical suspension velocity (i.e., $\mathrm{U} \geq \mathrm{U}_{\mathrm{CS}}$ ) are shown in the plots.

For the 2008 data (Figures E.19 to E.21), the relationships between $\mathrm{H}_{\mathrm{C}}$ and $\mathrm{U} \geq \mathrm{U}_{\mathrm{CS}}$ are generally linear for most sets of conditions displayed, with $\mathrm{H}_{\mathrm{C}}$ increasing as $\mathrm{U}$ increases (as expected). There is weak curvature in the relationship for a few cases. The slopes of the roughly linear relationships are generally similar within a given figure, but with noticeable differences (especially for 2008 15-in. tank data in Figure E.19). Differences in slopes of the relationships correspond to possible interactive effects on $\mathrm{H}_{\mathrm{C}}$ of $\mathrm{U}$ with other variables.

For the July 2007 (Figure E.17) and Fall 2007 data (Figure E.18), in some cases the HC versus U relationships are flat or negative for low velocities. This suggests that $U_{C S}$ may have been determined as too low a velocity in some cases (which may be because those test campaigns were earlier in the learning curve of performing these kinds of tests). Still, the relationships are generally linear, though curvature is apparent for some cases. Slopes are notably different, indicating possible interactive effects of other variables with $U$. 

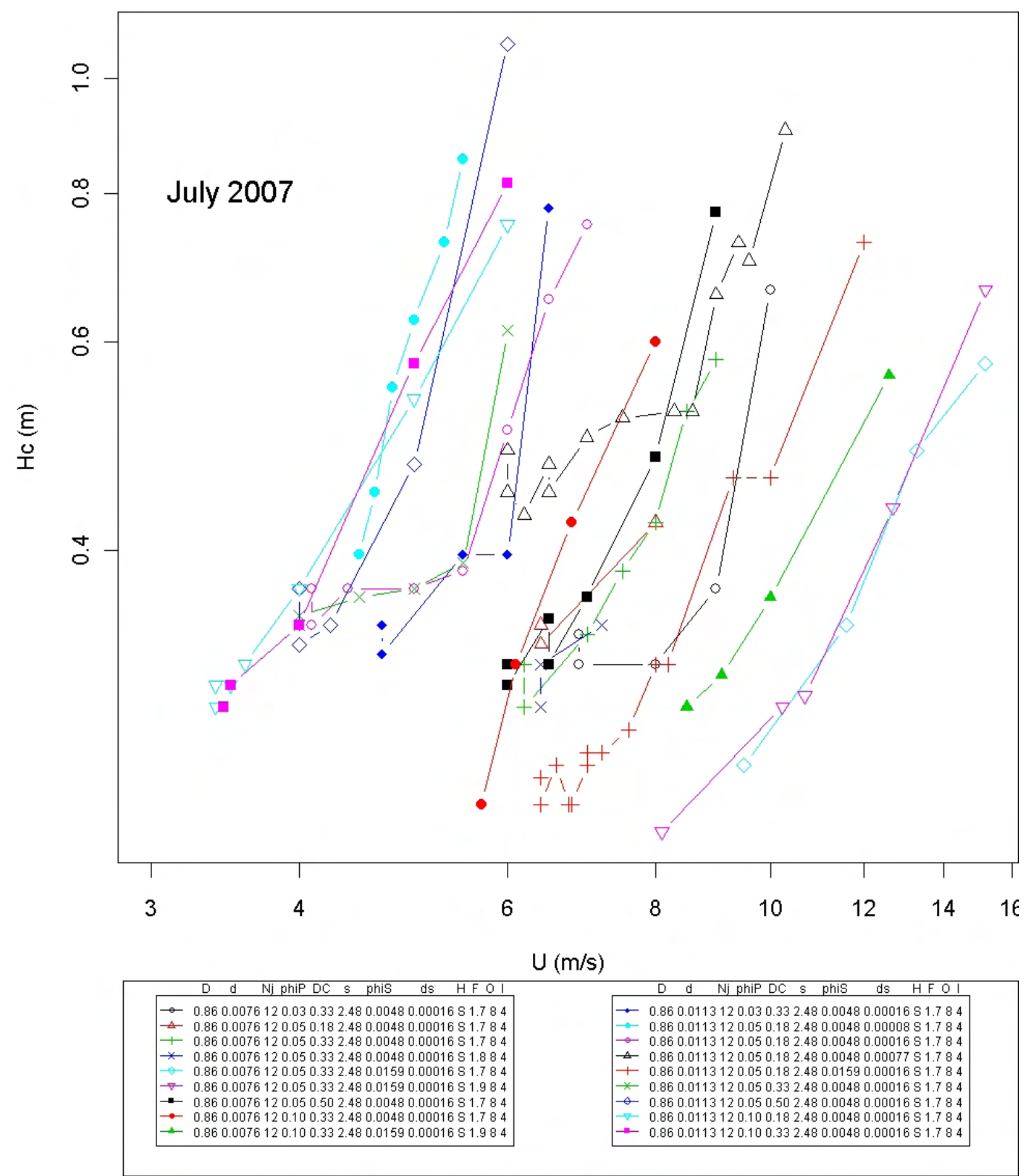

Figure E.17. Log-Log Plot of the Functional Relationship Between Cloud Height $\left(\mathrm{H}_{\mathrm{C}}\right)$ and Velocity (U) for Each Set of Test Conditions in the July 2007 Data Set. Only velocities greater than or equal to the critical suspension velocity $\left(\mathrm{U} \geq \mathrm{U}_{\mathrm{CS}}\right)$ are shown. Variables in the legend include $\mathrm{H}=$ head, $\mathrm{F}$ = vessel fill height (m), $\mathrm{O}=$ number of outer nozzles operating, and $\mathrm{I}=$ number of inner nozzles operating. 


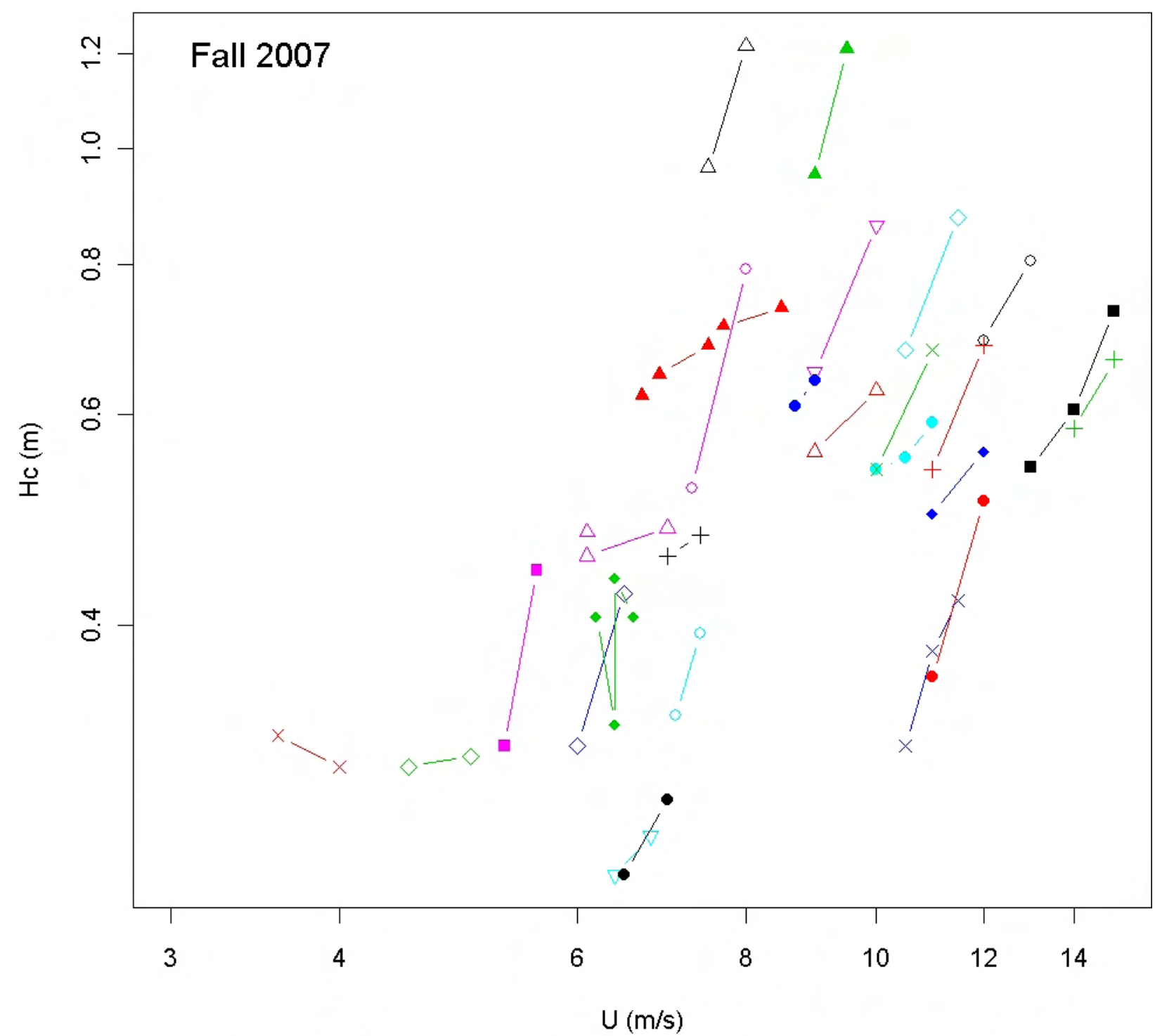

\begin{tabular}{|c|c|c|c|c|c|c|c|c|c|c|c|c|c|}
\hline & $\mathrm{D}$ & $d$ & Nj phiP DC & $s$ phis & ds $\mathrm{HFOl}$ & & $\mathrm{D}$ & d & Nj phiP DO & $\mathrm{s}$ & phis & ds & $\mathrm{HFOl}$ \\
\hline$\rightarrow$ & 0.86 & 0.00 & 80040.050 .182 & 2.480 .0048 & $0.00008 S 1.704$ & + & 0.86 & 0.00 & 76080.050 .3 & 2. & 480.004 & 0.00016 & 651.744 \\
\hline$\triangle$ & 0.86 & 0.00 & 76040.050 .182 & 2.480 .0048 & $0.00008 S 1.740$ & 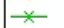 & 0.86 & 0.00 & 76080.050 .3 & 2. & 480.004 & 0.00018 & 651.780 \\
\hline+ & 0.86 & 0.00 & 6040.050 .182 & 2.480 .0048 & 0.0001681 .704 & 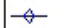 & 0.86 & 0.00 & 76120.050 .1 & & 480.004 & 0.00008 & 1851.784 \\
\hline$*$ & 0.86 & 0.00 & 76040.050 .182 & 2.480 .0048 & 0.0001681 .740 & $-7-$ & 0.86 & 0.00 & 76120.050 .1 & & 480.004 & 0.00018 & 651.784 \\
\hline$-\infty$ & 0.86 & 0.00 & 76040.050 .332 & 2.480 .0048 & $0.00008 \mathrm{~S} 1.704$ & $\rightarrow-$ & 0.86 & 0.00 & 76120.050 .3 & & 480.004 & 0.00008 & 1851.784 \\
\hline$\nabla$ & 0.86 & 0.00 & 76040.050 .332 & 2.480 .0048 & $0.00008 S 1.740$ & $\rightarrow-$ & 0.86 & 0.00 & 76120.050 .3 & 2. & 480.004 & 0.00016 & 651.784 \\
\hline$\rightarrow-$ & 0.86 & 0.00 & 76040.050 .332 & 2.480 .0048 & 0.0001651 .704 & 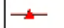 & 0.86 & 0.01 & 13040.050 .1 & & 480.004 & 0.00016 & 651.704 \\
\hline$\rightarrow-$ & 0.86 & 0.00 & 86040.050 .332 & 2.480 .0048 & $0.00016 S 1.740$ & $\rightarrow$ & 0.86 & 0.01 & 13040.050 .1 & 2. & 480.004 & 0.00016 & 651.740 \\
\hline$\leadsto$ & 0.86 & 0.00 & 76080.050 .182 & 2.480 .0048 & 0.0000851 .780 & $\rightarrow-$ & 0.86 & 0.01 & 13040.050 .3 & 32. & 480.004 & 0.00016 & 681.704 \\
\hline$\rightarrow-$ & 0.86 & 0.00 & 76080.050 .182 & 2.480 .0048 & 0.0001651 .744 & 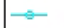 & 0.86 & 0.01 & 13040.050 .3 & & 480.004 & 0.00010 & 651.740 \\
\hline 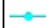 & 0.86 & 0.00 & 76080.050 .182 & 2.480 .0048 & $0.00016 S 1.780$ & $\triangle$ & 0.86 & 0.01 & 13080.050 .1 & & 480.004 & 0.00010 & 651.744 \\
\hline$\rightarrow$ & 0.86 & 0.00 & 76080.050 .332 & 2.480 .0048 & $0.00008 S 1.744$ & + & 0.86 & 0.01 & 13080.050 .3 & 32. & 480.004 & 0.00016 & 651.744 \\
\hline$\triangle$ & 0.86 & 0.00 & 76080.050 .332 & 2.480 .0048 & $0.00008 S 1.780$ & $\ddot{x}$ & 0.86 & 0.01 & 13120.050 .1 & & 480.004 & 0.00016 & 651.784 \\
\hline
\end{tabular}

Figure E.18. Log-Log Plot of the Functional Relationship Between Cloud Height $\left(\mathrm{H}_{\mathrm{C}}\right)$ and Velocity (U) for Each Set of Test Conditions in the Fall 2007 Data Set. Only velocities greater than or equal to the critical suspension velocity $\left(\mathrm{U} \geq \mathrm{U}_{\mathrm{CS}}\right)$ are shown. Variables in the legend include $\mathrm{H}=$ head, $\mathrm{F}$ = vessel fill height $(\mathrm{m}), \mathrm{O}=$ number of outer nozzles operating, and $\mathrm{I}=$ number of inner nozzles operating. 


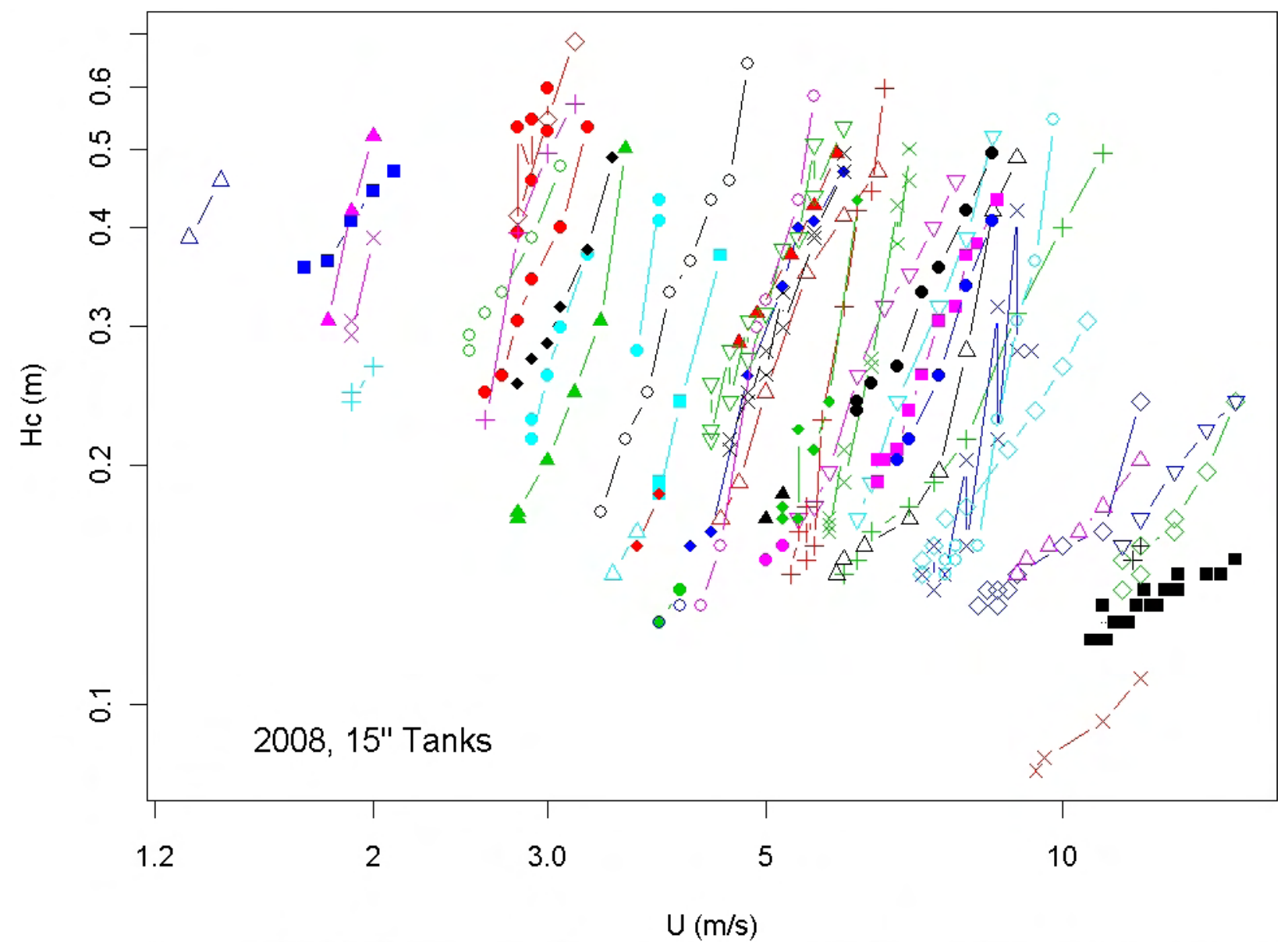

\begin{tabular}{|c|c|c|c|c|c|c|c|c|c|c|c|c|c|c|}
\hline & D & d & Nj phiP DC s & phis & ds & $\mathrm{HFOl}$ & & D & d & Nj phiP DC & s & phis & ds & $\mathrm{HFOl}$ \\
\hline$\rightarrow$ & 0.37 & 0.00 & 2120.050 .182$. & 2.480 .001 & 0.0000 & $7 \mathrm{E} 0.984$ & 十 & 0.37 & 0.00 & 22120.050 .334 & 4.18 & 30.015 & 0.0000 & $3 E 0.984$ \\
\hline$\triangle$ & 0.37 & 0.00 & 2120.050 .182$. & 2.480 .001 & 0.0001 & $6 \mathrm{E} 0.984$ & $*$ & 0.37 & 0.00 & 32120.050 .334 & 4.18 & 80.015 & 0.0001 & b 0.984 \\
\hline+ & 0.37 & 0.00 & 2120.050 .182$. & 2.480 .005 & 0.0001 & $6 \mathrm{E} 0.984$ & $-\infty$ & 0.37 & 0.00 & 32120.050 .334 & 4.18 & 80.045 & 0.0000 & BE 0.984 \\
\hline$*$ & 0.37 & 0.00 & 2120.050 .182 & 2.480 .015 & 0.0000 & $7 E 0.984$ & $\rightarrow$ & 0.37 & 0.00 & 2120.050 .334 & 4.18 & 80.060 & 0.0000 & BE 0.984 \\
\hline-4 & 0.37 & 0.00 & 2120.050 .182$. & 2.480 .045 & 0.0000 & $7 E 0.984$ & - & 0.37 & 0.00 & 32120.050 .662 & 2.48 & 30.015 & 0.0000 & $7 E 0.984$ \\
\hline$\nabla$ & 0.37 & 0.00 & 2120.050 .184 . & 4.180 .001 & 0.0000 & $8 \mathrm{E} 0.984$ & $\rightarrow$ & 0.37 & 0.00 & 22120.100 .182 & 2.48 & 0.015 & 0.0000 & $7 E 0.984$ \\
\hline 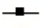 & 0.37 & 0.00 & 2120.050 .184$. & 4.180 .015 & 0.0000 & $8 \mathrm{E} 0.984$ & - & 0.37 & 0.00 & 32120.100 .332 & 2.48 & 80.015 & 0.0000 & $7 E 0.984$ \\
\hline$\rightarrow-$ & 0.37 & 0.00 & 2120.050 .332$. & 2.480 .001 & 0.0000 & 4 E 0.984 & $\rightarrow-$ & 0.37 & 0.00 & 32120.100 .662 & 2.48 & 30.015 & 0.0000 & $7 E 0.984$ \\
\hline 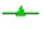 & 0.37 & 0.00 & 2120.050 .332 & 2.480 .001 & 0.0000 & $7 \mathrm{E} 0.984$ & $\rightarrow$ & 0.37 & 0.00 & 2120.150 .182 & 2.48 & 30.015 & 0.0000 & $7 E 0.984$ \\
\hline$\rightarrow-$ & 0.37 & 0.00 & 2120.050 .332$. & 2.480 .001 & 0.0001 & $6 \mathrm{E} 0.984$ & $\rightarrow$ & 0.37 & 0.00 & 32120.150 .332 & 2.48 & 30.015 & 0.0000 & $7 E 0.984$ \\
\hline$\rightarrow-$ & 0.37 & 0.00 & 2120.050 .332$. & 2.480 .005 & 0.0000 & $4 \mathrm{E} 0.984$ & $-\triangle$ & 0.37 & 0.00 & 32120.150 .662 & 2.48 & 30.015 & 0.0000 & $7 E 0.984$ \\
\hline$\rightarrow$ & 0.37 & 0.00 & 2120.050 .332 & 2.480 .005 & 0.0000 & $7 E 0.984$ & + & 0.37 & 0.00 & 19080.050 .332 & 2.48 & 80.001 & 0.0000 & $7 E 0.944$ \\
\hline$\triangle$ & 0.37 & 0.00 & 2120.050 .332$. & 2.480 .005 & 0.0001 & $6 \mathrm{E} 0.984$ & 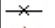 & 0.37 & 0.00 & 9080.050 .332 & 2.48 & 30.015 & 0.0000 & $7 E 0.944$ \\
\hline+ & 0.37 & 0.00 & 2120.050 .332 & 2.480 .010 & 0.0000 & $7 \mathrm{E} 0.984$ & $\rightarrow$ & 0.37 & 0.00 & 19080.100 .332 & 2.48 & 30.001 & 0.0000 & $7 E 0.944$ \\
\hline$\stackrel{x}{-}$ & 0.37 & 0.00 & 2120.050 .332$. & 2.480 .015 & 0.0000 & 7 E 0.984 & - & 0.37 & 0.00 & 19080.100 .332 & 2.48 & 30.015 & 0.0000 & $7 E 0.944$ \\
\hline$\rightarrow$ & 0.37 & 0.00 & 2120.050 .332$. & 2.480 .015 & 0.0001 & $6 \mathrm{E} 0.984$ & $\rightarrow-$ & 0.37 & 0.00 & 8080.050 .332 & 2.48 & 30.001 & 0.0000 & $7 \mathrm{E} 0.944$ \\
\hline$\nabla$ & 0.37 & 0.00 & 2120.050 .332$. & 2.480 .030 & 0.0000 & $7 \mathrm{E} 0.984$ & $\rightarrow$ & 0.37 & 0.00 & 80080.050 .332 & 2.48 & 30.015 & 0.0000 & $7 E 0.944$ \\
\hline$\rightarrow$ & 0.37 & 0.00 & 2120.050 .332$. & 2.480 .045 & 0.0000 & $7 \mathrm{E} 0.984$ & $\leftarrow$ & 0.37 & 0.00 & 88080.100 .332 & 2.48 & 30.001 & 0.0000 & $7 \mathrm{E} 0.944$ \\
\hline$\rightarrow-$ & 0.37 & 0.00 & 2120.050 .332$. & 2.480 .060 & 0.0000 & $7 \mathrm{E} 0.984$ & $\rightarrow$ & 0.37 & 0.00 & 88080.100 .332 & 2.48 & 30.015 & 0.0000 & $7 \mathrm{E} 0.944$ \\
\hline$\leftarrow$ & 0.37 & 0.00 & 2120.050 .334$. & 4.180 .000 & 0.0001 & $6 \mathrm{E} 0.984$ & $\rightarrow-$ & 0.37 & 0.00 & 95040.050 .332 & 2.48 & 80.015 & 0.0000 & $7 \mathrm{E} 0.940$ \\
\hline$\rightarrow$ & 0.37 & 0.00 & 2120.050 .334$. & 4.180 .001 & 0.0000 & $8 \mathrm{E} 0.984$ & $\rightarrow$ & 0.37 & 0.00 & 5040.100 .332 & 2.48 & 30.015 & 0.0000 & $7 \mathrm{E} 0.940$ \\
\hline$\rightarrow-$ & 0.37 & 0.00 & 2120.050 .334$. & 4.180 .001 & 0.0001 & $6 \mathrm{E} 0.984$ & $\triangle$ & 0.37 & 0.00 & 5080.050 .332 & 2.48 & 0.001 & 0.0000 & $7 \mathrm{E} 0.944$ \\
\hline$\rightarrow$ & 0.37 & 0.00 & 2120.050 .334$. & 4.180 .005 & 0.0000 & $8 \mathrm{E} 0.984$ & + & 0.37 & 0.00 & 5080.050 .332 & 2.48 & 0.015 & 0.0000 & 7 E 0.944 \\
\hline$\triangle$ & 0.37 & 0.00 & 2120.050 .334$. & 4.180 .005 & 00001 & $6 \mathrm{E} 0.984$ & $-*$ & 0.37 & 0.00 & 95080.100 .332 & 2.48 & 80.015 & 0.0000 & $7 \mathrm{E} 0.944$ \\
\hline
\end{tabular}

Figure E.19. Log-Log Plot of the Functional Relationship Between Cloud Height $\left(\mathrm{H}_{\mathrm{C}}\right)$ and Velocity (U) for Each Set of 15-in. Tank Test Conditions in the 2008 Data Set. Only velocities greater than or equal to the critical suspension velocity $\left(U \geq U_{C S}\right)$ are shown. Variables in the legend include $\mathrm{H}=$ head, $\mathrm{F}$ = vessel fill height $(\mathrm{m}), \mathrm{O}=$ number of outer nozzles operating, and $\mathrm{I}=$ number of inner nozzles operating. 


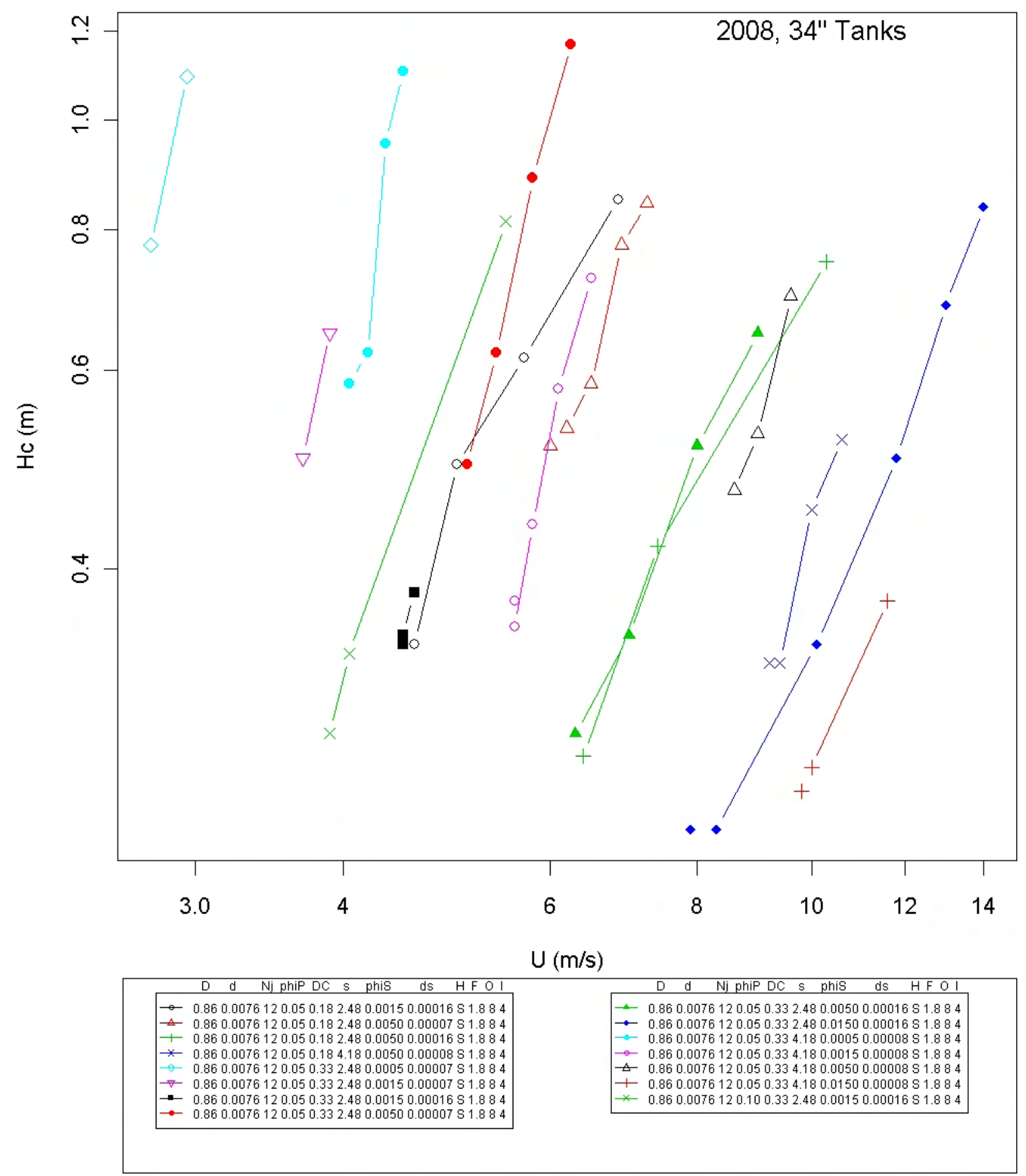

Figure E.20. Log-Log Plot of the Functional Relationship Between Cloud Height $\left(\mathrm{H}_{\mathrm{C}}\right)$ and Velocity (U) for Each Set of D = $0.860 \mathrm{~m}$ ( 34-in.) Tank Test Conditions in the 2008 Data Set. Only velocities greater than or equal to the critical suspension velocity ( $U \geq U_{C S}$ ) are shown. Variables in the legend include $\mathrm{H}=$ head, $\mathrm{F}$ = vessel fill height (m), $\mathrm{O}=$ number of outer nozzles operating, and I = number of inner nozzles operating. 


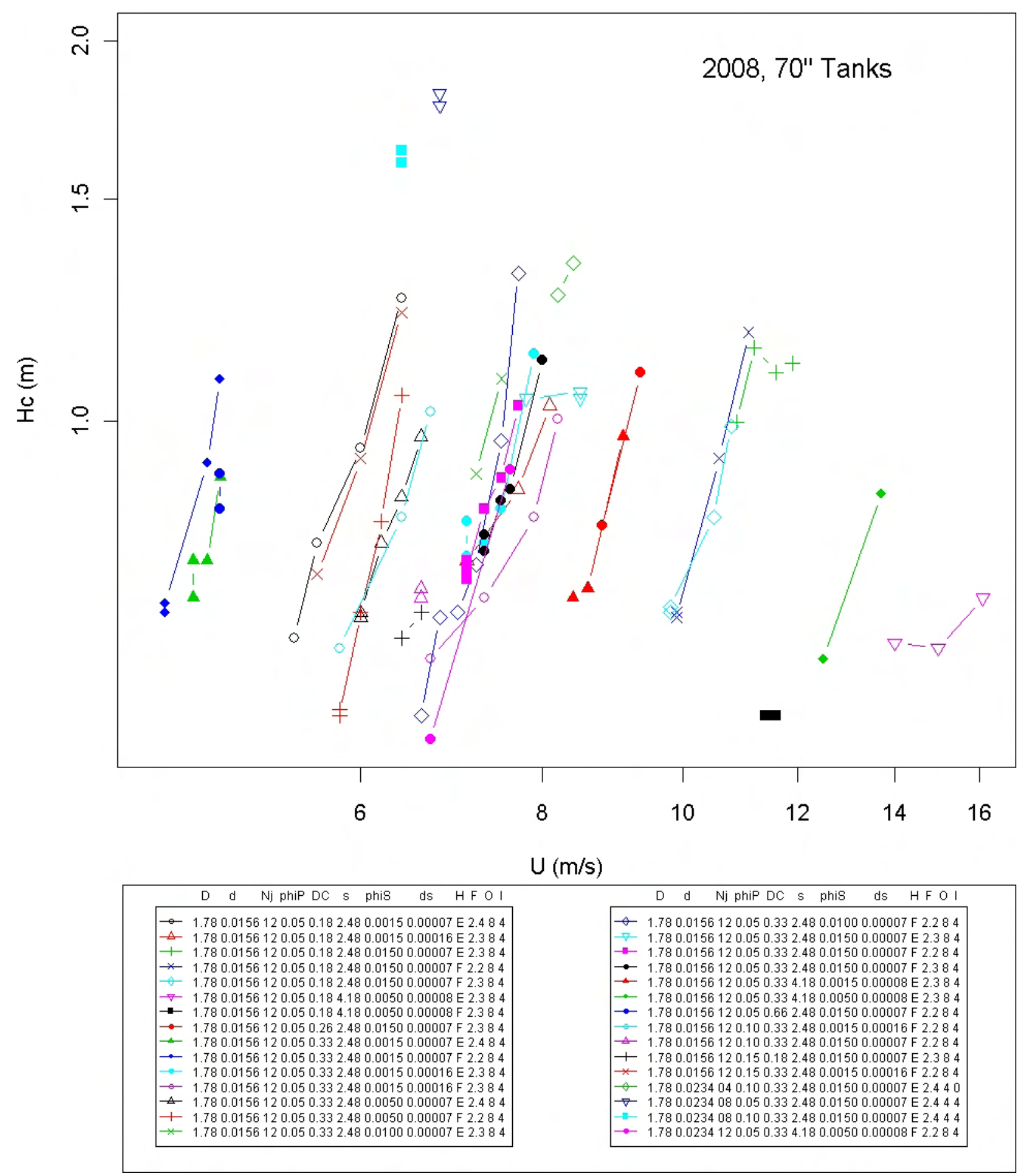

Figure E.21. Log-Log Plot of the Functional Relationship Between Cloud Height $\left(\mathrm{H}_{\mathrm{C}}\right)$ and Velocity (U) for Each Set of 70-in. Tank Test Conditions in the 2008 Data Set. Only velocities greater than or equal to the critical suspension velocity $\left(U \geq U_{C S}\right)$ are shown. Variables in the legend include $\mathrm{H}$ = head, $\mathrm{F}$ = vessel fill height $(\mathrm{m}), \mathrm{O}=$ number of outer nozzles operating, and $\mathrm{I}=$ number of inner nozzles operating. 
Figures E.22 to E.32 show functionality plots for cloud height at the critical suspension velocity $\left(\mathrm{H}_{\mathrm{CS}}\right)$ versus $\mathrm{D}, \mathrm{N}_{\mathrm{J}}, \mathrm{d}, \phi_{\mathrm{J}}, \phi_{\mathrm{p}}$, DC, $\mathrm{S}, \phi_{\mathrm{S}}, \mathrm{d}_{\mathrm{S}}, \mathrm{HS}$, and $\mathrm{U}_{\mathrm{T}}$ where these variables are defined in Table E.3. It was not possible to produce functionality plots for $\mathrm{H}_{\mathrm{C}}$ versus these test variables because cloud height observations were not made for specific velocity values for all tests. Thus there are no sets of variables (velocity and other test variables) with different sets of constant values for a given test variable on the $\mathrm{x}$-axis, and it was necessary to focus on functionality plots for $\mathrm{H}_{\mathrm{CS}}$ rather than $\mathrm{H}_{\mathrm{C}}$ for the test variables other than U.

The following observations are made regarding linearity and parallelism in the relationships for different sets of constant values of the remaining variables in each $\mathrm{H}_{\mathrm{CS}}$ functionality plot. The observations apply to the sets of conditions shown in each plot, and may or may not hold for other sets of conditions where there were not at least two data points to form a line segment.

- D (Figure E.22): Increasing D strongly increases $\mathrm{H}_{\mathrm{CS}}$ as expected. Most of the relationships are linear with similar slopes. However, significant curvature and differences in slope are seen for some cases. Note that the effects of D and HS are confounded in this plot, since including HS as a variable to define the groups would have resulted in no $\mathrm{D}=0.860$ data being plotted.

- $\mathrm{N}_{J}$ (Figure E.23): Increasing from 4 to 8 jets generally maintains or slightly increases $\mathrm{H}_{\mathrm{CS}}$, while increasing from 8 to 12 jets decreases $\mathrm{H}_{\mathrm{CS}}$. Curvature is apparent for several cases. Non-parallelism of slopes is also apparent, suggesting possible interactions with other variables.

- $\mathrm{d}$ (Figure E.24): The effect of $\mathrm{d}$ on $\mathrm{H}_{\mathrm{CS}}$ is relatively small, varying from weakly-positive to weaklynegative slopes. Curvature is weak for the three sets of conditions where it can be assessed.

- $\phi_{\mathrm{J}}$ (Figure E.25): The effect of $\phi_{\mathrm{J}}$ on $\mathrm{H}_{\mathrm{CS}}$ is relatively small, varying from weakly-positive to weakly-negative slopes. Curvature is weak for the three sets of conditions where it can be assessed.

- $\phi_{\mathrm{p}}$ (Figure E.26): The effect of $\phi_{\mathrm{p}}$ on $\mathrm{H}_{\mathrm{CS}}$ is relatively small for $\phi_{\mathrm{p}} \geq 0.05$, varying from weaklynegative to moderately-positive slopes. The relationships are roughly linear, having weak slopes varying around zero. However, two cases show weak curvature. There are only two cases with data for $\phi_{\mathrm{p}}$ increasing from 0.03 to 0.05 , with negligible effects on $\mathrm{H}_{\mathrm{CS}}$.

- DC (Figure E.27): When DC increases from 0.18 to $~ 0.33, \mathrm{H}_{\mathrm{CS}}$ generally has slopes that range from slightly negative to moderately positive. Hence, there is evidence of interactive effects of DC and other variables on $\mathrm{H}_{\mathrm{CS}}$. There are less data in the approximate range of $0.33<\mathrm{DC} \leq 0.66$, with $\mathrm{H}_{\mathrm{CS}}$ decreasing or increasing slightly over this range.

- $\phi_{\mathrm{S}}$ (Figure E.28): The majority of test data are for $\phi_{\mathrm{S}} \leq 0.015$, where increasing $\phi_{\mathrm{S}}$ moderately decreases $\mathrm{H}_{\mathrm{CS}}$ for most cases. For the three cases with data $\phi_{\mathrm{S}}>0.015$, the relationship with $\mathrm{H}_{\mathrm{CS}}$ flattens out or increases. For two cases, this tendency to increase $\mathrm{H}_{\mathrm{CS}}$ begins at $\phi_{\mathrm{S}} \sim 0.005$.

- $\mathrm{d}_{\mathrm{s}}$ (Figure E.29): Increasing the median solids particle size from $\sim 0.00007$ to $\sim 0.00016$ sometimes increases and sometimes decreases $\mathrm{H}_{\mathrm{CS}}$. Hence, there may be an interactive effect between $\mathrm{d}_{\mathrm{S}}$ and at least one other variable. For the two cases with data for $\mathrm{d}_{\mathrm{S}}$ increasing from $\sim 0.00004$ to $\sim 0.00007$, $\mathrm{H}_{\mathrm{CS}}$ decreased significantly. These two cases had strong curvature over the tested range of $\mathrm{d}_{\mathrm{s}}$. For the one case where $\mathrm{d}_{\mathrm{S}}$ ranged from $\sim 0.00018$ to $\sim 0.00077$, the positive slope was within the range of slopes for the other cases with smaller $\mathrm{d}_{\mathrm{S}}$ values. 


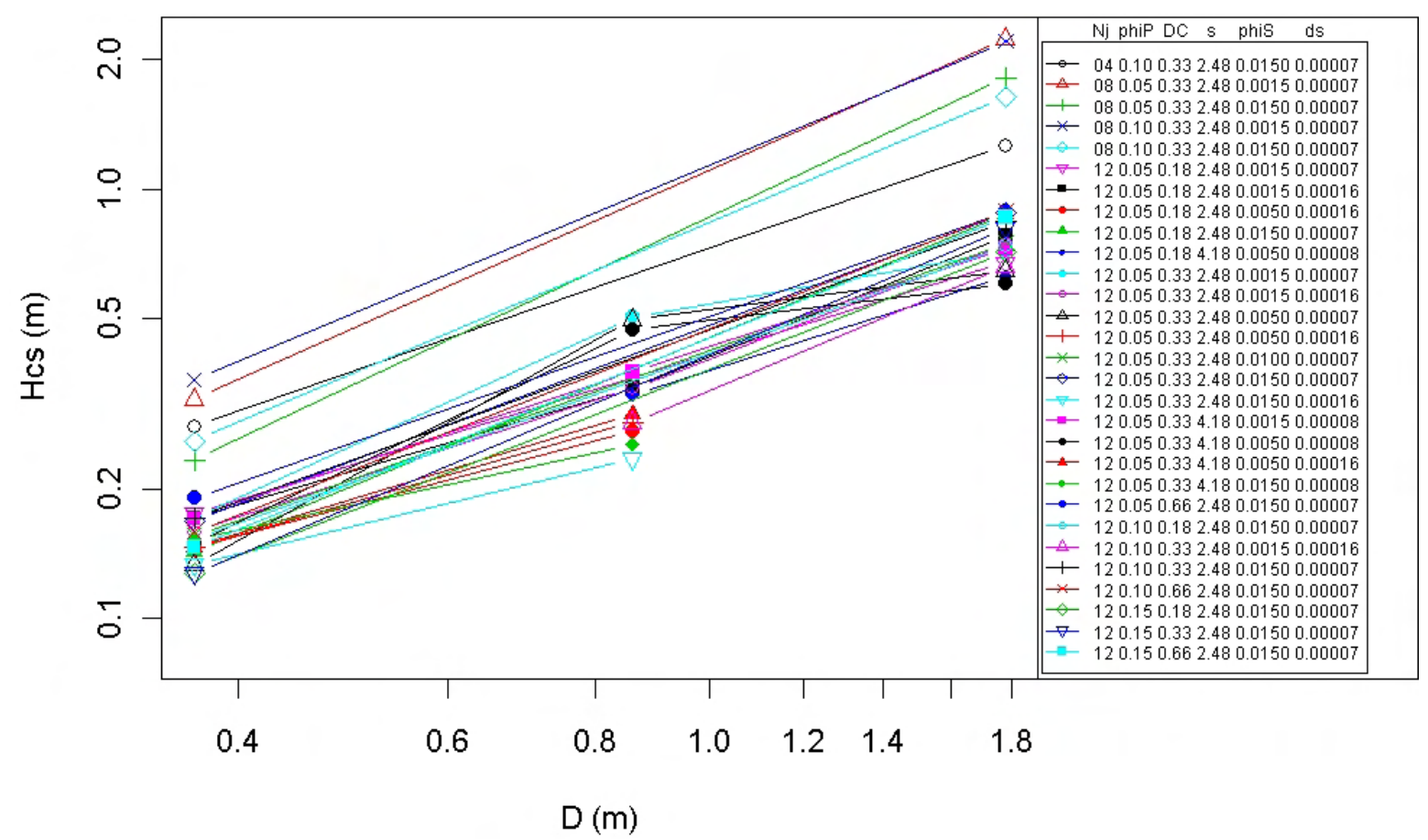

Figure E.22. Log-Log Plot of Functional Relationship Between Cloud Height at Critical Suspension Velocity $\left(\mathrm{H}_{\mathrm{CS}}\right)$ and Tank Diameter (D) for Constant Sets of Values of Other Test

Variables. The head shape (HS) variable was not used to define the groups, otherwise no $\mathrm{D}=0.860$ data would have plotted (since that was the only test tank with a spherical head shape). Hence, the effect of head shape as well as tank diameter is shown in the plot.

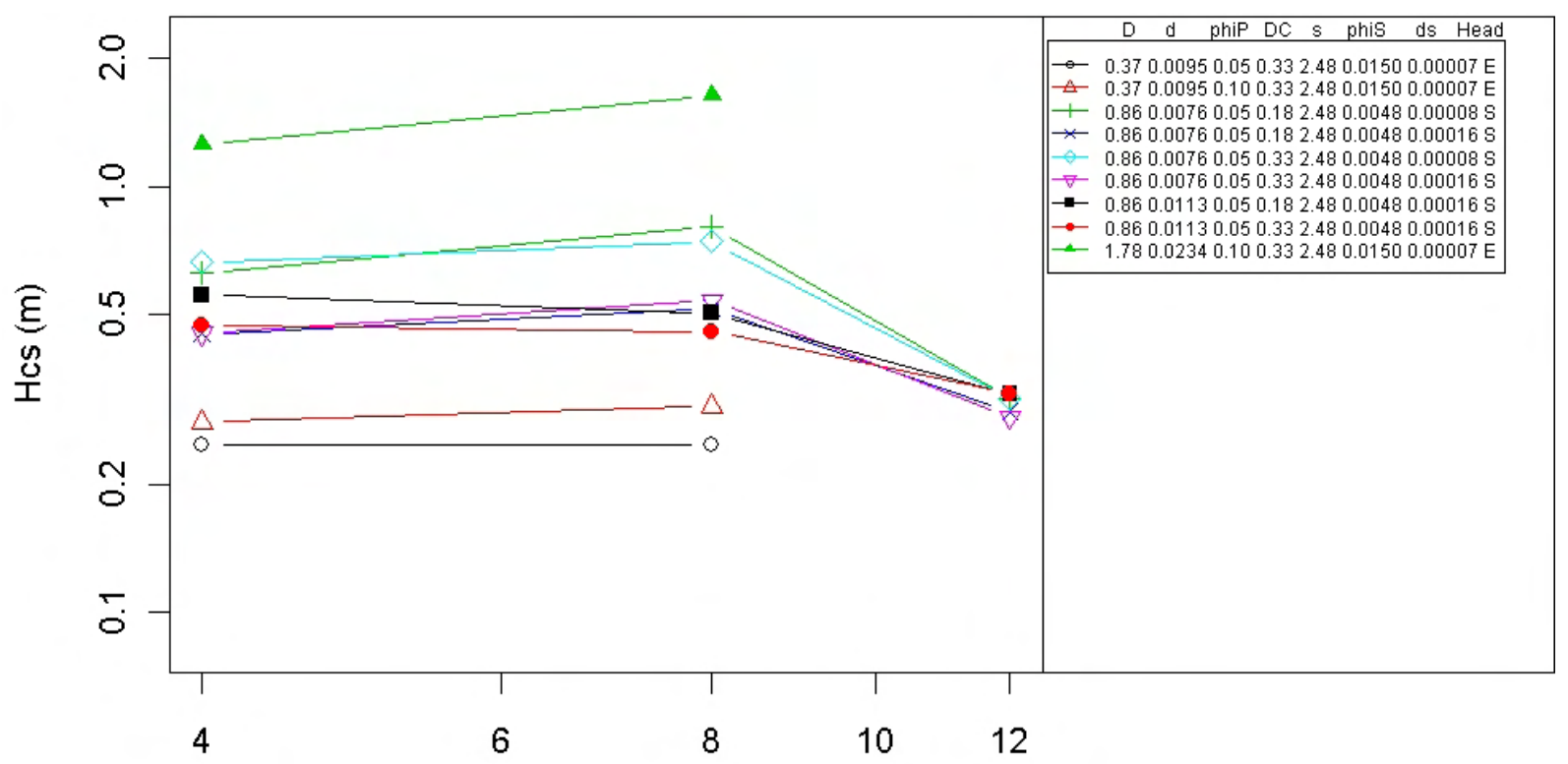

$\mathrm{Nj}$

Figure E.23. Log-Log Plot of Functional Relationship Between Cloud Height at Critical Suspension Velocity $\left(\mathrm{H}_{\mathrm{CS}}\right)$ and Number of Pulse Jets $\left(\mathrm{N}_{\mathrm{J}}\right)$ for Constant Sets of Values of Other Test Variables 


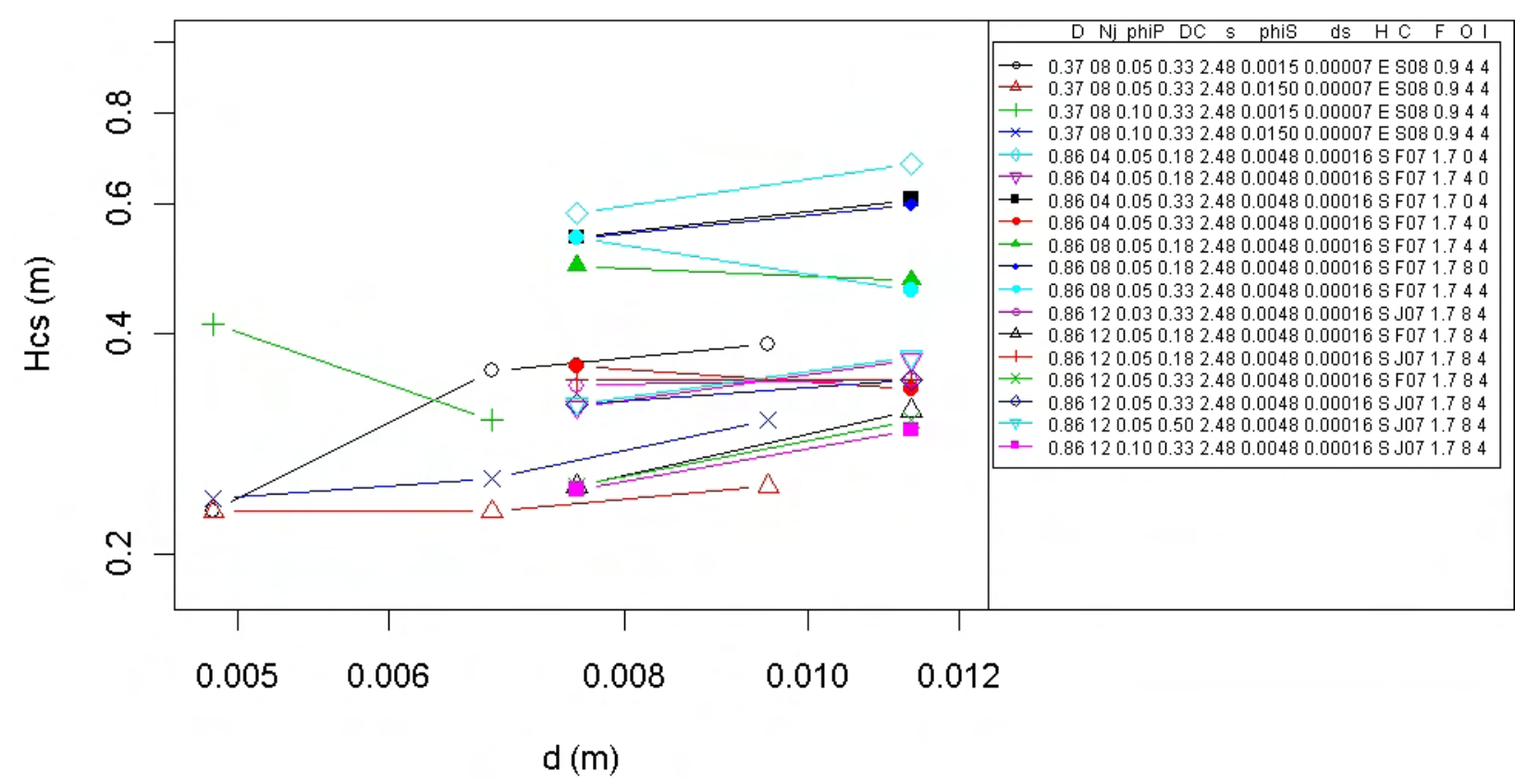

Figure E.24. Log-Log Plot of Functional Relationship Between Cloud Height at Critical Suspension Velocity $\left(\mathrm{H}_{\mathrm{CS}}\right)$ and Jet Nozzle Diameter (d) for Constant Sets of Values of Other Test Variables. Variables in the legend include $\mathrm{H}=$ head, $\mathrm{C}=$ test campaign, $\mathrm{F}=$ vessel fill height $(\mathrm{m}), \mathrm{O}=$ number of outer nozzles operating, and $\mathrm{I}$ = number of inner nozzles operating.

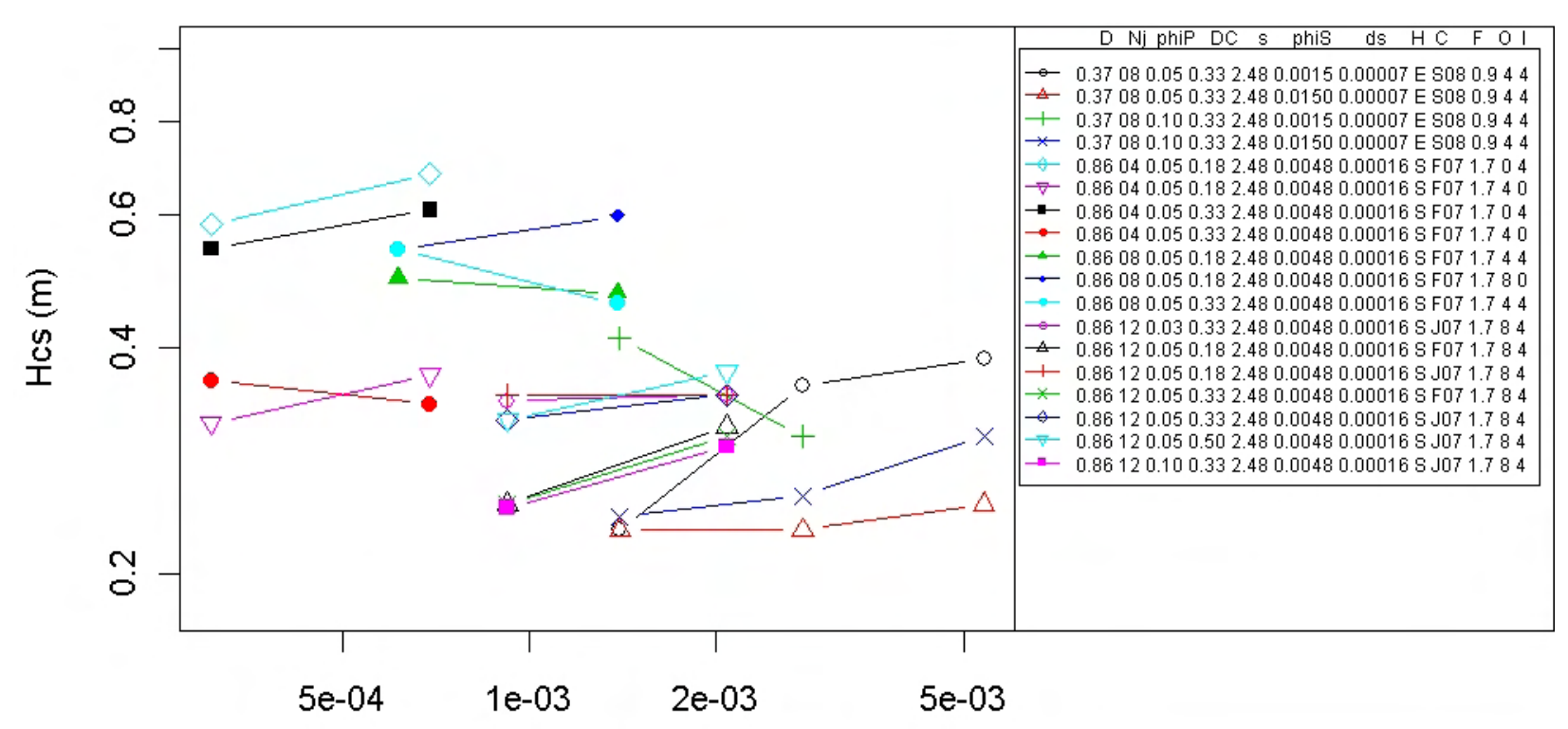

phiJ

Figure E.25. Log-Log Plot of the Functional Relationship Between Cloud Height at Critical Suspension Velocity $\left(\mathrm{H}_{\mathrm{CS}}\right)$ and Jet Density $\left(\phi_{\mathrm{J}}\right)$ for Constant Sets of Values of Other Test Variables. Variables in the legend include $\mathrm{H}=$ head, $\mathrm{C}$ = test campaign, $\mathrm{F}=$ vessel fill height $(\mathrm{m})$, $\mathrm{O}=$ number of outer nozzles operating, and $\mathrm{I}=$ number of inner nozzles operating. 


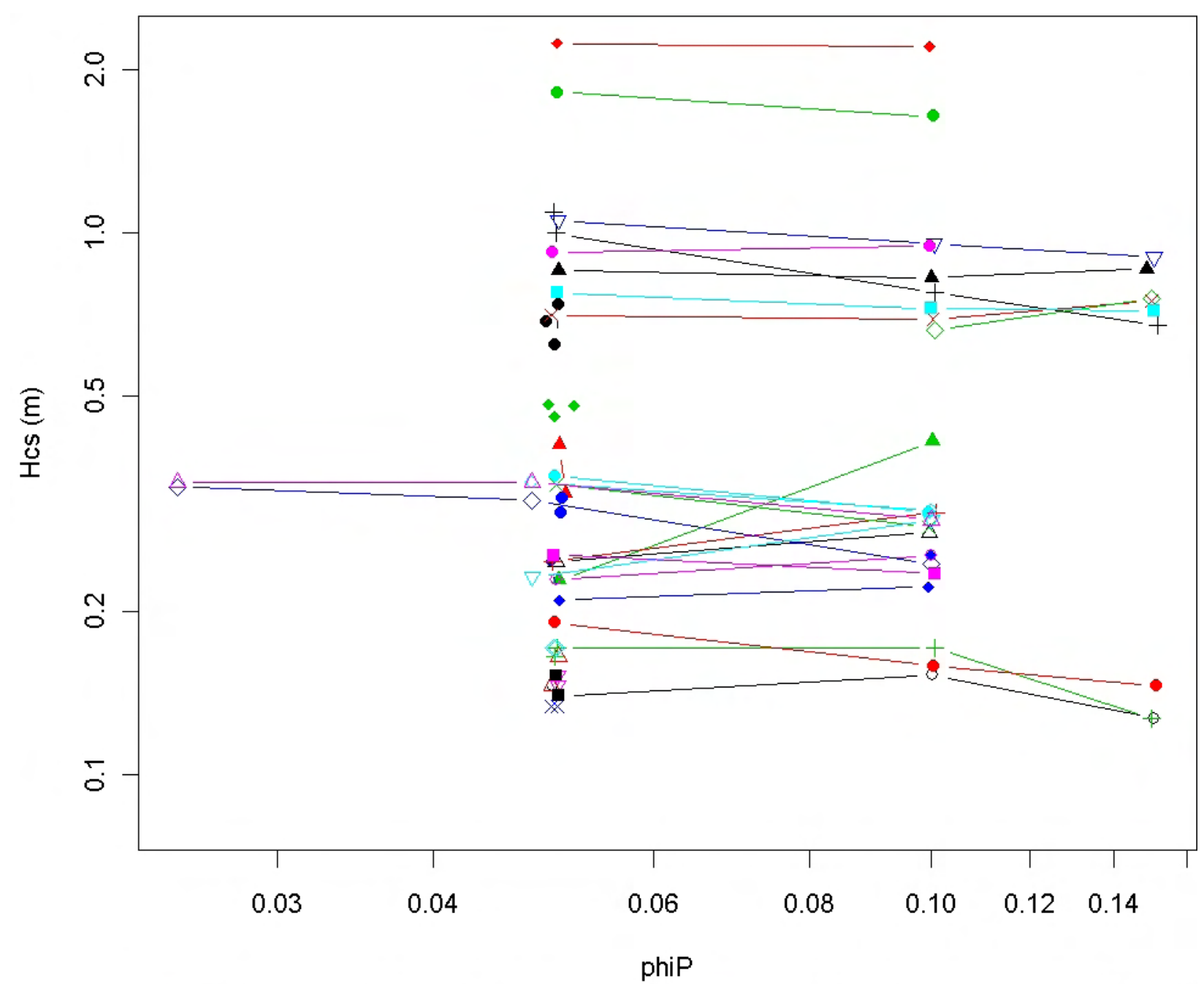

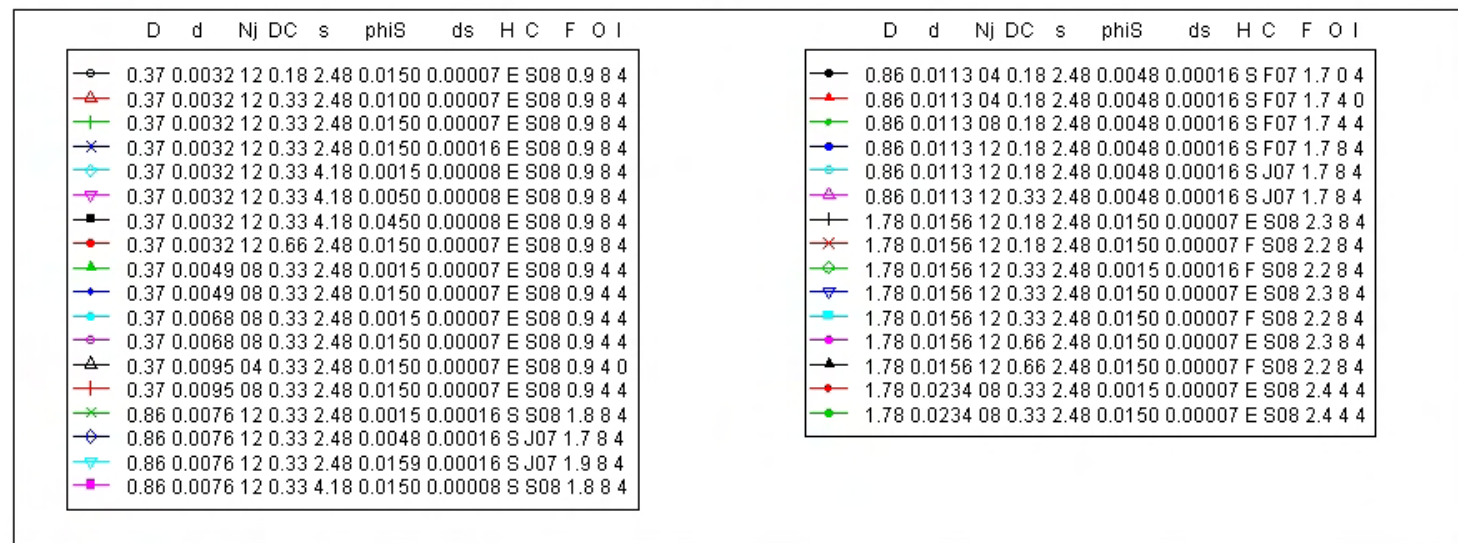

Figure E.26. Log-Log Plot of Functional Relationship Between Cloud Height at Critical Suspension Velocity $\left(\mathrm{H}_{\mathrm{CS}}\right)$ and Pulse Volume Fraction $\left(\phi_{\mathrm{p}}\right)$ for Constant Sets of Values of Other Test

Variables. Variables in the legend include $\mathrm{H}=$ head, $\mathrm{C}=$ test campaign, $\mathrm{F}=$ vessel fill height (m), $\mathrm{O}=$ number of outer nozzles operating, and $\mathrm{I}$ = number of inner nozzles operating. 


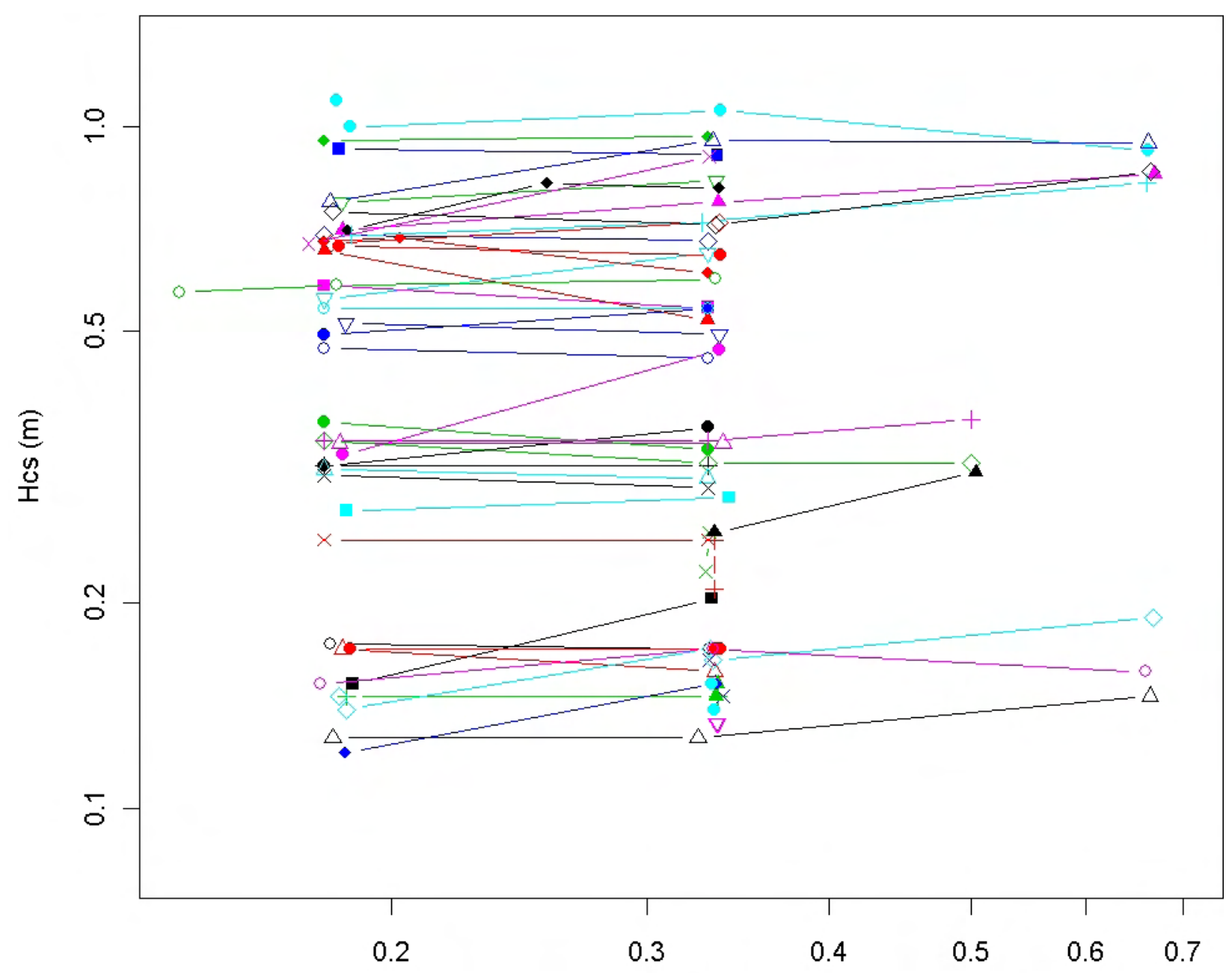

DC

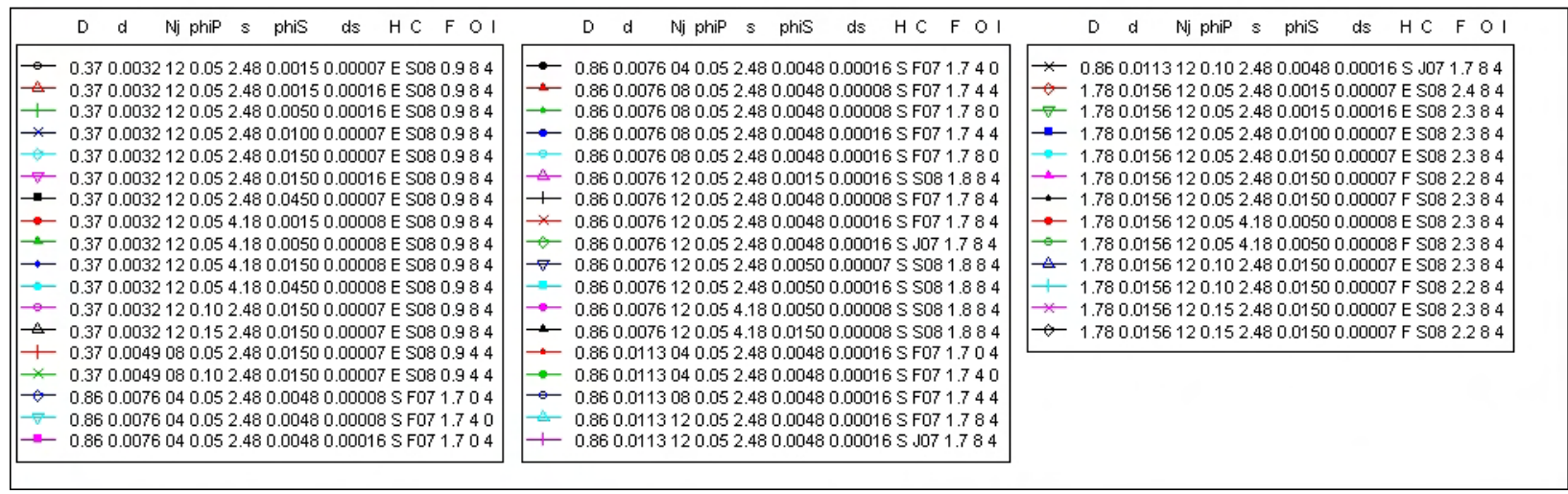

Figure E.27. Log-Log Plot of the Functional Relationship Between Cloud Height at Critical Suspension Velocity $\left(\mathrm{H}_{\mathrm{CS}}\right)$ and Duty Cycle (DC) for Constant Sets of Values of Other Test Variables. Variables in the legend include $\mathrm{H}=$ head, $\mathrm{C}$ = test campaign, $\mathrm{F}=$ vessel fill height (m), $\mathrm{O}=$ number of outer nozzles operating, and $\mathrm{I}=$ number of inner nozzles operating. 


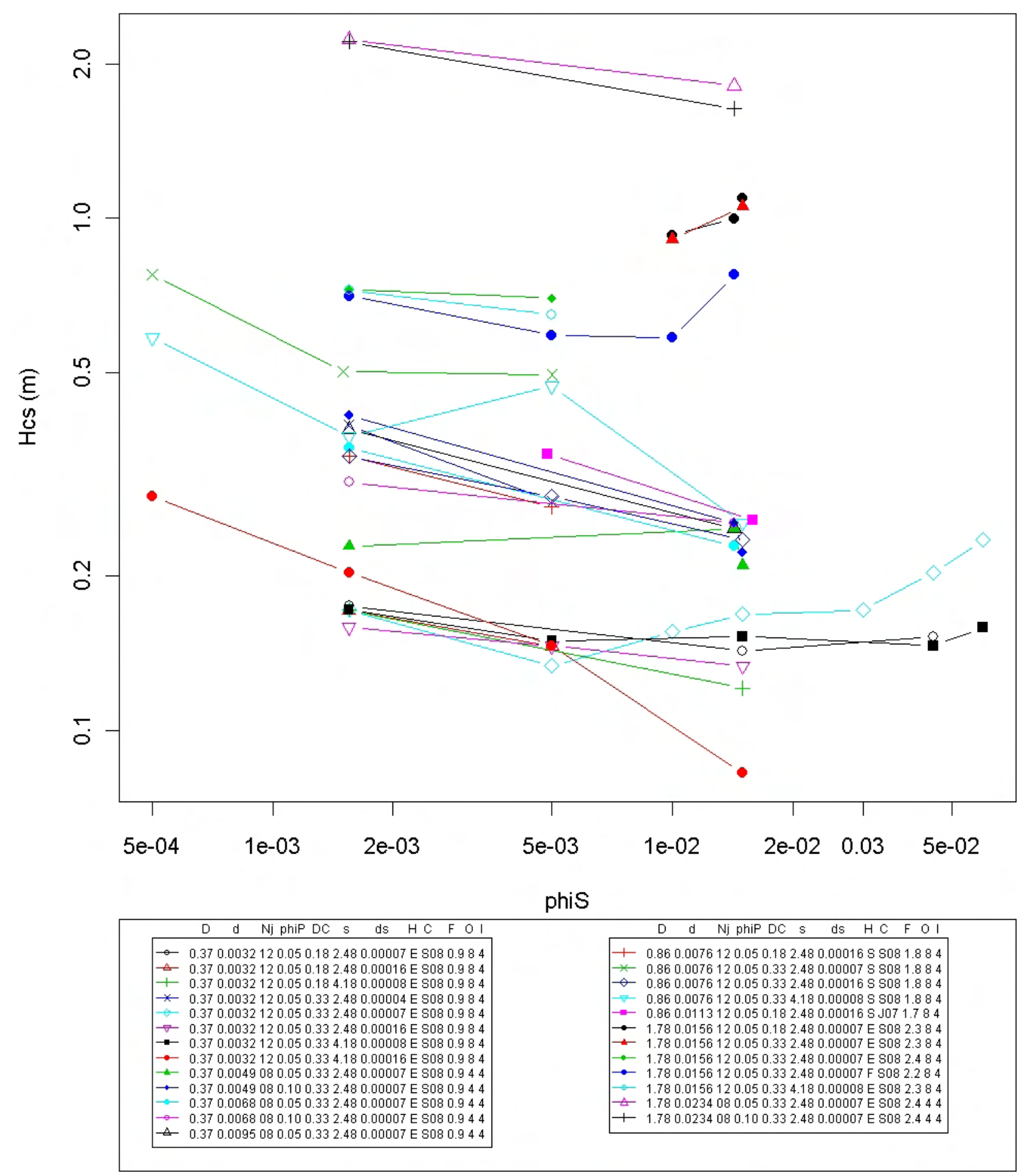

Figure E.28. Log-Log Plot of Functional Relationship Between Cloud Height at Critical Suspension Velocity $\left(\mathrm{H}_{\mathrm{CS}}\right)$ and Solids Volume Fraction $\left(\phi_{\mathrm{S}}\right)$ for Constant Sets of Values of Other Test Variables. Variables in the legend include $\mathrm{H}=$ head, $\mathrm{C}=$ test campaign, $\mathrm{F}=$ vessel fill height $(\mathrm{m}), \mathrm{O}=$ number of outer nozzles operating, and $\mathrm{I}=$ number of inner nozzles operating. 


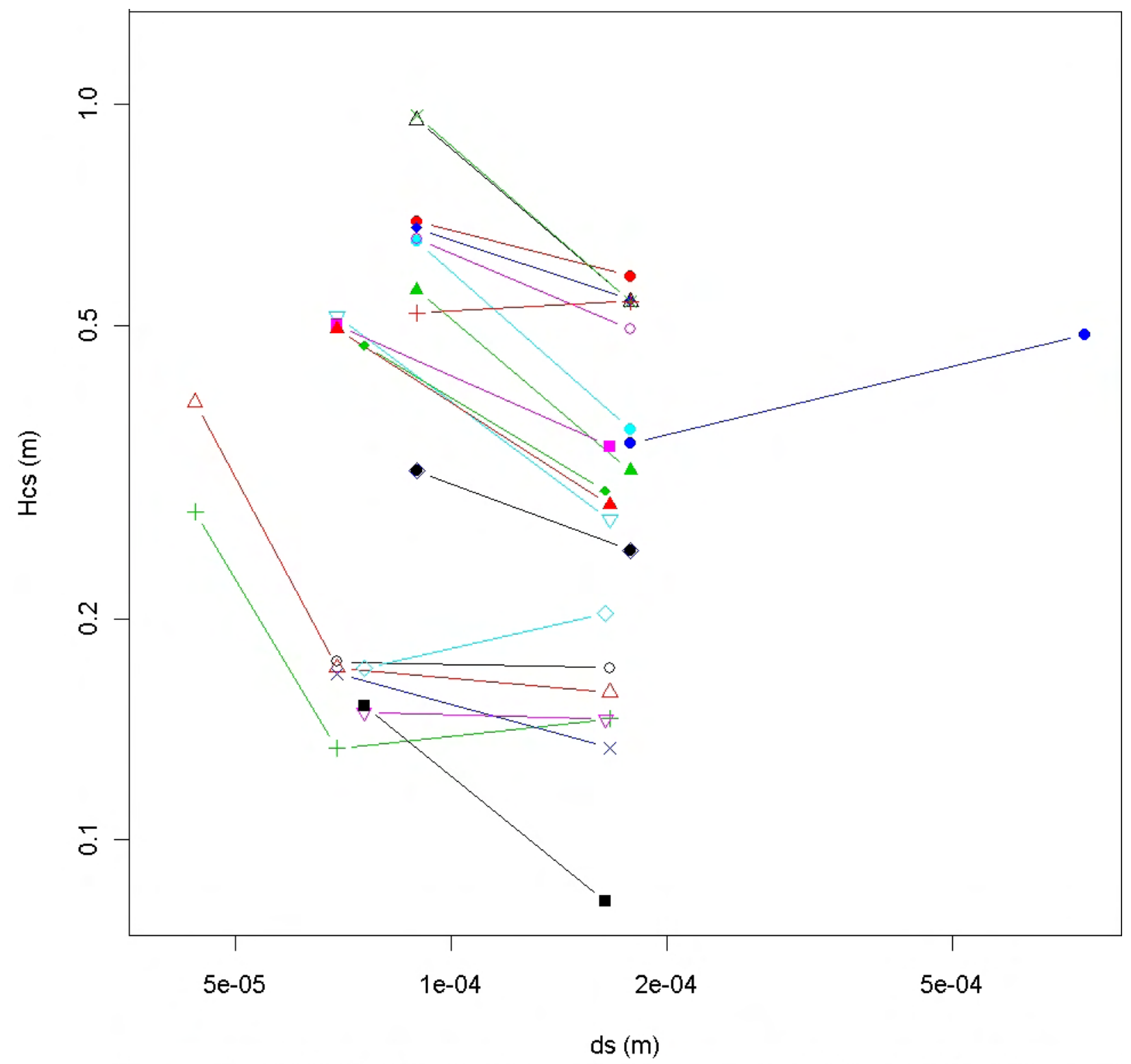

\begin{tabular}{|c|c|}
\hline 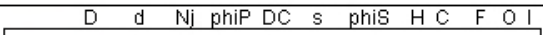 & 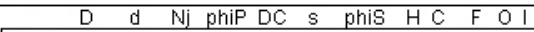 \\
\hline$\rightarrow 0.370 .0032120 .050 .182 .480 .0015$ E 5080.984 & $\rightarrow \quad 0.860 .0076040 .050 .332 .480 .0048 \mathrm{SF} 071.740$ \\
\hline$\triangle \quad 0.370 .0032120 .050 .332 .480 .0015 E S 080.984$ & $-\quad 0.860 .0076080 .050 .182 .480 .0048 \mathrm{SF}$ F07 1.744 \\
\hline$+\quad 0.370 .0032120 .050 .332 .480 .0050$ E S08 0.984 & $\triangle \quad 0.860 .0076080 .050 .182 .480 .0048$ SF07 1.780 \\
\hline$\star \quad 0.370 .0032120 .050 .332 .480 .0150$ E S08 0.984 & $+\quad 0.860 .0076080 .050 .332 .480 .0048 \mathrm{SF} 071.744$ \\
\hline$-\quad 0.370 .0032120 .050 .334 .180 .0015 E$ S08 0.984 & $+\quad 0.860 .0076080 .050 .332 .480 .0048$ S F07 1.780 \\
\hline$\rightarrow \quad 0.370 .0032120 .050 .334 .180 .0050$ E S08 0.984 & $\triangle-0.860 .0076120 .050 .182 .480 .0048 \mathrm{SF} F 71.784$ \\
\hline$\rightarrow \quad 0.370 .0032120 .050 .334 .180 .0150$ E S08 0.984 & $-\bar{\nabla} \quad 0.860 .0076120 .050 .182 .480 .0050 \mathrm{~S} S 081.884$ \\
\hline$\rightarrow \quad 0.860 .0076040 .050 .182 .480 .0048 \mathrm{SF} F 71.704$ & $=0.860 .0076120 .050 .332 .480 .0015 S 5081.884$ \\
\hline$\rightarrow \quad 0.860 .0076040 .050 .182 .480 .0048 \mathrm{SF} 071.740$ & $\rightarrow-0.860 .0076120 .050 .332 .480 .0048 \mathrm{SF} F 71.784$ \\
\hline$\rightarrow \quad 0.860 .0076040 .050 .332 .480 .0048 \mathrm{SF} 071.704$ & $\leftarrow \quad 0.860 .0076120 .050 .332 .480 .0050 \mathrm{~S} 5081.884$ \\
\hline & 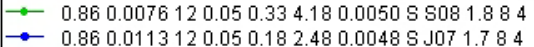 \\
\hline
\end{tabular}

Figure E.29. Log-Log Plot of Functional Relationship Between Cloud Height at Critical Suspension Velocity $\left(\mathrm{H}_{\mathrm{CS}}\right)$ and Solids Particle Diameter $\left(\mathrm{d}_{\mathrm{S}}=\mathrm{d}_{50}\right)$ for Constant Sets of Values of Other Test Variables. Variables in the legend include $\mathrm{H}=$ head, $\mathrm{C}=$ test campaign, $\mathrm{F}=$ vessel fill height (m), $\mathrm{O}=$ number of outer nozzles operating, and $\mathrm{I}=$ number of inner nozzles operating. 


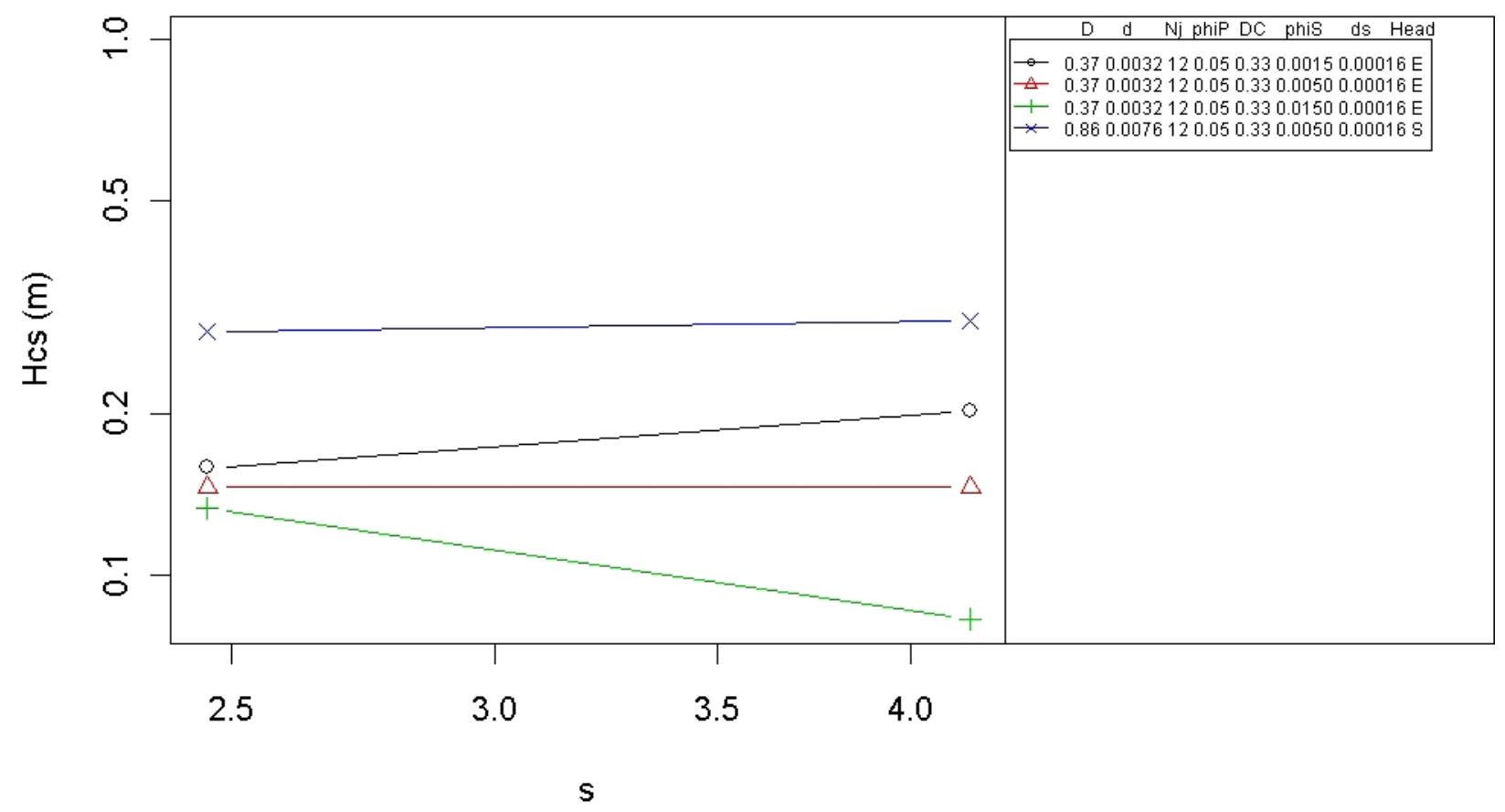

Figure E.30. Log-Log Plot of Functional Relationship Between Cloud Height at Critical Suspension Velocity $\left(\mathrm{H}_{\mathrm{CS}}\right)$ and Density Ratio (s) for Constant Sets of Values of Other Test Variables

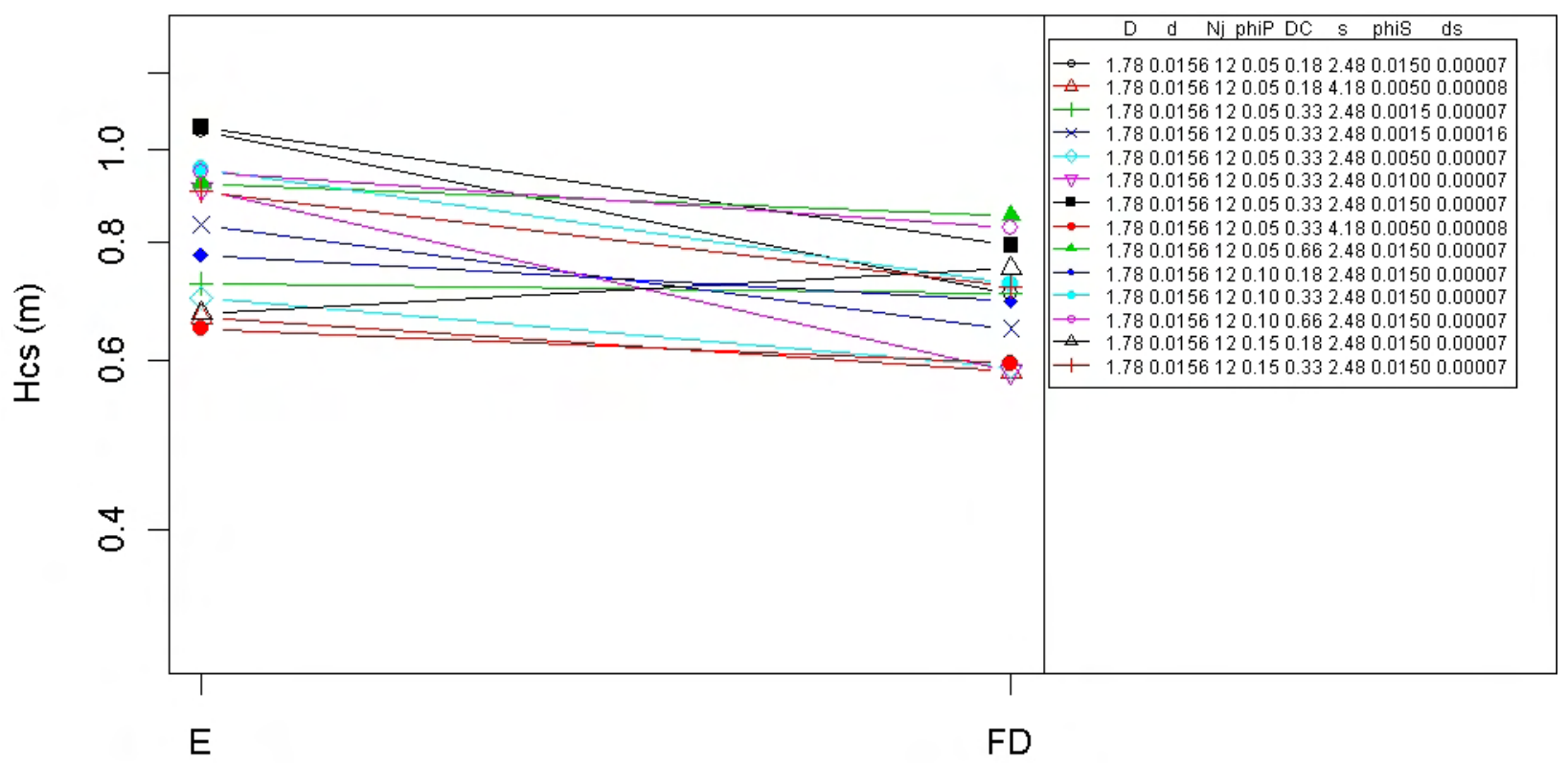

Head

Figure E.31. Log-Categorical Plot of the Functional Relationship Between Cloud Height at Critical Suspension Velocity $\left(\mathrm{H}_{\mathrm{CS}}\right)$ and Head Shape (HS) for Constant Sets of Values of Other Test Variables. No data are plotted for the spherical head shape (S) because it was only used in the $\mathrm{D}=0.860 \mathrm{~m}(\sim 34$-in.) tank. 


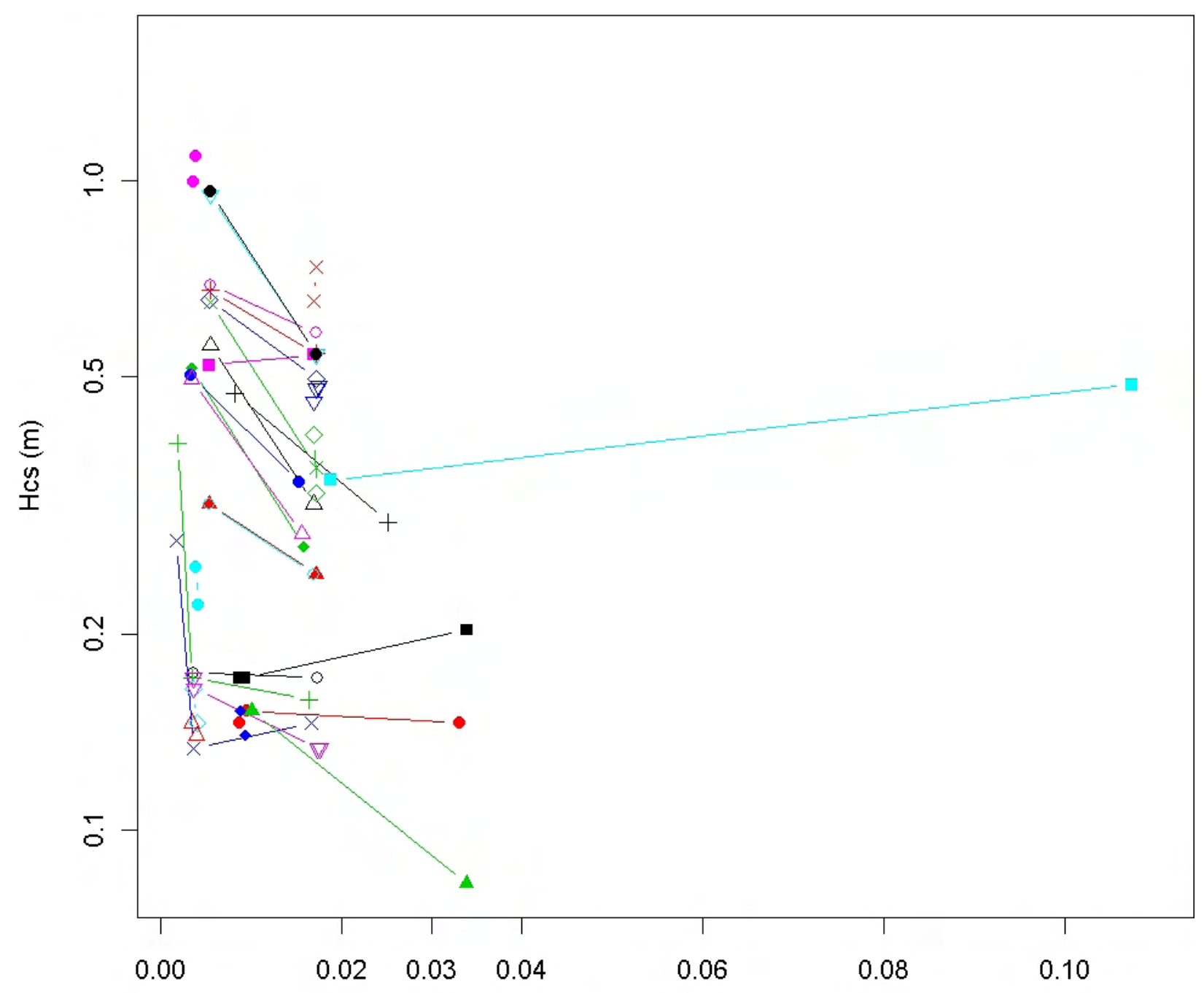

Ut $(\mathrm{m} / \mathrm{s})$

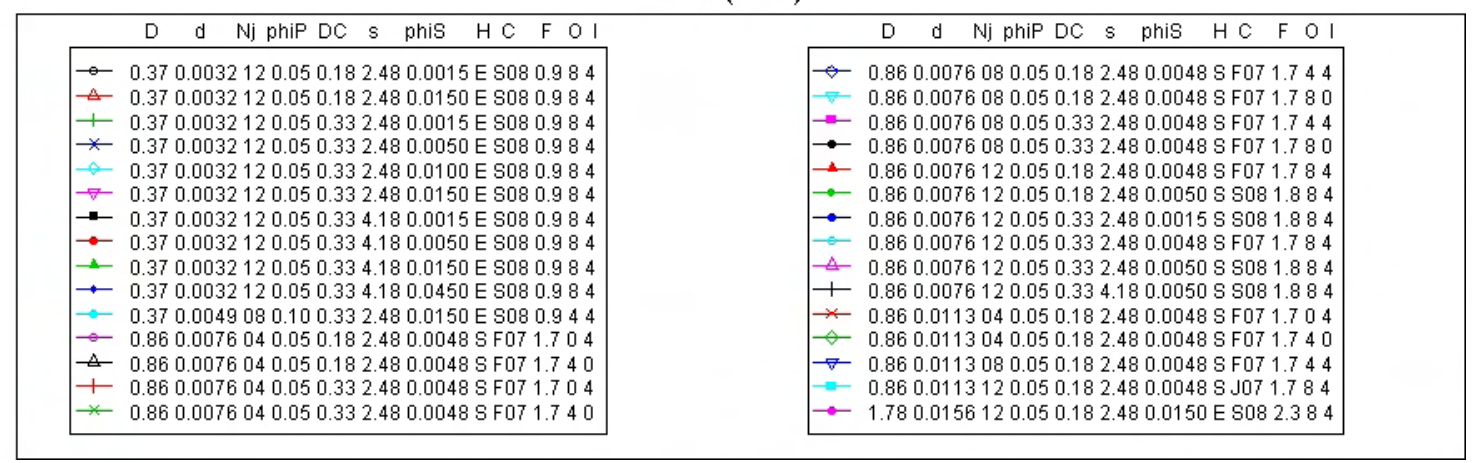

Figure E.32. Log-Log Plot of Functional Relationship Between Cloud Height at Critical Suspension Velocity $\left(\mathrm{H}_{\mathrm{CS}}\right)$ and Unhindered Terminal Settling Velocity $\left(\mathrm{U}_{\mathrm{T}}\right)$ for Constant Sets of Values of Other Test Variables. Because $U_{T}$ is calculated as a function of $d_{S}$ and $(s-1), d_{S}$ was not used to define the plotting sets in the legend. Hence, the effects of $U_{T}$ and $d_{S}$ are confounded in the plot. 
- s (Figure E.30): Increasing s tends to weakly affect $\mathrm{H}_{\mathrm{CS}}$, with slopes ranging from slightly positive to moderately negative. Hence, there is an indication of possible interactive effects of $s$ and other variables on $\mathrm{H}_{\mathrm{CS}}$. Only having data for four conditions in this plot limits the general conclusions that can be made.

- HS (Figure E.31): The flange-and-dish (FD) head shape tends to yield smaller $\mathrm{H}_{\mathrm{CS}}$ values than the elliptical (E) head shape. See Section E.2.4 for additional discussion. No data are plotted for the spherical (S) head shape, because that shape was only used in tests with the $\mathrm{D}=0.860 \mathrm{~m}$ ( 34-in.) tank, and thus there are no sets of conditions with values for E, FD, and S head shapes.

- $\mathrm{U}_{\mathrm{T}}$ (Figure E.32): Increasing $\mathrm{U}_{\mathrm{T}}$ tends to decrease $\mathrm{H}_{\mathrm{CS}}$, except for a couple of cases. The rate of decrease in $\mathrm{H}_{\mathrm{CS}}$ appears to decrease as $\mathrm{U}_{\mathrm{T}}$ increases, with even the possibility of $\mathrm{H}_{\mathrm{CS}}$ increasing after initial decreases with increasing $\mathrm{U}_{\mathrm{T}}$. For $\mathrm{U}_{\mathrm{T}}$ up to $\sim 0.035$, the slopes vary enough to suggest possible interactive effects with other variables. However, because $U_{\mathrm{T}}$ is calculated as a function of $\mathrm{d}_{\mathrm{S}}$ and ( $\mathrm{s}-1$, the $\mathrm{d}_{\mathrm{s}}$ variable was not used in the plotting groups shown in the legend of the figure. Hence, the effects of $\mathrm{U}_{\mathrm{T}}$ and $\mathrm{d}_{\mathrm{S}}$ on $\mathrm{H}_{\mathrm{CS}}$ are confounded, and any statements made here may be as much due to $d_{\mathrm{S}}$ effects as $\mathrm{U}_{\mathrm{T}}$ effects on $\mathrm{H}_{\mathrm{CS}}$.

These observations and the functionality plots on which they are based serve as a basis for assessing multiple-regression models developed for $\mathrm{H}_{\mathrm{C}}$ in Section F.3, Appendix F.

\section{E.2.4 Additional Investigation of Head Shape Effect}

The functionality plots for $\mathrm{U}_{\mathrm{CS}}$ versus $\mathrm{HS}$ and $\mathrm{H}_{\mathrm{CS}}$ versus $\mathrm{HS}$ suggest that $\mathrm{U}_{\mathrm{CS}}$ and $\mathrm{H}_{\mathrm{CS}}$ values tended to be smaller for FD heads than for $\mathrm{E}$ heads in 70-in. tank tests. However, it was only in 70-in. tank tests that the two head shapes were tested. Preliminary model development work with the 2008 data indicated that HS did not have statistically significant effects in predicting $\mathrm{U}_{\mathrm{CS}}$ or $\mathrm{H}_{\mathrm{CS}}$. Hence, additional investigations were undertaken. However, the results (tables and figures) in this subsection are for information purposes only.

Table E.4 summarizes the $\mathrm{U}_{\mathrm{CS}}$ and $\mathrm{H}_{\mathrm{CS}}$ data values from 2008 testing with the 70 -in. tank having $\mathrm{E}$ and FD heads. Ratios of FD to $E$ results for $\mathrm{U}_{\mathrm{CS}}$ and $\mathrm{H}_{\mathrm{CS}}$ are shown in the last two columns of Table E.4. For $\mathrm{U}_{\mathrm{CS}}$, all FD/E ratios are less than one except for Row \#8 (=1.00) and Row \#12 (1.06). For $\mathrm{H}_{\mathrm{CS}}$, all $\mathrm{FD} / \mathrm{E}$ ratios are less than one except for Row \#12 (=1.11). The FD/E ratios for $\mathrm{U}_{\mathrm{CS}}$ appear to possibly depend on the simulant, with the two lowest ratios $(0.81$ and 0.85$)$ for simulant s2d2, and ratios ranging from 0.88 to 1.06 for simulants s1d2 and s1d1. However, no such dependence is apparent for FD/E ratios for $\mathrm{H}_{\mathrm{CS}}$.

Figures E.33 to E.46 contain plots showing values of cloud height $\left(\mathrm{H}_{\mathrm{C}}\right.$, in meters) against target velocity $\left(\mathrm{U}, \mathrm{m} / \mathrm{s}\right.$ ) for cases where $\mathrm{U}$ is greater than or equal to the corresponding $\mathrm{U}_{\mathrm{Cs}}$ value. The plots were created for the 14 cases in Table E.4 that contain $\mathrm{H}_{\mathrm{C}}$ and $\mathrm{U}$ data for 70 -in.-diameter tanks with both $\mathrm{E}$ and FD head shapes. In each plot, all other test variables in the 2008 testing campaign remained constant. The plots are useful in assessing the differences that exist in $\mathrm{H}_{\mathrm{C}}$ as a function of $\mathrm{U}$ for the two different head shapes if all other variables were kept constant. Many of the plots lack sufficient data to make any clear determination if or how the $\mathrm{H}_{\mathrm{C}}$ versus $\mathrm{U}$ data differ for $\mathrm{E}$ and FD head shapes over the 14 cases. 
The objective of creating the plots in Figures E.33 to E.46 was to help determine if a simple empirical model or a single summary statistic (a ratio or difference) could be found that explained the difference in $\mathrm{H}_{\mathrm{C}}$ results for $\mathrm{E}$ and FD head shapes as a function of the other test variables. The lack of data, however, makes it difficult to visualize a consistent pattern and thus difficult to summarize the $\mathrm{H}_{\mathrm{C}}$ results for $\mathrm{E}$ vs. FD heads in a simple manner. For example, $\mathrm{U}_{\mathrm{CS}}$ and $\mathrm{H}_{\mathrm{CS}}$ values for $70 \mathrm{~F}$ tests tended to be less than the values for 70E tests, as shown in Table E.4. However, Figures E.33, E.34 and E.46 show $\mathrm{H}_{\mathrm{C}}$ results that are smaller for 70E than 70F tests, and this is order is suggested by other figures with less data. On the other hand, Figures E.35 and E.44 show $\mathrm{H}_{\mathrm{C}}$ results that are smaller for $70 \mathrm{~F}$ tests than $70 \mathrm{E}$ tests. This is also suggested by other figures with fewer data. Hence, no clear conclusions can be made about the effect of $\mathrm{E}$ versus FD differences in tank-head shape on $\mathrm{H}_{\mathrm{C}}$ results.

Table E.4. Comparison of $\mathrm{U}_{\mathrm{CS}}$ and $\mathrm{H}_{\mathrm{CS}}$ Data from 2008 Tests with Two Head Shapes (E and FD) on 70-in. Tanks. The values for $\mathrm{d}=0.613 \mathrm{~m}\left(\phi_{\mathrm{J}}=0.0009203\right)$ were constant for all data in the table.

\begin{tabular}{|c|c|c|c|c|c|c|c|c|c|c|c|c|}
\hline $\begin{array}{c}\text { Row } \\
\#\end{array}$ & Simulant & $\mathrm{s}$ & $\begin{array}{c}\mathrm{d}_{\mathrm{S}}=\mathrm{d}_{50} \\
(\mathrm{~m})\end{array}$ & $\phi_{\mathrm{p}}{ }^{(\mathrm{a})}$ & $\phi_{\mathrm{S}}$ & $\mathrm{DC}^{(\mathrm{a})}$ & $\begin{array}{l}U_{C S} E \\
(\mathrm{~m} / \mathrm{s})\end{array}$ & $\begin{array}{c}\mathrm{U}_{\mathrm{CS}} \mathrm{FD} \\
(\mathrm{m} / \mathrm{s})\end{array}$ & $\begin{array}{c}\mathrm{H}_{\mathrm{CS}} \mathrm{E} \\
\text { (in.) }\end{array}$ & $\begin{array}{c}\mathrm{H}_{\mathrm{CS}} \mathrm{FD} \\
\text { (in.) }\end{array}$ & $\mathrm{U}_{\mathrm{CS}}$ & $\begin{array}{l}\text { tio } \\
/ \mathrm{E} \\
\mathrm{H}_{\mathrm{CS}}\end{array}$ \\
\hline 1 & s1d2 & 2.48 & 0.0000693 & 0.05 & 0.00155 & 0.18 & 5.40 & $-{ }^{\text {(b) }}$ & 26.50 & - & - & - \\
\hline 2 & s1d2 & 2.48 & 0.0000693 & 0.05 & 0.00155 & 0.33 & 4.60 & 4.40 & 28.50 & 27.75 & 0.96 & 0.97 \\
\hline 3 & s1d2 & 2.48 & 0.0000693 & 0.05 & 0.00500 & 0.33 & 6.00 & 5.80 & 23.25 & & 0.97 & 0.85 \\
\hline 4 & s1d2 & 2.48 & 0.0000693 & 0.05 & 0.01000 & 0.33 & $7.13^{(\mathrm{c})}$ & 6.60 & $34.92^{(\mathrm{c})}$ & & 0.93 & 0.66 \\
\hline 5 & s1d2 & 2.48 & .0000693 & 0.05 & 0.01430 & 0.18 & 10.90 & $9.85^{(\mathrm{c})}$ & 39.25 & 27.75 & 0.90 & 0.71 \\
\hline 6 & s1d2 & 2.48 & 0000693 & 0.05 & 0.01430 & 0.26 & - & 8.80 & - & 32.50 & - & - \\
\hline 7 & s1d2 & 2.48 & 0.0000693 & 0.05 & 0.01430 & 0.33 & 7.80 & $7.18^{(\mathrm{c})}$ & 41.00 & $31.13^{(\mathrm{c})}$ & 0.92 & 0.76 \\
\hline 8 & & 2.48 & 0.0000693 & 0.05 & 0.01430 & 0.66 & 4.80 & 4.80 & & & 1.00 & 0.92 \\
\hline 9 & & .48 & 3 & 0.10 & 0.01 & & 8.70 & & & & 0.98 & 0.89 \\
\hline 10 & & & & & & & & & & & 0.89 & 0.76 \\
\hline 11 & & & & 0 & & & & & & & 0.96 & 0.87 \\
\hline 12 & & 2.48 & 693 & 0.15 & 0.01 & 0.18 & 6.40 & 6.80 & 26.50 & 29.50 & 1.06 & 1.11 \\
\hline 13 & & 2.48 & 0000693 & 0.15 & & 0.3 & 6.60 & 6.10 & 35.50 & & 0.92 & 0.80 \\
\hline 14 & & & 0000693 & 0.15 & & & - & 4.50 & - & 33.75 & - & - \\
\hline 15 & & & 8000 & & & & & - & & - & - & - \\
\hline 16 & & & & & & & & - & 41. & - & - & - \\
\hline 17 & & & & & & & & - & 30.50 & - & - & - \\
\hline 18 & & & 664 & 0.05 & & & 7.10 & 6.70 & 32.75 & & 0.94 & 0.78 \\
\hline 19 & s1d1 & 2.46 & 0001664 & 0.10 & & & - & 5.80 & - & 26.00 & - & - \\
\hline 20 & & 2.46 & 0001664 & 0.15 & 0.00155 & 0.33 & - & 5.60 & - & 29.75 & - & - \\
\hline 21 & s2d2 & & 0.0000 & 0.05 & 0.001 & 0.33 & 8.40 & - & & - & - & - \\
\hline 22 & & & & 0.05 & & & 14.00 & 11.40 & 26.25 & 23.00 & 0.81 & 0.88 \\
\hline 23 & s2d2 & & & & & & - & & - & & - & - \\
\hline 24 & s2d2 & 4.18 & 0.0000756 & 0.05 & 0.00500 & 0.33 & 12.50 & 10.60 & 25.50 & 23.50 & 0.85 & 0.92 \\
\hline
\end{tabular}

(a) Rounded.

(b) A dash (-) denotes the test was not performed.

(c) These are average values. 


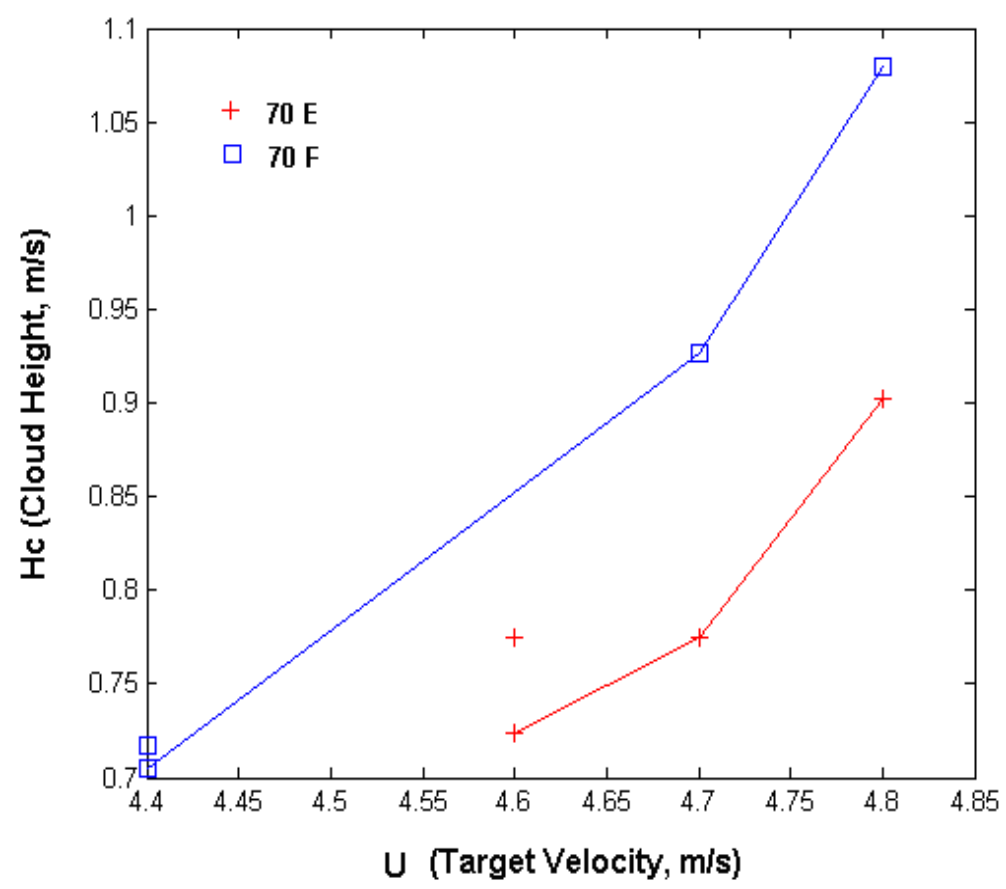

Figure E.33. Cloud Height $\left(\mathrm{H}_{\mathrm{C}}\right)$ Versus Target Velocity (U) Values for the 70E and 70F Head Shapes with $\mathrm{s}=2.48, \mathrm{~d}_{50}=6.93 \times 10^{-5}, \phi_{\mathrm{p}}=0.05, \phi_{\mathrm{s}}=0.00155$ and $\mathrm{DC}=0.33$

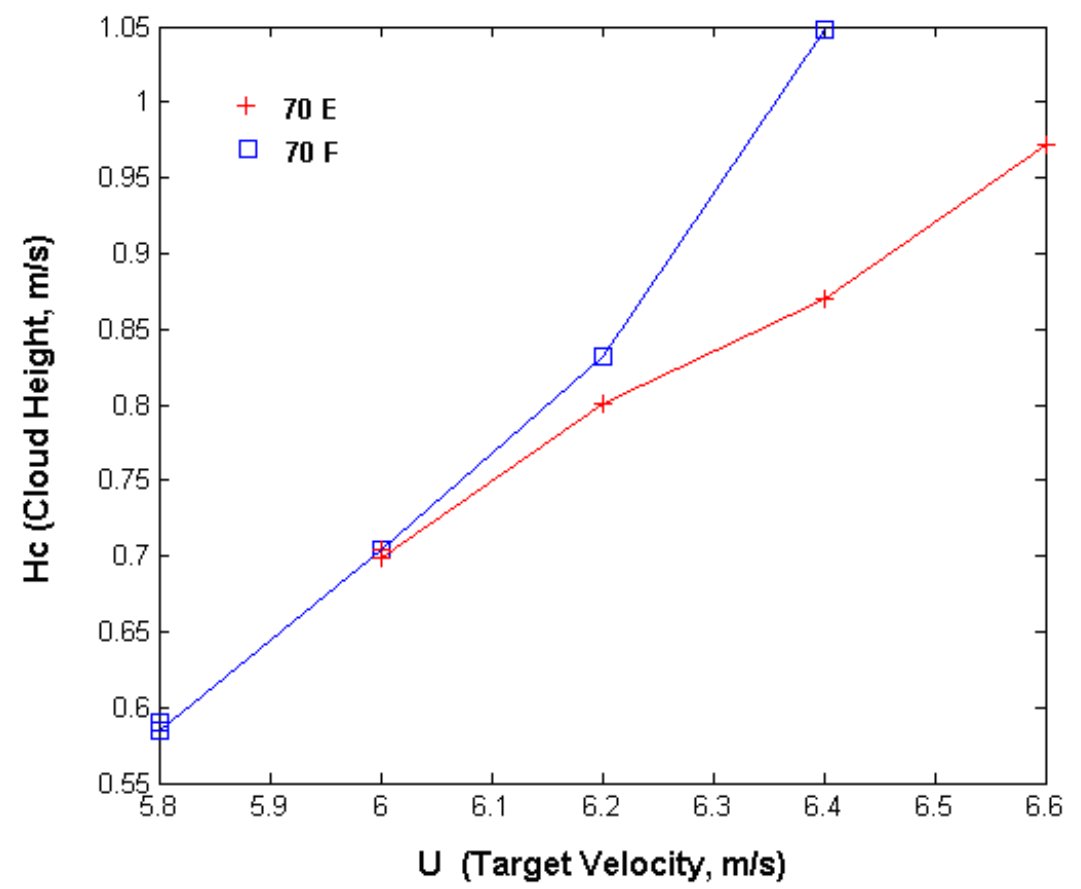

Figure E.34. Cloud Height $\left(\mathrm{H}_{\mathrm{C}}\right)$ Versus Target Velocity (U) Values for the 70E and 70F Head Shapes with $\mathrm{s}=2.48, \mathrm{~d}_{50}=6.93 \times 10^{-5}, \phi_{\mathrm{p}}=0.05, \phi_{\mathrm{S}}=0.005$ and $\mathrm{DC}=0.33$ 


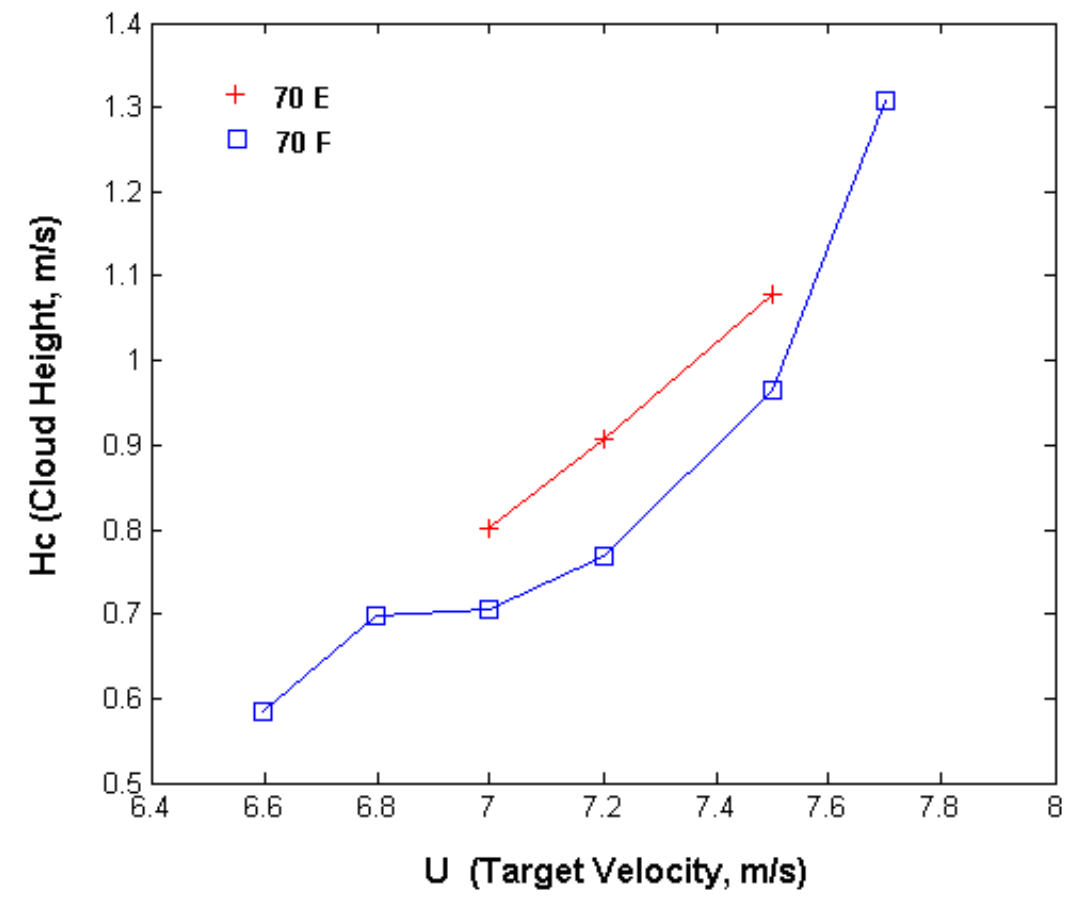

Figure E.35. Cloud Height $\left(\mathrm{H}_{\mathrm{C}}\right)$ Versus Target Velocity $(\mathrm{U})$ Values for the 70E and 70F Head Shapes with $\mathrm{s}=2.48, \mathrm{~d}_{50}=6.93 \times 10^{-5}, \phi_{\mathrm{p}}=0.05, \phi_{\mathrm{s}}=0.01$ and $\mathrm{DC}=0.33$

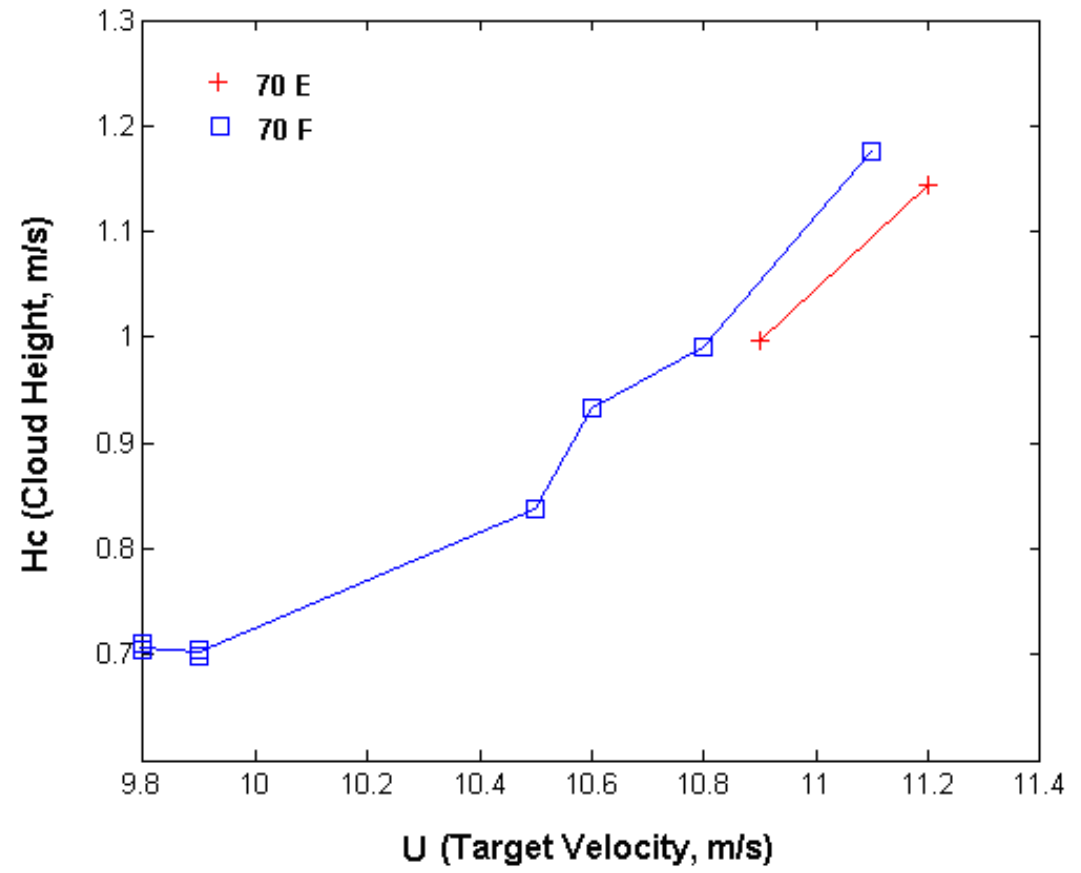

Figure E.36. Cloud Height $\left(\mathrm{H}_{\mathrm{C}}\right)$ Versus Target Velocity (U) Values for the 70E and 70F Head Shapes with $\mathrm{s}=2.48, \mathrm{~d}_{50}=6.93 \times 10^{-5}, \phi_{\mathrm{p}}=0.05, \phi_{\mathrm{S}}=0.0143$ and $\mathrm{DC}=0.18$ 


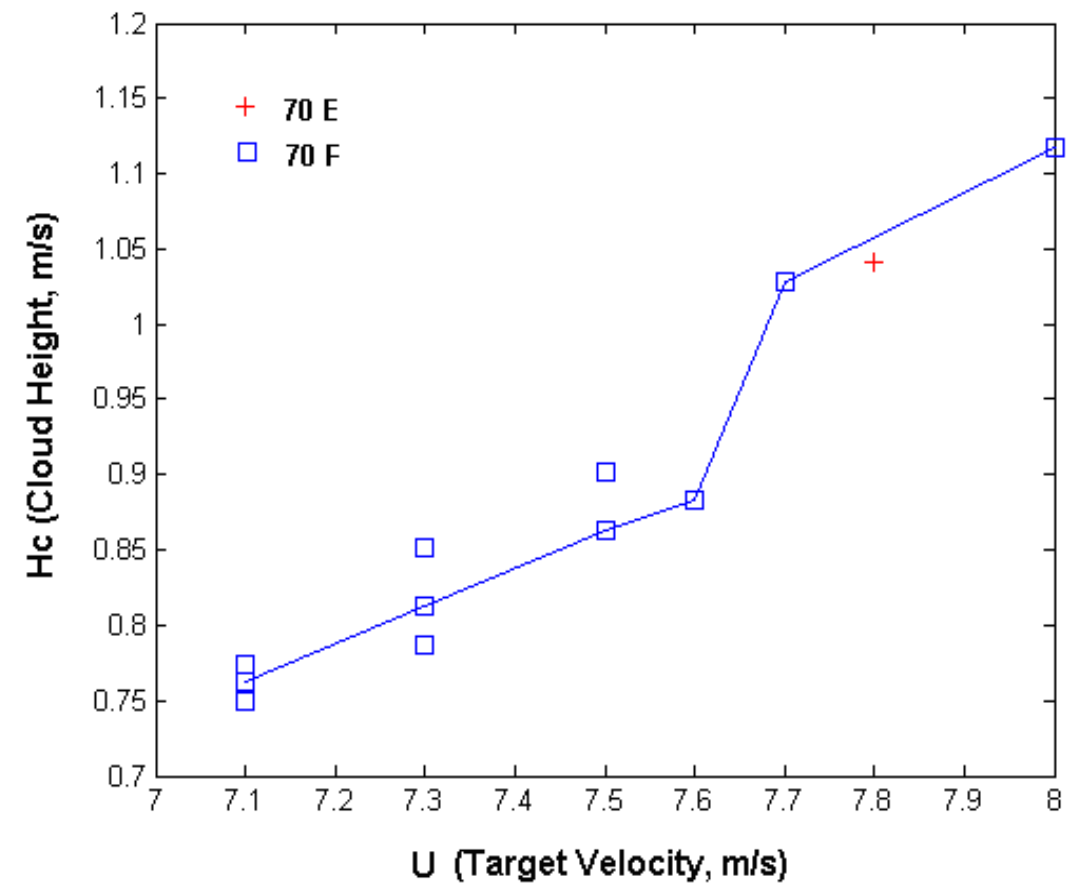

Figure E.37. Cloud Height $\left(\mathrm{H}_{\mathrm{C}}\right)$ Versus Target Velocity (U) Values for the 70E and 70F Head Shapes with $\mathrm{s}=2.48, \mathrm{~d}_{50}=6.93 \times 10^{-5}, \phi_{\mathrm{p}}=0.05, \phi_{\mathrm{S}}=0.0143$ and $\mathrm{DC}=0.33$

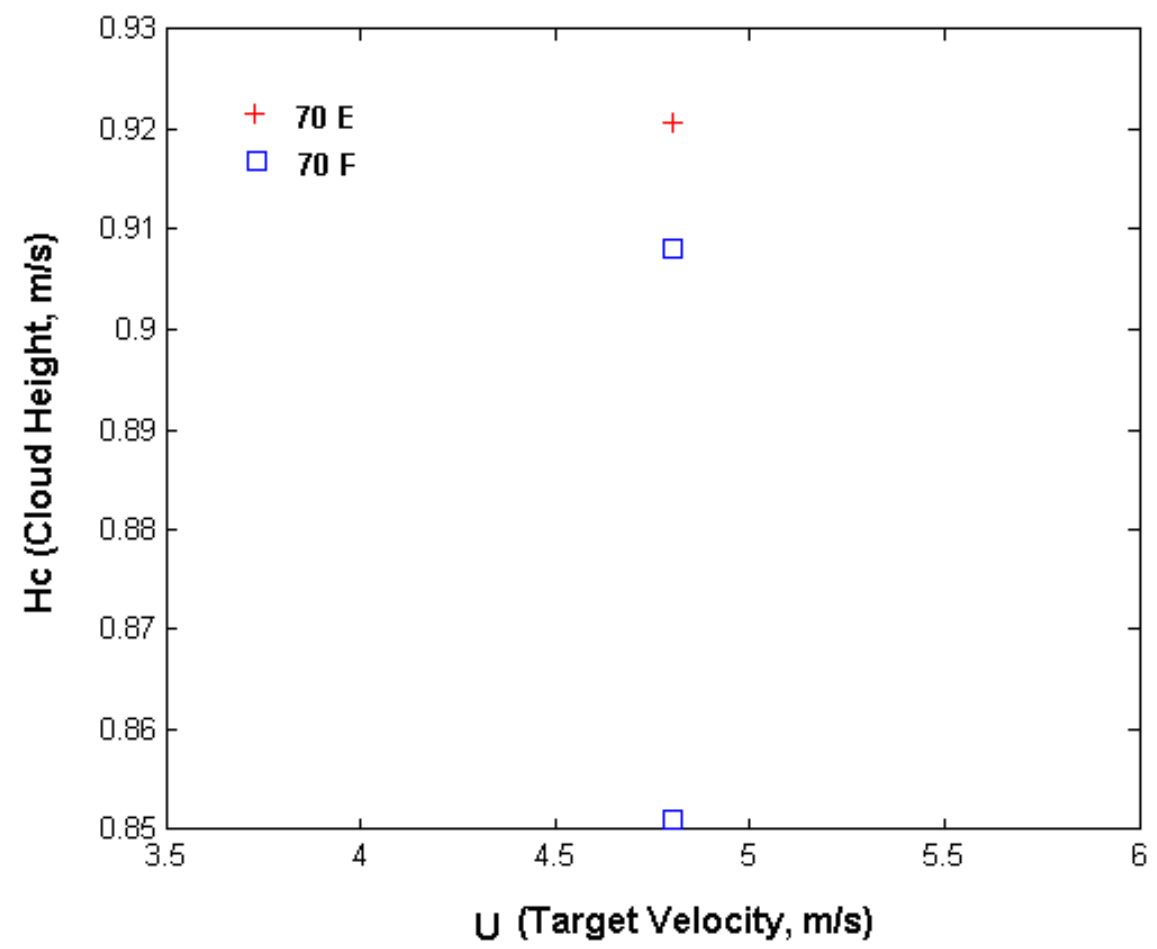

Figure E.38. Cloud Height $\left(\mathrm{H}_{\mathrm{C}}\right)$ Versus Target Velocity (U) Values for the 70E and 70F Head Shapes with $\mathrm{s}=2.48, \mathrm{~d}_{50}=6.93 \times 10^{-5}, \phi_{\mathrm{p}}=0.05, \phi_{\mathrm{s}}=0.0143$ and $\mathrm{DC}=0.66$ 


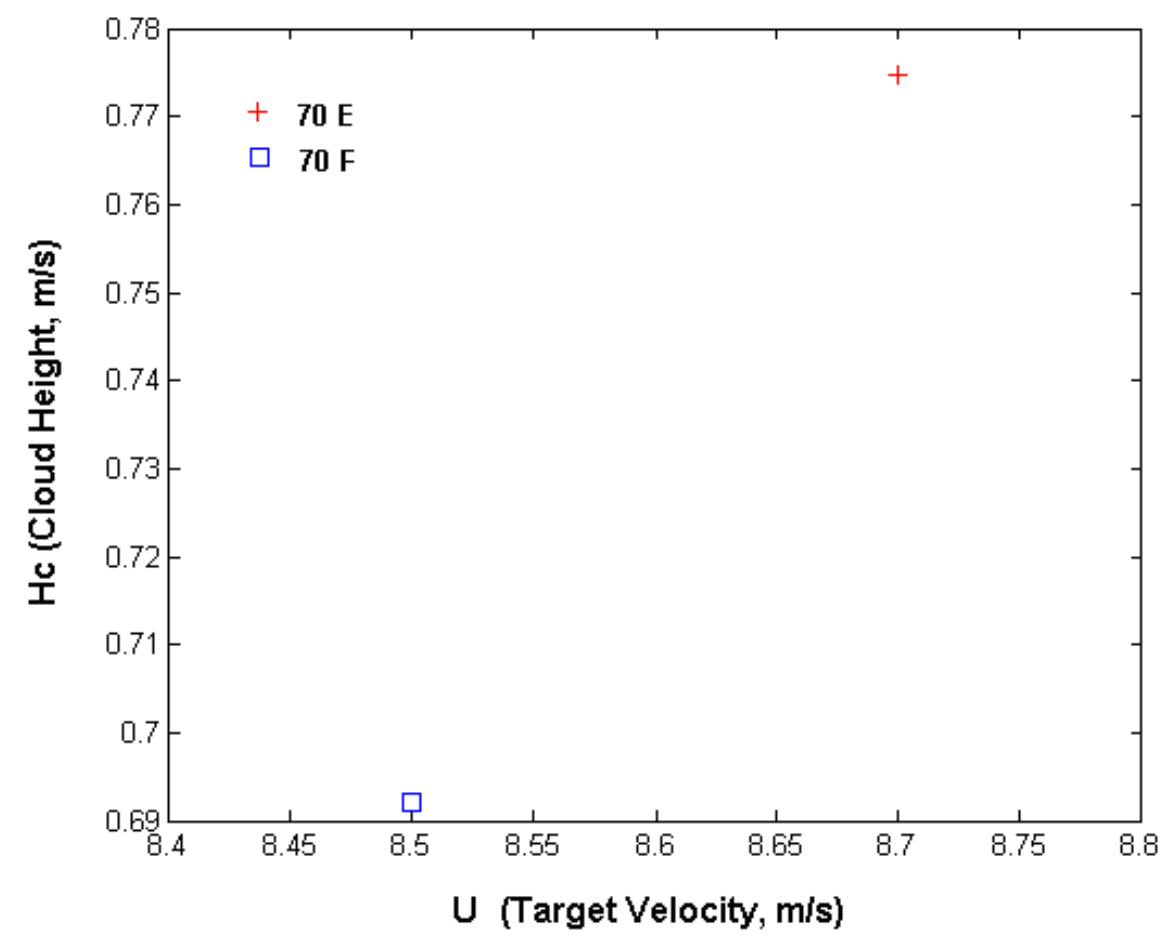

Figure E.39. Cloud Height $\left(\mathrm{H}_{\mathrm{C}}\right)$ Versus Target Velocity (U) Values for the 70E and 70F Head Shapes with $\mathrm{s}=2.48, \mathrm{~d}_{50}=6.93 \times 10^{-5}, \phi_{\mathrm{p}}=0.10, \phi_{\mathrm{S}}=0.0143$ and $\mathrm{DC}=0.18$

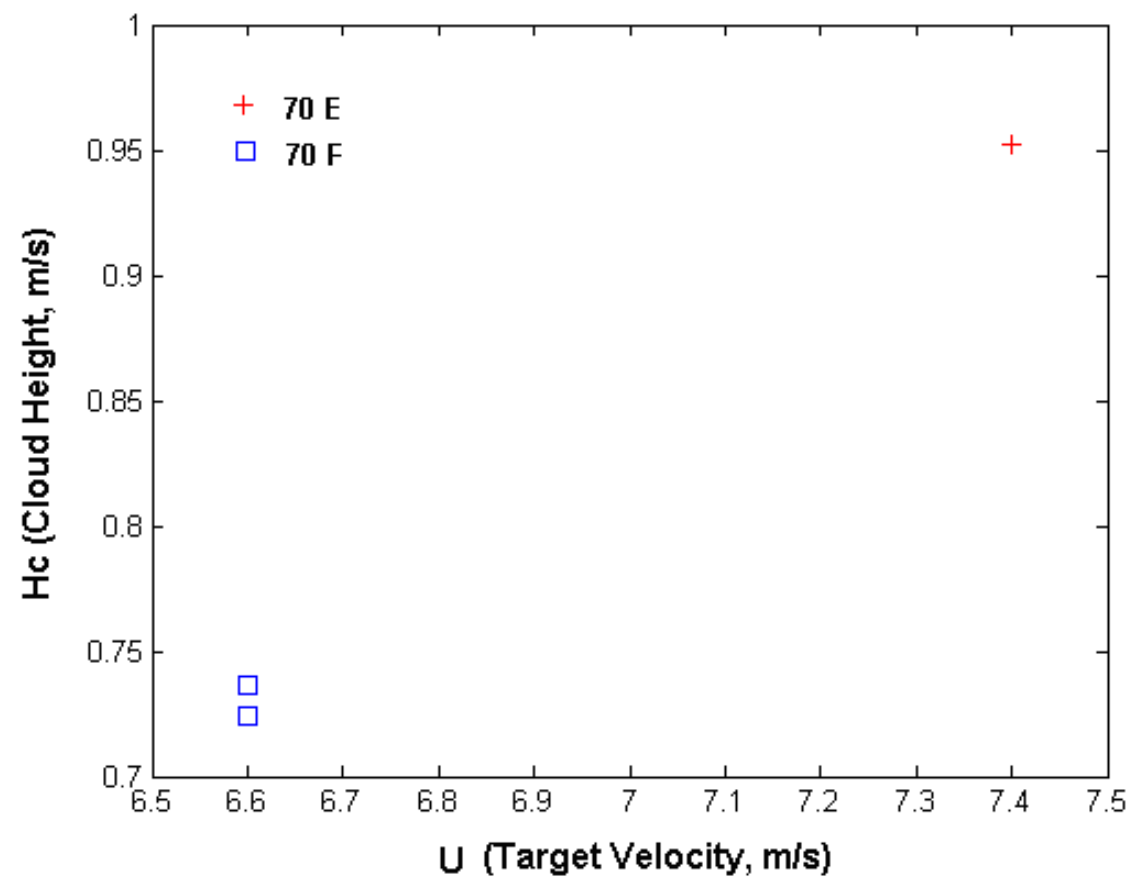

Figure E.40. Cloud Height $\left(\mathrm{H}_{\mathrm{C}}\right)$ Versus Target Velocity $(\mathrm{U})$ Values for the 70E and 70F Head Shapes with $\mathrm{s}=2.48, \mathrm{~d}_{50}=6.93 \times 10^{-5}, \phi_{\mathrm{p}}=0.10, \phi_{\mathrm{S}}=0.0143$ and $\mathrm{DC}=0.33$ 


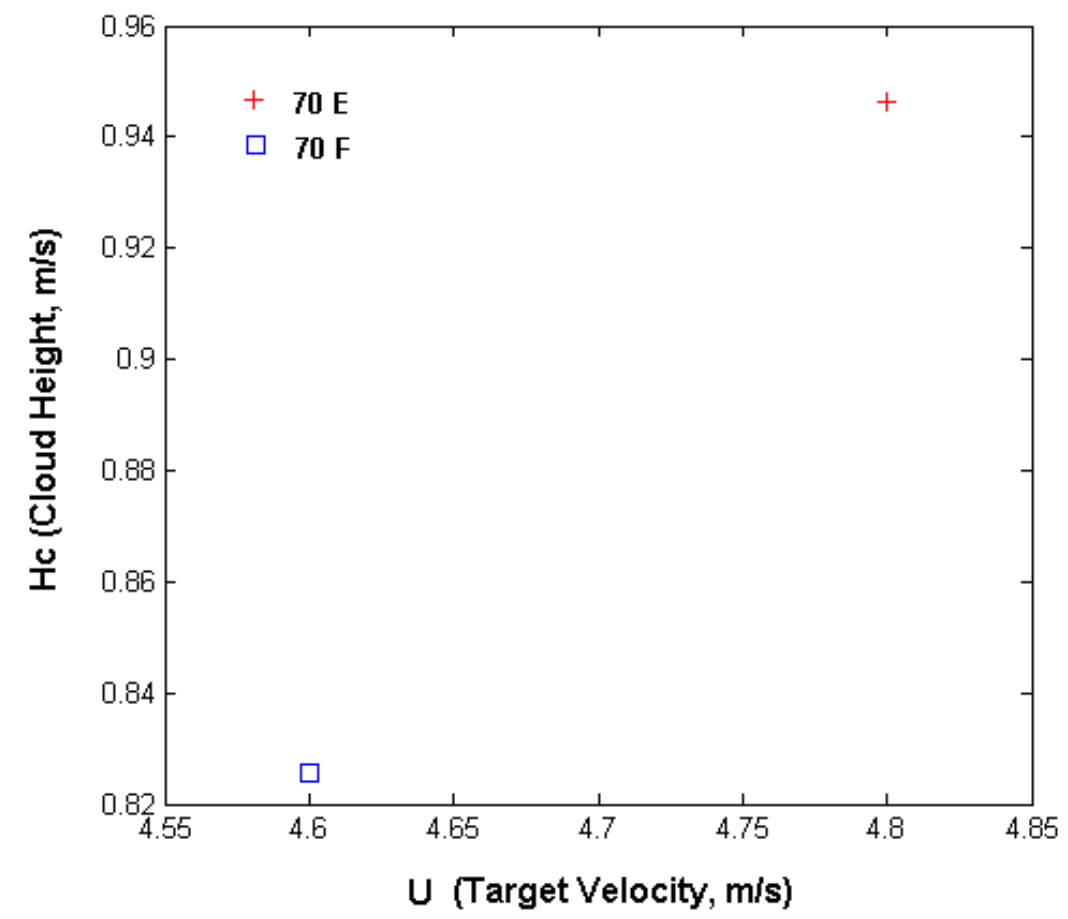

Figure E.41. Cloud Height $\left(\mathrm{H}_{\mathrm{C}}\right)$ Versus Target Velocity (U) Values for the 70E and 70F Head Shapes with $\mathrm{s}=2.48, \mathrm{~d}_{50}=6.93 \times 10^{-5}, \phi_{\mathrm{p}}=0.10, \phi_{\mathrm{S}}=0.0143$ and $\mathrm{DC}=0.66$

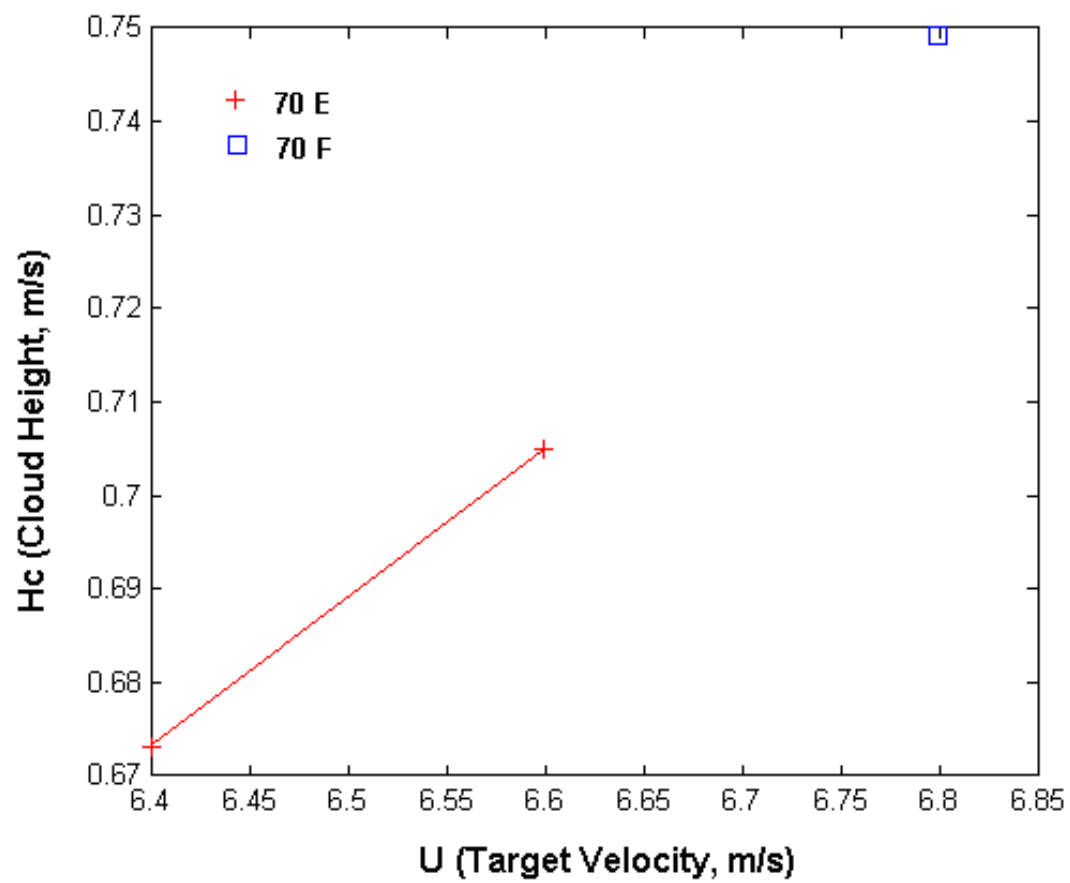

Figure E.42. Cloud Height $\left(\mathrm{H}_{\mathrm{C}}\right)$ Versus Target Velocity $(\mathrm{U})$ Values for the 70E and 70F Head Shapes with $\mathrm{s}=2.48, \mathrm{~d}_{50}=6.93 \times 10^{-5}, \phi_{\mathrm{p}}=0.15, \phi_{\mathrm{S}}=0.0143$ and $\mathrm{DC}=0.18$ 


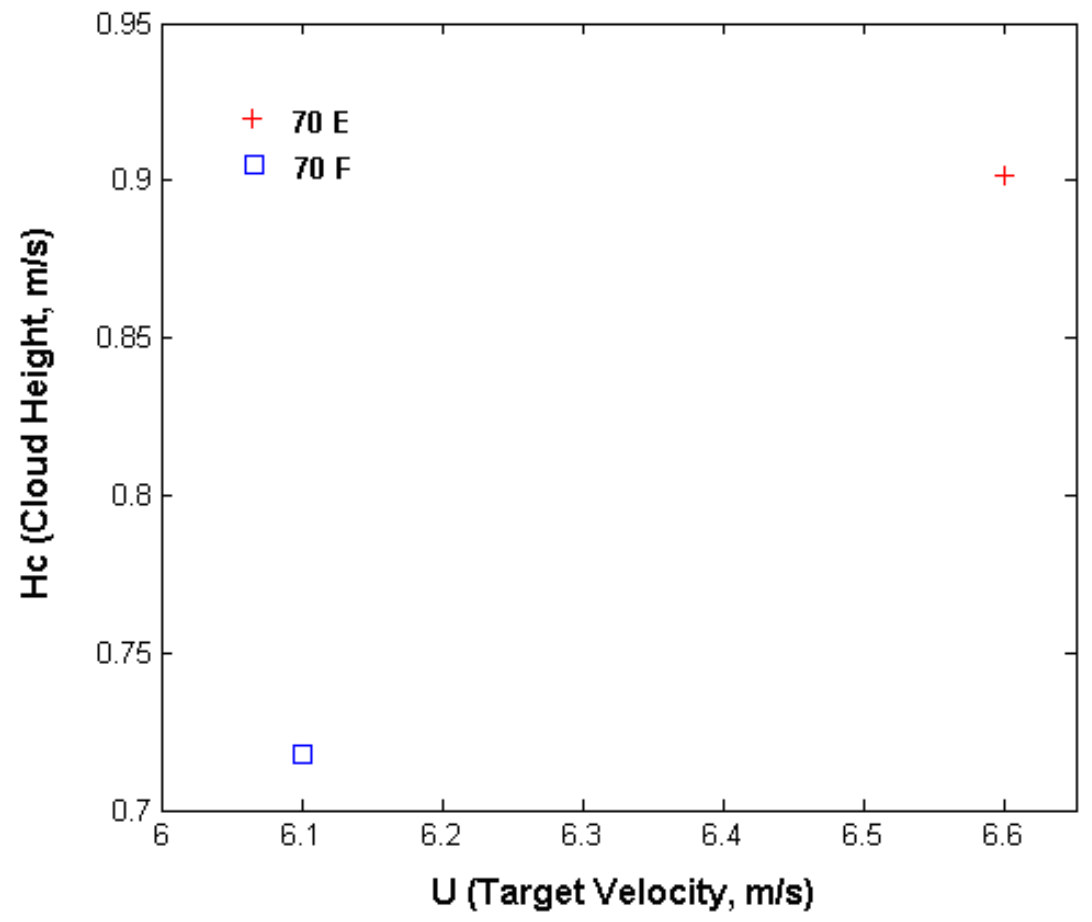

Figure E.43. Cloud Height $\left(\mathrm{H}_{\mathrm{C}}\right)$ Versus Target Velocity (U) Values for the 70E and 70F Head Shapes with $\mathrm{s}=2.48, \mathrm{~d}_{50}=6.93 \times 10^{-5}, \phi_{\mathrm{p}}=0.15, \phi_{\mathrm{S}}=0.0143$ and $\mathrm{DC}=0.33$

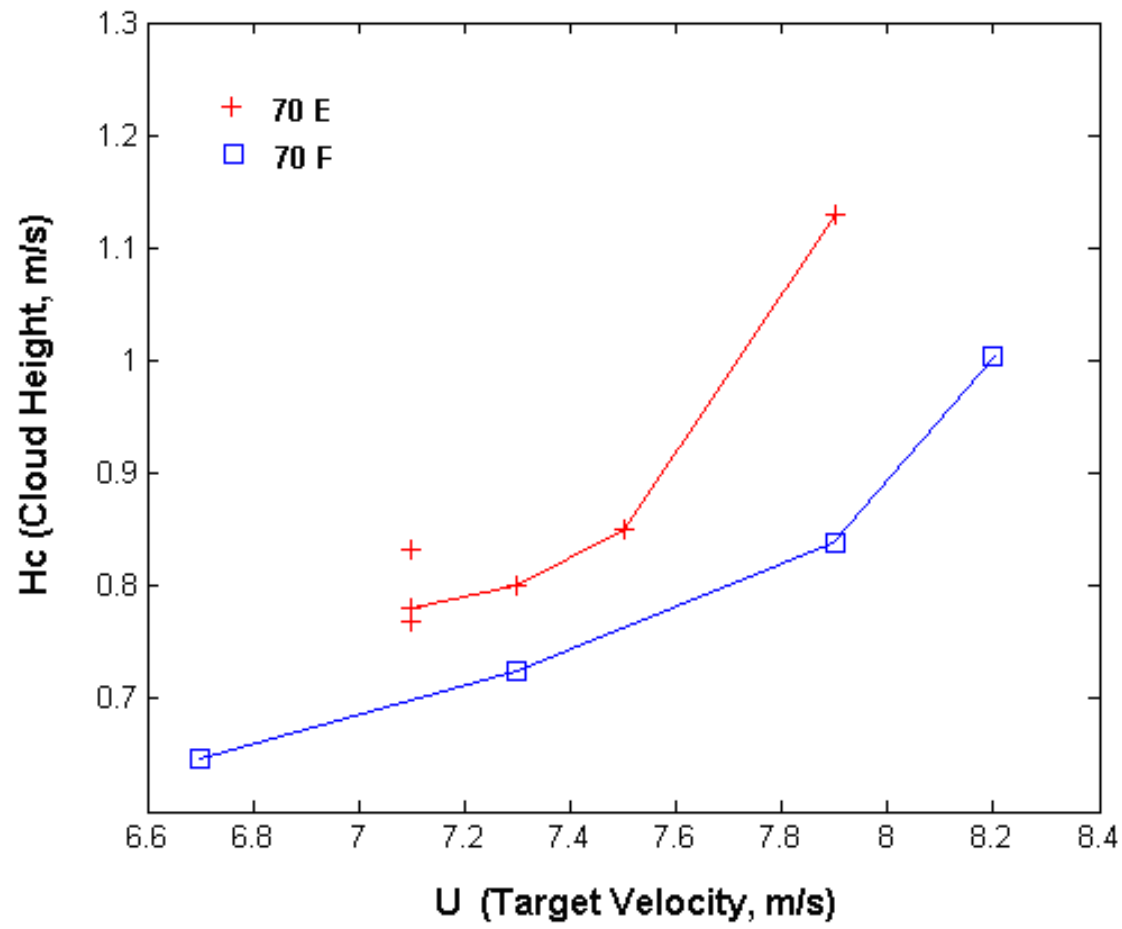

Figure E.44. Cloud Height $\left(\mathrm{H}_{\mathrm{C}}\right)$ Versus Target Velocity (U) Values for the 70E and 70F Head Shapes with $\mathrm{s}=2.46, \mathrm{~d}_{50}=1.664 \times 10^{-4}, \phi_{\mathrm{p}}=0.05, \phi_{\mathrm{S}}=0.00155$ and $\mathrm{DC}=0.33$ 


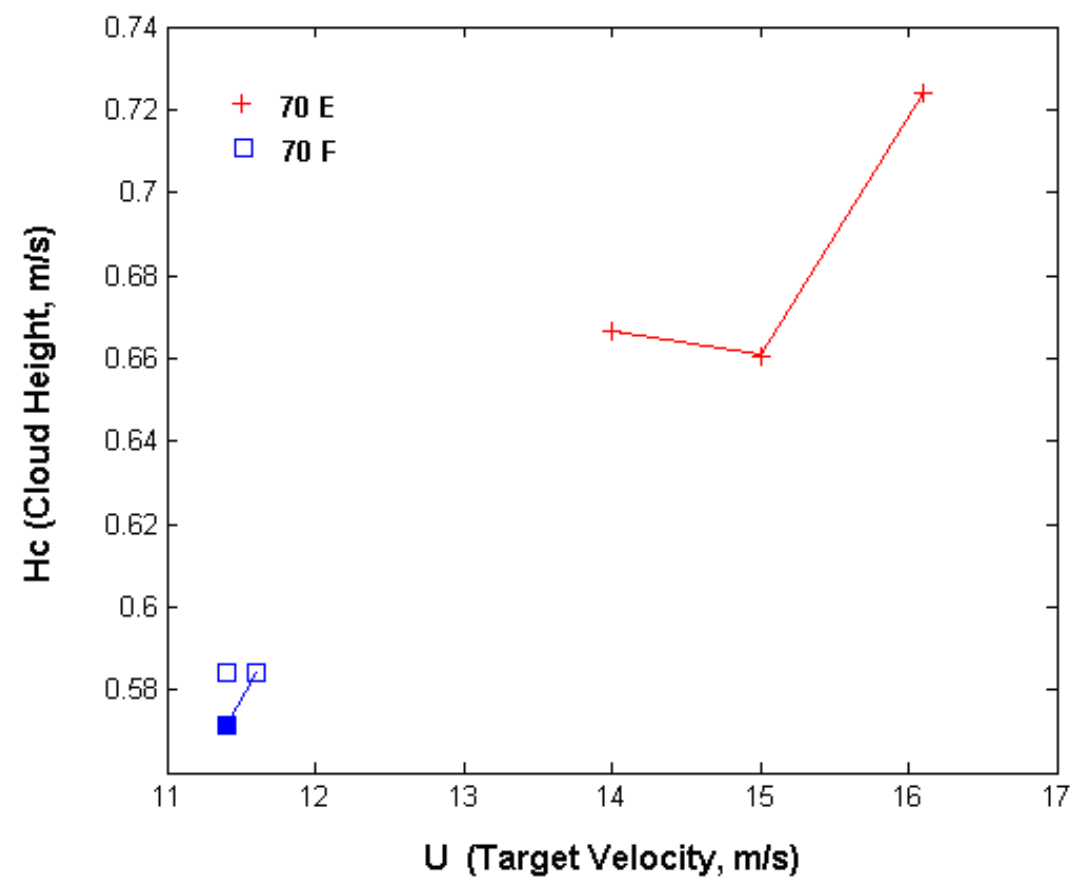

Figure E.45. Cloud Height $\left(\mathrm{H}_{\mathrm{C}}\right)$ Versus Target Velocity (U) Values for the 70E and 70F Head Shapes with $\mathrm{s}=4.18, \mathrm{~d}_{50}=7.56 \times 10^{-5}, \phi_{\mathrm{p}}=0.05, \phi_{\mathrm{S}}=0.005$ and $\mathrm{DC}=0.18$. The solid square has $\mathrm{DC}=0.14$.

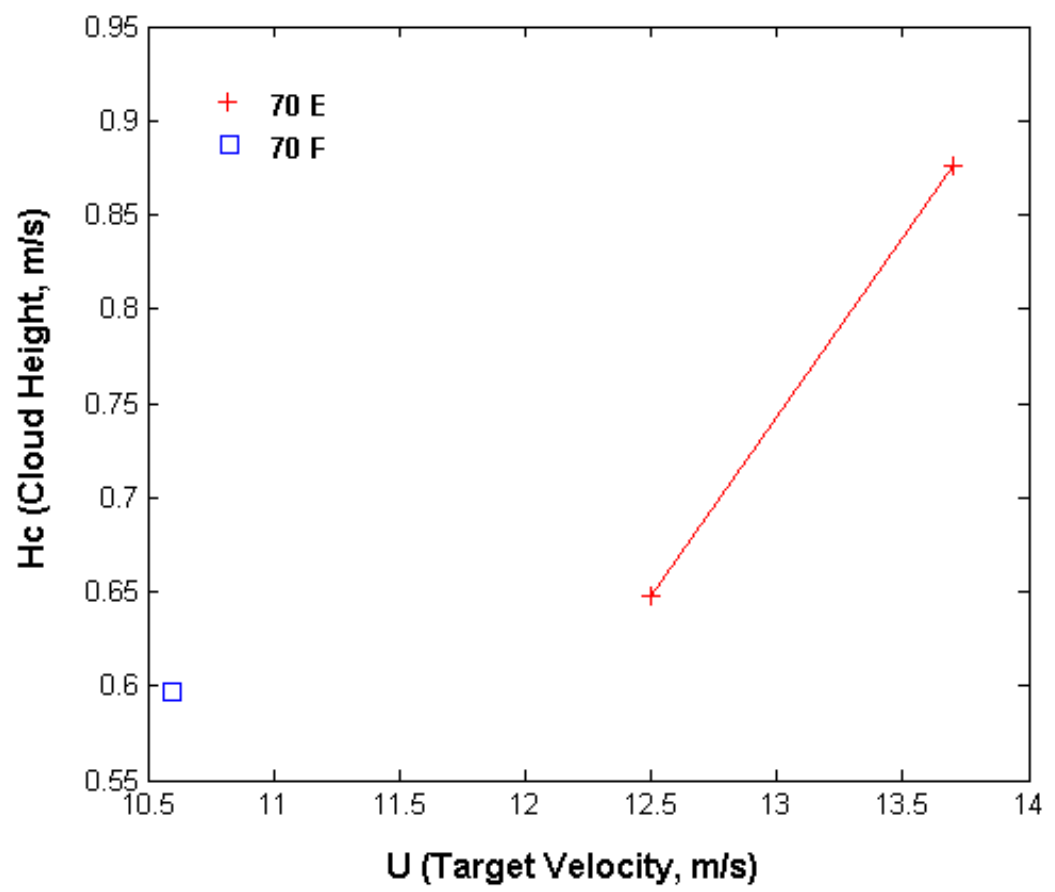

Figure E.46. Cloud Height $\left(\mathrm{H}_{\mathrm{C}}\right)$ Versus Target Velocity (U) Values for the 70E and 70F Head Shapes with $\mathrm{s}=4.18, \mathrm{~d}_{50}=7.56 \times 10^{-5}, \phi_{\mathrm{p}}=0.05, \phi_{\mathrm{s}}=0.005$ and $\mathrm{DC}=0.33$. 


\section{E.3 Replicate and Repeat Tests}

In performing experimental work, replicate tests of several test conditions should be included in each testing campaign to provide a basis for quantifying the experimental and measurement uncertainty in the response variables of interest. By replicate tests we mean tests performed at the same set of conditions but at different times, with tests at other sets of conditions intervening. Replicate tests performed in this way provide data subject to all of the sources of experimental and measurement variation/uncertainty. However, only limited replicate tests involving the July 2007 and Fall 2007 test campaigns were performed. In addition to replicate tests, some repeat testing was performed within the July 2007, Fall 2007 and 2008 test campaigns. By repeat tests we mean tests performed at the same conditions one after another (or close in time), without a change of simulant. Repeat testing only captures information about short-term testing and measurement uncertainties, which are typically much smaller than longer-term testing variations/uncertainties that would be captured by replicate testing. Table E.3 lists the test conditions investigated with near-replicate and near-repeat testing. The terms near-replicate and nearrepeat are used because the test conditions are close but not exactly the same for some test variables.

Table E.4 shows the five sets of near-replicate test results for $\mathrm{U}_{\mathrm{CS}}$ and $\mathrm{H}_{\mathrm{CS}}$ responses. Table E.4 lists the standard deviation (SD) and percent relative standard deviation (\%RSD) for $\mathrm{U}_{\mathrm{CS}}$ and $\mathrm{H}_{\mathrm{CS}}$ for each near-replicate set. Also listed are pooled (combined) values of SD and \%RSD for each of $\mathrm{U}_{\mathrm{CS}}$ and $\mathrm{H}_{\mathrm{CS}}$ over the five near-replicate sets. For $\mathrm{U}_{\mathrm{CS}}$, the pooled $\mathrm{SD}=0.224 \mathrm{~m} / \mathrm{s}$ and the pooled $\% \mathrm{RSD}=5.29$ for near-replicate experimental uncertainty. For $\mathrm{H}_{\mathrm{CS}}$, the pooled $\mathrm{SD}=0.040 \mathrm{~m}$ and the pooled $\% \mathrm{RSD}=$ 13.34 for near-replicate experimental uncertainty. Although not apparent from this small number of nearreplicate sets, the uncertainties in $\mathrm{U}_{\mathrm{CS}}$ and $\mathrm{H}_{\mathrm{CS}}$ are expected to increase with the values of these responses. Hence, the pooled \%RSD values are the more appropriate summary measure of near-replicate testing and measurement uncertainty.

Table E.5 shows the 13 sets of tests with near-repeat conditions, as well as SD and \%RSD values for each near-repeat set and pooled over the sets. Because near-repeat set \#11 has large values of SD and \%RSD for $\mathrm{U}_{\mathrm{CS}}$, pooled SD and \%RSD values were calculated across all near-repeat sets with and without set \#11. For $U_{\mathrm{CS}}$ without set \#11, the pooled $\mathrm{SD}=0.247 \mathrm{~m} / \mathrm{s}$ and the pooled $\% \mathrm{RSD}=4.12$ for near-repeat uncertainty. For $\mathrm{H}_{\mathrm{CS}}$, the pooled $\mathrm{SD}=0.019 \mathrm{~m}$ and the pooled \%RSD = 5.54 for near-repeat uncertainty. Although not apparent from this relatively small number of near-repeat sets, the uncertainties in $U_{\mathrm{CS}}$ and $\mathrm{H}_{\mathrm{CS}}$ are expected to increase with the values of these responses. Hence, the pooled \%RSD values are the more appropriate summary measure of near-repeat testing and measurement uncertainty.

Time and budget limitations did not permit processing the $\mathrm{H}_{\mathrm{C}}$ data set to identify near-replicate and near-repeat sets. The $\mathrm{H}_{\mathrm{CS}}$ near-replicate and near-repeat sets of data would be a subset of those sets of data for $\mathrm{H}_{\mathrm{C}}$. If the uncertainty in $\mathrm{H}_{\mathrm{C}}$ increases proportionally to the magnitude of $\mathrm{H}_{\mathrm{C}}$ as expected, then the pooled \%RSDs from near-replicate and near-repeat sets for $\mathrm{H}_{\mathrm{CS}}$ should be reasonable estimates of the \%RSDs for uncertainties in $\mathrm{H}_{\mathrm{C}}$.

As expected, uncertainties from the near-replicate sets are larger than from the near-repeat sets. Hence, uncertainties from the near-replicate sets should be used as estimates of uncertainties in $\mathrm{U}_{\mathrm{CS}}, \mathrm{H}_{\mathrm{CS}}$, and $\mathrm{H}_{\mathrm{C}}$ results. However, the limited nature of these estimates should be kept in mind. Also, the results indicate that the relative uncertainty in experimentally determining $\mathrm{H}_{\mathrm{CS}}$ (and presumably $\mathrm{H}_{\mathrm{C}}$ ) values is notably larger than the relative uncertainty in experimentally determining $\mathrm{H}_{\mathrm{C}}$ values. 
Table E.5. Near-Replicate and Near-Repeat Tests at Critical Suspension Conditions.

\begin{tabular}{|c|c|c|c|c|c|c|c|c|c|c|c|c|c|c|c|c|c|}
\hline $\begin{array}{l}\text { Row } \\
\text { Number }\end{array}$ & Case ID & Test & $\begin{array}{c}\text { Tank } \\
\text { Diameter } \\
\end{array}$ & $\begin{array}{c}\text { Solids } \\
\text { Density }\end{array}$ & \begin{tabular}{|c|c} 
Solids \\
Fraction
\end{tabular} & $\begin{array}{c}\text { Particle } \\
\text { Size }\end{array}$ & $\begin{array}{l}\text { Duty } \\
\text { Cycle } \\
\end{array}$ & \begin{tabular}{|c} 
Pulse \\
Volume \\
Fraction
\end{tabular} & \begin{tabular}{|c|} 
Number \\
Installed \\
Tubes \\
\end{tabular} & $\begin{array}{c}\# \\
\begin{array}{c}\# \\
\text { Operating } \\
\text { Tubes }\end{array} \\
\end{array}$ & $\begin{array}{c}\# \\
\text { Outer - } \\
\text { Layer } \\
\text { Tubes } \\
\end{array}$ & $\begin{array}{c}\text { \# Inner } \\
\text {-Layer } \\
\text { Tubes } \\
\end{array}$ & $\begin{array}{c}\text { Nozzle } \\
\text { Inner } \\
\text { Diameter }\end{array}$ & $\begin{array}{c}\text { Head } \\
\text { Shape } \\
\end{array}$ & $\begin{array}{c}\text { Discharge } \\
\text { Velocity }\end{array}$ & \multirow{3}{*}{$\begin{array}{l}\text { Near- } \\
\text { Repeat } \\
\text { Set }\end{array}$} & \multirow{3}{*}{$\begin{array}{l}\text { Near- } \\
\text { Replicate } \\
\text { Set }\end{array}$} \\
\hline text & text & text & in & $\mathrm{g} / \mathrm{cm}^{3}$ & fraction & $\mathbf{m}$ & fraction & fraction & $\#$ & $\#$ & $\#$ & $\#$ & in & text & $\mathbf{m} / \mathbf{s}$ & & \\
\hline MSS & ID & M/DDX & D & $\mathrm{S}$ & $\mathbf{f}_{\mathrm{S}}$ & $d_{50}\left(d_{s}\right)$ & DC & $\phi_{\mathrm{p}}$ & $\mathbf{N}$ & $\mathbf{N}_{J}$ & $\mathbf{N}_{\mathrm{O}}$ & $\mathbf{N}_{I}$ & d & HS & $\mathbf{U}$ & & \\
\hline 9150506 & 15E_4s1d1Xc_1 & $6 / 27 \mathrm{C}$ & 14.4375 & 2.46 & 0.015 & 0.00017 & 0.334 & 0.050 & 12 & 12 & 8 & 4 & 0.126 & E & 8.2 & 1 & $--^{(\mathrm{a})}$ \\
\hline 9150516 & 15E_4s1d1Xc_1 & $6 / 30 \mathrm{~A}$ & 14.4375 & 2.46 & 0.015 & 0.00017 & 0.335 & 0.050 & 12 & 12 & 8 & 4 & 0.126 & $\mathrm{E}$ & 8.6 & 1 & - \\
\hline 9150048 & 15E_4s1d2Rc_1 & 6/9B & 14.4375 & 2.48 & 0.01 & $6.9 \mathrm{E}-05$ & 0.338 & 0.050 & 12 & 12 & 8 & 4 & 0.126 & $\mathrm{E}$ & 5.3 & 2 & - \\
\hline 9150053 & 15E_4s1d2Rc_1 & $6 / 10 \mathrm{~A}$ & 14.4375 & 2.48 & 0.01 & $6.9 \mathrm{E}-05$ & 0.331 & 0.050 & 12 & 12 & 8 & 4 & 0.126 & $\mathrm{E}$ & 5.4 & 2 & - \\
\hline 9150063 & 15E_4s1d2Xc_1 & 6/10B & 14.4375 & 2.48 & 0.015 & $6.9 \mathrm{E}-05$ & 0.331 & 0.050 & 12 & 12 & 8 & 4 & 0.126 & $\mathrm{E}$ & 5.8 & 3 & - \\
\hline 9150108 & 15E_4s1d2Xc_1 & $6 / 11 \mathrm{C}$ & 14.4375 & 2.48 & 0.015 & $6.9 \mathrm{E}-05$ & 0.333 & 0.050 & 12 & 12 & 8 & 4 & 0.126 & $\mathrm{E}$ & 5.8 & 3 & - \\
\hline 9150083 & 15E_4s1d2Xd_1 & $6 / 11 \mathrm{~A}$ & 14.4375 & 2.48 & 0.015 & $6.9 \mathrm{E}-05$ & 0.184 & 0.050 & 12 & 12 & 8 & 4 & 0.126 & $\mathrm{E}$ & 7.2 & 4 & - \\
\hline 9150174 & 15E_4s1d2Xd_1 & $6 / 13 \mathrm{C}$ & 14.4375 & 2.48 & 0.015 & $6.9 \mathrm{E}-05$ & 0.186 & 0.050 & 12 & 12 & 8 & 4 & 0.126 & $E$ & 7.4 & 4 & - \\
\hline 9150412 & 15E_4s2d2Wc_1 & $6 / 24 B$ & 14.4375 & 4.18 & 0.045 & 7.6E-05 & 0.333 & 0.050 & 12 & 12 & 8 & 4 & 0.126 & $\mathrm{E}$ & 11.5 & 5 & - \\
\hline 9150419 & 15E_4s2d2Wc_1 & $6 / 25 \mathrm{~A}$ & 14.4375 & 4.18 & 0.045 & 7.6E-05 & 0.332 & 0.050 & 12 & 12 & 8 & 4 & 0.126 & E & 11.5 & 5 & - \\
\hline 9150345 & 15E_4s2d2Yc_1 & $6 / 19 \mathrm{C}$ & 14.4375 & 4.18 & 0.005 & 7.6E-05 & 0.335 & 0.050 & 12 & 12 & 8 & 4 & 0.126 & $\mathrm{E}$ & 7.6 & 6 & - \\
\hline 9150347 & 15E_4s2d2Yc_1 & $6 / 20 \mathrm{~A}$ & 14.4375 & 4.18 & 0.005 & 7.6E-05 & 0.334 & 0.050 & 12 & 12 & 8 & 4 & 0.126 & E & 7.6 & 6 & - \\
\hline 9150307 & 15E_4s2d2Zc_1 & $6 / 18 \mathrm{~B}$ & 14.4375 & 4.18 & 0.00155 & 7.6E-05 & 0.337 & 0.050 & 12 & 12 & 8 & 4 & 0.126 & $\mathrm{E}$ & 5.4 & 7 & - \\
\hline 9150312 & 15E_4s2d2Zc_1 & 6/19A & 14.4375 & 4.18 & 0.00155 & 7.6E-05 & 0.334 & 0.050 & 12 & 12 & 8 & 4 & 0.126 & $\mathrm{E}$ & 5.2 & 7 & - \\
\hline 7091025 & 34S_4p1d7YC_1 & 11/26B1 & 33.875 & 2.45 & 0.00487 & 0.00018 & 0.330 & 0.05105 & 12 & 12 & 8 & 4 & 0.297 & $\mathrm{~S}$ & 6.5 & - & 1 \\
\hline 20070105 & 34S_4p1d7YYc_8 & 7/16 A2 & 33.875 & 2.45 & 0.00487 & 0.00018 & 0.330 & 0.05 & 12 & 12 & 8 & 4 & 0.297 & $\mathrm{~S}$ & 6.4 & - & 1 \\
\hline 20070387 & 34S_4p1d7Yyc_8 & 7/19 A1 & 33.875 & 2.45 & 0.00487 & 0.00018 & 0.330 & 0.048 & 12 & 12 & 8 & 4 & 0.297 & $\mathrm{~S}$ & 6.2 & - & 1 \\
\hline 7090875 & 34S_4p1d7Yd_1 & 11/19A2 & 33.875 & 2.45 & 0.00487 & 0.00018 & 0.180 & 0.05325 & 12 & 12 & 8 & 4 & 0.297 & $\mathrm{~S}$ & 6.4 & - & 2 \\
\hline 20070441 & 34S_4p1d7Yd_8 & 7/19 A4 & 33.875 & 2.45 & 0.00487 & 0.00018 & 0.180 & 0.048 & 12 & 12 & 8 & 4 & 0.297 & $\mathrm{~S}$ & 6.4 & - & 2 \\
\hline 7090779 & 34S_6p1d7Yc_1 & 11/14D1 & 33.875 & 2.45 & 0.00487 & 0.00018 & 0.330 & 0.05109 & 12 & 12 & 8 & 4 & 0.446 & $\mathrm{~S}$ & 4.5 & - & 3 \\
\hline 20070627 & 34S_6p1d7Yyc_8 & $7 / 21 \mathrm{~A} 2$ & 33.875 & 2.45 & 0.00487 & 0.00018 & 0.330 & 0.048 & 12 & 12 & 8 & 4 & 0.446 & $\mathrm{~S}$ & 4.0 & - & 3 \\
\hline 7090095 & 34S_6p1d7YYd_0 & 10/18A2 & 33.875 & 2.45 & 0.00487 & 0.00018 & 0.180 & 0.052 & 12 & 8 & 4 & 4 & 0.446 & $\mathrm{~S}$ & 6.1 & 8 & - \\
\hline 7090244 & 34S_6p1d7YYd_0 & 10/26B2 & 33.875 & 2.45 & 0.00487 & 0.00018 & 0.180 & 0.050 & 12 & 8 & 4 & 4 & 0.446 & $\mathrm{~S}$ & 6.1 & 8 & - \\
\hline 7090758 & 34S_6p1d7Yydo & 11/14A2 & 33.875 & 2.45 & 0.00487 & 0.00018 & 0.180 & 0.050 & 12 & 8 & 4 & 4 & 0.446 & $\mathrm{~S}$ & 7.0 & 8 & - \\
\hline 7090136 & 34S_6p1d7YYd_6 & 10/18B2 & 33.875 & 2.45 & 0.00487 & 0.00018 & 0.180 & 0.051 & 12 & 4 & 4 & 0 & 0.446 & $\mathrm{~S}$ & 6.4 & 9 & - \\
\hline 7090298 & 34S_6p1d7Yyd_6 & 10/29B2 & 33.875 & 2.45 & 0.00487 & 0.00018 & 0.180 & 0.050 & 12 & 4 & 4 & 0 & 0.446 & $\mathrm{~S}$ & 6.2 & 9 & - \\
\hline
\end{tabular}

(a) A dash (-) indicates the test condition is not included in a near-replicate or near-repeat set. 
Table E.3. Near-Replicate and Near-Repeat Tests at Critical Suspension Conditions.

\begin{tabular}{|c|c|c|c|c|c|c|c|c|c|c|c|c|c|c|c|c|c|}
\hline $\begin{array}{l}\text { Row } \\
\text { Number }\end{array}$ & Case ID & Test & $\begin{array}{c}\text { Tank } \\
\text { Diameter } \\
\end{array}$ & $\begin{array}{c}\text { Solids } \\
\text { Density }\end{array}$ & \begin{tabular}{|c|} 
Solids \\
Fraction
\end{tabular} & \begin{tabular}{|c|} 
Particle \\
Size
\end{tabular} & $\begin{array}{l}\text { Duty } \\
\text { Cycle }\end{array}$ & \begin{tabular}{|c} 
Pulse \\
Volume \\
Fraction
\end{tabular} & \begin{tabular}{|c|} 
Number \\
Installed \\
Tubes \\
\end{tabular} & $\begin{array}{c}\# \\
\text { Operating } \\
\text { Tubes } \\
\end{array}$ & $\begin{array}{c}\# \\
\text { Outer - } \\
\text { Layer } \\
\text { Tubes } \\
\end{array}$ & $\begin{array}{c}\text { \# Inner } \\
\text {-Layer } \\
\text { Tubes } \\
\end{array}$ & $\begin{array}{c}\text { Nozzle } \\
\text { Inner } \\
\text { Diameter } \\
\end{array}$ & $\begin{array}{l}\text { Head } \\
\text { Shape } \\
\end{array}$ & $\begin{array}{c}\text { Discharge } \\
\text { Velocity }\end{array}$ & \multirow{3}{*}{$\begin{array}{l}\text { Near- } \\
\text { Repeat } \\
\text { Set }\end{array}$} & \multirow{3}{*}{$\begin{array}{c}\text { Near- } \\
\text { Replicate } \\
\text { Set }\end{array}$} \\
\hline text & text & text & in & $\mathrm{g} / \mathrm{cm}^{3}$ & fraction & $\mathbf{m}$ & fraction & fraction & $\#$ & $\#$ & $\#$ & $\#$ & in & text & $\mathbf{m} / \mathbf{s}$ & & \\
\hline MSS & ID & M/DDX & D & $\mathrm{S}$ & $\mathbf{f}_{\mathrm{s}}$ & $d_{50}\left(d_{s}\right)$ & DC & $\phi_{\mathrm{p}}$ & $\mathbf{N}$ & $\mathbf{N}_{J}$ & $\mathbf{N}_{\mathrm{O}}$ & $\mathbf{N}_{\mathbf{I}}$ & d & HS & $\mathbf{U}$ & & \\
\hline 7090208 & 34S_6p1d7YYd_1 & 10/26A2 & 33.875 & 2.45 & 0.00487 & 0.00018 & 0.180 & 0.051 & 12 & 12 & 8 & 4 & 0.446 & $\mathrm{~S}$ & 4.0 & 10 & $4 a$ \\
\hline 7090328 & 34S_6p1d7Yd_1 & 10/30A2 & 33.875 & 2.45 & 0.00487 & 0.00018 & 0.180 & 0.051 & 12 & 12 & 8 & 4 & 0.446 & $\mathrm{~S}$ & 3.6 & 10 & $4 \mathrm{~b}$ \\
\hline 20070750 & 34S_6p1d7Yyd_8 & $7 / 23 \mathrm{~A} 1$ & 33.875 & 2.45 & 0.00487 & 0.00018 & 0.180 & 0.048 & 12 & 12 & 8 & 4 & 0.446 & $\mathrm{~S}$ & 4.1 & - & $4 a, 4 b$ \\
\hline 7090184 & 34S_6p1d7Yd_9 & 10/19A2 & 33.875 & 2.45 & 0.00487 & 0.00018 & 0.180 & 0.050 & 12 & 4 & 0 & 4 & 0.446 & $\mathrm{~S}$ & 8.5 & 11 & - \\
\hline 7090360 & 34S_6p1d7Yd_9 & 10/30C2 & 33.875 & 2.45 & 0.00487 & 0.00018 & 0.180 & 0.050 & 12 & 4 & 0 & 4 & 0.446 & $\mathrm{~S}$ & 6.7 & 11 & - \\
\hline 700319 & 70F_4s1d2Vc_1 & $4 / 21 \mathrm{~A}$ & 70 & 2.48 & 0.0143 & $6.9 \mathrm{E}-05$ & 0.336 & 0.050 & 12 & 12 & 8 & 4 & 0.613 & FD & 7.1 & 12 & - \\
\hline 700430 & 70F_4s1d2Vc_1 & $4 / 29 \mathrm{~A}$ & 70 & 2.48 & 0.0143 & $6.9 \mathrm{E}-05$ & 0.336 & 0.050 & 12 & 12 & 8 & 4 & 0.613 & FD & 7.3 & 12 & - \\
\hline 700356 & 70F_4s1d2Vd_1 & $4 / 22 \mathrm{~A}$ & 70 & 2.48 & 0.0143 & $6.9 \mathrm{E}-05$ & 0.185 & 0.050 & 12 & 12 & 8 & 4 & 0.613 & FD & 9.9 & 13 & - \\
\hline 700415 & $70 \mathrm{~F}$ 4s $1 \mathrm{~d} 2 \mathrm{Vd} 1$ & $4 / 28 \mathrm{~A}$ & 70 & 2.48 & 0.0143 & $6.9 \mathrm{E}-05$ & 0.187 & 0.050 & 12 & 12 & 8 & 4 & 0.613 & FD & 9.8 & 13 & - \\
\hline
\end{tabular}

(a) A dash (-) indicates the test condition is not included in a near-replicate or near-repeat set. 
Table E.6. $\mathrm{U}_{\mathrm{CS}}$ and $\mathrm{H}_{\mathrm{CS}}$ Values, SDs, and \%RSDs for Near-Replicate Sets of M3 Mixing Tests

\begin{tabular}{|c|c|c|c|c|c|c|c|c|c|c|}
\hline \multirow[b]{2}{*}{$\begin{array}{l}\text { Near- } \\
\text { Replicate } \\
\text { Set }\end{array}$} & \multirow{2}{*}{ 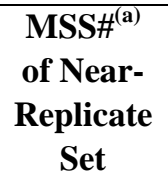 } & \multirow[b]{2}{*}{$\begin{array}{c}\text { Case ID of } \\
\text { Near-Replicate } \\
\text { Set }\end{array}$} & \multirow[b]{2}{*}{$\begin{array}{c}\text { Test } \\
\text { Number }\end{array}$} & \multicolumn{3}{|c|}{$\mathbf{U}_{\mathrm{CS}}$} & \multicolumn{4}{|c|}{$\mathbf{H}_{\mathrm{CS}}$} \\
\hline & & & & $\mathbf{m} / \mathbf{s}$ & $\begin{array}{l}\mathrm{SD}^{(\mathbf{b})} \\
(\mathrm{m} / \mathrm{s})\end{array}$ & $\% \mathrm{RSD}^{(\mathrm{c})}$ & in. & $\mathbf{m}$ & $\begin{array}{c}\mathrm{SD}^{(\mathbf{b})} \\
(\mathrm{m})\end{array}$ & $\% \mathrm{RSD}^{(\mathrm{c})}$ \\
\hline \multirow{3}{*}{1} & 7091025 & 34S_4p1d7Yc_1 & 11/26B1 & 6.5 & \multirow{3}{*}{0.153} & \multirow{3}{*}{2.40} & 9.75 & 0.2477 & \multirow{3}{*}{0.037} & \multirow{3}{*}{12.88} \\
\hline & 20070105 & 34S_4p1d7Yc_8 & 7/16 A2 & 6.4 & & & 11.625 & 0.2954 & & \\
\hline & 20070387 & 34S_4p1d7Yc_8 & 7/19 A1 & 6.2 & & & 12.625 & 0.3208 & & \\
\hline \multirow{2}{*}{2} & 7090875 & 34S_4p1d7Yd_1 & 11/19A2 & 6.4 & \multirow{2}{*}{0.000} & \multirow{2}{*}{0.00} & 9.75 & 0.2477 & \multirow{2}{*}{0.070} & \multirow{2}{*}{23.44} \\
\hline & 20070441 & 34S_4p1d7Yd_8 & 7/19 A4 & 6.4 & & & 13.625 & 0.3462 & & \\
\hline \multirow{2}{*}{3} & 7090779 & 34S_6p1d7Yc_1 & 11/14D1 & 4.5 & \multirow{2}{*}{0.354} & \multirow{2}{*}{8.32} & 12.00 & 0.3048 & \multirow{2}{*}{0.029} & \multirow{2}{*}{8.97} \\
\hline & 20070627 & 34S_6p1d7Yc_8 & 7/21 A2 & 4.0 & & & 13.625 & 0.3462 & & \\
\hline \multirow{2}{*}{$4 a$} & 7090208 & 34S_6p1d7Yd_1 & 10/26A2 & 4.0 & \multirow{2}{*}{0.071} & \multirow{2}{*}{1.75} & 12.00 & 0.3048 & \multirow{2}{*}{0.029} & \multirow{2}{*}{8.97} \\
\hline & 20070750 & 34S_6p1d7Yd_8 & 7/23 A1 & 4.1 & & & 13.625 & 0.3462 & & \\
\hline \multirow{2}{*}{$4 \mathrm{~b}$} & 7090328 & 34S_6p1d7Yd_1 & 10/30A2 & 3.6 & \multirow{2}{*}{0.354} & \multirow{2}{*}{9.18} & 12.75 & 0.3239 & \multirow{2}{*}{0.016} & \multirow{2}{*}{4.69} \\
\hline & 20070750 & 34S_6p1d7Yd_8 & 7/23 A1 & 4.1 & & & 13.625 & 0.3462 & & \\
\hline \multicolumn{5}{|c|}{ Pooled Over All 5 Near-Replicate Sets } & 0.224 & 5.29 & & & 0.040 & 13.32 \\
\hline
\end{tabular}

(a) MSS\# = Master Spreadsheet Number.

(b) $\mathrm{SD}=$ standard deviation.

(c) $\% \mathrm{RSD}=$ percent relative standard deviation $=100(\mathrm{SD} /$ mean $)$. 
Table E.7. $\mathrm{U}_{\mathrm{CS}}$ and $\mathrm{H}_{\mathrm{CS}}$ Values, \%RSDs, and Standard Deviations for Near-Repeat Sets of M3 Mixing Tests.

\begin{tabular}{|c|c|c|c|c|c|c|c|c|c|c|}
\hline \multirow[b]{2}{*}{$\begin{array}{c}\text { Near- } \\
\text { Repeat } \\
\text { Set }\end{array}$} & \multirow{2}{*}{$\begin{array}{c}\text { MSS\# }^{(a)} \\
\text { of Near- } \\
\text { Repeat } \\
\text { Set }\end{array}$} & \multirow[b]{2}{*}{$\begin{array}{c}\text { Case ID of } \\
\text { Near-Repeat } \\
\text { Set }\end{array}$} & \multirow[b]{2}{*}{$\begin{array}{c}\text { Test } \\
\text { Number }\end{array}$} & \multicolumn{3}{|c|}{$\mathbf{U}_{\mathrm{CS}}$} & \multicolumn{4}{|c|}{$\mathbf{H}_{\mathrm{CS}}$} \\
\hline & & & & $\mathbf{m} / \mathbf{s}$ & $\begin{array}{l}\mathrm{SD}^{(\mathbf{b})} \\
(\mathrm{m} / \mathrm{s})\end{array}$ & $\% \mathrm{RSD}^{(\mathrm{c})}$ & in. & $\mathbf{m}$ & $\begin{array}{l}\mathrm{SD}^{(\mathbf{b})} \\
(\mathrm{m})\end{array}$ & $\% \mathrm{RSD}^{(\mathrm{c})}$ \\
\hline \multirow[t]{2}{*}{ 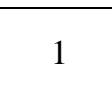 } & 9150506 & 15E_4s1d1Xc_1 & $6 / 27 C$ & 8.2 & \multirow{2}{*}{0.283} & \multirow{2}{*}{3.37} & 5.25 & 0.1334 & \multirow{2}{*}{0.000} & \multirow{2}{*}{0.00} \\
\hline & 9150516 & 15E_4s1d1Xc_1 & $6 / 30 \mathrm{~A}$ & 8.6 & & & 5.25 & 0.1334 & & \\
\hline \multirow{2}{*}{2} & 9150048 & 15E_4s1d2Rc_1 & $6 / 9 B$ & 5.3 & \multirow{2}{*}{0.071} & \multirow{2}{*}{1.32} & 5.75 & 0.1461 & \multirow{2}{*}{0.013} & \multirow{2}{*}{8.66} \\
\hline & 9150053 & 15E_4s1d2Rc_1 & $6 / 10 \mathrm{~A}$ & 5.4 & & & 6.50 & 0.1651 & & \\
\hline \multirow{2}{*}{3} & 9150063 & 15E_4s1d2Xc_1 & $6 / 10 \mathrm{~B}$ & 5.8 & \multirow{2}{*}{0.000} & \multirow{2}{*}{0.00} & 6.75 & 0.1715 & \multirow{2}{*}{0.004} & \multirow{2}{*}{2.67} \\
\hline & 9150108 & 15E_4s1d2Xc_1 & $6 / 11 C$ & 5.8 & & & 6.50 & 0.1651 & & \\
\hline \multirow{2}{*}{4} & 9150083 & 15E_4s1d2Xd_1 & $6 / 11 \mathrm{~A}$ & 7.2 & \multirow{2}{*}{0.141} & \multirow{2}{*}{1.94} & 5.75 & 0.1461 & \multirow{2}{*}{0.004} & \multirow{2}{*}{3.14} \\
\hline & 9150174 & 15E_4s1d2Xd_1 & $6 / 13 C$ & 7.4 & & & 5.50 & 0.1397 & & \\
\hline \multirow{2}{*}{5} & 9150412 & 15E_4s2d2Wc_1 & $6 / 24 B$ & 11.5 & \multirow{2}{*}{0.000} & 000 & 5.50 & 0.1397 & 900 & 615 \\
\hline & 9150419 & 15E_4s2d2Wc_1 & $6 / 25 \mathrm{~A}$ & 11.5 & & 0.00 & 6.00 & 0.1524 & 0.009 & 0.15 \\
\hline 6 & 9150345 & 15E_4s2d2Yc_1 & $6 / 19 C$ & 7.6 & $0 \cap 00$ & 0,00 & 6.00 & 0.1524 & 0 & 301 \\
\hline 6 & 9150347 & 15E_4s2d2Yc_1 & $6 / 20 \mathrm{~A}$ & 7.6 & 0.000 & 0.00 & 5.75 & 0.1461 & 0.004 & 3.01 \\
\hline 7 & 9150307 & 15E_4s2d2Zc_1 & $6 / 18 B$ & 5.4 & 0141 & 267 & 6.75 & 0.1715 & 0000 & 0 \\
\hline 1 & 9150312 & 15E_4s2d2Zc_1 & $6 / 19 \mathrm{~A}$ & 5.2 & 0.141 & 2.67 & 6.75 & 0.1715 & 0.000 & 0.00 \\
\hline & 7090095 & 34S_6p1d7YYd0 & 10/18A2 & 6.1 & & & 18.83 & 0.4783 & & \\
\hline 8 & 7090244 & 34S_6p1d7Yd_0 & 10/26B2 & 6.1 & 0.520 & 8.12 & 18.00 & 0.4572 & 0.014 & 2.88 \\
\hline & 7090758 & 34S_6p1d7Yd_0 & 11/14A2 & 7.0 & & & 19.00 & 0.4826 & & \\
\hline 9 & 7090136 & 34S_6p1d7Yd_6 & 10/18B2 & 6.4 & 0141 & & 13.00 & 0.3302 & 0,054 & 1463 \\
\hline$y$ & 7090298 & 34S_6p1d7Yd_6 & 10/29B2 & 6.2 & 0.141 & 2.24 & 16.00 & 0.4064 & 0.054 & 14.63 \\
\hline 10 & 7090208 & 34S_6p1d7Yd_1 & 10/26A2 & 4.0 & 0783 & 741 & 12.00 & 0.3048 & 0.012 & 420 \\
\hline 10 & 7090328 & 34S_6p1d7Yd_1 & 10/30A2 & 3.6 & 0.283 & 1.44 & 12.75 & 0.3239 & 0.013 & 4.29 \\
\hline 11 & 7090184 & 34S_6p1d7Yd_9 & 10/19A2 & 8.5 & 1.273 & & (d) & (d) & (d) & (d) \\
\hline 11 & 7090360 & 34S_6p1d7Yd_9 & 10/30C2 & 6.7 & 1.273 & $16 . / 5$ & (d) & (d) & (a) & (d) \\
\hline 17 & 700319 & 70F_4s1d2Vc_1 & $4 / 21 \mathrm{~A}$ & 7.1 & 014 & $10 \Omega$ & 30.50 & 0.7747 & דריח & ק כ כ \\
\hline 12 & 700430 & 70F_4s1d2Vc_1 & $4 / 29 \mathrm{~A}$ & 7.3 & 0.141 & & 32.00 & 0.8128 & 0.027 & 3.39 \\
\hline 13 & 700356 & 70F_4s1d2Vd_1 & $4 / 22 \mathrm{~A}$ & 9.9 & 0.071 & 0.72 & 27.75 & 0.7049 & 0.000 & 0.00 \\
\hline 13 & 700415 & 70F_4s1d2Vd_1 & $4 / 28 \mathrm{~A}$ & 9.8 & 0.071 & 0.12 & 27.75 & 0.7049 & 0.000 & 0.00 \\
\hline & Pooled Ove & r All 13 Near-Rep & eat Sets & & 0.415 & 5.98 & & & $\mathrm{~N} / \mathrm{A}^{(\mathrm{e})}$ & N/A \\
\hline & Pooled w & o Near-Repeat Se & \# 11 & & 0.247 & 4.12 & & & 0.019 & 5.54 \\
\hline
\end{tabular}

(a) MSS\# = Master Spreadsheet Number.

(b) $\mathrm{SD}=$ standard deviation.

(c) $\% \mathrm{RSD}=$ percent relative standard deviation $=100(\mathrm{SD} /$ mean $)$.

(d) Velocity (U) values differ too much to be considered near-repeat values for determining near-repeat sets of test conditions for $\mathrm{H}_{\mathrm{C}}$.

(e) $\mathrm{N} / \mathrm{A}=$ not applicable. 


\title{
Appendix F \\ Multiple Regression Modeling of Mixing Data
}

\author{
GF Piepel \\ BG Amidan \\ A Heredia-Langner
}





\section{Contents Contents}

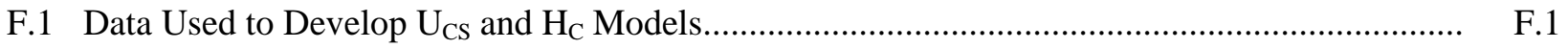

F.1.1 Data Sets Used to Fit $\mathrm{U}_{\mathrm{CS}}$ and $\mathrm{H}_{\mathrm{C}}$ Models ....................................................... F.1

F.1.2 Aspects of Experimental Data Collection ................................................................. F.2

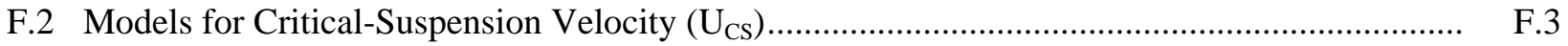

F.2.1 $\mathrm{U}_{\mathrm{CS}}$ Model Forms .................................................................................. F.

F.2.2 $\mathrm{U}_{\mathrm{CS}}$ Power-Law Model Forms ….................................................................. F.4

F.2.3 $\mathrm{U}_{\mathrm{CS}}$ Power-Law Models with Interaction Terms....................................................... F.6

F.2.4 Results for $\mathrm{U}_{\mathrm{CS}}$ Power-Law Models.................................................................... F.7

F.2.5 Results for $U_{\text {CS }}$ Power-Law Models with Interaction Terms ....................................... F. F.16

F.2.6 Comparison of $\mathrm{U}_{\mathrm{CS}}$ Models ................................................................................. F.20

F.3 Cloud Height $\left(\mathrm{H}_{\mathrm{C}}\right)$ Models ................................................................................... F. 21

F.3.1 $\mathrm{H}_{\mathrm{C}}$ Model Forms ….......................................................................................... F.

F.3.2 $\mathrm{H}_{\mathrm{C}}$ Power-Law Model Forms ................................................................................ F.22

F.3.3 $\mathrm{H}_{\mathrm{C}}$ Power-Law Models with Interaction Terms .......................................................... F. F.24

F.3.4 Results for $\mathrm{H}_{\mathrm{C}}$ Power-Law Models ............................................................................. F. F.24

F.3.5 Results for $\mathrm{H}_{\mathrm{C}}$ Power-Law Models with Interaction Terms....................................... F.33

F.3.6 Comparison of $\mathrm{H}_{\mathrm{C}}$ Models .......................................................................... F.36

F.4 Illustration of $\mathrm{U}_{\mathrm{CS}}$ and $\mathrm{H}_{\mathrm{C}}$ Model Application and Uncertainty Calculations ........................... F.38

F.5 Model Validity Region ........................................................................................................ F.47

F.6 Possible Future Activities ................................................................................................... F.4 F

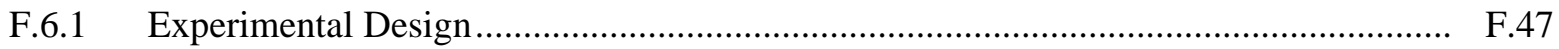

F.6.2 Other Data/Modeling Analyses .............................................................................. F.48

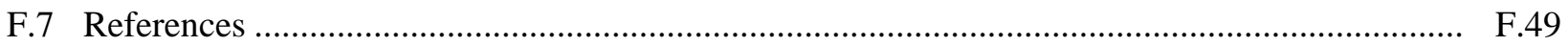




\section{Figures}

F.1 Performance of a Power-Law Equation to Relate Unhindered Terminal Settling Velocity $\left(\mathrm{U}_{\mathrm{T}}\right)$ to $\mathrm{s}-1$ and $\mathrm{d}_{\mathrm{S}}=\mathrm{d}_{50}$ for the Full Data Set

F.2 Log-Log Plot of Predicted Versus Measured $U_{\text {CS }}(\mathrm{m} / \mathrm{s})$ Values for the 9-Term Dimensional Model in Table F.1 Fit to the Full Data Set

F.3 Log-Log Plot of Predicted Versus Measured $U_{\mathrm{CS}}(\mathrm{m} / \mathrm{s})$ Values for the 9-Term Dimensional Model in Table F.2 Fit to the Trimmed Data Set....

F.4 Log-Log Plot of Predicted Versus Measured $U_{C S}(\mathrm{~m} / \mathrm{s})$ Values for the 9-Term Dimensionally Consistent Model in Table F.3 with 8 Coefficients Fit to the Full Data Set. ....

F.5 Log-Log Plot of Predicted Versus Measured $\mathrm{U}_{\mathrm{CS}}(\mathrm{m} / \mathrm{s})$ Values for the 9-Term Dimensionally Consistent Model in Table F.4 with 8 Coefficients Fit to Trimmed Data Set. .. F.15

F.6 Log-Log Plot of Predicted Versus Measured $U_{\mathrm{CS}}$ (in $\mathrm{m} / \mathrm{s}$ ) Values for the 12-Term Dimensional Model with Interactions in Table F.3 Fit to the Full Data Set....

F.7 Log-Log Plot of Predicted Versus Measured $U_{\text {CS }}(\mathrm{m} / \mathrm{s})$ Values for the 11-Term Dimensional Model with Interactions in Table F.4 Fit to the Trimmed Data Set.

F.8 Log-Log Plot of Predicted Versus Measured $U_{\mathrm{CS}}(\mathrm{m} / \mathrm{s})$ Values for the Nondimensional Model From Section 7.3.2 Developed Using the Full Data Set

F.9 Log-Log Plot of Predicted Versus Measured $\mathrm{H}_{\mathrm{C}}$ Values for the 11-Term Dimensional Model in Table F.8 Fit to the Full Data Set

F.10 Log-Log Plot of Predicted Versus Measured $\mathrm{H}_{\mathrm{C}}$ Values for the 10-Term Dimensional Model in Table F.9 Fit to the Trimmed Data Set

F.11 Log-Log Plot of Predicted Versus Measured $\mathrm{H}_{\mathrm{C}}(\mathrm{m})$ Values for 11-Term Dimensionally Consistent Model in Table F.10 with 10 Coefficients Fit to Full Data Set...

F.12 Log-Log Plot of Predicted Versus Measured $\mathrm{H}_{\mathrm{C}}(\mathrm{m})$ Values for 10-Term Dimensionally Consistent Model in Table F.11 with 9 Coefficients Fit to Trimmed Data Set.

F.13 Log-Log Plot of Predicted Versus Measured $\mathrm{H}_{\mathrm{C}}$ Values for the 13-Term Dimensional Model with Interactions in Table F.12 Fit to the Full Data Set.....

F.14 Log-Log Plot of Predicted Versus Measured $\mathrm{H}_{\mathrm{C}}$ Values for the 12-Term Dimensional Model with Interactions in Table F.13 Fit to the Trimmed Data Set

F.15 Log-Log Plot of Predicted Versus Measured $\mathrm{H}_{\mathrm{C}}(\mathrm{m} / \mathrm{s})$ Values for the Nondimensional Model from Section 7.3.2 Developed Using the Full Data Set.

\section{Tables}

F.1 Coefficients and Performance Summary for the 9-Term Linearized Power-Law Model on the Natural Logarithm of $U_{C S}$ Fit to the Full Data Set .....

F.2 Coefficients and Performance Summary for the 9-Term Linearized Power-Law Model on the Natural Logarithm of $\mathrm{U}_{\mathrm{CS}}$ Fit to the Trimmed Data Set.

F.3 Coefficients and Performance Summary for the Linearized Version of 9-Term Dimensionally Consistent Model on the Natural Logarithm of $U_{\mathrm{CS}}$ with 8 Coefficients Fit to the Full Data Set. 
F.4 Coefficients and Performance Summary for the Linearized Version of 9-Term

Dimensionally Consistent Model on Natural Logarithm of $U_{C s}$ with 8 Coefficients Fit to the

Trimmed Data Set

F.5 Coefficients and Performance Summary for the 12-Term Dimensional Model with Interactions for the Natural Logarithm of $U_{C S}$ Fit to the Full Data Set.

F.6 Coefficients and Performance Summary for the 11-Term Dimensional Model with Interactions for the Natural Logarithm of $\mathrm{U}_{\mathrm{CS}}$ Fit to the Trimmed Data Set

F.18

F.7. Coefficients of $U_{C S}$ Models Expressed in the Dimensional Form of Equation (F.8a).

F.8 Coefficients and Performance Summary for the 11-Term Linearized Power-Law Model on the Natural Logarithm of $\mathrm{H}_{\mathrm{C}}$ Fit to the Full Data Set.

F.9 Coefficients and Performance Summary for the 10-Term Linearized Power-Law Model on the Natural Logarithm of $\mathrm{H}_{\mathrm{C}}$ Fit to the Trimmed Data Set ....

F.10 Coefficients and Performance Summary for Linearized Version of 11-Term Dimensionally Consistent Model on Natural Logarithm of $\mathrm{H}_{\mathrm{C}}$ with 10 Coefficients Fit to the Full Data Set....

F.11 Coefficients and Performance Summary for the Linearized Version of the 10-Term Dimensionally Consistent Model on the Natural Logarithm of $\mathrm{H}_{\mathrm{C}}$ with 9 Coefficients Fit to the Trimmed Data Set

F.12 Coefficients and Performance Summary for the 13-Term Dimensional Model with Interactions on the Natural Logarithm of $\mathrm{H}_{\mathrm{C}}$ Fit to the Full Data Set....

F.13 Coefficients and Performance Summary for the 12-Term Dimensional Model with Interactions on the Natural Logarithm of $\mathrm{H}_{\mathrm{C}}$ Fit to the Trimmed Data Set

F.14 Coefficients of $\mathrm{H}_{\mathrm{C}}$ Models Fit to Full Data Set Expressed in the Dimensional Form of Equation (F.21a).

F.15 Values of Predictor Variables Selected to Illustrate Application of Models Fit to the Full Data Sets for $\mathrm{U}_{\mathrm{CS}}$ and $\mathrm{H}_{\mathrm{C}}$

F.16 Predictor Variable Values in Formats Needed to Illustrate Use of Models Fit to the Full Data Sets for $\mathrm{U}_{\mathrm{CS}}$ and $\mathrm{H}_{\mathrm{C}}$

F.17 Predicted $U_{\mathrm{CS}}$ and Corresponding 95\% CIs and 95\% SCIs Using Models Fit to the Full Data Set Applied to the Experimental Set of Conditions Shown in Tables F.15 and F.16

F.18 Predicted $\mathrm{H}_{\mathrm{C}}$ and Corresponding 95\% CIs and 95\% SCIs Using Models Fit to the Full Data Set Applied to the Experimental Set of Conditions Shown in Tables F.15 and F.16

F.19 Variance-Covariance Matrix for the 9-Term $\ln \left(\mathrm{U}_{\mathrm{CS}}\right)$ Model in F.1

F.20 Variance-Covariance Matrix for 12-Term $\ln \left(\mathrm{U}_{\mathrm{CS}}\right)$ Model in F.5

F.21 Variance-Covariance Matrix for 11-Term $\ln \left(\mathrm{H}_{\mathrm{C}}\right)$ Model in F.8

F.22 Variance-Covariance Matrix for 13-Term $\ln \left(\mathrm{H}_{\mathrm{C}}\right)$ Model in F.12

F.23 Ranges of Predictor Variables in the Full and Trimmed Data Sets Used to Develop $\mathrm{U}_{\mathrm{Cs}}$ and $\mathrm{H}_{\mathrm{C}}$ Multiple-Regression Models 


\section{Acronyms}

$\begin{array}{ll}\text { CI } & \text { confidence intervals } \\ \text { CL } & \text { confidence level } \\ \text { D } & \text { tank diameter (scale) } \\ \text { DC } & \text { duty cycle } \\ \text { E } & \text { elliptical head } \\ \text { F\&D } & \text { flange and dish head } \\ \text { H }_{C} & \text { cloud height } \\ \text { HS } & \text { head shape } \\ \text { LR } & \text { linear regression } \\ \text { MR } & \text { multiple regression } \\ \text { NLR } & \text { nonlinear regression } \\ \text { OLS } & \text { ordinary least squares } \\ \text { P } & \text { pulsed } \\ \text { RMSE } & \text { root-mean-square-error } \\ \text { RSM } & \text { response surface methodology } \\ \text { S } & \text { steady state } \\ \text { SCI } & \text { simultaneous confidence intervals } \\ \text { SD } & \text { standard deviation } \\ \text { U } & \text { target velocity } \\ \text { U } & \text { critical-suspension velocity } \\ \text { WLS } & \text { weighted least squares } \\ & \end{array}$

\section{Symbols}

$\mathrm{a}_{\mathrm{i}}$

$\mathrm{a}_{0}$

$b_{i}$

$\mathrm{b}_{0}$

d

D

$\mathrm{DC}$

$\frac{\mathrm{d}}{\mathrm{D}}$

$d_{S}$ model coefficients to be estimated using experimental data

multiplicative coefficient

model coefficients to be estimated using experimental data (nondimensional)

multiplicative coefficient (nondimensional)

jet nozzle diameter $(\mathrm{m})$

tank diameter $(\mathrm{m})$

duty cycle (nondimensional)

nondimensional pulse-jet diameter

solid s particle diameter $=\mathrm{d}_{50}=$ median particle diameter $(\mathrm{m})$ 


$\begin{array}{ll}\frac{\mathrm{U}^{2}}{\mathrm{D}(\mathrm{s}-1) \mathrm{g}} & \text { Froude number (nondimensional) } \\ \mathrm{g} & \text { gravity constant }\left(9.80665 \mathrm{~m} / \mathrm{s}^{2}\right) \\ \ln (\mathrm{)} & \text { natural logarithm of the variable in parentheses } \\ \mathrm{N}_{\mathrm{J}} & \text { number of operating jets } \\ \mathrm{s} & \text { density ratio of solids to liquid (nondimensional) } \\ \mathrm{U}_{\mathrm{CS}} & \text { critical-suspension velocity (m/s) } \\ \mathrm{U}_{\mathrm{T}} & \text { unhindered terminal settling velocity (m/s) } \\ \mathrm{U}_{\mathrm{T}} & \text { kinematic ratio (nondimensional) } \\ \mathrm{U} & \text { hindered terminal settling velocity } \\ \mathrm{U}_{\mathrm{TH}} & \text { kinematic viscosity } \\ v & \text { predictor variables }\end{array}$

\section{Greek Symbols}

$\phi_{\mathrm{S}} \quad$ solids volume fraction (nondimensional)

$\phi_{\mathrm{p}} \quad$ pulse volume fraction (nondimensional)

$\phi_{\mathrm{J}} \quad$ jet density $=\mathrm{N}_{\mathrm{J}}(\mathrm{d} / \mathrm{D})^{2}$ (nondimensional)

$\delta \quad$ multiplicative random error term

additive random error term 



\section{Appendix F}

\section{Multiple Regression Modeling of Mixing Data}

This appendix discusses the results from applying statistical methods for multiple regression (MR) to develop, evaluate, validate, and quantify prediction uncertainties of empirical models using the July 2007, Fall 2007, and 2008 mixing experimental data. Models are presented that relate two key mixing response variables to nondimensional and dimensional predictor variables. The key mixing response variables are critical-suspension velocity $\left(\mathrm{U}_{\mathrm{CS}}\right)$ and cloud height $\left(\mathrm{H}_{\mathrm{C}}\right)$. The predictor variables are generally test variables or functions of test variables. The statistical MR methods and formulas that were applied are discussed in Appendix D. References to specific sections of that appendix are cited where appropriate.

Section F.1 discusses the data used to develop MR models for $\mathrm{U}_{\mathrm{CS}}$ and $\mathrm{H}_{\mathrm{C}}$. Section F.2 presents the MR model results for $U_{\text {CS. }}$ Section F.3 presents the MR model results for $\mathrm{H}_{\mathrm{C}}$. Sections F.2 and F.3 discuss how the starting form of each model was obtained and how the starting model form was generalized and/or extended. Model forms were extended by applying stepwise regression methods (see Section D.4.2 of Appendix D) to identify two variable interaction terms that improved the fits of the models to the experimental data. The interaction terms selected were verified as being reasonable based on subject-matter knowledge and experience, as well as the functionality plots of the data (see Section E.2 of Appendix E). Section F.4 illustrates how the models developed in Sections F.2 and F.3 can be applied, using one set of experimental conditions as an example. Section F.4 also illustrates how confidence intervals around predicted values of either $\mathrm{U}_{\mathrm{CS}}$ or $\mathrm{H}_{\mathrm{C}}$ can be obtained. Section F.5 discusses the validity regions for the $\mathrm{U}_{\mathrm{CS}}$ and $\mathrm{H}_{\mathrm{C}}$ models presented. Section F.6 briefly mentions other analyses that weren't possible to perform as part of this work but may be useful to perform in the future.

The results of fitting the $\mathrm{U}_{\mathrm{CS}}$ and $\mathrm{H}_{\mathrm{C}}$ model forms to experimental data are presented in tables and figures of Sections F.2 and F.3. The results tables contain the fitted coefficients of the models, standard

deviations of the fitted coefficients, and goodness-of-fit summary statistics. Graphical displays that show how well the models fit the experimental data are also provided and discussed.

\section{F.1 Data Used to Develop $\mathrm{U}_{\mathrm{cs}}$ and $\mathrm{H}_{\mathrm{C}}$ Models}

Section F.1.1 discusses two data sets used to fit $\mathrm{U}_{\mathrm{CS}}$ and $\mathrm{H}_{\mathrm{C}}$ models. Section F.1.2 discusses aspects of the experimental collection of data that affect modeling and other data analyses.

\section{F.1.1 Data Sets Used to Fit $U_{c s}$ and $H_{C}$ Models}

Two sets of combined July 2007, Fall 2007, and 2008 data were used to fit $\mathrm{U}_{\mathrm{CS}}$ and $\mathrm{H}_{\mathrm{C}}$ models. The sets are generally referred to as "full” or "trimmed," as described below:

- Full Data Set: This data set contains the pulsed (i.e., not steady state) data from the July 2007, Fall 2007, and 2008 testing campaigns that met technical, data quality, and quality assurance requirements. Data with a return-line height less than $\mathrm{D}$ were removed, as were data with questionable $\mathrm{U}_{\mathrm{CS}}$ values (see Section E.1.1).

- $\quad$ For $\mathrm{U}_{\mathrm{CS}}$, this data set contains 173 data points. 
- $\quad$ For $\mathrm{H}_{\mathrm{C}}$, this data set contains 669 data points with target velocity (U) values greater than or equal to the corresponding critical-suspension velocity values (i.e., $\mathrm{U} \geq \mathrm{U}_{\mathrm{CS}}$ ).

- Trimmed Data Set: This data set is a trimmed version of the full data set. It excludes data with duty cycle (DC) $>0.41$ (which eliminates 11 of 173 test conditions), $\phi_{\mathrm{S}}>0.016$ (which eliminates 7 of 173 test conditions), and $\mathrm{d}_{\mathrm{S}}\left(\mathrm{d}_{50}\right)>1.8 \mathrm{E}-04$ (which eliminates 1 of 173 test conditions). Functionality plots for $\mathrm{U}_{\mathrm{CS}}$ and $\mathrm{H}_{\mathrm{CS}}$ versus DC (see Figures E.11 and E.26 in Appendix E) show a significant change in relationship when DC reaches $\sim 0.66$. Because there are limited data in the range $0.41 \leq$ DC $\leq 0.67$ to support modeling the more complicated relationship, it was decided to trim those data to obtain less complicated model forms that fit the experimental data better. Similarly, functionality plots for $\mathrm{U}_{\mathrm{CS}}$ and $\mathrm{H}_{\mathrm{CS}}$ versus $\phi_{\mathrm{S}}$ (see Figures E.12 and E.27 in Appendix E) show a significant change in relationship for $\phi_{\mathrm{S}} \geq \sim 0.016$. Because there are limited data (7 test conditions) in the range 0.016 $\leq \phi_{\mathrm{S}} \leq 0.06$ to support modeling the more complicated relationship, it was decided to trim those data to obtain less complicated model forms that fit the experimental data better. The full data set contains only one test condition with $\mathrm{d}_{\mathrm{S}} \sim 7.7 \mathrm{E}-04$, whereas the remaining conditions have $\mathrm{d}_{\mathrm{S}}<1.8 \mathrm{E}-04$.

However, as noted in Section E.1.1, where these trimmed data lie in the direction of the expected actual values for the system to which the data are extrapolated when they are being extrapolated, it may be beneficial to include them in spite of the potential for statistically undue influence on the fit.

- For $\mathrm{U}_{\mathrm{CS}}$, this data set contains 154 data points.

- $\quad$ For $\mathrm{H}_{\mathrm{C}}$, this data set contains 581 data points with $\mathrm{U} \geq \mathrm{U}_{\mathrm{CS}}$.

In both the full and trimmed data sets for $\mathrm{H}_{\mathrm{C}}$, only data with $\mathrm{U} \geq \mathrm{U}_{\mathrm{CS}}$ are included because the relationship between $H_{C}$ and $U$ changes significantly for velocities below $U_{C S}$. This portion of the $H_{C}$ versus $U$ relationship is not relevant to understanding how well tanks are mixed. Thus, only data with $\mathrm{U} \geq \mathrm{U}_{\mathrm{CS}}$ were retained in both the full and trimmed data sets for $\mathrm{H}_{\mathrm{C}}$.

Figures E.1 and E.3 in Appendix E contain dot and scatterplot matrix plots, respectively, for the predictor variables using the full data set. Figures E.2 and E.4 in Appendix E contain dot and scatterplot matrix plots, respectively, for the predictor variables using the trimmed data set.

\section{F.1.2 Aspects of Experimental Data Collection}

As discussed in Section D.2.2 of Appendix D, a restricted order of performing experimental tests rather than a randomized order likely causes groups of data to have different uncertainties and to be correlated, thus violating assumptions for ordinary least squares (OLS) regression methods. Several restrictions in the order of testing occurred for the M3 mixing tests. First, there were some differences between the July 2007, Fall 2007, and 2008 test campaigns, which were each performed in contiguous periods of time. Also, tests with a given scaled tank size were performed together. Once a given simulant was put in a tank, all tests with that simulant were performed. Other restrictions on the order of testing were also used in collecting the M3 mixing experimental data. These included collecting $\mathrm{H}_{\mathrm{C}}$ data at several velocities for a given set of test conditions.

The restrictions in the order of performing M3 mixing tests were substantial and likely result in a very complicated variance-covariance (i.e., uncertainty) structure for the resulting data. Rather than one magnitude of uncertainty in response variables $\left(\mathrm{U}_{\mathrm{CS}}\right.$ and $\left.\mathrm{H}_{\mathrm{C}}\right)$, there are several different magnitudes of uncertainties. There are also complicated covariances among subgroups of data. There are additional 
possible complications by not performing tests at a given "restriction level" in a randomized order but rather in an increasing or decreasing order according to the magnitude of a test variable. This can cause the effects of any uncontrolled variables, trends, etc., to be confounded with the effect of the test variable.

So the order in which M3 mixing tests were performed likely imposes a very complicated uncertainty structure on the resulting data and could have led to confounding of effects of uncontrolled variables with the effects of test variables. Sufficient replicate tests scattered throughout the testing would have provided some basis to investigate these concerns and to assess whether resulting multiple-regression models have a significant lack-of-fit (see Section D.3.2 of Appendix D). However, the number of replicate tests performed as part of the M3 testing work (see Section E.3 of Appendix E) were not sufficient for this purpose.

Ultimately, it was not possible, given existing limitations, to account in modeling efforts for the order in which the data were collected and the associated complicated uncertainty structure of the data. Hence, OLS regression methods (as discussed in Appendix D) were applied to obtain the results presented in Sections F.2 and F.3.

\section{F.2 Models for Critical-Suspension Velocity $\left(U_{c s}\right)$}

This section discusses the development, results, and uncertainties of $U_{\mathrm{CS}}$ models fit to the full and trimmed data sets described in Section F.1.

\section{F.2.1 $\quad U_{c s}$ Model Forms}

To develop a model form for $\mathrm{U}_{\mathrm{CS}}$, various functionality plots of $\mathrm{U}_{\mathrm{CS}} \mathrm{vs} . \mathrm{x}_{\mathrm{i}}$ (test variables) were investigated. Specifically, plots of

- $\mathrm{U}_{\mathrm{CS}}$ versus $\mathrm{X}_{\mathrm{i}}$

- $\mathrm{U}_{\mathrm{CS}}$ versus $\ln \left(\mathrm{x}_{\mathrm{i}}\right)$

- $\ln \left(\mathrm{U}_{\mathrm{CS}}\right)$ versus $\ln \left(\mathrm{x}_{\mathrm{i}}\right)$

- $\ln \left(\mathrm{U}_{\mathrm{CS}}\right)$ versus $\mathrm{x}_{\mathrm{i}}$

were considered. The goal was to identify the plot for each $\mathrm{x}_{\mathrm{i}}$ that gave linear or nearly-linear relationships for various combinations of other test variables. This would then provide the simplest relationship for that $\mathrm{x}_{\mathrm{i}}$, which would be more likely to support extrapolation (if needed). Each of the above types of functionality plots provided the "most linear" relationships for at least one $\mathrm{x}_{\mathrm{i}}$. Unfortunately, that greatly complicates the development of a model form relating $\mathrm{U}_{\mathrm{CS}}$ to all of the $\mathrm{x}_{\mathrm{i}}$. There was insufficient time and budget to develop and fit more complicated model forms that would be fully consistent with the results of the functionality-plot investigation for $\mathrm{U}_{\mathrm{Cs}}$. Also, there was concern about placing too much emphasis on the functionality plots, which only showed results for a fraction of the data (as discussed at the end of Section E.2.1).

Ultimately, the $\ln \left(\mathrm{U}_{\mathrm{CS}}\right)$ versus $\ln \left(\mathrm{x}_{\mathrm{i}}\right)$ plots (which are shown in Figures E.6 to E.16 of Appendix E as $\log$-log plots of $U_{C S}$ versus $x_{i}$ ) had linear or not too curvilinear relationships for all of the test variables. Hence, it was concluded that the corresponding power-law model form would be an adequate "firstorder" approximation of the true, unknown relationships between $\mathrm{U}_{\mathrm{CS}}$ and the $\mathrm{x}_{\mathrm{i}}$. It was recognized that 
adopting the power-law model form would result in some model lack-of-fit for some test variables. Based on the plots in Figures E.6 to E.16, these test variables are $\mathrm{N}_{J}$ (the number of operating jets), DC (duty cycle) $>0.33$ for some conditions, and $\phi_{\mathrm{S}}>0.015$. However, this situation was judged acceptable given the goal of using the models to perform coarse ratings of the mixing designs of WTP vessels. Also, fitting models to both "full" and "trimmed" data sets, as described in Section F.1.1, addresses some of these issues. More accurate $\mathrm{U}_{\mathrm{CS}}$ models could be developed in the future from the M3 mixing-test data, but they would have more complicated forms, require more time to develop, and require more advanced statistical fitting and uncertainty methods.

A statistical response surface methodology (RSM) approach to developing empirical models (Myers and Montgomery 1995) was also investigated in a preliminary manner. Specifically, model forms relating $\mathrm{U}_{\mathrm{CS}}\left[\right.$ or $\left.\ln \left(\mathrm{U}_{\mathrm{CS}}\right)\right]$ to first- and second-degree polynomial functions of the test variables $\mathrm{x}_{\mathrm{i}}$ were investigated. First- and second-order polynomials adequately approximate many functional forms based on Taylor-series approximation theory. Hence, the RSM approach has been widely and successfully used in many scientific, business, and industrial applications. However, the first-order polynomial model

$$
\ln \left(\mathrm{U}_{\mathrm{CS}}\right)=\mathrm{b}_{0}+\sum_{\mathrm{i}=1}^{\mathrm{K}} \mathrm{b}_{\mathrm{i}} \mathrm{x}_{\mathrm{i}}
$$

using the same predictor variables $\mathrm{x}_{\mathrm{i}}(\mathrm{I}=1,2, \ldots, \mathrm{K})$ as in Eq. (F.4a) and (F.4b) did not perform as well as power-law based models. Adding statistically significant quadratic [squared $\left(\mathrm{x}_{\mathrm{i}}\right)^{2}$ or interaction $\mathrm{x}_{\mathrm{i}} \mathrm{x}_{\mathrm{j}}$ ] terms via stepwise regression methods (see Section D.4.2 of Appendix D)

$$
\ln \left(\mathrm{U}_{\mathrm{CS}}\right)=\mathrm{b}_{0}+\sum_{\mathrm{i}=1}^{\mathrm{K}} \mathrm{b}_{\mathrm{i}} \mathrm{x}_{\mathrm{i}}+\text { Selected }\left\{\sum_{\mathrm{i}=1}^{\mathrm{K}} \mathrm{b}_{\mathrm{ii}} \mathrm{x}_{\mathrm{i}}^{2}+\sum_{\mathrm{i}=1}^{\mathrm{K}} \sum_{\mathrm{j}>\mathrm{i}}^{\mathrm{K}} \mathrm{b}_{\mathrm{ij}} \mathrm{x}_{\mathrm{i}} \mathrm{x}_{\mathrm{j}}\right\}
$$

yielded a second-order model that fit the $\mathrm{U}_{\mathrm{CS}}$ modeling data better than the first-order model. However, that model still did not perform as well as the power-law based models discussed subsequently. Also, an issue with RSM-type polynomial models is that they are generally not appropriate for extrapolation. Hence, the results of the first- and second-order polynomial modeling efforts for $\mathrm{U}_{\mathrm{CS}}$ are not discussed in this report.

\section{F.2.2 U Us Power-Law Model Forms}

The initial $\mathrm{U}_{\mathrm{CS}}$ model form considered was developed by generalizing the physical model for $\mathrm{U}_{\mathrm{CS}}$ discussed in Sections 7.3.2 and 7.3.4 of the report. Taking that form of the model, moving the predictor variables to the right side of the equation, expanding variables calculated as functions of other variables, and collecting similar terms yields the statistical model form:

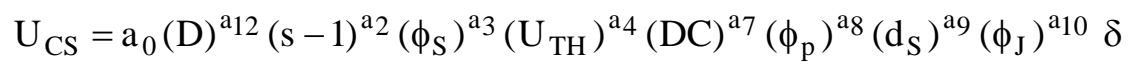

where

$$
\begin{aligned}
\mathrm{U}_{\mathrm{CS}} & =\text { critical-suspension velocity }(\mathrm{m} / \mathrm{s}) \\
\mathrm{a}_{0} & =\text { multiplicative coefficient } \\
\mathrm{a}_{\mathrm{i}} & =\text { model coefficients to be estimated using experimental data }
\end{aligned}
$$




$$
\begin{aligned}
\mathrm{D} & =\text { tank diameter }(\mathrm{m}) \\
\mathrm{s} & =\text { density ratio of solids to liquid (nondimensional) } \\
\phi_{\mathrm{S}} & =\text { solids volume fraction (nondimensional) } \\
\mathrm{U}_{\mathrm{TH}} & =\text { hindered terminal settling velocity }(\mathrm{m} / \mathrm{s}) \\
\mathrm{DC} & =\text { duty cycle (nondimensional) } \\
\phi_{\mathrm{p}} & =\text { pulse volume fraction (nondimensional) } \\
\mathrm{d}_{\mathrm{S}} & =\text { solid s particle diameter }=\mathrm{d}_{50}=\text { median particle diameter }(\mathrm{m}) \\
\phi_{\mathrm{J}} & =\text { jet density }=\mathrm{N}_{\mathrm{J}}(\mathrm{d} / \mathrm{D})^{2} \text { (nondimensional) } \\
\mathrm{N}_{\mathrm{J}} & =\text { number of operating jets } \\
\mathrm{d} & =\text { jet nozzle diameter (m) } \\
\delta & =\text { multiplicative random error term, as discussed in Section D.2.1, Appendix D. }
\end{aligned}
$$

Note that Eq. (F.1a) is a power-law model form, which was judged as adequate for first-order approximation and predictive purposes, as discussed above.

Because Eq. (F.1a) is nonlinear in its coefficients and has a multiplicative error structure, it can be converted to a model linear in its coefficients with an additive error structure by taking the natural logarithm of both sides, as discussed in Section D.2.1 of Appendix D. This yields the model

$$
\begin{aligned}
\ln \left(\mathrm{U}_{\mathrm{CS}}\right)= & \ln \left(\mathrm{a}_{0}\right)+\mathrm{a}_{12} \ln (\mathrm{D})+\mathrm{a}_{2} \ln (\mathrm{s}-1)+\mathrm{a}_{3} \ln \left(\phi_{\mathrm{S}}\right)+\mathrm{a}_{4} \ln \left(\mathrm{U}_{\mathrm{TH}}\right)+\mathrm{a}_{7} \ln (\mathrm{DC}) \\
& +\mathrm{a}_{8} \ln \left(\phi_{\mathrm{p}}\right)+\mathrm{a}_{9} \ln \left(\mathrm{d}_{\mathrm{S}}\right)+\mathrm{a}_{10} \ln \left(\phi_{\mathrm{J}}\right)+\varepsilon
\end{aligned}
$$

where

$$
\begin{aligned}
\ln () & =\text { natural logarithm of the variable in parentheses } \\
\varepsilon & =\text { additive random error term, as discussed in Section D.2.1 of Appendix D }
\end{aligned}
$$

and the remaining notation is as previously defined. The model form in Eq. (F.1b) can be fit by OLS linear regression (LR), whereas the model form in Eq. (F.1a) must be fit by weighted least squares (WLS) nonlinear regression (NLR). See Section D.2, Appendix D for more discussion of these issues.

Equations (F.1a) and (F.1b) can be expanded by substituting into them a generalization of the equation for $\mathrm{U}_{\mathrm{TH}}$ given by

This yields the model forms

$$
\mathrm{U}_{\mathrm{TH}}=\mathrm{U}_{\mathrm{T}}\left(1-\frac{\phi_{\mathrm{S}}}{0.5}\right)^{4.5}
$$

$$
\mathrm{U}_{\mathrm{CS}}=\mathrm{a}_{0}(\mathrm{D})^{\mathrm{a}_{1} 2}(\mathrm{~s}-1)^{\mathrm{a}_{2}}\left(\phi_{\mathrm{S}}\right)^{\mathrm{a}_{3}}\left(1-\frac{\phi_{\mathrm{S}}}{0.5}\right)^{\mathrm{a}_{5}}\left(\mathrm{U}_{\mathrm{T}}\right)^{\mathrm{a}_{6}}(\mathrm{DC})^{\mathrm{a}_{7}}\left(\phi_{\mathrm{p}}\right)^{\mathrm{a}_{8}}\left(\mathrm{~d}_{\mathrm{S}}\right)^{\mathrm{a}_{9}}\left(\phi_{\mathrm{J}}\right)^{\mathrm{a}_{1} 0} \delta
$$

and 


$$
\begin{aligned}
\ln \left(\mathrm{U}_{\mathrm{CS}}\right)= & \ln \left(\mathrm{a}_{0}\right)+\mathrm{a}_{12} \ln (\mathrm{D})+\mathrm{a}_{2} \ln (\mathrm{s}-1)+\mathrm{a}_{3} \ln \left(\phi_{\mathrm{S}}\right)+\mathrm{a}_{5} \ln \left(1-\frac{\phi_{\mathrm{S}}}{0.5}\right)+\mathrm{a}_{6} \ln \left(\mathrm{U}_{\mathrm{T}}\right) \\
& +\mathrm{a}_{7} \ln (\mathrm{DC})+\mathrm{a}_{8} \ln \left(\phi_{\mathrm{p}}\right)+\mathrm{a}_{9} \ln \left(\mathrm{d}_{\mathrm{S}}\right)+\mathrm{a}_{10} \ln \left(\phi_{\mathrm{J}}\right)+\varepsilon,
\end{aligned}
$$

where

$$
\begin{aligned}
& \mathrm{a}_{\mathrm{i}}=\text { model coefficients to be estimated using experimental data } \\
& \mathrm{U}_{\mathrm{T}}=\text { unhindered terminal settling velocity }(\mathrm{m} / \mathrm{s})
\end{aligned}
$$

and the other notation is as previously defined. The $\mathrm{a}_{6}$ and $\mathrm{a}_{5}$ coefficients in Eqs. (F.3a) and (F.3b) generalize, respectively, the 1.0 exponent (implied) on $U_{\mathrm{T}}$ and the 4.5 exponent on $\left(1-\phi_{\mathrm{S}} / 0.5\right)$ in Eq. (F.2).

Using a generalization of the formula $\phi_{\mathrm{J}}=\mathrm{N}_{\mathrm{J}}(\mathrm{d} / \mathrm{D})^{2}$ where $\mathrm{N}_{\mathrm{J}}$ and $\mathrm{d}$ are allowed to have their own coefficients and D is absorbed into the existing D term, the model forms in Eq. (F.3a) and (F.3b) can be further generalized as

$$
\mathrm{U}_{\mathrm{CS}}=\mathrm{a}_{0}(\mathrm{D})^{\mathrm{a}_{1}}(\mathrm{~s}-1)^{\mathrm{a}_{2}}\left(\phi_{\mathrm{S}}\right)^{\mathrm{a}_{3}}\left(1-\frac{\phi_{\mathrm{S}}}{0.5}\right)^{\mathrm{a}_{5}}\left(\mathrm{U}_{\mathrm{T}}\right)^{\mathrm{a}_{6}}(\mathrm{DC})^{\mathrm{a}_{7}}\left(\phi_{\mathrm{p}}\right)^{\mathrm{a}_{8}}\left(\mathrm{~d}_{\mathrm{S}}\right)^{\mathrm{a}_{9}}\left(\mathrm{~N}_{\mathrm{J}}\right)^{\mathrm{a}_{10}}(\mathrm{~d})^{\mathrm{a}_{11}} \delta
$$

and

$$
\begin{aligned}
\ln \left(\mathrm{U}_{\mathrm{CS}}\right)= & \ln \left(\mathrm{a}_{0}\right)+\mathrm{a}_{1} \ln (\mathrm{D})+\mathrm{a}_{2} \ln (\mathrm{s}-1)+\mathrm{a}_{3} \ln \left(\phi_{\mathrm{S}}\right)+\mathrm{a}_{5} \ln \left(1-\frac{\phi_{\mathrm{S}}}{0.5}\right)+\mathrm{a}_{6} \ln \left(\mathrm{U}_{\mathrm{T}}\right) \\
& +\mathrm{a}_{7} \ln (\mathrm{DC})+\mathrm{a}_{8} \ln \left(\phi_{\mathrm{p}}\right)+\mathrm{a}_{9} \ln \left(\mathrm{d}_{\mathrm{S}}\right)+\mathrm{a}_{10} \ln \left(\mathrm{N}_{\mathrm{J}}\right)+\mathrm{a}_{11} \ln (\mathrm{d})+\varepsilon,
\end{aligned}
$$

where all notation is as previously defined.

In summary, Eq. (F.4a) and (F.4b) are generalizations of the model forms in Eq. (F.1a) and (F.1b), where the latter are obtained from the former using the coefficient constraints $a_{6}=a_{4}, a_{5}=4.5 a_{4}$, $\mathrm{a}_{11}=2 \mathrm{a}_{10}$, and $\mathrm{a}_{1}=\mathrm{a}_{12}-2 \mathrm{a}_{10}$.

The model form for $\mathrm{U}_{\mathrm{CS}}$ in Sections 7.3.2 and 7.3.4 and the generalization of that model form in Eq. (F.4a) and (F.4b) do not contain a head shape (HS) term. The reason is that the data do not sufficiently support quantifying the effect of HS over the three tank sizes used in M3 testing. The spherical head (HS $=\mathrm{S}$ ) was used only in the 34-in. tank, which was used during all three test campaigns. The elliptical head (HS = E) was used only in the 15- and 70-in. tanks in 2008. The flange and dish head (HS = FD) was used only for some 70-in. tank tests in 2008. Section E.2.4 in Appendix E discusses differences in $\mathrm{U}_{\mathrm{CS}}$, $\mathrm{H}_{\mathrm{CS}}$, and $\mathrm{H}_{\mathrm{C}}$ data from tests in the 70-in. tank with elliptical (E) and FD head shapes. There is no way to know how these differences would translate to the 15-in., 34-in., or full-scale tanks.

\section{F.2.3 U U $\quad$ Power-Law Models with Interaction Terms}

Stepwise regression methods (see Section D.4.2, Appendix D) were used to augment $U_{C S}$ models of the form in Eq. (F.4b) with interaction terms of the form

$$
a_{i j} x_{j} \ln \left(x_{i}\right)
$$


This corresponds to augmenting models of the form in Eq. (F.4a) with interaction terms of the form

$$
x_{i}^{a_{i j} x_{j}}
$$

Allowing such interaction terms provides for models with power-law terms of the form

$$
x_{i}^{a_{i}+a_{i j} x_{j}}
$$

so the exponent [slope of the relationship between $\ln (\mathrm{y})$ and $\ln \left(\mathrm{x}_{\mathrm{i}}\right)$ ] can depend on other predictor variables $\left(\mathrm{x}_{\mathrm{j}}\right)$. The log-log functionality plots of $\mathrm{U}_{\mathrm{CS}}$ versus each test variable (see Section E.2.2 of Appendix E) show differences in slopes of relationships as other test variables change. Hence, there is strong evidence that suggests interaction terms of the above form may improve the predictive performance of mixing models, at least within the experimental region of the data. However, models with interaction terms can yield inaccurate predictions when extrapolated significantly outside the experimental region of data used to develop them. Hence, unless $U_{C S}$ models with interaction terms have been well validated for extrapolative use, it is recommended that only $\mathrm{U}_{\mathrm{CS}}$ models without interaction terms be used for extrapolative predictions.

\section{F.2.4 Results for $U_{c s}$ Power-Law Models}

The dimensional and corresponding dimensionally consistent model forms investigated for $\mathrm{U}_{\mathrm{CS}}$ are presented in Section F.2.4.1. The results of fitting the dimensional models for $U_{\mathrm{CS}}$ to the full and trimmed data sets are presented in Section F.2.4.2. The results of fitting the dimensionally consistent models for $\mathrm{U}_{\mathrm{CS}}$ are presented in Section F.2.4.3.

\section{F.2.4.1 Dimensional and Dimensionally Consistent Power-Law Model Forms for $U_{c s}$}

To begin, models of the form in Eq. (F.4b) were fit to the full and trimmed data sets described in Section F.1. For both data sets, the coefficients for the $s-1,\left(1-\phi_{\mathrm{S}} / 0.5\right), \mathrm{U}_{\mathrm{T}}$, and $\mathrm{d}_{\mathrm{S}}$ terms are statistically nonsignificant. There are two reasons for these results:

- The hindered terminal settling velocity $\left(\mathrm{U}_{\mathrm{TH}}\right)$ and unhindered terminal settling velocity $\left(\mathrm{U}_{\mathrm{T}}\right)$ are highly correlated for the full and trimmed data sets, as seen in Figure E.5 of Appendix E. This suggests that there may not be any additional value (within the region of test conditions investigated) to using $U_{T H}$ instead of $U_{T}$ in mixing response $\left(U_{C S}\right.$ or $\left.H_{C}\right)$ models. Because $\left(1-\phi_{S} / 0.5\right)$ is the term involved in converting $\mathrm{U}_{\mathrm{T}}$ to $\mathrm{U}_{\mathrm{TH}}$, the statistical nonsignificance of that term is understandable.

- $\mathrm{U}_{\mathrm{T}}$ is a complicated function of $\mathrm{s}-1$ and $\mathrm{d}_{\mathrm{S}}$, given by the equation

$$
\mathrm{U}_{\mathrm{T}}=\frac{v}{\mathrm{~d}_{\mathrm{S}}}\left[\sqrt{15+\frac{(\mathrm{s}-1) \mathrm{gd}_{\mathrm{S}}^{3} / \mathrm{v}^{2}}{0.3}}-\sqrt{15}\right]^{2}
$$

where $v$ is the kinematic viscosity, $\mathrm{g}$ is the gravity constant, and all other notation is as defined previously. However, over the variable space covered by the full and trimmed data sets, $\mathrm{U}_{\mathrm{T}}$, is represented extremely well by a power-law model in $s-1$ and $d_{s}$. This is shown in Figure F.1 for the full data set. Because the model of the form in Eq. (F.4a) already contains power-law terms for $\mathrm{s}-1$ 
and $d_{S}$, it is essentially redundant to have a power-law term for $U_{T}$ in models used to fit the full and trimmed data sets.

These two observations are conditional in the full and trimmed data sets described in Section F.1. Under other test conditions, unhindered or hindered terminal settling velocity may be useful in improving predictions of mixing responses such as $\mathrm{U}_{\mathrm{CS}}$ and $\mathrm{H}_{\mathrm{C}}$.

The two preceding observations, along with statistical methods for reducing terms in models (see Section D.4.1, Appendix D), led to dropping the $\left(1-\phi_{S} / 0.5\right)$ and $d_{S}$ terms from the model form in Eq. (F.4). It may seem more natural to drop $U_{T}$ than $d_{S}$ because $U_{T}$ is calculated using $d_{S}$ and $s-1$. However, $\mathrm{U}_{\mathrm{T}}$ is more physically meaningful as a predictor variable than $\mathrm{d}_{\mathrm{s}}$. Further, there was little difference in the goodness-of-fit of a model that retained $U_{\mathrm{T}}$ instead of $d_{\mathrm{S}}$. Models with $\left(1-\phi_{\mathrm{S}}\right)$ instead of $\left(1-\phi_{S} / 0.5\right)$ were also investigated, but that term was statistically nonsignificant for both the full and trimmed data sets.

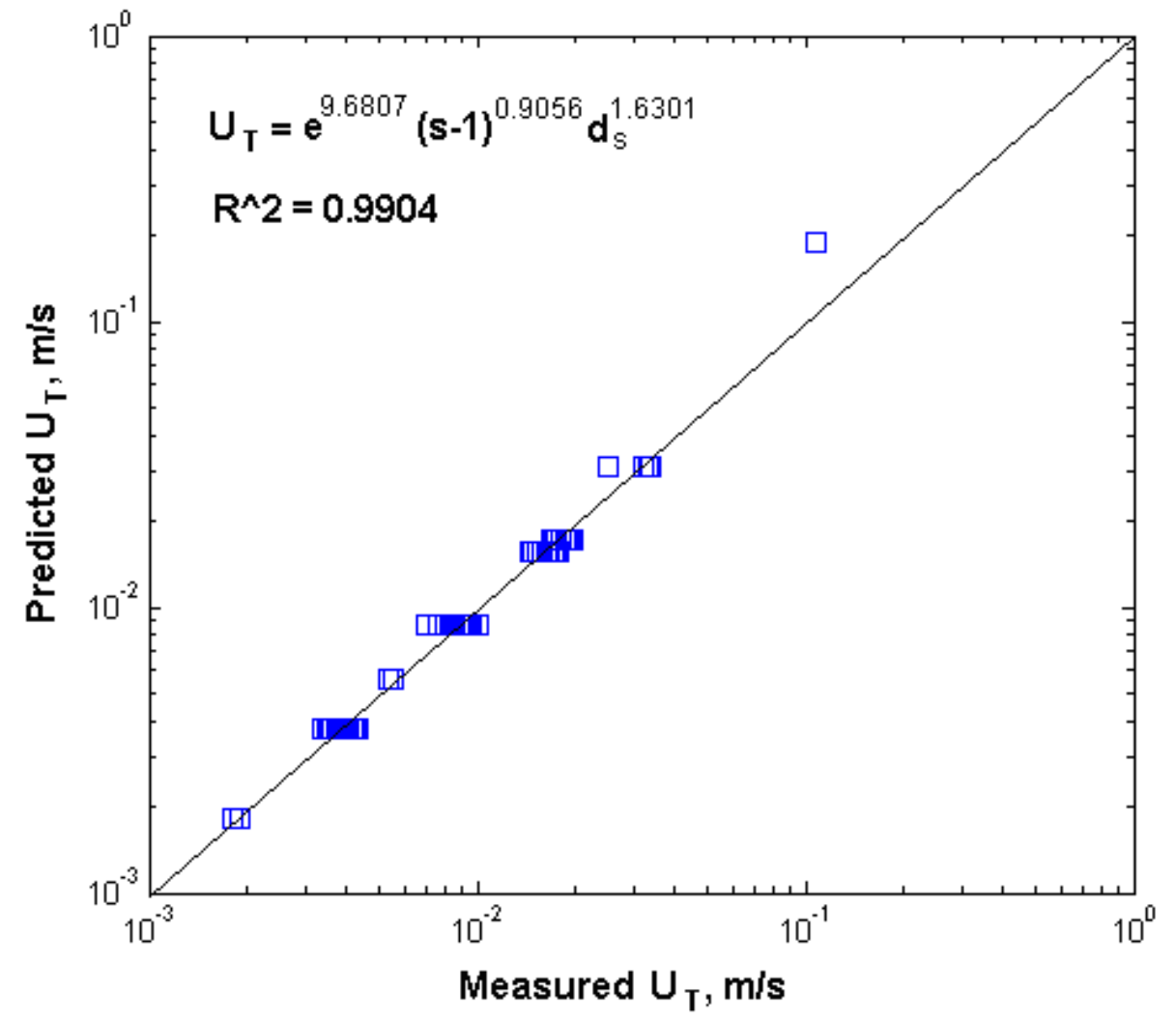

Figure F.1. Performance of a Power-Law Equation to Relate Unhindered Terminal Settling Velocity $\left(U_{T}\right)$ to $s-1$ and $d_{S}=d_{50}$ for the Full Data Set

The reduced forms of the models in Eq. (F.4a) and (F.4b) that resulted from dropping the $\left(1-\phi_{S} / 0.5\right)$ and $\mathrm{d}_{\mathrm{s}}$ terms are

$$
\mathrm{U}_{\mathrm{CS}}=\mathrm{a}_{0}(\mathrm{D})^{\mathrm{a}_{1}}(\mathrm{~s}-1)^{\mathrm{a}_{2}}\left(\phi_{\mathrm{S}}\right)^{\mathrm{a}_{3}}\left(\mathrm{U}_{\mathrm{T}}\right)^{\mathrm{a}_{6}}(\mathrm{DC})^{\mathrm{a}_{7}}\left(\phi_{\mathrm{P}}\right)^{\mathrm{a}_{8}}\left(\mathrm{~N}_{\mathrm{J}}\right)^{\mathrm{a}_{10}}(\mathrm{~d})^{\mathrm{a}_{11}} \delta
$$

and 


$$
\begin{aligned}
\ln \left(\mathrm{U}_{\mathrm{CS}}\right) & =\ln \left(\mathrm{a}_{0}\right)+\mathrm{a}_{1} \ln (\mathrm{D})+\mathrm{a}_{2} \ln (\mathrm{s}-1)+\mathrm{a}_{3} \ln \left(\phi_{\mathrm{S}}\right)+\mathrm{a}_{6} \ln \left(\mathrm{U}_{\mathrm{T}}\right)+\mathrm{a}_{7} \ln (\mathrm{DC}) \\
& +\mathrm{a}_{8} \ln \left(\phi_{\mathrm{p}}\right)+\mathrm{a}_{10} \ln \left(\mathrm{N}_{\mathrm{J}}\right)+\mathrm{a}_{11} \ln (\mathrm{d})+\varepsilon,
\end{aligned}
$$

All notation in Eq. (F.8a) and (F.8b) is as previously defined.

The coefficients estimated by fitting Eq. (F.8b) to the full or trimmed data sets by OLS MR may subsequently be written in the form of Eq. (F.8a). However, this will result in a dimensional constant $\mathrm{a}_{0}$ with units that may differ from those of subsumed physical constants (e.g., g) and dropped model terms. Unfortunately, there is not a unique set of dimensional consistency constraints that can be applied by fitting Eq. (F.8b) using restricted least squares (Section 9.5, Draper and Smith 1998) to impose dimensional consistency. Instead, a dimensionally consistent model form was developed starting from Eq. (F.8a), with the goal of retaining as much as possible of the generalizations added in Section F.2.2. The dimensionally consistent model for $\mathrm{U}_{\mathrm{CS}}$ that resulted from this process is

$$
\mathrm{U}_{\mathrm{CS}}=\mathrm{b}_{0} \mathrm{U}_{\mathrm{T}}\left(\frac{\mathrm{D}(\mathrm{s}-1) \mathrm{g}}{\mathrm{U}_{\mathrm{T}}^{2}}\right)^{\mathrm{b}_{1}}\left(\frac{\mathrm{d}}{\mathrm{D}}\right)^{\mathrm{b}_{2}}(\mathrm{~s}-1)^{\mathrm{b}_{3}} \mathrm{DC}^{\mathrm{b}_{4}} \phi_{\mathrm{S}}^{\mathrm{b}_{5}} \phi_{\mathrm{p}}^{\mathrm{b}_{6}} \mathrm{~N}_{\mathrm{J}}^{\mathrm{b}_{7}} \delta
$$

where

$$
\begin{aligned}
b_{0}= & \text { multiplicative coefficient (nondimensional) } \\
b_{i}= & \begin{array}{l}
\text { model coefficients }(i=1, \ldots, 7) \text { to be estimated using experimental data } \\
\text { (nondimensional) }
\end{array}
\end{aligned}
$$

$$
\begin{aligned}
\frac{\mathrm{D}(\mathrm{s}-1) \mathrm{g}}{\mathrm{U}_{\mathrm{T}}^{2}}= & \text { reciprocal of a Froude number based on unhindered terminal settling velocity } \\
& \text { (nondimensional) } \\
\mathrm{g}= & 9.80665\left(\mathrm{~m} / \mathrm{s}^{2}\right) \text { is the gravity constant } \\
\frac{\mathrm{d}}{\mathrm{D}}= & \text { nondimensional pulse-jet diameter }
\end{aligned}
$$

and all remaining notation is as defined previously. Because Eq. (F.9a) is nonlinear in its coefficients and has a multiplicative error structure, it can be converted to a model linear in its coefficients with an additive error structure by taking the natural logarithm of both sides, as discussed in Section D.2.1 of Appendix D. This yields the model

$$
\begin{aligned}
\ln \left(\mathrm{U}_{\mathrm{CS}}\right) & =\ln \left(\mathrm{b}_{0}\right)+\ln \left(\mathrm{U}_{\mathrm{T}}\right)+\mathrm{b}_{1} \ln \left(\frac{\mathrm{D}(\mathrm{s}-1) \mathrm{g}}{\mathrm{U}_{\mathrm{T}}^{2}}\right)+\mathrm{b}_{2} \ln \left(\frac{\mathrm{d}}{\mathrm{D}}\right)+\mathrm{b}_{3} \ln (\mathrm{s}-1)+\mathrm{b}_{4} \ln (\mathrm{DC}) \\
& +\mathrm{b}_{5} \ln \left(\phi_{\mathrm{S}}\right)+\mathrm{b}_{6} \ln \left(\phi_{\mathrm{p}}\right)+\mathrm{b}_{7} \ln \left(\mathrm{N}_{\mathrm{J}}\right)+\varepsilon
\end{aligned}
$$

The dimensionally consistent models in Eq. (F.9a) and (F.9b) can be considered as reduced forms of the dimensional models in Eq. (F.8a) and (F.8b), with the relationships among the coefficients given by 


$$
\begin{aligned}
& \mathrm{a}_{0}=\mathrm{b}_{0} \mathrm{~g}^{\mathrm{b}_{1}} \text { or } \ln \left(\mathrm{a}_{0}\right)=\ln \left(\mathrm{b}_{0}\right)+\mathrm{b}_{1} \ln (\mathrm{g}) \\
& \mathrm{a}_{1}=\mathrm{b}_{1}-\mathrm{b}_{2} \\
& \mathrm{a}_{2}=\mathrm{b}_{1}+\mathrm{b}_{3} \\
& \mathrm{a}_{3}=\mathrm{b}_{5} \\
& \mathrm{a}_{6}=1-2 \mathrm{~b}_{1} \\
& \mathrm{a}_{7}=\mathrm{b}_{4} \\
& \mathrm{a}_{8}=\mathrm{b}_{6} \\
& \mathrm{a}_{10}=\mathrm{b}_{7} \\
& \mathrm{a}_{11}=\mathrm{b}_{2}
\end{aligned}
$$

Note that the $\mathrm{U}_{\mathrm{CS}}$ dimensional models in Eq. (F.8a) and (F.8b) have 9 coefficients to be estimated using the data, whereas the dimensionally consistent models in Eq. (F.9a) and (F.9b) have only 8 coefficients to be estimated using the data. The difference exists because the leading $U_{\mathrm{T}}$ term (after the constant term) in Eq. (F.9a) and (F.9b) has an exponent/coefficient equal to 1. Suppose the $U_{T}$ term was given a separate exponent, $b_{8}$. That would give $a_{6}=b_{8}-2 b_{1}$. The model form in Eq. (F.9a) and (F.9b) extended in this way would be mathematically equivalent to the model form in Eq. (F.8a) and (F.8b). In other words, they would fit a given data set exactly the same, and predictions of $U_{\mathrm{CS}}$ would be exactly the same.

The dimensionless group D(s-1)g/ $\mathrm{U}_{\mathrm{T}}{ }^{2}$ in Equations (E.9a) and (E.9b) has the form of inverse Froude number, which would seem to invite a physical interpretation. However, the group was constructed only to infuse dimensional consistency into the resulting empirical model and is not necessarily physically meaningful. For example, this form ostensibly corresponds to the ratio of potential energy associated with the tank length scale and the kinetic energy associated with terminal velocity of particles relative to the fluid in which they are embedded. We would not anticipate this would correlate with $\mathrm{U}_{\mathrm{CS}}$ based on physical reasoning. Of course, once a dimensionally consistent empirical correlation is obtained, ultimately such dimensionless groups can be combined with other groups to form groups that can provide important physical insights about the correlation.

\section{F.2.4.2 Results of Fitting Dimensional Power-Law Model Forms for $U_{c s}$ to Full and Trimmed Data Sets}

The results of fitting the dimensional model form in Eq. (F.8b) to the full and trimmed data sets are given in Tables F.1 and F.2, respectively. Included in these tables are estimates of the model coefficients and their standard deviations. Also shown for each coefficient is its t-value (coefficient divided by its standard deviation) and p-value (statistical significance level). Traditionally, p-values lower than 0.05 indicate coefficients that are statistically significant (different from zero) with greater than $95 \%$ confidence. Further, p-values lower than 0.01 indicate high statistical significance (greater than $99 \%$ confidence), while values lower than 0.0001 indicate extremely high statistical significance (greater than 99.99\% confidence). All model terms in Table F.1 are statistically significant at a p-value of $<0.0001$. Model terms in Table F.2 are statistically significant at a p-value of $<0.0001$, except for $\ln (\mathrm{DC})$ with p-value $=0.0004$ and the constant term. 
Table F.1. Coefficients and Performance Summary for the 9-Term Linearized Power-Law Model on the Natural Logarithm of $\mathrm{U}_{\mathrm{CS}}$ Fit to the Full Data Set

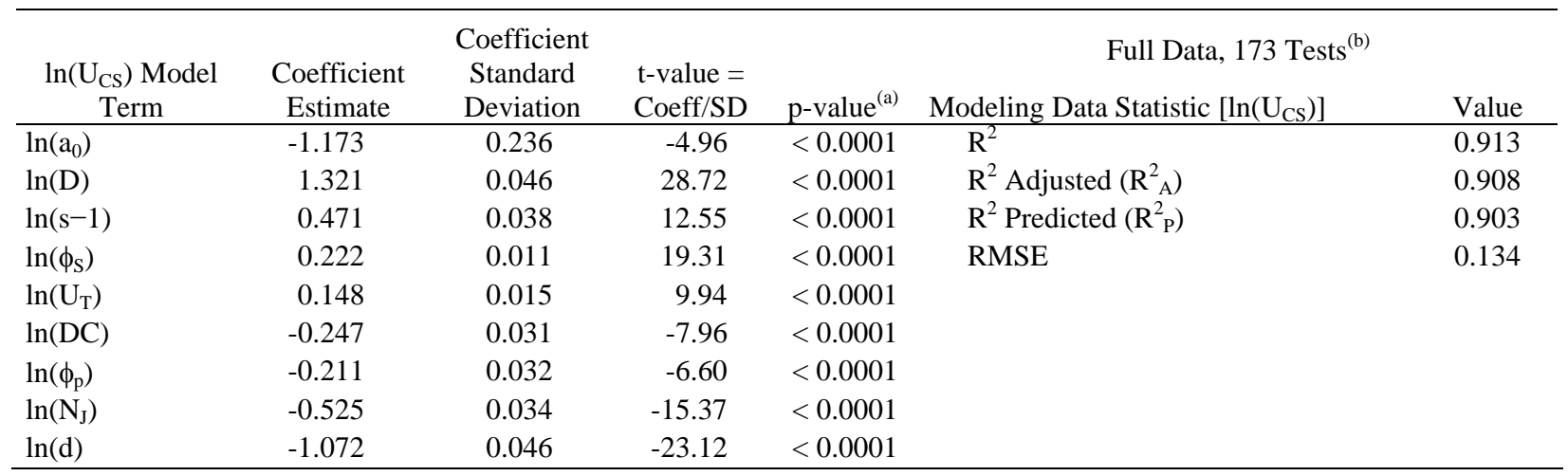

(a) Probability that the coefficient is not statistically significant (different from 0 ). Values less than $0.05,0.01$, and 0.0001 indicate strong, very strong, and extremely strong statistical significance of the coefficient and corresponding model term.

(b) Model evaluation and validation statistics are defined, respectively, in Sections D.3 and D.5 of Appendix D.

Table F.2. Coefficients and Performance Summary for the 9-Term Linearized Power-Law Model on the Natural Logarithm of $U_{C S}$ Fit to the Trimmed Data Set

\begin{tabular}{|c|c|c|c|c|c|c|}
\hline $\begin{array}{c}\ln \left(\mathrm{U}_{\mathrm{CS}}\right) \text { Model } \\
\text { Term }\end{array}$ & $\begin{array}{l}\text { Coefficient } \\
\text { Estimate }\end{array}$ & $\begin{array}{l}\text { Coefficient } \\
\text { Standard } \\
\text { Deviation }\end{array}$ & $\begin{array}{l}\text { t-value = } \\
\text { Coeff/SD }\end{array}$ & $p$-value ${ }^{(a)}$ & Modeling Data Statistic $\left[\ln \left(\mathrm{U}_{\mathrm{CS}}\right)\right]$ & Value \\
\hline $\ln \left(\mathrm{a}_{0}\right)$ & -1.093 & 0.232 & -4.72 & $<0.0001$ & $\mathrm{R}^{2}$ & 0.926 \\
\hline $\ln (\mathrm{D})$ & 1.369 & 0.045 & 30.63 & $<0.0001$ & $\mathrm{R}^{2}$ Adjusted $\left(\mathrm{R}_{\mathrm{A}}^{2}\right)$ & 0.922 \\
\hline $\ln (s-1)$ & 0.454 & 0.038 & 11.95 & $<0.0001$ & $\mathrm{R}^{2}$ Predicted $\left(\mathrm{R}_{\mathrm{P}}^{2}\right)$ & 0.916 \\
\hline $\ln \left(\phi_{\mathrm{S}}\right)$ & 0.245 & 0.013 & 19.56 & $<0.0001$ & RMSE & 0.126 \\
\hline $\ln \left(\mathrm{U}_{\mathrm{T}}\right)$ & 0.145 & 0.015 & 9.68 & $<0.0001$ & & \\
\hline $\ln (\mathrm{DC})$ & -0.132 & 0.037 & -3.60 & 0.0004 & & \\
\hline $\ln \left(\phi_{p}\right)$ & -0.220 & 0.032 & -6.78 & $<0.0001$ & & \\
\hline $\ln \left(\mathrm{N}_{\mathrm{J}}\right)$ & -0.522 & 0.033 & -15.91 & $<0.0001$ & & \\
\hline $\ln (d)$ & -1.108 & 0.045 & -24.47 & $<0.0001$ & & \\
\hline
\end{tabular}

(a) Probability that the coefficient is not statistically significant (different from 0). Values less than $0.05,0.01$, and 0.0001 indicate strong, very strong, and extremely strong statistical significance of the coefficient and corresponding model term.

(b) Model evaluation and validation statistics are defined, respectively, in Sections D.3 and D.5 of Appendix D. 
The right sides of Tables F.1 and F.2 list various summary statistics that provide measures of how well the 9-term models in Eq. (F.8a) and (F.8b) fit the full and trimmed data sets, respectively. These statistics are defined and discussed in Sections D.3.2 and D.3.3 of Appendix D. The summary statistics in Tables F.1 and F.2 indicate that the 9-term linearized power-law models fit the available data well. For example, $\mathrm{R}^{2}$ statistics show the 9-term model accounts for $91.3 \%$ of the variability in $\ln \left(\mathrm{U}_{\mathrm{CS}}\right)$ values for the full data and $92.6 \%$ for the trimmed data. As expected, this model form fits somewhat better for the trimmed data than for the full data. Because the differences between $\mathrm{R}^{2}$ and $\mathrm{R}_{\mathrm{A}}{ }_{\text {are }}$ small, there are no indications that the data have been over-fitted. Because the differences between $\mathrm{R}_{\mathrm{A}}^{2}$ and $\mathrm{R}_{\mathrm{P}}^{2}$ are small, there are no indications of highly influential data affecting the model fits.

Figures F.2 and F.3 show predicted-versus-measured plots, which provide a graphical view of how well the 9-term model form fits the full and trimmed data sets. In each plot, the predicted value of $U_{C S}$ is plotted on the y-axis (in log scale) and the measured (actual) values of $U_{\mathrm{CS}}$ are plotted on the $\mathrm{x}$-axis (also in log scale). The 45-degree line represents perfect prediction, where predicted $U_{\mathrm{CS}}$ values would exactly equal measured $U_{\mathrm{CS}}$ values. Section D.3.2 of Appendix D has further discussion of using predictedversus-measured plots to evaluate how well a model fits a data set.

Figures F.2 and F.3 show no obvious problems with the $U_{\text {Cs }}$ predictions made using the models in Tables F.1 and F.2, respectively. However, only the 2008 data spans most of the range of the $\mathrm{U}_{\mathrm{CS}}$ response. Both models tend to slightly overpredict the July 2007 data (most of those data are plotted above the $45^{\circ}$ line). This could be due to the relatively small number of July 2007 data points available.

In summary, inserting the coefficients from the $\mathrm{U}_{\mathrm{CS}}$ dimensional models without interactions fit to the full data set (Table F.1) into Eq. (F.8a) and (F.8b) results in the models

$$
\begin{aligned}
\mathrm{U}_{\mathrm{CS}} & =0.309(\mathrm{D})^{1.321}(\mathrm{~s}-1)^{0.471}\left(\phi_{\mathrm{S}}\right)^{0.222}\left(\mathrm{U}_{\mathrm{T}}\right)^{0.148}(\mathrm{DC})^{-0.247}\left(\phi_{\mathrm{p}}\right)^{-0.211} \\
& \times\left(\mathrm{N}_{\mathrm{J}}\right)^{-0.525}(\mathrm{~d})^{-1.072}
\end{aligned}
$$

and

$$
\begin{aligned}
\ln \left(\mathrm{U}_{\mathrm{CS}}\right) & =-1.173+1.321 \ln (\mathrm{D})+0.471 \ln (\mathrm{s}-1)+0.222 \ln \left(\phi_{\mathrm{S}}\right)+0.148 \ln \left(\mathrm{U}_{\mathrm{T}}\right) \\
& -0.247 \ln (\mathrm{DC})-0.211 \ln \left(\phi_{\mathrm{p}}\right)-0.525 \ln \left(\mathrm{N}_{\mathrm{J}}\right)-1.072 \ln (\mathrm{d})
\end{aligned}
$$

where all notation is as previously defined. Inserting the coefficients from the $\mathrm{U}_{\mathrm{CS}}$ dimensional models without interactions fit to the trimmed data set (Table F.2) into Eq. (F.8a) and (F.8b) results in the models

$$
\mathrm{U}_{\mathrm{CS}}=0.335(\mathrm{D})^{1.369}(\mathrm{~s}-1)^{0.454}\left(\phi_{\mathrm{S}}\right)^{0.245}\left(\mathrm{U}_{\mathrm{T}}\right)^{0.145}(\mathrm{DC})^{-0.132}\left(\phi_{\mathrm{p}}\right)^{-0.220}\left(\mathrm{~N}_{\mathrm{J}}\right)^{-0.522}(\mathrm{~d})^{-1.108}
$$

and

$$
\begin{aligned}
\ln \left(\mathrm{U}_{\mathrm{CS}}\right) & =-1.093+1.369 \ln (\mathrm{D})+0.454 \ln (\mathrm{s}-1)+0.245 \ln \left(\phi_{\mathrm{S}}\right)+0.145 \ln \left(\mathrm{U}_{\mathrm{T}}\right) \\
& -0.132 \ln (\mathrm{DC})-0.220 \ln \left(\phi_{\mathrm{p}}\right)-0.522 \ln \left(\mathrm{N}_{\mathrm{J}}\right)-1.108 \ln (\mathrm{d})
\end{aligned}
$$

where all notation is as previously defined. 


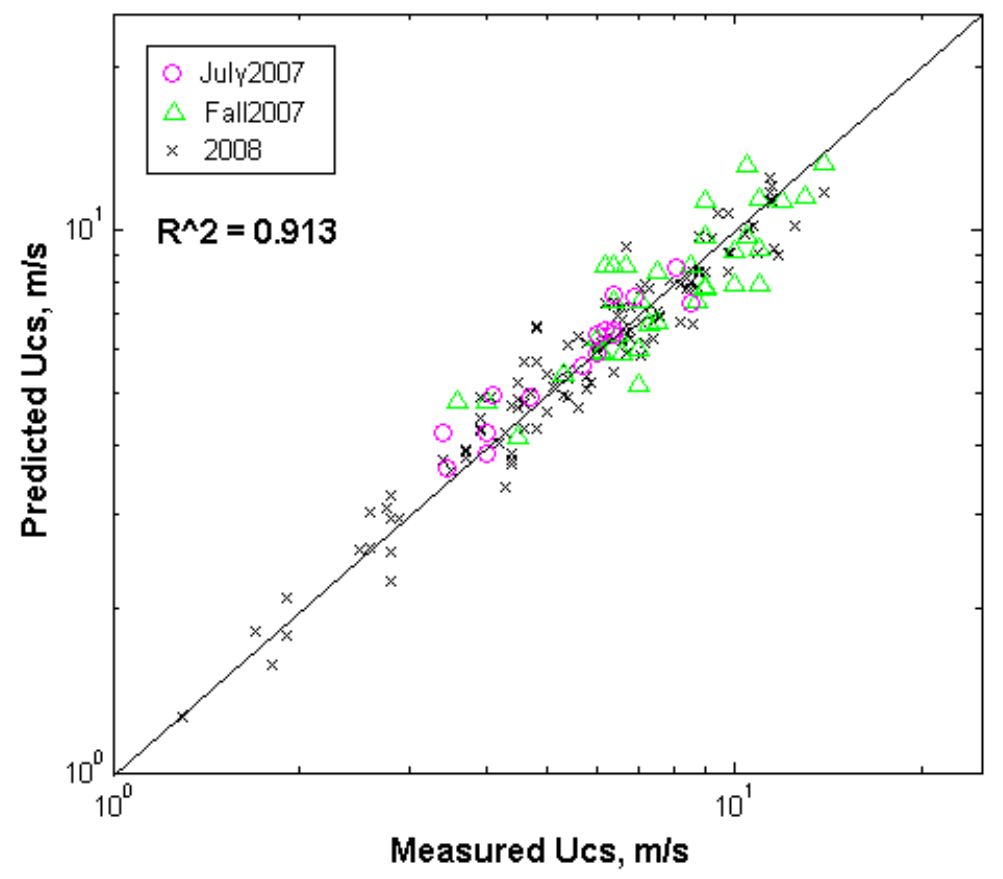

Figure F.2. Log-Log Plot of Predicted Versus Measured $U_{C S}(\mathrm{~m} / \mathrm{s})$ Values for the 9-Term Dimensional Model in Table F.1 Fit to the Full Data Set. The 45-degree line represents perfect prediction where predicted $U_{\mathrm{CS}}$ values equal measured $\mathrm{U}_{\mathrm{CS}}$ values.

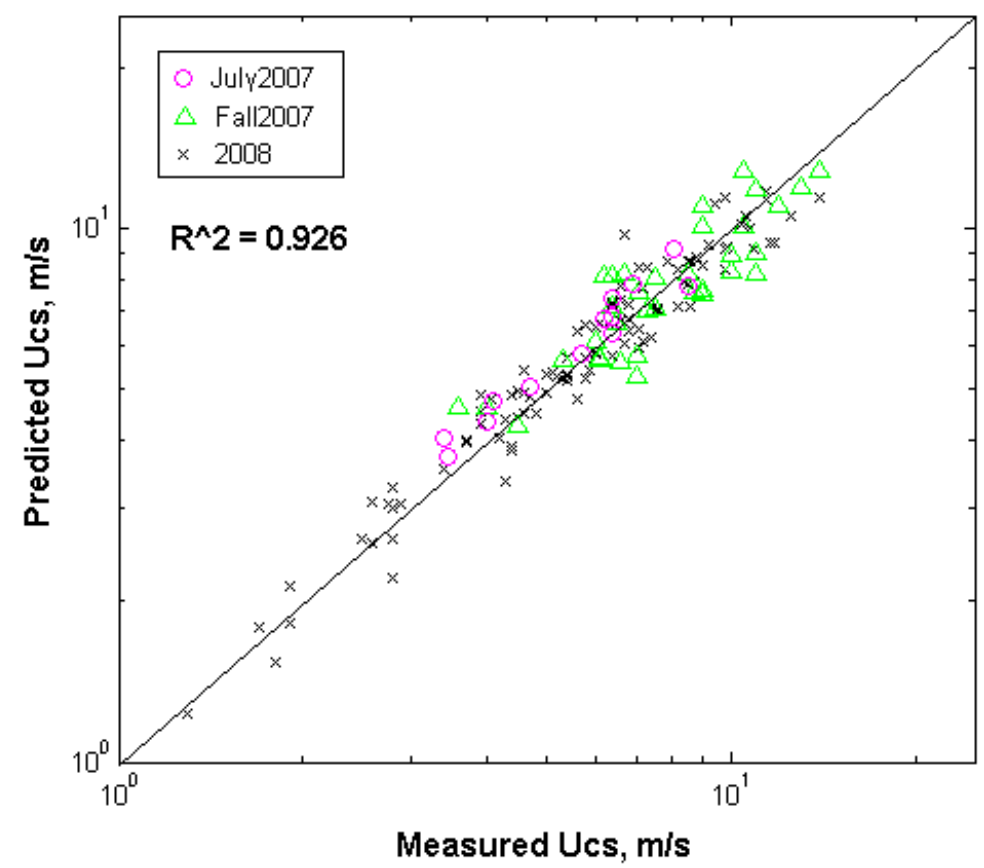

Figure F.3. Log-Log Plot of Predicted Versus Measured $U_{C S}(\mathrm{~m} / \mathrm{s})$ Values for the 9-Term Dimensional Model in Table F.2 Fit to the Trimmed Data Set. The 45-degree line represents perfect prediction where predicted $\mathrm{U}_{\mathrm{CS}}$ values equal measured $\mathrm{U}_{\mathrm{CS}}$ values. 


\section{F.2.4.3 Results of Fitting Dimensionally Consistent Power-Law Model Forms for $U_{c s}$ to Full and Trimmed Data Sets}

The dimensionally consistent model form in Eq. (F.9b) was fit to the full and trimmed data sets using restricted least squares (Draper and Smith 1998). The results for the full data set are given in Table F.3 and Figure F.4, while the results for the trimmed data set are given in Table F.4 and Figure F.5.

Table F.3. Coefficients and Performance Summary for the Linearized Version of 9-Term Dimensionally Consistent Model on the Natural Logarithm of $U_{\mathrm{CS}}$ with 8 Coefficients Fit to the Full Data Set

\begin{tabular}{|c|c|c|c|c|c|c|}
\hline \multirow{2}{*}{$\begin{array}{l}\ln \left(\mathrm{U}_{\mathrm{CS}}\right) \text { Model } \\
\text { Term }\end{array}$} & Coefficient & \multicolumn{2}{|l|}{ Coefficient } & \multicolumn{3}{|c|}{ Full Data, 173 Tests $^{(b)}$} \\
\hline & Estimate & Deviation & Coeff/SD & $p$-value ${ }^{(a)}$ & Modeling Data Statistic $\left[\ln \left(\mathrm{U}_{\mathrm{CS}}\right)\right]$ & Value \\
\hline $\ln \left(\mathrm{b}_{0}\right)$ & -1.297 & $-(\mathrm{c})$ & - & - & $\mathrm{R}^{2}$ & 0.867 \\
\hline $\ln \left(\mathrm{U}_{\mathrm{T}}\right)$ & 1.0 & N/A & N/A & N/A & $\mathrm{R}^{2}$ Adjusted $\left(\mathrm{R}_{\mathrm{A}}^{2}\right)$ & 0.861 \\
\hline $\ln \left[\mathrm{D}(\mathrm{s}-1) \mathrm{g} / \mathrm{U}_{\mathrm{T}}{ }^{2}\right]$ & 0.397 & - & - & - & $\mathrm{R}^{2}$ Predicted $\left(\mathrm{R}_{\mathrm{P}}^{2}\right)$ & -(c) \\
\hline $\ln (d / D)$ & -0.991 & - & - & - & RMSE & 0.165 \\
\hline $\ln (s-1)$ & 0.086 & - & - & - & & \\
\hline $\ln (\mathrm{DC})$ & -0.205 & - & - & - & & \\
\hline $\ln \left(\phi_{\mathrm{S}}\right)$ & 0.243 & - & - & - & & \\
\hline $\ln \left(\phi_{\mathrm{p}}\right)$ & -0.221 & - & - & - & & \\
\hline $\ln \left(\mathrm{N}_{\mathrm{J}}\right)$ & -0.511 & - & - & - & & \\
\hline
\end{tabular}

(a) Probability that the coefficient is not statistically significant (different from 0). Values less than 0.05, 0.01, and 0.0001 indicate strong, very strong, and extremely strong statistical significance of the coefficient and corresponding model term.

(b) Model evaluation and validation statistics are defined, respectively, in Sections D.3 and D.5 of Appendix D.

(c) Not available from software used to fit the model via restricted least squares. These could be obtained with additional work.

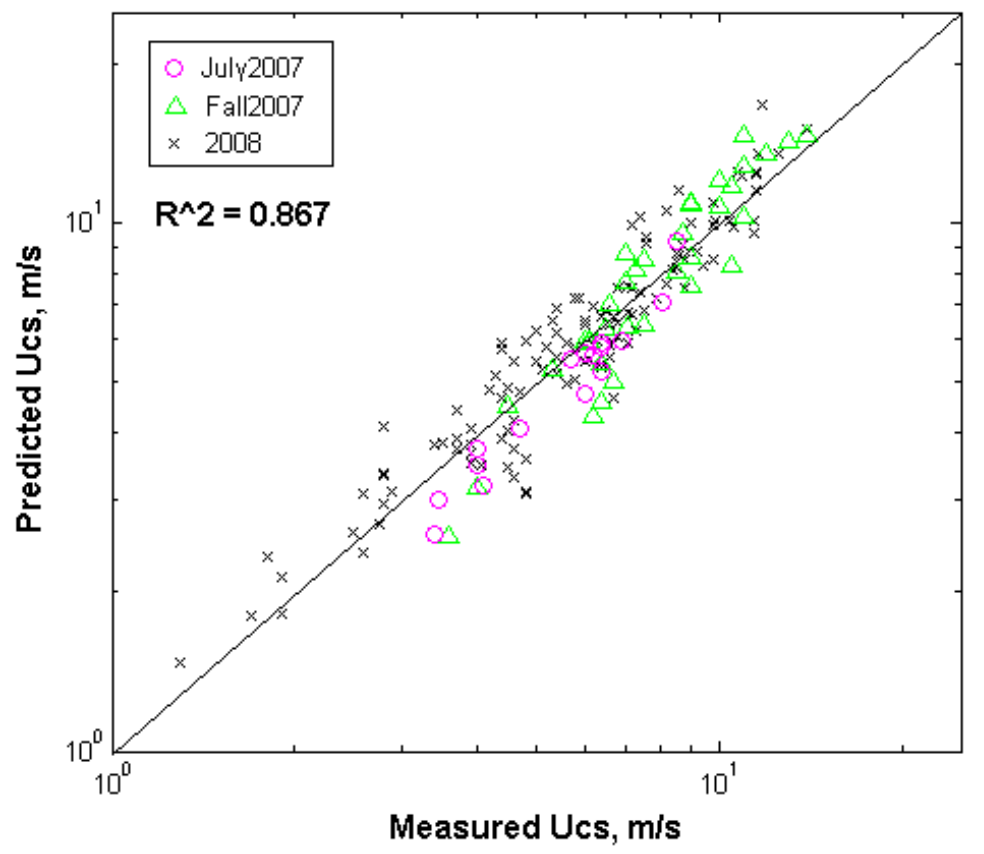

Figure F.4. Log-Log Plot of Predicted Versus Measured $U_{C S}(\mathrm{~m} / \mathrm{s})$ Values for the 9-Term Dimensionally Consistent Model in Table F.3 with 8 Coefficients Fit to the Full Data Set. The 45-degree line represents perfect prediction where predicted $U_{\mathrm{CS}}$ values equal measured $U_{\mathrm{CS}}$ values. 
Table F.4. Coefficients and Performance Summary for the Linearized Version of 9-Term Dimensionally Consistent Model on Natural Logarithm of $U_{C S}$ with 8 Coefficients Fit to the Trimmed Data Set

\begin{tabular}{|c|c|c|c|c|c|c|}
\hline \multirow{2}{*}{$\begin{array}{l}\ln \left(\mathrm{U}_{\mathrm{CS}}\right) \text { Model } \\
\text { Term }\end{array}$} & \multicolumn{3}{|c|}{ Coefficient } & \multicolumn{3}{|c|}{ Full Data, 154 Tests $^{(\mathrm{b})}$} \\
\hline & Estimate & Deviation & Coeff/SD & p-value ${ }^{(a)}$ & Modeling Data Statistic $\left[\ln \left(\mathrm{U}_{\mathrm{CS}}\right)\right]$ & Value \\
\hline $\ln \left(\mathrm{b}_{0}\right)$ & -1.242 & $-^{(\mathrm{c})}$ & - & - & $\mathrm{R}^{2}$ & 0.889 \\
\hline $\ln \left(\mathrm{U}_{\mathrm{T}}\right)$ & 1.0 & N/A & N/A & N/A & $\mathrm{R}^{2}$ Adjusted $\left(\mathrm{R}_{\mathrm{A}}^{2}\right)$ & 0.883 \\
\hline $\ln \left[\mathrm{D}(\mathrm{s}-1) \mathrm{g} / \mathrm{U}_{\mathrm{T}}{ }^{2}\right]$ & 0.400 & - & - & - & $\mathrm{R}^{2}$ Predicted $\left(\mathrm{R}_{\mathrm{P}}^{2}\right)$ & $-(\mathrm{c})$ \\
\hline $\ln (d / D)$ & -1.022 & - & - & - & RMSE & 0.154 \\
\hline $\ln (s-1)$ & 0.055 & - & - & - & & \\
\hline $\ln (\mathrm{DC})$ & -0.079 & - & - & - & & \\
\hline $\ln \left(\phi_{\mathrm{S}}\right)$ & 0.254 & - & - & - & & \\
\hline $\ln \left(\phi_{p}\right)$ & -0.223 & - & - & - & & \\
\hline $\ln \left(\mathrm{N}_{\mathrm{J}}\right)$ & -0.505 & - & - & - & & \\
\hline
\end{tabular}

(a) Probability that the coefficient is not statistically significant (different from 0 ). Values less than $0.05,0.01$, and 0.0001 indicate strong, very strong, and extremely strong statistical significance of the coefficient and corresponding model term.

(b) Model evaluation and validation statistics are defined, respectively, in Sections D.3 and D.5 of Appendix D.

(c) Not available from software used to fit the model via restricted least squares. These could be obtained with additional work.

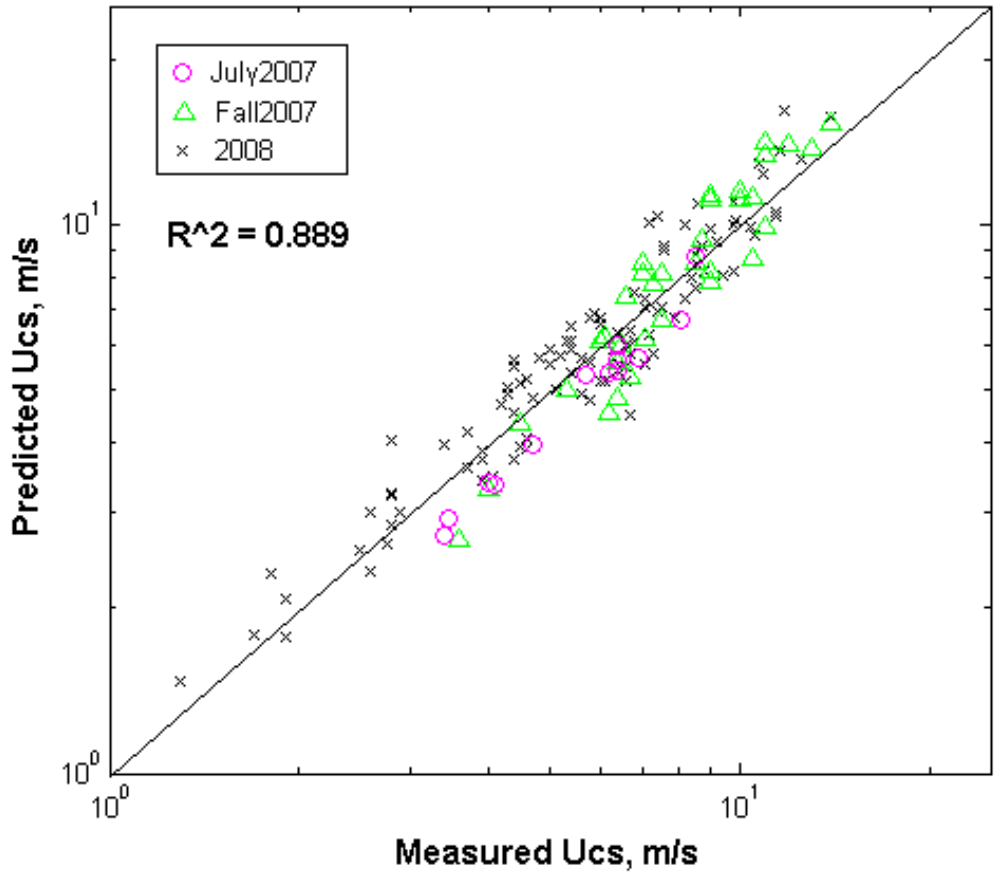

Figure F.5. Log-Log Plot of Predicted Versus Measured $U_{C S}(\mathrm{~m} / \mathrm{s})$ Values for the 9-Term Dimensionally Consistent Model in Table F.4 with 8 Coefficients Fit to Trimmed Data Set. The 45-degree line represents perfect prediction where predicted $U_{\mathrm{CS}}$ values equal measured $U_{\mathrm{CS}}$ values.

The $\mathrm{U}_{\mathrm{CS}}$ dimensionally consistent models in Tables F.3 and F.4 have $\mathrm{R}^{2}$ values somewhat lower than for the dimensional models in Tables F.1 and F.2. For the full data set, $\mathrm{R}^{2}=0.867$ for the dimensionally consistent model versus $\mathrm{R}^{2}=0.913$ for the dimensional model. For the trimmed data set, $\mathrm{R}^{2}=0.889$ for the dimensionally consistent model versus $\mathrm{R}^{2}=0.926$ for the dimensional model. As noted at the end of Section F.2.4.1, adding an exponent to the $\mathrm{U}_{\mathrm{T}}$ term would make the dimensionally consistent model mathematically equivalent to the dimensional model. This suggests the decrease in $\mathrm{R}^{2}$ (goodness of fit) 
for the dimensionally consistent model could be as a result of that model not capturing the effect of $U_{T}$ as well as the dimensional model.

Figures F.4 and F.5 for the full and trimmed data sets, respectively, show tendencies for the $\mathrm{U}_{\mathrm{CS}}$ dimensionally consistent models to 1 ) overpredict $U_{\mathrm{CS}}<\sim 2.0 \mathrm{~m} / \mathrm{s}, 2$ ) possibly overpredict $\mathrm{U}_{\mathrm{CS}}>\sim 10 \mathrm{~m} / \mathrm{s}$, and 3) slightly underpredict July 2007 data. The dimensional models tend to correct the first two issues (see Figures F.2 and F.3), but in turn have a tendency to slightly overpredict the July 2007 data. Ultimately, the dimensional model form fits the full and trimmed data sets better than the dimensionally consistent model form, but the differences are not major.

In summary, inserting the coefficients from the $\mathrm{U}_{\mathrm{CS}}$ dimensionally consistent models fit to the full data set (Table F.3) into Eq. (F.9a) and (F.9b) results in the models

$$
\mathrm{U}_{\mathrm{CS}}=0.273 \mathrm{U}_{\mathrm{T}}\left(\frac{\mathrm{D}(\mathrm{s}-1) \mathrm{g}}{\mathrm{U}_{\mathrm{T}}^{2}}\right)^{0.397}\left(\frac{\mathrm{d}}{\mathrm{D}}\right)^{-0.991}(\mathrm{~s}-1)^{0.086} \mathrm{DC}^{-0.205} \phi_{\mathrm{S}}^{0.243} \phi_{\mathrm{p}}^{-0.221} \mathrm{~N}_{\mathrm{J}}^{-0.511}
$$

and

$$
\begin{aligned}
\ln \left(\mathrm{U}_{\mathrm{CS}}\right) & =-1.297+\ln \left(\mathrm{U}_{\mathrm{T}}\right)+0.397 \ln \left(\frac{\mathrm{D}(\mathrm{s}-1) \mathrm{g}}{\mathrm{U}_{\mathrm{T}}^{2}}\right)-0.991 \ln \left(\frac{\mathrm{d}}{\mathrm{D}}\right)+0.086 \ln (\mathrm{s}-1) \\
& -0.205 \ln (\mathrm{DC})+0.243 \ln \left(\phi_{\mathrm{S}}\right)-0.221 \ln \left(\phi_{\mathrm{p}}\right)-0.511 \ln \left(\mathrm{N}_{\mathrm{J}}\right)
\end{aligned}
$$

where all notation is as previously defined. Inserting the coefficients from the $\mathrm{U}_{\mathrm{CS}}$ dimensionally consistent models fit to the trimmed data set (Table F.4) into Eq. (F.9a) and (F.9b) results in the models

$$
\mathrm{U}_{\mathrm{CS}}=0.289 \mathrm{U}_{\mathrm{T}}\left(\frac{\mathrm{D}(\mathrm{s}-1) \mathrm{g}}{\mathrm{U}_{\mathrm{T}}^{2}}\right)^{0.400}\left(\frac{\mathrm{d}}{\mathrm{D}}\right)^{-1.022}(\mathrm{~s}-1)^{0.055} \mathrm{DC}^{-0.079} \phi_{\mathrm{S}}^{0.254} \phi_{\mathrm{p}}^{-0.223} \mathrm{~N}_{\mathrm{J}}^{-0.505}
$$

and

$$
\begin{aligned}
\ln \left(\mathrm{U}_{\mathrm{CS}}\right) & =-1.242+\ln \left(\mathrm{U}_{\mathrm{T}}\right)+0.400 \ln \left(\frac{\mathrm{D}(\mathrm{s}-1) \mathrm{g}}{\mathrm{U}_{\mathrm{T}}^{2}}\right)-1.022 \ln \left(\frac{\mathrm{d}}{\mathrm{D}}\right)+0.055 \ln (\mathrm{s}-1) \\
& -0.079 \ln (\mathrm{DC})+0.254 \ln \left(\phi_{\mathrm{S}}\right)-0.223 \ln \left(\phi_{\mathrm{p}}\right)-0.505 \ln \left(\mathrm{N}_{\mathrm{J}}\right)
\end{aligned}
$$

where all notation is as previously defined.

\section{F.2.5 Results for $U_{c s}$ Power-Law Models with Interaction Terms}

As discussed in Section F.2.3, stepwise regression methods were used to add statistically significant interaction terms to the $U_{C S}$ models shown in Tables F.1 and F.2. The results are shown in Table F.5 and Figure F.6 for the full data set and in Table F.6 and Figure F.7 for the trimmed data set. Three interaction terms were added to the model for the full data set and only two to the model for the trimmed data set. Only one of the interaction terms added to each model is common to both, but that is likely because of the smaller test-variable space for the model fit to the trimmed data set. All of the model terms shown in Tables F.5 and F.6 are highly statistically significant, except for two linear terms for the trimmed data set 
that are included in the models because they are part of significant interactions. The constant term is not statistically significant for either the model of Table F.5 or the model of Table F.6.

Table F.5. Coefficients and Performance Summary for the 12-Term Dimensional Model with Interactions for the Natural Logarithm of $U_{\mathrm{CS}}$ Fit to the Full Data Set

\begin{tabular}{|c|c|c|c|c|c|c|}
\hline $\begin{array}{c}\ln \left(\mathrm{U}_{\mathrm{CS}}\right) \text { Model } \\
\text { Term }\end{array}$ & $\begin{array}{c}\text { Coefficient } \\
\text { Estimate }\end{array}$ & $\begin{array}{l}\text { Coefficient } \\
\text { Standard } \\
\text { Deviation }\end{array}$ & $\begin{array}{l}\text { t-value }= \\
\text { Coeff/SD }\end{array}$ & p-value ${ }^{(a)}$ & Modeling Data Statistic $\left[\ln \left(\mathrm{U}_{\mathrm{CS}}\right)\right]$ & Value \\
\hline $\ln \left(\mathrm{a}_{0}\right)$ & -0.428 & 0.229 & -1.87 & 0.0635 & $\mathrm{R}^{2}$ & 0.939 \\
\hline $\ln (\mathrm{D})$ & 1.186 & 0.053 & 22.32 & $<0.0001$ & $\mathrm{R}^{2}$ Adjusted $\left(\mathrm{R}_{\mathrm{A}}^{2}\right)$ & 0.935 \\
\hline $\ln (s-1)$ & 0.421 & 0.033 & 12.83 & $<0.0001$ & $\mathrm{R}^{2}$ Predicted $\left(\mathrm{R}_{\mathrm{P}}^{2}\right)$ & 0.930 \\
\hline $\ln \left(\phi_{S}\right)$ & 0.264 & 0.017 & 15.79 & $<0.0001$ & RMSE & 0.113 \\
\hline $\ln \left(\mathrm{U}_{\mathrm{T}}\right)$ & 0.082 & 0.020 & 4.02 & $<0.0001$ & & \\
\hline $\ln (\mathrm{DC})$ & 0.366 & 0.081 & 4.51 & $<0.0001$ & & \\
\hline $\ln \left(\phi_{\mathrm{p}}\right)$ & -0.210 & 0.027 & -7.69 & $<0.0001$ & & \\
\hline $\ln \left(\mathrm{N}_{\mathrm{J}}\right)$ & -0.545 & 0.030 & -18.48 & $<0.0001$ & & \\
\hline $\ln (d)$ & -1.116 & 0.040 & -28.19 & $<0.0001$ & & \\
\hline $\mathrm{DC} \ln \left(\mathrm{U}_{\mathrm{T}}\right)$ & 0.276 & 0.047 & 5.87 & $<0.0001$ & & \\
\hline $\mathrm{D} \ln (\mathrm{DC})$ & -0.170 & 0.039 & -4.38 & $<0.0001$ & & \\
\hline$\phi_{\mathrm{S}} \ln \left(\mathrm{U}_{\mathrm{T}}\right)$ & 0.897 & 0.327 & 2.74 & 0.0068 & & \\
\hline
\end{tabular}

(a) Probability that the coefficient is not statistically significant (different from 0 ). Values less than $0.05,0.01$, and 0.0001 indicate strong, very strong, and extremely strong statistical significance of the coefficient and corresponding model term.

(b) Model evaluation and validation statistics are defined, respectively, in Sections D.3 and D.5 of Appendix D.

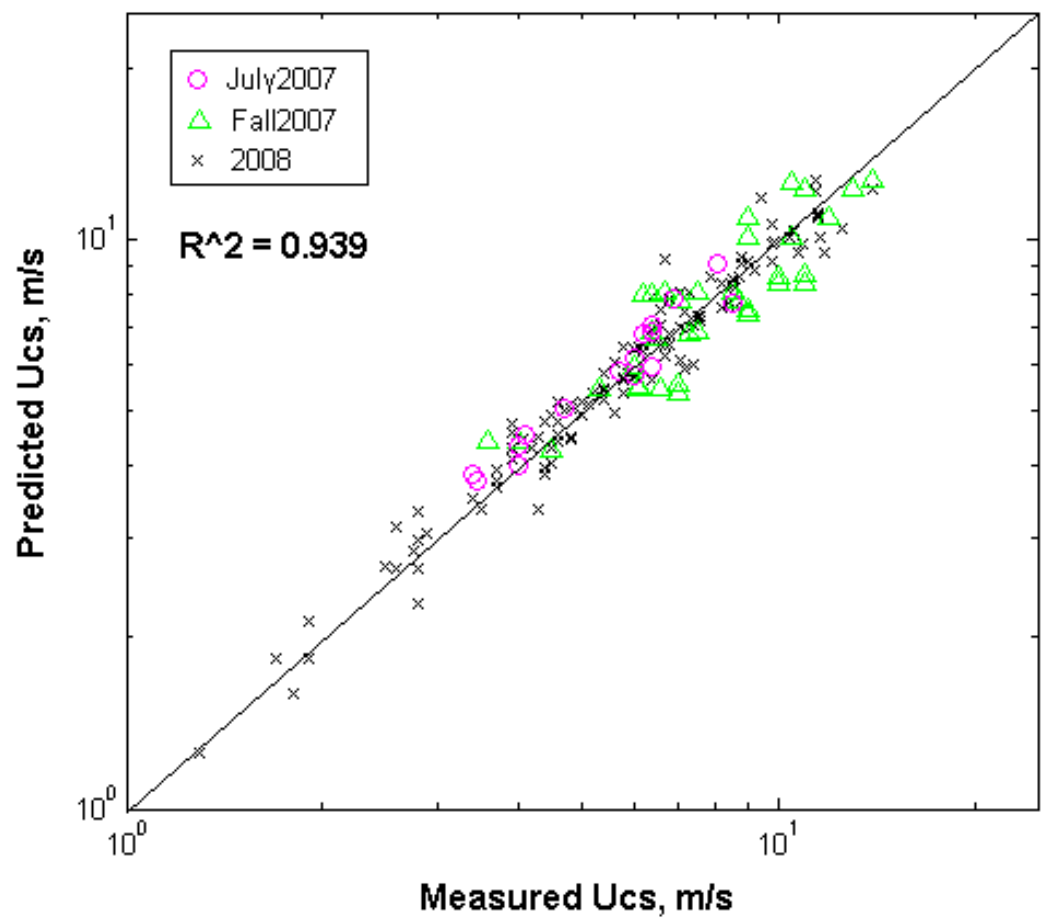

Figure F.6. Log-Log Plot of Predicted Versus Measured $\mathrm{U}_{\mathrm{CS}}$ (in $\mathrm{m} / \mathrm{s}$ ) Values for the 12-Term Dimensional Model with Interactions in Table F.3 Fit to the Full Data Set. The 45-degree line represents perfect prediction where predicted $\mathrm{U}_{\mathrm{CS}}$ values equal measured $\mathrm{U}_{\mathrm{CS}}$ values. 
Table F.6. Coefficients and Performance Summary for the 11-Term Dimensional Model with Interactions for the Natural Logarithm of $\mathrm{U}_{\mathrm{CS}}$ Fit to the Trimmed Data Set

\begin{tabular}{|c|c|c|c|c|c|c|}
\hline \multirow{2}{*}{$\begin{array}{c}\ln \left(\mathrm{U}_{\mathrm{CS}}\right) \text { Model } \\
\text { Term }\end{array}$} & \multirow{2}{*}{$\begin{array}{c}\text { Coefficient } \\
\text { Estimate }\end{array}$} & \multirow{2}{*}{$\begin{array}{c}\text { Coefficient } \\
\text { Standard } \\
\text { Deviation }\end{array}$} & \multirow{2}{*}{$\begin{array}{l}\text { t-value }= \\
\text { Coeff/SD }\end{array}$} & \multirow{2}{*}{$\underset{\text { (a) }}{\mathrm{p} \text {-value }}$} & \multicolumn{2}{|c|}{ Trimmed Data, 154 Tests $^{(\mathrm{b})}$} \\
\hline & & & & & Modeling Data Statistic $\left[\ln \left(\mathrm{U}_{\mathrm{CS}}\right)\right]$ & Value \\
\hline $\ln \left(\mathrm{a}_{0}\right)$ & -0.143 & 0.329 & -0.43 & 0.66 & $\mathrm{R}^{2}$ & 0.939 \\
\hline $\ln (\mathrm{D})$ & 1.221 & 0.062 & 19.83 & $<0.0001$ & $\mathrm{R}^{2}$ Adjusted $\left(\mathrm{R}_{\mathrm{A}}^{2}\right)$ & 0.935 \\
\hline $\ln (s-1)$ & 0.952 & 0.146 & 6.52 & $<0.0001$ & $\mathrm{R}^{2}$ Predicted $\left(\mathrm{R}_{\mathrm{P}}^{2}\right)$ & 0.929 \\
\hline $\ln \left(\phi_{\mathrm{S}}\right)$ & 0.247 & 0.012 & 21.26 & $<0.0001$ & RMSE & 0.115 \\
\hline $\ln \left(\mathrm{U}_{\mathrm{T}}\right)$ & 0.170 & 0.015 & 11.29 & $<0.0001$ & & \\
\hline $\ln (\mathrm{DC})$ & 0.038 & 0.057 & 0.67 & 0.50 & & \\
\hline $\ln \left(\phi_{\mathrm{p}}\right)$ & 0.094 & 0.091 & 1.04 & 0.30 & & \\
\hline $\ln \left(\mathrm{N}_{\mathrm{J}}\right)$ & -0.543 & 0.031 & -17.63 & $<0.0001$ & & \\
\hline $\ln (d)$ & -1.143 & 0.042 & -27.26 & $<0.0001$ & & \\
\hline$D \ln (\mathrm{DC})$ & -0.167 & 0.047 & -3.55 & 0.0005 & & \\
\hline$\phi_{p} \ln (s-1)$ & -10.302 & 2.714 & -3.80 & 0.0002 & & \\
\hline
\end{tabular}

(a) Probability that the coefficient is not statistically significant (different from 0). Values less than $0.05,0.01$, and 0.0001 indicate strong, very strong, and extremely strong statistical significance of the coefficient and corresponding model term. (b) Model evaluation and validation statistics are defined, respectively, in Sections D.3 and D.5 of Appendix D.

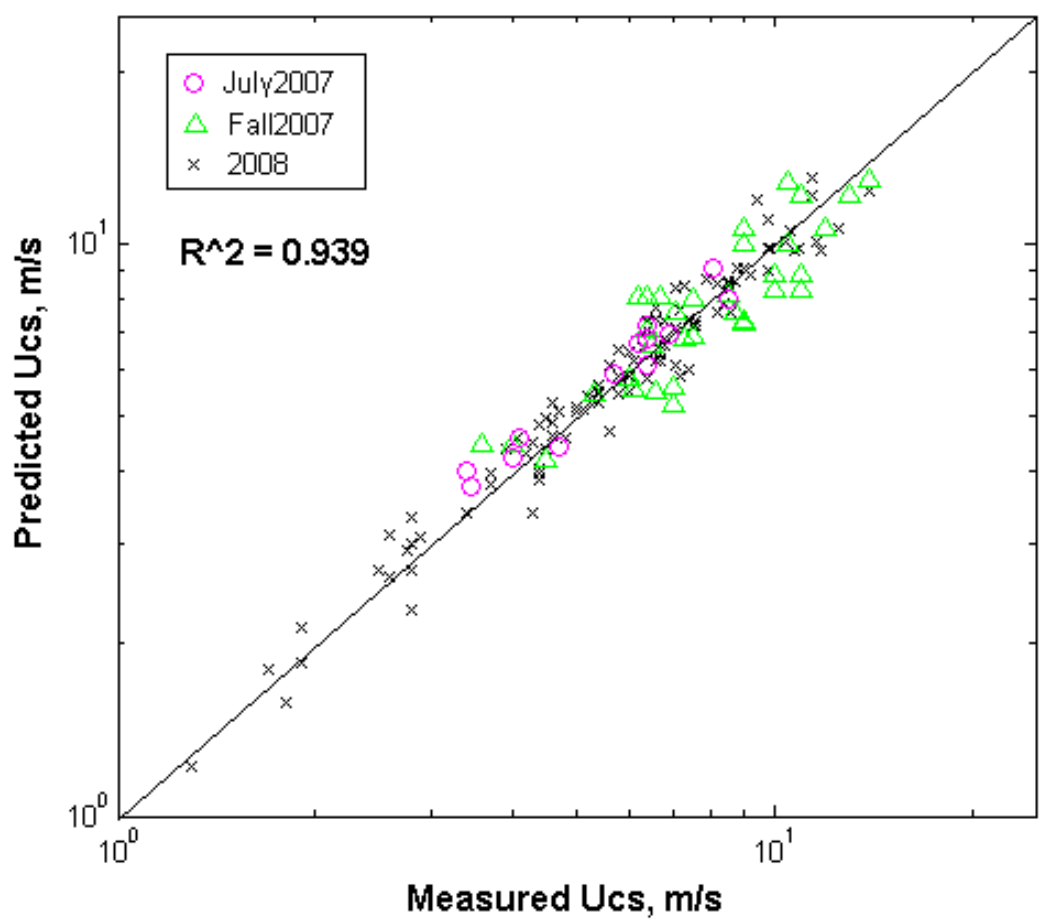

Figure F.7. Log-Log Plot of Predicted Versus Measured $U_{C S}(\mathrm{~m} / \mathrm{s})$ Values for the 11-Term Dimensional Model with Interactions in Table F.4 Fit to the Trimmed Data Set. The 45degree line represents perfect prediction where predicted $U_{\mathrm{CS}}$ values equal measured $U_{\mathrm{CS}}$ values. 
All of the summary statistics for the dimensional models with interactions for $\mathrm{U}_{\mathrm{CS}}$ in Tables F.5 and F.6 show improvement over the corresponding results for dimensional models without interactions in Tables F.1 and F.2. The $\mathrm{R}^{2}$ statistics in Table F.5 $\left(\mathrm{R}^{2}=0.939\right)$ and Table F.6 $\left(\mathrm{R}^{2}=0.939\right)$ indicate that the $\mathrm{U}_{\mathrm{CS}}$ dimensional models with interactions developed by stepwise selection fit the full and trimmed data sets very well. Because the values of $\mathrm{R}^{2}$ and $\mathrm{R}_{\mathrm{p}}^{2}$ in Tables F.5 and F.6 do not differ markedly from the corresponding $\mathrm{R}^{2}$ values, there are no indications that the $\mathrm{U}_{\mathrm{CS}}$ models with interaction terms over-fit the data or that there are any highly influential data.

Figure F.6 shows a predicted-versus-measured plot for the performance of the 12-term $\mathrm{U}_{\mathrm{CS}}$ dimensional model with interactions in Table F.5. In Figure F.6, the scatter around the perfect prediction $\left(45^{\circ}\right)$ line has been slightly reduced from that in Figure F.2 for the 9-term $\mathrm{U}_{\mathrm{CS}}$ dimensional model without interactions in Table F.1. Figure F.7 shows that predictions made for the trimmed data set are also improved when using the 11-term dimensional model with interactions compared to the 9-term dimensional model without interactions (Table F.2 and Figure F.3).

Based on Table F.5, the $\mathrm{U}_{\mathrm{CS}}$ dimensional models with interaction terms fit to the full data are

$$
\begin{aligned}
\mathrm{U}_{\mathrm{CS}} & =0.652(\mathrm{D})^{1.186}(\mathrm{~s}-1)^{0.421}\left(\phi_{\mathrm{S}}\right)^{0.264}\left(\mathrm{U}_{\mathrm{T}}\right)^{0.082+0.276(\mathrm{DC})+0.897\left(\phi_{\mathrm{S}}\right)} \\
& \times(\mathrm{DC})^{0.366-0.170(\mathrm{D})}\left(\phi_{\mathrm{p}}\right)^{-0.210}\left(\mathrm{~N}_{\mathrm{J}}\right)^{-0.545}(\mathrm{~d})^{-1.116}
\end{aligned}
$$

and

$$
\begin{aligned}
\ln \left(\mathrm{U}_{\mathrm{CS}}\right) & =-0.428+1.186 \ln (\mathrm{D})+0.421 \ln (\mathrm{s}-1)+0.264 \ln \left(\phi_{\mathrm{S}}\right) \\
& +\left[0.082+0.276(\mathrm{DC})+0.897\left(\phi_{\mathrm{S}}\right)\right] \ln \left(\mathrm{U}_{\mathrm{T}}\right)+[0.366-0.170(\mathrm{D})] \ln (\mathrm{DC}) \\
& -0.210 \ln \left(\phi_{\mathrm{p}}\right)-0.545 \ln \left(\mathrm{N}_{\mathrm{J}}\right)-1.116 \ln (\mathrm{d}),
\end{aligned}
$$

where all notation is as previously defined. Based on Table F.6, the $\mathrm{U}_{\mathrm{CS}}$ dimensional models with interaction terms fit to the trimmed data set are

$$
\begin{aligned}
\mathrm{U}_{\mathrm{CS}} & =0.867(\mathrm{D})^{1.221}(\mathrm{~s}-1)^{0.952-10.302\left(\phi_{\mathrm{p}}\right)}\left(\phi_{\mathrm{S}}\right)^{0.247}\left(\mathrm{U}_{\mathrm{T}}\right)^{0.170} \\
& \times(\mathrm{DC})^{0.038-0.167(\mathrm{D})}\left(\phi_{\mathrm{p}}\right)^{0.094}\left(\mathrm{~N}_{\mathrm{J}}\right)^{-0.543}(\mathrm{~d})^{-1.143}
\end{aligned}
$$

and

$$
\begin{aligned}
\ln \left(\mathrm{U}_{\mathrm{CS}}\right) & =-0.143+1.221 \ln (\mathrm{D})+\left[0.952-10.302\left(\phi_{\mathrm{p}}\right)\right] \ln (\mathrm{s}-1) \\
& +0.247 \ln \left(\phi_{\mathrm{S}}\right)+0.170 \ln \left(\mathrm{U}_{\mathrm{T}}\right)+[0.038-0.167(\mathrm{D})] \ln (\mathrm{DC}) \\
& +0.094 \ln \left(\phi_{\mathrm{p}}\right)-0.543 \ln \left(\mathrm{N}_{\mathrm{J}}\right)-1.143 \ln (\mathrm{d}),
\end{aligned}
$$

where all notation is as previously defined.

As discussed at the end of Section F.2.3, the $\mathrm{U}_{\mathrm{CS}}$ models with interaction terms may yield inaccurate predictions when extrapolated outside the experimental region of data used to develop them. Hence, unless additional work is performed to thoroughly validate these $U_{C S}$ models for extrapolative use, it is recommended that they only be used for interpolative use. 


\section{F.2.6 Comparison of $U_{c s}$ Models}

In this section the results for three $U_{\mathrm{CS}}$ models presented in Section F.2, namely the

- dimensional model without interactions (Section F.2.4.2)

- corresponding dimensionally consistent model (Section F.2.4.3)

- dimensional model with interactions (Section F.2.5)

are compared with the results of the nondimensional model for $\mathrm{U}_{\mathrm{CS}}$ from Sections 7.3.2 and 7.3.4.

Because the latter model was only fit using the full data set, the comparisons are based on that data.

Figure F.8 shows the predicted-versus-measured (PvM) plot and $\mathrm{R}^{2}$ [calculated using $\ln \left(\mathrm{U}_{\mathrm{CS}}\right)$ values] for the nondimensional $U_{C S}$ model from Sections 7.3.2 and 7.3.4. The goodness-of-fit of the nondimensional model (Figure F.8, $\mathrm{R}^{2}=0.896$ ) can be compared with the dimensional model without interactions (Figure F.2, $\mathrm{R}^{2}=0.913$ ), the dimensionally consistent model (Figure F.4, $\mathrm{R}^{2}=0.867$ ), and the dimensional model with interactions (Figure F.6, $\mathrm{R}^{2}=0.939$ ). Based on $\mathrm{R}^{2}$ values, the dimensional models with and without interactions provide the best fits to the full data set, followed by the nondimensional model and the dimensionally consistent model. The PvM plots for dimensional models without and with interactions (Figures F.2 and F.5) have less scatter for $U_{C S}$ values in the middle of the range tested than the PvM plot for the nondimensional model (Figure F.8). However, the latter plot looks very good. This suggests that some of the generalizations made in constructing the dimensional model form (see Section F.2.2) may be unneeded. If so, there may be a way to reduce the number of coefficients in the dimensional models and retain the improved fit to the data. However, it was not possible in the time available to pursue this idea.

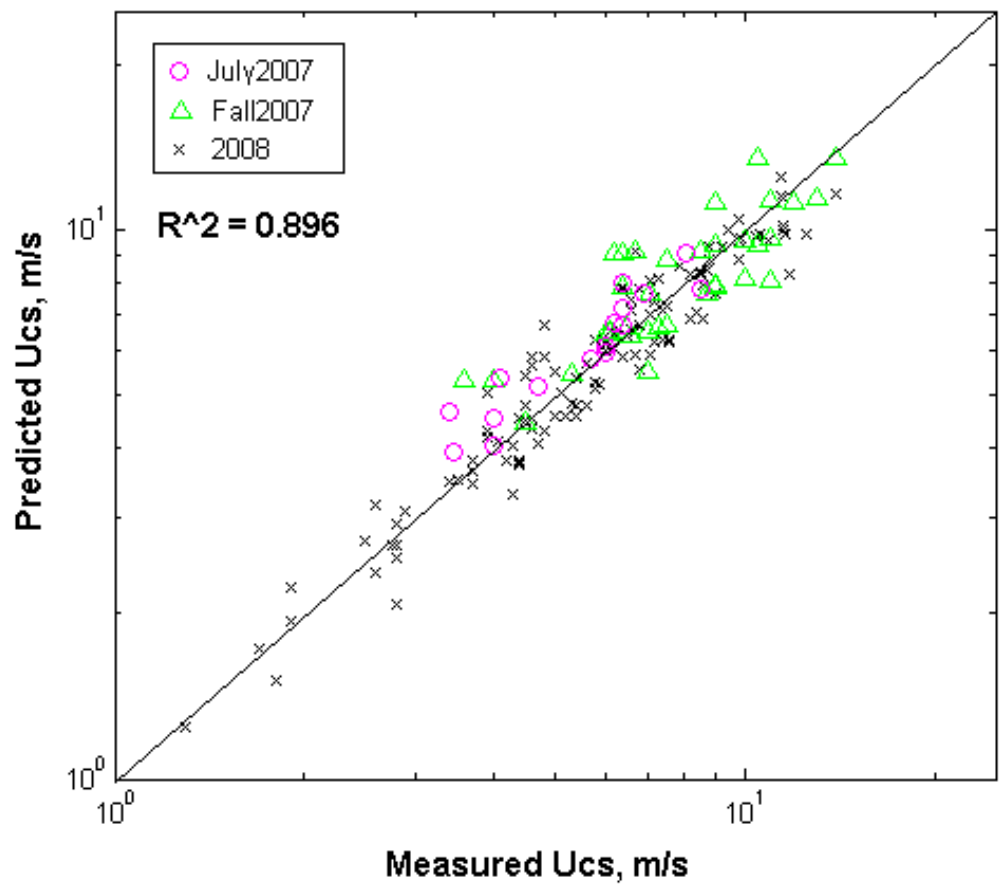

Figure F.8. Log-Log Plot of Predicted Versus Measured $U_{C S}(\mathrm{~m} / \mathrm{s})$ Values for the Nondimensional Model From Section 7.3.2 Developed Using the Full Data Set. The 45-degree line represents perfect prediction where predicted $U_{C S}$ values equal measured $U_{C S}$ values. 
Table F.7 compares the coefficients of several $\mathrm{U}_{\mathrm{CS}}$ models fitted using the full data set when those models are expressed in the dimensional form of Eq. (F.8a). The $\mathrm{U}_{\mathrm{CS}}$ models compared in this way include the 9-term dimensional model without interactions, the 8-term dimensionally consistent model, and the nondimensional model from Sections 7.3.2 and 7.3.4. Some variables in the nondimensional model cannot be expressed in power-law form; thus it was impossible to calculate all coefficients in the form of Eq. (F.8a) for that model. The 12-term dimensional model with interactions is not included in Table F.7 because the values of coefficients involving interactions depend on the variables involved in the interactions.

It is seen from Table F.7 that the coefficients of the three $U_{\mathrm{CS}}$ models expressed in dimensional form are similar for most of the predictor variables. It is of particular note that all three models have a similar coefficient for $\mathrm{D}$, which controls the scale effect. The most noticeable difference is the coefficient for $\mathrm{U}_{\mathrm{T}}$ in the nondimensional model, which is significantly larger than the $U_{\mathrm{T}}$ coefficient in the other two models. However, the nondimensional model has a $\left(1-\phi_{\mathrm{S}} / 0.5\right)^{1.944}$ term that offsets the impact of the larger $\mathrm{U}_{\mathrm{T}}$ coefficient.

Table F.7. Coefficients of $U_{C S}$ Models Expressed in the Dimensional Form of Equation (F.8a)

\begin{tabular}{lccc}
\hline $\begin{array}{l}\text { Model } \\
\text { Terms }\end{array}$ & $\begin{array}{c}\text { Dimensional } U_{\text {CS }} \text { Model } \\
\text { w/o Interactions } \\
\text { [Eq. (F.11a)] }\end{array}$ & $\begin{array}{c}\text { Dimensionally Consistent } U_{C S} \\
\text { Model w/o Interactions } \\
\text { [Eq. (F.10) \& (F.13a)] }\end{array}$ & $\begin{array}{c}\text { Nondimensional } \\
U_{C S} \text { Model from } \\
\text { Section 7.3.2 }\end{array}$ \\
\hline $\mathrm{a}_{0}$ & 0.309 & 0.273 & $(\mathrm{a})$ \\
$\mathrm{D}\left(\mathrm{a}_{1}\right)$ & 1.321 & 1.388 & 1.363 \\
$\mathrm{~s}-1\left(\mathrm{a}_{2}\right)$ & 0.471 & 0.483 & $(\mathrm{a})$ \\
$\phi_{\mathrm{S}}\left(\mathrm{a}_{3}\right)$ & 0.222 & 0.243 & 0.284 \\
$1-\phi_{\mathrm{S}}\left(\mathrm{a}_{14}\right)$ & $-\mathrm{b}^{\mathrm{b}}$ & - & - \\
$\mathrm{U}_{\mathrm{T}}\left(\mathrm{a}_{6}\right)$ & 0.148 & 0.206 & 0.432 \\
$\mathrm{DC}\left(\mathrm{a}_{7}\right)$ & -0.247 & -0.205 & -0.284 \\
$\phi_{\mathrm{p}}\left(\mathrm{a}_{8}\right)$ & -0.211 & -0.221 & -0.198 \\
$\mathrm{~N}_{\mathrm{J}}\left(\mathrm{a}_{10}\right)$ & -0.525 & -0.511 & -0.487 \\
$\mathrm{~d}\left(\mathrm{a}_{11}\right)$ & -1.072 & -0.991 & -0.974 \\
$1-\phi_{\mathrm{S}} / 0.5$ & - & - & 1.944 \\
\multicolumn{1}{c}{$\mathrm{R}^{2}$} & & & 0.896 \\
\hline
\end{tabular}

(a) Not expressible as a term in a power-law model.

(b) A dash (-) indicates the term is not included in the model.

\section{F.3 Cloud Height $\left(\mathrm{H}_{\mathrm{C}}\right)$ Models}

This section discusses the development, results, and uncertainties of $\mathrm{H}_{\mathrm{C}}$ models fit to the full and trimmed data sets described in Section F.1.

\section{F.3.1 $\quad \mathrm{H}_{\mathrm{C}}$ Model Forms}

To develop a model from for $\mathrm{H}_{\mathrm{C}}$, it would be desirable to investigate functionality plots for $\mathrm{H}_{\mathrm{C}} \mathrm{vs}$. $\mathrm{x}_{\mathrm{i}}$ (test variables), similar to the discussion for $U_{\mathrm{CS}}$ at the start of Section F.2.1. Such functionality plots would require plotting $\mathrm{H}_{\mathrm{C}}$ versus each $\mathrm{x}_{\mathrm{i}}$, with lines connecting groups of data points with constant values of the remaining test variables. Jet velocity $(U)$ is one of the test variables that strongly affects $\mathrm{H}_{\mathrm{C}}$, but 
the values of $U$ tested and even the ranges tested are not the same from test to test. Hence, it is not possible to produce functionality plots for other test variables with values of $U$ constant. In lieu of this, functionality plots of $\mathrm{H}_{\mathrm{CS}}$ [or $\ln \left(\mathrm{H}_{\mathrm{CS}}\right)$ ] versus the other $\mathrm{x}_{\mathrm{i}}\left[\right.$ or $\ln \left(\mathrm{x}_{\mathrm{i}}\right)$ ] were investigated. Along with those functionality plots, functionality plots of $\mathrm{H}_{\mathrm{C}}$ [or $\ln \left(\mathrm{H}_{\mathrm{C}}\right)$ ] versus $\mathrm{U}$ [or $\ln (\mathrm{U})$ ] were also investigated. The same kinds of investigations were performed as described for $\mathrm{U}_{\mathrm{CS}}$ at the start of Section F.2.1, so that discussion is not repeated here.

Ultimately, the $\ln \left(\mathrm{H}_{\mathrm{C}}\right)$ versus $\ln (\mathrm{U})$ plots (which are shown in Figures E.17 to E.21 of Appendix E as $\log$-log plots of $\mathrm{H}_{\mathrm{C}}$ versus $\mathrm{U}$ ) were strongly linear, although with some curvature for $\mathrm{U}$ values slightly above $\mathrm{U}_{\mathrm{CS}}$. Also, the $\ln \left(\mathrm{H}_{\mathrm{CS}}\right)$ versus $\ln \left(\mathrm{x}_{\mathrm{i}}\right)$ plots (which are shown in Figures E.22 to E.32 of Appendix E as log-log plots of $\mathrm{H}_{\mathrm{CS}}$ versus $\mathrm{x}_{\mathrm{i}}$ ) had linear or not too curvilinear relationships for all of the test variables. Hence, it was concluded that the corresponding power-law model form would be an adequate "firstorder" approximation of the true, unknown relationships between $\mathrm{H}_{\mathrm{C}}$ and the $\mathrm{x}_{\mathrm{i}}$. It was recognized that adopting the power-law model form would result in some model lack-of-fit for some test variables. Based on the plots in Figures E.17 to E.32, these test variables are $N_{J}$ (the number of operating jets), $\phi_{S}>$ 0.015 , and the smallest and largest values of $d_{S}$ and $U_{T}$ (for which there were very few tests performed). However, this situation was judged acceptable given the goal of using the models to perform coarse ratings of the mixing designs of WTP vessels. Also, fitting models to both "full" and "trimmed" data sets, as described in Section F.1.1, addresses some of these issues. More accurate $\mathrm{H}_{\mathrm{C}}$ models could be developed in the future from the M3 mixing-test data, but they would have more complicated forms, require more time to develop, and require more advanced statistical fitting and uncertainty methods.

The RSM modeling approach of using first- and second-order polynomial models to approximate the relationship between a response variable and multiple predictor variables was discussed for $\mathrm{U}_{\mathrm{CS}}$ at the end of Section F.2.1. Because the RSM approach did not perform as well for the easier-to-model $\mathrm{U}_{\mathrm{CS}}$ data, it was decided not to investigate the RSM approach for the more-difficult-to-model $\mathrm{H}_{\mathrm{C}}$ data. Another reason for not pursuing the RSM approach for modeling $\mathrm{H}_{\mathrm{C}}$ is the same as for $\mathrm{U}_{\mathrm{CS}}$, namely that polynomial models are generally not appropriate for extrapolative use.

\section{F.3.2 $\quad \mathrm{H}_{\mathrm{C}}$ Power-Law Model Forms}

The initial $\mathrm{H}_{\mathrm{C}}$ model form considered was developed by generalizing the physical model for $\mathrm{H}_{\mathrm{C}}$ discussed in Section 7.3.2. Starting with that form of the model, the natural logarithm of the left side is removed because of its small effect and the expectation of capturing that effect in another way. Then, moving the predictor variables on the left side to the right side of the equation, expanding variables calculated as functions of other variables, and collecting similar terms yields the statistical model form

$$
\mathrm{H}_{\mathrm{C}}=\mathrm{a}_{0}(\mathrm{D})^{\mathrm{a}_{13}}(\mathrm{~s}-1)^{\mathrm{a}_{2}}\left(\phi_{\mathrm{S}}\right)^{\mathrm{a}_{3}}\left(\mathrm{U}_{\mathrm{TH}}\right)^{\mathrm{a}_{4}}(\mathrm{DC})^{\mathrm{a} 7}\left(\phi_{\mathrm{p}}\right)^{\mathrm{a}_{8}}\left(\mathrm{~d}_{\mathrm{S}}\right)^{\mathrm{a}_{9}}\left(\phi_{\mathrm{J}}\right)^{\mathrm{a}_{10}}(\mathrm{U})^{\mathrm{a}_{12}} \delta
$$

where notation is as described previously. Equation (F.17a) was generalized to include a term involving $\mathrm{D}$, which does not appear in the $\mathrm{H}_{\mathrm{C}}$ model form discussed in Section 7.3.2. Note that Eq. (F.17a) is a power-law model form, which was judged as adequate for first-order approximation and predictive purposes, as discussed above.

Because Eq. (F.17a) is nonlinear in its coefficients and has a multiplicative error structure, it can be converted to a model linear in its coefficients with an additive error structure by taking the natural logarithm of both sides, as discussed in Section D.2.1 of Appendix D. This yields the model 


$$
\begin{aligned}
\ln \left(\mathrm{H}_{\mathrm{C}}\right)= & \ln \left(\mathrm{a}_{0}\right)+\mathrm{a}_{13} \ln (\mathrm{D})+\mathrm{a}_{2} \ln (\mathrm{s}-1)+\mathrm{a}_{3} \ln \left(\phi_{\mathrm{S}}\right)+\mathrm{a}_{4} \ln \left(\mathrm{U}_{\mathrm{TH}}\right)+\mathrm{a}_{7} \ln (\mathrm{DC}) \\
& +\mathrm{a}_{8} \ln \left(\phi_{\mathrm{p}}\right)+\mathrm{a}_{9} \ln \left(\mathrm{d}_{\mathrm{S}}\right)+\mathrm{a}_{10} \ln \left(\phi_{\mathrm{J}}\right)+\mathrm{a}_{12} \ln (\mathrm{U})+\varepsilon,
\end{aligned}
$$

where the notation is as previously defined. The model form in Eq. (F.17b) can be fit by OLS LR, whereas the model form in Eq. (F.17a) must be fit by WLS NLR. See Section D.2 of Appendix D for more discussion of these issues.

Equations (F.17a) and (F.17b) can be expanded by substituting into them a generalization of the equation for $\mathrm{U}_{\mathrm{TH}}$ given by

$$
\mathrm{U}_{\mathrm{TH}}=\mathrm{U}_{\mathrm{T}}\left(1-\frac{\phi_{\mathrm{S}}}{0.5}\right)^{4.5}
$$

This yields the model forms

$$
\mathrm{H}_{\mathrm{C}}=\mathrm{a}_{0}(\mathrm{D})^{\mathrm{a}_{13}}(\mathrm{~s}-1)^{\mathrm{a} 2}\left(\phi_{\mathrm{S}}\right)^{\mathrm{a}_{3}}\left(1-\frac{\phi_{\mathrm{S}}}{0.5}\right)^{\mathrm{a} 5}\left(\mathrm{U}_{\mathrm{T}}\right)^{\mathrm{a}_{6}}(\mathrm{DC})^{\mathrm{a} 7}\left(\phi_{\mathrm{p}}\right)^{\mathrm{a} 8}\left(\mathrm{~d}_{\mathrm{S}}\right)^{\mathrm{a} 9}\left(\phi_{\mathrm{J}}\right)^{\mathrm{a}_{10}}(\mathrm{U})^{\mathrm{a}_{12}} \delta
$$

and

$$
\begin{aligned}
\ln \left(\mathrm{H}_{\mathrm{C}}\right)= & \ln \left(\mathrm{a}_{0}\right)+\mathrm{a}_{13} \ln (\mathrm{D})+\mathrm{a}_{2} \ln (\mathrm{s}-1)+\mathrm{a}_{3} \ln \left(\phi_{\mathrm{S}}\right)+\mathrm{a}_{5} \ln \left(1-\frac{\phi_{\mathrm{S}}}{0.5}\right)+\mathrm{a}_{6} \ln \left(\mathrm{U}_{\mathrm{T}}\right) \\
& +\mathrm{a}_{7} \ln (\mathrm{DC})+\mathrm{a}_{8} \ln \left(\phi_{\mathrm{p}}\right)+\mathrm{a}_{9} \ln \left(\mathrm{d}_{\mathrm{S}}\right)+\mathrm{a}_{10} \ln \left(\phi_{\mathrm{J}}\right)+\mathrm{a}_{12} \ln (\mathrm{U})+\varepsilon,
\end{aligned}
$$

where the notation is as previously defined. The $\mathrm{a}_{6}$ and $\mathrm{a}_{5}$ coefficients in Eqs. (F.19a) and (F.19b) generalize, respectively, the 1.0 exponent (implied) on $U_{\mathrm{T}}$ and the 4.5 exponent on $\left(1-\phi_{\mathrm{S}} / 0.5\right)$ in Eq. (F.18).

Using a generalization of the formula $\phi_{\mathrm{J}}=\mathrm{N}_{\mathrm{J}}(\mathrm{d} / \mathrm{D})^{2}$ where $\mathrm{N}_{\mathrm{J}}$ and $\mathrm{d}$ are allowed to have their own coefficients and D is absorbed into the existing D term, the model forms in Eq. (F.19a) and (F.19b) can be further generalized as

$$
\begin{aligned}
& \mathrm{H}_{\mathrm{C}}=\mathrm{a}_{0}(\mathrm{D})^{\mathrm{a}_{1}}(\mathrm{~s}-1)^{\mathrm{a}_{2}}\left(\phi_{\mathrm{S}}\right)^{\mathrm{a}_{3}}\left(1-\frac{\phi_{\mathrm{S}}}{0.5}\right)^{\mathrm{a}_{5}}\left(\mathrm{U}_{\mathrm{T}}\right)^{\mathrm{a}_{6}}(\mathrm{DC})^{\mathrm{a}_{7}}\left(\phi_{\mathrm{P}}\right)^{\mathrm{a}_{8}}\left(\mathrm{~d}_{\mathrm{S}}\right)^{\mathrm{a}_{9}}
\end{aligned}
$$

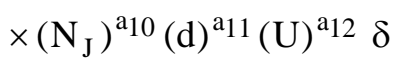

and

$$
\begin{aligned}
\ln \left(\mathrm{H}_{\mathrm{C}}\right)= & \ln \left(\mathrm{a}_{0}\right)+\mathrm{a}_{1} \ln (\mathrm{D})+\mathrm{a}_{2} \ln (\mathrm{s}-1)+\mathrm{a}_{3} \ln \left(\phi_{\mathrm{S}}\right)+\mathrm{a}_{5} \ln \left(1-\frac{\phi_{\mathrm{S}}}{0.5}\right)+\mathrm{a}_{6} \ln \left(\mathrm{U}_{\mathrm{T}}\right) \\
& +\mathrm{a}_{7} \ln (\mathrm{DC})+\mathrm{a}_{8} \ln \left(\phi_{\mathrm{p}}\right)+\mathrm{a}_{9} \ln \left(\mathrm{d}_{\mathrm{S}}\right)+\mathrm{a}_{10} \ln \left(\mathrm{N}_{\mathrm{J}}\right)+\mathrm{a}_{11} \ln (\mathrm{d})+\mathrm{a}_{12} \ln (\mathrm{U})+\varepsilon,
\end{aligned}
$$

where all notation is as previously defined.

As discussed, Eq. (F.20a) and (F.20b) are generalizations of the model forms in Eq. (F.17a) and (F.17b), where the latter are obtained from the former using the coefficient constraints $a_{6}=a_{4}, a_{5}=4.5 a_{4}$, $\mathrm{a}_{11}=2 \mathrm{a}_{10}$, and $\mathrm{a}_{1}=\mathrm{a}_{13}-2 \mathrm{a}_{10}$. 
Finally, note that none of the model forms discussed for $\mathrm{H}_{\mathrm{C}}$ contains an HS (head shape) term, for the same reasons discussed for $\mathrm{U}_{\mathrm{CS}}$ model forms at the end of Section F.2.2.

\section{F.3.3 $\quad H_{C}$ Power-Law Models with Interaction Terms}

Stepwise regression methods (see Section D.4.2, Appendix D) were used to augment $\mathrm{H}_{\mathrm{C}}$ models of the form in Eq. (F.20a) and (F.20b) with interaction terms of the same form as discussed for $U_{C S}$ in Section F.2.3. Functionality plots of $\mathrm{H}_{\mathrm{C}}$ and $\mathrm{H}_{\mathrm{CS}}$ versus test variables in Section E.2.3 of Appendix E indicate the interaction terms of the form shown in Section F.2.3 may improve the predictive performance of mixing models, at least within the experimental region of the data. However, models with interaction terms can yield inaccurate predictions when extrapolated significantly outside the experimental region of data used to develop them. Hence, unless $\mathrm{H}_{\mathrm{C}}$ models with interaction terms have been well validated for extrapolative use, it is recommended that only $\mathrm{H}_{\mathrm{C}}$ models without interaction terms be used for extrapolative predictions.

\section{F.3.4 Results for $\mathrm{H}_{\mathrm{C}}$ Power-Law Models}

The dimensional and corresponding dimensionally consistent model forms investigated for $\mathrm{H}_{\mathrm{C}}$ are presented in Section F.3.4.1. The results of fitting the dimensional models for $\mathrm{H}_{\mathrm{C}}$ to the full and trimmed data sets are presented in Section F.3.4.2. The results of fitting the dimensionally consistent models for $\mathrm{H}_{\mathrm{C}}$ are presented in Section F.3.4.3.

\section{F.3.4.1 Dimensional and Dimensionally Consistent Power-Law Model Forms for $\mathrm{H}_{\mathrm{C}}$}

To begin, models of the form in Eq. (F.20b) were fit to the full and trimmed data sets described in Section F.1. For the full data set, the $\mathrm{s}-1$ term was statistically nonsignificant. For the trimmed data set, the $s-1$ and $\left(1-\phi_{S} / 0.5\right)$ terms were statistically nonsignificant.

The statistical nonsignificance of the $s-1$ term for both the full and trimmed data sets was a result of the model form in Eq. (F.20b) including all three of the highly correlated terms $\mathrm{s}-1, \mathrm{~d}_{\mathrm{s}}$, and $\mathrm{U}_{\mathrm{T}}$ (as discussed in Section F.2.4). It was decided to drop $\mathrm{d}_{\mathrm{S}}$ from the model to rectify this problem. It may seem more natural to drop $U_{T}$ than $d_{S}$, because $U_{T}$ is calculated using $d_{S}$ and $s-1$; however, $U_{T}$ is more physically meaningful as a predictor variable than $\mathrm{d}_{\mathrm{s}}$. Further, there was little difference in the goodnessof-fit of a model that retained $U_{T}$ instead of $d_{S}$.

In addition, for reasons discussed in Section F.3.3, it was decided to delete the $\left(1-\phi_{S} / 0.5\right)$ term from the model. However, it was discovered in preliminary $\mathrm{H}_{\mathrm{C}}$ modeling work that a power-law term of the form $1-\phi_{\mathrm{S}}$ (in addition to a power-law term for $\phi_{\mathrm{S}}$ ) helped account for the $\mathrm{H}_{\mathrm{C}}$ dependence on the larger values of $\phi_{\mathrm{S}}$ in the full data set. Hence, models of the form

$$
\begin{aligned}
& \mathrm{H}_{\mathrm{C}}=\mathrm{a}_{0}(\mathrm{D})^{\mathrm{a}_{1}}(\mathrm{~s}-1)^{\mathrm{a}_{2}}\left(\phi_{\mathrm{S}}\right)^{\mathrm{a}_{3}}\left(1-\phi_{\mathrm{S}}\right)^{\mathrm{a}_{14}}\left(\mathrm{U}_{\mathrm{T}}\right)^{\mathrm{a}_{6}}(\mathrm{DC})^{\mathrm{a}_{7}}\left(\phi_{\mathrm{p}}\right)^{\mathrm{a} 8} \\
& \times\left(\mathrm{N}_{\mathrm{J}}\right)^{\mathrm{a} 10}(\mathrm{~d})^{\mathrm{a} 11}(\mathrm{U})^{\mathrm{a} 12} \delta
\end{aligned}
$$

and 


$$
\begin{aligned}
\ln \left(\mathrm{H}_{\mathrm{C}}\right)= & \ln \left(\mathrm{a}_{0}\right)+\mathrm{a}_{1} \ln (\mathrm{D})+\mathrm{a}_{2} \ln (\mathrm{s}-1)+\mathrm{a}_{3} \ln \left(\phi_{\mathrm{S}}\right)+\mathrm{a}_{14} \ln \left(1-\phi_{\mathrm{S}}\right)+\mathrm{a}_{6} \ln \left(\mathrm{U}_{\mathrm{T}}\right) \\
& +\mathrm{a}_{7} \ln (\mathrm{DC})+\mathrm{a}_{8} \ln \left(\phi_{\mathrm{p}}\right)+\mathrm{a}_{10} \ln \left(\mathrm{N}_{\mathrm{J}}\right)+\mathrm{a}_{11} \ln (\mathrm{d})+\mathrm{a}_{12} \ln (\mathrm{U})+\varepsilon,
\end{aligned}
$$

were considered, where all notation is as previously defined.

The coefficients estimated by fitting Eq. (F.21b) to the full or trimmed data sets by OLS MR may subsequently be written in the form of Eq. (F.21a). However, this will result in a dimensional constant $\mathrm{a}_{0}$ having units that may differ from those of subsumed physical constants (e.g., g) and dropped model terms. Unfortunately, there is not a unique set of dimensional-consistency constraints that can be applied by fitting Eq. (F.21b) using restricted-least-squares (Draper and Smith 1998, Section 9.5) to impose dimensional consistency. Instead, a dimensionally consistent model form was developed starting from Eq. (F.21a), with the goal of retaining as much as possible of the generalizations added in Section F.3.2. The dimensionally consistent model for $\mathrm{H}_{\mathrm{C}}$ that resulted from this process is

$$
\mathrm{H}_{\mathrm{C}}=\mathrm{b}_{0} \mathrm{D}\left(\frac{\mathrm{U}^{2}}{\mathrm{D}(\mathrm{s}-1) \mathrm{g}}\right)^{\mathrm{b}_{1}}\left(\frac{\mathrm{d}}{\mathrm{D}}\right)^{\mathrm{b}_{2}}(\mathrm{~s}-1)^{\mathrm{b}_{3}}\left(\frac{\mathrm{U}_{\mathrm{T}}}{\mathrm{U}}\right)^{\mathrm{b}_{4}} \mathrm{DC}^{\mathrm{b} 5} \phi_{\mathrm{S}}^{\mathrm{b}_{6}}\left(1-\phi_{\mathrm{S}}\right)^{\mathrm{b}_{7}} \phi_{\mathrm{p}}^{\mathrm{b}_{8}} \mathrm{~N}_{\mathrm{J}}^{\mathrm{b} 9} \delta
$$

where

$$
\begin{aligned}
\mathrm{b}_{\mathrm{i}} & =\begin{array}{l}
\text { model coefficients }(\mathrm{i}=0,1, \ldots, 9) \text { to be estimated using experimental data } \\
\text { (nondimensional) }
\end{array} \\
\frac{\mathrm{U}^{2}}{\mathrm{D}(\mathrm{s}-1) \mathrm{g}} & =\text { Froude number (nondimensional) } \\
\mathrm{g} & =9.80665\left(\mathrm{~m} / \mathrm{s}^{2}\right) \text { is the gravity constant } \\
\frac{\mathrm{U}_{\mathrm{T}}}{\mathrm{U}} & =\text { kinematic ratio (nondimensional) }
\end{aligned}
$$

and remaining notation is as defined previously. Because Eq. (F.22a) is nonlinear in its coefficients and has a multiplicative error structure, it can be converted to a model linear in its coefficients with an additive error structure by taking the natural logarithm of both sides, as discussed in Section D.2.1 of Appendix D. This yields the model:

$$
\begin{aligned}
\ln \left(\mathrm{H}_{\mathrm{C}}\right) & =\ln \left(\mathrm{b}_{0}\right)+\ln (\mathrm{D})+\mathrm{b}_{1} \ln \left(\frac{\mathrm{U}^{2}}{\mathrm{D}(\mathrm{s}-1) \mathrm{g}}\right)+\mathrm{b}_{2} \ln \left(\frac{\mathrm{d}}{\mathrm{D}}\right)+\mathrm{b}_{3} \ln (\mathrm{s}-1)+\mathrm{b}_{4}\left(\frac{\mathrm{U}_{\mathrm{T}}}{\mathrm{U}}\right) \\
& +\mathrm{b}_{5} \ln (\mathrm{DC})+\mathrm{b}_{6} \ln \left(\phi_{\mathrm{S}}\right)+\mathrm{b}_{7} \ln \left(1-\phi_{\mathrm{S}}\right)+\mathrm{b}_{8} \ln \left(\phi_{\mathrm{p}}\right)+\mathrm{b}_{9} \ln \left(\mathrm{N}_{\mathrm{J}}\right)+\varepsilon
\end{aligned}
$$

The dimensionally consistent models in Eq. (F.22a) and (F.22b) can be considered as reduced forms of the dimensional models in Eq. (F.21a) and (F.21b), with the relationships among the coefficients given by 


$$
\begin{aligned}
& \mathrm{a}_{0}=\mathrm{b}_{0} \mathrm{~g}^{-\mathrm{b}_{1}} \text { or } \ln \left(\mathrm{a}_{0}\right)=\ln \left(\mathrm{b}_{0}\right)-\mathrm{b}_{1} \ln (\mathrm{g}) \\
& \mathrm{a}_{1}=1-\mathrm{b}_{1}-\mathrm{b}_{2} \\
& \mathrm{a}_{2}=\mathrm{b}_{3}-\mathrm{b}_{1} \\
& \mathrm{a}_{3}=\mathrm{b}_{6} \\
& \mathrm{a}_{14}=\mathrm{b}_{7} \\
& \mathrm{a}_{6}=\mathrm{b}_{4} \\
& \mathrm{a}_{7}=\mathrm{b}_{5} \\
& \mathrm{a}_{8}=\mathrm{b}_{8} \\
& \mathrm{a}_{10}=\mathrm{b}_{9} \\
& \mathrm{a}_{11}=\mathrm{b}_{2} \\
& \mathrm{a}_{12}=2 \mathrm{~b}_{1}-\mathrm{b}_{4}
\end{aligned}
$$

Note that the $\mathrm{H}_{\mathrm{C}}$ dimensional models in Eq. (F.21a) and (F.21b) have 11 coefficients to be estimated using the data, whereas the dimensionally consistent models in Eq. (F.22a) and (F.22b) have only 10. The difference is because the leading D term (after the constant term) in Eq. (F.21a) and (F.21b) has an exponent/coefficient equal to 1 . If the $\mathrm{D}$ term were given a separate exponent, for instance, $\mathrm{b} 10$, that would give $a_{1}=b_{10}-b_{1}-b_{2}$. The model form in Eq. (F.22a) and (F.22b) extended in this way would be mathematically equivalent to the model form in Eq. (F.21a) and (F.21b). In other words, they would fit a given data set exactly the same, and predictions of $\mathrm{H}_{\mathrm{C}}$ would be exactly the same.

\section{F.3.4.2 Results of Fitting Dimensional Power-Law Model Forms for $\mathrm{H}_{\mathrm{C}}$ to Full and Trimmed Data Sets}

The results of fitting the dimensional model form in Eq. (F.21b) to the full and trimmed data sets are given in Tables F.8 and F.9, respectively. Included in these tables are estimates of the model coefficients and their standard deviations. Also shown for each coefficient is its t-value (coefficient divided by its standard deviation) and p-value (statistical significance level). Traditionally, p-values lower than 0.05 indicate statistically significant coefficients (different from zero) with greater than $95 \%$ confidence; p-values lower than 0.01 indicate high statistical significance (greater than $99 \%$ confidence), while values lower than 0.0001 indicate extremely high statistical significance (more than 99.99\% confidence).

In Table F.8 for the full data set, all model terms except the constant $\left[\ln \left(\mathrm{a}_{0}\right)\right]$ are statistically significant at a p-value of $<0.0001$. For the trimmed data, 10 of the 11 terms in Eq. (F.21b) were statistically significant. The $\left(1-\phi_{\mathrm{S}}\right)$ term was not statistically significant, so it was removed from the 10 -term model shown in Table F.9. The statistical nonsignificance of this term is reasonable because the trimmed data set removed data with values $\phi_{\mathrm{s}}>0.015$. It was for those data that the $\left(1-\phi_{\mathrm{S}}\right)$ term improved the fit to the full data set. Table F.9 shows that the other terms (except the constant) are statistically significant, with p-values of $<0.0001$.

The large negative coefficient of -17.502 on the $\left(1-\phi_{\mathrm{S}}\right)$ term in Table F.8 requires some additional explanation because it "stands out" compared to other coefficients. As seen in Table F.8, this term in the $\mathrm{H}_{\mathrm{C}}$ model is highly statistically significant. Having both $\phi_{\mathrm{S}}$ and $\left(1-\phi_{\mathrm{S}}\right)$ terms in the model serves to represent the curvature effect of $\phi_{\mathrm{S}}$ on $\mathrm{H}_{\mathrm{C}}$. This curvature can be seen in the functionality plot of $\phi_{\mathrm{S}}$ for 
Table F.8. Coefficients and Performance Summary for the 11-Term Linearized Power-Law Model on the Natural Logarithm of $\mathrm{H}_{\mathrm{C}}$ Fit to the Full Data Set

\begin{tabular}{|c|c|c|c|c|c|c|}
\hline \multirow{2}{*}{$\begin{array}{c}\ln \left(\mathrm{H}_{\mathrm{C}}\right) \text { Model } \\
\text { Term }\end{array}$} & \multirow{2}{*}{$\begin{array}{l}\text { Coefficient } \\
\text { Estimate }\end{array}$} & \multirow{2}{*}{$\begin{array}{c}\text { Coefficient } \\
\text { Standard } \\
\text { Deviation }\end{array}$} & \multirow{2}{*}{$\begin{array}{l}\text { t-value }= \\
\text { Coeff/SD }\end{array}$} & \multirow[b]{2}{*}{ p-value ${ }^{(a)}$} & \multicolumn{2}{|c|}{ Full Data, 669 Data Points ${ }^{(\mathrm{b})}$} \\
\hline & & & & & Modeling Data Statistic $\left[\ln \left(\mathrm{H}_{\mathrm{C}}\right)\right]$ & Value \\
\hline $\ln \left(\mathrm{a}_{0}\right)$ & 0.076 & 0.229 & 0.33 & 0.739 & $\mathrm{R}^{2}$ & 0.830 \\
\hline $\ln (\mathrm{D})$ & -1.191 & 0.097 & -12.31 & $<0.0001$ & $\mathrm{R}^{2}$ Adjusted $\left(\mathrm{R}_{\mathrm{A}}^{2}\right)$ & 0.828 \\
\hline $\ln (s-1)$ & -0.836 & 0.046 & -18.32 & $<0.0001$ & $\mathrm{R}^{2}$ Predicted $\left(\mathrm{R}_{\mathrm{P}}^{2}\right)$ & 0.825 \\
\hline $\ln \left(\phi_{\mathrm{S}}\right)$ & -0.623 & 0.026 & -24.24 & $<0.0001$ & RMSE & 0.258 \\
\hline $\ln \left(1-\phi_{\mathrm{S}}\right)$ & -17.502 & 1.622 & -10.79 & $<0.0001$ & & \\
\hline $\ln \left(\mathrm{U}_{\mathrm{T}}\right)$ & -0.412 & 0.018 & -22.46 & $<0.0001$ & & \\
\hline $\ln (\mathrm{DC})$ & 0.371 & 0.036 & 10.32 & $<0.0001$ & & \\
\hline $\ln \left(\phi_{\mathrm{p}}\right)$ & 0.218 & 0.039 & 5.63 & $<0.0001$ & & \\
\hline $\ln \left(\mathrm{N}_{\mathrm{J}}\right)$ & 0.330 & 0.050 & 6.66 & $<0.0001$ & & \\
\hline $\ln (d)$ & 1.722 & 0.086 & 19.95 & $<0.0001$ & & \\
\hline $\ln (\mathrm{U})$ & 1.378 & 0.066 & 20.98 & $<0.0001$ & & \\
\hline
\end{tabular}

(a) Probability that the coefficient is not statistically significant (different from 0 ). Values less than $0.05,0.01$, and 0.0001 indicate strong, very strong, and extremely strong statistical significance of the coefficient and corresponding model term. (b) Model evaluation and validation statistics are defined, respectively, in Sections D.3 and D.5 of Appendix D.

Table F.9. Coefficients and Performance Summary for the 10-Term Linearized Power-Law Model on the Natural Logarithm of $\mathrm{H}_{\mathrm{C}}$ Fit to the Trimmed Data Set

\begin{tabular}{|c|c|c|c|c|c|c|}
\hline \multirow{2}{*}{$\begin{array}{c}\ln \left(\mathrm{H}_{\mathrm{C}}\right) \text { Model } \\
\text { Term }\end{array}$} & \multicolumn{3}{|c|}{ Coefficient } & \multirow{2}{*}{$\underset{\text { (a) }}{\mathrm{p} \text {-value }}$} & \multicolumn{2}{|c|}{ Trimmed Data, 581 Data Points ${ }^{(b)}$} \\
\hline & Estimate & Deviation & Coeff/SD & & Modeling Data Statistic $\left[\ln \left(\mathrm{H}_{\mathrm{C}}\right)\right]$ & Value \\
\hline $\ln \left(\mathrm{a}_{0}\right)$ & 0.349 & 0.228 & 1.53 & 0.127 & $\mathrm{R}^{2}$ & 0.852 \\
\hline $\ln (\mathrm{D})$ & -1.327 & 0.101 & -13.13 & $<0.0001$ & $\mathrm{R}^{2}$ Adjusted $\left(\mathrm{R}_{\mathrm{A}}^{2}\right)$ & 0.850 \\
\hline $\ln (s-1)$ & -0.804 & 0.046 & -17.66 & $<0.0001$ & $\mathrm{R}^{2}$ Predicted $\left(\mathrm{R}_{\mathrm{P}}^{2}\right)$ & 0.847 \\
\hline $\ln \left(\phi_{\mathrm{S}}\right)$ & -0.572 & 0.021 & -26.76 & $<0.0001$ & RMSE & 0.242 \\
\hline $\ln \left(\mathrm{U}_{\mathrm{T}}\right)$ & -0.491 & 0.019 & -25.39 & $<0.0001$ & & \\
\hline $\ln (\mathrm{DC})$ & 0.348 & 0.038 & 9.12 & $<0.0001$ & & \\
\hline $\ln \left(\phi_{\mathrm{p}}\right)$ & 0.276 & 0.038 & 7.23 & $<0.0001$ & & \\
\hline $\ln \left(\mathrm{N}_{\mathrm{J}}\right)$ & 0.340 & 0.049 & 7.00 & $<0.0001$ & & \\
\hline $\ln (d)$ & 1.812 & 0.090 & 20.14 & $<0.0001$ & & \\
\hline $\ln (\mathrm{U})$ & 1.501 & 0.068 & 21.99 & $<0.0001$ & & \\
\hline
\end{tabular}

(a) Probability that the coefficient is not statistically significant (different from 0 ). Values less than $0.05,0.01$, and 0.0001 indicate strong, very strong, and extremely strong statistical significance of the coefficient and corresponding model term. (b) Model evaluation and validation statistics are defined, respectively, in Sections D.3 and D.5 of Appendix D.

$\mathrm{H}_{\mathrm{CS}}$ in Figure E.28 of Appendix E. A model like the one in Table F.8, but fit without the $\left(1-\phi_{\mathrm{S}}\right)$ term, shows biased predictions of $\mathrm{H}_{\mathrm{C}}$ for $\phi_{\mathrm{S}}>0.015$. Finally, when the coefficient -17.502 is combined with $\left(1-\phi_{\mathrm{S}}\right)$ values in the M3 test data set (ranging from 0.94 to 0.9995$)$, the range of contributions of this term to model predictions is smaller than for several other model terms. Hence, the model in Table F.8 with the $\left(1-\phi_{\mathrm{S}}\right)$ term having coefficient -17.502 is appropriate for the range of $\phi_{\mathrm{S}}$ studied in M3 testing. Because WTP vessels require only interpolating within the range of $\phi_{\mathrm{S}}$ studied in M3 testing, the $\mathrm{H}_{\mathrm{C}}$ model containing the $-17.502 \ln \left(1-\phi_{\mathrm{S}}\right)$ term is appropriate for use. 
The right sides of Tables F.8 and F.9 list various summary statistics that provide measures of how well the 11- and 10-term models based on Eq. (F.21b) fit the full and trimmed data sets, respectively. These summary statistics are defined and discussed in Sections D.3.2 and D.3.3 of Appendix D. The summary statistics in Tables F.8 and F.9 indicate that the linearized power-law models fit the available data reasonably well.

The 11-term model accounts for $83 \%$ of the variability in $\ln \left(\mathrm{H}_{\mathrm{C}}\right)$ values for the full data. The 10-term model accounts for $85.2 \%$ of the variability in $\ln \left(\mathrm{H}_{\mathrm{C}}\right)$ values for the trimmed data. The linearized powerlaw model form fits slightly better for the trimmed data set than for the full data set. In Tables F.8 and F.9 the differences between $\mathrm{R}^{2}$ and $\mathrm{R}_{\mathrm{A}}{ }_{\mathrm{A}}$ are small, so there are no indications that the full and trimmed data sets, respectively, have been over-fitted. Because the differences between $\mathrm{R}_{\mathrm{A}}{ }_{\text {and }} \mathrm{R}_{\mathrm{P}}{ }_{\mathrm{P}}$ are small in both tables, there are no indications of highly influential data affecting the model fits.

Figures F.9 and F.10 show predicted-versus-measured plots, which provide a graphical view of how well the 11- and 10-term model forms fit the full and trimmed data sets, respectively. In each plot, the predicted value of $\mathrm{H}_{\mathrm{C}}$ is plotted on the $\mathrm{y}$-axis (in log scale) and the measured values of $\mathrm{H}_{\mathrm{C}}$ are plotted on the $\mathrm{x}$-axis (also in log scale). The 45-degree line represents perfect prediction, where predicted $\mathrm{H}_{\mathrm{C}}$ values would exactly equal measured $\mathrm{H}_{\mathrm{C}}$ values. See Section D.3.2 of Appendix D for further discussion of using predicted-versus-measured plots to evaluate how well a model fits a data set.

From Figures F.9 and F.10 it is seen that only the 2008 data span the range of the $\mathrm{H}_{\mathrm{C}}$ response. The figures also show tendencies for the corresponding models in Tables F.8 and F.9 to overpredict $\mathrm{H}_{\mathrm{C}}$ below $\sim 0.2 \mathrm{~m}$. The models have a slight tendency to underpredict $\mathrm{H}_{\mathrm{C}}$ values between $\sim 0.3$ to $0.6 \mathrm{~m}$.

In summary, inserting the coefficients from the $\mathrm{H}_{\mathrm{C}}$ dimensional models without interactions fit to the full data set (Table F.8) into Eq. (F.21a) and (F.21b) results in the models

$$
\begin{aligned}
\mathrm{H}_{\mathrm{C}} & =1.079(\mathrm{D})^{-1.191}(\mathrm{~s}-1)^{-0.836}\left(\phi_{\mathrm{S}}\right)^{-0.623}\left(1-\phi_{\mathrm{S}}\right)^{-17.502}\left(\mathrm{U}_{\mathrm{T}}\right)^{-0.412}(\mathrm{DC})^{0.371} \\
& \times\left(\phi_{\mathrm{p}}\right)^{0.218}\left(\mathrm{~N}_{\mathrm{J}}\right)^{0.330}(\mathrm{~d})^{1.722}(\mathrm{U})^{1.378}
\end{aligned}
$$

and

$$
\begin{aligned}
\ln \left(\mathrm{H}_{\mathrm{C}}\right)= & 0.076-1.191 \ln (\mathrm{D})-0.836 \ln (\mathrm{s}-1)-0.623 \ln \left(\phi_{\mathrm{S}}\right)-17.502 \ln \left(1-\phi_{\mathrm{S}}\right) \\
& -0.412 \ln \left(\mathrm{U}_{\mathrm{T}}\right)+0.371 \ln (\mathrm{DC})+0.218 \ln \left(\phi_{\mathrm{p}}\right)+0.330 \ln \left(\mathrm{N}_{\mathrm{J}}\right)+1.722 \ln (\mathrm{d}) \\
& +1.378 \ln (\mathrm{U})
\end{aligned}
$$

where all notation is as previously defined. The $\left(1-\phi_{\mathrm{S}}\right)^{-17.502}$ and $-17.502 \ln \left(1-\phi_{\mathrm{S}}\right)$ terms in Eq. (F.24a) and (F.24b) are appropriate for the range of $\phi_{S}$ studied in M3 testing (0.0005-0.06). However, caution is advised if these $\mathrm{H}_{\mathrm{C}}$ models must be extrapolated to $\phi_{\mathrm{S}}$ values outside that range. 


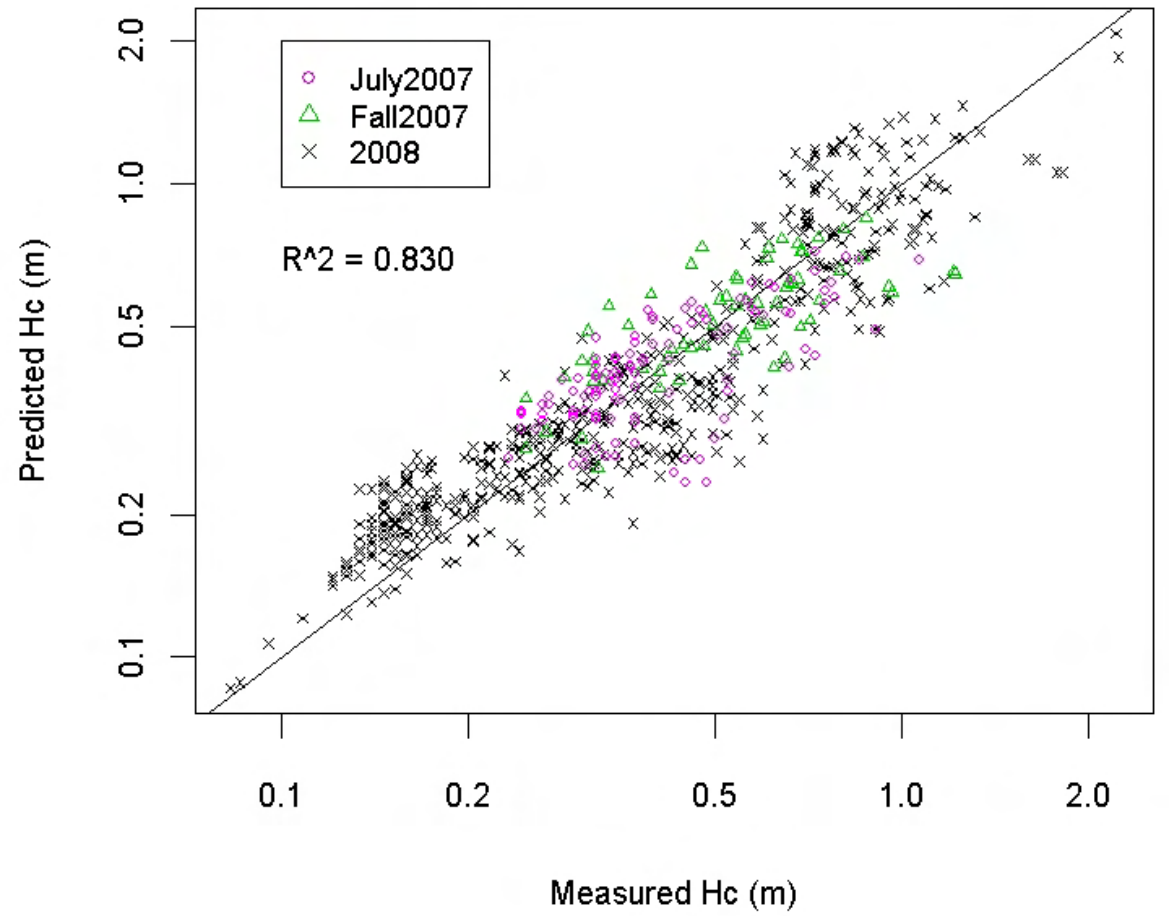

Figure F.9. Log-Log Plot of Predicted Versus Measured $\mathrm{H}_{\mathrm{C}}$ Values for the 11-Term Dimensional Model in Table F.8 Fit to the Full Data Set. The 45-degree line represents perfect prediction where predicted $\mathrm{H}_{\mathrm{C}}$ values equal measured $\mathrm{H}_{\mathrm{C}}$ values.

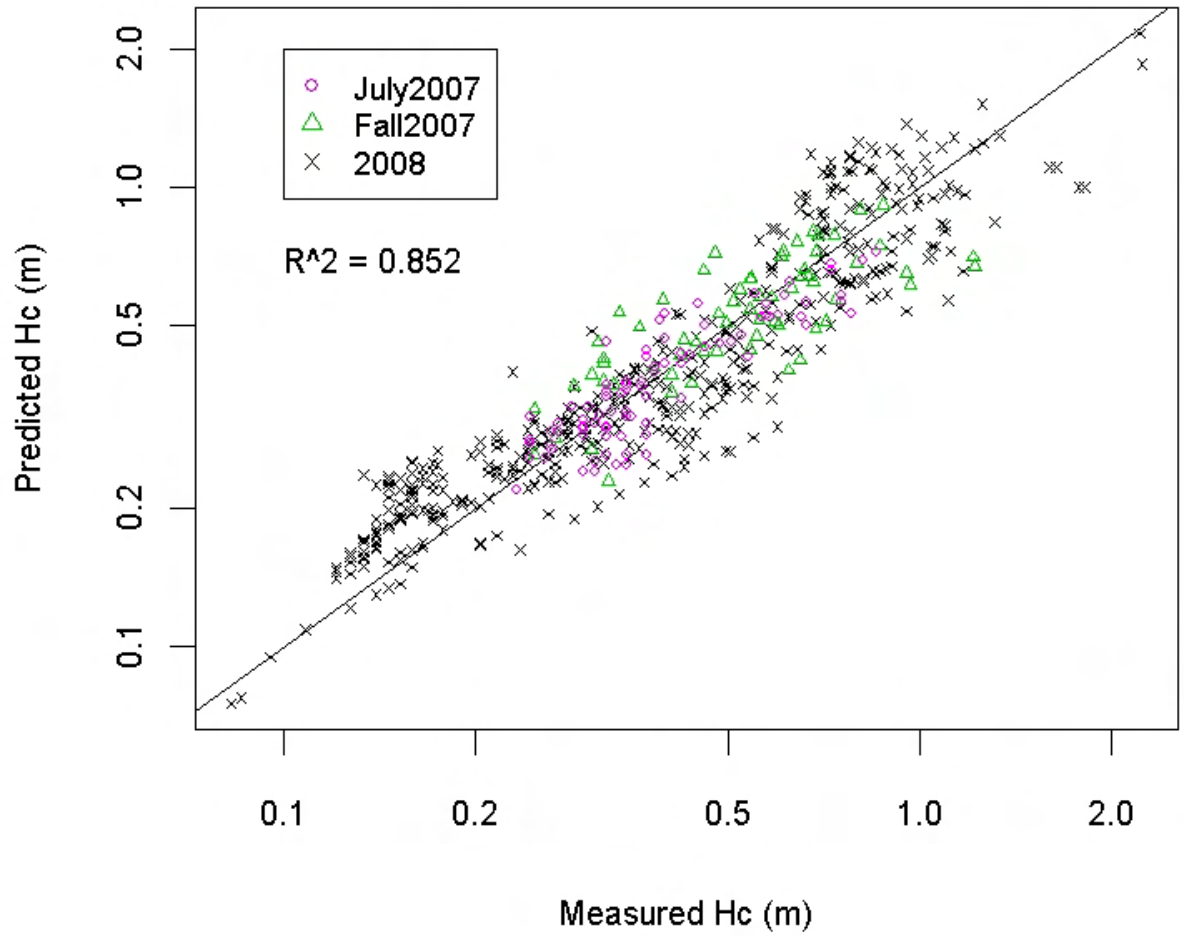

Figure F.10. Log-Log Plot of Predicted Versus Measured $\mathrm{H}_{\mathrm{C}}$ Values for the 10-Term Dimensional Model in Table F.9 Fit to the Trimmed Data Set. The 45-degree line represents perfect prediction where predicted $\mathrm{H}_{\mathrm{C}}$ values equal measured $\mathrm{H}_{\mathrm{C}}$ values. 
Inserting the coefficients from the $\mathrm{H}_{\mathrm{C}}$ dimensional models without interactions fit to the trimmed data set (Table F.9) into Eq. (F.21a) and (F.21b) results in models:

$$
\begin{aligned}
\mathrm{H}_{\mathrm{C}} & =1.418(\mathrm{D})^{-1.327}(\mathrm{~s}-1)^{-0.804}\left(\phi_{\mathrm{S}}\right)^{-0.572}\left(\mathrm{U}_{\mathrm{T}}\right)^{-0.491}(\mathrm{DC})^{0.348}\left(\phi_{\mathrm{p}}\right)^{0.276} \\
& \times\left(\mathrm{N}_{\mathrm{J}}\right)^{0.340}(\mathrm{~d})^{1.812}(\mathrm{U})^{1.501}
\end{aligned}
$$

and

$$
\begin{aligned}
\ln \left(\mathrm{H}_{\mathrm{C}}\right) & =0.349-1.327 \ln (\mathrm{D})-0.804 \ln (\mathrm{s}-1)-0.572 \ln \left(\phi_{\mathrm{S}}\right)-0.491 \ln \left(\mathrm{U}_{\mathrm{T}}\right) \\
& +0.348 \ln (\mathrm{DC})+0.276 \ln \left(\phi_{\mathrm{p}}\right)+0.340 \ln \left(\mathrm{N}_{\mathrm{J}}\right)+1.812 \ln (\mathrm{d})+1.501 \ln (\mathrm{U}),
\end{aligned}
$$

where all notation is as previously defined.

\section{F.3.4.3 Results of Fitting Dimensionally Consistent Power-Law Model Forms for $\mathrm{H}_{\mathrm{C}}$ to Full and Trimmed Data Sets}

The dimensionally consistent model form in Eq. (F.22b) was fit to the full and trimmed data sets using restricted least squares (Draper and Smith 1998). The results for the full data set are given in Table F.10 and Figure F.11; the results for the trimmed data set are given in Table F.11 and Figure F.12.

The $\mathrm{H}_{\mathrm{C}}$ dimensionally consistent models in Tables F.10 and F.11 have the same $\mathrm{R}^{2}$ values as the dimensional models in Tables F.8 and F.9. For the full data set $\mathrm{R}^{2}=0.830$ for each model, while for the trimmed data set $\mathrm{R}^{2}=0.852$ for each model. As noted at the end of Section F.3.4.1, adding an exponent to the $\mathrm{D}$ term would make the dimensionally consistent model mathematically equivalent to the dimensional model. However, that yielded an exponent close to 1 . Hence, the dimensional models for $\mathrm{H}_{\mathrm{C}}$ fit to the full and trimmed data sets are very close to being dimensionally consistent, which explains why the $\mathrm{R}^{2}$ values for the dimensional and dimensionally consistent $\mathrm{H}_{\mathrm{C}}$ models are the same to three decimal places.

The large negative coefficient of -17.206 on the $\left(1-\phi_{\mathrm{S}}\right)$ term in Table F.10 requires some additional explanation because it "stands out" compared to other coefficients. As seen in Table F.10, this term in the $\mathrm{H}_{\mathrm{C}}$ model is highly statistically significant. The remaining explanation of why this is an appropriate model term and cautions in using the model are the same as discussed in Section F.3.4.2, so that discussion is not repeated here.

Figures F.11 and F.12 for the full and trimmed data sets, respectively, show tendencies for the $\mathrm{H}_{\mathrm{C}}$ dimensionally-consistent models to overpredict $\mathrm{H}_{\mathrm{C}}<\sim 0.2 \mathrm{~m}$, and slight tendencies to under-predict $\mathrm{H}_{\mathrm{C}}$ from $\sim 0.3$ to $0.7 \mathrm{~m}$. Figures F.11 and F.12 are nearly identical to the corresponding plots for the dimensional models in Figures F.9 and F.10, respectively. This is a result of the dimensional and dimensionally consistent models for $\mathrm{H}_{\mathrm{C}}$ being nearly equivalent. 
Table F.10. Coefficients and Performance Summary for Linearized Version of 11-Term Dimensionally Consistent Model on Natural Logarithm of $\mathrm{H}_{\mathrm{C}}$ with 10 Coefficients Fit to the Full Data Set

\begin{tabular}{|c|c|c|c|c|c|c|}
\hline $\begin{array}{c}\ln \left(\mathrm{H}_{\mathrm{C}}\right) \text { Model } \\
\text { Term } \\
\end{array}$ & $\begin{array}{c}\text { Coefficient } \\
\text { Estimate }\end{array}$ & $\begin{array}{c}\text { Coefficient } \\
\text { Standard } \\
\text { Deviation } \\
\end{array}$ & $\begin{array}{l}\text { t-value }= \\
\text { Coeff/SD }\end{array}$ & p-value ${ }^{(a)}$ & Modeling Data Statistic $\left[\ln \left(\mathrm{H}_{\mathrm{C}}\right)\right]$ & Value \\
\hline $\ln \left(\mathrm{b}_{0}\right)$ & 1.112 & $-(\mathrm{c})$ & - & - & $\mathrm{R}^{2}$ & 0.830 \\
\hline $\ln (\mathrm{D})^{(\mathrm{d})}$ & 1.0 & N/A & N/A & N/A & $\mathrm{R}^{2}$ Adjusted $\left(\mathrm{R}_{\mathrm{A}}^{2}\right)$ & 0.828 \\
\hline $\ln \left[\mathrm{U}^{2} / \mathrm{D}(\mathrm{s}-1) \mathrm{g}\right]$ & 0.473 & - & - & - & $\mathrm{R}^{2}$ Predicted $\left(\mathrm{R}_{\mathrm{P}}^{2}\right)$ & -(c) $^{(\mathrm{s}}$ \\
\hline $\ln (d / D)$ & 1.693 & - & - & - & RMSE & 0.257 \\
\hline $\ln (s-1)$ & -0.356 & - & - & - & & \\
\hline $\ln \left(\mathrm{U}_{\mathrm{T}} / \mathrm{U}\right)$ & -0.410 & - & - & - & & \\
\hline $\ln (\mathrm{DC})$ & 0.364 & - & - & - & & \\
\hline $\ln \left(\phi_{S}\right)$ & -0.616 & - & - & - & & \\
\hline $\ln \left(1-\phi_{\mathrm{S}}\right)$ & -17.206 & - & - & - & & \\
\hline $\ln \left(\phi_{\mathrm{p}}\right)$ & 0.213 & - & - & - & & \\
\hline $\ln \left(\mathrm{N}_{\mathrm{J}}\right)$ & 0.320 & - & - & - & & \\
\hline
\end{tabular}

(a) Probability that the coefficient is not statistically significant (different from 0). Values less than 0.05, 0.01, and 0.0001 indicate strong, very strong, and extremely strong statistical significance of the coefficient and corresponding model term.

(b) Model evaluation and validation statistics are defined, respectively, in Sections D.3 and D.5 of Appendix D.

(c) Not available from software used to fit model using restricted least squares; could be determined with additional work.

(d) Restricted least squares was used to fit this model, with the coefficient of $\ln (\mathrm{D})$ restricted to be 1.0.

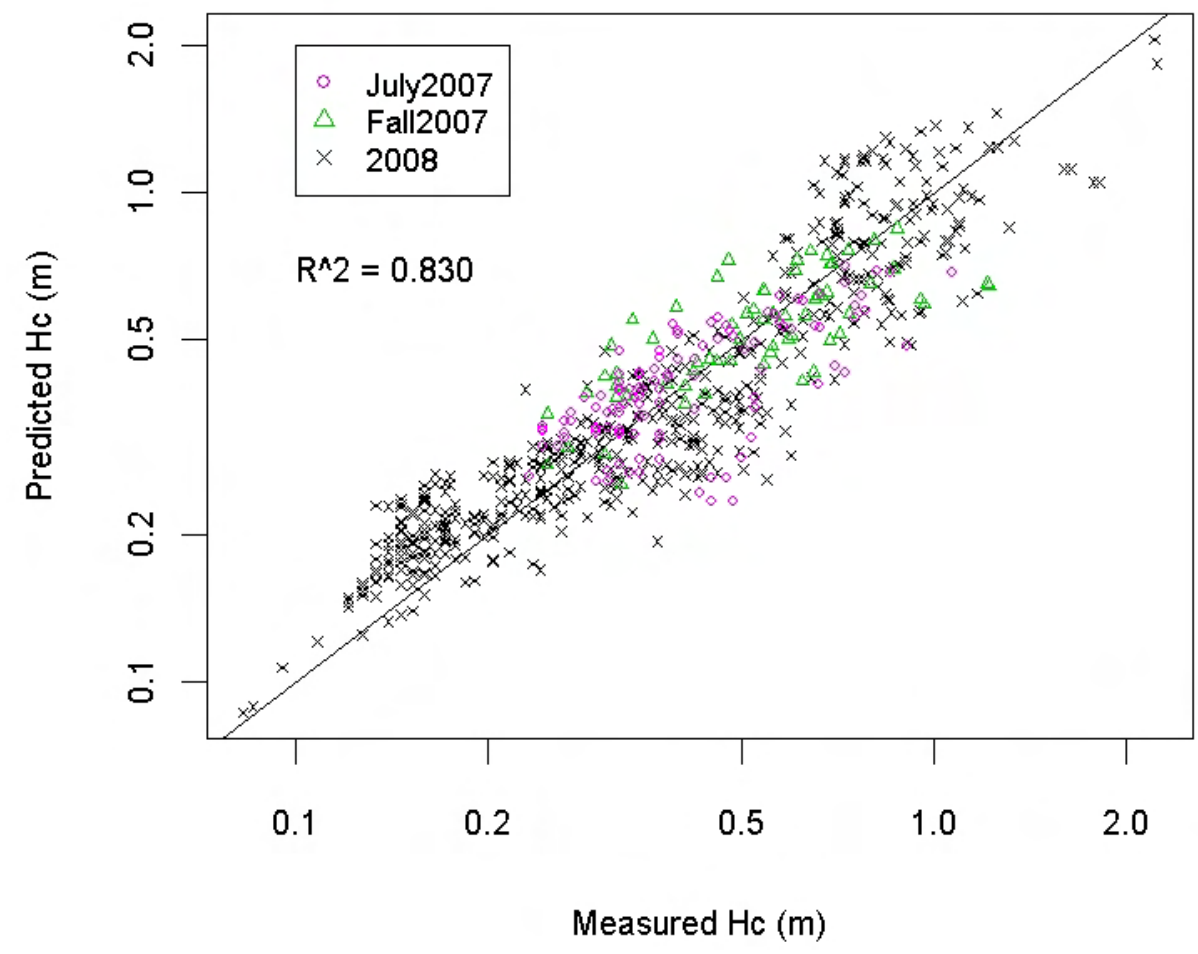

Figure F.11. Log-Log Plot of Predicted Versus Measured $H_{C}(m)$ Values for 11-Term Dimensionally Consistent Model in Table F.10 with 10 Coefficients Fit to Full Data Set. The 45-degree line represents perfect prediction where predicted $\mathrm{H}_{\mathrm{C}}$ values equal measured $\mathrm{H}_{\mathrm{C}}$ values. 
Table F.11. Coefficients and Performance Summary for the Linearized Version of the 10-Term Dimensionally Consistent Model on the Natural Logarithm of $\mathrm{H}_{\mathrm{C}}$ with 9 Coefficients Fit to the Trimmed Data Set

\begin{tabular}{|c|c|c|c|c|c|c|}
\hline \multirow{2}{*}{$\begin{array}{c}\ln \left(\mathrm{H}_{\mathrm{C}}\right) \text { Model } \\
\text { Term }\end{array}$} & \multicolumn{3}{|c|}{ Coefficient } & \multicolumn{3}{|c|}{ Full Data, 581 Tests $^{(b)}$} \\
\hline & Estimate & Deviation & Coeff/SD & $p$-value ${ }^{(a)}$ & Modeling Data Statistic $\left[\ln \left(\mathrm{H}_{\mathrm{C}}\right)\right]$ & Value \\
\hline $\ln \left(\mathrm{b}_{0}\right)$ & 1.566 & $-^{(c)}$ & - & - & $\mathrm{R}^{2}$ & 0.852 \\
\hline $\ln (\mathrm{D})^{(\mathrm{c})}$ & 1.0 & N/A & N/A & N/A & $\mathrm{R}^{2}$ Adjusted $\left(\mathrm{R}_{\mathrm{A}}^{2}\right)$ & 0.850 \\
\hline $\ln \left[\mathrm{U}^{2} / \mathrm{D}(\mathrm{s}-1) \mathrm{g}\right]$ & 0.513 & - & - & - & $\mathrm{R}^{2}$ Predicted $\left(\mathrm{R}_{\mathrm{P}}^{2}\right)$ & -(c) \\
\hline $\ln (\mathrm{d} / \mathrm{D})$ & 1.835 & - & - & - & RMSE & 0.242 \\
\hline $\ln (s-1)$ & -0.296 & - & - & - & & \\
\hline $\ln \left(\mathrm{U}_{\mathrm{T}} / \mathrm{U}\right)$ & -0.493 & - & - & - & & \\
\hline $\ln (\mathrm{DC})$ & 0.352 & - & - & - & & \\
\hline $\ln \left(\phi_{\mathrm{S}}\right)$ & -0.576 & - & - & - & & \\
\hline $\ln \left(\phi_{\mathrm{p}}\right)$ & 0.280 & - & - & - & & \\
\hline $\ln \left(\mathrm{N}_{\mathrm{J}}\right)$ & 0.348 & - & - & - & & \\
\hline
\end{tabular}

(a) Probability that the coefficient is not statistically significant (different from 0 ). Values less than $0.05,0.01$, and 0.0001 indicate strong, very strong, and extremely strong statistical significance of the coefficient and corresponding model term.

(b) Model evaluation and validation statistics are defined, respectively, in Sections D.3 and D.5 of Appendix D.

(c) Not available from output of software used to fit the model using restricted least squares. These could be determined with additional work.

(d) Restricted least squares was used to fit this model, with the coefficient of $\ln (\mathrm{D})$ restricted to be 1.0.

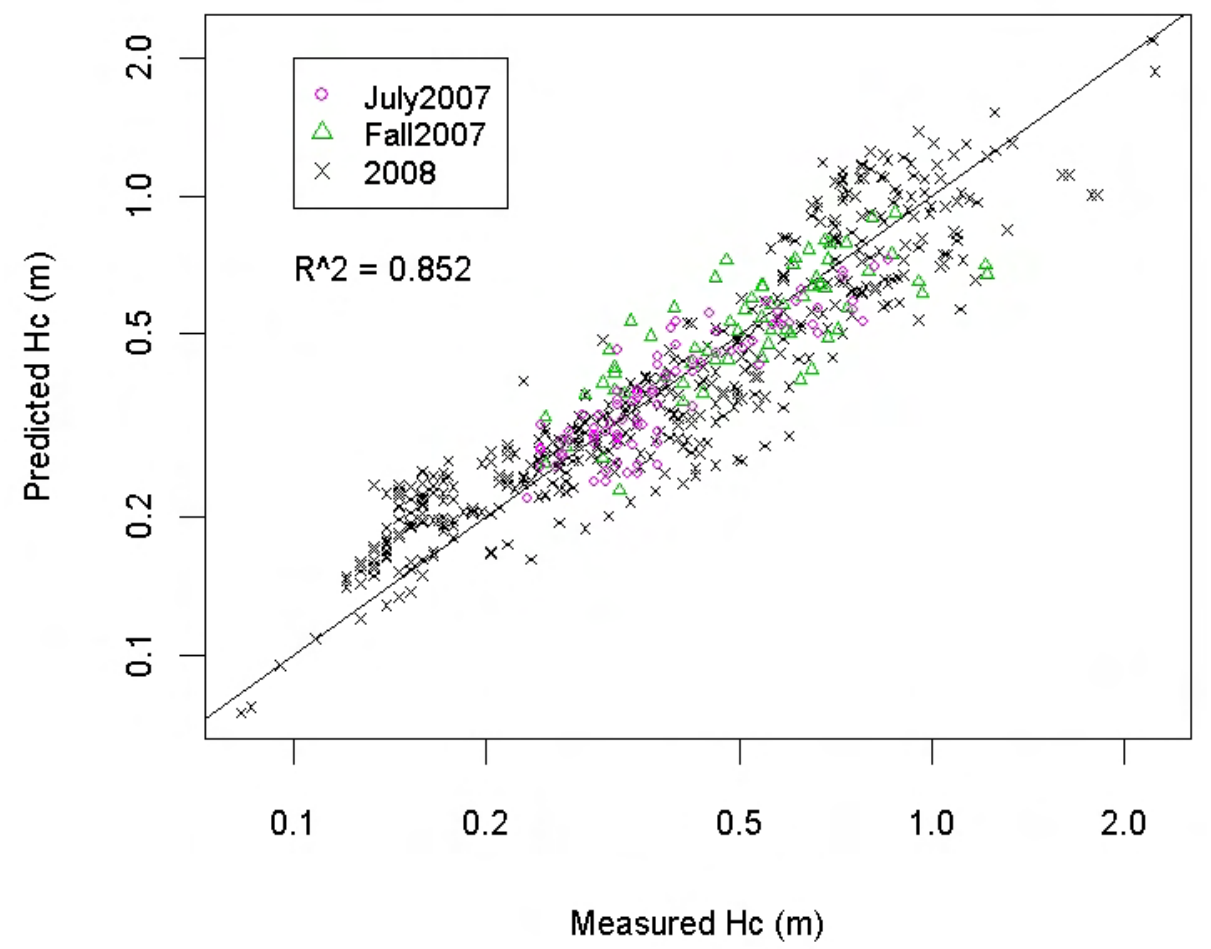

Figure F.12. Log-Log Plot of Predicted Versus Measured $H_{C}(m)$ Values for 10-Term Dimensionally Consistent Model in Table F.11 with 9 Coefficients Fit to Trimmed Data Set. 45-degree line represents perfect prediction where predicted $\mathrm{H}_{\mathrm{C}}$ values equal measured $\mathrm{H}_{\mathrm{C}}$ values. 
In summary, inserting the coefficients from the $\mathrm{H}_{\mathrm{C}}$ dimensionally consistent models fit to the full data set (Table F.10) into Eq. (F.22a) and (F.22b) results in the models

$$
\begin{aligned}
\mathrm{H}_{\mathrm{C}} & =3.040 \mathrm{D}\left(\frac{\mathrm{U}^{2}}{\mathrm{D}(\mathrm{s}-1) \mathrm{g}}\right)^{0.473}\left(\frac{\mathrm{d}}{\mathrm{D}}\right)^{1.693}(\mathrm{~s}-1)^{-0.356}\left(\frac{\mathrm{U}_{\mathrm{T}}}{\mathrm{U}}\right)^{-0.410} \mathrm{DC}^{0.364} \\
& \times \phi_{\mathrm{S}}^{-0.616}\left(1-\phi_{\mathrm{s}}\right)^{-17.206} \phi_{\mathrm{p}}^{0.213} \mathrm{~N}_{\mathrm{J}}^{0.320}
\end{aligned}
$$

and

$$
\begin{aligned}
& \ln \left(\mathrm{H}_{\mathrm{C}}\right)=1.112+\ln (\mathrm{D})+0.473 \ln \left(\frac{\mathrm{U}^{2}}{\mathrm{D}(\mathrm{s}-1) \mathrm{g}}\right)+1.693 \ln \left(\frac{\mathrm{d}}{\mathrm{D}}\right)-0.356 \ln (\mathrm{s}-1)-0.410 \ln \left(\frac{\mathrm{U}_{\mathrm{T}}}{\mathrm{U}}\right) \\
& +0.364 \ln (\mathrm{DC})-0.616 \ln \left(\phi_{\mathrm{S}}\right)-17.206 \ln \left(1-\phi_{\mathrm{S}}\right)+0.213 \ln \left(\phi_{\mathrm{p}}\right)+0.320 \ln \left(\mathrm{N}_{\mathrm{J}}\right)
\end{aligned}
$$

where all notation is as previously defined. The $\left(1-\phi_{\mathrm{S}}\right)^{-17.206}$ and $-17.206 \ln \left(1-\phi_{\mathrm{S}}\right)$ terms in Eq. (F.26a) and (F.26b) are appropriate for the range of $\phi_{S}$ studied in M3 testing (0.0005-0.06). However, caution is advised if these $\mathrm{H}_{\mathrm{C}}$ models must be extrapolated to $\phi_{\mathrm{S}}$ values outside that range.

Inserting the coefficients from the $\mathrm{H}_{\mathrm{C}}$ dimensionally consistent models fit to the trimmed data set (Table F.11) into Eq. (F.22a) and (F.22b) results in the models

$$
\begin{aligned}
\mathrm{H}_{\mathrm{C}} & =4.787 \mathrm{D}\left(\frac{\mathrm{U}^{2}}{\mathrm{D}(\mathrm{s}-1) \mathrm{g}}\right)^{0.513}\left(\frac{\mathrm{d}}{\mathrm{D}}\right)^{1.835}(\mathrm{~s}-1)^{-0.296}\left(\frac{\mathrm{U}_{\mathrm{T}}}{\mathrm{U}}\right)^{-0.493} \mathrm{DC}^{0.352} \\
& \times \phi_{\mathrm{S}}^{-0.576} \phi_{\mathrm{p}}^{0.280} \mathrm{~N}_{\mathrm{J}}^{0.348}
\end{aligned}
$$

and

$$
\begin{aligned}
& \ln \left(\mathrm{H}_{\mathrm{C}}\right)=1.566+\ln (\mathrm{D})+0.513 \ln \left(\frac{\mathrm{U}^{2}}{\mathrm{D}(\mathrm{s}-1) \mathrm{g}}\right)+1.835 \ln \left(\frac{\mathrm{d}}{\mathrm{D}}\right)-0.296 \ln (\mathrm{s}-1) \\
& -0.493 \ln \left(\frac{\mathrm{U}_{\mathrm{T}}}{\mathrm{U}}\right)+0.352 \ln (\mathrm{DC})-0.576 \ln \left(\phi_{\mathrm{S}}\right)+0.280 \ln \left(\phi_{\mathrm{p}}\right)+0.348 \ln \left(\mathrm{N}_{\mathrm{J}}\right)
\end{aligned}
$$

where all notation is as previously defined.

\section{F.3.5 Results for $\mathrm{H}_{\mathrm{C}}$ Power-Law Models with Interaction Terms}

As discussed in Section F.3.3, stepwise regression methods were used to add statistically significant interaction terms to the $\mathrm{H}_{\mathrm{C}}$ models shown in Tables F.8 and F.9. The results are shown in Table F.12 and Figure F.13 for the full data set and in Table F.13 and Figure F.14 for the trimmed data set. Two interaction terms were added to each model, with both of them being highly statistically significant. The first interaction term added was the same for each model, but the second one is different. The difference is a result of the smaller test-variable space for the model fit to the trimmed data. All of the model terms shown in Tables F.12 and F.13 (except for the constant term in Table F.12) are highly statistically significant. 
Table F.12. Coefficients and Performance Summary for the 13-Term Dimensional Model with Interactions on the Natural Logarithm of $\mathrm{H}_{\mathrm{C}}$ Fit to the Full Data Set

\begin{tabular}{|c|c|c|c|c|c|c|}
\hline \multirow{2}{*}{$\begin{array}{c}\ln \left(\mathrm{H}_{\mathrm{C}}\right) \text { Model } \\
\text { Term }\end{array}$} & \multirow{2}{*}{$\begin{array}{l}\text { Coefficient } \\
\text { Estimate }\end{array}$} & \multirow{2}{*}{$\begin{array}{l}\text { Coefficient } \\
\text { SD }\end{array}$} & \multirow{2}{*}{$\begin{array}{l}\text { t-value }= \\
\text { Coeff } / S D\end{array}$} & \multirow[b]{2}{*}{$p$-value ${ }^{(a)}$} & \multicolumn{2}{|c|}{ Full Data, 669 Data Points ${ }^{(\mathrm{b})}$} \\
\hline & & & & & Modeling Data Statistic $\left[\ln \left(\mathrm{H}_{\mathrm{C}}\right)\right]$ & Value \\
\hline $\ln \left(\mathrm{a}_{0}\right)$ & -0.467 & 0.228 & -2.05 & 0.0409 & $\mathrm{R}^{2}$ & 0.861 \\
\hline $\ln (\mathrm{D})$ & -0.820 & 0.095 & -8.60 & $<0.0001$ & $\mathrm{R}^{2}$ Adjusted $\left(\mathrm{R}_{\mathrm{A}}^{2}\right)$ & 0.858 \\
\hline $\ln (s-1)$ & -0.833 & 0.041 & -20.13 & $<0.0001$ & $\mathrm{R}^{2}$ Predicted $\left(\mathrm{R}_{\mathrm{P}}^{2}\right)$ & 0.856 \\
\hline $\ln \left(\phi_{\mathrm{S}}\right)$ & -0.880 & 0.032 & -27.76 & $<0.0001$ & RMSE & 0.234 \\
\hline $\ln \left(1-\phi_{\mathrm{S}}\right)$ & -59.975 & 6.098 & -9.84 & $<0.0001$ & & \\
\hline $\ln \left(\mathrm{U}_{\mathrm{T}}\right)$ & -0.505 & 0.018 & -27.49 & $<0.0001$ & & \\
\hline $\ln (\mathrm{DC})$ & 0.434 & 0.033 & 13.13 & $<0.0001$ & & \\
\hline $\ln \left(\phi_{\mathrm{p}}\right)$ & 0.292 & 0.036 & 8.18 & $<0.0001$ & & \\
\hline $\ln \left(\mathrm{N}_{\mathrm{J}}\right)$ & 0.497 & 0.047 & 10.53 & $<0.0001$ & & \\
\hline $\ln (d)$ & 1.979 & 0.081 & 24.39 & $<0.0001$ & & \\
\hline $\ln (\mathrm{U})$ & 1.731 & 0.070 & 24.79 & $<0.0001$ & & \\
\hline$D \ln \left(\phi_{\mathrm{S}}\right)$ & 0.153 & 0.013 & 11.42 & $<0.0001$ & & \\
\hline$\phi_{\mathrm{S}} \ln (\mathrm{U})$ & -16.176 & 2.571 & -6.29 & $<0.0001$ & & \\
\hline
\end{tabular}

(a) Probability that the coefficient is not statistically significant (different from 0 ). Values less than $0.05,0.01$, and 0.0001 indicate strong, very strong, and extremely strong statistical significance of the coefficient and corresponding model term.

(b) Model evaluation and validation statistics are defined, respectively, in Sections D.3 and D.5 of Appendix D.

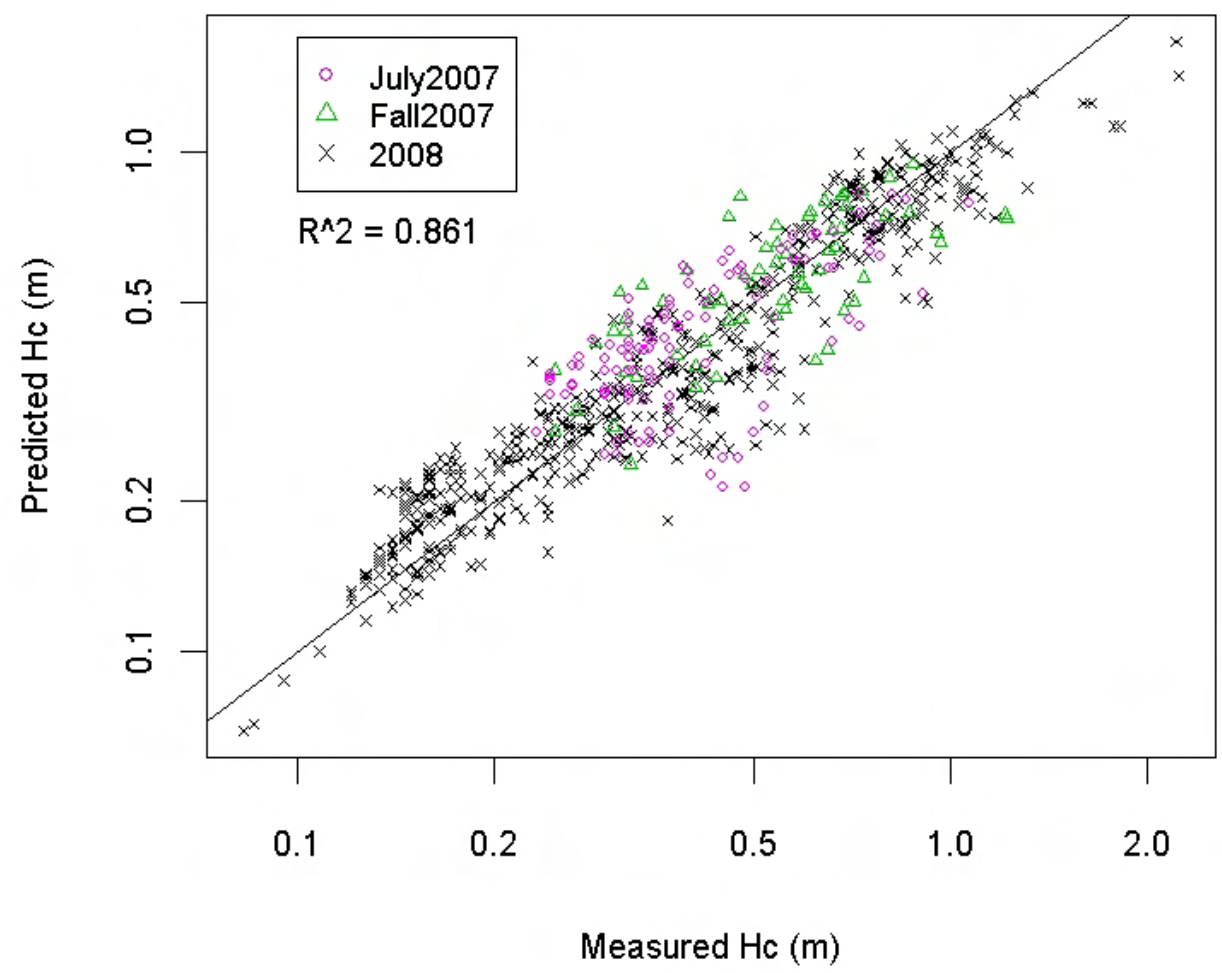

Figure F.13. Log-Log Plot of Predicted Versus Measured $\mathrm{H}_{\mathrm{C}}$ Values for the 13-Term Dimensional Model with Interactions in Table F.12 Fit to the Full Data Set. The 45-degree line represents perfect prediction where predicted $\mathrm{H}_{\mathrm{C}}$ values equal measured $\mathrm{H}_{\mathrm{C}}$ values. 
Table F.13. Coefficients and Performance Summary for the 12-Term Dimensional Model with Interactions on the Natural Logarithm of $\mathrm{H}_{\mathrm{C}}$ Fit to the Trimmed Data Set

\begin{tabular}{|c|c|c|c|c|c|c|}
\hline \multirow{2}{*}{$\begin{array}{c}\ln \left(\mathrm{H}_{\mathrm{C}}\right) \text { Model } \\
\text { Term }\end{array}$} & \multirow{2}{*}{$\begin{array}{c}\text { Coefficient } \\
\text { Estimate }\end{array}$} & \multirow{2}{*}{$\begin{array}{c}\text { Coefficient } \\
\text { SD }\end{array}$} & \multirow{2}{*}{$\begin{array}{l}\mathrm{t} \text {-value }= \\
\text { Coeff/SD }\end{array}$} & \multirow[b]{2}{*}{ p-value ${ }^{(a)}$} & \multicolumn{2}{|c|}{ Trimmed Data, 581 Data Points $^{(\mathrm{b})}$} \\
\hline & & & & & Modeling Data Statistic $\left[\ln \left(\mathrm{H}_{\mathrm{C}}\right)\right]$ & Value \\
\hline $\ln \left(\mathrm{a}_{0}\right)$ & 0.546 & 0.205 & 2.66 & 0.0080 & $\mathrm{R}^{2}$ & 0.884 \\
\hline $\ln (\mathrm{D})$ & -1.100 & 0.099 & -11.07 & $<0.0001$ & $\mathrm{R}^{2}$ Adjusted $\left(\mathrm{R}_{\mathrm{A}}^{2}\right)$ & 0.882 \\
\hline $\ln (s-1)$ & -0.362 & 0.090 & -4.01 & $<0.0001$ & $\mathrm{R}^{2}$ Predicted $\left(\mathrm{R}_{\mathrm{P}}^{2}\right)$ & 0.880 \\
\hline $\ln \left(\phi_{\mathrm{S}}\right)$ & -0.707 & 0.023 & -30.39 & $<0.0001$ & RMSE & 0.214 \\
\hline $\ln \left(\mathrm{U}_{\mathrm{T}}\right)$ & -0.579 & 0.019 & -31.10 & $<0.0001$ & & \\
\hline $\ln (\mathrm{DC})$ & 0.402 & 0.035 & 11.55 & $<0.0001$ & & \\
\hline $\ln \left(\phi_{\mathrm{p}}\right)$ & 0.356 & 0.035 & 10.29 & $<0.0001$ & & \\
\hline $\ln \left(\mathrm{N}_{\mathrm{J}}\right)$ & 0.470 & 0.044 & 10.59 & $<0.0001$ & & \\
\hline $\ln (d)$ & 2.088 & 0.083 & 25.16 & $<0.0001$ & & \\
\hline $\ln (\mathrm{U})$ & 1.848 & 0.071 & 25.99 & $<0.0001$ & & \\
\hline$D \ln \left(\phi_{\mathrm{S}}\right)$ & 0.124 & 0.012 & 10.10 & $<0.0001$ & & \\
\hline$U \ln (s-1)$ & -0.050 & 0.009 & -5.46 & $<0.0001$ & & \\
\hline
\end{tabular}

(a) Probability that the coefficient is not statistically significant (different from 0 ). Values less than $0.05,0.01$, and 0.0001 indicate strong, very strong, and extremely strong statistical significance of the coefficient and corresponding model term. (b) Model evaluation and validation statistics are defined, respectively, in Sections D.3 and D.5 of Appendix D.

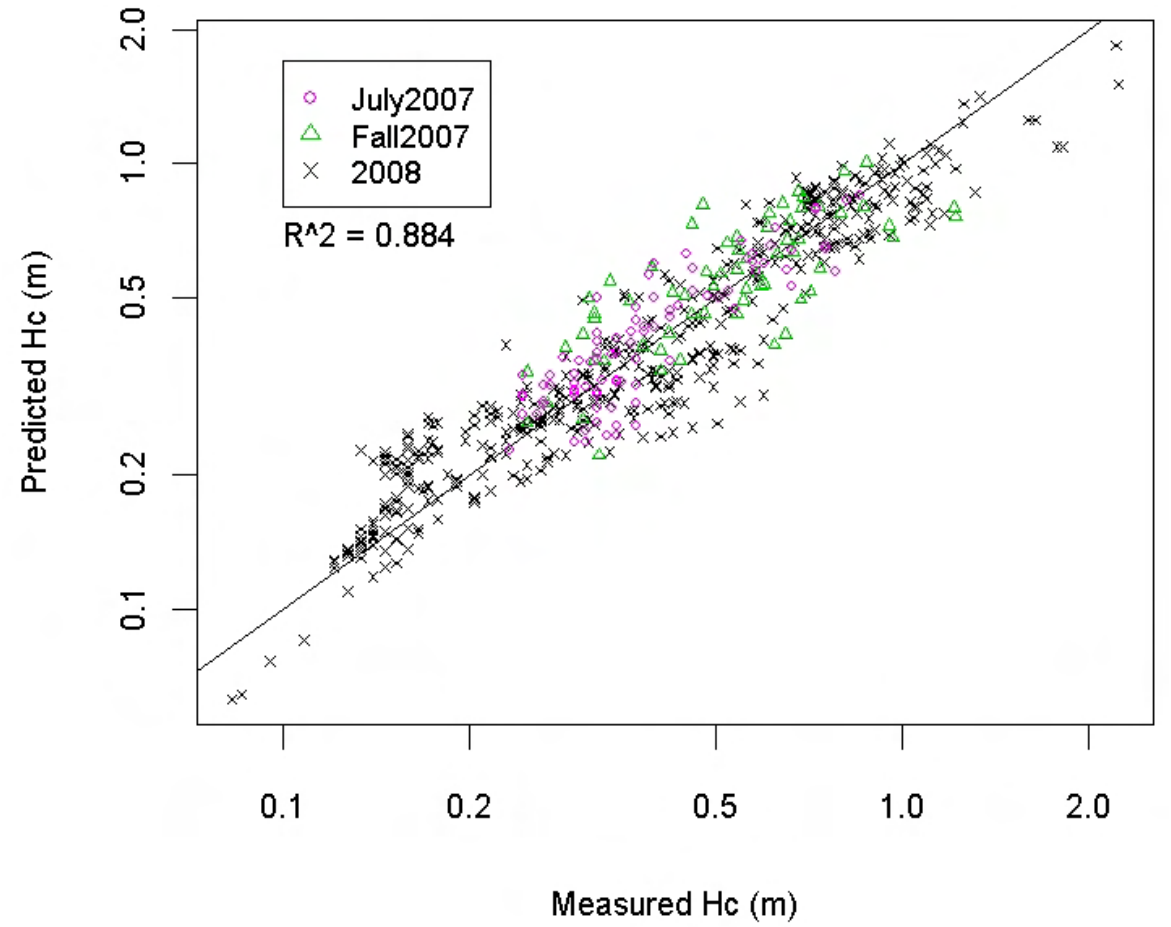

Figure F.14. Log-Log Plot of Predicted Versus Measured $\mathrm{H}_{\mathrm{C}}$ Values for the 12-Term Dimensional Model with Interactions in Table F.13 Fit to the Trimmed Data Set. The 45-degree line represents perfect prediction where predicted $\mathrm{H}_{\mathrm{C}}$ values equal measured $\mathrm{H}_{\mathrm{C}}$ values.

All of the summary statistics for the dimensional models with interactions for $\mathrm{H}_{\mathrm{C}}$ in Tables $\mathrm{F} .12$ and F.13 show improvement over the corresponding results for dimensional models without interactions in Tables F.8 and F.9. The $R^{2}$ statistics in Table F.12 $\left(R^{2}=0.861\right)$ and Table F.13 $\left(R^{2}=0.884\right)$ indicate that the $\mathrm{H}_{\mathrm{C}}$ dimensional models with interactions developed by stepwise selection fit the full and trimmed data sets reasonably well. Because the values of $\mathrm{R}_{\mathrm{A}}{ }_{\text {and }} \mathrm{R}_{\mathrm{p}}$ in Tables F.12 and F.13 do not differ markedly from the corresponding $\mathrm{R}^{2}$ values, there are no indications that the $\mathrm{H}_{\mathrm{C}}$ models over-fit the data or that there are any highly influential data. 
Figure F.13 shows a predicted-versus-measured plot for the performance of the 13-term $\mathrm{H}_{\mathrm{C}}$ dimensional model with interactions in Table F.12. In Figure F.13, the scatter around the perfect prediction $\left(45^{\circ}\right)$ line has been slightly reduced from that in Figure F.9 for the 11-term $\mathrm{H}_{\mathrm{C}}$ dimensional model without interactions in Table F.8. Figure F.14 shows that the predictions made for the trimmed data set are also improved when using the 12-term dimensional model with interactions compared to the 10-term dimensional model without interactions (Table F.9 and Figure F.10). The 12-term $\mathrm{H}_{\mathrm{C}}$ dimensional models with interaction terms in Tables F.12 and F.13 have partially corrected the tendencies to overpredict $\mathrm{H}_{\mathrm{C}}$ below $\sim 0.2$ and to underpredict in the approximate $\mathrm{H}_{\mathrm{C}}$ range of 0.3 to $0.6 \mathrm{~m}$, compared to the 11-term and 10term $\mathrm{H}_{\mathrm{C}}$ dimensional models without interaction terms in Tables F.8 and F.9. However, the dimensional models with interactions increase the tendency to underpredict $\mathrm{H}_{\mathrm{C}}$ values above $\sim 1 \mathrm{~m}$.

Based on Table F.12, the $\mathrm{H}_{\mathrm{C}}$ dimensional models with interactions fit to the full data set are

$$
\begin{aligned}
\mathrm{H}_{\mathrm{C}} & =0.627(\mathrm{D})^{-0.820}(\mathrm{~s}-1)^{-0.833}\left(\phi_{\mathrm{S}}\right)^{-0.880+0.153(\mathrm{D})}\left(1-\phi_{\mathrm{S}}\right)^{-59.975}\left(\mathrm{U}_{\mathrm{T}}\right)^{-0.505} \\
& \times(\mathrm{DC})^{0.434}\left(\phi_{\mathrm{p}}\right)^{0.292}\left(\mathrm{~N}_{\mathrm{J}}\right)^{0.497}(\mathrm{~d})^{1.979}(\mathrm{U})^{1.731-16.176\left(\phi_{\mathrm{S}}\right)}
\end{aligned}
$$

and

$$
\begin{aligned}
\ln \left(\mathrm{H}_{\mathrm{C}}\right) & =-0.467-0.820 \ln (\mathrm{D})-0.833 \ln (\mathrm{s}-1)+[-0.880+0.153(\mathrm{D})] \ln \left(\phi_{\mathrm{S}}\right) \\
& -59.975 \ln \left(1-\phi_{\mathrm{S}}\right)-0.505 \ln \left(\mathrm{U}_{\mathrm{T}}\right)+0.434 \ln (\mathrm{DC})+0.292 \ln \left(\phi_{\mathrm{p}}\right) \\
& +0.497 \ln \left(\mathrm{N}_{\mathrm{J}}\right)+1.979 \ln (\mathrm{d})+\left[1.731-16.176\left(\phi_{\mathrm{S}}\right)\right] \ln (\mathrm{U}),
\end{aligned}
$$

where all notation is as previously defined. Based on Table F.13, the $\mathrm{H}_{\mathrm{C}}$ dimensional models with interactions fit to the trimmed data set are

$$
\begin{aligned}
\mathrm{H}_{\mathrm{C}} & =1.726(\mathrm{D})^{-1.100}(\mathrm{~s}-1)^{-0.362-0.050(\mathrm{U})}\left(\phi_{\mathrm{S}}\right)^{-0.707+0.124(\mathrm{D})}\left(\mathrm{U}_{\mathrm{T}}\right)^{-0.579} \\
& \times(\mathrm{DC})^{0.402}\left(\phi_{\mathrm{p}}\right)^{0.356}\left(\mathrm{~N}_{\mathrm{J}}\right)^{0.470}(\mathrm{~d})^{2.088}(\mathrm{U})^{1.848}
\end{aligned}
$$

and

$$
\begin{aligned}
\ln \left(\mathrm{H}_{\mathrm{C}}\right) & =0.546-1.100 \ln (\mathrm{D})+[-0.362-0.050 \mathrm{U}] \ln (\mathrm{s}-1) \\
& +[-0.707+0.124(\mathrm{D})] \ln \left(\phi_{\mathrm{S}}\right)-0.579 \ln \left(\mathrm{U}_{\mathrm{T}}\right)+0.402 \ln (\mathrm{DC}) \\
& +0.356 \ln \left(\phi_{\mathrm{p}}\right)+0.470 \ln \left(\mathrm{N}_{\mathrm{J}}\right)+2.088 \ln (\mathrm{d})+1.848 \ln (\mathrm{U}),
\end{aligned}
$$

where all notation is as previously defined.

Similarly as discussed for $\mathrm{U}_{\mathrm{CS}}$ at the end of Section F.2.3, the $\mathrm{H}_{\mathrm{C}}$ models with interaction terms may yield inaccurate predictions when extrapolated outside the experimental region of data used to develop them. Hence, unless additional work is performed to thoroughly validate these $\mathrm{H}_{\mathrm{C}}$ models for extrapolative use, it is recommended that they only be used for interpolative use.

\section{F.3.6 Comparison of $\mathrm{H}_{\mathrm{C}}$ Models}

In this section the results for three $\mathrm{H}_{\mathrm{C}}$ models presented in Section F.3, namely the

- dimensional model without interactions (Section F.3.4.2)

- corresponding dimensionally consistent model (Section F.3.4.3) 
- dimensional model with interactions (Section F.3.5).

are compared to the results of the nondimensional model for $\mathrm{H}_{\mathrm{C}}$ from Section 7.3.2. Because the latter model was only fit using the full data set, the comparisons are based on that data.

Figure F.15 shows the predicted-versus-measured plot and $\mathrm{R}^{2}$ [calculating using $\ln \left(\mathrm{H}_{\mathrm{C}}\right)$ values] for the nondimensional $\mathrm{H}_{\mathrm{C}}$ model from Section 7.3.2. Figure F.15 shows that the nondimensional model tends to underpredict $\mathrm{H}_{\mathrm{C}}$ (sometimes significantly) for the Fall 2007 data. The model also tends to underpredict $\mathrm{H}_{\mathrm{C}}<\sim 0.35 \mathrm{~m}$ for the July 2007 data.

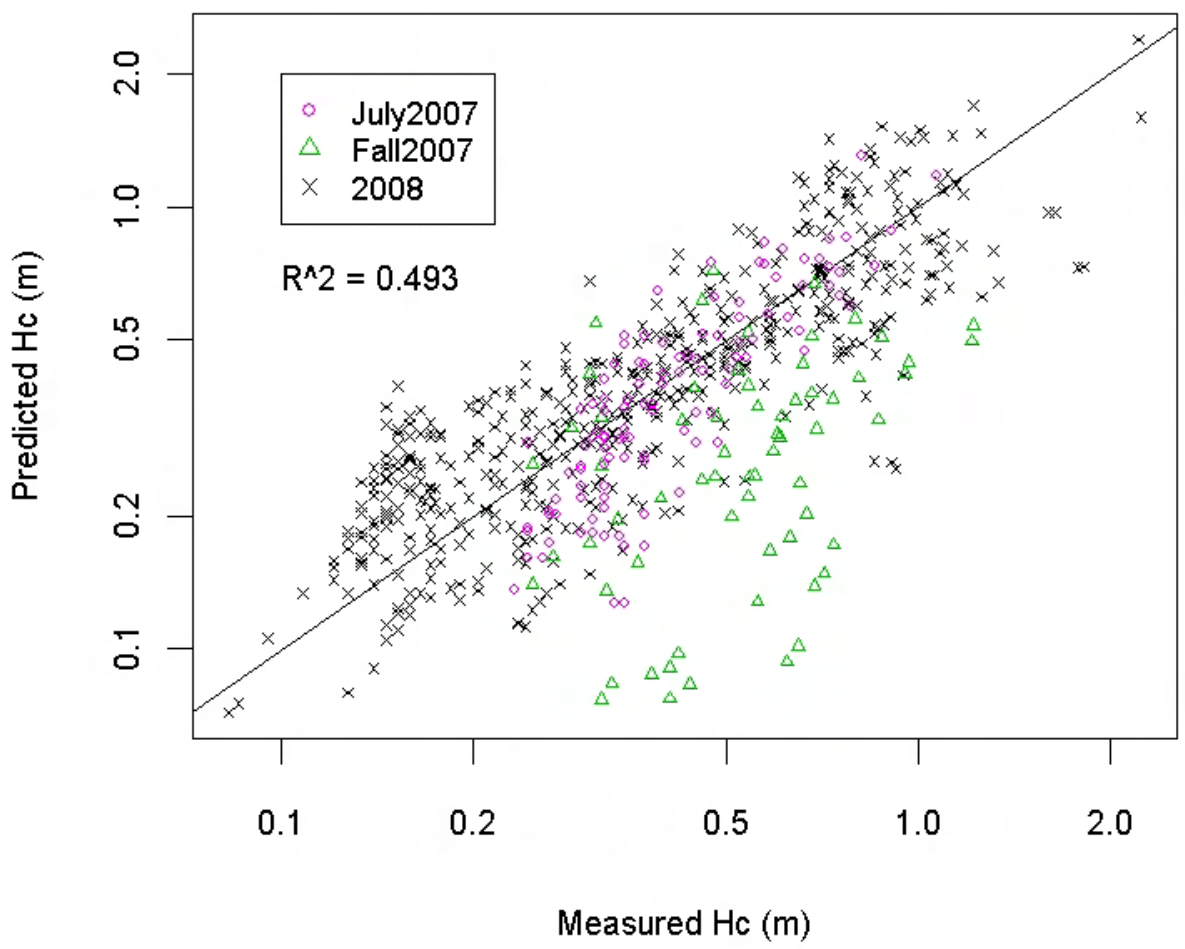

Figure F.15. Log-Log Plot of Predicted Versus Measured $\mathrm{H}_{\mathrm{C}}(\mathrm{m} / \mathrm{s})$ Values for the Nondimensional Model from Section 7.3.2 Developed Using the Full Data Set. The 45-degree line represents perfect prediction where predicted $\mathrm{H}_{\mathrm{C}}$ values equal measured $\mathrm{H}_{\mathrm{C}}$ values.

The goodness-of-fit of the nondimensional model (Figure F.15, $\mathrm{R}^{2}=0.493$ ) can be compared to the dimensional model without interactions (Figure F.9, $\mathrm{R}^{2}=0.830$ ), the dimensionally consistent model (Figure F.11, $\mathrm{R}^{2}=0.830$ ), and the dimensional model with interactions (Figure F.13, $\mathrm{R}^{2}=0.861$ ). The nondimensional model (from Section 7.3.2) is seen to predict significantly worse for the full data set than the other models (discussed in Section F.3). In addition to the observations made in the last paragraph, it is also noted that the nondimensional model produces considerably more scatter around the line of perfect prediction (Figure F.15) compared to the plots for the Appendix F.3 models (Figures F.9, F.11, and F.13).

Table F.14 compares the coefficients of several $\mathrm{H}_{\mathrm{C}}$ models fitted using the full data set when the models are expressed in the dimensional form of Eq. (F.21a). The $\mathrm{H}_{\mathrm{C}}$ models compared this way include:

- 11-term dimensional model without interactions, with 11 fitted coefficients

- 11-term dimensionally consistent model, with 10 fitted coefficients

- nondimensional model from Section 7.3.2, with 4 fitted coefficients. 
Some variables in the nondimensional model cannot be expressed in power-law form, and hence it was not possible to calculate all coefficients in the form of Eq. (F.21a) for that model. The 13-term dimensional model with interactions (with 13 fitted coefficients) is not included in Table F.14, because the values of coefficients containing interactions depend on the variables involved in the interactions.

Table F.14 shows that the coefficients of the dimensional and dimensionally consistent $\mathrm{H}_{\mathrm{C}}$ models expressed in dimensional form are very similar because the dimensional model is very close to dimensionally consistent without being forced to be so. Because of the mathematical form of the nondimensional model in Section 7.3.2, it was not possible to express several of its terms in power-law form and calculate coefficients for an equivalent model written in dimensional form. For the predictor variables where possible, the coefficients in the nondimensional model are noticeably different than these for the other two models. The coefficient for D (which controls the scale effect) in the nondimensional model is much different than the other two models, likely because the nondimensional model for $\mathrm{H}_{\mathrm{C}}$ does not explicitly include a D term with a separately estimable coefficient (i.e., D appeared only within a nondimensional variable expressed as a function of several test variables, with only one coefficient for the nondimensional variable).

Table F.14. Coefficients of $\mathrm{H}_{\mathrm{C}}$ Models Fit to Full Data Set Expressed in the Dimensional Form of Equation (F.21a)

\begin{tabular}{lccc}
\hline $\begin{array}{l}\text { Model } \\
\text { Terms }\end{array}$ & $\begin{array}{c}\text { Dimensional } \mathrm{H}_{\mathrm{C}} \text { Model } \\
\text { w/o Interactions } \\
\text { [Eq. }(\text { F.24a) }\end{array}$ & $\begin{array}{c}\text { Dimensionally Consistent } \mathrm{H}_{\mathrm{C}} \\
\text { Model w/o Interactions } \\
\text { [Eq. (F.23) \& (F.26a)] }\end{array}$ & $\begin{array}{c}\text { Nondimensional } \\
\mathrm{H}_{\mathrm{C}} \text { Model from } \\
\text { Section } 7.3 .2\end{array}$ \\
\hline $\mathrm{a}_{0}$ & 1.079 & 1.033 & $(\mathrm{a})$ \\
$\mathrm{D}\left(\mathrm{a}_{1}\right)$ & -1.191 & -1.166 & -3.428 \\
$\mathrm{~S}-1\left(\mathrm{a}_{2}\right)$ & -0.836 & -0.829 & $(\mathrm{a})$ \\
$\phi_{\mathrm{S}}\left(\mathrm{a}_{3}\right)$ & -0.623 & -0.616 & $(\mathrm{a})$ \\
$1-\phi_{\mathrm{S}}\left(\mathrm{a}_{14}\right)$ & -17.502 & -17.206 & $-{ }^{\text {(b) }}$ \\
$\mathrm{U}_{\mathrm{T}}\left(\mathrm{a}_{6}\right)$ & -0.412 & -0.410 & $(\mathrm{a})$ \\
$\mathrm{DC}\left(\mathrm{a}_{7}\right)$ & 0.371 & 0.364 & 1 \\
$\phi_{\mathrm{p}}\left(\mathrm{a}_{8}\right)$ & 0.218 & 0.213 & 0.698 \\
$\mathrm{~N}_{\mathrm{J}}\left(\mathrm{a}_{10}\right)$ & 0.330 & 0.320 & 1.714 \\
$\mathrm{~d}\left(\mathrm{a}_{11}\right)$ & 1.722 & 1.693 & 3.428 \\
$\mathrm{U}\left(\mathrm{a}_{12}\right)$ & 1.378 & 1.356 & $(\mathrm{a})$ \\
$1-\phi_{\mathrm{S}} / 0.5$ & - & - & $(\mathrm{a})$ \\
$\mathrm{R}^{2}$ & 0.830 & 0.830 & 0.493 \\
\hline
\end{tabular}

(a) Not expressible as a term in a power-law model.

(b) A dash (-) indicates the term is not included in the model.

\section{F.4 Illustration of $U_{C s}$ and $H_{C}$ Model Application and Uncertainty Calculations}

This section contains examples to illustrate applying selected models to obtain predicted $\mathrm{U}_{\mathrm{CS}}$ and $\mathrm{H}_{\mathrm{C}}$ values for a specific set of the eight predictor variables $\mathrm{D}, \mathrm{s}, \phi_{\mathrm{S}}, \mathrm{U}_{\mathrm{T}}, \mathrm{DC}, \phi_{\mathrm{p}}, \mathrm{N}_{\mathrm{J}}, \mathrm{d}$ (for $\mathrm{U}_{\mathrm{CS}}$ and $\mathrm{H}_{\mathrm{C}}$ models) and a ninth predictor variable $\mathrm{U}$ (for $\mathrm{H}_{\mathrm{C}}$ models). The examples also illustrate the application of statistical intervals to calculate uncertainties of predicted $\mathrm{U}_{\mathrm{CS}}$ and $\mathrm{H}_{\mathrm{C}}$ values. The formulas for calculating several kinds of statistical intervals are given in Section D.6 of Appendix D. In this section, the formulas for two-sided 95\% confidence intervals (CIs) and 95\% simultaneous confidence intervals (SCIs) are 
illustrated. The 95\% confidence level was chosen for illustrative purposes only. Other appropriate confidence levels, or other kinds of statistical intervals (e.g., prediction intervals), can be used depending on the application of the $\mathrm{U}_{\mathrm{CS}}$ and $\mathrm{H}_{\mathrm{C}}$ models.

The $U_{\mathrm{CS}}$ models selected to illustrate prediction and uncertainty calculations are the 1) 9-term dimensional model without interactions presented in Eq. (F.11b) and Table F.1, and 2) 12-term dimensional model with interactions shown in Eq. (F.15b) and Table F.5. These models were developed using the full data set for $\mathrm{U}_{\mathrm{CS}}$. The $\mathrm{H}_{\mathrm{C}}$ models selected to illustrate prediction and uncertainty calculations are the 1) 11-term dimensional model without interactions presented in Eq. (F.24b) and Table F.8, and 2) 13-term dimensional model with interactions shown in Eq. (F.28b) and Table F.12. These models were developed using the full data set for $\mathrm{H}_{\mathrm{C}}$. The dimensionally consistent models for $\mathrm{U}_{\mathrm{CS}}$ and $\mathrm{H}_{\mathrm{C}}$ are not included in the example calculations because the more complicated equations for calculating prediction uncertainty and statistical intervals were not available in the software used. There was insufficient time to find and program these equations into special-purpose software.

Values for the predictor variables chosen to illustrate the application of the $\mathrm{U}_{\mathrm{CS}}$ and $\mathrm{H}_{\mathrm{C}}$ models are shown in Table F.15. To apply the $\mathrm{U}_{\mathrm{CS}}$ and $\mathrm{H}_{\mathrm{C}}$ models to this set of predictor variable values, the relevant values of the predictor variables must be used to form the terms of the particular models. These values are shown in Table F.16 for each of the models.

Table F.15. Values of Predictor Variables Selected to Illustrate Application of Models Fit to the Full Data Sets for $\mathrm{U}_{\mathrm{CS}}$ and $\mathrm{H}_{\mathrm{C}}$

\begin{tabular}{ccc}
\hline Variable & $\begin{array}{c}\text { Measured } \\
\text { Value }\end{array}$ & $\begin{array}{c}\text { Natural Log of } \\
\text { Measured Value }\end{array}$ \\
\hline $\mathrm{D}$ & 1.7780 & 0.5755 \\
$(\mathrm{~s}-1)$ & 3.18 & 1.1569 \\
$\phi_{\mathrm{s}}$ & 0.005 & -5.2983 \\
$\mathrm{U}_{\mathrm{T}}$ & 0.0085 & -4.7725 \\
$\mathrm{DC}$ & 0.2367 & -1.4408 \\
$\phi_{\mathrm{p}}$ & 0.0501 & -2.9942 \\
$\mathrm{~N}_{\mathrm{J}}$ & 12 & 2.4849 \\
$\mathrm{~d}$ & 0.0234 & -3.7564 \\
$\mathrm{U}$ & 7.5 & 2.0149 \\
\hline
\end{tabular}

For each of the $\mathrm{U}_{\mathrm{CS}}$ and $\mathrm{H}_{\mathrm{C}}$ models, predicted $\ln \left(\mathrm{U}_{\mathrm{CS}}\right)$ and $\ln \left(\mathrm{H}_{\mathrm{C}}\right)$ values are obtained by multiplying the predictor variable values in the format needed for the specific model (from Table F.16) by the coefficients for that model, then summing the results. The coefficients for the 9- and 12-term $\mathrm{U}_{\mathrm{CS}}$ dimensional models without and with interactions are given in Tables F.1 and F.5, respectively. The coefficients for the 11- and the 13-term $\mathrm{H}_{\mathrm{C}}$ models without and with interaction are given in Tables F.8 and F.12, respectively. Using vector notation, the predicted values are calculated by

$$
\hat{y}(\mathbf{a})=\mathbf{a}^{\mathrm{T}} \mathbf{b}
$$

where $\hat{y}(\mathbf{a})$ is the predicted value of $\ln \left(\mathrm{U}_{\mathrm{CS}}\right)$ or $\ln \left(\mathrm{H}_{\mathrm{C}}\right)$, a is a vector of values from Table $\mathrm{F} .16$ chosen to match the terms in a given model, the superscript $\mathrm{T}$ represents a vector transpose, and $\mathbf{b}$ is the vector of coefficients for a given model. 
Table F.16. Predictor Variable Values in Formats Needed to Illustrate Use of Models Fit to the Full Data Sets for $\mathrm{U}_{\mathrm{CS}}$ and $\mathrm{H}_{\mathrm{C}}$

\begin{tabular}{|c|c|c|c|c|}
\hline \multirow[b]{4}{*}{ Model Term } & \multicolumn{4}{|c|}{ Values Needed for Model } \\
\hline & 9-Term $U_{\mathrm{CS}}$ & 12-Term $\mathrm{U}_{\mathrm{CS}}$ & 11-Term $\mathrm{H}_{\mathrm{C}}$ & 13-Term $\mathrm{H}_{\mathrm{C}}$ \\
\hline & Eq. (F.11b) & Eq. (F.15b) & Eq. (F.24b) & Eq. (F.28b) \\
\hline & Table F.1 & Table F.5 & Table F.8 & Table F.12 \\
\hline $\ln (\mathrm{D})$ & 0.5755 & 0.5755 & 0.5755 & 0.5755 \\
\hline $\ln (s-1)$ & 1.1569 & 1.1569 & 1.1569 & 1.1569 \\
\hline $\ln \left(\phi_{\mathrm{S}}\right)$ & -5.2983 & -5.2983 & -5.2983 & -5.2983 \\
\hline $\ln \left(1-\phi_{\mathrm{S}}\right)$ & - (a) & - & -0.0050 & -0.0050 \\
\hline $\ln \left(\mathrm{U}_{\mathrm{T}}\right)$ & -4.7725 & -4.7725 & -4.7725 & -4.7725 \\
\hline $\ln (\mathrm{DC})$ & -1.4408 & -1.4408 & -1.4408 & -1.4408 \\
\hline $\ln \left(\phi_{\mathrm{p}}\right)$ & -2.9937 & -2.9937 & -2.9937 & -2.9937 \\
\hline $\ln \left(\mathrm{N}_{\mathrm{J}}\right)$ & 2.4849 & 2.4849 & 2.4849 & 2.4849 \\
\hline $\ln (\mathrm{d})$ & -3.7564 & -3.7564 & -3.7564 & -3.7564 \\
\hline $\ln (\mathrm{U})$ & - & - & 2.0149 & 2.0149 \\
\hline $\mathrm{D} \ln (\mathrm{DC})$ & - & -2.5617 & - & - \\
\hline $\mathrm{DC} \ln \left(\mathrm{U}_{\mathrm{T}}\right)$ & - & -1.1297 & - & - \\
\hline$\phi_{\mathrm{S}} \ln \left(\mathrm{U}_{\mathrm{T}}\right)$ & - & -0.0239 & - & - \\
\hline $\mathrm{D} \ln \left(\phi_{\mathrm{S}}\right)$ & - & - & - & -9.4204 \\
\hline$\phi_{\mathrm{S}} \ln (\mathrm{U})$ & - & - & - & 0.0101 \\
\hline
\end{tabular}

The predicted $\ln \left(\mathrm{U}_{\mathrm{CS}}\right)$ and $\ln \left(\mathrm{H}_{\mathrm{C}}\right)$ values from each model are listed in the third columns of Tables F.17 and F.18, respectively. The predicted $\ln \left(\mathrm{U}_{\mathrm{CS}}\right)$ in $\ln (\mathrm{m} / \mathrm{s})$ units are easily converted to $\mathrm{U}_{\mathrm{CS}}$ units of $\mathrm{m} / \mathrm{s}$ by exponentiation. Similarly, the predicted $\ln \left(\mathrm{H}_{\mathrm{C}}\right)$ in $\ln (\mathrm{m})$ units can be converted to $\mathrm{H}_{\mathrm{C}}$ units of $\mathrm{m}$ by exponentiation. Column 4 of Tables F.17 and F.18 contain the predicted $U_{C S}$ value in $\mathrm{m} / \mathrm{s}$ and the predicted $\mathrm{H}_{\mathrm{C}}$ value in $\mathrm{m}$, respectively, for the selected set of predictor variable values. As discussed in Section D.6.5 of Appendix D, these back-transformed $U_{C s}$ and $H_{C}$ predictions in $\mathrm{m} / \mathrm{s}$ and $\mathrm{m}$ units, respectively, have a particular interpretation. They should be considered estimates of the true medians (not the true means) of the distributions of $\mathrm{U}_{\mathrm{CS}}$ and $\mathrm{H}_{\mathrm{C}}$ values that would result if the test were repeated multiple times by independently resetting the values of the predictor variables (in Table F.15) each time.

Equation (D.19a) in Appendix D can be used to calculate a two-sided CL\% CI for the true mean of $\ln \left(\mathrm{U}_{\mathrm{CS}}\right)$ or $\ln \left(\mathrm{H}_{\mathrm{C}}\right)$ employing the predictor variable values selected for this example. For the illustrations to follow, we use CL\% $=95 \%$. In the notation of Eq. (D.19a),

- $\mathrm{CL} \%=100(1-\alpha) \%=95 \%$, so $\alpha=0.05$

- Vector a contains entries corresponding to the terms in a given $\mathrm{U}_{\mathrm{CS}}$ or $\mathrm{H}_{\mathrm{C}}$ model, which are calculated using the set of predictor variable values in Tables F.15 and F.16

- Matrix A is formed from the data matrix used in the regression that generated a given $\mathrm{U}_{\mathrm{CS}}$ or $\mathrm{H}_{\mathrm{C}}$ model. Matrix $\mathbf{A}$ has the number of rows in the $\mathrm{U}_{\mathrm{CS}}$ or $\mathrm{H}_{\mathrm{C}}$ full modeling data set (173 and 669, respectively) and the number of columns corresponding to the number of terms in a given $\mathrm{U}_{\mathrm{CS}}$ dimensional model (9 or 12) or $\mathrm{H}_{\mathrm{C}}$ dimensional model (11 and 13). Each column is calculated according to the corresponding term in the model using the $\mathrm{U}_{\mathrm{CS}}$ or $\mathrm{H}_{\mathrm{C}}$ full data sets. 
To simplify the calculations, the first expression in Equation (D.19a) is used to calculate a 95\% CI on $\ln \left(\mathrm{U}_{\mathrm{CS}}\right)$ in units of $\ln (\mathrm{m} / \mathrm{s})$ or $\ln \left(\mathrm{H}_{\mathrm{C}}\right)$ in units of $\ln (\mathrm{m})$. The $\mathbf{C}_{\mathrm{U}}$ portion of Eq. (D.19a) is the variancecovariance matrix for the estimated model coefficients. The variance-covariance matrices for the 9- and 12-term $U_{\mathrm{CS}}$ dimensional models without and with interactions used in the illustrative example are listed in Tables F.19 and F.20, respectively. The variance-covariance matrices for the 11- and 13-term $\mathrm{H}_{\mathrm{C}}$ dimensional models without and with interactions used in the illustrative example are listed in Tables F.21 and F.22, respectively. The quantity $\sqrt{\mathbf{a}^{\mathrm{T}} \mathbf{C}_{\mathrm{U}} \mathbf{a}}$ is the standard deviation of a model prediction considered as a mean value. The value of this quantity for each model applied to the set of predictor variable values in Table F.16 is given in the fifth column of Table F.17 for $\mathrm{U}_{\mathrm{CS}}$ and the fifth column of Table F.18 for $\mathrm{H}_{\mathrm{C}}$.

The $95 \%$ CI values for the true mean $\ln \left(\mathrm{U}_{\mathrm{CS}}\right)$ in units of $\ln (\mathrm{m} / \mathrm{s})$ for the set of predictor-variable values in Table F.15, based on the 9- and 12-term $\ln \left(\mathrm{U}_{\mathrm{CS}}\right)$ models, are given in the sixth column of Table F.17. Similarly, the $95 \%$ CI values for the true mean $\ln \left(\mathrm{H}_{\mathrm{C}}\right)$ in units of $\ln (\mathrm{m})$ for the set of predictor-variable values in Table F.15, based on the 11- and 13-term $\ln \left(\mathrm{H}_{\mathrm{C}}\right)$ models, are given in the sixth column of Table F.18. Exponentiating the resulting 95\% CIs on the true mean value in $\ln (\mathrm{m} / \mathrm{s})$ or $\ln (\mathrm{m})$ units yields $95 \%$ CIs for the true median in $\mathrm{m} / \mathrm{s}$ or $\mathrm{m}$, respectively. For example, the 12-term model for $U_{C S}$ has $2.0536 \ln (\mathrm{m} / \mathrm{s})$ as the upper limit of the $95 \%$ CI on the true mean $\ln \left(U_{\mathrm{CS}}\right)$ for the predictorvariable values shown in Table F.15. Then $\mathrm{e}^{2.0536}=7.796 \mathrm{~m} / \mathrm{s}$ is the upper limit of the $95 \%$ CI on the true median $\mathrm{U}_{\mathrm{CS}}$ value at the set of predictor-variable values in Table F.15. The seventh column of Table F.17 contains $95 \%$ CIs for the true median $U_{C S}$ value for the set of predictor-variable values selected. Similarly, the seventh column in Table F.18 contains 95\% CIs for the true median $\mathrm{H}_{\mathrm{C}}$ value for the set of predictor-variable values selected.

As discussed in Section D.6.4 of Appendix D, there are times when a CL\% simultaneous confidence interval (CL\% SCI) may be preferred rather than a CL\% CI. This is particularly true when a regression model $\left(\mathrm{U}_{\mathrm{CS}}\right.$ or $\left.\mathrm{H}_{\mathrm{C}}\right)$ is to be used a large number of times for various sets of predictor-variable values from the model validity region. Equation (D.21a) in Appendix D can be used to calculate a 95\% SCI for the true mean of $\ln \left(\mathrm{U}_{\mathrm{CS}}\right)$ or the true mean of $\ln \left(\mathrm{H}_{\mathrm{C}}\right)$ for multiple sets of predictor-variable values in the model validity region. The resulting 95\% SCIs for those sets of predictor-variable values simultaneously have $95 \%$ confidence for containing their true mean values.

The $95 \%$ SCI values for the true mean $\ln \left(\mathrm{U}_{\mathrm{CS}}\right)$ in units of $\ln (\mathrm{m} / \mathrm{s})$ for the set of predictor-variable values in Table F.15, based on the 9- and 12-term $\ln \left(\mathrm{U}_{\mathrm{CS}}\right)$ models, are given in the eighth column of Table F.17. Similarly, the 95\% SCI values for the true mean $\ln \left(\mathrm{H}_{\mathrm{C}}\right)$ in units of $\ln (\mathrm{m})$ for the set of predictor-variable values in Table F.15, based on the 11- and 13-term $\ln \left(\mathrm{H}_{\mathrm{C}}\right)$ models, are given in the eighth column of Table F.18. Exponentiating the resulting 95\% SCIs for the mean in $\ln (\mathrm{m} / \mathrm{s})$ and $\ln (\mathrm{m})$ units yields 95\% SCIs for the median in $\mathrm{m} / \mathrm{s}$ (for $\mathrm{U}_{\mathrm{CS}}$ ) or $\mathrm{m}$ (for $\mathrm{H}_{\mathrm{C}}$ ) units. Column nine of Table F.17 contains 95\% SCIs for the true median $\mathrm{U}_{\mathrm{CS}}$ value for the set of predictor-variable values using the two $\ln \left(\mathrm{U}_{\mathrm{CS}}\right)$ models. Similarly, column nine of Table F.18 contains 95\% SCIs for the true median $\mathrm{H}_{\mathrm{C}}$ value for the set of predictor-variable values based on the two $\ln \left(\mathrm{H}_{\mathrm{C}}\right)$ models chosen for illustration. The $95 \%$ SCIs are larger than the corresponding 95\% CIs because of the simultaneous-confidence protection for multiple uses of the same model.

The uncertainties in model predictions of $\mathrm{U}_{\mathrm{CS}}$ and $\mathrm{H}_{\mathrm{C}}$ illustrated in Tables F.17 and F.18 include only the uncertainties associated with fitting measured $\mathrm{U}_{\mathrm{CS}}$ and $\mathrm{H}_{\mathrm{C}}$ values in the full data set to the $\mathrm{U}_{\mathrm{CS}}$ and $\mathrm{H}_{\mathrm{C}}$ models considered. The calculations for the 95\% CIs and 95\% SCIs do not include the uncertainties 
associated with the predictor-variable values (in Tables F.15 and F.16) substituted into the models. Predictor-variable uncertainties can be propagated through the models, and combined with model uncertainties, to obtain combined estimates of uncertainties (referred to as combined-confidence intervals) for $U_{C S}$ and $H_{C}$ predictions. This work was beyond the current scope, but could be performed in the future if desired. In the meantime, the interested reader is referred to Piepel et al. (2005) for extensive discussion, formulas, and applications of combined-confidence intervals.

The uncertainties in model predictions of $\mathrm{U}_{\mathrm{CS}}$ and $\mathrm{H}_{\mathrm{C}}$ models illustrated in Tables F.17 and F.18 do not include any additional uncertainties associated with extrapolating. The statistical formulas for CIs and SCIs include larger uncertainties when models are extrapolated, under the assumption the model form is correct both within the experimental region and outside that region where extrapolation is required. Thus, the extent to which a model form may be inappropriate for extrapolation is not accounted for in the statistical formulas for CIs and SCIs. Additional uncertainties or "margins" based on subject-matter knowledge and judgment must be used to account for uncertainties associated with any possible inadequacy of models for extrapolation.

As noted previously, it was not possible at this time to include in Tables F.17 and F.18 the example calculations for the dimensionally consistent models fitted to the full data set for $\mathrm{U}_{\mathrm{CS}}$ (Table F.3) and $\mathrm{H}_{\mathrm{C}}$ (Table F.10). However, the fits of those models to the full data sets are close $\left(\mathrm{U}_{\mathrm{CS}}\right)$ and very close $\left(\mathrm{H}_{\mathrm{C}}\right)$ to the fits of the corresponding dimensional models. Hence, the uncertainty calculations (i.e., predicted standard deviations and statistical intervals) for the dimensionally consistent models should be similar to the uncertainties for the dimensional models. 
Table F.17. Predicted $U_{\text {CS }}$ and Corresponding 95\% CIs and 95\% SCIs Using Models Fit to the Full Data Set Applied to the Experimental Set of Conditions Shown in Tables F.15 and F.16

\begin{tabular}{|c|c|c|c|c|c|c|c|c|}
\hline Response & Model & $\begin{array}{c}\text { Predicted } \\
\ln \left(\mathrm{U}_{\mathrm{Vs}}\right) \\
{[\ln (\mathrm{m} / \mathrm{s})]}\end{array}$ & $\begin{array}{c}\text { Predicted } \\
\mathrm{U}_{\mathrm{CS}}^{\text {(a) }} \\
{[\mathrm{m} / \mathrm{s}]}\end{array}$ & $\begin{array}{c}\text { SD of Predicted } \\
\ln \left(\mathrm{U}_{\mathrm{CS}}\right)^{(\mathrm{b})} \\
{[\ln (\mathrm{m} / \mathrm{s})]}\end{array}$ & $\begin{array}{c}95 \% \mathrm{CI} \\
\text { on } \mathrm{Mean} \ln \left(\mathrm{U}_{\mathrm{CS}}\right) \\
{[\ln (\mathrm{m} / \mathrm{s})]}\end{array}$ & $\begin{array}{c}95 \% \text { CI } \\
\text { on Median } U_{\mathrm{CS}} \\
{[\mathrm{m} / \mathrm{s}]}\end{array}$ & $\begin{array}{c}\text { 95\% SCI on Mean } \\
\ln \left(\mathrm{U}_{\mathrm{CS}}\right) \\
{[\ln (\mathrm{m} / \mathrm{s})]}\end{array}$ & $\begin{array}{c}\text { 95\% SCI on } \\
\text { Median } U_{\mathrm{CS}} \\
{[\mathrm{m} / \mathrm{s}]}\end{array}$ \\
\hline \multirow{2}{*}{$\mathrm{U}_{\mathrm{CS}}$} & $\begin{array}{l}\text { 9-Term Model } \\
\text { Table F.1 }\end{array}$ & $1.9594^{(\mathrm{c})}$ & 7.095 & 0.0367 & {$[1.8869,2.0319]$} & {$[6.599,7.628]$} & {$[1.8062,2.1126]$} & {$[6.087,8.270]$} \\
\hline & $\begin{array}{c}\text { 12-Term Model } \\
\text { Table F.5 }\end{array}$ & 1.9930 & 7.338 & 0.0317 & {$[1.9304,2.0556]$} & {$[6.892,7.812]$} & {$[1.8452,2.1408]$} & {$[6.329,8.507]$} \\
\hline
\end{tabular}

(a) For comparison purposes, the measured $U_{\mathrm{CS}}$ (in $\mathrm{m} / \mathrm{s}$ ) for the selected experiment is $7.5 \mathrm{~m} / \mathrm{s}$.

(b) The standard deviations are for the $\ln \left(\mathrm{U}_{\mathrm{CS}}\right)$ predictions considered to be the mean of such values for the experimental conditions selected.

(c) All calculations were performed using the experimental conditions, model coefficients, and variance-covariance matrix values given in tables of this report. The calculated $\ln (\mathrm{m} / \mathrm{s})$ values were rounded to four decimal places in this table. The $\mathrm{m} / \mathrm{s}$ values were calculated by exponentiating the corresponding $\ln (\mathrm{m} / \mathrm{s}) \mathrm{values}$ before rounding, then rounding the resulting values to three decimal places in this table.

Table F.18. Predicted $\mathrm{H}_{\mathrm{C}}$ and Corresponding 95\% CIs and 95\% SCIs Using Models Fit to the Full Data Set Applied to the Experimental Set of Conditions Shown in Tables F.15 and F.16

\begin{tabular}{|c|c|c|c|c|c|c|c|c|}
\hline Response & Model & $\begin{array}{c}\text { Predicted } \\
\ln \left(\mathrm{H}_{\mathrm{C}}\right) \\
{[\ln (\mathrm{m})]} \\
\end{array}$ & $\begin{array}{c}\text { Predicted } \\
\mathrm{H}_{\mathrm{C}}{ }^{(\mathrm{a})} \\
{[\mathrm{m}]} \\
\end{array}$ & $\begin{array}{c}\text { SD of Predicted } \\
\ln \left(\mathrm{H}_{\mathrm{C}}\right)^{(\mathrm{b})} \\
{[\ln (\mathrm{m})]}\end{array}$ & $\begin{array}{c}95 \% \text { CI } \\
\text { on Mean } \ln \left(\mathrm{H}_{\mathrm{C}}\right) \\
{[\ln (\mathrm{m})]} \\
\end{array}$ & $\begin{array}{c}\text { 95\% CI } \\
\text { on Median } \mathrm{H}_{\mathrm{C}} \\
{[\mathrm{m}]} \\
\end{array}$ & $\begin{array}{c}\text { 95\% SCI on Mean } \\
\ln \left(\mathrm{H}_{\mathrm{C}}\right) \\
{[\ln (\mathrm{m})]} \\
\end{array}$ & $\begin{array}{l}\text { 95\% SCI on } \\
\text { Median } \mathrm{H}_{\mathrm{C}} \\
{[\mathrm{m}]}\end{array}$ \\
\hline \multirow{2}{*}{$\mathrm{H}_{\mathrm{C}}$} & $\begin{array}{c}\text { 11-Term Model } \\
\text { Table F.8 }\end{array}$ & $-0.2811^{(\mathrm{c})}$ & 0.755 & 0.0391 & {$[-0.3579,-0.2043]$} & {$[0.699,0.815]$} & {$[-0.4552,-0.1070]$} & {$[0.634,0.899]$} \\
\hline & $\begin{array}{c}\text { 13-Term Model } \\
\text { Table F.12 }\end{array}$ & -0.3454 & 0.708 & 0.0366 & {$[-0.4173,-0.2735]$} & {$[0.659,0.761]$} & {$[-0.5192,-0.1716]$} & {$[0.595,0.842]$} \\
\hline
\end{tabular}

(a) For comparison purposes, the measured $\mathrm{H}_{\mathrm{C}}$ for the selected experiment is $0.610 \mathrm{~m}$.

(b) The standard deviations are for the $\ln \left(\mathrm{H}_{\mathrm{C}}\right)$ predictions considered to be the mean of such values for the experimental conditions selected.

(c) All calculations were performed using the experimental conditions, model coefficients, and variance-covariance matrix values given in tables of this report. The calculated $\ln (\mathrm{m})$ values were rounded to four decimal places in this table. The $\mathrm{m}$ values were calculated by exponentiating the corresponding $\ln (\mathrm{m}) \mathrm{values}$ before rounding, then rounding the resulting values to three decimal places in this table. 
Table F.19. Variance-Covariance Matrix for the 9-Term $\ln \left(U_{C S}\right)$ Model in Table F.1. The form of the variance-covariance matrix is presented in Eq. (D.17a) of Appendix D.

\begin{tabular}{|c|c|c|c|c|c|c|c|c|c|}
\hline Term & $\ln \left(a_{0}\right)$ & $\ln (\mathrm{D})$ & $\ln (s-1)$ & $\ln \left(\phi_{\mathrm{S}}\right)$ & $\ln \left(\mathrm{U}_{\mathrm{T}}\right)$ & $\ln (\mathrm{DC})$ & $\ln \left(\phi_{p}\right)$ & $\ln \left(\mathrm{N}_{\mathrm{J}}\right)$ & $\ln (d)$ \\
\hline $\ln \left(a_{0}\right)$ & $5.5867 \mathrm{E}-02$ & $-7.0942 \mathrm{E}-03$ & $6.1780 \mathrm{E}-04$ & 7.9473E-04 & $1.5499 \mathrm{E}-03$ & $1.3256 \mathrm{E}-03$ & $2.3676 \mathrm{E}-03$ & $2.5754 \mathrm{E}-04$ & 7.9282E-03 \\
\hline $\ln (\mathrm{D})$ & -7.0942E-03 & 2.1144E-03 & $-1.0798 \mathrm{E}-04$ & 4.4413E-06 & 1.3907E-05 & $1.0371 \mathrm{E}-04$ & 8.0392E-05 & $-6.5097 \mathrm{E}-04$ & $-1.9821 \mathrm{E}-03$ \\
\hline $\ln (s-1)$ & $6.1780 \mathrm{E}-04$ & $-1.0798 \mathrm{E}-04$ & $1.4103 \mathrm{E}-03$ & $1.0675 \mathrm{E}-05$ & $-9.3703 \mathrm{E}-05$ & $-7.5404 \mathrm{E}-05$ & $1.3929 \mathrm{E}-04$ & $-2.6554 \mathrm{E}-04$ & 1.7822E-04 \\
\hline $\ln \left(\phi_{\mathrm{S}}\right)$ & 7.9473E-04 & 4.4413E-06 & $1.0675 \mathrm{E}-05$ & 1.3212E-04 & 3.7488E-05 & $-6.9818 \mathrm{E}-06$ & $-5.4548 \mathrm{E}-05$ & $-5.5424 \mathrm{E}-06$ & 1.9858E-05 \\
\hline $\ln \left(\mathrm{U}_{\mathrm{T}}\right)$ & 1.5499E-03 & 1.3907E-05 & $-9.3703 E-05$ & 3.7488E-05 & 2.2314E-04 & 7.2970E-05 & 8.8712E-05 & 3.9990E-05 & $-6.2132 \mathrm{E}-06$ \\
\hline $\ln (\mathrm{DC})$ & $1.3256 \mathrm{E}-03$ & $1.0371 \mathrm{E}-04$ & $-7.5404 \mathrm{E}-05$ & $-6.9818 \mathrm{E}-06$ & 7.2970E-05 & $9.6501 \mathrm{E}-04$ & $-1.0773 \mathrm{E}-04$ & $-1.3120 \mathrm{E}-04$ & $-5.4146 \mathrm{E}-05$ \\
\hline $\ln \left(\phi_{\mathrm{p}}\right)$ & 2.3676E-03 & 8.0392E-05 & $1.3929 \mathrm{E}-04$ & $-5.4548 \mathrm{E}-05$ & 8.8712E-05 & -1.0773E-04 & 1.0249E-03 & $-8.2807 \mathrm{E}-05$ & $-1.4503 \mathrm{E}-04$ \\
\hline $\ln \left(\mathrm{N}_{\mathrm{J}}\right)$ & $2.5754 \mathrm{E}-04$ & $-6.5097 \mathrm{E}-04$ & $-2.6554 \mathrm{E}-04$ & $-5.5424 \mathrm{E}-06$ & 3.9990E-05 & $-1.3120 \mathrm{E}-04$ & $-8.2807 \mathrm{E}-05$ & $1.1684 \mathrm{E}-03$ & 6.5999E-04 \\
\hline $\ln (d)$ & 7.9282E-03 & $-1.9821 \mathrm{E}-03$ & $1.7822 \mathrm{E}-04$ & $1.9858 \mathrm{E}-05$ & $-6.2132 \mathrm{E}-06$ & $-5.4146 \mathrm{E}-05$ & $-1.4503 \mathrm{E}-04$ & 6.5999E-04 & 2.1518E-03 \\
\hline
\end{tabular}

Table F.20. Variance-Covariance Matrix for 12-Term $\ln \left(\mathrm{U}_{\mathrm{CS}}\right)$ Model in Table F.5. The form of the variance-covariance matrix is presented in Eq. (D.17a) of Appendix D.

\begin{tabular}{|c|c|c|c|c|c|c|c|c|c|c|c|c|}
\hline Term & $\ln \left(\mathrm{a}_{0}\right)$ & $\ln (\mathrm{D})$ & $\ln (s-1)$ & $\ln \left(\phi_{\mathrm{S}}\right)$ & $\ln \left(\mathrm{U}_{\mathrm{T}}\right)$ & $\ln (\mathrm{DC})$ & $\ln \left(\phi_{p}\right)$ & $\ln \left(\mathrm{N}_{\mathrm{J}}\right)$ & $\ln (d)$ & $\mathrm{DC} \ln \left(\mathrm{U}_{\mathrm{T}}\right)$ & $\mathrm{D} \ln (\mathrm{DC})$ & $\phi_{\mathrm{S}} \ln \left(\mathrm{U}_{\mathrm{T}}\right)$ \\
\hline $\ln \left(\mathrm{a}_{0}\right)$ & $5.2513 \mathrm{E}-02$ & $-4.2318 \mathrm{E}-03$ & $2.5304 \mathrm{E}-04$ & $1.3569 \mathrm{E}-03$ & $\begin{array}{l}-5.6816 \mathrm{E}-04 \\
\end{array}$ & $8.1916 \mathrm{E}-03$ & $1.9385 \mathrm{E}-03$ & 3.5809E-04 & $5.3144 \mathrm{E}-03$ & 4.9797E-03 & $4.8354 \mathrm{E}-04$ & $1.5924 \mathrm{E}-02$ \\
\hline $\ln (\mathrm{D})$ & $-4.2318 \mathrm{E}-03$ & 2.8229E-03 & $1.5716 \mathrm{E}-04$ & 1.1272E-05 & $-3.1212 \mathrm{E}-04$ & $-6.5651 \mathrm{E}-04$ & 1.7774E-04 & $-2.5884 \mathrm{E}-04$ & $-1.2435 \mathrm{E}-03$ & 4.9876E-04 & $1.4026 \mathrm{E}-03$ & $-5.8419 \mathrm{E}-04$ \\
\hline $\ln (s-1)$ & 2.5304E-04 & $1.5716 \mathrm{E}-04$ & $1.0771 \mathrm{E}-03$ & 4.6349E-05 & $-8.0130 \mathrm{E}-05$ & $-5.2108 \mathrm{E}-04$ & $1.0700 \mathrm{E}-04$ & $-1.3913 \mathrm{E}$ & 1.5817E-04 & $-1.1637 \mathrm{E}-04$ & 2.6922E-04 & $9.2838 \mathrm{E}-04$ \\
\hline $\ln \left(\phi_{\mathrm{S}}\right)$ & $1.3569 \mathrm{E}-03$ & $1.1272 \mathrm{E}-05$ & 4.6349E-05 & 2.7926E-04 & $-5.9619 \mathrm{E}-05$ & $1.7355 \mathrm{E}-04$ & $-4.5854 \mathrm{E}-05$ & $3.4862 \mathrm{E}-05$ & $-3.1679 \mathrm{E}-05$ & $1.1604 \mathrm{E}-04$ & $1.0074 \mathrm{E}-05$ & 03 \\
\hline $\ln \left(U_{T}\right)$ & $-5.6816 \mathrm{E}-04$ & $-3.1212 \mathrm{E}-04$ & $-8.0130 \mathrm{E}-05$ & $-5.9619 \mathrm{E}-05$ & 4.1342E-04 & $-7.1097 \mathrm{E}-04$ & $1.0375 \mathrm{E}-05$ & $-2.4799 \mathrm{E}-05$ & 3.9267E-06 & $-6.9289 \mathrm{E}-04$ & $-2.9545 \mathrm{E}-04$ & $-1.5566 \mathrm{E}-03$ \\
\hline $\ln (\mathrm{DC})$ & 8.1916E-03 & $-6.5651 \mathrm{E}-04$ & $-5.2108 \mathrm{E}-04$ & $1.7355 \mathrm{E}-04$ & $-7.1097 \mathrm{E}-04$ & 6.5950E-03 & $1.5480 \mathrm{E}-05$ & $-2.5241 \mathrm{E}-04$ & $-3.4425 \mathrm{E}-04$ & $3.0644 \mathrm{E}-03$ & $-1.0665 \mathrm{E}-03$ & $2.7320 \mathrm{E}-03$ \\
\hline $\ln \left(\phi_{\mathrm{p}}\right)$ & $1.9385 \mathrm{E}-03$ & 1.7774E-04 & $1.0700 \mathrm{E}-04$ & $-4.5854 \mathrm{E}-05$ & $1.0375 \mathrm{E}-05$ & $1.5480 \mathrm{E}-05$ & 7.4459E-04 & $-4.4438 \mathrm{E}-05$ & $-9.1289 \mathrm{E}-05$ & 1.4167E-04 & 1.1888E-04 & $-3.0264 \mathrm{E}-04$ \\
\hline $\ln \left(\mathrm{N}_{\mathrm{J}}\right)$ & 3.5809E-04 & $-2.5884 \mathrm{E}-04$ & $-1.3913 \mathrm{E}-04$ & $3.4862 \mathrm{E}-05$ & $-2.4799 \mathrm{E}-05$ & $-2.5241 \mathrm{E}-04$ & $-4.4438 E-05$ & 8.7029E-04 & 4.8734E-04 & 4.8972E-05 & $2.2106 \mathrm{E}-04$ & 8.3928E-04 \\
\hline $\ln (d)$ & $5.3144 \mathrm{E}-03$ & $-1.2435 \mathrm{E}-03$ & $1.5817 \mathrm{E}-04$ & $-3.1679 \mathrm{E}-05$ & 3.9267E-06 & $-3.4425 \mathrm{E}-04$ & $-9.1289 \mathrm{E}-05$ & 4.8734E-04 & $1.5661 \mathrm{E}-03$ & $-6.8671 \mathrm{E}-05$ & $1.8356 \mathrm{E}-04$ & $-1.1300 \mathrm{E}-03$ \\
\hline $\mathrm{DC} \ln \left(\mathrm{U}_{\mathrm{T}}\right)$ & 4.9797E-03 & 4.9876E-04 & $-1.1637 \mathrm{E}-04$ & $1.1604 \mathrm{E}-04$ & $-6.9289 \mathrm{E}-04$ & $3.0644 \mathrm{E}-03$ & $1.4167 \mathrm{E}-04$ & 4.8972E-05 & $-6.8671 \mathrm{E}-05$ & $2.2146 \mathrm{E}-03$ & 3.5311E-04 & 384E-03 \\
\hline$D \ln (\mathrm{DC})$ & 4.8354E-04 & $1.4026 \mathrm{E}-03$ & 2.6922E-04 & $1.0074 \mathrm{E}-05$ & $-2.9545 \mathrm{E}-04$ & $-1.0665 \mathrm{E}-03$ & $1.1888 \mathrm{E}-04$ & 2.2106E-04 & 1.8356 & 3.5311E-04 & $1.5054 \mathrm{E}-03$ & $-4.7733 E-04$ \\
\hline$\phi_{\mathrm{S}} \ln \left(\mathrm{U}_{\mathrm{T}}\right)$ & 1.5924E-02 & $-5.8419 \mathrm{E}-04$ & $9.2838 \mathrm{E}-04$ & 4.4313E-03 & $-1.5566 \mathrm{E}-03$ & $2.7320 \mathrm{E}-03$ & $-3.0264 \mathrm{E}-04$ & $8.3928 \mathrm{E}-04$ & $-1.1300 \mathrm{E}-03$ & $1.2884 \mathrm{E}-03$ & $-4.7733 \mathrm{E}-04$ & $1.0709 \mathrm{E}-01$ \\
\hline
\end{tabular}


Table F.21. Variance-Covariance Matrix for 11-Term $\ln \left(\mathrm{H}_{\mathrm{C}}\right)$ Model in Table F.8. The form of the variance-covariance matrix is presented in Eq. (D.17a) of Appendix D.

\begin{tabular}{|c|c|c|c|c|c|c|c|c|c|c|c|}
\hline Term & $\ln \left(\mathrm{a}_{0}\right)$ & $\ln (\mathrm{D})$ & $\ln (s-1)$ & $\ln \left(\phi_{\mathrm{S}}\right)$ & $\ln \left(1-\phi_{S}\right)$ & $\ln \left(U_{T}\right)$ & $\ln (\mathrm{DC})$ & $\ln \left(\phi_{\mathrm{p}}\right)$ & $\ln \left(\mathrm{N}_{\mathrm{J}}\right)$ & $\ln (d)$ & $\ln (\mathrm{U})$ \\
\hline $\ln \left(a_{0}\right)$ & 5.2319E-02 & $-1.0373 \mathrm{E}-02$ & $-2.5070 \mathrm{E}-04$ & $2.6905 \mathrm{E}-04$ & $5.1104 \mathrm{E}-02$ & $3.2619 \mathrm{E}-04$ & $2.4156 \mathrm{E}-03$ & 3.1577E-03 & $1.8299 \mathrm{E}-03$ & $1.0274 \mathrm{E}-02$ & $3.4980 \mathrm{E}-03$ \\
\hline $\ln (\mathrm{D})$ & $-1.0373 E-02$ & $9.3579 \mathrm{E}-03$ & $2.1857 \mathrm{E}-03$ & 1.6053E-03 & 2.6539E-02 & $1.1292 \mathrm{E}-03$ & $-1.2832 \mathrm{E}-03$ & $-8.8770 \mathrm{E}-04$ & $-3.3652 \mathrm{E}-03$ & $-8.1657 \mathrm{E}-03$ & $-5.5499 \mathrm{E}-03$ \\
\hline $\ln (s-1)$ & $-2.5070 \mathrm{E}-04$ & 2.1857E-03 & 2.0823E-03 & $5.9219 \mathrm{E}-04$ & $1.4325 \mathrm{E}-02$ & 2.7879E-04 & $-4.3658 \mathrm{E}-04$ & $-3.1116 \mathrm{E}-04$ & $-9.2726 \mathrm{E}-04$ & $-1.7203 E-03$ & $-1.8048 \mathrm{E}-03$ \\
\hline $\ln \left(\phi_{\mathrm{S}}\right)$ & 2.6905E-04 & 1.6053E-03 & 5.9219E-04 & $6.6120 \mathrm{E}-04$ & 2.9032E-02 & 2.3849E-04 & $-2.5030 \mathrm{E}-04$ & $-2.9795 E-04$ & $-5.0207 E-04$ & $-1.4151 \mathrm{E}-03$ & $-1.1953 \mathrm{E}-03$ \\
\hline $\ln \left(1-\phi_{S}\right)$ & 5.1104E-02 & 2.6539E-02 & $1.4325 \mathrm{E}-02$ & 2.9032E-02 & $2.6307 E+00$ & $1.1036 \mathrm{E}-03$ & $-1.7228 \mathrm{E}-03$ & $-7.5786 \mathrm{E}-03$ & $-3.2093 \mathrm{E}-03$ & $-2.9932 \mathrm{E}-02$ & $-1.8609 \mathrm{E}-02$ \\
\hline $\ln \left(\mathrm{U}_{\mathrm{T}}\right)$ & 3.2619E-04 & $1.1292 \mathrm{E}-03$ & 2.7879E-04 & 2.3849E-04 & $1.1036 \mathrm{E}-03$ & 3.3690E-04 & $-1.3124 \mathrm{E}-04$ & $-9.8969 \mathrm{E}-05$ & $-4.1674 \mathrm{E}-04$ & $-9.7981 E-04$ & -8.3773E-04 \\
\hline $\ln (\mathrm{DC})$ & $2.4156 \mathrm{E}-03$ & $-1.2832 \mathrm{E}-03$ & $-4.3658 \mathrm{E}-04$ & $-2.5030 \mathrm{E}-04$ & $-1.7228 \mathrm{E}-03$ & $-1.3124 \mathrm{E}-04$ & $1.2902 \mathrm{E}-03$ & $1.0281 \mathrm{E}-04$ & 4.1621E-04 & $1.1149 \mathrm{E}-03$ & $1.0281 \mathrm{E}-03$ \\
\hline $\ln \left(\phi_{\mathrm{p}}\right)$ & 3.1577E-03 & $-8.8770 \mathrm{E}-04$ & $-3.1116 \mathrm{E}-04$ & $-2.9795 E-04$ & $-7.5786 \mathrm{E}-03$ & $-9.8969 E-05$ & $1.0281 \mathrm{E}-04$ & $1.4940 \mathrm{E}-03$ & 3.9853E-04 & 7.0285E-04 & 8.7819E-04 \\
\hline $\ln \left(\mathrm{N}_{\mathrm{J}}\right)$ & $1.8299 \mathrm{E}-03$ & $-3.3652 E-03$ & $-9.2726 \mathrm{E}-04$ & $-5.0207 \mathrm{E}-04$ & $-3.2093 E-03$ & $-4.1674 \mathrm{E}-04$ & 4.1621E-04 & 3.9853E-04 & 2.4521E-03 & 2.9864E-03 & $1.9229 \mathrm{E}-03$ \\
\hline $\ln (d)$ & $1.0274 \mathrm{E}-02$ & -8.1657E-03 & $-1.7203 \mathrm{E}-03$ & $-1.4151 \mathrm{E}-03$ & $-2.9932 \mathrm{E}-02$ & $-9.7981 E-04$ & 1.1149E-03 & 7.0285E-04 & 2.9864E-03 & 7.4437E-03 & 4.7467E-03 \\
\hline $\ln (\mathrm{U})$ & 3.4980E-03 & $-5.5499 \mathrm{E}-03$ & $-1.8048 \mathrm{E}-03$ & $-1.1953 \mathrm{E}-03$ & $-1.8609 \mathrm{E}-02$ & -8.3773E-04 & $1.0281 \mathrm{E}-03$ & 8.7819E-04 & $1.9229 \mathrm{E}-03$ & 4.7467E-03 & 4.3154E-03 \\
\hline
\end{tabular}


Table F.22. Variance-Covariance Matrix for 13-Term $\ln \left(\mathrm{H}_{\mathrm{C}}\right)$ Model in Table F.12. The form of variance-covariance matrix is presented in Eq. (D.17a) of Appendix D.

\begin{tabular}{|c|c|c|c|c|c|c|c|c|}
\hline Term & $\ln \left(a_{0}\right)$ & $\ln (\mathrm{D})$ & $\ln (\mathrm{s}-1)$ & $\ln \left(\phi_{\mathrm{S}}\right)$ & $\ln \left(1-\phi_{\mathrm{S}}\right)$ & $\ln \left(\mathrm{U}_{\mathrm{T}}\right)$ & $\ln (\mathrm{DC})$ & $\ln \left(\phi_{p}\right)$ \\
\hline $\ln \left(\mathrm{a}_{0}\right)$ & $5.2051 \mathrm{E}-02$ & $-8.0973 E-03$ & $-3.2772 E-04$ & 1.3978E-03 & 5.9953E-01 & $5.2256 \mathrm{E}-04$ & $1.8925 \mathrm{E}-03$ & $2.5316 \mathrm{E}-03$ \\
\hline $\ln (\mathrm{D})$ & -8.0973E-03 & $9.1078 \mathrm{E}-03$ & $1.7744 \mathrm{E}-03$ & 7.1523E-04 & 1.6117E-02 & 6.6759E-04 & $-8.5565 E-04$ & $-4.8328 \mathrm{E}-04$ \\
\hline $\ln (s-1)$ & $-3.2772 \mathrm{E}-04$ & $1.7744 \mathrm{E}-03$ & $1.7127 \mathrm{E}-03$ & 4.7812E-04 & 4.6373E-03 & 2.2869E-04 & $-3.5974 \mathrm{E}-04$ & $-2.5760 \mathrm{E}-04$ \\
\hline $\ln \left(\phi_{\mathrm{S}}\right)$ & $1.3978 \mathrm{E}-03$ & 7.1523E-04 & 4.7812E-04 & $1.0064 \mathrm{E}-03$ & 1.1125E-01 & 3.5717E-04 & $-3.1322 \mathrm{E}-04$ & $-3.7026 \mathrm{E}-04$ \\
\hline $\ln \left(1-\phi_{S}\right)$ & 5.9953E-01 & 1.6117E-02 & 4.6373E-03 & 1.1125E-01 & $3.7183 \mathrm{E}+01$ & 2.2764E-02 & $-1.1710 \mathrm{E}-02$ & $-1.5768 \mathrm{E}-02$ \\
\hline $\ln \left(\mathrm{U}_{\mathrm{T}}\right)$ & $5.2256 \mathrm{E}-04$ & 6.6759E-04 & 2.2869E-04 & 3.5717E-04 & 2.2764E-02 & 3.3689E-04 & $-1.4990 \mathrm{E}-04$ & $-1.3152 \mathrm{E}-04$ \\
\hline $\ln (\mathrm{DC})$ & $1.8925 \mathrm{E}-03$ & $-8.5565 E-04$ & $-3.5974 \mathrm{E}-04$ & $-3.1322 \mathrm{E}-04$ & $-1.1710 \mathrm{E}-02$ & $-1.4990 \mathrm{E}-04$ & $1.0905 \mathrm{E}-03$ & $1.2123 \mathrm{E}-04$ \\
\hline $\ln \left(\phi_{\mathrm{p}}\right)$ & 2.5316 & $-4.8328 \mathrm{E}-04$ & $-2.5760 \mathrm{E}-04$ & -3.702 & $-1.5768 \mathrm{E}-02$ & $-1.3152 E-04$ & $1.2123 \mathrm{E}-04$ & $1.2723 \mathrm{E}-03$ \\
\hline $\ln \left(N_{J}\right)$ & 5.1907E-04 & $-2.4291 \mathrm{E}-03$ & $-7.5291 \mathrm{E}-04$ & $-7.2028 E-04$ & -7.1897E-02 & $-4.4437 \mathrm{E}-04$ & 4.0741E-04 & 4.0229E-04 \\
\hline $\ln (d)$ & $7.2169 \mathrm{E}-03$ & $-6.1183 E-03$ & $-1.4043 \mathrm{E}-03$ & $-1.6271 \mathrm{E}-03$ & $-1.1470 \mathrm{E}-01$ & $-9.6555 E-04$ & $1.0225 \mathrm{E}-03$ & 7.0139E-04 \\
\hline $\ln (U)$ & $-2.7550 \mathrm{E}-04$ & $-4.1280 \mathrm{E}-03$ & $-1.4470 \mathrm{E}-03$ & -1.6641E-03 & -2.2223E-01 & -8.8954E-04 & $9.6086 \mathrm{E}-04$ & $8.4660 \mathrm{E}-04$ \\
\hline$D \ln \left(\phi_{\mathrm{S}}\right)$ & $-2.1991 \mathrm{E}-04$ & 4.8177E-04 & $-2.5513 \mathrm{E}-06$ & $-2.6032 \mathrm{E}-04$ & $-2.4736 \mathrm{E}-02$ & $-1.0189 \mathrm{E}-04$ & 7.3623E-05 & 8.9114E-05 \\
\hline$\phi_{\mathrm{S}} \ln (\mathrm{U})$ & 2.4443E-01 & 6.1376E-03 & -3.2233E-03 & 3.4247E-02 & $1.5157 \mathrm{E}+01$ & 7.9033E-03 & $-3.2611 \mathrm{E}-03$ & $-2.6466 \mathrm{E}-03$ \\
\hline
\end{tabular}

\begin{tabular}{lrrrrr}
\hline \multicolumn{1}{c}{ Term } & \multicolumn{1}{c}{$\ln \left(\mathrm{N}_{\mathrm{J}}\right)$} & \multicolumn{1}{c}{$\ln (\mathrm{d})$} & \multicolumn{1}{c}{$\ln (\mathrm{U})$} & \multicolumn{1}{c}{$\mathrm{D} \ln \left(\phi_{\mathrm{S}}\right)$} & \multicolumn{1}{c}{$\phi_{\mathrm{S}} \ln (\mathrm{U})$} \\
\hline $\ln \left(\mathrm{a}_{0}\right)$ & $5.1907 \mathrm{E}-04$ & $7.2169 \mathrm{E}-03$ & $-2.7550 \mathrm{E}-04$ & $-2.1991 \mathrm{E}-04$ & $2.4443 \mathrm{E}-01$ \\
$\ln (\mathrm{D})$ & $-2.4291 \mathrm{E}-03$ & $-6.1183 \mathrm{E}-03$ & $-4.1280 \mathrm{E}-03$ & $4.8177 \mathrm{E}-04$ & $6.1376 \mathrm{E}-03$ \\
$\ln (\mathrm{s}-1)$ & $-7.5291 \mathrm{E}-04$ & $-1.4043 \mathrm{E}-03$ & $-1.4470 \mathrm{E}-03$ & $-2.5513 \mathrm{E}-06$ & $-3.2233 \mathrm{E}-03$ \\
$\ln \left(\phi_{\mathrm{S}}\right)$ & $-7.2028 \mathrm{E}-04$ & $-1.6271 \mathrm{E}-03$ & $-1.6641 \mathrm{E}-03$ & $-2.6032 \mathrm{E}-04$ & $3.4247 \mathrm{E}-02$ \\
$\ln \left(1-\phi_{\mathrm{S}}\right)$ & $-7.1897 \mathrm{E}-02$ & $-1.1470 \mathrm{E}-01$ & $-2.2223 \mathrm{E}-01$ & $-2.4736 \mathrm{E}-02$ & $1.5157 \mathrm{E}+01$ \\
$\ln \left(\mathrm{U}_{\mathrm{T}}\right)$ & $-4.4437 \mathrm{E}-04$ & $-9.6555 \mathrm{E}-04$ & $-8.8954 \mathrm{E}-04$ & $-1.0189 \mathrm{E}-04$ & $7.9033 \mathrm{E}-03$ \\
$\ln (\mathrm{DC})$ & $4.0741 \mathrm{E}-04$ & $1.0225 \mathrm{E}-03$ & $9.6086 \mathrm{E}-04$ & $7.3623 \mathrm{E}-05$ & $-3.2611 \mathrm{E}-03$ \\
$\ln \left(\phi_{\mathrm{p}}\right)$ & $4.0229 \mathrm{E}-04$ & $7.0139 \mathrm{E}-04$ & $8.4660 \mathrm{E}-04$ & $8.9114 \mathrm{E}-05$ & $-2.6466 \mathrm{E}-03$ \\
$\ln \left(\mathrm{N}_{\mathrm{J}}\right)$ & $2.2260 \mathrm{E}-03$ & $2.7638 \mathrm{E}-03$ & $2.0803 \mathrm{E}-03$ & $1.5828 \mathrm{E}-04$ & $-2.8007 \mathrm{E}-02$ \\
$\ln (\mathrm{d})$ & $2.7638 \mathrm{E}-03$ & $6.5819 \mathrm{E}-03$ & $4.5943 \mathrm{E}-03$ & $2.5777 \mathrm{E}-04$ & $-3.5504 \mathrm{E}-02$ \\
$\ln (\mathrm{U})$ & $2.0803 \mathrm{E}-03$ & $4.5943 \mathrm{E}-03$ & $4.8804 \mathrm{E}-03$ & $2.8035 \mathrm{E}-04$ & $-8.7147 \mathrm{E}-02$ \\
$\mathrm{D} \ln \left(\phi_{\mathrm{S}}\right)$ & $1.5828 \mathrm{E}-04$ & $2.5777 \mathrm{E}-04$ & $2.8035 \mathrm{E}-04$ & $1.7841 \mathrm{E}-04$ & $-7.8087 \mathrm{E}-03$ \\
$\phi_{\mathrm{S}} \ln (\mathrm{U})$ & $-2.8007 \mathrm{E}-02$ & $-3.5504 \mathrm{E}-02$ & $-8.7147 \mathrm{E}-02$ & $-7.8087 \mathrm{E}-03$ & $6.6119 \mathrm{E}+00$ \\
\hline
\end{tabular}




\section{F.5 Model Validity Region}

Multiple-regression models of the forms developed for $\mathrm{U}_{\mathrm{CS}}$ and $\mathrm{H}_{\mathrm{C}}$ in Sections F.2 and F.3 are typically restricted to use over the predictor-variable region covered by the data used to develop and fit the models.

Table F.23 summarizes the ranges of the predictor variables represented in the full and trimmed data sets used to develop $\mathrm{U}_{\mathrm{CS}}$ and $\mathrm{H}_{\mathrm{C}}$ models in this appendix. However, it may be possible to extrapolate such models for predictor variables [e.g., $\mathrm{D}$ = tank diameter (scale)] where the underlying power-law relationship (without or with interactions) is considered appropriate for extrapolation.

Table F.23. Ranges of Predictor Variables in the Full and Trimmed Data Sets Used to Develop $\mathrm{U}_{\mathrm{CS}}$ and $\mathrm{H}_{\mathrm{C}}$ Multiple-Regression Models

\begin{tabular}{|c|c|c|c|}
\hline \multirow[b]{2}{*}{ Variable } & \multirow[b]{2}{*}{ Units } & \multicolumn{2}{|c|}{ Data Set Used for Modeling } \\
\hline & & Full & Trimmed \\
\hline $\mathrm{D}$ & $\mathrm{m}$ & $0.3667-1.7780$ & $0.3667-1.7780$ \\
\hline $\mathrm{N}_{J}$ & number & $4-12$ & $4-12$ \\
\hline d & $\mathrm{m}$ & $0.0032-0.0234$ & $0.0032-0.0234$ \\
\hline$\phi_{\mathrm{p}}$ & none & $0.0250-0.1523$ & $0.0250-0.1523$ \\
\hline $\mathrm{U}_{\mathrm{T}}$ & $\mathrm{m} / \mathrm{s}$ & $0.0017-0.1074$ & $0.0017-0.0343$ \\
\hline DC & none & $0.1432-0.6692$ & $0.1432-0.3957$ \\
\hline s & $\mathrm{m}$ & $2.45-4.18$ & $2.45-4.18$ \\
\hline$\phi_{\mathrm{s}}$ & none & $0.0005-0.06$ & $0.0005-0.0159$ \\
\hline $\mathrm{d}_{\mathrm{S}}=\mathrm{d}_{50}{ }^{(\mathrm{a})}$ & $\mathrm{m}$ & $0.000044-0.000766$ & $0.000044-0.000178$ \\
\hline $\mathrm{U}\left(>\mathrm{U}_{\mathrm{CS}}\right)^{(\mathrm{b})}$ & $\mathrm{m} / \mathrm{s}$ & $1.30-16.10$ & $1.30-16.10$ \\
\hline HS & $\mathrm{E}, \mathrm{FD}, \mathrm{S}^{(\mathrm{c})}$ & All & All \\
\hline Jet Operation & $\mathrm{P}, \mathrm{S}^{(\mathrm{d})}$ & $\mathrm{P}$ & $\mathrm{P}$ \\
\hline \# Data Points, $\mathrm{U}_{\mathrm{CS}}$ & & 173 & 154 \\
\hline \# Data Points, $\mathrm{H}_{\mathrm{C}}$ & & 669 & 581 \\
\hline
\end{tabular}

(a) Even though $d_{S}$ was omitted from $U_{C S}$ and $H_{C}$ models in favor of $U_{T}$, its range is still given here.

(b) The ranges of $U>U_{C S}$ are over all test conditions. The range of $U$ varies for different test conditions, with some conditions having zero range (i.e., one $\mathrm{U}=\mathrm{U}_{\mathrm{CS}}$ ) or a small range.

(c) $\mathrm{E}=$ elliptical, FD = flange $\&$ dish, $\mathrm{S}=$ spherical.

(d) $\mathrm{P}=$ pulsed (i.e., $\mathrm{DC}<1$ ), $\mathrm{S}=$ steady state (i.e., $\mathrm{DC}=1$ ).

\section{F.6 Possible Future Activities}

Section F.6.1 discusses experimental design activities suggested for any future mixing experimental work. Section F.6.2 discusses other data/modeling analyses that were not possible to perform for this work but are suggested in the future.

\section{F.6.1 Experimental Design}

The ability to develop models relating $\mathrm{U}_{\mathrm{CS}}$ and $\mathrm{H}_{\mathrm{C}}$ to test (predictor) variables was limited by the distribution of combinations of test variables over the multivariate test-variable region. Many of the tests focused on test variables at design values, which increase model prediction uncertainties in other parts of the predictor-variable region, compared with what it could have been if a better distribution of test-variable combinations were selected. In the future, it is suggested that statistical experimental design methods be applied to help select the combinations of test variables to investigate. These methods provide for covering the relevant test-variable region, including irregularly-shaped regions that occur when some combinations of test variables are inappropriate or otherwise not of interest. Statistical experimental design methods also provide for selecting combinations of test variables (test matrix) to provide good support for estimating their individual and interactive effects. These methods thus can provide good support for developing accurate and precise models, for the same number or fewer tests that might 
otherwise be selected by non-statistical approaches. Of course, the statistical approach must be informed by mixing knowledge and experience, as well as the WTP mixing situations of interest. Thus, it is recommended that a combined approach using both statistical and subject-matter aspects be used to select test combinations for any future testing of tank mixing.

As discussed in Section F.1.2 (and Section D.2.2, Appendix D), the order in which test runs from a test matrix are performed can significantly affect the uncertainty and covariance structure of the resulting data set. The order that tests will be performed should be planned as part of the experimental design, so that the data structure obtained is no more complicated than necessary. Further, the experimental design process can also develop the test matrix so that appropriate statistical methods can be applied to account for the more complicated data structure resulting from necessary (or desirable) restrictions on randomization.

Finally, any future experimental mixing testing should include at least two to three replicates each of several test-variable combinations. Replicates involve testing the same set of test conditions at different times, interspersed with the other sets of test conditions in the test matrix. Replicates are contrasted to repeats, where the same set of test conditions is performed multiple times without different sets of test conditions intervening. In general, repeat tests significantly underestimate experimental uncertainty compared with accurate estimates that would be obtained using replicates. Replicates provide for quantifying experimental as well as measurement uncertainty in the data. Experimental uncertainty is generally much larger than measurement uncertainty, so it is important to quantify it properly using replicate tests and not repeat tests or repeat measurements. However, averaging repeat measurements to effectively reduce measurement uncertainty is a very good idea. If repeat measurements are averaged, the number averaged should always be the same. Otherwise, averaging different numbers of repeat values will violate the assumption of “constant variance” for least squares regression (see Section D.2.2 of Appendix D).

\section{F.6.2 Other Data/Modeling Analyses}

Several data/modeling analyses that weren't possible to perform as part of this work, but may be useful to perform in the future, are briefly mentioned.

- Other Model Forms: The work in this appendix was based on power-law forms of models (without and with interaction terms) for $U_{C S}$ and $H_{C}$. These forms of models fit the July 2007, Fall 2007, and 2008 data for $U_{C S}$ very well, and for $\mathrm{H}_{\mathrm{C}}$ reasonably well. However, there were indications in the functionality plots displayed in Section E.2 of Appendix E that other (non-power-law) functional relationships for some variables may yield better model forms. That is, there may be other model forms that better match the relationships in the data and yield more accurate and precise predictions. It can sometimes involve considerable work to develop model forms that include different functional relationship forms for different predictor variables and their interactions. However, such work may yield models that make more accurate predictions of mixing response variables with less uncertainty, especially when model extrapolation is necessary.

- Model Validation: MR models developed using a given data set should be validated using data not used to develop them.

- One way to do this is to split the data in the model development set, say with $80 \%$ in the modeling subset and $20 \%$ in the validation subset. This can be done in such a way that the full data set is split five times into five modeling subsets and five corresponding validation subsets, with the validation subsets being mutually exclusive. Then the average validation performance over the five validation subsets serves as a very good basis to assess validation performance. 
- Validation can also be performed using one or more separate sets of validation data (e.g., from previous testing). Ideally such data would support model performance assessment within the model region of validity (interpolation) as well as outside it (extrapolation). The dimensionally consistent models presented in this appendix were validated using the benchmarking data, as discussed in Section 8 of the main report.

However, it would be valuable to validate the models using any other separate data that becomes available.

Regardless of the way validation is performed, statistical prediction intervals (see Section D.6.3, Appendix D) can be used to assess with a specified confidence level whether model predictions are within statistical uncertainty of the measured values from the validation data set.

- Comparison of Multiple Regression Models with Models Develop by Physics-Based Approach: As discussed in Sections F.2.2 and F.3.2, the $\mathrm{U}_{\mathrm{CS}}$ and $\mathrm{H}_{\mathrm{C}}$ dimensional model forms investigated in Appendix $\mathrm{F}$ are generalizations of physics-based model forms developed in Section 7. Dimensionally consistent versions of the dimensional models were also investigated in Appendix F. It was possible in the time available only to perform a limited comparison of the $\mathrm{U}_{\mathrm{CS}}$ and $\mathrm{H}_{\mathrm{C}}$ models in Appendix $\mathrm{F}$ with those in Section 7.3.2. In the future, it would be worthwhile to further compare the results of the multiple-regression and physics-based approaches and obtain improved model forms based on a synthesis of these approaches.

- Uncertainties in Model Predictions: As discussed at the end of Section F.4, methods for quantifying and combining all uncertainties associated with mixing response models should be pursued. Statistical uncertainty intervals for quantifying model fitting uncertainty are presented in Section D.6 of Appendix D, and illustrated in Section F.4. Statistical intervals should be developed that combine model-fitting uncertainty with the uncertainty from propagating uncertainties in the predictor variables of a model. Methods for quantifying possible uncertainties associated with the form of the model should also be investigated. Or, operating margins should be developed that will protect against such uncertainties.

\section{F.7 References}

Draper NR and H Smith. 1998. Applied Regression Analysis, Third Edition. John Wiley and Sons, New York.

Myers RH, and DC Montgomery. 1995. Response Surface Methodology: Process and Product Optimization Using Designed Experiments, John Wiley and Sons, New York.

Piepel GF, BG Amidan, A Heredia-Langner, DR Weier, and SK Cooley. June 2005. Statistical Methods and Results for WTP IHLW and ILAW Compliance. PNWD-3568 (WTP-RPT-072) Rev. 1, Battelle - Pacific Northwest Division, Richland, Washington.

PNNL. August 2008. River Projection Project - Waste Treatment Plant Support Program Quality Assurance Manual (QAM). RPP-WTP-QA-003 Rev. 0, Pacific Northwest National Laboratory, Richland, Washington. 
PNNL-18098

WTP-RPT-182 Rev 0

\section{Distribution}

No. of

Copies

OFFSITE
No. of

Copies

ONSITE

32 Pacific Northwest National Laboratory

BG Amidan

K6-08

EBK Baer

K7-15

JA Bamberger(4)

K7-15

CA Burns

K3-61

KM Denslow

K5-26

CW Enderlin

K7-15

JA Fort

PA Gauglitz

MS Greenwood

BK Hatchell

MD Johnson

WL Kuhn

K7-15

K9-75

K5-26

K5-22

K6-96

K7-15

A Heredia-Langner

K6-08

PA Meyer (2)

MJ Minette (2)

K7-15

P7-25

GP Morgen

K5-17

GF Piepel

K6-08

PA Scott (4)

K7-15

GL Smith

K6-24

SF Snyder

K3-54

SK Sundaram

K6-24

K7-15

BE Wells

K7-15

M White

K3-52

Information Release (pdf)

4 Bechtel National, Inc.

$\begin{array}{ll}\text { F. Damerow } & \mathrm{H} 4-02 \\ \text { P. Keuhlen } & \mathrm{H} 4-02 \\ \text { WTP R\&T Docs (2) } & \mathrm{H} 4-02\end{array}$

3 Department of Energy

DH Alexander (2)

H6-60

LK Holton

H6-61

Dist. 1 